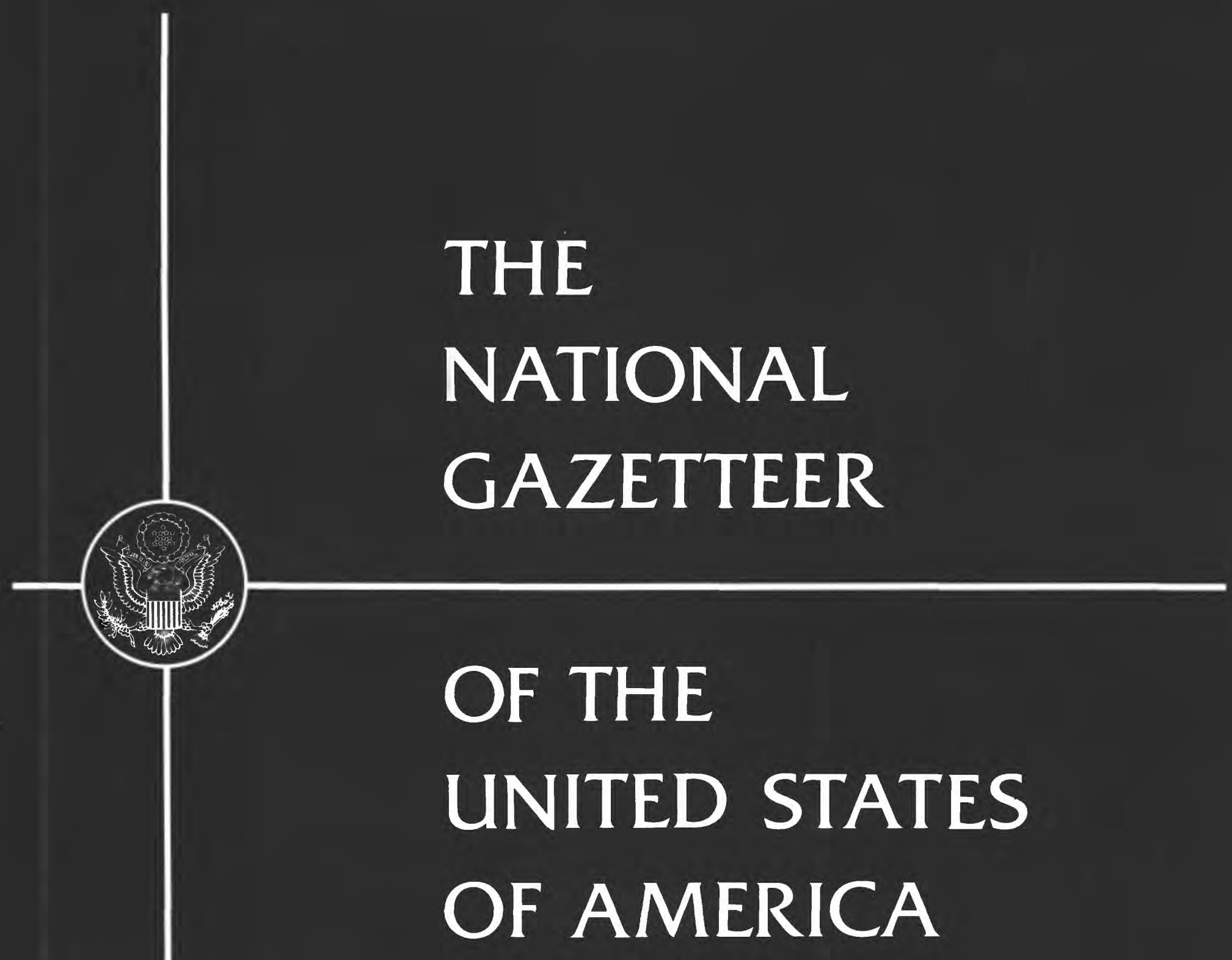

ARIZONA 1986 
THE NATIONAL GAZETTEER OF THE UNITED STATES OF AMERICA ARIZONA 1986 


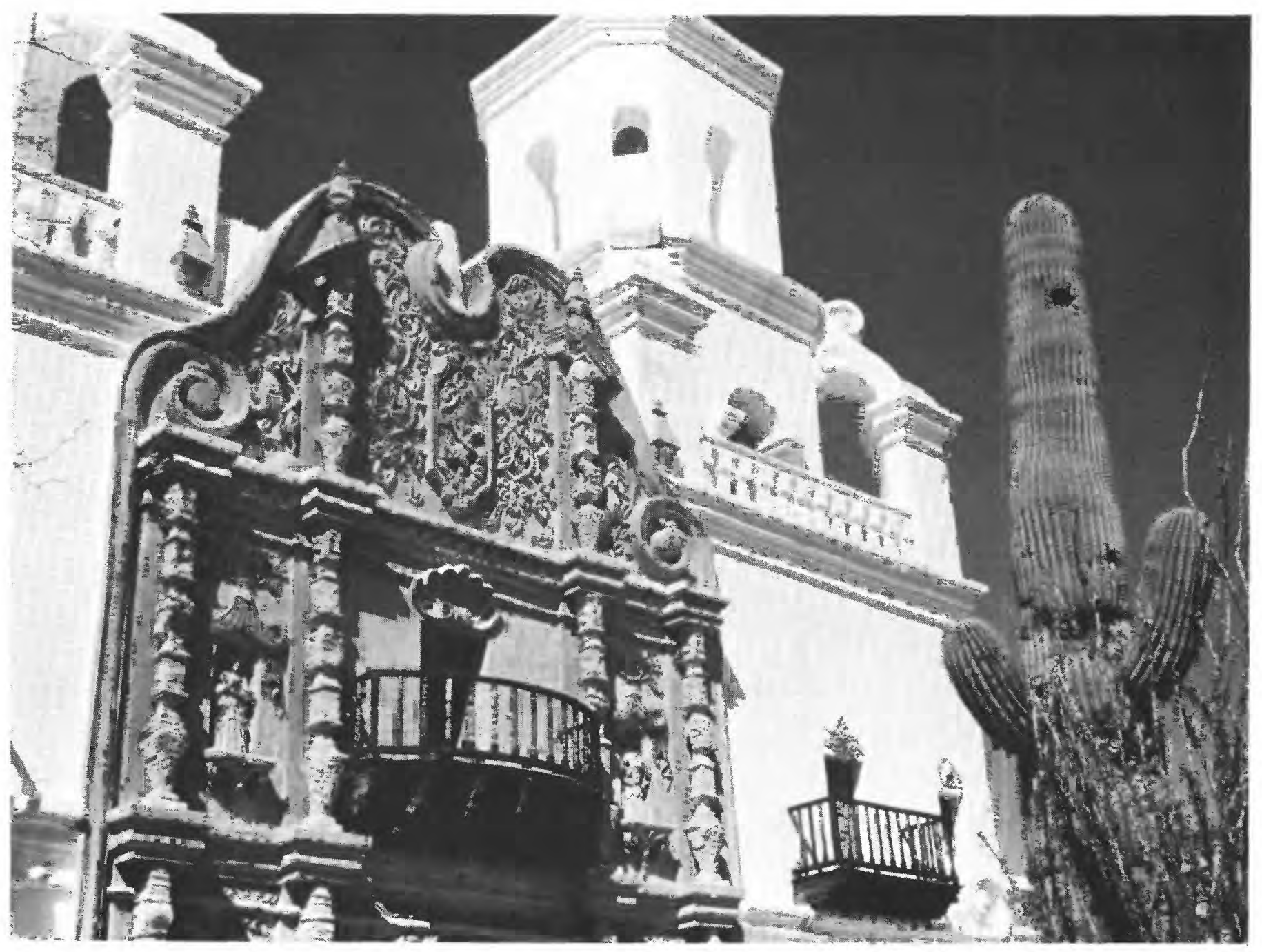

FRONTISPIECE-The 18th century mission of San Xavier del Bac, which is located a few miles south of the center of Tucson, reflects the Spanish and native American heritages of Arizona. The name honors the Jesuit missionary Saint Francis Xavier and also includes a Spanish recording of the Papago or Pima Indian word that refers to the place where the mission is located. Bac may mean "adobe house," "ruin," or possibly "well." The name Tucson is derived from Papago words meaning "black bottom," a reference to a dark volcanic stratum in nearby Sentinel Peak. 


\section{THE NATIONAL GAZETTEER OF THE UNITED STATES OF AMERICA- ARIZONA 1986}

U.S. GEOLOGICAL SURVEY PROFESSIONAL PAPER 1200-AZ

Prepared by the U.S. Geological Survey in cooperation with the U.S. Board on Geographic Names
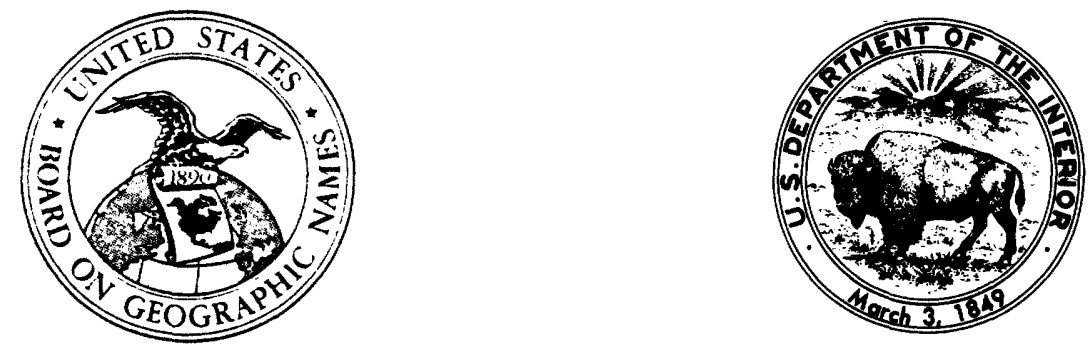

UNITED STATES GOVERNMENT PRINTING OFFICE: 1987 


\section{UNITED STATES DEPARTMENT OF THE INTERIOR}

Donald Paul Hodel, Secretary

GEOLOGICAL SURVEY

Dallas L. Peck, Director

UNITED STATES

BOARD ON GEOGRAPHIC NAMES

Sandra Shaw, Chairman

\section{Library of Congress Cataloging-in-Pubiication Data}

The National gazetteer of the United States of America. Arizona 1986.

(U.S. Geological Survey professional paper ; 1200-AZ)

1. Arizona-Gazetteers. I. Geological Survey (U.S.) II. United States. Board on Geographic Names. III. Series: U.S. Geological Survey professional paper ; 1200-AZ.

F809.N35 $1987 \quad 917.91^{\prime} 003^{\prime} 21 \quad 87-600043$

For sale by Books and Open-File Reports Section, U.S. Geological Survey, Federal Center, Box 25425, Denver, CO 80225 


\section{FOREWORD}

"The National Gazetteer of the United States of America" is a cooperative product of the U.S. Geological Survey and the U.S. Board on Geographic Names. The two organizations have a long history of cooperation in establishing uniform usage of geographic names on Federal maps, charts, and other publications. This cooperation, which has been a blending of technical talent and field-gathered information, has been mutually beneficial to the missions and programs of both organizations. The Board on Geographic Names is responsible for establishing official names for use throughout the Federal Government. The U.S. Geological Survey is responsible for the preparation and maintenance of the series of base maps of the Nation's lands and waters and for the publication of reports detailing the results of investigations of the Nation's mineral, energy, land, and water resources. In addition to being a principal user of the official names determined by the Board, the U.S. Geological Survey with its extensive field operations has collected much of the information necessary for making the decisions establishing those names.

The basis for the cooperation between the U.S. Geological Survey and the Board is the recognition that the use of standard geographic names is necessary for communication of geographical information. Geographic names are an essential part of our language and form a primary reference system that affects people every day of their lives. Geographic names have strong psychological significance because they are associated with the processes of thought that give people the ability to understand the world around them. They are used to identify cultural and administrative areas, define political boundaries, and determine property, mineral, and water rights.

"The National Gazetteer of the United States of America" is the result of a long-term effort to provide a standard reference to the Nation's named places, features, and areas. As early as 1892, with the support of the newly organized Board on Geographic Names and as part of the National Mapping Program, the U.S. Geological Survey began cataloging geographic names and producing a series of State gazetteers "designed as an aid in finding any geographic feature upon the atlas sheets published by the Geological Survey." Compilation was initially done by Henry Gannett, Chief Geographer, under the direction of John Wesley Powell, second Director of the Survey. Gannett was chairman of the Board on Geographic Names from 1894 until his death in 1914. Gazetteers for 12 States, Puerto Rico, Territory of Alaska, and Indian Territory (Oklahoma) were published between 1894 and 1906. However, largescale topographic mapping, from which the name information for the gazetteers was derived, was a slow process, and inadequate map coverage led to the suspension of the program.

The U.S. Geological Survey again began the systematic collection of geographic name information in 1976 when published large-scale topographic maps were available for more than 70 percent of the country. This information comprises a major part of the computerized National Geographic Names Data Base. This volume, the fourth of the USGS Professional Paper series, "The National Gazetteer of the United States of America," is derived from the data base.

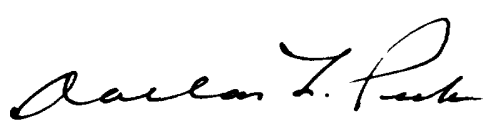

Dallas L. Peck

Director, U.S. Geological Survey

Department of the Interior

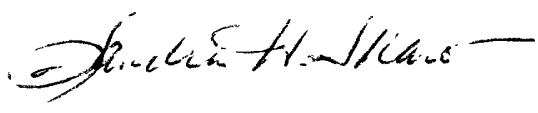

Sandra Shaw

Chairman, U.S. Board on Geographic Names 
UNITED STATES

BOARD ON GEOGRAPHIC NAMES

Sandra Shaw, Chairman

MEMBERS AS OF DECEMBER 1986

Department of State

Sandra Shaw, member

Daniel J. Dzurek, deputy

Postal Service

Eugene A. Columbo, member Jack Thompson, deputy

Department of the Interior

Rupert B. Southard, member Solomon M. Lang, deputy Tracy A. Fortmann, deputy

David E. Meier, deputy

Department of Agriculture

Sterling J. Wilcox, member Lewis G. Glover, deputy Harold L. Strickland, deputy Donald D. Loff, deputy

Department of Commerce. Charles E. Harrington, member Richard L. Forstall, deputy Roy G. Saltman, deputy

Government Printing Office Robert C. McArtor, member S. Jean McCormick, deputy

Library of Congress Ralph E. Ehrenberg, member David A. Smith, deputy

Department of Defense Maurice S. Stuckey, member Carl Nelius, deputy

Staff assistance for domestic geographic names provided by the U.S. Geological Survey

Communications about domestic names should be addressed to:

Donald J. Orth Executive Secretary Domestic Geographic Names Board on Geographic Names 523 National Center Reston, VA 22092 


\section{CONTENTS}

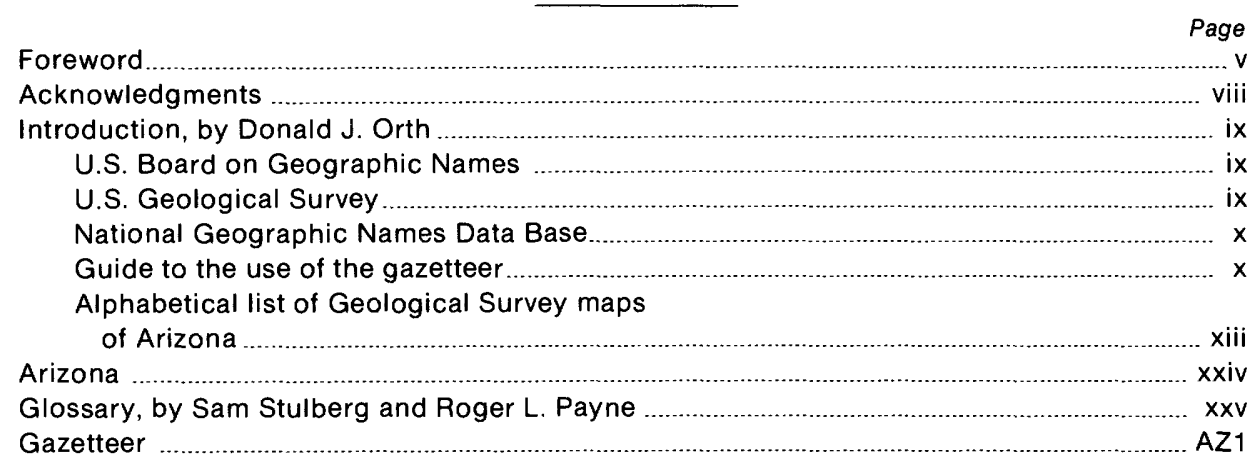

\section{ILLUSTRATIONS}

Frontispiece-Spanish mission of San Xavier del Bac
Figure 1. Map of Arizona counties
2. Translation of Father Kino's map of territory
now known as Arizona, 1705
3. William Hartley's map of Arizona, 1865




\section{ACKNOWLEDGMENTS}

The geographic names information in the Arizona volume of the National Gazetteer was compiled by the Geographic names staff in the U.S. Geological Survey in Reston, Virginia, and personnel of Arizona State University in Tempe, Arizona. Additional technical support was provided by the Arizona State Department of Lands in Phoenix. 


\section{THE NATIONAL GAZETTEER OF THE UNITED STATES-ARIZONA 1986}

\section{INTRODUCTION}

\author{
By Donald J. Orth
}

This gazetteer lists about 36,000 geographic names in alphabetical order for places, features, and areas within the State of Arizona. It is part of a series of State, territory, and other special listings of geographic names published as U.S. Geological Survey Professional Paper 1200 and collectively titled "The National Gazetteer of the United States of America." This series is prepared in cooperation with the U.S. Board on Geographic Names. Its purpose is to provide a national standard reference for research on geographic names and a base for other data systems. Separate volumes of the National Gazetteer are identified by principal geographic area or topic and year. Each volume will be revised periodically with the year of publication as part of the title. The information in the National Gazetteer may be kept up-to-date between revisions by noting appropriate changes and new name entries published in the reports of the U.S. Board on Geographic Names. These reports may be found in libraries or can be ordered directly from the Executive Secretary, Domestic Geographic Names, Board on Geographic Names, 523 National Center, Reston, VA 22092.

\section{UNITED STATES BOARD ON GEOGRAPHIC NAMES}

The United States Board on Geographic Names is a Federal body created in 1890 and established in its present form by public law in 1947. The purpose of the Board is to resolve name problems and to eliminate duplication of effort by Federal agencies responsible for the production of maps and other publications that use geographic names. Composed of representatives of Federal agencies, the Board is authorized to establish and maintain uniform geographic name usage throughout the Federal Government. Sharing its responsibilities with the Secretary of the Interior, the Board has developed principles, policies, and procedures governing the adoption and promulgation of both domestic and foreign geographic names as well as names for underseas and extraterrestrial features. Although established to serve the Federal Government as a central authority to which all name problems, name inquiries, and new

Users are urged to report errors, omissions, and any other information that may improve the usefulness of this publication. name proposals can be directed, the Board plays a similar role for the general public.

With respect to names used by Americans for places, features, and areas in the United States, its territories, and outlying areas, it is the policy of the Board to recognize present-day local usage or preferences where possible. To implement this policy, there is a close cooperation with State geographic boards, with State and local governments, and with the general public.

Where there is confusing duplication of local names or where a local name is derogatory to a particular person, race, or religion, the Board may disapprove such names and seek alternate local names for the features. In cases where local usage is conflicting or when a name is not used by many people, wellestablished documented names and names with historical significance are given added consideration. The Board also has a policy of not approving new domestic geographic names that commemorate or may be construed to commemorate living persons.

Any person or organization, public or private, may make inquiries or request the Board on Geographic Names to render formal decisions on proposed new names, proposed name changes, or names that are in conflict. Communications concerning domestic geographic names should be addressed to the Executive Secretary, Domestic Geographic Names, Board on Geographic Names, 523 National Center, Reston, VA 22092.

\section{U.S. GEOLOGICAL SURVEY}

The U.S. Geological Survey, established in 1879 as a bureau of the Department of the Interior, is the Federal Government's major earth-science fact-finding agency. The Survey's broad and diversified research programs aid in the management of the mineral, energy, land, and water resources of the United States. These programs play a vital role in furthering the Nation's welfare by providing information on the character, magnitude, location, and distribution of minerals and ores, the sources and supplies of water, and the natural Earth processes that must be understood to maintain environmental quality.

In support of the Survey's mission, its National Mapping Division provides geographic and cartographic information, maps, and technical assistance, and conducts related research in response to national mapping needs. The Division provides staff support for the 
domestic geographic names activities of the Board on Geographic Names, manages the national geographic names data system, provides a geographic names information service within the Survey and to the outside users of names information, and conducts research in support of national name standardization programs.

\section{NATIONAL GEOGRAPHIC NAMES DATA BASE}

This Gazetteer is derived from the National Geographic Names Data Base, which is part of a computerized Geographic Names Information System developed by the U.S. Geological Survey. The data base presently contains information for about two million names used throughout the United States, its territories, and outlying areas. Information within the system can be retrieved, manipulated, and arranged to meet the special needs of a wide variety of users in government, education, business, and industry, as well as those of private individuals. The system can furnish alphabetical and special listings in the form of bound reports, magnetic tapes, and microfiche. Information about available services and costs of the Geographic Names Information System (GNIS) may be obtained by writing to the Chief, Branch of Geographic Names, U.S. Geological Survey, 523 National Center, Reston, VA 22092.

\section{GUIDE TO THE USE OF THE GAZETTEER}

This gazetteer lists geographic names found on various maps, charts, and in other published documents; the names of railroads, streets, and roads are not included. The names are listed in alphabetical order and each is followed by seven categories of information. Except for variant name listings, each category of information is in a separate column on the gazetteer pages; the columns contain the following information, in order from left to right:

Name (1st column)-This column lists both the primary reference names and variant spellings as well as variant names, for the same features, in alphabetical order. Each variant spelling and name is listed in two places in the first column: under the principal name and in its proper alphabetical order in the gazetteer with a "see" reference to the primary name. The proper names of features, places, or areas generally are composed of two parts-a specific or substantive part and a generic part. The specific part normally precedes the generic in the majority of names in the United States. In these cases, the names are listed in alphabetical order according to the specific parts of the names, letter-by-letter, from beginning to end, ignoring spaces and printing marks. In the names of physical features where the generic parts precede the specific parts, the order is arbitrarily reversed in the gazetteer in order to make it easier to look up a name. In each case, the specific part is listed first, followed by a comma and the remaining part of the name:

\author{
Adams, Mount \\ Ann, Lake \\ Saint Louis, Bay \\ Woods, Lake of the
}

Definite-form names are also listed with the specific parts of the names first:
Crossing, The
Mesa, La
Racetrack, The

Exceptions to the above occur when populated places, localities, civil divisions, or any other cultural features (city, village, county, township, crossroad, and railroad siding) are named for physical features. These are always listed in normal order even though the generic parts of the names may precede the specific parts. A village or locality called "Mount Calvary" is listed in that order, while a physical feature with the same name is listed in reverse order, "Calvary, Mount."

Radio and television stations are listed together at the beginning of each alphabet letter according to their call letters followed by the type of station (AM, FM, or TV) and by the names of the communities they serve.

A few names listed in the gazetteer are followed by descriptive words in parentheses. These words or phrases give special information about name usage or about the specific place or feature. This information is generally self-explanatory, for example: (ruins), (subdivision), (shopping center), and (abandoned) refer to the present state of the place; and (old channel), (submerged), (foot bridge), and (siding) provide further description. The descriptive word (historical) refers to a feature that no longer exists.

Feature Class (2nd column)-The terms listed in this category identify the kinds of features or places to which the names apply. The meaning of the terms are very broad so that similar kinds of landscape features can be grouped into general classes. For example, the term "stream" includes all kinds of flowing water which locally may be called a creek, run, river, branch, bayou, or fork. See page $x x v$ for a list of these terms and their definitions. 
Status (3rd column)-Geographic names can be classified according to their use or official status as determined by the U.S. Board on Geographic Names. This category of information gives the status of each name in the gazetteer as determined by the Board. The designators and their meanings shown in this column are as follows:

BGN (date): This designator indicates that the written form of the name and its application has been determined by the Board on Geographic Names (BGN) to be official for use throughout the Federal Government. If a year date follows the "BGN" designation, the name and its application were subject to special research and decision by the Board and the decision was published during the year shown.

US (date): A geographic name and its applications listed with this designator were established by an Act of Congress and the name is official by law. The date is the year the law was passed.

ADMIN: The names of certain kinds of geographical entities such as counties, parks, forests, and townships, logically fall within the administrative jurisdictions of Federal, State, and local governmental organizations. The authority for establishing these names is based on recognized organic, inherent, or constitutional rights. The names listed with this designator are official for Federal usage.

UNOFF: The Board on Geographic Names has not established these names as official. They are included in the gazetteer for reference purposes.

VARIANT: A name with this designator is a written variant for a place, feature, or area that has another name as its official name. A "see" reference to the official name is given on the line below the entry along with information about the named entity. However, since this gazetteer is designed to be a reference tool, it does not always reflect the true relationship between the current and the historical name of a place. Historical places, such as forts, Indian villages, and small settlements, that once existed close to or within the current boundaries of a presentday populated place often are listed as separate places, but are also listed as appropriate variants.
County (4th column)-This is the name of the county in which the listed entity is located. If the place, feature, or area lies in more than one county, the county listed is the one in which the center of the feature is found; or, in the case of a stream, valley, or arroyo, the county listed is the one in which the feature's mouth is located. Figure 1 outlines the counties of Arizona.

Geographic Coordinates (5th column)-Latitudes and longitudes are given for the mouths of streams and valleys; centers of bays, islands, lakes, populated places, and other areal features; the extremities of points of land; the summits of mountains and hills; and the dams of reservoirs. The first two numbers are degrees, followed by two numbers for minutes, and the last two for seconds $\mathrm{N}$ (north) latitude. This sequence is followed by three, two, and two numbers respectively representing degrees, minutes, and seconds $W$ (west) longitude. Example: $354835 \mathrm{~N} 1104413 \mathrm{~W}$ reads 35 degrees, 48 minutes, 35 seconds north latitude and 110 degrees 44 minutes, 13 seconds west longitude.

Source (6th column)-The geographic coordinates are given for the source or heads of streams, valleys, and arroyos.

Elevation (7th column)-The specific or average elevation is given in feet above the National Geodetic Vertical Datum of 1929 (approximately sea level) for tops of peaks, mountains, ridges, and hills, the surfaces of lakes and reservoirs, the high points of passes and low points of basins, and the approximate centers of populated places.

Map (8th column)-Arizona is subdivided into 1,971 7.5minute quadrangle areas, each of which is covered by a 1:24,000-scale or $1: 25,000$-scale topographic map published by the U.S. Geological Survey. This column indicates the name of the map on which the named place or feature may be located, though not always labeled by name, since not all names are shown on the topographic maps. When ordering topographic maps from the U.S. Geological Survey's Distribution Branch refer to the map name, which may be found on the "Alphabetical List of U.S. Geological Survey Maps of Arizona" on page xiii. (Several names of U.S. Geological Survey maps have been abbreviated because of limitations of space. Both the full name and its abbreviation appear in the Alphabetical List.) 


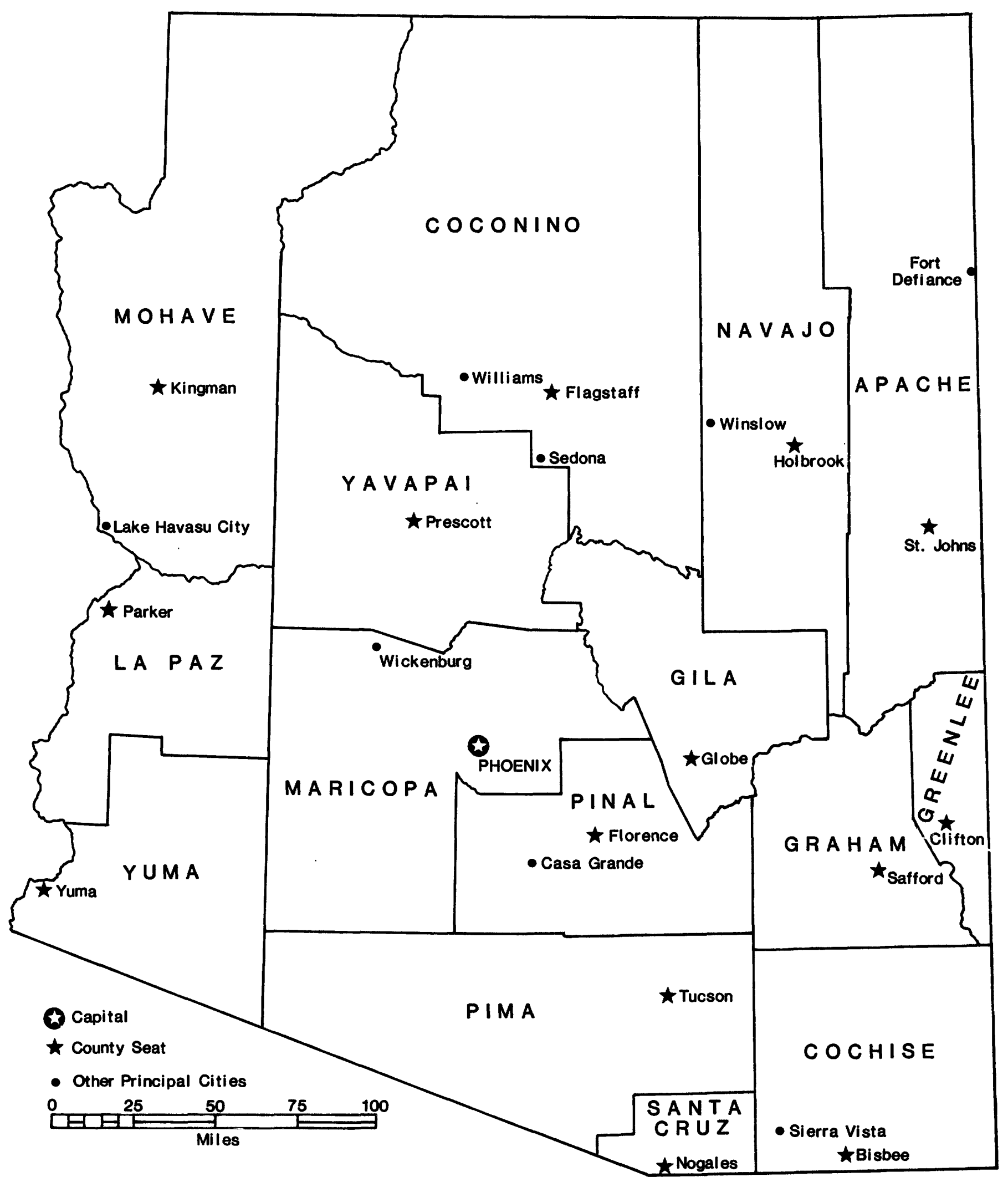

Figure 1.-Map of Arizona Counties 
State indexes to topographic maps are available from:

\section{Branch of Distribution}

U.S. Geological Survey
Map Distribution
Federal Center, BIdg. 41
Box 25286
Denver, CO 80225
(303) 234-7476
FTS 776-7476

Some names appear only on U.S. Forest Service maps. Even though the names are not labeled on U.S. Geological Survey maps, they will be referenced to the 1:24,000scale topographic map on which the named place or feature is located.

The U.S. Forest Service administrative areas in Arizona include the following:

Apache-Sitgreaves National Forest (NF)
Coconino NF
Coronado NF
Kaibab NF
Prescott NF
Tonto NF

Maps for these areas may be obtained from:

Department of Agriculture

U.S. Forest Service

Rocky Mountain Region

11177 West 8th Avenue

P.O. Box 25127

Lakewood, CO 80225

\section{ALPHABETICAL LIST OF GEOLOGICAL SURVEY TOPOGRAPHIC QUADRANGLE MAPS OF ARIZONA}

\author{
ADAMANA \\ ADAMS MESA \\ ADDITIONAL HILL \\ AGATE HOUSE \\ AGATHLA PEAK \\ AGUA CALIENTE \\ AGUA CALIENTE HILL \\ AGUA DULCE MTS \\ AGUILA \\ AGUILA MTS NE \\ AGUILA MTS NW \\ AGUILA MTS SE \\ AGUILA MTS SW \\ AGUIRRE PEAK
}

ANTELOPE KNOLL

ANTELOPE LAKE

ANTELOPE PEAK

ANTELOPE PEAK NE

ANTELOPE POINT

ANVIL ROCK

ANVIL ROCK RANCH

APACHE

APACHE BUTTE

APACHE JUNCTION

APACHE MAID MTN

APACHE PEAK

APPALOOSA RIDGE

ARCH TANK

ARIPINE

ARIVACA

ARIZONA CITY

ARLINGTON

ARMENTA WELL

ARMER MOUNTAIN

ARNOLD MESA

ARRASTRA MTN

ARRASTRA MTN NE

ARRASTRA MTN SE

ARROWHEAD BUTTE

ARROWHEAD BUTTE NE

ARROWHEAD MESA

ARTESIA

ARTESIA NE

ARTILLERY PEAK

ASH CREEK NE

ASH CREEK RANCH

ASH FORK

ASH PEAK

ASHURST LAKE

AUBREY PEAK

AUDLEY

AUSTIN PEAK

AVONDALE

AVONDALE SE

AVONDALE SW

AVRA

AZTEC HILLS

AZTEC NW

AZTEC PEAK

AZTEC SE

AZURE RIDGE

BABBITT WASH

BABOQUIVARI PEAK

BABY ROCKS

BAD BUG BUTTE

BADGER SPRING

BAGDAD

BAILEY PEAK

BALDY BASIN

BALDY BILL POINT

BALDY MTN

BARAGAN MTN

BARD

BARTH WELL

BARTLETT DAM

BARTLETT MTN

BASSETT PEAK

BAT CANYON
BAT CAVE

BAT SPRING

BATAMOTE HILLS

BATES WELL

BATTLE FLAT

BATTLESHIP BUTTE

BEACON WELL

BEAR HILLS

BEAR MOUNTAIN

BEAR RIDGE

BEARGRASS BASIN

BEAUTIFUL VALLEY WELL (BEAUTIFUL VAL WELL)

BEAVERHEAD

BECKERS BUTTE

BEE CANYON

BEECHER CANYON

BEESHSIKAD SPRING

BEGASHIBITO CANYON

BEHM MESA

BELLEMONT

BELMONT MTN

BEN NEVIS MTN

BENSON

BETATAKIN RUIN

BETTY WELL

BIG BUD TANK

BIG CHIEF TANK

BIG HORN

BIG HORN PEAK

BIG LAKE NORTH

BIG LAKE SOUTH

BIG LUE MTS

BIG MARIA MTS NE

BIG MARIA MTS SE

BIG MOUNTAIN DAM

BIG POINT

BIG PUG TANK

BIG SHIPP MTN

BIG SPRINGS

BIG WHISKER WELL

BIG WILLOW SPRING CANYON (BIG WILLOW SPR CAN)

BIRD SPRINGS WASH

BISBEE

BISBEE NE

BISBEE SE

BISCUIT FLAT

BISHOP LAKE

BISMARCK MESA

BITLABITO

BITTER SPRINGS

BLACK BUTTE

BLACK CANYON CITY

BLACK DIAMOND PEAK

BLACK GAP

BLACK HILLS

BLACK MESA WASH NE

BLACK MESA WASH NW

BLACK MOUNTAIN

BLACK PEAK

BLACK TANK

BLACKWATER

BLAIRS SPRING

BLANKENSHIP WELL 
BLOODY BASIN

BLUE

BLUE GAP

BLUE HOUSE MTN

BLUE JAY PEAK

BLUE MOON RESERVOIR

BLUE MOUNTAIN

BLUE PLATEAU

BLUE RIDGE RESERVOIR

BLUE SPRING

BLUE SPRING SE

BLUFF 3 SE (UT)

BLUFF 3 SW (UT)

BLYE CANYON NE

BLYE CANYON SE

BLYTHE

BLYTHE NE

BOB THOMPSON PEAK

BOBS WELL

BODAWAY MESA

BOGGY LAKE WELL

BOILING OVER WELL

BONELLI BAY

BONITA SPRING

BONITA TANK

BONITO PRAIRIE

BONITO ROCK

BOOGER CANYON

BOOT MESA

BOSQUE

BOTTLENECK WASH

BOULDER BEACH

BOULDER CANYON

BOULDER MTN

BOUNDARY BUTTE (UT)

BOUNDARY BUTTE

BOUNDARY CONE

BOUSE

BOUSE HILLS EAST

BOUSE HILLS WEST

BOUSE NW

BOUSE SW

BOWIE

BOWIE MTN NORTH

BOWIE MTN SOUTH

BOX K RANCH

BOZARTH MESA

BRANAMAN SPRING

BRANDENBURG MTN

BRIDGER POINT

BRIGHT ANGEL POINT

BRONCO GULCH

BROOKBANK POINT

BROOKLYN PEAK

BROWN MTN

BRUNO PEAK

BRUSHY CANYON

BRYAN MTS

BRYCE MOUNTAIN

BUCK MOUNTAINS

BUCK MOUNTAINS NE

BUCK MOUNTAINS SE

BUCK PASTURE CANYON

BUCK PEAK

BUCKET MTN
BUCKEYE

BUCKEYE NW

BUCKHEAD MESA

BUCKHORN

BUCKHORN MOUNTAIN

BUEHMAN CANYON

BUELL PARK

BUFFALO CROSSING

BUFFALO RANCH

BUFFALO TANKS

BUFORD HILL

BULL SPRING

BUMBLE BEE

BURNS SPRING

BURNT CORN SPRING

BURNT MILL RANCH

BURNT MOUNTAIN

BURNTWATER WASH

BURRO GAP

BURRO MESA

BURRO SPRING

BUTLER MOUNTAINS

BUTLER PASS

BUTLER WELL

BUTTERFIELD PASS

BUZZARD ROOST MESA

BYLAS

CABEZA PRIETA PEAK

CACTUS FLAT

CACTUS FOREST

CALDERWOOD BUTTE

CALLOWAY BUTTE

CALLVILLE BAY

CALVA

CAMERON NE

CAMERON NORTH

CAMERON SE

CAMERON SOUTH

CAMMERMAN WASH

CAMP VERDE

CAMP WOOD

CAMPBELL FRANCIS WASH (CAMPBELL FRANCIS WSH)

CAMPINI MESA

CAMPO BONITO

CANE

CANE SPRINGS

CANE SPRINGS MTN

CANE SPRINGS SE

CANELO PASS

CANYON DAY

CANYON DIABLO

CAPE ROYAL

CAPE SOLITUDE

CAPONERA PEAK

CARRISITO SPRING

CARRIZO

CARRIZO BUTTE

CARIZZO SE

CASA GRANDE EAST

CASE GRANDE MTS

CASA GRANDE WEST

CASNER BUTTE

CASSADORE SPRING
CASTANEDA HILLS

CASTANEDA HILLS SW

CASTLE CLIFF (UT)

CASTLE DOME PEAK

CASTLE PEAK

CASTLE ROCK

CAT MOUNTAIN

CATARACT TANK

CATHEORAL CANYON

CATHEORAL CAVES

CATTLE CANYON

CAVE CREEK

CEADRO SPRING

CEADRO SPRING SE

CEDAR BASIN

CEDAR CREEK

CEDAR LAKE WASH

CEDAR RIDGE

CEDAR TREE BENCH

CEDAR TREE HILLS

CEMENTOSA WASH

CENTENNIAL WASH

CERBAT

CERRO COLORADO

CERRO HUECO

CHAFIN WELL

CHAIYAHI FLAT

CHAIYAHI RIM NE

CHAIYAHI RIM SE

CHAIYAHI RIM SW

CHALK MOUNTAIN

CHAMBERS

CHAMISA TANK

CHANDLER

CHANDLER HEIGHTS

CHAPEL MTN

CHARLIE DIED TANK

CHAVEZ MTN EAST

CHAVEZ MTN NE

CHAVEZ MTN NW

CHAVEZ MTN WEST

CHEDISKI PEAK

CHEROKEE POINT

CHERRY

CHERRY SPRING PEAK

CHEVELON BUTTE

CHEVELON CROSSING

CHICO SHUNIE

CHIEF BUTTE

CHILCHINBITO

CHILCHINBITO CANYON

CHILDS MTN

CHIMNEY BUTTE

CHIMNEY CANYON

CHINDE MESA

CHINLE

CHINO VALLEY NORTH

CHINO VALLEY SOUTH

CHIRICAHUA BUTTE

CHIRICAHUA PEAK

CHIULI SHAIK

CHLORIDE

CHOLLA TANK

CHRISTMAS

CHRISTMAS PASS
CHROME BUTTE

CHRYSOTILE

CHUICHU

CHUKUT KUK

CHUPAN MTN

$\mathrm{CHURCH}$ ROCK

CIBECUE

CIBECUE PEAK

CIBOLA

CIBOLA SE

CIMARRON PEAK

CINDER HILL

CIPRIANO PASS

CITRUS VALLEY EAST

CITRUS VALLEY WEST

CLARK RANCH

CLARKDALE

CLAY HILLS 3 SE (UT)

CLAY HILLS 4 SE (UT)

CLAY SPRINGS

CLEAR CREEK RESERVOIR (CLEAR CREEK RES)

CLEAR WATER SPRING

CLEATOR

CLIFF ROSE HILL

CLIFTON

COAL MINE MESA

COAT SPRING

COBRE GRANDE MTN

COCHISE

COCHISE HEAD

COCHISE STRONGHOLD

COCONINO POINT

COCONINO POINT SE

COCORAQUE BUTTE

COFFEEPOT MTN

COLD SPRING

COLLEGE PEAKS

COLORADO CITY

COLUMBIA

COLUMBINE FALLS

COLUMBUS PEAK

COMOBABI

$\mathrm{CONCHO}$

CONCHO LAKE

CONE BUTTE

CONGRESS

CONGRESS SW

CONLEY WELL

COOKS MESA

COOLIDGE

COOLIDGE DAM

COOPER RIDGE

COOPER MTN

COPPEROPOLIS

COPPEROSITY HILLS

COPPERPLATE GULCH

CORDES JUNCTION

CORN CREEK

CORN CREEK PLATEAU

CORNFIELDS

CORNVILLE

CORONA DE TUCSON

CORONADO MTN

CORTEZ PEAK 
CORTEZ PEAK NW COTTON CENTER

COTTON CENTER NW COTTON CENTER SE COTTONWOOD COURTHOUSE WELL COVE

COW BUTTE

COW SPRINGS

COWLIC

COYOTE BUTTES

COYOTE HILLS

COYOTE PEAK

COYOTE WATER

CRATER CANYON

CREAMERY CANYON

CROOKTON

CROSS MOUNTAIN

CROSS ROADS

CROSSMAN PEAK

CROWN KING

CROZIER PEAK

CRYSTAL HILL

CUMERO CANYON

CUMERO MTN

CUNNINGHAM MTN

CUNNINGHAM PASS

CURRYS CORNER

CUTTER

CYPRESS BUTTE

DAGGER PEAK

DAGGS TANK

DAISY MOUNTAIN

DANCING ROCKS

DANE CANYON

DATE

DATE CREEK RANCH

DATE CREEK RANCH NW

DATE CREEK RANCH SE

DATE CREEK RANCH SW

DATELAND

DAVENPORT HILL

DAVIS DAM

DAVIS DAM SE

DAY SPRING

DE MOTTE PARK

DEAD MONKEY RIDGE

DEADMAN GAP

DEAN PEAK

DEEP CANYON SOUTH (UT)

DEEP LAKE

DEEPWELL RANCH

DEER TANK

DEL MERTO

DENDORA VALLEY

DENNEHOTSO

DESERT PEAK

DESERT VIEW

DESERT WELL

DEVILS HUMP

DEVILS SLIDE RAPIDS

DEWEY FLAT

DIAMOND BUTTE

DIAMOND JOE PEAK
DIAMOND PEAK

DIAMOND POINT

DIAZ PEAK

DIKE TANK

DILKON

DINNEBITO SPRING

DIPPING WATER WELL

DIX CREEK

DOG KNOBS

DOG POINT

DOLAN SPRINGS

DOME

DOME ROCK MTS SW

DOS CABEZAS

DOS CABEZAS SW

DOUBLE ADOBE

DOUBLE BUTTES

DOUBLE PEAK

DOUBTFUL CANYON

DOUGLAS

DOUGLAS NE

DOURINE CANYON

DOVE SPRING

DOVE SPRING SE

DRAGOON

DREW SPRING WELL

DRIFTWOOD CANYON

DRY LAKE NE

DRY LAKE NW

DRY MOUNTAIN

DUDLEYVILLE

DUGAS

DUNCAN

DUQUESNE

DURHAM HILLS

DUTCH BLUE CREEK

DUTCH FLAT NW

DUTCH FLAT SE

DUTCH FLAT SW

DUTCHMAN DRAW

DUTTON HILL

E C P PEAK

EAGER

EAGLE NEST MTN

EAGLETAIL MTS EAST

EAGLETAIL MTS WEST

EAST OF BUCK PEAK

EAST OF DOUGLAS

EAST OF KINLICHEE

EAST OF OLD LEUPP

EAST OF S P MTN

EAST OF UTTING

EAST PASS

EBERT MTN

ECHO CANYON

EDEN

EGLOFFSTEIN BUTTE

EL CAPITAN MTN

EL MIRAGE

ELBOW CANYON

ELEMENTS CANYON

ELEPHANT BUTTE

ELEPHANT BUTTE (UT)

ELEPHANT MTN
ELEVATOR MTN

ELFRIDA

ELGIN

ELLIOTT CANYON

ELOY NORTH

ELOY SOUTH

ELWOOD CANYON

EMMETT HILL

EMMETT WASH

EMPIRE RANCH

ENGESSER PASS

ENGESSER PASS SW

ENGINE MTN

ENID

ESCUDILLA MTN

ESPERANZA MILL

ESTLER PEAK

ESTRELLA

EUREKA RANCH

EXPLORERS MONUMENT

EXPLOSIVE ROCK

FACE CANYON

FAIRBANK

FAIRCHILD WELL

FAUGHT RIDGE

FERN GLEN CANYON

FERRY SWALE

FIFE PEAK

FINDLAY TANK

FIRE DANCE MESA

FIRE MOUNTAIN

FIRST FLAT MESA

FISHER HILLS

FISHTAIL

FITZGERALD HILL

FIVE BUTTES

FLAGSTAFF EAST

FLAGSTAFF WEST

FLATIRON MTN

FLATTOP HILL

FLORENCE

FLORENCE JUNCTION

FLORENCENE

FLORENCE SE

FLORES

FOREPAUGH PEAK

FORKS BUTTE

FORMASTER WELL

FORT DEFIANCE

FORT GRANT

FORT HUACHUCA

FORT MC DOWELL

FORT ROCK RANCH

FORT THOMAS

FORTIFIED MTN

FORTUNA

FORTUNA MINE

FORTUNA SW

FOSSIL BAY

FOUR PEAKS

FOURTH OF JULY BUTTE

FOWLER

FRANCONIA

FRAZIER WELLS
FRAZIER WELLS SW

FREDONIA

FREEZEOUT MTN

FRENCH BUTTE

FRESNO WASH

FRIENDLY CORNERS

FRITZ CANYON

GADSDEN

GAKOLIK MTS

GALLETA FLAT EAST

GALLETA FLAT WEST

GANADO

GANADO MESA

GANADO MESA SW

GAP TANK

GARCES MESAS NE

GARCES MESAS SE

GARFIAS MTN

GARLAND PRAIRIE

GARNET MTN

GARNET MTN NW

GARNET RIDGE

GARRETT BUTTE

GATEWAY RAPIDS

GENE WASH

GENTRY MTN

GEORGES BUTTE

GERONIMO

GIANTS CHAIR

GILA BEND

GILA BOX

GILA BUTTE

GILA BUTTE NW

GILA BUTTE SE

GILA PEAK

GILLESPIE

GILLISPIE MTN

GISELA

GLADDEN

GLEESON SE

GLEN CANYON CITY (UT)

GLENDALE

GLOBE

GOAT CAMP SPRING

GOLD SPRING

GOLDFIELD

GOLDTOOTH

GONZALES WASH

GOPHER SPRING

GOULDING SW (UT)

GOVERNORS PEAK

GRAMA DRAW

GRAMA SPRING

GRAND CANYON

GRAND CANYON CAVERNS

GRAND FALLS

GRAND FALLS NE

GRAND FALLS SE

GRAND FALLS SW

GRAND GULCH BENCH

GRANDVIEW POINT

GRANITE MTS NORTH

GRANITE MTN SOUTH

GRANITE PARK 


GRANITE REEF DAM
GRAPEVINE CANYON
GRASSHOPPER JUNCTION
GRASSHOPPER JUNCTION NW
(GRASSHOPPER JUNC NW
GRASSHOPPER JUNCTION SE
(GRASSHOPPER JUNC SE)
GRASSY MOUNTAIN
GRAY MOUNTAIN
GRAY SPOT ROCK (UT)
GRAYBACK
GRAYBACK MTS
GRAYS WELL NE
GREASEWOOD
GREASEWOOD MOUNTAIN
GREASEWOOD SPRING
GREAT SPRING
GREEN VALLEY
GREENBACK CREEK
GREENE RESERVOIR
GREENS PEAK
GREENWOOD PEAK
GREER
GREGORY BUTTE
GROOM CREEK
GROOM SPRING
GROWLER
GROWLER PEAK
GU ACHI
GU OIDAK
GU VO
GUADALUPE
GUADALUPE CANYON
GUADALUPE SPRING
GUNSIGHT
GUNSIGHT BUTTE
GUNSIGHT CANYON
GUNSIGHT POINT
GURLI PUT VO
GUTHRIE
GYP HILLS
GYP POCKET
GRE
GRA

HABERSTOCK HILL HACKBERRY HACKBERRY MTN HAIVANA NAKYA HALEY HILLS HAMILTON CROSSING HANCOCK KNOLLS HANKS DRAW HANNAGAN MEADOW HAPPY JACK HAPPY VALLEY HARBISON TANK HARCUVAR HARCUVAR PEAK HARD ROCKS HARDEN CIENEGA HARQUAHALA MTN HARRISBURG VALLEY HARRISON CANYON HARSHAW HASSAYAMPA HAT KNOLL
HAT MOUNTAIN HAT MOUNTAIN SW HAUKE MESA HAUNTED CANYON HAVASU FALLS

HAVASU LAKE HAVASUPAI POINT HAWLEY LAKE EAST HAWLEY LAKE WEST HAY HOLLOW

HAY LAKE

HAY MOUNTAIN

HAYDEN

HAYSTACK BUTTE

HAZEN HOLE TANK

HEARST MTN

HEATON KNOLLS

HEBER

HEDGPETH HILLS

HELL POINT

HELLHOLE BEND

HELVETIA

HEN SPRING

HENNESSY BUTTES

HEREFORD

HIBBARD

HIBERNIA PEAK

HICKEY MOUNTAIN

HICKIWAN

HIDDEN VALLEY

HIEROGLYPHIC MTS SW

HIGGINS TANK

HIGH LONESOME WELL HIGLEY

HILDALE (UT)

HILLER MOUNTAINS

HILLSIDE

HINDU CANYON

HITSON TANK

HOBBLE TANK

HOCKEY PUCK SPRING

HOGAN WELL

HOGANSAANI SPRING

HOLBROOK

HOLE IN ROCK VALLEY

HOLE-N-WALL CANYON

HOLY JOE PEAK

HOODOO KNOB

HOODOO WELL

HOOKERS HOT SPRINGS

HOOVER DAM

HOPE

HOPE SE

HOPE SW

HORN

HORNER MTN

HORSE FLAT

HORSE MESA

HORSE MESA DAM

HORSE TRAP MESA

HORSESHOE CIENEGA

HORSESHOE DAM

HORSETHIEF MESA

HOT ROCK MTN

HOT TAMALE PEAK
HOT WELL

HOTASON VO

HOTEVILLA

HOUCK

HOUSE ROCK

HOUSE ROCK SPRING

HOUSHOLDER PASS

HOWARD HILL

HOWARD LAKE

HOWARD MESA

HOWARD SPRING

HOWELL MESA

HUACHUCA CITY

HUACHUCA PEAK

HUALAPAI PEAK

HUALAPAI SPRING

HUALAPAI TANK

HUMBOLDT

HUMBOLDT MTN

HUMMINGBIRD SPRING

HUMPHREYS PEAK

HUMPY CAMP WELL

HUNT

HUNTERS POINT

HUTCH MTN

HYDER

HYDER NE

IBEX PEAK

ICEBERG CANYON

IMPERIAL RESERVOIR

INDIAN BUTTE

INDIAN PEAK

INDIAN PINE

INDIAN WELLS

INSCRIPTION HOUSE RUIN (INSCRIPTION HSE RUIN)

INSPIRATION

IRON MOUNTAIN

IRON SPRINGS

ISLA PINTA

IVES PEAK

\section{JACKSON MTN}

JACOB LAKE

JACOBS MONUMENT

JACOBS WELL

JADITO SPRING

JARVIS PEAK (UT)

JAVELINA PEAK

JAYCOX MTN

JAYNES

JEROME CANYON

JERUSALEM MTN

JOE WOODY WELL

JOES HILL

JOHN DAW MESA

JOHNSON LAKES (UT)

JOHNSON WELL

JONES HILL

JOSEPH CITY

JUMPUP POINT

JUNIPER MTS
KACHIINA POINT

KAIBAB

KAIBITO

KAISER SPRING

KAKA

KAKA NW

KANAB (UT)

KANAB POINT

KANABOWNITS SPRING

KAYENTA EAST

KAYENTA WEST

KAYLER BUTTE

KEAMS CANYON

KEARN LAKE

KEARNY

KEET SEEL RUIN

KEHL RIDGE

KENDRICK PEAK

KENNEDY PEAK

KIELBERG CANYON

KING ARTHUR CASTLE

KING CANYON

KINGMAN

KINGMAN AIRPORT

KINGMAN NW

KINGMAN SE

KINGMAN SW

KINLICHEE

KINNIKINICK LAKE

KINO PEAK

KINO SPRINGS

KINUSTA MESA

KIRKLAND

KITT PEAK

KLAGETOH NORTH

KLAGETOH SOUTH

KLONDIKE

KNOB HILL

KNOLL LAKE

KO VAYA

KOFA

KOFA BUTTE

KOFA DEEP WELL

KOHATK

KOHT KOHL HILL

KOM VO

KOTS KUG RANCH

KUPK

KYDESTEA SPRING

LA LESNA MTS

LA PAZ MTN

LA TORTUGA BUTTE

LAGUNA DAM

LAKE HAVASU CITY NORTH (LAKE HAVASU CITY N)

LAKE HAVASU CITY SOUTH

(LAKE HAVASU CITY S)

LAKE MONTEZUMA

LAKESIDE

LAMB WELL

LAND

LAS GUIJAS

LAS PLAYAS

LAST CHANCE CANYON 
LAVEEN

LAZY J RANCH

LE FEVRE RIDGE

LECHE-E ROCK

LEE MOUNTAIN

LEES FERRY

LEONARD CANYON

LESLIE CANYON

LEWIS SPRINGS

LIGURTA

LIMESTONE CANYON NORTH (LIMESTONE CANYON N)

LIMESTONE CANYON SOUTH (LIMESTONE CANYON S)

LIMESTONE PEAK

LION MOUNTAIN

LITTLE BLACK SPOT MTN (LTL BLACK SPOT MTN)

LITTLE CLAYHOLE VALLEY (LITTLE CLAYHOLE VAL)

LITTLE CREEK MOUNTAIN (UT) (LITTLE CREEK MTN)

LITTLE HARPO CANYON

LITTLE HORN MTS NE

LITTLE HORN MTS SE

LITTLE HORN PEAK

LITTLE LITHODENDRON TANK (LTL LITHODENDRON TK)

LITTLE MILKY WASH

LITTLE PARK LAKE

LITTLE ROUND ROCK

LITTLE TABLE TOP

LITTLE TANKS

LITTLE WHITE HOUSE RUINS

(LTL WHITE HSE RUINS)

LITTLE WOOD CANYON

LITTLEFIELD

LIVINGSTON HILLS

LIVINGSTON HILLS NW

LIZARD POINT

LOCHIEL

LOCKWOOD CANYON

LOCO KNOLL

LOHALI POINT

LONE BUTTE

LONE MOUNTAIN

LONE ROCK

LONE STAR MTN

LONG H RANCH

LONG HOUSE VALLEY

LONG MOUNTAIN

LONG TOM CANYON

LONG VALLEY

LOOKOUT MTN

LOST HORSE PEAK

LOST SPRING MTNE

LOST SPRING MTN W

LOW MOUNTAIN

LOWER LAKE MARY

LOWER WHEATFIELDS

LOY BUTTE

LUKACHUKAI

LUKEVILLE

LUNA LAKE

LUPTON
LUZENA

LYMAN LAKE

LYMAN LAKE SW

MAGMA

MAISH VAYA

MALPAIS HILL

MALPAIS MESA

MALPAIS MESA NE

MAMMOTH

MANESS PEAK

MANUEL SEEP

MANY FARMS

MANY FARMS NE

MANY FARMS SW

MANY GHOSTS HILL

MAPLE PEAK

MARANA

MARGIES PEAK

MARICOPA

MARKHAM CREEK

MARKHAM DAM

MARONEY WELL

MARSH PASS

MARSH PASS SE

MARSHALL BUTTE

MARTIN MTN

MARTIN WELL

MATTERHORN

MAVERICK

MAVERICK MTN

MAVERICK SW

MAY TANK POCKET

MAYER

MAZATZAL PEAK

MC CAULEY SINKS

MC CRACKEN PEAK

MC DONALD MTN

MC DOWELL PEAK

MC FADDEN PEAK

MC GREW SPRING

MC LELLAN RESERVOIR

MC MICKEN DAM

MC NARY

MC NEAL

MEADVIEW NORTH

MEADVIEW SOUTH

MEATH SPRING

MEDDLER WASH

MENAGERS LAKE

MERRIAM CRATER

MESA

MESA PARADA

MESA PARADA NW

MESA REDONDA

MESA REDONDA NW

MESCAL

MESCAL WARM SPRING

MESQUITE

MESQUITE JIM WELL

MESQUITENE

METEOR CRATER

METZGER TANK

MEXICAN CRY MESA

MEXICAN WATER
MEXICAN WATER SW

MICA MOUNTAIN

MIDDLE CAMP MTN

MIDDLE MESA

MIDDLE MTS NORTH

MIDDLE MTS SOUTH

MIDDLE POINT

MIDDLE VERDE

MIDDLE WATER SPRING

MIDWAY

MIDWAY NW

MIDWAY SW

MILDRED PEAK

MILKWEED CANYON NW

MILKWEED CANYON SE

MILKWEED CANYON SW

MILKY RANCH

MILLER PEAK

MILLER TANK

MINE MOUNTAIN

MINERAL MTN

MINNEHAHA

MITCHELL PEAK

MITTEN BUTTES

MITTEN PEAK

MIXON TANK

MOBILE

MOBILENE

MOBILE NW

MOCCASIN

MOENAVE

MOENAVE SE

MOENKOPI

MOHAVE MINE

MOHAVE PEAK

MOHAVE SPRINGS

MOHAWK

MOHAWK MTS NE

MOHAWK MTS NW

MOHAWK MTS SE

MOHAWK MTS SW

MOHAWK SE

MOHAWK SW

MOHON PEAK

MOI VAYA

MOLLY ANN DRAW

MONK DRAW

MONKEYS HEAD

MONREAL WELL

MONTEZUMA PASS

MONTEZUMA PEAK

MONTEZUMAS CHAIR

MONTEZUMAS CHAIR NW

MONUMENT BLUFF

MONUMENT POINT

MOON MTN

MOON MTN NE

MOON MTN SE

MORGAN BUTTE

MORIAH KNOLL

MORITZ RIDGE

MORMON FLAT DAM

MORMON LAKE

MORMON MOUNTAIN

MOSES ROCK (UT)
MOUNT AJO

MOUNT BALDY

MOUNT BANGS

MT BEAUTIFUL

MOUNT BIGELOW

MT DAVIS

MT DELLENBAUGH

MOUNT FAGAN

MOUNT FLOYD

MT GRAHAM

MOUNT HOPE

MT HOPKINS

MT HUGHES

MOUNT JOSH

MT LEMMON

MOUNT LOGAN

MT MANCHESTER

MOUNT NUTT

MT PERKINS

MT TIPTON

MT TIPTON NW

MT TIPTON SE

MOUNT TRIPLET

MT TRUMBULL

MT TRUMBULL NE

MT TRUMBUL SE

MT TURNBULL

MT WILSON

MT WRIGHTSON

MOUNTAIN SHEEP SPRING

(MTN SHEEP SPRING)

MOUNTAINAIRE

MUGGINS FLAT

MULE HOOF BEND

MULE WASH

MULESHOE RANCH

MUMMY CAVE RUINS

MUNDS DRAW

MUNDS MOUNTAIN

MUNDS PARK

MURPHY PEAK

MUSIC MOUNTAINS NE

MUSIC MOUNTAINS NW

MUSIC MOUNTAINS SE

MUSIC MOUNTAINS SW

MUSKHOG MOUNTAIN

MUSTANG KNOLL

MUSTANG MOUNTAINS

MUSTANG POINT

MYSTERY VALLEY

NA AH TEE CANYON

NACO

NANKOWEAP MESA

NATANES MTS NE

NATANES MTS NW

NATIONAL CANYON SW

NATIONAL TANK

NATURAL CORRAL

NAVAJO BEGAY (UT)

NAVAJO BRIDGE

NAVAJO NORTH

NAVAJO SOUTH

NAVAJO SPRINGS

NAZLINI 
NEEDLES

NEEDLES NE

NEEDLES NW

NEEDLES SW

NEGRO ED

NELSON

NELSON RESERVOIR

NELSON RESERVOIR NE

NEVERSWEAT RIDGE

NEW RIVER

NEW RIVER MESA

NEW RIVER SE

NEW WATER MTS

NEW WATER WELL

NEWBERRY MESA

NEWMAN PEAK

NICKSVILLE

NINEMILE SEEP

NINETYSIX HILLS NE

NINETYSIX HILLS NW

NINETYSIX HILLS SE

NINETYSIX HILLS SW

NO MANS MESA SOUTH (UT)

NOGALES

NORTH BUTTE

NORTH CANYON POINT

NORTH KOMELIK

NORTH MILL WELL

NORTH OF ISLA PINTA

NORTH OF ORACLE

NORTH OF ROLL

NORTH PEAK

NORTH TRIGO PEAKS

NOTTBUSCH BUTTE

NUTRIOSO

O W POINT

O'DONNEL CANYON

O'LEARY PEAK

O'NEILL HILLS

O'NEILL PASS

OAK CREEK MTN

OAK CREEK RANCH

OAK GROVE CANYON

OAK SPRINGS

OATMAN

OATMAN MOUNTAIN

ODART MTN

OKIE WELL

OLAF KNOLLS

OLD LEUPP

OLGA

ONE TOE RIDGE

ONION SPRING

ORACLE

ORACLE JUNCTION

ORAIBI

ORANGE BUTTE

ORO VALLEY

ORTEGA MTN

OSBORNE WELL

OUTLAW DRAW
OUTLAW HILL

OUTLAW MOUNTAIN

OWL HEAD

OWL SPRING

OWL VALLEY

OXBOW MTN

PADILLA MESA

PADILLA TANK

PAGE

PAGE SPRINGS

PAJARITO PEAK

PAKOON SPRINGS

PALM CANYON

PALMERITA RANCH

PALO ALTO RANCH

PALO VERDE

PALO VERDE CAMP

PALOMAS MTS EAST

PALOMAS MTS WEST

PAN TAK

PAPAGO FARMS

PARADISE CANYON

PARADISE VALLEY

PARALLEL CANYON

PARAMORE CRATER

PARK CREEK CABINS

PARKER

PARKS

PASTORA PEAK

PAT HILLS NORTH

PAT HILLS SOUTH

PATAGONIA

PAUL SPUR

PAULDEN

PAYSON NORTH

PAYSON SOUTH

PEACH SPRINGS

PEACH SPRINGS CANYON

PEACH SPRINGS NE

PEACOCK PEAK

PEARCE

PEDREGOSA MTS EAST

PEDREGOSA MTS WEST

PEEPLES VALLEY

PENA BLANCA LAKE

PENITAS HILLS

PENITENTIARY MOUNTAIN (PENITENTIARY MTN)

PEPPER CANYON

PEPPERSAUCE WASH

PERKINSVILLE

PERRYVILLE

PETERSON FLAT

PETRIFIED HOLLOW (UT)

PETROGLYPH WASH

PHANTOM RANCH

PHOENIX

PIA OIK

PICACHO

PICACHO BUTTE

PICACHO BUTTE SE

PICACHO COLORADO
PICACHO NW

PICACHO PASS

PICACHO RESERVOIR

PICACHO RESERVOIR SE

PICACHO SW

PICKETPOST MTN

PICTURE MTN

PIETY HILL

PILGRIM WASH

PILLARS OF HERCULES

PILLOW MTN

PILOT KNOB

PILOT ROCK

PIMA

PIMA BUTTE

PINAL PEAK

PINAL RANCH

PINE

PINE HOLLOW CANYON (UT)

PINE SPRINGS

PINEDALE

PINEY HILL

PINON

PINON NW

PINTA

PINTA PLAYA

PINYON MTN

PIPE SPRING

PIPE VALLEY

PIPESTEM MTN

PISINIMO

PIUTE POINT

PLANET

PLATT WELL

PLOMOSA PASS

POINT IMPERIAL

POINT OF PINES EAST

POINT OF PINES WEST

POINT OF THE MTN

POINT OF THE PINTAS

POLACCA

POLAND JUNCTION

POPCORN CANYON

PORCUPINE RIDGE

PORTAL

PORTAL NE

PORTAL PEAK

PORTER CANYON

POSTON

POTATO WASH NE

POTATO WASH NORTH

POTATO WASH SOUTH

POTTER MESA TANK

POTTER MTN

POVERTY FLAT

POVERTY KNOLL

POVERTY SPRING

POWELL PLATEAU

POWERLINE WELL

POZO NUEVO WELL

PRESCOTT

PRESCOTT VALLEY NORTH (PRESCOTT VALLEY N)

PRESCOTT VALLEY SOUTH (PRESCOTT VALLEY S)
PRESTON MESA NORTH

PRESTON MESA SOUTH

PRESTON WELL

PRESUMIDO PEAK

PRICE POINT

PROMONTORY BUTTE

PROSPECT POINT

PROSPECT SPRING

PUMP RANCH TANK

PURCELL CANYON

PURGATORY CANYON

PUTNAM WASH

PYEATT RANCH

QUAIL SPRING WASH

QUAKING ASPEN

QUARTERMASTER CANYON

QUARTERMASTER CANYON SW

(QUARTERMASTER CAN SW)

QUARTZSITE

QUAYLE HILL

QUEENS WELL

QUITOBAQUITO SPRINGS

RAILROAD PASS

RAINBOW BRIDGE (UT)

RATTLESNAKE HILL

RATTLESNAKE SPRING

RAVEN BUTTE

RAWHIDE MTN

RAWHIDE WASH

RED BIRD HILLS

RED BLUFF MTN EAST

RED BLUFF MTN NW

RED BLUFF MTN WEST

RED BUTTE

RED BUTTE SW

RED CLAY WASH

RED CORNFIELD MESA

RED HILL

RED HILL NE

RED HILL RANCH

RED HILL SW

RED KNOLL

RED LAKE

RED MESA

RED MOUNTAIN

RED PICACHO

RED POCKETS

RED POINT

RED POINT MESA

RED ROCK

RED SLIDE PEAK

RED TOP MTN

RED VALLEY

RED WILLOW SPRING

REDINGTON

REID VALLEY

REILEY PEAK

RELIC POINT

RENO PASS

RHODES CANYON

RHODES PEAK

RINCON PEAK

RINCON RANCH 
RINGBOLT RAPIDS

RIO RICO

ROBBERS ROOST CANYON

ROBINSON CANYON

ROBINSON MESA

ROCK CANYON

ROCK HEAD

ROCK HOUSE

ROCK POINT

ROCK POINT SW

ROCK STATION

ROCKINSTRAW MTN

ROCKY RIDGE NE

ROCKY RIDGE NW

ROCKY RIDGE SE

ROCKY RIDGE SW

RODEN CRATER

RODEO

ROLL

ROOF BUTTE

ROOSTER ROCK

ROSE PEAK

ROSE WELL CAMP EAST

ROSE WELL CAMP WEST

ROSEBUD TANK

ROTTEN BANANAS BUTTE

ROUGH ROCK

ROUGH ROCK NW

ROUND MTN

ROUND ROCK

ROUND TOP MTN

ROVER PEAK

RUBY

RUDD KNOLL

RUELAS CANYON

RUSSELL SPRING

RUSTLER PARK

RYAN DRAW

$S$ B POINT

SP MOUNTAIN

SABINO CANYON

SACATON

SACATON BUTTE

SACATON NE

SADDLE MTN

SAFFORD

SAGUARO GAP WELL

SAHUARITA

SAINT DAVID

SALADO

SALINA

SALOME

SALT RIVER PEAK

SALT TRAIL CANYON

SALTON TANKS

SAM POWELL PEAK

SAMANIEGO PEAK

SAN AGUSTIN

SAN BERNARDINO RANCH

SAN CARLOS

SAN CARLOS RESERVOIR

SAN CAYETANO MTS

SAN IGNACIO RANCH

SAN JOSE
SAN JUAN SPRING

SAN MIGUEL

SAN PEDRO

SAN PEDRO RANCH

SAN SIMON

SAN SIMON CIENEGA

SAN XAVIER MISSION

SAN XAVIER MISSION SW

(SAN XAVIER MSSN SW)

SAND SPRINGS

SAND WELLS

SANDERS

SANTA ROSA MTS NE

SANTA ROSA MTS NW

SANTA ROSA MTS SE

SANTA ROSA MTS SW

SASABE

SATAN BUTTE

SAUCITO MTN

SAUNDERS DRAW

SAWBUCK MTN

SAWIK MOUNTAIN

SAWMILL

SCHNEBLY WELL

SCRATCH CANYON

SECOND KNOLLS

SECRET PASS

SEDONA

SEEPAGE MTN

SELIGMAN EAST

SELIGMAN WEST

SELLS EAST

SELLS WEST

SAMANIEGO HILLS

SENATOR MTN

SENATOR MTN NE

SENATOR MTN NW

SENATOR MTN SW

SENTINEL

SENTINEL NE

SENTINEL PEAK

SENTINEL SE

SEPARATION CANYON

SEVEN SPRINGS

SEVENMILE MTS

SHADOW MTN WELL

SHEEP BASIN MTN

SHEEPSKIN WASH

SHELDON

SHERIDAN MTN

SHINARUMP POINT

SHINGLE MILL MTN

SHINUMO ALTAR

SHIVA TEMPLE

SHONGOPOVI

SHONTO

SHONTO BUTTE

SHONTO NW

SHONTO SE

SHOW LOW NORTH

SHOW LOW SOUTH

SIERRA ARIDA

SIERRA BONITA RANCH

SIERRA DE LA LECHUGILLA

(SIERRA LECHUGUILLA)
SIGNAL

SIGNAL MTN

SIKORT CHUAPO

SIL NAKYA

SILVER BELL EAST

SILVER BELL WEST

SILVER REEF MTS

SILVER REEF MTS SE

SILVER SPRINGS

SIMMONS

SIMMONS PEAK

SITGREAVES MTN

SITTING COYOTE HILL

SKELETON CANYON

SKULL CANYON

SKULL VALLEY

SLUMGULLION PASS

SMITH MESA

SMITH PEAK

SMITH PEAK NE

SMITH PEAK NW

SMITHSONIAN BUTTE (UT)

SMURR

SNAKE BUTTE

SNAP CANYON EAST

SNAP CANYON WEST

SNAP DRAW

SNOWFLAKE

SOCORRO MINE

SOCORRO PEAK

SOMBRERO PEAK

SOMERTON

SONOITA

SONSELA BUTTES

SONTAG CREEK

SONTAG MESA

SORREL HORSE MESA

SOUTH BUTTE

SOUTH KOMELIK

SOUTH OF BAILEY PEAK

SOUTH OF GILA BEND

SOUTH OF LUKEVILLE

SOUTH OF PAPAGO FARMS

(S OF PAPAGO FARMS)

SOUTH OF QUARTZSITE

SOUTH OF SENTINEL

SOUTH OF SOMERTON

SOUTH OF THEBA

SOUTH OF TINAJAS ALTAS

(S OF TINAJAS ALTAS)

SOUTHEAST OF SOMERTON

(SE OF SOMERTON)

SOWATS SPRING

SOZA CANYON

SOZA MESA

SPENCER CANYON

SPIDER ROCK

SPIRIT MTN NE

SPIRIT MTN NW

SPIRIT MTN SE

SPONSELLER MTN

SPOTTED MOUNTAIN

SPRING MTN

SPRING WATER CANYON

SPRINGERVILLE
SPRINGERVILLE NW

SQUARE BUTTE

SQUARE MOUNTAIN

SQUARETOP HILLS EAST

SQUARETOP HILLS WEST

SQUAW CREEK MESA

SQUAW MTN

SQUAW PEAK

ST GEORGE (UT)

ST GEORGE CANYON

ST JOHNS NORTH

ST JOHNS SOUTH

ST THOMAS GAP

STANDARD WASH

STANDING HORSE MESA

STANDING ROCKS

STANFIELD

STANFORD CANYON

STANFORD TANK

STAR MOUNTAIN

STAR WELL

STARK

STEAMBOAT CANYON

STEAMBOAT ROCK

STEAMBOAT ROCK NE

STEELE HILLS

STEVENS MTN

STEWART MTN

STINKING SPRINGS

STINKING SPRINGS MTN

STOCKTON HILL

STOCKTON PASS

STONE CABIN

STONEMAN LAKE

STOVE CANYON

STRAWBERRY

STRAWBERRY CRATER

STRAYHORSE

SUGARLOAF PEAK

SULLIVAN BUTTES

SULLIVAN DRAW NORTH

SULLIVAN DRAW SOUTH

SULPHUR HILLS

SULPHUR SPRING

SUN ALTAR

SUN VALLEY

SUNFLOWER BUTTE

SUNNYSLOPE

SUNRISE PEAK

SUNRISE SPRINGS

SUNSET CRATER EAST

SUNSET CRATER WEST

SUNSET PASS

SUNSET RIDGE

SUPAI

SUPAI CAMP

SUPAI CAMP SE

SUPERIOR

SUPERSTITION MTS SW

SURRENDER CANYON

SWANSEA

SWEATHOUSE PEAK

SWEDE PEAK

SWEETWATER MESA

SWISSHELM MTN 
SYCAMORE BASIN SYCAMORE POINT

TABLE MOUNTAIN

TACNA

TAH CHEE WASH

TALL MESA

TALL MOUNTAIN

TALL MOUNTAIN NW

TALL TREE MESA

TANNER SPRINGS

TANNER WELL

TANQUE

TANQUE VERDE PEAK

TAPEATS AMPHITHEATER

TATAHATSO POINT

TAYLOR

TEAPOT MOUNTAIN

TECOLOTE RANCH

TEEC NOS POS

TELEGRAPH WASH

TELEPHONE HILL

TEMPE

TEMPORAL PASS

TENMILE CEDARS

TERRY BENCHES

TEXAS HILL

THATCHER

THE BIG KNOLL

THE DIVIDE (UT)

THE GAP

THE GRANDSTAND

THE LANDMARK

THE MESAS

THE NARROWS

THE RINCON

THE TEMPLE

THEBA

THEODORE ROOSEVELT DAM (THEO. ROOSEVELT DAM)

THOMPSON POINT (UT)

THORN PEAK

THREE POINTS

THREE TURKEY CANYON

TIGER WELL

TILLIE HALL PEAK

TILLOTSON PEAK

TIN HOUSE

TIN MOUNTAIN

TIN MOUNTAIN NW

TINAJAS ALTAS

TINCANEBITTS POINT

TOADIMDAASKA MESA

TOH ATIN MESA EAST

TOH ATIN MESA WEST

TOH BIH NOSTENY

TOH CHIN LINI MESA

TOH DE NIIHE

TOH NE ZHONNIE SPRING

TOLAN

(TOH NE ZHONNIE SPR)

TOLANI LAKE

TOLAPAI SPRING

TOLLGATE TANK

TOM BROWN CANYON
TOM THUMB

TOMBSTONE

TOMBSTONE SE

TONALEA

TONOPAH

TONTO BASIN

TOOTHPICK RIDGE

TOPAWA

TOPOCK

TOPOCOBA HILLTOP

TORTOLITA MTS

TOVAR MESA EAST

TOVAR MESA WEST

TOYEI SCHOOL

TRAVERTINE RAPIDS

TRIGO PASS

TRINITY MTN

TRIPP CANYON

TRUXTON

TSAILE

TSAILE BUTTE

TSE ESGIZII

TSEYI-HATSOSI

TSIN NAAN TEE

TUBA CITY

TUBA CITY SE

TUBAC

TUCKAYOU SPRING

TUCKER MESA

TUCKER MESA NE

TUCKER MESA NW

TUCKER MESA SW

TUCSON

TUCSON EAST

TUCSON NORTH

TUCSON SE

TUCSON SW

TUDECOZ SPRING

TULE MESA

TULE MOUNTAINS

TULE TUBS

TULE WASH

TURKEY CANYON

TURKEY CANON NE

TURKEY MTN

TURKEY TRACK BUTTE

TURQUOISE MOUNTAIN

TURTLEBACK MTN

TUSAYAN EAST

TUSAYAN WEST

TWEED MINE

TWIN BUTTES

TWO BAR MTN

TWO RED MESAS

UNION HILLS

UNION PASS

UPPER WHEATFIELDS

URANIUM SPRING

UTTING

VAIL

VAINOM KUG

VAIVA VO

VALENCIA
VALENTINE

VALENTINE SE

VALLE BONITO

VALLE BONITO NE

VALLE TANK

VALLEY FARMS

VAMORI

VANAR

VANAR NW

VAYA CHIN

VEKOL MTS NE

VELASQUEZ BUTTE

VENTANA

VENTANA MESA

VERDE HOT SPRINGS

VERNON

VICKSBURG

VIRGIN PEAK

VOIGT RANCH

VOPOKI RIDGE

VOPOKI RIDGE SE

VOPOKI RIDGE SW

VULCANS THRONE

VULCANS THRONE SE

VULCANS THRONE SW

VULTURE MINE

VULTURE PEAK

WABAYUMA PEAK

WADDELL

WAGNER WASH WELL

WAGONER

WAHAK HOTRONTK

WALHALLA PLATEAU

WALKER BUTTE

WALKER CREEK RESERVOIR (WALKER CREEK RES)

WALKER MTN

WALNUT GROVE

WARM CREEK BAY

WARM SPRINGS

WARM SPRINGS CANYON

WARM SPRINGS SE

WARM SPRINGS SW

WASHINGTON DOME (UT)

WATER POCKETS

WATERMAN PEAK

WEAVER PEAK

WEAVERS NEEDLE

WEBB PEAK

WEBBER CANYON

WEBER PEAK

WEIMER POINT

WELDON HILL

WELLTON

WELLTON HILLS

WELLTON MESA

WELLTON SE

WEPO VILLAGE

WEST CANYON CREEK

WEST CLARK BENCH

WEST OF AVRA

WEST OF GREASEWOOD

MOUNTAIN
WEST OF GROWLER PEAK

WEST OF GUADALUPE CANYON

(W OF GUADALUPE CAN)

WEST OF LUKEVILLE

WEST OF MARANA

WEST OF PISINIMO

WEST OF QUITOBAQUITO SPRINGS

WEST OF VENTANA

WEST OF VOPOKI RIDGE

WEST OF WAHAK HOTRONTK

(W OF WAHAK HOTRONTK)

WEST OF WINDOW ROCK

WEST OF POKER MTN

WEST OF SUNSET MTN

WET BOTTOM MESA

WHALE MTN

WHIPPOORWILL SPRING

WHIRLWIND ROCK

WHITE AREA CANYON

WHITE CLAY

WHITE CONE

WHITE DOME

WHITE HILL

WHITE HILLS (UT)

WHITE HILLS EAST

WHITE HILLS WEST

WHITE HORSE HILLS

WHITE HORSE LAKE

WHITE MESA ARCH

WHITE MESA VILLAGE SE (UT) (WHITE MESA VIL SE)

WHITE POCKETS

WHITE POINT

WHITE ROCK WASH

WHITE SAGE FLAT

WHITE TANK MTS

WHITE TANK MTS NE

WHITE POINT SE

WHITE WATER TANK

WHITERIVER

WHITING KNOLL

WHITLOCK CIENEGA

WHITLOCK MTS NE

WHITLOCK PEAK

WHITMORE POINT

WHITMORE POINT SW

WHITEMORE POINT SE

WHITMORE RAPIDS

WICKENBURG

WICKENBURG SW

WIDE RUINS

WIDE RUINS SW

WIKIEUP

WILBUR CANYON

WILD BAND POCKETS

WILD COW LAKE

WILD HORSE MESA

WILDCAT HILL

WILDCAT RANCH

WILDCAT WELL

WILDHORSE MTN

WILHOIT

WILLCOX NORTH

(W OF GREASEWOOD MTN) WILLCOX SOUTH 


\author{
WILLIAMS NORTH \\ WILIAMS SOUTH \\ WILLOW BEACH \\ WILLOW MTN \\ WILLOW MTN SE \\ WILLOW SPRINGS \\ WILLOWS CAMP \\ WILSON MOUNTAIN \\ WINDOW MTN \\ WINDOW ROCK \\ WINDY HILL \\ WINDY VALLEY \\ WINEGLASS RANCH \\ WING MOUNTAIN \\ WINKELMAN \\ WINONA \\ WINSLOW \\ WINSLOW NE \\ WINSLOW NW \\ WINTERBURG \\ WITTMANN \\ WOLF HOLE MTN EAST \\ WOLF HOLE MTN WEST \\ WOODRUFF \\ WOODS CANYON \\ WOOLSEY PEAK \\ WRATHER ARCH \\ WUPATKI NE
}

WUPATKI SE

WUPATKI SW

YAMPAI

YAMPAI SE

YARNELL

YELLOW JACKET CANYON

YELLOW JOHN MTN

YELLOW MEDICINE BUTTE (YEL. MEDICINE BUTTE)

YELLOW ROCK POINT EAST (UT) (YELLOW ROCK POINT E)

YELLOW ROCK POINT WEST (UT) (YELLOW ROCK POINT W)

YELLOWHORSE FLAT

YORK

YOUNG

YUCCA

YUCCA HILL

YUCCANE

YUCCA NW

YUCCA SE

YUMA EAST

YUMA SE

YUMA WEST

YUNOSI POINT

ZENIFF

ZION RESERVOIR 


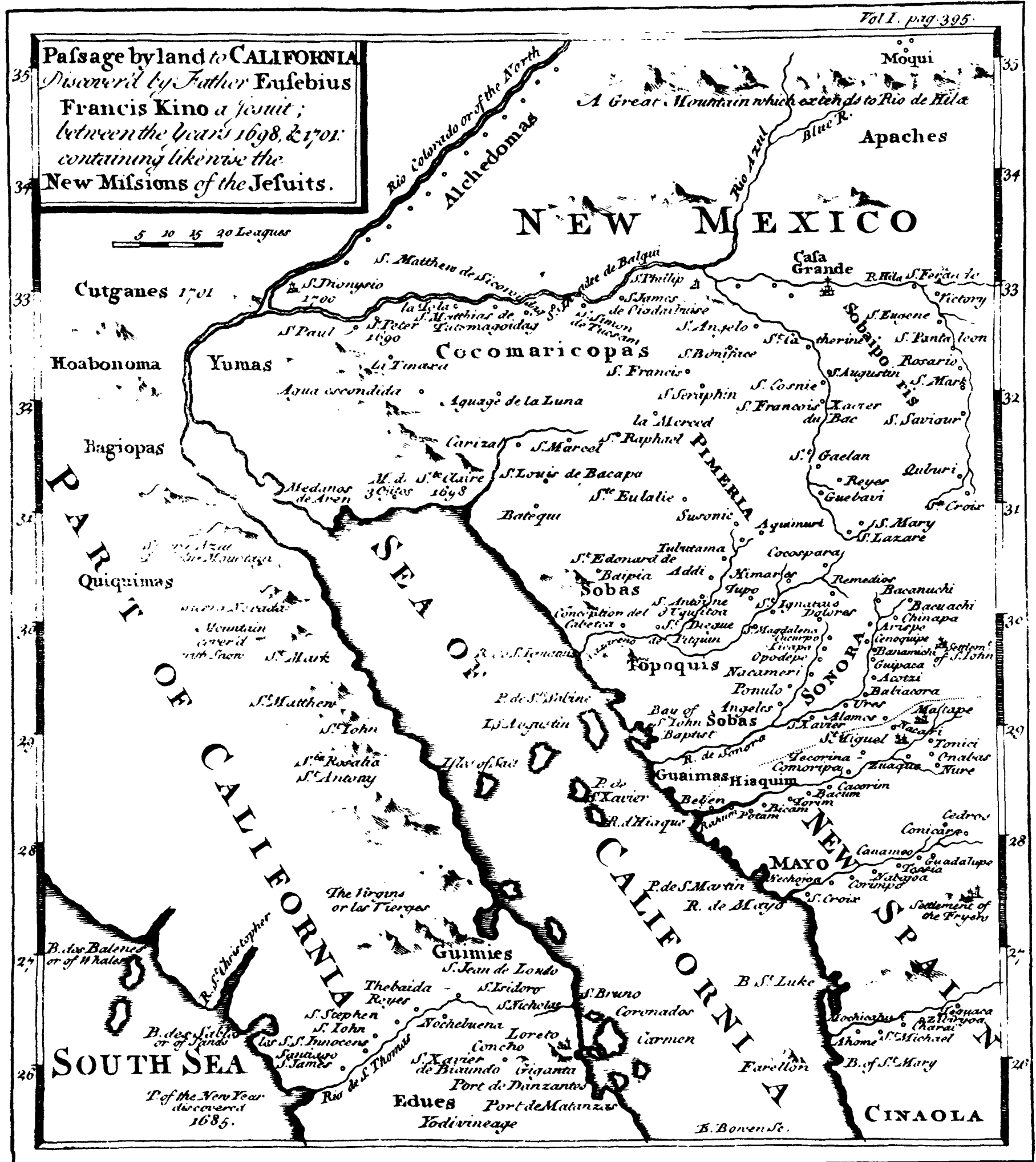

Figure 2.-A 1743 English version of Father Eusebio Kino's 1705 map representing part of what is now Arizona. Prior to Father Kino's expioration at the mouth of the Colorado River, California was thought to be an island, separated from North America by the Gulf of California. The southern part of the State of Arizona was known as Pimeria Alta (upper land of the Pimas) in Father Kino's time and was part of Spanish New Mexico. The name Arizona did not begin to appear on maps of the area until the mid-18th century. 


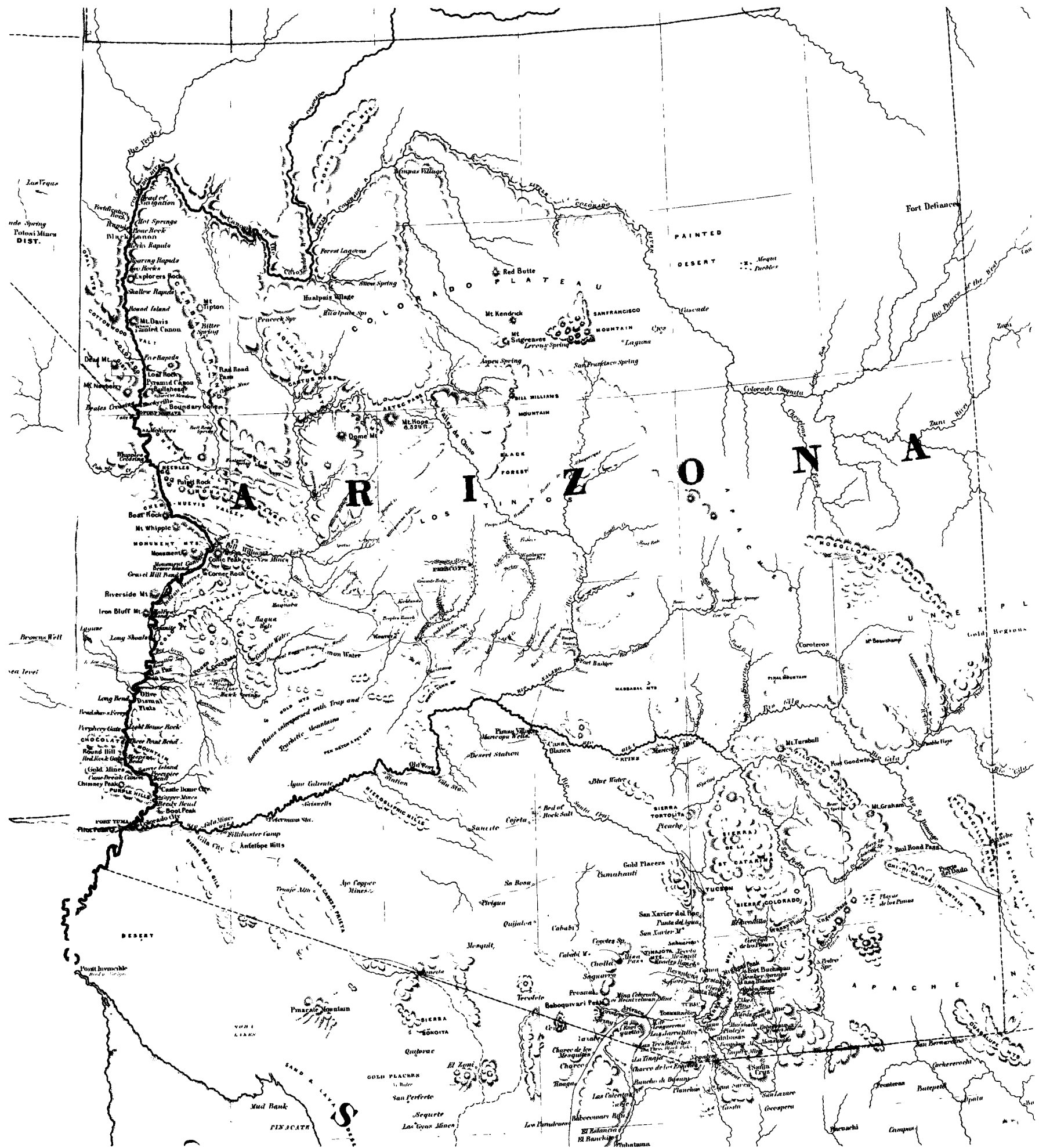

Figure 3.-William Hartley's Map of Arizona, 1865. This map depicts Arizona at the close of the American Civil War. The Gila River valley had been acquired from Mexico by the Gadsden Purchase of 1853, the Nation's last major change in its southern boundary. The Territory of Arizona had been separated from the Territory of New Mexico in 1863, and large areas of Arizona, especially in the north, were still unexplored. Note that the density of placenames is much greater along the Colorado River where steamboats conducted most of the commerce of the Territory until the coming of the railroads in the 1880 's. Not founded until 1870 , Phoenix is not shown. 


\section{ARIZONA}

Prior to the 1500's, territory now called Arizona was inhabited by Indians whose agrarian civilization left behind the famous pueblo ruins and cliff dwellings. Beginning in 1539, Spanish explorers entered the region in quest of the vast riches of gold rumored to be in the area. Their explorations were unproductive and the rumors of gold merely fabrications.

Spain took formal possession of this area in 1595 and called it New Mexico. Spanish missionaries followed in the 17th century and entered New Mexico to convert the Indians to Christianity. Under the rule of Spain, officials applied the name Sonora to what is now southern Arizona, and considered what is now northern Arizona as part of New Mexico. Because of its abundant mineral resources, especially silver, and because of its size, it became necessary to apply a placename to clarify areas referred to in reports. By 1730, Spaniards from the Basque country renamed the area Arizonac, either from the Basque words for "good oak trees" or "valuable ores," or from the Pima Papago Indian words, ali ("small") and shonak ("place of the spring") or "place of the small spring."

In 1848, at the close of the Mexican-American War, the United States received from Mexico nearly all the land between Texas and the California coast. When California became a State in 1850, the remainder of the Mexican Cession became the Territory of New Mexico. The Territory was enlarged by the land to the south of the Gila River, which was bought from Mexico in 1853 and is known as the Gadsden Purchase. Miners soon entered the area as a result of the Gadsden Purchase, and in 1854 they proposed to the Congress that a new Territory be established. They offered three possible names: Gadsonia, after the negotiator of the Purchase; Pimeria, from the local Pima Indians-a name used by the Spanish; or Arizona, from the old mining district. In 1856 a convention in Tucson, one of whose leaders was from the Arizona Mining and Trading Company, approved the name Arizona. The Confederate States of America declared Arizona to be a Territory of the Confederacy in 1861, but it was soon occupied for the Union by California volunteers. The Congress made Arizona a United States Territory in 1863 and the 48th State in 1912.

Arizona's capital was moved from place to place until Phoenix was chosen in 1889. The Territorial Government was organized at Navajo Springs at the end of 1863. It moved in early 1864 to Camp Whipple, near Prescott, and then to Prescott itself later that year. From 1867 to 1877 Tucson was the capital, followed by Prescott again from 1877 to 1889 . The name Navajo Springs was given in 1853 by Lieutenant (later Brigadier General) Amiel W. Whipple, U.S. Army (1818-1868), who noticed that the Navajo Indians used the water at the site and suggested it might be a stopping place for emigrants. He gave his name also to Camp Whipple, the military post set up to protect the miners near what is now Prescott. Prescott was named in 1864 for William $\mathrm{H}$. Prescott (1796-1859), the historian of Spanish America. Tucson is derived from the Papago Indian words for "black bottom," the original name for Sentinel Peak, at whose base Tucson lies. Because the earliest European settlers found at the site the remains of an ancient settlement, Phoenix was named after the mythological bird that rose from its own ashes after it was consumed by fire. The name was suggested by Darrell Duppa, an Englishman who was one of the first inhabitants. 


\section{GLOSSARY}

By Sam Stulberg and Roger L. Payne

Listed below are the common terms used to categorize each place, feature, or area identified by a geographic name. These terms appear in the second column of information on the gazetteer page. The terms and their definitions are applied broadly; they are not a dictionary of balanced, exclusive, or precise terminology for the identification and definition of cultural and natural features. Some examples of commonly used generic names are provided at the end of each definition to assist in understanding the range of meaning represented by the feature term. A name generic in plural form is identified by a term in singular form; a name like "Relic Islands" is identified as "island." The term "populated place" is abbreviated "ppl."

airport: a manmade facility maintained for the use of aircraft (airfield, airstrip, landing field, landing strip).

arch: a natural archlike opening in a rock mass (bridge, natural bridge, sea arch).

area: any one of several areally extensive natural features not included in other categories (badlands, barren, delta, fan, garden).

arroyo: a watercourse or channel through which water may occasionally flow (coulee, draw, gulley, wash).

bar: a natural accumulation of sand, gravel, or alluvium, or ledge of rock or coral forming an underwater or exposed embankment (ledge, reef, sandbar, shoal, spit).

basin: a natural depression or relatively low area enclosed by higher land (amphitheater, cirque, pit, sink).

bay: an indentation of a coast or shoreline enclosing a part of a body water; a body of water partly surrounded by land (arm, bight, cove, estuary, gulf, inlet, sound).

beach: the sloping shore along a body of water that is periodically washed by waves or tides and is usually covered by sand or gravel (coast, shore, strand).

bench: an area of relatively level land on the side of an elevation such as a hill, ridge, or mountain where the slope of the land rises on one side and descends on the opposite side (level).

bend: a curve in the course of a stream and (or) the land within the curve; a curve in a linear body of water (loop, meander).

bridge: a manmade structure carrying a trail, road, or other transportation system across a body of water or depression (causeway, overpass, trestle).

building: a manmade structure with walls and a roof for protection of people and (or) materials; churches, hospitals, and schools are special types of buildings and are assigned individual categories. canal: a manmade waterway used by watercraft or for drainage, irrigation, mining, or water power (ditch, lateral).

cape: a projection of land extending into a body of water (lae, neck, peninsula, point).

cave: a natural underground passageway or chamber, or a hollowed out cavity in the side of a cliff (cavern, grotto).

cemetery: a place or area for burying the dead (burial, burying ground, grave, memorial garden).

channel: a linear deep part of a body of water through which the main volume of water flows and which is frequently used as a route for water craft (passage, reach, strait, thorofare, thoroughfare).

church: a building used for religious worship (chapel, mosque, synagogue, tabernacle, temple).

civil: designates a political division formed for administrative purposes (borough, county, town, township).

cliff: a very steep or vertical slope (bluff, crag, head, headland, nose, overhang, pali, palisade, precipice, promontory, rim, rimrock).

crater: a circular depression at the summit of a volcanic cone or one on the surface of the land caused by either volcanism, meteoritic impact, or underground subsidence; a manmade depression caused by an explosion (caldera, lua).

crossing: a place where two or more routes of transportation form a junction or intersection (overpass, underpass).

dam: a water barrier or embankment built across the course of a stream or into or within a body of water to control and (or) impound the flow of water (breakwater, dike, jetty).

falls: a perpendicular or very steep descent of water in the course of a stream (cascade, cataract, waterfall).

flat: a relatively level area within a region of greater relief (clearing, glade, playa).

forest: a bounded area of woods, forest, or grassland under the administration of a political agency (national forest, national grasslands, State forest); see "woods."

gap: a low point or opening between hills or mountains or in a ridge or mountain range (col, notch, pass, saddle, water gap, wind gap).

geyser: an eruptive spring from which hot water, steam, and (or) mud, are periodically thrown.

glacier: a body or stream of ice moving outward and downslope from an area of accumulation; an area of relatively permanent snow/ice on the top of or side of a mountain (icefield, ice patch, snow patch).

gut: a relatively small coastal waterway connecting larger bodies of water or other waterways (creek, inlet, slough). 
harbor: a sheltered area of water where ships or other watercraft can anchor or dock (hono, port, road, roadstead).

hospital: a building where the sick or injured may receive medical or surgical attention (infirmary).

island: an area of dry or relatively dry land surrounded by water or low wetland (archipelago, atoll, cay, hammock, hummock, isla, isle, key, moku, rock).

isthmus: a narrow projection of land in a body of water connecting two larger land areas.

lake: a natural body of inland water (backwater, lac, lagoon, laguna, pond, pool, resaca, waterhole).

lava: a formation or feature resulting from the consolidation of molten rock on the surface of the Earth (kipuka, lava flow).

levee: a natural or manmade embankment flanking a stream (bank, berm).

locale: a place at which there is or was relatively minor human occupation or activity; does not include populated places (ppl), mines, and dams (battlefield, camp, farm, railroad siding, ranch, ruins, site, station, windmill).

mine: a place or area from which commercial minerals are or were removed from the Earth; does not include oilfield (pit, quarry, shaft).

oilfield: an area where petroleum is or was removed from the Earth.

other: this category is for miscellaneous named manmade entities that cannot readily be placed in the other feature classes listed here.

park: a place or area set aside for recreation or preservation of a cultural or natural resource and under some form of governmental administration; does not include a forest (national historical landmark, national park, State park, wilderness).

pillar: a vertical-standing, often spire-shaped, natural rock formation (chimney, monument, pinnacle, pohaku, rock tower).

plain: a region of general uniform slope, comparatively level and of considerable extent (grassland, highland, kula, plateau, upland).

ppi: populated place: a place or area with clustered or scattered buildings and a permanent human population (city, settlement, town, village).

range: a chain of hills or mountains; a somewhat linear mountainous or hilly area (cordillera, sierra).

rapids: a fast-flowing section of a stream, often shallower than other sections and with exposed rocks or boulders (riffle, ripple). reserve: a tract of land set aside for a specific use-does not include forests, civil divisions, or parks.

reservoir: an artificially impounded body of water (lake, tank).

ridge: an elevation with a narrow, linear crest; may be part of a hill or mountain (crest, cuesta, escarpment, hogback, lae, rim, spur).

school: a building or group of buildings used as an institution for study, teaching, and learning (academy, college, high school, university).

sea: a large body of salt water (gulf, ocean).

slope: a gently inclined part of the Earth's surface (grade, pitch).

spring: a place where underground water flows naturally to the surface of the Earth (seep).

stream: a linear body of water flowing on the Earth's surface (anabranch, awawa, bayou, branch, brook, creek, distributary, fork, kill, pup, rio, river, run, slough).

summit: a prominent elevation rising above the surrounding level of the Earth's surface; does not include ridges and ranges (ahu, bald, berg, butte, cerro, colina, cone, cumbre, dome, head, hill, horn, knob, knoll, manua, mesa, meseta, mesita, mound, mount, mountain, peak, puu, rock, sugarloaf, table, volcano).

swamp: poorly drained wetland, fresh or salt, wooded or grassy; possibly covered with open water (bog, cienaga, marais, marsh, pocosin).

tower: a manmade structure, higher than its diameter, generally used for observation, storage, or electronic transmission.

trail: a route for passage from one point to another; does not include roads or highways, categories or entities presently not included in this gazetteer (jeep trail, path, ski trail).

tunnei: a linear underground passageway open at both ends.

valley: a linear depression in the Earth's surface that generally slopes from one end to the other (barranca, canyon, chasm, cove, draw, glen, gorge, gulch, gulf, hollow, ravine).

well: a manmade shaft or hole in the Earth's surface used to obtain fluid or gaseous materials.

woods: a small area covered with a dense growth of trees; does not include an area of trees under the administration of a political agency; see "forest." 
THE GAZETTEER OF ARIZONA 

FEATURE CLASS

STATUS COUNTY

COORDINATE

MAP NAME

\section{A}

Aaivonam

See Ahe Vonam (historical)

$A$ and $A$ Shaft

$A$ and $F$ Trailer Court

$A$ and $F$ Trailer Park

Aasayij Wash

A A Tank

A Avenue School

Abanaugh Canyon

See Aubineau Canyon

Aband Well

A Bar Draw

A Bar Draw Tank

Abbie Loveland Tuller School, The

Abbot Canyon

Abbott Lateral

Abbot Windmill

Abdoul Canyon

Abe Lincoln Mine

Abineau Canyon

See Aubineau Canyon

Abode Creek

See Adobe Creek

Abra

Abra Plain, La

Abra Railroad Station

Abrigo Canyon

Abril Mine

Abshires Tank

\section{A B Young Trail}

Abyss, The

Acacia Campground

See Acacia Recreation Site One Hundred

Acacia Park Sixty Four

Acacia Recreation Site One

Hundred Sixty Four Acacia Campground

Acacia School

Academy of the Sacred Heart

A Canal

Accidental Mine

Acequia Ciudad

See Ciudad, Canal

(historical)

Acequias Villa

See Five Lower Branch,

Canal (historical)

Acequis Mesa (historical) Canal Eleven Branch

Acequis Mesa

See Mesa, Canal

Achi

(historical)

Acker Park

Ackre Lake

Acoma Park

Aconye Ridge (historical)

Acorno Park

Acorn Tank

Acorn Well

A-Cross Ranger Station

\begin{tabular}{|c|c|c|c|}
\hline \multirow[b]{2}{*}{$\begin{array}{l}\text { locale } \\
\text { mine } \\
\text { locale } \\
\text { locale } \\
\text { valley } \\
\text { reservoir } \\
\text { school }\end{array}$} & \multicolumn{2}{|l|}{ VARIANT } & \multirow[b]{2}{*}{$\begin{array}{l}321500 \mathrm{~N} 1120830 \mathrm{~W} \\
344554 \mathrm{~N} 1120724 \mathrm{~W} \\
331745 \mathrm{~N} 1115028 \mathrm{~W} \\
332940 \mathrm{~N} 1120637 \mathrm{~W} \\
363449 \mathrm{~N} 1100325 \mathrm{~W} \\
321626 \mathrm{~N} 1104015 \mathrm{~W} \\
312059 \mathrm{~N} 1093238 \mathrm{~W}\end{array}$} \\
\hline & $\begin{array}{l}\text { UNOFF } \\
\text { UNDFF } \\
\text { UNOFF } \\
\text { BGN } \\
\text { BGN } \\
\text { UNOFF }\end{array}$ & $\begin{array}{l}\text { Pima } \\
\text { Yavapai } \\
\text { Maricopa } \\
\text { Maricopa } \\
\text { Navajo } \\
\text { Pima } \\
\text { Cochise }\end{array}$ & \\
\hline valley & & Coconino & $352500 \mathrm{~N} 1114017 \mathrm{~W}$ \\
\hline $\begin{array}{l}\text { well } \\
\text { valley } \\
\text { reservoir } \\
\text { school }\end{array}$ & $\begin{array}{l}\text { UNOFF } \\
\text { BGN } \\
\text { BGN } \\
\text { UNOFF }\end{array}$ & $\begin{array}{l}\text { Yavapai } \\
\text { Santa Cruz } \\
\text { Santa Cruz } \\
\text { Pima }\end{array}$ & $\begin{array}{l}343231 \mathrm{~N} 1120319 \mathrm{~W} \\
312552 \mathrm{~N} 1103446 \mathrm{~W} \\
312719 \mathrm{~N} 1103145 \mathrm{~W} \\
321300 \mathrm{~N} 1105157 \mathrm{~W}\end{array}$ \\
\hline $\begin{array}{l}\text { valley } \\
\text { canal } \\
\text { locale } \\
\text { valley } \\
\text { mine }\end{array}$ & $\begin{array}{l}\text { BGN } \\
\text { BGN } \\
\text { BGN } \\
\text { BGN } \\
\text { UNOFF }\end{array}$ & $\begin{array}{l}\text { Cochise } \\
\text { Yuma } \\
\text { Cochise } \\
\text { Gila } \\
\text { Yavapai }\end{array}$ & $\begin{array}{l}313300 \mathrm{~N} 1095216 \mathrm{~W} \\
323415 \mathrm{~N} 1144200 \mathrm{~W} \\
313202 \mathrm{~N} 1095329 \mathrm{~W} \\
334800 \mathrm{~N} 1102023 \mathrm{~W} \\
340244 \mathrm{~N} 1123229 \mathrm{~W}\end{array}$ \\
\hline
\end{tabular}

363321N1101220W $\begin{aligned} & 1215 \text { Clarkdale } \\ & 115 \text { Chandler } \\ & \text { Phoenix } \\ & \text { Chilchinbito } \\ & \text { Agua Caliente Hill } \\ & \text { Douglas }\end{aligned}$

Cherry

Canelo Pass

Cane 10 Pass

Tucson East

$313116 \mathrm{~N} 1095625 \mathrm{~W}$

Gleeson SE

Somerton

Potter Mtn

335111N1101958W Carrizo SE

Morgan Butte

Paulden

West of Lukeville

Paulden

$312630 \mathrm{~N} 1095719 \mathrm{~W}$

Cochise Stronghold

Bishop Lake

$312458 \mathrm{~N} 1095831 \mathrm{~W}$

$315429 N 1095927 \mathrm{~W}$

$353547 N 1124251 \mathrm{~W}$

Wilson Mountain

$345808 N 1114457 \mathrm{~W}$

6000 Grand Canyon

$\begin{array}{llll}\text { trail } & \text { UNOFF } & \text { Coconino } & 345808 \text { N1114457W } \\ \text { cliff } & \text { BGN 1952 } & \text { Coconino } & 360340 \text { N1121025W } \\ \text { park } & \text { VARIANT } & \text { Maricopa } & 333214 \text { N1112554W }\end{array}$

Sunnys lope Mormon Flat Dam

$\begin{array}{llll}\text { park } & \text { ADMIN } & \text { Maricopa } & 333655 \text { N1120716W } \\ \text { park } & \text { ADMIN } & \text { Maricopa } & 333214 N 1112554 \mathrm{~W}\end{array}$

VARIANT

$\begin{array}{llll}\text { school } & \text { UNOFF } & \text { Maricopa } & 333658 \mathrm{~N} 1120723 \mathrm{~W} \\ \text { school } & \text { UNOFF } & \text { Pima } & 321554 \mathrm{N1} 105741 \mathrm{~W} \\ \text { canal } & \text { BGN } & \text { Yuma } & 323707 \mathrm{~N} 1143423 \mathrm{~W} \\ \text { mine } & \text { UNOFF } & \text { Yavapai } & 342647 \mathrm{N1122259W}\end{array}$

Sunnys lope Tucson North Yuma SE Groom Creek

$332720 \mathrm{~N} 1120155 \mathrm{~W}$

canal

canal

VARIANT

Maricopa

Maricopa

$332719 N 1120633 W$

BGN

VARIANT
VARIANT

Maricopa

$332505 N 1114929 W$

Mesa

Maricopa 332637N1114900W

locale BGN Pima 322040N1120051W

park ADMIN Yavapai $343246 \mathrm{~N} 1122928 \mathrm{~W}$

lake BGN Greenlee 333703N1092038W

park ADMIN Maricopa 333654N1121010W

ridge BGN 1917 Gila UNKNOWN

park

wes

well
locale

Maricopa

Gila

Graham

Gila
333700 N1120829W

$333607 N 1100202 \mathrm{~W}$

$330753 \mathrm{~N} 1101606 \mathrm{~W}$

$334326 \mathrm{~N} 1105936 \mathrm{~W}$ 
FEATURE NAME

Acuna Well

Adadka Spring

Adahchijiyahi Canyon

Adair Spring

Adair Wash

See Fools Hollow

Adamana

Adamana Interchange

Adams Butte

Adams Camp

Adams Canyon

Adams Canyon

Adams Elementary Schoo

Adams Flat

Adams Lateral

Adams Mesa

Adams Mine

Adams Mine

Adams Peak

Adams Ranch

Adams Ranch

Adams River

See Virgin River

Adams School

Adams Tank Cabin Tank

Adams Tank See Foster Tank

Adams Tank

Adansville Sanford

Adamsville Cemetery

Adams Well

Adams Well

A D Bar Ranch

Adbar Trail Fourteen

Additional $\mathrm{Hill}$

Adeii Eechii Cliffs

A-Diamond Ranch

Adid

See Gu Achi

Admiral Trailer Park

Adobe

Adobe Canyon

Adobe Canyon

Adobe Creek

Abode Creek

Adobe Dam Recreation Area

Adobe Flats

Adobe House Tank

Adobe House Well

Adobe Lake

Adobe Mountain

Adobe Mountain Trailer Park

Adobe Ranch

Adobe Spring

Adobe Tank

Adobe Tank

Adobe Wash

See Daniels Arroyo

Adobe We 11

Adobe Windmill

Adonde

Adoration Sanctuary Hospital

Ad Strip Airstrip

Advent ist Church

A D Wash

A-eightyone Tank

A-eighty Tank

African Lion (historical)

Agassiz Peak
FEATURE
CLASS

well

spring
valley

spring

valley

STATUS

COUNTY

UNOFF

BGN

BGN

BGN

Mavajo

ppl

crossing

locale

valley

valley

school

flat

canal

summit

BGN

UNOFF

BGN

BGN

BGN

$B G N$

UNOFF

BGN

BGN

BGN

min

UNOFF

summit

locale

locale

BGN

UNOFF

UNOFF

VARIANT

stream

school

UNOFF

BGN 1964

VARIANT

Pima

Navajo

Navajo

Navajo

Apache

Navajo

Maricopa

Santa Cruz

Cochise

Maricopa

Graham

Yuma

Maricopa

VARIANT

reservoir reservoir

locale

BGN

BGN

BGN
VARIANT

cemetery

we 11

well

locale

UNOFF

UNOFF

UNOFF

UNOFF

UNOFF

La Paz

Mohave

Cochise

Cochise

Cochise

Mohave

Maricopa

Coconino

trail

BGN

summit

cliff

locale

BGN

VARIANT

ppl

locale

ppl

valley

valley

strean

UNOFF

BGN

BGN

BGN

BGN 1980

Coconino

Coconino

Pinal

Pinal

Pima

Yuma

Greenlee

Greenlee

Coconino

Coconino

Pinal

Pima

Maricopa

Maricopa

Santa Cruz

Cochise

VARIANT

park

ADMIN Maricopa

flat BGN Yuma

reservoir

well

lake

summit

locale

locale

spring

reservoir

BGN

BGN

BGN

UNOFF

UNOFF

BGN

valley

well

locale

locale

hospital UNOF

airport ADMIN

church UNOFF

stream

BGN

reservoir $B G N$

reservoir

ridge

BGN

BGN 1917

BGN 1933
Pima

Yuma

Maricopa

Maricopa

Gila

Pima

Cochise

Maricopa

Maricopa

Pima

Yuma

Pima

Maricopa

Pinal

Yavapai

Gila

Navajo

Maricopa

Coconino

COORDINATE

$320331 \mathrm{~N} 1125621 \mathrm{~W}$ $364133 N 1103747 \mathrm{~W}$ $365043 \mathrm{~N} 1102059 \mathrm{~W}$ $340825 \mathrm{~N} 1095725 \mathrm{~W}$

341640 N $1100420 \mathrm{~W}$

345B36N109491BW $345959 N 1095405 \mathrm{~W}$ $354310 \mathrm{~N} 1101 \mathrm{~B} 51 \mathrm{~W}$ 333647 N1112006W

$312058 \mathrm{~N} 1103552 \mathrm{~W}$

321807 N1093624W

$332405 \mathrm{~N} 1115156 \mathrm{~W}$

$323920 \mathrm{~N} 1094754 \mathrm{~W}$

32342BN1144637W

333839 N1113525W

$332308 \mathrm{~N} 1132922 \mathrm{~W}$

$345808 \mathrm{~N} 1142332 \mathrm{~W}$

$320201 N 1100655 \mathrm{~W}$

$320109 \mathrm{~N} 1100626 \mathrm{~W}$

$320448 \mathrm{~N} 1100444 \mathrm{~W}$

$360818 \mathrm{~N} 1142531 \mathrm{~W}$

$332659 \mathrm{~N} 1120459 \mathrm{~W}$

$350703 \mathrm{~N} 1112718 \mathrm{~W}$

$350723 \mathrm{~N} 1112638 \mathrm{~W}$

$351133 \mathrm{~N} 1112322 \mathrm{~W}$

$330046 \mathrm{~N} 1112629 \mathrm{~W}$

$330128 \mathrm{~N} 1112429 \mathrm{~W}$

$315411 \mathrm{~N} 1123159 \mathrm{~W}$

$330243 \mathrm{~N} 1140442 \mathrm{~W}$

$332334 \mathrm{~N} 1091729 \mathrm{~W}$

$332610 \mathrm{~N} 1092259 \mathrm{~W}$

354448N1113854W

$354737 \mathrm{~N} 1110622 \mathrm{~W}$

$330603 \mathrm{~N} 1110047 \mathrm{~W}$

$321925 \mathrm{~N} 1120226 \mathrm{~W}$

$332703 \mathrm{~N} 1115930 \mathrm{~W}$

$334121 \mathrm{~N} 1120719 \mathrm{~W}$

$313837 \mathrm{~N} 1104254 \mathrm{~W}$ 
NATIONAL GAZETTEER--ARIZONA 1986

FEATURE NAME

Agate Bridge

Agate Canyon

Agate House

Agate Mountain

Agate Well

Agathla Needle

See Agathla Peak

Aga-thla-Needle

See Agathla Peak

Agathla Peak

Ag-ha-la

Aga-thla-Needle

Agathla Needle

Capital Rock

El Capitan

Ggathla

Lama Negra

Agency Peak

Agency Tank

Agency Tank

Ag-ha-la

See Agathla Peak

Agua, Cañada

Agua Blanca Spring

Agua Blanco Ranch

Agua Caliente

Santa Maria del Agua

Caliente

Agua Caliente Canyon Aqua Caliente Canyon

Agua Caliente Canyon

Agua Caliente Canyon

Agua Caliente Caves

Agua Caliente $\mathrm{Hill}$

Agua Caliente Mountains

Agua Caliente Ranch

Agua Caliente Saddle

Agua Caliente Spring

Agua Caliente Spring

Agua Caliente Wash

Agua Caliente Well

Agua Cercada Canyon

Agua Cercada Spring

Agua Cercada Tank

Agua Cercada Well

Agua Cereado Spring

Agua Chiquita Spring

Agua Dulce Mountains

See Quitobaquito Hills

Agua Dulce Mountains See Cipriano Hills

Agua Dulce Mountains O'Neil Hills O'Neill Hills

Agua Dulce Pass

Agua Dulce Spring

Agua Escondida See Tinajas Altas

Agua Escondido

See Tinajas Altas

Agua Fria

Agua Fria Canyon

See Agua Fria Canyon

Agua Fria Canyon

Agua Ria

Atacosa Canon

Atacosa Canyon

Atascosa Canyon

At ascoso Canon

Atascoso Canyon

Agua Fria Canyon

FEATURE

CLASS

STATUS

COUNTY

Apache

arch

valley

summit

well

summit

BGN

BGN 1908 Coconino

BGN Navajo

BGN Gila

UNDFF

VARIANT

Yavapai

Navajo

COORDINATE

345332N1094735W

$360832 \mathrm{~N} 1121651 \mathrm{~W}$

$344818 \mathrm{~N} 1095140 \mathrm{~W}$

$341131 N 1111444 \mathrm{~W}$

$343315 N 1131822 W$

364936 N1101330W

VARIANT

summit

summit

BGN 1915
VARIANT
VARIANT
VARIANT
VARIANT
VARIANT
VARIANT
VARIANT

Navajo

Navajo

summit

reservoir

BGN

BGN

BGN

VARIANT

summit

valley

spring

locale

locale

BGN

BGN

UNOFF

BGN

VARIANT

Pinal

Gila

Navajo

Navajo

Pima

Pima

Pima

Maricopa

$364936 \mathrm{~N} 1101330 \mathrm{~W}$

$364936 \mathrm{~N} 1101330 \mathrm{~W}$

$330240 \mathrm{~N} 1114356 \mathrm{~W}$

$332427 \mathrm{~N} 1102922 \mathrm{~W}$

$364936 \mathrm{~N} 1101330 \mathrm{~W}$

$322723 \mathrm{~N} 1110105 \mathrm{~W}$
$313307 \mathrm{~N} 1112550 \mathrm{~W}$

321559 N1112459W

325907 N1131925

spring

spring

strean

well

valley

spring

reservoir

well

spring

spring

summit

BGN
BGN
UNOFF
BGN
BGN
BGN
UNOFF
BGN
BGN
VARIAN

Pima

Pima

Pima

Santa Cruz

Santa Cruz

Santa Cruz

Santa Cruz

Santa Cruz

Maricopa

Pima

$321650 \mathrm{~N} 1104342 \mathrm{~W}$

$321436 \mathrm{~N} 1104712 \mathrm{~W}$

$321652 N 1104343 \mathrm{~W}$

$312633 \mathrm{~N} 1112124 \mathrm{~W}$

$312840 \mathrm{~N} 1111856 \mathrm{~W}$

$312822 \mathrm{~N} 1111909 \mathrm{~W}$

312740 N1112015

312654 N1110932W

$334239 N 1113651 \mathrm{~W}$

315843 N1130203W

VARIANT

summit

summit

BGN 1965 Pima

Pima

VARIANT

VARIANT

gap

spring

BGN

BGN

falls

VARIANT

Pima

Pina

Yuma

falls

VARIANT

Yuma

$320216 N 1125921 \mathrm{~W}$

$320320 N 1131157 \mathrm{~W}$

$320125 N 1130754 \mathrm{~W}$

$320122 \mathrm{~N} 1130830 \mathrm{~W}$

321842N1140303W

321842 N $1140303 \mathrm{~W}$

ppl

BGN

valley

valley

BGN

IANT

Maricopa

$333620 \mathrm{~N} 1121850 \mathrm{~W}$

$312832 N 1110018$

Santa Cruz

$312 B 32 N 1110018 \mathrm{~W}$

VARIANT

VARIANT

VARIANT

VARIANT

VARIANT

VARIANT

VARIANT
334944 N1095907W

$\begin{array}{llll}\text { valley } & \text { BGN } & \text { Pima } & 314433 \text { N1110130W } \\ & \text { VARIANT } & & \\ \text { valley } & \text { BGN 1892 } & \text { Santa Cruz } & 314459 \text { N1110134W } \\ \text { valley } & \text { BGN } & \text { Pima } & 321744 \text { N1104310W } \\ \text { cave } & \text { BGN } & \text { Santa Cruz } & 314115 N 1105731 W \\ \text { summit } & \text { BGN } & \text { Pima } & 321743 N 1103955 W \\ \text { summit } & \text { BGN } & \text { Yuma } & 325949 N 1131953 W \\ \text { locale } & \text { UNOFF } & \text { Pima } & 321657 N 1104343 W \\ \text { gap } & \text { BGN } & \text { Santa Cruz } & 314205 N 1105309 W \\ \text { spring } & \text { BGN } & \text { Santa Cruz } & 314143 N 1105746 W\end{array}$

7100 Agathla Peak

\begin{tabular}{|c|c|c|}
\hline $\begin{array}{c}\text { SOURCE } \\
\text { COORDINATE }\end{array}$ & $\begin{array}{l}\text { ELEV } \\
\text { FT }\end{array}$ & MAP NAME \\
\hline \multirow[t]{3}{*}{$360702 \mathrm{~N} 1121747 \mathrm{~W}$} & 2990 & $\begin{array}{l}\text { Adamana } \\
\text { Havasupai Point } \\
\text { Agate House } \\
\text { McDonald Mtn } \\
\text { Grayback Mts }\end{array}$ \\
\hline & 7100 & Agathla Peak \\
\hline & 2009 & $\begin{array}{l}\text { Sacaton } \\
\text { Natural Corral } \\
\text { Whiteriver }\end{array}$ \\
\hline $322951 \mathrm{~N} 1110109 \mathrm{~W}$ & 453 & $\begin{array}{l}\text { Ruelas Canyon } \\
\text { Wilbur Canyon } \\
\text { Waterman Peak } \\
\text { Agua Caliente }\end{array}$ \\
\hline
\end{tabular}

$314142 \mathrm{~N} 1105428 \mathrm{~W}$

$314142 \mathrm{~N} 1105428 \mathrm{~W}$ $322101 N 1103951 \mathrm{~W}$

Mt Hopkins

Agua Caliente Hill Mt Hopkins

5369 Agua Caliente $\mathrm{Hill}$

Agua Caliente Agua Caliente $\mathrm{Hill}$

$7240 \mathrm{Mt}$ Hopkins

Mt Hopkins

$322100 \mathrm{~N} 1103951 \mathrm{~W}$

Agua Caliente $\mathrm{Hill}$

Tucson East

Agua Caliente Hill

Bartlett Mtn

Bartlett Mtn

Bart lett Mtn

Bartlett Mtn

Ruby

Adams Mesa

O'Neill Hills

Agua Dulce Mts

Agua Dulce Mts

E1 Mirage

312538 N1110316W

Pena Blanca Lake 
FEATURE NAME

Agua Fria Creek

See Agua Fria River

Agua Fria River

Agua Fria Creek

Agua Frie

Agua Fria Union High School

Agua Frie

See Agua Fria River

Agua Frio (historical)

Aguaje Draw

\section{Aguajita Spring \\ Aguajita Wash \\ Aguajita Well \\ Agua LaVara \\ Agua la Vara \\ See Nawt Vaya \\ Agua Lavaria \\ See Nawt Vaya \\ Agua la Varia}

See Nawt Vaya

Agua Linda

Agua Linda Ranch

Agua Linda-Amado Interchange

Agua Linda Park Hall Park

Agua Linda Ranch

See Agua Linda

Agua Nueva Spring

Agua Prieta Substation

Agua Ria

See Agua Fria Canyon

Agua Sal Creek

Agua Sal Wash

Aguas Tank

Aguato

See Awatobi (site)

Agua Verde Creek

Agua Verde Range See Tanque Verde Ridge

Agua Wash

Aguila

Canon Water

Aguila Corral

Aguila Elementary School

Aguila Microwave Relay Station

Aguila Mountains

Aguila Post Office

Aguila Railroad Station

Aguilar School

Aguila Substation

Aguila Tank

Aguila Valley

Grace Valley

McMullen Valley

Aguinaldo Mine

Aguirre Lake

Aguirre Pass

Aguirre Peak Aguirres Peak

Aguirres Peak

See Aguirre Peak

Aguirre Valley

Aguirre Wash

Aguja Canyon

Agway Pond

Agway Valley Jagway Valley
Jagwey Valley

Agway Wash

Ahan Owuch

Ahela

Anuawooch

See Shipolovi

FEATURE
CLASS

STATUS

COUNTY

COORDINATE

SOURCE

COORDINATE

ELEV
FT

MAP NAME

stream
stream

VARIANT

Maricopa $\quad 332322 \mathrm{~N} 1122150 \mathrm{~W}$

BGN 1976 Maricopa $332322 N 1122150 \mathrm{~W}$

VARIANT

VARIANT

schoo

UNOFF

Maricopa

$332624 N 1122033 W$

$343700 N 1122353 W$

Avondale

VARIANT

Maricopa

locale

valley

$B G N$

BGN

Santa Cruz

$332322 \mathrm{~N} 1122150 \mathrm{~W}$

$312900 \mathrm{~N} 1105955 \mathrm{~K}$

$343417 N 1091311 \mathrm{~W}$

spring $B G N$

stream BGN Pima 315605 N1130040W

well

well

locale

locale

UNOFF

UNOFF

Pima

Pima

VARIANT

Pima

VARIANT

Pima

VARIANT

Pima

$315306 \mathrm{~N} 1111619$

320117N1113028

320159N1112918W

locale

locale

BGN

VARIANT

crossing

park

UNOFF

ADMIN

VARIANT

VARIANT

locale

spring

locale

valley

BEN

VARIANT

Santa Cruz

Santa Cruz

Maricopa

Santa Cruz

Pima

Cochise

Santa Cruz

320159N1112918W

320159N1112918w

314044 N1110340W

$314036 \mathrm{~N} 1110348 \mathrm{~W}$

$333127 N 1115336 \mathrm{~W}$

$314044 \mathrm{~N} 1110340 \mathrm{~W}$

$322333 \mathrm{~N} 1103823 \mathrm{~W}$

$312006 \mathrm{~N} 1093335 \mathrm{~W}$

$312832 \mathrm{~N} 1110018 \mathrm{~W}$

stream BGN Apache 362740N1092840W

valley BGN Apache 363246N1093101W

reservoir

BGN

VARIANT

locale

tream

ridge

stream

ppl

BGN

VARIANT

BGN

BGN

locale BGN

school

locale

summit

building

building

school

locale

reservoir

valley

UNOFF

BGN

BGN

UNOFF

UNOF

UNOFF

UNOFF

BGN

BGN 1964

VARIANT

VARIANT

mine

gap

summit

UNOFF

BGN

BGN

BGN 194

VARIANT

VARIANT

summit

valley

strean

valley

BGN
BGN

BGN

lake

valley

BGN

BGN

VARIANT

VARIANT

valley BGN

locale

BGN 1964

VARIANT

VARIANT

ppl

Pima

Navajo

Pima

Pima

Mohave

Maricopa

Pima

Maricopa

Maricopa

Yuma

Maricopa

Maricopa

Maricopa

Maricopa

(

Maricopa

$363246 \mathrm{~N} 1093101 \mathrm{~W}$

354331 N1101639W

$320300 \mathrm{~N} 1103815 \mathrm{~W}$

$321224 M 1103646 \mathrm{~W}$

$342851 N 1141615 \mathrm{~W}$

$335634 \mathrm{N1131024 \textrm {W }}$

321348N1103916

$335620 \mathrm{~N} 1131023 \mathrm{~W}$

$334139 \mathrm{~N} 1130535 \mathrm{~W}$

$323848 \mathrm{~N} 113202 \mathrm{TW}$

$335632 \mathrm{~N} 1131002 \mathrm{~W}$

$335640 \mathrm{~N} 1131012 \mathrm{~W}$

$332210 \mathrm{~N} 1115602 \mathrm{~W}$

$335640 \mathrm{~N} 1131045 \mathrm{~W}$

$321336 \mathrm{~N} 1103917 \mathrm{~W}$

$335906 \mathrm{N1} 125344 \mathrm{~W}$

$362053 \mathrm{~N} 1090913 \mathrm{~W}$

$362740 \mathrm{~N} 1092840 \mathrm{~W}$

$320131 N 1102913 W$

$343102 N 1141349$

Aguil

Tanque Verde Peak Aguila Hummingbird Spring Aguila Mts NE

Aguila

Aguila

Guadalupe Aguila

Tanque Verde Peak

335800 N1131800W

Out law Hill

315508 N1111710W

$313520 \mathrm{~N} 1113028 \mathrm{~W}$

$320829 \mathrm{~N} 1112406 \mathrm{~W}$

$313803 \mathrm{~N} 1113811 \mathrm{~W}$

Pima 313803N1113811W

Pinal 323355N1114413W

Pima 322838N1114734W

$322253 \mathrm{~N} 1102620 \mathrm{~W}$

$361826 \mathrm{~N} 1132932 \mathrm{~W}$

Mohave

Mohave

361827 N1132933W

Mohave

$362033 \mathrm{~N} 1132628 \mathrm{~W}$ $320833 \mathrm{~N} 1122034 \mathrm{~W}$

$321651 N 1113541 \mathrm{~W}$ $320733 \mathrm{~N} 1112443 \mathrm{~W}$ $322452 \mathrm{~N} 1102052 \mathrm{~W}$

Stevens Mtn Presumido Peak La Tortuga Butte 4923 Aguirre Peak

Greene Reservoir 
NATIONAL GAZETTEER--ARIZONA 1986 FEATURE NAME

Ahe Vonan (historical) Aaivonam Brownel1

Ah-ha Seyampa River See Hassayampa River Ah Hol Sah

Ah-le-la

See Shipolovi

Ah $\mathrm{Na} \mathrm{Na}$ Betoh

Aholi Park

Ahuato

See Awatobi (site)

Ah Villa Park

\section{Ahwatukee}

AIC Dam

Aikens Tank

Aire Libre Mobile Home Park

Airline Canal

Airplane Canyon Tank

Airplane Tank

Airport Tank

Airport Tank

Airport Tank

Airport Tank

Airport Tank

Airport Tank

Airport Well

Aja Ranch

Ajax Hill

Ajax Mine

Ajo

Ajo, Mount

Ajo Peaks

Sierra del Ajo

Ajo, Valley of the

Ajo Copper Mines

Ajo High School

Ajo Mountains

See Ajo Range

Ajo Municipal Airport

Ajo Peak Ajo Peaks

Ajo Peaks

See Ajo, Mount

Ajo Peaks

See Ajo Peak

Ajo Range

Ajo Mountains

Cerros de Santa Rosa

Nariz Mountains

Santa Rosa Mountains

Sierra de la Naril

Sierra de la Nariz

Sierra de Santa Rosa

Sierra del Ajo

Ajo Recreation Center

Ajo Way Interchange

AJ Tank

Akaba, Mount

Akaba Tank

Ak Chin

See Ali Ak Chin

Ak Chin

See San Serafin

Akchin

See San Serafin

Akchin

See Ak Chin

Ak Chin

Akchin
FEATURE
CLASS

STATUS COUNTY

COORDINATE

$321500 \mathrm{~N} 1120830 \mathrm{~W}$

locale

BGN 1941 Pima

VARIANT

VARIANT

VARIANT

stream

summit

pp)

spring

park

locale

park

BGN

VARIANT

Navajo

ADMIN Navajo

VARIANT

La Paz

aricopa
oconino
Mavajo
Mavajo
Maricopa
avajo
a Paz

$331920 \mathrm{N1124240 \textrm {W }}$

$364027 \mathrm{N1114107 \textrm {W }}$

$354830 \mathrm{~N} 1102944 \mathrm{~W}$

$360513 \mathrm{~N} 1102251 \mathrm{~W}$

$332435 \mathrm{N1} 120236 \mathrm{~W}$

$354331 N 1101639 \mathrm{~W}$

$341336 \mathrm{~N} 1141127 \mathrm{~W}$

ppl BGN Maricopa $332030 \mathrm{N1115900 \textrm {W }}$

dam UNOFF Yavapai $\quad 352227 N 1131747 \mathrm{~W}$

locale UNOFF Maricopa 333816N1120102W

canal BGN Maricopa 333040N1121953W

reservoir BGN Graham 330442N1093810W

reservoir BGN Coconino 345325N1112754W

reservoir BGN Pinal 323815N1105459W

reservoir BGN Maricopa 334416N1123755

reservoir BGN Navajo 334853N1095912W

reservoir

reservoir

reservoir

well

locale

summit

mine

mine

ppl

summit

Navajo

Yavapai

Coconino

Pima

Navajo

Cochise

Pima

Pinal

Pima

BGN 1945 Pima

VARIANT

VARIANT

$\begin{array}{lll}\text { valley } & \text { BGN 1964 } & \text { Pima } \\ \text { mine } & \text { UNOFF } & \text { Pima } \\ \text { school } & \text { UNOFF } & \text { Pima } \\ & \text { VARIANT } & \\ \text { range } & & \text { Pima } \\ \text { airport } & \text { ADMIN } & \text { Pima } \\ \text { summit } & \begin{array}{l}\text { BGN 1941 } \\ \text { VARIANT }\end{array} & \text { Pima } \\ & \text { VARIANT } & \end{array}$

$322530 \mathrm{~N} 1124600 \mathrm{~W}$

$322220 \mathrm{~N} 1125135 \mathrm{~W}$

$322229 \mathrm{~N} 1125131 \mathrm{~W}$

$320030 \mathrm{~N} 1124830 \mathrm{~W}$

$322710 \mathrm{~N} 1125140 \mathrm{~W}$

$322008 \mathrm{~N} 1125421 \mathrm{~W}$

$320136 N 1124124 W$

summ it

Pima

VARIANT

sumait

range

Pima

$322008 \mathrm{~N} 1125421 \mathrm{~W}$

320240 N1124104W

VARIANT

VARIANT

VARIANT

VARIAN

VARIANT

VARIANT

VARIANT

VARIANT

$\begin{array}{llll}\text { park } & \text { ADMIN } & \text { Pima } & 322239 N 1125132 \mathrm{~W} \\ \text { crossing } & \text { UNOFF } & \text { Pima } & 321040 \mathrm{~N} 1105906 \mathrm{~W} \\ \text { reservoir } & \text { BGN } & \text { Santa Cruz } & 312457 \mathrm{N1} 103915 \mathrm{~W} \\ \text { summit } & \text { BGN 1925 } & \text { Coconino } & 361900 \mathrm{~N} 1123755 \mathrm{~W} \\ \text { reservoir } & \text { BGN } & \text { Coconino } & 360644 \mathrm{~N} 1122703 \mathrm{~W} \\ \text { locale } & \text { VARIANT } & & \\ \text { Ppl } & \text { VARIANT } & \text { Pima } & 315129 \mathrm{~N} 1123224 \mathrm{~W} \\ \text { ppl } & \text { VARIANT } & \text { Pima } & 321715 \mathrm{~N} 1120030 \mathrm{~W} \\ & & \text { Pima } & 321715 \mathrm{~N} 1120030 \mathrm{~W}\end{array}$

VARIANT

$\begin{array}{ll}\text { Ppl } & \\ \text { PPI } & \text { BGN } 1941\end{array}$

VARIANT $\begin{array}{ll}\text { Pinal } & 330158 N 1120421 \mathrm{~W} \\ \text { Pinal } & 330158 N 1120421 \mathrm{~W}\end{array}$ $\begin{array}{cc}\text { SOURCE } & \text { ELEV } \\ \text { COORDINATE } & \text { FT }\end{array}$

Window Mtn

Bitter Springs

Hard Rocks

Phoenix

Cross Roads

1280 Guadalupe

Blye Canyon SE

King Canyon

1445 Union Hills

Bryce Mountain

Mormon Lake

Fortified Mtn

Daggs Tank

Whiteriver

Spotted Mountain

Sugarloaf Peak

Red Butte

Empire Ranch

5174 Hibbard

5320 Tombstone

Arivaca

Mineral Mtn

Ajo South

4808 Mount Ajo

Mount Ajo

Burro Gap

Ajo South

Ajo North

1458 Ajo North

2617 Chico Shunie

Ajo North

Tucson

Harshaw

5251 Havasu Falls

Chamisa Tank

Maricopa 
NATIONAL GAZETTEER--ARIZONA 1986

\begin{tabular}{|c|c|c|c|c|c|c|c|}
\hline FEATURE NAME & $\begin{array}{l}\text { FEATURE } \\
\text { CLASS }\end{array}$ & STATUS & COUNTY & COORDINATE & $\begin{array}{l}\text { SOURCE } \\
\text { COORDINATE }\end{array}$ & $\begin{array}{l}\text { ELEV } \\
\text { FT }\end{array}$ & MAP NAME \\
\hline $\begin{array}{c}\text { Aktjin } \\
\text { Ak Chin Community Airfield } \\
\text { Ak Chin Community Center } \\
\text { Ak-Chin Indian Reservation } \\
\text { Ak-Chin Reservation } \\
\text { Maricopa (Ak-Chin) } \\
\text { Reservation } \\
\text { Maricopa Indian } \\
\text { Reservation } \\
\text { Pima and Maricopa } \\
\text { Indian Reservation }\end{array}$ & $\begin{array}{l}\text { airport } \\
\text { building } \\
\text { reserve }\end{array}$ & $\begin{array}{l}\text { VARIANT } \\
\text { ADMIN } \\
\text { UNOFF } \\
\text { BGN } \\
\text { VARIANT } \\
\text { VARIANT } \\
\text { VARIANT } \\
\text { VARIANT }\end{array}$ & $\begin{array}{l}\text { Pinal } \\
\text { Pinal } \\
\text { Pinal }\end{array}$ & $\begin{array}{l}325910 \mathrm{~N} 1120130 \mathrm{~W} \\
330141 \mathrm{~N} 1120500 \mathrm{~W} \\
330145 \mathrm{~N} 1120452 \mathrm{~W}\end{array}$ & & 1210 & $\begin{array}{l}\text { Antelope Peak NE } \\
\text { Maricopa } \\
\text { Maricopa }\end{array}$ \\
\hline $\begin{array}{c}\text { Ak-Chin Reservation } \\
\text { See Ak-Chin Indian } \\
\text { Reservation }\end{array}$ & reserve & VARIANT & Pinal & $330145 N 1120452 W$ & & & \\
\hline $\begin{array}{l}\text { Akchin Well } \\
\text { Ak Chut Vaya } \\
\text { Akee-mull }\end{array}$ & $\begin{array}{l}\text { well } \\
\text { locale }\end{array}$ & $\begin{array}{l}\text { UNOFF } \\
\text { BGN } \\
\text { VARIANT }\end{array}$ & $\begin{array}{l}\text { Pima } \\
\text { Pima }\end{array}$ & $\begin{array}{l}321600 \mathrm{~N} 1115956 \mathrm{~W} \\
313750 \mathrm{~N} 1114832 \mathrm{~W}\end{array}$ & & 1887 & $\begin{array}{l}\text { Santa Rosa Mts SW } \\
\text { South Komelik }\end{array}$ \\
\hline $\begin{array}{l}\text { See Gila River } \\
\text { Akes (historical) } \\
\text { Ak Komelik } \\
\text { La Lesna } \\
\text { LaLesna } \\
\text { Shuunakia }\end{array}$ & $\begin{array}{l}\text { stream } \\
\text { locale } \\
\text { locale }\end{array}$ & $\begin{array}{l}\text { BGN } \\
\text { BGN } 1941 \\
\text { VARIANT } \\
\text { VARIANT } \\
\text { VARIANT }\end{array}$ & $\begin{array}{l}\text { Yuma } \\
\text { Santa Cruz } \\
\text { Pima }\end{array}$ & $\begin{array}{l}324311 \mathrm{~N} 1143316 \mathrm{~W} \\
313400 \mathrm{~N} 1104700 \mathrm{~W} \\
314304 \mathrm{~N} 1121202 \mathrm{~W}\end{array}$ & & & $\begin{array}{l}\text { Patagonia } \\
\text { La Lesna Mts }\end{array}$ \\
\hline $\begin{array}{l}\text { A K Ranch } \\
\text { Aktjin } \\
\text { See Ali Ak Chin } \\
\text { Aktjin } \\
\text { See San Serafin } \\
\text { Aktjin } \\
\text { See Ak Chin } \\
\text { Alabama Mine } \\
\text { Alahkai Wash } \\
\text { See Balakai Wash }\end{array}$ & $\begin{array}{l}\text { locale } \\
\text { locale } \\
\text { ppl } \\
\text { ppl } \\
\text { mine } \\
\text { valley }\end{array}$ & $\begin{array}{l}\text { UNOFF } \\
\text { VARIANT } \\
\text { VARIANT } \\
\text { VARIANT } \\
\text { UNOFF } \\
\text { VARIANT }\end{array}$ & $\begin{array}{l}\text { Maricopa } \\
\text { Pima } \\
\text { Pima } \\
\text { Pinal } \\
\text { Mohave } \\
\text { Apache }\end{array}$ & $\begin{array}{l}325237 \mathrm{~N} 1121500 \mathrm{~W} \\
315129 \mathrm{~N} 1123224 \mathrm{~W} \\
321715 \mathrm{~N} 1120030 \mathrm{~W} \\
330158 \mathrm{~N} 1120421 \mathrm{~W} \\
352027 \mathrm{~N} 1133600 \mathrm{~W} \\
360645 \mathrm{~N} 1093945 \mathrm{~W}\end{array}$ & & & Conley Well \\
\hline $\begin{array}{l}\text { Alambre Tank } \\
\text { Alambre Valley } \\
\text { Alambre Wash } \\
\text { Alambre Well } \\
\text { Alamito Canyon } \\
\text { Alamito Tank } \\
\text { Alamito Wash } \\
\text { Alamo } \\
\text { See Nawt Vaya } \\
\text { Alamo, Canal (historical) }\end{array}$ & $\begin{array}{l}\text { reservoir } \\
\text { valley } \\
\text { stream } \\
\text { well } \\
\text { valley } \\
\text { reservoir } \\
\text { stream } \\
\text { locale } \\
\text { canal }\end{array}$ & $\begin{array}{l}\text { BGN } \\
\text { BGN } \\
\text { BGN } \\
\text { UNOFF } \\
\text { BGN } \\
\text { BGN } \\
\text { BGN } \\
\text { VARIANT }\end{array}$ & $\begin{array}{l}\text { Pima } \\
\text { Pima } \\
\text { Pima } \\
\text { Pima } \\
\text { Pima } \\
\text { Pima } \\
\text { Pima } \\
\text { Pima } \\
\text { Maricopa }\end{array}$ & $\begin{array}{l}321805 N 1103624 W \\
315602 N 1113224 W \\
315812 N 1112329 W \\
315519 N 1113450 W \\
313603 N 1112153 W \\
312947 N 1112322 W \\
312 B 56 N 1112338 W \\
320159 N 1112918 W \\
332524 N 1121037 W\end{array}$ & $\begin{array}{l}315417 N 1113623 W \\
315417 N 1113623 W \\
313635 N 1112047 W \\
313023 N 1112344 W\end{array}$ & & $\begin{array}{l}\text { Piety Hill } \\
\text { Kitt Peak } \\
\text { Palo Alto Ranch } \\
\text { Kitt Peak } \\
\text { Arivaca } \\
\text { Cumero Mtn } \\
\text { Cumero Mtn }\end{array}$ \\
\hline $\begin{array}{l}\text { Alamo Canyon } \\
\text { Alamo Canyon } \\
\text { Alamo Canyon } \\
\text { Alamo Canyon } \\
\text { Al amo Canyon } \\
\text { Alamo Canyon } \\
\text { Alamo Canyon } \\
\text { Alamo Canyon Number One } \\
\text { See Pontatoc Canyon } \\
\text { Alamo Crossing (historical) } \\
\text { Alimo }\end{array}$ & $\begin{array}{l}\text { valley } \\
\text { valley } \\
\text { valley } \\
\text { valley } \\
\text { valley } \\
\text { valley } \\
\text { valley } \\
\text { valley } \\
\text { locale }\end{array}$ & $\begin{array}{l}\text { BGN } \\
\text { BGN } \\
\text { BGN } \\
\text { BGN } \\
\text { BGN } \\
\text { BGN } \\
\text { BGN } \\
\text { VARIANT } \\
\text { BGN } \\
\text { VARIANT }\end{array}$ & $\begin{array}{l}\text { Santa Cruz } \\
\text { Santa Cruz } \\
\text { Santa Cruz } \\
\text { Santa Cruz } \\
\text { Pima } \\
\text { Pima } \\
\text { Pinal } \\
\text { Pima } \\
\text { La Paz }\end{array}$ & $\begin{array}{l}312318 N 1110535 \mathrm{~W} \\
312437 N 1105737 \mathrm{~W} \\
313418 N 1105722 \mathrm{~W} \\
313755 \mathrm{~N} 1104207 \mathrm{~W} \\
320406 \mathrm{~N} 1124327 \mathrm{~W} \\
322503 \mathrm{~N} 1105525 \mathrm{~W} \\
331633 \mathrm{~N} 1111035 \mathrm{~W} \\
\\
322018 \mathrm{~N} 1105415 \mathrm{~W} \\
341538 \mathrm{~N} 1133455 \mathrm{~W}\end{array}$ & $\begin{array}{l}312150 \mathrm{~N} 1110845 \mathrm{~W} \\
312105 \mathrm{~N} 1110256 \mathrm{~W} \\
313221 \mathrm{~N} 1105726 \mathrm{~W} \\
313549 \mathrm{~N} 1103859 \mathrm{~W} \\
320400 \mathrm{~N} 1124202 \mathrm{~W} \\
322310 \mathrm{~N} 1105310 \mathrm{~W} \\
331256 \mathrm{~N} 1110954 \mathrm{~W}\end{array}$ & 1056 & $\begin{array}{l}\text { Pena Blanca Lake } \\
\text { Rio Rico } \\
\text { San Cayetano Mts } \\
\text { Sonoita } \\
\text { Mount Ajo } \\
\text { Oro Valley } \\
\text { Picketpost Mtn }\end{array}$ \\
\hline $\begin{array}{l}\text { Alamo Dam } \\
\text { Alamo Lake } \\
\text { Alamo Reservoir } \\
\text { Alamo Lake Dam } \\
\text { Alamo Lake State Park } \\
\text { Alamo Mine } \\
\text { Alamo Mine } \\
\text { Alamo Number Two Tank } \\
\text { Alamo Ranger Station } \\
\text { Alamo Reservoir } \\
\text { See Alamo Lake }\end{array}$ & $\begin{array}{l}\text { dam } \\
\text { reservoir } \\
\text { dam } \\
\text { park } \\
\text { mine } \\
\text { mine } \\
\text { reservoir } \\
\text { locale } \\
\text { reservoir }\end{array}$ & $\begin{array}{l}\text { UNOFF } \\
\text { BGN 1971 } \\
\text { VARIANT } \\
\text { UNOFF } \\
\text { ADMIN } \\
\text { UNOFF } \\
\text { UNOFF } \\
\text { BGN } \\
\text { UNOFF } \\
\text { VARIANT }\end{array}$ & $\begin{array}{l}\text { Mohave } \\
\text { Yuma } \\
\text { La Paz } \\
\text { La Paz } \\
\text { Santa Cruz } \\
\text { La Paz } \\
\text { Pinal } \\
\text { Gila } \\
\text { Yuma }\end{array}$ & $\begin{array}{l}341355 N 1133603 \mathrm{~W} \\
341356 \mathrm{~N} 1133607 \mathrm{~W} \\
341354 \mathrm{~N} 1133606 \mathrm{~W} \\
341430 \mathrm{~N} 1133500 \mathrm{~W} \\
312605 \mathrm{~N} 1111902 \mathrm{~W} \\
332420 \mathrm{~N} 1135317 \mathrm{~W} \\
331449 \mathrm{~N} 1111058 \mathrm{~W} \\
333006 \mathrm{~N} 1105128 \mathrm{~W} \\
341356 \mathrm{~N} 1133607 \mathrm{~W}\end{array}$ & & $\begin{array}{l}1235 \\
1070\end{array}$ & $\begin{array}{l}\text { Alamo Dam } \\
\text { Alamo Dam } \\
\text { Alamo Dam } \\
\text { Alamo Dam } \\
\text { Ruby } \\
\text { Buckeye NW } \\
\text { Mineral Mtn } \\
\text { Rockinstraw Mtn }\end{array}$ \\
\hline $\begin{array}{l}\text { Alamo Spring } \\
\text { Alamo Spring } \\
\text { Alamo Spring } \\
\text { Alamo Spring } \\
\text { Alamo Spring } \\
\text { Alamo Spring } \\
\text { Alamo Spring } \\
\text { Alamo Spring }\end{array}$ & $\begin{array}{l}\text { spring } \\
\text { spring } \\
\text { spring } \\
\text { spring } \\
\text { spring } \\
\text { spring } \\
\text { spring } \\
\text { spring }\end{array}$ & $\begin{array}{l}\text { BGN } \\
B G N \\
B G N \\
B G N \\
B G N \\
B G N \\
B G N \\
B G N\end{array}$ & $\begin{array}{l}\text { Santa Cruz } \\
\text { Santa Cruz } \\
\text { Cochise } \\
\text { Pima } \\
\text { Graham } \\
\text { Yuma } \\
\text { Mohave } \\
\text { Apache }\end{array}$ & $\begin{array}{l}312157 N 1110 B 19 W \\
313804 N 1103924 W \\
321311 N 1093034 \mathrm{~W} \\
322219 N 1103654 \mathrm{~W} \\
323248 \mathrm{~N} 1101822 \mathrm{~W} \\
332439 \mathrm{N1} 135522 \mathrm{~W} \\
342834 \mathrm{N1} 133044 \mathrm{~W} \\
362019 \mathrm{N1} 1094112 \mathrm{~W}\end{array}$ & & & $\begin{array}{l}\text { Alamo Spring } \\
\text { Sonoita } \\
\text { Dos Cabezas } \\
\text { Piety Hill } \\
\text { Bassett Peak } \\
\text { Owl Head } \\
\text { Signal Mtn } \\
\text { Many Farms SW }\end{array}$ \\
\hline
\end{tabular}


NATIONAL GAZETTEER--ARIZONA 1986

\section{FEATURE NAME}

Alano Wash

Alamo Wash

Alamo Wash

Alamo Wash

Alamo Well

Alamo Well

Alarcon Terrace

Alaska Mine

Alax Mine (historical)

Albatross Mine

Alberson Wash

Albers Tank

Albers Wash
Alberts Tank
Albert Well
Alboyd Spring
Alcatraz Point
Alchesa Canyon
See Alchesay Canyon
Alchesay Canyon
Alchesa Canyon
Alchesay Flat

Alchesay High School

Alchesay Springs Campground

Alchesay Tank

A1 Chuk Shon

See Ali Chukson

Alcorn Pond

Alcove Canyon

Alcove Creek

Alcove Creek

See Alcove Canyon

Alcove Mesa

Al Creek

Alcyone Mine

Alder Box Spring

Alder Canyon

See Alder Wash

Alder Canyon

Alder Canyon

Alder Creek

Alder Creek

Alder Creek

Alder Creek

Alder Creek

See West Fork Sycamore Creek

Alder Creek

Alder Creek

Alder Creek Spring

Alder Lake

Alder Peak

Alder Ridge

Alder Saddle

Alder Spring

Alder Spring

Alder Tank

Alder Trail

Alder Wash

Alder Canyon

Alegre Park

Alejandro Tank

Alex Spring

Alfa Fia Tank

Alfalfa Well

Al Fulton Point

Algerita Canyon

Alger School

Algodon

See Cactus Flat

Algodones Land Grant

\section{FEATURE}

CLASS

STATUS

stream

stream

BGN
$B G N$

stream

stream

well

well

bench

mine

mine

mine

arroyo

reservoir

$\begin{array}{ll}\text { BGN } & \text { Yuma } \\ \text { BGN } & \text { Apache } \\ \text { UNOFF } & \text { Pima } \\ \text { UNOFF } & \text { Maricopa } \\ \text { BGN 1908 } & \text { Coconino } \\ \text { UNOFF } & \text { Maricopa } \\ \text { UNOFF } & \text { Cochise } \\ \text { UNOFF } & \text { Pima } \\ \text { BGN } & \text { Yavapai } \\ \text { BGN } & \text { Coconino }\end{array}$

stream

well

spring

cliff

BGN
BGN

BGN
UNOFF

BGN

BGN

valley
valley

VARIANT

flat

BGN 1917

VARIANT

BGN

coconino

Yavapai

Pima

Coconino

Maricopa

Maricopa

Navajo

school UNOFF Navajo 335000N1095805W

park ADMIN Navajo 335526N1095608W

reservoir BGN Navajo 335641N1095523W

ppl

reservoir

VARIANT

valley

BGN

Pima

Mohave

1915 Apache

VARIANT

valley

VARIANT

Apache

$315449 N 1114755 \mathrm{~W}$

$362352 \mathrm{~N} 1132320 \mathrm{~W}$

$364715 N 1092520 \mathrm{~W}$

364715 N1092520W

$\begin{array}{llll}\text { summit } & \text { BGN } & \text { Apache } & 364010 \mathrm{~N} 1092201 \mathrm{~W} \\ \text { stream } & \text { BGN } & \text { Greenlee } & 332846 \mathrm{~N} 1091150 \mathrm{~W} \\ \text { mine } & \text { UNOFF } & \text { Mohave } & 345934 \mathrm{~N} 1142422 \mathrm{~W} \\ \text { spring } & \text { BGN } & \text { Pima } & 322737 \mathrm{~N} 1104216 \mathrm{~W} \\ & \text { VARIANT } & \text { Pinal } & 323240 \mathrm{~N} 1103004 \mathrm{~W} \\ \text { stream } & & \text { Pima } & 322844 \mathrm{~N} 1103843 \mathrm{~W} \\ \text { valley } & \text { BGN } & \text { Coconino } & 343406 \mathrm{~N} 1105245 \mathrm{~W} \\ \text { valley } & \text { BGN } & \text { Greenlee } & 331923 \mathrm{~N} 1091127 \mathrm{~W} \\ \text { stream } & \text { BGN } & \text { Gila } & 333127 \mathrm{~N} 1102939 \mathrm{~W} \\ \text { stream } & \text { BGN } & & \\ & & & \\ \text { stream } & \text { BGN } & \text { Maricopa } & 333557 \mathrm{~N} 1111919 \mathrm{~W} \\ \text { stream } & \text { BGN } & \text { Maricopa } & 335140 \mathrm{~N} 1113546 \mathrm{~W} \\ & \text { VARIANT } & & \\ \text { stream } & & \text { Maricopa } & 335551 \mathrm{~N} 1112836 \mathrm{~W} \\ & & & \\ \text { stream } & \text { BGN } & \text { Gila } & 340724 \mathrm{~N} 1112536 \mathrm{~W} \\ \text { stream } & \text { BGN } & \text { Coconino } & 343406 \mathrm{~N} 1105244 \mathrm{~W} \\ \text { spring } & \text { BGN } & \text { Maricopa } & 335347 \mathrm{~N} 1113019 \mathrm{~W} \\ \text { lake } & \text { BGN } & \text { Coconino } & 342241 \mathrm{~N} 1105753 \mathrm{~W} \\ \text { summit } & \text { BGN } & \text { Greenlee } & 332230 \mathrm{~N} 1091417 \mathrm{~W}\end{array}$

$333053 N 1091036$

6555

555 Kinusta Mesa Dutch Blue Creek Boundary Cone Mount Bigelow

$322606 \mathrm{~N} 1104456 \mathrm{~W}$

$342344 N 1105456$

$332213 N 1091438 \mathrm{~W}$

$333448 N 1102405 \mathrm{~W}$

333956 N1111928W

$335453 \mathrm{~N} 1113053 \mathrm{~W}$

340757 N1112908W $342356 \mathrm{~N} 1105459 \mathrm{~W}$

$\begin{array}{llll}\text { ridge } & \text { BGN } & \text { Gila } & 341935 N 1113103 W \\ \text { gap } & \text { BGN } & \text { Maricopa } & 334052 N 1111848 W\end{array}$

$\begin{array}{llll}\text { spring } & \text { BGN } & \text { Graham } & 323622 N 1095023 \mathrm{~W} \\ \text { spring } & B G N & \text { Greenlee } & 332125 N 1091236 \mathrm{~W}\end{array}$

$\begin{array}{llll}\text { spring } & B G N & \text { Greenlee } & 332125 N 1091236 \mathrm{~W} \\ \text { reservoir } & B G N & \text { Gila } & 341916 N 1113111 \mathrm{~W}\end{array}$

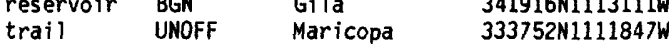

stream BGN Pinal 323240N1103004W

VARIANT

park ADMIN

Maricopa

$332830 \mathrm{~N} 1121200 \mathrm{~W}$

$343306 \mathrm{~N} 1091803 \mathrm{~W}$

$\begin{array}{lll}\text { spring } & \text { BGN } & \text { Yavapai } \\ \text { reservoir } & \text { BGN } & \text { Coconino } \\ \text { well } & \text { UNOFF } & \text { Pima } \\ \text { cliff } & \text { BGN } & \text { Gila } \\ \text { valley } & \text { BGN } & \text { Santa Cruz } \\ \text { school } & \text { UNOFF } & \text { Graham } \\ \text { ppl } & \text { VARIANT } & \text { Graham } \\ & \text { VARIANT } & \end{array}$

$344029 \mathrm{~N} 1120506 \mathrm{~W}$ 351918 N1114322

$315551 \mathrm{~N} 1103155 \mathrm{~W}$

$341746 \mathrm{~N} 1105339 \mathrm{~W}$

$313134 \mathrm{~N} 1102903 \mathrm{~W}$

$325116 \mathrm{~N} 1093434 \mathrm{~W}$

$324530 \mathrm{~N} 1094256 \mathrm{~W}$
Mount Bigelow

Grana Draw

Fritz Canyon

Cassadore Spring

Horse Mesa Dam

Maverick Mtn

Mazatzal Peak

Grama Draw

Lion Mountain Porcupine Ridge

6743 Fritz Canyon

Cane Springs Mtn

6447 Four Peaks

Stockton Pass

Fritz Canyon

Cane Springs Mtn

Four Peaks

Peppersauce Wash

Fowler

St Johns North

Cottonwood

Humphreys Peak

The Narrows

Woods Canyon

San Jose
Pyeatt Ranch 


\begin{tabular}{|c|c|c|c|c|c|c|c|}
\hline FEATURE NAME & $\begin{array}{l}\text { FEATURE } \\
\text { CLASS }\end{array}$ & STATUS & COUNTY & COORDINATE & $\begin{array}{l}\text { SOURCE } \\
\text { COORDINATE }\end{array}$ & $\begin{array}{l}\text { ELEV } \\
\text { FT }\end{array}$ & MAP NAME \\
\hline See Somerton & ppl & & Yuma & $323547 \mathrm{~N} 1144232 \mathrm{~W}$ & & & \\
\hline $\begin{array}{l}\text { Algonquin Mine } \\
\text { Algonquin Trail Two Hundred } \\
\text { Twentyfive } \\
\text { Algrim Wash } \\
\text { See Pilgrim Wash } \\
\text { Alhambra } \\
\text { Alhambra High School } \\
\text { Alhambra School } \\
\text { Alhambra Substation } \\
\text { Ali Ak Chin } \\
\text { Ak Chin } \\
\text { Aktjin } \\
\text { La Quituni }\end{array}$ & $\begin{array}{l}\text { stream } \\
\text { ppl } \\
\text { school } \\
\text { school } \\
\text { locale } \\
\text { locale }\end{array}$ & $\begin{array}{l}\text { UNOFF } \\
\text { UNOFF } \\
\text { VARIANT } \\
\text { BGN } \\
\text { UNOFF } \\
\text { UNOFF } \\
\text { UNOFF } \\
\text { BGN 1941 } \\
\text { VARIANT } \\
\text { VARIANT } \\
\text { VARIANT }\end{array}$ & $\begin{array}{l}\text { Mohave } \\
\text { Maricopa } \\
\text { Maricopa } \\
\text { Maricopa } \\
\text { Maricopa } \\
\text { Pima }\end{array}$ & $\begin{array}{l}341214 N 1121802 W \\
341153 N 1121747 W \\
345531 N 1134031 W \\
332954 N 1120801 W \\
333030 N 1120828 W \\
333010 N 1120819 W \\
333125 N 1120808 W \\
315129 N 1123224 W\end{array}$ & & 1128 & $\begin{array}{l}\text { Fowler } \\
\text { Glendale } \\
\text { Glendale } \\
\text { Glendale } \\
\text { Menagers Lake }\end{array}$ \\
\hline $\begin{array}{l}\text { Ali Chuk Valley } \\
\text { Ali Chuk Wash } \\
\text { Alicia Park } \\
\text { Alimo } \\
\text { See Alamo Crossing } \\
\text { (historical) }\end{array}$ & $\begin{array}{l}\text { valley } \\
\text { stream } \\
\text { park } \\
\text { locale }\end{array}$ & $\begin{array}{l}\text { BGN } \\
\text { BGN } \\
\text { AOMIN } \\
\text { VARIANT }\end{array}$ & $\begin{array}{l}\text { Pima } \\
\text { Pima } \\
\text { Maricopa } \\
\text { La Paz }\end{array}$ & $\begin{array}{l}315057 N 1123417 W \\
315016 N 1123357 W \\
333345 N 1120610 W \\
34153 B N 1133455 W\end{array}$ & $\begin{array}{l}315427 N 1123547 \mathrm{~W} \\
315214 \mathrm{~N} 1123554 \mathrm{~W}\end{array}$ & & $\begin{array}{l}\text { Menagers Lake } \\
\text { Menagers Lake } \\
\text { Sunnys lope }\end{array}$ \\
\hline $\begin{array}{l}\text { Ali Molina } \\
\text { Magdalena } \\
\text { Ali Molina Canyon } \\
\text { Ali Molina Wash }\end{array}$ & $\begin{array}{l}\text { locale } \\
\text { valley } \\
\text { stream }\end{array}$ & $\begin{array}{l}8 \text { GN } 1941 \\
\text { VARIANT } \\
\text { BGN } \\
\text { BGN }\end{array}$ & $\begin{array}{l}\text { Pima } \\
\text { Pima } \\
\text { Pima }\end{array}$ & $\begin{array}{l}315400 \mathrm{~N} 1114625 \mathrm{~W} \\
315311 \mathrm{~N} 1113 \mathrm{~B} 45 \mathrm{~W} \\
315526 \mathrm{~N} 1115111 \mathrm{~W}\end{array}$ & $\begin{array}{l}315421 N 1113647 \mathrm{~W} \\
315421 N 1113647 \mathrm{~W}\end{array}$ & & $\begin{array}{l}\text { Sells East } \\
\text { San Juan Spring } \\
\text { Sells East }\end{array}$ \\
\hline $\begin{array}{l}\text { Ali Oidak } \\
\text { Aloitak } \\
\text { Little Field } \\
\text { Little Field Is land } \\
\text { Alisa Pass } \\
\text { See Pan Tak Pass } \\
\text { Aliso Canyon } \\
\text { Aliso Canyon } \\
\text { Aliso Creek } \\
\text { See Gilson Wash }\end{array}$ & $\begin{array}{l}\text { gap } \\
\text { valley } \\
\text { valley } \\
\text { stream }\end{array}$ & $\begin{array}{l}\text { BGN } 1941 \\
\text { VARIANT } \\
\text { VARIANT } \\
\text { VARIANT } \\
\text { VARIANT } \\
\text { BGN } \\
\text { BGN } \\
\text { VARIANT }\end{array}$ & $\begin{array}{l}\text { Pima } \\
\text { Santa Cruz } \\
\text { Pima } \\
\text { Gila }\end{array}$ & $\begin{array}{l}315823 N 1113307 W \\
313545 N 1110252 W \\
321533 N 1103822 W \\
332052 N 1102653 W\end{array}$ & $\begin{array}{l}313420 \mathrm{~N} 1110653 \mathrm{~W} \\
321447 \mathrm{~N} 1103648 \mathrm{~W}\end{array}$ & & $\begin{array}{l}\text { Tubac } \\
\text { Agua Caliente Hill }\end{array}$ \\
\hline $\begin{array}{l}\text { Aliso Creek } \\
\text { See Ramboz Wash } \\
\text { Aliso Pass } \\
\text { See Pan Tak Pass } \\
\text { Aliso Spring } \\
\text { Aliso Spring } \\
\text { Aliso Spring } \\
\text { Alisos Well } \\
\text { Alitjukson } \\
\text { See Ali Chukson }\end{array}$ & $\begin{array}{l}\text { stream } \\
\text { gap } \\
\text { spring } \\
\text { spring } \\
\text { spring } \\
\text { well } \\
\text { ppl }\end{array}$ & $\begin{array}{l}\text { VARIANT } \\
\text { VARIANT } \\
\text { BGN } \\
\text { BGN } \\
\text { BGN } \\
\text { UNOFF } \\
\text { VARIANT }\end{array}$ & $\begin{array}{l}\text { Gila } \\
\text { Pima } \\
\text { Santa Cruz } \\
\text { Pima } \\
\text { Pima } \\
\text { Santa Cruz } \\
\text { Pima }\end{array}$ & $\begin{array}{l}332110 \mathrm{~N} 1103847 \mathrm{~W} \\
315823 \mathrm{~N} 1113307 \mathrm{~W} \\
313459 \mathrm{~N} 1110557 \mathrm{~W} \\
314408 \mathrm{~N} 1104810 \mathrm{~W} \\
320523 \mathrm{~N} 1103301 \mathrm{~W} \\
312245 \mathrm{~N} 1104507 \mathrm{~W} \\
315449 \mathrm{~N} 1114755 \mathrm{~W}\end{array}$ & & & $\begin{array}{l}\text { Tubac } \\
\text { Mt Wrightson } \\
\text { Rincon Peak } \\
\text { Cumero Canyon }\end{array}$ \\
\hline $\begin{array}{l}\text { Alit Ju Kson } \\
\text { See Ali Chukson } \\
\text { Ali Wua Pass } \\
\text { Gusano Pass } \\
\text { Aliza Pass } \\
\text { See Pan Tak Pass } \\
\text { Alkali Canyon } \\
\text { Alkali Canyon } \\
\text { Alkali Canyon } \\
\text { Alkali Flats } \\
\text { See Willcox Playa }\end{array}$ & $\begin{array}{l}\text { gap } \\
\text { valley } \\
\text { valley } \\
\text { valley } \\
\text { flat }\end{array}$ & $\begin{array}{l}\text { VARIANT } \\
\text { BGN } 1964 \\
\text { VARIANT } \\
\text { VARIANT } \\
\text { BGN } \\
\text { BGN } \\
\text { BGN } \\
\text { VARIANT }\end{array}$ & $\begin{array}{l}\text { Pima } \\
\text { Pima } \\
\text { Pima } \\
\text { Gila } \\
\text { Gila } \\
\text { Yavapai } \\
\text { Cochise }\end{array}$ & $\begin{array}{l}315823 \mathrm{~N} 1113307 \mathrm{~W} \\
334713 \mathrm{~N} 1102109 \mathrm{~W} \\
340124 \mathrm{~N} 1111644 \mathrm{~W} \\
341315 \mathrm{~N} 1120815 \mathrm{~W} \\
320822 \mathrm{~N} 1095046 \mathrm{~W}\end{array}$ & $\begin{array}{l}334651 \mathrm{~N} 1102055 \mathrm{~W} \\
340254 \mathrm{~N} 1111451 \mathrm{~W} \\
341316 \mathrm{~N} 1120629 \mathrm{~W}\end{array}$ & 2046 & $\begin{array}{l}\text { Carrizo SE } \\
\text { Gisela } \\
\text { Bumble Bee }\end{array}$ \\
\hline
\end{tabular}


FEATURE NAME

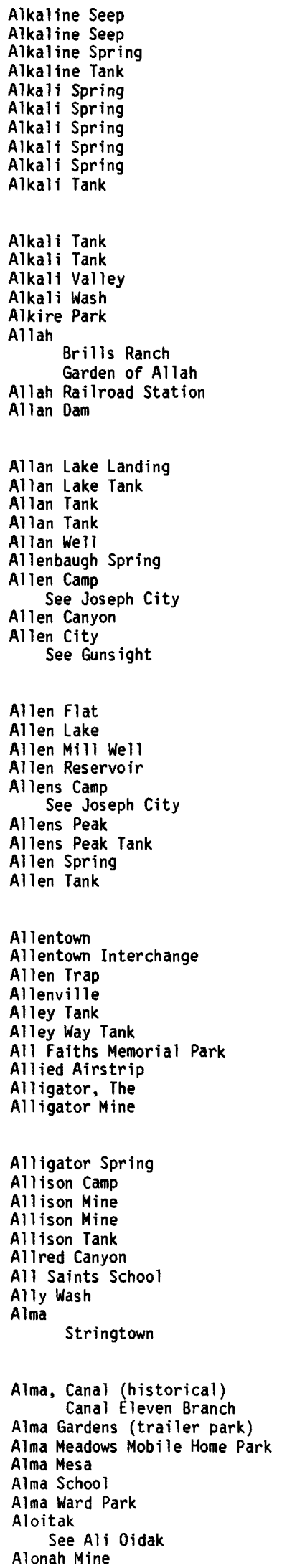

FEATURE

CLASS

\begin{tabular}{|c|c|c|c|}
\hline $\begin{array}{l}\text { spring } \\
\text { spring } \\
\text { spring } \\
\text { reservoir } \\
\text { spring } \\
\text { spring } \\
\text { spring } \\
\text { spring } \\
\text { spring } \\
\text { reservoir }\end{array}$ & $\begin{array}{l}\text { BGN } \\
\text { BGN } \\
\text { BGN } \\
\text { BGN } \\
\text { BGN } \\
\text { BGN } \\
\text { BGN } \\
\text { BGN } \\
\text { BGN } \\
\text { BGN }\end{array}$ & $\begin{array}{l}\text { Mohave } \\
\text { Mohave } \\
\text { Yavapai } \\
\text { Yavapai } \\
\text { Yavapai } \\
\text { Gila } \\
\text { Yavapai } \\
\text { Mohave } \\
\text { Mohave } \\
\text { Gila }\end{array}$ & $\begin{array}{l}364444 \mathrm{~N} 1134340 \mathrm{~W} \\
364607 \mathrm{~N} 1134222 \mathrm{~W} \\
343819 \mathrm{~N} 1125315 \mathrm{~W} \\
343852 \mathrm{~N} 1125257 \mathrm{~W} \\
335932 \mathrm{~N} 1122211 \mathrm{~W} \\
340727 \mathrm{~N} 1111820 \mathrm{~W} \\
343732 \mathrm{~N} 1123416 \mathrm{~W} \\
345805 \mathrm{~N} 1141743 \mathrm{~W} \\
350037 \mathrm{~N} 1132747 \mathrm{~W} \\
340230 \mathrm{~N} 1111513 \mathrm{~W}\end{array}$ \\
\hline $\begin{array}{l}\text { reservoir } \\
\text { reservoir } \\
\text { valley } \\
\text { stream } \\
\text { park } \\
\text { locale }\end{array}$ & $\begin{array}{l}\text { BGN } \\
\text { BGN } \\
\text { BGN } \\
\text { BGN } \\
\text { ADNIN } \\
\text { BGN } \\
\text { VARIANT } \\
\text { VARIANT }\end{array}$ & $\begin{array}{l}\text { Coconino } \\
\text { Coconino } \\
\text { Navajo } \\
\text { Yavapai } \\
\text { Maricopa } \\
\text { Maricopa }\end{array}$ & $\begin{array}{l}364420 \mathrm{~N} 1111605 \mathrm{~W} \\
364648 \mathrm{~N} 1111556 \mathrm{~W} \\
362126 \mathrm{~N} 1100154 \mathrm{~W} \\
342919 \mathrm{~N} 1124836 \mathrm{~W} \\
332601 \mathrm{~N} 1120540 \mathrm{~W} \\
335541 \mathrm{~N} 1124124 \mathrm{~W}\end{array}$ \\
\hline $\begin{array}{l}\text { building } \\
\text { dam }\end{array}$ & $\begin{array}{l}\text { UNOFF } \\
\text { UNOFF }\end{array}$ & $\begin{array}{l}\text { Maricopa } \\
\text { Graham }\end{array}$ & $\begin{array}{l}335540 \mathrm{~N} 1124125 \mathrm{~W} \\
331530 \mathrm{~N} 1095000 \mathrm{~W}\end{array}$ \\
\hline $\begin{array}{l}\text { locale } \\
\text { reservoir } \\
\text { reservoir } \\
\text { reservoir } \\
\text { well } \\
\text { spring }\end{array}$ & $\begin{array}{l}\text { BGN } \\
\text { BGN } \\
\text { BGN } \\
\text { BGN } \\
\text { UNOFF } \\
\text { BGN } \\
\text { VARIANT }\end{array}$ & $\begin{array}{l}\text { Coconino } \\
\text { Coconino } \\
\text { Graham } \\
\text { Coconino } \\
\text { Mohave } \\
\text { Gila }\end{array}$ & $\begin{array}{l}344931 \mathrm{~N} 1112609 \mathrm{~W} \\
344940 \mathrm{~N} 1112620 \mathrm{~W} \\
331259 \mathrm{~N} 1095029 \mathrm{~W} \\
351338 \mathrm{~N} 1115739 \mathrm{~W} \\
362315 \mathrm{~N} 1135708 \mathrm{~W} \\
34161 \mathrm{BN} 1105351 \mathrm{~W}\end{array}$ \\
\hline $\begin{array}{l}\text { ppl } \\
\text { valley }\end{array}$ & $\begin{array}{l}\text { BGN } \\
\text { VARIANT }\end{array}$ & $\begin{array}{l}\text { Navajo } \\
\text { Yavapai }\end{array}$ & $\begin{array}{l}345721 \mathrm{~N} 1102000 \mathrm{~W} \\
343124 \mathrm{~N} 1115049 \mathrm{~W}\end{array}$ \\
\hline locale & & Pima & $321500 \mathrm{~N} 1124500 \mathrm{~W}$ \\
\hline $\begin{array}{l}\text { flat } \\
\text { lake } \\
\text { well } \\
\text { reservoir }\end{array}$ & $\begin{array}{l}\text { BGN } \\
\text { BGN } \\
\text { UNOFF } \\
\text { BGN } \\
\text { VARIANT }\end{array}$ & $\begin{array}{l}\text { Cochise } \\
\text { Coconino } \\
\text { Yavapai } \\
\text { Graham }\end{array}$ & $\begin{array}{l}321334 \mathrm{~N} 1100810 \mathrm{~W} \\
352 \mathrm{~B} 07 \mathrm{~N} 1120427 \mathrm{~W} \\
340231 \mathrm{~N} 1121832 \mathrm{~W} \\
325000 \mathrm{~N} 1094735 \mathrm{~W}\end{array}$ \\
\hline $\begin{array}{l}\text { ppl } \\
\text { summit } \\
\text { reservoir } \\
\text { spring } \\
\text { reservoir }\end{array}$ & $\begin{array}{l}\text { BGN } \\
\text { BGN } \\
\text { BGN } \\
\text { BGN }\end{array}$ & $\begin{array}{l}\text { Navajo } \\
\text { Pinal } \\
\text { Pinal } \\
\text { Yavapai } \\
\text { Gila }\end{array}$ & $\begin{array}{l}345721 \mathrm{~N} 1102000 \mathrm{~W} \\
325613 \mathrm{~N} 1110931 \mathrm{~W} \\
325545 \mathrm{~N} 1110927 \mathrm{~W} \\
344051 \mathrm{~N} 1120543 \mathrm{~W} \\
340416 \mathrm{~N} 1104806 \mathrm{~W}\end{array}$ \\
\hline
\end{tabular}

locale BGN Apache $\quad 351731$ N1090928 crossing UNOFF Apache 351739 N1090925W

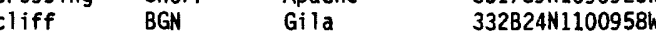
ppl

reservoir reservoir cemetery airport cliff

mine

spring
locale
mine
mine
reservoir
valley
school
stream
locale

locale

$\begin{array}{llll}\text { canal } & \text { BGN } & \text { Maricopa } & 332536 \mathrm{~N} 1114941 \mathrm{~W} \\ & \text { VARIANT } & & \\ \text { locale } & \text { UNOFF } & \text { Maricopa } & 332417 \mathrm{~N} 1115114 \mathrm{~W} \\ \text { locale } & \text { UNOFF } & \text { Maricopa } & 332417 \mathrm{~N} 1115125 \mathrm{~W} \\ \text { summit } & \text { BGN } & \text { Greenlee } & 332647 \mathrm{~N} 1090333 \mathrm{~W} \\ \text { schoo1 } & \text { UNOFF } & \text { Maricopa } & 332443 \mathrm{~N} 1115119 \mathrm{~W} \\ \text { park } & \text { AOMIN } & \text { Maricopa } & 332412 \mathrm{~N} 1115057 \mathrm{~W} \\ & \text { VARIANT } & & \\ \text { locale } & & \text { Pima } & 321 \mathrm{~B} 15 \mathrm{~N} 1120130 \mathrm{~W} \\ \text { mine } & \text { UNOFF } & \text { La Paz } & 332337 \mathrm{~N} 1135147 \mathrm{~W}\end{array}$

344347 N1105921W $350552 N 1094351 \mathrm{~W}$

$321145 N 1104535 \mathrm{~W}$ $320850 \mathrm{~N} 1105105 \mathrm{~W}$ $360443 N 1121007 \mathrm{~W}$ $342423 \mathrm{~N} 1122526 \mathrm{~W}$

$344342 \mathrm{~N} 1125550 \mathrm{~W}$ $314925 \mathrm{~N} 1113745 \mathrm{~W}$ $314859 \mathrm{~N} 1113759 \mathrm{~W}$ $332150 N 1134328 \mathrm{~W}$ $332930 \mathrm{~N} 1131418 \mathrm{~W}$ $332309 \mathrm{~N} 1105313 \mathrm{~W}$ $321300 \mathrm{~N} 1105803 \mathrm{~W}$ 342B01N1125313W $332448 \mathrm{~N} 1115119 \mathrm{~W}$ $\begin{array}{cc}\text { SOURCE } & \text { ELEV } \\ \text { COORDINATE } & \text { FT MAP NAME }\end{array}$

Mustang Knoll Wolf Hole Mtn West Sheridan Mtn Sheridan Mtn Governors Peak Gisela

Jerome Canyon Warm Springs Penitentiary Mtn Gisela

Many Ghosts Hill Leche-e Rock Hole In Rock Valley Bismarck Mesa Phoenix $361737 N 1095931 \mathrm{~W}$
$342855 \mathrm{~N} 1124710 \mathrm{~W}$

Wickenburg

Wickenburg Point of Pines West

7458 Hutch Mtn Hutch Mtn Bonita Tank Garland Prairie Pakoon Springs Woods Canyon

$342925 N 1115331 \mathrm{~W}$

Camp Verde

Deepwe 11 Ranch

Squaw Mtn Columbia

3022 Thatcher

2864 Ninetysix Hills NW Ninetys ix Hills NW Cottonwood Gentry Mtn

Houck

6120 Houck

Bronco Gulch Buckeye Hamilton Crossing Pinta

$332139 N 1105354 W$ Tucson East

2760 Tucson East Grand Canyon Groom Creek

Sheridan Mtn

3320 Chiuli Shaik Chiuli Shaik Cementosa Wash Cortez Peak NW Inspiration Tucson Hillside

Mesa

Mesa

1220 Mes

1220 Mesa

6640 Alma Mesa

Mesa

Mesa

Valencia 
AZ10

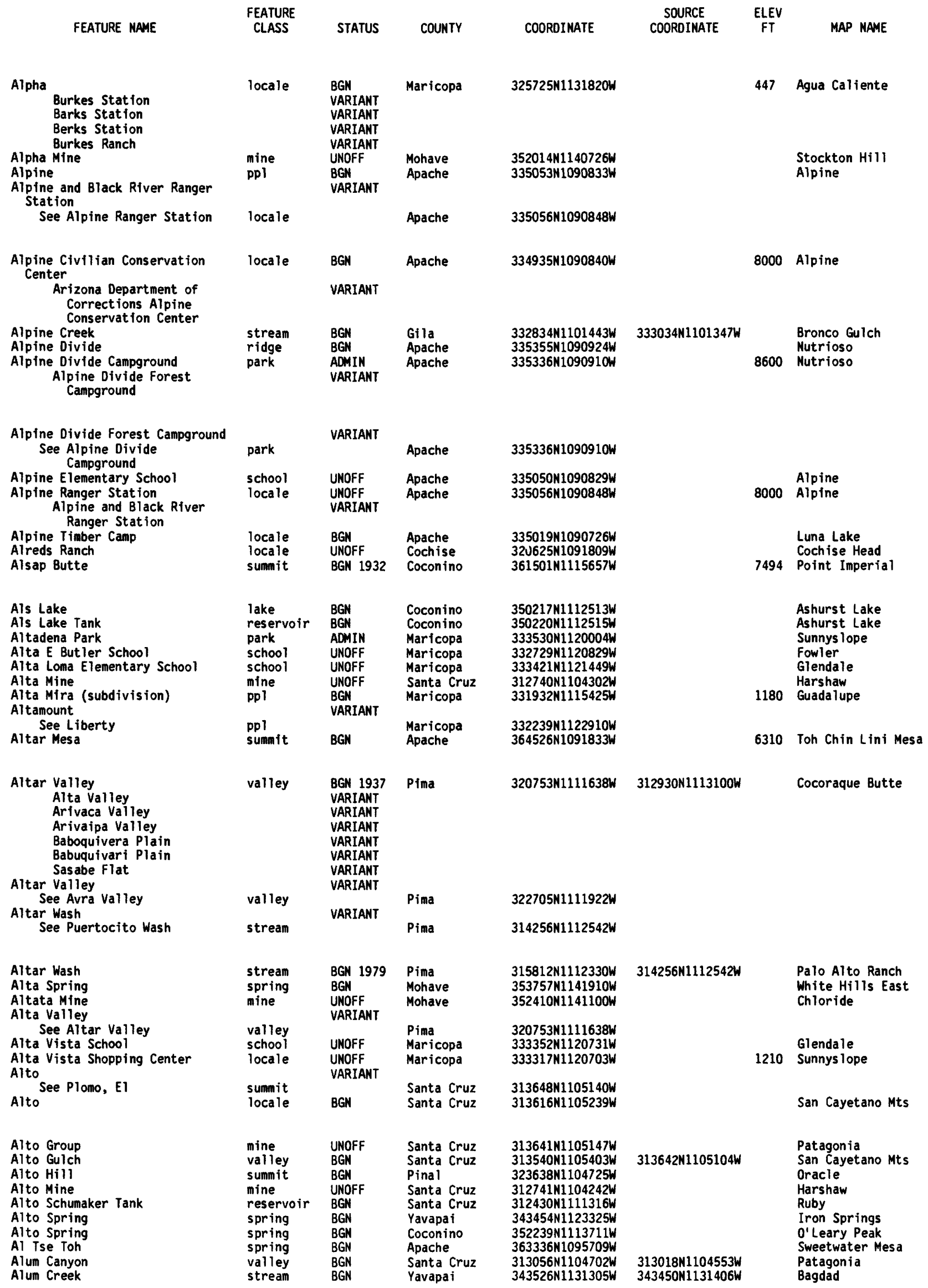

NATIONAL GAZETTEER--ARIZONA 1986 Berks Station

ine Civilian Conservation

ivide Campground

ine Divide Forest

ne Divide Forest Campground

ine and Black River anger Station

Alta E Butler School

tar Mes

Valley

Arivaipa Vall

Baboquivera Plain

tar Valley

r Wash

Atar Wash

Altata Mine

Altar valley

Alta Vista Shopping Center 


\section{FEATURE}

valley

Alvarez Mountains

Alva Shelly Reservoir

Alvernon Park

Alvord Park

Alzona Park

$$
\text { See Fowler }
$$

Amada Tank

Amado

Amado Mine

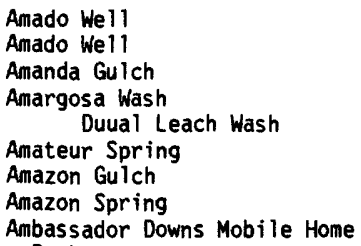

\section{Ambassador Mine}

Amberon Flat

Amberon Point

Amberwood (subdivision)

Amberwood II (subdivision)

Amberwood North (subdivision)

Ambrosia Landing Field

Ambrosia Mill

Ambush Water Pocket

Ambush Water Pocket

See Pen Pocket

Amended Dobson Estates Three

See Brighton Place (subdivision)

Amended Royal Estates West Five See Bristol Square (subdivision)

American Boy Mine

American Cement Corporation

Substation

American Dahk

See Dock

American Evangelist Day School American Evangel ist Lutheran Day Nursery American Evangel ist Lutheran Day Nursery

See American Evangelist Day School

American Flag $\mathrm{Hill}$

American $\mathrm{Hill}$

American Flag Ranch

American Flag Spring American Flag Springs

American Flag Springs

See American Flag Spring

American Gulch

American Gulch

American $\mathrm{Hill}$

See American Flag $\mathrm{Hill}$

American Indian Mission

American Institute for

Foreign Trade

American Legion Mine

American Mine

American Mine

American Mine

American Peak

American Ranch

American Tank

Amerone Spring Number One

ppl

ppl

mine

locale

locale

school

school

summit

locale

spring

spring

valley

valley

summit

church

school

mine

mine

mine

mine

summit

locale

\begin{tabular}{|c|c|c|c|}
\hline $\begin{array}{l}\text { valley } \\
\text { range } \\
\text { reservoir } \\
\text { park } \\
\text { park }\end{array}$ & $\begin{array}{l}\text { BGN } \\
\text { BGN } \\
\text { BGN } \\
\text { ADMIN } \\
\text { ADMIN } \\
\text { YARIANT }\end{array}$ & $\begin{array}{l}\text { Santa Cruz } \\
\text { Pima } \\
\text { Mohave } \\
\text { Pima } \\
\text { Maricopa }\end{array}$ & $\begin{array}{l}313018 \mathrm{~N} 1104553 \mathrm{~K} \\
314327 \mathrm{~N} 1115847 \mathrm{~W} \\
363238 \mathrm{~N} 1132505 \mathrm{~W} \\
321350 \mathrm{~N} 1105426 \mathrm{~W} \\
332239 \mathrm{~N} 1120759 \mathrm{~W}\end{array}$ \\
\hline $\begin{array}{l}\text { ppl } \\
\text { reservoir } \\
\text { ppl } \\
\text { mine }\end{array}$ & $\begin{array}{l}\text { BGN } \\
\text { BGN } \\
\text { UNOFF }\end{array}$ & $\begin{array}{l}\text { Maricopa } \\
\text { Santa Cruz } \\
\text { Santa Cruz } \\
\text { Pima }\end{array}$ & $\begin{array}{l}332705 N 1121211 \mathrm{~W} \\
312234 N 1110905 \mathrm{~W} \\
314228 \mathrm{~N} 1110350 \mathrm{~W} \\
313534 \mathrm{~N} 1112033 \mathrm{~W}\end{array}$ \\
\hline $\begin{array}{l}\text { well } \\
\text { well } \\
\text { valley } \\
\text { arroyo }\end{array}$ & $\begin{array}{l}\text { UNOFF } \\
\text { UNOFF } \\
\text { BGN } \\
\text { BGN } 1966 \\
\text { VARIANT }\end{array}$ & $\begin{array}{l}\text { Pina } \\
\text { Pima } \\
\text { Pinal } \\
\text { Pima }\end{array}$ & $\begin{array}{l}314207 N 1111806 \mathrm{~W} \\
314910 \mathrm{~N} 1105834 \mathrm{~W} \\
330950 \mathrm{~N} 1105855 \mathrm{~W} \\
315155 \mathrm{~N} 1110525 \mathrm{~W}\end{array}$ \\
\hline $\begin{array}{l}\text { spring } \\
\text { valley } \\
\text { spring } \\
\text { locale }\end{array}$ & $\begin{array}{l}\text { BGN } \\
\text { BGN } \\
\text { BGN } \\
\text { UNOFF }\end{array}$ & $\begin{array}{l}\text { Gila } \\
\text { Yavapai } \\
\text { Yavapai } \\
\text { Maricopa }\end{array}$ & $\begin{array}{l}332741 N 1105321 \mathrm{~h} \\
340600 \mathrm{~N} 1123349 \mathrm{k} \\
340518 \mathrm{~N} 1123301 \mathrm{~h} \\
332424 \mathrm{~N} 1114649 \mathrm{~h}\end{array}$ \\
\hline
\end{tabular}

spring
343456 N1120853W $340031 \mathrm{~N} 1092721 \mathrm{~W}$ $335942 \mathrm{~N} 1092731 \mathrm{~W}$ $332142 \mathrm{~N} 1115207 \mathrm{~W}$ $332045 \mathrm{~N} 1115041 \mathrm{H}$ $333935 \mathrm{~N} 1120845 \mathrm{~W}$ $334810 \mathrm{~N} 1131100 \mathrm{~W}$ 334759 N1131054W 360415 N1132729W

360416 N1132728W

reservoir

Mohave

VARIANT

$$
\text { UNOFF }
$$

VARIANT

Maricopa

VARIANT

Maricopa

Pinal

UNOFF

UNOFF

Yavapai

Pinal

Maricopa

VARIANT

VARIANT

VARIANT

reservoir
BGN

BGN

VARIANT

UNOFF

UNOFF

UNOFF

UNOFF

UNOFF

UNOFF

BGN

BGN

BGN
Maricopa

Pinal

Pinal

Pinal

Pinal

Yavapai

Gila

Pinal

Pinal

Mohave

Santa Cruz

Pinal

Mohave

Santa Cruz

Yavapai

Gila

Yavapai
Maricopa

$341441 \mathrm{N1} 112509 \mathrm{~W}$
332017 N1115147W

333524N1121123W

$324950 \mathrm{~N} 1113731 \mathrm{~W}$

$344636 \mathrm{~N} 1120500 \mathrm{~W}$

330756 N1114452W

$332957 N 1120553 W$

332957 N1120553W

323509 N1104337W

$323448 N 1104311 \mathrm{~W}$

$323255 \mathrm{~N} 1104227 \mathrm{~W}$

$323255 \mathrm{~N} 1104227 \mathrm{~W}$

$341130 \mathrm{~N} 1120953 \mathrm{~W}$

$341259 \mathrm{~N} 1121008 \mathrm{~W}$

341443N1111826W

$323509 \mathrm{~N} 1104337 \mathrm{~W}$

$330610 \mathrm{~N} 1115437 \mathrm{~W}$

$333725 \mathrm{~N} 1121059 \mathrm{~W}$

$351922 \mathrm{~N} 1140639 \mathrm{~W}$

$312717 \mathrm{N1} 104319 \mathrm{~W}$

$332001 \mathrm{~N} 1105902 \mathrm{~W}$

$341853 \mathrm{~N} 1133308 \mathrm{~W}$

312648 N $1104316 \mathrm{~W}$

$344026 \mathrm{~N} 1123236 \mathrm{~W}$

$341417 \mathrm{~N} 1112226 \mathrm{~W}$
$342833 \mathrm{~N} 1115055 \mathrm{~W}$

\begin{tabular}{|c|c|c|}
\hline \multirow[t]{2}{*}{$312621 \mathrm{~N} 1104446 \mathrm{~W}$} & & $\begin{array}{l}\text { Patagonia } \\
\text { Vamori } \\
\text { Little Tanks } \\
\text { Tucson } \\
\text { Fowler }\end{array}$ \\
\hline & & $\begin{array}{l}\text { Ruby } \\
\text { Amado } \\
\text { Arivaca }\end{array}$ \\
\hline $\begin{array}{l}330958 \mathrm{~N} 1105926 \mathrm{~W} \\
315149 \mathrm{~N} 1110635 \mathrm{~W}\end{array}$ & & $\begin{array}{l}\text { Cerro Colorado } \\
\text { Green Valley } \\
\text { Hot Tamale Peak } \\
\text { Esperanza Mill }\end{array}$ \\
\hline \multirow[t]{2}{*}{$340359 \mathrm{~N} 1123310 \mathrm{~W}$} & 1250 & $\begin{array}{l}\text { Inspiration } \\
\text { Morgan Butte } \\
\text { Morgan Butte } \\
\text { Mesa }\end{array}$ \\
\hline & $\begin{array}{l}1200 \\
1210 \\
1320\end{array}$ & $\begin{array}{l}\text { Humboldt } \\
\text { Greer } \\
\text { Big Lake North } \\
\text { Chandler } \\
\text { Chandler } \\
\text { Hedgpeth Hills } \\
\text { Tiger Well } \\
\text { Tiger Well } \\
\text { Whitmore Point SW }\end{array}$ \\
\hline
\end{tabular}

$\begin{array}{cc}\text { SOURCE } & \text { ELEV } \\ \text { COORDINATE } & \text { FT }\end{array}$

Casa Grande Mts Clarkdale

Phoenix

4B42 Campo Bonito

Campo Bonito

Campo Bonito

Bumble Bee

North Peak

Sacaton Butte Glendale

Stockton $\mathrm{Hill}$

Harshaw

Pinal Ranch

Artillery Peak

6212 Harshaw

Jerome Canyon

Payson South

Horner Mtn 


\begin{tabular}{|c|c|c|c|c|c|c|c|}
\hline FEATURE NAME & $\begin{array}{l}\text { FEATURE } \\
\text { CLASS }\end{array}$ & STATUS & COUNTY & COORDINATE & $\begin{array}{l}\text { SOURCE } \\
\text { COORDINATE }\end{array}$ & $\begin{array}{l}\text { ELEV } \\
\text { FT }\end{array}$ & MAP NAME \\
\hline $\begin{array}{l}\text { Amerone Spring Number Two } \\
\text { Amethyst Mine }\end{array}$ & $\begin{array}{l}\text { spring } \\
\text { mine }\end{array}$ & $\begin{array}{l}\text { BGN } \\
\text { UNOFF }\end{array}$ & $\begin{array}{l}\text { Yavapai } \\
\text { Maricopa }\end{array}$ & $\begin{array}{l}342 B 25 N 1115052 \mathrm{~W} \\
334021 \mathrm{~N} 1111954 \mathrm{~W}\end{array}$ & & & $\begin{array}{l}\text { Horner Mtn } \\
\text { Four Peaks }\end{array}$ \\
\hline $\begin{array}{l}\text { Amethyst Spring } \\
\text { Amigo Wash } \\
\text { Amity Ditch } \\
\text { Amole Dam } \\
\text { Amole Overpass } \\
\text { Amole Peak } \\
\text { Amole Peak }\end{array}$ & $\begin{array}{l}\text { spring } \\
\text { stream } \\
\text { canal } \\
\text { dam } \\
\text { crossing } \\
\text { summit }\end{array}$ & $\begin{array}{l}\text { BGN } \\
\text { BGN } \\
\text { BGN } \\
\text { UNOFF } \\
\text { UNOFF } \\
\text { BGN } 1969 \\
\text { VARIANT }\end{array}$ & $\begin{array}{l}\text { Maricopa } \\
\text { Pima } \\
\text { Apache } \\
\text { Santa Cruz } \\
\text { Pima } \\
\text { Pima }\end{array}$ & $\begin{array}{l}334016 \mathrm{~N} 1111956 \mathrm{~W} \\
313438 \mathrm{~N} 1112026 \mathrm{~W} \\
340555 \mathrm{~N} 1091855 \mathrm{~W} \\
313055 \mathrm{N1110554W} \\
315838 \mathrm{N1} 103049 \mathrm{~W} \\
321620 \mathrm{N1110915W}\end{array}$ & $313717 N 1111927 \mathrm{~W}$ & 4450 & $\begin{array}{l}\text { Four Peaks } \\
\text { Arivaca } \\
\text { Eagar } \\
\text { Tubac } \\
\text { The Narrows } \\
\text { Avra }\end{array}$ \\
\hline $\begin{array}{l}\text { See Wasson Peak } \\
\text { Amole Tank } \\
\text { Amos Lake }\end{array}$ & $\begin{array}{l}\text { summit } \\
\text { reservoir } \\
\text { lake }\end{array}$ & $\begin{array}{l}\text { BGN } \\
B G N\end{array}$ & $\begin{array}{l}\text { Pima } \\
\text { Santa Cruz } \\
\text { Navajo }\end{array}$ & $\begin{array}{l}321624 N 1110848 \mathrm{~W} \\
313312 \mathrm{~N} 1110938 \mathrm{~W} \\
340424 \mathrm{~N} 1095629 \mathrm{~W}\end{array}$ & & & $\begin{array}{l}\text { Murphy Peak } \\
\text { Indian Pine }\end{array}$ \\
\hline $\begin{array}{l}\text { Amos Mountain } \\
\text { Amos Point } \\
\text { Amos Ranch } \\
\text { Amos Spring } \\
\text { Amos Spring } \\
\text { Amos Tank } \\
\text { Amos Wash } \\
\text { Amphi Plaza } \\
\text { Amphitheater } \\
\text { Amphitheater High School }\end{array}$ & $\begin{array}{l}\text { summit } \\
\text { cliff } \\
\text { locale } \\
\text { spring } \\
\text { spring } \\
\text { reservoir } \\
\text { stream } \\
\text { locale } \\
\text { ppl } \\
\text { school }\end{array}$ & $\begin{array}{l}\text { BGN } \\
\text { BGN } \\
\text { UNOFF } \\
\text { BGN } \\
\text { BGN } \\
\text { BGN } \\
\text { BGN } \\
\text { BGN } \\
\text { BGN } \\
\text { UNOFF }\end{array}$ & $\begin{array}{l}\text { Navajo } \\
\text { Mohave } \\
\text { Navajo } \\
\text { Gila } \\
\text { Mohave } \\
\text { Gila } \\
\text { Gila } \\
\text { Pina } \\
\text { Pima } \\
\text { Pina }\end{array}$ & $\begin{array}{l}340436 \mathrm{~N} 1095641 \mathrm{~W} \\
355501 \mathrm{~N} 1133109 \mathrm{~W} \\
340527 \mathrm{~N} 1095941 \mathrm{~W} \\
334751 \mathrm{N1} 100710 \mathrm{~W} \\
355630 \mathrm{~N} 1133134 \mathrm{~W} \\
335015 \mathrm{~N} 1100657 \mathrm{~W} \\
334412 \mathrm{~N} 1100942 \mathrm{~W} \\
321553 \mathrm{~N} 1105737 \mathrm{~W} \\
321620 \mathrm{~N} 1105818 \mathrm{~W} \\
321606 \mathrm{~N} 1105824 \mathrm{~W}\end{array}$ & $335357 N 1100225 W$ & $\begin{array}{l}7293 \\
6054\end{array}$ & $\begin{array}{l}\text { Indian Pine } \\
\text { Amos Point } \\
\text { Indian Pine } \\
\text { Canyon Day } \\
\text { Amos Point } \\
\text { Canyon Day } \\
\text { Forks Butte } \\
\text { Tucson North } \\
\text { Tucson North } \\
\text { Tucson North }\end{array}$ \\
\hline $\begin{array}{l}\text { Amphitheater Junior High School } \\
\text { Amulet Mine Dump } \\
\text { Amusovi Mesa } \\
\text { See Little Black Spot } \\
\text { Mountain }\end{array}$ & $\begin{array}{l}\text { school } \\
\text { mine } \\
\text { summit }\end{array}$ & $\begin{array}{l}\text { UNOFF } \\
\text { UNOFF } \\
\text { VARIANT }\end{array}$ & $\begin{array}{l}\text { Pima } \\
\text { Yavapai } \\
\text { Navajo }\end{array}$ & $\begin{array}{l}321623 \mathrm{~N} 1105805 \mathrm{~W} \\
342755 \mathrm{~N} 1122143 \mathrm{~W} \\
360457 \mathrm{~N} 1101948 \mathrm{~W}\end{array}$ & & & $\begin{array}{l}\text { Tucson North } \\
\text { Poland Junction }\end{array}$ \\
\hline $\begin{array}{l}\text { Amuy Mine } \\
\text { Anaconda Spring } \\
\text { Analong Ranch } \\
\text { Anamax Park } \\
\text { Ancha, Sierra } \\
\text { Sierra Ancha Mountains }\end{array}$ & $\begin{array}{l}\text { mine } \\
\text { spring } \\
\text { locale } \\
\text { park } \\
\text { range }\end{array}$ & $\begin{array}{l}\text { UNOFF } \\
\text { BGN } \\
\text { UNOFF } \\
\text { ADMIN } \\
\text { BGN } 1932 \\
\text { VARIANT }\end{array}$ & $\begin{array}{l}\text { Yuma } \\
\text { Santa cruz } \\
\text { Cochise } \\
\text { Pima } \\
\text { Gila }\end{array}$ & $\begin{array}{l}332947 N 1140352 \mathrm{~W} \\
313746 \mathrm{~N} 1104758 \mathrm{~W} \\
320242 \mathrm{~N} 1092531 \mathrm{~W} \\
315555 \mathrm{~N} 1105917 \mathrm{~W} \\
335727 \mathrm{~N} 1111110 \mathrm{~W}\end{array}$ & & & $\begin{array}{l}\text { Livingston Hills } \\
\text { Mt Wrightson } \\
\text { Bowie Mtn South } \\
\text { Sahaurita } \\
\text { Picture Mtn }\end{array}$ \\
\hline $\begin{array}{l}\text { Ancho, Canal (historical) } \\
\text { Canal Fourteen } \\
\text { Ancient Tank } \\
\text { Andalucia Schoo1 } \\
\text { Andalusia (subdivision) } \\
\text { Anderson Butte } \\
\text { Anderson Canyon } \\
\text { Anderson Canyon } \\
\text { Anderson Canyon } \\
\text { Anderson Draw }\end{array}$ & $\begin{array}{l}\text { canal } \\
\text { reservoir } \\
\text { school } \\
\text { ppl } \\
\text { summit } \\
\text { valley } \\
\text { valley } \\
\text { valley } \\
\text { valley }\end{array}$ & $\begin{array}{l}\text { BGN } \\
\text { VARIANT } \\
\text { BGN } \\
\text { UNOFF } \\
\text { BGN } \\
\text { BGN } \\
\text { BGN } \\
\text { BGN } \\
\text { BGN } \\
\text { BGN }\end{array}$ & $\begin{array}{l}\text { Maricopa } \\
\text { Navajo } \\
\text { Maricopa } \\
\text { Maricopa } \\
\text { Yavapai } \\
\text { Mohave } \\
\text { Cochise } \\
\text { Coconino } \\
\text { Coconino }\end{array}$ & $\begin{array}{l}332842 \mathrm{~N} 1115148 \mathrm{~W} \\
343027 \mathrm{~N} 1103134 \mathrm{~W} \\
333011 \mathrm{~N} 1120938 \mathrm{~W} \\
333410 \mathrm{~N} 1115210 \mathrm{~W} \\
345127 \mathrm{~N} 1115800 \mathrm{~W} \\
315716 \mathrm{N1} 103134 \mathrm{~W} \\
320417 \mathrm{~N} 1092753 \mathrm{~W} \\
350639 \mathrm{N1} 110557 \mathrm{~W} \\
345805 \mathrm{~N} 1111939 \mathrm{~W}\end{array}$ & $\begin{array}{l}315232 \mathrm{~N} 1102512 \mathrm{~W} \\
320547 \mathrm{~N} 1092312 \mathrm{~W} \\
345805 \mathrm{~N} 1111940 \mathrm{~W} \\
345539 \mathrm{~N} 1112327 \mathrm{~W}\end{array}$ & $\begin{array}{l}1350 \\
4613\end{array}$ & $\begin{array}{l}\text { Mesa } \\
\text { Red Knoll } \\
\text { Glendale } \\
\text { Sawik Mountain } \\
\text { Page Springs } \\
\text { The Narrows } \\
\text { Bowie Mtn South } \\
\text { Meteor Crater } \\
\text { Kinnikinick Lake }\end{array}$ \\
\hline $\begin{array}{l}\text { Anderson Field } \\
\text { Anderson Lake } \\
\text { Anderson Mesa } \\
\text { Anderson Mesa } \\
\text { Anderson Mine } \\
\text { Anderson Mine } \\
\text { Anderson Ranch } \\
\text { Anderson Ranch } \\
\text { Anderson Spring } \\
\text { Anderson Spring }\end{array}$ & $\begin{array}{l}\text { flat } \\
\text { lake } \\
\text { summit } \\
\text { summit } \\
\text { mine } \\
\text { mine } \\
\text { locale } \\
\text { locale } \\
\text { spring } \\
\text { spring }\end{array}$ & $\begin{array}{l}\text { BGN } \\
\text { BGN } \\
\text { BGN } \\
\text { BGN } \\
\text { UNOFF } \\
\text { UNOFF } \\
\text { UNOFF } \\
\text { UNOFF } \\
\text { BGN } \\
\text { BGN }\end{array}$ & $\begin{array}{l}\text { Yavapai } \\
\text { Apache } \\
\text { Yavapai } \\
\text { Coconino } \\
\text { Santa Cruz } \\
\text { Yavapai } \\
\text { Maricopa } \\
\text { Coconino } \\
\text { Graham } \\
\text { Gila }\end{array}$ & $\begin{array}{l}344105 \mathrm{~N} 1124829 \mathrm{~W} \\
341559 \mathrm{~N} 1094217 \mathrm{~W} \\
344322 \mathrm{N1} 130013 \mathrm{~W} \\
350319 \mathrm{N1} 112623 \mathrm{~W} \\
313210 \mathrm{N1} 102740 \mathrm{~W} \\
341829 \mathrm{N1} 131629 \mathrm{~W} \\
332100 \mathrm{~N} 1113632 \mathrm{~W} \\
363913 \mathrm{N1} 115436 \mathrm{~W} \\
325935 \mathrm{~N} 1102541 \mathrm{~W} \\
331247 \mathrm{~N} 1103200 \mathrm{~W}\end{array}$ & & $\begin{array}{l}5779 \\
1446\end{array}$ & $\begin{array}{l}\text { Smith Mesa } \\
\text { Vernon } \\
\text { Behn Mesa } \\
\text { Ashurst Lake } \\
\text { Pyeatt Ranch } \\
\text { Arrastra Mtn SE } \\
\text { Desert Well } \\
\text { Emnett Hill } \\
\text { Booger Canyon } \\
\text { Coolidge Dam }\end{array}$ \\
\hline $\begin{array}{l}\text { Anderson Spring } \\
\text { Anderson Spring } \\
\text { Anderson Spring } \\
\text { Anderson Tank } \\
\text { Anderson Tank } \\
\text { Anderson Tank } \\
\text { Anderson Tank Number One } \\
\text { Anderson Tank Number Two } \\
\text { Anderson Well } \\
\text { Andrada Ranch }\end{array}$ & $\begin{array}{l}\text { spring } \\
\text { spring } \\
\text { spring } \\
\text { reservoir } \\
\text { reservoir } \\
\text { reservoir } \\
\text { reservoir } \\
\text { reservoir } \\
\text { well } \\
\text { locale }\end{array}$ & $\begin{array}{l}\text { BGN } \\
\text { BGN } \\
\text { BGN } \\
\text { BGN } \\
\text { BGN } \\
\text { BGN } \\
\text { BGN } \\
\text { BGN } \\
\text { UNOFF } \\
\text { UNOFF }\end{array}$ & $\begin{array}{l}\text { Gila } \\
\text { Yavapai } \\
\text { Coconino } \\
\text { Pinal } \\
\text { Gila } \\
\text { Coconino } \\
\text { Coconino } \\
\text { Coconino } \\
\text { Coconino } \\
\text { Pima }\end{array}$ & $\begin{array}{l}335211 \mathrm{~N} 1101139 \mathrm{~W} \\
340313 \mathrm{~N} 1122437 \mathrm{~W} \\
345800 \mathrm{~N} 1111847 \mathrm{~W} \\
324441 \mathrm{~N} 1104732 \mathrm{~W} \\
341727 \mathrm{N1110915W} \\
354916 \mathrm{~N} 1115202 \mathrm{~W} \\
345812 \mathrm{~N} 1112029 \mathrm{~W} \\
345800 \mathrm{~N} 1111855 \mathrm{~W} \\
350515 \mathrm{~N} 1110828 \mathrm{~W} \\
315632 \mathrm{~N} 1103855 \mathrm{~W}\end{array}$ & & & $\begin{array}{l}\text { Cone Butte } \\
\text { Copperopolis } \\
\text { Kinnikinick Lake } \\
\text { North of Oracle } \\
\text { Diamond Point } \\
\text { Peterson Flat } \\
\text { Kinnikinick Lake } \\
\text { Kinnikinick Lake } \\
\text { Anderson Canyon } \\
\text { Mount Fagan }\end{array}$ \\
\hline $\begin{array}{l}\text { Andrada Tank } \\
\text { Andrews Spring } \\
\text { Andrus Canyon } \\
\text { See Parashant Canyon } \\
\text { Andrus Canyon } \\
\text { Andrus Draw } \\
\text { Donsill Canyon } \\
\text { Andrus Draw }\end{array}$ & $\begin{array}{l}\text { reservoir } \\
\text { spring } \\
\text { valley } \\
\text { valley }\end{array}$ & $\begin{array}{l}\text { BGN } \\
\text { 8GN } \\
\text { VARIANT } \\
\text { BGN } \\
\text { VARIANT } \\
\text { VARIANT } \\
\text { VARIANT }\end{array}$ & $\begin{array}{l}\text { Pima } \\
\text { Coconino } \\
\text { Mohave } \\
\text { Mohave }\end{array}$ & $\begin{array}{l}314842 \mathrm{~N} 1103947 \mathrm{~W} \\
350933 \mathrm{~N} 1121520 \mathrm{~W} \\
360542 \mathrm{~N} 1131923 \mathrm{~W} \\
360855 \mathrm{~N} 1132104 \mathrm{~W}\end{array}$ & $361404 \mathrm{~N} 1133020 \mathrm{~W}$ & & $\begin{array}{l}\text { Empire Ranch } \\
\text { McLellan Reservoir }\end{array}$ \\
\hline
\end{tabular}


NATIONAL GAZETTEER--ARIZONA 1986

FEATURE NAME

See Andrus Canyon

Andrus Point

Andrus Spring

Andys Hole

Andys Pothole

An-e' etseghi

See Muerto, Canyon del

Anegam

Anegam Wash

Anegan Wash

Comobabi Wash

Pavo Kug Wash

Angeles Wash, Los

Angel Field

Angelica Wash

Angell

Laguna

Angell Railroad Station

Angel Point

Angels Gate

Angel Spring

Angels Window

Angel Trail Spring

Angle Canyon

Angle Orchard

Anguis House (historical)

Aniceto Spring

Anido Creek

See Tsitah Wash

Anillo Tank

Animas Mountain

See Animas Mountain, Las

Animas Mountain, Las

Animas Mountain

Las Animas Hills

Las Animas Mountains

Las Animas Range

Sierra de las Animas

Sierra las Animas

A-ninetyone Spring

A Ninetysix Spring

Anita Park

Anita Spring

Anita Station

Anita Tank

Anita Well

Gray Well

Mesquite Gray Well

Annabel Spring

Anna Lawrence Elementary School See Lawrence School

Anne Bee Well

\section{Annie Mine}

Ann Pond

Ansel Spring

Antares

Antelope Canyon

Antelope Canyon

Antelope Canyon

Antelope Creek

Antelope Creek

Antelope Creek

See Bumble Bee Creek

Antelope Creek

Antelope Creek

Antelope Wash

Antelope Dam

Antelope Detention Dam

Antelope Draw

Antelope Draw Tank

Antelope Flat

FEATURE

valley

summit

spring

bend

lake

valley

ppl

stream

stream

STATUS COUNTY

COORDINATE

Mohave

BGN Mohave

360855N1132104W

Mohave

BGN

BGN

BGN

VARIANT

BGN

BGN

BGN 1977

VARIANT

VARIANT

stream

airport

locale

building

summit

summit

spring

arch

BGN

ADMIN

BGN 1966

BGN

VARIANT

UNOFF

BGN

BGN 1906

$B G N$
$B G N$

Mohave

Coconino

Pima

$322458 \mathrm{~N} 1115919 \mathrm{~W}$

spring

valley

locale

locale

spring

stream

reservoir BGN

BGN

BGN

BGN

BGN

BGN

VARIANT

VARIANT

Yuma

Graham

Pima

Coconino

Coconino

La Paz

Coconino

Pinal

Coconino

$323634 \mathrm{~N} 109565 \mathrm{BW}$

$315754 \mathrm{~N} 1110347 \mathrm{~W}$

Santa Cruz 312130N1105040W

Apache

summi

BGN 1941 Pima

VARIANT

VARIANT

VARIANT

VARIANT

VARIANT

VARIANT

spring

spring

BGN

BGN

Navajo

Gila

locale

reservoir

BGN Coconino

VARIANT

VARIANT

spring

BGN

VARIANT

Pima

we 11

UNOFF

Pima

$365710 \mathrm{~N} 1112626 \mathrm{~W}$

stream

BGN

Yavapai

Yavapai

stream

stream

BGN

BGN
VARIANT

dam UNOFF

dam UNOFF

valley

reservoir

UNON
BGN

BGN
$361147 \mathrm{N1132157 \textrm {W }}$

361440 N1133010W

$343247 \mathrm{~N} 1132915 \mathrm{~W}$

$343814 \mathrm{~N} 1112606 \mathrm{~W}$

Apache 360835N1092920W

Pima 322222N1120149W

$321059 \mathrm{~N} 1114007 \mathrm{~W}$

$322729 \mathrm{~N} 1121126 \mathrm{~W}$

$320100 \mathrm{~N} 1114345 \mathrm{~W}$

Santa Rosa Mts NW

Black Hills

330156 N1142158W

$351144 N 1111812 W$

$351141 \mathrm{N1111817 \textrm {W }}$

$334648 N 1142053 \mathrm{~W}$

$360531 \mathrm{~N} 1115919 \mathrm{~W}$

$332746 \mathrm{~N} 1111242 \mathrm{~W}$

$360716 \mathrm{~N} 1115647 \mathrm{~W}$

$330622 \mathrm{~N} 1141533 \mathrm{~W}$

$315751 N 1110551 \mathrm{~W}$

Middle Mts North

4683 Fort Grant

Twin Buttes

Angell

Ange 11

Moon Mtn SE

Cape Royal

Iron Mountain

Cape Royal

Graham 330513N1094848W

Cochise 321802N1093542W

Grahan 323941N1094732W

Apache 341211N1094234W

$370944 N 1090 B 15 \mathrm{~W}$

$321444 \mathrm{~N} 1103520 \mathrm{~W}$

$314335 \mathrm{~N} 1114910 \mathrm{~W}$

314335 N1114910W

$321658 N 1093643 W$

Markham Creek

Luzena

Mt Graham

3720 Kino Springs

Boundary Butte

Mica Mountain

$335244 N 1095501 \mathrm{~W}$

$335621 N 1101821 \mathrm{~W}$

$315113 \mathrm{~N} 1091715 \mathrm{~W}$

spring BGN Cochise 315107N1091708W

$355143 \mathrm{~N} 1121453 \mathrm{~W}$

$355131 N 1121447 \mathrm{~W}$

BGN 1981 Santa Cruz 313606N1110615W

$322619 N 1104702 W$

320739 N1110413W

$313848 \mathrm{~N} 1111304 \mathrm{~W}$

$330018 \mathrm{~N} 1142046 \mathrm{~W}$

$362106 \mathrm{~N} 1132023 \mathrm{~W}$

$340210 \mathrm{~N} 1110029 \mathrm{~W}$

$352511 \mathrm{~N} 1134828 \mathrm{~W}$

$32302 \mathrm{BN} 1090208 \mathrm{~W}$

$353655 \mathrm{N114125 \textrm {IW }}$

331051 N1090257W

$340218 \mathrm{~N} 1124719 \mathrm{~W}$

$341119 N 1121005 \mathrm{~W}$
Yavapai

Coconino

Yavapai

Mohave

Coconino

Coconino

Coconino
341638 N1120847W $365710 \mathrm{~N} 1112632 \mathrm{~W}$

$345630 \mathrm{~N} 1124053 \mathrm{~W}$

363512 N1125930W

$344003 \mathrm{~N} 1112056 \mathrm{~W}$

$343933 \mathrm{~N} 1111936 \mathrm{~W}$

$354105 \mathrm{~N} 1115620 \mathrm{~W}$ $\begin{array}{cc}\text { SOURCE } & \text { ELEV } \\ \text { COORDINATE } & \text { FT }\end{array}$

5425 Whitmore Point

3048 South Komelik

Alchesay flat

Carrizo

Chiricahua Peak

Chiricahua Peak

Red Butte SW

Red Butte SW

Tubac 
FEATURE NAME

Antelope Flats

Antelope $\mathrm{Hill}$

Antelope Peak

Antelope $\mathrm{Hill}$

Antelope $\mathrm{Hill}$

Antelope $\mathrm{Hill}$

See Tanque Aloma

Antelope Hills

See Copper Mountains

Antelope Hills

Ante lope Hills

Antelope Hills

Antelope Hills

Antelope Hills Stage Station See Tanque Aloma

Antelope House Ruins

Antelope Is land

Lake Powell Is land

San Carlos Is land

Antelope Knoll

Antelope Knoll Pond

Antelope Lake

Antelope Lake Campground

Antelope Mesa

Antelope Mesa

Antelope Mesa

Antelope Mine

Antelope Mountain

Antelope Park

Antelope Park Tank

Antelope Pass

Antelope Peak

Antelope Peak

See Antelope Hill

Antelope Peak

Antelope Peak

Antelope Peak

Antelope Point

Antelope Point

Antelope Prairie

Antelope Ranch

Antelope Ranch Airport

Antelope Ravine

Antelope Ridge

Antelope Spring

Antelope Spring

Antelope Spring

Antelope Spring

Antelope Spring

Antelope Springs

Antelope Tank

Antelope Tank

Antelope Tank

Antelope Tank

Antelope Tank

Antelope Tank

Antelope Tank

Antelope Tank

Antelope Tank

Antelope Tank

Antelope Tank

Antelope Tank

Antelope Tank

Antelope Tank

Antelope Tank

Antelope Tank

Antelope Tank

Antelope Tank

Antelope Tank

Antelope Tank

Antelope Tank
FEATURE
CLASS

STATUS

COUNTY

COORDINATE

$\begin{array}{llll}\text { flat } & \text { BGN } & \text { Graham } & 332331 N 1101921 \mathrm{~W} \\ \text { summit } & \text { BGN } & \text { Yuma } & 324214 N 1140054 \mathrm{~W}\end{array}$

VARIANT

summit

summit

ppl

range

range

summit

summit
summit

BGN
BGN
VARIANT

VARIANT

Coconino

$352139 N 1115033 \mathrm{~W}$

$353302 \mathrm{~N} 1114056 \mathrm{~W}$

324150N1135725W

Yuma

VARIANT

BGN

BGN

BGN

Yuma

Yavapai

Pima

Graham

Apache

322912N1135857W

$345028 \mathrm{~N} 1120715 \mathrm{~W}$

$321153 \mathrm{~N} 1131639 \mathrm{~W}$

332417 N1101908W

$341118 \mathrm{~N} 1094444 \mathrm{~W}$

pp1

locale

VARIANT

sland

BGN

BGN 1976

Yuma

$324150 \mathrm{N1135725W}$

VARIANT

summit

reservoir

lake

BGN

BGN

BGN
ADMIN

Mohave

summit

summit

summit

mine

summit

flat

reservoir

gap

summit

BGN

$B G N$

$B G N$

UNOFF

BGN

BGN

BGN

BGN

VARIANT

summ it

$\begin{array}{ll}\text { summit } & \text { BGN } \\ \text { summit } & B G N \\ \text { summit } & B G N \\ \text { cliff } & B G N \\ \text { cliff } & B G N \\ \text { flat } & \text { BGN } \\ \text { locale } & \text { UNOFF } \\ \text { airport } & \text { AOMIN } \\ \text { valley } & \text { BGN } \\ \text { ridge } & \text { BGN }\end{array}$

Apache

mine

spring

spring

spring

spring

spring

reservoir

reservoir

reservoir

UNOFF

BGN

BGN

BGN

BGN

BGN

BGN

BGN

BGN

BGN
BGN

Coconino

reservoir $B G N$

reservoir BGN

reservoir $B G N$

reservoir BGN

reservoir $B G N$

reservoir $B G$

reservoir BGI

reservoir $B G$

reservoir $B G$

reservoir $B G$

reservoir $B G N$

reservoir $B G$

reservoir $B G$

reservoir $B G$

reservoir $B G$

reservoir $B G$

reservoir $B G N$

344442 N1104314W
Apache

Mohave

Apache

Apache

Greenlee

Greenlee

Navajo

Pinal

Apache

Coconino

Coconino

Coconino

Pinal

Yuma

Pinal

Pinal

Yavapai

Coconino

Apache

Coconino

Cochise

Yuma

Pinal

Cochise

Yavapai

Mohave

Mohave

Mohave

Cochise

Graham

Pinal

Gila

$360926 N 1092639 \mathrm{~W}$

365900N1112600W

364119 N1131227W

$364011 N 1131135$

$353019 N 1092013 \mathrm{~W}$

353018N1092010W

$331254 \mathrm{N1090612 \textrm {W }}$

$331255 N 1090838 \mathrm{~W}$

$354622 \mathrm{N1101230 \textrm {W }}$

$325332 \mathrm{N1} 105033 \mathrm{~W}$

$340546 \mathrm{~N} 1092753 \mathrm{~W}$

$35932 \mathrm{~N} 1113406 \mathrm{~W}$

$345936 \mathrm{~N} 1113338 \mathrm{~W}$

$363855 N 1113734 \mathrm{~W}$

$324035 \mathrm{~N} 1110118 \mathrm{~W}$

$324214 N 1140054 \mathrm{~W}$

324817N1121025W

325103N1105137W

$341255 \mathrm{N1124350 \textrm {W }}$

$360410 \mathrm{~N} 1123514 \mathrm{~W}$

$360856 \mathrm{N1} 093008 \mathrm{~W}$

$353353 \mathrm{~N} 1112533 \mathrm{~W}$

$321756 \mathrm{~N} 1101220 \mathrm{~W}$

$324300 \mathrm{N1140100 \textrm {W }}$

$323856 \mathrm{~N} 1105932 \mathrm{~W}$

$364503 N 1094447 \mathrm{~W}$

$323732 N 1105839$

$351706 \mathrm{N1122632W}$

$314026 \mathrm{N1} 1095403 \mathrm{~W}$

$341243 \mathrm{N1124228 \textrm {W }}$

$345804 N 1141825 \mathrm{~W}$

$365636 \mathrm{N1131437 \textrm {W }}$

$353602 \mathrm{N1141208W}$

$320918 N 1100133 \mathrm{~W}$

$323139 N 1100731 \mathrm{~W}$

$325018 N 1104957 \mathrm{~W}$

$332904 N 1102153 \mathrm{~W}$

$333819 N 1095554 \mathrm{~W}$

$341126 \mathrm{~N} 1120023 \mathrm{~W}$

$341610 \mathrm{~N} 1095340 \mathrm{~W}$

342647 N1120222W

$342812 \mathrm{~N} 1113647 \mathrm{~W}$

342849 N1093947W

343826 N1095607W

343919 N1111847W

$344340 \mathrm{~N} 1113756 \mathrm{~W}$

344511 N1132537W

$344609 \mathrm{~N} 1111030 \mathrm{~W}$

$344750 \mathrm{~N} 1130230 \mathrm{~W}$

$344824 N 1093304 W$

Coconino

Yavapai

Apache

Coconino

Yavapai

$44855 \mathrm{~N} 1111732 \mathrm{~W}$

$345000 \mathrm{~N} 1121237 \mathrm{~W}$

$345000 \mathrm{~N} 1130015 \mathrm{~W}$

SOURCE

COORDINATE

ELEV
FT

MAP NAME

815 Wellton Mesa

8243 Wing Mountain

7008 S P Mountain

Clarkdale Antelope $\mathrm{Hi}$ ils

4336 Sontag Mesa

Boundary Butte

Del Muerto

Page

5951 Antelope Knoll Antelope Knoll 


\section{FEATURE NAME}

Antelope Tank

Antelope Tank

Antelope Tank

Antelope Tank

See Grove Tank

Antelope Tank

Antelope Tank

Antelope Tank

Antelope Tank

Antelope Tank

Antelope Tank

Antelope Tank

Antelope Tank

Antelope Tank

Antelope Trail

Antelope Trail Spring

Antelope Union High School

Antelope Valley

See Upper Clayhole Valley

Antelope Valley

Antelope Valley

See Stanton

Antelope Valley Detention Dam

Antelope Wash

Antelope Wash

Antelope Wash

Antelope Wash

Antelope Wash

Antelope Wash

See Antelope Creek

Antelope Well

Antelope We I

Antelope Well

Antelope Well

Antelope Well

Antelope Well

Antler Mine

Ant ler Mine

Ant ler Spring

Antolini $\mathrm{Hil}$

Antonio Canyon

Antonio Tank

Antonio Tank

Anuawooch
See Ahan Owuch
Anvil Mountain
Anvil Ranch
Anvil Rock
Anvil Rock Ranch
Anvil Tank
A-one Bas in
A One Dam
A One Lake
A One Lake
A One Lake Campground
A One Mountain
See A I Mountain
A One Mountain Interchange
A- One Spring
Apache
Apache Acres Trailer Park
Apache Butte
Apache Butte
Apache Canyon
See Little Campaign Creek
Apache Canyon
Apache Canyon
Apache Canyon
Apache Canyon
Apache Cave
See Browns Cave

FEATURE

CLASS

STATUS

COUNTY

COORDINATE

reservoir

reservoir

reservoir

$B G N$
$B G N$
$B G N$

Mohave

Coconino

Yavapai

$345334 \mathrm{~N} 1132311 \mathrm{~W}$

$350232 \mathrm{~N} 1130231 \mathrm{~W}$

VARIANT

reservoir

reservoir

reservoir

reservoir

reservoir

reservoir

reservoir

reservoir

BGN
BGN
$B G N$
$B G N$
$B G N$
$B G N$
$B G N$
BGN

Coconino

Mohave

Coconino

Mohave

Coconino

Coconino

Coconino

Coconino

reservoir

spring

school

valley

valley

locale

dam

BGN Coconino

UNOFF

BGN

UNOFF
VARIANT

Apache

Apache

Yuma

Mohave

BGN

VARIANT

UNOFF

Mohave

Yavapai

Mohave

stream

stream

stream

stream

stream

stream

well

well

well

$\begin{array}{ll}\text { BGN } & \text { Pinal } \\ \text { BGN } & \text { Yavapai } \\ \text { BGN } & \text { Mohave } \\ \text { BGN } & \text { Coconino } \\ \text { BGN } & \text { Coconino } \\ \text { VARIANT } & \\ & \text { Coconino } \\ \text { UNOFF } & \text { Cochise } \\ \text { UNOFF } & \text { Pinal } \\ \text { UNOFF } & \text { Apache }\end{array}$

well

well

well

mine

mine

spring

valley

reservoir

reservoir

UNOFF

UNOFF

UNOFF

UNOFF

UNOFF

BGN

BGN

BGN

BGN

Mohave

Apache

Coconino

Mohave

Mohave

Mohave

Coconino

Santa Cruz

Santa Cruz

Pima

VARIANT

locale

sumait

locale

summit

locale

reservoir

basin

lake

BGN

UNOFF

BGN

UNOFF

BGN

BGN
UNOFF

BGN

reservoir

park

BGN

ADMIN

VARIANT

summ it

crossing

spring

locale

locale

summit

summit

UNOFF

BGN

BGN

UNOFF

BGN

BGN

Pima

La Paz

Pima

Yavapai

Yavapai

Pima

Yuma

Apache

Coconino

Apache

Apache

Coconino

Coconino

Navajo

Cochise

Maricopa

Apache
Navajo

VARIANT

stream

valley

valley

valley

valley

cave

$\begin{array}{ll}\text { BGN } & \text { Gila } \\ \text { BGN } & \text { Pima } \\ \text { BGN } & \text { Gima } \\ \text { BGN 1965 } & \text { Gila } \\ \text { VARIANT } & \\ & \text { Maricopa }\end{array}$

$352120 \mathrm{N1123440 \textrm {W }}$

$352515 \mathrm{~N} 1132735 \mathrm{~W}$

352720 N1122518W

$352822 \mathrm{~N} 1132134 \mathrm{~W}$

$353008 N 1115807 \mathrm{~W}$

$353612 N 1130427 W$

$353736 \mathrm{~N} 1130434 \mathrm{~W}$

$354037 N 1120143 W$

$354950 \mathrm{~N} 1115639 \mathrm{~W}$

364559 N1111915W

$360852 \mathrm{N1092637 \textrm {W }}$

$355438 \mathrm{~N} 1095857 \mathrm{~W}$

$324132 \mathrm{N1} 140119 \mathrm{~W}$

$363900 \mathrm{~N} 113000 \mathrm{WW}$

$363928 \mathrm{~N} 1130254 \mathrm{~W}$

$340955 \mathrm{~N} 1124343 \mathrm{~W}$

$363530 \mathrm{~N} 1125854 \mathrm{~W}$

$325052 \mathrm{~N} 1120610 \mathrm{~W}$

$345600 \mathrm{~N} 1123448 \mathrm{~W}$

$350029 N 1133934 \mathrm{~W}$

$353516 \mathrm{~N} 1111947 \mathrm{~W}$

354048 N1110839W

$365710 \mathrm{N1112632 \textrm {W }}$

$322325 \mathrm{~N} 1092349 \mathrm{~W}$

$325134 \mathrm{~N} 1104901 \mathrm{~W}$

$341825 N 1093122 \mathrm{~W}$

350049 N1134115W

$350352 \mathrm{~N} 1090843 \mathrm{~W}$

$352753 N 1114713 \mathrm{~W}$

$342245 N 1132447 \mathrm{~W}$

$345258 \mathrm{~N} 1135805 \mathrm{~W}$

$350407 N 1133107 \mathrm{~W}$

$351650 \mathrm{~N} 1122610 \mathrm{~W}$

$312031 \mathrm{~N} 1103950 \mathrm{~W}$

$312004 N 1103943 \mathrm{~W}$

$313441 N 1113835 \mathrm{~W}$

$320833 \mathrm{~N} 1122034 \mathrm{~W}$

$332314 N 1132020 \mathrm{~W}$

315849 N1112257W

$350256 \mathrm{~N} 1130704 \mathrm{~W}$

$350324 \mathrm{~N} 1130740 \mathrm{~W}$

$315859 N_{1} 112342 \mathrm{~W}$

$322041 N 1134810 \mathrm{~W}$

$340136 \mathrm{~N} 1093712 \mathrm{~W}$

$351346 \mathrm{~N} 1114231 \mathrm{~W}$

$340139 N 1093712 \mathrm{~W}$

$340140 \mathrm{~N} 1093722 \mathrm{~W}$

351 405N1114409W

$351152 N 1114431 \mathrm{~W}$

$340227 N 1095654 \mathrm{~W}$

$332502 \mathrm{~N} 1113605 \mathrm{~W}$

$335535 N 1093932 \mathrm{~W}$

$345540 \mathrm{~N} 1102640 \mathrm{~W}$

$333120 N 1105937 \mathrm{~W}$

$313420 \mathrm{N1111359 \textrm {W }}$

$315317 N 1103239 \mathrm{~W}$

$322625 N 1094901 \mathrm{~W}$

332947 N1105930W

325027 N1120837W

$345612 \mathrm{N1} 124450 \mathrm{~W}$

$350411 N 1135337 \mathrm{~W}$

$353203 \mathrm{~N} 1112527 \mathrm{~W}$

$353937 \mathrm{~N} 1110503 \mathrm{~W}$

$312031 N 1103550 \mathrm{~W}$

6046 Fitzgera1d Hill
Duquesne

Caponera Peak

2302 Phoenix

Palo Alto Ranch

5310 Anvil Rock

5250 Anvil Rock Ranch

Palo Alto Ranch

Cabeza Prieta Peak

Greens Peak

Flagstaff West

Greens Peak

Greens Peak

Flagstaff West

Indian Pine

4382 Apache

1600 Apache Junction

9773 Hawley Lake East

5186 Apache Butte

$313124 N 1111008 \mathrm{~W}$

$314929 \mathrm{~N} 1102556 \mathrm{~W}$

322816 N1094759W

$333041 \mathrm{~N} 1110101 \mathrm{~W}$

Murphy Peak

The Narrows

Greasewood Mountain 
FEATURE NAME

Apache Cemetery

Apache Chief Mine

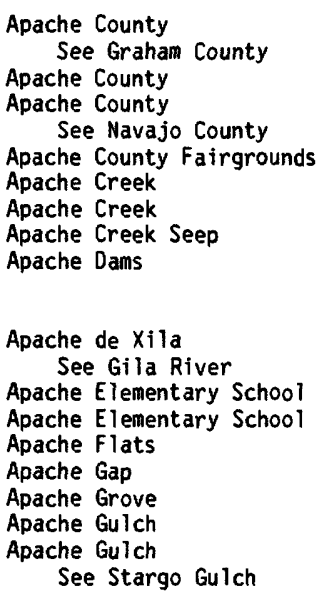

Apache Peak Well

Apache Plaza Shopping Center Apache Point

Apache Pond Dam Number One

Apache Pond Dam Number Two

Apache Pond Number One
FEATURE CLASS

\section{cemeter}

mine

UNOFF

UNOFF

COUNTY

Cochise

Yuma

VARIANT

civil

civil

civil

park

stream

stream

spring

dam

ADM
VARIA
ADM
BGN
BGN
BGN
UNO

stream

school

school

pp 1

gap

locale

arroyo

valley

VARIANT

UNOFF

UNOFF

BGN

BGN 1917

8GN

BGN

VARIANT

summit

ppl

airport

school

school

BGN

BGN
ADNIN

UNOFF

school

reservoir

park

reservoir

UNOFF

UNOFF
BGN

ADMIN

BGN

cliff

locale

summit

locale

locale

reservoir

trail

mine

mine

mine

BGN

BGN

UNOFF

UNOFF

BGN

BGN
UNOFF
UNOFF

UNOFF

UNOFF

Graham

Apache

Navajo

Apache

Greenlee

Yavapai

Yavapai

Santa Cruz

COORDINATE

$314043 \mathrm{~N} 1090749 \mathrm{~W}$

$333720 \mathrm{~N} 1140343 \mathrm{~W}$

$330100 \mathrm{~N} 1100100 \mathrm{~W}$

$350030 \mathrm{~N} 1092230 \mathrm{~W}$

$365615 N 1104845 \mathrm{~W}$

$343052 \mathrm{~N} 1092233 \mathrm{~W}$ $325206 \mathrm{~N} 1091149 \mathrm{~W}$

$345512 \mathrm{~N} 1125039 \mathrm{~W}$

$345328 \mathrm{~N} 1125300 \mathrm{~W}$

$312535 \mathrm{~N} 1111421 \mathrm{~W}$

$325900 \mathrm{~N} 1085815 \mathrm{~W}$

$345114 N 1125618 \mathrm{~W}$

Yuma

Cochise

Maricopa

Cochise

Maricopa

Greenlee

Greenlee

Greenlee

Gila

Pinal

Maricopa

Pinal

Pinal

Cochise

Maricopa

Maricopa

Pinal

mine

school

UNOFF

UNOFF

VARIANT

summit

forest

VARIANT

park

gap

gap

ADMIN

BGN

VARIANT

Pinal

Coconino

Coconino

Yavapai

Coconino

Yavapai

Yavapai

Pinal

Maricopa

Yuma

Gila

Navajo

Gila

Gila

Maricopa

Santa Cruz

Cochise

VARIANT

park

dam

summit

summit

summit

summ it

summit

summit

UNOFF

BGN

BGN

BGN

BGN

BGN

BGN 1931

VARIANT

VARIANT

Cochise

Santa Cruz

Cochise

Pima

Pinal

Maricopa

Maricopa

Maricopa

Gila

UNOFF

well

locale
cliff
dam

UNOFF

UNOFF

Maricopa

Maricopa

UNOFF

UNOFF

reservoir BGN

$324311 N 1143316 \mathrm{~W}$

$314123 \mathrm{~N} 1090250 \mathrm{~W}$

$332741 \mathrm{~N} 1115342 \mathrm{~W}$

$313329 \mathrm{~N} 1102143 \mathrm{~W}$

333113 N1112721W

$325211 \mathrm{~N} 1091123 \mathrm{~W}$

$325209 \mathrm{~N} 1091109 \mathrm{~W}$

$330255 \mathrm{~N} 1092055 \mathrm{~W}$

$333034 \mathrm{~N} 1110147 \mathrm{~W}$

$332454 \mathrm{~N} 1113256 \mathrm{~W}$

$332939 \mathrm{~N} 1113826 \mathrm{~W}$

$332332 \mathrm{~N} 1113338 \mathrm{~W}$

$332326 \mathrm{~N} 1113341 \mathrm{~W}$

$312104 N 1093142 \mathrm{~W}$

$333527 \mathrm{~N} 1112035 \mathrm{~W}$

$333437 N 1111511 \mathrm{~W}$

$331828 \mathrm{~N} 1112024 \mathrm{~W}$

331652N1110425W

$344241 \mathrm{~N} 1113111 \mathrm{~W}$

344333 N1113302W

344103 N1115028W

$344242 \mathrm{~N} 1113110 \mathrm{~W}$

$344154 N 1113806 \mathrm{~W}$

$344201 \mathrm{~N} 1113711 \mathrm{~W}$

331941 N1110455W

$334431 N 1131243 \mathrm{~W}$

$334840 \mathrm{~N} 1142414 \mathrm{~W}$

$335045 \mathrm{~N} 1103426 \mathrm{~W}$

$340116 \mathrm{~N} 1102852 \mathrm{~W}$

$333226 \mathrm{~N} 1104431 \mathrm{~W}$

324501N1101501W

331937N1115106W

$313027 \mathrm{~N} 1111140 \mathrm{~W}$

$320906 \mathrm{N109} 2852 \mathrm{~W}$

320859 N1092707W

$313012 \mathrm{~N} 1111119 \mathrm{~W}$

$314929 N 1102542 \mathrm{~W}$

$321702 \mathrm{~N} 1111130 \mathrm{~W}$ 
Apache Pond Number Two Apacheria

See Government Hill

Apacheria (historical)

Apache Ridge

Apache Spring

Apache Spring

Apache Spring

Apache Spring

Apache Spring

Apache Spring

Apache Spring

Apache Spring

Apache Spring

Apache Spring

Apache Spring

Apache Spring

Apache Springs

Apache Substation

Apache Tank

Apache Tank

Apache Tank

Apache Tank

Apache Tank

Apache Tank Number Two

Apache Terrace

Apache Trail

Apache Trail

Apache Wash

Apache Wash

Apache Wash

Apache Well

Apache Wells

Apache West Mobile Village

Apalee Spring

A Peak

Apex

See Sentinel Peak

Apex Mine

Apex Siding

$$
\text { See Apex }
$$

Apex Trick Tank

Apodaca Cemetery

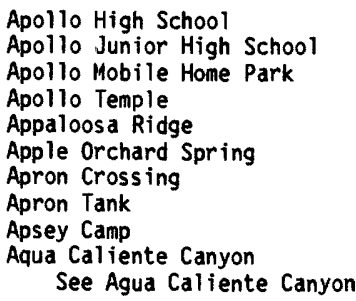

Apollo High School

Apollo Junior High School

Apollo Mobile Home Park

Apollo Temple

Appaloosa Ridge

Apple Orchard Spring

Apron Crossing

Apron Tank

Apsey Camp

Aqua Caliente Canyon See Agua Caliente Canyon

Aquarius Cliffs

Aquarius Mountains

Aquirre Valley

$$
\text { See Tat Momoli Wash }
$$

Arabian Mine

Arab Tank

Araby

Araby Road Overpass

Aragon Place

Aranaypa Canyon

See Aravaipa Canyon

Araster Spring

Arastor Spring

See Arrastra Spring

Aravaipa

Aravapai

\section{FEATURE}

CLASS

$\begin{array}{llll}\text { reservoir } & \text { BGN } & \text { Gila } & 335130 N 1100822 W \\ \text { ppl } & \text { VARIANT } & \text { Gila } & 334028 \text { N1110858W } \\ \text { locale } & \text { BGN } 1917 & \text { Gila } & 334035 \text { N1110900W }\end{array}$

\section{ridge}

spring

spring

spring

spring

spring

spring

spring

spring

$\begin{array}{ll}\text { BGN } & \text { Gila } \\ \text { BGN } & \text { Santa cruz } \\ \text { BGN } & \text { Pima } \\ \text { BGN } & \text { Cochise } \\ \text { BGN } & \text { Cochise } \\ \text { BGN } & \text { Pima } \\ \text { BGN } & \text { Graham } \\ \text { BGN } & \text { Gila } \\ \text { BGN } & \text { Gila } \\ \text { BGN } & \text { Gila }\end{array}$

$341347 N 1110709 \mathrm{~W}$

$314312 \mathrm{~N} 1104449 \mathrm{~W}$

$315011 N 1102925 \mathrm{~W}$

$320844 N 1092624 \mathrm{~W}$

$321153 N 1093801 \mathrm{~W}$

$322313 N 1104605 \mathrm{~W}$

$322848 N 1094731 \mathrm{~W}$

$330131 \mathrm{~N} 1104446 \mathrm{~W}$

$332909 \mathrm{~N} 1104335 \mathrm{~W}$

\begin{tabular}{|c|c|c|c|}
\hline $\begin{array}{l}\text { spring } \\
\text { spring } \\
\text { spring } \\
\text { spring } \\
\text { locale } \\
\text { reservoir } \\
\text { reservoir } \\
\text { reservoir } \\
\text { reservoir } \\
\text { reservoir }\end{array}$ & $\begin{array}{l}\text { BGN } \\
\text { BGN } \\
\text { BGN } \\
\text { BGN } \\
\text { UNOFF } \\
\text { BGN } \\
\text { BGN } \\
\text { BGN } \\
\text { BGN } \\
\text { BGN }\end{array}$ & $\begin{array}{l}\text { Maricopa } \\
\text { Apache } \\
\text { Coconino } \\
\text { Yavapai } \\
\text { Maricopa } \\
\text { Santa Cruz } \\
\text { Santa Cruz } \\
\text { Graham } \\
\text { Gila } \\
\text { Yavapai }\end{array}$ & $\begin{array}{l}335140 \mathrm{~N} 1120021 \mathrm{~W} \\
340144 \mathrm{N1} 1093529 \mathrm{~W} \\
352850 \mathrm{~N} 1122817 \mathrm{~W} \\
345144 \mathrm{~N} 1125610 \mathrm{~W} \\
332453 \mathrm{~N} 1114102 \mathrm{~W} \\
312606 \mathrm{N1} 104003 \mathrm{~W} \\
314327 \mathrm{~N} 1104311 \mathrm{~W} \\
323813 \mathrm{N1} 102203 \mathrm{~W} \\
333312 \mathrm{N1} 104612 \mathrm{~W} \\
350934 \mathrm{~N} 1131950 \mathrm{~W}\end{array}$ \\
\hline
\end{tabular}

$332956 \mathrm{~N} 1110059 \mathrm{~W}$

reservoir

reservoir $\quad B G N$

trail UNOFF Gila 332734 N1105045W

trail UNOFF Maricopa 333551N1111217W

stream BGN Graham 331320N1102337W

stream BGN Yuma 333817 N1140345W

stream BGN Maricopa 334340N1120252W

well UNOFF Pima 313142N1111142W

Maricopa 332734N1114237W

locale UNOFF Maricopa 332450N1115114W

spring

summit

locale BGN

BGN

VARIANT

locale

reservoir

cemetery

BGN

UNOFF

school

locale

summit

ridge

ridge

locale

reservoir

locale

valley

\section{UNOFF}

UNOFF

UNOFF

BGN 1906

BGN

BGN

$B G N$

BGN

BGN

VARIANT

Apache

334702N1091B15W

$331633 \mathrm{~N} 1102317 \mathrm{~W}$

$333602 N 1140129 \mathrm{~W}$

$335212 \mathrm{~N} 1120013 \mathrm{~W}$

Pima

$321237 N 1105930 \mathrm{~W}$

Pinal

$355635 \mathrm{~N} 1121106 \mathrm{~W}$

331B34N1110621W

Coconino

$355712 \mathrm{N11} 121016 \mathrm{~W}$

$321140 \mathrm{~N} 1101759 \mathrm{~W}$

$333317 \mathrm{N1120931 \textrm {W }}$

$320920 \mathrm{~N} 110581 \mathrm{BW}$

$333459 \mathrm{~N} 1121606 \mathrm{~W}$

$360655 \mathrm{~N} 1115249 \mathrm{~W}$

355508 N111052BW

$342304 \mathrm{~N} 1122155 \mathrm{~W}$

$342900 \mathrm{~N} 1130249 \mathrm{~W}$

$343009 \mathrm{~N} 1113437 \mathrm{~W}$

325808 N1 $103400 \mathrm{~W}$

314433N1110130W

Pima

cliff

range

BGN

VARIANT

stream

mine

reservoir

locale

crossing

UNOFF

UNOFF
BGN
BGN

UNOFF

BGN

valley

VARIANT

Mohave

Mohave

Pinal

Mohave

Apache

Yuma

Yuma

Greenlee

$344710 \mathrm{~N} 1132804 \mathrm{~W}$

$350500 \mathrm{~N} 1132730 \mathrm{~W}$

323907 N1114950W

$351135 N 1142607 \mathrm{~W}$

$341314 \mathrm{~N} 1094346 \mathrm{~W}$

$324032 \mathrm{~N} 1143117 \mathrm{~W}$

$324039 \mathrm{~N} 1143114 \mathrm{~W}$

$325820 \mathrm{~N} 1092125 \mathrm{~W}$

325045N1103810W

$\begin{array}{llll}\text { spring } & \text { BGN } & \text { Pima } & 322624 \text { N1104030W } \\ & \text { VARIANT } & & \\ \text { spring } & & \text { Gila } & 331751 \text { N1104632W } \\ \text { ppl } & \text { BGN 1912 } & \text { Graham } & 325726 \text { N1102116W }\end{array}$

$\begin{array}{lcc}\text { SOURCE } & \text { ELEV } & \\ \text { COORDINATE } & \text { FT } & \text { MAP NAME } \\ & & \text { Cone Butte }\end{array}$

Theo. Roosevelt Dam

Diamond Butte

Sonoita

Apache Peak

Bowie Mtn North

Simmons Peak

Mt Lemmon

Greasewood Mountain

Christmas

Cammerman Wash

Haunted Canyon

New River SE

Greens Peak

Stanford Tank

Camp Wood

Buckhorn

Harshaw

Sonoita

Kennedy Peak

Rockinstraw Mtn

Fort Rock Ranch

Rockinstraw Mtn

Explorers Monument

Globe

Pinyon Mtn

San Carlos Reservoir

Plomosa Pass

Union Hills

Murphy Peak

Buckhorn

1195 Mesa

Buffalo Crossing

6590 Tusayan West

Superior

Tusayan West

Wildhorse Mtn

Glendale

Tucson

1115 El Mirage

Cape Royal

Appaloosa Ridge

Poland Junction

Malpais Mesa NE

Buckhorn Mountain

Brandenburg Mtn

Cedar Basin

Penitentiary Mtn

Union Pass

Boundary Butte

212 Yuma East

Yuma East

Guthrie

Mount Bigelow

4600 Cobre Grande Mtn 


\begin{tabular}{|c|c|c|c|c|c|c|c|}
\hline FEATURE NAME & $\begin{array}{c}\text { FEATURE } \\
\text { CLASS }\end{array}$ & STATUS & COUNTY & COORDINATE & $\begin{array}{l}\text { SOURCE } \\
\text { COORDINATE }\end{array}$ & $\begin{array}{l}\text { ELEV } \\
\text { FT }\end{array}$ & MAP NAME \\
\hline $\begin{array}{l}\text { Aravaypa } \\
\text { Arayaipa } \\
\text { Arivaipa } \\
\text { Arivapah } \\
\text { Arivapai } \\
\text { Arivaypa } \\
\text { Dunlap }\end{array}$ & & $\begin{array}{l}\text { VARIANT } \\
\text { VARIANT } \\
\text { VARIANT } \\
\text { VARIANT } \\
\text { VARIANT } \\
\text { VARIANT } \\
\text { VARIANT }\end{array}$ & & & & & \\
\hline $\begin{array}{l}\text { Aravaipa Canyon } \\
\text { Aravaipa Valley } \\
\text { Aravapai Canyon } \\
\text { Aranaypa Canyon } \\
\text { Arayaipa Canyon } \\
\text { Arivaipa Canyon } \\
\text { Arivaipa Valley } \\
\text { Arivapah Canyon } \\
\text { Arivapai Canyon } \\
\text { Arivaypa Canyon }\end{array}$ & valley & $\begin{array}{l}\text { BGN } 1975 \\
\text { VARIANT } \\
\text { VARIANT } \\
\text { VARIANT } \\
\text { VARIANT } \\
\text { VARIANT } \\
\text { VARIANT } \\
\text { VARIANT } \\
\text { VARIANT } \\
\text { VARIANT }\end{array}$ & Pinal & $325045 \mathrm{~N} 1103810 \mathrm{~W}$ & $323645 \mathrm{~N} 1100650 \mathrm{~W}$ & & Brandenburg Mtn \\
\hline $\begin{array}{l}\text { Aravaipa Canyon Primitive Area } \\
\text { Aravaipa Primitive Area } \\
\text { Aravaipa Canyon Primitive } \\
\text { Area East Entrance } \\
\text { Aravaipa Creek } \\
\text { Aravaypa Creek } \\
\text { Aravapai Creek } \\
\text { Arayaipa Creek } \\
\text { Arivaipa Creek } \\
\text { Arivapah Creek } \\
\text { Arivapai Creek } \\
\text { Arivaypa Creek } \\
\text { Babiteoida Arronyo } \\
\text { Rio Arivapa }\end{array}$ & $\begin{array}{l}\text { park } \\
\text { locale } \\
\text { stream }\end{array}$ & $\begin{array}{l}\text { ADMIN } \\
\text { VARIANT } \\
\text { BGN } \\
\text { BGN } 1924 \\
\text { VARIANT } \\
\text { VARIANT } \\
\text { VARIANT } \\
\text { VARIANT } \\
\text { VARIANT } \\
\text { VARIANT } \\
\text { VARIANT } \\
\text { VARIANT } \\
\text { VARIANT }\end{array}$ & $\begin{array}{l}\text { Pinal } \\
\text { Graham } \\
\text { Pinal }\end{array}$ & $\begin{array}{l}325440 \mathrm{~N} 1102900 \mathrm{~W} \\
325354 \mathrm{~N} 1102622 \mathrm{~W} \\
325021 \mathrm{~N} 1104251 \mathrm{~W}\end{array}$ & $323538 \mathrm{~N} 1100615 \mathrm{~W}$ & & $\begin{array}{l}\text { Booger Canyon } \\
\text { Booger Canyon } \\
\text { Lookout Mtn }\end{array}$ \\
\hline $\begin{array}{l}\text { Aravaipa Farms } \\
\text { Aravaipa Primitive Area } \\
\text { See Aravaipa Canyon } \\
\text { Primitive Area }\end{array}$ & $\begin{array}{l}\text { locale } \\
\text { park }\end{array}$ & $\begin{array}{l}\text { BGN } \\
\text { VARIANT }\end{array}$ & $\begin{array}{l}\text { Pinal } \\
\text { Pinal }\end{array}$ & $\begin{array}{l}325116 \mathrm{~N} 1103621 \mathrm{~W} \\
325440 \mathrm{~N} 1102900 \mathrm{~W}\end{array}$ & & & Holy Joe Peak \\
\hline $\begin{array}{l}\text { Aravaipa Ranger Station } \\
\text { Aravaipa School } \\
\text { Aravaipa Valley } \\
\text { See Aravaipa Canyon } \\
\text { Aravapai } \\
\text { See Aravaipa }\end{array}$ & $\begin{array}{l}\text { locale } \\
\text { school } \\
\text { valley } \\
\text { ppl }\end{array}$ & $\begin{array}{l}\text { UNOFF } \\
\text { UNOFF } \\
\text { VARIANT } \\
\text { VARIANT }\end{array}$ & $\begin{array}{l}\text { Graham } \\
\text { Graham } \\
\text { Pinal } \\
\text { Graham }\end{array}$ & $\begin{array}{l}324707 \mathrm{~N} 1101622 \mathrm{~W} \\
325235 \mathrm{~N} 1102317 \mathrm{~W} \\
325045 \mathrm{~N} 1103810 \mathrm{~W} \\
325726 \mathrm{~N} 1102116 \mathrm{~W}\end{array}$ & & $\begin{array}{l}3666 \\
3280\end{array}$ & $\begin{array}{l}\text { Klondyke } \\
\text { Booger Canyon }\end{array}$ \\
\hline $\begin{array}{l}\text { Aravapai Canyon } \\
\text { See Aravaipa Canyon } \\
\text { Aravapai Creek } \\
\text { See Aravaipa Creek } \\
\text { Aravaypa } \\
\text { See Aravaipa } \\
\text { Aravaypa Creek } \\
\text { See Aravaipa Creek } \\
\text { Arayaipa } \\
\text { See Aravaipa }\end{array}$ & $\begin{array}{l}\text { valley } \\
\text { stream } \\
\mathrm{pp} 1 \\
\text { stream } \\
\mathrm{ppl}\end{array}$ & $\begin{array}{l}\text { VARIANT } \\
\text { VARIANT } \\
\text { VARIANT } \\
\text { VARIANT } \\
\text { VARIANT }\end{array}$ & $\begin{array}{l}\text { Pinal } \\
\text { Pinal } \\
\text { Graham } \\
\text { Pinal } \\
\text { Graham }\end{array}$ & $\begin{array}{l}325045 \mathrm{~N} 1103810 \mathrm{~W} \\
325021 \mathrm{~N} 1104251 \mathrm{~W} \\
325726 \mathrm{~N} 1102116 \mathrm{~W} \\
325021 \mathrm{~N} 1104251 \mathrm{~W} \\
325726 \mathrm{~N} 1102116 \mathrm{~W}\end{array}$ & & & \\
\hline $\begin{array}{l}\text { Arayaipa Canyon } \\
\text { See Aravaipa Canyon } \\
\text { Arayaipa Creek } \\
\text { See Aravaipa Creek } \\
\text { Arboretum Tank } \\
\text { Arcadia Campground } \\
\text { Arcadia Plaza Shopping Center } \\
\text { Arcadia Recreation Area } \\
\text { Arcadia Village Shopping Center } \\
\text { Arch Canyon }\end{array}$ & $\begin{array}{l}\text { valley } \\
\text { stream } \\
\text { reservoir } \\
\text { park } \\
\text { locale } \\
\text { park } \\
\text { locale } \\
\text { valley }\end{array}$ & $\begin{array}{l}\text { VARIANT } \\
\text { VARIANT } \\
\text { BGN } \\
\text { ADMIN } \\
\text { UNOFF } \\
\text { ADMIN } \\
\text { UNOFF } \\
\text { BGN }\end{array}$ & $\begin{array}{l}\text { Pinal } \\
\text { Pinal } \\
\text { Pinal } \\
\text { Graham } \\
\text { Maricopa } \\
\text { Graham } \\
\text { Maricopa } \\
\text { Pima }\end{array}$ & $\begin{array}{l}325045 \mathrm{~N} 1103810 \mathrm{~W} \\
325021 \mathrm{N1} 104251 \mathrm{~W} \\
331615 \mathrm{N1111004 \textrm {W }} \\
3238551094908 \mathrm{~W} \\
332944 \mathrm{~N} 1115843 \mathrm{~W} \\
323855 \mathrm{~N} 109490 \mathrm{~W} \\
303034 \mathrm{~N} 1115945 \mathrm{~W} \\
320220 \mathrm{~N} 1124300 \mathrm{~W}\end{array}$ & $320152 \mathrm{~N} 1124128 \mathrm{~W}$ & & $\begin{array}{l}\text { Picketpost Mtn } \\
\text { Mt Graham } \\
\text { Tempe } \\
\text { Mt Graham } \\
\text { Paradise Valley } \\
\text { Mount Ajo }\end{array}$ \\
\hline $\begin{array}{l}\text { Archibald Corral } \\
\text { Archibald Tank } \\
\text { Archies Tank } \\
\text { Archie Tank } \\
\text { Arch Mountain } \\
\text { Arch Tank } \\
\text { Arcosanti } \\
\text { Ardmore Mine } \\
\text { Argent ina Well } \\
\text { Argyle Mine }\end{array}$ & $\begin{array}{l}\text { locale } \\
\text { reservoir } \\
\text { reservoir } \\
\text { reservoir } \\
\text { summit } \\
\text { reservoir } \\
\text { ppl } \\
\text { mine } \\
\text { well } \\
\text { mine }\end{array}$ & $\begin{array}{l}\text { BGN } \\
\text { BGN } \\
\text { BGN } \\
\text { BGN } \\
\text { BGN } \\
\text { BGN } \\
\text { BGN } 1977 \\
\text { UNOFF } \\
\text { UNOFF } \\
\text { UNOFF }\end{array}$ & $\begin{array}{l}\text { Mohave } \\
\text { Yavapai } \\
\text { Coconino } \\
\text { Navajo } \\
\text { Mohave } \\
\text { Yuma } \\
\text { Yavapai } \\
\text { Pinal } \\
\text { Pima } \\
\text { Mohave }\end{array}$ & $\begin{array}{l}354312 \mathrm{~N} 1141025 \mathrm{~W} \\
345725 \mathrm{N1} 120903 \mathrm{~W} \\
345842 \mathrm{N1} 113307 \mathrm{~W} \\
343907 \mathrm{N1} 103904 \mathrm{~W} \\
360809 \mathrm{N1} 143336 \mathrm{~W} \\
331157 \mathrm{N1} 141157 \mathrm{~W} \\
342035 \mathrm{N1} 120600 \mathrm{~W} \\
324454 \mathrm{N1} 10540 \mathrm{~W} \\
313959 \mathrm{N1} 111153 \mathrm{~W} \\
352535 \mathrm{N1} 141111 \mathrm{~W}\end{array}$ & & 3335 & $\begin{array}{l}\text { Mt Tipton NW } \\
\text { Perkinsville } \\
\text { Mormon Mountain } \\
\text { Potato Wash North } \\
\text { Boulder Canyon } \\
\text { Arch Tank } \\
\text { Cordes Junction } \\
\text { Fortified Mtn } \\
\text { Saucito Mtn } \\
\text { Chloride }\end{array}$ \\
\hline
\end{tabular}


FEATURE NAME

Arido Creek

$$
\text { See Tsitah Wash }
$$

Ariel Point

Aripine

Joppa

Aripine Post Office

Aristocrat Trailer Park

Arivaca

Arivaca-Amado Interchange

Arivaca Coop Water Wells

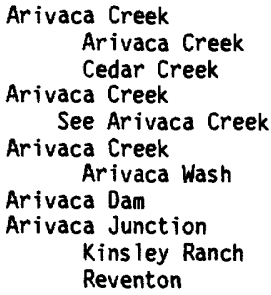

FEATURE
CLASS

STATUS

COUNTY

COORDINATE

$\begin{array}{lc}\text { SOURCE } & \text { ELEV } \\ \text { COORDINATE } & \text { FT }\end{array}$

MAP NAME

VARIANT

stream
cliff

cliff
locale

building

UNOFF

crossing

well

BGN 1906

Apache

$370944 N 1090815 \mathrm{~W}$

$360913 N 1120001 \mathrm{~W}$

$\begin{array}{lll}\text { BGN } 1906 & \begin{array}{l}\text { Coconino } \\ \text { BGN }\end{array} & 360913 N 1120001 W \\ \text { Navajo } & 342430 N 1102549 W\end{array}$

VARIANT

Maricopa 332941N1120345W

Pima $313429 N 1111954 \mathrm{~W}$

BGN

UNOFF

$314333 \mathrm{~N} 1110327 \mathrm{~W}$

Pima 313427N1111914W

strean

BGN 1983 Pima

$313706 \mathrm{~N} 1112427 \mathrm{~W}$

VARIANT

VARIANT

VARIANT

stream

stream

PGN 1979 Pima

Pima

VARIANT

dam UNOFF

UNOFF Pima

pp 1

VARIANT

VARIANT

$313706 \mathrm{~N} 1112427 \mathrm{~W}$

$313805 N 1112527 \mathrm{~W}$

$313200 \mathrm{~N} 1111518 \mathrm{~W}$

$314338 \mathrm{~N} 1110338 \mathrm{~W}$

313150 N1111728W Las Guijas

Pima

(n)

reservoir

locale

$313200 N 1111515 \mathrm{~W}$

$313339 N 1111744 \mathrm{~W}$

$313314 N 1112138 \mathrm{~W}$

$320753 \mathrm{~N} 1111638 \mathrm{~W}$

valley

BGN

VARIANT

stream

VARIANT

Pima

$313805 \mathrm{~N} 1112527 \mathrm{~W}$

$314256 \mathrm{~N} 1112542 \mathrm{~W}$

BGN 1979 Pima

VARIANT

Graham

$325726 \mathrm{~N} 1102116 \mathrm{~W}$

pp 1

VARIANT

valley

stream

range

valley

valley

VARIANT

Pinal

$325045 N 1103810 \mathrm{~W}$

VARIANT

Pinal

$325021 N 1104251 \mathrm{~W}$

VARIANT

Graham

323600 N1102100W

VARIANT

Pima

320753N1111638W

Pinal

325045 N1103810W

ppl

valley

stream

pp 1

valley

VARIANT

VARIANT

Graham

$325726 \mathrm{~N} 1102116 \mathrm{~W}$

Pinal

$325045 N 1103810 \mathrm{~W}$

VARIANT

Pinal

$325021 N 1104251 \mathrm{~W}$

VARIANT

Graham

325726N1102116W

VARIANT

Pinal

$325045 N 1103810 \mathrm{~W}$

VARIANT

stream

ppl

valley

stream

range

VARIANT

Pinal

$325021 N 1104251 W$

Graham

$325726 \mathrm{~N} 1102116 \mathrm{~W}$

VARIANT

Pinal

325045N1103810W

VARIANT

Pina 1

$325021 N 1104251 W$

VARIANT

Graham

$323600 \mathrm{~N} 1102100 \mathrm{~W}$

pp

crossing

BGN
UNOFF

Pinal

UNOFF

Pinal

$325104 \mathrm{~N} 1114249 \mathrm{~W}$

324911N1114057W

1436 Casa Grande Mts

ridge

ppl

VARIANT

Pinal

$324850 \mathrm{~N} 1114232 \mathrm{~W}$

school

UNOFF

Yuma

$324331 N 1143725 W$

332749 N1120302W

$332446 \mathrm{~N} 1113735 \mathrm{~W}$

locale

BGN

La Paz

340921N114173BW
Bright Angel Point Aripine

Day Spring

1120 Phoenix

Arivaca

Amado

Arivaca

313155N1111516W Wilbur Canyon

3070 Amado

Cerro Colorado

Arivaca

Arivaca

Arivaca

313805N1112527W Las Guijas
1465 Casa Grande Mts

Phoenix

1535 Buckhorn

Parker 
FEATURE

Arizona Bible School

Arizona Boys Ranch

Arizona Canal

Arizona Center for Women

(prison)

Arizona Childrens Colony

Arizona City

See Yuma

Arizona City

Arizona College of Technology

Arizona Correctional Training

Facility

Arizona Council of American

Youth Hostel

Arizona Cross Cut Canal

Arizona Oam Butte

Arizona Department of

Corrections Alpine

Conservation Center

See Alpine Civilian

Conservation Center

Arizona Desert School

Arizona Oivide

Arizona Falls Power House

Arizona Fish and Game

Department

Arizona Game \& Fish Region IV

Office

Arizona Game and Fish

Department

Arizona Game and Fish Region

Number Seven Office

Arizona Game and Fish Region

One Office

Arizona Girls Ranch

Arizona Gulch

Arizona Highway Department

Arizona Job College

Arizona Magma Mine

Arizona Mall of Tempe

Arizona Montana Mine

Arizona Mountains

See Pajarito Mountains

schoo

school

canal

locale

locale

ppl

ppl 1

school

locale

building

canal

summit

locale

STATUS

COUNTY

COORDINATE

SOURCE

COORDIMATE

ELEV
FT

MAP NAME

ebb Peak

Higley

Paradise Valley

Phoenix

Coolidge

325415N1113104W

$324331 \mathrm{N1143725 \textrm {W }}$

$324521 \mathrm{N1114013 \textrm {W }}$

$325057 \mathrm{~N} 1104145 \mathrm{~W}$

$320408 \mathrm{~N} 1105142 \mathrm{~W}$

$332213 \mathrm{~N} 1120315 \mathrm{~W}$

UNOFF

Maricopa

BGN Maricopa

VARIANT

Maricopa

$332751 \mathrm{N1115618 \textrm {W }}$

$333302 \mathrm{N111} 4049 \mathrm{~W}$

Apache

334935N1090840W

school UNOFF Pima

ridge $B G N$ Coconino

locale UNOFF Maricopa

$322103 \mathrm{~N} 1105658 \mathrm{~W}$

$351154 \mathrm{N1114449 \textrm {W }}$

$332927 \mathrm{N1115733 \textrm {W }}$

333729 N1120643W

building

UNOFF

Maricopa

324023N1143550W

building

UNOFF

Yuma

building

UNOFF

Coconino

350944N1113944W

Graham

324858N1095054W

340727 N1095512W

$332558 \mathrm{~N} 1114220 \mathrm{~W}$

$325548 \mathrm{N1102606 \textrm {W }}$

$332644 \mathrm{~N} 1120544 \mathrm{~W}$

$335338 \mathrm{N1114519 \textrm {W }}$

$352502 \mathrm{~N} 1141334 \mathrm{~W}$

$332220 \mathrm{~N} 1115346 \mathrm{~W}$

341211N1133835W

mine UNOFF Mohave

Maricopa

Santa Cruz

$312105 \mathrm{M} 1110556 \mathrm{~W}$

Arizona Pioneer Historical

Society

Arizona Pioneers Home

Arizona Pioneers Home Cemetery

Arizona Pittsburg Mine

Arizona Plateau

See Coconino Plateau

Arizona Public Service Salome Substation

Arizona Snow Bowl

Arizona-Sonora Desert Museum

Arizona Spring

Arizona State Capito

Arizona State College

Arizona State College at Tempe

Arizona State Fairgrounds

Arizona State Farm Labor Camp

Arizona State Highway Patrol

Arizona State Highway Patrol

Tower

range

building

UNOFF

building

cemetery

mine

UNOFF

UNOFF

UNOFF

plain

locale

VARIANT

locale

UNOFF

Pima

$321400 \mathrm{~N} 1105725 \mathrm{~W}$

Yavapai

Yavapai

Santa Cruz

$343222 \mathrm{N1122821 \textrm {W }}$

$343345 \mathrm{N1} 122907 \mathrm{~W}$

313749 N1105136W

Coconino

$355000 \mathrm{~N} 1123005 \mathrm{~W}$

334619 N1133537W

351949N1114219W

Coconino

building

UNOFF

Pima

spring

UNOFF

BGN

building

schoo 1

locale

locale

building

UNOFF

UNOFF

BGN

BGN

BGN
UNOFF

tower

UNOFF

Mohave

Maricopa

Coconino

Maricopa

Maricopa

Pinal

Pima

Maricopa

$321439 N 1111002 \mathrm{~W}$

$353201 \mathrm{N1} 141315 \mathrm{~W}$

$332653 \mathrm{~N} 1120547 \mathrm{~W}$

$351130 \mathrm{~N} 1113918 \mathrm{~W}$

$332502 N 1115605 \mathrm{~W}$

$332810 \mathrm{N11} 20550 \mathrm{~W}$

$323706 \mathrm{~N} 1113305 \mathrm{~W}$

$321226 \mathrm{~N} 1105735 \mathrm{~W}$

$331958 \mathrm{~N} 1120354 \mathrm{~W}$

Arizona State Hospital

Arizona State Prison

Arizona State Sanatorium

Arizona State School

Arizona State University Farm

Laboratory

Arizona Substation hospital UNOFF

hospital

locale

hospital

school

UMOFF

UNOFF

UNOFF

UNOFF

Maricopa

Maricopa

Pinal

Maricopa

Pima

Maricopa

$332714 N 1120131 \mathrm{~W}$

$332743 N 1115952 \mathrm{~W}$

$330138 \mathrm{~N} 1112220 \mathrm{~W}$

$332627 \mathrm{~N} 1115625 \mathrm{~W}$

$321414 N 1105923 \mathrm{~W}$

locale

UNOFF

Maricopa

$332845 \mathrm{~N} 1115806 \mathrm{~W}$
332046N1115356W
Tucson North

Flagstaff West

Tempe

Sunnys lope

Yuma East

Flagstaff West

Thatcher

7000 Indian Pine

Buckhorn

Booger Canyon

Phoenix

Casa Grande West

Chloride

Guadalupe

Reid Valley

Tucson

Prescott

Prescott

Mt Wrightson

Salome

Humphreys Peak

Brown Mtn

Mt Tipton

Phoenix

Flagstaff West

Tempe

Phoenix

1660 Friendly Corners

Tucson

Lone Butte

Phoenix

Tempe

Florence SE

Tempe

Tucson

Guadalupe

Tempe 
NATIONAL GAZETTEER--ARIZONA 1986

\begin{tabular}{|c|c|c|c|c|c|c|c|}
\hline FEATURE NAME & $\begin{array}{l}\text { FEATURE } \\
\text { CLASS }\end{array}$ & STATUS & COUNTY & COORDINATE & $\begin{array}{l}\text { SOURCE } \\
\text { COORDINATE }\end{array}$ & $\begin{array}{l}\text { ELEV } \\
\text { FT }\end{array}$ & MAP NAME \\
\hline $\begin{array}{c}\text { Arizona Sunshine School } \\
\text { Arizona Sun Sites } \\
\text { Suns ites }\end{array}$ & $\begin{array}{l}\text { school } \\
\text { ppl }\end{array}$ & $\begin{array}{l}\text { UNOFF } \\
\text { BGN } \\
\text { VARIANT }\end{array}$ & $\begin{array}{l}\text { Pima } \\
\text { Cochise }\end{array}$ & $\begin{array}{l}321433 \mathrm{~N} 1105225 \mathrm{~W} \\
315500 \mathrm{~N} 1095730 \mathrm{~W}\end{array}$ & & & $\begin{array}{l}\text { Tucson East } \\
\text { Cochise Stronghold }\end{array}$ \\
\hline $\begin{array}{l}\text { Arizona Victory Mine } \\
\text { Arizona Western College } \\
\text { Arizona Youth Center } \\
\text { Arizona Yucca Mine } \\
\text { Arkansas Guich } \\
\text { Arkansas Mountain } \\
\text { Arkansas Ranch } \\
\text { Arkansas Tank } \\
\text { Arkansas Tank } \\
\text { Arlene Tank }\end{array}$ & $\begin{array}{l}\text { mine } \\
\text { school } \\
\text { building } \\
\text { mine } \\
\text { valley } \\
\text { summit } \\
\text { locale } \\
\text { reservoir } \\
\text { reservoir } \\
\text { reservoir }\end{array}$ & $\begin{array}{l}\text { UNOFF } \\
\text { UNOFF } \\
\text { UNOFF } \\
\text { UNOFF } \\
\text { BGN } \\
\text { BGN } \\
\text { UNOFF } \\
\text { BGN } \\
\text { BGN } \\
\text { BGN }\end{array}$ & $\begin{array}{l}\text { Yavapai } \\
\text { Yuma } \\
\text { Pima } \\
\text { Mohave } \\
\text { Gila } \\
\text { Pima } \\
\text { Mohave } \\
\text { Gila } \\
\text { Coconino } \\
\text { Santa Cruz }\end{array}$ & $\begin{array}{l}342639 \mathrm{~N} 1122414 \mathrm{~W} \\
324125 \mathrm{~N} 1142940 \mathrm{~W} \\
322810 \mathrm{N1} 105517 \mathrm{~W} \\
343912 \mathrm{N11} 140911 \mathrm{~W} \\
332310 \mathrm{N1} 105025 \mathrm{~W} \\
322112 \mathrm{N1125220 \textrm {W }} \\
362027 \mathrm{N1130835 \textrm {W }} \\
332301 \mathrm{N1} 105151 \mathrm{~W} \\
351450 \mathrm{~N} 122115 \mathrm{~W} \\
312124 \mathrm{N1} 103135 \mathrm{~W}\end{array}$ & $332154 \mathrm{~N} 1105219 \mathrm{~W}$ & 6246 & $\begin{array}{l}\text { Groom Creek } \\
\text { Fortuna } \\
\text { Oro Valley } \\
\text { Buck Mountains } \\
\text { Globe } \\
\text { Ajo South } \\
\text { Mount Logan } \\
\text { Globe } \\
\text { McLellan Reservoir } \\
\text { Lochiel }\end{array}$ \\
\hline $\begin{array}{l}\text { Arlington } \\
\text { Arlington Canal } \\
\text { Arlington Elementary School } \\
\text { Arlington Mesa } \\
\text { Arlington Post office } \\
\text { Arlington School } \\
\text { Arlington State Wildlife Area } \\
\text { Arlington Station } \\
\text { Arlington Station } \\
\text { Arlington Substation }\end{array}$ & $\begin{array}{l}\text { ppl } \\
\text { canal } \\
\text { school } \\
\text { summit } \\
\text { building } \\
\text { school } \\
\text { park } \\
\text { locale } \\
\text { locale } \\
\text { locale }\end{array}$ & $\begin{array}{l}\text { BGN } \\
\text { BGN } \\
\text { UNOFF } \\
\text { BGN } \\
\text { UNOFF } \\
\text { UNOFF } \\
\text { ADMIN } \\
\text { BGN } \\
\text { BGN } \\
\text { UNOFF }\end{array}$ & $\begin{array}{l}\text { Maricopa } \\
\text { Maricopa } \\
\text { Maricopa } \\
\text { Maricopa } \\
\text { Maricopa } \\
\text { Maricopa } \\
\text { Maricopa } \\
\text { Maricopa } \\
\text { Maricopa } \\
\text { Maricopa }\end{array}$ & $\begin{array}{l}331932 \mathrm{~N} 1124548 \mathrm{~W} \\
331923 \mathrm{N1} 124323 \mathrm{~W} \\
331805 \mathrm{N1} 124645 \mathrm{~W} \\
332053 \mathrm{N1} 124451 \mathrm{~W} \\
331930 \mathrm{N1} 124545 \mathrm{~W} \\
331805 \mathrm{N1} 124648 \mathrm{~W} \\
331455 \mathrm{N1} 124622 \mathrm{~W} \\
332000 \mathrm{~N} 1124925 \mathrm{~W} \\
332002 \mathrm{~N} 1124931 \mathrm{~W} \\
332057 \mathrm{N1} 124948 \mathrm{~W}\end{array}$ & & 1172 & $\begin{array}{l}\text { Arlington } \\
\text { Hassayampa } \\
\text { Arlington } \\
\text { Hassayampa } \\
\text { Arlington } \\
\text { Arlington } \\
\text { Spring Mtn } \\
\text { Arlington } \\
\text { Arlington } \\
\text { Arlington }\end{array}$ \\
\hline $\begin{array}{l}\text { Arlington Valley } \\
\text { Armada Mine } \\
\text { Armenta Ranch } \\
\text { Armenta Well } \\
\text { Armer Gulch } \\
\text { Armer Mountain } \\
\text { Armor Mountain } \\
\text { Armer Tank } \\
\text { Armor Mountain } \\
\text { See Armer Mountain }\end{array}$ & $\begin{array}{l}\text { valley } \\
\text { mine } \\
\text { locale } \\
\text { well } \\
\text { valley } \\
\text { summit } \\
\text { reservoir } \\
\text { summit }\end{array}$ & $\begin{array}{l}\text { BGN } \\
\text { UNOFF } \\
\text { UNOFF } \\
\text { UNOFF } \\
\text { BGN } \\
\text { BGN } \\
\text { VARIANT } \\
\text { BGN } \\
\text { VARIANT }\end{array}$ & $\begin{array}{l}\text { Maricopa } \\
\text { Santa Cruz } \\
\text { Pinal } \\
\text { Pima } \\
\text { Gila } \\
\text { Gila } \\
\text { Gila } \\
\text { Gila }\end{array}$ & $\begin{array}{l}331412 \mathrm{~N} 1124638 \mathrm{~W} \\
313740 \mathrm{~N} 1104757 \mathrm{~W} \\
324004 \mathrm{N1114858W} \\
321119 \mathrm{N1124947 \textrm {W }} \\
334037 \mathrm{N1110328 \textrm {W }} \\
334915 \mathrm{N11} 10037 \mathrm{~W} \\
340129 \mathrm{~N} 1111100 \mathrm{~W} \\
334915 \mathrm{~N} 1110037 \mathrm{~W}\end{array}$ & $\begin{array}{l}331909 \mathrm{~N} 1124508 \mathrm{~W} \\
334940 \mathrm{~N} 1110059 \mathrm{~W}\end{array}$ & & $\begin{array}{l}\text { Spring Mtn } \\
\text { Mt Wrightson } \\
\text { Silver Reef Mts } \\
\text { Armenta Well } \\
\text { Windy Hill } \\
\text { Armer Mountain } \\
\text { Sheep Bas in Mtn }\end{array}$ \\
\hline $\begin{array}{l}\text { Armour Spring } \\
\text { Armstrong Dam } \\
\text { Armstrong Park } \\
\text { Armstrong Tank } \\
\text { Armstrong Waterhole } \\
\text { Armstrong Tank } \\
\text { Armstrong Waterhole } \\
\text { See Armstrong Tank } \\
\text { Armstrong Well } \\
\text { Arnett Canyon }\end{array}$ & $\begin{array}{l}\text { spring } \\
\text { dam } \\
\text { park } \\
\text { reservoir } \\
\text { reservoir } \\
\text { reservoir } \\
\text { well } \\
\text { valley }\end{array}$ & $\begin{array}{l}\text { BGN } \\
\text { UNOFF } \\
\text { ADMIN } \\
\text { BGN } \\
\text { VARIANT } \\
\text { BGN } \\
\text { VARIANT } \\
\text { UNOFF } \\
\text { BGN }\end{array}$ & $\begin{array}{l}\text { Santa Cruz } \\
\text { Graham } \\
\text { Maricopa } \\
\text { Graham } \\
\text { Coconino } \\
\text { Graham } \\
\text { Coconino } \\
\text { Pinal }\end{array}$ & $\begin{array}{l}314325 \mathrm{~N} 1105048 \mathrm{~W} \\
332430 \mathrm{N1} 100630 \mathrm{~W} \\
331825 \mathrm{N1} 115009 \mathrm{~W} \\
332434 \mathrm{N1} 100630 \mathrm{~W} \\
354910 \mathrm{~N} 1115440 \mathrm{~W} \\
332434 \mathrm{~N} 1100630 \mathrm{~W} \\
354920 \mathrm{N1} 115548 \mathrm{~W} \\
331643 \mathrm{N1} 11011 \mathrm{~W}\end{array}$ & $331219 \mathrm{N1110242 \textrm {W }}$ & 4704 & $\begin{array}{l}\text { Mt Wrightson } \\
\text { Ash Creek NE } \\
\text { Chandler } \\
\text { Ash Creek NE } \\
\text { Harbison Tank }\end{array}$ \\
\hline $\begin{array}{l}\text { Arnett Creek } \\
\text { Arnett Well } \\
\text { Arnold Canyon } \\
\text { Spring Creek } \\
\text { Spring Gulch } \\
\text { Arnold Lateral } \\
\text { Arnold Mesa } \\
\text { Arnold Mesa Tank } \\
\text { Arnold Place } \\
\text { Arnold Place Spring }\end{array}$ & $\begin{array}{l}\text { canal } \\
\text { sumnit } \\
\text { reservoir } \\
\text { locale } \\
\text { spring }\end{array}$ & $\begin{array}{l}\text { BGN } \\
\text { UNOFF } \\
\text { BGN 1968 } \\
\text { VARIANT } \\
\text { VARIANT } \\
\text { BGN } \\
\text { BGN } \\
\text { BGN } \\
\text { BGN } \\
\text { BGN }\end{array}$ & $\begin{array}{l}\text { Yuma } \\
\text { Yavapai } \\
\text { Yavapai } \\
\text { Yavapai } \\
\text { Yavapai }\end{array}$ & $\begin{array}{l}323851 \mathrm{~N} 1144331 \mathrm{~W} \\
342618 \mathrm{~N} 1115349 \mathrm{~W} \\
342621 \mathrm{N1} 115355 \mathrm{~W} \\
342712 \mathrm{~N} 1115503 \mathrm{~W} \\
342715 \mathrm{~N} 1115504 \mathrm{~W}\end{array}$ & $\begin{array}{l}331219 N 1110242 W \\
342747 N 1115323 W\end{array}$ & 6003 & $\begin{array}{l}\text { Yuma West } \\
\text { Arnold Mesa } \\
\text { Arnold Mesa } \\
\text { Arnold Mesa } \\
\text { Arnold Mesa }\end{array}$ \\
\hline $\begin{array}{l}\text { Arnold Spring } \\
\text { Arntz } \\
\text { Aros Ranch } \\
\text { Aros Wash } \\
\text { Arrastra Canyon } \\
\text { Arrastra Canyon } \\
\text { Arrastra Creek } \\
\text { Arrastra Mountain } \\
\text { Arrastra Spring } \\
\text { Arastor Spring }\end{array}$ & $\begin{array}{l}\text { spring } \\
\text { locale } \\
\text { locale } \\
\text { stream } \\
\text { valley } \\
\text { valley } \\
\text { stream } \\
\text { summit } \\
\text { spring }\end{array}$ & $\begin{array}{l}\text { BGN } \\
\text { BGN } \\
\text { UNOFF } \\
\text { BGN } \\
\text { BGN } \\
\text { BGN } \\
\text { BGN } \\
\text { BGN } \\
\text { BGN } \\
\text { VARIANT }\end{array}$ & $\begin{array}{l}\text { Yavapai } \\
\text { Navajo } \\
\text { Pina } \\
\text { Pina } \\
\text { Gila } \\
\text { Mohave } \\
\text { Yavapai } \\
\text { Mohave } \\
\text { Gila }\end{array}$ & $\begin{array}{l}342622 \mathrm{~N} 1115610 \mathrm{~W} \\
345609 \mathrm{N1} 100231 \mathrm{~W} \\
313447 \mathrm{N1113600W} \\
313528 \mathrm{~N} 1113319 \mathrm{~W} \\
331724 \mathrm{N1} 104401 \mathrm{~W} \\
342608 \mathrm{~N} 1133549 \mathrm{~W} \\
341941 \mathrm{N1} 122210 \mathrm{~W} \\
342516 \mathrm{~N} 1132253 \mathrm{~W} \\
331751 \mathrm{N1} 104632 \mathrm{~W}\end{array}$ & $\begin{array}{l}313449 \mathrm{~N} 1113539 \mathrm{~W} \\
331704 \mathrm{N1} 104701 \mathrm{~W} \\
342749 \mathrm{N1} 133328 \mathrm{~W} \\
341935 \mathrm{N1} 122403 \mathrm{~W}\end{array}$ & 4807 & $\begin{array}{l}\text { Arnold Mesa } \\
\text { Sun Valley } \\
\text { Presumido Peak } \\
\text { Presumido Peak } \\
\text { Cutter } \\
\text { Signal Mtn } \\
\text { Battle Flat } \\
\text { Arrastra Mtn } \\
\text { Pinal Peak }\end{array}$ \\
\hline $\begin{array}{l}\text { Arrastra Spring } \\
\text { Arrastra Spring } \\
\text { Arrastra Wash } \\
\text { Arrastra Well } \\
\text { Arrastre Creek } \\
\text { Arrastre Creek } \\
\text { Arrastre Gulch } \\
\text { Arrastre Gulch }\end{array}$ & $\begin{array}{l}\text { spring } \\
\text { spring } \\
\text { stream } \\
\text { well } \\
\text { stream } \\
\text { stream } \\
\text { valley } \\
\text { valley }\end{array}$ & $\begin{array}{l}\text { BGN } \\
\text { BGN } \\
\text { BGN } \\
\text { UNOFF } \\
\text { BGN } \\
\text { BGN } \\
\text { BGN } \\
\text { BGN }\end{array}$ & $\begin{array}{l}\text { Maricopa } \\
\text { Yavapai } \\
\text { Yuma } \\
\text { Mohave } \\
\text { Yavapai } \\
\text { Yavapai } \\
\text { Maricopa } \\
\text { Gila }\end{array}$ & $\begin{array}{l}335415 \mathrm{~N} 1115101 \mathrm{~W} \\
341937 \mathrm{N1} 122340 \mathrm{~W} \\
330208 \mathrm{~N} 1143456 \mathrm{~W} \\
343435 \mathrm{~N} 1141221 \mathrm{~W} \\
340704 \mathrm{~N} 1120959 \mathrm{~W} \\
341141 \mathrm{N1} 123230 \mathrm{~W} \\
334555 \mathrm{~N} 1131626 \mathrm{~W} \\
341029 \mathrm{~N} 1112409 \mathrm{~W}\end{array}$ & $\begin{array}{l}330421 \mathrm{N1} 143357 \mathrm{~W} \\
340952 \mathrm{~N} 1120741 \mathrm{~W} \\
341355 \mathrm{~N} 1124051 \mathrm{~W} \\
334757 \mathrm{N1} 131916 \mathrm{~W} \\
341235 \mathrm{~N} 1112310 \mathrm{~W}\end{array}$ & & $\begin{array}{l}\text { Humboldt Mtn } \\
\text { Battleship Butte } \\
\text { Picacho } \\
\text { Crossman Peak } \\
\text { Black Canyon City } \\
\text { Wagoner } \\
\text { Harquahala Mtn } \\
\text { North Peak }\end{array}$ \\
\hline
\end{tabular}




\begin{tabular}{|c|c|c|c|c|c|c|c|}
\hline FEATURE NAME & $\begin{array}{l}\text { FEATURE } \\
\text { CLASS }\end{array}$ & STATUS & COUNTY & COORDINATE & $\begin{array}{l}\text { SOURCE } \\
\text { COORDINATE }\end{array}$ & $\begin{array}{c}\text { ELEV } \\
\text { FT }\end{array}$ & MAP NAME \\
\hline $\begin{array}{l}\text { Arrastre Tank } \\
\text { Arrendondo Elementary School }\end{array}$ & $\begin{array}{l}\text { reservoir } \\
\text { school }\end{array}$ & $\begin{array}{l}\text { BGH } \\
\text { UNOFF }\end{array}$ & $\begin{array}{l}\text { Gila } \\
\text { Maricopa }\end{array}$ & $\begin{array}{l}341127 \mathrm{~N} 1112310 \mathrm{~W} \\
332302 \mathrm{~N} 1115455 \mathrm{~W}\end{array}$ & & & $\begin{array}{l}\text { North Peak } \\
\text { Tempe }\end{array}$ \\
\hline $\begin{array}{l}\text { Arrendondo Park } \\
\text { Arrieta Mine } \\
\quad \text { Reata Mine } \\
\text { Arrieta Wash } \\
\quad \text { Reata Wash } \\
\text { Arrouo Verde } \\
\text { See Lewis and Pranty Creek } \\
\text { Arroweed Spring } \\
\text { Arrowhead Butte } \\
\text { Arrowhead Butte }\end{array}$ & $\begin{array}{l}\text { park } \\
\text { mine } \\
\text { stream } \\
\text { stream } \\
\text { spring } \\
\text { summit } \\
\text { summit }\end{array}$ & $\begin{array}{l}\text { ADMIN } \\
\text { UNOFF } \\
\text { VARIANT } \\
\text { BGN } 1978 \\
\text { VARIANT } \\
\text { VARIANT } \\
\text { BGN } \\
\text { BGN } \\
\text { BGN }\end{array}$ & $\begin{array}{l}\text { Maricopa } \\
\text { Mohave } \\
\text { Navajo } \\
\text { Navajo }\end{array}$ & $\begin{array}{l}332304 N 1115500 \mathrm{~W} \\
313036 \mathrm{~N} 1112451 \mathrm{~W} \\
312950 \mathrm{~N} 1112702 \mathrm{~W} \\
\\
333208 \mathrm{~N} 1111815 \mathrm{~W} \\
350624 \mathrm{~N} 1133138 \mathrm{~W} \\
351736 \mathrm{~N} 1102207 \mathrm{~W} \\
352028 \mathrm{~N} 1095917 \mathrm{~W}\end{array}$ & $313045 \mathrm{~N} 1112429 \mathrm{~W}$ & & $\begin{array}{l}\text { Tempe } \\
\text { Wilbur Canyon } \\
\text { Cumero Mtn }\end{array}$ \\
\hline $\begin{array}{l}\text { Arrow Head Dam } \\
\text { Arrowhead Mall } \\
\text { Arrowhead Meadows Park } \\
\text { Arrowhead Mesa } \\
\text { Arrowhead Mountain } \\
\text { The Arrowhead } \\
\text { Arrowhead Plaza Shopping Center } \\
\text { Arrowhead Ranch } \\
\text { Arrowhead School } \\
\text { Arrowhead Sink }\end{array}$ & $\begin{array}{l}\text { dam } \\
\text { locale } \\
\text { park } \\
\text { summit } \\
\text { summit } \\
\text { locale } \\
\text { ppl } \\
\text { school } \\
\text { basin }\end{array}$ & $\begin{array}{l}\text { UNOFF } \\
\text { UNOFF } \\
\text { ADMIN } \\
\text { BGN } \\
\text { BGN } 1917 \\
\text { VARIANT } \\
\text { UNOFF } \\
\text { BGN } \\
\text { UNOFF } \\
\text { BGN }\end{array}$ & $\begin{array}{l}\text { Gila } \\
\text { Maricopa } \\
\text { Maricopa } \\
\text { Coconino } \\
\text { Maricopa } \\
\text { Maricopa } \\
\text { Maricopa } \\
\text { Maricopa } \\
\text { Coconino }\end{array}$ & $\begin{array}{l}333841 \mathrm{~N} 1101636 \mathrm{~W} \\
333452 \mathrm{~N} 1121612 \mathrm{~W} \\
331 \mathrm{~B} 30 \mathrm{~N} 1115152 \mathrm{~W} \\
363251 \mathrm{N1} 110824 \mathrm{~W} \\
335300 \mathrm{~N} 1112 \mathrm{~B} 00 \mathrm{~W} \\
\\
332852 \mathrm{~N} 1120908 \mathrm{~W} \\
334006 \mathrm{~N} 1121130 \mathrm{~W} \\
333724 \mathrm{~N} 1115956 \mathrm{~W} \\
353219 \mathrm{~N} 1112 \mathrm{~B} 5 \mathrm{~W}\end{array}$ & & $\begin{array}{l}1120 \\
6602\end{array}$ & $\begin{array}{l}\text { Popcorn Canyon } \\
\text { El Mirage } \\
\text { Chandler } \\
\text { Arrowhead Mesa } \\
\text { Reno Pass } \\
\text { Fowler } \\
\text { Hedgpeth Hills } \\
\text { Paradise Valley } \\
\text { Wupatki SW }\end{array}$ \\
\hline $\begin{array}{l}\text { Arrowhead Spring } \\
\text { Arrowhead Spring } \\
\text { Banegas Spring } \\
\text { Arrowhead Tank } \\
\text { Arrowhead Tank } \\
\text { Arrowhead Terrace } \\
\text { Arrowhead Water Tank } \\
\text { Arrowhead Wel1 } \\
\text { Arrow Tank } \\
\text { Arrowweed Canyon }\end{array}$ & $\begin{array}{l}\text { spring } \\
\text { spring } \\
\text { reservoir } \\
\text { reservoir } \\
\text { bench } \\
\text { reservoir } \\
\text { well } \\
\text { reservoir } \\
\text { valley }\end{array}$ & $\begin{array}{l}\text { BGN } \\
\text { BGN } \\
\text { VARIANT } \\
\text { BGN } \\
\text { BGN } \\
\text { BGN } \\
\text { BGN } \\
\text { UNOFF } \\
\text { BGN } \\
\text { BGN }\end{array}$ & $\begin{array}{l}\text { Mohave } \\
\text { Mohave } \\
\text { Gila } \\
\text { Coconino } \\
\text { Coconino } \\
\text { Pima } \\
\text { Yavapai } \\
\text { Yavapai } \\
\text { Mohave }\end{array}$ & $\begin{array}{l}34263 \mathrm{BN} 1133029 \mathrm{~W} \\
344035 \mathrm{~N} 1132400 \mathrm{~W} \\
\\
333840 \mathrm{~N} 1101637 \mathrm{~W} \\
353207 \mathrm{~N} 1112746 \mathrm{~W} \\
362109 \mathrm{~N} 1122433 \mathrm{~W} \\
320320 \mathrm{~N} 1103430 \mathrm{~W} \\
341107 \mathrm{~N} 1124936 \mathrm{~W} \\
345627 \mathrm{~N} 1120319 \mathrm{~W} \\
344111 \mathrm{~N} 1132520 \mathrm{~W}\end{array}$ & $344020 \mathrm{~N} 1132248 \mathrm{~W}$ & & $\begin{array}{l}\text { Signal Mtn } \\
\text { Elephant Mtn } \\
\text { Popcorn Canyon } \\
\text { Wupatki SW } \\
\text { Powell Plateau } \\
\text { Rincon Peak } \\
\text { Congress } \\
\text { Sycanore Bas in } \\
\text { Elephant Mtn }\end{array}$ \\
\hline $\begin{array}{l}\text { Artesa Mount } \\
\text { See Artesa Mountains } \\
\text { Artesa Mountains } \\
\text { Artesa Mount } \\
\text { Artesa Range } \\
\text { Artes ia Mountains } \\
\text { Sierra Arteza } \\
\text { Artesa Ranch } \\
\text { See Artesa } \\
\text { Artesa Range } \\
\text { See Artesa Mountains }\end{array}$ & $\begin{array}{l}\text { locale } \\
\text { summit }\end{array}$ & $\begin{array}{l}\text { VARIANT } \\
\text { BGN } 1941 \\
\text { VARIANT } \\
\text { VARIANT } \\
\text { VARIANT } \\
\text { VARIANT } \\
\text { VARIANT } \\
\text { VARIANT }\end{array}$ & $\begin{array}{l}\text { Pima } \\
\text { Pima }\end{array}$ & $\begin{array}{l}315358 \mathrm{~N} 1115106 \mathrm{~W} \\
315039 \mathrm{~N} 1115246 \mathrm{~W}\end{array}$ & & & Cowlic \\
\hline $\begin{array}{l}\text { Artesia } \\
\text { See Artesa } \\
\text { Artesia } \\
\text { Artesia Cemetery } \\
\text { Artesia Mountains } \\
\text { See Artesa Mountains } \\
\text { Artesia School } \\
\text { Art Hill } \\
\text { Arthur Pack Desert Golf Course } \\
\text { See Arthur Pack Regional } \\
\text { Park }\end{array}$ & $\begin{array}{l}\text { locale } \\
\text { locale } \\
\text { cemetery } \\
\text { summit } \\
\text { school } \\
\text { ridge } \\
\text { park }\end{array}$ & $\begin{array}{l}\text { VARIANT } \\
\text { BGN } \\
\text { UNOFF } \\
\text { VARIANT } \\
\text { UNOFF } \\
\text { BGN } \\
\text { VARIANT }\end{array}$ & $\begin{array}{l}\text { Pima } \\
\text { Graham } \\
\text { Graham } \\
\text { Pima } \\
\text { Graham } \\
\text { Cochise } \\
\text { Pima }\end{array}$ & $\begin{array}{l}31535 \mathrm{BN} 1115106 \mathrm{~W} \\
324153 \mathrm{~N} 1094225 \mathrm{~W} \\
324115 \mathrm{~N} 1094055 \mathrm{~W} \\
\\
315039 \mathrm{~N} 1115246 \mathrm{~W} \\
324113 \mathrm{~N} 1094144 \mathrm{~W} \\
312645 \mathrm{~N} 1095517 \mathrm{~W} \\
322230 \mathrm{~N} 1110312 \mathrm{~W}\end{array}$ & & & $\begin{array}{l}\text { Artesia } \\
\text { Artesia }\end{array}$ \\
\hline
\end{tabular}


NATIONAL GAZETTEER--ARIZONA 1986

Artillery Mountains Artillery Peaks

Artillery Peak

See Artillery Mountains

Arts Spring

Arts Tank

As a Spring

Asbestos Canyon

Asbestos Peak

See Asbestos Point

Asbestos Point Asbestos Peak

Asbestos Spring

Asbestos Tank

A Seventy-three, Lateral

Ashbrook Wash

Ashburn (historical)

Ashburn Mountain

Ashby Spring

Ash Canyon

Ash Canyon

Ash Canyon Spring

Ash Canyon Trail One Hundred Four

Ash Creek

Ash Creek

Ash Creek

Ash Creek

Ash Creek

Ash Creek
Hawk Hollow Creek

Ash Creek

Ash Creek

Ash Creek

Ash Creek

Ash Creek

Ash Creek

Ash Creek

Ash Creek

Ash Creek

Ash Creek

Ash Creek

Ash Creek

Ash Creek

Ash Creek

Ash Creek

Ash Creek

See Johnson Creek

Ash Creek

Ash Creek

See Ash Fork Draw

Ash Creek Black Hills

Ash Creek Canyon

Ash Creek Corral Spring

Ash Creek Dam

Ash Creek Falls

Ash Creek Ranch

Ash Creek Ridge

Ash Creek Ridge

Ash Creek School

Ash Creek Spring

Ash Creek Spring

Ash Creek Spring

Ash Creek Tank

Ash Creek Trail Three Hundred Seven

Ash Creek Trough

Ash Creek Well

Ash Creek Well

FEATURE
CLASS

STATUS COUNTY

COORDINATE

valley

range

summit

BGN Navajo

BGN 1967 Mohave

VARIANT

range

spring

VARIANT

BGN Mohave

reservoir

spring

valley

summit

summit

spring

reservoir

canal

BGN Coconino

BGN 1906 Mohave

VARIANT

Gila

BGN

BGN Gila

BGN Gila

arroyo

locale

summit

spring

valley

valley

spring

trail

stream

BGN

$\begin{array}{ll}\text { BGN } & \text { Maricopa } \\ \text { UNOFF } & \text { Santa Cruz } \\ \text { BGN } & \text { Santa Cruz }\end{array}$

BGN

BGN

BGN

BGN

BGN

UNOFF

Santa Cruz

Yavapai

BGN Cochise

stream

stream

stream

stream

stream

stream

stream

stream

stream

BGN Pima 315235N1111658W

BGN

BGN

BGN

1962 Graham

VARIANT

BGN 1975 Pinal

BGN Greenlee

BG

BGN

Greenlee

stream BGN Gila

stream

stream

stream

stream

stream

stream

stream

stream

stream

BGN

BGN

BGN
BGN

BGN

BGN

BGN

Yavapai

stream

BGN

VARIANT

stream

stream

valley

summit

valley

spring

dam

BGN

VARIANT

BGN Graham

BGN Gila

UNOFF Pinal

falls

locale

ridge

school

spring

spring

reservoir

trail

BGN

UNOFF

BGN

BGN

UNOFF

BGN

BGN

BGN

UNOFF

reservoir

well

BGN

UNOFF

UNOFF

$312255 \mathrm{~N} 1101328 \mathrm{~W}$
Gila

Gila

Cochise

Maricopa

Gila

Gila

Yavapai

Gila

Yavapai

Yavapai

Yavapai

Yavapai

344411N1100344W

342204N1133601W

342210N1133451W

$342204 N 1133601 \mathrm{~W}$

$321323 N 1103151 \mathrm{~W}$

$345432 \mathrm{~N} 1114117 \mathrm{~W}$

$342552 \mathrm{~N} 1132324 \mathrm{~W}$

$334547 N 1105656 \mathrm{~W}$

334547 N1105656W

335736 N1104730W

$335935 \mathrm{~N} 1105220 \mathrm{~W}$

335635 N1142410W

$333708 N 1114405 \mathrm{~W}$

$313714 N 1104301 \mathrm{~W}$

$313211 N 1103830 \mathrm{~W}$

331629 N1104939W

$312944 N 1105140 \mathrm{~W}$

$343913 \mathrm{~N} 1120800 \mathrm{~W}$

315027 N1094002W

$320411 N 1102011 \mathrm{~W}$

$322339 \mathrm{~N} 1095745 \mathrm{~W}$

$323140 \mathrm{~N} 1100239 \mathrm{~W}$

$325440 \mathrm{~N} 1094912 \mathrm{~W}$

$330130 \mathrm{~N} 1104353 \mathrm{~W}$

$332450 \mathrm{~N} 1090906 \mathrm{~W}$

332707 N1101025W

$333533 \mathrm{~N} 1111737 \mathrm{~W}$

334714 N1111532W

334754 N1103929W

$335754 \mathrm{N1} 105403 \mathrm{~W}$

340104 N1122040W

341201 N1122458W

$341714 \mathrm{N1112225 \textrm {W }}$

$341741 \mathrm{N1} 122929 \mathrm{~W}$

$341934 \mathrm{N1} 120430 \mathrm{~W}$

$342715 \mathrm{~N} 1124747 \mathrm{~W}$

344122 N1131948W

$350015 N 1132643 W$

$351217 N 1122857 \mathrm{~W}$

$353525 N 1140945 \mathrm{~W}$

$351204 N 1123223 \mathrm{~W}$

$323120 \mathrm{~N} 1100853 \mathrm{~W}$

$321521 N 1100551 \mathrm{~W}$

$335333 \mathrm{~N} 1105542 \mathrm{~W}$

$325900 \mathrm{~N} 1102922 \mathrm{~W}$

$321724 N 1100339 W$

$324347 N 1095336 \mathrm{~W}$

$332151 N 1100124 \mathrm{~W}$

$315159 \mathrm{~N} 1093934 \mathrm{~W}$

$342304 \mathrm{~N} 1122530 \mathrm{~W}$

$315236 \mathrm{~N} 1093811 \mathrm{~W}$

$334623 N 1111745 \mathrm{~W}$

$335834 \mathrm{~N} 1105521 \mathrm{~W}$

353559 N1141054W

$315302 \mathrm{~N} 1111452 \mathrm{~W}$

324538 N1095218W

Pima

Graham

Yavapai

Yavapai

$340314 \mathrm{~N} 1122335 \mathrm{~W}$

$342936 \mathrm{~N} 1120458 \mathrm{~W}$

343611 N1120552W

360510 N1115544W

333740 N1114722W

$\begin{array}{ccc}\begin{array}{c}\text { SOURCE } \\ \text { COOROINATE }\end{array} & \begin{array}{c}\text { ELEV } \\ \text { FT }\end{array} & \text { MAP NAME } \\ 344107 \text { N1100815W } & & \begin{array}{l}\text { Tenmile Cedars } \\ \text { Artillery Peak }\end{array} \\ & 3213 & \text { Artillery Peak }\end{array}$

Mica Mountain

Munds Park

Arrastra Mtn

6652 Aztec Peak

Rock House

Rock House

Poston

Granite Reef Dam

4375 Mt Hughes

5444 Mt Hughes 
FEATURE NAME

Ashdale Ranger Station

Asher

Asher Hills

Ash Flat

Ash Fork

Ashfork ishfork

See Ash Fork

Ash Fork Cemetery

Ash Fork Draw

See Johnson Creek

Ashfork Draw

See Johnson Creek

Ashfork Draw

See Ash Fork Draw

Ash Fork Draw

Ash Creek

Ashfork Draw

Partridge Creek

Ash Fork Elementary School

Ash Fork High School

Ash Fork Landing Strip Santa Fe Airport

Ash Fork Post Office

Ash Fork Railroad Station

Ash Fork Santa Fe Railroad

Company Water Tank

Ash Fork Substation

Ash Gulch

\section{Ash Hill Terrace}

\section{See Walpi}

Ashhurst Point

Ash Mountain

Ash Peak

See Montezuna Peak

Ash Peak

See Bob Thompson Peak

Ash Peak

Ash Peak Canyon

Sheldon Wash

Ash Peak Mine

Ashrama Ranch

Ash Spring

Ash Spring

Hackberry Spring

Ash Spring

Ash Spring

Ash Spring

Ash Spring

See Bootlegger Spring

Ash Spring

Ash Spring

Ash Spring

Ash Spring

Ash Spring

Ash Spring

Ash Spring Canyon Hackberry Gulch

Ash Spring Creek

Ash Spring Tank

\author{
Ash Spring Wash \\ Ash Tank \\ Ash Tank \\ Ash Timber Spring \\ Ashurst \\ Ashurst Cemetery \\ Ashurst Hayden Da \\ Ashurst Lake \\ Ashurst Lake Campground \\ Ashurst Lake Dam
}

Ashurst Run

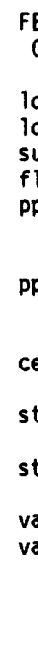

FEATURE

CLASS
locale
locale
summit
flat
ppl

STATUS
UNOFF
BGN
BGN
BGN
BGN 1964
VARIANT
VARIANT

COUNTY

Maricopa

Yuma

Maricopa

Graham

Yavapai

ppl

Yavapai

COORDINATE

335747 N1115233W

$324032 \mathrm{~N} 1140422 \mathrm{~W}$

$334342 \mathrm{~N} 1114203 \mathrm{~W}$

$331730 \mathrm{~N} 1095501 \mathrm{~W}$

$351330 \mathrm{~N} 1122900 \mathrm{~W}$

$351330 \mathrm{~N} 1122900 \mathrm{~W}$

cemetery

UNOFF

VARIANT

Yavapai

$351354 N 1122842 \mathrm{~W}$

Coconino

$351217 N 1122 B 57 W$

stream

valley

VARIANT

VARIANT

Coconino

$351217 N 1122857 \mathrm{~W}$

Yavapai

Yavapai

VARIANT

VARIAN

VARIANT

$\begin{array}{ll}\text { school } & \text { UNOFF } \\ \text { school } & \text { UNOFF } \\ \text { airport } & \text { ADMIN } \\ & \text { VARIANT } \\ \text { building } & \text { UNOFF } \\ \text { building } & \text { UNOFF } \\ \text { reservoir } & \text { BGN } \\ \text { locale } & \text { UNOFF } \\ \text { valley } & \text { BGN }\end{array}$

Yavapai

Yavapai

Yavapai

Yavapai

Yavapai

Yavapai

Yavapai

Cochise

VARIANT

locale

summit

summit

summit

summit

summit

valley

mine

locale

spring

spring

spring

spring

spring

spring

BGN

VARIANT

VARIANT

BGN

BGN 1962

VARIANT

Navajo

Navajo

Gila

Cochise

Cochise

Graham

Greenlee

UNOFF Greenlee

UNOFF

BGN 1964

VARIANT

BGN

BGN

BGN

VARIANT

Pima

Pinal

Greenlee

Greenlee

Gila

Gila

Gila

spring

BGN

spring

spring

spring

spring

strean

reservoir

BGN

BGN

BGN

BGN

BGN

BGN 1964

VARIANT

BGN
BGN

stream

reservoir

reservoir

spring

ppl

cemetery

dam

lake

park

dam

BGN

BGN

BGN

BGN

UNOFF

UNOFF

BGN

ADMIN
UNOFF

Yavapai

Yavapai

Yavapai

Yavapai

Yavapai

Yavapi

Greenlee

Yavapai

Gila

Gila

Yavapai

Coconino

Graham

Graham

Graham

Pinal

Coconino

Coconino

Coconino

stream
BGN
$351204 \mathrm{~N} 1123223 \mathrm{~W}$

$351204 \mathrm{~N} 1123223 \mathrm{~W}$

351320 N1122912W

$351315 \mathrm{~N} 1122908 \mathrm{~W}$

351355 N1122910W

351323N1122906W

$351332 \mathrm{~N} 1122915 \mathrm{~W}$

$351335 \mathrm{~N} 1122914 \mathrm{~W}$

351309 N1122859W

321950 N1093811W

354956 N $1102350 \mathrm{~W}$

341729 N1102145W

$334702 N 1103445 \mathrm{~W}$

$312130 \mathrm{~N} 1101545 \mathrm{~W}$

312204N1101435W

$324506 \mathrm{~N} 1091539 \mathrm{~W}$

$324830 \mathrm{~N} 1091045 \mathrm{~W}$

324547 N1091529W

$320223 N 1102 B 11 W$

$330455 N 1102755 \mathrm{~W}$

$330612 \mathrm{~N} 1091620 \mathrm{~W}$

$332546 \mathrm{~N} 1090739 \mathrm{~W}$

$333025 N 1104915 \mathrm{~W}$

$335840 \mathrm{~N} 1111515 \mathrm{~W}$

$335841 \mathrm{~N} 1111551 \mathrm{~W}$

$340500 \mathrm{~N} 1115213 \mathrm{~W}$

$340953 \mathrm{~N} 1122818 \mathrm{~W}$

$341320 \mathrm{~N} 1122210 \mathrm{~W}$

$342649 \mathrm{~N} 1115953 \mathrm{~W}$

343821 N1120719W

$345310 \mathrm{~N} 1125218 \mathrm{~W}$

$330632 \mathrm{~N} 1091702 \mathrm{~W}$

$340458 \mathrm{N1115044 \textrm {W }}$

$334635 \mathrm{~N} 1103410 \mathrm{~W}$

$332939 N 1105111 \mathrm{~W}$

$342040 \mathrm{~N} 1122747 \mathrm{~W}$

$344716 \mathrm{~N} 1111032 \mathrm{~W}$

$330549 \mathrm{~N} 1094926 \mathrm{~W}$

$325903 \mathrm{~N} 1095554 \mathrm{~W}$

$325940 \mathrm{~N} 1095649 \mathrm{~W}$

$330601 N 1111446 \mathrm{~W}$

$350109 \mathrm{N11} 12411 \mathrm{~W}$

$350109 \mathrm{~N} 1112425 \mathrm{~W}$

$350130 \mathrm{~N} 1112348 \mathrm{~W}$

Coconino

352035 N112252OW

Cathedral Caves

$321535 \mathrm{~N} 1094126 \mathrm{~W}$

$330700 \mathrm{~N} 1091400 \mathrm{~W}$

340432N1115255W

333118 N1 104658W

350043N1112409W $345429 N 1112422 \mathrm{~W}$

6954 Clay Springs

5440 Mule Hoof Bend

5585 Ash Peak

Sheldon

Ash Peak

Galleta Flat West

Rawhide Mtn

Clifton

Dutch Blue Creek

Rockinstraw Mtn 
NATIONAL GAZETTEER--ARIZONA 1986

FEATURE NAME

Ashurst Spring
Ashurst Tank
Ash Wash
Asi-Va Spring
Asolido Wash
Aso Number Two Tank
Aso Pass
Aso Ranch
Aso Tank
Aspen Butte
Aspen Campground
Aspen Canyon
Aspen Canyon
Aspen Creek
Aspen Creek Spring
Aspen Forest Camp
Aspen Grove Wash
Aspen Hill
Aspen Lake
Aspen Lake
Aspen Recreation Area
Aspen Ridge
Aspen Spring
Aspen Spring.
Aspen Spring
Aspen Spring
See Clover Spring
Aspen Spring
Aspen Spring
Aspen Spring
Aspen Spring
Aspen Spring Ranch
Aspen Spring Tank
Aspen Tank
Aspen Tank
Aspen Tank
Aspen Tank
See Water Haul Tank
Aspen Tank
As
Aspon

Aspen Wash

Burnt Corn Wash

Aspen Wash

Assamp

See Hassayampa River

Assamp River

See Hassayampa River

Assan Dechali Spring

Association Tank

Association Tank

Assumption

See Salt River

Assuption

See Salt River

As-Thon-Sosie Mesa

See Azansosi Mesa

Asthonsosie Mesa

See Azansosi Mesa

Ast in Spring

Astin Tank

Aswan Tank

Atacosa Canon

See Agua Fria Canyon

Atacosa Canyon

See Agua Fria Canyon

Atacosa Mountain

$$
\text { See Atascosa Peak }
$$

Atacosa Mountains

See Tumacacori Mountains

Atacosa Peak

See Atascosa Peak

\section{FEATURE}

CLASS

STATUS

spring

reservoir

stream

spring

stream

reservoir

gap

locale

reservoir

BGN
BGN
BGN
BGN
BGN
BGN
BGN
UNOFF
BGN

summit

park

valley

valley

stream

spring

valley

summit

lake

$\begin{array}{ll}\text { BGN } & \text { Apache } \\ \text { ADMIN } & \text { Apache } \\ \text { BGN } & \text { Apache } \\ \text { BGN } & \text { Apache } \\ \text { BGN } & \text { Yavapai } \\ \text { BGN } & \text { Yavapai } \\ \text { ADNIN } & \text { Apache } \\ \text { BGN } & \text { Navajo } \\ \text { BGN } & \text { Coconino } \\ \text { BGN } & \text { Coconino }\end{array}$

lake

park

ridge

spring

spring

spring

spring

spring

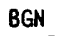

ADMIN

BGN

BGN

BGN

VARIANT

BGN

BGN

spring
spring

spring

reservoir

reservoir

reservoir

reservoir

BGN

BGN
UNOFF
BGN

BGN

BGN

VARIANT

reservoir

locale

BGN

valley

BGN 1968

valley

VARIANT

BGN

VARIANT

stream

VARIANT

stream

spring

reservoir $B G N$

reservoir BG

BGN

Maricopa

Maricopa

Navajo

Navajo

Coconino

VARIANT

stream

VARIANT

stream

summit

summit

spring

reservoir

VARIANT

VARIANT

BGN

BGN

reservoir

BGN

valley

VARIANT

VARIANT

valley

summit

range

VARIANT

VARIANT

VARIANT

summit

summit

BGN 1983 Apache
COORDINATE

$350131 N 1112249 \mathrm{~W}$

$345437 \mathrm{~N} 1112424 \mathrm{~W}$

$315407 \mathrm{~N} 1112339 \mathrm{~W}$

$354937 \mathrm{~N} 1102939 \mathrm{~W}$

$313650 \mathrm{N1} 113509 \mathrm{~W}$

$351336 \mathrm{~N} 111543 \mathrm{BW}$

$341551 N 1130913 \mathrm{~W}$

353359 N1113934W

$334644 N 1121123 \mathrm{~W}$

$334905 N 1093649 \mathrm{~W}$

$334827 N 1091856 \mathrm{~W}$

$354134 \mathrm{~N} 1090603 \mathrm{~W}$

361728 N1095159W

$343157 \mathrm{~N} 1122819 \mathrm{~W}$

$343001 \mathrm{N1} 123136 \mathrm{~W}$

$334823 N 1091848 \mathrm{~W}$

$362058 \mathrm{~N} 1100332 \mathrm{~W}$

$351126 \mathrm{~N} 1120741 \mathrm{~W}$

341749 N1105119W

$342035 \mathrm{~N} 1104458 \mathrm{~W}$

341957 N1105630W

$335337 \mathrm{~N} 1094108 \mathrm{~W}$

$341024 \mathrm{~N} 1094305 \mathrm{~W}$

$342917 N 1111136 \mathrm{~W}$

$343002 N 1123106 \mathrm{~W}$

$351354 N 1121211 \mathrm{~W}$

$351 \mathrm{~B} 16 \mathrm{~N} 1113 \mathrm{~B} 3 \mathrm{WW}$

$362624 N 1100050 \mathrm{~W}$

$362942 N 1091113 \mathrm{~W}$

$36482 B N 1103107 W$

$350740 \mathrm{~N} 1114708 \mathrm{~W}$

$350739 \mathrm{~N} 1114710 \mathrm{~W}$

$351111 N 1120820 \mathrm{~W}$

$351841 N 1113818 \mathrm{~W}$

$352016 \mathrm{~N} 1114721 \mathrm{~W}$

$352017 \mathrm{~N} 1114719 \mathrm{~W}$

$352030 \mathrm{~N} 1114720 \mathrm{~W}$

$361400 N 1095345 W$

362340 N1100418W

$361724 N 1095157 W$

362628 N1100340W

$331920 \mathrm{~N} 1124240 \mathrm{~W}$

$331920 \mathrm{N1124240 \textrm {W }}$

$351333 \mathrm{~N} 110174 \mathrm{BW}$

$343546 \mathrm{~N} 1104019 \mathrm{~W}$

$344347 \mathrm{N1} 112210 \mathrm{~W}$

$354218 N 1090822 W$

$362052 N 1094953 \mathrm{~W}$

$342955 \mathrm{~N} 1123233 \mathrm{~W}$

$362841 N 1100207 w$

$$
7650
$$

In Rock Valley

liams South

0 W Point

Brookbank Point

7603 Woods Canyon

Hawley Lake East

Boundary Butte

Dane Canyon

Iron Springs

Humphreys Peak

Chilchinbito Canyon

Lukachukai

Tall Mountain

73BO Bellemont

Bellemont

Williams South

Humphreys Peak

Wing Mountain

Sunset Crater West

Blue Gap

Chilchinbito Canyon

Rotten Bananas Butte Potato Wash South

Turkey Mtn

San Bernardino Ranch San Bernardino Ranch

Long Valley

Del Muerto

$360852 N 1092647 W$

Ata Deeza 
NATIONAL GAZETTEER--ARIZONA 1986

\begin{tabular}{|c|c|c|c|c|c|c|c|}
\hline FEATURE NAME & $\begin{array}{l}\text { FEATURE } \\
\text { CLASS }\end{array}$ & STATUS & COUNTY & COORDINATE & $\begin{array}{l}\text { SOURCE } \\
\text { COORDINATE }\end{array}$ & $\begin{array}{c}\text { ELEV } \\
\text { FT }\end{array}$ & MAP NAME \\
\hline $\begin{array}{l}\text { Middle Mesa } \\
\text { Atascacita Springs } \\
\text { Atoscaceta Spring } \\
\text { Atoscacita Spring } \\
\text { Atascocita Draw } \\
\text { Atasco Mountains } \\
\text { See Atascosa Mountains } \\
\text { Atascosa Canyon } \\
\text { Atascosa Canyon } \\
\text { See Agua Fria Canyon }\end{array}$ & $\begin{array}{l}\text { spring } \\
\text { valley } \\
\text { summit } \\
\text { valley } \\
\text { valley }\end{array}$ & $\begin{array}{l}\text { VARIANT } \\
\text { BGN } \\
\text { VARIANT } \\
\text { VARIANT } \\
\text { BGN } \\
\text { VARIANT }\end{array}$ & $\begin{array}{l}\text { Apache } \\
\text { Santa Cruz } \\
\text { Santa Cruz } \\
\text { Santa Cruz }\end{array}$ & $\begin{array}{l}341007 \text { N1093101W } \\
341844 \text { N1092552W } \\
312729 N 1110813 \mathrm{~W} \\
312409 \text { N1111110W } \\
312832 \mathrm{~N} 111001 \mathrm{BW}\end{array}$ & $341203 \mathrm{~N} 1092953 \mathrm{~W}$ & & $\begin{array}{l}\text { Whiting Knoll } \\
\text { Lyman Lake SW }\end{array}$ \\
\hline $\begin{array}{l}\text { Atascosa Lookout Number One } \\
\text { Hundred } \\
\text { Atascosa Mountain } \\
\text { See Atascosa Peak } \\
\text { Atascosa Mountain } \\
\text { See Atascosa Mountains } \\
\text { Atascosa Mountains } \\
\text { See Tumacacori Mountains } \\
\text { Atascosa Mountains } \\
\text { Atasco Mountains } \\
\text { Atascosa Mountain } \\
\text { Atascoso Range } \\
\text { Tumacacori Mountains }\end{array}$ & $\begin{array}{l}\text { summit } \\
\text { summit } \\
\text { range } \\
\text { summit }\end{array}$ & $\begin{array}{l}\text { UNOFF } \\
\text { VARIANT } \\
\text { VARIANT } \\
\text { VARIANT } \\
\text { BGN } \\
\text { VARIANT } \\
\text { VARIANT } \\
\text { VARIANT } \\
\text { VARIANT }\end{array}$ & $\begin{array}{l}\text { Santa Cruz } \\
\text { Santa Cruz } \\
\text { Santa Cruz } \\
\text { Santa Cruz }\end{array}$ & $\begin{array}{l}312517 \mathrm{~N} 1110846 \mathrm{~W} \\
312557 \mathrm{~N} 1110849 \mathrm{~W} \\
312729 \mathrm{~N} 1110813 \mathrm{~W} \\
313327 \mathrm{~N} 1110713 \mathrm{~W} \\
312729 \mathrm{~N} 1110813 \mathrm{~W}\end{array}$ & & 6249 & Ruby \\
\hline $\begin{array}{l}\text { Atascosa Peak } \\
\text { Atacosa Mountain } \\
\text { Atacosa Peak } \\
\text { Atascosa Mountain } \\
\text { Atascosa Ridge } \\
\text { Atascosa Ridge } \\
\text { See Atascosa Peak } \\
\text { Atascosa Spring } \\
\text { Atascosa Trail Tank } \\
\text { Atascoso Canon } \\
\text { See Agua Fria Canyon }\end{array}$ & $\begin{array}{l}\text { summit } \\
\text { spring } \\
\text { reservoir } \\
\text { valley }\end{array}$ & $\begin{array}{l}\text { BGN } 1942 \\
\text { VARIANT } \\
\text { VARIANT } \\
\text { VARIANT } \\
\text { VARIANT } \\
\text { VARIANT } \\
\text { BGN } 1942 \\
\text { BGN } \\
\text { VARIANT }\end{array}$ & $\begin{array}{l}\text { Santa Cruz } \\
\text { Santa Cruz } \\
\text { Santa Cruz } \\
\text { Santa Cruz }\end{array}$ & $\begin{array}{l}312557 \text { N1110849W } \\
312430 \mathrm{~N} 1111043 \mathrm{~W} \\
312433 \mathrm{~N} 1110850 \mathrm{~W} \\
312832 \mathrm{~N} 1110018 \mathrm{~W}\end{array}$ & & 6440 & $\begin{array}{l}\text { Ruby } \\
\text { Ruby }\end{array}$ \\
\hline $\begin{array}{l}\text { Atchison Topeka and Santa Fe } \\
\text { Underpass } \\
\text { Atchley Canyon } \\
\text { Athos } \\
\text { Atkin-Larson Tank } \\
\text { Atkin Spring } \\
\text { Atkinsville Wash } \\
\text { See Atkinville Wash } \\
\text { Atkins Well } \\
\text { Atkins Well }\end{array}$ & $\begin{array}{l}\text { crossing } \\
\text { valley } \\
\text { locale } \\
\text { reservoir } \\
\text { spring } \\
\text { valley } \\
\text { well } \\
\text { well }\end{array}$ & $\begin{array}{l}\text { UNOFF } \\
\text { BGN } \\
\text { BGN } \\
\text { BGN } \\
\text { BGN } \\
\text { VARIANT } \\
\text { UNOFF } \\
\text { UNOFF }\end{array}$ & $\begin{array}{l}\text { Coconino } \\
\text { Pima } \\
\text { Mohave } \\
\text { Mohave } \\
\text { Mohave } \\
\text { Mohave } \\
\text { Yavapai } \\
\text { Mohave }\end{array}$ & $\begin{array}{l}351528 \mathrm{~N} 1120935 \mathrm{~W} \\
322813 \mathrm{~N} 1104035 \mathrm{~W} \\
345700 \mathrm{~N} 1140819 \mathrm{~W} \\
362857 \mathrm{~N} 1132940 \mathrm{~W} \\
365155 \mathrm{~N} 1134222 \mathrm{~W} \\
370150 \mathrm{~N} 1133756 \mathrm{~W} \\
350410 \mathrm{~N} 1124645 \mathrm{~W} \\
365329 \mathrm{~N} 1130837 \mathrm{~W}\end{array}$ & $322551 \mathrm{~N} 110425 \mathrm{WW}$ & 4930 & $\begin{array}{l}\text { Williams North } \\
\text { Mount Bigelow } \\
\text { Yucca NW } \\
\text { Poverty Knoll } \\
\text { Wolf Hole Mtn West } \\
\text { Red Mountain } \\
\text { Lost Spring Mtn West }\end{array}$ \\
\hline $\begin{array}{l}\text { Atkin Tank } \\
\text { See Cox-Atkin Tank } \\
\text { Atkinville Wash } \\
\text { Atkinsville Wash } \\
\text { Atlantic Orain } \\
\text { Atlantic Spring } \\
\text { Atoko Point } \\
\text { Atoscaceta Spring } \\
\text { See Atascacita Springs } \\
\text { Atoscacita Spring } \\
\text { See Atascacita Springs }\end{array}$ & $\begin{array}{l}\text { reservoir } \\
\text { valley } \\
\text { stream } \\
\text { spring } \\
\text { cliff } \\
\text { spring } \\
\text { spring }\end{array}$ & $\begin{array}{l}\text { VARIANT } \\
\text { BGN } 1979 \\
\text { VARIANT } \\
\text { BGN } \\
\text { BGN } \\
\text { BGN } 1906 \\
\text { VARIANT } \\
\text { VARIANT }\end{array}$ & $\begin{array}{l}\text { Mohave } \\
\text { Mohave } \\
\text { Mohave } \\
\text { Mohave } \\
\text { Coconino } \\
\text { Apache } \\
\text { Apache }\end{array}$ & $\begin{array}{l}343027 N 1141922 W \\
351209 N 1140432 W \\
361241 N 1115558 W \\
341007 N 1093101 W \\
341007 N 1093101 W\end{array}$ & $365509 \mathrm{~N}_{1133325 \mathrm{~W}}$ & & $\begin{array}{l}\text { Lizard Point } \\
\text { Lake Havasu City N } \\
\text { Kingman } \\
\text { Walhalla Plateau }\end{array}$ \\
\hline $\begin{array}{l}\text { Atoscos Mountains } \\
\quad \text { See Tumacacori Mountains } \\
\text { Atravesada Canyon, Cañada } \\
\text { Atsadahs idahi } \\
\text { Atterbury Wash } \\
\text { Aubineau Canyon } \\
\text { Abineau Canyon }\end{array}$ & $\begin{array}{l}\text { range } \\
\text { valley } \\
\text { summit } \\
\text { arroyo } \\
\text { valley }\end{array}$ & $\begin{array}{l}\text { VARIANT } \\
\text { BGN } \\
\text { BGN } \\
\text { BGN } \\
\text { BGN } \\
\text { VARIANT }\end{array}$ & $\begin{array}{l}\text { Santa Cruz } \\
\text { Pima } \\
\text { Apache } \\
\text { Pima } \\
\text { Coconino }\end{array}$ & $\begin{array}{l}313327 \mathrm{~N} 1110713 \mathrm{~W} \\
321853 \mathrm{~N} 1102 \mathrm{~B} 33 \mathrm{~W} \\
360112 \mathrm{~N} 1095418 \mathrm{~W} \\
321109 \mathrm{~N} 1104852 \mathrm{~W} \\
352500 \mathrm{~N} 1114017 \mathrm{~W}\end{array}$ & $\begin{array}{l}321706 \mathrm{~N} 1102650 \mathrm{~W} \\
320620 \mathrm{~N} 1104605 \mathrm{~W} \\
352058 \mathrm{~N} 1114018 \mathrm{~W}\end{array}$ & 7291 & $\begin{array}{l}\text { Soza Canyon } \\
\text { Toadindaaska Mesa } \\
\text { Tucson East } \\
\text { White Horse Hills }\end{array}$ \\
\hline
\end{tabular}


NATIONAL GAZETTEER--ARIZONA 1986

FEATURE NAME
Abanaugh Canyon
Aubineau Peak
Aubrey
See Aubrey Landing
(historical)
Aubrey City
See Aubrey Landing
(historical)
Aubrey Cliffs
Aubrey Hills
Williams Mountains
Aubrey Landing (historical)
Aubrey
Aubrey City
Aubry
Sand Creek
Williams
Williams Fork

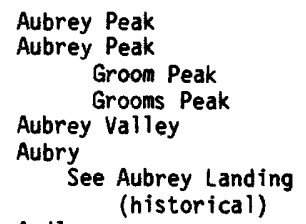

\begin{tabular}{|c|c|c|c|c|c|c|}
\hline $\begin{array}{l}\text { FEATURE } \\
\text { CLASS }\end{array}$ & STATUS & COUNTY & COORDINATE & $\begin{array}{l}\text { SOURCE } \\
\text { COORDINATE }\end{array}$ & $\begin{array}{l}\text { ELEV } \\
\text { FT }\end{array}$ & MAP NAME \\
\hline summit & $\begin{array}{l}\text { VARIANT } \\
\text { BGN } \\
\text { VARIANT }\end{array}$ & Coconino & $352119 N 1113933 \mathrm{~W}$ & & $11 B 3$ & Humphreys Peak \\
\hline locale & & Mohave & $341800 \mathrm{~N} 1140436 \mathrm{~W}$ & & & \\
\hline & VARIANT & & & & & \\
\hline locale & & Mohave & $341800 \mathrm{~N} 1140436 \mathrm{~W}$ & & & \\
\hline $\begin{array}{l}\text { cliff } \\
\text { summit }\end{array}$ & $\begin{array}{l}\text { BGN } \\
\text { BGN } 1972 \\
\text { VARIANT }\end{array}$ & $\begin{array}{l}\text { Coconino } \\
\text { Mohave }\end{array}$ & $\begin{array}{l}360223 N 1130517 W \\
342115 N 1140908 W\end{array}$ & & & $\begin{array}{l}\text { Vulcans Throne SE } \\
\text { Gene Wash }\end{array}$ \\
\hline locale & $\begin{array}{l}\text { BGN } \\
\text { VARIANT } \\
\text { VARIANT } \\
\text { VARIANT } \\
\text { VARIANT } \\
\text { VARIANT } \\
\text { VARIANT }\end{array}$ & Mohave & $341800 \mathrm{~N} 1140436 \mathrm{~W}$ & & & Monkeys Head \\
\hline $\begin{array}{l}\text { summit } \\
\text { summit }\end{array}$ & $\begin{array}{l}\text { BGN } \\
\text { BGN } \\
\text { VARIANT } \\
\text { VARIANT }\end{array}$ & $\begin{array}{l}\text { Mohave } \\
\text { Mohave }\end{array}$ & $\begin{array}{l}342355 \mathrm{~N} 1134750 \mathrm{~W} \\
343947 \mathrm{~N} 1134342 \mathrm{~W}\end{array}$ & 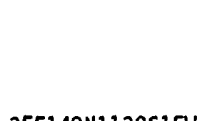 & $\begin{array}{l}2953 \\
5078\end{array}$ & $\begin{array}{l}\text { McCracken Peak } \\
\text { Aubrey Peak }\end{array}$ \\
\hline valley & $\begin{array}{l}\text { BGN } \\
\text { VARIANT }\end{array}$ & Yavapai & $351759 \mathrm{~N} 1125811 \mathrm{~W}$ & $355149 \mathrm{~N} 1130615 \mathrm{~W}$ & & Seligman West \\
\hline locale & & Mohave & 341B00N1140436W & & & \\
\hline $\begin{array}{l}\text { ppl } \\
\text { building }\end{array}$ & $\begin{array}{l}\text { BGN } \\
\text { UNOFF }\end{array}$ & $\begin{array}{l}\text { Yavapai } \\
\text { Yavapai }\end{array}$ & $\begin{array}{l}352406 \mathrm{~N} 1130218 \mathrm{~W} \\
352412 \mathrm{~N} 1130140 \mathrm{~W}\end{array}$ & & & $\begin{array}{l}\text { Audley } \\
\text { Audley }\end{array}$ \\
\hline $\begin{array}{l}\text { reservoir } \\
\text { spring } \\
\text { valley } \\
\text { stream } \\
\text { summit } \\
\text { reservoir } \\
\text { mine } \\
\text { spring } \\
\text { valley }\end{array}$ & $\begin{array}{l}\text { BGN } \\
\text { BGN } \\
\text { BGN } \\
\text { BGN } \\
\text { BGN } \\
\text { BGN } \\
\text { UNOFF } \\
\text { BGN } \\
\text { BGN } \\
\text { VARIANT }\end{array}$ & $\begin{array}{l}\text { Yavapai } \\
\text { Navajo } \\
\text { Greenlee } \\
\text { Apache } \\
\text { Greenlee } \\
\text { Greenlee } \\
\text { Santa Cruz } \\
\text { Yavapai } \\
\text { Mohave }\end{array}$ & $\begin{array}{l}352351 \mathrm{~N} 1130147 \mathrm{~W} \\
354916 \mathrm{~N} 1102941 \mathrm{~W} \\
332731 \mathrm{~N} 1090 \mathrm{~B} 46 \mathrm{~W} \\
335720 \mathrm{~N} 1091257 \mathrm{~W} \\
333131 \mathrm{~N} 1090854 \mathrm{~W} \\
332829 \mathrm{~N} 1090917 \mathrm{~W} \\
312627 \mathrm{~N} 1104350 \mathrm{~W} \\
342234 \mathrm{~N} 1122544 \mathrm{~W} \\
365537 \mathrm{~N} 1123656 \mathrm{~W}\end{array}$ & $\begin{array}{l}333034 \mathrm{~N} 1090859 \mathrm{~W} \\
335247 \mathrm{~N} 1091320 \mathrm{~W} \\
365725 \mathrm{~N} 1124120 \mathrm{~W}\end{array}$ & & $\begin{array}{l}\text { Audley } \\
\text { Polacca } \\
\text { Dutch Blue Creek } \\
\text { Nutrioso } \\
\text { Bear Mountain } \\
\text { Dutch Blue Creek } \\
\text { Harshaw } \\
\text { Groom Creek } \\
\text { Fredonia }\end{array}$ \\
\hline $\begin{array}{l}\text { spring } \\
\text { locale } \\
\text { park }\end{array}$ & $\begin{array}{l}\text { BGN } \\
\text { BGN } \\
\text { ADMIN }\end{array}$ & $\begin{array}{l}\text { Mohave } \\
\text { Yavapai } \\
\text { Navajo }\end{array}$ & $\begin{array}{l}365525 \mathrm{~N} 1123905 \mathrm{~W} \\
343659 \mathrm{~N} 1115449 \mathrm{~W} \\
342013 \mathrm{~N} 1101620 \mathrm{~W}\end{array}$ & & & $\begin{array}{l}\text { Kaibab } \\
\text { Middle Verde } \\
\text { Clay Springs }\end{array}$ \\
\hline $\begin{array}{l}\text { locale } \\
\text { mine } \\
\text { summit }\end{array}$ & $\begin{array}{l}\text { BGN } \\
\text { UNOFF } \\
\text { BGN } \\
\text { VARIANT }\end{array}$ & $\begin{array}{l}\text { Santa Cruz } \\
\text { Santa Cruz } \\
\text { Mohave }\end{array}$ & $\begin{array}{l}312 \mathrm{~B} 09 \mathrm{~N} 1111605 \mathrm{~W} \\
312 \mathrm{~B} 06 \mathrm{~N} 1111610 \mathrm{~W} \\
350534 \mathrm{~N} 1133054 \mathrm{~W}\end{array}$ & & $\begin{array}{l}4320 \\
5690\end{array}$ & $\begin{array}{l}\text { Bartlett Mtn } \\
\text { Bartlett Mtn } \\
\text { Aust in Peak }\end{array}$ \\
\hline $\begin{array}{l}\text { reservoir } \\
\text { well }\end{array}$ & UNOFF & $\begin{array}{l}\text { Graham } \\
\text { Apache }\end{array}$ & $\begin{array}{l}32481 B N 1100527 W \\
352551 N 1092404 W\end{array}$ & & 6695 & Wide Ruins \\
\hline $\begin{array}{l}\text { ppl } \\
\text { canal } \\
\text { reservoir } \\
\text { stream } \\
\text { school }\end{array}$ & $\begin{array}{l}\text { BGN } \\
\text { BGN } \\
\text { BGN } \\
\text { BGN } \\
\text { UNOFF } \\
\text { VARIANT }\end{array}$ & $\begin{array}{l}\text { Maricopa } \\
\text { Yuma } \\
\text { Coconino } \\
\text { Mohave } \\
\text { Pinal }\end{array}$ & $\begin{array}{l}333911 \mathrm{~N} 1120911 \mathrm{~W} \\
323855 \mathrm{~N} 1143810 \mathrm{~W} \\
350732 \mathrm{~N} 1114512 \mathrm{~W} \\
343046 \mathrm{~N} 1142015 \mathrm{~W} \\
323617 \mathrm{~N} 1103744 \mathrm{~W}\end{array}$ & 343138 N1141650W & 1300 & $\begin{array}{l}\text { Hedgpeth Hills } \\
\text { Yuma West } \\
\text { Bellemont } \\
\text { Lake Havasu City N } \\
\text { Campo Bonito }\end{array}$ \\
\hline $\begin{array}{l}\text { range } \\
\text { spring }\end{array}$ & $\begin{array}{l}\text { BGN } \\
\text { VARIANT }\end{array}$ & $\begin{array}{l}\text { Yuma } \\
\text { Cochise }\end{array}$ & $\begin{array}{l}334127 \mathrm{~N} 1142011 \mathrm{~W} \\
315402 \mathrm{~N} 1092206 \mathrm{~W}\end{array}$ & & & Rustler Park \\
\hline valley & & Pima & $322705 \mathrm{~N} 1111922 \mathrm{~W}$ & & & \\
\hline ppl & $\begin{array}{l}8 \mathrm{GN} \\
\text { VARIANT } \\
\text { VARIANT }\end{array}$ & Maricopa & $332608 \mathrm{~N} 1122056 \mathrm{~W}$ & & & Avondale \\
\hline $\begin{array}{l}\text { park } \\
\text { school } \\
\text { school } \\
\text { building }\end{array}$ & $\begin{array}{l}\text { AOMIN } \\
\text { UNOFF } \\
\text { UNOFF } \\
\text { UNOFF } \\
\text { VARIANT }\end{array}$ & $\begin{array}{l}\text { Maricopa } \\
\text { Maricopa } \\
\text { Maricopa } \\
\text { Maricopa }\end{array}$ & $\begin{array}{l}332609 \mathrm{~N} 1122040 \mathrm{~W} \\
332605 \mathrm{~N} 1122100 \mathrm{~W} \\
332640 \mathrm{~N} 1122055 \mathrm{~W} \\
332607 \mathrm{~N} 1122028 \mathrm{~W}\end{array}$ & & & $\begin{array}{l}\text { Tolleson } \\
\text { Tolleson } \\
\text { Tolleson } \\
\text { Tolleson }\end{array}$ \\
\hline $\begin{array}{l}\text { ppl } \\
\text { locale }\end{array}$ & UNOFF & $\begin{array}{l}\text { Maricopa } \\
\text { Maricopa }\end{array}$ & $\begin{array}{l}332608 \mathrm{~N} 1122056 \mathrm{~W} \\
332604 \mathrm{~N} 1122110 \mathrm{~W}\end{array}$ & & & Tolleson \\
\hline $\begin{array}{l}\text { building } \\
\text { locale } \\
\text { locale }\end{array}$ & $\begin{array}{l}\text { UNOFF } \\
\text { BGN } \\
\text { BGN }\end{array}$ & $\begin{array}{l}\text { Maricopa } \\
\text { Pima } \\
\text { Pinal }\end{array}$ & $\begin{array}{l}332627 N 1122054 \mathrm{~W} \\
321940 \mathrm{~N} 1111303 \mathrm{~W} \\
323307 \mathrm{~N} 1111810 \mathrm{~W}\end{array}$ & & 2205 & $\begin{array}{l}\text { Tolleson } \\
\text { Avra } \\
\text { Red Rock }\end{array}$ \\
\hline
\end{tabular}




\section{FEATURE NAME}

Avra Cotton Gin

Avra Valley

Altar Valley Avivaca Valley

Avra Valley Airport

Aura Valley Road Interchange

A-vuc-hoo-mar-lish

See Casa Blanca

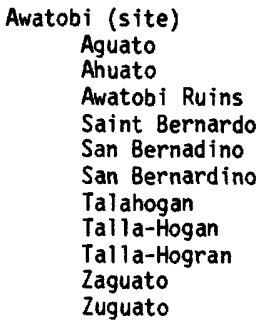

Awatobi Ruins

$$
\text { See Awatobi (site) }
$$

Aztec Amphitheater

Aztec Creek

Aztec Group Mines

Aztec Gulch

Aztec Hills

Aztec Interchange

Aztec Lodge

Aztec Mill (historical)

Aztec Mountains See Mohon Mountains Aztec Pass

Aztec Peak

Aztec Tank

Aztec Tank

Azure Ridge Draw

Azurite Mine

$A Z$ Well

A 1 Mountain A One Mountain Crater $\mathrm{Hill}$

A-1 Trailer Park

A 8.4 Lateral

A 8.9 Lateral

A $8.9 \mathrm{~N}$ Lateral

A 9.4 Lateral
FEATURE

CLASS

locale

valley

airport

crossing

ppl

locale

BGN 19

VARIANT

VARIANT

VARIANT

VARIANT

VARIANT
VARIANT

VARIANT

VARIANT

VARIANT

VARIANT

VARIANT

VARIANT

locale

spring

valley

stream

summit

park

cliff

locale

summit

summit

VARIAMT

BGN 1960

VARIANT

VARIANT

VARIANT

VARIANT

VARIANT

summit

stream

VARIANT

reservoir

locale

bas in

strean

mine

valley

crossing

ppl

mine

\section{BGN}

BGN 1908

BGN 1950

UNOFF

BGN

BGN

UNOFF

BGN

UNOFF

Mavajo

Maricopa

Coconino

Yuma

Coconino

Coconino

Santa Cruz

Santa Cruz

Yuma

Yuma

Gila

Santa Cruz

VARIANT

range

valley

reservoir

reservoir

valley

mine

summit

BGN

BGN

BGN

BGN

BGN
UNOFF

UNOFF

UNOFF

VARIANT

Mohave

Yavapai

Gila

Coconino

Coconino

Mohave

Gila

Coconino

VARIANT

$\begin{array}{llll}\text { locale } & \text { UNOFF } & \text { Maricopa } & 332655 N 1120030 \mathrm{~W} \\ \text { canal } & \text { BGN } & \text { Yuma } & 323654 N 1143503 \mathrm{~W} \\ \text { canal } & \text { BGN } & \text { Yuma } & 323707 N 1143635 \mathrm{~W} \\ \text { canal } & \text { BGN } & \text { Yuma } & 32371 \mathrm{BN} 1143535 \mathrm{~W} \\ \text { canal } & \text { BGN } & \text { Yuma } & 323641 \mathrm{~N} 1143628 \mathrm{~W}\end{array}$

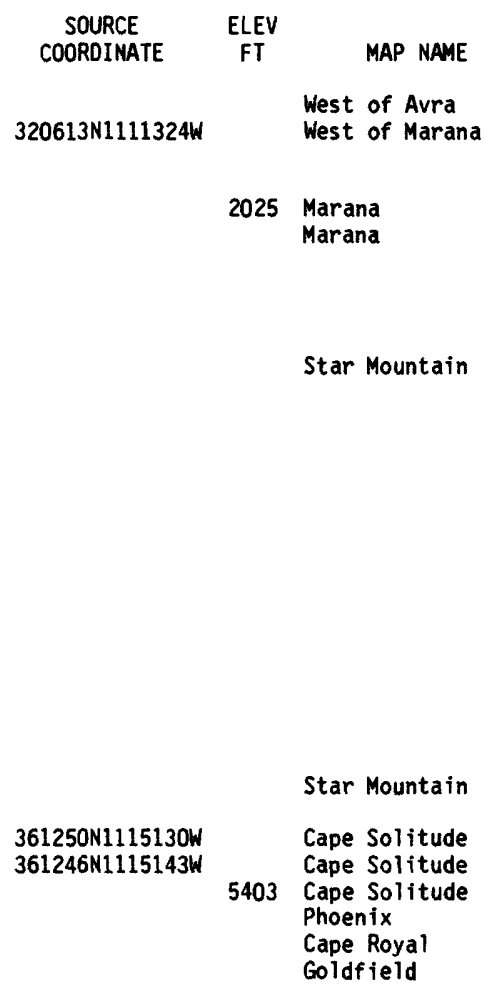

6691 Boot Mesa

365252 N1102114W

$331920 \mathrm{~N} 1124240 \mathrm{~W}$

$344045 \mathrm{~N} 1110337 \mathrm{~W}$ $324928 \mathrm{~N} 1132657 \mathrm{~W}$ $361017 \mathrm{~N} 1122717 \mathrm{~W}$

$370652 \mathrm{~N} 1105823 \mathrm{~W}$

$313036 \mathrm{~N} 1104454 \mathrm{~W}$ $313022 \mathrm{~N} 1104548 \mathrm{~W}$ $324626 \mathrm{~N} 1132713 \mathrm{~W}$ $324928 \mathrm{N1132628 \textrm {W }}$ $335042 \mathrm{~N} 1105806 \mathrm{~W}$ $313046 \mathrm{~N} 1104745 \mathrm{~W}$

Aztec Hills

Explorers Monument

Rainbow Bridge

Mt Hughes

Patagonia

Aztec Hills

Aztec Hills

Aztec Peak

Patagonia

$345648 \mathrm{~N} 1131745 \mathrm{~W}$

$345830 \mathrm{~N} 1123800 \mathrm{~W}$ $334844 N 1105417 \mathrm{~W}$ $343741 \mathrm{~N} 1110405 \mathrm{~W}$ 361514112509 $332134 \mathrm{~N} 1105109 \mathrm{~W}$ $344057 N 1110332 \mathrm{~W}$

$351405 \mathrm{~N} 1114409 \mathrm{~W}$

345830N1130200W Mount Hope

7694 Aztec Peak Quayle Hill

Happy Jack

$361600 \mathrm{~N} 1140525 \mathrm{~W}$

Azure Ridge

6503 Quayle Hill

8302 Flagstaff West 
FEATURE CLASS

COORDINATE

$\begin{array}{cc}\text { SOURCE } & \text { ELEV } \\ \text { COORDINATE } & \text { FT }\end{array}$

MAP NAME
B

Baah Lokaa Ridge

Baaki

See Casa Blanca

Babbit Spring

Babbit Tank

Babbit Tank

Babbit Tank

Babbitt Lake

Babbitt Tank

Babbitt Tank

Babbitt Tank

Babbitt Tank

Babbitt Tank Canyon

Babbitt Wash

Babbitt Water Catchment

Babbit Winter

Babcock Canyon

Babcock Spring

Babcock Tank

Babes Hole

See Kelsey Spring

Babes Hole Spring Hole Spring

Babiteoida Arronyo

See Aravaipa Creek

Babocomari Ranch

Babocomari River

Baboquerque Fields See Haivana Nakya

Baboquivari Canyon

Baboquivari High School

Baboquivari Mountains

Baboquivavari Range

Baboquiveri Mountains

Baboquiveri Range

Pozo Verde Mountains

Sierra del Babuquibari

Sierra det Babuqibari

Sierra Babququvari

Srerra Babuquivari

Baboquivari Peak

Baboquiverai Peak

Baboquiveri Peak

Baboquivori Paek

Babuquiburi Peak

Comobabi Peak

Mount Babuquiburi

Papago Peak

Picacho del Babuquivar

Pico del Babuquivari

Baboquivari Valley

Baboquivari Wash

Baboquivavari Range See Baboquivari Mountains

Baboquiverai Peak

$$
\text { See Baboquivari Peak }
$$

Baboquivera Plain See Altar Valley

Baboquiveri Mountains See Baboquivari Mountains

$\begin{array}{ll}\text { ppl } & \text { VAR } \\ \text { spring } & \text { BGN } \\ \text { reservoir } & B G N \\ & \\ & \\ \text { reservoir } & \text { BGN } \\ \text { reservoir } & B G N \\ \text { lake } & B G N \\ \text { reservoir } & B G N \\ \text { reservoir } & B G N \\ \text { reservoir } & B G N \\ \text { reservoir } & B G N \\ \text { valley } & B G N \\ \text { stream } & B G M \\ \text { basin } & B G N \\ & \end{array}$

BGN
VARIANT

Coconino

353959 N1111706W

$330713 N 1115315 \mathrm{~W}$

$350401 N 1113216 \mathrm{~W}$

$344431 \mathrm{~N} 1110223 \mathrm{~W}$

Coconino

Coconino

$350726 \mathrm{~N} 1111108 \mathrm{~W}$

354949N1115924W

$353333 \mathrm{~N} 1114916 \mathrm{~W}$

$344050 \mathrm{~N} 1105206 \mathrm{~W}$

$345103 \mathrm{~N} 1103443 \mathrm{~W}$

$351426 \mathrm{N1121350 \textrm {W }}$

$354226 \mathrm{N1121955 \textrm {W }}$

$345213 \mathrm{~N} 1103154 \mathrm{~W}$

$351354 \mathrm{~N} 1110938 \mathrm{~W}$

$343813 \mathrm{N1104925 \textrm {W }}$

$\begin{array}{llll}\text { locale } & \text { BGN } & \text { Coconino } & 343731 \text { N1104957W } \\ \text { valley } & \text { BGN } & \text { Graham } & 323808 \text { N1095943W } \\ \text { spring } & \text { BGN } & \text { Graham } & 324134 \text { N1095943W } \\ \text { reservoir } & \text { BGN } & \text { Graham } & 324051 \text { N1100006W } \\ & \text { VARIANT } & & \\ \text { spring } & & \text { Coconino } & 350432 \mathrm{~N} 1115604 \mathrm{~W} \\ \text { spring } & \text { BGN } & \text { Coconino } & 350423 \mathrm{~N} 1115619 \mathrm{~W} \\ & \text { VARIANT } & & \\ & \text { VARIANT } & & \\ \text { stream } & & \text { Pinal } & 325021 \mathrm{~N} 1104251 \mathrm{~W}\end{array}$

stream

$\begin{array}{llll}\text { locale } & \text { UNOFF } & \text { Cochise } & 313749 \text { N1102717W } \\ \text { stream } & \text { BGN } & \text { Cochise } & 314320 \mathrm{~N} 1101136 \mathrm{~W}\end{array}$

pp 1

valley

school

range

VARIANT

UNOFF Pima

BGN 1941 Pima

VARIANT

VARIANT

VARIANT

VARIANT

VARIANT

VARIANT

VARIANT

VARIANT

summit

BGN 1941

VARIANT

VARIANT

VARIANT

VARIANT

VARIANT

VARIANT

VARIANT

VARIANT

VARIANT

$320024 \mathrm{~N} 1114247 \mathrm{~W}$

$314700 N 1113724 h$

315502 N1115140

$314723 \mathrm{~N} 1113510 \mathrm{~W}$

$324105 \mathrm{~N} 1100000 \mathrm{~W}$

Lower Lake Mary

Quayle Hill

Anderson Canyon

Harbison Tank

Chapel Mtn

Chevelon Butte

McCauley Sinks

Williams South

Miller Tank

McCauley Sinks

Babbitt Wash

Chevelon Butte

Chevelon Butte

Webb Peak

Webb Peak

Blue Jay Peak

Sycamore Point

$313922 N 1103608$

Mustang Mountains Fairbank

314632N1113530W Baboquivari Peak

Sells East

7111 Baboquivari Peak

314616 N1113542W

7734 Baboquivari Peak

$314523 \mathrm{~N} 1115321 \mathrm{~W}$

$320048 \mathrm{~N} 1114344 \mathrm{~W}$

San Migue 1

$\begin{array}{ll}\text { strean } & B G N \\ \text { str } & \text { BARIAN }\end{array}$

Pima

$314632 \mathrm{~N} 1113530 \mathrm{~W}$

Cowlic

$314616 \mathrm{~N} 1113542 \mathrm{~W}$

$320753 \mathrm{~N} 1111638 \mathrm{~W}$

314723N1113510W

Baboquiveri Peak See Baboquivari Peak

summit

VARIANT

Baboquiveri Range See Baboquivari Mountains

range

VARIANT

See Baboquivari Peak

Babuquiburi Peak

See Baboquivari Peak

Babuquivari Plain

summit

VARIANT

VARIANT

VARIANT

Pima

Pima

Pima

Pima
$314616 \mathrm{~N} 1113542 \mathrm{~W}$

314723N1113510W

$314616 N 1113542 W$

314616N1113542W 


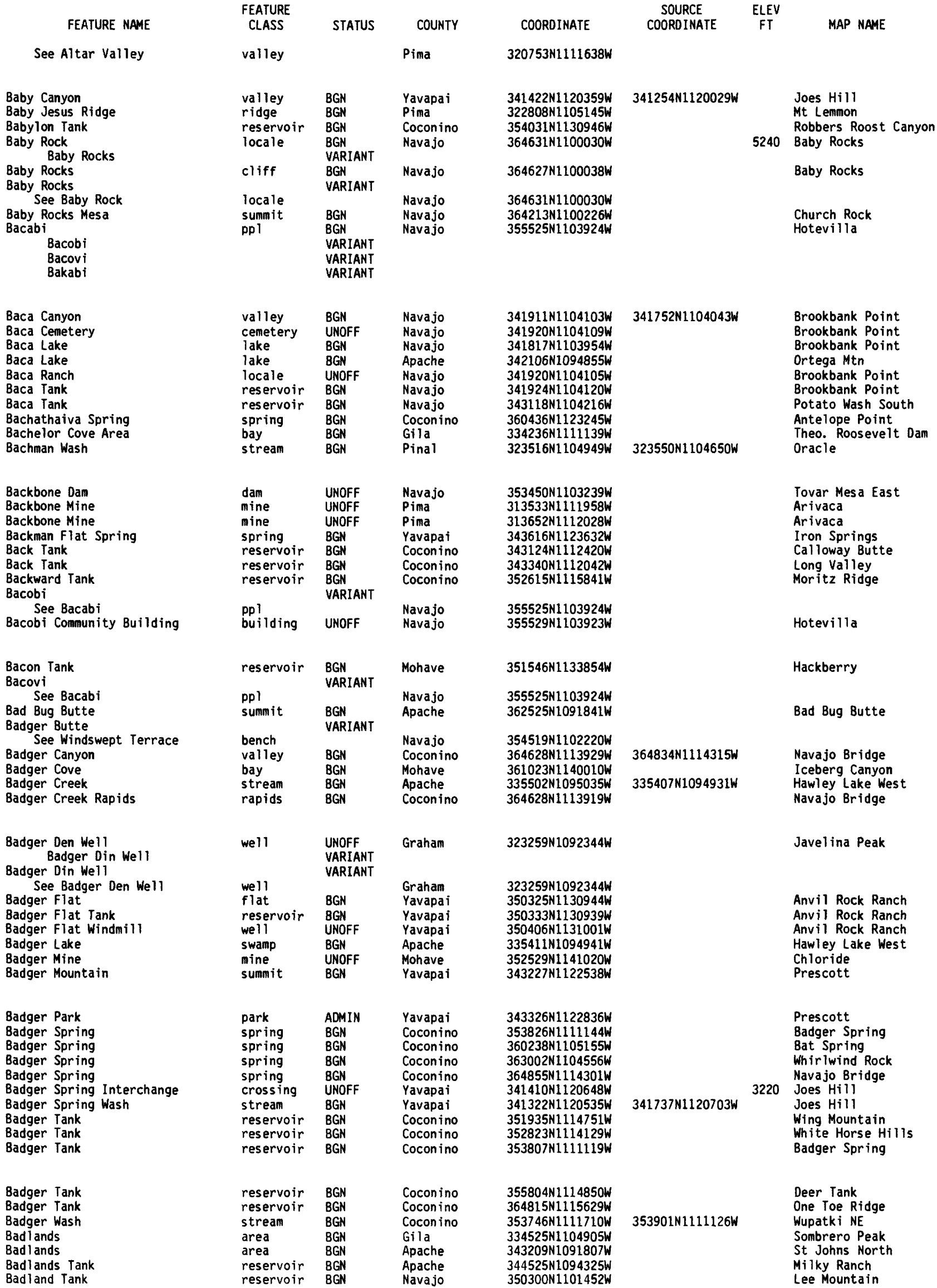


NATIONAL GAZETTEER--ARIZONA 1986 FEATURE NAME

Bad Luck Spring

Bad Medicine Butte

Bad Spring

Bagby Ranch

Bagdad

Bagdad Airport

Bagdad Elementary School

Bagdad High School

Bagdad Hospital

Bagdad Open Pit Mine

Bagdad Post Office

Bagdad Tailings Dam

Baggs Reservoir

See White Mountain Lake

Bagley Flat

Bagley Flat Recreation Sit

Bagley Tank

Bagnal Draw

Bagnall Hollow

$$
\text { See Fools Hollow }
$$

Bagnal Tank

Bagnal Wash

Bagwell Ranch

Baha Diversion Dam

Baha Ranch

Baha Spring

Baha Spring Number Two

Baha Tank

Ba Ha Zohnnie Betoh

Bahe Adakai Wel

Bahki

See Casa Blanca

Bailey Hill

Bailey Peak

Mamatotk Peak

Bailey Point

Bailey Ranch

Baileys

See Viason Chin

Bailiey Tank

Bailey Tank

Bailey Tank

Bailey Wash

Bailey Well

Bain Spring

Bajillo de las Chivas

Bakabi

See Bacabi

Bakarich-McCool Ranch

Baker Butte

Baker Canyon

Baker Canyon

Baker Canyon

Baker Hill

Baker Horse Mountain

See Baker Mountain

Baker Lake

Baker Lateral

Baker Mine

Baker Mountain

Baker Horse Mountain

Fray Marcos

Horse Mountain

Lookout Mountain

Baker Mounta in

Baker Peaks

Baker Pond

See Government Tank

Baker Ranch

Bakers Acres Airstrip

Bakers Pass

FEATURE

CLASS

spring

summit

spring

$B G N$
$B G N$
$B G N$

local

airport ADIN

UNOFF

$\begin{array}{ll}\text { school } & \text { UNOFF } \\ \text { hospital } & \text { UNOFF }\end{array}$

mine

building

UNOFF

UNOFF

UNOFF

reservoir

VARIANT

dam UNOFF

locale

spring

spring

reservoir

spring

well

ppl

ridge

UNOFF

BGN

$B G N$

Navajo

VARIANT

summit

1964 Cochise

VARIANT

summ

Summit
locale

UNOFF

VARIANT

locale

reservoir

reservoir

reservoir

strean

well

spring

BGN

BGN

BGN

BGN

UNOFF
BGN

flat

ppl

locale

summit

valley

valley

valley

summit

summ it

BGN

VARIANT

Cochise

$B G N$

$B N$

BGN

BGN

VARIANT

Cochise

Cochise

Graham

Graham

Gi1a

335602N1095810W

335551 N1095823W

$342002 N 1102508 \mathrm{~W}$

$341955 \mathrm{~N} 1102515 \mathrm{~W}$

$355934 \mathrm{~N} 1121606 \mathrm{~W}$

$323434 \mathrm{~N} 1093108 \mathrm{~W}$

$313148 \mathrm{~N} 1101211 \mathrm{~W}$

$325319 N 1092937 \mathrm{~W}$

VARIANT

VARIANT
VARIANT

VARIANT

VARIANT

BGM

summit $B G$

BGN

Gila

Yuma

VARIANT

reservoir

airport

UNOFF

ADMIN

BGN

Cochise

Graham

Pinal

\begin{tabular}{|c|c|c|c|}
\hline $\begin{array}{l}\text { lat } \\
\text { ark } \\
\text { eservoir } \\
\text { alley }\end{array}$ & $\begin{array}{l}\text { BGN } \\
\text { ADMIN } \\
\text { BGN } \\
\text { BGN }\end{array}$ & $\begin{array}{l}\text { Maricopa } \\
\text { Maricopa } \\
\text { Maricopa } \\
\text { Navajo }\end{array}$ & $\begin{array}{l}333402 \mathrm{~N} 1112915 \mathrm{~W} \\
333410 \mathrm{~N} 1112921 \mathrm{~W} \\
333221 \mathrm{~N} 1112847 \mathrm{~W} \\
341641 \mathrm{~N} 1100439 \mathrm{~W}\end{array}$ \\
\hline $\begin{array}{l}\text { lley } \\
\text { servoir } \\
\text { ream } \\
\text { cale } \\
\text { m }\end{array}$ & $\begin{array}{l}\text { BGN } \\
\text { BGN } \\
\text { UNOFF } \\
\text { UNOFF }\end{array}$ & $\begin{array}{l}\text { Navajo } \\
\text { Navajo } \\
\text { Navajo } \\
\text { Cochise } \\
\text { Navajo }\end{array}$ & $\begin{array}{l}341640 \mathrm{~N} 1100420 \mathrm{~W} \\
342337 \mathrm{~N} 1102315 \mathrm{~W} \\
342558 \mathrm{~N} 1102257 \mathrm{~W} \\
315528 \mathrm{~N} 1090735 \mathrm{~W} \\
335512 \mathrm{~N} 1095600 \mathrm{~W}\end{array}$ \\
\hline
\end{tabular}

Yavapai
UMOFF Navajo

335517 N1095633W

$335522 \mathrm{~N} 109563 \mathrm{WW}$

$360241 \mathrm{~N} 1103733 \mathrm{~W}$

361834N1112043W

$330713 \mathrm{~N} 1115315 \mathrm{~W}$

$312655 \mathrm{~N} 1095532 \mathrm{~W}$

$315317 \mathrm{~N} 1122555 \mathrm{~W}$

341306N1100824W

$342118 \mathrm{~N} 1102338 \mathrm{~W}$

(2)

Aripine

Aripine

Portal

Alchesay Flat

Alchesay Flat

Alchesay Flat

Alchesay Flat

Alchesay Flat

Rocky Ridge SW

5332 Preston Well

Bisbee

2951 Bailey Peak

6934 Day Spring

$320055 \mathrm{~N} 1121723 \mathrm{~W}$

$342014 \mathrm{~N} 1102549 \mathrm{~W}$

$313607 N 1112942 \mathrm{~W}$

$341441 \mathrm{~N} 1123010 \mathrm{~W}$

$313346 \mathrm{~N} 1113253 \mathrm{~W}$

$355525 \mathrm{~N} 1103924 \mathrm{k}$

$342707 \mathrm{N1112240 \textrm {W }}$

$312048 \mathrm{~N} 1090351 \mathrm{~W}$

$314734 \mathrm{~N} 1091507 \mathrm{~W}$

$323002 \mathrm{~N} 1100940 \mathrm{~W}$

$335032 N 1105619 W$

$\begin{array}{llll}\text { lake } & \text { BGN } & \text { Coconino } & 342716 \mathrm{~N} 1112346 \mathrm{~W} \\ \text { canal } & \text { BGN } & \text { Yuma } & 323824 N 1143950 \mathrm{~W}\end{array}$

mine UNOFF 315848 N1125220W

summit BGN 1932 Gila 335032 N1105619W

$335716 \mathrm{N1112237 \textrm {W }}$

$323836 \mathrm{N1135950 \textrm {W }}$

$321413 \mathrm{~N} 1092138 \mathrm{~W}$

$325052 \mathrm{~N} 1093410 \mathrm{~W}$

$323405 N 1114311 \mathrm{~W}$

344816 N1 $120806 \mathrm{~W}$

rmon Flat Dam Flat Dam Da

4960 Canelo Pass

Day Spring

Day Spring

Metzger Tank

Wilbur Canyon

Tanque

Wagoner

Presumido Peak

4341 Lewis Springs

8077 Pine

$312603 \mathrm{~N} 1090220 \mathrm{~W}$

$314908 \mathrm{N1091458 \textrm {W }}$

$325432 \mathrm{~N} 1092939 \mathrm{~W}$

Guadalupe Canyon

Chiricahua Peak

Gila Box

The Mesas

Pine

Yuma West

Lukeville

7579 Az tec Peak

4055 Reno Pass

1415 Tacna

3100 San Jose

1591 Greene Reservoir Munds Draw 
FEATURE NAME

Bakers Pass Tank
Baker Spring
Baker Spring
Baker Spring
Baker Spring
Bakers Tanks
See Baker Tanks
Baker Tank
Baker Tanks
Bakers Tanks
Bakerville
Baker Well
Baker Well
Bako-shi-bito Canyon
See Begashibito Canyon
Balakai Mesa
Balukai Mesa
Salah-Kai Mesa
Salahkai Mesa
Sa La kai Mesa
Tse Lagai
Balukai Point
Salahkai Point
Balakai Point
Alahkai Wash
Tse-Ba-Zi-Ni Wash

Balanced Rock

Balanced Rock Canyon

Balanced Rock Mesa

Balboa Tank

Bald $\mathrm{Hill}$

Bald $\mathrm{Hill}$

Bald Hill

Bald $\mathrm{Hill}$

Bald Mountain

Bald Hil

See Glassford Hill

\section{Bald $\mathrm{Hill}$}

Bald Hill Tank

Bald Hill Tank Number Five

Bald Hill Tank Number Four

Bald Hill Tank Number One

Bald Hill Tank Number One

Bald Hill Tank Number Three

Bald Hill Tank Number Two

Bald Hill Tank Number Two

Bald Hill Well

\section{Bald Knob \\ Bald Mesa \\ Bald Mesa Tank \\ Bald Mountain \\ Bald Mountain \\ See Comet Peak \\ Bald Mountain \\ See Bald Hill \\ Bald Mountain \\ Bald Mountain}

Bald Mountain

See Glassford Hill

Bald Mountain Round $\mathrm{Hill}$

Bald Mountain

Bald Mountain Spring

Bald Point

Bald Ridge

Bald Ridge Number One Tank

Bald Ridge Number Two Tank

Baldridge Tank

Baldwin Draw

\section{FEATURE}

CLASS

STATUS

COUNTY

reservoir

spring

spring

spring

spring

BGN

BGN

BGN

BGN
BGN

Yavapai

Cochise

Coconino

Yavapai

Mohave

VARIANT

reservoir

reservoir

reservoir BGI

ppl

well

well

valley

summit

BGN 191

VARIANT

VARIANT

VARIANT

VARIANT

summit BGN 1967

VARIANT

valley $\quad$ BGN 1967

BGN 1967

VARIANT
VARIANT

VARIANT

$\begin{array}{ll}\text { pillar } & \text { BGN } \\ \text { valley } & \text { BGN } \\ \text { summit } & \text { BGN } \\ \text { reservoir } & \text { BGN } \\ \text { summit } & \text { BGN } \\ \text { summit } & \text { BGN } \\ \text { summit } & \text { BGN } \\ & \text { VARIANT } \\ \text { summit } & \text { BGN } \\ & \text { VARIANT } \\ \text { summit } & \end{array}$

\section{Yuma}

Gila

Yuma

Cochise

Gila

Mohave

Coconino

Apache

Apache

Apache

Apache

Apache

Coconino

Mohave

Coconino

Coconino

Santa Cruz

Yavapai

Yavapai

Yavapai

Yavapai

summit

BGN

reservoir

reservoir
reservoir

reservoir

reservoir

reservoir

reservoir

reservoir

well

BGN
BGN
$B G N$
$B G N$
$B G N$
BGN
BGN
BGN
UNOFF

Yavapai

Coconino

Yavapai

Yavapai

Yavapai

Yavapai

Yavapai

Yavapai

Yavapai

Yavapai

summit

flat

reservoir

summit

BGN

BGN
BGN
BGN

BGN

VARIANT

summit

VARIANT

summit

summit

BGN

Cochise

Coconino

Coconino

Cochise

Pinal

summit

BGN

Yavapai

Yavapai

VARIANT

summit

summit

summit

spring

summit

ridge

reservoir

reservoir

BGN
VARIA
BGN
BGN
BGN
BGN
BGN

Yavapai

Yavapai

Coconino

Yavapai

Navajo

Cochise

Cochise

Cochise

reservoir

valley

Cochise
$344938 \mathrm{~N} 1120812 \mathrm{~W}$

$312256 N 1090332 \mathrm{~W}$

$342729 \mathrm{N1112342 \textrm {W }}$

$343958 N 1123509 \mathrm{~W}$

$350109 N 1141736 \mathrm{~W}$

$323726 N 1140032 \mathrm{~W}$

$341026 \mathrm{~N} 1110128 \mathrm{~W}$

$323726 \mathrm{~N} 1140032 \mathrm{~W}$

$312522 \mathrm{~N} 1095312 \mathrm{~W}$

$331214 N 1103545 \mathrm{~W}$

$342457 N 1134426 \mathrm{~W}$

360844N1105959W

$355902 N 1095614 W$

$355100 \mathrm{~N} 1095000 \mathrm{~W}$

$360645 N 1093945$

(35

4

COOROINATE

$\begin{array}{cc}\text { SOURCE } & \text { ELEV } \\ \text { COORDINATE } & \text { FT }\end{array}$

MAP NAME

Munds Draw

Guadalupe Spring

Pine

Jerome Canyon

Mount Nutt

Diamond Butte

524 Wellton SE

Bisbee

Coolidge Dan

Signal

Beeshsikad Spring

6930 Steamboat Rock

Toh De Niihe

$360117 N 1111129 \mathrm{~W}$

$361039 \mathrm{~N} 1135610 \mathrm{~W}$

$355624 N 1122220 \mathrm{~W}$

$313609 N 1103114 \mathrm{~W}$

34011 ON1121508W

342718N1115631W

343444N111382OW

343522N1122253W

$345408 N 1122121 \mathrm{~W}$

$352318 \mathrm{~N} 1115205 \mathrm{~W}$

$343506 N 1113927 \mathrm{~W}$

$343507 \mathrm{~N} 1113905 \mathrm{~W}$

$342754 N 1115619 \mathrm{~W}$

$343445 N 1113724 \mathrm{~W}$

$343433 N 1113748 \mathrm{~W}$

$34271 B N 1115653 \mathrm{~W}$

$343421 N 111385 B W$

$342827 \mathrm{N1} 115816 \mathrm{~W}$

361312 N1135243W

Moenkopi

Snap Canyon West

6095 Chaiyahi Flat

Metzger Tank

5051 O'Donnell Canyon

3801 Columbia

6089 Arnold Mesa

6182 Walker Mtn

$313128 N 1093137 \mathrm{~W}$

343657 N1111910W

$343629 N 1111946 \mathrm{~W}$

320B42N1102459W

33173BN1111606W

$342718 N 1115631 \mathrm{~W}$

$342804 \mathrm{N1} 122312 \mathrm{~W}$

$343406 N 1124815 \mathrm{~W}$

$343522 N 1122253 \mathrm{~W}$

$345243 \mathrm{~N} 1125056 \mathrm{~W}$

351912 N112012OW

$345330 \mathrm{~N} 1125059 \mathrm{~W}$

$341901 \mathrm{~N} 1101835 \mathrm{~W}$

$322310 \mathrm{~N} 1100955 \mathrm{~W}$

$322243 \mathrm{~N} 1100818 \mathrm{~W}$

$322222 \mathrm{~N} 1100924 \mathrm{~W}$

315308 N1092319W

$342321 \mathrm{~N} 1103542 \mathrm{~W}$

$342120 \mathrm{~N} 1103752 \mathrm{~W}$
7298 Groom Creek

5756 Martin Mtn

4686 Hell Point Kendrick Peak

Walker Mtn

Walker Mtn

Arnold Mesa Buckhorn Mountain

Walker Mtn

Arnold Mesa

Walker Mtn

Arnold Mesa

5035 Leslie Canyon

Long Valley

Long Valley

5324 Happy Valley

5900 Indian Peak

7997 Sitgreaves Mtn

Indian Peaks

Clay Springs

The Mesas

The Mesas

Hookers Hot Springs

Fife Peak

Heber 
NATIONAL GAZETTEER--ARIZONA 1986 FEATURE NAME

Baldwin Place

Baldwins Crossing

Baldwin Spring

Baldwin Tank

Baldwin Tank

Baldwin Tank

Baldy

See Wrightson, Mount

Baldy, Mount

Baldy Bas in

Baldy Bill Point

Baldy Canyon

Baldy Mountain

See Wrightson, Mount

Baldy Mountain

Baldy Mountain

Baldy Peak

Baldy Peak

Baldy Peak Mountain

Mount Baldy

Thomas Peak

Baldy Peak Mountain See Baldy Peak

Baldy Saddle

Baldy Spring

Baldy Trail

Baldy Trail

Baldy Trap

Baldy Tunnel Spring

Baldy Wilderness, Mount

Balke Cabin

Balky Spring

Balky Tank

Bal lantine Canyon

Ballard, Mount

Ballard Tank

Ballard Tank

Ball Court Wash

Ballit Mine

Balloon Cabin Spring Baloon Cabin Spring

Ball Tank

Baloon Cabin Spring See Balloon Cabin Spring

Balsz Schoo

Baltimore Spring

Balukai Mesa

$$
\text { See Balakai Mesa }
$$

Balukai Point See Balakai Point

Balukai Wash

See Balakai Wash

Bam Boo Ranch

Bambo Wash

See Tyende Creek

Bambo Wash

See Chilchinbito Wash

Banana Spring

Banco Ridge

Banco Ridge

Bandeja Wel

Bandit Tank

Band Valley

Bandy Tank

Banegas Spring

See Arrowhead Spring

Banegas Well

Banfield Mountain

Banfield Spring

Banfield Tank

Bangs, Mount

Banjo Bill Campground
FEATURE CLASS

locale

locale

pring

reservoir

reservoir

summit

summit

bas in

valley

summit

summit

summit

summit

summit

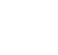

\begin{tabular}{|c|c|c|c|}
\hline \multirow{2}{*}{\multicolumn{2}{|c|}{ VARIANT }} & \multirow{3}{*}{$\begin{array}{l}\text { Apache } \\
\text { Santa Cruz } \\
\text { Santa Cruz }\end{array}$} & \multirow{8}{*}{$\begin{array}{l}335422 \mathrm{~N} 1093344 \mathrm{~W} \\
314200 \mathrm{~N} 1105055 \mathrm{~W} \\
314155 \mathrm{~N} 1105044 \mathrm{~W} \\
334056 \mathrm{~N} 1111742 \mathrm{~W} \\
334247 \mathrm{~N} 1111636 \mathrm{~W} \\
341143 \mathrm{~N} 1122712 \mathrm{~W} \\
331545 \mathrm{~N} 1104608 \mathrm{~W} \\
335601 \mathrm{~N} 1093118 \mathrm{~W} \\
333918 \mathrm{~N} 1091955 \mathrm{~W}\end{array}$} \\
\hline & & & \\
\hline oring & BGN & & \\
\hline rall & UNOFF & Gila & \\
\hline ai 1 & UNOFF & Gila & \\
\hline & BGN & Yavapai & \\
\hline ing & BGN & Gila & \\
\hline $\begin{array}{l}\text { immit } \\
\text { cale }\end{array}$ & $\begin{array}{l}B G N \\
B G N\end{array}$ & $\begin{array}{l}\text { Apache } \\
\text { Greenlee }\end{array}$ & \\
\hline
\end{tabular}

$\begin{array}{llll}\text { spring } & \text { BGN } & \text { Yavapai } & 343306 \mathrm{~N} 1120522 \mathrm{~W} \\ \text { reservoir } & \text { BGN } & \text { Yavapai } & 343150 \mathrm{~N} 1120548 \mathrm{~W} \\ \text { valley } & \text { BGN } & \text { Maricopa } & 334552 \mathrm{~N} 1112606 \mathrm{~W} \\ \text { summit } & \text { BGN } & \text { Cochise } & 312636 \mathrm{~N} 1095731 \mathrm{~W} \\ \text { reservoir } & \text { BGN } & \text { Navajo } & 342529 \mathrm{~N} 1101209 \mathrm{~W} \\ \text { reservoir } & \text { BGN } & \text { Mohave } & 365025 \mathrm{~N} 1131706 \mathrm{~W} \\ \text { stream } & \text { BGN } & \text { Coconino } & 353245 \mathrm{~N} 1112916 \mathrm{~W} \\ \text { mine } & \text { UNOFF } & \text { Yuma } & 334701 \mathrm{N1} 134324 \mathrm{~W} \\ \text { spring } & \text { BGN } & \text { Maricopa } & 335503 N 1112526 \mathrm{~W}\end{array}$

spring

VARIANT

reservoir $\quad B G$

spring

school

summit

summit

valley

locale

stream

valley

spring

ridge

well

reservoir

VARIANT

UNOFF

BGN

VARIANT

VARIANT

VARIANT

UNOFF

VARIANT

VARIANT

BGN

BGN

BGN

UNOFF

valley

reservoir $B G$

spring
well

summit

spring

reservoir

summit

park
COOROINATE

341708 N1122905W

$344926 \mathrm{~N} 1114825 \mathrm{~W}$

$312724 N 1103451 \mathrm{~W}$

350218N1101355W

314146 N1105052W

$335422 N 1093344 W$

$355625 N 1123212$

$333324 N 1092511 \mathrm{~W}$

$334256 \mathrm{~N} 1111504 \mathrm{~W}$

$314146 N 1105052 W$

$330934 N 1090434 \mathrm{~W}$

$335221 \mathrm{~N} 1122026 \mathrm{~W}$

$315046 \mathrm{~N} 1112004 \mathrm{~W}$

$335422 N 1093344 \mathrm{~W}$
$332407 N 1110614 \mathrm{~W}$

314449N1115904W

364955N1094300W

$363438 \mathrm{~N} 1100316 \mathrm{~W}$

$335254 N 1100018$

$321707 N 1102636 \mathrm{~W}$

321800 N1102607W

$321323 \mathrm{~N} 1125519 \mathrm{~W}$

350447 N1121229W

$363032 N 1092450 \mathrm{~W}$

$331137 N 1141235 \mathrm{~W}$

$344035 N 1132400$

$343845 N 1133904 \mathrm{~W}$

$343811 N 1112641 \mathrm{~W}$

$343904 \mathrm{~N} 1112711 \mathrm{~W}$

$343804 \mathrm{~N} 1112617 \mathrm{~W}$

$364733 \mathrm{~N} 1135115 \mathrm{~W}$

345741 N1114509W reservoir BG
$342340 N 1094725 \mathrm{~W}$

$\begin{array}{cc}\text { SOURCE } & \text { ELEV } \\ \text { COORDINATE } & \text { FT }\end{array}$

MAP NAME

Battleship Butte Sedona

Haunted Canyon

Canelo Pass

Mesa Redonda

Lee Mountain

Mount Baldy

Baldy Bas in

Baldy Bill Point

333951 N1111750W

Four Peaks

6403 Harden Cienega

2757 Baldy Mtn

4120 Penitas Hills

1140 Mount Baldy

8800 Mt Wrightson

Mt Wrightson

Four Peaks

Four Peaks

Minnehaha

Pinal Peak

Mount Baldy

9180 Hannagan Meadow

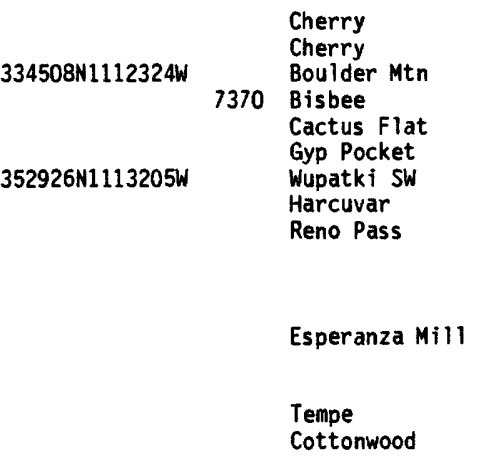

Vamori 


\begin{tabular}{|c|c|c|c|c|c|c|c|}
\hline FEATURE NAME & $\begin{array}{l}\text { FEATURE } \\
\text { CLASS }\end{array}$ & STATUS & COUNTY & COORDINATE & $\begin{array}{l}\text { SOURCE } \\
\text { COORDINATE }\end{array}$ & $\begin{array}{l}\text { ELEV } \\
\text { FT }\end{array}$ & MAP NAME \\
\hline $\begin{array}{l}\text { Banjo Canyon } \\
\text { Banjo Tank } \\
\text { Bankhead Tank } \\
\text { Banks Ranch } \\
\text { Banks Tank } \\
\text { Banks Tank } \\
\text { Banks Tank } \\
\text { Banner Canyon } \\
\text { See Boner Canyon } \\
\text { Banner Mine }\end{array}$ & $\begin{array}{l}\text { valley } \\
\text { reservoir } \\
\text { reservoir } \\
\text { locale } \\
\text { reservoir } \\
\text { reservoir } \\
\text { reservoir } \\
\text { valley } \\
\text { mine }\end{array}$ & $\begin{array}{l}\text { BGN } \\
\text { BGN } \\
\text { BGN } \\
\text { UNOFF } \\
\text { BGN } \\
\text { BGN } \\
\text { BGN } \\
\text { VARIANT } \\
\text { UNOFF }\end{array}$ & $\begin{array}{l}\text { Greenlee } \\
\text { Greenlee } \\
\text { Coconino } \\
\text { Graham } \\
\text { Coconino } \\
\text { Coconino } \\
\text { Coconino } \\
\text { Mohave } \\
\text { Pima }\end{array}$ & $\begin{array}{l}332316 \mathrm{~N} 1090247 \mathrm{~W} \\
332158 \mathrm{~N} 1090408 \mathrm{~W} \\
351132 \mathrm{~N} 1115600 \mathrm{~W} \\
322827 \mathrm{~N} 1095741 \mathrm{~W} \\
353808 \mathrm{~N} 1123010 \mathrm{~W} \\
354744 \mathrm{~N} 1114711 \mathrm{~W} \\
355504 \mathrm{~N} 1122031 \mathrm{~W} \\
344422 \mathrm{~N} 1133612 \mathrm{~W} \\
315317 \mathrm{~N} 1111707 \mathrm{~W}\end{array}$ & $332157 \mathrm{~N} 1090509 \mathrm{~W}$ & & $\begin{array}{l}\text { Alma Mesa } \\
\text { Maple Peak } \\
\text { Garland Prairie } \\
\text { W of Greasewood Mtn } \\
\text { Tin House } \\
\text { Peterson Flat } \\
\text { Metzger Tank }\end{array}$ \\
\hline $\begin{array}{l}\text { Banner Mine } \\
\text { Banner Wash } \\
\text { Bannie Mine } \\
\text { Bannie Mine Dump } \\
\text { Bannie Tank Number One } \\
\text { Bannie Tank Number Two } \\
\text { Banning Creek } \\
\text { Banning Toll Station } \\
\text { Banning Wash } \\
\text { Bannon (Site) }\end{array}$ & $\begin{array}{l}\text { mine } \\
\text { stream } \\
\text { mine } \\
\text { mine } \\
\text { reservoir } \\
\text { reservoir } \\
\text { stream } \\
\text { locale } \\
\text { stream } \\
\text { locale }\end{array}$ & $\begin{array}{l}\text { UNOFF } \\
\text { BGN } \\
\text { UNOFF } \\
\text { UNOFF } \\
\text { BGN } \\
\text { BGN } \\
\text { BGN } \\
\text { UNOFF } \\
\text { BGN } \\
\text { BGN }\end{array}$ & $\begin{array}{l}\text { Pima } \\
\text { Pima } \\
\text { Yavapai } \\
\text { Yavapai } \\
\text { Yavapai } \\
\text { Yavapai } \\
\text { Cochise } \\
\text { Cochise } \\
\text { Gila } \\
\text { Apache }\end{array}$ & $\begin{array}{l}315903 \mathrm{~N} 1110451 \mathrm{~W} \\
315707 \mathrm{~N} 1112338 \mathrm{~W} \\
342936 \mathrm{~N} 1122036 \mathrm{~W} \\
342941 \mathrm{~N} 1122042 \mathrm{~W} \\
342930 \mathrm{~N} 1122035 \mathrm{~W} \\
342942 \mathrm{~N} 1122006 \mathrm{~W} \\
312956 \mathrm{~N} 1100009 \mathrm{~W} \\
312858 \mathrm{~N} 1095858 \mathrm{~W} \\
334609 \mathrm{~N} 1104900 \mathrm{~W} \\
341514 \mathrm{~N} 1094431 \mathrm{~W}\end{array}$ & $\begin{array}{l}315335 \mathrm{~N} 1111501 \mathrm{~W} \\
312800 \mathrm{~N} 1095622 \mathrm{~W} \\
335025 \mathrm{~N} 1104639 \mathrm{~W}\end{array}$ & & $\begin{array}{l}\text { Twin Buttes } \\
\text { Palo Alto Ranch } \\
\text { Poland Junction } \\
\text { Poland Junction } \\
\text { Poland Junction } \\
\text { Poland Junction } \\
\text { Hereford } \\
\text { Bisbee } \\
\text { Sombrero Peak } \\
\text { Vernon }\end{array}$ \\
\hline $\begin{array}{l}\text { Bannon Creek } \\
\text { Baños Well } \\
\text { Banta Point } \\
\text { Banty Creek } \\
\text { Banty Creek } \\
\text { Bapchule } \\
\text { Bapchule Community Center } \\
\text { Baptist Hospital of Scottsdale } \\
\text { See Scottsdale Memorial } \\
\text { Hospital }\end{array}$ & $\begin{array}{l}\text { stream } \\
\text { well } \\
\text { cliff } \\
\text { stream } \\
\text { strean } \\
\text { ppl } \\
\text { building } \\
\text { hospital }\end{array}$ & $\begin{array}{l}\text { BGN } \\
\text { UNOFF } \\
\text { BGN } 1932 \\
\text { BGN } \\
\text { BGN } \\
\text { BGN } \\
\text { UNOFF } \\
\text { VARIANT }\end{array}$ & $\begin{array}{l}\text { Yavapai } \\
\text { Pima } \\
\text { Coconino } \\
\text { Gila } \\
\text { Yavapai } \\
\text { Pinal } \\
\text { Pinal } \\
\text { Maricopa }\end{array}$ & $\begin{array}{l}343103 N 1122835 \mathrm{~W} \\
314515 \mathrm{~N} 1110950 \mathrm{~W} \\
361304 \mathrm{~N} 1115445 \mathrm{~W} \\
333338 \mathrm{~N} 1100307 \mathrm{~W} \\
340147 \mathrm{~N} 1122604 \mathrm{~W} \\
330811 \mathrm{~N} 1115221 \mathrm{~W} \\
330814 \mathrm{~N} 1115242 \mathrm{~W} \\
332917 \mathrm{~N} 1115520 \mathrm{~W}\end{array}$ & $\begin{array}{l}342902 \mathrm{~N} 1122456 \mathrm{~W} \\
332755 \mathrm{~N} 1100121 \mathrm{~W} \\
340516 \mathrm{~N} 1122630 \mathrm{~W}\end{array}$ & 6522 & $\begin{array}{l}\text { Prescott } \\
\text { Batamote Hills } \\
\text { Walhalla Plateau } \\
\text { Georges Butte } \\
\text { Copperopol is } \\
\text { Gila Butte } \\
\text { Gila Butte NW }\end{array}$ \\
\hline $\begin{array}{l}\text { Baragan Mountain } \\
\text { Baragan Mountains } \\
\text { Baragon Mountains } \\
\text { Pass Mountain } \\
\text { Baragan Mountains } \\
\text { See Baragan Mountain } \\
\text { Baragan Wash } \\
\text { Baragan We11 } \\
\text { Baragon Mountains } \\
\text { See Baragan Mountain }\end{array}$ & $\begin{array}{l}\text { sumit } \\
\text { stream } \\
\text { well } \\
\text { summit }\end{array}$ & $\begin{array}{l}\text { BGN } \\
\text { VARIANT } \\
\text { VARIANT } \\
\text { VARIANT } \\
\text { VARIANT } \\
\text { BGN } \\
\text { UNOFF } \\
\text { VARIANT }\end{array}$ & $\begin{array}{l}\text { Yuma } \\
\text { Yuma } \\
\text { Yuma } \\
\text { Yuma }\end{array}$ & $\begin{array}{l}330538 \mathrm{~N} 1132659 \mathrm{~W} \\
325531 \mathrm{N1132515 \textrm {W }} \\
325958 \mathrm{~N} 1132530 \mathrm{~W} \\
330538 \mathrm{~N} 1132659 \mathrm{~W}\end{array}$ & $330528 \mathrm{~N} 1132839 \mathrm{~W}$ & 1284 & $\begin{array}{l}\text { Aztec NW } \\
\text { Aztec NW }\end{array}$ \\
\hline $\begin{array}{l}\text { Barajita Valley } \\
\text { Barajito Valley } \\
\text { Barajita Well } \\
\text { Barajito Valley } \\
\text { See Barajita Valley } \\
\text { Barbara Well } \\
\text { Bar Basin } \\
\text { See Y Bar Basin } \\
\text { Barbenceta Butte } \\
\text { Barbencita Butte } \\
\text { Barbeneeta Butte }\end{array}$ & $\begin{array}{l}\text { valley } \\
\text { well } \\
\text { valley } \\
\text { well } \\
\text { basin } \\
\text { summit }\end{array}$ & $\begin{array}{l}\text { BGN } 1941 \\
\text { VARIANT } \\
\text { UNOFF } \\
\text { VARIANT } \\
\text { UNOFF } \\
\text { VARIANT } \\
\text { BGN } 1932 \\
\text { VARIANT } \\
\text { VARIANT }\end{array}$ & $\begin{array}{l}\text { Pina } \\
\text { Pima } \\
\text { Pima } \\
\text { Navajo } \\
\text { Gila } \\
\text { Coconino }\end{array}$ & $\begin{array}{l}315750 \mathrm{~N} 1123440 \mathrm{~W} \\
320436 \mathrm{~N} 1124014 \mathrm{~W} \\
315750 \mathrm{~N} 1123440 \mathrm{~W} \\
343329 \mathrm{~N} 1095702 \mathrm{~W} \\
340303 \mathrm{~N} 1112728 \mathrm{~W} \\
361802 \mathrm{~N} 1115244 \mathrm{~W}\end{array}$ & $320626 \mathrm{~N} 1123657 \mathrm{~W}$ & 4699 & $\begin{array}{l}\text { Pia Oik } \\
\text { Mount Ajo }\end{array}$ \\
\hline $\begin{array}{l}\text { Barbencita Butte } \\
\text { See Barbenceta Butte } \\
\text { Barbeneeta Butte } \\
\text { See Barbenceta Butte } \\
\text { Barber Gene Mine } \\
\text { Barber Lake } \\
\text { Barbershop Canyon } \\
\text { Barbershop Spring } \\
\text { Bar Boot Ranch } \\
\text { Barcelona North School }\end{array}$ & $\begin{array}{l}\text { summit } \\
\text { summit } \\
\text { mine } \\
\text { lake } \\
\text { valley } \\
\text { spring } \\
\text { locale } \\
\text { school }\end{array}$ & $\begin{array}{l}\text { VARIANT } \\
\text { VARIANT } \\
\text { UNOFF } \\
\text { BGN } \\
\text { BGN } \\
\text { BGN } \\
\text { UNOFF } \\
\text { UNOFF }\end{array}$ & $\begin{array}{l}\text { Coconino } \\
\text { Coconino } \\
\text { Yuma } \\
\text { Coconino } \\
\text { Coconino } \\
\text { Coconino } \\
\text { Cochise } \\
\text { Maricopa }\end{array}$ & $\begin{array}{l}361802 N 1115244 \mathrm{~W} \\
361802 \mathrm{~N} 1115244 \mathrm{~W} \\
335721 \mathrm{~N} 1135913 \mathrm{~W} \\
343130 \mathrm{~N} 1111026 \mathrm{~W} \\
343301 \mathrm{~N} 1110943 \mathrm{~W} \\
342618 \mathrm{~N} 1111137 \mathrm{~W} \\
313831 \mathrm{~N} 1092614 \mathrm{~W} \\
333159 \mathrm{~N} 1120915 \mathrm{~W}\end{array}$ & $342442 \mathrm{~N} 1111232 \mathrm{~W}$ & & $\begin{array}{l}\text { Bouse Hills West } \\
\text { Blue Ridge Reservoir } \\
\text { Blue Ridge Reservoir } \\
\text { Dane Canyon } \\
\text { Bruno Peak } \\
\text { Glendale }\end{array}$ \\
\hline $\begin{array}{l}\text { Barcelona School } \\
\text { Barcelona South School } \\
\text { Barchas Ranch } \\
\text { Bar Cross Tank } \\
\text { Bar D Corral } \\
\text { Bardman Canyon } \\
\text { Bar Doney Tank } \\
\text { Bar Doney Well } \\
\text { Bard Ranch } \\
\text { Bardshare Spring }\end{array}$ & $\begin{array}{l}\text { school } \\
\text { school } \\
\text { locale } \\
\text { reservoir } \\
\text { locale } \\
\text { valley } \\
\text { reservoir } \\
\text { well } \\
\text { locale } \\
\text { spring }\end{array}$ & $\begin{array}{l}\text { UNOFF } \\
\text { UNOFF } \\
\text { UNOFF } \\
\text { BGN } \\
\text { BGN } \\
\text { BGN } \\
\text { BGN } \\
\text { UNOFF } \\
\text { UNOFF } \\
\text { BGN }\end{array}$ & $\begin{array}{l}\text { Maricopa } \\
\text { Maricopa } \\
\text { Cochise } \\
\text { Coconino } \\
\text { Coconino } \\
\text { Greenlee } \\
\text { Coconino } \\
\text { Coconino } \\
\text { Maricopa } \\
\text { Yavapai }\end{array}$ & $\begin{array}{l}333154 N 1120914 \mathrm{~W} \\
333153 \mathrm{~N} 1120916 \mathrm{~W} \\
312826 \mathrm{N1} 101751 \mathrm{~W} \\
350040 \mathrm{~N} 1120532 \mathrm{~W} \\
344140 \mathrm{~N} 1112210 \mathrm{~W} \\
334319 \mathrm{~N} 1091648 \mathrm{~W} \\
353634 \mathrm{~N} 1112306 \mathrm{~W} \\
353754 \mathrm{~N} 1112443 \mathrm{~W} \\
334440 \mathrm{~N} 1122431 \mathrm{~W} \\
343353 \mathrm{~N} 1120116 \mathrm{~W}\end{array}$ & $334548 \mathrm{~N} 1091530 \mathrm{~W}$ & 1489 & $\begin{array}{l}\text { Glendale } \\
\text { Glendale } \\
\text { Miller Peak } \\
\text { White Horse Lake } \\
\text { Turkey Mtn } \\
\text { Hannagan Meadow } \\
\text { Wupatki SW } \\
\text { Gray Mountain } \\
\text { McMicken Dam } \\
\text { Cherry }\end{array}$ \\
\hline
\end{tabular}


FEATURE NAME

Bard Spring

Bar D Tank

Bar Eleven Well

Bar F Bar Detention

Bar F Bar Detention Dam

Bar F Bar Ranch

Bar F Canyon

Barfoot Lookout

Barfoot Park

Barfoot Peak

Barfoot Spring
Bargaman Draw
Bargaman Park
Bargaman Park Tank
Barge Mountain, La
Bargman Tank
Bar H Creek
Bar Heart Ranch
Bar Heart Ranch Landing Strip
Bar H Spring
Bar I-L Wash
Bar in Well
Barkdol Spring
See Peach Orchard Spring
Barkerville
Barkley Lateral
Barks Canyon
Barks Canyon
Barksdale Tank
Barks Station
See Alpha

Barks Station

See San Bernardino

Barley Patch Tank

Barlow Pass

Bar L Y Ranch

Bar M Canyon

Barnes Butte

Barnes Field House

Barnes Peak

Barnes Ranch

Barnes Spring
Barnes Tunnel
Barnes Wash
Barnett Camp
Barnett Spring
Barnett Tank
Barney Canyon
Barney Oraw
Barney Dry Dam
Barney Flat
Barney Knoll
Barney Pasture
Barney Pasture Burn
Barney Ranch
Barney Ridge
Barney Spring
Barney Spring Canyon
Barney Tank
Barney Tank
Barney Well
Barney Well
Barney Williams Dam Tank
Barnhardt Canyon
Barnhardt Mesa
Barnhardt Mesa Tank
Barnhardt Tank
Barnhardt Trail
Barnum Rock
Bar-N Well
Barpit Tank

\section{FEATURE}

STATUS

COUNTY

COORDINATE

$\begin{array}{lll}\text { spring } & \text { BGN } & \text { Coconino } \\ \text { reservoir } & \text { BGN } & \text { Coconino } \\ \text { well } & \text { UNOFF } & \text { Gila } \\ \text { reservoir } & \text { BGN } & \text { Gila } \\ \text { dam } & \text { UNOFF } & \text { Gila } \\ \text { locale } & \text { UNOFF } & \text { Gila } \\ \text { valley } & \text { BGN } & \text { Greenlee } \\ \text { locale } & \text { BGN } & \text { Cochise } \\ \text { flat } & \text { BGN } & \text { Cochise } \\ \text { summit } & \text { BGN } & \text { Cochise }\end{array}$

spring

valley

rlat

summit

reservoir

strean

locale

airport

spring

strean

wel 1

spring

locale

canal

valley

valley

reservoir

locale

$\begin{array}{ll}\text { BGN } & \text { Cochise } \\ \text { BGN } & \text { Coconino } \\ \text { BGN } & \text { Coconino } \\ \text { BGN } & \text { Coconino } \\ \text { BGN } & \text { Pinal } \\ \text { BGN } & \text { Coconino } \\ \text { BGN } & \text { Apache } \\ \text { UNOFF } & \text { Coconino } \\ \text { ADMIN } & \text { Coconino }\end{array}$

Apache

UNOFF

VARIANT

BGN

BGN

BGN

BGN

VARIANT

Mohave

Apache

Gila

Pinal

Yuma

Pinal

Mohave

Mohave

Maricopa

VARIANT

locale reservoir

gap

locale

valley

summit

building

summ it

locale

BGN
BGN
UNOFF
BGN
BGN 1938
UNOFF
BGN
UNOFF

Maricopa

Gila

Graham

Pima

Coconino

Maricopa

Cochise

Gila

Cochise

\begin{tabular}{|c|c|c|c|}
\hline $\begin{array}{l}\text { spring } \\
\text { cave } \\
\text { stream } \\
\text { locale } \\
\text { spring } \\
\text { reservoir } \\
\text { valley } \\
\text { valley } \\
\text { dain } \\
\text { flat }\end{array}$ & $\begin{array}{l}\text { BGN } \\
\text { UNOFF } \\
\text { BGN } \\
\text { BGN } \\
\text { BGN } \\
\text { BGN } \\
\text { BGN } \\
\text { BGN } \\
\text { UNOFF } \\
\text { BGN }\end{array}$ & $\begin{array}{l}\text { Gila } \\
\text { Gila } \\
\text { Gila } \\
\text { Pinal } \\
\text { Gila } \\
\text { Yavapai } \\
\text { Gila } \\
\text { Coconino } \\
\text { Coconino } \\
\text { Coconino }\end{array}$ & $\begin{array}{l}332848 \mathrm{~N} 1105741 \mathrm{~W} \\
332909 \mathrm{~N} 1105816 \mathrm{~W} \\
333009 \mathrm{~N} 1105931 \mathrm{~W} \\
331909 \mathrm{~N} 1110920 \mathrm{~W} \\
341146 \mathrm{~N} 1112753 \mathrm{~W} \\
341336 \mathrm{~N} 1125339 \mathrm{~W} \\
332429 \mathrm{~N} 1105418 \mathrm{~W} \\
345919 \mathrm{~N} 1121750 \mathrm{~W} \\
352749 \mathrm{~N} 1122354 \mathrm{~W} \\
351008 \mathrm{~N} 1120917 \mathrm{~W}\end{array}$ \\
\hline
\end{tabular}

well UNOFF Yavapai

well

reservoir

valley

summit

reservoir

reservoir

trail

pillar

well

reservoir

UNOFF
BGN
BGN
BGN
BGN
BGN
UNOFF
BGN
UNOFF
BGN

$\begin{array}{cc}\text { SOURCE } & \text { ELEV } \\ \text { COORDINATE } & \text { FT }\end{array}$

MAP NAME

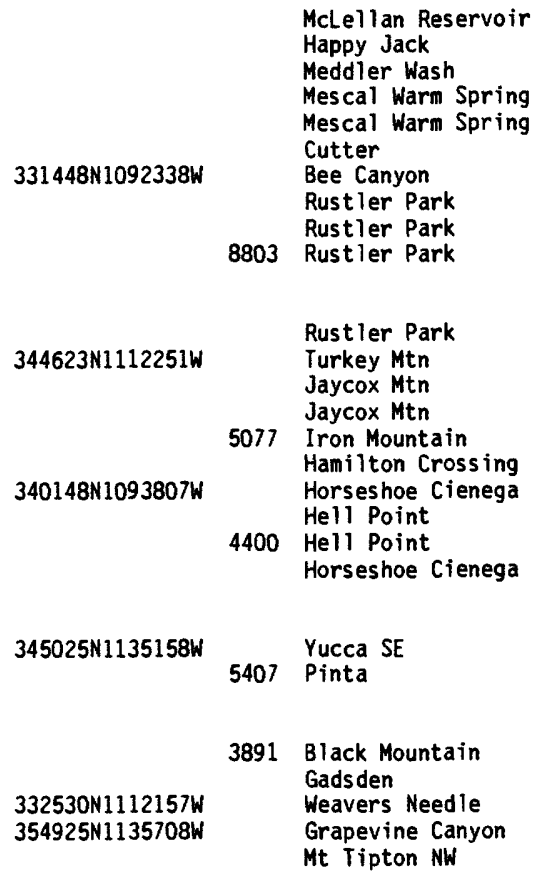

Mclellan Reservoir Happy Jack Meddler Wash Mescal Warm Spring Mescal Warm Spring

331448N1092338W $\quad \begin{aligned} & \text { Cutter } \\ & \text { Bee Canyon }\end{aligned}$ Rust ler Park Rustler Park

8803 Rustler Park

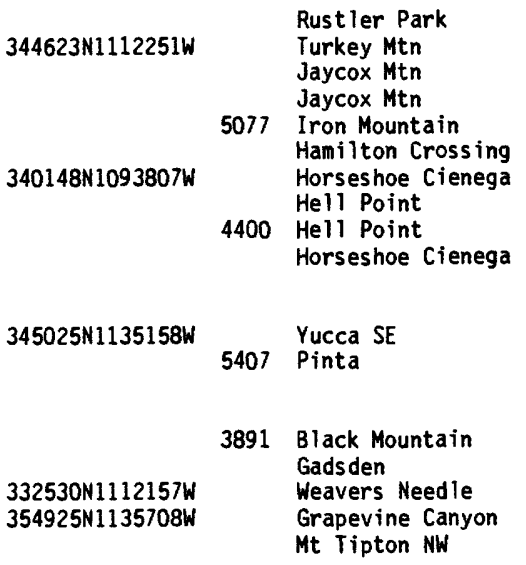

Salt River Peak

6670 Point of Pines West Soza Canyon

345119N1112928W Stoneman Lake

1745 Tempe

Fort Huachuca

5028 Inspiration Vanar Salt River Peak Picketpost Mtn North Peak

O'Neill Pass

Inspiration

Hell Point

Stanford Tank

Williams South
7305

$345914 N 1114929 W$

\begin{tabular}{|c|c|}
\hline $345914 \mathrm{~N} 1114929 \mathrm{~W}$ & $\begin{array}{l}\text { Williams South } \\
\text { Wilson Mountain } \\
\text { Wilson Mountain } \\
\text { Happy Valley } \\
\text { Dutton Hill } \\
\text { Wilson Mountain } \\
\text { Dutton Hill } \\
\text { Matterhorn } \\
\text { Williams South } \\
\text { Sheridan Mtn }\end{array}$ \\
\hline $340510 \mathrm{~N} 1112838 \mathrm{~W}$ & $\begin{array}{l}\text { Cross Mtn } \\
\text { Crown King } \\
\text { Gisela } \\
\text { Mazatzal Peak } \\
\text { Mazatzal Peak } \\
\text { Mazatzal Peak } \\
\text { Mazatzal Peak } \\
\text { Mount Bigelow } \\
\text { Fairchild Well } \\
\text { Humboldt Mtn }\end{array}$ \\
\hline
\end{tabular}

Wilson Mountain

Williams South

Cross Mtn

Mazatzal Peak

Humboldt Mtn
$351008 \mathrm{~N} 1120917 \mathrm{~W}$

$350950 \mathrm{~N} 1120827 \mathrm{~W}$ $345933 \mathrm{~N} 1114917 \mathrm{~W}$ $345933 \mathrm{~N} 1114858 \mathrm{~W}$

$321231 \mathrm{N1102622 \textrm {W }}$

$350024 N 1114812 \mathrm{~W}$

$345937 \mathrm{~N} 1114829 \mathrm{~W}$

$350045 N 1114653 \mathrm{~W}$

$350051 \mathrm{~N} 1121836 \mathrm{~W}$

$351006 \mathrm{~N} 1120937 \mathrm{~W}$

$344036 \mathrm{~N} 1125848 \mathrm{~W}$

$350837 \mathrm{~N} 1131132 \mathrm{~W}$

$340744 N 1121800 \mathrm{~W}$

$340655 \mathrm{~N} 1112147 \mathrm{~W}$

$340610 \mathrm{~N} 1112358 \mathrm{~W}$

$340605 \mathrm{~N} 1112340 \mathrm{~W}$

$340629 \mathrm{~N} 1112337 \mathrm{~W}$

$340456 \mathrm{~N} 1112823 \mathrm{~W}$

$322408 \mathrm{~N} 1104138 \mathrm{~W}$

$345901 \mathrm{~N} 1091634 \mathrm{~W}$

$335837 \mathrm{~N} 1114806 \mathrm{~W}$

$332401 N 1105629 \mathrm{~N}$

350417 N1121742

ima

Apache

Maricopa 


\begin{tabular}{|c|c|c|c|c|c|c|c|}
\hline FEATURE NAME & $\begin{array}{l}\text { FEATURE } \\
\text { CLASS }\end{array}$ & STATUS & COUNTY & COORDINATE & $\begin{array}{c}\text { SOURCE } \\
\text { COORDINATE }\end{array}$ & $\begin{array}{l}\text { ELEV } \\
\text { FT }\end{array}$ & MAP NAME \\
\hline $\begin{array}{l}\text { Barranca Creek } \\
\text { Barranca Creek } \\
\text { Lewis and Pranty Creek } \\
\text { Barranca Creek } \\
\text { See Barranca Creek } \\
\text { Barranca Grande } \\
\text { See Barranca Grande } \\
\text { Barranca Grande } \\
\text { Barranca Grande } \\
\text { Box Canyon } \\
\text { Box Creek }\end{array}$ & $\begin{array}{l}\text { stream } \\
\text { valley } \\
\text { valley }\end{array}$ & $\begin{array}{l}\text { BGN } 1918 \\
\text { VARIANT } \\
\text { VARIANT } \\
\text { VARIANT } \\
\text { VARIANT } \\
\text { BGN } 1918 \\
\text { VARIANT } \\
\text { VARIANT } \\
\text { VARIANT }\end{array}$ & $\begin{array}{l}\text { Maricopa } \\
\text { Maricopa } \\
\text { Maricopa }\end{array}$ & $\begin{array}{l}333435 \mathrm{~N} 1112111 \mathrm{~W} \\
333436 \mathrm{~N} 1112111 \mathrm{~W} \\
333436 \mathrm{~N} 1112111 \mathrm{~W}\end{array}$ & $333105 \mathrm{~N} 1111121 \mathrm{~W}$ & & Horse Mesa Dam \\
\hline $\begin{array}{l}\text { Barrata } \\
\text { Barrelas } \\
\text { See Barriles Tank } \\
\text { Barrel Butte } \\
\text { See Nipple Butte } \\
\text { Barrel Cactus Tank } \\
\text { Barrel Canyon } \\
\text { Barrel Spring } \\
\text { Barrel Spring } \\
\text { Barrel Spring }\end{array}$ & $\begin{array}{l}\text { reservoir } \\
\text { reservoir } \\
\text { summit } \\
\text { reservoir } \\
\text { valley } \\
\text { spring } \\
\text { spring } \\
\text { spring }\end{array}$ & $\begin{array}{l}\text { BGN } \\
\text { VARIANT } \\
\text { VARIANT } \\
\text { BGN } \\
\text { BGN } \\
\text { BGN } \\
\text { BGN } \\
\text { BGN }\end{array}$ & $\begin{array}{l}\text { Yavapai } \\
\text { Santa Cruz } \\
\text { Navajo } \\
\text { Pima } \\
\text { Pima } \\
\text { Pima } \\
\text { Cochise } \\
\text { Pima }\end{array}$ & $\begin{array}{l}350243 \mathrm{~N} 1122418 \mathrm{~W} \\
312935 \mathrm{~N} 1104653 \mathrm{~W} \\
353247 \mathrm{~N} 1102459 \mathrm{~W} \\
313220 \mathrm{~N} 1112853 \mathrm{~W} \\
315207 \mathrm{~N} 1104035 \mathrm{~W} \\
315158 \mathrm{~N} 1104104 \mathrm{~W} \\
320029 \mathrm{~N} 1091802 \mathrm{~W} \\
321817 \mathrm{~N} 1104651 \mathrm{~W}\end{array}$ & $315002 \mathrm{~N} 1104355 \mathrm{~W}$ & 3638 & $\begin{array}{l}\text { Wilbur Canyon } \\
\text { Empire Ranch } \\
\text { Empire Ranch } \\
\text { Cochise Head } \\
\text { Sabino Canyon }\end{array}$ \\
\hline $\begin{array}{l}\text { Barrel Spring } \\
\text { Barrel Spring } \\
\text { Barrel Spring } \\
\text { Barrel Spring } \\
\text { Barrel Spring } \\
\text { Barrel Tank } \\
\text { Barret Spring } \\
\text { Barrett Cakp } \\
\text { Barrie Island } \\
\text { Barriles Ranch }\end{array}$ & $\begin{array}{l}\text { spring } \\
\text { spring } \\
\text { spring } \\
\text { spring } \\
\text { spring } \\
\text { reservoir } \\
\text { spring } \\
\text { locale } \\
\text { island } \\
\text { locale }\end{array}$ & $\begin{array}{l}\text { BGN } \\
\text { BGN } \\
\text { BGN } \\
\text { BGN } \\
\text { BGN } \\
\text { BGN } \\
\text { BGN } \\
\text { BGN } \\
\text { BGN } \\
\text { UNOFF }\end{array}$ & $\begin{array}{l}\text { Gila } \\
\text { Yavapai } \\
\text { Yavapai } \\
\text { Yavapai } \\
\text { Mohave } \\
\text { Pima } \\
\text { Cochise } \\
\text { Cochise } \\
\text { Yuma } \\
\text { Pinal }\end{array}$ & $\begin{array}{l}334301 \mathrm{~N} 1104004 \mathrm{~W} \\
341126 \mathrm{~N} 1124050 \mathrm{~W} \\
341404 \mathrm{~N} 1121336 \mathrm{~W} \\
341720 \mathrm{~N} 1122243 \mathrm{~W} \\
350457 \mathrm{~N} 1133053 \mathrm{~W} \\
314829 \mathrm{~N} 1104429 \mathrm{~W} \\
315705 \mathrm{~N} 1095820 \mathrm{~W} \\
314707 \mathrm{~N} 1095131 \mathrm{~W} \\
335900 \mathrm{~N} 1143200 \mathrm{~W} \\
323335 \mathrm{~N} 1110117 \mathrm{~W}\end{array}$ & & & $\begin{array}{l}\text { Haystack Butte } \\
\text { Yarnell } \\
\text { Bumble Bee } \\
\text { Battleship Butte } \\
\text { Austin Peak } \\
\text { Empire Ranch } \\
\text { Cochise Stronghold } \\
\text { Turquoise Mountain } \\
\text { Big Maria Mts NE } \\
\text { Tortolita Mts }\end{array}$ \\
\hline $\begin{array}{l}\text { Barriles Tank } \\
\text { Barrelas } \\
\text { Barringer Crater } \\
\text { See Meteor Crater } \\
\text { Barrons Cabin } \\
\text { Barrow Tank } \\
\text { Bars Canyon } \\
\text { Bar T Bar Ranch } \\
\text { Bar Thirtyseven Ranch } \\
\text { Bar Thirty Seven Tank }\end{array}$ & $\begin{array}{l}\text { reservoir } \\
\text { crater } \\
\text { locale } \\
\text { reservoir } \\
\text { valley } \\
\text { locale } \\
\text { locale } \\
\text { reservoir }\end{array}$ & $\begin{array}{l}\text { BGN } 1982 \\
\text { VARIANT } \\
\text { VARIANT } \\
\text { BGN } \\
\text { BGN } \\
\text { BGN } \\
\text { UNOFF } \\
\text { UNOFF } \\
\text { BGN }\end{array}$ & $\begin{array}{l}\text { Coconino } \\
\text { Maricopa } \\
\text { Yavapai } \\
\text { Gila } \\
\text { Gila } \\
\text { Yavapai } \\
\text { Yavapai }\end{array}$ & $\begin{array}{l}312935 \mathrm{~N} 1104653 \mathrm{~W} \\
350141 \mathrm{~N} 1110121 \mathrm{~W} \\
334234 \mathrm{~N} 1131247 \mathrm{~W} \\
343003 \mathrm{~N} 1113502 \mathrm{~W} \\
340257 \mathrm{~N} 1112430 \mathrm{~W} \\
340334 \mathrm{~N} 1112148 \mathrm{~W} \\
344741 \mathrm{~N} 1125951 \mathrm{~W} \\
344739 \mathrm{~N} 1130013 \mathrm{~W}\end{array}$ & $340215 \mathrm{~N} 1112743 \mathrm{~W}$ & $\begin{array}{l}3100 \\
5830\end{array}$ & $\begin{array}{l}\text { Little Horn Peak } \\
\text { Buckhorn Mtn } \\
\text { Mazatzal Peak } \\
\text { Gisela } \\
\text { Camp Wood } \\
\text { Scratch Canyon }\end{array}$ \\
\hline $\begin{array}{l}\text { Barth Lake } \\
\text { Barth Well } \\
\text { Bartlett Dam } \\
\text { Bartlett Lake Recreation Site } \\
\text { Bartlett Mountain } \\
\text { Bartlett Reservoir } \\
\text { Bartolo Canyon } \\
\quad \text { Cedar Canyon } \\
\text { Bartolo Mountain } \\
\text { Bartol Spring }\end{array}$ & $\begin{array}{l}\text { lake } \\
\text { well } \\
\text { dam } \\
\text { park } \\
\text { summit } \\
\text { reservoir } \\
\text { valley } \\
\text { summit } \\
\text { spring }\end{array}$ & $\begin{array}{l}\text { BGN } \\
\text { UNOFF } \\
\text { UNOFF } \\
\text { ADMIN } \\
\text { BGN } \\
\text { BGN } \\
\text { BGN } 1983 \\
\text { VARIANT } \\
\text { BGN } \\
\text { BGN }\end{array}$ & $\begin{array}{l}\text { Apache } \\
\text { Apache } \\
\text { Maricopa } \\
\text { Maricopa } \\
\text { Santa Cruz } \\
\text { Maricopa } \\
\text { Santa Cruz } \\
\text { Santa Cruz } \\
\text { Yavapai }\end{array}$ & $\begin{array}{l}345823 \mathrm{~N} 1090702 \mathrm{~W} \\
345728 \mathrm{~N} 1090341 \mathrm{~W} \\
334905 \mathrm{~N} 1113751 \mathrm{~W} \\
335024 \mathrm{~N} 1113819 \mathrm{~W} \\
312407 \mathrm{~N} 1111521 \mathrm{~W} \\
334905 \mathrm{~N} 1113751 \mathrm{~W} \\
313119 \mathrm{~N} 1111557 \mathrm{~W} \\
313034 \mathrm{~N} 1111212 \mathrm{~W} \\
340952 \mathrm{~N} 1121929 \mathrm{~W}\end{array}$ & 312836 N1111231W & 5382 & $\begin{array}{l}\text { Barth Well } \\
\text { Barth Well } \\
\text { Bartlett Dam } \\
\text { Bartlett Dan } \\
\text { Bartlett Mtn } \\
\text { Bartlett Dan } \\
\text { Murphy Peak } \\
\text { Murphy Peak } \\
\text { Crown King }\end{array}$ \\
\hline $\begin{array}{l}\text { Barts Crossing } \\
\text { See West Chevelon Crossing } \\
\text { Barts Crossing } \\
\text { Bar U Bar Ranch } \\
\text { Bar U Bar Ranch } \\
\text { Bar U Bar Tank } \\
\text { Bar X Canyon } \\
\text { Bar X Tank } \\
\text { Bar X Tank } \\
\text { Bar X Trick Tank }\end{array}$ & $\begin{array}{l}\text { locale } \\
\text { locale } \\
\text { locale } \\
\text { locale } \\
\text { reservoir } \\
\text { valley } \\
\text { reservoir } \\
\text { reservoir } \\
\text { reservoir }\end{array}$ & $\begin{array}{l}\text { VARIANT } \\
\text { BGN } \\
\text { UNOFF } \\
\text { UNOFF } \\
\text { BGN } \\
\text { BGN } \\
\text { BGN } \\
\text { BGN } \\
\text { BGN }\end{array}$ & $\begin{array}{l}\text { Coconino } \\
\text { Coconino } \\
\text { Yavapai } \\
\text { Yavapai } \\
\text { Yavapai } \\
\text { Graham } \\
\text { Graham } \\
\text { Gila } \\
\text { Graham }\end{array}$ & $\begin{array}{l}342817 \mathrm{~N} 1105528 \mathrm{~W} \\
342820 \mathrm{~N} 1105550 \mathrm{~W} \\
343648 \mathrm{~N} 1124501 \mathrm{~W} \\
343649 \mathrm{~N} 1124456 \mathrm{~W} \\
343650 \mathrm{~N} 1124517 \mathrm{~W} \\
323126 \mathrm{~N} 1095151 \mathrm{~W} \\
323208 \mathrm{~N} 1094939 \mathrm{~W} \\
341255 \mathrm{~N} 110585 \mathrm{~W} \\
323302 \mathrm{~N} 1095002 \mathrm{~W}\end{array}$ & $323303 \mathrm{~N} 1094959 \mathrm{~W}$ & & $\begin{array}{l}\text { Porcupine Ridge } \\
\text { Martin Mtn } \\
\text { Skull Vall ley } \\
\text { Mart in Mtn } \\
\text { Stockton Pass } \\
\text { Stockton Pass } \\
\text { Oxbow Mtn } \\
\text { Stockton Pass }\end{array}$ \\
\hline $\begin{array}{l}\text { Bar X Wash } \\
\text { Basalt Canyon } \\
\text { Basalt Cliffs } \\
\text { Basalt Creek } \\
\text { Bascom Tank Canyon } \\
\text { See Baskin Tank Canyon } \\
\text { Basco Tank } \\
\text { Baseline, Canal (historical) } \\
\text { Basel ine Substation } \\
\text { Basel ine Tank }\end{array}$ & $\begin{array}{l}\text { stream } \\
\text { valley } \\
\text { cliff } \\
\text { stream } \\
\text { valley } \\
\text { reservoir } \\
\text { canal } \\
\text { locale } \\
\text { reservoir }\end{array}$ & $\begin{array}{l}\text { BGN } \\
\text { BGN } \\
\text { BGN } 1906 \\
\text { BGN } 1932 \\
\text { VARIANT } \\
\text { BGN } \\
\text { BGN } \\
\text { UNOFF } \\
\text { BGN }\end{array}$ & $\begin{array}{l}\text { Graham } \\
\text { Coconino } \\
\text { Coconino } \\
\text { Coconino } \\
\text { Gila } \\
\text { Coconino } \\
\text { Maricopa } \\
\text { Maricopa } \\
\text { Greenlee }\end{array}$ & $\begin{array}{l}355950 \mathrm{~N} 1093340 \mathrm{~W} \\
360545 \mathrm{~N} 1115022 \mathrm{~W} \\
360632 \mathrm{~N} 1115225 \mathrm{~W} \\
360545 \mathrm{~N} 1115022 \mathrm{~W} \\
333956 \mathrm{~N} 1100840 \mathrm{~W} \\
345122 \mathrm{~N} 1113519 \mathrm{~W} \\
332234 \mathrm{~N} 1121333 \mathrm{~W} \\
332155 \mathrm{~N} 1114127 \mathrm{~W} \\
332130 \mathrm{~N} 1092523 \mathrm{~W}\end{array}$ & $\begin{array}{l}323048 \mathrm{~N} 1095230 \mathrm{~W} \\
360856 \mathrm{~N} 1115315 \mathrm{~W} \\
360856 \mathrm{~N} 1115315 \mathrm{~W}\end{array}$ & & $\begin{array}{l}\text { W of Greasewood Mtn } \\
\text { Desert View } \\
\text { Desert View } \\
\text { Desert View }\end{array}$ \\
\hline
\end{tabular}


NATIONAL GAZETTEER--ARIZONA 1986

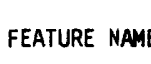

Baseline Tank Number Two Baseline Village Shopping

Center

Basha Elementary School Saint Mary/Basha

Basin, The Elementary School

Bas in, The

Bas in, The

Bas in Lake

\section{Bas in Mine}

Bas in Spring

Bas in Spring

Bas in Spring

Bas in Spring

Bas in Tank

Bas in Tank

Bas in Tank

Bas in Tank

Bas in Tank

Bas in Tank

Bas in Tank

Bas in Tank

Bas in Tank

Basin Trail Two Hundred

Fortyseven

Bas in Well

Bas in Well

Basket Burn

See Hoa Murk

Basking Ridge (subdivision)

Baskin Tank

Baskin Tank Canyon Bascom Tank Canyon

Bassarisc Tank

Bass Canyon

Bass Canyon

Bass Canyon

\section{Bassett Peak}

Bassett Tank

Bass Point

Bass Point

Bass Pond Tank

Bass Rapids

Bass Spring

Bass Tank

Bass Tank

Bass Tank

\section{Bass Tomb \\ Bass Trai \\ Batamote Hills \\ atamote Mountain \\ Batamote Mountains \\ Batamote Ranch \\ Batamote Tank \\ Batamote Tank \\ Batamote Wash \\ Batamote Wash \\ Batamote Well \\ Batamote Well \\ Bat Canyon \\ Bat Canyon \\ Bat Canyon}

See Holy Grail Temple

See Batamote Mountains

Batamote Mountain Batemote Mountain

Batamote Pasture Tank

\begin{tabular}{|c|c|c|c|}
\hline $\begin{array}{l}\text { FEATURE } \\
\text { CLASS }\end{array}$ & STATUS & COUNTY & COORDINATE \\
\hline $\begin{array}{l}\text { reservoir } \\
\text { locale }\end{array}$ & $\begin{array}{l}\text { BGN } \\
\text { UNOFF }\end{array}$ & $\begin{array}{l}\text { Greenlee } \\
\text { Maricopa }\end{array}$ & $\begin{array}{l}332154 \mathrm{~N} 1092624 \mathrm{~W} \\
332240 \mathrm{~N} 1115432 \mathrm{~W}\end{array}$ \\
\hline school & $\begin{array}{l}\text { UNOFF } \\
\text { VARIANT }\end{array}$ & Maricopa & $331850 \mathrm{~N} 1115047 \mathrm{~W}$ \\
\hline $\begin{array}{l}\text { bas in } \\
\text { bas in } \\
\text { flat } \\
\text { lake }\end{array}$ & $\begin{array}{l}\text { BGN } \\
\text { BGN } 1932 \\
\text { BGN } \\
\text { BGN }\end{array}$ & $\begin{array}{l}\text { Pinal } \\
\text { Coconino } \\
\text { Yavapai } \\
\text { Apache }\end{array}$ & $\begin{array}{l}325150 \mathrm{~N} 1103315 \mathrm{~W} \\
361611 \mathrm{~N} 1120628 \mathrm{~W} \\
342929 \mathrm{~N} 1113836 \mathrm{~W} \\
335459 \mathrm{~N} 1092605 \mathrm{~W}\end{array}$ \\
\hline $\begin{array}{l}\text { mine } \\
\text { spring } \\
\text { spring } \\
\text { spring } \\
\text { spring } \\
\text { reservoir } \\
\text { reservoir } \\
\text { reservoir } \\
\text { reservoir } \\
\text { reservoir }\end{array}$ & $\begin{array}{l}\text { UNOFF } \\
\text { BGN } \\
\text { BGN } \\
\text { BGN } \\
\text { BGN } \\
\text { BGN } \\
\text { BGN } \\
\text { BGN } \\
\text { BGN } \\
\text { BGN }\end{array}$ & $\begin{array}{l}\text { Santa Cruz } \\
\text { Santa Cruz } \\
\text { Pima } \\
\text { Maricopa } \\
\text { Coconino } \\
\text { Santa Cruz } \\
\text { Santa Cruz } \\
\text { Pima } \\
\text { Greenlee } \\
\text { Greenlee }\end{array}$ & $\begin{array}{l}312852 \mathrm{~N} 1104256 \mathrm{~W} \\
31251 \mathrm{~N} 1104532 \mathrm{~W} \\
314811 \mathrm{~N} 1104656 \mathrm{~W} \\
335717 \mathrm{~N} 1113818 \mathrm{~W} \\
361559 \mathrm{~N} 1120626 \mathrm{~W} \\
312655 \mathrm{~N} 1110357 \mathrm{~W} \\
312952 \mathrm{~N} 1110605 \mathrm{~W} \\
314033 \mathrm{~N} 1111417 \mathrm{~W} \\
325318 \mathrm{~N} 1092029 \mathrm{~W} \\
331454 \mathrm{~N} 1090955 \mathrm{~W}\end{array}$ \\
\hline $\begin{array}{l}\text { reservoir } \\
\text { reservoir } \\
\text { reservoir } \\
\text { reservoir } \\
\text { reservoir } \\
\text { reservoir } \\
\text { trail }\end{array}$ & $\begin{array}{l}\text { BGN } \\
\text { BGN } \\
\text { BGN } \\
\text { BGN } \\
\text { BGN } \\
\text { BGN } \\
\text { UNOFF }\end{array}$ & $\begin{array}{l}\text { Gila } \\
\text { Gila } \\
\text { Coconino } \\
\text { Coconino } \\
\text { Mohave } \\
\text { Yavapai } \\
\text { Cochise }\end{array}$ & $\begin{array}{l}333738 \mathrm{~N} 1100011 \mathrm{~W} \\
334412 \mathrm{~N} 1103639 \mathrm{~W} \\
343640 \mathrm{~N} 1111556 \mathrm{~W} \\
344811 \mathrm{~N} 111385 \mathrm{~W} \\
350727 \mathrm{~N} 1132234 \mathrm{~W} \\
352254 \mathrm{~N} 1131658 \mathrm{~W} \\
315140 \mathrm{~N} 1091430 \mathrm{~W}\end{array}$ \\
\hline $\begin{array}{l}\text { well } \\
\text { we } 11\end{array}$ & $\begin{array}{l}\text { UNOFF } \\
\text { UNOFF }\end{array}$ & $\begin{array}{l}\text { Mohave } \\
\text { Coconino }\end{array}$ & $\begin{array}{l}351521 \mathrm{~N} 1142320 \mathrm{~W} \\
354002 \mathrm{~N} 1110012 \mathrm{~W}\end{array}$ \\
\hline
\end{tabular}

VARIANT

locale

ppl

reservoir

valley

reservoir

valley

valley

valley

summit

reservoir

cape

cliff

rapids

spring

reservoir

reservoir

reservoir

$\begin{array}{ll}\text { BGN } & \text { Pima } \\ \text { BGN } & \text { Maricopa } \\ \text { BGN } & \text { Gila } \\ \text { VARIANT } & \text { Gila } \\ \text { BGN } & \text { Pima } \\ \text { BGN } & \text { Cochise } \\ \text { BGN } & \text { Pinal }\end{array}$

321647 N1124000W

$333822 \mathrm{~N} 1115609 \mathrm{~W}$

$333736 \mathrm{~N} 1101006 \mathrm{~W}$

333956N1100840W

32040BN1131200W

$322056 \mathrm{~N} 1101510 \mathrm{~W}$

$323218 \mathrm{~N} 1110420 \mathrm{~W}$

$361339 \mathrm{N1} 122022 \mathrm{~W}$

$\begin{array}{lll}\text { BGN } & \text { Graham } & 323022 \mathrm{~N} 1101645 \mathrm{~W} \\ \text { BGN } & \text { Gila } & 340659 \mathrm{~N} 1111846 \mathrm{~W} \\ \text { BGN } & \text { Gila } & 334046 \mathrm{~N} 1110752 \mathrm{~W} \\ \text { BGN } & \text { Coconino } & 345804 \mathrm{N1112712W} \\ \text { BGN } & \text { Yavapai } & 350541 \mathrm{~N} 1122153 \mathrm{~W} \\ \text { BGN } 1932 & \text { Coconino } & 361353 \mathrm{~N} 1122021 \mathrm{~W} \\ \text { BGN } & \text { Pinal } & 323148 \mathrm{~N} 1110329 \mathrm{~W} \\ \text { BGN } & \text { Cochise } & 312552 \mathrm{~N} 1092551 \mathrm{~W} \\ \text { BGN } & \text { Graham } & 322640 \mathrm{~N} 1101236 \mathrm{~W} \\ \text { BGN } & \text { Coconino } & 36053 \mathrm{BN} 1122225 \mathrm{~W}\end{array}$

sumait

trail

summit

VARIANT

UNOFF

BGN

VARIANT

summit

summit

BGN

VARIANT

VARIANT

reservoir

BGN

Coconino

Coconino

Pima

Pima

Pina

Pima

UNOFF

$\begin{array}{ll}\text { locale } & \text { UNOFF } \\ \text { reservoir } & B G N \\ \text { reservoir } & B G N\end{array}$

reservoir

stream

stream

well

we 11

valley

valley

valley
BGN 1979

BGN

UNOFF

UNOFF

BGN

BGN

BGN
361629N1121B13W

361650 N1121952

314531N1111440W

$322756 \mathrm{~N} 1124515 \mathrm{~W}$

$322756 \mathrm{~N} 1124515 \mathrm{~W}$

314737 N1111349W $\begin{array}{lc}\text { SOURCE } & \text { ELEV } \\ \text { COORDINATE } & \text { FT MAP NAME }\end{array}$

Bee Canyon

Tempe

Chandler

Holy Joe Peak

Little Park Lane

Hackberry Mtn

9039 Big Lake North

Harshaw

Cumero Canyon

Helvetia

Horseshoe Dam

Little Park Lane

Pena Blanca Lake

Pena Blanca Lake

Saucito Mtn

Guthrie

Dix Creek

5523 Velasquez Butte

Chrysotile

Long Valley

Munds Mountain

Penitentiary Mtn

Blye Canyon NE

Portal Peak

Burns Spring

5099 Rock Head

1510 Currys Corner

Forks Butte

Forks Butte

Agua Dulce Mts

Soza Mesa

Tortolita Mts

$323134 \mathrm{~N} 1110223 \mathrm{H}$

$361141 \mathrm{~N} 1122220 \mathrm{~W}$

Havasupai Point

7663 Bassett Peak

Gisela

Theo. Roosevelt Dam

Mormon Lake

Matterhorn

Havasupai Point

Tortolita Mts

College Peaks

The Mesas

Piute Point

King Arthur Castle

Batamote Hills

Batamote Hills

Batamote Hills

Cocoraque Butte

Saucito Mtn

$314710 \mathrm{~N} 1111337 \mathrm{~W}$

Oracle Junction

Batamote $\mathrm{Hill}$ s

Ajo North

Copperplate Gulch

Carrizo

Bat Canyon 


\section{FEATURE NAME}

Bat Canyon

Bat Cave

Bat Cave

Bat Cave Tank

Bateman Spring

Batemote Mountain See Batamote Mountains

Bates Canyon

Bates Oraw

Bates Mountains

See Cipriano Hills

Bates Mountains Growler Mountains Puerto Blanco Mountains

Bates Tank

Bates Tank

Bates Wash

See Growler Wash

Bates Well

Bates Well

Bates Well Mountains

See Puerto Blanco Mountains

Bathtub Forest Camp

Bathtub Spring

Bath Tub Spring

Bath Tub Tank

Bathtub Water

Bat Rock

Bat Spring

Bat Tank

Battle Cove Ruins

Battle Creek Canal

Battle Flat

Batt leground Creek

Battleground Number One Tank

Battleground Ridge

Battleground Tank

Battle Mountain

Battle of Big Ory Wash

His torical Marker

Battle of Big Dry Wash

His torical Monument

Battleship, The

Battleship, The

Battleship Butte

Battleship Mountain

Battleship Mountain

See Batt leship Peak

Batt leship Mountain

Battleship Mountain

See Nutt, Mount

Battleship Peak

Batt leship Mountain

Battle Tank

Batt Tank

Bat Well

Baumkirchner Mine

Bawcom Tank Rawcom Tank

Baxter Tank

Bayless Ranch

Baysag Point

See Boysag Point

Bays inger Drain

B Bar B Ranch

B Canal

Beach Tank

Beacon $\mathrm{Hill}$

Beacon Power Plant

Beacon Tank

Beacon Wel

Beacon Wel

Beacon Well
FEATURE

CLASS

valley

cave

cave

reservoir

spring

summit

valley

valley

summit

STATUS

COUNTY

BGN Apache

BGN

$B G N$

BGN

BGN

VARIANT

BGN Pima

BGN Graha

VARIANT

Greenlee

Mohave

Santa Cruz

Mohave

Pinal

Graham

Pima

summit

BGN 1964 Pima

VARIANT

VARIANT

reservoir

BGN

reservoir

BGN

VARIANT

strean

wel

locale

UNOFF

UNOF

BGN

range

VARIANT

Cochise

Cochise

Yuma

Yavapai

Pima

Pima

COORDINATE

$360606 N 1092043 \mathrm{~W}$

$330125 N 1092443 \mathrm{~W}$

$360254 \mathrm{~N} 1134806 \mathrm{~W}$

$313137 N 1104042 \mathrm{~W}$

$342902 \mathrm{~N} 1134648 \mathrm{~W}$

322756 N1124515W

$325822 \mathrm{~N} 1103156 \mathrm{~W}$

$330836 \mathrm{~N} 1100751 \mathrm{~W}$

$320216 N 1125921 \mathrm{~W}$

320630 N1125700W

314650 N1102008W

315237 N1092313W

323233N1132550W

343113 N1115840W

321012 N1125702W

320016 N1125126W

park

spring

spring

lake

summit

spring

reservoir

locale

canal

ADN
BGN
BGN
BGN
BGN
BGN
BGN
BGN
BGN
BGN

Cochise

Cochise

Pinal

Santa Cruz

Santa Cruz

Apache

Coconino

Graham

Apache

Graham

flat

stream

reservoir

ridge

reservoir

summit

park

park

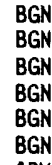

BGN
$B G N$
$B G N$

$B G N$

BGN

ADMIN

Yavapai

Apache

Apache

Coconino

Coconino

Graham

Coconino

ADMIN

Coconino

314646 N1091835W

315157 N1102404W

$332505 \mathrm{~N} 1110246 \mathrm{~W}$

314037 N110460OW

$313952 \mathrm{~N} 1104709 \mathrm{~W}$

360540 N1092104W

$360139 \mathrm{~N} 1105049 \mathrm{~W}$

$324040 \mathrm{~N} 1092027 \mathrm{~W}$

$360916 \mathrm{~N} 10926$

$325740 \mathrm{~N} 1095405 \mathrm{~W}$

$341816 \mathrm{~N} 1122107 \mathrm{~W}$

$333916 \mathrm{~N} 1093055 \mathrm{~W}$

333859 N1093132W

$343148 \mathrm{~N} 1111343 \mathrm{~W}$

$343226 \mathrm{~N} 1111343 \mathrm{~W}$

$323942 N 1100150 \mathrm{~W}$

$342715 \mathrm{~N} 111150 \mathrm{OW}$

$343246 \mathrm{~N} 1111312 \mathrm{~W}$

summit

summit

summit

summit

BGN

Apache

BGN 1932 Coconino

BGN Yavapai

BGN Maricopa

summit

summit

summit

summit

Yuma

BGN Mohave

VARIANT

BGN

Mohave

VARIANT

reservoir

reservoir

well

mine

reservoir

BGN

UNOFF

UNOFF

BGN 1973 VARIANT

reservoir

locale

BGN

UNOFF

cliff

VARIANT

Coconino

Yavapai

Pima

Cochise

Coconino

Gila

Pima

Mohave

$345140 \mathrm{~N} 1094659 \mathrm{~W}$

$360432 \mathrm{~N} 1120816 \mathrm{~W}$

341848 N1122858

$332958 \mathrm{NI112353 \textrm {W }}$

$340428 \mathrm{~N} 1134827 \mathrm{~W}$

$350427 \mathrm{~N} 1142252 \mathrm{~W}$

350516 N1142110W

$340428 \mathrm{~N} 1134827 \mathrm{~W}$

344418 N1105553W

$341235 \mathrm{~N} 1120400 \mathrm{~W}$

$322843 \mathrm{~N} 1104116 \mathrm{~W}$

$312400 \mathrm{~N} 1101449 \mathrm{~W}$

344245 N1111308W

$331544 N 1103134 \mathrm{~W}$

322337 N11 02729W

362046 N1124441W

$\begin{array}{llll}\text { stream } & \text { BGN } & \text { Mohave } & 342830 \mathrm{~N} 1141718 \mathrm{~W} \\ \text { locale } & \text { UNOFF } & \text { Pinal } & 332601 \mathrm{~N} 1112855 \mathrm{~W} \\ \text { canal } & \text { BGN } & \text { Yuma } & 323940 \mathrm{~N} 1143350 \mathrm{~W} \\ \text { reservoir } & \text { BGN } & \text { Pima } & 315502 \mathrm{~N} 1104233 \mathrm{~W} \\ \text { summit } & \text { BGN } & \text { Coconino } & 351522 \mathrm{~N} 1120350 \mathrm{~W} \\ \text { locale } & \text { BGN } & \text { Coconino } & 362414 \mathrm{~N} 1111337 \mathrm{~W} \\ \text { reservoir } & \text { BGN } & \text { Coconino } & 350356 \mathrm{~N} 1105846 \mathrm{~W} \\ \text { well } & \text { UNOFF } & \text { Cochise } & 315509 \mathrm{~N} 1102133 \mathrm{~W} \\ \text { well } & \text { UNOFF } & \text { Coconino } & 350430 \mathrm{~N} 110585 \mathrm{~W} \\ \text { locale } & \text { BGN } & \text { Apache } & 350353 \mathrm{~N} 1091553 \mathrm{~W}\end{array}$

\begin{tabular}{|c|c|c|}
\hline $\begin{array}{l}\text { SOURCE } \\
\text { COORDINATE }\end{array}$ & $\begin{array}{c}\text { ELEV } \\
\text { FT }\end{array}$ & MAP NAME \\
\hline $360457 \mathrm{~N} 1092146 \mathrm{~W}$ & & $\begin{array}{l}\text { Spider Rock } \\
\text { Copperplate Gulch } \\
\text { Bat Cave } \\
\text { Mt Hughes } \\
\text { McCracken Peak }\end{array}$ \\
\hline \multirow[t]{5}{*}{$\begin{array}{l}325838 \mathrm{~N} 1102822 \mathrm{~W} \\
330402 \mathrm{~N} 1101326 \mathrm{~W}\end{array}$} & & $\begin{array}{l}\text { Brandenburg Mtn } \\
\text { Calva }\end{array}$ \\
\hline & & Kino Peak \\
\hline & & $\begin{array}{l}\text { McGrew Spring } \\
\text { Fife Peak }\end{array}$ \\
\hline & & $\begin{array}{l}\text { Middle Verde } \\
\text { Bates Well }\end{array}$ \\
\hline & 6557 & $\begin{array}{l}\text { Chiricahua Peak } \\
\text { Apache Peak } \\
\text { Haunted Canyon } \\
\text { Mt Wrightson } \\
\text { Mt Wrightson } \\
\text { Spider Rock } \\
\text { Bat Spring } \\
\text { Whitlock Mts NE } \\
\text { Del Muerto } \\
\text { Eden }\end{array}$ \\
\hline
\end{tabular}

$333919 \times 1093204$

Battle Flat

Maverick

Maverick

Blue Ridge Reservoir

Blue Ridge Reservoir

5518 Blue Jay Peak

Dane Canyon

Blue Ridge Reservoir

Agate House

Grand Canyon

Battleship Butte

2797 Goldfield

4165 Oatman

2579 Butler Pass

Hamilton Crossing

Joes $\mathrm{Hill}$

Mount Bigelow

Nicksville

Hay Lake

Bucket Mtn

Redington

342853 N1141650W

Lake Havasu City S 
NATIONAL GAZETTEER--ARIZONA 1986 FEATURE NAME

Be Akeghalchee
Beal Ditch
Beale Mountain
Beale Point
Beales Crossing
Beale Spring
Beale Spring
Beal Lake
Beal Lake
See Topock Marsh

Beal Tank

Beaner Well

Bean Belly Well

Bean Canyon

Bean Dam Tank

Bean Hole Ranch

Bean Pass

Bean Patch

Bean Patch Tank

Bean Patch Well

Bean Peaks

Bean Spring

Bear Bas in

Bear Beaver Ridge

Bear Canyon

Bear Canyon

Bear Canyon

Bear Canyon

Bear Canyon

Bear Canyon

Bear Canyon

Bear Canyon

Bear Canyon

Bear Canyon

Bear Canyon

Bear Canyon

See Black Mesa Canyon

Bear Canyon

Bear Canyon

Bear Canyon

Bear Canyon

Bear Canyon

Bear Canyon

Bear Canyon

Bear Canyon

Oak Spring Canyon

Bear Canyon

Bear Canyon

Bear Canyon

Bear Canyon

Bear Canyon

Bear Canyon

Bear Canyon Campground

Bear Canyon Dam

Bear Canyon Junction

Bear Canyon Lake

Willow Springs Lake

Bear Canyon Lake Recreation Area

Bear Canyon Mine

Bear Canyon Number One

Bear Canyon Picnic Area

Bear Canyon Spring

Bear Canyon Tank

Bear Canyon Tank

Bear Canyon Tank

Bear Canyon Trail

Bear Canyon Trail Twenty-Nine

Bear Canyon Two Hundred

Ninety-Nine Trai 1
FEATURE

CLASS

STATUS

COUNTY

COORDINATE

$360252 N 1095254 \mathrm{~W}$

lake BGN Apache

canal BGN Mohave 344621N1143145

$352210 \mathrm{~N} 1115445$

cliff BGN 1908 Coconino 361712N1122723W

locale BGN Mohave 350240N114371BW

spring BGN Mohave $351216 \mathrm{~N} 1140457 \mathrm{~W}$

spring BGN Coconino 352144N1115442W

lake

swamp

VARIANT

Mohave

$344635 N 1143049 \mathrm{~W}$

well

well

valley

reservoir

locale

gap

reservoir

ervoir BGN

well

Mohave

$341455 N 1114605 \mathrm{~W}$

$333515 N 1141510$

333019N1103524k

$321013 \mathrm{N1093541 \textrm {W }}$

$350313 N 1122158 \mathrm{~W}$

363839 N1115307

$32224 \mathrm{BN} 1133805 \mathrm{~W}$

$344035 N 1090908$

$341905 \mathrm{~N} 1111640 \mathrm{~W}$

$343946 \mathrm{~N} 1090925 \mathrm{~W}$

summit

spring

bas in

ridge

valley

valley

valley

valley

valley

valley

$\begin{array}{ll}\text { BGN } & \text { Yavapai } \\ \text { BGN } & \text { Navajo } \\ \text { BGN } & \text { Graham } \\ \text { BGN } & \text { Coconino } \\ \text { BGN } & \text { Pima } \\ \text { BGN } & \text { Cochise } \\ \text { BGN } & \text { Cochise } \\ \text { BGN } & \text { Pima } \\ \text { BGN } & \text { Graham } \\ \text { BGN } & \text { Graham }\end{array}$

342858 N1122752W

355218 N1102238W

324601 N1095652W

$342509 \mathrm{~N} 1110038 \mathrm{~W}$

$314303 \mathrm{~N} 1113901 \mathrm{~W}$

$314708 \mathrm{~N} 1091806 \mathrm{~W}$

$321551 N 1093112 W$

$321810 \mathrm{~N} 1104759 \mathrm{~W}$

322B10N1101920

$322904 \mathrm{~N} 1101256 \mathrm{~W}$

valley

valley

valley

valley

11ey

valley

valley
valley

valley

BGN
BGN
BGN
BGN
BGN
VARIANT

Graham

Graham

Green lee

Graham

Greenlee

$323454 N 1094818 \mathrm{~W}$

$325355 \mathrm{~N} 1102504 \mathrm{~W}$

$330649 \mathrm{~N} 1092822 \mathrm{~W}$

$330700 \mathrm{~N} 1093925 \mathrm{~W}$

$332020 \mathrm{~N} 1092 \mathrm{~B} 15$

Gila

BGN Gila

BGN Greenlee

$332434 N 1102441 \mathrm{~W}$

$333018 \mathrm{~N} 1102008 \mathrm{~W}$

$333025 \mathrm{~N} 1091226 \mathrm{~W}$

$333217 N 1092344 \mathrm{~W}$

valley

valley

valley

valley

valley

valley

valley

valley

valley

BGN Navajo

BGN Navajo

Navajo

BGN 1974 Gila

VARIANT

BGN

BGN

BGN

Gila

Coconino

Coconino

$334653 \mathrm{~N} 1100051 \mathrm{~W}$

341329 N1102618W

$341530 \mathrm{~N} 1101408 \mathrm{~W}$

341957 N1103914W

$342131 \mathrm{~N} 1112847 \mathrm{~W}$

$342226 \mathrm{~N} 1111709 \mathrm{~W}$

$342724 \mathrm{~N} 1110003 \mathrm{~W}$

$343216 \mathrm{~N} 1111214 \mathrm{~W}$

$343256 \mathrm{~N} 1112616 \mathrm{~W}$

valley

BGN Yavapai 345507N1121645W

BGN Apache

ADMIN

locale

reservoir

UNOFF Coconino

BGN

Gila

$354455 N 1092020 \mathrm{~N}$

$322227 \mathrm{~N} 1104128 \mathrm{~W}$

$342425 \mathrm{~N} 1110003 \mathrm{~W}$

$333211 \mathrm{~N} 1102337 \mathrm{~W}$

$342425 \mathrm{~N} 1110003 \mathrm{~W}$

BGN 1973 Coconino

park

ADMIN

Coconino

$342422 \mathrm{~N} 1110012 \mathrm{~W}$

mine

UNOFF

Gila

333207 N1102000W

$\begin{array}{llll}\text { reservoir } & \text { BGN } & \text { Gila } & 334907 \text { N1100022W } \\ \text { park } & \text { ADMIN } & \text { Pima } & 322228 \text { N1104124W }\end{array}$

$\begin{array}{llll}\text { park } & \text { ADMIN } & \text { Pima } & 322228 N 1104124 \mathrm{~W} \\ \text { spring } & \text { BGN } & \text { Gila } & 333813 N 1103241 \mathrm{~W}\end{array}$

reservoir BGN Gila

reservoir BGN Gila 34220BN1111816W

trail UNOFF Greenlee 332300N1092619W

trail UNOFF Pima 322014N1104600W

reservoir BGN Mohave $353412 \mathrm{~N} 1134008 \mathrm{~W}$
$344551 N 1143157 \mathrm{~W}$

reservoir BGN Graham 330241N1094133W $\begin{array}{ccc}\text { SOURCE } & \text { ELEV } \\ \text { COORDINATE } & \text { FT MAP NAME }\end{array}$

Toadindaaska Mesa Needles

7722 Parks

Powell Plateau

Davis Dam SE

Kingman

Parks

Needles

Bloody Bas in

Cunningham Mtn

$321213 N 1093409$

3454 Sevenmile Mts

Dos Cabezas

Matterhorn

Emmett $\mathrm{Hill}$

Point of the Pintas

Valle Bonito

Payson North

valle Bonito

Groom Creek

Polacca

Shingle Mill Mtn

Knoll Lake

Aguirre Peak

Chiricahua Peak

Luzena

Sabino Canyon

Cherry Spring Peak

The Mesas

Stockton Pass

Booger Canyon

Copperplate Gulch

Bryce Mountain

Bee Canyon

Sontag Creek

Bear Mountain

Baldy Bill Point

Canyon Day

Bear Ridge

Pinedale

Brookbank Point

Buckhead Mesa

Kehl Ridge

Porcupine Ridge

Blue Ridge Reservoir

Calloway Butte

$350513 N 1121035 \mathrm{~W}$

Hell Point

East of Kinlichee

5900 Agua Caliente Hill Knoll Lake

4588 Cassadore Spring

Knoll Lake

Knoll Lake

Sontag Creek

Canyon Day

Agua Caliente Hill

Chrysotile

Bryce Mountain

Canyon Day

Payson North

Robinson Mes a

Sabino Canyon

Milkweed Canyon SW 


\section{FEATURE NAME}

Bear Canyon Two hundred

ninety-nine Trail

Bear Canyon Well

Bear Cienega

Bear Cienega

Bear Cienega Creek

Bear Creek

Bear Creek

Bear Creek

Bear Creek

Bear Creek
Sontag Creek
Bear Creek
Bear Creek
Bear Creek
Bear Creek
Bear Creek
Bear Creek
Bear Creek
Bear Creek Camp
Bear Creek Spring
See Mud Springs
Bear Creek Tank
Bear Creek Tank
Bear Cub Spring
Beard Canyon
Beards ley
See Beards ley Railroad
Station
Beards ley

Beardsley

$$
\begin{aligned}
& \text { Beards ley } \\
& \text { Station }
\end{aligned}
$$

Beardsley Canal

Beardsley Railroad Station Beardsley

Beards ley Substation

Beard Spring

Bear Fall Point

Bear Flat

Bear Flat

Bear Flat Campground

Bear Flat Creek

Bear Flat Pleasant Valley Trail
Bear Flat Trail Tank
Beargrass Basin
Beargrass Flat
Bear Grass Tank
Bear Grass Tank
Bear Grass Tank
Bear Gulch
Bear Head Canyon
Bear Headland

Bear Head Mountain

Bear Head Mountain

See Juniper Mountain

Bear Head Spring

Bearhide Canyon

Bearhide Spring

Bear Hill

See Three, Hill

Bear Hills

Plomosa Mountains

Bear Jaw Canyon

Bear Lake

Bear Mine

Bear Mountain

Bear Mountain

Bear Mountain

Dome Mountain

Bear Mountain

Bear Number One Spring

See Bear Spring Number One
FEATURE

CLASS

STATUS

COUNTY

COORDINATE

$\begin{array}{ll}\text { trail } & \text { UNOFF } \\ \text { we11 } & \text { UNOFF } \\ \text { swamp } & \text { BGN } \\ \text { swamp } & \text { BGN } \\ \text { stream } & \text { BGN } \\ \text { stream } & \text { BGN } \\ \text { stream } & \text { BGN } \\ \text { stream } & \text { BGN } \\ \text { stream } & \text { BGN } \\ & \\ & \\ \text { stream } & \text { BGN } \\ & \text { VARIANT } \\ \text { stream } & \text { BGN } \\ \text { stream } & \text { BGN } \\ \text { stream } & \text { BGN } \\ \text { stream } & \text { BGN } \\ \text { stream } & \text { BGN } \\ \text { stream } & \text { BGN } \\ \text { stream } & \text { BGN } \\ \text { locale } & \text { BGN }\end{array}$

Graham

Greenlee

Apache

Apache

Apache

Cochise

Pima

Coch ise

Greenlee

Gila

Apache

Gila

Yavapai

Gila

Navajo

Yavapai

Yavapai

Yavapai

VARIANT

spring

reservoir

reservoir

spring

valley

building

ppl

canal

building

locale

spring

clif

park
stream

trail

reservoir

bas in

flat

reservoir

reservoir

reservoir

valley

valley

summit

summit

spring

valley

spring

summit

ridge

valley

lake

mine

summit

summit

summit

summit

spring
BGN

BGN

BGN

VARIANT

BGN

BGN

UNOFF

UNOFF

BGN

BGN

BGN

BGN

ADMIN

BGN

UNOFF
BGN
BGN
BGN
BGN
BGN
BGN
BGN
BGN
BGN

\section{Yuma}

Gavapa

Gila

Coconino

Maricopa

Maricopa

Maricopa

Maricopa

Maricopa

Coconino

Coconino

Gila

Yavapai

Gila

Navajo

Gila

Gila

Graham

Pima

Gila

Yavapai

Cochise

Gila

Coconino

BGN 1965
VARIANT

BGN

BGN

BGN

VARIANT

BGN

VARIANT

BGN
BGN
UNOFF
BGN
BGN
BGN
VARIANT
BGN
VARIANT

VARIANT
Gila

Gila

Gila

Gila

Gila

Coconino

Yuma

Coconino

Coconino

Yuma

Greenlee

Gila

Yavapai

Yavapai

Pinal
$323614 N 1094816 \mathrm{~W}$

332032 N1092801W

$334720 N 1093053 \mathrm{~W}$

$335802 N 1093808 \mathrm{~W}$

$340054 N 1093843 \mathrm{~W}$

$312043 \mathrm{~N} 1102218 \mathrm{~W}$

$321128 \mathrm{~N} 1102517 \mathrm{~W}$

$322136 \mathrm{~N} 1101133 \mathrm{~W}$

331638 N1091333W

332615 N1102038W

333910 N1093000W

$335046 \mathrm{~N} 1105853 \mathrm{~W}$

$340122 \mathrm{~N} 1113437 \mathrm{~W}$

$340329 N 1112146 \mathrm{~W}$

$340503 \mathrm{~N} 1104353 \mathrm{~W}$

$341900 \mathrm{~N} 1121809 \mathrm{~W}$

$345310 N 1131551 \mathrm{~W}$

$345300 \mathrm{~N} 1131437 \mathrm{~W}$

$333508 \mathrm{~N} 1102036 \mathrm{~W}$

340347 N1112310W

$345242 \mathrm{~N} 1131421 \mathrm{~W}$

$334005 N 1103832 \mathrm{~W}$

$352035 \mathrm{~N} 1113916 \mathrm{~W}$

334009 N1122315W

$333941 N 1122242 W$

$333855 \mathrm{~N} 1122655 \mathrm{~W}$

334009 N1122315W

$333938 N 1122241 \mathrm{~W}$

$352045 \mathrm{~N} 1113956 \mathrm{~W}$

360739 N1123311W

341710 N1110400W

$344149 \mathrm{~N} 1130149 \mathrm{~W}$

$341701 \mathrm{~N} 1110403 \mathrm{~W}$

$335940 \mathrm{~N} 1095314 \mathrm{~W}$

341621 N1110157W

$341604 \mathrm{~N} 1110116 \mathrm{~W}$

$330536 \mathrm{~N} 1101216 \mathrm{~W}$

$330239 N 1102919 \mathrm{~W}$

$313302 \mathrm{~N} 1111135 \mathrm{~W}$

$335008 \mathrm{~N} 1102945 \mathrm{~W}$

$342406 N 1114747 \mathrm{~W}$

320933N1092508W

$335830 N 1110645 \mathrm{~W}$

$361806 \mathrm{~N} 1123631 \mathrm{~W}$

335540N1110730W

$335625 \mathrm{~N} 1111020 \mathrm{~W}$

$335654 \mathrm{~N} 1110742 \mathrm{~W}$

$341639 \mathrm{~N} 1110445 \mathrm{~W}$

341733 N1110450W

$350605 \mathrm{~N} 1120414 \mathrm{~W}$

$334028 \mathrm{~N} 1135511 \mathrm{~W}$

$352438 N 1113628 \mathrm{~W}$

$362217 N 1120847 \mathrm{~W}$

$334036 \mathrm{~N} 1141911 \mathrm{~W}$

$333200 \mathrm{~N} 1090838 \mathrm{~W}$

$335607 \mathrm{~N} 1103205 \mathrm{~W}$

$345450 \mathrm{~N} 1125834 \mathrm{~W}$

$345507 \mathrm{~N} 1115301 \mathrm{~W}$

$332732 \mathrm{~N} 1110959 \mathrm{~W}$

\begin{tabular}{|c|c|c|}
\hline $\begin{array}{l}\text { SOURCE } \\
\text { COORDINATE }\end{array}$ & $\begin{array}{c}\text { ELEV } \\
\text { FT }\end{array}$ & MAP NAME \\
\hline & & Stockton Pass \\
\hline $\begin{array}{l}5806 \mathrm{~N} 1093812 \mathrm{~W} \\
2420 \mathrm{~N} 1101928 \mathrm{~W} \\
1306 \mathrm{~N} 1103124 \mathrm{~W} \\
2153 \mathrm{~N} 1100632 \mathrm{~W} \\
1934 \mathrm{~N} 1091653 \mathrm{~W}\end{array}$ & 4986 & $\begin{array}{l}\text { Bee Canyon } \\
\text { Bonito Rock } \\
\text { Hawley Lake East } \\
\text { Horseshoe Cienega } \\
\text { Montezuma Pass } \\
\text { Happy Valley } \\
\text { Hookers Hot Springs } \\
\text { Fritz Canyon }\end{array}$ \\
\hline $3538 \mathrm{~N} 1102126 \mathrm{~W}$ & & Sontag Mesa \\
\hline $\begin{array}{l}34010 \mathrm{~N} 1092113 \mathrm{~W} \\
34912 \mathrm{~N} 1110029 \mathrm{~W} \\
40114 \mathrm{~N} 1112946 \mathrm{~W} \\
40333 \mathrm{~N} 1112328 \mathrm{~W} \\
40816 \mathrm{~N} 1104516 \mathrm{~W} \\
41356 \mathrm{~N} 1122039 \mathrm{~W} \\
45246 \mathrm{~N} 1131240 \mathrm{~W}\end{array}$ & 5550 & $\begin{array}{l}\text { Hoodoo Knob } \\
\text { Aztec Peak } \\
\text { Table Mountain } \\
\text { Gisela } \\
\text { Oak Creek Ranch } \\
\text { Battle Flat } \\
\text { Mohon Peak } \\
\text { Sunrise Peak }\end{array}$ \\
\hline
\end{tabular}

$352050 N 1114027 \mathrm{~W}$

Mazatzal Peak

Sunrise Peak

Haystack Butte

Humphreys Peak

McMicken Dam

McMicken Dan

McMicken Dam

McMicken Dam

Humphreys Peak

Topocoba Hilltop

4960 Promontory Butte

Behm Mesa

Promontory Butte

$335837 N 1094907 W$

Alchesay Flat

$320800 \mathrm{~N} 1092458 \mathrm{~W}$

$335550 \mathrm{~N} 1110820 \mathrm{~W}$

Promontory Butte Promontory Butte

Beargrass Bas in

Rawhide Mtn

Murphy Peak

Beckers Butte

Horner Mtn

Bowie Mtn North

Copper Mtn

6650 Copper Mtn

Picture Mtn

Promontory Butte

Promontory Butte

Bear Hills

$352121 N 1113914 \mathrm{~W}$

O' Leary Peak Kanabownits Spring

Middle Camp Mtn

8550 Bear Mountain

6424 Blue House Mtn

Juniper Mts

6506 Loy Butte 
NATIONAL GAZETTEER--ARIZONA 1986

FEATURE NAME

Bear Park

Bear Paw Spring

Bear Playground Spring

Bear Railroad Station

Bear Ridge

Bear Saddle

Bear Seep Tank

Bear Sign Canyon

Bear Sign Tank

Bear Spring

Bear Spring

Bear Spring

Bear Spring

Bear Spring

Bear Spring

Bear Spring

Bear Spring

Bear Spring

Bear Spring

Bear Spring

Bear Spring

Bear Spring

Bear Spring

Bear Spring

Bear Spring

Bear Spring

Bear Spring

Bear Spring

Bear Spring

Bear Spring

Bear Spring

Bear Spring

Bear Spring

Bear Spring

Bear Spring

Bear Spring

Bear Spring

Bear Spring

Bear Spring Canyon

Bear Spring Canyon

Bear Spring Canyon

Bear Spring Numb

Bear Number One Spring

Bear Spring Pass

Bear Spring Ranch

Knape Ranch

Bear Springs

Bear Springs

Bear Springs

Bear Springs Canyon

Bear Springs Draw

Bear Springs Flat

Bear Springs Knoll

Bear Springs Tank

Bear Springs Trail One

Hundred Ten

Bear Springs Wash

Bear Tank

Bear Tank

Bear Tank

Bear Tank

Bear Tank

Bear Tank

Bear Tank

Bear Tank

Bear Tank

Bear Tank

Bear Tank

Bear Tank

Bear Tank

Bear Tank

\section{FEATURE}

flat

spring

spring

building

gap

reservoir

valley

reservoir

spring

STATUS
BGN
BGN
BGN
UNOFF
BGN
BGN
BGN
BGN
BGN
BGN

COUNTY

COORDINATE

Coconino

Coconino

Navajo

Yavapai

Navajo

Pima

Coconino

Yavapai

Cochise

Cochise

$345222 \mathrm{~N} 1112749 \mathrm{~W}$

$352033 \mathrm{~N} 1113932 \mathrm{~W}$

$340205 N 1100729 \mathrm{~W}$

$345634 \mathrm{~N} 1121451 \mathrm{~W}$

$341251 \mathrm{~N} 1102437 \mathrm{~W}$

$322335 \mathrm{~N} 1104030 \mathrm{~W}$

$345640 \mathrm{~N} 1113212 \mathrm{~W}$

$345643 \mathrm{~N} 1114739 \mathrm{~W}$

$322357 N 1091146 \mathrm{~W}$

$312422 \mathrm{~N} 1101923 \mathrm{~W}$

spring BGN Santa Cruz 314100N1104810W

spring

spring

spring

spring

spring

spring

spring

spring

spring

spring

spring

spring

spring

spring

spring

spring

spring

spring

ima 314630N1102738w

Cochise 314926N1091901W

Pima 320605N1102922W

Cochise 320819N1092533W

Pima

Graham

Graham

Graham

Graham

$321345 \mathrm{~N} 1102836 \mathrm{~W}$

$323836 \mathrm{~N} 1095417 \mathrm{~W}$

$324522 \mathrm{~N} 1102340 \mathrm{~W}$

$325821 N 1093733 \mathrm{~W}$

$330209 N 1094106 \mathrm{~W}$

Greenlee 331617N1090638W

$332423 \mathrm{~N} 1092414 \mathrm{~W}$

Greenlee 332557N1091637W

Greenlee 333122N1091005W

$334208 \mathrm{~N} 1111949 \mathrm{~W}$

Apache 334946N1091043W

Gila 335038N1112303W

Maricopa 335100N1112418W

Navajo 335256N1095917W

Gila 335908N1100447W

$\begin{array}{lll}\text { spring } B G N & \text { Gila } & 340216 N 1112833 W\end{array}$

spring BGN Gila $\quad 341515 N 1105942 \mathrm{~W}$

spring

spring

spring

spring

spring

valley

valley

Yavapai

Yavapai

Navajo

Apache

Coconino

Pima

Graham

$342450 \mathrm{N11}$

$342537 \mathrm{~N} 11$

343949 N1124642W

$355538 \mathrm{~N} 1104250 \mathrm{~W}$

$361138 \mathrm{~N} 1091746 \mathrm{~W}$

$362210 \mathrm{~N} 1121028 \mathrm{~W}$

$314807 \mathrm{N1103038 \textrm {W }}$

$325653 \mathrm{~N} 1093319 \mathrm{~W}$

valley $\quad B$

Navajo 341112N1104444W

$332732 \mathrm{~N} 1110959 \mathrm{~W}$

gap

ocale

Pinal

Cochise 320719N1092516W

Cochise 320822N1092535W

$325100 \mathrm{~N} 1095655 \mathrm{~W}$

spring

spring

spring

valley

Graham

Navajo

Coconino

$341908 \times 1102732$

$350506 \mathrm{~N} 1121054 \mathrm{~W}$

325339 N1103408W

325037 N1103030W

valley BGN Navajo 342049N1102611W

flat BGN Graham

summit

reservoir $B G$

trail UNOFF

Graham

$350505 \mathrm{~N} 1121053 \mathrm{~W}$

312424N1101919W

stream $\quad B G N$

reservoir BGN

reservoir $B G$

reservoir

reservoir $B G$

reservoir $B G$

reservoir BG

reservoir

reservoir $B G$

reservoir BGN

reservoir $B G$

reservoir $B G$

reservoir

BGN

Graham

Santa Cruz

Cochise

Green lee

$325132 N 1095825 \mathrm{~W}$

$312651 \mathrm{~N} 1103009 \mathrm{~W}$

322148 N1101005

$332220 \mathrm{~N} 1092705 \mathrm{~W}$

$314703 \mathrm{~N} 1102659 \mathrm{~W}$

$325741 \mathrm{~N} 1093742 \mathrm{~W}$

341051 N1104620W

$341816 \mathrm{~N} 1102748 \mathrm{~W}$

$335328 N 1102053 \mathrm{~W}$

$335919 N 1100252 \mathrm{~W}$

$341516 N 1101315 \mathrm{~W}$

Navajo 341903N1102738W

Coconino 343012N1112710W

Yavapai 345732N1121530W

Coconino 350B05N1113415W

Coconino 350825N1120210W

$351110 \mathrm{~N} 1121412 \mathrm{~W}$

Coconino $351400 N 1114650 \mathrm{~W}$

reservoir BGN

Coconino

$355000 \mathrm{~N} 1114530 \mathrm{~W}$

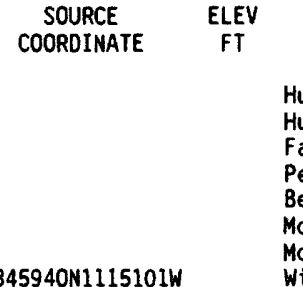

MAP NAME

Hutch Mtn

umphreys Peak

Faught Ridge

Perkinsville

Bear Ridge

Mount Bigelow

ormon Mountain

ilson Mountain

Orange Butte

Miller Peak

Mt Wrightson

Apache Peak

Chiricahua Peak

Galleta Flat West

Bowie Mtn North

Happy Valley

Webb Peak

Oak Grove Canyon

Weber Peak

Bryce Mountain

Maple Peak

Robinson Mesa

Rose Peak

Bear Mountain

Four Peaks

Alpine

Boulder Mtn

Boulder Mtn

Alchesay Flat

Round Top Mtn

Mazatzal Peak

Woods Canyon

Kehl Ridge

Horner Mtn

Smith Mesa

Hotevilla

Mummy Cave Ruins

Kanabownits Spring

Spring Water Canyon

Lone Star Mtn

Chediski Peak 


\section{FEATURE NAME}

Bear Tank

Bear Tank Canyon

Bear Thicket Creek

Bear Track Canyon

Bear Track Tank

Bear Track Tank

Bear Trail Canyon

Bear Trap Spring

Bear Valley

Bear Valley

Bear Valley Mountains

See Pajarito Mountains

Bear Valley Ranch

Bear Wallow

Bear Wallow Campground

Bear Wallow Canyon

Bear Wallow Canyon

Bear Hallow Creek

Bear Wallow Spring

Bear Hallow Spring

Bearwallow Spring

Bear Wallow Spring

Bear Wallow Spring

See Bearwallow Spring

Bear Well

Bear Willow Ridge

Beasley Ditch

Beasley Flat

Beas ley Lake

Beatosa Canyon

See Bellotosa Canyon

Beatosa Tank

See Bellotosa Tank

Beauchamp Canyon

Beauford Mount ain

See Humboldt Mountain

Beautiful, Mount

Beautiful Valley

Beautiful Valley Well

Beauty Springs

Beaver Canyon

Beaver Canyon

Beaver Canyon

Beaver Canyon

See Houston Draw

Beaver Canyon

Beaver Creek

Beaver Creek

Beaver Creek

Wet Beaver Creek

Beaver Creek

See Wet Beaver Creek

Beaver Creek Campground

Beaver Creek Ranch

Beaver Creek Ranger Station

Beaver Creek School

Beaver Dam

Beaverdam

See Littlefield

Beaver Dam

Beaverdam

Littlefield

Beaverdam

See Beaver Dam

Beaver Dam Creek

See Beaver Dam Wash

Beaver Dam Forest Camp

Beaver Dam Mountains

Beaver Dam Park

Beaver Dam Tank

Beaver Dam Wash

Beaver Dam Wash

Beaver Dam Creek

\section{FEATURE}

CLASS

STATUS

reservoir

valley

stream

valley

reservoir

reservoir

valley

pring

basin

valley

range

locale

bas in

park

valley

valley

stream

spring

spring

spring

BGN Coconino

BGN Pinal

BGN Pinal

Yavapai

Greeniee

Yavapai

BGN Apache

BGN Yavapai

BGN Greenlee

VARIANT

UNOFF

BGN

ADMIN

BGN

BGN

BGN

Greenlee

Santa Cruz

Panta

Pima

Navajo

Coconino

Graham

Cochise

BGN Pima

BGN 1975 Graham

VARIANT

VARIANT

spring Graham

well

ridge

canal

flat

lake

UNOFF

UNOFF
BGN

BGN

BGN

Pima

Coconino

Coconino

Yavapai

Coconino

VARIANT

valley

reservoir

valley

VARIANT

Santa Cruz

BGN

VARIANT

summit

summit

valley

well

BGN

BGN

Maricopa

Navajo

Apache

UNOFF Apache

spring

valley

valley

valley

valley

valley

stream

stream

stream

$B G-$
$B G$
$B G$
$B G$
$V A R$

BGN Greenlee

Navajo

Coconino

VARIANT

Coconino

Greenlee

BGN Gila

BGN Yavapai

VARIANT

VARIANT

stream

park

locale

locale

school

swamp

pp 1

locale

ADMIN

UNOFF

UNOFF

UNOFF

BGN

VARIANT

VARIANT

VARIANT

Yavapai

Yavapa

Yavapa

Yavapa

Yavapa

Apache

Mohave

Mohave

VARIANT

locale

VARIANT

valley

locale

range

flat

reservoir

stream

valley
UNOFF

BGN

BGN

BGN

BGN

BGN 1974

VARIANT
Mohave

Mohave

Apache

Mohave

Apache

Apache

Apache

Mohave
$312525 \mathrm{~N} 1105742 \mathrm{~W}$

$312359 \mathrm{~N} 1110043 \mathrm{~W}$

$325716 \mathrm{~N} 1100909 \mathrm{~W}$

$335852 \mathrm{~N} 1114752 \mathrm{~W}$

$355201 \mathrm{~N} 1104453 \mathrm{~W}$

$361143 \mathrm{~N} 1093434 \mathrm{~W}$

355515 N1093350W

$325959 \mathrm{~N} 1095356 \mathrm{~W}$

$332423 N 1085932 \mathrm{~W}$

$340548 \mathrm{NI} 100328 \mathrm{~W}$

342648 NI110120W

343228 N1111133W

$361656 \mathrm{~N} 1124350 \mathrm{~W}$

$334346 N 1092108 \mathrm{~W}$

334824 N1102546W

343426 NI115115W

$361330 \mathrm{~N} 1124715 \mathrm{~W}$

$334023 \mathrm{~N} 1091311 \mathrm{~W}$

334909 N1102530W

$343758 N 1114931 \mathrm{~W}$

$325448 N 1101025 W$

ELEV

COORDINATE FT MAP NAME

332133N1110842W $\quad$ Prospect Point

Haunted Canyon

$342 B 09 N 1$

$363848 N 1091742 W$

Mayer

Big Lue Mts

Mayer

Kinusta Mes a

Camp Wood

Ruby

333147N1090901W Blue

$340928 \mathrm{~N} 1101559 \mathrm{~W}$

$345251 \mathrm{~N} 1114241 \mathrm{~W}$

$333555 \mathrm{~N} 1092652 \mathrm{~W}$

Jackson Mtn

Mt Beautiful

Chinle

Ganado One NE

Thatcher

Alma Mesa

Faught Ridge

Knoll Lake

Havasu Falls Hannagan Meadow

Beckers Butte 
NATIONAL GAZETTEER--ARIZONA 1986

FEATURE NAME

Pine Park Canyon

West Fork Beaver Wash

Beaver Dam Wash Bridge
Beaver Dam Wash Well
Beaver Falls
Beaverhead
Beaverhead Flat
Beaverhead Tank
Beaverhead Tank Number One
Beaverhead Tank Number Two
Beaver Is land
See Deer Island
Beaver Island
Beaver Park
Beaver Point
Beaver Tank
Beaver Turkey Ridge
Becker Creek
Becker Lake
Becner Lake
Becker Ranch
Becker Reservoir Dam
Beckers Butte
Beckers Butte Roadside Table
Becker Spring
Beck Spring
Beck Tank
Beclabito Wash
Bittabito Creek
Bitiabito Wash
Becner Lake
See Becker Lake

Beda Tohie

Bed Blanket Cave

Bedford Tank

Bedivere Point

Bedrock Canyon

Bedrock Canyon

Bedrock City (recreation site)

Bedrock Rapids

Beebhak

See Sil Nakya

Beebhak

See Bibyak

Bee Canyon

Bee Canyon

Bee Canyon

Bee Canyon

Bee Canyon

Bee Canyon Wash

Beecher Canyon

Beecher Spring

Beecher Tank

Beech Spring

Bee Cienega

Bee Cistern

Bee Dan

Beef Corral Dam

Beef Corral Draw

Beef Corral Tank

Beef Eater Canyon

Beehbito Spring

Beehive

Beehive Canyon

Beehive Dam

Beehive Mine

Beehive Peak

Beehive Rock

Beehive Ruins

Beehive Spring

Beehive Tank

\section{FEATURE}

STATUS

COUNTY

COORDINATE

VARIANT

VARIANT

\begin{tabular}{|c|c|c|c|}
\hline $\begin{array}{l}\text { bridge } \\
\text { well } \\
\text { falls } \\
\text { cliff } \\
\text { flat } \\
\text { reservoir } \\
\text { reservoir } \\
\text { reservoir }\end{array}$ & $\begin{array}{l}\text { UNOFF } \\
\text { UNOFF } \\
\text { BGN } 1932 \\
\text { BGN } \\
\text { BGN } \\
\text { BGN } \\
\text { BGN } \\
\text { BGN } \\
\text { VARIANT }\end{array}$ & $\begin{array}{l}\text { Apache } \\
\text { Apache } \\
\text { Coconino } \\
\text { Yavapai } \\
\text { Yavapai } \\
\text { Yavapai } \\
\text { Yavapai } \\
\text { Yavapai }\end{array}$ & $\begin{array}{l}344009 \mathrm{~N} 1094322 \mathrm{~W} \\
344035 \mathrm{~N} 1094233 \mathrm{~W} \\
361657 \mathrm{~N} 1124343 \mathrm{~W} \\
344448 \mathrm{~N} 1114505 \mathrm{~W} \\
344227 \mathrm{~N} 1114922 \mathrm{~W} \\
344348 \mathrm{~N} 1114559 \mathrm{~W} \\
344301 \mathrm{~N} 1114916 \mathrm{~W} \\
344258 \mathrm{~N} 1114919 \mathrm{~W}\end{array}$ \\
\hline is land & & La Paz & 340700 N1142 \\
\hline $\begin{array}{l}\text { island } \\
\text { flat } \\
\text { cliff } \\
\text { reservoir } \\
\text { ridge } \\
\text { strean } \\
\text { lake }\end{array}$ & $\begin{array}{l}\text { BGN } \\
\text { BGN } \\
\text { BGN } \\
\text { BGN } \\
\text { BGN } \\
\text { BGN } 1971 \\
\text { BGN } \\
\text { VARIANT }\end{array}$ & $\begin{array}{l}\text { Mohave } \\
\text { Coconino } \\
\text { Mohave } \\
\text { Greenlee } \\
\text { Coconino } \\
\text { Apache } \\
\text { Apache }\end{array}$ & $\begin{array}{l}342518 N 1141728 \mathrm{~W} \\
342353 N 1110224 \mathrm{~W} \\
342344 \mathrm{~N} 1141512 \mathrm{~W} \\
332255 \mathrm{~N} 1090327 \mathrm{~W} \\
342432 \mathrm{~N} 1110241 \mathrm{~W} \\
340008 \mathrm{~N} 1093448 \mathrm{~W} \\
340909 \mathrm{~N} 1091823 \mathrm{~W}\end{array}$ \\
\hline $\begin{array}{l}\text { locale } \\
\text { dam }\end{array}$ & $\begin{array}{l}\text { UNOFF } \\
\text { UNOFF }\end{array}$ & $\begin{array}{l}\text { Santa Cruz } \\
\text { Apache }\end{array}$ & $\begin{array}{l}313116 N 11028 \\
340734 N 10905\end{array}$ \\
\hline $\begin{array}{l}\text { summit } \\
\text { locale } \\
\text { spring } \\
\text { spring } \\
\text { reservoir } \\
\text { stream }\end{array}$ & $\begin{array}{l}\text { BGN } 1960 \\
\text { UNOFF } \\
\text { BGN } \\
\text { BGN } \\
\text { BGN } \\
\text { BGN } 1983 \\
\text { VARIANT } \\
\text { VARIANT } \\
\text { VARIANT }\end{array}$ & $\begin{array}{l}\text { Gila } \\
\text { Gila } \\
\text { Apache } \\
\text { Yavapai } \\
\text { Yavapai } \\
\text { San Juan (NM) }\end{array}$ & $\begin{array}{l}334825 \mathrm{~N} 1102730 \mathrm{~W} \\
334829 \mathrm{~N} 1102754 \mathrm{~W} \\
340401 \mathrm{~N} 1093459 \mathrm{~W} \\
342904 \mathrm{~N} 1122050 \mathrm{~W} \\
341841 \mathrm{~N} 1114201 \mathrm{~W} \\
365422 \mathrm{~N} 1085532 \mathrm{~W}\end{array}$ \\
\hline & & pa & 340909 N109] \\
\hline
\end{tabular}

\begin{tabular}{|c|c|c|c|}
\hline $\begin{array}{l}\text { spring } \\
\text { cave } \\
\text { reservoir } \\
\text { cliff } \\
\text { valley } \\
\text { valley } \\
\text { park } \\
\text { rapids }\end{array}$ & $\begin{array}{l}\text { BGN } \\
\text { BGN } \\
\text { BGN } \\
\text { BGN } 1908 \\
\text { BGN } 1932 \\
\text { BGN } \\
\text { ADMIN } \\
\text { BGN 1932 } \\
\text { VARIANT }\end{array}$ & $\begin{array}{l}\text { Navajo } \\
\text { Mohave } \\
\text { Coconino } \\
\text { Coconino } \\
\text { Coconino } \\
\text { Coconino } \\
\text { Coconino } \\
\text { Coconino }\end{array}$ & $\begin{array}{l}363228 \mathrm{~N} 1102900 \mathrm{~W} \\
363258 \mathrm{~N} 1125606 \mathrm{~W} \\
345334 \mathrm{~N} 1113057 \mathrm{~W} \\
361512 \mathrm{~N} 1121411 \mathrm{~W} \\
361937 \mathrm{~N} 1122735 \mathrm{~W} \\
363000 \mathrm{~N} 1115253 \mathrm{~W} \\
353830 \mathrm{~N} 1120830 \mathrm{~W} \\
361948 \mathrm{~N} 1122741 \mathrm{~W}\end{array}$ \\
\hline
\end{tabular}

pp 1

Pima

$321318 N 1114857 W$

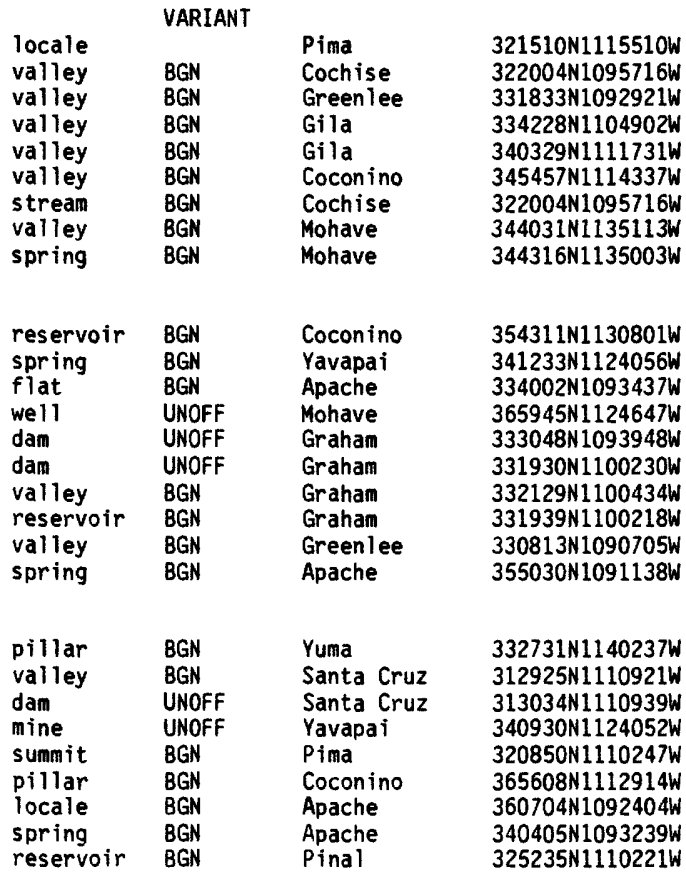

Potter Mesa Tank Potter Mesa Tank Havasu Falls Lake Montezuma Lake Montezuma

Lake Montezuma Lake Montezuma Lake Montezuma

335756 N1093414W

Lake Havasu City S Knol1 Lake Lake Havasu City S Alma Mesa

Knol1 Lake Greens Peak 6910 Springerville

Pyeatt Ranch Nelson Reservoir NE

4896 Beckers Butte Beckers Butte Greens Peak Poland Junction Verde Hot Springs

$365044 \mathrm{~N} 1090422 \mathrm{~W}$ Bitlabito

Long House Valley Heaton Knolls Mormon Mountain Kanabownits Spring Powell Plateau Buffalo Tanks

Valle Tank $361956 \mathrm{~N} 1122128 \mathrm{~W}$ Powell Plateau

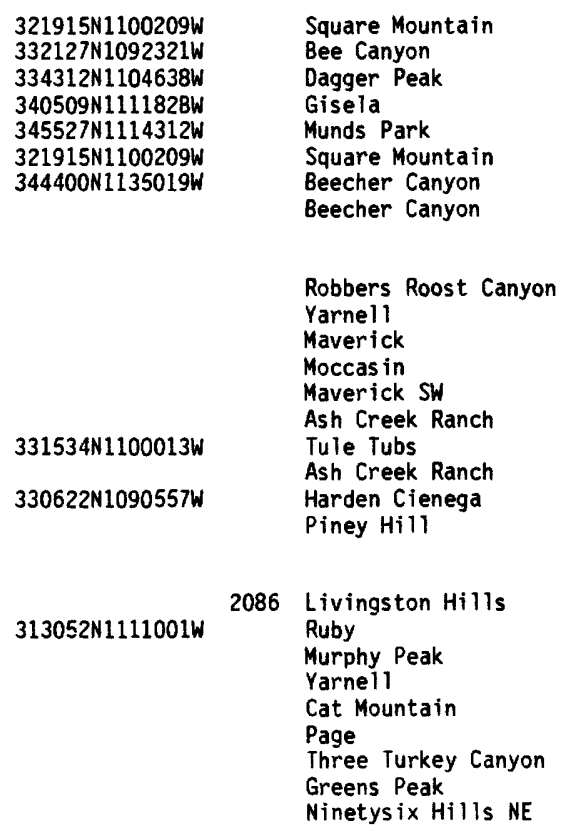


FEATURE NAME

Beehive Tank

Beehive Tank

Beehive Well

Beehouse Canyon

Beehouse Spring

Beehouse Tank

Beekid Halani Tank

Beeler Creek

Beeline Tank

Beeline Tank

Beeline Tank

Bee Mesa

Bee Mountain

Beer Bottle Wash

Beer Bottle Well

Beers Well

Bee Seep Tank

Beeshsikad Spring

Bee Spring

Bee Spring

Bee Spring

Bee Spring

Bee Spring Point

Bee Springs

Bee Springs Tank

Bee Tank

Bee Tank

Bee Tree Spring

Bee Tree Tank

Bee Tree Tanks

Beetso Well

Bee We11

Begashibito Canyon

Bako-shi-bito Canyon Begashi-bito Canyon Begashi-Bito Canyon Begashibito Creek Bekishi-bito Canyon

Begashi-bito Canyon

See Begashibito Canyon

Begashi-Bito Canyon

See Begashibito Canyon

Begashibito Creek

See Begashibito Canyon

Begashibito Wash

Begashinitani Canyon

Begay Well

Begay We1

Begay Windmill

Be He Lini Spring

Behihlih

Behm Mesa

Behm Mesa Tank

Be-ite-Lini Spring

Bek-i hatso

See Bekihatso

Bekihatso

Bek- $i$ hatso

Big Lakes

Pra ga at zo Lake

Pragaatzo

Prahaatzo

Bekihatso Wash

Bekishi-bito Canyon See Begashibito Canyon

Belaire Manor (trailer park)

Bel-Aire Trailer Park

Bel Air Plaza Shopping Center

Belknap Tank

Bell

Bellavista Farms

\section{FEATURE}

CLASS

STATUS COUNTY

reservoir

BGN

Greenlee

COORDINATE

331340N1091244W

$\begin{array}{llll}\text { reservoir } & \text { BGN } & \text { Yuma } & 332746 \text { N1140244W }\end{array}$

well

valley

spring

reservoir

reservoir

stream

reservoir

reservoir

reservoir

UNOFF
BGN
BGN
BGN
BGN
BGN
BGN
BGN
BGN

Yavapai

Yavapai

Yavapai

Coconino

Greenlee

Maricopa

Gila

sumnit

summit

stream

well

wel1

reservoir

spring

spring

spring

spring

BGN
BGN
BGN
UNOFF
UNOF
BGN
BGN
BGN
BGN
BGN

Greenlee

Maricopa

Maricopa

Maricopa

Pima

Gila

Apache

Graham

Greenlee

Gila

spring
cliff

spring

reservoir

reservoir

reservoir

spring

reservoir

reservoir

well

well
valley

BGN
BGN
BGN
BGN
BGN
BGN
BGN
BGN
BGN

Coconino

Coconino

Mohave

Greenlee

Pinal

Graham

Gila

Gila

Gila

Coconino $324924 N 1104823 \mathrm{~W}$

$341906 \mathrm{~N} 1114935 \mathrm{~W}$

341846 N1114944W

$342527 N 1115514 \mathrm{~W}$

$354138 \mathrm{~N} 1110831 \mathrm{~W}$

$332833 \mathrm{~N} 1091118 \mathrm{~W}$

$333600 \mathrm{~N} 1113538 \mathrm{~W}$

$335742 \mathrm{~N} 1112330 \mathrm{~W}$

$340956 \mathrm{~N} 1111959 \mathrm{~W}$

330904 N1091244W

$334646 \mathrm{~N} 1113736 \mathrm{~W}$

$333808 \mathrm{~N} 1125020 \mathrm{~W}$

333931 N1125500W

$320559 \mathrm{~N} 1112025 \mathrm{~W}$

$342034 \mathrm{~N} 1112316 \mathrm{~W}$

$355533 \mathrm{~N} 1095354 \mathrm{~W}$

330559 N1101844W

$331220 \mathrm{~N} 1091831 \mathrm{~W}$

$340400 \mathrm{~N} 1111801 \mathrm{~W}$

$362704 N 1121904 \mathrm{~W}$

$36271 B N 1122034 \mathrm{~W}$

$345309 \mathrm{~N} 1135455 \mathrm{~W}$

$331955 \mathrm{~N} 1092556 \mathrm{~W}$

$324945 \mathrm{~N} 1110046 \mathrm{~W}$

$333048 \mathrm{~N} 1093945 \mathrm{~W}$

$331540 \mathrm{~N} 1105634 \mathrm{~W}$

$342004 \mathrm{N1113006 \textrm {W }}$

$341840 \mathrm{N1} 113836 \mathrm{~W}$

$355412 \mathrm{N1} 105536 \mathrm{~W}$

331056 N1101704W

360844N1105959W

Graham

BGN 1915

VARIANT

VARIANT

VARIANT

VARIANT

VARIANT

valley

VARIANT

valley

VARIANT

Coconino

360844N1105959W

Coconino

$360844 N 1105959 W$

VARIANT

valley

valley

valley

we 11

well

locale

spring

area

summit

reservoir

spring

lake

lake

BGN
BGN
UNOFF
UNOFF
BGN
BGN
BGN
BGN

UNOFF

UNOFF

BGN

BGN

VARIANT

Apache

BGN 1915

VARIANT

VARIANT

VARIANT

VARIANT

VARIANT

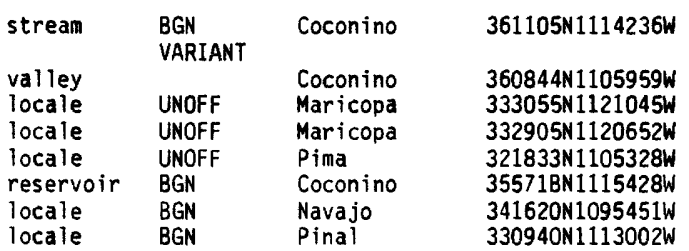

Coconino 360844N1105959W

Coconino 361333N1105913W

Navajo

Apache

Coconino

Coconino

Apache

Coconino

$370007 \mathrm{~N} 1103217 \mathrm{~W}$

$351932 \mathrm{~N} 1090418 \mathrm{~W}$

$361832 \mathrm{~N} 1112750 \mathrm{~W}$

$363522 \mathrm{~N} 1104742 \mathrm{~W}$

$352722 N 1092733 \mathrm{~W}$

$344122 \mathrm{~N} 1130535 \mathrm{~W}$

344153 N1130428W

354451 N1092712W

360007 N1093833W

360007 N1093833W $\begin{array}{cc}\text { SOURCE } & \text { ELEV } \\ \text { COORDINATE } & F T\end{array}$

Big Lue Mts

Wintersburg

3026 Putnan

Tule Mesa

Tule Mesa

Arnold Mesa

$333052 N 1090914 W$

Badger Spring

Outch Blue Creek

Stewart Mtn

Reno Pass

Payson South

6432 Dix Creek

33392BN1125641W $2947 \begin{aligned} & \text { Bartlett Dam } \\ & \text { Star Well } \\ & \text { Belmont Mtn }\end{aligned}$

2519 Three Points

Buckhead Mesa

Beeshsikad Spring

Mt Turnball

Mitchell Peak

Gisela

Quaking Aspen

Quaking Aspen

Wabayuma Peak

Bee Canyon

Ninetysix Hills SE

Maverick SW

Pinal Ranch

Cane Springs Mtn

Verde Hot Springs

5815 Coal Mine Mesa

Dewey Flat

Begashibito Canyon

364634N1103738W Begashibito Canyon

$365716 \mathrm{N1102826 \textrm {W }}$

6104 Lupton

The Gap

Whirlwind Rock

Wide Ruins

Begashibito Canyon

5433 Behm Mesa

Behm Mesa

Kinlichee

Toh De Niihe

362021N1113702W

Salt Trail Canyon 
NATIONAL GAZETTEER--ARIZONA 1986

FEATURE NAME

Bella Vista Neighborhood Park

Bella Vista School

Bell Butte

Bell Butte

Bell Butte

Bell Butte Spring

Bell Canyon

Bell Canyon Tank

Bell Cow Canyon

Bell Cow Tank

Bellemont

Belimont

Bellemont Flat

Bellemont Siding

Belle of Arizona Mine

Belle Spring

Bell levue

Bell Gulch

Bell Gulch Spring

Bell Mare Mining Camp

(historical)

Bell Mine

Bellmont

See Bellemont

Bell Mountain

Bellota Canyon

Bellota Ranch

Bellota Spring

Bellota Spring

Bellota Tank

Bellotosa Canyon Beatosa Canyon

Bellotosa Tank Beatosa Tank

Bellows Canyon Tripp Canyon

Bellows Spring

Bellows Spring

Bell Plaza Shopping Center

Bell Ranch

Bell Rock

Bell Rock Spring

Bells, Cave of The

Bells Canyon

Bell Square Shopping Center

Bellis Spring

Bell Tank

Bell Trail

Bell West Plaza Shopping Center Bell West Shopping Center

Bell West Shopping Center

See Bell West Plaza Shopping Center

Belmont Canyon
Beimont Mine
Belmont Mine
Belmont Mountain
Beimont Mountains
Belnap Reservoir
Benally Well
Benchmark Mountain
Bench Tank
Bench Tank
Bench Tank
Bench Tank
Bench We11
Bender Mine
Bender Tank
Bender Wash
Benedict (historical)
Benedict, Mount

Belmont Canyon

Belmont Mountain

Beimont Mountains

Benally Well

Benchmark Mountain

Bench Tank

Bench Tank

Bench Tank

Bench We 11

Benedict (historical)

Benedict, Mount

\section{FEATURE}

CLASS

STATUS

park

ADMIN

Cochise

school

summit

summit

spring

valley

reservoir

valley

reservoir

ppl

UNOFF
BGN
BGN
BGN
BGN
BGN
BGN
BGN
BGN
BGN 1911
VARIANT

Cochise

Maricopa

Navajo

Mavajo

Yavapai

Yavapai

Navajo

Mavajo

Coconino

VARIANT

$\begin{array}{ll}\text { flat } & \text { BGM } \\ \text { locale } & \text { BGM } \\ \text { mine } & \text { UNOF } \\ \text { spring } & \text { BG } \\ \text { locale } & B G M \\ \text { valley } & \text { BGM } \\ \text { spring } & \text { BGM } \\ \text { locale } & \text { UNOF }\end{array}$

locale

mine

$\begin{array}{ll}\text { BGN } & \text { Coconino } \\ \text { BGN } & \text { Coconino } \\ \text { UNOFF } & \text { Yuma } \\ \text { BGN } & \text { Coconino } \\ \text { BGN } & \text { Gila } \\ \text { BGN } & \text { Gila } \\ \text { BGN } & \text { Gila } \\ \text { UNOFF } & \text { Santa Cruz } \\ & \\ \text { UNOFF } & \text { Pima }\end{array}$

$351424 N 1114919 \mathrm{~W}$ $351407 \mathrm{N1115004 \textrm {W }}$ $333843 N 1140454 \mathrm{~W}$ $351214 \mathrm{~N} 1114316 \mathrm{~W}$ $331955 \mathrm{~N} 1105634 \mathrm{~W}$ $333228 \mathrm{~N} 1105919 \mathrm{~W}$ $333055 \mathrm{~N} 1105717 \mathrm{~W}$ $313430 \mathrm{~N} 1105020 \mathrm{~W}$

320238N1130955W

VARIANT

ppl
summit
valley
locale
spring
spring
reservoir
valley

\section{$B G N$}

BGN

UNOFF
BGN
BGN

$B G N$

BGN 1978 VARIANT

Coconino

Pima

Santa Cruz

Pima

Santa Cruz

Pima

Santa Cruz

Santa Cruz

reservoir
valley
spring
spring
locale
locale
summit
spring

BGN
VARIANT

BGN 1975

VARIANT

BGN

BGN
UNOFF

UNOFF

BGN

Santa Cruz

Graham

Santa Cruz

Yavapai

Maricopa

Maricopa

Yavapai

Yavapai

cave

valley
locale

spring

reservoir

trail

local

valley

mine

mine

summit

range

reservoir

well

summit

reservoir

reservoir

BGN

BGN

UNOFF

BGN

BGN

UNOFF

VARIANT

VARIANT

Santa Cruz

Yavapai

Maricopa

Yavapai

Coconino

Yavapai

Maricopa

Maricopa

reservoir

reservoir

well

mine

reservoir

stream

locale

summit

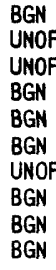

UNOFF

UNOFF

BGN

BGN 1963

BGN

BGN

BGN

BGN

BGN
UNOFF

UNOFF

UNOFF

BGN
$B G N$
$B G N$

$B G N$
$B G N$
Pinal

Santa Cruz

Pinal

Maricopa

Maricopa

Mohave

Coconino

Yavapai

Graham

Green lee

Navajo

Gila

Yavapai

Santa Cruz

Mohave

Maricopa

Santa Cruz

Santa Cruz
$351417 N 1114958 \mathrm{~W}$

$320332 \mathrm{N1112916 \textrm {W }}$

$312538 \mathrm{~N} 1110316 \mathrm{~W}$

$321935 \mathrm{N1} 103803 \mathrm{~W}$

$312512 \mathrm{~N} 1110552 \mathrm{~W}$

$322125 \mathrm{N1} 103610 \mathrm{~W}$

$312433 \mathrm{~N} 1110634 \mathrm{~W}$

$312525 \mathrm{N1} 105742 \mathrm{~W}$

312359N1110043W

324612 N1100433W

314159 N1105100W

$343108 \mathrm{~N} 1122458 \mathrm{~W}$

$333830 N 1110153 \mathrm{~W}$

$331547 \mathrm{N1} 115148 \mathrm{~W}$

$344801 \mathrm{N1114550 \textrm {W }}$

$344751 N 1114552 \mathrm{~W}$

$314342 \mathrm{~N} 1104604 \mathrm{~W}$

$342531 \mathrm{N1} 124616 \mathrm{~W}$

$332333 \mathrm{N1115144 \textrm {W }}$

$342452 \mathrm{M} 1124630 \mathrm{~W}$

$344719 \mathrm{N1} 111842 \mathrm{~W}$

$343950 \mathrm{~N} 1113845 \mathrm{~W}$

$333825 \mathrm{~N} 1120758 \mathrm{~W}$

$312435 N 1110851 W$

3713 San Pedro

Pena Blanca Lake

3960 Agua Caliente Hill

Pena Blanca Lake

Piety $\mathrm{Hill}$

312316N1110145W Rio Rico

$333825 N 1120758 \mathrm{~W}$

$342317 N 1124733 \mathrm{~W}$

Mt Wrights on

1205 Mesa

Bismarck Mesa

Jaycox Mtn

Casner Butte

Hedgpeth Hills

331608 N1110519W $312205 N 1104142 \mathrm{~W}$

$331620 N 1110431 \mathrm{~W}$

$333841 \mathrm{~N} 1125557 \mathrm{~W}$

$333832 N 1125401 \mathrm{~W}$

362257 N1132408W

$361617 N 1112012 \mathrm{~W}$

$340321 N 1115913 \mathrm{~W}$

$324133 N 1094627 \mathrm{~W}$

$330829 N 1091102 \mathrm{~W}$

$34025 B N 1103943 \mathrm{~W}$

$340327 N 1110042 \mathrm{~W}$

$341114 N 1121324 \mathrm{~W}$

$312700 \mathrm{~N} 1104258 \mathrm{~W}$

$354014 \mathrm{~N} 1133642 \mathrm{~W}$

$325513 \mathrm{~N} 1124206 \mathrm{~W}$

$312240 \mathrm{~N} 1105658 \mathrm{~W}$

$312346 \mathrm{~N} 110552 \mathrm{WW}$

Pena Blanca Lake

Mt Wrightson

Prescott

Chandler

919 Sedona

Sedona

\begin{tabular}{|c|c|c|}
\hline $331621 \mathrm{~N} 1110434 \mathrm{~W}$ & $\begin{array}{l}5325 \\
5855\end{array}$ & $\begin{array}{l}\text { Superior } \\
\text { Duquesne } \\
\text { Superior } \\
\text { Belmont Mtn } \\
\text { Belmont Mtn } \\
\text { Poverty Knoll } \\
\text { Preston Well } \\
\text { Cooks Mesa } \\
\text { Mt Graham } \\
\text { Dix Creek }\end{array}$ \\
\hline
\end{tabular}

Oak Creek Ranch

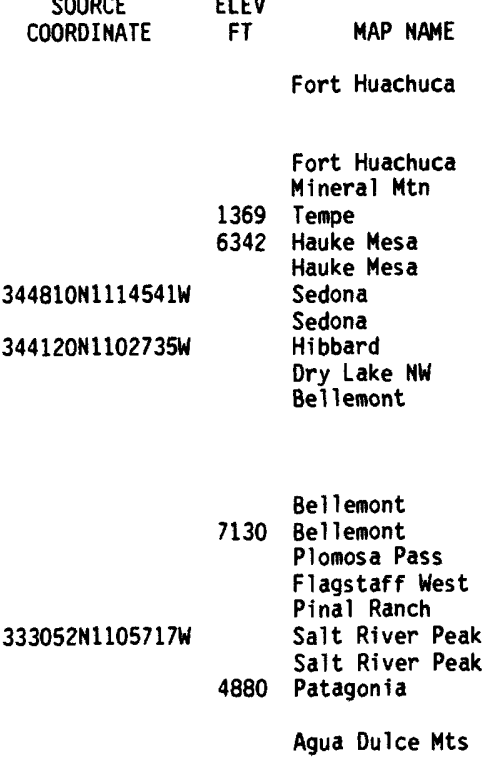


Benedicts (historical)

Benedict Spring

Benedict Tank

Benham Ranch

Benham Tank

Ben Hur Mine

Benjamin Franklin School

Benjamin Gulch

Benjamin Spring

Ben Lomond Mines

Bennett Butler Tank

Bennett Corral

Bennett Ranch

Bennett Spring

Bennett Spring

Bennett Tank

Bennett Tank

Bennett Wash

Bennett Wash

Ben Nevis Mountain

Benny Creek

Benny Creek Campground

Benny Tank

$$
\text { See Sonny Tank }
$$

Ben Railroad Station

Bens Dam Tank

Benson

Benson Airport

Benson Cemetery

Benson City Hall

Benson Elementary School

Benson High School

Benson Highway-Valencia Road

Interchange

Benson Hospital

Benson Interchange

Benson Junction

Benson Junction Railroad

Station

Benson Junior High School

Benson Post Office

Benson Spring

Benson Spring Canyon

Benson Wells

Bens Spring

Bens Tank

Ben Tank

Ben Tank

Bent Knee Wash

Bent ley Well

Benton

See H U Bar Ranch

Benton Creek

Benton Creek

Benton Falls Tank

Bentonite Tank

Bentonite Tank

Benton Mine

Benton Spring

Benton Tank

Bent Tree

See Preston Hills

(subdivision)

Benzes Draw

Bercich Peak

See Montezuma Peak

Bercich Ranch

Bergemeyer Cove

Berger Butte

See Martinez $\mathrm{Hill}$

Bergier Ranch

\section{FEATURE}

CLASS

locale

spring

BGN
BGN

COUNTY

COORDINATE

Santa Cruz

Gila

reservoir

locale

reservoir

mine

school

valley

spring

mine

reservoir

locale

BGN

Coconino

Coconino

UNOFF

UNOFF Gila

BGN Yavapai

BGN Yavapa

UNOFF Pima

BGN Coconino

Coconino

locale

spring

spring

reservoir

reservoir

stream

stream

stream

park

$\begin{array}{ll}\text { UNOFF } & \text { Cochise } \\ \text { BGN } & \text { Coconino } \\ \text { BGN } & \text { Coconino } \\ \text { BGN } & \text { Santa Cruz } \\ \text { BGN } & \text { Cochise } \\ \text { BGN } & \text { Yuma } \\ \text { BGN } & \text { Graham } \\ \text { BGN } & \text { Pima } \\ \text { BGN } & \text { Apache } \\ \text { ADMIN } & \text { Apache }\end{array}$

730 N1095608W

$351351 \mathrm{~N} 1121245 \mathrm{~W}$

363908N1105831W

$312449 \mathrm{~N} 1103803 \mathrm{~W}$

$314646 \mathrm{~N} 1100355 \mathrm{~W}$

$324619 \mathrm{~N} 1141949 \mathrm{~W}$

$324940 \mathrm{~N} 1093435 \mathrm{~W}$

$320339 \mathrm{NI} 120831 \mathrm{~W}$

$340354 N 1092721 \mathrm{~W}$

340239 N $1092655 \mathrm{~W}$

reservoir building

pp1

airport

cemetery

building

school

school

VARIANT

UNOFF

BGN
BGN

crossing

hospital

crossing

locale

building

school

building

spring

valley

well

spring

reservoir

reservoir

reservoir

valley

well

locale

stream

stream

reservoir

reservoir

reservoir

mine

spring

reservoir

pp 1

valley

summit

locale

bay

summit

locale
ADMIN

UNOFF

UNOFF

UNOFF

UNOFF

Santa Cruz

Pinal

Apache

Cochise

Cochise

Cochise

Cochise

Cochise

Cochise

UNOFF

Pima

UNOFF

UNOFF

BGN

UNOFF

UNOFF

UNOF

BGN

BGN
UNOFF
BGN
BGN
BGN
BGN
BGN
UNOFF
VARIANT

Cochise

Cochise

Cochise

Cochise

Cochise

Cochise

Pinal

Pinal

Pima

Yavapai

Greenlee

Cochise

Greenlee

Apache

Maricopa

Greenlee

BGN
BGN
BGN
BGN
BGN
UNOFF
BGN
BGN
VARIANT

Greenlee

Apache

Greenlee

Greenlee

Coconino

Santa Cruz

Santa Cruz

Green lee

VARIANT

Maricopa

BGN

VARIANT

$312035 \mathrm{~N} 1110445 \mathrm{~W}$

$325821 \mathrm{~N} 1115440 \mathrm{~W}$ $350735 \mathrm{~N} 1091716 \mathrm{~W}$ $315804 \mathrm{~N} 1101738 \mathrm{~W}$ $315749 \mathrm{~N} 1101533 \mathrm{~W}$ $315733 \mathrm{~N} 1101817 \mathrm{~W}$ $315754 \mathrm{~N} 1101749 \mathrm{~W}$ $315747 \mathrm{N1} 101800 \mathrm{~W}$ $315755 \mathrm{~N} 1101800 \mathrm{~W}$

320804 N1105323W

$315754 \mathrm{~N} 1101832 \mathrm{~W}$ $315800 \mathrm{~N} 1101725 \mathrm{~W}$

$314421 \mathrm{~N} 1101151 \mathrm{~W}$ 314420 N1101151W

$315751 \mathrm{~N} 1101757 \mathrm{~W}$

$315803 \mathrm{~N} 1101745 \mathrm{~W}$

331758 N1111150W

331747 N1111205W

$314627 N 1105243 \mathrm{~W}$ $340914 \mathrm{~N} 1121630 \mathrm{~W}$ $330357 N 1090313 \mathrm{~W}$ $313435 \mathrm{~N} 1090408 \mathrm{~W}$

$331218 N 1092907 \mathrm{~W}$ $352323 \mathrm{~N} 1092957 \mathrm{~W}$ 335035 N1120124N

332458 N1091115W

332437 N1091130W 340047 N $1091558 \mathrm{~W}$ $332503 \mathrm{~N} 1091242 \mathrm{~W}$

$334043 \mathrm{~N} 1090334 \mathrm{~W}$

$355906 \mathrm{~N} 1115222 \mathrm{~W}$

$312026 \mathrm{~N} 1104139 \mathrm{~W}$

312039 N1104130W

$332611 \mathrm{~N} 1091345 \mathrm{~W}$

333505 N1115200W

$343821 N 1094852 W$

$312130 \mathrm{~N} 1101545 \mathrm{~W}$

$312025 \mathrm{~N} 1102916 \mathrm{~W}$

351305 N1143405W

BAR

Santa Cruz

Mohave

Pima

UNOFF

SOURCE

COORDINATE FT

MAP NAME

3680 Kino Springs Velasquez Butte

Metzger Tank

Williams South

Williams South

Weber Peak

Inspiration

Prescott

Poland Junction

Ben Nevis Mtn

Porcupine Ridge

Two Red Mesas

Black Diamond Peak

Williams South

Two Red Mesas

Harshaw

Haberstock $\mathrm{Hill}$

Dome 
NATIONAL GAZETTEER--ARIZONA 1986

\section{FEATURE NAME}

Bergier Tank Berkshire Village

\section{Berks Station}

See Alpha

Berks Station

See San Bernardino

Bermuda Falls Spring

Bernarde Mine

Bernardino

Berney Park

Berry

See Grandview Trail

Berry

Berry Knoll

Berry Railroad Station

Berry Ranch Strip

Berry Spring

Berry Tank

Berry Tank

Berry Tank Number Two

Berry Trail

See Grandview Trail

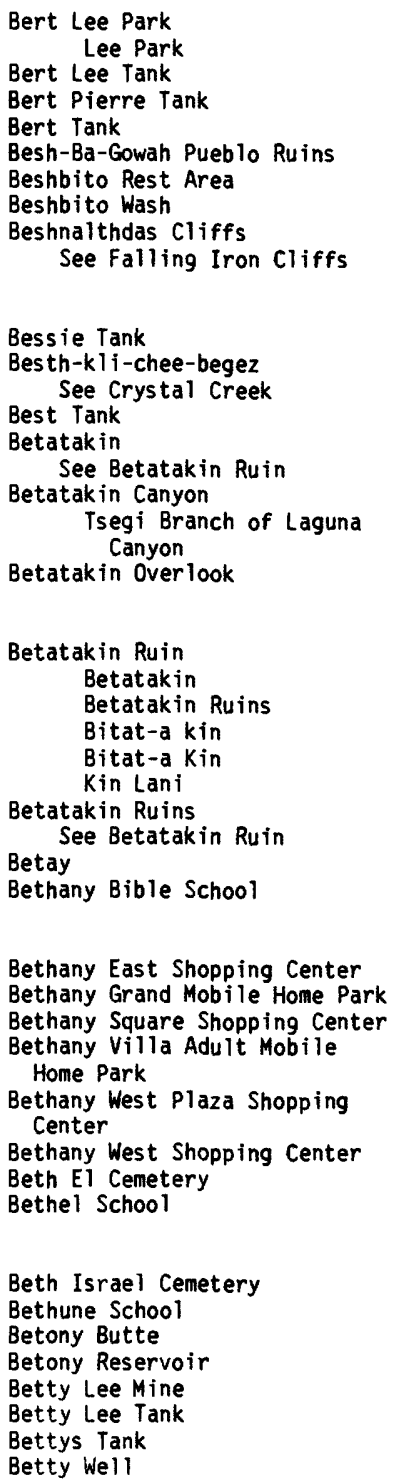

VARIANT

$\begin{array}{lll}\text { locale } & & \text { Maricopa } \\ \text { locale } & \text { VARIANT } & \text { Maricopa } \\ \text { spring } & \text { BGN } & \text { Gila } \\ \text { mine } & \text { UNOFF } & \text { La Paz } \\ \text { locale } & \text { BGN } & \text { Cochise } \\ \text { park } & \text { AOMIN } & \text { Maricopa }\end{array}$

trail

locale

summit

building

airport

spring

reservoir

reservoir

reservoir

trail

BGN
BGN
VARIANT
UNOFF
ADMIN
BGN
BGN
BGN
BGN
VARIANT

Coconino

Mohave

Mohave

Mohave

Pinal

Yavapai

Mohave

Mohave

Mohave

Coconino

flat

reservoir reservoir

reservoir

locale

locale

stream

cliff

stream

reservoir

locale

valley

locale

locale

locale
summit
school

school

locale

locale

locale

locale

locale

locale

cemetery

school

cemetery

school

summit

reservoir

mine

reservoir

reservoir

well

\begin{tabular}{|c|c|c|c|c|c|c|}
\hline $\begin{array}{l}\text { FEATURE } \\
\text { CLASS }\end{array}$ & STATUS & COUNTY & COORDINATE & $\begin{array}{l}\text { SOURCE } \\
\text { COORDINATE }\end{array}$ & $\begin{array}{c}\text { ELEV } \\
\text { FT }\end{array}$ & MAP NAME \\
\hline $\begin{array}{l}\text { reservoir } \\
\text { locale }\end{array}$ & $\begin{array}{l}\text { BGN } \\
\text { UNOFF }\end{array}$ & $\begin{array}{l}\text { Santa Cruz } \\
\text { Pima }\end{array}$ & 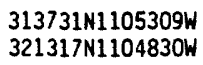 & & 2650 & $\begin{array}{l}\text { Mt Hopkins } \\
\text { Tucson East }\end{array}$ \\
\hline
\end{tabular}

$325725 \mathrm{~N} 1131820 \mathrm{~W}$

$325906 \mathrm{~N} 1131925 \mathrm{~W}$ 335120 N1105023W $341146 \mathrm{~N} 1133915 \mathrm{~W}$ $313038 N 1091844 \mathrm{~W}$ 332628 N1120214W

360108 N1115835W
BGN 1966
VARIANT

BGN

BGN

BGN

BGN
UNOFF

UNOFF

VARIANT

Coconino

Coconino

Navajo

Coconino

Gila

Apache

Navajo

Apache

Yavapai

VARIANT

Apache

Yavapai

Navajo

BGN Navajo

VARIANT

BGN

BGN

VARIANT

VARIANT

VARIANT

VARIANT

VARIANT

VARIANT

BGN

UNOFF

Navajo

Maricopa 333132N1120456W

UNOFF Maricopa

UNOFF Maricopa

UNOFF Maricopa

Maricopa

UNOFF

Maricopa

UNOFF

UNOFF

UNOFF

Maricopa

Maricopa

Maricopa

UNOFF
UNOFF
BGN
BGN
UNOFF
BGN
BGN
UNOFF

Maricopa

Maricopa

Navajo

Navajo

Yuma

Yuma

Yavapai

Apache
$364102 N 1103206 \mathrm{~W}$

$351510 \mathrm{~N} 1135816 \mathrm{~W}$

$363024 N 1131221 \mathrm{~W}$

$351441 \mathrm{~N} 1135846 \mathrm{~W}$

$341513 \mathrm{~N} 1122 \mathrm{~B} 53 \mathrm{~W}$

350727 N1134540W

$351417 N 1135744 \mathrm{~W}$

$351419 \mathrm{~N} 1135616 \mathrm{~W}$

360108N1115835W

$345530 \mathrm{~N} 1113245 \mathrm{~W}$

$345543 N 1113332 \mathrm{~W}$

$342258 \mathrm{N1102316 \textrm {W }}$

$345550 \mathrm{~N} 1113302 \mathrm{~W}$

$332257 \mathrm{N1} 104622 \mathrm{~W}$

$354601 \mathrm{N1095910 \textrm {W }}$

$353909 \mathrm{~N} 1100143 \mathrm{~W}$

360947 N1090302W

343433N1113543W

$360452 N 1090856 \mathrm{~W}$

340904 N111 4613W

$364102 \mathrm{~N} 1103206 \mathrm{~W}$ $364109 \mathrm{N1} 103042 \mathrm{~W}$

$364054 N 1103151 W$

$364102 \mathrm{N1103206 \textrm {W }}$

$333122 \mathrm{~N} 1120253 \mathrm{~W}$

$333134 \mathrm{~N} 1120952 \mathrm{~W}$

$333130 \mathrm{~N} 1120900 \mathrm{~W}$

$333134 \mathrm{N1120948 \textrm {W }}$

333130N1120908W

$333129 \mathrm{~N} 1120656 \mathrm{~W}$

$332733 \mathrm{N1} 120642 \mathrm{~W}$

$333226 \mathrm{~N} 1120515 \mathrm{~W}$

$332640 \mathrm{~N} 1120758 \mathrm{~W}$

$332601 \mathrm{N1} 120527 \mathrm{~W}$

$353439 \mathrm{N1} 101736 \mathrm{~W}$

$353348 \mathrm{~N} 1101717 \mathrm{~W}$

$323028 N 1135941 \mathrm{~W}$

$323002 \mathrm{~N} 1135837 \mathrm{~W}$

$345542 \mathrm{~N} 1122013 \mathrm{~W}$

$351944 \mathrm{~N} 1094834 \mathrm{~W}$
Sombrero Peak

Reid Valley

Pedregosa Mts East

Phoenix

Kingman Airport

6585 Moriah Knoll

Ratt lesnake $\mathrm{Hill}$

1195 Enid

Battleship Butte

Dean Peak

Ratt lesnake $\mathrm{Hill}$

Ratt lesnake Hill

$355228 N 1095459 \mathrm{~W}$

Mormon Mountain

Mormon Mountain

Aripine

Mormon Mountain

Globe

Big Willow Spr Can

Tsin Naan Tee

Buckhorn Mountain

Bloody Bas in

Betatakin Ruin

Betatakin Ruin

Betatakin Ruin

5529 Leche-e Rock

Sunnys lope

1180 Sunnys lope

1150 Glendale

1158 Glendale

1150 Glendale

1158 Glendale

1160 Sunnys lope

Phoenix

Sunnys lope

Fowler

Phoen ix

6482 Hauke Mes a

Hauke Mesa

Mohawk SW

Mohawk SW

Hell Point

5811 Betty We 11 
NATIONAL GAZETTEER--ARIZONA 1986

FEATURE NAME

Between The Rocks

Beunaventura

See Mishongnovi

Bevering Gulch

Beverly Trailer Park

Beyerville

Beyota Tank

B Flat Tank

Bianco Road Interchange

Bias Canyon

Bibyak

Beebhak

Sil Nakya

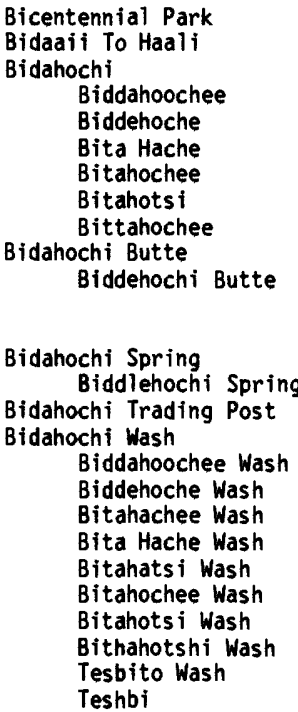

Big Bend Number One Tank Big Bend Number Two Tank Big Bend Wash

\section{FEATURE \\ CLASS}

gap

ppl

valley

locale

ppl

reservoir

reservoir

crossing

valley

locale

$$
\begin{aligned}
& \text { STATUS } \\
& \text { BGN } \\
& \text { VARIANT }
\end{aligned}
$$

COUNTY

Apache

Navajo

$\begin{array}{ll}\text { BGN } & \text { Yavapai } \\ \text { UNOFF } & \text { Maricopa } \\ \text { BGN } & \text { Santa Cruz } \\ \text { BGN } & \text { Pima } \\ \text { BGN } & \text { Mohave } \\ \text { UNOFF } & \text { Pinal } \\ \text { BGN } & \text { Yavapai } \\ \text { BGN } & \text { Pima } \\ \text { VARIANT } & \\ \text { VARIANT } & \end{array}$

park

spring

locale

ADMIN
BGN
BGN
VARIA

VARIANT

VARIANT

VARIANT

VARIANT

VARIANT

summit

VARIANI
BGN
VARIANI

VARIANT

Maricopa

Coconino

Navajo

$333102 \mathrm{~N} 1121238 \mathrm{~W}$

$353103 \mathrm{~N} 1110146 \mathrm{~W}$

352437 N110034OW

Navajo

$352421 N 1100317 \mathrm{~W}$

$352410 N 1100345 \mathrm{~W}$

$352431 N 1100344 \mathrm{~W}$

$351815 N 1100615 \mathrm{~W}$

Navajo

Navajo

BGN 1981 Navajo

BGN 1981
VARIANT

VARIANT

VARIANT

VARIANT

VARIANT

VARIANT

VARIANT

VARIANT

VARIANT

VARIANT

VARIANT

locale

stream

VARIANT

Navajo

Navajo

Navajo

Navajo

Navajo

summit

VARIANT

spring

park

spring

reservoir

crossing

locale

valley

VARIANT

Navinajo

ADMIN Maricopa

BGN

BGN

BGN

UNOFF

BGN

VARIANT

reservoir

dam

bend

bend

ppl

stream

valley

BGN

VARIANT

BGN

VARIANT

BGN

VARIANT

Pima

Navajo

Coconino

Apache

Apache

Yuma

Coconino

Apache

Mohave

Mohave

Maricopa

Cochise

Mohave

reservoir

reservoir

valley
BGN

BGN
BGN
Cochise

Cochise

Mohave
$352437 N 1100340 \mathrm{~W}$

$351815 N 1100615 \mathrm{~W}$

$352437 \mathrm{N1100340 \textrm {W }}$

351815 N1 100615W

$352421 \mathrm{~N} 1100317 \mathrm{~W}$

352410 N1100345W $332205 \mathrm{N1} 115740 \mathrm{~W}$ $322811 \mathrm{~N} 1104058 \mathrm{~W}$ $334937 \mathrm{~N} 1095645 \mathrm{~W}$ $350311 \mathrm{N1} 111146 \mathrm{~W}$ $351655 \mathrm{~N} 1091421 \mathrm{~W}$ 351649N1091451W

$334731 \mathrm{~N} 1142616 \mathrm{~W}$

352039 N1123058W

340330N1094330W $350617 \mathrm{~N} 1143706 \mathrm{~W}$ $365017 N 1135844 \mathrm{~W}$

$325652 \mathrm{~N} 1124258 \mathrm{~W}$ $313527 N 1092910 \mathrm{~W}$

$365029 N 1135853 \mathrm{~W}$

$313432 \mathrm{~N} 1092401 \mathrm{~W}$ $313447 N 1092600 \mathrm{~W}$
$365029 \mathrm{~N} 1135853 \mathrm{~W}$ $\begin{array}{lc}\text { SOURCE } & \text { ELEV } \\ \text { COORDINATE } & \text { FT }\end{array}$

MAP NAME

Mexican Cry Mesa

343326N1131202W Bagdad

1210 Mesa

3680 Rio Rico

Caponer

Bull Spring

1388 Chuichu

344515N1114230W Lake Montezuma

Santa Rosa Mts SW

Glendale

White Water Tank

Indian Wells

6285 Indian Wells

Indian Wells

Indian Wells

Five Buttes
352850 N1100242W

Five Buttes

\section{Guadalupe \\ Mount Bigelow Whiteriver Anderson Canyon \\ 6000 Houck \\ Houck}

Horse Trap Mesa

Oavis Dam SE

Elbow Canyon

Pedregosa Mts West

Pedregosa Mts West Pedregosa Mts West Elbow Canyon 
NATIONAL GAZETTEER--ARIZONA 1986

FEATURE NAME

Big Bend Creek

Big Bertha Tank

Big Bertha Tank

Big Bertha Wash

Big Bill Tank

Big Black Mesa

Black Mesa

Big Blue Mountains

See Big Lue Mountains

Big Boni Dan

Big Bonita

See Big Bonito Creek

Big Bonito Creek

Big Bonita

Big Boy Mine

Big Boy Tank

Big Brushy Dam

Big Brushy Tank

Big Buckhorn Tank

Big Buck Tank

Big Bud Tank

Big Bug Creek

Bigbug Creek

Bug Creek

Bigbug Creek

See Big Bug Creek

Big Bug Mesa Bigbug Mesa

Bigbug Mesa

See Big Bug Mesa

Big Bug Mountains (historical)

Big Bull Canyon

Big Canon

See Grand Canyon

Big Canyon

Big Canyon

Big Canyon

Big Canyon Creek

Big Canyon

Big Canyon

Big Canyon

See Grand Canyon

Big Canyon

Big Canyon Creek

See Big Canyon

Big Canyon Tank Number One

Big Canyon Tank Number Two

Big Carrizo Wash

See Lithodendron Wash

Big Casa Blanca Canyon

Big Cave Ruins

Big Cedar Trap

Big Chair

Big Cherry Creek

Big Chief Mine

Big Chief Tank

Big Chino Valley

Chino Valley

Val me China

Val de Chino

Big Chino Wash$$
\text { Chino Creek }
$$

Big Cienega Mountain

Big Cove

Big Cove Canyon

Big Creek

Big Curve Shopping Center

Big Dam

Big Dan Reservoir

Big Dam Tank

FEATURE

CLASS

STATUS

COUNTY

COORDINATE

VARIANT

reservoir

reservoir

stream

reservoir

summit

BGN

$B G N$

BGN

BGN 1963

VARIANT

Pinal

Maricopa

Pinal

Coconino

Yavapai

VARIANT

sumnit

dam

stream

stream

mine

reservoir

dam

UNOFF

VARIANT

$\begin{array}{ll}\text { Greenlee } & 330424 N 1090620 \mathrm{~W} \\ \text { Graham } & 332112 \mathrm{~N} 1100830 \mathrm{~W}\end{array}$

$333415 N 1095614 W$

$333415 N 1095614 \mathrm{~W}$

BGN
VARIANT

UNOFF

Navajo

Navajo

Mohave

BGN

Coconino

$352001 \mathrm{~N} 1140911 \mathrm{~W}$

$353712 \mathrm{~N} 1122151 \mathrm{~W}$

$332235 N 1101917 \mathrm{~W}$

reservoir

reservoir

reservoir

reservoir

stream

BGN
BGN
BGN

BGN

BGN 1943

VARIANT

VARIANT

VARIANT

strean

sumait

BGN 1943

VARIANT

Yavapa

Yavapai

Graham

$341216 \mathrm{~N} 1114643 \mathrm{~W}$

Coconino $353407 N 1124847 \mathrm{~W}$

Yavapai 341854N1120357W

$341854 \mathrm{N1120357W}$

$342519 N 1122131 \mathrm{~W}$

VARIANT

summit

summit

valley

valley

valley

valley

valley

BGN

BGN

BGN

VARIANT

BGN

BGN

VARIANT

Yavapa

Yavapa

Navajo

Mohave

Graham

Gila

Gila

valley

valley

BGN

BGN

VARIANT

valle

valley

valley

reservoir

BGN

VARIANT

reservoir

BGN

BGN

BGN

strean

valle

locale

cliff

summit

stream

mine

reservoir

valley

BGN 1978

BGN

BGN
BGN
$B G N$

UNOFF

BGY

BGN 1975 Yaconino

VARIANT

VARIANT

VARIANT

stream

BGN 1975

VARIANT

VARIANT

summit BGN

basin $\quad B G N$

valley

strean

locale

dam

BGY

reservoir UNOFF

Apache

reservoir BGN

Yavapai

$341854 N 1120357 \mathrm{~W} \quad 342523 \mathrm{~N} 1122308 \mathrm{~W}$

$350335 N 1125033 W$

$342519 \mathrm{~N} 1122131 \mathrm{~W}$

$342000 \mathrm{~N} 1123000 \mathrm{~W}$

$344946 \mathrm{~N} 1103241 \mathrm{~W}$

$360646 \mathrm{~N} 1135943 \mathrm{~W}$

$325003 \mathrm{~N} 1093633 \mathrm{~W}$

$335346 \mathrm{N1101011 \textrm {W }}$

$341250 \mathrm{~N} 1110850 \mathrm{~W}$

$341731 N 1104415$

$342019 N 1110545 \mathrm{~W}$

$360646 \mathrm{~N} 1135943 \mathrm{~W}$

$361042 \mathrm{N1114216 \textrm {W }}$

$335346 \mathrm{~N} 1101011 \mathrm{~W}$

$335623 \mathrm{~N} 1100400 \mathrm{~W}$

$335539 \mathrm{~N} 1100530 \mathrm{~W}$

345816N1095650W

$313545 \mathrm{~N} 1104325 \mathrm{~W}$ $361239 \mathrm{~N} 1092212 \mathrm{~W}$

$333419 \mathrm{N1} 102809 \mathrm{~W}$

$365543 \mathrm{~N} 1100342 \mathrm{~W}$

$334954 \mathrm{N1110512 \textrm {W }}$

$342455 \mathrm{~N} 1122940 \mathrm{~W}$

$353605 N 1130058 \mathrm{~W}$

$345020 \mathrm{~N} 1122700 \mathrm{H}$

314110 N1105025W

335311 N1110502W

Mummy Cave Ruins

Cassadore Spring

Mitten Buttes

Groom Creek

Big Chief Tank

351135N1124950W Paulden

$345255 \mathrm{~N} 1122845 \mathrm{~W}$

353830 N1125700W

Paulden

340217 N1093336W $361548 N 1130045 \mathrm{~W}$

$363455 N 1123728 \mathrm{~W}$

323443N1095744K $43715 \mathrm{~W}$

$351749 \mathrm{~N} 1132150 \mathrm{~W}$

353203N1094302

$363542 \mathrm{~N} 1123240 \mathrm{~W}$

9635 Greens Peak

Mt Trumbuli SE

Jumpup Point

Fort Grant

Yuna East

Blye Canyon SE

Sunrise Springs

Red Mountain 
NATIONAL GAZETTEER--ARIZONA 1986

\section{FEATURE NAME}

Big Dam Wash

Big Di amond Creek

See Diamond Creek

Big Dick Canyon

Big Dike Reservoir

Big Ditch

Big Dome

Big Draw

Big Draw Tank

Big Draw Tank

Big D Reservoir

Big Dry Canyon

Big Dry Fork

See Chet Tank

Big Dry Wash

See Chet Tank

Big Dry Wash

See Chevelon Creek

Bigelow, Mount

Bige low Peak

Bigelow Spring

Big E Tank

Big Eye Mine

Big Eye Wash

Big Field

See Gu Oidak

Big Fields

See Gu Oidak

Big Fields Wash

See Sells Wash

Big Fill Lake

Big Flat Tank

Big Flow

Big Freeman Tank Chuning Tank

Big Gadwell Windmill

Big Granite Wash Granite Water

Big Gypsum Ledges

Bighams Lake

Big Hells Gate

Big Hill

Big Hocter Tank

Big Hogan

Big Hole Tank

Big Hole Tank

Big Hole Tank

Big Hollow Wash

Big Horn

Buzzard Ranch

Big Horn (historical)

Big Horn Mine

Bighorn Mountain

Big Horn Mountains

See Mohawk Mountains

Big Horn Mountains

Bighorn Mountains

Goat Mountains

Bighorn Mountains

See Big Horn Mountains

Bighorn Peak

See Big Horn Peak

Big Horn Peak Bighorn Peak

Big Horn Well

Big Ikie Tank

Big Indian Tank

Big Jim Tank

Big Johnnie Gulch

Big Johnnie Shaft

Big Kelley Tank

\section{FEATURE}

STATUS

valley

stream

valley

canal

summit

valley

reservoir

reservoir

reservoir

valley

reservoir

reservoir

stream

summit

summit

spring

well

mine

stream

ppl

pp 1

stream

ake

reservoir

falls

reservoir

locale

stream

cliff

reservoir

gap

summit

reservoir

summit

reservoir

reservoir

reservoir

stream

locale

(1)

\begin{tabular}{|c|c|}
\hline $\begin{array}{l}\text { locale } \\
\text { mine } \\
\text { summit }\end{array}$ & $\begin{array}{l}\text { BGN } \\
\text { UNOFF } \\
\text { BGN } \\
\text { VARIANT }\end{array}$ \\
\hline $\begin{array}{l}\text { range } \\
\text { range }\end{array}$ & $\begin{array}{l}\text { BGN } 1962 \\
\text { VARIANT } \\
\text { VARIANT }\end{array}$ \\
\hline
\end{tabular}

range

summit

summit

well

reservoir

reservoir

reservoir

valley

mine
ARIANT

Maricopa

VARIANT

BGN
VARIANT

Yuma

Mohave

Apache

Cochise

Coconino

Apache

Mohave

Pinal

Pinal

Navajo

Pima

Coconino

Yuma

Yuma

Pima

Pima

Pima

BGN

$B G N$

BGN 1976

ARI

BGN

VARIANT

BGN

\section{BGN}

BGN
BGN

$B G N$

GN

BGN

BGN

BGN

VARIANT

Coconino

Yavapai

Apache

Coconino

Cochise

Yuma

Mohave

Navajo

Yavapai

Yavapai

Coconino

Navajo

Gila.

Coconino

Apache

Maricopa

$$
\text { Maricopa }
$$

\section{Maricopa}

Maricopa

BGN 1962

VARIANT

UNOFF

BGN

$B G N$

BGN

BGN
UNOFF

Maricopa

Yavapai

Navajo

Coconino

Gila

Gila

Coconino
COORDINATE

$353355 N 1094825 \mathrm{~W}$

335335N1095601W

$331744 \mathrm{~N} 1140009 \mathrm{~W}$

$363947 \mathrm{N1} 130052 \mathrm{~W}$

$340519 \mathrm{N1091820 \textrm {W }}$

$330826 \mathrm{~N} 1105831 \mathrm{~W}$

$320322 \mathrm{~N} 1095449 \mathrm{~W}$

$350353 \mathrm{~N} 1115209 \mathrm{~W}$

$350446 \mathrm{~N} 1094008 \mathrm{~W}$

363517 N1132132W

$331902 N 1092 B 30 \mathrm{~W}$

325640 N1102833W

325640N1102833W

$345704 \mathrm{N110311BW}$

322454N1104250W

$342924 \mathrm{~N} 1122334 \mathrm{~W}$

$340400 \mathrm{N1092128 \textrm {W }}$

353440 N1125707W

$330231 \mathrm{~N} 1140600 \mathrm{~W}$

$324542 \mathrm{~N} 1140230 \mathrm{~W}$

315518N1120234h

315518N1120234W

315552N1121120W

$351256 \mathrm{~N} 1113406 \mathrm{~W}$

$342535 \mathrm{~N} 1115812 \mathrm{~W}$

361409 N1091920W

352930N1123327W

$313444 \mathrm{~N} 1095554 \mathrm{~W}$

335245N1135211W

360412 N1142453W

$355247 \mathrm{N1} 100440 \mathrm{~W}$

$335832 \mathrm{~N} 1122510 \mathrm{~W}$

$343750 \mathrm{N1113345}$

353534N1120234W

$365452 \mathrm{~N} 1100432 \mathrm{~W}$

334433N1102210W

$343928 \mathrm{~N} 1112229 \mathrm{~W}$

$353655 \mathrm{N1} 120137 \mathrm{~W}$

$343448 \mathrm{~N} 1092456 \mathrm{~W}$

325134N1122331W

$333015 N 1131220 \mathrm{~W}$

332516 N1135130W

$322239 N 1105523 \mathrm{~W}$

$323526 \mathrm{~N} 1133849 \mathrm{~W}$

$333833 \mathrm{~N} 1130923 \mathrm{~W}$

$333833 N 1130923 W$

$333630 \mathrm{~N} 1130900 \mathrm{~W}$ $333630 \mathrm{~N} 1130900 \mathrm{~W}$

$332934 \mathrm{~N} 1130636 \mathrm{~W}$ $345522 \mathrm{~N} 1131314 \mathrm{~W}$ $350240 \mathrm{~N} 1095954 \mathrm{~W}$ $360730 \mathrm{~N} 1122358 \mathrm{~W}$ $332511 \mathrm{~N} 1104800 \mathrm{~W}$ $332614 \mathrm{~N} 1104611 \mathrm{~W}$

$345940 \mathrm{~N} 1110828 \mathrm{~W}$

\begin{tabular}{|c|c|c|}
\hline $\begin{array}{l}\text { SOURCE } \\
\text { COORDINATE }\end{array}$ & $\begin{array}{c}\text { ELEV } \\
F T\end{array}$ & MAP NAME \\
\hline $353333 \mathrm{~N} 1093704 \mathrm{~W}$ & & Greas ewood \\
\hline $\begin{array}{l}331948 \mathrm{~N} 1140109 \mathrm{~W} \\
320406 \mathrm{~N} 1100501 \mathrm{~W}\end{array}$ & & $\begin{array}{l}\text { Palm Canyon } \\
\text { Little Clayhole Val } \\
\text { Eagar } \\
\text { Hot Tamale Peak } \\
\text { Cochise } \\
\text { Dutton Hill }\end{array}$ \\
\hline $332154 N 1092252 \mathrm{~W}$ & & $\begin{array}{l}\text { Pinta } \\
\text { Russell Spring } \\
\text { Bee Canyon }\end{array}$ \\
\hline & & Mount Bigelow \\
\hline $330136 \mathrm{~N} 1140614 \mathrm{~W}$ & 6731 & $\begin{array}{l}\text { Groom Creek } \\
\text { Eagar } \\
\text { Rhodes Canyon } \\
\text { Slumgullion Pass } \\
\text { Red Bluff Mtn East }\end{array}$ \\
\hline
\end{tabular}

Flagstaff East

Arnold Mesa

Mummy Cave Ruins

Eagle Nest Mtn

Potter Mtn

Bouse Hills East

Boulder Canyon

Low Mountain

Garfias Mtn

6608 Apache Maid Mtn

Hobble Tank

Mitten Buttes

Popcorn Canyon

Turkey Mtn

$342054 N 1092816 \mathrm{~W}$

Hobble Tank

Zion Reservoir

1722 Big Horn

Big Horn Peak

Valencia

5640 Oro Valley

Little Horn Peak

3481 Big Horn Peak

Saddle Mtn

Sunrise Peak

Ltl Lithodendron Tk 
FEATURE NAME

Big Kimble Mine
Big Knoll, The
Red Butte
Big Lake
Big Lake
Big Lake
Big Lake
Big Lake, The
Big Lake Dam

Big Lake Forest Camp

Big Lake Knoll

Big Lakes

See Bekihatso

Big Leroux Spring

Big Leroux Spring

See Leroux Spring

Bigler Ponds

Biglers Reservoir

Bigler Tank

\section{Bigler Tank \\ Bigler Tank \\ Bigler Trick Tank \\ Bigler Wash \\ Big Limestone Tank \\ Big Lue Canyon \\ Big Lue Mountain \\ See Big Lue Mountains \\ Big Lue Mountains \\ Big Blue Mountains \\ Big Lue Mountain \\ Blackjack Rim}

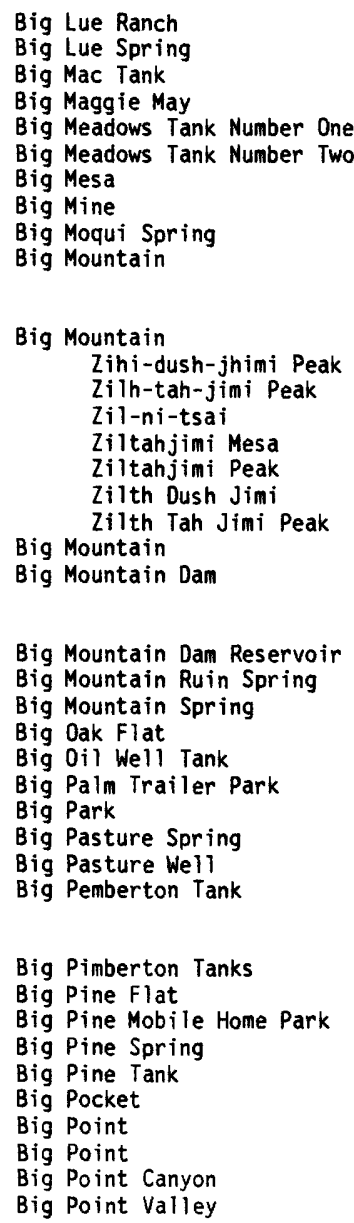

\begin{tabular}{|c|c|c|c|}
\hline $\begin{array}{l}\text { FEATURE } \\
\text { CLASS }\end{array}$ & STATUS & COUNTY & COORDINATE \\
\hline $\begin{array}{l}\text { mine } \\
\text { summit }\end{array}$ & $\begin{array}{l}\text { UNOFF } \\
\text { BGN } 1979 \\
\text { VARIANT }\end{array}$ & $\begin{array}{l}\text { Mohave } \\
\text { Coconino }\end{array}$ & $\begin{array}{l}341530 \mathrm{~N} 1134208 \mathrm{~W} \\
365036 \mathrm{~N} 1115108 \mathrm{~W}\end{array}$ \\
\hline $\begin{array}{l}\text { lake } \\
\text { lake } \\
\text { lake } \\
\text { reservoir } \\
\text { flat } \\
\text { dam }\end{array}$ & $\begin{array}{l}\text { BGN } \\
\text { BGN } \\
\text { BGN } \\
\text { BGN } \\
\text { BGN } \\
\text { UNOFF }\end{array}$ & $\begin{array}{l}\text { Apache } \\
\text { Apache } \\
\text { Apache } \\
\text { Apache } \\
\text { Coconino } \\
\text { Apache }\end{array}$ & $\begin{array}{l}335320 \mathrm{~N} 1092448 \mathrm{~W} \\
343051 \mathrm{~N} 1091433 \mathrm{~W} \\
362845 \mathrm{~N} 1091052 \mathrm{~W} \\
335312 \mathrm{~N} 1092500 \mathrm{~W} \\
355551 \mathrm{~N} 1111003 \mathrm{~W} \\
335312 \mathrm{~N} 1092500 \mathrm{~W}\end{array}$ \\
\hline $\begin{array}{l}\text { park } \\
\text { summit }\end{array}$ & $\begin{array}{l}\text { ADMIN } \\
\text { BGN } \\
\text { VARIANT }\end{array}$ & $\begin{array}{l}\text { Apache } \\
\text { Apache }\end{array}$ & $\begin{array}{l}335241 N 1092430 \mathrm{~W} \\
335143 \mathrm{~N} 1092327 \mathrm{~W}\end{array}$ \\
\hline $\begin{array}{l}\text { lake } \\
\text { spring }\end{array}$ & $\begin{array}{l}\text { BGN } \\
\text { VARIANT }\end{array}$ & $\begin{array}{l}\text { Apache } \\
\text { Coconino }\end{array}$ & $\begin{array}{l}360007 \mathrm{~N} 1093 \mathrm{~B} 33 \mathrm{~W} \\
351736 \mathrm{~N} 1114327 \mathrm{~W}\end{array}$ \\
\hline $\begin{array}{l}\text { spring } \\
\text { lake } \\
\text { reservoir } \\
\text { reservoir }\end{array}$ & $\begin{array}{l}\text { BGN } \\
B G N \\
B G N\end{array}$ & $\begin{array}{l}\text { Coconino } \\
\text { Graham } \\
\text { Graham } \\
\text { Navajo }\end{array}$ & $\begin{array}{l}351736 \mathrm{~N} 1114327 \mathrm{~W} \\
325107 \mathrm{~N} 109565 \mathrm{~W} \\
325335 \mathrm{~N} 1095408 \mathrm{~W} \\
342110 \mathrm{~N} 110432 \mathrm{~W}\end{array}$ \\
\hline $\begin{array}{l}\text { reservoir } \\
\text { reservoir } \\
\text { reservoir } \\
\text { stream } \\
\text { reservoir } \\
\text { valley }\end{array}$ & $\begin{array}{l}\text { BGN } \\
\text { BGN } \\
\text { BGN } \\
\text { BGN } \\
\text { BGN } \\
\text { BGN } \\
\text { VARIANT }\end{array}$ & $\begin{array}{l}\text { Navajo } \\
\text { Navajo } \\
\text { Navajo } \\
\text { Graham } \\
\text { Coconino } \\
\text { Greenlee }\end{array}$ & $\begin{array}{l}342555 \mathrm{~N} 1103220 \mathrm{~W} \\
343622 \mathrm{~N} 1102558 \mathrm{~W} \\
343354 \mathrm{~N} 1103857 \mathrm{~W} \\
325454 \mathrm{~N} 1095346 \mathrm{~W} \\
352130 \mathrm{~N} 1121631 \mathrm{~W} \\
330820 \mathrm{~N} 1090532 \mathrm{~W}\end{array}$ \\
\hline $\begin{array}{l}\text { summit } \\
\text { summit }\end{array}$ & BGN 1963 & $\begin{array}{l}\text { Greenlee } \\
\text { Greenlee }\end{array}$ & $\begin{array}{l}330424 N 1090620 \mathrm{~W} \\
330424 \mathrm{~N} 1090620 \mathrm{~W}\end{array}$ \\
\hline
\end{tabular}

$\begin{array}{lc}\text { SOURCE } & \text { ELEV } \\ \text { COORDINATE } & \text { FT }\end{array}$

awhide Wash

6844 The Big Knoll

8975 Big Lake North

Kearn Lake

Lukachukai

Big Lake North

Goldtooth

Big Lake North

Big Lake North

9415 Big Lake South

Humphreys Peak

Shingle Mill Mtn

Eden

Brookbank Point

Heber

Zeniff

Potato Wash South

Eden

325037 N $1095637 \mathrm{~W}$

Hearst Mtn

330414N109055IW Harden Cienega

7022 Big Lue Mts

$330504 N 1090503 \mathrm{~W}$ 330528 N1090510W $330941 \mathrm{~N} 1122121 \mathrm{~W}$

$335804 \mathrm{~N} 1115315 \mathrm{~W}$

$340117 \mathrm{~N} 1093424 \mathrm{~W}$

340119 N1093351W

$325505 \mathrm{~N} 1090741 \mathrm{~W}$

$323727 \mathrm{~N} 1110403 \mathrm{~W}$

$343511 N 1111152 \mathrm{~W}$

$340347 \mathrm{~N} 1100106 \mathrm{~W}$

361812 N1102835W

\begin{tabular}{|c|c|c|}
\hline $340000 \mathrm{~N} 1115354 \mathrm{~W}$ & 7079 & $\begin{array}{l}\text { Big Lue Mts } \\
\text { Big Lue Mts } \\
\text { Mobile NE } \\
\text { New River Mesa } \\
\text { Greens Peak } \\
\text { Greens Peak } \\
\text { York } \\
\text { Tortolita Mts } \\
\text { Blue Ridge Reservoir } \\
\text { Faught Ridge }\end{array}$ \\
\hline & 7144 & Owl Valley \\
\hline
\end{tabular}

Fire Dance Mesa

Big Mountain Dam

$\begin{array}{ll}\text { Apache } & 362754 \mathrm{~N} 1092522 \mathrm{~W} \\ \text { Navajo } & 360851 \mathrm{~N} 1102819 \mathrm{~W}\end{array}$

$360850 \mathrm{~N} 1102814 \mathrm{~W}$

$361312 \mathrm{~N} 1103200 \mathrm{~W}$

$361311 N 1102832 \mathrm{~W}$

$334303 \mathrm{~N} 1111807 \mathrm{~W}$

$344150 \mathrm{~N} 1102405 \mathrm{~W}$

$332745 \mathrm{~N} 1115845 \mathrm{~W}$

$344657 \mathrm{~N} 1114550 \mathrm{~W}$

$345607 \mathrm{~N} 1134002 \mathrm{~W}$

$333120 N 1104958 \mathrm{~W}$

$340129 N 1125531 \mathrm{~W}$

Big Mtn. Dan

Rocky Ridge NE

Big Mountain Dam

Four Peaks

Dry Lake NW

1185 Tempe

Sedona

Pilgrim Wash

Rockinstraw Mtn

Congress SW

Forepaugh Peak

Tonto Bas in

$335955 \mathrm{~N} 1130004 \mathrm{~W}$

$334512 N 1112140 \mathrm{~W}$

$334534 \mathrm{~N} 1112143 \mathrm{~W}$

$340914 \mathrm{~N} 1100631 \mathrm{~W}$

$365248 \mathrm{~N} 1115702 \mathrm{~W}$

$361523 \mathrm{~N} 1125849 \mathrm{~W}$

$365455 \mathrm{~N} 1102639 \mathrm{~W}$

$361520 \mathrm{N1} 130033 \mathrm{~W}$

361648 N1125910W

$361526 N 1101111 W \quad 361639 N 1101214 W$
Tempe

Tonto Bas in

Show Low South

Poverty Flat

Fern Glen Canyon

Big Point

Mt Trumbull SE

Toh NE Zhonnie Spr 
FEATURE NAME

Big Pond

Big Pond

Big Pond Tank

Big Popcorn Tank

Big Popcorn Water Hole

Big Popcorn Water Hole

See Big Popcorn Tank

Big Prairie

Big Pug Tank

Big Purcell Tank

\section{Big Rebel Mine \\ Big Red Hill Tank \\ Big Reef Mill \\ Big Reservoir \\ Big Ridge \\ Big Ridge \\ Big Ridge \\ See Pinnacle Ridge \\ Big Ridge, The}

Big Ridge Tank

Big Rincon Tank

Big Rock Detention

Big Rock Point

Big Rock Spring

Big Rock Tank

Big Round Tank

Big Saddle

Big Saddle

Big Saddle Camp

Big Saddle Point

Big Sand Bar

Big Sand Wash

Big Sand Wash

Big Sandy River

Big Sandy River

See Knight Creek

Big Sandy Spring

Big Sandy Wash

See Knight Creek

Big Sheep Corral

Big Shipp Mountain

Big Shipp Wash

Big Sink

Big Sowats Canyon

Big Spar Mine

Big Spreader Tank

Big Spring

Big Spring

Big Spring

Big Spring

Big Spring

Big Spring

See Gold Tooth Smith Spring

Big Spring

Big Spring

Big Spring

Big Spring

Big Spring

Big Spring

Big Spring

See South Big Spring

Big Spring Whitmore Spring

Big Spring

See Peck Wash

Big Spring Canyon

Big Spring Canyon

Big Spring Canyon

Big Spring Canyon

Big Spring Canyon

Shinumo Creek

South Big Spring Canyon
FEATURE
CLASS

STATUS

COUNTY

COOROINATE

lake

reservoir

reservoir

reservoir

BGN

BGN
BGN
BGN

VARIANT

VARIANT

reservoir

flat

reservoir BGN

reservoir BGN

mine

reservoir

locale

reservoir $B G$

ridge $\quad B G N$

ridge

ridge

ridge

reservoir

UNOFF Yavapai

BGN

BGN

BGN
BGN
VARIANT

VARIANT

reservoir

reservoir

cliff

spring

reservoir

reservoir

gap

gap

locale
cliff

BGN

$B G N$

BGN

BGN

BGN

BGN

BGN

BGN

BGN

$B G N$

BGN

rapids

stream

stream

stream

BGN

BGN

BGN

BGN

VARIANT

stream

spring

stream

locale

BGN

VARIANT

BGN

summit

stream

bas in

valley

mine

reservoir

spring

spring

spring

spring

spring

spring

spring

spring

spring

spring

spring

spring

spring

BGN

BGN

BGN

UNOFF

$B G N$

$B G N$

BGN

BGN
BGN

BGN

VARIANT

BGN

BGN

BGN

BGN

BGN

Pinal

Gohave

Gila

Gila

Graham

Navajo

Yavapai

Coconino

Coconino

Gila

Coconino

Coconino

Coconino

Gila

Maricopa

Gila

Coconino

Gila

Coconino

Navajo

Maricopa

Coconino

Coconino

Coconino

Mohave

Cochise

Mohave

Mohave

Mohave

Mohave

Mohave

Coconino

Yavapai

Yavapai

Coconino

Coconino

Maricopa

Pinal

Graham

Graham

Graham

Maricopa

Maricopa

Gila

Navajo

Navajo

Yavapai

Yavapai

Coconino

Coconino

Coconino

Mohave

BGN

VARIANT

VARIANT

stream

valley

valley

valley

valley

valley

BGN

BGN

BGN

BGN 196

BGN 1964

VARIANT

VARIANT

$23947 \mathrm{~N} 1105926 \mathrm{~W}$

$334312 \mathrm{~N} 1101732 \mathrm{~W}$

$332436 \mathrm{~N} 1094332 \mathrm{~W}$

$351051 N 1130135 \mathrm{~W}$

341B23N1123539W

$361930 \mathrm{~N} 1113944 \mathrm{~W}$

$364200 \mathrm{~N} 1120849 \mathrm{~W}$

365009 N1115444W

$355251 \mathrm{N1} 110525 \mathrm{~W}$

341417 N1110118W

$334952 \mathrm{~N} 1112845 \mathrm{~W}$

$331235 \mathrm{~N} 1104210 \mathrm{~W}$

$363058 \mathrm{~N} 1105209 \mathrm{~W}$

$334129 N 1112102 \mathrm{~W}$

$362645 \mathrm{~N} 1122331 \mathrm{~W}$

$355543 \mathrm{~N} 1144226 \mathrm{~W}$

$320419 N 1092717 \mathrm{~W}$

364938 NI $125311 \mathrm{~W}$

$345521 N 1133734 \mathrm{~W}$

$342855 \mathrm{~N} 1133122 \mathrm{~W}$

362005 N1114533W

343612 N11 $30248 \mathrm{~W}$ 362947 NI132724W $333424 N 1105103 \mathrm{~W}$ $334312 \mathrm{~N} 1101732 \mathrm{~W}$

$342719 \mathrm{~N} 1102042 \mathrm{~W}$

$353246 \mathrm{~N} 1122448 \mathrm{~W}$ $335753 \mathrm{NI} 122903 \mathrm{~W}$

$341347 \mathrm{~N} 1110146 \mathrm{~W}$

$331210 \mathrm{~N} 1104402 \mathrm{~W}$

$344031 \mathrm{NI} 111222 \mathrm{~W}$

$344129 \mathrm{NI} 103142 \mathrm{~W}$

$362718 N 1122411 \mathrm{~W}$

$362654 \mathrm{N1} 122325 \mathrm{~W}$

$341838 \mathrm{~N} 1133133 \mathrm{~W}$

$320524 N 1092359 \mathrm{~W}$

$364520 \mathrm{~N} 1125532 \mathrm{~W}$

$345521 \mathrm{N1133734W}$

$345521 N 1133734 \mathrm{~W}$

$343213 N 1130128 \mathrm{~W}$

$365315 \mathrm{~N} 1115336 \mathrm{~W}$ 
NATIONAL GAZETTEER--ARIZONA 1986 FEATURE NAME

Big Springs

Big Springs Canyon

Big Springs Point

ig Springs Ranger Station

ig Springs Wash

See Peck Wash

Big Spring Wash

Big Spring Wash

Big Spur Tank

Big Steve Mine

Big Stick Mine

Big Sullivan Tank

Big Supai Tank

Big Tank

Big Tank

Big Tank

Big Tank

Big Tank

Big Tank

Big Tank

Big Tank

Big Tank

Big Tank

Big Tank

Big Tank

Big Tank

Big Tank

Big Tank

Big Tank

Big Tank

Big Tank

Big Tank Detention Dan

Big Tanks

Big Tank Series

Big Tank Well

Big Trough Spring

Big Turkey Tank

Big Valley

Big Warren Reservoir

Big Was

See Chukut Kuk Wash

Big Wash

Big Wash

Big Wash

Big Wash

See Box 0 Wash

Big Wash

Big Wash

Big Wash

Big Wash Well

Big Water

Debebekid Lake

Big Whisker Well

Big Wilderness Wash

Big Willow Spring

Big Willow Spring Canyon

Big Windmill

Big Windmill

Bihilinie Canyon

Bijaadibae

Bi Keesh Wash

Bi Kleesh Wash

Bi Kleesh Wash

See Bi Keesh Wash

Biko Hodo Klizg

Biko Hodo Klizg.

Boo-koo-dol-klish Canyon

Bukudotk 1 ish

Bukudotklish Canyon

Dotklish Canyon

Dot Klish Wash

FEATURE

CLASS

STATUS

COUNTY

COORDINATE

pp 1

$\begin{array}{ll}\text { Dpl } & \text { BGN } \\ \text { valley } & \text { BGN } \\ \text { cliff } & \text { BGN } \\ \text { locale } & \text { UNOFF } \\ & \text { VARIANT } \\ \text { stream } & \\ \text { strean } & \text { BGN } 1962 \\ \text { stream } & \text { BGN } \\ \text { reservoir } & \text { BGN }\end{array}$

Coconino

Mohave

Coconino

Coconino

Graham

Graham

Grahan

Gila

Santa Cruz

mine

mine

reservoir

reservoir

reservoir

reservoir

reservoir $B G$

reservoir BGN

reservoir $B G$

reservoir $B G$

reservoir BG

reservoir

reservoir

reservoir

reservoir

reservoir

reservoir

reservoir

reservoir

reservoir $B G$

reservoir

dam

reservoir

reservoir

well

spring

reservoir

valley

reservoir

stream

Mohave

BGN

VARIANT

Pima

stream

stream

stream

stream

stream

stream

stream

we 1

lake

well

valley

spring

valley

locale

locale

valley

summit

valley

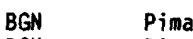

BGN

Pima

Pinal

VARIANT

BGN Pinal

BGN

$B G N$

$8 G N$

VARIANT

Navajo

BGN Apache

BGN

Coconino

BGN Apache

BGN Apache

Apache

VARIANT

VARIANT

valley

valley

BGN 1968

Apache

VARIANT

VARIANT

VARIANT

VARIANT

VARIANT
UNOFF Yavapai 342140N1131208W

Coconino 353820N1124525W

Coconino 351414N1121608W

Santa Cruz 312939N1111106W

Cochise 313355N1090433W

Pima 321739N1103028W

Graham 322718N1094714W

Greenlee $\quad 323127 \mathrm{N1090833 \textrm {W }}$

Pinal $323416 \mathrm{N1} 113512 \mathrm{~W}$

Pinal 324303N1110142W

BGN Pinal 325720N1102844W

Pinal 325720N1102844W

$\begin{array}{ll}\text { Gila } & 331311 N 1105428 \mathrm{~W} \\ \text { Gila } & 340512 N 1105415 \mathrm{~W}\end{array}$

Yavapai 340535N1124641W

Gila $340810 \mathrm{~N} 1111652 \mathrm{~W}$

Gila 341550N1112741W

Navajo 342529N1101656W

Navajo 343658N1102522W

Apache 350732N1094240W

Coconino 353230N1121638W

BGN Coconino 360621N1122758W

UNOFF Greenlee 323124N1090830W

BGN Greenlee 331319N1090951W

UNDFF Graham 323636N1100649W

BGN Gila $334203 N 1102103 W$

$\begin{array}{ll}\text { Gila } & 334203 \mathrm{~N} 1102103 \mathrm{~W} \\ \text { Gila } & 335630 \mathrm{~N} 1110057 \mathrm{~W}\end{array}$

UGNOFF Mohave

UNOFF Coconino 362720N1110154W

BGN Apache 353559N1094440W

BGN Apache 354804N1095608W

$354514 N 1095841 \mathrm{~W}$

$342413 \mathrm{~N} 1123853 \mathrm{~W}$

$344303 \mathrm{N1} 104547 \mathrm{~W}$

$362641 \mathrm{N1092709 \textrm {W }}$

$362519 \mathrm{~N} 1091745 \mathrm{~W}$

$355639 \mathrm{~N} 1093834 \mathrm{~W}$

354926 N1093248W

$353318 N 1094223 \mathrm{~W}$

354842N1095500W

Chevelon Butte
Fire Dance Mes

6378 Bad Bug Butte

Tolani

Young

Flores

Payson South

Big Pug Tank

Zeniff

North Mill Well

Mixon Tank

Chamisa Tank

Relic Point

Dix Creek

Sierra Bonita Ranch

Popcorn Canyon

Copper Mtn

Little Clayhole Val

Kots Kug Ranch

Clark Ranch

Tule Wash

Goldtooth

Chloride

Toh NE Zhonnie Spr

Big Whisker Well

Sunrise Springs

Big Willow Spr Can

$355639 N 1093834 \mathrm{~W}$

$355325 \mathrm{~N} 1112641 \mathrm{~W}$

363445 N1101220W

Cameron North

Grasshopper Junction 


\begin{tabular}{|c|c|c|c|c|c|c|c|}
\hline FEATURE NAME & $\begin{array}{l}\text { FEATURE } \\
\text { CLASS }\end{array}$ & STATUS & COUNTY & COORDINATE & $\begin{array}{l}\text { SOURCE } \\
\text { COORDINATE }\end{array}$ & $\begin{array}{c}\text { ELEV } \\
\text { FT }\end{array}$ & MAP NAME \\
\hline $\begin{array}{l}\text { Moenkopi Canyon } \\
\text { Moenkopi Creek }\end{array}$ & & $\begin{array}{l}\text { VARIANT } \\
\text { VARIANT }\end{array}$ & & & & & \\
\hline $\begin{array}{l}\text { Biko Hodo Klizg. } \\
\text { Boo-koo-dol-klish Canyon } \\
\text { See Biko Hodo Klizg } \\
\text { Bilasha } \\
\text { Bill Arp Creek } \\
\text { Rock Creek } \\
\text { Bill Arp Mine } \\
\text { Bill Arp Mine Spring } \\
\text { Bill Arp Spring } \\
\text { Bill Back Butte }\end{array}$ & $\begin{array}{l}\text { valley } \\
\text { summit } \\
\text { stream } \\
\text { mine } \\
\text { spring } \\
\text { spring } \\
\text { summit }\end{array}$ & $\begin{array}{l}\text { BGN } \\
\text { BGN } 1972 \\
\text { VARIANT } \\
\text { UNOFF } \\
\text { BGN } \\
\text { BGN } \\
\text { BGN }\end{array}$ & $\begin{array}{l}\text { Coconino } \\
\text { Apache } \\
\text { Yavapai } \\
\text { Yavapai } \\
\text { Yavapai } \\
\text { Yavapai } \\
\text { Coconino }\end{array}$ & $\begin{array}{l}355325 \mathrm{~N} 1112641 \mathrm{~W} \\
362033 \mathrm{~N} 1092537 \mathrm{~W} \\
341335 \mathrm{~N} 1121237 \mathrm{~W} \\
341331 \mathrm{N1121315 \textrm {W }} \\
341346 \mathrm{~N} 1121315 \mathrm{~W} \\
341309 \mathrm{~N} 1121406 \mathrm{~W} \\
344527 \mathrm{~N} 1112730 \mathrm{~W}\end{array}$ & $341258 \mathrm{N1121505 \textrm {W }}$ & 7743 & $\begin{array}{l}\text { Tall Tree Mesa } \\
\text { Bumble Bee } \\
\text { Bumble Bee } \\
\text { Bumble Bee } \\
\text { Bumble Bee } \\
\text { Hutch Mtn }\end{array}$ \\
\hline $\begin{array}{l}\text { Bill Back Park } \\
\text { Bill Back Spring } \\
\text { Bill Canyon } \\
\text { Bill Dick Spring } \\
\text { Bill Dick Tank } \\
\text { Bill Earl Spring } \\
\text { Billie Creek } \\
\text { See Billy Creek } \\
\text { Billings Gap } \\
\text { Billings Gap Tank }\end{array}$ & $\begin{array}{l}\text { flat } \\
\text { spring } \\
\text { valley } \\
\text { spring } \\
\text { reservoir } \\
\text { spring } \\
\text { stream } \\
\text { gap } \\
\text { reservoir }\end{array}$ & $\begin{array}{l}\text { BGN } \\
\text { BGN } \\
\text { BGN } \\
\text { BGN } \\
\text { BGN } \\
\text { BGN } \\
\text { VARIANT } \\
\text { BGN } \\
\text { BGN }\end{array}$ & $\begin{array}{l}\text { Coconino } \\
\text { Coconino } \\
\text { Graham } \\
\text { Coconino } \\
\text { Coconino } \\
\text { Apache } \\
\text { Navajo } \\
\text { Apache } \\
\text { Apache }\end{array}$ & $\begin{array}{l}344550 \mathrm{~N} 1112707 \mathrm{~W} \\
344757 \mathrm{~N} 1113042 \mathrm{~W} \\
325616 \mathrm{~N} 1092643 \mathrm{~W} \\
344705 \mathrm{~N} 1112828 \mathrm{~W} \\
343752 \mathrm{~N} 1112310 \mathrm{~W} \\
334344 \mathrm{~N} 1092310 \mathrm{~W} \\
\\
341018 \mathrm{~N} 1095848 \mathrm{~W} \\
34562 \mathrm{BN} 1094410 \mathrm{~W} \\
345639 \mathrm{~N} 1094403 \mathrm{~W}\end{array}$ & $325922 \mathrm{N1092B15W}$ & & $\begin{array}{l}\text { Hutch Mtn } \\
\text { Stoneman Lake } \\
\text { Gila Box } \\
\text { Hutch Mtn } \\
\text { Happy Jack } \\
\text { Hoodoo Knob } \\
\text { Sorrel Horse Mesa } \\
\text { Sorrel Horse Mesa }\end{array}$ \\
\hline $\begin{array}{l}\text { Billingsley Creek } \\
\text { Billingsley Dam } \\
\text { Billingsley Number Four Dam } \\
\text { Billingsley Number Three Dam } \\
\text { Billingsley Number Two Dam } \\
\text { Billings ley Reservoir Number } \\
\text { Four } \\
\text { Billingsley Reservoir Number } \\
\text { Three } \\
\text { Billings ley Reservoir Number } \\
\text { Two }\end{array}$ & $\begin{array}{l}\text { stream } \\
\text { dam } \\
\text { dam } \\
\text { dam } \\
\text { dam } \\
\text { reservoir } \\
\text { reservoir } \\
\text { reservoir }\end{array}$ & $\begin{array}{l}\text { BGN } \\
\text { UNOFF } \\
\text { UNOFF } \\
\text { UNOFF } \\
\text { UNOFF } \\
\text { BGN } \\
\text { BGN } \\
\text { BGN }\end{array}$ & $\begin{array}{l}\text { Graham } \\
\text { Graham } \\
\text { Yavapai } \\
\text { Yavapai } \\
\text { Yavapai } \\
\text { Yavapai } \\
\text { Yavapai } \\
\text { Yavapai }\end{array}$ & $\begin{array}{l}325611 N 1095206 \mathrm{~W} \\
325648 \mathrm{~N} 1095100 \mathrm{~W} \\
341348 \mathrm{~N} 1125036 \mathrm{~W} \\
341454 \mathrm{~N} 1125130 \mathrm{~W} \\
341342 \mathrm{~N} 1125124 \mathrm{~W} \\
341348 \mathrm{~N} 1125036 \mathrm{~W} \\
341454 \mathrm{~N} 1125130 \mathrm{~W} \\
341342 \mathrm{~N} 1125124 \mathrm{~W}\end{array}$ & $325927 N 1094752 \mathrm{~W}$ & & $\begin{array}{l}\text { Pima } \\
\text { Pima } \\
\text { Congress } \\
\text { Congress } \\
\text { Congress } \\
\text { Congress } \\
\text { Congress } \\
\text { Congress }\end{array}$ \\
\hline $\begin{array}{l}\text { Billingsley Spring } \\
\text { Bill Lee Spring } \\
\text { Bill McClintock Draw } \\
\text { Bill Riley Creek } \\
\text { Bill Riley Spring } \\
\text { Bill Schroeder Tank } \\
\text { Bill Simms Spring } \\
\text { Bill Spring } \\
\text { Bills Spring } \\
\text { Bills Tank }\end{array}$ & $\begin{array}{l}\text { spring } \\
\text { spring } \\
\text { valley } \\
\text { stream } \\
\text { spring } \\
\text { reservoir } \\
\text { spring } \\
\text { spring } \\
\text { spring } \\
\text { reservoir }\end{array}$ & $\begin{array}{l}\text { BGN } \\
\text { BGN } \\
\text { BGN } \\
\text { BGN } \\
\text { BGN } \\
\text { BGN } \\
\text { BGN } \\
\text { BGN } \\
\text { BGN } \\
\text { BGN }\end{array}$ & $\begin{array}{l}\text { Yavapai } \\
\text { Gila } \\
\text { Coconino } \\
\text { Apache } \\
\text { Apache } \\
\text { Gila } \\
\text { Graham } \\
\text { Gila } \\
\text { Pima } \\
\text { Gila }\end{array}$ & $\begin{array}{l}341627 N 1125632 \mathrm{~W} \\
334240 \mathrm{~N} 1105045 \mathrm{~W} \\
342735 \mathrm{~N} 1110923 \mathrm{~W} \\
340155 \mathrm{~N} 1092322 \mathrm{~W} \\
335926 \mathrm{~N} 1092325 \mathrm{~W} \\
335139 \mathrm{~N} 1101945 \mathrm{~W} \\
332517 \mathrm{~N} 1095602 \mathrm{~W} \\
340044 \mathrm{~N} 1104810 \mathrm{~W} \\
315303 \mathrm{~N} 1111246 \mathrm{~W} \\
342224 \mathrm{~N} 1113648 \mathrm{~W}\end{array}$ & $\begin{array}{l}342424 \mathrm{~N} 1111010 \mathrm{~W} \\
335922 \mathrm{~N} 1092315 \mathrm{~W}\end{array}$ & & $\begin{array}{l}\text { Date } \\
\text { Oagger Peak } \\
\text { Oane Canyon } \\
\text { Greer } \\
\text { Big Lake North } \\
\text { Carrizo SE } \\
\text { Natanes Mts NW } \\
\text { Gentry Mtn } \\
\text { Samaniego Peak } \\
\text { Cane Springs Mtn }\end{array}$ \\
\hline $\begin{array}{l}\text { Bills Tank } \\
\text { Bills Tank } \\
\text { Bills Tank } \\
\text { Bill Tank } \\
\text { Bill West Tank } \\
\text { Bill Williams Fork } \\
\text { See Bill Williams River } \\
\text { Bill Williams Fork } \\
\text { See Trout Creek } \\
\text { Bill Williams Fork River } \\
\text { See Bill Williams River }\end{array}$ & $\begin{array}{l}\text { reservoir } \\
\text { reservoir } \\
\text { reservoir } \\
\text { reservoir } \\
\text { reservoir } \\
\text { stream } \\
\text { stream } \\
\text { stream }\end{array}$ & $\begin{array}{l}\text { BGN } \\
\text { BGN } \\
\text { BGN } \\
\text { BGN } \\
\text { BGN } \\
\text { VARIANT } \\
\text { VARIANT } \\
\text { VARIANT }\end{array}$ & $\begin{array}{l}\text { Yavapai } \\
\text { Coconino } \\
\text { Coconino } \\
\text { Coconino } \\
\text { Yavapai } \\
\text { Yuma } \\
\text { Mohave } \\
\text { Yuma }\end{array}$ & $\begin{array}{l}343510 \mathrm{~N} 1114823 \mathrm{~W} \\
345243 \mathrm{~N} 1111658 \mathrm{~W} \\
355337 \mathrm{~N} 1122520 \mathrm{~W} \\
350626 \mathrm{~N} 1114801 \mathrm{~W} \\
342949 \mathrm{~N} 1120733 \mathrm{~W} \\
341816 \mathrm{~N} 1140804 \mathrm{~W} \\
345521 \mathrm{~N} 1133735 \mathrm{~W} \\
341816 \mathrm{~N} 1140804 \mathrm{~W}\end{array}$ & & & $\begin{array}{l}\text { Camp Verde } \\
\text { Kinnikinick Lake } \\
\text { Box K Ranch } \\
\text { Dutton Hill } \\
\text { Mayer }\end{array}$ \\
\hline $\begin{array}{l}\text { Bill Williams Mountain } \\
\text { Bill Williams Mountains } \\
\text { Williams Mountains } \\
\text { Bill Williams Mountains } \\
\text { See Mohave Mountains } \\
\text { Bill Williams River } \\
\text { Bill Williams Fork } \\
\text { Bill Williams Fork River } \\
\text { Williams River } \\
\text { Bill Willians Spring }\end{array}$ & $\begin{array}{l}\text { range } \\
\text { stream }\end{array}$ & $\begin{array}{l}\text { BGN } \\
\text { BGN } 1961 \\
\text { VARIANT } \\
\text { VARIANT } \\
\text { BGN } 1943 \\
\text { VARIANT } \\
\text { VARIANT } \\
\text { VARIANT } \\
\text { BGN }\end{array}$ & $\begin{array}{l}\text { Coconino } \\
\text { Mohave }\end{array}$ & $\begin{array}{l}351158 \mathrm{~N} 1121215 \mathrm{~W} \\
342000 \mathrm{~N} 1140146 \mathrm{~W} \\
343818 \mathrm{~N} 1142314 \mathrm{~W} \\
341816 \mathrm{~N} 1140804 \mathrm{~W}\end{array}$ & $341838 N 1133133 \mathrm{~W}$ & 8800 & $\begin{array}{l}\text { Williams South } \\
\text { Monkeys Head }\end{array}$ \\
\hline $\begin{array}{l}\text { Bill Willians Spring } \\
\text { Bill Williams Tank } \\
\text { Bill Woods Tank } \\
\text { Billy Back Draw } \\
\text { Billy Back Spring } \\
\text { Billy Back Tank } \\
\text { Billy Creek }\end{array}$ & $\begin{array}{l}\text { spring } \\
\text { reservoir } \\
\text { reservoir } \\
\text { valley } \\
\text { spring } \\
\text { reservoir } \\
\text { stream }\end{array}$ & $\begin{array}{l}\text { BGN } \\
B G N \\
B G N \\
B G N \\
B G N \\
B G N \\
B G N\end{array}$ & $\begin{array}{l}\text { Pima } \\
\text { Cochise } \\
\text { Santa Cruz } \\
\text { Coconino } \\
\text { Coconino } \\
\text { Coconino } \\
\text { Navajo }\end{array}$ & $\begin{array}{l}322629 \mathrm{~N} 1104742 \mathrm{~W} \\
315400 \mathrm{~N} 1102642 \mathrm{~W} \\
312454 \mathrm{~N} 1102953 \mathrm{~W} \\
350303 \mathrm{~N} 1111956 \mathrm{~W} \\
350102 \mathrm{~N} 1112054 \mathrm{~W} \\
350300 \mathrm{~N} 1111956 \mathrm{~W} \\
341018 \mathrm{~N} 1095848 \mathrm{~W}\end{array}$ & $\begin{array}{l}350020 \mathrm{~N} 1112116 \mathrm{~W} \\
340645 \mathrm{~N} 1095347 \mathrm{~W}\end{array}$ & & $\begin{array}{l}\text { Mt Lemmon } \\
\text { Mescal } \\
\text { Huachuca Peak } \\
\text { Ell jott Canyon } \\
\text { Elliott Canyon } \\
\text { Elliott Canyon } \\
\text { Lakeside }\end{array}$ \\
\hline
\end{tabular}


NATIONAL GAZETTEER--ARIZONA 1986 FEATURE NAME

Billie Creek

Billy Goat Knolls

Billy Goat Spring

Billy Goat Wash

Billy Lawrence Canyon

Billy Lawrence Creek

Billy Lynch Well

Billy Mack Mine

Billy Mack Mountain

Billy Sink

Billy Spring

Billy Spring

Billys Tank

Billy Tank

Billy Wash

Biltmore Fashion Park

Shopping Center

Biltmore Gates (subdivision)

Biltmore Greens III

(subdivision)

Biltmore Shopping Center

Biltmore Villas (subdivision)

Bimetals Mine

Bingham Peak

See Brigham Peak

Binghampton Mine

Bingham Ranch

Binne Etteni Canyon

Birchett Park

Birch Mesa

Birch Mesa Airport

See Payson Airport

Birch Mesa Tanks

Birdcage Windmill

Bird Canyon

Bird Canyon

Bird Nest Hill

Bird Spring

Bird Spring Canyon

Bird Springs

Bird Springs Wash

Bird Tank

Bird Tank

Birkner Tank

Bisbee

See Lowe 11

Bisbee

Bisbee City Hall

Bisbee-Douglas International

Airport

Bisbee High School

Bisbee Junction

Bisbee Junction Railroad

Station

Bisbee Municipal Airport

Bisbee Post Office

Bisbee Railroad Station

Bisbee West

Biscuit Flat

Biscuit Hill

Biscuit Hill Tank

Biscuit Peak

Biscuit Peak Spring

Biscuit Tank

Bisdotl' is desaki

See Round Rock

Bis-E-Ahi Wash

See Bis Ii Ah Wash

Bis-E-Ah Wash

See Bis Ii Ah Wash

Bishop and Burr Reservoir

\section{FEATURE \\ CLASS}

STATUS
VARIANT

BGN Apache 354230N1090350W

$\begin{array}{llll}\text { stream } & \text { BGN } & \text { Coconino } & 362011 N 1112923 \mathrm{~W} \\ \text { valley } & \text { BGN } & \text { Gila } & 335231 \mathrm{N1105256 \textrm {W }} \\ \text { stream } & \text { BGN } & \text { Gila } & 335231 \mathrm{~N} 1105256 \mathrm{~W} \\ \text { well } & \text { UNOFF } & \text { Apache } & 352418 \mathrm{~N} 1093711 \mathrm{~W} \\ \text { mine } & \text { UNOFF } & \text { Yuma } & 341121 \mathrm{~N} 1141123 \mathrm{~W} \\ \text { summit } & \text { BGN } & \text { Yuma } & 341132 \mathrm{~N} 1141100 \mathrm{~W} \\ \text { basin } & \text { BGN } & \text { Coconino } & 364155 \mathrm{~N} 1121220 \mathrm{~W} \\ \text { spring } & \text { BGN } & \text { Yavapai } & 342805 \mathrm{~N} 1130830 \mathrm{~W} \\ \text { spring } & \text { BGN } & \text { Coconino } & 360711 \mathrm{~N} 1111711 \mathrm{~W} \\ \text { reservoir } & \text { BGN } & \text { Coconino } & 343223 \mathrm{~N} 1111514 \mathrm{~W}\end{array}$

reservoir BGN Yavapai 342349N1114854W

stream BGN Navajo 350858N1101631W

locale UNOFF Maricopa 333038N1120139W

ppl BGN Maricopa 333121N1120100W

BGN Maricopa

locale UNOFF Maricopa 332850N1120144W

ppl BGN Maricopa 333045N1120115W

mine UNOFF Yavapai 341453N1121344W

$\begin{array}{llll}\text { summit } & \text { VARIANT } & \text { Greenlee } & 332607 \text { N1091830W } \\ \text { mine } & \text { UNOFF } & \text { Yavapai } & 342721 \text { N1121138W } \\ \text { locale } & \text { UNOFF } & \text { Pima } & 322715 \mathrm{~N} 1102900 \mathrm{~W} \\ \text { valley } & \text { BGN } & \text { Coconino } & 364014 \mathrm{N1104951 \textrm {W }} \\ \text { park } & \text { ADMIN } & \text { Maricopa } & 332454 \mathrm{N1115618W} \\ \text { summit } & \text { BGN } & \text { Gila } & 341515 \mathrm{~N} 1112003 \mathrm{~W} \\ & \text { VARIANT } & & \\ \text { airport } & & \text { Gila } & 341524 N 1112020 \mathrm{~W} \\ \text { reservoir } & \text { BGN } & \text { Gila } & 341523 \mathrm{~N} 1112212 \mathrm{~W}\end{array}$

reservoir BGN Gila $341523 \mathrm{~N} 1112212 \mathrm{~W}$

locale BGN Graham 323753N1100B06W

valley BGN Pima 321935N1104931W

valley BGN Greenlee 331121N1091317W

summit BGN Pima 315702N1115718W

spring BGN Yavapai $340559 \mathrm{~N} 1121345 \mathrm{~W}$

valley BGN Navajo 341213N1102300W

spring BGN Navajo 351836N1103729W

valley BGN Navajo 351644N1104446h

reservoir BGN

reservoir BGN Coconino 351946N1120607W

reservoir BGN Greenlee 331215N1092356W

$\mathrm{pp} 1$

ppl

building

airport

school

ppl

building

VARIANT

ADMIN

Cochise

$312540 \mathrm{~N} 1095335 \mathrm{~W}$

$312653 \mathrm{~N} 1095540 \mathrm{~W}$

$312630 \mathrm{~N} 1095445 \mathrm{~W}$

$312803 \mathrm{~N} 1093610 \mathrm{~W}$

$312450 \mathrm{~N} 1095318 \mathrm{~W}$

$312105 \mathrm{~N} 1095308$

$312102 \mathrm{~N} 1095313 \mathrm{~W}$

airport ADMIN Cochise 312150N1095257W

building UNOFF Cochise 312628N1095455W

building UNOFF Cochise 312532N1095330W

mine UNOFF

mine

summit

reservoir

summit

spring

reservoir

BGN

BGN

BGN

BGN

BGN 1975

Cochise

Cochise

Yavapai

Yavapai

Graham

Graham

Maricopa

$312458 \mathrm{N1095613 \textrm {W }}$

$334722 \mathrm{~N} 1120946 \mathrm{~W}$

$350612 \mathrm{~N} 1130806 \mathrm{~W}$

$350617 \mathrm{~N} 1130757 \mathrm{~W}$

$324316 \mathrm{~N} 1102543 \mathrm{~W}$

$324251 \mathrm{~N} 1102500 \mathrm{~W}$

$334817 \mathrm{~N} 1120828 \mathrm{~W}$

$\begin{array}{lll}\text { locale } & \text { VARIANT } & \\ \text { valley } & \text { VARIANT } & \text { Apache } \\ \text { valley } & \text { VARIANT } & \text { Apache } \\ \text { reservoir } & \text { BGN } & \begin{array}{l}\text { Apache } \\ \text { Mohave }\end{array}\end{array}$

summit SARIANT

summit BGN Coconino 362004N1113313W $\begin{array}{cc}\text { SOURCE } & \text { ELEV } \\ \text { COORDINATE } & \text { FT MAP NAME }\end{array}$

Bodaway Mesa

Window Rock

362048N1113208W The Gap

335155N1105435W Aztec Peak

335155N1105435W Aztec Peak

6177 Klagetoh South

Cross Roads

1237 Cross Roads

Jacob Lake

Thorn Peak

Moenave SE

Long Valley

Horner Mtn

\begin{tabular}{|c|c|c|}
\hline \multirow[t]{2}{*}{$363627 \mathrm{~N} 1104820 \mathrm{~W}$} & 5237 & $\begin{array}{l}\text { Mayer } \\
\text { Redington } \\
\text { Inscription Hse Ruin } \\
\text { Tempe } \\
\text { Payson North }\end{array}$ \\
\hline & & Payson North \\
\hline \multirow[t]{3}{*}{$\begin{array}{l}322218 \mathrm{~N} 1104913 \mathrm{~W} \\
331316 \mathrm{~N} 1091414 \mathrm{~W}\end{array}$} & $\begin{array}{l}2819 \\
5207\end{array}$ & $\begin{array}{l}\text { Eureka Ranch } \\
\text { Sabino Canyon } \\
\text { Dix Creek } \\
\text { Sells West } \\
\text { Black Canyon City } \\
\text { Bear Ridge } \\
\text { Elephant Butte } \\
\text { Bird Springs Wash } \\
\text { Portal Peak } \\
\text { Sitgreaves Mtn }\end{array}$ \\
\hline & & Coronado Mtn \\
\hline & & $\begin{array}{l}\text { Bisbee } \\
\text { Bisbee } \\
\text { Douglas NE } \\
\text { Bisbee } \\
\text { Naco } \\
\text { Naco }\end{array}$ \\
\hline
\end{tabular}

4783 Naco

Bisbee

Bisbee

Bisbee

Biscuit Flat

5320 Anvil Rock Ranch

Anvil Rock Ranch

Rhodes Peak

Rhodes Peak

Biscuit Flat $\begin{aligned} 350419 N 1101321 W & \begin{array}{l}\text { Rotten Bananas Butte } \\ \text { Sunnys lope }\end{array} \\ 1260 & \begin{array}{l}\text { Sunnys lope } \\ \text { Sunnys lope }\end{array} \\ 1340 & \begin{array}{l}\text { Phoenix } \\ \text { Sunnys lope } \\ \text { Bumble Bee }\end{array}\end{aligned}$

$\begin{aligned} 350419 N 1101321 W & \begin{array}{l}\text { Rotten Bananas Butte } \\ \text { Sunnys lope }\end{array} \\ 1260 & \begin{array}{l}\text { Sunnys lope } \\ \text { Sunnys lope }\end{array} \\ 1340 & \begin{array}{l}\text { Phoenix } \\ \text { Sunnys lope } \\ \text { Bumble Bee }\end{array}\end{aligned}$

$\begin{aligned} 350419 N 1101321 W & \begin{array}{l}\text { Rotten Bananas Butte } \\ \text { Sunnys lope }\end{array} \\ 1260 & \begin{array}{l}\text { Sunnys lope } \\ \text { Sunnys lope }\end{array} \\ 1340 & \begin{array}{l}\text { Phoenix } \\ \text { Sunnys lope } \\ \text { Bumble Bee }\end{array}\end{aligned}$

$\begin{aligned} 350419 N 1101321 W & \begin{array}{l}\text { Rotten Bananas Butte } \\ \text { Sunnys lope }\end{array} \\ 1260 & \begin{array}{l}\text { Sunnys lope } \\ \text { Sunnys lope }\end{array} \\ 1340 & \begin{array}{l}\text { Phoenix } \\ \text { Sunnys lope } \\ \text { Bumble Bee }\end{array}\end{aligned}$

$\begin{aligned} 350419 N 1101321 W & \begin{array}{l}\text { Rotten Bananas Butte } \\ \text { Sunnys lope }\end{array} \\ 1260 & \begin{array}{l}\text { Sunnys lope } \\ \text { Sunnys lope }\end{array} \\ 1340 & \begin{array}{l}\text { Phoenix } \\ \text { Sunnys lope } \\ \text { Bumble Bee }\end{array}\end{aligned}$

$\begin{aligned} 350419 N 1101321 W & \begin{array}{l}\text { Rotten Bananas Butte } \\ \text { Sunnys lope }\end{array} \\ 1260 & \begin{array}{l}\text { Sunnys lope } \\ \text { Sunnys lope }\end{array} \\ 1340 & \begin{array}{l}\text { Phoenix } \\ \text { Sunnys lope } \\ \text { Bumble Bee }\end{array}\end{aligned}$

$\begin{aligned} 350419 N 1101321 W & \begin{array}{l}\text { Rotten Bananas Butte } \\ \text { Sunnys lope }\end{array} \\ 1260 & \begin{array}{l}\text { Sunnys lope } \\ \text { Sunnys lope }\end{array} \\ 1340 & \begin{array}{l}\text { Phoenix } \\ \text { Sunnys lope } \\ \text { Bumble Bee }\end{array}\end{aligned}$ 


\begin{tabular}{|c|c|c|c|c|c|c|c|}
\hline FEATURE NAME & $\begin{array}{l}\text { FEATURE } \\
\text { CLASS }\end{array}$ & STATUS & COUNTY & COOROINATE & $\begin{array}{l}\text { SOURCE } \\
\text { COORDINATE }\end{array}$ & $\begin{array}{l}\text { ELEV } \\
\text { FT }\end{array}$ & MAP NAME \\
\hline $\begin{array}{l}\text { Bishop Camp } \\
\text { Bishop Creek } \\
\text { Bishop Knoll }\end{array}$ & $\begin{array}{l}\text { locale } \\
\text { stream } \\
\text { summit }\end{array}$ & $\begin{array}{l}\text { BGN } \\
\text { BGN } \\
\text { BGN }\end{array}$ & $\begin{array}{l}\text { Coconino } \\
\text { Yavapai } \\
\text { Gila }\end{array}$ & $\begin{array}{l}360 \mathrm{~B} 30 \mathrm{~N} 1124 \mathrm{~B} 49 \mathrm{~W} \\
341422 \mathrm{~N} 1120358 \mathrm{~W} \\
340852 \mathrm{~N} 1111733 \mathrm{~W}\end{array}$ & $341755 \mathrm{~N} 1114720 \mathrm{~W}$ & 4838 & $\begin{array}{l}\text { Yunosi Point } \\
\text { Joes Hill } \\
\text { Payson South }\end{array}$ \\
\hline $\begin{array}{l}\text { Bishop Knoll Tank } \\
\text { Bishop Lake } \\
\text { See Bishop Lake } \\
\text { Bishop Lake } \\
\text { Bishop Lake } \\
\text { Bishop Lake } \\
\text { See Stone Lake } \\
\text { Bishop Nose } \\
\text { Bishop Peak Tank } \\
\text { Bishop Place }\end{array}$ & $\begin{array}{l}\text { reservoir } \\
\text { basin } \\
\text { basin } \\
\text { lake } \\
\text { summit } \\
\text { mine } \\
\text { locale }\end{array}$ & $\begin{array}{l}\text { BGN } \\
\text { VARIANT } \\
\text { BGN } 1976 \\
\text { VARIANT } \\
\text { VARIANT } \\
\text { BGN } \\
\text { UNOFF } \\
\text { BGN }\end{array}$ & $\begin{array}{l}\text { Coconino } \\
\text { Gila } \\
\text { Gila } \\
\text { Coconino }\end{array}$ & $\begin{array}{l}340 \mathrm{~B} 45 \mathrm{~N} 1111803 \mathrm{~W} \\
353120 \mathrm{~N} 1124040 \mathrm{~W} \\
353120 \mathrm{~N} 1124040 \mathrm{~W} \\
352810 \mathrm{~N} 1123815 \mathrm{~W} \\
340849 \mathrm{~N} 1111548 \mathrm{~W} \\
340902 \mathrm{~N} 1111805 \mathrm{~W} \\
352737 \mathrm{~N} 1124320 \mathrm{~W}\end{array}$ & & 4425 & $\begin{array}{l}\text { Payson South } \\
\text { Payson South } \\
\text { Mount Floyd }\end{array}$ \\
\hline $\begin{array}{l}\text { Bishops Nose } \\
\text { Bishop Spring } \\
\text { Bishop Spring } \\
\text { Bishops Tank } \\
\text { Bishop Tank } \\
\text { Bishop Tank } \\
\text { Bis Ii Ah Wash } \\
\text { Bis-ii-ah Wash } \\
\text { See Bis Ii Ah Wash } \\
\text { Bis Ii Ah Wash } \\
\text { Bis-E-Ahi Wash } \\
\text { Bis-E-Ah Wash } \\
\text { Bis-ij-ah Wash }\end{array}$ & $\begin{array}{l}\text { pillar } \\
\text { spring } \\
\text { spring } \\
\text { reservoir } \\
\text { reservoir } \\
\text { reservoir } \\
\text { stream } \\
\text { valley } \\
\text { valley }\end{array}$ & $\begin{array}{l}\text { BGN } \\
\text { BGN } \\
\text { BGN } \\
\text { BGN } \\
\text { BGN } \\
\text { BGN } \\
\text { BGN } \\
\text { VARIANT } \\
\text { BGN } \\
\text { VARIANT } \\
\text { VARIANT } \\
\text { VARIANT }\end{array}$ & $\begin{array}{l}\text { Navajo } \\
\text { Yavapai } \\
\text { Yavapai } \\
\text { Coconino } \\
\text { Santa Cruz } \\
\text { Coconino } \\
\text { Apache } \\
\text { Apache } \\
\text { Apache }\end{array}$ & $\begin{array}{l}344104 \mathrm{~N} 1100510 \mathrm{~W} \\
341432 \mathrm{~N} 1115308 \mathrm{~W} \\
341718 \mathrm{~N} 1114930 \mathrm{~W} \\
365827 \mathrm{~N} 1113540 \mathrm{~W} \\
312622 \mathrm{~N} 1103108 \mathrm{~W} \\
361013 \mathrm{~N} 1124516 \mathrm{~W} \\
355230 \mathrm{~N} 1093237 \mathrm{~W} \\
360015 \mathrm{~N} 1093402 \mathrm{~W} \\
360015 \mathrm{~N} 1093402 \mathrm{~W}\end{array}$ & $\begin{array}{l}354903 \mathrm{~N} 1093001 \mathrm{~W} \\
354830 \mathrm{~N} 1093000 \mathrm{~W}\end{array}$ & & $\begin{array}{l}\text { Tenmile Cedars } \\
\text { Brooklyn Peak } \\
\text { Tule Mesa } \\
\text { Ferry Swale } \\
\text { Canelo Pass } \\
\text { Yunosi Point } \\
\text { Ganado Mesa } \\
\text { Ltl White Hse Ruins }\end{array}$ \\
\hline $\begin{array}{l}\text { Bismarck Canyon } \\
\text { See Bismark Canyon } \\
\text { Bismarck Lake } \\
\text { Bismarck Mesa } \\
\text { Bismarck Mountain } \\
\text { See Thompson Peak } \\
\text { Bismark Canyon } \\
\text { Bismarck Canyon } \\
\text { Bismark Mountain } \\
\text { Bita Hache } \\
\text { See Bidahochi }\end{array}$ & $\begin{array}{l}\text { valley } \\
\text { reservoir } \\
\text { summit } \\
\text { summit } \\
\text { valley } \\
\text { summit } \\
\text { locale }\end{array}$ & $\begin{array}{l}\text { VARIANT } \\
\text { BGN } 1934 \\
\text { BGN } \\
\text { VARIANT } \\
\text { BGN } \\
\text { VARIANT } \\
\text { BGN } \\
\text { VARIANT }\end{array}$ & $\begin{array}{l}\text { Mohave } \\
\text { Coconino } \\
\text { Yavapai } \\
\text { Yavapai } \\
\text { Mohave } \\
\text { Yavapai } \\
\text { Navajo }\end{array}$ & $\begin{array}{l}352122 \mathrm{~N} 1140958 \mathrm{~W} \\
352151 \mathrm{N1} 114315 \mathrm{~W} \\
342840 \mathrm{~N} 1124723 \mathrm{~W} \\
\\
342914 \mathrm{~N} 1125604 \mathrm{~W} \\
352122 \mathrm{~N} 1140958 \mathrm{~W} \\
342859 \mathrm{~N} 1125629 \mathrm{~W} \\
352437 \mathrm{~N} 1100340 \mathrm{~W}\end{array}$ & $352151 N 1140741 \mathrm{~W}$ & 4596 & $\begin{array}{l}\text { Humphreys Peak } \\
\text { Bismarck Mesa } \\
\text { Cerbat } \\
\text { Hillside }\end{array}$ \\
\hline $\begin{array}{l}\text { Bitahachee Wash } \\
\text { See Bidahochi Wash } \\
\text { Bita Hache Wash } \\
\text { See Bidahochi Wash } \\
\text { Bitahatsi Wash } \\
\text { See Bidahochi Wash } \\
\text { Bitahochee } \\
\text { See Bidahochi } \\
\text { Bitahochee Wash } \\
\text { See Bidahochi Wash }\end{array}$ & $\begin{array}{l}\text { stream } \\
\text { stream } \\
\text { stream } \\
\text { locale } \\
\text { stream }\end{array}$ & $\begin{array}{l}\text { VARIANT } \\
\text { VARIANT } \\
\text { VARIANT } \\
\text { VARIANT } \\
\text { VARIANT }\end{array}$ & $\begin{array}{l}\text { Navajo } \\
\text { Navajo } \\
\text { Navajo } \\
\text { Navajo } \\
\text { Navajo }\end{array}$ & $\begin{array}{l}351815 N 1100615 \mathrm{~W} \\
351815 \mathrm{~N} 1100615 \mathrm{~W} \\
351815 \mathrm{~N} 1100615 \mathrm{~W} \\
352437 \mathrm{~N} 1100340 \mathrm{~W} \\
351815 \mathrm{~N} 1100615 \mathrm{~W}\end{array}$ & & & \\
\hline $\begin{array}{l}\text { Bitahotsi } \\
\text { See Bidahochi } \\
\text { Bitahotsi Wash } \\
\text { See Bidahochi Wash } \\
\text { Bitat-a Kin } \\
\text { See Betatakin Ruin } \\
\text { Bitat-a kin } \\
\text { See Betatakin Ruin } \\
\text { Bithahotshi Wash } \\
\text { See Bidahochi Wash }\end{array}$ & $\begin{array}{l}\text { locale } \\
\text { stream } \\
\text { locale } \\
\text { locale } \\
\text { stream }\end{array}$ & $\begin{array}{l}\text { VARIANT } \\
\text { VARIANT } \\
\text { VARIANT } \\
\text { VARIANT } \\
\text { VARIANT }\end{array}$ & $\begin{array}{l}\text { Navajo } \\
\text { Navajo } \\
\text { Navajo } \\
\text { Navajo } \\
\text { Navajo }\end{array}$ & $\begin{array}{l}352437 \mathrm{~N} 1100340 \mathrm{~W} \\
351815 \mathrm{~N} 1100615 \mathrm{~W} \\
364102 \mathrm{~N} 1103206 \mathrm{~W} \\
364102 \mathrm{~N} 1103206 \mathrm{~W} \\
351815 \mathrm{~N} 1100615 \mathrm{~W}\end{array}$ & & & \\
\hline $\begin{array}{l}\text { Bitlabito } \\
\text { Bitlabito Wash } \\
\text { See Beclabito Wash } \\
\text { Bitsihuit-so } \\
\text { See Bitsihuitsos Butte } \\
\text { Bitsihuitsoe Butte } \\
\text { See Bitsihuitsos Butte } \\
\text { Bitsi Huitsos Butte } \\
\text { See Bitsihuitsos Butte } \\
\text { Bits ihuitsos Butte } \\
\text { Bitsi Huitsos Butte } \\
\text { Bitsihuit-so } \\
\text { Bitsihuitsoe Butte } \\
\text { Pitsebytso } \\
\text { Pitsehytso }\end{array}$ & $\begin{array}{l}\text { locale } \\
\text { stream } \\
\text { summit } \\
\text { summit } \\
\text { summit } \\
\text { summit }\end{array}$ & $\begin{array}{l}\text { BGN } \\
\text { VARIANT } \\
\text { VARIANT } \\
\text { VARIANT } \\
\text { VARIANT } \\
\text { BGN } 1915 \\
\text { VARIANT } \\
\text { VARIANT } \\
\text { VARIANT } \\
\text { VARIANT } \\
\text { VARIANT }\end{array}$ & $\begin{array}{l}\text { Apache } \\
\text { San Juan (NM) } \\
\text { Apache } \\
\text { Apache } \\
\text { Apache } \\
\text { Apache }\end{array}$ & $\begin{array}{l}365028 N 1090111 W \\
365422 N 1085532 W \\
362453 N 1094952 W \\
362453 N 1094952 W \\
362453 N 1094952 W \\
362453 N 1094952 W\end{array}$ & & 6270 & Bitlabito \\
\hline
\end{tabular}


NATIONAL GAZETTEER--ARIZONA 1986 FEATURE NAME

Bittabito Creek

See Beclabito Wash Bittahochee

See Bidahochi

Bitter Creek

Bitter Creek

Bitter Creek

Bitter Creek

Bitter Creek

Bitter Creek

Bitter Seeps Wash

Bitter Spring

Bitter Spring

Bitter Spring

Bitter Spring

See Cedar Spring

Bitter Spring

Bitter Spring

Bitter Spring

Bitter Springs

Bitter Spring Wash

Bitters Well

See Sif Vaya

Bitter Water Bas in

Bitter Water Springs

Bitter Water Wash

Bitterwater Well

Bitter Well

See Vekol Mountains

Bitter Well

Bitter Well

Bitter Well

See Sif Vaya

Bitter Well Mountains

See Vekol Mountains

Bitter Wells

See Sif Vaya

Bitter Well Wash

Bitumul Tank

Bixby Number One Well

Bixby Ranch

Bixby Well Number Two

Bixler Mountain

Bixler Tank

BK Tank

Black Alder Spring

Black Bear Spring

Black Bear Spring

Black Bear Spring

Black Beauty Mine

Black Beauty Mine

Blackberry Spring

Blackberry Spring

Black Bess Shaft

Black Bil

See Black Bottom Crater

Black Bill Park

Black Bill Tank

Blackbird Mine

Black Bottom Crater Black Bill Flat Black Hill Park Cohonini Park

Blackbridge Picnic Area

Black Brush Flat

Blackburn Tank

Black Butte

Black Butte

Black Butte

Black Butte

Black Butte

Black Butte
FEATURE CLASS

STATUS

COUNTY

COORDINATE

VARIANT San Juan (NM) 365422N1085532W

$\begin{array}{llll}\text { stream } & \text { VARIANT } & \text { San Juan (NM) } & 365422 \mathrm{~N} 1085532 \mathrm{~W} \\ \text { locale } & & \text { Navajo } & 352437 \mathrm{~N} 1100340 \mathrm{~W}\end{array}$

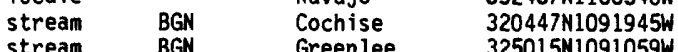

stream BGN Yavapai 335906N1122210W

stream BGN Mohave 344208N1132350W

stream BGN Yavapai 344636N1120253W

strean

spring

spring

spring

spring

spring

spring

pp

BGN Mohave

BGN Graham

BGN Graham

BGN

VARIANT

Mohave

BGN

BGN

BGN

valley

locale

basin

spring

valley

well

range

well

well

BGN

VARIANT

BGN

Apache

BGN Apache

BGN Apache

VARIANT

Pinal

Pinal
Pinal

locale

range

locale

stream

reservoir

well

locale
well
summit
reservoir
reservoir
spring
spring
spring
spring
mine

UNOFF

UNOFF

BGN

BGN

BGN

$B G N$

$B G N$

BGN

BGN

UNOFF

mine

spring

spring

UNOFF

BGN

BGN

UNOFF

VARIANT

crater

flat

reservoir

mine

crater

BGN 1933 Coconino

Coconino

NOFF Yuma

BGN Coconino

VARIANT

VARIANT

VARIANT

$\begin{array}{ll}\text { park } & \text { ADMIN } \\ \text { flat } & \text { BGN } \\ \text { reservoir } & \text { BGN } \\ \text { summit } & \text { BGN } \\ \text { summit } & \text { BGN } \\ \text { summit } & B G N \\ \text { summit } & \text { BGN } \\ \text { summit } & \text { BGN } \\ \text { summit } & \text { BGN }\end{array}$

Green lee

Coconino

Gila

Pima

Maricopa

Graham

Pinal

Maricopa

Maricopa
364712N1123B06W

$324601 N 1102252 \mathrm{~W}$

$330514 N 1101840 \mathrm{~W}$

$332035 \mathrm{~N} 1110517 \mathrm{~W}$

$352747 N 1140731 \mathrm{~W}$

$361415 \mathrm{~N} 1105400 \mathrm{~W}$

$363136 N 1123306 \mathrm{~W}$

$363933 \mathrm{~N} 1113844 \mathrm{~W}$

$363743 N 1113913 \mathrm{~W}$

361413 N1105536W

$323705 \mathrm{~N} 1120650 \mathrm{~W}$

$361241 \mathrm{N1094817 \textrm {W }}$

$361548 N 1095433 \mathrm{~W}$

360129N1094B04W

$323521 \mathrm{N1120718 \textrm {W }}$

$323703 N 1120645 \mathrm{~W}$

$361652 \mathrm{~N} 1105329 \mathrm{~W}$

323705N1120650W

323521 N1120718W

323705 N1120650W

$323633 \mathrm{~N} 1115604 \mathrm{k}$

$343043 N 1104032$

$333145 \mathrm{~N} 1104823 \mathrm{~W}$

$332738 N 1105031 \mathrm{~W}$

$333006 \mathrm{~N} 1104415 \mathrm{~W}$

$351139 \mathrm{N1121354 \textrm {W }}$

$351145 N 1121322 \mathrm{~W}$

$322221 N 1111842 W$

$341853 \mathrm{~N} 1114859 \mathrm{~W}$

$312310 \mathrm{~N} 1101715 \mathrm{~W}$

$334047 \mathrm{~N} 1111804 \mathrm{~W}$

341329N1102553K

$334403 N 1140045$

351848 N1140705W

$333255 \mathrm{~N} 1110356 \mathrm{~W}$

$335436 \mathrm{~N} 1115051 \mathrm{~W}$

$332234 \mathrm{~N} 1105945 \mathrm{~W}$

$352354 \mathrm{~N} 1112340 \mathrm{~W}$

$351846 N 1113237 \mathrm{~K}$

$351605 \mathrm{~N} 111335 \mathrm{BW}$

$335547 \mathrm{~N} 1135849 \mathrm{~W}$

$352354 \mathrm{~N} 1112340 \mathrm{~W}$

$330152 \mathrm{~N} 1091658 \mathrm{~W}$

65B28N1105603W

$341215 N 1113323 \mathrm{~W}$

$320333 \mathrm{~N} 1121259 \mathrm{~W}$

$324235 \mathrm{~N} 1124046 \mathrm{~W}$

$325020 \mathrm{MI1} 102606 \mathrm{~W}$

$325646 \mathrm{~N} 1113929 \mathrm{~W}$

$331501 \mathrm{N1125700 \textrm {W }}$

$335035 N 1130104 \mathrm{~W}$ stream BGN Mohave 344032N1133453W

$361244 N 1094825 \mathrm{~W}$
$320510 \mathrm{~N} 1092024 \mathrm{~W}$

$325318 N 1085718 \%$

$335 B 31 N 1122932 \mathrm{~W}$

$344539 \mathrm{~N} 1132610 \mathrm{~W}$

$344425 \mathrm{~N} 1132650 \mathrm{~W}$

344447 N1120710W

365059N1123910W

$361707 N 1104719 W$

Lohali Point

Lohali Point

$361603 \mathrm{~N} 1095622 \mathrm{~W}$

Tah Chee Wash

6055 Salina

Kohatk

5538 Tonalea

$323705 N 1120839 w$

North Kome lik

Potato Wash South

Rockinstraw Mtn

3169 Globe

4839 Chrome Butte

8404 Williams South

Williams South

West of Avra

Tule Mesa

Miller Peak

Four Peaks

Bear Ridge

Plomosa Pass

Stockton $\mathrm{Hill}$

Two Bar Mtn

Humboldt Mtn

Inspiration

Sunset Crater West

Sunset Crater West

Bouse Hills West

6068 Strawberry Crater

Clifton

Chaiyahi Flat

Cypress Butte

2838 Ben Nevis Mtn

1772 Hat Mountain

4573 Oak Grove Canyon

1786 Casa Crande East

1493 Gillespie

3612 Black Butte 
FEATURE NAME

Black Butte

Black Butte

Black Butte

Black Butte

Black Butte

Black Butte

Black Butte Mine

Black Butte Spring

Black Butte Spring

Black Butte Tank

Black Butte Tank

Black Butte Wash

Black Canon

See Black Canyon

Black Canyon

Black Canyon

Black Canyon

Black Canyon

Black Canyon (historical)

Black Canyon

Black Canyon

Black Canyon

Black Canyon

Black Canyon

Black Canyon

Black Canyon

Black Canyon

Brookbank Canyon

Buckskin Canyon

Black Canon

Lower Black Canyon

Black Canyon

Black Canyon

Black Canyon

See Black Canyon City

Black Canyon Campground

Black Canyon City

Black Canyon

Canon

Canyon

Goddards

Black Canyon City Post Office Black Canyon Creek

Black Canyon Dam

Black Canyon Greyhound Park

Black Canyon Interchange

Black Canyon Lake

Black Canyon Reservoir

Black Canyon Rim Campground

Black Canyon School Canon Elementary School Canon School

Black Canyon Shooting Range Black Canyon Shopping Center

Black Canyon Spring

Black Canyon Spring

Black Canyon Spring

Black Canyon Spring

Black Canyon Spring

Black Canyon Tank

Black Canyon Tank

Black Canyon Wash See Westwater Wash

Black Canyon Wash

Black Canyon Wash See Hackberry Wash

Black Canyon Wel

Black Canyon Well

Black Canyon Windmill

\section{FEATURE}

summ it

STATUS

COUNTY

BGN

Yavapai

COORDINATE

340146 N1122753W

summit

sumanit

sumanit

summ it

mine

spring

spring

reservoir

reservoir

BGN Yuma 340436N1133252W

BGN Yuma 340436N1133252W

$\begin{array}{lll}\text { BGN } & \text { Yavapai } & 344854 N 1130430 \mathrm{~W} \\ \text { BGN } & \text { Mohave } & 345625 \mathrm{~N} 1132208 \mathrm{~W}\end{array}$

BGN Navajo 351750N1100557W

BGN Mohave 355533N1143329W

$323153 N 1141610 \mathrm{~W}$

BGN $\quad$ Yavapai 34700 31120619W

BGN Navajo 351759N1100529W

BGN Yavapai 342428N1120105W

Mohave 345634N1132303W

stream

BGN

VARIANT

valley

valley

valley

valley

valley

valley

valley

valley

valley

valley

valley

valley

valley

valley

valley

BGN

BGN

BGN

BGN 1917

BGN

BGN

Yavapai

340214N1122655W

$354820 \mathrm{~N} 1144239 \mathrm{~W}$

$323814 \mathrm{~N} 1100918 \mathrm{~W}$

$325509 \mathrm{~N} 1092712 \mathrm{~W}$

$325721 \mathrm{~N} 1102524 \mathrm{~W}$

$325810 \mathrm{~N} 1093237 \mathrm{~W}$

$333200 \mathrm{~N} 1112700 \mathrm{~W}$

$335923 \mathrm{~N} 1095426 \mathrm{~W}$

$340617 \mathrm{N1120936 \textrm {W }}$

BGN Yavapai

BGN
BGN
BGN

BGN

BGN

VARIANT

VARIANT

VARIANI

VARIANT

VARIANT

Yavapai

Mohave

Yavapai

Mohave

Navajo

Mohave

(2)

342149 N1125559W

$342 B 17 N 1125134 \mathrm{~W}$

$343147 \mathrm{~N} 1132656 \mathrm{~W}$

$344105 \mathrm{~N} 1115750 \mathrm{~W}$

$344521 \mathrm{N1132940 \textrm {W }}$

$344738 \mathrm{~N} 1103621 \mathrm{~W}$

354820N1144239W

$340214 N 1122959 W$

$323600 \mathrm{~N} 1101600 \mathrm{~W}$

$325244 \mathrm{~N} 1092316 \mathrm{~W}$

$325932 \mathrm{N1} 102427 \mathrm{~W}$

$325930 \mathrm{~N} 1093547 \mathrm{~W}$

UNKNOWN

$340323 \mathrm{~N} 1095511 \mathrm{~W}$

$341420 \mathrm{~N} 1121256 \mathrm{~W}$

$342304 N 1125051 \mathrm{~W}$

$343234 N 1124917 \mathrm{~W}$

$342522 N 1132211 \mathrm{~W}$

$344020 N 1120741 \mathrm{~W}$

$344635 N 1132814 \mathrm{~W}$

341902 N1104119W

$360145 N 1144319 W$

$363502 \mathrm{~N} 1134702 \mathrm{~W}$ $363619 N 1130427 \mathrm{~W}$

$363633 \mathrm{~N} 1134706 \mathrm{~W}$

$363413 N 1130413 \mathrm{~W}$

$340415 \mathrm{~N} 1120900 \mathrm{~W}$

$341942 \mathrm{~N} 1104210 \mathrm{~W}$

$340415 \mathrm{~N} 1120900 \mathrm{~W}$

park

park

ADMIN

Yavapa

BGN 1965 Yavapai

VARIANT

VARIANT

VARIANT

VARIANT

building

strea

dam

park

crossing

lake

reservoir

park

school

UNOFF

UNOFF
BGN
BGN

park

locale

spring

spring

spring

spring

spring

reservoir

reservoir

BGN

BGN

Yavapai

stream
stream

stream

well

well

well
Yavapa

Yavapai

Yavapai

Graham

Yavapai

Mohave
340358 N1120857W $340414 N 1120925 \mathrm{~W}$ $341948 \mathrm{~N} 1104200 \mathrm{~W}$ $340513 \mathrm{~N} 1120854 \mathrm{~W}$ $340506 \mathrm{~N} 1120836 \mathrm{~W}$ $341940 \mathrm{~N} 1104200 \mathrm{~W}$ $363413 \mathrm{N1130413W}$ $341819 N 1104431 \mathrm{~W}$ 340418 N1120914W

334B20N1120902W $333310 \mathrm{N1} 120637 \mathrm{~W}$ $325753 \mathrm{~N} 1102523 \mathrm{~W}$ $340145 \mathrm{~N} 1095408 \mathrm{~W}$ $342825 \mathrm{~N} 1132331 \mathrm{~W}$ 343949 N1120720W $344517 N 1132937 \mathrm{~W}$ $340042 \mathrm{~N} 1095426 \mathrm{~W}$ $354309 \mathrm{~N} 1134926 \mathrm{~W}$

$341904 \mathrm{N1} 130850 \mathrm{~W}$ $342120 \mathrm{N1} 131225 \mathrm{~W}$

$342122 \mathrm{N1} 131222 \mathrm{~W}$ $323736 \mathrm{~N} 1100949 \mathrm{~W}$ $342623 \mathrm{~N} 1120118 \mathrm{~W}$ $364919 \mathrm{~N} 1132111 \mathrm{~W}$
BGN

UNOFF

ADMIN

ADMIN

VARIANT

VARIANT

ADMIN

UNOFF

BGN

BGN

BGN

Yavapai

Navajo

Yavapai

Yavapai

Navajo

Mohave

Navajo

Yavapai

Maricopa

Maricopa

Graham

Navajo

Mohave

Yavapai

Mohave

Navajo

Mohave

VARIANT

341420N1121254W

UNOFF 
NATIONAL GAZETTEER--ARIZONA 1986

FEATURE NAME

Blackcat Mine

Black Cave

Black Circle Mountain

Black Creek

Black Creek Valley

Black Creek Valley See Red Valley

Black Cross Butte

Black Cross Butte

Black Dahlia Mine

Black Diamond

Black Diamond Mine

Black Diamond Mine

Black Diamond Mine

Black Diamond Peak

Black Diamond Spring

See Diamond Spring

Black Diamond Tank

Black Dike Mine

Black Dome

Black Draw

Black Eagle Canyon

Black Eagle Mine

Black Eagle Mine

Black Eagle Mine

Black Falls

Black Falls Bible Church

Black Falls Crossing

Blackfield Canyon

Blackfoot Mine

Black Forest

See Prescott National Forest

Black Forest

Black Gap

Black Gap

Black Gap

Black Gap Well

Black Grama Tank

Blackhawk Mine

Black Hawk Mine

Black Hawk Mine

Blackhawk Mines

Black Hawk Tank

Black Hill

See Black Mountain

Black Hill

Black Hill

See Black Mountain

Black Hill

Black Hill

Black Hill

Black Hill

Black Hill Park

See Black Bottom Crater

Black Hills

See Peloncillo Mountains

Black Hills

Black Hills

Black Hills

Black Hills

Black Hills

Black Hills

See Littie Black Hills

Black Hills

Black Hills

Black Hills

Black Hills

Black Hills

See Black Mountain

Black Hills

\section{FEATURE}

CLASS

mine

cave

summit

stream

valley

valley

summit

summit

mine

locale

mine

mine

summit

spring

reservoir

mine

summit

valley

valley

STATUS

COUNTY

COORDINATE

UNOFF

Yuma

Yavapai

$334458 \mathrm{~N} 1134109 \mathrm{~W}$

$335853 \mathrm{~N} 1122027 \mathrm{~W}$

BGN Pima 321921N1122908W

BGN 1959 Apache 351600N1091400W

BGN Apache

VARIANT

Apache

17 Maricopa

BGN Maricopa

UNOFF

BGN

Yuma

Cochise

$333103 \mathrm{~N} 1111614 \mathrm{~W}$

$333355 \mathrm{~N} 1112129 \mathrm{~W}$

$331615 \mathrm{~N} 1135717 \mathrm{~W}$

$315037 N 1095422 W$

$331446 \mathrm{~N} 1143524 \mathrm{~W}$

UNOFF Maricopa 334530N1130900W

UNOFF Mohave 341941N1133231W

BGN Cochise 315105N1095608W

VARIANT

Cochise

BGN Cochise

UNOFF

BGN Yuma

BGN Cochise

Graham

mine

mine UNOFF

UNOFF

falls $B G N$

church UNOFF

locale

valley

mine

forest

BGN

BGN

UNOFF

Santa Cruz

Santa Cruz

Mohave

Coconino

Coconino

Coconino

Green lee

Mohave

Yavapai

$315055 \mathrm{~N} 1095520 \mathrm{~W}$

$315049 \mathrm{~N} 1095416 \mathrm{~W}$

$315556 \mathrm{N1111659W}$

$330844 N 1134833 W$

$312056 \mathrm{~N} 1091558 \mathrm{~W}$

$323422 \mathrm{~N} 1101824 \mathrm{~W}$

$312704 \mathrm{NI} 104256 \mathrm{~W}$

$313913 N 1105225 \mathrm{~W}$

$350057 N 1142158 \mathrm{~W}$

$353351 \mathrm{~N} 1111612 \mathrm{~W}$

$353434 \mathrm{~N} 1110549 \mathrm{~W}$

$353413 \mathrm{~N} 1111630 \mathrm{~W}$

$324312 \mathrm{~N} 1090650 \mathrm{~W}$

352351 N1141047W

$343500 \mathrm{~N} 1123600 \mathrm{~W}$

\begin{tabular}{|c|c|c|c|}
\hline $\begin{array}{l}\text { woods } \\
\text { gap } \\
\text { gap } \\
\text { locale } \\
\text { well } \\
\text { reservoir } \\
\text { mine } \\
\text { mine } \\
\text { mine } \\
\text { mine }\end{array}$ & $\begin{array}{l}\text { BGN } \\
\text { BGN } \\
\text { BGN } \\
\text { BGN } \\
\text { UNOFF } \\
\text { BGN } \\
\text { UNOFF } \\
\text { UNOFF } \\
\text { UNOFF } \\
\text { UNOFF }\end{array}$ & $\begin{array}{l}\text { Apache } \\
\text { Cochise } \\
\text { Maricopa } \\
\text { Maricopa } \\
\text { Maricopa } \\
\text { Gila } \\
\text { Pima } \\
\text { Maricopa } \\
\text { Yavapai } \\
\text { Maricopa }\end{array}$ & $\begin{array}{l}350639 \mathrm{~N} 1094741 \mathrm{~W} \\
312419 \mathrm{~N} 1095247 \mathrm{~W} \\
324530 \mathrm{~N} 1124925 \mathrm{~W} \\
324746 \mathrm{~N} 1124800 \mathrm{~W} \\
324251 \mathrm{~N} 1125003 \mathrm{~W} \\
334750 \mathrm{~N} 1101301 \mathrm{~W} \\
315152 \mathrm{~N} 1111353 \mathrm{~W} \\
334218 \mathrm{~N} 1131019 \mathrm{~W} \\
343556 \mathrm{~N} 1120146 \mathrm{~W} \\
332608 \mathrm{~N} 1123738 \mathrm{~W}\end{array}$ \\
\hline reservoir & $\begin{array}{l}\text { BGN } \\
\text { VARIANT }\end{array}$ & Pima & $315215 \mathrm{~N} 1111209 \mathrm{~W}$ \\
\hline $\begin{array}{l}\text { summit } \\
\text { summit }\end{array}$ & $\begin{array}{l}\text { BGN } \\
\text { VARIANT }\end{array}$ & $\begin{array}{l}\text { Pima } \\
\text { Pinal }\end{array}$ & $\begin{array}{l}320500 \mathrm{~N} 1110317 \mathrm{~W} \\
330808 \mathrm{~N} 1112036 \mathrm{~W}\end{array}$ \\
\hline $\begin{array}{l}\text { summit } \\
\text { summit } \\
\text { summit } \\
\text { summit } \\
\text { summit }\end{array}$ & $\begin{array}{l}\text { BGN } \\
\text { BGN } \\
\text { BGN } \\
\text { BGN }\end{array}$ & $\begin{array}{l}\text { Maricopa } \\
\text { Yavapai } \\
\text { Yavapai } \\
\text { Yavapai } \\
\text { Apache }\end{array}$ & $\begin{array}{l}334855 \mathrm{N1} 115627 \mathrm{~W} \\
340029 \mathrm{N1} 125022 \mathrm{~W} \\
340109 \mathrm{N1} 121829 \mathrm{~W} \\
344145 \mathrm{~N} 1122250 \mathrm{~W} \\
365756 \mathrm{~N} 1093607 \mathrm{~W}\end{array}$ \\
\hline
\end{tabular}

VARIANT

crater

range

range

ridge

summit

summit

summit

VARIANT

$\begin{array}{ll} & \text { Graham } \\ \text { BGN } & \text { Yavapai } \\ \text { BGN } & \text { Graham } \\ \text { BGN } & \text { Pima } \\ \text { BGN } & \text { Pima } \\ \text { BGN } & \text { Pima } \\ \text { VARIANT } & \end{array}$

Pinal

summit

summit

summit

summit
summit

Yuma

Graham

VARIANT

Maricopa

Yavapai $\begin{array}{cc}\text { SOURCE } & \text { ELEV } \\ \text { COORDINATE } & \text { FT }\end{array}$

MAP NAME

Hope

Governors Peak

2368 Hickiwan

Houck

Hunters Point

4806 Horse Mesa Dam

3351 Horse Mesa Dam

Kofa Butte

Black Oiamond Peak

Hidden Valley

Tiger Well

Artillery Peak

7114 Black Diamond Peak

Biack Diamond Peak

Stevens Mtn

313417 N1091010W

2236 Engesser Pass

San Bernardino Ranch

Bassett Peak

Harshaw

Mt Wrightson

Mount Nutt

Wupatki SE

White Water Tank

Wupatki SE

323914N1091037W Duncan

Kachina Point

Bisbee

Black Gap

Black Gap

Midway

Cone Butte

Batamote Hills

Little Horn Peak

Cherry

Buckeye NW

Batamote Hills

1785 Florence NE

2770 Flores

2946 Columbia

5030 Chino Valley South

5293 Walker Creek Res 
NATIONAL GAZETTEER--ARIZONA 1986

\begin{tabular}{|c|c|c|c|c|c|c|c|}
\hline FEATURE NAME & $\begin{array}{l}\text { FEATURE } \\
\text { CLASS }\end{array}$ & STATUS & COUNTY & COORDINATE & $\begin{array}{l}\text { SOURCE } \\
\text { CDORDINATE }\end{array}$ & $\begin{array}{c}\text { ELEV } \\
\text { FT }\end{array}$ & MAP NAME \\
\hline $\begin{array}{l}\text { Black Hills } \\
\text { Black Hills } \\
\text { Black Hills Mine }\end{array}$ & $\begin{array}{l}\text { summit } \\
\text { summit } \\
\text { mine }\end{array}$ & $\begin{array}{l}\text { BGN } \\
\text { BGN } \\
\text { UNOFF }\end{array}$ & $\begin{array}{l}\text { Yavapai } \\
\text { Yavapai } \\
\text { Pinal }\end{array}$ & $\begin{array}{l}343314 N 1115619 W \\
344008 N 1120613 W \\
323238 N 1103236 W\end{array}$ & & 3324 & $\begin{array}{l}\text { Middle Verde } \\
\text { Cottonwood } \\
\text { Peppersauce Wash }\end{array}$ \\
\hline $\begin{array}{l}\text { Black Hills Mine } \\
\text { Black Hills Tank } \\
\text { Black Hills Tank } \\
\text { Black Hill Tank } \\
\text { Black Hill Tank } \\
\text { Black Hill Tank } \\
\text { Black Hill Tank } \\
\text { Black Hill Tank } \\
\text { Black Hill Wash } \\
\text { Black Horse } \\
\text { See Blackhorse Creek }\end{array}$ & $\begin{array}{l}\text { mine } \\
\text { reservoir } \\
\text { reservoir } \\
\text { reservoir } \\
\text { reservoir } \\
\text { reservoir } \\
\text { reservoir } \\
\text { reservoir } \\
\text { stream } \\
\text { stream }\end{array}$ & $\begin{array}{l}\text { UNOFF } \\
\text { BGN } \\
\text { BGN } \\
\text { BGN } \\
\text { BGN } \\
\text { BGN } \\
\text { BGN } \\
\text { BGN } \\
\text { BGN } \\
\text { VARIANT }\end{array}$ & $\begin{array}{l}\text { Yavapai } \\
\text { Pinal } \\
\text { Yavapai } \\
\text { Pima } \\
\text { Maricopa } \\
\text { Yavapai } \\
\text { Yavapai } \\
\text { Yavapai } \\
\text { Yavapai } \\
\text { Apache }\end{array}$ & $\begin{array}{l}340257 \mathrm{~N} 1124327 \mathrm{~W} \\
331230 \mathrm{~N} 1110434 \mathrm{~W} \\
345624 \mathrm{~N} 1121105 \mathrm{~W} \\
315023 \mathrm{~N} 1111955 \mathrm{~W} \\
334507 \mathrm{~N} 1114805 \mathrm{~W} \\
340050 \mathrm{~N} 1125057 \mathrm{~W} \\
342255 \mathrm{~N} 1115545 \mathrm{~W} \\
344039 \mathrm{~N} 1122142 \mathrm{~W} \\
341842 \mathrm{~N} 1120318 \mathrm{~W} \\
363742 \mathrm{~N} 1090733 \mathrm{~W}\end{array}$ & $341954 \mathrm{~N} 1120238 \mathrm{~W}$ & & $\begin{array}{l}\text { Sam Powell Peak } \\
\text { Teapot Mountain } \\
\text { Perkinsville } \\
\text { Penitas Hills } \\
\text { Wildcat Hill } \\
\text { Flores } \\
\text { Arnold Mesa } \\
\text { Prescott Valley N } \\
\text { Cordes Junction }\end{array}$ \\
\hline $\begin{array}{l}\text { Blackhorse Creek } \\
\text { Black Horse } \\
\text { Blackhorse Wash } \\
\text { Blackhorse Wash } \\
\text { See Tyende Creek } \\
\text { Blackie Spring } \\
\text { Blackies-Tank } \\
\text { Blackie Trap Canyon } \\
\text { Black Inky Spring } \\
\text { Black Jack Canyon }\end{array}$ & $\begin{array}{l}\text { stream } \\
\text { arroyo } \\
\text { stream } \\
\text { spring } \\
\text { reservoir } \\
\text { valley } \\
\text { spring } \\
\text { valley }\end{array}$ & $\begin{array}{l}\text { BGN } 1915 \\
\text { VARIANT } \\
\text { BGN } \\
\text { VARIANT } \\
\text { BGN } \\
\text { BGN } \\
\text { BGN } \\
\text { BGN } \\
\text { BGN }\end{array}$ & $\begin{array}{l}\text { Apache } \\
\text { Apache } \\
\text { Apache } \\
\text { Gila } \\
\text { Yavapai } \\
\text { Navajo } \\
\text { Mohave } \\
\text { Greenlee }\end{array}$ & $\begin{array}{l}363742 \mathrm{~N} 1090733 \mathrm{~W} \\
364945 \mathrm{~N} 1094259 \mathrm{~W} \\
364955 \mathrm{~N} 1094300 \mathrm{~W} \\
334200 \mathrm{~N} 1104030 \mathrm{~W} \\
342833 \mathrm{~N} 1113320 \mathrm{~W} \\
341244 \mathrm{~N} 1102619 \mathrm{~W} \\
350343 \mathrm{~N} 1135848 \mathrm{~W} \\
330101 \mathrm{~N} 1091014 \mathrm{~W}\end{array}$ & $\begin{array}{l}364618 N 1091054 W \\
363925 N 1095551 W\end{array}$ & & $\begin{array}{l}\text { Haystack Butte } \\
\text { Strawberry } \\
\text { Bear Ridge } \\
\text { Hualapai Peak } \\
\text { Rattlesnake Spring }\end{array}$ \\
\hline $\begin{array}{l}\text { Black Jack Cave } \\
\text { Blackjack Mine } \\
\text { Blackjack Mountain } \\
\text { See Blackjack Mountains } \\
\text { Blackjack Mountains } \\
\text { Blackjack Mountain } \\
\text { Black Jack Point } \\
\text { See Blackjack Point } \\
\text { Blackjack Point } \\
\text { Black Jack Point }\end{array}$ & $\begin{array}{l}\text { cave } \\
\text { mine } \\
\text { summit } \\
\text { summit }\end{array}$ & $\begin{array}{l}\text { BGN } \\
\text { UNOFF } \\
\text { VARIANT } \\
\text { BGN } 1967 \\
\text { VARIANT } \\
\text { VARIANT } \\
\text { BGN } 1968 \\
\text { VARIANT }\end{array}$ & $\begin{array}{l}\text { Greenlee } \\
\text { Pima } \\
\text { Gila } \\
\text { Gila }\end{array}$ & $\begin{array}{l}330229 \mathrm{~N} 1090624 \mathrm{~W} \\
322540 \mathrm{~N} 1120718 \mathrm{~W} \\
334115 \mathrm{~N} 1104200 \mathrm{~W} \\
334115 \mathrm{~N} 1104200 \mathrm{~W} \\
\\
340250 \mathrm{~N} 1115230 \mathrm{~W} \\
340250 \mathrm{~N} 1115230 \mathrm{~W}\end{array}$ & & & $\begin{array}{l}\text { Big Lue Mts } \\
\text { Drew Spring Well }\end{array}$ \\
\hline $\begin{array}{l}\text { Blackjack Rim } \\
\quad \text { See Big Lue Mountains } \\
\text { Black Jack Spring } \\
\text { Black Jack Spring } \\
\text { Blackjack Spring } \\
\text { Black Jack Spring } \\
\text { Blackjack Spring } \\
\text { Black Jack Spring } \\
\text { Blackjack Spring } \\
\text { Black Jack Spring }\end{array}$ & $\begin{array}{l}\text { summit } \\
\text { spring } \\
\text { spring } \\
\text { spring } \\
\text { spring } \\
\text { spring } \\
\text { spring } \\
\text { spring } \\
\text { spring }\end{array}$ & $\begin{array}{l}\text { VARIANT } \\
\text { BGN } \\
\text { BGN } \\
\text { BGN } \\
\text { BGN } \\
\text { BGN } \\
\text { BGN } \\
\text { BGN } \\
\text { BGN }\end{array}$ & $\begin{array}{l}\text { Greenlee } \\
\text { Greenlee } \\
\text { Maricopa } \\
\text { Yavapai } \\
\text { Yavapai } \\
\text { Yavapai } \\
\text { Yavapai } \\
\text { Mohave } \\
\text { Yavapai }\end{array}$ & $\begin{array}{l}330424 N 1090620 \mathrm{~W} \\
330227 \mathrm{~N} 1090637 \mathrm{~W} \\
332837 \mathrm{~N} 1110755 \mathrm{~W} \\
341042 \mathrm{~N} 1123840 \mathrm{~W} \\
341315 \mathrm{~N} 1122604 \mathrm{~W} \\
342033 \mathrm{~N} 1122804 \mathrm{~W} \\
343858 \mathrm{~N} 1124425 \mathrm{~W} \\
350225 \mathrm{~N} 1133115 \mathrm{~W} \\
353516 \mathrm{~N} 1123320 \mathrm{~W}\end{array}$ & & & $\begin{array}{l}\text { Big Lue Mts } \\
\text { Iron Mountain } \\
\text { Yarnell } \\
\text { Minnehaha } \\
\text { Battleship Butte } \\
\text { Mt Josh } \\
\text { Aust in Peak } \\
\text { Iron Springs }\end{array}$ \\
\hline $\begin{array}{l}\text { Black Jack Tank } \\
\text { Blackjack Tank } \\
\text { Blackjack Tank } \\
\text { Blackjack Tank } \\
\text { Black Jack Tank } \\
\text { Blackjack Tank } \\
\text { Blackjack Wash } \\
\text { Black Knob } \\
\text { Black Knob } \\
\text { Black Knob } \\
\text { Black Peak } \\
\text { Lava Butte } \\
\text { Pogue } \\
\text { Shadow Mountain }\end{array}$ & $\begin{array}{l}\text { reservoir } \\
\text { reservoir } \\
\text { reservoir } \\
\text { reservoir } \\
\text { reservoir } \\
\text { reservoir } \\
\text { stream } \\
\text { summit } \\
\text { summit } \\
\text { summit }\end{array}$ & $\begin{array}{l}\text { BGN } \\
\text { BGN } \\
\text { BGN } \\
\text { BGN } \\
\text { BGN } \\
\text { BGN } \\
\text { BGN } \\
\text { BGN } \\
\text { BGN } \\
\text { BGN } 1915 \\
\text { VARIANT } \\
\text { VARIANT } \\
\text { VARIANT } \\
\text { VARIANT }\end{array}$ & $\begin{array}{l}\text { Gila } \\
\text { Yavapai } \\
\text { Yavapai } \\
\text { Gila } \\
\text { Gila } \\
\text { Coconino } \\
\text { Gila } \\
\text { Cochise } \\
\text { Coconino } \\
\text { Coconino }\end{array}$ & $\begin{array}{l}334241 N 1103523 W \\
340221 N 1115156 \mathrm{~W} \\
340311 N 1115310 \mathrm{~W} \\
340708 \mathrm{~N} 1111043 \mathrm{~W} \\
342158 \mathrm{~N} 1113302 \mathrm{~W} \\
345308 \mathrm{~N} 1113214 \mathrm{~W} \\
334045 \mathrm{~N} 1104436 \mathrm{~W} \\
312350 \mathrm{N1} 1094853 \mathrm{~W} \\
355510 \mathrm{N1} 112758 \mathrm{~W} \\
355901 \mathrm{N11} 12748 \mathrm{~W}\end{array}$ & $333736 \mathrm{~N} 1104306 \mathrm{~W}$ & $\begin{array}{l}5837 \\
4640 \\
5422\end{array}$ & $\begin{array}{l}\text { Chrysotile } \\
\text { Rover Peak } \\
\text { Cooks Mesa } \\
\text { Sheep Basin Mtn } \\
\text { Cane Springs Mtn } \\
\text { Mormon Mountain } \\
\text { Haystack Butte } \\
\text { Bisbee NE } \\
\text { Cameron North } \\
\text { Cameron North }\end{array}$ \\
\hline $\begin{array}{l}\text { Black Knoll } \\
\text { Black Knolls } \\
\text { Black Knolls } \\
\text { Black Knoll Tank } \\
\text { Black Mesa } \\
\text { Black Mesa } \\
\text { Black Mesa } \\
\text { Black Mesa } \\
\text { Black Mesa } \\
\text { Black Mesa }\end{array}$ & $\begin{array}{l}\text { summit } \\
\text { summit } \\
\text { summit } \\
\text { reservoir } \\
\text { summit } \\
\text { summit } \\
\text { summit } \\
\text { summit } \\
\text { summit } \\
\text { summit }\end{array}$ & $\begin{array}{l}\text { BGN } \\
\text { BGN } \\
B G N \\
\text { BGN } \\
\text { BGN } \\
\text { BGN } \\
\text { BGN } \\
\text { BGN } \\
\text { BGN } \\
\text { BGN }\end{array}$ & $\begin{array}{l}\text { Apache } \\
\text { Mohave } \\
\text { Mohave } \\
\text { Apache } \\
\text { Pima } \\
\text { Graham } \\
\text { Maricopa } \\
\text { Gila } \\
\text { La Paz } \\
\text { Gila }\end{array}$ & $\begin{array}{l}345440 \mathrm{~N} 1094124 \mathrm{~W} \\
365108 \mathrm{~N} 1130417 \mathrm{~W} \\
365737 \mathrm{~N} 1133915 \mathrm{~W} \\
345325 \mathrm{~N} 1094330 \mathrm{~W} \\
312949 \mathrm{~N} 1112233 \mathrm{~W} \\
331307 \mathrm{~N} 1094325 \mathrm{~W} \\
332826 \mathrm{~N} 1112429 \mathrm{~W} \\
332846 \mathrm{~N} 1102244 \mathrm{~W} \\
333556 \mathrm{~N} 1140116 \mathrm{~W} \\
333851 \mathrm{~N} 1105324 \mathrm{~W}\end{array}$ & & $\begin{array}{l}5964 \\
4993 \\
3592 \\
\\
4651 \\
6270 \\
2850\end{array}$ & $\begin{array}{l}\text { Sorrel Horse Mesa } \\
\text { Formaster Well } \\
\text { Purgatory Canyon } \\
\text { Sorrel Horse Mesa } \\
\text { Cumero Mtn } \\
\text { Park Creek Cabins } \\
\text { Goldfield } \\
\text { Natural Corral } \\
\text { Crystal Hill } \\
\text { Meddler Wash }\end{array}$ \\
\hline $\begin{array}{l}\text { Black Mesa } \\
\text { See Sheep Mesa } \\
\text { Black Mesa }\end{array}$ & $\begin{array}{l}\text { summit } \\
\text { summit }\end{array}$ & $\begin{array}{l}\text { VARIANT } \\
\text { BGN } 1965\end{array}$ & $\begin{array}{l}\text { Maricopa } \\
\text { Maricopa }\end{array}$ & $\begin{array}{l}334302 \mathrm{~N} 1113402 \mathrm{~W} \\
334337 \mathrm{~N} 1113522 \mathrm{~W}\end{array}$ & & 2991 & Adams Mesa \\
\hline
\end{tabular}


NATIONAL GAZETTEER--ARIZONA 1986

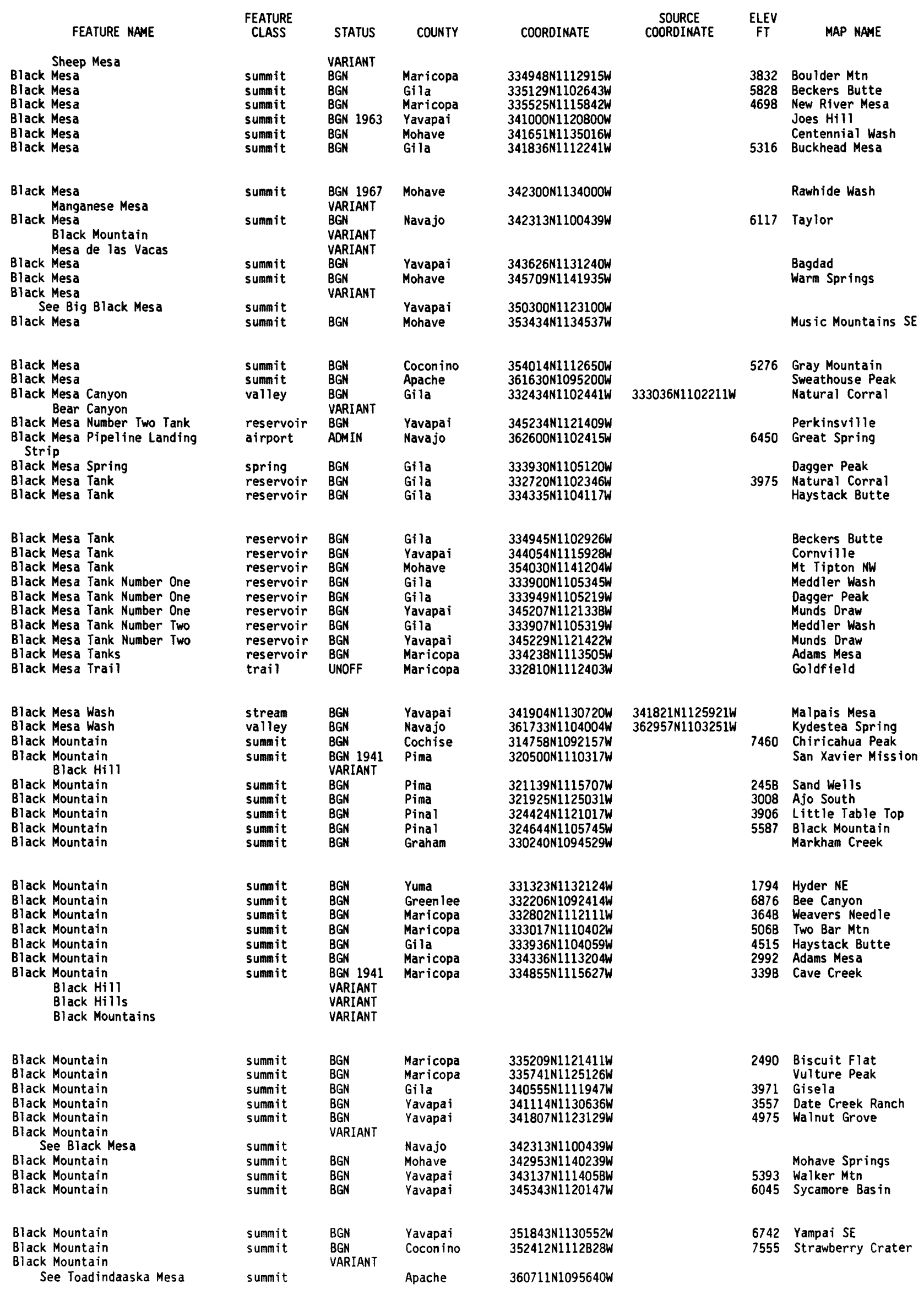


NATIONAL GAZETTEER--ARIZONA 1986

FEATURE NAME

Black Mountain Canyon Devils Windpipe

Black Mountain Canyon Tank

Black Mountain Mission

Black Mountains

See Peloncillo Mountains

Black Mountains

Black Mountains

Black Range

Sacramento Range

Saint James Range

Sierra de Santiago

Ute Mountains

Black Mountains

See Pine Mountain

Black Mountains

See Black Mountain

Black Mountain Summit Park

Black Mountain Tank

Black Mountain Tank

Black Mountain Tank

Black Mountain Tank

Black Mountain Tank

Black Mountain Trading Post

Black Mountain Wash

Black Mountain Wash

Black Mountain Well

Black Mountain Well

Black Mountain Well

Black Nugget Mine

Black Oak Cemetery

Black Pass

Black Pass Tank

Black Peak

Black Peak

Black Peak

Black Peak

See Black Knob

Black Peak

Black Pearl Mine

Black Pearl Mine

Black Pinnacle

Black Rock

Sajini Butte

Tsezhini

Black Pinnacle Campground

Black Pinnacle Spring

Black Point

Black Point

Black Point

Black Point Reservoir

Black Point Tank

Black Prince Mine

Black Princess Mine

Black Queen Mine

Black Queen Mine

Black Queen Mine

Black Range

See Black Mountains

Black Range Mine

Black Ranger

See Slate Mountains

Black Ridge

Black Ridge

Black Ridge

Black River

See Salt River

Black River

Salt River
South Fork Salt River
FEATURE
CLASS

valley

reservoir

church

range

range
range

VARIANT
VARIANT
VARIANT
VARIANT
VARIANT

summit

VARIANT

Maricopa

$334456 \mathrm{~N} 1112401 \mathrm{~W}$

Maricopa

park

reservoir

reservoir

reservoir

reservoir

reservoir

locale

stream

valley

well

ADNI
BGN
BGN
BGN
BGN
BGN
BGN
BGN
BGN
UNDFF

we11

well

mine

cenetery

gap

reservoir

summit

summit

summit

sumnit

summit

mine

mine

pillar

park

spring

bench

$$
\begin{aligned}
& \text { BGN } \\
& \text { BGN } \\
& \text { BGN } \\
& \text { BGN } \\
& \text { BGN }
\end{aligned}
$$

UNOFF
UNOFF

UNOFF

UNOFF

VARIANT

Maricopa

Greenle

Gila

Yavapai

Yavapai

Coconino

Apache

Gila

Apache

Pina

Pinal

Yavapai

Maricopa

Santa Cruz

Coconino

Coconino

Santa Cruz

Gila

Yuma

Coconino

BGN

UNOFF

UNOFF

BGN 1915

VARIANT

VARIANT

VARIANT

ADMIN

BGN

BGN

Apache

Apache
Coconino

361650 N1091133

$61429 \mathrm{~N} 1090951 \mathrm{~W}$

$354116 \mathrm{~N} 1112133 \mathrm{~W}$

cliff BGN Pinal 331918N1111910W

summit

reservoir

reservoir

mine

mine

mine

mine

mine

range

BGN

BGN
BGN
UNOFF

UNOFF

UNOFF

UNOFF

UNOFF

VARIANT

Graham

Mohave

Graham

Pima

Pima

Maricopa

Maricopa

Maricopa

Mohave

mine

range

ridge

ridge

ridge

stream

stream

UNOFF

VARIANT

BGN

8GN

BGN

BGN

VARIANT

BGN

VARIAN

VARIANT

Mohave

Pinal

Maricopa

Yavapai

Apache

Maricopa

Gila

$363900 \mathrm{N1} 130226 \mathrm{~W}$

$330021 \mathrm{N1094451 \textrm {W }}$

$321223 \mathrm{~N} 1121317 \mathrm{~W}$

314057 N1111654W

$332808 \mathrm{~N} 1112913$

$334510 \mathrm{N1} 131400 \mathrm{~W}$

352B14N1143038W

$345731 N 1142327 \mathrm{~W}$

323203 N1115259W

$335446 \mathrm{~N} 1113230 \mathrm{~W}$

$341903 \mathrm{~N} 1114153 \mathrm{~W}$

$343203 \mathrm{~N} 1093151 \mathrm{~W}$

$332252 \mathrm{~N} 1121844 \mathrm{~W}$

334420 N1101330W $\begin{array}{lc}\text { SOURCE } & \text { ELEV } \\ \text { COORDINATE } & \text { FT MAP NAME }\end{array}$

343107N1113640W Walker Mtn

Buckhorn Mountain Blue Gap

Ives Peak

Spirit Mtn NE

Cave Creek

Robinson Mesa

Gisela

Walker Mtn

Sycamore Bas in

Red Mesa

Blue Gap

Gisela

$340701 \mathrm{~N} 1111913 \mathrm{~W}$

361133 N1094852W 2203 Many Farms
Sand Wells

Little Table Top

Yampai SE

Tiger Well

O'Donnell Canyon

Mountainaire

Dutton Hill

5086 Bartlett Mtn

4795 Globe

1665 Black Peak

5879 The Gap

Belmont Mtn

Behm Mes a

7938 Tsaile

7040 Tsaile

Lower Wheatfields Wupatki NE

Florence Junction Geronimo

Little Clayhole Val

Bryce Mountain

Maish Vaya

Cerro Colorado

Goldfield

Little Horn Peak

Tiger Well

Boundary Cone

Lion Mountain Verde Hot Springs Stinking Springs

Forks Butte 
NATIONAL GAZETTEER--ARIZONA 1986

FEATURE NAME

Black River Pump Station Black River Crossing

Black River Number Two Tank

Black River Pumping Station

Black River Pump Station

See Black River

Black River Tank

Black Rock

Black Rock

See Black Pinnacle

Black Rock

Black Rock

Black Rock

Black Rock

Black Rock

Black Rock

See Fluted Rock

Black Rock

See Black Rock Butte

Black Rock

Black Rock

Black Rock Butte

Black Rock

Sa-jini

Sazini Butte

Sezhini Butte$$
\text { Tsezhini }
$$

Black Rock Cairn Well

Black Rock Canyon

Black Rock Canyon

Black Rock Canyon

Black Rock Canyon

Black Rock Canyon

See Black Rock Gulch

Black Rock Canyon Spring

Black Rock Canyon Well

Black Rock Dam Tank

Black Rock Gulch Black Rock Canyon

Black Rock Hill

Black Rock Interchange

Black Rock Mine

Black Rock Mine

Black Rock Mine

Black Rock Mine

Black Rock Mountain

Black Rock Point

Black Rock Point

See Chezhindeza Mesa

Black Rock Pond

Black Rock Ranch

Black Rock Ridge

Black Rock Ridge

Black Rocks, The The Rocks

Black Rock Spring

Black Rock Spring

Black Rock Spring

Black Rock Spring

Black Rock Spring

Black Rock Spring

Black Rock Standing

Black Rock Tank

Black Rock Trai

Black Rock Trail Two Hundred

Ninety Two

Black Rock Wash

Black Rock Wash

Black Rock Wash

Blackrock Wash

Black Rock Wash

\section{FEATURE}

CLASS

STATUS

COUNTY

COORDINATE

$\begin{array}{ll} & \text { VARIANT } \\ \text { locale } & \text { BGN } \\ \text { reservoir } & \text { BGN } \\ \text { locale } & \text { UNOFF } \\ & \text { VARIANT } \\ \text { locale } & \\ \text { reservoir } & \text { BGN } \\ \text { pillar } & \text { BGN } \\ \text { pillar } & \text { VARIANT }\end{array}$

Gila

Apache

Graham

Gila

Apache

Coconino

pillar

summ it

summit

summit

summit

summit

summit

summit

\section{BGN}

BGN

BGN

BGN
VARIANT

VARIANT

BGN

local
summit

BGN

BGN 1959

VARIANT

VARIANT

VARIANT

VARIANT

well UNOFF

$\begin{array}{ll}\text { valley } & B G N \\ \text { valley } & B G N\end{array}$

BGN

valley

valley

BGN

BGN

VARIANT

valley

spring

well

reservoir
valley

BGN

UNOFF

BGN

BGN 1979

summit $\quad B G N$

Coconino

Graham

Yavapai

Navajo

Apache

Apache

Apache

Apache

Gila

Apache

Apache

Navajo

$360916 N 1092613 \mathrm{~W}$

$365132 N 1090503 \mathrm{~W}$ $365518 \mathrm{~N} 1132142 \mathrm{~W}$

Apache

Mohave

Mohave

Apache

Mohave

Graham

Mohave

Yuma

crossing

mine

mine

mine

mine

summit

365827 N1134334W

365011 N1090548W

$365431 N 1132142 \mathrm{~W}$

$325448 \mathrm{~N} 1101445 \mathrm{~W}$

$365827 N 1134334 \mathrm{~W}$

333524N1133844W

365856 N1133840W

$330518 N 1143532 \mathrm{~W}$

$331824 N 1105557 \mathrm{~W}$

$334408 N 1131059$

$340424 N 1123453 \mathrm{~W}$

$340424 N 1123453 \mathrm{~W}$
$364623 \mathrm{~N} 1134826 \mathrm{~W}$

365129 N1091523W

$\begin{array}{llll}\text { summit } & \text { Apache } & 365138 N 1091520 W \\ \text { lake } & \text { BGN } & \text { Navajo } & 362044 N 1102224 W\end{array}$

locale UNOFF Navajo 350845N1101642W

ridge BGN Coconino $362428 N 1113802 \mathrm{~W}$

$\begin{array}{llll}\text { ridge } & \text { BGN } & \text { Coconino } & 362428 N 1113802 \mathrm{~W} \\ \text { ridge } & B G N & \text { Apache } & 364857 \text { N1090358W }\end{array}$

summit BGN Mohave 363736 N1130719W

spring

spring

spring

spring

spring

VARIANT

BGN Gila

$331627 \mathrm{~N} 1105641 \mathrm{~W}$

Yavapai 343716N1120739W

Navajo 350830N1101650W

Mohave 353040N1134346W

Apache $\quad 361000 \mathrm{~N} 1091830 \mathrm{~W}$

spring BGN Mohave 364843N1134307W

pillar BGN Navajo 364414 N1101316W

reservoir BGN Yavapai 341939N1121605W

trail UNOFF Apache 360730N1091941W

trail UNOFF Graham 325520N1101308W

$\begin{array}{llll}\text { stream BGN Graham } & \text { 330218N1095701W }\end{array}$

stream BGN Yuma 330340N1143828W

stream BGN Mohave 345733N1141139W

stream

Apache

valley

BGN

Navajo $\begin{array}{ll}\text { SOURCE } & \text { ELEV } \\ \text { COORDINATE } & \text { FT }\end{array}$

Forks Butte

Natanes Mts ME

Stove Canyon

Natanes Mts NE

5773 Blue Spring

5220 Horsethief Mesa

4782 Jackson Mtn

Morgan Butte

5802 Rotten Bananas Butte Window Rock

6664 Boiling Over Well

4475 Pinal Ranch

7618 Mumny Cave Ruins

$\begin{array}{lll}325600 \mathrm{~N} 1101830 \mathrm{~W} & 6540 & \begin{array}{l}\text { Great Spring } \\ \text { Jackson Mtn } \\ \text { Del Muerto }\end{array} \\ 361029 \mathrm{~N} 1091605 \mathrm{~W} & 364802 \mathrm{~N} 1090734 \mathrm{~W} & \begin{array}{l}\text { Bitlabito } \\ \text { Rock Canyon }\end{array} \\ 365308 \mathrm{~N} 1132142 \mathrm{~W} & 3640 & \begin{array}{l}\text { Bitlabito } \\ \text { Rock Canyon } \\ \text { Jackson Mtn } \\ \text { Purgatory Canyon }\end{array}\end{array}$

1414 Hope SW

Purgatory Canyon

Picacho

Pinal Ranch

Little Horn Peak

Morgan Butte

7375 Mount Bangs

Toh Chin Lini Mesa

Red Slide Peak

5186 Rotten Bananas Butte

Shinumo Altar

Bitlabito

Little Clayhole Val

Pinal Ranch

Humboldt

Rotten Bananas Butte

Milkweed Canyon SW

Mummy Cave Ruins

Wolf Hole Mtn West

5868 Kayenta East

Battle Flat

Mummy Cave Ruins

Jackson Mtn

$325655 \mathrm{N1101014 \textrm {W }}$

$330539 N 1143503 \mathrm{~W}$

$350414 N 1140215 \mathrm{~W}$

Fort Thomas

Picacho SW

Yucca NW

Horse Mesa

Chilchinbito Canyon 
FEATURE NAME

Black Rock Well

Black Sage Canyon

Black Seep

Blacksmith Canyon

Blacksmith Canyon Well

Blacksmith Tunnel

Black Soil Spring

Black Soil Wash

Black Spot Reservoir

Black Spring

Black Spring

Black Spring

Black Stump Valley

Blacktail Canyon

Blacktail Canyon

Blacktail Canyon

Blacktail Hil

Blacktail Spring

Blacktail Spring

Blacktail Tank

Blacktail Valley

Blacktail Wash

Blacktail Windmill

Black Tank

Black Tank

Black Tank

Black Tank

Black Tank

Black Tank

Black Tank

Black Tank

Black Tank

Black Tank

Black Tank

Black Tank

Black Tank

Black Tank

Black Tank

Black Tank

Black Tank

Black Tank

Black Tank

Black Tank

Black Tank

Black Tank

Black Tank Camp

Black Tank Wash

Black Tank Wel1

Black Tank Well

Black Top Mesa

Black Tunnel

Black Valley

Black Wash

Blackwater

Oo-Kut

Standing Tre

Uhs Kug

Blackwater Commun ity Center and School

Blackwater Creek

Blackwater Lateral

Blackwater Spring

Black Well

Black Willow Spring

Black Willow Spring

Black Wood Dam

Black Wood $\mathrm{Hill}$

Bladder Canyon

Soldier Camp Wash
FEATURE
CLASS

$\begin{array}{ll}\text { well } & \text { UNOFF } \\ \text { valley } & \text { BGN } \\ \text { spring } & \text { BGN } \\ \text { valley } & \text { BGN } \\ \text { well } & \text { UNOFF } \\ \text { mine } & \text { UNOFF } \\ \text { spring } & \text { BGN } \\ \text { stream } & \text { BGN } \\ \text { reservoir } & \text { BGN }\end{array}$

park

spring

spring

valley

valley

valley

valley

summit

spring

spring

reservoir

valley

stream

locale

reservoir

reservoir

reservoir

reservoir

reservoir

reservoir

$\begin{array}{ll}\text { AOMIN } & \text { Pinal } \\ \text { BGN } & \text { Cochise } \\ \text { BGN } & \text { Coconino } \\ \text { BGN } & \text { Apache } \\ \text { BGN } & \text { Santa Cruz } \\ \text { BGN } & \text { Cochise } \\ \text { BGN 1932 } & \text { Coconino } \\ \text { BGN } & \text { Cochise } \\ \text { BGN } & \text { Cochise } \\ \text { BGN } & \text { Pina }\end{array}$

332401 N1110833W

312600 N1101617W

$350801 \mathrm{~N} 1114117 \mathrm{~W}$

362109 N1095749W

$312210 \mathrm{~N} 1102802 \mathrm{~W}$

$313401 N 1102504 \mathrm{~W}$

$361422 \mathrm{~N} 1122818 \mathrm{~W}$

315818 N1095750

$313135 \mathrm{~N} 1102448 \mathrm{~W}$

$314724 N 1102927 \mathrm{~W}$

BGN Pima 315334N1104106W

BGN 1908 Coconino 361639N1122517W

BGN Cochise

BGN

BGN

BGN

BGN

BGN

BGN

BGN

Cochise

Santa Cruz

Pima

Cochise

Pima

Pinal

Maricopa

reservoir

reservoir

reservoir

reservoir

reservoir

reservoir

reservoir

reservoir

reservoir

reservoir

BGN

Graham

Yuma

Greenlee

Maricopa

La Paz

Apache

Yavapai

Coconino

Coconino

Mohave

reservoir

reservoir

reservoir

reservoir

reservoir

reservoir

locale

trean

well

well

sumait

mine

valley

strean

ppl

school

Coconino

Coconino

Coconino

Coconino

Coconino

Coconino

Coconino

Coconino

Pinal

Maricopa

BGN

UNOFF

BGN

VARIANT

BGN

Pinal

Gila

Coconino

Mohave

VARIANT

VARIANT

VARIANT

UNOFF

Pinal

$\begin{array}{ll}\text { BGN } & \text { Yavapai } \\ \text { BGN } & \text { Pinal } \\ \text { BGN } & \text { Yavapai } \\ \text { UNOFF } & \text { Cochise } \\ \text { BGN } & \text { Mohave } \\ \text { BGN } & \text { Mohave } \\ \text { UNOFF } & \text { Apache } \\ \text { BGN } & \text { Apache } \\ \text { BGN } & \text { Gila }\end{array}$

VARIANT

Gila

stream
canal
spring
well
spring
spring
dam
summit
valley

spring
BGN

Gila
$344140 \mathrm{~N} 1093627 \mathrm{~W}$

345422N1115742W

$350543 N 1114621 \mathrm{~W}$

$352255 \mathrm{~N} 1113942 \mathrm{~W}$

$352450 \mathrm{~N} 1132856 \mathrm{~W}$

353441 N1113715W

$353800 \mathrm{~N} 1113430 \mathrm{~W}$

$353809 \mathrm{N1} 124056 \mathrm{~W}$

$353906 \mathrm{~N} 1121909 \mathrm{~W}$

353952N1121820W

$354530 \mathrm{~N} 1130402 \mathrm{~W}$

$353817 N 1124117 \mathrm{~W}$

$360305 \mathrm{~N} 1123543 \mathrm{~W}$

323421 N1105655

$323815 \mathrm{~N} 1125625 \mathrm{~W}$

$332711 \mathrm{N1112238 \textrm {W }}$

$332350 \mathrm{~N} 1105817 \mathrm{~W}$

$365545 \mathrm{~N} 1115755 \mathrm{~W}$

$361838 N 1135913 \mathrm{~W}$

$330152 \mathrm{~N} 1113455 \mathrm{~W}$

$330154 N 1113544 W$

$341146 \mathrm{~N} 1123436 \mathrm{~W}$

$330205 \mathrm{~N} 1113336 \mathrm{~W}$

$341326 \mathrm{~N} 1123956 \mathrm{~W}$

$315100 \mathrm{~N} 1101818 \mathrm{~W}$

343947 N1132121W

362037 N1135708

$361123 N 1090638$

$361132 \mathrm{~N} 1091653 \mathrm{~W}$

$334545 \mathrm{~N} 1104828 \mathrm{~W}$

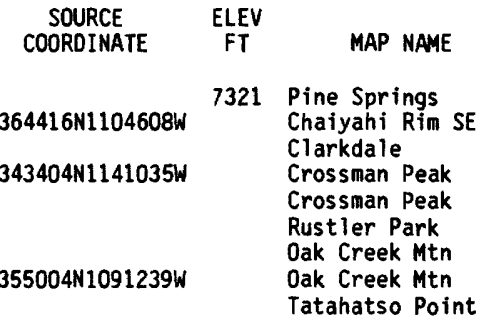

Iron Mountain

Miller Peak

Flagstaff West

Tah Chee Wash

312323N1102625W Campini Mesa

Explorers Monument

5495 Cochise Stronghold

Pyeatt Ranch

Apache Peak

Mount Fagan

Powell Plateau

Huachuca City

Potter Mtn

Ruby

Mildred Peak

Black Diamond Peak

Cocoraque Butte

Tortolita Mts

Midway NW

Cobre Grande Mtn

Arch Tank

Bee Canyon

New River SE

Osborne Well

Stinking Springs Mtn Loy Butte

\section{$355200 \mathrm{~N} 1123837 \mathrm{~W}$}

241 Dutton Hill

White Horse Hills

Cherokee Point

East of S P Mtn

Campbell Francis Wsh

Black Tank

Miller Tank

Miller Tank

Frazier Wells

5300 Black Tank

Antelope Point

Oracle Junction Midway $\mathrm{NW}$

3354 Goldfield

Inspiration

$365503 N 1115832 \mathrm{~W}$

Poverty Flat

362230 N1140731W

Gyp Hills

1386 Blackwater

Blackwater

334959 N1104418W
Wagoner

Blackwater

McGrew Spring

Negro Ed

Gyp Hills

Mummy Cave Ruins

Mummy Cave Ruins

Sombrero Peak 
NATIONAL GAZETTEER-ARIZONA 1986

\section{FEATURE NAME}

Blade Rock

Blade Tank

Blain Point

Blair Canyon

$$
\text { Webb Canyon }
$$

Blair Pas

Blairs Spring

Blairs Spring Wash

Blaisdell

Blake Place

Blake Pond

Blake Pond

Sullivan Reservoir

Blake School

Blakes Lambing Grounds

Blalack

See Gila Center

Blalack

Blanca, Sierra

Blanco Mountains Sierra Blanca Mountains Sierra Blanco

Blanca, Sierra

Blanchard Spring

Blancho Spring

Blanco, Cerro

Blanco Canyon

Blanco Mountains See Cobre Ridge

Blanco Mountains

See Blanca, Sierra

Blanco Tank

Blanco Wash

Blanco Well

Bland Creek

$\mathrm{Bl}$ and $\mathrm{Hill}$

Bland Mine

Bland Mine

Bland Mine

Blankenship Bend

Blankenship Valley

Blankenship Well

Blanko Tank

Blank Tank

See Torrance Well

Blau fluss

See Salt River

Blazed Ridge

Blazed Tank

Blazed Tank

Bleak Spring

Blecha Ranch

Bledsoe

Blenman School

Blevens Wash

Blevens Wash Well

Blevins Draw

Blevins Lake

Blind Canyon

Blind Draw Tank

Blind Goddess Mine

$B$ lind Indian Creek

Blind Lake Tank

Blindman Butte

Blind Spring

Bliss Pond

Bliss Pond Number Three

Bliss Pond Number Two

Block 77 (park)

See Patriot Square

Blodgett Bas in

Blodgett Mine

\begin{tabular}{|c|c|c|c|}
\hline $\begin{array}{l}\text { FEATURE } \\
\text { CLASS }\end{array}$ & STATUS & COUNTY & COORDINATE \\
\hline $\begin{array}{l}\text { summit } \\
\text { reservoir } \\
\text { summit } \\
\text { valley }\end{array}$ & $\begin{array}{l}\text { BGN } \\
\text { BGN } \\
\text { BGN } \\
\text { BGN } 1962 \\
\text { VARIANT }\end{array}$ & $\begin{array}{l}\text { Apache } \\
\text { Coconino } \\
\text { Navajo } \\
\text { Graham }\end{array}$ & $\begin{array}{l}360 \mathrm{~B} 34 \mathrm{~N} 1093009 \mathrm{~W} \\
345132 \mathrm{~N} 1112309 \mathrm{~W} \\
341942 \mathrm{~N} 1102106 \mathrm{~W} \\
324540 \mathrm{~N} 109560 \mathrm{~W}\end{array}$ \\
\hline $\begin{array}{l}\text { gap } \\
\text { spring } \\
\text { stream } \\
\text { locale }\end{array}$ & $\begin{array}{l}\text { BGN } \\
B G N \\
B G N \\
B G N\end{array}$ & $\begin{array}{l}\text { Yavapai } \\
\text { Navajo } \\
\text { Navajo } \\
\text { Yuma }\end{array}$ & $\begin{array}{l}343741 \text { N1123421 } \\
350435 N 1101618 \\
350409 N 1102219 \\
324245 N 1142533\end{array}$ \\
\hline $\begin{array}{l}\text { locale } \\
\text { lake } \\
\text { reservoir }\end{array}$ & $\begin{array}{l}\text { BGN } \\
\text { BGN } \\
\text { BGN } \\
\text { VARIANT }\end{array}$ & $\begin{array}{l}\text { Pinal } \\
\text { Mohave } \\
\text { Mohave }\end{array}$ & $\begin{array}{l}324827 N 110311 \\
365252 N 113251 \\
363936 \times 113315\end{array}$ \\
\hline $\begin{array}{l}\text { school } \\
\text { area }\end{array}$ & $\begin{array}{l}\text { UNOFF } \\
\text { BGN } \\
\text { VARIANT }\end{array}$ & $\begin{array}{l}\text { Yuma } \\
\text { Mohave }\end{array}$ & $\begin{array}{l}340901 N 114174 \\
365947 N 113440\end{array}$ \\
\hline $\begin{array}{l}\text { locale } \\
\text { locale } \\
\text { summit }\end{array}$ & $\begin{array}{l}\text { BGN } \\
\text { BGN } 1941 \\
\text { VARIANT } \\
\text { VARIANT }\end{array}$ & $\begin{array}{l}\text { Yuma } \\
\text { Yuma } \\
\text { Pima }\end{array}$ & $\begin{array}{l}324157 N 114304 \\
324200 N 114290 \\
321245 N 112143\end{array}$ \\
\hline
\end{tabular}

$\begin{array}{llll}\text { summit } & \text { BGN } & \text { Cochise } & 321904 N 1101830 \mathrm{~W} \\ \text { spring } & \text { BGN } & \text { Yavapai } & 341604 N 1121439 \mathrm{~W} \\ \text { spring } & \text { BGN } & \text { Yavapai } & 341512 N 1121732 \mathrm{~W} \\ \text { cliff } & \text { BGN } & \text { Pima } & 315750 N 1130427 \mathrm{~W} \\ \text { valley } & \text { BGN } & \text { Apache } & 343330 N 1091107 \mathrm{~W} \\ & \text { VARIANT } & & \\ \text { ridge } & \text { Vanta Cruz } & 312754 N 1111715 \mathrm{~W} \\ \text { summit } & \text { VARIANT } & \text { Pima } & 321245 N 1121437 \mathrm{~W} \\ \text { reservoir } & \text { BGN } & \text { Pima } & 314433 N 1112653 \mathrm{~W}\end{array}$

$\begin{array}{llll}\text { stream } & \text { BGN } & \text { Pima } & 322707 N 1111936 \mathrm{~W} \\ \text { wel1 } & \text { UNOFF } & \text { Apache } & 343521 N 1090730 \mathrm{~W} \\ \text { stream } & \text { BGN } & \text { Yavapai } & 342821 N 1125315 \mathrm{~W} \\ \text { summit } & \text { BGN } & \text { Yavapai } & 341312 \mathrm{~N} 1121023 \mathrm{~W} \\ \text { mine } & \text { UNOFF } & \text { Santa Cruz } & 313619 \mathrm{~N} 1105110 \mathrm{~W} \\ \text { mine } & \text { UNOFF } & \text { Yavapai } & 341306 \mathrm{~N} 112101 \mathrm{~W} \\ \text { mine } & \text { UNOFF } & \text { Yavapai } & 343148 \mathrm{~N} 1131747 \mathrm{~W} \\ \text { bend } & \text { BGN } & \text { Mohave } & 343540 \mathrm{~N} 1142548 \mathrm{~W} \\ \text { basin } & \text { BGN } & \text { Mohave } & 343601 N 1142434 \mathrm{~W} \\ \text { wel1 } & \text { UNOFF } & \text { Pima } & 315126 \mathrm{~N} 1124424 \mathrm{~W}\end{array}$

reservoir BGN Coconino 354712N1123450W

well MARIANT Maricopa 335818N1130305W

stream VARIANT Maricopa 332252N1121844W

ridge BGN Coconino 342827N1111754W

reservoir BGN Coconino 343136N1111927W

reservoir BGN Coconino 343201N1111546W

spring BGN Pinal 324936N1102920W

locale UNOFF Maricopa 333119N1130809W

locale BGN Cochise 312652N1101B22W

school UNOFF Pima 321433N1105537W

stream BGN Gila $333455 N 1105954$ W

well UNOFF Gila 333335N1105800W

valley BGN Cochise 314559N1091039W

lake BGN Navajo 342357N1102927W

valley BGN Cochise 312306N1101851W

reservoir BGN Coconino 344107N1112202W

mine UNOFF Mohave 354406N1142314W

stream BGN Yavapai 341240N1123216W

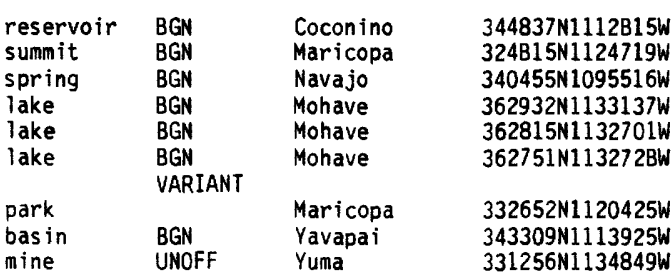

A265

\begin{tabular}{|c|c|c|}
\hline $\begin{array}{l}\text { SOURCE } \\
\text { COORDINATE }\end{array}$ & $\begin{array}{l}\text { ELEV } \\
\text { FT }\end{array}$ & MAP NAME \\
\hline $324244 \mathrm{~N} 1095529 \mathrm{~W}$ & & $\begin{array}{l}\text { Chinle } \\
\text { Hutch Mtn } \\
\text { Clay Springs } \\
\text { Shingle Mill Mtn }\end{array}$ \\
\hline $350403 N 1101549 \mathrm{~W}$ & & $\begin{array}{l}\text { Jerome Canyon } \\
\text { Blairs Spring } \\
\text { Blairs Spring } \\
\text { Fortuna }\end{array}$ \\
\hline
\end{tabular}

Holy Joe Peak Yellowhorse Flat Sullivan Oraw North

Parker

Purgatory Canyon

La Paz Mtn Maish Vaya

343653N1090028W $4351 \begin{aligned} & \text { Soza Mesa } \\ & \text { Cleator } \\ & \text { Battle Flat } \\ & \text { Quitobaquito Springs } \\ & \text { Kearn Lake }\end{aligned}$

\begin{tabular}{|c|c|c|}
\hline $\begin{array}{l}321554 N 1112659 \mathrm{~W} \\
342351 \mathrm{~N} 1124905 \mathrm{~W}\end{array}$ & 3776 & $\begin{array}{l}\text { West of Marena } \\
\text { Kearn Lake } \\
\text { Hillside } \\
\text { Bumble Bee } \\
\text { Patagonia } \\
\text { Bumble Bee } \\
\text { Grayback Mts } \\
\text { Castle Rock } \\
\text { Castle Rock } \\
\text { Blankenship Well }\end{array}$ \\
\hline & 1197 & $\begin{array}{l}\text { Keh1 Ridge } \\
\text { Long Valley } \\
\text { Long Valley } \\
\text { Oak Grove Canyon } \\
\text { Big Horn Peak }\end{array}$ \\
\hline $\begin{array}{l}333104 N 1105643 \mathrm{~W} \\
314505 \mathrm{~N} 1091014 \mathrm{~W} \\
312336 \mathrm{~N} 1101810 \mathrm{~W} \\
341654 \mathrm{~N} 1122409 \mathrm{~W}\end{array}$ & & $\begin{array}{l}\text { Miller Peak } \\
\text { Tucson } \\
\text { Salt River Peak } \\
\text { Salt River Peak } \\
\text { Portal Peak } \\
\text { Aripine } \\
\text { Miller Peak } \\
\text { Turkey Mtn } \\
\text { White Hills West } \\
\text { Wagoner }\end{array}$ \\
\hline & & $\begin{array}{l}\text { Hutch Mtn } \\
\text { Black Gap } \\
\text { Indian Pine } \\
\text { Poverty Spring } \\
\text { Poverty Knoll } \\
\text { Poverty Knoll }\end{array}$ \\
\hline & & $\begin{array}{l}\text { Wa1ker Mtn } \\
\text { Engesser Pass }\end{array}$ \\
\hline
\end{tabular}


FEATURE NAME

Blodgett Tank

Blondy Water

Bloodsucker Wash

Bloodsucker Wash

Blood Tank

Bloody Bas in

Bloody Bas in Canyon

Bloody Bas in Dam

Bloody Basin Interchange

Bloody Bas in Tank

Bloody Tank

Bloody Tanks

Bloody Tanks Wash

Bloom School

Blow Down Tank

Blower Spring

Blowout

Blowout Creek

Blowout Mountain

Blowout Spring

Blowout Tank

Bloxton

See Circle Z Ranch
Blue Whittum
Bluebell
See Blue Bell (site)
Blue Bell (site)
Bluebell
Bluebell Gulch

Bluebell Gulch

Bluebell Mine

Blue Bell Mine

Bluebell Mine

Blue Bell Mobile Home Park

Bluebird Canyon

Bluebird Canyon Wash

Bluebird Mine

Bluebird Mine

Bluebird Mine

Bluebird Mine

Bluebird Mine

Bluebird Mine

Bluebird Spring

Bluebird Spring

Bluebird Spring

Bluebird Well

Blue Bucket Mine

Blue Canyon

See Bonito Creek

Blue Canyon

Blue Canyon

See Bonito Canyon

Blue Canyon

Bukudotklish

Bukudotkl ish Canyon

Dot Klish Canyon

Moenkopi Canyon

Blue Canyon Trading Post

Blue Canyon Wash

See Bonito Creek

Blue Canyon Well

Blue $\mathrm{Cl}$ ay $\mathrm{Hill}$

Blue Clay Reservoir

Blue Clay Well

Bive Creek

See Little Blue Creek

Blue Crossing Campground

Blue Dam

Blue Dog Ridge

8lue Forest

See Blue Mesa
FEATURE

CLASS

STATUS

COUNTY

COORDINATE

$\begin{array}{ll}\text { reservoir } & \text { BGN } \\ \text { spring } & \text { BGN } \\ \text { stream } & \text { BGN } \\ \text { stream } & \text { BGN } \\ \text { reservoir } & \text { BGN } \\ \text { basin } & B G N \\ \text { valley } & \text { BGN } \\ \text { dam } & \text { UNOFF } \\ \text { crossing } & \text { UNOFF } \\ \text { reservoir } & \text { BGN }\end{array}$

reservoir $B G$

reservoir $B G$

stream BGN

reservoir

spring

bas in

stream

summit

spring

locale

locale

locale

locale

valley

UNOFF

BGN

BGN

$B G N$

BGN

BGN

VARIANT

BGN

VARIANT

VARIANT

BGN

VARIANT

BGN

mine

mine

mine

valley

stream

mine

mine

mine

mine

mine

mine

spring

spring

spring

wine

stream

valley

UNOFF

UNOFF

UNOFF

UNOFF

BGM

$B G N$

UNOFF

UNOFF

UNOFF

UNOFF

UNOFF

UNOFF

$B G N$

$B G N$

BGN

UNOFF

UNOFF

VARIANT

BGN

VARIANT

valle

valley

BGN 1968

VARIANT

VARIANT

VARIANT

VARIANT

locale BGN

VARIANT

stream

we 1

summit

UNOFF

reservoir

we 11

BGN

UNOFF

VARIANT

$\begin{array}{ll}\text { stream } & \\ \text { park } & \text { AOMIN }\end{array}$

dam

ridge

AOMIN

BGN

VARIANT

area
Yavapai

Gila

Pinal

Pinal

Apache

Yavapai

Graham

Graham

Yavapai

Graham

Coconino

Gila

Gila

Pima

Coconino

Yavapai

Yavapai

Yavapai

Yavapai

Yavapai

Coconino

Coconino

$360917 N 1105322 \mathrm{~W}$

$354400 N 1090412 W$

Apache

343313N1113908W

$332117 N 1105141 \mathrm{~W}$

$324802 \mathrm{~N} 1104658 \mathrm{~W}$

$341810 \mathrm{~N} 1093012 \mathrm{~W}$

$341029 N 1114811 \mathrm{~W}$

$333434 N 1095831 \mathrm{~W}$

$333255 \mathrm{~N} 1095910 \mathrm{~W}$

$341703 \mathrm{~N} 1120711 \mathrm{~W}$

$333256 \mathrm{~N} 1095908 \mathrm{~W}$

$354728 \mathrm{~N} 1115308 \mathrm{~W}$

$332249 \mathrm{~N} 1105358 \mathrm{~W}$

$332438 \mathrm{~N} 1105026 \mathrm{~W}$

$321432 \mathrm{N1104850 \textrm {W }}$

$362410 \mathrm{~N} 1121100 \mathrm{~W}$

$342258 N 1122827 \mathrm{~W}$

$34412 \mathrm{~N} 1123816 \mathrm{~W}$

$341316 \mathrm{~N} 1123921 \mathrm{~W}$

$344306 \mathrm{~N} 1120608 \mathrm{~W}$

345842N1114153W

$312956 \mathrm{~N} 1104845 \mathrm{~W}$

$333636 N 1090622 W$

$342013 N 1121249 W$

$342013 \mathrm{~N} 1121249 \mathrm{~W}$

331024N1105914W

$341216 \mathrm{~N} 1133754 \mathrm{~W}$

$342022 \mathrm{~N} 1121425 \mathrm{~W}$

$351939 \mathrm{N1140700 \textrm {W }}$

$332616 \mathrm{~N} 1120736 \mathrm{~W}$

$354736 \mathrm{~N} 1101616 \mathrm{~W}$

$354936 \mathrm{~N} 1101729 \mathrm{~W}$

$320403 N 1100517 \mathrm{~W}$

$321237 \mathrm{~N} 1125656 \mathrm{~W}$

$324547 \mathrm{~N} 1102814 \mathrm{~W}$

$332724 \mathrm{~N} 1112913 \mathrm{~W}$

$335222 \mathrm{~N} 1111345 \mathrm{~W}$

$355340 \mathrm{~N} 1140831 \mathrm{~W}$

$324638 \mathrm{~N} 1102823 \mathrm{~W}$

$354720 \mathrm{~N} 1101430 \mathrm{~W}$

$354857 \mathrm{~N} 1103217 \mathrm{~W}$

$351034 \mathrm{N1091216 \textrm {W }}$

$341055 \mathrm{~N} 1124532 \mathrm{~W}$

$354400 N 1090412 \mathrm{~W}$

$343603 \mathrm{~N} 1130630 \mathrm{~W}$

$354500 N 1090458 \mathrm{~W}$ $361027 \mathrm{~N} 1105254 \mathrm{~W}$

Coconino

Apache

Coconino

Navajo

Greenlee

Greenlee

Yavapai

Gila

Apache

$\begin{array}{cc}\text { SOURCE } & \text { ELEV } \\ \text { COORDINATE } & \text { FT }\end{array}$

Walker Mtn

Pinal Peak

North of Oracle

Putnam Wash

Cerro Hueco

Bloody Bas in

Elwood Canyon

Elwood Canyon

Cordes Junction

5732 Elwood Canyon

Harbison Tank

Inspiration

Globe

Tucson East

De Motte Park

Groom Creek

Yarnell

$344302 N 1120624 W$

Cottonwood

Yarnell

Cottonwood

Munds Park

6240 Blue

4220 Cleator

$331052 N 1105814 W$

Hot Tamale Peak

Reid Valley

Cleator

Stockton Hill

$354708 N 1101405 W$

1055 Fowler

Sun Altar

Sun Altar

Dragoon

Bates Well

Oak Grove Canyon

Goldfield

Greenback Creek

Garnet Mtn NW

Oak Grove Canyon

Keams Canyon

Shongopovi

Tolapai Spring

Congress 


\section{FEATURE
CLASS}

STATUS

COUNTY

reservoir
gap
locale
building
ridge
school
reservoir
flat
reservoir
summit

BGN
BGN
BGN
UNOFF
BGN
UNOFF
BGN
BGN
BGN
BGN

Gila

Blue Fox Tank

Blue Gap

Blue Gap Chapter House

Blue Gap Point

Blue Gap School

Blue Grade Tank

Blue Grass Cienega

Bluegrass Tank

Blue $\mathrm{Hil}$

Blue Hills

Biue Hills Farms

Blue Holes Spring

Blue Hope Mine

Blue House Mountain

Bluejay Mine

Blue Jay Peak

Blue Jay Ridge

Blue Jay Tank

Blue Knolls

Blue Lake

Blue Lake

Blue Lake Campground

Blue Lake Dam

Blue Ledge Spring

Blue Mary Spring

Blue Mary Spring

Blue Mesa

$$
\text { Blue Forest }
$$

Blue Mesa Spring

Blue Monster Spring

Blue Moon Bench

Blue Moon Reservoir

Blue Mountain

Blue Mountain

Blue Mountain

Blue Mountain

Blue Mountain

Blue Mountain

Blue Mountain Canyon

\section{Blue Mountains}

\section{See Blue Range}

Blue Mountain Spring

Blue Mountain Spring

Blue Mountain Tank

Blue Mud Spring

Blue Nose Mine

Blue Palm Mobile Home Park

Blue Peak

Blue Peak

Blue Peak Canyon

Blue Plateau

Blue Point

Blue Point

Blue Point

Blue Point

Blue Point Forest Camp

Blue Point Picnic Area

Blue Point Ranger Station

Blue Post Office

Blue Range

Blue Mountains

Blue Ranger Station

Blue Ribbon Tank

Blue Ridge

Blue Ridge

Blue Ridge

Blue Ridge Campground

Blue Ridge Catchment Dam

Blue Ridge Dam

$\begin{array}{llll}\text { summit } & \text { BGN } & \text { Gila } & 335049 N 1111027 \mathrm{~W} \\ \text { ppl } & \text { BGN } & \text { Yavapai } & 343115 N 1121745 \mathrm{~W} \\ \text { spring } & \text { BGN } & \text { Greenlee } & 330843 N 1091026 \mathrm{~W} \\ \text { mine } & \text { UNOFF } & \text { Maricopa } & 33435 \mathrm{BN} 1130756 \mathrm{~W} \\ \text { summit } & \text { BGN } & \text { Gila } & 335 \mathrm{~B} 5 \mathrm{~N} 1103438 \mathrm{~W} \\ \text { mine } & \text { UNOFF } & \text { Pima } & 315257 N 1104619 \mathrm{~W} \\ \text { summit } & \text { BGN } 1932 & \text { Graham } & 324435 \mathrm{~N} 1100146 \mathrm{~W} \\ \text { ridge } & \text { BGN } & \text { Graham } & 324531 N 1100158 \mathrm{~W} \\ \text { reservoir } & \text { BGN } & \text { Graham } & 325736 \mathrm{~N} 1101824 \mathrm{~W} \\ \text { summit } & \text { BGN } & \text { Mohave } & 365757 N 1124235 \mathrm{~W}\end{array}$

lake BGN Apache 340401N1094808W

reservoir BGN Coconino 363012N110451BW

park ADMIN Navajo $341606 \mathrm{~N} 1103916 \mathrm{~W}$

Uam UNF Coconino 363012N1104518W

spring BGN Cochise 321527N1093947W

spring BGN Mohave 345007N1135336W

spring BGN Mohave $345617 \mathrm{N1133145 \textrm {W }}$

area BGN Apache 345633N1094549W

spring BGN

spring BGN Yavapai 343613N1120013W

bench BGN Coconino 361822N1114437W

reservoir BGN Coconino 361B20N1114205W

summit BGN Cochise 320111N1091218W

summit BGN Maricopa 335103N1114635W

sumit BGN Apache 340429N1094806W

summit $\quad$ BGN $\quad$ Yavapai 343731 N1130607W

summit BGN Coconino 353555N1131252W

summit BGN Mohave 355655N1132750W

valley BGN Coconino 354351N1131810W

\begin{tabular}{|c|c|c|c|}
\hline \multirow{2}{*}{\multicolumn{2}{|c|}{$\begin{array}{ll} & \text { VARIANT } \\
\text { range } & \end{array}$}} & \multirow{3}{*}{$\begin{array}{l}\text { Greenlee } \\
\text { Pinal }\end{array}$} & \multirow{8}{*}{$\begin{array}{l}332742 \mathrm{~N} 1092232 \mathrm{~W} \\
330844 \mathrm{~N} 1103107 \mathrm{~W} \\
335046 \mathrm{~N} 1114622 \mathrm{~W} \\
353703 \mathrm{~N} 1131231 \mathrm{~W} \\
350520 \mathrm{~N} 1133500 \mathrm{~W} \\
312653 \mathrm{~N} 1104356 \mathrm{~W} \\
332703 \mathrm{~N} 1120711 \mathrm{~W} \\
333343 \mathrm{~N} 1091747 \mathrm{~W}\end{array}$} \\
\hline & & & \\
\hline & BGN & & \\
\hline & BGN & Maricopa & \\
\hline . & $B C$ & Coconino & \\
\hline & & Moh & \\
\hline & UiforF & Santa Cruz & \\
\hline & BGN 1969 & $\begin{array}{l}\text { Maricopa } \\
\text { Greenlee }\end{array}$ & \\
\hline & & & $334943 N 111$ \\
\hline
\end{tabular}

valley BGN Gila $\quad 334906$ N1111016W $334941 \mathrm{N1110853 \textrm {W }}$

$324742 N 1123243 W$

$333336 \mathrm{~N} 1113416 \mathrm{~W}$

$354431 \mathrm{N1} 104915 \mathrm{~W}$

$360103 N 1110028 \mathrm{~W}$

$355943 \mathrm{~N} 1105954 \mathrm{~W}$

$333320 \mathrm{~N} 1113420 \mathrm{~W}$

$333320 \mathrm{~N} 1113430 \mathrm{~W}$

$333310 \mathrm{~N} 1113623 \mathrm{~W}$

$333640 \mathrm{~N} 1090626 \mathrm{~W}$

UNOFF Maricopa

Greenlee

$332742 N 1092232 \mathrm{~W}$

$333546 \mathrm{~N} 1090739 \mathrm{~W}$

$324346 \mathrm{~N} 1111333 \mathrm{~W}$

$325044 \mathrm{~N} 1101324 \mathrm{~W}$

$332756 \mathrm{~N} 1113100 \mathrm{~W}$

343453N1111513W

$343529 \mathrm{~N} 1111201 \mathrm{~W}$

340907 N1095511W

$343318 \mathrm{~N} 111110 \mathrm{OW}$ $\begin{array}{cc}\text { SOURCE } & \text { ELEV } \\ \text { COORDINATE } & \text { FT MAP NAME }\end{array}$

Cibecue Peak

Blue Gap

6500 Blue Gap

Blue Gap

Round Rock

Blue Gap

Casner Butte

Indian Pine

Pinedale

Fire Dance Mesa

Greenback Creek

Prescott Valley S

Dix Creek

Little Horn Peak

6417 Blue House Mtn

Corona de Tucson

Blue Jay Peak

Tripp Canyon

Cobre Grande Mtn

Kaibab

MeNary

Whirlwind Rock Brookbank Point

Whirlwind Rock

Railroad Pass

Creamery Canyon

Tom Brown Canyon

5600 Adamana

Round Rock

Cherry

Blue Moon Reservoir

Blue Moon Reservoir

5783 Blue Mountain

3169 Wildcat $\mathrm{Hill}$

7789 MeNary

5550 Behm Mesa

Grand Canyon Caverns

$353908 N 1131143 W$

6580 Price Point

Peach Springs NE

Coolidge Dam

Wildcat Hill

Grand Canyon Caverns

Aust in Peak

Harshaw

1070 Phoenix

9346 Strayhorse

47BO Greenback Creek

Greenback Creek

Blue Plateau

2400 Stewart Mtn

Garces Mesas NE

6049 Tuba City SE

6049 Coal Mine Mesa

Stewart Mtn

Stewart Mtn

Stewart Mtn

Blue

Robinson Mesa

Bear Mountain

Durham Hills

5907 Buford Hill

Apache Junction

Long Valley

Blue Ridge Reservoir

Lakeside

6720 Blue Ridge Reservoir 


\begin{tabular}{|c|c|c|c|c|c|c|c|}
\hline FEATURE MAME & $\begin{array}{l}\text { FEATURE } \\
\text { CLASS }\end{array}$ & STATUS & COUNTY & COORDIMATE & $\begin{array}{l}\text { SOURCE } \\
\text { COORDINATE }\end{array}$ & $\begin{array}{c}\text { ELEV } \\
\text { FI }\end{array}$ & MAP NAME \\
\hline $\begin{array}{l}\text { Blue Ridge Elementary School } \\
\text { Blue Ridge High School } \\
\text { Blue Ridge Junior High School } \\
\text { Blue Ridge Maintenance Yard } \\
\text { Blue Ridge Mountain } \\
\text { Blue Ridge Reservoir } \\
\text { Blueridge Tank } \\
\text { Blue Ridge Tank } \\
\text { Blue River } \\
\text { See Colorado River }\end{array}$ & $\begin{array}{l}\text { school } \\
\text { school } \\
\text { school } \\
\text { locale } \\
\text { summit } \\
\text { reservoir } \\
\text { reservoir } \\
\text { reservoir } \\
\text { stream }\end{array}$ & $\begin{array}{l}\text { UNOFF } \\
\text { UNOFF } \\
\text { UNOFF } \\
8 G N \\
8 G N \\
\text { BGN } \\
\text { BGN } \\
\text { BGN } \\
\text { VARIANT }\end{array}$ & $\begin{array}{l}\text { Navajo } \\
\text { Navajo } \\
\text { Navajo } \\
\text { Coconino } \\
\text { Navajo } \\
\text { Coconino } \\
\text { Navajo } \\
\text { Coconino } \\
\text { Yuma }\end{array}$ & $\begin{array}{l}340853 \mathrm{~N} 1105805 \mathrm{~W} \\
340857 \mathrm{N1} 095758 \mathrm{~W} \\
340909 \mathrm{~N} 1105831 \mathrm{~W} \\
343650 \mathrm{~N} 1111112 \mathrm{~W} \\
340915 \mathrm{~N} 1095451 \mathrm{~W} \\
343312 \mathrm{N1} 111102 \mathrm{~W} \\
341028 \mathrm{~N} 1095438 \mathrm{~W} \\
343456 \mathrm{~N} 1111431 \mathrm{~W} \\
\\
315400 \mathrm{~N} 1145700 \mathrm{~W}\end{array}$ & & $\begin{array}{l}7656 \\
6720\end{array}$ & $\begin{array}{l}\text { Lakeside } \\
\text { Lakeside } \\
\text { Lakeside } \\
\text { Blue Ridge Reservoir } \\
\text { Lakeside } \\
\text { Blue Ridge Reservoir } \\
\text { Lakes ide } \\
\text { Blue Ridge Reservoir }\end{array}$ \\
\hline $\begin{array}{l}\text { Blue River } \\
\text { Rio Azul } \\
\text { Blue River }\end{array}$ & stream & $\begin{array}{l}\text { BGN } \\
\text { VARIANT } \\
\text { VARIANT }\end{array}$ & Greenlee & $331233 \mathrm{M} 1091128 \mathrm{~W}$ & $334311 \mathrm{~N} 1090240 \mathrm{~W}$ & & Dix Creek \\
\hline $\begin{array}{l}\text { See Salt River } \\
\text { Blue River } \\
\text { Blue River One Hundred One } \\
\text { Trail }\end{array}$ & $\begin{array}{l}\text { stream } \\
\text { stream } \\
\text { trail }\end{array}$ & $\begin{array}{l}\text { BGN } \\
\text { UNOFF }\end{array}$ & $\begin{array}{l}\text { Maricopa } \\
\text { Graham } \\
\text { Green lee }\end{array}$ & $\begin{array}{l}332252 \mathrm{~N} 1121844 \mathrm{~W} \\
332423 \mathrm{~N} 1102308 \mathrm{~W} \\
332535 \mathrm{~N} 1091118 \mathrm{~W}\end{array}$ & $333525 \mathrm{~N} 1101546 \mathrm{~W}$ & & $\begin{array}{l}\text { Natural Corral } \\
\text { Dutch Blue Creek }\end{array}$ \\
\hline $\begin{array}{l}\text { Blue Rock } \\
\text { Blue Rock Butte } \\
\text { Blue Rock Spring } \\
\text { Blue Rock Tank } \\
\text { Blue Rock Tank } \\
\text { Blue Rock Tank } \\
\text { Blue School } \\
\text { Blue Sky Mobile Estates } \\
\text { Blue Spring } \\
\text { Blue Spring }\end{array}$ & $\begin{array}{l}\text { summit } \\
\text { summit } \\
\text { spring } \\
\text { reservoir } \\
\text { reservoir } \\
\text { reservoir } \\
\text { school } \\
\text { locale } \\
\text { spring } \\
\text { spring }\end{array}$ & $\begin{array}{l}\text { BGN } \\
\text { BGN } \\
\text { BGN } \\
\text { BGN } \\
\text { BGN } \\
\text { BGN } \\
\text { UNOFF } \\
\text { UNOFF } \\
\text { BGN } \\
\text { BGN }\end{array}$ & $\begin{array}{l}\text { Mohave } \\
\text { Gila } \\
\text { Yavapai } \\
\text { Yuma } \\
\text { Yavapai } \\
\text { Mohave } \\
\text { Greenlee } \\
\text { Maricopa } \\
\text { Pinal } \\
\text { Maricopa }\end{array}$ & $\begin{array}{l}342300 \mathrm{~N} 1133138 \mathrm{~W} \\
334850 \mathrm{~N} 1101214 \mathrm{~W} \\
343832 \mathrm{N1} 121111 \mathrm{~W} \\
330220 \mathrm{~N} 1140632 \mathrm{~W} \\
342158 \mathrm{~N} 1115230 \mathrm{~W} \\
352147 \mathrm{~N} 1140101 \mathrm{~W} \\
333754 \mathrm{~N} 1090546 \mathrm{~W} \\
333210 \mathrm{~N} 1120940 \mathrm{~W} \\
332518 \mathrm{N11} 10603 \mathrm{~W} \\
333640 \mathrm{~N} 1112606 \mathrm{~W}\end{array}$ & & $\begin{array}{l}6200 \\
1165\end{array}$ & $\begin{array}{l}\text { Signal Mtn } \\
\text { Cone Butte } \\
\text { Hickey Mountain } \\
\text { Slumgullion Pass } \\
\text { Dugas } \\
\text { Stockton Hill } \\
\text { Maness Peak } \\
\text { Glendale } \\
\text { Haunted Canyon } \\
\text { Mormon Flat Dam }\end{array}$ \\
\hline $\begin{array}{l}\text { Blue Spring } \\
\text { Blue Spring } \\
\text { Blue Spring } \\
\text { Blue Spring } \\
\text { Blue Spring Canyon } \\
\text { Blue Springs Trail } \\
\text { Blue Star Claim } \\
\text { Blue Star Mobile Home Park } \\
\text { Bluestem Tank } \\
\text { Blue Stem Wash } \\
\text { Blue Wash }\end{array}$ & $\begin{array}{l}\text { spring } \\
\text { spring } \\
\text { spring } \\
\text { spring } \\
\text { valley } \\
\text { trail } \\
\text { mine } \\
\text { locale } \\
\text { reservoir } \\
\text { valley }\end{array}$ & $\begin{array}{l}\text { BGN } \\
\text { BGN } \\
\text { BGN } \\
\text { BGN } \\
\text { BGN } \\
\text { UNOFF } \\
\text { UNOFF } \\
\text { UNOFF } \\
\text { BGN } \\
\text { BGN } 1964 \\
\text { VARIANT }\end{array}$ & $\begin{array}{l}\text { Mavajo } \\
\text { Gila } \\
\text { Mohave } \\
\text { Coconino } \\
\text { Navajo } \\
\text { Coconino } \\
\text { Yuma } \\
\text { Maricopa } \\
\text { Mavajo } \\
\text { Coconino }\end{array}$ & $\begin{array}{l}340419 \mathrm{~N} 1101842 \mathrm{~W} \\
341007 \mathrm{N1} 111943 \mathrm{~W} \\
344833 \mathrm{N1} 132440 \mathrm{~W} \\
360700 \mathrm{~N} 1114134 \mathrm{~W} \\
340358 \mathrm{~N} 1101907 \mathrm{~W} \\
360500 \mathrm{N1} 114631 \mathrm{~W} \\
334651 \mathrm{~N} 1133144 \mathrm{~W} \\
332502 \mathrm{N1} 113541 \mathrm{~W} \\
341727 \mathrm{~N} 1095333 \mathrm{~W} \\
354626 \mathrm{~N} 1120345 \mathrm{~W}\end{array}$ & $355244 \mathrm{~N} 1115735 \mathrm{~W}$ & 1605 & $\begin{array}{l}\text { Limestone Canyon S } \\
\text { Payson South } \\
\text { Cedar Basin } \\
\text { Blue Spring } \\
\text { Limestone Canyon S } \\
\text { Desert View } \\
\text { Salome } \\
\text { Apache Junction } \\
\text { Silver Springs } \\
\text { Red Butte }\end{array}$ \\
\hline $\begin{array}{l}\text { Blue Tank } \\
\text { Blue Tank } \\
\text { Blue Tank } \\
\text { Blue Tank } \\
\text { Blue Tank Canyon } \\
\text { Blue Tank Canyon } \\
\text { Blue Tank Wash } \\
\text { Blue Tank Wash } \\
\text { Blue Vista } \\
\text { Blue Wash }\end{array}$ & $\begin{array}{l}\text { reservoir } \\
\text { reservoir } \\
\text { reservoir } \\
\text { reservoir } \\
\text { valley } \\
\text { valley } \\
\text { stream } \\
\text { stream } \\
\text { locale } \\
\text { stream }\end{array}$ & $\begin{array}{l}\text { BGN } \\
\text { BGN } \\
\text { BGN } \\
\text { BGN } \\
\text { BGN } \\
\text { BGN } \\
\text { BGN } \\
\text { BGN } \\
\text { BGN } \\
\text { BGN }\end{array}$ & $\begin{array}{l}\text { Greenlee } \\
\text { Gila } \\
\text { Yavapai } \\
\text { Apache } \\
\text { Maricopa } \\
\text { Maricopa } \\
\text { Maricopa } \\
\text { Mohave } \\
\text { Green lee } \\
\text { Maricopa }\end{array}$ & $\begin{array}{l}331521 \mathrm{~N} 1090401 \mathrm{~W} \\
332003 \mathrm{~N} 1104827 \mathrm{~W} \\
342904 \mathrm{N1} 113336 \mathrm{~W} \\
345855 \mathrm{~N} 1094208 \mathrm{~W} \\
333452 \mathrm{~N} 1112304 \mathrm{~W} \\
334356 \mathrm{N1} 131727 \mathrm{~W} \\
335913 \mathrm{N1} 124358 \mathrm{~W} \\
345639 \mathrm{N1} 134327 \mathrm{~W} \\
333709 \mathrm{~N} 1090457 \mathrm{~W} \\
334013 \mathrm{~N} 1125159 \mathrm{~W}\end{array}$ & $\begin{array}{l}333652 N 1112139 W \\
334805 N 1132044 W \\
340139 N 1123313 W \\
345813 N 1135504 W \\
333935 N 1125714 W\end{array}$ & & $\begin{array}{l}\text { Maple Peak } \\
\text { Pinal Peak } \\
\text { Strawberry } \\
\text { Sorrel Horse Mesa } \\
\text { Mormon Flat Dam } \\
\text { Weldon Hill } \\
\text { Wickenburg } \\
\text { Pilgrim Wash } \\
\text { Blue } \\
\text { Star Well }\end{array}$ \\
\hline $\begin{array}{l}\text { Blue Wash } \\
\text { Blue Wash }\end{array}$ & strean & $\begin{array}{l}\text { BGN } \\
\text { VARIANT }\end{array}$ & Maricopa & $335221 \mathrm{~N} 1114803 \mathrm{~W}$ & $335257 N 1115043 \mathrm{~W}$ & & Wildcat Hill \\
\hline $\begin{array}{l}\text { See Blue Stem Wash } \\
\text { Blue Water } \\
\text { Blue Water Marina Park } \\
\text { Bluff Cienega Creek } \\
\text { Bluff Hollow } \\
\text { Bluff Mountain }\end{array}$ & $\begin{array}{l}\text { valley } \\
\text { locale } \\
\text { park } \\
\text { stream } \\
\text { valley }\end{array}$ & $\begin{array}{l}\text { BGN } \\
\text { ADMIN } \\
\text { BGN } \\
\text { BGN } \\
\text { VARIANT }\end{array}$ & $\begin{array}{l}\text { Coconino } \\
\text { Pina } 1 \\
\text { Yuma } \\
\text { Apache } \\
\text { Graham }\end{array}$ & $\begin{array}{l}354626 \mathrm{~N} 1120345 \mathrm{~W} \\
325700 \mathrm{~N} 111500 \mathrm{~W} \\
341009 \mathrm{~N} 1141558 \mathrm{~W} \\
334431 \mathrm{~N} 1093232 \mathrm{~W} \\
325610 \mathrm{~N} 1094940 \mathrm{~W}\end{array}$ & $\begin{array}{l}334744 N 1093251 \mathrm{~W} \\
325653 \mathrm{~N} 1094904 \mathrm{~W}\end{array}$ & & $\begin{array}{l}\text { Casa Grande West } \\
\text { Parker } \\
\text { Maverick } \\
\text { Pima }\end{array}$ \\
\hline $\begin{array}{l}\text { See Bluff Spring Mountain } \\
\text { Bluff Saddle }\end{array}$ & $\begin{array}{l}\text { summit } \\
\text { gap }\end{array}$ & BGN & $\begin{array}{l}\text { Pinal } \\
\text { Pinal }\end{array}$ & $\begin{array}{l}332556 \mathrm{~N} 1112103 \mathrm{~W} \\
332535 \mathrm{~N} 1112128 \mathrm{~W}\end{array}$ & & & Weavers Needle \\
\hline $\begin{array}{l}\text { Bluff Spring } \\
\text { Bluff Spring }\end{array}$ & spring & $\begin{array}{l}\text { BGN } \\
\text { VARIANT }\end{array}$ & Graham & $323852 \mathrm{~N} 1101637 \mathrm{~W}$ & & & Kennedy Peak \\
\hline $\begin{array}{l}\text { See Crystal Spring } \\
\text { Bluff Spring } \\
\text { Bluff Springs } \\
\text { Crystal Spring }\end{array}$ & $\begin{array}{l}\text { spring } \\
\text { spring }\end{array}$ & $\begin{array}{l}\text { BGN } 1976 \\
\text { VARIANT } \\
\text { VARIANT }\end{array}$ & $\begin{array}{l}\text { Pinal } \\
\text { Pinal }\end{array}$ & $\begin{array}{l}332524 \mathrm{~N} 1112004 \mathrm{~W} \\
332535 \mathrm{~N} 1112005 \mathrm{~W}\end{array}$ & & & Weavers Needle \\
\hline $\begin{array}{l}\text { Bluff Spring } \\
\text { Bluff Spring } \\
\text { See Sanders Spring } \\
\text { Bluff Spring }\end{array}$ & $\begin{array}{l}\text { spring } \\
\text { spring } \\
\text { spring }\end{array}$ & $\begin{array}{l}\text { BGN } \\
\text { VARIANT }\end{array}$ & $\begin{array}{l}\text { Gila } \\
\text { Gila } \\
\text { Apache }\end{array}$ & $\begin{array}{l}333145 N 1105630 \mathrm{~W} \\
334345 \mathrm{~N} 1103711 \mathrm{~W} \\
340919 \mathrm{~N} 1093609 \mathrm{~W}\end{array}$ & & & Salt River Peak \\
\hline
\end{tabular}


NATIONAL GAZETTEER--ARIZONA 1986

\section{FEATURE NAME}

Bluff Spring Canyon

Bluff Spring Mountain Bluff Mountain

Bluff Spring Mountain Canyon

Bluff Spring Mountain Spring Bluff Spring Spring

Bluff Springs

See Bluff Spring

Bluff Spring Spring

See Bluff Spring Mountain Spring

Bluff Tank

Blumberg Canyon

Blye Canyon

Blye Tank

Bly Tank

B Main Lateral

BM Spring

Board Cabin Draw

Board Canyon

Board Creek

Board Creek Spring

Boardinghouse Canyon

Boardshack Knoll

Board Spring

Board Tank

Board Tree Saddle

Board Tree Saddle Tank

Board Tree Spring

Boat Spring

Boaz Mine

Bobbie Mine

Bobbie Tank

Bob Brown Tank

Bob Brown Well

Bobby Spring

Bobby Tank

Bobcat Bas in

Bobcat Butte

Bobcat Creek

Bobcat Hills

Bobcat Reservoir

Bobcat Tank

Bobcat Tank

Bobcat Tank

Bobcat Tank Number Two

Bobcat Windmill

Bob Crowder Memorial Dam

Bob Lee Spring

Boblitt Cemetery

Bobo Spring

Bobs Flat
Bobs Tank
Bobs Tank
Bobs Tank
Bobs Tank
Bobs Well
Bobtail Bas in
Bob Tail Dam
Bobtail Ridge
Bobtail Spring
Bob Tail Tank
Bob Thompson Peak
Ash Peak
Bodaway Mesa
Bodaway Water
Bodaway Well
Bodie Canyon
Bodie Mine
Bodie Spring
Bodie Wash
See Scotia Canyon

\section{FEATURE}

STATUS

valley

summit

valley

spring

spring

spring

BGN

BGN

BGN

1968

VARIANT

VARIANT

VARIANT

Pinal

Pinal

COUNTY

inal

Pinal

Pinal

and

reservoir

valley

valley

reservoir

canal

spring

valley

valley

stream

spring

valley

summit

reservoir

gap

reservoir

spring

spring

gine

$\begin{array}{lll}\text { BGN } & \text { Greenlee } & 331 \text { B31N1092522W } \\ \text { BGN } & \text { Cochise } & 320040 \text { N1091712W } \\ \text { BGN } & \text { Mohave } & 352654 \text { N1132805W } \\ \text { BGN } & \text { Mohave } & 352817 N 1132426 \mathrm{~W} \\ \text { BGN } & \text { Coconino } & 354901 \text { N112065BW } \\ \text { BGN } & \text { Yuma } & 323610 N 1143750 W \\ \text { BGN } & \text { Pinal } & 332548 N 1110330 W \\ \text { BGN } & \text { Gila } & 340805 N 1110601 W \\ \text { BGN } & \text { Greenlee } & 332900 N 1091317 W \\ \text { BGN } & \text { Yavapai } & 342525 N 1123131 W\end{array}$

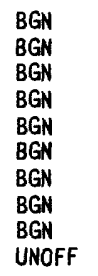

mine

reservoir

reservoir

well

spring

reservoir

bas in

summit

stream

ridge

Yavapai

Gila

Apache

Maricopa

Gila

Gila

Gila

Gila

Yavapai

Yavapai

UNOFF Pina

Pima

Pima

Pima

Mohave

Santa Cruz 312548N1110515W

Graham 332521N1094B59W

Navajo 352816N1102414k

Graham 332622N1095010W

Greenlee

reservoir

reservoir

reservoir

reservoir

reservoir

locale

dam

spring

cemetery

spring

flat

reservoir

reservoir

reservoir

reservoir BG

well

bas in

dam

ridge

pring

reservoir

summ it

summit

spring

well

valley

mine

spring

valley

312500 N1102550W $\begin{array}{lc}\text { SOURCE } & \text { ELEV } \\ \text { COORDINATE } & \text { FT MAP NAME }\end{array}$

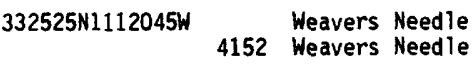

$332600 \mathrm{~N} 1112034 \mathrm{~W} \quad$ Weavers Needle

Weavers Needle

\begin{tabular}{|c|c|c|}
\hline $\begin{array}{l}315929 \mathrm{~N} 1091743 \mathrm{~W} \\
352811 \mathrm{N1132516 \textrm {W }}\end{array}$ & & $\begin{array}{l}\text { Bee Canyon } \\
\text { Cochise Head } \\
\text { Cherokee Point } \\
\text { Cherokee Point } \\
\text { Red Butte } \\
\text { Somerton } \\
\text { Haunted Canyon }\end{array}$ \\
\hline $\begin{array}{l}340836 \mathrm{~N} 1110257 \mathrm{~W} \\
332816 \mathrm{~N} 1091420 \mathrm{~W} \\
342759 \mathrm{~N} 1123311 \mathrm{~W}\end{array}$ & & $\begin{array}{l}\text { Diamond Butte } \\
\text { Dutch Blue Creek } \\
\text { Wilhoit }\end{array}$ \\
\hline $341011 \mathrm{~N} 1113054 \mathrm{~W}$ & $\begin{array}{l}9524 \\
6007\end{array}$ & $\begin{array}{l}\text { Wilhoit } \\
\text { Cypress Butte } \\
\text { Mount Baldy } \\
\text { New River Mesa } \\
\text { Diamond Butte } \\
\text { McFadden Peak } \\
\text { McFadden Peak } \\
\text { McFadden Peak } \\
\text { Cottonwood } \\
\text { Minnehaha }\end{array}$ \\
\hline
\end{tabular}

Twin Buttes

Scratch Canyon

Saucito Mtn

Saucito Mtn

Aust in Peak

Pena Blanca Lake

Stove Canyon

6472 Shonto Butte

Stove Canyon

$332407 N 1095000 \mathrm{~W}$

$323324 N 1090741 \mathrm{~W}$

$364134 N 1130802 W$

$332603 N 1094923 W$

$334205 N 1090626 \mathrm{~W}$

$335 \mathrm{~B} 49 \mathrm{~N} 1102233 \mathrm{~W}$

$333514 \mathrm{~N} 1110129 \mathrm{~W}$

350049 N1092453W

$332830 \mathrm{~N} 1134336 \mathrm{~W}$

$321230 N 1093145 \mathrm{~W}$

$315631 \mathrm{~N} 1103646 \mathrm{~W}$

330057 N1094207W

$334733 N 1121332 \mathrm{~W}$

341137 N1120356 W

$345524 \mathrm{~N} 1130834 \mathrm{~K}$

350522 N1114559W

340645 N1140639W

331537 N1105149W

$331530 N 1095142 \mathrm{~W}$

331616 N1105025W

$331514 \mathrm{~N} 1105008 \mathrm{~W}$

$332748 N 1095644 \mathrm{~W}$

$312204 N 1101435 \mathrm{~W}$

$362100 \mathrm{~N} 1113412 \mathrm{~W}$

$361913 N 1113416 \mathrm{~W}$

$361910 \mathrm{~N} 1112 \mathrm{~B} 36 \mathrm{~W}$

$311900 \mathrm{~N} 1103100 \mathrm{~W}$

$342053 \mathrm{~N} 1122518 \mathrm{~W}$

$342016 \mathrm{~N} 1122418 \mathrm{~W}$

312617 N1102522W
Whit lock Peak

Antelope Knoll

6106 Stove Canyon

Maness Peak

Cibecue Peak

Two Bar Mtn

6216 Navajo Springs

Perryville

Dos Cabezas

Prescott

The Narrows

Bryce Mountain

Biscuit Flat

Joes $\mathrm{Hill}$

Sunrise Peak

Dutton $\mathrm{Hill}$

Bobs Well

Pinal Peak

Point of Pines West

Pinal Peak

Pinal Peak

6167 Natanes Mts NW

7325 Bob Thompson Peak

Bodaway Mesa

Bodaway Mesa

The Gap

Lochiel

Battleship Butte

Battleship Butte 


\begin{tabular}{|c|c|c|c|c|c|c|c|}
\hline FEATURE NAME & $\begin{array}{l}\text { FEATURE } \\
\text { CLASS }\end{array}$ & STATUS & COUNTY & COORDINATE & $\begin{array}{l}\text { SOURCE } \\
\text { COORDINATE }\end{array}$ & $\begin{array}{l}\text { ELEV } \\
\text { FT }\end{array}$ & MAP NAME \\
\hline $\begin{array}{l}\text { Bodkin Tank } \\
\text { Boedecker Tank } \\
\text { Boevers Well } \\
\text { Bogard Wash } \\
\text { Bogart Wash } \\
\text { Bog Butte } \\
\text { Bog Creek } \\
\text { Bog Creek } \\
\text { See Little Bog Creek } \\
\text { Boggs Ranch }\end{array}$ & $\begin{array}{l}\text { reservoir } \\
\text { reservoir } \\
\text { well } \\
\text { stream } \\
\text { stream } \\
\text { summit } \\
\text { stream } \\
\text { stream } \\
\text { locale }\end{array}$ & $\begin{array}{l}\text { BGN } \\
\text { BGN } \\
\text { UNOFF } \\
\text { BGN } \\
\text { BGN } \\
\text { BGN } \\
\text { BGN } \\
\text { VARIANT } \\
\text { UNOFF }\end{array}$ & $\begin{array}{l}\text { Yavapai } \\
\text { Cochise } \\
\text { Mohave } \\
\text { Pinal } \\
\text { Pinal } \\
\text { Apache } \\
\text { Apache } \\
\text { Apache } \\
\text { Cochise }\end{array}$ & 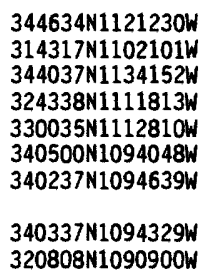 & $\begin{array}{l}324616 \mathrm{~N} 1105903 \mathrm{~W} \\
325802 \mathrm{~N} 1112546 \mathrm{~W} \\
340424 \mathrm{~N} 1093846 \mathrm{~W}\end{array}$ & B825 & $\begin{array}{l}\text { Munds Draw } \\
\text { Huachuca City } \\
\text { Aubrey Peak } \\
\text { Picacho Pass } \\
\text { Florence } \\
\text { Horseshoe Cienega } \\
\text { McNary }\end{array}$ \\
\hline $\begin{array}{l}\text { Boggs Ranch } \\
\text { Boggy Creek } \\
\text { Boggy Creek } \\
\text { See Lofer Cienega Creek } \\
\text { Boggy Creek } \\
\text { Boggy Lake Well } \\
\text { Boggy Tank } \\
\text { Boggy Tank } \\
\text { Bog Hole Tank } \\
\text { Bog Ranch }\end{array}$ & $\begin{array}{l}\text { locale } \\
\text { stream } \\
\text { stream } \\
\text { stream } \\
\text { well } \\
\text { reservoir } \\
\text { reservoir } \\
\text { reservoir } \\
\text { locale }\end{array}$ & $\begin{array}{l}\text { UNOFF } \\
\text { BGN } \\
\text { VARIANT } \\
\text { BGN } \\
\text { UNOFF } \\
\text { BGN } \\
\text { BGN } \\
\text { BGN } \\
\text { UNOFF }\end{array}$ & $\begin{array}{l}\text { Graham } \\
\text { Apache } \\
\text { Apache } \\
\text { Apache } \\
\text { Apache } \\
\text { Yavapai } \\
\text { Coconino } \\
\text { Santa Cruz } \\
\text { Maricopa }\end{array}$ & 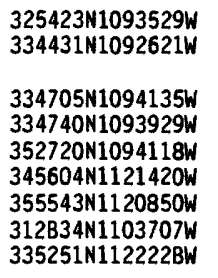 & $335202 \mathrm{~N} 1093647 \mathrm{~W}$ & 6242 & $\begin{array}{l}\text { Marshall Butte } \\
\text { Boggy Lake Well } \\
\text { Perkinsville } \\
\text { Tusayan West } \\
\text { Canelo Pass } \\
\text { Governors Peak }\end{array}$ \\
\hline $\begin{array}{l}\text { Bog Spring } \\
\text { Bog Sppings } \\
\text { Bog Springs Campground } \\
\text { Bog Tank } \\
\text { Bog Tank } \\
\text { Bog Tank Dam } \\
\text { Bog Tank Picnic Ground } \\
\text { Bohee Tank } \\
\text { Bohme Ranch } \\
\text { Bohme Spring }\end{array}$ & $\begin{array}{l}\text { spring } \\
\text { spring } \\
\text { park } \\
\text { reservoir } \\
\text { reservoir } \\
\text { dam } \\
\text { park } \\
\text { reservoir } \\
\text { locale } \\
\text { spring }\end{array}$ & $\begin{array}{l}\text { BGN } \\
\text { BGN } \\
\text { ADMIN } \\
\text { BGN } \\
\text { BGN } \\
\text { UNOFF } \\
\text { ADMIN } \\
\text { BGN } \\
\text { UNOFF } \\
\text { BGN }\end{array}$ & $\begin{array}{l}\text { Gila } \\
\text { Santa Cruz } \\
\text { Pima } \\
\text { Apache } \\
\text { Coconino } \\
\text { Apache } \\
\text { Apache } \\
\text { Gila } \\
\text { Gila } \\
\text { Gila }\end{array}$ & $\begin{array}{l}334655 \mathrm{~N} 1102205 \mathrm{~W} \\
314317 \mathrm{~N} 1105145 \mathrm{~W} \\
313336 \mathrm{N1} 105228 \mathrm{~W} \\
340250 \mathrm{~N} 1094055 \mathrm{~W} \\
344743 \mathrm{~N} 1111057 \mathrm{~W} \\
340248 \mathrm{~N} 1094100 \mathrm{~W} \\
340305 \mathrm{~N} 1094330 \mathrm{~W} \\
334541 \mathrm{~N} 1102414 \mathrm{~W} \\
332440 \mathrm{~N} 110555 \mathrm{~W} \\
332747 \mathrm{~N} 1105336 \mathrm{~W}\end{array}$ & & $\begin{array}{l}5060 \\
\text { B182 }\end{array}$ & $\begin{array}{l}\text { Carrizo SE } \\
\text { Mt Wrightson } \\
\text { Mt Wrightson } \\
\text { Horseshoe Cienega } \\
\text { Chavez Mtn West } \\
\text { Horseshoe Cienega } \\
\text { Horseshoe Cienega } \\
\text { Beckers Butte } \\
\text { Inspiration } \\
\text { Inspiration }\end{array}$ \\
\hline $\begin{array}{l}\text { Bohner Canyon } \\
\text { See Boner Canyon } \\
\text { Boice Tank } \\
\text { Boiler Spring } \\
\text { Boiler Tank } \\
\text { Boiling Over Wash } \\
\text { Boiling Over Well } \\
\text { Boiling Spring } \\
\text { Boiling Spring } \\
\text { To-haul-hace } \\
\text { Tohal ushi }\end{array}$ & $\begin{array}{l}\text { valley } \\
\text { reservoir } \\
\text { spring } \\
\text { reservoir } \\
\text { valley } \\
\text { well } \\
\text { spring } \\
\text { spring }\end{array}$ & $\begin{array}{l}\text { VARIANT } \\
\text { BGN } \\
\text { BGN } \\
\text { BGN } \\
\text { BGN } \\
\text { UNOFF } \\
\text { BGN } \\
\text { BGN 1915 } \\
\text { VARIANT } \\
\text { VARIANT }\end{array}$ & $\begin{array}{l}\text { Mohave } \\
\text { Pima } \\
\text { Yavapai } \\
\text { Yavapai } \\
\text { Apache } \\
\text { Apache } \\
\text { Graham } \\
\text { Navajo }\end{array}$ & $\begin{array}{l}344422 \mathrm{~N} 1133612 \mathrm{~W} \\
313909 \mathrm{N1112410 \textrm {W }} \\
343748 \mathrm{~N} 1120739 \mathrm{~W} \\
344438 \mathrm{~N} 1114022 \mathrm{~W} \\
363948 \mathrm{~N} 1091057 \mathrm{~W} \\
363913 \mathrm{~N} 1091207 \mathrm{~W} \\
330943 \mathrm{~N} 1093409 \mathrm{~W} \\
364300 \mathrm{~N} 1103130 \mathrm{~W}\end{array}$ & $363503 \mathrm{~N} 1091617 \mathrm{~W}$ & & $\begin{array}{l}\text { Las Guijas } \\
\text { Hickey Mountain } \\
\text { Casner Butte } \\
\text { Boiling Over Well } \\
\text { Boiling Over Well } \\
\text { Elevator Mtn } \\
\text { Betatakin Ruin }\end{array}$ \\
\hline $\begin{array}{l}\text { Bolas Blancas Wash } \\
\text { Bolix Hollow } \\
\text { Bollen Wash } \\
\text { Bollin Tank } \\
\text { Bolsa Canyon } \\
\text { Bolsa Tank } \\
\text { Bolt Canyon } \\
\text { Bomboy Mine } \\
\text { Bon } \\
\text { Bonanza Bill Flat }\end{array}$ & $\begin{array}{l}\text { stream } \\
\text { basin } \\
\text { stream } \\
\text { reservoir } \\
\text { valley } \\
\text { reservoir } \\
\text { valley } \\
\text { mine } \\
\text { locale } \\
\text { flat }\end{array}$ & $\begin{array}{l}\text { BGN } \\
\text { BGN } \\
\text { BGN } \\
\text { BGN } \\
\text { BGN } \\
\text { BGN } \\
\text { BGN } \\
\text { UNOFF } \\
\text { BGN } \\
\text { BGN }\end{array}$ & $\begin{array}{l}\text { Pima } \\
\text { Yavapai } \\
\text { Graham } \\
\text { Pinal } \\
\text { Cochise } \\
\text { Santa Cruz } \\
\text { Pima } \\
\text { Pinal } \\
\text { Pinal } \\
\text { Greenlee }\end{array}$ & $\begin{array}{l}314637 \mathrm{~N} 1112344 \mathrm{~W} \\
344757 \mathrm{~N} 1131420 \mathrm{~W} \\
322844 \mathrm{~N} 1102912 \mathrm{~W} \\
325411 \mathrm{~N} 1111753 \mathrm{~W} \\
312612 \mathrm{~N} 1095944 \mathrm{~W} \\
312817 \mathrm{~N} 1111222 \mathrm{~W} \\
321853 \mathrm{~N} 1102834 \mathrm{~W} \\
331909 \mathrm{~N} 1111248 \mathrm{~W} \\
325817 \mathrm{~N} 1115428 \mathrm{~W} \\
333358 \mathrm{~N} 1090323 \mathrm{~W}\end{array}$ & $\begin{array}{l}314208 \mathrm{~N} 1111524 \mathrm{~W} \\
322924 \mathrm{~N} 1102136 \mathrm{~W} \\
31263 \mathrm{BN} 1095736 \mathrm{~W} \\
321533 \mathrm{~N} 1103059 \mathrm{~W}\end{array}$ & & $\begin{array}{l}\text { Fresno Wash } \\
\text { Burro Mesa } \\
\text { Redington } \\
\text { Cactus Forest } \\
\text { Bisbee } \\
\text { Ruby } \\
\text { Soza Canyon } \\
\text { Picketpost Mtn } \\
\text { Stanfield } \\
\text { Blue }\end{array}$ \\
\hline $\begin{array}{l}\text { Bonanza Bill Point } \\
\text { Bonanza Mine } \\
\text { Bonanza Mine } \\
\text { Bonanza Mine } \\
\text { Bonanza Mine } \\
\text { Bonanza Tunnel } \\
\text { Bonanza Wash } \\
\text { Bona Venture Mobile Home Park } \\
\text { Bond Canyon } \\
\text { Bondesson Lateral }\end{array}$ & $\begin{array}{l}\text { summit } \\
\text { mine } \\
\text { mine } \\
\text { mine } \\
\text { mine } \\
\text { mine } \\
\text { arroyo } \\
\text { locale } \\
\text { valley } \\
\text { canal }\end{array}$ & $\begin{array}{l}\text { BGN } \\
\text { UNOFF } \\
\text { UNOFF } \\
\text { UNOFF } \\
\text { UNOFF } \\
\text { UNOFF } \\
\text { BGN } \\
\text { UNOFF } \\
\text { BGN } \\
\text { BGN }\end{array}$ & $\begin{array}{l}\text { Greenlee } \\
\text { Santa Cruz } \\
\text { Yuma } \\
\text { Mohave } \\
\text { Mohave } \\
\text { Gila } \\
\text { Mohave } \\
\text { Maricopa } \\
\text { Santa Cruz } \\
\text { Yuma }\end{array}$ & $\begin{array}{l}333327 \mathrm{~N} 1090347 \mathrm{~W} \\
312223 \mathrm{~N} 1104109 \mathrm{~W} \\
335538 \mathrm{~N} 1133514 \mathrm{~W} \\
341703 \mathrm{~N} 1133940 \mathrm{~W} \\
354435 \mathrm{~N} 1142313 \mathrm{~W} \\
332559 \mathrm{~N} 1105244 \mathrm{~W} \\
343252 \mathrm{~N} 1132259 \mathrm{~W} \\
333855 \mathrm{~N} 1120347 \mathrm{~W} \\
313540 \mathrm{~N} 1105403 \mathrm{~W} \\
323707 \mathrm{~N} 1144234 \mathrm{~W}\end{array}$ & $\begin{array}{l}343037 N 1131850 \mathrm{~W} \\
313841 \mathrm{~N} 1105118 \mathrm{~W}\end{array}$ & 8133 & $\begin{array}{l}\text { Blue } \\
\text { Duquesne } \\
\text { Cunningham Pass } \\
\text { Rawhide Wash } \\
\text { White Hills West } \\
\text { Inspiration } \\
\text { Kaiser Spring } \\
\text { Union Hills } \\
\text { San Cayetano Mts } \\
\text { Somerton }\end{array}$ \\
\hline $\begin{array}{l}\text { Bond Spring } \\
\text { Bonds Trailer Park } \\
\text { Bone Dam } \\
\text { Bonehead Bas in } \\
\text { Bonehead Catchment } \\
\text { Bonehead Mesa } \\
\text { Bonehead Spring } \\
\text { Bonehead Spring } \\
\text { Bonehead Tank } \\
\text { Bone Hollow }\end{array}$ & $\begin{array}{l}\text { spring } \\
\text { locale } \\
\text { dam } \\
\text { basin } \\
\text { reservoir } \\
\text { summit } \\
\text { spring } \\
\text { spring } \\
\text { reservoir } \\
\text { valley }\end{array}$ & $\begin{array}{l}\text { BGN } \\
\text { UNOFF } \\
\text { UNOFF } \\
\text { BGN } \\
\text { BGN } \\
\text { BGN } \\
\text { BGN } \\
\text { BGN } \\
\text { BGN } \\
\text { BGN }\end{array}$ & $\begin{array}{l}\text { Cochise } \\
\text { Maricopa } \\
\text { Graham } \\
\text { Greenlee } \\
\text { Gila } \\
\text { Greenlee } \\
\text { Greenlee } \\
\text { Gila } \\
\text { Gila } \\
\text { Coconino }\end{array}$ & $\begin{array}{l}312304 \mathrm{~N} 1101748 \mathrm{~W} \\
332456 \mathrm{~N} 1115040 \mathrm{~W} \\
331718 \mathrm{~N} 110000 \mathrm{~W} \\
332902 \mathrm{~N} 1090746 \mathrm{~W} \\
335055 \mathrm{~N} 1102226 \mathrm{~W} \\
332905 \mathrm{~N} 1090713 \mathrm{~W} \\
332852 \mathrm{~N} 1090745 \mathrm{~W} \\
335154 \mathrm{~N} 1102126 \mathrm{~W} \\
335134 \mathrm{~N} 1102049 \mathrm{~W} \\
363247 \mathrm{~N} 1123023 \mathrm{~W}\end{array}$ & & 1235 & $\begin{array}{l}\text { Miller Peak } \\
\text { Mesa } \\
\text { Ash Creek Ranch } \\
\text { Dutch Blue Creek } \\
\text { Carrizo SE } \\
\text { Alma Mesa } \\
\text { Dutch Blue Creek } \\
\text { Carrizo SE } \\
\text { Carrizo SE } \\
\text { Jumpup Point }\end{array}$ \\
\hline
\end{tabular}


NATIONAL GAZETTEER--ARIZONA 1986

FEATURE NAME

Bone Hollow Tank

Bonel1 Bay

Bonelli Landing

Boner Canyon

Banner Canyon

Bohner Canyon

Bonner Canyon

Bones Canyon

Williams Creek

Bone Spring

Bone Spring Canyon

Bone Spring Well

Bones Spring

Bone Tank

Boneyard

Boneyback Peak

Greenback Butte

Greenback Peak

Harrahs Peak

Nahche Mountain

Natchez Mountain

Boney Lake

Bonillas School

Bonita

Bonita, Lake

Bonita Camp

Bonita Canyon

Bonita Canyon

Bonita Creek

Bonito Creek

Gila Bonita Creek

Rio Azul

Rio Bonita

West Fork Bonito creek

Bonita Creek

See Little Bonito Creek

Bonita Creek

Fuller Creek

Perley Creek

Bonita Creek

See Bonito Creek

Bonita Creek

Bonita Dam

Bonita Elementary School

Bonita School

Boni Tank

Bonita Park

Bonita School

See Bonita Elementary School

Bonita Spring

Bonita Spring

Bonita Spring

Bonita Tank

Bonita Tank

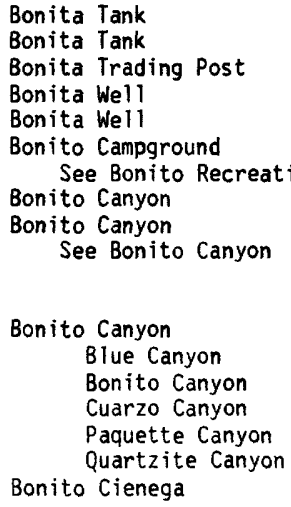

Bonito Cienega

$\begin{array}{ll}\begin{array}{l}\text { FEATURE } \\ \text { CLASS }\end{array} & \text { STATUS } \\ & \\ \text { reservoir } & \text { BGN } \\ \text { bay } & \text { BGN } \\ \text { locale } & \text { BGN } \\ \text { valley } & \text { BGN } \\ & \text { VARIANT } \\ & \text { VARIANT } \\ & \text { VARIANT } \\ \text { valley } & \text { BGN } \\ & \text { VARIANT } \\ \text { spring } & \text { BGN } \\ & \\ & \\ \text { valley } & \text { BGN } \\ \text { well } & \text { UNOFF } \\ \text { spring } & \text { BGN } \\ \text { reservoir } & \text { BGN } \\ \text { locale } & \text { BGN } \\ \text { summit } & \text { BGN 1917 } \\ & \text { VARIANT } \\ & \text { VARIANT } \\ & \text { VARIANT } \\ & \text { VARIANT } \\ & \text { VARIANT }\end{array}$

lake

school

reservoir

locale

valley

valley

stream

BGN Apache

UNOFF

$B G N$
$B G N$
$B G N$

BGN

BGN

BGN 1962

VARIANT

VARIANT

VARIANT

VARIANT

VARIANT

VARIANT

stream

stream

VARIANT

BGN 1974

VARIANT

VARIANT

VARIANT

stream

stream

dam

school

BGN

UNOFF Coconino

UNOFF Graham

VARIANT

reservoir

flat

BGN

school

spring

spring

spring

reservoir

reservoir

reservoir

ppl

well

well

park

valley

valley

BGN

BGN

UNOFF

VARIANT

BGN

VARIANT

valley

BGN 19B3

VARIANT

VARIANT

VARIANT

VARIANT

VARIANT

flat BGN
Coconino 363327N1122723W

Mohave 360406N1142720W

Mohave 360500N1142852W

$344422 \mathrm{~N} 1133612 \mathrm{~W}$

Apache

Graham

Graham

Graham

Yavapa

Graham

Gila

Pima

Graham

Maricopa

Santa Cruz

Cochise

Graham

Apache

Gila

Apache
Coconin
Graham
Graham

Graham

Cochise

Graham

Cochise

Graham

Mohave

Santa Cruz

Graham

Coconino

Coconino

Apache

Pima

Graham

Coconino

Pinal

Apache

Apache

Apache

334937 N1095045W

331759N1100720W

$331122 \mathrm{~N} 1101302 \mathrm{~W}$

331425 N1101102W

342445 N112232BW

$331703 \mathrm{~N} 1100539 \mathrm{~W}$

$335245 \mathrm{~N} 109161 \mathrm{BW}$

335142 N1110953W

$321255 \mathrm{~N} 1105324 \mathrm{~W}$

$323523 \mathrm{~N} 1095807 \mathrm{~W}$

$334344 \mathrm{~N} 1122221 \mathrm{~W}$

$330353 \mathrm{~N} 1093430 \mathrm{~W}$

$312320 \mathrm{~N} 1111905 \mathrm{~W}$

320029 N1092120W

325336 N1092840W

$342056 \mathrm{~N} 1111421 \mathrm{~W}$

$354400 \mathrm{~N} 1090412 \mathrm{~W}$

$362232 \mathrm{~N} 1122 \mathrm{~B} 33 \mathrm{~W}$

$331012 \mathrm{~N} 1094524 \mathrm{~W}$

323512 N1095B23W

$332113 \mathrm{~N} 110082 \mathrm{BW}$

320154N1091905W

323512N1095823W

320146 N1091910W

330511 N1093638W

$343439 \mathrm{N1} 134155 \mathrm{~W}$

$350013 N 1113541 \mathrm{~W}$

$352914 \mathrm{~N} 1114127 \mathrm{~W}$

$354411 \mathrm{~N} 1090411 \mathrm{~W}$

$320031 \mathrm{~N} 1125 \mathrm{~B} 29 \mathrm{~W}$

$330745 \mathrm{~N} 1093924 \mathrm{~W}$

$352209 \mathrm{~N} 1113230 \mathrm{~W}$

$323336 \mathrm{~N} 110381 \mathrm{BW}$

354500 N1090458W

335312 N1093422W
$343215 N 1091415 \mathrm{~W}$
312711 N1111724W

$320258 \mathrm{~N} 1091906 \mathrm{~W}$

331833 N1094821W

Kearn Lake

Tucson

Fort Grant

Calderwood Butte

Bonita Spring

Bartlett Mtn

Cochise Head

Gila Box

$334130 \mathrm{~N} 1094715 \mathrm{~W}$

$342439 \mathrm{~N} 1111245 \mathrm{~W}$

Diamond Point

362419 N1122826W

Tapeats Amphitheater

Bonita Tank

Fort Grant

$331012 N 1094535 \mathrm{~W}$

$323344 N 1104455 W$

4952 Branaman Spring

Cochise Head

Cochise Head

Bonita Spring

Groom Spring

Bartlett Mtn

Bonita Tank

Lower Lake Mary

6964 White Horse Hills

Window Rock

Kino Peak

Park Creek Cabins

$354500 \mathrm{~N} 1090458 \mathrm{~W} \quad 355116 \mathrm{~N} 1090727 \mathrm{~W}$

Fort Defiance

Mount Baldy 


\begin{tabular}{|c|c|c|c|c|c|c|c|}
\hline FEATURE NAME & $\begin{array}{l}\text { FEATURE } \\
\text { CLASS }\end{array}$ & STATUS & COUNTY & COORDINATE & $\begin{array}{l}\text { SOURCE } \\
\text { COORDINATE }\end{array}$ & $\underset{\text { FT }}{\text { ELEV }}$ & MAP NAME \\
\hline $\begin{array}{l}\text { Bonito Creek } \\
\text { See Bonita Creek } \\
\text { Bonito Creek } \\
\text { See Little Bonito Creek }\end{array}$ & $\begin{array}{l}\text { stream } \\
\text { stream }\end{array}$ & $\begin{array}{l}\text { VARIANT } \\
\text { VARIANT }\end{array}$ & $\begin{array}{l}\text { Graham } \\
\text { Apache }\end{array}$ & $\begin{array}{l}325336 \mathrm{~N} 1092840 \mathrm{~W} \\
334130 \mathrm{~N} 1094715 \mathrm{~W}\end{array}$ & & & \\
\hline $\begin{array}{l}\text { Bonito Creek } \\
\text { 8lue Canyon } \\
\text { Blue Canyon Wash } \\
\text { Bonita Creek } \\
\text { Quartzite Canyon } \\
\text { Bonito Flat }\end{array}$ & stream & $\begin{array}{l}\text { BGN } 1983 \\
\text { VARIANT } \\
\text { VARIANT } \\
\text { VARIANT } \\
\text { VARIANT } \\
\text { VARIANT }\end{array}$ & Apache & $354400 \mathrm{~N} 1090412 \mathrm{~W}$ & $355020 \mathrm{~N} 1091206 \mathrm{~W}$ & & Window Rock \\
\hline $\begin{array}{l}\text { See Bonito Park } \\
\text { Bonito Lava Flow } \\
\text { Bonito Mine } \\
\text { Bonito Park } \\
\text { Bonito Flat } \\
\text { Bonito Valley } \\
\text { Valley Bonito }\end{array}$ & $\begin{array}{l}\text { flat } \\
\text { lava } \\
\text { mine } \\
\text { flat }\end{array}$ & $\begin{array}{l}\text { BGN } \\
\text { UNOFF } \\
\text { BGN } 1933 \\
\text { VARIANT } \\
\text { VARIANT } \\
\text { VARIANT }\end{array}$ & $\begin{array}{l}\text { Coconino } \\
\text { Coconino } \\
\text { Pinal } \\
\text { Coconino }\end{array}$ & $\begin{array}{l}352206 \mathrm{~N} 1113316 \mathrm{~W} \\
352217 \mathrm{N1113120 \textrm {W }} \\
323326 \mathrm{N1104410 \textrm {W }} \\
352206 \mathrm{~N} 1113316 \mathrm{~W}\end{array}$ & & & $\begin{array}{l}\text { Sunset Crater West } \\
\text { Campo Bonito } \\
\text { Sunset Crater West }\end{array}$ \\
\hline $\begin{array}{l}\text { Bonito Prairie } \\
\text { Bonito Recreation Site } \\
\text { Bonito Campground }\end{array}$ & $\begin{array}{l}\text { flat } \\
\text { park }\end{array}$ & $\begin{array}{l}\text { BGN } \\
\text { ADMIN } \\
\text { VARIANT }\end{array}$ & $\begin{array}{l}\text { Navajo } \\
\text { Coconino }\end{array}$ & $\begin{array}{l}334142 \mathrm{~N} 1095556 \mathrm{~W} \\
352209 \mathrm{N1113230 \textrm {W }}\end{array}$ & & 6960 & $\begin{array}{l}\text { Bonito Prairie } \\
\text { Sunset Crater West }\end{array}$ \\
\hline $\begin{array}{l}\text { Bonito Rock } \\
\text { Bonito Rock Cienega } \\
\text { Bonito Spring } \\
\text { Bonito Spring } \\
\text { Bonito Valle } \\
\text { Bonito Valley } \\
\text { See Bonito Park }\end{array}$ & $\begin{array}{l}\text { summit } \\
\text { swamp } \\
\text { spring } \\
\text { spring } \\
\text { valley } \\
\text { flat }\end{array}$ & $\begin{array}{l}\text { BGN } \\
\text { BGN } \\
\text { BGN } \\
\text { BGN } \\
\text { BGN } \\
\text { VARIANT }\end{array}$ & $\begin{array}{l}\text { Apache } \\
\text { Apache } \\
\text { Apache } \\
\text { Apache } \\
\text { Apache } \\
\text { Coconino }\end{array}$ & $\begin{array}{l}334649 \mathrm{~N} 1093657 \mathrm{~W} \\
334729 \mathrm{N1093558 \textrm {W }} \\
354811 \mathrm{N1090544 \textrm {W }} \\
355027 \mathrm{N1091021 \textrm {W }} \\
343816 \mathrm{N1091228 \textrm {W }} \\
352206 \mathrm{~N} 1113316 \mathrm{~W}\end{array}$ & $344012 \mathrm{~N} 1090600 \mathrm{~W}$ & & $\begin{array}{l}\text { Bonito Rock } \\
\text { Bonito Rock } \\
\text { Fort Defiance } \\
\text { Piney Hill } \\
\text { Valle Bonito }\end{array}$ \\
\hline $\begin{array}{l}\text { Bonito Valley (historical) } \\
\text { Bonner Canyon }\end{array}$ & valley & BGN 1915 & Apache & $354508 \times 1090458 \mathrm{~W}$ & $354526 \mathrm{~N} 1090840 \mathrm{~W}$ & & Fort Defiance \\
\hline $\begin{array}{l}\text { See Boner Canyon } \\
\text { Bonnie Bell Mine } \\
\text { Bonnie Blink } \\
\text { Bonnie Brae Ranch } \\
\text { Bonnie Brennan Elementary } \\
\text { School }\end{array}$ & $\begin{array}{l}\text { valley } \\
\text { mine } \\
\text { ppl } \\
\text { locale } \\
\text { school }\end{array}$ & $\begin{array}{l}\text { UNOFF } \\
\text { BGN } \\
\text { UNOFF } \\
\text { UNOFF }\end{array}$ & $\begin{array}{l}\text { Mohave } \\
\text { Maricopa } \\
\text { Cochise } \\
\text { Pima } \\
\text { Navajo }\end{array}$ & $\begin{array}{l}344422 \mathrm{~N} 1133612 \mathrm{~W} \\
335537 \mathrm{N1121044 \textrm {W }} \\
313248 \mathrm{~N} 1102218 \mathrm{~W} \\
322250 \mathrm{N11} 10038 \mathrm{~W} \\
350227 \mathrm{N1104329W}\end{array}$ & & & $\begin{array}{l}\text { New River } \\
\text { Fort Huachuca } \\
\text { Ruelas Canyon } \\
\text { Wins low }\end{array}$ \\
\hline $\begin{array}{l}\text { Booger Canyon } \\
\text { Booger Spring }\end{array}$ & $\begin{array}{l}\text { valley } \\
\text { spring }\end{array}$ & $\begin{array}{l}B G N \\
B G N\end{array}$ & $\begin{array}{l}\text { Pinal } \\
\text { Cochise }\end{array}$ & 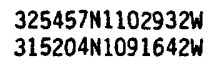 & $325848 \mathrm{~N} 1102654 \mathrm{~W}$ & & $\begin{array}{l}\text { Booger Canyon } \\
\text { Chiricahua Peak }\end{array}$ \\
\hline $\begin{array}{l}\text { Booker T Washington School } \\
\text { Boomerang Mine } \\
\text { Boondock Tank } \\
\text { Boone Moore Spring } \\
\text { Boone Moore Wash } \\
\text { Boone Moore Well } \\
\text { Boone Tank } \\
\text { Boone Well } \\
\text { Boo Tank } \\
\text { Booth Elementary School }\end{array}$ & $\begin{array}{l}\text { School } \\
\text { summit } \\
\text { reservoir } \\
\text { spring } \\
\text { stream } \\
\text { well } \\
\text { reservoir } \\
\text { well } \\
\text { reservoir } \\
\text { school }\end{array}$ & $\begin{array}{l}\text { UNOFF } \\
\text { BGN } \\
\text { BGN } \\
\text { BGN } \\
\text { BGN } \\
\text { UNOFF } \\
\text { BGN } \\
\text { UNOFF } \\
\text { BGM } \\
\text { UNOFF }\end{array}$ & $\begin{array}{l}\text { Maricopa } \\
\text { Pinal } \\
\text { Coconino } \\
\text { Gila } \\
\text { Gila } \\
\text { Gila } \\
\text { Coconino } \\
\text { Graham } \\
\text { Graham } \\
\text { Pima }\end{array}$ & 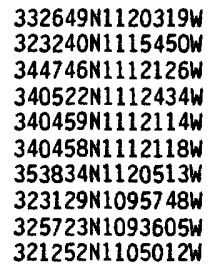 & $340454 \mathrm{~N} 1112551 \mathrm{~W}$ & 4467 & $\begin{array}{l}\text { Phoenix } \\
\text { North Komelik } \\
\text { Jaycox Mtn } \\
\text { Mazatzal Peak } \\
\text { Gisela } \\
\text { Gisela } \\
\text { Molly Anne Draw } \\
\text { Fort Grant } \\
\text { Lone Star Mtn } \\
\text { Tucson East }\end{array}$ \\
\hline $\begin{array}{l}\text { Booth Hills } \\
\text { Boothill Cemetery } \\
\text { Booth Spring } \\
\text { Boot Junior Tank } \\
\text { Boot Lake } \\
\text { Boot leg Canyon } \\
\text { Bootleg Dam } \\
\text { Bootlegger Crossing } \\
\text { Boot legger Saddle } \\
\text { Boot legger Spring }\end{array}$ & $\begin{array}{l}\text { summit } \\
\text { cemetery } \\
\text { spring } \\
\text { reservoir } \\
\text { lake } \\
\text { valley } \\
\text { dam } \\
\text { locale } \\
\text { gap } \\
\text { spring }\end{array}$ & $\begin{array}{l}\text { BGN } \\
\text { UNOFF } \\
\text { BGN } \\
\text { BGN } \\
\text { BGN } \\
\text { BGN } \\
\text { UNOFF } \\
\text { BGN } \\
\text { BGN } \\
\text { BGN }\end{array}$ & $\begin{array}{l}\text { Maricopa } \\
\text { Cochise } \\
\text { Gila } \\
\text { Coconino } \\
\text { Coconino } \\
\text { Yavapai } \\
\text { Navajo } \\
\text { Coconino } \\
\text { Cochise } \\
\text { Pima }\end{array}$ & 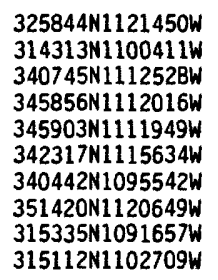 & 342320N1115603W & 6750 & $\begin{array}{l}\text { Haley Hills } \\
\text { Tombstone } \\
\text { North Peak } \\
\text { Kinnikinick Lake } \\
\text { Kinnikinick Lake } \\
\text { Arnold Mesa } \\
\text { Indian Pine } \\
\text { Davenport Hill } \\
\text { Rustler Park } \\
\text { Apache Peak }\end{array}$ \\
\hline $\begin{array}{l}\text { Boot legger Spring } \\
\text { Boot legger Spring } \\
\text { Boot legger Spring } \\
\text { Boot legger Spring } \\
\text { Boot legger Spring } \\
\text { Ash Spring } \\
\text { Bootlegger Spring } \\
\text { Boot legger Spring } \\
\text { Boot legger Spring } \\
\text { Boot legger Spring }\end{array}$ & $\begin{array}{l}\text { spring } \\
\text { spring } \\
\text { spring } \\
\text { spring } \\
\text { spring } \\
\text { spring } \\
\text { spring } \\
\text { spring } \\
\text { spring }\end{array}$ & $\begin{array}{l}\text { BGN } \\
\text { BGN } \\
\text { BGN } \\
\text { BGN } \\
\text { BGN } \\
\text { VARIANT } \\
\text { BGN } \\
\text { BGN } \\
\text { BGN } \\
\text { BGN }\end{array}$ & $\begin{array}{l}\text { Pima } \\
\text { Graham } \\
\text { Gila } \\
\text { Pinal } \\
\text { Gila } \\
\text { Yavapai } \\
\text { Yavapai } \\
\text { Yavapai } \\
\text { Coconino }\end{array}$ & 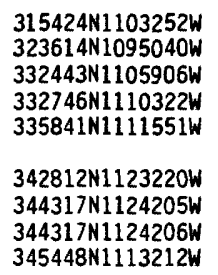 & & & $\begin{array}{l}\text { The Narrows } \\
\text { Stockton Pass } \\
\text { Inspiration } \\
\text { Haunted Canyon } \\
\text { Kayler Butte } \\
\text { Withoit } \\
\text { Mt Josh } \\
\text { Mt Josh } \\
\text { Mormon Mountain }\end{array}$ \\
\hline $\begin{array}{l}\text { Boot legger Tank } \\
\text { Boot legger Tank } \\
\text { Boot legger Trap Spring } \\
\text { Boot legger Wash }\end{array}$ & $\begin{array}{l}\text { reservoir } \\
\text { reservoir } \\
\text { spring } \\
\text { stream }\end{array}$ & $\begin{array}{l}B G N \\
B G N \\
B G N \\
B G N\end{array}$ & $\begin{array}{l}\text { Maricopa } \\
\text { Coconino } \\
\text { Pinal } \\
\text { Maricopa }\end{array}$ & $\begin{array}{l}334659 \mathrm{~N} 1114715 \mathrm{~W} \\
345830 \mathrm{~N} 1113327 \mathrm{~W} \\
332655 \mathrm{~N} 1110213 \mathrm{~W} \\
333 \mathrm{~B} 00 \mathrm{~N} 1124135 \mathrm{~W}\end{array}$ & 333916 N1124133W & & $\begin{array}{l}\text { Wildcat Hill } \\
\text { Mormon Mountain } \\
\text { Haunted Canyon } \\
\text { Daggs Tank }\end{array}$ \\
\hline
\end{tabular}




\section{FEATURE NAME}

Boot legger Well

Boot leg Lake

Bootleg Lake Campground

Bootleg Saddle

Bootleg Spring

Bootleg Spring

Bootleg Spring

Boot leg Tank

Bootles Canyon

Boot Mesa

Boot Peak

Boot Stock Tank

Boot Tank

Booze Crossing

Boquillas

Boquillas Ranch

Boras Mine

Border Creek

See Tuna Creek

Border land Trading Post

Border Mine

Border Tank

Border Tank

Border Tank

Border Well

Bored Spring

\section{Boriana Canyon}

Boriana Mines

Boriana Well

Borree Corner

Borrego Tank

See Borrego Trick Tank

Borrego Trick Tank Borrego Tank

Borrow Pit Number One Tank

Borrow Pit Number Three Tank

Borrow Pit Number Two Tank

Borrow Pit Tank

Borrow Pit Tank

Borrow Pit Tank

Borrow Tank

Borton School

Bos Arnegos Mine

Bosco Tank

Bos ley Ranch

Bosque

Bosque Cemetery

Bosque Spring

Bosque Well

Boss Ranch

Boss Ranch

Boston Arizona Mine

Boston Gulch

Boston Tank

Boswell Memorial Hospital

Boswell Memorial Hospital

Heliport

\section{Boswell Tank}

Boswell Tank

Bota Chiquita Spring

Bottle Butte

Bottle Canyon

$$
\text { Squaw Cree }
$$

Bott leneck Wash

Bcttleneck Wash

Bott leneck Wash Dam

Bott leneck Windmil1

Bottle Spring

Bottle Spring

Bott le Spring Tank

Bott le Tank

\section{FEATURE
CLASS}

STATUS

COUNTY

COORDINATE

$\begin{array}{ll}\text { we11 } & \text { UNOFF } \\ \text { reservoir } & \text { BGN } \\ \text { park } & \text { ADMIN } \\ \text { gap } & \text { BGN } \\ \text { spring } & \text { BGN } \\ \text { spring } & \text { BGN }\end{array}$

Pima

Navajo

Navajo

Greenlee

Gila

spring

reservoir BGN

summit $\quad B G N$

summit BGN

reservoir $B G$

reservoir BGN

locale BGN

locale

UNOFF

Gila

Yavapai

Maricopa

Navajo

Yuma

Cochise

Coconino

Mohave

Cochise

Cochise

$315429 N 1103223 \mathrm{~W}$

$340433 \mathrm{~N} 1095546 \mathrm{~W}$

$340415 \mathrm{~N} 1095502 \mathrm{~W}$

$330817 \mathrm{N1091409 \textrm {W }}$

$333415 N 1104237 \mathrm{~W}$

$341852 \mathrm{~N} 1110357 \mathrm{~W}$

$342023 \mathrm{~N} 1111916 \mathrm{~W}$

$342237 \mathrm{N1} 115200 \mathrm{~W}$

$334833 \mathrm{~N} 1113950 \mathrm{~W}$

365324 N1101B31W

$324731 N 1142353 \mathrm{~W}$

$313932 \mathrm{~N} 1092638 \mathrm{~W}$

$345853 \mathrm{~N} 1112014 \mathrm{~W}$

$364900 \mathrm{~N} 1123601 \mathrm{~W}$

314619 N1101339W

314148 N1101046W

$\begin{array}{ll}\text { mine } & \text { UNOFF } \\ \text { stream } & \text { VARIANT } \\ \text { locale } & \text { BGN } \\ \text { mine } & \text { UNOFF } \\ \text { reservoir } & \text { BGN } \\ \text { reservoir } & \text { BGN } \\ \text { reservoir } & \text { BGN } \\ \text { well } & \text { UNOFF } \\ \text { spring } & \text { BGN }\end{array}$

Cochise

Coconino

Navajo

Pima

Santa Cruz

Santa Cruz

Pina

Pinal

Pinal

$312446 N 1095444 \mathrm{~W}$

$360834 \mathrm{~N} 1121525 \mathrm{~W}$

350838 N1102B $44 \mathrm{~W}$

$312651 \mathrm{N1} 112512 \mathrm{~W}$

$312215 \mathrm{~N} 1111102 \mathrm{~W}$

$312339 \mathrm{~N} 1111340 \mathrm{~W}$

$314526 \mathrm{~N} 1111931 \mathrm{~W}$

$323513 \mathrm{~N} 1102739 \mathrm{~W}$

$331615 N 1110527 \mathrm{~W}$

\begin{tabular}{|c|c|c|c|}
\hline $\begin{array}{l}\text { valley } \\
\text { mine } \\
\text { well } \\
\text { locale }\end{array}$ & $\begin{array}{l}\text { BGN } \\
\text { UNOFF } \\
\text { UNOFF } \\
\text { BGN } \\
\text { VARIANT }\end{array}$ & $\begin{array}{l}\text { Mohave } \\
\text { Mohave } \\
\text { Mohave } \\
\text { Pinal }\end{array}$ & $\begin{array}{l}345347 \mathrm{~N} 1135701 \mathrm{~W} \\
345617 \mathrm{~N} 1135456 \mathrm{~W} \\
345531 \mathrm{~N} 1135546 \mathrm{~W} \\
325824 \mathrm{~N} 1113329 \mathrm{~W}\end{array}$ \\
\hline $\begin{array}{l}\text { servoir } \\
\text { servoir }\end{array}$ & $\begin{array}{l}\text { BGN } \\
\text { VARIANT }\end{array}$ & $\begin{array}{l}\text { Coconino } \\
\text { Coconino }\end{array}$ & $\begin{array}{l}352656 \mathrm{~N} 1114155 \mathrm{~W} \\
352656 \mathrm{~N} 1114155 \mathrm{~W}\end{array}$ \\
\hline $\begin{array}{l}\text { servoir } \\
\text { servoir }\end{array}$ & $\begin{array}{l}\text { BGN } \\
\text { BGN }\end{array}$ & $\begin{array}{l}\text { Coconino } \\
\text { Coconino }\end{array}$ & $\begin{array}{l}344504 \mathrm{~N} 1112520 \mathrm{~W} \\
344110 \mathrm{~N} 1112245 \mathrm{~W}\end{array}$ \\
\hline
\end{tabular}

reservoir BGN

reservoir BGN

reservoir BGN

reservoir BGN

reservoir BGN

school

mine

reservoir

locale

locale

UNOFF

BGN

BGN

cemetery UNOFF

spring

well

locale

locale

mine

valley

reservoir $B G$

hospital UNOFF

airport

\section{BGN}

UNOFF

UNOFF

UNOFF

UNOFF

BGN

UNOFF

Coconino

Gila

Navajo

Coconino

Coconino

Pima

Santa Cruz

Maricopa

Graham

Maricopa

$344518 \mathrm{~N} 1112535 \mathrm{~W}$

$333 \mathrm{~B} 22 \mathrm{N1} 1103400 \mathrm{~W}$

$340306 \mathrm{~N} 1101303 \mathrm{~W}$

343629 N1111228W

$351032 \mathrm{~N} 1121128 \mathrm{~W}$

$321223 \mathrm{~N} 1105729 \mathrm{~W}$

$312513 \mathrm{~N} 1111441 \mathrm{~W}$

$334645 \mathrm{~N} 1120240 \mathrm{~W}$

$323328 \mathrm{~N} 1101147 \mathrm{~W}$

$325759 \mathrm{~N} 1123551 \mathrm{~W}$

Maricopa 325826N1123346W Apache 340933N1093928

Maricopa 325742N1123548W

Santa Cruz 313214N1102927W

Cochise 313506N1092014W

Yavapai 343126 N1123645W

Pima

Mohave

Maricopa

$314419 \mathrm{~N} 1104410 \mathrm{~W}$

353232N1133939W

$333614 \mathrm{N11} 121658$

$333613 N 1121651 \mathrm{~W}$

Maricopa

\begin{tabular}{|c|c|c|c|}
\hline $\begin{array}{l}\text { reservoir } \\
\text { reservoir } \\
\text { spring } \\
\text { summit } \\
\text { valley }\end{array}$ & $\begin{array}{l}\text { BGN } \\
\text { BGN } \\
\text { BGN } \\
\text { BGN } \\
\text { BGN } 1975 \\
\text { VARIANT }\end{array}$ & $\begin{array}{l}\text { Coconino } \\
\text { Coconino } \\
\text { Cochise } \\
\text { Coconino } \\
\text { Graham }\end{array}$ & $\begin{array}{l}344602 \mathrm{~N} 1112334 \mathrm{~W} \\
352605 \mathrm{~N} 1113559 \mathrm{~W} \\
321254 \mathrm{~N} 1093309 \mathrm{~W} \\
344321 \mathrm{~N} 1112403 \mathrm{~W} \\
324530 \mathrm{~N} 1101900 \mathrm{~W}\end{array}$ \\
\hline $\begin{array}{l}\text { stream } \\
\text { stream } \\
\text { dam } \\
\text { locale }\end{array}$ & $\begin{array}{l}\text { BGN } \\
\text { BGN } \\
\text { UNOFF } \\
\text { BGN }\end{array}$ & $\begin{array}{l}\text { Yavapai } \\
\text { Mohave } \\
\text { Yavapai } \\
\text { Mohave }\end{array}$ & $\begin{array}{l}343943 \mathrm{~N} 1122455 \mathrm{~W} \\
350444 \mathrm{~N} 1133840 \mathrm{~W} \\
343948 \mathrm{~N} 1122456 \mathrm{~W} \\
350616 \mathrm{~N} 1134547 \mathrm{~W}\end{array}$ \\
\hline $\begin{array}{l}\text { spring } \\
\text { spring } \\
\text { reservoir }\end{array}$ & $\begin{array}{l}\text { BGN } \\
\text { BGN } \\
\text { BGN }\end{array}$ & $\begin{array}{l}\text { Gila } \\
\text { Cecenino } \\
\text { Cecenino }\end{array}$ & $\begin{array}{l}340845 \mathrm{~N} 1105014 \mathrm{~W} \\
344315 \mathrm{~N} 1112406 \mathrm{~W} \\
344308 \mathrm{~N} 1112352 \mathrm{~W} \\
341007 \mathrm{~N} 114701 \mathrm{~W}\end{array}$ \\
\hline
\end{tabular}

$314504 N 1104552 W$

$\begin{array}{cc}\text { SOURCE } & \text { ELEV } \\ \text { COORDINATE } & \text { FT MAP NAME }\end{array}$

The Narrows

Indian Pine

7080 Indian Pine

Dix Creek

Chrome Butte

Promontory Butte

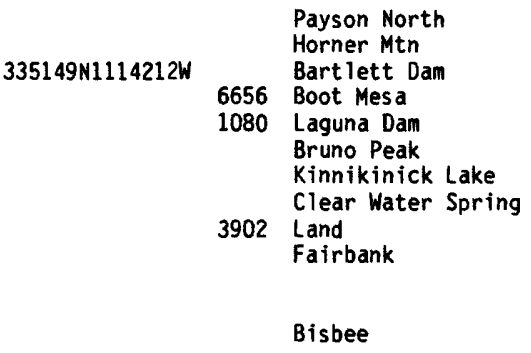

5421 Standing Horse Mesa

Cumero Mtn

Alamo Spring

Ruby

Penitas Hills

3310 Kielberg Canyon

Superior

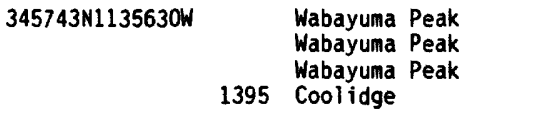

White Horse Hills

Hutch Mtn

Happy Jack

Hutch Mtn

Chrysotile

Long Tom Canyon

Blue Ridge Reservoir

Williams South

Tucson

Ruby

New River SE

4700 Harrison Canyon

Bosque

Bosque

Boundary Butte

991 Bosque

Pyeatt Ranch

Pedregosa Mts East

Iron Springs

Sonoita

Milkweed Canyon SW

El Mirage

1163 El Mirage

Hutch Mtn

O'Leary Peak

Dos Cabezas

Happy Jack

$324300 \mathrm{N1} 102020 \mathrm{~W}$

Klond ike

343627 N1122915W

Chino Valley South

Bott leneck Wash

Chino Valley South

4270 Dean Peak

Parallel Canyon

Happy Jack

Happy Jack

Bloody Bas in 
FEATURE NAME

Bottle Tank

Bottom City

See Lehi

Bottom

Bottomless Pits

Bottomless Pits

See Bottomless Pit

Bottom Tank

Boucher Creek

Long Creek

Boucher Rapids

Boucher Trail

Boulder Bas in

Callville Basin

Lower Bas in

Lower Division

Lower lake

Boulder Bobs Cabin

Boulder Campground

See Boulder Recreation

Site One Hundred

Forty Eight

Boulder Canyon

Boulder Canyon

Boulder Canyon

See East Boulder Canyon

Boulder Canyon

Boulder Canyon

Dry Cimarron Canyon

Boulder Canyon

Boulder Canyon

Boulder Canyon

Boulder Canyon Tank Number One

Boulder Canyon Tank Number Two

Boulder Creek

See La Barge Creek

Boulder Creek

Boulder Creek

Boulder Creek

Boulder Creek

Boulder Creek

Boulder Creek

See Tuna Creek

Boulder Creek Trail

Boulder Dam

Boulder Dam

See Hoover Dam

Boulder Dam National

Recreation Area

See Lake Mead National

Recreation Area

Boulder Dam Spring

Boulder Dam Tank

Boulder Inn

Boulder Mine

Boulder Mountain

Boulder Mountain

$$
\text { Pine Ridge }
$$

Boulder Mountain

See Genung Mountain

Boulder Mountain Spring

Boulder Narrows

Boulder Pass

Boulder Recreation site One

Hundred Forty Eight Boulder Campground

Boulders, The

Boulder Spring

Boulder Spring

Boulder Tank

Boulder Tank

\begin{tabular}{|c|c|c|c|c|c|c|}
\hline $\begin{array}{l}\text { FEATURE } \\
\text { CLASS }\end{array}$ & STATUS & COUNTY & COORDINATE & $\begin{array}{l}\text { SOURCE } \\
\text { COORDINATE }\end{array}$ & $\begin{array}{l}\text { ELEV } \\
\text { FT }\end{array}$ & MAP NAME \\
\hline reservoir & $\begin{array}{l}\text { BGN } \\
\text { VARIANT }\end{array}$ & Coconino & $344301 \mathrm{~N} 1112309 \mathrm{~W}$ & & & Happy Jack \\
\hline $\begin{array}{l}\text { ppl } \\
\text { bas in }\end{array}$ & $\begin{array}{l}\text { BGN } 1952 \\
\text { VARIANT } \\
\text { VARIANT }\end{array}$ & $\begin{array}{l}\text { Maricopa } \\
\text { Coconino }\end{array}$ & $\begin{array}{l}332732 \mathrm{N1} 114846 \mathrm{~W} \\
351215 \mathrm{N1} 113420 \mathrm{~W}\end{array}$ & & & Flagstaff East \\
\hline basin & & Coconino & $351215 \mathrm{~N} 1113420 \mathrm{~W}$ & & & \\
\hline $\begin{array}{l}\text { reservoir } \\
\text { stream }\end{array}$ & $\begin{array}{l}\text { BGN } \\
\text { BGN } 1932 \\
\text { VARIANT }\end{array}$ & $\begin{array}{l}\text { Navajo } \\
\text { Coconino }\end{array}$ & $\begin{array}{l}345612 N 1103626 \mathrm{~W} \\
360655 \mathrm{~N} 1121348 \mathrm{~W}\end{array}$ & $360439 \mathrm{~N} 1121627 \mathrm{~W}$ & & $\begin{array}{l}\text { Hibbard } \\
\text { Grand Canyon }\end{array}$ \\
\hline $\begin{array}{l}\text { rapids } \\
\text { trail } \\
\text { basin }\end{array}$ & $\begin{array}{l}\text { BGN } 1932 \\
\text { UNOFF } \\
\text { BGN } 1947 \\
\text { VARIANT } \\
\text { VARIANT } \\
\text { VARIANT } \\
\text { VARIANT }\end{array}$ & $\begin{array}{l}\text { Coconino } \\
\text { Coconino } \\
\text { Mohave }\end{array}$ & $\begin{array}{l}360700 \mathrm{~N} 1121345 \mathrm{~W} \\
360500 \mathrm{~N} 1121340 \mathrm{~W} \\
360630 \mathrm{~N} 1144236 \mathrm{~W}\end{array}$ & & & $\begin{array}{l}\text { Grand Canyon } \\
\text { Grand Canyon } \\
\text { Hoover Dam }\end{array}$ \\
\hline & $\begin{array}{l}\text { BGN } \\
\text { VARIANT }\end{array}$ & Maricopa & $334934 \mathrm{~N} 1112636 \mathrm{~W}$ & & & Boulder Mtn \\
\hline park & & Maricopa & $333154 \mathrm{~N} 1112528 \mathrm{~W}$ & & & \\
\hline $\begin{array}{l}\text { valley } \\
\text { valley }\end{array}$ & $\begin{array}{l}\text { BGN } \\
\text { BGN } \\
\text { VARIANT }\end{array}$ & $\begin{array}{l}\text { Pima } \\
\text { Cochise }\end{array}$ & $\begin{array}{l}320156 \mathrm{~N} 1124244 \mathrm{~W} \\
321217 \mathrm{~N} 1093812 \mathrm{~W}\end{array}$ & $\begin{array}{l}320156 \mathrm{~N} 1124202 \mathrm{~W} \\
321327 \mathrm{~N} 1093650 \mathrm{~W}\end{array}$ & & $\begin{array}{l}\text { Mount Ajo } \\
\text { Simmons Peak }\end{array}$ \\
\hline $\begin{array}{l}\text { valley } \\
\text { valley }\end{array}$ & $B G N$ & $\begin{array}{l}\text { Pinal } \\
\text { Maricopa }\end{array}$ & $\begin{array}{l}332755 \mathrm{~N} 1112323 \mathrm{~W} \\
333055 \mathrm{~N} 1112438 \mathrm{~W}\end{array}$ & $332755 N 1112325 \mathrm{~W}$ & & Mormon Flat Dam \\
\hline valley & $\begin{array}{l}\text { BGN } \\
\text { VARIANT }\end{array}$ & Yavapai & $342334 \mathrm{~N} 1113856 \mathrm{~W}$ & $342908 \mathrm{~N} 1113704 \mathrm{~W}$ & & Hackberry Mtn \\
\hline $\begin{array}{l}\text { valley } \\
\text { valley } \\
\text { valley } \\
\text { reservoir } \\
\text { reservoir }\end{array}$ & $\begin{array}{l}\text { BGN } \\
\text { BGN } \\
\text { BGN } \\
\text { BGN } \\
\text { BGN } \\
\text { VARIANT }\end{array}$ & $\begin{array}{l}\text { Yavapai } \\
\text { Mohave } \\
\text { Mohave } \\
\text { Yavapai } \\
\text { Yavapai }\end{array}$ & $\begin{array}{l}343509 \mathrm{~N} 1115757 \mathrm{~W} \\
360813 \mathrm{~N} 1143720 \mathrm{~W} \\
365026 \mathrm{~N} 1135401 \mathrm{~W} \\
343326 \mathrm{~N} 1115958 \mathrm{~W} \\
343323 \mathrm{~N} 1115957 \mathrm{~W}\end{array}$ & $\begin{array}{l}343316 \mathrm{~N} 1115959 \mathrm{~W} \\
360905 \mathrm{~N} 1143251 \mathrm{~W} \\
364904 \mathrm{~N} 1135103 \mathrm{~W}\end{array}$ & & $\begin{array}{l}\text { Middle Verde } \\
\text { Boulder Canyon } \\
\text { Elbow Canyon } \\
\text { Middle Verde } \\
\text { Middle Verde }\end{array}$ \\
\hline $\begin{array}{l}\text { stream } \\
\text { strear }\end{array}$ & $B G N$ & $\begin{array}{l}\text { Maricopa } \\
\text { Maricopa }\end{array}$ & $\begin{array}{l}333135 N 1112515 \mathrm{~W} \\
333743 \mathrm{~N} 1112649 \mathrm{~W}\end{array}$ & $334039 \mathrm{~N} 1111943 \mathrm{~W}$ & & Mine Mountain \\
\hline $\begin{array}{l}\text { stream } \\
\text { stream } \\
\text { stream } \\
\text { stream }\end{array}$ & $\begin{array}{l}\text { BGN } \\
\text { BGN } \\
\text { BGN } \\
\text { BGN } 1906 \\
\text { VARIANT }\end{array}$ & $\begin{array}{l}\text { Maricopa } \\
\text { Yavapai } \\
\text { Yavapai } \\
\text { Coconino }\end{array}$ & $\begin{array}{l}335043 \mathrm{~N} 1112745 \mathrm{~W} \\
335812 \mathrm{~N} 1121223 \mathrm{~W} \\
343656 \mathrm{~N} 1131829 \mathrm{~W} \\
360406 \mathrm{~N} 1120112 \mathrm{~W}\end{array}$ & $\begin{array}{l}334831 \mathrm{~N} 1112314 \mathrm{~W} \\
340904 \mathrm{~N} 1121839 \mathrm{~W} \\
344451 \mathrm{~N} 113012 \mathrm{~W} \\
360307 \mathrm{~N} 1120257 \mathrm{~W}\end{array}$ & & $\begin{array}{l}\text { Boulder Mtn } \\
\text { New River } \\
\text { Grayback Mts } \\
\text { Phantom Ranch }\end{array}$ \\
\hline $\begin{array}{l}\text { stream } \\
\text { trail } \\
\text { dam }\end{array}$ & $\begin{array}{l}\text { UNOFF } \\
\text { UNOFF } \\
\text { VARIANT }\end{array}$ & $\begin{array}{l}\text { Coconino } \\
\text { Maricopa } \\
\text { Coconino }\end{array}$ & $\begin{array}{l}360834 N 1121525 W \\
335006 N 1112444 \mathrm{~W} \\
350325 N 1105828 \mathrm{~W}\end{array}$ & & & $\begin{array}{l}\text { Boulder Mtn } \\
\text { Tucker Mesa SW }\end{array}$ \\
\hline
\end{tabular}

Mohave 360058N1144414W

VARIANT

\begin{tabular}{|c|c|c|c|}
\hline park & & Mohave & $360056 \mathrm{~N} 1144412 \mathrm{~W}$ \\
\hline $\begin{array}{l}\text { spring } \\
\text { reservoir } \\
\text { locale } \\
\text { mine } \\
\text { summit } \\
\text { summit }\end{array}$ & $\begin{array}{l}\text { BGN } \\
\text { BGN } \\
\text { BGN } \\
\text { UNOFF } \\
\text { BGN } \\
\text { BGN }\end{array}$ & $\begin{array}{l}\text { Yavapai } \\
\text { Yavapai } \\
\text { Mohave } \\
\text { Mohave } \\
\text { Pinal } \\
\text { Maricopa }\end{array}$ & 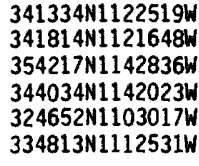 \\
\hline
\end{tabular}

Minnehaha

Battle Flat White Hills West Franconia

5339 Holy Joe Peak

6320 Boulder Mtn

Boulder Mtn Emmett Wash Boulder Mtn Mormon Flat Dam

3B85 Boulder Mtn Sombrero Peak

Kingman SE Pena Blanca Lake Ruby 
NATIONAL GAZETTEER--ARIZONA 1986

\section{FEATURE NAME}

Ruby Tank

Boulder Tank

Boulder Tank

Boulder Tank

Boulder Tank

Boulder Tank

Boulder Tank

Boulder Tank

Boulder Tank

Boulder Trail

Boulder Wash

Boulder Well

Boulder Well

Boul in Tank

Boul in Trick Tank

Boundary Butte

Boundary Cone

Boundary $\mathrm{Hill}$

Boundary Mine (historical)

Boundary Mountains

See Chuska Mountains

Boundary Ridge Saddle Mountain

Boundary Spring Coon Spring Tank

Boundary Spring

Boundary Spring

Boundary Spring

Boundary Tank

Boundary Tank

Boundary Tank

Boundary Tank

Boundary Tank

Boundary Tank

Boundary Tank

Boundary Tank

Boundary Tank

Boundary Tank

Boundary Tanks

Bouquet Ranch

Bourdon Tank

Bourdon Windmill

Bourgate High School

Bourke Canyon

Bourke Point

Bourke Tank

Bouse

Bouse Airport

Bouse Hills

Bouse Wash

See Upper Bouse Wash

Bouse Wash

Upper Bouse Wash

Bow and Arrow Park

Bowdon Tank

Bower Tank

Bowie

Bowie Airport

Bowie Elementary School

Bowie High School

Bowie Junction

See Luzena

Bowie Junction (historical)

Bowie Mountain

Bowie Post Office

Bowie Railroad Station

Bowie Substation

Bowie Turbine Station

Bowl Creek
FEATURE

STATUS

COUNTY

COORDINATE

VARIANT

reservoir

reservoir

reservoir

reservoir

reservoir

reservoir

BGN

BGN

BGN

BGN

reservoir

reservoir

reservoir

trail

valley

well

well

reservoir

locale

summit

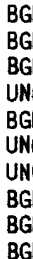

summit

summit

mine

range

ridge

reservoir

spring

BGN

BGN

UNOFF

Maricopa

MNOFF Mohave

Mohave

Mohave
Coconino

Coconino

Apache

Mohave

Mohave

Santa Cruz

14540 N1102906

$314627 N 1103224 \mathrm{~W}$

$320835 \mathrm{~N} 1102629 \mathrm{~W}$

$342337 N 1114703 \mathrm{~W}$

$344003 \mathrm{~N} 1111411 \mathrm{~W}$

$344438 \mathrm{~N} 1125928 \mathrm{~W}$

$345346 N 1132224 \mathrm{~W}$

$353008 \mathrm{~N} 1130050 \mathrm{~W}$

$355944 \mathrm{~N} 1134939 \mathrm{~W}$

332902N1112332W

$360532 \mathrm{~N} 1131416 \mathrm{~W}$

$342218 \mathrm{~N} 1123312 \mathrm{~W}$

$350635 \mathrm{~N} 1140432 \mathrm{~W}$

$352337 \mathrm{N1} 120239 \mathrm{~W}$

$352336 \mathrm{~N} 1120514 \mathrm{~W}$

$340740 N 1094026 \mathrm{~W}$

Apache $363500 N 1091700 \mathrm{~W}$

Coconino 361924N1115514W

Apache

$341034 N 1093844 W$

Graham

$325 B 45 N 1101922 \mathrm{~W}$

spring

spring

reservoir

reservoir

reservoir

reservoir

reservoir

reservoir

reservoir

reservoir

BGN Yavapai

Yavapai

Santa Cruz

Coch ise

Graham

Graham

Gila

Apache

Apache

Yavapai

reservoir

reservoir

reservoir

locale

reservoir

locale

school

valley

cliff

reservoir

BGN

BGN

UNOFF

BGN

BGN

UNOFF

BGN

BGN 1932

Coconino

Coconino

Apache

Gila

Navajo

Navajo

Maricopa

Navajo

Coconino

Navajo

pp 1 BGN

airport

BGN
VARIANT

La Paz

La Paz

summit

BGN

La Paz

stream Yuma

stream BGN 1964 La Paz

park

VARIANT

ADMIN Coconino

reservoir BGN Coconino

$342623 \mathrm{~N} 1122420 \mathrm{~W}$

$344042 \mathrm{~N} 1125633 \mathrm{~W}$

$312342 \mathrm{~N} 1111537 \mathrm{~W}$

$315724 \mathrm{~N} 1092628 \mathrm{~W}$

$322635 \mathrm{~N} 110112 \mathrm{BW}$

$322948 \mathrm{~N} 1094323 \mathrm{~W}$

$340442 \mathrm{~N} 1104633 \mathrm{~W}$

$340652 \mathrm{~N} 1094532 \mathrm{~W}$

$341524 N 1094919 \mathrm{~W}$

$344927 \mathrm{N1122303 \textrm {W }}$

$350323 \mathrm{~N} 1111855 \mathrm{~W}$

$352452 \mathrm{~N} 1123057 \mathrm{~W}$

$340948 \mathrm{~N} 1093817 \mathrm{~W}$

$335050 \mathrm{~N} 1111446 \mathrm{~W}$

$341544 \mathrm{~N} 1095156 \mathrm{~W}$

$34152 B N 1095232 \mathrm{~W}$

$333009 \mathrm{~N} 1120731 \mathrm{~W}$

$335149 \mathrm{N1095711W}$

$361647 \mathrm{N1115623 \textrm {W }}$

$335237 N 1095751 \mathrm{~W}$

$335557 N 1140018 W$

$335600 \mathrm{~N} 1135945 \mathrm{~W}$

$335704 \mathrm{N1135418W}$

$333900 \mathrm{~N} 1134530 \mathrm{~W}$

$340250 \mathrm{~N} 1141942 \mathrm{~W}$

$350949 N 1113945 \mathrm{~W}$

$351113 N 1120915 \mathrm{~W}$

reservoir BGN Cochise 313818N1092330W

ppl BGN Cochise

airport ADMIN Cochise

school UNOFF Cochise

school UNOFF Cochise

locale

locale

summit

building

VARIAN

Cochise

Cochise

Cochise

$321935 \mathrm{~N} 1092911 \mathrm{~W}$

$321929 \mathrm{~N} 1092915 \mathrm{~W}$

$321930 \mathrm{~N} 1092922 \mathrm{~W}$

$322117 \mathrm{~N} 1093734 \mathrm{~W}$

$322145 \mathrm{~N} 1093730 \mathrm{~W}$

$320726 \mathrm{~N} 1092552 \mathrm{~W}$

$321934 \mathrm{~N} 1092908 \mathrm{~W}$

$\begin{array}{lll}\text { building } & \text { UNOFF } & \text { Cochise } \\ \text { locale } & \text { UNOFF } & \text { Cochise } \\ \text { locale } & \text { UNOFF } & \text { Cochise }\end{array}$

$321942 \mathrm{~N} 1092913 \mathrm{~W}$

$321955 \mathrm{~N} 1092 \mathrm{~B} 30 \mathrm{~W}$

$321901 \mathrm{~N} 1094115 \mathrm{~W}$

$323322 \mathrm{~N} 1105736 \mathrm{~W}$

$\begin{array}{cc}\text { SOURCE } & \text { ELEV } \\ \text { COORDINATE } & \text { FT MAP NAME }\end{array}$

Apache Peak

Spring Water Canyon

Happy Valley

Horner Mtn

Hay Lake

Sheridan Mtn

Mohon Peak

Big Chief Tank

Quartermaster Canyon

Goldfield

360629N1131443W Vulcans Throne SW

Walnut Grove

Kingman SE

Squaw Mtn

Howard Mesa

9263 Boundary Butte

3430 Boundary Cone

Iceberg Canyon

Harshaw

Point Imperial

Boundary Butte

Cobre Grande Mtn

Groom Creek

Sheridan Mtn

Bart lett Mtn

Fife Peak

The Mesas

Monk Draw

Gentry Mtn

McNary

Ortega Mtn

Chino Valley North

Elliott Canyon

Eagle Nest Mtn

Boundary Butte 
$$
\text { FEATURE }
$$

\begin{tabular}{|c|c|c|c|}
\hline $\begin{array}{l}\text { EATURE } \\
\text { CLASSS }\end{array}$ & STATUS & COUNTY & COORDINATE \\
\hline $\begin{array}{l}\text { cemetery } \\
\text { locale } \\
\text { spring } \\
\text { flat } \\
\text { reservoir } \\
\text { basin }\end{array}$ & $\begin{array}{l}\text { UNOFF } \\
\text { UNOFF } \\
\text { BGN } \\
\text { BGN } \\
\text { BGN } \\
\text { BGN }\end{array}$ & $\begin{array}{l}\text { Apache } \\
\text { Graham } \\
\text { Pima } \\
\text { Coconino } \\
\text { Coconino } \\
\text { Graham }\end{array}$ & $\begin{array}{l}352509 \mathrm{~N} 1090626 \mathrm{~W} \\
330341 \mathrm{N1} 102307 \mathrm{~W} \\
314705 \mathrm{N1} 104545 \mathrm{~W} \\
343725 \mathrm{N1} 112401 \mathrm{~W} \\
343723 \mathrm{N1} 112351 \mathrm{~W} \\
325729 \mathrm{N1} 101356 \mathrm{~W}\end{array}$ \\
\hline $\begin{array}{l}\text { bas in } \\
\text { bas in } \\
\text { bas in } \\
\text { bend } \\
\text { summit } \\
\text { valley } \\
\text { valley } \\
\text { locale } \\
\text { valley } \\
\text { valley }\end{array}$ & $\begin{array}{l}\text { BGN } \\
\text { BGN } \\
\text { BGN } \\
\text { BGN } \\
\text { BGN } \\
\text { BGN } \\
\text { BGN } \\
\text { UNOFF } \\
\text { BGN } \\
\text { BGN }\end{array}$ & $\begin{array}{l}\text { Graham } \\
\text { Greenlee } \\
\text { Yavapai } \\
\text { Yavapai } \\
\text { Mohave } \\
\text { Gila } \\
\text { Coconino } \\
\text { Maricopa } \\
\text { Pima } \\
\text { Santa Cruz }\end{array}$ & $\begin{array}{l}330024 \mathrm{~N} 1101600 \mathrm{~W} \\
333305 \mathrm{~N} 1091146 \mathrm{~W} \\
340234 \mathrm{N1} 124402 \mathrm{~W} \\
34035 \mathrm{BN} 1122844 \mathrm{~W} \\
361519 \mathrm{N1} 135714 \mathrm{~W} \\
340427 \mathrm{N1} 111706 \mathrm{~W} \\
360602 \mathrm{N1} 1120542 \mathrm{~W} \\
334423 \mathrm{N1} 113934 \mathrm{~W} \\
322200 \mathrm{N1} 104628 \mathrm{~W} \\
313245 \mathrm{N1} 1103742 \mathrm{~W}\end{array}$ \\
\hline $\begin{array}{l}\text { valley } \\
\text { valley } \\
\text { valley } \\
\text { valley } \\
\text { valley } \\
\text { valley }\end{array}$ & $\begin{array}{l}\text { BGN } \\
\text { BGN } \\
\text { BGN } \\
\text { BGN } \\
\text { BGN } \\
\text { BGN } \\
\text { VARIANT }\end{array}$ & $\begin{array}{l}\text { Cochise } \\
\text { Pima } \\
\text { Pima } \\
\text { Graham } \\
\text { Pinal } \\
\text { Gila }\end{array}$ & $\begin{array}{l}313723 \mathrm{~N} 1092806 \mathrm{~W} \\
314806 \mathrm{N1} 104 \mathrm{~B} 26 \mathrm{~W} \\
322006 \mathrm{N1} 105425 \mathrm{~W} \\
330308 \mathrm{~N} 1095719 \mathrm{~W} \\
330542 \mathrm{N1111327W} \\
332511 \mathrm{~N} 1104800 \mathrm{~W}\end{array}$ \\
\hline $\begin{array}{l}\text { valley } \\
\text { valley } \\
\text { valley }\end{array}$ & $\begin{array}{l}\text { BGN } \\
B G N\end{array}$ & $\begin{array}{l}\text { Maricopa } \\
\text { Greenlee } \\
\text { Yavapai }\end{array}$ & $\begin{array}{l}333436 \mathrm{~N} 1112111 \mathrm{~W} \\
334356 \mathrm{~N} 1090321 \mathrm{~W} \\
340214 \mathrm{~N} 1122153 \mathrm{~W}\end{array}$ \\
\hline $\begin{array}{l}\text { valley } \\
\text { valley } \\
\text { valley } \\
\text { valley } \\
\text { valley } \\
\text { valley } \\
\text { valley } \\
\text { valley } \\
\text { valley } \\
\text { locale }\end{array}$ & $\begin{array}{l}\text { BGN } \\
B G N \\
B G N \\
B G N \\
B G N \\
B G N \\
B G N \\
B G N \\
B G N \\
B G N\end{array}$ & $\begin{array}{l}\text { Yavapai } \\
\text { Gila } \\
\text { Yavapai } \\
\text { Vavapa } \\
\text { Coconino } \\
\text { Mohave } \\
\text { Apache } \\
\text { Coconino } \\
\text { Mohave } \\
\text { Coconino }\end{array}$ & 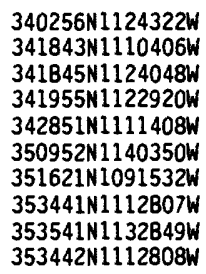 \\
\hline $\begin{array}{l}\text { spring } \\
\text { reservoir } \\
\text { reservoir } \\
\text { reservoir } \\
\text { arroyo } \\
\text { stream } \\
\text { well } \\
\text { locale } \\
\text { summit } \\
\text { summit }\end{array}$ & $\begin{array}{l}\text { BGN } \\
\text { BGN } \\
\text { BGN } \\
\text { BGN } \\
\text { BGN } \\
\text { BGN } \\
\text { UNOFF } \\
\text { BGN } \\
\text { BGN } \\
\text { BGN }\end{array}$ & $\begin{array}{l}\text { Apache } \\
\text { Yavapai } \\
\text { Mohave } \\
\text { Mohave } \\
\text { Pima } \\
\text { Mohave } \\
\text { Mohave } \\
\text { Yavapai } \\
\text { Yuma } \\
\text { Coconino }\end{array}$ & $\begin{array}{l}351708 \mathrm{~N} 1091535 \mathrm{~W} \\
341811 \mathrm{N1} 124044 \mathrm{~W} \\
353420 \mathrm{NI} 133010 \mathrm{~W} \\
353412 \mathrm{N1} 133029 \mathrm{~W} \\
315100 \mathrm{~N} 110522 \mathrm{~W} \\
343700 \mathrm{~N} 1133407 \mathrm{~W} \\
343833 \mathrm{N1} 132530 \mathrm{~W} \\
341725 \mathrm{N1} 124124 \mathrm{~W} \\
334126 \mathrm{N1} 140435 \mathrm{~W} \\
351517 \mathrm{N1} 120610 \mathrm{~W}\end{array}$ \\
\hline
\end{tabular}

SOURCE
COORDINATE

Surrender Canyon Rawhide Mtn Helvetia Calloway Butte Calloway Butte Jackson Mtn

Mt Turnbal Bear Mountain Sam Powell Peak Copperopol is Gyp Hills

Gisela

Phantom Ranch Fort Mc Dowell Sabino Canyon

Mt Hughes

$322413 N 1104525$

$313942 \mathrm{~N} 1092209 \mathrm{~N}$ $314855 \mathrm{~N} 1104527 \mathrm{~W}$ $322135 \mathrm{N1} 105251 \mathrm{~W}$ 330639 N1095508W $331247 \mathrm{~N} 1110958 \mathrm{H}$ $332524 \mathrm{N1} 104717 \mathrm{~W}$

$334508 \mathrm{~N} 1090328 \mathrm{~W}$ $340222 \mathrm{~N} 1122229 \mathrm{~W}$

$340235 \mathrm{~N} 1124149 \mathrm{~W}$ $341 B 26 \mathrm{~N} 1110315 \mathrm{~W}$ $341725 \mathrm{~N} 1124116 \mathrm{~W}$ $342329 \mathrm{~N} 1122742 \mathrm{~W}$ $342733 \mathrm{~N} 1111414 \mathrm{~W}$ $351033 \mathrm{N1140401 \textrm {W }}$ $351811 \mathrm{N1091641 \textrm {W }}$ $353432 \mathrm{~N} 1112821 \mathrm{~W}$ $353436 \mathrm{~N} 1133010 \mathrm{~W}$

Pedregosa Mts West Helvetia

Tucson North Fort Thomas North Butte Globe

Maness Peak Columbia

Sam Powell Peak Promontory Butte Peeples Valley Battleship Butte Dane Canyon

Kingman

Burntwater Wash

Wupatki SW

Peach Springs

Wupatki SW

Burntwater Wash Peeples Valley Milkweed Canyon SE Milkweed Canyon SE Helvetia

314806 N1104B30

Greenwood Peak Elephant Mtn Peeples Valley Plomosa Pass

7400 Sitgreaves Mtn
Sowats Spring Box K Ranch Box K Ranch Ninetysix Hills NW Ninetysix Hills NE $325213 \mathrm{~N} 1110041 \mathrm{~W} \quad$ North Butte Box K Ranch

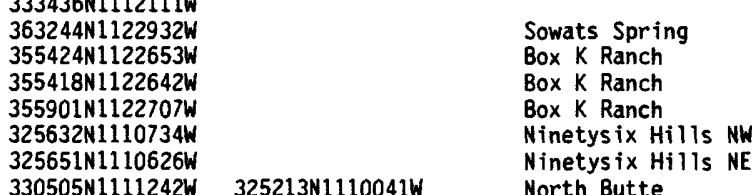

Mt Lemmon

The Mesas Beargrass Basin Cibecue Young Red Top Mtn Minnehaha Burns Spring Standing Rocks Forks Butte

Page Springs Diamond Point Arnold Mesa Arnold Mesa 


\begin{tabular}{|c|c|c|c|c|c|c|c|}
\hline FEATURE NAME & $\begin{array}{l}\text { FEATURE } \\
\text { CLASS }\end{array}$ & STATUS & COUNTY & COORDINATE & $\begin{array}{l}\text { SOURCE } \\
\text { COORDINATE }\end{array}$ & $\begin{array}{c}\text { ELEV } \\
\text { FT }\end{array}$ & MAP NAME \\
\hline $\begin{array}{l}\text { Box Wash } \\
\text { Boyce Spring } \\
\text { Boy Creek Canpground } \\
\text { Boyd Knoll } \\
\text { Boyd Mountain } \\
\text { Boyd Mountain Spring }\end{array}$ & $\begin{array}{l}\text { stream } \\
\text { spring } \\
\text { park } \\
\text { summit } \\
\text { summit } \\
\text { spring }\end{array}$ & $\begin{array}{l}\text { BGN } \\
\text { BGN } \\
\text { ADMIN } \\
\text { BGN } \\
\text { BGN } \\
\text { BGN }\end{array}$ & $\begin{array}{l}\text { Maricopa } \\
\text { Apache } \\
\text { Apache } \\
\text { Coconino } \\
\text { Gila } \\
\text { Gila }\end{array}$ & $\begin{array}{l}334051 \mathrm{~N} 1124613 \mathrm{~W} \\
340325 \mathrm{~N} 1094619 \mathrm{~W} \\
340314 \mathrm{~N} 1094510 \mathrm{~W} \\
351208 \mathrm{~N} 1121720 \mathrm{~W} \\
340833 \mathrm{~N} 1112644 \mathrm{~W} \\
340851 \mathrm{~N} 1112547 \mathrm{~W}\end{array}$ & $335406 \mathrm{~N} 1125027 \mathrm{~W}$ & $\begin{array}{l}6858 \\
4705\end{array}$ & $\begin{array}{l}\text { Star Well } \\
\text { McNary } \\
\text { McNary } \\
\text { McLellan Reservoir } \\
\text { North Peak } \\
\text { North Peak }\end{array}$ \\
\hline $\begin{array}{l}\text { Boyd Reid Tank } \\
\text { Boyd Tank } \\
\text { Boyer Canyon } \\
\text { Boyer Gap } \\
\text { Boyer Ridge } \\
\text { Boyer Trail One Hundred } \\
\text { Fortyeight } \\
\text { Boynton Canyon } \\
\text { Boynton Lake } \\
\text { Boynton Lake Dam }\end{array}$ & $\begin{array}{l}\text { reservoir } \\
\text { reservoir } \\
\text { valley } \\
\text { gap } \\
\text { ridge } \\
\text { trail } \\
\text { valley } \\
\text { reservoir } \\
\text { dam }\end{array}$ & $\begin{array}{l}\text { BGN } \\
\text { BGN } \\
\text { BGN } \\
\text { BGN } \\
\text { BGN } \\
\text { UNOFF } \\
\text { BGN } \\
\text { BGN } \\
\text { UNOFF }\end{array}$ & $\begin{array}{l}\text { Coconino } \\
\text { Pima } \\
\text { Gila } \\
\text { Yuma } \\
\text { Gila } \\
\text { Gila } \\
\text { Yavapai } \\
\text { Apache } \\
\text { Apache }\end{array}$ & $\begin{array}{l}350252 \mathrm{~N} 1111257 \mathrm{~W} \\
313732 \mathrm{~N} 1111125 \mathrm{~W} \\
334808 \mathrm{~N} 1110531 \mathrm{~W} \\
334356 \mathrm{~N} 1141925 \mathrm{~W} \\
334938 \mathrm{~N} 1110418 \mathrm{~W} \\
335025 \mathrm{~N} 1110125 \mathrm{~W} \\
\\
345329 \mathrm{~N} 1115015 \mathrm{~W} \\
341224 \mathrm{~N} 1093606 \mathrm{~W} \\
341224 \mathrm{~N} 1093606 \mathrm{~W}\end{array}$ & $345639 N 1115323 W$ & B51 & $\begin{array}{l}\text { Anderson Canyon } \\
\text { Saucito Mtn } \\
\text { Armer Mountain } \\
\text { Middle Camp Mtn } \\
\text { Armer Mountain } \\
\text { Armer Mountain } \\
\\
\text { Wilson Mountain } \\
\text { Whiting Knoll } \\
\text { Whiting Knoll }\end{array}$ \\
\hline $\begin{array}{l}\text { Boynton Pass } \\
\text { Boysag Canyon } \\
\text { Boysag Point } \\
\text { Baysag Point } \\
\text { Boysag Rim } \\
\text { Boy Scout Camp } \\
\text { Boy Scout Camp } \\
\text { Boy Scout Camp } \\
\text { Boy Scout Campgrounds } \\
\text { Boy Scout Spring }\end{array}$ & $\begin{array}{l}\text { gap } \\
\text { valley } \\
\text { cliff } \\
\text { cliff } \\
\text { park } \\
\text { park } \\
\text { park } \\
\text { park } \\
\text { spring }\end{array}$ & $\begin{array}{l}\text { BGN } \\
\text { BGN } 1925 \\
\text { BGN } 1925 \\
\text { VARIANT } \\
\text { BGN } 1925 \\
\text { ADMIN } \\
\text { ADMIN } \\
\text { ADMIN } \\
\text { ADMIN } \\
\text { BGN }\end{array}$ & $\begin{array}{l}\text { Yavapai } \\
\text { Mohave } \\
\text { Mohave } \\
\text { Mohave } \\
\text { Pima } \\
\text { Yuma } \\
\text { Gila } \\
\text { Pima } \\
\text { Pima }\end{array}$ & $\begin{array}{l}345351 \mathrm{~N} 1115138 \mathrm{~W} \\
362045 \mathrm{~N} 1124440 \mathrm{~W} \\
362046 \mathrm{~N} 1124441 \mathrm{~W} \\
362045 \mathrm{~N} 1124440 \mathrm{~W} \\
322431 \mathrm{N1} 104254 \mathrm{~W} \\
325920 \mathrm{~N} 1142830 \mathrm{~W} \\
34183 \mathrm{BN} 111030 \mathrm{~W} \\
322153 \mathrm{~N} 1124942 \mathrm{~W} \\
322440 \mathrm{~N} 1104323 \mathrm{~W}\end{array}$ & & $\begin{array}{l}7900 \\
5640\end{array}$ & $\begin{array}{l}\text { Wilson Mountain } \\
\text { Havasu Falls } \\
\text { Havasu Falls } \\
\text { Havasu Falls } \\
\text { Mount Bigelow } \\
\text { Little Picacho Peak } \\
\text { Promontory Butte } \\
\text { Ajo South } \\
\text { Mount Bigelow }\end{array}$ \\
\hline $\begin{array}{l}\text { Boy Scout Spring } \\
\text { Boy Spring } \\
\text { Boys Ranch Post Office } \\
\text { Boy Tank } \\
\text { Bozarth Mesa } \\
\text { Bozarth Point } \\
\quad \text { Wilder Mesa }\end{array}$ & $\begin{array}{l}\text { spring } \\
\text { spring } \\
\text { building } \\
\text { reservoir } \\
\text { summit } \\
\text { cape }\end{array}$ & $\begin{array}{l}\text { BGN } \\
\text { BGN } \\
\text { UNOFF } \\
\text { BGN } \\
\text { BGN } \\
\text { BGN } \\
\text { VARIANT }\end{array}$ & $\begin{array}{l}\text { Gila } \\
\text { Apache } \\
\text { Maricopa } \\
\text { Gila } \\
\text { Yavapai } \\
\text { Yavapai }\end{array}$ & $\begin{array}{l}341840 \mathrm{~N} 1112203 \mathrm{~W} \\
340420 \mathrm{~N} 1094702 \mathrm{~W} \\
331554 \mathrm{~N} 111390 \mathrm{~W} \\
341759 \mathrm{~N} 1110546 \mathrm{~W} \\
344343 \mathrm{~N} 1131052 \mathrm{~W} \\
344029 \mathrm{~N} 1131440 \mathrm{~W}\end{array}$ & & 4870 & $\begin{array}{l}\text { Payson North } \\
\text { McNary } \\
\text { Higley } \\
\text { Promontory Butte } \\
\text { Bozarth Mesa } \\
\text { Bozarth Mesa }\end{array}$ \\
\hline $\begin{array}{l}\text { Bozarth Ranch } \\
\text { Bradberry } \\
\text { Brad Creek }\end{array}$ & $\begin{array}{l}\text { locale } \\
\text { locale } \\
\text { stream }\end{array}$ & $\begin{array}{l}\text { UNOFF } \\
\text { BGN } \\
\text { BGN }\end{array}$ & $\begin{array}{l}\text { Yavapai } \\
\text { Cochise } \\
\text { Cochise }\end{array}$ & $\begin{array}{l}344125 N 1131322 W \\
322437 N 1101843 W \\
320622 N 1091810 W\end{array}$ & $320657 \mathrm{~N} 1091938 \mathrm{~W}$ & $\begin{array}{l}4012 \\
4040\end{array}$ & $\begin{array}{l}\text { Bozarth Mesa } \\
\text { Cherry Spring Peak } \\
\text { Cochise Head }\end{array}$ \\
\hline $\begin{array}{l}\text { Bradford Mine } \\
\text { Bradford Well } \\
\text { Bradley Bay } \\
\text { Bradley Point } \\
\text { Brads Canyon } \\
\text { Bradshaw City } \\
\text { Bradshaw City Cemetery } \\
\text { Bradshaw Ferry (site) } \\
\text { Bradshaws Ferry } \\
\text { La Paz Ferry } \\
\text { Olive City } \\
\text { Oliva }\end{array}$ & $\begin{array}{l}\text { mine } \\
\text { well } \\
\text { bay } \\
\text { cliff } \\
\text { valley } \\
\text { locale } \\
\text { cemetery } \\
\text { locale }\end{array}$ & $\begin{array}{l}\text { UNOFF } \\
\text { UNOFF } \\
\text { BGN } \\
\text { BGN } 1932 \\
\text { BGN } \\
\text { BGN } \\
\text { UNOFF } \\
\text { BGN } \\
\text { VARIANT } \\
\text { VARIANT } \\
\text { VARIANT } \\
\text { VARIANT }\end{array}$ & $\begin{array}{l}\text { Santa Cruz } \\
\text { La Paz } \\
\text { Mohave } \\
\text { Coconino } \\
\text { Pinal } \\
\text { Yavapai } \\
\text { Yavapai } \\
\text { La Paz }\end{array}$ & $\begin{array}{l}313043 N 1104921 \mathrm{~W} \\
333840 \mathrm{~N} 1134505 \mathrm{~W} \\
361057 \mathrm{~N} 1140241 \mathrm{~W} \\
360619 \mathrm{~N} 1120319 \mathrm{~W} \\
332619 \mathrm{~N} 111165 \mathrm{~W} \\
341148 \mathrm{~N} 1122118 \mathrm{~W} \\
341130 \mathrm{~N} 1122120 \mathrm{~W} \\
333720 \mathrm{~N} 114303 \mathrm{~W}\end{array}$ & $332706 \mathrm{~N} 1111635 \mathrm{~W}$ & & $\begin{array}{l}\text { Patagonia } \\
\text { Vicksburg } \\
\text { Iceberg Canyon } \\
\text { Phantom Ranch } \\
\text { Weavers Needle } \\
\text { Crown King } \\
\text { Crown King } \\
\text { Blythe }\end{array}$ \\
\hline $\begin{array}{l}\text { Bradshaw Mountain High School } \\
\text { Bradshaw Mountains } \\
\text { Bradshaws Ferry } \\
\text { See Olive City (historical) } \\
\text { Bradshaws Ferry } \\
\text { See Bradshaw Ferry (site) } \\
\text { Bradshaw Spring } \\
\text { Bradshaw Tank } \\
\text { Bradshaw Trail } \\
\text { Brads Water }\end{array}$ & $\begin{array}{l}\text { school } \\
\text { range } \\
\text { ppl } \\
\text { locale } \\
\text { spring } \\
\text { reservoir } \\
\text { trail } \\
\text { spring }\end{array}$ & $\begin{array}{l}\text { UNOFF } \\
\text { BGN } 1972 \\
\text { VARIANT } \\
\text { VARIANT } \\
\text { BGN } \\
\text { BGN } \\
\text { UNOFF } \\
\text { BGN }\end{array}$ & $\begin{array}{l}\text { Yavapai } \\
\text { Yavapai } \\
\text { La Paz } \\
\text { La Paz } \\
\text { Yavapai } \\
\text { Gila } \\
\text { Yavapai } \\
\text { Pinal }\end{array}$ & $\begin{array}{l}343233 \mathrm{~N} 1121458 \mathrm{~W} \\
342329 \mathrm{~N} 1122152 \mathrm{~W} \\
333640 \mathrm{~N} 1143130 \mathrm{~W} \\
333720 \mathrm{~N} 1143030 \mathrm{~W} \\
340448 \mathrm{~N} 1122936 \mathrm{~W} \\
342204 \mathrm{~N} 1112724 \mathrm{~W} \\
341550 \mathrm{~N} 1122116 \mathrm{~W} \\
332626 \mathrm{~N} 1111653 \mathrm{~W}\end{array}$ & & & $\begin{array}{l}\text { Copperopolis } \\
\text { Buckhead Mesa } \\
\text { Battle Flat } \\
\text { Weavers Needle }\end{array}$ \\
\hline $\begin{array}{l}\text { Brady Butte } \\
\text { Brady Butte Tank } \\
\text { Brady Canyon } \\
\text { Brady Canyon } \\
\text { Brady Canyon } \\
\text { Brady Canyon } \\
\text { See Jacks Canyon } \\
\text { Brady Canyon } \\
\text { Brady Park } \\
\text { Brady Peak }\end{array}$ & $\begin{array}{l}\text { summit } \\
\text { reservoir } \\
\text { valley } \\
\text { valley } \\
\text { valley } \\
\text { valley } \\
\text { valley } \\
\text { flat } \\
\text { summit }\end{array}$ & $\begin{array}{l}\text { BGN } \\
\text { BGN } \\
\text { BGN } \\
\text { BGN } \\
\text { BGN } \\
\text { VARIANT } \\
\text { BGN } \\
\text { BGN } \\
\text { BGN } 1932\end{array}$ & $\begin{array}{l}\text { Yavapai } \\
\text { Yavapai } \\
\text { Gila } \\
\text { Gila } \\
\text { Coconino } \\
\text { Coconino } \\
\text { Mohave } \\
\text { Apache } \\
\text { Coconino }\end{array}$ & $\begin{array}{l}342116 \mathrm{~N} 1121920 \mathrm{~W} \\
342148 \mathrm{~N} 1121939 \mathrm{~W} \\
340221 \mathrm{~N} 1111817 \mathrm{~W} \\
340448 \mathrm{~N} 1110433 \mathrm{~W} \\
344101 \mathrm{~N} 1113125 \mathrm{~W} \\
\\
344101 \mathrm{~N} 1113125 \mathrm{~W} \\
362020 \mathrm{~N} 1130255 \mathrm{~W} \\
341107 \mathrm{~N} 1093745 \mathrm{~W} \\
361435 \mathrm{~N} 1115747 \mathrm{~W}\end{array}$ & $\begin{array}{l}340225 \mathrm{~N} 1112116 \mathrm{~W} \\
340229 \mathrm{~N} 1110820 \mathrm{~W} \\
344246 \mathrm{~N} 1112622 \mathrm{~W}\end{array}$ & 6402 & $\begin{array}{l}\text { Battle Flat } \\
\text { Battle Flat } \\
\text { Gisela } \\
\text { Buzzard Roost Mesa } \\
\text { Apache Maid Mtn }\end{array}$ \\
\hline $\begin{array}{l}\text { Brady Spring } \\
\text { Brady Spring } \\
\text { Brady Tank }\end{array}$ & $\begin{array}{l}\text { spring } \\
\text { spring } \\
\text { reservoir }\end{array}$ & $\begin{array}{l}\text { BGN } \\
B G N \\
B G N\end{array}$ & $\begin{array}{l}\text { Apache } \\
\text { Yavapai } \\
\text { Pinal }\end{array}$ & $\begin{array}{l}341037 \mathrm{~N} 1093740 \mathrm{~W} \\
343036 \mathrm{~N} 1122111 \mathrm{~W} \\
324648 \mathrm{~N} 111125 \mathrm{BW}\end{array}$ & & & $\begin{array}{l}\text { Boundary Butte } \\
\text { Prescott Valley S } \\
\text { Ninetysix Hills SW }\end{array}$ \\
\hline
\end{tabular}


FEATURE NAME

Brady Tank

Brady Tanks

Brady Wash

Braemar VII (subdivision)

Braewood Park Breawo Park

Brahma Draw

Brahma Tank

Brahma Tank

Brahma Tank

Brahma Temple

Branaman

Brannaman

Branaman Cave

Branaman Spring

Branaman Tank

Branch Creek Dam

Branch Creek Tank

Brandenburg Mountain

Brandenburg Wash

Brandon Tank

Brandywine (subdivision)

Brannaman

See Branaman

Brannigan Flat

Brannigan Flat Tank

Brannigan Park

Brannigan Tank

Brass Cap Point

Brasswell Canyon

Brave Bull Ranch Resort Airport

Bravo Park

Brawley Wash Brawly Wash

Brawly Wash

See Brawley Wash

Bray Creek

Brayton

See Bouse

Brazo de Miraflores

See Gila River

Breadpan Canyon

Breadpan Mountain

Bread Pan Spring

See Breadpan Spring

Breadpan Spring

Bread Pan Spring

Breadpan Tank

Bread Spring

Breakdown Saddle

Breakfast Canyon

Breawo Park

See Braewood Park

Breckenridge Manor

(subdivision)

Breed Spring

Breezy Lake

Breezy Number One Tank

Breezy Number Two Tank

Breezy Point

Breezy Tank

Breezy Waters Valley See Ha-whi-yalin Wash

Brenda

Brentwood Mobile Manor

Brentwood West (trailer park)

Brett Tank

Brewer Spring

Brewery Gulch

Brewery Gulch Interchange

Brewster WeI

\section{FEATUR
CLASS}

reservoir

reservoir

stream

pp1

park

valley

reservoir

reservoir

rumnit

locale

cave

spring

reservoir

dam

reservoir

summit

stream

reservoir

ppl

locale

flat

reservoir

flat

reservoir

cape

valley

airport

park

stream

stream

stream

ppl

stream

valley

summit

spring

spring

reservoir

spring

gap

valley

park

ppl

spring

lake

reservoir

reservoir

cliff

reservoir

stream

locale

locale

locale

reservoir

spring

valley

crossing

well

BGN

UNOFF
UNOFF

$B G N$

BGN

UNOFF

\section{$B G N$}

BGN
BGN

BGN

BGN

ADMIN

ADMIN

BGN

BGN

BGN

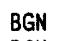

$B G N$
$B G N$
$B G N$

BGN

BGN

BGN

BGN

UNOFF

UNOFF
STATUS COUNTY

BGN Coconino

BGN Coconino

Pinal

Maricopa

Maricopa

Navajo

Maricopa

Yavapai

BGN Navajo

BGN 1906 Coconino

BGN

Pinal

Graham

Graham

Graham

Gila

8GN Gila

Pinal

Pinal

Coconino

Maricopa

VARIANT

Pinal

Coconino

Coconino

Coconino

VARIANT

VARIANT

Coconino

Yuma

Graham

Pima

Pima

Pima

Pima

Gila

VARIANT

VARIANT

BGN
VARIAN

La Paz

Yuma

Gila

Gila

BGN 1981 Gila

VARIANT

VARIANT

Gila

Gila

Gila

Pima

Maricopa

Maricopa

Coconino

Coconino

BGN Coconino

BGN Coconino

BGN 1932 Coconino

BGN Coconino

Navajo

Yuma

Maricopa

Maricopa

Yavapai

Gila

Cochise

Cochise

Gila

COORDINATE

$344135 N 1113043 \mathrm{~W}$ $344035 \mathrm{~N} 1112855 \mathrm{~W}$ 325139 N1112747W $333435 N 1121220 \mathrm{~W}$ $333503 \mathrm{~N} 1121448 \mathrm{~W}$

341919 N1103215W

335457 N1130309W $340350 \mathrm{~N} 1125520 \mathrm{~W}$ $341916 \mathrm{~N} 1103223 \mathrm{~W}$ 360749 N1120217W 330305 N1105440W

$331953 \mathrm{~N} 1101254 \mathrm{~W}$ $331951 N 1101257 \mathrm{~W}$ $332109 \mathrm{~N} 1101406 \mathrm{~W}$ $331518 \mathrm{~N} 1104312 \mathrm{~W}$

$331518 \mathrm{~N} 1104311 \mathrm{~W}$ $325304 N 1103543 \mathrm{~W}$ 325246 N1103457W $343914 N 1112832 \mathrm{~W}$ 333817 N1120825W

$330305 \mathrm{N1} 105440 \mathrm{~W}$ $351533 N 1115057 \mathrm{~W}$ $351624 N 1115122 \mathrm{~W}$ $351625 \mathrm{~N} 1115306 \mathrm{~W}$

351707 N1115303W $332559 \mathrm{~N} 1140446 \mathrm{~W}$ $330453 \mathrm{N1094724 \textrm {W }}$ $322950 \mathrm{N1} 105325 \mathrm{~W}$ 321009 N1105703W $322540 \mathrm{~N} 1111724 \mathrm{~W}$

$322540 \mathrm{N1111724W}$

$342239 N 1112052 \mathrm{~W}$

335557 N1140018W

$324311 N 1143316 \mathrm{~W}$ $340629 \mathrm{~N} 1110520 \mathrm{~W}$ $340354 N 1110 B 41 \mathrm{~W}$

$340615 N 1110558 \mathrm{~W}$

$340615 N 1110558 \mathrm{~W}$

$340335 N 1110812 \mathrm{~W}$

$334014 N 1101022 \mathrm{~W}$

340649 N1111500

$321933 \mathrm{~N} 1104850 \mathrm{~W}$

$333503 \mathrm{~N} 1121448 \mathrm{~W}$

$332146 \mathrm{~N} 1114745 \mathrm{~W}$

$342819 N 1105221 \mathrm{~W}$

$345950 \mathrm{N1112302W}$

350012 N1112309W

$345927 \mathrm{NI} 112248 \mathrm{~W}$

$360454 N 1121242 W$

$350908 \mathrm{~N} 1113145 \mathrm{~W}$

$353556 \mathrm{~N} 1102434 \mathrm{~W}$ $334047 \mathrm{~N} 1135638 \mathrm{~W}$

$332509 \mathrm{N11} 14504 \mathrm{~W}$

$332436 \mathrm{~N} 1114535 \mathrm{~W}$

345657 N1131100W

$340530 \mathrm{~N} 1105215 \mathrm{~W}$

$312632 \mathrm{~N} 1095449 \mathrm{~W}$ 


\begin{tabular}{|c|c|c|c|c|c|c|c|}
\hline FEATURE NAME & $\begin{array}{l}\text { FEATURE } \\
\text { CLASS }\end{array}$ & STATUS & COUNTY & COORDINATE & $\begin{array}{l}\text { SOURCE } \\
\text { COORDINATE }\end{array}$ & $\begin{array}{c}\text { ELEV } \\
\text { FT }\end{array}$ & MAP NAME \\
\hline $\begin{array}{l}\text { Brewster Well } \\
\text { Brichta School } \\
\text { Brick Mine } \\
\text { Bricks Windmill } \\
\text { Brick Tank } \\
\text { Brickwood Canyon }\end{array}$ & $\begin{array}{l}\text { well } \\
\text { school } \\
\text { mine } \\
\text { locale } \\
\text { reservoir } \\
\text { valley }\end{array}$ & $\begin{array}{l}\text { UNOFF } \\
\text { UNOFF } \\
\text { UNOFF } \\
\text { BGN } \\
\text { BGN } \\
\text { BGN }\end{array}$ & $\begin{array}{l}\text { Gila } \\
\text { Pima } \\
\text { Santa Cruz } \\
\text { Yavapai } \\
\text { Yavapai } \\
\text { Santa Cruz }\end{array}$ & $\begin{array}{l}333152 \mathrm{~N} 1104505 \mathrm{~W} \\
321431 \mathrm{~N} 1110042 \mathrm{~W} \\
312741 \mathrm{~N} 1111508 \mathrm{~W} \\
340920 \mathrm{~N} 1124406 \mathrm{~W} \\
340721 \mathrm{~N} 1124356 \mathrm{~W} \\
312012 \mathrm{~N} 1105110 \mathrm{~W}\end{array}$ & $312036 \mathrm{~N} 1105329 \mathrm{~W}$ & 2364 & $\begin{array}{l}\text { Rockinstraw Mtn } \\
\text { Cat Mountain } \\
\text { Bart lett Mtn } \\
\text { Yarnell } \\
\text { Sam Powell Peak } \\
\text { Kino Spring }\end{array}$ \\
\hline $\begin{array}{l}\text { Brickwoods Ranch (historical) } \\
\text { Bridge Canyon } \\
\text { Bridge Canyon } \\
\text { See Lower Granite Gorge } \\
\text { Bridge Canyon Rapids } \\
\text { Bridge Dam } \\
\text { Bridge Park } \\
\text { Bridgeport (subdivision) } \\
\text { Bridgeport } \\
\text { Bridgers Knoll }\end{array}$ & $\begin{array}{l}\text { locale } \\
\text { valley } \\
\text { valley } \\
\text { rapids } \\
\text { dam } \\
\text { park } \\
\text { ppl } \\
\text { ppl } \\
\text { summit }\end{array}$ & $\begin{array}{l}\text { UNOFF } \\
\text { BGN } \\
\text { VARIANT } \\
\text { BGN } \\
\text { UNOFF } \\
\text { ADMIN } \\
\text { BGN } \\
\text { BGN } \\
\text { BGN }\end{array}$ & $\begin{array}{l}\text { Santa Cruz } \\
\text { Mohave } \\
\text { Mohave } \\
\text { Mohave } \\
\text { Graham } \\
\text { Yuma } \\
\text { Maricopa } \\
\text { Yavapai } \\
\text { Coconino }\end{array}$ & $\begin{array}{l}312012 \mathrm{~N} 1105101 \mathrm{~W} \\
354626 \mathrm{~N} 1133122 \mathrm{~W} \\
360800 \mathrm{~N} 1135719 \mathrm{~W} \\
354632 \mathrm{~N} 1133126 \mathrm{~W} \\
324515 \mathrm{~N} 1092924 \mathrm{~W} \\
324336 \mathrm{~N} 1143733 \mathrm{~W} \\
332052 \mathrm{~N} 1115200 \mathrm{~W} \\
344317 \mathrm{~N} 1115945 \mathrm{~W} \\
362502 \mathrm{~N} 1122638 \mathrm{~W}\end{array}$ & $354336 \mathrm{~N} 1133259 \mathrm{~W}$ & $\begin{array}{l}1200 \\
3260 \\
6603\end{array}$ & $\begin{array}{l}\text { Separation Canyon } \\
\text { Tollgate Tank } \\
\text { Yuma West } \\
\text { Chandler } \\
\text { Cornville } \\
\text { Tapeats Amphitheater }\end{array}$ \\
\hline $\begin{array}{l}\text { Bridge Tank } \\
\text { Bridge Tank } \\
\text { Bridge Tank } \\
\text { Bridge Tank } \\
\text { Bridge Washer Tank } \\
\text { Bridie Creek } \\
\quad \text { Willow Branch } \\
\text { Bridle Trail } \\
\text { Briggs } \\
\text { Briggs }\end{array}$ & $\begin{array}{l}\text { reservoir } \\
\text { reservoir } \\
\text { reservoir } \\
\text { reservoir } \\
\text { reservoir } \\
\text { stream } \\
\text { trail } \\
\text { ppl } \\
\text { locale }\end{array}$ & $\begin{array}{l}\text { BGN } \\
\text { BGN } \\
\text { BGN } \\
\text { BGN } \\
\text { BGN } \\
\text { BGN } \\
\text { VARIANT } \\
\text { UNOFF } \\
\text { BGN } \\
\text { BGN }\end{array}$ & $\begin{array}{l}\text { Pima } \\
\text { Graham } \\
\text { Gila } \\
\text { Coconino } \\
\text { Gila } \\
\text { Yavapai } \\
\text { Coconino } \\
\text { Cochise } \\
\text { Yavapai }\end{array}$ & $\begin{array}{l}315014 \mathrm{~N} 1112449 \mathrm{~W} \\
325013 \mathrm{~N} 1092657 \mathrm{~W} \\
341954 \mathrm{N1} 112615 \mathrm{~W} \\
351302 \mathrm{~N} 1122339 \mathrm{~W} \\
331701 \mathrm{N1} 103141 \mathrm{~W} \\
342245 \mathrm{~N} 1131117 \mathrm{~W} \\
\\
345319 \mathrm{N1114526 \textrm {W }} \\
312506 \mathrm{~N} 1095347 \mathrm{~W} \\
340339 \mathrm{N1} 22830 \mathrm{~W}\end{array}$ & $343604 N 1130831 W$ & & $\begin{array}{l}\text { Fresno Wash } \\
\text { Tollgate Tank } \\
\text { Buckhead Mesa } \\
\text { Ash Fork } \\
\text { Bucket Mtn } \\
\text { Thorn Peak } \\
\text { Wilson Mountain } \\
\text { Bisbee } \\
\text { Copperopolis }\end{array}$ \\
\hline $\begin{array}{l}\text { Brigham Peak } \\
\text { Bingham Peak } \\
\text { Bright Angel Canyon } \\
\text { Bright Angel Canyon } \\
\text { Bright Angel Creek } \\
\text { Silver Creek } \\
\text { Bright Angel Point } \\
\text { Bright Angel Point } \\
\text { See North Rim } \\
\text { Bright Angel Spring }\end{array}$ & $\begin{array}{l}\text { summit } \\
\text { valley } \\
\text { valley } \\
\text { stream } \\
\text { cliff } \\
\text { locale } \\
\text { spring }\end{array}$ & $\begin{array}{l}\text { BGN } \\
\text { VARIANT } \\
\text { BGN } \\
\text { BGN } 1906 \\
\text { BGN 1906 } \\
\text { VARIANT } \\
\text { BGN 1906 } \\
\text { VARIANT } \\
\text { BGN } 1932\end{array}$ & $\begin{array}{l}\text { Greenlee } \\
\text { Pinal } \\
\text { Coconino } \\
\text { Coconino } \\
\text { Coconino } \\
\text { Coconino } \\
\text { Coconino }\end{array}$ & $\begin{array}{l}332607 N 1091830 \mathrm{~W} \\
324820 \mathrm{~N} 1103551 \mathrm{~W} \\
360602 \mathrm{~N} 1120543 \mathrm{~W} \\
360555 \mathrm{~N} 1120532 \mathrm{~W} \\
361135 \mathrm{~N} 1120253 \mathrm{~W} \\
361238 \mathrm{~N} 1120338 \mathrm{~W} \\
361313 \mathrm{~N} 1120402 \mathrm{~W}\end{array}$ & $\begin{array}{l}324850 \mathrm{~N} 1103256 \mathrm{~W} \\
361414 \mathrm{N1120014W} \\
361811 \mathrm{~N} 1120124 \mathrm{~W}\end{array}$ & 7066 & $\begin{array}{l}\text { Rose Peak } \\
\text { Holy Joe Peak } \\
\text { Phantom Ranch } \\
\text { Phantom Ranch } \\
\text { Bright Angel Point } \\
\text { Bright Angel Point }\end{array}$ \\
\hline $\begin{array}{c}\text { Bright Angel Trail } \\
\text { Cameron Trail } \\
\text { Bright Angel Wash } \\
\text { Brighter Days Mine } \\
\text { Brighton Place (subdivision) } \\
\text { Amended Dobson Estates } \\
\text { Three } \\
\text { Brills Ranch } \\
\text { See Allah } \\
\text { Brimhall Well }\end{array}$ & $\begin{array}{l}\text { trail } \\
\text { stream } \\
\text { mine } \\
\text { ppl }\end{array}$ & $\begin{array}{l}\text { UNOFF } \\
\text { VARIANT } \\
\text { BGN } \\
\text { UNOFF } \\
\text { BGN } \\
\text { VARIANT } \\
\text { VARIANT } \\
\text { UNOFF }\end{array}$ & $\begin{array}{l}\text { Coconino } \\
\text { Coconino } \\
\text { Mohave } \\
\text { Maricopa }\end{array}$ & $\begin{array}{l}360409 \mathrm{~N} 1120756 \mathrm{~W} \\
360013 \mathrm{~N} 1121238 \mathrm{~W} \\
352443 \mathrm{~N} 1140850 \mathrm{~W} \\
332017 \mathrm{~N} 1115147 \mathrm{~W}\end{array}$ & $360312 \mathrm{~N} 1120853 \mathrm{~W}$ & 3282 & $\begin{array}{l}\text { Grand Canyon } \\
\text { Grand Canyon } \\
\text { Chloride } \\
\text { Chandler }\end{array}$ \\
\hline $\begin{array}{l}\text { Brindle Pup Mine } \\
\text { Brinkerhoff Well } \\
\text { Brinkley Spring } \\
\text { Brinkmeyer Point } \\
\text { Brins Mesa } \\
\text { Brintley Well } \\
\text { Bristol Park } \\
\text { See Eastmoor Park } \\
\text { Bristol Square (subdivision) } \\
\text { Amended Royal Estates } \\
\text { West Five }\end{array}$ & $\begin{array}{l}\text { mine } \\
\text { well } \\
\text { spring } \\
\text { summit } \\
\text { summit } \\
\text { well } \\
\text { park } \\
\text { ppl }\end{array}$ & $\begin{array}{l}\text { UNOFF } \\
\text { UNOFF } \\
\text { BGN } \\
\text { BGN } \\
\text { BGN } \\
\text { UNOFF } \\
\text { VARIANT } \\
\text { BGN } \\
\text { VARIANT }\end{array}$ & $\begin{array}{l}\text { Yavapai } \\
\text { Mohave } \\
\text { Pima } \\
\text { Navajo } \\
\text { Coconino } \\
\text { Yuma } \\
\text { Pima } \\
\text { Maricopa }\end{array}$ & $\begin{array}{l}343845 \mathrm{~N} 1120655 \mathrm{~W} \\
364951 \mathrm{N1} 25845 \mathrm{~W} \\
322611 \mathrm{N1} 104717 \mathrm{~W} \\
341834 \mathrm{~N} 1102311 \mathrm{~W} \\
345430 \mathrm{N1114620W} \\
333431 \mathrm{~N} 1140523 \mathrm{~W} \\
321211 \mathrm{~N} 1105554 \mathrm{~W} \\
333524 \mathrm{~N} 1121123 \mathrm{~W}\end{array}$ & & $\begin{array}{l}7086 \\
5449\end{array}$ & $\begin{array}{l}\text { Cottonwood } \\
\text { Maroney Well } \\
\text { Mt Lemmon } \\
\text { Day Spring } \\
\text { Wilson Mountain } \\
\text { Crystal Hill }\end{array}$ \\
\hline $\begin{array}{l}\text { Bristow Seep Spring } \\
\text { Bristow Spring } \\
\text { Bristow Tank } \\
\text { Bristow Tank } \\
\text { Brittenham Tank } \\
\text { Britten Ranch } \\
\text { Broad Canyon } \\
\text { Broad Draw } \\
\text { Broadmor School } \\
\text { Broadwater Drain }\end{array}$ & $\begin{array}{l}\text { spring } \\
\text { spring } \\
\text { reservoir } \\
\text { reservoir } \\
\text { reservoir } \\
\text { locale } \\
\text { valley } \\
\text { valley } \\
\text { school } \\
\text { stream }\end{array}$ & $\begin{array}{l}\text { BGN } \\
\text { BGN } \\
\text { BGN } \\
\text { BGN } \\
\text { BGN } \\
\text { UNOFF } \\
\text { BGN } \\
\text { BGN } \\
\text { UNOFF } \\
\text { BGN }\end{array}$ & $\begin{array}{l}\text { Coconino } \\
\text { Coconino } \\
\text { Coconino } \\
\text { Coconino } \\
\text { Navajo } \\
\text { Pima } \\
\text { Mohave } \\
\text { Gila } \\
\text { Maricopa } \\
\text { Mohave }\end{array}$ & $\begin{array}{l}345307 N 1113542 W \\
345205 N 1113431 W \\
344146 N 1112245 W \\
345211 N 1113350 W \\
342021 N 1101413 W \\
315315 N 1111637 W \\
362353 N 1130320 W \\
341949 N 1111105 W \\
332419 N 1115557 W \\
342815 N 1141911 W\end{array}$ & $\begin{array}{l}362541 \mathrm{~N} 1130004 \mathrm{~W} \\
341813 \mathrm{~N} 1110958 \mathrm{~W} \\
342852 \mathrm{~N} 1141852 \mathrm{~W}\end{array}$ & & $\begin{array}{l}\text { Mormon Mountain } \\
\text { Stoneman Lake } \\
\text { Happy Jack } \\
\text { Stoneman Lake } \\
\text { Pinedale } \\
\text { Stevens Mtn } \\
\text { Mt Trumbull NE } \\
\text { Oiamond Point } \\
\text { Tempe } \\
\text { Lake Havasu City S }\end{array}$ \\
\hline $\begin{array}{l}\text { Broadway Plaza Service } \\
\text { Shopping Center } \\
\text { Broadway Rural Shopping Center } \\
\text { Broadway Seven Thousand }\end{array}$ & $\begin{array}{l}\text { locale } \\
\text { locale }\end{array}$ & $\begin{array}{l}\text { UNOFF } \\
\text { UNOFF } \\
\text { UNOFF }\end{array}$ & $\begin{array}{l}\text { Maricopa } \\
\text { Pima }\end{array}$ & $\begin{array}{l}332424 N 1115615 \mathrm{~W} \\
332422 \mathrm{~N} 1115525 \mathrm{~W} \\
321312 \mathrm{~N} 1105032 \mathrm{~W}\end{array}$ & & 2610 & $\begin{array}{l}\text { Tempe } \\
\text { Tempe } \\
\text { Tucson East }\end{array}$ \\
\hline
\end{tabular}




\section{FEATURE NAME}

Broadway Trailer Court Broadway Village Shopping Center

Brockett Tank

Brockie Tank

Brockmonte Canyon

Brody Creek Fuller Creek

Brody Hills

Brody Hills Tank

Brody Seep

Broken Arrow Ranch

Broken Axle Tank

Broken Dam Tank

Broken Dam Tank

Broken Dam Tank

Broken Dam Tank

Broken Foot Well

Broken Home We 11

Broken Horn Canyon

Broken Iron Spring

Broken Tank

Broken Tank

Broken Tank

Broken Tank

Broken Tank

Broken Trough Spring

Broke Tank

Broke Tanks

Brolliar Park

Brolliar Tank

Broncho Canyon

See Bronco Canyon

Broncho Mountain

See Bronco Butte

Bronco Butte Broncho Mountain Horse Mountain

Bronco Butte

Bronco Canyon Broncho Canyon

Bronco Canyon

Bronco Creek

Bronco Creek

Bronco Creek

Bronco Gulch

Bronco Hill

See Brunckow $\mathrm{Hill}$

Bronco Spring

Bronco Tank

Bronco Tank

Bronco Tank

Bronco Wash

Bronk Lateral

Bronkow Hill

See Brunckow Hill

Bronson Canyon Hays tack Creek

Bronson Spring

Bronson Spring

Bronson Trick Tank

Bronze, Walls of Palisades of Fish Creek Canyon

Bronze Boot (trailer park)

Brookbank Canyon

Brookbank Canyon

Brookbank Canyon

See Black Canyon

Brookbank Point
FEATURE
CLASS

STATUS

COUNTY

COORDINATE

locale

reservoir

reservoir

UNOFF

Maricopa

Pima

BGN

Yavapai

Coconino

valley

stream

BGN

BGN

VARIANT

summi

reservoir $\quad B G$

locale

BGN

BGN
UNOFF

servoir

reservoir BGN

reservoir BGN

reservoir

reservoir

well

well

valley

spring

reservoir

reservoir

reservoir

reservoir

Yavapai

Gila

Gila

Gila

Yavapai

Cochise

Coconino

Navajo

Coconino

\section{BGN}

BGN

UNOFF

UNOFF

BGN

BGN

BGN

BGN

BGN

BGN

Yavapai

Coconino

Yavapai

Apache

Graham

Apache

Santa Cruz

Maricopa

Navajo

Apache

reservoir $B G$

spring

BGN

BGN

reservoir BGN

reservoir $B G N$

flat

BGN

reservoir BGN

valley

VARIANT

Coconino

Pima

Cochise

Pima

Coconino

Coconino

Gila

Maricopa

summit

VARIANT

summit

BGN 1917

VARIANT

VARIANT

summit

BGN

valley

valley

stream

stream

BGN

VARIANT

BGN

BGN

BGN

BGN

Maricopa

Maricopa

Gila

Gila

Maricopa

Mohave

valley

BGN

Graham

summit

spring

reservoir

reservoir

reservoir

stream

canal

summit

BGN

BGN

BGN

BGN

BGN

VARIANT

Cochise

Gila

Graham

Maricopa

Gila

Mohave

Yuma

Cochise

valley

BGN 1967

VARIANT

spring

reservoir

cliff

BGN

BGN

BGN 19

VARIANT

locale

valley

UNOFF

BGN

valley

BGN

VARIANT

valley

BGN
$332427 \mathrm{N1120614 \textrm {W }}$ $321318 N 1105540 \mathrm{~W}$

$343625 N 1113802 W$

$343642 \mathrm{~N} 1112201 \mathrm{~W}$

$343818 N 1125316$

$342207 N 1111645 \mathrm{~W}$

$342158 \mathrm{~N} 1111525 \mathrm{~W}$

$342150 \mathrm{~N} 1111513 \mathrm{~W}$

$340431 \mathrm{~N} 1112909 \mathrm{~W}$

312530 N1101510W

$355214 N 1123349 \mathrm{~W}$

$345110 \mathrm{~N} 1095433 \mathrm{~W}$

$345308 \mathrm{~N} 1110143 \mathrm{~W}$

$350835 N 1130644 \mathrm{~W}$

$351508 \mathrm{~N} 1121813 \mathrm{~W}$

$350511 N 1131325 \mathrm{~W}$

351506 N1091557W

$323247 N 1102011 \mathrm{~W}$

$362820 N 1092729 \mathrm{w}$

$312855 \mathrm{~N} 1111125 \mathrm{~W}$

334000 N1123911W

$342557 \mathrm{~N} 1104120 \mathrm{~W}$

$343643 \mathrm{~N} 1095038 \mathrm{~W}$

$344405 N 1104824 \mathrm{~W}$

314538 N1113452W

313631 N1095609

315809 N1111115

$345101 \mathrm{N1112820 \textrm {W }}$

$345111 N 1112845 \mathrm{~W}$

334216N1101238W

333318 N1111615W

$333318 N 1111615 \mathrm{~W}$

$335405 \mathrm{~N} 1115225 \mathrm{~W}$

$334216 \mathrm{N1101238 \textrm {W }}$

$334917 N 1105047 \mathrm{~W}$ $333648 \mathrm{~N} 1111308 \mathrm{~W}$

$335748 \mathrm{~N} 1115203 \mathrm{~W}$

$344037 N 1133508 \mathrm{~W}$

$332622 \mathrm{N1101242W}$

$313702 \mathrm{~N} 1100926 \mathrm{~W}$

$333719 \mathrm{N1111344 \textrm {W }}$

$332313 \mathrm{~N} 1100831 \mathrm{~W}$

$334628 \mathrm{~N} 1120659 \mathrm{~W}$

334951 N1104828W

$344030 N 1133643 \mathrm{~W}$

$323656 \mathrm{~N} 1144133 \mathrm{~W}$

313702N1100926W

$334150 N 1104042 \mathrm{~W}$

334247 N1103733W

$334250 \mathrm{~N} 1103658 \mathrm{~W}$

$334140 N 1103711 \mathrm{~W}$

UNKNOWN

$332909 N 1120239 \mathrm{~W}$

342937 N1103732W

$343702 N 1103350$

$344738 \mathrm{~N} 1103621 \mathrm{~W}$

341945 N1 $104450 \mathrm{~W}$

\begin{tabular}{ccl}
$\begin{array}{c}\text { SOURCE } \\
\text { COORDINATE }\end{array}$ & $\begin{array}{c}\text { ELEV } \\
\text { FT }\end{array}$ & \multicolumn{1}{c}{ MAP NAME } \\
& $\begin{array}{l}1050 \\
2470\end{array}$ & $\begin{array}{l}\text { Phoenix } \\
\text { Tucson } \\
\text { Walker Mtn } \\
\text { Long Valley }\end{array}$ \\
& & \\
344133 N1125237W & $\begin{array}{l}\text { Sheridan Mtn } \\
\text { Payson North }\end{array}$ \\
& $\begin{array}{l}\text { Payson North } \\
\text { Payson North } \\
\text { Mazatzal Peak } \\
\text { Miller Peak } \\
\text { Rosebud Tank } \\
\text { Padilla Tank } \\
\text { Chavez Mtn NE }\end{array}$
\end{tabular}

Squaw Peak

Hearst Mtn

Anvil Rock Ranch

Burntwater Wash 
NATIONAL GAZETTEER--ARIZONA 1986

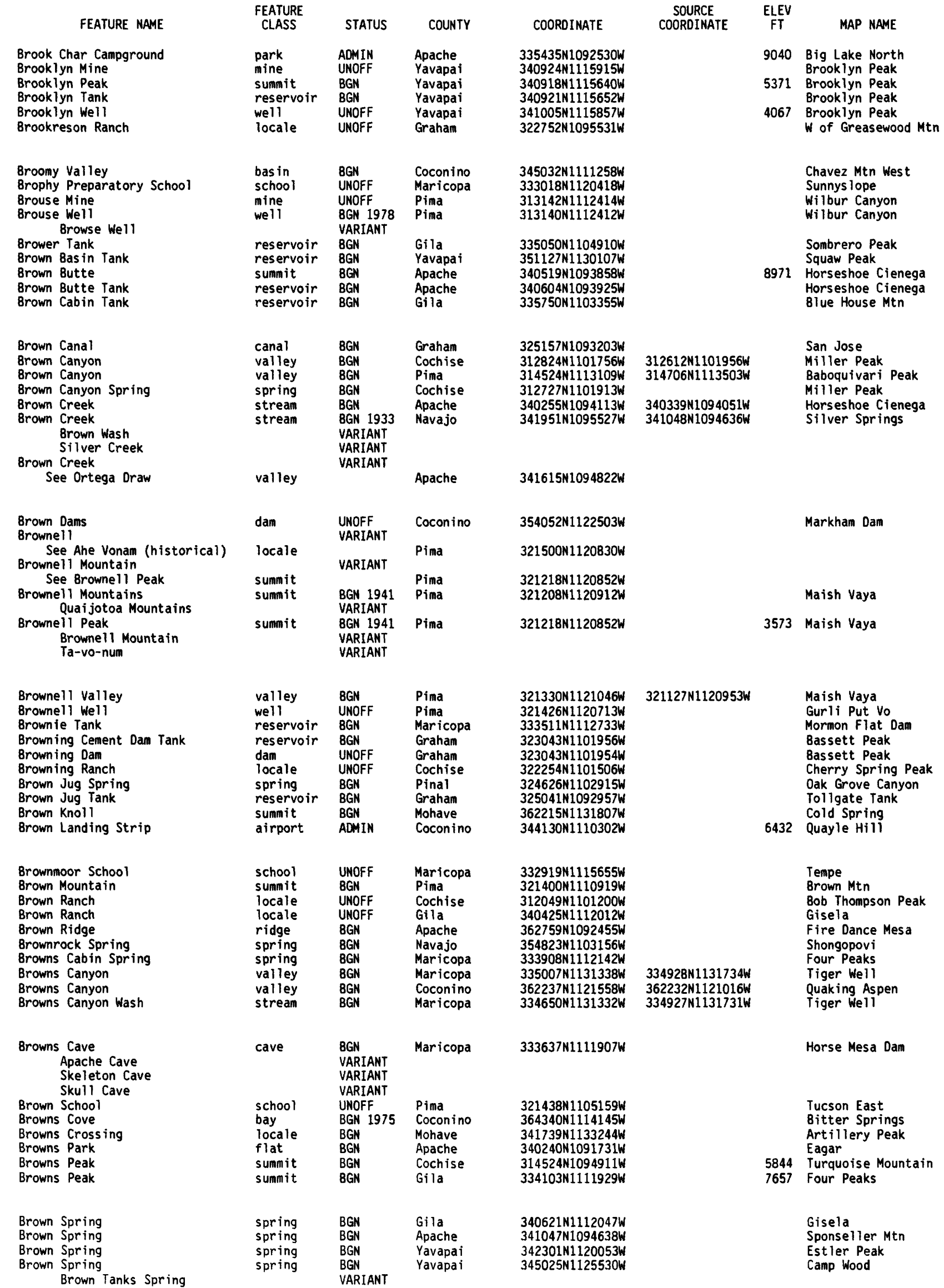




\section{FEATURE NAME}

Brown Springs

Brown Springs Ranch

Browns Ranch

Browns Reservoir

Browns Riffle

Rapid Number One

Hundred Eight

Rapid Number $10 \mathrm{~B}$

Browns Tank

Browns Wash

Browns Well

Browns Well

Browns Well

Brown Tank

Brown Tank

Brown Tank

Brown Tank

Brown Tanks

Brown Tanks Spring

See Brown Spring

Brown Wash

Brown Wash

Brown Wash

See Brown Creek

Brown Wash

Brown Well

Browse Tank

Browse Tank

Browse We11

See Brouse Well

BR Tank

Bruce, Mount

Bruce Place Tank

Bruce Spring

Brule Huffman Park

Brunckow Hill

Bronco Hill

Bronkow Hill

Brunner Canyon

See South Bruno Canyon

Brunner Canyon

See Bruno Canyon

Brunner Peak

See Bruno Peak

Bruno Canyon

Brunner Canyon

Bruno Peak

Brunner Peak

Bruno Tank

Bruno Tank

Brunson Ranch

Brunson Tank

Brusally Tank

Brush Bas in Tank

Brush Canyon

See Brushy Canyon

Brush Canyon

Brush Canyon

Brush Corral Canyon Indian Springs Canyon

Brush Corral Canyon

Brush Corral Creek

See Davis Wash

Brush Corrals

Brush Corral Spring

Brush Corral Tank

Brush Mountain

Brush Pasture Tank

Brush Spring

Brush Spring

Brush Spring

\section{FEATURE}

spring

locale

locale

reservoir

rapids

$$
\text { BGI }
$$

STATUS

COUNTY

COORDINATE

342440 N1114722W

$342440 \mathrm{N1114711 \textrm {W }}$

334647 N111502OW

$362338 \mathrm{N11} 32053 \mathrm{~W}$

$364345 \mathrm{N1114140 \textrm {W }}$

BARIANT

VARIANT stream

well

we11

reservoir

reservoir

reservoir

reservoir

reservoir

$\begin{array}{ll}\text { BGN } & \text { Graham } \\ \text { BGN } & \text { Pinal } \\ \text { UNOFF } & \text { Pinal } \\ \text { UNOFF } & \text { Maricopa } \\ \text { UNOFF } & \text { La Paz } \\ \text { BGN } & \text { Pima } \\ \text { BGN } & \text { Coconino } \\ \text { BGN } & \text { Coconino } \\ \text { BGN } & \text { Coconino } \\ \text { BGN } & \text { Coconino }\end{array}$

325117 N1095258W $324235 \mathrm{~N} 1105719 \mathrm{~W}$ 324254 N1105644W $325650 \mathrm{~N} 1131836 \mathrm{~W}$ 334517 N1133500W 314449 N1112751W $344124 \mathrm{N1110204 \textrm {W }}$ $351558 \mathrm{~N} 1122646 \mathrm{~W}$ $351558 \mathrm{~N} 1122646 \mathrm{~W}$ $350127 \mathrm{~N} 1105447 \mathrm{~W}$

VARIANT

spring

stream

stream

stream

stream

well

reservoir

reservoir

BGN

BGN

Variant Apajo

BGN Apache

UNOFF Pima

BGN Gila

BGN Coconino

VARIANT

well

reservoir summit

reservoir

spring

park

summit

BGN

BGN

BGN

$B G N$

ADMIN

BGN 1977

VARIANT

VARIANT

VARIANT

valley

valley

sumit

valley

summit

reservoir

reservoir

locale

reservoir

reservoir

reservoir

valley

valley

valley

valley

valley

stream

locale

spring

reservoir

summit

reservoir

spring

spring

we 11
VARIANT

VARIANT

BGN 1960

VARIANT
BGN 1960

VARIANT

BGM

BGN

$B G N$

$B G N$

BGN
VARIANT

BGN
BGN

BGN

VARIANT

BGN

VARIANT

BGN

BGN

$B G N$
$B G N$

Cochise

Cochise

Cochise

Cochise

Cochise

Cochise

Coconino

Gila

Maricopa

Apache

Yavapai

Santa Cruz

Cochise

Graham

Maricopa

Gila

Maricopa

Pima

Maricopa

Gila

Navajo

Gila

BGN

BGN
Maricopa

Yavapai

Gila
345025 N1125530W

$314940 \mathrm{~N} 1112414 \mathrm{~W}$

340956 N109435OW

341951 N1095527W

$345418 N 1091412 \mathrm{~W}$

$314622 \mathrm{~N} 1112843 \mathrm{~W}$

$341307 \mathrm{~N} 111263 \mathrm{WW}$

$352202 \mathrm{~N} 1112633 \mathrm{~W}$

$313140 \mathrm{~N} 1112412 \mathrm{~W}$

$352250 \mathrm{~N} 1115541 \mathrm{~W}$

$314232 \mathrm{~N} 1102937 \mathrm{~W}$

$344404 N 1113438 \mathrm{~W}$

343111N1120919W

$321440 \mathrm{~N} 1095030 \mathrm{~W}$

$313702 \mathrm{N1100926 \textrm {W }}$

314233N1092514W

314429N1092750W

$314325 \mathrm{~N} 1092318 \mathrm{~W}$

314429 N1092750W

$314325 N 1092318 \mathrm{~W}$

$314230 \mathrm{~N} 1092500 \mathrm{~W}$

341917 N1104630W

$335623 \mathrm{N1} 112139 \mathrm{~W}$

$341415 \mathrm{~N} 1094855 \mathrm{~W}$

$340335 \mathrm{~N} 1115209 \mathrm{~W}$

$313125 \mathrm{N1} 102906 \mathrm{~W}$

$322424 \mathrm{~N} 1100948 \mathrm{~W}$

323B28N110212OW

$334725 \mathrm{~N} 1113019 \mathrm{~W}$

$341231 \mathrm{N1110902 \textrm {W }}$

$333539 \mathrm{~N} 1111320 \mathrm{~W}$

$322355 \mathrm{~N} 1103624 \mathrm{~W}$

$334839 \mathrm{~N} 1113117 \mathrm{~W}$

$341230 \mathrm{~N} 1111030 \mathrm{~W}$

$340005 \mathrm{~N} 1103936 \mathrm{~W}$

340819 N1110102W

$335421 \mathrm{~N} 1113113 \mathrm{~W}$

$342202 \mathrm{~N} 1114743 \mathrm{~W}$

$333553 \mathrm{~N} 1104623 \mathrm{~W}$
$335457 \mathrm{~N} 1113052 \mathrm{~W}$

$\begin{array}{ccc}\text { SOURCE } & \text { ELEV } \\ \text { COORDINATE } & \text { FT }\end{array}$

Horner Mtn

Horner Mtn

Wi Idcat Hill

Jones $\mathrm{Hill}$

Bitter Springs

324418N1105612W

Shingle Mill Mtn

Fortified Mtn

Fortified Mtn

Agua Caliente

Salome

Las Guijas

Quayle Hill

Fitzgerald Hill

Metzger Tank

Tucker Mesa SW

314706N1113503W Fresno Wash

340B54N1094334W Boundary Butte

345820 N1090932W

Wild Cow Lake

Fresno Wash

North Peak 


\section{FEATURE NAME}

8rush Tank

Brush Tank

Brush Tank

Brush Top Tank

Brushy Bas in

Brushy Basin

Brushy Basin

Brushy Bas in

Brushy Bas in

Brushy Basin

Brushy Bas in

Brushy Bas in

Brushy Bas in Canyon

Brushy Bas in Spring

Brushy Bas in Spring

Brushy Basin Spring

Brushy Basin Spring

Brushy Bas in Spring

Brushy Bas in Tank

Brushy Bas in Tank

Brushy Bas in Tank

Brushy Bas in Tank

Brushy Bas in Tank

Brushy Bas in Well

Brushy Canyon Brush Canyon

Brushy Canyon

Brushy Canyon
Brushy Canyon
Brushy Canyon
Brushy Canyon
Brushy Canyon
Brushy Canyon
Brushy Canyon
Brushy Canyon
Brushy Canyon
Bushy Canyon
Brushy Canyon Tank
Brushy Canyon Tank Number One
Brushy Canyon Tank Number Two
Brushy Creek
Brushy Creek
Brushy Creek
Brushy Flat Tank
Brushy Hollow
Brushy Hollow Canyon
Brushy Hollow

Brushy Hollow

Brushy Hollow Canyon

See Brushy Hollow

Brushy Hollow Tank

Brushy Mesa

Brushy Mountain Bushy Mountain

Brushy Mountain

Brushy Mountain

Brushy Mountain

Brushy Mountain

Brushy Mountain

Brushy Mountain

Brushy Prong

Brushy Spring

Brushy Spring

Brushy Spring

Brushy Spring

Brushy Spring

Brushy Spring

Little Brushy Spring

\section{FEATURE}

reservoir

reservoir

reservoir

reservoir

bas in

basin

bas in

bas in

bas in

bas in

bas in

bas in

valley

spring

spring

spring

spring

spring

reservoir

reservoir

reservoir

reservoir

well

valley

valley

STATUS

COUNTY

COORDINATE

$322442 \mathrm{~N} 1100818 \mathrm{~W}$

$345935 \mathrm{~N} 1124925 \mathrm{~W}$

$360036 \mathrm{~N} 1121431 \mathrm{~W}$

$335355 \mathrm{~N} 1104707 \mathrm{~W}$

$333338 N 1103207 \mathrm{~W}$

$334231 \mathrm{~N} 1112152 \mathrm{~W}$

$334354 \mathrm{~N} 1102606 \mathrm{~W}$

Maricopa

Gila

Gila

Mohave 342815N1115631W

Yavapai 344921N1130845W

Yavapai 345438N1131931W

Yavapai

Maricopa

$334333 N 1112207 \mathrm{~W}$

Gila

Yavapai

$340850 \mathrm{~N} 1111631 \mathrm{~W}$

$341856 \mathrm{~N} 112194 \mathrm{BW}$

Yavapai 345419N1131935W

Gila 333300N1103207W

Gila 334311N1102844W

Gila

Yavapai

Yavapai

Mohave

Santa Cruz

$341949 N 1112257 W$
$344412 N 1131129 W$

$344924 \mathrm{~N} 1130849 \mathrm{~W}$

$344036 \mathrm{~N} 1132554 \mathrm{~W}$

$313125 \mathrm{~N} 1102906 \mathrm{~W}$

Cochise

314245N1091342W

$313010 \mathrm{~N} 1102550 \mathrm{~W}$

31460BN1091456h

$314534 \mathrm{~N} 1092040 \mathrm{~W}$

$320442 \mathrm{~N} 1091418 \mathrm{~W}$

$321545 \mathrm{~N} 1093619 \mathrm{~W}$

$325653 \mathrm{~N} 1091549 \mathrm{~W}$

$330021 \mathrm{~N} 1093412 \mathrm{~W}$

334449 N1102651W

$340337 \mathrm{~N} 1110426 \mathrm{~W}$

$340719 \mathrm{~N} 1120038 \mathrm{~W}$

Graham

Gila

Yavapai

valley

valley

BGN

VARIANT

reservoir

reservoir

reservoir

stream

stream

stream

reservoir

valley

valley

BGN
BGN
BGN
BGN
BGN
BGN
BGN
BGN 1980
VARIANT
BGN

Greenlee

Gila

Gila

Cochise

Graham

Yavapai

Apache

Gila

Gila

VARIANT

valley

reservoir

summit

summit

summit

summit

summit

summit

summit

summit

stream

spring

spring

spring

spring

spring

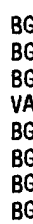

BGN

Gila

Gila

Gila

Greenlee

ARIANT

Graham

Maricopa

Apache

Apache

Yavapai

Yavapai

Yavapai

Graham

Maricopa

Maricopa

Gila

Gila

Apache

BGN 1977

$\begin{array}{ll}\text { spring } & \text { BGN } \\ \text { spring } & B G N \\ \text { spring } & B G N \\ \text { reservoir } & B G N\end{array}$

$314943 N 1091901 \mathrm{~W}$

$320357 \mathrm{~N} 1091742 \mathrm{~W}$

$321355 \mathrm{~N} 1093652 \mathrm{~W}$

325841 N1091518W

$330121 \mathrm{N1093618 \textrm {W }}$

$334131 N 1102 B 10 \mathrm{~W}$

$340222 \mathrm{~N} 1110536 \mathrm{~W}$

$341838 \mathrm{~N} 1112313 \mathrm{~W}$

330419 N1091159W

$334943 \mathrm{~N} 1102747 \mathrm{~W}$

$334931 \mathrm{~N} 1102736 \mathrm{~W}$

$314521 \mathrm{~N} 1092047 \mathrm{~W}$

$331106 \mathrm{~N} 1093006 \mathrm{~W}$

$341026 \mathrm{~N} 1115023 \mathrm{~W}$

$34075 B N 1094904 W$

$340446 \mathrm{~N} 1111614 \mathrm{~W}$

$314944 \mathrm{~N} 1091916 \mathrm{~W}$

$331256 \mathrm{~N} 1093522 \mathrm{~W}$

$341412 \mathrm{~N} 1115115 \mathrm{~W}$

340454N1111307w

$341203 \mathrm{~N} 111294 \mathrm{BW} \quad 341106 \mathrm{~N} 1113022 \mathrm{~W}$

$340446 \mathrm{~N} 1111614 \mathrm{~W}$

$340436 \mathrm{N1111331 \textrm {W }}$

$341802 \mathrm{~N} 1113022 \mathrm{~W}$

$330710 \mathrm{~N} 1091121 \mathrm{~W}$

$331243 \mathrm{~N} 1093611 \mathrm{~W}$

$335103 \mathrm{~N} 1114103 \mathrm{~W}$

$340559 \mathrm{~N} 1094357 \mathrm{~W}$

$340726 \mathrm{~N} 1094826 \mathrm{~W}$

$343310 \mathrm{~N} 1124515 \mathrm{~W}$

$344912 \mathrm{~N} 1125011 \mathrm{~W}$

$342449 \mathrm{~N} 1114358 \mathrm{~W}$

$330026 \mathrm{~N} 1102235 \mathrm{~W}$

$332910 \mathrm{~N} 1110551 \mathrm{~W}$

$332940 \mathrm{~N} 1110329 \mathrm{~W}$

$333828 \mathrm{~N} 1104001 \mathrm{~W}$

$334112 \mathrm{~N} 1103835 \mathrm{~W}$

$340757 N 1094837 \mathrm{~W}$

$342400 \mathrm{~N} 1114308 \mathrm{~W}$

$343246 \mathrm{~N} 1124546 \mathrm{~W}$

$352421 N 1140712 \mathrm{~W}$

$33124 B N 1093414 \mathrm{~W}$

Grahan

Cochise $\begin{array}{cc}\text { SOURCE } & \text { ELEV } \\ \text { COORDINATE } & \text { FT MAP NAME }\end{array}$

Indian Peaks

Grand Canyon

Rock House

Sevenmile Mts

Four Peaks

Brushy Canyon

Buckhead Mesa

Arnold Mesa

Elephant Mtn

Burro Mesa

Mohon Peak

McDonald Mtn

Two Bar Mtn

Four Peaks

Payson South

Battle Flat

Mohon Peak

4130 Sevenmile Mts

Brushy Canyon

Buckhead Mesa

Bozarth Mesa

Burro Mesa

3704 Elephant Mtn

Huachuca Peak

Apache

$340524 \mathrm{~N} 111595 \mathrm{BW}$

Chiricahua Peak

Blue Mountain

Luzena

Guthrie

Bonita Spring

Brushy Canyon

Buzzard Roost Mesa

Squaw Creek Mesa

Buckhead Mesa

Rattlesnake Spring

Beckers Butte

Beckers Butte

Chiricahua Peak

Elevator Mtn

Bloody Bas in

Sponseller Mtn

Gisela

North Peak

Sheep Bas in Mtn

$314430 \mathrm{~N} 1091352 \mathrm{~W}$

Martin Mtn

Seepage Mtn 


\begin{tabular}{|c|c|c|c|c|c|c|c|}
\hline FEATURE NAME & $\begin{array}{l}\text { FEATURE } \\
\text { CLASS }\end{array}$ & STATUS & COUNTY & COORDINATE & $\begin{array}{l}\text { SOURCE } \\
\text { COORDINATE }\end{array}$ & $\begin{array}{c}\text { ELEV } \\
\text { FT }\end{array}$ & MAP NAME \\
\hline $\begin{array}{l}\text { Brushy Tank } \\
\text { Brushy Tank } \\
\text { Brushy Tank } \\
\text { Brushy Tank } \\
\text { Brushy Tank } \\
\text { Brushy Tank }\end{array}$ & $\begin{array}{l}\text { reservoir } \\
\text { reservoir } \\
\text { reservoir } \\
\text { reservoir } \\
\text { reservoir } \\
\text { reservoir }\end{array}$ & $\begin{array}{l}\text { BGN } \\
\text { BGN } \\
\text { BGN } \\
\text { BGN } \\
\text { BGN } \\
\text { BGN }\end{array}$ & $\begin{array}{l}\text { Cochise } \\
\text { Graham } \\
\text { Graham } \\
\text { Greenlee } \\
\text { Apache } \\
\text { Gila }\end{array}$ & $\begin{array}{l}314544 N 1093514 \mathrm{~W} \\
324709 \mathrm{~N} 1100613 \mathrm{~W} \\
330723 \mathrm{~N} 1095226 \mathrm{~W} \\
330738 \mathrm{~N} 1091141 \mathrm{~W} \\
333523 \mathrm{~N} 1094208 \mathrm{~W} \\
334331 \mathrm{N1} 102707 \mathrm{~W}\end{array}$ & & & $\begin{array}{l}\text { Stanford Canyon } \\
\text { Tripp Canyon } \\
\text { Markham Creek } \\
\text { Dix Creek } \\
\text { Maverick SW } \\
\text { Brushy Canyon }\end{array}$ \\
\hline $\begin{array}{l}\text { Brushy Tank } \\
\text { Brushy Tank } \\
\text { Brushy Tank } \\
\text { Brushy Top Mountain } \\
\text { Brushy Wash } \\
\text { Brushy Wash } \\
\text { Brushy Wash Spring } \\
\text { Bryan Mountains } \\
\text { Mohawk Mountains } \\
\text { Bryant Canyon }\end{array}$ & $\begin{array}{l}\text { reservoir } \\
\text { reservoir } \\
\text { reservoir } \\
\text { summit } \\
\text { stream } \\
\text { stream } \\
\text { spring } \\
\text { summit } \\
\text { valley }\end{array}$ & $\begin{array}{l}\text { BGN } \\
\text { BGN } \\
\text { BGN } \\
\text { BGN } \\
\text { BGN } \\
\text { BGN } \\
\text { BGN } \\
\text { BGN } \\
\text { VARIANT } \\
\text { BGN }\end{array}$ & $\begin{array}{l}\text { Gila } \\
\text { Gila } \\
\text { Yavapai } \\
\text { Gila } \\
\text { Graham } \\
\text { Yavapai } \\
\text { Yavapai } \\
\text { Yuma } \\
\text { Gila }\end{array}$ & $\begin{array}{l}340504 N 1111304 W \\
341744 N 1112249 W \\
344925 N 1125035 W \\
335427 N 1104707 W \\
325816 N 1101051 W \\
342406 N 1120746 W \\
343846 N 1120212 W \\
321827 N 1132245 W \\
340455 N 1110429 W\end{array}$ & $\begin{array}{l}330222 \mathrm{~N} 1101222 \mathrm{~W} \\
343013 \mathrm{~N} 1121052 \mathrm{~W}\end{array}$ & 5900 & $\begin{array}{l}\text { Sheep Bas in Mtn } \\
\text { Buckhead Mesa } \\
\text { Seepage Mtn } \\
\text { Rock House } \\
\text { Jackson Mtn } \\
\text { Mayer } \\
\text { Cottonwood } \\
\text { Bryan Mts } \\
\text { Buzzard Roost Mesa }\end{array}$ \\
\hline $\begin{array}{l}\text { Bryant Canyon Spring } \\
\text { Bryant Canyon Tank } \\
\text { Bryant Mountain } \\
\text { Bryant Point } \\
\text { Bryce } \\
\text { Bryce Cemetery } \\
\text { Bryce Horse Camp Tank } \\
\text { Bryce Knoll } \\
\text { Bryce Mountain } \\
\text { Bryce Peak }\end{array}$ & $\begin{array}{l}\text { spring } \\
\text { reservoir } \\
\text { summit } \\
\text { summit } \\
\text { ppl } \\
\text { cemetery } \\
\text { reservoir } \\
\text { summit } \\
\text { summit }\end{array}$ & $\begin{array}{l}\text { BGN } \\
\text { BGN } \\
\text { BGN } \\
\text { BGN } \\
\text { BGN } \\
\text { UNOFF } \\
\text { BGN } \\
\text { BGN } \\
\text { BGN } \\
\text { VARIANT }\end{array}$ & $\begin{array}{l}\text { Gila } \\
\text { Gila } \\
\text { Gila } \\
\text { Navajo } \\
\text { Graham } \\
\text { Graham } \\
\text { Graham } \\
\text { Graham } \\
\text { Graham }\end{array}$ & $\begin{array}{l}340357 \mathrm{~N} 1110148 \mathrm{~W} \\
340412 \mathrm{~N} 1110116 \mathrm{~W} \\
340305 \mathrm{~N} 1110026 \mathrm{~W} \\
341836 \mathrm{~N} 1101842 \mathrm{~W} \\
325544 \mathrm{~N} 1094938 \mathrm{~W} \\
325609 \mathrm{~N} 1094920 \mathrm{~W} \\
331345 \mathrm{~N} 1094417 \mathrm{~W} \\
324907 \mathrm{~N} 1095718 \mathrm{~W} \\
330112 \mathrm{~N} 1094018 \mathrm{~W}\end{array}$ & & $\begin{array}{l}6812 \\
5334 \\
7298\end{array}$ & $\begin{array}{l}\text { Buzzard Roost Mesa } \\
\text { Buzzard Roost Mesa } \\
\text { Buzzard Roost Mesa } \\
\text { Clay Springs } \\
\text { Pima } \\
\text { Pima } \\
\text { Park Creek Cabins } \\
\text { Shingle Mill Mtn } \\
\text { Bryce Mountain }\end{array}$ \\
\hline $\begin{array}{l}\text { Bryce Peak } \\
\text { See Bryce Mountain } \\
\text { Bryce Ranch } \\
\text { Bryce Tank } \\
\text { Bryce Wash }\end{array}$ & $\begin{array}{l}\text { summit } \\
\text { locale } \\
\text { reservoir }\end{array}$ & $\begin{array}{l}\text { VARIANT } \\
\text { UNOFF } \\
\text { BGN } \\
\text { VARIANT }\end{array}$ & $\begin{array}{l}\text { Graham } \\
\text { Graham } \\
\text { Mohave }\end{array}$ & $\begin{array}{l}330112 \mathrm{~N} 1094018 \mathrm{~W} \\
330022 \mathrm{~N} 1094151 \mathrm{~W} \\
355646 \mathrm{~N} 1135540 \mathrm{~W}\end{array}$ & & 5140 & $\begin{array}{l}\text { Bryce Mountain } \\
\text { Grapevine Canyon }\end{array}$ \\
\hline $\begin{array}{l}\text { See Peck Wash } \\
\text { BS Gap } \\
\text { BSK Mine } \\
\text { BS Tank } \\
\text { BS Tank }\end{array}$ & $\begin{array}{l}\text { stream } \\
\text { gap } \\
\text { mine } \\
\text { reservoir } \\
\text { reservoir }\end{array}$ & $\begin{array}{l}\text { BGN } \\
\text { UNOFF } \\
\text { BGN } \\
\text { BGN }\end{array}$ & $\begin{array}{l}\text { Graham } \\
\text { Graham } \\
\text { Pima } \\
\text { Graham } \\
\text { Coconino }\end{array}$ & $\begin{array}{l}325506 \mathrm{~N} 1095000 \mathrm{~W} \\
333435 \mathrm{~N} 1093538 \mathrm{~W} \\
322543 \mathrm{~N} 1113250 \mathrm{~W} \\
333226 \mathrm{~N} 1093623 \mathrm{~W} \\
353352 \mathrm{~N} 1115509 \mathrm{~W}\end{array}$ & & & $\begin{array}{l}\text { Freezeout Mtn } \\
\text { Silver Bell West } \\
\text { Freezeout Mtn } \\
\text { Ebert Mtn }\end{array}$ \\
\hline $\begin{array}{l}\text { BT Butte } \\
\text { Bubbling Spring } \\
\text { Bubbling Spring Canyon } \\
\text { Bubbling Spring Valley } \\
\text { Bubbling Well } \\
\text { Bubby Buttes } \\
\text { Twin Buttes } \\
\text { Bubby Buttes }\end{array}$ & $\begin{array}{l}\text { summit } \\
\text { spring } \\
\text { valley } \\
\text { valley } \\
\text { well } \\
\text { summit }\end{array}$ & $\begin{array}{l}\text { BGN } \\
\text { BGN } \\
\text { BGN } \\
\text { BGN } \\
\text { UNOFF } \\
\text { BGN 1981 } \\
\text { VARIANT } \\
\text { VARIANT }\end{array}$ & $\begin{array}{l}\text { Yavapai } \\
\text { Navajo } \\
\text { Navajo } \\
\text { Apache } \\
\text { Gila } \\
\text { Yavapai }\end{array}$ & $\begin{array}{l}344441 \mathrm{~N} 1125316 \mathrm{~W} \\
364435 \mathrm{~N} 1103412 \mathrm{~W} \\
364308 \mathrm{~N} 1103226 \mathrm{~W} \\
361258 \mathrm{~N} 1090315 \mathrm{~W} \\
332250 \mathrm{~N} 1105315 \mathrm{~W} \\
343626 \mathrm{~N} 1124938 \mathrm{~W}\end{array}$ & $\begin{array}{l}364512 N 1103341 \mathrm{~W} \\
361144 N 1090402 \mathrm{~W}\end{array}$ & 4550 & $\begin{array}{l}\text { Sheridan Mtn } \\
\text { Betatakin Ruin } \\
\text { Betatakin Ruin } \\
\text { Upper Wheatfields } \\
\text { Inspiration } \\
\text { Martin Mtn }\end{array}$ \\
\hline $\begin{array}{l}\text { See Twin Buttes } \\
\text { Buchanan Canyon }\end{array}$ & $\begin{array}{l}\text { summit } \\
\text { valley }\end{array}$ & BGN & $\begin{array}{l}\text { Yavapai } \\
\text { Greenlee }\end{array}$ & $\begin{array}{l}343744 N 1124601 W \\
332045 N 1085947 W\end{array}$ & $332027 N 1090512 \mathrm{~W}$ & & Maple Peak \\
\hline $\begin{array}{l}\text { Buchanan Tank } \\
\text { Buckalou Creek } \\
\text { Buckalou Tank } \\
\text { Buckaroo Flats } \\
\text { Buckaroo Tank } \\
\text { Buck Bas in } \\
\text { Buck Bas in } \\
\text { Buck Bas in } \\
\text { Buck Basin Spring } \\
\text { Buck Bas in Spring }\end{array}$ & $\begin{array}{l}\text { reservoir } \\
\text { stream } \\
\text { reservoir } \\
\text { flat } \\
\text { reservoir } \\
\text { basin } \\
\text { basin } \\
\text { basin } \\
\text { spring } \\
\text { spring }\end{array}$ & $\begin{array}{l}\text { BGN } \\
\text { BGN } \\
\text { BGN } \\
\text { BGN } \\
\text { BGN } \\
\text { BGN } \\
\text { BGN } \\
\text { BGN } \\
\text { BGN } \\
\text { BGN }\end{array}$ & $\begin{array}{l}\text { Greenlee } \\
\text { Greenlee } \\
\text { Greenlee } \\
\text { Gila } \\
\text { Gila } \\
\text { Gila } \\
\text { Maricopa } \\
\text { Yavapai } \\
\text { Gila } \\
\text { Maricopa }\end{array}$ & $\begin{array}{l}332026 \mathrm{~N} 1090410 \mathrm{~W} \\
334333 \mathrm{~N} 1090908 \mathrm{~W} \\
334248 \mathrm{~N} 1090929 \mathrm{~W} \\
335520 \mathrm{~N} 1110347 \mathrm{~W} \\
335523 \mathrm{~N} 1110434 \mathrm{~W} \\
334538 \mathrm{~N} 1112005 \mathrm{~W} \\
335721 \mathrm{N1114654W} \\
341615 \mathrm{~N} 1115131 \mathrm{~W} \\
334627 \mathrm{~N} 1112024 \mathrm{~W} \\
335719 \mathrm{N1114724W}\end{array}$ & $334218 \mathrm{~N} 1091007 \mathrm{~W}$ & & $\begin{array}{l}\text { Maple Peak } \\
\text { Beaverhead } \\
\text { Beaverhead } \\
\text { Copper Mtn } \\
\text { Copper Mtn } \\
\text { Tonto Bas in } \\
\text { Humboldt Mtn } \\
\text { Tule Mesa } \\
\text { Tonto Bas in } \\
\text { Humboldt Mtn }\end{array}$ \\
\hline $\begin{array}{l}\text { Buck Basin Tank } \\
\text { Buck Basin Tank } \\
\text { Buckbed Number Two Tank } \\
\text { Buckbed Spring } \\
\text { Buckbed Tank Number One } \\
\text { Buckbed Wash } \\
\text { Buckbed Wash } \\
\text { See CF Canyon } \\
\text { Buck Butte } \\
\text { Buck Butte Tank }\end{array}$ & $\begin{array}{l}\text { reservoir } \\
\text { reservoir } \\
\text { reservoir } \\
\text { spring } \\
\text { reservoir } \\
\text { stream } \\
\text { valley } \\
\text { summit } \\
\text { reservoir }\end{array}$ & $\begin{array}{l}\text { BGN } \\
\text { BGN } \\
\text { BGN } \\
\text { BGN } \\
\text { BGN } \\
\text { BGN } 1976 \\
\text { VARIANT } \\
\text { BGN } \\
\text { BGN }\end{array}$ & $\begin{array}{l}\text { Gila } \\
\text { Yavapai } \\
\text { Yavapai } \\
\text { Yavapai } \\
\text { Yavapai } \\
\text { Yavapai } \\
\text { Yavapai } \\
\text { Coconino } \\
\text { Coconino }\end{array}$ & $\begin{array}{l}340148 \mathrm{~N} 1111200 \mathrm{~W} \\
341617 \mathrm{~N} 1115132 \mathrm{~W} \\
343224 \mathrm{~N} 1120104 \mathrm{~W} \\
343213 \mathrm{~N} 1120128 \mathrm{~W} \\
343353 \mathrm{~N} 1120039 \mathrm{~W} \\
343115 \mathrm{~N} 1120159 \mathrm{~W} \\
\\
343016 \mathrm{~N} 1120117 \mathrm{~W} \\
344137 \mathrm{~N} 1112716 \mathrm{~W} \\
344130 \mathrm{~N} 1112752 \mathrm{~W}\end{array}$ & $343325 N 1120111 W$ & 7097 & $\begin{array}{l}\text { Sheep Basin Mtn } \\
\text { Tule Mesa } \\
\text { Cherry } \\
\text { Cherry } \\
\text { Cherry } \\
\text { Cherry }\end{array}$ \\
\hline $\begin{array}{l}\text { Buck Canyon } \\
\text { Buck Canyon } \\
\text { Buck Canyon } \\
\text { Buck Canyon } \\
\text { Buck Creek }\end{array}$ & $\begin{array}{l}\text { valley } \\
\text { valley } \\
\text { valley } \\
\text { valley } \\
\text { stream }\end{array}$ & $\begin{array}{l}\text { BGN } \\
B G N \\
B G N \\
B G N \\
B G N\end{array}$ & $\begin{array}{l}\text { Cochise } \\
\text { Graham } \\
\text { Greenlee } \\
\text { Pinal } \\
\text { Cochise }\end{array}$ & $\begin{array}{l}313311 \mathrm{~N} 1095232 \mathrm{~W} \\
323854 \mathrm{~N} 1102558 \mathrm{~W} \\
325615 \mathrm{~N} 1091425 \mathrm{~W} \\
330534 \mathrm{~N} 1102935 \mathrm{~W} \\
31310 \mathrm{~N} 1091826 \mathrm{~W}\end{array}$ & $\begin{array}{l}313232 \mathrm{~N} 1095505 \mathrm{~W} \\
323928 \mathrm{~N} 1102504 \mathrm{~W} \\
325355 \mathrm{~N} 1091 \mathrm{~B} 41 \mathrm{~W} \\
330511 \mathrm{~N} 1102834 \mathrm{~W} \\
313820 \mathrm{~N} 1092121 \mathrm{~W}\end{array}$ & & $\begin{array}{l}\text { Potter Mtn } \\
\text { Rhodes Peak } \\
\text { York } \\
\text { Rawhide Mtn } \\
\text { Pedregosa Mts East }\end{array}$ \\
\hline
\end{tabular}


NATIONAL GAZETTEER--ARIZONA 1986

\section{FEATURE NAME}

Buck Creek

See Yeager Canyon

Buck Creek Tank

Buck Dam

Buckelew Spring

Bucket Mountain

Bucket Mountain Tank

Bucket Spring

Buckeye

$$
\text { Sydney }
$$

Buckeye Apache Mine

Buckeye Canal

Buckeye Canyon

Buckeye City Hall

Buckeye Copper Mine

Buckeye Copper Mine

Buckeye Copper Mine Well

Buckeye Elementary School Buckeye Grammar Schoo

Buckeye FRS Dam Number One

Buckeye FRS Dam Number Three

Buckeye FRS Dam Number Two

Buckeye Grammar School

See Buckeye Elementary School

Buckeye Hills

Buckeye Hills Recreation Area

Buckeye Mill

Buckeye Mine

Buckeye Mountain

Buckeye Municipal Airport

Buckeye Post office

Buckeye Public Library

Buckeye Shaft

Buckeye Sports Field

Buckeye Substation

Buckeye Town Park

Buckeye Union High School

Buckeye Valley

Buckeye Wash

Buckeye Wash

Buck Farm Canyon

Buckhead Canyon

Buckhead Draw

Buckhead Mesa

Buckhead Point

Buckhead Ridge

Buckhead Tank

Buckhead Tank

Buckhead Tank

Buckhead Tank

Buck Holes Tank

Buckhorn

Buckhorn Bas in

Buckhorn Bas in

Buckhorn Canyon

Buckhorn Creek

Buckhorn Creek

Buckhorn Draw

Buckhorn Draw

Buckhorn Hill

Buckhorn Mine

Buckhorn Mine

Buckhorn Mountain

Buckhorn Mountain

Buckhorn Mountains

Buckhorn Point

Buckhorn Post Office

Buckhorn Ranch

Buckhorn Ridge
FEATURE

$$
\text { CLASS }
$$

STATUS

COUNTY

COOROINATE

valley
reservoir
dam

VARIANT

BGN

spring $\quad B G$

Coconino

Cochise

Yavapai

$343359 \mathrm{~N} 1110832 \mathrm{~W}$

$313307 \mathrm{~N} 1095241 \mathrm{~W}$

$350323 N 1130504 \mathrm{~W}$

341201N1093950W

summit

reservoir

spring

ppl

mine

canal

valley

mine

BGN Gila

BGN Gila

BGN Yavapai

BGN Maricopa

VARIANT

UNOFF Cochise

BGN Maricopa

BGN

UNOFF

UNOFF

Cochise

Maricopa

Maricopa

mine

well

school

dam

dam

school

\section{UNOFF}

UNOFF

UNOFF
VARIANT

VARIANT
UNOFF

UNOFF

UNOFF

VARIANT

Maricopa

Maricopa

Maricopa

Maricopa

Maricopa

Maricopa

Maricopa

$331900 N 1103354 \mathrm{~W}$

331922N1103402W

$341531 N 1121811 \mathrm{~W}$

332213 N1123459W

$321515 N 1093503 \mathrm{~W}$

$332307 \mathrm{~N} 1123221 \mathrm{~W}$

321717 N1093301W

$332215 N 1123500 \mathrm{~W}$

$331205 N 1125207 \mathrm{~W}$

331337 N1125210W

$331205 N 1125209 \mathrm{~W}$

332209N1123456W

$332530 \mathrm{~N} 1123731 \mathrm{~W}$

$332736 \mathrm{~N} 1123118 \mathrm{~W}$

$332618 \mathrm{~N} 1123518 \mathrm{~W}$

332209N1123456W

$\begin{array}{ll}\text { summit } & \text { BGN } \\ \text { park } & \text { ADMIN } \\ \text { locale } & \text { BGN } \\ \text { mine } & \text { UNOFF } \\ \text { mine } & \text { UNOFF } \\ \text { summit } & \text { BGN } \\ \text { airport } & \text { ADMIN } \\ \text { building } & \text { UNOFF } \\ \text { building } & \text { UNOFF } \\ \text { mine } & \text { UNOFF }\end{array}$

bas in
Maricopa

Maricopa

Coch ise

Cochise

Pinal

Gil

Maricopa

Maricopa

Maricopa

Gila

park

locale

park

school

valley

arroyo

stream

valley

valley

valley

ADMIN

UNOFF

ADMIN

UNOFF

BGN

$B G N$
$B G N$

BGN

BGN

BGN

summit BGN

cliff

ridge

reservoir

reservoir

reservoir

reservoir

reservoir

ppl

BGN
$B G N$
$B G N$
$B G N$
$B G N$
$B G N$
$B G N$
$B G N$
$B G N$

Maricopa

Maricopa

Maricopa

Maricopa

Maricopa

Graham

Cochise

Coconino

Gila

Gila

Gila

Coconino

Coconino

Gila

Gila

Yavapai

Coconino

Maricopa

Maricopa

Cochise

basin BGN Gila

valley

strean

stream

valley

valley

summit

mine

mine

summit

BGN

BGN

BGN

BGN

GN

UNOFF

UNOFF

Cochise

Gila

Yavapai

Navajo

Navajo

Navajo

Yavapai

Yavapai

Gila

summit $\quad B G N$

summit

Coconino

Yavapai

Coconino

Maricopa

$\begin{array}{lll}\text { locale } & \text { UNOFF } & \text { Coconino } \\ \text { ridge } & B G N & \text { Maricopa }\end{array}$

$\begin{array}{lll}\text { locale } & \text { UNOFF } & \text { Coconino } \\ \text { ridge } & \text { BGN } & \text { Maricopa }\end{array}$

$331700 \mathrm{~N} 1123831 \mathrm{~W}$

331717 N1123905

$321522 N 1093454 \mathrm{~W}$

$321427 \mathrm{~N} 1093506 \mathrm{~W}$

$330814 \mathrm{~N} 1105440 \mathrm{~W}$

$332534 \mathrm{~N} 1104525 \mathrm{~W}$

$332530 \mathrm{~N} 1124050 \mathrm{~W}$

332213 N1123510

$332209 \mathrm{~N} 1123456 \mathrm{~W}$

$332526 \mathrm{~N} 1104549 \mathrm{~W}$

$332154 \mathrm{~N} 1123515 \mathrm{~W}$

$332613 \mathrm{~N} 1123530 \mathrm{~W}$

332219N1123433W

$332225 N 1123436 \mathrm{~W}$

$332124 N 1124317 \mathrm{~W}$

$322559 N 1092111 \mathrm{~W}$

$322017 N 1093025 W$

362418 N1115248

341540N1112844W

$341903 \mathrm{N1} 112420 \mathrm{~W}$

341941 N1112639W

$345948 \mathrm{~N} 1114647 \mathrm{~W}$

345948 N1114744W

$341642 \mathrm{~N} 1112658 \mathrm{~W}$

$341921 N 1112533 \mathrm{~W}$

342806 N1114054W

$343901 N 1112518 \mathrm{~W}$

334639 N1125958

$332456 \mathrm{~N}$

$320418 \mathrm{~N} 1092221 \mathrm{~W}$

333944N1111336W

$320947 \mathrm{~N} 1102557 \mathrm{~W}$

$333831 N 1111203$

$340045 \mathrm{~N} 1122429 \mathrm{~W}$

342716 N1103951W

344117 N1101238W

$343908 \mathrm{~N} 1101126 \mathrm{~W}$

$340145 N 1122943$

341816 N1124745W

333930N1111710W

$343440 \mathrm{~N} 1113212 \mathrm{~W}$

$335924 \mathrm{~N} 1122754 \mathrm{~W}$

$332457 \mathrm{~N} 1114210 \mathrm{~W}$

$343515 \mathrm{~N} 1113110 \mathrm{~W}$
363949 N1123428W 
FEATURE NAME

Buckhorn Shopping Center Buckhorn Slope Tank

Buckhorn Spring

Buckhorn Spring

Buckhorn Spring

Buckhorn Spring

Buckhorn Spring

Buckhorn Spring

Buckhorn Tank

Buckhorn Tank

Buckhorn Tank

Buckhorn Tank

Buckhorn Tank

Buckhorn Tank

Buckhorn Tank

Buckhorn Tank

Buckhorn Tank

Buckhorn Tank

Buckhorn Tank

Buckhorn Tank

Buckhorn Tank

Buckhorn Tank

Buckhorn Tank Number Five

Buckhorn Tank Number Four

Buckhorn Tank Number One

Buckhorn Tank Number Three

Buckhorn Tank Number Two

Buckhorn Tanks

Buckhorn Trail

Buckhorn Water Tank

Buck Lake

Bucklar Tank

Buckley Tunnel Spring

Buckman flat Spring

Buck Mountain

See Buck Peak

Buck Mountain

Buck Mountain

Buck Mountain

Buck Mountain Lookout Tower

Buck Mountains

Buck Mountain Tank

See Buck Peak Tank

Buck Mountain Tank

Buck Mountain Tank Number Two

Buck Mountain Wash

Buck Park

Buck Pasture Canyon

Buck Pasture Windmill

Buck Peak

Buck Mountain

Buck Peak

Lauffer Mountain

Buck Peak Tank

Buck Mountain Tank

Buck Ridge

Buck Ridge

Buck Ridge Cabin

Buck Ridge Point

Buck Rodgers Trading Post

Buck Rogers Well

Buckshot Spring

Buckshot Spring

Buckshot Tank

Buckskin Canyon

Bucksk in Canyon

Buckskin Canyon

See Black Cany

Buckskin $\mathrm{Hills}$

Bucksk in Mountai

Buckskin Mountains

\section{FEATURE}

CLASS

STATUS

COUNTY

COORDINATE

$\begin{array}{ll}\text { locale } & \text { UNOFF } \\ \text { reservoir } & 8 G N \\ \text { spring } & \text { BGN } \\ \text { spring } & \text { BGN }\end{array}$

Maricopa

$\begin{array}{ll}\text { spring } & \text { BGN } \\ \text { spring } & \text { BGN } \\ \text { spring } & \text { BGN } \\ \text { spring } & \text { BGN } \\ \text { reservoir } & \text { BGN } \\ \text { reservoir } & \text { BGN } \\ \text { reservoir } & \text { BGN } \\ \text { reservoir } & \text { BGN } \\ \text { reservoir } & \text { BGN } \\ \text { reservoir } & \text { BGN }\end{array}$

Yavapai

VARIANT

summit

BGN

summit

summit

summit

tower

range

reservoir

reservoir

BGN

BGN

UNOFF

VARIANT

Yuma

BGN

reservoir BGN

flat

valley

well

summit

summit

BGN

BGN

BGN

UNOFF

BGN

VARIANT

BGN

reservoir

VARIANT

BGN

Gila

ridg

ridge

locale

cliff

locale

well

spring

spring

spring

valley

BGN

BGN

$B G N$

BGN

$B G N$

UNOFF

BGN

BGN

BGN

BGN

valley $B G N$

valley

summit

summit

range
BGN

VARIANT

BGN

BGN

BGN 1961
Coconino

Cochise

Gila

Gila

Yavapai

Mohave

Mohave

Yuma

Pima

Pima

Green lee

Graham

Maricopa

Maricopa

Navajo

Navajo

Navajo

Mohave

Coconino

Navajo

Coconino

Coconino

Coconino

Coconino

Yavapai

Coconino

Yavapai

Yavapai

Yavapai

Yavapai

Coconino

Coconino

Coconino

Coconino

Mohave

Yuma

Coconino

Coconino

Mohave

Green lee

Coconino

Coconino

Yuma

Yuma

332459 N1114200W

$343517 \mathrm{~N} 1113216 \mathrm{~W}$

$320939 \mathrm{~N} 1102549 \mathrm{~W}$

$332418 \mathrm{~N} 1105620 \mathrm{~W}$

$333935 \mathrm{~N} 1111312 \mathrm{~W}$

$340022 \mathrm{~N} 1122807 \mathrm{~W}$

$361910 \mathrm{~N} 1135822 \mathrm{~W}$

$362255 \mathrm{~N} 1124642 \mathrm{~W}$

$321410 \mathrm{~N} 1134758 \mathrm{~W}$

321721 N1103934k

$321800 \mathrm{~N} 1103256 \mathrm{~W}$

$332021 \mathrm{~N} 1091319 \mathrm{~W}$

$333435 N 1093441 \mathrm{~W}$

$334516 \mathrm{~N} 1124244 \mathrm{~W}$

$334619 \mathrm{~N} 1114330 \mathrm{~W}$

$335151 \mathrm{~N} 1095204 \mathrm{~W}$

$341141 N 1095124 \mathrm{~W}$

$342644 \mathrm{~N} 1104122 \mathrm{~W}$

342729 N1135642W

$343454 \mathrm{~N} 1110646 \mathrm{~W}$

$343831 \mathrm{~N} 1101415 \mathrm{~W}$

$64030 \mathrm{~N} 1123011 \mathrm{~K}$

$343356 N 1113141 \mathrm{~W}$

$343430 \mathrm{~N} 1113141 \mathrm{~W}$

$343457 N 1113256 \mathrm{~W}$

$343422 \mathrm{~N} 1113315 \mathrm{~W}$

$343407 N 1113209 \mathrm{~W}$

$343423 \mathrm{~N} 1125303 \mathrm{~W}$

$343543 N 1114034 \mathrm{~W}$

$343500 \mathrm{N1125238 \textrm {W }}$

$364210 \mathrm{~N} 1121 \mathrm{~B} 06 \mathrm{~W}$

$354923 N 1115258 \mathrm{~W}$

$345418 N 1133416 \mathrm{~W}$

$343615 N 1123631 \mathrm{~W}$

$322257 N 1135337 \mathrm{~W}$

$334104 N 1104503 \mathrm{~W}$

$344001 \mathrm{~N} 1112452 \mathrm{~W}$

$352920 \mathrm{~N} 1120133 \mathrm{~W}$

$344001 \mathrm{~N} 1112452 \mathrm{~W}$

344059 N11 $40843 \mathrm{~W}$

$322306 N 1135457 \mathrm{~W}$

$344001 \mathrm{~N} 1112520 \mathrm{~W}$

$343932 \mathrm{~N} 1112438 \mathrm{~W}$ 344453N1141408W

$331321 \mathrm{~N} 1091741 \mathrm{~W}$

365859 N1121550W

$362829 \mathrm{~N} 1111616 \mathrm{~W}$

$322257 \mathrm{~N} 1135337 \mathrm{~W}$

$335412 N 1110405 W$

$322306 \mathrm{~N} 1135457 \mathrm{~W}$

$350020 \mathrm{~N} 1115645 \mathrm{~W}$

$364206 \mathrm{~N} 1121720 \mathrm{~W}$

$345950 \mathrm{~N} 1115555 \mathrm{~W}$

$364154 \mathrm{~N} 1122015 \mathrm{~W}$

$351551 \mathrm{~N} 1125729 \mathrm{~W}$

$314841 \mathrm{~N} 1095741 \mathrm{~W}$

335452N1092832W

$312833 \mathrm{~N} 1110410 \mathrm{~W}$

$340704 N 1123254 \mathrm{~W}$

Santa Cruz

Yavapai

$341406 \mathrm{~N} 1103332 \mathrm{~W}$

$344738 \mathrm{~N} 1103621 \mathrm{~W}$

$342741 \mathrm{N1113802 \textrm {W }}$

$365833 \mathrm{~N} 1120613 \mathrm{~W}$

$340919 \mathrm{~N} 1134948 \mathrm{~W}$

$\begin{array}{cc}\text { SOURCE } & \text { ELEV } \\ \text { COORDINATE } & \text { FT MAP NAME }\end{array}$

Buckhorn

Buckhorn Mountain

Happy Valley

Inspiration

Theo. Roosevelt Dam

Copperopolis

Gyp Hills

Hitson Tank

Tule Mountains

Agua Caliente Hill

Piety Hill

Fritz Canyon

Freezeout Mtn

Wickenburg SW

Bart lett Dam

Corn Creek Plateau

Sponseller Mtn

Hanks Draw

Castaneda Hills

Leonard Canyon

Flattop $\mathrm{Hill}$

Gunsight Point

Buckhorn Mtn

Buckhorn Mountain

Buckhorn Mountain 
NATIONAL GAZETTEER--ARIZONA 1986 FEATURE NAME

Monument Mountains Williams Mountains

Buckskin Mountains

Bucksk in Mountain State Park

Buckskin Ranch

Buckskin Saddle

Buckskin Spring

Buckskin Tank

Bucksk in Tank

Buckskin Wash

Buck Spring

uck Spring

Buck Springs Canyon

Buck Springs Guard Station

Buck Springs Ridge

Buck Spring Tank

Bucks Well

Buck Tank

Buck Tank

Buck Tank

Buck Tank

Buck Tank

Buck Tank

Buck Tank

Buck Tank

Buck Tank

Buck Tank

Buck Tank

Buck Tank

Buck Tank

Cow Crossing Tank
Buck Tank

See Cow Crossing Tank

Buck Tank

Buck Tank

Buck Tank

Buck Tank

Buck Tank

Buck Tank Canyon

Buck Tanks

Bucky O' Neil Hil

Bud Antle Ranch Airstrip

Buddah Temple

See Buddha Cloister

Buddha Cloister Buddah Temple

Buddha Temple

Buddy Tank

Buds Tank

Bud Walker Park

Budweiser Spring

Budwe iser Tank

Buehman Canyon

Buell Mountain

Buell Park

Buells Park

Jewell Park

Yule Park

Buells Park

See Buell Park

Buell Wash

Buena Ayres

See Buenos Aires

Buena High School

Buena School

Buena Tank

Buenavante (subdivision)

Buena Vista

Buena Vista Creek

Buena Vista Lake

Buena Vista Peak

FEATURE

CLASS

STATUS

COUNTY

COORDINATE

ridge

well

BGN

reservoir

reservoir $B G$

reservoir $B G$

reservoir $B G$

reservoir $B G$

reservoir BGN

reservoir BGN

reservoir BGN

reservoir BGN

reservoir BGN

reservoir BGN

reservoir

BGN 1976

VARIANT

VARIANT

reservoir

reservoir

BGN

Coconino

Coconino 353033N1120223W

$354844 \mathrm{~N} 1125936 \mathrm{~W}$

reservoir $B G$

cliff

airport

summit

BGN

VARIANT

Gila

$355223 \mathrm{~N} 1121 \mathrm{~B} 29 \mathrm{~W}$

$340210 \mathrm{~N} 1111146 \mathrm{~W}$

$312619 N 1095450 \mathrm{~W}$

$323731 N 1111955 W$

Pinal

Coconino

summit
summit
reservoir
reservoir
park
spring
reservoir
valley
summit

Coconino $314655 \mathrm{~N} 1111604 \mathrm{~W}$ 355509 N1090612W AARIANT VARIANT VARIANT

VARIANT

flat

stream

BGN
VARIANT

locale

UNOFF

Apache

Apache

Pima

Cochise

stream

summit

BGN
SOURCE

COORDINATE FT

MAP NAME

\begin{tabular}{|c|c|c|c|}
\hline $\begin{array}{l}\text { summit } \\
\text { park }\end{array}$ & $\begin{array}{l}\text { BGN } \\
\text { ADMIN }\end{array}$ & $\begin{array}{l}\text { Coconino } \\
\text { La Paz }\end{array}$ & $\begin{array}{l}365652 N 1120952 W \\
341527 N 1140939 W\end{array}$ \\
\hline $\begin{array}{l}\text { locale } \\
\text { gap } \\
\text { spring } \\
\text { reservoir } \\
\text { reservoir } \\
\text { stream } \\
\text { spring } \\
\text { spring } \\
\text { valley } \\
\text { locale }\end{array}$ & $\begin{array}{l}\text { UNOFF } \\
\text { BGN } \\
\text { BGN } \\
\text { BGN } \\
\text { BGN } \\
\text { BGN } \\
\text { BGN } \\
\text { BGN } \\
\text { BGN } \\
\text { UNOFF }\end{array}$ & $\begin{array}{l}\text { Graham } \\
\text { Cochise } \\
\text { Yavapai } \\
\text { Navajo } \\
\text { Yavapai } \\
\text { Navajo } \\
\text { Yavapai } \\
\text { Coconino } \\
\text { Coconino } \\
\text { Coconino }\end{array}$ & $\begin{array}{l}323227 \mathrm{~N} 1101306 \mathrm{~W} \\
314927 \mathrm{N1} 1091921 \mathrm{~W} \\
340634 \mathrm{N1} 123206 \mathrm{~W} \\
340625 \mathrm{~N} 1104402 \mathrm{~W} \\
342755 \mathrm{~N} 1113839 \mathrm{~W} \\
342546 \mathrm{~N} 1103541 \mathrm{~W} \\
343749 \mathrm{N1} 120419 \mathrm{~W} \\
351120 \mathrm{~N} 1120240 \mathrm{~W} \\
342849 \mathrm{N1} 110524 \mathrm{~W} \\
342636 \mathrm{~N} 1110824 \mathrm{~W}\end{array}$ \\
\hline
\end{tabular}

reservoir BGN

reservoir BGN Coconino 352323N1125352W

reservoir BGN Coconino 355223N1121B29W

valley $B G N$

$360841 \mathrm{~N} 1120557 \mathrm{~W}$

$360841 N 1120557 \mathrm{~W}$

$360909 \mathrm{~N} 1120555 \mathrm{~W}$ $350758 \mathrm{~N} 1112724 \mathrm{~W}$ $322300 \mathrm{~N} 1125142 \mathrm{~W}$ $332457 \mathrm{~N} 1140206 \mathrm{~W}$ $351124 N 1114545 \mathrm{~W}$ $322506 \mathrm{~N} 1103031 \mathrm{~W}$

$322330 \mathrm{~N} 1103958 \mathrm{~W}$

flat BGN 1915 Apache 355400N1090548W

$355400 \mathrm{~N} 1090548 \mathrm{~W}$ $355219 \mathrm{~N} 1090258 \mathrm{~W}$

$313116 \mathrm{~N} 1113924 \mathrm{~W}$

$313320 \mathrm{~N} 1101530 \mathrm{~W}$

School UNOFF Cochise 313318N1101523W

reservoir BGN Pima 314438N1112359W

PD1 BGN Maricopa 333556N1115517W

$325037 \mathrm{N1093341 \textrm {W }}$

Gila 335347 N1111823W

$\begin{array}{ll}\text { Santa Cruz } & 312245 N 110510 \mathrm{BW} \\ \text { Cochise } & 315500 \mathrm{~N} 1091622 \mathrm{~W}\end{array}$

355602 N1090909W

Fort Defiance

Fort Huachuca

Fort Huachuca Las Guijas

1390 Paradise Valley

$335450 \mathrm{~N} 1112214 \mathrm{~W}$

San Jose

Kayler Butte

Cumero Canyon

Rust ler Park

Creatte

Knoll Lake

Dane Canyon

Neill Pass

Alma Mesa

Hackberry Mtn

Porcupine Ridge

Potato Wash North

Hay Lake

Winona

Teservoir

Fitzgerald Hill

Red Mesa

Dike Tank

Howard $\mathrm{Hill}$

Sheep Bas in Mtn

Bisbee

Bright Angel Point

right Angel Point

Winona

North

ingston $\mathrm{Hill}$ is

Buell Park 


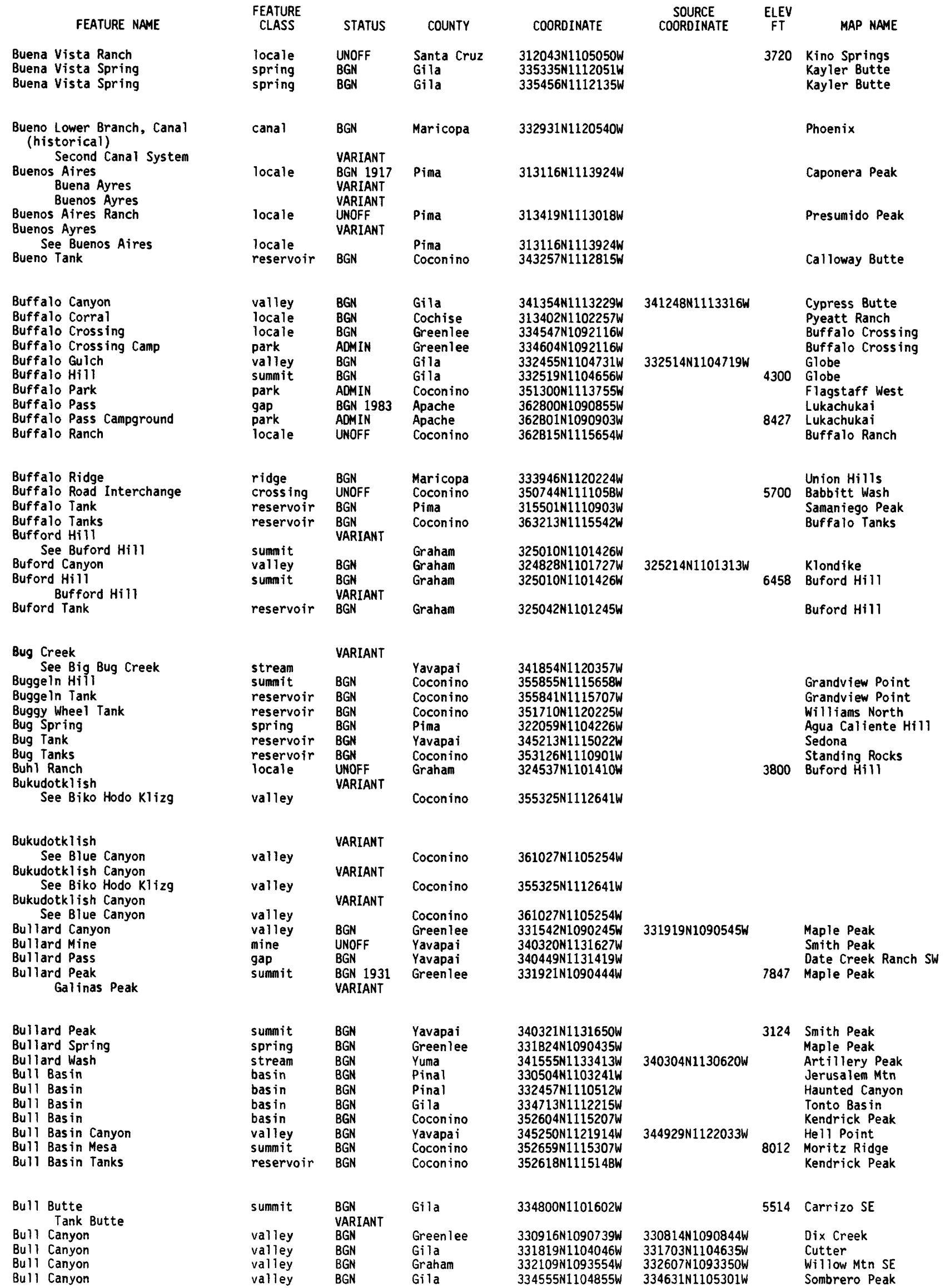


NATIONAL GAZETTEER--ARIZONA 1986 FEATURE NAME

8ull Canyon

Bull Canyon

Bull Canyon

Bull Canyon

Bull Canyon Spring

Bull Cienega

Bull Cienega Creek Bull Cieniga Creek

Bull Cienega Spring

Bull Cieniga Creek

See Bull Cienega Creek

Bull Creek

Bull Creek

Bull Creek

Bull Creek

Bull Creek Cienega

Bull Creek Tank

Bulldog Canyon

Bulldog Mesa

Bulldog Mine

Bulldog Mountains

See Goldfield Mountains

Bullidog Wash

Bulldozer Mine

Bullfight Tank

Bull Flat Canyon

Bullfrog (historical)

Bullfrog Canyon

Bullfrog Ridge

Bullfrog Spring

Bullhead City

Bullhead City Airport

Bul thead City Elementary School

Bullhead City Post office

Bullhead Rock

See Bulls Head Rock

Bull Hill

Bull Hole

Bull Hollow Bull Hollow Canyon

Bull Hollow Canyon

See Bull Hollow

Bullion Mine

Bullion Plaza School

Bull Mountain

Bull Mountain

Bull Mountain Tank

Bullock Canyon

Bullock Corrals Spring

Bullock Tank

Bul1 Pass

Bull Pasture

Bull Pasture

Bull Pasture

Bull Pasture Spring

Bu11 Pasture Tank Bull Spring

Bull Pasture Tank

Bull Pasture Tank

Bull Pasture Tank

Bull Pasture Tank

Bull Pasture Tank

Bull Pasture Tank

Bull Pasture Windmill

Bull Pen Ranch

Bull Point

Bull Point Wash

Bull Pond

Bull Pond

Bull Ranch

Bull Run Creek

\section{FEATURE}

valley

valley

valley

BGN Apache

BGN Navajo

BGN Mohave

BGN $\quad$ Yavapai

spring

flat

stream

spring

stream

stream

stream

stream

BGN

BGN

BGN

BGN 1964

VARIAINT

BGN
VARIANT

Maricopa

Apache

Navajo

Navajo

Navajo

BGN Greenlee

BGN

BGN

Apache
Navajo

stream

flat

reservoir

valley

summit

mine

BGN Yavapai

BGN Apache

BGN Maricopa

BGN Yavapai

UNOFF

VARIANT

summit

stream

mine

BGN

UNOFF

Pinal

Maricopa

Maricopa

Pima

reservoir

valley

summit

valley

ridge

spring

ppl

airport

school

building

BGN

Coconino

Gila

BGN 1917 Maricopa

BGN Gila

BGN

BGN

ADMIN

UNOFF

UNOFF

Gila

Gila

Mohave

Mohave

Mohave

Mohave

VARIANT

is land

summit

bend

valley

valley

mine

school

BGN Gohave

BGN $\quad$ Gavapa

BGN 1973 Navajo

VARIANT

VARIANT

Navajo

UNOFF Mohave

Mohave
Gila

summit

summit

valley

spring

reservoir

gap

flat

flat

valley

BGN
BGN
BGN
BGN
BGN
BGN
BGN
BGN
BGN
BGN

reservoir

reservoir

reservoir

reservoir

reservoir

reservoir

reservoir

locale

locale

summit

valley

lake

lake

locale
stream

Mohave

Coconin

Graham

$\begin{array}{ll}\text { UNOFF } & \text { Yavapai } \\ \text { BGN } & \text { Mohave } \\ \text { BGN } & \text { Mohave } \\ \text { BGN } & \text { Mohave } \\ \text { BGN } & \text { Mohave } \\ \text { UNOFF } & \text { Graham } \\ \text { BGN } & \text { Yavapa }\end{array}$

BGN Navajo

COORDINATE

$334732 \mathrm{~N} 1090955 \mathrm{~W}$ $340629 \mathrm{N1101306 \textrm {W }}$ 344510 N1133540 $350034 \mathrm{~N} 1131450 \mathrm{~W}$

$333236 \mathrm{~N} 1110522 \mathrm{~W}$

$335520 N 1093533 \mathrm{~W}$

$340117 \mathrm{~N} 1095408 \mathrm{~W}$

$340348 N 1095315 \mathrm{~W}$

340117 N1095408W

$332516 \mathrm{~N} 1091114 \mathrm{~W}$

$334034 \mathrm{~N} 1093847 \mathrm{~W}$

$335938 \mathrm{N1} 1095330 \mathrm{~W}$

344556 N1130838W $333953 \mathrm{~N} 1093824 \mathrm{~W}$ $335826 \mathrm{~N} 1095255 \mathrm{~W}$ $333253 N 1113419$

340117 N1115104W

$332743 \mathrm{~N} 1113036 \mathrm{~W}$

$333112 \mathrm{~N} 1113046 \mathrm{~W}$

$332513 \mathrm{~N} 1113327 \mathrm{~W}$

$315225 \mathrm{~N} 1104751 \mathrm{~W}$

$344926 \mathrm{~N} 1110919 \mathrm{~W}$

$341237 \mathrm{~N} 1104517 \mathrm{~W}$

$334000 \mathrm{~N} 1112700 \mathrm{~W}$

$341344 N 1113159 \mathrm{~W}$

$341215 \mathrm{~N} 1113209 \mathrm{~W}$

341311N1113200W

$350852 \mathrm{~N} 1143403 \mathrm{~W}$

$350952 \mathrm{~N} 1143352 \mathrm{~W}$

$350842 \mathrm{N1} 143354 \mathrm{~W}$

$350907 N 1143358 \mathrm{~W}$

351217 N1143422W

$332823 \mathrm{N1} 104759 \mathrm{~W}$

$343307 \mathrm{N1113404 \textrm {W }}$

$342318 \mathrm{N1100707W}$

$342318 N 1100707 \mathrm{~W}$

$352507 \mathrm{N1} 141058 \mathrm{~W}$

$332338 \mathrm{N1} 105214 \mathrm{~W}$

Gila 334752N1112243W

Mohave 351623N1140405W

Gila 334315N1110345W

Pima 322257N1103307W

Pima 322056N1103546W

Yavapai 350004N1122808W

Pima 320046N1124134W

Gila 333305N1102642W

$365622 \mathrm{~N} 1125057 \mathrm{~W}$

$320057 \mathrm{N1124128 \textrm {W }}$

$33322 \mathrm{BN} 1102716 \mathrm{~W}$

$335919 N 1095520 \mathrm{~W}$

$340207 \mathrm{~N} 1101321 \mathrm{~W}$

$350233 \mathrm{~N} 1130749 \mathrm{~W}$

$353226 \mathrm{~N} 1131956 \mathrm{~W}$

$353631 \mathrm{~N} 1121515 \mathrm{~W}$

$354422 \mathrm{~N} 1113021 \mathrm{~W}$

$324013 \mathrm{~N} 1101026 \mathrm{~W}$

$343226 \mathrm{~N} 1114137 \mathrm{~W}$

$361955 \mathrm{~N} 1131451 \mathrm{~W}$

$361638 \mathrm{~N} 1131443 \mathrm{~W}$

$363025 \mathrm{~N} 1133243 \mathrm{~W}$

$323126 \mathrm{~N} 1101225 \mathrm{~W}$

$342551 \mathrm{N1114626 \textrm {W }}$

\begin{tabular}{ccl}
$\begin{array}{c}\text { SOURCE } \\
\text { COORDINATE }\end{array}$ & ELEV & \multicolumn{1}{c}{ MAP NAME } \\
& FT & \\
$334848 N 1091043 \mathrm{~W}$ & & Alpine \\
$340845 N 1101459 \mathrm{~W}$ & & Long Tom Canyon \\
$345023 N 1132740 \mathrm{~W}$ & & Wikieup \\
$345716 \mathrm{~N} 1131614 \mathrm{~W}$ & & Anvil Rock Ranch
\end{tabular}

Two Bar Mtn

Mount Baldy

Alchesay Flat

Indian Pine

332656N1091436W Dutch Blue Creek

Odart Mtn

335809N1094827W Alchesay Flat

344817N1130528W Ash Fork

Odart Mtn

Alchesay Flat

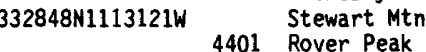

Apache Junction

332847N1113153W Apache Junction

Helvetia

Parallel Canyon

Mormon Flat Dam

Cypress Butte

Cypress Butte 
FEATURE NAME

Bull Run Spring

Bull Run Tank

Bull Run Trai

Bull Saddle

Bullshead

See Bulls Head Rock

Bulls Head Rock Bullhead Rock Bullshead

Bull Spring

See BuIl Pasture Tank

Bull Spring

Bu11 Spring

Bull Spring

Bull Spring

Bull Spring

Bull Spring

Bull Spring

Bull Spring

Bull Spring

Bull Spring

Bull Spring

Bull Spring Canyon

Bull Spring Mesa

Bull Springs

Bull Springs Mine

Bull Spring Tank

Bull Spring Wash

Bul1 Spring Well

Bull Tank

Bull Tank

Bull Tank

Bull Tank

Bull Tank

Bull Tank

Bul1 Tank

Bu11 Tank

Bull Tank

Bull Tank

Bull Tank

Bull Tank

Bull Tank

Bull Tank

Bull Tank

Bull Tank

Bull Tank

Bull Tank

Bull Tank

Bull Tank

Bull Tank Canyon

Bull Tank Mesa

Bull Water Spring

BuIl Well

Bulrush Canyon

Bulrush Point

Bulrush Wash

Bulrush Wash

Bumblebee

See Bumble Bee

Bumble Bee

Bumblebee

Bumble Bee Creek

Bumblebee Creek

Bumble Bee Creek

Antelope Creek

Bumblebee Creek

Bumblebee Wash

Bumblebee Creek

See Bumble Bee Creek

Bumble Bee Creek

See Bumble Bee

\section{FEATURE}

STATUS

$\begin{array}{llll}\text { spring } & \text { BGN } & \text { Yavapai } & 341023 N 1122249 \mathrm{~W} \\ \text { reservoir } & \text { BGN } & \text { Yavapai } & 342612 N 1114332 \mathrm{~W}\end{array}$

trail UNOFF Yavapai $341423 \mathrm{N1122013 \textrm {W }}$

gap

is land

is land

VARIANT

(n)

BGN

VARIANT

VARIANT

reservoir

BGN

spring

spring

BGN
BGN

spring

spring

spring

spring

spring

spring

spring

valley

\section{BGN}

BGN

BGN

BGN

BGN

BGN

BGN

BGN

BGN
BGN

summit

spring

mine

reservoir

stream

well

reservoir

reservoir

reservoir

reservoir

$\begin{array}{ll}\text { BGN } & \text { Gila } \\ \text { BGN } & \text { Graham }\end{array}$

UNOFF

BGN

UNOFF

BGN

BGN

BGN

reservoir

reservoir

reservoir

reservoir

reservoir

reservoir

reservoir

reservoir

reservoir

reservoir

$B G N$
$B G N$
$B G N$

BGN

BGN

BGN

BGN

BGN

reservoir

BGN

reservoir

reservoir

reservoir

reservoir

reservoir

valley

summit

spring

well

Greenlee

$330815 N 1090843 \mathrm{~W}$

Mohave

Mohave

$351217 N 1143422 \mathrm{~W}$

$351217 N 1143422 \mathrm{~W}$

Gila

Santa Cruz

Cochise 313058 N1095713W

Pima

Gila

Gila

Yavapai

Gila

Yavapai

Yavapai

Mohave

Mohave

Gila

Santa Cruz

Santa Cruz

Yavapai

Graham

Graham

Apache

Gila

Gila

Yavapai

Gila

Yavapai

Yavapai

Coconino

Coconino

Navajo

Yavapai

Coconino

Yavapai

Coconino

Coconino

Coconino

Coconino

Coconino

Gila

Gila

Yavapai

Yavapai

valley

cliff

stream

stream

ppl

$\mathrm{pp} 1$

stream

BGN

BGN

BGN

VARIANT

Mohave

Mohave

Mohave

Mohave

Yavapai

Yavapai

BGN 1972

VARIANT

VARIANT

stream

BGN 1972

VARIANT

VARIANT

VARIANT

VARIANT

stream

VARIANT

pp 1

Yavapai

Yavapai

341203 N1120908W

$353123 \mathrm{~N} 1120600 \mathrm{~W}$

355519 N1114540W

$341414 \mathrm{~N} 1110502 \mathrm{~W}$

$341922 \mathrm{~N} 1113423 \mathrm{~W}$

$364657 N 1123714 \mathrm{~W}$

$363554 \mathrm{~N} 1123839 \mathrm{~W}$

$364234 \mathrm{~N} 1124848 \mathrm{~W}$

$364657 \mathrm{N1123714 \textrm {W }}$

$341203 \mathrm{~N} 1120908 \mathrm{~W}$

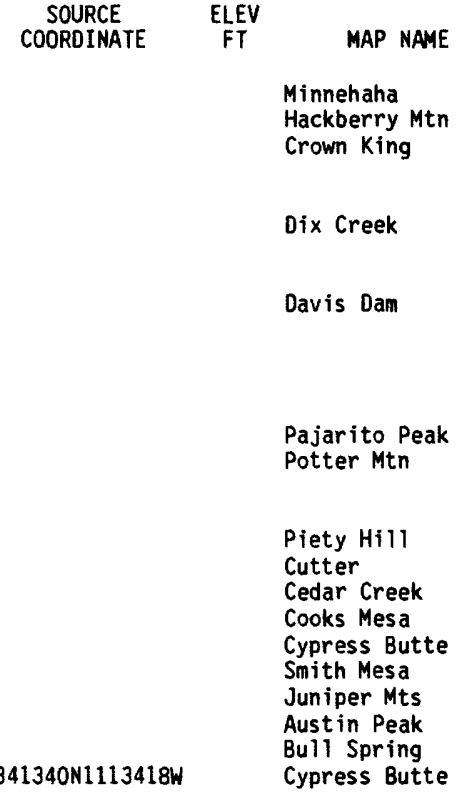

5536 Cypress Butte

Markham Creek

Mt Hopkins

Pajarito Peak

$343722 N 1131035 \mathrm{~W}$

5487 Point of Pines West

Harrison Canyon

West Poker Mtn

Windy $\mathrm{Hill}$

Round Top Mtn

Joes Hill

Promontory Butte

Cane Springs Mtn

Prescott Valley

Sheridan Mtn

Chevelon Butte

Chevelon Butte

Relic Point

Scratch Canyon

Hutch Mtn

King Canyon

Perkinsville

Tucker Mesa SW

Cataract Tank

Hobble Tank

Deer Tank

$341631 N 1105941 \mathrm{~W}$

Diamond Butte

5484 Cane Springs Mtn

Sheridan Mtn

King Canyon

$364236 \mathrm{~N} 1125001 \mathrm{~W}$

Clear Water Spring

Grama Spring

Sunshine Ridge

Clear Water Spring

364527 N1124659W

2573 Bumble Bee

$334512 N 1111412 W \quad 334406 N 1111812 W$

Greenback Creek 


\begin{tabular}{|c|c|c|c|c|c|c|c|}
\hline FEATURE NAME & $\begin{array}{l}\text { FEATURE } \\
\text { CLASS }\end{array}$ & STATUS & COUNTY & COORDINATE & $\begin{array}{l}\text { SOURCE } \\
\text { COORDINATE }\end{array}$ & $\begin{array}{c}\text { ELEV } \\
\text { FT }\end{array}$ & MAP NAME \\
\hline $\begin{array}{l}\text { Bumble Bee Interchange } \\
\text { Bumblebee Tank }\end{array}$ & $\begin{array}{l}\text { crossing } \\
\text { reservoir }\end{array}$ & $\begin{array}{l}\text { UNOFF } \\
\text { BGN }\end{array}$ & $\begin{array}{l}\text { Yavapai } \\
\text { Cochise }\end{array}$ & $\begin{array}{l}340811 N 1120844 \mathrm{~W} \\
315315 \mathrm{~N} 1092555 \mathrm{~W}\end{array}$ & & & $\begin{array}{l}\text { Bumble Bee } \\
\text { Fife Peak }\end{array}$ \\
\hline $\begin{array}{l}\text { Bumblebee Wash } \\
\quad \text { See Bumble Bee Creek } \\
\text { Bumpy Road Well } \\
\text { Bums Tank } \\
\text { Bumstead } \\
\text { Bumstead Railroad Station } \\
\text { Bunch Reservoir } \\
\text { Bunch Reservoir Dam } \\
\text { Bundy Ponds } \\
\text { Bundy Tank }\end{array}$ & $\begin{array}{l}\text { stream } \\
\text { well } \\
\text { reservoir } \\
\text { pp } 1 \\
\text { building } \\
\text { reservoir } \\
\text { dam } \\
\text { lake } \\
\text { reservoir }\end{array}$ & $\begin{array}{l}\text { VARIANT } \\
\text { UNOFF } \\
\text { BGN } \\
\text { BGN } \\
\text { UNOFF } \\
\text { BGN } \\
\text { UNOFF } \\
\text { BGN } \\
\text { BGN }\end{array}$ & $\begin{array}{l}\text { Yavapai } \\
\text { Coconino } \\
\text { Yavapai } \\
\text { Maricopa } \\
\text { Maricopa } \\
\text { Apache } \\
\text { Apache } \\
\text { Mohave } \\
\text { Mohave }\end{array}$ & $\begin{array}{l}341119 \mathrm{~N} 1121005 \mathrm{~W} \\
350354 \mathrm{~N} 1110655 \mathrm{~W} \\
344645 \mathrm{~N} 1114937 \mathrm{~W} \\
333424 \mathrm{~N} 1122122 \mathrm{~W} \\
333424 \mathrm{~N} 1122122 \mathrm{~W} \\
340233 \mathrm{~N} 1092644 \mathrm{~W} \\
340233 \mathrm{~N} 1092644 \mathrm{~W} \\
363837 \mathrm{~N} 1125808 \mathrm{~W} \\
362501 \mathrm{~N} 1131820 \mathrm{~W}\end{array}$ & & $\begin{array}{l}5565 \\
1120 \\
8256\end{array}$ & $\begin{array}{l}\text { Meteor Crater } \\
\text { Sedona } \\
\text { El Mirage } \\
\text { El Mirage } \\
\text { Greer } \\
\text { Greer } \\
\text { Wild Band Pockets } \\
\text { Jones Hill }\end{array}$ \\
\hline $\begin{array}{l}\text { Bunger Point } \\
\text { Bunger Ranch } \\
\text { Bunker Hill } \\
\text { Bunker Hill Mine } \\
\text { Bunker Hill Mine } \\
\text { Bunker Hill Spring } \\
\text { Bunker Mine } \\
\text { Bunker Peak } \\
\text { Bunkers Cemetery } \\
\text { Bunker Spring }\end{array}$ & $\begin{array}{l}\text { summit } \\
\text { locale } \\
\text { summit } \\
\text { mine } \\
\text { mine } \\
\text { spring } \\
\text { mine } \\
\text { summit } \\
\text { cemetery } \\
\text { spring }\end{array}$ & $\begin{array}{l}\text { BGN } \\
\text { UNOFF } \\
\text { BGN } \\
\text { UNOFF } \\
\text { UNOFF } \\
\text { BGN } \\
\text { UNOFF } \\
\text { BGN } \\
\text { UNOFF } \\
\text { BGN }\end{array}$ & $\begin{array}{l}\text { Navajo } \\
\text { Navajo } \\
\text { Coconino } \\
\text { Pinal } \\
\text { Yuna } \\
\text { Coconino } \\
\text { Yavapai } \\
\text { Maricopa } \\
\text { Greenlee } \\
\text { Yavapai }\end{array}$ & $\begin{array}{l}341821 \mathrm{~N} 1103649 \mathrm{~W} \\
341839 \mathrm{~N} 1103627 \mathrm{~W} \\
345912 \mathrm{~N} 1115501 \mathrm{~W} \\
324412 \mathrm{~N} 1102842 \mathrm{~W} \\
334554 \mathrm{~N} 1133222 \mathrm{~W} \\
345900 \mathrm{~N} 1115523 \mathrm{~W} \\
343644 \mathrm{~N} 1120234 \mathrm{~W} \\
334351 \mathrm{~N} 1122306 \mathrm{~W} \\
330336 \mathrm{~N} 1092021 \mathrm{~W} \\
343548 \mathrm{~N} 1120255 \mathrm{~W}\end{array}$ & & $\begin{array}{l}7444 \\
6757\end{array}$ & $\begin{array}{l}\text { Outlaw Draw } \\
\text { Outlaw Draw } \\
\text { Loy Butte } \\
\text { Rhodes Peak } \\
\text { Salone } \\
\text { Loy Butte } \\
\text { Cherry } \\
\text { McMicken Dan } \\
\text { Clifton } \\
\text { Cherry }\end{array}$ \\
\hline $\begin{array}{l}\text { Bunker Tank } \\
\text { Bunker Tank } \\
\text { Bunkerville Mountains } \\
\text { See Virgin Mountains } \\
\text { Bunningwater } \\
\text { See French Creek } \\
\text { Bunny Tank } \\
\text { See Sonny Tank } \\
\text { Bunny Tank } \\
\text { Bunyan Peak }\end{array}$ & $\begin{array}{l}\text { reservoir } \\
\text { reservoir } \\
\text { range } \\
\text { strean } \\
\text { reservoir } \\
\text { reservoir } \\
\text { summit }\end{array}$ & $\begin{array}{l}\text { BGN } \\
\text { BGN } \\
\text { VARIANT } \\
\text { VARIANT } \\
\text { VARIANT } \\
\text { BGN } \\
\text { BGN }\end{array}$ & $\begin{array}{l}\text { Maricopa } \\
\text { Coconino } \\
\text { Mohave } \\
\text { Yuma } \\
\text { Santa Cruz } \\
\text { Navajo } \\
\text { Maricopa }\end{array}$ & $\begin{array}{l}334239 \mathrm{~N} 1122240 \mathrm{~W} \\
352140 \mathrm{~N} 1122649 \mathrm{~W} \\
364905 \mathrm{~N} 1135032 \mathrm{~W} \\
333655 \mathrm{~N} 1141410 \mathrm{~W} \\
\\
312035 \mathrm{~N} 1110445 \mathrm{~W} \\
340032 \mathrm{~N} 1104234 \mathrm{~W} \\
330651 \mathrm{~N} 1125752 \mathrm{~W}\end{array}$ & & 2410 & $\begin{array}{l}\text { Oak Creek Ranch } \\
\text { Citrus Valley West }\end{array}$ \\
\hline $\begin{array}{l}\text { Bunyan Substation } \\
\text { Burch } \\
\text { Burchan Plaza Shopping Center } \\
\text { Burch Peak } \\
\text { Burdette Dan } \\
\text { Bureau of Indian Affairs } \\
\text { Coolidge Office } \\
\text { Bureau of Indian Affairs } \\
\text { Ranger Station } \\
\text { Burger Well }\end{array}$ & $\begin{array}{l}\text { locale } \\
\text { locale } \\
\text { locale } \\
\text { summit } \\
\text { dam } \\
\text { building } \\
\text { locale } \\
\text { locale }\end{array}$ & $\begin{array}{l}\text { UNOFF } \\
\text { BGN } \\
\text { UNOFF } \\
\text { BGN } \\
\text { UNOFF } \\
\text { UNOFF } \\
\text { UNOFF } \\
\text { BGN }\end{array}$ & $\begin{array}{l}\text { Maricopa } \\
\text { Gila } \\
\text { Pima } \\
\text { Mohave } \\
\text { Grahan } \\
\text { Pinal } \\
\text { Navajo } \\
\text { Maricopa }\end{array}$ & $\begin{array}{l}330131 \mathrm{~N} 1130210 \mathrm{~W} \\
332638 \mathrm{~N} 1104953 \mathrm{~W} \\
321345 \mathrm{~N} 1105228 \mathrm{~W} \\
345004 \mathrm{~N} 1135104 \mathrm{~W} \\
331142 \mathrm{~N} 1095400 \mathrm{~W} \\
325834 \mathrm{~N} 1113104 \mathrm{~W} \\
340243 \mathrm{~N} 1102904 \mathrm{~W} \\
332530 \mathrm{~N} 1130705 \mathrm{~W}\end{array}$ & & 2550 & $\begin{array}{l}\text { Dendora Valley } \\
\text { Globe } \\
\text { Tucson East } \\
\text { Diamond Joe Peak } \\
\text { Gila Peak } \\
\text { Coolidge } \\
\text { Cibecue } \\
\text { Cortez Peak }\end{array}$ \\
\hline $\begin{array}{l}\text { Burgess Peak } \\
\text { Burgundy Hill (subdivision) } \\
\quad \text { Montana del Sur } \\
\text { Burke Mountain } \\
\text { Burke Ranch } \\
\text { Burke Spring } \\
\text { Burkes Ranch } \\
\text { See Alpha } \\
\text { Burkes Ranch } \\
\text { See San Bernardino }\end{array}$ & $\begin{array}{l}\text { summit } \\
\text { ppl } \\
\text { summit } \\
\text { locale } \\
\text { spring } \\
\text { locale } \\
\text { locale }\end{array}$ & $\begin{array}{l}\text { BGN } \\
\text { BGN } \\
\text { VARIANT } \\
\text { BGN } \\
\text { UNOFF } \\
\text { BGN } \\
\text { VARIANT } \\
\text { VARIANT }\end{array}$ & $\begin{array}{l}\text { Pinal } \\
\text { Maricopa } \\
\text { Navajo } \\
\text { Greenlee } \\
\text { Yavapai } \\
\text { Maricopa } \\
\text { Maricopa }\end{array}$ & $\begin{array}{l}325403 \mathrm{~N} 1114617 \mathrm{~W} \\
332148 \mathrm{~N} 1115835 \mathrm{~W} \\
341136 \mathrm{~N} 1101916 \mathrm{~W} \\
333855 \mathrm{~N} 1090525 \mathrm{~W} \\
344206 \mathrm{~N} 1124839 \mathrm{~W} \\
325725 \mathrm{~N} 1131820 \mathrm{~W} \\
325906 \mathrm{~N} 1131925 \mathrm{~W}\end{array}$ & & $\begin{array}{l}1315 \\
7110 \\
5800\end{array}$ & $\begin{array}{l}\text { Casa Grande West } \\
\text { Guadalupe } \\
\text { Limestone Canyon N } \\
\text { Maness Peak } \\
\text { Smith Mesa }\end{array}$ \\
\hline $\begin{array}{l}\text { Burkes Station } \\
\text { See Alpha } \\
\text { Burkes Station } \\
\text { See San Bernardino } \\
\text { Burk Spring } \\
\text { Burk Street School } \\
\text { Burleson Canyon } \\
\text { Burleson Park } \\
\text { Burleson Well } \\
\text { Burmister Tank }\end{array}$ & $\begin{array}{l}\text { locale } \\
\text { locale } \\
\text { spring } \\
\text { school } \\
\text { arroyo } \\
\text { flat } \\
\text { well } \\
\text { reservoir }\end{array}$ & $\begin{array}{l}\text { VARIANT } \\
\text { VARIANT } \\
\text { BGN } \\
\text { UNOFF } \\
\text { BGN } \\
\text { BGN } \\
\text { UNOFF } \\
\text { BGN }\end{array}$ & $\begin{array}{l}\text { Maricopa } \\
\text { Maricopa } \\
\text { Apache } \\
\text { Maricopa } \\
\text { Greenlee } \\
\text { Maricopa } \\
\text { Pima } \\
\text { Yavapai }\end{array}$ & $\begin{array}{l}325725 \mathrm{~N} 1131820 \mathrm{~W} \\
325906 \mathrm{~N} 1131925 \mathrm{~W} \\
335719 \mathrm{~N} 1092029 \mathrm{~W} \\
332210 \mathrm{~N} 1114655 \mathrm{~W} \\
324319 \mathrm{~N} 1090508 \mathrm{~W} \\
325720 \mathrm{~N} 1124303 \mathrm{~W} \\
32272 \mathrm{BN} 1103530 \mathrm{~W} \\
341947 \mathrm{~N} 1115838 \mathrm{~W}\end{array}$ & $324442 \mathrm{~N} 1090355 \mathrm{~W}$ & & $\begin{array}{l}\text { Rudd Knoll } \\
\text { Chandler } \\
\text { Duncan } \\
\text { Gila Bend } \\
\text { Buehman Canyon } \\
\text { Dugas }\end{array}$ \\
\hline $\begin{array}{l}\text { Burnett Well } \\
\text { Burney Mines } \\
\text { Burning Rock Well } \\
\text { Burns } \\
\text { Burns ide Well } \\
\text { Burns Park } \\
\text { Burn Spring } \\
\text { Burns Railroad Station } \\
\text { Burns Ranch }\end{array}$ & $\begin{array}{l}\text { well } \\
\text { mine } \\
\text { well } \\
\text { locale } \\
\text { well } \\
\text { park } \\
\text { spring } \\
\text { building } \\
\text { locale }\end{array}$ & $\begin{array}{l}\text { UNOFF } \\
\text { UNOFF } \\
\text { UNOFF } \\
\text { BGN } \\
\text { UNOFF } \\
\text { ADMIN } \\
\text { BGN } \\
\text { UNOFF } \\
\text { UNOFF }\end{array}$ & $\begin{array}{l}\text { Pinal } \\
\text { Pinal } \\
\text { Navajo } \\
\text { Pinal } \\
\text { Apache } \\
\text { Pima } \\
\text { Mohave } \\
\text { Pinal } \\
\text { Pinal }\end{array}$ & $\begin{array}{l}324118 \mathrm{~N} 1112050 \mathrm{~W} \\
323307 \mathrm{~N} 1104754 \mathrm{~W} \\
362225 \mathrm{~N} 1101805 \mathrm{~W} \\
330046 \mathrm{~N} 1115001 \mathrm{~W} \\
352852 \mathrm{~N} 1091421 \mathrm{~W} \\
321329 \mathrm{~N} 1105327 \mathrm{~W} \\
350841 \mathrm{~N} 1135154 \mathrm{~W} \\
330046 \mathrm{~N} 1105001 \mathrm{~W} \\
332206 \mathrm{~N} 1112221 \mathrm{~W}\end{array}$ & & $71 B 4$ & $\begin{array}{l}\text { Picacho Pass } \\
\text { Oracle } \\
\text { Red Slide Peak } \\
\text { Hayden } \\
\text { Uranium Spring } \\
\text { Tucson } \\
\text { Hualapai Spring } \\
\text { Hayden } \\
\text { Florence Junction }\end{array}$ \\
\hline
\end{tabular}




\section{FEATURE NAME}

Burns Ranch

Burns Spring

Burns Spring Canyon

Burns Well

Burns Well

Burn Tank

Burn Tank

Burn Tank

Burn Tank

Burn Tank

Burnt Bas in Tank

Burnt Canyon

Burnt Canyon

Burnt Spring Canyon

Burnt Springs Canyon

Burnt Canyon

Burnt Canyon Point

Burnt Canyon Point

Burnt Canyon Spring

Burnt Canyon Tank

Burnt Corn

Burnt Corn Spring

Not-tahn-de-lit

Nottahndelit Spring

Burnt Corn Valley

Burnt Corn Wash

See Polacca Wash

Burnt Corn Wash

First Mesa Wash

Polacca Creek

Polacca Wash

Tah-chito Creek

Burnt Corn Wash

See Aspen Wash

Burnt Corral Campground

Burnt Corral Canyon

Burnt Corral Creek See Willow Creek

Burnt Corral Creek

Burnt Corral Creek

Burnt Corral Draw

Burnt Corral Point

Burnt Corral Ridge

Burnt Corral Rin

Burnt Corral Spring

Burnt Corral Spring

Burnt Ground Spring

Burnt Hole Canyon

Burnt Hole Spring Number One

Burnt Hole Spring Number Two

Burnt Knoll

Burnt Mill Ranch

Gold Bas in

Burnt Mill Spring

Burnt Mountain

Turt leback Mountain

Burnt Mountain

Burnt Piñon Wash

Burnt Place Valley

Burnt Point

Burnt Spring

Burnt Spring Canyon

See Burnt Canyon

Burnt Springs Canyon

See Burnt Canyon

Burnt Stump Mesa

Burnt Stump Mesa Tank

Burnt Tank

Burnt Tank

Burnt Trees Wash

Burnt Trough Spring

\section{FEATURE
CLASS}

STATUS COUNTY

locale

UNOFF

Mohave

COORDINATE

351857 N1142453W

spring BGN Mohave 351B52N1142451W

valley BGN Mohave 351946N1142701W

well

well

reservoir

reservoir

reservoir

reservoir

reservoir

UNOFF Apache

UNOFF Mohave

Pinal

Gila

Coconino

Coconino

Coconino

Yavapai

valley

valley

$B G N$

Yavapai

Mohave

VARIANT

valley

cliff

summit

spring

reservoir.

cliff

spring

valley

stream

stream

VARIANT

BGN Mohave

BGN

BGN

BGN
BGN

BGN

BGN

Mohave

Mohave

Mohave

Gila

Navajo

BGN 1969 Navajo

VARIANT

VARIANT

BGN

VARIANT

BGN 196B

VARIANT

VARIANT

VARIANT
VARIANT

VARIANT

Navajo

Coconino

Navajo

valley

VARIANT

park

valley

stream

stream

stream

valley

cliff

ridge

ridge

spring

spring

spring

valley

reservoir

reservoir

sumpit

locale

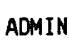

Apache

BGN Maricopa

VARIANT

Apache

BGN Apache

BGN 1965 Maricopa

BGN Greenlee

BGN

Coconino

BGN Coconino

BGN Coconino

BGN Apache

Mohave

Yavapai

Yavapai

Yavapai

Yavapai

BGN Apache

UNOFF Mohave

VARIANT

spring

summit

summit

valley

valley

cliff

spring

valley

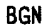

BGN 1963

BGN
BGN
$B G N$

BGN

BGN

BGN
VARIANT

Mohave

VARIANT

valley

summit

reservoir

reservoir

reservoir

valley

spring

$345241 \mathrm{N1} 1090803 \mathrm{~W}$

$351920 \mathrm{~N} 1142416 \mathrm{~W}$

$341328 \mathrm{~N} 1104935 \mathrm{~W}$

$345320 \mathrm{~N} 1112 \mathrm{~B} 4 \mathrm{OW}$

$345911 \mathrm{~N} 1115112 \mathrm{~W}$

$350635 \mathrm{~N} 1120713 \mathrm{~W}$

$344000 \mathrm{~N} 1113558 \mathrm{~W}$

$343917 \mathrm{~N} 1120653 \mathrm{~W}$

355811N1134459W

$364641 \mathrm{N1123957 \textrm {W }}$

$364353 \mathrm{~N} 1123917 \mathrm{~W}$

$360412 \mathrm{~N} 1134120 \mathrm{~W}$

$360412 \mathrm{~N} 1133943 \mathrm{~W}$

$333929 N 1105221 \mathrm{~W}$

$360738 \mathrm{~N} 1100652 \mathrm{~W}$

$360758 N 1100714 W$

$360001 N 1100819 W$

$352133 \mathrm{~N} 1105028 \mathrm{~W}$

$35590 \mathrm{BN} 1100835 \mathrm{~W}$

$361400 N 1095345 \mathrm{~W}$

$333735 \mathrm{~N} 1111215 \mathrm{~W}$

$362947 N 1122458 \mathrm{~W}$

$33340 \mathrm{BN} 1095249 \mathrm{~W}$

$333526 \mathrm{~N} 1095018 \mathrm{~W}$

$333725 \mathrm{~N} 1111210 \mathrm{~W}$

$333105 \mathrm{~N} 1091922 \mathrm{~W}$

$362908 \mathrm{N11} 22424 \mathrm{~W}$

$362918 \mathrm{~N} 1121943 \mathrm{~W}$

$362943 \mathrm{~N} 1122121 \mathrm{~W}$

$333454 \mathrm{~N} 1094440 \mathrm{~W}$

$365719 \mathrm{~N} 1124630 \mathrm{~W}$

$340935 \mathrm{~N} 1121527 \mathrm{~W}$

$340311 \mathrm{N1115656 \textrm {W }}$

$340342 N 1115803 \mathrm{~W}$

$340341 \mathrm{~N} 1115814 \mathrm{~W}$

$341628 \mathrm{~N} 1093840 \mathrm{~W}$

$354910 \mathrm{~N} 1140858 \mathrm{~W}$

Apache

Maricopa

Apache

Apache

Gila

Yavapai

$340820 \mathrm{N1093500 \textrm {W }}$

$333300 \mathrm{N11} 30440 \mathrm{~W}$

$335108 \mathrm{~N} 1093455 \mathrm{~W}$

$354111 \mathrm{~N} 1092608 \mathrm{~W}$

362718 N1101233W

342431 N1111210W

$342317 \mathrm{~N} 1114224 \mathrm{~W}$

355811 N1134459W

$355811 \mathrm{N1134459W}$

$330835 \mathrm{~N} 1090617 \mathrm{~W}$

$344023 \mathrm{NI} 120848 \mathrm{~W}$

$350625 \mathrm{~N} 1114905 \mathrm{~W}$

364154 N1101104W

Coconino

Navajo

Yavapai

$340632 \mathrm{~N} 1122939 \mathrm{~W}$
$323300 \mathrm{~N} 1104620 \mathrm{~W}$

361159N1100418W

$361616 N 10958840$

$344149 N 1120813 W$

364351N1124119W

Findlay Tank

6102 Tincanebitts Point

Tincanebitts Point

Dagger Peak

6855 Burnt Corn Spring

Burnt Corn Spring

Pinon

Echo Canyon

340339 N1115907W

$333741 N 1094136 \mathrm{~W}$

$333742 \mathrm{~N} 1110925 \mathrm{~W}$

$333116 \mathrm{~N} 1091830 \mathrm{~W}$

$354335 N 1092025 \mathrm{~W}$

$362425 N 1101142 \mathrm{~W}$

$330829 N 1090615 \mathrm{~W}$ 
NATIONAL GAZETTEER--ARIZONA 1986

\section{FEATURE NAME}

Burnt Wash

Burnt Wash Number One Spring

Burnt Wash Spring

Burnt Wash Spring

Burntwater Trading Post

Burntwater Wash

Burntwater Well

Burnt We 11

Burnt Well Wells

Burnt Wells

See Burnt Well

Burris Park

Burro, Mount

Burro Butte

Burro and Cottonwood Well

Burro Bas in

Burro Bas in

Burro Bas in

Burro Butte

See Burro, Mount

Burro Canyon

Burro Canyon

Burro Canyon

Burro Canyon

Burro Canyon

Burro Canyon

Burro Canyon

Burro Canyon Wash

Burro Cliffs

Burro Creek

Burro Creek

Burro Creek Campground

Burro Creek Spring

Burro Creek Tank

Burro Flaco Tank

Burro Flats

Burro Gap

Burro Gap

Burro John

Burro Mesa

Burro Mesa

Burro Mesa Dam

Burro Mesa Tank

Burro Mine

Burro Mine

Burro Mountain

Burro Mountain

Burro Mountain

Burro Peak

Burro Point

Burro Pond

See Vopolo Havoka

Burro Pond Village See Vopolo Havoka

Burro Pond Villages

See Vopolo Havoka

Burro Saddle

Burro Spring

Burro Spring

Burro Spring

Burro Spring

Burro Spring

Burro Spring

Burro Spring

Burro Spring

Burro Spring

Burro Spring

Burro Spring

Burro Spring

Burro Spring
FEATURE

CLASS

STATUS

COUNTY

Yavapai

spring

$B G N$

Yavapai

$\begin{array}{ll}\text { spring } & \text { BGN } \\ \text { spring } & \text { BGN } \\ \text { locale } & \text { BGN } \\ \text { valley } & \text { BGN } \\ \text { well } & \text { UNOFF } \\ \text { well } & \text { UNOFF } \\ & \text { VARIAN } \\ \text { well } & \text { UNOFF } \\ & \text { VARIAN }\end{array}$

Yavapai

Yavapai

Apache

Apache

Apache

Maricopa

Yuma

Maricopa

COORDINATE

$343722 \mathrm{~N} 1124410 \mathrm{~W}$

343758 N1124402W

$343758 \mathrm{~N} 1124402 \mathrm{~W}$

$351844 \mathrm{~N} 1091831 \mathrm{~W}$

$351437 N 1091659 \mathrm{~W}$

$351854 N 1091829 \mathrm{~W}$

$333155 N 1130851 \mathrm{~W}$

340517 N1132629W

$333155 \mathrm{~N} 1130851 \mathrm{~W}$

park

park summit

ADMIN Pinal

BGN 1925 Coconino

VARIANT

well

bas in

bas in

bas in

summit

valley

UNOFF

BGN

BGN Pina?

VARIANT

Coconino

BGN Santa Cruz

valley

valley

valley

valley

valley

valley

strean

cliff

stream

stream

BGN Yuma 332455N1140133W

BGN Mohave 343623N1140856W

BGN Coconino

BGN 1910 Coconino

BGN Mohave

BGN Coconino

BGN Coconino

Mohave

Mima

Mohave

park

spring

reservoir

reservoir

flat

gap

gap

locale

summit

summit

dam

reservoir

mine

mine

mine

summit
summit

summit

summit

cliff

locale

ADMIN Mohave 343217N1132657W

BGN Apache 335542N1092638W

BGN Yavapai 345102N1130521W

$325950 \mathrm{~N} 1111008 \mathrm{~W}$

Yavapai $\quad 335557 \mathrm{N1122331 \textrm {W }}$

$\begin{array}{ll}\text { Cochise } & 315143 \mathrm{~N} 1102558 \mathrm{~W} \\ \text { Pima } & 322414 \mathrm{~N} 1124133 \mathrm{~W}\end{array}$

Yavapai

331116N1091107W

$344847 N 1131238 \mathrm{~W}$

$344916 \mathrm{~N} 1131256 \mathrm{~W}$

$344916 \mathrm{~N} 1131256 \mathrm{~W}$

$313632 \mathrm{~N} 1105117 \mathrm{~W}$

$343333 \mathrm{~N} 1132938 \mathrm{~W}$

$315210 \mathrm{~N} 1115220 \mathrm{~W}$

$335503 \mathrm{~N} 109283 \mathrm{OW}$

$343124 \mathrm{~N} 1130029 \mathrm{~W}$

$343408 \mathrm{~N} 1133322 \mathrm{~W}$

$360450 \mathrm{~N} 1144255 \mathrm{~W}$

$314533 \mathrm{~N} 1115525 \mathrm{~W}$

locale

locale

gap

spring

spring

spring

spring

spring

spring

spring

spring

spring

spring

spring

spring

spring

SOURCE
COORDIMATE

MAP NAME

\begin{tabular}{|c|c|c|}
\hline $344044 N 1124343 W$ & & $\begin{array}{l}\text { Skull valley } \\
\text { Mount Josh }\end{array}$ \\
\hline $352050 \mathrm{~N} 1091919 \mathrm{~W}$ & 6456 & $\begin{array}{l}\text { Mt Josh } \\
\text { Mt Josh } \\
\text { Burntwater Wash } \\
\text { Sanders } \\
\text { Burntwater Wash } \\
\text { Big Horn Peak }\end{array}$ \\
\hline & & E C P Peak \\
\hline
\end{tabular}

Casa Grande East

5684 Topocoba Hilltop

Crossman Peak

Agua Caliente $\mathrm{Hill}$

Heavers Needle

McCauley Sinks

312716N1105056W Rio Rico

$332238 \mathrm{~N} 1140202 \mathrm{~W}$

$343306 \mathrm{~N} 1141051 \mathrm{~W}$

$354545 \mathrm{N1114103W}$

$361605 \mathrm{~N} 1122111 \mathrm{~W}$

$361552 \mathrm{N1130151W}$

364753N1120810W

$355337 \mathrm{N1113633 \textrm {W }}$

$322309 \mathrm{~N} 1103958 \mathrm{~W}$

$345646 \mathrm{~N} 1130037 \mathrm{~W}$

Livingston $\mathrm{Hills}$

Crossman Peak

Willows Camp

Havasupai Point

Mt Trumbull SE

House Rock Spring SE

Cameron South

Elephant Mtn

Buehman Canyon

Greenwood Peak

1960 Kaiser Spring

Big Lake North Scratch Canyon Ninetysix Hills NW

Garfias Mtn

Apache Peak

Burro Gap

Crown King

5169 Dix Creek

4705 Burro Mesa

Burro Mesa

Burro Mesa

Patagonia

Kaiser Spring

3049 Topaw

9680 Big Lake North

3578 Big Shipp Mtn

2708 Greenwood Peak

Hoover Dam

\author{
Lone Star Mtn \\ Portal Peak \\ Apache Peak \\ Quitobaquito Springs \\ Hot Tamale Peak \\ Haunted Canyon \\ Baldy Mtn \\ Garfias Mtn \\ Copperopol is \\ Arrastra Mtn SE \\ Elephant Mtn \\ Sheridan Mtn \\ Kinnikinick Lake \\ Burns Spring
}




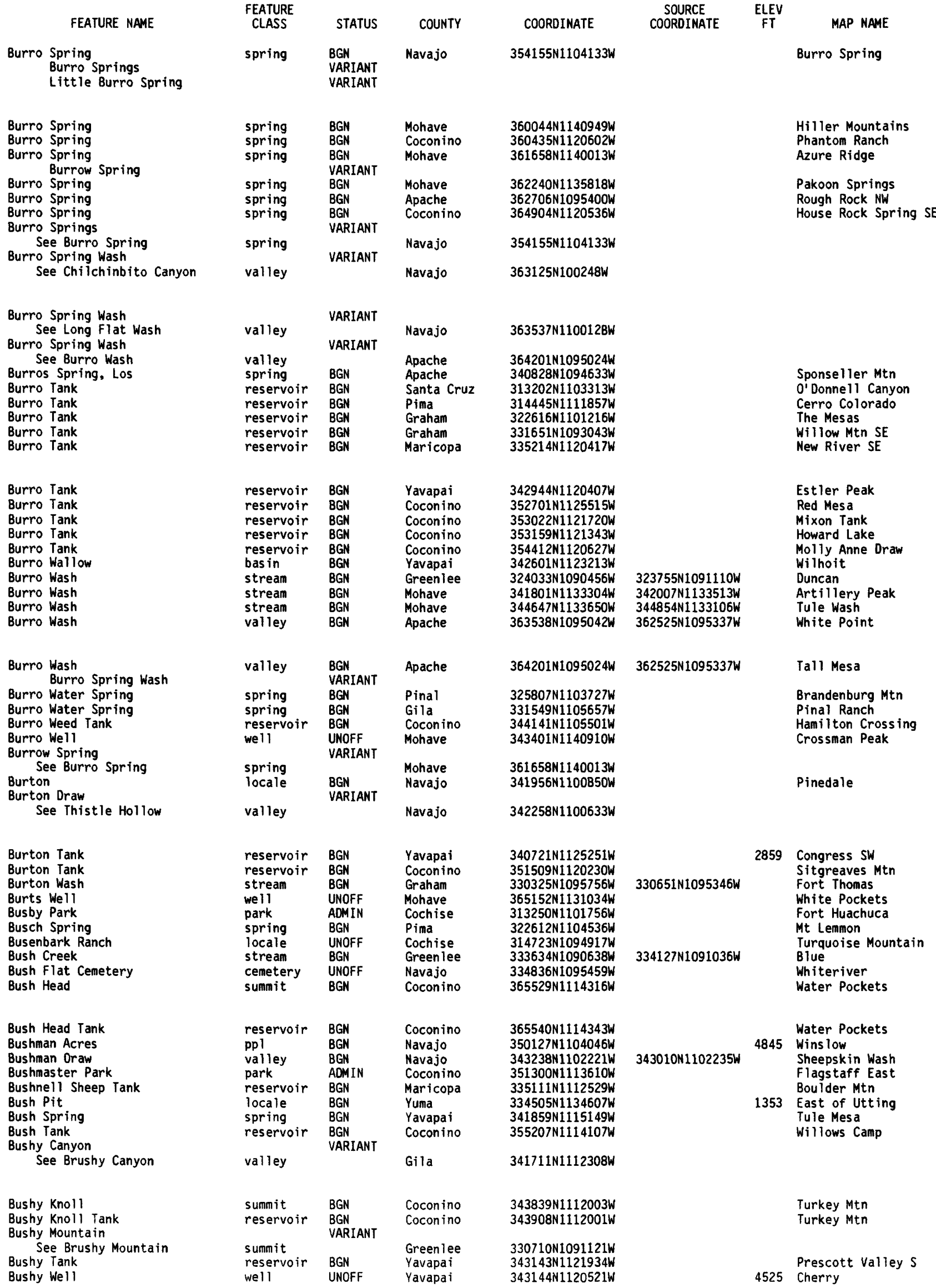


NATIONAL GAZETTEER--ARIZONA 1986 FEATURE NAME

Buss Ranch

Buss Tank

Buss Tank

Buster Brown Tank

Buster Mine

Buster Mountain

Buster Spring

Busterville Mine

Bustoz School

Butcher Camp

Butcher Corral Point

Butcher Creek

Butcher Jones Picnic Area

Butcherknife Canyon

Butcher Knife Canyon

Butcherknife Hill

Butcherknife Tank

Butcher Windmill

Butch Nichols Tank

Butch Tank

Butler Avenue Interchange

Butler Canyon

Butler Mountain

But ler Mountains

Butler Pass

Butler Point

Butler Spring Mikes Spring

Butler Valley Cactus Plain Cunningham Valley

Butler Valley Dam

But ler Wash

Butler Well

Clara Well

Butta Tank

Butte, The

Butte City

See Tempe

Butte Creek

Butte Creek

Butte Creek

But te Mine

But te Peak

Butterball Tank

Butterfield Park

Butterfield Pass

Butterfield Stage Route

(historical)

Butterfield Trail Campsite

Butterfly Butte

Butterfly Cienega

Butterfly Cienega

Butterfly Creek

Butterfly Mountain

Butterfly Peak

Butterfly Peak Natural Area

Butterfly Spring

Butternut Mine

Butternut Spring

Buttes, The

Buttes Spring

Buttes Spring

Buttes Spring

Buttes Well

Butte Tank

Butte Tank

Butte Tank

Butte Tank

Butte Tank

Butte Tank
FEATURE

CLASS

locale

reservoir

reservoir $B G$

mine

summit

spring

mine

school

locale

cliff

park

valley

valle

summit

reservoir

locale

reservoir

reservoir $B G$

crossing UNOFF

valley

summit

UNOFF

BGN

BGN
UNOFF

UNOFF

BGN

BGN

BGN

ADMIN

$B G N$

BGN
$B G N$
$B G$
$B G$
$B G$
$B G$
UN
$B G$
$B G$
$B G$

gap

summit

spring

valley

(am

stream

well

BGN
BGN
BGN
BGN
BGN
UNOFF
BGN
BGN
BGN

Coconino

Coconino

Mohave

Yavapai

Coconino

Coconino

Apache

Apache

Yuma

BGK Vuma

BGN Navajo

BARIANT Yavapai

BGN

VARIANT

VARIANT

UNOFF

UNOFF

BGN

VARIANT

Yuma

La Paz

Graham

Yuma

reservoir

summit

BGN

Gila

t

VARIANT

stream

stream

stream

mine

summit

reservoir

BGN

BGN

BGN

UNOFF

BGN

park ADMIN

gap

trail

UNOFF

park

summit

flat

swamp

stream

summit

summit

park

spring

mine

spring

summit

spring

spring

spring

well

ADMIN Maricopa

BGN Apache

BGN

BGN

BGN

BGN

Greenlee

Apache

Apache

Maricopa

\section{BGN Pima}

ADMIN Pima

BGN Yavapai

UNOFF Yavapa

BGN

BGN

BGN

BGN

BGN

UNOFF

Yavapai

Gila

Yavapai

Yavapa

Yavapai

Gila

reservoir

reservoir

reservoir

reservoir

reservoir

reservoir

BGN
$B G N$
$B G N$
$B G N$
$B G N$
$B G N$

COORDINATE

$351801 N 1121823 W$

$345103 \mathrm{~N} 1111755 \mathrm{~W}$

$351803 \mathrm{~N} 1121821 \mathrm{~W}$

$352611 N 1124045 \mathrm{~W}$

341527 N1122210W

$322415 N 1105345 \mathrm{~W}$

$322426 \mathrm{~N} 1105321 \mathrm{~W}$

321941 N1111052W

$332303 \mathrm{~N} 1115345 \mathrm{~W}$

$354451 \mathrm{~N} 1141503 \mathrm{~W}$

$343830 \mathrm{~N} 1131141 \mathrm{~W}$

$341813 \mathrm{~N} 1112027 \mathrm{~W}$

$333435 \mathrm{~N} 1113047 \mathrm{~W}$

$331153 \mathrm{~N} 1092935 \mathrm{~W}$

$350838 \mathrm{~N} 1123747 \mathrm{~W}$

$353234 \mathrm{~N} 1115814 \mathrm{~W}$

$353212 \mathrm{~N} 1115702 \mathrm{~W}$

$354420 \mathrm{~N} 1141508 \mathrm{~W}$

$350443 \mathrm{~N} 1131919 \mathrm{~W}$

344758 N1112942W

340058 N1092709W

$341050 \mathrm{~N} 1094228 \mathrm{~W}$

$322318 N 1141448 \mathrm{~W}$

$340300 \mathrm{~N} 1134900 \mathrm{~W}$

$341926 \mathrm{~N} 110184 \mathrm{BW}$

$341539 \mathrm{N1} 122600 \mathrm{~W}$

$335604 \mathrm{~N} 1134832 \mathrm{~W}$

$335630 \mathrm{~N} 1134954 \mathrm{~W}$

$325335 \mathrm{~N} 1094703 \mathrm{~W}$

$340122 \mathrm{~N} 1134402 \mathrm{~W}$

$325824 N 1094353$

$332527 \mathrm{~N} 1104104 \mathrm{~W}$

$330243 \mathrm{~N} 1103059 \mathrm{~W}$

$332453 \mathrm{~N} 1115431 \mathrm{~W}$

$334627 \mathrm{N1} 104035 \mathrm{~W}$

343249 N1122825W

$343708 \mathrm{~N} 1131303 \mathrm{~W}$

$331522 \mathrm{~N} 1125640 \mathrm{~W}$

$335345 N 1115135 \mathrm{~W}$

$335806 \mathrm{~N} 1101824 \mathrm{~W}$

$324036 \mathrm{~N} 1140807 \mathrm{~W}$

$330249 \mathrm{~N} 1122805 \mathrm{~W}$

$330005 \mathrm{~N} 1123558 \mathrm{~W}$

$330215 \mathrm{~N} 1122924 \mathrm{~W}$

353739 N1090558W

$333701 \mathrm{~N} 1092009 \mathrm{~W}$

$334650 \mathrm{~N} 1093457 \mathrm{~W}$

$334628 \mathrm{~N} 1093606 \mathrm{~W}$

$331345 \mathrm{~N} 1121303 \mathrm{~W}$

$334924 N 1093240 \mathrm{~W}$

$322553 \mathrm{~N} 1104348 \mathrm{~W}$

$322622 \mathrm{~N} 1104323 \mathrm{~W}$

$344225 \mathrm{N11} 20818 \mathrm{~W}$

$342634 \mathrm{~N} 1121701 \mathrm{~W}$

342611 N1121728W

$341336 \mathrm{~N} 1111028 \mathrm{~W}$

$343052 \mathrm{~N} 1123656 \mathrm{~W}$

$343058 \mathrm{~N} 1123655 \mathrm{~W}$

343907 N1124539W

340709N1105710W

$324220 \mathrm{~N} 1124002 \mathrm{~W}$

$331734 \mathrm{~N} 1092610 \mathrm{~W}$

$333324 \mathrm{~N} 1103852 \mathrm{~W}$

$334446 \mathrm{~N} 1103950 \mathrm{~W}$

$334656 \mathrm{N1} 11054 \mathrm{BW}$

$335350 \mathrm{~N} 1101221 \mathrm{~W}$

\begin{tabular}{|c|c|c|}
\hline $\begin{array}{l}\text { SOURCE } \\
\text { COORDINATE }\end{array}$ & $\begin{array}{c}\text { ELEV } \\
\text { FT }\end{array}$ & $\begin{array}{l}\quad \text { MAP MAME } \\
\text { Hearst Mtn } \\
\text { Jaycox Mtn } \\
\text { Hearst Mtn } \\
\text { Mount Floyd }\end{array}$ \\
\hline $\begin{array}{l}1748 \mathrm{~N} 1111910 \mathrm{~W} \\
1338 \mathrm{~N} 1092530 \mathrm{~W}\end{array}$ & 4595 & $\begin{array}{l}\text { Battle Flat } \\
\text { Oro Valley } \\
\text { Oro Valley } \\
\text { Avra } \\
\text { Tempe } \\
\text { White Hills East } \\
\text { Bozarth Hesa } \\
\text { Payson North } \\
\text { Stewart Mtn } \\
\text { Coronado Mtn }\end{array}$ \\
\hline $0536 \mathrm{~N} 1123420 \mathrm{~W}$ & 7188 & $\begin{array}{l}\text { Picacho Butte } \\
\text { Ebert Mtn } \\
\text { Ebert Mtn } \\
\text { White Hills East } \\
\text { Devils Hump } \\
\text { Hutch Mtn } \\
\text { Flagstaff East } \\
\text { Greer }\end{array}$ \\
\hline & 8367 & $\begin{array}{l}\text { Boundary Butte } \\
\text { Cipriano Pass }\end{array}$ \\
\hline
\end{tabular}

But ler Pass

Clay Springs

Battleship Butte

340611N1132841W Bouse Hills East

Bouse Hills East

Pima

Butler Well

Cammerman Wash

4297 Jerusalem Mtn 
FEATURE NAME

Butte Tank

Butte Tank

Butte Tank

Butte Tank

Butte Tank

Butte Tank

Butte Tank

Butte Tank

Butte Wash

Button Flat Tank

Button Mine

Buttons Ranch

Button Tank

Buzan Canyon

Buzzard Canyon

Buzzard Gulch Trailer Park

Buzzard Knoll

Buzzard Mine

Buzzard Ranch

See Big Horn

Buzzard Ridge

Buzzard Roost

Buzzard Roost Camp

Buzzard Roost Canyon Buzzards Roost Canyon

Buzzard Roost Canyon

Buzzard Roost Creek

Buzzard Roost Mesa

Buzzard Roost Mesa Tank

Number One

Buzzard Roost Mesa Tank

Number Two

Buzzard Roost Spring

Buzzard Roost Spring

Buzzard Roost Tank

Buzzard Roost Wash

Buzzard Spring

Buzzard Spring

Buzzard Spring

Buzzards Roost Canyon

See Buzzard Roost Canyon

Buzzard Tank

Buzzard Tank

Buzzard Tank

Bylas

Bylas Atheltic Field

Bylas Day School

Byous Butte

Hackberry Butte

Byous Spring

Bypass Tank

Byrant Ridge Tank

Byrd Ranch

Byrds Mobile Park

Byrne School

B 3.7 Latera

B 3.8 Lateral

B 5.5 W Latera

B 6.2 E Lateral

B 7.0 Lateral

B 8.0 N Latera

B 8.55 Lateral
FEATURE
CLASS

reservoir

reservoir

reservoir

reservoir

STATUS

COUNTY

BGN Apache

BGN

BGN

BGN

reservoir

reservoir

reservoir

reservoir

valley

well

reservoir

mine

locale

reservoir

BGN
BGN
BGN

BGN

BGN

UNOFF

BGN

UNOFF
UNOFF

BGN

valley

valley

locale

summit

mine

locale

ridge

summit

locale

valley

valley

stream

summit

reservoir

reservoir

spring

BGN

BGN

UNOFF

BGN

UNOFF

VARIANT

BGN

BGN

BGN

BGN

VARIANT

BGN

BGN

BGN

BGN

BGN

BGN

spring

reservoir

stream

spring

spring

spring

valley

reservoir

reservoir

reservoir

ppl

park

school

summit

spring

reservoir

reservoir

locale

locale

school

canal

canal

canal

canal

canal

canal

canal

Mohave

Coconino

Mohave

Mohave

Yavapai

Cochise

Gila

Yavapai

Coconino

Coconino

Pinal

Greenlee

Navajo

Coconino

Yavapai

Maricopa

Coconino

Pinal

Gila

Greenlee

Gila

Yavapai

Gila

Gila

Gila

Pinal

BGN

BGN

BGN

BGN

VARIANT

BGN

BGN

BGN

BGN

ADMIN
UNDFF

BGN
VARIANT

BGN

BGN

BGN

$\begin{array}{ll}\text { UNOFF } & \text { Maricopa } \\ \text { UNOFF } & \text { Yuma } \\ \text { BGN } & \text { Yuma } \\ \text { BGN } & \text { Yuma } \\ \text { BGN } & \text { Yuma } \\ \text { BGN } & \text { Yuma } \\ \text { BGN } & \text { Yuma } \\ \text { BGN } & \text { Yuma } \\ \text { BGN } & \text { Yuma }\end{array}$

Greenlee

Greenlee

Yavapai

Yavapai

Coconino

Greenlee

Yavapai

Coconino

Coconino

Graham

Graham

Graham

Pinal

Pinal

Coconino

Gila

Graham

Yuma

$\begin{array}{ll}\text { Apache } & 340740 \mathrm{~N} 1093950 \mathrm{~W} \\ \text { Gila } & 341315 \mathrm{~N} 1111036 \mathrm{~W} \\ \text { Coconino } & 344136 \mathrm{~N} 111255 \mathrm{BW} \\ \text { Coconino } & 344218 \mathrm{~N} 1112421 \mathrm{~W}\end{array}$

$344226 N 1132214 W$

$345003 N 1111919 W$

$351452 \mathrm{~N} 1135144 \mathrm{~W}$

$352839 \mathrm{~N} 1135005 \mathrm{~W}$

$344801 \mathrm{~N} 1123619 \mathrm{~W}$

$322450 N 1091531 \mathrm{~W}$

$342155 \mathrm{~N} 1113129 \mathrm{~W}$

340957 N1122417W

$365847 \mathrm{~N} 1122246 \mathrm{~W}$

$351805 N 1121631 \mathrm{~W}$

$325416 \mathrm{~N} 1103410 \mathrm{~W}$

$332238 \mathrm{~N} 1085835 \mathrm{~W}$

345509 N1100904W

$350525 \mathrm{~N} 1121301 \mathrm{~W}$

$342431 N 1122837 W$

$325134 N 1122331 W$

$350048 \mathrm{~N} 1114847 \mathrm{~W}$

$332251 \mathrm{~N} 1111621 \mathrm{~W}$

$340035 \mathrm{~N} 1110428 \mathrm{~W}$

325637 N1091445W

$340121 \mathrm{~N} 1110445 \mathrm{~W}$

$340359 \mathrm{~N} 1122847 \mathrm{~W}$

$340202 N 1110327 \mathrm{~W}$

340129 N1110303W

$340124 N 1110309 W$

324709N1103249W

$330334 N 1091018 \mathrm{~W}$

$330339 N 1090923 \mathrm{~W}$

$342312 \mathrm{~N} 1123238 \mathrm{~W}$

$342311 N 1123207 \mathrm{~W}$

$350025 \mathrm{~N} 1114932 \mathrm{~W}$

351451 N1101730W

$325637 N 1091445 \mathrm{~W}$

$342300 \mathrm{~N} 1114042 \mathrm{~W}$

$345236 \mathrm{~N} 1110846 \mathrm{~W}$

$350500 \mathrm{~N} 1111925 \mathrm{~W}$

330819 N1100728W

$330715 \mathrm{~N} 1100631 \mathrm{~W}$

$330740 \mathrm{~N} 1100652 \mathrm{~W}$

$332200 \mathrm{~N} 1111239 \mathrm{~W}$

$332123 \mathrm{~N} 1111229 \mathrm{~W}$

$344905 \mathrm{~N} 1110718 \mathrm{~W}$

340357 N1105922W

$323136 \mathrm{~N} 1101214 \mathrm{~W}$

$332537 N 1122105 \mathrm{~W}$

$324152 \mathrm{~N} 1143744 \mathrm{~W}$

$324056 \mathrm{~N} 1143507 \mathrm{~W}$

$324009 \mathrm{~N} 1143530 \mathrm{~W}$

$323852 \mathrm{N1} 143435 \mathrm{~W}$

$323825 \mathrm{~N} 1143422 \mathrm{~W}$

$323758 \mathrm{~N} 1143615 \mathrm{~W}$

$323824 N 1143642 \mathrm{~W}$

$323813 N 1143709 \mathrm{~W}$

\begin{tabular}{|c|c|c|}
\hline $\begin{array}{l}\text { SOURCE } \\
\text { COORDINATE }\end{array}$ & $\begin{array}{c}\text { ELEV } \\
\text { FT }\end{array}$ & MAP NAME \\
\hline & & $\begin{array}{l}\text { Boundary Butte } \\
\text { McDonald Mtn } \\
\text { Happy Jack } \\
\text { Happy Jack }\end{array}$ \\
\hline $45019 N 1123405 \mathrm{~W}$ & 3741 & $\begin{array}{l}\text { Negro Ed } \\
\text { Jaycox Mtn } \\
\text { Hualapai Spring } \\
\text { Antares } \\
\text { Sullivan Buttes } \\
\text { Martin Well } \\
\text { Cane Springs Mtn } \\
\text { Minnehaha } \\
\text { Shinarump Point } \\
\text { Hearst Mtn }\end{array}$ \\
\hline $\begin{array}{l}25523 N 1103655 \mathrm{~W} \\
32042 \mathrm{~N} 1090525 \mathrm{~W}\end{array}$ & $\begin{array}{l}5200 \\
6666\end{array}$ & $\begin{array}{l}\text { Brandenburg Mtn } \\
\text { Alma Mesa } \\
\text { Holbrook } \\
\text { May Tank Pocket } \\
\text { Groom Creek }\end{array}$ \\
\hline & 3754 & $\begin{array}{l}\text { Dutton Hill } \\
\text { Weavers Needle } \\
\text { Buzzard Roost Mesa }\end{array}$ \\
\hline $30546 N 10908$ & & York \\
\hline
\end{tabular}

335747 N1110324W $340336 \mathrm{~N} 1123142 \mathrm{~W}$

Buzzard Roost Mesa Copperopolis

Buzzard Roost Mesa Buzzard Roost Mesa

Buzzard Roost Mesa

Holy Joe Peak

Rattlesnake Spring Rattlesnake Spring

Wilhoit

Wilhoit

Dutton $\mathrm{Hi} 1$

5765 Rotten Bananas Butte

Hackberry Mtn

Chavez Mtn NW

Elliott Canyon

Bylas

Geronimo

2640 Bylas 
FEATURE CLASS

Cababi

See Ko Vaya

Cababi Mine

Caballeros Peaks

Caballo Tank

C A Bar Canyon

See Skully Creek

C A Bar Canyon

C A Creek

Lop Ear Creek

C A Bar Creek

C A Creek

Lop Ear Creek

Cabeza de Gigante

See Castle Dome Mountains

Cabeza Prieta Game Range

Cabeza Prieta Mountains

See Tule Mountains

Cabeza Prieta Mountains

Mesa de Malpais

Sierra de la Cabeza

Prieta

Sierra del Tule

Tule Mountains

Cabeza Prieta Pass Teuajo Alta

Cabeza Prieta Peak

Cabeza Prieta Tank

See Cabeza Prieta Tanks

Cabeza Prieta Tanks Cabeza Prieta Tank

Cabezas Spring

Cabin Oraw

Cabin Draw

Cabin Draw

Cabin Draw Tank

Cabin Flat Tanks

Cabin Spring

Cabin Spring

Cabin Spring

Cabin Spring

Cabin Tank

Cabin Tank

Cabin Tank

\section{Cabin Tank \\ Cabin Tank \\ Cabin Tank \\ See Adams Tank \\ Cabin Tank \\ Cabin Tank \\ Cabin Trail Tank \\ Cabin Valley \\ Cabin Valley Tank \\ Cabin Wash}

Cable Crossing (historical)

Cable Tank

Cache Cienega

C A Creek

See C A Bar Creek

$C$ A Creek

See C A Bar Canyon

Cactus

Cactus Bas in

Cactus Butte

Cactus Butte Spring

Cactus Canyon

Cactus Canyon

Cactus Canyon

See Cataract Canyon

Cactus Canyon

See Havasu Canyon

valley

ppl
mine
summit
reservoir
stream
valley

stream

ran
park
ran
ran

range
park
range
range

BGN 1962

VARIANT

VARIANT

VARIANT

ADMIN

BGN

VARIANT

VARIANT

VARIANT

VARIANT

gap

summit

reservoir

reservoir

spring

valley

valley

VARIANT

BGN
VARIANT

BGN

VARIANT

BGN Mohave

BGN Gila

Coconino

valley

reservoir

reservoir

spring

spring

spring

spring

reservoir

reservoir

reservoir

BGN
BGN
BGN
BGN
$B G N$
BGN
BGN
BGN
BGN
BGN

reservoir

reservoir

reservoir

reservoir

reservoir

reservoir

valley

reservoir

valley

BGN

VARIANT

BGN

BGN

BGN

BGN

locale

reservoir

flat

BGN 1910 Coconino

BGN Coconino

BGN

stream

VARIANT

valley

ppl

bas in

VARIANT

summit

BGN

BGN

$B G N$

spring

valley

valley

BGN

BGN

VARIANT

valley

VARIANT

Gila

Yavapai

Coconino

Yavapai

Greenlee

Maricopa

Yavapai

Gila

Grahan

Coconino

Coconino
Pima 320437N1115341W

Pima 315940N1115200W

Maricopa 335124N1124703W

$313403 \mathrm{~N} 1112215 \mathrm{~W}$

$325600 \mathrm{~N} 1091005 \mathrm{~W}$

$325600 \mathrm{~N} 1091248 \mathrm{~W}$

$325818 \mathrm{~N} 1090929 \mathrm{~W}$

Sells East

3044 Vulture Mine

Arivaca

York

325555N1091300W 330123N1090533W York

$330504 N 1140834 \mathrm{~W}$ $321500 \mathrm{~N} 1132700 \mathrm{~W}$

$321109 \mathrm{~N} 1134735 \mathrm{~W}$

$322059 N 1134924 \mathrm{~W}$

Cabeza Prieta Peak

Cabeza Prieta Peak

321B51N1134926W

$321719 \mathrm{~N} 1134828 \mathrm{~W}$

Cabeza Prieta Peak

2559 Cabeza Prieta Peak

$321827 \mathrm{~N} 1134809 \mathrm{~W}$

$321827 \mathrm{N1134809W}$

$345301 \mathrm{N1132945 \textrm {W }}$

$342035 \mathrm{~N} 1110558 \mathrm{~W}$

$343650 \mathrm{~N} 1105725 \mathrm{~W}$

$343351 N 1105428 \mathrm{~W}$

$350706 \mathrm{~N} 1111945 \mathrm{~W}$

$350719 \mathrm{~N} 1112005 \mathrm{~W}$

$352615 \mathrm{~N} 1114723 \mathrm{~W}$

$341717 \mathrm{~N} 1115249 \mathrm{~W}$

$343756 \mathrm{~N} 1121006 \mathrm{~W}$

$344710 \mathrm{N1124952 \textrm {W }}$

$345429 \mathrm{~N} 1133118 \mathrm{~W}$

$341645 N 1111101 \mathrm{~W}$

$343112 \mathrm{~N} 1113618 \mathrm{~W}$

$344628 \mathrm{~N} 1111754 \mathrm{~W}$

Yavapai 345320N1130409W

$345520 \mathrm{~N} 1115935 \mathrm{~W}$

$350703 \mathrm{N111271BW}$

$350706 \mathrm{~N} 1112723 \mathrm{~W}$

$355257 \mathrm{N1114623 \textrm {W }}$

$340214 N 1110128 \mathrm{~W}$

$363636 \mathrm{~N} 1130315 \mathrm{~W}$

$363624 N 1130303 \mathrm{~W}$

$345312 \mathrm{~N} 1130502 \mathrm{~W}$

$361800 \mathrm{~N} 1124500 \mathrm{~W}$

$351945 \mathrm{~N} 1123153 \mathrm{~W}$

$333555 \mathrm{~N} 1092103 \mathrm{~W}$

$325555 \mathrm{~N} 1091300 \mathrm{~W}$

$325600 \mathrm{~N} 1091248 \mathrm{~W}$

$333555 \mathrm{~N} 1120147 \mathrm{~W}$

$341856 \mathrm{~N} 1120135 \mathrm{~W}$

334559N1110908W

345637 N1130200W

$334645 N 1110831 W$

$331544 \mathrm{~N} 1100158 \mathrm{~W}$

$360143 \mathrm{~N} 1123124 \mathrm{~W}$

$361248 \mathrm{~N} 1124059 \mathrm{~W}$

361828 N1124540W
$342036 \mathrm{N1110827W}$

$363534 N 1130157 \mathrm{~W}$

$331616 \mathrm{~N} 1100221 \mathrm{~W}$

$350555 \mathrm{~N} 1112500 \mathrm{~W}$

Cabeza Prieta Peak

Gonzales Wash

Promontory Butte

Grama Draw

Elliott Canyon

Elliott Canyon

632 Kendrick Peak

Dugas

Hickey Mountain

Seepage Mtn

Tom Brown Canyon

Diamond Point

Buckhorn Mountain

Jaycox Mtn

Mount Hope

Loy Butte

Ashurst Lake

Deer Tank

Buzzard Roost Mesa

Hat Knoll

Hat Knoll

Mount Hope

$S$ B Point

Horse Trap Mesa

Strayhorse

Sunnys lope

Cordes Junction

3668 Greenback Creek

Greenback Creek

Ash Creek Ranch

Antelope Point 


\begin{tabular}{|c|c|c|c|c|c|c|c|}
\hline FEATURE NAME & $\begin{array}{l}\text { FEATURE } \\
\text { CLASS }\end{array}$ & STATUS & COUNTY & COORDINATE & $\begin{array}{c}\text { SOURCE } \\
\text { COORDINATE }\end{array}$ & $\begin{array}{l}\text { ELEV } \\
\text { FT }\end{array}$ & MAP NAME \\
\hline $\begin{array}{l}\text { Cactus Cove Trailer Park } \\
\text { Cactus Dam } \\
\text { Cactus Flat }\end{array}$ & $\begin{array}{l}\text { locale } \\
\text { dam } \\
\text { flat }\end{array}$ & $\begin{array}{l}\text { UNOFF } \\
\text { UNOFF } \\
\text { BGN }\end{array}$ & $\begin{array}{l}\text { Maricopa } \\
\text { Graham } \\
\text { Navajo }\end{array}$ & $\begin{array}{l}332708 N 1120654 \mathrm{~W} \\
324529 \mathrm{~N} 1094243 \mathrm{~W} \\
342446 \mathrm{~N} 1101152 \mathrm{~W}\end{array}$ & & 1070 & $\begin{array}{l}\text { Phoenix } \\
\text { Safford } \\
\text { Cactus Flat }\end{array}$ \\
\hline $\begin{array}{l}\text { Cactus Flat } \\
\text { Algodon } \\
\text { Cactus Flat Windmill } \\
\text { Cactus Forest } \\
\text { Cactus Gale V (subdivision) } \\
\text { Cactus Gardens Mobile Home Park } \\
\text { Cactus Hill Ranch } \\
\text { Cactus Mountain } \\
\text { Cactus Mountain } \\
\text { Cactus Park }\end{array}$ & $\begin{array}{l}\text { ppl } \\
\text { locale } \\
\text { ppl } \\
\text { ppl } \\
\text { locale } \\
\text { locale } \\
\text { summit } \\
\text { summit } \\
\text { park }\end{array}$ & $\begin{array}{l}\text { BGN } \\
\text { VARIANT } \\
\text { BGN } \\
\text { BGN } \\
\text { BGN } \\
\text { UNOFF } \\
\text { UNOFF } \\
\text { BGN } \\
\text { BGN } \\
\text { ADMIN }\end{array}$ & $\begin{array}{l}\text { Graham } \\
\text { Navajo } \\
\text { Pinal } \\
\text { Maricopa } \\
\text { Maricopa } \\
\text { Pinal } \\
\text { Yavapai } \\
\text { Mohave } \\
\text { Maricopa }\end{array}$ & 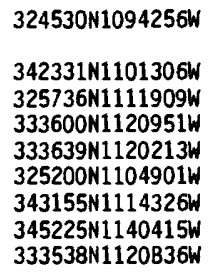 & & $\begin{array}{l}6214 \\
1230 \\
1480 \\
4256\end{array}$ & $\begin{array}{l}\text { Safford } \\
\text { Cactus Flat } \\
\text { Cactus Forest } \\
\text { Glendale } \\
\text { Sunnys lope } \\
\text { Putnam Wash } \\
\text { Walker Mtn } \\
\text { Yucca SE } \\
\text { Glendale }\end{array}$ \\
\hline $\begin{array}{l}\text { Cactus Pass } \\
\text { See Tuckayou Wash } \\
\text { Cactus Picnic Area } \\
\text { Cactus Plain } \\
\text { Cactus Plain } \\
\text { See Butler Valley } \\
\text { Cactus Plaza Shopping Center } \\
\text { Cactus Queen Mine } \\
\text { Cactus Ridge } \\
\text { Cactus Tank }\end{array}$ & $\begin{array}{l}\text { stream } \\
\text { park } \\
\text { plain } \\
\text { valley } \\
\text { locale } \\
\text { mine } \\
\text { ridge } \\
\text { reservoir }\end{array}$ & $\begin{array}{l}\text { VARIANT } \\
\text { ADMIN } \\
\text { BGN } \\
\text { VARIANT } \\
\text { UNOFF } \\
\text { UNOFF } \\
\text { BGN } \\
\text { BGN }\end{array}$ & $\begin{array}{l}\text { Mohave } \\
\text { Pima } \\
\text { Yuma } \\
\text { Yuma } \\
\text { Maricopa } \\
\text { Mohave } \\
\text { Gila } \\
\text { Pima }\end{array}$ & $\begin{array}{l}351111 \mathrm{~N} 1132739 \mathrm{~W} \\
32190 \mathrm{BN} 1104853 \mathrm{~W} \\
340129 \mathrm{~N} 1135812 \mathrm{~W} \\
335604 \mathrm{~N} 1134832 \mathrm{~W} \\
332222 \mathrm{~N} 1123456 \mathrm{~W} \\
341702 \mathrm{~N} 1134138 \mathrm{~W} \\
340341 \mathrm{~N} 1112622 \mathrm{~W} \\
315738 \mathrm{~N} 1112856 \mathrm{~W}\end{array}$ & & 1275 & $\begin{array}{l}\text { Sunnys lope } \\
\text { Rawhide Wash } \\
\text { Mazatzal Peak } \\
\text { Palo Alto Ranch }\end{array}$ \\
\hline $\begin{array}{l}\text { Cactus Villa (subdivision) } \\
\text { Cactus Well } \\
\text { Cactus Wren Mobile Park } \\
\text { Caddo Canyon } \\
\text { Caddo Point } \\
\text { Caddo Point Tank } \\
\text { Cadillac Tank } \\
\text { Cadillac Tank } \\
\text { Cadillac Wash } \\
\text { Caesar Tank }\end{array}$ & $\begin{array}{l}\text { ppl } \\
\text { well } \\
\text { locale } \\
\text { valley } \\
\text { cliff } \\
\text { reservoir } \\
\text { reservoir } \\
\text { reservoir } \\
\text { stream } \\
\text { reservoir }\end{array}$ & $\begin{array}{l}\text { BGN } \\
\text { UNOFF } \\
\text { UNOFF } \\
\text { BGN } \\
\text { BGN } \\
\text { BGN } \\
\text { BGN } \\
\text { BGN } \\
\text { BGN } \\
\text { BGN }\end{array}$ & $\begin{array}{l}\text { Maricopa } \\
\text { Gila } \\
\text { Maricopa } \\
\text { Navajo } \\
\text { Navajo } \\
\text { Navajo } \\
\text { Pinal } \\
\text { Coconino } \\
\text { Cochise } \\
\text { Maricopa }\end{array}$ & $\begin{array}{l}333518 \mathrm{~N} 1115116 \mathrm{~W} \\
331737 \mathrm{~N} 1104058 \mathrm{~W} \\
332512 \mathrm{~N} 1113752 \mathrm{~W} \\
340455 \mathrm{~N} 1103054 \mathrm{~W} \\
340330 \mathrm{~N} 1103139 \mathrm{~W} \\
340419 \mathrm{~N} 1103127 \mathrm{~W} \\
324106 \mathrm{~N} 1110636 \mathrm{~W} \\
353330 \mathrm{~N} 1115220 \mathrm{~W} \\
320044 \mathrm{~N} 1101819 \mathrm{~W} \\
324826 \mathrm{~N} 1122643 \mathrm{~W}\end{array}$ & $\begin{array}{l}340443 N 1103237 \mathrm{~W} \\
315505 \mathrm{~N} 1102340 \mathrm{~W}\end{array}$ & $\begin{array}{l}1400 \\
3409 \\
1540 \\
6124\end{array}$ & $\begin{array}{l}\text { Sawik Mountain } \\
\text { Cutter } \\
\text { Buckhorn } \\
\text { Spotted Mountain } \\
\text { Spotted Mountain } \\
\text { Spotted Mountain } \\
\text { Chief Butte } \\
\text { Chapel Mtn } \\
\text { Galleta Flat East } \\
\text { Big Horn }\end{array}$ \\
\hline $\begin{array}{l}\text { Caffrey Tank } \\
\text { Cahon Reservoir } \\
\text { See Slade Reservoir } \\
\text { Cahon Reservoir } \\
\text { See Atcheson Reservoir } \\
\text { Cahoon Lateral } \\
\text { Cahoots Airport } \\
\text { Cahuabi } \\
\text { See Ko Vaya } \\
\text { Caine Tank }\end{array}$ & $\begin{array}{l}\text { reservoir } \\
\text { reservoir } \\
\text { reservoir } \\
\text { canal } \\
\text { airport } \\
\text { ppl } \\
\text { reservoir }\end{array}$ & $\begin{array}{l}\text { BGN } \\
\text { VARIANT } \\
\text { VARIANT } \\
\text { BGN } \\
\text { ADMIN } \\
\text { VARIANT } \\
\text { BGN }\end{array}$ & $\begin{array}{l}\text { Coconino } \\
\text { Apache } \\
\text { Apache } \\
\text { Yuma } \\
\text { Coconino } \\
\text { Pima } \\
\text { Navajo }\end{array}$ & 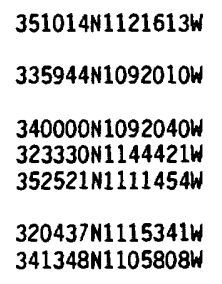 & & 4960 & $\begin{array}{l}\text { Somerton } \\
\text { Grand Falls }\end{array}$ \\
\hline $\begin{array}{l}\text { Cairo Hill } \\
\text { Cajon Tank } \\
\text { Cajon Tank } \\
\text { Cajote Spring } \\
\text { See Pan Tak } \\
\text { Cake Mountain } \\
\text { Cake Mountain Spring } \\
\text { Sycamore Spring } \\
\text { Calabasas } \\
\text { Calabazas } \\
\text { Kitchen Ranch }\end{array}$ & $\begin{array}{l}\text { summit } \\
\text { reservoir } \\
\text { reservoir } \\
\text { locale } \\
\text { summit } \\
\text { spring } \\
\text { ppl }\end{array}$ & $\begin{array}{l}\text { BGN } \\
\text { BGN } \\
\text { BGN } \\
\text { VARIANT } \\
\text { BGN } \\
\text { BGN } 1975 \\
\text { VARIANT } \\
\text { BGN } \\
\text { VARIANT } \\
\text { VARIANT }\end{array}$ & $\begin{array}{l}\text { Pinal } \\
\text { Pima } \\
\text { Coconino } \\
\text { Pima } \\
\text { Graham } \\
\text { Graham } \\
\text { Santa Cruz }\end{array}$ & $\begin{array}{l}331015 \mathrm{~N} 1105846 \mathrm{~W} \\
313119 \mathrm{N111} 1037 \mathrm{~W} \\
354408 \mathrm{~N} 1123201 \mathrm{~W} \\
320042 \mathrm{~N} 1113353 \mathrm{~W} \\
324357 \mathrm{N1} 102514 \mathrm{~W} \\
324406 \mathrm{N1} 102449 \mathrm{~W} \\
312802 \mathrm{N1} 105829 \mathrm{~W}\end{array}$ & & 2521 & $\begin{array}{l}\text { Hot Tamale Peak } \\
\text { Murphy Peak } \\
\text { Tin House }\end{array}$ \\
\hline $\begin{array}{l}\text { Calabasas Canyon } \\
\text { See Calabasas Picnic Area } \\
\text { Calabasas Canyon } \\
\text { Calabasas Hotel (historical) } \\
\text { Calabasas Picnic Area } \\
\text { Calabasas Canyon } \\
\text { Calabasas Private Land Grant } \\
\text { (historical) } \\
\text { Calabasas Store (historical) } \\
\text { Calabasas Tank }\end{array}$ & $\begin{array}{l}\text { park } \\
\text { valley } \\
\text { locale } \\
\text { park } \\
\text { civil } \\
\text { locale } \\
\text { reservoir }\end{array}$ & $\begin{array}{l}\text { VARIANT } \\
\text { BGN } \\
\text { UNOFF } \\
\text { ADMIN } \\
\text { VARIANT } \\
\text { ADMIN } \\
\text { BGN } \\
\text { BGN }\end{array}$ & $\begin{array}{l}\text { Santa Cruz } \\
\text { Santa Cruz } \\
\text { Santa Cruz } \\
\text { Santa Cruz } \\
\text { Santa Cruz } \\
\text { Santa Cruz } \\
\text { Santa Cruz }\end{array}$ & $\begin{array}{l}312305 \mathrm{~N} 1110305 \mathrm{~W} \\
312732 \mathrm{~N} 1105907 \mathrm{~W} \\
312748 \mathrm{~N} 1115808 \mathrm{~W} \\
312305 \mathrm{~N} 1110305 \mathrm{~W} \\
312423 \mathrm{~N} 1105500 \mathrm{~W} \\
312700 \mathrm{~N} 1105809 \mathrm{~W} \\
312205 \mathrm{~N} 1110302 \mathrm{~W}\end{array}$ & $312026 \mathrm{~N} 1110507 \mathrm{~W}$ & $\begin{array}{l}3460 \\
3920\end{array}$ & $\begin{array}{l}\text { Rio Rico } \\
\text { Rio Rico } \\
\text { Pena Blanca Lake } \\
\text { Rio Rico } \\
\text { Rio Rico } \\
\text { Pajarito Peak }\end{array}$ \\
\hline $\begin{array}{l}\text { Calabassas School } \\
\text { Calabazas } \\
\text { See Calabasas } \\
\text { Calahan Draw } \\
\text { Calamity Cave Cliff Dwelling } \\
\text { Calamity Wash } \\
\text { Calcite Mine }\end{array}$ & $\begin{array}{l}\text { school } \\
\text { ppl } \\
\text { valley } \\
\text { locale } \\
\text { stream } \\
\text { mine }\end{array}$ & $\begin{array}{l}\text { BGN } \\
\text { BGN } \\
\text { BGN } \\
\text { UNOFF }\end{array}$ & $\begin{array}{l}\text { Santa Cruz } \\
\text { Santa Cruz } \\
\text { Gila } \\
\text { Navajo } \\
\text { Maricopa } \\
\text { Yuma }\end{array}$ & $\begin{array}{l}313028 \mathrm{~N} 1110055 \mathrm{~W} \\
312802 \mathrm{~N} 1105829 \mathrm{~W} \\
341750 \mathrm{~N} 1112125 \mathrm{~W} \\
364915 \mathrm{~N} 1103325 \mathrm{~W} \\
335759 \mathrm{~N} 1124241 \mathrm{~W} \\
334714 \mathrm{~N} 1134149 \mathrm{~W}\end{array}$ & $\begin{array}{l}341726 \mathrm{~N} 1112041 \mathrm{~W} \\
340023 \mathrm{~N} 1124037 \mathrm{~W}\end{array}$ & & $\begin{array}{l}\text { Payson North } \\
\text { Tall Mountain } \\
\text { Wickenburg } \\
\text { Harcuvar }\end{array}$ \\
\hline
\end{tabular}


NATIONAL GAZETTEER--ARIZONA 1986

FEATURE NAME

Calcite Wash

Calcord Canyon

Colcord Canyon

Calcord Spring

Colcord Spring

Calcord Springs

Calderwood

See Calderwood Station

Calderwood Butte

Calderwood Station

Calderwood

Calera Draw

Calera Tank

\section{Calera Wash}

Calf Creek

Calf Creek Tank

Calf Pasture Tank

Calf Pasture Tank Number One

Calf Pen Canyon

Calf Spring

Calf Spring

Calf Tank

Caliche, Canal (historical)

\section{Caliche Spring \\ Calicke Park \\ Caliente, Tanko \\ California Gulch \\ California Gulch \\ California Gulch California Wash \\ California Gulch \\ Cal ifornia Gulch \\ See Walnut Gulch \\ California Mine \\ California Mine \\ California Mine \\ California Spring \\ California Wash \\ California Wash \\ See California Gulch \\ California Wash \\ See Walnut Gulch \\ California Well}

\section{Calitre Mountains \\ See Galiuro Mountains \\ Calitro Mountains \\ See Galiuro Mountains \\ Caliuro Mountains \\ See Galiuro Mountains \\ Calizo Mountains \\ See Galiuro Mountains \\ Callahan Creek \\ Callahan Mine \\ Callahan Tank \\ Callero Well \\ Calles Spring \\ Calloway Butte \\ Calloway Lake \\ Calloway Tank \\ Callville Basin See Boulder Bas in \\ Cal Tank \\ Calumet}

Calumet Gulch

Calumet Mine

Calumet Mine

Calva

Dewey
Calva Draw

Calva Railroad Station
FEATURE

CLASS

stream

valley

STATUS

COUNTY

BGN Yuma

VARIAN

Coconino

COORDINATE

334253N1134851W

$350343 \mathrm{~N} 1115729 \mathrm{~W}$

spring
spring
locale
summit
locale
valley
reservoir
stream
stream
reservoir
reservoir
reservoir
valley
spring
spring
reservoir
canal

BGN

VARIANT

VARIANT

Coconino

350437 N1115822W

Maricopa

335507 N1112450W

$\begin{array}{lll} & \text { Maricopa } & 333820 N 1121840 \mathrm{~W} \\ \text { BGN } & \text { Maricopa } & 334356 \mathrm{~N} 1121635 \mathrm{~W}\end{array}$

BGN Maricopa 333820N1121840W

VARIANT

BGN Santa Cruz 314245N1110825W

$\begin{array}{ll}\text { Santa Cruz } & 314245 \mathrm{~N} 1110825 \mathrm{~W} \\ \text { Pima } & 315553 \mathrm{~N} 1112038 \mathrm{~W}\end{array}$

$313903 N 1111949 \mathrm{~W}$

$334456 \mathrm{~N} 1101407 \mathrm{~W}$

$334706 \mathrm{~N} 1101224 \mathrm{~W}$

$335412 \mathrm{~N} 1102213 \mathrm{~W}$

$335438 \mathrm{~N} 1102151 \mathrm{~W}$

342649 N1113159W

$325741 \mathrm{~N} 1101444 \mathrm{~W}$

$330643 \mathrm{~N} 1093056 \mathrm{~W}$

$340203 N 1105245 \mathrm{~W}$

$332906 \mathrm{~N} 1115106 \mathrm{~W}$

spring BGN Mohave 345531N1141314W

park ADMIN Maricopa 333523N1121806W

summit BGN Mohave 352640N1141313W

reservoir BGN Yavapai 342057N1114038W

valley BGN Santa Cruz 312255N1111515W

valley BGN Pima 314654N1104427W

BCN 1978 Cochise

valley

VARIANT

BGN

VARIANT

valley

Cochise

Cochise

min

mine

mine

spring

stream

valley

valley

well

UNOFF

UNOFF

UNOFF

BGN

BGN

VARIANT

VARIANT

UNOFF

Santa Cruz

Pima

Yavapai

Santa Cruz

Cochise

Cochise

Cochise

Yavapai

$321727 N 1093938$

321727 N1093939W

322122N1093652W

$312452 N 1111423 \mathrm{~W}$

$315621 \mathrm{~N} 1103850 \mathrm{~W}$

$342818 N 1121811 \mathrm{~W}$

$312435 \mathrm{~N} 1111413 \mathrm{~W}$

$314905 \mathrm{~N} 1101304 \mathrm{~W}$

$321727 N 1093938 \mathrm{~W}$

$322122 \mathrm{~N} 1093652 \mathrm{~W}$

$342730 \mathrm{~N} 1124131 \mathrm{~W}$

VARIANT

range

range

Graham

$323600 \mathrm{N1102100 \textrm {W }}$

323600N1102100W

323600N1102100W

range

range

strea

VARIANT

Graham

Graham

VARIANT

mine

reservoir

well

spring

summit

lake

reservoir

bas in

reservoir

locale

valley

mine

mine

ppl

valley

building
BGN Graha

UNOFF Gila

BGN Gila

UNOFF

BGN

Coconino

Coconir

BGN

\section{Mohave}

Gila

BGN

BGN Pinal

UNOFF Cochise

UNOFF

BGY

VARIANT

BGN

UNOFF
Graham

Graham

Graham
$323600 \mathrm{~N} 1102100 \mathrm{~W}$

$340913 \mathrm{~N} 1112456 \mathrm{~W}$

341220N1112254

$341211 \mathrm{~N} 1112244 \mathrm{~N}$

$342227 \mathrm{~N} 1090526 \mathrm{~W}$

352133N1143019W

$343146 \mathrm{~N} 1112857 \mathrm{~W}$

$343130 N 1112815$

34305 ON $1112733 \mathrm{~W}$

360630N1144236W

$340914 \mathrm{~N} 1111814 \mathrm{~W}$

$312115 N 1093625 \mathrm{~W}$

$331046 \mathrm{~N} 1105929 \mathrm{~W}$

$312438 N 1095302 \mathrm{~W}$

331107 N1105853W

$331050 \mathrm{~N} 1101109 \mathrm{~W}$

$331037 \mathrm{~N} 1101307 \mathrm{~W}$

$331050 \mathrm{~N} 1101059 \mathrm{~W}$

$\begin{array}{cc}\text { SOURCE } & \text { ELEV } \\ \text { COORDINATE } & \text { FT }\end{array}$

MAP NAME

334904N1134302W Vicksburg

350606 N1120110W Sycamore Point

\begin{tabular}{|c|c|c|}
\hline & & $\begin{array}{l}\text { Sycamore Point } \\
\text { Reno Pass }\end{array}$ \\
\hline & 1703 & $\begin{array}{l}\text { Calderwood Butte } \\
\text { Calderwood Butte }\end{array}$ \\
\hline $313942 \mathrm{~N} 1110822 \mathrm{~W}$ & 3153 & $\begin{array}{l}\text { Saucito Mtn } \\
\text { Stevens Mtn }\end{array}$ \\
\hline $\begin{array}{l}313718 \mathrm{~N} 1111915 \mathrm{~W} \\
334753 \mathrm{~N} 1101147 \mathrm{~W}\end{array}$ & & $\begin{array}{l}\text { Cerro Colorado } \\
\text { Forks Butte } \\
\text { Cone Butte } \\
\text { Carrizo } \\
\text { Carrizo } \\
\text { Strawberry } \\
\text { Jackson Mtn } \\
\text { Bonita Spring } \\
\text { Young } \\
\text { Mesa }\end{array}$ \\
\hline
\end{tabular}

Yucca NW

E) Mirage

5121 Chloride

Verde Hot Springs

Bartlett Mtn

Empire Ranch

Railroad Pass

Simmons Peak

Ruby

Mount Fagan

Poland Junction

Ruby

314958N1102009W Land

Kirkland

340850N1112738W North Peak

North Peak
North Peak

Piney Hill Spirit Mtn SE

6860 Calloway Butte

Calloway Butte

Calloway Butte

Payson South

Douglas

331130N1105811W

Hot Tamale Peak

Bisbee

Hot Tamale Peak

330433 N1101534W

2579

Calva

Calva 


\section{FEATURE NAME}

Calvary Cemetery

Calvary Cemetery

Calvin Spring

Cam-Boh Picnic Area

Cambridge Heights (subdivision)

Camel

Camel Back

Came lback Cemetery

Came lback East Shops Shopping Center

Camelback Estates IV

(subdivision)

Camelback High School

Camelback Hospital

Camelback Mal

Came lback Mountain

Came lback Mountain

Camel Back Mountain See Camelback Mountain

Came lback Mountain Camel Back Mountain Camelsback Mountain

Camelback Mountain Park

Came lback Peak

Came lback Shopping Center

Camelback Shopping Center

Camelback Spring

Camelback Trailer Ranch

Camelback Village Square Shopping Center

Came lback Walk

Camelback West Shops Shopping Center

Camel Butte

Camel Francis Lake See Youngs Lake

Came lot Luxury Homes

(subdivision)

Camels Back

Camelsback Lake Camelsback Reservoir

Came lsback Mountain See Camelback Mounta in

Came lsback Reservoir See Camelsback Lake

Came is Peak See Comet Peak

Camel Tank

Camel Tank

Camel Tank

Camelview Plaza Shopping Center

Cameron

Cameron Airport

Cameron Gauging Station

Cameron Spring

Cameron Spring

Camerons Stock Tank

Camerons Tank

Cameron Trail

See Bright Angel Trail

Camillo Tank

Camino, Canal (historical)

Camino Oel Diablo Camino del Diablo

Camino Del Diablo

(approximate west route)

Camino Del Diablo

(approximate east route)

Camino Del Diablo

(approximate west route)

Camino del Diablo

\section{FEATURE}

CLASS

STATUS

COUNTY

COORDINATE

cemetery

cemetery

UNOFF

Cochise

Coconino

Gila

$312014 N 1093217 \mathrm{~W}$

$351059 \mathrm{~N} 1113926 \mathrm{~W}$

$340925 \mathrm{N1111807 \textrm {W }}$

\begin{tabular}{ll} 
park & ADMIN \\
pp1 1 & BGN \\
ppl 1 & BGN \\
bend & BGN \\
cemetery & UNOFF \\
locale & UNOFF \\
\hline
\end{tabular}

Pima

Maricopa

Maricopa

Graham

Maricopa

Maricopa

pp 1

schoo

BGN

Maricopa

UNOFF

Maricopa

321908N1110956W

$332115 \mathrm{~N} 1115847 \mathrm{~W}$

$330300 \mathrm{~N} 1131635 \mathrm{~W}$

$325559 \mathrm{N1} 1092630 \mathrm{~W}$

$333128 \mathrm{~N} 1115555 \mathrm{~W}$

$333033 \mathrm{~N} 1120043 \mathrm{~W}$

333351 N1115825W

333018N1120118W

hospital UNOFF

locale

summit

summit

summit

summit

park

UNOFF

BGN

BGN

VARIANT

BGN 1941

VARIANT

ADMIN

summit BGI

locale UNOFF

locale UNOFF

spring

locale

locale

$B G N$

UNOFF

UNOFF

park

locale

ADMIN

UNOFF

Maricopa 333043N1120025W

Maricopa

$322152 \mathrm{~N} 1125241 \mathrm{~W}$

$332513 \mathrm{~N} 1105505 \mathrm{~W}$

Maricopa 333052N1115740W

Maricopa 333052N1115740W

Maricopa

333053N1115739W

Gila

Maricopa

Maricopa

Gila

Maricopa

Maricopa

Maricopa

Maricopa

$334017 \mathrm{~N} 1111619 \mathrm{~W}$

$333036 \mathrm{~N} 1120246 \mathrm{~W}$

$333036 \mathrm{~N} 1120 \mathrm{BO} 5 \mathrm{~W}$

$334030 \mathrm{~N} 1111626 \mathrm{~W}$

$332 \mathrm{~B} 12 \mathrm{~N} 1120214 \mathrm{~W}$

$333038 \mathrm{~N} 1120459 \mathrm{~W}$

$333406 \mathrm{~N} 1115340 \mathrm{~W}$

333031 N1120BO5W

\begin{tabular}{|c|c|c|c|}
\hline summit & $\begin{array}{l}\text { BGN } \\
\text { VARIANT }\end{array}$ & Navajo & $365712 \mathrm{~N} 1100429 \mathrm{~W}$ \\
\hline $\begin{array}{l}\text { lake } \\
\text { ppl }\end{array}$ & $B G N$ & $\begin{array}{l}\text { Coconino } \\
\text { Maricopa }\end{array}$ & $\begin{array}{l}350512 N 1112815 \mathrm{~W} \\
332137 \mathrm{N1115523W}\end{array}$ \\
\hline $\begin{array}{l}\text { summit } \\
\text { reservoir }\end{array}$ & $\begin{array}{l}\text { BGN } \\
\text { US } 1962 \\
\text { VARIANT } \\
\text { VARIANT }\end{array}$ & $\begin{array}{l}\text { Cochise } \\
\text { Graham }\end{array}$ & $\begin{array}{l}321608 \times 1094157 \mathrm{~W} \\
325600 \mathrm{~N} 1092700 \mathrm{~W}\end{array}$ \\
\hline Immit & & Maricopa & $333052 \mathrm{~N} 1115740 \mathrm{~W}$ \\
\hline
\end{tabular}

VARIANT

reservoir

summit

reservoir

reservoir

reservoir

locale

pp1

airport

locaie

spring

rpring

reservoir

trail

reservoir

canal

trail

trai

trail

trail

VARIANT

Graham

Pinal

BGN

BGN

BGN

UNOFF

ADMIN

UNOFF

BGN

BGN

BGN

VARIANT

BGN

UNOFF

VARIANT

Yavapai

Yavapai

Yavapai

Maricopa

Coconino

Coconino

Coconino

Gila

Yavapai

Pima

Pima

Coconino

Coconino

Maricopa

Yuma

UNOFF

Yuma

UNOFF

Yuma

UNOFF

Yuma

VARIANT

$355339 \mathrm{~N} 1112256 \mathrm{~W}$

354B30N1112630W

$331835 \mathrm{~N} 1105330 \mathrm{~W}$

$341141 \mathrm{N1} 123339 \mathrm{~W}$

$321502 N 1125550 \mathrm{~W}$

$321947 \mathrm{~N} 1124714 \mathrm{~W}$

$360409 \mathrm{~N} 1120756 \mathrm{~W}$

$345503 \mathrm{~N} 1112241 \mathrm{~W}$

$332 B 18 N 1115106 \mathrm{~W}$

$321453 \mathrm{~N} 1135259 \mathrm{~W}$
SOURCE COORDINATE

ELEV
FT

MAP NAME

Douglas

Flagstaff West

Payson South

Avra

1300 Guadalupe

557 Hyder SE

Gila Box

Paradise valley

1210 Sunnys lope

1370 Paradise Valley

Sunnys lope

Sunnys lope

Paradise Valley

2573 Chico Shunie

4907 Inspiration

2704 Paradise Valley

Paradise Valley

5663 Four Peaks

1150 Sunnys lope

$113 B$ Glendale

Four Peaks

1120 Phoenix

1130 Sunnys lope

Paradise Valley

1138 Glendale

Mitten Buttes

1185 Guadalupe

6337 Railroad Pass

Tollgate Tank

Congress SW

Yampai

Audley

Paradise Valley

Cameron North

$333010 \mathrm{N1} 115553 \mathrm{~W}$

$355233 \mathrm{~N} 1112444 \mathrm{~V}$

4210 Cameron North

4567 Cameron South

Pinal Ranch

Wagoner

Chico Shunie

Ajo South

Mormon Lake

Mesa

Sierra Lechuguilla

Cipriano Pass

Wellton Hills

Fortuna SW 
NATIONAL GAZETTEER--ARIZONA 1986

\begin{tabular}{|c|}
\hline FEATURE MAME \\
\hline $\begin{array}{l}\text { See Camino Del Diablo } \\
\text { Camino Orain, El } \\
\text { Camino Lower Branch, Canal } \\
\text { (historical) }\end{array}$ \\
\hline $\begin{array}{l}\text { Cammerman Spring } \\
\text { Cammerman Wash } \\
\text { Cammerman Well } \\
\text { Camop Bowie } \\
\text { See Camp Bowie } \\
\text { Camote } \\
\text { See Shaotkam } \\
\text { Campaign Creek } \\
\text { Campaign Well } \\
\text { Campanile, The }\end{array}$ \\
\hline $\begin{array}{l}\text { Camp Apache } \\
\text { See Fort Apache } \\
\text { Campbell } \\
\text { Campbell Avenue Interchange } \\
\text { Campbell Blue Creek } \\
\text { Campbells Blue Creek } \\
\text { Campbell Crater } \\
\text { Campbell Creek } \\
\text { Campbell Draw Tank } \\
\text { Campbell Flat }\end{array}$ \\
\hline $\begin{array}{l}\text { Campbell Flat } \\
\text { Campbell Francis Wash } \\
\text { Campbell Hill } \\
\text { Campbell House Claim } \\
\text { Campbell Plaza Shopping Center } \\
\text { Campbells Blue Creek } \\
\text { See Campbe11 Blue Creek } \\
\text { Campbells Flat } \\
\text { Campbells Flat Spring } \\
\text { Campbell Spring }\end{array}$ \\
\hline $\begin{array}{l}\text { Campbell Tank } \\
\text { Campbell Tank } \\
\text { Campbell Tank } \\
\text { Campbell Tanks } \\
\text { Camp Bird Mine } \\
\text { Camp Bird Well } \\
\text { Camp B Mine } \\
\text { Camp Bowie } \\
\text { Apache Pass } \\
\text { Camop Bowie } \\
\text { Fort Bowie } \\
\text { Fort Bowie Military } \\
\text { Reservation } \\
\text { 01d Fort Bowie (ruins) }\end{array}$ \\
\hline
\end{tabular}

Camp Cameron (historical)

Camp Canyon

Camp Carlock Water Tank

Camp Civitan

Camp Clover Ranger Station

Camp Colorado

See Fort Mohave

Camp Cotton

Camp Creek

Camp Creek

See Pine Creek

Camp Creek
Camp Creek
Camp Creek Mine
Camp Creek Spring
Camp Crittenden
See Fort Crittenden
(historical)
Camp Date Creek
Camp Dyer Diversion Dam
Camp Geronimo

Camp Good News

Camp Goodwin (historical)

VARIANT

VARIANT

VARIANT

VARIANT

stream

Maricopa

$$
\begin{aligned}
& \text { FEAT } \\
& \text { CLASS } \\
& \text { tra } \\
& \text { stre } \\
& \text { canal } \\
& \\
& \text { spr } \\
& \text { stre } \\
& \text { wel } \\
& \text { park } \\
& \text { ppl } \\
& \text { stre } \\
& \text { wel } \\
& \text { pil }
\end{aligned}
$$

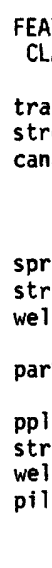

mine

crossing

stream

crater

stream

stream

reservoir
flat

flat

stream

summit

mine

locale

stream

flat

spring

spring

reservoir

reservoir

reservoir

reservoir

mine

well

mine

park

UNOFF
UNOFF
BGN
VARIANT
BGN
BGH

Navajo 334726N1095917W

Cochise 312528N1095321W

Pima 321038N1105637W

Greenlee 334311N1090239W

Coconino

Gila

Coconino

$351602 N 1111851 \mathrm{~W}$

$335920 \mathrm{~N} 1104555 \mathrm{~W}$

$344341 \mathrm{N1113053 \textrm {W }}$

333143N1090600W

334705 N1091248W

$354417 N 1113145 \mathrm{~W}$

$335604 N 1130329 \mathrm{~W}$

$334552 \mathrm{~N} 1133247 \mathrm{~W}$

$321528 \mathrm{N1105637 \textrm {W }}$

334311 N1090239W

$341030 \mathrm{N11} 23055 \mathrm{~W}$

$34105 \mathrm{BN} 1123059 \mathrm{~W}$

344454N1112944W

$335531 N 1130055 \mathrm{~W}$

344422N1112936W

$351135 \mathrm{N1} 113031 \mathrm{~W}$

$350855 \mathrm{N1121411 \textrm {W }}$

$341004 N 1122851 \mathrm{~W}$

$340957 \mathrm{N1} 122854 \mathrm{~W}$

$340137 N 1123512 \mathrm{~W}$

UNOFF

UNOFF

ADMIN
320859N1092707W

\begin{tabular}{|c|c|c|}
\hline $334835 \mathrm{~N} 1091516 \mathrm{~W}$ & 2500 & $\begin{array}{l}\text { Bisbee } \\
\text { Tucson } \\
\text { Maness Peak }\end{array}$ \\
\hline $335816 \mathrm{NL104917W}$ & 6270 & $\begin{array}{l}\text { Merriam Crater } \\
\text { Rock House } \\
\text { Apache Maid Mtn } \\
\text { Blue }\end{array}$ \\
\hline $353 \mathrm{~B} 27 \mathrm{N1113423 \textrm {W }}$ & $\begin{array}{l}2636 \\
2400\end{array}$ & $\begin{array}{l}\text { Alpine } \\
\text { Campbell Francis Wsh } \\
\text { Forepaugh Peak } \\
\text { Salome } \\
\text { Tucson North }\end{array}$ \\
\hline & & $\begin{array}{l}\text { Wagoner } \\
\text { Wagoner } \\
\text { Happy Jack }\end{array}$ \\
\hline & & $\begin{array}{l}\text { Forepaugh Peak } \\
\text { Happy Jack } \\
\text { Flagstaff East } \\
\text { Willians South } \\
\text { Minnehaha } \\
\text { Minnehaha } \\
\text { Morgan Butte } \\
\text { Bowie Mtn North }\end{array}$ \\
\hline
\end{tabular}

Lake Havasu City $S$ Mesa

Cammerman Wash

4339 Cammerman Wash
Cammerman Wash $\begin{array}{ll}332731 N 1110820 W & \text { Two Bar Mtn } \\ \text { Two Bar Mtn }\end{array}$

The Temple

$\begin{array}{llll}\text { locale } & \text { BGN } & \text { Pima } & 314700 \mathrm{~N} 1104530 \mathrm{~W} \\ \text { valley } & \text { BGN } & \text { Yavapai } & 340624 \mathrm{~N} 1120245 \mathrm{~W} \\ \text { reservoir } & \text { BGN } & \text { Gila } & 331923 \mathrm{~N} 1105130 \mathrm{~W} \\ \text { locale } & \text { BGN } & \text { Coconino } & 351930 \mathrm{~N} 1121109 \mathrm{~W} \\ \text { locale } & \text { UNOFF } & \text { Coconino } & 351413 \mathrm{~N} 1121255 \mathrm{~W} \\ & \text { VARIANT } & & \\ \text { locale } & & \text { Mohave } & 350235 \mathrm{~N} 1143718 \mathrm{~W} \\ \text { locale } & \text { BGN } & \text { Yavapai } & 350417 \mathrm{N1123135 \textrm {W }} \\ \text { stream } & \text { BGN } & \text { Maricopa } & 334530 \mathrm{~N} 1113014 \mathrm{~W}\end{array}$

Heivetia

Squaw Creek Mesa Pinal Peak

6560 Williams North

Williams South

$334617 N 1112541 W$

5680 Picacho Butte SE Maverick Mtn

334532N1113015W

\begin{tabular}{|c|c|c|c|}
\hline $\begin{array}{l}\text { stream } \\
\text { ppl } \\
\text { mine } \\
\text { spring }\end{array}$ & $\begin{array}{l}\text { BGN } \\
\text { BGN } \\
\text { UNOFF } \\
\text { BGN } \\
\text { VARIANT }\end{array}$ & $\begin{array}{l}\text { Maricopa } \\
\text { Maricopa } \\
\text { Yuma } \\
\text { Maricopa }\end{array}$ & $\begin{array}{l}334616 \mathrm{~N} 1113951 \mathrm{~W} \\
335442 \mathrm{~N} 1114858 \mathrm{~W} \\
331705 \mathrm{~N} 1132053 \mathrm{~W} \\
334536 \mathrm{~N} 1112944 \mathrm{~W}\end{array}$ \\
\hline locale & & Santa Cruz & $313940 \mathrm{~N} 1104200 \mathrm{~W}$ \\
\hline $\begin{array}{l}\text { locale } \\
\text { dam } \\
\text { locale }\end{array}$ & $\begin{array}{l}\text { BGN } \\
\text { UNOFF } \\
\text { BGN }\end{array}$ & $\begin{array}{l}\text { Yavapai } \\
\text { Maricopa } \\
\text { Gila }\end{array}$ & $\begin{array}{l}341551 N 1125528 \mathrm{~W} \\
335018 \mathrm{~N} 1121612 \mathrm{~W} \\
342431 \mathrm{~N} 1112234 \mathrm{~W}\end{array}$ \\
\hline $\begin{array}{l}\text { locale } \\
\text { locale }\end{array}$ & $\begin{array}{l}\text { BGN } \\
B G N\end{array}$ & $\begin{array}{l}\text { Yavapai } \\
\text { Graham }\end{array}$ & $\begin{array}{l}342825 \mathrm{~N} 1122739 \mathrm{~W} \\
330520 \mathrm{~N} 1100327 \mathrm{~W}\end{array}$ \\
\hline
\end{tabular}

$335613 \mathrm{~N} 1114850 \mathrm{~W}$

(3)

(3)

(3)

\begin{tabular}{|c|c|c|}
\hline $335613 \mathrm{~N} 1114850 \mathrm{~W}$ & & $\begin{array}{l}\text { Bartlett Dam } \\
\text { Humboldt Mtn } \\
\text { Nottbusch Butte } \\
\text { Boulder Mtn }\end{array}$ \\
\hline & 5600 & $\begin{array}{l}\text { Date } \\
\text { Baldy Mtn } \\
\text { Pine }\end{array}$ \\
\hline & $\begin{array}{l}5920 \\
2652\end{array}$ & $\begin{array}{l}\text { Groom Creek } \\
\text { Geronimo }\end{array}$ \\
\hline
\end{tabular}




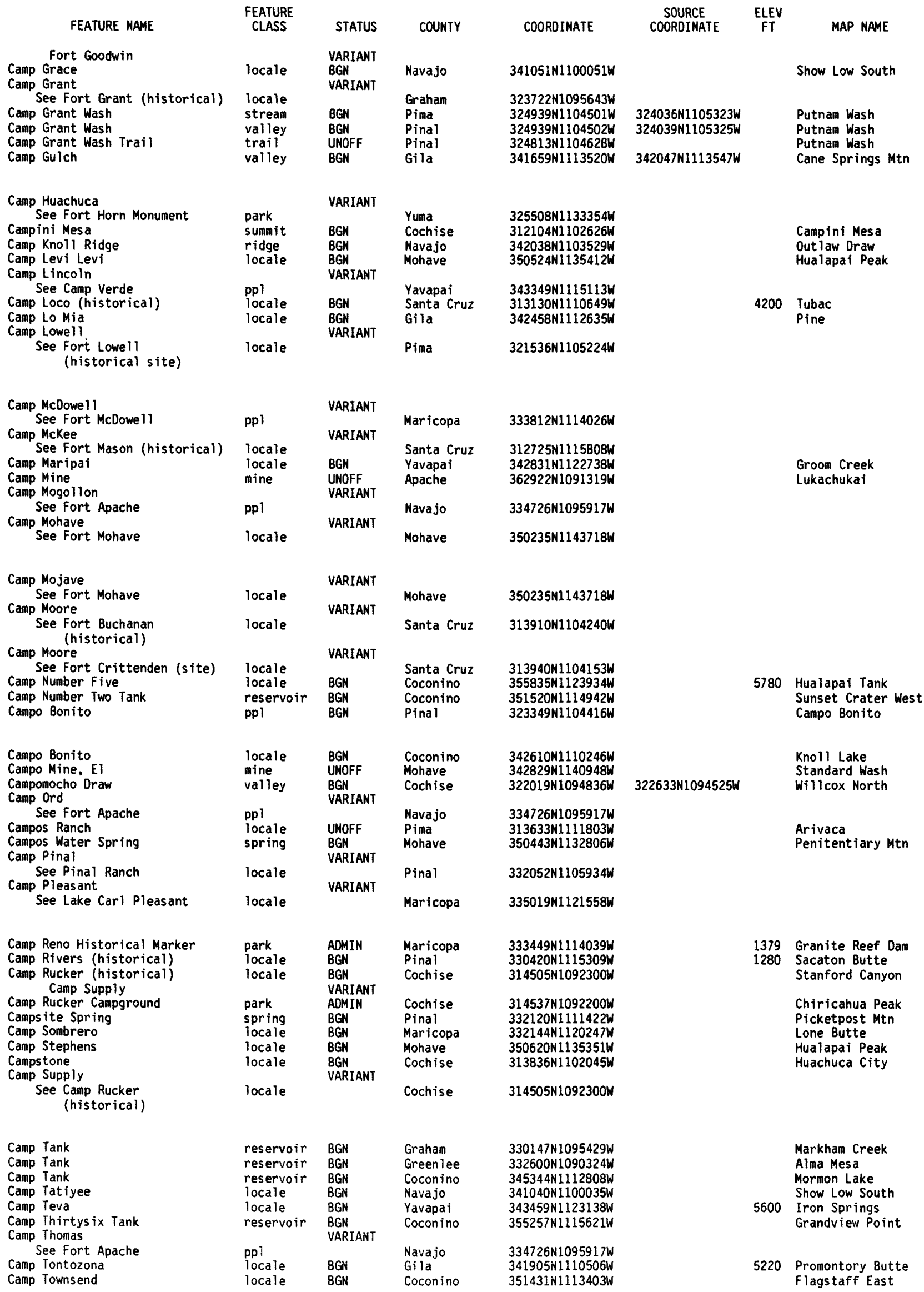


NATIONAL GAZETTEER--ARIZONA 1986

FEATURE

CLASS

flat

Camp Two Flat

Campus Tank

Camp Utah

See Lehi

Camp Verde

Camp Lincoln

Fort Verde

Verde

Camp Verde Airstrip

Camp Verde Elementary School

Camp Verde Indian Reservation Camp Verde Reservation

Camp Verde Post Office

Camp Verde Ranger Station

Camp Verde Reservation

See Camp Verde Indian Reservation

Camp Verde School

Camp Wallen (historical)

New Post

Huachuca

Fort Wallen

Camp Wamatochick
Camp Wemaloch

Camp Well

Camp Wemaloch

See Camp Wamatochick

Camp Whipple

See Fort Whipple

Camp Wood

Camp Wood Corner Dam

Camp Wood Mountain

Camp Wood Mountain Seep Spring See Camp Wood Mountain Spring

Camp Wood Mountain Spring Camp Wood Mountain Seep Spring

Camp Wood Ranger Guard Station Camp Wood Tank

Canaan Gap

Canada De La Poloma

See Paloma, Cañada de la

Cañada del Oro Four

Cañada Granda Tank

Canadian Mines

Canal, The

Canal Ancho

See Fourteen, Canal (historical)

Canal Casas

See Eleven, Canal

(historical)

Canal Cashion

See Twelve, Canal

(historical)

Canal Colinas

See Five, Canal

(historical)

Canal Cottonwood

See Seven Lower Branch, Canal (historical)

Canal del Rio

See Six, Canal (historical)

spring

spring

locaie

reservoir

gap

valley

trail

reservoir

mine

strean

canal

canal

UNOFF Pima 322725N1104B53W

BGN Coconino 350016N1113234

UNOFF Gila 334821N1103230w

BGN Navajo 343131N1100434

VARIANT

Maricopa

$332844 N 1115228 \mathrm{~W}$

Maricopa

$332713 \mathrm{~N} 1114821 \mathrm{~W}$

VARIANT

canal

Maricopa

$332352 \mathrm{~N} 1121625 \mathrm{~W}$

VARIANT

canal

Maricopa

$332708 \mathrm{~N} 1120912 \mathrm{~W}$

VARIANT

canal

canal

VARIANT

Maricopa

$332400 \mathrm{~N} 1120151 \mathrm{~W}$

Maricopa

$332620 \mathrm{~N} 1121004 \mathrm{~W}$

Canal Eleven

See Casas, Canal

(historical)

Canal Eleven

See Mesa, Canal

(historical)

Canal Eleven Branch canal

VARIANT

Maricopa

$332610 \mathrm{~N} 1115010 \mathrm{~W}$

canal

VARIANT

Maricopa

$332637 \mathrm{~N} 1114900 \mathrm{~W}$ $\begin{array}{cc}\text { SOURCE } & \text { ELEV } \\ \text { COORDINATE } & \text { FT MAP NAME }\end{array}$

ng Mountain

Uranium Spring

3147 Camp Verde

3175 Camp Verde

Camp Verde

Middle Verde

Camp Verde

Camp Verde

Camp Verde

Fort Huachuca NE

Groom Creek

Bott leneck Wash

5706 Camp Wood

Camp Wood

Camp Wood

Camp Wood

Camp Wood

Camp Wood

Lost Spring Mtn West

Mt Lemmon

Lower Lake Mary

Mule Hoof Bend

342716N1095830W Snowflake 


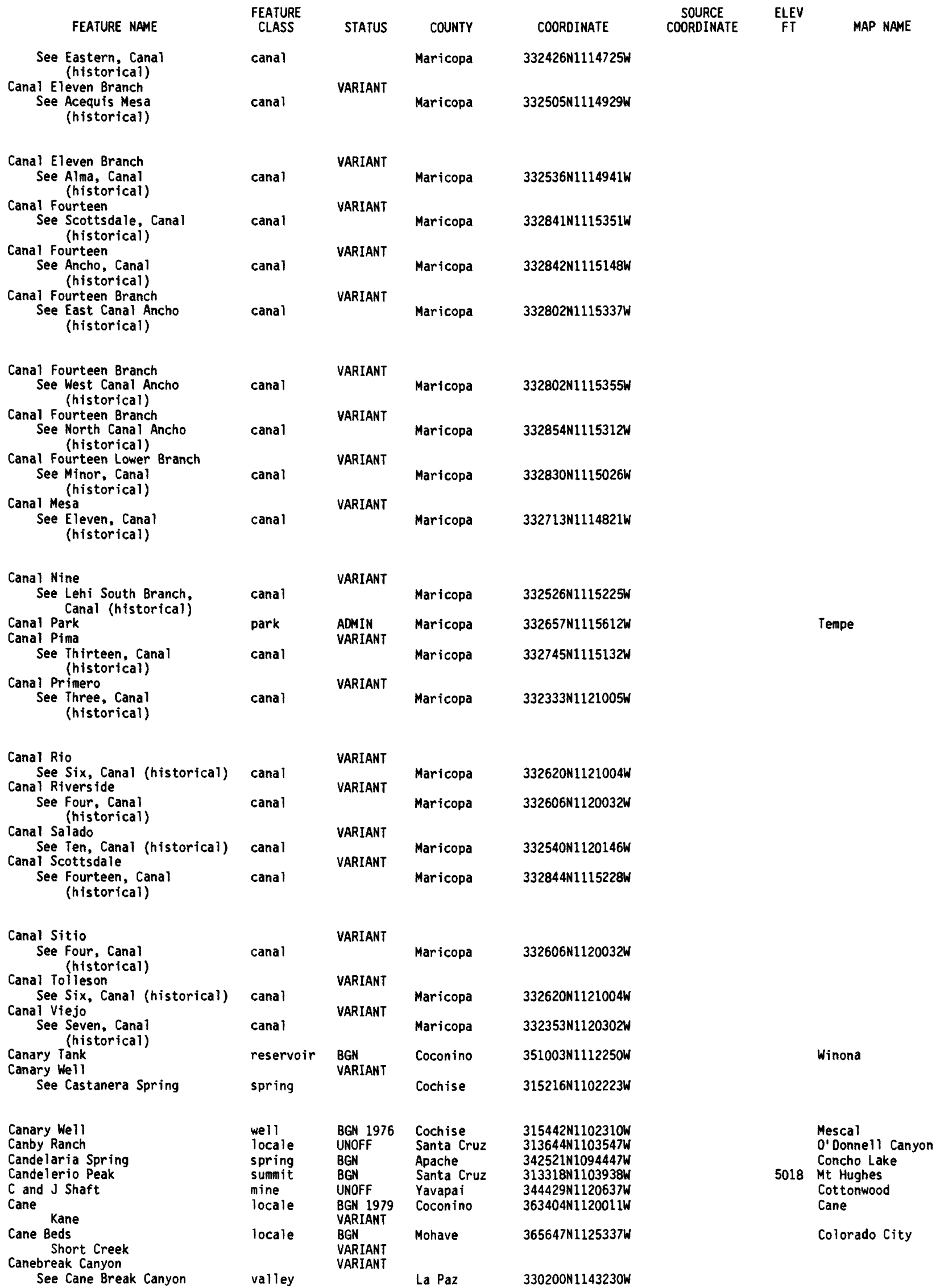


NATIONAL GAZETTEER--ARIZONA 1986

FEATURE NAME

Cane Break Canyon Canebreak Canyon

Cane Cairn Kane Cairn

Cane Canyon

Kane Canyon

Cane Creek

See Cane Spring Canyon

Canela

See Canelo

Canela Hills

See Canelo Hills

Canelo

Canela

Canille

Canelo Hills

Canela Hills

Canille Hills

Canille Mountains

La Sierra de las Osos

Canellos

Sierra de la Santa Cruz

Canelo Hills Ranch

Canelo Pass

Canelo Ranger Station

Cane Ridge

Kane Ridge

Cane Spring

Cane Spring

Cane Spring

See Pasture Spring

Cane Spring

Pasture Spring

Cane Spring
Cane Spring
Cane Spring
Cane Spring
Cane Spring
Cane Spring
See Cane Springs
Cane Spring Canyon
See Kane Spring Canyon
Cane Spring Canyon
Horse Creek
Cane Spring Canyon
Cane Creek
Cane Spring Mountain
See Cane Springs Mountain
Cane Springs
Cane Springs
Cane Springs
Cane Spring
Kane Spring
Kane Springs

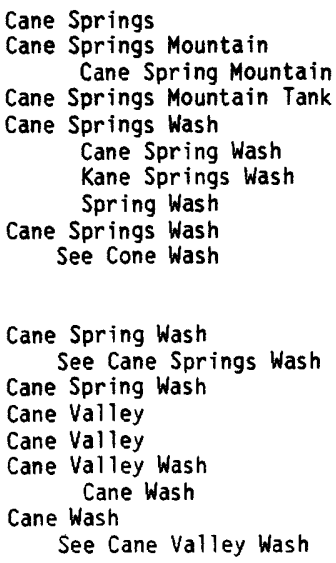

FEATURE CLASS

STATUS COUNTY

La Paz

valley

BGN

VARIANT

locale

valley

BGN 1979

VARIANT

Coconino

VARIANT

VARIANT

valley

locale

VARIANT

Gila

Santa Cruz

COORDINATE

330200 N1143230W

ELEV

MAP NAME

$30215 N 1143400 \mathrm{~W}$

Picacho

362911 N1120915W

5360 Buffalo Tanks

Buffalo Tanks

$335740 N 1112257 \mathrm{~W}$

(a)

VARIANT

summit

locale

BGN

VARIANT

VARIANT

summit

BGN 1923

VARIANT

VARIANT

VARIANT

VARIANT

VARIANT

gap

locale

ridge

spring

spring

spring

spring

UNOFF Santa Cruz

Santa Cruz

Santa Cruz

$313203 N 1103139 \mathrm{~W}$

$313002 \mathrm{~N} 1103329 \mathrm{~W}$

$313303 \mathrm{~N} 1103055 \mathrm{~W}$

BGN 1979 Coconino 363138N1120613W

VARIANT

BGN

Gila

Maricopa

$333234 \mathrm{N1110320 \textrm {W }}$

$333751 \mathrm{~N} 1112239 \mathrm{~W}$

VARIANT

Gila

$335343 \mathrm{~N} 1110955 \mathrm{~W}$

$335408 \mathrm{N1111023 \textrm {W }}$

BGN 1965
VARIANT

spring

spring

spring

spring

spring

spring

valley

valley

BGN

BGN

BGN

BGN

BGN

VARIANT

VARIANT

BGN

VARIANT

valley

BGN

VARIANT

VARIANT

summit

spring

spring

spring

BGN Graham

BGN Mohave

BGN 1979 Coconino

VARIANT

VARIANT

VARIANT

spring

summit BGN 1968

VARIANT

reservoir BGN

stream

BGN

VARIANT

VARIANT

VARIANT

VARIANT

Mohave

VARIANT

stream

stream

stream

valley

stream

stream

$\begin{array}{ll}\text { BGN } & \text { Mohave } \\ \text { BGN } & \text { Mohave } \\ \text { BGN } & \text { Apache } \\ \text { BGN } & \text { Navajo } \\ \text { VARIANT } & \text { Apache } \\ \text { VARIANT } & \end{array}$

Apache
$345637 N 1134304 W$

335820N1112327W

$341709 \mathrm{~N} 1113221 \mathrm{~W}$

$353540 \mathrm{~N} 1141020 \mathrm{~W}$

$360915 \mathrm{~N} 1131427 \mathrm{~W}$

$363508 \mathrm{N1120240 \textrm {W }}$

330607 N1105711W

$333529 N 1112629 \mathrm{~W}$

$333927 N 1112034 W$

Mormon Flat Dam

$335740 N 1112257 \mathrm{~W}$

335903N1112550W

Reno Pass

341808 N1113327W

$331148 \mathrm{~N} 1100202 \mathrm{~W}$

34552BN1133955W

363508 N1120240W

$363916 N 1134705 \mathrm{~W}$

$341808 \mathrm{N1} 113327 \mathrm{~W}$

$341832 \mathrm{~N} 1113338 \mathrm{~W}$

$345446 \mathrm{~N} 1133726 \mathrm{~W}$

Cane Springs

Bylas

Pilgrim Wash

Cane

$345446 \mathrm{~N} 1133726 \mathrm{~W}$

$353556 \mathrm{~N} 1140433 \mathrm{~W}$

$365 B 29 N 1095044 \mathrm{~W}$

364721 N1100742W

$370251 \mathrm{~N} 1095156 \mathrm{~W}$

$353519 N 1141144 \mathrm{~W}$

365136N1095B58W

$364742 \mathrm{~N} 1101446 \mathrm{~W}$

365829 N1095044W
$363345 \mathrm{~N} 1100703 \mathrm{~W}$

345637 N1134304W
Mt Tipton SE

Garnet Ridge

Agathla Peak

Garnet Ridge 
AZ106

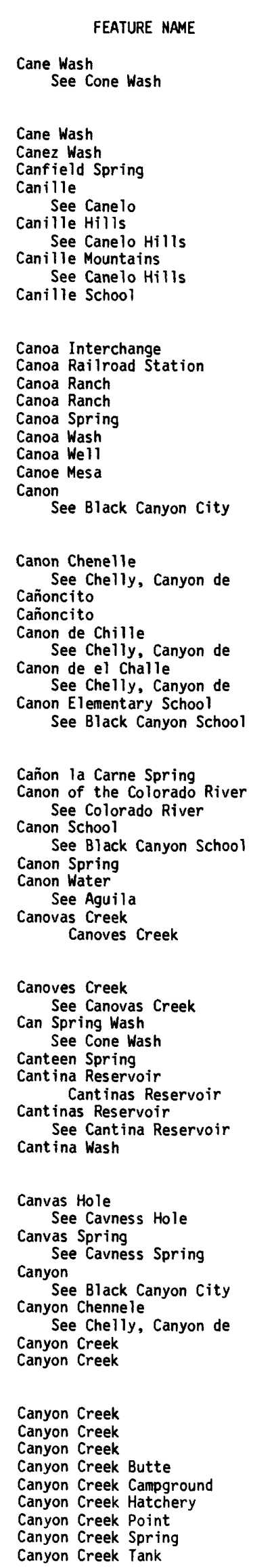

NATIONAL GAZETTEER--ARIZONA 1986

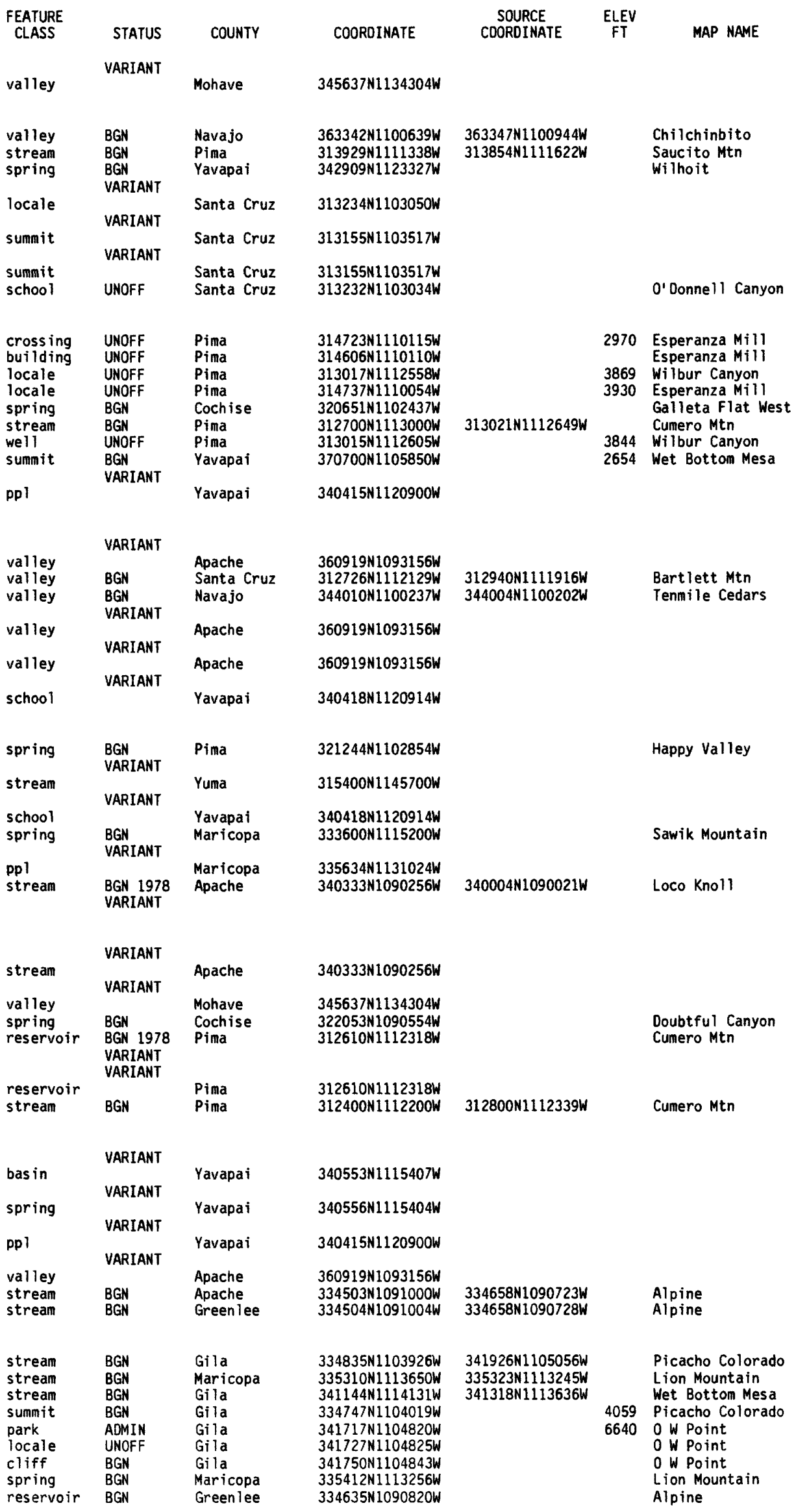


NATIONAL GAZETTEER--ARIZONA 1986

\section{FEATURE NAME}

Canyon Creek Tank

Canyon Dam

Canyon Day

Canyon Day Flat Village

Canyon Day Flat Village

See Canyon Day

Canyon Day Tank

Canyon de Chelly

See Chelly, Canyon de

Canyon de Chelly National Park

Canyon de Chelly Trading Post

Canyon de Chelly Visitor Center Canyon del Oro High School

Canyon de la Pino

See Pino, Canyon de la

Canyon del Muerta School

Canyon del Muerto

See Maverick Canyon

Canyon del Muerto School

Canyon Diablo

See Lawton Canyon

Canyon Diablo

Canyon Diablo Dan

Canyon Diablo Railroad Station

Canyon Diablo Reservoir

Canyon Diablo Wash

Canyon Diablo Wash

See Diablo, Canyon

Canyon Diablo Well

Canyon Lake

Canyon Meadow

Canyon Mouth Dam

Canyon Padre

See Padre Canyon

Canyon Point Campground

See Canyon Point Recreation Area

Canyon Point Recreation Area

Canyon Point Campground

Canyon Ridge

Canyon Run (subdivision)

Canyon Seep

Canyon Spring

Canyon Spring

Canyon Spring

Canyon Station Spring

Canyon Tank

Canyon Tank

Canyon Tank

Canyon Tank

Canyon Tank

Canyon Trails Mobile Home Park

Canyon Trigo

See Muerto, Canyon del

Canyon View (subdivision)

Canyon Viewpoint Canyon View Point

Canyon View Point

See Canyon Viewpoint

Canyon Village (trailer park)

Canyon Windmi11

Cape, The

Cape Hor

See Rincon Pass

Cape Royal

Capgage Wash

Capital Butte

See Capitol Butte

Capital Dome Mountains

See Castle Dome Mountains

Capital Rock

\section{FEATURE}

STATUS

COUNTY

reservoir

BGN

Apache

dan

pp 1

UNOF

VARIANT

VARIANT

ppl

BGN

VARIANT

valley

park

locale

AOMIN

BGN

building

school

UNOFF

VARIANT

valley

school

valley

school

valley

locale

dam

building

arroyo

valley

well

reservoir

flat

UNOFF

VARIANT

UNOFF

VARIANT

Apache

Gila

Gila

Apache

Apache

Apache

Apache

Pima

Pima

Apache

Graham

Apache

Maricopa

BGN

UNOFF

UNOFF

BGN

BGN

VARIANT

UNOFF

BGN

BGN

dam

UNOFF

valley

VARIANT

park

park

ridge

pp 1

VARIANT

Coconino

Coconino

Coconino

Coconino

Coconino

Coconino

Coconino

Maricopa

Apache

Yavapai

Coconino

Coconino

Coconino

ADMIN

VARIANT

BGN Mohave

Maricopa

spring

spring

spring

spring

spring

reservoir

reservoir

reservoir

reservoir

reservoir

BGN
$B G N$
$B G N$
$B G N$
$B G N$
$B G N$
$B G N$
$B G N$
$B G N$
$B G N$

Yavapai

Gila

Mohave

Mohave

Mohave

Pina

Navajo

Yavapa

Coconino

Mohave

locale

UNOFF

valley

pp1

locale

locale

locale

locale

cliff

gap

cliff
stream

summit

range

VARIANT
$334722 N 1090718 W$

$340018 N 1092012 \mathrm{~W}$

$334705 N 1100133 \mathrm{~W}$

$334705 \mathrm{~N} 1100133 \mathrm{~W}$

$334823 \mathrm{~N} 1100142 \mathrm{~W}$

$360919 \mathrm{~N} 1093156 \mathrm{~W}$

360919 N1093030

$360906 \mathrm{~N} 1093249 \mathrm{~W}$

360911 N1093218W

$322228 \mathrm{~N} 1105812 \mathrm{~W}$

$321544 N 1103742 \mathrm{~W}$

$361120 \mathrm{~N} 1092610 \mathrm{~W}$

$331339 N 1093 B 14 \mathrm{~W}$

361120 N1092609W

UNKNOWN

$350946 \mathrm{~N} 1110701 \mathrm{~W}$

$350130 \mathrm{~N} 1110000 \mathrm{~W}$

$350947 \mathrm{~N} 1110703 \mathrm{~W}$

$350130 \mathrm{~N} 1110000 \mathrm{~W}$

$351746 \mathrm{~N} 1105918 \mathrm{~W}$

$351746 \mathrm{~N} 1105918 \mathrm{~W}$

$350147 \mathrm{~N} 1110355 \mathrm{~W}$

$333313 N 1112631 \mathrm{~W}$

362817 N109203BW

351620 N1125718W

351300 N $1110630 \mathrm{~W}$

341905N1104929W

341905 N1104929W

$360559 \mathrm{~N} 1143754 \mathrm{~W}$

331958N1115254W

$344046 \mathrm{~N} 1124958 \mathrm{~W}$

$334040 \mathrm{~N} 1111242 \mathrm{~W}$

$353155 \mathrm{~N} 1140840 \mathrm{~W}$

$365209 \mathrm{~N} 1133005 \mathrm{~W}$

$352131 \mathrm{~N} 1140544 \mathrm{~W}$

$314503 N 1111222 \mathrm{~W}$

$334942 \mathrm{~N} 1095610 \mathrm{~W}$

$345704 \mathrm{~N} 1121242 \mathrm{~W}$

$351 B 00 \mathrm{~N} 1121349 \mathrm{~W}$

353518 N1140324W

334129N1120636W

$360835 \mathrm{~N} 1092920 \mathrm{~W}$

333921 N1120911W

354513 N1134306W

$354513 N 1134306 \mathrm{~W}$

333537 N1120654W

$323800 \mathrm{~N} 1100544 \mathrm{~W}$

314922N1102405W

UNKNOWN

$360703 \mathrm{~N} 1115654 \mathrm{~W}$

$324746 \mathrm{~N} 1104107 \mathrm{~W}$

$345310 \mathrm{~N} 1114 \mathrm{~B} 22 \mathrm{~W}$

VARIANT

$\begin{array}{cc}\text { SOURCE } & \text { ELEV } \\ \text { COORDINATE } & \text { FT }\end{array}$

MAP NAME

Luna Lake

Eagar

Canyon Day

Canyon Day

Chinle

Chinle

Chinle

Tucson North

Del Muerto

Del Muerto

Canyon Diablo

Meteor Crater

Canyon Diablo

Meteor Crater

351610 N1105926W

East of 01d Leupp

5538 Meteor Crater

1660 Mormon Flat Dan

Bad Bug Butte

Seligman West

0 Woint

Hoover Dan

1190 Guadalupe

Smith Mesa

Theo. Roosevelt Dan

Mt Tipton

Wolf Hole Mtn East

Stockton $\mathrm{Hill}$

Batamote Hills

Whiteriver

Perkinsville

Willians North 
FEATURE MAME

See Agathla Peak

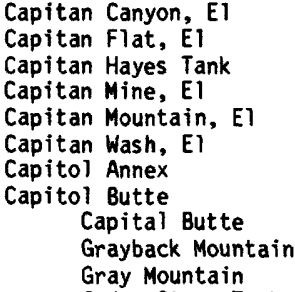

\section{FEATURE}

CLASS

STATUS

COUNTY

Mavajo

summit

$\begin{array}{lll}\text { valley } & \text { BGN } & \text { Gila } \\ \text { flat } & \text { BGN } & \text { Navajo } \\ \text { reservoir } & \text { BGN } & \text { Gila } \\ \text { mine } & \text { UNOFF } & \text { Gila } \\ \text { summit } & \text { BGN } & \text { Gila } \\ \text { stream } & \text { BGN } & \text { Navajo } \\ \text { building } & \text { UNOFF } & \text { Maricopa } \\ \text { summit } & \text { BGN 1971 } & \text { Yavapai } \\ & \text { VARIANT } & \\ & \text { VARIANT } & \\ & \text { VARIANT } & \\ & \text { VARIANT }\end{array}$

VARIANT

range

school

building

summit

reservoir

reservoir

locale

spring

reservoir

UMOFF

UNOFF

BGN

BGN

BGN

UNOFF

BGN

valley

reservoir

reservoir

valley

summit

valley

stream

gap

summit

BGN

BGN

BGN 1932

BGN 1906

BGN 1957

BGN 1927

VARIANT

BGN 1906

VARIANT

valley

stream

summit

ppl

airport

airpor

building

park

valley

trail

spring

stream

stream

well

hospital

school

reservoir

locale

reservoir

BGN

1932 Coconino

BGN

BGN

ADMIN

ADMIN

UNOFF

ADMIN

BGN

UNOFF

Yuma

Maricopa

Maricopa

Pima

Coconino

Maricopa

Gila

Greenlee

Santa Cruz

Santa Cruz

Santa Cruz

Coconino

Coconino

Coconino

Coconino

Coconino

Coconino

Pima

Maricopa

Maricopa

Maricopa

Maricopa

Maricopa

Pima

Pima

reservoir

mine

reservoir

dam

BGN

VARIANT

BGN

UNOFF

UNOFF

UNOFF

BGN

UNOFF

BGN

Pima

Apache

Graham

Mohave

Pima

Maricopa

Mavajo

Apache

Maricopa

BGN

UNOFF

BGN

VARIANT

VARIANT

VARIANT

reservoir

VARIANT

Apache

Gila

Gila

Maricopa

Maricopa

Gila

VARIANT

summit

spring

reservoir

loca

we?l

BGN
BGN
BGN
UNDFF
UNOFF

Gila Graham Greenlee

Greenlee

La Paz

Yuma
COORDINATE

$364936 \mathrm{~N} 1101330 \mathrm{~W}$

$330840 N 1104753 \mathrm{~W}$

$365626 \mathrm{~N} 1101850 \mathrm{~W}$

$332032 \mathrm{~N} 1104409 \mathrm{~W}$

$331218 \mathrm{~N} 1104829 \mathrm{~W}$

$331200 \mathrm{~N} 1104520 \mathrm{~W}$

365747 N1101911W

$332658 \mathrm{~N} 1120539 \mathrm{~W}$

$345310 \mathrm{~N} 1114822 \mathrm{~W}$

364840 N1101428W

SOURCE ELEV

MAP NAME

331432N1104739W Boot Mesa

Cutter

El Capitan Mtn

6568 E1 Capitan Mtn

Boot Mesa

Phoenix

6355 Wilson Mountain
$330504 \mathrm{~N} 1140834 \mathrm{~W}$ $332706 \mathrm{~N} 1120539 \mathrm{~W}$ $332705 \mathrm{~N} 1120647 \mathrm{~W}$ 313408 N1113750W $313425 \mathrm{~N} 1113731 \mathrm{~W}$ $352939 \mathrm{~N} 1115403 \mathrm{~W}$ $332719 \mathrm{~N} 1120855 \mathrm{~W}$ $331507 N 1105634 \mathrm{~W}$ $332559 \mathrm{~N} 1090447 \mathrm{~W}$

312749 N1105924W $312355 \mathrm{~N} 1110257 \mathrm{~W}$

$312507 \mathrm{~N} 1110146 \mathrm{~W}$ $361521 N 1124137 \mathrm{~W}$ $361032 \mathrm{~N} 1115030 \mathrm{~W}$ $360906 \mathrm{~N} 1114858 \mathrm{~W}$ $360905 \mathrm{~N} 1114854 \mathrm{~W}$

$361430 \mathrm{~N} 1122912 \mathrm{~W}$ $360332 \mathrm{~N} 1115033 \mathrm{~W}$

$\begin{array}{ll}360513 N 1115145 \mathrm{~W} & 360313 \mathrm{~N} 1115054 \mathrm{~W} \\ 360513 \mathrm{~N} 1115145 \mathrm{~W} & 360313 \mathrm{~N} 1115054 \mathrm{~W}\end{array}$ $322152 \mathrm{~N} 1125432 \mathrm{~W}$ $334920 \mathrm{~N} 1115503 \mathrm{~W}$ $334905 \mathrm{~N} 1115350 \mathrm{~W}$ $334924 \mathrm{~N} 1115519 \mathrm{~W}$ $334929 \mathrm{~N} 1115520 \mathrm{~W}$ 334933 N1115514W $322636 \mathrm{~N} 1105333 \mathrm{~W}$ $322630 \mathrm{~N} 1105210 \mathrm{~W}$

322621N1105133W

$345859 N 1094727 W$ $330537 \mathrm{~N} 1100144 \mathrm{~W}$ $351042 \mathrm{~N} 1132116 \mathrm{~W}$ $321313 N 1105832 \mathrm{~W}$ $332730 \mathrm{~N} 1120753 \mathrm{~W}$ 342027 N1101023W $341206 \mathrm{~N} 1094131 \mathrm{~W}$ $334550 \mathrm{~N} 1113455 \mathrm{~W}$

$333523 \mathrm{~N} 1094838 \mathrm{~W}$ $332305 \mathrm{~N} 1105920 \mathrm{~W}$ $332330 \mathrm{N1} 105942 \mathrm{~W}$ $335112 \mathrm{~N} 1121607 \mathrm{~W}$

335112N1121607W

334132N11D33D6W

$333938 \mathrm{~N} 1103339 \mathrm{~W}$ $324202 \mathrm{~N} 1094704 \mathrm{~W}$ 
NATIONAL GAZETTEER--ARIZONA 1986 FEATURE NAME

Carmen

Carminati School

Carnation Mine

Carne, Cañon la

Carnegie Library

Carnero Creek

Carnero Lake

Carnero Lake Dam See Taylor Reservoir Dam

Carnero Spring

Carney Spring

Carney Springs Campground

Carol Number One Tank

Carol Number Two Tank

Carol Spring

Car1 Spring

Carol Spring Mountain Carl Spring Mountain Corral Spring Mountain Timber Camp Mountain

Carol Tank

Carpas Wash

Carpenter Gulch

Carpenter Junior High School

Carpenter Ranch

Carpenters Cave

Carpenter Tank

Pratt Lake Pratt Tank

Carpenter Well

Carr Canyon

Carr Canyon Ranch

Carreta Windmill

See Cedar Windmill

Carrico Spring

Carrigan Peak

See Clara Peak

Carrigan Well

See Osborne Well

Carrillo School

Carrisito Spring

Carriso Mountains

See Carrizo Mountains

Carristo Spring

Carrizo

Carrizo

See Teec Nos Pos

Carrizo Butte

Carrizo Creek

Carrizo Creek

See Lithodendron Wash

Carrizo Creek

See Dead Wash

Carrizo Creek

See Carrizo Wash

Carrizo Mission School

Carrizo Mountain

See Carrizo Mountains

Carrizo Mountains

Carriso Mountains

Carrizo Mountain

Dzil Naozill

Carrizo Ranch

Carrizo Ridge

Carrizo Tank

Carrizo Wash

See Lithodendron Wash

Carrizo Wash

See Little Lithodendron

Carrizo Wash

\begin{tabular}{|c|c|c|c|c|c|c|}
\hline $\begin{array}{l}\text { FEATURE } \\
\text { CLASS }\end{array}$ & STATUS & COUNTY & COORDINATE & $\begin{array}{l}\text { SOURCE } \\
\text { COOROINATE }\end{array}$ & $\begin{array}{l}\text { ELEV } \\
\text { FT }\end{array}$ & MAP NAME \\
\hline $\begin{array}{l}\text { ppl } \\
\text { school } \\
\text { mine }\end{array}$ & $\begin{array}{l}\text { BGN } \\
\text { UNOFF } \\
\text { UNOFF }\end{array}$ & $\begin{array}{l}\text { Santa Cruz } \\
\text { Maricopa } \\
\text { Yuma }\end{array}$ & $\begin{array}{l}313514 N 1110308 \mathrm{~W} \\
332313 \mathrm{N1} 115545 \mathrm{~W} \\
341156 \mathrm{~N} 1140846 \mathrm{~W}\end{array}$ & & 3242 & $\begin{array}{l}\text { Tubac } \\
\text { Tempe } \\
\text { Cross Roads }\end{array}$ \\
\hline $\begin{array}{l}\text { valley } \\
\text { building } \\
\text { stream } \\
\text { lake }\end{array}$ & $\begin{array}{l}\text { BGN } \\
\text { UNOFF } \\
\text { BGN } \\
\text { BGN } \\
\text { VARIANT }\end{array}$ & $\begin{array}{l}\text { Pima } \\
\text { Yuma } \\
\text { Apache } \\
\text { Apache }\end{array}$ & $\begin{array}{l}321225 \mathrm{~N} 1102852 \mathrm{~W} \\
324314 \mathrm{~N} 1143723 \mathrm{~W} \\
341630 \mathrm{~N} 1092144 \mathrm{~W} \\
340657 \mathrm{~N} 1093139 \mathrm{~W}\end{array}$ & $\begin{array}{l}321304 N 1102843 W \\
340638 N 1093140 W\end{array}$ & 9033 & $\begin{array}{l}\text { Happy Valley } \\
\text { Yuma East } \\
\text { Lyman Lake } \\
\text { Greens Peak }\end{array}$ \\
\hline $\begin{array}{l}\text { dam } \\
\text { spring } \\
\text { spring } \\
\text { park } \\
\text { reservoir }\end{array}$ & $\begin{array}{l}\text { BGN } \\
\text { BGN } \\
\text { ADMIN } \\
\text { BGN }\end{array}$ & $\begin{array}{l}\text { Apache } \\
\text { Apache } \\
\text { Pinal } \\
\text { Pinal } \\
\text { Gila }\end{array}$ & $\begin{array}{l}360636 \mathrm{~N} 1093142 \mathrm{~W} \\
340607 \mathrm{~N} 1093211 \mathrm{~W} \\
332355 \mathrm{~N} 1112203 \mathrm{~W} \\
332349 \mathrm{~N} 1112205 \mathrm{~W} \\
33415 \mathrm{BN} 1103207 \mathrm{~W}\end{array}$ & & & $\begin{array}{l}\text { Greens Peak } \\
\text { Weavers Needle } \\
\text { Weavers Needle } \\
\text { Chrysotile }\end{array}$ \\
\hline $\begin{array}{l}\text { reservoir } \\
\text { spring }\end{array}$ & $\begin{array}{l}\text { BGN } \\
\text { BGN } \\
\text { VARIANT }\end{array}$ & $\begin{array}{l}\text { Gila } \\
\text { Gila }\end{array}$ & $\begin{array}{l}334236 \mathrm{~N} 1103146 \mathrm{~W} \\
334132 \mathrm{~N} 1103306 \mathrm{~W}\end{array}$ & & & $\begin{array}{l}\text { Chrysotile } \\
\text { Chrysotile }\end{array}$ \\
\hline summit & $\begin{array}{l}\text { BGN } 1967 \\
\text { VARIANT } \\
\text { VARIANT } \\
\text { VARIANT }\end{array}$ & Gila & $333938 \mathrm{~N} 1103339 \mathrm{~W}$ & & 6629 & Chrysotile \\
\hline $\begin{array}{l}\text { reservoir } \\
\text { stream } \\
\text { valley }\end{array}$ & $\begin{array}{l}\text { BGN } \\
B G N \\
B G N\end{array}$ & $\begin{array}{l}\text { Gila } \\
\text { Pinal } \\
\text { Yavapai }\end{array}$ & $\begin{array}{l}334134 \mathrm{~N} 1103255 \mathrm{~W} \\
323235 \mathrm{~N} 1105607 \mathrm{~W} \\
340303 \mathrm{~N} 1121747 \mathrm{~W}\end{array}$ & $\begin{array}{l}323456 \mathrm{~N} 1110056 \mathrm{~W} \\
340409 \mathrm{~N} 1121744 \mathrm{~W}\end{array}$ & & $\begin{array}{l}\text { Chrysotile } \\
\text { Oracle Junction } \\
\text { Columbia }\end{array}$ \\
\hline $\begin{array}{l}\text { school } \\
\text { locale } \\
\text { cave } \\
\text { reservoir }\end{array}$ & $\begin{array}{l}\text { UNOFF } \\
\text { UNOFF } \\
\text { BGN } \\
\text { BGN } 1973 \\
\text { VARIANT } \\
\text { VARIANT }\end{array}$ & $\begin{array}{l}\text { Santa Cruz } \\
\text { Pinal } \\
\text { Graham } \\
\text { Coconino }\end{array}$ & $\begin{array}{l}312102 \mathrm{~N} 1105623 \mathrm{~W} \\
323210 \mathrm{~N} 1110652 \mathrm{~W} \\
325722 \mathrm{~N} 1101131 \mathrm{~W} \\
344936 \mathrm{~N} 1111409 \mathrm{~W}\end{array}$ & & & $\begin{array}{l}\text { Nogales } \\
\text { Tortolita Mts } \\
\text { Jackson Mtn } \\
\text { Chavez Mtn West }\end{array}$ \\
\hline $\begin{array}{l}\text { well } \\
\text { valley } \\
\text { locale }\end{array}$ & $\begin{array}{l}\text { UNOFF } \\
\text { BGN } \\
\text { UNOFF } \\
\text { VARIANT }\end{array}$ & $\begin{array}{l}\text { Pima } \\
\text { Cochise } \\
\text { Cochise }\end{array}$ & $\begin{array}{l}313158 \mathrm{~N} 1112741 \mathrm{~W} \\
312724 \mathrm{~N} 1101420 \mathrm{~W} \\
312633 \mathrm{~N} 1101701 \mathrm{~W}\end{array}$ & $312453 \mathrm{~N} 1101835 \mathrm{~W}$ & & $\begin{array}{l}\text { Wilbur Canyon } \\
\text { Nicksville } \\
\text { Miller Peak }\end{array}$ \\
\hline well & & Pima & $313522 N 1111154 W$ & & & \\
\hline spring & $\begin{array}{l}\text { BGN } \\
\text { VARIANT }\end{array}$ & Pinal & $325327 \mathrm{N1103728W}$ & & & Brandenburg Mtn \\
\hline summit & VARIANT & Yuma & $340950 \mathrm{~N} 1134840 \mathrm{~W}$ & & & \\
\hline $\begin{array}{l}\text { well } \\
\text { school } \\
\text { spring }\end{array}$ & $\begin{array}{l}\text { UNOFF } \\
\text { BGN } \\
\text { VARIANT }\end{array}$ & $\begin{array}{l}\text { Yuma } \\
\text { Pima } \\
\text { Apache }\end{array}$ & $\begin{array}{l}340747 \mathrm{~N} 1140414 \mathrm{~W} \\
321255 \mathrm{~N} 1105827 \mathrm{~W} \\
343114 \mathrm{~N} 1090429 \mathrm{~W}\end{array}$ & & & $\begin{array}{l}\text { Tucson } \\
\text { Carrisito Spring }\end{array}$ \\
\hline $\begin{array}{l}\text { range } \\
\text { spring }\end{array}$ & BGN & $\begin{array}{l}\text { Apache } \\
\text { Pinal }\end{array}$ & $\begin{array}{l}364842 \mathrm{~N} 1091025 \mathrm{~W} \\
323124 \mathrm{N1} 104959 \mathrm{~W}\end{array}$ & & & Oracle \\
\hline pp1 & $\begin{array}{l}\text { BGN } \\
\text { VARIANT }\end{array}$ & Gila & $335938 \mathrm{~N} 1101717 \mathrm{~W}$ & & & Carrizo \\
\hline $\begin{array}{l}\text { ppl } \\
\text { summit } \\
\text { stream }\end{array}$ & $\begin{array}{l}\text { BGN } \\
\text { BGN } \\
\text { VARIANT }\end{array}$ & $\begin{array}{l}\text { Apache } \\
\text { Navajo } \\
\text { Gila }\end{array}$ & $\begin{array}{l}365516 \mathrm{~N} 1090506 \mathrm{~W} \\
345700 \mathrm{~N} 1095649 \mathrm{~W} \\
334702 \mathrm{~N} 1101935 \mathrm{~W}\end{array}$ & $341733 N 1103944 W$ & 5435 & $\begin{array}{l}\text { Carrizo Butte } \\
\text { Carrizo SE }\end{array}$ \\
\hline stream & VARIANT & Navajo & $345816 \mathrm{~N} 1095650 \mathrm{~W}$ & & & \\
\hline stream & VARIANT & Apache & $345859 N 1094727 \mathrm{~W}$ & & & \\
\hline valley & & Apache & $343620 \mathrm{~N} 1092606 \mathrm{~W}$ & & & \\
\hline school & $\begin{array}{l}\text { UNOFF } \\
\text { VARIANT }\end{array}$ & Apache & $365413 \mathrm{~N} 1090614 \mathrm{~W}$ & & & Teec Nos Pos \\
\hline $\begin{array}{l}\text { range } \\
\text { range }\end{array}$ & $\begin{array}{l}\text { BGN } 1915 \\
\text { VARIANT } \\
\text { VARIANT } \\
\text { VARIANT }\end{array}$ & $\begin{array}{l}\text { Apache } \\
\text { Apache }\end{array}$ & $\begin{array}{l}364842 \mathrm{~N} 1091025 \mathrm{~W} \\
364842 \mathrm{~N} 1091025 \mathrm{~W}\end{array}$ & & 9412 & Pastora Peak \\
\hline $\begin{array}{l}\text { locale } \\
\text { ridge } \\
\text { reservoir }\end{array}$ & $\begin{array}{l}\text { UNOFF } \\
\text { BGN } \\
\text { BGN }\end{array}$ & $\begin{array}{l}\text { Pima } \\
\text { Navajo } \\
\text { Gila }\end{array}$ & $\begin{array}{l}313201 \mathrm{~N} 1113409 \mathrm{~W} \\
341421 \mathrm{~N} 1103533 \mathrm{~W} \\
335905 \mathrm{~N} 1101614 \mathrm{~W}\end{array}$ & & 3862 & $\begin{array}{l}\text { Presumido Peak } \\
\text { Pepper Canyon } \\
\text { Carrizo }\end{array}$ \\
\hline $\begin{array}{l}\text { stream } \\
\text { stream }\end{array}$ & $\begin{array}{l}\text { VARIANT } \\
\text { VARIANT }\end{array}$ & $\begin{array}{l}\text { Navajo } \\
\text { Navajo }\end{array}$ & $\begin{array}{l}345816 \mathrm{~N} 1095650 \mathrm{~W} \\
345822 \mathrm{~N} 1095721 \mathrm{~W}\end{array}$ & & & \\
\hline valley & $B G N$ & Apache & $343620 \mathrm{~N} 1092606 \mathrm{~W}$ & $343700 \mathrm{~N} 1084654 \mathrm{~W}$ & & Zion Reservoir \\
\hline
\end{tabular}


NATIONAL GAZETTEER--ARIZONA 1986

\begin{tabular}{|c|c|c|c|c|c|c|c|}
\hline FEATURE NAME & $\begin{array}{l}\text { FEATURE } \\
\text { CLASS }\end{array}$ & STATUS & COUNTY & COOROINATE & $\begin{array}{l}\text { SOURCE } \\
\text { COORDINATE }\end{array}$ & $\begin{array}{c}\text { ELEV } \\
\text { FT }\end{array}$ & MAP NAME \\
\hline $\begin{array}{l}\text { Carrizo Creek } \\
\text { Largo Creek } \\
\text { Carrizo Wash Bridge } \\
\text { Carrizo Well }\end{array}$ & $\begin{array}{l}\text { bridge } \\
\text { well }\end{array}$ & $\begin{array}{l}\text { VARIANT } \\
\text { VARIANT } \\
\text { UNOFF } \\
\text { UNOFF }\end{array}$ & $\begin{array}{l}\text { Apache } \\
\text { Pima }\end{array}$ & $\begin{array}{l}343654 \mathrm{~N} 1091904 \mathrm{~W} \\
313208 \mathrm{~N} 1111842 \mathrm{~W}\end{array}$ & & & $\begin{array}{l}\text { St Johns North } \\
\text { Arivaca }\end{array}$ \\
\hline $\begin{array}{l}\text { Carr Lake } \\
\text { Carr Lake } \\
\text { Carr Lake Draw } \\
\text { Carr Lake Tank } \\
\text { Carr Mountain } \\
\text { Carroll Canyon } \\
\text { Carroll Catchment Tank } \\
\text { Carroll Spring } \\
\text { Carrol Tank } \\
\text { Carrol Well }\end{array}$ & $\begin{array}{l}\text { lake } \\
\text { lake } \\
\text { valley } \\
\text { reservoir } \\
\text { sumnit } \\
\text { valley } \\
\text { reservoir } \\
\text { spring } \\
\text { reservoir } \\
\text { well }\end{array}$ & $\begin{array}{l}\text { BGN } \\
\text { BGN } \\
\text { BGN } \\
\text { BGN } \\
\text { BGN } \\
\text { BGN } \\
\text { BGN } \\
\text { BGN } \\
\text { BGN } \\
\text { UNOFF }\end{array}$ & $\begin{array}{l}\text { Coconino } \\
\text { Navajo } \\
\text { Navajo } \\
\text { Navajo } \\
\text { Gila } \\
\text { Yavapai } \\
\text { Mohave } \\
\text { Gila } \\
\text { Mohave } \\
\text { Yavapai }\end{array}$ & $\begin{array}{l}342146 \mathrm{~N} 1105927 \mathrm{~W} \\
345041 \mathrm{~N} 1095537 \mathrm{~W} \\
344816 \mathrm{~N} 1100308 \mathrm{~W} \\
345048 \mathrm{~N} 1095545 \mathrm{~W} \\
334905 \mathrm{~N} 1105704 \mathrm{~W} \\
344936 \mathrm{~N} 1114834 \mathrm{~W} \\
363012 \mathrm{N1} 131818 \mathrm{~W} \\
340801 \mathrm{~N} 1105013 \mathrm{~W} \\
363217 \mathrm{N1} 130835 \mathrm{~W} \\
340756 \mathrm{~N} 1124136 \mathrm{~W}\end{array}$ & $\begin{array}{l}345015 N 1095136 \mathrm{~W} \\
345215 \mathrm{~N} 1114850 \mathrm{~W}\end{array}$ & 7619 & $\begin{array}{l}\text { Woods Canyon } \\
\text { Padilla Tank } \\
\text { Woodruff } \\
\text { Padilla Tank } \\
\text { Aztec Peak } \\
\text { Sedona } \\
\text { Russell Spring } \\
\text { Parallel Canyon } \\
\text { Moriah Knoll } \\
\text { Yarnell }\end{array}$ \\
\hline $\begin{array}{l}\text { Carr Peak } \\
\text { Carr Peak } \\
\text { Carr Peak - Canyon Loop } \\
\text { Carr Tank } \\
\text { Carruthers Canyon } \\
\text { Redrock Canyon } \\
\text { Carson Junior High School } \\
\text { Carson Junior High School } \\
\text { Carson Mesa } \\
\text { Carson Plains } \\
\text { See Sonoran Desert }\end{array}$ & $\begin{array}{l}\text { Summit } \\
\text { summit } \\
\text { trail } \\
\text { reservoir } \\
\text { valley } \\
\text { school } \\
\text { school } \\
\text { summit } \\
\text { plain }\end{array}$ & $\begin{array}{l}\text { BGN } \\
\text { BGN } \\
\text { UNOFF } \\
\text { BGN } \\
\text { BGN } \\
\text { VARIANT } \\
\text { UNOFF } \\
\text { UNOFF } \\
\text { BGN 1915 } \\
\text { VARIANT }\end{array}$ & $\begin{array}{l}\text { Cochise } \\
\text { Gila } \\
\text { Cochise } \\
\text { Coconino } \\
\text { Cochise } \\
\text { Pima } \\
\text { Maricopa } \\
\text { Apache } \\
\text { Maricopa }\end{array}$ & $\begin{array}{l}312446 \mathrm{~N} 1101814 \mathrm{~W} \\
334840 \mathrm{~N} 1105610 \mathrm{~W} \\
312605 \mathrm{~N} 1101641 \mathrm{~W} \\
352620 \mathrm{N11} 13408 \mathrm{~W} \\
321817 \mathrm{~N} 1101147 \mathrm{~W} \\
321108 \mathrm{~N} 1104930 \mathrm{~W} \\
332530 \mathrm{N11} 15059 \mathrm{~W} \\
363751 \mathrm{N1} 1093704 \mathrm{~W} \\
325500 \mathrm{~N} 1124000 \mathrm{~W}\end{array}$ & $322111 N 1100525 \mathrm{~W}$ & 7604 & $\begin{array}{l}\text { Miller Peak } \\
\text { Aztec Peak } \\
\text { Miller Peak } \\
\text { O'Leary Peak } \\
\text { Hookers Hot Springs } \\
\text { Tucson East } \\
\text { Mesa } \\
\text { Dancing Rocks }\end{array}$ \\
\hline $\begin{array}{l}\text { Cart Cabin Tank } \\
\text { Carter Canyon } \\
\text { See Middle Wash } \\
\text { Carter Canyon } \\
\text { Carter Canyon } \\
\text { Carter Canyon Number Thirty } \\
\text { four Trail } \\
\text { Carter Flat } \\
\text { Carter Flat Spring } \\
\text { Carter Lateral }\end{array}$ & $\begin{array}{l}\text { reservoir } \\
\text { stream } \\
\text { valley } \\
\text { valley } \\
\text { trail } \\
\text { flat } \\
\text { spring } \\
\text { canal }\end{array}$ & $\begin{array}{l}\text { BGN } \\
\text { VARIANT } \\
\text { BGN } \\
\text { BGN } \\
\text { UNOFF } \\
\text { BGN } \\
\text { BGN } \\
\text { BGN }\end{array}$ & $\begin{array}{l}\text { Coconino } \\
\text { Graham } \\
\text { Pima } \\
\text { Graham } \\
\text { Graham } \\
\text { Yavapai } \\
\text { Yavapai } \\
\text { Yuma }\end{array}$ & $\begin{array}{l}343134 N 1112104 \mathrm{~W} \\
325013 \mathrm{~N} 1095550 \mathrm{~W} \\
322618 \mathrm{N1} 104532 \mathrm{~W} \\
324709 \mathrm{~N} 1095832 \mathrm{~W} \\
324555 \mathrm{~N} 1095850 \mathrm{~W} \\
\\
342419 \mathrm{~N} 1125915 \mathrm{~W} \\
342405 \mathrm{~N} 1125916 \mathrm{~W} \\
323335 \mathrm{~N} 1144342 \mathrm{~W}\end{array}$ & $\begin{array}{l}322626 N 1104637 W \\
324352 N 1095927 W\end{array}$ & & $\begin{array}{l}\text { Long Valley } \\
\text { Mt Lemmon } \\
\text { Shingle Mill Mtn } \\
\text { Shingle Mill Mtn } \\
\text { Hillside } \\
\text { Hillside } \\
\text { Somerton }\end{array}$ \\
\hline $\begin{array}{l}\text { Carter Ranch } \\
\text { Carter Sawmill Spring } \\
\text { Carters Camp } \\
\quad \text { See Summerhaven } \\
\text { Carter Tank } \\
\text { Carter Tank } \\
\text { Carter Tank } \\
\text { Carter Windmill } \\
\text { Cart Ridge } \\
\text { Cartwright }\end{array}$ & $\begin{array}{l}\text { locale } \\
\text { spring } \\
\text { ppl } \\
\text { reservoir } \\
\text { reservoir } \\
\text { reservoir } \\
\text { locale } \\
\text { ridge } \\
\text { ppl }\end{array}$ & $\begin{array}{l}\text { UNOFF } \\
\text { BGN } \\
\text { VARIANT } \\
\text { BGN } \\
\text { BGN } \\
\text { BGN } \\
\text { BGN } \\
\text { BGN } \\
\text { BGN }\end{array}$ & $\begin{array}{l}\text { Yavapai } \\
\text { Grahan } \\
\text { Pima } \\
\text { Graham } \\
\text { Yavapai } \\
\text { Yavapai } \\
\text { Yavapai } \\
\text { Coconino } \\
\text { Maricopa }\end{array}$ & $\begin{array}{l}341740 \mathrm{~N} 1123324 \mathrm{~W} \\
324438 \mathrm{~N} 1095939 \mathrm{~W} \\
322619 \mathrm{~N} 1104533 \mathrm{~W} \\
324725 \mathrm{~N} 1095829 \mathrm{~W} \\
342222 \mathrm{~N} 1123455 \mathrm{~W} \\
345226 \mathrm{~N} 1125728 \mathrm{~W} \\
341812 \mathrm{N1} 124420 \mathrm{~W} \\
343530 \mathrm{~N} 1110522 \mathrm{~W} \\
332850 \mathrm{~N} 1121111 \mathrm{~W}\end{array}$ & & 1085 & $\begin{array}{l}\text { Walnut Grove } \\
\text { Webb Peak } \\
\text { Shingle Mill Mtn } \\
\text { Walnut Grove } \\
\text { Camp Wood } \\
\text { Peeples Valley } \\
\text { Leonard Canyon } \\
\text { Fowler }\end{array}$ \\
\hline $\begin{array}{l}\text { Cartwright Plaza Shopping } \\
\text { Center } \\
\text { Cartwright Ranch } \\
\text { Cartwright School } \\
\text { Carver High School } \\
\text { Carver Park } \\
\text { Carver School } \\
\text { Casa Adobes Shopping Plaza } \\
\text { Casa Blanca (historical) } \\
\text { Casa Blanca } \\
\text { A-vuc-hoo-mar-lish } \\
\text { Baaki } \\
\text { Bahki } \\
\text { Fort Barrett } \\
\text { Pima Villages } \\
\text { Whites Mill }\end{array}$ & $\begin{array}{l}\text { locale } \\
\text { locale } \\
\text { school } \\
\text { school } \\
\text { park } \\
\text { school } \\
\text { locale } \\
\text { locale } \\
\text { ppl }\end{array}$ & $\begin{array}{l}\text { UNOFF } \\
\text { UNOFF } \\
\text { UNOFF } \\
\text { UNOFF } \\
\text { ADMIN } \\
\text { UNOFF } \\
\text { UNOFF } \\
\text { BGN } \\
\text { BGN } \\
\text { VARIANT } \\
\text { VARIANT } \\
\text { VARIANT } \\
\text { VARIANT } \\
\text { VARIANT } \\
\text { VARIANT }\end{array}$ & $\begin{array}{l}\text { Maricopa } \\
\text { Maricopa } \\
\text { Maricopa } \\
\text { Maricopa } \\
\text { Yuma } \\
\text { Yuma } \\
\text { Pima } \\
\text { Santa Cruz } \\
\text { Pinal }\end{array}$ & $\begin{array}{l}332848 \mathrm{~N} 1121009 \mathrm{~W} \\
335748 \mathrm{~N} 1115156 \mathrm{~W} \\
332847 \mathrm{N1} 121102 \mathrm{~W} \\
332626 \mathrm{N1} 120403 \mathrm{~W} \\
324305 \mathrm{~N} 1143802 \mathrm{~W} \\
324302 \mathrm{N1} 143806 \mathrm{~W} \\
322010 \mathrm{N1} 105840 \mathrm{~W} \\
313600 \mathrm{N1} 104300 \mathrm{~W} \\
330713 \mathrm{~N} 1115315 \mathrm{~W}\end{array}$ & & 2540 & $\begin{array}{l}\text { Fowler } \\
\text { Humboldt Mtn } \\
\text { Fowler } \\
\text { Phoenix } \\
\text { Yuma West } \\
\text { Yuma West } \\
\text { Tucson North } \\
\text { Mt Hughes } \\
\text { Sacaton Butte }\end{array}$ \\
\hline $\begin{array}{l}\text { Casa Blanca Canal } \\
\text { Casa Blanca Church } \\
\text { Casa Blanca Interchange } \\
\text { Casa Blanca Plaza Shopping } \\
\text { Center } \\
\text { Casa de Francisco Mobile Home }\end{array}$ & $\begin{array}{l}\text { canal } \\
\text { church } \\
\text { crossing } \\
\text { locale } \\
\text { locale }\end{array}$ & $\begin{array}{l}\text { BGN } \\
\text { UNOFF } \\
\text { UNOFF } \\
\text { UNOFF } \\
\text { UNOFF }\end{array}$ & $\begin{array}{l}\text { Pinal } \\
\text { Pinal } \\
\text { Pinal } \\
\text { Pima } \\
\text { Maricopa }\end{array}$ & $\begin{array}{l}330439 N 1114335 \mathrm{~W} \\
330716 \mathrm{~N} 1115454 \mathrm{~W} \\
330704 \mathrm{~N} 1115028 \mathrm{~W} \\
321859 \mathrm{~N} 1105829 \mathrm{~W} \\
332220 \mathrm{~N} 1120410 \mathrm{~W}\end{array}$ & & $\begin{array}{l}2450 \\
1220\end{array}$ & $\begin{array}{l}\text { Sacaton } \\
\text { Sacaton Butte } \\
\text { Gila Butte } \\
\text { Tucson North } \\
\text { Lone Butte }\end{array}$ \\
\hline $\begin{array}{l}\text { Casa del Oro } \\
\text { Casa del Sol Resorts (trailer }\end{array}$ & $\begin{array}{l}\text { locale } \\
\text { locale }\end{array}$ & $\begin{array}{l}\text { BGN } \\
\text { UNOFF }\end{array}$ & $\begin{array}{l}\text { Pinal } \\
\text { Maricopa }\end{array}$ & $\begin{array}{l}323439 \mathrm{~N} 110503 \mathrm{BW} \\
333505 \mathrm{~N} 1121215 \mathrm{~W}\end{array}$ & & 1170 & $\begin{array}{l}\text { Oracle } \\
\text { Glendale }\end{array}$ \\
\hline
\end{tabular}


NATIONAL GAZETTEER--ARIZONA 1986

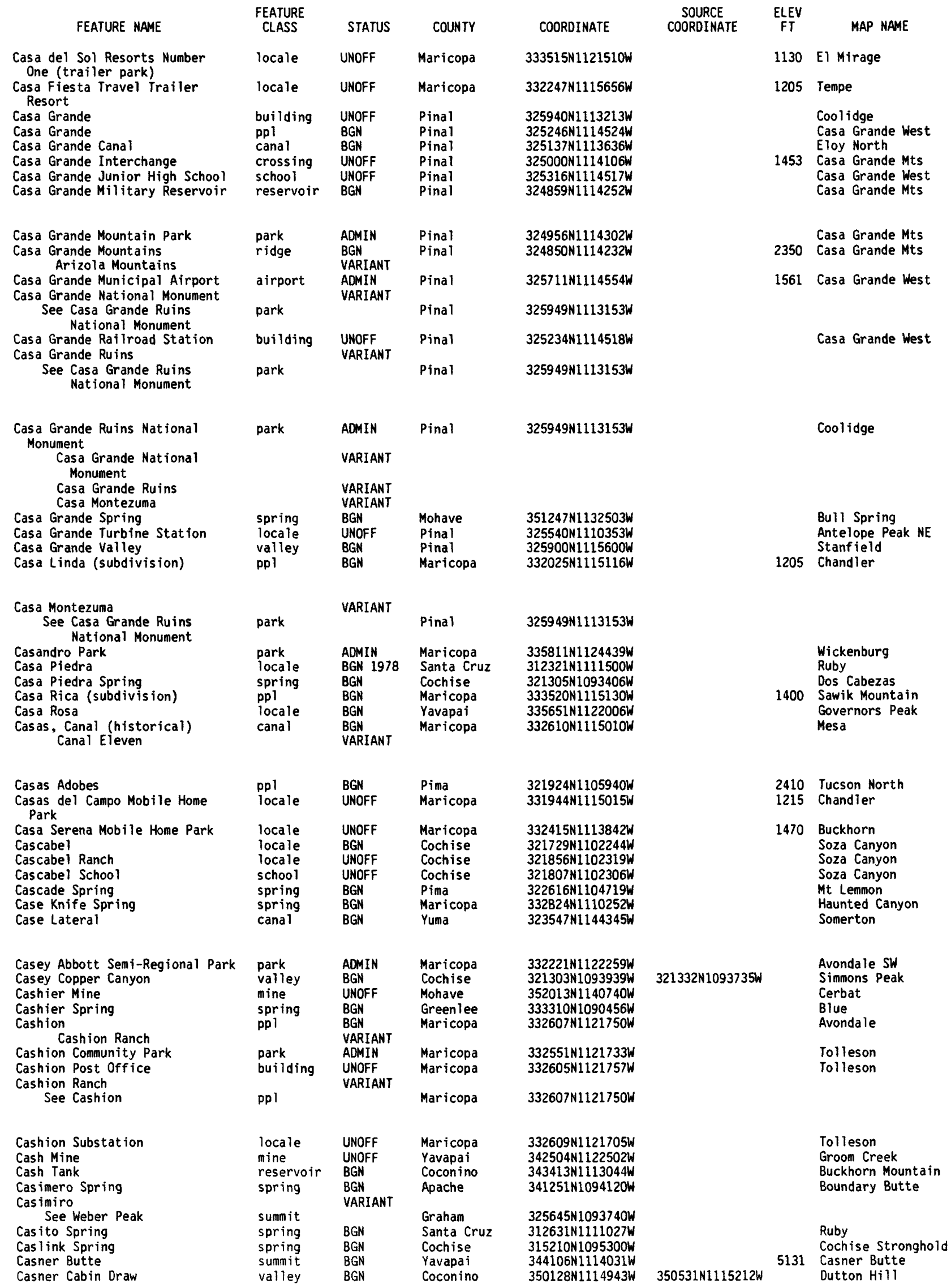




\section{FEATURE NAME}

Casner Canyon

Casner Canyon

Casner Canyon Eleven Trail

Casner Canyon Tank

Casner Mountain

Casner Mountain Tank

Casner Mountain Tank

Casner Mountain Trail Eight

Casner Park

Casner Park

Casner Park Tank

Casner Tank

Casner Tank

Casner Tank

Casper Spring Tank
Cassadore Creek Natural Corral Creek

Cassadore Mountain

Cassadore Spring

Cassadore Tank

\section{Cassidy Spring}

$$
\text { Cathey Spring }
$$

Castaneda Hills

Castaneda Peak

Castaneda Wash

Castaneda Well

Castanera Spring

$$
\text { Canary Well }
$$

Castersen Seep

Castillo Nuevo Mobile Home Park

Castle Butte

Castle Butte

Castle Butte

See Castle Buttes

Castle Butte

Castle Butte

$$
\text { See Dilkon }
$$

Castle Buttes

Castle Butte

Castle Butte Tank

Castle Butte Wash

See Coyote Wash

Castle Canyon

Castle Canyon

Castle Canyon Mesa

(subdivision)

Castle Creek

Castle Creek

Castle Creek

Castle Creek Cabin

Castle Creek Trail

Castle Dome

Castle Dome

Castle Dome

See Castle Dome Peak

Castle Dome

Cast le Dome Mountain

Castle Dome

See Castle Dome Landing

Castle Dome AHP

Castle Dome City

See Castle Dome Landing

Castle Dome Concentrator

Castle Dome County

See Yuma County

Castle Dome Landing

Castle Dome

Castle Dome City

Castle Dome Mine

Castle Dome Mine

Castle Dome Mountain

\section{FEATURE
CLASS}

STATUS

COUNTY

valley
valley
trail
reservoir
summit
reservoir
reservoir
trail
flat
flat

\section{$B G N$}

UNOFF

BGN

$B G N$
$B G N$
$B G N$

UNOFF

BGN

flat

reservoir

reservoir

reservoir

reservoir

reservoir

stream

summit

spring

reservoir

BGN

BGN

BGN

BGN

VARIANT

BGN

$B G N$

BGN

spring

BGN 1975

VARIANT

summit

summit

stream

wel

spring

spring

locale

BGN

$B G N$

BGN

UNOFF

BGN 1976

VARIANT

BGN
UNOFF

Coconino

Yavapai

Yavapai

Yavapai

Yavapai

Yavapai

Coconino

Coconino

Coconino

Coconino

Coconino

Coconino

Cochise

Gila

Gila

Gila

Gila

summit

summit

BGN

BGN

VARIANT

summit

locale

BGN

VARIANT

locale

summit

BGK

VARIANT

reservoir BGK

Graham

Mohave

Mohave

Mohave

Mohave

Cochise

Gila

Marícopa

Santa Cruz

Navajo

Coconino

Navajo

Navajo

Coconino

Gila

COORDINATE

$344047 \mathrm{~N} 1114106 \mathrm{~W}$ $345337 \mathrm{~N} 1114348 \mathrm{~W}$ $345333 N 1114312 \mathrm{~W}$ 344133 N1113949W 345656 N1115910W $345530 N_{11} 15903 \mathrm{~W}$ $345720 \mathrm{~N} 1115858 \mathrm{~W}$ $345643 N 1115907 \mathrm{~W}$ $344124 N 1112550 \mathrm{~W}$ $345538 \mathrm{~N} 1113457 \mathrm{~W}$

$345533 N 1113511 \mathrm{~W}$ $350153 N 1110932$ $350328 N 1115057 \mathrm{~W}$ $350346 \mathrm{~N} 1115447 \mathrm{~W}$ $312910 \mathrm{~N} 1090436 \mathrm{~W}$ 332904 NI102452W

$332930 \mathrm{~N} 1102237 \mathrm{~W}$

$333043 \mathrm{~N} 1102400 \mathrm{~W}$

$333117 \mathrm{NI} 102418 \mathrm{~W}$

$323525 N 1101407 \mathrm{~W}$

$342517 N 1135742 \mathrm{~W}$ 342556 N1135738W

$341540 \mathrm{~N} 1135633 \mathrm{~W}$ $342604 N 1135414 \mathrm{~W}$

$315216 \mathrm{~N} 1102223 \mathrm{~W}$

$340526 \mathrm{~N} 1112757 \mathrm{~W}$

332436 NI114535W

$313216 \mathrm{~N} 1104719 \mathrm{~W}$

351937 NI $102411 \mathrm{~W}$

361053N1110932W

$351817 \mathrm{~N} 1102053 \mathrm{~W}$

$352307 N 1101912 \mathrm{~W}$

361053 NI110932

335615 NI 105130W

VARIANT

valley

valley

valley

ppl

BGN 1932 Coconino

BGN

$B G N$

Coconino

stream

stream

stream

BGN

BGN

BGN

Greenlee

Yavapai

Yavapa

Yavapai

trail

UNOFF

BGN

Yavapai

summit

summit

summit

VARIANT

Yuma

BGN 1932 Maricopa

VARIANT

locale

airport

ADMIN

Yuma

Yuma

VARIANT

locale

building

UNOFF VARIANT

civil

locale

BGN

VARIANT

VARIANT

mine UNOFF

mine UNOFF

Yuma

Gila

Yuma
Yuma

Yuma

Gila

VARIANT

$\begin{array}{cc}\text { SOURCE } & \text { ELEV } \\ \text { COORDINATE } & \text { FT MAP NAME }\end{array}$

$\begin{array}{ll}344221 N 1113845 \mathrm{~W} & \begin{array}{l}\text { Casner Butte } \\ \text { 345259N1114202W }\end{array} \\ \text { Munds Park } \\ \text { Munds Park } \\ \text { Casner Butte } \\ \text { Loy Butte } \\ \text { Loy Butte } \\ \text { Loy Butte } \\ \text { Loy Butte } \\ \text { Happy Jack } \\ \text { Mormon Mountain }\end{array}$

Mormon Mountain Anderson Canyon Dutton $\mathrm{Hill}$

Sycamore Point

333405N1102447W $\quad \begin{aligned} & \text { Guadalupe Spring } \\ & \text { Natural Corral }\end{aligned}$

4637 Natural Corral

4031 Cassadore Spring

Cassadore Spring

Harrison Canyon

Castaneda Hills

342939 N1135420W

Castaneda Hills SW Castaneda Hills

5170 McGrew Spring

Mazatzal Peak

1270 Mes

Patagonia

6491 Chimney Butte

French Butte

Tuba City 
NATIONAL GAZETTEER--ARIZONA 1986

\begin{tabular}{|c|c|c|c|c|c|c|c|}
\hline FEATURE NAME & $\begin{array}{l}\text { FEATURE } \\
\text { CLASS }\end{array}$ & STATUS & COUNTY & COORDINATE & $\begin{array}{l}\text { SOURCE } \\
\text { COORDINATE }\end{array}$ & $\begin{array}{l}\text { ELEV } \\
\text { FT }\end{array}$ & MAP NAME \\
\hline $\begin{array}{l}\text { See Castle Done } \\
\text { Castle Dome Mountains } \\
\text { Cabeza de Gigante } \\
\text { Capital Dome Mountains } \\
\text { Capitol Dome Mountains } \\
\text { Castle Dome Range } \\
\text { Castle Dome Peak } \\
\text { Castle Dome } \\
\text { Castle Dome Plain }\end{array}$ & $\begin{array}{l}\text { summit } \\
\text { plain }\end{array}$ & $\begin{array}{l}\text { BGN } \\
\text { VARIANT } \\
\text { VARIANT } \\
\text { VARIANT } \\
\text { VARIANT } \\
\text { BGN } \\
\text { VARIANT } \\
\text { BGN }\end{array}$ & $\begin{array}{l}\text { Maricopa } \\
\text { Yuma }\end{array}$ & $\begin{array}{l}330504 N 1140833 \mathrm{~W} \\
325150 \mathrm{~N} 1141135 \mathrm{~W}\end{array}$ & & 3788 & $\begin{array}{l}\text { Castle Dome Peak } \\
\text { Red Bluff Mtn West }\end{array}$ \\
\hline $\begin{array}{l}\text { Castle Dome Ranch } \\
\text { Castle Dome Range }\end{array}$ & locale & $\begin{array}{l}\text { UNOFF } \\
\text { VARIANT }\end{array}$ & Cochise & $313213 \mathrm{~N} 1092706 \mathrm{~W}$ & & & Pedregosa Mts West \\
\hline $\begin{array}{l}\text { See Castle Dome Mountains } \\
\text { Castle Dome Wash } \\
\text { Castle Hot Springs } \\
\text { Castle Hot Springs Station } \\
\text { Castle Lake } \\
\text { Castle Mountains } \\
\quad \text { Cimarron Mountains }\end{array}$ & $\begin{array}{l}\text { range } \\
\text { stream } \\
\text { ppl } \\
\text { building } \\
\text { lake } \\
\text { summit }\end{array}$ & $\begin{array}{l}\text { BGN } \\
\text { BGN } \\
\text { UNOFF } \\
\text { BGN } 1932 \\
\text { BGN } 1964 \\
\text { VARIANT }\end{array}$ & $\begin{array}{l}\text { Yuma } \\
\text { Yuma } \\
\text { Yavapai } \\
\text { Maricopa } \\
\text { Coconino } \\
\text { Pima }\end{array}$ & $\begin{array}{l}330504 N 1140834 \mathrm{~W} \\
324551 \mathrm{N1} 142333 \mathrm{~W} \\
335900 \mathrm{~N} 1122135 \mathrm{~W} \\
335101 \mathrm{~N} 1123715 \mathrm{~W} \\
362036 \mathrm{~N} 1121 \mathrm{~B} 11 \mathrm{~W} \\
322433 \mathrm{~N} 1121349 \mathrm{~W}\end{array}$ & $330022 \mathrm{~N} 1141735 \mathrm{~W}$ & & $\begin{array}{l}\text { Laguna Dam } \\
\text { Governors Peak } \\
\text { Wittmann } \\
\text { King Arthur Castle } \\
\text { Ventana }\end{array}$ \\
\hline Castle Peak & summit & $B G N$ & Gila & $335656 \mathrm{~N} 110501 \mathrm{BW}$ & & 6287 & Rock House \\
\hline $\begin{array}{l}\text { Castle Peak } \\
\text { Castle Point } \\
\text { Castle Reef } \\
\text { Castle Rock } \\
\text { Castle Rock } \\
\text { Castle Rock } \\
\text { Castle Rock } \\
\text { Castle Rock } \\
\text { Castle Rock } \\
\text { Castle Rock }\end{array}$ & $\begin{array}{l}\text { summit } \\
\text { cliff } \\
\text { bar } \\
\text { cliff } \\
\text { pillar } \\
\text { pillar } \\
\text { pillar } \\
\text { pillar } \\
\text { summit } \\
\text { summit }\end{array}$ & $\begin{array}{l}\text { BGN } \\
\text { BGN } \\
\text { BGN } 1948 \\
\text { BGN } \\
\text { BGN } \\
\text { BGN } \\
\text { BGN } \\
\text { BGN } \\
\text { BGN } \\
\text { BGN }\end{array}$ & $\begin{array}{l}\text { Mohave } \\
\text { Coconino } \\
\text { Mohave } \\
\text { Cochise } \\
\text { Greenlee } \\
\text { Yavapai } \\
\text { Mohave } \\
\text { Mohave } \\
\text { Santa Cruz } \\
\text { Yavapai }\end{array}$ & $\begin{array}{l}361102 \mathrm{~N} 1133405 \mathrm{~W} \\
363431 \mathrm{N1121955W} \\
360326 \mathrm{~N} 1144348 \mathrm{~W} \\
312632 \mathrm{~N} 1095502 \mathrm{~W} \\
333955 \mathrm{~N} 1091245 \mathrm{~W} \\
340701 \mathrm{~N} 1122842 \mathrm{~W} \\
343353 \mathrm{~N} 1142332 \mathrm{~W} \\
351437 \mathrm{~N} 1140734 \mathrm{~W} \\
312259 \mathrm{~N} 1110607 \mathrm{~W} \\
340938 \mathrm{~N} 1122150 \mathrm{~W}\end{array}$ & & $\begin{array}{l}8 B 61 \\
4634 \\
4503\end{array}$ & $\begin{array}{l}\text { Castle Peak } \\
\text { Big Springs } \\
\text { Hoover Dam } \\
\text { Bisbee } \\
\text { Beaverhead } \\
\text { Copperopolis } \\
\text { Castle Rock } \\
\text { Kingman NW } \\
\text { Pena Blanca Lake } \\
\text { Crown King }\end{array}$ \\
\hline $\begin{array}{l}\text { Castle Rock } \\
\text { Castle Rock } \\
\text { Castle Rock Bay } \\
\text { Castle Rock Dam } \\
\text { Castle Rocks (historical) } \\
\text { Towers of Cibola } \\
\text { Castle Rocks } \\
\text { Castle Rock Spring } \\
\text { Castle Rock Tank } \\
\text { Castle Rock Tank }\end{array}$ & $\begin{array}{l}\text { summit } \\
\text { summit } \\
\text { bay } \\
\text { dam } \\
\text { summit } \\
\text { summit } \\
\text { spring } \\
\text { reservoir } \\
\text { reservoir }\end{array}$ & $\begin{array}{l}\text { BGN } \\
\text { BGN } \\
\text { BGN } \\
\text { UNOFF } \\
\text { BGN 1917 } \\
\text { VARIANT } \\
\text { BGN } \\
\text { BGN } \\
\text { BGN } \\
\text { BGN }\end{array}$ & $\begin{array}{l}\text { Yuma } \\
\text { Yavapai } \\
\text { Mohave } \\
\text { Yuma } \\
\text { Maricopa } \\
\text { Coconino } \\
\text { Yavapai } \\
\text { Pima } \\
\text { Yuma }\end{array}$ & $\begin{array}{l}341520 \mathrm{~N} 1140727 \mathrm{~W} \\
343818 \mathrm{~N} 1125409 \mathrm{~W} \\
343350 \mathrm{~N} 1142338 \mathrm{~W} \\
330245 \mathrm{~N} 1140436 \mathrm{~W} \\
\text { UNKNOWN } \\
360916 \mathrm{~N} 1111302 \mathrm{~W} \\
340648 \mathrm{~N} 1122850 \mathrm{~W} \\
313143 \mathrm{~N} 1112539 \mathrm{~W} \\
330245 \mathrm{~N} 1140436 \mathrm{~W}\end{array}$ & & 1150 & $\begin{array}{l}\text { Tuba City } \\
\text { Copperopolis } \\
\text { Wilbur Canyon } \\
\text { Slumgullion Pass }\end{array}$ \\
\hline $\begin{array}{l}\text { Castle Spring } \\
\text { Castle Tank } \\
\text { Castle Temple }\end{array}$ & $\begin{array}{l}\text { spring } \\
\text { reservoir }\end{array}$ & $\begin{array}{l}\text { BGN } \\
\text { BGN } \\
\text { VARIANT }\end{array}$ & $\begin{array}{l}\text { Coconino } \\
\text { Santa Cruz }\end{array}$ & $\begin{array}{l}363510 \mathrm{~N} 1122029 \mathrm{~W} \\
312700 \mathrm{~N} 111052 \mathrm{BW}\end{array}$ & & & $\begin{array}{l}\text { Big Springs } \\
\text { Pena Blanca Lake }\end{array}$ \\
\hline $\begin{array}{c}\text { See Castor Temple } \\
\text { Castor Temple } \\
\text { Castle Temple }\end{array}$ & $\begin{array}{l}\text { summit } \\
\text { summit }\end{array}$ & $\begin{array}{l}\text { BGN } 1964 \\
\text { VARIANT }\end{array}$ & $\begin{array}{l}\text { Coconino } \\
\text { Coconino }\end{array}$ & $\begin{array}{l}360735 \mathrm{~N} 1121915 \mathrm{~W} \\
360735 \mathrm{~N} 1121915 \mathrm{~W}\end{array}$ & & 6215 & Havasupai Point \\
\hline $\begin{array}{l}\text { Catalina } \\
\quad \text { Vista Catalina }\end{array}$ & ppl & $\begin{array}{l}\text { BGN } 1981 \\
\text { VARIANT }\end{array}$ & Pima & $323000 \mathrm{~N} 1105514 \mathrm{~W}$ & & & Oro Valley \\
\hline $\begin{array}{l}\text { Catalina Camp } \\
\text { Catalina Foothills }\end{array}$ & $\begin{array}{l}\text { locale } \\
\text { ppl }\end{array}$ & $\begin{array}{l}\text { BGN } \\
\text { BGN }\end{array}$ & $\begin{array}{l}\text { Pima } \\
\text { Pima }\end{array}$ & $\begin{array}{l}322854 \mathrm{~N} 1104529 \mathrm{~W} \\
321752 \mathrm{~N} 1105505 \mathrm{~W}\end{array}$ & & 2580 & $\begin{array}{l}\text { Mt Lemmon } \\
\text { Tucson North }\end{array}$ \\
\hline $\begin{array}{c}\text { Catalina Foothills School } \\
\text { Murphey School }\end{array}$ & school & $\begin{array}{l}\text { UNOFF } \\
\text { VARIANT }\end{array}$ & Pima & $321715 \mathrm{~N} 1105623 \mathrm{~W}$ & & & Tucson North \\
\hline $\begin{array}{l}\text { Catalina High School } \\
\text { Catalina Junior High School } \\
\text { Catalina Park } \\
\text { Catalina Ravine } \\
\text { Catalina School } \\
\text { Catalina Tank } \\
\text { Catalina Village (trailer park) } \\
\text { Catalina Wash }\end{array}$ & $\begin{array}{l}\text { school } \\
\text { school } \\
\text { park } \\
\text { valley } \\
\text { school } \\
\text { reservoir } \\
\text { locale } \\
\text { stream }\end{array}$ & $\begin{array}{l}\text { UNOFF } \\
\text { UNOFF } \\
\text { ADMIN } \\
\text { BGN } \\
\text { UNOFF } \\
\text { BGN } \\
\text { UNOFF } \\
\text { BGN }\end{array}$ & $\begin{array}{l}\text { Pima } \\
\text { Pima } \\
\text { Pima } \\
\text { Pinal } \\
\text { Maricopa } \\
\text { Pinal } \\
\text { Maricopa } \\
\text { Pinal }\end{array}$ & $\begin{array}{l}321442 \mathrm{~N} 1105454 \mathrm{~W} \\
321503 \mathrm{~N} 1105530 \mathrm{~W} \\
321401 \mathrm{~N} 1105757 \mathrm{~W} \\
323544 \mathrm{~N} 1105225 \mathrm{~W} \\
333151 \mathrm{~N} 1120823 \mathrm{~W} \\
323547 \mathrm{~N} 1105145 \mathrm{~W} \\
332735 \mathrm{~N} 1120846 \mathrm{~W} \\
323444 \mathrm{~N} 1103108 \mathrm{~W}\end{array}$ & $\begin{array}{l}323557 \mathrm{~N} 1105120 \mathrm{~W} \\
323044 \mathrm{~N} 1104335 \mathrm{~W}\end{array}$ & 1065 & $\begin{array}{l}\text { Tucson } \\
\text { Tucson North } \\
\text { Tucson } \\
\text { Oracle } \\
\text { Glendale } \\
\text { Oracle } \\
\text { Fowler } \\
\text { Peppersauce Wash }\end{array}$ \\
\hline $\begin{array}{l}\text { Catalina Well } \\
\text { Cataract Canyon } \\
\text { Cataract Canyon } \\
\text { Cactus Canyon } \\
\text { Havasu Canyon } \\
\text { Cataract Canyon }\end{array}$ & $\begin{array}{l}\text { well } \\
\text { valley } \\
\text { valley }\end{array}$ & $\begin{array}{l}\text { UNOFF } \\
\text { BGN } \\
\text { BGN } 1964 \\
\text { VARIANT } \\
\text { VARIANT } \\
\text { VARIANT }\end{array}$ & $\begin{array}{l}\text { Pinal } \\
\text { Gila } \\
\text { Coconino }\end{array}$ & $\begin{array}{l}323407 N 1105519 \mathrm{~W} \\
335453 N 1110227 \mathrm{~W} \\
361248 \mathrm{~N} 1124059 \mathrm{~W}\end{array}$ & $\begin{array}{l}335648 \mathrm{~N} 1110444 \mathrm{~W} \\
351216 \mathrm{~N} 112113 \mathrm{BW}\end{array}$ & & $\begin{array}{l}\text { Oracle Junction } \\
\text { Copper Mtn } \\
\text { Supai }\end{array}$ \\
\hline $\begin{array}{c}\text { See National Canyon } \\
\text { Cataract Creek } \\
\text { Cedar Creek } \\
\text { Havasu Creek }\end{array}$ & $\begin{array}{l}\text { valley } \\
\text { stream }\end{array}$ & $\begin{array}{l}8 \mathrm{GN} \\
\text { VARIANT } \\
\text { VARIANT }\end{array}$ & $\begin{array}{l}\text { Coconino } \\
\text { Coconino }\end{array}$ & $\begin{array}{l}361524 N 1125329 \mathrm{~W} \\
361300 \mathrm{~N} 1124110 \mathrm{~W}\end{array}$ & $351215 N 1121139 \mathrm{~W}$ & & Supai \\
\hline $\begin{array}{l}\text { Cataract Creek } \\
\text { See Havasu Creek }\end{array}$ & strean & VARIANT & Coconino & $361828 N 1124540 \mathrm{~W}$ & & & \\
\hline
\end{tabular}




\section{FEATURE NAME}

Cataract Lake

Cataract Lake Campground

Cataract Pumping Station

Cataract Tank

Cataract Tank

Cataract Well

Cat Canyon

Catch Bas in

Cat Claw Spring

Catclaw Tank

Cat Creek

Caterpillar Proving Grounds

See White Tanks Proving Grounds

Caterpillar Tank

Caterpillar Tank

Catfish Paradise

Catfish Tank

Cathedral Caves

Cathedral Cove

See Wishing Well Cove

Cathedral Rock

Cathedral Rock

Cathedral Rock Sunset Rock

Cathedral Rock

Cathedral Rock

Cathedral Rock

See Copperosity Hills

Cathedral Rock

Cathedral Rock Court House Rock

Cathedral Rock

See Five Mile Point

Cathedral Stairs

Cathedral Tank

Cathedral Wash

Cathey Spring

See Cassidy Spring

Cat Hills

Cat Hills Tank

Cathol ic Peak

Catholic Peak Tank

Cat Mountain

Cat Spring

Cattail Rush

Cattail Spring

Cattail Spring

Cattail Wash

Cattail Well

Cat Tank

Cat Tank

Cat Tank

Cat Tank

Cattle Canyon

Cattle Guard Pond

Cattle Guard Tank

Cattleguard Well

Cat Track Tank

Cattrack Tank

Caufman Tank

Cautiva Tank

Cavalay Park

Cavalliere Ranch

Cave Buttes Dam

Cave Buttes Recreation Area

Cave Canyon

Cave Canyon

Cave Canyon

Cholla Canyon
FEATURE
CLASS

STATUS

COUNTY

lake

park

reservoir

well

valley

well

BGN 1964

ADMIN

Coconino

Coconino

$B G N$

BGN

UNOFF

UNOFF

Gila

Coconino

Coconino

Graham

Yuma

spring BGN

reservoir

BGN
BGN

BGN

VARIANT

locale

reservoir

reservoir

locale

reservoir $B G$

cave $B G N$

bay

pillar

pillar
pillar

summit

summit

summit

$$
\text { VARIANT }
$$

Gila

Yavapai

Greenlee

Maricopa

BGN

BGN

Maricopa

Yavapai

Mohave

Gila

Yavapai

Mohave

$B G N$

BGN

BGN 1969

VARIANT

BGN

BGN

VARIANT

summit

summit

BGN

BGN

VARIANT

summit

cliff

reservoir

arroyo

BGN

Yavapai

VARIANT

spring

summit

reservoir

summit

reservoir

summit

spring

spring

spring

spring

valley

BGN
$B G N$
$B G N$
$B G N$
$B G N$
$B G N$
$B G$
$B G$
$B G$
$B G$

well

reservoir

reservoir

reservoir

reservoir

valley

lake

reservoir

well

reservoir

UNOFF

BGN

BGN
BGN

BGN

$B G N$
$B G N$
$B G N$

UNOFF

BGN

reservoir

reservoir

reservoir

ppl

locale

dam

park

valley

valley

valley

BGN

BGN

$B G N$

BGN
UNOFF

UNOFF

AOMIN

BGN

BGN 1962

BARIANT

Pina

Pinal

Gila

Gila

Navajo

Navajo

Mohave
Coconino

Apache

Coconino

Pima

Graham

Coconino

Coconino

Navajo

Mohave

Gila

Yavapai

Pima

Coconino

Coconino

Santa Cruz

Cochise

Mohave

Maricopa

Maricopa

Cochise

Pinal

Gila

valley

BGN

Navajo

COOROIMATE

$351502 \mathrm{~N} 1121257 \mathrm{~W}$

$351458 \mathrm{N1} 121249 \mathrm{~W}$

$353130 \mathrm{~N} 1120957 \mathrm{~K}$

$335633 N 1110346 \mathrm{~W}$

$352727 \mathrm{~N} 1121717 \mathrm{~W}$ $355741 \mathrm{~N} 1122319 \mathrm{~W}$ $325344 N 1092831 \mathrm{~W}$ $322423 \mathrm{~N} 1135535 \mathrm{~W}$

$335442 N 1102614$

341757 N1131813

334411 N1090642W

$332956 \mathrm{~N} 1122958 \mathrm{~W}$

$334642 \mathrm{~N} 1121902 \mathrm{~W}$

$352259 \mathrm{~N} 1125911 \mathrm{~W}$

$344442 N 1142912 W$

334456 N1095B18W

$350736 N 1123454 W$

$360830 \mathrm{~N} 1143452 \mathrm{~W}$

$322309 N 1105034 \mathrm{~W}$

$350348 \mathrm{~N} 1142705 \mathrm{~W}$

$364942 \mathrm{~N} 111382 \mathrm{OW}$

$315324 N 1090933 \mathrm{~W}$

$323241 \mathrm{~N} 1121047 \mathrm{~W}$

323242N1121124W

$343921 N 1142715 \mathrm{~W}$

$344912 N 1114733 \mathrm{~W}$

364920 N1113830W

$360453 \mathrm{~N} 1121153 \mathrm{~W}$

$350746 \mathrm{~N} 1123532 \mathrm{~W}$

$365018 \mathrm{~N} 1113700 \mathrm{~W}$

323525N1101407W

325759 N1111415W

$325924 \mathrm{~N} 1111520 \mathrm{~W}$

$340319 \mathrm{~N} 1105123 \mathrm{~W}$

$340331 \mathrm{~N} 1105024 \mathrm{~W}$

$321103 \mathrm{~N} 1110337 \mathrm{~W}$

$355854 \mathrm{~N} 1101535 \mathrm{~W}$

$340402 \mathrm{~N} 1100525 \mathrm{~W}$

$342609 \mathrm{~N} 1133133 \mathrm{~W}$

$361350 \mathrm{~N} 1111509 \mathrm{~W}$

360449 N1090856W

361347 N1111510W

$321204 N 1111827 \mathrm{~W}$

$324341 N 1092238 \mathrm{~W}$

$345015 \mathrm{~N} 1113819 \mathrm{~W}$

$350825 \mathrm{~N} 1120310 \mathrm{~W}$

$365810 \mathrm{~N} 1103240 \mathrm{~W}$

$364453 \mathrm{~N} 1130441 \mathrm{~W}$

$333643 \mathrm{~N} 110195 \mathrm{BW}$

$342442 \mathrm{~N} 1120221 \mathrm{~W}$

321709 N1104155W

344931 N1112323W

$354722 \mathrm{~N} 1130702 \mathrm{~W}$

$312036 \mathrm{~N} 1105225 \mathrm{~W}$

$313308 \mathrm{~N} 1102145 \mathrm{~W}$

$345233 \mathrm{~N} 1135841 \mathrm{~W}$

333936 N112051BW

$334358 \mathrm{~N} 1120217 \mathrm{~W}$

$312008 \mathrm{~N} 1102300 \mathrm{~W}$ 
NATIONAL GAZETTEER--ARIZONA 1986 FEATURE NAME

FEATURE
CLASS

Cave Canyon

Columbine Canyon

Cave Canyon Trail One Hundred
Forty-Seven

Cave Creek

Cave Creek

South Fork Cave Creek

Cave Creek

Cave Creek

Cave Creek

Cave Creek

Little Maggie May

Cave Creek

Cave Creek (subdivision)

Cave Creek Cavecreek

Cavecreek

See Cave Creek

Cave Creek Campground

Cave Creek Canyon

Cave Creek Cemetery

Cave Creek Dam

Cave Creek Park

Cave Creek Post Office

Cave Creek Ranger Station

Cave Creek Recreation Area

Cave Creek Recreation Area Cave Creek

Semi-regional Park

Cave Creek Reservoir

Cave Creek School

Cave Creek Semi-regional Park See Cave Creek Recreation Area

Cave Creek Spring

Cave Draw

Oak Spring Draw

Cave Draw Tank

Cave Hill

See 01d Caves Crater

Cave Mountain

Cave Mountain

Cave Ridge

Cave Road Tank

Cave Ruin

Cave Spring

Cave Spring

Cave Spring

Cave Spring

Cave Spring

Cave Spring

Cave Spring

Cave Spring

Cave Spring

Cave Spring Campground

Cave Spring Rapids

Cave Tank

Cave Tank

Cave Tank

Cave Tank

Cavett School

Cave Wash

Caviglia Tank

Cavness Hole Canvas Hole

Cavness Ranch

Cavness Spring

$$
\text { Canvas Spring }
$$

Cavot Interchange

Cayetano Mountains

See San Cayetano Mountains valle

trail

stream

stream

strean

stream

stream

strean

stream

ppl

ppl

ppl

ppl
park

valley

cemetery

dam

park

building

locale

park

park

STATUS

COUNTY

GGN 1948 Mohave

VARIANT

UNOFF

Santa Cruz

BGN

BGN 1959

VARIANT

BGN

BGN

Santa Cruz

Cochise

Graham

Green lee

BGN Yuma

BGN 1968 Maricopa

VARIANT

BGN

BGM

BGN 1968 Maricopa

VARIANT

VARIANT

ADMIN

Maricopa

Maricopa

BGN

UNOFF
UNOFF

UNOFF

ADMIN

UNOFF

UNOFF

ADMIN

ADMIN

Cochise

Maricopa

Maricopa

Maricopa

Maricopa

Maricopa

Cochise

Maricopa

VARIANT

$$
\begin{aligned}
& \text { rese } \\
& \text { schoo } \\
& \text { park } \\
& \text { spri } \\
& \text { vall } \\
& \text { rese } \\
& \text { crat }
\end{aligned}
$$

$\begin{array}{ll}\text { summit } & \text { BGN } 1941 \\ \text { summit } & B G N\end{array}$

$\begin{array}{ll}\text { ridge } & B G N \\ \text { reservoir } & B G N\end{array}$

locale $B G N$

locale

spring

spring

spring

spring

BGN

BGN

BGN

BGN

spring

spring

spring

spring

park

rapids

reservoir

reservoir

reservoir

reservoir

BGN
BGN
BGN
BGN
ADNI
BGN
BGN
BGN
BGN
BGN

schoo

stream

reservoir

bas in

UNOF

locale

spring

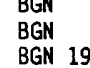

BGN 1980
VARIANT

VARIANT

BGN 19B0

VARIANT

crossing UNOFF

VARIANT.

summit summit BGN

COORDINATE

360529N1135514W

314247 N1104921W

$314308 \mathrm{N1104530 \textrm {W }}$

315820N1090300W

$324545 N 1094750 \mathrm{~W}$

$331152 \mathrm{~N} 1091922 \mathrm{~W}$

$333128 \mathrm{~N} 1140637 \mathrm{~W}$ $333400 \mathrm{~N} 1120630 \mathrm{~W}$

$334503 \mathrm{~N} 1101421 \mathrm{~W}$

$333700 \mathrm{~N} 1120205 \mathrm{~W}$

335000N1115700W

$335000 \mathrm{~N} 1115700 \mathrm{~W}$

335831N1115157W

315346 N1090947W

334859 N1115324

334332N1120247W

$333601 N 11206364$

$334953 \mathrm{~N} 1115648 \mathrm{~W}$

$335101 N 1114933 \mathrm{~W}$

$315320 \mathrm{~N} 1091006 \mathrm{~W}$

$335010 \mathrm{~N} 1115900 \mathrm{~W}$

315301N1091030W

$\begin{array}{lc}\text { SOURCE } & \text { ELEV } \\ \text { COORDINATE } & \text { FT }\end{array}$

MAP NAME

360226N1135530W Columbine Falls

Mt Wrightson

Mt Wrightson

Portal NE

Thatcher 


\begin{tabular}{|c|c|c|c|c|c|c|c|}
\hline FEATURE NAME & $\begin{array}{l}\text { FEATURE } \\
\text { CLASS }\end{array}$ & STATUS & COUNTY & COORDINATE & $\begin{array}{l}\text { SOURCE } \\
\text { COORDINATE }\end{array}$ & $\begin{array}{l}\text { ELEV } \\
\text { FT }\end{array}$ & MAP NAME \\
\hline $\begin{array}{l}\text { Cazador } \\
\text { Ccamp Grant } \\
\text { See Fort Grant (State }\end{array}$ & $\begin{array}{l}\text { locale } \\
\text { school }\end{array}$ & $\begin{array}{l}\text { BGN } \\
\text { VARIANT }\end{array}$ & $\begin{array}{l}\text { Cochise } \\
\text { Graham }\end{array}$ & $\begin{array}{l}312929 N 1092518 \mathrm{~W} \\
323722 \mathrm{~N} 1095643 \mathrm{~W}\end{array}$ & & & College Peaks \\
\hline $\begin{array}{l}\text { CCA Tower } \\
\text { CC Canyon } \\
\text { CCC Camp Well } \\
\text { CCC Canyon } \\
\text { CCC Canyon } \\
\text { CCC Dam }\end{array}$ & $\begin{array}{l}\text { tower } \\
\text { valley } \\
\text { well } \\
\text { valley } \\
\text { valley } \\
\text { dam }\end{array}$ & $\begin{array}{l}\text { UNOFF } \\
\text { BGN } \\
\text { UNOFF } \\
\text { BGN } \\
\text { BGN } \\
\text { UNOFF }\end{array}$ & $\begin{array}{l}\text { Cochise } \\
\text { Navajo } \\
\text { Cochise } \\
\text { Santa Cruz } \\
\text { Yavapai } \\
\text { Santa Cruz }\end{array}$ & $\begin{array}{l}315900 \mathrm{~N} 1101203 \mathrm{~W} \\
341204 \mathrm{~N} 1102257 \mathrm{~W} \\
321658 \mathrm{~N} 1093327 \mathrm{~W} \\
313210 \mathrm{~N} 1104500 \mathrm{~W} \\
344519 \mathrm{N1121356 \textrm {W }} \\
313639 \mathrm{N1110550W}\end{array}$ & $\begin{array}{l}341235 N 1102147 \mathrm{~W} \\
313147 N 1104441 \mathrm{~W} \\
344505 N 1121133 \mathrm{~W}\end{array}$ & & $\begin{array}{l}\text { Saint David } \\
\text { Bear Ridge } \\
\text { Luzena } \\
\text { Mt Hughes } \\
\text { Munds Draw } \\
\text { Tubac }\end{array}$ \\
\hline $\begin{array}{l}\text { CCC One Tank } \\
\text { CCC Spring } \\
\text { CCC Tank } \\
\text { CCC tank } \\
\text { CCC Tank } \\
\text { CCC Tank } \\
\text { CCC Trail Reservoir } \\
\text { CCC Two Tank } \\
\text { CC Fireman Cabin } \\
\text { CC Flat }\end{array}$ & $\begin{array}{l}\text { reservoir } \\
\text { spring } \\
\text { reservoir } \\
\text { reservoir } \\
\text { reservoir } \\
\text { reservoir } \\
\text { reservoir } \\
\text { reservoir } \\
\text { locale } \\
\text { flat }\end{array}$ & $\begin{array}{l}\text { BGN } \\
B G N \\
B G N \\
B G N \\
B G N \\
B G N \\
B G N \\
B G N \\
B G N \\
B G N\end{array}$ & $\begin{array}{l}\text { Gila } \\
\text { Pima } \\
\text { Santa Cruz } \\
\text { Maricopa } \\
\text { Greenlee } \\
\text { Yavapai } \\
\text { Mohave } \\
\text { Gila } \\
\text { Apache } \\
\text { Apache }\end{array}$ & $\begin{array}{l}332013 \mathrm{~N} 1104822 \mathrm{~W} \\
320726 \mathrm{~W} 1103420 \mathrm{~W} \\
312735111035 \mathrm{~W} \\
331445 \mathrm{~N} 112305 \mathrm{~W} \\
331628 \mathrm{~W} 1092146 \mathrm{~W} \\
344513 \mathrm{~N} 1121329 \mathrm{~W} \\
364113 \mathrm{~N} 1124745 \mathrm{~W} \\
332015 \mathrm{~N} 1104813 \mathrm{~W} \\
340650 \mathrm{~N} 109373 \mathrm{~W} \\
340644 \mathrm{~N} 1093818 \mathrm{~W}\end{array}$ & & & $\begin{array}{l}\text { Pinal Peak } \\
\text { Rincon Peak } \\
\text { Pena Blanca Lake } \\
\text { Margies Peak } \\
\text { Pipestem Mtn } \\
\text { Munds Draw } \\
\text { Sunshine Ridge } \\
\text { Pinal Peak } \\
\text { Horseshoe Cienega } \\
\text { Horseshoe Cienega }\end{array}$ \\
\hline $\begin{array}{l}\text { CC Franey Spring } \\
\text { CC Hall Spring } \\
\text { CC Lake } \\
\text { CC Lake Spring } \\
\text { CC Tank } \\
\text { CC Tank } \\
\text { C-Dart Spring } \\
\text { Ceadro Spring } \\
\text { Ceadro Well } \\
\text { Cecil Davis Park }\end{array}$ & $\begin{array}{l}\text { spring } \\
\text { spring } \\
\text { lake } \\
\text { spring } \\
\text { reservoir } \\
\text { reservoir } \\
\text { spring } \\
\text { spring } \\
\text { well } \\
\text { park }\end{array}$ & $\begin{array}{l}\text { BGN } \\
\text { BGN } \\
\text { BGN } \\
\text { BGN } \\
\text { BGN } \\
\text { BGN } \\
\text { BGN } \\
\text { BGN } \\
\text { UNOFF } \\
\text { ADMIN }\end{array}$ & $\begin{array}{l}\text { Apache } \\
\text { Apache } \\
\text { Apache } \\
\text { Apache } \\
\text { Greenlee } \\
\text { Maricopa } \\
\text { Gila } \\
\text { Apache } \\
\text { Apache } \\
\text { Mohave }\end{array}$ & $\begin{array}{l}340718 \mathrm{~N} 1093744 \mathrm{~W} \\
34018 \mathrm{~N} 1093735 \mathrm{~W} \\
340720 \mathrm{~N} 1093907 \mathrm{~W} \\
340726 \mathrm{~N} 1093844 \mathrm{~W} \\
332016 \mathrm{~N} 109235 \mathrm{~W} \\
335644 \mathrm{~N} 1114906 \mathrm{~W} \\
335958 \mathrm{~N} 1100120 \mathrm{~W} \\
344918 \mathrm{~N} 1090903 \mathrm{~W} \\
344958 \mathrm{~N} 1090931 \mathrm{~W} \\
351144 \mathrm{~N} 1140120 \mathrm{~W}\end{array}$ & & & $\begin{array}{l}\text { Horseshoe Cienega } \\
\text { Horseshoe Cienega } \\
\text { Horseshoe Cienega } \\
\text { Horseshoe Cienega } \\
\text { Bee Canyon } \\
\text { Humboldt Mtn } \\
\text { Round Top Mtn } \\
\text { Ceadro Spring } \\
\text { Ceadro Spring } \\
\text { Kingman }\end{array}$ \\
\hline $\begin{array}{l}\text { Cecil Pond } \\
\text { Cecil Tank } \\
\text { Cecil Well } \\
\text { Cedar } \\
\text { Cedar Bas in } \\
\text { Cedar Bas in } \\
\text { Cedar Bas in } \\
\text { Cedar Bas in } \\
\text { Cedar Bas in } \\
\text { Cedar Bas in }\end{array}$ & $\begin{array}{l}\text { reservoir } \\
\text { reservoir } \\
\text { well } \\
\text { locale } \\
\text { bas in } \\
\text { basin } \\
\text { basin } \\
\text { bas in } \\
\text { bas in } \\
\text { bas in }\end{array}$ & $\begin{array}{l}\text { BGN } \\
\text { BGN } \\
\text { UNOFF } \\
\text { BGN } \\
\text { BGN } \\
\text { BGN } \\
\text { BGN } \\
\text { BGN } \\
\text { BGN } \\
\text { BGN }\end{array}$ & $\begin{array}{l}\text { Mohave } \\
\text { Coconino } \\
\text { Yavapai } \\
\text { Mohave } \\
\text { Pinal } \\
\text { Maricopa } \\
\text { Yavapai } \\
\text { Gila } \\
\text { Yavapai } \\
\text { Mohave }\end{array}$ & $\begin{array}{l}364052 \mathrm{~N} 1131705 \mathrm{~W} \\
350347 \mathrm{~N} 1114639 \mathrm{~W} \\
341352 \mathrm{~N} 1125649 \mathrm{~W} \\
344643 \mathrm{~N} 1134737 \mathrm{~W} \\
332715 \mathrm{~N} 1111549 \mathrm{~W} \\
333222 \mathrm{~N} 1111016 \mathrm{~W} \\
335744 \mathrm{~N} 1122520 \mathrm{~W} \\
341031 \mathrm{N1113650 \textrm {W }} \\
341724 \mathrm{N1114159W} \\
344718 \mathrm{~N} 1132340 \mathrm{~W}\end{array}$ & & & $\begin{array}{l}\text { The Grandstand } \\
\text { Dutton Hill } \\
0^{\prime} \text { Nei11 Pass } \\
\text { Oiamond Joe Peak } \\
\text { Weavers Needle } \\
\text { Pinyon Mtn } \\
\text { Garfias Mtn } \\
\text { Cypress Butte } \\
\text { Verde Hot Springs } \\
\text { Cedar Basin }\end{array}$ \\
\hline $\begin{array}{l}\text { Cedar Bas in } \\
\text { Cedar Bas in } \\
\text { Cedar Bas in } \\
\text { Cedar Bas in Camp } \\
\text { Cedar Bas in Canyon } \\
\text { Cedar Bas in Canyon } \\
\text { Cedar Bas in Dam } \\
\text { Cedar Bas in Spring } \\
\text { Cedar Bas in Spring } \\
\text { Cedar Bas in Tank }\end{array}$ & $\begin{array}{l}\text { basin } \\
\text { basin } \\
\text { basin } \\
\text { locale } \\
\text { valley } \\
\text { valley } \\
\text { dam } \\
\text { spring } \\
\text { spring } \\
\text { reservoir }\end{array}$ & $\begin{array}{l}\text { BGN } \\
\text { BGN } \\
B G N \\
B G N \\
B G N \\
\text { BGN } \\
\text { UNOFF } \\
\text { BGN } \\
\text { BGN } \\
\text { BGN }\end{array}$ & $\begin{array}{l}\text { Mohave } \\
\text { Mohave } \\
\text { Mohave } \\
\text { Mohave } \\
\text { Pinal } \\
\text { Mohave } \\
\text { Gila } \\
\text { Maricopa } \\
\text { Gila } \\
\text { Gila }\end{array}$ & $\begin{array}{l}350440 \mathrm{~N} 1133251 \mathrm{~W} \\
350605 \mathrm{~N} 113232 \mathrm{~W} \\
352625 \mathrm{~N} 1140612 \mathrm{~W} \\
344728 \mathrm{~N} 1132345 \mathrm{~W} \\
332823 \mathrm{~N} 1111650 \mathrm{~W} \\
350723 \mathrm{~N} 1133252 \mathrm{~W} \\
334615 \mathrm{~N} 1102335 \mathrm{~W} \\
3332241111006 \mathrm{~W} \\
341045 \mathrm{~N} 1113640 \mathrm{~W} \\
334615 \mathrm{~N} 1102335 \mathrm{~W}\end{array}$ & $\begin{array}{l}332650 \mathrm{~N} 1111538 \mathrm{~W} \\
350509 \mathrm{N1133405W}\end{array}$ & 4600 & $\begin{array}{l}\text { Austin Peak } \\
\text { Penitentiary Mtn } \\
\text { Elements Canyon } \\
\text { Cedar Bas in } \\
\text { Weavers Needle } \\
\text { Austin Peak } \\
\text { Beckers Butte } \\
\text { Pinyon Mtn } \\
\text { Cyyress Butte } \\
\text { Beckers Butte }\end{array}$ \\
\hline $\begin{array}{l}\text { Cedar Bas in Tank } \\
\text { Cedar Bas in Tank } \\
\text { Cedar Basin Tank } \\
\text { Cedar Bench } \\
\text { Cedar Bench } \\
\text { Cedar Bench } \\
\text { Cedar Bench Tank } \\
\text { Cedar Bench Tank Number One } \\
\text { Cedar Bench Tank Number Two } \\
\text { Cedar Berry Bob Tank }\end{array}$ & $\begin{array}{l}\text { reservoir } \\
\text { reservoir } \\
\text { reservoir } \\
\text { bench } \\
\text { bench } \\
\text { bench } \\
\text { reservoir } \\
\text { reservoir } \\
\text { reservoir } \\
\text { reservoir }\end{array}$ & $\begin{array}{l}B G N \\
B G N \\
B G N \\
B G N \\
B G N \\
B G N \\
B G N \\
B G N \\
B G N \\
B G N\end{array}$ & $\begin{array}{l}\text { Yavapai } \\
\text { Yavapai } \\
\text { Mohave } \\
\text { Gila } \\
\text { Yavapai } \\
\text { Yavapai } \\
\text { Yavapai } \\
\text { Yavapai } \\
\text { Yavapai } \\
\text { Yavapai }\end{array}$ & $\begin{array}{l}335738 \mathrm{~N} 1122530 \mathrm{~W} \\
341740 \mathrm{~N} 1114204 \mathrm{~W} \\
35055 \mathrm{~N} 113250 \mathrm{~W} \\
341824 \mathrm{~N} 1113726 \mathrm{~W} \\
342252 \mathrm{~N} 1114813 \mathrm{~W} \\
343339 \mathrm{~N} 1114119 \mathrm{~W} \\
342253 \mathrm{~N} 1114822 \mathrm{~W} \\
343309 \mathrm{~N} 1114128 \mathrm{~W} \\
34330 \mathrm{~N} 111415 \mathrm{~W} \\
351721 \mathrm{~N} 1124505 \mathrm{~W}\end{array}$ & & & $\begin{array}{l}\text { Garfias Mtn } \\
\text { Verde Hot Springs } \\
\text { Penitentiary Mtn } \\
\text { Cane Springs Mtn } \\
\text { Horner Mtn } \\
\text { Walker Mtn } \\
\text { Horner Mtn } \\
\text { Walker Mtn } \\
\text { Walker Mtn } \\
\text { Seligman East }\end{array}$ \\
\hline $\begin{array}{l}\text { Cedar Canyon } \\
\text { See Bartolo Canyon } \\
\text { Cedar Canyon } \\
\text { Cedar Canyon } \\
\text { Cedar Canyon } \\
\text { Cedar Canyon } \\
\text { Cedar Canyon } \\
\text { Cedar Canyon } \\
\text { Cedar Canyon } \\
\text { Cedar Canyon Tank }\end{array}$ & $\begin{array}{l}\text { valley } \\
\text { valley } \\
\text { valley } \\
\text { valley } \\
\text { valley } \\
\text { valley } \\
\text { valley } \\
\text { valley } \\
\text { reservoir }\end{array}$ & $\begin{array}{l}\text { VARIANT } \\
\text { BGN } \\
\text { BGN } \\
\text { BGN } \\
\text { BGN } \\
\text { BGN } \\
\text { BGN } \\
B G N 1906 \\
B G N\end{array}$ & $\begin{array}{l}\text { Santa Cruz } \\
\text { Pima } \\
\text { Pima } \\
\text { Navajo } \\
\text { Yavapai } \\
\text { Mohave } \\
\text { Coconino } \\
\text { Coconino } \\
\text { Navajo }\end{array}$ & $\begin{array}{l}313119 \mathrm{~N} 111155 \mathrm{~W} \\
313620 \mathrm{~W} 1111332 \mathrm{~W} \\
314 \mathrm{~B} 4 \mathrm{~N} 1103539 \mathrm{~W} \\
340334 \mathrm{N1101023 \textrm {W }} \\
341742 \mathrm{~N} 1121335 \mathrm{~W} \\
352853 \mathrm{N1} 140630 \mathrm{~W} \\
353502 \mathrm{~N} 1112926 \mathrm{~W} \\
360250 \mathrm{~N} 111405 \mathrm{~W} \\
340345 \mathrm{~N} 1101210 \mathrm{~W}\end{array}$ & $\begin{array}{l}313342 \mathrm{~N} 1110906 \mathrm{~W} \\
314901 \mathrm{N1} 103757 \mathrm{~W} \\
340420 \mathrm{~N} 1100602 \mathrm{~W} \\
342144 \mathrm{N1121410 \textrm {W }} \\
352526 \mathrm{N1140903W} \\
353402 \mathrm{~N} 1112849 \mathrm{~W} \\
360158 \mathrm{~N} 1114941 \mathrm{~W}\end{array}$ & & $\begin{array}{l}\text { Murphy Peak } \\
\text { Spring Water Canyon } \\
\text { Long Tom Canyon } \\
\text { Cleator } \\
\text { Elements Canyon } \\
\text { Wupatki SW } \\
\text { Blue Spring } \\
\text { Long Tom Canyon }\end{array}$ \\
\hline Cedar Corral & ocale & $B G N$ & nal & 5807 N1103642W & & & Brandenburg $\mathrm{N}$ \\
\hline
\end{tabular}


NATIONAL GAZETTEER--ARIZONA 1986

FEATURE NAME

Cedar Creek

Cedar Creek

See Arivaca Creek

Cedar Creek

Cedar Creek

Cedar Creek

Cedar Creek

Cedar Creek

See Cataract Creek

Cedar Creek

Cedar Creek Crossing

Cedar Creek Rodeo Grounds

Cedar Creek Tank

Cedar Dam

Cedar Dam

Cedar Orift Fence Tank

Cedar Flat

Cedar Flat

Cedar Flat

Cedar Flat

Cedar Flat

Cedar Flat Tank

Cedar Flat Tank

Cedar Flat Tank

Cedar Gap Tank

Cedar Glade Cemetery

Cedar Groves Park

Cedar Knoll

Cedar Knol

Cedar Knoll Tank

Cedar Lake

Cedar Lake Reservoir

Cedar Lake Wash

Cedar Log Spring

Cedar Mesa

Cedar Mesa

Cedar Mesa

See Howell Mesa

Cedar Mesa Canyon

Cedar Mesa Tank

Cedar Mesa Tank

Cedar Mesa Tanks

Cedar Mill

Cedar Mountain

Cedar Mountain

Cedar Mountain

Cedar Mountain

Cedar Mountain

Cedar Mountain

Cedar Mountain Tank

Cedar Mountain Trick Tank

Cedar Pocket Reservoir

Cedar Pockets Wash

$$
\text { Cedar Wash }
$$

Cedar Point Interchange

Cedar Point Tank

Cedar Point Trading Post

Cedar Pond

Cedar Pond

Cedar Ranch
Cedar Ridge
Cedar Ridge
Cedar Ridge
Cedar Ridge
Cedar Ridge
Cedar Ridge (subdivision)
Cedar Ridge Reservoir
Cedar Ridge Trading Post
Cedars, The

Cedar Salt Ground

Cedar Spring
FEATURE

CLASS

STATUS COUNTY

stream

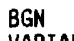

stream

stream

stream

stream

stream

stream

VARIANT

Pima

BGM Pima

Pinal

$\begin{array}{ll}\text { BGN } & \text { Gila } \\ \text { BGN } & \text { Yavapai }\end{array}$

BGN Coconino

VARIANT

Coconino

COOROINATE

COORDIMATE ELEV

MAP NAME

$\begin{array}{ll}\text { ppl } & \text { BGN } \\ \text { locale } & \text { BGN } \\ \text { locale } & \text { UNOFF } \\ \text { reservoir } & \text { BGN } \\ \text { dam } & \text { UNOFF } \\ \text { dam } & \text { UNOFF } \\ \text { reservoir } & \text { BGN } \\ \text { flat } & \text { BGN } \\ \text { flat } & \text { BGN } \\ \text { flat } & \text { BGN }\end{array}$

Gila

Gila

Gila

Gila

Pima

Coconino

Gila

Pima

Grahan

Gila

flat

flat

reservoir

reservoir

reservoir BGN

cemetery UNOFF

park

summit

summit

BGN
BGN
BGN
BGN
BGN
BGN
UNOFF
ADNIN
BGN
BGN

Gila

Yavapai

Gila

Yavapai

Yavapai

Gila

Yavapai

Pima

Mohave

Coconino

reservoir

lake

reservoir

stream

spring

summit

summit

summit

valley

\section{BGN}

Gila
Navajo

Navajo

Apache

Cochise

Gila

Yavapai

ARIANT

Coconino

Gila

reservoir

reservoir

reservoir

locale

summit

summit

summit

summit.

summit

summit

BGN

Gila

Gila

Navajo

Yavapai

Grahan

Pinal

Yavapai

Coconino

1906 Coconino

Coconino

reservoir BGN Yavapai

reservoir

reservoir

valley

BGN

Yavapai

Mohave

Mohave
Mohave

BGN 1981
VARIANT

crossing UNOFF Apache

reservoir BGN Graham

locale BGN Apache

lake

BGN

$\begin{array}{ll}\text { locale } & \text { UNOF} \\ \text { ridge } & B G N\end{array}$

ridge

ridge

ridge

pidge

ppl
reservoir

locale

woods

Mohave
Mohave

Coconino

Coconino

Coconino

Coconino

Mohave

Mohave

Maricopa

Coconino

Coconino

Yavapai

flat

spring

BGN

Yavapai

Cochise
313424N1111957W

$313706 \mathrm{~N} 1112427 \mathrm{~W}$

$331450 N 1105640 \mathrm{~W}$

$334807 \mathrm{~N} 1101823 \mathrm{~W}$

$341740 \mathrm{~N} 1121330 \mathrm{~W}$

$345746 \mathrm{N1} 120135 \mathrm{~W}$

$361300 \mathrm{~N} 1124110 \mathrm{~W}$

$335344 N 1101023 \mathrm{~W}$

$335155 \mathrm{~N} 1101202 \mathrm{~W}$

$335316 \mathrm{~N} 1101055 \mathrm{~W}$

$331531 \mathrm{~N} 1105142 \mathrm{~W}$

$313425 \mathrm{~N} 1111025 \mathrm{~W}$

$350500 \mathrm{~N} 1111649 \mathrm{~W}$

$334835 \mathrm{~N} 1101241 \mathrm{~W}$

$314539 \mathrm{~N} 1104753 \mathrm{~W}$

$323307 \mathrm{~N} 1101951 \mathrm{~W}$

$341524 N 1112659 \mathrm{~W}$

$341607 \mathrm{~N} 1112648 \mathrm{~W}$

$343538 \mathrm{~N} 1113619 \mathrm{~W}$

$341601 \mathrm{N1112656 \textrm {W }}$

$342545 \mathrm{~N} 1113934 \mathrm{~W}$

$343608 \mathrm{~N} 1113630 \mathrm{~W}$

$334732 \mathrm{~N} 1100516 \mathrm{~W}$

$345830 \mathrm{~N} 1122316 \mathrm{~W}$

$321004 N 1105001 \mathrm{~W}$

$364437 \mathrm{N1} 124854 \mathrm{~W}$

$364821 \mathrm{N1122501 \textrm {W }}$

$340716 N 1112414 \mathrm{~W}$

$343012 \mathrm{N1101323 \textrm {W }}$

$344305 \mathrm{~N} 1092908 \mathrm{~W}$

$343916 \mathrm{~N} 1092906 \mathrm{~W}$

$321223 \mathrm{~N} 1093137 \mathrm{~W}$

$342014 N 1112334 \mathrm{~W}$

$344056 \mathrm{~N} 1125330 \mathrm{~W}$

$355626 \mathrm{N1105133W}$

$341907 N 1112248 \mathrm{~W}$

$342020 \mathrm{~N} 1112139 \mathrm{~W}$

$342031 N 1112245 \mathrm{~W}$

$340127 N 1101555 \mathrm{~W}$

$342819 \mathrm{~N} 1115945 \mathrm{~W}$

$324541 \mathrm{N1} 100527 \mathrm{~W}$

$325313 \mathrm{~N} 1105127 \mathrm{~W}$

$343334 \mathrm{~N} 1114059 \mathrm{~W}$

$352333 \mathrm{~N} 1120657 \mathrm{~W}$

$360309 \mathrm{N1} 114621 \mathrm{~W}$

$370024 N 1114143 \mathrm{~W}$

$343355 N 1114048 \mathrm{~W}$

$340728 N 1114938 \mathrm{~W}$

$361735 \mathrm{~N} 1132635 \mathrm{~W}$

$365726 \mathrm{~N} 1134713 \mathrm{~W}$

$351416 \mathrm{~N} 1091806 \mathrm{~W}$

$325228 \mathrm{~N} 1100504 \mathrm{~W}$

$351421 N 1091759 \mathrm{~W}$

361748 N1132629W

$362933 \mathrm{N1131734 \textrm {W }}$

$353234 \mathrm{~N} 1114703 \mathrm{~W}$

$352902 \mathrm{~N} 1113202 \mathrm{~W}$

$360349 \mathrm{N1120520 \textrm {W }}$

$362653 \mathrm{~N} 1113404 \mathrm{~W}$

$365217 N 1125352 W$

$365633 \mathrm{~N} 1124219 \mathrm{~W}$

$332000 \mathrm{~N} 1115042 \mathrm{~W}$

$364920 \mathrm{~N} 1122445 \mathrm{~W}$

$362331 \mathrm{~N} 1113127 \mathrm{~W}$

$342111 N 1114610 \mathrm{~W}$

$343812 \mathrm{~N} 1125224 \mathrm{~W}$

$321234 N 1093828 W$
313157N1111515W Arivaca

331551N1105052W Hot Tamale Peak

Carrizo SE

Cleator

Sycamore Basin

$342226 \mathrm{~N} 1121725 \mathrm{~W}$
$350109 \mathrm{~N} 1120703 \mathrm{~W}$

Cedar Creek

Cone Butte

Cedar Creek

Pinal Peak

Murphy Peak

Elliott Canyon

Cone Butte

5760 Helvetia

5124 Bassett Peak

Buckhead Mesa

Buckhead Mesa

Buckhorn Mountain Buckhead Mesa

Hackberry Mtn 


\section{FEATURE NAME}

Cedar Spring

Cedar Spring

Cedar Spring

Cedar Spring

Cedar Spring

Cedar Spring

Cedar Spring

Cedar Spring

Cedar Spring

Cedar Spring

Cedar Spring

Cedar Spring

Cedar Spring

Cedar Spring

Cedar Spring Bitter Spring

Cedar Spring

Cedar Spring

Cedar Spring

Cedar Spring

Cedar Spring

Cedar Spring

See Cedar Springs

Cedar Spring Canyon

Cedar Springs

Cedar Springs

Cedar Spring

Tees To

Cedar Springs Butte

Cedar Tank

Cedar Tank

Cedar Tank

Cedar Tank

Cedar Tank

Cedar Tank

Water Hole

Cedar Tank

Cedar Tank

Cedar Tank

Cedar Tank

Cedar Tank

Cedar Tank

Cedar Tank

Cedar Tank

Cedar Tank Canyon

Cedar Tree Bench

Cedar Tree Hills

Cedar Wash

Cedar Wash

Cedar Wash

See Tappan Wash

Cedar Wash

Cedar Wash

See Cedar Pockets Wash

Cedar Well

Cedar Well

Cedar Windmill

Carreta Windmill

Cedric Tank

Cedric Well

Celebration Wash

Celedonio Tank

Cellar Bas in

Cellar Basin Trail

See Wagoner Trail Number Two Hundred Thirteen

Cellar Creek

Cellar Creek

See Cellar Springs Creek

Cellar Spring

See Cellar Springs

\section{FETURE}

spring

spring

spring

spring

spring

spring

spring

spring

STATUS

COUNTY

COORDINATE

BGN Pina

BGN 322450N1103627

Gila

Greenlee

Gila

Gila

Navajo

Yavapai

spring

spring

spring

spring

spring

spring

spring

spring
spring

spring

spring

spring

locale

valley

spring

locale

$\begin{array}{lll}\text { BGN } & \text { Yavapai } & 340959 \mathrm{~N} 1122707 \mathrm{~W} \\ \text { BGN } & \text { Yavapai } & 342246 \mathrm{N1114856 \textrm {W }} \\ \text { BGN } & \text { Yavapai } & 342714 \mathrm{N1114056 \textrm {W }} \\ \text { BGN } & \text { Yavapai } & 342945 \mathrm{N1120012W} \\ \text { BGN } & \text { Yavapai } & 343809 \mathrm{N1123535 \textrm {W }} \\ \text { BGN } & \text { Mohave } & 350057 \mathrm{N1135240W} \\ \text { BGN } & \text { Mohave } & 352747 \mathrm{N1140731 \textrm {W }} \\ \text { VARIANT } & \text { Mohave } & 353405 \mathrm{~N} 1134558 \mathrm{~W} \\ \text { BGN } & \text { Mohave } & 354638 \mathrm{N1} 135809 \mathrm{~W} \\ \text { BGN } & \text { Mohave } & \end{array}$

BGN 1906 Coconino 360521N1121041W

BGN Mohave 36092BN1131930W

BGN Mohave 363359N1140029W

VARIANT

Greenlee

BGN

BGN

VARIANT
VARIANT

Grahan

Navajo

$352706 \mathrm{~N} 1102149 \mathrm{~W}$

$333542 \mathrm{~N} 1090850 \mathrm{~W}$

324637 N1100906W

$352706 \mathrm{~N} 1102149 \mathrm{~W}$

summit

reservoir

reservoir

reservoir

reservoir

reservoir

reservoir

reservoir

reservoir

\begin{tabular}{|c|c|c|}
\hline & $\begin{array}{l}\text { Graham } \\
\text { Cochise } \\
\text { Cochise } \\
\text { Pima } \\
\text { Graham } \\
\text { Pinal } \\
\text { Yavapai }\end{array}$ & $\begin{array}{l}324610 \mathrm{~N} 1100922 \mathrm{~W} \\
312 \mathrm{~W} 15 \mathrm{~N} 1090434 \mathrm{~W} \\
314831 \mathrm{~N} 1100248 \mathrm{~W} \\
315925 \mathrm{~N} 110375 \mathrm{~W} \\
324420 \mathrm{~N} 1091955 \mathrm{~W} \\
332105 \mathrm{~N} 1110727 \mathrm{~W} \\
342136 \mathrm{N1} 121631 \mathrm{~W}\end{array}$ \\
\hline & $\begin{array}{l}\text { Yavapai } \\
\text { Yavapai }\end{array}$ & $\begin{array}{l}342835 \mathrm{~N} 1120559 \mathrm{~W} \\
342913 \mathrm{~N} 1115929 \mathrm{~W}\end{array}$ \\
\hline
\end{tabular}

reservoir

reservoir

reservoir

reservoir

reservoir

reservoir

valley

bench

summit

stream

stream

stream

stream
valley

valley

well

well

well

reservoir

well

valley

reservoir

bas in

trail

stream

stream

VARIAN

ARIANT

BGN

BGN

BGN

BGN

VARIANT

Yavapai

BGN 1964 Coconino

BGN

UNOFF

UNOFF

AARIANT

VARIANT
Apache

Coconino

Coconino

Coconino

Coconino

Yavapai

Coconino

Coconino

Mohave

Coconino

Mohave

Mohave

Pima

Yavapai

Pima

Mohave

Mohave

Navajo.

Yavapai

Vavapai

Yavapai

Gila

Yavapai

$344542 \mathrm{~N} 1113757 \mathrm{~W}$

$345526 \mathrm{~N} 1094321 \mathrm{~W}$

$350005 \mathrm{~N} 1121629 \mathrm{~W}$

$351905 \mathrm{~N} 1122613 \mathrm{~W}$

$353232 \mathrm{~N} 1114640 \mathrm{~W}$

$353238 \mathrm{N1114600 \textrm {W }}$

$344728 \mathrm{N111} 3910 \mathrm{~W}$

$364832 \mathrm{~N} 1110823 \mathrm{~W}$

$363142 \mathrm{~N} 1113325 \mathrm{~W}$

$345915 \mathrm{~N} 1134746 \mathrm{~W}$

354829N1113016w

$362512 \mathrm{~N} 1135513 \mathrm{~W}$

365726 N1134713W

$313454 \mathrm{N1111145 \textrm {W }}$

$342116 \mathrm{~N} 1121357 \mathrm{~W}$

$313522 \mathrm{~N} 1111154 \mathrm{~W}$

$343252 \mathrm{~N} 1134900 \mathrm{~W}$

$343259 \mathrm{~N} 1134807 \mathrm{~W}$

$362212 \mathrm{~N} 1100427 \mathrm{~W}$

$351837 N 1131143 \mathrm{~W}$

$341342 \mathrm{~N} 1122743 \mathrm{~W}$

$341204 \mathrm{N1122500 \textrm {K }}$

$334503 \mathrm{~N} 1110047 \mathrm{~W}$

$341444 \mathrm{~N} 1123016 \mathrm{~W}$
$355257 \mathrm{~N} 1112608 \mathrm{~K}$
SOURCE
COORDINATE

MAP NAME

Buehman Canyon

Bassett Peak

Two Bar Mtn

Bear Mountain

Mule Hoof Bend

Cedar Creek

Alchesay Flat

Copperopolis

Minnehaha

Horner Mtn

Hackberry Mtn

Estler Peak

Jerome Canyon

Hualapai Peak

Chloride

Music Mountains SE

Quartermaster Can SW

Grand Canyon

Whitmore Point

Virgin Peak

333650N1090824W Bear Mountain

Buford $\mathrm{Hill}$

Dilkon

5140 Buford Hill

Guadalupe Spring

Haberstock Hill

Mount Fagan

Whitlock Mts NE

Superior

Battle Flat

Estler Peak

Arnold Mesa

Munds Mountain

Adamana One NW

Matterhorn

Fitzgerald $\mathrm{Hill}$

Chapel Mtn

Chapel Mtn

Munds Mountain

Cedar Tree Bench

Cedar Tree Hills

$350036 \mathrm{~N} 1135322 \mathrm{~W}$

Hibernia Peak

$352855 \mathrm{~N} 1114605 \mathrm{~W}$

Coconino Point SE

363740 N1140340W

Pakoon Springs

3812 Murphy Peak

Cleator

Murphy Peak

Dutch Flat SE

Dutch Flat SE

Hole In Rock Valley Sugarloaf Peak

Minnehaha

334656 N1105918W

Armer Mountain 
NATIONAL GAZETTEER--ARIZONA 1986

Centennial

FEATURE
CLASS
stream
stream
spring
stream

STATUS

COUNTY

COORDINATE

VARIANT

Yavapai

VARIANT

BGN 1972

Yavapai

VARIANT

stream

BGN 1972 Yavapai

VARIANT

VARIANT

locale

valley

valley

reservoir

reservoir

reservoir

reservoir

BGN Pima

BGN

BGN

$B G N$

BGN

BGN

reservoir

reservoir

reservoir

reservoir

reservoir

BGN
BGN
BGN

BGN

BGN

BGN

VARIANT

VARIANT

stream BGN

VARIANT

summit

spring

spring

spring

reservoir

reservoir

reservoir

reservoir

reservoir

reservoir

Cochise

Graham

Mohave

Pina

Cochise

Cochise

Pima

Graham

Gila

Navajo

Coconino

Yuma

Yuma

reservoir

BGN

reservoir BG

reservoir

spring

spring

spring

valley

reservoir

Yavapai

Cochise

Navajo

spring

spring
valley

ridge

ridge

reservoir

reservoir

reservoir

BGN Navajo

Navajo

BGN 1963 Yuma

VARIANT

BGN

BGN

$B G N$

Santa Cruz

Santa Cruz

stream BGN

Maricopa

reservoir

VARIANT

Yuma

reservoir

VARIANT

stream

VARIANT

Yuma

cliff

BGN

Yuma
SOURCE

ELEV

AZ119

$341324 N 1122900 \mathrm{~W}$

$341444 N 1123016 \mathrm{~W}$

Yavapai 341324N1122900W

BGN
BGN
BGN
BGN
BGN
BGN
BGN
BGN
BGN
BGN

reservoir BG

reservoir BGN

$321437 N 1093412 \mathrm{~W}$

Greenlee 330720N1091607W

Pinal 332542N1110701W

Pima 315806N1124122W

Pima 321647N1103112W

Pinal 325645N1102920W

Greenlee 331154N1092930W

$331614 N 1090353 \mathrm{~W}$

Gila 333140N1104900W

Yavapai 341038N1114859W

Navajo 344328N1102306W

Navajo 345101N1104325W

Yavapai 345738N1122348W

Yavapai 345904N1124835W

Mohave 350224N1132325W

$324830 \mathrm{~N} 1102838 \mathrm{~W}$

Coconino $360732 \mathrm{~N} 1130357 \mathrm{~W}$

Navajo 335942N1103043W

$340329 \mathrm{~N} 1103231 \mathrm{~W}$

340437 N1103302W

$340131 \mathrm{~N} 1103143 \mathrm{~W}$

$344720 \mathrm{N1} 125140 \mathrm{~W}$

$313248 \mathrm{~N} 1102236 \mathrm{~W}$

$313206 N 1102325 \mathrm{~W}$

$\begin{array}{ll}\text { Yuma } & 332032 N 1132441 W \\ \text { Yuma } & 332032 N 1132441 W\end{array}$

$312915 \mathrm{~N} 1111705 \mathrm{~W}$

$313314 \mathrm{~N} 1103247 \mathrm{~W}$

314038 N1113429W

reservoir BGN Pima 315330N1104020W

reservoir BGN Gila 335222N1101021W

$335744 \mathrm{~N} 1124300 \mathrm{~W}$

$332224 \mathrm{~N} 1134419 \mathrm{~W}$

$332224 \mathrm{~N} 1134419 \mathrm{~W}$

$331840 \mathrm{~N} 1134016 \mathrm{~W}$

$315300 \mathrm{~N} 1091604 \mathrm{~W}$

$333410 N 1132105 \mathrm{~W}$
Minnehaha

Wagoner

Tanque Verde Peak

Luzena

Kielberg Canyon

Little Clayhole Val

Happy Valley

Hookers Hot Springs

Muskhog Mountain

Mt Lemmon

Bassett Peak

Red Knoll

Gray Mountain

Cementosa Wash

Cementosa Wash

Minnehaha

Dos Cabezas

Clifton

Haunted Canyon

Diaz Peak

Piety Hill

Booger Canyon

Coronado Mtn

Maple Peak

Rockinstraw Mtn

Bloody Bas in

Dry Lake NW

Relic Point

Paulden

Indian Peaks

Penitentiary Mtn

Oak Grove Canyon

Vulcans Throne

Blue House Mtn

Spotted Mountain

Spotted Mountain

Seepage Mtn

Pyeatt Ranch

Nottbusch Butte

Bartlett Mtn

$0^{\prime}$ Donnell Canyon

Mildred Peak

Mount Fagan

Cone Butte

Wickenburg

Rustler Park

Courthouse Well
Sombrero Peak 


FEATURE NAME
Centennial
See Nords Ranch
Centennial Center
Centennial Farms
Centennial Friendship Park
Centennial Narrows Dam
Centennial Valley
See Harquahala Plain
Centennial Wash
Cullen Wash

Centennial Wash

Centeot 1, Point

Centeot I Point

Center Creek

Centerfire Canyon

See Centerfire Creek

Centerfire Creek Centerfire Canyon

Centerfire Creek

Center Mountain

Center Point

Center Ridge Tank

Center Tank

Center Tank

Center Tank

Center Valley

Centervilie

Cent ipede Mesa

Centipede Spring

Central

Contral Arizona College

Central Arizona Project

Aqueduct

Central Canal

Central Cemetery

Central Detention Dan

Central Drain

Central Drain

Central Elementary School

Central Heights

Central Heights School

Central High School

Central Market Shopping

Center

Central Park

Central Park

Central Park Village (trailer park)

Central Post Office

Central Ridge (subdivision)

Central School

Central Schoo

Central School

Central Stub Number One

Central Stub Number Two Drain

Central Wash

Centroid Mine

Centura West (subdivision)

Century Mine

Cerbat

Cerbat Canyon

Cerbat Mine

Cerbat Mountains

Cerbat Range

Cerbat Peak

Cerbat Range

See Cerbat Mountains

Cerbat Wash

Cereus Tank

Cerritas de los Linderos

See Lesna Peak

FEATURE
CLASS

STATUS

COUNTY

VARIANT

locale building

locale

park

dam

plain

strean

stre

cliff
cliff

stream

stream

stream

stream

summit

cliff

reservoir

reservoir

reservoir

reservoir

valley

pp 1

summit

spring

ppl

school

canal

canal

cemetery

dam

canal

canal

school

ppl

\begin{tabular}{|c|c|c|c|}
\hline $\begin{array}{l}\text { school } \\
\text { school } \\
\text { locale }\end{array}$ & $\begin{array}{l}\text { UNOFF } \\
\text { UNOFF } \\
\text { UNOFF }\end{array}$ & $\begin{array}{l}\text { Gila } \\
\text { Maricopa } \\
\text { Maricopa }\end{array}$ & 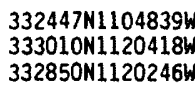 \\
\hline $\begin{array}{l}\text { park } \\
\text { park } \\
\text { locale }\end{array}$ & $\begin{array}{l}\text { ADMIN } \\
\text { ADMIN } \\
\text { UNOFF }\end{array}$ & $\begin{array}{l}\text { Maricopa } \\
\text { Maricopa } \\
\text { Maricopa }\end{array}$ & $\begin{array}{l}332619 N 1120417 \mathrm{~W} \\
333442 \mathrm{~N} 1121416 \mathrm{~W} \\
333819 \mathrm{~N} 1120432 \mathrm{~W}\end{array}$ \\
\hline $\begin{array}{l}\text { building } \\
\mathrm{ppl}\end{array}$ & $\begin{array}{l}\text { UNOFF } \\
\text { BGN }\end{array}$ & $\begin{array}{l}\text { Graham } \\
\text { Maricopa }\end{array}$ & $\begin{array}{l}325210 N 109472 \\
331910 N 111530\end{array}$ \\
\hline
\end{tabular}

school UNOFF

school UNOFF

school UNOFF

canal

canal

stream

mine

ppl

mine

locale

$8 \mathrm{GN}$

BGN

BGN

UNOFF

BGN

UNOFF

BGN

valley $B G N$

mine

range

summit

UNOFF

BGN

VARIANT

BGN VARIANT

range

stream

reservoir

BGN

BGN

summit
Yuma

Maricopa

Maricop

Maricopa

La Paz

Maricopa

Maricopa

Mohave

Coconino

Coconino

Gila

Greenlee

Greenlee

Apache

Gila

Mohave

Gila

Apache

Gila

Apache

Yavapai

Yavapai

Gila

Graham

Pinal

La Paz

Yuma

Graham

Y)

Yuma

Maricopa

Gila

Maricopa

Cochise

Pinal

Pinal

Yuma

Yuma

Graham

Yuma

Maricopa

Mohave

Mohave

Mohave

Mohave

Mohave

Mohave

Mohave

Mohave

Yuma

Pima
$341454 N 1135053 \mathrm{~W}$

$360908 \mathrm{N1122649 \textrm {W }}$

$360903 \mathrm{~N} 1122625 \mathrm{~W}$

$340729 \mathrm{~N} 1112602 \mathrm{~W}$

$333900 \mathrm{~N} 1090533 \mathrm{~W}$ $333900 \mathrm{~N} 1090533 \mathrm{~W}$

334247 N1092618W

$335146 \mathrm{~N} 1105521 \mathrm{~W}$

361051 N1140218W $334640 \mathrm{~N} 1110444 \mathrm{~W}$ 332032N1104750W

$334944 N 1091145 \mathrm{~W}$

$342246 \mathrm{~N} 1111926 \mathrm{~W}$

$362032 \mathrm{~N} 1095605 \mathrm{~W}$

$344535 N 1120321 \mathrm{~W}$

$343601 \mathrm{N1131421 \textrm {W }}$

$333410 \mathrm{~N} 1110525 \mathrm{~W}$

$325203 \mathrm{~N} 1094732 \mathrm{~W}$

$325730 \mathrm{~N} 1113905 \mathrm{~W}$

341710 N1140610W

$323839 \mathrm{N1144152W}$

$325132 N 1094757 \mathrm{~W}$

$325112 N 1094748 \mathrm{~W}$

$324114 N 1144015 \mathrm{~W}$

$333444 N 11$

$332445 \mathrm{~N}$

$312635 \mathrm{~N} 1095450 \mathrm{~W}$

$324516 \mathrm{~N} 1113310 \mathrm{~W}$

$325244 \mathrm{~N} 1114512 \mathrm{~W}$

$324140 \mathrm{~N} 1144015 \mathrm{~W}$

$324209 \mathrm{~N} 1144047 \mathrm{~W}$

$325107 N 1094753 \mathrm{~W}$

335647 N1133316

$332738 \mathrm{~N} 1121115 \mathrm{~W}$

3507 48N1134926\%

351811 N114082OW

$351811 \mathrm{N1140921 \textrm {W }}$

351849N1140756W

352552N1141001W

$351705 \mathrm{~N} 1140641 \mathrm{~W}$

$352552 \mathrm{~N} 1141001 \mathrm{~W}$

350831 N1141238W

$332237 \mathrm{~N} 1140349 \mathrm{~W}$

$312949 \mathrm{~N} 1112423 \mathrm{~W}$

$\begin{array}{cc}\text { SOURCE } & \text { ELEV } \\ \text { COORDINATE } & \text { FT MAP NAME }\end{array}$

Mes a

Cortez Peak NW

Calderwood Butte

Harrisburg Valley

340100N1130920W Arlington

342600N1134611W Swansea

Explorers Monument Explorers Monument Mazatzal Peak

334219N1090857W Maness Peak

334851N1092814W Hoodoo Knob

7474 Aztec Peak

Iceberg Canyon Armer Mountain Pinal Peak

Alpine

$361848 N 1095725 \mathrm{~W}$

Tah Chee Wash

Clarkdale

Bagdad

Two Bar Mtn

Thatcher

Casa Grande East

Monkeys Head

Yuma West

Thatcher

Thatcher

Somerton

Yuma West

Glendale

Globe

Globe

Sunnys lope

Phoenix

Phoenix

Glendale

1370 Union Hills

2860 Thatcher

1190 Guadalupe

Bisbee

Eloy North

Casa Grande West

Yuma West

Yuma West

Thatcher

Cunningham Pass

1060 Fowler

Hualapai Spring

Cerbat

351857 N1140643W

Cerbat

Cerbat

Chloride

5198 Stockton $\mathrm{Hill}$

351857 N1140654W

Kingman NW 
NATIONAL GAZETTEER--ARIZONA 1986

\begin{tabular}{|c|c|c|c|c|c|c|c|}
\hline FEATURE NAME & $\begin{array}{l}\text { FEATURE } \\
\text { CLASS }\end{array}$ & STATUS & COUNTY & COOROINATE & $\begin{array}{l}\text { SOURCE } \\
\text { COORDINATE }\end{array}$ & $\begin{array}{c}\text { ELEV } \\
\text { FT }\end{array}$ & MAP NAME \\
\hline $\begin{array}{l}\text { Cerrito de la Angostura } \\
\text { Cerro Colorado Mine } \\
\text { Cerro Colorado Tank } \\
\text { Cerro Colorado Wash } \\
\text { Cerro de Fresnal } \\
\text { See Fresnal, Cerro del } \\
\text { Cerro de Jaralitio } \\
\text { See Fraguita Peak } \\
\text { Cerro del Tecolote } \\
\text { See Kupk Hills }\end{array}$ & $\begin{array}{l}\text { ridge } \\
\text { mine } \\
\text { reservoir } \\
\text { stream } \\
\text { summit } \\
\text { summit } \\
\text { summit }\end{array}$ & $\begin{array}{l}\text { BGN } \\
\text { UNOFF } \\
\text { BGN } \\
\text { BGN } \\
\text { VARIANT } \\
\text { VARIANT } \\
\text { VARIANT }\end{array}$ & $\begin{array}{l}\text { Pima } \\
\text { Pima } \\
\text { Pima } \\
\text { Pima } \\
\text { Pima } \\
\text { Santa Cruz } \\
\text { Pima }\end{array}$ & $\begin{array}{l}314943 \mathrm{~N} 1123330 \mathrm{~W} \\
313932 \mathrm{~N} 1111619 \mathrm{~W} \\
314028 \mathrm{~N} 1111543 \mathrm{~W} \\
313910 \mathrm{N1111508 \textrm {W }} \\
312635 \mathrm{~N} 1112509 \mathrm{~W} \\
313025 \mathrm{~N} 1111955 \mathrm{~W} \\
315453 \mathrm{~N} 1121556 \mathrm{~W}\end{array}$ & 313950N1111752W & & $\begin{array}{l}\text { Menagers Lake } \\
\text { Cerro Colcrado } \\
\text { Cerro Colorado } \\
\text { Cerro Colorado }\end{array}$ \\
\hline $\begin{array}{l}\text { Cerro del Temporal } \\
\text { See Windy Hill } \\
\text { Cerro de Tacca } \\
\text { See Picacho Peak } \\
\text { Cerro Gordo Tank } \\
\text { Cerro Montosa } \\
\text { See Middle Windmill } \\
\text { Cerro Negro } \\
\text { See Trigo, Cerro } \\
\text { Cerro Prieto Wash }\end{array}$ & $\begin{array}{l}\text { summit } \\
\text { summit } \\
\text { reservoir } \\
\text { locale } \\
\text { summit } \\
\text { stream }\end{array}$ & $\begin{array}{l}\text { VARIANT } \\
\text { VARIANT } \\
\text { BGN } \\
\text { VARIANT } \\
\text { VARIANT } \\
\text { BGN }\end{array}$ & $\begin{array}{l}\text { Gila } \\
\text { Pinal } \\
\text { Gila } \\
\text { Pima } \\
\text { Apache } \\
\text { Pima }\end{array}$ & $\begin{array}{l}334026 \mathrm{~N} 1110440 \mathrm{~W} \\
323806 \mathrm{~N} 1112400 \mathrm{~W} \\
333549 \mathrm{~N} 1100315 \mathrm{~W} \\
320819 \mathrm{~N} 1112243 \mathrm{~W} \\
341135 \mathrm{~N} 1093413 \mathrm{~W} \\
315105 \mathrm{~N} 1112429 \mathrm{~W}\end{array}$ & $315101 \mathrm{~N} 1111504 \mathrm{~W}$ & & Georges Butte \\
\hline $\begin{array}{l}\text { Cerros de Santa Rosa } \\
\text { See Ajo Range } \\
\text { Cerro Tank } \\
\text { Cerro Trigo Tank } \\
\text { Cervantis Well } \\
\text { See Stan Shuatuk } \\
\text { Cesela Park } \\
\text { CF Canyon } \\
\text { Buckbed Wash } \\
\text { CF Tank }\end{array}$ & $\begin{array}{l}\text { range } \\
\text { reservoir } \\
\text { reservoir } \\
\text { locale } \\
\text { park } \\
\text { valley } \\
\text { reservoir }\end{array}$ & $\begin{array}{l}\text { VARIANT } \\
\text { BGN } \\
\text { BGN } \\
\text { VARIANT } \\
\text { ADMIN } \\
\text { BGN } 1976 \\
\text { VARIANT } \\
\text { BGN }\end{array}$ & $\begin{array}{l}\text { Pima } \\
\text { Pima } \\
\text { Apache } \\
\text { Pima } \\
\text { Maricopa } \\
\text { Yavapai } \\
\text { Maricopa }\end{array}$ & $\begin{array}{l}320240 \mathrm{~N} 1124104 \mathrm{~W} \\
321854 \mathrm{~N} 1103938 \mathrm{~W} \\
341142 \mathrm{~N} 1093337 \mathrm{~W} \\
\\
314756 \mathrm{~N} 1121759 \mathrm{~W} \\
332140 \mathrm{~N} 1115654 \mathrm{~W} \\
343016 \mathrm{~N} 1120117 \mathrm{~W} \\
334944 \mathrm{~N} 1120901 \mathrm{~W}\end{array}$ & $343355 \mathrm{~N} 1120040 \mathrm{~W}$ & & $\begin{array}{l}\text { Guadalupe } \\
\text { Cherry } \\
\text { Biscuit Flat }\end{array}$ \\
\hline $\begin{array}{l}\text { CF Tank } \\
\text { Chador Mobile Home Park } \\
\text { Cha-ez-kia } \\
\text { See Chaistla Butte } \\
\text { Cha-ez-kla Butte } \\
\text { See Chaistla Butte } \\
\text { Cha-ez-kla Rock } \\
\text { See Chaistla Butte } \\
\text { Chaffee Field Parade Ground } \\
\text { Chaf in Well }\end{array}$ & $\begin{array}{l}\text { reservoir } \\
\text { locale } \\
\text { summit } \\
\text { summit } \\
\text { summit } \\
\text { locale } \\
\text { well }\end{array}$ & $\begin{array}{l}\text { BGN } \\
\text { UNOFF } \\
\text { VARIANT } \\
\text { VARIANT } \\
\text { VARIANT } \\
\text { UNOFF } \\
\text { UNOFF }\end{array}$ & $\begin{array}{l}\text { Yavapai } \\
\text { Maricopa } \\
\text { Navajo } \\
\text { Navajo } \\
\text { Navajo } \\
\text { Cochise } \\
\text { Apache }\end{array}$ & $\begin{array}{l}343224 \mathrm{~N} 1115930 \mathrm{~W} \\
333447 \mathrm{~N} 1121505 \mathrm{~W} \\
364651 \mathrm{~N} 1101224 \mathrm{~W} \\
364651 \mathrm{~N} 1101224 \mathrm{~W} \\
\\
364651 \mathrm{N1} 101224 \mathrm{~W} \\
313348 \mathrm{~N} 1102023 \mathrm{~W} \\
350858 \mathrm{~N} 1090632 \mathrm{~W}\end{array}$ & & 1120 & $\begin{array}{l}\text { Fort Huachuca } \\
\text { Chaf in Well }\end{array}$ \\
\hline $\begin{array}{l}\text { Chagit Vo } \\
\text { Chain Link Tank } \\
\text { Chair Crossing } \\
\text { Chaistla Bu } \\
\text { See Chaistla Butte } \\
\text { Chaist la Butte } \\
\text { Cha istl a Butte } \\
\text { Cha istla Butte } \\
\text { Cha-ez-kia } \\
\text { Cha-ez-kla Butte } \\
\text { Cha-ez-kla Rock } \\
\text { Chaistla Bu }\end{array}$ & $\begin{array}{l}\text { lake } \\
\text { reservoir } \\
\text { locale } \\
\text { summit } \\
\text { summit }\end{array}$ & $\begin{array}{l}\text { BGN } \\
\text { BGN } \\
\text { BGN } \\
\text { VARIANT } \\
\text { BGN } \\
\text { VARIANT } \\
\text { VARIANT } \\
\text { VARIANT } \\
\text { VARIANT } \\
\text { VARIANT } \\
\text { VARIANT }\end{array}$ & $\begin{array}{l}\text { Pima } \\
\text { Pinal } \\
\text { Coconino } \\
\text { Navajo } \\
\text { Navajo }\end{array}$ & $\begin{array}{l}320931 N 1123247 \mathrm{~W} \\
323235 \mathrm{~N} 104452 \mathrm{~W} \\
365222 \mathrm{~N} 1113540 \mathrm{~W} \\
364651 \mathrm{~N} 1101224 \mathrm{~W} \\
364651 \mathrm{~N} 1101224 \mathrm{~W}\end{array}$ & & & $\begin{array}{l}\text { Hotason Vo } \\
\text { Campo Bonito } \\
\text { Ferry Swale }\end{array}$ \\
\hline $\begin{array}{l}\text { Cha istla Butte } \\
\text { See Chaistla Butte } \\
\text { Cha istl a Butte } \\
\text { See Chaistla Butte } \\
\text { Chaiyahi Creek } \\
\text { Chaiyahi Flat } \\
\text { Chaiyahi Rim } \\
\text { Chakpahu } \\
\text { Chalender } \\
\text { Chalender Underpass }\end{array}$ & $\begin{array}{l}\text { summit } \\
\text { summit } \\
\text { stream } \\
\text { flat } \\
\text { cliff } \\
\text { locale } \\
\text { locale } \\
\text { crossing }\end{array}$ & $\begin{array}{l}\text { VARIANT } \\
\text { VARIANT } \\
\text { BGN } \\
\text { BGN } \\
\text { BGN } \\
\text { BGN } \\
\text { BGN } \\
\text { UNOFF }\end{array}$ & $\begin{array}{l}\text { Navajo } \\
\text { Navajo } \\
\text { Coconino } \\
\text { Coconino } \\
\text { Coconino } \\
\text { Navajo } \\
\text { Coconino } \\
\text { Coconino }\end{array}$ & $\begin{array}{l}364651 \mathrm{~N} 1101224 \mathrm{~W} \\
364651 \mathrm{~N} 1101224 \mathrm{~W} \\
364954 \mathrm{~N} 1105745 \mathrm{~W} \\
365445 \mathrm{~N} 1105428 \mathrm{~W} \\
365623 \mathrm{~N} 1105410 \mathrm{~W} \\
354543 \mathrm{~N} 1101020 \mathrm{~W} \\
351404 \mathrm{~N} 1120128 \mathrm{~W} \\
351532 \mathrm{~N} 1120152 \mathrm{~W}\end{array}$ & $365338 \mathrm{N1} 104852 \mathrm{~W}$ & & $\begin{array}{l}\text { Chaiyahi Rim SW } \\
\text { Chaiyahi Flat } \\
\text { Chaiyahi Flat } \\
\text { Keams Canyon } \\
\text { Davenport Hill } \\
\text { Williams North }\end{array}$ \\
\hline $\begin{array}{l}\text { Chalk Canyon } \\
\text { Chalk Creek } \\
\text { Chalk Creek } \\
\text { Chalk Creek Tank } \\
\text { Chalk Creek Well } \\
\text { Chalk Mountain } \\
\text { Chalk Mountain } \\
\text { Chalk Peak } \\
\text { Chalk Point Spring } \\
\text { Chalk Reservoir }\end{array}$ & $\begin{array}{l}\text { valley } \\
\text { stream } \\
\text { stream } \\
\text { reservoir } \\
\text { well } \\
\text { summit } \\
\text { summit } \\
\text { summit } \\
\text { spring } \\
\text { reservoir }\end{array}$ & $\begin{array}{l}\text { BGN } \\
\text { BGN } \\
\text { BGN } \\
\text { BGN } \\
\text { UNOFF } \\
\text { BGN } \\
\text { BGN } \\
\text { BGN } \\
\text { BGN } \\
\text { BGN }\end{array}$ & $\begin{array}{l}\text { Maricopa } \\
\text { Pima } \\
\text { Gila } \\
\text { Gila } \\
\text { Gila } \\
\text { Gila } \\
\text { Yavapai } \\
\text { Greenlee } \\
\text { Yavapai } \\
\text { Pinal }\end{array}$ & $\begin{array}{l}335535 \mathrm{~N} 1115649 \mathrm{~W} \\
322659 \mathrm{~N} 1105636 \mathrm{~W} \\
333924 \mathrm{~N} 1105039 \mathrm{~W} \\
334150 \mathrm{~N} 1105240 \mathrm{~W} \\
334131 \mathrm{~N} 1105228 \mathrm{~W} \\
335916 \mathrm{~N} 1110903 \mathrm{~W} \\
340204 \mathrm{~N} 1114233 \mathrm{~W} \\
330421 \mathrm{~N} 1091216 \mathrm{~W} \\
343222 \mathrm{~N} 1113 \mathrm{~B} 19 \mathrm{~W} \\
323048 \mathrm{~N} 1105754 \mathrm{~W}\end{array}$ & $\begin{array}{l}335612 \mathrm{~N} 1115549 \mathrm{~W} \\
323116 \mathrm{~N} 1105834 \mathrm{~W} \\
334046 \mathrm{~N} 1105410 \mathrm{~W}\end{array}$ & $\begin{array}{l}5946 \\
27 \mathrm{B3} \\
5274\end{array}$ & $\begin{array}{l}\text { New River Mesa } \\
\text { Oro Valley } \\
\text { Dagger Peak } \\
\text { Meddler Wash } \\
\text { Dagger Peak } \\
\text { Picture Mtn } \\
\text { Chalk Mountain } \\
\text { Rattlesnake Spring } \\
\text { Walker Mtn } \\
\text { Oracle Junction }\end{array}$ \\
\hline
\end{tabular}


FEATURE
CLASS STATUS COUNTY

Chalk Spring

Chalk Spring

Chalk Spring

Chalk Spring

Chalk Spring

Chalk Spring

Chalk Spring

Chalk Spring

Chalk Spring

Chalk Spring

Chalk Spring

Chalk Spring

Chalk Spring Canyon

Chalk Spring Number Two

Chalk Tank

Chalk Tank

Chalk Tank

Chalk Tank

Chalk Tank

Chalk Tank

Chalk Tank Canyon

Chalk Wash

Chalky Butte Well

Chalky Spring

Challe Canyon

See Chelly, Canyon de

Chamberlain Canyon

Chamberlain Tank

Chamberlain Trail

Chambers

Chambers Draw

Chambers Interchange

Chambers Railroad Station

Chambers Windmill

Chamisa Tank

Chamise Tank

Chamise Tank

Chamiso

Chamiso Railroad Station

Champie Ranch

Champie School

Champion Creek

Champion Mine

Champion Spring

Champion Tank

Champion Well

Champurrado Tank

Champurrado Wash

Champurrado Wash Tank

Champurrado Well

Chandler

Chandler Junction

Chandler City Park

See Doctor Chandler Memorial Park

Chandler Community Hospital

Chandler Gardens Mobile Home Park

Chandler Heights

Chandler Heights Post Office

Chandler Heights School

Chandler High School

Chandler Junction

See Chandler

Chandler Junior High Schoo

Chandler Maintenance Yard

Chandler Meadows Mobile Home

Park

Chandler Municipal Airport

Chandler Post office spring

spring

spring

spring

spring

spring

spring

spring

spring

spring

spring

valley

spring

reservoir

reservoir

reservoir

reservoir

reservoir

reservoir

BGN
BGN
BGN
BGN
BGN
BGN
BGN
BGN
BGN
BGN

Gila

Maricopa

Maricopa

Maricopa

Gila

Yavapai

Yavapai

Yavapai

Mohave

Yavapai

BGN Mohave

BGN Mohave

Mohave

Maricopa

Gila

Yuma

Gila

Gila

Maricopa

Yavapai

valley

stream

well

spring

valley

valley

reservoir

trail

locale

BGN
BGN
UNOFF
BGN

Yavapai

Yuma

Maricopa

VARIANT

BGN

BGN

Apache

Mohave

Santa Cruz

Gila

Apache

arroyo BGN Apache

crossing

building

locale

reservoir

reservoir

reservoir

locale

building

locale

BGN

UNOFF

BGN

BGN

BGN

BGN

UNOFF

Apache

Apache

Apache

Navajo

Cochise

Cochise

Yavapai

school

stream

mine

spring

reservoir

well

reservoir

stream

reservoir

well

UNOFF
BGN

BGN
UNOFF

Yavapai

Gila

Mohave

Gila

BGN Gila

UNOFF

BGN

Pima

Pina

Pina

Pima

ppl

BGN

Maricopa

VARIANT

VARIANT

park

hospital

UNOFF

locale UNOFF

Maricopa

Maricopa

Maricopa

school

school

pp 1

school

locale

locale

UNOFF

airport

building
UNOFF Maricopa

UNOFF Maricopa

VARIANT

Maricopa

Maricopa

$\begin{array}{ll}\text { UNOFF } & \text { Maricopa } \\ \text { UNOFF } & \text { Maricopa }\end{array}$

Maricopa

Maricopa ppl BGN Maricopa
COORDIMATE

$335017 \mathrm{~N} 1111946 \mathrm{~W}$

$335543 \mathrm{~N} 1115557 \mathrm{~W}$

$335608 \mathrm{N1} 113142 \mathrm{~W}$

$335910 \mathrm{N11} 13932 \mathrm{~W}$

$341021 N 1113400 \mathrm{~W}$

$342319 \mathrm{~N} 1114200 \mathrm{~W}$

$342324 \mathrm{~N} 1121746 \mathrm{~W}$

$344336 \mathrm{~N} 1132624 \mathrm{~W}$

$345110 \mathrm{~N} 1131538 \mathrm{~W}$

$350215 \mathrm{~N} 1132447 \mathrm{~W}$

$352016 \mathrm{~N} 1142803 \mathrm{~W}$

$344240 \mathrm{N1} 132807 \mathrm{~W}$

$335617 \mathrm{~N} 1113224 \mathrm{~W}$

$332116 \mathrm{~N} 1103330 \mathrm{~W}$

$333659 \mathrm{~N} 1140135 \mathrm{~W}$

$334050 \mathrm{N1} 105402 \mathrm{~W}$

$334926 \mathrm{N1} 102316 \mathrm{~W}$

33531 9N1113302W

$342326 \mathrm{~N} 1115134 \mathrm{~W}$

$342143 \mathrm{~N} 1115558 \mathrm{~W}$

$333902 \mathrm{N11} 140314 \mathrm{~W}$

$333330 \mathrm{~N} 1103830 \mathrm{~W}$

335117 N1 121836W

360919 N1093156W

$363037 \mathrm{N1123911 \textrm {W }}$

312217 N1104739W

$341226 \mathrm{N1} 105813 \mathrm{~W}$

$351119 \mathrm{N1} 092557 \mathrm{~W}$

$335452 \mathrm{~N} 1092128 \mathrm{~W}$

$351125 \mathrm{~N} 1092606 \mathrm{~W}$

$351113 \mathrm{~N} 1092604 \mathrm{~W}$

$351039 \mathrm{~N} 1092513 \mathrm{~W}$

$360332 \mathrm{~N} 1122542 \mathrm{~W}$

$344436 \mathrm{~N} 1102609 \mathrm{~W}$

$344840 \mathrm{~N} 1102323 \mathrm{~W}$

$315934 \mathrm{~N} 1102114 \mathrm{~W}$

$315936 \mathrm{N1} 102124 \mathrm{~W}$

$340106 \mathrm{~N} 1122115 \mathrm{~W}$

$340110 \mathrm{~N} 1122058 \mathrm{~W}$

$332730 \mathrm{~N} 1103324 \mathrm{~W}$

$351736 \mathrm{~N} 1140 \mathrm{~B} 46 \mathrm{~W}$

$332901 N 1104033 \mathrm{~W}$

$332823 \mathrm{~N} 1104100 \mathrm{~W}$

$332840 \mathrm{~N} 1103701 \mathrm{~W}$

$314908 \mathrm{~N} 1111306 \mathrm{~W}$

$314646 \mathrm{~N} 1112106 \mathrm{~W}$

314757 N1111259W

$314919 \mathrm{~N} 1111301 \mathrm{~W}$

$331822 \mathrm{~N} 1115026 \mathrm{~W}$

$331814 N 1115025 \mathrm{~W}$

$33181 B N 1114928 \mathrm{~W}$

$331836 \mathrm{~N} 1114958 \mathrm{~W}$

$331243 \mathrm{~N} 1114108 \mathrm{~W}$

$331452 \mathrm{N11} 13805 \mathrm{~W}$

$331241 N 1114124 \mathrm{~W}$

$331832 \mathrm{~N} 1115031 \mathrm{~W}$

$331822 \mathrm{~N} 1115026 \mathrm{~W}$

$331839 \mathrm{~N} 1115044 \mathrm{~W}$

$331800 \mathrm{N1115020 \textrm {W }}$

331904N1115002W

$331602 \mathrm{~N} 1114852 \mathrm{~W}$

331818N1115030W

$\begin{array}{cc}\text { SOURCE } & \text { ELEV } \\ \text { COORDINATE } & \text { FT }\end{array}$

Tonto Bas in

New River Mesa

Lion Mountain

Horseshoe Dam 
NATIONAL GAZETTEER--ARIZONA 1986

FEATURE NAME

Chandler Springs

Chandler Substation

Chandler Tank

Chaney Place

Chango Tank

Channel Island

Channel Reef

Channel Tank

Chaol Canyon

Outch Canyon

Chaparal

See Chaparral (historical)

Chaparral (subdivision)

Chaparral (historical) Chaparal

Chaparral Gulch

Chaparral High School

Chaparral Park

Chaparral Park

Chaparral School

Chaparral Spring

Chaparral Tank

Chapel Mountain

Chapel of the Holy Cross

Chape I Tank

Chapin Wash

Chapman Tank

Chapo Ranch (historical)

Chapparal Mobile Village

Chapparal Park

Chapparal Tank

Chappo Spring

Chapter House (sawmill)

Chapter House (St Michaels)

Chapter House (Nazlini)

Chapter House (Pinon)

Chapter House (Chinie)

Charco

Charcoal Canyon

Charcoal Gulch

Juniper Gulch

Charcoal Gulch

Charcoal Spring

Charcoal Spring

Charcoal Tank

See Charco Tank

Charcoal Tank

Charco De La Piedra See Charco de la Piedra

Charco de la Piedra

Charco De La Piedra

Hota Son Von

Hotashonevo

Hoto Von Soto

Charco Tank Charcoal Tank

Charco Tank

Charco Tank

Charco Tank

Charco Tank

Char leau Gap

See Charouleau Gap

Charlebois Canyon

Charlebois Spring

Charlebois Tanks

Charlebois Trail

Charles Dam

See Charlies Dam

Charles Mine

Charles Spring

$$
\text { Charlies Spring }
$$

Charleston

Charleston Station
FEATURE
CLASS

STATUS COUNTY

Navajo

spring $B G N$

locale UNOFF

reservoir $B G N$

locale $B G$

reservoir $B G M$

island $B G N$

reservoir $B G$

valley BGN 1915

VARIANT

Maricopa

Graham

Graham

Santa Cruz

Mohave

Mohave

Cochise

Coconino

locale

ppl

locale

valley

schoo

park

park

school

BGN

BGN 1902

VARIANT

JNOFF

ADMIN

ADMIN

UNOFF

spring $B$

summit $B G N$

church UNOFF

reservoir $B G N$

stream BGI

reservoir BGN

locale UNOFF

locale UNOFF

park

ADMIN

reservoir

spring

building

building

building

building

building

locale

valley

valley

BGN

BGN

UNOFF

UNOFF

$B G N$

UNOFF

BGN

BGN

BGN 1972

VARIANT

Yavapai

Maricopa

Yavapai

Yavapai

Maricopa

Maricopa

Maricopa

Maricopa

Yavapai

Yavapai

Coconino

Coconino

Coconino

Mohave

Pima

Santa Cruz

Maricopa

Maricopa

Coconino

Mohave

Apache

Apache

Apache

Navajo

Apache

Pima

Mohave

Yavapai

valley

spring

BGN

BGN

Yavapai

Yavapai

Mohave

VARIANT

reservoir

reservoir BGN

VARIANT

ppl
ppl

BGN 1941 Pima

VARIANT

VARIANT

VARIANT

VARIANT

reservoir

reservoir

reservoir

reservoir

gap

valley

BGN

VARIANT

BGN

BGN

BGN

BGN

VARIANT

spring

BGN

reservoir

trail

BGN

UNOFF

dam

spring

spring

UNOFF

BGN

VARIANT

BGN

VARIANT

Graham

Navajo

Coconino
COORDINATE

$352236 \mathrm{~N} 1102829 \mathrm{~W}$ $332032 \mathrm{~N} 1115026 \mathrm{~W}$ $324915 \mathrm{~N} 1094912 \mathrm{~W}$ $322900 \mathrm{~N} 1092048 \mathrm{~W}$ $312 B 33 N 1104915 \mathrm{~W}$ $360142 \mathrm{~N} 1140830 \mathrm{~W}$ $360150 \mathrm{~N} 1140842 \mathrm{~W}$ $322347 N 1100855$ W $365125 \mathrm{~N} 1111245 \mathrm{~W}$

342830 N1121900W

$333836 \mathrm{~N} 1121044 \mathrm{~W}$

$342830 \mathrm{~N} 1121900 \mathrm{~W}$

342927 N1121348W

$333436 N 1115552 \mathrm{~W}$

$332644 \mathrm{~N} 1114709 \mathrm{~W}$

$333055 \mathrm{~N} 1115424 \mathrm{~W}$

$333629 \mathrm{N1} 120823 \mathrm{~W}$

$342829 \mathrm{~N} 1122054 \mathrm{~W}$ $342925 \mathrm{~N} 1122005 \mathrm{~W}$

$353654 \mathrm{~N} 1114802 \mathrm{~W}$ 344955 N1114557W $353626 \mathrm{~N} 1114725 \mathrm{~W}$ $341656 \mathrm{~N} 1133413 \mathrm{~W}$ $313506 \mathrm{~N} 1111016 \mathrm{~W}$

313807 N1102938W

$332242 N 1120446$

$333838 \mathrm{~N} 1121054 \mathrm{~W}$

$353229 N 1120057 \mathrm{~W}$

$345113 \mathrm{~N} 1134921 \mathrm{~W}$ 350357 N1090954W $353910 \mathrm{N1090537 \textrm {W }}$ $355347 \mathrm{~N} 1092701 \mathrm{~W}$ $360606 \mathrm{~N} 1101$ 360909 N1093330W $321502 \mathrm{~N} 1123619 \mathrm{~W}$ $351805 \mathrm{~N} 1140806 \mathrm{~W}$ $340935 \mathrm{~N} 1122152 \mathrm{~W}$

$343145 \mathrm{~N} 1121918 \mathrm{~W}$ $343044 N 1121940 \mathrm{~W}$ $351740 \mathrm{~N} 1140731 \mathrm{~W}$

322751 N1092533W

351527 N1122832W

$321447 \mathrm{N1123615}$

$321447 \mathrm{N1} 123615$

$322751 N 1092533 \mathrm{~W}$

$333407 \mathrm{~N} 1134436 \mathrm{~W}$

$334359 \mathrm{~N} 1095727 \mathrm{~W}$

$340750 \mathrm{~N} 1100732 \mathrm{~W}$

$350024 \mathrm{~N} 1113712 \mathrm{~W}$

Pinal 323105N1104830W

$\begin{array}{ll}\text { Pinal } & 332728 N 1112041 \mathrm{~W} \\ \text { Pinal } & 332735 \mathrm{~N} 1112031 \mathrm{~W}\end{array}$

$350121 N 1111417 \mathrm{~W}$

$332730 \mathrm{~N} 1112426 \mathrm{~W}$

$320338 \mathrm{~N} 1103454 \mathrm{~W}$

$\begin{array}{ll}\text { Pima } & 313934 N 1111859 W \\ \text { Yavapai } & 341059 N 1122805 W\end{array}$

Cochise 313755N1101025W

$364159 N 1110627 W$

$351654 \mathrm{~N} 1140639 \mathrm{~W}$

$341210 \mathrm{~N} 1122146 \mathrm{~W}$

$343006 \mathrm{~N} 1121942 \mathrm{~W}$

Prescott Valley Prescott Valley

Cerbat

Fitzgerald Hill

Hotason vo

$332819 \mathrm{~N} 1112041 \mathrm{~W}$ 
FEATURE NAME

Charleston Lead Mine

Charleston Station See Charleston

Charles W Harris School

Charles Williams Spring

Charley Bell Well

See Charlie Bell Well

Charley Day Well

Charley Tank

Charley Tank

Charley Thompson Springs

Charley Well

Charlie Bell Pass

Charlie Bell Well Charley Bell Well

Charlie Bent Well

Charlie Died Tank

Charlie Dike

Charlie Moore Mountain

Charlie Moore Place

Charlie Ross Tank

Charlies Dam

Charles Dam

Charlie Secody Well

Charlies Spring See Charles Spring

Charlies Well

Charlie Tank

Charlie Tank

Charlie Well

Charlie Weston Tank

Charlo Juan Well

Charoleau Gap

See Charouleau Gap

Charouleau Gap

Charleau Gap

Charoleau Gap

Char Tank

Chartz Spring

Charvoidles Spring

Charybdis Butte

Chase Creek

Chase Creek

Chase Spring

Chasm Creek

Chatfield Pond

Chat 1 in Well

Chatterly Ranch

Chaves (historical)

Chaves Interchange

Chavez Crossing Campground

Chavez Oraw

Chavez Draw Tank

Chavez Mountain

Chavez Pass

Chavez Pass Ditch

Chavez Ranch

Chavez Spring

Shamrod Spring

Shamrod Springs

Chavez Spring

Chavez Tank

Chavez Tank

Chavez Well

Chediski Butte

See Lost Tank Ridge

Chediski Butte

See Chediski Mountain

Chediski Farms

Chediski Mountain Chediski Butte

FEATURE
CLASS

mine STATUS COUNTY

UNOFF

Cochise

COORDINATE

$313926 \mathrm{~N} 1100915 \mathrm{~W}$

VARIANT

locale

school

spring

well

well

reservoir

spring

UNOFF

BGN

VARIANT

$\begin{array}{lll} & \text { Pima 322306N1130608W }\end{array}$

UNOFF Coconino

BGN Yavapai

BGN

BGN

wel

gap

wet1

well

cliff

summit

locale

reservoir

UNOFF Graham

BGN Pima

VARIANT

UNOFF Pima

BGN Yuma

BGN Pinal

dam

well

well

spring

well

reservoir

reservoir

well

reservoir

well

gap

gap

gap

reservoir

spring

spring

summit

stream

stream

spring

stream

lake

well

locale

locale

crossing UNOFF

park ADMIN

valley

reservoir

summit

gap

canal

locale

spring

spring

reservoir

reservoir

well

ridge

summit

locale

summit
BGN

BGN

BGN

UNOFF

VARIANT

UNOFF

VARIANT

UNOFF

BGN

BGN

UNOFF
BGN

Greenlee

Greenlee

Navajo

Pima

Coconino

Yavapai

Pima

Gila

Maricopa

Yavapai

Yavapai

UNOFF

VARIANT

Pima

Pinal

Pinal

VARIANT

VARIANT

BGN Pinal

BGN Yavapa

Apache

Coconino

BGN Greenlee

BGN Gila

BGN Apache

Yavapai

Graham

Gila

Coconino

Santa Cruz

Santa Cruz

Coconino

BGN Coconino

BGN Coconino

Coconino

Coconino

Coconino

BGN ANOFF Apache

BGN 1982 Pima

VARIANT

VARIANT

BGN

Coconino

BGN

BGN

VARIANT

VARIANT

BGN

BGN

VARIANT

Gila
$350849 \mathrm{~N} 1125540 \mathrm{~W}$

$334622 \mathrm{N1093124 \textrm {W }}$
Cocon ino

Graham

$360832 \mathrm{N1111412W}$

$350207 \mathrm{N1131818 \textrm {W }}$

355609N1120656W

$330837 \mathrm{~N} 1101415 \mathrm{~W}$

$322338 \mathrm{~N} 1130509 \mathrm{~W}$

$322306 \mathrm{~N} 1130608 \mathrm{~W}$

$314322 \mathrm{~N} 1113539 \mathrm{~W}$

$331447 \mathrm{~N} 1135317 \mathrm{~W}$

$323301 \mathrm{N1} 102812 \mathrm{~W}$

$332141 \mathrm{N1090613W}$

$332323 \mathrm{~N} 1090247 \mathrm{~W}$

$343234 \mathrm{~N} 1102857 \mathrm{~W}$

$320338 N 1103454 W$

$361017 N 1111903 \mathrm{~W}$

$341059 \mathrm{~N} 1122805 \mathrm{~W}$

$320449 \mathrm{N1} 103428 \mathrm{~W}$

$333404 \mathrm{~N} 1110130 \mathrm{~W}$

$334625 \mathrm{~N} 1115655 \mathrm{~W}$

$342826 \mathrm{N1} 123821 \mathrm{~W}$

$314240 \mathrm{~N} 1113814 \mathrm{~W}$

$323105 N 1104830 \mathrm{~W}$

$323105 \mathrm{~N} 1104830 \mathrm{~W}$

$325540 \mathrm{N1} 111912 \mathrm{~W}$

$342654 \mathrm{~N} 1125238 \mathrm{~W}$

$360850 \mathrm{~N} 1121530 \mathrm{~W}$

$330325 \mathrm{~N} 1091757 \mathrm{~W}$

$342248 \mathrm{N1} 111657 \mathrm{~W}$

$340212 \mathrm{~N} 1090445 \mathrm{~W}$

$342647 \mathrm{N1} 114721 \mathrm{~W}$

$325024 \mathrm{N1095236 \textrm {W }}$

$332842 \mathrm{~N} 1103348 \mathrm{~W}$

$365731 \mathrm{N1122234 \textrm {W }}$

$313900 N 1110240 \mathrm{~W}$

$313910 \mathrm{~N} 1110332 \mathrm{~W}$

345036N1114634W

$344432 \mathrm{N1110534W}$

$344523 N 1110708 \mathrm{~W}$

$344629 N 1110722 \mathrm{~W}$

344649 N1110827W

$345014 N 111041 \mathrm{BW}$

$342245 N 1092401 \mathrm{~W}$

$315205 N 1104647 \mathrm{~W}$

343147 N1110722W

$331145 N 1092235 \mathrm{~W}$

$342556 \mathrm{~N} 1111822 \mathrm{~W}$

$342801 \mathrm{N1115251 \textrm {W }}$

$350132 \mathrm{~N} 1114102 \mathrm{~W}$

$352930 \mathrm{~N} 1113425 \mathrm{~W}$

$344633 \mathrm{~N} 1110837 \mathrm{~W}$

$340835 N 1104604 \mathrm{~W}$

$340810 N 1104321 \mathrm{~W}$

$\begin{array}{ll}\text { Navajo } & 340810 \mathrm{~N} 1104321 \mathrm{~W} \\ \text { Navajo } & 34074 \mathrm{BN} 1104249 \mathrm{~W} \\ \text { Navajo } & 340810 \mathrm{~N} 1104321 \mathrm{~W}\end{array}$

$\begin{array}{cc}\text { SOURCE } & \text { ELEV } \\ \text { COORDIMATE } & \text { FT MAP NAME }\end{array}$

Fairbank

Fowler

Gentry Mtn

Tuba City

Devils Hump

6645 Tusayan East

Fort Thomas

Calva

Growler Peak

Growler Peak

Mildred Peak

Charlie Oied Tank

Kielberg Canyon 
FEATURE CLASS

STATUS

COUNTY

Chediski Mountain See Chediski Peak

Chediski Peak

Chediski Mountain

Chediski Ridge

Chediski Tank

Chee Dodge Ranch

Cheese Spring

Chefs Pond

Chelly, Canyon de

Canon Chenelle

Canon de Chille

Canon de el Challe

Canyon Chennele

Canyon de Chelly

Challe Canyon

Chelly Canyon

Chgelley Canyon

De Chelly Canyon

Chelly Canyon

See Chelly, Canyon de

Chemehuevi Mountains

See Mohave Mountains

Chemehuevi Point

Chemehuevis Mountains

See Mohave Mountains

Cheme-Huevis Valley

See Chemehuevi Valley

Chemehuevi Valley

Cheme-Huevis Valley

Chemehuevi Wash

Chemise Wash

See Chimney Wash

Cheney Draw

Cheney Flat

Cheney Lake

Chenlini Wash

See Kit Sili Wash

Cheops Pyramid

Cherioni Wash Growler Wash

Cherokee (historical town)

Cherokee Avenue Park

Cherokee Elementary School

Cherokee Mobile Village

Cherokee Point

Cherokee Tank

Cherokee Wash

Cherry

Cherry Canyon

Cherry Canyon

Cherry Creek

Cherry Creek

Cherry Creek

Cherry Creek

Cherry Creek

Cherry Creek Hill

Cherry Creek Railroad Station

Cherry Creek Spring

Cherry Creek Tank

Cherry Creek Trail Two

Hundred Fourteen

Cherry Creek Well

Cherry Flat Recreation Area

Cherry King Mine

Cherry Number One Tank

Cherry Number Three Tank

Cherry Number Two Tank

Cherry Spring

Cherry Spring

Cherry Spring

Cherry Spring

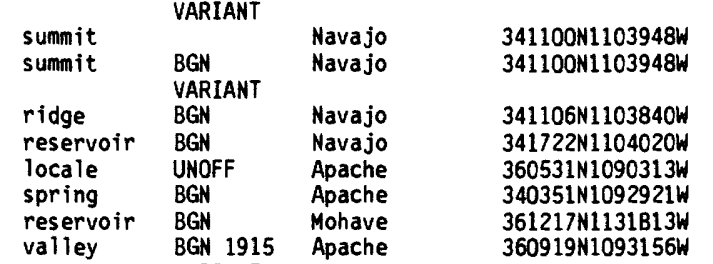

VARIANT

VARIANT

VARIANT

VARIANT

VARIANT

VARIANT

VARIANT

VARIANT

VARIANT

valley

VARIANT

range
cliff

range

bas in

bas in

stream

stream

valley

flat

lake

stream

summit

stream

local

school

locale

summit

reservoir

arroyo

locale

valley

valley

BGN 1908

VARIANT

VARIANT

BGN

VARIANT

Apache

Mohave

Coconino

Mohave

Mohave

Mohave

BGN

VARIANT

BGN

BGN

BGN

VARIANT

BGN 1906

BGN

VARIANT

Mohave

Apache

Apache

Apache

Apache

Apache

Coconino

Pima

BGN
ADMI
UNOF
UNOF
BGN
BGN
BGN
BGN
BGN
BGN

stream

strean

strean

stream

stream

summit

building

spring

reservoir

$\begin{array}{ll}\text { well } & \text { UNOF } \\ \text { park } & \text { ADMIN } \\ \text { mine } & \text { UNOF } \\ \text { reservoir } & \text { BGN } \\ \text { reservoir } & \text { BGN } \\ \text { reservoir } & \text { BGN } \\ \text { spring } & \text { BGN } \\ \text { spring } & \text { BGN } \\ \text { spring } & \text { 8GN } \\ \text { spring } & \text { BGN }\end{array}$

$\begin{array}{ll}\text { Mohave } & 352845 \mathrm{~N} 1133030 \mathrm{~W} \\ \text { Pima } & 321405 \mathrm{~N} 1105948 \mathrm{~W} \\ \text { Maricopa } & 333355 \mathrm{~N} 1115730 \mathrm{~W} \\ \text { Maricopa } & 332502 \mathrm{~N} 1113634 \mathrm{~W} \\ \text { Mohave } & 352840 \mathrm{N1} 132757 \mathrm{~W} \\ \text { Mohave } & 352808 \mathrm{~N} 1133018 \mathrm{~W} \\ \text { Mohave } & 352921 \mathrm{N1} 133003 \mathrm{~W} \\ \text { Yavapai } & 343517 \mathrm{N1} 120228 \mathrm{~W} \\ \text { Cochise } & 315458 \mathrm{N1} 102858 \mathrm{~W} \\ \text { Coconino } & 350925 \mathrm{~N} 1112856 \mathrm{~W}\end{array}$

Santa Cruz 312638N1103507W

Gila 334016 N1104801W

Yavapai

Gila

Yavapai

Gila

Yavapai

Gila

Gila

Yavapai

Yavapai

Gila

Yavapai

Gila

Gila

Gila

Cochise

Pinal

Pinal

Gila
342622N114184BW

$342306 \mathrm{N1092356 \textrm {W }}$

$343812 \mathrm{~N} 1094614 \mathrm{~W}$

$343748 N 1094604 \mathrm{~W}$

$341021 \mathrm{N1092BO}$ W

(360705N1120717W

$320938 \mathrm{~N} 1125508 \mathrm{~W}$

$334016 \mathrm{~N} 1104801 \mathrm{~W}$

$341828 \mathrm{~N} 1112033 \mathrm{~W}$

$343750 \mathrm{~N} 1115503 \mathrm{~W}$

$340930 \mathrm{~N} 1105211 \mathrm{~W}$

343127N1121417W

$335131 \mathrm{~N} 1110531 \mathrm{~W}$

$340525 \mathrm{~N} 1105545 \mathrm{~W}$

$341150 \mathrm{~N} 1122850 \mathrm{~W}$

$343601 \mathrm{~N} 1115709 \mathrm{~W}$

$332144 \mathrm{~N} 1105236 \mathrm{~W}$

$343614 \mathrm{~N} 1120219 \mathrm{~W}$

$335110 \mathrm{~N} 1105142 \mathrm{~W}$

$35152 \mathrm{~N} 1105204 \mathrm{~W}$

$335130 \mathrm{~N} 1105145 \mathrm{~W}$

$322446 \mathrm{~N} 1101806 \mathrm{~W}$

$323100 \mathrm{~N} 1105013 \mathrm{~W}$

$332452 \mathrm{~N} 1110509 \mathrm{~W}$

$332634 \mathrm{~N} 1105756 \mathrm{~W}$ $\begin{array}{cc}\text { SOURCE } & \text { ELEV } \\ \text { COORDINATE } & \text { FT MAP NAME }\end{array}$

$\begin{array}{ll}7462 & \text { Chediski Peak } \\ & \text { Chediski Peak } \\ \text { Brookbank Point } \\ \text { Sonsela Buttes } \\ \text { Greer } \\ \text { Whitmore Point } \\ \text { Chinle }\end{array}$

Explorers Monument

Lake Havasu City S

$343012 \mathrm{~N} 1141404 \mathrm{~W}$

Lake Havasu City S

34283BN1095040W

Little Milky Ranch Little Milky Ranch Springerville NW

315918 N1124759W

5392 Phantom Ranch

Bates Well

4460 Truxton

Tucson

Paradise Valley

1590 Apache Junction

5744 Cherokee Point

4516 Truxton

$352824 \mathrm{~N} 1132800 \mathrm{~W}$

Truxton

Cherry

$\begin{array}{ll}315339 \mathrm{~N} 1102602 \mathrm{~W} & \text { Mescal } \\ 350712 \mathrm{~N} 1113112 \mathrm{~W} & \text { Winona }\end{array}$

$312740 \mathrm{N1102952W}$

$341426 \mathrm{~N} 1104903 \mathrm{~W}$

$341008 \mathrm{~N} 1122426 \mathrm{~W}$

$341936 \mathrm{~N} 1112219 \mathrm{~W}$

$343813 \mathrm{~N} 1120407 \mathrm{~W}$

Canelo Pass

Dagger Peak

Wagoner

Payson North

Cornville

6202 Parallel Canyon

4500 Humbolt

Armer Mountain

Oxbow Mtn

Minnehaha

Middle Verde

Pinal Ranch

Cherry

Sombrero Peak

Sombrero Peak

Sombrero Peak

Cherry Spring Peak

Oracle

Haunted Canyon

Inspiration 


FEATURE
CLASS

Cherry Spring

Cherry Spring

Cherry Spring

Cherry Spring

Cherry Spring Canyon

Cherry Spring Peak

Cherry Tank

Cherry Tank

Cherry Trap Spring

Cherry Tree Spring

Cherry Tree Tank

Cherry Tree Tank

Cherry Valley Ranch

Cherry Valley Wash

Cherum Peak

Cherum Tank

Chesapeake Drain

Chesapeake Wash

Chesley Flat

Ches ley-Wams lee Dam

Ches ley Wash

Chesser Canyon

Chester Tank

Chestnutt Park

Chetco

Chet Spring

Chet Tank

Big Dry Fork

Big Dry Wash

Clevelon Fork

Clevion Creek

Clevlons Fork

East Clear Creex

Shevion Creek

Chevalons Butte

See Chevelon Butte

Chevellons Butte

See Chevelon Butte

Chevelon Butte

Chevalons Butte

Chevellons Butte

Chevelons Butte

Shevlons Butte

Chevelon Butte School

Chevelon Butte Tank

Chevelon Canyon

Chevelon Canyon Campground

Chevelon Canyon Dam

Chevelon Canyon Lake

Chevelon Creek

Big Dry Wash

Chevelous Fork

Chevion Creek

Chevion Fork

East Clear Creek

Shevion

Chevelon Crossing

Chevelon Lake Campground

Chevelon Ranger Station

Chevelon Ridge

Chevelon Ridge Truck Trail

Chevelons Butte

See Chevelon Butte

Chevelon Tank

Chevelous Fork

See Chevelon Creek

Chevion Creek

See Chevelon Creek

Chevlon Fork

See Chevelon Creek

Chewed Nose Springs

Cheyava Falls

\section{CLASS}

reservoir reservoir

locale

stream

summit

reservoir

strean

stream

flat

dam

stream

valley

reservoir

park

locale

spring

reservoir

summit

summit

reservoir

valley

park

dam

reservoir

stream

local

summit

reservoir

stream

stream

strean

spring

falls
STATUS

COUNTY

spring
spring
spring
spring
valley
summit
reservoir
reservoir
spring
spring

BGN
BGN
BGN
BGN
BGN
BGN
BGN
BGN
BGN
BGN

BGN
BGN
UNOF
BGN
BGN
BGN
BGN
BGN
BGN

BGN
UNOFF

$B G N$
$B G N$
$B G N$
$B G N$
$B G N$
$B G N$
$B G N$
$B G N$
$B G N$

$\begin{array}{ll}\text { Gila } & 332650 \mathrm{~N} 1105334 \mathrm{~W} \\ \text { Gila } & 333233 \mathrm{~N} 1104538 \mathrm{~W} \\ \text { Yavapai } & 341047 \mathrm{N1} 12292 \mathrm{~W} \\ \text { Gila } & 341451 \mathrm{N1} 11034 \mathrm{~W} \\ \text { Cochise } & 322240 \mathrm{~N} 1102249 \mathrm{~W} \\ \text { Cochise } & 322533 \mathrm{~N} 1101738 \mathrm{~W} \\ \text { Gila } & 341931 \mathrm{N11} 12216 \mathrm{~W} \\ \text { Coconino } & 350758 \mathrm{~N} 1112945 \mathrm{~W} \\ \text { Yavapai } & 341054 \mathrm{~N} 1122645 \mathrm{~W} \\ \text { Graham } & 324938 \mathrm{~N} 1101254 \mathrm{~W}\end{array}$

Graham

Coconino

Yavapai

Pinal

Pinal

Mohave

Mohave

Mohave

Mohave

Graham

Graham

BGN

BGN

ADMIN

BGN
BGN

BGN

VARIANT

VARIANT

VARIANT

VARIANT

VARIANT

VARIANT

VARIANT

Graham

Greenlee

Yavapai

Maricopa

Apache

Santa Cruz

$343634 N 1112917 \mathrm{~W}$

$345333 \mathrm{~N} 1130932 \mathrm{~W}$

$323611 \mathrm{~N} 1104455 \mathrm{~W}$

$323923 \mathrm{~N} 1104050 \mathrm{~W}$

$352352 \mathrm{N1} 140816 \mathrm{~W}$

$352351 \mathrm{~N} 1140644 \mathrm{~W}$

$342730 \mathrm{~N} 1141622 \mathrm{~W}$

342656 N1141719W

$324300 \mathrm{~N} 1095620 \mathrm{~W}$

$325453 \mathrm{~N} 1094720 \mathrm{~W}$

$325450 N 1094724 W$

$330911 N 1092218 \mathrm{~W}$

$343049 N 1122344 \mathrm{~W}$

$333014 N 1115354 \mathrm{~W}$

$351259 N 1092001 \mathrm{~W}$

$313800 \mathrm{~N} 1104317 \mathrm{~W}$

Pinal

$325640 \mathrm{~N} 1102833 \mathrm{~W}$

$325953 \mathrm{~N} 1094532 \mathrm{~W}$

331016 N1092035W

$342755 \mathrm{~N} 1141530 \mathrm{~W}$

$342832 \mathrm{N1141404W}$

VARIANT

VARIANT

Coconino

Coconino

Coconino

BGN 1930

VARIANT

VARIANT

VARIANT

VARIANT

school UNOFF

Coconino

BGN

Coconino

BGN 1973

ADMIN

UNOFF

BGN

BGN

VARIANT

VARIANT

VARIANT

VARIANT

VARIANT

VARIANT

locale $B G N$

AOMIN

UNOFF

BGN

UNOFF

VARIANT

BGN

VARIANT

Coconino

Coconino

Coconino

Navajo

VARIANT

VARIA
BGN

BGN 1932
Navajo

Apache

Coconino
$343209 \mathrm{~N} 1105504 \mathrm{~W}$

344133N1105053W

344133N1105053W

$344133 \mathrm{~N} 1105053 \mathrm{~W}$

345537 N1103147W

$343528 \mathrm{~N} 1104717 \mathrm{~W}$

$343040 \mathrm{~N} 1104927 \mathrm{~W}$

$343040 \mathrm{~N} 1104927 \mathrm{~W}$

345704 N1103118W

342130 N1105319W
360158 N1095821
6945 Chevelon Butte

Grama Draw

342130N1105319W $\quad \begin{aligned} & \text { Chevelon Butte } \\ & \text { Hibbard } \\ & \text { Chevelon Crossing } \\ & \text { Chevelon Crossing } \\ & \text { Chevelon Crossing }\end{aligned}$

Hibbard

$343536 \mathrm{~N} 1104714 \mathrm{~W}$

$343044 \mathrm{~N} 1104927 \mathrm{~W}$

$343228 \mathrm{~N} 1105456 \mathrm{~W}$

$342355 N 1105323 \mathrm{~W}$

342649N1105129W

$344133 N 1105053 \mathrm{~W}$

345345N1103433W

345704 N1103118W

345704N1103118W

$345704 \mathrm{N1103118W}$

$360846 \mathrm{~N} 1115825 \mathrm{~W}$

Chevelon Crossing

6440 Chevelon Crossing

Grama Draw

Porcupine Ridge

Weimar Point

Hibbard

Toadindaaska Mes a Walhalla Plateau

Inspiration

Rockinstraw Mtn

Diamond

Redington

Cherry Spring Peak

Payson North

Winona

Minnehaha

Buford $\mathrm{Hill}$

Calloway Butte

Sunrise Peak

Campo Bonito

Mammoth

Elements Canyon

Lake Havasu City S

Lake Havasu City $S$

Pina

Mitchell Peak

Prescott

dise Valley

Sanders

Sonoita

Booger Canyon 
NATIONAL GAZETTEER--ARIZONA 1986

FEATURE NAME

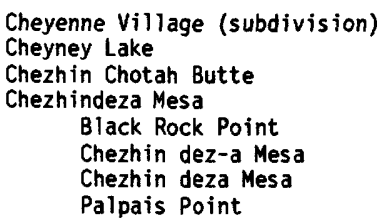

Chilchinbito Creek (historical)

Chilchinbito Spring

Chilchinbito Trading Post

Chilchinbito Wash

$$
\text { Bambo Wash }
$$

Chilchinbito Well

Chilchinvito Canyon
FEATURE

CLASS

STATUS

ppl

summit

summit

BGN

BG

BGN

BGN 1915

VARIANT

VARIANT

VARIANT

VARIANT

summ it

VARIANT

summit

valley

valley

ppl

VARIANT

VARIANT

BGN

BGN 1941 Pinal

VARIANT

clif

locale

BGN

Pima

VARIANT

VARIANT

VARIANT

VARIANT reservoir

BGN

VARIANT

reservoir

stream

BGN

VARIANT

locale

locale

valley

summit

pillar

well

reservoir

reservoir

reservoir

cemetery

BGN

BGN

BGN
BGN

UNOFF

BGN

BGN

BGN

BGN

UNOFF

summit $\quad B G M$

ridge

reservoir

stream

summit

summit

cliff

reservoir

BGN

BGN 1917

VARIANT

BGN

BGN

BGN 1932

BGN 1925

BGN

BGN

ppl

VARIANT

pp1

VARIANT

ppl

valley

BGN

VARIANT

VARIANT

VARIANT

BGN

VARIANT

VARIANT

VARIANT

VARIANT

VARIANT

VARIANT

VARIANT

stream

spring

valley

BGN 1915

BGN

BGN

BGN

VARIANT

UNOFF

Coconino

Mohave

Pima

Pima

Pima

Pima

Pima

Pima

Coconino

Pima

Mohave

Navajo

Pinal

Santa Cruz

Maricopa

Coconino

Coconino

Cochise

Coconino

Coconino

Santa Cruz

Navajo

Navajo

Navajo

Navajo

Navajo

wel
Navajo

Navajo

Navajo

Navajo
315608 N1114649W

$363000 \mathrm{~N} 1100000 \mathrm{~W}$ $363057 N 1100347 \mathrm{~W}$
COORDINATE

$333600 \mathrm{~N} 1120815 \mathrm{~W}$

$341154 \mathrm{~N} 1093058 \mathrm{~W}$

351854 N1102123W

$365138 \mathrm{~N} 1091520 \mathrm{~W}$

65138 N1091520W

365138N1091520W

$360919 \mathrm{~N} 1093156 \mathrm{~W}$

$321542 \mathrm{~N} 1133039 \mathrm{~W}$

323209N1120804W

$321530 \mathrm{~N} 1133152 \mathrm{~W}$

Is la Pint

1901 Copperosity Hills

$361026 \mathrm{~N} 1115333 \mathrm{~W}$

$360628 \mathrm{~N} 1123319 \mathrm{~W}$

$363130 \mathrm{~N} 1132030 \mathrm{~W}$

$321315 \mathrm{N1} 105721 \mathrm{~W}$

$320055 \mathrm{~N} 1121723 \mathrm{~W}$

$321940 \mathrm{N1125646 \textrm {W }}$

$321907 \mathrm{~N} 1130040 \mathrm{~W}$

$321 \mathrm{~B} 31 \mathrm{N1125705 \textrm {W }}$

$321823 \mathrm{~N} 1130039 \mathrm{~W}$

$321940 \mathrm{~N} 1125603 \mathrm{~W}$

$352501 N 1113507 \mathrm{~W}$

$315715 \mathrm{Nl} 112603 \mathrm{~W}$

$363130 \mathrm{~N} 1132030 \mathrm{~W}$

335520N1095620W

$323756 \mathrm{~N} 1110420 \mathrm{~W}$

312B29N1104440W

UNKNOWN

$361140 \mathrm{~N} 1123123 \mathrm{~W}$

$355510 \mathrm{~N} 1110 \mathrm{~B} 18 \mathrm{~W}$

$312641 \mathrm{N1095433 \textrm {W }}$

$362101 N 1123809 \mathrm{~W}$

362031 N1123719W

$312225 \mathrm{~N} 1110931 \mathrm{~W}$

$360500 N 1102221 \mathrm{~W}$

$363138 \mathrm{~N} 1100454 \mathrm{~W}$

$363138 \mathrm{~N} 1100454 \mathrm{~W}$

$36313 \mathrm{BN} 1100454 \mathrm{~W}$

$363125 N 100248 W$

$362724 N 1100345 \mathrm{~W}$

6217 Wathalla Plateau Sells East

Antelope Point

321250N1105307W Tucson

$322018 N 1125406 \mathrm{~W}$

Chico Shunie Temporal Pass Chico Shunie Temporal Pass Chico Shunie

O'Leary Peak

Palo Alto Ranch

Russe 11 Spring

Alchesay Flat

33B3 Chief Butte

Harshaw

Topocoba Hilltop

Goldtooth

5896 Bisbee

4433 Havasu Falls

Fossil Bay

Alamo Spring

LtI Black Spot Mtn

Chilchinbito

Chilchinbito 


\begin{tabular}{|c|c|c|c|c|c|c|c|}
\hline FEATURE NAME & $\begin{array}{l}\text { FEATURE } \\
\text { CLASS }\end{array}$ & STATUS & COUNTY & COORDINATE & $\begin{array}{l}\text { SOURCE } \\
\text { COORDINATE }\end{array}$ & $\begin{array}{c}\text { ELEV } \\
\text { FT }\end{array}$ & MAP NAME \\
\hline $\begin{array}{l}\text { See Chilchinbito Canyon } \\
\text { Chilchinvito Canyon } \\
\text { See Chilchinbito Canyon }\end{array}$ & $\begin{array}{l}\text { valley } \\
\text { valley }\end{array}$ & VARIANT & $\begin{array}{l}\text { Navajo } \\
\text { Navajo }\end{array}$ & $\begin{array}{l}363125 \mathrm{~N} 100248 \mathrm{~W} \\
363125 \mathrm{~N} 100248 \mathrm{~W}\end{array}$ & & & \\
\hline $\begin{array}{l}\text { Chil-Chi-vi-to Canyon } \\
\text { See Chilchinbito Canyon } \\
\text { Childers Knoll } \\
\text { See Twin Butte } \\
\text { Childers Seep } \\
\text { Childers Spring } \\
\text { Childers Well } \\
\text { Childers Well } \\
\text { Childers Well } \\
\text { Childrens Hospital }\end{array}$ & $\begin{array}{l}\text { valley } \\
\text { summit } \\
\text { spring } \\
\text { spring } \\
\text { well } \\
\text { well } \\
\text { well } \\
\text { hospital }\end{array}$ & $\begin{array}{l}\text { VARIANT } \\
\text { VARIANT } \\
\text { BGN } \\
\text { BGN } \\
\text { UNOFF } \\
\text { UNOFF } \\
\text { UNOFF } \\
\text { UNOFF }\end{array}$ & $\begin{array}{l}\text { Navajo } \\
\text { Mohave } \\
\text { Gila } \\
\text { Gila } \\
\text { Yavapai } \\
\text { Mohave } \\
\text { Mohave } \\
\text { Maricopa }\end{array}$ & $\begin{array}{l}363125 \mathrm{~N} 100248 \mathrm{~W} \\
363310 \mathrm{~N} 1131935 \mathrm{~W} \\
341315 \mathrm{~N} 1113642 \mathrm{~W} \\
341157 \mathrm{~N} 1113610 \mathrm{~W} \\
341536 \mathrm{~N} 1125159 \mathrm{~W} \\
363432 \mathrm{~N} 1132017 \mathrm{~W} \\
364528 \mathrm{~N} 1130811 \mathrm{~W} \\
332726 \mathrm{~N} 1120230 \mathrm{~W}\end{array}$ & & & $\begin{array}{l}\text { Cypress Butte } \\
\text { Cypress Butte } \\
\text { Weaver Peak } \\
\text { Russell Spring } \\
\text { White Pockets } \\
\text { Phoenix }\end{array}$ \\
\hline $\begin{array}{l}\text { Childress Tank } \\
\text { Childs } \\
\text { Childs } \\
\text { Childs and Altwilkle Mine } \\
\text { Childs Mountain } \\
\text { Childs Powerplant } \\
\text { Childs Powerplant Tank } \\
\text { Childs Ranch } \\
\text { Childs Valley } \\
\text { Childs Wash } \\
\text { See Tenmile Wash }\end{array}$ & $\begin{array}{l}\text { reservoir } \\
\text { ppl } \\
\text { locale } \\
\text { mine } \\
\text { summit } \\
\text { locale } \\
\text { reservoir } \\
\text { locale } \\
\text { valley } \\
\text { stream }\end{array}$ & $\begin{array}{l}\text { BGN } \\
\text { BGN } \\
\text { BGN } \\
\text { UNOFF } \\
\text { BGN } \\
\text { UNOFF } \\
\text { BGN } \\
\text { UNOFF } \\
\text { BGN } \\
\text { VARIANT }\end{array}$ & $\begin{array}{l}\text { Gila } \\
\text { Pima } \\
\text { Yavapai } \\
\text { Pinal } \\
\text { Pima } \\
\text { Yavapai } \\
\text { Yavapai } \\
\text { Pima } \\
\text { Maricopa } \\
\text { Yuma }\end{array}$ & $\begin{array}{l}341755 \mathrm{~N} 1111557 \mathrm{~W} \\
322710 \mathrm{~N} 1125034 \mathrm{~W} \\
342702 \mathrm{~N} 1114400 \mathrm{~W} \\
324502 \mathrm{~N} 1102859 \mathrm{~W} \\
322555 \mathrm{~N} 1125645 \mathrm{~W} \\
342059 \mathrm{~N} 1114154 \mathrm{~W} \\
342117 \mathrm{~N} 1114132 \mathrm{~W} \\
322922 \mathrm{~N} 1125225 \mathrm{~W} \\
323504 \mathrm{~N} 1131536 \mathrm{~W} \\
\\
325213 \mathrm{~N} 1132833 \mathrm{~W}\end{array}$ & $322926 \mathrm{~N} 1125355 \mathrm{~W}$ & 2846 & $\begin{array}{l}\text { Payson North } \\
\text { Ajo North } \\
\text { Hackberry Mtn } \\
\text { Oak Grove Canyon } \\
\text { Childs Mtn } \\
\text { Verde Hot Springs } \\
\text { Verde Hot Springs } \\
\text { Ajo North } \\
\text { Aguila Mts SE }\end{array}$ \\
\hline $\begin{array}{l}\text { Chilean Mill } \\
\text { Chilechinbito } \\
\text { See Chilchinbito } \\
\text { Chili Spring } \\
\text { Chilito (historical) } \\
\text { Chilito Mine } \\
\text { Chill Heal Spring } \\
\text { Chillicut Spring } \\
\text { Chilson Cabin } \\
\text { See Chilson Camp }\end{array}$ & $\begin{array}{l}\text { locale } \\
\text { ppl } \\
\text { spring } \\
\text { locale } \\
\text { mine } \\
\text { spring } \\
\text { spring } \\
\text { locale }\end{array}$ & $\begin{array}{l}\text { BGN } \\
\text { VARIANT } \\
\text { BGN } \\
\text { BGN } \\
\text { UNOFF } \\
\text { BGN } \\
\text { BGN } \\
\text { VARIANT }\end{array}$ & $\begin{array}{l}\text { Yavapai } \\
\text { Navajo } \\
\text { Navajo } \\
\text { Gila } \\
\text { Gila } \\
\text { Mohave } \\
\text { Gila } \\
\text { Yavapai }\end{array}$ & $\begin{array}{l}340904 N 1122333 W \\
363138 N 1100454 W \\
354815 N 1101119 W \\
330400 N 1104747 W \\
330400 N 1104746 W \\
361301 N 1135917 W \\
334008 N 1111738 W \\
340504 N 1112931 W\end{array}$ & & & $\begin{array}{l}\text { Keams Canyon } \\
\text { Hayden } \\
\text { Hayden } \\
\text { Snap Canyon West } \\
\text { Four Peaks }\end{array}$ \\
\hline $\begin{array}{l}\text { Chilson Camp } \\
\text { Chilson Cabin } \\
\text { Chilson Canal } \\
\text { Chilson Landing Strip } \\
\text { Chilson Mesa Tank } \\
\text { Chilson Spring } \\
\text { Chilson Tank } \\
\text { Chilson Tank } \\
\text { Chilson Tank } \\
\text { Chiltepines Wash }\end{array}$ & $\begin{array}{l}\text { locale } \\
\text { canal } \\
\text { airport } \\
\text { reservoir } \\
\text { spring } \\
\text { reservoir } \\
\text { reservoir } \\
\text { reservoir } \\
\text { stream }\end{array}$ & $\begin{array}{l}\text { BGN } \\
\text { VARIANT } \\
\text { BGN } \\
\text { ADMIN } \\
\text { BGN } \\
\text { BGN } \\
\text { BGN } \\
\text { BGN } \\
\text { BGN } \\
\text { BGN }\end{array}$ & $\begin{array}{l}\text { Yavapai } \\
\text { Coconino } \\
\text { Coconino } \\
\text { Coconino } \\
\text { Yavapai } \\
\text { Coconino } \\
\text { Coconino } \\
\text { Coconino } \\
\text { Pima }\end{array}$ & $\begin{array}{l}340504 N 1112931 W \\
344448 N 1111406 W \\
350145 N 1105905 W \\
343336 N 1112145 W \\
340509 N 1112925 W \\
344400 N 1111338 W \\
345149 N 1112251 W \\
350619 N 1110255 W \\
315009 N 1112421 W\end{array}$ & $314727 N 1113249 \mathrm{~W}$ & 5661 & $\begin{array}{l}\text { Mazatzal Peak } \\
\text { Hay Lake } \\
\text { Tucker Mesa SW } \\
\text { Long Valley } \\
\text { Mazatzal Peak } \\
\text { Hay Lake } \\
\text { Hutch Mtn } \\
\text { Meteor Crater } \\
\text { Fresno Wash }\end{array}$ \\
\hline $\begin{array}{l}\text { Chimena Natural Area } \\
\text { Chimenea Canyon } \\
\text { Chimenea Well } \\
\text { Chimhuevis Mountains } \\
\text { See Mohave Mountains } \\
\text { Chiminea Peak } \\
\text { Chimney, The } \\
\text { Chimney Butte } \\
\text { Chimney Butte Spring } \\
\text { Chimney Canyon }\end{array}$ & $\begin{array}{l}\text { park } \\
\text { valley } \\
\text { well } \\
\text { range } \\
\text { summit } \\
\text { pillar } \\
\text { summit } \\
\text { spring } \\
\text { valley }\end{array}$ & $\begin{array}{l}\text { ADNIN } \\
\text { BGN } \\
\text { UNOFF } \\
\text { VARIANT } \\
\text { BGN } \\
\text { BGN } \\
\text { BGN } \\
\text { BGN } \\
\text { BGN }\end{array}$ & $\begin{array}{l}\text { Pima } \\
\text { Pima } \\
\text { Pima } \\
\text { Mohave } \\
\text { Santa Cruz } \\
\text { Graham } \\
\text { Navajo } \\
\text { Navajo } \\
\text { Santa Cruz }\end{array}$ & $\begin{array}{l}320910 N 1103225 W \\
320822 N 1103621 W \\
315401 N 1103425 W \\
\\
343818 N 1142314 W \\
312857 N 1111351 W \\
325337 N 1102454 W \\
351802 N 1102433 W \\
351918 N 1102519 W \\
313144 N 1111508 W\end{array}$ & $312 \mathrm{~B} 1 \mathrm{BN} 1111435 \mathrm{~W}$ & $\begin{array}{r}4918 \\
6553\end{array}$ & $\begin{array}{l}\text { Ruby } \\
\text { Booger Canyon } \\
\text { Chimney Butte } \\
\text { Chimney Butte } \\
\text { Arivaca }\end{array}$ \\
\hline $\begin{array}{l}\text { Chimney Canyon } \\
\text { Chimney Canyon } \\
\text { Chimney Canyon } \\
\text { Chimney Hill (subdivision) } \\
\text { Chimney Rock } \\
\text { Chimney Rock } \\
\text { Chimney Rock } \\
\text { Chimney Rock } \\
\text { Chimney Rock Canyon } \\
\text { Chimney Rock Creek }\end{array}$ & $\begin{array}{l}\text { valley } \\
\text { valley } \\
\text { valley } \\
\text { ppl } \\
\text { pillar } \\
\text { pillar } \\
\text { pillar } \\
\text { summit } \\
\text { valley } \\
\text { stream }\end{array}$ & $\begin{array}{l}\text { BGN } \\
B G N \\
B G N \\
B G N \\
B G N \\
B G N \\
B G N \\
B G N \\
B G N \\
B G N\end{array}$ & $\begin{array}{l}\text { Pima } \\
\text { Pima } \\
\text { Navajo } \\
\text { Maricopa } \\
\text { Pima } \\
\text { Yavapai } \\
\text { Mohave } \\
\text { Yavapai } \\
\text { Greenlee } \\
\text { Pima }\end{array}$ & $\begin{array}{l}320238 N 1103403 \mathrm{~W} \\
321609 \mathrm{N1} 102916 \mathrm{~W} \\
345253 \mathrm{~N} 1102849 \mathrm{~W} \\
333505 \mathrm{~N} 1115120 \mathrm{~W} \\
322000 \mathrm{~N} 1103625 \mathrm{~W} \\
343159 \mathrm{~N} 1130130 \mathrm{~W} \\
365005 \mathrm{~N} 1130927 \mathrm{~W} \\
34523 \mathrm{BN} 1114843 \mathrm{~W} \\
331056 \mathrm{~N} 1090606 \mathrm{~W} \\
322049 \mathrm{~N} 1103526 \mathrm{~W}\end{array}$ & $\begin{array}{l}330914 N 1090446 \mathrm{~W} \\
321911 \mathrm{~N} 1103514 \mathrm{~W}\end{array}$ & $\begin{array}{l}1390 \\
4046 \\
2665\end{array}$ & $\begin{array}{l}\text { Rincon Peak } \\
\text { Soza Canyon } \\
\text { Apache Butte } \\
\text { Sawik Mountain } \\
\text { Piety Hill } \\
\text { Big Shipp Mtn } \\
\text { White Pockets } \\
\text { Wilson Mountain } \\
\text { Harden Cienega } \\
\text { Piety Hill }\end{array}$ \\
\hline $\begin{array}{l}\text { Chimney Spring } \\
\text { Chimney Spring } \\
\text { Chimney Spring } \\
\text { Chimney Spring } \\
\text { Chimney Spring } \\
\text { Chimney Tank } \\
\text { Chimney Tank }\end{array}$ & $\begin{array}{l}\text { spring } \\
\text { spring } \\
\text { spring } \\
\text { spring } \\
\text { spring } \\
\text { reservoir } \\
\text { reservoir }\end{array}$ & $\begin{array}{l}\text { BGN } \\
\text { BGN } \\
\text { BGN } \\
\text { BGN } \\
\text { BGN } \\
\text { BGN } \\
\text { BGN }\end{array}$ & $\begin{array}{l}\text { Pima } \\
\text { Pima } \\
\text { Pinal } \\
\text { Apache } \\
\text { Coconino } \\
\text { Pima } \\
\text { Coconino }\end{array}$ & $\begin{array}{l}320450 \mathrm{~N} 1103230 \mathrm{~W} \\
322502 \mathrm{~N} 1103750 \mathrm{~W} \\
331239 \mathrm{N1} 105634 \mathrm{~W} \\
342201 \mathrm{~N} 1092627 \mathrm{~W} \\
351549 \mathrm{~N} 1114027 \mathrm{~W} \\
315017 \mathrm{~N} 1111200 \mathrm{~W} \\
350052 \mathrm{~N} 1111243 \mathrm{~W}\end{array}$ & & & $\begin{array}{l}\text { Rincon Peak } \\
\text { Mount Bigelow } \\
\text { Hot Tamale Peak } \\
\text { Lyman Lake SW } \\
\text { Humphreys Peak } \\
\text { Batamote Hills } \\
\text { Anderson Canyon }\end{array}$ \\
\hline
\end{tabular}




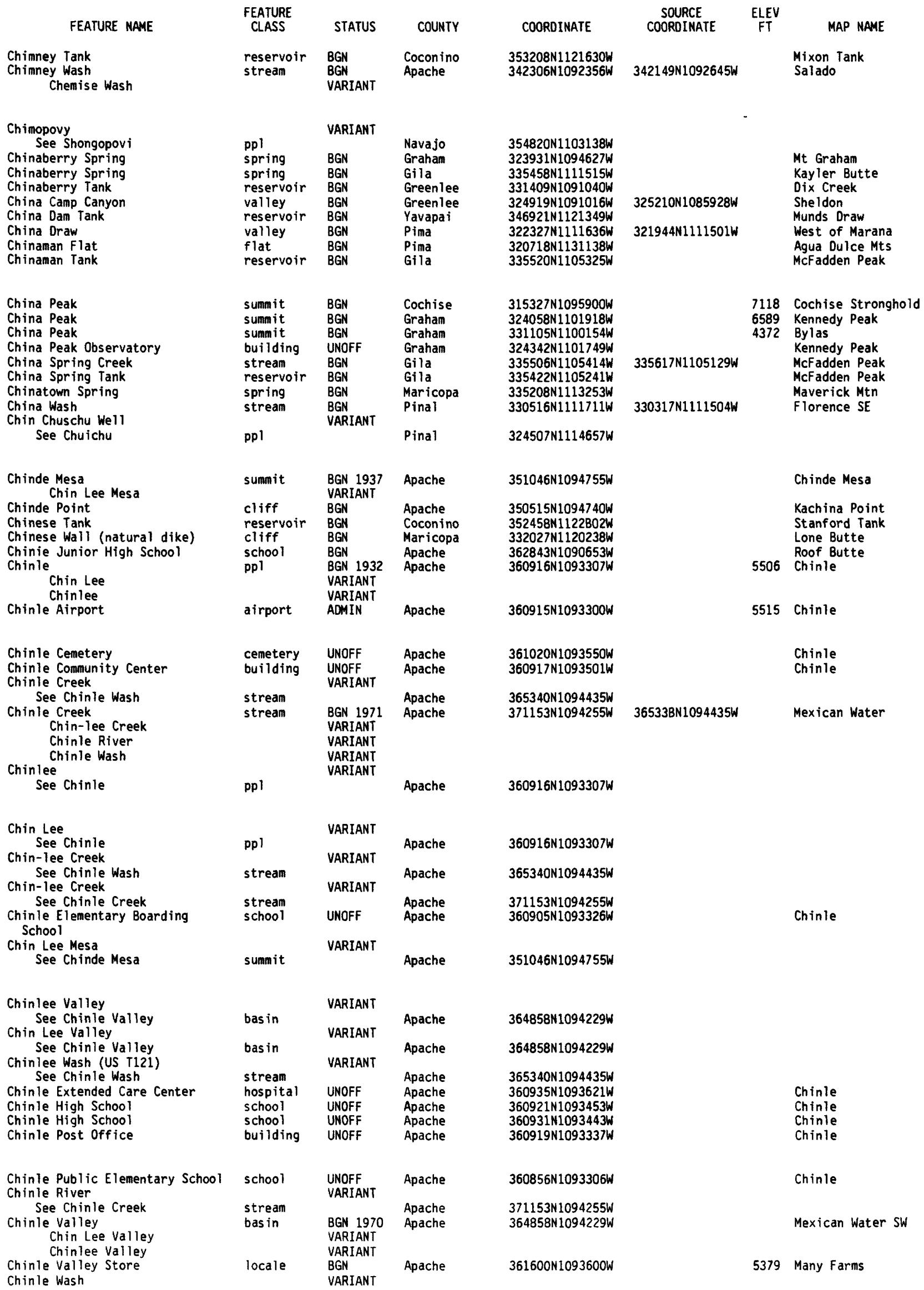


AZ130

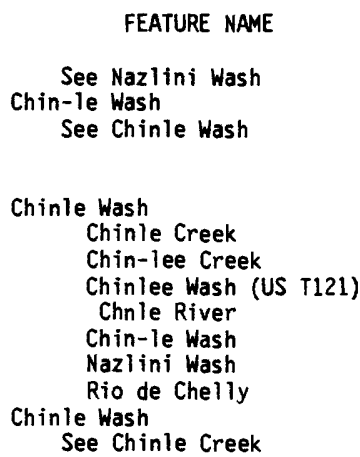

NATIONAL GAZETTEER--ARIZONA 1986$$
\begin{aligned}
& \text { FEA } \\
& \text { st } \\
& \text { st } \\
& \text { st } \\
&
\end{aligned}
$$

FEATURE

strean

strean

strean

strean

reservoir

valley

bas in

valley

stream

valley

cliff

cliff

spring

spring

spring

locale

reservoir

locale

reservoir

reservoir

reservoir $B G$

valley

valley

valley

valley

pp

cenetery

canal

building

school

stream

stream

well

spring

spring

reservoir

stream

locale

summit

summit

\section{STATUS}

VARIANT

BGN 1983 Apache

VARIANT

VARIANT

VARIANT

VARIANT

VARIANT

VARIANT

VARIANT

VARIANT

\section{BGN}

VARIANT

BGN

BGN

VARIANT

BGN

BGN

BGN

BGN

BGN

VARIANT

BGN

BGN

VARIANT

BGN
BGN
BGN

BGN

VARIANT

VARIANT

VARIANT

VARIANT

BGN

UNOFF

BGN

UNOFF

UNOFF

VARIANT

BGN

UNOFF

VARIANT

Navajo

Yavapai

Coconino

Yavapai

Yavapa $i$

Yavapai

Yavapai

Yavapai

Yavapai

Yavapai

Yavapai

Yavapai

Yavapai

Yavapai

Yavapai

Navajo

BGN

VARIANT

8GN

VARIANT

BGN

VARIANT

BGN

VARIANT

VARIANT

VARIANT

VARIANT

reserve

UNOFF

Navajo

Gila

Coconino

Gila

Gila
$334213 \mathrm{~N} 1095522 \mathrm{~W}$

$352325 \mathrm{~N} 1125827 \mathrm{~W}$

$352426 \mathrm{~N} 1125001 \mathrm{~W}$

$343600 \mathrm{~N} 1121600 \mathrm{~W}$

$351400 \mathrm{~N} 1125225 \mathrm{~W}$

344645N1122220W

$345020 \mathrm{~N} 1122700 \mathrm{~W}$

$345020 \mathrm{~N} 1122700 \mathrm{~W}$

344527 N1122711W

$344353 \mathrm{~N} 1122810 \mathrm{~W}$

$344137 \mathrm{~N} 1122533 \mathrm{~W}$

$344512 N 1122754 \mathrm{~W}$

$344446 \mathrm{~N} 1122711 \mathrm{~W}$

$345255 \mathrm{~N} 1122845 \mathrm{~W}$

$351546 \mathrm{~N} 1125733 \mathrm{~W}$

$352045 \mathrm{~N} 1125833 \mathrm{~W}$

$353854 N 1125346 \mathrm{~W}$

$340830 \mathrm{N1095217 \textrm {W }}$

340830 N1095217W

334946N1101304W

$361128 N 1114811 \mathrm{~W}$

$313532 \mathrm{~N} 1091424 \mathrm{~W}$

333341 N1100742W

$333341 \mathrm{~N} 1100742 \mathrm{~W}$

Chino Valley North Chino Valley South Chino Valley South

Chino Valley North

Chino Valley South

Seligman West

Seligman West

Sponseller Mtn

Cone Butte

Paramore Crater

VARIANT 
NATIONAL. GAZETTEER--ARIZONA 1986 FEATURE MAME

See Chiricahua Mountains Chiricahua Mountains

Chi-ri-ca-hua Mountain

Chiricahua Mational Monument

Chiricahua Peak

Chiricahua Siding Tank

Chiricahua Tank

Chiricahua Wilderness

Chirichua Butte See Chiricahua Butte

Chirreones Arroyo

Chirreon Wash

Chittakow Draw

Chitty Canyon

Chitty Canyon Trail Thirty Four

Chiu-chius-chiu

See Chuichu

Chiu Chiuschu

See Chuichu

Chiu Chuischa

See Chuichu

Chiu Chuischui

See Chuich

Chiuli

See Chiulikam

Chiulikan

Chiuli

Chiuli Kam

Pozo Colorado

Salcilla

Sauceda

Sauceda Well

Saucida

Saucita

Saucito

Suwuki vaya

Tschiulikan

Vokivaxia

Chiuli Kam

See Chiulikam
Chiuli Shaik
Fresnal
Ioxikux
Kohi Kug
Koxikux
Resnal
Tshiuliseik

Chivas Tank

Chivas Wash, Las

Chiva Tank

Chivo Falls

Chiwap Park

Chiweton $\mathrm{Hill}$

Chlarsons Canyon

See Frye Canyon

Chloride

Chloride Community Park

Chloride Elementary School

Chloride Post Office

Chnle River

See Chinle Wash

Chocolate Mountain

See Chocolate Mountains

Chocolate Mountains

Chocolate Mountain

Trigo Mountains

Choctaw Mine

Choffo Tank

Choiskai Mountains See Chuska Mountains

Cholla Basin

Cholla Bay Area

Cholla Bottom Ash Pond

BGN 1941

\section{FEATURE \\ CLASS}

STATUS

COUNTY

COORDIMATE

Cochise

range
range

VARIANT

reservoir $B G N$

reservoir BGN

park ADMIN

summit

valley

strean

valley

valley

trail

pp 1

VARIANT

BGN

BGN

BGN

UNOFF

VARIANT

\section{(1)}

ppl

ppl

pp 1

locale

locale

VARIANT

VARIANT

VARIANT

VARIANT

VARIANT

BGN 1941
VARIANT

VARIANT

VARIANT

VARIAYT

VARIANT

VARIANT

VARIANT

VARIANT

VARIANT

VARIANT

VARIANT

VARIANT

VARIANT

VARIANT

locale
locale

BARIANT

VARIANT

VARIANT

VARIANT

VARIANT

VARIANT

reservoir BGN

Santa Cruz 313025N1105611W

stream
reservoir

falls

park

summit

valley

ppl

park

school

BGN

BGN

ADMIN

BGN

VARIANT

Maricopa

Pina

Pinal

$324507 N 1114657 W$

Pinal

324507 N1114657W

Pinal

324507 N1114657W

Maricopa

Maricopa

$323428 \mathrm{~N} 1123131 \mathrm{~W}$

$323428 \mathrm{~N} 1123131 \mathrm{~W}$

$333228 N 1092355 \mathrm{~W}$

$324507 N 1114657 \mathrm{~W}$

BGN

ADMIN

UNOFF

building

UNOFF

VARIANT

strean

summit

VARIANT

summit

BGN

VARIANT

VARIANT

mine

UNOFF

reservoir

BGN

range

VARIANT

bay

reservoir $B G N$
Santa Cruz 314005N1110347W Pima 321631N1103629W

3ima 321529N1103543W

Maricopa 332544N1120240W

Pina 315234N1121151W

Graham

Mohave

Mohave

Mohave

Mohave

Apache

Yuma
Yuma

Santa Cruz

Pima

Apache

Maricopa

Gila

Navajo
$324546 N 1094752 \mathrm{~W}$

352452 N1141155

$352442 \mathrm{~N} 1141155 \mathrm{~W}$

$352553 \mathrm{~N} 1141222 \mathrm{~W}$

$352453 N 1141155 \mathrm{~W}$

$365340 \mathrm{~N} 1094435 \mathrm{~W}$

$331105 \mathrm{~N} 1142329 \mathrm{~W}$

$331105 \mathrm{~N} 1142329 \mathrm{~W}$

$312939 \mathrm{~N} 1111610 \mathrm{~W}$

$313241 \mathrm{~N} 1112745 \mathrm{~W}$

363500 N1091700W

$335801 N 1120205 \mathrm{~W}$

$334308 \mathrm{~N} 1111158 \mathrm{~W}$

345800 NI $101718 \mathrm{~W}$
$323725 \mathrm{~N} 1105017 \mathrm{~W}$

$323420 \mathrm{~N} 1110124 \mathrm{~W}$

$3323420 \mathrm{~N} 1110124 \mathrm{~W}$

$333420 \mathrm{~N} 1092255 \mathrm{~W}$

$\begin{array}{lc}\text { SOURCE } & \text { ELEV } \\ \text { COORDIMATE } & \text { FT MAP NAME }\end{array}$

Fife Peak

Cochise Head

9798 Chiricahua Peak Paramore Crater Portal

Chiricahua Peak

Fortified Mtn Oracle Junction San Carlos Reservoir Baldy Bill Point Baldy Bill Point

Tom Thumb

Chiuli Shaik

San Cayetano Mts

313912 N1110B09W

Amado

Piety $\mathrm{Hill}$

Piety $\mathrm{Hill}$

2021 Kupk

4009 Chloride

Chloride

Chloride

Chloride

Red $\mathrm{Hill}$

Bartlett Mtn

Wilbur Canyon

Daisy Mountain

Theo. Rooseveit Dam

Joseph City 
FEATURE NAME

Cholla Bottom Ash Pond Dam

Cholla Canyon

Cholla Canyon

See Cave Canyon

Cholla Cooling Pond Dam

Cholla Fly Ash Pond

Cholla Fly Ash Pond Dam

Cholla High School

Cholla Lake

Cholla Mountain

Cholla Mountain

Cholla Mountain, La

Cholla Park

Cholla Park

See Scottsdale Horsemens Park

Cholla Pass

Cholla Power Generating Plant

Cholla Ridge Tank

Cholla School

Cholla School

See Roadrunner School

Cholla Spring

Cholla Spring

Cholla Tank

Cholla Tank

Cholla Tank

Cholla Tank

Cholla Tank

Cholla Tank, La

Cholla Tank, La

Cholla Wash, La

Chono Tank

Chot Vaya

Choulic

See Sand Wells

Choul ik

Tjuulik

Choulik

See Choulic

Choyojdolid $\mathrm{Hill}$

Christensen Ranch

Christenson Rest Area See Munds Park Rest Area

Christian Indian School

Christian School

Christiansen Ranch

Christie Tank

Christina Draw

Christina Draw Tank

Christman Oetention Dam

Christman Pond

Christmas

Christmas Gift Mine

Christmas Gift Mine

Christmas Mill and Mine

Christmas Pass

Christmas Spring

See Leroux Spring

Christmas Tailings Oam Number Five

Christmas Tailings Dam Number

$$
\text { One }
$$

Christmas Tailings Dam Number

Seven

Christmas Tailings Dam Number

Christmas Tailings Dam Number Three

Christmas Tailings Dam Number

Two

\section{FEATURE}

STATUS

COUNTY

COORDINATE

SOURCE

COORDINATE

ELEV
FT

MAP NAME

$\begin{array}{llll}\text { dam } & \text { UNOFF } & \text { Navajo } & 345800 N 1101718 \mathrm{~W} \\ \text { valley } & \begin{array}{l}\text { BGN } \\ \text { Gila }\end{array} & 333843 \mathrm{N1110641 \textrm {W }} \\ \text { valley } & \text { VARIANT } & \text { Gila } & 333955 \mathrm{~N} 1110635 \mathrm{~W} \\ \text { dam } & \text { UNOFF } & \text { Navajo } & 345718 \text { N1101636W }\end{array}$

$333829 \mathrm{N1} 110706 \mathrm{~W}$

Joseph City

Windy Hill

dam UNOFF Navajo 345718N1101636W

reservoir BGN Navajo 345736N1101600W

dam UNOFF Navajo 345736N1101600W

school UNOFF Pima 321220N1110035W

reservoir BGN Navajo 345550N1101659W

summ it

summ it

BGI

BGN

BGN

AOMIN

park

Maricopa

Yuma

$335215 N 1121911 \mathrm{~W}$

$333636 \mathrm{~N} 1141857 \mathrm{~W}$

$333525 \mathrm{~N} 1121023 \mathrm{~W}$

Maricopa

333754N1115302W

$\begin{array}{llll}\text { gap } & \text { BGN } & \text { Pima } & 320640 \text { N1131059W } \\ \text { locale } & \text { UNOFF } & \text { Navajo } & 345622 \text { N1101750W } \\ \text { reservoir } & \text { BGN } & \text { Gila } & 334050 \text { N1105707W } \\ \text { school } & \text { UNOFF } & \text { Maricopa } & 333526 \text { N1120731W } \\ & \text { VARIANT } & & \\ \text { school } & & \text { Maricopa } & 333527 N 1120010 \mathrm{~W} \\ \text { spring } & \text { BGN } & \text { Maricopa } & 335752 \mathrm{N1120211W} \\ \text { spring } & \text { BGN } & \text { Maricopa } & 335805 N 1113808 \mathrm{~W} \\ \text { reservoir } & \text { BGN } & \text { Yuma } & 332656 \mathrm{~N} 1134951 \mathrm{~W} \\ \text { reservoir } & \text { BGN } & \text { Maricopa } & 333022 \mathrm{~N} 1112500 \mathrm{~W}\end{array}$

reservoir

reservoir

reservoir

reservoir

well

locale

\section{BGN}

BGN

BGN

BGN

BGN

BGN
VARIANT

(1)

BGN 1941

VARIANT

VARIANT

Gila

Gila

Navajo

Pina

Pima

Yuma

Pima

Pima

Pima

VARIANT

locale

BGM

summit

locale

BGN
UNOFF

VARIANT

locale

school

school

locale UNOFF

reservoir BGN

Pima

Apache

Cochise

Coconino

Yavapai

Maricopa

Cochise

Yavapai

$333638 \mathrm{~N} 1110229 \mathrm{~W}$

$334952 \mathrm{~N} 1111304 \mathrm{~W}$

$341420 N 1095642 \mathrm{~W}$

$315036 \mathrm{~N} 1112204 \mathrm{~W}$

$315342 \mathrm{~N} 1112033 \mathrm{~W}$

$334104 \mathrm{~N} 1141322 \mathrm{~W}$

$313651 N 1113832 \mathrm{~W}$

$320 \mathrm{~B} 43 \mathrm{~N} 1115250 \mathrm{~W}$

$314002 \mathrm{~N} 1114634 \mathrm{~W}$

valley BGN Yavapai 344208 N1120001W

reservoir BG

dam UNOFF

reservoir

ppl

mine

mine

mine

gap

spring

BGN

BGN

UNOFF

UNOFF
UNOFF

BGN

VARIANT

Yavapai

Mohave

Mohave

Gila

Santa Cruz

Pinal

Gila

Yuma

Coconino

$314002 \mathrm{~N} 1114634 \mathrm{~W}$

$354228 \mathrm{~N} 1092311 \mathrm{~W}$

$314506 \mathrm{~N} 1095018 \mathrm{~W}$

$345712 \mathrm{~N} 1114014 \mathrm{~W}$

$344507 \mathrm{~N} 1115323 \mathrm{~W}$

$333006 \mathrm{~N} 1120651 \mathrm{~W}$

$312013 \mathrm{~N} 1094709 \mathrm{~W}$

$344929 N 1130156 \mathrm{~W}$

344151 N1120150W

$362619 N 1132520 \mathrm{~W}$

$362632 N 1132547 \mathrm{~W}$

$330344 N 1104431 \mathrm{~W}$

$313133 \mathrm{~N} 1104302 \mathrm{~W}$

$323627 \mathrm{N1120253 \textrm {H }}$

$330330 \mathrm{~N} 1104445 \mathrm{~W}$

$321643 \mathrm{~N} 1134142 \mathrm{~W}$

$351736 \mathrm{~N} 1114327 \mathrm{~W}$

dam UNOFF Gila

$330318 N 1104424 W$

$330318 \mathrm{~N} 1104424 \mathrm{~W}$

330318 N1104424W

$330318 N 1104424 \mathrm{~W}$

$330318 \mathrm{~N} 1104424 \mathrm{~W}$

$344152 \mathrm{~N} 1120226 \mathrm{~W}$

Cottonwood

Poverty Knoll

Poverty Knoll

Christmas

Mt Hughes

Kohatk

Christmas

Christmas Pass

Christmas

Christmas

Christmas

Christmas

Christmas

Christmas 
NATIONAL GAZETTEER--ARIZONA 1986

\section{FEATURE NAME}

Christmas Tree Dam

Chris tmas Tree Lake

Christmas Tree Tank

Christopher City University of Arizona

Christopher Creek

Christopher Creek

Christopher Creek Campground

Christopher Mountain

Christopher Tank

Chris-Town Mall

Christown Plaza

Chris-Town Travel Trailer and

Mobile Home Park

Christvale

See Stoval

Chrome Butte

Chromo Butte

Chromo Butte

See Chrome Butte

Chrysotile

See Stoval

Chrytoval

See Mohawk

$\mathrm{CH}$ Tank

Chuapo

See Gu Chuapo

Chuar Butte

Chuarooum Peak

Chuar Canyon

See Lava Canyon

Chuar Creek

Chuar Creek

See Lava Creek

Chuar Lava Hill

Chuarooum Peak

See Chuar Butte

Chuar Valley

Chubb Mountain

Chu Chew

See Chuichu

Chuck Box Fire Station

Chuck Box Lake

Chuck Box Tank

Chuckwalla Canyon

Chuckwalla Cove

Chui Chiuschu

See Chuichu

Chuichu

Chin Chuschu Wel

Chiu-chius-chiu

Chiu Chiuschu

Chiu Chuischa

Chiu Chuischui

Chui Chuschu

Chu Chew

Chui Chiuschu

Chuische

Tjuitjo

Tshuhutsho

Chuichu Road Underpass

Chui Chuschu

$$
\text { See Chuichu }
$$

Chuische

See Chuichu

Chui Tontk Valley

Chui Vaya (Site)

Chui Vaya Well

Chukar Wash

Chukson

\section{FEATURE}

CLASS

STATUS COUNTY

COORDINATE

dan

reservoir BGM

locale BGN

$\begin{array}{llll}\text { stream BGN } & \text { Gila } & 341837 N 1110421 W\end{array}$

BGN

ADMIN

Gila

ridge

reservoir

locale

locale

BGN

BGN

UNOFF

locale UNOFF

Gila

Maricopa

Maricopa

Maricopa

VARIANT

locale

summit

BGN 1969

VARIANT

Yuma

Gila

VARIANT

summ

locale

BGN

VARIANT

locale

locale

reservoir

VARIANT

reservoir BGN

locale

VARIANT

summit BGN 1906 Coconino 361138N1114929W

VARIANT

VARIANT

valley

stream

stream

summit

VARIANT

sumanit

BGN

VARIANT

valley

BGN

summit $\quad$ BGN

ppl

lake

reservoir

valley

bay

ppl

UNOFF

$B G N$

BGN

BGN

VARIANT

ppl

BGN 1941 Pinal

VARIANT

VARIANT

VARIANT

VARIANT

VARIANT

VARIANT

VARIANT

VARIANT

VARIANT

VARIANT

VARIANT

\begin{tabular}{|c|c|c|}
\hline crossing & $\begin{array}{l}\text { UNOFF } \\
\text { VARIANT }\end{array}$ & Pinal \\
\hline ppl & VARIANT & Pinal \\
\hline $\begin{array}{l}\text { ppl } \\
\text { bas in } \\
\text { locale } \\
\text { well } \\
\text { stream } \\
\text { ppl }\end{array}$ & $\begin{array}{l}\text { BGN } \\
\text { BGN } \\
\text { UNOFF } \\
\text { BGN } \\
\text { BGN }\end{array}$ & $\begin{array}{l}\text { Pinal } \\
\text { Pima } \\
\text { Pima } \\
\text { Pima } \\
\text { Gila } \\
\text { Pima }\end{array}$ \\
\hline
\end{tabular}

$333015 \mathrm{~N} 1104135 \mathrm{~W}$

$334425 N 1103358 \mathrm{~W}$

324554N1133717W

$324336 \mathrm{N1134516 \textrm {W }}$

$334827 N 1095812 \mathrm{~W}$

315340N1113950W

$360 B 23 N 1114901 \mathrm{~W}$

360819N1114900W

$360954 N 1115148 \mathrm{~W}$

$360842 \mathrm{N1114931 \textrm {W }}$

36113BN1114929W

Coconino

$360843 \mathrm{~N} 1115034 \mathrm{~W}$ $334923 \mathrm{NL1} 110658 \mathrm{~W}$

$32457 \mathrm{~N} 1114657 \mathrm{~W}$

$341438 \mathrm{~N} 1104024 \mathrm{~W}$

$344307 N 1103112 \mathrm{~W}$

$334100 \mathrm{~N} 1111018 \mathrm{~W}$

$361158 \mathrm{NI} 140216 \mathrm{~W}$

$324507 N 1114657 \mathrm{~W}$

$324507 N 1114657 W$

Theo. Roosevelt Dan

$324941 N 1114524 \mathrm{~W}$

$324507 N 1114657 W$

$324507 N 1114657 \mathrm{~W}$

$322432 \mathrm{N1} 121015 \mathrm{~W}$

$313929 N 1114037 \mathrm{~W}$

$313929 \mathrm{~N} 1114036 \mathrm{~W}$

$333712 \mathrm{~N} 1111243 \mathrm{~W}$

$315447 \mathrm{~N} 1114746 \mathrm{~W}$
$334017 N 1111123$

Potato

Iceberg Canyon

1457 Chuichu

Chuichu

\begin{tabular}{|c|c|c|}
\hline \multirow[t]{2}{*}{$\begin{array}{l}\text { SOURCE } \\
\text { COORDINATE }\end{array}$} & $\begin{array}{c}\text { ELEV } \\
\text { FT }\end{array}$ & MAP NAME \\
\hline & & $\begin{array}{l}\text { Hawley Lake East } \\
\text { Hawley Lake East } \\
\text { Tule Mesa } \\
\text { Tucson North }\end{array}$ \\
\hline \multirow[t]{2}{*}{$342207 \mathrm{~N} 1110118 \mathrm{~W}$} & 5800 & $\begin{array}{l}\text { Promontory Butte } \\
\text { Promontory Butte } \\
\text { Promontory Butte }\end{array}$ \\
\hline & 1140 & $\begin{array}{l}\text { Promontory Butte } \\
\text { Promontory Butte } \\
\text { Sunnys lope } \\
\text { Sunnys lope } \\
\text { Sunnys lope }\end{array}$ \\
\hline & 5771 & Chrome Butte \\
\hline
\end{tabular}

6394 Cape Solitude

3945 Cape Solitude

Cape Solitude

Chediski Peak

$333839 N 1111318 \mathrm{~W}$

2163 Window Mtn Aguirre Peak Aguirre Peak Pinyon Mtn

2594 Sells East 


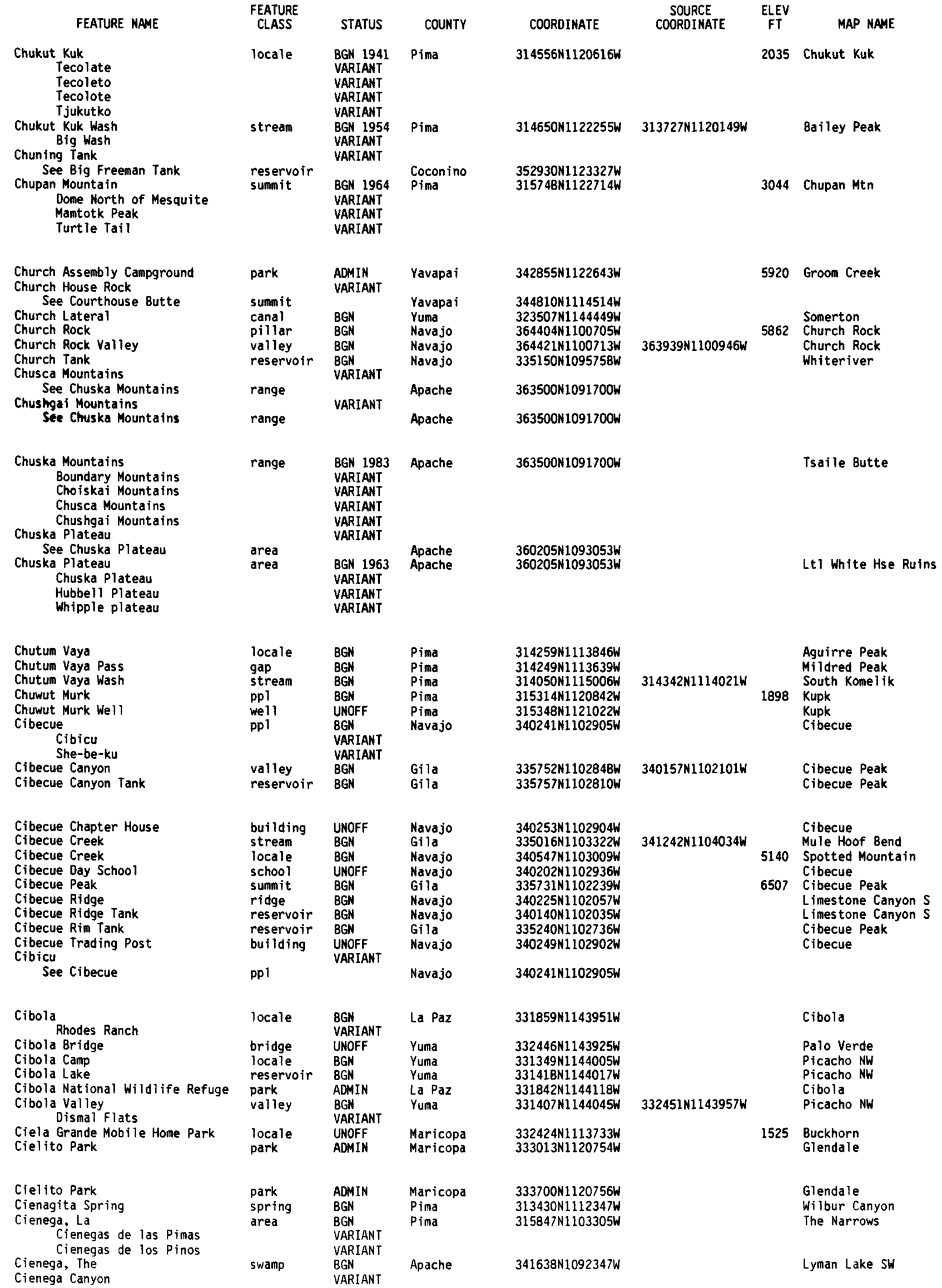


NATIONAL GAZETTEER--ARIZONA 1986

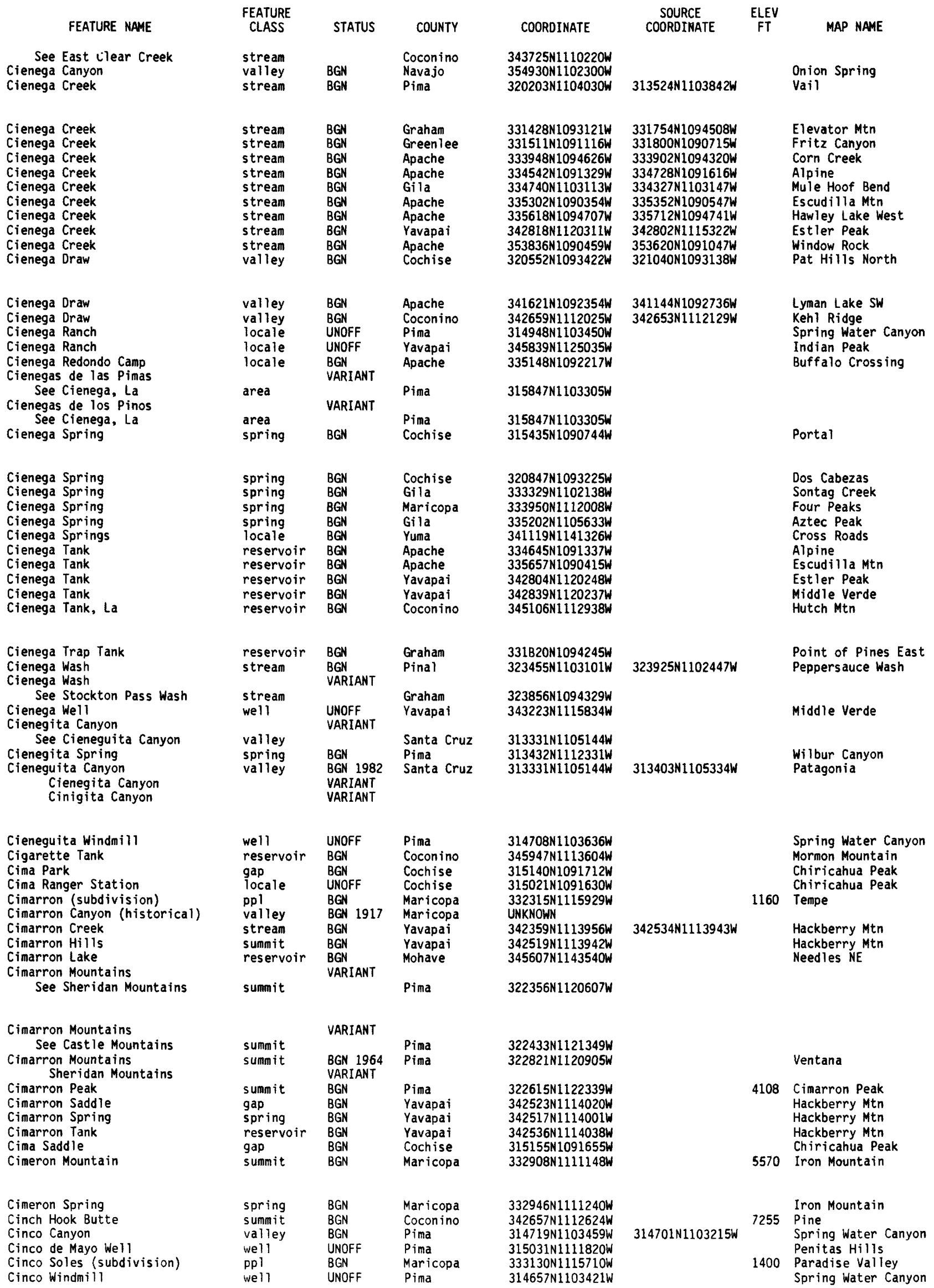




\begin{tabular}{|c|c|c|c|c|c|c|c|}
\hline FEATURE NAME & $\begin{array}{l}\text { FEATURE } \\
\text { CLASS }\end{array}$ & STATUS & COUNTY & COORDINATE & $\begin{array}{l}\text { SOURCE } \\
\text { COORDINATE }\end{array}$ & $\begin{array}{l}\text { ELEV } \\
\text { FT }\end{array}$ & MAP NAME \\
\hline $\begin{array}{l}\text { Cinder Basin } \\
\text { Cinder Flat } \\
\text { Cinder Hill } \\
\text { Cinder Hills }\end{array}$ & $\begin{array}{l}\text { basin } \\
\text { flat } \\
\text { summit } \\
\text { summit }\end{array}$ & $\begin{array}{l}B G N \\
B G N \\
B G N \\
B G N\end{array}$ & $\begin{array}{l}\text { Coconino } \\
\text { Coconino } \\
\text { Cochise } \\
\text { Coconino }\end{array}$ & $\begin{array}{l}351835 \mathrm{~N} 1112322 \mathrm{~W} \\
351746 \mathrm{~N} 1112808 \mathrm{~W} \\
312605 \mathrm{~N} 1091838 \mathrm{~W} \\
352031 \mathrm{N1} 112608 \mathrm{~W}\end{array}$ & & 4745 & $\begin{array}{l}\text { Sunset Crater East } \\
\text { Sunset Crater East } \\
\text { Cinder Hill } \\
\text { Sunset Crater East }\end{array}$ \\
\hline $\begin{array}{l}\text { Cinder Knoll } \\
\text { Cinder Knoll Pond } \\
\text { Cinder Lake } \\
\text { Cinder Mountain } \\
\text { Cinder Mountain } \\
\text { Cinder Pit Tank } \\
\text { Cinder Point Mountain } \\
\text { Cinder Point Tank } \\
\text { Cinder Tank } \\
\text { Cinder Tank }\end{array}$ & $\begin{array}{l}\text { summit } \\
\text { reservoir } \\
\text { flat } \\
\text { summit } \\
\text { summit } \\
\text { reservoir } \\
\text { summit } \\
\text { reservoir } \\
\text { reservoir } \\
\text { reservoir }\end{array}$ & $\begin{array}{l}\text { BGN } \\
\text { BGN } \\
B G N \\
B G N \\
\text { BGN } \\
B G N \\
B G N \\
B G N \\
B G N \\
B G N\end{array}$ & $\begin{array}{l}\text { Mohave } \\
\text { Mohave } \\
\text { Coconino } \\
\text { Maricopa } \\
\text { Coconino } \\
\text { Coconino } \\
\text { Apache } \\
\text { Apache } \\
\text { Apache } \\
\text { Yavapai }\end{array}$ & $\begin{array}{l}362951 \mathrm{~N} 1132329 \mathrm{~W} \\
362953 \mathrm{~N} 1132345 \mathrm{~W} \\
351911 \mathrm{~N} 1113059 \mathrm{~W} \\
324729 \mathrm{N1} 130100 \mathrm{~W} \\
351308 \mathrm{N1112431W} \\
344709 \mathrm{~N} 1112959 \mathrm{~W} \\
340345 \mathrm{~N} 1093807 \mathrm{~W} \\
340351 \mathrm{~N} 1093752 \mathrm{~W} \\
340320 \mathrm{~N} 1093812 \mathrm{~W} \\
344552 \mathrm{~N} 1113453 \mathrm{~W}\end{array}$ & & $\begin{array}{l}5331 \\
982 \\
6807\end{array}$ & $\begin{array}{l}\text { Poverty Knoll } \\
\text { Poverty Knoll } \\
\text { Sunset Crater West } \\
\text { Sentinel SE } \\
\text { Winona } \\
\text { Hutch Mtn } \\
\text { Horseshoe Cienega } \\
\text { Horseshoe Cienega } \\
\text { Horseshoe Cienega } \\
\text { Stoneman Lake }\end{array}$ \\
\hline $\begin{array}{l}\text { Cinder Tank } \\
\text { Cinder Tank } \\
\text { Cinega Canyon } \\
\text { Cinema Park Village Shopping } \\
\text { Center } \\
\text { Cinesa Tank } \\
\text { Cinigita Canyon } \\
\text { See Cieneguita Canyon } \\
\text { Cinigita Tank } \\
\text { Cinnabar } \\
\quad \text { See Cinnabar Mine }\end{array}$ & $\begin{array}{l}\text { reservoir } \\
\text { reservoir } \\
\text { valley } \\
\text { locale } \\
\text { reservoir } \\
\text { valley } \\
\text { reservoir } \\
\text { mine }\end{array}$ & $\begin{array}{l}\text { BGN } \\
\text { BGN } \\
\text { BGN } \\
\text { UNOFF } \\
\text { BGN } \\
\text { VARIANT } \\
\text { BGN } \\
\text { VARIANT }\end{array}$ & $\begin{array}{l}\text { Coconino } \\
\text { Coconino } \\
\text { Navajo } \\
\text { Maricopa } \\
\text { Coconino } \\
\text { Santa Cruz } \\
\text { Santa Cruz } \\
\text { Yuma }\end{array}$ & $\begin{array}{l}352433 \mathrm{~N} 1124635 \mathrm{~W} \\
353214 \mathrm{~N} 1113726 \mathrm{~W} \\
355015 \mathrm{~N} 1101400 \mathrm{~W} \\
333103 \mathrm{~N} 1120347 \mathrm{~W} \\
\\
353230 \mathrm{~N} 1114108 \mathrm{~W} \\
\\
313331 \mathrm{~N} 1105144 \mathrm{~W} \\
313340 \mathrm{~N} 1105202 \mathrm{~W} \\
333212 \mathrm{~N} 1141915 \mathrm{~W}\end{array}$ & $355405 \mathrm{~N} 1100454 \mathrm{~W}$ & 1150 & $\begin{array}{l}\text { Trinity Mtn } \\
\text { East of } S \text { P Mtn } \\
\text { Keams Canyon } \\
\text { Sunnys lope } \\
\text { S P Mountain }\end{array}$ \\
\hline $\begin{array}{l}\text { Cinnabar Mine } \\
\text { Cinnabar } \\
\text { Cinnabar Mine } \\
\text { Cinnabar Wash } \\
\text { See Ehrenberg Wash } \\
\text { Cinnabar Wash } \\
\text { Cintura Hill } \\
\text { Cinyon Otah } \\
\text { Ci-pau-lo-vi } \\
\text { See Shipolovi }\end{array}$ & $\begin{array}{l}\text { mine } \\
\text { mine } \\
\text { stream } \\
\text { valley } \\
\text { summit } \\
\text { summit } \\
\text { ppl }\end{array}$ & $\begin{array}{l}\text { UNOFF } \\
\text { VARIANT } \\
\text { UNOFF } \\
\text { VARIANT } \\
\text { BGN } \\
\text { BGN } \\
\text { BGN } \\
\text { VARIANT }\end{array}$ & $\begin{array}{l}\text { Yuma } \\
\text { Gila } \\
\text { Yuma } \\
\text { La Paz } \\
\text { Cochise } \\
\text { Coconino } \\
\text { Navajo }\end{array}$ & $\begin{array}{l}333212 \mathrm{~N} 1141915 \mathrm{~W} \\
335730 \mathrm{~N} 1112334 \mathrm{~W} \\
333643 \mathrm{~N} 1143107 \mathrm{~W} \\
333618 \mathrm{~N} 1142959 \mathrm{~W} \\
312847 \mathrm{~N} 1095117 \mathrm{~W} \\
363047 \mathrm{~N} 1113819 \mathrm{~W} \\
\\
354830 \mathrm{~N} 1102944 \mathrm{~W}\end{array}$ & $333643 N 1143835 W$ & 6141 & $\begin{array}{l}\text { Cunningham Mtn } \\
\text { Reno Pass }\end{array}$ \\
\hline $\begin{array}{l}\text { Cipriano Hills } \\
\text { Agua Dulce Mountains } \\
\text { Bates Mountains } \\
\text { Growler Mountains } \\
\text { Cipriano Pass } \\
\text { Cipriano Pass } \\
\text { Cipriano Well } \\
\text { Henrys Well } \\
\text { Circe Flat } \\
\text { Circle Bar Draw }\end{array}$ & $\begin{array}{l}\text { gap } \\
\text { gap } \\
\text { well } \\
\text { flat } \\
\text { valley }\end{array}$ & $\begin{array}{l}\text { BGN } 1964 \\
\text { VARIANT } \\
\text { VARIANT } \\
\text { VARIANT } \\
\text { BGN } \\
\text { BGN } \\
\text { UNOFF } \\
\text { VARIANT } \\
\text { BGN } \\
\text { BGN }\end{array}$ & $\begin{array}{l}\text { Pima } \\
\text { Yuma } \\
\text { Pima } \\
\text { Apache } \\
\text { Coconino }\end{array}$ & $\begin{array}{l}315920 N 1130107 W \\
322525 N 1140835 W \\
320005 N 1130134 W \\
335748 N 1090411 W \\
343021 N 1104928 W\end{array}$ & $342417 N 1105342 \mathrm{~W}$ & & $\begin{array}{l}\text { Quitobaquito Springs } \\
\text { Cipriano Pass } \\
\text { Pozo Nuevo Well } \\
\text { Escudilla Mtn } \\
\text { Chevelon Crossing }\end{array}$ \\
\hline $\begin{array}{l}\text { Circle City } \\
\text { Circle City Community Hall } \\
\text { Circle I Hills } \\
\text { Circle M Spring } \\
\text { Circle Ranch } \\
\text { Circle Seven Ranch } \\
\text { Circle Shopping Center } \\
\text { Circle S Wash } \\
\text { Circle Tank } \\
\text { Circle Tank }\end{array}$ & $\begin{array}{l}\text { ppl } \\
\text { building } \\
\text { range } \\
\text { spring } \\
\text { locale } \\
\text { locale } \\
\text { locale } \\
\text { stream } \\
\text { reservoir } \\
\text { reservoir }\end{array}$ & $\begin{array}{l}\text { BGN } \\
\text { UNOFF } \\
\text { BGN } \\
\text { BGN } \\
\text { UNOFF } \\
\text { UNOFF } \\
\text { UNOFF } \\
\text { BGN } \\
\text { BGN } \\
\text { BGN }\end{array}$ & $\begin{array}{l}\text { Maricopa } \\
\text { Maricopa } \\
\text { Cochise } \\
\text { Gila } \\
\text { Gila } \\
\text { Gila } \\
\text { Maricopa } \\
\text { Pinal } \\
\text { Maricopa } \\
\text { Yavapai }\end{array}$ & $\begin{array}{l}334857 \mathrm{~N} 1123446 \mathrm{~W} \\
334852 \mathrm{~N} 1123450 \mathrm{~W} \\
322157 \mathrm{~N} 1094927 \mathrm{~W} \\
334826 \mathrm{~N} 1112253 \mathrm{~W} \\
335319 \mathrm{~N} 1105819 \mathrm{~W} \\
332707 \mathrm{~N} 1103317 \mathrm{~W} \\
333615 \mathrm{~N} 1121725 \mathrm{~W} \\
325253 \mathrm{~N} 1105649 \mathrm{~W} \\
334604 \mathrm{~N} 1120408 \mathrm{~W} \\
340446 \mathrm{~N} 1115622 \mathrm{~W}\end{array}$ & $324930 \mathrm{~N} 1105527 \mathrm{~W}$ & 3135 & $\begin{array}{l}\text { Wittmann } \\
\text { Wittmann } \\
\text { Willcox North } \\
\text { Boulder Mtn } \\
\text { McFadden Peak } \\
\text { Dourine Canyon } \\
\text { El Mirage } \\
\text { Crozier Peak } \\
\text { New River SE } \\
\text { Cooks Mesa }\end{array}$ \\
\hline $\begin{array}{l}\text { Circle Tank } \\
\text { Circle Tanks } \\
\text { Circle Z Ranch } \\
\text { Bloxton } \\
\text { Sanford Ranch } \\
\text { Circular Tank } \\
\text { Circular White Ridge } \\
\text { Cisco Canyon (historical) } \\
\text { Cisco Mine } \\
\text { Cisten Tank }\end{array}$ & $\begin{array}{l}\text { reservoir } \\
\text { reservoir } \\
\text { locale } \\
\text { reservoir } \\
\text { ridge } \\
\text { valley } \\
\text { mine } \\
\text { reservoir }\end{array}$ & $\begin{array}{l}\text { BGN } \\
\text { BGN } \\
\text { UNOFF } \\
\text { VARIANT } \\
\text { VARIANT } \\
\text { BGN } \\
\text { BGN } \\
\text { BGN } 1917 \\
\text { UNOFF } \\
\text { BGN }\end{array}$ & $\begin{array}{l}\text { Coconino } \\
\text { Coconino } \\
\text { Maricopa } \\
\text { Apache } \\
\text { Coconino }\end{array}$ & $\begin{array}{l}364121 \mathrm{~N} 1111200 \mathrm{~W} \\
364005 \mathrm{~N} 1112312 \mathrm{~W} \\
\text { UNKNOWN } \\
362927 \mathrm{~N} 1091347 \mathrm{~W} \\
354141 \mathrm{~N} 1120706 \mathrm{~W}\end{array}$ & & 3900 & $\begin{array}{l}\text { Horsethief Mesa } \\
\text { Dead Monkey Ridge } \\
\text { Lukachukai } \\
\text { Molly Anne Oraw }\end{array}$ \\
\hline $\begin{array}{l}\text { Cistern Canyon } \\
\text { Citadel Ruin } \\
\text { Citadel Sink } \\
\text { Citadel Wash } \\
\text { Citizen Canyon } \\
\text { Citizen Tank }\end{array}$ & $\begin{array}{l}\text { valley } \\
\text { locale } \\
\text { basin } \\
\text { stream } \\
\text { valley } \\
\text { reservoir }\end{array}$ & $\begin{array}{l}\text { BGN } \\
\text { BGN } \\
B G N \\
B G N \\
\text { BGN } \\
\text { BGN }\end{array}$ & $\begin{array}{l}\text { Greenlee } \\
\text { Coconino } \\
\text { Coconino } \\
\text { Coconino } \\
\text { Greenlee } \\
\text { Greenlee }\end{array}$ & $\begin{array}{l}331041 \mathrm{~N} 1092922 \mathrm{~W} \\
353357 \mathrm{~N} 1112815 \mathrm{~W} \\
353351 \mathrm{N1} 112 \mathrm{~B} 1 \mathrm{BW} \\
353704 \mathrm{~N} 1111910 \mathrm{~W} \\
331419 \mathrm{~N} 1090258 \mathrm{~W} \\
331555 \mathrm{~N} 1090329 \mathrm{~W}\end{array}$ & $\begin{array}{l}331238 N 1092559 \mathrm{~W} \\
353318 \mathrm{~N} 1112819 \mathrm{~W} \\
331728 \mathrm{~N} 1090030 \mathrm{~W}\end{array}$ & 5312 & $\begin{array}{l}\text { Coronado Mtn } \\
\text { Wupatki SW } \\
\text { Wupatki SW } \\
\text { Wupatki SE } \\
\text { Harden Cienega } \\
\text { Maple Peak }\end{array}$ \\
\hline
\end{tabular}


NATIONAL GAZETTEER--ARIZONA 1986

FEATURE NAME

Citrus Ditch

Citrus Gardens (trailer park)

Citrus Grove Trailer Court

Citrus Grove Trailer Park

Citrus Hills (subdivision)

Citrus Park (Siding)

Citrus Park

Citrus Valley

Citrus Valley Interchange

City Creek

City Creek Well

City Dam

City $\mathrm{Hill}$

City Park

\section{City Park}

City Park

City Reservoir

Ciudad, Canal (historical)

C J Jorgenson School

C K Canyon

C K Tank

C K Well

Clack Canyon

$C$ Lake

Clan House 1

$\mathrm{Clanton} \mathrm{Hills}$ See Gila Bend Mountains

Clanton Hills

Clantons Well

See Clanton Well

Clanton Wash

Clanton Wel

Clantons Well

Clara Peak

Carrigan Peak

Corrigan Peak

Gallagher Peak

Karrigan Peak

Kerrigan Peak

Klara Peak

Clara Well

See Butler Well

Claremont Place (subdivision)

Clarendon School

Clarey Ranch

Clark And Kinneys Spring See Silver Springs

Clark Canyon

Clarkdale

Clarkdale Elementary School Clarkdale-Jerome Elementary School

Clarkdale-Jerome El lementary School

See Clarkdale Elementary School

Clarkdale Junior High School

Clarkdale Park

Clarkdale Post office

Clarkdale Railroad Station

Clark Mine

Clark Park

Clark Park Trail Three

hundred one

Clark Peak

Clark Peak Ranger Station

Clark Ranch

Clark Ranch

Clark Ranch

Clark Ranch

\section{FEATURE}

CLASS

STATUS

COUNTY

canal

locale

$\begin{array}{ll}\text { ocale } & \text { UNOFF } \\ \text { ocale } & \text { UNOFF }\end{array}$

pp

local

ppl

valley

crossing

strean

well

dam

summi

park

BGN
BGN
BGN
BGN
UNOFF
BGN
UNOFF
UNOFF
BGN
ADMIN

park

park

reservoir

canal

school

valley

reservoir

well

valley

ADMIN

ADMIN

BGN

BGN

VARIANT

UNOFF

BGN

BGN

UNOFF

BGN

lake $\quad B G$

locale

BGN

UNOFF
VARIANT

range

summit

well

strean

well

summit

BGN 1963

VARIANT

BGN

UNOFF

VARIANT

BGN 1966 Yuma

VARIANT

VARIANT

VARIANT

VARIANT

VARIANT

VARIANT

VARIANT

wel

ppl

school

locale

spring

valley

ppl

school

BGN

Yuma

Maricopa

UNOFF Maricopa

UNOFF

VARIANT

$B G N$
$B G N$

BGN

VARIANT

VARIANT

school

schoo

park

building

building

mine

park

summit

locale

locale
locale
locale

locale

Maricopa

Maricopa

Maricopa

Maricopa

Maricopa

Gila

Goconino

Pinal

Yuma

Coconino

Maricopa

Maricopa

Gila

Gila

Gila
Mohave

Coconino

Pinal

Maricopa

Yuma

Yuma

Yuma

Pima

Navajo

Cochise

Yavapai

Yavapai

Yavapai

UNOFF

ADMIN

UNOFF

UNOFF

UNOFF

ADMIN
UNOFF

Yavapai

Yavapai

Yavapai

Yavapa

Pima

Maricopa

BGN 1932

Graham

UNOFF

Graham
Graham

UNOFF

UNOFF

UNOFF

UNOFF
Maricopa

Maricopa

344622N1120308W 332517 N1114433W $332452 \mathrm{~N} 1115107 \mathrm{~W}$ 333320 N1120425W

$332245 N 1120230 \mathrm{~W}$ $333206 \mathrm{~N} 1122535 \mathrm{~W}$

$333255 \mathrm{~N} 1122637 \mathrm{~W}$ $330240 N 1125853 \mathrm{~W}$

$325555 \mathrm{~N} 1124813 \mathrm{~W}$

$341327 \mathrm{~N} 1112757 \mathrm{~W}$

$341255 \mathrm{~N} 1112840 \mathrm{~W}$

$351400 \mathrm{~N} 1121222 \mathrm{~W}$

$343453 \mathrm{~N} 1123356 \mathrm{~W}$

323629N1103800W

$324300 N 1143731 \mathrm{~W}$

$324522 N 1113315 \mathrm{~W}$

$351400 \mathrm{~N} 1121122 \mathrm{~W}$

$332720 \mathrm{~N} 1120155 \mathrm{~W}$

$332354 N 1120541 \mathrm{~W}$

$332144 \mathrm{~N} 1103639 \mathrm{~W}$

$332443 \mathrm{~N} 1104100 \mathrm{~W}$

332610 N1103931W

350925N1140518W

353053N1123609W

$325937 \mathrm{~N} 1113202 \mathrm{~W}$

$331321 N 1130214 \mathrm{~W}$

331718 N1132751W

331632 N1132613W

$325639 \mathrm{~N} 1132412$

$331632 N 1132613 \mathrm{~W}$

$340122 \mathrm{~N} 1134402 \mathrm{~W}$

$333142 \mathrm{~N} 1120230 \mathrm{~W}$

$332926 \mathrm{~N} 1120515 \mathrm{~W}$

$341952 \mathrm{N1} 095527 \mathrm{~W}$

320428N1100933

$344616 \mathrm{~N} 1120326 \mathrm{~W}$

344622 N1120308

44616 N1120319w

344614 N1120319W

$344616 \mathrm{~N} 1120324 \mathrm{~W}$

344635 N1120319W

$315422 N 1111644 \mathrm{~W}$

$332432 \mathrm{~N} 1115654 \mathrm{~W}$

$324315 N 1095906 \mathrm{~W}$

324317 N1095903W

$324300 \mathrm{~N} 1095836 \mathrm{~W}$

$313239 \mathrm{~N} 1111625 \mathrm{~W}$

Santa Cruz 313526N1103021W

Santa Cruz 323911N1103516W

$\begin{array}{ll}\text { Pinal } & 323911 N 1103516 W \\ \text { Pinal } & 332104 N 1105928 W\end{array}$
$330329 \mathrm{~N} 1125626 \mathrm{~W}$

340950 N1134840W

$322130 \mathrm{~N} 1110839 \mathrm{~W}$
COORDINATE

320426 N1100839W

1200 Sunnys lope

Phoenix

Avra

3545 San Pedro Ranch

Clarkdale

\begin{tabular}{|c|c|c|}
\hline $\begin{array}{l}\text { SOURCE } \\
\text { COORDINATE }\end{array}$ & $\begin{array}{c}\text { ELEV } \\
\text { FT }\end{array}$ & MAP NAME \\
\hline & $\begin{array}{l}1235 \\
1220\end{array}$ & $\begin{array}{l}\text { Citrus Valley West } \\
\text { Buckhorn } \\
\text { Mesa } \\
\text { Sunnys lope }\end{array}$ \\
\hline $330045 \mathrm{~N} 1124826 \mathrm{~W}$ & 1170 & $\begin{array}{l}\text { Phoenix } \\
\text { Waddell } \\
\text { Waddell } \\
\text { Citrus Valley West }\end{array}$ \\
\hline $340927 \mathrm{~N} 1113109 \mathrm{~W}$ & 6321 & $\begin{array}{l}\text { Smurr } \\
\text { North Peak } \\
\text { North Peak } \\
\text { Williams South } \\
\text { Iron Springs } \\
\text { Campo Bonito }\end{array}$ \\
\hline & & $\begin{array}{l}\text { Yuma West } \\
\text { Eloy North } \\
\text { Williams South } \\
\text { Phoenix }\end{array}$ \\
\hline $351325 \mathrm{~N} 1140458 \mathrm{~W}$ & & $\begin{array}{l}\text { Phoenix } \\
\text { Bucket Mtn } \\
\text { Cammerman Wash } \\
\text { Cammerman Wash } \\
\text { Kingman }\end{array}$ \\
\hline & & $\begin{array}{l}\text { Howard Spring } \\
\text { Coolidge }\end{array}$ \\
\hline & & Nottbusch Butte \\
\hline $330726 \mathrm{~N} 1132756 \mathrm{~W}$ & 1123 & $\begin{array}{l}\text { Aztec NW } \\
\text { Nottbusch Butte }\end{array}$ \\
\hline
\end{tabular}

2395 Swansea

Clarkdale

Clarkdale

Clarkdale

Stevens Mtn

Tempe

Webb Peak 


\begin{tabular}{|c|c|c|c|c|c|c|c|}
\hline FEATURE NAME & $\begin{array}{l}\text { FEATURE } \\
\text { CLASS }\end{array}$ & STATUS & COUNTY & COORDINATE & $\begin{array}{l}\text { SOURCE } \\
\text { COORDIMATE }\end{array}$ & $\underset{F T}{E L E V}$ & MAP NAME \\
\hline $\begin{array}{l}\text { Clark School } \\
\text { Clark Spring } \\
\text { Clark Spring } \\
\text { Clark Spring } \\
\text { Clark Street School } \\
\text { Clarks Valley } \\
\text { See Lake Mary Valley }\end{array}$ & $\begin{array}{l}\text { school } \\
\text { spring } \\
\text { spring } \\
\text { spring } \\
\text { school } \\
\text { valley }\end{array}$ & $\begin{array}{l}\text { UNOFF } \\
\text { BGN } \\
\text { BGN } \\
\text { BGN } \\
\text { UNOFF } \\
\text { VARIANT }\end{array}$ & $\begin{array}{l}\text { Pinal } \\
\text { Cochise } \\
\text { Pinal } \\
\text { Yavapai } \\
\text { Yavapai } \\
\text { Coconino }\end{array}$ & $\begin{array}{l}323927 \mathrm{~N} 1103517 \mathrm{~W} \\
312541 \mathrm{~N} 1101626 \mathrm{~W} \\
324139 \mathrm{~N} 1102856 \mathrm{~W} \\
343616 \mathrm{~N} 1123401 \mathrm{~W} \\
344453 \mathrm{~N} 1120647 \mathrm{~W} \\
350902 \mathrm{~N} 1113556 \mathrm{~W}\end{array}$ & & & $\begin{array}{l}\text { Clark Ranch } \\
\text { Miller Peak } \\
\text { Rhodes Peak } \\
\text { Iron Springs } \\
\text { Cottonwood }\end{array}$ \\
\hline $\begin{array}{l}\text { Clarks Well } \\
\text { Clark Tank } \\
\text { Clark Tank } \\
\text { Clark Tank } \\
\text { Clark Valley } \\
\text { See Lake Mary Valley } \\
\text { Clark Wash } \\
\text { Clark Well } \\
\text { Clark Well } \\
\text { Claude Birdseye Point }\end{array}$ & $\begin{array}{l}\text { well } \\
\text { reservoir } \\
\text { reservoir } \\
\text { reservoir } \\
\text { valley } \\
\text { stream } \\
\text { well } \\
\text { locale } \\
\text { cliff }\end{array}$ & $\begin{array}{l}\text { UNOFF } \\
\text { BGN } \\
\text { BGN } \\
\text { BGN } \\
\text { VARIANT } \\
\text { BGN } \\
\text { UNOFF } \\
\text { BGN } \\
\text { BGN } 1965\end{array}$ & $\begin{array}{l}\text { Yuma } \\
\text { Maricopa } \\
\text { Gila } \\
\text { Coconino } \\
\text { Coconino } \\
\text { Pinal } \\
\text { Coconino } \\
\text { Apache } \\
\text { Coconino }\end{array}$ & $\begin{array}{l}331830 \mathrm{~N} 1141413 \mathrm{~W} \\
335805 \mathrm{~N} 1130405 \mathrm{~W} \\
341026 \mathrm{~N} 1105820 \mathrm{~W} \\
352205 \mathrm{~N} 1120441 \mathrm{~W} \\
\\
350902 \mathrm{~N} 1113556 \mathrm{~W} \\
323943 \mathrm{~N} 1103553 \mathrm{~W} \\
350402 \mathrm{~N} 1113444 \mathrm{~W} \\
351838 \mathrm{~N} 1094315 \mathrm{~W} \\
360950 \mathrm{~N} 1121058 \mathrm{~W}\end{array}$ & $324145 \mathrm{~N} 1102819 \mathrm{~W}$ & $\begin{array}{l}5897 \\
6975\end{array}$ & $\begin{array}{l}\text { Clark Ranch } \\
\text { Lower Lake Mary } \\
\text { Tanner Springs } \\
\text { Shiva Temple }\end{array}$ \\
\hline $\begin{array}{l}\text { Claude Black Tank } \\
\text { Clawson School } \\
\text { Clayhole Wash } \\
\text { Clayhole Well } \\
\text { Clay Knoll } \\
\text { Clay Lost Tank Canyon } \\
\text { See Clay Tank Canyon } \\
\text { Clay Mine Wash } \\
\text { Clay Park } \\
\text { Claypool }\end{array}$ & $\begin{array}{l}\text { reservoir } \\
\text { school } \\
\text { stream } \\
\text { well } \\
\text { summit } \\
\text { valley } \\
\text { stream } \\
\text { flat } \\
\text { ppl }\end{array}$ & $\begin{array}{l}\text { BGN } \\
\text { UNOFF } \\
\text { BGN } \\
\text { UNOFF } \\
\text { BGN } \\
\text { VARIANT } \\
\text { BGN } \\
\text { BGN } \\
\text { BGN }\end{array}$ & $\begin{array}{l}\text { Coconino } \\
\text { Cochise } \\
\text { Mohave } \\
\text { Mohave } \\
\text { Graham } \\
\text { Mohave } \\
\text { Graham } \\
\text { Coconino } \\
\text { Gila }\end{array}$ & $\begin{array}{l}350023 N 1113958 \mathrm{~W} \\
312027 N 1093233 \mathrm{~W} \\
365821 \mathrm{~N} 1131606 \mathrm{~W} \\
364328 \mathrm{~N} 1130407 \mathrm{~W} \\
324733 \mathrm{~N} 1094318 \mathrm{~W} \\
\\
355141 \mathrm{N1} 133959 \mathrm{~W} \\
330303 \mathrm{~N} 1095653 \mathrm{~W} \\
345302 \mathrm{~N} 1113907 \mathrm{~W} \\
332440 \mathrm{~N} 1105031 \mathrm{~W}\end{array}$ & $364004 \mathrm{~N} 1130112 \mathrm{~W}$ & 3334 & $\begin{array}{l}\text { Mountainaire } \\
\text { Douglas } \\
\text { Rock Canyon } \\
\text { Little Clayhole Val } \\
\text { Safford }\end{array}$ \\
\hline $\begin{array}{l}\text { Claypool Clinic } \\
\text { Claypool Post Office } \\
\text { Clay Seep Spring } \\
\text { Clay Spring } \\
\text { Clay Spring } \\
\text { Clay Spring } \\
\text { Clay Spring } \\
\text { Clay Spring } \\
\text { Clay Spring } \\
\text { Clay Springs }\end{array}$ & $\begin{array}{l}\text { hospital } \\
\text { building } \\
\text { spring } \\
\text { spring } \\
\text { spring } \\
\text { spring } \\
\text { spring } \\
\text { spring } \\
\text { spring } \\
\text { spring }\end{array}$ & $\begin{array}{l}\text { UNOFF } \\
\text { UNOFF } \\
\text { BGN } \\
\text { BGN } \\
\text { BGN } \\
\text { BGN } \\
\text { BGN } \\
\text { BGN } \\
\text { BGN } \\
\text { BGN }\end{array}$ & $\begin{array}{l}\text { Gila } \\
\text { Gila } \\
\text { Yavapai } \\
\text { Graham } \\
\text { Gila } \\
\text { Mavajo } \\
\text { Gila } \\
\text { Mavajo } \\
\text { Mohave } \\
\text { Mohave }\end{array}$ & $\begin{array}{l}332439 N 1105046 \mathrm{~W} \\
332437 \mathrm{N1} 105033 \mathrm{~W} \\
344240 \mathrm{N1} 125307 \mathrm{~W} \\
330041 \mathrm{N1} 101214 \mathrm{~W} \\
334044 \mathrm{~N} 1104356 \mathrm{~W} \\
340443 \mathrm{~N} 1102616 \mathrm{~W} \\
341256 \mathrm{~N} 1105215 \mathrm{~W} \\
352540 \mathrm{N1} 101131 \mathrm{~W} \\
364925 \mathrm{~N} 1132826 \mathrm{~W} \\
354346 \mathrm{~N} 1135202 \mathrm{~W}\end{array}$ & & & $\begin{array}{l}\text { Globe } \\
\text { Globe } \\
\text { Sheridan Mtn } \\
\text { Beargrass Basin } \\
\text { Haystack Butte } \\
\text { Cibecue } \\
\text { Parallel Canyon } \\
\text { Ma Ah Tee Canyon } \\
\text { Hole-n-wall Canyon } \\
\text { Music Mountains ME }\end{array}$ \\
\hline $\begin{array}{l}\text { Clay Springs } \\
\text { Clay Springs Post Office } \\
\text { Clay Springs School } \\
\text { Clay Springs Tank } \\
\text { Clays Well Canyon } \\
\text { Clay Tank } \\
\text { Clay Tank } \\
\text { Clay Tank } \\
\text { Clay Tank } \\
\text { Clay Tank }\end{array}$ & $\begin{array}{l}\text { ppl } \\
\text { building } \\
\text { school } \\
\text { reservoir } \\
\text { valley } \\
\text { reservoir } \\
\text { reservoir } \\
\text { reservoir } \\
\text { reservoir } \\
\text { reservoir }\end{array}$ & $\begin{array}{l}\text { BGN } \\
\text { UNOFF } \\
\text { UNOFF } \\
\text { BGN } \\
\text { BGN } \\
\text { BGN } \\
\text { BGN } \\
\text { BGN } \\
\text { BGN } \\
\text { BGN }\end{array}$ & $\begin{array}{l}\text { Navajo } \\
\text { Mavajo } \\
\text { Navajo } \\
\text { Navajo } \\
\text { Yavapai } \\
\text { Cochise } \\
\text { Greenlee } \\
\text { Mavajo } \\
\text { Apache } \\
\text { Coconino }\end{array}$ & $\begin{array}{l}342142 N 1101741 \mathrm{~W} \\
342145 \mathrm{~N} 1101745 \mathrm{~W} \\
341634 \mathrm{N1} 101750 \mathrm{~W} \\
342602 \mathrm{~N} 1101757 \mathrm{~W} \\
342200 \mathrm{~N} 1115755 \mathrm{~W} \\
314738 \mathrm{~N} 1100526 \mathrm{~W} \\
325511 \mathrm{N1} 1091532 \mathrm{~W} \\
342940 \mathrm{~N} 1104346 \mathrm{~W} \\
344829 \mathrm{N1} 1093125 \mathrm{~W} \\
344926 \mathrm{~N} 1111856 \mathrm{~W}\end{array}$ & $342324 N 1115415 W$ & $\begin{array}{l}6312 \\
6300\end{array}$ & $\begin{array}{l}\text { Clay Springs } \\
\text { Clay Springs } \\
\text { Clay Springs } \\
\text { Big Pug Tank } \\
\text { Dugas } \\
\text { Haberstock Hill } \\
\text { Guthrie } \\
\text { Hanks Oraw } \\
\text { Seven Springs } \\
\text { Jaycox Mtn }\end{array}$ \\
\hline $\begin{array}{l}\text { Clay Tank } \\
\text { Clay Tank } \\
\text { Clay Tank Canyon } \\
\text { Clay Lost Tank Canyon } \\
\text { Horse Flat Canyon } \\
\text { Clay Well } \\
\text { Clear Creek } \\
\text { Clear Creek } \\
\text { See West Clear Creek } \\
\text { Clear Creek } \\
\text { See East Clear Creek }\end{array}$ & $\begin{array}{l}\text { well } \\
\text { stream } \\
\text { stream } \\
\text { stream }\end{array}$ & $\begin{array}{l}\text { BGN } \\
\text { BGN } \\
\text { BGN } \\
\text { VARIANT } \\
\text { VARIANT } \\
\text { UNOFF } \\
\text { BGN } \\
\text { VARIANT } \\
\text { VARIANT }\end{array}$ & $\begin{array}{l}\text { Graham } \\
\text { Greenlee } \\
\text { Yavapai } \\
\text { Coconino }\end{array}$ & $\begin{array}{l}345305 \mathrm{~N} 1112916 \mathrm{~W} \\
354807 \mathrm{~N} 1134820 \mathrm{~W} \\
355141 \mathrm{N1} 133959 \mathrm{~W} \\
323655 \mathrm{~N} 1091718 \mathrm{~W} \\
331639 \mathrm{~N} 1091136 \mathrm{~W} \\
343015 \mathrm{~N} 1114940 \mathrm{~W} \\
343725 \mathrm{~N} 1110220 \mathrm{~W}\end{array}$ & $332225 \mathrm{~N} 1091748 \mathrm{~W}$ & 4914 & $\begin{array}{l}\text { Mormon Lake } \\
\text { Horse Flat } \\
\text { Spencer Canyon } \\
\text { Whitlock Cienega } \\
\text { Fritz Canyon }\end{array}$ \\
\hline $\begin{array}{l}\text { Clear Creek } \\
\text { East Clear Creek } \\
\text { Clear Creek } \\
\text { Clear Creek } \\
\text { Clear Creek Bridge } \\
\text { Clear Creek Campground } \\
\text { Clear Creek Canyon } \\
\text { See McCarty Draw } \\
\text { Clear Creek Cemetery } \\
\text { Clear Creek Dam Number One }\end{array}$ & $\begin{array}{l}\text { stream } \\
\text { stream } \\
\text { ppl } \\
\text { bridge } \\
\text { park } \\
\text { valley } \\
\text { cemetery } \\
\text { dam }\end{array}$ & $\begin{array}{l}\text { BGN } 1966 \\
\text { VARIANT } \\
\text { BGN } 1906 \\
\text { BGN } \\
\text { UNOFF } \\
\text { ADMIN } \\
\text { VARIANT }\end{array}$ & $\begin{array}{l}\text { Navajo } \\
\text { Coconino } \\
\text { Yavapai } \\
\text { Navajo } \\
\text { Yavapai } \\
\text { Coconino } \\
\text { Yavapai } \\
\text { Navajo }\end{array}$ & $\begin{array}{l}345920 \mathrm{~N} 1103815 \mathrm{~W} \\
\\
360455 \mathrm{~N} 1120207 \mathrm{~W} \\
343119 \mathrm{~N} 1114904 \mathrm{~W} \\
345805 \mathrm{~N} 1103845 \mathrm{~W} \\
343055 \mathrm{~N} 1114552 \mathrm{~W} \\
\\
343209 \mathrm{~N} 1111445 \mathrm{~W} \\
343134 \mathrm{~N} 1114938 \mathrm{~W} \\
345812 \mathrm{~N} 1103830 \mathrm{~W}\end{array}$ & $\begin{array}{l}343725 \mathrm{~N} 1110220 \mathrm{~W} \\
361108 \mathrm{~N} 1115710 \mathrm{~W}\end{array}$ & & $\begin{array}{l}\text { Clear Creek Res } \\
\text { Phantom Ranch } \\
\text { Camp Verde } \\
\text { Clear Creek Res } \\
\text { Camp Verde }\end{array}$ \\
\hline $\begin{array}{l}\text { Clear Creek Lake } \\
\text { Clear Creek Number Four Spring } \\
\text { Clear Creek Number One Spring }\end{array}$ & $\begin{array}{l}\text { reservoir } \\
\text { spring } \\
\text { spring }\end{array}$ & $\begin{array}{l}\text { BGN } \\
\text { BGN } \\
\text { BGN }\end{array}$ & $\begin{array}{l}\text { Navajo } \\
\text { Yavapai } \\
\text { Yavapai }\end{array}$ & $\begin{array}{l}345818 \mathrm{~N} 1103736 \mathrm{~W} \\
343240 \mathrm{~N} 1113725 \mathrm{~W} \\
343147 \mathrm{~N} 1113926 \mathrm{~W}\end{array}$ & & & $\begin{array}{l}\text { Clear Creek Res } \\
\text { Buckhorn Mtn } \\
\text { Walker Mtn }\end{array}$ \\
\hline
\end{tabular}


FEATURE NAME

Clear Creek Number Three Spring

Clear Creek Number Two Dam

Clear Creek Number Two Spring

Clear Creek Reservoir

Clear Creek Ridge Tank

Clear Creek Trail

Clear Fork

See West Clear Creek

FEATURE

STATUS

spring

dam.

spring

reservoir

reservoir

trail

BGN
UNOFF
BGN
BGN
BGN
UNOFF
VARIANT

COUNTY

Yavapai

Navajo

Yavapai

Navajo

Greenlee

Coconino

Clear Lake

Clear Lake Tank

Clear Tank

Clearview Heights

Clearview Hills (subdivision)

Clearwater Drain

Clear Water Point

Clearwater Spring

Clear Water Spring

Cleator

Cleaveland

Clemans Tank

Clemenceau Verde

Clemenceau-Cottonwood Airport See Cottonwood Airport

Clemenceau Public School

Clemente Windmill

Clement Powell Butte

Cleopatra Mine

Cleveland Spring

Clevelon Fork

See Chet Tank

Clevlon Creek

See Chet Tank

Clevlons Fork

See Chet Tank

Click Tank

Cliff Dwellers Lodge Airport Cliff Dwelling Airport

Cliff Oweller Spring

Cliff Dwelling

Cliff Dwelling Airport

See Cliff Dwellers Lodge Airport

Cliff Dwelling Tank

Clifford Wash

Clifford Well

Cliff Ranch

Cliff Rose Hill

Cliff Rose Hill Wash

Cliffrose Tank

Cliff Rose Tank

Cliffs

Cliff Spring

Cliff Spring

Cliff Spring

Cliff Spring

Cliff Spring

Cliff Spring

Cliff Spring Canyon

Cliff Springs

Cliff Spring Valley

Cliff Tank

Cliff Tank

Clifton

Clifton Catholic Cemetery

Clifton Cemetery

Clifton City Hall

Clifton High School

Clifton Hot Springs

Clifton Peak

Clifton Post office
Yavapai

Yuma

stream

lake

reservoir

reservoir

ppl

pp1

canal

cliff

spring

spring

ppi

BGN
BGN
$B G N$
BGN
BGN
BGN
BGN
BGN
BGN
BGN

pp 1

reservoir

locale

BGN Greenlee

BGN Pinal

BGN 1930 Yavapai

VARIANT

VARIANT

airport

school

iocale

sumpit

mine

UNOFF

BGN

Mohave

spring

reservoir

BGN

VARIANT

Greenlee

Pinal

reservoir

reservoir

reservoir

airport

VARIANT

VARIANT

Pinal

Pinal

BGM Yavapa

ADMIN

VARIANT

Coconino

spring

locale

BGN

BGN

VARIANT

airport

reservoir

stream

well

locale

summit

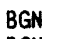

BGN

BGN

UNOFF

BGN

Coconino

Yavapai

Coconino

Navajo

Cochise

Pima

Graham

Mavajo

valley

BGM Mavajo

reservoir

reservoir

locale

spring

spring

spring

spring

spring

spring

valley

spring

valley

reservoir

reservoir

ppl

cemetery

cemetery

building

school

Gila

Navajo

Coconino

Yavapai

Mohave

Coconino

Coconino

Mavajo

Navajo

Navajo

Coconino

Navajo

Navajo

Yavapai

Greenlee

Greenlee

Greenlee

Greenlee

Green lee

spring BGN Greenlee

$\begin{array}{lll}\text { summit } & \text { BGN } & \text { Greenlee } \\ \text { building } & \text { UNOFF } & \text { Greenlee }\end{array}$
COORDIMATE

$343222 N 1113727 \mathrm{~W}$

$345818 \mathrm{~N} 1103736 \mathrm{~W}$

$343147 \mathrm{~N} 1113910 \mathrm{~W}$

$345809 \mathrm{~N} 1103832 \mathrm{~W}$

$331902 \mathrm{~N} 1091320 \mathrm{~W}$

$360558 \mathrm{~N} 1120324 \mathrm{~W}$

$343015 M 1114940 \mathrm{~W}$

$330158 \mathrm{~N} 1143126 \mathrm{~W}$

$345204 \mathrm{N1} 094126 \mathrm{~W}$

$340340 \mathrm{~N} 1110004 \mathrm{~W}$

$345430 \mathrm{~N} 1100844 \mathrm{~W}$

$333203 \mathrm{~N} 1115905 \mathrm{~W}$

$342800 \mathrm{N1141624 \textrm {W }}$

364555 N1123643W

$340159 \mathrm{N1} 102434 \mathrm{~W}$

$364618 N 1123701 W$

$341643 N 1121356 \mathrm{~W}$

$334318 \mathrm{~N} 1091650 \mathrm{~W}$

$325237 \mathrm{N1112016 \textrm {W }}$

$344355 \mathrm{N1120133 \textrm {W }}$

$344348 \mathrm{~N} 1120204 \mathrm{~W}$

$344425 N 1120132 \mathrm{~W}$

$314443 N 1113430 \mathrm{~W}$

360859 N1120459W

$341912 \mathrm{N1134331W}$

333833N1090846W

$325640 \mathrm{N11} 102833 \mathrm{~W}$

325640 N1102833W

$325640 \mathrm{~N} 1102833 \mathrm{~W}$

$351519 N 1124953 \mathrm{~W}$

$364405 \mathrm{~N} 1114505 \mathrm{~W}$

$361219 N 1120341 \mathrm{~W}$

$345245 \mathrm{~N} 1121755 \mathrm{~W}$

$364405 \mathrm{N1114505 \textrm {W }}$

$340125 \mathrm{~N} 1104131 \mathrm{~W}$

$314907 \mathrm{~N} 1101247 \mathrm{~W}$

$313438 \mathrm{~N} 1111404 \mathrm{~W}$

$323700 \mathrm{N1094425 \textrm {W }}$

315140 N1095657W

$362423 \mathrm{~N} 1101120 \mathrm{~N}$

$362037 \mathrm{M1101206 \textrm {W }}$

$335007 N 1102838 \mathrm{~W}$

$340950 \mathrm{~N} 1100215 \mathrm{~W}$

$351318 \mathrm{~N} 1113432 \mathrm{~W}$

$344245 \mathrm{~N} 1120559 \mathrm{~W}$

$353445 \mathrm{N11} 141057 \mathrm{~W}$

$360727 \mathrm{N1115707 \textrm {W }}$

$360838 \mathrm{~N} 1112030 \mathrm{~W}$

$361727 \mathrm{N1} 100913 \mathrm{~W}$

$364537 \mathrm{N1104010 \textrm {W }}$

$364308 \mathrm{~N} 1104027 \mathrm{~W}$

$342406 \mathrm{~N} 1105702 \mathrm{~W}$

361657 N1100930W

$335434 \mathrm{~N} 1095922 \mathrm{~W}$

$345818 \mathrm{~N} 1120653 \mathrm{~W}$

$330303 N 1091744 \mathrm{~W}$

$330257 N 1091847 \mathrm{~W}$

$330146 \mathrm{~N} 1091553 \mathrm{~W}$

$330322 \mathrm{~N} 1091749 \mathrm{~W}$

330242N1091735W

$330322 \mathrm{N1} 1091830 \mathrm{~W}$

$330346 \mathrm{~N} 1091735 \mathrm{~W}$

$330322 \mathrm{~N} 1091831 \mathrm{~W}$

SOURCE
COORDINATE

Buckhorn Mtn

Clear Creek Res

Walker Mtn

Clear Creek Res

Fritz Canyon

Phantom Ranch

Picacho

Milky Ranch

Buzzard Roost Mesa

5200 Holbrook

1380 Paradise Valley

Lake Havasu City S

Clear Water Spring

Cibecue

Clear Water Spring

Cleator

7690 Hannagan Meadow

Cactus Forest 


\begin{tabular}{|c|c|c|c|c|c|c|c|}
\hline FEATURE NAME & $\begin{array}{l}\text { FEATURE } \\
\text { CLASS }\end{array}$ & STATUS & COUNTY & COORDIMATE & $\begin{array}{l}\text { SOURCE } \\
\text { COORDINATE }\end{array}$ & $\begin{array}{c}\text { ELEV } \\
\text { FT }\end{array}$ & MAP NAME \\
\hline $\begin{array}{l}\text { Clifton Public School } \\
\text { See Laugharn Elementary } \\
\text { School } \\
\text { Clifton Railroad Station } \\
\text { Climax Mine } \\
\text { Climax Mine } \\
\text { Climax Mine }\end{array}$ & $\begin{array}{l}\text { school } \\
\text { building } \\
\text { mine } \\
\text { mine } \\
\text { mine }\end{array}$ & $\begin{array}{l}\text { UNOFF } \\
\text { UNOFF } \\
\text { UNOFF } \\
\text { UNOFF }\end{array}$ & $\begin{array}{l}\text { Greenlee } \\
\text { Greenlee } \\
\text { Yuma } \\
\text { Yavapai } \\
\text { Yavapai }\end{array}$ & $\begin{array}{l}330236 \mathrm{~N} 1091734 \mathrm{~W} \\
330315 \mathrm{~N} 1091750 \mathrm{~W} \\
334605 \mathrm{~N} 1140315 \mathrm{~W} \\
335920 \mathrm{N1} 123224 \mathrm{~W} \\
342444 \mathrm{~N} 1123128 \mathrm{~W}\end{array}$ & & & $\begin{array}{l}\text { Clifton } \\
\text { Ibex Peak } \\
\text { Red Picacho } \\
\text { Wilhoit }\end{array}$ \\
\hline $\begin{array}{l}\text { Climax Mine } \\
\text { Cline Cabin } \\
\text { Cline Creek } \\
\text { See Sycamore Creek } \\
\text { Cline Creek } \\
\text { Cottomwood Creek } \\
\text { Cline Mesa } \\
\text { Cline Mesa } \\
\text { Cline Pasture Tank } \\
\text { Cline Point }\end{array}$ & $\begin{array}{l}\text { mine } \\
\text { locale } \\
\text { stream } \\
\text { stream } \\
\text { summit } \\
\text { summit } \\
\text { reservoir } \\
\text { summit }\end{array}$ & $\begin{array}{l}\text { UNOFF } \\
\text { BGN } \\
\text { VARIANT } \\
\text { BGN } 1967 \\
\text { VARIANT } \\
\text { BGN } \\
\text { BGN } \\
\text { BGN } \\
\text { BGN }\end{array}$ & $\begin{array}{l}\text { Mohave } \\
\text { Maricopa } \\
\text { Gila } \\
\text { Maricopa } \\
\text { Gila } \\
\text { Gila } \\
\text { Gila } \\
\text { Navajo }\end{array}$ & $\begin{array}{l}355635 \mathrm{~N} 1140638 \mathrm{~W} \\
334340 \mathrm{~N} 1112405 \mathrm{~W} \\
334902 \mathrm{~N} 1111642 \mathrm{~W} \\
351622 \mathrm{~N} 1105533 \mathrm{~W} \\
334801 \mathrm{~N} 1111207 \mathrm{~W} \\
340443 \mathrm{~N} 1110242 \mathrm{~W} \\
340752 \mathrm{~N} 1105530 \mathrm{~W} \\
341920 \mathrm{~N} 1102213 \mathrm{~W}\end{array}$ & $335548 \mathrm{~N} 1115804 \mathrm{~W}$ & & $\begin{array}{l}\text { Daisy Mountain } \\
\text { Greenback Creek } \\
\text { Buzzard Roost Mesa } \\
\text { Oxbow Mtn } \\
\text { Clay Springs }\end{array}$ \\
\hline $\begin{array}{l}\text { Cline Ranch } \\
\text { Cline Tank } \\
\text { Cline Well } \\
\text { Cline Well } \\
\text { Clino Tank } \\
\text { Clinton Ranch } \\
\text { Clintons Pool } \\
\text { Clints Tank } \\
\text { Clints Well } \\
\text { Clints Well Campground } \\
\text { See Clint Wells Campground }\end{array}$ & $\begin{array}{l}\text { locale } \\
\text { reservoir } \\
\text { well } \\
\text { well } \\
\text { reservoir } \\
\text { locale } \\
\text { reservoir } \\
\text { reservoir } \\
\text { ppl } \\
\text { park }\end{array}$ & $\begin{array}{l}\text { UNOFF } \\
\text { BGN } \\
\text { UNOFF } \\
\text { UNOFF } \\
\text { BGN } \\
\text { UNOFF } \\
\text { BGN } \\
\text { BGN } \\
\text { BGN } \\
\text { UARIANT }\end{array}$ & $\begin{array}{l}\text { Cochise } \\
\text { Maricopa } \\
\text { Cochise } \\
\text { Maricopa } \\
\text { Navajo } \\
\text { Cochise } \\
\text { Coconino } \\
\text { Coconino } \\
\text { Coconino } \\
\text { Coconino }\end{array}$ & $\begin{array}{l}312304 \mathrm{~N} 1100602 \mathrm{~W} \\
335114 \mathrm{~N} 1120855 \mathrm{~W} \\
315400 \mathrm{~N} 1102032 \mathrm{~W} \\
335411 \mathrm{~N} 1120148 \mathrm{~W} \\
341410 \mathrm{~N} 1101905 \mathrm{~W} \\
312238 \mathrm{~N} 1100731 \mathrm{~W} \\
344230 \mathrm{~N} 1111510 \mathrm{~W} \\
343520 \mathrm{~N} 1111721 \mathrm{~W} \\
343316 \mathrm{~N} 1111844 \mathrm{~W} \\
343316 \mathrm{~N} 1111851 \mathrm{~W}\end{array}$ & & & $\begin{array}{l}\text { Hereford } \\
\text { Biscuit Flat } \\
\text { Benson } \\
\text { Daisy Mountain } \\
\text { Limestone Canyon N } \\
\text { Nicksville } \\
\text { Turkey Mtn } \\
\text { Long Valley } \\
\text { Long Valley }\end{array}$ \\
\hline $\begin{array}{l}\text { Clint Wells Campground } \\
\text { Clints Well Campground } \\
\text { Clip See Clip Mill (site) } \\
\text { Clip Mill (site) } \\
\text { Clip } \\
\text { Clip Mill Site } \\
\text { Clip Mill Site } \\
\text { See Clip Mill (site) } \\
\text { Clip Mine } \\
\text { Silver Clip Clain }\end{array}$ & $\begin{array}{l}\text { locale } \\
\text { mine }\end{array}$ & $\begin{array}{l}\text { ADMIN } \\
\text { VARIANT } \\
\text { VARIANT } \\
\text { BGN } \\
\text { VARIANT } \\
\text { VARIANT } \\
\text { VARIANT } \\
\text { UNOFF } \\
\text { VARIANT }\end{array}$ & $\begin{array}{l}\text { Yuma } \\
\text { La Paz }\end{array}$ & $\begin{array}{l}343316 \mathrm{~N} 1111851 \mathrm{~W} \\
331111 \mathrm{~N} 1144015 \mathrm{~W} \\
331111 \mathrm{~N} 1144015 \mathrm{~W}\end{array}$ & & 6880 & Hidden Valley \\
\hline $\begin{array}{l}\text { Clipper Wash } \\
\text { Clipper Well } \\
\text { Clip Wash } \\
\text { Clopton Ranch } \\
\text { Clothopas Temple } \\
\text { See Klothos Temple } \\
\text { Clothos Temple } \\
\text { See Klothos Temple } \\
\text { Cloudburst Canyon } \\
\text { Cloudburst Spring }\end{array}$ & $\begin{array}{l}\text { stream } \\
\text { well } \\
\text { stream } \\
\text { locale } \\
\text { summit } \\
\text { summit } \\
\text { valley } \\
\text { spring }\end{array}$ & $\begin{array}{l}\text { BGN } \\
\text { UNOFF } \\
\text { BGN } \\
\text { UNOFF } \\
\text { VARIANT } \\
\text { VARIANT } \\
\text { BGN } \\
\text { BGN }\end{array}$ & $\begin{array}{l}\text { Yavapai } \\
\text { Yavapai } \\
\text { Yuma } \\
\text { Pima } \\
\text { Yuma } \\
\text { Yuma } \\
\text { Gila } \\
\text { Gila }\end{array}$ & $\begin{array}{l}343252 \mathrm{~N} 1121444 \mathrm{~W} \\
343343 \mathrm{~N} 1121838 \mathrm{~W} \\
331123 \mathrm{~N} 1144008 \mathrm{~W} \\
320914 \mathrm{~N} 1102712 \mathrm{~W} \\
\\
324540 \mathrm{~N} 1141548 \mathrm{~W} \\
\\
324540 \mathrm{~N} 1141548 \mathrm{~W} \\
335259 \mathrm{~N} 1112308 \mathrm{~W} \\
335305 \mathrm{~N} 1112318 \mathrm{~W}\end{array}$ & $\begin{array}{l}343149 \mathrm{~N} 1122042 \mathrm{~W} \\
330822 \mathrm{~N} 1143514 \mathrm{~W}\end{array}$ & 4064 & $\begin{array}{l}\text { Humboldt } \\
\text { Prescott Valley S } \\
\text { Picacho NW } \\
\text { Happy Valley }\end{array}$ \\
\hline $\begin{array}{l}\text { Clounch Well } \\
\text { Clover Camp } \\
\text { Clover Canyon } \\
\text { Clover Canyon } \\
\quad \text { Forty Four Canyon } \\
\text { Clover Creek } \\
\text { Clover Creek } \\
\text { Clover Creek } \\
\text { Cloverleaf (subdivision) } \\
\text { Cloverleaf Ranch }\end{array}$ & $\begin{array}{l}\text { well } \\
\text { locale } \\
\text { valley } \\
\text { valley } \\
\text { stream } \\
\text { stream } \\
\text { stream } \\
\text { ppl } \\
\text { locale }\end{array}$ & $\begin{array}{l}\text { UNOFF } \\
\text { BGN } \\
\text { BGN } \\
\text { BGN } 1981 \\
\text { VARIANT } \\
\text { BGN } \\
\text { BGN } \\
\text { BGN } 1981 \\
\text { BGN } \\
\text { UNOFF }\end{array}$ & $\begin{array}{l}\text { Coconino } \\
\text { Graham } \\
\text { Gila } \\
\text { Coconino } \\
\text { Graham } \\
\text { Gila } \\
\text { Coconino } \\
\text { Maricopa } \\
\text { Yavapai }\end{array}$ & $\begin{array}{l}350403 \mathrm{~N} 1110048 \mathrm{~W} \\
332655 \mathrm{~N} 1095149 \mathrm{~W} \\
340219 \mathrm{~N} 1110434 \mathrm{~W} \\
343306 \mathrm{~N} 1112411 \mathrm{~W} \\
\\
332918 \mathrm{~N} 1095409 \mathrm{~W} \\
34132 \mathrm{BN} 1113751 \mathrm{~W} \\
343306 \mathrm{~N} 1112411 \mathrm{~W} \\
332040 \mathrm{~N} 1115145 \mathrm{~W} \\
343751 \mathrm{~N} 1115431 \mathrm{~W}\end{array}$ & $\begin{array}{l}340102 \mathrm{~N} 1110759 \mathrm{~W} \\
342858 \mathrm{~N} 1112255 \mathrm{~W} \\
332150 \mathrm{~N} 1094932 \mathrm{~W} \\
341413 \mathrm{~N} 1113553 \mathrm{~W} \\
342858 \mathrm{~N} 1112255 \mathrm{~W}\end{array}$ & 1200 & $\begin{array}{l}\text { Meteor Crater } \\
\text { Stove Canyon } \\
\text { Buzzard Roost Mesa } \\
\text { Calloway Butte } \\
\text { Natanes Mts NW } \\
\text { Wet Bottom Mesa } \\
\text { Calloway Butte } \\
\text { Chandler } \\
\text { Cornville }\end{array}$ \\
\hline $\begin{array}{l}\text { Clover Point Tank } \\
\text { Clover Spring } \\
\text { Clover Spring } \\
\text { Clover Spring } \\
\text { Clover Spring } \\
\text { Clover Spring } \\
\text { Aspen Spring } \\
\text { Clover Spring Tank } \\
\text { Clover Tank } \\
\text { Clover Tank }\end{array}$ & $\begin{array}{l}\text { reservoir } \\
\text { spring } \\
\text { spring } \\
\text { spring } \\
\text { spring } \\
\text { spring } \\
\text { reservoir } \\
\text { reservoir } \\
\text { reservoir }\end{array}$ & $\begin{array}{l}\text { BGN } \\
\text { BGN } \\
\text { BGN } \\
\text { BGN } \\
\text { BGN } \\
\text { BGN } \\
\text { VARIANT } \\
\text { BGN } \\
\text { BGN } \\
\text { BGN }\end{array}$ & $\begin{array}{l}\text { Coconino } \\
\text { Maricopa } \\
\text { Gila } \\
\text { Gila } \\
\text { Coconino } \\
\text { Coconino } \\
\text { Gila } \\
\text { Gila } \\
\text { Coconino }\end{array}$ & $\begin{array}{l}343238 \mathrm{~N} 1112136 \mathrm{~W} \\
332819 \mathrm{~N} 1111522 \mathrm{~W} \\
340139 \mathrm{~N} 1110622 \mathrm{~W} \\
342007 \mathrm{~N} 1112940 \mathrm{~W} \\
343021 \mathrm{~N} 1112141 \mathrm{~W} \\
351354 \mathrm{~N} 1121211 \mathrm{~W} \\
\\
340132 \mathrm{~N} 1110609 \mathrm{~W} \\
335103 \mathrm{~N} 1101524 \mathrm{~W} \\
343321 \mathrm{~N} 1112102 \mathrm{~W}\end{array}$ & & & $\begin{array}{l}\text { Long Valley } \\
\text { Weavers Needle } \\
\text { Buzzard Roost Mesa } \\
\text { Buckhead Mesa } \\
\text { Long Valley } \\
\text { Williams South } \\
\text { Buzzard Roost Mesa } \\
\text { Carrizo SE } \\
\text { Long Valley }\end{array}$ \\
\hline $\begin{array}{l}\text { Clover Tank } \\
\text { Clover Wash }\end{array}$ & $\begin{array}{l}\text { reservoir } \\
\text { stream }\end{array}$ & $\begin{array}{l}\text { BGN } \\
\text { BGN }\end{array}$ & $\begin{array}{l}\text { Coconino } \\
\text { Gila }\end{array}$ & $\begin{array}{l}345158 \mathrm{~N} 111293 \mathrm{BW} \\
340430 \mathrm{~N} 1112051 \mathrm{~W}\end{array}$ & $340422 \mathrm{~N} 1112613 \mathrm{~W}$ & & $\begin{array}{l}\text { Hutch Mtn } \\
\text { Gisela }\end{array}$ \\
\hline
\end{tabular}




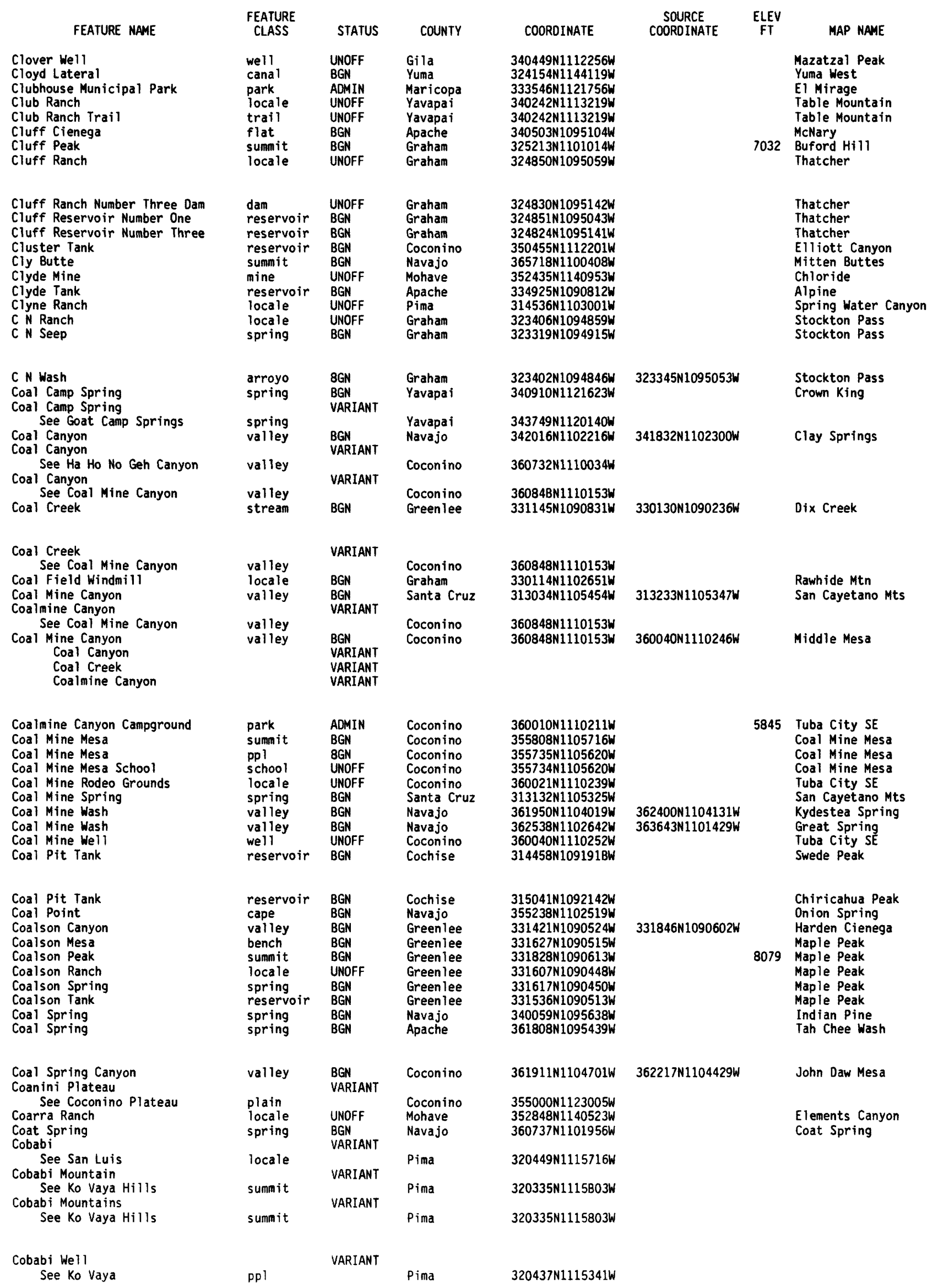




\begin{tabular}{|c|c|c|c|c|c|c|c|}
\hline FEATURE NAME & $\begin{array}{l}\text { FEATURE } \\
\text { CLASS }\end{array}$ & STATUS & COUNTY & COOROINATE & $\begin{array}{l}\text { SOURCE } \\
\text { COORDINATE }\end{array}$ & $\begin{array}{l}\text { ELEV } \\
\text { FT }\end{array}$ & MAP NAME \\
\hline $\begin{array}{l}\text { Cobble Flat } \\
\text { Cobblestone Square } \\
\text { (subdivision) } \\
\text { Cobra Head Canyon } \\
\text { Cobra Loma Mine } \\
\text { Cobre Grande Mine } \\
\text { Cobre Grande Mountain } \\
\text { Cobre Grande Mountains }\end{array}$ & $\begin{array}{l}\text { flat } \\
\text { ppl } \\
\text { valley } \\
\text { mine } \\
\text { mine } \\
\text { summit }\end{array}$ & $\begin{array}{l}\text { BGN } \\
\text { BGN } \\
\text { BGN } \\
\text { UNOFF } \\
\text { UNOFF } \\
\text { BGN } \\
\text { VARIANT }\end{array}$ & $\begin{array}{l}\text { Coconino } \\
\text { Maricopa } \\
\text { Navajo } \\
\text { Cochise } \\
\text { Graham } \\
\text { Graham }\end{array}$ & $\begin{array}{l}350304 N 1120345 \mathrm{~W} \\
333605 \mathrm{~N} 1115819 \mathrm{~W} \\
\\
364008 \mathrm{~N} 1102 \mathrm{~B} 29 \mathrm{~W} \\
315323 \mathrm{~N} 1095743 \mathrm{~W} \\
325834 \mathrm{~N} 1101734 \mathrm{~W} \\
325801 \mathrm{~N} 1101732 \mathrm{~W}\end{array}$ & $364247 \mathrm{~N} 1102728 \mathrm{~W}$ & 1390 & $\begin{array}{l}\text { White Horse Lake } \\
\text { Paradise Valley } \\
\text { Marsh Pass } \\
\text { Cochise Stronghold } \\
\text { Cobre Grande Mtn } \\
\text { Cobre Grande Mtn }\end{array}$ \\
\hline $\begin{array}{l}\text { Cobre Grande Mountains } \\
\text { See Cobre Grande Mountain } \\
\text { Cobre Grande Peak } \\
\text { Cobre Mountain } \\
\text { Cobre Ridge } \\
\text { Blanco Mountains } \\
\text { Oro Blanco Mountains } \\
\text { Coburn Spring } \\
\text { Coburn Spring Number Two } \\
\text { Coburn Tank }\end{array}$ & $\begin{array}{l}\text { summit } \\
\text { summit } \\
\text { summit } \\
\text { ridge } \\
\text { spring } \\
\text { spring } \\
\text { reservoir }\end{array}$ & $\begin{array}{l}\text { VARIANT } \\
\text { BGN } \\
\text { BGN } \\
\text { BGN } 1942 \\
\text { VARIANT } \\
\text { VARIANT } \\
\text { BGN } \\
\text { BGN } \\
\text { BGN }\end{array}$ & $\begin{array}{l}\text { Graham } \\
\text { Graham } \\
\text { Santa Cruz } \\
\text { Santa Cruz }\end{array}$ & $\begin{array}{l}325 B 01 N 1101732 \mathrm{~W} \\
325 \mathrm{~B} 23 \mathrm{~N} 1101448 \mathrm{~W} \\
312655 \mathrm{~N} 1111738 \mathrm{~W} \\
312754 \mathrm{~N} 1111715 \mathrm{~W} \\
333145 \mathrm{~N} 1104146 \mathrm{~W} \\
333117 \mathrm{N1} 104144 \mathrm{~W} \\
333201 \mathrm{N1} 104230 \mathrm{~W}\end{array}$ & & & $\begin{array}{l}\text { Jackson Mtn } \\
\text { Bartlett Mtn } \\
\text { Bartlett Mtn } \\
\text { Chrome Butte } \\
\text { Chrome Butte } \\
\text { Chrome Butte }\end{array}$ \\
\hline $\begin{array}{l}\text { Coburn Well } \\
\text { Coches Canyon } \\
\text { See Turkey Creek } \\
\text { Coches Canyon } \\
\text { Coches Ridge } \\
\text { Coches Spring } \\
\quad \text { Encinas Spring } \\
\text { Coches Tank } \\
\text { Coches Well } \\
\text { Coches Windmill }\end{array}$ & $\begin{array}{l}\text { well } \\
\text { stream } \\
\text { valley } \\
\text { ridge } \\
\text { spring } \\
\text { reservoir } \\
\text { well } \\
\text { locale }\end{array}$ & $\begin{array}{l}\text { UNOFF } \\
\text { VARIANT } \\
\text { BGN } \\
\text { BGN } \\
\text { BGN } 1978 \\
\text { VARIANT } \\
\text { BGN } \\
\text { UNOFF } \\
\text { BGN }\end{array}$ & $\begin{array}{l}\text { Gila } \\
\text { Santa Cruz } \\
\text { Pima } \\
\text { Pima } \\
\text { Pima } \\
\text { Pima } \\
\text { Pima } \\
\text { Pima }\end{array}$ & $\begin{array}{l}333121 \mathrm{~N} 1104123 \mathrm{~W} \\
313514 \mathrm{~N} 1102949 \mathrm{~W} \\
312604 \mathrm{~N} 1112134 \mathrm{~W} \\
312749 \mathrm{~N} 1112348 \mathrm{~W} \\
313122 \mathrm{~N} 1112425 \mathrm{~W} \\
\\
312752 \mathrm{~N} 1112513 \mathrm{~W} \\
312857 \mathrm{~N} 1112316 \mathrm{~W} \\
312841 \mathrm{~N} 1112359 \mathrm{~W}\end{array}$ & $312825 \mathrm{~N} 1112252 \mathrm{~W}$ & & $\begin{array}{l}\text { Bartlett Mtn } \\
\text { Cumero Mtn } \\
\text { Wilbur Canyon } \\
\text { Cumero Mtn } \\
\text { Cumero Mtn } \\
\text { Cumero Mtn }\end{array}$ \\
\hline $\begin{array}{l}\text { Coche Tank } \\
\text { Cochiba Well } \\
\text { See Siovi Shuatak } \\
\text { Cochibo } \\
\text { See Siovi Shuatak } \\
\text { Cochibo Well } \\
\text { See Siovi Shuatak } \\
\text { Cochie Canyon } \\
\text { Cochie Spring } \\
\text { Cochise }\end{array}$ & $\begin{array}{l}\text { reservoir } \\
\text { locale } \\
\text { locale } \\
\text { locale } \\
\text { valley } \\
\text { spring } \\
\text { mine }\end{array}$ & $\begin{array}{l}\text { BGN } \\
\text { VARIANT } \\
\text { VARIANT } \\
\text { VARIANT } \\
\text { BGN } \\
\text { BGN } \\
\text { UNOFF }\end{array}$ & $\begin{array}{l}\text { Pima } \\
\text { Pima } \\
\text { Pima } \\
\text { Pima } \\
\text { Pima } \\
\text { Pinal } \\
\text { Cochise }\end{array}$ & $\begin{array}{l}312658 N 1112307 \mathrm{~W} \\
315703 N 1123551 \mathrm{~W} \\
315703 \mathrm{~N} 1123551 \mathrm{~W} \\
315703 \mathrm{~N} 1123551 \mathrm{~W} \\
322916 \mathrm{~N} 1110720 \mathrm{~W} \\
323128 \mathrm{N1110427W} \\
312629 \mathrm{~N} 1095425 \mathrm{~W}\end{array}$ & $323113 \mathrm{~N} 1110346 \mathrm{~W}$ & & $\begin{array}{l}\text { Ruelas Canyon } \\
\text { Tortolita Mts } \\
\text { Bisbee }\end{array}$ \\
\hline $\begin{array}{l}\text { Cochise } \\
\text { Cochise Butte } \\
\text { Cochise College Airport } \\
\text { Cochise County } \\
\text { See Santa Cruz County } \\
\text { Cochise County } \\
\text { Pima County } \\
\text { Pimeria Alta } \\
\text { Dona Ana County } \\
\text { Ewell County }\end{array}$ & $\begin{array}{l}\text { ppl } \\
\text { summit } \\
\text { airport } \\
\text { civil } \\
\text { civil }\end{array}$ & $\begin{array}{l}\text { BGN } \\
\text { BGN } 1932 \\
\text { ADMIN } \\
\text { VARIANT } \\
\text { ADMIN } \\
\text { VARIANT } \\
\text { VARIANT } \\
\text { VARIANT } \\
\text { VARIANT }\end{array}$ & $\begin{array}{l}\text { Cochise } \\
\text { Coconino } \\
\text { Cochise } \\
\text { Santa Cruz } \\
\text { Cochise }\end{array}$ & $\begin{array}{l}320649 \mathrm{~N} 1095516 \mathrm{~W} \\
361245 \mathrm{~N} 1115257 \mathrm{~W} \\
312215 \mathrm{~N} 1094121 \mathrm{~W} \\
313100 \mathrm{~N} 1110001 \mathrm{~W} \\
315555 \mathrm{~N} 1094430 \mathrm{~W}\end{array}$ & & 4225 & $\begin{array}{l}\text { Cochise } \\
\text { Walhalla Plateau } \\
\text { Paul Spur }\end{array}$ \\
\hline $\begin{array}{l}\text { Cochise County Airport } \\
\text { Cochise County Courthouse } \\
\text { Cochise County Fairgrounds } \\
\text { Cochise County Hospital } \\
\text { Cochise County Junior College } \\
\text { Cochise Elementary School } \\
\text { Cochise Gardens } \\
\text { Cochise Head } \\
\text { Cochise Interchange } \\
\text { Cochise Mine }\end{array}$ & $\begin{array}{l}\text { airport } \\
\text { building } \\
\text { locale } \\
\text { hospital } \\
\text { school } \\
\text { school } \\
\text { cemetery } \\
\text { summit } \\
\text { crossing } \\
\text { mine }\end{array}$ & $\begin{array}{l}\text { ADMIN } \\
\text { UNOFF } \\
\text { ADMIN } \\
\text { UNOFF } \\
\text { UNOFF } \\
\text { UNOFF } \\
\text { UNOFF } \\
\text { BGN } \\
\text { UNOFF } \\
\text { UNOFF }\end{array}$ & $\begin{array}{l}\text { Cochise } \\
\text { Cochise } \\
\text { Cochise } \\
\text { Cochise } \\
\text { Cochise } \\
\text { Cochise } \\
\text { Cochise } \\
\text { Cochise } \\
\text { Cochise } \\
\text { Cochise }\end{array}$ & $\begin{array}{l}321439 \mathrm{~N} 1095336 \mathrm{~W} \\
312632 \mathrm{~N} 1095516 \mathrm{~W} \\
312233 \mathrm{~N} 1093234 \mathrm{~W} \\
312152 \mathrm{~N} 1093541 \mathrm{~W} \\
312158 \mathrm{~N} 1094120 \mathrm{~W} \\
320646 \mathrm{~N} 1095510 \mathrm{~W} \\
315658 \mathrm{~N} 1101726 \mathrm{~W} \\
320333 \mathrm{~N} 109175 \mathrm{~W} \\
321032 \mathrm{~N} 1095652 \mathrm{~W} \\
315841 \mathrm{~N} 1091116 \mathrm{~W}\end{array}$ & & $\mathrm{~B} 113$ & $\begin{array}{l}\text { Red Bird Hills } \\
\text { Bisbee } \\
\text { Douglas NE } \\
\text { Douglas } \\
\text { Paul Spur } \\
\text { Cochise } \\
\text { Benson } \\
\text { Cochise Head } \\
\text { Red Bird Hills } \\
\text { Portal }\end{array}$ \\
\hline $\begin{array}{l}\text { Cochise Overpass } \\
\text { Cochise Peak } \\
\text { Cochise Plaza Shopping Center } \\
\text { Cochise Post Office } \\
\text { Cochise Power Plant } \\
\text { Cochise Stronghold } \\
\text { Cochise Stronghold Campground } \\
\text { Cochise Stronghold Canyon East } \\
\text { See Stronghold Canyon East } \\
\text { Cochise Stronghold Indian } \\
\text { Museum }\end{array}$ & $\begin{array}{l}\text { crossing } \\
\text { summit } \\
\text { locale } \\
\text { building } \\
\text { locale } \\
\text { area } \\
\text { park } \\
\text { valley } \\
\text { building }\end{array}$ & $\begin{array}{l}\text { UNOFF } \\
\text { BGN } \\
\text { UNOFF } \\
\text { UNOFF } \\
\text { UNOFF } \\
\text { BGN } \\
\text { ADMIN } \\
\text { VARIANT } \\
\text { UNOFF }\end{array}$ & $\begin{array}{l}\text { Cochise } \\
\text { Cochise } \\
\text { Cochise } \\
\text { Cochise } \\
\text { Cochise } \\
\text { Cochise } \\
\text { Cochise } \\
\text { Cochise } \\
\text { Cochise }\end{array}$ & $\begin{array}{l}320759 N 1095435 \mathrm{~W} \\
315340 \mathrm{~N} 1095806 \mathrm{~W} \\
313320 \mathrm{~N} 1101633 \mathrm{~W} \\
320650 \mathrm{~N} 1095513 \mathrm{~W} \\
320331 \mathrm{~N} 1095327 \mathrm{~W} \\
315509 \mathrm{~N} 1095908 \mathrm{~W} \\
315530 \mathrm{~N} 1095800 \mathrm{~W} \\
315709 \mathrm{~N} 1095641 \mathrm{~W} \\
315329 \mathrm{~N} 1101301 \mathrm{~W}\end{array}$ & & 4163 & $\begin{array}{l}\text { Red Bird Hills } \\
\text { Cochise Stronghold } \\
\text { Fort Huachuca } \\
\text { Cochise } \\
\text { Cochise } \\
\text { Cochise Stronghold } \\
\text { Cochise Stronghold }\end{array}$ \\
\hline $\begin{array}{l}\text { Cochise Visitor Center } \\
\text { Cochivo }\end{array}$ & building & $\begin{array}{l}\text { UNOFF } \\
\text { VARIANT }\end{array}$ & Cochise & $321630 \mathrm{~N} 1095026 \mathrm{~W}$ & & & Willcox North \\
\hline
\end{tabular}


NATIONAL GAZETTEER--ARIZONA 1986

FEATURE NAME

See Siovi Shuatak

Cochran

Cochrane Hill

Jumpoff $\mathrm{Hill}$

Cochran Railroad Station

Cochran Tank

Cochran Tank

Cocio Wash

Cocklebur

See Vaiva Vo

Cockleburr

See Vaiva Vo

Cock leburr Spring

Cock lebur Tank

Cockscomb, The

Cockscomb, The

Cockscomb, The

Cockscomb Butte

Cocks Combs

The Cocks Combs

Cocomunga Canyon

Coconino

Coconino

See Ryan

Coconino Caverns

See Grand Canyon Caverns

Coconino Caverns

See Grand Canyon Caverns

Coconino County

$$
\text { Yavapai County }
$$

Coconino County Fairgrounds

and Park

See Fort Tuthill County Park

Coconino County Highway

Department

Coconino Dam

Coconino High School

Coconino Lake

Coconino National Forest

Coconino Plateau

See Mogollon Plateau

Coconino Platea

Arizona Plateau

Coanini Plateau

Colorado Plateau

Plateau of Arizona

San Francisco Plateau

Coconino Point

Coconino Railroad Station

Coconino Rim

Coconino Siding

Coconino Substation

Coconino Wash

Coconino Wash Tank

Cocopah Damsite Number Three

$$
\text { See Imperial Dam }
$$

Cocopah Drain

Cocopah Elementary School

Cocopah Indian Reservation

Cocopa Reservoir

East Cocopah Reservation

West Cocopah Reservation Yuma Indian Reservation

Cocopah Point

See Cocopa Point

Cocopa Point

Cocopah Point

Cocopa Reservoir

See Cocopah Indian

Reservation

\section{FEATURE}

CLASS

STATUS

COUNTY

locale

locale

summ it

building

reservoir

reservoir

stream

$\begin{array}{ll}\text { ppl } & \text { VARIANT } \\ \text { ppl } & \text { VARIANT } \\ \text { spring } & \text { BGN } \\ \text { reservoir } & \text { BGN } \\ \text { ridge } & \text { BGN } \\ \text { ridge } & \text { BGN } \\ \text { summit } & \text { BGN } \\ \text { summit } & \text { BGN }\end{array}$

Pinal

Pinal

Yavapai

Pima

Mohave

Mohave

Yavapai

Navajo

ridge

BGN 1964

VARIANT

valley
locale

locale

cave

ppl

civil

ADMI

VARIANT

VARIANT

park

building

$\begin{array}{ll}\text { dam } & \text { UNOFF } \\ \text { school } & \text { UNOFF }\end{array}$

school

reservoir

forest

plain

plain

\section{BGN}

ADMIN

VARIANT

BGN 1906

VARIANT

VARIANT

VARIANT

VARIANT

VARIANT

cliff

cliff

locale

locale

stream

reservoir

dam

cana?

school

reserve

UNO

VARIANT

VARIANT

VARIANT

VARIANT

VARIANT

cliff

BGN 1906

VARIANT

Coconino

Coconino

$360517 N 1121443 \mathrm{~W}$

$360517 \mathrm{N11} 21443 \mathrm{~W}$
Coconino

Gila

Coconino

Coconino

Coconino

Coconino

Coconino

Coconino

350833N1114116W

351036N1113930W

$350018 \mathrm{~N} 1112350 \mathrm{~W}$

351258 N1113722W

$350018 \mathrm{~N} 1112354 \mathrm{~W}$

350001 N1114000W

353500 N1113500W

$355000 \mathrm{~N} 1123005 \mathrm{~W}$
355401 N1113405W $355930 \mathrm{~N} 1121141 \mathrm{~W}$ $355410 \mathrm{~N} 1113512 \mathrm{~W}$ $360010 \mathrm{~N} 1121142 \mathrm{~W}$ $351034 \mathrm{~N} 1113911 \mathrm{~W}$

360147 N1122951W

$355834 \mathrm{~N} 1121010 \mathrm{~W}$

325259 N1142748W

$323406 \mathrm{~N} 1144028 \mathrm{~W}$
COORDINATE

reserve VARIANT

\begin{tabular}{ccl}
$\begin{array}{c}\text { SOURCE } \\
\text { COORDINATE }\end{array}$ & $\begin{array}{c}\text { ELEV } \\
\text { FT }\end{array}$ & \multicolumn{1}{c}{ MAP NAME } \\
& $6954 \begin{array}{l}\text { North Butte } \\
\text { Sunset Crater East } \\
\\
\end{array}$ \\
& $\begin{array}{l}\text { North Butte } \\
\text { Young } \\
\text { Camp Verde } \\
\text { W22352N1112944W }\end{array}$ & West of Marana
\end{tabular}

Bloody Bas in Buehman Canyon Snap Canyon West Pakoon Springs

5009 Wilson Mountain

5949 French Butte

Little Park Lane

Gisela

Tusayan West

Grand Canyon

Flagstaff West

Ashurst Lake

Flagstaff East

7130 Ashurst Lake

Mountainaire

Rosebud Tank

$355328 N 1115808$

Coconino Point Tusayan West Coconino Point

6400 Grand Canyon

Flagstaff West

Chamisa Tank

Tusayan West

Somerton

Paradise Valley

Duncan

Grand Canyon 


\section{FEATURE NAME}

Cocoraqu Butte

See Cocoraque Butte

Cocoraque Butte

Cocoraqu Butte

Cocoraqui Butte

Corcoraque Butte

Cocoraque Ranch

Cocoraqui Butte

See Cocoraque Butte

C 0 O Mine

$C$ O D Mine

C 0 D Ranch

C O D Spring

Coe School

Cofer Dan

Cofer Hot Spring

Coffee Canyon

Coffee Creek

Coffee Flat

Coffee Flat Canyon

Coffee Flat Mountain

Coffee Flat Trail

Coffee Lake

Coffeepot

Coffeepot Canyon

Coffee Pot Dam

Coffeepot Mountain

Coffeepot Rock

Coffeepot Tank

Coffeepot Well

Coffee Pot Well

Coffee Tank

Coffee Tank

Coffelt Lamoreaux Park Coffelt Park

Coffelt Park

See Coffelt Lamoreaux Park

Coffinger Park

Cogdill Center

Cogswe 11 Butte

Cohenour Mine

Cohenour Spring

Cohenour Spring

See Coyote Spring

Cohonini Park

See Black Botton Crater Cohota

See Kohatk

Coin Spring

Cojate

See Kohatk

Cojela

See Kohatk

Cojeta

See Kohatk

Colbath Tank

Colbath Tank

Colbath Wash

Colbath Well

Colcord Canyon

Colcord Canyon

Colcord Canyon

See Calcord Canyon

Colcord Mountain

Colcord Mountain Estates

Colcord Spring

Colcord Spring

See Calcord Spring

Colcord Tank

Cold Creek

Rustlers Canyon
FEATURE
CLASS

STATUS

COUNTY

COORDINATE

Pima

VARIANT

summit

sumnit

BGN 1917
VARIANT
VARIANT

VARIANT

VARIANT

locale

UNOFF

Pima

VARIANT

summit

mine

mine

locale

spring

dam

spring

valley

strea

flat

valley

summit

trail

locale

valley

dam

summit

UNOFF
UNOFF
UNOFF
BGN
UNOFF
UNOFF
BGN
BGN

Pima

Yuma

Mohave
Pinal

Pinal
Mohave

Maricopa

Mohave

Mohave

Gila

BGN 1970

BGN

$B G N$

BGN

UNOFF

BGN

$B G N$

UNOFF

BGN

Yavapa

Pinal

Pinal

Pinal

Pinal

Coconino

Gila

Gila

Pima

summi

reservoir

well

well

BGN

BGN

UNOFF

reservoir

reservoir

park

BGN

$B G N$

ADMIN

VARIAN

VARIANT

park

Yavapa $i$

Gila

Pina

Gila

Pinal

Graham

Maricopa

Maricopa

321316N1112029W

$321316 \mathrm{~N} 1112029 \mathrm{~W}$

321320N1112101W

$321316 \mathrm{N1112029 \textrm {W }}$

$332112 N 1135329 \mathrm{~W}$

352044N1140614W

$323602 \mathrm{N1} 104410 \mathrm{~W}$

$352025 \mathrm{~N} 1140507 \mathrm{~W}$

$332842 \mathrm{N11} 20829 \mathrm{~W}$

$350849 N 1134035 \mathrm{~W}$

$344144 N 1133423 \mathrm{~W}$

$332337 \mathrm{N1105222 \textrm {W }}$

344816 N1115541W

$332359 \mathrm{N1111714 \textrm {W }}$

$332300 \mathrm{N1111715 \textrm {W }}$

$332526 \mathrm{~N} 1111713 \mathrm{~W}$

$332358 N 1111809 \mathrm{~W}$

$361840 \mathrm{~N} 1121025 \mathrm{~W}$

$340222 \mathrm{N1111110 \textrm {W }}$

$340231 N 1111128 \mathrm{~W}$

$333306 \mathrm{~N} 1103230 \mathrm{~W}$

$322856 \mathrm{N1123722 \textrm {W }}$

345304 N111472BW

$340216 \mathrm{N1111111 \textrm {K }}$

322B57N1123838W

$333257 \mathrm{N1103132 \textrm {W }}$

$323415 \mathrm{N1113721 \textrm {W }}$

$323859 N 1102348 \mathrm{~W}$

$332600 \mathrm{N1} 120601 \mathrm{~W}$

332600N1120601W

park

locale

summit

mine

spring

ADMIN

BGN

BGN 1966

UNOFF

BGN

VARIANT

spring

VARIANT

crater

ppl

VARIANT

Maricopa

Coconino

Coconino

Mohave

Mohave

Mohave

Coconino

Pinal

$335821 \mathrm{N1} 124355 \mathrm{~W}$

$351109 \mathrm{N111} 3836 \mathrm{~W}$

$362335 \mathrm{N1} 122905 \mathrm{~W}$

360435 N1143443W

$352358 \mathrm{N1} 140400 \mathrm{~W}$

35372BN1134800W

352354N1112340

323442N112001BW

spri

ppI

BGN

VARIANT

Mohave

Pinal

pp1

VARIANT

ppes

ppl

reservoir

stream

VARIANT

Pinal

Pinal

BGN Navajo

$B G N$
$B G N$

Navajo

Navajo

well

valley

valley

UNOFF

BGN

Navajo

valley

summit

locale

spring

spring

BGN

BGN

BGN

VARIANT

Maricopa

Gila

Coconino

Gila

Gila

Yavapa i

Coconino

reservoir

stream

BGN

BARIANT

$\begin{array}{cc}\text { SOURCE } & \text { ELEV } \\ \text { COORDINATE } & \text { FT MAP NAME }\end{array}$

2758 Cocoraque Butte

Cocoraque Butte

Kofa Butte

Stockton $\mathrm{Hill}$

Campo Bonito

Stockton Hill

Fowler

Tin Mountain NW

Wikieup

332310N1105156W Globe

345525N1115830W Page Springs

Weavers Needle Weavers Needle

4621 Weavers Needle

Weavers Needle

Kanabownits Spring

Sheep Bas in Mtn

Sevenmile Mts

3466 Coffepot Mtn

Wilson Mountain 
NATIONAL GAZETTEER--ARIZONA 1986

FEATURE NAME

Coldfield

See Supi Oidak

Cold Spring

Cold Spring

Cold Spring

Cold Spring

Cold Spring

Cold Spring

Cold Spring

Cold Spring

Cold Spring

Cold Spring

Cold Spring

Cold Spring

Cole Spring

Cold Spring Canyon

Cold Spring Canyon

Cold Spring Canyon Coldwater Canyon

Cold Spring Mountain

Cold Spring Point

Cold Springs

Cold Springs

Cold Spring Wash

Cold Spring Wash

Cold Spring Wash Pond

Cold Tank

Cold Water Canyon

Coldwater Canyon

See Cold Spring Canyon

Cold Water Creek

Cold Water Seep

Cold Water Spring

Cold Water Spring

Cold Water Spring

Coldwater Spring

Coldwater Spring

Cold Water Tank

Coldwater Tank Number One

Coldwater Tank Number Two

Cold Water Trail

Cold Water Trail Number

Twenty Seven

Cold Water Wash

Cole

Cole

See Coledon

Cole Campbel1 Tank

Coledon

Cole

Coleman Creek

Coleman Knoll

Coleman Lake

Coleman Ranch

Coleman Spring

Cole Number Three

Cole Park

Cole Spring

Cole Spring

See Cold Spring

Coles Wash

Cole Well

Cole Well

Colfred

Colfred Airport

Colfred Floodway

College Observatory

College of Ganado

College Park (subdivision)

College Park Shopping Center

College Park Shopping Center
FEATURE
CLASS

locale
spring
spring
spring
spring
spring

VARIANT

COORDINATE

$314107 N 1114632 \mathrm{~W}$

$320954 N 1102457 \mathrm{~W}$

$322648 \times 1104623 \mathrm{~W}$

$\begin{array}{ll}\text { Pima } & 322648 N 1104623 \mathrm{~W} \\ \text { Greenlee } & 330040 \mathrm{~N} 1090536 \mathrm{~W} \\ \text { Graham } & 330145 \mathrm{~N} 1101930 \mathrm{~W} \\ \text { Graham } & 331335 \mathrm{~N} 1093958 \mathrm{~W}\end{array}$

$\begin{array}{ll}\text { Pima } & 322648 N 1104623 \mathrm{~W} \\ \text { Greenlee } & 330040 \mathrm{~N} 1090536 \mathrm{~W} \\ \text { Graham } & 330145 \mathrm{~N} 1101930 \mathrm{~W} \\ \text { Graham } & 331335 \mathrm{~N} 1093958 \mathrm{~W}\end{array}$

Graham

spring BGN Gila 333107N1102759W

$\begin{array}{llll}\text { spring } & B G N & \text { Apache } & 340706 N 1094306 \mathrm{~W} \\ \text { spring } & B G N & \text { Gila } & 342058 N 1111546 \mathrm{~W}\end{array}$

Yavapai 344004N1131424W

spring BGN Yavapai 345038N1130802W

spring BGN Mohave 362126N1131549W

BGN

Gila

valley

summit

summit

spring

spring

stream

valley

lake

reservoir

VARIANT

BGN

$B G N$

BGN

BGN

BGN

$B G N$

BGN

valley BGN Gila

valley

stream

spring

spring

spring

spring

spring

spring

VARIANT

Yavapai

Greenlee

Mohave

Graham

Yavapa

Apache

Mohave

Mohave

Yavapai

BGN Yavapai

BGN Gila

330632N1090817W

Maricopa 334204N1112348W

Yavapai 342136N1114736W

Coconino 342928N1111753W

Coconino 361132N1105839W

reservoir BGN Yavapai 344619N1125110W

reservoir BGN Yavapai 342138 N1114434W

reservoir BGN Yavapai 342149N1114458W

trail UNOFF Yavapai $342313 N 1114732 \mathrm{~W}$

trail UNOFF

arroyo BGN Apache 354615N1090610W

mine UNOFF Cochise 312505N1095423W

locale

VARIANT

Maricopa

$325735 N 1123800 \mathrm{~W}$

reservoir

locale

stream

summit

swamp

locale

spring

mine

park

BGH

VARIANT

BGN

BGN Greenlee

BGN Coconino

BGN Coconino

UNOFF Pima

UNOFF Cochise

ADMIN Maricopa

$\begin{array}{llll}\text { spring } & \text { BGN } & \text { Mohave } & \end{array}$

spring

stream

stream

well

locale

airport

channel

building

BGN Yavapa

UNOFF Maricopa

UNOFF Maricopa

BGN

ADMII

BGN

UNOFF

Yuma

Yuma

Yuma

school UNOFF Apache

ppl BGN Maricopa

locale UNOFF Maricopa

locale

UNOFF

Maricopa

$350648 \mathrm{~N} 1130235 \mathrm{~W}$

$325735 \mathrm{~N} 1123800 \mathrm{~W}$

$334420 N 1090933 \mathrm{~W}$

$350935 \mathrm{~N} 1121051 \mathrm{~W}$

$350854 \mathrm{~N} 1121040 \mathrm{~W}$

$320018 \mathrm{~N} 1112641 \mathrm{~W}$

$335608 \mathrm{~N} 1092632 \mathrm{~W}$

$312440 \mathrm{~N} 1095431 \mathrm{~W}$

$332305 \mathrm{~N} 1115402 \mathrm{~W}$

$362126 \mathrm{~N} 1131549 \mathrm{~W}$

$335416 \mathrm{~N} 1121640 \mathrm{~W}$

$332009 \mathrm{~N} 1130416 \mathrm{~W}$

$332859 N 1130529 \mathrm{~W}$

324216 N1135403W

$324141 N 1135312 \mathrm{~W}$

$324356 \mathrm{~N} 1135526 \mathrm{~W}$

$351103 \mathrm{~N} 1113909 \mathrm{~W}$

$354243 \mathrm{~N} 1093241 \mathrm{~W}$

$333739 \mathrm{~N} 1121040 \mathrm{~W}$

$332245 \mathrm{N11} 15543 \mathrm{~W}$

$333038 \mathrm{N1120756 \textrm {W }}$
BGN Apache

$335312 N 1105538 \mathrm{~W}$

Mt Lenno

Big Lue Mts

Park Creek Cabins

Cassadore Spring

Horseshoe Cienega

Payson North

Bozarth Mesa

Burro Mesa

Piney Hill

Cold Spring

325415N1101044W Jackson Mtn

$334924 N 1105346 \mathrm{~W}$

Sombrero Peak

$345344 N 1130901 \mathrm{~W}$

Burro Mesa

7054 Rattlesnake Spring

Cold Spring

Fort Thomas

Iron Springs

Cold Spring

Cold Spring

Cold Spring

McFadden Peak

342220 N1114819W

Horner Mtn

Rockinstraw Mtn

Ratt lesnake Spring

Mine Mountain

Tule Mesa

Kehl Ridge

Begashibito Canyon

Seepage Mtn

Verde Hot Springs

Verde Hot Springs

Horner Mtn

Horner Mtn

Fort Defiance

Bisbee

Anvil Rock

875 Gila Bend

$334838 N 1090927 W$

Beaverhead

7658 Williams South

Williams South

San Pedro

Big Lake North

Bisbee

Tempe

Cold Spring

$335804 N 1121829 W$

1240 Hedgpeth Hills

Temp

1138 Glendale

Governors Peak

Forth of July Butte

Saddle Mtn

Tacna

Tacna

Flagstaff West 


\section{FEATURE NAME}

College Peaks

Collier School

Collie Well

Collins Canyon

Collins Mine

Collins Spring

Collins Spring

Collins Tank

Collins Tank

Collins Wash

Collom Mine

Collorado

See Little Colorado River

Coimonero Canal

Colnez Smith School Smith Elementary School

Colonel Spring Forest Camp

Colonial Coronita (subdivision)

Colonia Verde Shopping Center

Colonnade, The The Colonade

Colony Biltmore IV

(subdivision)

Colony South (subdivision)

Colony Wash

Colorado

See Little Colorado River

Colorado, Cerro

Colorado Chiquita See Little Colorado River

Colorado Chiquito See Little Colorado River

Colorado City See Yuma

Colorado City

Short Creek

Colorado City Elementary School

Colorado City Municipal Airport

Colorado City Post Office

Colorado Clark Mine

Colorado Crossing

See Pearce Ferry

Colorado Gulch

Colorado Gulch

Colorado Mine

Colorado Mountains, Cerro

Colorado Plateau

See San Francisco Plateau

Colorado Plateau

See Mogolion Plateau

Colorado Plateau

See Coconino Plateau

Colorado River

Blue River

Canon of the Colorado

River

Grand River

North Fork of Grand River

Colorado River Day School

Colorado River Gorge Outlook

Colorado River Indian Agency

Headquarters

Colorado River Indian

Reservation

Indian Reserve

Colorado River Water

Pollution Control Center

Colorado Spring

Colorado Spring

Colorado Tank

Colorado Valley
FEATURE

CLASS

STATUS

COUNTY

COORDINATE

summit

schoo

well

valley

mine

spring

BGN

UNOFF

UNOFF

BGN

UNOFF

BGN

spring

$B G N$

reservoir BGN

reservoir $B G$

stream

mine

stream

canal

school

locale

ppl

locale

summit

ppl

pp 1

arroyo

stream

summit

BGN

stream

stream

ppl

ppl

school

airport

building

mine

locale

valley

valley

mine

summit

plain

BGN

BGN

UNOFF

BGN 1906

VARIANT

BGN

BGN

BGN

VARIANT

Cochise

Pima

Santa Cruz

Santa Cruz

Yuma

Cochise

312718 N1092517W

$321635 \mathrm{N1} 104755 \mathrm{~W}$

$313419 N 1103414 \mathrm{~W}$

$312610 \mathrm{~N} 1102722 \mathrm{~W}$

331956N1132514W

312613N1102715W

$342012 \mathrm{N1123436 \textrm {W }}$

$312726 \mathrm{N1102912 \textrm {W }}$

344829 N1121139W

$321436 \mathrm{~N} 1102320 \mathrm{~W}$

$340807 N 1112648 \mathrm{~W}$

$361128 \mathrm{N1114811 \textrm {W }}$

$324510 \mathrm{~N} 1090836 \mathrm{~W}$

$313310 N 1102003 \mathrm{~W}$

$334739 N 1092451 \mathrm{~W}$

$331816 \mathrm{N1114745W}$

$321501 N 1105029 \mathrm{~W}$

360948N1120722W

333055N1120126W

Maricopa

Maricopa

Maricopa

Coconino

$333717 N 1120637 \mathrm{~W}$

$333541 \mathrm{N1114212W}$

$361128 N 1114811 \mathrm{~W}$

314017N1111601W

Pima

Coconino

36112BN1114811W

VARIANT

VARIANT

Coconino

Yuma

Mohave

BGN 1961

Mohave

AOMIN Mohave

UNOFF Mohave

UNOFF

VARIANT

Pima

Mohave

BGN Pima

BGN Greenlee

UNOFF

BGN

VARIANT

Yuma

Coconino

361128N1114811W

$324331 \mathrm{~N} 1143725 \mathrm{~W}$

$365925 \mathrm{~N} 1125830 \mathrm{~W}$

365930 N1125818W

365658 N1130050W

$365930 \mathrm{~N} 1125822 \mathrm{~W}$

313904 N1111705W

$360700 \mathrm{~N} 1140000 \mathrm{~W}$

$314630 \mathrm{~N} 1104300 \mathrm{~N}$

$330634 N 1091736$

330015N1141004I

314210 N1111516

$353000 \mathrm{~N} 1122500 \mathrm{~W}$

VARIANT

plain

plain

strea

VARIANT

Coconino

$353500 N 1113500 \mathrm{~W}$

Coconino

VARIANT

VARIANT

UNOFF
BGN

locale

UNOFF

Yuma

building

UNOFF

$340415 \mathrm{~N} 1142325 \mathrm{~W}$

340853 N1141811W

reserve

UNOFF

La Paz

334730 N1142500W

$340837 N 1141823 W$

building

UNOFF

La Paz

341333 N1122634W

spring

BGN

spring

reservoir

BGN

VARIANT

$\begin{array}{ll}\text { Mohave } & 342749 N 1132454 \mathrm{~W} \\ \text { Pinal } & 325526 \mathrm{~N} 1111519 \mathrm{~W}\end{array}$
$355511 N 1113346 \mathrm{~W}$

$\begin{array}{cc}\text { SOURCE } & \text { ELEV } \\ \text { COORDINATE } & \text { FT }\end{array}$

6391 College Peaks Sabino Canyon O'Donnel1 Canyon Huachuca Peak Nottbusch Butte Huachuca Peak

Walnut Grove Huachuca Peak

Munds Draw

Happy Valley

North Peak

Sheldon

Fort Huachuca

Big Lake South

1240 Chandler

2520 Sabino Canyon

7296 8right Angel Point

1200 Sunnys lope

1310 Sunnys lope

333612 N1114540W

Granite Reef Dam

4207 Cerro Colorado

Colorado City

Colorado City

4840 Lost Spring Mtn East Colorado City

Cerro Colorado

$314632 \mathrm{~N} 1104421 \mathrm{~W}$

330737 N1091926W

Empire Ranch

Clifton

Castle Dome Peak

Cerro Colorado

Parker SW

Coconino Point

Parker

Moon Mtn

Parker

Minnehaha

Arrastra Mtn

Cactus Forest 
NATIONAL GAZETTEER--ARIZONA 1986 FEATURE NAME

See La Posa Plain

Colorado Wash

Colorado Wash

Colossal Cave

Colossal Cave Park

Colrio Mine

Colter Butte

Colter Creek

Colter Reservoir

Colter Spring

Colton Crater

Columbia 160

Columbia Mine

Columbine Canyon

See Cave Canyon

Columbine Falls Emery Falls

Columbine Ranger Station

Columbine Spring

Columbine Spring

Columbine Spring

Columbus Peak

Columbus Point

Columbus Wash

Colville Dikes

See Porras Dikes

Colvin-Jones Canal

Coma-a Spring

See Comar Spring

Comanche Creek

Comanche Park

Comanche Point

Comar Spring

Coma-a Spring

Comar Springs

K-ai Bito

Kaibito

Comar Springs

Comate See Comar Spring

See Shaotkam

Combination Mine

Comb Ridge

Comely

See South Komelik

Comet Peak

Bald Mountain

Camels Peak

Comets Peak

Cornet Peak

Comets Peak

See Comet Peak

Comet Spring, The

Comeva

See Kom vo

Committee Tank

Commonwealth Mine

Community Service Center and

School

Community Tank

Community Tank

Comobabi

Comobabi Pass

Comobabi Peak

See Baboquivari Peak

Comobabi Wash

Comobavi Wash

Comobabi Wash

See Anegan Wash

Comobabi Well

FEATURE
CLASS

STATUS

COUNTY

COORDINATE

plain

stream

strean

cave

park

mine

summit

stream

lake

spring

crater

locale

mine

valley

falls

BGN
BGN
BGN
ADMIN
UNOFF
BGN 1932

La Paz

Pima

Yuma

Pima

Yuma

Coconino

BGN Apache

BGN

BGN

BGN 1971

VARIANT

BGN

UNOFF

VARIANT

BGN 1948 Mohave

VARIANT

locale

spring

spring
spring

summit

cliff

stream

summit

canal

UNOFF

BGN

BGN

BGN

BGN

BGN 1932

BGN

VARIANT

BGN

Graham

Maricopa

Navajo

Yavapai

Maricopa

Coconino

Maricopa

Navajo

Graham

VARIANT

spring

stream

park

summit

spring

BGN 1932

ADMIN

BGN 1906

BGN

VARIANT

VARIANT

VARIANT

VARIANT

VARIANT

VARIAN

ppl

mine
ridge

locale

summit

UNOFF

BGN 1915

VARIANT

BGN 1932

VARIANT

VARIANT

VARIANT

VARIANT

Navajo

Coconino

Maricopa

Coconino

Navajo

VARIANT

summit

spring

ppl

ppl

mine

school

reservoir

BGN

VARIANT

Pinal

Cochise

Pima

BGN

UNOFF

UNOFF

Coconino

Cochise

Pinal

Navajo

BGN

ppl

gap

BGN

Coconino

Pima

Pima

VARIANT

summit

stream

BGN 1977 Pima

VARIANT

VARIANT

strean

well

UNOFF reservoir BGN

330334N1095812W
334400 N1141000W

313953 N1111329W

$333740 \mathrm{~N} 1140639 \mathrm{~W}$

$320345 N 1103755$

320354 N1103749W

$334143 N 1142029 \mathrm{~W}$

$361416 N 1115507 \mathrm{~W}$

$335819 N 1091231 \mathrm{~W}$

335632 N 1092857

324257 N1100111W

353242N1113810W

340201 N1121835W

$331028 \mathrm{~N} 1110926 \mathrm{~W}$

$360529 N 1135514 W$

$360534 N 1135517 W$

$324220 \mathrm{~N} 1095433 \mathrm{~W}$

$335502 \mathrm{~N} 1114906 \mathrm{~W}$

$335631 \mathrm{N1095510 \textrm {W }}$

344358 N1120705

$331612 \mathrm{~N} 1131802 \mathrm{~W}$

$360459 \mathrm{~N} 1121309 \mathrm{~W}$

$325903 N 1131654 \mathrm{~W}$

364539 N1101007W

$353151 \mathrm{N1102456 \textrm {W }}$ 360657 N1114937W $333257 \mathrm{~N} 1115349 \mathrm{~W}$

$360534 N 1114813 \mathrm{~W}$

$353151 N 1102456 \mathrm{~W}$

360543N1114759W Desert View

Paradise Valley

7073 Desert View

Egloffstein Butte

$314126 \mathrm{~N} 1111524 \mathrm{~W} \quad$ Saucito Mtn

333655N1140543W Plomosa Pass

Vail

Vail

7256 Walhalla Plateau

335508N1091818W Nutrioso

9308 Big Lake North

$6232 \mathrm{~S}$

Columbia

Mineral Mtn

Columbine Falls

Webb Peak

Humboldt Mtn

Alchesay Flat

Cottonwood

331657N1131910W Grand Canyon

Fort Thomas $\begin{array}{cc}\text { SOURCE } & \text { ELEV } \\ \text { COORDINATE } & \text { FT NAP NAME }\end{array}$

7180 Groom Creek

Baby Rocks

2691 Florence Junction

$314320 \mathrm{~N} 1114620$

$331738 \mathrm{~N} 1111606 \mathrm{~W}$

$331738 \mathrm{~N} 1111606 \mathrm{~W}$

$320444 N 1092237 \mathrm{~W}$

$315735 N 1122054 \mathrm{~W}$

$345152 \mathrm{~N} 1114204 \mathrm{~W}$

$315404 \mathrm{~N} 1094856 \mathrm{~W}$

$330702 \mathrm{~N} 1115303 \mathrm{~W}$

341846 N1100926W

352421 N1115541W

$320329 \mathrm{~N} 1114758 \mathrm{~W}$

320359 N1114B29

$314616 \mathrm{~N} 1113542 \mathrm{~W}$

$315550 \mathrm{~N} 1114755 \mathrm{~W}$

320450 N1114710W

321059 N1114007W

320252 N1114832W
Bowie Mtn South

Munds Mountain

Pearce

Pinedale

Moritz Ridge

Comobabi

Comobabi

Sells East

Comobabi
Sacaton Butte 


\begin{tabular}{|c|c|c|c|c|c|c|c|}
\hline FEATURE NAME & $\begin{array}{l}\text { FEATURE } \\
\text { CLASS }\end{array}$ & STATUS & COUNTY & COORDINATE & $\begin{array}{l}\text { SOURCE } \\
\text { COORDINATE }\end{array}$ & $\begin{array}{c}\text { ELEV } \\
\text { FT }\end{array}$ & MAP NAME \\
\hline $\begin{array}{l}\text { Comobari Mountains } \\
\text { North Comobabi Mountains } \\
\text { Comobavi Mountains }\end{array}$ & range & $\begin{array}{l}\text { BGN } \\
\text { VARIANT } \\
\text { VARIANT }\end{array}$ & Pima & $320714 N 111475 \mathrm{BW}$ & & 4420 & Comobabi \\
\hline $\begin{array}{l}\text { See South Comobabi } \\
\text { Mountains }\end{array}$ & range & & Pima & $320026 \mathrm{~N} 1115223 \mathrm{~W}$ & & & \\
\hline $\begin{array}{l}\text { Comobavi Wash } \\
\text { See Comobabi Wash } \\
\text { Comoro Canyon } \\
\text { See Cumero Canyon } \\
\text { Comoro Fresno Canyon } \\
\text { See Cumero Canyon }\end{array}$ & $\begin{array}{l}\text { stream } \\
\text { valley } \\
\text { valley }\end{array}$ & $\begin{array}{l}\text { VARIANT } \\
\text { VARIANT } \\
\text { VARIANT }\end{array}$ & $\begin{array}{l}\text { Pina } \\
\text { Santa Cruz } \\
\text { Santa Cruz }\end{array}$ & $\begin{array}{l}315550 \mathrm{~N} 1114755 \mathrm{~W} \\
312400 \mathrm{~N} 1105241 \mathrm{~W} \\
312400 \mathrm{~N} 1105241 \mathrm{~W}\end{array}$ & & & \\
\hline $\begin{array}{l}\text { Comot } \\
\text { See Vakamok } \\
\text { Comote } \\
\text { See Shaotkam } \\
\text { Comoti } \\
\text { See Vakamok } \\
\text { Comoti } \\
\text { See Shaotkam } \\
\text { Comova Kom Vo } \\
\text { See Kom }\end{array}$ & $\begin{array}{l}\text { locale } \\
\text { ppl } \\
\text { locale } \\
\text { ppl } \\
\text { ppl }\end{array}$ & $\begin{array}{l}\text { VARIANT } \\
\text { VARIANT } \\
\text { VARIANT } \\
\text { VARIANT } \\
\text { VARIANT }\end{array}$ & $\begin{array}{l}\text { Pima } \\
\text { Pima } \\
\text { Pima } \\
\text { Pima } \\
\text { Pima }\end{array}$ & $\begin{array}{l}314220 N 1120149 \mathrm{~W} \\
314610 \mathrm{~N} 1122435 \mathrm{~W} \\
314220 \mathrm{~N} 1120149 \mathrm{~W} \\
314610 \mathrm{~N} 1122435 \mathrm{~W} \\
315735 \mathrm{~N} 1122054 \mathrm{~W}\end{array}$ & & & \\
\hline $\begin{array}{l}\text { Comovo } \\
\text { See Kon Vo } \\
\text { Comovo Valley } \\
\text { See Kom Vo Valley } \\
\text { Compadre Mine } \\
\text { Company Tank } \\
\text { Compartidero, Arroyo del } \\
\text { Compartidero Flats } \\
\text { Compass Tank } \\
\text { Compressor Tank }\end{array}$ & $\begin{array}{l}\text { ppl } \\
\text { valley } \\
\text { mine } \\
\text { reservoir } \\
\text { valley } \\
\text { flat } \\
\text { reservoir } \\
\text { reservoir }\end{array}$ & $\begin{array}{l}\text { VARIANT } \\
\text { VARIANT } \\
\text { UNOFF } \\
\text { BGN } \\
\text { BGN } \\
\text { BGN } \\
\text { BGN } \\
\text { BGN }\end{array}$ & $\begin{array}{l}\text { Pima } \\
\text { Pima } \\
\text { Santa Cruz } \\
\text { Mohave } \\
\text { Pima } \\
\text { Pima } \\
\text { Pima } \\
\text { Pima }\end{array}$ & $\begin{array}{l}315735 N 1122054 \mathrm{~W} \\
314934 \mathrm{~N} 1122205 \mathrm{~W} \\
313847 \mathrm{~N} 1105233 \mathrm{~W} \\
354202 \mathrm{~N} 1135053 \mathrm{~W} \\
313502 \mathrm{~N} 1113033 \mathrm{~W} \\
313147 \mathrm{~N} 111311 \mathrm{~W} \\
321816 \mathrm{~N} 1103554 \mathrm{~W} \\
314312 \mathrm{~N} 1111312 \mathrm{~W}\end{array}$ & $313252 \mathrm{~N} 1113404 \mathrm{~W}$ & & $\begin{array}{l}\text { Mt Hopkins } \\
\text { Music Mountains NE } \\
\text { Presumido Peak } \\
\text { Presumido Peak } \\
\text { Piety Hill } \\
\text { Saucito Mtn }\end{array}$ \\
\hline $\begin{array}{l}\text { Constock Childrens Hospital } \\
\text { Constock-Dexter Mine } \\
\text { Constock Hill } \\
\text { Constock Wash } \\
\text { Concaba } \\
\text { See Moenkopi } \\
\text { Concentrator Hill } \\
\text { Concho } \\
\text { Concho Bill Spring } \\
\text { Concho Creek }\end{array}$ & $\begin{array}{l}\text { hospital } \\
\text { mine } \\
\text { summit } \\
\text { strean } \\
\text { pp1 } \\
\text { summit } \\
\text { ppl } \\
\text { spring } \\
\text { stream }\end{array}$ & $\begin{array}{l}\text { UNOFF } \\
\text { UNOFF } \\
\text { BGN } \\
\text { BGN } \\
\text { VARIANT } \\
\text { BGN } \\
\text { BGN } \\
\text { BGN } \\
\text { BGN }\end{array}$ & $\begin{array}{l}\text { Pima } \\
\text { Yavapai } \\
\text { Cochise } \\
\text { Pinal } \\
\text { Coconino } \\
\text { Pima } \\
\text { Apache } \\
\text { Apache } \\
\text { Apache }\end{array}$ & $\begin{array}{l}321425 N 1105719 \mathrm{~W} \\
343701 \mathrm{~N} 1131235 \mathrm{~W} \\
314310 \mathrm{~N} 1100425 \mathrm{~W} \\
331936 \mathrm{~N} 1110607 \mathrm{~W} \\
\\
360640 \mathrm{~N} 1111318 \mathrm{~W} \\
322148 \mathrm{~N} 1125123 \mathrm{~W} \\
342831 \mathrm{N1093619W} \\
334948 \mathrm{~N} 1092202 \mathrm{~W} \\
343530 \mathrm{~N} 1093356 \mathrm{~W}\end{array}$ & $332014 N 1110431 \mathrm{~W}$ & 5931 & $\begin{array}{l}\text { Ajo South } \\
\text { Concho } \\
\text { Buffalo Crossing } \\
\text { Stinking Springs }\end{array}$ \\
\hline $\begin{array}{l}\text { Concho Flat } \\
\text { Concho Flat Wash } \\
\text { Concho Lake } \\
\text { Concho Spring } \\
\text { Concho Spring Knoll } \\
\text { Concho Springs Dam } \\
\text { Con Clair Spring } \\
\text { Concrete Dam } \\
\text { Concrete Dam } \\
\text { See Hassayampa Check Dam }\end{array}$ & $\begin{array}{l}\text { flat } \\
\text { stream } \\
\text { reservoir } \\
\text { spring } \\
\text { summit } \\
\text { dam } \\
\text { spring } \\
\text { dam } \\
\text { dam }\end{array}$ & $\begin{array}{l}\text { BGN } \\
\text { BGN } \\
\text { BGN } \\
\text { BGN } \\
\text { BGN } \\
\text { UNOFF } \\
\text { BGN } \\
\text { UNOFF } \\
\text { VARIANT }\end{array}$ & $\begin{array}{l}\text { Navajo } \\
\text { Navajo } \\
\text { Apache } \\
\text { Apache } \\
\text { Apache } \\
\text { Apache } \\
\text { Coconino } \\
\text { Pina } \\
\text { Yavapai }\end{array}$ & $\begin{array}{l}343212 \mathrm{~N} 1100113 \mathrm{~W} \\
343254 \mathrm{~N} 1100334 \mathrm{~W} \\
342656 \mathrm{~N} 1093740 \mathrm{~W} \\
342710 \mathrm{~N} 1093729 \mathrm{~W} \\
342442 \mathrm{~N} 1093703 \mathrm{~W} \\
342648 \mathrm{~N} 1093706 \mathrm{~W} \\
352817 \mathrm{N1} 122916 \mathrm{~W} \\
321020 \mathrm{~N} 1111853 \mathrm{~W} \\
342545 \mathrm{~N} 1122532 \mathrm{~W}\end{array}$ & $342835 \mathrm{~N} 1095805 \mathrm{~W}$ & $\begin{array}{l}6296 \\
6717\end{array}$ & $\begin{array}{l}\text { Snowf lake } \\
\text { Snowf lake } \\
\text { Concho Lake } \\
\text { Concho Lake } \\
\text { Concho } \\
\text { Concho } \\
\text { Stanford Tank } \\
\text { Cocoraque Butte }\end{array}$ \\
\hline $\begin{array}{l}\text { Concrete Dam } \\
\text { Concrete Tank } \\
\text { Concrete Tank } \\
\text { Concrete Tank } \\
\text { Condon Tank } \\
\text { Cone Butte } \\
\text { Cone Butte Tank } \\
\text { Conejo Tank } \\
\text { Cone Mine } \\
\text { C One Wash }\end{array}$ & $\begin{array}{l}\text { dam } \\
\text { reservoir } \\
\text { reservoir } \\
\text { reservoir } \\
\text { reservoir } \\
\text { summit } \\
\text { reservoir } \\
\text { reservoir } \\
\text { mine } \\
\text { stream }\end{array}$ & $\begin{array}{l}\text { UNOFF } \\
\text { BGN } \\
\text { BGN } \\
\text { BGN } \\
\text { BGN } \\
\text { BGN } \\
\text { BGN } \\
\text { BGN } \\
\text { UNOFF } \\
\text { BGN }\end{array}$ & $\begin{array}{l}\text { Coconino } \\
\text { Cochise } \\
\text { Gila } \\
\text { Yavapai } \\
\text { Yavapai } \\
\text { Gila } \\
\text { Gila } \\
\text { Yavapai } \\
\text { Mohave } \\
\text { Navajo }\end{array}$ & $\begin{array}{l}351418 \mathrm{~N} 1121118 \mathrm{~W} \\
315322 \mathrm{~N} 1092612 \mathrm{~W} \\
332739 \mathrm{~N} 1101829 \mathrm{~W} \\
345757 \mathrm{~N} 1115350 \mathrm{~W} \\
342011 \mathrm{~N} 1123812 \mathrm{~W} \\
334618 \mathrm{~N} 1101224 \mathrm{~W} \\
334631 \mathrm{~N} 1101142 \mathrm{~W} \\
351627 \mathrm{~N} 1131717 \mathrm{~W} \\
345908 \mathrm{~N} 1142521 \mathrm{~W} \\
340211 \mathrm{~N} 1102841 \mathrm{~W}\end{array}$ & $340737 N 1102703 \mathrm{~W}$ & 4111 & $\begin{array}{l}\text { Williams South } \\
\text { Fife Peak } \\
\text { Sontag Mesa } \\
\text { Loy Butte } \\
\text { Peeples Valley } \\
\text { Cone Butte } \\
\text { Cone Butte } \\
\text { Blye Canyon SE } \\
\text { Boundary Cone } \\
\text { Cibecue }\end{array}$ \\
\hline $\begin{array}{l}\text { Cone wash } \\
\text { See Cone Wash } \\
\text { Cone Wash } \\
\text { Can Spring Wash } \\
\text { Cane Springs Wash } \\
\text { Cane Wash } \\
\text { Cone wash } \\
\text { Kane Springs Wash }\end{array}$ & $\begin{array}{l}\text { valley } \\
\text { valley }\end{array}$ & $\begin{array}{l}\text { VARIANT } \\
\text { BGN } \\
\text { VARIANT } \\
\text { VARIANT } \\
\text { VARIANT } \\
\text { VARIANT } \\
\text { VARIANT }\end{array}$ & $\begin{array}{l}\text { Mohave } \\
\text { Mohave }\end{array}$ & $\begin{array}{l}345637 \mathrm{N1134304W} \\
345637 \mathrm{N1} 134304 \mathrm{~W}\end{array}$ & $345805 N 1135510 \mathrm{~W}$ & & Pilgrim Wash \\
\hline $\begin{array}{l}\text { Confidence Peak } \\
\text { Confucius Temple } \\
\text { Twin Butte }\end{array}$ & $\begin{array}{l}\text { summit } \\
\text { summit }\end{array}$ & $\begin{array}{l}\text { BGN } \\
\text { BGN } 1906 \\
\text { VARIANT }\end{array}$ & $\begin{array}{l}\text { Pima } \\
\text { Coconino }\end{array}$ & $\begin{array}{l}322447 \mathrm{~W} 1113057 \mathrm{~W} \\
361049 \mathrm{~N} 1121316 \mathrm{~W}\end{array}$ & & $\begin{array}{l}3765 \\
7081\end{array}$ & $\begin{array}{l}\text { Silver Bell West } \\
\text { Shiva Temple }\end{array}$ \\
\hline
\end{tabular}




\begin{tabular}{|c|c|c|c|c|c|c|c|}
\hline FEATURE NAME & $\begin{array}{l}\text { FEATURE } \\
\text { CLASS }\end{array}$ & STATUS & COUNTY & COORDINATE & $\begin{array}{l}\text { SOURCE } \\
\text { COORDINATE }\end{array}$ & $\begin{array}{l}\text { ELEV } \\
\text { FT }\end{array}$ & MAP NAME \\
\hline $\begin{array}{l}\text { Congdon } \\
\text { Conger } \\
\text { Conger Creek } \\
\text { Conger Dam } \\
\text { Conger Mine } \\
\text { Conger Spring } \\
\text { Conger Tank } \\
\text { Conger Tank } \\
\text { Conger Water Spring } \\
\text { Congress } \\
\text { Congress Junction } \\
\text { Weaver }\end{array}$ & $\begin{array}{l}\text { ridge } \\
\text { locale } \\
\text { stream } \\
\text { dam } \\
\text { mine } \\
\text { spring } \\
\text { reservoir } \\
\text { reservoir } \\
\text { spring } \\
\text { ppl }\end{array}$ & $\begin{array}{l}\text { 8GN } \\
\text { BGN } \\
\text { BGN } \\
\text { UNOFF } \\
\text { UNOFF } \\
\text { BGN } \\
\text { BGN } \\
\text { BGN } \\
\text { BGN } \\
\text { BGN } 1972 \\
\text { VARIANT } \\
\text { VARIANT }\end{array}$ & $\begin{array}{l}\text { Cochise } \\
\text { Maricopa } \\
\text { Yavapai } \\
\text { Yavapai } \\
\text { Yavapai } \\
\text { Yavapai } \\
\text { Yavapai } \\
\text { Yavapai } \\
\text { Yavapai } \\
\text { Yavapai }\end{array}$ & $\begin{array}{l}312538 \mathrm{~N} 1095444 \mathrm{~W} \\
332223 \mathrm{~N} 1123927 \mathrm{~W} \\
344606 \mathrm{~N} 1131254 \mathrm{~W} \\
344507 \mathrm{~N} 1130 \mathrm{~B} 38 \mathrm{~W} \\
343653 \mathrm{~N} 1120136 \mathrm{~W} \\
344528 \mathrm{~N} 1130707 \mathrm{~W} \\
344506 \mathrm{~N} 1130 \mathrm{~B} 35 \mathrm{~W} \\
344602 \mathrm{~N} 1130536 \mathrm{~W} \\
344338 \mathrm{~N} 1125702 \mathrm{~W} \\
340945 \mathrm{~N} 1125100 \mathrm{~W}\end{array}$ & $344706 \mathrm{~N} 1130104 \mathrm{~W}$ & & $\begin{array}{l}\text { Bisbee } \\
\text { Hass ayampa } \\
\text { Burro Mesa } \\
\text { Burro Mesa } \\
\text { Cherry } \\
\text { Scratch Canyon } \\
\text { Burro Mesa } \\
\text { Scratch Canyon } \\
\text { Sheridan Mtn } \\
\text { Congress }\end{array}$ \\
\hline $\begin{array}{l}\text { Congress Cemetery } \\
\text { Congress Junction } \\
\text { See Congress } \\
\text { Congress Junction } \\
\text { Congress Mine } \\
\text { Congress Post Office } \\
\text { Congress Railroad Station } \\
\text { Congress School } \\
\text { Congress Street Interchange } \\
\text { Conic Peak } \\
\text { See Monkeys Head }\end{array}$ & $\begin{array}{l}\text { cemetery } \\
\text { ppl } \\
\text { locale } \\
\text { mine } \\
\text { building } \\
\text { building } \\
\text { school } \\
\text { crossing } \\
\text { summit }\end{array}$ & $\begin{array}{l}\text { UNOFF } \\
\text { VARIANT } \\
\text { BGN } \\
\text { UNOFF } \\
\text { UNOFF } \\
\text { UNOFF } \\
\text { UNOFF } \\
\text { UNOFF } \\
\text { VARIANT }\end{array}$ & $\begin{array}{l}\text { Yavapai } \\
\text { Yavapai } \\
\text { Yavapai } \\
\text { Yavapai } \\
\text { Yavapai } \\
\text { Yavapai } \\
\text { Yavapai } \\
\text { Pima } \\
\text { Yuma }\end{array}$ & $\begin{array}{l}341123 \mathrm{~N} 1125115 \mathrm{~W} \\
340945 \mathrm{~N} 1125100 \mathrm{~W} \\
340946 \mathrm{~N} 1125039 \mathrm{~W} \\
341203 \mathrm{~N} 1125100 \mathrm{~W} \\
340942 \mathrm{~N} 1125106 \mathrm{~W} \\
340930 \mathrm{~N} 1125040 \mathrm{~W} \\
340940 \mathrm{~N} 1125047 \mathrm{~W} \\
321315 \mathrm{~N} 1105845 \mathrm{~W} \\
\\
341602 \mathrm{~N} 1140658 \mathrm{~W}\end{array}$ & . & 2340 & $\begin{array}{l}\text { Congress } \\
\text { Congress } \\
\text { Congress } \\
\text { Congress } \\
\text { Congress } \\
\text { Tucson }\end{array}$ \\
\hline $\begin{array}{l}\text { Coniza Mesa } \\
\text { See Toh Chin Lini Mesa } \\
\text { Conkl in Creek } \\
\text { Conkl in Creek Campgrounds } \\
\text { Conkl in Ridge } \\
\text { Conklin Spring } \\
\text { Conley Points } \\
\text { Indian Delias Place } \\
\text { Conley Ranch } \\
\text { Conley Spring Wash }\end{array}$ & $\begin{array}{l}\text { summit } \\
\text { stream } \\
\text { park } \\
\text { ridge } \\
\text { spring } \\
\text { summit } \\
\text { locale } \\
\text { stream }\end{array}$ & $\begin{array}{l}\text { VARIANT } \\
\text { BGN } \\
\text { ADMIN } \\
\text { BGN } \\
\text { BGN } \\
\text { BGN } \\
\text { VARIANT } \\
\text { UNOFF } \\
\text { BGN }\end{array}$ & $\begin{array}{l}\text { Apache } \\
\text { Greenlee } \\
\text { Greenlee } \\
\text { Apache } \\
\text { Apache } \\
\text { Gila } \\
\text { Yuma } \\
\text { Pinal }\end{array}$ & $\begin{array}{l}364912 \mathrm{~N} 1091547 \mathrm{~W} \\
334150 \mathrm{~N} 1092736 \mathrm{~W} \\
333650 \mathrm{~N} 1092427 \mathrm{~W} \\
335023 \mathrm{~N} 1092512 \mathrm{~W} \\
335100 \mathrm{~N} 1092519 \mathrm{~W} \\
331719 \mathrm{~N} 1112105 \mathrm{~W} \\
\\
340408 \mathrm{~N} 1133256 \mathrm{~W} \\
331935 \mathrm{~N} 1110541 \mathrm{~W}\end{array}$ & $331908 \mathrm{~N} 1110512 \mathrm{~W}$ & B760 & $\begin{array}{l}\text { Hoodoo Knob } \\
\text { Baldy Bill Point } \\
\text { Big Lake South } \\
\text { Big Lake South } \\
\text { Payson North } \\
\text { Alamo Dam SE } \\
\text { Superior }\end{array}$ \\
\hline $\begin{array}{l}\text { Conley Tank } \\
\text { Connally Point } \\
\text { Connally Point Tank } \\
\text { Connect icut Mine } \\
\text { Connell Gulch } \\
\text { Connell Mountains } \\
\text { Connell Seep } \\
\text { Connell Seep Spring } \\
\text { Connell Seep Spring } \\
\text { See Connell Seep }\end{array}$ & $\begin{array}{l}\text { reservoir } \\
\text { summit } \\
\text { reservoir } \\
\text { mine } \\
\text { valley } \\
\text { range } \\
\text { spring } \\
\text { spring }\end{array}$ & $\begin{array}{l}\text { BGN } \\
\text { BGN } \\
\text { BGN } \\
\text { UNOFF } \\
\text { BGN } \\
\text { BGN } \\
\text { BGN } \\
\text { VARIANT } \\
\text { VARIANT }\end{array}$ & $\begin{array}{l}\text { Maricopa } \\
\text { Gila } \\
\text { Gila } \\
\text { Santa Cruz } \\
\text { Yavapai } \\
\text { Yavapai } \\
\text { Yavapai }\end{array}$ & $\begin{array}{l}330358 \mathrm{~N} 1122444 \mathrm{~W} \\
341 \mathrm{~B} 00 \mathrm{~N} 1112355 \mathrm{~W} \\
341815 \mathrm{~N} 1112451 \mathrm{~W} \\
313937 \mathrm{~N} 1105202 \mathrm{~W} \\
344444 \mathrm{~N} 1125957 \mathrm{~W} \\
344510 \mathrm{~N} 1125738 \mathrm{~W} \\
344651 \mathrm{~N} 1125711 \mathrm{~W} \\
344651 \mathrm{~N} 1125711 \mathrm{~W}\end{array}$ & $344635 N 1125806 \mathrm{~W}$ & 5550 & $\begin{array}{l}\text { Butterfield Pass } \\
\text { Buckhead Mesa } \\
\text { Buckhead Mesa } \\
\text { Mt Wrightson } \\
\text { Sheridan Mtn } \\
\text { Camp Wood } \\
\text { Camp Wood }\end{array}$ \\
\hline $\begin{array}{l}\text { Conner Park } \\
\text { Conners Hump } \\
\text { Connolly Field } \\
\text { Connolly Intermediate School } \\
\text { Connolly Junior High } \\
\text { School } \\
\text { Connolly Junior High School } \\
\text { See Connolly Intermediate } \\
\text { School } \\
\text { Connor Canyon }\end{array}$ & $\begin{array}{l}\text { park } \\
\text { summit } \\
\text { park } \\
\text { school }\end{array}$ & $\begin{array}{l}\text { ADMIN } \\
\text { BGN } \\
\text { ADMIN } \\
\text { UNOFF } \\
\text { VARIANT } \\
\text { VARIANT }\end{array}$ & $\begin{array}{l}\text { Pima } \\
\text { Coconino } \\
\text { Maricopa } \\
\text { Maricopa }\end{array}$ & $\begin{array}{l}321525 \mathrm{~N} 1105621 \mathrm{~W} \\
352423 \mathrm{~N} 1115813 \mathrm{~W} \\
332416 \mathrm{~N} 1115350 \mathrm{~W} \\
332416 \mathrm{~N} 1115356 \mathrm{~W}\end{array}$ & $334846 \mathrm{~N} 1105833 \mathrm{~W}$ & 7332 & $\begin{array}{l}\text { Tueson North } \\
\text { Moritz Ridge } \\
\text { Tempe } \\
\text { Tempe }\end{array}$ \\
\hline $\begin{array}{l}\text { Connor Wash } \\
\text { Conocido Park } \\
\text { Con Quien } \\
\text { See Siovi Shuatak } \\
\text { Conquistador Aisle } \\
\text { Cardenas Aisle } \\
\text { Conquistador Isle } \\
\text { Conquistador Isle } \\
\text { See Conquistador Aisle } \\
\text { Consolidated Canal }\end{array}$ & $\begin{array}{l}\text { stream } \\
\text { park } \\
\text { locale } \\
\text { gap }\end{array}$ & $\begin{array}{l}\text { BGN } \\
\text { ADMIN } \\
\text { VARIANT } \\
\text { BGN } 1908 \\
\text { VARIANT } \\
\text { VARIANT } \\
\text { VARIANT } \\
\text { BGN }\end{array}$ & $\begin{array}{l}\text { Gila } \\
\text { Maricopa } \\
\text { Pima } \\
\text { Coconino }\end{array}$ & $\begin{array}{l}334242 N 1110107 \mathrm{~W} \\
333 \mathrm{~B} 00 \mathrm{~N} 1120728 \mathrm{~W} \\
315703 \mathrm{~N} 1123551 \mathrm{~W} \\
361430 \mathrm{~N} 1122912 \mathrm{~W}\end{array}$ & $334835 \mathrm{~N} 1105844 \mathrm{~W}$ & & $\begin{array}{l}\text { Windy Hill } \\
\text { Hedgpeth Hills }\end{array}$ \\
\hline $\begin{array}{l}\text { Consolidated Canal East Branch } \\
\text { Cons Tank } \\
\text { Constellation } \\
\text { Constellation Park } \\
\text { Constitution School } \\
\text { Contact } \\
\text { Contact Canyon } \\
\text { Contact Spring } \\
\text { Contact Trick Tank }\end{array}$ & $\begin{array}{l}\text { canal } \\
\text { reservoir } \\
\text { ppl } \\
\text { park } \\
\text { school } \\
\text { mine } \\
\text { valley } \\
\text { spring } \\
\text { reservoir }\end{array}$ & $\begin{array}{l}\text { BGN } \\
\text { BGN } \\
\text { BGN } \\
\text { ADMIN } \\
\text { UNOFF } \\
\text { UNOFF } \\
\text { BGN } \\
\text { BGN } \\
\text { BGN }\end{array}$ & $\begin{array}{l}\text { Maricopa } \\
\text { Coconino } \\
\text { Yavapai } \\
\text { Maricopa } \\
\text { Maricopa } \\
\text { Cochise } \\
\text { Gila } \\
\text { Gila } \\
\text { Gila }\end{array}$ & $\begin{array}{l}331658 \mathrm{~N} 1114856 \mathrm{~W} \\
345030 \mathrm{~N} 1113850 \mathrm{~W} \\
340348 \mathrm{~N} 1123454 \mathrm{~W} \\
335855 \mathrm{~N} 1124210 \mathrm{~W} \\
333910 \mathrm{~N} 1120530 \mathrm{~W} \\
312448 \mathrm{~N} 1095545 \mathrm{~W} \\
341616 \mathrm{~N} 1112631 \mathrm{~W} \\
341732 \mathrm{~N} 1112604 \mathrm{~W} \\
341647 \mathrm{~N} 1112556 \mathrm{~W}\end{array}$ & $341754 \mathrm{~N} 1112514 \mathrm{~W}$ & & $\begin{array}{l}\text { Chandler } \\
\text { Munds Mountain } \\
\text { Morgan Butte } \\
\text { Wickenburg } \\
\text { Union Hillis } \\
\text { Bisbee } \\
\text { Buckhead Mesa } \\
\text { Buckhead Mesa } \\
\text { Buckhead Mesa }\end{array}$ \\
\hline
\end{tabular}




\begin{tabular}{|c|c|c|c|c|c|c|c|}
\hline FEATURE NAME & $\begin{array}{l}\text { FEATURE } \\
\text { CLASS }\end{array}$ & STATUS & COUNTY & COORDINATE & $\begin{array}{l}\text { SOURCE } \\
\text { COORDINATE }\end{array}$ & $\begin{array}{l}\text { ELEV } \\
\text { FT }\end{array}$ & MAP NAME \\
\hline Contempo Tempe (trailer park) & locale & UNOFF & Maricopa & $332325 N 1115820 \mathrm{~W}$ & & 1170 & Tempe \\
\hline $\begin{array}{l}\text { Contention } \\
\text { Cont inental } \\
\text { Mesquit } \\
\text { Continental Airport } \\
\text { Cont inental Dam Number Three } \\
\text { Cont inental Interchange } \\
\text { Continental Mine } \\
\text { Continental Mine } \\
\text { Continental Mountain } \\
\text { Continental Number One Dam }\end{array}$ & $\begin{array}{l}\text { locale } \\
\text { ppl } \\
\text { airport } \\
\text { dam } \\
\text { crossing } \\
\text { mine } \\
\text { mine } \\
\text { summit } \\
\text { dam }\end{array}$ & $\begin{array}{l}\text { BGN } \\
\text { BGN } \\
\text { VARIANT } \\
\text { ADMIN } \\
\text { UNOFF } \\
\text { UNOFF } \\
\text { UNOFF } \\
\text { UNOFF } \\
\text { BGN } \\
\text { UNOFF }\end{array}$ & $\begin{array}{l}\text { Cochise } \\
\text { Pima } \\
\text { Pima } \\
\text { Coconino } \\
\text { Pima } \\
\text { Yuma } \\
\text { Yavapai } \\
\text { Maricopa } \\
\text { Coconino }\end{array}$ & $\begin{array}{l}314608 \mathrm{~N} 1101205 \mathrm{~W} \\
315108 \mathrm{~N} 1105827 \mathrm{~W} \\
\\
315037 \mathrm{~N} 1105834 \mathrm{~W} \\
351112 \mathrm{~N} 1113448 \mathrm{~W} \\
315105 \mathrm{~N} 1105935 \mathrm{~W} \\
341325 \mathrm{~N} 1140029 \mathrm{~W} \\
342932 \mathrm{~N} 1123449 \mathrm{~W} \\
335247 \mathrm{~N} 1115327 \mathrm{~W} \\
351154 \mathrm{~N} 1113512 \mathrm{~W}\end{array}$ & & $\begin{array}{l}2870 \\
2910\end{array}$ & $\begin{array}{l}\text { Land } \\
\text { Green Valley } \\
\text { Green Valley } \\
\text { Flagstaff East } \\
\text { Green Valley } \\
\text { Osborne Well } \\
\text { Wilhoit } \\
\text { New River Mesa } \\
\text { Flagstaff East }\end{array}$ \\
\hline $\begin{array}{l}\text { Continental Number Two Dam } \\
\text { Continental School } \\
\text { Continental Shopping Plaza } \\
\text { Continental Spring } \\
\text { Continental Tank } \\
\text { Continental Tempe (subdivision) } \\
\text { Continental Tunnel } \\
\text { Continental Village } \\
\text { (subdivision) } \\
\text { Contrary Tank }\end{array}$ & $\begin{array}{l}\text { dam } \\
\text { school } \\
\text { locale } \\
\text { spring } \\
\text { reservoir } \\
\text { ppl } \\
\text { mine } \\
\text { ppl } \\
\text { reservoir }\end{array}$ & $\begin{array}{l}\text { UNOFF } \\
\text { UNOFF } \\
\text { UNOFF } \\
\text { BGN } \\
\text { BGN } \\
\text { BGN } \\
\text { UNOFF } \\
\text { BGN }\end{array}$ & $\begin{array}{l}\text { Coconino } \\
\text { Pima } \\
\text { Pima } \\
\text { Gila } \\
\text { Gila } \\
\text { Maricopa } \\
\text { Gila } \\
\text { Maricopa }\end{array}$ & $\begin{array}{l}351108 \mathrm{~N} 1113512 \mathrm{~W} \\
315031 \mathrm{~N} 1105725 \mathrm{~W} \\
315116 \mathrm{~N} 1105943 \mathrm{~W} \\
332516 \mathrm{~N} 1105828 \mathrm{~W} \\
332604 \mathrm{~N} 1105847 \mathrm{~W} \\
332105 \mathrm{~N} 1115446 \mathrm{~W} \\
332510 \mathrm{~N} 1105724 \mathrm{~W} \\
333410 \mathrm{~N} 1115129 \mathrm{~W} \\
344840 \mathrm{~N} 1120841 \mathrm{~W}\end{array}$ & & $\begin{array}{l}2890 \\
1185 \\
1360\end{array}$ & $\begin{array}{l}\text { Flagstaff East } \\
\text { Green Valley } \\
\text { Green Valley } \\
\text { Inspiration } \\
\text { Inspiration } \\
\text { Guadalupe } \\
\text { Inspiration } \\
\text { Sawik Mountain } \\
\text { Munds Draw }\end{array}$ \\
\hline $\begin{array}{l}\text { Contreras Canyon } \\
\text { Contreras Mesa } \\
\text { Contreras Ranch } \\
\text { Contreras Spring } \\
\text { Contreras Wash } \\
\text { Contreras Wash } \\
\text { Contzen Pass } \\
\text { Converse Lateral } \\
\text { Convert School } \\
\text { Convict Tank }\end{array}$ & $\begin{array}{l}\text { valley } \\
\text { summit } \\
\text { locale } \\
\text { spring } \\
\text { stream } \\
\text { stream } \\
\text { gap } \\
\text { canal } \\
\text { school } \\
\text { reservoir }\end{array}$ & $\begin{array}{l}\text { BGN } \\
\text { BGN } \\
\text { UNOFF } \\
\text { BGN } \\
\text { BGN } \\
\text { BGN } \\
\text { BGN } \\
\text { BGN } \\
\text { UNOFF } \\
\text { BGN }\end{array}$ & $\begin{array}{l}\text { Pima } \\
\text { Yavapai } \\
\text { Yavapai } \\
\text { Yavapai } \\
\text { Pima } \\
\text { Yavapai } \\
\text { Pima } \\
\text { Yuma } \\
\text { Pima } \\
\text { Gila }\end{array}$ & $\begin{array}{l}315106 N 1113204 W \\
343955 N 1131031 W \\
343704 N 1123801 W \\
343711 N 1123715 W \\
315213 N 1112924 W \\
343819 N 1131052 W \\
321931 N 1110737 W \\
323520 N 1144436 W \\
321127 N 1105825 W \\
332050 N 1104823 W\end{array}$ & $\begin{array}{l}315022 N 1113417 \mathrm{~W} \\
315022 \mathrm{~N} 1113417 \mathrm{~W} \\
343953 \mathrm{~N} 1130800 \mathrm{~W}\end{array}$ & & $\begin{array}{l}\text { Baboquivari Peak } \\
\text { Bozarth Mesa } \\
\text { Skull Valley } \\
\text { Iron Springs } \\
\text { Fresno Wash } \\
\text { Bozarth Mesa } \\
\text { Avra } \\
\text { Somerton } \\
\text { Tucson } \\
\text { Pinal Peak }\end{array}$ \\
\hline $\begin{array}{l}\text { Conway Corral } \\
\text { Conway Ranch } \\
\text { Conway Spring } \\
\text { Cook Canyon } \\
\text { Cook Mine } \\
\text { Cook Mine } \\
\text { Cook Pond } \\
\text { Cook Ranch } \\
\text { Cook Reservoir } \\
\text { Cooksie Dam }\end{array}$ & $\begin{array}{l}\text { locale } \\
\text { locale } \\
\text { spring } \\
\text { valley } \\
\text { mine } \\
\text { mine } \\
\text { reservoir } \\
\text { locale } \\
\text { reservoir } \\
\text { dam }\end{array}$ & $\begin{array}{l}\text { BGN } \\
\text { UNOFF } \\
\text { BGN } \\
\text { BGN } \\
\text { UNOFF } \\
\text { UNOFF } \\
\text { BGN } \\
\text { UNOFF } \\
\text { BGN } \\
\text { UNOFF }\end{array}$ & $\begin{array}{l}\text { Gila } \\
\text { Gila } \\
\text { Gila } \\
\text { Mohave } \\
\text { Gila } \\
\text { Mohave } \\
\text { Mohave } \\
\text { Gila } \\
\text { Graham } \\
\text { Yavapai }\end{array}$ & $\begin{array}{l}340236 \mathrm{~N} 1111033 \mathrm{~W} \\
335209 \mathrm{~N} 1110824 \mathrm{~W} \\
340229 \mathrm{~N} 1110955 \mathrm{~W} \\
350950 \mathrm{~N} 1140418 \mathrm{~W} \\
341200 \mathrm{~N} 1105648 \mathrm{~W} \\
345637 \mathrm{~N} 1142231 \mathrm{~W} \\
362745 \mathrm{~N} 1132356 \mathrm{~W} \\
334526 \mathrm{~N} 1104825 \mathrm{~W} \\
324628 \mathrm{~N} 1094333 \mathrm{~W} \\
350817 \mathrm{~N} 1131046 \mathrm{~W}\end{array}$ & $351304 \mathrm{~N} 1140627 \mathrm{~W}$ & & $\begin{array}{l}\text { Sheep Bas in Mtn } \\
\text { Greenback Creek } \\
\text { Sheep Bas in Mtn } \\
\text { Kingman } \\
\text { Oxbow Mtn } \\
\text { Boundary Cone } \\
\text { Poverty Knoll } \\
\text { Sombrero Peak } \\
\text { Safford } \\
\text { Cross Mtn }\end{array}$ \\
\hline $\begin{array}{l}\text { Cooks Lake } \\
\text { Cooks Mesa } \\
\text { Cooks Mesa Tank Number One } \\
\text { Cooks Ranch } \\
\text { Cookstove Draw } \\
\text { Cookstove Tank } \\
\text { Cooks Trick Tank } \\
\text { Cook Tank } \\
\text { Cook Tank } \\
\text { Cooley Dam }\end{array}$ & $\begin{array}{l}\text { Swamp } \\
\text { summit } \\
\text { reservoir } \\
\text { locale } \\
\text { valley } \\
\text { reservoir } \\
\text { reservoir } \\
\text { reservoir } \\
\text { reservoir } \\
\text { dam }\end{array}$ & $\begin{array}{l}\text { BGN } \\
\text { BGN } \\
\text { BGN } \\
\text { UNOFF } \\
\text { BGN } \\
\text { BGN } \\
\text { BGN } \\
\text { BGN } \\
\text { BGN } \\
\text { UNOFF }\end{array}$ & $\begin{array}{l}\text { Pinal } \\
\text { Yavapai } \\
\text { Yavapai } \\
\text { Yavapai } \\
\text { Coconino } \\
\text { Greenlee } \\
\text { Gila } \\
\text { Coconino } \\
\text { Yavapai } \\
\text { Navajo }\end{array}$ & $\begin{array}{l}325141 N 1104311 \mathrm{~W} \\
340507 \mathrm{N1115446 \textrm {W }} \\
340315 \mathrm{~N} 1115339 \mathrm{~W} \\
340332 \mathrm{~N} 1115645 \mathrm{~W} \\
350053 \mathrm{~N} 1114413 \mathrm{~W} \\
332042 \mathrm{~N} 1090306 \mathrm{~W} \\
341110 \mathrm{~N} 1105619 \mathrm{~W} \\
344136 \mathrm{~N} 1111819 \mathrm{~W} \\
359103 \mathrm{~N} 1131043 \mathrm{~W} \\
340418 \mathrm{~N} 1095500 \mathrm{~W}\end{array}$ & $350037 \mathrm{~N} 1114148 \mathrm{~W}$ & 3820 & $\begin{array}{l}\text { Lookout Mtn } \\
\text { Cooks Mesa } \\
\text { Cooks Mesa } \\
\text { Cooks Mesa } \\
\text { Mountainaire } \\
\text { Maple Peak } \\
\text { Oxbow Mtn } \\
\text { Turkey Mtn } \\
\text { Cross Mtn } \\
\text { Indian Pine }\end{array}$ \\
\hline $\begin{array}{l}\text { Cooley Knoll } \\
\text { Cooley Lake } \\
\text { Cooley Lake Campground } \\
\text { Cooley Mountain } \\
\text { Cooley Ranch } \\
\text { Cooley Spring } \\
\text { Coolidge } \\
\text { Coolidge Dam } \\
\text { Needles Eye } \\
\text { Coolidge Dam }\end{array}$ & $\begin{array}{l}\text { summit } \\
\text { reservoir } \\
\text { park } \\
\text { summit } \\
\text { locale } \\
\text { spring } \\
\text { ppl } \\
\text { dam } \\
\text { ppl }\end{array}$ & $\begin{array}{l}\text { BGN } \\
\text { BGN } \\
\text { ADMIN } \\
\text { BGN } \\
\text { UNOFF } \\
\text { BGN } \\
\text { BGN } \\
\text { UNOFF } \\
\text { VARIANT } \\
\text { BGN }\end{array}$ & $\begin{array}{l}\text { Navajo } \\
\text { Navajo } \\
\text { Navajo } \\
\text { Navajo } \\
\text { Navajo } \\
\text { Navajo } \\
\text { Pinal } \\
\text { Gila } \\
\text { Gila }\end{array}$ & $\begin{array}{l}341938 N 1095747 \mathrm{~W} \\
340416 \mathrm{~N} 1095500 \mathrm{~W} \\
340413 \mathrm{~N} 1095455 \mathrm{~W} \\
340342 \mathrm{~N} 1095423 \mathrm{~W} \\
340405 \mathrm{~N} 1095434 \mathrm{~W} \\
340356 \mathrm{~N} 1095444 \mathrm{~W} \\
325840 \mathrm{~N} 1113101 \mathrm{~W} \\
331029 \mathrm{~N} 1103138 \mathrm{~W} \\
\\
331055 \mathrm{~N} 1103133 \mathrm{~W}\end{array}$ & & $\begin{array}{l}6461 \\
7080\end{array}$ & $\begin{array}{l}\text { Silver Springs } \\
\text { Indian Pine } \\
\text { Indian Pine } \\
\text { Indian Pine } \\
\text { Indian Pine } \\
\text { Indian Pine } \\
\text { Coolidge } \\
\text { Coolidge Dam } \\
\text { Coolidge Dam }\end{array}$ \\
\hline $\begin{array}{l}\text { Coolidge Florence Municipal } \\
\text { Airport }\end{array}$ & airport & AOMIN & Pinal & $325600 \mathrm{~N} 1112530 \mathrm{~W}$ & & 1587 & Valley Farms \\
\hline $\begin{array}{l}\text { Coolidge High School } \\
\text { Coolidge Mine } \\
\text { Coolidge Municipal Airport } \\
\text { Coolidge Railroad Station } \\
\text { Coolidge Reservoir }\end{array}$ & $\begin{array}{l}\text { school } \\
\text { mine } \\
\text { airport } \\
\text { building }\end{array}$ & $\begin{array}{l}\text { UNOFF } \\
\text { UNOFF } \\
\text { ADMIN } \\
\text { UNOFF } \\
\text { VARIANT }\end{array}$ & $\begin{array}{l}\text { Pinal } \\
\text { Yavapai } \\
\text { Pinal } \\
\text { Pinal }\end{array}$ & $\begin{array}{l}325853 \mathrm{~N} 1113148 \mathrm{~W} \\
340146 \mathrm{~N} 1121828 \mathrm{~W} \\
325800 \mathrm{~N} 1113245 \mathrm{~W} \\
325846 \mathrm{~N} 1113054 \mathrm{~W}\end{array}$ & & 1402 & $\begin{array}{l}\text { Coolidge } \\
\text { Columbia } \\
\text { Coolidge } \\
\text { Coolidge }\end{array}$ \\
\hline $\begin{array}{l}\text { See San Carlos Reservoir } \\
\text { Coolidge Square Shopping Center } \\
\text { Cool Spring }\end{array}$ & $\begin{array}{l}\text { reservoir } \\
\text { locale } \\
\text { spring }\end{array}$ & $\begin{array}{l}\text { UNOFF } \\
\text { BGN }\end{array}$ & $\begin{array}{l}\text { Gila } \\
\text { Pinal } \\
\text { Mohave }\end{array}$ & $\begin{array}{l}331030 \mathrm{~N} 1103130 \mathrm{~W} \\
325912 \mathrm{~N} 1113127 \mathrm{~W} \\
350055 \mathrm{~N} 1141914 \mathrm{~W}\end{array}$ & & & $\begin{array}{l}\text { Coolidge } \\
\text { Mount Nutt }\end{array}$ \\
\hline
\end{tabular}


NATIONAL GAZETTEER--ARIZONA 1986 FEATURE NAME FEATURE
CLASS

Rail Road Spring

Cool Water Spring

Cooly Spring

Coon Bluff Forest Camp

Coon Butte

See Meteor Crater

Cooncan Mine

Coon Canyon

Coon Creek

Coon Creek

Coon Creek

Coon Creek Butte

Coon Creek Spring

Coon Creek Spring

Coon Mountain

See Meteor Crater

Coon Mountain

Coons Can We11

See Siovi Shuatak

Coon Spring

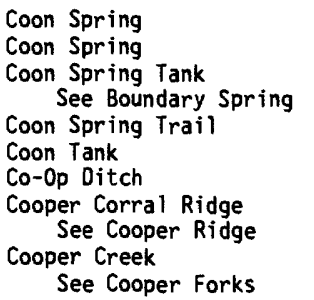

Cooper Farm Landing Strip

Cooper Forks

$$
\text { Cooper Creek }
$$

Cooper Lateral

Cooper Mine Trading Post

Cooper Mine Well (dry)

Cooper Peak

Cooper Ridge

Cooper Corral Ridge

Cooper Tank

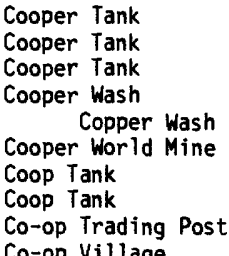

Co-op Village

Co-op Village Cemetery

Coors Mine

Coors Well

Cope Butte

Copeka

See Kupk

Copeka

See Shopishk

Copeka Mountains

See Kupk Hills

Copeke Mountain

See Kupk Hills

Copeland Draw

Copper Age Mine

Copper and Gold Mine

Copperas Canyon

Copperas Spring

Copperas Tank

Copper Basin

STATUS

COUNTY

COOROINATE

VARIANT

spring
spring
summit
locale
crater
mine
valley
stream

BGN
BGN
BGN
BGN
VARIANT
UNOFF
BGN
BGN
BGN

Apache

Graham

Maricopa

Maricopa

Coconino

Pima

Apache

Gila

Apache

stream

summit

spring

spring

crater

summit

locale

spring

BGN

BGN
$B G N$
BGN

VARIANT

BGN

VARIANT

BGN Gima

Mohave

Gila

Gila

Gila

spring

reservoir

trail

reservoir

canal

ridge

stream

BGN

VARIANT

Gila

BGN Coconino

BGN Maricopa

VARIANT Coconino

VARIANT

Gila

airport

stream

ADM

canal

locale

well

summit

ridge

reservoir

reservoir

reservoir

summit

stream

mine

reservoir

reservoir

locale

ppl

cemetery

mine

well

UNOFF

BGN 1906

VARIANT

locale

pp 1

VARIANT

summit

VARIANT

Yavapai

Gila

Yuma

Coconino

Coconino

Cochise

Coconino

Graham

Coconino

Coconino

Yavapai

Yavapai

Pima

Yavapai

Coconino

Navajo

Maricopa

Maricopa

Yavapai

Yavapai

Coconino

Pima

Pinal

Pima

VARIANT

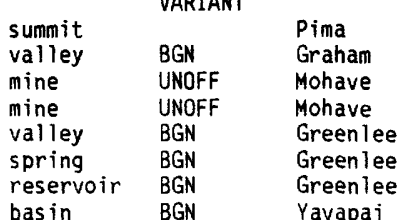

SOURCE

COORDINATE

ELEV

FT

MAP NAME

Coconino 350141N1110121W

341121 N1093858W

$315703 \mathrm{~N} 1123551 \mathrm{~W}$

$332539 N 1110103 \mathrm{~W}$

spring BGN Apache 340337N1092210W

$341033 N 1093843 W$

341034 N1093844W

$334650 \mathrm{~N} 1105430 \mathrm{~W}$

$345908 \mathrm{~N} 1105202 \mathrm{~W}$

$331651 \mathrm{~N} 1121105 \mathrm{~W}$

364833N1121154W

$335034 N 1105138 W$

$344433 N 1122725 \mathrm{~W}$

$335034 \mathrm{~N} 1105138 \mathrm{~W}$

$324240 \mathrm{~N} 1144316 \mathrm{~W}$

$363751 \mathrm{~N} 111265 \mathrm{OW}$

$363627 \mathrm{~N} 1112553 \mathrm{~W}$

$321243 \mathrm{~N} 1093439 \mathrm{~W}$

$364833 N 1121154 W$

$331010 \mathrm{~N} 1100303 \mathrm{~W}$

$351424 \mathrm{~N} 1121739 \mathrm{~W}$

$351845 \mathrm{~N} 1121536 \mathrm{~W}$

$344956 \mathrm{~N} 1123336 \mathrm{~W}$

$354721 \mathrm{~N} 1123643 \mathrm{~W}$

$315138 N 1104601 \mathrm{~W}$

$344600 \mathrm{~N} 1124600 \mathrm{~W}$

$352012 \mathrm{N11} 14640 \mathrm{~W}$

360605 N1101313W

332011 N1121226W

331938 N1121128W

$343110 \mathrm{~N} 1131740 \mathrm{~W}$

$343114 N 1131740 \mathrm{~W}$

$360514 N 1121148 \mathrm{~W}$

$315525 N 1121247 W$

324317 N1114652W

$315453 N 1121556 \mathrm{~W}$
$315453 N 1121556 \mathrm{~W}$

$323146 \mathrm{~N} 1101208 \mathrm{~W}$ $352339 \mathrm{~N} 1141042 \mathrm{~W}$

$352106 \mathrm{~N} 1140700 \mathrm{~W}$

$331413 \mathrm{~N} 1090608 \mathrm{~W}$

$331610 \mathrm{~N} 1090534 \mathrm{~W}$

$331712 \mathrm{~N} 1090528 \mathrm{~W}$

$340818 \mathrm{~N} 1122028 \mathrm{~W}$
Lukachukai

Oak Grove Canyon

1593 Granite Reef Dam

Granite Reef Dam

Ko Vaya

Eagar

Dagger Peak

Hawley Lake West

$34705 \mathrm{~N} 1105602 \mathrm{~W}$

$335425 \mathrm{~N} 1094739 \mathrm{~W}$

Elbow Canyon

5528 Aztec Peak

Dagger Peak

Aztec Peak

8009 Boundary Butte

Haunted Canyon

Eagar

Boundary Butte

Aztec Peak

Rock Station

Laveen

$335118 N 1105031 \mathrm{~W}$

Chino Valley South

Sombrero Peak

Yuma West

6080 Dead Monkey Ridge

Dove Spring

7950 Dos Cabezas

House Rock Spring SW

Bylas

McLellan Reservoir

Hearst Mtn

$344410 N 1123354 W$

Sullivan Buttes

Sullivan Buttes

Helvetia

Seepage Mtn

6340 Pinon

Laveen

1023 Laveen

Grayback Mts

3445 Grayback Mts

4538 Grand Canyon

323151N1101321W $\quad \begin{aligned} & \text { Harrison Canyon } \\ & \text { Chloride } \\ & \text { Stockton Hill } \\ & \text { Harden Cienega } \\ & \text { Maple Peak } \\ & \text { Maple Peak } \\ & \text { Crown King }\end{aligned}$




\section{FEATURE NAME}

Copper Bas in

Copper Basin Road Spring

Copper Bas in Spring

Copper Bas in Wash

Copper Bottom Mine

Copper Bottom Pass

Copper Butte

Copper Butte

Copper Camp

See Copper $\mathrm{Hill}$

Copper Camp

Copper Canp Creek

Copper Canyon

Copper Canyon

Copper Canyon

Copper Canyon

Copper Canyon

Copper Canyon

Copper Canyon

Copper Canyon

Copper Canyon Spring

Copper Canyon Substation

Copper Chief Mine

Copper Chief Mine

Copper Chief Spring

Copper Cities Tailings Dam

Number Eight

Copper Cities Tailings Dam

Number Nine

Copper Cities Tailings Dam

Number Ten

Copper Cities Tailings Dam

Number Two

Copper City (historical)

Copper Creek

Copper Creek

Copper Creek

Copper Creek

Copper Creek

Copper Creek

Copper Creek

See Mackenzie Wash

Copper Creek

Copper Creek

Copper Creek Cabin

Copper Creek Mesa

Copper Creek Spring

Copper Creek Tank

Copper Creek Windmill

Copper Crown Mine

Copper Duke Mine

Copper Fork Tank

Copper Giant Mine

Copper Giant Mine

Copper Glance Mine

Copper Glance Mine

Copper Glance Trail One

Hundred Seventeen

Copper Gulch

Copper Gulch

See Copper Hill

Copper $\mathrm{Hill}$

Copper Hill

Copper Camp

Copper Gulch

Copper Hills Tank

Copper Hill Tank

Copper Hill Wash

Copper Kettle Trailer Villa

Copper King

\section{FEATURE
CLASS}

STATUS

COUNTY

Yavapai

bas in

BGN

spring

spring

stream

mine

gap

sumnit

summit

mine

locale

BGN
BGN
BGN
UNOFF
BGN
BGN
BGN
UNOFF
VARIANT

Yavapai

Yavapai

Yavapai

Yuma

Yuma

Pima

Pinal

Pinal

Gila

locale

stream

valley

valley

va11ey

valley

valley

valley

valley
valley

BGN Yavapai

BGN Maricopa

BGN

BGN

BGN

BGN

BGN

BGN

BGN 1908

Maricopa
Cochise

Santa Cruz

Pima

Graham

Pinal

Pinal

Yavapa

Coconino

spring

locale

mine

mine

spring

dan

dam

BGN
UNOFF

UNOFF

UNOFF

UNOFF

Graham

Yavapai

Yuma

Yavapai

Yavapai

Gila

dam

UNOFF

Gila

UNOFF

Gila

dam

UNOFF

Gila

locale

stream

stream

stream

strean

stream

stream

stream

BGN

BGN

BGN

BGN

BGN

BGN

BGN
VARIANT

strean

stream

locale

summit

spring

reservoir

locale

mine

mine

reservoir

BGN

BGN

BGN

BGN

BGN

BGN

UNOFF

mine

mine

mine

mine

trail

valley

locale

summit

UNOFF

UNOFF

UNOFF

UNOFF

UNOFF

Gila

Pina]

Pinal

Yavapai

Yavapai

Yavapai

Yavapai

Mohave

Mohave

Pinal

Yavapai

Yavapai

Yavapai

Yavapai

Yavapai

Yavapai

Pima

Gila

Yuma

Mohave

Cochise

Pima

Cochise

Gila

VARIANT

Gila

Gila

locale

BGN

VARIANT

VARIANT

reservoir

reservoir

stream

locale

mine

COORDINATE

342922N1123459W

342B57N1123353W

$340753 \mathrm{~N} 1122107 \mathrm{~W}$

$342555 \mathrm{~N} 1124132 \mathrm{~W}$

$333439 N 1142007 \mathrm{~W}$

$333444 N 1142008 \mathrm{~W}$

$322346 \mathrm{~N} 1113102 \mathrm{~W}$

$330920 \mathrm{~N} 1110346 \mathrm{~W}$

$330853 \mathrm{~N} 1110341 \mathrm{~W}$

332549N1104550W

$341726 \mathrm{~N} 1123538 \mathrm{~W}$

$335748 \mathrm{~N} 1113636 \mathrm{~W}$

$312021 \mathrm{N1} 101941 \mathrm{~W}$

$313925 \mathrm{~N} 1105207 \mathrm{~W}$

$322227 N 1125734 \mathrm{~W}$

$325719 \mathrm{N1} 101936 \mathrm{~W}$

$330353 N 1104322 \mathrm{~W}$

$331023 \mathrm{~N} 1110035 \mathrm{~W}$

$343236 \mathrm{~N} 1115156 \mathrm{~W}$

$361430 \mathrm{~N} 1122224 \mathrm{~W}$

325711 N1101849W

34322BN1115241W

$333143 \mathrm{~N} 1142305 \mathrm{~W}$

$344202 \mathrm{~N} 1120532 \mathrm{~W}$

$344125 \mathrm{~N} 1120609 \mathrm{~W}$

$332900 \mathrm{~N} 1105000 \mathrm{~W}$

332800 N1105300W

332B00N1105530W

$332800 \mathrm{~N} 1105000 \mathrm{~W}$

332621 N1104608W

$323213 \mathrm{~N} 1105604 \mathrm{~W}$

$324116 \mathrm{~N} 1103646 \mathrm{~W}$

340649 N1122043W

$341338 N 1120026 \mathrm{~W}$

$342551 N 112310$

$343625 \mathrm{~N} 1131353 \mathrm{~W}$

344937N1140958W

345302 N1135710W

$324503 \mathrm{N1} 102833 \mathrm{~W}$

$341250 \mathrm{~N} 1115839 \mathrm{~W}$

$343603 \mathrm{~N} 1131223 \mathrm{~W}$

$340 \mathrm{~B} 17 \mathrm{N1} 122019 \mathrm{~W}$

$341106 \mathrm{~N} 1115423 \mathrm{~W}$

$342725 \mathrm{N1} 123212 \mathrm{~W}$

$341953 \mathrm{~N} 1123604 \mathrm{~W}$

$315210 \mathrm{N1} 104733 \mathrm{~W}$

335305 N1104916

$333155 \mathrm{~N} 1142415 \mathrm{~W}$

$352027 \mathrm{~N} 1133706 \mathrm{~W}$

$312513 \mathrm{~N} 1102131 \mathrm{~W}$

$315607 N 1111817 \mathrm{~W}$

$312520 \mathrm{~N} 1102121 \mathrm{~W}$

$332406 \mathrm{~N} 1104721 \mathrm{~W}$

$332549 \mathrm{~N} 1104550 \mathrm{~W}$

$332522 \mathrm{~N} 1104558 \mathrm{~W}$

332549 N1104550W 


\section{FEATURE NAME}

Copper King Canyon

Copper King Hill

Copper King Mine

Copper King Mountain

Copper Mine

Copper Mine Tank

Copper Mountain

Copper Mountain

Copper Mountain

Copper Mountain

Copper Mountain

Copper Mountain Dam

Copper Mountain Mine

Copper Mountain Mine

Copper Mountain Points Tank

Copper Mountains

Antelope Hills

Copper Mountain Tank

Copper Mountain Tank

Copperopolis

See Copperosity Mine

Copperopol is

See Chiapuk

Copperopol is

Copperopol is Creek

Copperosity

See Chiapuk

Copperosity Hills Cathedral Rock

Copperosity Mine Copperopol is

Copper Peak

Copperplate Gulch

Copper Prince Mine

Copper Queen

Copper Queen Mine

Copper Queen Mine

Copper Railroad Station

Copper Reef Mine

Copper Reef Mountain

Copper Ridge

Copper Spring

Copper Springs

Copper Springs Canyon

Copper Standard Mine

Copper Substation

Copper Tank

Copper Tank

Copper Valley

Copper Vault Tunnel

Copper Wash

Copper Wash

See Mackenzie Creek

Copper Wash

See Cooper Wash

Copper Well

Copper World Mine

Coral Sands Mobile Estates

Corbell Park

Corbet Tank

Corbett Dam

Corbett Dam Reservoir

Corcoraque Butte

See Cocoraque Butte

Cordes

Cordes Junction

Cordes Junction Interchange

Cordes Lakes

Cordes Landing Strip

Cordes Peak
FEATURE
CLASS

STATUS

COUNTY

COORDINATE

valley
summit
mine
summit
locale
reservoir
summit
summit
summit
summit
summit
dam

mine

mine

range

reservoir

reservoir

mine

$B G N$
$B G N$

Cochise

Cochise

$\begin{array}{ll}\text { UNOFF } & \text { Yavapai } \\ \text { BGN } & \text { Greenlee } \\ \text { BGN } & \text { Apache } \\ \text { BGN } & \text { Pinal } \\ \text { BGN } & \text { Santa Cruz } \\ \text { BGN } & \text { Greenlee } \\ \text { BGN } & \text { Gila } \\ \text { BGN } & \text { Gila } \\ \text { BGN } & \text { Yavapai } \\ \text { UNOFF } & \text { Gila }\end{array}$

330712 N1091950W

$365006 \mathrm{N1090338 \textrm {W }}$

$324354 \mathrm{N1} 110757 \mathrm{~W}$

$313258 \mathrm{~N} 1103825 \mathrm{~W}$

$330452 \mathrm{N1} 1092325 \mathrm{~W}$

$335530 \mathrm{~N} 1110603 \mathrm{~W}$

$341325 \mathrm{~N} 1113114 \mathrm{~W}$

$342430 \mathrm{~N} 1121042 \mathrm{~W}$

$331934 \mathrm{N1103230 \textrm {W }}$

320547 N1124501W

$361005 \mathrm{~N} 1132007 \mathrm{~W}$

$335450 \mathrm{N1110611W}$

$322912 \mathrm{~N} 1135857 \mathrm{~W}$

$331934 \mathrm{N1} 103231 \mathrm{~W}$

$335540 \mathrm{N1110521 \textrm {W }}$

323330N1120746W

pp 1

locale BGN Yavapai

stream

mine

ppl

summit

Yavapai

VARIANT

BGN 1941 Pinal

mine UNOFF

VARIANT

summit

BGN

Pinal

Yuma

valley BGN Greenle

mine UNOFF Pinal

mine

mine

mine

mine UNOFF Graham

sumit BGN Graham

ridge BGN Yavapai

spring

BGN

spring $\quad B G N$

valley

locale

reservoir

reservoir

valley

mine

strean

$B G N$

BGN

UNOFF

BGN

BGN

BGN

BNOFF

BGN

VARIANT

strean

strea

well

mine

mine

park

ADMIN Maricopa

BGN Navajo

dam UNOFF Coconino

reservoir BGN Coconino

summit VARIANT Pima

locale BGN Yavapai 341812N1120958W

locale BGN Yavapai $341956 \mathrm{~N} 1120711 \mathrm{~W}$

crossing UNOFF Yavapai 341945N1120712W

ppl BGN Yavapai 341B28N1130610W

airport AOMIN Yavapai 341B20N1130950W

summit BGN Yavapai 341 B20N1120851W

$1123643 W$

$321940 N 1091314 W$

$332515 \mathrm{~N} 1113458 \mathrm{~W}$

332107N1115512W

$354538 \mathrm{~N} 1120058 \mathrm{~W}$

$354537 N 1120058 \mathrm{~W}$

\begin{tabular}{|c|c|c|}
\hline $\begin{array}{l}\text { SOURCE } \\
\text { COORDINATE }\end{array}$ & $\begin{array}{c}\text { ELEV } \\
\text { FT }\end{array}$ & MAP NAME \\
\hline $312708 \mathrm{N1095333 \textrm {W }}$ & 5751 & $\begin{array}{l}\text { Bisbee } \\
\text { Bisbee }\end{array}$ \\
\hline & $\begin{array}{l}6 B 26 \\
\\
\\
5244 \\
6676 \\
3683 \\
5026\end{array}$ & $\begin{array}{l}\text { Bagdad } \\
\text { Clifton } \\
\text { Bitlabito } \\
\text { Durham Hills } \\
\text { Mt Hughes } \\
\text { Copperplate Gulch } \\
\text { Copper Mtn } \\
\text { Cypress Butte } \\
\text { Mayer } \\
\text { Bucket Mtn }\end{array}$ \\
\hline & & $\begin{array}{l}\text { Tillotson Peak } \\
\text { Whitmore Point } \\
\text { Copper Mtn } \\
\text { Buck Peak } \\
\text { Bucket Mtn } \\
\text { Copper Mtn }\end{array}$ \\
\hline 340701 N1122739W & & $\begin{array}{l}\text { Copperopol is } \\
\text { Copperopol is } \\
\text { Copperopol is }\end{array}$ \\
\hline & & Copperosity Hills \\
\hline & & Copperosity Hills \\
\hline
\end{tabular}

1109 Moon Mtn SE

330630 N1092413W

Copperplate Gulch

Oak Grove Canyon

Bisbee

Mayer

Red Butte SW

Chino Valley North

Rawhide Mtn

5431 Rawhide Mtn

Grayback Mts

Brook lyn Peak

Clark Ranch

Pinal Ranch

Silver Reef Mts

Chandler

Brooklyn Peak

Prospect Point

Hyder ME

Pinal Ranch

$331448 N 1131624$

Agua Caliente

$331605 N 1131429 \mathrm{~W}$
San Simon

Wabayuma Peak

1640 Apache Junction Guadalupe

Clear Creek Res

Red Butte

Red Butte

3771 Cleator

Cordes Junction

3800 Cordes Junction

Cordes Junction

3810 Cleator

4231 Cleator 
Cordes Tank

Cordillera Del Tule

See Tule Mountains

Cordillera del Tule

See Tule Mountains

Cordones, The
Cordova School
Cordova Tank
Corduroy Creek
Corduroy Creek
Forestdale Creek
Corduroy Wash
Corey Drain
Corgett Wash
Corgiat Wash

Corgiat Wash

Cork

See Corgett Wash

Cork, The

Cork Spring

Cormorant Cliffs

Corn Canyon

See Korn Canyon

Corn Creek

Corn Creek

See Little Bonito Creek

\begin{tabular}{lll}
$\begin{array}{l}\text { FEATURE } \\
\text { CLASS }\end{array}$ & STATUS & \multicolumn{1}{c}{ COUNTY } \\
reservoir & $\begin{array}{l}\text { BGN } \\
\text { VARIANT }\end{array}$ & Yavapai \\
range & VARIANT & Yuma \\
range & & YUma \\
& & \\
sumnit & BGN & Pinal \\
school & UNOFF & Maricopa \\
reservoir & BGN & Pima \\
stream & BGN & Greenlee \\
stream & BGN & Gila \\
& VARIANT & \\
stream & BGN & Coconino \\
canal & BGN & Yuma \\
stream & BGN & Maricopa \\
& VARIANT & \\
& &
\end{tabular}

COORDINATE

350031N1122510W

321109 N1134735W

$321109 \mathrm{~N} 1134735 \mathrm{~W}$

$323236 \mathrm{~N} 1105413 \mathrm{~W}$

$333112 \mathrm{N1120757 \textrm {W }}$

$313949 \mathrm{~N} 1112844 \mathrm{~W}$

$333830 \mathrm{~N} 1092106 \mathrm{~W}$

$335943 \mathrm{~N} 1101731 \mathrm{~W}$

$342916 \mathrm{~N} 1112544 \mathrm{~W}$

$323718 N 1143842 \mathrm{~W}$

$332158 \mathrm{~N} 1122715 \mathrm{~W}$

Corn Creek

See Corn Creek Wash

Corn Creek

See Polacca Wash

Corn Creek

See Jadito Wash

Corn Creek

See Coyote Wash

Corn Creek Plateau

Corn Creek Tank

Corn Creek Wash
Corn Creek
Oraibi Wash
Cornel ius Tank
Corner Dam
Corner Lake
Corner Lake
Corner Rock
Corner Rock
See Giers Mountain

Corner Rock Reservoir

Corner Salt Well Tank

Corner Spring

Corner Spring

Corner Tank

Corner Tank

Corner Tank

Corner Tank

Corner Tank

Corner Tank

Corner Tank

Corner Tank

Corner Tank

Corner Tank

Corner Tank

Corner Tank

Corner Tank

Corner Tank

Corner Tank

Corner Tank

Corner Tank

Corner Tank

Corner Tank

Corner Tank

Corner Tanks
VARIANT

strean

locale

spring

cliff

valley

stream

stream

BGN

BGN

BGN

BGN
VARIANT

BGN

VARIANT

Maricopa

Graham

Mohave

Mohave

Cochise

Apache

Apache

VARIANT

stream

stream

stream

valley

plain

reservoir

VARIAMT

Coconino

351621N1105534W

Coconino

Coconino

$352133 \mathrm{~N} 1105028 \mathrm{~W}$

VARIANT

BGN
BGN

stream

BGN

VARIANT

reservoir

dam

lake

lake

pillar

summit

BGN

UNOFF

BGN

BGN

BGN

VARIANT

reservoir

reservoir

spring

reservoir

reservoir

reservoir

reservoir

reservoir

reservoir

reservoir

reservoir

reservoir

reservoir

reservoir

reservoir

reservoir

reservoir

reservoir

reservoir

BGN

BGN

BGN

$B G N$

BGN

BGN

BGN

BGN

BGN

Navajo

Apache

Apache

Coconino

Maricopa

Yavapai

Coconino

Coconino

Coconino

Yuma

$332158 \mathrm{~N} 1122715 \mathrm{~W}$

$325725 \mathrm{~N} 1095505 \mathrm{~W}$

$361912 \mathrm{~N} 1124729 \mathrm{~W}$

$361229 \mathrm{~N} 1140113 \mathrm{~W}$

$312945 \mathrm{~N} 1102855 \mathrm{~W}$

$333825 \mathrm{~N} 1095237 \mathrm{~W}$

334130 N1094715W

352133N1105028W

$352330 \mathrm{~N} 1104445 \mathrm{~W}$

$334015 \mathrm{~N} 1095324 \mathrm{~W}$

$351621 N 1105534 W$

$335716 \mathrm{~N} 1125712 \mathrm{~W}$

$351605 \mathrm{~N} 1131740 \mathrm{~W}$

$345748 \mathrm{~N} 1112138 \mathrm{~W}$

$350315 \mathrm{~N} 1110522 \mathrm{~W}$

341406 N1140807W

Coconino

Apache

Yavapai

Navajo

Santa Cruz

Pima

Graham

Graham

Graham

Pinal

Graham

Graham

Greenlee

Greenlee

Greenlee

Gila

Gila

Coconino

Navajo

Coconino

reservoir

reservoir

reservoir

reservoir

reservoir
BGN

BGN

$B G N$
$B G N$
$B G N$
Coconino

Coconino

Coconino

Mohave

Cochise
$334648 \mathrm{~N} 1094811 \mathrm{~W}$

$362310 \mathrm{~N} 1113828 \mathrm{~W}$ $\begin{array}{cc}\text { SOURCE } & \text { ELEV } \\ \text { COORDINATE } & \text { FT }\end{array}$

MAP NAME

Meath Spring

Oracle Junction

Glendale

Las Guijas

Hannagan Meadow

$\begin{array}{ll}333520 N 1092145 \mathrm{~W} & \text { Hannagan } \\ 340627 \mathrm{~N} 1095046 \mathrm{~W} & \text { Carrizo }\end{array}$

342709N1112535W Pine

Somerton

331758N1121919W Avondale SW

334517N1094502W Bonito Prairie

4347 S B Point

$S$ B Point

Iceberg Canyon

Corn Creek Plateau Bonito Prairie

East of old Leupp

Outlaw Hill

Blye Canyon SE

Kinnikinick Lake

Meteor Crater

Shinumo Altar

Shinumo Altar

Potter Mesa Tank

Morgan Butte

Shongopovi

Bartlett Mtn

Batamote Hills

Greasewood Mountain

Stockton Pass

Whit lock Mts NE

North of Oracle

Buford $\mathrm{Hil}$

Gila Box

Rattlesnake Spring

Pipestem Mtn

Bee Canyon

Cammerman Wash

Cedar Creek

Pine

Zeniff

Lower Lake Mary

Sycamore Point

Elliott Canyon

Elliott Canyon

Red Lake

McGrew Spring 


\section{FEATURE NAME}

Corner Well

Corner Willow Creek Tank

Corner Windmill

Cornet Peak

See Comet Peak

Cornfield Canyon

Cornfield Mountain

Cornfields

Cornfields Wash

See Pueblo Colorado Wash

Cornfields Well

Cornfield Valley

Corn Rock

Cornstalk Flat

Cornstalk Flat Tank

Cornucopia Mine
Cornville
Cornville Ditch
Cornville Post Office
Cornwall Basin
Cornwall Basin Spring
Cornwall Canyon
Corn Wash
See Jadito Wash
Corn Wash
$\quad$ See Tees Toh Wash

Corn Wash
See Coyote Wash
Cornwater Spring
Corodope Spring
Coronada School
Corona del Sol High School
Corona de Tucson
Coronado
Coronado Butte
Coronado Camp
Coronado Elementary School
Coronado Evaporation Reservoir
Coronado Generating Station Dam
Coronado Gulch
Coronado Incline
Coronado Memorial Headquarters
Coronado Mesa (historical)
Fish Creek Hill
Coronado Mesa
$\quad$ See Fish Creek Mountain
Con

Coronado Mesa

Coronado Mine

Coronado Mobile Hone Park

Coronado Mountain

Coronado Mountains (historical) Pinal Mountains Signal Mountains

Coronado National Forest

Coronado National Memorial

Coronado Park

Coronado Peak

Coronado Peak Trail

Coronado Plateau

See Marcos Terrace

Coronado Post Office

Coronado Ridge

Coronado School

Coronado School

Coronado Spring

Coronado Substation

Coronado Summit (historical)
The Summit
Coronado Summit
See Fish Creek Peak
Coronado Tank

FEATURE

STATUS

COUNTY

COORDINATE

$\begin{array}{ll}\text { well } & \text { UNOFF } \\ \text { reservoir } & \text { BGN }\end{array}$

UNOFF

BGN

VARIANT

summit

Pima

Apache

Pima

Pinal

valley

summit

BGN

BGM

arroyo

arroyo

valley

summit

flat

reservoir

$\begin{array}{ll}\text { mine } & \text { UNOFF } \\ \text { ppl } & \text { BGN } \\ \text { canal } & \text { BGN } \\ \text { building } & \text { UNOFF } \\ \text { basin } & \text { BGN } \\ \text { spring } & \text { BGN } \\ \text { valley } & \text { BGN } \\ & \text { VARIANT } \\ \text { stream } & \end{array}$

Cochise

Yavapai

VARIANT

UNOFF

BGN

BGN

BGN

Apache

Navajo

Apache

Coconino

Navajo

Yavapai

Yavapai

Maricopa

Yavapai

Yavapai

Yavapai

Mohave

Mohave

Mohave

Coconino

VARIANT

stream

Navajo

VARIANT

valley

spring

spring

school

school

ppl

locale

summit

locale

school

valley

slope

building

summit

sumnit

summit

mine

locale

summit

summit

forest

park ADMII

park ADMIN

BGN
UNOFF

UNOFF

BGN

DIANT

Cochise

Cochise

Maricopa

summit

BGN 1957

Cochise

trail

UNOFF

VARIANT

bench

building

ridge

UNOFF

UNOFF

UNOFF
UNOFF

UNOF

UNOFF

Cochise

Coconino

Pima

Greenlee

Pima

Apache

Greenlee

Cochise

summit

BGN 1917

Maricopa

summit

VARIAN

reservoir BGN Pinal
$315744 \mathrm{NI} 130504 \mathrm{~W}$

$333815 N 1094952 \mathrm{~W}$

$32070 \mathrm{BN} 1111916 \mathrm{~W}$

$331738 N 1111606 \mathrm{~W}$

$320201 \mathrm{N1101847 \textrm {W }}$ $343652 \mathrm{~N} 1124400 \mathrm{~W}$

$353908 \mathrm{~N} 1094043 \mathrm{~W}$

$351620 \mathrm{~N} 1100850 \mathrm{~W}$

$354004 N 1094102 \mathrm{~W}$

$363253 \mathrm{~N} 1113710 \mathrm{~W}$

354809 N $1102923 \mathrm{~b}$

$341419 N 1115815 \mathrm{~W}$

$341353 \mathrm{~N} 1115838 \mathrm{~W}$

$335805 \mathrm{~N} 1112850 \mathrm{~W}$

$344304 N 1115515 \mathrm{~W}$

$344315 \mathrm{~N} 1115514 \mathrm{~W}$

$344302 \mathrm{~N} 1115520 \mathrm{~W}$

$350612 \mathrm{~N} 1132945 \mathrm{~W}$

$350607 N 1132923 \mathrm{~W}$

$343612 \mathrm{~N} 1132000 \mathrm{~W}$

352133N1105028W

$352941 N 1103449 W$

52330N1104445W

$331703 \mathrm{~N} 1105709 \mathrm{~W}$

$314200 \mathrm{~N} 1113500 \mathrm{~W}$

$332933 \mathrm{~N} 1115523 \mathrm{~W}$

331934 N1115535W

$315755 \mathrm{~N} 1104630 \mathrm{~W}$

$330700 \mathrm{~N} 1092305 \mathrm{~W}$

$360015 \mathrm{~N} 1115637 \mathrm{~W}$

$323144 \mathrm{~N} 1104658 \mathrm{~W}$

$330436 \mathrm{~N} 1092158 \mathrm{~W}$

$343336 \mathrm{~N} 1091636 \mathrm{~W}$

$343336 \mathrm{~N} 1091636 \mathrm{~W}$

$330633 \mathrm{~N} 1092302 \mathrm{~W}$

$330650 \mathrm{~N} 1092350 \mathrm{~W}$

$312040 \mathrm{~N} 1101525 \mathrm{~W}$

$333026 \mathrm{~N} 1111502 \mathrm{~W}$

$333026 \mathrm{~N} 1111502 \mathrm{~W}$

$333318 \mathrm{~N} 1112028 \mathrm{~W}$

$330620 \mathrm{~N} 1092405 \mathrm{~W}$

$332448 \mathrm{~N} 1114619 \mathrm{~W}$

$330747 \mathrm{~N} 1092406 \mathrm{~W}$

UNKNOWH

$323000 \mathrm{~N} 1104000 \mathrm{~W}$

$312100 \mathrm{~N} 1101700 \mathrm{~W}$

$332805 \mathrm{~N} 1120317 \mathrm{~W}$

$312045 \mathrm{~N} 1101702 \mathrm{~W}$

312050N1101705W

$361317 N 1122609 \mathrm{~W}$

$321345 \mathrm{N1105235 \textrm {W }}$

$330752 \mathrm{~N} 1092629 \mathrm{~W}$

$322831 \mathrm{N1105510 \textrm {W }}$

$343027 \mathrm{N1092136 \textrm {W }}$

$331002 \mathrm{~N} 1092205 \mathrm{~W}$

$320015 \mathrm{~N} 1101007 \mathrm{~W}$

$333123 \mathrm{~N} 1111710 \mathrm{~W}$

333123N1111710W

$324124 \mathrm{~N} 1105819 \mathrm{~W}$
SOURCE
COORDINATE

Quitobaquito Springs

Corn Creek

2491 Three Points

Galleta Flat East

5477 Skull Valley

Cornfields

Cedar Tree Hills

Polacca

Brooklyn Peak

Brooklyn Peak

Reno Pass

Cornville

Cornville

Cornville

Penitentiary Mtn

Penitentiary Mtn

$343945 N 1132244 W$

Grayback Mts

Pinal Ranch

Mildred Peak

Tempe

Guadalupe

3355 Corona de Tucson

6400 Copperplate Gulch

7108 Cape Royal

Oracle

Clifton

St Johns North

St Johns North

Copperplate Gulch

Copperplate Gulch

5359 Montezuma Pass

Horse Mesa Dam

3190 Horse Mesa Dan

Copperplate Gulch

1255 Mesa

7503 Coronado Mtn

Campo Bonito

Montezuma Pass Phoenix

6864 Montezuma Pass Montezuma Pass

Tucson

Coronado Mtn

Oro valley

St Johns North

Mitchell Peak

San Pedro Ranch

3910 Horse Mesa Dam

Fortified Mtn 


\begin{tabular}{|c|c|c|c|c|c|c|c|}
\hline FEATURE NAME & $\begin{array}{l}\text { FEATURE } \\
\text { CLASS }\end{array}$ & STATUS & COUNTY & COORDINATE & $\begin{array}{l}\text { SOURCE } \\
\text { COORDINATE }\end{array}$ & $\begin{array}{l}\text { ELEV } \\
\text { FT }\end{array}$ & MAP NAME \\
\hline $\begin{array}{l}\text { Coronado Trail } \\
\text { Coronado Village } \\
\text { Coronado Village Shopping } \\
\text { Center } \\
\text { Coronado Wash }\end{array}$ & $\begin{array}{l}\text { trail } \\
\text { ppl } \\
\text { locale } \\
\text { stream }\end{array}$ & $\begin{array}{l}\text { UNOFF } \\
\text { BGN } \\
\text { UNOFF }\end{array}$ & $\begin{array}{l}\text { Greenlee } \\
\text { Cochise } \\
\text { Cochise } \\
\text { Pinal }\end{array}$ & $\begin{array}{l}332806 \mathrm{~N} 1092147 \mathrm{~W} \\
313255 \mathrm{N1} 102050 \mathrm{~W} \\
313313 \mathrm{~N} 1101520 \mathrm{~W} \\
324137 \mathrm{N1111602W}\end{array}$ & $324252 \mathrm{~N} 1105506 \mathrm{~W}$ & & $\begin{array}{l}\text { Rose Peak } \\
\text { Fort Huachuca } \\
\text { Fort Huachuca } \\
\text { Picacho Pass }\end{array}$ \\
\hline $\begin{array}{l}\text { Coronado Well } \\
\text { Corona Speedway } \\
\text { Coronation Peak }\end{array}$ & $\begin{array}{l}\text { well } \\
\text { locale }\end{array}$ & $\begin{array}{l}\text { UNOFF } \\
\text { BGN } \\
\text { VARIANT }\end{array}$ & $\begin{array}{l}\text { Pinal } \\
\text { Pima }\end{array}$ & $\begin{array}{l}323857 N 1105843 W \\
320214 N 1104712 W\end{array}$ & & . & $\begin{array}{l}\text { Fortified Mtn } \\
\text { Tucson SE }\end{array}$ \\
\hline $\begin{array}{l}\text { See Klothos Temple } \\
\text { Corona Village (subdivision) } \\
\text { Corona Wash } \\
\text { Corona Well } \\
\text { Coroteros }\end{array}$ & $\begin{array}{l}\text { summit } \\
\text { ppl } \\
\text { stream } \\
\text { well }\end{array}$ & $\begin{array}{l}\text { BGN } \\
\text { BGN } \\
\text { UNOFF } \\
\text { VARIANT }\end{array}$ & $\begin{array}{l}\text { Yuma } \\
\text { Maricopa } \\
\text { Pima } \\
\text { Pima }\end{array}$ & $\begin{array}{l}324540 \mathrm{~N} 1141548 \mathrm{~W} \\
331905 \mathrm{~N} 1115528 \mathrm{~W} \\
313229 \mathrm{~N} 1112336 \mathrm{~W} \\
313219 \mathrm{~N} 1112344 \mathrm{~W}\end{array}$ & $313112 \mathrm{~N} 1112455 \mathrm{~W}$ & 1175 & $\begin{array}{l}\text { Guadalupe } \\
\text { Wilbur Canyon } \\
\text { Wilbur Canyon }\end{array}$ \\
\hline $\begin{array}{l}\text { See San Carlos (historical) } \\
\text { Corral Canyon }\end{array}$ & $\begin{array}{l}\text { locale } \\
\text { valley }\end{array}$ & BGN & $\begin{array}{l}\text { Gila } \\
\text { Santa Cruz }\end{array}$ & $\begin{array}{l}331155 N 1102420 \mathrm{~W} \\
312728 \mathrm{~N} 1104016 \mathrm{~W}\end{array}$ & $312557 \mathrm{~N} 1104235 \mathrm{~W}$ & & Harshaw \\
\hline $\begin{array}{l}\text { Corral Mountain } \\
\text { Corral Nueva Spring } \\
\text { See Corral Nuevo } \\
\text { Corral Nuevo } \\
\text { Corral Nueva Spring } \\
\text { Corral Pond } \\
\text { Corral Spring } \\
\text { Corral Spring } \\
\text { Corral Spring } \\
\text { Corral Spring }\end{array}$ & $\begin{array}{l}\text { summit } \\
\text { locale } \\
\text { locale } \\
\text { reservoir } \\
\text { spring } \\
\text { spring } \\
\text { spring } \\
\text { spring }\end{array}$ & $\begin{array}{l}\text { BGN } \\
\text { VARIANT } \\
\text { BGN } \\
\text { VARIANT } \\
\text { BGN } \\
\text { BGN } \\
\text { BGN } \\
\text { BGN } \\
\text { BGN }\end{array}$ & $\begin{array}{l}\text { Pinal } \\
\text { Santa Cruz } \\
\text { Santa Cruz } \\
\text { Mohave } \\
\text { Graham } \\
\text { Apache } \\
\text { Yavapai } \\
\text { Yavapai }\end{array}$ & $\begin{array}{l}330402 N 1103813 \mathrm{~W} \\
312851 N 1111044 \mathrm{~W} \\
312851 \mathrm{N1111044W} \\
362153 \mathrm{~N} 1132040 \mathrm{~W} \\
323816 \mathrm{N1101936W} \\
340908 \mathrm{~N} 1092744 \mathrm{~W} \\
341147 \mathrm{N1122035W} \\
341304 \mathrm{~N} 1115039 \mathrm{~W}\end{array}$ & & & $\begin{array}{l}\text { Ruby } \\
\text { Cold Spring } \\
\text { Kennedy Peak } \\
\text { Springerville NW } \\
\text { Crown King } \\
\text { Bloody Basin }\end{array}$ \\
\hline $\begin{array}{l}\text { Corral Spring } \\
\text { Corral Spring Mountain } \\
\text { See Carol Spring Mountain } \\
\text { Corral Tank } \\
\text { Corral Tank } \\
\text { Corral Tank } \\
\text { Corral Tank } \\
\text { Corral Tanks } \\
\text { Corral Tanks } \\
\text { Corral Valley }\end{array}$ & $\begin{array}{l}\text { spring } \\
\text { summit } \\
\text { reservoir } \\
\text { reservoir } \\
\text { reservoir } \\
\text { reservoir } \\
\text { reservoir } \\
\text { reservoir } \\
\text { valley }\end{array}$ & $\begin{array}{l}\text { BGN } \\
\text { VARIANT } \\
\text { BGN } \\
\text { BGN } \\
\text { BGN } \\
\text { BGN } \\
\text { BGN } \\
\text { BGN } \\
\text { BGN }\end{array}$ & $\begin{array}{l}\text { Mohave } \\
\text { Gila } \\
\text { Graham } \\
\text { Coconino } \\
\text { Yavapai } \\
\text { Mohave } \\
\text { Apache } \\
\text { Apache } \\
\text { Coconino }\end{array}$ & $\begin{array}{l}345503 \mathrm{~N} 1140123 \mathrm{~W} \\
333938 \mathrm{~N} 1103339 \mathrm{~W} \\
323752 \mathrm{~N} 1101800 \mathrm{~W} \\
345632 \mathrm{~N} 1112200 \mathrm{~W} \\
352029 \mathrm{~N} 1131423 \mathrm{~W} \\
361008 \mathrm{~N} 1134441 \mathrm{~W} \\
345026 \mathrm{~N} 1093754 \mathrm{~W} \\
345052 \mathrm{~N} 1093734 \mathrm{~W} \\
365206 \mathrm{~N} 1120154 \mathrm{~W}\end{array}$ & $364709 \mathrm{~N} 1115814 \mathrm{~W}$ & & $\begin{array}{l}\text { Kennedy Peak } \\
\text { Kinnikinick Lake } \\
\text { Sugarloaf Peak } \\
\text { Snap Draw } \\
\text { Milky Ranch } \\
\text { Milky Ranch } \\
\text { House Rock Spring }\end{array}$ \\
\hline $\begin{array}{l}\text { Corral Well } \\
\text { Corral Well } \\
\text { Corral Well } \\
\text { Correjo Crossing } \\
\text { Correllos House (historical) } \\
\text { Corrigan Peak } \\
\text { See Clara Peak } \\
\text { Corta Junction } \\
\text { Cortaro } \\
\text { Cortaro Railroad Station }\end{array}$ & $\begin{array}{l}\text { well } \\
\text { well } \\
\text { well } \\
\text { locale } \\
\text { locale } \\
\text { summit } \\
\text { locale } \\
\text { locale } \\
\text { building }\end{array}$ & $\begin{array}{l}\text { UNOFF } \\
\text { UNOFF } \\
\text { UNOFF } \\
\text { BGN } \\
\text { BGN } \\
\text { VARIANT } \\
\text { BGN } \\
\text { BGN } \\
\text { UNOFF }\end{array}$ & $\begin{array}{l}\text { Graham } \\
\text { Graham } \\
\text { Yavapai } \\
\text { Apache } \\
\text { Santa Cruz } \\
\text { Yuma } \\
\text { Cochise } \\
\text { Pima } \\
\text { Pima }\end{array}$ & $\begin{array}{l}325046 \mathrm{~N} 1100305 \mathrm{~W} \\
325759 \mathrm{~N} 1100350 \mathrm{~W} \\
350148 \mathrm{N1} 124920 \mathrm{~W} \\
340530 \mathrm{~N} 1091211 \mathrm{~W} \\
312124 \mathrm{~N} 1105044 \mathrm{~W} \\
\\
340950 \mathrm{~N} 1134840 \mathrm{~W} \\
312346 \mathrm{N1} 1095259 \mathrm{~W} \\
322122 \mathrm{N1110516 \textrm {W }} \\
322135 \mathrm{~N} 1110517 \mathrm{~W}\end{array}$ & & $\begin{array}{l}5302 \\
3720\end{array}$ & $\begin{array}{l}\text { Tripp Canyon } \\
\text { Telegraph Wash } \\
\text { Red Mountain } \\
\text { Nelson Reservoir } \\
\text { Kino Springs }\end{array}$ \\
\hline $\begin{array}{l}\text { Cortaro Road Interchange } \\
\text { Cortez High School } \\
\text { Cortez Park } \\
\text { Cortez Park } \\
\text { Cortez Peak } \\
\text { Cort Well } \\
\text { Corva } \\
\text { Corva Hill } \\
\text { Corva Tank } \\
\text { Cosnino }\end{array}$ & $\begin{array}{l}\text { crossing } \\
\text { school } \\
\text { park } \\
\text { park } \\
\text { summit } \\
\text { well } \\
\text { locale } \\
\text { summit } \\
\text { reservoir } \\
\text { locale }\end{array}$ & $\begin{array}{l}\text { UNOFF } \\
\text { UNOFF } \\
\text { ADMIN } \\
\text { ADMIN } \\
\text { BGN } \\
\text { UNOFF } \\
\text { BGN } \\
\text { BGN } \\
\text { BGN } \\
\text { BGN }\end{array}$ & $\begin{array}{l}\text { Pima } \\
\text { Maricopa } \\
\text { Maricopa } \\
\text { Maricopa } \\
\text { Maricopa } \\
\text { Yavapai } \\
\text { Coconino } \\
\text { Coconino } \\
\text { Coconino } \\
\text { Coconino }\end{array}$ & $\begin{array}{l}322131 \mathrm{~N} 1110521 \mathrm{~W} \\
333401 \mathrm{~N} 1120734 \mathrm{~W} \\
333412 \mathrm{~N} 1120754 \mathrm{~W} \\
333412 \mathrm{~N} 1120755 \mathrm{~W} \\
331548 \mathrm{~N} 1131342 \mathrm{~W} \\
342921 \mathrm{~N} 112380 \mathrm{~W} \\
351631 \mathrm{N1} 122055 \mathrm{~W} \\
351621 \mathrm{~N} 1122037 \mathrm{~W} \\
351556 \mathrm{~N} 1122037 \mathrm{~W} \\
351220 \mathrm{~N} 1112827 \mathrm{~W}\end{array}$ & & 2523 & $\begin{array}{l}\text { Jaynes } \\
\text { Glendale } \\
\text { Glendale } \\
\text { Glendale } \\
\text { Cortez Peak } \\
\text { Kirkland } \\
\text { Hearst Mtn } \\
\text { Hearst Mtn } \\
\text { Hearst Mtn } \\
\text { Winona }\end{array}$ \\
\hline $\begin{array}{l}\text { Cosnino Interchange } \\
\text { Cosnino Overpass } \\
\text { Cosnino Railroad Station } \\
\text { Cosnino Tank } \\
\text { Cosper } \\
\text { Costa Plente, Rancho }\end{array}$ & $\begin{array}{l}\text { crossing } \\
\text { crossing } \\
\text { building } \\
\text { reservoir } \\
\text { locale } \\
\text { locale }\end{array}$ & $\begin{array}{l}\text { UNOFF } \\
\text { UNOFF } \\
\text { UNOFF } \\
\text { BGN } \\
\text { BGN } \\
\text { UNOFF }\end{array}$ & $\begin{array}{l}\text { Coconino } \\
\text { Coconino } \\
\text { Coconino } \\
\text { Coconino } \\
\text { Greenlee } \\
\text { Santa Cruz }\end{array}$ & $\begin{array}{l}351205 \mathrm{~N} 1112833 \mathrm{~W} \\
351256 \mathrm{~N} 1113137 \mathrm{~W} \\
351220 \mathrm{~N} 1112828 \mathrm{~W} \\
351052 \mathrm{~N} 1112816 \mathrm{~W} \\
333100 \mathrm{~N} 1091240 \mathrm{~W} \\
314059 \mathrm{~N} 1103235 \mathrm{~W}\end{array}$ & & 4830 & $\begin{array}{l}\text { Winona } \\
\text { Flagstaff East } \\
\text { Winona } \\
\text { Winona } \\
\text { Bear Mountain } \\
\text { Elgin }\end{array}$ \\
\hline
\end{tabular}


FEATURE NAME $\begin{gathered}\text { FEATURE } \\ \text { CLASS }\end{gathered}$

CLASS

STATUS

Costello Spring

Co Tank

Coters Tank

Cotton Center

Cotton City

See Eloy

Cotton Dam

Cotton Flat

Cotton Spring

Cotton Wash

See Cottonwood Wash

Cottonwood

Cottonwood

Cottonwood

Cottonwood Airport

Clemenceau-Cottonwood Airport

Cottonwood Bas in

Cottonwood Bas in

Cottonwood Bas in

Cottonwood Bas in Spring

See Cottonwood

Cottonwood Box Spring

Cottonwood Cabin

Cottonwood Camp

Cottonwood Camp

Cottonwood Canyon

Cottonwood Canyon

Cottonwood Canyon

Cottonwood Canyon

Cottonwood Canyon

Cottonwood Canyon

Cottonwood Spring Canyon

Cottonwood Canyon

Cottonwood Canyon

Cottonwood Canyon

Cottonwood Canyon

Cottonwood Canyon

Cottonwood Canyon

Cottonwood Canyon

Cottonwood Canyon

Cottonwood Canyon

Cottonwood Canyon

Cottonwood Canyon

Cottonwood Canyon

Cottonwood Canyon

Cottonwood Canyon

Cottonwood Canyon

See Sycamore Canyon

Cottonwood Canyon

Cottonwood Canyon

Cottonwood Canyon

Cottonwood Canyon

Cottonwood Canyon

Cottonwood Canyon

Cottonwood Canyon

Cottonwood Canyon

Cottonwood Canyon Shingle Canyon

Cottonwood Canyon Seachi Canyon

Cottonwood Canyon

Cottonwood Canyon

Cottonwood Canyon

Cottonwood Canyon

Cottonwood Canyon

Cottonwood Canyon

Cottonwood Canyon

Cottonwood Canyon Trail Two Hundred Sixtys ix $\begin{array}{llll}\text { spring } & B G N & \text { Cochise } & 314852 N 1100012 W \\ \text { reservoir } & B G N & \text { Coconino } & 352052 N 1123014 W\end{array}$

Mohave 345248N1132311W

locale BGN Maricopa 330514N1123958W

pp 1

dam UNOFF Ynal

flat

spring BGN Mohave 345718N1133025W

stream Graham 325452N1094937W

locale BGN Pinal 330426N1114200W

ppl BGN Yavapai 344421N1120033W

ppl BGN Apache 360423N1095330W

airport ADMIN Yavapai 344348N1120204W

VARIANT

bas in BGN Maricopa 334737N1113528W

basin BGN Gila 335528N1112631W

bas in BGN Yavapai 342906N1114546W

VARIANT

$\begin{array}{lll}\text { spring Gila } & 335850 N 1112107 W\end{array}$

spring BGN Gila 334401N1104025W

locale BGN Yavapai 344352N1125334W

locale BGN Maricopa 333724N1112648W

locale BGN Coconino 361007N1120227W

valley BGN Santa Cruz 312337N1105257W

valley BGN Santa Cruz 313838N1110201W

valley BGN Cochise 315028N1092650W

valley BGN Cochise 315611N1102048

valley BGN Pinal 323019N1110904

valley

VARIANT

valley

valley

valley

valley

valley

valley

valley

valley

valley

valley

BGN Graham

BGN Grahan

BGN Grahan

$B$ Pinal

BGN Graham

BGN Graham

BGN Graha

Maricopa

valley

valley

valley

valley

valley

valley

valley

valley

BGN Navajo

BGN Gila

BGN Navajo

BGN Yavapai

VARIANT

BGN Yavapai

BGN Yavapai

BGN Yavapai

BGN Apache

valley

valley

valley

valley

valley

BGN

BGN

BGN

BGN

VARIANT

valley

valley

BGN 198

VARIANT

valley

BGN

$B G N$

Yavapai

Yavapai

Mohave

Mohave

Mohave

Apache

Apache

Navajo

valley

valley

valley

valley

valley

trail

BGN

BGN

BGN

BGN

$B G N$

UNOFF

$360918 N 1093058 \mathrm{~W}$

$361007 \mathrm{~N} 1104452 \mathrm{~W}$

361949 N1125324W $362040 N 1095245 \mathrm{~W}$

Mohave

San Juan (NM) 364527N1085810

Mohave 365638N1132013W

Cohise

$365842 \mathrm{~N} 1125437 \mathrm{~W}$

$315000 \mathrm{~N} 1092200 \mathrm{~W}$
BGN Pinal
COUNTY

COORDINATE

SOURCE COORDINATE

ELEV
FT

MAP NAME

Haberstock $\mathrm{Hill}$ Horse Trap Mesa Chapel Mtn Gonzales Wash

712 Cotton Center

Picacho Butte SE

Luna Lake

Tom Brown Canyon

1293 Sacaton

3314 Cottonwood

Toadindaaska Mesa

3550 Cottonwood

Maverick Mtn

Reno Pass

Horner Mtn

Haystack Butte

Sheridan Mtn

Mormon Flat Dam

Bright Angel Point

Rio Rico

Amado

314106 N1105249W

$314948 N 1092117 \mathrm{~W}$

$323204 N 1110224 \mathrm{~W}$

$325303 N 1101112 \mathrm{~W}$

Benson

Desert Peak

Tripp Canyon

Cobre Grande Mtn

Jackson Mtn

Lone Star Mtn

San Carlos Reservoir

Florence NE

Dewey Flat

Willow Mtn SE

Willow Mtn SE

Picketpost Mtn

Weavers Needle

Alchesay Flat

Gisela

Long Ton Canyon

Congress

O'Neill Pass

Arnold Mesa

Thorn Peak

The Rincon

Bismarck Mesa

Muleshoe Ranch

Creamery Canyon

Oatman

Kingman SE

Ganado One NE

Chinle

Rocky Ridge NW

$361034 N 1093054$

$330634 \mathrm{~N} 1103701 \mathrm{~W}$

$361920 \mathrm{~N} 1125722 \mathrm{~W}$

$362229 \mathrm{~N} 1095022 \mathrm{~W}$

$364817 N 1090619 \mathrm{~W}$

365511 N1131B14W

$370332 \mathrm{~N} 1125303 \mathrm{~W}$

Fern Glen Canyon

Tah Chee Wash

Bitlabito

Rock Canyon

Colorado City

Chiricahua Peak 


\begin{tabular}{|c|c|c|c|c|c|c|c|}
\hline FEATURE NAME & $\begin{array}{l}\text { FEATURE } \\
\text { CLASS }\end{array}$ & STATUS & COUNTY & COORDINATE & $\begin{array}{l}\text { SOURCE } \\
\text { COORDINATE }\end{array}$ & $\begin{array}{l}\text { ELEV } \\
\text { FT }\end{array}$ & MAP NAME \\
\hline $\begin{array}{l}\text { Cottonwood Circle Two Hundred } \\
\text { Thirtythree }\end{array}$ & trail & UNOFF & Cochise & $314358 \times 1091951 W$ & & & Swede Peak \\
\hline Cottonwood Cliffs & cliff & $B G N$ & Mohave & $352051 \mathrm{~N} 1133749 \mathrm{~W}$ & & & Hackberry \\
\hline $\begin{array}{l}\text { Cottonwood Corral Spring } \\
\text { See Cottonwood Spring } \\
\text { Cottonwood Cove } \\
\text { Cottonwood Cove Spring } \\
\text { Cottonwood Creek } \\
\text { Cottonwood Creek } \\
\text { Cottonwood Creek } \\
\text { Cottonwood Creek } \\
\text { Cottonwood Creek } \\
\text { See Cottonwood Wash }\end{array}$ & $\begin{array}{l}\text { reservoir } \\
\text { valley } \\
\text { spring } \\
\text { stream } \\
\text { stream } \\
\text { stream } \\
\text { stream } \\
\text { stream }\end{array}$ & $\begin{array}{l}\text { VARIANT } \\
\text { BGN } \\
\text { BGN } \\
\text { BGN } \\
\text { BGN } 1960 \\
\text { BGN } \\
\text { BGN } \\
\text { VARIANT }\end{array}$ & $\begin{array}{l}\text { Cochise } \\
\text { Coconino } \\
\text { Pima } \\
\text { Cochise } \\
\text { Cochise } \\
\text { Cochise } \\
\text { Graham } \\
\text { Graham }\end{array}$ & $\begin{array}{l}314405 N 1091858 \mathrm{~W} \\
365808 \mathrm{~N} 1115930 \mathrm{~W} \\
322540 \mathrm{~N} 1103716 \mathrm{~W} \\
312134 \mathrm{~N} 1091537 \mathrm{~W} \\
314522 \mathrm{~N} 1092140 \mathrm{~W} \\
320527 \mathrm{N1091906 \textrm {W }} \\
325129 \mathrm{~N} 1095231 \mathrm{~W} \\
325452 \mathrm{~N} 109493 \mathrm{~W}\end{array}$ & 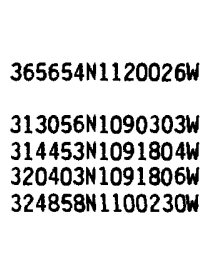 & & $\begin{array}{l}\text { Poverty Flat } \\
\text { Buehman Canyon } \\
\text { San Bernardino Ranch } \\
\text { Chiricahua Peak } \\
\text { Cochise Head } \\
\text { Shingle Mill Mtn }\end{array}$ \\
\hline $\begin{array}{l}\text { Cottonwood Creek } \\
\text { Cottonwood Creek }\end{array}$ & stream & $\begin{array}{l}\text { BGN } 1962 \\
\text { VARIANT }\end{array}$ & Greenlee & $325535 \mathrm{~N} 1091225 \mathrm{~W}$ & $325905 \mathrm{~N} 1090455 \mathrm{~W}$ & & York \\
\hline $\begin{array}{l}\text { See Skully Creek } \\
\text { Cottonwood Creek } \\
\text { Cottonwood Creek } \\
\text { Cottonwood Creek } \\
\text { Cottonwood Creek }\end{array}$ & $\begin{array}{l}\text { stream } \\
\text { stream } \\
\text { stream } \\
\text { stream }\end{array}$ & $\begin{array}{l}\text { BGN } \\
\text { BGN } \\
\text { BGN } \\
\text { VARIANT }\end{array}$ & $\begin{array}{l}\text { Greeniee } \\
\text { Greenlee } \\
\text { Pinal } \\
\text { Maricopa }\end{array}$ & $\begin{array}{l}325600 N 1091005 \mathrm{~W} \\
325700 \mathrm{~N} 1090329 \mathrm{~W} \\
330950 \mathrm{N1112505W} \\
333358 \mathrm{~N} 1112747 \mathrm{~W}\end{array}$ & $\begin{array}{l}325830 \mathrm{~N} 1090315 \mathrm{~W} \\
331242 \mathrm{N1111002W} \\
334139 \mathrm{N1112004W}\end{array}$ & & $\begin{array}{l}\text { Tillie Hall Peak } \\
\text { Magma } \\
\text { Mormon Flat Dam }\end{array}$ \\
\hline $\begin{array}{c}\text { See Skunk Creek } \\
\text { Cottonwood Creek } \\
\text { Cottonwood Creek } \\
\text { Walnut Creek }\end{array}$ & $\begin{array}{l}\text { stream } \\
\text { stream } \\
\text { stream }\end{array}$ & $\begin{array}{l}\text { BGN } 1917 \\
\text { BGN } 1965 \\
\text { VARIANT }\end{array}$ & $\begin{array}{l}\text { Maricopa } \\
\text { Maricopa } \\
\text { Gila }\end{array}$ & $\begin{array}{l}333658 N 1121437 W \\
333957 N 1110753 W \\
334951 N 1111628 W\end{array}$ & $\begin{array}{l}333546 \mathrm{~N} 1110744 \mathrm{~W} \\
335152 \mathrm{~N} 1111604 \mathrm{~W}\end{array}$ & & $\begin{array}{l}\text { Theo. Roosevelt Dam } \\
\text { Tonto Bas in }\end{array}$ \\
\hline $\begin{array}{l}\text { Cottonwood Creek } \\
\text { See Walnut Creek } \\
\text { Cottonwood Creek } \\
\text { Cottonwood Creek } \\
\text { Cottonwood Creek } \\
\text { Cottonwood Creek } \\
\text { Cottonwood Creek } \\
\text { Cottonwood Creek } \\
\text { Cottonwood Creek } \\
\text { Cottonwood Creek }\end{array}$ & $\begin{array}{l}\text { stream } \\
\text { stream } \\
\text { stream } \\
\text { stream } \\
\text { stream } \\
\text { stream } \\
\text { stream } \\
\text { stream } \\
\text { stream }\end{array}$ & $\begin{array}{l}\text { VARIANT } \\
\text { BGN } 1965 \\
\text { BGN } \\
\text { BGN } \\
\text { BGN } \\
\text { BGN } \\
\text { BGN } \\
\text { BGN } \\
\text { BGN }\end{array}$ & $\begin{array}{l}\text { Gila } \\
\text { Maricopa } \\
\text { Yavapai } \\
\text { Gila } \\
\text { Yavapai } \\
\text { Yavapai } \\
\text { Yavapai } \\
\text { Gila } \\
\text { Yavapai }\end{array}$ & $\begin{array}{l}335152 \mathrm{N1111604W} \\
335328 \mathrm{~N} 1115712 \mathrm{~W} \\
335332 \mathrm{N1121734W} \\
335811 \mathrm{N1111902W} \\
335859 \mathrm{~N} 1121736 \mathrm{~W} \\
340207 \mathrm{N1121349W} \\
34119 \mathrm{N1} 123226 \mathrm{~W} \\
341247 \mathrm{N1} 11382 \mathrm{~W} \\
341557 \mathrm{N1} 125532 \mathrm{~W}\end{array}$ & $\begin{array}{l}335514 N 1115150 \mathrm{~W} \\
33550 \mathrm{BN} 1122358 \mathrm{~W} \\
335945 \mathrm{~N} 1112145 \mathrm{~W} \\
340316 \mathrm{N1121948W} \\
340610 \mathrm{~N} 1121728 \mathrm{~W} \\
341222 \mathrm{N1124011W} \\
341417 \mathrm{N1113619W} \\
342045 \mathrm{~N} 1124711 \mathrm{~W}\end{array}$ & & $\begin{array}{l}\text { New River Mesa } \\
\text { Governors Peak } \\
\text { Kayler Butte } \\
\text { Governors Peak } \\
\text { Black Canyon City } \\
\text { Wagoner } \\
\text { Wet Bottom Mesa } \\
\text { Date }\end{array}$ \\
\hline $\begin{array}{l}\text { Cottonwood Creek } \\
\text { Cottonwood Creek }\end{array}$ & stream & $\begin{array}{l}\text { BGN } \\
\text { VARIANT }\end{array}$ & Yavapai & $343054 N 1130441 W$ & $343251 \mathrm{N1130605 \textrm {W }}$ & & Big Shipp Mtn \\
\hline $\begin{array}{l}\text { See Cottonwood Wash } \\
\text { Cottonwood Creek } \\
\text { Cottonwood Wash } \\
\text { White Cliff Creek } \\
\text { Willow Creek } \\
\text { Cottonwood Creek }\end{array}$ & $\begin{array}{l}\text { stream } \\
\text { stream }\end{array}$ & $\begin{array}{l}\text { BGN } 1979 \\
\text { VARIANT } \\
\text { VARIANT } \\
\text { VARIANT } \\
\text { VARIANT }\end{array}$ & $\begin{array}{l}\text { Navajo } \\
\text { Mohave }\end{array}$ & $\begin{array}{l}343130 \mathrm{~N} 1100440 \mathrm{~W} \\
350818 \mathrm{~N} 1133340 \mathrm{~W}\end{array}$ & $351226 \mathrm{~N} 1133140 \mathrm{~W}$ & & Tin Mountain \\
\hline $\begin{array}{l}\text { See Willow Creek } \\
\text { Cottonwood Creek } \\
\text { See Cline Creek }\end{array}$ & $\begin{array}{l}\text { stream } \\
\text { stream }\end{array}$ & & $\begin{array}{l}\text { Mohave } \\
\text { Maricopa }\end{array}$ & $\begin{array}{l}351011 N 1133110 \mathrm{~W} \\
351622 \mathrm{~N} 1105533 \mathrm{~W}\end{array}$ & & & \\
\hline $\begin{array}{l}\text { Cottonwood Creek } \\
\text { Cottonwood Creek } \\
\text { Cottonwood Creek } \\
\text { Cottonwood Creek Cemetery } \\
\text { Cottonwood Creek School } \\
\text { Cottonwood Day School } \\
\text { Cottonwood Ditch } \\
\text { Cottonwood Draw } \\
\text { Cottonwood Wash } \\
\text { Cottonwood Elementary School }\end{array}$ & $\begin{array}{l}\text { stream } \\
\text { stream } \\
\text { stream } \\
\text { cemetery } \\
\text { school } \\
\text { school } \\
\text { canal } \\
\text { valley } \\
\text { school }\end{array}$ & $\begin{array}{l}\text { BGN } \\
\text { BGN } 1906 \\
\text { BGN } \\
\text { UNOFF } \\
\text { UNOFF } \\
\text { UNOFF } \\
\text { BGN } \\
\text { BGN } \\
\text { VARIANT } \\
\text { UNOFF }\end{array}$ & $\begin{array}{l}\text { Mohave } \\
\text { Coconino } \\
\text { Mohave } \\
\text { Cochise } \\
\text { Cochise } \\
\text { Apache } \\
\text { Yavapai } \\
\text { Cochise } \\
\text { Pinal }\end{array}$ & $\begin{array}{l}352206 \mathrm{~N} 1134002 \mathrm{~W} \\
3600303 \mathrm{~N} 111590 \mathrm{~W} \\
365407 \mathrm{~N} 1123345 \mathrm{~W} \\
312722 \mathrm{~N} 1090726 \mathrm{~W} \\
312700 \mathrm{~N} 1090740 \mathrm{~W} \\
360425 \mathrm{~N} 1095326 \mathrm{~W} \\
344324 \mathrm{N1115959W} \\
312134 \mathrm{~N} 1091536 \mathrm{~W} \\
325347 \mathrm{~N} 1114441 \mathrm{~W}\end{array}$ & $\begin{array}{l}351907 N 1133454 \mathrm{~W} \\
360016 \mathrm{N1115846 \textrm {W }} \\
370545 \mathrm{N1123730W}\end{array}$ & & $\begin{array}{l}\text { Hackberry } \\
\text { Cape Royal } \\
\text { Fredonia } \\
\text { Guadalupe Spring } \\
\text { Lazy J Ranch } \\
\text { Toadinaska Mesa } \\
\text { Cornville } \\
\text { San Bernardino Ranch } \\
\text { Mammoth }\end{array}$ \\
\hline $\begin{array}{l}\text { Cottonwood Gulch } \\
\text { cottonwood Gulch } \\
\text { cottonwood Gulch } \\
\text { Cottonwood Hill } \\
\text { Cottonwood Kids Park } \\
\text { Cottonwood Landing Field } \\
\text { Cottonwood Mesa } \\
\text { Cottonwood Mountain } \\
\quad \text { Cottonwood Mountains } \\
\text { Cottonwood Mounta in }\end{array}$ & $\begin{array}{l}\text { valley } \\
\text { valley } \\
\text { valley } \\
\text { summit } \\
\text { park } \\
\text { airport } \\
\text { summit } \\
\text { summit } \\
\text { summit }\end{array}$ & $\begin{array}{l}\text { BGN } \\
\text { BGN } \\
\text { BGN } \\
\text { BGN } \\
\text { ADMIN } \\
\text { ADMIN } \\
\text { BGN } \\
\text { BGN } 1975 \\
\text { VARIANT } \\
\text { BGN }\end{array}$ & $\begin{array}{l}\text { Gila } \\
\text { Gila } \\
\text { Yavapai } \\
\text { Pinal } \\
\text { Yavapai } \\
\text { Mohave } \\
\text { Yavapai } \\
\text { Graham } \\
\text { Gila }\end{array}$ & $\begin{array}{l}332252 \mathrm{~N} 1105836 \mathrm{~W} \\
332811 \mathrm{N1105402W} \\
340052 \mathrm{~N} 1121042 \mathrm{~W} \\
325027 \mathrm{N1} 10565 \mathrm{~W} \\
344358 \mathrm{~N} 1120036 \mathrm{~W} \\
352907 \mathrm{N1} 14395 \mathrm{~W} \\
342332 \mathrm{N1115710W} \\
325240 \mathrm{N1} 101147 \mathrm{~W} \\
340343 \mathrm{~N} 1111546 \mathrm{~W}\end{array}$ & $\begin{array}{l}332338 \mathrm{~N} 1105626 \mathrm{~W} \\
332720 \mathrm{~N} 110550 \mathrm{~W} \\
340146 \mathrm{~N} 1121232 \mathrm{~W}\end{array}$ & $\begin{array}{l}4420 \\
680 \\
7481 \\
4497\end{array}$ & $\begin{array}{l}\text { Inspiration } \\
\text { Inspiration } \\
\text { Black Canyon City } \\
\text { Black Mountain } \\
\text { Cottonwood } \\
\text { Spirit Mtn NW } \\
\text { Arnold Mesa } \\
\text { Jackson Mtn } \\
\text { Gisela }\end{array}$ \\
\hline $\begin{array}{l}\text { Cottonwood Mountain } \\
\text { Cottonwood Mountains } \\
\text { Cottonwood Mountains }\end{array}$ & $\begin{array}{l}\text { Summit } \\
\text { range }\end{array}$ & $\begin{array}{l}\text { BGN } \\
\text { BGN } \\
\text { VARIANT }\end{array}$ & $\begin{array}{l}\text { Yavapai } \\
\text { Mohave }\end{array}$ & $\begin{array}{l}344706 \mathrm{~N} 1125105 \mathrm{~W} \\
351954 \mathrm{~N} 1133401 \mathrm{~W}\end{array}$ & & 6466 & $\begin{array}{l}\text { Seepage Mtn } \\
\text { Valentine SE }\end{array}$ \\
\hline $\begin{array}{l}\text { See Cottonwood Mountain } \\
\text { Cottonwood Mountain Trail }\end{array}$ & $\begin{array}{l}\text { summit } \\
\text { trail }\end{array}$ & & $\begin{array}{l}\text { Graham } \\
\text { Graham }\end{array}$ & $\begin{array}{l}325240 \mathrm{~N} 1101147 \mathrm{~W} \\
323634 \mathrm{N1} 101805 \mathrm{~W}\end{array}$ & & & Bassett Peak \\
\hline
\end{tabular}


NATIONAL GAZETTEER--ARIZONA 1986

FEATURE MAME

Cottonwood Number Two Tank Cottonwood-Oak Creek School Cottonwood Park

Cottonwood Pass

Sycamore Pass

Cottonwood Peak Cottonwood Point

Cottonwood Ranch

Cottonwood Ranch (subdivision)

Cottonwood Resrvoir

Cottonwood Ridge

Cottonwood Ridge

Cottonwood Saddle

Cottonwood Seep

Cottonwood Seep

Cottonwood Spring

Cottonwood Corral Spring

Cottonwood Spring

Cottonwood Spring

Cottonwood Spring

Cottonwood Spring

Cottonwood Spring

Cottonwood Spring

Cottonwood Spring

Cottonwood Spring

Cottonwood Spring

Cottonwood Spring

Cottonwood Spring

Cottonwood Spring

Cottonwood Spring

Cottonwood Spring

Cottonwood Spring

Cottonwood Spring

Cottonwood Spring

Cottonwood Spring

Cottonwood Spring

Cottonwood Spring

Cottonwood Spring

Cottonwood Spring

Cottonwood Spring

Cottonwood Spring

Cottonwood Spring

Cottonwood Spring

Cottonwood Spring

Cottonwood Spring

Cottonwood Spring

Cottonwood Bas in Spring

Cottonwood Spring

Cottonwood Spring

Cottonwood Spring

Cottonwood Spring

Cottonwood Spring

Cottonwood Spring

Cottonwood Spring

Cottonwood Spring

See Sycamore Spring

Cottonwood Spring

Cottonwood Spring

Cottonwood Spring

Cottonwood Spring

Cottonwood Spring

Cottonwood Spring

Cottonwood Spring

Cottonwood Spring

Cottonwood Spring

Cottonwood Spring

Cottonwood Spring

Cottonwood Spring

Cottonwood Spring

Cottonwood Spring
FEATURE

reservoir
school
park
gap

$$
\begin{aligned}
& \text { summit } \\
& \text { cliff } \\
& \text { build } \\
& \text { local } \\
& \text { ppl } \\
& \text { reser } \\
& \text { ridge } \\
& \text { ridge } \\
& \text { gap } \\
& \text { sprin }
\end{aligned}
$$$$
\text { spring }
$$$$
\text { spring } \quad B G
$$$$
\text { spring }
$$$$
\text { spring }
$$$$
\text { spring }
$$$$
\text { spring }
$$$$
\text { spring }
$$$$
\text { spring }
$$

spring

spring

spring

spring

spring

spring

spring

spring

spring

spring

spring

spring

spring

spring

spring

spring

spring

spring

spring

spring

spring

spring

spring

spring

spring

spring

spring

spring

$$
\begin{aligned}
& \text { BGN } \\
& \text { BGN } \\
& \text { VARIAM } \\
& \text { BGN } \\
& \text { BGN } \\
& \text { BGN } \\
& \text { BGN } \\
& \text { BGN } \\
& \text { BGN } \\
& \text { BGN }
\end{aligned}
$$

STATUS

COUNTY

COORDIMATE

SOURCE

ELEV

MAP NAME

BGN Navajo 342259N1102010W

UNOFF Yavapai 344426N1120124W

ADMIN Apache 354310N1093155W

Yuma

$335255 \mathrm{~N} 1133901 \mathrm{~W}$

BGN Cochise 315134N1102417W

$365806 \mathrm{~N} 1125633 \mathrm{~W}$

$344424 N 1120114 \mathrm{~W}$

$320013 N 1110851 \mathrm{~W}$

$333620 \mathrm{~N} 1121350 \mathrm{~W}$

$352851 \mathrm{N1142246 \textrm {W }}$

341058 N1100732W

$362824 \mathrm{~N} 1135529 \mathrm{~W}$

$315142 \mathrm{~N} 1102347 \mathrm{~W}$

$341537 \mathrm{~N} 1102026 \mathrm{~W}$

$350117 N 1093243 \mathrm{~W}$

$314405 N 1091858 \mathrm{~W}$

$312814 \mathrm{~N} 1110645 \mathrm{~W}$

$313253 \mathrm{~N} 1103805 \mathrm{~W}$

$313910 \mathrm{~N} 1104222 \mathrm{~W}$

$314435 \mathrm{~N} 1102705 \mathrm{~W}$

314435N1102705W

$323229 \mathrm{M} 1110350 \mathrm{~W}$

$325710 \mathrm{~N} 1101524 \mathrm{~W}$

Cochise

Pinal

$\begin{array}{lll}\text { BGN } & \text { Graham } & 325742 \mathrm{~N} 1093925 \mathrm{~W} \\ \text { BGN } & \text { Graham } & 325822 \mathrm{~N} 1102527 \mathrm{~W} \\ \text { BGN } & \text { Graham } & 325951 \mathrm{~N} 1093132 \mathrm{~W} \\ \text { BGN } & \text { Graham } & 330008 \mathrm{~N} 1101223 \mathrm{~W} \\ \text { BGN } & \text { Pinal } & 330420 \mathrm{~N} 1104109 \mathrm{~W} \\ \text { BGN } & \text { Graham } & 330601 \mathrm{~N} 1092959 \mathrm{~W} \\ \text { BGN } & \text { Graham } & 330922 \mathrm{~N} 1102536 \mathrm{~W} \\ \text { BGN } & \text { Greenlee } & 330930 \mathrm{~N} 1092735 \mathrm{~W} \\ \text { BGN } & \text { Pinal } & 331322 \mathrm{~N} 1105714 \mathrm{~W} \\ \text { BGN } & \text { Greenlee } & 331448 N 1092411 \mathrm{~W}\end{array}$

BGN Graham 331505N1093453W

BGN Greenlee 331625N1092842W

$331738 N 1101333 \mathrm{~W}$

Gila 332748N1105431W

Maricopa 332953 N1113000W

Gila 333021N1104711W

Maricopa 333702 N1110717W

$334347 \mathrm{~N} 1103941 \mathrm{~W}$

Gila 334835N1104840W

$335006 \mathrm{~N} 1131643 \mathrm{~W}$

$335445 \mathrm{~N} 1115357 \mathrm{~W}$

$335850 \mathrm{N1112107 \textrm {W }}$

$340052 \mathrm{~N} 1102756 \mathrm{~W}$

$340121 \mathrm{~N} 1122314 \mathrm{~W}$

$340132 N 1095621 \mathrm{~W}$

$340412 \mathrm{~N} 1115247 \mathrm{~W}$

$340744 N 1110858 \mathrm{~W}$

$340859 \mathrm{~N} 1115135 \mathrm{~W}$

$341023 \mathrm{N1} 100858 \mathrm{~W}$

VARIANT

spring

spring

spring

spring

spring

spring

$B G$
$B G$
$B G$
$B G$
$B G$
$B G$
$B G$

spring

spring

spring

spring

spring

spring

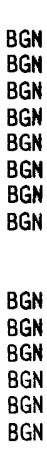

Gila

Yavapai

Gila

Yavapai

Yavapai

Mohave

Yavapai

Mohave

Mohave

Yavapai

Mohave

Mohave

Mohave

Mohave

Mohave
$341342 \mathrm{~N} 1110211 \mathrm{~W}$

$341956 \mathrm{~N} 1122749 \mathrm{~W}$

$342237 \mathrm{~N} 1112835 \mathrm{~W}$

$342915 \mathrm{~N} 1114612 \mathrm{~W}$

$343101 \mathrm{~N} 1115215 \mathrm{~W}$

$343343 N 1141018 \mathrm{~W}$

$343449 \mathrm{~N} 1120223 \mathrm{~W}$

$344842 \mathrm{~N} 1135345 \mathrm{~W}$

344946 N1132623W

345017 N1131700W

$345635 N 1135610 \mathrm{~W}$

$350356 N 1142235 \mathrm{~W}$

$350617 \mathrm{~N} 1135858 \mathrm{~W}$

$350801 \mathrm{~N} 1132455 \mathrm{~W}$

$351725 \mathrm{~N} 1142152 \mathrm{~W}$
Big Pug Tank

Cottonwood

Ganado

Harcuvar Peak

7100 Apache Peak

Colorado City

Cottonwood

3560 San Xavier Mssn. SW

1170 Glendale

Red Top Mtn

Pakoon Springs

Apache Peak

Clay Springs

Navajo South

Swede Peak

Pena Blanca Lake

Mt Hughes

Sonoita

Mustang Mountains

Chiricahua Peak

Tortolita Mts

Cobre Grande Mtn

Weber Peak

Booger Canyon

Lone Star Mtn

Beargrass Basin

Christmas

Copperplate Gulch

Coronado Mtn

Hot Tamale Peak

Coronado Mtn

Willow Mtn SE

Bee Canyon

Branaman Spring

Inspiration

Apache Junction

Rockinstraw Mtn

Grasshopper Junc NW

San Carlos Reservoir 
FEATURE NAME

Cottonwood Spring

Cottonwood Spring

Cottonwood Spring

Cottonwood Spring

Cottonwood Spring

Cottonwood Spring

Cottonwood Spring

Cottonwood Spring

Cottonwood Spring

Cottonwood Spring

Cottonwood Spring

Cottonwood Spring

Cottonwood Spring

Cottonwood Spring

Cottonwood Spring

Cottonwood Spring

Cottonwood Spring

Cottonwood Spring

Cottonwood Spring

Cottonwood Spring

Cottonwood Spring Canyon

See Cottonwood Canyon

Cottonwood Springs

Cottonwood Springs

Cottonwoods Spring

Cottonwood Substation

Cottonwood Tailings Pond

Cottonwood Tank

Cottonwood Tank

Cottonwood Tank

Cottonwood Tank

Cottonwood Tank

Cottonwood Tank

Cottonwood Tank

Cottonwood Tank

Cottonwood Tank

Cottonwood Tank

Cottonwood Tank

Cottonwood Tank

Cottonwood Tank

Cottonwood Tank

Cottonwood Tank

Cottonwood Tank

Cottonwood Valley

Cottonwood valy

Cottonwood Valy

See Cottonwood Valley

Cottonwood Wash

Cottonwood Wash

Cottonwood Wash

Cotton Wash

Cottonwood Creek

Cottonwood Wash

Cottonwood Wash

Cottonwood Wash

Cottonwood Creek

Cottonwood Wash

Cottonwood Wash

See Knight Creek

Cottonwood Wash

Pueblo Colorado Wash

Cottonwood Wash

See Cottonwood Creek

Cottonwood Wash

Cottonwood Wash

See Cottonwood Draw

Cottonwood Wash

See Mackelprang Wash

Cottonwood Wash

See Salt Seeps Wash

cottonwood Wash
FEATURE

CLASS

STATUS COUNTY

Navajo

spring

pring

spring

\section{BGN
$B G N$
$B G N$ \\ BGN}

Navajo

Mohave

Navajo

spring

spring

spring

spring

spring

spring

spring

spring

spring

spring

$\begin{array}{ll}\text { BGN } & \text { Mohave } \\ \text { BGN } & \text { Mohave } \\ \text { BGN } & \text { Navajo } \\ \text { BGN } & \text { Apache } \\ \text { BGN } & \text { Coconino } \\ \text { BGN } & \text { Navajo } \\ \text { BGN } & \text { Navajo } \\ \text { BGN } & \text { Mohave } \\ \text { BGN } & \text { Navajo } \\ \text { BGN } & \text { Coconino }\end{array}$

5N1143010W

$355915 N 1133140 \mathrm{~W}$

$360934 \mathrm{~N} 1104315 \mathrm{~W}$

$361059 N 1092744 \mathrm{~W}$

$361205 N 1111342 \mathrm{~W}$

$361344 \mathrm{~N} 1100921 \mathrm{~W}$

361811 N1103858W

$361949 \mathrm{~N} 1125504 \mathrm{~W}$

$361950 \mathrm{~N} 1103220 \mathrm{~W}$

$363135 \mathrm{~N} 1123243 \mathrm{~W}$

spring

spring

spring

spring

spring

valley

spring

spring

BGN
BGN
BGN
BGN
BGN
BGN
VARIANT

Apache

Mohave

Coconino

Mohave

Mohave

Mohave

Graham

Yavapai

$363442 N 1091233 \mathrm{~W}$

$364315 \mathrm{~N} 1135230 \mathrm{~W}$

$364547 \mathrm{~N} 1114555 \mathrm{~W}$

$365555 \mathrm{~N} 1131305 \mathrm{~W}$

$365828 N 1123602 \mathrm{~W}$

$365926 \mathrm{~N} 1125515 \mathrm{~W}$

$324955 \mathrm{~N} 1100610 \mathrm{~W}$

$342414 \mathrm{~N} 1131446 \mathrm{~W}$

$344420 \mathrm{~N} 1125153 \mathrm{~W}$

spring BGN Maricopa 333653N1111545W

locale UNOFF Yavapai $344436 \mathrm{~N} 1120205 \mathrm{~W}$

reservoir BGN Gila 332308N1105759W

reservoir BGN Cochise 314417N1091B45W

$325016 \mathrm{~N} 1100733 \mathrm{~W}$

reservoir BGN Greenlee 331700N1092534W

reservoir BGN Gila

reservoir BGN Greenlee 333032N1092313W

reservoir BGN Maricopa 334741N1113546W

reservoir BGN Gila $340320 \mathrm{~N} 1111444 \mathrm{~W}$

reservoir BGN Yavapai 340400N1115211W

reservoir BGN

reservoir BGN

$342343 \mathrm{M} 1115813 \mathrm{~W}$

reservoir BGN Navajo 344239 N1100619W

reservoir BGN Yavapai $345645 \mathrm{~N} 1130 \mathrm{B0}$ W

reservoir BGN Coconino 362023N1113010W

$340747 \mathrm{~N} 1110835 \mathrm{~W}$

Mohave

$353040 N 1143952 \mathrm{~W}$

$352234 N 1143559 \mathrm{~W}$

$353040 \mathrm{~N} 1143952 \mathrm{~W}$

$324110 \mathrm{~N} 1103654 \mathrm{~W}$

$325149 \mathrm{~N} 1094257 \mathrm{~W}$

$323613 N 1104354 W$

$325814 N 1093936 \mathrm{~W}$

$325115 N 1095300 \mathrm{~W}$

stream

stream

Graham

BGN 1962

stream

strean

strean

BGN

BGN

BGN 1964

Pinal

Gila

Navajo

$325823 \mathrm{~N} 1110726 \mathrm{~W}$

$333949 \mathrm{~N} 1110133 \mathrm{~W}$

$343130 \mathrm{~N} 1100440 \mathrm{~W}$

$324906 \mathrm{~N} 1105506 \mathrm{~W}$

$334459 \mathrm{~N} 1110000 \mathrm{~W}$

$341430 \mathrm{~N} 1102000 \mathrm{~W}$

$344911 N 1094848 \mathrm{~W}$

$345521 \mathrm{~N} 1133734 \mathrm{~W}$

$350010 \mathrm{~N} 1103915 \mathrm{~W}$

$351620 \mathrm{~N} 1100850$

VARIANT

BGN 1974 Mohave

VARIANT

VARIANT

stream

strean

BGN

Mohave

Mohave

valley

VARIANT

Cochise

$35081 B N 1133340 \mathrm{~W}$

365641 N1125926W

$312134 \mathrm{~N} 1091536 \mathrm{~W}$

VARIANT

valley

VARIAMT

Navajo

valley

valley
Navajo

Apache
350858 N1101642W

$350915 \mathrm{~N} 1101315 \mathrm{~W}$

36083BN1093422W
ELEV

MAP NAME

Sunflower Butte

White Cone

Mt Tipton

First Flat Mesa

Mt Perkins

Amos Point

Rocky Ridge NW

Del Muerto

Tuba City

Pinon NW

Kydestea Spring

Fern Glen Canyon

Red Willow Spring

Jumpup Point

Cove

Jacobs We11

The Big Knoll

Lost Spring Mtn West

Fredonia

Colorado City

Thorn Peak

Smith Mesa

Horse Mesa Dam

Cottonwood

Inspiration

Swede Peak

Mt Lemmon

Buford Hill

Bee Canyon

Pinal Ranch

Baldy Bill Point

Maverick Mtn

Sheep Bas in Mtn

Rover Peak

Red Top Mtn

Cypress Butte

Arnold Mesa

Tenmile Cedars

5668 Sunrise Peak

Bodaway Mesa

McDonald Mtn

Mt Davis

Clark Ranch

Safford

Pima

Ninetysix Hills NE

Windy $\mathrm{Hill}$

Snowflake

Hay Hollow

Wins low

Colorado City 
NATIONAL, GAZETTEER--ARIZONA 1986

\begin{tabular}{|c|c|c|c|c|c|c|c|}
\hline FEATURE NAME & $\begin{array}{l}\text { FEATURE } \\
\text { CLASS }\end{array}$ & STATUS & COUNTY & COORDINATE & $\begin{array}{l}\text { SOURCE } \\
\text { COORDINATE }\end{array}$ & $\begin{array}{c}\text { ELEV } \\
\text { FT }\end{array}$ & MAP NAME \\
\hline $\begin{array}{l}\text { Ho-Hos-Keli Wash } \\
\text { Cottonwood Wash } \\
\text { Cottonwood Wash } \\
\text { Cottonwood Wash } \\
\text { Cottonwood Wash Bridge }\end{array}$ & $\begin{array}{l}\text { valley } \\
\text { valley } \\
\text { valley } \\
\text { bridge }\end{array}$ & $\begin{array}{l}\text { VARIANT } \\
\text { BGN } \\
\text { BGN } \\
\text { BGN } \\
\text { UNOFF }\end{array}$ & $\begin{array}{l}\text { Mohave } \\
\text { Navajo } \\
\text { Mohave } \\
\text { Navajo }\end{array}$ & $\begin{array}{l}361907 \mathrm{~N} 1135925 \mathrm{~W} \\
363849 \mathrm{~N} 1101049 \mathrm{~W} \\
365827 \mathrm{N11} 131546 \mathrm{~W} \\
350020 \mathrm{~N} 1103910 \mathrm{~W}\end{array}$ & $\begin{array}{l}364724 N 1135034 W \\
363744 N 1101312 W \\
365507 N 1130537 W\end{array}$ & & $\begin{array}{l}\text { Gyp Hills } \\
\text { Kayenta East } \\
\text { Rock Canyon } \\
\text { Wins low }\end{array}$ \\
\hline $\begin{array}{l}\text { Cottonwood Wash Dam } \\
\text { Cottonwood Wash Spring } \\
\text { Cottonwood Well } \\
\text { Cottonwood Well } \\
\text { Cottonwood Well } \\
\text { Cottonwood Well } \\
\text { Cottonwood Well } \\
\text { Cottonwood Well } \\
\text { Cottonwood Windmill } \\
\text { Cottonwood Windmill }\end{array}$ & $\begin{array}{l}\text { dam } \\
\text { spring } \\
\text { well } \\
\text { well } \\
\text { well } \\
\text { well } \\
\text { well } \\
\text { well } \\
\text { locale } \\
\text { locale }\end{array}$ & $\begin{array}{l}\text { UNOFF } \\
\text { BGN } \\
\text { UNOFF } \\
\text { UNOFF } \\
\text { UNOFF } \\
\text { UNOFF } \\
\text { UNOFF } \\
\text { UNOFF } \\
\text { BGN } \\
\text { BGN }\end{array}$ & $\begin{array}{l}\text { Gila } \\
\text { Yavapai } \\
\text { Pinal } \\
\text { Gila } \\
\text { Yavapai } \\
\text { Mohave } \\
\text { Navajo } \\
\text { Apache } \\
\text { Pima } \\
\text { Yavapai }\end{array}$ & $\begin{array}{l}332300 \mathrm{~N} 1105812 \mathrm{~W} \\
345118 \mathrm{~N} 1124650 \mathrm{~W} \\
332258 \mathrm{~N} 1111033 \mathrm{~W} \\
333249 \mathrm{~N} 1104005 \mathrm{~W} \\
342915 \mathrm{~N} 1114416 \mathrm{~W} \\
350212 \mathrm{~N} 1141959 \mathrm{~W} \\
350231 \mathrm{N1} 102605 \mathrm{~W} \\
355944 \mathrm{~N} 1093207 \mathrm{~W} \\
314539 \mathrm{~N} 1103704 \mathrm{~W} \\
340428 \mathrm{~N} 1121635 \mathrm{~W}\end{array}$ & & $\begin{array}{l}4278 \\
5009\end{array}$ & $\begin{array}{l}\text { Inspiration } \\
\text { Seepage Mtn } \\
\text { Iron Mountain } \\
\text { Chrome Butte } \\
\text { Hackberry Mtn } \\
\text { Mount Nutt } \\
\text { Humpy Camp Well } \\
\text { Ganado One NE } \\
\text { Spring Water Canyon } \\
\text { Columbia }\end{array}$ \\
\hline $\begin{array}{l}\text { Cottonwood Windmill } \\
\text { Cott Tank } \\
\text { Cougar Canyon } \\
\text { Cougar Canyon } \\
\text { Cougar Canyon Tank } \\
\text { Cougar Lake } \\
\text { Cougar Mine } \\
\text { Cougar Mine } \\
\text { Cougar Tank } \\
\text { Cougar Tank }\end{array}$ & $\begin{array}{l}\text { locale } \\
\text { reservoir } \\
\text { valley } \\
\text { valley } \\
\text { reservoir } \\
\text { lake } \\
\text { mine } \\
\text { mine } \\
\text { reservoir } \\
\text { reservoir }\end{array}$ & $\begin{array}{l}\text { BGN } \\
\text { BGN } \\
\text { BGN } \\
\text { BGN } \\
\text { BGN } \\
\text { BGN } \\
\text { UNOFF } \\
\text { UNOFF } \\
\text { BGN } \\
\text { BGN }\end{array}$ & $\begin{array}{l}\text { Navajo } \\
\text { Santa Cruz } \\
\text { Gila } \\
\text { Yavapai } \\
\text { Yavapai } \\
\text { Coconino } \\
\text { Yavapai } \\
\text { Yavapai } \\
\text { Yavapai } \\
\text { Coconino }\end{array}$ & $\begin{array}{l}363818 \mathrm{~N} 1101142 \mathrm{~W} \\
312954 \mathrm{~N} 1103639 \mathrm{~W} \\
334236 \mathrm{~N} 1105207 \mathrm{~W} \\
340357 \mathrm{~N} 1114958 \mathrm{~W} \\
340420 \mathrm{~N} 1115020 \mathrm{~W} \\
362858 \mathrm{~N} 1121124 \mathrm{~W} \\
340216 \mathrm{~N} 1121809 \mathrm{~W} \\
341102 \mathrm{~N} 1122007 \mathrm{~W} \\
340414 \mathrm{N1115103W} \\
36091 \mathrm{BN} 1130229 \mathrm{~W}\end{array}$ & $\begin{array}{l}334353 \mathrm{~N} 1105530 \mathrm{~W} \\
340304 \mathrm{~N} 1115107 \mathrm{~W}\end{array}$ & & $\begin{array}{l}\text { Kayenta East } \\
\text { Canelo Pass } \\
\text { Dagger Peak } \\
\text { Rover Peak } \\
\text { Rover Peak } \\
\text { Kanabownits Spring } \\
\text { Columbia } \\
\text { Crown King } \\
\text { Rover Peak } \\
\text { Vulcans Throne }\end{array}$ \\
\hline $\begin{array}{l}\text { Coughran Canyon } \\
\text { Cowghran Canyon } \\
\text { Skull Valley } \\
\text { Skull Valley Wash } \\
\text { Coughran Ranch } \\
\text { Coulee Tank } \\
\text { Coulter Cabin } \\
\text { Coulter Hill } \\
\text { Coulter Mountain } \\
\text { Coulter Park }\end{array}$ & $\begin{array}{l}\text { locale } \\
\text { reservoir } \\
\text { locale } \\
\text { summit } \\
\text { summit } \\
\text { flat }\end{array}$ & $\begin{array}{l}\text { BGN } 1979 \\
\text { VARIANT } \\
\text { VARIANT } \\
\text { VARIANT } \\
\text { UNOFF } \\
\text { BGN } \\
\text { BGN } \\
\text { BGN } \\
\text { BGN } \\
\text { BGN }\end{array}$ & $\begin{array}{l}\text { Cochise } \\
\text { Gila } \\
\text { Coconino } \\
\text { Coconino } \\
\text { Coconino } \\
\text { Coconino }\end{array}$ & $\begin{array}{l}312804 \mathrm{~N} 1100429 \mathrm{~W} \\
340256 \mathrm{~N} 1112015 \mathrm{~W} \\
350115 \mathrm{~N} 1113641 \mathrm{~W} \\
350011 \mathrm{~N} 1113620 \mathrm{~W} \\
350029 \mathrm{N1} 113748 \mathrm{~W} \\
350105 \mathrm{~N} 1113714 \mathrm{~W}\end{array}$ & $343321 N 1124302 W$ & 7712 & $\begin{array}{l}\text { Hereford } \\
\text { Gisela } \\
\text { Lower Lake Mary } \\
\text { Lower Lake Mary } \\
\text { Mountainaire } \\
\text { Lower Lake Mary }\end{array}$ \\
\hline $\begin{array}{l}\text { Coulter Park Tank } \\
\text { Coulter Ridge } \\
\text { Coulter Tank } \\
\text { Coulter Tank } \\
\text { Council Rock } \\
\text { Country Club Annex Park } \\
\text { Holly Park }\end{array}$ & $\begin{array}{l}\text { reservoir } \\
\text { ridge } \\
\text { reservoir } \\
\text { reservoir } \\
\text { pillar } \\
\text { park }\end{array}$ & $\begin{array}{l}\text { BGN } \\
\text { BGN } \\
\text { BGN } \\
\text { BGN } \\
\text { BGN } \\
\text { ADNIN } \\
\text { VARIANT }\end{array}$ & $\begin{array}{l}\text { Coconino } \\
\text { Coconino } \\
\text { Apache } \\
\text { Coconino } \\
\text { Cochise } \\
\text { Pima }\end{array}$ & $\begin{array}{l}350131 \mathrm{~N} 1113728 \mathrm{~W} \\
350048 \mathrm{~N} 1113756 \mathrm{~W} \\
342357 \mathrm{~N} 1091019 \mathrm{~W} \\
350018 \mathrm{~N} 1113801 \mathrm{~W} \\
315433 \mathrm{~N} 1100156 \mathrm{~W} \\
321143 \mathrm{~N} 1105525 \mathrm{~W}\end{array}$ & & 5128 & $\begin{array}{l}\text { Lower Lake Mary } \\
\text { Mountainaire } \\
\text { Mesa Parada NW } \\
\text { Mountainaire } \\
\text { Knob Hill } \\
\text { Tucson }\end{array}$ \\
\hline $\begin{array}{l}\text { Country Club Trailer Grove } \\
\text { Country Cousins Mobile Mecca } \\
\text { Country Estates (subdivision) }\end{array}$ & $\begin{array}{l}\text { locale } \\
\text { locale } \\
\text { ppl }\end{array}$ & $\begin{array}{l}\text { UNOFF } \\
\text { UNOFF } \\
\text { BGN }\end{array}$ & $\begin{array}{l}\text { Maricopa } \\
\text { Maricopa } \\
\text { Yavapai }\end{array}$ & $\begin{array}{l}332852 \mathrm{~N} 1120030 \mathrm{~W} \\
332333 \mathrm{~N} 1114958 \mathrm{~W} \\
343215 \mathrm{~N} 1115057 \mathrm{~W}\end{array}$ & & $\begin{array}{l}1165 \\
1205 \\
3060\end{array}$ & $\begin{array}{l}\text { Phoenix } \\
\text { Mesa } \\
\text { Camp Verde }\end{array}$ \\
\hline $\begin{array}{l}\text { Country Fair Shopping Center } \\
\text { Country Gable Park } \\
\text { Country Gables Park } \\
\text { Country Greens at Villa de } \\
\text { Paz (subdivision) }\end{array}$ & $\begin{array}{l}\text { locale } \\
\text { park } \\
\text { park } \\
\text { ppl }\end{array}$ & $\begin{array}{l}\text { UNOFF } \\
\text { ADMIN } \\
\text { ADMIN } \\
\text { BGN }\end{array}$ & $\begin{array}{l}\text { Pima } \\
\text { Maricopa } \\
\text { Maricopa } \\
\text { Maricopa }\end{array}$ & $\begin{array}{l}321222 \mathrm{~N} 1105223 \mathrm{~W} \\
333715 \mathrm{~N} 1120738 \mathrm{~W} \\
333720 \mathrm{~N} 1121012 \mathrm{~W} \\
33300 \mathrm{BN} 1121709 \mathrm{~W}\end{array}$ & & $\begin{array}{l}2590 \\
1040\end{array}$ & $\begin{array}{l}\text { Tucson East } \\
\text { Glendale } \\
\text { Glendale } \\
\text { El Mirage }\end{array}$ \\
\hline $\begin{array}{l}\text { Country Hills Mobile Estates } \\
\text { Country Horizons (subdivision) } \\
\text { Country Line Interchange } \\
\text { Country Manor Subdivision } \\
\text { Mini Park }\end{array}$ & $\begin{array}{l}\text { locale } \\
\text { ppl } \\
\text { crossing } \\
\text { park }\end{array}$ & $\begin{array}{l}\text { UNOFF } \\
\text { BGN } \\
\text { UNOFF } \\
\text { ADMIN }\end{array}$ & $\begin{array}{l}\text { Maricopa } \\
\text { Maricopa } \\
\text { Coconino } \\
\text { Maricopa }\end{array}$ & $\begin{array}{l}332745 N 1121856 \mathrm{~W} \\
333425 \mathrm{~N} 1115330 \mathrm{~W} \\
351301 \mathrm{~N} 112261 \mathrm{~W} \\
332710 \mathrm{~N} 1114802 \mathrm{~W}\end{array}$ & & $\begin{array}{l}995 \\
1350\end{array}$ & $\begin{array}{l}\text { Tolleson } \\
\text { Paradise Valley } \\
\text { Ash Fork } \\
\text { Mesa }\end{array}$ \\
\hline $\begin{array}{l}\text { Country Manor Subdivision } \\
\text { Water Retention Basin } \\
\text { Country Meadows (subdivision) } \\
\text { Country Ridge (subdivision) } \\
\text { Country Side Estates Park Site } \\
\text { Countryside Mobile Home Park } \\
\text { Country Trace (subdivision) } \\
\text { Country Villa (trailer park) } \\
\text { County Fair West (subdivision) } \\
\text { County Line Tank }\end{array}$ & $\begin{array}{l}\text { reservoir } \\
\text { ppl } \\
\text { ppl } \\
\text { park } \\
\text { locale } \\
\text { ppl } \\
\text { locale } \\
\text { ppl } \\
\text { reservoir }\end{array}$ & $\begin{array}{l}\text { BGN } \\
\text { BGN } \\
\text { BGN } \\
\text { ADNIN } \\
\text { UNOFF } \\
\text { BGN } \\
\text { UNOFF } \\
\text { BGN } \\
\text { BGN }\end{array}$ & $\begin{array}{l}\text { Maricopa } \\
\text { Maricopa } \\
\text { Maricopa } \\
\text { Maricopa } \\
\text { Maricopa } \\
\text { Maricopa } \\
\text { Maricopa } \\
\text { Maricopa } \\
\text { Apache }\end{array}$ & $\begin{array}{l}332710 \mathrm{~N} 1114800 \mathrm{~W} \\
333357 \mathrm{~N} 1121702 \mathrm{~W} \\
333924 \mathrm{~N} 1120722 \mathrm{~W} \\
332342 \mathrm{~N} 1114542 \mathrm{~W} \\
332234 \mathrm{~N} 1120605 \mathrm{~W} \\
333805 \mathrm{~N} 1115535 \mathrm{~W} \\
33262 \mathrm{~N} 1122016 \mathrm{~W} \\
332 \mathrm{~B} 40 \mathrm{~N} 1121145 \mathrm{~W} \\
334317 \mathrm{~N} 1095327 \mathrm{~W}\end{array}$ & & $\begin{array}{l}1105 \\
1350 \\
1115 \\
1500 \\
970 \\
1070\end{array}$ & $\begin{array}{l}\text { Mesa } \\
\text { El Mirage } \\
\text { Union Hills } \\
\text { Mesa } \\
\text { Phoenix } \\
\text { Currys Corner } \\
\text { Tolleson } \\
\text { Fowler } \\
\text { Bonito Prairie }\end{array}$ \\
\hline $\begin{array}{l}\text { County Tank } \\
\text { County Well } \\
\text { Coupon Tank } \\
\text { Court House Butte } \\
\text { See Courthouse Rock } \\
\text { Courthouse Butte }\end{array}$ & $\begin{array}{l}\text { reservoir } \\
\text { well } \\
\text { reservoir } \\
\text { summit } \\
\text { summit }\end{array}$ & $\begin{array}{l}\text { BGN } \\
\text { UNOFF } \\
\text { BGN } \\
\text { VARIANT } \\
\text { BGN }\end{array}$ & $\begin{array}{l}\text { Coconino } \\
\text { Yuma } \\
\text { Graham }\end{array}$ & $\begin{array}{l}350223 \mathrm{~N} 1121338 \mathrm{~W} \\
325128 \mathrm{~N} 1132126 \mathrm{~W} \\
333015 \mathrm{~N} 109500 \mathrm{~W}\end{array}$ & & 5451 & $\begin{array}{l}\text { Hearst Mtn } \\
\text { Dome } \\
\text { West Poker Mtn }\end{array}$ \\
\hline
\end{tabular}


NATIONAL GAZETTEER--ARIZONA 1986

\begin{tabular}{|c|c|c|c|c|c|c|c|}
\hline FEATURE NAME & $\begin{array}{l}\text { FEATURE } \\
\text { CLASS }\end{array}$ & STATUS & COUNTY & COORDINATE & $\begin{array}{l}\text { SOURCE } \\
\text { COORDINATE }\end{array}$ & $\begin{array}{c}\text { ELEV } \\
\text { FT }\end{array}$ & MAP NAME \\
\hline $\begin{array}{l}\text { Church House Rock } \\
\text { Courthouse Mountain } \\
\text { Courthouse Mountain } \\
\text { See Courthouse Rock }\end{array}$ & $\begin{array}{l}\text { summit : } \\
\text { summit }\end{array}$ & $\begin{array}{l}\text { VARIANT } \\
\text { BGN } \\
\text { VARIANT }\end{array}$ & $\begin{array}{l}\text { Yuma } \\
\text { Yuma }\end{array}$ & $\begin{array}{l}331209 \mathrm{~N} 1135057 \mathrm{~W} \\
332751 \mathrm{~N} 1132135 \mathrm{~W}\end{array}$ & & 2413 & Engesser Pass \\
\hline $\begin{array}{l}\text { Courthouse Rock } \\
\text { Court House Butte } \\
\text { Courthouse Mountain } \\
\text { Court House Rock } \\
\text { See Cathedral Rock } \\
\text { Courthouse Well } \\
\text { Courthouse Well } \\
\text { Court land } \\
\text { Coury Park } \\
\text { See Oury Park }\end{array}$ & $\begin{array}{l}\text { summit } \\
\text { well } \\
\text { well } \\
\text { locale } \\
\text { park }\end{array}$ & $\begin{array}{l}\text { BGN } 1963 \\
\text { VARIANT } \\
\text { VARIANT } \\
\text { VARIANT } \\
\text { UNOFF } \\
\text { UNOFF } \\
\text { BGN } \\
\text { VARIANT }\end{array}$ & $\begin{array}{l}\text { Yavapai } \\
\text { Maricopa } \\
\text { Coconino } \\
\text { Cochise } \\
\text { Pima }\end{array}$ & $\begin{array}{l}332751 \mathrm{~N} 1132135 \mathrm{~W} \\
344912 \mathrm{~N} 1114733 \mathrm{~W} \\
333121 \mathrm{~N} 113175 \mathrm{BW} \\
350301 \mathrm{~N} 1111409 \mathrm{~W} \\
314612 \mathrm{~N} 1094829 \mathrm{~W} \\
321348 \mathrm{~N} 1105851 \mathrm{~W}\end{array}$ & & 2874 & $\begin{array}{l}\text { Courthouse Well } \\
\text { Anderson Canyon } \\
\text { Turquoise Mountain }\end{array}$ \\
\hline $\begin{array}{l}\text { Covered Wagon Mobile Home Park } \\
\text { Covered Well } \\
\text { See Maish Vaya } \\
\text { Covered Wells } \\
\text { Kia Hoa Toak } \\
\text { Quigotoa } \\
\text { Quijotia } \\
\text { Quijotoa } \\
\text { Rabaho } \\
\text { Tjiuvak }\end{array}$ & $\begin{array}{l}\text { locale } \\
\text { ppl } \\
\text { locale }\end{array}$ & $\begin{array}{l}\text { UNOFF } \\
\text { VARIANT } \\
\text { BGN } \\
\text { VARIANT } \\
\text { VARIANT } \\
\text { VARIANT } \\
\text { VARIANT } \\
\text { VARIANT } \\
\text { VARIANT }\end{array}$ & $\begin{array}{l}\text { Maricopa } \\
\text { Pima } \\
\text { Pima }\end{array}$ & $\begin{array}{l}333155 \mathrm{~N} 1120645 \mathrm{~W} \\
321001 \mathrm{~N} 1120736 \mathrm{~W} \\
321000 \mathrm{~N} 1120730 \mathrm{~W}\end{array}$ & & 1170 & $\begin{array}{l}\text { Sunnys lope } \\
\text { Casa Grande Mts }\end{array}$ \\
\hline $\begin{array}{l}\text { Covered Wells } \\
\text { See Maish Vaya } \\
\text { Cover Lake } \\
\text { Cove School } \\
\text { Cove Spring } \\
\text { Cove Spring } \\
\text { Cove Tank } \\
\text { Cove Tank } \\
\text { Cove Wash } \\
\text { Cove Well }\end{array}$ & $\begin{array}{l}\text { ppl } \\
\text { lake } \\
\text { school } \\
\text { spring } \\
\text { spring } \\
\text { reservoir } \\
\text { reservoir } \\
\text { stream } \\
\text { well }\end{array}$ & $\begin{array}{l}\text { VARIANT } \\
\text { BGN } \\
\text { UNOFF } \\
\text { BGN } \\
\text { BGN } \\
\text { BGN } \\
\text { BGN } \\
\text { BGN } \\
\text { UNOFF }\end{array}$ & $\begin{array}{l}\text { Pima } \\
\text { Apache } \\
\text { Apache } \\
\text { Graham } \\
\text { Mohave } \\
\text { Graham } \\
\text { Yavapai } \\
\text { Apache } \\
\text { Graham }\end{array}$ & $\begin{array}{l}321001 N 1120736 \mathrm{~W} \\
335331 \mathrm{~N} 1095036 \mathrm{~W} \\
363332 \mathrm{~N} 1091303 \mathrm{~W} \\
323258 \mathrm{~N} 1094824 \mathrm{~W} \\
363258 \mathrm{~N} 1135953 \mathrm{~W} \\
323921 \mathrm{N1} 1092633 \mathrm{~W} \\
344232 \mathrm{~N} 1113550 \mathrm{~W} \\
363843 \mathrm{~N} 1090434 \mathrm{~W} \\
323823 \mathrm{~N} 1092734 \mathrm{~W}\end{array}$ & $363247 N 1091642 \mathrm{~W}$ & 3526 & $\begin{array}{l}\text { Hawley Lake West } \\
\text { Cove } \\
\text { Stockton Pass } \\
\text { Red Pockets } \\
\text { Dry Mountain } \\
\text { Apache Maid Mtn } \\
\text { Horse Mesa } \\
\text { Dry Mountain }\end{array}$ \\
\hline $\begin{array}{l}\text { Cowbell Lake } \\
\text { Cowboy Butte } \\
\text { Tank Butte } \\
\text { Cowboy Butte } \\
\text { Cowboy Canyon } \\
\text { Cowboy Canyon } \\
\text { Cowboy Flat } \\
\text { Cowboy Junior Tank } \\
\text { Cowboy Mine } \\
\text { Cowboy Mine }\end{array}$ & $\begin{array}{l}\text { lake } \\
\text { summit } \\
\text { summit } \\
\text { valley } \\
\text { valley } \\
\text { flat } \\
\text { reservoir } \\
\text { mine } \\
\text { mine }\end{array}$ & $\begin{array}{l}\text { BGN } \\
\text { BGN } \\
\text { VARIANT } \\
\text { BGN } \\
\text { BGN } \\
\text { BGN } \\
\text { BGN } \\
\text { BGN } \\
\text { UNOFF } \\
\text { UNOFF }\end{array}$ & $\begin{array}{l}\text { La Paz } \\
\text { Gila } \\
\text { Coconino } \\
\text { Cochise } \\
\text { Gila } \\
\text { Cochise } \\
\text { Coconino } \\
\text { Gila } \\
\text { Yavapai }\end{array}$ & $\begin{array}{l}330611 \mathrm{~N} 1144210 \mathrm{~W} \\
334730 \mathrm{~N} 1101505 \mathrm{~W} \\
365842 \mathrm{~N} 1123126 \mathrm{~W} \\
322044 \mathrm{~N} 1093942 \mathrm{~W} \\
335915 \mathrm{~N} 1102403 \mathrm{~W} \\
312646 \mathrm{~N} 1090315 \mathrm{~W} \\
345829 \mathrm{~N} 1113519 \mathrm{~W} \\
330752 \mathrm{~N} 1105044 \mathrm{~W} \\
343319 \mathrm{~N} 1131039 \mathrm{~W}\end{array}$ & $\begin{array}{l}321621 N 1094226 \mathrm{~W} \\
340313 \mathrm{~N} 1102132 \mathrm{~W}\end{array}$ & 5048 & $\begin{array}{l}\text { Picacho SW } \\
\text { Carrizo SE } \\
\text { Fredonia } \\
\text { Railroad Pass } \\
\text { Cibecue Peak } \\
\text { Guadalupe Spring } \\
\text { Mormon Mountain } \\
\text { El Capitan Mtn } \\
\text { Bagdad }\end{array}$ \\
\hline $\begin{array}{l}\text { Cowboy Peaks } \\
\text { Cowboy Spring } \\
\text { Cowboy Spring } \\
\text { Cowboy Spring } \\
\text { Cowboy Swimming Hole } \\
\text { Cowboy Tank } \\
\text { Cowboy Tank } \\
\text { Cowboy Tank } \\
\text { Cowboy Tank } \\
\text { Cowboy Tank }\end{array}$ & $\begin{array}{l}\text { summit } \\
\text { spring } \\
\text { spring } \\
\text { spring } \\
\text { spring } \\
\text { reservoir } \\
\text { reservoir } \\
\text { reservoir } \\
\text { reservoir } \\
\text { reservoir }\end{array}$ & $\begin{array}{l}\text { BGN } \\
B G N \\
B G N \\
B G N \\
B G N \\
B G N \\
B G N \\
B G N \\
B G N \\
B G N\end{array}$ & $\begin{array}{l}\text { Yavapai } \\
\text { Gila } \\
\text { Gila } \\
\text { Apache } \\
\text { Cochise } \\
\text { Pima } \\
\text { Graham } \\
\text { Gila } \\
\text { Yavapai } \\
\text { Coconino }\end{array}$ & $\begin{array}{l}343335 \mathrm{~N} 113105 \mathrm{BW} \\
335923 \mathrm{~N} 1102401 \mathrm{~W} \\
335924 \mathrm{~N} 1100122 \mathrm{~W} \\
340301 \mathrm{~N} 1094337 \mathrm{~W} \\
321631 \mathrm{~N} 1093242 \mathrm{~W} \\
315222 \mathrm{~N} 1110933 \mathrm{~W} \\
330925 \mathrm{~N} 1094328 \mathrm{~W} \\
334739 \mathrm{~N} 1101520 \mathrm{~W} \\
344004 \mathrm{~N} 1123801 \mathrm{~W} \\
345820 \mathrm{~N} 1113438 \mathrm{~W}\end{array}$ & & & $\begin{array}{l}\text { Bagdad } \\
\text { Cibecue Peak } \\
\text { Round Top Mtn } \\
\text { Horseshoe Cienega } \\
\text { Luzena } \\
\text { Batamote Hills } \\
\text { Park Creek Cabins } \\
\text { Carrizo SE } \\
\text { Mt Josh } \\
\text { Mormon Mountain }\end{array}$ \\
\hline $\begin{array}{l}\text { Cowboy Tank } \\
\text { Cowboy Wash } \\
\text { Cow Butte } \\
\text { Cow Butte } \\
\text { Cow Butte Tank } \\
\text { Cow Camp } \\
\text { Cow Canyon }\end{array}$ & $\begin{array}{l}\text { reservoir } \\
\text { stream } \\
\text { summit } \\
\text { summit } \\
\text { reservoir } \\
\text { locale } \\
\text { valley }\end{array}$ & $\begin{array}{l}\text { BGN } \\
\text { BGN } \\
\text { BGN } \\
\text { BGN } \\
\text { BGN } \\
\text { BGN } \\
\text { BGN }\end{array}$ & $\begin{array}{l}\text { Coconino } \\
\text { Yavapai } \\
\text { Apache } \\
\text { Apache } \\
\text { Gila } \\
\text { Mohave } \\
\text { Greenlee }\end{array}$ & $\begin{array}{l}352521 \mathrm{~N} 1120548 \mathrm{~W} \\
342909 \mathrm{~N} 1131056 \mathrm{~W} \\
365759 \mathrm{~N} 1091152 \mathrm{~W} \\
365759 \mathrm{~N} 1091152 \mathrm{~W} \\
335250 \mathrm{~N} 1102005 \mathrm{~W} \\
353416 \mathrm{~N} 1142812 \mathrm{~W} \\
331558 \mathrm{~N} 1091715 \mathrm{~W}\end{array}$ & 331748 N1092110W & $\begin{array}{l}5670 \\
5670\end{array}$ & $\begin{array}{l}\text { Squaw Mtn } \\
\text { Thorn Peak } \\
\text { Cow Butte } \\
\text { Cow Butte } \\
\text { Carrizo } \\
\text { Middle Water Spring } \\
\text { Pipestem Mtn }\end{array}$ \\
\hline
\end{tabular}


NATIONAL GAZETTEER--ARIZONA 1986

FEATURE NAME

Cow Canyon

Cow Canyon

Cow Canyon

Cow Canyon

See Crow Canyon

Cow Canyon

Cow Canyon

Cow Creek

Cow Creek

Cow Creek

Cow Creek

Cow Creek Spring

Cow Crossing Tank

See Buck Tank

Cow Crossing Tank Buck Tank

Cowden City Park

Cowden Ranch

Cowell Spring

Cow Flat

Cow Flat

Cow Flat

Cow Flat Mountain

Cowghran Canyon

See Coughran Canyon

Cow Head Saddle

Cowhead Tank

Cowhead Tank

Cowhead Tank

Cowhead Tank

Cowhead Tank

Cow Head Trail Spring

Cowhead Well

Cow $\mathrm{Hill}$

Cow Hill Tank

Cow Lake

Cow Lake

Cowlic

Cow Pasture Butte

Cow Spring

See Popcorn Spring

Cow Spring

Cow Spring

Cow Spring

Cow Springs

Cow Springs

Cow Springs Trading Post

Cow Tank

Cow Tank

Cow Tank

Cow Tank

Cow Tank

Cow Tank

Cow Tank

Cow Trap Tank

Cox-Atkin Tank

Atkin Tank

Coxcomb Hill

Cox Corral Tank

Cox Gulch

Cox Pond

Cox Ranch

Cox Spring

Cox Tank

Cox Tank

Coyote

$$
\text { See Pan Tak }
$$

Coyote Bas in

Coyote Bas in Ranch

Coyote Butte

Coyote Butte

\section{FEATURE}

valley

valley

valley

$\begin{array}{ll}\text { BGN } & \text { Greenlee } \\ \text { BGN } & \text { Yavapai } \\ \text { BGN } & \text { Gila }\end{array}$

COORDINATE

$333622 \mathrm{N1090642 \textrm {W }}$ $341758 \mathrm{~N} 1115917 \mathrm{~W}$ 342257 N1112054W

SOURCE COORDIMATE

ELEV
FT

MAP NAME

$333331 \mathrm{N1090406 \textrm {W }}$

$341833 \mathrm{~N} 1115643 \mathrm{~W}$

$342517 N 1112015 \mathrm{~W}$

Kehl Ridge

\section{VARIANT}

valley

valley

valley

stream

stream

stream

spring

reservoir

$\begin{array}{ll}\text { BGN } & \text { Mohave } \\ \text { BGN } & \text { Moconino } \\ \text { BGN } & \text { Yavapai } \\ \text { BGN } & \text { Gila } \\ \text { BGN } & \text { Mohave } \\ \text { BGN 1979 } & \text { Yavapai } \\ \text { BGN } & \text { Mohave } \\ \text { VARIANT } & \\ & \text { Coconino }\end{array}$

344909 N1134227W 351129 N1105610W $363630 \mathrm{~N} 1135546 \mathrm{~W}$ $335827 \mathrm{N1121736 \textrm {W }}$ $341215 N 1104503 \mathrm{~W}$ $344221 \mathrm{~N} 1140716 \mathrm{~W}$ $350335 N 1131905 \mathrm{~W}$ $350520 \mathrm{~N} 1133306 \mathrm{~W}$

$350553 \mathrm{~N} 1110059 \mathrm{~W}$ $364019 \mathrm{~N} 1134914 \mathrm{~N}$ $340509 \mathrm{~N} 1122228 \mathrm{~W}$ $341300 \mathrm{~N} 1104056 \mathrm{~W}$ $344623 \mathrm{~N} 1135109 \mathrm{~W}$ $345520 \mathrm{~N} 1130900 \mathrm{~W}$

351854N1123110W

reservoir BGN 1976
VARIANT

park

locale UNOFF

spring

flat

flat

flat

summit

valley

BGN

BGN

$B G M$

BGI

BGN

VARIANT

gap

reservoir

reservoir

reservoir

reservoir

reservoir

spring

well

summit

reservoir

BGN
BGN
BGN
BGN
BGN
BGN
BGN
UNOFF
BGN
BGN

Coconino

351916 N1123155W

$332701 \mathrm{N1121554 \textrm {W }}$

$350844 N 1125455 \mathrm{~W}$

$\begin{array}{ll}\text { Yavapai } & 350844 N 1125455 W \\ \text { Yavapai } & 343504 N 1123129 W\end{array}$

Greenlee 333324N1090413W

Navajo 341346N1104227W

Yavapai 345618N1120317W

335904 N1105502W

Yavapai

343010 N1124143W

$321213 \mathrm{~N} 1103554 \mathrm{~W}$

$312407 N 1105841 \mathrm{~W}$

$324848 \mathrm{~N} 1105035 \mathrm{~W}$

$324850 \mathrm{~N} 1105036 \mathrm{~W}$

$333215 N 1092912 \mathrm{~W}$

344309 N1111109W

320908 N1103300W

$324817 \mathrm{~N} 1104720 \mathrm{~W}$

$345226 \mathrm{~N} 1112049 \mathrm{~W}$

345148 N1112059W

$\begin{array}{llll}\text { lake } & \text { BGN } & \text { Navajo } & 342013 N 1095348 \mathrm{~W} \\ \text { lake } & \text { BGN } & \text { Coconino } & 345313 \mathrm{~N} 1111848 \mathrm{~W} \\ \text { ppl } & \text { BGN } & \text { Pima } & 314830 \mathrm{~N} 1115918 \mathrm{~W} \\ \text { summit } & \text { BGN } & \text { Gila } & 335240 \mathrm{~N} 1102037 \mathrm{~W} \\ & \text { VARIANT } & & \\ \text { spring } & & \text { Gila } & 334318 \mathrm{~N} 1101831 \mathrm{~W} \\ \text { spring } & \text { BGN } & \text { Navajo } & 354142 \mathrm{~N} 1100039 \mathrm{~W} \\ \text { spring } & \text { BGN } & \text { Apache } & 361746 \mathrm{~N} 1094926 \mathrm{~W} \\ \text { spring } & \text { BGN } & \text { Apache } & 363138 \mathrm{~N} 1091840 \mathrm{~W} \\ \text { spring } & \text { BGN } & \text { Apache } & 355734 \mathrm{~N} 1095502 \mathrm{~W}\end{array}$

locale BGN Coconino 362447N1104918

locale BGN $\quad$ Coconino $362445 \mathrm{~N} 1104912 \mathrm{~W}$

reservoir BGN Coconino 344000N1112050W

$344902 \mathrm{~N} 1112901 \mathrm{~W}$

reservoir BGN 1977 Coconino 350520N1121650W

reservoir BGN Coconino 353204N1120827W

reservoir BGN Coconino

reservoir BGN Coconino 354352N1120930W

reservoir BGN Coconino 344431N1110530W

reservoir $\quad B G$

VARIANT

summit BGN

reservoir $B G$

reserv

reservoir

locale

spring

reservoir

reservoir

BGN

BGN

UNOFF

BGN

$B G$

BGN

Mohave

Coconino

$351929 \mathrm{~N} 1121530 \mathrm{~W}$

Santa Cruz $312826 N 1104713 W$

Mohave 363653N1133540W

Graham 324208N1091335W

Yavapai 343156N1120650W

$350724 N 1115101 \mathrm{~W}$
$363625 \mathrm{~N} 1132825 \mathrm{~W}$

$312707 N 1104546 W$

VARIANT

locale

bas in

$\mathrm{ppl}$

summ it

summit

$\begin{array}{ll}\text { BGN } & \text { Pima } \\ \text { BGN } & \text { Coconino } \\ \text { BGN } 1977 & \text { Coconino } \\ \text { BGN } & \text { Coconino }\end{array}$

$320042 \mathrm{~N} 1113353 \mathrm{~W}$

$345040 \mathrm{~N} 1112530 \mathrm{~W}$

$345033 \mathrm{~N} 1112549 \mathrm{~W}$

$335115 \mathrm{~N} 1103040 \mathrm{~W}$

$365804 \mathrm{~N} 1120038 \mathrm{~W}$
Tucker Mesa NW

Red Pockets

Governors Peak

Parallel Canyon

Buck Mountains ME

Devils Hump

Aust in Peak

Horse Trap Mesa

Tolleson

Purcell Canyon

Iron Springs

Bive

Chediski Peak

Sycamore Bas in

0574 McFadden Peak

Mica Mountain

Rio Rico

Putnam Wash

Putnam Wash

Baldy Bill Point

Hay Lake

Mica Mountain

Putnam Wash

7582 Jaycox Mtn

7326 Jaycox Mtn

Silver Springs

Kinnikinick Lake

2098 Cowlic

6251 Carrizo

Ts in Naan Tee

Sweathouse Peak

Mexican Cry Mesa

Beeshsikad Spring

Cow Springs

Cow Springs

Turkey Mtn

Hutch Mtn

Kinnikinick Lake

Matterhorn

Howard Lake

Standing Rocks

Valle Tank

Quayle Hill

5164 Little Tanks

7045 Hearst Mtn

Freezeout Mtn

Cumero Canyon

Sullivan Draw South

Hot Well

Dutton $\mathrm{Hill}$

Little Tanks

Hutch Mtn

Hutch Mtn

5615 Mule Hoof Bend

6340 Coyote Buttes 
FEATURE NAME

Coyote Canyon

Coyote Canyon

Coyote Canyon

Coyote Canyon

Coyote Canyon
Coyote Canyon
Coyote Canyon
Coyote Creek
Coyote Creek
Coyote Creek
See Morrison Creek
Coyote Creek
$\quad$ Mamie Creek
Coyote Creek

See Coyote Wash

Coyote Field

Coyote Hills

Coyote Hold Dan

Coyote Hole Spring Coyote Spring

Coyote Holes Spring

Coyote Hole Tank

Coyote Indian Village

$$
\text { See Pan Tak }
$$

Coyote Joe Rock

Coyote Knoll

Coyote Lake See Pratt Lake

Coyote Mine

Coyote Mountains

Coyote Park Tank

Coyote Pass

Coyote Pass

Coyote Peak

Coyote Peak

Coyote Peak

Coyote Peak Tank

Coyote Pup Tank

Coyote Ranch

Coyote Ranch

Coyote Reservoir See H-V Reservoir

Coyotero Hills

Coyote Spring

Coyote Spring

Coyote Spring

Coyote Spring

Coyote Spring

Coyote Spring

Coyote Spring

Coyote Spring

See Coyote Hole Spring

Coyote Spring

Coyote Spring

Coyote Spring

Coyote Spring

Coyote Spring

Coyote Spring

Coyote Spring

Coyote Spring

Coyote Spring

Coyote Spring

Coyote Spring

Coyote Spring

Coyote Spring

Coyote Spring

Coyote Spring

Cohenour Spring

Coyote Spring

Kohinoor Spring

Coyote Spring

\section{FEATUR} CLASS

STATUS

COUNTY

valley

valley

valley

valley

$\begin{array}{ll}\text { BGN } & \text { Cochise } \\ \text { BGN } & \text { Pima } \\ \text { BGN } & \text { Gila }\end{array}$

BGN 1977 Gila

valley

valley

valley

stream

stream

strean

stream

strean

BGI

BGN Yavapai

BGN Mohave

BGN Apache

BARIANT Apache

VARIANT

VARIANT

Apache

COORDINATE

$313338 \mathrm{~N} 1102302 \mathrm{~W}$ 313507 N1114048W $332850 \mathrm{~N} 1104850 \mathrm{~W}$ $334931 \mathrm{~N} 1103233 \mathrm{~W}$

$344225 \mathrm{~N} 1121301 \mathrm{~W}$ $345246 \mathrm{N1} 130510 \mathrm{~W}$ $361800 \mathrm{~N} 1134204$ $335050 \mathrm{~N} 1091818 \mathrm{~W}$

335712N1094530W

$335925 \mathrm{~N} 1090350 \mathrm{~W}$

$341815 N 1092123 W$

$360632 N 1090944 W$

loca

dam

spring

spring

spring

reservoir

locale

pillar

BGN

BGN

UNOFF

BGN

VARIANT

BGN

VARIANT

sumit

BGN

Pima

Apache

Gila

Gila

Mohave

Gila

Pima

Navajo

$321155 \mathrm{~N} 1113947 \mathrm{~W}$

341016 N1091410

$331722 N 1103751 \mathrm{~W}$

$331658 \mathrm{~N} 1103756 \mathrm{~W}$

$351302 N 1140652 \mathrm{~W}$

$331721 \mathrm{~N} 1103750 \mathrm{~W}$

$320042 N 1113353 \mathrm{~W}$

$350923 \mathrm{~N} 1101412 \mathrm{~W}$

$324804 N 1095410 \mathrm{~W}$

340132N1090415W

$330405 N 1133730 \mathrm{~N}$

$315956 \mathrm{~N} 1113210 \mathrm{~W}$

$345917 \mathrm{~N} 1113851 \mathrm{~W}$

$313626 \mathrm{~N} 1113858 \mathrm{~W}$

$351232 \mathrm{~N} 1140609 \mathrm{~W}$

$323044 \mathrm{~N} 1140019 \mathrm{~W}$

$324930 \mathrm{~N} 1110414 \mathrm{~W}$

ummi

summit

$B G N$
$B G N$

summit

reservoir

locale

locale

reservoir

summit

reservoir

spring

BGN

BGN

UNOFF

UNOFF

VARIANT

BGN 1917 Gila

BGN

spring

spring

spring

spring

spring

spring

spring

spring

spring

BGN

BGN

BGN

BGN

BGN

VARIANT

BGN

BGN

BGN

spring

spring

spring

spring

spring

spring

spring

spring

spring

spring

\section{BGN}

BGN

BGK

BGN

BGN

BGN

BGN

BGN

BGN

spring

BGN

spring

BGN

VARIANT

VARIANT

spring

BGN

spring

$332904 N 1134334 W$

$332940 \mathrm{~N} 1134606 \mathrm{~W}$

44919N1113904W

324939N1110304W

$341018 N 1090845 \mathrm{~W}$

$340243 \mathrm{~N} 1090315 \mathrm{~W}$

UNKNOWN

345637N1132950

315058 N1102630

$320231 \mathrm{~N} 1103413 \mathrm{~W}$

$322711 \mathrm{M1} 104119$

$325825 \mathrm{~N} 1090548 \mathrm{~W}$

$330019 N 1094141 \mathrm{~W}$

$331234 N 1095712 \mathrm{~W}$

$331658 \mathrm{~N} 1103756 \mathrm{~W}$

$332155 \mathrm{~N} 1105655 \mathrm{~W}$

$332845 \mathrm{~N} 1104736 \mathrm{~W}$

$334435 \mathrm{~N} 1112228 \mathrm{~W}$

Maricopa

$334906 \mathrm{~N} 1095442 \mathrm{~W}$

$335047 \mathrm{~N} 1102532 \mathrm{~W}$

$335132 N 1100258 \mathrm{~W}$

$341017 N 1090917 \mathrm{~W}$

$341155 N 1115037 \mathrm{~W}$

342640 N1110920W

$344233 \mathrm{~N} 1121202 \mathrm{~W}$

$352041 \mathrm{~N} 1102754 \mathrm{~W}$

352914 N1112135

353046 N1100835W

$353159 \mathrm{~N} 1143004 \mathrm{~W}$

$353728 N 1134800 \mathrm{~W}$

$353911 \mathrm{~N} 1103350 \mathrm{~W}$

$355015 \mathrm{~N} 1102302 \mathrm{~W}$

\section{$\begin{array}{cc}\text { SOURCE } & \text { ELEV } \\ \text { COORDINATE } & \text { FT }\end{array}$ \\ 313237N1102441W}

MAP NAME $313842 \mathrm{~N} 1113824 \mathrm{~W}$ $332839 N 1104717 \mathrm{~W}$ $335058 N 1102917 \mathrm{~W}$

Pyeatt Ranch Caponera Peak Globe

Mule Hoof Bend

344253N1121054W $345410 \mathrm{~N} 1130950 \mathrm{~W}$ $361906 \mathrm{~N} 1134150 \mathrm{~W}$ $334859 \mathrm{~N} 1091044 \mathrm{~W}$ $335758 \mathrm{~N} 1094244 \mathrm{~W}$

$335925 N 1090350 \mathrm{~W}$

Hickey Mountain Mount Hope Mustang Point Buffalo Crossing Hawley Lake West

Lyman Lake

Black Hills

7810 Coyote Hills Cutter

Cutter

Kingman

Cutter

Turkey Track Butte

3900 Shingle Mill Mtn

Palomas Mts West

Kitt Peak

Munds Park

Caponera Peak

Kingman

2808 Wellton SE

3973 Ninetysix Hills SE

2300 Coyote Peak 
NATIONAL GAZETTEER--ARIZONA 1986

\section{FEATURE NAME}

Coyote Spring

Coyote Spring

Coyote Spring

Coyote Spring

Coyote Spring

Coyote Spring

See Pan Tak

Coyote Springs

Coyote Springs

Coyote Springs

See Maito

Coyote Springs

Coyotes Spring

See Pan Tak

Coyote Tank

Coyote Tank

Coyote Tank

Coyote Tank

Coyote Tank

Coyote Tank

Coyote Tank

Coyote Tank

Coyote Tank

Coyote Tank

Coyote Tank

Coyote Tank

Coyote Tank

Coyote Tank

Coyote Tank

Coyote Tank

Coyote Tank

Coyote Tank

Coyote Tank

Coyote Tank

Coyote Tank

Coyote Tank

Coyote Valley

Coyote Village

Coyote Wash

Coyote Wash

Coyote Wash

Coyote Wash

Coyote Wash

Coyote Wash

Coyote Wash

Coyote Wash

Coyote Wash

See Crystal Creek

Coyote Wash

Coyote Creek

Coyote Wash

Coyote Wash

Coyote Wash

Coyote Wash

Castle Butte Wash

Corn Creek

Corn Wash

Ki-ote-Te wash

South Fork Corn Wash

Whe-yol-da-sah Wash

Coyote Wash Channel

Coyote Water

Coyote Water

See Maito

Coyote Well

Coyote Well

Coyote Well

Coyote Well

Coyote Well

Coyote Well
FEATURE
CLASS

STATUS

COUNTY

COORDINATE

spring

spring

spring

spring

\section{BGN}

Mohave

Mohave

spring

locale

spring

spring

spring

locale

locale

BGN

VARIANT

BGN

BGN

VARIANT

BGN

VARIANT

Coconino

Pima

Maricopa

Navajo

Apache

Apache

Pina

reservoir

reservoir

reservoir

reservoir

reservoir

reservoir

reservoir

reservoir

reservoir

BGN
$B G N$
$B G N$
$B G N$
$B G N$
$B G N$
$B G N$
$B G N$
$B G N$
$B G N$

reservoir

reservoir

reservoir

reservoir

reservoir

reservoir

reservoir

reservoir

reservoir

BGN
$B G N$
$B G N$
$B G N$
$B G N$
$B G N$
$B G N$
$B G N$
$B G N$
$B G N$

reservoir reservoir

valley

BGN

BGN

VARIANT

locale

stream

stream

stream

stream

stream

stream

stream

stream

stream

stream

stream

valley

valley

$B G N$
$B G N$
$B G I$
$B G I$
$B G$

$B G N$

$B G N$

BGN

$B G N$

BGN

BGN
$B G N$
$B G N$

BGN

BGN

VARIANT

BGN

BGN

valley

\section{BGN 1968}

VARIANT

VARIANT

VARIANT

VARIANT

VARIANT

VARIANT

cana

reservoir

BGN

VARIANT

spring

Yuma

Yuma

Apache

$324131 N 1140938 \mathrm{~W}$

321958 N1135924W

$361615 \mathrm{~N} 1094250 \mathrm{~W}$

well UNOFF

well

well

well

well

well

355938N1100116W

$365612 \mathrm{~N} 1132153 \mathrm{~W}$

365708N1120207W

$320042 \mathrm{~N} 1113353 \mathrm{~W}$

$361615 \mathrm{N1094250 \textrm {W }}$

361538N1094256W

$320042 \mathrm{Ni113353W}$

$312212 \mathrm{~N} 1110901 \mathrm{~W}$

$313729 \mathrm{N1113822 \textrm {W }}$

$315030 \mathrm{N1} 100534 \mathrm{~W}$

$324824 N 1095408 \mathrm{~W}$

324918 N1091659W

$325312 \mathrm{N1092537 \textrm {W }}$

$332222 \mathrm{N1} 092810 \mathrm{~W}$

$335034 \mathrm{N1} 1091409 \mathrm{~W}$

335310N1100119W

Yavapai 341753N1121611W

Navajo $343607 \mathrm{Ni1} 101518 \mathrm{~W}$

Coconino 344400N1110737W

344551Ni130349W

Navajo 344831Ni104144W

$\begin{array}{ll}\text { Yavapai } & 345005 N 1112354 \mathrm{~W} \\ & 345307 \mathrm{N1130548W}\end{array}$

Coconino 352747N1122109W

Coconino 352931Ni121822W

Pima

Pima

Greenlee

Graha

Graham

Maricopa

Apache

Coconino

Coconino

Navajo

$351359 \mathrm{N1104648 \textrm {W }}$

$352244 \mathrm{N1104341 \textrm {W }}$

Santa Cruz 313737 N1110930W

Pima $320007 \mathrm{N1113308 \textrm {W }}$

$320007 \mathrm{~N} 1113308 \mathrm{~W}$

UNOFF

UNOFF

UNOFF
361838 N1134134W

$362457 \mathrm{Ni130759 \textrm {W }}$

$335209 \mathrm{N1122206 \textrm {W }}$

$352330 \mathrm{~N} 1104445 \mathrm{~W} \quad 352619 \mathrm{~N} 1101459 \mathrm{~W}$

$313755 \mathrm{N1113818W}$

$320501 \mathrm{N1103737 \textrm {W }}$

$323257 \mathrm{N1} 090658 \mathrm{~W}$

321711N1135601W

$330056 N 1094145 \mathrm{~W}$

$331750 \mathrm{N1102004 \textrm {W }}$

$334143 \mathrm{N11} 30051 \mathrm{~W}$

$344147 N 1121426 \mathrm{~W}$

$360242 N 1090154 \mathrm{~W}$

$365105 \mathrm{~N} 1120440 \mathrm{~W}$

$351735 \mathrm{~N} 1103529 \mathrm{~W}$

$353028 \mathrm{N1101238 \textrm {W }}$
Yuma

Yavapai 341123N1125534W
Maricopa $\quad 334144 \mathrm{~N} 1125515 \mathrm{~W}$

AZ165

ELEV

Low Mountain Mustang Point Mt Trumbull Nh Rock Canyon

Coyote Buttes

Baldy Mtn

Shonto Butte

Many Farms SW

Alamo Spring

Caponera Peak

Saucito Mtn

Haberstock $\mathrm{Hi} 11$

Shingle Mill Mtn

Ash Peak

Gila Box

Ninetysix Hills NW

Bee Canyon

Nutrioso

Round Top Mtn

Battle Flat

Groom Spring

Calloway Butte

Sheepskin Wash

Hay Lake

Scratch Canyon

Relic Point

Hutch Mtn

Mount Hope

Cataract Tank

Cataract Tank

Pine Hollow Canyon

Presumido Peak

Vail

Round Mtn

Wellton 
NATIONAL GAZETTEER--ARIZONA 1986

\section{FEATURE NAME}

Coyote Well

Coyote We11

Coyote Wells (dry)

Coyote Windmill

Cozen Canyon

CP Butte

C P Flat

C P Spring

CP Tank

Crabtree Butte

Crabtree Creek

Crabtree Park

Crabtree Spring

Crabtree Spring

Crabtree Trail Twenty-two

Crabtree Wash

Crackerbox Canyon

See East Miller Canyon

Crackerbox Canyon

Crackerbox Spring

Cracker Box Tank

Cracker jack Mesa

Cracker jack Mine

Crackerjack Ridge

Cracker Jack Tank See Cracker jack Tank Cracker jack Tank Cracker Jack Tank

Cracker jack Tank

Crack in Rock Ruins

Crack in Rock Trail

Crack Tank

Crack Tank

Cradle Tank

Crag

Cragin School

Craig

See El Tule

Craig Ranch

Craigs Knoll

Cramer Mine

Cramer Tank

Cramm Mountain

Gramm Mountain

Cran Ranch

$$
\text { Kram Ranch }
$$

Crane Lake

Crane School

Cranes Nest Rapids

Crappie Cove

Crapshooter Tank

Crash-up Mountain

Crassman Peak

See Crossman Peak

Crater, The

Crater Canyon

Crater Canyon

Crater $\mathrm{Hill}$

See A 1 Mountain

Crater Lake

Crater Lake

Crater Lake

Crater Mound

See Meteor Crater

Crater Mountain

See Meteor Crater

Crater Mountain

Crater Mountains

See Crater Range

Crater Range

Crater Mountains
FEATURE

CLASS

wel

well

well

locale

COUNTY

COORDINATE

343059N1134303W

$353630 \mathrm{N1} 134558 \mathrm{~W}$

$322358 \mathrm{~N} 1092033 \mathrm{~W}$

$314020 \mathrm{N1094610 \textrm {W }}$

valley

summit

flat

spring

reservoir

sumnit

strean

park

spring

spring

trai

stream

BGN

valley

valley

spring

reservoir

summit

mine

ridge

$\begin{array}{ll}\text { BGN } & \text { Apache } \\ \text { BGN } & \text { Yavapai } \\ \text { BGN } & \text { Graham } \\ \text { BGN } & \text { Maricopa } \\ \text { BGN } & \text { Yavapai } \\ \text { BGN } & \text { Maricopa } \\ \text { BGN } & \text { Greenlee } \\ \text { ADMIN } & \text { Greenlee } \\ \text { BGN } & \text { Maricopa } \\ \text { BGN } & \text { Maricopa }\end{array}$

$334055 \mathrm{~N} 1094307 \mathrm{~W}$ $340622 \mathrm{N1115042 \textrm {W }}$

$324305 N 1095811 \mathrm{~W}$

$335714 \mathrm{N1115014W}$

$340636 \mathrm{~N} 1115049 \mathrm{~W}$

$335000 N 1112719 \mathrm{~W}$

$332956 \mathrm{N1092242 \textrm {W }}$

$333250 \mathrm{N109} 1948 \mathrm{~W}$

$333335 \mathrm{N1111536 \textrm {W }}$

$334929 \mathrm{N1112351 \textrm {W }}$

$333111 \mathrm{N1092040 \textrm {W }}$ $333424 \mathrm{~N} 1111519 \mathrm{~W}$

$343000 \mathrm{~N} 1111456 \mathrm{~W}$

$343015 \mathrm{N1111453 \textrm {W }}$

342950N1111450W

$345338 \mathrm{~N} 1113310 \mathrm{~W}$

$341739 \mathrm{N1112521 \textrm {W }}$

$341704 N 1112515$

$341611 \mathrm{N1112315}$

reservoir

reservoir

reservoir

locale

trail

reservoir

reservoir

reservoir

locale

school

locale

locale

summit

mine

reservoir

summit

lake

school

rapids

bay

reservoir

sumnit

summit

VARIANT

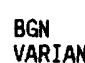

VARIANT

BGN

BGN

UNOFF

$B G N$
$B G N$
$B G N$

BGN

BGN

UNOFF

VARIANT

UNOFF

BGN

UNOFF

BGN

BGN

VARIANT

Apache

Apache

335441 N1090853W

Gila 341647N1112545W

Coconino

Apache

Grahan

Mohave

Pima

UNOFF

VARIANT

BGN

Pina

Apache

Mohave

Mohave

Santa Cruz

Yavapai

Maricopa

$353744 \mathrm{~N}$

$361000 \mathrm{N1} 1092537 \mathrm{~W}$

$353214 N 1135653 \mathrm{~W}$

314117 N1111534W

$331804 \mathrm{~N} 1125405 \mathrm{~W}$

$321537 \mathrm{N1} 105609 \mathrm{~W}$

342247 N1092348W

$362725 N 1130819 \mathrm{~W}$

$362743 \mathrm{N1} 130928 \mathrm{~W}$

$312517 N 1111408 \mathrm{~W}$

$350819 \mathrm{N1} 122359 \mathrm{~W}$

$335821 \mathrm{N1115407 \textrm {W }}$

63822N1115155W

363148 N1120854W

$324238 \mathrm{~N} 1144003 \mathrm{~W}$

$355435 \mathrm{~N} 1144220 \mathrm{~W}$

bas in

valley

valley

summit

lake

lake

crater

crater

summit

range

range
$324020 \mathrm{N1} 100914 \mathrm{~W}$
BGN

BGN

BGN

BGN

VARIANT

$360734 \mathrm{~N} 1140517 \mathrm{~W}$

$345954 \mathrm{N1113627 \textrm {W }}$

$332852 \mathrm{~N} 1104600 \mathrm{~W}$

343257N1141112W

BGN

BGN

BGN

VARIANT

BGN

BGN

VARIANT

VARIANT

BGN

BGN
VARIAN

Mohave

Coconino

Gila

Mohave

Apache

Yavapai

Coconino

$350519 \mathrm{N1092347 \textrm {W }}$

$335906 \mathrm{~N} 1122212 \mathrm{~W}$

$353805 \mathrm{N1130158 \textrm {W }}$

Coconino

$351405 \mathrm{~N} 1114409 \mathrm{~W}$

$345049 \mathrm{~N} 1111230 \mathrm{~W}$

351914 N1114558W

$352502 \mathrm{N1114838 \textrm {W }}$

$350141 N 1110121 \mathrm{~W}$

Coconino

Coconino

$350141 N 1110121 \mathrm{~W}$

$343356 \mathrm{N1120311 \textrm {W }}$

$\begin{array}{lll} & \text { Maricopa } & 323656 \mathrm{N1125902W} \\ \text { BGN } & \text { Maricopa }\end{array}$

VARIANT

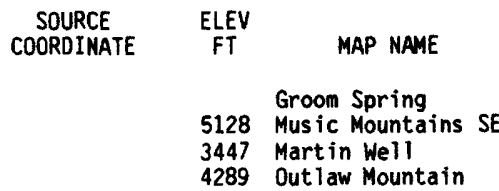

$334259 N 1093920 \mathrm{~W}$

Odart Mtn

Rover Peak

Webb Peak

Humboldt Mtn

Rover Peak

Robinson Mesa

Strayhorse

Horse Mesa Dan

Boulder Mtn

Strayhorse

333306N1111545W Horse Mesa Dam

342640N1111550W

Blue Ridge Reservoir Dane Canyon

Mormon Mountain

5493 Buckhead Mesa

Buckhead Mes a

Buckhead Mesa

Nutrioso

Buckhead Mesa 
NATIONAL GAZETTEER--ARIZONA 1986

\section{FEATURE NAME}

Crater Sinks

Crater Spring

Crater Spring Tank

Crater Tank

Crater Tank

Crater Well

Crater 160

See Colton Crater

Cravey Well

Crawford Hill

Craycroft

Craycroft School

Crazy Bas in Creek

Crazy Cow Tank

Crazy Creek

Crazy Creek Bridge

Crazy Horse Creek

Crazy Horse Spring

Crazy Horse Wash

Crazy Jug Canyon

Crazy Jug Point

Crazy Jug Spring

Crazy Park

Crazy Park Canyon

Crazy Park Tank

Crazy Water Spring

Crazy Woman Wash

Creamery Canyon

Creasey Ranch

Creek Spring

Cregier Airport

Creighton Dam

Creighton Reservoir

Creighton School

Cremation Creek

Cremation Point

See Shoshone Point

Creosote Flat Tank

Crescent Lake

Crescent Lake Dam

Crescent Mine

Crescent Ravine

Crescent Ridge

Crescent Spring

Crescent Tank

Crescent Tank

Crescent Tank

Cresenta Park

Crest Trail

Crest Trail Number One

Hundred Three

Miller Peak Trail

Crest Trail Two Hundred Seventy

Crestriew (subdivision)

Crestwood Shopping Center

Creswell Tank

Creswell Trick Tank

Crevice Point

Crevis Well

Cripple Cat Tank

Cripple Tank

Crismon, Canal (historical)

Crissman Spring

Critchlow flat

Critie Mine

Crittenden (site)

Crizaba Mine

Crocker Spring

Crockett Cabin

Crockett School

Crockett Spring

\section{FEATURE}

CLASS

STATUS

COUNTY

bas in

spring

reservoir

\section{$B G N$}

BGN

Yavapai

Coconino

reservoir

reservoir

well

BGN Yavapa

UNOFF Coconino

crater

well

summit

locale

school

stream

reservoir

stream

stream

spring

stream

valley

cape

spring

flat

$\begin{array}{ll} & \text { Cocon } \\ \text { UNOFF } & \text { Yuma } \\ & \text { Santa }\end{array}$

BGN Santa Cruz

BGN Pima

UNOFF Pima

Yavapai

BGN Coconino

BGN Apache

Apache

BGN Graham

BGN Graham

BGN Coconino

Coconino

Coconino

Coconino

valley

reservoir

spring

stream

valley

locale

spring

airport

dam

reservoir

BGN

BGN Coconino

BGN Coconino

Navajo

Yuma

Mohave

Cochise

Gila

Pima

Cochise

Cochise

school UNOFF Maricopa

stream BGN 1906 Coconino

cliff

reservoir

lake

dam

mine

valley

ridge

spring

reservoir

reservoir

reservoir

park

trail

trail

pp 1

locale

reservoir

reservoir

cliff

well

reservoir

reservoir

canal

spring

VARIANT

Yavapa

Apache

UNOFF Apache

$B G N$

Pinal

BGN 1908 Coconino

BGN Mohave

BGN

BGN

BGN

Maricopa

UNOFF Cochise

VARIANT

UNOFF

Cochise

BGN Maricopa

UNOFF Maricopa

BGN Coconino

BGN Coconino

BGN Navajo

UNOFF Coconino

BGN

BGN

Yuma

Maricopa

Yavapa $i$

flat BGN Apache

mine

locale

mine

spring

locale

school

spring$$
\begin{aligned}
& \text { BGN } \\
& \text { UNOF } \\
& \text { BGN } \\
& \text { UNOF } \\
& \text { BGN } \\
& \text { BGN } \\
& \text { UNOF } \\
& \text { BGN }
\end{aligned}
$$

Yuma

Santa Cruz

Navajo

Yavapai

Maricopa

Pinal
BGN Coconino

trail

UNOFF Yavapai
COORDINATE

$350425 N 1114701 W$

$343351 \mathrm{N1} 120247 \mathrm{~W}$

$352436 \mathrm{N1114843W}$

343440 N1120235W

$353801 \mathrm{N1} 130036 \mathrm{~W}$

$360503 \mathrm{~N} 1111358 \mathrm{~W}$

$353242 \mathrm{~N} 1113810 \mathrm{~W}$

$332621 \mathrm{N1135014W}$

$312009 \mathrm{~N} 1105652 \mathrm{~W}$

$321225 \mathrm{~N} 1105229 \mathrm{~W}$

$320804 \mathrm{~N} 1105229 \mathrm{~W}$

$341454 \mathrm{~N} 1121342 \mathrm{~W}$

$355715 \mathrm{~N} 1115547 \mathrm{~W}$

$350627 N 1093519 \mathrm{~W}$

$350643 \mathrm{~N} 1093519 \mathrm{~W}$

324031 N1095003W

$324715 N 1101125 \mathrm{~W}$

$324536 \mathrm{~N} 1101332 \mathrm{~W}$

$362302 \mathrm{~N} 1122309 \mathrm{~W}$

$362534 \mathrm{~N} 1122410 \mathrm{~W}$

362551 N1122239W

$345742 N 1114314 \mathrm{~W}$

$345840 \mathrm{~N} 1114355 \mathrm{~W}$

$345742 \mathrm{~N} 1114334 \mathrm{~W}$

$352447 \mathrm{~N} 1100858 \mathrm{~W}$

$332356 \mathrm{~N} 1143837 \mathrm{~W}$

344B02N1135649W

$320145 N 1093037 \mathrm{~W}$

$340229 \mathrm{~N} 1105332 \mathrm{~W}$

$321158 \mathrm{~N} 1104724 \mathrm{~W}$

$322235 \mathrm{~N} 1093330 \mathrm{~W}$

$322335 \mathrm{N1093330 \textrm {W }}$

$332758 \mathrm{~N} 1120114 \mathrm{~W}$ 360528 N1120344W

$360241 N 1120332 \mathrm{~W}$

$344016 \mathrm{~N} 1114759 \mathrm{~W}$

$335432 \mathrm{~N} 1092507 \mathrm{~W}$

$335500 \mathrm{~N} 1092536 \mathrm{~W}$

$340307 \mathrm{~N} 1121841 \mathrm{~W}$

$323621 \mathrm{~N} 1105730 \mathrm{~W}$

$361744 N 1121326 \mathrm{~W}$

$352225 \mathrm{~N} 1134939 \mathrm{~W}$

$315747 N 1092511 \mathrm{~W}$

$323557 \mathrm{N1} 105925 \mathrm{~W}$

343621 N1095435W

$332624 N 112211 \mathrm{BW}$

312947 N1102455W

$312404 N 1101834 W$

$315110 \mathrm{~N} 1091719 \mathrm{~W}$

331811 N1115630W

$332914 \mathrm{~N} 1120249 \mathrm{~W}$

343429 N1105500W

$343425 \mathrm{~N} 1105503 \mathrm{~W}$

$363035 \mathrm{~N} 1100624 \mathrm{~W}$

$361926 \mathrm{~N} 1111927 \mathrm{~W}$

$345908 \mathrm{~N} 1131204 \mathrm{~W}$

$332402 \mathrm{~N} 1140131 \mathrm{~W}$

332827 N111475BW

$342504 N 1113958 \mathrm{~W}$

$342536 \mathrm{~N} 1094302 \mathrm{~W}$

$335729 \mathrm{~N} 1133438 \mathrm{~W}$

$313437 \mathrm{~N} 1104342 \mathrm{~W}$

$340029 \mathrm{~N} 1120449 \mathrm{~W}$

$335306 \mathrm{~N} 1095924 \mathrm{~W}$

$341338 \mathrm{~N} 1115348 \mathrm{~W}$

$332716 \mathrm{~N} 1120010 \mathrm{~W}$

$332624 \mathrm{~N} 1110 \mathrm{~B} 05 \mathrm{~W}$

AZ167 


\begin{tabular}{|c|c|c|c|c|c|c|c|}
\hline FEATURE NAME & $\begin{array}{l}\text { FEATURE } \\
\text { CLASS }\end{array}$ & STATUS & COUNTY & COORDINATE & $\begin{array}{l}\text { SOURCE } \\
\text { COORDINATE }\end{array}$ & $\begin{array}{c}\text { ELEV } \\
\text { FT }\end{array}$ & MAP NAME \\
\hline $\begin{array}{l}\text { Crockett Spring } \\
\text { Croft Lateral }\end{array}$ & $\begin{array}{l}\text { spring } \\
\text { canal }\end{array}$ & $\begin{array}{l}B G M \\
B G N\end{array}$ & $\begin{array}{l}\text { Pinal } \\
\text { Yuma }\end{array}$ & 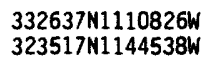 & & & $\begin{array}{l}\text { Iron Mountain } \\
\text { Gadsden }\end{array}$ \\
\hline $\begin{array}{l}\text { Cronley Wash } \\
\text { Crooked Creek }\end{array}$ & stream & $\begin{array}{l}\text { BGN } \\
\text { VARIANT }\end{array}$ & Pinal & $324636 \mathrm{~N} 1104034 \mathrm{~W}$ & $324504 \mathrm{~N} 1104456 \mathrm{~W}$ & & Lookout Mtn \\
\hline $\begin{array}{l}\text { See Little Bonito Creek } \\
\text { Crooked Creek } \\
\text { Lower Cienega Creek }\end{array}$ & $\begin{array}{l}\text { stream } \\
\text { stream }\end{array}$ & $\begin{array}{l}\text { BGN } \\
\text { VARIANT }\end{array}$ & $\begin{array}{l}\text { Apache } \\
\text { Apache }\end{array}$ & $\begin{array}{l}334130 \mathrm{~N} 1094715 \mathrm{~W} \\
334708 \mathrm{~N} 1094209 \mathrm{~W}\end{array}$ & 335151N1093733W & & Marshall Butte \\
\hline $\begin{array}{l}\text { Crooked Finger Spring } \\
\text { Crooked Leg Tank } \\
\text { Crooked Ridge } \\
\text { Crooked Ridge } \\
\text { Crooked Tank }\end{array}$ & $\begin{array}{l}\text { spring } \\
\text { reservoir } \\
\text { ridge } \\
\text { ridge } \\
\text { reservoir }\end{array}$ & $\begin{array}{l}\text { BGN } \\
\text { BGN } \\
\text { BGN } \\
\text { BGN } \\
\text { BGN }\end{array}$ & $\begin{array}{l}\text { Navajo } \\
\text { Yavapai } \\
\text { Navajo } \\
\text { Coconino } \\
\text { Graham }\end{array}$ & $\begin{array}{l}360145 \mathrm{~N} 1101900 \mathrm{~W} \\
341934 \mathrm{N1} 121634 \mathrm{~W} \\
341853 \mathrm{~N} 1102400 \mathrm{~W} \\
362204 \mathrm{~N} 1112147 \mathrm{~W} \\
323952 \mathrm{~N} 1102302 \mathrm{~W}\end{array}$ & & & $\begin{array}{l}\text { Ltl Black Spot Mtn } \\
\text { Battle Flat } \\
\text { Day Spring } \\
\text { Preston Well } \\
\text { Rhodes Peak }\end{array}$ \\
\hline $\begin{array}{l}\text { Crook National Forest } \\
\text { (historical) }\end{array}$ & forest & ADMIN & Gila & $324501 N 1101501 \mathrm{~W}$ & & & Klondyke \\
\hline $\begin{array}{l}\text { Tonto National Forest } \\
\text { Graham Forest Reserve } \\
\text { Apache National Forest } \\
\text { Crook National Forest }\end{array}$ & & $\begin{array}{l}\text { VARIANT } \\
\text { VARIANT } \\
\text { VARIANT } \\
\text { VARIANT }\end{array}$ & & & & & \\
\hline $\begin{array}{l}\text { See Tonto Mational Forest } \\
\text { Crooks Canyon } \\
\text { Crooks Mesa } \\
\text { Crookton }\end{array}$ & $\begin{array}{l}\text { forest } \\
\text { valley } \\
\text { summit } \\
\text { locale }\end{array}$ & $\begin{array}{l}\text { BGN } \\
B G N \\
B G N\end{array}$ & $\begin{array}{l}\text { Gila } \\
\text { Yavapai } \\
\text { Greenlee } \\
\text { Yavapai }\end{array}$ & $\begin{array}{l}335000 \mathrm{~N} 1112500 \mathrm{~W} \\
341742 \mathrm{N1} 122813 \mathrm{~W} \\
333150 \mathrm{~N} 1091514 \mathrm{~W} \\
351743 \mathrm{~N} 1124226 \mathrm{~W}\end{array}$ & $342442 \mathrm{~N} 1122627 \mathrm{~W}$ & 5695 & $\begin{array}{l}\text { Battleship Butte } \\
\text { Strayhorse } \\
\text { Crookton }\end{array}$ \\
\hline $\begin{array}{l}\text { Crookton Interchange } \\
\text { Pineveta Interchange }\end{array}$ & crossing & $\begin{array}{l}\text { UNOFF } \\
\text { VARIAMT }\end{array}$ & Yavapai & $351346 \mathrm{~N} 1123505 \mathrm{~W}$ & & 5060 & Cathedral Caves \\
\hline $\begin{array}{l}\text { Crookton Overpass } \\
\text { Crook Tunnel } \\
\text { Crosby Crossing } \\
\text { Crosby Detention Dam } \\
\text { Crosby Mine } \\
\text { Crosby Mountain } \\
\text { Crosby Mountain Tank } \\
\text { Crosby Peak }\end{array}$ & $\begin{array}{l}\text { crossing } \\
\text { tunnel } \\
\text { locale } \\
\text { dam } \\
\text { mine } \\
\text { summit } \\
\text { reservoir } \\
\text { summit }\end{array}$ & $\begin{array}{l}\text { UNOFF } \\
\text { UNOFF } \\
\text { BGN } \\
\text { UNOFF } \\
\text { UNOFF } \\
\text { BGN } \\
\text { BGN } \\
\text { BGN }\end{array}$ & $\begin{array}{l}\text { Yavapai } \\
\text { Cochise } \\
\text { Apache } \\
\text { Mohave } \\
\text { Yavapai } \\
\text { Yavapai } \\
\text { Yavapai } \\
\text { Yavapai }\end{array}$ & $\begin{array}{l}351726 \mathrm{~N} 1124355 \mathrm{~W} \\
312017 \mathrm{N1094926 \textrm {W }} \\
335442 \mathrm{~N} 1092040 \mathrm{~W} \\
362706 \mathrm{~N} 1131406 \mathrm{~W} \\
342916 \mathrm{~N} 1130611 \mathrm{~W} \\
342915 \mathrm{~N} 1130735 \mathrm{~W} \\
34283 \mathrm{~N} 1130821 \mathrm{~W} \\
343315 \mathrm{~N} 1131221 \mathrm{~W}\end{array}$ & & $\begin{array}{l}4344 \\
4378\end{array}$ & $\begin{array}{l}\text { Crookton } \\
\text { Bisbee SE } \\
\text { Rudd Knoll } \\
\text { Mt Trumbull NW } \\
\text { Malpais Mesa NE } \\
\text { Thorn Peak } \\
\text { Thorn Peak } \\
\text { Bagdad }\end{array}$ \\
\hline $\begin{array}{l}\text { Crosby Reservoir } \\
\text { Crosby Tank }\end{array}$ & & $\begin{array}{l}\text { BGN } \\
\text { VARIANT }\end{array}$ & Mohave & $362430 \mathrm{~N} 1131430 \mathrm{~W}$ & & & Mt Trumbull NW \\
\hline & reservoir & $\begin{array}{l}\text { BGN } \\
\text { VARIANT }\end{array}$ & Yavapai & $343011 \mathrm{N1130812 \textrm {W }}$ & & & Bagdad \\
\hline $\begin{array}{l}\text { See Crosby Reservoir } \\
\text { Crosby Tank } \\
\text { Crosby Tank Reservoir } \\
\text { Crossbred Tank } \\
\text { Cross Canyon } \\
\text { Cross Canyon }\end{array}$ & $\begin{array}{l}\text { reservoir } \\
\text { reservoir } \\
\text { reservoir } \\
\text { reservoir } \\
\text { valley } \\
\text { valley }\end{array}$ & $\begin{array}{l}B G N \\
B G N \\
B G N \\
B G N \\
B G N\end{array}$ & $\begin{array}{l}\text { Mohave } \\
\text { Mohave } \\
\text { Mohave } \\
\text { Apache } \\
\text { Pinal } \\
\text { Apache }\end{array}$ & $\begin{array}{l}362430 \mathrm{~N} 1131430 \mathrm{~W} \\
362743 \mathrm{~N} 1131346 \mathrm{~W} \\
362459 \mathrm{N1} 131400 \mathrm{~W} \\
341036 \mathrm{~N} 1093513 \mathrm{~W} \\
331704 \mathrm{N1110554W} \\
354050 \mathrm{~N} 1092503 \mathrm{~W}\end{array}$ & $\begin{array}{l}331715 \mathrm{~N} 1110449 \mathrm{~W} \\
353951 \mathrm{N1092233W}\end{array}$ & & $\begin{array}{l}\text { Mt Trumbull NW } \\
\text { Mt Trumbull NW } \\
\text { Whiting Knoll } \\
\text { Superior } \\
\text { Kinlichee }\end{array}$ \\
\hline $\begin{array}{l}\text { Cross Canyon Recreation Area } \\
\text { Cross Canyon Trading Post } \\
\text { Cross Current Rapids } \\
\text { Cross Cut Power Plant } \\
\text { Cross D Tank } \\
\text { Crossed Arrows Park } \\
\text { Cross F Ranch } \\
\text { Cross F Spring } \\
\text { Cross Hill } \\
\text { Cross Junior High School }\end{array}$ & $\begin{array}{l}\text { park } \\
\text { locale } \\
\text { rapids } \\
\text { locale } \\
\text { reservoir } \\
\text { park } \\
\text { locale } \\
\text { spring } \\
\text { sumit } \\
\text { school }\end{array}$ & $\begin{array}{l}\text { ADMIN } \\
\text { BGN } \\
\text { BGN } \\
\text { BGN } \\
\text { BGN } \\
\text { ADMIN } \\
\text { UNOFF } \\
\text { BGM } \\
\text { BGN } \\
\text { UNOFF }\end{array}$ & $\begin{array}{l}\text { Apache } \\
\text { Apache } \\
\text { Mohave } \\
\text { Maricopa } \\
\text { Yavapai } \\
\text { Maricopa } \\
\text { Maricopa } \\
\text { Maricopa } \\
\text { Pima } \\
\text { Pima }\end{array}$ & $\begin{array}{l}354307 \mathrm{~N} 1092255 \mathrm{~W} \\
354307 \mathrm{N1} 1092356 \mathrm{~W} \\
355558 \mathrm{~N} 1144245 \mathrm{~W} \\
332623 \mathrm{~N} 1115646 \mathrm{~W} \\
345635 \mathrm{~N} 1120346 \mathrm{~W} \\
333715 \mathrm{~N} 1115655 \mathrm{~W} \\
335504 \mathrm{N1} 112847 \mathrm{~W} \\
335513 \mathrm{~N} 1122829 \mathrm{~W} \\
320018 \mathrm{~N} 1103450 \mathrm{~W} \\
322038 \mathrm{~N} 1105914 \mathrm{~W}\end{array}$ & & 7040 & $\begin{array}{l}\text { Kinlichee } \\
\text { Kinlichee } \\
\text { Ringbolt Rapids } \\
\text { Tempe } \\
\text { Sycamore Basin } \\
\text { Paradise Valley } \\
\text { Reno Pass } \\
\text { Reno Pass } \\
\text { Rincon Peak } \\
\text { Tucson North }\end{array}$ \\
\hline $\begin{array}{l}\text { Cross J Windmill } \\
\text { Crossman Peak } \\
\text { Crassman Peak } \\
\text { Grassman Peak } \\
\text { Grossman Peak }\end{array}$ & $\begin{array}{l}\text { locale } \\
\text { summit }\end{array}$ & $\begin{array}{l}\text { BGN } \\
\text { BGN } \\
\text { VARIANT } \\
\text { VARIANT } \\
\text { VARIANT }\end{array}$ & $\begin{array}{l}\text { Cochise } \\
\text { Mohave }\end{array}$ & 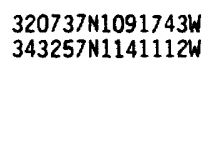 & & 5100 & $\begin{array}{l}\text { Little Wood Canyon } \\
\text { Crossman Peak }\end{array}$ \\
\hline $\begin{array}{l}\text { Cross Mountain } \\
\text { Cross Mountain Dam } \\
\text { Cross P Ranch } \\
\text { Crossroad Tank } \\
\text { Cross Tank }\end{array}$ & $\begin{array}{l}\text { summit } \\
\text { dam } \\
\text { locale } \\
\text { reservoir } \\
\text { reservoir }\end{array}$ & $\begin{array}{l}\text { BGN } \\
\text { UNOFF } \\
\text { UNOFF } \\
\text { BGN } \\
\text { BGN }\end{array}$ & $\begin{array}{l}\text { Yavapai } \\
\text { Yavapai } \\
\text { Gila } \\
\text { Coconino } \\
\text { Gila }\end{array}$ & 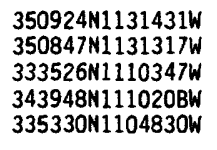 & & $\begin{array}{l}6463 \\
2600\end{array}$ & $\begin{array}{l}\text { Cross Mountain } \\
\text { Cross Mtn } \\
\text { Two Bar Mtn } \\
\text { Quayle Hill } \\
\text { Rock House }\end{array}$ \\
\hline $\begin{array}{l}\text { Cross Triangle Ranch } \\
\text { Cross Triangle Ranch } \\
\text { Cross U Ranch } \\
\text { Cross X Ranch } \\
\text { Cross Y Ranch Airstrip } \\
\text { Cross Y Tank } \\
\text { Croton Springs } \\
\text { Crouch Creek } \\
\text { Crouch Mesa }\end{array}$ & $\begin{array}{l}\text { locale } \\
\text { locale } \\
\text { locale } \\
\text { locale } \\
\text { airport } \\
\text { reservoir } \\
\text { spring } \\
\text { stream } \\
\text { reservoir }\end{array}$ & $\begin{array}{l}\text { UNOFF } \\
\text { UNOFF } \\
\text { UNOFF } \\
\text { UNOFF } \\
\text { AOMIN } \\
\text { BGN } \\
\text { BGN } \\
\text { BGN } \\
\text { BGN }\end{array}$ & $\begin{array}{l}\text { Pinal } \\
\text { Yavapai } \\
\text { Yavapai } \\
\text { Cochise } \\
\text { Yavapai } \\
\text { Gila } \\
\text { Cochise } \\
\text { Gila } \\
\text { Gila }\end{array}$ & $\begin{array}{l}324304 \mathrm{~N} 1110822 \mathrm{~W} \\
344555 \mathrm{N1} 124040 \mathrm{~W} \\
344822 \mathrm{N1124507 \textrm {W }} \\
321126 \mathrm{N11} 100906 \mathrm{~W} \\
340700 \mathrm{~N} 1120540 \mathrm{~W} \\
341322 \mathrm{N1105830 \textrm {W }} \\
320946 \mathrm{~N} 109560 \mathrm{~W} \\
340259 \mathrm{~N} 1105341 \mathrm{~W} \\
341000 \mathrm{~N} 1105325 \mathrm{~W}\end{array}$ & $340834 \mathrm{~N} 1105005 \mathrm{~W}$ & 4640 & $\begin{array}{l}\text { Durham Hills } \\
\text { Simmons } \\
\text { Seepage Mtn } \\
\text { Deepwell Ranch } \\
\text { Squaw Creek Mes a } \\
\text { Oxbow Mtn } \\
\text { Red Bird Hills } \\
\text { Young } \\
\text { Oxbow Mtn }\end{array}$ \\
\hline
\end{tabular}


NATIONAL GAZETTEER--ARIZONA 1986

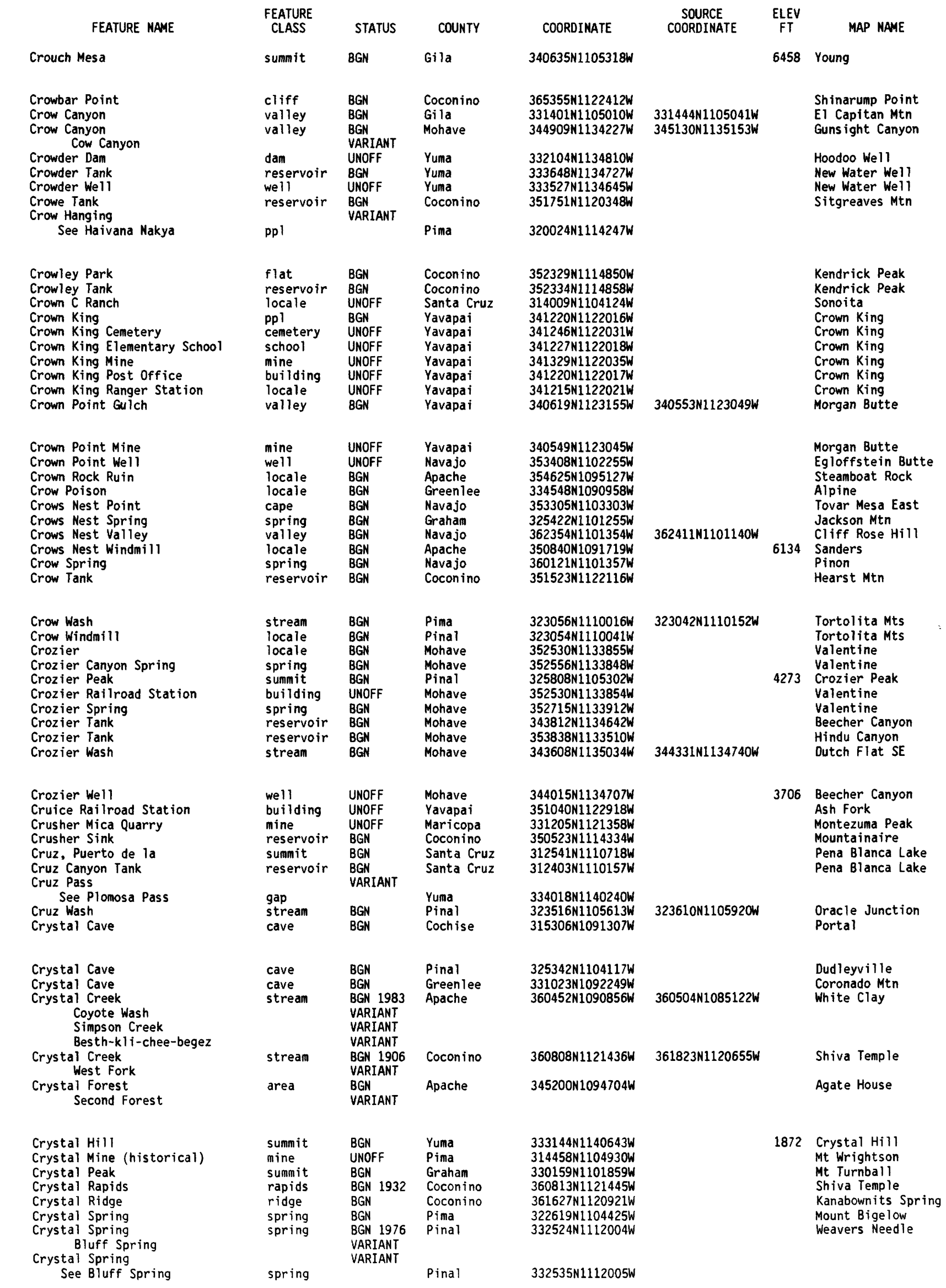


FEATURE CLASS

\section{STATUS}

COUNTY

\section{COORDINATE}

Crystal Spring

Crystal Spring/Butterfly Trail

Crystal Wel

Crystal Wel Crystal Windmill

Crystal Windmill See Crystal Well

Crystoval

See Stoval

C S Canyon

C T Spring

Cuadro Wash

Cuarzo Canyon

$$
\text { See Bonito Canyon }
$$

Cuates Butte

Cuba Mine

Cubb Canyon See Cub Canyon

Cub Canyon Cubb Canyon

Cub Headland

Cub Lake

Cubo See Gu Vo

Cubo Hills See Gu Vo Hills

Cub Spring

Cub Springs

Cucamonga Junct ion

Cuerda de Lena Cuerda de Lena Wash

Cuerda de Lena Wash See Cuerda de Lena

Cueto Well

Cuff Button Spring

Cuisanto Well

Culbertson Memorial Church

Cullen Wash See Centennial Wash

Cullings Well

See Miller Reservoir

Cullins Well

See Miller Reservoir

Culver Spring

Culvert Tank

Culvert Tank

Cumahaut $i$

Cumaro Canyon Cumero Canyon

Cumaro Spring Cumero Spring

Cumaro Wash Martinez Wash

Cumero Canyon Comoro Canyon Comoro Fresno Canyon Cumero Canyon

See Cumaro Canyon

Cumero Mountain

Cumero Spring

See Cumaro Spring

Cumming Ranch

Cummings Lateral

Cummings Mesa

Cummings Mesa

Cummings Reservoir

Cummings Reservoir Dam

Cummings Tank

Cunningham Canyon

Cunningham Creek
$22435 \mathrm{~N} 1122041 \mathrm{~W}$ $362325 \mathrm{N1120545 \textrm {W }}$ $322530 \mathrm{~N} 1104245 \mathrm{~W}$

\begin{tabular}{|c|c|c|c|}
\hline $\begin{array}{l}\text { spring } \\
\text { spring } \\
\text { trail } \\
\text { well } \\
\text { well }\end{array}$ & $\begin{array}{l}\text { BGN } \\
\text { BGN } \\
\text { UNOFF } \\
\text { UNOFF } \\
\text { UNOFF } \\
\text { VARIANT } \\
\text { VARIANT }\end{array}$ & $\begin{array}{l}\text { Yavapai } \\
\text { Coconino } \\
\text { Pima } \\
\text { Mohave } \\
\text { Pima }\end{array}$ & $\begin{array}{l}342435 \mathrm{~N} 1122041 \mathrm{~W} \\
362325 \mathrm{~N} 1120545 \mathrm{~W} \\
322530 \mathrm{~N} 1104245 \mathrm{~W} \\
315548 \mathrm{~N} 1102850 \mathrm{~W} \\
315549 \mathrm{N1} 102849 \mathrm{~W}\end{array}$ \\
\hline well & & Pima & $315549 \mathrm{~N} 1102 \mathrm{~B} 49 \mathrm{~W}$ \\
\hline locale & VAKIANI & Yuma & $324554 \mathrm{~N} 1133717 \mathrm{~W}$ \\
\hline
\end{tabular}

locale

Yuma

$\begin{array}{llll}\text { valley } & \text { BGN } & \text { Mohave } & 345640 \text { N1132030W } \\ \text { spring } & \text { BGN } & \text { Navajo } & 340804 \text { N1103027W }\end{array}$

stream BGN Pima 313605N1113215W

valley

summit

mine

valley

valley

VARIANT

BGN

UNOFF

VARIANT

BGN 1964

VARIANT

Apache

Navajo

cliff

lake

ppl

summit

spring

spring

locale

stream

VARIANT

VARIANT

BGN

BGN

BGN

BGN

VARIANT

VARIANT

strean

well

spring

well

church

stream

reservoir

Coconino

ches

reservoir

spring

reservoir

reservoir

locale

valley

spring

stream

valley

valley

summit

spring

locale UNOFF

canal

summit

summit

reservoir

dam

reservoir

valley

stream
UNOFF

BGN

UNOFF

UNOFF

VARIANT

VARIANT

VARIAN

BGN

BGN

BGN 1975

VARIANT

VARIANT

BGN 1975 Pima

VARIANT

BGN 1982

VARIANT

VARIANT

BGN

VARIANT

\section{Pima}

Graham

Santa Cruz

Pinal

Maricopa

Yuma

\section{Yuma}

Yavapai

Navajo

Coconino

Pima

Pima

Pima

Pima

Santa Cruz

Pima

Pima

Pina

UNOFF
BGN
BGN

BGN

BGN

UNOFF

BGN

BGN

BGN

Yuma

Coconino

Coconino

Pima

Pima

Cochise

Mohave

Graham
$351320 \mathrm{N11} 22307 \mathrm{~W}$
Navajo

Pima

Pima

Graham

Gila

Coconino

Pima

320512N1102913W

Santa Cruz 312954N1110255W
$312 B 16$ N1105520W

$341745 \mathrm{~N} 1124720 \mathrm{~W}$

$341115 \mathrm{~N} 1101135 \mathrm{~W}$

$341115 \mathrm{~N} 1101135 \mathrm{~W}$

$361345 \mathrm{~N} 1123920 \mathrm{~W}$

$341211 \mathrm{~N} 1100121 \mathrm{~W}$

$320356 \mathrm{~N} 1123336 \mathrm{~W}$

$320059 \mathrm{~N} 1123254 \mathrm{~W}$

$330210 N 1094012 \mathrm{~W}$

$335842 \mathrm{Nl} 100350 \mathrm{~W}$

$351809 \mathrm{NL} 122305 \mathrm{~W}$

320938 N1125508W

$320938 \mathrm{~N} 1125508 \mathrm{~W}$ $325206 \mathrm{~N} 1092305 \mathrm{~W}$ $332821 \mathrm{~N} 1110416 \mathrm{~W}$

$314015 \mathrm{~N} 1110909 \mathrm{~W}$

330715 N1115423W

331637N1124820W

$335457 N 1132417 W$

335457 N1132417W

$342607 \mathrm{~N} 1121916 \mathrm{~W}$

343240 N1095340W

$322700 \mathrm{~N} 1114800 \mathrm{~W}$

$320150 \mathrm{~N} 1102836 \mathrm{~W}$

315909 N1102950W

$312400 \mathrm{~N} 1105241 \mathrm{~W}$

320233N1102819W

312646 N1104528W

$320150 \mathrm{~N} 1102836 \mathrm{~W}$

$312851 \mathrm{~N} 1112607 \mathrm{~W}$

$320512 N 1102913 \mathrm{~W}$

$345654 N 1131850 \mathrm{~W}$

313650N1113509W

$341240 \mathrm{~N} 1101007 \mathrm{~W}$

321610 N1124830W

320504 N1102955W

365930 N1112248

$370205 \mathrm{~N} 1110022 \mathrm{~W}$

$321610 \mathrm{Nl103930 \textrm {W }}$

321610 N1103930W

314501 N1092200W

361411 N1134815W

$324032 \mathrm{~N} 1095330 \mathrm{~W}$

Poland Junction Dog Point

$4359 \begin{aligned} & \text { Mescal } \\ & \text { Mescal }\end{aligned}$

Mohon Peak

Pepper Canyon

Presumido Peak

Rio Rico

Weaver Peak

Red Top Mtn

Supai

Show Low South

Bryce Mountain

Round Top Mtn

Fitzgerald Hill

Bates Well

Tollgate Tank Haunted Canyon

Saucito Mtn

Sacaton Butte 
NATIONAL GAZETTEER--ARIZONA 1986

FEATURE NAME

Cunningham Mine

Cunningham Mountain

Cunningham Pass

Cunninhan Pass

Cunninghams Canyon

Cunningham Valley See Butler Valley

Cunningham Wash

Cunninham Pass

See Cunningham Pass

Cupel Mine

Cupe Seep

Cuprite Mine

Cuprite Mine

Cup Tank

Curiel Elementary School Annex

Curiel School

Curiel School Mini Park Site

Curley School

Curley Seep

Curley Seep Tank

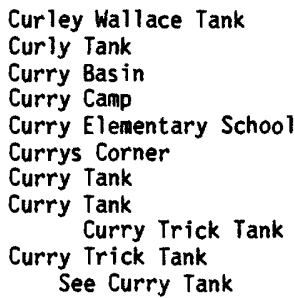

Curtice Mine
Curtis Canal

Curtis Railroad Station

Curtiss

Curt is Spring

Curtis Tank

Curtis Wash

Curt is Well

Curt is Windmill

Curve Reservoir

Curve Wash

Cuter Place Tank

Cuter Tank

Cutfoot Wash

Cutler Pockets

Cutler Pockets

Cutoff Canyon

Cutter

Cutter Ranch

Cutter Tank

Cutter Tank

Cyclone Dan

Cyclone HIII

Cyclone Lake Canpground

Cyclone Tank

Cyclopic

Cyclopic Pumping Station

Cyclops

See Chief One-Eye

(historical)

Cypress Butte

Cypress Canyon

Cypress Creek

Cypress Estates (trailer park)

Cypress Forest Camp

Cypress $\mathrm{Hill}$

Cypress Mountain

Cypress Peak

Cypress Ridge
FEATURE
CLASS

STATUS

COUNTY

COORDINATE

$361533 N 1134758 W$

$333412 \mathrm{~N} 1142056 \mathrm{~W}$

$33571 B N 1133316 \mathrm{~W}$

gap

valley

valley

stream

gap

mine

spring

mine

reservoir

school

school

park

school

spring

reservoir

reservoir

reservoir

basin

locale

school

ppl

reservoir

reservoir

BGN $\quad$ Yuma

VARIANT

BGN Mohave

VARIANT

BGN

VARIANT

Yuma
Yuma

UNOFF

Yuma

BGN Mohave

UNOFF

UNOFF

BGN

La Pa

Pinal

AOMIN Pinal

UNOFF

$B G N$
$B G N$

Pima

Coconino

Coconino

BGN

BGN

BGN
BGN

UNOFF

BGN

BGN

VARIANT

VARIANT

reservoir

Coconino

Greenlee

Gila

Pinal

Maricopa

Maricopa

Coconino

Coconino

Coconino

mine

canal

building

locale

spring

reservoir

strean

well

locale

reservoir

UNOFF
BGN
UNOFF
BGN
BGN
BGN
BGN
UNOFF
BGN
BGN

Pima

Graham

Cochise

Cochise

Cochise

Cochise

Cochise

Coconino

Cochise

Coconino

stream BGN Coconino

reservoir

reservoir

stream

basin

bas in

valley

locale

locale

reservoir

$B G N$

BGN

BGN

BGN

BGN

BGN

$B G N$

UNOFF

Coconino

Coconino

Navajo

Mohave

Coconino

Cochise

Gila

Gila

Gila

reservoir $B G N$

dam UNOFF

summit

park

reservoir

locale

building

BGN

BGN

BGN

BGN

VARIANT

ridge

Coconino

Apache

Graham

Apache

Apache

Mohave

Mohave

Maricopa

summit

valley

stream

locale

locale

summit

summit

summit

ridge
$335851 \mathrm{~N} 1113306 \mathrm{~W}$

\begin{tabular}{|c|c|c|}
\hline $\begin{array}{l}\text { BGN } \\
\text { BGN } \\
\text { BGN } \\
\text { UNOFF } \\
\text { BGN } \\
\text { BGN } \\
\text { BGN } \\
\text { BGN } \\
\text { BGN }\end{array}$ & $\begin{array}{l}\text { Yavapai } \\
\text { Gila } \\
\text { Yavapai } \\
\text { Maricopa } \\
\text { Cochise } \\
\text { Gila } \\
\text { Yavapai } \\
\text { Maricopa } \\
\text { Maricopa }\end{array}$ & $\begin{array}{l}340818 \mathrm{~N} 1113644 \mathrm{~W} \\
341653 \mathrm{~N} 1112343 \mathrm{~W} \\
344606 \mathrm{~N} 113093 \mathrm{~W} \\
332458 \mathrm{~N} 1114520 \mathrm{~W} \\
314631 \mathrm{~N} 1091841 \mathrm{~W} \\
341307 \mathrm{~N} 1111452 \mathrm{~W} \\
344007 \mathrm{~N} 1130141 \mathrm{~W} \\
335042 \mathrm{~N} 1112342 \mathrm{~W} \\
335851 \mathrm{~N} 1113306 \mathrm{~W}\end{array}$ \\
\hline
\end{tabular}

$362058 \mathrm{~N} 1130235 \mathrm{~W}$

$335604 N 1134832 \mathrm{~W}$

$335237 \mathrm{N1} 135859 \mathrm{~W}$

$33571 \mathrm{BN} 1133316 \mathrm{~W}$

$351906 \mathrm{~N} 1140600 \mathrm{~W}$

$361357 \mathrm{N1} 132001 \mathrm{~W}$

$315540 \mathrm{~N} 1104234 \mathrm{~W}$

$335711 \mathrm{N1133350 \textrm {W }}$

$335022 \mathrm{~N} 1102744 \mathrm{~W}$

$324425 \mathrm{~N} 1113331 \mathrm{~W}$

$324425 N 1113331 \mathrm{~W}$

$322218 \mathrm{~N} 1125153 \mathrm{~W}$

$352633 \mathrm{~N} 1114545 \mathrm{~W}$

$352703 \mathrm{N1} 11462 \mathrm{~W}$

354827 N1120353W

$330932 N 1091051 \mathrm{~W}$

$34044 \mathrm{BN} 1111601 \mathrm{~W}$

$324032 \mathrm{~N} 1114118 \mathrm{~W}$

$332413 N 1115401 W$

$334155 \mathrm{N1115528 \textrm {W }}$

351906 N1115648W

$355601 \mathrm{~N} 1121520 \mathrm{~W}$

$355601 \mathrm{~N} 1121520 \mathrm{~W}$

$315054 N 1104604 \mathrm{~W}$

$325719 N 1095325 \mathrm{~W}$

$315305 \mathrm{~N} 1101345 \mathrm{~W}$

$315304 N 1101345 \mathrm{~W}$

$321337 N 1093125 \mathrm{~W}$

$314818 N 1100527 \mathrm{~W}$

$315032 \mathrm{N1101214 \textrm {W }}$

$362009 \mathrm{~N} 1112914 \mathrm{~W}$

$314738 \mathrm{NL} 100906 \mathrm{~W}$

$362000 \mathrm{~N} 1113926 \mathrm{~W}$

$363422 \mathrm{~N} 1113 \mathrm{~B} 1 \mathrm{TW}$ $344120 N 1113158 \mathrm{~W}$

$344232 \mathrm{N1} 113252 \mathrm{~W}$

364509 N1101939W

363151 N1130510W

$320933 \mathrm{~N} 1092635 \mathrm{~W}$

332110N1103907W

$332042 \mathrm{~N} 1103930 \mathrm{~W}$

$331923 N 1104159 \mathrm{~W}$

$344233 \mathrm{~N} 1113253 \mathrm{~W}$

$340048 \mathrm{~N} 1094612 \mathrm{~W}$

$324140 \mathrm{~N} 1094513 \mathrm{~W}$

$340040 N 1094405 \mathrm{~W}$

340054N1094413W

$354658 \mathrm{~N} 1141443 \mathrm{~W}$

$354553 \mathrm{~N} 1141709 \mathrm{~W}$

UNKNOWN
SOURCE
COORDINATE

MAP NAME

Grand Gulch Bench

3316 Cunningham Mtn

2563 Cunningham Pass

$362054 \mathrm{~N} 1130044 \mathrm{~W}$

Mt Trumbull SE

$340925 N 1133457 \mathrm{~W}$

Bouse Hills West

Stockton $\mathrm{Hill}$

Whitmore Point

Mount Fagan

Cunninghan Pass

Beckers Butte

Eloy South

Eloy North

Eloy South

Ajo South

Kendrick Peak

Kendrick Peak

Red Butte 
NATIONAL GAZETTEER--ARIZONA 1986

AZ172

FEATURE NAME

Cypress Spring

Cypress Tank

Cypress Thicket

Cyprus Park
FEATURE

CLASS

spring

reservoir

woods

park

\section{STATUS}

COUNTY

Yavapai

Gila

Gila

Maricopa
COOROINATE

$343936 N 1130214 W$

334452N1103634W

$341045 \mathrm{~N} 1112554 \mathrm{~W}$

$332327 \mathrm{N111} 5502 \mathrm{~W}$

\begin{tabular}{ccc}
$\begin{array}{c}\text { SOURCE } \\
\text { COORDINATE }\end{array}$ & $\begin{array}{c}\text { ELEV } \\
\text { FT }\end{array}$ & \multicolumn{1}{c}{ MAP NAME } \\
& Behm Mesa \\
& $\begin{array}{l}\text { Chrysotile } \\
\text { North Peak } \\
\text { Tempe }\end{array}$
\end{tabular}

$312246 N 1101945 \mathrm{~W}$ 332348N1112115W $332348 \mathrm{~N} 1112135 \mathrm{~W}$ 344907 N1115421W $344953 \mathrm{~N} 1115421 \mathrm{~W}$ $343215 N 1094221 \mathrm{~W}$ $333606 \mathrm{~N} 1101628 \mathrm{~W}$

Dad Jones Tank Number Two

Dad Patterson Tank

Dads Lookout

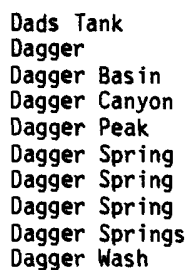

Daggs Dam

Daggs Reservoir

Daggs Reservoir See White Mountain Lake

Daggs Tank

Daggs Wash

Dago Spring

Dag Tank

Dahlizin Mesa

See Little Black Spot Mountain

\begin{tabular}{|c|c|c|c|}
\hline $\begin{array}{l}\text { locale } \\
\text { ridge } \\
\text { mine } \\
\text { reservoir } \\
\text { reservoir } \\
\text { reservoir } \\
\text { summit }\end{array}$ & $\begin{array}{l}\text { UNOFF } \\
\text { BGN } \\
\text { UNOFF } \\
\text { BGN } \\
\text { BGN } \\
\text { BGN } \\
\text { BGN }\end{array}$ & $\begin{array}{l}\text { Cochise } \\
\text { Pinal } \\
\text { Pinal } \\
\text { Yavapai } \\
\text { Yavapai } \\
\text { Apache } \\
\text { Gila }\end{array}$ & $\begin{array}{l}312246 N 1101945 \mathrm{~W} \\
332348 \mathrm{~N} 1112115 \mathrm{~W} \\
332348 \mathrm{~N} 1112135 \mathrm{~W} \\
344907 \mathrm{~N} 1115421 \mathrm{~W} \\
344953 \mathrm{~N} 1115421 \mathrm{~W} \\
343215 \mathrm{~N} 1094221 \mathrm{~W} \\
333606 \mathrm{~N} 1101628 \mathrm{~W}\end{array}$ \\
\hline $\begin{array}{l}\text { reservoir } \\
\text { locale } \\
\text { basin } \\
\text { valley } \\
\text { summit } \\
\text { spring } \\
\text { spring } \\
\text { spring } \\
\text { spring } \\
\text { stream }\end{array}$ & $\begin{array}{l}\text { BGN } \\
\text { BGN } \\
\text { BGN } \\
\text { BGN } \\
\text { BGN } \\
\text { BGN } \\
\text { BGN } \\
\text { BGN } \\
\text { BGN } \\
\text { BGN }\end{array}$ & $\begin{array}{l}\text { Gila } \\
\text { Gila } \\
\text { Gila } \\
\text { Gila } \\
\text { Gila } \\
\text { Gila } \\
\text { Gila } \\
\text { Gila } \\
\text { Gila } \\
\text { Gila }\end{array}$ & $\begin{array}{l}335750 \mathrm{~N} 1105500 \mathrm{~W} \\
334140 \mathrm{~N} 1104845 \mathrm{~W} \\
334208 \mathrm{~N} 1104642 \mathrm{~W} \\
334123 \mathrm{~N} 1104833 \mathrm{~W} \\
334154 \mathrm{~N} 1104725 \mathrm{~W} \\
333100 \mathrm{~N} 1105500 \mathrm{~W} \\
333111 \mathrm{~N} 1105500 \mathrm{~W} \\
334207 \mathrm{~N} 1104734 \mathrm{~W} \\
334429 \mathrm{~N} 1110435 \mathrm{~W} \\
334214 \mathrm{~N} 1110538 \mathrm{~W}\end{array}$ \\
\hline
\end{tabular}

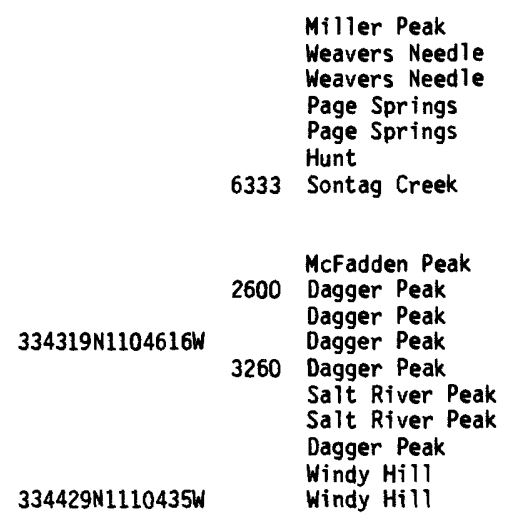

dam UNOFF Navajo 342154N1100003W

reservoir BGN Navajo 342154N1100003W

$342156 N 1095923 \mathrm{~W}$

reservoir Navajo

$\begin{array}{llll}\text { reservoir } & \text { BGN } & \text { Maricopa } & 334351 \text { N1124359W } \\ \text { stream } & B G N & \text { Maricopa } & 333537 \text { N1124402W }\end{array}$

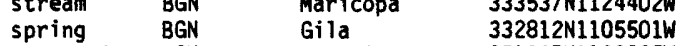

reservoir BGN Coconino 351937N1120625W

summit Navajo 360457N1101948W

Daily Mine Group

Dairy Canyon

Dairy Mountain

Dairy Spring

Dairy Spring

Dairy Springs Campground

Dairy Tank

Daisy Mine

Daisy Mountain

Daisy Shaft

Daisy Tank

Daley Park

Dalkai Spring

Dallas

Dalton Tank

Dam Canyon

Damfino Canyon

Dam Number One

Dam Number Two

Damoff Cabin

Damon Lake

Dam Tank

Dam Tank

Dam Tank

Dana Butte

Danas Trailer Ranch

Dance Tank

Dance Tank

Dancing Rocks

Dandrea

\begin{tabular}{|c|c|c|c|}
\hline $\begin{array}{l}\text { mine } \\
\text { valley } \\
\text { summit } \\
\text { spring } \\
\text { spring } \\
\text { park } \\
\text { reservoir } \\
\text { mine } \\
\text { summit } \\
\text { mine }\end{array}$ & $\begin{array}{l}\text { UNOFF } \\
\text { BGN } \\
\text { BGN } \\
\text { BGN } \\
\text { BGN } \\
\text { ADMIN } \\
\text { BGN } \\
\text { UNOFF } \\
\text { BGN } \\
\text { UNOFF }\end{array}$ & $\begin{array}{l}\text { Pima } \\
\text { Gila } \\
\text { Yavapai } \\
\text { Yavapai } \\
\text { Coconino } \\
\text { Coconino } \\
\text { Coconino } \\
\text { Maricopa } \\
\text { Maricopa } \\
\text { Pima }\end{array}$ & $\begin{array}{l}322816 \mathrm{~N} 1104346 \mathrm{~W} \\
332408 \mathrm{N1} 105130 \mathrm{~W} \\
345413 \mathrm{~N} 1130013 \mathrm{~W} \\
345439 \mathrm{~N} 1125944 \mathrm{~W} \\
345713 \mathrm{~N} 1112850 \mathrm{~W} \\
345722 \mathrm{N111} 2905 \mathrm{~W} \\
345713 \mathrm{~N} 1112850 \mathrm{~W} \\
335336 \mathrm{~N} 1120536 \mathrm{~W} \\
335300 \mathrm{~N} 1120608 \mathrm{~W} \\
322513 \mathrm{~N} 1113222 \mathrm{~W}\end{array}$ \\
\hline $\begin{array}{l}\text { reservoir } \\
\text { park } \\
\text { spring } \\
\text { mine } \\
\text { reservoir } \\
\text { valley } \\
\text { valley } \\
\text { dam } \\
\text { dam } \\
\text { locale }\end{array}$ & $\begin{array}{l}\text { BGN } \\
\text { ADMIN } \\
\text { BGN } \\
\text { UNOFF } \\
\text { BGN } \\
\text { BGN } \\
\text { BGN } \\
\text { UNOFF } \\
\text { UNOFF } \\
\text { BGN }\end{array}$ & $\begin{array}{l}\text { Yavapai } \\
\text { Maricopa } \\
\text { Navajo } \\
\text { Cochise } \\
\text { Navajo } \\
\text { Greenlee } \\
\text { Coconino } \\
\text { Mohave } \\
\text { Mohave } \\
\text { Apache }\end{array}$ & $\begin{array}{l}345544 \mathrm{~N} 1121604 \mathrm{~W} \\
332435 \mathrm{~N} 1115554 \mathrm{~W} \\
352220 \mathrm{~N} 101121 \mathrm{~W} \\
312516 \mathrm{~N} 1095409 \mathrm{~W} \\
342318 \mathrm{~N} 110183 \mathrm{~W} \\
333740 \mathrm{~N} 1090551 \mathrm{~W} \\
345206 \mathrm{~N} 1114432 \mathrm{~W} \\
351547 \mathrm{~N} 1132214 \mathrm{~W} \\
351533 \mathrm{~N} 1132023 \mathrm{~W} \\
335258 \mathrm{~N} 1093508 \mathrm{~W}\end{array}$ \\
\hline $\begin{array}{l}\text { lake } \\
\text { reservoir } \\
\text { reservoir } \\
\text { reservoir } \\
\text { summit } \\
\text { locale } \\
\text { reservoir } \\
\text { reservoir } \\
\text { pillar }\end{array}$ & $\begin{array}{l}\text { BGN } \\
\text { BGN } \\
\text { BGN } \\
\text { BGN } \\
\text { BGN } 1906 \\
\text { UNOFF } \\
\text { BGN } \\
\text { BGN } \\
\text { BGN }\end{array}$ & $\begin{array}{l}\text { Apache } \\
\text { Yavapai } \\
\text { Yavapai } \\
\text { Yavapai } \\
\text { Coconino } \\
\text { Maricopa } \\
\text { Coconino } \\
\text { Coconino } \\
\text { Apache }\end{array}$ & $\begin{array}{l}354150 \mathrm{~N} 1090445 \mathrm{~W} \\
344844 \mathrm{~N} 1124015 \mathrm{~W} \\
344845 \mathrm{~N} 1124044 \mathrm{~W} \\
344921 \mathrm{~N} 1121349 \mathrm{~W} \\
360529 \mathrm{~N} 1120859 \mathrm{~W} \\
332459 \mathrm{~N} 1113619 \mathrm{~W} \\
344347 \mathrm{~N} 1105953 \mathrm{~W} \\
354205 \mathrm{~N} 1121433 \mathrm{~W} \\
363947 \mathrm{~N} 1093512 \mathrm{~W} \\
342153 \mathrm{~N} 112233 \mathrm{~W}\end{array}$ \\
\hline
\end{tabular}

Show Low North Show Low North

Daggs Tank Wagner Wash Well Inspiration Sitgreaves Mtn Globe

7165 Mount Hope Juniper Mts Mormon Lake

7180 Sycamore Point Sycamore Point Daisy Mountain

3176 Daisy Mountain Silver Bell West

Camp Wood

Tempe Sunflower Butte Bisbee Big Pug Tank Blue

$333811 N 1090319 \mathrm{~W}$

Munds Mountain Blye Canyon SE Blye Canyon SE Mount Baidy

Window Rock

Simmons

Simmons

Munds Draw

5030 Grand Canyon

1590 Apache Junction Hamilton Crossing Valle Tank

5559 Dancing Rocks

Battleship Butte 
NATIONAL GAZETTEER--ARIZONA 1986

\section{FEATURE NAME}

Dandrea Spring

Dandy Mine

Dandy Tank

Dandy Wire Spring

$$
\text { Pine Spring }
$$

Dane Canyon

Danelle Plaza Shopping Center

Dane Ridge

Danes Dam

Dane Spring

Dane Tank

Danger Spring

Danger Wash

Daniel C Lincoln Elementary School

David C Lincoln Elementary School

Daniel Lateral

Daniells Well

Daniels Arroyo Adobe Wash

Daniels Camp Canyon

Daniels Gulch

Daniels Mine

Daniels Spring

Daniels Tank

Danish Hollow

Dankworth Lake

Dan Neal Spring

Dannys Lower Spring

Dan Saddle

Dansill Canyon

Dansil Spring

Dans Spring

Danstone Springs

Dan Tank

Dan Tank

Daou Tank

Darby Arroyo

Darby Well

Dardanelles Mine

Dark Canyon

Dark Canyon

Dark Canyon

Dark Canyon

Dark Canyon

Dark Canyon Spring

Darling

Darling Cinder Pit

Darling Mine

Darling Railroad Station

Darly Mine Group

Darnell Peak

Darton Dome Turkey Ridge

Dart Ranch

Dart Tank

Darwin Plateau

Daryls Well

D A Tank Number One

D A Tank Number Two

Date

Date Creek

Date Creek Mountains

Date Creek Ranch

Date Creek Well

Dateland

Dateland Airfield

Dateland Highway Yard

Dateland Interchange

Dateland Radar Tower

\section{FEATURE}

CLASS

STATUS

COUNTY

COORDINATE

spring

reservoir

spring

valley

locale

ridge

dam

spring

BGN

$341539 N 1122508$

VARIANT

BGN
UNOFF

BGN

UNOFF

Coconino

Maricopa

Coconino

Yavapai

34302BN1110905W

$342933 \mathrm{~N} 1110831 \mathrm{~K}$

341159N1114912W

342800N1110854K

reservoir

spring

strean

BGN

Coconino

Navajo

school

BGN

UNOFF

Cochise

Yavapai

343157 N1110857W

$361124 N 1103848 \mathrm{~W}$

$312614 N 1091943 \mathrm{~W}$

343449N1131018W

VARIANT

canal

well

BGN

UNOFF

Yuma

BGN 1965 Maricopa

VARIANT

323947 N1144337W

$320957 \mathrm{N1} 125706 \mathrm{~W}$

$323044 N 1131456 \mathrm{~W}$

\section{BGN Greenlee}

valley

mine

spring

reservoir

valley

reservoir

spring

spring

gap

BGN

BGN

BGN

BGN

BGN

BGN

BGN

BGN

valley

spring

pring

spring

reservoir

reservoir
reservoir

valley

well
mine

BGN
BGN
BGN
BGN
BGN
BGN
BGN
BGN
UNOFF

Yavapai

Santa Cruz

Gila

Maricopa

Navajo

Grahan

Gila

Yavapai

Pima

$325039 \mathrm{~N} 1090611 \mathrm{~W}$

342340N1121643W

314331N1105213W

335317 N1112150W

$335628 N 1130549 \mathrm{~W}$

$341742 N 1101335 \mathrm{~W}$

$324314 \mathrm{~N} 1094209 \mathrm{~W}$

$334103 \mathrm{~N} 1111806 \mathrm{~W}$

$341438 \mathrm{N1121601 \textrm {V }}$

322852N1104454W

Mohave

Mohave

Yavapai

Apache

Santa Cruz

Pima

Gila

Pima

Pima

Mohave

valley

valley

valley

valley

valley

spring

locale

bas in

mine

building

BGM

Santa Cruz

Pinal

Graham

Greenlee

Greenlee

Graham

Coconino

Coconino

Yuma

Coconino

mine UNOFF Pima

summit

summ it

locale

reservoir

plain

well

reservoir

reservoir

BGN Cochise

BGN 1971 Coconino

ARIANT

UNOF

Santa Cruz

1908 Coconino

UNOFF Mohave

BGN

BGN

Yavapai

locale

strean

range

locale

well

ppl

airport

locale

crossing

BGN Yavapai

BGN

BGN

UNOFF

UNOFF

BGN

ADMIN

UNOFF

tower
361142N1132423W

$361101 \mathrm{~N} 1132800 \mathrm{~W}$

$342013 N 1115015 \mathrm{~W}$

340922N1094747W

$312422 \mathrm{N1} 103142 \mathrm{~W}$

$322730 \mathrm{~N} 1103957 \mathrm{~W}$

$332151 \mathrm{~N} 1104522 \mathrm{~W}$

$322238 \mathrm{~N} 1124729 \mathrm{~W}$

$322014 N 1125100$

352541N1141058W

$313718 \mathrm{N1} 104246 \mathrm{~W}$

$324502 N 1102952 \mathrm{~W}$

325342N1100702W

$325409 \mathrm{N1} 091934 \mathrm{~K}$

$331058 \mathrm{N1} 092720 \mathrm{~W}$

$325256 \mathrm{N1100B57 \textrm {W }}$

$351202 \mathrm{N1112359 \textrm {W }}$

$351335 \mathrm{~N} 1112433 \mathrm{~W}$

$334416 \mathrm{N1} 141958 \mathrm{~W}$

351203N1112357W

$322817 \mathrm{N1} 104346 \mathrm{~W}$

$314917 \mathrm{~N} 1090828 \mathrm{~W}$

$352339 \mathrm{~N} 1113108 \mathrm{~W}$

314657 N1092517W

312743 N1111619W

$361201 \mathrm{~N} 1122318 \mathrm{~W}$

$344055 \mathrm{~N} 1134650 \mathrm{~W}$

$344610 N 1115215$

$34462 B N 1115237 \mathrm{~W}$

$341855 \mathrm{~N} 1125503 \mathrm{~W}$

$341759 \mathrm{~N} 1132814 \mathrm{~W}$

341347 N1125559W

$341338 \mathrm{~N} 1130142 \mathrm{~W}$

341047 N1131853W

$324747 \mathrm{~N} 1133225 \mathrm{~W}$

$324848 \mathrm{~N} 1133116 \mathrm{~W}$

$324815 \mathrm{~N} 1133228 \mathrm{~W}$

$324802 \mathrm{~N} 1133225 \mathrm{~W}$

324818 N1133117W
BGN Coconino 353635N1143035W 


\begin{tabular}{|c|c|c|c|c|c|c|c|}
\hline FEATURE NAME & $\begin{array}{l}\text { FEATURE } \\
\text { CLASS }\end{array}$ & STATUS & COUNTY & COORDINATE & $\begin{array}{l}\text { SOURCE } \\
\text { COORDINATE }\end{array}$ & $\begin{array}{l}\text { ELEV } \\
\text { FT }\end{array}$ & MAP NAME \\
\hline $\begin{array}{l}\text { Dateland School } \\
\text { Date Railroad Station } \\
\text { Datry Spring } \\
\text { Daumler Park } \\
\text { Dave Joy Point } \\
\text { Davenport Hill } \\
\text { Davenport Knoll } \\
\text { Davenport Lake } \\
\text { Davenport Peak } \\
\text { Davenport Tank }\end{array}$ & $\begin{array}{l}\text { school } \\
\text { building } \\
\text { spring } \\
\text { park } \\
\text { cliff } \\
\text { summit } \\
\text { summit } \\
\text { lake } \\
\text { summit } \\
\text { reservoir }\end{array}$ & $\begin{array}{l}\text { UNOFF } \\
\text { UNOFF } \\
\text { BGN } \\
\text { ADMIN } \\
\text { BGN } \\
\text { BGN } \\
\text { BGN } \\
\text { BGN } \\
\text { BGN } \\
\text { BGN }\end{array}$ & $\begin{array}{l}\text { Yuma } \\
\text { Yavapai } \\
\text { Yavapai } \\
\text { Maricopa } \\
\text { Coconino } \\
\text { Coconino } \\
\text { Coconino } \\
\text { Coconino } \\
\text { Yavapai } \\
\text { Coconino }\end{array}$ & $\begin{array}{l}324825 \mathrm{~N} 1133226 \mathrm{~W} \\
341821 \mathrm{~N} 1125451 \mathrm{~W} \\
345439 \mathrm{~N} 1125944 \mathrm{~W} \\
332356 \mathrm{~N} 1115305 \mathrm{~W} \\
345856 \mathrm{~N} 1115237 \mathrm{~W} \\
351325 \mathrm{~N} 1120548 \mathrm{~W} \\
350635 \mathrm{~N} 1120941 \mathrm{~W} \\
351541 \mathrm{~N} 1120431 \mathrm{~W} \\
340016 \mathrm{~N} 1113634 \mathrm{~W} \\
350617 \mathrm{~N} 1121030 \mathrm{~W}\end{array}$ & & $\begin{array}{l}7805 \\
4010\end{array}$ & $\begin{array}{l}\text { Dateland } \\
\text { Date } \\
\text { Juniper Mts } \\
\text { Tempe } \\
\text { Loy Butte } \\
\text { Davenport Hill } \\
\text { May Tank Pocket } \\
\text { Sitgreaves Mtn } \\
\text { Table Mountain } \\
\text { May Tank Pocket }\end{array}$ \\
\hline $\begin{array}{l}\text { Davenport Wash } \\
\text { Dave Pond } \\
\text { Daves Tank } \\
\text { Daves Tank } \\
\text { Daves Tank } \\
\text { Daves Well } \\
\text { David C Lincoln El ementary } \\
\text { School }\end{array}$ & $\begin{array}{l}\text { stream } \\
\text { reservoir } \\
\text { reservoir } \\
\text { reservoir } \\
\text { reservoir } \\
\text { well }\end{array}$ & $\begin{array}{l}\text { BGN } \\
\text { BGN } \\
\text { BGN } \\
\text { BGN } \\
\text { BGN } \\
\text { UNOFF } \\
\text { VARIANT }\end{array}$ & $\begin{array}{l}\text { Maricopa } \\
\text { Mohave } \\
\text { Coconino } \\
\text { Coconino } \\
\text { Coconino } \\
\text { Mohave }\end{array}$ & $\begin{array}{l}335734 \mathrm{~N} 1114116 \mathrm{~W} \\
362913 \mathrm{~N} 1132522 \mathrm{~W} \\
343806 \mathrm{~N} 1111838 \mathrm{~W} \\
344426 \mathrm{~N} 1111708 \mathrm{~W} \\
353425 \mathrm{~N} 1120309 \mathrm{~W} \\
365132 \mathrm{~N} 1125605 \mathrm{~W}\end{array}$ & 340407 N1113128W & & $\begin{array}{l}\text { Horseshoe Dam } \\
\text { Poverty Knoll } \\
\text { Turkey Mtn } \\
\text { Turkey Mtn } \\
\text { Hobble Tank } \\
\text { Maroney Well }\end{array}$ \\
\hline $\begin{array}{c}\text { See Daniel C Lincoln } \\
\text { Elementary School }\end{array}$ & school & & Yavapai & 343449 N1131018N & & & \\
\hline $\begin{array}{l}\text { Davidson Canyon } \\
\text { Davidson Canyon } \\
\text { Davidson Ranch } \\
\text { Davidson School } \\
\text { Davidson Spring } \\
\text { Davidson Tank } \\
\text { Davidson Well } \\
\text { David Tank } \\
\text { Davis, Mount } \\
\text { Davis, Mount }\end{array}$ & $\begin{array}{l}\text { valley } \\
\text { valley } \\
\text { locale } \\
\text { school } \\
\text { spring } \\
\text { reservoir } \\
\text { well } \\
\text { reservoir } \\
\text { summit } \\
\text { summit }\end{array}$ & $\begin{array}{l}\text { BGN } \\
\text { BGN } \\
\text { UNOFF } \\
\text { UNOFF } \\
\text { BGN } \\
\text { BGN } \\
\text { UNOFF } \\
\text { BGN } \\
\text { BGN } \\
\text { BGN }\end{array}$ & $\begin{array}{l}\text { Pima } \\
\text { Pima } \\
\text { Graham } \\
\text { Pima } \\
\text { Pima } \\
\text { Graham } \\
\text { Pima } \\
\text { Coconino } \\
\text { Yavapai } \\
\text { Mohave }\end{array}$ & $\begin{array}{l}320103 N 1103833 W \\
320144 N 1131553 W \\
325219 N 1102202 W \\
321557 N 1105429 W \\
315629 N 1103836 W \\
325619 N 1101847 W \\
320205 N 1112335 W \\
354100 N 1113454 W \\
342532 N 1122349 W \\
353216 N 1143742 W\end{array}$ & $\begin{array}{l}314928 N 1104245 W \\
320519 N 1131334 W\end{array}$ & $\begin{array}{l}2662 \\
2034\end{array}$ & $\begin{array}{l}\text { Vail } \\
\text { O'Neill Hills } \\
\text { Klondyke } \\
\text { Tucson North } \\
\text { Mount Fagan } \\
\text { Cobre Grande Mtn } \\
\text { San Pedro } \\
\text { Campbell Francis Wsh } \\
\text { Groom Creek } \\
\text { Mt Davis }\end{array}$ \\
\hline $\begin{array}{l}\text { Davis Canyon } \\
\text { Davis Canyon } \\
\text { Davis Creek } \\
\text { Davis Dam } \\
\text { Davis Dam } \\
\text { Davis Dam } \\
\text { Davis Dam } \\
\text { Davis Dunkirk Mine } \\
\text { Davis Mesa } \\
\text { Davis Monthan Hospital }\end{array}$ & $\begin{array}{l}\text { valley } \\
\text { valley } \\
\text { stream } \\
\text { dam } \\
\text { dam } \\
\text { dam } \\
\text { ppl } \\
\text { mine } \\
\text { summit } \\
\text { hospital }\end{array}$ & $\begin{array}{l}\text { BGN } \\
\text { BGN } \\
\text { BGN } \\
\text { UNDFF } \\
\text { UNOFF } \\
\text { UNOFF } \\
\text { BGN } \\
\text { UNOFF } \\
\text { BGN } \\
\text { UNOFF }\end{array}$ & $\begin{array}{l}\text { Cochise } \\
\text { Gila } \\
\text { Apache } \\
\text { Apache } \\
\text { Mohave } \\
\text { Coconino } \\
\text { Mohave } \\
\text { Yavapai } \\
\text { Pima } \\
\text { Pima }\end{array}$ & $\begin{array}{l}321716 \mathrm{~N} 1101152 \mathrm{~W} \\
332352 \mathrm{~N} 1105231 \mathrm{~W} \\
340135 \mathrm{~N} 1091100 \mathrm{~W} \\
335936 \mathrm{~N} 1094529 \mathrm{~W} \\
351157 \mathrm{~N} 1143413 \mathrm{~W} \\
352511 \mathrm{~N} 1121814 \mathrm{~W} \\
351048 \mathrm{~N} 1143356 \mathrm{~W} \\
342459 \mathrm{~N} 1122653 \mathrm{~W} \\
322814 \mathrm{~N} 1103752 \mathrm{~W} \\
321024 \mathrm{~N} 1105131 \mathrm{~W}\end{array}$ & 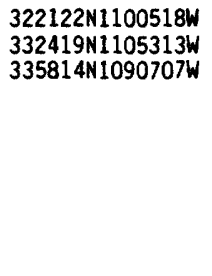 & & $\begin{array}{l}\text { Hookers Hot Springs } \\
\text { Inspiration } \\
\text { Nelson Reservoir } \\
\text { Hawley Lake West } \\
\text { Davis Dam } \\
\text { Cataract Tank } \\
\text { Davis Dam } \\
\text { Groom Creek } \\
\text { Mount Bigelow } \\
\text { Tucson East }\end{array}$ \\
\hline $\begin{array}{l}\text { Davis Mountain } \\
\text { Davis Plain } \\
\text { Davis Ranch } \\
\text { Davis Ranch } \\
\text { Davis Ranch } \\
\text { Davis School } \\
\text { Davis School } \\
\text { Davis Spring } \\
\text { Davis Spring } \\
\text { Davis Spring }\end{array}$ & $\begin{array}{l}\text { summit } \\
\text { plain } \\
\text { locale } \\
\text { locale } \\
\text { locale } \\
\text { school } \\
\text { school } \\
\text { spring } \\
\text { spring } \\
\text { spring }\end{array}$ & $\begin{array}{l}\text { BGN } \\
\text { BGN } \\
\text { UNOFF } \\
\text { UNOFF } \\
\text { UNOFF } \\
\text { UNOFF } \\
\text { UNOFF } \\
\text { BGN } \\
\text { BGN } \\
\text { BGN }\end{array}$ & $\begin{array}{l}\text { Cochise } \\
\text { Yuma } \\
\text { Pinal } \\
\text { Greenlee } \\
\text { Maricopa } \\
\text { Pima } \\
\text { Pima } \\
\text { Pima } \\
\text { Graham } \\
\text { Maricopa }\end{array}$ & $\begin{array}{l}315814 N 1091120 \mathrm{~W} \\
322818 \mathrm{~N} 1141639 \mathrm{~W} \\
323227 \mathrm{~N} 1111221 \mathrm{~W} \\
325611 \mathrm{~N} 1091245 \mathrm{~W} \\
332002 \mathrm{~N} 1130454 \mathrm{~W} \\
321344 \mathrm{~N} 1105843 \mathrm{~W} \\
321705 \mathrm{~N} 1110007 \mathrm{~W} \\
322721 \mathrm{~N} 1103824 \mathrm{~W} \\
330202 \mathrm{~N} 1102241 \mathrm{~W} \\
333443 \mathrm{~N} 1111224 \mathrm{~W}\end{array}$ & & $\begin{array}{l}5762 \\
3400\end{array}$ & $\begin{array}{l}\text { Portal } \\
\text { Vopoki Ridge } \\
\text { Desert Peak } \\
\text { York } \\
\text { Columbus Peak } \\
\text { Tucson } \\
\text { Jaynes } \\
\text { Mount Bigelow } \\
\text { Rawhide Mtn } \\
\text { Pinyon Mtn }\end{array}$ \\
\hline $\begin{array}{l}\text { Davis Spring Number Two } \\
\text { Davis Spring Trail Twenty-eight } \\
\text { Davis Tank } \\
\text { Davis Tank } \\
\text { Davis Wash } \\
\text { Brush Corral Creek } \\
\text { Davis Well } \\
\text { Da Wa Ke } \\
\text { Dawings Pass } \\
\text { See Downing Pass }\end{array}$ & $\begin{array}{l}\text { spring } \\
\text { trail } \\
\text { reservoir } \\
\text { reservoir } \\
\text { stream } \\
\text { well } \\
\text { summit } \\
\text { gap }\end{array}$ & $\begin{array}{l}\text { BGN } \\
\text { UNOFF } \\
\text { BGN } \\
\text { BGN } \\
\text { BGN } \\
\text { VARIANT } \\
\text { UNOFF } \\
\text { BGN } \\
\text { VARIANT }\end{array}$ & $\begin{array}{l}\text { Yavapai } \\
\text { Pima } \\
\text { Santa Cruz } \\
\text { Cochise } \\
\text { Maricopa } \\
\text { Maricopa } \\
\text { Navajo } \\
\text { Cochise }\end{array}$ & $\begin{array}{l}342443 \mathrm{~N} 1122206 \mathrm{~W} \\
322804 \mathrm{~N} 1103630 \mathrm{~W} \\
312128 \mathrm{~N} 1110304 \mathrm{~W} \\
314548 \mathrm{~N} 1092430 \mathrm{~W} \\
333539 \mathrm{~N} 1111320 \mathrm{~W} \\
\\
331946 \mathrm{~N} 1130542 \mathrm{~W} \\
355123 \mathrm{~N} 1103400 \mathrm{~W} \\
315627 \mathrm{~N} 1091854 \mathrm{~W}\end{array}$ & $333255 \mathrm{~N} 1111122 \mathrm{~W}$ & & $\begin{array}{l}\text { Poland Junction } \\
\text { Buehman Canyon } \\
\text { Pajarito Peak } \\
\text { Stanford Canyon } \\
\text { Pinyon Mtn } \\
\text { Forth of July Butte } \\
\text { Shongopovi }\end{array}$ \\
\hline $\begin{array}{l}\text { Dawn Lake } \\
\text { Dawson Tank } \\
\text { Day Mine Wash } \\
\text { Day Mine Windmill } \\
\text { Day Peaks } \\
\text { Day Ranch } \\
\text { Day Ranch } \\
\text { Day School Wash } \\
\text { Day Spring } \\
\text { Day Tank }\end{array}$ & $\begin{array}{l}\text { lake } \\
\text { reservoir } \\
\text { stream } \\
\text { locale } \\
\text { summit } \\
\text { locale } \\
\text { locale } \\
\text { stream } \\
\text { spring } \\
\text { reservoir }\end{array}$ & $\begin{array}{l}\text { BGN } \\
\text { BGN } \\
\text { BGN } \\
\text { BGN } \\
\text { BGN } \\
\text { UNOFF } \\
\text { UNOFF } \\
\text { BGN } \\
\text { BGN } \\
\text { BGN }\end{array}$ & $\begin{array}{l}\text { Maricopa } \\
\text { Yavapai } \\
\text { Graham } \\
\text { Graham } \\
\text { Gila } \\
\text { Pima } \\
\text { Greenlee } \\
\text { Navajo } \\
\text { Navajo } \\
\text { Navajo }\end{array}$ & $\begin{array}{l}333636 \mathrm{~N} 1121619 \mathrm{~W} \\
351356 \mathrm{~N} 1123838 \mathrm{~W} \\
330419 \mathrm{~N} 109595 \mathrm{~W} \\
330826 \mathrm{~N} 1095626 \mathrm{~W} \\
332551 \mathrm{~N} 1105408 \mathrm{~W} \\
320304 \mathrm{~N} 1103811 \mathrm{~W} \\
323255 \mathrm{~N} 1090414 \mathrm{~W} \\
340310 \mathrm{~N} 1102854 \mathrm{~W} \\
341830 \mathrm{~N} 1102636 \mathrm{~W} \\
342543 \mathrm{~N} 1102228 \mathrm{~W}\end{array}$ & $340554 N 1102711 \mathrm{~W}$ & 4704 & $\begin{array}{l}\text { El Mirage } \\
\text { Picacho Butte } \\
\text { Fort Thomas } \\
\text { Gila Peak } \\
\text { Inspiration } \\
\text { Vail } \\
\text { Round Mtn } \\
\text { Cibecue } \\
\text { Day Spring } \\
\text { Big Pug Tank }\end{array}$ \\
\hline
\end{tabular}


NATIONAL GAZETTEER--ARIZONA 1986

\section{FEATURE NAME}

Day Wash

Daze

Daze Canyon

Daze Lake

Dazen Canyon

Daze Railroad Station

Daze Tank

Daze Tank

D Bar H Tank

Dead Boy Point

Dead Bull Mine

Dead Cow Canyon

See Walnut Canyon

Dead Cow Canyon

Dead Cow Gulch

Dead Cow Spring

Dead Cow Tank

Dead Cow Tank

Dead Cow Tank

Dead Cow Tank

Dead Creek

See Dead Wash

Dead Horse Dan

Dead Horse Draw

Dead Horse Flat

Dead Horse Mesa

Dead Horse Point

Dead Horse Ranch State Park Dead Horse State Park

Dead Horse State Park

See Dead Horse Ranch State Park

Dead Horse Tank

Dead Horse Tank

Dead Horse Tank

Dead Horse Tank

Dead Horse Tank

Dead Horse Tank

Dead Horse Tank

Dead Horse Wash

See Jackrabbit Wash

Dead Horse Wash

Dead Indian Canyon

Dead Lake Tank

Deadman Canyon Deadmans Canyon

Deadman Canyon

Deadman Canyon

Deadman Canyon

Deadman Canyon

Deadman Canyon

Deadman Creek

Deadman Flat

Deadman Gap

Deadman Knoll

Deadman Knoll

Deadman Mesa

Deadman Mesa

Deadman Mesa

Deadman Mesa

Deadman Pass

Deadman Peak

Deadman Pocket

Deadman Ridge

Deadmans Canyon

See Deadman Canyon

Deadman Spring

Deadmans Wash

Deadman Tank

Deadman Tank

Deadman Tank

\section{FEATURE \\ CLASS}

STATUS

COUNTY

COORDINATE

stream
locale

valley

lake

valley

building

reservoir

reservoir $B G$

reservoir $B G$

mine

valley

valley

valley

spring

reservoir

reservoir

reservoir

BGN
BGN
BGN
$B G N$
BGN
UNOFF
BGN
BGN
$B G N$

Navajo

Coconino

Navajo

Coconino

Navajo

Coconino

Navajo

Coconino

Pinal

BGN

UNOFF

VARIANT

BGN 1974 Gila

BGN Yavapai

$B G N$

$B G N$

BGN

$B G N$

Gila

Mohave

Navajo

reservoir $B G$

stream

dam

valley

flat

summit

summit

park

BGN
VARIANT

Mohave

Apache

UNOFF Yavapai

BGN

$B G N$

$B G N$

$B G N$

ADMIN

VARIANT

Navajo

Mohave

Navajo

Yavapai

VARIANT

park

Yavapai

reservoir

reservoir

reservoir

reservoir

reservoir

reservoir

reservoir

$B G N$
$B G N$
$B G N$
$B G N$
$B G N$
$B G N$
$B G N$

Maricopa

Apache

Navajo

Coconino

Coconino

Coconino

Yavapai

VARIANT

strean

stream BGN 1978

valley $\quad B G N$

reservoir

valley

valley

valley

valley

BGN

BGN

VARIANT

BGN

BGN

BGN

Maricopa

Maricopa

Coconino

Apache

Graham

Graham

Graham

Graham

valley

valley

stream

flat

gap

summit

umm it

summit

summit

summit

BGN Gila

BGN Gila

Yavapai

Yavapai

Maricopa

Coconino

Mohave

Graham

Gila

summit $\quad B G N$

gap

summit

bas in

ridge

valley

spring

stream

reservoir

$B G N$

Coconino

Pima

Graham

Graham

ARIANT

reservoir $B G$

reservoir $\quad B G N$

Graham

Mohave

Cochise

Graham

Graham

Yuma

$342715 \mathrm{~N} 1101730 \mathrm{~W}$

$351456 \mathrm{~N} 1122413 \mathrm{~W}$

$343233 \mathrm{~N} 1104305 \mathrm{~W}$

$344412 \mathrm{~N} 1111158 \mathrm{~W}$

$340903 \mathrm{~N} 1104207 \mathrm{~W}$

$351458 \mathrm{~N} 1122358 \mathrm{~W}$

$343028 \mathrm{~N} 1104352 \mathrm{~W}$

$344332 \mathrm{~N} 1111420 \mathrm{~W}$

$325748 N 1110102 \mathrm{~W}$

$340411 N 1111355 \mathrm{~W}$

$323218 \mathrm{~N} 1104307 \mathrm{~W}$

341623 N1112921W

$341828 \mathrm{~N} 1112938 \mathrm{~W}$

$341255 N 1121207 \mathrm{~W}$

$335921 \mathrm{~N} 1104730 \mathrm{~W}$

$334713 N 1101327 W$

$343 B 10 N 1132232 \mathrm{~W}$

$345004 \mathrm{~N} 1095836 \mathrm{~W}$

352655N1133350W

$345859 \times 1094727 \mathrm{~W}$

$352220 \mathrm{~N} 1131505 \mathrm{~W}$

$342242 \mathrm{~N} 1102937 \mathrm{~K}$

$340027 N 1092303 \mathrm{~W}$

$361943 N 1124401 \mathrm{~W}$

$342035 \mathrm{~N} 1102913 \mathrm{H}$

$344514 N 1120048 \mathrm{~W}$

344514N1120048W

334321 N1130437W

$341626 \mathrm{N1093019 \textrm {W }}$

$342054 \mathrm{N1102904 \textrm {W }}$

343529 N1112701W

$345854 N 1112113 \mathrm{~W}$

$350902 \mathrm{N1} 120719 \mathrm{~W}$

$351400 \mathrm{~N} 1125204 \mathrm{~W}$

333019 N1124430W

$334731 \mathrm{N1125845 \textrm {W }}$

355636 N1113803W

$345229 N 1093959 \mathrm{~W}$

324529 N1094500W

$325048 N 1092518 \mathrm{~W}$

$325341 \mathrm{N1092827 \textrm {W }}$

$330736 \mathrm{N1094047 \textrm {W }}$

333909 N1110708W

340457 N1105549W

$340003 \mathrm{N1114236 \textrm {W }}$

$352737 \mathrm{N111} 3345 \mathrm{~W}$

$323137 \mathrm{N1125054 \textrm {W }}$

$350740 \mathrm{~N} 1121626 \mathrm{~W}$

$363809 \mathrm{~N} 1130943 \mathrm{~W}$

$324451 \mathrm{N1094803 \textrm {W }}$

$342240 \mathrm{~N} 1113803 \mathrm{~W}$

$342328 N 1113512 \mathrm{~W}$

$352651 \mathrm{N1113214 \textrm {W }}$

$313925 N 1113823 \mathrm{~K}$

$324353 N 1094804 \mathrm{~W}$

$350033 \mathrm{~N} 1120423 \mathrm{~W}$

$324252 \mathrm{~N} 109492 \mathrm{OW}$

$324529 \mathrm{~N} 1094500 \mathrm{~W}$

$345410 \mathrm{~N} 1140031 \mathrm{~W}$

$312710 \mathrm{~N} 1092056 \mathrm{~W}$

323931 N1095855W

342048 N1102906W

$341905 \mathrm{~N} 1113003 \mathrm{~W}$

$341207 N 1121533 \mathrm{~W}$

$312806 \mathrm{~N} 1092153 \mathrm{~W}$ 
FEATURE NAME

Deadman Tank

Deadman Tank

Deadman Tank

Deadman Tank

Deadman Tanks

Deadman Valley

Deadman Wash

Deadman Wash

Deadman Wash

Deadman Wash

See Kingman Wash

Dead Mexican Canyon

Dead Mexican Creek

Dead Monkey Ridge

Dead Mule Canyon

Dead OId Mans Pond

See Gurli Put Vo

Dead Pine Spring

Dead River

See Dead Wash

Dead River Bridge

Dead Steer Bas in

Dead Steer Mesa

Dead Wash

Carizo Creek

Carrizo Creek

Dead Creek

Dead River

Rio de la Iara

Rio de la Xara

Deadwood Draw

Deadwood Draw Tank Number One

Deadwood Draw Tank Number Two

Deadwood Point

Deadwood Tank

Deadwood Trai

Deane Peak

See Dean Peak

Dean Mine

Dean Peak

Deane Peak

Dean Tank

De Anza Park

De Anza Village

Death Trap Canyon

Death Trap Spring

Death Valley Lake

Death Valley Spring

Debebekid Lake See Big Water

Debebekid Lake

Debebekid Lake

Te-ye-ba-a-kit Lake

Debebekid Lake

See Debebekid Lake

De Borde Ranch

Deception Gulch

De Chelly Canyon See Chelly, Canyon de

Decker Tank

Decker Tank

Decker Tank

Decker Wash

Decorator Square Shopping Center

Deem Hills Hedgpeth $\mathrm{Hills}$

Deep Canyon

Deep Canyon

Deep Cienega

Deep Cienega

Deep Creek

Deep Creek

\section{FEATURE}

CLASS

reservoir BGN

reservoir BGN

reservoir BGN

reservoir BGN

reservoir BGM

valley $B G N$

stream BGN

stream

strea

valley

valley

strean

ridge

valley

locale

spring

\section{BGN}

$B G N$
$B G N$

BGN

VARIANT

BGN

VARIANT

stream

bridge

bas in

summit

stream

UNOF

BGN

BGN 1939

VARIANT

VARIANT

VARIANT

VARIANT

VARIANT

VARIANT

valley

reservoir

cliff

reservoir

trail

summit

mine

summit

BGN

BGN

BGN

UNOFF

VARIANT

UNOFF

BGN 1930

VARIANT

reservoir $B G$

park

valley

spring

Take

spring

BGN

ADMIN

BGN

BGN

BGN

BGN

VARIANT

lake

BGN 197

VARIANT

VARIANT

Yavapai

Yavapai

Yavapai

Yavapa

Coconino

Yavapai

Mohave

Mohave

Mohave

Cochise

Pima

Cochise

Pima

Pima

Mohave

Navajo

Navajo

VARIANT

lake

locale

valley

UNOFF

BGN

VARIANT

valley

reservoir

reservoir BG

ir BGN

$\begin{array}{ll}\text { reservoir } & B G N \\ \text { stream } & B G N\end{array}$

locale UNOFF

summit

valley

valley

flat

flat

stream
stream

Apache

Gila
COORDINATE

$332354 N 1100048 \mathrm{~W}$

$342150 N 1113849 \mathrm{~W}$

$345945 \mathrm{~N} 1120320 \mathrm{~W}$

352649 N1113537W

350723N1121631W

$361639 N 1102204 \mathrm{~W}$

$330438 N 1132534 \mathrm{~W}$

$334623 N 1121324 \mathrm{~W}$

$353445 N 1111705 W$

360159 N1144216W

314449 N1094830W

$340950 \mathrm{~N} 1123549 \mathrm{~W}$

$364224 N 1112625$ W

343006 N1124039W

$321214 N 1120108 \mathrm{~W}$

$322613 N 1104709 W$

$345859 \mathrm{~N} 1094727 \mathrm{~W}$

$350505 N 1094222 \mathrm{~W}$

$345111 \mathrm{N1} 125120 \mathrm{~W}$

324837 N1095909W

$345859 \mathrm{~N} 1094727 \mathrm{~W}$

\begin{tabular}{|c|c|c|}
\hline $\begin{array}{l}\text { SOURCE } \\
\text { COORDINATE }\end{array}$ & $\begin{array}{l}\text { ELEV } \\
\text { FT }\end{array}$ & MAP NAME \\
\hline $\begin{array}{l}361516 \mathrm{~N} 1101926 \mathrm{~W} \\
332340 \mathrm{~N} 1133004 \mathrm{~W} \\
335237 \mathrm{~N} 1120545 \mathrm{~W}\end{array}$ & 4929 & $\begin{array}{l}\text { Ash Creek NE } \\
\text { Verde Hot Springs } \\
\text { Sycamore Bas in } \\
\text { O'Leary Peak } \\
\text { Matterhorn } \\
\text { Red Slide Peak } \\
\text { Baragan Mtn } \\
\text { Biscuit Flat }\end{array}$ \\
\hline $352313 \mathrm{~N} 1114206 \mathrm{~W}$ & & Wupatki SE \\
\hline \multirow[t]{2}{*}{$\begin{array}{l}314555 \mathrm{~N} 1095244 \mathrm{~W} \\
341002 \mathrm{~N} 1123759 \mathrm{~W}\end{array}$} & & $\begin{array}{l}\text { Outlaw Mountain } \\
\text { Wagoner } \\
\text { Dead Monkey Ridge } \\
\text { Skull Valley }\end{array}$ \\
\hline & & Mt Lemmon \\
\hline $351756 N 1093344 \mathrm{~W}$ & 5542 & $\begin{array}{l}\text { Pinta } \\
\text { Seepage Mtn } \\
\text { Shingle Mill Mtn } \\
\text { Adamana }\end{array}$ \\
\hline
\end{tabular}

$343903 N 1114328 \mathrm{~W}$

$343854 N 1113912 \mathrm{~W}$

$343921 N 1114044 \mathrm{~W}$

$343934 \mathrm{~N} 1114113 \mathrm{~W}$

345724N1114212

$343910 \mathrm{~N} 1114019 \mathrm{~W}$

350703 N1135201W

$350755 \mathrm{~N} 1135208 \mathrm{~W}$

$350703 \mathrm{NI} 135201 \mathrm{~W}$

$321742 N 1090649 \mathrm{~W}$

$321306 \mathrm{~N} 1105814$

313306 N1102030W

$314724 N 1102853 \mathrm{~W}$

314741 N1102704W

362146 N1131459W

$362224 N 1131540 \mathrm{~W}$

$362121 N 1101021 \mathrm{~W}$

362237 N1101313W

343758 N1113828W

Casner Butte

Casner Butte

Casner Butte

Casner Butte

Munds Park

Casner Butte

Hualapai Spring

8013 Dean Peak

Doubtful Canyon

Tucson

$314705 N 1102603 W$

Fort Huachuca

Apache Peak

Apache Peak

Mount Logan

Cold Spring

7281 Cliff Rose Hill

$362237 \mathrm{~N} 1101313 \mathrm{~W}$

$323053 \mathrm{~N} 1100943 \mathrm{~W}$

$344612 \mathrm{N1120235 \textrm {W }}$

$344434 N 1120647 \mathrm{~W}$

4640 Harrison Canyon

Clarkdale

19N1093156

$342115 N 1102552 \mathrm{~W}$

$342617 \mathrm{~N} 1102304 \mathrm{~W}$

$343052 \mathrm{~N} 1102217 \mathrm{~W}$

343117 N1102507W

$321504 N 1105537 W$

341805 N110282BW

Day Spring

Aripine

Sheepskin Wash

Zeniff

334343N1120905W

2380 Tucson North

Hedgpeth Hills

332247 N1104904W 332106N1105017W

$345523 \mathrm{~N} 1125954 \mathrm{~W}$

Globe

$345210 \mathrm{~N} 1130511 \mathrm{~W}$

$333937 \mathrm{~N} 1092043 \mathrm{~W}$

$334953 \mathrm{~N} 1093002 \mathrm{~W}$

334555 N1104B55

$334810 \mathrm{~N} 1105303 \mathrm{~W}$

335040 N1094700W
Scratch Canyon Hannagan Meadow Bon i to Rock Sombrero Peak Corn Creek Plateau 
FEATURE CLASS
STATUS

COUNTY
COORDINATE

$\begin{array}{cc}\text { SOURCE } & \text { ELEV } \\ \text { COORDINATE } & \text { FT }\end{array}$

MAP NAME
Deep Creek

Deep Creek Tank

Deep Hole Tank

Deep Lake

Deep Lake

Deep Lake

Deep Lake Tank

Deep Lake Tank

Deep Tank

Deep Tank

Deep Tank

Deepwater Bend

Deep Well

Deep We 11

Deep Well

Deep We 11

Deep Well

Deep Well

Deep Well

Deep Well

Deep We11

Deep Well

Deep Well Canyon Hackberry Wash

Deepwell Ranch

Deep Well Ranch

Deep Well Ranch

Deep Wells

Deep Well Tank

Deep Well Windmill

Deer Bas in

Deer Camp

Deer Canyon

Deer Canyon

Deer Canyon Well

Deer Creek

Deer Creek

Deer Creek

Deer Creek

old Deer Creek

Deer Creek

Deer Creek

Deer Creek

Deer Creek

Deer Creek

Deer Creek

See South Fork Deer Creek

Deer Creek

Deer Creek

Deer Creek (subdivision)

Deer Creek Cabin

Deer Creek Falls

Deer Creek Ranch

Deer Creek Tank

Deer Dam Tank

Deer Flat

Deer Flat

Deer Flat Tank

Deer Flat Tank

Deerhead Creek

Deer Head Spring

Deerhead Spring

Deer $\mathrm{Hill}$

Deer Hollow

Deering Park Estates

Deering Spring

Deer Is land

Deer Lake

$$
\text { Beaver Is land }
$$

Deer Lake Canyon

\begin{tabular}{|c|c|c|c|}
\hline $\begin{array}{l}\text { stream } \\
\text { reservoir } \\
\text { reservoir } \\
\text { lake } \\
\text { lake } \\
\text { lake } \\
\text { reservoir } \\
\text { reservoir } \\
\text { reservoir } \\
\text { reservoir }\end{array}$ & $\begin{array}{l}\text { BGN } \\
B G N \\
B G N \\
B G N \\
B G N \\
B G N \\
B G N \\
B G N \\
B G N \\
B G N\end{array}$ & $\begin{array}{l}\text { Gila } \\
\text { Gila } \\
\text { Yavapai } \\
\text { Navajo } \\
\text { Apache } \\
\text { Coconino } \\
\text { Apache } \\
\text { Coconino } \\
\text { Navajo } \\
\text { Yavapai }\end{array}$ & 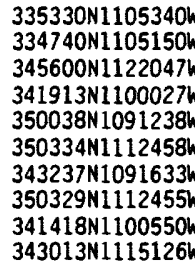 \\
\hline $\begin{array}{l}\text { reservoir } \\
\text { bend } \\
\text { well } \\
\text { well } \\
\text { well } \\
\text { well } \\
\text { well } \\
\text { well } \\
\text { well } \\
\text { well }\end{array}$ & $\begin{array}{l}\text { BGN } \\
\text { BGN } \\
\text { UNOFF } \\
\text { UNOFF } \\
\text { UNOFF } \\
\text { UNOFF } \\
\text { UNOFF } \\
\text { UNOFF } \\
\text { UNOFF } \\
\text { UNOFF }\end{array}$ & $\begin{array}{l}\text { Coconino } \\
\text { La Paz } \\
\text { Cochise } \\
\text { Cochise } \\
\text { Pima } \\
\text { Pinal } \\
\text { Pinal } \\
\text { Graham } \\
\text { Yuma } \\
\text { Coconino }\end{array}$ & $\begin{array}{l}352908 N 1114355 \\
333400 N 1143400 \\
313021 N 1092133 \\
320257 N 1093541 \\
322957 N 1103702 \\
323201 N 1105751 \\
323903 N 1104617 \\
325025 N 1101805 \\
331556 N 1135834 \\
344749 N 1110520\end{array}$ \\
\hline
\end{tabular}

$350415 \mathrm{N1102911 \textrm {W }}$

$350700 \mathrm{N1125951 \textrm {W }}$

313012N1092052W

$320947 \mathrm{~N} 1100948 \mathrm{~W}$

$321520 \mathrm{N1104250 \textrm {W }}$

$324543 \mathrm{~N} 1111936 \mathrm{~W}$

$342056 \mathrm{~N} 1125349 \mathrm{~W}$

$331209 \mathrm{~N} 1112158 \mathrm{~W}$

$314417 \mathrm{N1095751 \textrm {W }}$

reservoir $B$ UNOFF Yavapai

$\begin{array}{lll}\text { reservoir } & B G N & \text { Pinal } \\ \text { locale } & B G N & \text { Cochise }\end{array}$

bas in

locale

valley

valley

well

stream

strean

strean

strean

\section{BGM Yavapai 342B10N1113854W}

BGN Pima 320B42N1104038W

BGN Mohave 343436N1140703W

BGN Navajo 345236N1103043W

UNOFF Mohave 343413N1140715

BGN 1978 Cochise 314040N1090545W

BGN Pima 321144N1102504W

BGN Grahan 324205N1101235W

BGN Pinal

VARIANT

stream

stream

stream

stream

stream

stream

stream

pp)

$\begin{array}{lll}\text { BGN } & \text { Pinal } & 330251 \text { N1104254W } \\ \text { BGN } & \text { Gila } & 333430 N 1100336 \mathrm{~W} \\ \text { BGN } & \text { Gila } & 334109 \text { N1100956W } \\ \text { BGN } & \text { Apache } & 334806 \mathrm{~N} 1091926 \mathrm{~W} \\ \text { BGN } & \text { Gila } & 335111 \mathrm{N1105933 \textrm {W }} \\ \text { VARIANT } & & \\ & \text { Gila } & 340255 \mathrm{~N} 1112233 \mathrm{~W} \\ \text { BGN } & \text { Gila } & 340431 \mathrm{~N} 1112014 \mathrm{~W} \\ \text { BGN 1964 } & \text { Coconino } & 362317 \mathrm{~N} 1123029 \mathrm{~W} \\ \text { BGN } & \text { Maricopa } & 333500 \mathrm{~N} 1121303 \mathrm{~W}\end{array}$

$334926 \mathrm{~N} 1110039 \mathrm{~W}$

$323956 \mathrm{~N} 1101710 \mathrm{~W}$

$36231 \mathrm{BN} 1123032 \mathrm{~W}$

$323936 \mathrm{~N} 1101615 \mathrm{~W}$

$334233 \mathrm{~N} 1100710 \mathrm{~W}$

$323110 \mathrm{N1094434 \textrm {W }}$

$335731 N 1114757 \mathrm{~W}$

341927 N1112101W

$341934 \mathrm{N1112132 \textrm {W }}$

355640N1132921

$331335 \mathrm{~N} 1092650 \mathrm{~W}$

reservoir BGM

stream $B G N$

spring $B G N$

spring $B G N$

summit $\quad B G N$

valley

ppl

spring

is land

lake

lake
valley
$321153 \mathrm{~N} 1103200 \mathrm{~W}$

331355 N1092510W

$333826 \mathrm{~N} 1110859 \mathrm{~W}$

$320748 \mathrm{~N} 1131148 \mathrm{~W}$

$343210 N 1123356 \mathrm{~W}$

$314833 \mathrm{~N} 1104537 \mathrm{~W}$

340700 N1142230W

$342246 \mathrm{N1} 105303 \mathrm{~W}$
$342326 \mathrm{~N} 1105628 \mathrm{~W}$
$330218 \mathrm{~N} 1102637 \mathrm{~W}$

$333035 \mathrm{~N} 1100350 \mathrm{~W}$

$334224 \mathrm{~N} 1100700 \mathrm{~W}$

$335112 \mathrm{~N} 1092224 \mathrm{~W}$

340057 N1112936W

$362651 \mathrm{~N} 1122442 \mathrm{~W}$

$\begin{array}{ll}\text { 335336N1105529w } & \text { McFadden Peak } \\ \text { Sombrero Peak } & \text { Hell Point } \\ \text { Show Low North } & \text { Deep Lake } \\ \text { Ashurst Lake } & \text { St Johns North } \\ \text { Ashurst Lake } & \text { Show Low South } \\ \text { Camp Verde } \\ \\ \\ \text { White Horse Hills } \\ \text { Blythe } \\ \text { Pedregosa Mts East } \\ \text { Pat Hills North } \\ \text { Buehman Canyon } \\ \text { Oracle Junction } \\ \text { North of Oracle } \\ \text { Klondike } \\ \text { Kofa Butte } \\ \text { Chavez Mtn East }\end{array}$

5071 Humpy Camp We11

Turkey Canyon

Pedregosa Mts East

Deepwell Ranch

2780 Agua Caliente Hill

Picacho Reservoir SE

Date

Florence NE

Hay Mountain

Hackberry Mtn

Tanque Verde Peak

Buck Mountains SE

Hibbard

Buck Mts SE

Skull Canyon

Happy Valley

Eureka Ranch

Booger Canyon

Christmas

Georges Butte

Forks Butte

Big Lake South

Aztec Peak

$331347 \mathrm{~N} 1092505 \mathrm{~W}$

Gisela

Fishtail

1160 Glendale

Kennedy Peak

Fishtail

Kennedy Peak

5703 Velasquez Butte

Gillespie Mtn

Humboldt Mtn

Payson North

Payson North

Price Point

Coronado Mtn

Mica Mountain

Coronado Mt

3831 Theo. Roosevelt Dam

$N$ of Agua Dulca Mts

320429 N1131326W

6120 Iron Springs

Helvetia

Parker SW

Porcupine Ridge

Porcupine Ridge 
FEATURE NAME

Deer Lick Canyon

Deer Lick Spring

Deer Lodge

Deer Mountain

Deer Mountain

Deer Mountain

Deer Mountain Tank

Deer Mountain Wash

Deer Pass Ranch

Deer Seep Tank

Deer Spring

Deer Spring

Deer Spring

Deer Spring

Deer Spring

Deer Spring

Deer Spring

Deer Spring

Deer Spring

Deer Spring

Deer Spring

Deer Spring

Deer Spring

Deer Spring

Deer Spring Creek

Deer Spring Mountain

Deer Springs Canyon

Deer Springs Canyon

Deer Springs Creek

Deer Springs Guard Station

Deer Tank

Deer Tank

Deer Tank

Deer Tank

Deer Tank

Deer Tank

Deer Tank

Deer Tank

Deer Tank

Deer Tank

Deer Tank

Deer Tank

Deer Tank

Deer Tank

Deer Tank

Deer Tank

Deer Tanks

Deer Tank Wash

Deer Trail Mine

Deer Trail Tank

Deer Valley

Deer Valley

Deer Valley Airport

See Phoenix Deer Valley Municipal Airport

Deer Valley Filtration Plant

Deer Valley Interchange

Deer Valley Motorcycle Park

Deer Valley Plaza Shopping

Center

Deer Valley School

Deer Valley Shopping Center

Deer Valley Substation

Deer Water Well

Deer Well

de Hannon, Rancho

Dehorn

DeHlose Spring

Dejolie Tank

De La Fontaine Mine
FEATURE
CLASS

STATUS

COUNTY

COORDINATE

valley
spring
locale
summit
summit
summit
reservoir
arroyo
locale
reservoir

BGN
BGN
BGN
BGN
BGN
BGN
BGN
BGN
UNOFF
BGN

Navajo

Yavapai

Coconino

Greenlee

Yavapai

Yavapai

Yavapai

Yavapai

Yavapai

Coconino

spring

spring

spring

spring

spring

spring

spring

spring

spring

BGN

BGN

BGN

BGN

BGN

BGN

BGN

BGN

BGN

BGN

spring

spring

spring

spring

stream

valley

valley

stream

locale

$B G N$

BGN

BGN

BGN

BGN

BGN

BGN

BGN

UNOFF

Cochise

Cochise

Graham

Green lee

Pinal

Gila

Yavapai

Navajo

Yavapai

Yavapai

Yavapai

Yavapai

Coconino

Navajo

Gila

Navajo

Greenlee

Navajo

Apache

Navajo

reservoir

reservoir

reservoir

reservoir

reservoir

reservoir

reservoir

reservoir

reservoir

reservoir

BGN

BGN

$B G N$

BGN

BGN

BGN

BGN

BGN

reservoir

reservoir

reservoir

reservoir

reservoir

reservoir

reservoir

strean

reservoir

BGN

BGN

BGN

BGN

$B G N$

BGN

BGN

BGN

Grahan

Greenlee

Gila

Gila

Gila

Yavapai

Yavapai

Yavapai

Apache

Yavapai

Yavapai

Coconino

Coconino

Coconino

Coconino

Coconino

Cochise

Coconino

Mohave

Mohave

valley
Ppl

BGN Maricopa

Maricopa

airport

VARIANT

building UNDFF

crossing UNOFF

park ADMIN

locale

UNOFF

Maricopa

Maricopa

Maricopa

Maricopa

schoo

chool

UNOFF

UNOFF

locale

well

we11

locale

locale

spring

reservoir

mine

$341813 \mathrm{~N} 1101638 \mathrm{~W}$

342957 N1122552

$353032 N 1131107 \mathrm{~W}$

$333836 \mathrm{~N} 1090744 \mathrm{~W}$

$343855 \mathrm{~N} 1131948 \mathrm{~W}$

$350012 \mathrm{~N} 1125938 \mathrm{~W}$

343849 N1131838W

$343710 \mathrm{~N} 1131828 \mathrm{~W}$

$344806 \mathrm{~N} 1115240 \mathrm{~W}$

344932N1112243W

$313205 \mathrm{~N} 1102550 \mathrm{~W}$

$315012 \mathrm{~N} 1091610 \mathrm{~W}$

$330120 \mathrm{N1} 101719 \mathrm{~W}$

331550N1090611W

332520N1110916W

$334744 \mathrm{N1} 100858 \mathrm{~W}$

$341725 \mathrm{N1} 122723 \mathrm{~W}$

$341755 N 1102554 \mathrm{~W}$

$342022 \mathrm{~N} 1121849 \mathrm{~W}$

342752NI130757W

$343033 \mathrm{~N} 1122702 \mathrm{~W}$

$343935 \mathrm{~N} 1125100 \mathrm{~W}$

$362359 \mathrm{N1} 123004 \mathrm{~W}$

$364846 \mathrm{~N} 1103434 \mathrm{~W}$

$335836 \mathrm{~N} 1100126 \mathrm{~W}$

$340040 \mathrm{N1095825 \textrm {W }}$

$331514 N 1090600 \mathrm{~W}$

$341016 \mathrm{N1102728 \textrm {W }}$

$355155 \mathrm{~N} 1090845 \mathrm{~W}$

$341752 \mathrm{~N} 1102551 \mathrm{~W}$

$324702 \mathrm{~N} 1100531 \mathrm{~W}$

$332124 \mathrm{~N} 1092418 \mathrm{~W}$

$333203 \mathrm{~N} 1100216 \mathrm{~W}$

$335448 \mathrm{~N} 1100227 \mathrm{~W}$

$340445 \mathrm{~N} 1104907 \mathrm{~W}$

$341613 \mathrm{~N} 1114438 \mathrm{~W}$

$345400 \mathrm{~N} 1125548 \mathrm{~W}$

$345859 \mathrm{~N} 1125639 \mathrm{~W}$

$350611 N 1091444 \mathrm{~W}$

$351336 \mathrm{~N} 1125034 \mathrm{~W}$

$351428 \mathrm{~N} 1130208 \mathrm{~W}$

$352240 \mathrm{~N} 1114719 \mathrm{~W}$

$352540 \mathrm{~N} 1122106 \mathrm{~W}$

$353232 \mathrm{~N} 1114142 \mathrm{~W}$

$353603 \mathrm{MI} 125706 \mathrm{~W}$

$355915 \mathrm{M} 11$

$355535 \mathrm{~N} 1114604 \mathrm{~W}$

341731N1133923W

$363840 N 1123853 \mathrm{~W}$

$333702 \mathrm{~N} 1120958 \mathrm{~W}$

$334102 \mathrm{NI1} 20803 \mathrm{~W}$

334113N1120457W

$333408 \mathrm{N1120726 \textrm {W }}$

$334102 \mathrm{~N} 1120642 \mathrm{~W}$

$334123 N 1120339 \mathrm{~W}$

$333830 \mathrm{~N} 1120552 \mathrm{~W}$

Maricopa $\quad 333921 N 1121719 \mathrm{~W}$

Maricopa $\quad 333918 \mathrm{N1120907 \textrm {W }}$

$\begin{array}{ll}\text { Maricopa } & 333918 N 1120907 \mathrm{~W} \\ \text { Apache } & 345555 \mathrm{~N} 1090450 \mathrm{~W}\end{array}$

Yavapai $\quad 342804 N 1130727 \mathrm{~W}$

Cochise 312938N1095937W

$333137 \mathrm{~N} 110104$ 
NATIONAL GAZETTEER--ARIZONA 1986 FEATURE NAME

Delaney Tank

Delaney Wash

Delaney Well

de la Osa, Rancho

De La Ossa Well

Delaware Mine

Delaware Wash

Delchay Butte

Delia Well

Delicias Park

Della Tank

Dellenbaugh, Mount

Del Monte Gulch

Del Monte Shopping Center

Del Muerto

See Maverick Canyon

Del Muerto

Del Muerto Canyon

See Muerto, Canyon del

Del Norte Shopping Center

Delodo Draw

Delodo Tank

Delong Ranch

Del Pasco Mine

Del Rio

Postle Ranch

Del Rio Dam

Del Rio Mine

Del Rio Railroad Station

Del Rio Ranch

Del Rio Springs

Del Shay Basin

Del Shay Creek

Del Shay Spring

Del Shay Trail

Delta Tank

Deluge Wash

DeLuxe Trailer Court

Demaray Point

Demetrie Wash

Demetrie Well

Democrat Mesa

Democrat Mine

Demonstration $\mathrm{Hill}$

Dellotte Campground

De Motte Park

$$
\text { V T Park }
$$

V T Park Tourist Ranch

Denabeto Spring

See Dinnebito Spring

Denabeto Wash

$$
\text { See Dinnebito Wash }
$$

Denahatso

See Dennehotso

Dendora Ranch

Dendora Substation

Dendora Valley

Denebito Wash

See Dinnebito Wash

Denehotso

See Dennehotso

Deneth Chahis Spring

Denezipi Spring

Dennehotso

Denahatso

Denehotso

Dinnehotso

Dennehotso Canyon

Sahotsaidbeazhe Canyon

Sa Hot soid be azhe

Canyon

Sahotsoid Beazhe Canyon

Tsehotsoi Bizazhe Canyon

\section{FEATURE
CLASS}

STATUS

COUNTY

$\begin{array}{ll}\text { reservoir } & \text { BGN } \\ \text { stream } & \text { BGN } \\ \text { well } & \text { UNOFF } \\ \text { locale } & \text { UNOFF } \\ \text { well } & \text { UNOFF } \\ \text { mine } & \text { UNOFF } \\ \text { stream } & \text { BGN } \\ \text { summit } & \text { BGN 1917 } \\ \text { well } & \text { UNOFF } \\ \text { park } & \text { ADMIN }\end{array}$

Navajo

Maricopa

Maricopa

Pima

Yuma

Gila

Gila

Maricopa

Yavapai

Maricopa

reservoir $B G$

valley

locale

valley

pp 1

BGN

UNOFF

VARIANT

Coconino

Mohave

Yavapai

Pima

Graham

Apache

valley

BGN

VARIANT

locale

UNOFF

Apach

valley

reservoir BGH

locale

mine

locale

BGN

UNOFF

UNOFF

BGN

dam

VARIANT

mine

UNOFF

UNOFF

building UNOFF

UNOFF

spring $B G N$

$\begin{array}{ll}\text { bas in } & B G N \\ \text { stream } & B G N\end{array}$

$\begin{array}{ll}\text { stream } & B G N \\ \text { spring } & B G N\end{array}$

$\begin{array}{ll}\text { spring } & \text { BGN } \\ \text { trall } & \text { UNOFF }\end{array}$

reservoir BGN

stream BGN

locale UNOFF

cliff

BGN 1964

stream

BG

$\begin{array}{ll}\text { well } & \text { UNOFF } \\ \text { summit } & \text { BGN } \\ \text { mine } & \text { UNOFF } \\ \text { summit } & \text { BGN } \\ \text { park } & \text { ADMIN } \\ \text { flat } & \text { BGN 1926 } \\ & \text { VARIANT } \\ & \text { VARIANT } \\ & \text { VARIANT }\end{array}$

spring

Navajo

Navajo

Graham

Yavapai

Yavapai

Yavapai

Pima

Yavapai

Yavapai

Yavapai

Gila

Gila

Gila

Gila

Coconino

Mohave

Maricopa

Coconino

Pima

Pima

Greenlee

Mohave

Cochise

Coconino

Coconino

Coconino

COORDINATE

$345314 \mathrm{~N} 1095248 \mathrm{~W}$

$332633 N 1125432 \mathrm{~W}$

$332934 \mathrm{N1125922W}$

$12943 N 1113344 \mathrm{~N}$

$332248 N 1140133 \mathrm{~W}$

$341050 \mathrm{N1112217 \textrm {W }}$

$340929 \mathrm{~N} 1112418 \mathrm{~W}$

UNKNOWN

342939N1124101W

333237 N1120949W

$353930 \mathrm{~N} 1113651 \mathrm{~W}$

$360631 \mathrm{N1133226 \textrm {W }}$

$344357 N 1120244 \mathrm{~W}$

320918N1105839W

331339 N1093814W

$361105 \mathrm{N1092632W}$

360835 N1092920W

321620 N1105909W

342B46N1104256W

$342757 N 1104225 \mathrm{~W}$

323139 N1091508W

341352N1122044W

$344923 N 1122634 \mathrm{~W}$

$344915 N 1122751 W$

$315225 \mathrm{~N} 1104800 \mathrm{~W}$

$345057 \mathrm{~N} 1122706 \mathrm{~W}$

344949 N1122658W

344915 N1122640W

$335910 \mathrm{~N} 1111359 \mathrm{~W}$

$340021 \mathrm{N1111541 \textrm {W }}$

335818 N1111405

340044N1111442W

$351321 N 1122110 \mathrm{~W}$

$344910 \mathrm{~N} 1133713 \mathrm{~W}$

$332706 \mathrm{~N} 1120615 \mathrm{~W}$

360600 N1120245

$314816 \mathrm{N1110020 \textrm {W }}$

$314815 N 1110157 \mathrm{~W}$

325737 N1091045

$350407 N 1135147 \mathrm{~W}$

313359 N1102310W

$362525 \mathrm{~N} 1120749 \mathrm{~W}$

$362509 \mathrm{~N} 1120756 \mathrm{~W}$

354749 N1105437W

VARIANT

valley

ppl

locale

locale

valley

valley

pp 1

VARIANT

Coconino

352845N1111415W

Apache

UNOFF

UNOFF

BGN

VARIANT

Maricopa

Maricopa

Maricopa

$352845 N 1111415 W$

$330235 \mathrm{~N} 1130348 \mathrm{~W}$

$330133 \mathrm{~N} 1125525 \mathrm{~W}$

330309N1130453W

Coconino

$352845 N 1111415$

VARIANT

Apache

352845 N1111415W

spring BGN Navajo

spring BGK

spring

BGN

BGN 1971

VARIANT

VARIANT

valley BGN 1971 Apache

VARIANT

VARIAN

VARIANT

VARIANT

$360441 \mathrm{N1100639 \textrm {W }}$

$355905 \mathrm{~N} 1100556 \mathrm{~W}$ summit BGN 1932

\begin{tabular}{ccc}
$\begin{array}{c}\text { SOURCE } \\
\text { COORDINATE }\end{array}$ & $\begin{array}{c}\text { ELEV } \\
\text { 332927N1130121W }\end{array}$ & \multicolumn{1}{c}{ MAP NAME } \\
& $\begin{array}{l}\text { Carrizo Butte } \\
\text { Tonopah } \\
\text { Tonopah } \\
\text { Sasabe } \\
\text { Livingston Hills } \\
\text { Payson South } \\
\text { North Peak }\end{array}$ \\
& $\begin{array}{l}\text { Kirkland } \\
\text { Glendale }\end{array}$
\end{tabular}

Campbell Francis Wsh

$344345 N 1120608 \mathrm{~W}$

7072 Mt Dellenbaugh

Cottonwood

2480 Tucson

Del Muerto

2320 Tucson North

342648 N1104219W

Hanks Draw

Hanks Draw

Whit lock Cienega

Crown King

Chino Valley North

Chino Valley North

Helvetia

Chino Valley North

Chino Valley North

Chino Valley North

Picture Mtn

Gisela

Picture Mtn

Sheep Bas in Mtn

McLellan Reservoir

345006N1135124W Tule Wash

1075 Phoenix

315334N1111149W $\begin{array}{ll}5200 & \begin{array}{l}\text { Phantom Ranch } \\ \text { Esperanza Mill }\end{array}\end{array}$

Esperanza Mill

York

Dean Peak

Pyeatt Ranch

De Motte Park

Kanabownits Spring

Dendora valley

Citrus valley West

330706N1130517W Dendora Valley 
FEATURE NAME

Tsehotsoibizazhe Canyon

Dennehotso Recreation Area
Dennis Creek
Dennison
Dennison Interchange
Dennison Picnic Ground
Dennison Well
Dennis Spring
Dennis Tank
Dennis Weaver Park
Denny Dunn Park

Denny Mountain
Dennys Ranch
Dent and Sayer Ranch
Dent and Sayer Tank
Denton Trail
Denton Trough Spring
Dent Tank
Dent Tank
Denver Elementary School
Denver Hill

Denver Hill

Department of Health Indian

Hospital

Depot Tank

Depression Canyon

Depression Tank

Derby Mine

Dern Mine

Derrick Canyon

Derrick Pocket

Derrick Trail

Derrio Canyon

Desaki Mesa

See White Top Mesa

Deserama Mobile Ranch

Desert, Lake in the

Desert Aire Park

Desert Bell Estates II

(subdivision)

Desert Botanical Gardens

Desert Cove School

Desert Facade

Desert Farms Well One

Desert Farms Well Two

Desert Foothills Amphitheater

Desert Gem Mobile Home Park

Desert Highlands

Desert Hills Interchange

Desert-Ho Ranch

Desert Horizon Elementary School

Desert Lake Tank

Desert Lawn Cemetery

Desert Lawn Memorial Park

Desert Mine

Desert Peak

Desert Pines (subdivision)

Desert Proving Grounds General Motors Desert Proving Grounds General Motors Proving Ground

Desert Queen Mine

Desert Queen Mine

Desert Queen Mine

Desert Rest

Desert Ridge (subdivision)

Desert Rose Mine

Desert Sage

$$
\text { See Twin Knolls (trailer }
$$
park)

FEATURE
CLASS

STATUS

COUNTY

COOROINATE

$\begin{array}{lc}\text { SOURCE } & \text { ELEV } \\ \text { COORDINATE } & \text { FT }\end{array}$

MAP NAME

VARIANT

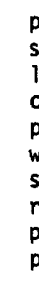

\begin{tabular}{|c|c|c|c|}
\hline $\begin{array}{l}\text { summit } \\
\text { locale } \\
\text { locale } \\
\text { reservoir } \\
\text { trail } \\
\text { spring } \\
\text { reservoir } \\
\text { reservoir } \\
\text { school } \\
\text { summit }\end{array}$ & $\begin{array}{l}\text { BGN } \\
\text { UNOFF } \\
\text { UNOFF } \\
\text { BGN } \\
\text { UNOFF } \\
\text { BGN } \\
\text { BGN } \\
\text { BGN } \\
\text { UNOFF } \\
\text { BGN }\end{array}$ & $\begin{array}{l}\text { Yavapai } \\
\text { Yavapai } \\
\text { Coconino } \\
\text { Coconino } \\
\text { Gila } \\
\text { Gila } \\
\text { Coconino } \\
\text { Coconino } \\
\text { Maricopa } \\
\text { Yavapai }\end{array}$ & $\begin{array}{l}345249 \mathrm{~N} 1131643 \mathrm{~W} \\
352512 \mathrm{~N} 1131835 \mathrm{~W} \\
353629 \mathrm{~N} 1115618 \mathrm{~W} \\
354420 \mathrm{~N} 111455 \mathrm{~W} \\
334728 \mathrm{~N} 1111945 \mathrm{~W} \\
334709 \mathrm{~N} 1112002 \mathrm{~W} \\
352210 \mathrm{~N} 1115127 \mathrm{~W} \\
355127 \mathrm{~N} 1120039 \mathrm{~W} \\
331752 \mathrm{~N} 1115050 \mathrm{~W} \\
340202 \mathrm{~N} 1123356 \mathrm{~W}\end{array}$ \\
\hline
\end{tabular}

hospital UNOFF Navajo

reservoir BGN Navajo

valley BGN Pinal

reservoir BGN Coconino

mine

mine

valley

basin

UNOFF

UNOFF

BGN

$B G N$

trail UNOFF

Yavapai

Cochise

Gila

Gila

Gila

valley

BGN

sumnit

locale

lake

park

ppl

park

school

VARIANT

Pinal

UNOFF

BGN

BGN

BGN

Maricopa

Pinal

Pima

Maricopa

354847N1101130W

$350110 \mathrm{~N} 1095311 \mathrm{~W}$

$325851 N 1103717 \mathrm{~W}$

351249 N1122413W

$343321 \mathrm{~N} 1123417 \mathrm{~W}$

312549 N1095314W

$341108 \mathrm{~N} 1110943 \mathrm{~W}$

$341026 \mathrm{~N} 1110927 \mathrm{~W}$

342015 N1110450

$323056 N 1110951 \mathrm{~W}$

363158 N1095004W

$332503 \mathrm{~N} 1114642 \mathrm{~W}$

$325556 \mathrm{~N} 1113850 \mathrm{~W}$

$321243 \mathrm{N1} 105240 \mathrm{~W}$

$333924 \mathrm{~N} 1120304 \mathrm{~W}$

Maricopa

$332733 \mathrm{~N} 1115635 \mathrm{~W}$

$333506 \mathrm{~N} 1120118 \mathrm{~W}$

cliff BGN 1906 Coconino 361447N1114849W

well UNOFF Maricopa 332053N1125504W

well UNOFF Maricopa 332118N1125606W

locale BGN Maricopa $334924 \mathrm{N1115432 \textrm {W }}$

locale UNOFF Maricopa 332711N1121151W

pp1 BGN Maricopa $334310 \mathrm{N1115255 \textrm {W }}$

crossing UNOFF Maricopa 335215N1120844W

$332650 \mathrm{~N} 1130939 \mathrm{H}$

$\begin{array}{llll}\text { locale } & \text { UNOFF } & \text { Maricopa } & 332658 \mathrm{~N} 1130939 \mathrm{~W} \\ \text { school } & \text { UNOFF } & \text { Maricopa } & 332912 \mathrm{N1} 121432 \mathrm{~W}\end{array}$

reservoir

cemetery UNOFF Mohave 345322N1143229W

cemetery UNOFF Yuma $324206 \mathrm{N1143703 \textrm {W }}$

$\begin{array}{lll}\text { mine UNOFF Yuma } & 334545 N 1134325 \mathrm{~W}\end{array}$

summit BGN Pinal $\quad 323541$ N1111445W

locale BGY

$333815 N 1120835 \mathrm{~W}$

VARIANT

VARIANT

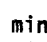

mine

mine

cemetery

ppl

mine

UNOFF

UNOFF

UNOFF

UNOFF

BGN

UNOFF
Pinal 323601N1115320W

$333724 N 1140631 \mathrm{~W}$

Yuma 334630N1134344W

Cochise $\quad 321957$ N1092909W

Maricopa $333803 N 1115551 W$

Maricopa

$332448 \mathrm{~N} 1113902 \mathrm{~W}$
Maricopa 334301N1130915W

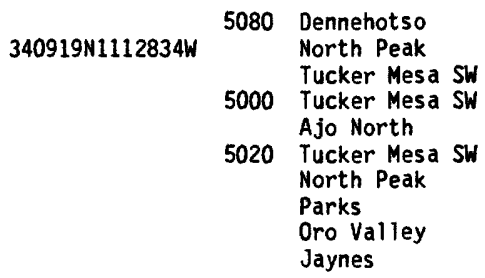

5794 Mohon Peak

5520 Blye Canyon NE

Ebert Mtn

Lockwood Canyon

Tonto Bas in

Tonto Bas in

Wing Mountain

Red Butte

Chandler

Morgan Butte

Keams Canyon

$325529 N 1103723 \mathrm{~W}$

Lt I Lithodendron Tk

Ash Fork

6400 Iron Springs

Bisbee

341152N1111039W McDonaid Mtn

McDonald Mtn

Promontory Butte

$323300 \mathrm{~N} 1110209 \mathrm{~W}$

Desert Peak

1255 Mesa

Casa Crande East

Tucson

1440 Union Hills

Tempe

Sunnys lope

Cape Solitude

912 Gillespie

Gillespie

Cave Creek

1045 Fowler

2300 Currys Corner

Biscuit Flat

1132 Cortez Peak NW

Fowler

New River SE

Needles NE

Yuma East

Harcuvar

2608 Desert Peak

1300 Hedgpeth Hills Desert Well
North Komelik Crystal Hill

Harcuvar

Bowie

1495 Currys Corner

Little Horn Peak 


\begin{tabular}{|c|c|c|c|c|c|c|c|}
\hline FEATURE NAME & $\begin{array}{l}\text { FEATURE } \\
\text { CLASS }\end{array}$ & STATUS & COUNTY & COORDINATE & $\begin{array}{l}\text { SOURCE } \\
\text { COORDINATE }\end{array}$ & $\begin{array}{l}\text { ELEV } \\
\text { FT }\end{array}$ & MAP NANE \\
\hline Desert Sage Mobile Manor & locale & UNOFF & Maricopa & $332748 \mathrm{~N} 1115849 \mathrm{~W}$ & & 1180 & Tempe \\
\hline $\begin{array}{l}\text { Desert Sage Post Office } \\
\text { Desert Samaritan Hospital } \\
\text { Desert Sands Junior High School } \\
\text { Desert Sands Mobile Home Park } \\
\text { Desert Shadows School } \\
\text { Desert Springs Park } \\
\text { See Sandpiper Park } \\
\text { Desert Square Shopping Center } \\
\text { Desert Station } \\
\text { Desert Station } \\
\text { See Desert Wells }\end{array}$ & $\begin{array}{l}\text { building } \\
\text { hospital } \\
\text { school } \\
\text { locale } \\
\text { school } \\
\text { park } \\
\text { locale } \\
\text { locale } \\
\text { ppl }\end{array}$ & $\begin{array}{l}\text { UNOFF } \\
\text { UNOFF } \\
\text { UNOFF } \\
\text { UNOFF } \\
\text { UNOFF } \\
\text { VARIANT } \\
\text { UNOFF } \\
\text { BGN } \\
\text { VARIANT }\end{array}$ & $\begin{array}{l}\text { Maricopa } \\
\text { Maricopa } \\
\text { Maricopa } \\
\text { Maricopa } \\
\text { Maricopa } \\
\text { Maricopa } \\
\text { Pima } \\
\text { Maricopa } \\
\text { Yuma }\end{array}$ & $\begin{array}{l}332453 \mathrm{~N} 1113905 \mathrm{~W} \\
332322 \mathrm{~N} 1115238 \mathrm{~W} \\
333010 \mathrm{~N} 1121146 \mathrm{~W} \\
334133 \mathrm{~N} 1120704 \mathrm{~W} \\
333622 \mathrm{~N} 1115712 \mathrm{~W} \\
333656 \mathrm{~N} 1115616 \mathrm{~W} \\
321133 \mathrm{~N} 1105020 \mathrm{~W} \\
330151 \mathrm{~N} 1122957 \mathrm{~W} \\
334230 \mathrm{~N} 1134915 \mathrm{~W}\end{array}$ & & $\begin{array}{l}1200 \\
1380\end{array}$ & $\begin{array}{l}\text { Buckhorn } \\
\text { Tempe } \\
\text { Glendale } \\
\text { Union Hills } \\
\text { Paradise Valley } \\
\text { Tucson East } \\
\text { Butterfield Pass }\end{array}$ \\
\hline $\begin{array}{l}\text { Desert Tank } \\
\text { Desert Tank } \\
\text { Desert Valley Estates } \\
\text { (subdivision) } \\
\text { Desert View } \\
\text { Navajo Point } \\
\text { Desert View Campground } \\
\text { Desert View Point } \\
\text { Navajo Point } \\
\text { Desert View School }\end{array}$ & $\begin{array}{l}\text { reservoir } \\
\text { reservoir } \\
\text { ppl } \\
\text { locale } \\
\text { park } \\
\text { summit } \\
\text { school }\end{array}$ & $\begin{array}{l}\text { BGN } \\
\text { BGN } \\
\text { BGN } \\
\text { BGN } 1932 \\
\text { VARIANT } \\
\text { ADMIN } \\
\text { BGN } 1932 \\
\text { VARIANT } \\
\text { UNOFF }\end{array}$ & $\begin{array}{l}\text { Maricopa } \\
\text { Mohave } \\
\text { Maricopa } \\
\text { Coconino } \\
\text { Coconino } \\
\text { Coconino } \\
\text { Maricopa }\end{array}$ & $\begin{array}{l}333942 \mathrm{~N} 1131736 \mathrm{~W} \\
342958 \mathrm{~N} 1135735 \mathrm{~W} \\
333918 \mathrm{~N} 1120552 \mathrm{~W} \\
360234 \mathrm{~N} 1114933 \mathrm{~W} \\
\\
360232 \mathrm{~N} 1114926 \mathrm{~W} \\
360230 \mathrm{~N} 1114926 \mathrm{~W} \\
333345 \mathrm{~N} 1120405 \mathrm{~W}\end{array}$ & & $\begin{array}{l}1868 \\
1375 \\
7438 \\
7450 \\
7450\end{array}$ & $\begin{array}{l}\text { Weldon Hill } \\
\text { Castaneda Hills } \\
\text { Union Hills } \\
\text { Desert View } \\
\text { Cape Solitude } \\
\text { Cape Solitude } \\
\text { Sunnys lope }\end{array}$ \\
\hline $\begin{array}{l}\text { Desert Village Mobile Home Park } \\
\text { Desert Villas (subdivision) } \\
\text { Desert Vista Estates III } \\
\text { (subdivision) } \\
\text { Desert Well } \\
\text { Desert Wells } \\
\text { Desert Well } \\
\text { Desert Well } \\
\text { See Nolic } \\
\text { Desert Well } \\
\text { See Desert Wellis }\end{array}$ & $\begin{array}{l}\text { locale } \\
\text { ppl } \\
\text { ppl } \\
\text { well } \\
\text { well } \\
\text { locale } \\
\text { ppl }\end{array}$ & $\begin{array}{l}\text { UNOFF } \\
\text { BGN } \\
\text { BGN } \\
\text { UNOFF } \\
\text { VARIANT } \\
\text { UNOFF } \\
\text { VARIANT } \\
\text { VARIANT }\end{array}$ & $\begin{array}{l}\text { Maricopa } \\
\text { Maricopa } \\
\text { Maricopa } \\
\text { Maricopa } \\
\text { Maricopa } \\
\text { Pima } \\
\text { Yuma }\end{array}$ & $\begin{array}{l}332445 \mathrm{~N} 1113721 \mathrm{~W} \\
332110 \mathrm{~N} 1115825 \mathrm{~W} \\
332525 \mathrm{~N} 1113744 \mathrm{~W} \\
332106 \mathrm{~N} 1113630 \mathrm{~W} \\
334543 \mathrm{~N} 1124629 \mathrm{~W} \\
320207 \mathrm{~N} 1115707 \mathrm{~W} \\
334230 \mathrm{~N} 1134915 \mathrm{~W}\end{array}$ & & $\begin{array}{l}1540 \\
1275 \\
1570\end{array}$ & $\begin{array}{l}\text { Apache Junction } \\
\text { Guadalupe } \\
\text { Buckhorn } \\
\text { Desert Well } \\
\text { Vulture Mine }\end{array}$ \\
\hline $\begin{array}{l}\text { Desert Well Number One } \\
\text { Desert Well Number Two } \\
\text { Desert Wells } \\
\text { See Desert Well } \\
\text { Desert Wells } \\
\text { Desert Station } \\
\text { Desert Well } \\
\text { Vicksburg Junction } \\
\text { Desert Wind II (subdivision) } \\
\text { Deshgish Butte }\end{array}$ & $\begin{array}{l}\text { well } \\
\text { well } \\
\text { well } \\
\text { ppl }\end{array}$ & $\begin{array}{l}\text { UNOFF } \\
\text { UNOFF } \\
\text { VARIANT } \\
\text { BGN } 1964 \\
\text { VARIANT } \\
\text { VARIANT } \\
\text { VARIANT } \\
\text { BGN } \\
\text { BGN }\end{array}$ & $\begin{array}{l}\text { Pinal } \\
\text { Pinal } \\
\text { Maricopa } \\
\text { Yuma }\end{array}$ & $\begin{array}{l}331310 \mathrm{~N} 1112139 \mathrm{~W} \\
331301 \mathrm{~N} 1112131 \mathrm{~W} \\
332106 \mathrm{~N} 1113630 \mathrm{~W} \\
334230 \mathrm{~N} 1134915 \mathrm{~W}\end{array}$ & & $\begin{array}{l}1410 \\
6412\end{array}$ & $\begin{array}{l}\text { Florence NE } \\
\text { Florence NE } \\
\text { Vicksburg }\end{array}$ \\
\hline $\begin{array}{l}\text { Desierto de Altar } \\
\text { See Sonoran Desert } \\
\text { Desierto Grande } \\
\text { See Sonoran Desert } \\
\text { De Soto Mine } \\
\text { De Soto Tank } \\
\text { DeSpain Tank } \\
\text { Despoblado, El } \\
\text { Deswood Spring } \\
\text { Detention Basin }\end{array}$ & $\begin{array}{l}\text { plain } \\
\text { plain } \\
\text { mine } \\
\text { reservoir } \\
\text { reservoir } \\
\text { plain } \\
\text { spring } \\
\text { basin }\end{array}$ & $\begin{array}{l}\text { VARIANT } \\
\text { VARIANT } \\
\text { UNOFF } \\
\text { BGN } \\
\text { BGN } \\
\text { BGN } 1917 \\
\text { BGN } \\
\text { BGN }\end{array}$ & $\begin{array}{l}\text { Maricopa } \\
\text { Maricopa } \\
\text { Yavapai } \\
\text { Yavapai } \\
\text { Navajo } \\
\text { Maricopa } \\
\text { Apache } \\
\text { Maricopa }\end{array}$ & $\begin{array}{l}325500 \mathrm{~N} 1124000 \mathrm{~W} \\
325500 \mathrm{~N} 1124000 \mathrm{~W} \\
341707 \mathrm{~N} 1121708 \mathrm{~W} \\
341710 \mathrm{~N} 1121618 \mathrm{~W} \\
343018 \mathrm{~N} 1102754 \mathrm{~W} \\
\text { UNKNOWN } \\
363010 \mathrm{~N} 1092218 \mathrm{~W} \\
333156 \mathrm{~N} 1122836 \mathrm{~W}\end{array}$ & & & $\begin{array}{l}\text { Battle Flat } \\
\text { Battle Flat } \\
\text { Zeniff } \\
\text { Mexican Cry Mesa } \\
\text { Waddell }\end{array}$ \\
\hline $\begin{array}{l}\text { Detention Number Five } \\
\text { Detention Number Four } \\
\text { Detention Number One } \\
\text { Detention Number Six } \\
\text { Detention Number Three } \\
\text { Detention Number Two } \\
\text { Detrital Reefs } \\
\text { Detrital Valley } \\
\text { Detrital Wash } \\
\text { Deubendorff Rapids }\end{array}$ & $\begin{array}{l}\text { reservoir } \\
\text { reservoir } \\
\text { reservoir } \\
\text { reservoir } \\
\text { reservoir } \\
\text { reservoir } \\
\text { bar } \\
\text { valley } \\
\text { stream } \\
\text { rapids }\end{array}$ & $\begin{array}{l}\text { BGN } \\
\text { BGN } \\
\text { BGN } \\
\text { BGN } \\
\text { BGN } \\
\text { BGN } \\
\text { BGN } \\
\text { BGN } \\
\text { BGN } \\
\text { BGN } 1932\end{array}$ & $\begin{array}{l}\text { Gila } \\
\text { Gila } \\
\text { Gila } \\
\text { Gila } \\
\text { Gila } \\
\text { Gila } \\
\text { Mohave } \\
\text { Mohave } \\
\text { Mohave } \\
\text { Coconino }\end{array}$ & $\begin{array}{l}334453 \mathrm{~N} 1103035 \mathrm{~W} \\
334434 \mathrm{~N} 1102957 \mathrm{~W} \\
334349 \mathrm{~N} 1103046 \mathrm{~W} \\
334455 \mathrm{~N} 1103131 \mathrm{~W} \\
334434 \mathrm{~N} 1103044 \mathrm{~W} \\
334356 \mathrm{~N} 1103023 \mathrm{~W} \\
360542 \mathrm{~N} 1142719 \mathrm{~W} \\
360308 \mathrm{~N} 1142811 \mathrm{~W} \\
360237 \mathrm{~N} 1142740 \mathrm{~W} \\
362044 \mathrm{~N} 1122715 \mathrm{~W}\end{array}$ & $\begin{array}{l}352235 N 1141612 W \\
352235 N 1141612 W\end{array}$ & & $\begin{array}{l}\text { Chrysotile } \\
\text { Brushy Canyon } \\
\text { Chrysotile } \\
\text { Chrysotile } \\
\text { Chrysotile } \\
\text { Chrysotile } \\
\text { Bonelli Bay } \\
\text { Bonelli Bay } \\
\text { Bonelli Bay } \\
\text { Powell Plateau }\end{array}$ \\
\hline $\begin{array}{l}\text { De vaca Terrace } \\
\text { Deva Temple } \\
\text { Devi1 Dog Canyon } \\
\text { Devil Dog Interchange } \\
\text { Pine Springs Interchange }\end{array}$ & $\begin{array}{l}\text { bench } \\
\text { summit } \\
\text { valley } \\
\text { crossing }\end{array}$ & $\begin{array}{l}\text { BGN } 1908 \\
\text { BGN } 1906 \\
\text { BGN } \\
\text { UNOFF } \\
\text { VARIANT }\end{array}$ & $\begin{array}{l}\text { Coconino } \\
\text { Coconino } \\
\text { Yavapai } \\
\text { Coconino }\end{array}$ & $\begin{array}{l}361450 \mathrm{~N} 1122701 \mathrm{~W} \\
360907 \mathrm{~N} 1120153 \mathrm{~W} \\
350514 \mathrm{~N} 1122359 \mathrm{~W} \\
351313 \mathrm{~N} 1121634 \mathrm{~W}\end{array}$ & $351126 \mathrm{~N} 1121400 \mathrm{~W}$ & 7339 & $\begin{array}{l}\text { Explorers Monument } \\
\text { Bright Angel Point } \\
\text { Meath Spring } \\
\text { McLellan Reservoir }\end{array}$ \\
\hline $\begin{array}{l}\text { Devil Dog Tank } \\
\text { Devil Hills } \\
\text { Devils Bathtub }\end{array}$ & $\begin{array}{l}\text { reservoir } \\
\text { summit } \\
\text { reservoir }\end{array}$ & $\begin{array}{l}\text { BGN } \\
\text { BGN } \\
\text { BGN }\end{array}$ & $\begin{array}{l}\text { Coconino } \\
\text { Yuma } \\
\text { Yavapai }\end{array}$ & $\begin{array}{l}350909 \mathrm{~N} 1121842 \mathrm{~W} \\
322341 \mathrm{~N} 1134331 \mathrm{~W} \\
345225 \mathrm{~N} 1131620 \mathrm{~W}\end{array}$ & & & $\begin{array}{l}\text { MeLellan Reservoir } \\
\text { Point of the Pintas } \\
\text { Pilot Knob }\end{array}$ \\
\hline
\end{tabular}




\section{FEATURE NAME}

Devils Bathtub

Devils Bridge

Devils Cache

See Devils Cash Box

Devils Canyon

See Lawton Canyon

Devils Canyon

Devils Canyon

Devils Canyon

Devils Canyon

Devils Canyon

Devils Canyon

Devils Canyon

Devils Canyon Tank

Devils Canyon Well

Devils Canyon 237

Devils Cash Box Devils Cache

Devils Chair

Devils Chasm

Devils Den Canyon

Devils Dining Room

Devils Head

Devils Hole

Devils Hump

Devils Hump Tank

Devils Jawbone Tank

Devils Kitchen

Devils Nest Mine

Devils Playground Tank

Devils Pocket

Devils Slide Rapids

Devils Washboard

Devils Windpipe

See Black Mountain Canyon

Devils Windpipe

Devil Tank

Devine, Mount

DeVore Spring

DeVore Wash

DeVore Well

Dewdrop Spring

Dewey

See Calva

Dewey Woolseyes

Dewey Flat

Dewey Flat Dam

Dewey Flat Well

Dewey Grade Tank

Dewey Mahone Spring

Peacock Spring

Dewey Post Office

Dewey Tank

Dewogibito

See Greasewood Spring

Dexter School

D-five Spring

D-five Tank

o Hill

Diablito Mountain

See Diablo Mountain

Diablito Mountain

Diablito Spring

Diablito Tank

Diablo, Canyon

Diablo, Canyon

Diablo, Canyon Canyon Diablo Wash

Diablo Canyon

Diablo Canyon
FEATURE
CLASS

STATUS

COUNTY

COORDINATE

$\begin{array}{llll}\text { Spring } & \text { BGN } & \text { Pima } & \text { 321150N1103243W } \\ \text { bridge } & \text { UNOFF } & \text { Yavapai } & \text { 345352N1114825W }\end{array}$

SOURCE
COORDINATE

ELEV
FT

MAP NAME

VARIANT

ridge

valley

valley

valley

valley

valley

valley

VARIANT

$B G N$
$B G N$
$B G N$
$B G N$
$B G N$
$B G N$

Santa Cruz

314106 N1105454W

Maricopa

Cochise

Pinal

Greenlee

Pinal

Gila

Mohave

$\begin{array}{ll}\text { valley } & \text { BGN } \\ \text { reservoir } & \text { BGN } \\ \text { well } & \text { UNOFF } \\ \text { trail } & \text { UNOFF } \\ \text { ridge } & \text { BGN } \\ \text { basin } & \text { VARIANT } \\ \text { baN } \\ \text { valley } & \text { BGN } \\ \text { valley } & \text { BGN } \\ \text { area } & \text { BGN }\end{array}$

Navajo

Cochise

Mohave

Cochise

Santa Cruz

Coconino

Gila

Greenlee

Coconino

summit $B G$

BGN

BGN

Coconino

Graham

Mohave

reservoir BGN

reservoir $B G$

area BGN

mine UNOFF

reservoir $B G$

basin $B G N$

rapids $B G N$

cliff $B G N$

valley

valley
valley

reservoir

summit

spring

strean

well

spring

Mohave

Yavapai

Yavapai

Yavapai

Gila

Coconino

Mohave

UNKNOWN

314514N1092253W

$325848 \mathrm{N1103553 \textrm {W }}$

$330316 \mathrm{N1091734 \textrm {W }}$

$331300 \mathrm{~N} 1105944 \mathrm{~W}$

$335033 \mathrm{N1110919W}$

$343108 \mathrm{N1133613 \textrm {W }}$

$361233 \mathrm{N1100328 \textrm {W }}$

$314430 \mathrm{N1} 092235 \mathrm{~W}$

$343750 N 1134202$

$314330 \mathrm{~N} 1092245 \mathrm{~W}$

$314106 \mathrm{~N} 1105454 \mathrm{~W}$

351417 N1113637W

$334934 \mathrm{~N} 1105120 \mathrm{~N}$

$332042 N 1090156$

$345019 N 1114514 \mathrm{~K}$

$351432 \mathrm{~N} 1113638 \mathrm{~W}$

$325125 N 1101308 \mathrm{~W}$

$350632 \mathrm{~N} 1132034 \mathrm{~W}$

$350622 \mathrm{N1132105 \textrm {W }}$

$343025 N 1114143 \mathrm{~W}$

$345310 \mathrm{N1114654 \textrm {W }}$

340939N1124230W

$335645 \mathrm{N1} 105140 \mathrm{~W}$

350851 N1121852W

$355548 \mathrm{N1} 134250 \mathrm{~W}$

333800 N1091119W

343054N1114351

343113 N111391OW

$325121 \mathrm{N1101304 \textrm {W }}$

320754N1114813W

$334204 N 1104839 \mathrm{~W}$

$333320 \mathrm{~N} 1105311 \mathrm{~W}$

$333130 \mathrm{N1} 105430 \mathrm{~W}$

$362343 \mathrm{N1} 133149 \mathrm{~W}$

\section{VARIANT}

ppl locale BGN

flat BARIANT

dam UNOFF

well UNOFF

reservoir $B G$

spring

BGN

VARIANT

Graham

Yavapai

331050 N1101109W

$343148 \mathrm{N1} 121426 \mathrm{~W}$

Graham

Graham

Graham

Coconino

Mohave

\section{UNOFF}

reservoir BGN

VARIANT

spring

school

spring

reservoir

UNOFF

BGN

BGN

summit

BGN

VARIANT

summit

Yavapai

Navajo

Navajo

Yavapai

Gila

Gila

Cochise

Santa Cruz

331201 N1101528W

331001 N1101458

$331145 \mathrm{~N} 1101514 \mathrm{~W}$

350549 N1113928W

$353021 N 1133741 \mathrm{~W}$

343146 N1121430W

$344941 \mathrm{N1103739 \textrm {W }}$

352526 N1095434W

$343303 \mathrm{~N} 1122815 \mathrm{~W}$

$335056 \mathrm{~N} 1100546 \mathrm{~W}$

$335222 \mathrm{~N} 1100621 \mathrm{~W}$

$312045 \mathrm{~N} 1092829 \mathrm{~W}$

$313901 N 1110723 \mathrm{~W}$

$\begin{array}{lll}\text { summit } & \text { BGN 1978 } & \text { Santa Cruz } \\ \text { spring } & \text { BGN } & \text { Santa Cruz } \\ \text { reservoir } & \text { BGN } & \text { Santa Cruz } \\ \text { valley } & \text { BGN } & \text { Pima } \\ \text { valley } & \text { BGN } & \text { Yuma } \\ \text { valley } & \text { BGN } & \text { Coconino } \\ & \text { VARIANT } & \\ \text { valley } & \text { BGN } & \text { Pima } \\ \text { valley } & \text { BGN } & \text { Pima }\end{array}$

314040 N1110710W

$313818 \mathrm{~N} 1110722 \mathrm{~W}$

$314051 \mathrm{N1110630 \textrm {W }}$

$320047 \mathrm{N1124352 \textrm {W }}$

$325206 \mathrm{~N} 1132823 \mathrm{~W}$

$351746 \mathrm{~N} 1105918 \mathrm{~W}$

$314634 N 1113052 \mathrm{~W}$

$322320 \mathrm{~N} 1103545 \mathrm{~W}$

314411 N1092213

$330100 \mathrm{~N} 1103303 \mathrm{~W}$

$330412 \mathrm{~N} 1091646 \mathrm{~W}$

$332151 \mathrm{~N} 1110031 \mathrm{~W}$

$335111 \mathrm{~N} 1111002 \mathrm{~W}$

$343830 \mathrm{N1134053 \textrm {W }}$

361658 N1095853W

Bruno Peak

Bubrey Peak

Bruno Peak

Mt Hopkins

334811 N1105330W

$332056 \mathrm{~N} 1090445 \mathrm{~W}$

Flagstaff East

Sombrero Peak

Maple Peak

Sedona

Flagstaff East

Buford $\mathrm{Hill}$

5723 Devils Hump

Devils Hump

Walker Mtn

Wilson Mountain

Yarnell

Rock House

Beaverhead

343023 N1113738W

Walker Mtn

Buford Hill

4783 Sil Nakya

Dagger Peak

332754 N1105705W

Salt River Peak

Salt River Peak

Poverty Spring

Humboldt

Dewey Flat

Calva

Dewey Flat

Mountainaire

Humbolt

Relic Point

Prescott

Canyon Day

Canyon Day

East of Douglas

320020 N1124303W 325017 N11 $32536 \mathrm{~W}$

McLellan Reservoir

Devils Slide Rapids

Mi lkweed Canyon SW 
NATIONAL GAZETTEER--ARIZONA 1986

\section{FEATURE NAME}

Diablo Mountain Diablito Mountain

Diablo Mountains

Diablo Pass

ablo Stadium

See Tempe Municipal Stadium

Diablo Tank

Diablo Tank

Diablo Tank

Diablo Wash

Diablo Well

Diablo Well

Dial Canyon

Dial Spring

Dial Tank

Dial Wash

Diamond A Windmill

Diamond Bar Canyon

Diamond Bar Peak

Diamond Bar Ranch

Diamond Bar Ranch

Diamond Bar Spring

Diamond Bell Ranch

Diamond Butte

Diamond Butte

Diamond Butte

Diamond Canyon

See Diamond Creek

Diamond Canyon Rio de San Alex

Diamond Creek

$$
\text { Big Diamond Creek }
$$

Diamond Creek

Diamond Canyon

Diamond Creek Canyon

Rio de San Alexo

Diamond Creek Campsite Number

Five

Diamond Creek Campsite Number Four

Diamond Creek Campsite Number Three

Diamond Creek Canyon See Diamond Creek

Diamond Creek Community Center

Diamond Creek Junction

Campground

Diamond Creek Number Two

Campground

Diamond Creek Rapids

Diamond Creek Spring

See Diamond Spring

Diamond Creek Spring

Diamond E Spring

Diamond Fields

Diamond Joe Peak

Diamond Mountain

Diamond Mountain

See Indian Spring Peak

Diamond M Spring

Diamond M Tank

Diamond Park

Diamond Peak

Diamond Point

Diamond Point Lookout Tower

Diamond Point Tank

Diamond Ranch

Diamond Rim

Diamond Rock Campground

Diamond Rock Forest Camp

Diamond Spring

FEATURE
CLASS

summit

STATUS

COUNTY

COORDINATE

VARIANT

summit
gap

BGN

Pima

VARIANT

building

reservoir

reservoir

stream

well

well

\section{BGN
BGN}

BGN
$B G N$
$B G N$

$B G N$

UNOFF

UNOFF

Maricopa

Pima

Coconino

Santa Cruz

Pima

Santa Cruz

BGN Pima

summit

summit

summit

stream

valley

stream

BGN
BGN
BGN

Apache

Gila

VARIANT

Mohave

Mohave

BGN

VARIANT

Navajo

stream BGN

Mohave

park

ADMIN

Apache

VARIANT

strea

UNOFF

Mohave

Navajo

Coconino
313901N1110723W

$\begin{array}{llll}\text { valley } & \text { BGN } & \text { Graham } & 322606 N 1094337 \mathrm{~W} \\ \text { spring } & \text { BGN } & \text { Graham } & 322618 N 1094354 \mathrm{~W} \\ \text { reservoir } & \text { BGN } & \text { Graham } & 322741 \text { N1094443W } \\ \text { stream } & \text { BGN } & \text { Cochise } & 322548 N 1093131 \mathrm{~W} \\ \text { well } & \text { UNOFF } & \text { Pima } & 314937 N 1103623 \mathrm{~W} \\ \text { valley } & \text { BGN } & \text { Graham } & 330936 \mathrm{N1100201W} \\ \text { summit } & \text { BGN } & \text { Graham } & 331351 N 1100010 \mathrm{~W} \\ \text { locale } & \text { UNOFF } & \text { Graham } & 331239 N 1100057 \mathrm{~W} \\ \text { locale } & \text { UNOFF } & \text { Mohave } & 355245 N 1135934 \mathrm{~W} \\ \text { spring } & \text { BGN } & \text { Graham } & 331317 N 1100040 \mathrm{~W}\end{array}$

$320002 \mathrm{~N} 1124308 \mathrm{~W}$

$334045 \mathrm{~N} 1141806 \mathrm{~W}$

$332404 \mathrm{~N} 1115810 \mathrm{~W}$

$314634 \mathrm{~N} 1113052 \mathrm{~W}$

$320043 \mathrm{~N} 1124320 \mathrm{~W}$

$344844 \mathrm{~N} 1111342 \mathrm{~W}$

$314115 \mathrm{~N} 1110332 \mathrm{~W}$

$313305 \mathrm{~N} 1112408 \mathrm{~W}$

$313945 \mathrm{~N} 1110639 \mathrm{~W}$

$313952 \mathrm{~N} 1110748 \mathrm{~W}$

SOURCE
COOROINAT

AZ183

COORDINATE FT MAP NAME

4953 Amado

Mount Ajo

Middle Camp Mtn

Baboquivari Peak

Mount Ajo

Chavez Mtn West

Amado

Wilbur Canyon

Amado

322805N1094458W Monk Oraw

Monk Draw

Monk Draw

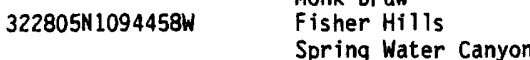

331422N1095945W Bylas

5324 Bylas

Bylas

Grapevine Canyon

Bylas

$315824 \mathrm{~N} 1111654 \mathrm{~W}$

$335411 \mathrm{N1093824 \textrm {W }}$

$340927 \mathrm{~N} 1110631 \mathrm{~W}$

$363409 \mathrm{~N} 1132222 \mathrm{~W}$

354558 N1132222W

$354600 \mathrm{~N} 1132216 \mathrm{~W}$

$354751 \mathrm{~N} 1131230 \mathrm{~W}$

$335335 N 1095601 \mathrm{~W}$

$335446 N 1093737 W$

Alchesay Flat

$354558 \mathrm{~N} 1132222 \mathrm{~W}$

$355113 \mathrm{~N} 1131342 \mathrm{~W}$

Diamond Peak

$335528 \mathrm{~N} 1094335 \mathrm{~W}$

8400 Hawley Lake East

$335600 N 1094234 \mathrm{~W}$

9119 Hawley Lake East

7760 Hawley Lake West

$335702 N 1094550 \mathrm{~W}$

$354558 \mathrm{~N} 1132222 \mathrm{~W}$

335307 N1095700W

335337 N1095601W

$335428 \mathrm{~N} 1095506 \mathrm{~W}$

354553 N1132232W

354249 N1131538W

$354310 \mathrm{~N} 1131350 \mathrm{~W}$

$320933 \mathrm{~N} 1102048 \mathrm{~W}$

$364846 \mathrm{~N} 1095322 \mathrm{~W}$

$345012 \mathrm{~N} 1134522 \mathrm{~W}$

$335110 \mathrm{~N} 1130000 \mathrm{~W}$

$335125 \mathrm{~N} 1113055 \mathrm{~W}$

332119 N1105356W

343545 N1114239W

$332320 \mathrm{~N} 1115649 \mathrm{~W}$

$354604 \mathrm{~N} 1132111 \mathrm{~W}$

$341715 \mathrm{~N} 1111132 \mathrm{~W}$

341727 N1111131W

$341833 \mathrm{~N} 1111035 \mathrm{~W}$

$335217 \mathrm{~N} 1112818 \mathrm{~W}$

$341754 \mathrm{~N} 1111214 \mathrm{~W}$

334907 N1091758W

334904 N1091758W

$315055 \mathrm{~N} 1095520 \mathrm{~W}$
5512 Alchesay Flat

5320 Alchesay Flat

5460 Alchesay Flat

Travertine Rapids

Robbers Roost Canyon

Wildhorse Mtn

Red Point

5182 Diamond Joe Peak

5120 Bouider Mtn

Pinal Ranch

Walker Mtn

Tempe

3512 Diamond Peak

6380 Diamond Point

Diamond Point

Diamond Point

Boulder Mtn

Diamond Point

8000 Buffalo Crossing

Buffalo Crossing

Black Diamond Peak 
NATIONAL GAZETTEER--ARIZONA 1986

FEATURE NAME

Black Dianond Spring

Diamond Spring
Diamond Spring
Diamond Creek Spring
Diamond Tank
Dianond Two Ranch
Dianond Valley
Diana Temple
No Mans Land
Dianes Tank
Diaz Peak

Diaz Spire
Dibe Chaa Valley
Dibe Chaa Well
Dickenson Flat
Dickenson Flat Tank
Dickey Spring
Dickey Wash
Dick Hart Draw
Dick Hart Ridge
Dick Hart Tank

Dick Hart Tank
Dick Peak
Dickson Tank
Dicks Peak
Dicks Peak Tank
Dick Spring
Dicks Spring
Dick Spring Canyon
Dicks Spring Canyon
$\quad$ Dicks Spring Creek
Dick Spring Wash

Dick Spring Creek

Dick Spring Wash See Dick Spring Canyon

Dicks Spring

See Dick Spring

Dicks Spring Canyon See Dick Spring Canyon

Dicks Spring Creek

See Dick Spring Canyon

Dicks Tank

\section{Dick Williams Creek \\ Dietz School \\ Digger Creek \\ See Digger Wash \\ Digger Wash \\ Dikger Creek \\ Dike Pond
Dike Tank \\ Dilcon Oike Tank \\ See Dilkon}

Dilcon School

Dilkon

Castle Butte

Dilcon

Maddox
Stiles

Dilkon Hill

Dilkon Indian Mission

Dillon Field

Dillon Tank

Dillon Wash

Dill Well

Dimario Place

Dime Gulch

Dime Pond

Oimple Mine

Dine Bito Spring

See Dinnebito Spring
FEATURE

CLASS

STATUS

COUNTY

VARIANT

$\begin{array}{llll}\text { spring } & \text { BGN } & \text { Gila } & 341728 N 1111146 \mathrm{~W} \\ \text { spring } & \text { BGN } & \text { Coconino } & 354249 \text { N1131538W } \\ & \text { VARIANT } & & \\ \text { reservoir } & \text { BGN } & \text { Navajo } & 335402 N 1095411 \mathrm{~W} \\ \text { locale } & \text { UNOFF } & \text { Yavapai } & 341330 \mathrm{~N} 1123217 \mathrm{~W} \\ \text { ppl } & \text { BGN } & \text { Yavapai } & 343405 \mathrm{~N} 112222 \mathrm{~W} \\ \text { summit } & \text { BGN 1908 } & \text { Coconino } & 360619 \text { N1121653W } \\ \text { reservoir } & \text { VARIANT } & & \\ \text { summit } & \text { BGN } 1945 & \text { Coconino } & 344436 \mathrm{~N} 1110055 \mathrm{~W} \\ \text { Pima } & 315804 \mathrm{~N} 1123943 \mathrm{~W}\end{array}$

pillar BGN 1945 Pima

well

flat

reservoir

spring

stream

valley

ridge

reservoir

reservoir

summit

reservoir

summit

reservoir

spring

valley

BGN 1945 Pima

UNOFF

BGN

BGN

BGN

BGN

BGN

BGN

BGN

BGN

BGN

BGN

BGN
BGN
VARIANT

BGN
VARIANT

BGN

VARIANT

VARIANT

VARIANT

valley

spring

valley

valley

reservoir

BGN

VARIANT

Gila

Gila

VARIANT

VARIANT

VARIANT

BGN

strean
schoo

stream

stream

reservoir

reservoir

locale

BGN

UNOFF

VARIANT

BGN

VARIANT

BGN

BGN

VARIANT

\section{sctoos}

locale

BGN

VARIANT

VARIANT

VARIANT

VARIANT

summit $B G N$

school UNOFF

flat BGN

reservoir BGN

$\begin{array}{ll}\text { stream } & \text { BGN } \\ \text { well } & \text { UNOFF } \\ \text { locale } & \text { BGN } \\ \text { valley } & \text { BGN } \\ \text { lake } & \text { BGN } \\ \text { mine } & \text { UNOFF } \\ & \text { VARIANT } \\ \text { spring } & \end{array}$

Apache

Coconino

Coconino

Graham

Maricopa

Coconino

Coconino

Coconino

Yavapai

Santa Cruz

Pima

Gila

Gila

$315814 N 1124015 \mathrm{~W}$

$364102 \mathrm{~N} 1093753 \mathrm{~W}$
$363626 \mathrm{~N} 1094117 \mathrm{~W}$

$342505 \mathrm{~N} 1112427 \mathrm{~W}$

342502N1112430W

$324642 \mathrm{N1095312 \textrm {W }}$

$332513 N 1124825 \mathrm{~W}$

$343256 \mathrm{~N} 1111037 \mathrm{~W}$

$343025 \mathrm{~N} 1111050 \mathrm{~W}$

$344832 \mathrm{N1105727 \textrm {W }}$

$343257 \mathrm{~N} 1131346 \mathrm{~W}$

$321335 \mathrm{~N} 1092338 \mathrm{~W}$

$313133 N 1110942 \mathrm{~W}$

$313205 N 1111042 \mathrm{~W}$

$330910 \mathrm{~N} 1103508 \mathrm{~W}$

$330835 N 1103454 \mathrm{~W}$

$\begin{array}{ll}\text { Gila } & 330835 \mathrm{~N} 1103454 \mathrm{~W} \\ \text { Coconino } & 344423 \mathrm{~N} 1112733 \mathrm{~W}\end{array}$

$330835 N 1103454 W$

$330835 \mathrm{N1} 103454 \mathrm{~W}$

330835N1103454W

$342140 \mathrm{~N} 1110545 \mathrm{~W}$

$321200 \mathrm{~N} 1104947 \mathrm{~W}$

350642N1100409

Navajo

Mohave

Coconino

363807 N1131921W

354921N1125410W

Navajo

352307 N1101912W

Navajo

Navajo

$352212 \mathrm{~N} 1101947 \mathrm{~W}$

352307 N1101912W

Navajo

$352258 \mathrm{~N} 1101923 \mathrm{~W}$

352009 N1102002W

$344057 N 1124555 \mathrm{~W}$

$344120 N 1124527 \mathrm{~W}$

344823N1123720W $320050 \mathrm{~N} 1112408 \mathrm{~W}$

332240 N1104859W

$332447 \mathrm{N1104641 \textrm {W }}$

$362841 \mathrm{N1} 132802 \mathrm{~W}$

$315541 N 1104231 \mathrm{~W}$

Mohave

354749 N1105437W
Coconino
$342745 N 1111140 \mathrm{~W}$

331346 N1 103738W

$333123 \mathrm{~N} 1124728 \mathrm{~W}$

342913N1111108W

$363526 \mathrm{~N} 1094416 \mathrm{~W}$

Rock Point

5284 Rock Point SW

Pine
Pine

Shingle Mill Mtn

Wintersburg

Blue Ridge Reservoir

Oane Canyon

Blue Ridge Reservoir

Sunset Pass

Bagdad

Bowie Mtn North

5396 Murphy Peak

Murphy Peak

Coolidge Dam

Coolidge Dam

Happy Jack

331351N1103830W

Coolidge Dam

330910N1103508W

$342307 N 1110435 W$

Promontory Butte

Tucson East

$351022 N 1094851 W$

Hennessy Buttes

The Grandstand Dike Tank

French Butte

5885 Dilkon
$344601 N 1123321 W$

332457 N1104615W 
NATIONAL GAZETTEER--ARIZONA 1986 FEATURE NAME

Dine Bito Wash

See Dinnebito Wash

Dines Tank

Dinnebito

See Sand Springs

Dinnebito Spring

Denabeto Spring

Dine Bito Spring

Tenebito Spring

Tinebbito Spring

Dinnebito Trading Post

See Sand Springs

Dinnebito Trading Post

Dinnebito Wash

Denabeto Wash

Denebito Wash

Dine Bito Wash

Tenebito Wash

Tinebbito Wash

Dinnehotso

See Dennehotso

Dinne Mesa

See Toh At in Mesa

Dinner Canyon

Dinner Canyon

Dinner Creek

See East Spear Creek

Dinner Creek

Dinner Flat

Dinner Pocket

Dinner Pockets Canyon

Dinner Pockets Trick Tank

Dinner Spring

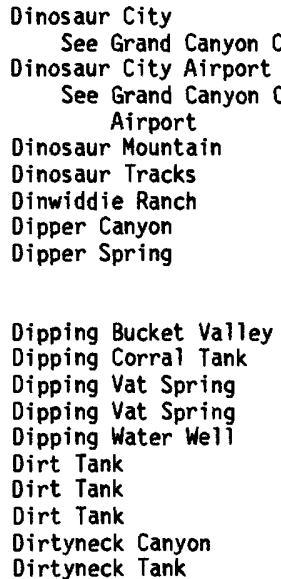

Dipping Bucket Valley

Dipping Corral Tank

Dipping Vat Spring

Dipping Vat Spring

Dipping Water Wel

Dirt Tank

Dirt Tank

Dirt Tank

Dirtyneck Canyon

Dirtyneck Tank

Disappointment Creek

See Dripping Spring Wash Dismal flats

See Cibola Valley

Disquiba Canyon

Distaff Mine

Distillery Canyon

Distillery Canyon Spring

Ditch Mountain

Ditch Pond

Ditch Pond

Ditch Tank

Dutch Tank

Ditch Tank

Ditch Tank

Ditch Tank

Diversion Park

Diversion Tank
FEATUR

$$
\text { CLASS }
$$

STATUS

COUNTY

COOROINATE

$352845 N 1111415 \mathrm{~W}$

valley

VARIANT

reservoir BG

ppl.

spring

VARIANT

BGN 1967

VARIANT

VARIANT

VARIANT

VARIANT
VARIANT

ppl

locale

valley

BGN 191

VARIANT

VARIANT

VARIANT

VARIANT

VARIANT

pp

ppl

summit

VARIANT

Apache

Apache

valley
valley
stream
stream
flat
basin
valley
reservoir
spring

BGN Gila

BGN Gila

VARIANT

Gila

BGN Gila

Coconino

Coconino

Mohave

VARIANT

ppl

airport

VARIANT

Coconino

Coconino

summ it

area
local

locale
valley

spring

BGN

BGN

UNOFF

BGN

Pinal

Coconino

Cochise

Yavapai

Gila

valley

reservoir BGN

BGN

$B G N$

spring BGN

reservoir $\quad B G N$

reservoir BGN

reservoir BGN

valley

BGN

Navajo

Navajo

Apache

Apache

Apache

Cochise

Cochise

Pinal

Coconino

Coconino

VARIANT

strean

valley

valley

mine

valley

spring

sumit

VARIANT

Gila

Yuma

BGN Coconino

UNOFF

BGN

BGN

BGN

BGN

Mohave

Pina

Pima

Mohave

reservoir $B G N$

reservoir BGN

reservoir

reservoir

reservoir BGN

flat

reservoir BGN

$354749 \mathrm{~N} 1105437 \mathrm{~W}$

$330459 N 1104229$

$331407 N 1144045 \mathrm{~W}$

$60402 N 1123627 \mathrm{~W}$ 352505 N1141119W $320241 \mathrm{~N} 1103315 \mathrm{~W}$ $320332 N 1103208 \mathrm{~W}$ $314126 \mathrm{~N} 1104800 \mathrm{~W}$ $362117 \mathrm{N1} 132149 \mathrm{~W}$

$\begin{array}{ll}\text { Mohave } & 362618 \mathrm{N1132345W} \\ \text { Apache } & 340202 \mathrm{N1090517W}\end{array}$

Coconino

Coconino

$343035 \mathrm{~N} 1112557 \mathrm{~W}$

345251 N1111914W

$345356 \mathrm{~N} 1112627 \mathrm{~W}$

Coconino

344651N111261

Coconino

$313341 \mathrm{~N} 1110905 \mathrm{~W}$
BGN Mohave

reservoir $352109 \mathrm{N1} 093414 \mathrm{~W}$
$342926 \mathrm{~N} 1110517 \mathrm{~W}$

354308 N $1105557 \mathrm{~W}$

Knoll Lake

Dinnebito Spring

$354308 \mathrm{~N} 1105557 \mathrm{~W}$

$360320 \mathrm{~N} 1103546 \mathrm{~W}$

$352845 \mathrm{~N} 1111415 \mathrm{~W}$

$362745 N 1100720 \mathrm{~W}$

Rocky Ridge SE Grand Falls
$352845 \mathrm{~N} 1111415 \mathrm{~W}$

$365435 N 1092415 \mathrm{~W}$

$335849 N 1105845 \mathrm{~W}$ 340000 N1110115W

$335848 N 1105845$

$340104 N 1110237 \mathrm{~W}$

$365508 \mathrm{~N} 1133916 \mathrm{~W}$

$355926 \mathrm{~N} 1132830 \mathrm{~W}$

$363418 N 1123749 \mathrm{~W}$

$363323 N 1123520$

$345752 N 1133146 \mathrm{~W}$

353142N1131350W

$353141 N 1131440 \mathrm{~W}$

$332208 \mathrm{~N} 1112631 \mathrm{~W}$

$360603 \mathrm{~N} 1111920 \mathrm{~W}$

$312417 N 1100556 \mathrm{~W}$

342813N1124608W

$335642 \mathrm{~N} 1112145 \mathrm{~W}$

362753 N1101148W $341258 \mathrm{~N} 1095900 \mathrm{~W}$ $335532 \mathrm{~N} 1092445 \mathrm{~W}$ $341223 N 1094705$ $314340 \mathrm{N1} 091420 \mathrm{~W}$ $315315 N 1102453 \mathrm{~W}$ 325617 N1102747W

$343011 N 1112150 \mathrm{~W}$ $343005 N 1112137 \mathrm{~W}$

$342935 N 1124412 W$

2370 Moenave SE
Hereford Bismarck Mesa Kayler Butte

363109N1101201W

Cliff Rose Hill

Lakes ide

Big Lake North

Sponseller Mtn

5956 Dipping Water Well

Apache

Mescal

Booger Canyon

$342755 N 1112218 \mathrm{~W}$

Long Valley

Long Valley

\begin{tabular}{|c|c|}
\hline $\begin{array}{l}335930 \mathrm{~N} 1105720 \mathrm{~W} \\
335916 \mathrm{~N} 1105656 \mathrm{~W}\end{array}$ & $\begin{array}{l}\text { McFadden Peak } \\
\text { Copper Mtn }\end{array}$ \\
\hline $33563 B N 1105814 W$ & $\begin{array}{l}\text { Buzzard Roost Mesa } \\
\text { Purgatory Canyon } \\
\text { Price Point }\end{array}$ \\
\hline $363302 \mathrm{~N} 1123518 \mathrm{~W}$ & $\begin{array}{l}\text { Grama Spring } \\
\text { Jumpup Point } \\
\text { Tom Brown Canyon }\end{array}$ \\
\hline
\end{tabular}

360309N1123859W Antelope Point

Rincon Peak

Rincon Peak

6440 Mt Wrightson

Cold Spring

Poverty Knoll

Loco Knoll

Calloway Butte Kinnikinick Lake Mormon Lake Hutch Mtn

Murphy Peak 


\section{FEATURE NAME}

Diversion Tank

Dives, The

Dives Mine

Divide

Divide, The

Divide, The

Divide Canyon

Divided Spring

Divided Water Spring

Divider Well

$$
\text { See Gray Well }
$$

Divide Spring

Divide Tank
Divide Tank
Divide Tank
Divide Tank
Divide Tank
Divide Tanks
Divide Well
Dividing Canyon
Dividing Canyon
Dividing Canyon Tank

Divil Tank

Divil Tank

Diving Board Tanks

Division Spring

Division Tank

Division Tank

Division Tank

Division Tank

Division We11

Dix Creek

See Right Prong Dix Creek

Dix Creek

See Left Prong Dix Creek

Dix Creek

Dixie

Dixie Canyon

See Scherer Canyon

Dixie Canyon

Dixie Canyon Ranch

Dixie Gold Mine

Dixie Mine

\section{Dixie Mine}

Dixie Peak

Dixie Queen Mine

Dix Mesa

Dix Mesa Number Two Tank

Dixon Camp

Dixon Spring

Dixon Spring

Dix Saddle Number One Tank

Dix Saddle Number Two Tank

D K Well

D-Nine Tank

Doak Spring

Doanville

See Palomas

Dobbins Knol

Dobbs Buttes

Dobbs Well

Dobell Tank

Dobson

Dobson Bench

Dobson Peak

$$
\text { Dodson Peak }
$$

Dobson Plaza Shopping Center

Dobson Ranch

Dobson Shores (subdivision)

Doby Tank

Doc Carter Spring

\section{FEATURE
CLASS}

STATUS

COUNTY

cliff

BGN

Coconino

Mohave

mine

locale

gap

gap

valley

spring

spring

well

spring

$\begin{array}{ll}\text { UNOFF } & \text { Yuma } \\ \text { BGN } & \text { Yavap } \\ \text { BGN } & \text { Cochise } \\ \text { BGN } & \text { Navajo } \\ \text { BGN } & \text { Mohave } \\ \text { BGN } & \text { Gila } \\ \text { BGN } & \text { Gila } \\ \text { VARIANT } & \end{array}$

VARIANT

Santa Cruz

BGN

Greenlee

reservoir

reservoir

reservoir

reservoir

reservoir

reservoir

well

arroyo

valley

reservoir

BGN
BGN
BGN
BGN
BGN
BGN
UNOFF
BGN
BGN
BGN

Navajo

Maricopa

Yavapai

Coconino

Coconino

Greenlee

Mavajo

Navajo

Yavapa

Mohave

Yavapai

reservoir

reservoir

reservoir

spring

reservoir

reservoir

reservoir

reservoir

well

stream

BGN Cochise

Cochise

Pima

Gila

Cochise

Greenlee

Apache

Apache

BGN

BGN

VARIANT

Yavapai

Greenlee

VARIANT

stream

stream

locale

valley

valley

locale

mine

mine

mine

summit

mine

summit

reservoir

locale

spring

spring

reservoir

reservoir

BGN

BGN

VARIANT

BGN 1960

UNOFF

UNOFF

UNOFF

Greenlee

Greenlee

Maricopa

Cochise

Cochise

Cochise

Mohave

Santa Cruz

UNOFF Maricopa

BGN

BGN

Maricopa

Mohave

BGN Greenlee

BGN Gila

BGN Yuma

BGN Gila

BGN Greenlee

BGN Greenlee

well

UNOFF

Yavapai

spring

BGN

locale

summit

summit

well

reservoir

locale

bench

summit

locale

ppl

ppl

spring
COORDINATE

$345532 \mathrm{~N} 1110758 \mathrm{~W}$

$365355 \mathrm{N1} 134048 \mathrm{~W}$

$330659 N 1143508 \mathrm{~W}$

$340006 \mathrm{~N} 1125420 \mathrm{~W}$

$312730 \mathrm{~N} 1095632 \mathrm{~W}$

$344126 \mathrm{~N} 1100619 \mathrm{~W}$

$345857 \mathrm{N1} 133303 \mathrm{~W}$

$340454 N 1105322 \mathrm{~W}$

$340419 \mathrm{~N} 1105259 \mathrm{~W}$

$312525 N 1110939 \mathrm{~W}$

$331222 \mathrm{~N} 1091739 \mathrm{~W}$

$335715 N 1095314 W$

$335719 N 1125327 \mathrm{~W}$

$342907 N 1113645 \mathrm{~W}$

$344235 N 1111611 \mathrm{~W}$

$344639 N 1112909 \mathrm{~W}$

$325052 \mathrm{~N} 1091730 \mathrm{~W}$

$342028 N 1100306 \mathrm{~W}$

$345903 N 1132451 \mathrm{~W}$

$350656 \mathrm{~N} 1130845 \mathrm{~W}$

313431 N1092209W

$313745 \mathrm{~N} 1092048 \mathrm{~W}$

$314352 \mathrm{~N} 1111801 \mathrm{~W}$

$334248 \mathrm{~N} 1104055 \mathrm{~W}$

$314325 \mathrm{~N} 1092046 \mathrm{~W}$

$331952 \mathrm{~N} 1092738 \mathrm{~W}$

$341209 \mathrm{~N} 1094535 \mathrm{~W}$

$344536 \mathrm{N1} 115040 \mathrm{~W}$

343703N1123631W

$331110 N 1090923 W$

$331110 \mathrm{~N} 1090923 \mathrm{~W}$

$331227 N 1090941 \mathrm{~W}$

$332134 N 1124525 \mathrm{~W}$

$312935 \mathrm{~N} 1095332 \mathrm{~W}$

$313012 \mathrm{~N} 1095102 \mathrm{~W}$

$313026 N 1095057 \mathrm{~W}$

$353037 N 1143212 \mathrm{~W}$

$313743 \mathrm{~N} 1104941 \mathrm{~W}$

$331622 N 1130136 \mathrm{~W}$

$331511 \mathrm{~N} 1130330 \mathrm{~W}$

$353038 \mathrm{~N} 1143133 \mathrm{~W}$

$330946 \mathrm{~N} 1090718 \mathrm{~W}$

$331055 N 1090819 \mathrm{~W}$

$332844 N 1105437 \mathrm{~W}$

$325939 N 1140439 \mathrm{~W}$

$332843 \mathrm{~N} 1105412 \mathrm{~W}$

$33092 \mathrm{BN} 1090715 \mathrm{~W}$

$330912 \mathrm{~N} 1090655 \mathrm{~W}$

$344844 N 1120047 \mathrm{~W}$

$343046 \mathrm{~N} 1120710 \mathrm{~W}$

$331558 \mathrm{~N} 1105154 \mathrm{~W}$

325432N1132850W

341703 N1094718W

$320454 N 1112725 \mathrm{~W}$

$320243 \mathrm{~N} 1113126 \mathrm{~W}$

$344748 N 1095454 \mathrm{~W}$

$322824 N 1111730 \mathrm{~W}$

365439 N1123101W

314519 N1091626W

$332338 \mathrm{~N} 1115220 \mathrm{~W}$

$332214 N 1115225 \mathrm{~W}$

$332237 \mathrm{~N} 1115248 \mathrm{~W}$

$353957 N 1121037 \mathrm{~W}$

$330106 \mathrm{~N} 1140812 \mathrm{~W}$

$\begin{array}{cc}\text { SOURCE } & \text { ELEV } \\ \text { COORDINATE } & \text { FT }\end{array}$

MAP NAME

Chavez Mtn NW

Purgatory Canyon

Picacho

Congress SW

Bisbee

Tenmile Cedars

350143N1133255W Tom Brown Canyon

Young

Mitchell Peak

Alches ay Flat

Outlaw Hill

Strawberry

Turkey Mtn

Hutch Mtn

Ash Peak

Show Low North

350827 N1130658W

Anvil Rock Ranch

Gonzales Wash

Anvil Rock Ranch 
NATIONAL GAZETTEER--ARIZONA 1986 FEATURE NAME

Doce Siding

Doce Tank

Dock Anerican Dahk

Dock Railroad Station

Doctor Chandler Memoria Doctors Hospital

See Humana Phoenix Hospital Doctor Spring

Dodd Tank

Dodge Nevada Canal

Dodge Tank

Dodge Tank Wash

Dodge Wash

Dodson Peak

See Dobson Peak

Dodson Wash

Dods on Wash

Mortensen Wash

Morterson Wash

Doe Mountain

Doe Peak

Doeskin Tank

Doe Tank

Doe Tank

Doe Tank

Doe Tank

Doe Tank

Dog Canyon

Dog Fiat Tank

Doghouse, The

Dog House Spring

Dogie Spring

Dogie Tank

Dogie Tank

Dog Knobs

Dog Knobs Lake

Dog Knobs Trick Tank

Dog Lake

Dog Point

Dog Rock

Dog Spring

Dog Spring

Dog Town Campground

See Dogtown Reservoir Campground

Dogtown Darn

Dogtown Mine

Dogtown Picnic Ground

Dogtown Reservoir

Dogtown Reservoir Campground Dog Town Campground

Dogtown Tank

Dogtown Tank

Dogtown Wash

Dog Valley

Dog Valley Tank

Dog Valley Well

Dog Water Mine

Dogwater Well

Dog Well

Dogwood Spring

Doh Halian

Dohner Tank

Doh Yai Nos Cly

Doland Mine

Dolan Springs

Dolan Springs

Dolan Springs Post Office

Dolittle Pond
FEATURE

CLASS

STATUS

COUNTY

locale $B G N$

reservoir $B G$

locale BGN

park ADMIN

ADMIN
VARIANT

VARIANT

hospital

spring BGM

reservoir $B G N$

canal

BGN

reservoir

stream

stream

BGN

BGN

VARIANT

summit

stream

stream

BGN
BGN
VARIANT

VARIANT

summit VARIAM

Yavapai

summit

BGN Maricopa

reservoir BGN

reservoir BGI

reservoir $B G$

reservoir BGN

reservoir BGI

reservoir BGN

valley BG

reservoir BGN

pillar

BGN

spring

spring

reservoir

summit

lake

reservoir

lake

cliff

summit

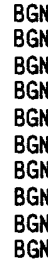

spring

spring

BGN

park

dam

mine

park

reservoir

park

BGN

BGN

BGN

$B G N$

BGN

BGN
BGN

Yavapai

Navajo

Yavapai

Yavapai

Coconino

Coconino

Coconino

Greenlee

Yavapai

Gila

Maricopa

Coconino

Yavapai

Coconino

Coconino

Coconino

Coconino

Coconino

Apache

Yavapai

Navajo

Coconino

Coconino

Pima

UNOF

UNOFF

ADM IN

BGN

ADMIN

VARIANT

Coconino

Coconino

reservoir

reservoir

stream

valley

reservoir

well

mine

well

well

spring

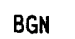

Yavapai

Coconino

Coconino

Coconino

Coconino

Cocon ino

Grahan

Coconino

Navajo

Greenlee

spring BGN Navajo

reservoir

spring

mine

spring

ppl

building

reservoir
$345325 \mathrm{~N} 1115136 \mathrm{~W}$

COORDINATE

$343556 \mathrm{~N} 1123617 \mathrm{~W}$

$343532 \mathrm{~N} 1123540 \mathrm{~W}$

$330756 \mathrm{~N} 1114452 \mathrm{~W}$

$330754 N 1114450 \mathrm{~W}$

$331814 N 1115025 \mathrm{~W}$

$332846 \mathrm{~N} 1120207 \mathrm{~W}$

$322923 \mathrm{~N} 1104208 \mathrm{~W}$

$360518 N 1122359 \mathrm{~W}$

325724N1095549W

$323455 \mathrm{~N} 1104550 \mathrm{~W}$

$323041 \mathrm{N1} 105220 \mathrm{~W}$

$323325 \mathrm{~N} 1104749 \mathrm{~W}$

$314519 N 1091626 \mathrm{~W}$

$325321 \mathrm{~N} 1104336 \mathrm{~W}$

$342758 \mathrm{~N} 1100858 \mathrm{~W}$

$335632 \mathrm{~N} 1121041 \mathrm{~W}$

$342801 N 1114134 \mathrm{~W}$

$342207 \mathrm{~N} 1102040 \mathrm{~W}$

$342705 \mathrm{~N} 1114440 \mathrm{~W}$

$344432 \mathrm{~N} 1113849 \mathrm{~W}$

$351910 N 1121832 \mathrm{~W}$

$352401 \mathrm{~N} 1122750 \mathrm{~W}$

$362753 \mathrm{~N} 1120053 \mathrm{~W}$

$331246 \mathrm{~N} 1091458 \mathrm{~W}$

$340222 \mathrm{~N} 1122705 \mathrm{~W}$

331841 N1104906W

$332807 N 1111608 \mathrm{~W}$

$345544 \mathrm{~N} 1120001 \mathrm{~W}$

$353900 \mathrm{~N} 1115527 \mathrm{~W}$

$354101 \mathrm{~N} 1115556 \mathrm{~W}$

$353221 N 1115400 \mathrm{~W}$

$362518 \mathrm{~N} 1120520 \mathrm{~W}$

$362758 \mathrm{~N} 1120322 \mathrm{~W}$

$360826 \mathrm{~N} 1092922 \mathrm{~W}$

$341235 \mathrm{~N} 1114939 \mathrm{~W}$

$352234 \mathrm{N1100526 \textrm {W }}$

351233 N1120726W

$351236 \mathrm{~N} 1120742 \mathrm{~W}$

$315704 \mathrm{~N} 1110635 \mathrm{~W}$

$351250 N 1120738 \mathrm{~W}$

$351240 N 1120731 \mathrm{~W}$

$351233 \mathrm{~N} 1120726 \mathrm{~W}$

$342457 N 1115837 \mathrm{~W}$

$351256 \mathrm{~N} 1120720 \mathrm{~W}$

$351 B 40 N 1121055 \mathrm{~W}$

345647 N1110540W

$345450 \mathrm{~N} 1110256 \mathrm{~W}$

345351 N1110155W

$325221 \mathrm{~N} 1101 \mathrm{B5} 3 \mathrm{~W}$

$361350 N 1111037$

$352303 \mathrm{~N} 110$

333327 N1092808W

$352526 \mathrm{~N} 1100944 \mathrm{~W}$

$341057 \mathrm{~N} 1100102 \mathrm{~W}$

$360409 \mathrm{N1} 100552 \mathrm{~W}$

$335308 \mathrm{~N} 1133756 \mathrm{~W}$

$353559 \mathrm{~N} 1141456 \mathrm{~W}$

$353531 \mathrm{~N} 1141621 \mathrm{~W}$

$353511 \mathrm{~N} 1141640 \mathrm{~W}$

$363857 \mathrm{~N} 1131715 \mathrm{~W}$
343911 N1110729W

\begin{tabular}{|c|c|c|}
\hline \multirow[t]{5}{*}{$\begin{array}{l}\text { SOURCE } \\
\text { COORDINATE }\end{array}$} & $\begin{array}{c}\text { ELEV } \\
\text { FT }\end{array}$ & MAP NAME \\
\hline & & $\begin{array}{l}\text { Iron Springs } \\
\text { Iron Springs }\end{array}$ \\
\hline & & Chandler Heights \\
\hline & & $\begin{array}{l}\text { Chandler Heights } \\
\text { Chandler }\end{array}$ \\
\hline & & $\begin{array}{l}\text { Mount Bigelow } \\
\text { Chamisa Tank } \\
\text { Eden }\end{array}$ \\
\hline $\begin{array}{l}323059 \mathrm{~N} 1104843 \mathrm{~W} \\
323455 \mathrm{~N} 1104549 \mathrm{~W}\end{array}$ & & $\begin{array}{l}\text { Oracle } \\
\text { Oracle } \\
\text { Oracle }\end{array}$ \\
\hline $\begin{array}{l}324958 \mathrm{~N} 1105017 \mathrm{~W} \\
341913 \mathrm{N1} 101321 \mathrm{~W}\end{array}$ & & $\begin{array}{l}\text { Dudleyville } \\
\text { Cactus Flat }\end{array}$ \\
\hline
\end{tabular}

2681 New River Hackberry Mtn

Clay Springs

Hackberry Mtn

Casner Butte

Hearst Mtn

Stanford Tank

Dog Point

Big Lue Mts

Copperopol is

Pinal Peak

Weavers Needle

Quayle Hill

Sycamore Bas in

Dog Knobs

Dog Knobs

Ebert Mtn

Dog Point

Dog Point

Del Muerto

Bloody Basin

Indian Wells

7067 Williams South

Twin Buttes

Williams South 
FEATURE NAME

Dollar Mark Tank

Dollar More Tank

Doll 8aby Ranch

Dollbeer Mobile Home Ranch

Dolphin Well

Dome, The

Dome, The

Dome Bas in Mine

Dome Canal

Dome Lateral

Dome Mountain

See Dome Rock Mountains

Dome Mountain

Dome Mountain

See Bear Mountain

Dome Mountains

See Dome Rock Mountains

Dome North of Mesquite

See Chupan Mountain

Dome Pocket

Dome Protective Channel

Dome Rock Interchange

Dome Rock Mountains

Avie Tok-a-va

Dome Mountain

Dome Mountains

Dome Rock Range

La Paz Mountains

Sierra de San Pedro

Sierra Mo-Quin-To-Ora

Dome Rock Range

See Dome Rock Mountains

Dome Spring

Dome Trail

Dome Valley

Domingo Tank

Domino Mine

Dona Ana County See Cochise County

Dona Ana County See Yuma County

Donahue Tank

Donaldson Dam

Donaldson Mine

Donaldson Ranch

Donaldson School

Donaldson Tank

Donald W. Waddell Dam

See Carl Pleasant Dam

Don Amegus Mine

See Dos Amigos Mine

Don Diego Tank

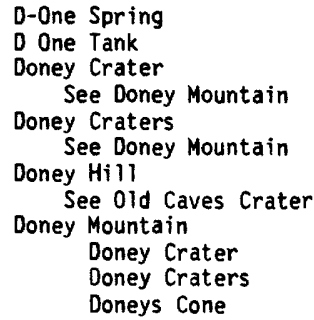

Doney Mountain Wash

Doney Park

Doneys Cone

See Doney Mountain

Don Jose Corral

Don Juan Flat

\begin{tabular}{|c|c|c|c|}
\hline $\begin{array}{l}\text { FEATURE } \\
\text { CLASS }\end{array}$ & STATUS & COUNTY & COORDINATE \\
\hline $\begin{array}{l}\text { reservoir } \\
\text { reservoir }\end{array}$ & $\begin{array}{l}\text { BGN } \\
\text { BGN }\end{array}$ & $\begin{array}{l}\text { Coconino } \\
\text { Yavapai }\end{array}$ & $\begin{array}{l}351421 \mathrm{~N} 1114122 \mathrm{~W} \\
342747 \mathrm{~N} 1114216 \mathrm{~W}\end{array}$ \\
\hline $\begin{array}{l}\text { locale } \\
\text { locale } \\
\text { well } \\
\text { ppl } \\
\text { summit } \\
\text { summit } \\
\text { mine } \\
\text { canal } \\
\text { canal } \\
\text { range }\end{array}$ & $\begin{array}{l}\text { UNOFF } \\
\text { UNOFF } \\
\text { UNOFF } \\
\text { BGN } \\
\text { BGN } \\
\text { BGN } \\
\text { UNOFF } \\
\text { BGN } \\
\text { BGN } \\
\text { VARIANT }\end{array}$ & $\begin{array}{l}\text { Gila } \\
\text { Maricopa } \\
\text { Cochise } \\
\text { Yuma } \\
\text { Cochise } \\
\text { Mohave } \\
\text { Yuma } \\
\text { Yuma } \\
\text { Yuma } \\
\text { Yuma }\end{array}$ & $\begin{array}{l}341318 N 1112807 \mathrm{~W} \\
332445 \mathrm{~N} 1113852 \mathrm{~W} \\
315304 \mathrm{~N} 1102317 \mathrm{~W} \\
324519 \mathrm{~N} 1142141 \mathrm{~W} \\
314239 \mathrm{~N} 1100702 \mathrm{~W} \\
361633 \mathrm{~N} 1125358 \mathrm{~W} \\
334451 \mathrm{~N} 1142021 \mathrm{~W} \\
324616 \mathrm{~N} 1141956 \mathrm{~W} \\
324159 \mathrm{~N} 1141444 \mathrm{~W} \\
334127 \mathrm{~N} 1142011 \mathrm{~W}\end{array}$ \\
\hline S umm it & $\begin{array}{l}\text { BGN } \\
\text { VARIANT }\end{array}$ & Maricopa & $333010 \mathrm{~N} 1113238 \mathrm{~W}$ \\
\hline summit & & Yavapai & $345450 \mathrm{~N} 1125834 \mathrm{~W}$ \\
\hline range & VARIANT & Yuma & $334127 \mathrm{~N} 1142011 \mathrm{~W}$ \\
\hline $\begin{array}{l}\text { summit } \\
\text { basin } \\
\text { canal } \\
\text { crossing }\end{array}$ & $\begin{array}{l}\text { BGN } \\
\text { BGN } \\
\text { UNOFF }\end{array}$ & $\begin{array}{l}\text { Pima } \\
\text { Mohave } \\
\text { Yuma } \\
\text { Yuma }\end{array}$ & $\begin{array}{l}315748 \mathrm{~N} 1122714 \mathrm{~W} \\
361807 \mathrm{~N} 1125334 \mathrm{~W} \\
324340 \mathrm{~N} 1141709 \mathrm{~W} \\
333848 \mathrm{~N} 1142003 \mathrm{~W}\end{array}$ \\
\hline range & $\begin{array}{l}\text { BGN } \\
\text { VARIANT } \\
\text { VARIANT } \\
\text { VARIANT } \\
\text { VARIANT } \\
\text { VARIANT } \\
\text { VARIANT } \\
\text { VARIANT } \\
\text { VARIANT }\end{array}$ & Yuma & $334127 N 1142011 \mathrm{~h}$ \\
\hline range & & Yuma & 334127 N1142011 \\
\hline $\begin{array}{l}\text { spring } \\
\text { trail } \\
\text { valley } \\
\text { reservoir } \\
\text { mine }\end{array}$ & $\begin{array}{l}\text { BGN } \\
\text { UNOFF } \\
\text { BGN } \\
\text { BGN } \\
\text { UNOFF } \\
\text { VARIANT }\end{array}$ & $\begin{array}{l}\text { Mohave } \\
\text { Mohave } \\
\text { Yuma } \\
\text { Coconino } \\
\text { Santa Cruz }\end{array}$ & $\begin{array}{l}361700 \mathrm{~N} 1125335 \mathrm{~W} \\
361633 \mathrm{~N} 1125422 \mathrm{~W} \\
324450 \mathrm{~N} 1142016 \mathrm{~W} \\
352030 \mathrm{~N} 1114357 \mathrm{~W} \\
312819 \mathrm{~N} 1104716 \mathrm{~W}\end{array}$ \\
\hline civil & VARIANT & Cochise & $315555 \mathrm{~N} 1094430 \mathrm{~W}$ \\
\hline $\begin{array}{l}\text { civil } \\
\text { reservoir }\end{array}$ & & $\begin{array}{l}\text { Yuma } \\
\text { Gila }\end{array}$ & $\begin{array}{l}330001 \mathrm{~N} 1140010 \mathrm{~W} \\
34222 \mathrm{BN} 1112547 \mathrm{~W}\end{array}$ \\
\hline
\end{tabular}

reservoir BGN Gila 34222BN1112547W

\begin{tabular}{|c|c|c|c|}
\hline $\begin{array}{l}\text { dam } \\
\text { mine } \\
\text { locale } \\
\text { school } \\
\text { reservoir }\end{array}$ & $\begin{array}{l}\text { UNOFF } \\
\text { UNOFF } \\
\text { UNOFF } \\
\text { UNOFF } \\
\text { BGN } \\
\text { VARIANT }\end{array}$ & $\begin{array}{l}\text { Pima } \\
\text { Yuma } \\
\text { Pima } \\
\text { Pima } \\
\text { Coconino }\end{array}$ & $\begin{array}{l}320853 \mathrm{~N} 1111700 \mathrm{~W} \\
323404 \mathrm{~N} 1140456 \mathrm{~W} \\
321057 \mathrm{~N} 1111700 \mathrm{~W} \\
322000 \mathrm{~N} 1110040 \mathrm{~W} \\
355248 \mathrm{~N} 1121244 \mathrm{~W}\end{array}$ \\
\hline & VARIANT & Maricopa & $335112 N 112160$ \\
\hline $\begin{array}{l}\text { ine } \\
\text { eservoir }\end{array}$ & $B G N$ & $\begin{array}{l}\text { Santa Cruz } \\
\text { Yuma }\end{array}$ & $\begin{array}{l}312500 N 1111 \\
323715 N 1132\end{array}$ \\
\hline
\end{tabular}

spring BGN Yavapai 343734N1124328W

reservoir BGN Yavapai 343704N1124131W

Coconino 353220N1112355W

summit

crater

summit

VARIANT

VARIANT

BGN 197

VARIANT

VARIANT

VARIANT

flat

VARIANT

summit

locale

$353631 N 1111915$

$351612 \mathrm{~N} 1113100 \mathrm{~W}$

$353220 \mathrm{~N} 1112355 \mathrm{~W}$

$324826 \mathrm{N11} 102750 \mathrm{~W}$
BGN

VARIANT

\begin{tabular}{ccl}
$\begin{array}{c}\text { SOURCE } \\
\text { COORDINATE }\end{array}$ & $\begin{array}{c}\text { ELEV } \\
\text { FT }\end{array}$ & \multicolumn{1}{c}{ MAP NAME } \\
& & $\begin{array}{l}\text { Flagstaff West } \\
\text { Hackberry Mtn }\end{array}$ \\
& 1480 & $\begin{array}{l}\text { North Peak } \\
\text { Buckhorn } \\
4993\end{array}$ \\
191 & $\begin{array}{l}\text { Mescal } \\
\text { Dome } \\
\text { Tombstone }\end{array}$ \\
5487 & $\begin{array}{l}\text { Fern Glen Canyon } \\
\text { Middle Camp Mtn } \\
\text { Dome } \\
\text { Wellton }\end{array}$
\end{tabular}

3381 Stewart Mtn

Fern Glen Canyon Ligurta Middle Camp Mtn

Middle Camp Mtn

Fern Glen Canyon Ligurta

Humphreys Peak

Cumero Canyon

8uckhead Mesa

Cocoraque Butte Wellton SE

Cocoraque 8utte Jaynes

Tusayan West

Aguila Mts SE

Nt Josh

Skull valley

5589 Wupatki SW

$353215 N 1112411 W$

Wupatki SE

Sunset Crater West 
NATIONAL GAZETTEER--ARIZONA 1986

\section{FEATURE NAME}

See San Juan Flat

Donkey Canyon

Donkey Lake

Donkey Spring

Donkey Spring

Donkey Spring Canyon Polacca Wash

Don Luis

Don Luis School

Donnelly Canyon

See Donnelly Wash

Donnelly Ranch San Gregorio

Donnelly Wash Donnelly Canyon

Donnet-Fry Ranch

Donney Tank

Do Nothing Canyon

Do Nothing Tank

Donovan Lateral

Donovan Tank

Dons Camp

Donsill Canyon

See Andrus Canyon

Don Smith Spring

Dons Tank

Dons Tank

Dons Tank

Don Tank

Don Tank

Doodlebug Diggings

Doodlebug Tank

Doonys io

See Yuma

Door Spring, The

Dorado Wash, El

Dorens Defeat Canyon

Dorens Defeat Spring

Dorens Defeat Tank

Dorothy Canyon

Dorothy Stinson Elementary School Stinson School

Dorothy Tank

Dorsey Guich

Dorsey Spring

Dos Amigos Mine Don Amegus Mine

Dos Cabezas

See Dos Cabezas Mountains

Dos Cabezas

See Dos Cabezas Peaks

Dos Cabezas Dos Cabezos

Dos Cabezas Catchment

Dos Cabezas Mountains Dos Cabezas

Dos Cabezas Range

Dos Cabezas Peaks

Dos Cabezas

Dos Cabezos Peaks

Dos Cabezas Range

See Dos Cabezas Mountains

Dos Cabezos

See Dos Cabezas

Dos Cabezos Peaks

See Dos Cabezas Peaks

Dos Condado Station (electric

substation)

Dos Lomitas

Dos Lomitas Ranch Picnic Area

$341150 \mathrm{~N} 1103706 \mathrm{~W}$

331932N1112129W
FEATURE
CLASS

STATUS

COUNTY

COORDINATE

340815 N1094010W

flat

valley
lake

spring

BGN

Apache

Pinal

Navajo

Mavajo

spring

valley

BGN

BGN

VARIANT

ppl

school

stream

locale

stream

BGN

VARIANT

UNOFF

VARIANT

BGN

VARIANT

locale

reservoir

valley

reservoir

canal

reservoir

locale

valley

spring

UNOFF

BGN

BGN

BGN

BGN

BGN

VARIANT

BGN

reservoir $B G$

reservoir BGN

reservoir $B G$

reservoir BGN

reservoir

mine

reservoir

ppl

spring

UNOFF

UNOF

BGN
VARIANT

BGN

strean

valley

spring

reservoir

valley

school

reservoir

valley

spring BGN

mine UNOFF

VARIANT

VARIANT

ridge

summit

ppl

reservoir

VARIANT

BGN 1947 VARIANT

BGN

Navajo

Navajo

Cochise

Cochise

Pinal

Pinal

Pinal

Coconino

Greenlee

Greenlee

Yuma

Pima

Pinal

Mohave

Greenlee

$331628 \mathrm{N1} 110535 \mathrm{~W}$

$355611 \mathrm{~N} 1102026 \mathrm{~W}$

360010N1100137W

$361019 N 1100319 \mathrm{~W}$

312409 N1095458W

$312331 \mathrm{N1095507 \textrm {W }}$

$330530 \mathrm{~N} 1111055 \mathrm{~W}$

330213N1110913W

330530 N1111055W

$313502 N 1101131 \mathrm{~W}$

$344322 \mathrm{N1112421 \textrm {W }}$

$331712 N 1090704 \mathrm{~W}$

$331712 \mathrm{~N} 1090704 \mathrm{~V}$

$323904 \mathrm{~N} 1143842 \mathrm{~W}$

$322236 \mathrm{~N} 1103426 \mathrm{~W}$

$332341 \mathrm{N1112108 \textrm {W }}$

$360855 N 1132104 \mathrm{~W}$

331250 N1091543W

Pima

Grahan

Pinal

Graham

Maricopa

Yavapai

Santa Cruz

Yuma

$314938 \mathrm{~N} 1111444 \mathrm{~W}$

330423N1093723W

$325638 \mathrm{N1093401 \textrm {W }}$

$330 \mathrm{~B} 25 \mathrm{~N} 1122531 \mathrm{~W}$

$343435 \mathrm{~N} 1121904 \mathrm{~K}$

313756N1110550W

324331N1143725W

331030N1091916W

$342918 N 1142127 \mathrm{~W}$

$342643 N 1114124 \mathrm{M}$

$342605 \mathrm{~N} 1114022 \mathrm{~W}$

$342647 \mathrm{~N} 1113826 \mathrm{~W}$

$335939 \mathrm{~N} 1122235 \mathrm{~W}$

$324854 \mathrm{N1} 1094254 \mathrm{~W}$

Yavapa

Yavapai

Graham

Coconino

$353916 \mathrm{~N} 1121531 \mathrm{~W}$

$330728 \mathrm{~N} 1091715 \mathrm{~W}$

$330810 N 1091921 \mathrm{~W}$

Coconino

Santa Cruz

$350316 \mathrm{~N} 1115640 \mathrm{~W}$

312500 N1111432w

Cochise

321230 N1093431W

Cochise

Cochise

Cochise

21324N109363BW

321031 N1093646W

321211M1093356W

$321230 \mathrm{N1093431W}$

GGN 1947 Cochise

ridge

VARIANT

VARIANT

summit $\quad$ BGN 1947

VARIANT

VARIANT

VARIANT

ridge

VARIAN

pp1

Cochise

$321230 \mathrm{~N} 1093431 \mathrm{~W}$

Cochise

321031N1093646W

VARIANT

summit

locale

UNOFF

Cochise

Graham

$321324 \mathrm{~N} 1093638 \mathrm{~W}$

$324625 \mathrm{~N} 1093718 \mathrm{~W}$

summit $\quad B G N$

UNOFF
$315156 \mathrm{~N} 1124518 \mathrm{~W}$

$315203 N 1124541 \mathrm{~W}$

$\begin{array}{cc}\text { SOURCE } & \text { ELEV } \\ \text { COORDINATE } & \text { FT MAP NAME }\end{array}$

331641N1110427W Superior

Pepper Canyon

Wepo Village

361615N1095810 Whippoorwill Spring

Burnt Corn Spring

Bisbee

Bisbee

North Butte

North Butte

Lewis Springs

Happy Jack

Maple Peak

Maple Peak

Yuma West

Buehman Canyon

Weavers Needle

Mitchell Peak

Batamote Hills

4935 Bonita Spring

Florence Junction

Lone Star Mtn

Mobile NW

Prescott Valley S

Amado

Mitchell Peak

Lake Havasu City S

Hackberry Mtn

Hackberry Mtn

Hackberry Mtn

Garfias Mtn

Safford

Miller Tank 
FEATURE NAME

Dos Nogales See Nogales

Dosoris Canyon

Dosoris Spring

Dos Palmas Well

Dos Picachos

Dos Playas

Dos S Ranch

Doss Windmil

Dos Titos

Dotklish Canyon

See Biko Hodo Klizg

Dot Klish Canyon

See Blue Canyon

Dot Klish Wash

See Biko Hodo Klizg

Dotson Spring

Double Adobe

Double A Knoll

Double A Railroad Station

Double A Ranch

Double Arch Canyon

Double A Tank

Double Butte

See Double Buttes

Double Buttes

See Double Peaks

Double Buttes

Double Butte

Double Cabin

Double Cabin Park

Double Cabin Spring

Double Cienega

Double Cienega Creek

Double Circle Ranch

Eagle Ranch

Little Steves Ranch

Double Circle Tank

Double Circle Tank

Double Corral Spring

Double Corral Tank

Double Corral Tank

Double Corral Trough

Double Crater Janus Crater

Double Dan Tank

Double Eagle Mine

Double Eagle Mine

Double E Tank

Double F Tank

Double Grantham Tank

Double Header Mine

Double Knobs

Double Knobs Tank

Double Knolls

Double Mill Ranch

Double 0 Ranch

Double 0 Tank

Double Peak

Double Peaks

Double Peaks

See Double Peak

Double Peaks

Double Buttes

Double R Canyon

Double R Springs

Double Springs

Double Springs Campground

Double Tank

Double Tank

See Sandy Tank
FEATURE
CLASS

STATUS

pp1

valley

VARIANT

BGN
BGN

well

summit

plain

locale

locale

summit

valley

valley

$\begin{array}{ll}\text { UNOFF } & \text { Maricopa } \\ \text { BGN } & \text { Yuma } \\ \text { BGN } & \text { Yuma } \\ \text { UNOFF } & \text { Maricopa } \\ \text { BGN } & \text { Yavapai } \\ \text { BGN } & \text { Pima } \\ \text { VARIANT } & \\ \text { VARIANT } & \text { Coconino } \\ & \text { Coconino }\end{array}$

$4211 \mathrm{~N} 1124126 \mathrm{~W}$

$333720 \mathrm{~N} 1140448 \mathrm{~W}$

$321139 \mathrm{N1132016 \textrm {W }}$

$334517 N 1113012 \mathrm{~W}$

$340421 N 1121513 \mathrm{~W}$

$321633 \mathrm{~N} 1112650 \mathrm{~W}$

$355325 N 1112641 \mathrm{~W}$

361027 N1105254W

VARIANT

valley
spring
ppl
summit
building
locale
valley
reservoir

BGN

BGN

BGN
BGN
UNDFF

UNOFF

UNOFF

BGN

BGN

summit

VARIANT

summit

summit

locale

flat

spring

flat

stream

locale

VARIANT
BGN
VARIANT
BGN
BGN
BGN
BGN
BGN
UNOFF
VARIANT
VARIANT

Coconino

Coconino

Cochise

Coconino

Coconino

Coconino

Navajo

Coconino

Gila

$355325 \mathrm{~N} 1112641 \mathrm{~W}$

$360 B 30 N 1111441 \mathrm{~W}$

$312800 N 1094122 \mathrm{~W}$

351951 N1122352W

$351833 \mathrm{~N} 1122509 \mathrm{~W}$

$351902 \mathrm{~N} 1122402 \mathrm{~W}$

$365106 \mathrm{N1100211W}$

351915N1122410W

$335630 \mathrm{~N} 1104501 \mathrm{~W}$

$330622 \mathrm{~N} 1111143 \mathrm{~W}$

$335630 \mathrm{~N} 1104501 \mathrm{~W}$

$342644 N 1110331 \mathrm{~W}$

$344821 \mathrm{N1112636 \textrm {W }}$

$342645 \mathrm{~N} 1110335 \mathrm{~W}$

$333626 \mathrm{~N} 1092321 \mathrm{~W}$

$333833 N 1092207 \mathrm{~W}$

332009 N1092935W

Green

Greenlee

VARIANT

reservoir

reservoir

spring

reservoir

reservoir

well

crater

reservoir

mine

\section{BGN}

BGN

BGN

BGN

UNOFF

UGN 1971

VARIANT

BGN

UNOFF

Grahan

Coconino

Gila

Gila

Yavapai

Gila

Coconino

Coconino

Yuma

mine

UNOFF Maricopa

reservoir

reservoir

reservoir

mine

summit

reservoir

summit

locale

locale

BGN

BGN

BGN

UNOFF

BGN

BGN

UNOFF

Coconino

Santa Cruz

Gila

Santa Cruz

Coconino

Coconino

Maricopa

Cochise

UNOFF Yavapai

reservoir

BGN

summit

Yavapai

VARIANT

VARIANT

summit

summit

valley

spring

spring

BGN

VARIANT

BGN Cochise

BGN Cochise

BGN Coconino

park

reservoir

ADMIN

BGN
VARIANT

Coconino

Santa Cruz

Santa Cruz
$332855 N 1095654 \mathrm{~W}$

$343814 \mathrm{~N} 1111504 \mathrm{~W}$

$333643 \mathrm{~N} 1103950 \mathrm{~W}$

$340622 \mathrm{~N} 1110744 \mathrm{~W}$

$340840 \mathrm{~N} 1115240 \mathrm{~W}$

$333506 \mathrm{~N} 1110604 \mathrm{~W}$

$352034 \mathrm{N1112649W}$

$351546 \mathrm{~N} 1121710 \mathrm{~W}$

$323240 \mathrm{~N} 1140610 \mathrm{~W}$

$344359 \mathrm{~N} 1112004 \mathrm{~W}$

$312404 \mathrm{~N} 1103754 \mathrm{~W}$

$334405 \mathrm{~N} 1105535 \mathrm{~W}$

$313752 \mathrm{~N} 1104814 \mathrm{~W}$

$354233 \mathrm{~N} 1115808 \mathrm{~W}$

$354311 \mathrm{N1} 115 \mathrm{~B} 37 \mathrm{~W}$

$332500 \mathrm{~N} 1113858 \mathrm{~W}$

$351116 N 1125317 \mathrm{~W}$

$350846 N 1125137 W$

$324507 N 1115937 \mathrm{~W}$

$324507 N 1115937 \mathrm{~W}$

$330622 \mathrm{~N} 1111143 \mathrm{~W}$

$322116 N 1101419 \mathrm{~W}$

$322251 \mathrm{N1101454 \textrm {W }}$

$345628 \mathrm{~N} 1112936 \mathrm{~W}$

$345634 N 1112930 \mathrm{~W}$

$313055 N 1103352 W$

$313836 \times 1110944 \mathrm{~W}$
$332134 N 1131613 \mathrm{~W}$

$\begin{array}{cc}\text { SOURCE } & \text { ELEV } \\ \text { COORDINATE } & \text { FT }\end{array}$

342535N1122824W Groom Creek Groom Creek

Daggs Tank

2695 Crystal Hill Antelope $\mathrm{Hill}$ s Maverick Mt

3369 Columbia Waterman Peak

5056 Tuba City Double Adobe

6461 Fitzgerald Hill Fitzgerald Hill Fitzgerald Hill Baby Rocks Fitzgerald Hill

5732 Rock House

7420 Knoll Lake Hutch Mtn Knoll Lake Baldy Bill Point Hannagan Meadow Bee Canyon

6231 Natanes Mts NW Turkey Mtn Chrome Butte Sheep Bas in Mtn Brooklyn Peak

Two Bar Mtn

Sunset Crater East

Hearst Mtn

Wellton SE

Columbus Peak

Turkey Mtn 
NATIONAL GAZETTEER--ARIZONA 1986

FEATURE NAME

Double Tank

Double Tank

Double Tank

Double Tank

Double Tank

Double Tank

Double Tank

Double Tank

Double Tank

Double Tank

Double Tank

Double Tank

Double Tanks

Double Top

Double T Ranch

Doubletree Canyon (subdivision)

Double Trough Spring

Oouble Trough Spring

Double Troughs Spring

Double X Ranch

Double Z Windmil1

Doubtful Canyon

Doubtful Canyon

Doubtful Tank

Doubtful Tank

Doughboy Shaft

Dougherty Canyon

Dougherty Spring

Dougherty Tank

Douglas

Douglas Camp Spring

Douglas Canyon

See North Fork Douglas Canyon

Douglas Canyon

Douglas High School

Douglas Monitoring Station

Douglas Municipal Airport

Douglas Municipal Pumping Plant

Douglas Post office

Douglas Ranch

Douglas School

See Walter Douglas School

Douglas Substation

Douglas Well

Dourine Canyon

Dourine Detention Dam

Dourine Pasture

Dourine Tank

Dove Canyon

Dover Spring

Dove Spring

Dove Spring

Dove Spring

Dove Spring

Dove Spring

Dove Tank

Dove Tank

Dove Tank

Dove Tank

Dove Tank

Dowdle Canyon

See West Sawmill Canyon

Dowdle Tank

Dowling Ranch

Downing Pass

Dawings Pass

Downs Cabin

Downs School

Downtown Post office

Downtown Station Post Office
FEATURE

CLASS

reservoir

reservoir

reservoir

reservoir BGN

reservoir

reservoir

reservoir BGN

reservoir BGN

reservoir BGN

reservoir BGN

reservoir

summit $B G N$

locale UNOFF

ppl

$\begin{array}{llll}\text { spring } & \text { BGN } & \text { Graham } & 323921 \text { N1101720W } \\ \text { spring } & \text { BGN } & \text { Yavapai } & 340400 N 1122850 \mathrm{~W} \\ \text { spring } & \text { BGN } & \text { Graham } & 330440 \mathrm{~N} 1102343 \mathrm{~W} \\ \text { locale } & \text { UNOFF } & \text { Mohave } & 315913 \mathrm{~N} 1102759 \mathrm{~W} \\ \text { locale } & \text { BGN } & \text { Cochise } & 320854 \text { N1092941W } \\ \text { valley } & \text { BGN } & \text { Cochise } & 322038 N 1090055 \mathrm{~W} \\ \text { valley } & \text { BGN } & \text { Gila } & 341852 \mathrm{~N} 1110432 \mathrm{~W} \\ \text { reservoir } & \text { BGN } & \text { Coconino } & 344756 \mathrm{N1112039W} \\ \text { reservoir } & \text { BGN } & \text { Apache } & 345724 N 1094153 \mathrm{~W} \\ \text { mine } & \text { UNOFF } & \text { Gila } & 332602 N 1104747 \mathrm{~W}\end{array}$

mine

valley

spring

reservoir

ppl

spring

BGN Yavapai

BGN Coconino

BGN 1943 Cochise

BGN

VARIANT

valley

valley
school

BGN 1975

UNOFF

locale

airport

building

building

locale

school

locale

well

valley

BGN

ADMIN

BGN

UNOFF

UNOFF

VARIANT

UNOFF

UNOFF

BGN

$\begin{array}{ll}\text { dam } & \text { UNOFF } \\ \text { flat } & \text { BGN } \\ \text { reservoir } & \text { BGN } \\ \text { valley } & \text { BGN } \\ \text { spring } & \text { BGN } \\ \text { spring } & \text { BGN } \\ \text { spring } & \text { BGN } \\ \text { spring } & \text { BGN } \\ \text { spring } & \text { BGN } \\ \text { spring } & \text { BGN }\end{array}$

Gila

Gila

Gila

Santa Cruz

Navajo

Coconino

Navajo

Navajo

Navajo

Coconino

$343616 N 1125043 \mathrm{~W}$

343710N1125101W

$354028 N 1113317 \mathrm{~W}$

$312040 \mathrm{~N} 1093241 \mathrm{~W}$

321349 N1103622W

323718N1101918W

$323734 N 1102110 \mathrm{~W}$ 312102 N1093214W

$313015 N 1093921 \mathrm{~W}$

312030 N1093015W

$312120 \mathrm{~N} 1093513 \mathrm{~W}$

312039 N1093308W

$314218 \mathrm{~N} 1104244 \mathrm{~W}$

$321601 N 1105937 \mathrm{~W}$

$312046 \mathrm{~N} 1093222 \mathrm{~W}$

$312357 N 1104731 \mathrm{~W}$

332419N1102803W

$332300 \mathrm{~N} 1103130 \mathrm{~W}$

$332419 \mathrm{~N} 1103258 \mathrm{~W}$

$332540 \mathrm{~N} 1103209 \mathrm{~W}$

$312504 N 1103339 \mathrm{~W}$

$354652 N 1100756$

345227 N1112223W

$354950 \mathrm{~N} 1103206 \mathrm{~W}$

$355432 N 1103922 \mathrm{~W}$

360121 N1104108W

363322 N1112550W

reservoir BGN

reservoir BGN

reservoir BGN

reservoir BGN

reservoir BGN

valley

reservoir

locale

gap

BGN

UNOFF

BGN 1978

VARIANT

Santa Cruz

Santa Cruz

Navajo

Coconino

Coconino

Pima

Grahan

Pima

Cochise

locale

school

$B G N$

building

building
$312320 \mathrm{~N} 1110014 \mathrm{~W}$

$340727 \mathrm{~N} 1100917 \mathrm{~W}$

$345254 N 1112117 \mathrm{~W}$

$352811 \mathrm{~N} 1113247 \mathrm{~W}$

$314653 N 1105053 \mathrm{~W}$

325210 N1101651W

$315313 \mathrm{~N} 1125009 \mathrm{~W}$

315627 N1091854W

$333214 \mathrm{~N} 1091228 \mathrm{~W}$

$332924 \mathrm{~N} 112 \mathrm{Dg} 39 \mathrm{~W}$

321312 N1 $105821 \mathrm{~W}$

$332715 \mathrm{~N} 1120427 \mathrm{~W}$ reservoir BGY

$312510 \mathrm{~N} 1103212 \mathrm{~W}$

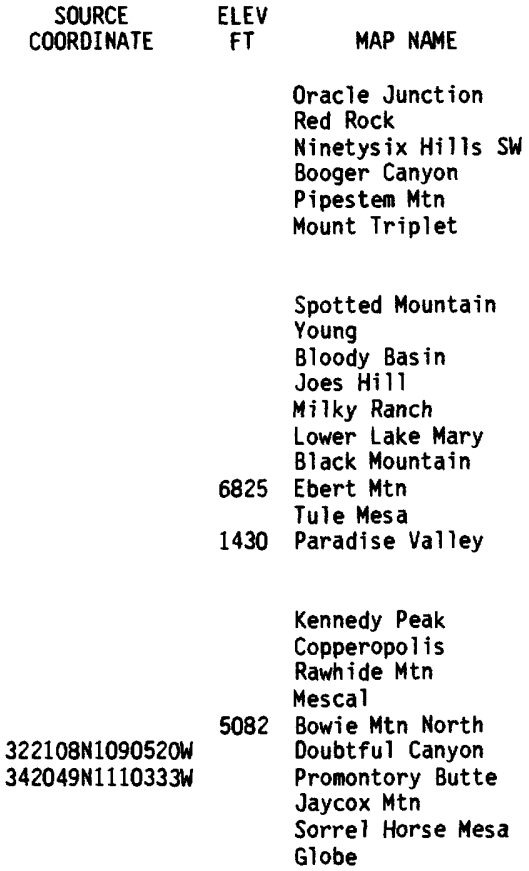

$\begin{array}{cc}\text { SOURCE } & \text { ELEV } \\ \text { COORDINATE } & \text { FT MAP NAME }\end{array}$

Oracle Junction Red Rock

Ninetysix Hills SW

Booger Canyon

Pipestem Mtn

Mount Triplet

Spotted Mountain

Young

Bloody Basin

Joes Hill

Milky Ranch

Lower Lake Mary

Black Mountain

6825 Ebert Mtn

Tule Mesa

1430 Paradise Valley

Kennedy Peak

Copperopol is

Rawhide Mtn

Mescal

322108 N1090520W

5082 Bowie Mtn North Doubtful Canyon

Promontory Butte

Jaycox Mtn

Sorrel Horse Mesa

Globe

343801 N1124902W

Martin Mtn

Mart in Mtn

Campbell Francis Wsh

4004 Douglas

Mica Mountain

$323752 \mathrm{~N} 1101732 \mathrm{~W}$

Bassett Peak

Douglas

McNeal

4129 Douglas

Douglas

Douglas

Sonoita

Douglas

Cumero Canyon

Natural Corra

$332645 N 1103423 W$

Dourine Canyon

Dourine Canyon

Dourine Canyon

Canelo Pass

Keams Canyon

Jaycox Mtn

Shongopovi

Hotevilla

Rocky Ridge Sh

5830 Dove Spring

Pena Blanca Lake

Canelo Pass

Long Tom Canyon

Kinnikinick Lake

o'Leary Peak

Klondike

Lukeville

6353 Rustler Park

5200 Bear Mountain

Fowler

Tucson

Phoenix 


\begin{tabular}{|c|c|c|c|c|c|c|c|}
\hline FEATURE NAME & $\begin{array}{l}\text { FEATURE } \\
\text { CLASS }\end{array}$ & STATUS & COUNTY & COORDIMATE & $\begin{array}{l}\text { SOURCE } \\
\text { COORDINATE }\end{array}$ & $\begin{array}{c}\text { ELEV } \\
\text { FT }\end{array}$ & MAP NAME \\
\hline $\begin{array}{l}\text { Downtown Tucson Airport } \\
\text { Down Under Tank } \\
\text { Dowozhiebito Canyon } \\
\text { Dow Spring } \\
\text { Dox Castle } \\
\text { Dox Temple }\end{array}$ & $\begin{array}{l}\text { airport } \\
\text { reservoir } \\
\text { valley } \\
\text { spring } \\
\text { summit }\end{array}$ & $\begin{array}{l}\text { ADMIN } \\
\text { BGN } \\
\text { BGN } \\
\text { BGN } \\
\text { BGN } 1908 \\
\text { VARIANT }\end{array}$ & $\begin{array}{l}\text { Pima } \\
\text { Santa Cruz } \\
\text { Navajo } \\
\text { Coconino } \\
\text { Coconino }\end{array}$ & $\begin{array}{l}321110 \mathrm{~N} 1105655 \mathrm{~W} \\
313110 \mathrm{N1103546W} \\
364119 \mathrm{N1103034W} \\
350918 \mathrm{~N} 1115906 \mathrm{~W} \\
361445 \mathrm{~N} 1121915 \mathrm{~W}\end{array}$ & $364948 \mathrm{N1} 102737 \mathrm{~W}$ & $\begin{array}{l}2490 \\
4720\end{array}$ & $\begin{array}{l}\text { Tucson } \\
\text { O'Donnell Canyon } \\
\text { Betatakin Ruin } \\
\text { Garland Prairie } \\
\text { Havasupai Point }\end{array}$ \\
\hline $\begin{array}{l}\text { Dox Temple } \\
\text { See Dox Castle } \\
\text { Doyle Mountain } \\
\text { Doyle Peak } \\
\text { Doyle Saddle } \\
\text { Doyle Spring } \\
\text { Doyle Tank } \\
\text { Dozer Hill } \\
\text { Dozer Tank } \\
\text { Drachman School }\end{array}$ & $\begin{array}{l}\text { summit } \\
\text { summit } \\
\text { summit } \\
\text { gap } \\
\text { spring } \\
\text { reservoir } \\
\text { summit } \\
\text { reservoir } \\
\text { school }\end{array}$ & $\begin{array}{l}\text { VARIANT } \\
\text { BGN } \\
\text { BGN } \\
\text { BGN } 1933 \\
\text { BGN } \\
\text { BGN } \\
\text { BGN } \\
\text { BGN } \\
\text { UNOFF }\end{array}$ & $\begin{array}{l}\text { Coconino } \\
\text { Apache } \\
\text { Coconino } \\
\text { Coconino } \\
\text { Coconino } \\
\text { Coconino } \\
\text { Pinal } \\
\text { Coconino } \\
\text { Pima }\end{array}$ & $\begin{array}{l}361445 N 1121915 W \\
341327 N 1094722 W \\
351948 N 1113844 W \\
351922 N 1114016 W \\
351955 N 1113933 W \\
350940 \mathrm{~W} 1114328 \mathrm{~W} \\
330801 N 1111841 \mathrm{~W} \\
343621 \mathrm{N1} 112342 \mathrm{~W} \\
321245 \mathrm{~N} 1105813 \mathrm{~W}\end{array}$ & & $\begin{array}{l}7658 \\
1146 \\
1135 \\
1869\end{array}$ & $\begin{array}{l}\text { Sponseller Mtn } \\
\text { Humphreys Peak } \\
\text { Humphreys Peak } \\
\text { Humphreys Peak } \\
\text { Flagstaff West } \\
\text { Florence ME } \\
\text { Calloway Butte } \\
\text { Tucson }\end{array}$ \\
\hline $\begin{array}{l}\text { Draghi Mine } \\
\text { Dragon, The } \\
\text { Dragon Creek } \\
\quad \text { East Fork Dragon Creek } \\
\text { Dragon Head } \\
\text { Dragon Mine } \\
\text { Dragon Z Mine } \\
\text { Dragoon } \\
\text { Dragoon Camp } \\
\text { Dragoon Camp Tank }\end{array}$ & $\begin{array}{l}\text { mine } \\
\text { ridge } \\
\text { stream } \\
\text { summit } \\
\text { mine } \\
\text { mine } \\
\text { ppl } \\
\text { locale } \\
\text { reservoir }\end{array}$ & $\begin{array}{l}\text { UNOFF } \\
\text { BGN 1906 } \\
\text { BGN } 1906 \\
\text { VARIANT } \\
\text { BGN } 1906 \\
\text { UNOFF } \\
\text { UNOFF } \\
\text { BGN } \\
\text { BGN } \\
\text { BGN }\end{array}$ & $\begin{array}{l}\text { Yuma } \\
\text { Coconino } \\
\text { Coconino } \\
\text { Coconino } \\
\text { Maricopa } \\
\text { Santa Cruz } \\
\text { Cochise } \\
\text { Cochise } \\
\text { Cochise }\end{array}$ & $\begin{array}{l}323254 \mathrm{~N} 1140807 \mathrm{~W} \\
361358 \mathrm{N1} 121035 \mathrm{~W} \\
361010 \mathrm{~N} 1121213 \mathrm{~W} \\
\\
361151 \mathrm{N1121048W} \\
335552 \mathrm{~N} 1123827 \mathrm{~W} \\
313638 \mathrm{~N} 1104753 \mathrm{~W} \\
320141 \mathrm{N1} 100217 \mathrm{~W} \\
315035 \mathrm{~N} 1095456 \mathrm{~W} \\
315035 \mathrm{~N} 1095510 \mathrm{~W}\end{array}$ & $361541 \mathrm{~N} 1120741 \mathrm{~W}$ & $\begin{array}{l}7764 \\
4615\end{array}$ & $\begin{array}{l}\text { Wellton Hills } \\
\text { Shiva Temple } \\
\text { Shiva Temple } \\
\text { Shiva Temple } \\
\text { Wickenburg } \\
\text { Patagonia } \\
\text { Dragoon } \\
\text { Black Diamond Peak } \\
\text { Black Diamond Peak }\end{array}$ \\
\hline $\begin{array}{l}\text { Dragoon Creek } \\
\text { See Sycamore Creek } \\
\text { Dragoon Creek } \\
\text { See Dragoon Fork } \\
\text { Dragoon Fork } \\
\text { See Sycamore Creek } \\
\text { Dragoon Fork } \\
\text { See Dragoon Fork } \\
\text { Dragoon Fork } \\
\text { Dragoon Creek } \\
\text { Dragoon Fork } \\
\text { Lagoon Fork }\end{array}$ & $\begin{array}{l}\text { stream } \\
\text { stream } \\
\text { stream } \\
\text { stream } \\
\text { stream }\end{array}$ & $\begin{array}{l}\text { VARIANT } \\
\text { VARIANT } \\
\text { VARIANT } \\
\text { VARIANT } \\
\text { BGN } 1905 \\
\text { VARIANT } \\
\text { VARIANT } \\
\text { VARIANT }\end{array}$ & $\begin{array}{l}\text { Yavapai } \\
\text { Yavapai } \\
\text { Yavapai } \\
\text { Yavapai } \\
\text { Yavapai }\end{array}$ & $\begin{array}{l}341928 \mathrm{~N} 1120412 \mathrm{~W} \\
345148 \mathrm{~N} 1120439 \mathrm{~W} \\
341928 \mathrm{~N} 1120412 \mathrm{~W} \\
345148 \mathrm{~N} 1120439 \mathrm{~W} \\
345148 \mathrm{~N} 1120439 \mathrm{~W}\end{array}$ & $350920 \mathrm{~N} 1115950 \mathrm{~W}$ & & Clarkdale \\
\hline $\begin{array}{l}\text { Dragoon Interchange } \\
\text { Dragoon Mountains } \\
\quad \text { Dragoon Range } \\
\text { Dragoon Pass } \\
\text { Dragoon Peak } \\
\text { Dragoon Post Office } \\
\text { Dragoon Railroad Station } \\
\text { Dragoon Range } \\
\text { See Dragoon Mountains } \\
\text { Dragoon Spring }\end{array}$ & $\begin{array}{l}\text { crossing } \\
\text { range } \\
\text { gap } \\
\text { summit } \\
\text { building } \\
\text { building } \\
\text { range } \\
\text { spring }\end{array}$ & $\begin{array}{l}\text { UNOFF } \\
\text { BGN } \\
\text { VARIANT } \\
\text { BGN } \\
\text { BGN } \\
\text { UNOFF } \\
\text { UNOFF } \\
\text { VARIANT } \\
\text { BGN }\end{array}$ & $\begin{array}{l}\text { Cochise } \\
\text { Cochise } \\
\text { Cochise } \\
\text { Cochise } \\
\text { Cochise } \\
\text { Cochise } \\
\text { Cochise } \\
\text { Cochise }\end{array}$ & 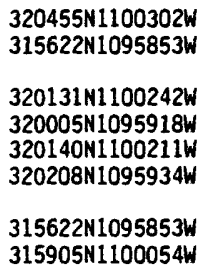 & & 6533 & $\begin{array}{l}\text { Dragoon } \\
\text { Cochise Stronghold } \\
\text { Dragoon } \\
\text { Cochise } \\
\text { Dragoon } \\
\text { Cochise }\end{array}$ \\
\hline $\begin{array}{l}\text { Dragoon Wash } \\
\text { Drag Spring } \\
\text { Drake } \\
\text { Drake } \\
\text { Drake Railroad Station } \\
\text { Drake Tank } \\
\text { Draper Canyon } \\
\text { Dreamland Villa } \\
\text { Dreamy Draw } \\
\text { Dreamy Draw Dam }\end{array}$ & $\begin{array}{l}\text { stream } \\
\text { spring } \\
\text { ppl } \\
\text { locale } \\
\text { building } \\
\text { reservoir } \\
\text { valley } \\
\text { locale } \\
\text { arroyo } \\
\text { dam }\end{array}$ & $\begin{array}{l}\text { BGN } \\
\text { BGN } \\
\text { BGN } \\
\text { BGN } \\
\text { UNOFF } \\
\text { BGN } \\
\text { BGN } \\
\text { BGN } \\
\text { BGN } \\
\text { UNOFF }\end{array}$ & $\begin{array}{l}\text { Cochise } \\
\text { Coconino } \\
\text { Yavapai } \\
\text { Mohave } \\
\text { Yavapai } \\
\text { Yavapai } \\
\text { Yavapai } \\
\text { Maricopa } \\
\text { Maricopa } \\
\text { Maricopa }\end{array}$ & $\begin{array}{l}315425 \mathrm{~N} 1101441 \mathrm{~W} \\
354322 \mathrm{~N} 1105736 \mathrm{~W} \\
345853 \mathrm{~N} 1122232 \mathrm{~W} \\
350224 \mathrm{~N} 1140716 \mathrm{~W} \\
345854 \mathrm{~N} 1122233 \mathrm{~W} \\
345725 \mathrm{~N} 1122258 \mathrm{~W} \\
343618 \mathrm{~N} 1124818 \mathrm{~W} \\
332517 \mathrm{~N} 1114236 \mathrm{~W} \\
333231 \mathrm{~N} 1120251 \mathrm{~W} \\
333342 \mathrm{~N} 1120154 \mathrm{~W}\end{array}$ & $\begin{array}{l}320121 \mathrm{~N} 1100244 \mathrm{~W} \\
343548 \mathrm{~N} 1124520 \mathrm{~W} \\
333410 \mathrm{~N} 1120130 \mathrm{~W}\end{array}$ & 2516 & $\begin{array}{l}\text { Saint David } \\
\text { Sand Springs } \\
\text { Paulden } \\
\text { Kingman SE } \\
\text { Paulden } \\
\text { Paulden } \\
\text { Smith Mesa } \\
\text { Buckhorn } \\
\text { Sunnys lope } \\
\text { Sunnys lope }\end{array}$ \\
\hline $\begin{array}{l}\text { Orew Spring Well } \\
\text { Orew Tank } \\
\text { Orew Wash } \\
\text { Orexe } 1 \text { Heights } \\
\text { Orexel School } \\
\text { Orift Fence Dam } \\
\text { Orift Fence Lake } \\
\text { Orift Fence Lake Campground } \\
\text { Orift Fence Spring } \\
\text { Orift Fence Tank }\end{array}$ & $\begin{array}{l}\text { well } \\
\text { reservoir } \\
\text { stream } \\
\text { ppl } \\
\text { school } \\
\text { dam } \\
\text { reservoir } \\
\text { park } \\
\text { spring } \\
\text { reservoir }\end{array}$ & $\begin{array}{l}\text { UNOFF } \\
\text { BGN } \\
\text { BGN } \\
\text { BGN } \\
\text { UNOFF } \\
\text { UNOFF } \\
\text { BGN } \\
\text { ADMIN } \\
\text { BGN } \\
\text { BGN }\end{array}$ & $\begin{array}{l}\text { Pima } \\
\text { Cochise } \\
\text { Pinal } \\
\text { Pima } \\
\text { Pima } \\
\text { Apache } \\
\text { Apache } \\
\text { Apache } \\
\text { Coconino } \\
\text { Graham }\end{array}$ & $\begin{array}{l}322601 N 1120644 \mathrm{~W} \\
315004 \mathrm{~N} 1100009 \mathrm{~W} \\
324804 \mathrm{~N} 1105145 \mathrm{~W} \\
320 \mathrm{~B} 28 \mathrm{~N} 1110140 \mathrm{~W} \\
320852 \mathrm{~N} 1105637 \mathrm{~W} \\
33491 \mathrm{BN} 1093218 \mathrm{~W} \\
334917 \mathrm{~N} 1093215 \mathrm{~W} \\
334916 \mathrm{~N} 1093218 \mathrm{~W} \\
342842 \mathrm{~N} 1111036 \mathrm{~W} \\
330646 \mathrm{~N} 1094040 \mathrm{~W}\end{array}$ & $324653 \mathrm{~N} 1105642 \mathrm{~W}$ & 8960 & $\begin{array}{l}\text { Drew Spring Well } \\
\text { Haberstock Hill } \\
\text { Putnam Wash } \\
\text { Cat Mountain } \\
\text { Tucson } \\
\text { Bonito Rock } \\
\text { Bonito Rock } \\
\text { Bonito Rock } \\
\text { Dane Canyon } \\
\text { Bryce Mountain }\end{array}$ \\
\hline $\begin{array}{l}\text { Drift Fence Tank } \\
\text { Drift Hills } \\
\text { Driftwood Canyon }\end{array}$ & $\begin{array}{l}\text { reservoir } \\
\text { ridge } \\
\text { valley }\end{array}$ & $\begin{array}{l}\text { BGN } \\
B G N \\
B G N\end{array}$ & $\begin{array}{l}\text { Gila } \\
\text { Yuma } \\
\text { Coconino }\end{array}$ & $\begin{array}{l}335057 \mathrm{~N} 1102031 \mathrm{~W} \\
321554 \mathrm{~N} 1134049 \mathrm{~W} \\
360811 \mathrm{~N} 1123840 \mathrm{~W}\end{array}$ & $360451 \mathrm{~N} 1124031 \mathrm{~W}$ & & $\begin{array}{l}\text { Carrizo SE } \\
\text { Christmas Pass } \\
\text { Supai }\end{array}$ \\
\hline
\end{tabular}


FEATURE NAME

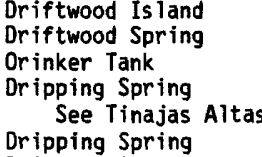

SOURCE
COORDINATE

Iceberg Canyon

Cactus Flat

Patagonia

Apache Peak

Portal Peak Happy Valley

4080 Javelina Peak

El Capitan Mtn

Weavers Needle

Crystal Hill

Sombrero Peak Governors Peak

Alamo Dan SE

Long Tom Canyon Cleator

Clarkdale

Mount Nutt

Grand Canyon Yellow John Mtn

Hayden

Kino Peak

Bucket Mtn

Buckhead Mesa

Pine

El Capitan Mtn

Bottleneck Wash

Bucket Mtn

Grand Canyon Christmas

Aust in Peak Clarkdale

$350345 N 1133641 \mathrm{~W}$

$344803 N 1120542 W$

Christmas 


\section{FEATURE NAME}

Drive Canyon

Driveway Hall Spring

Oriveway Pond

Driveway Tank

Oriveway Tank

Oriveway Tank

Oriveway Well

Driveway Well

Dromedary Creek

Dromedary Peak

Drowned Timber Tank

Drummond Plateau

Drum Tank

Dry Beaver Creek

Dry Bone Tank

Dry Camp

Dry Camp Canyon

Dry Camp Spring

Dry Canyon

Dry Canyon

Dry Caood Canyon

Ory Canyon

Ory Canyon

Dry Canyon

Dry Canyon

Dry Canyon

Dry Canyon

Dry Canyon

Dry Canyon

Ory Canyon Spring

Dry Canyon Spring

Dry Canyon Spring

Dry Canyon Tank

Dry Canyon Tank

Dry Canyon Well

Dry Cimarron Canyon

See Boulder Canyon

Dry Creek

Dry Creek

Dry Creek

Dry Creek

Dry Creek

See Sycamore Creek

Ory Creek

Tule Canyon

Dry Creek

Dry Creek

Dry Creek

Dry Creek

Dry Creek

See Tule Canyon

Dry Creek Spring

Dry Creek Spring Number One

Dry Creek Spring Number Two

Dry Creek Tank

Dry Creek Tanks

Dry Creek Trough

Dry Creek Well

Dry Dam

Dry Dam

Dry Dude Creek

Dry Farm Wash

Dry Lake

See Willcox Playa

Dry Lake

Dry Lake

Dry Lake

Dry Lake

Dry Lake

Ory Lake

Dry Lake
FEATURE
CLASS

STATUS

COUNTY

valley

spring

reservoir

reservoir

reservoir

reservoir

well

well

stream

BGN
BGN
$B G N$
$B G N$
BGN
BGN
UNOFF
UNOFF
BGN

Greenlee

Apache

Mohave

Apache

Yavapai

Coconino

Yavapai

Yavapai

Greenlee

summit

reservoir

plain

reservoir

stream

reservoir

locale

valley

spring

valley

valley

valley

valley

valley

valley

valley

valley

valley

valley

BGN Pina

GGN Coconino

BGN 1908

BGN

$B G N$

$B G N$

BGN

BGN

BGN

BGN 1959

VARIANT

BGN

$B G N$

$B G N$

BGN

BGN

$B G N$

$B G N$

$B G N$

Coconino

Yavapai

Gila

Pinal

Pinal

Pinal

Cochise

spring

spring

spring

reservoir

reservoir

well

valley

stream

stream

BGN Cochise

$B G N$

BGN

$B G N$

BGN

UNOFF

VARIANT

BGN
BGN

Santa Cruz

Cochise

Pinal

Graham

Apache

Gila

Navajo

Mohave

Mohave

$\begin{array}{lll}\text { stream } & \text { BGN } & \text { Gila } \\ \text { stream } & \text { BGN } & \text { Gila } \\ & \text { VARIANT } & \\ \text { stream } & & \text { Yavapai } \\ \text { stream } & \text { BGN 1968 } & \text { Yavapa } \\ & \text { VARIANT } & \\ \text { stream } & \text { BGN } & \text { Yavapai } \\ \text { stream } & \text { BGN } & \text { Yavapai } \\ \text { stream } & \text { BGN } & \text { Yavapai } \\ \text { stream } & \text { BGN } & \text { Navajo }\end{array}$

VARIANT

valley

spring

spring

spring

reservoir

reservoir

reservoir

well

dam

dam

stream

stream

flat

lake

ake

lake

lake
lake

lake

lake

BGN Gila

$\begin{array}{lll} & \text { Yavapai } & 342023 N 1115438 \mathrm{~W} \\ \text { BGN } 1935 & \text { Yavapai } & 344300 \mathrm{~N} 1125229 \mathrm{~W} \\ \text { BGN } & \text { Yavapai } & 342057 \mathrm{N1} 11563 \mathrm{~W} \\ \text { BGN } & \text { Yavapai } & 34202 \mathrm{BN} 1115444 \mathrm{~W} \\ \text { BGN } & \text { Apache } & 345551 \text { 11094402W } \\ \text { BGN } & \text { Apache } & 345515 \mathrm{~N} 1094833 \mathrm{~W} \\ \text { BGN } & \text { Gila } & 341240 \mathrm{~N} 1105718 \mathrm{~W} \\ \text { UNOFF } & \text { Gila } & 334218 N 1105155 \mathrm{~W} \\ \text { UNOFF } & \text { Pima } & 313528 N 1111343 \mathrm{~W}\end{array}$

UNOFF Navajo

BGN Apache

VARIANT

BGN

$B G N$

$B G N$

BGN

BGN

BGN

$B G N$
COORDINATE

$330044 N 1091822 \mathrm{~W}$

$340856 \mathrm{~N} 1093457 \mathrm{~W}$

364111 N1133210

$340922 \mathrm{~N} 1093407 \mathrm{~W}$

$343324 \mathrm{~N} 1115822 \mathrm{~W}$

$343344 \mathrm{~N} 1111640 \mathrm{~W}$

344119 N1123814

$344119 N 1123815 \mathrm{~W}$

$325753 \mathrm{~N} 1090853 \mathrm{~W}$

$331512 \mathrm{~N} 1111511 \mathrm{~W}$

$351628 \mathrm{~N} 1114948 \mathrm{~W}$

361127 N1122429W

344647 N1113228W

343758 N1114931W

$335331 \mathrm{N1104945 \textrm {W }}$

$324721 \mathrm{N1103213 \textrm {W }}$

$324635 \mathrm{~N} 1103515 \mathrm{~W}$

$330423 \mathrm{~N} 1102911 \mathrm{~W}$

313700N1104410W

$314618 \mathrm{~N} 1102026 \mathrm{~W}$

323207 N1110610W

$325312 \mathrm{~N} 1093002 \mathrm{~W}$

$340443 \mathrm{~N} 1091801 \mathrm{~W}$

$341412 \mathrm{~N} 1110511 \mathrm{~W}$

$341539 \mathrm{~N} 1102713 \mathrm{~W}$

360147 N1134707

$362848 \mathrm{~N} 1133852 \mathrm{~W}$

314641 N1102145W

$314741 \mathrm{N1102331 \textrm {W }}$

$325814 \mathrm{~N} 1093545 \mathrm{~W}$

$313356 \mathrm{~N} 1095235 \mathrm{~W}$

$325545 \mathrm{~N} 1093414 \mathrm{~W}$

$314659 \mathrm{~N} 1102347 \mathrm{~W}$

$342334 \mathrm{N1113856 \textrm {W }}$

$325754 \mathrm{~N} 1093213 \mathrm{~W}$

$333442 \mathrm{~N} 1094001 \mathrm{~W}$

$333944 \mathrm{N1} 105058 \mathrm{~W}$ $340958 \mathrm{~N} 1105838 \mathrm{~W}$

341928N1120412W

$342050 \mathrm{~N} 1115648 \mathrm{~W}$

$342128 \mathrm{~N} 1120355 \mathrm{~W}$

$344347 \mathrm{N1} 125325 \mathrm{~W}$

$344813 \mathrm{~N} 1115245 \mathrm{~W}$

$345739 \mathrm{~N} 1095300 \mathrm{~W}$ $\begin{array}{cc}\text { SOURCE } & \text { ELEV } \\ \text { COORDINATE } & \text { FT }\end{array}$

MAP NAME

330019 N1091708W

N51114252W

324711N1102842W

$313214 N 1095604 \mathrm{~W}$

313919 N1104507W

$314822 \mathrm{~N} 1102503 \mathrm{~W}$ $323243 \mathrm{~N} 1110418 \mathrm{~W}$ $325634 N 1093544 \mathrm{~W}$ 340301 N1091935W $341436 \mathrm{~N} 1110308 \mathrm{~W}$ $341801 \mathrm{N1102917 \textrm {W }}$ $360856 \mathrm{~N} 1134308 \mathrm{~W}$ $362343 \mathrm{~N} 1134059 \mathrm{~W}$

3016 Florence Junction Wing Mountain Explorers Monument Stoneman Lake Lake Montezuma Rock House Holy Joe Peak Holy Joe Peak Rawhide Mtn

Potter Mtn

Mt Hughes

McGrew Spring Tortolita Mts Lone Star Mtn Eagar

Diamond Butte Day Spring

Bat Cave

Last Chance Canyon

McGrew Spring

Apache Peak

Lone Star Mtn

Potter Mtn

Lone Star Mtn

5163 Apache Peak 
FEATURE NAME

Dry Lake

Dry Lake

Dry Lake

Dry Lake Dam

Dry Lake Hills Dry Lake Mountain

Ory Lake Lookout

Dry Lake Mountain See Dry Lake Hills

Dry Lakes

Dry Lakes

Dry Lakes

Dry Lake Stock Tank

Dry Lakes Well

Dry Lake Tank

Dry Lake Tank

Ory Lake Tank

Dry Lake Tank

Dry Lake Tank

Dry Lake Tank

Dry Lake Tank

Ory Lake Tank

Ory Lake Tank

Ory Lake Wash

Dry Mesa

Dry Mesa

Dry Mesa Dam

Dry Mesa Tank

Ory Mountain

Dry Park

Dry Park Lakes

Ory Park Lookout

Dry Pasture We11

Dry Pocket Tank

Dry Pocket Wash

Dry Prong

Dry Prong

See Ory Prong Creek

Ory Prong Canyon

Ory Prong Creek Dry Prong

Dry Prong Dam

Dry Prong Tank

Ory Prong Tank

Dry Prong Trail Forty-five

Dry Reservoir

Ory Spring Well

Ory Tank

Dry Tank

Dry Tank

Ory Tank

Dry Tank

Ory Tank

Dry Tank

Dry Tank

Ory Trap Tank

Dry Valley

Dry Valley Tank

Dry Wash

Dry Wash

Dry Wash

Dry Wash Mineral Creek

Dry Weather Ford Tank

Dry Well

Dry Well

Dry Well

Dry Well

D-Six Pond

D-Six Reservoir

\section{FEATURE
CLASS}

STATUS

COUNTY

reservoir

reservoir

reservoir

dam

summit

BGN

BGN Coconino

UNOFF Graham

VARIANT

locale

BGN

VARIANT

summit

lak

lake

reservoir

well

reservoir

reservoir

reservoir

reservoir

reservoir

BGN
BGN
BGN
BGN
UNOFF
BGN
BGN
BGN
BGN
BGN

reservoir

reservoir

reservoir

reservoir

stream

summit

summit

dam

reservoir

summit

\section{BGN}

BGN

BGN
BGN
BGN

BGN

BGN

BGN

BGN

BGN

flat

lake

locale

well

reservoir

stream

stream

stream

valley

\section{BGN}

BGN

UNOFF

BGH

BGN
BGN
BGN

BGN

BGN

strean

dam

reservoir

reservoir

trail

reservoir

well

reservoir

reservoir

BGN 1969

VARIANT

UNOFF

BGN

BGN

UNOFF

UNOF
BGN
BGN

reservoir

reservoir

reservoir

reservoir

reservoir

reservoir

reservoir

valley

reservoir

stream

\section{BGN}

BGN

BGN

BGN

BGN

$B G N$

BGN

BGN

BGN

stream

stream

valley

stream

reservoir

well

we 11

well

well

reservoir

BGN Yavapai

BGN Coconino

Pinal

Gila

Gila

Pima

Maricopa

Yuma

Mohave

Mohave
COORDINATE

$325037 \mathrm{N1094000 \textrm {W }}$

$351634 \mathrm{~N} 1120510 \mathrm{~W}$

$332048 \mathrm{N1} 1094900 \mathrm{~W}$

351558N1113811W

$332135 \mathrm{~N} 1094958 \mathrm{~W}$

$351558 N 1113811 W$

$321559 N 1094809 \mathrm{~W}$

$340350 \mathrm{~N} 1090848 \mathrm{~W}$

$333623 N 1090345 \mathrm{~W}$

$324512 \mathrm{~N} 1100304 \mathrm{~W}$

$340409 \mathrm{N1} 1090854 \mathrm{~W}$

331557 N1105450W

$332205 \mathrm{~N} 1091400 \mathrm{~W}$

$333759 N 1102155 \mathrm{~W}$

$335339 \mathrm{N1} 113201 \mathrm{~W}$

340351N109100BW

$343836 \mathrm{N1095329W}$

344111 N1120714W

345837 N1112B43W

$353153 \mathrm{~N} 1115412 \mathrm{~W}$

$325036 \mathrm{~N} 1094119 \mathrm{~W}$

$363008 N 1092058 \mathrm{~W}$

$365312 N 1091945 \mathrm{~W}$

$333046 \mathrm{~N} 1103836 \mathrm{~W}$

$333047 \mathrm{N1103837 \textrm {W }}$

$324117 N 1092822 \mathrm{~W}$

$362713 N 1121444 W$

362509 N1121358W

$362708 \mathrm{~N} 1121415 \mathrm{~W}$

$344515 N 1103203 \mathrm{~W}$

$341013 N 1111427 \mathrm{~W}$

$340846 N 1111319 \mathrm{~W}$

$330454 N 1094907 \mathrm{~W}$

332937 N1092B08W

$331553 \mathrm{N1} 1090856 \mathrm{~W}$

332937N1092808W

333409 N1093435W

$333130 N 1093030 \mathrm{~W}$

$331755 N 1090657 \mathrm{~W}$

$333212 \mathrm{~N} 1093052 \mathrm{~W}$

$333043 N 1092810 \mathrm{~W}$

$331441 N 1120554 \mathrm{~W}$

$353321 \mathrm{N1111113 \textrm {W }}$

$312247 N 1110921 \mathrm{~W}$

$314525 \mathrm{N1112451W}$

$331044 N 1111926 \mathrm{~W}$

$331620 \mathrm{~N} 1111718 \mathrm{~W}$

$340110 \mathrm{~N} 1125904 \mathrm{~W}$

$342427 \mathrm{~N} 1102018 \mathrm{~W}$

$342901 \mathrm{~N} 1130900 \mathrm{~W}$

$351445 \mathrm{~N} 1114343 \mathrm{~W}$

$340556 \mathrm{~N} 1100401 \mathrm{~W}$

340709N1100038W

$335751 \mathrm{N1} 121725 \mathrm{~W}$

340557 N1114154W

$361306 \mathrm{~N} 1113537 \mathrm{~W}$

$331633 \mathrm{~N} 1115800 \mathrm{~W}$

$331633 \mathrm{~N} 1105759 \mathrm{~W}$

$333100 \mathrm{~N} 1105142 \mathrm{~W}$

315741 N1123442W

$325541 \mathrm{N1121257 \textrm {W }}$

$332203 \mathrm{~N} 1135902 \mathrm{~W}$

353721 N1135037W

$363536 \mathrm{~N} 1131856 \mathrm{~W}$

$325118 N 1093846 \mathrm{~W}$

$\begin{array}{lc}\text { SOURCE } & \text { ELEV } \\ \text { COORDINATE } & \text { FT }\end{array}$

Safford

6974 Point of Pines West

Williams North

Point of Pines West

Humphreys Peak

7434 Point of Pines West

Willcox North

Nelson Reservoir

Blue

Tripp Canyon

7598 Nelson Reservoir

Pinal Ranch

Fritz Canyon

Popcorn Canyon

Lion Mountain

Nelson Reservoir

Hay Hollow

Cottonwood

Mormon Lake

Ebert Mtn Safford

5930 Mexican Cry Mesa

Toh At in Mesa East

Chrome Butte

Chrome Butte 
FEATURE NAME

See D-Six Pond

D $S$ Ranch

D S Ranch Tank

D Tank

DT Tank

DT TANK

Dubacher Canyon Dubacher Gulch

Dubacher Gulch

See Dubacher Canyon

Duberry Spring

Dublin

Duckbill

Man Head

Duck Lake

Duck Lake

Duck Lake

Duck Lake Tank

Ducksnest Lake

Duck Spring

Duck Tank

Duck Tank

Duck Tank

Duck Tank

Duck Tank

Duck Tank

Dude Creek

Dude Lake

Dude Mountain

Dude Tank

Dudley Lake

Dudley Mine

Dudleyville

Duett Branch Tank

Duett Tank

Duff Brown Tank

Duff Flat Duff Mesa

Duff Mesa

See Duff Flat

Duff Spring

Duff Tank

Duffy School

Dugan Mine

Dugan Ranch

Dugan Rock Tank

Dugan Tank

Dugan Tank

Dugan Wash

Dugas

Dugas Interchange

Dugout Valley

Oug Road Mountain

Dugwell Canyon

Duke City Logging Camp

Duke Cree

Duke Peak

Duke Ranch

Duke Tank Number One

Ouke Tank Number Two

Dumas Tank

Dumbbell Ranch

Dump Tank

Dunbar Mine

Dunbar School

Duncan

Duncan Cemetery

Duncan Elementary School

Duncan Municipal Airport

Duncan Post Office

Duncan Railroad Station
FEATURE
CLASS

STATUS

COUNTY

COORDINATE

reservoir

locale

reservoir

reservoir

reservoir

reservoir

valley

valley

$\begin{array}{ll}\text { UNOFF } & \text { Mohave } \\ \text { BGN } & \text { Coconino } \\ \text { BGN } & \text { Coconino } \\ \text { BGN } & \text { Coconino } \\ \text { BGN } & \text { Coconino } \\ \text { BGN 1960 } & \text { Cochise } \\ \text { VARIANT } & \\ \text { VARIANT } & \end{array}$

Cochise

$312618 N 1095428 \mathrm{~W}$

$\begin{array}{llll}\text { spring } & \text { BGN } & \text { Maricopa } & 335617 N 1114642 \mathrm{~W} \\ \text { ppl } & \text { BGN } & \text { Graham } & 325346 N 1095001 \mathrm{~W}\end{array}$

$\begin{array}{llll}\text { ppl } & \text { BGN } & \text { Graham } & 325346 N 1095001 \mathrm{~W} \\ \text { summit } & \text { BGN 1982 } & \text { Pima } & 320230 \mathrm{~N} 1103243 \mathrm{~W}\end{array}$

VARIANT

lake

lake

reservoir

reservoir

lake

spring

BGN

BGN

BGN

Navajo

Coconino

Navajo

Navajo

Coconino

$335824 N 1095136 \mathrm{~W}$

$351638 \mathrm{~N} 1120118 \mathrm{~W}$

$342050 N 1095757 \mathrm{~W}$

343802NI103038W

345917 N1112354W

342149 N111 4630W

reservoir $B G$

reservoir BGN

reservoir $B G$

reservoir $B G$

reservoir $B G$

reservoir $B G$

stream

lake

Tuke

reservoir

BGN

BGN

lake

mine

reservoir

reservoir

reservoir

flat

BGN

UNOFF

BGN

BGN

BGN

BGN 1976

VARIANT

flat

Pima

Maricopa

Gila

Gila

Gila

Yavapai

Gila

Coconino

Coconino

Coconino

315823N1104012

333909 N1124610W

$334137 N 1095540 \mathrm{~W}$

$340524 \mathrm{N1} 111124 \mathrm{~W}$

$340530 \mathrm{~N} 1111130 \mathrm{~W}$

344830N1122237W

$342306 \mathrm{~N} 1111627 \mathrm{~W}$

342550 N1111329w

351603 NII $20641 \mathrm{~W}$

$351650 \mathrm{N1122100 \textrm {W }}$

Coconino

Santa Cruz

Pinal

Gila

Gila

Coconino

Yavapai

Yavapai

$342612 \mathrm{~N} 1105756 \mathrm{~W}$

$312223 N 1104135$

325819 NI 104633W

$335450 N 1104831 \mathrm{~W}$

$335413 N 1104809 \mathrm{~W}$

$353626 \mathrm{~N} 1123617 \mathrm{~W}$

$344956 \mathrm{~N} 1120205 \mathrm{~W}$

344956 N1120205W

spring $B G$

$\begin{array}{ll}\text { reservoir } & B G N \\ \text { school } & \text { UNOF }\end{array}$

mine

locale

reservoir

reservoir

reservoir

stream

locale

crossing

valley

summit

valley

locale

stream

summit

reservoir

reservoir

locale UNOFF

reservoir

mine

school

ppl

cemetery

school

airport

building

building
BGN

BGN
UNOFF
UNOFF
UNOFF
BGN
BGN
BGN
BGN

Yavapai

Yavapai

Pima

Yavapai

Yavapai

Yavapai

Pinal

Yavapa

Yavapai

Yavapai

UNOFF

BGN

$B G N$

BGN

BGN

Grahan

Coconino

Coconino

Yavapai

Yavapai

Apache

Yavapai

Maricopa

Greenlee

Greenlee

Greenlee

Greenlee

Greenlee

345233N1121726W

345216 N1121624I

321346 N1 $105255 \mathrm{~W}$

$340113 \mathrm{N11} 22839 \mathrm{~W}$

$340804 \mathrm{~N} 1114652 \mathrm{~W}$

$340909 \mathrm{~N} 1114635 \mathrm{~W}$

$332102 \mathrm{~N} 1110819 \mathrm{~W}$

340842N1114543W

340047 N1122727

342143N1115840W

342411 N1120423W

362831 N1LO1B44W

$320518 N 1092230 \mathrm{~W}$

344044 N1134725W

$343215 \mathrm{~N} 1105503 \mathrm{~W}$

334802N1093501W

$330019 N 1102224 \mathrm{~W}$

334826 N1093432W

344146 N1111029

$344143 \mathrm{~N} 1111034 \mathrm{~W}$

$344616 \mathrm{~N} 1114634 \mathrm{~W}$

344207 N1124810W

$334834 \mathrm{~N} 1090422 \mathrm{~W}$

$350514 N 1125140 \mathrm{~W}$

$332625 \mathrm{~N} 1120502 \mathrm{~W}$

$324317 \mathrm{~N} 1090617 \mathrm{~W}$

324227 N1090600W

$324331 \mathrm{~N} 1090630 \mathrm{~W}$

324137 N1090743W

$324318 \mathrm{~N} 1090618 \mathrm{~W}$

Greenlee

$324315 N 1090611 \mathrm{~W}$

$\begin{array}{lc}\text { SOURCE } & \text { ELEV } \\ \text { COORDINATE } & \text { FT }\end{array}$

Frazier Wells S

Hockey Puck Spring

Rhodes Canyon

May Tank Pocket

Williams North

312729N1095413W Bisbee

Humboldt Mtn

Pima

B434 Mica Mountain

Hawley Lake West

Sitgreaves Mtn

Silver Springs

Potato Wash NE

Mormon Lak

Tule Mesa

Mount Fagan

Star Well 


\section{FEATURE NAME}

Duncan Tank

Duncan Union High School

Dundee Shaft

Dunhill Meadows (subdivision)

Dunhill Place (subdivision)

Dunigan Spring

Dunlap

See Aravaipa

Dunlap Mine

Dunlap Village Shopping Center

Dunn Butte

Dunn Spring

Dunn Springs Mountain

Dunns We 11

Dunn rank

Dun Well

Dupont Cabin

Dupont Canyon

Dupont Tank

Duppa Butte

Duppa Station

See New River

Duppa Villa Park

See Edison Park

Duquesne

Duquesne Mine

Duquesne School

Duquesne Spring

Duquesne Wash

Duran Ranch

Durant Tank

Durazno Canyon

Durazo Canyon

Durezo Canyon

Durezo Canyon

See Durazo Canyon

Durfee Corral

Durfee Crossing

Durfee Draw

Durfee Tank

Durfee Tank

Durhan Hills

Durham Wash

Durkee Canyon

Durkee Windmil 11

Dushey Canyon

Dushey Tank

Dusk File (subdivision)

Dust Bowl Tank

Dust Bowl Tank

Dusty Tank

Dutch Blue Creek

Dutch Butte

Dutch Cabin Spring

Dutch Canyon

See Dutton Canyon

Dutch Canyon

See Chaol Canyon

Dutch Flat

Dutch Henry Canyon

Dutch Henry Two hundred

ninety seven Trail

Dutch Henry Well

Dutch Joe Lookout

Dutch Joe Ranch

Dutch John Spring

Dutch Kid Knoll

Dutch Kid Tank

Dutch Kid Tank

Outch Kid Tank
FEATURE
CLASS

STATUS COUNTY

COORDINATE

$\begin{array}{ll}\text { reservoir } & \text { BGN } \\ \text { school } & \text { UNOFF } \\ \text { mine } & \text { UNOFF } \\ \text { school } & \text { UNOFF } \\ \text { ppl } & \text { BGN } \\ \text { ppl } & \text { BGN } \\ \text { spring } & \text { BGN } \\ & \text { VARIANT } \\ \text { ppl } & \end{array}$

Mohave

Greenlee

Yavapai

Pima

Maricopa

Maricopa

Greenlee

pp 1

Graham

mine
locale
summit
spring
summit
well
reservoir
well
locale
valley

UNOFF

UNOFF

Maricopa

Coconino

Cochise

Cochise

$\begin{array}{ll}\text { UNOFF } & \text { Pima } \\ \text { BGN } & \text { Coconino }\end{array}$

UNOFF

La Paz

Gila

Gila

reservoir

summit BGN 1932 Coconino

BGN

Gila

ppl

Maricopa

park

ppl

school

spring

VARIANT

stream

locale

reservoir

valley

valley

\section{BGN}

UNOFF

UNOFF

Maricopa

Santa Cruz

Santa Cruz

Santa Cruz

Gila

\section{BGN}

UNOFF

BGN

Santa Cruz

Santa Cruz

Navajo

Pima

BGN 1979 Cochise

VARIANT

valle

locale

BGN

Cochise

Coconino

Coconino

valle

reservoir

summit

stream

valley

locale

valley

reservoir

ppl

Coconino

Yavapai

Coconino

Pinal

Pinal

Graham

Graham

Maricopa

Maricopa

Maricopa

reservoir BGN Gila

reservoir $B G N$

reservoir

stream

summit

spring

valley

valley

$B G N$
$B G N$
$B G N$

BGN 1979

Coconino

Coconino

Greenlee

Greenlee

Graham

VARIANT

Coconino

VARIANT

Coconino

flat

valley
trail

BGN

well

locale

locale

spring

summit

reservoir

BGN
UNOFF

Mohave

Grahan

UNOFF Graham

BGN

UNOFF

BGN

BGN

Coconino

Coconino

Pima

Coconino

Yavapai

reservoir BGN

reservoir BGN
Coconino

Coconino
$362155 \mathrm{~N} 1132052 \mathrm{~W}$

$324328 \mathrm{~N} 1090632 \mathrm{~W}$

344506 N1120602W

$321158 \mathrm{~N} 1104655 \mathrm{~W}$

$333019 \mathrm{~N} 1121329 \mathrm{~W}$

$333835 \mathrm{~N} 1120910 \mathrm{~W}$

$330236 \mathrm{~N} 1090625 \mathrm{~W}$

$325726 \mathrm{~N} 1102116 \mathrm{~W}$

$342519 N 1132117 \mathrm{~W}$

$333400 N 1120803 \mathrm{~W}$

$360502 \mathrm{~N} 1115932 \mathrm{~W}$

$320716 \mathrm{~N} 1091545 \mathrm{~W}$

$320639 N 1091654 \mathrm{~W}$

$322348 \mathrm{~N} 1125430 \mathrm{~W}$

350616 N1112353W

$335420 \mathrm{~N} 1110455 \mathrm{~W}$

$335321 \mathrm{~N} 1110246 \mathrm{~W}$

$335414 \mathrm{~N} 1110442 \mathrm{~W}$

361428 N1115357W

$335457 N 1120807 W$

$332729 \mathrm{~N} 1120220 \mathrm{~W}$

$312215 \mathrm{~N} 1104105 \mathrm{~W}$

$312211 \mathrm{~N} 1104122 \mathrm{~W}$

$312240 \mathrm{~N} 1104103 \mathrm{~W}$

332439 N1105837W

311838 N1103648W

$342615 \mathrm{~N} 1105247 \mathrm{~W}$

$344100 \mathrm{~N} 1104315 \mathrm{~W}$

313909 N1112052W

312958 N1095427W

312958 N1095427W

343521 N1104752W

343426 N1104815W

$343439 \mathrm{~N} 1104745 \mathrm{~W}$ $343042 N 1115544 W$

$343055 \mathrm{~N} 1104830 \mathrm{~W}$

$324326 \mathrm{NI} 110901 \mathrm{~W}$

$324059 \mathrm{N1} 112047 \mathrm{~W}$

$323710 \mathrm{~N} 1100710 \mathrm{~W}$

$324043 N 1100233 \mathrm{~W}$

$335319 N 1131651 \mathrm{~W}$

$335315 \mathrm{~N} 1131807 \mathrm{~N}$

$332054 \mathrm{N111} 15505 \mathrm{~W}$

334712 N1110137W

$355023 \mathrm{~N} 1121946 \mathrm{~W}$

$351012 \mathrm{~N} 1112609 \mathrm{~W}$

$332427 \mathrm{~N} 1090918 \mathrm{~N}$

$335934 \mathrm{~N} 1121358 \mathrm{~W}$

$330055 N 1101242 \mathrm{~W}$

361655 N1122305W

$365125 \mathrm{~N} 1111245 \mathrm{~W}$

$343918 \mathrm{~N} 1135727 \mathrm{~W}$

323834 N1094350W

$323650 \mathrm{~N} 1094625 \mathrm{~W}$

$323658 \mathrm{~N} 1094427 \mathrm{~W}$

$342925 \mathrm{~N} 1105730 \mathrm{~W}$

$342901 \mathrm{~N} 1105712 \mathrm{~W}$

$314345 \mathrm{~N} 1105140 \mathrm{~W}$

$350810 \mathrm{~N} 1121550 \mathrm{~W}$

$344906 \mathrm{~N} 1115731 \mathrm{~W}$

345927 N1115938W

$350747 \mathrm{~N} 1121650 \mathrm{~W}$

\begin{tabular}{|c|c|c|}
\hline \multirow[t]{2}{*}{$\begin{array}{c}\text { SOURCE } \\
\text { COORDINATE }\end{array}$} & $\begin{array}{c}\text { ELEV } \\
\text { FT }\end{array}$ & MAP NAME \\
\hline & $\begin{array}{l}1085 \\
1290\end{array}$ & $\begin{array}{l}\text { Cold Spring } \\
\text { Duncan } \\
\text { Clarkdale } \\
\text { Tucson East } \\
\text { Glendale } \\
\text { Hedgpeth Hills } \\
\text { Big Lue Mts }\end{array}$ \\
\hline
\end{tabular}

Arrastra Mtn NE

Glendale

5714 Cape Royal

Cochise Head

6505 Cochise Head

Childs Mtn

Ashurst Lake

Bouse Hills East

$335441 \mathrm{~N} 1110506 \mathrm{~W} \quad$ Copper Mtn

Copper Mtn

Walhalla Plateau

Duques ne

Duquesne

Harshaw

Inspiration 
NATIONAL GAZETTEER--ARIZONA 1986

\section{FEATURE NAME}

Outch Kid Tank

Dutchman Draw

Dutchman Draw

Dutchman Flat

Dutchman Grave Spring

Dutch Mans Butte See Dutchwoman Butte Dutchmans Trail

Outchman Tank

Dutchman Tank

Dutchman Tank

Dutchman Tank

Dutchman Tank

Dutchman Wash

Dutch Mountain

Dutch Oven Spring

Dutch Pasture Canyon

Dutch Pasture Tank

Dutch Pasture Well

Dutchs Tank

Dutchs Tank

Dutch Tank

$$
\text { See Ditch Tank }
$$

Dutch Tank

Dutch Valley

Dutch Valley Tank

Dutchwoman Butte

Dutch Mans Butte Dutchwomen Butte

Dutchwoman Tank

Dutchwomen Butte See Dutchwoman Butte

Dutton Canyon Dutch Canyon

Dutton $\mathrm{Hill}$

Dutton Point

Dutton Ranch

Dutton Spring Kaibab Spring

Duual Leach Wash

Duval See Amargos a Wash

Duval Interchange See Duval Mine Road

Duval Lake Interchange

Duval Leach Flood Dam Number One

Duval Mine

Duval Mine Road Interchange Duval Interchange

Duwuz libito

See Greasewood Spring

DVR Airport

D-W Ranch

Dwyer Wel

Dye Ranch

Dye Ridge

Dyer Spring

Dye Windmill

Dyke Canyon

Dyke Pond Tank

Dyke Tank

Dynamite $\mathrm{Hill}$

Dynamite Tank

Dysart (historical)

Dysart Elementary School

Dysart High School

Dysart Schoo

Dysart Substation
CLASS

$\begin{array}{lll}\text { reservoir } & \text { BGN } & \text { Coconino } \\ \text { valley } & \text { BGN } & \text { Mohave } \\ \text { valley } & \text { BGN } & \text { Mohave } \\ \text { flat } & \text { BGN } & \text { Mohave } \\ \text { spring } & \text { BGN } & \text { Yavapai } \\ \text { summit } & \text { VARIANT } & \text { Gila } \\ \text { trail } & \text { UNOFF } & \text { Pinal }\end{array}$

reservoir BGN

reservoir $B G$

reservoir $B G$

reservoir $B G N$

reservoir $B G$

stream BGN

summit $\quad B G N$

spring $B G$

valley $B G N$

well

reservoir

reservoir

reservoir

reservoir

valley

reservoir

summit

UNOFF

$B G N$

BGN

VARIANT

BGN

$B G N$

$B G N$

BGN

VARIANT

VARIANT

Santa Cruz

Mohave

Mohave

Mohave

Mohave

Mohave

Apache

Greenlee

Graham

Graham

Graham

Navajo

Coconino

Apache

Coconino

Mohave

Mohave

Gila

reservoir BGN

VARIANT

summit
valley

summit

cliff

locale

spring

arroyo

BGN 1964

VARIANT

BGN

BGN 1932

UNOFF

BGN

VARIANT

Gila

Gila

Coconino

Coconino

Coconino

Mohave

Coconino

VARIANT

school locale

crossing

$$
\text { BGN }
$$

VARIANT

reservoir BGN

dam

UNOFF

mine

UNOFF

crossing

UNOFF

VARIAN

VARIANT

spring

airport

locale

well

local

ridge

ADMIN

UNOFF

UNOFF

UNOFF

BGN

spring

BGN

locale

valley

reservoir

reservoir

summit

reser

ppl

school

BGN

BGN

VARIANT

BGN

$B G N$

BGN

$B G N$

BGN

UNOFF

UNOFF

school

UNOFF

UNOFF

Pima

Pima

Pima

Pina

Pima

Pima

Pima

Navajo

Yuma

Mohave

Maricopa

Coconino

Coconino

Yavapai

Cochise

Yavapa

Yavapa $i$

Yavapai

Coconino

Navajo

Maricopa

Maricopa

Maricopa

locale
Maricopa

Maricopa
COORDINATE

$51139 \mathrm{~N} 1115924 \mathrm{~W}$

$364020 \mathrm{~N} 1132620 \mathrm{~W}$ 365803 N1132906 364855 NII 32645

340657 NIII 383IW

$334635 N 1110603 \mathrm{~W}$

332605 N1111959V

$312827 \mathrm{N1110557 \textrm {W }}$

$352850 \mathrm{~N} 1134050 \mathrm{~W}$

$364044 N 1132723 \mathrm{~W}$

$364057 \mathrm{~N} 1134020 \mathrm{~N}$

$364915 \mathrm{~N} 1132631 \mathrm{~W}$

365945 N1 $132855 \mathrm{~W}$

$341848 \mathrm{NI} 094421 \mathrm{~W}$

333357 N1090723W

$330710 N 1100301 \mathrm{~W}$

331047 N1095841W

$331035 N 1095837 \mathrm{~W}$

$342648 N 1102747 \mathrm{~W}$

345024 N1113731W

$340202 \mathrm{~N} 1090517 \mathrm{~W}$

345103 N1112039W

$363204 N 1131154 \mathrm{~V}$

363139 N1131144k

$334635 N 1110603 \mathrm{~W}$

334624NIII053IW

334635 N1110603W 361655 N1122305W

$350706 \mathrm{N1114933 \textrm {W }}$ $361714 \mathrm{NI122139 \textrm {W }}$

$352542 \mathrm{N1} 135903 \mathrm{~W}$ UNKNOWN

$315155 \mathrm{~N} 1110525 \mathrm{~W}$ 315554N1105727W

315421N1105907w

315154 N1110618W 315154N1110618W

315120N1110733W

352526 N1095434W

$324247 \mathrm{~N} 1135344 \mathrm{~W}$

$350859 \mathrm{NI} 135358 \mathrm{~W}$

$332143 \mathrm{~N} 1125640 \mathrm{~W}$

$342736 \mathrm{~N} 1105442 \mathrm{~W}$

342607 N1105608

$343646 \mathrm{~N} 1120628 \mathrm{~W}$

313344 N1094503W

$340458 \mathrm{~N} 1115822 \mathrm{~W}$

$343931 N 1125217 \mathrm{~W}$

$40422 N 1115844 \mathrm{~W}$

$360804 \mathrm{~N} 1111323 \mathrm{~W}$

$340638 \mathrm{~N} 1095957 \mathrm{~W}$

$333652 \mathrm{~N} 112192 \mathrm{BW}$

$333452 \mathrm{~N} 1122023 \mathrm{~W}$

$333517 \mathrm{N1122026 \textrm {W }}$

$333542 \mathrm{N1} 122031 \mathrm{~W}$
315421N1105907W

$333525 \mathrm{~N} 1122023 \mathrm{~W}$

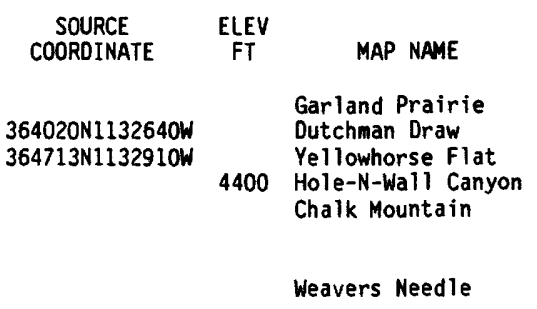

$\begin{array}{ll} & \begin{array}{l}\text { Pena Blanca Lake } \\ \text { Valentine } \\ \text { Dutchman Draw } \\ \text { Cane Springs } \\ \text { Hole-N-Wall Canyon } \\ \text { Yellowhorse Flat }\end{array} \\ 365634 \text { N1132930W } 7128 & \begin{array}{l}\text { Vernon } \\ \text { Blue } \\ \text { Geronimo } \\ \text { Gila Peak }\end{array}\end{array}$

Gila Peak

Aripine

Munds Mountain

363014N1131139W $\quad \begin{aligned} & \text { Jaycox Mtn } \\ & \text { Moriah Knoll } \\ & \text { Moriah Knoll }\end{aligned}$

5021 Armer Mountain 
NATIONAL GAZETTEER--ARIZONA 1986

\begin{tabular}{|c|c|c|c|c|}
\hline FEATURE NAME & $\begin{array}{l}\text { FEATURE } \\
\text { CLASS }\end{array}$ & STATUS & COUNTY & COORDINATE \\
\hline $\begin{array}{c}\text { Dzil-le-sa-a Mesa } \\
\text { See Little Black Spot } \\
\text { Mountain }\end{array}$ & & VARIANT & Navajo & 360457 N1101948W \\
\hline $\begin{array}{l}\text { Dzillibai } \\
\text { Dzil Naozill }\end{array}$ & summit & $\begin{array}{l}\text { BGN } \\
\text { VARIANT }\end{array}$ & Apache & $360436 \mathrm{~N} 1095845 \mathrm{~W}$ \\
\hline $\begin{array}{l}\text { See Carrizo Mountains } \\
\text { Dzilnez Mesa } \\
\text { See Tall Mountain }\end{array}$ & range & VARIANT & Apache & $\begin{array}{l}364842 N 1091025 \mathrm{~W} \\
364731 \mathrm{~N} 1103537 \mathrm{~W}\end{array}$ \\
\hline $\begin{array}{l}\text { Dzilth-dazzni Mesa } \\
\text { See Little Black Spot } \\
\text { Mountain }\end{array}$ & summit & VARIANT & Navajo & 360457 N1101948W \\
\hline
\end{tabular}

Eads Wash

Eagar

Eagar Elementary School

Eagar-Slade Dam

Eagle Canyon

Eagle Crag

Eagle Crag Ruin

Eagle Creek

East Fork Eagle Creek

Prieto Creek Rio Prieto

Eagle Creek

See Middle Prong Creek

Eagle Creek

See East Eagle Creek

Eagle Creek Pumping Station

Eagle Dam

Eagle Eye Mine

Eagle Eye Mountain

Eagle Eye Peak

Eagle Eye Ranch

Eagle Eye Substation

Eagle Eye Substation

Eagle Head Rock

Eagle Landing

See Planet Ranch

Eagle Mine

Eagle Mountain

Eagle Nest

Eagle Nest Canyon

Eagle Nest Mountain

Eagle Nest Point

Eagle Nest Railroad Station

Eagle Nest Reservoir

Eagle Pass

See Stockton Pass

Eagle Pass

Eagle Pass

Eagle Pass

Eagle Peak

Eagle Peak

Eagle Peak

Eagle Point

Eagle Point Well

Eagle Ranch

See Double Circle Ranch

Eagle Rock

Eagle Rock

Eagle Rock

Eagle Rock

Eagle Rock Well

Eagle Roost Airstrip

Eagles Eye, The

\begin{tabular}{|c|c|c|c|c|c|c|}
\hline $\begin{array}{l}\text { stream } \\
\text { ppl } \\
\text { school } \\
\text { dam } \\
\text { valley } \\
\text { summit } \\
\text { locale }\end{array}$ & $\begin{array}{l}\text { BGN } \\
\text { BGN } \\
\text { UNOFF } \\
\text { UNOFF } \\
\text { BGN } \\
\text { BGN } \\
\text { BGN }\end{array}$ & $\begin{array}{l}\text { Gila } \\
\text { Apache } \\
\text { Apache } \\
\text { Apache } \\
\text { Yuma } \\
\text { Apache } \\
\text { Apache }\end{array}$ & $\begin{array}{l}333712 \mathrm{~N} 1105720 \mathrm{~W} \\
340640 \mathrm{~N} 1091727 \mathrm{~W} \\
340628 \mathrm{~N} 1091730 \mathrm{~W} \\
340000 \mathrm{~N} 1092000 \mathrm{~W} \\
321539 \mathrm{~N} 1133023 \mathrm{~W} \\
354902 \mathrm{~N} 1094923 \mathrm{~W} \\
354536 \mathrm{~N} 1095154 \mathrm{~W}\end{array}$ & $333432 \mathrm{~N} 1105638 \mathrm{~W}$ & 6590 & $\begin{array}{l}\text { Salt River Peak } \\
\text { Eagar } \\
\text { Eagar } \\
\text { Eagar } \\
\text { Isla Pinta } \\
\text { Steamboat Rock } \\
\text { Steamboat Rock }\end{array}$ \\
\hline strean & $\begin{array}{l}\text { BGN } 1969 \\
\text { VARIANT } \\
\text { VARIANT } \\
\text { VARIANT } \\
\text { VARIANT }\end{array}$ & Greenlee & $325736 \mathrm{~N} 1092420 \mathrm{~W}$ & 332937 N1092B08W & & Gila Box \\
\hline & VARIANT & Greenlee & $332633 \mathrm{~N} 1092925 \mathrm{~W}$ & & & \\
\hline $\begin{array}{l}\text { stream } \\
\text { locale } \\
\text { dam }\end{array}$ & $\begin{array}{l}\text { UNOFF } \\
\text { UNOFF }\end{array}$ & $\begin{array}{l}\text { Greenlee } \\
\text { Greenlee } \\
\text { Grahan }\end{array}$ & $\begin{array}{l}332937 N 1092 B 08 W \\
330329 N 1092618 W \\
331700 N 1093045 W\end{array}$ & & & $\begin{array}{l}\text { Copperplate Gulch } \\
\text { Willow Mtn SE }\end{array}$ \\
\hline $\begin{array}{l}\text { mine } \\
\text { summit } \\
\text { summit } \\
\text { locale } \\
\text { locale } \\
\text { locale } \\
\text { summit }\end{array}$ & $\begin{array}{l}\text { UNOFF } \\
\text { BGN } \\
\text { BGN } \\
\text { UNOFF } \\
\text { UNOFF } \\
\text { UNOFF } \\
\text { BGN 1917 } \\
\text { VARIANT }\end{array}$ & $\begin{array}{l}\text { Yuma } \\
\text { Maricopa } \\
\text { Maricopa } \\
\text { Maricopa } \\
\text { Maricopa } \\
\text { Yuma } \\
\text { Maricopa }\end{array}$ & $\begin{array}{l}333546 \mathrm{~N} 1135342 \mathrm{~W} \\
335318 \mathrm{~N} 1131038 \mathrm{~W} \\
335327 \mathrm{~N} 1131006 \mathrm{~W} \\
335348 \mathrm{~N} 1130947 \mathrm{~W} \\
335420 \mathrm{~N} 1131708 \mathrm{~W} \\
335421 \mathrm{~N} 1131707 \mathrm{~W} \\
\text { UNKNOWN }\end{array}$ & & 2858 & $\begin{array}{l}\text { New Water Mts } \\
\text { Aguila } \\
\text { Aguila } \\
\text { Aguila } \\
\text { Harquahala Mtn } \\
\text { Gladden }\end{array}$ \\
\hline $\begin{array}{l}\text { locale } \\
\text { mine }\end{array}$ & UNOFF & $\begin{array}{l}\text { Yuma } \\
\text { Yuma }\end{array}$ & $\begin{array}{l}341444 \mathrm{~N} 1135702 \mathrm{~W} \\
331627 \mathrm{~N} 1135736 \mathrm{~W}\end{array}$ & & & Kofa Butte \\
\hline $\begin{array}{l}\text { summit } \\
\text { cliff } \\
\text { valley } \\
\text { summit } \\
\text { cliff } \\
\text { building } \\
\text { reservoir }\end{array}$ & $\begin{array}{l}\text { BGN } \\
\text { BGN } \\
\text { BGN } \\
\text { BGN } \\
\text { BGN } \\
\text { UNOFF } \\
\text { BGN } \\
\text { VARIANT }\end{array}$ & $\begin{array}{l}\text { Maricopa } \\
\text { Apache } \\
\text { Apache } \\
\text { Coconino } \\
\text { Navajo } \\
\text { Coconino } \\
\text { Coconino }\end{array}$ & $\begin{array}{l}332002 N 1123306 \mathrm{~W} \\
363113 N 1091803 \mathrm{~W} \\
363507 N 1091942 \mathrm{~W} \\
352318 N 1123053 \mathrm{~W} \\
352359 N 1101624 \mathrm{~W} \\
352311 N 1123257 \mathrm{~W} \\
362446 \mathrm{~N} 1113438 \mathrm{~W}\end{array}$ & $363325 N 1091851 \mathrm{~W}$ & $\begin{array}{l}5656 \\
6392\end{array}$ & $\begin{array}{l}\text { Buckeye } \\
\text { Mexican Cry Mesa } \\
\text { Mexican Cry Mesa } \\
\text { Eagle Nest Mtn } \\
\text { Dilkon } \\
\text { Eagle Nest Mtn } \\
\text { Cedar Ridge }\end{array}$ \\
\hline $\begin{array}{l}\text { gap } \\
\text { gap }\end{array}$ & BGN & $\begin{array}{l}\text { Graham } \\
\text { Graham }\end{array}$ & $\begin{array}{l}323529 \mathrm{~N} 1095115 \mathrm{~W} \\
324601 \mathrm{~N} 1100857 \mathrm{~W}\end{array}$ & & & Buford $\mathrm{Hill}$ \\
\hline $\begin{array}{l}\text { gap } \\
\text { gap } \\
\text { summit } \\
\text { summit } \\
\text { summit } \\
\text { summit } \\
\text { weil }\end{array}$ & $\begin{array}{l}\text { BGN } \\
\text { BGN } \\
\text { BGN } \\
\text { BGN } \\
\text { BGN } \\
\text { BGN } \\
\text { UNOFF } \\
\text { VARIANT }\end{array}$ & $\begin{array}{l}\text { Maricopa } \\
\text { Coconino } \\
\text { Cochise } \\
\text { Gila } \\
\text { Yavapai } \\
\text { Mohave } \\
\text { Mohave }\end{array}$ & $\begin{array}{l}332025 N 1120220 \mathrm{~W} \\
363341 \mathrm{~N} 1122843 \mathrm{~W} \\
320934 \mathrm{~N} 1102457 \mathrm{~W} \\
335400 \mathrm{~N} 1112425 \mathrm{~W} \\
344257 \mathrm{~N} 1124604 \mathrm{~W} \\
342339 \mathrm{~N} 1133901 \mathrm{~W} \\
342427 \mathrm{~N} 113384 \mathrm{BW}\end{array}$ & & $\begin{array}{l}5177 \\
6612 \\
5690\end{array}$ & $\begin{array}{l}\text { Lone Butte } \\
\text { Sowats Spring } \\
\text { Happy Valley } \\
\text { Reno Pass } \\
\text { Smith Mesa } \\
\text { Signal } \\
\text { Signal }\end{array}$ \\
\hline $\begin{array}{l}\text { locale } \\
\text { pillar }\end{array}$ & BGN & $\begin{array}{l}\text { Greenlee } \\
\text { Yavapai }\end{array}$ & $\begin{array}{l}332009 \mathrm{~N} 1092935 \mathrm{~W} \\
340050 \mathrm{~N} 1122052 \mathrm{~W}\end{array}$ & & & Columbia \\
\hline $\begin{array}{l}\text { pillar } \\
\text { summit } \\
\text { summit } \\
\text { well } \\
\text { airport } \\
\text { summit }\end{array}$ & $\begin{array}{l}\text { BGN } \\
\text { BGN } \\
\text { BGN } \\
\text { UNOFF } \\
\text { ADNIN } \\
\text { BGN }\end{array}$ & $\begin{array}{l}\text { Coconino } \\
\text { Graham } \\
\text { Apache } \\
\text { Mohave } \\
\text { Maricopa } \\
\text { Yuma }\end{array}$ & $\begin{array}{l}352028 \mathrm{~N} 1115908 \mathrm{~W} \\
323929 \mathrm{~N} 1095044 \mathrm{~W} \\
354650 \mathrm{~N} 1095220 \mathrm{~W} \\
344111 \mathrm{~N} 1134726 \mathrm{~W} \\
335520 \mathrm{~N} 1131000 \mathrm{~W} \\
333540 \mathrm{~N} 1135411 \mathrm{~W}\end{array}$ & & 2202 & $\begin{array}{l}\text { Parks } \\
\text { Mt Graham } \\
\text { Steamboat Rock } \\
\text { Beecher Canyon } \\
\text { Aguila } \\
\text { New Water Mts }\end{array}$ \\
\hline
\end{tabular}

AZ199

$\begin{array}{cc}\text { SOURCE } & \text { ELEV } \\ \text { COORDINATE } & \text { FT }\end{array}$

6630 Toadindaaska Mesa 
FEATURE NAME

Eagles Nest Mine

Eagle Spring

Eagle Spring

Eagle Spring

Eagle Spring

Eagle Tail Mine

Eagle Tail Mountains

See Eagletail Mountains

Eagletail Mountains

Eagle Tail Mountains Gold Mountains

Eagletail Peak

Eagle Tail Peak

The Eagletail

Eagle Tail Peak

See Eagletail Peak

Eagletail Tank

Eagle Tank

Eagle Tank Jeager Tanks

Eagle Tank

Eagle Tank

Eagle Tank

Eagle Wash

Eagle Wash

Earis Tank

Earl Creek

Earl Park Dam

Earl Park Lake

Earl Park Tank

Earl Pond

Earl Reservoir

Earls Tank

Earthexn Tank

Earven Flat

Earven Ranch

East Antelope Creek

East Ash Creek

East Ash Fork Interchange

East Ash Spring

East Babcock Canyon

East Bear Canyon

East Bonito Prairie Tank

East Boulder Canyon

Boulder Canyon

East Fork Boulder Canyon

East Boulder Trail

East Bowie Interchange

East Branch Indian Hollow

East Branch Squaw Creek

East Bray Creek

East Broomy Valley Tank

East Brown Tank

East Bucket Mountain Dam

East Buckskin Tank

East Burn Tank

East Buzzard Point

East Canal Ancho (historical) Canal Fourteen Branch

East Canyon

East Cedar Creek

East Cedar Mountain

East Cedar Tank

East Central Drain

East Clear Creek

See Chet Tank

East Clear Creek

Cienega Canyon

Clear Creek

East Clear Creek

\section{FEATURE}

CLASS

mine

spring

spring

spring

spring

mine

ridge

ridge

summit

STATUS

COUNTY

COORDINATE

$\begin{array}{ll}\text { UNOFF } & \text { Yuma } \\ \text { BGN } & \text { Cochise } \\ \text { BGN } & \text { Pima } \\ \text { BGN } & \text { Pinal }\end{array}$

$341235 \mathrm{~N} 1140838 \mathrm{~W}$

$315009 \mathrm{~N} 1091646 \mathrm{~W}$

$322741 \mathrm{N1} 104034 \mathrm{~W}$

$332230 \mathrm{~N} 1111452 \mathrm{~W}$

BGN Graham 332530N1095531W

Yavapai 341334N1122105W

$332630 \mathrm{~N} 1132134 \mathrm{~W}$

$332630 \mathrm{~N} 1132134 \mathrm{~W}$

BGN 1963 Maricopa 332412N113181BW

VARIANT

VARIANT

VARIANT

VARIANT

summit

reservoir

reservoir

reservoir

reservoir

reservoir

reservoir

VARIANT

BGN
BGN
BGN
VARIA

VARIANT

BGN

BGN

stream

stream

stream

dam

reservoir

reservoir

lake

reservoir

reservoir

$\begin{array}{ll}\text { BGN } & \text { Pinal } \\ \text { BGN } & \text { Yuma } \\ \text { BGN } & \text { Yavapa } \\ \text { BGN } & \text { Apache } \\ \text { UNOFF } & \text { Apache } \\ \text { BGN } & \text { Apache } \\ \text { BGN } & \text { Apache } \\ \text { BGN } & \text { Mohave } \\ \text { BGN } & \text { Mohave } \\ \text { BGN } & \text { Yavapa }\end{array}$

reservoir

flat.

locale

stream

stream

crossing

spring

valley

valley

reservoir

Greenlee

Yavapai

BGN

BGN

BGN

BGN

BGN

UNOFF

BGN

BGN

BGN

Maricopa

Yuma

Maricopa

$333159 \mathrm{~N} 1132014 \mathrm{~W}$

$321502 \mathrm{~N} 1133054 \mathrm{~W}$

$323718 \mathrm{~N} 1131938 \mathrm{~W}$

$332031 \mathrm{~N} 1092629 \mathrm{~W}$

$344250 \mathrm{N1} 124540 \mathrm{~W}$

35003BN1131230W

$325843 \mathrm{~N} 1105541 \mathrm{~W}$

$341403 \mathrm{~N} 1141101 \mathrm{~W}$

$340900 \mathrm{~N} 1124528 \mathrm{~W}$

$335915 \mathrm{~N} 1094437 \mathrm{~W}$

$335906 \mathrm{~N} 1094406 \mathrm{~W}$

$335902 \mathrm{~N} 1094406 \mathrm{~W}$

$335927 \mathrm{N1} 094256 \mathrm{~W}$

$363828 \mathrm{~N} 1130725 \mathrm{~W}$

$363529 N 1125451 \mathrm{~W}$

$345515 N 1114842 \mathrm{~W}$

$322730 \mathrm{~N} 1101205 \mathrm{~W}$

$325210 \mathrm{~N} 1093115 \mathrm{~W}$

325140 N1093400W

$341201 \mathrm{~N} 1124234 \mathrm{~W}$

$350315 \mathrm{~N} 1132645 \mathrm{~W}$

$351315 \mathrm{~N} 1122825 \mathrm{~W}$

343928 N1120830W

$324105 \mathrm{~N} 1095954 \mathrm{~W}$

$342746 \mathrm{~N} 1111230 \mathrm{~W}$

333738 N1095423W

valley

BGN 1969

VARIANT

VARIANT

trail UNOFF Pinal

crossing

valley

stream

stream

reservoir

reservoir

UNOFF

BGN

BGN

$B G N$
$B G N$
$B G N$

BGN

dam

reservoir

reservoir

cliff

canal

valley

stream

summit

reservoir

UNOFF Gila

BGN Navajo

BGN Navajo

BGN Coconino

BGN Maricopa

VARIANT

BGN Cochise

BGN Gila

BGN Yavapai

BGN

canal
reservoir
stream

BGN

VARIANT

BGN 196

VARIANT

VARIANT

VARIANT

$332755 N 1112323 \mathrm{~W}$

$332703 \mathrm{~N} 1112300 \mathrm{~W}$

$321902 \mathrm{~N} 1092650 \mathrm{~W}$

$362706 \mathrm{~N} 1121859 \mathrm{~W}$

$340847 \mathrm{~N} 1115600 \mathrm{~W}$

$342302 \mathrm{~N} 1112009 \mathrm{~W}$

$345009 \mathrm{~N} 1111214 \mathrm{~W}$

$354933 \mathrm{~N} 1121859 \mathrm{~W}$

$331920 \mathrm{~N} 1103136 \mathrm{~W}$

$342020 \mathrm{~N} 1103354 \mathrm{~W}$

$34030 \mathrm{BN} 1100523 \mathrm{~W}$

$350056 \mathrm{~N} 1114729 \mathrm{~W}$

$332802 \mathrm{~N} 1115337 \mathrm{~W}$

$321700 \mathrm{~N} 1093815 \mathrm{~W}$

$335352 \mathrm{~N} 1101017 \mathrm{~W}$

$340602 \mathrm{~N} 1114711 \mathrm{~W}$

$353242 \mathrm{~N} 1114557 \mathrm{~W}$

Coconino

323846 N1144029W

$325640 \mathrm{~N} 1102833 \mathrm{~W}$

343725 N1110220W

\begin{tabular}{ccc} 
SOURCE & ELEV & \multicolumn{1}{c}{ MAP NAME } \\
COORDINATE & FT & \\
& $\begin{array}{l}\text { Cross Roads } \\
\text { Chiricahua Peak } \\
\text { Mount Bigelow } \\
\text { Picketpost Mtn }\end{array}$ \\
& \\
& Natanes Mts NW \\
& Crown King
\end{tabular}

Eagletail Mts East

3300 Eagletail Mts East

Courthouse Well

Is la Pinta

Aguila Mts SE

Bee Canyon

Smith Mesa

Anvil Rock Ranch

$325412 \mathrm{~N} 1105338 \mathrm{~W}$

341244N1140817W

$335756 \mathrm{~N} 1094049 \mathrm{~W}$

$332502 \mathrm{~N} 1112150 \mathrm{~W}$

Crozier Peak

Cross Roads

Congress

Hawley Lake East

Hawley Lake East

B255 Hawley Lake East

Hawley Lake East

Little Clayhole Val

Heaton Knolls

Wilson Mountain

The Mesas

San Jose

San Jose

$341304 \mathrm{~N} 1124027 \mathrm{~W}$

350537 N1132416W

$324234 \mathrm{~N} 1095828 \mathrm{~W}$

$342505 \mathrm{~N} 1111302 \mathrm{~W}$

5120 Ash Fork

Hickey Mountain

Webb Peak

Dane Canyon

Bonito Prairie

Goldfield

$362624 N 1121529 \mathrm{~W}$

$341021 \mathrm{~N} 1115348 \mathrm{~W}$

342519 N1111930W

$321526 \mathrm{~N} 1093556 \mathrm{~W}$

$342755 \mathrm{~N} 1112025 \mathrm{~W}$

Goldfield

Bowie

Quaking Aspen

Brooklyn Peak

Kehl Ridge

Chavez Mtn West 
NATIONAL GAZETTEER--ARIZONA 1986 FEATURE NAME

See Chevelon Creek

East Clear Creek

See Clear Creek

East Cocopah Reservation

See Cocopah Indian

Reservation

East Compadre Shaft

East Copper Spring

Little Copper Spring

East Dam

East Dam Tailings Pond

East Deer Tank

East Diamond Spring

East Divide Two hundred

eighty seven Trail

East Drain

East Drain

East Drain Extension

East Eagle Creek

Eagle Creek

East Fork Eagle Creek

East Eagle Trail Thirty-Three

East Eaton Canyon

East Elk Spring

East End

Easter Mountain

Eastern, Canal (historical) Canal Eleven Branch

Eastern Arizona Junior College

Eastern Arizona Junior

College Campus

See Gila Pueblo Campus Community College

Extension

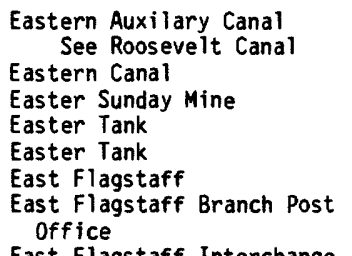

East Flagstaff Interchange

East Flagstaff Junior High School

East Fork

East Fork Apache Canyon

East Fork Baldy Trail

Ninetyfive

East Fork Bass Canyon

East Fork Black River

East Fork Boulder Canyon See East Boulder Canyon

East Fork Bronco Creek

East Fork Brookbank Canyon

East Fork Cañada del Oro

East Fork Canyon Creek

East Fork Carbon Creek

East Fork Castle Creek

East Fork Chevelon Canyon

East Fork Community Center

East Fork Cooper Canyon

East Fork Cottonwood Wash

East Fork Davidson Canyon

East Fork Dinnebito Wash

East Fork Dragon Creek See Dragon Creek

East Fork Dry Creek

East Fork Eagle Creek See Eagle Creek
FEATUR

CLASS

STATUS

COUNTY

COORDINATE

345704N1103118W

stream

stream

VARIANT

Navajo

Navajo

$345920 \mathrm{~N} 1103815 \mathrm{~W}$

VARIANT

reserve

mine

spring

dam

reservoir

reservoir

spring

trai

UNOFF

canal

canal

canal

stream

$\begin{array}{ll} & \text { VARIANT } \\ \text { VARIANT } & \\ \text { UNOFF } & \end{array}$

valley

BGN

spring

summit

summit

canal

school

BGN

$B G N$

BGN

VARIANT

UNOFF

VARIANT

school

Yuma

Yuma

Yuma

Greenlee

Greenlee

Cochise

Coconino

Maricopa

Cochise

Maricopa

Graham

Gila

VARIANT

cana

canal

mine

reservoir

reservoir

pp 1

building

BGN

UNOFF

BGN

BGN

BGN

UNOFF

crossing UNOFF

UNOFF

BGN

locale

valley

trail

BGN

UNOFF

Maricopa

Maricopa

Cochise

Coconino

Mohave

Coconino

Coconino

Coconino

Coconino

valley

BGN

Navajo

Pima

Apache

stream

(

Cochise

Apache

valley

Pinal

stream

valley

valley

stream

stream

stream

valley

building

valley

stream

BGN Maricopa

BGN Navajo

Pima

Coconino

Coconino

Yavapai

Coconino

Navajo

Navajo

valley

valley

BGN

VARIANT

stream

stream

BGN

Pima

Navajo

Coconino

VARIANT

Apache

stream
$351307 N 1113649 \mathrm{~W}$

$323715 \mathrm{~N} 1144545 \mathrm{~W}$

313842 N1105207W

$342906 \mathrm{~N} 1123213 \mathrm{~W}$

315027 N1104238W

$322259 \mathrm{~N} 1124939 \mathrm{~W}$

333228 N $1100102 \mathrm{~W}$

$335155 N 1112915 \mathrm{~W}$

323107 N1101646W

323B52N1143927

$340333 \mathrm{~N} 1142044 \mathrm{~W}$

323838 N1143820

$332937 \mathrm{N1092808 \textrm {W }}$

$332955 \mathrm{~N} 1092345 \mathrm{~W}$

321746 N1093422W

$352235 \mathrm{~N} 1115912 \mathrm{~W}$

$334047 \mathrm{~N} 1114759 \mathrm{~W}$

$315433 \mathrm{~N} 1102542 \mathrm{~W}$

332426N1114725W

$325038 N 1094546 \mathrm{~W}$

$332153 \mathrm{~N} 1104600 \mathrm{~W}$

$331634 \mathrm{~N} 1114251 \mathrm{~W}$

$331546 \mathrm{~N} 1114651 \mathrm{~W}$

$312545 \mathrm{~N} 1094950 \mathrm{~W}$

$345734 N 1110846 \mathrm{~W}$

$352748 \mathrm{~N} 1133952 \mathrm{~W}$

351241 N1113645W

$351222 \mathrm{~N} 1113648 \mathrm{~W}$

$351302 N 1113448 W$

334753N1095547W

$313330 N 1111241 \mathrm{~W}$

$335740 \mathrm{~N} 1092 \mathrm{~B} 12 \mathrm{~W}$

322422N1101311

$334503 N 1092144 \mathrm{~W}$

$332755 \mathrm{~N} 1112323 \mathrm{~W}$

$335719 N 1115135 \mathrm{~W}$

342206 N $1104143 \mathrm{~W}$

$322942 N 1104652 \mathrm{~W}$

$341708 \mathrm{~N} 1104817 \mathrm{~W}$

$360941 N 1115012 \mathrm{~W}$

$340400 \mathrm{~N} 1122849 \mathrm{~W}$

$342936 \mathrm{~N} 1104914 \mathrm{~W}$

$334834 \mathrm{N1}$

$370210 \mathrm{~N} 1102759 \mathrm{~W}$

341549 N1102026W

315111 N1104010W $361701 \mathrm{~N} 1102258 \mathrm{~W}$

$361010 \mathrm{~N} 1121213 \mathrm{~W}$

$345510 N 1094754 \mathrm{~W}$

$325736 \mathrm{~N} 1092420 \mathrm{~W}$

$\begin{array}{cc}\text { SOURCE } & \text { ELEV } \\ \text { COORDINATE } & \text { FT }\end{array}$

Parker SE

Yuma West

Robinson Mesa

Robinson Mesa

Luzena

Moritz Ridge

4067 McDowell Peak

Mescal

Mesa

Thatcher

Chand ler

Bisbee NE

Chavez Mtn NW

Valentine

Flagstaff East

Flagstaff East

Flagstaff East

Flagstaff East

$313201 N 1111008 \mathrm{~W}$

5240

teriver

Murphy Peak

Big Lake North

The Mesas

Buffalo Crossing

335432N101234

$335529 \mathrm{~N} 1115039 \mathrm{~W}$ 342109 N1 104204W $322705 \mathrm{~N} 1104527 \mathrm{~W}$

$341959 \mathrm{~N} 1104704 \mathrm{~W}$

$361141 \mathrm{~N} 1115134 \mathrm{~W}$

$340656 \mathrm{~N} 112283 \mathrm{BW}$

342650 N1104829W

$365821 \mathrm{~N} 1102419 \mathrm{~W}$

$341423 N 1101844 \mathrm{~W}$

Humboldt Mtn Brookbank Point

Mt Lemmon

$0 \mathrm{~W}$ Point

Cape Solitude 


\begin{tabular}{|c|c|c|c|c|c|c|c|}
\hline FEATURE NAME & $\begin{array}{l}\text { FEATURE } \\
\text { CLASS }\end{array}$ & STATUS & COUNTY & COORDINATE & $\begin{array}{l}\text { SOURCE } \\
\text { COORDINATE }\end{array}$ & $\begin{array}{c}\text { ELEV } \\
\text { FT }\end{array}$ & MAP NAME \\
\hline $\begin{array}{l}\text { East Fork Eagle Creek } \\
\text { See East Eagle Creek } \\
\text { East Fork Hardscrabble Creek } \\
\text { See Hardscrabble Creek }\end{array}$ & $\begin{array}{l}\text { stream } \\
\text { stream }\end{array}$ & $\begin{array}{l}\text { VARIANT } \\
\text { VARIANT }\end{array}$ & $\begin{array}{l}\text { Greenlee } \\
\text { Yavapai }\end{array}$ & $\begin{array}{l}332937 N 1092808 \mathrm{~W} \\
341859 N 1113954 \mathrm{~W}\end{array}$ & & & \\
\hline $\begin{array}{l}\text { East Fork Hess Draw } \\
\text { East Fork Horton Creek } \\
\text { East Fork Larson Draw } \\
\text { East Fork Little Colorado River } \\
\text { East Fork McCanyon } \\
\text { East Fork Mission School } \\
\text { East Fork North Canyon Creek } \\
\text { East Fork Parashant Wash } \\
\text { East Fork Phoenix Park Canyon } \\
\text { East Fork Potato Patch Draw }\end{array}$ & $\begin{array}{l}\text { valley } \\
\text { stream } \\
\text { valley } \\
\text { stream } \\
\text { valley } \\
\text { school } \\
\text { stream } \\
\text { valley } \\
\text { valley } \\
\text { valley }\end{array}$ & $\begin{array}{l}\text { BGN } \\
\text { BGN } \\
\text { BGN } \\
\text { BGN } \\
\text { BGN } \\
\text { UNOFF } \\
\text { BGN } \\
\text { BGN } 1973 \\
\text { BGN } \\
\text { BGN }\end{array}$ & $\begin{array}{l}\text { Navajo } \\
\text { Gila } \\
\text { Navajo } \\
\text { Apache } \\
\text { Coconino } \\
\text { Navajo } \\
\text { Maricopa } \\
\text { Mohave } \\
\text { Navajo } \\
\text { Coconino }\end{array}$ & $\begin{array}{l}342105 N 1102957 W \\
342200 N 1110351 W \\
343510 N 1103528 W \\
340014 N 1092721 W \\
350318 N 1121342 W \\
334752 N 1095553 W \\
335958 N 1120251 W \\
361439 N 1133409 W \\
341426 N 1103157 W \\
325738 N 1092420 W\end{array}$ & $\begin{array}{l}341927 \mathrm{~N} 1102943 \mathrm{~W} \\
342235 \mathrm{~N} 1110229 \mathrm{~W} \\
343154 \mathrm{~N} 1103711 \mathrm{~W} \\
335511 \mathrm{~N} 1093145 \mathrm{~W} \\
350715 \mathrm{~N} 1121047 \mathrm{~W} \\
\\
340119 \mathrm{~N} 1120120 \mathrm{~W} \\
360903 \mathrm{~N} 1133204 \mathrm{~W} \\
341709 \mathrm{~N} 1103109 \mathrm{~W} \\
342528 \mathrm{~N} 1104727 \mathrm{~W}\end{array}$ & & $\begin{array}{l}\text { Day Spring } \\
\text { Promontory Butte } \\
\text { Red Knoll } \\
\text { Greer } \\
\text { May Tank Pocket } \\
\text { Whiteriver } \\
\text { Daisy Mountain } \\
\text { Castle Peak } \\
\text { Pepper Canyon } \\
\text { Weimar Point }\end{array}$ \\
\hline $\begin{array}{l}\text { East Fork Woods Canyon } \\
\text { East Fork Wright Canyon } \\
\text { East Fort } \\
\text { East Gate } \\
\text { East Gate Plaza Shopping Center } \\
\text { East Gate Shopping Center } \\
\text { East Globe Elementary School } \\
\text { East Globe School } \\
\text { East Globe School } \\
\text { See East Globe Elementary } \\
\text { School }\end{array}$ & $\begin{array}{l}\text { valley } \\
\text { valley } \\
\text { locale } \\
\text { locale } \\
\text { locale } \\
\text { locale } \\
\text { school }\end{array}$ & $\begin{array}{l}\text { BGN } \\
\text { BGN } \\
\text { BGN } \\
\text { BGN } \\
\text { UNOFF } \\
\text { UNOFF } \\
\text { UNOFF } \\
\text { VARIANT } \\
\text { VARIANT }\end{array}$ & $\begin{array}{l}\text { Coconino } \\
\text { Mohave } \\
\text { Yavapai } \\
\text { Cochise } \\
\text { Pima } \\
\text { Maricopa } \\
\text { Gila } \\
\text { Gila }\end{array}$ & $\begin{array}{l}342022 \mathrm{~N} 1105706 \mathrm{~W} \\
351933 \mathrm{~N} 1132922 \mathrm{~W} \\
340949 \mathrm{~N} 1121516 \mathrm{~W} \\
313427 \mathrm{~N} 1101853 \mathrm{~W} \\
321410 \mathrm{~N} 1105220 \mathrm{~W} \\
332800 \mathrm{~N} 1115537 \mathrm{~W} \\
332342 \mathrm{~N} 1104634 \mathrm{~W} \\
332342 \mathrm{~N} 1104634 \mathrm{~W}\end{array}$ & $\begin{array}{l}342224 \mathrm{~N} 1105803 \mathrm{~W} \\
351747 \mathrm{~N} 1133045 \mathrm{~W}\end{array}$ & $\begin{array}{l}6386 \\
2320\end{array}$ & $\begin{array}{l}\text { Woods Canyon } \\
\text { Tuckayou Spring } \\
\text { Crown King } \\
\text { Fort Huachuca } \\
\text { Tucson East } \\
\text { Tempe } \\
\text { Globe }\end{array}$ \\
\hline $\begin{array}{l}\text { East Gypsum Bay } \\
\text { East Hearn Lateral } \\
\text { East High School } \\
\text { East Holbrook Interchange } \\
\text { East Indian Tank } \\
\text { East Jack Tank } \\
\text { East Joy Well } \\
\text { East Kingman Interchange } \\
\text { East Lacy Fork } \\
\text { East Lake }\end{array}$ & $\begin{array}{l}\text { bay } \\
\text { canal } \\
\text { school } \\
\text { crossing } \\
\text { reservoir } \\
\text { reservoir } \\
\text { well } \\
\text { crossing } \\
\text { valley } \\
\text { lake }\end{array}$ & $\begin{array}{l}\text { BGN } \\
\text { BGN } \\
\text { UNOFF } \\
\text { UNOFF } \\
\text { BGN } \\
\text { BGN } \\
\text { UNOFF } \\
\text { UNOFF } \\
\text { BGN } \\
\text { BGN }\end{array}$ & $\begin{array}{l}\text { Mohave } \\
\text { Yuma } \\
\text { Maricopa } \\
\text { Navajo } \\
\text { Navajo } \\
\text { Mohave } \\
\text { Maricopa } \\
\text { Mohave } \\
\text { Gila } \\
\text { Coconino }\end{array}$ & $\begin{array}{l}360638 \mathrm{~N} 1142422 \mathrm{~W} \\
323430 \mathrm{~N} 1144332 \mathrm{~W} \\
332717 \mathrm{~N} 1115833 \mathrm{~W} \\
345626 \mathrm{~N} 1100740 \mathrm{~W} \\
342817 \mathrm{~N} 1103134 \mathrm{~W} \\
352032 \mathrm{~N} 1132021 \mathrm{~W} \\
334536 \mathrm{~N} 1120249 \mathrm{~W} \\
351308 \mathrm{~N} 1140042 \mathrm{~W} \\
335747 \mathrm{~N} 1110324 \mathrm{~W} \\
363412 \mathrm{~N} 1121048 \mathrm{~W}\end{array}$ & 335659 N1110023W & 5240 & $\begin{array}{l}\text { Bonelli Bay } \\
\text { Somerton } \\
\text { Tempe } \\
\text { Holbrook } \\
\text { Heber } \\
\text { Blye Canyon SE } \\
\text { New River SE } \\
\text { Kingman } \\
\text { Copper Mtn } \\
\text { Telephone Hill }\end{array}$ \\
\hline $\begin{array}{l}\text { East lake Park } \\
\text { East Leonard Canyon } \\
\quad \text { Leonard Canyon } \\
\text { East Leonard Canyon } \\
\text { See Leonard Canyon } \\
\text { East Leonard Canyon Creek } \\
\text { East Lincoln Ridge } \\
\text { East Main Canal } \\
\text { East Mesa } \\
\text { East Mesa }\end{array}$ & $\begin{array}{l}\text { valley } \\
\text { stream } \\
\text { ridge } \\
\text { canal } \\
\text { summit } \\
\text { summit }\end{array}$ & $\begin{array}{l}\text { ADMIN } \\
\text { BGN 1973 } \\
\text { VARIANT } \\
\text { VARIANT } \\
\text { BGN } \\
\text { BGN } \\
\text { BGN } \\
\text { BGN } \\
\text { BGN }\end{array}$ & $\begin{array}{l}\text { Coconino } \\
\text { Coconino } \\
\text { Navajo } \\
\text { Yuma } \\
\text { Coconino } \\
\text { Apache }\end{array}$ & $\begin{array}{l}343725 \mathrm{~N} 1110222 \mathrm{~W} \\
342408 \mathrm{~N} 1110644 \mathrm{~W} \\
341935 \mathrm{~N} 1102751 \mathrm{~W} \\
324133 \mathrm{~N} 1143820 \mathrm{~W} \\
353427 \mathrm{~N} 1112751 \mathrm{~W} \\
363620 \mathrm{~N} 1091555 \mathrm{~W}\end{array}$ & $342410 \mathrm{~N} 1110526 \mathrm{~W}$ & $\begin{array}{l}5445 \\
7630\end{array}$ & $\begin{array}{l}\text { Knoll Lake } \\
\text { Day Spring } \\
\text { Yuma West } \\
\text { Wupatki SW } \\
\text { Mexican Cry Mesa }\end{array}$ \\
\hline $\begin{array}{l}\text { East Mesa } \\
\text { East Mesa } \\
\text { East Mesa Mine } \\
\text { East Miller Canyon } \\
\text { Crackerbox Canyon } \\
\text { Fuller Canyon } \\
\text { East Mill Well } \\
\text { East Mini Well Park } \\
\text { East Mitten Butte } \\
\text { Eastmoor Park } \\
\text { Bristol Park }\end{array}$ & $\begin{array}{l}\text { summit } \\
\text { ppl } \\
\text { mine } \\
\text { valley }\end{array}$ & $\begin{array}{l}\text { BGN } \\
\text { BGN } \\
\text { UNOFF } \\
\text { BGN 1966 } \\
\text { VARIANT } \\
\text { VARIANT } \\
\text { UNOFF } \\
\text { ADMIN } \\
\text { BGN } \\
\text { ADMIN } \\
\text { VARIANT }\end{array}$ & $\begin{array}{l}\text { Maricopa } \\
\text { Maricopa } \\
\text { Navajo } \\
\text { Pima }\end{array}$ & $\begin{array}{l}365347 N 1132412 \mathrm{~W} \\
332455 \mathrm{~N} 1113926 \mathrm{~W} \\
363621 \mathrm{~N} 1091549 \mathrm{~W} \\
343000 \mathrm{~N} 1111456 \mathrm{~W} \\
\\
330058 \mathrm{~N} 1131311 \mathrm{~W} \\
331834 \mathrm{~N} 1114955 \mathrm{~W} \\
365918 \mathrm{N1} 100409 \mathrm{~W} \\
321211 \mathrm{~N} 1105554 \mathrm{~W}\end{array}$ & $342640 \mathrm{~N} 1111655 \mathrm{~W}$ & 4792 & $\begin{array}{l}\text { Yellowhorse Flat } \\
\text { Buckhorn } \\
\text { Mexican Cry Mesa } \\
\text { Blue Ridge Reservoir } \\
\text { Oatman Mountain } \\
\text { Chandler } \\
\text { Mitten Buttes } \\
\text { Tucson }\end{array}$ \\
\hline $\begin{array}{l}\text { East Mountain } \\
\text { East Newman Hill } \\
\text { East Newman Park } \\
\text { East New Water Tank } \\
\text { East Ninemile Well }\end{array}$ & $\begin{array}{l}\text { summit } \\
\text { summit } \\
\text { flat } \\
\text { reservoir } \\
\text { well }\end{array}$ & $\begin{array}{l}\text { BGN } \\
\text { BGN } \\
B G N \\
\text { BGN } \\
\text { UNOFF }\end{array}$ & $\begin{array}{l}\text { Gila } \\
\text { Coconino } \\
\text { Coconino } \\
\text { Mohave } \\
\text { Apache }\end{array}$ & $\begin{array}{l}331659 \mathrm{~N} 1104702 \mathrm{~W} \\
352338 \mathrm{~N} 1115151 \mathrm{~W} \\
350044 \mathrm{~N} 1113953 \mathrm{~W} \\
355740 \mathrm{~N} 1135002 \mathrm{~W} \\
345928 \mathrm{~N} 1093109 \mathrm{~W}\end{array}$ & & $\begin{array}{l}6892 \\
8518\end{array}$ & $\begin{array}{l}\text { Pinal Peak } \\
\text { Kendrick Peak } \\
\text { Mountainaire } \\
\text { Quartermaster Canyon } \\
\text { Ninemile Seep }\end{array}$ \\
\hline
\end{tabular}


NATIONAL GAZETTEER--ARIZONA 1986 FEATURE NAME

East Park

East Park

East Park Dam

East Pass

East Pasture Tank

East Pasture Tank

East Pasture Well

East Peak

East Pershing Plaza

East Phoenix

See Phoenix

East Plantsite

East Plantsite School

See Murdock Elementary School

East Pocket

East Pocket Knob

East Pocket Lookout Tower

East Pocket Tank

East Point

East Polecat Canyon

East Quartzsite Interchange

East Rimmy Tank

East Rim Viewpoint

East Salt Shed Dam

East Salt Shed Tank

East San Simon Interchange

East Sawmill Canyon Sawmill Canyon

East School

East Side Cemetery

East Side Shopping Center

East Side Tank

East Side Tank

East Side Windmill

East Snowflake Ditch

East Soldier Tank

East Spear Creek Dinner Creek

East Spider Tank

East Spring

East Spring Canyon Dam

East Steep Hill Valley

East Sunset Mountain

East Tank

East Tank

East Tank

East Tank

East Tank

East Tank

East Tank

East Tank

East Tank

East Tank

East Tank

East Tank

East Tank

East Tank

East Tank

East Tank

East Taylor Ditch

East Ten Tank

East Three Tank

East Tule Well

East Turkey Creek

Turkey Creek

East Turkey Tank

East Twin Wash

East Two Tank

East Verde River

East Walnut Canyon
FEATURE

CLASS

STATUS

COUNTY

COORDINATE

park ADMIN Pinal 325233N1114420W

park ADMIN Pinal 325849N1113048W

dam UNOFF Maricopa 333442N1120418W

gap BGN Maricopa 323708N1130418W

reservoir BGN Yavapai 342526N1120209W

reservoir BGN Apache 350116N1090618W

locale BGN $\quad$ Apache 350308 N1090607W

summit BGN $\quad$ Cochise 315139 N1102301W

ppl BGN Cochise 313318N1102035W

ppl

ppl

school

VARIANT

Maricopa

Greenlee

VARIAN

Greenlee

$332654 \mathrm{~N} 1120424 \mathrm{~W}$

$330249 N 1091905 \mathrm{~W}$

$330245 N 1091905 \mathrm{~W}$

$\begin{array}{llll}\text { basin } & \text { BGN } & \text { Coconino } & 345758 N 1114623 \mathrm{~W} \\ \text { summit } & \text { BGN } & \text { Coconino } & 345832 \mathrm{N1114604W} \\ \text { tower } & \text { UNOFF } & \text { Coconino } & 345832 N 1114604 \mathrm{~W} \\ \text { reservoir } & \text { BGN } & \text { Coconino } & 345806 \mathrm{N1114613W} \\ \text { cape } & \text { BGN } 1948 & \text { Mohave } & 360748 N 1142245 \mathrm{~W} \\ \text { valley } & \text { BGN } & \text { Cochise } & 321608 N 1093815 \mathrm{~W} \\ \text { crossing } & \text { UNOFF } & \text { La Paz } & 333957 N 1141203 \mathrm{~W} \\ \text { reservoir } & \text { BGN } & \text { Coconino } & 354126 \mathrm{N1112445W} \\ \text { locale } & \text { BGN } & \text { Coconino } & 362507 N 1120513 \mathrm{~W} \\ \text { dam } & \text { UNOFF } & \text { Graham } & 332130 \mathrm{~N} 1093836 \mathrm{~W}\end{array}$

reservoir BGN Graham 332117N1093845W

crossing UNOFF Cochise 321528N1091110W

valley BGN 1981 Pima 314333N1104938W

School UARIANT

cemetery

locale

reservoir

locale

canal

stream

reservoir

spring

dam

valley

UNOFF

UNOFF

BGN

BGN

$B G N$

Pinal

Apache

Pima

Graham

Coconino

Yavapai

$325222 \mathrm{NI} 114427$

$343045 \mathrm{~N} 1091944 \mathrm{~W}$

$321420 \mathrm{~N} 1105435 \mathrm{~W}$

$323353 \mathrm{~N} 1094235 \mathrm{~W}$

363818 N1122600

341657 N1124024W

$343023 N 1100337 \mathrm{~W}$

344818 N1111200W

335848 N1105845W

354018 N1112B49W

$325559 \mathrm{N1} 094751 \mathrm{~W}$

$323847 N 1094510 \mathrm{~W}$

$361608 \mathrm{~N} 1100324 \mathrm{~W}$

$345027 N 1105357 \mathrm{~W}$

reservoir BGN Santa Cruz 313142N1104053W

reservoir BGN Santa Cruz 313611N1102846W

reservoir

reservoir $B G$

reservoir $B G$

reservoir $B G$

reservoir $B G$

reservoir

reservoir

reservoir BGN

reservoir $B G N$

reservoir $B G$

reservoir $B G N$

reservoir BGN

reservoir $B G N$

canal

reservoir

reservoir

well

Cochise

Pina

Maricopa

Gila

Gila

Yavapai

Gila

Coconino

Yavapai

331153N1121911W

$332055 N 1104517 \mathrm{~W}$

$333507 \mathrm{N1110209 \textrm {W }}$

$340543 \mathrm{~N} 1131107 \mathrm{~W}$

342002 N1112912W

$343517 \mathrm{~N} 1112148 \mathrm{~W}$

$343727 \mathrm{N1123627 \textrm {W }}$

Coconino 344129N1112207W

Coconino 344934N1112725W

Coconi

Apache

Mohave

Nava jo

Santa Cruz

Santa Cruz

$B G N$

UNOFF

Graham

350227 N1092034W

$350233 N 1093628 \mathrm{~W}$

$354616 \mathrm{~N} 1135437 \mathrm{~W}$

$342627 \mathrm{~N} 1100412 \mathrm{~W}$

$312220 \mathrm{N1} 103823 \mathrm{~W}$

$312254 \mathrm{N1} 103859 \mathrm{~W}$

331903 N1095215

VARIANT

$315955 \mathrm{~N} 1090736 \mathrm{~W}$

reservoir

stream

BGN

BGN

valley BGN

$312231 \mathrm{N1103850 \textrm {W }}$

Gila $\quad 341711 \mathrm{~N} 1113951 \mathrm{~W}$ reservoir
SOURCE

COORDINATE

ELEV

MAP NAME

Casa Crande East

Coolidge

Sunnys lope

East Pass

Estler Peak

High Lonesome Wel

6641 High Lonesome We11

6681 Apache Peak

Fort Huachuca

Clifton

Wilson Mountain

7196 Wilson Mountain

Wilson Mountain

Wilson Mountain

Middle Point

$321534 N 1093656 \mathrm{~W}$

Railroad Pass

918 Quartzsite

Gray Mountain

Dog Point

Point of Pines East

5998 Point of Pines East San Simon

$314336 \mathrm{~N} 1104930 \mathrm{~N}$

Sonoita

Casa Grande Mts

St Johns Nor

2475 Tucson

Gillespie Mt

Toothpick Ridge

Peeples Valley

Snowf lake

Chavez Mtn West

McFadden Peak

335640 N1105810w

Gray Mountain

Pima

Mt Graham

361633N1100426W Hole In Rock Valley

6840 Sunset Pass

Mt Hughes

Pyeatt Ranch

Apache

Fresno Wash

Mobile NE

Pinal Peak

Two Bar Mtn

Date Creek Ranch SW

Buckhead Mesa

Long Valley

Iron Springs

Turkey Mtn

Hutch Mtn

Beacon Well

Navajo South

Quartermaster Can SW

Taylor

Duquesne

Harshaw

5228 Point of Pines West

$315330 \mathrm{~N} 1091645 \mathrm{~W}$

Portal

Juniper Mts

Carrizo Butte

Harshaw

Verde Hot Springs

$342701 N 1111506 \mathrm{~W}$

$342010 \mathrm{~N} 1112915 \mathrm{~W}$ 


\section{FEATURE NAME}

East Washboard Wash

Eastwater Canyon

Eastwater Spring

East Well

East Well

East We

East Well Number Eleven

East Whitetail Creek

East Whitetail Creek Whitetail Creek

East White Tail Trail Two

Hundred Fif tythree

East Willcox Interchange

East Windmill

East Windmi 11

East Windmil

East Windmil

East Windmil

East Wing Mountain

East Wing Tank

Eastwood Creek

East Yard

East Yucca Interchange

East Yuma Interchange

East Zuni Windmill

Eaton Tank

Ebens Spring

Eberhardt Ranch

Eberling Tank

Ebert Mountain

Ebert Tank

E B Spring

E B Tank

ECC Peak

ECP Peak

Echinique Draw

Echinique Place

Echinique Tank

Echo Canyon

Echo Canyon

Echo Canyon

Echo Canyon

Echo Canyon

Echo Canyon Bow

Echo Canyon Park

Echo Cave Ruin

Echo Cliffs

Hambl in Ridge Vermillion Cliffs

Echols Spring

Echo Park

Echo Park

Echo Peak

Echo Spring

Echo Spring

Echo Spring

Echo Spring Mountain

Ecks Mountain

Ecks Tank

E C Nash School

See Nash School

ECP Peak

See ECC Peak

E C P Peak

E Cross L Spring

E Cross L Trail Number Two

Hundred Eighty One

Eda Hugkam Swadag

Eddie Was

Eddy Place
FEATURE

CLASS

STATUS

COUNTY

COORDINATE

stream
valley
spring
locale
well

BGN Navajo

BGN Gila

BGN Gila

UNOFF Maricopa

Maricopa

well

well

stream

stream

trail

crossing

well

UNOFF

UNOFF

$B G N$

$B G N$

1978 Cochise

UNOFF

Cochise

UNOFF

UNOFF

Cochise

Apache

locale

locale

locale

locale

summit

reservoir

stream

locale

crossing

crossing

BGN

$B G N$

$B G N$

$B G N$

BGN

BGN

$B G N$

UNOFF

UNOFF

well

reservoir

spring

locale

reservoir

summit

reservoir

spring

reservoir

summit

UNOFF Apache

Cochise

Yavapai

Navajo

Apache

Maricopa

Coconino

Yavapa $i$

Yuma

Mohave

Yuma

$B G M$
$B G$
$U M G$
$B G$
$B G$
$B G$
$B G$

Apache

Mohave

Apache

Pinal

Pima

Coconino

Coconino

Gila

Gila

La Paz

VARIANT

valley

BGN

locale

reservoir

valley

valley

valley

valley

valley

bas in

park

$B G$
$B G$
$B G$
$B G$
$B G$
$B G N$
$B G Y$
$B G$
$B G$
$A D$

Coconino

Coconino

Coconino

Cochise

Gila

Maricopa

Coconino

Navajo

Maricopa

Maricopa

locale

cliff

BGN Navajo

BGN 1982

VARIANT

spring

flat

park

summit

spring

BGN
BGN

BDN
BGN

BGN

BGN
BGN

Coconino

Graham

Cochise

Pina

Coconino

Pima

Navajo

spring BGN

summit

summit

reservoir

BGN

Navajo

Navajo

Apache

Apache

school

BARIANT

Pima

summit

VARIANT

summit

BGN

La Paz

Yuma

Yavapai

trail

UNOFF

Yavapa

spring

stream

BGN

Pima

Yavapai

Yavapai

$344500 \mathrm{Ni} 100904 \mathrm{~W}$

$332716 \mathrm{Ni110003 \textrm {W }}$ $332603 \mathrm{N110572BW}$

$332712 \mathrm{N1114903 \textrm {W }}$

$333210 \mathrm{N1124903 \textrm {W }}$

340949 N1132353W

$342244 \mathrm{~N} 110113 \mathrm{BW}$

350338N1090341W

$315950 N 1091503 \mathrm{~W}$

$320855 N 1090926 \mathrm{~W}$

320346N1091900W

$321832 \mathrm{~N} 1094735 \mathrm{~W}$

$343048 \times 1094751 \mathrm{~W}$

$321315 N 1091944 \mathrm{~W}$

$342044 N 1123943 \mathrm{~W}$

343917 N1100442W

$350128 \times 1092007 \mathrm{~W}$

334431 N1121239W

351601 N1114622W

$342922 \mathrm{~N} 1125409 \mathrm{~W}$

$324059 N 1143444 \mathrm{~W}$

$345243 \mathrm{~N} 1140 \mathrm{~B} 5 \mathrm{OW}$

$324020 \mathrm{~N} 1142913 \mathrm{~W}$

343841N1093258W

$342636 \mathrm{~N} 1135343 \mathrm{~W}$

$341057 N 1094643 \mathrm{~W}$

323017 N1111044W

$321517 \mathrm{~N} 112490 \mathrm{BW}$

$353330 \mathrm{~N} 1115612 \mathrm{~W}$

$353427 \mathrm{~N} 1115712 \mathrm{~W}$

$334701 N 1100913 \mathrm{~W}$

$334533 \mathrm{~N} 1100935 \mathrm{~W}$

335729N1133310W

$344505 \mathrm{Ni} 105627 \mathrm{~W}$ $344304 \mathrm{~N} 1105758 \mathrm{~W}$ $344335 \times 1105638$ $320010 \mathrm{~N} 1091953 \mathrm{~W}$ 332344 N1104730 $333106 \mathrm{~N} 1115759 \mathrm{~W}$ $351452 \mathrm{~N} 1120921 \mathrm{~W}$ $355426 \mathrm{~N} 1101346 \mathrm{~W}$ $333108 \mathrm{~N} 1115800 \mathrm{~N}$ $333106 \mathrm{~N} 1115816 \mathrm{~W}$

$365422 \mathrm{~N} 1100454 \mathrm{~W}$ $362445 \mathrm{~N} 1113129 \mathrm{~W}$

$323402 N 1102003 \mathrm{~W}$ $320023 \mathrm{~N} 1091921 \mathrm{~W}$ $321316 \mathrm{~N} 1105819 \mathrm{~W}$ $365012 \mathrm{~N} 1113509 \mathrm{~W}$ $321655 \mathrm{~N} 1103910 \mathrm{~W}$

$351706 \mathrm{~N} 1101940 \mathrm{~W}$

355348 N1100936W 351739 N1101911W $341325 \mathrm{~N} 1094547 \mathrm{~W}$

341317 N1094635W

321519N1105850W

335729 N1133310 W 340023 N1132846W $342225 \mathrm{~N} 1122633 \mathrm{~W}$

342238N1122545W

320B24N1114755W

335811N1123247W 
NATIONAL GAZETTEER--ARIZONA 1986

\begin{tabular}{|c|c|c|c|c|c|c|c|}
\hline FEATURE NAME & $\begin{array}{l}\text { FEATURE } \\
\text { CLASS }\end{array}$ & STATUS & COUNTY & COORDINATE & $\begin{array}{l}\text { SOURCE } \\
\text { COORDINATE }\end{array}$ & $\begin{array}{c}\text { ELEV } \\
\text { FT }\end{array}$ & MAP NAME \\
\hline $\begin{array}{l}\text { Eddy Tank } \\
\text { Eden } \\
\text { Eden Post Office } \\
\text { Eden Spring } \\
\text { Edgar Canyon }\end{array}$ & $\begin{array}{l}\text { reservoir } \\
\text { ppl } \\
\text { building } \\
\text { spring } \\
\text { valley }\end{array}$ & $\begin{array}{l}\text { BGN } \\
\text { BGN } \\
\text { UNOFF } \\
\text { BGN } \\
\text { BGN }\end{array}$ & $\begin{array}{l}\text { Coconino } \\
\text { Graham } \\
\text { Graham } \\
\text { Graham } \\
\text { Pina }\end{array}$ & $\begin{array}{l}351840 \mathrm{~N} 1121519 \mathrm{~W} \\
325740 \mathrm{~N} 1095341 \mathrm{~W} \\
325744 \mathrm{~N} 1095337 \mathrm{~W} \\
325830 \mathrm{~N} 1095241 \mathrm{~W} \\
322643 \mathrm{~N} 1102940 \mathrm{~W}\end{array}$ & $322348 \mathrm{~N} 1104027 \mathrm{~W}$ & 2750 & $\begin{array}{l}\text { Hearst Mtn } \\
\text { Eden } \\
\text { Eden } \\
\text { Eden } \\
\text { Redington }\end{array}$ \\
\hline $\begin{array}{l}\text { Edge Butte } \\
\text { Edgewater Well } \\
\text { Edison Park } \\
\quad \text { Duppa Villa Park } \\
\text { Edison School } \\
\text { Edison School } \\
\text { Ed Lamb Point } \\
\text { Ed Loy Tank } \\
\text { Eds Camp } \\
\text { Eds Field }\end{array}$ & $\begin{array}{l}\text { summit } \\
\text { well } \\
\text { park } \\
\text { school } \\
\text { school } \\
\text { cliff } \\
\text { reservoir } \\
\text { locale } \\
\text { airport }\end{array}$ & $\begin{array}{l}\text { BGN } \\
\text { UNOFF } \\
\text { ADNIN } \\
\text { VARIANT } \\
\text { UNOFF } \\
\text { UNOFF } \\
\text { BGN } \\
\text { BGN } \\
\text { BGN } \\
\text { ADNIN }\end{array}$ & $\begin{array}{l}\text { Navajo } \\
\text { Coconino } \\
\text { Maricopa } \\
\text { Maricopa } \\
\text { Maricopa } \\
\text { Mohave } \\
\text { Yavapai } \\
\text { Mohave } \\
\text { Pinal }\end{array}$ & $\begin{array}{l}351210 \mathrm{~N} 1101325 \mathrm{~W} \\
360845 \mathrm{~N} 1111527 \mathrm{~W} \\
332729 \mathrm{~N} 1120220 \mathrm{~W} \\
\\
332530 \mathrm{~N} 1114845 \mathrm{~W} \\
332729 \mathrm{~N} 1120236 \mathrm{~W} \\
365930 \mathrm{~N} 1124105 \mathrm{~W} \\
344647 \mathrm{N1} 115046 \mathrm{~W} \\
350202 \mathrm{~N} 1141933 \mathrm{~W} \\
324115 \mathrm{~N} 1113012 \mathrm{~W}\end{array}$ & & 6058 & $\begin{array}{l}\text { Turkey Track Butte } \\
\text { Moenave } \\
\text { Phoenix } \\
\text { Mesa } \\
\text { Phoenix } \\
\text { Kaibab } \\
\text { Sedona } \\
\text { Mount Nutt } \\
\text { Eloy South }\end{array}$ \\
\hline $\begin{array}{l}\text { Ed Walker Tank } \\
\text { Edwards Lateral } \\
\text { Edwards Lookout Tower } \\
\text { Edwards Mine } \\
\text { Edwards Park } \\
\text { Edwards Peak } \\
\text { Edwards Ranch (historical) } \\
\text { Edwards Spring } \\
\text { Edwards Spring } \\
\text { Edwards Spring } \\
\text { See Gold Tooth Smith Spring }\end{array}$ & $\begin{array}{l}\text { reservoir } \\
\text { canal } \\
\text { locale } \\
\text { mine } \\
\text { flat } \\
\text { summit } \\
\text { locale } \\
\text { spring } \\
\text { spring } \\
\text { spring }\end{array}$ & $\begin{array}{l}\text { BGN } \\
\text { BGN } \\
\text { BGN } \\
\text { UNOFF } \\
\text { BGN } \\
\text { BGN } \\
\text { UNOFF } \\
\text { BGN } \\
\text { BGN } \\
\text { VARIANT }\end{array}$ & $\begin{array}{l}\text { Apache } \\
\text { Yuma } \\
\text { Graham } \\
\text { Pima } \\
\text { Gila } \\
\text { Gila } \\
\text { Santa Cruz } \\
\text { Gila } \\
\text { Gila } \\
\text { Gila }\end{array}$ & $\begin{array}{l}340339 \mathrm{~N} 1093517 \mathrm{~W} \\
323335 \mathrm{~N} 1144645 \mathrm{~W} \\
332823 \mathrm{~N} 1095648 \mathrm{~W} \\
313210 \mathrm{~N} 1112038 \mathrm{~W} \\
334931 \mathrm{~N} 1112214 \mathrm{~W} \\
334950 \mathrm{~N} 1112133 \mathrm{~W} \\
313422 \mathrm{~N} 1110250 \mathrm{~W} \\
335005 \mathrm{~N} 1105300 \mathrm{~W} \\
335227 \mathrm{~N} 1111323 \mathrm{~W} \\
335738 \mathrm{~N} 1112516 \mathrm{~W}\end{array}$ & & $\begin{array}{l}6404 \\
5782 \\
3240\end{array}$ & $\begin{array}{l}\text { Greens Peak } \\
\text { Gadsden } \\
\text { Natanes Mts NW } \\
\text { Arivaca } \\
\text { Tonto Bas in } \\
\text { Tonto Bas in } \\
\text { Tubac } \\
\text { AzteC Peak } \\
\text { Greenback Creek }\end{array}$ \\
\hline $\begin{array}{l}\text { Edwards Tank } \\
\text { Eggshell Arch } \\
\text { Egloffstein Butte } \\
\text { Egypt } \\
\text { See Goodyear } \\
\text { Ehrenberg } \\
\text { Mineral City } \\
\text { Ehrenberg Bridge } \\
\text { Ehrenberg Point } \\
\text { Ehrenberg Wash } \\
\text { Cinnabar Wash }\end{array}$ & $\begin{array}{l}\text { reservoir } \\
\text { arch } \\
\text { summit } \\
\text { ppl } \\
\text { ppl } \\
\text { bridge } \\
\text { cliff } \\
\text { stream }\end{array}$ & $\begin{array}{l}\text { BGN } \\
\text { BGN } \\
\text { BGN } \\
\text { VARIANT } \\
\text { BGN } \\
\text { VARIANT } \\
\text { UNOFF } \\
\text { BGN } 1932 \\
\text { BGN } \\
\text { VARIANT }\end{array}$ & $\begin{array}{l}\text { Greenlee } \\
\text { Coconino } \\
\text { Navajo } \\
\text { Maricopa } \\
\text { Yuma } \\
\text { Yuma } \\
\text { Coconino } \\
\text { Yuma }\end{array}$ & $\begin{array}{l}331720 \mathrm{~N} 1092527 \mathrm{~W} \\
364054 \mathrm{~N} 1104725 \mathrm{~W} \\
353444 \mathrm{~N} 1102430 \mathrm{~W} \\
\\
332607 \mathrm{~N} 1122127 \mathrm{~W} \\
333615 \mathrm{~N} 1143128 \mathrm{~W} \\
\\
333617 \mathrm{~N} 1143145 \mathrm{~W} \\
361523 \mathrm{~N} 1115654 \mathrm{~W} \\
333643 \mathrm{~N} 1143107 \mathrm{~W}\end{array}$ & $332952 \mathrm{~N} 1142103 \mathrm{~W}$ & 6669 & $\begin{array}{l}\text { Bee Canyon } \\
\text { Inscription Hse Ruin } \\
\text { Egloffstein Butte }\end{array}$ \\
\hline $\begin{array}{l}\text { Ehrhardt Park } \\
\text { Eight, Canal (historical) } \\
\text { Eight, Tank } \\
\text { Eighteen Bells Mobile Home Park } \\
\text { Eighteen Tank } \\
\text { Eightmile Creek } \\
\text { Eightmile Gap } \\
\text { Eightmile Well } \\
\text { Eight Sect ion Tank } \\
\text { Eight Tank }\end{array}$ & $\begin{array}{l}\text { park } \\
\text { canal } \\
\text { reservoir } \\
\text { locale } \\
\text { reservoir } \\
\text { stream } \\
\text { valley } \\
\text { well } \\
\text { reservoir } \\
\text { reservoir }\end{array}$ & $\begin{array}{l}\text { AOMIN } \\
\text { BGN } \\
\text { BGN } \\
\text { UNOFF } \\
\text { BGN } \\
\text { BGN } \\
\text { BGN } \\
\text { UNOFF } \\
\text { BGN } \\
\text { BGN }\end{array}$ & $\begin{array}{l}\text { Maricopa } \\
\text { Maricopa } \\
\text { Coconino } \\
\text { Maricopa } \\
\text { Coconino } \\
\text { Yavapai } \\
\text { Coconino } \\
\text { Yuma } \\
\text { Pinal } \\
\text { Yavapai }\end{array}$ & $\begin{array}{l}332315 \mathrm{~N} 1115255 \mathrm{~W} \\
332625 \mathrm{~N} 1115102 \mathrm{~W} \\
352509 \mathrm{~N} 1113346 \mathrm{~W} \\
333832 \mathrm{~N} 1120234 \mathrm{~W} \\
353037 \mathrm{~N} 1121110 \mathrm{~W} \\
351105 \mathrm{~N} 1123535 \mathrm{~W} \\
365914 \mathrm{~N} 1122303 \mathrm{~W} \\
333428 \mathrm{~N} 1141455 \mathrm{~W} \\
325932 \mathrm{~N} 1110230 \mathrm{~W} \\
340322 \mathrm{~N} 1131258 \mathrm{~W}\end{array}$ & $\begin{array}{l}352215 \mathrm{~N} 1123615 \mathrm{~W} \\
370059 \mathrm{~N} 1122408 \mathrm{~W}\end{array}$ & $\begin{array}{l}1025 \\
3039\end{array}$ & $\begin{array}{l}\text { Tempe } \\
\text { Mesa } \\
\text { O'Leary Peak } \\
\text { Union Hills } \\
\text { Howard Lake } \\
\text { Cathedral Caves } \\
\text { Shinarump Point } \\
\text { South of Quartzs ite } \\
\text { Ninetysix Hills NE } \\
\text { Date Creek Ranch SW }\end{array}$ \\
\hline $\begin{array}{l}\text { Eighty, Tank } \\
\text { Eightyeight Mine } \\
\text { Eightyfive Bar Spring } \\
\text { Eightynine A Tank } \\
\text { Eightynine Tank } \\
\text { Eighty Spring } \\
\text { Eightythree Mile Rapids } \\
\text { Eileen Spring } \\
\text { Eisenhauer Canyon } \\
\text { Eisenhauer Spring }\end{array}$ & $\begin{array}{l}\text { reservoir } \\
\text { mine } \\
\text { spring } \\
\text { reservoir } \\
\text { reservoir } \\
\text { spring } \\
\text { rapids } \\
\text { spring } \\
\text { valley } \\
\text { spring }\end{array}$ & $\begin{array}{l}\text { BGN } \\
\text { UNOFF } \\
\text { BGN } \\
\text { BGN } \\
\text { BGN } \\
\text { BGN } \\
\text { BGN } \\
\text { BGN } \\
\text { BGN } \\
\text { BGN }\end{array}$ & $\begin{array}{l}\text { Pima } \\
\text { Yavapai } \\
\text { Gila } \\
\text { Coconino } \\
\text { Coconino } \\
\text { Cochise } \\
\text { Coconino } \\
\text { Mohave } \\
\text { Gila } \\
\text { Gila }\end{array}$ & $\begin{array}{l}321757 N 1113258 \mathrm{~W} \\
340921 \mathrm{~N} 1120756 \mathrm{~W} \\
335659 \mathrm{~N} 1100045 \mathrm{~W} \\
350439 \mathrm{~N} 1114349 \mathrm{~W} \\
353521 \mathrm{~N} 1113243 \mathrm{~W} \\
312145 \mathrm{~N} 1101757 \mathrm{~W} \\
360436 \mathrm{~N} 1120139 \mathrm{~W} \\
354503 \mathrm{~N} 1141640 \mathrm{~W} \\
340638 \mathrm{~N} 1112416 \mathrm{~W} \\
340613 \mathrm{~N} 1112553 \mathrm{~W}\end{array}$ & $340602 \mathrm{~N} 1112655 \mathrm{~W}$ & & $\begin{array}{l}\text { Koht Kohl Hill } \\
\text { Bumble Bee } \\
\text { Round Top Mtn } \\
\text { Mountainaire } \\
\text { East of S P Mtn } \\
\text { Montezuma Pass } \\
\text { Phantom Ranch } \\
\text { Senator Mtn } \\
\text { Mazatzal Peak } \\
\text { Mazatzal Peak }\end{array}$ \\
\hline $\begin{array}{l}\text { Eisenhower Dam } \\
\text { See Glen Canyon Dam } \\
\text { Eisenhower Elementary School } \\
\text { E J Smith Tank }\end{array}$ & $\begin{array}{l}\text { dam } \\
\text { school } \\
\text { reservoir }\end{array}$ & $\begin{array}{l}\text { VARIANT } \\
\text { UNOFF } \\
\text { BGN }\end{array}$ & $\begin{array}{l}\text { Coconino } \\
\text { Maricopa } \\
\text { Navajo }\end{array}$ & $\begin{array}{l}365608 \mathrm{~N} 1112859 \mathrm{~W} \\
332550 \mathrm{~N} 1114924 \mathrm{~W} \\
342229 \mathrm{~N} 1101841 \mathrm{~W}\end{array}$ & & & $\begin{array}{l}\text { Mesa } \\
\text { Clay Springs }\end{array}$ \\
\hline
\end{tabular}


FEATURE NAME

E K Tank

Elaine Castle

Elaine Lake

E) Bosquecito Picnic Area

Elbow Canyon

Elbow Point

Elbow Spring

El Burrito Childrens Camp

El Camino Mobile Home Park

E L Camp

El Canto Ranch

E1 Capitan

See Agathla Peak

El Capitan (historical)

El Cazador Ranch

El Cerro del Fresnal

See Fresnal, Cerro del

ELC Flat

El Con Regional Shopping Center Elden Mesa See Elden Mountain

Elden Mountain Elden Mesa

Elden Mountain Lookout Tower

Elden Pueblo

Elden Ranger Station

Elden Spring

Elderberry Spring

Elderberry Spring

Elderberry Spring Campground

Elder Gulch

El Desierto Pintado See Painted Desert

Eldon Palmer Reservoir

EI Dorado Medical Center

El Dorado Mobile Home Resort

Eldorado Park

E1 Dorado School

Elefante Spring

Elements Canyon

Elements Spring

Elephant Back Mountain

Elephant Butte

Elephant Butte

Elephant Butte

Elephant Corral Spring

Elephant Curve

Elephant Feet

Elephant Grass Spring

Elephant Head

Elephant Head Tank

Elephant Hill

Elephant Mountain

Elephant Mountain

Elephants Feet Rest Area

Elephants Foot

Elephants Tooth

Elevation Group Mines

Elevator Mountain

Eleven, Canal (historical) Canal Casas Canal Mesa

Eleven L Ranch

Eleven Mile Corner

Eleven Mile Corner School

Elevenmile Spilliway

El Frida

See Elfrida

El Frida
FEATUR
CLASS

reservoir

summit

reservoir

park

valley

cliff

spring

locale

locale

locale

locale

summit

locale

locale

summit

flat

locale

summit

summ it

tower

locale

locale

spring

spring

spring

park

valley

plain

reservoir

hospital

locale

park

schoo

spring

valley

spring

summit

summit

summit

summit

spring

bend

pillar

spring

summit

summit

summit

summit

pillar

pillar

mine

summit

canal

locale

locale

school

dam

$\mathrm{pp} 1$
$\mathrm{pp} 1$

STATUS

COUNTY

BGN Coconino

BGN 1908 Coconino

Coconino

ADMIN Pima

BGN Mohave

BGN Navajo

BGN Yavapai

BGN Yavapai

UNOFF Maricopa

BGN Yavapai

UNOFF

VARIANT

BGN Navajo

UNOFF Gila

VARIANT

Pima

UNOFF

VARIANT

BGN 1911

VARIANT

UNOFF

BGN

\section{BGN}

$B G N$

BGN

ADMIN

BGN

VARIANT

BGN

UNOFF
UNOFF

\section{ADMIN}

UNOFF

$B G N$

BGN

BGN

BGN

BGN

BGN

BGN

BGN

BGN Coconino

BGN Apache

BGN Santa Cruz

Gila

Maricopa

Mohave

Coconino

Mohave

BGN
UNOFF

BGN

VARIANT

VARIANT

UNOFF

BGN

UNOFF

BGN

Mohave

Santa Cruz

Graham

Maricopa

Yavapai

Pinal

Pinal

Yuma

VARIANT

BGN 1941

VARIANT

Cochise

Cochise
COORDINATE

$351042 N 1121558$

$361816 \mathrm{~N} 1121703 \mathrm{~W}$

$351118 N 1113512 \mathrm{~W}$

$320322 N 1103759 \mathrm{~W}$

$364750 \mathrm{~N} 1135600 \mathrm{~W}$

353452N1103729W

$344028 \mathrm{N1124714 \textrm {W }}$

$343047 \mathrm{~N} 1123133 \mathrm{~W}$

333848 N1120139W

$350129 N 1130712 \mathrm{~W}$

313401N1110233W

$364936 \mathrm{~N} 1101330 \mathrm{~W}$

331218 N1104830W

$314830 \mathrm{~N} 1112429 \mathrm{~W}$

312635 N1112509W

$335457 N 1090312 \mathrm{~W}$

$321326 \mathrm{~N} 1105458 \mathrm{~W}$

$351441 N 1113617 \mathrm{~W}$

351441N1113617W

$351425 \mathrm{~N} 1113550 \mathrm{~W}$

$351433 \mathrm{~N} 1113402 \mathrm{~W}$

$351345 \mathrm{~N} 1113453 \mathrm{~W}$

351338 N1113558W

$330130 \mathrm{~N} 1102258 \mathrm{~W}$

344534 N1120905

340236N1091754h

$330740 \mathrm{~N} 1105826 \mathrm{~W}$

353001 N1100500W

$325750 \mathrm{~N} 1095833 \mathrm{~W}$

$321418 \mathrm{~N} 1105114 \mathrm{~W}$

332751N1115920W

332814 N1115455W

$20022 N 1092416 \mathrm{~W}$

321347 N1093020W

$352826 \mathrm{~N} 1140348 \mathrm{~W}$

$352744 N 1140359 \mathrm{~W}$

333754 N1140527W

$332003 N 1111638 \mathrm{~W}$

$352156 \mathrm{~N} 1103037 \mathrm{~W}$

$365742 \mathrm{~N} 1100439 \mathrm{~W}$

335937N1110119W

$341220 \mathrm{~N} 1124649 \mathrm{~W}$

$361952 N 1105527 \mathrm{~W}$

360428 N1092034W

$314327 N 1105618 \mathrm{~W}$

$341419 N 1112032 \mathrm{~W}$

353447 N11 43935W

$335344 N 1115856 \mathrm{~W}$

343949 N1132451

$361942 N 1105525$

$364716 N 1124947 \mathrm{~W}$

$350129 N 1142214 \mathrm{~W}$

$313116 \mathrm{N1104322W}$

$331338 \mathrm{~N} 1093456 \mathrm{~W}$

$332713 N 1114821 \mathrm{~W}$

335B52N1122558W

$325246 \mathrm{~N} 1113359 \mathrm{~W}$

$325333 \mathrm{~N} 1113400 \mathrm{~W}$

323944N1144453W

314107 N1094111W

$\begin{array}{cc}\text { SOURCE } & \text { ELEV } \\ \text { COORDINATE } & \text { FT MAP NAME }\end{array}$

McLellan Reservoir

7420 King Arthur Castle Babbitt Wash

$364601 N 1135145 W$

3440 Vail

Elbow Canyon

Tovar Mesa West

Smith Mesa

Iron Springs

1450 Union Hills

5300 Anvil Rock

3257 Tubac

El Capitan Mtn

Fresno Wash

Escudilla Mtn 
NATIONAL GAZETTEER--ARIZONA 1986

FEATURE NAME

Elfrida Elementary School

Elgin

Elgin Elementary Schoo

Elgin Park

Elgin School

Elgo Dam

El Grande Shopping Center

El ise Well

Eli Tanks

Elk Canyon

Elk Cienega

Elk Detention

Elkhart

Elkhart Mine

Elk Hill

See Two, Hill

Elk Hill

Elkhorn Ranch

Elkhorn Tank

Elkhorn Tank

Elkhorn Tank

Elk Meadows

Elk Ridge

Elks Hospital

Elks Park

Elk Spring

Elk Spring

Elk Spring

Elk Spring Cienega

Elk Springs Draw

Elks Well

Elk Tank

Elk Tank

Elk Tank

Elk Tank

Elk Tank

Elk Tank

Elk Tank

Elk Tank

Elk Tank

Elk Tank

Elk Tank

Elk Trick Tank

Ella Mae Well

Ellas Draw

Ellinwood Ranch

Elliott, Mount

Elliott Canyon

Elliott Park

Elliott Spring

Elliott Tank

Ellis Lateral

Ellison Cabin Two hundred

eighty three Trail

Ellison Creek

Ellison Creek

Moore Creek

Ellison Creek Tank

Ellison Mine

Ellison Place

E11ison Ranch

Ellis Ranch

Ell is Ranch

Ell is Wiltbank Dam

E1l is Wiltbank Reservoir

Ellsworth Hills

Ellsworth Park

Ellsworth Point

Ellsworth Ranch

Ellsworth Irick Tank

Ellsworth Trick Tank

\section{FEATURE}

CLASS

STATUS

COUNTY

COORDINATE

$\begin{array}{llll}\text { school } & \text { UNOFF } & \text { Cochise } & 314110 \text { N1094045W } \\ \text { ppl } & \text { BGN } & \text { Santa Cruz } & 313935 N 1103129 \mathrm{~W} \\ \text { school } & \text { UNOFF } & \text { Santa Cruz } & 313944 N 1103157 \mathrm{~W} \\ \text { park } & \text { ADMIN } & \text { Maricopa } & 331748 \mathrm{~N} 1115016 \mathrm{~W} \\ \text { school } & \text { UNOFF } & \text { Santa Cruz } & 313944 \text { N1113126W }\end{array}$

school UNOFF Santa Cruz 313944N1113126W

dam UNOFF Gila 332312N1102548W

$\begin{array}{llll}\text { locale } & \text { UNOFF } & \text { Pima } & 321220 N 1105412 \mathrm{~W} \\ \text { well } & \text { UNOFF } & \text { Pinal } & 323145 \mathrm{~N} 1105128 \mathrm{~W} \\ \text { reservoir } & \text { BGN } & \text { Coconino } & 350229 \mathrm{~N} 1111519 \mathrm{~W} \\ \text { valley } & \text { BGN } & \text { Apache } & 335059 \mathrm{~N} 1094437 \mathrm{~W} \\ \text { flat } & \text { BGN } & \text { Apache } & 334357 \mathrm{~N} 1093328 \mathrm{~W} \\ \text { reservoir } & \text { BGN } & \text { Gila } & 331219 \mathrm{~N} 1104206 \mathrm{~W} \\ \text { locale } & \text { BGN } & \text { La Paz } & 335131 \mathrm{N1132645 \textrm {W }} \\ \text { mine } & \text { UNOFF } & \text { Mohave } & 352517 \mathrm{~N} 1141109 \mathrm{~W} \\ & \text { VARIANT } & & \\ \text { summit } & & \text { Coconino } & 350523 \mathrm{~N} 1120400 \mathrm{~W}\end{array}$

summit

summit BGN

reservoir

reservoir $B G N$

lat

liff $\quad B G N$

park ADMIN Maricop

Gila

spring

spring

flat

valley

well

reservoir

reservoir

reservoir $B G$

reservoir $B G N$

reservoir $B G N$

reservoir

reservoir $B G$

reservoir $B G$

reservoir $B G$

reservoir $B G N$

reservoir $B G$

reservoir

well

valley

locale

BGN Apache

Coconino

Apache

Navajo

Yavapai

Apache

Coconino

Coconino

Coconino

Coconino

Coconino

Coconino

Coconino

Coconino

Coconino

Coconino

Gila

Apache

Apache

Gila

$\begin{array}{llll}\text { summit } & \text { BGN } & \text { Yavapai } & 342811 N 1122008 \mathrm{~W} \\ \text { valley } & \text { BGN } & \text { Coconino } & 350604 N 1111310 \mathrm{~W} \\ \text { park } & \text { ADMIN } & \text { Pinal } & 325245 \mathrm{~N} 1114456 \mathrm{~W} \\ \text { spring } & \text { BGN } & \text { Coconino } & 350042 \mathrm{~N} 1111941 \mathrm{~W} \\ \text { reservoir } & \text { BGN } & \text { Coconino } & 350318 \mathrm{~N} 1111624 \mathrm{~W} \\ \text { canal } & \text { BGN } & \text { Yuma } & 323414 \mathrm{~N} 1144711 \mathrm{~W} \\ \text { trail } & \text { UNOFF } & \text { Graham } & 330104 \mathrm{~N} 1101915 \mathrm{~W} \\ & & & \\ \text { stream } & \text { BGN } & \text { Navajo } & 340005 \mathrm{~N} 1104307 \mathrm{~W} \\ \text { stream } & \text { BGN } & \text { Gila } & 342109 \mathrm{~N} 1111646 \mathrm{~W}\end{array}$

$352615 \mathrm{~N} 1120334 \mathrm{~W}$

$314910 \mathrm{~N} 1113217 \mathrm{~W}$

$343215 N 1110654 \mathrm{~W}$

344456 N1111BO2W

$344601 N 1112413 \mathrm{~W}$

$350330 \mathrm{~N} 1113339 \mathrm{~W}$

$350602 \mathrm{~N} 1121343 \mathrm{~W}$

$321409 \mathrm{~N} 1110029 \mathrm{~W}$

$332851 \mathrm{~N} 1115904 \mathrm{~W}$

$331740 \mathrm{~N} 1104246 \mathrm{~W}$

$340528 \mathrm{~N} 1094021 \mathrm{~W}$

350439 N1112706W

340551 N1094023W

$341018 \mathrm{~N} 1095333 \mathrm{~W}$

$344148 N 1120738 \mathrm{~W}$

$341113 \mathrm{~N} 1094104 \mathrm{~W}$

$343557 \mathrm{N1111146 \textrm {W }}$

$344435 N 1105404 \mathrm{~W}$

$344713 \mathrm{~N} 1112056 \mathrm{~W}$

$344805 \mathrm{~N} 1113145 \mathrm{~W}$

$345056 \mathrm{~N} 1112921 \mathrm{~W}$

350843 N1121610W

$352150 \mathrm{~N} 1114722 \mathrm{~W}$

$352345 \mathrm{~N} 1115335 \mathrm{~W}$

352416 N1121959W

$360740 \mathrm{~N} 1130220 \mathrm{~W}$

$331547 N 1104416 \mathrm{~W}$

$354242 N 1093311 \mathrm{~W}$

$314232 \mathrm{~N} 1110927 \mathrm{~W}$

$341237 \mathrm{~N} 1110158 \mathrm{~W}$

313928 N1110906W

$42109 \mathrm{~N} 1111646 \mathrm{~W}$

$340207 N 1104525 \mathrm{~W}$

$34082 B N 1110439 \mathrm{~W}$

$330035 \mathrm{~N} 1101854 \mathrm{~W}$

$334815 \mathrm{~N} 1105017 \mathrm{~W}$

$322052 \mathrm{~N} 1100148 \mathrm{~W}$

$331928 \mathrm{~N} 1105440 \mathrm{~W}$

$340524 \mathrm{~N} 1092812 \mathrm{~W}$

$\begin{array}{ll}\text { Apache } & 340524 N 1092812 W \\ \text { Navajo } & 341231 N 1100118 W\end{array}$

$\begin{array}{llll}\text { reservoir } & \text { BGN } & \text { Apache } & 340524 N 1092812 \mathrm{~W} \\ \text { summit } & \text { BGN } & \text { Navajo } & 341231 \mathrm{N1100118W} \\ \text { park } & \text { ADMIN } & \text { Maricopa } & 332443 \mathrm{~N} 1124840 \mathrm{~W}\end{array}$

summit BGN Navajo 341821N1102150W

locale UNOFF Pinal 331126N1112259W

reservoir BGN Navajo $342802 \mathrm{N1} 104346 \mathrm{~W}$

reservoir BGN Coconino 343545 N1105612W $\begin{array}{ccc}\text { SOURCE } & \text { ELEV } \\ \text { COORDINATE } & \text { FT MAP NAME }\end{array}$

Elfrida

Elgin

Chandler

Elgin

Natural Corral

2530 Tucson

Oracle

Elliott Canyon

Marshall Butte

Maverick

Mescal Warm Spring

2000 Socorro Peak

Chloride

7160 Howard Mesa

3691 Baboquivari Peak

Leonard Canyon

Turkey Mtn

Hutch Mtn

Lower Lake Mary

May Tank Pocket

Cat Mountain

Tempe

Cutter

Horseshoe Cienega

Ashurst Lake

Horseshoe Cienega

$340924 N 1094615 \mathrm{~W}$

Lakes ide

Hickey Mountain

Boundary Butte

Blue Ridge Reservoir

Hamilton Crossing

Jaycox Mtn

Stoneman Lake

Hutch Mtn

McLellan Reservoir

Wing Mountain

Moritz Ridge

Cataract Tank

Vulcans Throne

Cutter

6335 Ganado

Saucito Mtn

Diamond Butte

$350036 \mathrm{~N} 1111946 \mathrm{~W}$

6980 Poland Junction

Anderson Canyon

Casa Grande East

Elliott Canyon

6112 Elliott Canyon

Gadsden

Mt Turnbull

$340527 N 1104835 \mathrm{~W}$

Oak Creek Ranch

Payson North

Gentry Mtn

Diamond Butte

Mt Turnball

Sombrero Peak

Muskhog Mountain

5059 Pinal Ranch

Greer

B353 Greer

Show Low South

Mesa

6948 Clay Springs

Magma

Hanks Draw

Grama Draw 


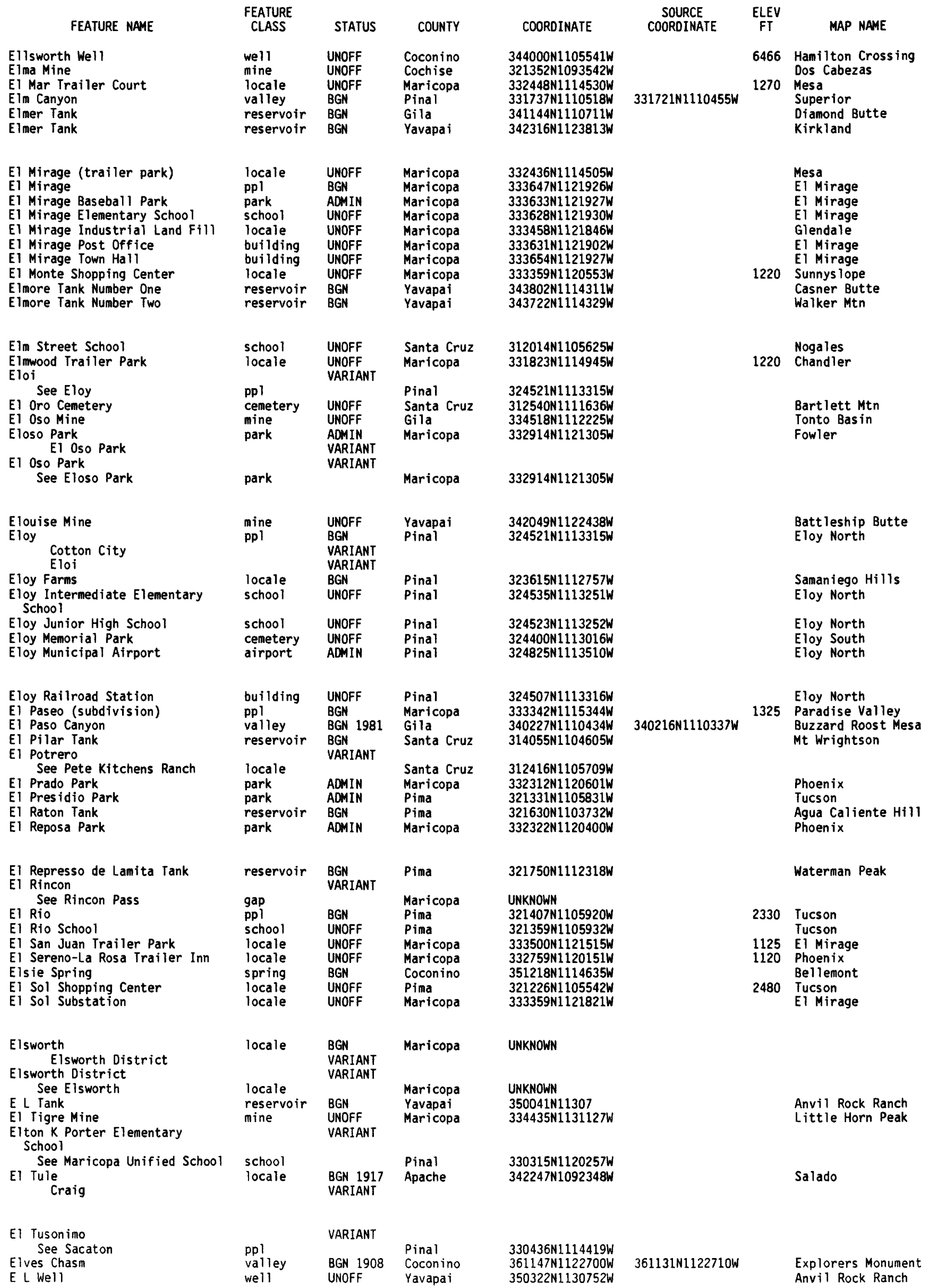


NATIONAL GAZETTEER--ARIZONA 1986

\section{FEATURE NAME}

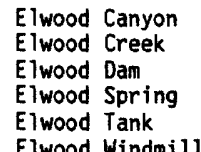

Elwood Windmill

Ely Tank

Emerald Acres Number Two Subdivision Water Retention Bas in

Emerald Acres Subdivision Number Two Mini Park

Emerald Gulch

Emerald Isle Mine

Emerald Point

Emeraid Spring

Emerson School

Emerson School

Emerson School

Emery

Emery Falls

See Columbine Falls

Emery Park

Emery Park Post Office

Emigrant Canyon

Emigrant Canyon Trail Two

Hundred Fiftyfive

Emigrant $\mathrm{Hills}$

Emigrant Pass

Emigrant Springs

Emigrant Tank

Emika

Emita

Emily Gray Junior High School

Emily Pond

Eminence Break

Emita See Emika

Emma, Mount

Emmanual Mission

See Emmanuel Mission

Emmanuel Mission

Emmanual Mission

Emmett Hill

Emmett Spring

Emmett Wash

Emperor and Duchess Mine

Empey Pond

Empire Flat

Empire Gulch

Empire Mine

Empire Mountains

Empire Ranch

Empire Ranch Airport

\section{Empire School}

Empire Well

Emsco Mine

Encanto Lagoon

Encanto Park

Encanto School

Encinas Spring

See Coches Spring

Encinas Tank

Encinoso Picnic Area

Encinos Wash, Los

Encino Tank

End Canyon

Enders Mine

Endfield Tank

FEATURE
CLASS

STATUS

COUNTY

$\begin{array}{ll}\text { valley } & \text { BGN } \\ \text { stream } & \text { BGN } \\ \text { dam } & \text { UNOFF } \\ \text { spring } & \text { BGN } \\ \text { reservoir } & \text { BGN } \\ \text { locale } & \text { BGN }\end{array}$

reservoir $B G$

reservoir BGN

valley

mine

BGN

cliff

UNOFF

Graham

Graham

Graham

Gila

Graham

Graham

$$
\text { sp }
$$

Coconino

Coconino

Maricopa

Cochise

Mohave $333402 \times 10955$ $332005 N 1105447 \mathrm{~W}$ $333230 \mathrm{~N} 1095247 \mathrm{~W}$ 333301 N1095328

mine UNOFF Santa Cruz 312204N1104134W park ADMIN

$\begin{array}{llll}\text { spring } & \text { BGN } & \text { Graham } & 324208 \text { N1095306W } \\ \text { school } & \text { UNOFF } & \text { Maricopa } & 3325231115102 \mathrm{~W} \\ \text { school } & \text { UNOFF } & \text { Maricopa } & 332 B 0711120350 \mathrm{~W} \\ \text { school } & \text { UNOFF } & \text { Coconino } & 351201 \text { N1113906W } \\ \text { pp1 } & \text { BGN } & \text { Graham } & 330411 \text { N1100059W } \\ \text { falls } & \text { VARIANT } & & \\ \text { ppl } & \text { BGN } & \text { Mohave } & 360534 N 1135517 \mathrm{~W} \\ \text { building } & \text { UNOFF } & \text { Pima } & 320828 N 1105719 \mathrm{~W} \\ \text { valley } & \text { BGN } & \text { Cochise } & 320825 \text { N1105741W } \\ \end{array}$
$354057 \mathrm{~N} 1112220 \mathrm{~W}$

$332317 \mathrm{N1114755 \textrm {W }}$

$332317 \mathrm{~N} 1114755 \mathrm{~W}$

$314302 \mathrm{~N} 1100242 \mathrm{~W}$ $352144 \mathrm{~N} 1141130 \mathrm{~W}$ $361808 \mathrm{~N} 1121934 \mathrm{~W}$

$314037 \mathrm{~N} 1100434 \mathrm{~W}$ $333232 \mathrm{~N} 1095245 \mathrm{~W}$

SOURCE
COORDINAT ELEV MAP NAME

\section{$333036 \mathrm{~N} 1095239 \mathrm{~W}$} $333032 \mathrm{~N} 1095238 \mathrm{~W}$

\section{Elwood Canyon Elwood Canyon Elwood Canyon Pinal Ranch \\ 5811 Elwood Canyon \\ Elwood Canyon}

Winona

Wupatki NE

Mesa

Mesa

Tombs tone

Cerbat

King Arthur Castle

Webb Peak

Mesa

Phoen ix

Flagstaff West

Geronimo

Tucson

$\begin{array}{ll}320421 \text { N1092044W } & \begin{array}{l}\text { Tucs on } \\ \text { Bowie Mtn North }\end{array}\end{array}$

trail UNOFF Cochise 320555N1092126W

summit BGN Cochise 321016N1092321W

gap BGN Cochise 320456N1092029W

spring BGN Apache 351027N1091940W

reservoir BGN Cochise 320653N1092217W

locale BGN 1941 Pima 322600N1122909W

school VARIANT Pima 321709N1104520W

reservoir BGN Mohave 365033N1132555W

cliff BGN Coconino 362917N1114351W

locale VARIANT Pima 322600N1122909W

summit BGN Mohave 361552N1131015W

church VARIANT Apache 364808N1092348W

church BGN Apache 364808N109234BW

$\begin{array}{lll} & \text { VARIANT } \\ \text { VARIANT } & & \\ \text { summit } & \text { BGN } & \end{array}$

spring BGN Coconino 364240N1115229W

$\begin{array}{llll}\text { spring } & \text { BGN } & \text { Coconino } & 364240 N 1115229 \\ \text { stream } & B G N & \text { Coconino } & 363848 \text { N1114859W }\end{array}$

$\begin{array}{lll}\text { stream } & \text { BGN } & \text { Coconino } \\ \text { mine } & \text { UNOFF Pima } & 360126 \mathrm{~N} 1115053 \mathrm{~W}\end{array}$

$\begin{array}{llll}\text { mine } & \text { UNOFF } & \text { Pima } & 320126 N 1115053 \mathrm{~W} \\ \text { lake } & \text { BGN } & \text { Mohave } & 362435 N 1133422 \mathrm{~W}\end{array}$

$\begin{array}{llll}\text { lake } & \text { BGN } & \text { Mohave } & 362435 N 1133422 W \\ \text { flat } & \text { BGN } & \text { Yuma } & 341322 N 1141137 W\end{array}$

valley BGN Pima $314752 \mathrm{N1103532W}$

summit BGN Pima 315301N1103B28W

locale UNOFF Pima 314707N1103830W

airport ADMIN Pima 314737 N1103750W

$364303 N 1115221 W$

Cochise Head

Bowie Mtn North

Cochise Head

Sanders

Cochise Head

Cimarron Peak

Sabino Canyon

Hole-N-Wall Canyon

Shinumo Altar

7702 Mount Logan

Walker Butte

Emmett Hill

\begin{tabular}{|c|c|c|c|}
\hline $\begin{array}{l}\text { school } \\
\text { well } \\
\text { mine } \\
\text { lake } \\
\text { park } \\
\text { school }\end{array}$ & $\begin{array}{l}\text { UNOFF } \\
\text { UNOFF } \\
\text { UNDFF } \\
\text { BGN } \\
\text { ADMIN } \\
\text { UNOFF }\end{array}$ & $\begin{array}{l}\text { Pima } \\
\text { Pima } \\
\text { Gila } \\
\text { Maricopa } \\
\text { Maricopa } \\
\text { Maricopa }\end{array}$ & $\begin{array}{l}314652 \mathrm{~N} 1104218 \mathrm{~W} \\
314657 \mathrm{N1104054W} \\
334651 \mathrm{N1103128W} \\
332831 \mathrm{N1120517W} \\
332839 \mathrm{N1120530W} \\
332917 \mathrm{N1120523W}\end{array}$ \\
\hline $\begin{array}{l}\text { spring } \\
\text { reservoir } \\
\text { park }\end{array}$ & $\begin{array}{l}\text { VARIANI } \\
\text { BGN } \\
\text { ADMIN }\end{array}$ & $\begin{array}{l}\text { Pima } \\
\text { Pima } \\
\text { Coconino }\end{array}$ & $\begin{array}{l}313122 \mathrm{~N} 1112425 \mathrm{~W} \\
313050 \mathrm{~N} 1112315 \mathrm{~W} \\
345532 \mathrm{~N} 1114405 \mathrm{~W}\end{array}$ \\
\hline $\begin{array}{l}\text { stream } \\
\text { reservoir } \\
\text { valley } \\
\text { mine } \\
\text { reservoir }\end{array}$ & $\begin{array}{l}\text { BGN } \\
\text { BGN } \\
\text { BGN } \\
\text { UNOFF } \\
\text { BGN }\end{array}$ & $\begin{array}{l}\text { Pima } \\
\text { Yavapai } \\
\text { Coconino } \\
\text { Gila } \\
\text { Gila }\end{array}$ & $\begin{array}{l}313528 \mathrm{~N} 1113319 \mathrm{~W} \\
345507 \mathrm{N1} 131035 \mathrm{~W} \\
364118 \mathrm{N1104945W} \\
334846 \mathrm{N1} 103032 \mathrm{~W} \\
334715 \mathrm{~N} 1100800 \mathrm{~W}\end{array}$ \\
\hline
\end{tabular}

$314654 N 1104427 W$

Emmett $\mathrm{Hill}$

Comobabi

Poverty Spring

Cross Roads

Spring Water Canyon

Duquesne

Mount Fagan

Empire Ranch

4660 Empire Ranch

Empire Ranch

Empire Ranch

Mule Hoof Bend

Phoenix

Phoenix

Phoenix

Wilbur Canyon

Munds Park

$313357 N 1113735 \mathrm{~W}$

Presumido Peak

Sunrise Peak

Inscription Hse Ruin

Mule Hoof Bend

Cone Butte 
NATIONAL GAZETTEER--ARIZONA 1986

\section{FEATURE NAME}

Escalante Wash

Escapule Mine

Escarpada, Mesa Fortress $\mathrm{Hill}$

Es-cim-en zeen Spring See Eskiminzin Spring Escobedo Park

Escondido Park

Escondido Spring

Escondido Spring

Escondido Tank

Escondido Wash

Escondido Wash

Escondido Well

Escondido Well

Escudilla Mountain

$$
\text { Escudillo }
$$

Escudilla Mountains Eskadere Mountains

Escudilla Mountain Tank Escudillo

See Escudilla Mountain

Esitty Valley

Eskadere Mountains

See Escudilla Mountains

Eskimazene Ranch

Eskimenzene Spring

See Eskiminzin Spring

Eskimenzin Spring See Eskiminzin Spring

Eskiminzin Fort Rock

Eskiminzin Spring

Es-cim-en zeen Spring

Eskimenzene Spring

Eskimenz in Spring

Eskiminzin Wash

Eskimo Tank

Eskimo Wel 1

Esmond

Espanto Mountain

Espee Camp

Espejo Butte

Espejo Creek

Espejo Spring

Janus Spring

Esperanza, Rancho del

Esperanza Mill

Esperanza Pit

Esperanza Tailings Dam

Esperanza Tank

Esperanza Wash

Esperanza Well

Esperero Canyon

Esperero Wash

Espero

See Sprucedale

Espil Ranch

Espinosa Tank

Espinosa Well

Espiritu Canyon

Espiritu Well

Esplanada (subdivision)

Esplanade Bench

Esplins Corra

Esplin Tank

Esplin Twin Tanks

See Twin Tanks

Espuma, Monte de la

Ess Creek

Ess Spring

Estados de La Mancha II

(subdivision)
FEATURE
CLASS

STATUS

COUNTY

stream

mine

cliff

BGN

UNOFF Cochise

VARIANT

$\begin{array}{lll} & \text { VARIANT } & \\ \text { spring } & & \text { Pinal } \\ \text { park } & \text { AOMIN } & \text { Maricopa } \\ \text { park } & \text { ADMIN } & \text { Maricopa } \\ \text { spring } & \text { BGN } & \text { Pima } \\ \text { spring } & \text { BGN } & \text { Yavapai } \\ \text { reservoir } & \text { BGN } & \text { Maricopa } \\ \text { arroyo } & \text { BGN } & \text { Pima } \\ \text { stream } & \text { BGN } & \text { Pima }\end{array}$

UNOFF

Santa Cruz

well

summit

UNOFF

Apache

VARIANT

summit

BGN 1917

BGN

summit

valley

summit

BGN

VARIANT

Apache

Apache

Apache

Navajo

Apache

locale

UNOFF

VARIANT

spring

spring

pillar

spring

VARIANT

BGN 1930

BGN 1979

VARIANT

VARIANT

VARIANT

stream BGN 1979 Pinal 325550N1104413W

reservoir

well

locale

summit

locale

summit

stream

spring

UNOFF Navajo

BGN Pima

BGN Maricopa

BGN Coconino

BGN 1932 Coconino

BGN 1932 Coconino

BGN 1915 Coconino

VARIANT

$\begin{array}{lll}\text { locale } & \text { UNOFF } & \text { Pima } \\ \text { mine } & \text { UNOFF } & \text { Pima } \\ \text { mine } & \text { UNOFF } & \text { Pima } \\ \text { dam } & \text { UNOFF } & \text { Pima } \\ \text { reservoir } & \text { BGN } & \text { Pima } \\ \text { stream } & \text { BGN } & \text { Pima } \\ \text { wel1 } & \text { UNOFF } & \text { Pima } \\ \text { valley } & \text { BGN } & \text { Pima } \\ \text { stream } & \text { BGN } & \text { Pima } \\ & \text { VARIANT } & \end{array}$

locale

locale UNOFF Coconino 352643N1113629W

reservoir BGN Pima $314 B 11 N 1112522 \mathrm{~W}$

well UNOFF Pima 31482BN1112431W

valley BGN Pima 321B53N1102B34W

well UNOFF Pima 321535N1102B51W

ppl BGN Maricopa 332109N1115049W

bench 1975 Coconino 361200N1130500W

locale BGN Mohave 364621N1125711W

reservoir BGN Mohave $362025 \mathrm{~N} 1133456 \mathrm{~W}$

reservoir VARIANT Mohave 363830N1132616W

summit BGN 1917 Pinal UNKNOWN

stream

spring

ppl

$\begin{array}{lll}\text { BGN } & \text { Apache } & 334003 N 1093138 \mathrm{~W} \\ \text { BGN } & \text { Apache } & 334049 \mathrm{~N} 109330 \mathrm{BW}\end{array}$

BGN 1917 Maricopa

reservoir BGN

$325525 N 1103745 W$

Dudleyville Dry Lake NW Dry Lake NW Tucson SE

Brandenburg Mtn Brandenburg Mtn

1835 Mobile

5790 Howard Spring

Desert View

360703N1114B00W Desert View

Avra

Esperanza Mill

Batamote Hills

Twin Buttes

Esperanza Mill

Esperanza Mill

Esperanza Mill

$31530 \mathrm{BN} 1111000 \mathrm{~W}$

Sabino Canyon

$322259 N 1105043 \mathrm{~W}$

Sabino Canyon

\begin{tabular}{|c|c|c|}
\hline $321315 \mathrm{~N} 1102 \mathrm{~B} 49 \mathrm{~W}$ & $\begin{array}{l}1205 \\
5336\end{array}$ & $\begin{array}{l}\text { 0'Leary Peak } \\
\text { Fresno Wash } \\
\text { Fresno Wash } \\
\text { Soza Canyon } \\
\text { Soza Canyon } \\
\text { Chandler } \\
\text { Havasupai Point } \\
\text { Maroney Well } \\
\text { Wildcat Ranch }\end{array}$ \\
\hline $33404 \mathrm{BN} 1093307 \mathrm{~W}$ & 1350 & $\begin{array}{l}\text { Maverick } \\
\text { Maverick } \\
\text { Paradise valley }\end{array}$ \\
\hline
\end{tabular}




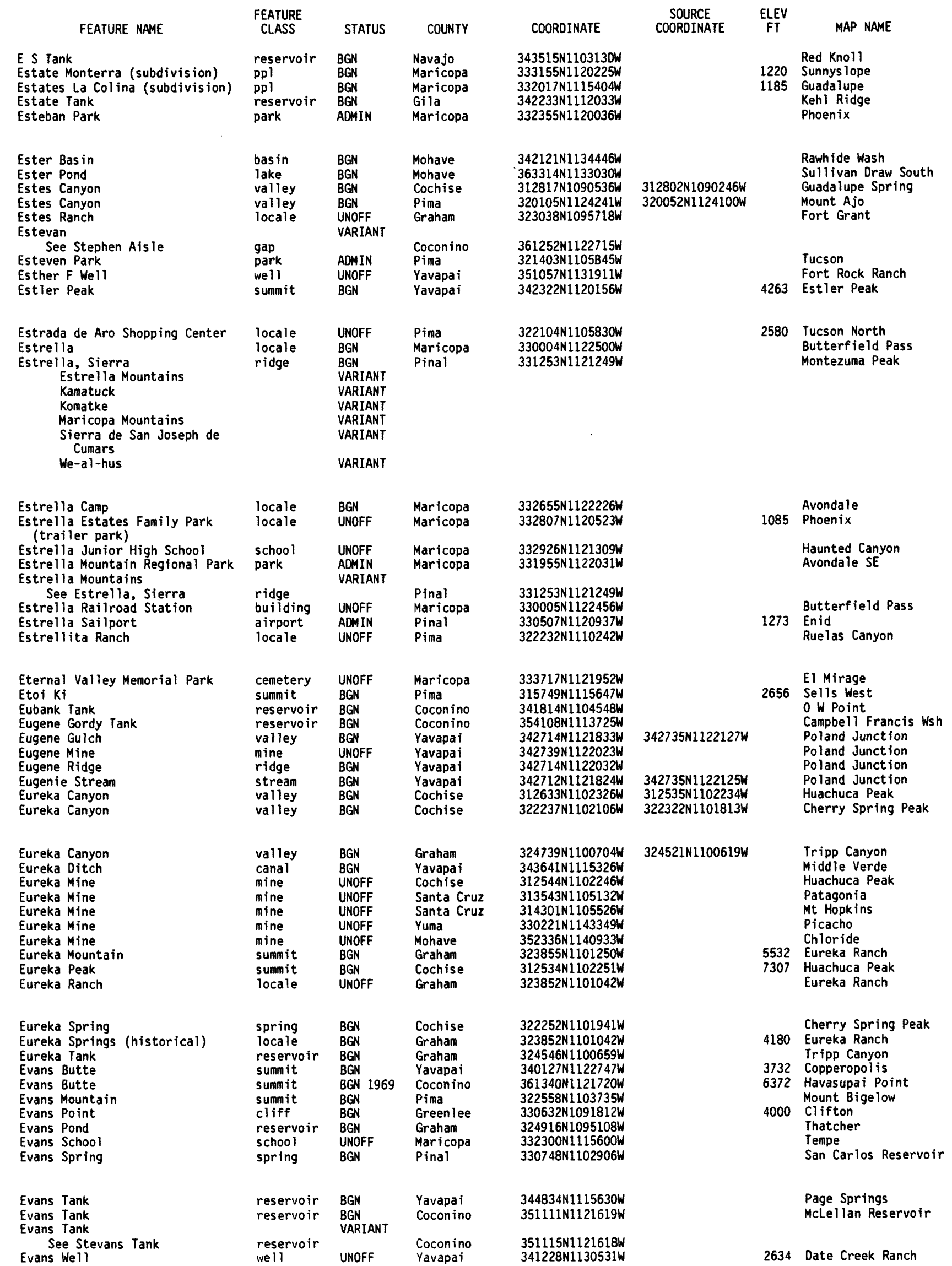


MATIONAL GAZETTEER--ARIZONA 1986

FEATURE NAME

Evelen Charco Tank

Evening Star Mine

Evening Star Mine

Everett Tank

Everett Windmill

\section{Evergreen Cemetery}

Evergreen Cemetery

Evergreen Park

Evergreen School

Evergreen Station

Evergreen Substation

Evergreen Villa Mobile Home Park

Everhart Ranch

Evolution Amphitheater

Ewe 11 County See Cochise County

Ewing Ranch

Excalibur

Excelsior Mine

Exchange Tank

Excursion Mine

Explorers Monument

Marcos Monument

Explorers Pass

Explorers Rock

See Fire Mountain

Exposed Reef Mine

Ez-Kim-In-Zin Picnic Area

\section{FEATURE \\ CLASS}

STATUS

COUNTY

Pima

reservoir

mine

mine

reservoir

UNOFF

UNOFF

BGN

well

UNOFF

cenetery UNOFF

cemetery

park

school

locale

locale

locale

locale

bas in

civil

locale

summit

reservoir

mine

summ it

valley

UNOFF

ADMIN

UNOF

BGN

UNOFF

UNOFF

UNOFF

BGN 1908

Yuma

Maricopa

Coconino

Santa Cruz

Cochise

Pima

Maricopa

Pinal

Maricopa

Maricopa

Maricopa

Santa Cruz

Coconino

VARIANT

UNOFF

BGN 1908

UNOFF

BGM

UNOFF

UNOFF
BGN 1908

VARIANT

BGN

Cochise

Santa Cruz

Coconino

Mohave

Mavajo

Gila

Coconino

Yuma

COORDINATE

321540N1124450W

$331716 \mathrm{~N} 1135846 \mathrm{~W}$

$334202 \mathrm{~N} 1131251 \mathrm{~W}$

$350654 N 1115355 \mathrm{~W}$

$312224 \mathrm{N1} 103826 \mathrm{~W}$

312550 N1095321W

$321546 \mathrm{~N} 1105857 \mathrm{~W}$

$332528 \mathrm{~N} 1115015 \mathrm{~W}$

$325303 \mathrm{N1} 114410 \mathrm{~W}$

$333011 \mathrm{N1114843 \textrm {W }}$

$333003 \mathrm{~N} 1114740 \mathrm{~W}$

331942N1115113W

$313439 N 1103627 \mathrm{~W}$

$361300 \mathrm{~N} 1122250 \mathrm{~W}$

315555 N $1094430 \mathrm{~W}$

$313330 \mathrm{N1} 103143 \mathrm{~W}$

$361545 N 1121515 \mathrm{~W}$

354807 N1141149W

$342835 \mathrm{~N} 1102350 \mathrm{~W}$

$341150 \mathrm{N1} 112411 \mathrm{~W}$

$361221 \mathrm{N1} 122642 \mathrm{~W}$

$335500 N 1142845 W$

VARIANT

sumrit

mine

park
Mohave

UNOFF

ADMIN
Santa Cruz

$354059 \mathrm{N1} 143844 \mathrm{~W}$

$312940 \mathrm{N1} 104450 \mathrm{~W}$

$321710 \mathrm{NII11} 1007 \mathrm{~W}$

$\begin{array}{cc}\text { SOURCE } & \text { ELEV } \\ \text { COORDINATE } & \text { FT }\end{array}$

MAP NAME

Sikort Chuapo

Kofa Butte

Little Horn Peak

Sycamore Point

Duquesne

Bisbee

Tucson North

Mesa

Casa Crande East

Sawik Mountain

Sawik Mountain

1210 Chandler

O'Donnell Canyon

Explorers Monument

O' Donnell Canyon

7051 King Arthur Castle

Burnt Mill Ranch

Aripine

North Peak

Explorers Monument

Imperial Reservoir

Harshaw

Avra
Faber Canyon

Faber Spring

Face Mountain

Face Mountain

See Montezuma Head

Face Rock

Facing Red Points

Faculty Springs

Fagan, Mount

Fain Mountain

Fain Spring

Fain Tank

Fain Tank

Fairbank

Fairbank Railroad Station

Fairbanks Park

Fairchild Draw

Fairchild Ranch

Fairchild Well

Fair Lanes Village Center

Fair Oaks

Fairview

See Glenbar

Fairview

See Lakeside

Fairview Ranch

Fairview Substation

Fairwood VIII (subdivision)

FAI Seventeen Interchange

Falcon Divide

Falcon Field Airport

Falcon Park

Falcon Substation

Falcon Valley

\begin{tabular}{|c|c|c|c|}
\hline $\begin{array}{l}\text { valley } \\
\text { spring } \\
\text { summit }\end{array}$ & $\begin{array}{l}\text { BGN } \\
\text { BGN } \\
\text { BGN } \\
\text { VARIANT }\end{array}$ & $\begin{array}{l}\text { Pima } \\
\text { Pima } \\
\text { Maricopa }\end{array}$ & $\begin{array}{l}314621 \mathrm{~N} 1105148 \mathrm{~W} \\
314545 \mathrm{~N} 1105128 \mathrm{~W} \\
330829 \mathrm{~N} 1131210 \mathrm{~W}\end{array}$ \\
\hline $\begin{array}{l}\text { summit } \\
\text { pillar }\end{array}$ & $B G N$ & $\begin{array}{l}\text { Maricopa } \\
\text { Apache }\end{array}$ & $\begin{array}{l}330915 \mathrm{~N} 1131240 \mathrm{~W} \\
360636 \mathrm{~N} 1092116 \mathrm{~W}\end{array}$ \\
\hline $\begin{array}{l}\text { cape } \\
\text { spring } \\
\text { summit } \\
\text { summit } \\
\text { spring } \\
\text { reservoir } \\
\text { reservoir } \\
\text { ppl } \\
\text { building } \\
\text { park }\end{array}$ & $\begin{array}{l}\text { BGN } \\
\text { BGN } \\
\text { BGN } \\
\text { BGN } \\
\text { BGN } \\
\text { BGN } \\
\text { BGN } \\
\text { BGN } \\
\text { UNOFF } \\
\text { ADMIN }\end{array}$ & $\begin{array}{l}\text { Mavajo } \\
\text { Mohave } \\
\text { Pima } \\
\text { Coconino } \\
\text { Coconino } \\
\text { Yavapai } \\
\text { Coconino } \\
\text { Cochise } \\
\text { Cochise } \\
\text { Cochise }\end{array}$ & $\begin{array}{l}363959 \mathrm{~N} 1100723 \mathrm{~W} \\
351202 \mathrm{N1} 133328 \mathrm{~W} \\
315338 \mathrm{N1} 104334 \mathrm{~W} \\
344906 \mathrm{N1} 113042 \mathrm{~W} \\
344906 \mathrm{~N} 1113126 \mathrm{~W} \\
343030 \mathrm{~N} 1121829 \mathrm{~W} \\
343621 \mathrm{N1} 112123 \mathrm{~W} \\
314254 \mathrm{~N} 1101105 \mathrm{~W} \\
314247 \mathrm{~N} 1101105 \mathrm{~W} \\
313738 \mathrm{~N} 1101945 \mathrm{~W}\end{array}$ \\
\hline $\begin{array}{l}\text { valley } \\
\text { locale } \\
\text { well } \\
\text { locale } \\
\text { locale }\end{array}$ & $\begin{array}{l}\text { BGN } \\
\text { UNOFF } \\
\text { UNOFF } \\
\text { UNOFF } \\
\text { BGN } \\
\text { VARIANT }\end{array}$ & $\begin{array}{l}\text { Coconino } \\
\text { Cochise } \\
\text { Apache } \\
\text { Maricopa } \\
\text { Yavapai }\end{array}$ & $\begin{array}{l}343121 \mathrm{~N} 1110219 \mathrm{~W} \\
313103 \mathrm{~N} 1090751 \mathrm{~W} \\
345552 \mathrm{~N} 1091746 \mathrm{~W} \\
332303 \mathrm{~N} 1115530 \mathrm{~W} \\
344325 \mathrm{~N} 1124540 \mathrm{~W}\end{array}$ \\
\hline $\begin{array}{l}\mathrm{ppl} \\
\mathrm{ppl}\end{array}$ & VARIANT & $\begin{array}{l}\text { Graham } \\
\text { Navajo }\end{array}$ & $\begin{array}{l}325500 \mathrm{~N} 1095127 \mathrm{~W} \\
340916 \mathrm{~N} 1095822 \mathrm{~W}\end{array}$ \\
\hline $\begin{array}{l}\text { locale } \\
\text { locale } \\
\text { ppl } \\
\text { crossing } \\
\text { ridge } \\
\text { airport } \\
\text { park } \\
\text { locale } \\
\text { valley }\end{array}$ & $\begin{array}{l}\text { UNOFF } \\
\text { UNOFF } \\
\text { BGN } \\
\text { UNOFF } \\
\text { BGN } \\
\text { ADMIN } \\
\text { ADMIN } \\
\text { UNOFF } \\
\text { BGN }\end{array}$ & $\begin{array}{l}\text { Cochise } \\
\text { Cochise } \\
\text { Maricopa } \\
\text { Coconino } \\
\text { Pinal } \\
\text { Maricopa } \\
\text { Maricopa } \\
\text { Maricopa } \\
\text { Pinal }\end{array}$ & $\begin{array}{l}312335 \mathrm{~N} 1101351 \mathrm{~W} \\
312149 \mathrm{~N} 1093311 \mathrm{~W} \\
333516 \mathrm{~N} 1121220 \mathrm{~W} \\
351019 \mathrm{~N} 1113941 \mathrm{~W} \\
323636 \mathrm{~N} 1105847 \mathrm{~W} \\
332735 \mathrm{~N} 1114339 \mathrm{~W} \\
332734 \mathrm{~N} 1120756 \mathrm{~W} \\
332804 \mathrm{~N} 1114406 \mathrm{~W} \\
323423 \mathrm{~N} 1105641 \mathrm{~W}\end{array}$ \\
\hline
\end{tabular}

314412N1105109W Helvetia

2041 Yel. Medicine Butte

Spider Rock

Church Rock

Tin Mountain

6186 Mount Fagan

7571 Stoneman Lake

Stoneman Lake

Prescott Valley $S$

Long Valley

Fairbank

Fairbank

Huachuca City

$342647 N 1110424 W$

Leonard Canyon

4654 Paramore Crater

Fairchild Well

Tempe

Smith Mesa

Nicksville

Douglas

1175 Glendale

6860 Flagstaff West

Oracle Junction

1387 Buckhorn

Fowler

Buckhorn

Oracle Junction 
FEATURE NAME

Falcon Valley Ranch

Falfa

Fall Canyon

Fall Canyon

Fall Creek

Fall Creek

Falling Iron Cliffs

Falls, The

Beshnalthdas Cliffs

Fall Spring

Fall Spring

Falls Spring

Falls Springs Wash

Fall Tank

Fan, The

Fan Is land

Farallon (historical)

Faraway Ranch

Faraway Tank

Faraway Wash

Far End Canyon

Farm Aero Airport

Farm Dam Draw Farm Tank Draw

Farm Dam Tank

Farmers Canal

Farm Tank Draw See Farm Dam Draw

Farrar Gulch

See Ferra Gulch

Farrar Peak

See Sawtooth Mountain

Farrar Peak

See Ferra Peak

Farrell Mountain

Farrell Spring

Farre11 Spring

Farrel Mountain

Far Spiral Canyon

Far Tank

Fat Jack Mine

Fatty Tank

Faught Canyon

Faught Ridge

Faught Ridge Lookout

Faulkner Lateral

Favour Tank

Fawn Spring

Fay Canyon

Fay Canyon

Fay Canyon Arch

Feaster

Federal Mine

Feed Box Spring

Feeder Drain Number Five

Feeder Drain Number Four

Feed Trough See Santa Fe Tank

Feed Trough Tank

Fees Junior High School

Felipe Pass

Felton Mountain

Felton Spring

Felton Spring

Felton Tank

Female Canyon

Female Point

Female Rock

Fence Canyon

Fenceline Tank

FEATURE
CLASS

locale

STATUS

COUNTY

COOROINATE

323515N1105623W

locale

valley

valley

valley

stream

strean

cliff

falls

spring

UNOFF

Pinal

BGN Maricopa 332046N1114955W

BGN Mohave 352715 N1140810W

BGN Mohave

Coconino

Greenlee

Coconino

BGN

BGN 1983 Apache

VARIANT

BGN

BGN

Yavapai

Yavapai

spring
spring
stream
reservoir
flat
summit
locale
locale
reservoir
stream

BGN Mohave

BGN Mohave

BGN

BGN

BGN

BGN

UNOFF

BGN

BGN

valley
airport
arroyo

reservoir

canal

arroyo

BGN

ADMIN

BGN

VARIANT

BGN

VARIANT

Mohave

Graham

Graham

Coconino

Santa Cruz

Cochise

Pinal

Pinal

Coconino

Maricopa

Coconino

Coconino

Yuma

Coconino

valley

VARIANT

Yuma

$355559 N 1131934 \mathrm{~W}$

$334411 \mathrm{~N} 1090423 \mathrm{~W}$

$365033 \mathrm{~N} 1113350 \mathrm{~W}$

360947 N $1090302 \mathrm{~W}$

342731N1114709W

343624N1120635W

$352718 \mathrm{~N} 1140814 \mathrm{~W}$

350748 N1135318W

$343146 \mathrm{~N} 1141557 \mathrm{~W}$

$323934 \mathrm{~N} 1092338 \mathrm{~W}$

$322543 \mathrm{~N} 1092118 \mathrm{~W}$

$361527 N 1122148 \mathrm{~W}$

$313055 \mathrm{~N} 1104750 \mathrm{~W}$

$320029 N 1092218$

$323422 \mathrm{~N} 1105855 \mathrm{~W}$

323235N1105608W

$364639 \mathrm{~N} 1104949 \mathrm{~W}$

$332535 \mathrm{~N} 1121004 \mathrm{~W}$

$354307 N 1123653 \mathrm{~W}$

354545N1124320 W

$325625 \mathrm{~N} 1132502 \mathrm{~W}$

$354307 N 1123653 \mathrm{~W}$

333814N1142320W

summit

VARIANT

summit

summ it

spring

spring

summit

valley

reservoir

mine

reservoir

valley

ridge

locale

canal

reservoir

spring

valley

valley

\section{VARIANT}

Yuma

Yuma

BGN

BGN

BGN

BGN

BGN

BGN

UNOFF

Yavapa

BGN Mohave

Navajo

Navajo

Yuma

arch

locale

mine

spring

canal

reservoir

reservoir

school

gap

summit

spring

spring

reservoir

valley

ridge

pillar

valley

reservoir
Coconino

Coconino

Yavapai

Coconino

BGN

BGN

BGN

BGN Yavapai 345434N1115137W

BGN Apache 335930N1090841W

UNOFF Yavapai

BGN Gila

BGN Yuma

BGN Yuma

VARIANT

Coconino

UNOFF

Maricopa

BGN
BGN
BGN
BGN
BGN
BGN
BGN
BGN
BGN
BGN

BGN Coconino
333647N1142128W

333648 N1142129W

$330015 N 1093329 W$

$312616 \mathrm{~N} 1104154 \mathrm{~W}$

$330116 \mathrm{~N} 1093231 \mathrm{~W}$

$350327 \mathrm{~N} 1132820 \mathrm{~W}$

$360932 N 1092734 \mathrm{~W}$

$340935 N 1121923 W$

$331542 \mathrm{~N} 1105500 \mathrm{~W}$

$353041 \mathrm{N1132035 \textrm {W }}$

$340328 \mathrm{~N} 1100320 \mathrm{~W}$

$340355 \mathrm{~N} 1100430 \mathrm{~W}$

323639 N1144426W

350710N1120033W

$362017 \mathrm{N1120903 \textrm {W }}$

$345249 \mathrm{N1} 115033 \mathrm{~W}$

$350908 \mathrm{~N} 1113610 \mathrm{~W}$

$335930 N 1090841 \mathrm{~W}$

343647N1120310W

$335401 N 1101919 \mathrm{~W}$

$340549 \mathrm{~N} 1141817 \mathrm{~W}$

340510N1142001W

$352208 \mathrm{~N} 1123516 \mathrm{~W}$

$352218 \mathrm{N1} 123605 \mathrm{~W}$

$332212 N 1115454 W$

$332305 N 1141828 \mathrm{~W}$

$340052 \mathrm{~N} 1111542 \mathrm{~W}$

$335756 \mathrm{~N} 1111537 \mathrm{~W}$

$340113 \mathrm{~N} 1111542 \mathrm{~W}$

335702 N1101700W

363044 N1092045W

$363222 \mathrm{~N} 1092002 \mathrm{~W}$

$363125 \mathrm{~N} 1092004 \mathrm{~W}$

$362717 \mathrm{~N} 1115616 \mathrm{~W}$

$343105 \mathrm{~N} 1094145 \mathrm{~W}$

\begin{tabular}{|c|c|c|}
\hline $\begin{array}{l}\text { SOURCE } \\
\text { COORDINATE }\end{array}$ & $\begin{array}{c}\text { ELEV } \\
\text { FT }\end{array}$ & $\begin{array}{c}\text { MAP NAME } \\
\text { Oracle Junction }\end{array}$ \\
\hline $\begin{array}{l}352654 N 1140952 W \\
355600 N 1132344 W \\
360824 N 1124546 W \\
334251 N 1090535 W \\
364346 N 111362 B W\end{array}$ & & $\begin{array}{l}\text { Chandler } \\
\text { Chloride } \\
\text { Granite Park } \\
\text { Yunosi Point } \\
\text { Maness Peak } \\
\text { Ferry Swale } \\
\text { Upper Wheatfields }\end{array}$ \\
\hline & & $\begin{array}{l}\text { Horner Mtn } \\
\text { Cherry }\end{array}$ \\
\hline
\end{tabular}

Chloride

Rattlesnake $\mathrm{Hill}$

343247N1141136W Lake Havasu City N Dry Mountain

5085 King Arthur Castle

4000 Patagonia

Cochise Head

Oracle Junction

$323435 N 1110119 W$

Oracle Junction

364625 N1104144W

Chaiyahi Rim SE

354554N1124152W

1030 Fowler

Tin House

Hazen Hole Tank

Aztec NW 
NATIONAL GAZETTEER--ARIZONA 1986 FEATURE NAME FEATURE CLASS STATUS

COUNTY COORDINATE

$\begin{array}{ll}\text { Yavapai } & 351229 \mathrm{~N} 1123917 \mathrm{~W} \\ \text { Mohave } & 351830 \mathrm{~N} 1135422 \mathrm{~W} \\ \text { Coconino } & 362425 \mathrm{~N} 1122238 \mathrm{~W} \\ \text { Mohave } & 361941 \mathrm{~N} 1132052 \mathrm{~W} \\ \text { Coconino } & 362426 \mathrm{~N} 1122030 \mathrm{~W} \\ \text { Greenlee } & 330723 \mathrm{~N} 1091229 \mathrm{~W} \\ \text { Apache } & 340532 \mathrm{~N} 1093425 \mathrm{~W} \\ \text { Navajo } & 341415 \mathrm{~N} 1100755 \mathrm{~W} \\ \text { Yavapai } & 342054 \mathrm{~N} 112154 \mathrm{~W} \\ \text { Yavapai } & 342602 \mathrm{~N} 1120053 \mathrm{~W}\end{array}$

Fence Line Tank Fence Line Tank Fence Point Fence Pond

Fence Ridge

Fence Tank

Fence Tank

Fence Tank

Fence Tank

Fence Tank

Fench Wash

$$
\text { See Finch Wash }
$$

Fen Lake

See Fen Lake

Fen Lake

Fen Lake

Swampy Lake

Fenion Bend

Fennemore

Fennemore Railroad Station

Fenner

Fenner Railroad Station

Fenster School

Fenster School Airport

Ferg Pond

Ferguson Place Windmill

Fergus on Ridge

Fergus on Tank

Ferguson Valley

Ferichs We11

Fern Canyon

See Fern Glen Canyon

Ferndell Spring

Fern Feather Tank

Fern Feather Wash

Fern Glen Canyon

Fern Canyon

Fern Glen Rapids

Fern Mountain

Fern Mountain Tank

Ferno Mesa

Fernow Tank

Ferns Tank

Fernstrom Tank Firstrum Tank

Fern Tank

Fern Tank

Ferosa Canyon

Feroz Terrace

Ferra Gulch

Farrar Gulch

Ferra Peak

See Sawtooth Mountain

Ferra Peak

Farrar Peak

Ferry Swale

See Ferry Swale Canyon

Ferry Swale

Ferry Swale Canyon

Ferry Swale

Festerling Mine

F H Tank

FH-three Tank

Fiber King Mine

Fiddler Camp Spring

Fidel Windmill

Field Canyon

See South Field Canyon

Field Canyon Spring

Field Dam

Field Elementary School

$\begin{array}{ll}\text { reservoir } & \text { BGN } \\ \text { reservoir } & \text { BGN } \\ \text { cliff } & B G N \\ \text { lake } & B G N \\ \text { ridge } & B G N \\ \text { reservoir } & \text { BGN } \\ \text { reservoir } & \text { BGN } \\ \text { reservoir } & \text { BGN } \\ \text { reservoir } & B G N \\ \text { reservoir } & \text { BGN }\end{array}$

VARIANT

stream

lake

lake

bend

locale

building

BGN

uilding

school

airport

locale

ridge

reservoir

well

UNOFF

ADMIN

BGN

BGN

BGN

BGN

UNOFF

VARIANT

valley

spring

reservoir

stream

valley

rapids

summit

reservoir

summit

reservoir

reservoir

reservoir

reservoir

reservoir

valley

bench

valley

BGN

BGN

BGN

BGN 1964

VARIANT

BGN Mohave

BGN 1933 Coconino

Coconino

BGN

BGN

BGN

BGN

VARIANT

BGN

BGN

BGN

BGN

BGN 1980

VARIANT

Coconino

Coconino

Mohave

Pima

Coconino

Mohave

Santa Cruz

Coconino

Yuma

VARIANT

summit

summit

BGN

VARIANT

VARIANT

valley

valley

valley

mine

BGN 1979

BGN 1979

VARIANT

UNOFF

Yuma

Yuma

Coconino

Coconino

Coconino

Cochise

reservoir

reservoir

mine

spring

locale

valley

spring

reservoir

school
BGN Coconino

BGN

UNOFF

BGN

BGN

BGN
BGN

BGN
UNOFF
Coconi

Gila

Graham

Graham

Graham

Coconino

Maricopa
342754N1124139W

361959 N1121B53W

361959 N1121853W

354613N1144153W

$333413 \mathrm{~N} 1122536 \mathrm{~W}$

$333401 \mathrm{~N} 1122535 \mathrm{~W}$

315812N1101350W

315750 N1 $101429 \mathrm{~W}$

$321540 \mathrm{~N} 1105516 \mathrm{~W}$

$321822 \mathrm{~N} 1104 \mathrm{~B} 55 \mathrm{~W}$

$363150 N 1132203 \mathrm{~W}$

342048 N1124358

$345506 \mathrm{~N} 1130205 \mathrm{~W}$

$36310 B N 1134440 \mathrm{~W}$

343331N1124313W

$351802 \mathrm{N1} 134510 \mathrm{~W}$

$361535 \mathrm{~N} 1125505 \mathrm{~W}$

$331712 \mathrm{~N} 1104928$ $350620 \mathrm{~N} 1102904 \mathrm{~W}$ 350143 N1103110W

$361535 \mathrm{~N} 1125505 \mathrm{~W}$

$361529 \mathrm{~N} 1125501 \mathrm{~W}$ $352056 \mathrm{~N} 1114419 \mathrm{~W}$ 352117 N1114410W

352049 N1122749W $350127 N 1115219 \mathrm{~W}$ $363007 \mathrm{~N} 1131413 \mathrm{~W}$

$314013 \mathrm{~N} 1112205 \mathrm{~W}$

$345925 N_{1113959 W}$ $365114 N 1125603 \mathrm{~W}$ $313337 \mathrm{~N} 1102857 \mathrm{~W}$

$361950 \mathrm{~N} 1122450 \mathrm{~W}$

333814 NI 142320W

313230 N1102624W

333945 N1142259W

$333647 \mathrm{~N} 1142128 \mathrm{~W}$

$333648 \mathrm{~N} 1142129 \mathrm{~W}$

$365400 \mathrm{~N} 1113125 \mathrm{~W}$

$365610 \mathrm{~N} 1113355 \mathrm{~W}$ $365400 \mathrm{NII} 13125 \mathrm{~W}$

315137 N1095644W

$365940 \mathrm{~N} 1113745 \mathrm{~W}$ $365615 \mathrm{~N} 1113825 \mathrm{~W}$

$344026 \mathrm{~N} 1112212 \mathrm{~W}$

$344735 N 1112624 \mathrm{~W}$

$335006 \mathrm{NI} 103543 \mathrm{~W}$

330158 N1101151W

$345241 \mathrm{~N} 1103946 \mathrm{~W}$

$323928 \mathrm{~N} 1102135 \mathrm{~W}$

$323 \mathrm{~B} 42 \mathrm{~N} 1102252 \mathrm{~W}$

$352702 \mathrm{~N} 1124234 \mathrm{~W}$

332545 N1114649W

351313NI102257W

Picacho Butte

Kingman Airport

Tapeats Amphitheater

Cold Spring

Quaking Aspen

Rattlesnake Spring

Greens Peak

Red Top Mtn

Battle Flat

Estler Peak

King Arthur Castle

Willow Beach

Waddell

Wadde 11

Saint Oavid

Saint David

Tucson North

2750 Sabino Canyon

Russe11 Spring

Peeples Valley

6532 Mount Hope

St George Canyon

Sku 11 Valley

Peacock Peak

Pinal Peak

Humpy Camp We 1

Rincon Ranch

Fern Glen Canyon

Fern Glen Canyon

8772 Humphreys Peak

Humphreys Peak

Fitzgerald $\mathrm{Hill}$

Dutton Hill

Moriah Knoll

Cerro Colorado

Munds Park

Maroney We 11

Pyeatt Ranch 


\section{FEATURE NAME}

Field Pond

Fields Spring

Fields Tank

Field Tank

Fiesta Mall

Fiesta Park (trailer park) Fiesta Travel Trailer Park

Fiesta Travel Trailer Park See Fiesta Park (trailer park)

Fiesta Village Shopping Center Fife Canyon

Fife Canyon Trail Two Hundred Fiftyeight

Fife Peak

Fife Saddle

Fifteenrile Canyon

Fifteenmile Corral

Fifteen Tank

Fifteenth Street Park

Fifteenth Street School

Fifth Street Park

Fifty Dollar Spring

Fiftyeight Tank

Fiftyfive Tank

Fiftynine Tank

Fiftyseven Tank

Fiftysix Tank

Fig Spring

Fig Spring

Fig Spring

Fig Spring

Fig Tree Spring

Fig Tree Spring

Figueroa Ranch

Figueroa Tank

Figure Four Canyon

Filarea Tank

Filarea Tank

Filaria Spring

Filibuster

See Filibusters Camp

Filibusters Camp Filibuster

Filleman Tank

Filler Ditch

Fillibuster Camp

See Noah

Fillmore Tank

Filtro Tank

Final, Cape

Final Point

Finch Spring

Finch Wash

Fench Wash

French Wash

Finch Windmill

Findlay Knolls

Findlay Tank

Fine Wash

Finger Butte

Finger Point Rock

Finger Rock

Finger Rock

Finger Rock Canyon

Finger Rock Spring

Finley and Adams Canyon

Finleys (historical)

Finley Spring

Finley Tank
FEATURE

CLASS

COORDINATE

$62628 \mathrm{~N} 1132128 \mathrm{~W}$

$344037 \mathrm{N1} 120449 \mathrm{~W}$

$352937 \mathrm{~N} 1131517 \mathrm{~W}$

$351634 \mathrm{N1135604 \textrm {W }}$

$332326 \mathrm{~N} 1115135 \mathrm{~W}$

$332517 \mathrm{~N} 1114454 \mathrm{~W}$

locale UWOFF

locale UNOFF

VARIANT

Maricopa

VARIANT

locale

Maricopa

$332517 N 1114454 W$

locale

valley

trail

summit

gap

valley

reservoir

park

UNOFF

Maricopa

Cochise

Cochise

BGN Cochise

Cochise

Graham

Graham

Coconino

Cochise

school UNOFF Cochise

park

spring

reservoir

reservoir

reservoir

reservoir

reservoir

spring

spring

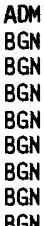

spring

spring

spring

spring

locale

reservoir

valley

reservoir

reservoir

spring

locale

locale

reservoir

canal

locale

reservoir

reservoir

BGN
$B G N$
$B G N$
$B G N$
UNO
$B G N$
$B G N$
$B G N$
$B G N$
$B G N$

Cochise

Pinal

Coconino

Coconino

Coconino

Coconino

Gila

Pinal

Maricopa

$332338 \mathrm{~N} 1115126 \mathrm{~W}$ $315749 \mathrm{~N} 1092549 \mathrm{~W}$ $315558 \mathrm{~N} 1092400 \mathrm{~W}$

$315518 \mathrm{~N} 1092423 \mathrm{~W}$

$315424 \mathrm{~N} 1092218 \mathrm{~W}$

$331315 \mathrm{~N} 1093036 \mathrm{~W}$

$331130 \mathrm{N1093032 \textrm {W }}$

$353802 \mathrm{~N} 1120356 \mathrm{~W}$

$312107 \mathrm{N1} 1093225 \mathrm{~W}$

$312057 \mathrm{N1093255 \textrm {W }}$

$312026 \mathrm{~N} 1093217 \mathrm{~W}$

$332500 \mathrm{~N} 1110058 \mathrm{~W}$

$344353 \mathrm{~N} 1112115 \mathrm{~W}$

$344737 \mathrm{~N} 1112010 \mathrm{~W}$

$344825 \mathrm{N1} 112020 \mathrm{~W}$

344701 N1111950W

$334124 N 1101959 \mathrm{~W}$

$332024 \mathrm{N1} 110536 \mathrm{~W}$

335707 N1120351W

Yavapai

Mohave

Pima

Yavapai

Pima

Yuma

Mohave

Mohave

Coconino

Pinal

$341703 \mathrm{N1130813W}$

$350423 \mathrm{~N} 1141827 \mathrm{~W}$

$315137 \mathrm{N1} 104445 \mathrm{~W}$

$345558 \mathrm{~N} 1122125 \mathrm{~W}$

$313747 \mathrm{N11} 12511 \mathrm{~W}$

330749 N1140608W

365441 N1135337W

354238 N1141013W

$364735 N 1123351 \mathrm{~W}$

$331422 \mathrm{~N} 1110758 \mathrm{~W}$

$365211 N 1134913 W$

Yura

Yura

VARIANT

BGN

BGN

VARIANT

Greenlee

Apache

Yuma
Gila

Pima

cliff BGN 1906 Coconino

cliff

spring

stream

locale

summit

reservoir

stream

BGN

$B G N$

BGN

VARIAN

BGN

$B G N$
$B G N$
$B G N$

summit

summit

pillar

pillar

valley

spring

valley

locale

spring

reservoir
Greenlee

Yavapai

Yavapai

Mohave

Mohave

Graham

Mohave

Navajo

Pima

Coconino

Pima

Pima

Santa Cruz

Santa Cruz

Pima

Santa Cruz
$324050 \mathrm{~N} 1140320 \mathrm{~W}$

$324050 \mathrm{N11} 40320 \mathrm{~W}$

$331854 \mathrm{~N} 1092117 \mathrm{~W}$

340129 N1092710W

$324105 N 1140117 \mathrm{~W}$

341350 N1105843W

$320904 \mathrm{~N} 1112158 \mathrm{~W}$

360833 N1115426W

$331046 \mathrm{~N} 1092159 \mathrm{~W}$

$343055 \mathrm{N1} 12355 \mathrm{WW}$

342754 N1124139W

$343143 N 1123517 W$

$\begin{array}{cc}\text { SOURCE } & \text { ELEV } \\ \text { COORDINATE } & \text { FT }\end{array}$ MAP NAME

Fife Peak

Fife Peak

6816 Fife Peak

Rustler Park

Elevator Mtn

Elevator Mtn

Molly Anne Oraw

Douglas

Douglas

Douglas

Haunted Canyon

Turkey Mtn

Jaycox Mtn

Jaycox Mtn

Jaycox Mtn

Popcorn Canyon

Superior

Daisy Mountain

Ives Peak

Mount Nutt

Empire Ranch

Hell Point

Las Guijas

Kofa Deep Well

Littlefield

Mt Tipton NW

Clear Water Spring

Mineral Mtn

7916 Walhalla Plateau 
FEATURE CLASS
COUNTY

Fire Clay Tank

Fire Line Tank

Fire Mountain

$$
\text { Explorers Rock }
$$

Fire Mountains

See Sam Francisco Mountain

Fireplace Spring

Fire Point

Fire Ridge

Fire Tank

Fire Tank

Fir Spring

Fir Spring

Fir Spring

First Avenue Elementary School

First Bas in Tank

First Bench of Wilson Mountain

First Canyon

First Day of Summer Well

First Flat Mesa

First Forest

First Hollow

First Hollow Spring

First Hollow Tank

First Knoll

First Laguna

$$
\text { See Laguna }
$$

First Mesa

First Mesa Wash

See Polacca Wash

First Mesa Wash

See Burnt Corn Wash

First National Well

First Reservoir

Firstrum Tank

See Fernstron Tank

First Tank

First Tank

First Trail Canyon

First view

First Water Canyon

First Water Creek

First Water Ranch

Fir Tree Alcove

Fir Tree Canyon

Fischer Ranch

Fishbaugh Lateral

Fishbench Tank

Fishbone Creek

See Fishhook Creek

Fishburn

$$
\text { See Ventana }
$$

Fish Canyon

Fish Creek See Horse Camp Draw

Fish Creek

Fish Creek

Twenty Four Oraw

Twenty-four Draw

Fish Creek (historical town)

Frasier

stream
valley
lake
valley
strean
lake
spring
reservoir
ppl
summit

BGN
$B G N$
$B G N$
$B G N$
$B G N$
$B G N$
$B G N$
$B G N$
$B G N$
$B G N$

$\begin{array}{ll}\text { Gila } & 335204 \mathrm{~N} 1105217 \mathrm{~W} \\ \text { Navajo } & 364058 \mathrm{N1} 103140 \mathrm{~W} \\ \text { Maricopa } & 331610 \mathrm{N1115752 \textrm {W }} \\ \text { Navajo } & 334942 \mathrm{N1095145 \textrm {W }} \\ \text { Navajo } & 334934 \mathrm{N1095141 \textrm {W }} \\ \text { Apache } & 334746 \mathrm{N1091717W} \\ \text { Apache } & 340905 \mathrm{~N} 1094307 \mathrm{~W} \\ \text { Navajo } & 335201 \mathrm{~N} 1095233 \mathrm{~W} \\ \text { Maricopa } & 333436 \mathrm{~N} 1115853 \mathrm{~W} \\ \text { Yavapai } & 342200 \mathrm{~N} 1123520 \mathrm{~W}\end{array}$

reservoir

reservoir

summit

BGN Yavapai

BGN Coconino

Mohave

VARIANT

summit

spring

cliff

ridge

reservoir

Coconino

Yavapai

BGN 1932 Coconino

BGN

BG

Greenlee

Gila

reservoir

spring

spring

spring

school

reservoir

summit

valley

well

summit

BGN Coconino

BGN Gila

Navajo

Navajo

Pinal

Gila

Coconino

Coconino

Coconino

Coconino
Navajo

area BGN Apache

valley

spring

reservoir

sumit

ppl

summit

strean

BGN

BGN

BGN

BGN

VARIANT

Navajo

Navajo

Navajo

Navajo

Yuna

BGN

VARIANT

Navajo

Coconino

$342212 N 1123538 \mathrm{~W}$

$344130 \mathrm{~N} 1111754 \mathrm{~W}$

354059 N11 $43844 \mathrm{~W}$

$352027 \mathrm{~N} 1114057 \mathrm{~W}$

$343340 \mathrm{~N} 1123203 \mathrm{~W}$

$362121 N 1122139 \mathrm{~W}$

$333246 N 1090607 \mathrm{~W}$

$342244 N 1112109 \mathrm{~W}$

$345125 N 1113325 \mathrm{~W}$

$335404 N 1100538 \mathrm{~W}$

$363853 \mathrm{~N} 1102035 \mathrm{~W}$

$364314 \mathrm{~N} 1103346 \mathrm{~W}$

$323547 \mathrm{~N} 1103816 \mathrm{~W}$

$335115 N 1110747 \mathrm{~W}$

$345444 \mathrm{~N} 1114419 \mathrm{~W}$

$365956 \mathrm{N1} 105612 \mathrm{~W}$

$355734 \mathrm{~N} 1105828 \mathrm{~W}$

$353459 \mathrm{N1} 100856 \mathrm{~W}$

$345336 \mathrm{~N} 1094 \mathrm{~B} 47 \mathrm{~W}$ $340221 N 1100024 W$

$340338 \mathrm{~N} 1095828 \mathrm{~W}$

$340326 \mathrm{~N} 1095857 \mathrm{~W}$

341518 N1095819W

$324908 \mathrm{~N} 1142905 \mathrm{~W}$

$355920 \mathrm{~N} 1101307 \mathrm{~W}$

$352133 \mathrm{~N} 1105028 \mathrm{~W}$

stream

well
reservoir

VARIANT

reservoir

reservoir

reservoir

valley

summit

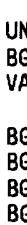

Navajo

Cochise

Coconino

$355908 \mathrm{~N} 1100835 \mathrm{~W}$

$322255 \mathrm{~N} 1091857 \mathrm{~W}$

362238 N1113615W

VARIANT

Pima

$314013 N 1112205 \mathrm{~W}$

$344728 \mathrm{~N} 1131305 \mathrm{~W}$

$324718 \mathrm{~N} 1101845 \mathrm{~W}$

344639 N1120828W

Graham

valley

strean

locale

cave

valley

locale

canal

reservoir

BGN Gila

BGN 1965 Maricopa

UNOFF

BGN

BGN

UNOFF

BGN

VARIANT

stream

Maricopa

Apache

Apache

Cochise

Yuma

Greenlee

Greenlee

$334408 M 1105754 \mathrm{~W}$

$333213 N 1112640 \mathrm{~W}$

$332839 \mathrm{~N} 1112615 \mathrm{~W}$

$361235 \mathrm{~N} 1092146 \mathrm{~W}$

361217 N1092152W

$321511 \mathrm{~N} 1095504 \mathrm{~W}$

$323630 \mathrm{~N} 1144102 \mathrm{~W}$

$334200 \mathrm{~N} 1092540 \mathrm{~W}$

$333514 N 1091001 \mathrm{~W}$

VARIANT

ppl
valley

BGN

VARIANT

arroyo

stream

stream

BGN

VARIANT

VARIANT

pp) BGN 1917
Greenlee

Pima

Pima

Apache

Apache

Maricopa

$322758 \mathrm{~N} 1121433 \mathrm{~W}$

314409 N1104027W

$340314 N 1093356 \mathrm{~W}$

$334239 \mathrm{~N} 1092633 \mathrm{~W}$
333200 N1111820W $\begin{array}{lc}\text { SOURCE } & \text { ELEV } \\ \text { COORDINATE } & \text { FT }\end{array}$

MAP NAME

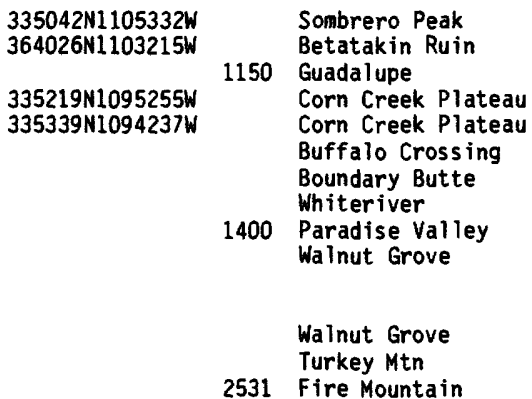

Iron Springs

King Arthur Castle

Blue

Kehl Ridge

Stoneman Lake

Round Top Mtn

Kayenta West

Betatakin Ruin

Campo Bonito

Greenback Creek

Munds Park

$370030 \mathrm{~N} 1105312 \mathrm{~W} \quad$ Chaiyahi Flat

Coal Mine Mesa

First Flat Mesa

Adamana

Faught Ridge

Indian Pine

Indian Pine

6814 Silver Springs

Echo Canyon

3463 Martin We11

Cedar Ridge

Mart in Mtn

Burro Mesa

$324613 N 1102042 \mathrm{~W}$ Klondike

334533N1105632W Meddler Wash

332623N1112552W Mormon Flat Dam

Goldfield

Mumny Cave Ruins

Mumny Cave Ruins

Square Mountain

Somerton

Hoodoo Knob

$314531 N 1104747 \mathrm{~W}$

Sonoita

$333602 \mathrm{~N} 1092100 \mathrm{~W}$

$340155 \mathrm{~N} 1093148 \mathrm{~W}$

Hoodoo Knob

Greer

Horse Mesa Dam 


\begin{tabular}{|c|c|c|c|c|c|c|c|}
\hline FEATURE NAME & $\begin{array}{l}\text { FEATURE } \\
\text { CLASS }\end{array}$ & STATUS & COUNTY & COORDINATE & $\begin{array}{l}\text { SOURCE } \\
\text { COORDINATE }\end{array}$ & $\begin{array}{l}\text { ELEV } \\
\text { FT }\end{array}$ & MAP NAME \\
\hline Frasiers Station & & VARIANT & & & & & \\
\hline $\begin{array}{l}\text { Fish Creek Corral } \\
\text { Fish Creek Hill } \\
\text { See Fish Creek Mountain } \\
\text { Fish Creek Hill } \\
\text { See Coronado Mesa } \\
\text { (historical) }\end{array}$ & $\begin{array}{l}\text { locale } \\
\text { summit } \\
\text { summit }\end{array}$ & $\begin{array}{l}\text { BGN } \\
\text { VARIANT } \\
\text { VARIANT }\end{array}$ & $\begin{array}{l}\text { Apache } \\
\text { Maricopa } \\
\text { Maricopa }\end{array}$ & $\begin{array}{l}340448 \mathrm{~N} 1092728 \mathrm{~W} \\
333026 \mathrm{~N} 1111502 \mathrm{~W} \\
333026 \mathrm{~N} 1111502 \mathrm{~W}\end{array}$ & & & Greer \\
\hline $\begin{array}{c}\text { Fish Creek Mountain } \\
\text { Coronado Mesa } \\
\text { Fish Creek Hill }\end{array}$ & summit & $\begin{array}{l}\text { BGN } 1917 \\
\text { VARIANT } \\
\text { VARIANT }\end{array}$ & Maricopa & $333026 \mathrm{~N} 1111502 \mathrm{~W}$ & & 4940 & Horse Mesa Dam \\
\hline $\begin{array}{l}\text { Fish Creek Peak } \\
\text { Coronado Summit } \\
\text { The Summit }\end{array}$ & summit & $\begin{array}{l}\text { BGN } \\
\text { VARIANT } \\
\text { VARIANT }\end{array}$ & Maricopa & $333123 \mathrm{~N} 1111710 \mathrm{~W}$ & & 3910 & Horse Mesa Dam \\
\hline $\begin{array}{l}\text { Fisher and Fry Lake } \\
\text { Fisher Basin } \\
\text { Fisher Basin Spring } \\
\text { Fisher Spring }\end{array}$ & $\begin{array}{l}\text { lake } \\
\text { basin } \\
\text { spring }\end{array}$ & $\begin{array}{l}\text { BGN } \\
\text { BGN } \\
\text { BGN } 1975 \\
\text { VARIANT }\end{array}$ & $\begin{array}{l}\text { Coconino } \\
\text { Graham } \\
\text { Graham }\end{array}$ & $\begin{array}{l}350547 \mathrm{~N} 1113001 \mathrm{~W} \\
325601 \mathrm{~N} 1101415 \mathrm{~W} \\
325603 \mathrm{~N} 1101410 \mathrm{~W}\end{array}$ & & & $\begin{array}{l}\text { Lower Lake Mary } \\
\text { Jackson Mtn } \\
\text { Jackson Mtn }\end{array}$ \\
\hline $\begin{array}{l}\text { Fisher Basin Trail Sixty four } \\
\text { Fisher Camp } \\
\text { Fisher Canyon } \\
\text { Fisher Hills } \\
\text { Fisher Mesa } \\
\text { Fisher Point }\end{array}$ & $\begin{array}{l}\text { trail } \\
\text { locale } \\
\text { valley } \\
\text { summit } \\
\text { summit } \\
\text { cliff }\end{array}$ & $\begin{array}{l}\text { UNOFF } \\
\text { BGN } \\
\text { BGN } \\
\text { BGN } \\
\text { BGN } \\
\text { BGN }\end{array}$ & $\begin{array}{l}\text { Graham } \\
\text { Mohave } \\
\text { Graham } \\
\text { Cochise } \\
\text { Gila } \\
\text { Coconino }\end{array}$ & $\begin{array}{l}325614 \mathrm{~N} 1101308 \mathrm{~W} \\
341745 \mathrm{~N} 134515 \mathrm{~W} \\
325523 \mathrm{~N} 1101312 \mathrm{~W} \\
322332 \mathrm{~N} 1093452 \mathrm{~W} \\
340710 \mathrm{~N} 1112328 \mathrm{~W} \\
350909 \mathrm{~N} 1113536 \mathrm{~W}\end{array}$ & $325643 \mathrm{~N} 1101404 \mathrm{~W}$ & 4812 & $\begin{array}{l}\text { Jackson Mtn } \\
\text { Centennial Wash } \\
\text { Jackson Mtn } \\
\text { Fisher Hills } \\
\text { Mazatzal Peak } \\
\text { Flagstaff East }\end{array}$ \\
\hline $\begin{array}{l}\text { Fishers Landing } \\
\text { Fishers Landing Airport } \\
\text { Fisher Spring }\end{array}$ & $\begin{array}{l}\text { ppl } \\
\text { dirport }\end{array}$ & $\begin{array}{l}\text { BGN } \\
\text { ADMIN } \\
\text { VARIANT }\end{array}$ & $\begin{array}{l}\text { Yuma } \\
\text { Yuma }\end{array}$ & $\begin{array}{l}325822 \mathrm{~N} 1142746 \mathrm{~W} \\
325812 \mathrm{N114} 2726 \mathrm{~W}\end{array}$ & & 199 & $\begin{array}{l}\text { Imperial Reservoir } \\
\text { Imperial Reservoir }\end{array}$ \\
\hline $\begin{array}{l}\text { See Fisher Bas in Spring } \\
\text { Fisher Spring } \\
\text { Fisher Spring } \\
\text { Fishers Spring } \\
\text { Fisher Tank } \\
\text { Fisher Tank } \\
\text { Fisher Tank }\end{array}$ & $\begin{array}{l}\text { spring } \\
\text { spring } \\
\text { spring } \\
\text { spring } \\
\text { reservoir } \\
\text { reservoir } \\
\text { reservoir }\end{array}$ & $\begin{array}{l}\text { BGN } \\
\text { BGN } \\
\text { BGN } \\
\text { BGN } \\
\text { BGN } \\
\text { BGN }\end{array}$ & $\begin{array}{l}\text { Graham } \\
\text { Maricopa } \\
\text { Coconino } \\
\text { Coconino } \\
\text { Yavapai } \\
\text { Coconino } \\
\text { Coconino }\end{array}$ & $\begin{array}{l}325603 \mathrm{~N} 1101410 \mathrm{~W} \\
334437 \mathrm{N1112443 \textrm {W }} \\
365207 \mathrm{N1113839 \textrm {W }} \\
351000 \mathrm{~N} 1114556 \mathrm{~W} \\
340240 \mathrm{~N} 1112840 \mathrm{~W} \\
3510211114531 \mathrm{~W} \\
354506 \mathrm{~N} 1114528 \mathrm{~W}\end{array}$ & & & $\begin{array}{l}\text { Mine Mountain } \\
\text { Navajo Bridge } \\
\text { Bellemont } \\
\text { Mazatzal Peak } \\
\text { Bellemont } \\
\text { Peterson Flat }\end{array}$ \\
\hline $\begin{array}{l}\text { Fisher Tank Number One } \\
\text { Fisher Tank Number Two } \\
\text { Fishhook Creek } \\
\text { Fishbone Creek }\end{array}$ & $\begin{array}{l}\text { reservoir } \\
\text { reservoir } \\
\text { stream }\end{array}$ & $\begin{array}{l}\text { BGN } \\
\text { BGN } \\
\text { BGN } \\
\text { VARIANT }\end{array}$ & $\begin{array}{l}\text { Coconino } \\
\text { Coconino } \\
\text { Greenlee }\end{array}$ & $\begin{array}{l}343829 \mathrm{~N} 1110855 \mathrm{~W} \\
343835 \mathrm{~N} 110859 \mathrm{~W} \\
333514 \mathrm{N1091001 \textrm {W }}\end{array}$ & $333828 \mathrm{~N} 1091154 \mathrm{~W}$ & & $\begin{array}{l}\text { Hay Lake } \\
\text { Hay Lake } \\
\text { Bear Mountain }\end{array}$ \\
\hline $\begin{array}{l}\text { Fishhook Springs } \\
\text { Fishhook Well } \\
\text { Fish Pond Lake } \\
\text { Fishtail } \\
\text { Fishtail Canyon } \\
\text { Fish Tail Canyon } \\
\text { See Palm Canyon }\end{array}$ & $\begin{array}{l}\text { spring } \\
\text { well } \\
\text { reservoir } \\
\text { summit } \\
\text { valley } \\
\text { valley }\end{array}$ & $\begin{array}{l}\text { BGN } \\
\text { UNOFF } \\
\text { BGN } \\
\text { BGN } \\
\text { BGN } \\
\text { VARIANT }\end{array}$ & $\begin{array}{l}\text { Graham } \\
\text { Graham } \\
\text { Apache } \\
\text { Coconino } \\
\text { Yuma } \\
\text { Yuma }\end{array}$ & $\begin{array}{l}331307 N 1095852 \mathrm{~W} \\
331251 \mathrm{N1095932 \textrm {W }} \\
361323 \mathrm{~N} 1091201 \mathrm{~W} \\
362600 \mathrm{~N} 1123433 \mathrm{~W} \\
332048 \mathrm{N1140553 \textrm {W }} \\
332134 \mathrm{N1140620 \textrm {W }}\end{array}$ & $332121 \mathrm{N1140545 \textrm {W }}$ & 6092 & $\begin{array}{l}\text { Gila Peak } \\
\text { Gila Peak } \\
\text { Lower Wheatfields } \\
\text { Fishtail } \\
\text { Palm Canyon }\end{array}$ \\
\hline $\begin{array}{l}\text { Fishtail Canyon } \\
\text { Fishtail Point }\end{array}$ & valley & $\begin{array}{l}\text { BGN } \\
\text { VARIANT }\end{array}$ & Coconino & $362413 N 1123314 \mathrm{~W}$ & $362656 \mathrm{~N} 1123220 \mathrm{~W}$ & & Fishtail \\
\hline $\begin{array}{l}\text { See Paguekwash Point } \\
\text { Fishtail Point } \\
\text { Fishtail Rapids } \\
\text { Fish Tank } \\
\text { Fish Tank } \\
\text { Fish Tank } \\
\text { Fish Wash } \\
\text { Fish Well Corral }\end{array}$ & $\begin{array}{l}\text { cliff } \\
\text { cliff } \\
\text { rapids } \\
\text { reservoir } \\
\text { reservoir } \\
\text { reservoir } \\
\text { valley } \\
\text { locale }\end{array}$ & $\begin{array}{l}\text { BGN } \\
\text { BGN } 1932 \\
\text { BGN } \\
\text { BGN } \\
\text { BGN } \\
\text { BGN } \\
\text { BGN }\end{array}$ & $\begin{array}{l}\text { Mohave } \\
\text { Coconino } \\
\text { Coconino } \\
\text { Pima } \\
\text { Green lee } \\
\text { Navajo } \\
\text { Apache } \\
\text { Pima }\end{array}$ & $\begin{array}{l}362224 \mathrm{~N} 1124023 \mathrm{~W} \\
362501 \mathrm{N1123458 \textrm {W }} \\
362400 \mathrm{~N} 1123315 \mathrm{~W} \\
314526 \mathrm{N1112159W} \\
333920 \mathrm{~W} 1092222 \mathrm{~W} \\
340418 \mathrm{~N} 1103907 \mathrm{~W} \\
354415 \mathrm{~N} 109281 \mathrm{~W} \\
314442 \mathrm{~N} 1104616 \mathrm{~W}\end{array}$ & 353916 N1092634W & 5480 & $\begin{array}{l}\text { Fishtail } \\
\text { Fishtail } \\
\text { Penitas Hills } \\
\text { Hannagan Meadow } \\
\text { Oak Creek Ranch } \\
\text { Kinlichee } \\
\text { Mt Wrightson }\end{array}$ \\
\hline $\begin{array}{l}\text { Fiske Butte } \\
\text { Fissure Peak } \\
\text { Fitch Corral } \\
\text { Fitch Park } \\
\text { Fitzgerald Hill } \\
\text { Fitz Well } \\
\text { Five, Canal (historical) } \\
\text { Canal Colinas }\end{array}$ & $\begin{array}{l}\text { summit } \\
\text { summit } \\
\text { locale } \\
\text { park } \\
\text { summit } \\
\text { well } \\
\text { canal }\end{array}$ & $\begin{array}{l}\text { BGN } 1908 \\
\text { BGN } \\
\text { BGN } \\
\text { ADMIN } \\
\text { BGN } \\
\text { UNOFF } \\
\text { BGN } \\
\text { VARIANT }\end{array}$ & $\begin{array}{l}\text { Coconino } \\
\text { Cochise } \\
\text { Cochise } \\
\text { Maricopa } \\
\text { Coconino } \\
\text { Pinal } \\
\text { Maricopa }\end{array}$ & $\begin{array}{l}361407 \mathrm{~N} 1122306 \mathrm{~W} \\
312649 \mathrm{~N} 1095748 \mathrm{~W} \\
315352 \mathrm{~N} 1092009 \mathrm{~W} \\
332542 \mathrm{~N} 1114940 \mathrm{~W} \\
351804 \mathrm{N1122522 \textrm {W }} \\
323936 \mathrm{~N} 1104530 \mathrm{~W} \\
332708 \mathrm{~N} 1120912 \mathrm{~W}\end{array}$ & & & $\begin{array}{l}\text { Explorers Monument } \\
\text { Bisbee } \\
\text { Rustler Park } \\
\text { Mesa } \\
\text { Fitzgerald Hill } \\
\text { North of Oracle } \\
\text { Fowler }\end{array}$ \\
\hline $\begin{array}{l}\text { Five Buttes } \\
\text { Five Corners }\end{array}$ & $\begin{array}{l}\text { summit } \\
\text { locale }\end{array}$ & $\begin{array}{l}\mathrm{BGN} \\
\mathrm{BGN}\end{array}$ & $\begin{array}{l}\text { Navajo } \\
\text { Yavapai }\end{array}$ & $\begin{array}{l}351707 \mathrm{N1100427W} \\
342510 \mathrm{~N} 1122305 \mathrm{~W}\end{array}$ & & & $\begin{array}{l}\text { Five Buttes } \\
\text { Groom Creek }\end{array}$ \\
\hline $\begin{array}{l}\text { Five Houses } \\
\text { Five Houses Butte }\end{array}$ & locale & $\begin{array}{l}\text { BGN } \\
\text { VARIANT }\end{array}$ & Navajo & $354834 \mathrm{~N} 1102158 \mathrm{~W}$ & & & Sun Altar \\
\hline $\begin{array}{l}\text { See Windswept Terrace } \\
\text { Five Houses Butte } \\
\text { Five Hundred Four Trick Tank } \\
\text { Five Lower Branch, Canal }\end{array}$ & $\begin{array}{l}\text { bench } \\
\text { ridge } \\
\text { reservoir } \\
\text { canal }\end{array}$ & $\begin{array}{l}B G N \\
B G N \\
B G N\end{array}$ & $\begin{array}{l}\text { Navajo } \\
\text { Navajo } \\
\text { Navajo } \\
\text { Maricopa }\end{array}$ & $\begin{array}{l}354519 \mathrm{~N} 1102220 \mathrm{~W} \\
354610 \mathrm{~N} 1102000 \mathrm{~W} \\
343203 \mathrm{~N} 1104216 \mathrm{~W} \\
332719 \mathrm{~N} 112063 \mathrm{~W}\end{array}$ & & & $\begin{array}{l}\text { Sun Alter } \\
\text { Potato Wash South } \\
\text { Phoenix }\end{array}$ \\
\hline
\end{tabular}


NATIONAL GAZETTEER--ARIZONA 1986

FEATURE
CLASS

Acequias Villa

Fivemile Creek

Fivemile Draw

Fivemite Hill

Fivemile Lake

Fivemile Lake

Fivenile Landing

Fivemile Pass

Fivemile Pass Tank

Fivemile Pass Tank Number One

Fivenile Pass Tank Number Two

Five Mile Peak

See Fivenile Peak

Fivemile Peak

Five Mile Peak

Five Mile Point Cathedral Rock

Five Mile Reservoir

Fivemile Wash

Fivemile Wash

Fivemile Wash

Fivemile Wash

Five Mile Wash Dam

Five $0^{\prime}$ clock Wash

See Sand Wash

Five Point Mountain Five Points Mountain

Five Points Mountain

See Five Point Mountain

Five Points Park

Five Rapids (historical)

Five Wells

Fix Tank

Flag, Rio de

Flag Wash

River de Flag

San Fancisco Wash

Flag Mine

Flag Spring

Flagstaff

Flagstaff City Park

Flagstaff City Reservoirs

Flagstaff City Well Five Flagstaff City Well Four

Flagstaff City Well One

Flagstaff City Well Three

Fiagstaff City Well Two

Fiagstaff Community Hospital

Flagstaff Compressor Station

Flagstaff Department of

Public Safety Heliport

Flagstaff Fire Station Number

One

Fiagstaff Fire Station Number Two

Fiagstaff High School

Flagstaff Junior High School

Flagstaff Mall Heliport

Flagstaff Plaza Shopping Center

Flagstaff Railroad Station

Flagstaff Spring

Flagstone Tank

Flag Tail Spring

See Flagtail Spring

Flagtail Spring

$$
\text { Flag Tail Spring }
$$

Flag Tank

Flag Tank

Flag Wash

Flag Wash

ppl BGN 1943

Coconino

UNOFF

airport ADMIN

\begin{tabular}{|c|c|}
\hline $\begin{array}{l}\text { stream } \\
\text { valley }\end{array}$ & $\begin{array}{l}\text { VARIANT } \\
\text { BGN } \\
\text { BGN }\end{array}$ \\
\hline $\begin{array}{l}\text { summit } \\
\text { lake } \\
\text { lake } \\
\text { locale } \\
\text { gap } \\
\text { reservoir } \\
\text { reservoir } \\
\text { reservoir }\end{array}$ & $\begin{array}{l}\text { BGN } \\
\text { BGN } \\
\text { BGN } \\
\text { BGN } \\
\text { BGN } \\
\text { BGN } \\
\text { BGN } \\
\text { BGN } \\
\text { VARIANT }\end{array}$ \\
\hline
\end{tabular}

$344731 \mathrm{~N} 1143019 \mathrm{~W}$ summit

summit

summit

reservoir

stream

stream

stream

stream

dam$$
\text { BGN }
$$

VARIANT

BGN 1969

VARIANT

BGN

BGN

BGN

BGN

UNOFF

VARIANT

strean

summit

BGN

VARIANT

summit

park

rapids

well

VARIANT

strean

BGN 196 VARIANT

VARIANT

VARIANT

mine UARIA

spring $B G N$

reservoir

ADMIN

ohave

Mohave

Coconi

Coconino

Coconino

Coconino

Mohave

Yavapai

Coconino

Pinal

Pinal

Navajo

Graham

Navajo

Coconino

Navajo

Greenlee

Pinal

Pinal

Pima

Mohave

Coconino

Coconino

Coconino

well UNOFF

well UNOFF

well

well

well

UNOFF

UNOFF

locale UNOFF

building

UNOFF

Coconino

Coconino

Coconino

Coconino

Coconino

Coconino

Coconino

Coconino

Coconino

COORDINATE

$315642 \mathrm{~N} 1093448 \mathrm{~W}$ $343530 \mathrm{~N} 1100457 \mathrm{~W}$

$340530 \mathrm{~N} 1141628 \mathrm{~W}$

342505 N1105900W

$342610 \mathrm{~N} 1112952 \mathrm{~W}$

344743 N1143018W

343809 N1113314W

$343800 \mathrm{~N} 1113251 \mathrm{~W}$

$343819 \mathrm{~N} 1113318 \mathrm{~W}$

$343814 N 1113349 W$

330037 N1114428W

$330037 \mathrm{~N} 1114428 \mathrm{~W}$

364920N1113830W

$345018 \mathrm{~N} 1100842 \mathrm{~W}$

$331107 \mathrm{~N} 1101036 \mathrm{~W}$

345302 N1100755

$355606 \mathrm{~N} 1112503$

$345018 N 1100842 \mathrm{~W}$

$331710 \mathrm{~N} 1100651 \mathrm{~W}$

$345049 \mathrm{~N} 1142237 \mathrm{~W}$

$344653 \mathrm{~N} 1101016 \mathrm{~W}$

$360348 \mathrm{~N} 1111854 \mathrm{~W}$

$324555 N 1090920 \mathrm{~W}$

$332032 \mathrm{~N} 1105826 \mathrm{~W}$

$332032 \mathrm{~N} 1105826 \mathrm{~W}$

$321243 N 1105807 \mathrm{~W}$

$352400 \mathrm{~N} 1143800 \mathrm{w}$

$351758 \mathrm{~N} 1134900 \mathrm{~W}$

353414 N1120140W

$351430 \mathrm{~N} 1112500 \mathrm{~W}$

351525 N1114410W

$350440 \mathrm{~N} 1135259 \mathrm{~W}$

$350436 \mathrm{~N} 1142210 \mathrm{~W}$

$351153 \mathrm{N1113902W}$

$351225 N 1113935 \mathrm{~W}$

$351419 N 1113946 \mathrm{~W}$

$350857 \mathrm{N1114417 \textrm {W }}$

$350906 \mathrm{~N} 1114409 \mathrm{~W}$

$350924 \mathrm{~N} 1114401 \mathrm{~W}$

350933N1114408 350916N1114408W $351232 \mathrm{~N} 1113843 \mathrm{~W}$

$351339 \mathrm{~N} 1113320 \mathrm{~W}$

$351135 N 1113958 \mathrm{~W}$

$351156 \mathrm{~N} 1113855 \mathrm{~W}$

building UNOFF

Coconino

$351218 \mathrm{~N} 1113655 \mathrm{~W}$

school UNOFF

school UNOFF

airport ADMIN

locale UNOFF

building UNOFF

spring

reservoir

spring

VARIANT

Coconino

Coconino

Coconino

Coconino

Coconino

Coconino

Coconino

Pima

spring

reservoir

reservoir

stream

$\begin{array}{ll}\text { BGN } & \text { Pima } \\ \text { VARIANT } & \\ \text { BGN } & \text { Coconino } \\ \text { BGN } & \text { Coconino } \\ \text { BGN } & \text { Pinal }\end{array}$

$351216 \mathrm{~N} 1113900 \mathrm{~W}$

$351215 \mathrm{~N} 1113914 \mathrm{~W}$

$351325 \mathrm{~N} 1113457 \mathrm{~W}$

$351225 \mathrm{~N} 1113850 \mathrm{~W}$

$351148 N 1113858 \mathrm{~W}$

$352024 \mathrm{~N} 1114003 \mathrm{~W}$

$352524 \mathrm{~N} 1123423 \mathrm{~W}$

$321514 \mathrm{~N} 1102940 \mathrm{~W}$

$321514 N 1102940 W$

$350253 \mathrm{~N} 1115352 \mathrm{~W}$

$350534 \mathrm{N1} 120519 \mathrm{~W}$

$323541 \mathrm{~N} 1104145 \mathrm{~W}$

$\begin{array}{cc}\text { SOURCE } & \text { ELEV } \\ \text { COORDINATE } & \text { FT MAP NAME }\end{array}$

315434N1092137W Pat Hills South

Snowflake

Parker SE

Porcupine Ridge

Pine

Needles

Apache Maid Mtn Apache Maid Mtn Apache Maid Mtn

Apache Maid Mtn

1982 Sacaton

4000 Navajo Bridge

Porter Canyon

Calva

Needles

Holbrook

Cameron North

Porter Canyon

5491 Pinal Ranch

Tucs on

Spirit Mtn NW

4050 Peacock Peak

Hobble Tank

Winona

Hualapai Peak Mount Nutt

Flagstaff West

Flagstaff West

Flagstaff West

Fiagstaff West

Flagstaff West

Fiagstaff West

Flagstaff West

Flagstaff West

Flagstaff West

Flagstaff East

6990 Flagstaff West

Flagstaff West

Flagstaff East

Flagstaff West

Flagstaff West

6835 Flagstaff East

Flagstaff West 
FEATURE NAME

See Flag, Rio de

Flake Ranch

Flake Tank

Flake Windmill

Flamingo Mobile Home Resort

Flamingo Reef

Flanders Ranch

Flanigan Tank

Flash Creek

Flat, Tank in

Flatbottom Pond

Flat Butte

Flat Dam

Flat Draw Tank

Flatiron, The

Flatiron Butte

Flatiron Mesa

Flatiron Mountain

Flatiron Well

Flat Mesa

Flat Mesa
Flat Mesa

See Gray Mesa

Flat Mesa

Flat Mesa

Flat Pond

Flat Rock

Flat Rock

Flat Rock Reservoir

Flat Rock Spring

Flat Rock Spring

Flat Rock Windmill

Flat Tank

Flat Tank

Flat Top

Flat Top

Flat Top Mountain

Table Top

Flat Top

Table Top Mountain

Flattop

Flat Top

Flat Top Butte

Flat Top Butte

Smith Butte

Flat Top Detention Dam

Flattop Draw

Flat Top Mountain

Flat Top Mountain

Flat Top Mountain Flat Tops Mountain Flat Tops Peak

Flat Top Mountain See Flat Top

Flattop Reservoir

Flat Tops

Flattops, The

Flat Tops Mounta in

See Flat Top Mountain

Flat Tops Peak

See Flat Top Mountain

Flat Top Tank

Flattop Wash

Flattop Windmill

Flax

See Little Colorado River

Flax River

See Little Colorado River

Flemming Spring

Flemming Wash

\section{FEATURE
CLASS}

STATUS

stream

reservoir UNOFF

locale

BGN

BGN

$\begin{array}{ll}\text { locale } & \text { UNOFF } \\ \text { bar } & \text { BGN } \\ \text { locale } & \text { UNOFF } \\ \text { reservoir } & \text { BGN } \\ \text { stream } & \text { BGN } \\ \text { reservoir } & \text { BGN } \\ \text { lake } & \text { BGN } \\ \text { summit } & \text { BGN } \\ \text { dam } & \text { UNOFF } \\ \text { reservoir } & \text { BGN }\end{array}$

summit $\quad B G$

summit

summit

summit

well

summit

summit

summit

summ it

BGN

BGN

BGN

UNOFF

BGN

BGN

BGN

summit

lake

pillar

ppl

reservoir

spring

spring

well

reservoir

reservoir

BGN

BGN

$B G N$

BGN

$B G N$
$B G N$

BGN
BGN
UNOFF

BGN

summit $\quad B G$

summit

BGN

BGN 197

VARIANT

VARIANT

VARIANT

summit BGN

summit

summit

summit

summ it

BGN

BGN

BGN

VARIANT

dam

valley

summit

summit

summit

UNOFF

BGN

BGN

BGN

$B G N$

BGN

VARIANT

VARIANT

summit

BGN

reservoir

summit

summit

BGN

Apache

summit

VARIANT

summit

reservoir

VARIANT

BGN

locale

BGN

VARIANT

stream

stream

spring

VARIAN

BGN
BGN
COUNTY

Maricopa

Mohave

Cochise

Coconino

Apache

Navajo

Navajo

Coconino

Coconino

Pinal

Coconino

Gila

Maricopa

Maricopa

Coconino

Navajo

Navajo

Coconino

Coconino

Mohave

Coconino

Apache

Apache

Maricopa

Mohave

Apache

Cochise

Maricopa

Graham

Apache

Yavapai

Mohave

Mohave

Yuma

Navajo

Mohave

Mohave

Santa Cruz

Panta Cru

Gila

Apache

Mohave

Coconino

Gila

Gila

COORDINATE

$351430 \mathrm{~N} 1112500 \mathrm{~W}$ 342359N1102621W 342533 N1102429 344637 N1101102W

333134N1120956W $360818 N 1143749 \mathrm{~W}$ $320732 N 1094623 \mathrm{~W}$ 352423N1115911W 334506 N1094040W $343901 \mathrm{~N} 1103015 \mathrm{~W}$ 362719 N1133420W $352321 N 1101618 \mathrm{~W}$ 354247 N $1123501 \mathrm{~W}$ 344141 N1112205W

332558N1112644W 361503 N1125053W $331446 N 1102901 \mathrm{~W}$ $333412 \mathrm{~N} 1124954 \mathrm{~W}$ $333425 \mathrm{~N} 1125117 \mathrm{~W}$ $351106 N 1122107 \mathrm{~W}$ $352709 \mathrm{~N} 1101505 \mathrm{~W}$

352830 N1100830W $354847 N 1104921 \mathrm{~W}$

363211 N1104717W $362835 N 1132411$ $360958 N 1111517 \mathrm{~W}$ $360020 N 1093318 \mathrm{~W}$ $355920 \mathrm{~N} 1093238 \mathrm{~W}$ $332850 \mathrm{~N} 1110300 \mathrm{~W}$ $353025 N 1134032 \mathrm{~W}$ $360010 \mathrm{~N} 1093314 \mathrm{~W}$ $314242 \mathrm{~N} 1091410 \mathrm{~W}$ 335048 N1121259W

$324052 \mathrm{~N} 1091251 \mathrm{~W}$ 340520 N $1091550 \mathrm{~W}$

$344705 \mathrm{~N} 1125026 \mathrm{~W}$ 344729 N1140149W 364706 N1130745W $330752 N 1133703 \mathrm{~W}$ $351102 N 1101855 \mathrm{~W}$

$364554 N 1130754 \mathrm{~W}$ $364740 N 1130855$ 344000 N1100934 $312302 N 1111336 \mathrm{~W}$ $325154 \mathrm{~N} 1103442$ 332657 N1105439W

340520 N1091550W

$364821 N 1130340 \mathrm{~W}$ $365227 N 1123309$ 344954N1094917W

332657 N1105439W

332657N1105439W 344736 N1140004W $344828 \mathrm{~N} 1140933 \mathrm{~W}$ $343914 \mathrm{~N} 1100 \mathrm{~B} 25 \mathrm{~W}$

Navajo

Coconino

$361128 N 1114811 W$

Coconino Maricopa

Maricopa

SOURCE COOROINATE ELEV
FT MAP NAME

$\begin{array}{rll} & & \begin{array}{l}\text { Aripine } \\ \text { Aripine } \\ \text { Porter Canyon }\end{array} \\ \text { 335224N1093602W } 1150 & \begin{array}{l}\text { Glendale } \\ \text { Callville Bay } \\ \text { Willcox South } \\ \text { Moritz Ridge } \\ \text { Marshall Butte } \\ \text { Potato Wash NE } \\ \text { Poverty Spring } \\ \text { Dilkon }\end{array} \\ & 54330 \begin{array}{l}\text { Tin House } \\ \text { Turkey Mtn }\end{array}\end{array}$

5320 S B Point

3111 San Carlos Reservoir

1770 Flatiron Mtn

Flatiron Mtn

McLellan Reservoir Dilkon 
NATIONAL GAZETTEER--ARIZONA 1986

\section{FEATURE NAME}

Fletcher Tank

Flicker Spring

Flint Creek

Flint Knoll

Flint Lateral

Floating House Ruins

Floe Tank

Flood Dan Tank

Flora Thew Schoo

Flora View School

Florence

Florence Boulevard Interchange See Interchange One Hundred Nintyfour

Florence Canal

Florence Casa Grande Canal

Florence Casa Grande Canal

Extension

Florence Cemetery

Florence Crittenden Home

Florence Diversion Dam Florence Retarding Dam

Florence Elementary School

Florence Junction

Florence Junction Airport

Florence Retarding Dam

See Florence Diversion Dam Florence Station

Florence Union High School

Flores

Flores Mine, Los

Flores Railroad Station

Florida Canyon Stone Cabin Canyon

Florida Canyon Wash

Florida Dam

Florida Mine

Florida Saddle

Florida Spring

Florida Work Center

Flower Pot

Flowerpot Tank

Flower Pot Well

Flower Ranch Tank

Flower Spring
Flower Tank
Flower Tank
Flowing Well
Flowing Wells High School
Flowing Wells Junior High
Flowing Wells Plaza Shopping
Center
Floy (site)
Floyd, Mount

Floyd Tank
Flume Hollow
Flume Mountain
Fluted Rock
Black Rock
Silh-Tusayan
Zildassaani
Zilh-Tusayan

Fluted Rock Well

Flute Well

Flux (historical)

Flux Canyon

Flying A Ranch Airport

Flying B Ranch

Flying Butte

Flying Dares Ranch Airstrip

\section{FEATURE
CLASS}

STATUS

COUNTY

COORDINATE

reservoir
spring
stream
summit

\section{BGN}

Pinal

Pima

1932 Coconino

Navajo

$\begin{array}{ll}\text { canal } & \text { BGN } \\ \text { locale } & \text { BGN } \\ \text { reservoir } & \text { BGN } \\ \text { reservoir } & \text { BGN } \\ \text { school } & \text { UNOFF } \\ \text { school } & \text { UNOFF } \\ \text { ppl } & \text { BGN } \\ & \text { VARIANT } \\ \text { crossing } & \end{array}$

Yuma

Apache

Yavapai

Yavapai

Maricopa

Maricopa

Pinal

crossing

Pinal

$\begin{array}{llll}\text { canal } & \text { BGN } & \text { Pinal } & 325934 N 1112437 \mathrm{~W} \\ \text { canal } & \text { BGN } & \text { Pinal } & 325713 \mathrm{~N} 1112621 \mathrm{~W} \\ \text { canal } & \text { BGN } & \text { Pinal } & 325121 \mathrm{~N} 1113328 \mathrm{~W} \\ & & & \\ \text { cemetery } & \text { UNOFF } & \text { Pinal } & 330020 \mathrm{~N} 1112301 \mathrm{~W} \\ \text { park } & \text { ADNIN } & \text { Maricopa } & 332728 \mathrm{~N} 1120333 \mathrm{~W} \\ \text { dam } & \text { UNOFF } & \text { Pinal } & 330524 \mathrm{~N} 1111730 \mathrm{~W} \\ & \text { VARIANT } & & \\ \text { school } & \text { UNOFF } & \text { Pinal } & 330140 \mathrm{~N} 1112303 \mathrm{~W} \\ \text { locale } & \text { BGN } & \text { Pinal } & 331534 \mathrm{~N} 1112011 \mathrm{~W}\end{array}$

locale

airport

dam

locale

school

locale

mine

building

BGN

Pinal

$331513 N 1112048 \mathrm{~W}$

$330524 \mathrm{~N} 1111730 \mathrm{~W}$

$330322 \mathrm{~N} 1112318 \mathrm{~W}$

$330121 \mathrm{~N} 1112215 \mathrm{~W}$

$340345 \mathrm{~N} 1124915 \mathrm{~W}$

$324703 \mathrm{~N} 1142318 \mathrm{~W}$

$340356 \mathrm{~N} 1124920 \mathrm{~W}$

$314628 \mathrm{~N} 1105202 \mathrm{~W}$

BGN 1959 Pina

VARIANT

$\begin{array}{llll}\text { arroyo } & \text { BGN } & \text { Pima } & 314940 \mathrm{~N} 1105935 \mathrm{~W} \\ \text { dam } & \text { UNOFF } & \text { Pima } & 314530 \mathrm{N1} 105037 \mathrm{~W} \\ \text { mine } & \text { UNOFF } & \text { Pima } & 314430 \mathrm{N1} 104955 \mathrm{~W} \\ \text { gap } & \text { BGN } & \text { Santa Cruz } & 314324 \mathrm{~N} 1105017 \mathrm{~W} \\ \text { Spring } & \text { BGN } & \text { Santa Cruz } & 314343 \mathrm{~N} 1105030 \mathrm{~W} \\ \text { locale } & \text { UNOFF } & \text { Pima } & 314540 \mathrm{~N} 1105041 \mathrm{~W} \\ \text { pillar } & \text { BGN } & \text { Yavapai } & 343012 \mathrm{~N} 1115812 \mathrm{~W} \\ \text { reservoir } & \text { BGN } & \text { Yavapai } & 343016 \mathrm{~N} 1115809 \mathrm{~W} \\ \text { well } & \text { UNOFF } & \text { Maricopa } & 333843 \mathrm{~N} 1124317 \mathrm{~W} \\ \text { reservoir } & \text { BGN } & \text { Graham } & 323440 \mathrm{~N} 1101259 \mathrm{~W}\end{array}$

spring BGN Navajo

Maricopa 333514N1113700W

well UNOFF Apache 344200N1091445W

school UNOFF Pima 321629N1105943W

school UNOFF Pima 321616N1110049W

locale

summit

BGN

Pima

$321617 \mathrm{~N} 1105936 \mathrm{~W}$

$342014 N 1094338 \mathrm{~W}$

$352334 \mathrm{~N} 1124324 \mathrm{~W}$

reservoir

valley

summit

summit

reservoir

reservoir

well

\section{BGN}

BGN

BGN 1915 Apache

VARIANT

VARIANT

VARIANT

VARIANT

BGN
UNOFF

Apache

Apache

well

UNOFF

locale

valley

airport

locale

summit

airport
NAFF Navajo

Santa Cruz

BGN Santa Cruz

ADMIN Maricopa

UNOFF
Santa Cruz

Navajo

Yavapai
$352303 \mathrm{~N} 1124132 \mathrm{~W}$

$341336 \mathrm{~N} 1112721 \mathrm{~W}$

$34111 B N 1095639 W$

$355309 \mathrm{~N} 1091454 \mathrm{~W}$

$355605 \mathrm{~N} 1091356 \mathrm{~W}$

$355220 \mathrm{~N} 1103840 \mathrm{~W}$

$313117 \mathrm{~N} 1114639 \mathrm{~W}$

$313015 N 1104639 W$

330850 N1121600W

$313043 \mathrm{~N} 1102927 \mathrm{~W}$

$350815 \mathrm{N1} 101354 \mathrm{~W}$

$340043 \mathrm{~N} 1131208 \mathrm{~W}$ $\begin{array}{ccc}\text { SOURCE } & \text { ELEV } \\ \text { COORDINATE } & \text { FT MAP NAME }\end{array}$

Ninetysix Hills SW

Mt Lemmon

361242N1121521W Havasupai Point

5972 Taylor

Yuma West

Mexican Water

Meath Spring

Indian Peaks

Tempe

1490 Florence

Valley Farms

Valley Farms

Eloy North

Florence

Phoenix

Florence SE

Florence

1884 Florence Junction

1892 Florence Junction

Florence

Florence

2603 Flores

Laguna Dan

Flores

314340N1105025W Helvetia

$314635 \mathrm{~N} 1105215 \mathrm{~W} \quad$ Green Valley

Helvetia

Mt Wrightson

7800 Mt Wrightson

Mt Wrightson

Helvetia

Middle Verde

Middle Verde

Daggs Tank

Harrison Canyon

Polacca

O'Donnel1 Canyon

Stewart Mtn

Valle Bonito

Tucs on North

Jaynes

2310 Tucson North

6425 Vernon

7441 Mount Floyd

341241 N1112322W

Mount Floyd

North Peak

Lakeside

B304 Sawmill
Sawmill

Sawmill

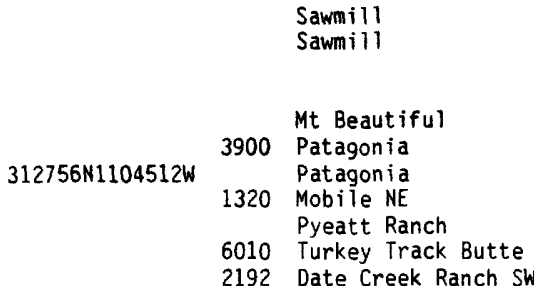




\section{FEATURE NAME}

Flying E Guest Ranch Airport

Flying $H$ Ranch

Flying $H$ Ranch

Flying H Spring

Flying $H$ Tank

Flying J Ranch Airstrip

Flying M Ranch

Flying M Tank

Flying R Ranch

Flying UW Ranch

Flying $V$ Canyon

Flying $\vee$ Maintenance Yard

Flying $V$ Pasture Tank

Flying $V$ Ranch

Flying $\vee$ Spring

Flying $V$ Tank Number One

Flying $V$ Well

Flying W Ranch

Flying W Ranch

Fly Ranch

Flys Park

Flys Peak

Fogg Cabin

Fogle Tank

Folette Spring

Foley Dam

Folley Park

Fontana Creek See Spring Creek

Fool Hollow

See Right Hand Draw

Fool Hollow

See Fools Hollow

Fool Hollow Dam

Fool Hollow Draw See Fools Hollow

Fools Canyon

Fools Gulch

Fools Hollow

Adair Wash Bagnall Hollow Fool Hollow Fool Hollow Draw

Fools Hollow Campground

Fools Hollow Lake

Fools Hollow Ridge

Fools Peak

Foo Tank

Foot Canyon

Foote Creek

Foote Creek Mesa

Foote Creek Seventy-six Trail

Foote Draw

Foote Ranch

Footes Spring

Foote Wash Dam

Foothill Shopping Center

Foot In Tree Tank

Forbay Bridge

Forbing Park

Force Tank

Ford Elementary School

Ford Mine

Fordville

Forebay, The

Foreman Wash See Forman Wash

Foreman We 1

Foremaster Tank

Forepaugh

Forepaugh Airport
FEATURE
CLASS

STATUS

COUNTY

COORDINATE

airport

locale

locale

\section{ADMIN}

UNOFF

Maricopa

Cochise

Gila

$335700 \mathrm{~N} 1124800 \mathrm{~W}$

$312346 \mathrm{N1101434 \textrm {W }}$

$334721 \mathrm{N1104952 \textrm {W }}$

\begin{tabular}{|c|c|c|c|}
\hline $\begin{array}{l}\text { spring } \\
\text { reservoir } \\
\text { airport } \\
\text { locale } \\
\text { reservoir } \\
\text { locale } \\
\text { locale } \\
\text { valley } \\
\text { locale } \\
\text { reservoir }\end{array}$ & $\begin{array}{l}\text { BGN } \\
\text { BGN } \\
\text { ADMIN } \\
\text { UNOFF } \\
\text { BGN } \\
\text { UNOFF } \\
\text { UNOFF } \\
\text { BGN } \\
\text { UNOFF } \\
\text { BGN }\end{array}$ & $\begin{array}{l}\text { Gila } \\
\text { Coconino } \\
\text { Graham } \\
\text { Coconino } \\
\text { Coconino } \\
\text { Santa Cruz } \\
\text { Pinal } \\
\text { Gila } \\
\text { Gila } \\
\text { Gila }\end{array}$ & $\begin{array}{l}335406 \mathrm{~N} 1102538 \mathrm{~W} \\
35225 \mathrm{~N} 1121827 \mathrm{~W} \\
325052 \mathrm{~N} 1095252 \mathrm{~W} \\
345545 \mathrm{~N} 1112457 \mathrm{~W} \\
345536 \mathrm{~N} 1112457 \mathrm{~W} \\
312459 \mathrm{N1} 1104213 \mathrm{~W} \\
325338 \mathrm{~N} 1105039 \mathrm{~W} \\
334823 \mathrm{~N} 1102746 \mathrm{~W} \\
335414 \mathrm{~N} 1102154 \mathrm{~W} \\
335406 \mathrm{~N} 1102023 \mathrm{~W}\end{array}$ \\
\hline
\end{tabular}

local

spring

reservoir

locale

locale

locale

locale

flat

summit

locale

UNOFF

BGN

$B G N$

BGN

UNOFF

UNOFF

UNOF

BGN

BGN

reservoir

spring

dam

park

stream

valley

valley

dam

valley

valley

valley

valley

\section{BGN}

BGN

ADMIN

VARIANT

VARIANT

VARIANT

Gila

Gila

Gila

Gila

Cochise

Gila

Gila

Cochise

Cochise

Greenlee

Yavapai

Navajo

Yavapai

Maricopa

Gila

Navajo

Navajo

UNOFF

VARIANT

BGN

BGN

BGN

VARIANT

VARIANT

VARIANT

VARIANT

park

reservoir

ridge

summit

reservoir

valley

stream

summit

trail

valley

locale

spring

dam

locale

reservoir

bridge

ppl

reservoir

school

mine

ADMIN
BGN
BGN
BGN
BGN
BGN
BGN
BGN
UNOFF
BGN

Navajo

Navajo

Navajo

Mohave

Mohave

Navajo

Greenlee

Greenlee

Greenlee

Graham

UNOFF

BGN

UNOFF

UNOFF

BGN

UNOFF

BGN

BGN

UNOFF

Graham

Santa Cruz

Graham

Maricopa

Coconino

Mohave

Yavapai

Mohave

Pima

Pinal

locale

BGN

reservoir $B G$

stream

well

reservoir

locale

airport
$340159 \mathrm{~N} 1105034 \mathrm{~W}$

$335205 \mathrm{~N} 1102417 \mathrm{~W}$

$335213 \mathrm{~N} 1102421 \mathrm{~W}$

$335147 \mathrm{~N} 1102546 \mathrm{~W}$

$321745 N 1094255 \mathrm{~W}$

$340625 \mathrm{~N} 1110518 \mathrm{~W}$

$332611 \mathrm{~N} 1105405 \mathrm{~W}$

$315252 \mathrm{~N} 1091702 \mathrm{~W}$

$315222 \mathrm{~N} 1091659 \mathrm{~W}$

334227 N1090330W

$340434 \mathrm{~N} 1130724 \mathrm{~W}$

$340548 N 1095709 \mathrm{~W}$

351011N1123058W

331749 N1114954W

340953N1111009W

$341526 \mathrm{~N} 1100408 \mathrm{~W}$

341640 N1100420W

$341640 \mathrm{~N} 1100422 \mathrm{~W}$

$341640 \mathrm{~N} 110042 \mathrm{OW}$

$340410 \mathrm{~N} 1123923 \mathrm{~W}$

$341136 \mathrm{~N} 1124635 \mathrm{~W}$

$341640 \mathrm{~N} 1100420 \mathrm{~W}$
$341624 \mathrm{~N} 1100427 \mathrm{~W}$ $341639 \mathrm{N1} 100420 \mathrm{~W}$ $341415 \mathrm{~N} 1100436 \mathrm{~W}$ $341809 N 1134201 \mathrm{~V}$ 352517 N1135923W $341215 \mathrm{~N} 1102945 \mathrm{~W}$ $333523 \mathrm{~N} 1090852 \mathrm{~W}$ $333709 \mathrm{~N} 1090822 \mathrm{~W}$ $333857 \mathrm{~N} 1091000 \mathrm{~W}$ $324758 \mathrm{~N} 1093907 \mathrm{~W}$

$322719 N 1092916 \mathrm{~W}$

$312617 \mathrm{~N} 1111455 \mathrm{~W}$ $324636 \mathrm{~N} 1093918 \mathrm{~W}$

$332335 \mathrm{~N} 1120419 \mathrm{~W}$

$344138 \mathrm{~N} 1111709 \mathrm{~W}$

$351155 \mathrm{~N} 1143402 \mathrm{~W}$
SOURCE

COOROINATE

ELEV
FT

MAP NAME

2417 Vulture Peak Nicksville Sombrero Peak

Cibecue Peak Cataract Tank

3100 Shingle Mill Mtn Mormon Lake Mormon Lake

Harshaw

Winkelman

Beckers Butte

Carrizo

Carrizo

Gentry Mtn

Beckers Butte Beckers Butte Beckers Butte

4752 Railroad Pass Buzzard Roost Mesa Inspiration Rustler Park 9666 Chiricahua Peak 6400 Maness Peak

Date Creek Ranch SE Indian Pine Cathedra1 Caves Chandler

Show Low North

$340930 \mathrm{~N} 1123659 \mathrm{~W}$

$341203 N 1124534$

$341144 \mathrm{~N} 1100429 \mathrm{~W}$

Sam Powell Peak

Congress

Show Low North 
FEATURE NAME

Forepaugh Peak

Forepaugh Railroad Station

Forepaugh Tank

Forepaugh Tank

Forepaw

See Four Peaks

Forest Boundry Tank

Forestdale Canyon

Forestdale Canyon Tank

Forestdale Creek

See Corduroy Creek

Forestdale Creek

Forestdale Spring

Forestdale Tank

Forestdale Trading Post

Forest $\mathrm{Hill}$

Forest Lake Chapter House

Forest Lakes Estates

Forest Lake Wash

Forest Lake Well

Forest Ranch Windmill

Forest Service Tank

Forest Tank

Forest Tank

Forest Tank

Forest Windmill

Fork Canyon

$$
\text { See Dyke Canyon }
$$

Forked Pine Campground

Forked Pine Picnic Area

Fork Rock Creek

Fort Rock Creek

Forks Butte

Fork Spring

Fork Spring

Forks Tank

Fork Tank

Fork Tank

Fork Tank

Forman Ranch

Forman Wash

Foreman Wash

Formaster Tank

Formaster Well

Forrest

Forrest Airport

Forrest Ranch Forrests Ranch

Forrests Ranch

See Forrest Ranch

Forster Canyon

Forster Rapids

Foster Rapids

Forst Spring

Fortaleza Indian Ruins

Fort Apache

Camp Apache

Camp Mogollon

Camp Ord

Camp Thomas Fort Apache Reservation White Mountain Indian

Reservation

Fort Apache Junction

Fort Apache Post office

Fort Apache Reservation See Fort Apache Indian Reservation

Fort Apache Tank

Fort Apache Tank Number One

\begin{tabular}{|c|c|c|c|}
\hline $\begin{array}{l}\text { FEATURE } \\
\text { CLASS }\end{array}$ & STATUS & COUNTY & COOROINATE \\
\hline $\begin{array}{l}\text { summit } \\
\text { building }\end{array}$ & $\begin{array}{l}\text { BGN } \\
\text { UNOFF }\end{array}$ & $\begin{array}{l}\text { Maricopa } \\
\text { Maricopa }\end{array}$ & $\begin{array}{l}335945 \mathrm{~N} 1130401 \mathrm{~W} \\
335819 \mathrm{~N} 1130240 \mathrm{~W}\end{array}$ \\
\hline $\begin{array}{l}\text { reservoir } \\
\text { reservoir }\end{array}$ & $\begin{array}{l}\text { BGN } \\
\text { BGN } \\
\text { VARIANT }\end{array}$ & $\begin{array}{l}\text { Maricopa } \\
\text { Maricopa }\end{array}$ & $\begin{array}{l}335607 N 1125904 W \\
335653 N 1130147 W\end{array}$ \\
\hline $\begin{array}{l}\text { summit } \\
\text { reservoir } \\
\text { valley } \\
\text { reservoir }\end{array}$ & $\begin{array}{l}\text { BGN } \\
\text { BGN } \\
\text { BGN } \\
\text { VARIANT }\end{array}$ & $\begin{array}{l}\text { Yuma } \\
\text { Cochise } \\
\text { Navajo } \\
\text { Navajo }\end{array}$ & $\begin{array}{l}335204 N 1140515 W \\
314158 N 1091405 W \\
340740 N 1100559 W \\
341050 N 1100311 W\end{array}$ \\
\hline $\begin{array}{l}\text { stream } \\
\text { stream }\end{array}$ & $B G N$ & $\begin{array}{l}\text { Gila } \\
\text { Navajo }\end{array}$ & $\begin{array}{l}335943 \mathrm{~N} 1101731 \mathrm{~W} \\
340646 \mathrm{~N} 1100754 \mathrm{~W}\end{array}$ \\
\hline $\begin{array}{l}\text { spring } \\
\text { reservoir } \\
\text { locale } \\
\text { summit } \\
\text { building } \\
\text { ppl } \\
\text { valley } \\
\text { well } \\
\text { locale } \\
\text { reservoir }\end{array}$ & $\begin{array}{l}\text { BGN } \\
\text { BGN } \\
\text { BGN } \\
\text { BGN } \\
\text { UNOFF } \\
\text { BGN } \\
\text { BGN } \\
\text { UNOFF } \\
\text { UNOFF } \\
\text { BGN }\end{array}$ & $\begin{array}{l}\text { Navajo } \\
\text { Navajo } \\
\text { Navajo } \\
\text { Cochise } \\
\text { Navajo } \\
\text { Coconino } \\
\text { Navajo } \\
\text { Navajo } \\
\text { Gila } \\
\text { Coconino }\end{array}$ & $\begin{array}{l}340838 \mathrm{~N} 1100624 \mathrm{~W} \\
340848 \mathrm{~N} 1100342 \mathrm{~W} \\
340840 \mathrm{~N} 1100615 \mathrm{~W} \\
320739 \mathrm{~N} 1102552 \mathrm{~W} \\
361735 \mathrm{~N} 1101807 \mathrm{~W} \\
342020 \mathrm{~N} 1104757 \mathrm{~W} \\
362336 \mathrm{~N} 1101703 \mathrm{~W} \\
362232 \mathrm{~N} 1101349 \mathrm{~W} \\
331638 \mathrm{~N} 1104510 \mathrm{~W} \\
350053 \mathrm{~N} 1113600 \mathrm{~W}\end{array}$ \\
\hline $\begin{array}{l}\text { reservoir } \\
\text { reservoir } \\
\text { reservoir } \\
\text { locale }\end{array}$ & $\begin{array}{l}\text { BGN } \\
\text { BGN } \\
\text { BGN } \\
\text { BGN } \\
\text { VARIANT }\end{array}$ & $\begin{array}{l}\text { Santa Cruz } \\
\text { Cochise } \\
\text { Coconino } \\
\text { Yavapai }\end{array}$ & $\begin{array}{l}313352 N 1102958 W \\
315031 N 1095314 W \\
344025 N 1111515 W \\
342633 N 1123704 W\end{array}$ \\
\hline $\begin{array}{l}\text { valley } \\
\text { park } \\
\text { park } \\
\text { stream }\end{array}$ & $\begin{array}{l}\text { ADMIN } \\
\text { ADMIN } \\
\text { BGN } 1979 \\
\text { VARIANT }\end{array}$ & $\begin{array}{l}\text { Yavapai } \\
\text { Coconino } \\
\text { Coconino } \\
\text { Yavapai }\end{array}$ & $\begin{array}{l}340458 N 1115822 W \\
350116 N 1112354 W \\
350118 N 1112353 W \\
350335 N 1131905 W\end{array}$ \\
\hline
\end{tabular}

$\begin{array}{cc}\text { SOURCE } & \text { ELEV } \\ \text { COORDINATE } & \text { FT }\end{array}$

3098 Forepaugh Peak Forepaugh Peak

Outlaw Hill

Forepaugh Peak

Apache

Show Low South

Show Low South

341228N1100514W Long Tom Canyon

Show Low South

Show Low South

6079 Show Low South

6114 Happy Valley

Red Slide Peak

$0 \mathrm{~W}$ Point

362230N1101312W Yucca Hill

7267 Cliff Rose Hill

Pinal Peak

Lower Lake Mary

Pyeatt Ranch Black Diamond Peak Turkey Mtn

Wilhoit

7100 Ashurst Lake Ashurst Lake Devils Hump

$334331 \mathrm{N1101245W}$ $335400 \mathrm{~N} 1101444 \mathrm{~W}$ 342055N1131521W

$332044 N 1092533 \mathrm{~W}$

$331615 \mathrm{N1105208 \textrm {W }}$

$344811 \mathrm{N1113510 \textrm {W }}$

$344811 \mathrm{~N} 1113510 \mathrm{~W}$

$324027 \mathrm{~N} 1110340 \mathrm{~W}$

$324035 \mathrm{~N} 1110416 \mathrm{~W}$

$324120 \mathrm{~N} 1110118 \mathrm{~W}$

5403 Forks Butte

Cedar Creek

Arrastra Mtn SE

Bee Canyon

Pinal Peak

Stoneman Lake

Stoneman Lake

Chief Butte

Pinal

locale UNOFF Pinal

VARIANT

BGN

UNOFF

locale BGN

airport ADMIN

locale UNOFF

VARIANT

VARIANT

locale

valley

BGN 1925

BGN 1925

VARIANT

Mohave

$365334 N 1125814 \mathrm{~W}$

$312200 \mathrm{~N} 1094337 \mathrm{~W}$

Cochise 312205N1094025W

Cochise $\quad 312635 N 1094946 \mathrm{~W}$

Cochise 312635N1094946W

Coconino 361440N1123115W

Coconino $361455 N 1123118 \mathrm{~W}$

spring BGN Apache 364833N1091420W

locale BGN Maricopa $330015 \mathrm{~N} 1124528 \mathrm{~W}$

ppl BGN Navajo 334726 N1095917W

VARIANT

VARIANT

VARIANT

VARIANT

reserve BGN

BARIANT

Navajo

$335500 \mathrm{~N} 1101000 \mathrm{~W}$

$361302 \mathrm{~N} 1123029 \mathrm{~W}$

Topocoba Hilltop

Topocoba Hilltop

Citrus Valley East

$334723 \mathrm{~N} 1100004 \mathrm{~W}$

$335500 \mathrm{~N} 1101000 \mathrm{~W}$

reserve

UNOFF

Navajo

reservoir BGN Navajo

$334721 \mathrm{~N} 1095834 \mathrm{~W}$

$334712 \mathrm{~N} 1095903 \mathrm{~W}$
Pastora Peak

Whiteriver

Cedar Creek

Canyon Day

Colorado City

Paul Spur

Paul Spur

Bisbee NE

Whiteriver

Whiteriver 
NATIONAL GAZETTEER--ARIZONA 1986

\begin{tabular}{|c|c|c|c|c|c|c|c|}
\hline FEATURE NAME & $\begin{array}{l}\text { FEATURE } \\
\text { CLASS }\end{array}$ & STATUS & COUNTY & COORDINATE & $\begin{array}{l}\text { SOURCE } \\
\text { COORDINATE }\end{array}$ & $\begin{array}{l}\text { ELEV } \\
\text { FT }\end{array}$ & MAP NAME \\
\hline $\begin{array}{l}\text { Fort Badger (historical) } \\
\text { Fort Barrett } \\
\text { See Casa Blanca }\end{array}$ & $\begin{array}{l}\text { locale } \\
\text { ppl }\end{array}$ & $\begin{array}{l}\text { BGN } \\
\text { VARIANT }\end{array}$ & $\begin{array}{l}\text { Maricopa } \\
\text { Pinal }\end{array}$ & $\begin{array}{l}333200 \mathrm{~N} 1113900 \mathrm{~W} \\
330713 \mathrm{~N} 1115315 \mathrm{~W}\end{array}$ & & & Granite Reef Dam \\
\hline $\begin{array}{l}\text { Fort Basin Tank } \\
\text { Fort Bowie } \\
\text { See Camp Bowie } \\
\text { Fort Bowie Military Reservation } \\
\text { See Camp Bowie } \\
\text { Fort Bowie Ruins } \\
\text { Old Fort Bowie } \\
\text { Fort Buchanan (historical) } \\
\text { Camp Moore } \\
\text { Fort Buchanan (site) }\end{array}$ & $\begin{array}{l}\text { reservoir } \\
\text { park } \\
\text { park } \\
\text { locale } \\
\text { locale }\end{array}$ & $\begin{array}{l}\text { BGN } \\
\text { VARIANT } \\
\text { VARIANT } \\
\text { BGN } \\
\text { VARIANT } \\
\text { BGN } \\
\text { VARIANT } \\
\text { BGN }\end{array}$ & $\begin{array}{l}\text { Yavapai } \\
\text { Cochise } \\
\text { Cochise } \\
\text { Cochise } \\
\text { Santa Cruz } \\
\text { Santa Cruz }\end{array}$ & $\begin{array}{l}342713 \mathrm{~N} 1131152 \mathrm{~W} \\
320859 \mathrm{~N} 1092707 \mathrm{~W} \\
320859 \mathrm{~N} 1092707 \mathrm{~W} \\
320 \mathrm{~B} 33 \mathrm{~N} 1092617 \mathrm{~W} \\
313910 \mathrm{~N} 1104240 \mathrm{~W}\end{array}$ & & & $\begin{array}{l}\text { Thorn Peak } \\
\text { Bowie Mtn North } \\
\text { Elgin } \\
\text { Sonoita }\end{array}$ \\
\hline $\begin{array}{l}\text { Fort Buchanan } \\
\text { See Fort Crittenden (site) } \\
\text { Fort Canyon } \\
\text { Fort Crittenden (site) } \\
\text { Camp Moore } \\
\text { Fort Buchanan } \\
\text { 01d Fort Crittenden } \\
\text { Fort Crittenden (historical) } \\
\text { Camp Crittenden } \\
\text { Fort Defiance }\end{array}$ & $\begin{array}{l}\text { locale } \\
\text { valley } \\
\text { locale }\end{array}$ & $\begin{array}{l}\text { VARIANT } \\
\text { BGN } \\
\text { BGN } \\
\text { VARIANT } \\
\text { VARIANT } \\
\text { VARIANT } \\
\text { BGN } \\
\text { VARIANT } \\
\text { BGN }\end{array}$ & $\begin{array}{l}\text { Santa Cruz } \\
\text { Apache }\end{array}$ & $\begin{array}{l}313940 \mathrm{~N} 1104200 \mathrm{~W} \\
354440 \mathrm{~N} 1090433 \mathrm{~W}\end{array}$ & $314223 \mathrm{~N} 1104520 \mathrm{~W}$ & 6836 & $\begin{array}{l}\text { Sonoita } \\
\text { Window Rock }\end{array}$ \\
\hline $\begin{array}{l}\text { Fort Defiance Elementary School } \\
\text { Fort Defiance Junior High } \\
\text { School } \\
\text { Fort Defiance Post Office } \\
\text { Fort Defiance Trading Post } \\
\text { Fort Garrett (ruin) } \\
\text { Fort Garrett Point } \\
\text { Fort Goodwin } \\
\text { See Camp Goodwin } \\
\text { (historical) }\end{array}$ & $\begin{array}{l}\text { school } \\
\text { school } \\
\text { building } \\
\text { locale } \\
\text { locale } \\
\text { cliff } \\
\text { locale }\end{array}$ & $\begin{array}{l}\text { UNOFF } \\
\text { UNOFF } \\
\text { UNOFF } \\
\text { BGN } \\
\text { BGN } \\
\text { BGN } \\
\text { VARIANT }\end{array}$ & $\begin{array}{l}\text { Apache } \\
\text { Apache } \\
\text { Apache } \\
\text { Apache } \\
\text { Mohave } \\
\text { Mohave } \\
\text { Graham }\end{array}$ & $\begin{array}{l}354424 \mathrm{~N} 1090404 \mathrm{~W} \\
354422 \mathrm{~N} 1090357 \mathrm{~W} \\
354456 \mathrm{~N} 1090450 \mathrm{~W} \\
354454 \mathrm{~N} 1090449 \mathrm{~W} \\
360 \mathrm{~B} 09 \mathrm{N1} 134806 \mathrm{~W} \\
360717 \mathrm{~N} 1134610 \mathrm{~W} \\
330520 \mathrm{~N} 1100327 \mathrm{~W}\end{array}$ & & & $\begin{array}{l}\text { Window Rock } \\
\text { Window Rock } \\
\text { Window Rock } \\
\text { Window Rock } \\
\text { Snap Canyon East } \\
\text { Bat Cave }\end{array}$ \\
\hline $\begin{array}{l}\text { Fort Grant (State Industrial } \\
\text { School) } \\
\text { Ccamp Grant } \\
\text { Fort Grant Military } \\
\text { Reservation } \\
\text { Old Camp Grant } \\
\text { Fort Grant (historical) } \\
\text { Camp Grant } \\
\text { Fort Grant Military Reservation } \\
\text { See Fort Grant (State } \\
\text { Industrial School) }\end{array}$ & school & $\begin{array}{l}\text { UNOFF } \\
\text { VARIANT } \\
\text { VARIANT } \\
\text { VARIANT } \\
\text { BGN } \\
\text { VARIANT } \\
\text { VARIANT }\end{array}$ & Graham & $\begin{array}{l}323722 N 1095643 \mathrm{~W} \\
323722 N 1095643 \mathrm{~W}\end{array}$ & & & Fort Grant \\
\hline $\begin{array}{l}\text { Fort Grant Road Interchange } \\
\text { Fort Grant Vista Point } \\
\text { Fort Horn Monument } \\
\text { Camp Huachuca } \\
\text { Fort Huachuca Military } \\
\text { Reservation } \\
\text { U.S. Electronics } \\
\text { Proving Ground } \\
\text { Fort Huachuca Military } \\
\text { Reservation } \\
\text { See Fort Horn Monument }\end{array}$ & $\begin{array}{l}\text { crossing } \\
\text { locale } \\
\text { park }\end{array}$ & $\begin{array}{l}\text { UNOFF } \\
\text { BGN } \\
\text { ADMIN } \\
\text { VARIANT } \\
\text { VARIANT } \\
\text { VARIANT } \\
\text { VARIANT }\end{array}$ & $\begin{array}{l}\text { Cochise } \\
\text { Graham } \\
\text { Yuma }\end{array}$ & 325508 N1133354W & & & $\begin{array}{l}\text { Willcox North } \\
\text { Webb Peak } \\
\text { Horn }\end{array}$ \\
\hline $\begin{array}{l}\text { Fortieth Street School } \\
\text { Fortification Hill } \\
\quad \text { Fortification Mountain } \\
\text { Fortification Mountain } \\
\text { See Fortification Hill } \\
\text { Fort ification Ridge } \\
\text { Fort ified Peak } \\
\text { Fort Lowell (historical site) } \\
\text { Camp Lowell } \\
\text { Fort Lowell Park }\end{array}$ & $\begin{array}{l}\text { summit } \\
\text { ridge } \\
\text { summit } \\
\text { locale } \\
\text { park }\end{array}$ & $\begin{array}{l}\text { UNOFF } \\
\text { BGN } \\
\text { VARIANT } \\
\text { VARIANT } \\
\text { BGN } \\
\text { BGN } \\
\text { BGN } \\
\text { VARIANT } \\
\text { ADMIN }\end{array}$ & $\begin{array}{l}\text { Mohave } \\
\text { Mohave } \\
\text { Pinal } \\
\text { Pima } \\
\text { Pima }\end{array}$ & $\begin{array}{l}332508 \mathrm{~N} 1115942 \mathrm{~W} \\
360239 \mathrm{~N} 1144050 \mathrm{~W} \\
360239 \mathrm{~N} 1144050 \mathrm{~W} \\
360516 \mathrm{~N} 1143948 \mathrm{~W} \\
324238 \mathrm{~N} 1105604 \mathrm{~W} \\
321536 \mathrm{~N} 1105224 \mathrm{~W} \\
321532 \mathrm{~N} 1105215 \mathrm{~W}\end{array}$ & & 2460 & $\begin{array}{l}\text { Hoover Dam } \\
\text { Fort if ied Mtn } \\
\text { Sabino Canyon } \\
\text { Sabino Canyon }\end{array}$ \\
\hline $\begin{array}{l}\text { Fort Lowell School } \\
\text { Fort Lowell Shopping Center } \\
\text { Fort McDonald } \\
\text { Fort McDowell } \\
\text { Camp McDowell } \\
\text { McDowell }\end{array}$ & $\begin{array}{l}\text { school } \\
\text { locale } \\
\text { locale } \\
\text { ppl }\end{array}$ & $\begin{array}{l}\text { UNOFF } \\
\text { UNOFF } \\
\text { BGN } \\
\text { BGN } \\
\text { VARIANT } \\
\text { VARIANT }\end{array}$ & $\begin{array}{l}\text { Pima } \\
\text { Pima } \\
\text { Gila } \\
\text { Maricopa }\end{array}$ & $\begin{array}{l}321439 \mathrm{~N} 1105256 \mathrm{~W} \\
321555 \mathrm{~N} 1105603 \mathrm{~W} \\
341406 \mathrm{~N} 1112051 \mathrm{~W} \\
333812 \mathrm{~N} 1114026 \mathrm{~W}\end{array}$ & & 2410 & $\begin{array}{l}\text { Tucs on } \\
\text { Tucs on North } \\
\text { Payson South } \\
\text { Fort Mc Dowell }\end{array}$ \\
\hline
\end{tabular}


NATIONAL GAZETTEER--ARIZONA 1986

\section{FEATURE NAME}

Fort McDowell Indian Reservation

Fort McDowell Reservation

Fort McDowell Res ervation

See Fort McDowell Indian

Reservation

Fort Mason (historical)
Camp McKee
0ld Fort Mason
Fort Misery
Fort Mohave
Camp Colorado
Camp Mohave
Camp Mojave
Fort Mohave
Fort Mohave
See Fort Mohave
Fort Mohave Indian Reservation
Fort Mohave Reservation
Fort Mohave Reservation
See Fort Mohave Indian
Reservation
Fort Moroni
See Fort Valley
Fort Pearce Wash
Fort Pierce Dry Wash
Fort Pierce Wash
Pierce Creek
Pierce Wash
Short Creek

Fort Pierce Dry Wash

See Fort Pearce Wash

Fort Pierce Wash

See Fort Pearce Wash

Fortress $\mathrm{Hill}$

See Escarpada, Mesa

Fort River Caves (subdivision)

Fort Rock

See Fort Rock Ranch

Fort Rock Creek

See Fork Rock Creek

Fort Rock Ranch

Fort Rock

Mount Hope

Fort Thomas

Maxey

Fort Thomas Canal

Fort Thomas Elementary School

Fort Thomas High School

Fort Thomas Union High School

Fort Thomas Post Office

Fort Thomas Union High School

See Fort Thomas High School

Fort Thomas Ward Cemetery

Fort Tule

Fort Tuthill

Fort Tuthill County Park Coconino County

Fort Tyson Fairgrounds and Park

See Quartzsite

Fort Tyson

See 01d Fort Tyson
Fortuna
Fortuna Station
Ming Spur

Nine Mile Station

Fortuna Interchange

Fortuna Mine

Fortuna Mine

La Fortuna Mine

\begin{tabular}{|c|c|c|c|c|c|c|}
\hline $\begin{array}{l}\text { FEATURE } \\
\text { CLASS }\end{array}$ & STATUS & COUNTY & COORDINATE & $\begin{array}{l}\text { SOURCE } \\
\text { COORDINATE }\end{array}$ & $\begin{array}{c}\text { ELEV } \\
\text { FT }\end{array}$ & MAP NAME \\
\hline reserve & $B G N$ & Maricopa & $334000 \mathrm{~N} 1114000 \mathrm{~W}$ & & & Fort McDowell \\
\hline & $\begin{array}{l}\text { VARIANT } \\
\text { VARIANT }\end{array}$ & & & & & \\
\hline reserve & & Maricopa & $334000 \mathrm{~N} 111400 \mathrm{OW}$ & & & \\
\hline locale & $\begin{array}{l}\text { BGN } \\
\text { VARIANT } \\
\text { VARIANT }\end{array}$ & Santa Cruz & $312725 \mathrm{~N} 1115808 \mathrm{~W}$ & & 3430 & Rio Rico \\
\hline $\begin{array}{l}\text { locale } \\
\text { locale }\end{array}$ & $\begin{array}{l}\text { BGN } \\
\text { BGN } 1972 \\
\text { VARIANT } \\
\text { VARIANT } \\
\text { VARIANT } \\
\text { VARIANT } \\
\text { VARIANT }\end{array}$ & $\begin{array}{l}\text { Yavapai } \\
\text { Mohave }\end{array}$ & $\begin{array}{l}340825 \mathrm{~N} 1122157 \mathrm{~W} \\
350235 \mathrm{~N} 1143718 \mathrm{~W}\end{array}$ & & 541 & $\begin{array}{l}\text { Crown King } \\
\text { Davis Dam SE }\end{array}$ \\
\hline locale & & Mohave & $350235 \mathrm{N1143718 \textrm {W }}$ & & & \\
\hline reserve & $\begin{array}{l}\text { BGN } \\
\text { VARIANT } \\
\text { VARIANT }\end{array}$ & Mohave & $345730 \mathrm{~N} 1143729 \mathrm{~W}$ & & & Needles NE \\
\hline reserve & & Mohave & $345730 \mathrm{~N} 1143729 \mathrm{~W}$ & & & \\
\hline $\begin{array}{l}\text { valley } \\
\text { stream }\end{array}$ & $\begin{array}{l}\text { VARIANT } \\
\text { BGN } 1979 \\
\text { VARIANT } \\
\text { VARIANT } \\
\text { VARIANT } \\
\text { VARIANT } \\
\text { VARIANT }\end{array}$ & $\begin{array}{l}\text { Coconino } \\
\text { Mohave }\end{array}$ & $\begin{array}{l}351410 \mathrm{~N} 1114441 \mathrm{~W} \\
\text { 370430N1133433W }\end{array}$ & $365821 \mathrm{~N} 1131605 \mathrm{~W}$ & & Yellowhorse Flat \\
\hline & VARIANT & & & & & \\
\hline & VARIANT & Mohave & $3 / 0430 \mathrm{NL133433 \textrm {W }}$ & & & \\
\hline stream & VARIANT & Mohave & $370430 \mathrm{~N} 1133433 \mathrm{~W}$ & & & \\
\hline $\begin{array}{l}\text { cliff } \\
\text { pp1 }\end{array}$ & $\begin{array}{l}\text { BGN } \\
\text { VARIANT }\end{array}$ & $\begin{array}{l}\text { Maricopa } \\
\text { Yavapai }\end{array}$ & $\begin{array}{l}\text { UNKNOWN } \\
343405 N 1115047 \mathrm{~W}\end{array}$ & & 3080 & Camp Verde \\
\hline & VARIANT & Yavapai & $350848 N 1131937 \mathrm{~W}$ & & & \\
\hline stream & & Yavapai & $350335 \mathrm{N1131905W}$ & & & \\
\hline locale & $\begin{array}{l}\text { UNOFF } \\
\text { VARIANT } \\
\text { VARIANT }\end{array}$ & Yavapai & $350848 N 1131937 \mathrm{~W}$ & & & Fort Rock Ranch \\
\hline pp1 & $\begin{array}{l}\text { BGN } \\
\text { VARIANT }\end{array}$ & Graham & $330213 N 1095753 \mathrm{~W}$ & & 2713 & Fort Thomas \\
\hline $\begin{array}{l}\text { canal } \\
\text { school } \\
\text { school }\end{array}$ & $\begin{array}{l}\text { BGN } \\
\text { UNOFF } \\
\text { UNOFF } \\
\text { VARIANT }\end{array}$ & $\begin{array}{l}\text { Graham } \\
\text { Graham } \\
\text { Graham }\end{array}$ & $\begin{array}{l}330214 N 1095818 \mathrm{~W} \\
330205 \mathrm{~N} 1095750 \mathrm{~W} \\
330210 \mathrm{~N} 1095740 \mathrm{~W}\end{array}$ & & & $\begin{array}{l}\text { Fort Thomas } \\
\text { Markham Creek } \\
\text { Markham Creek }\end{array}$ \\
\hline building & $\begin{array}{l}\text { UNOFF } \\
\text { VARIANT }\end{array}$ & Graham & $330213 \mathrm{N1095746 \textrm {W }}$ & & 2700 & Markham Creek \\
\hline $\begin{array}{l}\text { school } \\
\text { cemetery } \\
\text { locale } \\
\text { ppl } \\
\text { park }\end{array}$ & $\begin{array}{l}\text { UNOFF } \\
\text { BGN } \\
\text { BGN } \\
\text { AOMIN } \\
\text { VARIANT }\end{array}$ & $\begin{array}{l}\text { Graham } \\
\text { Graham } \\
\text { Yavapai } \\
\text { Coconino } \\
\text { Coconino }\end{array}$ & $\begin{array}{l}330210 \mathrm{~N} 1095740 \mathrm{~W} \\
330403 \mathrm{~N} 1100122 \mathrm{~W} \\
340012 \mathrm{~N} 1121602 \mathrm{~W} \\
350830 \mathrm{~N} 1114137 \mathrm{~W} \\
350833 \mathrm{~N} 1114116 \mathrm{~W}\end{array}$ & & 7000 & $\begin{array}{l}\text { Geronimo } \\
\text { Columbia } \\
\text { Flagstaff West } \\
\text { Flagstaff West }\end{array}$ \\
\hline ppl & VARIANT & Yuma & 333950N1141345W & & & \\
\hline & VARIANT & & & & & \\
\hline $\begin{array}{l}\text { locale } \\
\text { locale }\end{array}$ & $\begin{array}{l}\text { BGN } \\
\text { VARIANT } \\
\text { VARIANT } \\
\text { VARIANT }\end{array}$ & $\begin{array}{l}\text { Yuma } \\
\text { Yuma }\end{array}$ & $\begin{array}{l}333957 \mathrm{N11} 141308 \mathrm{~W} \\
324126 \mathrm{~N} 1142708 \mathrm{~W}\end{array}$ & & & Fortuna \\
\hline $\begin{array}{l}\text { crossing } \\
\text { mine } \\
\text { mine }\end{array}$ & $\begin{array}{l}\text { UNOFF } \\
\text { UNOFF } \\
\text { UNOFF } \\
\text { VARIANT }\end{array}$ & $\begin{array}{l}\text { Yuma } \\
\text { Pima } \\
\text { Yuma }\end{array}$ & $\begin{array}{l}324014 \mathrm{~N} 1142636 \mathrm{~W} \\
315307 \mathrm{~N} 1111428 \mathrm{~W} \\
323306 \mathrm{~N} 1141948 \mathrm{~W}\end{array}$ & & & $\begin{array}{l}\text { Fortuna } \\
\text { Samaniego Peak } \\
\text { Fortuna Mine }\end{array}$ \\
\hline
\end{tabular}


NATIONAL GAZETTEER--ARIZONA 1986

\begin{tabular}{|c|c|c|c|c|c|c|c|}
\hline FEATURE NAME & $\begin{array}{l}\text { FEATURE } \\
\text { CLASS }\end{array}$ & STATUS & COUNTY & COORDIMATE & $\begin{array}{l}\text { SOURCE } \\
\text { COORDINATE }\end{array}$ & $\begin{array}{l}\text { ELEV } \\
\text { FT }\end{array}$ & MAP NAME \\
\hline $\begin{array}{l}\text { Fortuna Mine } \\
\text { Fortuna Peak } \\
\text { Fortuna Station } \\
\text { See Fortuna } \\
\text { Fortuna Wash } \\
\text { Fortuna Wash } \\
\text { Fortune Ranch } \\
\text { Fort Valley } \\
\text { Fort Moroni } \\
\text { Leroux Prairie }\end{array}$ & $\begin{array}{l}\text { mine } \\
\text { summit } \\
\text { locale } \\
\text { stream } \\
\text { stream } \\
\text { locale } \\
\text { valley }\end{array}$ & $\begin{array}{l}\text { UNOFF } \\
\text { BGN } \\
\text { VARIANT } \\
\text { BGN } \\
\text { BGN } \\
\text { UNOFF } \\
\text { BGN } 1933 \\
\text { VARIANT } \\
\text { VARIANT }\end{array}$ & $\begin{array}{l}\text { Pinal } \\
\text { Pinal } \\
\text { Yuma } \\
\text { Yuma } \\
\text { Pinal } \\
\text { Santa Cruz } \\
\text { Coconino }\end{array}$ & $\begin{array}{l}332103 \mathrm{~N} 1110530 \mathrm{~W} \\
332125 \mathrm{N1110512W} \\
324126 \mathrm{~W} 1142708 \mathrm{~W} \\
324239 \mathrm{N1142638 \textrm {W }} \\
332030 \mathrm{N1110514W} \\
313217 \mathrm{N1104337W} \\
351410 \mathrm{~W} 1114441 \mathrm{~W}\end{array}$ & $\begin{array}{l}323640 \mathrm{N1141903W} \\
332115 \mathrm{N1110521 \textrm {W }} \\
351624 \mathrm{N1} 1114306 \mathrm{~W}\end{array}$ & 5269 & $\begin{array}{l}\text { Fortuna } \\
\text { Superior } \\
\text { Mt Hughes } \\
\text { Flagstaff West }\end{array}$ \\
\hline $\begin{array}{l}\text { Fort Valley Experimental Forest } \\
\text { Fort Valley Experimental } \\
\text { Forest Station } \\
\text { Fort Verde } \\
\text { See Camp Verde } \\
\text { Fort Verde Estates } \\
\text { (subdivision) } \\
\text { Fort Wailen } \\
\text { See Camp Wallen } \\
\text { (historical) }\end{array}$ & $\begin{array}{l}\text { forest } \\
\text { locale }\end{array}$ & $\begin{array}{l}\text { ADMIN } \\
\text { BGN } \\
\text { VARIANT } \\
\text { BGN } \\
\text { VARIANT }\end{array}$ & $\begin{array}{l}\text { Yavapai } \\
\text { Yavapai } \\
\text { Cochise }\end{array}$ & $\begin{array}{l}343349 N 1115113 W \\
343226 \mathrm{~N} 1115122 \mathrm{~W}\end{array}$ & & 3070 & $\begin{array}{l}\text { Humphreys Peak } \\
\text { Humphreys Peak }\end{array}$ \\
\hline $\begin{array}{l}\text { Fort Whipple } \\
\text { Camp Whipple } \\
\text { Whipple Barracks } \\
\text { Fort Whipple } \\
\text { See Whipple } \\
\text { Forty Caves Canyon } \\
\text { Fortyfour Canyon } \\
\text { Forty Four Canyon } \\
\text { See Clover Canyon } \\
\text { Fortyfour Spring }\end{array}$ & $\begin{array}{l}\text { locale } \\
\text { valley } \\
\text { valley } \\
\text { valley } \\
\text { spring }\end{array}$ & $\begin{array}{l}\text { BGN } \\
\text { VARIANT } \\
\text { VARIANT } \\
\text { VARIANT } \\
\text { BGN } \\
\text { BGN } 1981 \\
\text { VARIANT } \\
\text { BGN }\end{array}$ & $\begin{array}{l}\text { Yavapai } \\
\text { Coconino } \\
\text { Coconino } \\
\text { Coconino } \\
\text { Coconino }\end{array}$ & $\begin{array}{l}343324 N 1122656 \mathrm{~W} \\
365106 \mathrm{N1104851W} \\
342950 \mathrm{~N} 1112204 \mathrm{~W} \\
343306 \mathrm{~N} 1112411 \mathrm{~W} \\
342906 \mathrm{N111} 2216 \mathrm{~W}\end{array}$ & $\begin{array}{l}365223 \mathrm{~N} 1104516 \mathrm{~W} \\
342806 \mathrm{~N} 1112240 \mathrm{~W}\end{array}$ & & $\begin{array}{l}\text { Chaiyahi Rim SE } \\
\text { Kehi Ridge }\end{array}$ \\
\hline $\begin{array}{l}\text { Fortyfour Tank } \\
\text { Fortymile Desert Tank } \\
\text { Fortynine Hill } \\
\text { Fortynine Wash } \\
\text { Fortyseven Ranch } \\
\text { Fort Yuma Indian Reservation } \\
\quad \text { Fort Yuma Reservation } \\
\text { Fort Yuma Reservation } \\
\text { See Fort Yuma Indian } \\
\quad \text { Reservation }\end{array}$ & $\begin{array}{l}\text { reservoir } \\
\text { reservoir } \\
\text { summit } \\
\text { strean } \\
\text { locale } \\
\text { reserve } \\
\text { reserve }\end{array}$ & $\begin{array}{l}\text { BGN } \\
\text { BGN } \\
\text { BGN } \\
\text { BGN } \\
\text { UNOFF } \\
\text { BGN } \\
\text { VARIANT } \\
\text { VARIANT }\end{array}$ & $\begin{array}{l}\text { Coconino } \\
\text { Maricopa } \\
\text { Coconino } \\
\text { Pima } \\
\text { Cochise } \\
\text { Yuma }\end{array}$ & $\begin{array}{l}343851 \text { N1111812W } \\
330150 \mathrm{~N} 1122959 \mathrm{~W} \\
351554 \mathrm{N1115337W} \\
315033 \mathrm{N1103505W} \\
3135541095043 \mathrm{~W} \\
323700 \mathrm{~N} 1143230 \mathrm{~W}\end{array}$ & $315008 \mathrm{~N} 1103854 \mathrm{~W}$ & 7864 & $\begin{array}{l}\text { Turkey Mtn } \\
\text { Butterf ield Pass } \\
\text { Parks } \\
\text { Spring Water Canyon } \\
\text { Gleeson SE } \\
\text { Yuma East }\end{array}$ \\
\hline $\begin{array}{l}\text { Fossil Bay } \\
\text { Fossil Canyon } \\
\text { Fossil Creek } \\
\text { Fossil Mountain } \\
\text { Fossil Pocket } \\
\text { Fossil Rapids } \\
\text { Fossil Springs } \\
\text { Foster Canyon } \\
\text { Foster Ranch } \\
\text { Foster Rapids } \\
\text { See Forster Rapids }\end{array}$ & $\begin{array}{l}\text { basin } \\
\text { valley } \\
\text { stream } \\
\text { summit } \\
\text { bas in } \\
\text { rapids } \\
\text { spring } \\
\text { valley } \\
\text { locale } \\
\text { rapids }\end{array}$ & $\begin{array}{l}\text { BGN } 1932 \\
\text { BGN } 1932 \\
\text { BGN } \\
\text { BGN } 1932 \\
\text { BGN } \\
\text { BGN } 1932 \\
\text { BGN } \\
\text { BGN } \\
\text { UNOFF } \\
\text { VARIANT }\end{array}$ & $\begin{array}{l}\text { Coconino } \\
\text { Coconino } \\
\text { Gila } \\
\text { Coconino } \\
\text { Yavapai } \\
\text { Coconino } \\
\text { Yavapai } \\
\text { Coconino } \\
\text { Coconino } \\
\text { Coconino }\end{array}$ & 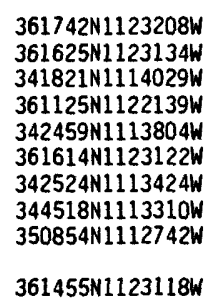 & $344710 \mathrm{~N} 1112932 \mathrm{~W}$ & & $\begin{array}{l}\text { Fossil Bay } \\
\text { Fossil Bay } \\
\text { Verde Hot Springs } \\
\text { Havasupai Point } \\
\text { Hackberry Mtn } \\
\text { Fossil Bay } \\
\text { Strawberry } \\
\text { Stoneman Lake } \\
\text { Winona }\end{array}$ \\
\hline $\begin{array}{l}\text { Foster Spring } \\
\text { Foster Tank } \\
\text { Adans Tank } \\
\text { Foster Well } \\
\text { Foudy Ranch } \\
\text { Fountain East (trailer park) } \\
\text { Fountains East Mobile } \\
\text { Home Park } \\
\text { The Fountain East } \\
\text { Mobile Home Park }\end{array}$ & $\begin{array}{l}\text { spring } \\
\text { reservoir } \\
\text { well } \\
\text { locale } \\
\text { locale }\end{array}$ & $\begin{array}{l}\text { BGN } \\
\text { BGN } 1964 \\
\text { VARIANT } \\
\text { UNOFF } \\
\text { UNOFF } \\
\text { UNOFF } \\
\text { VARIANT } \\
\text { VARIANT }\end{array}$ & $\begin{array}{l}\text { Coconino } \\
\text { Coconino } \\
\text { Navajo } \\
\text { Cochise } \\
\text { Maricopa }\end{array}$ & $\begin{array}{l}344622 N 1113023 \mathrm{~W} \\
350723 \mathrm{~N} 1112638 \mathrm{~W} \\
350601 \mathrm{N1102833 \textrm {W }} \\
312526 \mathrm{N1100001W} \\
332437 \mathrm{N1114158W}\end{array}$ & & 5248 & $\begin{array}{l}\text { Stoneman Lake } \\
\text { Ashurst Lake } \\
\text { Humpy Camp Well } \\
\text { Hereford } \\
\text { Buckhorn }\end{array}$ \\
\hline $\begin{array}{l}\text { Fountain Hills } \\
\text { Fountain Hills Airport } \\
\text { Fountain Hills Dam } \\
\text { Fountain Hills Dam Number } \\
\text { Eleven }\end{array}$ & $\begin{array}{l}\text { ppl } \\
\text { airport } \\
\text { dam } \\
\text { dam }\end{array}$ & $\begin{array}{l}\text { BGN } \\
\text { ADMIN } \\
\text { UNOFF } \\
\text { UNOFF }\end{array}$ & $\begin{array}{l}\text { Maricopa } \\
\text { Maricopa } \\
\text { Maricopa } \\
\text { Maricopa }\end{array}$ & $\begin{array}{l}333642 \mathrm{~N} 1114300 \mathrm{~W} \\
333050 \mathrm{~N} 1114257 \mathrm{~W} \\
333600 \mathrm{~N} 1114218 \mathrm{~W} \\
333700 \mathrm{~N} 1114418 \mathrm{~W}\end{array}$ & & 1606 & $\begin{array}{l}\text { Granite Reef Dam } \\
\text { Granite Reef Dam } \\
\text { Granite Reef Dam } \\
\text { Granite Reef Dam }\end{array}$ \\
\hline $\begin{array}{l}\text { Fountain Hills Dam Number Four } \\
\text { Fountain Hills Dam Number } \\
\text { Nineteen }\end{array}$ & $\begin{array}{l}\text { dam } \\
\text { dam }\end{array}$ & $\begin{array}{l}\text { UNOFF } \\
\text { UNOFF }\end{array}$ & $\begin{array}{l}\text { Maricopa } \\
\text { Maricopa }\end{array}$ & $\begin{array}{l}333618 \mathrm{~N} 1114336 \mathrm{~W} \\
333542 \mathrm{~N} 1114348 \mathrm{~W}\end{array}$ & & & $\begin{array}{l}\text { Granite Reef Dam } \\
\text { Granite Reef Dam }\end{array}$ \\
\hline $\begin{array}{l}\text { Fountain Hills Dam Number Seven } \\
\text { Fountain Hills Dam Number Six }\end{array}$ & $\begin{array}{l}\text { dam } \\
\text { dam }\end{array}$ & $\begin{array}{l}\text { UNOFF } \\
\text { UNOFF }\end{array}$ & $\begin{array}{l}\text { Maricopa } \\
\text { Maricopa }\end{array}$ & $\begin{array}{l}333624 \mathrm{~N} 1114459 \mathrm{~W} \\
333736 \mathrm{~N} 1114440 \mathrm{~W}\end{array}$ & & & $\begin{array}{l}\text { Granite Reef Dam } \\
\text { Granite Reef Dam }\end{array}$ \\
\hline
\end{tabular}




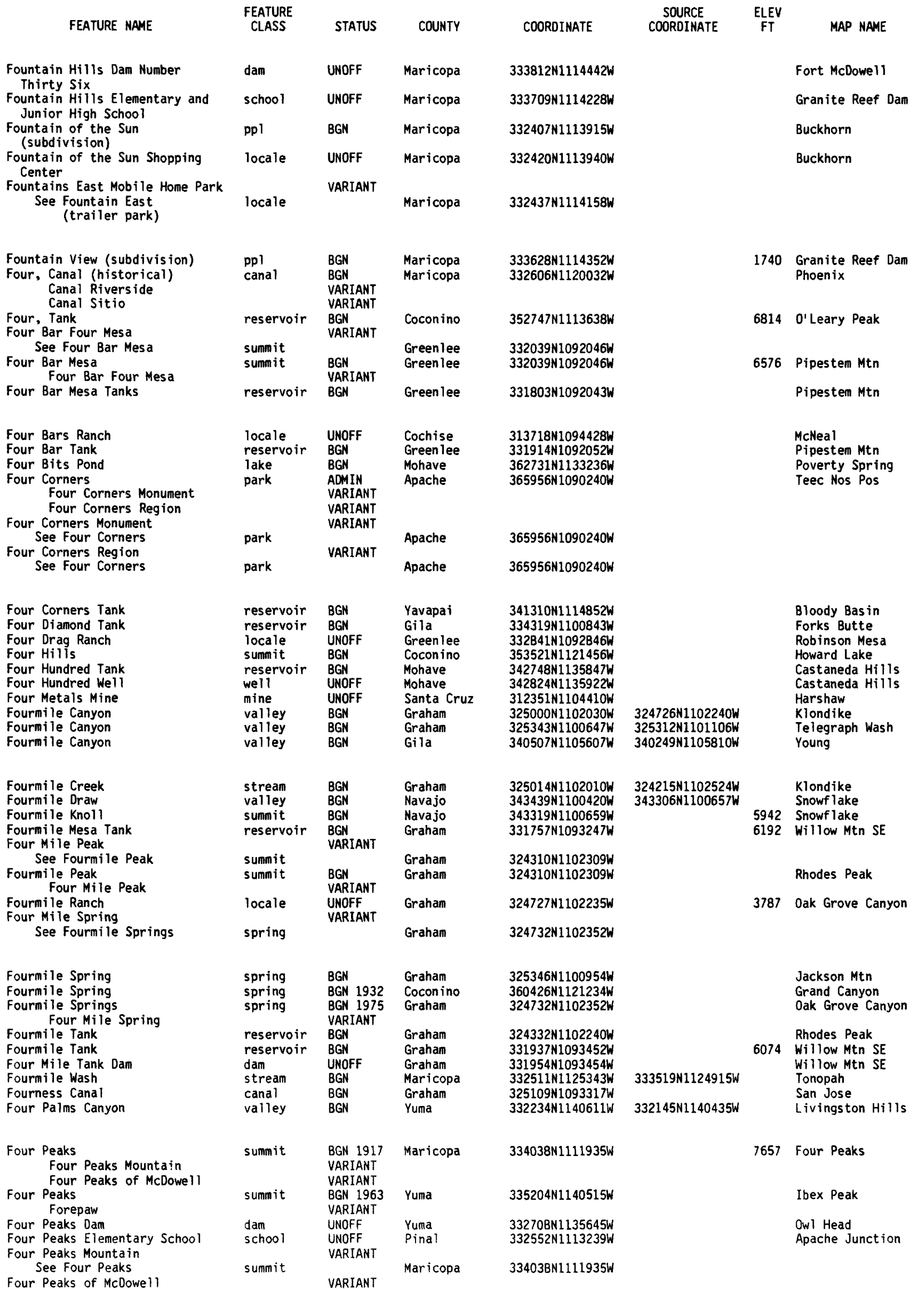




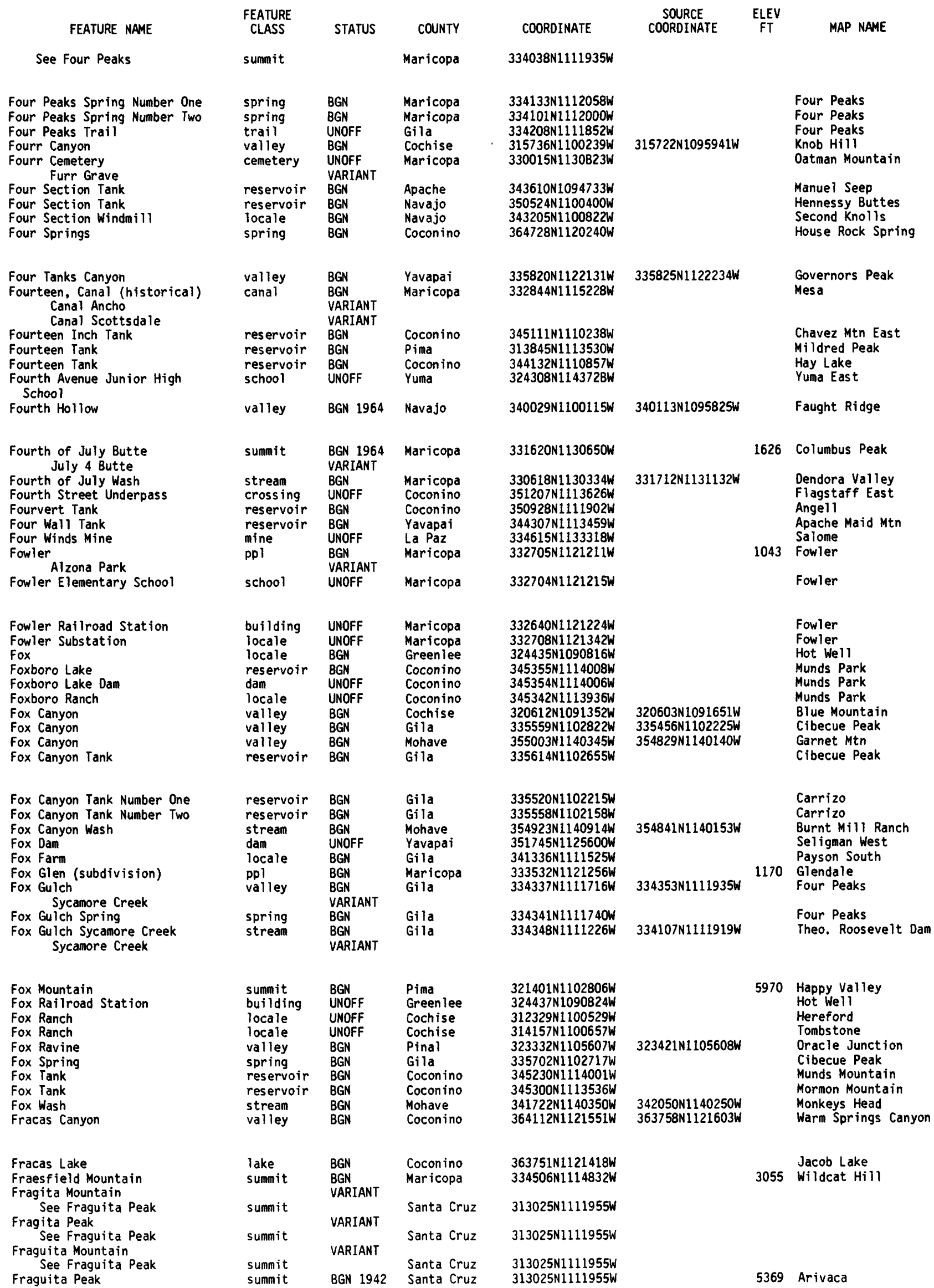


NATIONAL GAZETTEER--ARIZONA 1986 FEATURE NAME

Cerro de Jaralito Fragita Mountain Fragita Peak

Fraguita Mountain

Fraquita Mountain

Fraquita Peak

Mount Fraguita

Mount Roddick

Yellow Jacket Hill

Fraguita Spring
Fraguita Wash
Fraguita Wash
Fram Field
Francis, Mount
Francisco Elias Esquer Park
Francisco Grande
Francisco Lake
Francis Crater
Francis Creek

Francis Creek Camp
Francis Tank
Francois Matthes Point
Franconia
Franconia Wash
Franco Ranch
Fran Day Spring
Frank Borman Junior High School
Frank Davis Ranch
Frank Isaac Spring

Frankl in
Frankl in Lateral
Franklin School
Franklin School
Frankl ins Hole
See Meteor Crater
Frankl in Tank
Franks
Franks Canyon
Frank School

Franks Lake
Franks Tank
Franks Tank
Franks Tank
Frank Tank
Franz Spring
Fraquita Mountain
See Fraguita Peak
Fraquita Peak
See Fraguita Peak

Fraser Canyon See Randolph Canyon

Fraser Canyon

Frasers Ranch

Pineair Ranch

Reavis Ranch

Reevis Ranch

Frasier

See Fish Creek

(historical town)

Frasiers Station

See Fish Creek (historical town)

Frates Lateral

Fray Marcos

See Baker Mountain

Fray Marcos de Niza

Historical Monument

Frazier Ranch

Fraziers Well

See Frazier Wells

$\begin{array}{ll}\text { spring } & \text { BGN } \\ \text { stream } & \text { BGN 1942 } \\ \text { valley } & \text { BGN } \\ \text { airport } & \text { ADMIN } \\ \text { summit } & \text { BGN } \\ \text { park } & \text { ADMIN } \\ \text { park } & \text { ADMIN } \\ \text { reservoir } & \text { BGN } \\ \text { crater } & \text { BGN } \\ \text { stream } & \text { BGN }\end{array}$

$\begin{array}{ll}\text { locale } & \text { BGN } \\ \text { reservoir } & \text { BGN } \\ \text { cliff } & \text { BGN } \\ \text { locale } & \text { BGN } \\ \text { stream } & \text { BGN } \\ \text { locale } & \text { UNOFF } \\ \text { spring } & \text { BGN } \\ \text { school } & \text { UNOFF } \\ \text { locale } & \text { UNOFF } \\ \text { spring } & \text { BGN }\end{array}$

\begin{tabular}{|c|c|c|c|}
\hline $\begin{array}{l}\text { ppl } \\
\text { canal } \\
\text { school } \\
\text { school }\end{array}$ & $\begin{array}{l}\text { BGN } \\
\text { BGN } \\
\text { UNOFF } \\
\text { UNOFF } \\
\text { VARIANT }\end{array}$ & $\begin{array}{l}\text { Green lee } \\
\text { Yuma } \\
\text { Maricopa } \\
\text { Maricopa }\end{array}$ & $\begin{array}{l}324039 \mathrm{~N} 1090443 \mathrm{~W} \\
323612 \mathrm{~N} 1144355 \mathrm{~W} \\
332452 \mathrm{~N} 1114926 \mathrm{~W} \\
332755 \mathrm{~N} 1120540 \mathrm{~W}\end{array}$ \\
\hline $\begin{array}{l}\text { crater } \\
\text { reservoir } \\
\text { area } \\
\text { valley } \\
\text { school }\end{array}$ & $\begin{array}{l}\text { BGN } \\
\text { BGN } \\
\text { BGN } \\
\text { UNOFF }\end{array}$ & $\begin{array}{l}\text { Coconino } \\
\text { Gila } \\
\text { Coconino } \\
\text { Coconino } \\
\text { Maricopa }\end{array}$ & $\begin{array}{l}350141 \mathrm{~N} 1110121 \mathrm{~W} \\
341642 \mathrm{~N} 1111318 \mathrm{~W} \\
365645 \mathrm{~N} 1115241 \mathrm{~W} \\
363341 \mathrm{~N} 1121235 \mathrm{~W} \\
332214 \mathrm{~N} 1115744 \mathrm{~W}\end{array}$ \\
\hline $\begin{array}{l}\text { lake } \\
\text { reservoir } \\
\text { reservoir } \\
\text { reservoir } \\
\text { reservoir } \\
\text { spring }\end{array}$ & $\begin{array}{l}\text { BGN } \\
\text { BGN } \\
\text { BGN } \\
\text { BGN } \\
\text { BGN } \\
\text { BGN } \\
\text { VARIANT }\end{array}$ & $\begin{array}{l}\text { Coconino } \\
\text { Apache } \\
\text { Coconino } \\
\text { Yavapai } \\
\text { Coconino } \\
\text { Greenlee }\end{array}$ & $\begin{array}{l}363049 \mathrm{~N} 1121058 \mathrm{~W} \\
344558 \mathrm{~N} 1093904 \mathrm{~W} \\
344842 \mathrm{~N} 1113030 \mathrm{~W} \\
350028 \mathrm{~N} 1130501 \mathrm{~W} \\
345105 \mathrm{~N} 1113146 \mathrm{~W} \\
333252 \mathrm{~N} 1090420 \mathrm{~W}\end{array}$ \\
\hline summi & VARIANT & $\begin{array}{l}\text { Santa Cruz } \\
\text { Santa Cruz }\end{array}$ & $313025 \mathrm{~N} 1111955 \mathrm{~W}$ \\
\hline
\end{tabular}

VARIANT

VARIANT

VARIAN

VARIAN

VARIANT

VARIANT

VARIANT

VARIANT

Pima Santa Cruz 313505N1112105W Pima 313505N1112105W

Maricopa 333145N1121630W

Yavapai 342920N1123205W

Pima 321420N1105853W

Pinal 325258N1115056W

Apache 350121N1091526W

Coconino 351631N11111907W

Yavapai 344428N1131434W

Mohave 345021N1132139W

Pima 320520N1120205W

Coconino 360919N1115904W

Mohave 344422N1141603W

Mohave 344416N1141530W

Pima 320247N1105045W

Apache 340804N1093310W

$332925 \mathrm{~N} 1121035 \mathrm{~W}$

$332925 \mathrm{~N} 121035 \mathrm{~W}$

Greenlee

Navajo 362502N1104452W

VARIANT

valley

valley

BGN

BGN 1978

VARIANT

VARIANT

VARIANT

VARIANT

ppl

Pinal

Pinal

Maricopa

Maricopa

$333200 \mathrm{~N} 1111820 \mathrm{~W}$

VARIANT

ppl

canal

summit

park

locale

well
BGN

VARIANT

ADMIN

UNOFF

VARIANT

\section{Maricopa}

Yuma

Gila

Santa Cruz

Santa Cruz

Coconino
FEATURE

CLASS

STATUS

COUNTY

COORDINATE

$\begin{array}{cc}\text { SOURCE } & \text { ELEV } \\ \text { COORDINATE } & \text { FT }\end{array}$

MAP NAME
$332332 \mathrm{~N} 1111652 \mathrm{~W}$

$332339 \mathrm{~N} 1111532 \mathrm{~W}$

$332928 \mathrm{N11} 10917 \mathrm{~W}$

$362842 N 1120909 \mathrm{~W}$

$313014 N 1112009 \mathrm{~W}$

$313003 \mathrm{~N} 1112007 \mathrm{~W}$

Arivaca

Arivaca

1060 El Mirage

Tucson

Casa Grande West

Beacon Well

345340N1132540W 6397 Merriam Crater

4200 Pilot knob

Vainom Kug

8020 Walhalla Plateau

Franconia

Franconia

Tucson SE

Whiting Knoll

Fowler

4400 Ratt lesnake Spring

Black Mesa Wash NW

3740 Duncan

Somerton

Mesa

Phoenix

Diamond Point Poverty Flat

Telephone Hill

Guadalupe

Telephone Hill Milky Ranch

Stoneman Lake

Anvil Rock

Stoneman Lake

Blue

$332438 \mathrm{~N} 1111227 \mathrm{~W} \quad$ Weavers Needle

Iron Mountain

Gads den

Duquesne

O'Donnell Canyon 


FEATURE NAME
See Frazier Wells
Frazier Tank
Frazier Well
See Frazier Wells
Frazier Well
See Frazier Wells
Frazier Wells
Frazier Well
Fraziers Well

$$
\begin{aligned}
& \text { FEA } \\
& \text { CLAS } \\
& \text { ppl } \\
& \text { res } \\
& \text { wel } \\
& \text { ppl } \\
& \text { wel }
\end{aligned}
$$$$
\begin{aligned}
& \text { Frazier Wells } \\
& \text { Frazier Well } \\
& \text { Fraziers Well } \\
& \text { Freckles Tank } \\
& \text { Fred Cook Tank } \\
& \text { Fred Haught Canyon } \\
& \text { Fred Haught Ridge } \\
& \text { Fred Haught Spring } \\
& \text { Fred Jackson Spring } \\
& \text { Fredonia }
\end{aligned}
$$

Fredonia Dam

Fredonia Elementary School

Fredonia High School

Fred Pranty Cabin

Freds Tank

Freds Tank

Fred Tank

Fred T. Colter Dam

See Glen Canyon Dam

Freedom Park

Freenan

Freeman Dam

See Freeman Wash

Freeman Flat

Freeman Interchange

Freeman Spring

Freeman Tank

Freeman Tank

Freeman Wash

Freeman Wash Dam

See Freeman Wash Retarding Dam

Freeman Wash Retarding Dam Freeman Dam

Freeman Wash Dam

Free Spring

Frees Wash

Fries Wash

Free Tank

\begin{tabular}{|c|c|c|c|}
\hline $\begin{array}{l}\text { FEATURE } \\
\text { CLASS }\end{array}$ & STATUS & COUNTY & COORDINATE \\
\hline $\begin{array}{l}\mathrm{ppl} 1 \\
\text { reservoir }\end{array}$ & BGN & $\begin{array}{l}\text { Coconino } \\
\text { Santa Cruz }\end{array}$ & $\begin{array}{l}354657 \mathrm{~N} 1130417 \mathrm{~W} \\
313609 \mathrm{~N} 1103608 \mathrm{~W}\end{array}$ \\
\hline well & VARIANT & Coconino & 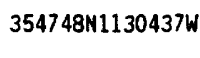 \\
\hline $\begin{array}{l}\text { ppl } \\
\text { well }\end{array}$ & $\begin{array}{l}\text { UNOFF } \\
\text { VARIANT } \\
\text { VARIANT }\end{array}$ & $\begin{array}{l}\text { Coconino } \\
\text { Coconino }\end{array}$ & 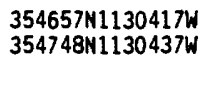 \\
\hline
\end{tabular}

$\begin{array}{cc}\text { SOURCE } & \text { ELEV } \\ \text { COORDINATE } & \text { FT }\end{array}$

$\begin{array}{llll}\text { ppl } & \text { BGN } & \text { Coconino } & \text { 354657N1130417W } \\ & \begin{array}{l}\text { VARIANT } \\ \text { VARIANT }\end{array} & & \\ \text { reservoir } & \text { BGN } & \text { Yavapai } & 342554 \text { N1113705W } \\ \text { reservoir } & \text { BGN } & \text { Yavapai } & 350520 N 1131740 \mathrm{~W} \\ \text { valley } & \text { BGN } & \text { Coconino } & 342923 N 1111336 \mathrm{~W} \\ \text { ridge } & \text { BGN } & \text { Coconino } & 3428511111239 \mathrm{~W} \\ \text { spring } & \text { BGN } & \text { Coconino } & 34292111111325 \mathrm{~W} \\ \text { spring } & \text { BGN } & \text { Mohave } & 354205 \text { N1135243W } \\ \text { ppl } & \text { BGN } & \text { Mohave } & 365644 \text { N1123133W }\end{array}$

$\begin{array}{llll}\text { dam } & \text { UNOFF } & \text { Coconino } & 365706 \text { N1123100W } \\ \text { school } & \text { UNOFF } & \text { Coconino } & 365552 \text { N1123138W }\end{array}$

$\begin{array}{llll}\text { school UNOFF } & \text { Coconino } & 365552 \mathrm{~N} 1123138 \mathrm{~W} \\ \text { school } & \text { UNOFF } & \text { Coconino } & 365552 \mathrm{~N} 1123135 \mathrm{~W}\end{array}$

$340416 \mathrm{~N} 1111005 \mathrm{~W}$

reservoir BGN Coconino 344311M1112659W

$\begin{array}{llll}\text { reservoir } & \text { BGN } & \text { Coconino } & 351802 N 1120045 W \\ \text { reservoir } & \text { BGN } & \text { Gila } & 340727 N 1110406 W\end{array}$

VARIANT

dam

Coconino

park ADMIN

Pina

36560BN1112859W

$321152 \mathrm{~N} 1105308 \mathrm{~W}$

locale $\begin{aligned} & \text { BGN } \\ & \text { VARIANT Maricopa 325045N1121745W }\end{aligned}$

dam Graham 32484BN1094406W

flat BGM Graham 324747N1094430W

crossing UNOFF Maricopa 325057N1121907W

spring BGN Santa Cruz 313410N1103213W

reservoir BGN Pinal 324422N1110547W

Coconino $353032 \mathrm{M1123004 \textrm {W }}$

\begin{tabular}{l} 
stream BGM Graham 324900N1094354W \\
\hline
\end{tabular}

Freeway Airport

Freeway Plaza Shopping Center

Freeway Tank

Freezeout Creek

Freezeout Dam

Freezeout Mountain

Freezeout Spring

Freezeout Tank

Freezeout Well

Frehner Canyon

Freidlein Prairie

Freight Trail Tank

Fremont Junior High School

Fremont Peak

Fremont Saddle

Fremont Saddle

French Butte

French Creek Bunningwater

French Creek

$\begin{array}{ll}\text { dam } & \text { VARIANT } \\ \text { dam } & \text { UNOFF } \\ & \text { VARIANT } \\ & \text { VARIANT } \\ \text { spring } & \text { BGN } \\ \text { stream } & \text { BGN } \\ & \text { VARIANT } \\ \text { reservoir } & \text { BGN }\end{array}$

Graham

Graham

Coconino

Mohave

$324558 N 1094631 W$

Mt Hughes

Frazier Wells

6058 Frazier Wells

342728N1111326W $\quad \begin{aligned} & \text { Strawberry } \\ & \text { Devils Hump } \\ & \text { Dane Canyon } \\ & \text { Dane Canyon } \\ & \text { Dane Canyon } \\ & \text { Music Mountains NW } \\ & 4671 \text { Fredonia }\end{aligned}$

Fredonia

Fredonia

Fredonia

Sheep Basin Mtn

Happy Jack

Williams North

Buzzard Roost Mesa

Tucson

Lost Horse Peak

Safford

Lost Horse Peak

O' Donnell Canyon

Chief Butte

Howard Spring

Safford

Safford

324848 N1094406W

$345210 \mathrm{~N} 1112959 \mathrm{~W}$ 351754N1135714W

350653M1135205W

Hutch Mtn

Kingman Airport

Coconino

$344245 \mathrm{~N} 1110327 \mathrm{~W}$

Quayle Hill

\begin{tabular}{|c|c|c|c|}
\hline $\begin{array}{l}\text { airport } \\
\text { locale } \\
\text { reservoir } \\
\text { stream } \\
\text { dam } \\
\text { summit } \\
\text { spring } \\
\text { reservoir } \\
\text { well } \\
\text { valley }\end{array}$ & $\begin{array}{l}\text { ADMIN } \\
\text { UNOFF } \\
\text { BGN } \\
\text { BGN } \\
\text { UNOFF } \\
\text { BGN } \\
\text { BGN } \\
\text { BGN } \\
\text { UNDFF } \\
\text { BGN }\end{array}$ & $\begin{array}{l}\text { Pima } \\
\text { Maricopa } \\
\text { Yavapai } \\
\text { Graham } \\
\text { Graham } \\
\text { Graham } \\
\text { Gila } \\
\text { Graham } \\
\text { Graham } \\
\text { Mohave }\end{array}$ & $\begin{array}{l}321640 \mathrm{~N} 1110030 \mathrm{~W} \\
333829 \mathrm{N1} 120707 \mathrm{~W} \\
351747 \mathrm{N1} 130139 \mathrm{~W} \\
332905 \mathrm{~N} 1094447 \mathrm{~W} \\
332930 \mathrm{~N} 1094200 \mathrm{~W} \\
333334 \mathrm{~N} 1093642 \mathrm{~W} \\
334430 \mathrm{N1} 104043 \mathrm{~W} \\
332616 \mathrm{N1} 100734 \mathrm{~W} \\
332624 \mathrm{N1} 100659 \mathrm{~W} \\
365129 \mathrm{N1} 135423 \mathrm{~W}\end{array}$ \\
\hline
\end{tabular}

$333318 N 1093635 \mathrm{~W}$

2290 Jaynes Union Hills Ynion Hills Yampai SE Sawbuck Mtn

7719 Freezeout Mtn Haystack Butte Bronco Gulch

4361 Ash Creek ME

$365015 \mathrm{~N} 1135045 \mathrm{~W}$ Elbow Canyon

$\begin{array}{llll}\text { flat } & \text { BGN } & \text { Coconino } & 351740 \text { N1114130W } \\ \text { reservoir } & B G N & \text { Coconino } & 344359 \text { N1111106W }\end{array}$

$\begin{array}{llll}\text { reservoir } & \text { BGN } & \text { Coconino } & 344359 N 1111106 \mathrm{~W} \\ \text { school } & \text { UNOFF } & \text { Maricopa } & 332556 \mathrm{~N} 1114055 \mathrm{~W}\end{array}$

sumper it BGN 1933 Coconino 351923N1113937W

gap BGN Pinal 332456N1112149

$\begin{array}{llll}\text { gap } & \text { BGN } 1933 & \begin{array}{l}\text { Coconino } \\ \text { sumajo }\end{array} & \text { 351937N1113904W } \\ \text { summit } & \text { BGN } & \text { 351645N1102119W }\end{array}$

stream BGN Yuma 333655 N1141410W

stream

VARIANT

BGN

Yavapai

$335543 \mathrm{~N} 1121855 \mathrm{~W}$

$332501 N 1140006 \mathrm{~W}$

Humphreys Peak Hay Lake

1196 Humphreys Peak Weavers Meedle Humphreys Peak

6456 French Butte South of Quartzsite

French Gap

gap BGN Graham

$324414 \mathrm{~N} 1102338 \mathrm{~W}$

340613N1122331W

Governors Peak

Rhodes Peak Rhodes Peak 
NATIONAL GAZETTEER--ARIZONA 1986

FEATURE NAME

French Gulch

French Joe Camp

French Joe Canyon

French Joe Peak

French Joe Spring

French Joe Tank

French Lilly Mine

Frenchman Mountain

See Tank Mountains

Frenchman Tank

Frenchman Tank

French Wash

See Finch Wash

Frenchy Canyon

Frenchy $\mathrm{Hil}$

Frenchy Spring Tank

Frerichs Well

Fresnal

See Pitoikam

Fresnal

See Chiuli Shaik

Fresnal, Cerro del

Cerro de Fresnal

Fresnal Mountain

El Cerro del Fresnal

Fresnal Canyon

Fresnal Canyon

Fresnal Canyon

Fresnal Creek

See Fresnal Wash

Fresnal Dam

Fresnal Hill

Fresnal Mountain

See Fresnal, Cerro del

Fresnal Wash

Fresnal Wash

Fresnal Creek

Fresnal Wash

Fresnal Wash

Fresnal Well

See Pitoikan

Fresno Canyon

Fresno Canyon

Fresno Canyon

Fresno Spring

Fresno Spring

Fresno Spring

Fresno Spring

Fresno Tank

Fresno Wash

Fresno Well

Freya Castle

Friendly Corners

Friendly Pines Camp

Friend Mine

Friendship Park

Fries Wash

See Frees Wash

Frio Spring

Frisco Canyon

Frisco River

See San Francisco River

Fritche Tank

Fritsche Tank

Fritsche Well

Fritz Canyon

Fritz Ranch

Fritz Springs See Lewis Springs

Fritz Tank

Froelich Ranch

Frog Lake
FEATURE

CLASS

STATUS COUNTY

COORDINATE

valley

valley

summit

spring

reservoir

mine

ridge

BGN
BGN
$B G N$
BGN
BGN
BGN
UNOFF
VARIANT

Yavapai

Cochise

Cochise

Cochise

Cochise

Yuma

reservoir

$B G N$

Yuma

VARIANT

stream

valley

summit

reservoir

well

BGN

BGN

BGN

UNOFF

locale

VARIANT

Coconíno

Yavapai

Coconino

Coconino

Coconino

Mohave

Pima

VARIANT

locale

summit

8GN 1978

VARIANT

VARIANT

valley

valley

valley

BGN

BGN

BGN

VARIANT

stream

Pima

ima

Pima

Pina

Pima

da

summit

BGN

VARIANT

summit

stream

stream

strean

stream

locale

$B G N$

BGN 1941

VARIANT

Pima

BGN

Graham

Pima

valley
valley
valley
spring
spring
spring
spring
reservoir
stream
well

$\begin{array}{ll}\text { BGN } & \text { Santa Cruz } \\ \text { BGN } & \text { Santa Cruz } \\ \text { BGN } & \text { Pima } \\ \text { BGN } & \text { Santa Cruz } \\ \text { BGN } & \text { Santa Cruz } \\ \text { BGN } & \text { Pina } \\ \text { BGN } & \text { Pima } \\ \text { BGN } & \text { Gila } \\ \text { BGN } & \text { Pima } \\ \text { UNOFF } & \text { Pima }\end{array}$

summit

ppl

locale

mine

park

stream

spring

valley

stream

BGN 1906

BGN

NOFF Grahan

ADMIN Yuma

VARIANT

VARIANT

Greenlee

Apache

$\begin{array}{llll}\text { reservoir } & \text { BGN } & \text { Yavapai } & 345829 \text { N1124749W } \\ \text { reservoir } & \text { BGN } & \text { Yavapai } & 350134 \text { N1123501W } \\ \text { well } & \text { UNOFF } & \text { Yavapai } & 345802 \text { N1124257W } \\ \text { valley } & \text { BGN } & \text { Greenlee } & 331819 \text { N1091126W } \\ \text { locale } & \text { UNOFF } & \text { Greenlee } & 331921 \text { N1091121W } \\ & \text { VARIANT } & & \\ \text { locale } & & \text { Cochise } & 313452 \text { N1100829W } \\ \text { reservoir } & \text { BGN } & \text { Yavapai } & 343947 \text { N1113433W } \\ \text { locale } & \text { UNOFF } & \text { Graham } & 322610 \mathrm{N1100649W} \\ \text { lake } & \text { BGN } & \text { Cochise } & 313929 \text { N1095212W }\end{array}$

342754 N1124139W

$351154 \mathrm{~N} 1120029 \mathrm{~W}$

351921N1120258W

$351910 \mathrm{~N} 1120239 \mathrm{~W}$

351641 N1134455W

314840 N1114044W

314943 NIII $3846 \mathrm{~W}$

$312635 \mathrm{N1112509 \textrm {W }}$

$314938 N 1113 B 23 \mathrm{~W}$

$315540 \mathrm{~N} 1111432 \mathrm{~W}$

$323340 \mathrm{~N} 1110550 \mathrm{~W}$

315000 N1120215W

312710 N1112605W

$314729 \mathrm{~N} 1114216 \mathrm{~W}$

$312635 \mathrm{~N} 1112509 \mathrm{~W}$

$314941 \mathrm{N1} 20111 \mathrm{~W}$

$315000 \mathrm{~N} 1120215 \mathrm{~W}$

$315836 \mathrm{~N} 1112259 \mathrm{~W}$

324247 N1101157W

$314840 \mathrm{~N} 1114044 \mathrm{~W}$

$312852 \mathrm{~N} 1105517 \mathrm{~W}$

$312922 \mathrm{~N} 1110511 \mathrm{~W}$

$315306 \mathrm{~N} 1103256 \mathrm{~W}$

$313025 N 1110649 \mathrm{~W}$

$321010 \mathrm{~N} 1104050 \mathrm{~W}$

$321142 \mathrm{~N} 1102706 \mathrm{~W}$

$340501 \mathrm{N1110831 \textrm {W }}$

$315318 \mathrm{~N} 1112402 \mathrm{~W}$

$313907 \mathrm{N1111127W}$

360640 N1115610W

$323704 \mathrm{N1113301 \textrm {W }}$

$342831 \mathrm{N1122655 \textrm {W }}$

$330210 N 1102321 \mathrm{~W}$

322910 N1144655W

$351754 \mathrm{~N} 1135714 \mathrm{~W}$

331908 N1105149W

325832 N1092218W

\begin{tabular}{ccc} 
SOURCE & ELEV & \multicolumn{1}{c}{ MAP NAME } \\
341741N1123929W & FT & $\begin{array}{l}\text { Wagoner } \\
\text { McGrew Spring } \\
\text { 314935N1102452W }\end{array} 7675 \begin{array}{l}\text { McGrew Spring } \\
\text { Apache Peak } \\
\text { Apache Peak } \\
\text { McGrew Spring } \\
\text { Cleator }\end{array}$
\end{tabular}

Engesser Pass

Cataract Tank

4541 Cumero Mtn

$315034 N 1113437 \mathrm{~W}$

$315339 N 1111233 \mathrm{~W}$

$323214 N 1110213 \mathrm{~W}$

Chiuli Shaik Samaniego Peak Tortolita Mts

$313400 N 1104627 \mathrm{~W}$

315213N1112924W

$313235 N 1105445 \mathrm{~W}$

$313118 \mathrm{~N} 1110808 \mathrm{~W}$

314908 N1102848

Rio Rico

Pena Blanca Lake

The Narrows

Tubac

Patagonia

Tanque Verde Peak

Happy Valley

Sheep Bas in Mtn

Palo Alto Ranch

Saucito Mtn

7299 Cape Royal

1672 Friendly Corners

6040 Groom Creek

Rawhide Mtn

Gadsden

Pinal Peak

Guthrie

Indian Peaks Picacho Butte SE

331916 N1090657W

429

4321 Fritz Canyon

Apache Maid Mtn

5030 Reiley Peak

Out law Mountain 
FEATURE NAME

$$
\begin{aligned}
& \text { FEATURE } \\
& \text { CLASS }
\end{aligned}
$$

Frog Pond

Frog Pond

Frog Pool

Frog Pool

Frog Spring

Frog Spring

Frog Spring

Frog Spring

Frog Tank

Frog Tank

Frog Tanks

See Pleasant, Lake

Frog Tanks

See Lake Carl Pleasant

Frog Tanks Dam

See Carl Pleasant Dam

Frog Wel1

Frontiertown Plaza Shopping Center

Frontier Village Shopping

Center

Frost Mine
Frost Tank
Frost Tank
Frozen Feet Windmill
Fruchthendler School
See Jacob C Fruchthendler
$\quad$ Elementary School
Fruitland Cemetery
Fry Garden Canyon
$\quad$ Garden Canon

Fry Canyon

Fry Canyon

Frye (historical)

Frye Canyon

Chlarsons Canyon

Fryes Canyon

Frye Canyon

See Spring Canyon

Frye Creek

Fryes Creek

Frye Creek Dan

See Frye Creek Retarding Dan

Frye Creek Retarding Dam Frye Creek Dam

Frye Mesa

Frye Mesa Reservoir

Frye Mesa Reservoir Dam

Fryer Tank

Fryes Canyon

See Frye Canyon

Fryes Creek

See Frye Creek

Frye Teen Center

Frye Trail Twelve

Fry Lake

Fry Mine

Fry Park

F S Tank

Fucson

See Tucson

Fuel Tank

Fuenle Park

Fues Hil

Fues Spring

Fulcher Ranch

Fulghum Tank

Fullbright Windmill

Fuller Bas in

Fuller Canyon

dam

well
locale

locale

mine

well

school

ppl

valley

valley

locale

valley

valley

stream

dam

dam

summit

dam

valley

stream

building

trail

lake

flat

ppl

park

summit

spring

locale

locale

bas in

$\begin{array}{llll}\text { reservoir } & \text { BGN } & \text { Gila } & 335050 N 1102522 \mathrm{~W} \\ \text { reservoir } & \text { BGN } & \text { Gila } & 340823 N 1104849 \mathrm{~W} \\ \text { reservoir } & \text { BGN } & \text { Coconino } & 350103 \mathrm{~N} 1121445 \mathrm{~W} \\ \text { reservoir } & \text { BGN } & \text { Coconino } & 350108 \mathrm{~N} 1121517 \mathrm{~W} \\ \text { spring } & \text { BGN } & \text { Graham } & 322950 \mathrm{~N} 1094727 \mathrm{~W} \\ \text { spring } & \text { BGN } & \text { Maricopa } & 332939 \mathrm{N1} 111301 \mathrm{~W} \\ \text { spring } & \text { BGN } & \text { Yavapai } & 340829 \mathrm{N1114648 \textrm {W }} \\ \text { spring } & \text { BGN } & \text { Mohave } & 361001 \mathrm{~N} 1131821 \mathrm{~W} \\ \text { reservoir } & \text { BGN } & \text { Santa Cruz } & 312825 \mathrm{~N} 1111146 \mathrm{~W} \\ \text { reservoir } & \text { BGN } & \text { Coconino } & 345728 \mathrm{~N} 1113921 \mathrm{~W}\end{array}$

reservoir BGN Santa Cruz

reservoir VARIANT Maricopa 335112N1121607W

locale VARIANT

VARIAN

Maricopa

Maricopa

Pima

Maricopa

Pima

UNOFF

UNOFF Mohave

reservoir

reservoir

BGN

VARIANT

cemetery

UNOFF

BGN

VARIANT

VARIANT

BGN

BGN

BGN

BGN 1962

VARIANT

VARIANT

VARIANT

BGN 1962

Grahan

Greenlee

Coconino

Graham

Graham

Santa Cruz

Cochise

VARIANT

VARIANT

reservoir

reservoir

UNOFF

VARIANT

BGN

BGN

UNOFF

VARIANT

Graham

Graham

Graham

Graham

Graham

Graham

VARIANT

reservoir

UNOFF

UNOFF
UNOFF

$8 \mathrm{GN}$

UNOFF

BGN

VARIANT

reservoir

reservoir

BGN
ADM
BGN
BGN
UNO
BGN
BGN
BGN

Coconino

Coconino

Greenlee

Cochise

Cochise

Cochise

$331155 \mathrm{~N} 1092115 \mathrm{~W}$
$335019 N 1121558 \mathrm{~W}$

$335112 N 1121607 \mathrm{~W}$

$321040 \mathrm{~N} 1115057 \mathrm{~W}$

332846 N1115528W

$321435 N 1105433 W$

$351009 \mathrm{~N} 1135104 \mathrm{~W}$

$341136 \mathrm{~N} 1095845 \mathrm{~W}$

$342506 \mathrm{~N} 1102551 \mathrm{~W}$

$361221 \mathrm{~N} 1091824 \mathrm{~W}$

$321605 N 1104957 \mathrm{~W}$

$314010 \mathrm{~N} 1103339 \mathrm{~W}$

$313324 N 1101740 \mathrm{~W}$

331121 N1092013W

$350341 \mathrm{N1} 114310 \mathrm{~W}$

$324510 \mathrm{~N} 1094957 \mathrm{~W}$

324546 N $1094752 \mathrm{~W}$

$331204 N 1092212 \mathrm{~W}$

$350336 \mathrm{~N} 1114607 \mathrm{~W}$

$324203 \mathrm{~N} 1095308 \mathrm{~W}$

480

Mountainaire

Thatcher

Hualapai Spring

Lakeside

Aripine

Mummy Cave Ruins

Elgin

Fort Huachuca

$324830 \mathrm{~N} 1094745 \mathrm{~W}$

$325010 \mathrm{~N} 1094542 \mathrm{~W}$

$324512 N 1094958 \mathrm{~W}$

Thatcher

$324942 \mathrm{~N} 1094542 \mathrm{~W}$

$324942 \mathrm{~N} 1094542 \mathrm{~W}$

Thatcher

$324541 \mathrm{N109} 4941 \mathrm{~W}$

$324512 \mathrm{N1} 095000 \mathrm{~W}$

$324512 \mathrm{~N} 1095000 \mathrm{~W}$

$350 \mathrm{~B} 56 \mathrm{~N} 1112 \mathrm{~B} 20 \mathrm{~W}$

324546 N1094752W

$325010 \mathrm{N1094542 \textrm {W }}$

$331756 \mathrm{N1115008W}$

$350346 \mathrm{~N} 1114802 \mathrm{~W}$

$354726 N 1141544 \mathrm{~W}$

$350405 N 1114704 \mathrm{~W}$

$343104 \mathrm{N111} 4206 \mathrm{~W}$

321318N1105533W

$340743 N 1125502 \mathrm{~W}$

$333950 \mathrm{~N} 1120604 \mathrm{~W}$

$351758 \mathrm{N1} 120 \mathrm{BO}$ W

$351755 \mathrm{~N} 1120825 \mathrm{~W}$

$325958 \mathrm{~N} 1091058 \mathrm{~W}$

$32163 \mathrm{BN} 1100633 \mathrm{~W}$

$314244 \mathrm{~N} 1094953 \mathrm{~W}$

$321656 \mathrm{~N} 1093720 \mathrm{~W}$
Thatcher

Thatcher

Thatcher

Winona

Chandler

Mitchell Peak

Dutton Hill

Senator Mtn

Dutton Hill

Walker Mtn

O'Neill Pass

Union Hills

7033 Williams North

Willians North

4000 York

Muskhog Mountain

Out law Mountain

Luzena 
NATIONAL GAZETTEER--ARIZONA 1986 FEATURE NAME

See Hi Fuller Canyon

Fuller Canyon

See East Miller Canyon

Fuller Canyon

Fuller Creek

See Bonita Creek

Fuller Creek

Fuller Creek

See Brody Creek

Fuller Lateral

Fuller Mesa

Fuller Mesa Tank

Fuller Mesa Tank Number Two

Fuller Ranch (subdivision)

Fuller School

Fuller Seep

See Horse Camp Seep

Fuller Seep

Fuller Spirng

See Hi Fuller Spring

Fuller Spring

Fullers Ranch (historical)

Fullers Spring

Fuller Tank

Fuller Tank

Fuller Tank

Fuller Tank

Fulmer Ranch

Fulton Canyon

Fulton Canyon

Fulton Canyon Tank

Fulton Ranch

Fulton Spring

Fulton Tank

Furguson Tank

Furr Grave

See Fourr Cemetery

F U Tank

Fye Airstrip

FY Ranch

FY Tank

FEATURE
CLASS

STATUS

COUNTY

Coconino

COORDINATE

342848 N1111541W

VARIANT

valley

valley

stream

stream

stream

canal

summit

reservoir

reser

BGN

ppl

school

BGN

UNOFF

VARIANT

spring

BGN

VARIANT

spring
spring

spring

loca

reservoir $B G$

reservoir $B G$

reservoir $B G N$

reservoir $B G N$

locale UNOFF

$\begin{array}{ll}\text { valley } & B G N \\ \text { reservoir } & B G N\end{array}$

locale

spring

reservoir

reservoir

UNOFF

BGN

BGN

VARIANT

cemetery

reservoir

airport

locale

reservoir
BGN

ADMIN

BGN

Maricopa

Pinal

Coconino

Coconino
Coconino 343000N1111456W

Coconino 361340N1120330W

Gila

Gila

Gila

Yuma

Gila

Gila

Maricopa

icopa

Yavapa

Coconino

Gila

Santa Cruz

Navajo

Coconino

Yavapaj

Coconino

Coconino

Graham

Coconino

Coconino

Cochise

Coconino

Coconino

Coconino
$354217 \mathrm{N1} 122300 \mathrm{~W}$ spring $B G N$

reservoir $B G$
342056 N1111421W

$342200 \mathrm{~N} 1111422 \mathrm{~W}$

342207 N1111645W

$323205 N 1144436 \mathrm{~W}$

$341041 \mathrm{N1110417W}$

$341023 N 1110401 \mathrm{~W}$

$341005 \mathrm{~N} 1110326 \mathrm{~W}$

$332417 \mathrm{~N} 1114702 \mathrm{~W}$

332221 N111540OW

340646N1112929W

$340921 N 1113248 \mathrm{~W}$

342817 N1111538W

$342436 \mathrm{~N} 1112831 \mathrm{~W}$

$312921 N 1115231 \mathrm{~W}$

365804 N1103500W

343155N1111928

$344503 \mathrm{~N} 1114653 \mathrm{~W}$

351243 N1114405W

$323314 N 1101307 \mathrm{~W}$

$345208 \mathrm{~N} 1112642 \mathrm{~W}$

$345432 \mathrm{~N} 1112722 \mathrm{~W}$

345208 N1112640W

$320244 N 1100441 \mathrm{~W}$

$45301 \mathrm{N1112640 \textrm {W }}$

$345452 \mathrm{~N} 1112725 \mathrm{~W}$

354420 N1124630W

$330015 N 1130823 \mathrm{~W}$

$342315 N 1113127 \mathrm{~W}$

$325500 \mathrm{~N} 1114200 \mathrm{~W}$

$351846 \mathrm{~N} 1121651 \mathrm{~W}$

$351842 \mathrm{~N} 1121642 \mathrm{~W}$

\begin{tabular}{|c|c|c|}
\hline $361735 N 1120134 W$ & & Bright Angel Point \\
\hline \multirow[t]{6}{*}{$342421 \mathrm{~N} 1111307 \mathrm{~W}$} & & Diamond Point \\
\hline & 5886 & $\begin{array}{l}\text { Somerton } \\
\text { Diamond Butte }\end{array}$ \\
\hline & 1240 & $\begin{array}{l}\text { Diamond Butte } \\
\text { Diamond Butte } \\
\text { Mesa } \\
\text { Guadalupe }\end{array}$ \\
\hline & & Cypress Butte \\
\hline & & Pine \\
\hline & 4880 & $\begin{array}{l}\text { Rio Rico } \\
\text { Cattle Canyon } \\
\text { Long Valley } \\
\text { Sedona } \\
\text { Flagstaff West } \\
\text { Markhan Dam } \\
\text { Harrison Canyon } \\
\text { Hutch Mtn } \\
\text { Mormon Lake } \\
\text { Hutch Mtn }\end{array}$ \\
\hline \multirow{2}{*}{344916 N1112430W } & & $\begin{array}{l}\text { Dragoon } \\
\text { Mormon Lake } \\
\text { Mormon Lake } \\
\text { Rose Well Camp East }\end{array}$ \\
\hline & 1398 & $\begin{array}{l}\text { Strawberry } \\
\text { Casa Grande East } \\
\text { Hearst Mtn } \\
\text { Hearst Mtn }\end{array}$ \\
\hline
\end{tabular}

$334952 \mathrm{~N} 1095546 \mathrm{~W}$ $342932 \mathrm{~N} 1123511 \mathrm{~W}$ $330225 \mathrm{~N} 1103440 \mathrm{~K}$ $325915 \mathrm{~N} 1101809 \mathrm{~W}$ $331243 \mathrm{~N} 1125415 \mathrm{~W}$ $330945 \mathrm{~N} 1125936 \mathrm{~W}$ $351618 N 1131452 \mathrm{~W}$ $315216 \mathrm{~N} 1124712 \mathrm{~W}$ $343913 \mathrm{~N} 1120619 \mathrm{~W}$

344147 N1120740W

6105 Whiteriver

3ilhoit Jerusalem Mtn Cobre Grande Mtn

valley BGN Pina

well UNOFF

we11 UNOFF

$\begin{array}{ll}\text { reservoir } & B G N \\ \text { well } & \text { UNOFF }\end{array}$

valley BGN

Yavari

Pima

Yavapai

Gaddes Canyon Trail

Gaddes Spring

Gaddis Canyon

Gadd is Canyon Spring

Gaddis Spring

Gadd is Wash

Gadi i Ahi Tank

Gadsden

Gadsden Elementary School

Gadsden Park

Gadsden Peak

West Twin Peak $344052 \mathrm{~N} 1120801 \mathrm{~W}$

trail UNOFF Yavapai

$\begin{array}{lll}\text { spring } & \text { BGN } & \text { Yavapai } \\ \text { valley } & \text { BGN } & \text { Yavapai } \\ \text { spring } & \text { BGN } & \text { Yavapai } \\ \text { spring } & \text { BGN } & \text { Mohave } \\ \text { stream } & \text { BGN } & \text { Yavapai } \\ \text { reservoir } & \text { BGN } & \text { Coconino } \\ \text { ppl } & \text { BGN } & \text { Yuma } \\ \text { school } & \text { UNOFF } & \text { Yuma } \\ \text { park } & \text { ADMIN } & \text { Yuma } \\ \text { summit } & \text { BGN } & \text { Pima }\end{array}$

$344123 \mathrm{~N} 1120750 \mathrm{~W}$

$343355 \mathrm{~N} 1115416 \mathrm{~W}$

$343320 N 1115532 W$

$351949 N 1140451 \mathrm{~W}$

$343449 \mathrm{~N} 1115242 \mathrm{~W}$

$353826 \mathrm{~N} 1110717 \mathrm{~W}$

$323316 \mathrm{~N} 1144703 \mathrm{~W}$

$323317 \mathrm{N1144657W}$

$323323 \mathrm{~N} 1144707 \mathrm{~W}$

$315740 \mathrm{NI1} 24910 \mathrm{~W}$ $\begin{array}{cc}\text { SOURCE } & \text { ELEV } \\ \text { COORDINATE } & \text { FT }\end{array}$

Hearst Mtn 
FEATURE NAME

Gadsden Post Office

Gadsden Purchase

Gadsden Shaft

Gadwe 11 Canyon

Gadwell Tank

Gael

See Tanque Aloma

Gah Chidi

Gainey Ranch

Gakolik Mountains

Galahad Point

Galena

Galena

Galena Gulch

Galeros Butte

Gale School

Gale Tank

Galeyville

Galinas Peak

See Bullard Peak

Gal inas Tank Gallinas Tank

Galiuro Mountains

Arivaipa Mountains

Arivaypa Mountains

Calitre Mountains

Calitro Mountains

Caliuro Mountains

Calizo Mountains

Saltire Mountains

Sierra Galiuro Mountains

Gallagher Peak

See Clara Peak

Gallegos Springs

Gallegos Well

Galleta Flat

Galleta Well

Galleto Tank

Gallinas, El Cerrito de

Gallinas Tank

See Gal inas Tank

\section{Gallineta Wash}

Gallo Tank

Galloway Canyon

Gazzoway

Gazzoway Canyon

Galloway Wash

Gallups

Galveston Elementary School

Gambler Corral Wash

Gambler Lake

Gambler Lake Wash

Gambusi Lake

Game Tank

Ganado

Gando Trading Post

Pueblo Colorado

Pueblo Ganado

Wukopapabi

Ganado Airport

Ganado Community Cemetery

Ganado Dam

Ganado Elementary School

Ganado High School

Ganado Junior High School

Ganado Lake

Ganado Lake Campground

Ganado Lake Well

Ganado Mesa

Ganado Mission Cemetery

Ganado Post Office

\section{FEATURE}

CLASS

building

area

mine

valley

reservoir

pp1
summit

summ it

summit

cliff

mine

ppl

valley

summit

school

reservoir

locale

summit

reservoir

range

VARIANT

BGN 1975

VARIANT

VARIANT

VARIANT

VARIANT

VARIANT

VARIANT

VARIANT

VARIANT

VARIANT

spring $B G$

well

flat

well

reservoir

summ it

reservoir

UNOFF

BGN

UNOFF

BGN

BGN

VARIANT

reservoir

valley

BGN

BGN 1932

VARIANT

VARIANT

strean

locale

school

valley

lake

BGN

BGN

UNOFF

BGN

BGN

valley

reservoir

ppl

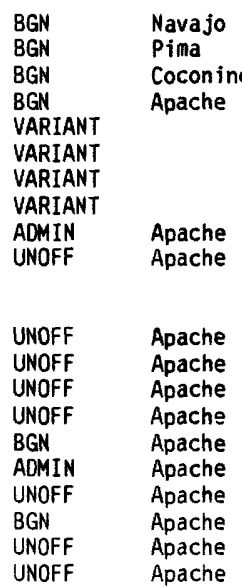

Graham

\section{Apache}

Apache

Cochise

Maricopa

Pima

Pima

Coconino

Gila

Maricopa

Navajo

Navajo

irport

cemetery

dam

schoo

school

school

reservoir

park

well

summit

cemetery

building

UNOFF
COORDINATE

$323329 \mathrm{~N} 1144704 \mathrm{~W}$ $323300 \mathrm{~N} 1144700 \mathrm{~W}$

313611 N1095421W

313317 N1095736W

324150 N1135725W

$354443 \mathrm{~N} 1093919 \mathrm{~W}$

$333416 \mathrm{~N} 1115500 \mathrm{~W}$

321752 N1123119W

$361624 \mathrm{~N} 1121458 \mathrm{~W}$

$312450 \mathrm{~N} 1095334 \mathrm{~W}$ $312519 N 1095333 \mathrm{~W}$ $342837 \mathrm{~N} 1121414 \mathrm{~W}$

$361150 \mathrm{~N} 1115141 \mathrm{~W}$

$321246 \mathrm{~N} 1104754 \mathrm{~W}$

$345924 \mathrm{N1121001 \textrm {W }}$

315701 N1091304W

$331921 N 1090444 W$

Greenlee

Coconino

351935N1114417W

$323600 \mathrm{~N} 1102100 \mathrm{~W}$

Maricopa

Coconino

Coconino

Maricopa

$340950 \mathrm{N1} 134840 \mathrm{~W}$

342635 N1090426

$342707 N 1090505 \mathrm{~W}$

320037 N1102241W

$331931 N 1125503 W$

$331700 \mathrm{~N} 1130410 \mathrm{~W}$

$321540 \mathrm{~N} 1112340 \mathrm{~W}$

$351935 N 1114417 W$

313651 N1113508W

$355251 N 1120234$

362037N1122703W

$335023 \mathrm{~N} 1115703 \mathrm{~W}$

$340443 \mathrm{~N} 1111109 \mathrm{~W}$

331845 N1114950

$362618 N 1101438$

$362543 \mathrm{~N} 1101329 \mathrm{~W}$

$362625 \mathrm{~N} 1101333 \mathrm{~W}$

$321436 \mathrm{~N} 1104102 \mathrm{~W}$

$355330 \mathrm{~N} 1121312 \mathrm{~W}$

$354241 \mathrm{~N} 1093229 \mathrm{~W}$

$354205 \mathrm{~N} 1093035 \mathrm{~W}$ $354157 \mathrm{N1} 1093229 \mathrm{~W}$

$354200 \mathrm{~N} 1093000 \mathrm{~W}$

$354238 \mathrm{~N} 1093214 \mathrm{k}$

$354244 \mathrm{N1093156 \textrm {W }}$

$354237 N 1093153 \mathrm{~W}$

$354353 \mathrm{~N} 1093105 \mathrm{~W}$

$354400 \mathrm{~N} 1093125 \mathrm{~W}$

$354455 \mathrm{~N} 1093046 \mathrm{~W}$

$354729 \mathrm{~N} 1093256 \mathrm{~W}$

$354234 \mathrm{~N} 1093240 \mathrm{~W}$

$354238 \mathrm{~N} 1093230 \mathrm{~W}$
344434N1120550

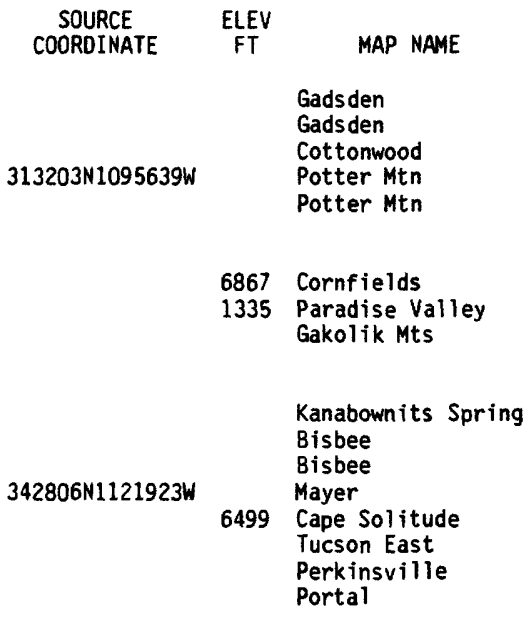

6867 Cornfields

1335 Paradise Valley Gakolik Mts

Kanabownits Spring

Bisbee

Bisbee

342806N1121923W Mayer

6499 Cape Solitude

Tucson East

Perkinsville

Portal

Humphreys Peak

Bassett Peak

$313825 \mathrm{~N} 1113741 \mathrm{~W}$

$335153 \mathrm{~N} 1114946 \mathrm{~W}$

$362454 N 1101237 W$
Presumido Peak

Tusayan East

Powell Plateau

Cave Creek

Sheep Bas in Mtn

Chandler

Rose $\mathrm{Hil}$

Cliff Rose $\mathrm{Hill}$

Tanque Verde Peak

Tusayan West

6386 Ganado

6662 Ganado

Ganado

Mesa Parada

leta Flat West

illespie

Ganado

Ganado

Ganado

Ganado

6431 Ganado

6440 Ganado

6442 Ganado

Ganado Mesa

Ganado

Ganado 


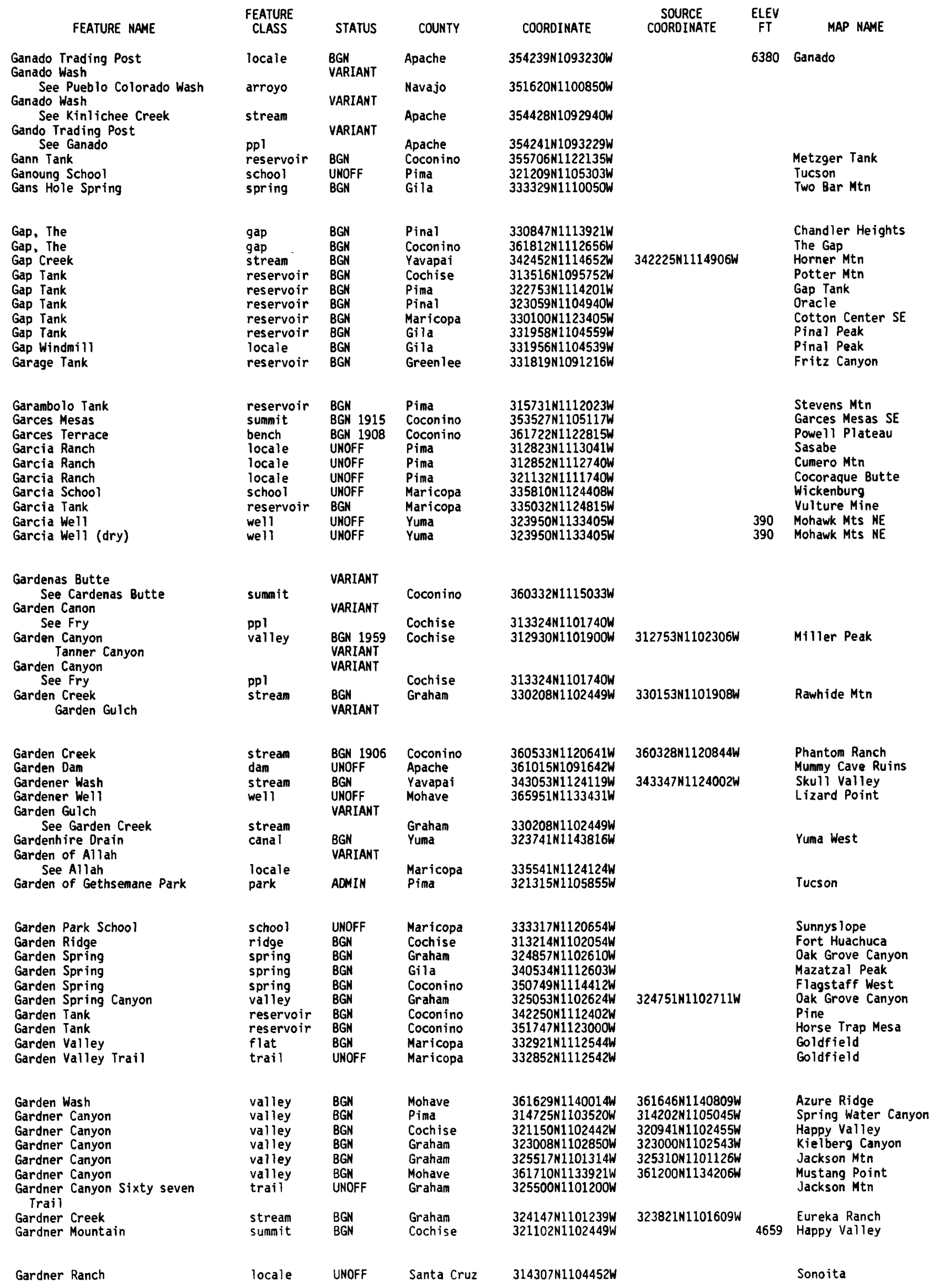




\section{FEATURE NAME}

Gardner Reservoir

See Overnight Pond

Gardner Reservoir

Gardner Tank

Gardner Windmill

Garfias Creek

See Garfias Wash

Garfias Mountain

Garfias Wash

Garfias Creek

$$
\begin{gathered}
\text { FEATURE } \\
\text { CLASS }
\end{gathered}
$$

Garfield Gulch

Garfield Peak

Garfield School

Garjon Tank

Garland Interchange

Garland Prairie

Garland Prairie Tank

Garland Spring

Garland Windmill

Garlic Well

Garnet Canyon

Garnet Mountain

Garnet Ridge

Garnet Spring

Garnet Tank

Garrett Ranch

Garrett Tank

Garris Knoll

Garrison Park

Garven Lateral

Gary David Tank

Gary Well

Gash Flat

Gash Mountain

Gash Tank

Gas light Square Shopping Center

Gas Line Tank

Gas Line Tank

Gaspe

See Walpi

Gas Tank

Gatagama Point

Gatagama Terrace

Gates and Mullen Spring

Gates Cabin Tank

Gates Pass

Gate Spring

Gates Spring

Gates Tank

Gateway Canyon

See Mohawk Canyon

Gateway Cove

Gateway Rapids

Gatewood Canyon

Gatewood Housing

Gat lin Cemetery

Gat lin Ranch

Gato, 0jo

Gato Tank

Gavilan Canyon

Gavilan Peak

Gavilan Peak

Gawain Abyss

Gayle Tank

Gazelle Mine

Gazzoway

See Galloway Canyon

Gazzoway Canyon

See Galloway Canyon

$G$ Bar Ranch

$G$ Castro (historical) lake

reservoir

reservoir

locale

stream

summit

stream

STATUS

COUNTY

VARIANT

$B$

BGN

BGN

VARIANT

BGN

VARIANT

valley

summit

school

reservoir

crossing

flat

reservoir

spring

locale

well

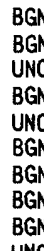

BGN Greenlee

$B G N$

UNOFF

$B G N$

UNOFF

$B G N$

BGN

BGN

UNOFF

valle
summit
ridge

spring

reservoir

locale

reservoir

summit

park

canal

BGN 1908

BGN

1915

BGN

BGN

UNOFF

BGN

BGN

ADMII

reservoir

well

flat

summit

reservoir

locale

reservoir

reservoir

locale

BGN
UNOFF
BGN

BGN

BGN

$B G N$

BGN

VARIANT

\section{reservoir}

cliff

bench

spring

reservoir

gap

spring

spring

reservoir

valley

$B G N$

BGN 1925

BGN

$B G N$

(

GN

BGN

VARIANT

bay

rapids

valley

ppl

cenetery

locale

spring

reservoir

valley

summit

BGN
BGN
BGN
BGN
UNOFF
UNOFF
BGN
BGN
BGN
BGN

summit

valley
reservoir

mine

BGN

BGN 1908 Maricopa

1908 Coconino

UNOFF

VARIANT

valley

VARIANT

valley

locale

locale

Maricopa

Coconino

Coconino

Coconino

Coconino
Coconino

Cochise

Coconino

Mohave

Apache

Coconino

Cochise

Coconino

Apache

Yavapai

Coconino

Cima

Coconino

Coconino

Coconino

Pinal

Coconino

Navajo

Yavapai

Coconino

Mohave

Coconino

Santa Cruz

Yavapai

Yavapai

Coconino

Mohave

Coconino

Cavajo

Santa Cruz

Santa Cruz

Apache

inal

Greenlee

Yavapai

Coconino

UNOFF Coconino

BGN
$330755 N 1092157 \mathrm{~W}$

$315953 \mathrm{~N} 1092138 \mathrm{~W}$

332729 N1120311K

$350735 \mathrm{~N} 1115329 \mathrm{~W}$

$351530 \mathrm{~N} 1120719 \mathrm{~W}$

$351122 \mathrm{~N} 1115731 \mathrm{~W}$

$351343 N 1115543 \mathrm{~W}$

$351116 N 1115949 \mathrm{~W}$

$314334 N 1094951 \mathrm{~K}$

344326N1105126W

$361248 \mathrm{N1122520 \textrm {W }}$

$354813 N 1140230 \mathrm{~W}$

$370046 \mathrm{Nl} 094329 \mathrm{~W}$

354BO4N11 40154W

$350430 \mathrm{~N} 1115211 \mathrm{~W}$

$321 B 05 N 1091545 \mathrm{~W}$

$351856 \mathrm{~N} 1124216 \mathrm{~W}$

$341240 N 1093842 \mathrm{~W}$

$344415 \mathrm{~N} 1120125 \mathrm{~W}$

$323521 \mathrm{N1} 144215 \mathrm{~W}$

$344535 \mathrm{N1111607 \textrm {W }}$

$315303 \mathrm{~N} 1102959 \mathrm{~W}$

$345002 \mathrm{~N} 1112913 \mathrm{~W}$

344949 N1112926W

$345005 \mathrm{N1112904 \textrm {W }}$

321507 N1105030W

$324115 \mathrm{~N} 1111342 \mathrm{~W}$

$352257 \mathrm{N1123520 \textrm {W }}$

354956N1102350W

$344727 N 1121702 \mathrm{~W}$

$362133 \mathrm{~N} 1123453 \mathrm{~W}$

$362159 \mathrm{~N} 1123514 \mathrm{~W}$

$364904 \mathrm{~N} 1134737 \mathrm{~W}$

$350338 \mathrm{~N} 1113941 \mathrm{~W}$

$321320 \mathrm{~N} 1110601 \mathrm{~W}$

$313154 \mathrm{N1} 103855 \mathrm{~W}$

$342102 \mathrm{~N} 1122316 \mathrm{~W}$

$343208 \mathrm{~N} 1122400 \mathrm{~W}$

361353N1125755W

$360104 N 1141636 \mathrm{~W}$

361407 N1 125807W

$340824 \mathrm{~N} 1104249 \mathrm{~W}$

$313318 N 1102005$

$313216 \mathrm{N1104458 \textrm {W }}$

$313148 \mathrm{~N} 1104638 \mathrm{~W}$

$341450 \mathrm{~N} 1093345 \mathrm{~W}$

$324902 \mathrm{~N} 1110900 \mathrm{~W}$

$331950 \mathrm{~N} 1090438 \mathrm{~W}$

$335425 \mathrm{~N} 1120724 \mathrm{~W}$

361416 N1121639W

$330716 \mathrm{~N} 1091202 \mathrm{~W}$

$341005 N 1122129 \mathrm{~W}$

362037 N1122703W 
NATIONAL GAZETTEER--ARIZONA 1986

\section{FEATURE NAME}

Gears Ranch

Geary Spring

Geddes Tank

Geesaman Mine Group

Geesaman Spring

Geesaman Wash

Geike Monument

See Geikie Peak

Geikie Peak

Geike Monument

Gem Acres Interchange

Geme lo Tank

Gem Shaft

Genega de los Pimas

See Mountain View

General Grant Mine

General Hitchcock Picnic Area

General Motors Desert Proving Grounds

See Desert Proving Grounds

FEATURE
CLASS

STATUS

COUNTY

COORDINATE

locale

spring

reservoir

mine

spring

stream

summit

s ummit

$\begin{array}{ll}\text { UNOFF } & \text { Cochise } \\ \text { BGN } & \text { Yavapai } \\ \text { BGN } & \text { Coconino } \\ \text { UNOFF } & \text { Pima } \\ \text { BGN } & \text { Pima } \\ \text { BGN } & \text { Pinal } \\ \text { VARIANT } & \\ \text { BGN 1908 } & \text { Coconino } \\ \text { VARIANT } & \end{array}$

$315120 \mathrm{~N} 1093635 \mathrm{~W}$ $342152 \mathrm{~N} 1121302 \mathrm{~W}$ $355609 \mathrm{~N} 1121646 \mathrm{~W}$ $322834 \mathrm{~N} 1104355 \mathrm{~W}$ $322844 N 1104315 \mathrm{~W}$ $323048 \mathrm{N1} 103314 \mathrm{~W}$

$360759 \mathrm{~N} 1121608 \mathrm{~W}$ $360759 \mathrm{~N} 1121608 \mathrm{~W}$ VARIANT

reservoir

mine

locale

mine

park

UNOFF

BGN

Mohave
Pima

UNOFF Gila

VARIANT

Pima

UNOFF Maricopa

ADMIN

VARIANT

locale

Maricopa

General Motors Proving Ground See Desert Proving Grounds General Myers School

General Springs

General Springs Cabin

General Springs Canyon

General Springs Ranger Station

Geneva Reservoir

Gentry Campground

Gentry Canyon

Gentry Canyon
Gentry Canyon
Gentry Canyon Spring
Gentry Creek
Gentry Mesa Tank
Gentry Mountain
Gentry Ridge
Gentry Spring
Gentry Tank
Gentry Tank
Gentry Tank
Gentry Trail Tank
Genung Mountain
Boulder Mountain
Genung Spring
Geology Vista
George Canyon
George Ditch
George Hill Spring Canyon
George Hill Tank

George Hill Tank

George Lateral

Georges Bas in

Georges Bas in Creek

Georges Bas in Dam

Georges Butte

Georges Butte Tank

Georges Canyon

Georges Lake Tank

George Smith Historical

Monument

George Spring
Georges Spring
Georges Spring
George Tank
George Tank
George Washington School
George Well
George Wise Spring
George Wood Canyon
Geowic
See Chiawuli Tak

locale
school
spring
building
valley
locale
reservoir
park
valley

VARIANT

$\begin{array}{ll}\text { UNOFF } & \text { Maricopa } \\ \text { BGN } & \text { Cochise } \\ \text { BGN } & \text { Coconino } \\ \text { BGN } & \text { Coconino } \\ \text { UNOFF } & \text { Coconino } \\ \text { BGN } & \text { Coconino } \\ \text { ADMIN } & \text { Apache } \\ \text { BGN } & \text { Navajo } \\ \text { Navajo }\end{array}$

valley

valley

spring

stream

reservoir

summit

ridge

spring

reservoir

reservoir

BGN
BGN
BGN
BGN
BGN
BGN
BGN
BGN
BGN
BGN

locale

reservoir

summit

spring

locale

valley

canal

valley

reservoir

BGN

BGN

VARIANT

BGN

BGN

BGN

BGN

canal

reservoir

stream

dam

summit

reservoir

valley

reservoir

park

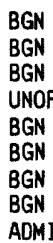

Navajo
Coconino
Gila
Gila
Gila
Gila
Coconino
Coconino
Gila
Gila

Coconino

Navajo

Yavapai

Yavapai

Pima

Graham

Maricopa

Graham

Greenlee

Yuma

Gila

Gila

Gila

Gila

Gila

Cochise

Apache

Coconino

$\begin{array}{lll}\text { spring } & \text { BGN } & \text { Mohave } \\ \text { spring } & \text { BGN } & \text { Pima } \\ \text { spring } & \text { BGN } & \text { Mohave } \\ \text { reservoir } & \text { BGN } & \text { Pima } \\ \text { reservoir } & \text { BGN } & \text { Apache } \\ \text { school } & \text { UNOFF } & \text { Gila } \\ \text { well } & \text { UNOFF } & \text { Graham } \\ \text { spring } & \text { BGN } & \text { Santa Cruz } \\ \text { valley } & \text { BGN } & \text { Yavapai } \\ & \text { VARIANT } & \\ \text { locale } & & \text { Pima }\end{array}$

$360955 \mathrm{~N} 1131950 \mathrm{~W}$

$322431 \mathrm{~N} 1103644 \mathrm{~W}$

$361005 \mathrm{~N} 1131948 \mathrm{~W}$

$315159 \mathrm{~N} 1111449 \mathrm{~W}$

$335210 \mathrm{~N} 1090805 \mathrm{~W}$

$332435 \mathrm{~N} 1105101 \mathrm{~W}$

$330910 \mathrm{~N} 1094213 \mathrm{~W}$

$313129 \mathrm{N1} 10520 \mathrm{BW}$

$345618 \mathrm{~N} 1125659 \mathrm{~W}$
SOURCE

COORDINATE

ELEV
FT

MAP NAME

Squaretop Hills East Cleator

Metzger Tank

Mount Bigelow

Mount Bigelow

322802N1104348W Peppersauce Wash

5004 Havasupai Point

Yucca

Esperanza Mill

Globe

Belmont Mtn

Mount Bigelow

Fort Huachuca

Dane Canyon

Kehl Ridge

342656N1111432W Blue Ridge Reservoir

7200 Keh1 Ridge

Greens Peak

Brookbank Point

340851N1104920W Oak Creek Ranch

341810N1104307W Brookbank Point

342407N1110420W Porcupine Ridge

Gentry Mtn

Gentry Mtn

Gentry Mtn

6587 Gentry Mtn

Knoll Lake

Knoll Lake

Gentry Mtn

Gentry Mtn

Knoll Lake

Oak Creek Ranch

4664 Yarnel

Peeples Valley

$330644 N 1095328$

Fort Thomas

Tempe

Gila Box

Guthrie

Yuma West

Velasquez Butte

333739 N1100403W

Velasquez Butte

Velasque Butte

6301 Georges Butte

Georges Butte

College Peaks

Alpine

Tonalea

Whitmore Point

Buehman Canyon

Whitmore Point

Batamote $\mathrm{Hills}$

Nutrioso

Globe

Park Creek Cabins

Patagonia

Juniper Mts 
FEATURE NAME

Gerald Hills

Gerald Hills Tank

Gerald Spring

Gerald Wash

Gerald Well

Gerard High School

Germann

Germ Tank

Gerome Spring

Geronimo

Geronimo, Mount

Geron imo Cave

Geronimo Dam

Geronimo Head

Geronimo Meadow

Geronimo Number Two Tank

Geronimo Post Office

Geronimo Spring

Geronimo Spring

Geron imo Surrender Monument

Geronimo Surrender Site

Geronimo Tank

Geron imo Tank

Geronimo Trail

Geronimo Trap

Geshi Canyon

Getz

Getz Railroad Station

Getz Ranch

Getz School

Getz Well

Geyler Tank

Geyser Dam

G-five Farm Spring

G-five Farm Tank

G-five Tank

Ggathla

See Agathla Peak

Ghaaghaztail

Ghost, The

Ghost Tank

Giacoma Camp

Giant Butte

See Giants Chair

Giant Canyon

Giant Chair

See Giants Chair

Giant Logs

Giant Mine

$$
\text { inbow Forest }
$$

Giants Chair

Giant Butte

Giant Chair$$
\text { Hoyap }
$$

Gibbon Mountain

Gibbon Springs

Gibbons Spring

Gibbs Tank

Gibb Wash

Gibraltar Mountain

Gibson

Gibson Arroyo

Gibson Canyon - Deadman

Hiline Trail

Gibson Creek

Gibson Creek

Gibson Lateral

Gibson Neighborhood Park

Gibson Peak

Gibson Ranch

Gibson Ranch
FEATURE
CLASS

STATUS

COUNTY

summit

reservoir

spring

well

school

locale

reservoir

spring

locale

cave

summit

reservoir

building

spring

spring

park

locale

reservoir

reservoi

trail

cliff

valley

locale

building

locale

school

well

reservoir

dam

spring

reservoir

reservoir

summit

flat

summit

reservoir

locale

pillar

valley

pillar

area

mine

pillar

sumpit

summit
spring

spring

reservoir

strean

summit.

ppl

valley

trail

stream

strean

canal

park

summit

locale

locale

BGN
BGN
BGN
BGN
UNOFF
UNOFF
BGN
BGN
BGN
BGN

Gila

Gila

Gila

Gila

Gila

Maricopa

Maricopa

Navajo

Mohave

Graham

BGN Pinal

BGN $\quad$ Navajo

BGN 1917 Maricopa

BGN Pima

BGN Coconino

UNOFF

$B G N$

BGN

ADMIN

Graham

Gi la

Coconino

Cochise

BGN
BGN
BGN
UNOFF
BGN
BGN
BGN
UNOFF
UNOFF
UNOFF

Cochise

Coconino

Coconino

Cochise

Gila

Coconino

Mohave

Mohave

Maricopa

UNOF

BGN

UGNF

BGN

BGN

VARIANT

Maricopa

Coconino

Yuma

Gila

Gila

Gila

BGN

BGN

Apache

Coconino

BGN Gila

BGN

VARIANT

BGN

VARIANT

Navajo

VARIANT

UNOFF

BGN

VARIANT

VARIANT

VARIANT

BGN

BGN

BGN

BGN

BGN

BGN

Pima

Graham

Pima

Yuma

BGN Pima

UNOFF

Pima

BGN Graham

BGN Gila

BGN Yuma

ADMIN Pima

BDM

UNOFF

Gila

Cochise

Navajo

Navajo

COORDINATE

332932N1105322W $332919 N 1105135 \mathrm{~W}$

$333145 N 1103027 \mathrm{~W}$

$332 B 58 N 1105059 \mathrm{~W}$

$332858 \mathrm{~N} 1105214 \mathrm{~W}$

$332820 \mathrm{~N} 1115915 \mathrm{~W}$

331641 N1114007W

34152BN1101050W

345718 N1133159

$330437 \mathrm{~N} 1100204 \mathrm{~W}$

330804 N1102953W

$334935 \mathrm{~N} 1095211 \mathrm{~W}$

$330606 \mathrm{~N} 1094430 \mathrm{~W}$

$333013 \mathrm{~N} 1112306 \mathrm{~W}$

$322125 \mathrm{~N} 1104941 \mathrm{~W}$

345615 N1114025W

$330436 \mathrm{~N} 1100157 \mathrm{~W}$

$342420 \mathrm{~N} 1112135 \mathrm{~W}$

$350440 \mathrm{~N} 1115648$

314129 N1090743W

313548 N1090420W

$345629 \mathrm{~N} 1114026 \mathrm{~W}$

$352710 N 1120712 \mathrm{~W}$

312058 N1093030W

333228 N1102928W

$364346 \mathrm{~N} 1105048 \mathrm{~W}$

351217 N1140110

351207 N1140120W

$351040 \mathrm{~N} 1135301 \mathrm{~W}$

$332222 \mathrm{~N} 1115700 \mathrm{~W}$

$325216 \mathrm{~N} 1122653 \mathrm{~W}$

$352320 N 1114337 \mathrm{~W}$

$332402 \mathrm{~N} 1135802 \mathrm{~W}$

$335315 N 1100442 \mathrm{~W}$

335325N1100349W

335317 N1100321

364936N1101330W

$360337 \mathrm{~N} 1095 \mathrm{~B} 36 \mathrm{~W}$

$360217 \mathrm{~N} 1110006 \mathrm{~W}$

$335129 \mathrm{~N} 1100527 \mathrm{~W}$

332809 N1105501W

$354329 \mathrm{~N} 1103158 \mathrm{~W}$

361227 N1092157W

$354329 \mathrm{~N} 1103158 \mathrm{~W}$

344900 N1095155W

312411N1105455W

354329 N1103158W

$322015 N 1104444 W$

$321816 \mathrm{~N} 1104623 \mathrm{~W}$

$340838 \mathrm{~N} 1092755 \mathrm{~W}$

324819 N1100128

$322937 \mathrm{~N} 1104036 \mathrm{~W}$

341003 N1140724W

$322243 \mathrm{~N} 1125220 \mathrm{~W}$

$322236 \mathrm{~N} 1125242 \mathrm{~W}$

324143 N1095112W

$324123 N 1094812 \mathrm{~W}$

$340826 \mathrm{~N} 1111605 \mathrm{~W}$

$324010 \mathrm{~N} 1144012 \mathrm{~W}$

$322252 \mathrm{~N} 1125230 \mathrm{~W}$ 
NATIONAL GAZETTEER--ARIZONA 1986

FEATURE NAME

Gibson Spring

Gibson Tank

Gibson Tank

Giddings Grave

Giers Bas in

Giers Mountain

Corner Rock

Giers Wash

Gigantes Buttes, LoS

Gila Bend

Big Bend

Gila Bend Station

Gila Ranch

Gila Station

01d Fort

Opansoitak

Opasoitac

Rinconada

San Simon y Judas

Santos Apostoles San

Simon y Judas

Tesota

Tezotal

Uhupat Oidak

Uparsoytac

Upasoitac

Uupatoitak

Gila Bend Canal

Gila Bend Elementary School

Gila Bend High School

Gila Bend Indian Reservation

Gila Bend Mountains

Clanton Hills

Pen Hatch A Pet Mountains

Gila Bend Municipal Airport

Gila Bend Post Office

Gila Bend Railroad Station

Gila Bend Station

See Gila Bend

Gila Bend Substation

Gila Bend Town Hall

Gi la Bonita Creek

See Bonita Creek

Gila Box

Gila Butte

Gila Center

Blalack

Gila City

See Ligurta

Gila City Mountains

See Gila Mountains

Gila Compressor Station

Gila Compressor Station

Airstrip

Gila County

Pinal County

Maricopa County

Yavapai County

Pinal County

Maricopa County

Yavapai County

Gila County Courthouse

Gila County Fair Ground and Race Track

Gila County Hospital

Gila Crossing

Komatke

Gila Crossing Day School

Gila Main Canal

Gila Monster (historical)

Gila Monster Canyon

Gila Monster Mine

Gila Mountains

\section{FEATURE}

CLAS

STATUS COUNTY

COORDINATE

$\begin{array}{lll}\text { spring } & \text { BGN } & \text { Gila } \\ \text { reservoir } & \text { BGN } & \text { Maricopa }\end{array}$

334723N1121025W

reservoir BGN Yaval 340630N1125750W

cemetery UNOFF Cochise 322015N1090312W

bas in BGN Yuma 341510N1140823W

summit BGN Yuma 341406N1140807W

stream VARIANT

summit

BGN

Yuma

Apache

$341530 \mathrm{~N} 1140748 \mathrm{~W}$

$363542 \mathrm{~N} 1092422 \mathrm{~W}$

ppl

BGN

VARIANT

Maricopa

$325652 \mathrm{~N} 1124258 \mathrm{~W}$

VARIANT

VARIANT

VARIANT

VARIANT

VARIANT

VARIANT

VARIANT

VARIANT

VARIANT

VARIANT

VARIANT

VARIANT

VARIANT

VARIANT

canal BGN Maricopa

school UNOFF Maricopa

school

range

a irport

building

building

pp

ppl

building

stream

valley

summit

locale

locale

range

locale

airport

civil

BGN

BGN 1963

VARIANT

VARIANT

ADNIM

UNOFF

UNDFF

VARIANT

Maricopa

Maricopa

Maricopa

Maricopa

Maricopa

Maricopa

Maricopa

Maricopa

Maricopa

Graham

Graham

Pinal

BGN

BGN

BGN
VARIANT

Yuma

VARIANT

VARIANT

Yuma

Yuma

Maricopa

Maricopa

Gila

ADMIM

VARIANT

VARIANT

VARIANT

VARIANT

VARIANT

VARIANT

$\begin{array}{llll}\text { building } & \text { UNOFF } & \text { Gila } & 332346 \text { N1104710W } \\ \text { locale } & \text { BGN } & \text { Gila } & 332520 \text { N1104250W }\end{array}$

hospital UNOFF Gila 332336N1104626W

ppl BGN Maricopa 331636N1120958W

VARIANT

canal UNOFF

BGN 1917 Maricopa

valley

mine

range
330127N112391BW

$325705 \mathrm{~N} 1124303 \mathrm{~W}$

$25711 \mathrm{N1} 124300 \mathrm{~W}$

$330030 \mathrm{N1124600 \textrm {W }}$

$331321 \mathrm{N1130214 \textrm {W }}$

$325729 \mathrm{N1} 124039 \mathrm{~W}$

$325652 \mathrm{~N} 1124302 \mathrm{~W}$

$325645 \mathrm{~N} 1124250 \mathrm{~W}$

$325652 \mathrm{M} 112425 \mathrm{BW}$

$325623 \mathrm{N1} 124530 \mathrm{~W}$ 325655N1124310W

$325336 \mathrm{N1092B40 \textrm {W }}$ $325323 \mathrm{~N} 1092838 \mathrm{~W}$ $330920 \mathrm{N1115141 \textrm {W }}$

$324157 \mathrm{N1} 143044 \mathrm{~W}$

32402BN1141739W

$323430 \mathrm{N1141833 \textrm {W }}$

$331504 \mathrm{N1124836 \textrm {W }}$

$331535 \mathrm{~N} 112485 \mathrm{OW}$

$333100 \mathrm{~N} 1103100 \mathrm{~W}$

$331632 \mathrm{~N} 1121001 \mathrm{~W}$

$325057 \mathrm{N1142633 \textrm {W }}$

UNKNOWN

313611N1093211W 313B4BN1093124W

$321746 \mathrm{~N} 1110714 \mathrm{~W}$

$323430 \mathrm{~N} 1141833 \mathrm{~W}$ $\begin{array}{cc}\text { SOURCE } & \text { ELEV } \\ \text { COORDINATE } & \text { FT }\end{array}$

Payson South

Biscuit Flat

Congress SW

Doubtful Canyon

Gene Wash

1888 Cross Roads

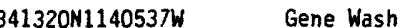

6460 Round Rock

736 Gila Bend
Cotton Center

Gila Bend

Gila Bend

Citrus Valley East

Quail Spring Wash

77B Gila Bend

Gila Bend

Gila Bend

Smurr

Gila Bend

325830N1092233W Gila Box

1656 Gila Butte

Yuma East
Arlington

Sevenmile Mts

Globe

3760 Cammerman Wash

Globe

1037 Laveen

Montezuma Peak

Laguna Dam

Leslie Canyon

Jaynes

Fortuna Mine 


\begin{tabular}{|c|c|c|c|c|c|c|c|}
\hline FEATURE NAME & $\begin{array}{l}\text { FEATURE } \\
\text { CLASS }\end{array}$ & STATUS & COUNTY & COORDINATE & $\begin{array}{l}\text { SOURCE } \\
\text { COORDINATE }\end{array}$ & $\begin{array}{l}\text { ELEV } \\
\text { FT }\end{array}$ & MAP NAME \\
\hline $\begin{array}{l}\text { Gila City Mountains } \\
\text { Sierra de la Gila } \\
\text { Gila Mountains } \\
\text { Gila Range }\end{array}$ & range & $\begin{array}{l}\text { VARIANT } \\
\text { VARIANT } \\
\text { BGN } 1962 \\
\text { VARIANT }\end{array}$ & Graham & $330655 \mathrm{~N} 1095117 \mathrm{~W}$ & & & Markham Creek \\
\hline $\begin{array}{l}\text { Gila Peak } \\
\text { Gila Port Airport } \\
\text { Gila Pueblo Campus Community } \\
\text { College Extension } \\
\text { Eastern Arizona Junior } \\
\text { College Campus }\end{array}$ & $\begin{array}{l}\text { summit } \\
\text { airport } \\
\text { school }\end{array}$ & $\begin{array}{l}\text { BGN } \\
\text { ADMIN } \\
\text { UNOFF } \\
\text { VARIANT }\end{array}$ & $\begin{array}{l}\text { Graham } \\
\text { Maricopa } \\
\text { Gila }\end{array}$ & $\begin{array}{l}331135 \mathrm{~N} 1095705 \mathrm{~W} \\
332440 \mathrm{~N} 1121121 \mathrm{~W} \\
332153 \mathrm{~N} 1104600 \mathrm{~W}\end{array}$ & & $\begin{array}{l}6629 \\
1000\end{array}$ & $\begin{array}{l}\text { Gila Peak } \\
\text { Fowler } \\
\text { Pinal Peak }\end{array}$ \\
\hline $\begin{array}{l}\text { Gila Ranch } \\
\text { See Gila Bend } \\
\text { Gila Range }\end{array}$ & $\mathrm{ppl}$ & $\begin{array}{l}\text { VARIANT } \\
\text { VARIANT }\end{array}$ & Maricopa & $325652 \mathrm{~N} 1124258 \mathrm{~W}$ & & & \\
\hline $\begin{array}{l}\text { See Gila Mountains } \\
\text { Gila Range } \\
\text { Gila Reservation Career Center } \\
\text { Gila River } \\
\text { Akee-mull } \\
\text { Apache de Xila } \\
\text { Brazo de Miraflores } \\
\text { Hah-quah-sa eel } \\
\text { Hela River } \\
\text { Jila River } \\
\text { Rio Azul } \\
\text { Rio de las Balsas } \\
\text { Rio del los Apostoles } \\
\text { Rio Gila } \\
\text { Rio del Mombre Jesus } \\
\text { Zila River }\end{array}$ & $\begin{array}{l}\text { range } \\
\text { range } \\
\text { building } \\
\text { strean }\end{array}$ & $\begin{array}{l}\text { BGN } \\
\text { UNOFF } \\
\text { BGN } 1969 \\
\text { VARIANT } \\
\text { VARIANT } \\
\text { VARIANT } \\
\text { VARIANT } \\
\text { VARIANT } \\
\text { VARIANT } \\
\text { VARIANT } \\
\text { VARIANT } \\
\text { VARIANT } \\
\text { VARIANT } \\
\text { VARIANT } \\
\text { VARIANT }\end{array}$ & $\begin{array}{l}\text { Graham } \\
\text { Maricopa } \\
\text { Pinal } \\
\text { Yuma }\end{array}$ & $\begin{array}{l}330655 N 1095117 W \\
331915 N 1120554 W \\
330432 N 1114528 W \\
324311 N 1143316 W\end{array}$ & $331047 \mathrm{N1081220 \textrm {W }}$ & & $\begin{array}{l}\text { Lone Butte } \\
\text { Gila Butte SE } \\
\text { Yuma East }\end{array}$ \\
\hline $\begin{array}{c}\text { Gila River Canyon } \\
\text { Gila River Indian Reservation } \\
\text { Gila River Reservation }\end{array}$ & $\begin{array}{l}\text { valley } \\
\text { reserve }\end{array}$ & $\begin{array}{l}\text { BGN } \\
\text { UNOFF } \\
\text { VARIANT }\end{array}$ & $\begin{array}{l}\text { Maricopa } \\
\text { Pinal }\end{array}$ & $\begin{array}{l}330436 \mathrm{~N} 1130054 \mathrm{~W} \\
321000 \mathrm{~N} 1115200 \mathrm{~W}\end{array}$ & $330301 \mathrm{~N} 1125903 \mathrm{~W}$ & & $\begin{array}{l}\text { Dendora Valley } \\
\text { Gila Butte }\end{array}$ \\
\hline $\begin{array}{c}\text { Gila River Ranch } \\
\text { Gila River Reservation } \\
\text { See Gila River Indian } \\
\text { Reservation }\end{array}$ & $\begin{array}{l}\text { locale } \\
\text { reserve }\end{array}$ & $\begin{array}{l}\text { UNOFF } \\
\text { VARIANT }\end{array}$ & $\begin{array}{l}\text { Maricopa } \\
\text { Pinal }\end{array}$ & $\begin{array}{l}325451 \mathrm{~N} 1125334 \mathrm{~W} \\
321000 \mathrm{~N} 1115200 \mathrm{~W}\end{array}$ & & & Theba \\
\hline $\begin{array}{l}\text { Gila Station } \\
\text { See Gila Bend } \\
\text { Gila Substation }\end{array}$ & $\begin{array}{l}\text { ppl } \\
\text { locale }\end{array}$ & $\begin{array}{l}\text { VARIANT } \\
\text { UNOFF }\end{array}$ & $\begin{array}{l}\text { Maricopa } \\
\text { Maricopa }\end{array}$ & $\begin{array}{l}325652 \mathrm{~N} 1124258 \mathrm{~W} \\
331817 \mathrm{~N} 1115656 \mathrm{~W}\end{array}$ & & & Guadalupe \\
\hline $\begin{array}{l}\text { Gila Tank } \\
\text { Gila Valley } \\
\quad \text { Safford Valley }\end{array}$ & $\begin{array}{l}\text { reservoir } \\
\text { valley }\end{array}$ & $\begin{array}{l}\text { BGN } \\
\text { BGN } 1962 \\
\text { VARIANT }\end{array}$ & $\begin{array}{l}\text { Gila } \\
\text { Graham }\end{array}$ & $\begin{array}{l}335102 \mathrm{~N} 1102626 \mathrm{~W} \\
331100 \mathrm{~N} 1101300 \mathrm{~W}\end{array}$ & $325000 \mathrm{~N} 1093500 \mathrm{~W}$ & & $\begin{array}{l}\text { Beckers Butte } \\
\text { Calva }\end{array}$ \\
\hline $\begin{array}{l}\text { Gila Valley Lookout } \\
\text { Gila Vista Junior High School } \\
\text { Gila Well } \\
\text { Gilbert } \\
\text { Gilbert Canyon } \\
\text { Gilbert Estates Phase Two } \\
\text { Mini Park }\end{array}$ & $\begin{array}{l}\text { locale } \\
\text { school } \\
\text { well } \\
\text { ppl } \\
\text { valley } \\
\text { park }\end{array}$ & $\begin{array}{l}\text { BGN } \\
\text { UNOFF } \\
\text { UNOFF } \\
\text { BGN } \\
\text { BGN } \\
\text { ADMIN }\end{array}$ & $\begin{array}{l}\text { Maricopa } \\
\text { Yuma } \\
\text { Graham } \\
\text { Maricopa } \\
\text { Mohave } \\
\text { Maricopa }\end{array}$ & $\begin{array}{l}331952 \mathrm{~N} 1120335 \mathrm{~W} \\
324113 \mathrm{~N} 1143653 \mathrm{~W} \\
325807 \mathrm{~N} 1095511 \mathrm{~W} \\
332110 \mathrm{~N} 1114718 \mathrm{~W} \\
360719 \mathrm{~N} 1143536 \mathrm{~W} \\
332641 \mathrm{~N} 1114728 \mathrm{~W}\end{array}$ & $360435 N 1143643 W$ & & $\begin{array}{l}\text { Lone Butte } \\
\text { Yuma East } \\
\text { Eden } \\
\text { Chandler } \\
\text { Petroglyph Wash } \\
\text { Mesa }\end{array}$ \\
\hline $\begin{array}{l}\text { Gilbert Estates Phase Two } \\
\text { Water Retention Basin } \\
\text { Gilbert High School } \\
\text { Gilbert Junior High School } \\
\text { Gilbert Lateral } \\
\text { Gilbert Park } \\
\text { Gilbert Plaza Shopping Center } \\
\text { Gilbert Post Office } \\
\text { Gilbert School } \\
\text { Gilbert Substation }\end{array}$ & $\begin{array}{l}\text { reservoir } \\
\text { school } \\
\text { school } \\
\text { canal } \\
\text { park } \\
\text { locale } \\
\text { building } \\
\text { school } \\
\text { locale }\end{array}$ & $\begin{array}{l}\text { BGN } \\
\text { UNOFF } \\
\text { UNOFF } \\
\text { BGN } \\
\text { ADMIN } \\
\text { UNOFF } \\
\text { UNOFF } \\
\text { UNOFF } \\
\text { UNOFF }\end{array}$ & $\begin{array}{l}\text { Maricopa } \\
\text { Maricopa } \\
\text { Maricopa } \\
\text { Yuma } \\
\text { Pinal } \\
\text { Maricopa } \\
\text { Maricopa } \\
\text { Maricopa } \\
\text { Maricopa }\end{array}$ & $\begin{array}{l}332641 \mathrm{~N} 1114728 \mathrm{~W} \\
332043 \mathrm{~N} 1114735 \mathrm{~W} \\
332055 \mathrm{~N} 1114723 \mathrm{~W} \\
324035 \mathrm{~N} 1144205 \mathrm{~W} \\
335257 \mathrm{~N} 1114413 \mathrm{~W} \\
332610 \mathrm{~N} 1114716 \mathrm{~W} \\
332116 \mathrm{~N} 1114719 \mathrm{~W} \\
332056 \mathrm{~N} 1114730 \mathrm{~W} \\
332150 \mathrm{~N} 1114820 \mathrm{~W}\end{array}$ & & & $\begin{array}{l}\text { Mesa } \\
\text { Chandler } \\
\text { Chandler } \\
\text { Yuma West } \\
\text { Casa Grande East } \\
\text { Mesa } \\
\text { Chandler } \\
\text { Chandler } \\
\text { Mesa }\end{array}$ \\
\hline $\begin{array}{l}\text { Gilbert Well } \\
\text { Gilda Spring } \\
\text { Gililland Intermediate School } \\
\text { See Gililland Junior High } \\
\text { School }\end{array}$ & $\begin{array}{l}\text { well } \\
\text { spring } \\
\text { school }\end{array}$ & $\begin{array}{l}\text { UNOFF } \\
\text { BGN } \\
\text { VARIANT }\end{array}$ & $\begin{array}{l}\text { Gila } \\
\text { Cochise } \\
\text { Maricopa }\end{array}$ & $\begin{array}{l}332349 N 1103931 \mathrm{~W} \\
315136 \mathrm{~N} 1095648 \mathrm{~W} \\
332505 \mathrm{~N} 111571 \mathrm{BW}\end{array}$ & & & $\begin{array}{l}\text { Cammerman Wash } \\
\text { Black Oiamond Peak }\end{array}$ \\
\hline $\begin{array}{l}\text { Gililland Junior High School } \\
\text { Gilill and Intermediate } \\
\text { School }\end{array}$ & school & $\begin{array}{l}\text { UNOFF } \\
\text { VARIANT }\end{array}$ & Maricopa & $332505 \mathrm{~N} 1115718 \mathrm{~W}$ & & & Tempe \\
\hline $\begin{array}{l}\text { Gillard Hot Springs } \\
\text { Morenci Hot Springs }\end{array}$ & spring & $\begin{array}{l}\text { BGN } \\
\text { VARIANT }\end{array}$ & Greenlee & $325823 N 1092059 \mathrm{~W}$ & & & Guthrie \\
\hline $\begin{array}{l}\text { Gillespie (historical) } \\
\text { Gillespie } \\
\text { Gillespie Cueto Tank } \\
\text { Gillespie Dam }\end{array}$ & $\begin{array}{l}\text { locale } \\
\text { locale } \\
\text { reservoir } \\
\text { dam }\end{array}$ & $\begin{array}{l}\text { BGN } \\
\text { BGN } \\
\text { BGN } \\
\text { UNOFF }\end{array}$ & $\begin{array}{l}\text { Graham } \\
\text { Maricopa } \\
\text { Graham } \\
\text { Maricopa }\end{array}$ & $\begin{array}{l}323337 N 1094532 \mathrm{~W} \\
331542 \mathrm{~N} 1125850 \mathrm{~W} \\
325128 \mathrm{~N} 1092137 \mathrm{~W} \\
331345 \mathrm{~N} 1124607 \mathrm{~W}\end{array}$ & & 4333 & $\begin{array}{l}\text { Stockton Pass } \\
\text { Gillespie } \\
\text { Ash Peak } \\
\text { Spring Mtn }\end{array}$ \\
\hline
\end{tabular}




\begin{tabular}{|c|c|c|c|c|c|c|c|}
\hline FEATURE NAME & $\begin{array}{l}\text { FEATURE } \\
\text { CLASS }\end{array}$ & STATUS & COUNTY & COORDINATE & $\begin{array}{l}\text { SOURCE } \\
\text { COORDINATE }\end{array}$ & $\begin{array}{l}\text { ELEV } \\
\text { FT }\end{array}$ & MAP NAME \\
\hline $\begin{array}{l}\text { Peoria Dan } \\
\text { Gillespie Flat } \\
\text { Gillespie Mountain } \\
\text { Gillespie Ranch } \\
\text { Gillespie Wash } \\
\text { Gillespie Wash } \\
\text { See Stockton Pass Wash }\end{array}$ & $\begin{array}{l}\text { flat } \\
\text { summit } \\
\text { locale } \\
\text { stream } \\
\text { stream }\end{array}$ & $\begin{array}{l}\text { VARIANT } \\
\text { BGN } \\
\text { BGN } \\
\text { UNOFF } \\
\text { BGN } \\
\text { VARIANT }\end{array}$ & $\begin{array}{l}\text { Apache } \\
\text { Graham } \\
\text { Graham } \\
\text { Graham } \\
\text { Graham }\end{array}$ & $\begin{array}{l}340825 \mathrm{~N} 1093803 \mathrm{~W} \\
323434 \mathrm{~N} 1094356 \mathrm{~W} \\
3250271092239 \mathrm{~W} \\
323402 \mathrm{~N} 1094539 \mathrm{~W} \\
323856 \mathrm{~N} 1094329 \mathrm{~W}\end{array}$ & 323105 N1094710W & 5216 & $\begin{array}{l}\text { Boundary Butte } \\
\text { Gillespie Mtn } \\
\text { Tollgate Tank } \\
\text { Stockton Pass }\end{array}$ \\
\hline $\begin{array}{l}\text { Gillespie Well } \\
\text { Gillette } \\
\text { Gilliand Gap } \\
\text { See Gilliland Gap } \\
\text { Gilliand Spring } \\
\text { See Gilliland Spring } \\
\text { Gilliland Gap } \\
\text { Gilliand Gap } \\
\text { Gilliland Spring } \\
\text { Gilliand Spring }\end{array}$ & $\begin{array}{l}\text { well } \\
\text { locale } \\
\text { gap } \\
\text { spring } \\
\text { gap } \\
\text { spring }\end{array}$ & $\begin{array}{l}\text { UNOFF } \\
\text { BGN } \\
\text { VARIANT } \\
\text { VARIANT } \\
\text { BGN } 1974 \\
\text { VARIANT } \\
\text { BGN 1974 } \\
\text { VARIANT }\end{array}$ & $\begin{array}{l}\text { Graham } \\
\text { Yavapai } \\
\text { Gila } \\
\text { Gila } \\
\text { Gila } \\
\text { Gila }\end{array}$ & $\begin{array}{l}323407 \mathrm{N1094538 \textrm {W }} \\
340108 \mathrm{~N} 1120946 \mathrm{~W} \\
341900 \mathrm{~N} 1111320 \mathrm{~W} \\
341901 \mathrm{N1111311 \textrm {W }} \\
341900 \mathrm{~N} 1111320 \mathrm{~W} \\
341901 \mathrm{~N} 1111311 \mathrm{~W}\end{array}$ & & 4260 & $\begin{array}{l}\text { Diamond Point } \\
\text { Diamond Point }\end{array}$ \\
\hline $\begin{array}{l}\text { Gillispie Canyon } \\
\text { Gillman Canyon } \\
\text { Gillmore Spring } \\
\text { See Gilmore Spring } \\
\text { Gilman Ranch } \\
\text { Gilman Tank } \\
\text { Gilmore Spring } \\
\text { Gilmore Spring } \\
\text { Gillmore Spring } \\
\text { Gilroy Canyon }\end{array}$ & $\begin{array}{l}\text { valley } \\
\text { valley } \\
\text { spring } \\
\text { locale } \\
\text { reservoir } \\
\text { spring } \\
\text { spring } \\
\text { valley }\end{array}$ & $\begin{array}{l}\text { BGN } \\
\text { BGN } \\
\text { VARIANT } \\
\text { UNOFF } \\
\text { BGN } \\
\text { BGN } \\
\text { BGN } 1974 \\
\text { VARIANT } \\
\text { BGN }\end{array}$ & $\begin{array}{l}\text { Greenlee } \\
\text { Graham } \\
\text { Gila } \\
\text { Graham } \\
\text { Graham } \\
\text { Gila } \\
\text { Gila } \\
\text { Mohave }\end{array}$ & $\begin{array}{l}323443 \mathrm{~N} 1090651 \mathrm{~W} \\
322628 \mathrm{~N} 1094934 \mathrm{~W} \\
340924 \mathrm{~N} 1111959 \mathrm{~W} \\
322756 \mathrm{N1094843 \textrm {W }} \\
322540 \mathrm{N1094710W} \\
340848 \mathrm{N1112010 \textrm {W }} \\
340924 \mathrm{N1111959W} \\
344227 \mathrm{~N} 1134729 \mathrm{~W}\end{array}$ & $\begin{array}{l}32365 \mathrm{BN} 1091243 \mathrm{~W} \\
322929 \mathrm{~N} 1094752 \mathrm{~W}\end{array}$ & & $\begin{array}{l}\text { Round Mtn } \\
\text { Greasewood Mountain } \\
\text { Greasewood Mountain } \\
\text { Greas ewood Mountain } \\
\text { Payson South } \\
\text { Payson South } \\
\text { Beecher Canyon }\end{array}$ \\
\hline $\begin{array}{l}\text { Gilson Creek } \\
\text { See Gilson Wash } \\
\text { Gilson Wash } \\
\text { Aliso Creek } \\
\text { Gilson Creek } \\
\text { Gilson Wash } \\
\text { See Ranch Creek } \\
\text { Gilson Well } \\
\text { Gil Water Tank } \\
\text { Gimme Tank }\end{array}$ & $\begin{array}{l}\text { strean } \\
\text { well } \\
\text { reservoir } \\
\text { reservoir }\end{array}$ & $\begin{array}{l}\text { VARIANT } \\
\text { BGN } 1968 \\
\text { VARIANT } \\
\text { VARIANT } \\
\text { VARIANT } \\
\text { UNOFF } \\
\text { BGN } \\
\text { BGN }\end{array}$ & $\begin{array}{l}\text { Gila } \\
\text { Gila } \\
\text { Pima } \\
\text { Gila }\end{array}$ & $\begin{array}{l}332110 \mathrm{~N} 1103847 \mathrm{~W} \\
332200 \mathrm{N1} 103540 \mathrm{~W} \\
312705 \mathrm{N1112620 \textrm {W }} \\
333645 \mathrm{~N} 1102115 \mathrm{~W}\end{array}$ & $332101 \mathrm{~N} 1103915 \mathrm{~W}$ & $\begin{array}{l}2997 \\
585 B\end{array}$ & $\begin{array}{l}\text { Bucket Mtn } \\
\text { Cumero Mtn } \\
\text { Sontag Creek }\end{array}$ \\
\hline $\begin{array}{l}\text { Ginn Spring } \\
\text { Girdner Tank } \\
\text { Girdner Tank } \\
\text { Girl Scout Camp } \\
\text { Girl Scout Spring } \\
\text { Gisela } \\
\text { Gisela Mountain } \\
\text { Gisela Tank } \\
\text { GJ Filleman Ranch } \\
\text { Gladden }\end{array}$ & $\begin{array}{l}\text { spring } \\
\text { reservoir } \\
\text { reservoir } \\
\text { locale } \\
\text { spring } \\
\text { ppl } \\
\text { summit } \\
\text { reservoir } \\
\text { locale } \\
\text { locale }\end{array}$ & $\begin{array}{l}\text { BGN } \\
\text { BGN } \\
\text { BGN } \\
\text { UNOFF } \\
\text { BGN } \\
\text { BGN } \\
\text { BGN } \\
\text { BGN } \\
\text { UNOFF } \\
\text { BGN }\end{array}$ & $\begin{array}{l}\text { Gila } \\
\text { Yavapai } \\
\text { Coconino } \\
\text { Pima } \\
\text { Pima } \\
\text { Gila } \\
\text { Gila } \\
\text { Gila } \\
\text { Greenlee } \\
\text { Yuma }\end{array}$ & 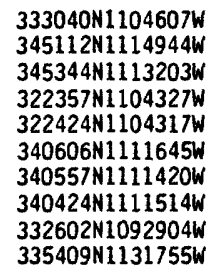 & & $\begin{array}{l}7640 \\
5398 \\
5200\end{array}$ & $\begin{array}{l}\text { Rockinstraw Mtn } \\
\text { Sedona } \\
\text { Mormon Mountain } \\
\text { Mount Bigelow } \\
\text { Mount Bigelow } \\
\text { Gisela } \\
\text { Sheep Bas in Mtn } \\
\text { Gisela } \\
\text { Robinson Mesa } \\
\text { Gladden }\end{array}$ \\
\hline $\begin{array}{l}\text { Glade Dam } \\
\text { Glade Tank } \\
\text { Gladiator Mine } \\
\text { Gladiator Spring } \\
\text { Glance Creek } \\
\text { Glance Mine } \\
\text { Gla She Spring } \\
\text { Glassford Hill } \\
\text { Bald Hill } \\
\text { Bald Mountain } \\
\text { Malpais Mountain } \\
\text { Mirror Mounta in }\end{array}$ & $\begin{array}{l}\text { dam } \\
\text { reservoir } \\
\text { mine } \\
\text { spring } \\
\text { stream } \\
\text { mine } \\
\text { spring } \\
\text { summit }\end{array}$ & $\begin{array}{l}\text { UNOFF } \\
\text { BGN } \\
\text { UNOFF } \\
\text { BGN } \\
\text { BGN } \\
\text { UNOFF } \\
\text { BGN } \\
\text { BGN } 1932 \\
\text { VARIANT } \\
\text { VARIANT } \\
\text { VARIANT } \\
\text { VARIANT }\end{array}$ & $\begin{array}{l}\text { Gila } \\
\text { Gila } \\
\text { Yavapai } \\
\text { Yavapai } \\
\text { Cochise } \\
\text { Cochise } \\
\text { Navajo } \\
\text { Yavapai }\end{array}$ & $\begin{array}{l}334008 \mathrm{~N} 1102648 \mathrm{~W} \\
334008 \mathrm{N1102647 \textrm {W }} \\
341359 \mathrm{N1121959 \textrm {W }} \\
341417 \mathrm{N1122005 \textrm {W }} \\
312427 \mathrm{N1} 1094508 \mathrm{~W} \\
312205 \mathrm{N1} 1094900 \mathrm{~W} \\
335906 \mathrm{N1} 1095814 \mathrm{~W} \\
343522 \mathrm{N1} 122253 \mathrm{~W}\end{array}$ & $312340 \mathrm{~N} 1095042 \mathrm{~W}$ & 6178 & $\begin{array}{l}\text { Brushy Canyon } \\
\text { Brushy Canyon } \\
\text { Crown King } \\
\text { Crown King } \\
\text { Bisbee NE } \\
\text { Bisbee SE } \\
\text { Alchesay Flat } \\
\text { Prescott }\end{array}$ \\
\hline $\begin{array}{l}\text { Glass Tank } \\
\text { Gleason Flat } \\
\text { Gleed Tank } \\
\text { Gleen Spring } \\
\text { See Glenn Spring } \\
\text { Gleeson } \\
\text { Gleeson Substation } \\
\text { Glenbar } \\
\text { Fairview } \\
\text { Hogtown } \\
\text { Matthewsville }\end{array}$ & $\begin{array}{l}\text { reservoir } \\
\text { flat } \\
\text { reservoir } \\
\text { spring } \\
\mathrm{ppl} \\
\text { locale } \\
\mathrm{ppl}\end{array}$ & $\begin{array}{l}\text { BGN } \\
\text { BGN } \\
\text { BGN } \\
\text { VARIANT } \\
\text { BGN } \\
\text { UNOFF } \\
\text { BGN } \\
\text { VARIANT } \\
\text { VARIANT } \\
\text { VARIANT }\end{array}$ & $\begin{array}{l}\text { Cochise } \\
\text { Gila } \\
\text { Yavapai } \\
\text { Cochise } \\
\text { Cochise } \\
\text { Cochise } \\
\text { Graham }\end{array}$ & $\begin{array}{l}314430 \mathrm{N1} 1091300 \mathrm{~W} \\
334620 \mathrm{N1104117 \textrm {W }} \\
351724 \mathrm{N1} 123820 \mathrm{~W} \\
\\
314943 \mathrm{~N} 1102358 \mathrm{~W} \\
314402 \mathrm{N1} 1094945 \mathrm{~W} \\
314350 \mathrm{N1} 1094950 \mathrm{~W} \\
325500 \mathrm{~N} 1095127 \mathrm{~W}\end{array}$ & & & $\begin{array}{l}\text { Apache } \\
\text { Picacho Colorado } \\
\text { Crookton }\end{array}$ \\
\hline Glenbar Cemetery & cemetery & UNOFF & Graham & $325510 \mathrm{~N} 1095225 \mathrm{~W}$ & & & Pima \\
\hline
\end{tabular}


FEATURE NAME

Glen Canyon

Mound Canyon

Monument Canyon

Glen Canyon Dam

Eisenhower Dam

Fred T. Colter Dam

Glen Canyon Dam Visitor Center

Glen Canyon Generating Station

Glen Canyon National

Recreation Area

Glen Canyon Reservoir See Powe 11, Lake

Glen Canyon Substation

Glen Canyon Trailer Park

Glendale

Glendale City $\mathrm{Hall}$

Glendale Community College

Glendale Community Park

Glendale Memorial Cemetery

Glendale Municipal Airport

Glendale Plaza

Glendale Plaza Shopping Center

Glendale Post Office

Glendale School Number Four

Glendale School Number One

Glendale School Number Two

Glendale Shopping Center

Glendale Water Tank

Triangulation Station

Glendale West Mobile Home Park

Glen Fairs Shopping Center

Glen Ilah

Glen L Downs School

Glen Livet Dan

Glen Livet Reservoir

Glen Loe Dan

Glenn, Mount

Glenn Lakes

Glenn Spring

Gleen Spring

Glenn Tank

Glenn Tank

Glen Oaks

Glen Oaks Spring

Glenview Estates (subdivision)

Glenwood Plaza Shopping Center

Gleshbito Wash

Glidden Well

Glinns Falls

See Glynns Falls

Glint Mine

Globe

Globe City

Globe City

See Globe

Globe City Hall

Globe High School

Globe Hills

Globe Municipal Airport

Globe-San Carlos

Regional Air Facility

Globe Post Office

Globe Rajiroad Station

Globe-San Carlos Regional Air Facility

See Globe Municipal Airport Glofer Spring

Glory Hole, The

Glory Hole Mine

Glory Hole Mine

Glove Mine

\begin{tabular}{|c|c|c|}
\hline $\begin{array}{l}\text { FEATURE } \\
\text { CLASS }\end{array}$ & STATUS & COUN \\
\hline valley & $\begin{array}{l}\text { BGN } \\
\text { VARIANT }\end{array}$ & Coconi \\
\hline dam & $\begin{array}{l}\text { VARIANT } \\
\text { UNOFF } \\
\text { VARIANT } \\
\text { VARIANT }\end{array}$ & Coconi \\
\hline $\begin{array}{l}\text { building } \\
\text { locale } \\
\text { park }\end{array}$ & $\begin{array}{l}\text { UNOFF } \\
\text { UNOFF } \\
\text { ADMIN }\end{array}$ & $\begin{array}{l}\text { Coconino } \\
\text { Coconino } \\
\text { Coconino }\end{array}$ \\
\hline
\end{tabular}

VARIANT

$\begin{array}{llll}\text { reservoir } & & \text { Coconino } & 365610 \mathrm{~N} 1112900 \mathrm{~W} \\ \text { locale } & \text { UNOFF } & \text { Coconino } & 365555 \mathrm{~N} 1112905 \mathrm{~W} \\ \text { locale } & \text { UNOFF } & \text { Maricopa } & 333220 \mathrm{~N} 1120648 \mathrm{~W} \\ \text { ppl } & \text { BGN } & \text { Maricopa } & 333219 \mathrm{~N} 1121107 \mathrm{~W} \\ \text { building } & \text { UNOFF } & \text { Maricopa } & 333220 \mathrm{~N} 1121105 \mathrm{~W} \\ \text { school } & \text { UNOFF } & \text { Maricopa } & 333411 \mathrm{~N} 1121124 \mathrm{~W} \\ \text { park } & \text { ADMIN } & \text { Maricopa } & 333125 \mathrm{~N} 1121104 \mathrm{~W} \\ \text { cemetery } & \text { UNOFF } & \text { Maricopa } & 333307 \mathrm{~N} 1121127 \mathrm{~W} \\ \text { airport } & \text { ADMIN } & \text { Maricopa } & 333413 \mathrm{~N} 1121339 \mathrm{~W}\end{array}$

$333216 \mathrm{~N} 1121010 \mathrm{~W}$

locale BGN Maricopa

locale UNOFF Maricopa

building UNOFF Maricopa

school UNOFF Maricopa

school UNOFF Maricopa

school UNOFF Maricopa

locale UNOFF Maricopa

locale BGN Maricopa

locale UNOFF Maricopa

$\begin{array}{lll}\text { locale } & \text { UNOFF } & \text { Maricopa } \\ \text { ppl } & \text { BGN } & \text { Yavapai } \\ \text { school } & \text { UNOFF } & \text { Maricopa } \\ \text { dam } & \text { BGN } & \text { Apache } \\ \text { reservoir } & \text { BGN } & \text { Apache } \\ \text { dam } & \text { UNOFF } & \text { Apache } \\ \text { summit } & \text { BGN } & \text { Cochise } \\ \text { lake } & \text { BGN } & \text { Coconino } \\ \text { spring } & \text { BGN 1976 } & \text { Cochise }\end{array}$

reservoir

locale

spring

pp 1

locale

valley

well

falls VARIANT

Cochise

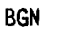

BGN

BGN

BGN

BGN

UNOFF

UNOFF

UNOFF

VARIANT

mine UNOFF

mine

VARIANT

VARIANT

ppl

building

school

summit

airport

UNOFF

UNOFF

BGN

ADMIN

VARIANT

Cochise

Greenlee

Yavapai

Yavapai

Maricopa

Maricopa

Navajo

Yavapai

Yuma

Yavapai

Gila

Gila

Gila

Gila

Gila

Gila

building

UNOFF

UNOF

VARIANT

Gila

Gila

airport

spring

bend

mine

mine

mine

$\begin{array}{lll} & \text { Gila } & 332110 N 1103945 \mathrm{~W} \\ \text { BGN 1983 } & \text { Apache } & 360500 \mathrm{~N} 1091900 \mathrm{~W} \\ \text { BGN } & \text { Mohave } & 344736 \mathrm{~N} 1143201 \mathrm{~W} \\ \text { UNOFF } & \text { Pinal } & 324537 \mathrm{N1102924W} \\ \text { UNOFF } & \text { Yuma } & 334845 \mathrm{~N} 1134337 \mathrm{~W} \\ \text { UNOFF } & \text { Santa Cruz } & 313937 \mathrm{~N} 1105656 \mathrm{~W}\end{array}$

$333132 \mathrm{~N} 1121115 \mathrm{~W}$

$341254 \mathrm{~N} 1124530 \mathrm{~W}$

$332924 \mathrm{~N} 1120938 \mathrm{~W}$

$340142 \mathrm{~N} 1091307 \mathrm{~W}$

$340142 \mathrm{~N} 1091307 \mathrm{~W}$

$340124 N 1091342 \mathrm{~W}$

$315707 N 1095910 \mathrm{~W}$

$314943 \mathrm{~N} 1102358 \mathrm{~W}$

$314112 \mathrm{~N} 1092408 \mathrm{~W}$

$331623 \mathrm{~N} 1092351 \mathrm{~W}$

$342635 \mathrm{~N} 1123252 \mathrm{~W}$

$342635 \mathrm{~N} 1123307 \mathrm{~W}$

$331 B 15 N 1115524 \mathrm{~W}$

$333036 \mathrm{~N} 1121205 \mathrm{~W}$

$351812 \mathrm{~N} 1101053 \mathrm{~W}$

$345505 N 1122045 \mathrm{~W}$

323517N1133910W

340159 N1121824W

332339 N1104709W

$332339 \mathrm{~N} 1104709 \mathrm{~W}$

$332347 \mathrm{~N} 1104717 \mathrm{~W}$

$332338 \mathrm{~N} 1104650 \mathrm{~W}$

332BOON1104629W

$332110 \mathrm{~N} 1103945 \mathrm{~W}$ $\begin{array}{cc}\text { SOURCE } & \text { ELEV } \\ \text { COORDINATE } & \text { FT MAP NAME }\end{array}$

Ferry Swale

Page

Page

Ferry Swale

Page

1180 Sunnys lope

Glendale

Glendale

Glendale

Glendale

Glendale

1137 Glendale

Glendale

1166 Glendale

Glendale

Glendale

Glendale

Giendale

Glendale

Glendale

1105 Glendale

Columbia

$352601 N 1101153 W$

Glendale

Congress

Fowler

Nelson Reservoir

Nelson Reservoir

Nelson Reservoir

7519 Cochise Stronghold

Telephone Hill

Apache Peak

Bruno Peak

Bee Canyon

Wilhoit

Wilhoit

1170 Guadalupe

Glendale

Sunflower Butte

Seepage Mtn

3509 Glob

Globe

Globe

Globe

3228 Cutter

Globe

Globe

Spider Rock

Needles

Oak Grove Canyon

Harcuvar

Mt Hopkins 
NATIONAL GAZETTEER--ARIZONA 1986

\section{FEATURE NAME}

Glover Tank

Glynns Falls Glinns Falls

Gnat Tank

Gnat Tank

Gnat Tank

Gnat Tank

Gneiss Canyon

Gneiss Canyon Rapids

Goat Camp

Goat Camp

Goat Camp Canyon

Goat Camp Canyon

Goat Camp Canyon

Goat Camp Creek

Goat Camp Spring

Goat Camp Spring

Goat Camp Spring

Goat Camp Springs

Coal Camp Spring

Goat Canyon

Goat Canyon

Goat Canyon

Goat Canyon

Goat Hill

Goat $\mathrm{Hill}$

Goat Mountain

Goat Mountains

See Big Horn Mountains

Goat Peak

Goat Peak

Goat Peak

Goat Peak Spring

Goat Ranch

Goat Ranch

Goat Ranch Draw

Goat Ranch Spring

Goat Spring

Goat Spring

Goat Spring

See Government Spring

Goat Spring

Goat Spring

Goat Spring

Goat Tank

Goat Tank

Goatwater Spring

Goatwater Spring

Goat Water Tank

Goat Well

Goat Well Drop Structure Dam

Gobbler Knob

Gobbler Peak

Gobbler Point

Gobbler Seep

Gobbler Tank

Godard Tank

Goddards

See Black Canyon City

Goddard Tank Number One

Goddard Tank Number Two

Godfrey Mines

Gods Pocket

Gods Pocket

Gohke Tank

Go John Canyon

Go John Mountain

Gokasmuk

See Topawa

Goklish Canyon

Golconda Mine 325527 N1092923W $332909 \mathrm{~N} 1111450 \mathrm{~W}$

range
summit

Maricopa

$330405 \mathrm{N1} 101812 \mathrm{~W}$

$314507 \mathrm{~N} 1102800 \mathrm{~W}$

spring

spring

spring

VARIANT

$335559 \mathrm{~N} 1091418 \mathrm{~W}$

$340653 \mathrm{~N} 1095033 \mathrm{~W}$

$343933 \mathrm{~N} 1120004 \mathrm{~W}$

reservoir BGN Yavapa

Yavapai

$315811 \mathrm{~N} 1120452$

\begin{tabular}{|c|c|c|c|}
\hline $\begin{array}{l}\text { FEATURE } \\
\text { CLASS }\end{array}$ & STATUS & COUNTY & COORDINATE \\
\hline $\begin{array}{l}\text { reservoir } \\
\text { falls }\end{array}$ & $\begin{array}{l}\text { BGN } \\
\text { BGN } \\
\text { VARIANT }\end{array}$ & $\begin{array}{l}\text { Greenlee } \\
\text { Yuma }\end{array}$ & $\begin{array}{l}332657 \mathrm{~N} 1092649 \mathrm{~W} \\
323517 \mathrm{~N} 1133910 \mathrm{~W}\end{array}$ \\
\hline $\begin{array}{l}\text { reservoir } \\
\text { reservoir } \\
\text { reservoir } \\
\text { reservoir } \\
\text { valley } \\
\text { rapids } \\
\text { locale }\end{array}$ & $\begin{array}{l}\text { BGN } \\
B G N \\
B G N \\
B G N \\
B G N \\
B G N \\
B G N\end{array}$ & $\begin{array}{l}\text { Pima } \\
\text { Yavapai } \\
\text { Yavapai } \\
\text { Mohave } \\
\text { Mohave } \\
\text { Mohave } \\
\text { Graham }\end{array}$ & $\begin{array}{l}321744 \mathrm{~N} 1104147 \mathrm{~W} \\
342 \mathrm{~B} 28 \mathrm{~N} 1113444 \mathrm{~W} \\
344515 \mathrm{~N} 1113310 \mathrm{~W} \\
352630 \mathrm{~N} 1132333 \mathrm{~W} \\
354653 \mathrm{~N} 113315 \mathrm{~W} \\
354700 \mathrm{~N} 1133155 \mathrm{~W} \\
330259 \mathrm{~N} 1101330 \mathrm{~W}\end{array}$ \\
\hline $\begin{array}{l}\text { locale } \\
\text { valley } \\
\text { valley } \\
\text { valley } \\
\text { stream } \\
\text { spring } \\
\text { spring } \\
\text { spring } \\
\text { spring }\end{array}$ & $\begin{array}{l}\text { BGN } \\
\text { BGN } \\
\text { BGN } \\
\text { BGN } \\
\text { BGN } \\
\text { BGN } \\
\text { BGN } \\
\text { BGN } \\
\text { BGN } \\
\text { VARIANT }\end{array}$ & $\begin{array}{l}\text { Yavapai } \\
\text { Greenlee } \\
\text { Gila } \\
\text { Gila } \\
\text { Gila } \\
\text { Yavapai } \\
\text { Yavapai } \\
\text { Yavapai } \\
\text { Yavapai }\end{array}$ & $\begin{array}{l}343140 \mathrm{~N} 1123759 \mathrm{~W} \\
324821 \mathrm{~N} 1091012 \mathrm{~W} \\
341449 \mathrm{~N} 1114130 \mathrm{~W} \\
341516 \mathrm{~N} 1111559 \mathrm{~W} \\
341441 \mathrm{~N} 1114140 \mathrm{~W} \\
340644 \mathrm{~N} 1115517 \mathrm{~W} \\
341220 \mathrm{~N} 1123933 \mathrm{~W} \\
342613 \mathrm{~N} 1115201 \mathrm{~W} \\
343749 \mathrm{~N} 1120140 \mathrm{~W}\end{array}$ \\
\hline
\end{tabular}

$\begin{array}{cc}\text { SOURCE } & \text { ELEV } \\ \text { COORDINATE } & \text { FT }\end{array}$

MAP NAME

Robinson Mesa Mohawk Mts SW

Agua Caliente $\mathrm{Hill}$

Strawberry

Stoneman Lake

Cherokee Point

354532N1133404W Separation Canyon

Separation Canyon

Beargrass Basin

Skull Valley

$\begin{array}{ll}325050 \mathrm{~N} 1090005 \mathrm{~W} & \text { Sheldon } \\ 341419 \mathrm{~N} 1113743 \mathrm{~W} & \text { Wet Bottom Mesa }\end{array}$

$\begin{array}{ll}341419 \mathrm{~N} 1113743 \mathrm{~W} & \text { Wet Bottom Mesd } \\ 341621 \mathrm{~N} 1111812 \mathrm{~W} & \text { Payson North }\end{array}$

341419N1113749W Wet Bottom Mesa

Cooks Mesa

Yarne 11

Horner Mtn

Cottonwood

$313102 \mathrm{~N} 1104740 \mathrm{~W}$ $325513 \mathrm{~N} 1101609 \mathrm{~W}$

$324812 \mathrm{~N} 1095455 \mathrm{~W}$

$331939 \mathrm{~N} 1120519 \mathrm{~W}$

$333620 \mathrm{N1} 111556 \mathrm{~W}$

$333833 \mathrm{~N} 1130923 \mathrm{~W}$

$341434 N 1115618 W$

$343736 \mathrm{~N} 1120433 \mathrm{~W}$

$345051 \mathrm{~N} 1124 \mathrm{BOOW}$

$343715 \mathrm{~N} 1120403 \mathrm{~W}$

$312918 \mathrm{~N} 1095608 \mathrm{~W}$

$34181 \mathrm{BN} 1121912 \mathrm{~W}$

$343955 \mathrm{N1095029W}$

$330400 \mathrm{~N} 1094653 \mathrm{~W}$

$341430 \mathrm{~N} 1120942 \mathrm{~W}$

$\begin{array}{llll}\text { spring } & \text { BGN } & \text { Yuma } & 341537 N 1140648 \mathrm{~W} \\ \text { spring } & \text { BGN } & \text { Navajo } & 355556 \mathrm{N1} 102949 \mathrm{~W} \\ \text { spring } & \text { BGN } & \text { Apache } & 365355 \mathrm{~N} 1090630 \mathrm{~W} \\ \text { reservoir } & \text { BGN } & \text { Graham } & 324055 \mathrm{~N} 1094523 \mathrm{~W} \\ \text { reservoir } & \text { BGN } & \text { Coconino } & 352945 N 1113805 \mathrm{~W} \\ \text { spring } & \text { BGN } & \text { Pinal } & 331734 N 1105756 \mathrm{~W} \\ \text { spring } & \text { BGN } & \text { Pinal } & 331753 N 1105746 \mathrm{~W} \\ \text { reservoir } & \text { BGN } & \text { Graham } & 325031 N 1101045 \mathrm{~W} \\ \text { well } & \text { UNOFF } & \text { Pima } & 314501 N 1102801 \mathrm{~W} \\ \text { dam } & \text { UNOFF } & \text { Graham } & 324218 N 1093300 \mathrm{~W}\end{array}$

$344429 N 1094229 \mathrm{~W}$

313312N1104744W Patagonia

325754N1101721W Cobre Grande Mtn

$325922 \mathrm{~N} 1092917 \mathrm{~W}$

$332712 \mathrm{~N} 1111404 \mathrm{~W}$ Iron Mountain

3769 Shingle Mill Mtn

Lone Butte

3670 Horse Mesa Dam

4968 Brooklyn Peak

6655 Cottonwood

5406 Seepage Mtn Cherry

Bisbee

4431 Battle Flat

Little Milky Ranch

Mt Turnbull

Apache Peak

Markham Creek

Monkeys Head

Onion Spring

Teec Nos Pos

Mt Graham

White Horse Hills

Pinal Ranch

Pinal Ranch

Buford Hill

5192 Apache Peak

Artesia NE

Juniper Mts

$345 \mathrm{~B} 56 \mathrm{~N} 1125552 \mathrm{~W}$

$333815 \mathrm{~N} 1092740 \mathrm{~W}$

$341145 \mathrm{~N} 1100518 \mathrm{~W}$

$343209 \mathrm{~N} 1111756 \mathrm{~W}$

340415 N1120900W

$344210 N 1120213 \mathrm{~W}$

$324710 \mathrm{~N} 1091459 \mathrm{~W}$

$344947 N 1103319 \mathrm{~W}$

$334939 N 1115809 \mathrm{~W}$

$335017 \mathrm{~N} 1115820 \mathrm{~W}$

$361308 N 1135653 W$

334959 N1115B59W

$\begin{array}{llll}\text { ppl } & & \text { Pima } & 314850 \mathrm{~N} 1114930 \mathrm{~W} \\ \text { valley } & \text { BGN } & \text { Navajo } & 335430 \mathrm{~N} 1095452 \mathrm{~W} \\ \text { mine } & \text { UNOFF } & \text { Mohave } & 351927 \text { N1140740W }\end{array}$ 
FEATURE NAME

Goldbadge Gold Bar Mine

Gold Basin

Gold Bas in

See Burnt Mill Ranch

Gold Bas in Canyon

Gold Bas in Tank

Gold Bas in Well

Goldbaum Canyon

Gold Bell Mine

Goldbug Mine

Gold Bug Mine

Goldbug Tunne 1

Gold Bullion Mine

Gold Bullion Mine

Gold Bullion Mine

Gold Butte

Gold Camp

Gold Chain Mine

Gold Coin Mine

Gold Cord Mine

Gold Creek

Gold Creek

Gold Creek Tank

Gold Creek Well

Gold Dome Mine

Gold Dust Mine

Gold Eagle Mine

Golden Aster Creek

Golden Bell Mine

Golden Belt Mine

Golden Bucks in Mine

Golden Dam Tank

Golden Door Mine

Golden Dream Mine

Golden Eagle Mine

Golden Eagle Mine

Golden Gate Mine

Golden Gate Mine

Golden Gate Mountain

Golden Gem Mine

Golden Harp Mine

Golden Hillside Mines

Golden Idol Mine

Golden Key Mine

Golden Mile Mine

Golden Roll Dam

Golden Roll Spring

Golden Roll Tank

Golden Rule Mine

Golden Rule Mine

Golden Rule Peak

Golden Star Mine

Golden Treasure Mine

Golden Turkey Mine

Golden West Estates

(subdivision)

Golden Wonder Mine

Golder Dan

Goldfield

Youngsberg

Goldfield Mine

Goldfield Mine Water Tower

Gold Field Mountains

See Goldfield Mountains

Goldfield Mountains

Bulldog Mountains

Gold Field Mountains

Harosoma

Harosoma Mountains

Harosoma Ridge

Jarosoma Mountains

Orohai
FEATURE
CLASS

STATUS

COUNTY

\begin{tabular}{|c|c|c|}
\hline $\begin{array}{l}\text { locale } \\
\text { mine } \\
\text { basin }\end{array}$ & $\begin{array}{l}\text { BGN } \\
\text { UNOFF } \\
\text { BGN } \\
\text { VARIANT }\end{array}$ & $\begin{array}{l}\text { Maricopa } \\
\text { Yavapai } \\
\text { Mohave }\end{array}$ \\
\hline $\begin{array}{l}\text { locale } \\
\text { valley } \\
\text { reservoir } \\
\text { well } \\
\text { valley } \\
\text { mine }\end{array}$ & $\begin{array}{l}\text { BGN } \\
\text { BGN } \\
\text { UNOFF } \\
\text { BGN } \\
\text { UNOFF }\end{array}$ & $\begin{array}{l}\text { Mohave } \\
\text { Yavapai } \\
\text { Yavapai } \\
\text { Yavapai } \\
\text { Santa Cruz } \\
\text { Pinal }\end{array}$ \\
\hline
\end{tabular}

COORDIMATE

333639 N112201BW

$340505 N 1123409 \mathrm{~W}$

$354709 \mathrm{~N} 1141046 \mathrm{~W}$

354910N1140B58W

$345224 N 1121 B 12 \mathrm{~W}$

$344952 \mathrm{~N} 1121858 \mathrm{~W}$

$344946 \mathrm{~N} 1121852 \mathrm{~W}$

312751 N1104015

$324306 \mathrm{~N} 1112220 \mathrm{~W}$

$\begin{array}{ll}\text { mine } & \text { UNOFF } \\ \text { mine } & \text { UNOFF } \\ \text { mine } & \text { UNOFF } \\ \text { mine } & \text { UNOFF } \\ \text { mine } & \text { UNOFF } \\ \text { mine } & \text { UNOFF } \\ \text { summit } & \text { BGN } \\ \text { locale } & \text { BGN } \\ \text { mine } & \text { UNOFF } \\ \text { mine } & \text { UNOFF }\end{array}$

Mohave

Mohave

Graham

Pima

Maricopa

Yavapai

Navajo

Cochise

Mohave

Yavapai

mine

stream

stream

well

mine

mine

mine

stream

UNOFF

BGN

BGN

UNOFF

UNOFF

UNOFF
UNOFF

UNOFF

BGN

mine UNOFF

mine UNOF

mine UNOFF

reservoir BGN

mine UNOFF

mine

mine

mine

mine

mine

summit

UNOFF
UNOFF

UNOFF

UNOFF

BGN

Maricopa

Gila

Gila

Gila

Gila

Mohave

Mohave

Yavapai

Yavapai

Pinal

$\begin{array}{ll}\text { mine } & \text { UNOFF } \\ \text { mine } & \text { UNOFF } \\ \text { mine } & \text { UNOFF } \\ \text { mine } & \text { UNOFF } \\ \text { mine } & \text { UNOFF } \\ \text { mine } & \text { UNOFF } \\ \text { dam } & \text { UNOFF } \\ \text { spring } & \text { BGN } \\ \text { reservoir } & \text { BGN } \\ \text { mine } & \text { UNOFF }\end{array}$

Yavapai

Coconino

Coconino

Mohave

Yuma

Yuma

Yavapai

Pima

Mohave

Pima

$342536 \mathrm{~N} 1133836 \mathrm{~W}$

$354032 \mathrm{~N} 1143139 \mathrm{~W}$

$324430 \mathrm{~N} 1095958 \mathrm{~W}$

$314326 N 1113551 \mathrm{~W}$

$334234 \mathrm{~N} 1131425 \mathrm{~W}$

$343558 \mathrm{~N} 1120323 \mathrm{~W}$

$335250 \mathrm{~N} 1095602 \mathrm{~W}$

$314125 N 1095316 \mathrm{~W}$

$351543 \mathrm{~N} 1143001 \mathrm{~W}$

$343315 N 1120404 W$

$334121 \mathrm{N1131258 \textrm {W }}$

335305 N1105330W

335856N1111BO4W

$335945 \mathrm{~N} 1112206 \mathrm{~W}$

$340005 \mathrm{~N} 1112128 \mathrm{~W}$

444024N1142611W

$350052 N 1142335 \mathrm{~W}$

$343600 \mathrm{~N} 1120121 \mathrm{~W}$

$340538 \mathrm{~N} 1122630 \mathrm{~W}$

330601 N1110308W

$341620 \mathrm{~N} 1121212 \mathrm{~W}$

$350017 N 1121237 \mathrm{~W}$

$350608 \mathrm{~N} 1111258 \mathrm{~W}$

353206 N1143227W

323539 N1141851K

$334052 N 1133455 \mathrm{~W}$

342320 N1122B47W

$314805 \mathrm{~N} 1104539 \mathrm{~W}$

355657 N11 40754W

$321232 N 1110619 \mathrm{~W}$

Mohave 351818N1140807W

Yuma

Maricopa

Yavapai

Mohave

Mohave

Gila

Gila

Gila

Cochise

mine

summi

mine

mine

mine

ppl

mine UNOFF

dan

locale

UNOFF

BGN

UNOFF

UNOFF

NOFF

UNOFF

VARIANT

Maricopa

Mohave

Pima

La Paz

Yavapai

(3)

332831 N1112838W

$343614 N 1120159 \mathrm{~W}$

$343145 N 1132349 \mathrm{~W}$

355506 N11 $14081 \mathrm{BW}$

$334647 \mathrm{M} 1102235$

$334612 \mathrm{~N} 1102151 \mathrm{~W}$

334647 N1102235

$320141 \mathrm{~N} 1095806 \mathrm{~W}$

$335255 \mathrm{~N} 1112555 \mathrm{~W}$

$355326 N 1141539 \mathrm{~W}$

$313736 \mathrm{~N} 1112014 \mathrm{~W}$

$335502 N 1134037 \mathrm{~W}$

$341611 \mathrm{~N} 1121216 \mathrm{~W}$

Maricopa 332520N1114530W

Gila

Pinal

$341238 \mathrm{~N} 1112209 \mathrm{~W}$

$323254 \mathrm{~N} 1105100 \mathrm{~W}$

$332732 \mathrm{~N} 1112912 \mathrm{~W}$

mine

tower

UNOFF Pinal

332729 N1112928W

$332730 \mathrm{~N} 1112929 \mathrm{~W}$

$333112 \mathrm{~N} 1113046 \mathrm{~W}$

summit

UNOFF
VARIAN

Pinal

Maricopa

$333112 \mathrm{N1113046 \textrm {W }}$

BGN 1932
VARIANT

VARIANT

VARIANT

VARIANT

VARIANT

VARIANT

VARIANT

VARIANT

\begin{tabular}{|c|c|c|}
\hline \multirow[t]{2}{*}{$\begin{array}{l}\text { SOURCE } \\
\text { COORDINATE }\end{array}$} & $\begin{array}{l}\text { ELEV } \\
\text { FT }\end{array}$ & MAP MAME \\
\hline & & $\begin{array}{l}\text { El Mirage } \\
\text { Morgan Butte } \\
\text { Burnt Mill Ranch }\end{array}$ \\
\hline $345001 N 1121 B 44 W$ & & $\begin{array}{l}\text { King Canyon } \\
\text { King Canyon } \\
\text { King Canyon }\end{array}$ \\
\hline \multirow[t]{2}{*}{$312715 \mathrm{N1} 104149 \mathrm{~W}$} & & $\begin{array}{l}\text { Harshaw } \\
\text { Picacho Pass }\end{array}$ \\
\hline & & $\begin{array}{l}\text { Signal } \\
\text { Mohave Mine } \\
\text { Webb Peak } \\
\text { Mildred Peak } \\
\text { Little Horn Peak } \\
\text { Cherry } \\
\text { Alchesay Flat } \\
\text { Hay Mountain } \\
\text { Spirit Mtn SE } \\
\text { Cherry }\end{array}$ \\
\hline
\end{tabular}

$335210 \mathrm{~N} 1105440 \mathrm{~W}$

Little Horn Peak

McFadden Peak

Kayler Butte

Kayler Butte

Gisela

Topock

Oatman

Cherry

Copperopolis

Grayback

Cleator

May Tank Pocket

Anderson Canyon

Mt Perkins

Fortuna Mine

Harrisburg Valley

Groom Creek

Helvetia

Garnet Mtn NW

4288 Cat Mountain

Cerbat

Palomas Mts West

Goldfield

Cherry

Kaiser Spring

Garnet Mtn NW

Beckers Butte

Carrizo SE

Beckers Butte

Cochise

Reno Pass

3863 Senator Mtn NE 


\begin{tabular}{|c|c|c|c|c|c|c|c|}
\hline FEATURE NAME & $\begin{array}{l}\text { FEATURE } \\
\text { CLASS }\end{array}$ & STATUS & COUNTY & COORDINATE & $\begin{array}{l}\text { SOURCE } \\
\text { COORDINATE }\end{array}$ & $\begin{array}{l}\text { ELEV } \\
\text { FT }\end{array}$ & MAP NAME \\
\hline $\begin{array}{l}\text { rohai Mountains } \\
\text { ronai Mountain } \\
\text { ellow Iron Mountains }\end{array}$ & & $\begin{array}{l}\text { VARIANT } \\
\text { VARIANT } \\
\text { VARIANT }\end{array}$ & & & & & \\
\hline
\end{tabular}

Goldfield Substation

See Goldfield Switc
Substation Goldfield Switching Substation
Goldfield Substation

Goldfish Tank

Gold Gulch

Gold Gulch

Gold Gulch

Gold Gulch

Gold Gulch

Gold Gulch

Gold Gulch

Gold Gulch Corral

Gold Gulch Dam

Gold $\mathrm{Hill}$

Gold Hill

Gold Hill

Gold Hill

Gold Hill

Gold Hill Mine

Gold Hill Mine

Gold Hill Mine

Gold Hill Spring

Gold Hill Tank

Gold King Mine

Gold King Mine

Gold King Spring

Goldmine Mountain

Gold Mountains

See Eagletail Mountains

Gold Nugget Mine

Gold Prince Mine

Goldroad (site)

Goldroad Mine

Goldroad Mine

Goldroad Well (flowing)

Gold Spring

Gold Spring

Gold Spring

Gold Spring Mine

Gold Spring Wash

Gold Star Mine

Gold Star Mine

Gold Tank

Goldtooth

Gold Tooth Smith Spring

Big Spring

Edwards Spring

Oak Spring

\author{
Goldtooth Spring \\ Goldtooth Windmill \\ Gold Trail Mine \\ Gold Trail Spring \\ Goldtrap Ranch \\ Goldtrap Tank \\ Goldwater Lake \\ See Lower Goldwater Lake \\ Goldwater Lake \\ See Upper Goldwater Lake \\ Goldwater Lakes \\ See Lower Goldwater Lake \\ Goldwater Mine \\ Goldwater Tank \\ Goldwater Well \\ Gomez Creek
}

locale
locale
reservoir
valley
valley
valley
valley

VARIANT

$\begin{array}{lll} & \text { Pinal } & 332708 \text { N1113026W } \\ \begin{array}{l}\text { UNOFF } \\ \text { VARIANT }\end{array} & \text { Pinal } & 332708 \text { N1113026W } \\ \text { BGN } & \text { Gila } & 341341 \text { N1112430W } \\ \text { BGN } & \text { Cochise } & 312009 \text { N1095009W } \\ \text { BGN } & \text { Graham } & 323104 \text { N1101920W } \\ \text { BGN } & \text { Graham } & 323209 \text { N1092825W } \\ \text { BGN } & \text { Graham } & 323553 \text { N1095705W }\end{array}$

valley

valley

valley

valley

locale

dam

summit

summit

summit

summit

summit $\quad B G$

summit BGN Gila

mine UNOFF

mine

mine

reservoir

mine UNOFF

spring

summit BGN

ridge

mine

mine

locale

mine

mine

well

spring

spring

spring

mine

stream

mine

mine

locale

spring

BGN Greenlee 330300N1092553W

BGN Gila

Navajo

BGN Gila

BGN Graham

BGN

Cochise

$322013 \mathrm{~N} 1090914 \mathrm{~W}$

Maricopa 335324N1115118W

Yavapai 340234N1121732W

Gila 340928N1112449W

Coconino 360640N1114432W

Pima 315305N1111632W

Gila 340927N1112447W

Mohave 355413N1141243W

Maricopa 335329N1115136W

Gila 340925N1112430W

Yavapai 341505N1121943W

Mohave

Yavapai 341509N1121923W

BGN
VARIANT

UNOFF

UNOFF

BGN

UNOFF

UNOFF

UNOFF

BGN

Pinal

Yuma

Yuma

Cochise

Mohave

Mohave

Mohave

Mohave

Greenlee

$\begin{array}{ll}\text { BGN } & \text { Mohave } \\ \text { BGN } & \text { Coconino }\end{array}$

UNOFF Yavapai

BGN Coconino

UNOFF Yavapai

UNOFF Mohave

BGN Yavapai

BGN Coconino

BGN 1965 Gila

VARIANT

VARIANT

VARIANT

spring
locale

mine

mine

locale

reservoir

reservoir

reservoir

BGN
BGN

UGN

BGN

UNOFF

BGN
VARIANT

VARIANT

Coconino

Navajo

Mohave

Mohave

Coconino

331108 N1113742W

$332630 \mathrm{~N} 1132134 \mathrm{~W}$

$333937 N 1140347 \mathrm{~W}$

$321140 \mathrm{N1093438 \textrm {W }}$

$350248 \mathrm{~N} 1142244 \mathrm{~W}$

350221 N1142209W

$350241 \mathrm{N1} 142237 \mathrm{~W}$

$350117 N 1141822 W$

330417 N1091420W

342838 N1140949W

$354604 \mathrm{~N} 1110426 \mathrm{~W}$

$340208 \mathrm{~N} 1121851 \mathrm{~W}$

$354412 \mathrm{~N} 1110643 \mathrm{~W}$

$343103 \mathrm{~N} 1123737 \mathrm{~W}$

$352256 \mathrm{~N} 1140829 \mathrm{~W}$

$345122 \mathrm{~N} 1121843 \mathrm{~W}$

$355501 \mathrm{N1110853 \textrm {W }}$

335738 N1112516W

$354604 N 1110425 \mathrm{~W}$

$\begin{array}{ll} & \begin{array}{l}\text { North Peak } \\ \text { 312451N1095133W }\end{array} \\ \text { Bisbee SE } \\ \text { 323420N1102039W } & \text { Bassett Peak } \\ \text { 321336N1093726W } & \text { Javelina Peak } \\ 323831 \text { N1095334W } & \text { Fort Grant }\end{array}$

$330500 \mathrm{~N} 1092308 \mathrm{~W}$

$332450 \mathrm{~N} 1105730 \mathrm{~W}$

$335338 \mathrm{~N} 1095103 \mathrm{~W}$

$340 B 22 \mathrm{~N} 1110407 \mathrm{~W}$

Copperplate Gulch

Haunted Canyon

Alchesay Flat

Diamond Butte

Fort Grant

Inspiration

5941 Bisbee NE

San Simon

Humboldt Mtn

3891 Columbia

North Peak

6175 Blue Spring

4041 Stevens Mtn

North Peak

Garnet Mtn NW

Humboldt Mtn

North Peak

Battle Flat

Dean Peak

Battle Flat

2448 Chandler Heights

Plomosa Pass

Dos Cabezas

Oatman

Mount Nutt

Oatman

Mount Nutt

Rattlesnake Spring

Standard Wash

Gold Spring

Columbia

Rock Head

Skull Valley

Chloride

King Canyon

Goldtooth

Reno Pass

Moenkopi

$360605 \mathrm{~N} 1111433 \mathrm{~W}$

$360837 \mathrm{~N} 1103201 \mathrm{~W}$

$350240 \mathrm{~N} 1141733 \mathrm{~W}$

$350233 \mathrm{~N} 1141718 \mathrm{~W}$

352309 N1123236W

$352318 \mathrm{~N} 1123229 \mathrm{~W}$

Yavapai

342954N1122724W

Yavapai

$342955 \mathrm{~N} 1122657 \mathrm{~W}$

VARIANT

reservoir

mine

reservoir

well

UNOFF

$B G N$

UNOFF

Yavapai

Mohave

Apache
$342954 \mathrm{~N} 1122724 \mathrm{~W}$

$342414 N 1122942 \mathrm{~W}$

345718 N1132056W

$341817 \mathrm{~N} 1090614 \mathrm{~W}$

340151 N1095116W
Rocky Ridge NE

Mount Nutt

Mount Nutt

Eagle Nest Mtn

Eagle Nest Mtn
Groom Creek

Mohon Peak

The Rincon

$340551 N 1094946 \mathrm{~W}$

McNary 
FEATURE NAME

Gompers Rehabilitation Center G-one Well

Gontiel Rapids (historical)

Gonzales Canyon

Gonzales Pass

Gonzales Pass Canyon

Gonzales Spring

Gonzales Tank

Gonzales Tank

Gonzales Tank

Gonzales Wash

Gonzales Wash

Gonzales Well

Gonza lo Tank Number One

Gonza lo Tank Number Two

Good Earth Mine

Good Enough Mine

Good Enough Ridge

Good Enough Tank

Gooding Research Natural Area

Good Luck Spring

Good Luck Well

Good Luck Well

Goodman Mine

Goodman Ranch

Goodman Slough

Goodman Tank

Goodman Wash

Goodman Wash

See La Paz Wash

Good News Mission

Goodrich Spring

Good Samaritan Hospital

Good Samaritan Hospital

Hel iport

Good Shepherd Convent

Good Shepherd Mission

Good Shepherd School for Girls

Good Spring

Goodwater

Goodwater Tank

Good We 11

Goodwin

Goodwin Canyon

Goodwin Canyon

Goodwin Mesa

Goodwin Spring

Goodwin Spring

Goodwin Wash

Goodyear

Egypt

Goodyear Farms

Goodyear Air Force Auxillary Field

See Memorial Airfield

Goodyear Cemetery

Goodyear Farms

See Goodyear

Goodyear Post Office

Goodyear Shopping Center

Goodyear Substation

Goodyear Town Hall

Gooseberry Butte

Gooseberry Creek

Gooseberry Oam Lake

Gooseberry Spring

Gooseberry Springs

Goosehead Rock

Goose Lake

Goose Lake

Goose Lake

\section{FEATURE}

CLASS

STATUS

COUNTY

COORDINATE

building

well

rapids

UNOFF

UNOFF

Maricopa

Gila

valley

Maricopa

gap

valley

reservoir

reservoir

reservoir

stream

stream

reservoir

BGN
BGN
BGN
BGN
BGN
BGN
BGN
BGN
UNOFF
BGN

Pinal

Pinal

Mohave

Pinal

Coconino

Coconino

Yuma

Mohave

La Paz

Coconino

reservoir

mine

mine

BGN

UNOFF

Coconino

Maricopa

Pima

ridge $B G N$ Coconino

reservoir

park

spring

locale

mine

BGN

ADMIN

BGN

BGN

BGN

UNOFF

Coconino

Santa Cruz

Apache

Apache

Apache

Yuma

local

stream

reservoir

stream

UNOFF

BGN

Pina

Yuma

Yuma

stream

church

spring

hospital

VARIANT

Yuma

Apache

UNOFF

BGN

Cochise

Maricopa

Maricopa

church

church

school

spring

locale

reservoir

well

locale

valley

valley

UNOFF Maricopa

UNOFF Apache

UNOFF

BGN

BGN

BGN

BGN

BGN

BGN

summ it

spring

spring

stream

BGN

BGN

BGN

VARIANT

VARIANT

VARIANT

airport

UNOFF VARIANT

pp 1

building

locale

locale

building

summit

stream

lake

UNOFF

UNOFF

UNOFF

UNOFF

BGK

BGN

BGN

spring

spring
pillar

lake

BGN

BGN

BGN

VARIANT
Maricopa

Maricopa 333315N1120553W

Greenlee 330956N1092351W

Navajo 345931N1095639W

Mohave 343047 N1132543W

Navajo 350140N1102933W

$342121 \mathrm{N1122245 \textrm {W }}$

$321032 \mathrm{~N} 1092650 \mathrm{~W}$

Graham

Mohave

Cochise

Yavapai

Graham

Maricopa

$325810 \mathrm{~N} 1101142 \mathrm{~W}$

$320926 \mathrm{~N} 1092835 \mathrm{~W}$

$330025 \mathrm{N1101426 \textrm {W }}$

$344706 \mathrm{~N} 1132149 \mathrm{~W}$

$320959 \mathrm{~N} 1092723 \mathrm{~W}$

$340750 \mathrm{~N} 1122945 \mathrm{~W}$

$330451 \mathrm{~N} 1100045 \mathrm{~W}$

$332607 N 1122127 \mathrm{~W}$

$325810 \mathrm{~N} 1101142 \mathrm{~W}$

Maricopa

331430 N1115400W

$331410 N 1115055 \mathrm{~W}$

Maricopa

Maricopa

Maricopa

Maricopa

Maricopa

Apache

Apache

Apache

Apache

Coconino

Pima

Maricopa

Mohave
$332607 N 1122127 \mathrm{~W}$

$332609 N 1122126 \mathrm{~W}$

$332610 \mathrm{~N} 1122130 \mathrm{~W}$

$331 \mathrm{BO} 6 \mathrm{~N} 1114922 \mathrm{~W}$

$332609 \mathrm{~N}$

(126N

$340214 N 1095126 \mathrm{~W}$

$340405 \mathrm{~N} 1094953 \mathrm{~W}$

$340653 N 1094118 \mathrm{~W}$

$344855 \mathrm{~N} 1112405 \mathrm{~W}$

$322229 \mathrm{~N} 1104214 \mathrm{~W}$

$33554 \mathrm{BN} 1131006 \mathrm{~W}$

344809 N1143119W

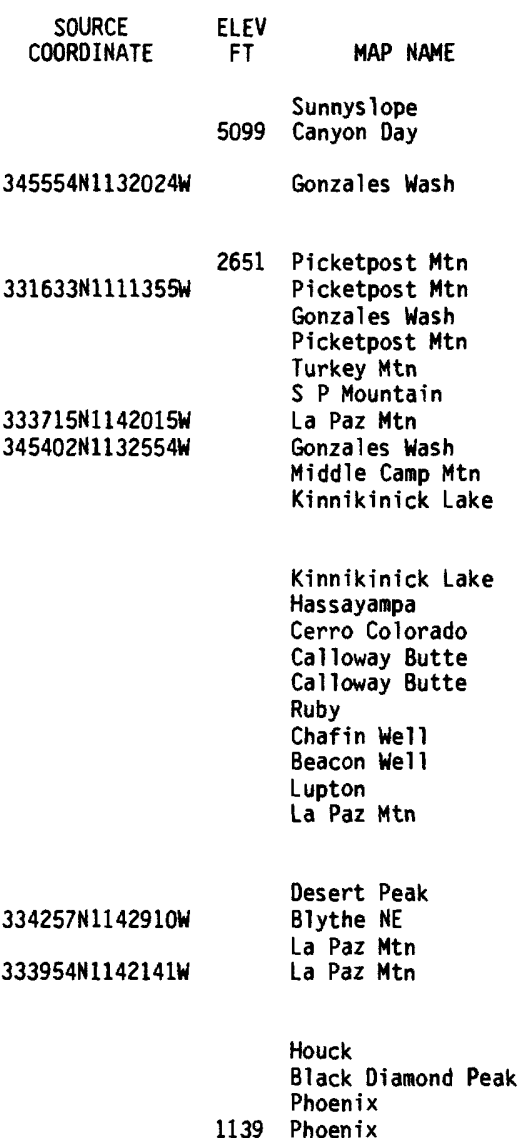

Sunnys lope

Window Rock

Sunnys lope

Coronado Mtn

Carrizo Butte

2140 Kaiser Spring

4968 Humpy Camp Well

Battleship Butte

Bowie Mtn North

Jackson Mtn

Pilot Knob

Bowie Mtn North

Minnehaha

Geronimo

Avondale

Gila Butte 


\begin{tabular}{|c|c|c|c|c|c|c|c|}
\hline FEATURE NAME & $\begin{array}{l}\text { FEATURE } \\
\text { CLASS }\end{array}$ & STATUS & COUNTY & COORDINATE & $\begin{array}{l}\text { SOURCE } \\
\text { COORDINATE }\end{array}$ & $\begin{array}{c}\text { ELEV } \\
\text { FT }\end{array}$ & MAP NAME \\
\hline $\begin{array}{l}\text { See Topock Marsh } \\
\text { Gooseneck, The } \\
\text { Goose Neck Trick Tank } \\
\text { Goose Spring }\end{array}$ & $\begin{array}{l}\text { swamp } \\
\text { bend } \\
\text { reservoir } \\
\text { spring }\end{array}$ & $\begin{array}{l}\text { BGN } \\
\text { BGN } \\
\text { BGN }\end{array}$ & $\begin{array}{l}\text { Mohave } \\
\text { Coconino } \\
\text { Coconino } \\
\text { Gila }\end{array}$ & $\begin{array}{l}344635 \mathrm{~N} 1143049 \mathrm{~W} \\
363235 \mathrm{~N} 1123338 \mathrm{~W} \\
363350 \mathrm{~N} 1123050 \mathrm{~W} \\
332414 \mathrm{~N} 1105900 \mathrm{~W}\end{array}$ & & & $\begin{array}{l}\text { Jumpup Point } \\
\text { Jumpup Point } \\
\text { Inspiration }\end{array}$ \\
\hline $\begin{array}{l}\text { Gopher Spring } \\
\text { Gopher Spring } \\
\text { Gopher Tank } \\
\text { Gordon Camp } \\
\text { Gordon Canyon } \\
\text { Gordon Canyon } \\
\text { Gordon Canyon Creek } \\
\text { Gordon Canyon Ranch } \\
\text { Gordon Canyon Spring } \\
\text { Gordon Mountain, Cerro }\end{array}$ & $\begin{array}{l}\text { spring } \\
\text { spring } \\
\text { reservoir } \\
\text { locale } \\
\text { valley } \\
\text { valley } \\
\text { stream } \\
\text { locale } \\
\text { spring } \\
\text { summit }\end{array}$ & $\begin{array}{l}\text { BGN } \\
\text { BGN } \\
\text { BGN } \\
\text { BGN } \\
\text { BGN } \\
\text { BGN } \\
\text { BGN } \\
\text { UNOFF } \\
\text { BGN } \\
\text { BGN }\end{array}$ & $\begin{array}{l}\text { Navajo } \\
\text { Coconino } \\
\text { Gila } \\
\text { Cochise } \\
\text { Gila } \\
\text { Mohave } \\
\text { Gila } \\
\text { Gila } \\
\text { Mohave } \\
\text { Apache }\end{array}$ & $\begin{array}{l}352 \mathrm{~B} 59 \mathrm{~N} 1100953 \mathrm{~W} \\
362103 \mathrm{~N} 1110324 \mathrm{~W} \\
335556 \mathrm{~N} 1101446 \mathrm{~W} \\
315240 \mathrm{~N} 1095848 \mathrm{~W} \\
341158 \mathrm{~N} 1110317 \mathrm{~W} \\
344720 \mathrm{~N} 1132612 \mathrm{~W} \\
341430 \mathrm{~N} 1105900 \mathrm{~W} \\
341705 \mathrm{~N} 1105606 \mathrm{~W} \\
344756 \mathrm{~N} 1132510 \mathrm{~W} \\
340734 \mathrm{~N} 1094337 \mathrm{~W}\end{array}$ & $\begin{array}{l}341814 \mathrm{~N} 1105445 \mathrm{~W} \\
344 \mathrm{~B} 53 \mathrm{~N} 1132713 \mathrm{~W} \\
341700 \mathrm{~N} 110554 \mathrm{~W}\end{array}$ & 9161 & $\begin{array}{l}\text { Na Ah Tee Canyon } \\
\text { Gopher Spring } \\
\text { Cedar Creek } \\
\text { Cochise Stronghold } \\
\text { Diamond Butte } \\
\text { Cedar Basin } \\
\text { Oxbow Mtn } \\
\text { Woods Canyon } \\
\text { Cedar Basin } \\
\text { Boundary Butte }\end{array}$ \\
\hline $\begin{array}{l}\text { Goswick Canyon } \\
\text { Goswick Canyon Tank } \\
\text { Goswick Lake Tank } \\
\text { Goswick Tank } \\
\text { Wickiup Tank } \\
\text { Goswick Tank } \\
\text { Goswick Tank } \\
\text { Gothic Mesa } \\
\text { Gothic Mesas } \\
\text { Gothic Mesas } \\
\text { See Gothic Mesa }\end{array}$ & $\begin{array}{l}\text { valley } \\
\text { reservoir } \\
\text { reservoir } \\
\text { reservoir } \\
\text { reservoir } \\
\text { reservoir } \\
\text { summit }\end{array}$ & $\begin{array}{l}\text { BGN } \\
\text { BGN } \\
\text { BGN } \\
\text { BGN } \\
\text { VARIANT } \\
\text { BGN } \\
\text { BGN } \\
\text { BGN } 1915 \\
\text { VARIANT } \\
\text { VARIANT }\end{array}$ & $\begin{array}{l}\text { Gila } \\
\text { Gila } \\
\text { Yavapai } \\
\text { Yavapai } \\
\text { Yavapai } \\
\text { Coconino } \\
\text { Apache }\end{array}$ & $\begin{array}{l}341257 \mathrm{~N} 1110822 \mathrm{~W} \\
341423 \mathrm{~N} 1110702 \mathrm{~W} \\
343501 \mathrm{~N} 1114134 \mathrm{~W} \\
343410 \mathrm{~N} 1114605 \mathrm{~W} \\
\\
343412 \mathrm{~N} 1114606 \mathrm{~W} \\
344011 \mathrm{~N} 1112730 \mathrm{~W} \\
365954 \mathrm{~N} 1093500 \mathrm{~W} \\
365954 \mathrm{~N} 1093500 \mathrm{~W}\end{array}$ & $341446 \mathrm{~N} 1110818 \mathrm{~W}$ & 0904 & $\begin{array}{l}\text { McDonald Mtn } \\
\text { Diamond Butte } \\
\text { Walker Mtn } \\
\text { Camp Verde } \\
\text { Camp Verde } \\
\text { Happy Jack } \\
\text { Walker Creek Res }\end{array}$ \\
\hline $\begin{array}{l}\text { Gothic Wash } \\
\text { Gothic Wash } \\
\text { Gothic Wash } \\
\text { See Gothic Wash } \\
\text { Gothic Wash } \\
\text { See Walker Creek } \\
\text { Goudy Canyon } \\
\text { Goudy Canyon Wash } \\
\text { Goudy Creek } \\
\text { Goudy Creek } \\
\text { See Goudy Canyon Wash }\end{array}$ & $\begin{array}{l}\text { arroyo } \\
\text { stream } \\
\text { valley } \\
\text { stream }\end{array}$ & $\begin{array}{l}\text { BGN } 1968 \\
\text { VARIANT } \\
\text { VARIANT } \\
\text { VARIANT } \\
\text { BGN } \\
\text { BGN } \\
\text { VARIANT } \\
\text { VARIANT }\end{array}$ & $\begin{array}{l}\text { Apache } \\
\text { Apache } \\
\text { Graham } \\
\text { Graham }\end{array}$ & $\begin{array}{l}371340 \mathrm{~N} 1094008 \mathrm{~W} \\
371340 \mathrm{~N} 1094008 \mathrm{~W} \\
365742 \mathrm{~N} 1094133 \mathrm{~W} \\
323902 \mathrm{~N} 1095710 \mathrm{~W} \\
323514 \mathrm{~N} 1095836 \mathrm{~W} \\
323514 \mathrm{~N} 1095836 \mathrm{~W}\end{array}$ & $\begin{array}{l}324255 N 1095623 W \\
324239 N 1095623 W\end{array}$ & & Toh At in Mesa West \\
\hline $\begin{array}{l}\text { Goudy Spring } \\
\text { Goulding Well } \\
\text { Gould Mine } \\
\text { Gould Springs } \\
\text { Gould Wash } \\
\text { Gourd Flat } \\
\text { Gourd Flat Canyon } \\
\text { Government Canyon } \\
\text { Government Canyon } \\
\text { Government Canyon Spring }\end{array}$ & $\begin{array}{l}\text { spring } \\
\text { well } \\
\text { mine } \\
\text { spring } \\
\text { stream } \\
\text { flat } \\
\text { valley } \\
\text { valley } \\
\text { valley } \\
\text { spring }\end{array}$ & $\begin{array}{l}\text { BGN } \\
\text { UNOFF } \\
\text { UNOFF } \\
\text { BGN } \\
\text { BGN } \\
\text { BGN } \\
\text { BGN } \\
\text { BGN } \\
\text { BGN } \\
\text { BGN }\end{array}$ & $\begin{array}{l}\text { Graham } \\
\text { Navajo } \\
\text { Pima } \\
\text { Gila } \\
\text { Yuma } \\
\text { Navajo } \\
\text { Navajo } \\
\text { Yavapai } \\
\text { Yavapai } \\
\text { Yavapai }\end{array}$ & $\begin{array}{l}324006 \mathrm{~N} 1095650 \mathrm{~W} \\
365833 \mathrm{~N} 1101349 \mathrm{~W} \\
321532 \mathrm{~N} 1110948 \mathrm{~W} \\
341342 \mathrm{~N} 1112503 \mathrm{~W} \\
332519 \mathrm{~N} 1143757 \mathrm{~W} \\
342012 \mathrm{~N} 1101921 \mathrm{~W} \\
342007 \mathrm{~N} 1101926 \mathrm{~W} \\
343330 \mathrm{~N} 1122649 \mathrm{~W} \\
345416 \mathrm{~N} 1121322 \mathrm{~W} \\
343046 \mathrm{~N} 1122602 \mathrm{~W}\end{array}$ & $\begin{array}{l}331513 N 1141922 W \\
341919 N 1102109 W \\
343026 N 1122535 \mathrm{~W} \\
350154 \mathrm{~N} 1120848 \mathrm{~W}\end{array}$ & & $\begin{array}{l}\text { Webb Peak } \\
\text { Mystery Valley } \\
\text { Avra } \\
\text { North Peak } \\
\text { Palo Verde } \\
\text { Clay Springs } \\
\text { Clay Springs } \\
\text { Prescott } \\
\text { Perkinsville } \\
\text { Prescott }\end{array}$ \\
\hline $\begin{array}{l}\text { Government Draw } \\
\text { Government Heights School } \\
\text { Government Hill } \\
\text { Government Hill } \\
\text { Government Hill } \\
\text { Apacheria } \\
\text { Government Hole } \\
\text { Government Knoll } \\
\text { See Wild Bill Hill } \\
\text { Government Knolls } \\
\text { See Wild Bill Hill }\end{array}$ & $\begin{array}{l}\text { valley } \\
\text { school } \\
\text { summit } \\
\text { summit } \\
\text { ppl } \\
\text { reservoir } \\
\text { summit } \\
\text { summit }\end{array}$ & $\begin{array}{l}\text { BGN } \\
\text { UNOFF } \\
\text { BGN } \\
\text { BGN } \\
\text { BGN } \\
\text { VARIANT } \\
\text { BGN } \\
\text { VARIANT } \\
\text { VARIANT }\end{array}$ & $\begin{array}{l}\text { Cochise } \\
\text { Pima } \\
\text { Pinal } \\
\text { Coconino } \\
\text { Gila } \\
\text { Coconino } \\
\text { Coconino } \\
\text { Coconino }\end{array}$ & $\begin{array}{l}313453 \mathrm{~N} 1100839 \mathrm{~W} \\
321043 \mathrm{~N} 1105811 \mathrm{~W} \\
332427 \mathrm{~N} 1110435 \mathrm{~W} \\
351950 \mathrm{~N} 1115737 \mathrm{~W} \\
334028 \mathrm{~N} 1110858 \mathrm{~W} \\
352049 \mathrm{~N} 1115507 \mathrm{~W} \\
351935 \mathrm{~N} 1115102 \mathrm{~W} \\
351935 \mathrm{~N} 1115102 \mathrm{~W}\end{array}$ & 314207 N1095820W & $\begin{array}{l}5445 \\
8433\end{array}$ & $\begin{array}{l}\text { Lewis Springs } \\
\text { Tucson } \\
\text { Haunted Canyon } \\
\text { Parks } \\
\text { Theo. Roosevelt Dam } \\
\text { Parks }\end{array}$ \\
\hline $\begin{array}{l}\text { Government Knolls } \\
\text { Government Mesa } \\
\text { Government Mountain } \\
\text { Government Mountain }\end{array}$ & $\begin{array}{l}\text { summit } \\
\text { summit } \\
\text { summit } \\
\text { summit }\end{array}$ & $\begin{array}{l}\text { BGN } \\
B G N \\
B G N \\
B G N\end{array}$ & $\begin{array}{l}\text { Coconino } \\
\text { Greenlee } \\
\text { Pinal } \\
\text { Coconino }\end{array}$ & $\begin{array}{l}352105 \mathrm{~N} 1115204 \mathrm{~W} \\
332947 \mathrm{~N} 1090743 \mathrm{~W} \\
331447 \mathrm{~N} 1105757 \mathrm{~W} \\
352107 \mathrm{~N} 1115427 \mathrm{~W}\end{array}$ & & $\begin{array}{l}7210 \\
8324\end{array}$ & $\begin{array}{l}\text { Wing Mountain } \\
\text { Dutch Blue Creek } \\
\text { Hot Tamale Peak } \\
\text { Parks }\end{array}$ \\
\hline
\end{tabular}




\begin{tabular}{|c|c|c|c|c|c|c|c|}
\hline FEATURE NAME & $\begin{array}{l}\text { FEATURE } \\
\text { CLASS }\end{array}$ & STATUS & COUNTY & COORDINATE & $\begin{array}{l}\text { SOURCE } \\
\text { COORDINATE }\end{array}$ & $\begin{array}{c}\text { ELEV } \\
\text { FT }\end{array}$ & MAP NAME \\
\hline $\begin{array}{l}\text { Government Peak } \\
\text { Government Prairie } \\
\text { Government Reservoir } \\
\text { Government Spring } \\
\text { Government Spring } \\
\text { Government Spring } \\
\text { Goat Spring }\end{array}$ & $\begin{array}{l}\text { summit } \\
\text { flat } \\
\text { lake } \\
\text { spring } \\
\text { spring } \\
\text { spring }\end{array}$ & $\begin{array}{l}\text { BGN } \\
\text { BGN } \\
\text { BGN } \\
\text { BGN } \\
\text { BGN } \\
\text { BGN } 1972 \\
\text { VARIANT }\end{array}$ & $\begin{array}{l}\text { Cochise } \\
\text { Coconino } \\
\text { Coconino } \\
\text { Graham } \\
\text { Pinal } \\
\text { Yavapai }\end{array}$ & $\begin{array}{l}321213 N 1093039 \mathrm{~W} \\
351857 \mathrm{~N} 1115459 \mathrm{~W} \\
364952 \mathrm{~N} 1120918 \mathrm{~W} \\
324427 \mathrm{~N} 1100133 \mathrm{~W} \\
331516 \mathrm{~N} 1105707 \mathrm{~W} \\
341430 \mathrm{~N} 1120942 \mathrm{~W}\end{array}$ & & 7580 & $\begin{array}{l}\text { Dos Cabezas } \\
\text { Parks } \\
\text { Cooper Ridge } \\
\text { Blue Jay Peak } \\
\text { Pinal Ranch } \\
\text { Bumble Bee }\end{array}$ \\
\hline $\begin{array}{l}\text { Government Spring } \\
\text { Government Spring } \\
\text { Government Spring } \\
\text { Government Spring } \\
\text { Government Spring } \\
\text { Government Spring Forest Camp } \\
\text { Government Spring Gulch } \\
\text { Government Spring Wash } \\
\text { Government Tank } \\
\text { Baker Pond }\end{array}$ & $\begin{array}{l}\text { spring } \\
\text { spring } \\
\text { spring } \\
\text { spring } \\
\text { spring } \\
\text { locale } \\
\text { valley } \\
\text { stream } \\
\text { reservoir }\end{array}$ & $\begin{array}{l}\text { BGN } \\
\text { BGN } \\
\text { BGN } \\
\text { BGN } \\
\text { BGN } \\
\text { BGN } \\
\text { BGN } \\
\text { BGN } \\
\text { BGN } \\
\text { VARIANT }\end{array}$ & $\begin{array}{l}\text { Yavapai } \\
\text { Yavapai } \\
\text { Yavapai } \\
\text { Yavapai } \\
\text { Coconino } \\
\text { Apache } \\
\text { Yavapai } \\
\text { Yavapai } \\
\text { Cochise }\end{array}$ & $\begin{array}{l}342323 N 1115053 W \\
342742 N 1120144 W \\
342929 N 1123304 W \\
345349 N 1125610 W \\
361110 N 1112253 W \\
335950 N 1092751 W \\
342615 N 1120343 W \\
34132 B N 1120818 W \\
321413 N 1092138 W\end{array}$ & $\begin{array}{l}342831 \mathrm{~N} 1120003 \mathrm{~W} \\
341503 \mathrm{~N} 1121130 \mathrm{~W}\end{array}$ & & $\begin{array}{l}\text { Horner Mtn } \\
\text { Estler Peak } \\
\text { Wilhoit } \\
\text { Juniper Mts } \\
\text { Willow Springs } \\
\text { Big Lake North } \\
\text { Estler Peak } \\
\text { Bumble Bee } \\
\text { Little Wood Canyon }\end{array}$ \\
\hline $\begin{array}{l}\text { Government Tank } \\
\text { Government Tank } \\
\text { Government Tank } \\
\text { Government Tank } \\
\text { Government Tank } \\
\text { Government Tank } \\
\text { Government Tank Canyon }\end{array}$ & $\begin{array}{l}\text { reservoir } \\
\text { reservoir } \\
\text { reservoir } \\
\text { reservoir } \\
\text { reservoir } \\
\text { reservoir }\end{array}$ & $\begin{array}{l}\text { BGN } \\
\text { BGN } \\
\text { BGN } \\
\text { BGN } \\
\text { BGN } \\
\text { BGN } \\
\text { VARIANT }\end{array}$ & $\begin{array}{l}\text { Pima } \\
\text { Maricopa } \\
\text { Navajo } \\
\text { Mohave } \\
\text { Coconino } \\
\text { Coconino }\end{array}$ & $\begin{array}{l}321957 \mathrm{~N} 1103657 \mathrm{~W} \\
331550 \mathrm{~N} 112520 \mathrm{WW} \\
342 \mathrm{~B} 06 \mathrm{~N} 1101929 \mathrm{~W} \\
350714 \mathrm{~N} 1134322 \mathrm{~W} \\
351719 \mathrm{~N} 1113333 \mathrm{~W} \\
354942 \mathrm{~N} 1120140 \mathrm{~W}\end{array}$ & & & $\begin{array}{l}\text { Piety Hill } \\
\text { Arlington } \\
\text { Big Pug Tank } \\
\text { Bottleneck Wash } \\
\text { Sunset Crater West } \\
\text { Red Butte }\end{array}$ \\
\hline $\begin{array}{l}\text { See Western Canyon } \\
\text { Government Trick Tank } \\
\text { Government Wash }\end{array}$ & $\begin{array}{l}\text { valley } \\
\text { reservoir } \\
\text { stream }\end{array}$ & $\begin{array}{l}B G N \\
B G N\end{array}$ & $\begin{array}{l}\text { Santa Cruz } \\
\text { Coconino } \\
\text { Mohave }\end{array}$ & $\begin{array}{l}313120 N 1103145 \mathrm{~W} \\
344135 \mathrm{~N} 1105603 \mathrm{~W} \\
342447 \mathrm{~N} 1133431 \mathrm{~W}\end{array}$ & $342656 \mathrm{~N} 1132714 \mathrm{~W}$ & & $\begin{array}{l}\text { Hamilton Crossing } \\
\text { Signal Mtn }\end{array}$ \\
\hline $\begin{array}{l}\text { Government Well } \\
\text { Government Well } \\
\text { Governor Hunt Tomb } \\
\text { Governors Peak } \\
\text { Gowan Mine } \\
\text { Grace Brethren School } \\
\text { Grace Valley } \\
\text { See McMullen Valley } \\
\text { Grace Valley } \\
\text { See Aguila Valley }\end{array}$ & $\begin{array}{l}\text { well } \\
\text { well } \\
\text { cemetery } \\
\text { summit } \\
\text { mine } \\
\text { school } \\
\text { valley } \\
\text { valley }\end{array}$ & $\begin{array}{l}\text { UNOFF } \\
\text { UNOFF } \\
\text { UNOFF } \\
\text { BGN } \\
\text { UNOFF } \\
\text { UNOFF } \\
\text { VARIANT } \\
\text { VARIANT }\end{array}$ & $\begin{array}{l}\text { Maricopa } \\
\text { Yuma } \\
\text { Maricopa } \\
\text { Yavapai } \\
\text { Gila } \\
\text { Maricopa } \\
\text { Yuma } \\
\text { Maricopa }\end{array}$ & $\begin{array}{l}332944 N 1112758 W \\
333544 N 1132314 W \\
332707 N 1115637 W \\
335827 N 1122218 W \\
341510 N 1112532 W \\
333128 N 1120718 W \\
33434 B N 1133719 W \\
335906 N 1125344 W\end{array}$ & & $\begin{array}{l}1405 \\
3260\end{array}$ & $\begin{array}{l}\text { Goldfield } \\
\text { Lone Mountain } \\
\text { Tempe } \\
\text { Governors Peak } \\
\text { Buckhead Mesa } \\
\text { Sunnys lope }\end{array}$ \\
\hline $\begin{array}{l}\text { Grade Tank } \\
\text { Grade Tank } \\
\text { Grady Gammage Memorial } \\
\text { Auditorium }\end{array}$ & $\begin{array}{l}\text { reservoir } \\
\text { reservoir } \\
\text { building }\end{array}$ & $\begin{array}{l}\text { BGN } \\
\text { BGN } \\
\text { UNOFF }\end{array}$ & $\begin{array}{l}\text { Navajo } \\
\text { Coconino } \\
\text { Maricopa }\end{array}$ & $\begin{array}{l}341333 N 1101649 W \\
345134 N 1112636 \mathrm{~W} \\
332458 \mathrm{~N} 1115614 \mathrm{~W}\end{array}$ & & & $\begin{array}{l}\text { Limestone Canyon N } \\
\text { Hutch Mtn } \\
\text { Tempe }\end{array}$ \\
\hline $\begin{array}{l}\text { Graham } \\
\text { Graham, Mount } \\
\text { Graham Mountain } \\
\text { Graham Peak } \\
\text { High Peak } \\
\text { Graham Canal }\end{array}$ & $\begin{array}{l}\text { ppl } \\
\text { summit }\end{array}$ & $\begin{array}{l}\text { BGN } \\
\text { BGN } 1950 \\
\text { VARIANT } \\
\text { VARIANT } \\
\text { VARIANT } \\
\text { BGN }\end{array}$ & $\begin{array}{l}\text { Graham } \\
\text { Graham }\end{array}$ & $\begin{array}{l}325230 \mathrm{~N} 1094424 \mathrm{~W} \\
324206 \mathrm{~N} 1095215 \mathrm{~W}\end{array}$ & & $\begin{array}{l}3016 \\
1072\end{array}$ & $\begin{array}{l}\text { Safford } \\
\text { Mt Graham }\end{array}$ \\
\hline $\begin{array}{l}\text { Graham Cemetery } \\
\text { Graham County } \\
\text { Apache County } \\
\text { Pima County }\end{array}$ & $\begin{array}{l}\text { cemetery } \\
\text { civil }\end{array}$ & $\begin{array}{l}\text { UNOFF } \\
\text { AOMIN } \\
\text { VARIANT } \\
\text { VARIANT }\end{array}$ & $\begin{array}{l}\text { Graham } \\
\text { Graham }\end{array}$ & $\begin{array}{l}325236 \mathrm{~N} 109440 \mathrm{BW} \\
330100 \mathrm{~N} 1100100 \mathrm{~W}\end{array}$ & & & $\begin{array}{l}\text { Weber Peak } \\
\text { Geronimo }\end{array}$ \\
\hline $\begin{array}{l}\text { Graham County Courthouse } \\
\text { Graham County Fair Ground } \\
\text { Graham Forest Reserve } \\
\text { See Crook National Forest } \\
\text { (historical) }\end{array}$ & $\begin{array}{l}\text { building } \\
\text { locale } \\
\text { forest }\end{array}$ & $\begin{array}{l}\text { UNOFF } \\
\text { UNOFF } \\
\text { VARIANT }\end{array}$ & $\begin{array}{l}\text { Graham } \\
\text { Graham } \\
\text { Gila }\end{array}$ & $\begin{array}{l}325000 N 1094259 W \\
324713 N 1094218 W \\
324501 N 1101501 W\end{array}$ & & 2920 & $\begin{array}{l}\text { Safford } \\
\text { Safford }\end{array}$ \\
\hline Graham Lateral & canal & BGN & Yuma & $323612 \mathrm{~N} 1144440 \mathrm{~W}$ & & & Somerton \\
\hline $\begin{array}{l}\text { Graham Mountain } \\
\text { See Pinaleno Mountains } \\
\text { Graham Mountain } \\
\text { See Graham, Mount } \\
\text { Graham Mountains } \\
\text { See Pinaleno Mountains } \\
\text { Graham Peak } \\
\text { See Graham, Mount } \\
\text { Graham Ranch } \\
\text { Graham Well }\end{array}$ & $\begin{array}{l}\text { range } \\
\text { summit } \\
\text { range } \\
\text { summit } \\
\text { locale } \\
\text { well }\end{array}$ & $\begin{array}{l}\text { VARIANT } \\
\text { VARIANT } \\
\text { VARIANT } \\
\text { VARIANT } \\
\text { UNOFF } \\
\text { UNOFF }\end{array}$ & $\begin{array}{l}\text { Graham } \\
\text { Graham } \\
\text { Graham } \\
\text { Graham } \\
\text { Mohave } \\
\text { Yuma }\end{array}$ & $\begin{array}{l}323827 N 1095035 W \\
324206 N 1095215 W \\
323827 N 1095035 W \\
324206 N 1095215 W \\
362753 N 1130153 W \\
335725 N 1134900 W\end{array}$ & & & $\begin{array}{l}\text { Mt Trumbull NE } \\
\text { Bouse Hills East }\end{array}$ \\
\hline $\begin{array}{l}\text { Grama Canyon } \\
\text { Grandma Canyon }\end{array}$ & valley & $\begin{array}{l}\text { BGN } \\
\text { VARIANT }\end{array}$ & Mohave & $363354 \mathrm{N1123859W}$ & $363810 \mathrm{~N} 1124811 \mathrm{~W}$ & & Grama Spring \\
\hline $\begin{array}{l}\text { Grama Draw } \\
\text { Grama Point }\end{array}$ & $\begin{array}{l}\text { valley } \\
\text { cliff }\end{array}$ & $\begin{array}{l}\text { BGN } \\
\text { BGN } 1906\end{array}$ & $\begin{array}{l}\text { Coconino } \\
\text { Coconino }\end{array}$ & $\begin{array}{l}343606 \mathrm{~N} 1105632 \mathrm{~W} \\
361239 \mathrm{~N} 1121259 \mathrm{~W}\end{array}$ & $343002 \mathrm{~N} 1105657 \mathrm{~W}$ & 7600 & $\begin{array}{l}\text { Grama Draw } \\
\text { Shiva Temple }\end{array}$ \\
\hline
\end{tabular}




\section{FEATURE NAME}

Grama Ridge

Grama Spring

Grama Tank

Grama Trick Tank

Gramm Mountain

See Cramm Mountain

Granada Park

Granada Schoo

Grancen Railroad Station

Grand Army of Republic Mine

Grand Avenue School

Grand Avenue Shopping Center

Grand Canal

Grand Canon

See Grand Canyon

Grand Canon of the Colorado

See Grand Canyon

FEATURE
CLASS

ridge

spring

reservoir

reservoir

summit

park

school

building

mine

school

locale

cana

valley

valley

valley

Grand Canyon

Big Canon

Big Canyon

Grand Canon

Grand Canon of the Colorado

Grand Canyon of the Colorado

Great Canyon

Puerto de Bucareli

Grand Canyon

Grand Canyon Bridge See Navajo Bridge

Grand Canyon Caverns Coconino Caverns

Grand Canyon Caverns Coconino Caverns Dinosaur City

Grand Canyon Caverns Airport Dinosaur City Airport

Grand Canyon College

Grand Canyon Elementary School

Grand Canyon Forest Reserve See Grand Canyon Natural Game Preserve

Grand Canyon High School

Grand Canyon Hospital

Grand Canyon Lodge

Grand Canyon National Park

Grand Canyon National Park

Airport

Grand Canyon National Park

Visitor Center

Grand Canyon Natural Game

Preserve Grand Canyon Forest Reserve

Grand Canyon Navajo Tribal Park Grand Canyon of the Colorado See Grand Canyon

Grand Canyon Railroad Station

Grand Canyon Tank

Grand Canyon Trading Post

Grand $\mathrm{Cliff}$ Range See Grand Wash $\mathrm{Cl}$ iffs

Grande Spring

Grande Tank

Grande Tank, El

Grandeur Point

Grand Falls

Grand Falls Campground

Grand Gulch Bench

Grand Gulch Canyon

Grand Gulch Mine

pp

bridg

cave

pp 1

airport

park

school

hospital

building

park

airport

building

park

park

valley

building

reservoir

local

cliff

spring

reservoir

reservoir

summit

falls

park

bench

valley

mine
STATUS

COUNTY

COORDINATE

$343348 N 1105702 \mathrm{~W}$

$363521 \mathrm{N1123946 \textrm {W }}$

$324 \mathrm{~B} 47 \mathrm{N11} 100432 \mathrm{~W}$

343150N1105648W

335821 N1115407W

Maricopa

ADMIN

UNOFF

UNOFF

UNOF

UNOFF

UNOFF

BGN

VARIANT

VARIANT

Maricopa

Maricopa

Pima

Mohave

Maricopa

Maricopa

Maricopa

Mohave

Mohave

BGN 1925

VARIANT

VARIANT

VARIANT

VARIANT

VARIANT

VARIANT

VARIANT

BGN

VARIANT

BGN 1980

VARIANT

BGN 1980

VARIANT

VARIANT

ADMIN

VARIANT

Coconino

Coconino

$360316 \mathrm{~N} 1120819 \mathrm{~W}$

$364904 \mathrm{~N} 1113751 \mathrm{~W}$

$353107 N 1131305 \mathrm{~W}$

$353142 \mathrm{~N} 1131350 \mathrm{~W}$

$353141 \mathrm{~N} 1131440 \mathrm{~W}$

school UNOFF Maricopa 333040N1120748W

school UNOFF Coconino 360308N1120810W

VARIANT

UNOFF

UNOFF

UNOFF

ADMIN

ADMIN

UNOFF

ADMIN

VARIANT

ADMIN

VARIANT

UNOFF
Coconino

360319N1120715W

Coconino

362000 N1123030W

Coconino

Coconino

Coconino

Coconino

Coconino

Coconino

$361900 \mathrm{~N} 1115000 \mathrm{~W}$

$360646 \mathrm{~N} 1135943 \mathrm{~W}$

$360324 \mathrm{~N} 1120806 \mathrm{~W}$

$351754 \mathrm{~N} 1114604 \mathrm{~W}$

351927 N1120914W

$363600 \mathrm{~N} 1134600 \mathrm{~W}$

$350526 \mathrm{~N} 1135954 \mathrm{~N}$

$312725 N 1104806 \mathrm{~W}$

$341326 \mathrm{~N} 1110600 \mathrm{~W}$

$360352 \mathrm{~N} 1120713 \mathrm{~W}$

$352539 \mathrm{~N} 1111200 \mathrm{~W}$

$352543 \mathrm{~N} 1111145 \mathrm{~W}$

$362023 \mathrm{~N} 1134602 \mathrm{~W}$

$362212 N 1134945 \mathrm{~W}$

361934 N1134727W

SOURCE
COORDINATE

MAP NAME

Grama Draw

Grama Spring

Tripp Canyon

Grama Draw

Sunnys lope

Sunnys lope

Tucson SW

White Hills West

Phoenix

1145 El Mirage

Sunnys lope

Grand Canyon

Grand Canyon Caverns

5415 Grand Canyon Caverns

5386 Grand Canyon Caverns

Glendale

Grand Canyon

Grand Canyon

Grand Canyon

Bright Angel Point

Grand Canyon

6606 Tusayan West

6880 Phantom Ranch

Kanab Point

Tatahatso Point

Grand Canyon

Wing Mountain

Williams North

Hualapai Peak

Cumero Canyon

Diamond Butte

Phantom Ranch

Grand Falls

4650 Grand Falls

$362128 \mathrm{~N} 1134703 \mathrm{~W}$

Grand Gulch Bench Grand Gulch Bench Grand Gulch Bench 


\begin{tabular}{|c|c|c|c|c|c|c|c|}
\hline FEATURE NAME & $\begin{array}{l}\text { FEATURE } \\
\text { CLASS }\end{array}$ & STATUS & COUNTY & COOROINATE & $\begin{array}{l}\text { SOURCE } \\
\text { COORDINATE }\end{array}$ & $\begin{array}{l}\text { ELEV } \\
\text { FT }\end{array}$ & MAP NAME \\
\hline $\begin{array}{l}\text { Grand Gulch Wash } \\
\text { Grandma Canyon }\end{array}$ & valley & $\begin{array}{l}\text { BGN } \\
\text { VARIANT }\end{array}$ & Mohave & $362129 \mathrm{~N} 1135533 \mathrm{~W}$ & $362212 \mathrm{~N} 1134944 \mathrm{~W}$ & & Gyp Hills \\
\hline $\begin{array}{l}\text { See Grama Canyon } \\
\text { Grand Missouri Adult Mobile } \\
\text { Home Park }\end{array}$ & $\begin{array}{l}\text { valley } \\
\text { locale }\end{array}$ & UNOFF & $\begin{array}{l}\text { Mohave } \\
\text { Maricopa }\end{array}$ & $\begin{array}{l}363354 \mathrm{~N} 1123859 \mathrm{~W} \\
333106 \mathrm{N1} 120910 \mathrm{~W}\end{array}$ & & 1150 & Glenda le \\
\hline $\begin{array}{l}\text { Grand Pacific Mine } \\
\text { Grandpa Wash }\end{array}$ & $\begin{array}{l}\text { mine } \\
\text { valley }\end{array}$ & $\begin{array}{l}\text { UNOFF } \\
\text { BGN }\end{array}$ & $\begin{array}{l}\text { Pinal } \\
\text { Yavapai }\end{array}$ & $\begin{array}{l}331610 \mathrm{~N} 1110413 \mathrm{~W} \\
343813 \mathrm{N1115404 \textrm {W }}\end{array}$ & $344022 \mathrm{~N} 1115217 \mathrm{~W}$ & & $\begin{array}{l}\text { Superior } \\
\text { Cornville }\end{array}$ \\
\hline $\begin{array}{l}\text { Grand Prize Mine } \\
\text { Grand Reef Mine } \\
\text { Granite Reef Mine }\end{array}$ & $\begin{array}{l}\operatorname{mine} \\
\operatorname{mine}\end{array}$ & $\begin{array}{l}\text { UNOFF } \\
\text { UNOFF } \\
\text { VARIANT }\end{array}$ & $\begin{array}{l}\text { Pinal } \\
\text { Graham }\end{array}$ & $\begin{array}{l}325309 \mathrm{~N} 1105711 \mathrm{~W} \\
325259 \mathrm{~N} 1101900 \mathrm{~W}\end{array}$ & & & $\begin{array}{l}\text { Crozier Peak } \\
\text { Cobre Grande Mtn }\end{array}$ \\
\hline $\begin{array}{l}\text { Grand Reef Mountain } \\
\text { Grand River }\end{array}$ & summit & $\begin{array}{l}\text { BGN } \\
\text { VARIANT }\end{array}$ & Graham & $325327 N 1101923 W$ & & 4610 & Cobre Grande Mtn \\
\hline $\begin{array}{l}\text { See Colorado River } \\
\text { Grand Scenic Divide } \\
\text { Grands tand, The } \\
\text { Grand View } \\
\text { Grandview Lookout Tower }\end{array}$ & $\begin{array}{l}\text { stream } \\
\text { ridge } \\
\text { ridge } \\
\text { locale } \\
\text { tower }\end{array}$ & $\begin{array}{l}\text { BGN } 1932 \\
\text { BGN } \\
\text { BGN } \\
\text { UNOFF }\end{array}$ & $\begin{array}{l}\text { Yuma } \\
\text { Coconino } \\
\text { Mohave } \\
\text { Yavapai } \\
\text { Coconino }\end{array}$ & $\begin{array}{l}315400 \mathrm{~N} 1145700 \mathrm{~W} \\
361222 \mathrm{N1122113 \textrm {W }} \\
364355 \mathrm{N1131630 \textrm {W }} \\
34251 \mathrm{N1124921 \textrm {W }} \\
355728 \mathrm{N1115714W}\end{array}$ & & 7531 & $\begin{array}{l}\text { Havasupai Point } \\
\text { The Grandstand } \\
\text { Bismarck Mesa } \\
\text { Grandview Point }\end{array}$ \\
\hline $\begin{array}{l}\text { Grandview Mobile Home Park } \\
\text { Grandview Overlook } \\
\text { Grand View Peak } \\
\text { Grandview Plaza Shopping Center } \\
\text { Grandview Point } \\
\text { Grand View Railroad Station } \\
\text { Grandview School } \\
\text { Grandview Tank } \\
\text { Grandview Trail } \\
\text { Berry } \\
\text { Berry Trail } \\
\text { Grand View Trail }\end{array}$ & $\begin{array}{l}\text { locale } \\
\text { locale } \\
\text { summit } \\
\text { locale } \\
\text { cliff } \\
\text { building } \\
\text { school } \\
\text { reservoir } \\
\text { trail }\end{array}$ & $\begin{array}{l}\text { UNOFF } \\
\text { BGN } \\
\text { BGN } \\
\text { UNOFF } \\
\text { BGN } 1932 \\
\text { UNOFF } \\
\text { UNOFF } \\
\text { BGN } \\
\text { BGN } 1932 \\
\text { VARIANT } \\
\text { VARIANT } \\
\text { VARIANT }\end{array}$ & $\begin{array}{l}\text { Maricopa } \\
\text { Apache } \\
\text { Graham } \\
\text { Maricopa } \\
\text { Coconino } \\
\text { Yavapai } \\
\text { Maricopa } \\
\text { Yavapai } \\
\text { Coconino }\end{array}$ & $\begin{array}{l}332834 \mathrm{~N} 1120040 \mathrm{~W} \\
340137 \mathrm{N1091823 \textrm {W }} \\
324312 \mathrm{N1095630 \textrm {W }} \\
333037 \mathrm{N1121105 \textrm {W }} \\
355946 \mathrm{N1115907 \textrm {W }} \\
342502 \mathrm{N1124914 \textrm {W }} \\
3330311120511 \mathrm{~W} \\
335743 \mathrm{~N} 1122830 \mathrm{~W} \\
360108 \mathrm{~N} 1115835 \mathrm{~W}\end{array}$ & & $\begin{array}{l}1155 \\
9618\end{array}$ & $\begin{array}{l}\text { Phoenix } \\
\text { Eagar } \\
\text { Webb Peak } \\
\text { Glendale } \\
\text { Grandview Point } \\
\text { Bismarck Mesa } \\
\text { Sunnyslope } \\
\text { Garfias Mtn } \\
\text { Cape Royal }\end{array}$ \\
\hline $\begin{array}{l}\text { Grand View Trail } \\
\text { See Grandview Trail } \\
\text { Grand Wash } \\
\text { Grand Wash }\end{array}$ & $\begin{array}{l}\text { trail } \\
\text { stream }\end{array}$ & $\begin{array}{l}\text { VARIANT } \\
\text { BGN } \\
\text { VARIANT }\end{array}$ & $\begin{array}{l}\text { Coconino } \\
\text { Mohave }\end{array}$ & $\begin{array}{l}360108 \mathrm{~N} 1115835 \mathrm{~W} \\
361529 \mathrm{~N} 1140016 \mathrm{~W}\end{array}$ & $363215 \mathrm{~N} 1134638 \mathrm{~W}$ & & Azure Ridge \\
\hline $\begin{array}{l}\text { See Pocum Wash } \\
\text { Grand Wash Bay } \\
\text { Grand Wash Canyon } \\
\text { Grand Wash Cliffs }\end{array}$ & $\begin{array}{l}\text { valley } \\
\text { bay } \\
\text { valley }\end{array}$ & $\begin{array}{l}\text { BGN } \\
\text { BGN } 1948 \\
\text { VARIANT }\end{array}$ & $\begin{array}{l}\text { Mohave } \\
\text { Mohave } \\
\text { Mohave }\end{array}$ & $\begin{array}{l}363215 N 1134638 \mathrm{~W} \\
361319 N 1140022 \mathrm{~W} \\
361143 \mathrm{~N} 1140016 \mathrm{~W}\end{array}$ & $361000 \mathrm{~N} 1140028 \mathrm{~W}$ & 1157 & $\begin{array}{l}\text { Iceberg Canyon } \\
\text { Iceberg Canyon }\end{array}$ \\
\hline $\begin{array}{l}\text { See Upper Grand Wash Cliffs } \\
\text { Grand Wash Cliffs } \\
\text { Grand Cliff Range } \\
\text { Grand Wash Fault } \\
\text { Lower Grand Wash Cliffs } \\
\text { Lower Grand Wash Ledge }\end{array}$ & $\begin{array}{l}\text { cliff } \\
\text { cliff }\end{array}$ & $\begin{array}{l}\text { BGN } \\
\text { VARIANT } \\
\text { VARIANT } \\
\text { VARIANT } \\
\text { VARIANT }\end{array}$ & $\begin{array}{l}\text { Mohave } \\
\text { Mohave }\end{array}$ & $\begin{array}{l}361150 \mathrm{~N} 1134340 \mathrm{~W} \\
363600 \mathrm{~N} 1134600 \mathrm{~W}\end{array}$ & & & Grapevine Canyon \\
\hline $\begin{array}{l}\text { Grand Wash Fault } \\
\text { See Grand Wash Cliffs } \\
\text { Grand Wash Valley } \\
\text { Granger Tank } \\
\text { Granger Well } \\
\text { Granite } \\
\text { Granite Airport } \\
\text { Granite Basin } \\
\text { Granite Basin } \\
\text { Granite Basin }\end{array}$ & $\begin{array}{l}\text { cliff } \\
\text { valley } \\
\text { reservoir } \\
\text { well } \\
\text { locale } \\
\text { airport } \\
\text { basin } \\
\text { basin } \\
\text { basin }\end{array}$ & $\begin{array}{l}\text { VARTANT } \\
\text { BGN } \\
\text { BGN } \\
\text { UNOFF } \\
\text { BGN } \\
\text { ADMIN } \\
\text { BGN } \\
\text { BGN } \\
\text { BGN }\end{array}$ & $\begin{array}{l}\text { Mohave } \\
\text { Mohave } \\
\text { Santa Cruz } \\
\text { Santa Cruz } \\
\text { Yavapai } \\
\text { Maricopa } \\
\text { Pinal } \\
\text { Gila } \\
\text { Yavapai }\end{array}$ & $\begin{array}{l}363600 \mathrm{~N} 1134600 \mathrm{~W} \\
361528 \mathrm{~N} 1140016 \mathrm{~W} \\
312139 \mathrm{~N} 1104720 \mathrm{~W} \\
312127 \mathrm{N1} 104755 \mathrm{~W} \\
3441441122431 \mathrm{~W} \\
333230 \mathrm{~N} 1115848 \mathrm{~W} \\
330622 \mathrm{N1103811 \textrm {W }} \\
332810 \mathrm{N1} 105618 \mathrm{~W} \\
340700 \mathrm{~N} 1113425 \mathrm{~W}\end{array}$ & $363216 \mathrm{~N} 1134638 \mathrm{~W}$ & $\begin{array}{l}4896 \\
1450\end{array}$ & $\begin{array}{l}\text { Azure Ridge } \\
\text { Kino Springs } \\
\text { Kino Springs } \\
\text { Chino Valley South } \\
\text { Paradise Valley } \\
\text { Christmas } \\
\text { Inspiration } \\
\text { Table Mountain }\end{array}$ \\
\hline $\begin{array}{l}\text { Granite Bas in } \\
\text { Granite Bas in } \\
\text { Granite Bas in Campground } \\
\text { Granite Bas in Dam } \\
\text { Granite Bas in Lake } \\
\text { Granite Bas in Picnic Area } \\
\text { Granite Basin Spring } \\
\text { Granite Bas in Summer Homes } \\
\text { Granite Bas in View Point } \\
\text { Granite Butte }\end{array}$ & $\begin{array}{l}\text { basin } \\
\text { basin } \\
\text { park } \\
\text { dam } \\
\text { reservoir } \\
\text { park } \\
\text { spring } \\
\text { ppl } \\
\text { area } \\
\text { summit }\end{array}$ & $\begin{array}{l}\text { BGN } \\
\text { BGN } \\
\text { ADMIN } \\
\text { UNOFF } \\
\text { BGN } \\
\text { ADMIN } \\
\text { BGN } \\
\text { BGN } \\
\text { BGN } \\
\text { BGN }\end{array}$ & $\begin{array}{l}\text { Yavapai } \\
\text { Yavapai } \\
\text { Yavapai } \\
\text { Yavapai } \\
\text { Yavapai } \\
\text { Yavapai } \\
\text { Gila } \\
\text { Yavapai } \\
\text { Yavapai } \\
\text { Gila }\end{array}$ & $\begin{array}{l}343519 \mathrm{~N} 1124633 \mathrm{~W} \\
343700 \mathrm{~N} 1123309 \mathrm{~W} \\
343640 \mathrm{~N} 1123245 \mathrm{~W} \\
343704 \mathrm{N11} 123205 \mathrm{~W} \\
343703 \mathrm{~N} 1123254 \mathrm{~W} \\
343650 \mathrm{~N} 1123245 \mathrm{~W} \\
334900 \mathrm{~N} 110465 \mathrm{~W} \\
34368 \mathrm{~N} 1123312 \mathrm{~W} \\
343550 \mathrm{~N} 1123210 \mathrm{~W} \\
332708 \mathrm{~N} 1103753 \mathrm{~W}\end{array}$ & & $\begin{array}{r}5640 \\
5680 \\
5220\end{array}$ & $\begin{array}{l}\text { Martin Mtn } \\
\text { Iron Springs } \\
\text { Iron Springs } \\
\text { Iron Springs } \\
\text { Iron Springs } \\
\text { Iron Springs } \\
\text { Sombrero Peak } \\
\text { Iron Springs } \\
\text { Iron Springs } \\
\text { Cammerman Wash }\end{array}$ \\
\hline $\begin{array}{l}\text { Granite Butte Dam } \\
\text { Granite Butte Tank } \\
\text { Granite Canyon } \\
\text { Granite Canyon } \\
\text { Granite Canyon }\end{array}$ & $\begin{array}{l}\text { dam } \\
\text { reservoir } \\
\text { valley } \\
\text { valley }\end{array}$ & $\begin{array}{l}\text { UNOFF } \\
\text { BGN } \\
\text { BGN } \\
\text { BGN } \\
\text { VARIANT }\end{array}$ & $\begin{array}{l}\text { Gila } \\
\text { Gila } \\
\text { Cochise } \\
\text { Mohave }\end{array}$ & $\begin{array}{l}332748 \mathrm{~N} 1103707 \mathrm{~W} \\
332749 \mathrm{N1} 103707 \mathrm{~W} \\
320330 \mathrm{N1} 101008 \mathrm{~W} \\
351939 \mathrm{N1} 142705 \mathrm{~W}\end{array}$ & 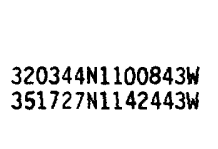 & & $\begin{array}{l}\text { Dourine Canyon } \\
\text { Dourine Canyon } \\
\text { San Pedro Ranch } \\
\text { Burns Spring }\end{array}$ \\
\hline $\begin{array}{l}\text { See Granite Park Canyon } \\
\text { Granite Cove } \\
\text { Granite Creek } \\
\text { Granite Creek Dam } \\
\text { Granite Creek Overpass }\end{array}$ & $\begin{array}{l}\text { valley } \\
\text { bay } \\
\text { stream } \\
\text { dam } \\
\text { crossing }\end{array}$ & $\begin{array}{l}\text { BGN } \\
\text { BGN } \\
\text { UNOFF } \\
\text { UNOFF }\end{array}$ & $\begin{array}{l}\text { Coconino } \\
\text { Mohave } \\
\text { Yavapai } \\
\text { Yavapai } \\
\text { Yavapai }\end{array}$ & $\begin{array}{l}355806 \mathrm{~N} 1131849 \mathrm{~W} \\
360103 \mathrm{N1} 140856 \mathrm{~W} \\
345146 \mathrm{~N} 1122552 \mathrm{~W} \\
343544 \mathrm{N1} 122454 \mathrm{~W} \\
343325 \mathrm{~N} 1122650 \mathrm{~W}\end{array}$ & $342958 \mathrm{N1123031 \textrm {W }}$ & & $\begin{array}{l}\text { Hiller Mountains } \\
\text { Chino Valley North } \\
\text { Prescott } \\
\text { Prescott }\end{array}$ \\
\hline
\end{tabular}


FEATURE
CLASS

STATUS

$$
\text { COUNTY }
$$

$\begin{array}{cc}\text { SOURCE } & \text { ELEV } \\ \text { COORDINATE } & \text { FT }\end{array}$ MAP NAME
Granite Creek Park

Granite Dam

Granite Dells

Granite Dells

Granite Falls

See Granite Rapids

Granite Gorge

Granite Gorge of Shivwits

Division

See Lower Granite Gorge

Ganite Hills

Granite Knob

Granite Knob

Granite Mountain

Granite Mountain

Granite Mountain

Granite Mountain

Granite Mountain

Granite Mountain

Granite Mountain

Granite Mountain

Granite Mountain

Granite Mountain Junior High School

Granite Mountains

See Growler Mountains

Granite Mountains

Granite Mountain Tank

Granite Mountain Tank Number

Granite Mountain Trail Number

Two Hundred Sixty One

Granite Narrows

Granite Park

Granite Park Canyon Granite Canyon

Granite Pass Tank (dry)

Granite Peak

Granite Peak

Granite Peak

\section{Granite Peak}

Granite Peak

Granite Peak

Granite Point

Granite Point

Granite Range

See Prieta, Sierra

Granite Rapids

Granite Falls

Monument Creek Rapid

Granite Reef Dam

Granite Reef Estates

Granite Reef Forest Camp

Granite Reef Mine

See Grand Reef Mine

Granite Reef Mountain

See Sawik Mountain

Granite Ridges

Granite Spring

Granite Spring

Granite Spring

Granite Spring Granite Springs

Granite Spring

Granite Spring Canyon

Granite Spring Rapids

Granite Springs

See Granite Spring

Granite Springs Canyon

Granite Spring Trail

\begin{tabular}{|c|c|c|c|c|c|}
\hline $\begin{array}{l}\text { park } \\
\text { dam } \\
\text { valley } \\
\text { locale }\end{array}$ & $\begin{array}{l}\text { ADMIN } \\
\text { UNOFF } \\
\text { BGN } \\
\text { BGN }\end{array}$ & $\begin{array}{l}\text { Yavapai } \\
\text { Santa Cruz } \\
\text { Yavapai } \\
\text { Yavapai }\end{array}$ & $\begin{array}{l}343259 \mathrm{~N} 1122800 \mathrm{~W} \\
312623 \mathrm{~N} 1111240 \mathrm{~W} \\
343653 \mathrm{~N} 1122503 \mathrm{~W} \\
343621 \mathrm{~N} 1122442 \mathrm{~W}\end{array}$ & $343504 \mathrm{~N} 1122516 \mathrm{~W}$ & $\begin{array}{l}\text { Prescott } \\
\text { Ruby } \\
\text { Prescott } \\
\text { Prescott }\end{array}$ \\
\hline $\begin{array}{l}\text { rapids } \\
\text { valley }\end{array}$ & $\begin{array}{l}\text { BGN } 1925 \\
\text { VARIANT }\end{array}$ & $\begin{array}{l}\text { Coconino } \\
\text { Coconino }\end{array}$ & $\begin{array}{l}360554 \mathrm{~N} 1121101 \mathrm{~W} \\
362205 \mathrm{N1122810W}\end{array}$ & $360235 \mathrm{~N} 1121827 \mathrm{~W}$ & Powell Plateau \\
\hline valley & & Mohave & $360800 \mathrm{~N} 1135719 \mathrm{~W}$ & & \\
\hline
\end{tabular}

summit BGN Pinal 324949N1111851W

summit BGN Pinal 330444N1113812W

summit BGN Yavapai 345124N1125431W

summit BGN Pima 314528N1104604W

summit BGN Pinal 330944N1110135W

summit BGN Maricopa 332616N1131835

summit BGN Gila 333113 N1110340W

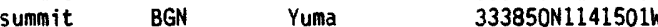

summit BGN Maricopa 334700N1114814h

summit BGN Maricopa 33472BN1113338W

summit BGN Yavapai 343526N1130831W

summit BGN Yavapai 343B26N1123432W

school UNOFF Yavapai 343425N1122950W

$\begin{array}{ll} & \text { Summit VANT } \\ & 322127 N 1130511 \mathrm{~W}\end{array}$

$\begin{array}{lll}\text { summit } & \text { B } \\ \text { summit } & \text { BGN } 1965 \text { Pima } & 32214 N 1131825 \mathrm{~W}\end{array}$

$\begin{array}{llll}\text { summit } & \text { BGN } 1965 & \text { Pima } & \text { 322414N1131825W } \\ \text { reservoir } & \text { BGN } & \text { Yavapai } & 341623 N 111500 \mathrm{~W}\end{array}$

reservoir BGN Yavapai 341548N1115406W

trail UNOFF Yavapai 343718N1123340W

$362316 \mathrm{~N} 1123020 \mathrm{~W}$

$355814 \mathrm{N1131B54W}$ $355806 \mathrm{N1131B49W}$

flat

valley

reservoir

summit

summit

summit

BGN 1932 Coconino

BAN Coconino 355806N11313

BGN Pima

$B G N$ Cochise

BGN Cochise

$321902 \mathrm{~N} 1131525 \mathrm{~W}$

$312442 \mathrm{~N} 110194 \mathrm{IW}$

$314630 \mathrm{~N} 1102616 \mathrm{~W}$

330240N110170BW

355715 N1130B4OW

1537 Sacaton

6625 Camp Wood

5960 Helvetia

4052 Teapot Mountain

2241 Eagletail Mts East

5106 Two Bar Mtn

Middle Camp Mtn

3526 Wildcat Hill

4699 Maverick Mtn

Bagdad

7295 Jerome Canyon

Prescott

Granite Mts North

Dugas

Dugas

Iron Springs

Fishtail

Granite Park

Granite Park

Granite Mts South

Miller Peak

7420 Apache Peak

Mt Turnball

$\begin{array}{llll}\text { summit } & \text { BGN } & \text { Gila } & 333624 N 1105001 W \\ \text { summit } & \text { BGN } & \text { Yavapai } & 341624 N 1115337 \mathrm{~W}\end{array}$

summit BGN Mohave 344608N1135110W

summit BGN Gila 332137N1105258W

locale BGN La Paz 334000 N1143200W

range

VARIANT

Yavapai 343126N1123411W

BGN 1932 Coconino 360554N1121101W

VARIANT

VARIANT

dam UNOFF Maricopa 33305BN1114126W

ppl BGN Maricopa 332621N1114101W

locale BGN Maricopa 333053N1114052W

mine

325259N1101900W

summit

ridge

spring

spring

Graham

$333212 \mathrm{~N} 1114538 \mathrm{~W}$

$343845 \mathrm{~N} 1131 \mathrm{B1ON}$

31512BN1095912W

333658 N1104944W

spring BGN Gila 333919N1111610W

spring BGN Gila $333932 \mathrm{~N} 1104339 \mathrm{~W}$

spring BGN Yavapai 342122N1121B3BW

valley BGN $\quad$ Coconino 354929 N1131946W

$\begin{array}{llll}\text { valley } & \text { BGN } & \text { Coconino } & 354929 N 1131946 \mathrm{~W} \\ \text { rapids } & \text { BGN } & \text { Mohave } & 354927 N 1131953 \mathrm{~W}\end{array}$

354753 N1131440W

VARIANT

spring

valley

BGN

UNOFF
Gila 333932N1104339W

Gila 332330N1105236W

$334018 N 1111432$
$332250 N 1105213 W$
4941 Rockinstraw Mtn

5686 Dugas

7069 Diamond Joe Peak

5286 Pinal Ranch

Blythe NE

Grand Canyon

1313 Granite Reef Dam 8uckhorn Granite Reef Dam

Negro Ed

Black Diamond Peak Rockinstraw Mtn

Four Peaks Haystack Butte

Battle Flat

Diamond Peak

Diamond Peak

Inspiration

Theo. Roosevelt Dam 


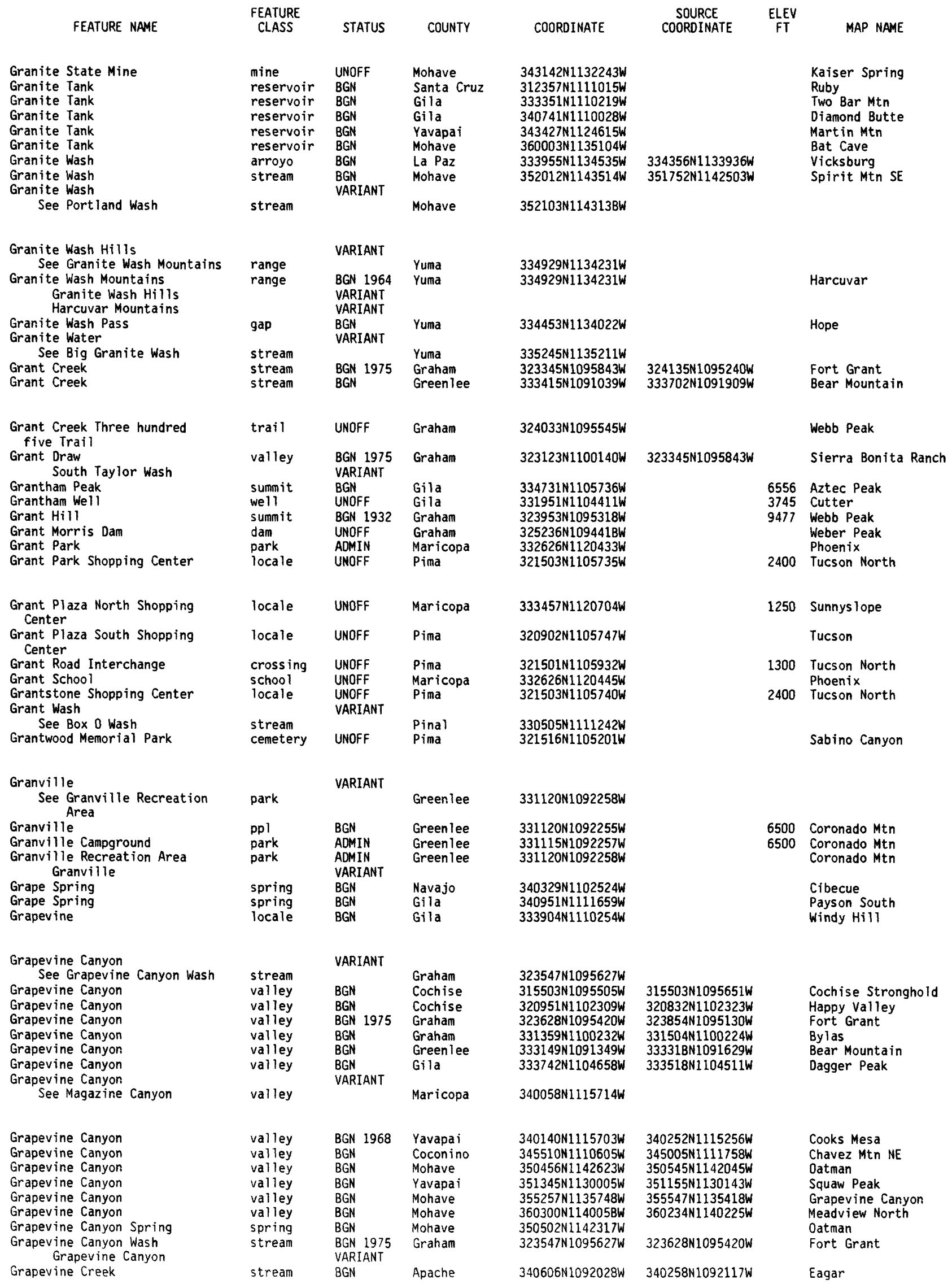


FEATURE NAME

Grapevine Creek

Grapevine Creek

Grapevine Draw

Grapevine Gulch

Grapevine Landing Strip

Grapevine Mesa

Grapevine Mesa

Grapevine Rapids

Grapevine Spring

Grapevine Spring

Grapevine Spring

Grapevine Spring

Grapevine Spring

Grapevine Spring

Grapevine Spring

Grapevine Spring

Grapevine Spring

Grapevine Spring

Grapevine Spring

Grapevine Spring

Grapevine Spring

Grapevine Spring Grapevine Springs

Grapevine Spring

Grapevine Spring

Grapevine Spring

Grapevine Spring

Grapevine Spring

Grapevine Spring

Grapevine Spring

Grapevine Spring

Grapevine Spring

Grapevine Spring

Grapevine Spring

Grapevine Spring

Grapevine Spring

Grapevine Spring

Grapevine Spring

Grapevine Spring

Grapevine Springs

See Grapevine Spring

Grapevine Springs

Grapevine Springs

Grapevines Windmill

Grapevine Tank

Grapevine Tank

Grapevine Tank

Grapevine Tank

Grapevine Tank

Grapevine Tank Number One

Grapevine Tank Number Two

Grapevine Wash

Grapevine Wash

Grapevine Well

Grapevine Wel

Grapevine We11

Grapevine Well

Grapevine Well

Grasmoen Substation

Grass Canyon

Grass Canyon

Grass Flat Tank

Grass Flat Tank

Grasshopper

Grasshopper Butte

Grasshopper Flat

Grasshopper Flat Tank

Grasshopper Junction

Grasshopper Point

Grasshopper Spring

Grasshopper Tank
FEATURE

CLASS

STATUS COUNTY

COOROINATE

stream

stream

valley

valley

airport

summit

summit

rapids

spring

spring

$\begin{array}{ll}\text { BGN } & \text { Yavapai } \\ \text { BGN 1906 } & \text { Coconino } \\ \text { BGN } & \text { Navajo } \\ \text { BGN } & \text { Yavapai } \\ \text { AOMIN } & \text { Gila } \\ \text { BGN } & \text { Yavapai } \\ \text { BGN } & \text { Mohave } \\ \text { BGN 1932 } & \text { Coconino } \\ \text { BGN } & \text { Santa Cruz } \\ \text { BGN } & \text { Cochise }\end{array}$

$342550 \mathrm{~N} 1121557 \mathrm{~W}$

$360326 \mathrm{~N} 1120002 \mathrm{~W}$

$34304 B N 1104441 \mathrm{~W}$

$343431 \mathrm{~N} 1121503 \mathrm{~W}$

$333 B 24 N 1110322 \mathrm{~W}$

$340154 N 1115441 \mathrm{~W}$

$355828 \mathrm{~N} 1140348 \mathrm{~W}$

$360333 \mathrm{~N} 1120009 \mathrm{~W}$

312857 N1111752W

320848 N1102318W

spring

spring

spring

spring

spring

spring

spring

spring

BGN Graham

BGN Graham

Graham

Gila

Gila

Pinal

Graham

Pinal

Gila

Gila

spring

spring

spring

spring

spring

spring

spring

spring

spring

Maricopa

Gila

BGN
BGN
VARIANT

BGN

BGN

BGN

BGN

Gila

Gila

Yavapai

Yavapai

Yavapai

spring

spring

spring

spring

spring

spring

spring

spring

spring

Yavapai

Coconino

Mohave

Mohave

Mohave

Mohave

Mohave

Mohave

Mohave

ARIANT

Gila

$\begin{array}{llll}\text { spring } & \text { BGN } & \text { Yuma } & 341708 \text { N1132237W } \\ \text { spring } & \text { BGN } & \text { Yavapai } & 342536 \mathrm{N1121952W} \\ \text { locale } & \text { BGN } & \text { Cochise } & 314325 \mathrm{~N} 1095639 \mathrm{~W} \\ \text { reservoir } & \text { BGN } & \text { Yavapai } & 340143 \mathrm{~N} 1115507 \mathrm{~W} \\ \text { reservoir } & \text { BGN } & \text { Yavapai } & 340209 \mathrm{~N} 1115106 \mathrm{~W} \\ \text { reservoir } & \text { BGN } & \text { Coconino } & 343110 \mathrm{~N} 1104521 \mathrm{~W} \\ \text { reservoir } & \text { BGN } & \text { Mohave } & 350443 \mathrm{~N} 1132250 \mathrm{~W} \\ \text { reservoir } & \text { BGN } & \text { Mohave } & 352802 \mathrm{~N} 1134142 \mathrm{~W} \\ \text { reservoir } & \text { BGN } & \text { Coconino } & 345057 \text { N1111707W } \\ \text { reservoir } & \text { BGN } & \text { Coconino } & 345109 \mathrm{~N} 1111647 \mathrm{~W}\end{array}$

$\begin{array}{llll}\text { stream } & \text { BGN } & \text { Maricopa } & 335058 \text { N1115445W } \\ \text { valley } & \text { BGN 1948 } & \text { Mohave } & 360646 \text { N1135943W } \\ \text { well } & \text { UNOFF } & \text { Yavapai } & 341808 \text { N1115620W } \\ \text { well } & \text { UNOFF } & \text { Yavapai } & 343619 \text { N1121114W } \\ \text { well } & \text { UNOFF } & \text { Coconino } & 345306 \text { N1110820W } \\ \text { well } & \text { UNOFF } & \text { Mohave } & 355401 \text { N1140120W } \\ \text { well } & \text { UNOFF } & \text { Navajo } & 362522 \text { N1102655W } \\ \text { locale } & \text { UNOFF } & \text { Maricopa } & 333034 \text { N1121307W } \\ \text { valley } & \text { BGN } & \text { Pima } & 320553 \text { N1124304W } \\ \text { valley } & \text { BGN } 1932 & \text { Coconino } & 362047 \text { N1122120W }\end{array}$

323658 N $1095347 \mathrm{~W}$

324256N1102026W

$330924 N 1103545 \mathrm{~W}$

$331405 \mathrm{~N} 1090736 \mathrm{~W}$

$331415 \mathrm{~N} 1110056 \mathrm{~W}$

$332510 \mathrm{~N} 1110343 \mathrm{~W}$

$332648 \mathrm{~N} 1105555 \mathrm{~W}$

$333729 \mathrm{~N} 1104650 \mathrm{~W}$

$335029 \mathrm{~N} 1115534 \mathrm{~W}$

$335439 \mathrm{~N} 1111317 \mathrm{~W}$

$340214 N 1115407 \mathrm{~W}$

$340924 N 1111913 \mathrm{~W}$

$341238 N 1112357 \mathrm{~W}$

$342258 \mathrm{~N} 1122734 \mathrm{~W}$

$343244 \mathrm{~N} 1124623 \mathrm{~W}$

343559 N1120757W

$344935 N 1125435 \mathrm{~W}$

$345131 N 1111547 \mathrm{~W}$

$345136 \mathrm{~N} 1135213 \mathrm{~W}$

$351233 \mathrm{~N} 1140535 \mathrm{~W}$

352922 N1134155W

$353559 \mathrm{~N} 1141126 \mathrm{~W}$

$360239 N 1140130 W$

335439 N1111317W

$362047 \mathrm{~N} 1122120 \mathrm{~W}$

$333455 \mathrm{~N} 1095441 \mathrm{~W}$

345859 N1112750W

$340432 \mathrm{~N} 1103747 \mathrm{~W}$

$340558 \mathrm{Ni} 103720 \mathrm{~W}$

$345147 \mathrm{~N} 1114741 \mathrm{~W}$

$345132 \mathrm{N1} 114925 \mathrm{~W}$

$352349 \mathrm{~N} 1141532 \mathrm{~W}$

$345313 \mathrm{~N} 111435 \mathrm{OW}$

$343330 \mathrm{~N} 1124443 \mathrm{~W}$

$341110 \mathrm{~N} 1105906 \mathrm{~W}$
$335402 \mathrm{~N} 1115233 \mathrm{~W}$ $355528 \mathrm{~N} 1135325 \mathrm{~W}$

\begin{tabular}{|c|c|c|}
\hline $\begin{array}{l}\text { SOURCE } \\
\text { COORDINATE }\end{array}$ & $\begin{array}{c}\text { ELEV } \\
\text { FT }\end{array}$ & MAP NAME \\
\hline $\begin{array}{l}342548 \mathrm{~N} 1122003 \mathrm{~W} \\
355935 \mathrm{~N} 1115928 \mathrm{~W} \\
342846 \mathrm{~N} 1104715 \mathrm{~W} \\
343836 \mathrm{~N} 1120937 \mathrm{~W}\end{array}$ & & $\begin{array}{l}\text { Poland Junction } \\
\text { Phantom Ranch } \\
\text { Potato Wash South } \\
\text { Prescott Valley S }\end{array}$ \\
\hline & 2340 & $\begin{array}{l}\text { Windy Hill } \\
\text { Cooks Mesa } \\
\text { Meadview South } \\
\text { Phantom Ranch } \\
\text { Bartlett Mtn } \\
\text { Happy Valley }\end{array}$ \\
\hline
\end{tabular}

Fort Grant

Kennedy Peak

Mt Turnball

Coolidge Dam

Dix Creek

Teapot Mountain

Bylas

Haunted Canyon

Inspiration

Rockinstraw Mtn

Cave Creek

Picture Mtn

Cooks Mesa

Payson South

North Peak

Minnehaha

Groom Creek

Mart in Mtn

Humboldt

Camp Wood

Jaycox Mtn

Diamond Joe Peak

Wabayuma Peak

Kingman

Valent ine

Mt Tipton

Meadview North

Gyp Hills

Palmerita Ranch

Poland Junction

4858 Hay Mountain

Cooks Mesa

Rover Peak

Chevelon Crossing

Penitentiary Mtn

valent ine

Jaycox Mtn

Jaycox Mtn

Cave Creek

Columbine Falls

Dugas

5344 Humbold

Chavez Mtn NW

Meadowview South

Great Spring

Glendale

Mount Ajo

$320520 \mathrm{~N} 1124234 \mathrm{~W}$

King Arthur Castle

Elwood Canyon

Mormon Lake

5912 Oak Creek Ranch

6434 Spotted Mounta in

Sedona

Sedona

Grasshopper Junction

Munds Park

Skull Valley

Oxbow Mtn 
FEATURE NAME

Grasshopper Tank Grasshopper Tank Number Two Grassie Point Reservoir Grassman Peak

See Crossman Peak

Grass Mountain

See Grassy Mountain

Grass Shack Spring

Grass Tank

Grass Valley (historical) Tonto Creek Valley

Grass Wash

Grassy Hill

Grassy Knolls

Grassy Knoll Tank

Grassy Mountain

Grassy Mountain

Grassy Mountain

Grass Mountain

Grassy Mountain Tank

Grassy Mountain Windmi11

Grassy Peak

Grassy Ridge

Grassy Ridge Spring

Grassy Spring

Grassy Tank

Grassy Tank

Grato Park

Gravel Draw Pond

Gravel Dug Well

Graveled Hill

Gravel Hill Bend

Gravel Pit Tank

Gravel Spring Canyon

See Grover Spring Canyon

Gravel Tank

Gravel Tank

Gravel Wash

Graver Wash

Graver Wash

Graveyard Canyon

Graveyard Canyon

Graveyard Gulch

Graveyard Wash

Graveyard Wash

Graveyard Wash Dam

See Graveyard Wash

Retarding Dam

Graveyard Wash Retarding Dam Graveyard Wash Dam

Grayback

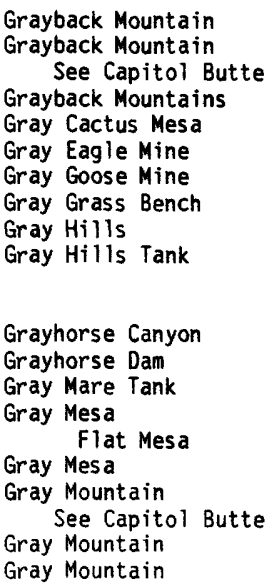

Grayback Mountain

See Capitol Butt
Sel Mountain

ayback Mountains

Gray Hills

Grayhorse Canyon

Grayhorse Dam

Flat Mes

Gray Mountain

Gray Mountain

Gray Mountain

FEATURE
CLASS
reservoir
reservoir
reservoir
summit
summit
spring
reservoir
valley

STATUS COUNTY

COORDINATE

BGN Gil

BGN Navajo

BGN

VARIANT

Mohave

Mohave

VARIANT

BGN

BGN

VARIANT

Mohave

Pima

Green lee

Gila

stream

summit

summit

reservoir

summ it

summit

summ it

reservoir

locale

BGN
BGN

Yochise

Apache

Green lee

Yavapai

BGN

BGN

VARIANT

Greenlee

BGN Yavapai

summit

ridge

spring

spring

reservoir

reservoir

park

well

summit

BGN

BGN 1975

BGN

BGN

$B G N$
$B G N$
$A D M I N$

ADMIN

BGN

UNOFF

BGN

Graham

Graham

Graham

Mohave

Apache

Yavapai

Maricopa

Mohave

Navajo

Navajo

bend
reservoir

BGN

La Paz

Greenlee

valley

reservoir

reservoir

stream

arroyo

stream

valley

valley

valley

stream

stream

dam

dam

BGN Gavajo

$B G N$
$B G N$
$B G N$

BGN

BGN

BGN

Gila

Coconino

Yuma

Yavapai

Yavapa

Gila

BGN

BGN

VARIANT

Cochise

Mohave

Graham

UNOFF

VARIANT

Graham

Pinal

summit

BGN

summ it

BGN

VARIANT

summit

range

summit

mine

mine

bench

summit

reservoir

BGN

$B G N$

UENOFF

UNOFF
UNOFF

BGN

$B G N$

dam

reservoir

summit

UNOFF

BGN

BGN 1975

VARIANT

summit

BGN

VARIANT

summit

summit

BGN

BGN

Coconino
3421 45N1113121W

340402N1103808W

343257N1141112W

$361640 \mathrm{N1132801W}$ $321109 \mathrm{~N} 1103527 \mathrm{~W}$

$332124 \mathrm{~N} 1092705 \mathrm{~W}$

340442N1111710W

$340734 N 1111510 \mathrm{~W}$

Mica Mountain

Bee Canyon

Gisela

$335603 N 1131034 \mathrm{~W}$

$312713 N 1095136 \mathrm{~W}$

$345439 \mathrm{~N} 1114916 \mathrm{~W}$

344453 N1093611W

$330842 \mathrm{~N} 1090500 \mathrm{~W}$

$343112 \mathrm{~N} 1115707 \mathrm{~W}$

$361640 N 1132801 \mathrm{~W}$

$331725 \mathrm{~N} 1090646 \mathrm{~W}$

$343110 \mathrm{~N} 1115736 \mathrm{~W}$

$323613 N 1102212 \mathrm{~W}$

$323745 N 1102225 \mathrm{~W}$

$323610 \mathrm{~N} 1102122 \mathrm{~W}$

$361602 \mathrm{~N} 1132840 \mathrm{~W}$

$335908 \mathrm{~N} 1093002 \mathrm{~W}$

$342238 N 1123443 \mathrm{~W}$

$333507 \mathrm{~N} 1120150 \mathrm{~W}$

364748 N1132456W

$344029 \mathrm{~N} 110065 \mathrm{OW}$

$340110 \mathrm{~N} 1142630 \mathrm{~W}$

334046 N1092620W

$342115 \mathrm{~N} 1102050 \mathrm{~W}$

341857 N1112157W

$345741 \mathrm{~N} 1112841 \mathrm{~W}$

$330511 \mathrm{~N} 1140429 \mathrm{~W}$

$345532 \mathrm{~N} 1124950 \mathrm{~W}$

345529 N1124942

$332345 \mathrm{~N} 1104737 \mathrm{~W}$

$340257 N 1105358 \mathrm{~W}$

$313755 \mathrm{N1} 101047 \mathrm{~W}$

$324851 \mathrm{~N} 1094221 \mathrm{~W}$

$342827 \mathrm{~N} 1133723 \mathrm{~W}$

324800 N1094312

324800 N1094312W

$330436 \mathrm{~N} 1110552 \mathrm{~W}$

$342456 \mathrm{~N} 1130042 \mathrm{~W}$

$345310 \mathrm{~N} 1114822 \mathrm{~W}$

$343207 N 1131615 \mathrm{~W}$

$361944 N 1091758 \mathrm{M}$

341557 N1121308W

$363004 N 1113928 \mathrm{~W}$

$365006 \mathrm{~N} 1101129 \mathrm{~W}$

$345010 \mathrm{~N} 1121703 \mathrm{~W}$

$323155 \mathrm{~N} 1090607 \mathrm{~W}$

$323227 \mathrm{~N} 1090428 \mathrm{~W}$

$331538 \mathrm{~N} 1103256 \mathrm{~W}$

$352830 \mathrm{~N} 1100830 \mathrm{~W}$

$364503 N 1110114 \mathrm{~W}$

$345310 \mathrm{~N} 1114822 \mathrm{~W}$

$355347 \mathrm{~N} 1113658 \mathrm{~W}$

$355830 \mathrm{~N} 1092524 \mathrm{~W}$

$335239 \mathrm{~N} 1130417 \mathrm{~W}$

6597 Aguila

4873 Wilson Mountain

6317 Harden Cienega

Middle Verde

6595 Grassy Mountain

Maple Peak

Middle Verde

6690 Bassett Peak

Kennedy Peak

Bassett Peak

Grassy Mountain Stinking Springs Mtn 


\section{FEATURE NAME}

Gray Mountain
Gray Point
Gray Point
Gray Ranch
Gray Ridge
Gray Ridge
Gray School
Grays Gulch
Grays Gulch Mine
Gray Spot Wash
Gray Spring
Grays Ranch
Grays Spring
Gray Tank
Gray Tank
Gray Tanks
Gray Wash
Gray Wash
Gray Wash
Gray Well
Divider Well

Gray Well

See Anita Well

Gray Whiskers

Greaser Wash

Greasewood

School House Canyon

See Upper Greasewood Trading Post

Greasewood Flat

Greasewood Lake

Greasewood Mountain

Greasewood Place

Greasewood Spring Dewogibito Duwuz libito

Greasewood Tank

Greasewood Wash

Greaswood Airport

Greasy Spoon Tank

Great Canyon

See Grand Canyon

Great Colorado Valley

Great Dane Tank

Great Eastern Mine

Greaterville

Greaterville

Greaterville Gulch See Ophir Gulch

Greaterville Gulch

See Louisiana Gulch

Greaterville Gulch

Great Mohave Wall

Great Plain, The

Great Silver Mine

Great Southern Mine

Great Spring

Great Spring Tank

Great Thumb Mesa

Great Thumb Point

Great West Mine

Grebe Bay

Greeley Dam

Greeley Tank

Greely Hall

Green Acres Memorial Gardens Cemetery

Green Acres Mobile and

Recreational Vehicle Park

Green Acres Trailer Court

Greenback Butte

See Boneyback Peak
FEATURE
CLASS

STATUS COUNTY

ppl

cliff

cliff

locale

ridge

ridge

school

valley

mine

stream

$\begin{array}{ll}\text { BGN } & \text { Coconino } \\ \text { BGN } & \text { Coconino } \\ \text { BGN } & \text { Navajo } \\ \text { UNOFF } & \text { Yavapai } \\ \text { BGN } & \text { Navajo } \\ \text { BGN } & \text { Apache } \\ \text { UNOFF } & \text { Maricopa } \\ \text { BGN } & \text { Maricopa } \\ \text { UNOFF } & \text { Maricopa } \\ \text { BGN } & \text { Coconino }\end{array}$

COOROINATE

$354445 \mathrm{~N} 1112822 \mathrm{~W}$

$363107 N 1114047 \mathrm{~W}$

$364500 \mathrm{~N} 1100509 \mathrm{~W}$

$345307 \mathrm{~N} 1115823 \mathrm{~W}$

$354554 \mathrm{~N} 1101513 \mathrm{~W}$

$362842 N 1092608 \mathrm{~W}$

$332545 \mathrm{~N} 1120413 \mathrm{~W}$

$335749 \mathrm{~N} 1115541 \mathrm{~W}$

$335920 \mathrm{~N} 1115553 \mathrm{~W}$

362B15N1113406W

spring BGN Coconino 350735N1115740W

locale UNOFF Pima 315131N1124429W

spring BGN Pima 315420N1111230W

reservoir BGN Yavapai $\quad 345246 \mathrm{N1} 115844 \mathrm{~W}$

reservoir BGN Navajo 345545 N1095729W

reservoir BGN Yuma 331227N1141150W

stream BGN Mohave 343834N1133403W

Coconino 363301N1113746W

stream BGN Coconino 363303N1113745W

BGN 1978

VARIANT

$312525 \mathrm{~N} 1110939 \mathrm{~W}$

$340024 N 1115348 \mathrm{~W}$

$362621 \mathrm{~N} 1113626 \mathrm{~W}$

$\begin{array}{lc}\text { SOURCE } & \text { ELEV } \\ \text { COORDINATE } & \text { FT }\end{array}$

MAP NAME

Gray Mountain

Tanner Well

5505 Church Rock

Loy Butte

Sun Altar

Fire Dance Mesa

Phoenix

New River Mesa

New River Mes

Cedar Ridge

Garland Prairie

Blankenship Well

Samaniego Peak

Loy Butte

Carrizo Butte

Arch Tank

Wikieup

$343944 N 1132917 \mathrm{~W}$

$363044 N 1113835 \mathrm{~W}$

Tanner Well

Tanner Well

Murphy Peak

$313606 \mathrm{~N} 1110615 \mathrm{~W}$

$365808 \mathrm{~N} 1100813 \mathrm{~W}$

$325445 \mathrm{~N} 1091203 \mathrm{~W}$

353121N1095124W

$325652 \mathrm{~N} 1090517$

6384 Mystery Valley

York

ppl BGN

Navajo

$362206 \mathrm{~N} 1091440 \mathrm{~W}$

locale

flat

Apache

$364654 N 1095333 \mathrm{~W}$

$360950 \mathrm{~N} 1110715 \mathrm{~W}$

$322932 \mathrm{~N} 1094650 \mathrm{~W}$

$361055 \mathrm{~N} 1110601 \mathrm{~W}$

$352526 \mathrm{~N} 1095434 \mathrm{~W}$

area BGN Coconino

spring BGN 1915 Navajo

VARIANT

VARIANT

reservoir BGN Graham

stream BGN Apache

airport ADMIN Navajo

$322858 \mathrm{~N} 1094709 \mathrm{~W}$

$362454 \mathrm{~N} 1091608 \mathrm{~W}$

$353102 N 1095145 \mathrm{~W}$

$345154 N 1115157 \mathrm{~W}$

$362124 N 1091203 \mathrm{~W}$

Greasewood Mounta

6000 Greasewood

Sedona

$360646 \mathrm{~N} 1135943 \mathrm{~W}$

$331730 \mathrm{~N} 1144000 \mathrm{~W}$

$351449 N 1115622 \mathrm{~W}$

$323545 \mathrm{~N} 1120802 \mathrm{~W}$

$314548 \mathrm{~N} 1104456 \mathrm{~W}$

$314550 \mathrm{~N} 1104458 \mathrm{~W}$

ppl BGN Pima

ppl BGN PIMA

valley PARIANT

valley VARIANT Pima

314408 N1 $104030 \mathrm{~W}$

$314436 \mathrm{~N} 1104215 \mathrm{~W}$

$\begin{array}{llll}\text { valley } & \text { BGN } & \text { Pima } & 314555 N 1103642 W \\ \text { cliff } & \text { BGN 1932 } & \text { Coconino } & 360347 N 1121009 W \\ \text { plain } & \text { BGN 1941 } & \text { Pima } & 314714 N 1121922 W \\ \text { mine } & \text { UNOFF } & \text { Santa Cruz } & 312849 \text { N1104239W } \\ \text { mine } & \text { UNOFF } & \text { Yavapai } & 335955 \text { N1123559W } \\ \text { Spring } & \text { BGN } & \text { Navajo } & 362717 N 1102407 W \\ \text { reservoir } & \text { BGN } & \text { Pima } & 314505 N 1102800 W \\ \text { summit } & \text { BGN } 1932 & \text { Coconino } & 362021 N 1123057 W \\ \text { cape } & \text { BGN 1932 } & \text { Coconino } & 362041 \text { N1122849W } \\ \text { mine } & \text { UNOFF } & \text { Mohave } & 353625 N 1143020 W\end{array}$

$314607 N 1104053 \mathrm{~W}$

Spring Water Canyon

Grand Canyon

Papago Farms

Harshaw

Red Picacho

Great Spring

Apache Peak

Fossil Bay

Powell Plateau

Mt Perkins

The Temple

Blye Canyon SE

Squaw Peak

Fort Huachuca

1200 Tempe

cemetery UNOFF Maricopa 332711N1115420W

locale UNOFF Maricopa 332701N1120655W

$332455 \mathrm{~N} 1115256 \mathrm{~W}$

1070 Phoenix

1200 Tempe 
FEATURE CLASS

STATUS

COUNTY

$\begin{array}{lll}\text { locale } & \text { BGN } & \text { Pinal } \\ \text { stream } & \text { BGN } & \text { Gila } \\ \text { mine } & \text { UNOFF } & \text { Pinal } \\ & \text { VARIANT } & \\ \text { summit } & & \text { Gila } \\ \text { summit } & \text { BGN 1965 } & \text { Gila } \\ \text { Veservoir } & \text { VARIANT } & \\ \text { BGN } & \text { Gila } \\ \text { reservoir } & \text { BGN } & \text { Gila } \\ \text { basin } & \text { BGN } & \text { Gila }\end{array}$

Greenback Camp

Greenback Creek

Greenback Mine

Greenback Peak

See Boneyback Peak

Greenback Peak

Lookout Mountain

Greenback Saddle Tank

Greenback Tank

Greenback Valley

Greenbriar (subdivision)

Greenbrier East (subdivision)

Green Brush Draw

See Greenbush Draw

Greenbush Draw Green Brush Oraw

Green Cabin

Green Can Tank

Green Canyon

See Hoovey Canyon

Green Canyon

Greene Canal

Greene Ranch

Greene Reservoir

Green Reservoir Greenes Reservoir

Greene Reservoir Dam

Green Reservoir Dam

Greenes Reservoir

See Greene Reservoir

Greenes Wash

See Greene Wash

Greene Wash

Green Reservoir Outlet

Greenes Wash

Greens Reservoir Outlet

Quajata Creek

Quajote Wash

Quajoto Wash

Quijotoa Draw

Santa Cruz River

Greenfield Estates
(subdivision)

reenfield Junior High School

Greenfield Park

Greenfield Park (subdivision)

Green Fields School

Green Gate We 11

Green Gulch

Green Gulch Spring

Green Gulch Tank

Greenhaven Mobile Park

Greenhead Tank

Greenhorn Canyon

Greenhorn Tank

Green House Spring

Greenhouse Spring

Green Howard Tank

$$
\text { Howard Pond }
$$

Green land Glades

See Walhalla Glades

Green land Lake

Greenland Plateau

See Walhalla Plateau

Greenland Spring

Green Lantern Wash

Greenlee County

Greenlee County Airport

Greenlee County Fairgrounds

Green Mine

Green Mountain
Pp1 $1-B G N$

pp1

valley

valley

locale

reservoir

valley

BGN

BGN

VARIANT

BGN

VARIANT

BGN

BGN

valley

stream

locale

reservoir

dam

Maricopa

Cochise

Cochise

Yuma

Santa Cruz

Cochise

BGN 1960 Cochise

BGN

UNOFF

BGN

VARIANT

VARIANT

dam UNOFF

VARIANT

VARIANT

reservoir

Pinal

Santa Cruz

Pinal

Pinal

Pinal

VARIANT

stream

stream

BGN 194
VARIANT
VARIANT
VARIANT
VARIANT
VARIANT
VARIANT
VARIANT
VARIANT

Pinal

Pinal

VARIANT

pp

park

park

school

well

valley

spring

reservoir

locale

reservoir

valley

reservoir

spring

spring

reservoir

flat

lake $B G N$

plain

spring

stream

civil

airport

locale

mine

summit
UNOF

ADMIN

BGN

UNOFF

UNOFF

BGN

$B G N$

UNOFF Maricopa

BGN

$B G N$
$B G N$

$B G N$

BGN

BGN

VARIANT

VARIANT

VARIANT

Maricopa

Maricopa

Maricopa

Maricopa

Pima

Maricopa

Yavapai

Yavapa

Yavapai

Apache

Gila

Gila

Graham

Gila

Coconino

Coconino

Coconino

Coconino

BGN 1906 Coconino

BGN

ADMIN

ADMIN

UNOFF

UNOFF

BGN
Pina?

Greenlee

Greenlee

Greenlee

Pima

Pima
332525 N1114406W

$332254 \mathrm{N1120325 \textrm {W }}$ $332402 \mathrm{N1} 114420 \mathrm{~W}$ $332517 \mathrm{~N} 1114347 \mathrm{~W}$ $321900 \mathrm{~N} 1110210 \mathrm{~W}$ $325113 \mathrm{~N} 1124820 \mathrm{~W}$ $343025 \mathrm{N1121340 \textrm {W }}$ $343144 \mathrm{~N} 1121942 \mathrm{~W}$ $343159 \mathrm{N1121915 \textrm {W }}$

332727 N1115846W $335235 \mathrm{~N} 1091455 \mathrm{~W}$ $341627 N 1113531 \mathrm{~W}$ $341727 \mathrm{N1113437 \textrm {W }}$ $330227 \mathrm{N1102153 \textrm {W }}$ $331506 \mathrm{~N} 1105020 \mathrm{~W}$

34392BN1111320W

361005 N1115653W

361435 N1115928W

$361139 N 1115843 \mathrm{~W}$ $361438 \mathrm{N1120001 \textrm {W }}$ $325526 \mathrm{N1104342 \textrm {W }}$ $332230 \mathrm{~N} 1092230 \mathrm{~W}$ $325710 \mathrm{N1091235 \textrm {W }}$

$324415 \mathrm{~N} 1090545 \mathrm{~W}$

$315953 \mathrm{~N} 1115149 \mathrm{~W}$

$322337 \mathrm{N1104114W}$
SOURCE
COORDINATE

MAP NAME

Copperosity Hills

Tonto Bas in

Copperosity Hills

6535 Copper Mtn

Copper Mtn

Greenback Creek

Greenback Creek

1210 Glendale

1420 Paradise Valley

12010 N1095428W

Hereford

Salton Tanks

Pajarito Peak

Rustler Park

Greene Reservoir

Lochiel

Greene Reservoir

Greene Reservoir

$343102 \mathrm{~N} 1122022 \mathrm{~W}$

1320 Buckhorn

Phoenix

1290 Buckhor

1325 Buckhorn

Jaynes

Black Gap

Humboldt

Prescott Valley S

Prescott Valley

1175 Tempe

Nutrioso

$341910 \mathrm{~N} 1113406 \mathrm{~W}$

Cane Springs Mtn Cane Springs Mtn

Mt Turnball

Pinal Peak

Hay Lake

Waihalla Plateau

Bright Angel Point Dudleyville Robinson Mesa

3811 York

Duncan

Sells East

7890 Mount Bigelow 


\section{FEATURE}

CLASS
COUNTY

COORDINATE

dam
reservoir
mine
reservoir
dam
stream
sumit
reservoir
area
well
spring
spring
spring
valley
valley
stream
reservoir
reservoir
reservoir
reservoir
reservoir
reservoir
locale
ppl
locale

Green Mountain Tank

Green Quartz Mine

Green Reservoir

See Greene Reservoir

Green Reservoir Dam

See Greene Reservoir Dam

Green Reservoir Outlet

See Greene Wash

Greens Peak

Greens Peak Tank

Green Spot

Green Spot We1

Green Spring

Green Spring

Green Spring

Green Spring Canyon

See Surprise Canyon

Green Spring Canyon

Greens Reservoir Outlet

See Greene Wash

Green Tank Surprise Creek

Green Tank

Green Tank

Green Tank

Green Tank

Green Tanks

Green Tank Windmi11

Greentrails (subdivision)

Green Tree Mobile Home Park

Green Valley

Green Valley

Tecota

Green Valley Creek

Green Valley Hills King Ride

Green Valley Interchange

Green Valley Park

Green Valley Shopping Plaza

Green Valley Tank

Green Valley Trailer Park

Greenwade Ranch

Green Waterhole Spring

Green Water Tank

Greenway Cross

Greenway High School

Greenway Park V (subdivision)

Greenway School

Greenway Sports Complex

Greenway Terrace Shopping

Center

Greenwood

Greenwood Cemetery

Greenwood Peak

Greenwood Spring

Greenwood Well

Greer

Greer Campground

Greer Lakes

Greer Lakes Campground

Greer Lateral

Greer Place

Greer Spring

Greer Windmill

Gregg Bas in

Greggs Ferry (submerged ruin) Scanion Ferry

Greggs Hideout

Osprey Bay

Gregg Tank
UNOFF

$\begin{array}{ll}\begin{array}{l}\text { Graham } \\ \text { Graham } \\ \text { Mohave }\end{array} & \begin{array}{l}332130 \mathrm{~N} 1100418 \mathrm{~W} \\ 332113 \mathrm{~N} 1100314 \mathrm{~W}\end{array} \\ \text { Pinal } & 345746 \mathrm{~N} 1142417 \mathrm{~W} \\ & 323642 \mathrm{~N} 1114110 \mathrm{~W} \\ \text { Pinal } & 323642 \mathrm{~N} 1114110 \mathrm{~W} \\ & \\ \text { Pinal } & 325352 \mathrm{~N} 1115644 \mathrm{~W} \\ \text { Apache } & 340643 \mathrm{~N} 1093425 \mathrm{~W}\end{array}$

$340640 \mathrm{~N} 1093310 \mathrm{~W}$

$341123 \mathrm{~N} 1092411 \mathrm{~W}$

$341121 \mathrm{~N} 1092409 \mathrm{~W}$

$322705 \mathrm{~N} 1104446 \mathrm{~W}$

$324630 \mathrm{~N} 1095416 \mathrm{~W}$

$360538 \mathrm{~N} 1132826 \mathrm{~W}$

$355116 \mathrm{~N} 1133940 \mathrm{~W}$

$355846 \mathrm{~N} 1133334 \mathrm{~W}$

$325352 \mathrm{~N} 1115644 \mathrm{~W}$

324312N1111031W

$334242 \mathrm{~N} 1123829 \mathrm{~W}$

$340316 \mathrm{~N} 1093544 \mathrm{~W}$

$343937 \mathrm{~N} 1111406 \mathrm{~W}$

$350859 \mathrm{~N} 1122545 \mathrm{~W}$

$315829 \mathrm{~N} 1111323 \mathrm{~W}$

$340851 \mathrm{~N} 1122555 \mathrm{~W}$

$333823 \mathrm{~N} 1120346 \mathrm{~W}$

$331830 \mathrm{~N} 1114947 \mathrm{~W}$

valley BGN Gila

$\mathrm{ppl}$

stream

range

crossing

park

locale

reservoir

BGN

VARIANT

BGN Gila

BGN Gila

VARIANT

UNOFF

Pima

Maricopa

Maricopa 332534N1120310

Pima 315207N1105931W

Gila 341434N1111212W

locale UNOFF Maricopa 332337N1120033W

locale UNOFF Greenlee 332050N1092903W

spring BGN Yavapai 351216N1130103W

reservoir BGN Navajo 343201N1100900W

pillar BGN Pima 322152N1125242W

school UNOFF Maricopa 333735N1120836W

Maricopa

school UNOFF Cochise

building UNOFF Maricopa

locale UNOFF

$333744 N 1115751 \mathrm{~W}$

$312501 \mathrm{~N} 1095248 \mathrm{~W}$

$333743 \mathrm{~N} 1121349 \mathrm{~W}$

$333722 \mathrm{~N} 1121610 \mathrm{~W}$

$343028 \mathrm{~N} 1133538 \mathrm{~W}$

$332721 \mathrm{~N} 1120635 \mathrm{~W}$

$343007 \mathrm{~N} 1133002 \mathrm{~W}$

$342940 \mathrm{~N} 1133048 \mathrm{~W}$

$343924 \mathrm{~N} 1134122 \mathrm{~W}$

$340036 \mathrm{~N} 1092729 \mathrm{~W}$

340059 N1092704W

$340213 \mathrm{~N} 1092614 \mathrm{~W}$

$340140 \mathrm{~N} 1092547 \mathrm{~W}$

$324120 \mathrm{~N} 1144104 \mathrm{~W}$

$343612 \mathrm{~N} 1093616 \mathrm{~W}$

$331543 \mathrm{~N} 1104709 \mathrm{~W}$

$343252 \mathrm{~N} 1093726 \mathrm{~W}$

$360607 \mathrm{~N} 1140707 \mathrm{~W}$

$360420 \mathrm{~N} 1140727 \mathrm{~W}$

BGN 1983 Mohave 360030N1141400W

bay

VARIANT

reservoir
SOURCE ELEV

MAP NAME

Ash Creek Ranch

Ash Creek Ranch

Boundary Cone

1013 Greens Peak

Greens Peak

Springerville NW

Springerville NW

Mount Bigelow

Shingle Mill Mtn

Whitmore Point SW

360544N1132820W Amos Point

Durham Hills

Daggs Tank

Greens Peak

Hay Lake

Ash Fork

Samaniego Peak

4745 Minnehaha

1380 Union Hills

1220 Chandler

341401N1111853W Payson South

2900 Green Valley

341705 N1110642W

McDonald Mtn McDonald Mtn

2890 Green Valley

Phoenix

2900 Green Valley

McDonald Mtn

1130 Phoenix

4800 Bee Canyon

Squaw Peak

Second Knolls

Chico Shunie

Hedgpeth Hills

1455 Currys Corner Bisbee Hedgpeth Hills

1175 El Mirage

Greenwood Peak Phoenix

4339 Greenwood Peak

Signal Mtn

3841 Aubrey Peak

Greer

Greer

Greer

B400 Greer

Yuma West

Stinking Springs

Pinal Peak

Stinking Springs

Meadview North

880 Meadview North

Hiller Mountains

Red Butte 
FEATURE NAME

Gregoria Tank

Grenego Canyon

See Miller Canyon

Grennan Tank

Mines

Grey Hill Wash

Grey Hill Well

Greyhouse Well

Grey Mountain

Grey Peak

Greys Peak

Pistola Peak

Grey Points

Grey Shaft

Greys Peak

See Grey Peak

Greys Peak Spring

Grey Tunnel

Grey Water Draw

See Tolapai Draw

Greywater Wash

See Tolapai Draw

G R Herberger Park

Gridley Junior High School

Grief Hill

Grief Hills Spring Number One Grief Hills Spring Number Two

Grief Hill Wash

Griffin Ranch

Griff in Tank

Griff in Wash

Griffith

Griffith Interchange

Griffith Knoll

Griffith School

Griffiths Spring

Griffiths Tank

Griffith Tank

Griffith Wash

Griggs

Grimes Spring Silver Spray Spring

Grindstone Mountain

Grindstone Spring

Grindstone Tank

Grindstone Tank

Grindstone Wash

Grindstone Wash

See M C Canyon

Gringo Gulch

Grinnell Station

See Stoval

Gripe

Griswells (historical)

Grizzles Orchard

Grizzly Bear Spring

Grizzly Mountain

Groom Creek

Groom Creek

Groom Creek Loop Number Three

Hundred Seven

Groom Creek Loop Trail

Grooming Spring

Groom Peak

Grooms Peak

Groom Peak

See Aubrey Peak

Grooms $\mathrm{Hill}$

Grooms Peak

See Groom Peak
FEATURE
CLASS

STATUS

COUNTY

reservoir

BGN

Yavapai

COORDINATE

$350955 N 1123840 \mathrm{~W}$

VARIANT

valley

reservoir

mine

valley

well

well

summit

BGN

$B G N$

UNOFF

BGN

UNOFF

BGN

BGN

VARIANT

VARIANT

Coconino

Santa Cruz

Navajo

Yuma

Navajo

Apache

Apache

Ohave

Greenlee

$343259 \mathrm{~N} 1111417 \mathrm{~W}$

$312532 \mathrm{~N} 1104048 \mathrm{~W}$

$342942 \mathrm{~N} 1102129 \mathrm{~W}$

$324456 \mathrm{~N} 1142339 \mathrm{~W}$

$362612 \mathrm{~N} 1101418 \mathrm{~W}$

363650 N1090810W

365558 N1093939W

$344254 \mathrm{~N} 1132516 \mathrm{~W}$

$331346 \mathrm{~N} 1092429 \mathrm{~W}$

1101358W

BGN Mohave

UNOFF

mine

summit

spring

VARIANT

mine

UNOFF

VARIANT

valley

valley

VARIANT

park

school

summit

spring

locale

reservoir

stream

locale

AOMI
UNOF
BGN
BGN
BGN
BGN
UNOFF
BGN
BGN
BGN

crossing

summit

school

spring

reservoir

reservoir

stream

locale

spring

UNOF
BGN
UNOF
BGN
BGN
BGN
BGN
BGN
BGN

BGN Mohave

Mohave

Maricopa

VARIANT

Coconino

Mohave

Mohave

Maricopa

Gila

summit

spring

reservoir

reservoir

stream

BGN
BGN

BGN

BGN 19

valley

valley

VARIANT

BGN

VARIANT

locale

Navajo

Yavapai

Yavapai

Coconino

Yavapai

Yavapai

Santa Cruz

Yuma

365655 N1134408W

$332504 \mathrm{~N} 1104641 \mathrm{~W}$

$331346 \mathrm{~N} 1092429 \mathrm{~W}$

$331400 \mathrm{~N} 109232 \mathrm{BW}$

$315928 N 1091647 \mathrm{~W}$

351257N1091932W

$351257 N 1091932 \mathrm{~W}$

$332927 N 1115720 \mathrm{~W}$

$321312 \mathrm{~N} 1104724 \mathrm{~W}$

$343332 \mathrm{~N} 1115648 \mathrm{~W}$

$343343 \mathrm{~N} 1115606 \mathrm{~W}$

$343407 \mathrm{~N} 1115631 \mathrm{~W}$

$343530 \mathrm{~N} 1115307 \mathrm{~W}$

$333624 \mathrm{~N} 1103922 \mathrm{~W}$

$355 B 49 N 1121303 \mathrm{~W}$

$333957 \mathrm{~N} 1105940 \mathrm{~W}$

$350400 \mathrm{~N} 1140657 \mathrm{~W}$

$350201 N 1140747 \mathrm{~W}$

$362218 \mathrm{~N} 1131852 \mathrm{~W}$

$332808 \mathrm{~N} 1115858 \mathrm{~W}$

$350702 \mathrm{~N} 1114232 \mathrm{~W}$

$350657 \mathrm{~N} 1114225 \mathrm{~W}$

$350344 \mathrm{~N} 1140610 \mathrm{~W}$

$350143 \mathrm{~N} 1141247 \mathrm{~W}$

$332935 \mathrm{~N} 1122543 \mathrm{~W}$

$341238 \mathrm{~N} 111233 \mathrm{BW}$

$350523 N 1140354 W$

$334715 N 1095201 \mathrm{~W}$

$343240 \mathrm{~N} 1123714 \mathrm{~W}$

$345338 \mathrm{~N} 1115947 \mathrm{~W}$

$345917 \mathrm{~N} 1121748 \mathrm{~W}$

$345544 \mathrm{~N} 1121700 \mathrm{~W}$

$345532 \mathrm{~N} 1121632 \mathrm{~W}$

313359 N1104630W

324554N1133717W

ppl

locale

locale

spring

summit

stream

pp 1

trail

BGN

BGN

$B G N$
$B G N$
$B G N$

BGN

BGN

UNOFF

trail

UNOFF

Graham

Yuma

Cochise

Gila

Gila

Yavapai

Yavapai

Yavapai

$324845 \mathrm{~N} 1093605 \mathrm{~W}$

$325300 \mathrm{~N} 1133000 \mathrm{~W}$

$314515 \mathrm{~N} 1094453 \mathrm{~W}$

$332325 \mathrm{~N} 110592 \mathrm{BW}$

$332353 N 1105954 \mathrm{~W}$

$342716 N 1122923 \mathrm{~W}$

$342832 \mathrm{~N} 1122550 \mathrm{~W}$

$342743 \mathrm{~N} 1122411 \mathrm{~W}$

342737 N1122518W

$354820 \mathrm{~N} 1103125 \mathrm{~W}$

spring

summ it

BGN

BGN

VARIANT

VARIAN

summ it

summit

BGN

VARIANT

Yavapai

$343947 N 1134342 W$

$340316 \mathrm{~N} 1123152 \mathrm{~W}$

343737 N1133912W

$\begin{array}{cc}\text { SOURCE } & \text { ELEV } \\ \text { COORDINATE } & \text { FT MAP NAME }\end{array}$

Picacho Butte

Purgatory Canyon

Globe

Coronado Mtn

Rustler Park

Tempe

Tucson East

5320 Middle Verde

Middle Verde

Middle Verd

343413N1115701W Middle Verde

Chrome Butte

Tusayan West

$334237 N 1105512 \mathrm{~W}$

Kingman SE

Kingman SW

5573 Cold Spring

Tempe 
NATIONAL GAZETTEER--ARIZONA 1986

\section{FEATURE NAME}

Grooms Peak

See Aubrey Peak

Groom Spring

Groom Spring Wash

Groover Lateral

Grossman Peak

See Crossman Peak

Gross Spring

Gross Spring

Grosvenor Hills

Ground Tank

Grove Creek

See Red Creek

Grover Canyon

Grover Point

Grover Spring

Grover Spring Canyon

Gravel Spring Canyon

Grove Tank

Antelope Tank

Growler

Growler Canyon

Growler Creek

See Growler Wash

Growler Mountains

See Cipriano Hills

Growler Mountains

See Bates Mountains

Growler Mountains

Granite Mountains

Growler Pass

Growler Peak

Growler Railroad Station

Growler Valley

Growler Wash

See Cherioni Wash

Growler Wash

Bates Wash

Growler Creek

San Cristobas Wash

Grumble Wells

Grumell Well

Grunow Memorial Clinic

Gruwell Canyon

Gruwell Spring

Gruwell Well

G S Skiff School

Gu Achi

Adid

Kait jimok

Kuarchi

Kuatshi

San Francisco del Adid

Santa Rosa

Santa Rosa Well

Gu Achi Childrens Shrine

Gu Achi Mountains

See Santa Rosa Mountains

Gu Achi Peak

Santa Rosa Mountain

Santa Rosa Muntain

Gu Achi Wash

Guadalupe

See Guadalupe Mountains

Guadalupe

Guadalupe Canyon

Guadalupe Cemetery

Guadalupe Cruz (historical)

Guadalupe Dam

Guadalupe Mountain

Guadalupe Mountains

FEATURE
CLASS

STATUS

COUNTY

COORDINATE

VARIANT

summi

Mohave

spring

stream

canal

BGN

BGN

VARIANT

summit

spring

summit

reservoir

Mohave

BGN

BGN

BGN

stream

Mohave

Mohave

Yuma

Gila

valley

summit

spring

valley

reservoir

locale

valley

stream

BGN Gila

BGN Navajo

BGN Navajo

BGN 1964 Navajo

VARIANT

BGN 1976 Coconino

VARIANT

BGN Yuma

BGN

VARIANT

Pima

Yuma

VARIANT

summit

summit

VARIANT

summit

BGN 196

VARIANT

gap

summ it

building

BGN 1964

BGN 1965 Pima

UNOFF Yuma

valley

Yuma

VARIANT

stream

stream

BGN

VARIANT

VARIANT

well VARIANT

well

UNOFF

hospital UNOFF

valley BGN

spring

well

school

pp 1

BGN

UNOFF

UNOFF

BGN 1941

VARIANT

VARIANT

VARIANT

VARIANT

VARIANT

VARIANT

VARIANT

Pima

Maricopa

Gila

VARIAN

BGN Pima

VARIANT

range

Maricopa

valley BGN Cochise

cemetery UNOFF Maricopa

locale BGN Santa Cruz

dam

UNOFF

Maricopa

Yuma
SOURCE

ELEV

AZ259

$343947 N 1134342 W$

$343529 N 1134359 \mathrm{~W}$

$342916 \mathrm{~N} 1133717 \mathrm{~W}$

$323124 N 1144725 \mathrm{~W}$

343759 N1134314W

Groom Spring

Signal Mtn

Gadsden

$\begin{array}{ll}\text { Mohave } & 352125 N 1140908 W \\ \text { Santa Cruz } & 313435 N 1105410 W \\ \text { Gila } & 333342 N 1105442 W\end{array}$

$340954 \mathrm{~N} 1143112 \mathrm{~W}$

332429 N1105049W

$341905 N 1102131 \mathrm{~W}$

341904 N1102156W

$342115 N 1102050 \mathrm{~W}$

$352120 N 1123440 \mathrm{~W}$

$324 B 56 \mathrm{~N} 1134754 \mathrm{~W}$

$321012 N 1125631 \mathrm{~W}$

323233N1132550W

$\begin{array}{llll}\text { church } & \text { UNOFF } & \text { Pima } & 322019 \mathrm{N1120359 \textrm {W }} \\ \begin{array}{llll}\text { Vange } \\ \text { summit }\end{array} & \text { BGN 1941 } & \text { Pima } & 322322 \mathrm{N1115210 \textrm {W }} \\ & \text { Pima } & 322052 \mathrm{N1115234 \textrm {W }}\end{array}$

$332348 N 1105037 W$

$341845 N 1102155 W$

Clay Springs

Clay Springs

Kingman

Cerbat

San Cayetano Mts

Salt River Peak

Horse Trap Mesa

322 Growler

Bates Wel

$320216 N 1125921 \mathrm{~W}$

320630N1125700W

$322127 N 1130511 \mathrm{~W}$

$321100 \mathrm{~N} 1125530 \mathrm{~W}$

$322435 \mathrm{~N} 1130601 \mathrm{~W}$

324856 N1134754W

$323210 \mathrm{~N} 1132235 \mathrm{~W}$

320938 N112550BW

323233N1132550W

320937 N1125506W

Aguila Mts SW

$324 \mathrm{~B} 35 \mathrm{~N} 1111400 \mathrm{~W}$

$332249 N 1131035 \mathrm{~W}$

$332758 \mathrm{~N} 1120340 \mathrm{~W}$

$340920 \mathrm{~N} 1105437 \mathrm{~W}$

340B23N1105028

2227 Ninetysix Hills SW

Cortez Peak NW

Phoenix

$332605 \mathrm{~N} 1120236 \mathrm{~W}$

$321925 \mathrm{~N} 1120226 \mathrm{~W}$

Oxbow Mtn

Young

Phoenix

Gu Achi

Gu Achi

4556 Santa Rosa Mts SW

$321627 \mathrm{~N} 1121551 \mathrm{~W}$

Gu Achi

$312000 \mathrm{~N} 1090300 \mathrm{~W}$

$332215 N 1115744 \mathrm{~W}$

Guadalupe

$312035 \mathrm{~N} 1090346 \mathrm{~W}$

$332257 \mathrm{~N} 1115716 \mathrm{~W}$

$312113 \mathrm{~N} 1105030 \mathrm{~W}$

$332136 \mathrm{~N} 1115800 \mathrm{~W}$

$334002 \mathrm{~N} 1140331 \mathrm{~W}$

$312000 \mathrm{~N} 1090300 \mathrm{~W}$

312756 N1090229W

Guadalupe Canyon

Tempe

3720 Kino Springs

Guadalupe

Plomosa Pas

Guadalupe Canyon 


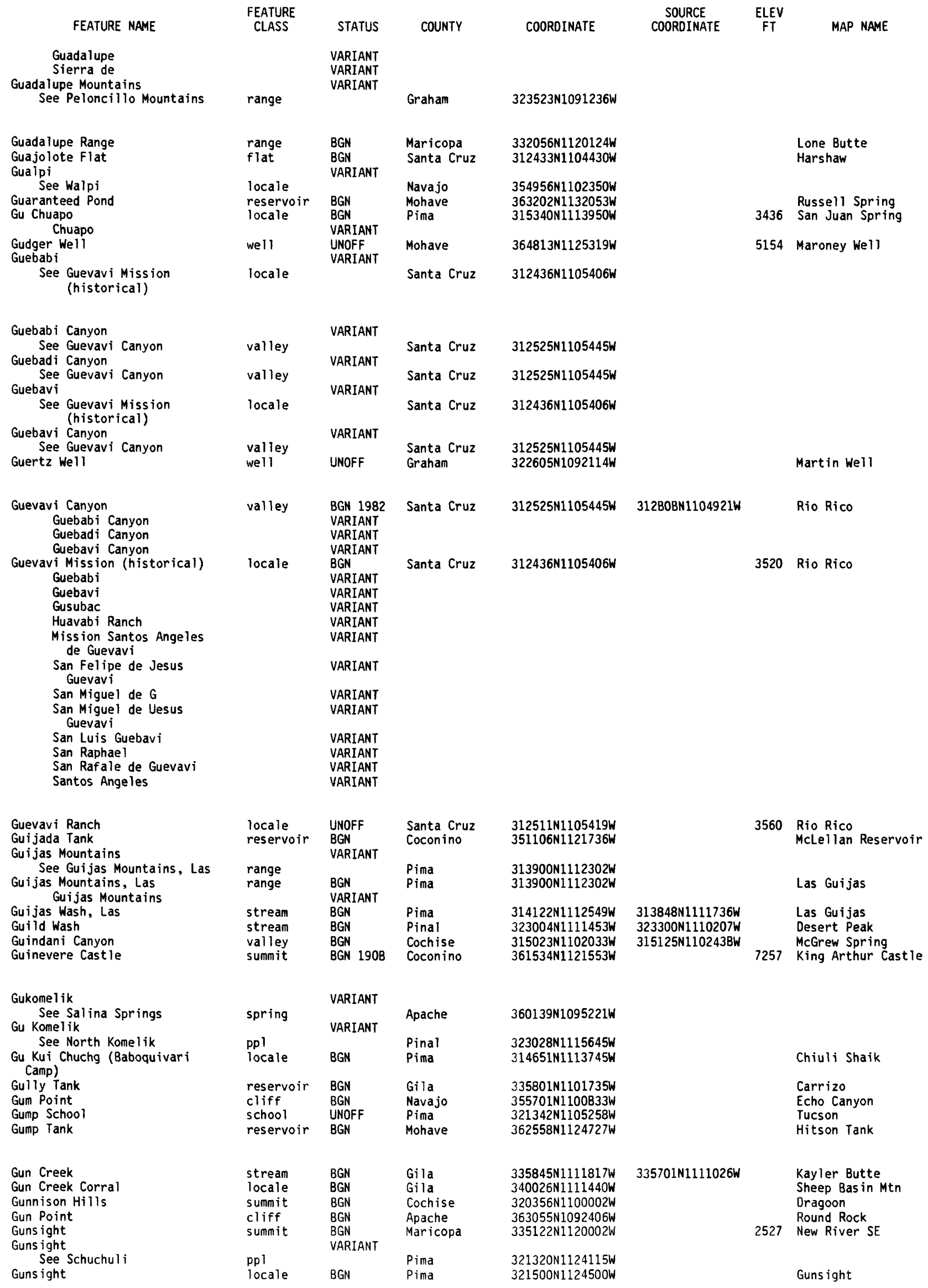


NATIONAL GAZETTEER--ARIZONA 1986

FEATURE NAME

Guns ight We 11

Allen City

Gunsight Butte

Guns ight Canyon

Gunsight Canyon

Guns ight Cemetery

Guns ight Gap

Gunsight Hills

Gunsight Mountain Soto Peak

Gunsight Mountains

See Pozo Redondo Mountains

FEATURE

STATUS

COUNTY

COORDINATE

SOURCE
ELEV

MAP NAME

VARIANT

VARIANT

summit
valley
valley
cemetery
gap
summit
summit
summit

$\begin{array}{ll}\text { 8GN } & \text { Gila } \\ \text { BGN } & \text { Mohave } \\ \text { BGN } & \text { Coconino } \\ \text { UNOFF } & \text { Pima } \\ \text { BGN } & \text { Gila } \\ \text { BGN 1941 } & \text { Pima } \\ \text { BGN } & \text { Pima } \\ \text { VARIANT } & \\ \text { VARIANT } & \\ & \text { Pima }\end{array}$

Gunsight Notch

Gunsight Pass

Gunsight Point

Guns ight Ranch

Guns ight Ranch

See Schuchuli

Gunsight Range

See Pozo Redondo Mountains

Gunsight Tank

Gunsight Tank

Gunsight Valley

Gunsight Wash

Guns ight Well

See Schuchuli

Gunsight Well

See Gunsight

Gun Tank

Gun Tank

Gunther Castle

Gunther Tank

Gu Oidak

Big Field

Big Fields

Kuoitak

Gu Oidak Valley

Gu Oidak Wash

$$
\text { Sells Wash }
$$

Gu Oidak Wash

See Sells Wash

Gu Oidak Wash

See Vamori Wash

Gurli Put Vo

Dead Old Mans Pond

Koli-pat-vooka

Kol ipatvooka

Gurry Well

Gusano Pass

See Ali Wua Pass

Gus Spring

Gus Tank

Gus Tank

Gust James Wash

Gusubac

See Guevavi Mission (historical)

Guswert Canyon

Guthrie

Guthrie Canyon

Guthrie Mountain

Guthrie Mountain

Guthrie Peak

Guthrie Railroad Station

Guthrie Ranch

Guthrie Tank

Gu Vo

Cubo

Kerwo

Gu Vo Hills gap BGN Yuma 333458N1135250W

gap BGN Pima 315100N1104532W

cliff BGN Coconino 364004N1123649W

locale UNOFF Pima 315713N1111419W

ppl

VARIANT

Pima

VARIANT

summit

reservoir

BGN

Pima

Gila

$321320 \mathrm{~N} 1124115 \mathrm{~W}$

reservoir

BGN

Coconino

321841N1124152W

$364136 \mathrm{~N} 1123606 \mathrm{~W}$

valley

stream

pp 1

BGN 1964 Pima

BARIANT Pima

VARIANT Pima

locale

reservoir

reservoir

summit

VARIANT

BGN

Gila

BGN 1906 Coconino

reservoir

BGN

pp 1

BGN 1941 Pima

VARIANT

VARIANT

VARIANT

valley

arroyo

BGN

VARIANT

VARIANT

stream

stream

VARIANT

Pima

Pima

locale

BGN 1941 Pima

VARIANT

VARIANT

$\begin{array}{ll} & \text { VARIANT } \\ \text { We11 UNOFF }\end{array}$

gap

VARIANT

La Paz

Pima

spring

BGN

BGN

BGN Coconino

reservoir

Coconino

stream BGN Pinal

locale

VARIANT

valley

locale

summit

summit

summit

$B G M$
$B G$
$B G$
$B G$
$B G$
$B G$

building

locale

reservoir

ppl

UNOFF

UNOFF

BGN 1941

VARIANT

VARIANT

VARIANT

summit BGN 1941 Pima

$321400 \mathrm{~N} 1124430 \mathrm{~W}$

321509 N1124907W

$321320 \mathrm{~N} 1124115 \mathrm{~W}$

$321500 \mathrm{~N} 1124500 \mathrm{~W}$

$335922 \mathrm{~N} 1111622 \mathrm{~W}$

$340358 N 1110913 \mathrm{~W}$

$361234 \mathrm{~N} 1115219 \mathrm{~N}$

$313040 \mathrm{~N} 1104225 \mathrm{~W}$

315518N1120234W

$315625 \mathrm{~N} 1121354 \mathrm{~W}$

$315530 \mathrm{~N} 1120925 \mathrm{~W}$

315552N1121120W

315750 N1121935W

321214 N1120108W

325527 N1140048W

$315415 \mathrm{~N} 1123712 \mathrm{~W}$

325447 N1090909W

$342357 \mathrm{~N} 1113407 \mathrm{~W}$

$354000 \mathrm{~N} 1130726 \mathrm{~W}$

$323828 N 1103441 \mathrm{~W}$

$312436 \mathrm{~N} 1105406 \mathrm{~W}$

$330204 N 1092537 \mathrm{~W}$

$325646 \mathrm{~N} 1091509 \mathrm{~W}$

325619 N1091510W

$322156 \mathrm{N1103917W}$

$325621 \mathrm{N1091609 \textrm {W }}$

$325313 \mathrm{~N} 1091852 \mathrm{~W}$

Pima

Greenlee

Greenlee

Greenlee $\quad 325637$ N1091514W

Cochise

Greenlee

$325419 \mathrm{~N} 1091521 \mathrm{~W}$

$320356 \mathrm{~N} 1123336 \mathrm{~W}$

320059 N1123254W
$335638 \mathrm{~N} 1105126 \mathrm{~W}$

$344716 \mathrm{~N} 1133705 \mathrm{~W}$

$364340 \mathrm{~N} 1123649 \mathrm{~W}$

$321300 \mathrm{~N} 1124040 \mathrm{~W}$

$333143 \mathrm{~N} 1110227 \mathrm{~W}$

$321054 \mathrm{~N} 1123955$

$315746 \mathrm{~N} 1111428 \mathrm{~W}$

$321841 N 1124152 \mathrm{~W}$

$\begin{array}{lll}344718 \text { N1134655W } & 6242 \begin{array}{l}\text { Rock House } \\ \text { Tule Wash } \\ \text { 364250N1123448W }\end{array} & \begin{array}{l}\text { Gunsight Point } \\ \text { Gunsight } \\ \text { Two Bar Mtn } \\ \text { Guns ight }\end{array} \\ & 4680 \begin{array}{l}\text { Samaniego Peak }\end{array}\end{array}$

New Water Mts

Helvet ia

Gunsight Point

Samaniego Peak

McFadden Peak

Guns ight Point

321230N1123700W Guns ight

320929N1123545W Ajo South

$320701 N 1120240 \mathrm{~W}$

Gurli Put Vo

Ibex Peak

York

Strawberry

Crater Canyon

324111 N1102936W

Clark Ranch

$330115 N 1092750 \mathrm{~W}$

$325448 \mathrm{~N} 1091703 \mathrm{~W}$

Copperplate Gulch

3414 Guthrie

6464 Agua Caliente $\mathrm{Hill}$

4495 Guthrie

6571 Guthrie

3414 Guthrie

Tombstone

Guthrie

Gu Vo

Gu vo
315500 N1120310W $\quad$ Kupk 


\section{FEATURE NAME}

Cubo Hills

Gu Vo Pass

Gu Vo Wash

Guys Tank

Guys Wel

$G$ Wash

G Wash Tank

Gwyneth Ham Elementary School

Gyberg Tank

Gyetta Tan

Gyp Hills

Gyp Pocket

Gyp Pocket Tank

Gyp Reservoir

Gypsum Creek

Gyps um Ledges

Gypsum Point

Gypsum Mine

Gypsum Mines (abandoned)

Gypsum Point

See Gypsum Ledges

Gypsum Reefs

Gyp Wash

\section{FEATURE \\ CLASS}

STATUS

COUNTY

VARIANT

gap

BGN

stream

reservoir

well

stream

reservoir

reservoir

reservoir

range

bas in

BGN
BGN
UNOFF
BGN
BGN
UNOFF
BGN
BGN
BGN
BGN

reservoir

reservoir

stream

bench

mine

mine

bench

bar

valley
BGN Mohave

BGN

BGN

BGN 1948

VARIANT

UNOFF

UNOFF

VARIANT

BGN

BGN

Mohave

Apache

Mohave

Yuma

Pinal

Mohave

Mohave

Mohave
Pima

Pima

Cochise

Navajo

Gila

Gila

Yuma

Yavapai

Yavapai

Mohave

Mohave
COORDINATE

$320400 N 1123500 \mathrm{~W}$

$320239 N 1122223 W$

$313353 \mathrm{~N} 1095921 \mathrm{~W}$

$342319 \mathrm{~N} 1095638 \mathrm{~W}$

$335020 \mathrm{N1101331 \textrm {W }}$

$334953 \mathrm{~N} 1100942 \mathrm{~W}$

$324116 \mathrm{~N} 1143640 \mathrm{~W}$

$344450 \mathrm{N11} 15757 \mathrm{~W}$

$342335 \mathrm{~N} 1115915 \mathrm{~W}$

$361814 N 1135413 \mathrm{~W}$

$365050 \mathrm{~N} 1132118 \mathrm{~W}$

$365047 \mathrm{N1132108 \textrm {W }}$

$363524 \mathrm{~N} 1132030 \mathrm{~W}$

370B43N1095133W

$360427 N 1142418 \mathrm{~W}$

$323808 \mathrm{~N} 1140417 \mathrm{~W}$

$325243 \mathrm{~N} 1114129 \mathrm{~W}$

$360427 N 11424184$

$360643 \mathrm{N1142546 \textrm {W }}$

$361531 \mathrm{~N} 1135646 \mathrm{~W}$ $\begin{array}{cc}\text { SOURCE } & \text { ELEV } \\ \text { COORDINATE } & F T\end{array}$

MAP NAME

Gu Vo

320139N1124042W Pisinimo

Potter Mtn

6186 Mesa Redonda NW

Cone Butte

Cone Butte

Yuma East

Cornville

Arnold Mesa

Gyp Hills

Gyp Pocket

Gyp Pocket

Russell Spring

Rooster Rock

Bonelli Bay

Wellton Mesa

Saddle Mtn

Bonelli Bay

Gyp Hills
$\mathrm{H}$

Haal-Muihedak

See Hali Murk

Haas Canyon

Haberstock $\mathrm{Hill}$

Haberstock Wash

Habo Canyon

See Hobo Canyon

Haby Spring

Hacienda del Santa Rita

(historical)

Hacienda de Valencia (trailer park)

Hacienda Los Encino

Haciendas del Lago

(subdivision)

Hacienda Solano Park (trailer park)

Hackataia

See Hakatai Canyon

Hackberry

Hackberry (siding)

Hackberry Basin

Hackberry Bas in

Hackberry Bas in Spring

Hackberry Butte

See Byous Butte

Hackberry Butte

Hackberry Canyon

Hackberry Canyon

Hackberry Canyon

Hackberry Canyon

Hackberry Canyon

Hackberry Canyon

Hackberry Creek

Hackberry Creek

Hackberry Creek

Hackberry Creek

Hackberry Oraw

Hackberry Oraw

$$
\text { Triplet Wash }
$$

$\begin{array}{llll}\text { stream } & \text { BGN } & \text { Coconino } & 353942 \mathrm{~N} 1110905 \mathrm{~W} \\ & \text { VARIANT } & \text { Pima } & 320004 \mathrm{~N} 1121737 \mathrm{~W} \\ \text { locale } & & \text { Pinal } & 330241 \mathrm{N1103616 \textrm {W }} \\ \text { valley } & \text { BGN } & \text { Cochise } & 314900 \mathrm{~N} 1100032 \mathrm{~W} \\ \text { summit } & \text { BGN } & \text { Cochise } & 314803 \mathrm{~N} 1100345 \mathrm{~W} \\ \text { stream } & \text { BGN } & & \\ & \text { VARIANT } & & \\ \text { valley } & & \text { Greenlee } & 332238 \mathrm{~N} 1091008 \mathrm{~W} \\ \text { spring } & \text { BGN } & \text { Graham } & 324756 \mathrm{~N} 1101709 \mathrm{~W}\end{array}$

locale BGN Santa Cruz 313529N1105453W

locale UNOFF Maricopa 332436N1114401W

$\begin{array}{llll}\text { locale } & \text { BGN } & \text { Santa Cruz } & 313932 N 1103848 \mathrm{~W} \\ \text { ppl } & \text { BGN } & \text { Maricopa } & 333440 N 1115216 \mathrm{~W}\end{array}$

$\begin{array}{llll}\text { locale } & \text { BGN } & \text { Santa Cruz } & 313932 N 1103848 \mathrm{~W} \\ \text { ppl } & \text { BGN } & \text { Maricopa } & 333440 N 1115216 \mathrm{~W}\end{array}$

locale UNOFF Maricopa 33181BN1114725W

VARIANT

valley

ppl

BGN

Coconino

Mohave

$361441 N 1122304 W$

$352209 \mathrm{~N} 1134335 \mathrm{~W}$

locale BGN Mohave 352244N1134346W

basin BGN 1965 Gila 335505N1111557W

bas in BGN Yavapai 342641N1114043W

spring BGN Gila 335539N1111525W

summit

summit

valley

valley

VARIANT

Pinal

BGN Pinal

$B G$

Graham

Greenlee

valley

valley

valley

stream

stream

stream

strean

valley

$\begin{array}{ll}\text { BGN } & \text { Pinal } \\ \text { BGN } & \text { Yavapai } \\ \text { BGN } & \text { Mohave } \\ \text { BGN } & \text { Pinal } \\ \text { BGN } & \text { Graham } \\ \text { BGN } & \text { Gila } \\ \text { BGN } & \text { Yavapai } \\ \text { BGN } & \text { Graham } \\ \text { BGN } & \text { Graham }\end{array}$

VARIANT
$332200 \mathrm{~N} 1111239 \mathrm{~W}$

$332310 \mathrm{~N} 1111229 \mathrm{~W}$ $322235 \mathrm{~N} 1101436 \mathrm{~W}$ $325945 \mathrm{~N} 1101122 \mathrm{~W}$ 330907 N1091634W $330131 \mathrm{N1} 101317 \mathrm{~W}$ $330924 \mathrm{~N} 1091829 \mathrm{~W}$

$332231 \mathrm{~N} 1111136 \mathrm{~W}$ 342728 N1114305W $35135 \mathrm{BN} 1140440 \mathrm{~W}$ $331625 \mathrm{N1} 110138 \mathrm{~W}$ $332202 \mathrm{~N} 1102637 \mathrm{~W}$ $333849 \mathrm{~N} 1111232 \mathrm{~W}$ $342042 \mathrm{~N} 1120948 \mathrm{~W}$ $324930 \mathrm{~N} 1100615 \mathrm{~W}$ $331321 \mathrm{~N} 1102151 \mathrm{~W}$

332253 N1111243W $342549 \mathrm{~N} 1113929 \mathrm{~W}$ $351454 \mathrm{~N} 1140653 \mathrm{~W}$ $331515 N 1110332 \mathrm{~W}$ $332506 \mathrm{~N} 1101416 \mathrm{~W}$ $333925 \mathrm{~N} 1111615 \mathrm{~W}$ $342340 \mathrm{~N} 1121643 \mathrm{~W}$ $324933 \mathrm{~N} 1100922 \mathrm{~W}$ $332109 \mathrm{~N} 1102038 \mathrm{~W}$
$322405 \mathrm{N1} 101455 \mathrm{~W}$

$354017 N 1110154 W$

$330503 N 1103331 W$

314933N1095811W

5047 Haberstock Hill

Haberstock Hill

Klondike

4320 San Cayetano Mts

Buckhorn

Sonoita

1370 Sawik Mountain

1250 Chandler

Hackberry

Valentine Kayler Butte Hackberry Mtn Kayler Butte

4230 Iron Mountain Hookers Hot Springs Jackson Mtn Mitchell Peak

Iron Mount ain Hackberry Mtn

Kingman

Superior

San Carlos

Theo. Rooseveit Dam

Cleator

Tripp Canyon

Dewey Flat 
NATIONAL GAZETIEER--ARIZONA 1986 FEATURE NAME Hackberry Gulch

Hackberry Gulch See Ash Spring Canyon

Hackberry Gulch

Hackberry Gulch

See Hodgkins Gulch

Hackberry Mes a

Hackberry Mesa

Hackberry Mine

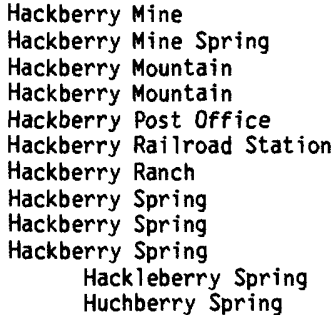

FEATURE

\begin{tabular}{|c|c|c|c|}
\hline $\begin{array}{l}\text { school } \\
\text { valley }\end{array}$ & $\begin{array}{l}\text { UNOFF } \\
\text { BGN } \\
\text { VARIANT }\end{array}$ & $\begin{array}{l}\text { Mohave } \\
\text { Pinal }\end{array}$ & $\begin{array}{l}352206 N 1134331 \\
330610 N 1105704\end{array}$ \\
\hline $\begin{array}{l}\text { valley } \\
\text { valley }\end{array}$ & $\begin{array}{l}\text { BGN } 1964 \\
\text { VARIANT }\end{array}$ & $\begin{array}{l}\text { Greenlee } \\
\text { Greenlee }\end{array}$ & $\begin{array}{l}330632 N 1091702 \\
331042 N 1091255\end{array}$ \\
\hline $\begin{array}{l}\text { valley } \\
\text { summit } \\
\text { summit } \\
\text { mine }\end{array}$ & $\begin{array}{l}\text { BGN } \\
\text { BGN } \\
\text { UNOFF }\end{array}$ & $\begin{array}{l}\text { Yavapai } \\
\text { Maricopa } \\
\text { Yavapai } \\
\text { Pinal }\end{array}$ & $\begin{array}{l}341435 N 1123323 \\
332949 N 1112550 \\
343405 N 1130004 \\
330042 N 1105608\end{array}$ \\
\hline $\begin{array}{l}\text { mine } \\
\text { spring } \\
\text { summit } \\
\text { summit } \\
\text { building } \\
\text { building } \\
\text { locale } \\
\text { spring } \\
\text { spring } \\
\text { spring }\end{array}$ & $\begin{array}{l}\text { UNOFF } \\
\text { BGN } \\
\text { BGN } \\
\text { BGN } \\
\text { UNOFF } \\
\text { UNOFF } \\
\text { UNOFF } \\
\text { BGN } \\
\text { BGN } \\
\text { BGN 1964 } \\
\text { VARIANT }\end{array}$ & $\begin{array}{l}\text { Mohave } \\
\text { Yavapai } \\
\text { Gila } \\
\text { Yavapai } \\
\text { Mohave } \\
\text { Mohave } \\
\text { Graham } \\
\text { Cochise } \\
\text { Cochise } \\
\text { Graham }\end{array}$ & $\begin{array}{l}352059 N 1134558 \\
342455 N 112162 \\
334135 N 110541 \\
342526 N 1114236 \\
352206 N 1134236 \\
352215 N 1134322 \\
323905 N 109200 \\
321933 N 1101740 \\
322408 N 109424 \\
325823 N 109402\end{array}$ \\
\hline
\end{tabular}

spring

spring

spring

spring

spring

spring

spring
spring

VARIANT

BGN Graham 330016N1093110W

BGN Pinal 330045N1105610W

VARIANT

BGN

BGN

BGN

BGN

BGN

spring $\quad B G N$

$\begin{array}{ll}\text { spring } & 8 G N \\ \text { spring } & B G N\end{array}$

spring $\quad B G N$

spring

spring

spring

spring

spring

spring

spring

spring

reservoir

reservoir

reservoir

reservoir $B G$

reservoir $B G$

stream BGN

stream

BGN

stream

stream

stream

stream

BGN

VARIANT

BGN

BGN

VARIANT

stream

valley

VARIANT

well

UNOFF

we 11

well

locale

valley

mine

spring

UNOFF

UNOFF

BGN
BGN
BGN

UNOFF

VARIANT

reservoir $8 \mathrm{GN}$
$342835 N 1133344 \mathrm{~N}$
Greenlee

Graham

Pinal

Maricopa

Gila

Gila

Gila

Gila

Gila

Gila

Yavapai

Yavapai

Mohave

Yavapai

$330612 \mathrm{N1091620 \textrm {W }}$

$332005 N 1101934 \mathrm{~W}$

$332203 N 1102247 \mathrm{~W}$

$332247 N 1111221 \mathrm{~W}$

332944N1112630W

333049 N1104B3OW

$333324 N 1110509 \mathrm{~W}$

$333855 \mathrm{~N} 1111256 \mathrm{~W}$

334130 N1105516

$334417 N 1104416 \mathrm{~W}$

334550 N1 $105025 \mathrm{~W}$

$334552 N 1110833 \mathrm{~W}$

$340058 \mathrm{~N} 1122329 \mathrm{~W}$

$342602 \mathrm{~N} 1114118 \mathrm{~W}$

$343212 \mathrm{~N} 1123642 \mathrm{~W}$

$345 B 12 N 1133854 \mathrm{~W}$ 342602N1114118W

$325403 \mathrm{~N} 1110102 \mathrm{~W}$

$350151 \mathrm{~N} 1131040 \mathrm{~W}$

$353115 \mathrm{~N} 1135254 \mathrm{~W}$

332059 N1101950W

$332011 N 1101941 \mathrm{~W}$

312610 N1091944W

$330254 \mathrm{~N} 1105456 \mathrm{~W}$

$312945 N 1092239 \mathrm{~W}$

325547 N1105606W

$341318 \mathrm{~N} 1120103 \mathrm{~W} \quad 341100 \mathrm{~N} 1115639 \mathrm{~W}$

$342122 \mathrm{~N} 1131222 \mathrm{~W}$

342937 N1120453W

$352126 \mathrm{~N} 1134125 \mathrm{~W}$

341542 N1130210W

Yavapai

Mohave

Mohave

$353722 \mathrm{~N} 1140259 \mathrm{~W}$

Cochise

$313012 \mathrm{~N} 1092052 \mathrm{~W}$

$333920 N 1105540 \mathrm{~W}$

323818 N1104639W $324253 \mathrm{~N} 1105130 \mathrm{~W}$

313329 N1094813W

$342117 \mathrm{N1} 123636 \mathrm{~W}$

$363301 \mathrm{~N} 1123905 \mathrm{~W}$

$363501 N 1124752 \mathrm{~W}$

363749 N1125424W

Mohave

Graham

$325 \mathrm{~B} 23 \mathrm{~N} 1094025 \mathrm{~W}$ $363649 \mathrm{~N} 1125054 \mathrm{~W}$ $\begin{array}{ll}\text { SOURCE } & \text { ELEV } \\ \text { COORDINATE } & \text { FT }\end{array}$

\begin{tabular}{|c|c|c|}
\hline \multicolumn{2}{|l|}{$330819 N 1105521 \mathrm{~W}$} & $\begin{array}{l}\text { Hackberry } \\
\text { Kearny }\end{array}$ \\
\hline $330902 \mathrm{~N} 1091213 \mathrm{~W}$ & & Dix Creek \\
\hline & 2793 & $\begin{array}{l}\text { Goldfield } \\
\text { Big Shipp Mtn } \\
\text { Kearny }\end{array}$ \\
\hline & $\begin{array}{l}4498 \\
5831\end{array}$ & $\begin{array}{l}\text { Peacock Peak } \\
\text { Poland Junction } \\
\text { Meddler Wash } \\
\text { Hackberry Mtn } \\
\text { Hackberry } \\
\text { Hackberry } \\
\text { Whit lock Mts NE } \\
\text { Soza Mesa } \\
\text { Monk Draw } \\
\text { Weber Peak }\end{array}$ \\
\hline
\end{tabular}

Bonita Spring

Kearny

Mount Triplet

San Carlos

Iron Mountain

Goldfield

Rockinstraw Mtn

Two Bar Mtn

Theo, Roosevelt Dam

Meddler Wash

Haystack Butte

Sombrero Peak

Greenback Creek

Copperopolis

Signal Mtn

Iron Springs

Pilgrim Wash

Hackberry Mtn

Ninetysix Hills NE

Anvil Rock Ranch

Music Mountains SW

Mount Triplet

Mount Triplet

Cinder Hill

Kearny

Joes Hill

Malpais Mesa SW

Estler Peak

Hackberry

Meddler Wash

North of Oracle

North of Oracle

4219 Gleeson SE

Walnut Grove

Grama Spring

Robinson Canyon

Robinson Canyon 


\begin{tabular}{|c|c|c|c|c|c|c|c|}
\hline FEATURE NAME & $\begin{array}{l}\text { FEATURE } \\
\text { CLASS }\end{array}$ & STATUS & COUNTY & COORDINATE & $\begin{array}{l}\text { SOURCE } \\
\text { COORDINATE }\end{array}$ & $\begin{array}{c}\text { ELEV } \\
\text { FT }\end{array}$ & MAP NAME \\
\hline $\begin{array}{l}\text { Hacquehila Mountains } \\
\text { See Harquahala Mountains }\end{array}$ & range & VARIANT & Yuma & $334842 \mathrm{~N} 1132147 \mathrm{~W}$ & & & \\
\hline $\begin{array}{l}\text { Hades Knoll } \\
\text { Hades Lake } \\
\text { Hagen Canyon } \\
\text { Hagen Creek } \\
\text { Hagen Draw } \\
\text { Hagen Ranch } \\
\text { Hagen Ranch } \\
\text { Hagens Point } \\
\text { Hagen Tank } \\
\text { Hagen Well }\end{array}$ & $\begin{array}{l}\text { summit } \\
\text { lake } \\
\text { valley } \\
\text { stream } \\
\text { valley } \\
\text { locale } \\
\text { locale } \\
\text { cliff } \\
\text { reservoir } \\
\text { well }\end{array}$ & $\begin{array}{l}\text { BGN } \\
8 G N \\
8 G N \\
\text { BGN } \\
\text { BGN } \\
\text { UNOFF } \\
\text { UNOFF } \\
\text { BGN } \\
\text { BGN } \\
\text { UNOFF }\end{array}$ & $\begin{array}{l}\text { Mohave } \\
\text { Coconino } \\
\text { Pinal } \\
\text { Greenlee } \\
\text { Greenlee } \\
\text { Gila } \\
\text { Pinal } \\
\text { Graham } \\
\text { Gila } \\
\text { Gila }\end{array}$ & $\begin{array}{l}362042 N 1125107 W \\
361543 N 1120452 W \\
325316 N 1103413 W \\
333835 N 1092144 W \\
333835 N 1092143 W \\
330939 N 1105232 W \\
331514 N 1105705 W \\
323804 N 1095048 W \\
332014 N 1104712 W \\
331850 N 1103303 W\end{array}$ & $\begin{array}{l}325202 \mathrm{~N} 1103147 \mathrm{~W} \\
333703 \mathrm{N1092140W} \\
333701 \mathrm{N1092139W}\end{array}$ & $\begin{array}{l}8891 \\
3470\end{array}$ & $\begin{array}{l}\text { S B Point } \\
\text { Little Park Lane } \\
\text { Brandenburg Mtn } \\
\text { Hannagan Meadow } \\
\text { Hannagan Meadow } \\
\text { Sonora } \\
\text { Pinal Ranch } \\
\text { Mt Graham } \\
\text { Pinal Peak } \\
\text { Bucket Mtn }\end{array}$ \\
\hline $\begin{array}{l}\text { Haguaba } \\
\text { See Harcuvar Peak } \\
\text { Hagua Hali } \\
\text { See Utting } \\
\text { Ha-hi-yalin Wash } \\
\text { See Ha-whi-yalin Wash } \\
\text { Ha Ho No Geh Canyon } \\
\text { Coal Canyon } \\
\text { Hah-quah-sa eel } \\
\text { See Gila River }\end{array}$ & $\begin{array}{l}\text { summit } \\
\text { locale } \\
\text { stream } \\
\text { valley }\end{array}$ & $\begin{array}{l}\text { VARIANT } \\
\text { VARIANT } \\
\text { VARIANT } \\
\text { BGN } \\
\text { VARIANT } \\
\text { VARIANT }\end{array}$ & $\begin{array}{l}\text { Yuma } \\
\text { Yuma } \\
\text { Navajo } \\
\text { Coconino }\end{array}$ & $\begin{array}{l}335459 \mathrm{~N} 1133824 \mathrm{~W} \\
335020 \mathrm{~N} 1135310 \mathrm{~W} \\
353556 \mathrm{~N} 1102434 \mathrm{~W} \\
360732 \mathrm{~N} 1110034 \mathrm{~W} \\
324311 \mathrm{~N} 1143316 \mathrm{~W}\end{array}$ & $355404 \mathrm{~N} 1105328 \mathrm{~W}$ & & Middle Mesa \\
\hline $\begin{array}{l}\text { Haigler Canyon } \\
\text { Haigler Creek } \\
\text { Haines Flat } \\
\text { The Flat } \\
\text { The Haines Flat } \\
\text { The Hanes Flat } \\
\text { Hair Clipper Wash } \\
\text { Hairpin Spring } \\
\text { Hairpin Spring } \\
\text { Haist Mine }\end{array}$ & $\begin{array}{l}\text { stream } \\
\text { dam } \\
\text { spring } \\
\text { mine }\end{array}$ & $\begin{array}{l}\text { BGN } \\
\text { BGN } \\
\text { BGN } 1964 \\
\text { VARIANT } \\
\text { VARIANT } \\
\text { VARIANT } \\
\text { BGK } \\
\text { UNOFF } \\
\text { BGN } \\
\text { UNOFF }\end{array}$ & $\begin{array}{l}\text { Mohave } \\
\text { Gila } \\
\text { Gila } \\
\text { Santa Cruz }\end{array}$ & $\begin{array}{l}345637 N 1134304 \mathrm{~W} \\
330000 \mathrm{~N} 1104730 \mathrm{~W} \\
332223 \mathrm{~N} 1105650 \mathrm{~W} \\
312509 \mathrm{N1} 104307 \mathrm{~W}\end{array}$ & $\begin{array}{l}341420 \mathrm{~N} 1105640 \mathrm{~W} \\
341250 \mathrm{~N} 1104935 \mathrm{~W}\end{array}$ & & $\begin{array}{l}\text { Pilgrim Wash } \\
\text { Hayden } \\
\text { Pinal Ranch } \\
\text { Harshaw }\end{array}$ \\
\hline $\begin{array}{l}\text { Haivana Nakya } \\
\text { Baboquerque Fields } \\
\text { Crow Hanging } \\
\text { Havana Nakya } \\
\text { Havanaki } \\
\text { San Ysidro } \\
\text { Santa Cruz }\end{array}$ & $\mathrm{pp} 1$ & $\begin{array}{l}8 G N 1941 \\
\text { VARIANT } \\
\text { VARIANT } \\
\text { VARIANT } \\
\text { VARIANT } \\
\text { VARIANT } \\
\text { VARIANT }\end{array}$ & Pima & $320024 N 1114247 \mathrm{~W}$ & & & Haivana Nakya \\
\hline $\begin{array}{l}\text { Haivan Vaya } \\
\text { Hakatai Canyon } \\
\text { Hackataia }\end{array}$ & $\begin{array}{l}\text { locale } \\
\text { valley }\end{array}$ & $\begin{array}{l}\text { BGN } \\
\text { BGN } 1910 \\
\text { VARIANT }\end{array}$ & $\begin{array}{l}\text { Pima } \\
\text { Coconino }\end{array}$ & $\begin{array}{l}313635 \mathrm{~N} 1115222 \mathrm{~W} \\
361441 \mathrm{~N} 1122304 \mathrm{~W}\end{array}$ & $361655 \mathrm{~N} 1122123 \mathrm{~W}$ & 2829 & $\begin{array}{l}\text { San Miguel } \\
\text { Explorers Monument }\end{array}$ \\
\hline $\begin{array}{l}\text { Hakatai Rapids } \\
\text { Hale Elementary School } \\
\text { Hale Tank } \\
\text { Hale Tank } \\
\text { Haley Hills } \\
\text { Haleys Mountain } \\
\text { Haley Spring } \\
\text { Haleys Spring } \\
\text { Haleys Wash } \\
\text { Half Barrel Spring }\end{array}$ & $\begin{array}{l}\text { rapids } \\
\text { school } \\
\text { reservoir } \\
\text { reservoir } \\
\text { summit } \\
\text { summit } \\
\text { spring } \\
\text { spring } \\
\text { arroyo } \\
\text { spring }\end{array}$ & $\begin{array}{l}\text { BGN } 1932 \\
\text { UNOFF } \\
\text { BGN } \\
\text { BGN } \\
\text { BGN } \\
\text { BGN } \\
\text { BGN } \\
\text { BGN } \\
\text { BGN } \\
\text { BGN }\end{array}$ & $\begin{array}{l}\text { Coconino } \\
\text { Maricopa } \\
\text { Gila } \\
\text { Gila } \\
\text { Pinal } \\
\text { Pinal } \\
\text { Pinal } \\
\text { Mohave } \\
\text { Mohave } \\
\text { Gila }\end{array}$ & $\begin{array}{l}361437 \mathrm{~N} 1122312 \mathrm{~W} \\
332630 \mathrm{~N} 1114648 \mathrm{~W} \\
331604 \mathrm{~N} 1105558 \mathrm{~W} \\
340642 \mathrm{~N} 1111853 \mathrm{~W} \\
325804 \mathrm{~N} 1121047 \mathrm{~W} \\
331039 \mathrm{N1} 105724 \mathrm{~W} \\
331056 \mathrm{~N} 1105538 \mathrm{~W} \\
343442 \mathrm{~N} 1132415 \mathrm{~W} \\
343250 \mathrm{~N} 113242 \mathrm{~W} \\
335101 \mathrm{~N} 1104735 \mathrm{~W}\end{array}$ & 343607 N1132438W & 4566 & $\begin{array}{l}\text { Explorers Monument } \\
\text { Mesa } \\
\text { Pinal Ranch } \\
\text { Gisela } \\
\text { Haley Hills } \\
\text { Hot Tamale Peak } \\
\text { Hot Tamale Peak } \\
\text { Kaiser Spring } \\
\text { Kaiser Spring } \\
\text { Sombrero Peak }\end{array}$ \\
\hline $\begin{array}{l}\text { Half Dome } \\
\text { See Segeke Butte } \\
\text { Half Moon Ridge } \\
\text { Half Moon Spring } \\
\text { Half Moon Spring } \\
\text { Halfmoon Tank } \\
\text { Halfmoon Tank } \\
\text { Half Moon Tank } \\
\text { Halfmoon Valley } \\
\text { Half Pint Tank }\end{array}$ & $\begin{array}{l}\text { summit } \\
\text { ridge } \\
\text { spring } \\
\text { spring } \\
\text { reservoir } \\
\text { reservoir } \\
\text { reservoir } \\
\text { valley } \\
\text { reservoir }\end{array}$ & $\begin{array}{l}\text { VARIANT } \\
\text { BGN } \\
\text { BGN } \\
\text { BGN } \\
\text { BGN } \\
\text { BGN } \\
\text { BGN } \\
\text { BGN } \\
\text { BGN }\end{array}$ & $\begin{array}{l}\text { Navajo } \\
\text { Gila } \\
\text { Graham } \\
\text { Gila } \\
\text { Cochise } \\
\text { Cochise } \\
\text { Pinal } \\
\text { Cochise } \\
\text { Coconino }\end{array}$ & $\begin{array}{l}364717 N 1101618 W \\
334734 N 1110949 W \\
323508 N 1094928 W \\
340639 N 1112559 W \\
313539 N 1092135 W \\
315443 N 1095835 W \\
325824 N 1110949 W \\
313533 N 1092130 W \\
350124 N 1113736 W\end{array}$ & $313720 \mathrm{~N} 1092225 \mathrm{~W}$ & & $\begin{array}{l}\text { Greenback Creek } \\
\text { Stockton Pass } \\
\text { Mazatzal Peak } \\
\text { Pedregosa Mts East } \\
\text { Cochise Stronghold } \\
\text { Ninetysix Hills NW } \\
\text { Pedregosa Mts East } \\
\text { Mountainaire }\end{array}$ \\
\hline $\begin{array}{l}\text { Half Section Tank } \\
\text { Halfway Bend } \\
\text { Halfway Corral } \\
\text { Halfway Detention Dam } \\
\text { Halfway House } \\
\text { Halfway House Tank } \\
\text { Halfway Picnic Area } \\
\text { Halfway Ranch } \\
\text { Halfway Tank }\end{array}$ & $\begin{array}{l}\text { reservoir } \\
\text { bend } \\
\text { locale } \\
\text { dam } \\
\text { locale } \\
\text { reservoir } \\
\text { park } \\
\text { locale } \\
\text { basin }\end{array}$ & $\begin{array}{l}\text { BGN } \\
\text { BGN } \\
\text { BGN } \\
\text { UNOFF } \\
\text { BGN } \\
\text { BGN } \\
\text { ADMIN } \\
\text { UNOFF } \\
\text { BGN }\end{array}$ & $\begin{array}{l}\text { Green lee } \\
\text { La Paz } \\
\text { Maricopa } \\
\text { Graham } \\
\text { Yavapai } \\
\text { Yavapai } \\
\text { Coconino } \\
\text { Navajo } \\
\text { Yuma }\end{array}$ & $\begin{array}{l}334626 \mathrm{~N} 1090840 \mathrm{~W} \\
335000 \mathrm{~N} 1144500 \mathrm{~W} \\
324612 \mathrm{~N} 1123132 \mathrm{~W} \\
324436 \mathrm{~N} 1093242 \mathrm{~W} \\
344752 \mathrm{~N} 1130419 \mathrm{~W} \\
344752 \mathrm{~N} 1130416 \mathrm{~W} \\
345724 \mathrm{~N} 1114515 \mathrm{~W} \\
344221 \mathrm{~N} 1100818 \mathrm{~W} \\
322018 \mathrm{~N} 1135139 \mathrm{~W}\end{array}$ & & $\begin{array}{l}1723 \\
5600 \\
5035\end{array}$ & $\begin{array}{l}\text { Alpine } \\
\text { Big Maria Mts SE } \\
\text { Blue Plateau } \\
\text { Artesia NE } \\
\text { Scratch Canyon } \\
\text { Scratch Canyon } \\
\text { Wilson Mountain } \\
\text { Flattop Hill } \\
\text { Cabeza Prieta Peak }\end{array}$ \\
\hline
\end{tabular}


NATIONAL GAZETTEER--ARIZONA 1986

\section{FEATURE NAME}

Halfway Tank

Halfway Tank

Halfway Tank

Halfway Tank

Halfway Tank

Halfway Well

Half White Mountain

Hali Murk

Haal-Muihedak

Hardimui

Harle Muheta

Har lemuheta

Mesqual

Mesquit

Hali Murk Wash

Hallburn Ridge

Hall Butte

Hall Canyon

See Tillie Hall Canyon

Hall Cienega

Hall Creek

Hall Forest Camp

Hal Imark Pond

Hall Park

See Agua Linda Park

Hall Point

Halls Mesa

Halls Ranch

Halls Tank

Halls Tank Number One

Halls Tank Number Three

Halls Tank Number Two

Ha11 Tank

Hall Tank

Hall Tank

Hall Tank

Hall Valley

See Little Rainbow Valley

Ha11 Well

Hambl in Ridge

See Echo Cliffs

Hambl in Ridge

Hambl in Spring

Hamblin Tank

Hamblin Wash

Hamburg Mine

Hamidreek Point

See Hamidrik Point

Hamidrik Point Hamidreek Point

Hamilton Canyon

Hamilton Corner

Hamilton Crossing

Hamilton Mesa

Hamilton Shaft

Hamilton Spring

Hamilton Tank

Haml in Wash

Hammer Tank

Hammond Ranch

Hampe Ranch

See Rucker Canyon Ranch

Hampson Mine

Ham Tank

Hance Canyon

Hance Creek

Hance Mesa Tank

Hance Rapids

Hance Spring

Hance Spring

Hance Tank

$$
\begin{aligned}
& \text { FEATUR } \\
& \text { CLASS } \\
& \text { reservo } \\
& \text { reservo } \\
& \text { reserv } \\
& \text { reserv } \\
& \text { reserv } \\
& \text { well } \\
& \text { summit } \\
& \text { locale } \\
&
\end{aligned}
$$

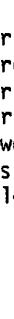$$
\text { locale } B G N
$$

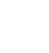$$
\begin{array}{llll} 
& & & \\
\text { stream } & \text { BGN } & \text { Pima } & 315826 N 1121855 \mathrm{~W} \\
\text { ridge } & \text { BGN } & \text { Navajo } & 364109 \mathrm{N1101134W}
\end{array}
$$$$
\text { summit BGN } 1932 \text { Coconino 360449N1115835W }
$$$$
\text { valley VARIANT Greenlee 325859N1090254W }
$$

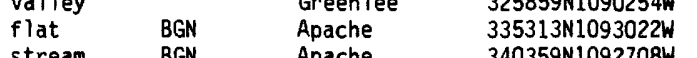$$
\text { stream BGN Apache 340359N1092708W }
$$$$
\text { reservoir BGN Mohave 362632N1132428W }
$$$$
\text { park Maricopa 333127N1115336W }
$$

\begin{tabular}{|c|c|c|c|}
\hline $\begin{array}{l}\text { FEATURE } \\
\text { CLASS }\end{array}$ & STATUS & COUNTY & COORDINATE \\
\hline reservoir & BGN & Gila & $333826 \mathrm{~N} 1100213 \mathrm{~K}$ \\
\hline $\begin{array}{l}\text { reservoir } \\
\text { reservoir } \\
\text { reservoir } \\
\text { reservoir } \\
\text { well } \\
\text { summit } \\
\text { locale }\end{array}$ & $\begin{array}{l}\text { BGN } \\
\text { BGN } \\
\text { BGN } \\
\text { BGN } \\
\text { UNOFF } \\
\text { BGN } \\
\text { BGN 1941 } \\
\text { VARIANT } \\
\text { VARIANT } \\
\text { VARIANT } \\
\text { VARIANT } \\
\text { VARIANT } \\
\text { VARIANT }\end{array}$ & $\begin{array}{l}\text { Navajo } \\
\text { Yavapai } \\
\text { Yavapai } \\
\text { Coconino } \\
\text { Mohave } \\
\text { Yuma } \\
\text { Pima }\end{array}$ & $\begin{array}{l}342213 \mathrm{~N} 1101141 \mathrm{~K} \\
344749 \mathrm{~N} 112142 \mathrm{~W} \\
345650 \mathrm{~N} 1120542 \mathrm{~W} \\
355810 \mathrm{~N} 1120151 \mathrm{~K} \\
343759 \mathrm{N1} 134429 \mathrm{~W} \\
324652 \mathrm{N1132705} \\
320004 \mathrm{~N} 1121737 \mathrm{~W}\end{array}$ \\
\hline $\begin{array}{l}\text { stream } \\
\text { ridge } \\
\text { summit }\end{array}$ & $\begin{array}{l}\text { BGN } \\
\text { BGN } \\
\text { BGN } 1932 \\
\text { VARIANT }\end{array}$ & $\begin{array}{l}\text { Pima } \\
\text { Navajo } \\
\text { Coconino }\end{array}$ & $\begin{array}{l}315826 \mathrm{~N} 1121855 \mathrm{~W} \\
364109 \mathrm{~N} 1101134 \mathrm{~W} \\
360449 \mathrm{~N} 1115835 \mathrm{~W}\end{array}$ \\
\hline $\begin{array}{l}\text { valley } \\
\text { flat } \\
\text { stream } \\
\text { locale } \\
\text { reservoir }\end{array}$ & $\begin{array}{l}\text { BGN } \\
\text { BGN } \\
\text { BGN } \\
\text { BGN } \\
\text { VARIANT }\end{array}$ & $\begin{array}{l}\text { Greenlee } \\
\text { Apache } \\
\text { Apache } \\
\text { Apache } \\
\text { Mohave }\end{array}$ & $\begin{array}{l}325859 \mathrm{~N} 1090254 \mathrm{~W} \\
335313 \mathrm{~N} 109302 \mathrm{~W} \\
340359 \mathrm{~N} 1092708 \mathrm{~W} \\
334751 \mathrm{~N} 1091951 \mathrm{~K} \\
362632 \mathrm{~N} 1132428 \mathrm{~W}\end{array}$ \\
\hline park & & Maricopa & $333127 N 1115336 \mathrm{~W}$ \\
\hline
\end{tabular}

\section{summit BGN Navajo 342103N1102423W}

summit BGN Graham 324735N1094614W

locale UNOFF Apache 340841N1093203W

reservoir BGN Apache 340924N1093057W

reservoir BGN Apache 341058N1093255W

reservoir BGN Apache 340701N1093316W

reservoir BGN Apache 340917N1093220W

reservoir BGN Pima 315715N1111746W

reservoir BGN Apache 334937N1090722W

reservoir BGN Navajo 342054N1102427W

reservoir BGN Coconino 352820N1114002W

valley VARIANT Maricopa 331030N1124230W

well UNOFF Yuma 330145 N1132255W

cliff VARIANT Coconino 362445N1113129W

ridge BGN Coconino 361600N1112458W

spring BGN Apache 342409N1093050W

reservoir BGN Apache 334919N1090646W

stream BGN Coconino 360147N1112335W

$\begin{array}{llll}\text { mine } & \begin{array}{l}\text { UNOFF } \\ \text { VARIANT }\end{array} & \text { Cochise } & \text { 312528N1101930W } \\ \text { cliff } & \text { Coconino } & 362016 \text { N1123502W } \\ \text { cliff } & \text { BGN 1925 } & \text { Coconino } & 362016 \text { N1123502W } \\ & \text { VARIANT } & \text { Greeniee } & 330821 \text { 11091041W } \\ \text { valley } & \text { BGN } & \text { Maricopa } & 331452 N 1115026 \mathrm{~W} \\ \text { locale } & \text { BGN } & \text { Coconino } & 343917 \text { N1105949W } \\ \text { locale } & \text { BGN } & \text { Greenlee } & 330703 \text { N1090950W } \\ \text { summit } & \text { BGN } & \text { 332302N1105846W } \\ \text { mine } & \text { UNOFF } & \text { Gila } & \end{array}$

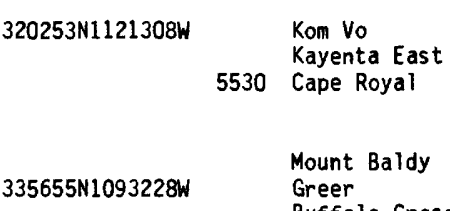

335655 N1093228W

\begin{tabular}{|c|c|c|}
\hline $320253 \mathrm{~N} 1121308 \mathrm{~W}$ & 5530 & $\begin{array}{l}\text { Kom Vo } \\
\text { Kayenta East } \\
\text { Cape Royal }\end{array}$ \\
\hline \multirow[t]{4}{*}{$335655 \mathrm{~N} 1093228 \mathrm{~W}$} & & $\begin{array}{l}\text { Mount Baldy } \\
\text { Greer } \\
\text { Buffalo Crossing } \\
\text { Poverty Knoll }\end{array}$ \\
\hline & & $\begin{array}{l}\text { Day Spring } \\
\text { Thatcher } \\
\text { Whiting Knoll } \\
\text { Whiting Knoll } \\
\text { Whiting Knoll } \\
\text { Greens Peak } \\
\text { Whiting Knoll } \\
\text { Stevens Mtn } \\
\text { Luna Lake } \\
\text { Day Spring }\end{array}$ \\
\hline & & White Horse Hills \\
\hline & & Baragan Mtn \\
\hline \multirow[t]{3}{*}{$362240 \mathrm{~N} 1113216 \mathrm{~W}$} & & $\begin{array}{l}\text { The Gap } \\
\text { Concho } \\
\text { Luna Lake } \\
\text { Shadow Mtn Well }\end{array}$ \\
\hline & & Miller Peak \\
\hline & & Fossil Bay \\
\hline $330547 N 1091034 \mathrm{~W}$ & $\begin{array}{l}1219 \\
6367\end{array}$ & $\begin{array}{l}\text { Dix Creek } \\
\text { Gila Butte } \\
\text { Hamilton Crossing } \\
\text { Rattlesnake Spring } \\
\text { Inspiration }\end{array}$ \\
\hline $340146 \mathrm{~N} 1123322 \mathrm{~W}$ & & $\begin{array}{l}\text { Rattlesnake Spring } \\
\text { Dix Creek } \\
\text { Morgan Butte } \\
\text { Harbison Tank } \\
\text { Sonoita }\end{array}$ \\
\hline 355851 N1115838W & & $\begin{array}{l}\text { Harshaw } \\
\text { Williams South } \\
\text { Cape Royal }\end{array}$ \\
\hline $355840 \mathrm{~N} 1115730 \mathrm{~W}$ & & $\begin{array}{l}\text { Cape Royal } \\
\text { Estler Peak } \\
\text { Cape Royal } \\
\text { Walker Mtn } \\
\text { Cherry } \\
\text { Walker Mtn }\end{array}$ \\
\hline
\end{tabular}

Pinedale

Munds Draw Sycamore Bas in Tusayan East Aubrey Peak Aztec Hills Pisinimo
Walker Mtn 


\section{FEATURE NAME}

Hance Trail

Hancock Butte

Hancock Canyon

Hancock Knoll

Hancock Knolls

Hancock Ranch

Hancock Tank

Hancock Tank

Handcock Tank

Hands Pass

Hanegras Plain

See Ranegras Plain

Hanging Rock Spring

Hanging Water Well

Hangmans Canyon

Hanks Corral

Hanks Draw

Hanks Tank

Hanks Tank

Hanks Trading Post

Hanks Trick Tank

Han Tey Tank

Hanna Dam

Hannagan Campground

Hannagan Creek Hannegan Creek

Hannagan Meadow Hannegan Meadow

Hannah Hot Spring

Hannah Spring Creek

See Hannah Springs Creek

Hannah Springs Creek Hannah Spring Creek

Hanna Lateral

Hannegan Creek

See Hannagan Creek

Hannegan Meadow

See Hannagan Meadow

Hano

Hansbrough-Richard Rapids

See Hansbrough-Richards Rapid

Hansbrough-Richards Rapid Hansbrough-Richard Rapids

Hansen Canyon
See Two E Wash
Hansen Canyon
See K H Canyon
Hansen Canyon
Hansen Junction
See West Chandler
Hansen Tank
Hansen Tank
Hanson Tank
Happy Camp
Happy Camp Canyon
Happy Camp Canyon
Happy Camp Canyon
Happy Camp Spring
Happy Camp Tank
Happy Camp Wash
Happy Camp Well
Happy Camp Well
Happy Days Travel Trailer Park

Happy Hollow Canyon
Happy Jack
Happy Jack Mine
Happy Jack Ranger Station
Happy Jack Tank
Happy Jack Underpass
Happy Jack Wash

\section{FEATURE \\ CLASS}

STATUS

trail

summit

valley

UNOFF

BGN 1932

summit

BGN

summit

locale

reservoir

reservoir

reservoir

gap

plain

spring

well

BGN

UNOFF

$B G N$

$B G N$
$B G N$
$B G N$

VARIANT

$B G N$

UNOFF

valley

locale

valley

reservoir

reservoir

locale

reservoir

reservoir

dam

park

BGN
$B G N$
$B G N$
$B G N$
$B G N$
$B G N$
$B G N$
$B G N$
UNOFF

$B G N$

G

$B G N$

BGN

ADMIN

stream

locale

BGN

VARIAN

BGN

VARIANT

spring

VARIANT

strean

stream

canal

BGN

VARIANT

BGI

VARIANT

stream

locale

ppl

rapids

rapids

VARIANT

BGN 1915
VARIANT

BGN 1975

VARIANT

VARIANT

strea

valley

valley

locale

reservoir

reservoir

reservoir

VARIANT

BGN

VARIANT

locale

valley

valley

valley

spring

reservoir

strean

well

well

locale

$\begin{array}{lll}\text { valley } & \text { BGN } & \text { Yavapai } \\ \text { ppl } & \text { BGN } & \text { Coconino } \\ \text { mine } & \text { UNOFF } & \text { Santa Cruz } \\ \text { locale } & \text { UNOFF } & \text { Coconino } \\ \text { reservoir } & \text { BGN } & \text { Coconino } \\ \text { crossing } & \text { UNOFF } & \text { Mohave } \\ \text { stream } & \text { BGN } & \text { Mohave }\end{array}$

COUNFY

Coconino

Coconino

Mohave

Mohave

Yavapai

Navajo

Coconino

Coconino

Cochise

Yuma

Gila

Apache

Santa Cruz

Graham

Navajo

Yavapai

Coconino

Coconino

Navajo

Yuma

Pima

Greenlee

Greenlee

Greenlee

Greenlee

Greenlee Greenlee

Yuma

Greenlee

Greenlee

Navajo

Coconino

Coconino

COORDINATE

360113N1115546W $361541 \mathrm{N1115826 \textrm {W }}$ $364908 \mathrm{~N} 1135459 \mathrm{~W}$ $362503 \mathrm{~N} 1125748 \mathrm{~W}$

$362509 N 1125802 \mathrm{~W}$ $345616 \mathrm{~N} 1115536 \mathrm{~W}$ $343312 N 1104438 \mathrm{~W}$ $343556 \mathrm{~N} 1110946 \mathrm{~W}$ $350010 N 1115229 \mathrm{~W}$ $315927 N 1091741 \mathrm{~W}$

$333916 \mathrm{~N} 1134835 \mathrm{~W}$ $341256 \mathrm{~N} 1112506 \mathrm{~W}$ $353945 N 1094318 \mathrm{~W}$

312948 N1105129W $32470 \mathrm{BN} 1102648 \mathrm{~W}$ $342720 \mathrm{~N} 1103913 \mathrm{~W}$ $343152 \mathrm{~N} 1120339 \mathrm{~W}$ $343324 N 1111719 \mathrm{~W}$ $353533 \mathrm{~N} 1113138 \mathrm{~W}$ $342501 N 1104246 \mathrm{~W}$ $331520 \mathrm{N1132145 \textrm {W }}$ $314950 \mathrm{~N} 110473 \mathrm{BW}$ 333809 N1091934W

$334207 N 1091444 W$

333832N1091924W

332401N1090907W

$332352 \mathrm{~N} 1090922 \mathrm{~W}$ $332352 \mathrm{~N} 1090922 \mathrm{~W}$

324042N1144000W

$334207 N 1091444 \mathrm{~W}$

$333832 \mathrm{~N} 1091924 \mathrm{~W}$ $355013 \mathrm{~N} 1102330 \mathrm{~W}$

363442N1114729W

363442N1114729W

Graham

Grahan

Graham

Maricopa

Navajo

Navajo

Mohave

Pinal

Cochise

Pinal

Yuma

Pinal

Yavapai

Cochise

Yuma

Yavapai

Maricopa

324038N1101134W

$323955 \mathrm{~N} 1101000 \mathrm{~W}$

$324055 \mathrm{~N} 1101040 \mathrm{~W}$

$331819 N 1115642 \mathrm{~W}$

$340717 \mathrm{N1095816 \textrm {W }}$

$341213 \mathrm{~N} 1100419 \mathrm{~W}$

$352138 \mathrm{~N} 1132356 \mathrm{~W}$

331836N1110827W $321420 \mathrm{~N} 1093057 \mathrm{~W}$ $331745 \mathrm{~N} 1110851 \mathrm{~W}$

$335921 \mathrm{N1132424 \textrm {W }}$ $331835 \mathrm{~N} 1110825 \mathrm{~W}$ $350139 \mathrm{~N} 1125546 \mathrm{~W}$ $321652 \mathrm{N109} 2734 \mathrm{~W}$ $335739 N 1132513 \mathrm{~W}$ $350102 \mathrm{~N} 1125614 \mathrm{~W}$ $332524 \mathrm{N1} 11345 \mathrm{OW}$

$344835 \mathrm{~N} 1131031 \mathrm{~W}$

$344436 \mathrm{~N} 1112424 \mathrm{~W}$

313611 11104851W

$344425 \mathrm{~N} 1112437 \mathrm{~W}$

$344456 \mathrm{~N} 1112352 \mathrm{~W}$

$344853 \mathrm{~N} 1140845 \mathrm{~W}$

$344840 \mathrm{~N} 1140933 \mathrm{~W}$

\begin{tabular}{ccc}
$\begin{array}{c}\text { SOURCE } \\
\text { COORDINATE }\end{array}$ & $\begin{array}{c}\text { ELEV } \\
\text { FT }\end{array}$ & \multicolumn{1}{c}{ MAP NAME } \\
364824N1135054W & $\begin{array}{l}\text { Cape Royal } \\
\text { Point Imperial } \\
\text { Elbow Canyon } \\
\text { Hancock Knolls }\end{array}$ \\
6450 & \\
& $\begin{array}{l}\text { Hancock Knolls } \\
\text { Loy Butte } \\
\text { Potato Wash South } \\
\text { Blue Ridge Reservoir } \\
\text { Dutton Hill } \\
\text { Rustler Park }\end{array}$ \\
& 6649
\end{tabular}

North Peak

Cornfields

313237 N1105016W

$342416 \mathrm{~N} 1104330 \mathrm{~W}$

Cumero Canyon

0ak Grove Canyon

Hanks Draw

Cherry

Long Valley

East of $S$ P Mtn

Hanks Draw

Columbus Peak

Helvetia

9141 Hannagan Meadow

333812N1091853W

Beaverhead

Hannagan Meadow

Dutch Blue Creek

Dutch Blue Creek

Yuma West

Polacca

North Canyon Point

$324421 \mathrm{~N} 1100417 \mathrm{~W}$

Eureka Ranch

Indian Pine

Show Low South

Tuckayou Spring

$321254 \mathrm{~N} 1093401 \mathrm{~W}$ $331957 N 1110724 \mathrm{~W}$ $340050 \mathrm{~N} 1132627 \mathrm{~W}$

Oos Cabezas

Picketpost Mtn

Webber Canyon

Picketpost Mtn

$321403 N 1093033 \mathrm{~W}$

Turkey Canyon

Bowie

Webber Canyon 6165 Turkey Canyon 


\section{FEATURE NAME}

Happy Tank

Happy Valley

Happy Valley Interchange

Happy Valley Lookout

Happy Valley Ranch

(subdivision)

Happy Valley Saddle

Harbison Tank

Harcuvar

Harcuvar Mountains

See Granite Wash Mountains

Harcuvar Mountains

Harquar Mountains

Huacavah

Huacavah Mountains

Harcuvar Mountains

Harcuvar Peak

$$
\text { Haguaba }
$$

Harcuvar Railiroad Station

Harcuvar Tank

Harden Cienega Creek

Hardimui

See Hali Murk

Hardimui

See Viason Chin

Harding Point

Harding School

Harding Spring

Hard Luck Ranch

Hard Luck Tank

Hard Pond

Hard Rock Mesa

Hard Rocks

Hard Rocks Dam

Hardscrabble Canyon

Hardscrabble Creek

East Fork Hardscrabble Creek

Hardscrabble Mesa

Hardscrabble Spring

Hardscrabble Tank

Hardscrabble Wash

Hardshell Mine

Hard Spring

Hardt Creek

Hardt Creek Well

Hardt imes Mine

Hardt Tank

Hardy

Hardy $\mathrm{Hill}$

Hardy Mounta in

Hardy-Schell Tank

Hardyville (historical)

Hardyville Mill (ruins)

Hardy Winter Camp

Harelson School
Winifred Harelson
Elementary School

Hargan Mine

Hargua Hala

See Nords Ranch

Harlemuheta

See Hali Murk

Harle Muheta

See Hali Murk

Harl Tank

Harman Tank

Harmonia Villa

See Harmony villa

Harmon Lateral

Harmon Park

\section{FEATURE \\ CLASS}

reservoir

basin

STATUS

COUNTY

COORDINATE

$343053 \mathrm{~N} 1102057 \mathrm{~W}$

$320912 \mathrm{~N} 1102756 \mathrm{~W}$

$334246 \mathrm{~N} 1120700 \mathrm{~W}$

locale BGN Pima 321006N1103121W

ppl BGN Maricopa 334257N1115357W

gap BGN Pima 320924N1103128W

reservoir BGN Coconino 354724N1115354W

ppl BGN Yuma 334536N1133909W

range

range

VARIANT

Yuma

La Paz

$334929 \mathrm{~N} 1134231 \mathrm{~W}$

VARIANT

VARIANT

\begin{tabular}{|c|c|c|c|}
\hline $\begin{array}{l}\text { ange } \\
\text { umm it }\end{array}$ & $\begin{array}{l}\text { BGN } \\
\text { BGN } \\
\text { VARIANT }\end{array}$ & $\begin{array}{l}\text { Yavapai } \\
\text { Yuma }\end{array}$ & $\begin{array}{l}340344 \mathrm{~N} 1132207 \mathrm{~W} \\
335459 \mathrm{~N} 1133824 \mathrm{~W}\end{array}$ \\
\hline $\begin{array}{l}\text { building } \\
\text { reservoir } \\
\text { stream }\end{array}$ & $\begin{array}{l}\text { UNOFF } \\
\text { BGN } \\
\text { BGN } \\
\text { VARIANT }\end{array}$ & $\begin{array}{l}\text { La Paz } \\
\text { Yavapai } \\
\text { Greenlee }\end{array}$ & $\begin{array}{l}334537 N 1133913 \mathrm{~W} \\
340103 \mathrm{~N} 1130915 \mathrm{~W} \\
331203 \mathrm{~N} 1090812 \mathrm{~W}\end{array}$ \\
\hline locale & & Pima & 320004 N1121737 \\
\hline locale & & Pima & $320055 \mathrm{~N} 1121723 \mathrm{~V}$ \\
\hline $\begin{array}{l}\text { cliff } \\
\text { school } \\
\text { spring } \\
\text { locale } \\
\text { reservoir } \\
\text { reservoir } \\
\text { summit } \\
\text { locale } \\
\text { dam } \\
\text { valley }\end{array}$ & $\begin{array}{l}\text { BGN } \\
\text { UNOFF } \\
\text { BGN } \\
\text { UNOFF } \\
\text { BGN } \\
\text { BGN } \\
\text { BGN } \\
\text { BGN } \\
\text { UNOFF } \\
\text { BGN }\end{array}$ & $\begin{array}{l}\text { Coconino } \\
\text { Pinal } \\
\text { Mohave } \\
\text { Santa Cruz } \\
\text { Coconino } \\
\text { Mohave } \\
\text { Coconino } \\
\text { Navajo } \\
\text { Navajo } \\
\text { Gila }\end{array}$ & $\begin{array}{l}350115 \mathrm{~N} 1114549 \mathrm{~W} \\
331716 \mathrm{N1} 110635 \mathrm{~W} \\
354014 \mathrm{N1} 134143 \mathrm{~W} \\
313130 \mathrm{~N} 1104826 \mathrm{~W} \\
344841 \mathrm{N1111930W} \\
363940 \mathrm{~N} 1132844 \mathrm{~W} \\
363233 \mathrm{~N} 1104950 \mathrm{~W} \\
360442 \mathrm{N1} 10261 \mathrm{~W} \\
360215 \mathrm{~N} 1102 \mathrm{~B} 40 \mathrm{~W} \\
34185 \mathrm{BN} 1113952 \mathrm{~W}\end{array}$ \\
\hline
\end{tabular}

valley

stream

BGN

VARIANT

summit

spring

reservoir

stream

mine

spring

$B G N$

BGN

BGN

BGN
UNOFF

BNOF

stream

BGN

well

mine

reservoir

locale

summit

summit

reservoir

ppl

locale

Jocale

UNOFF

UNOFF

BGN

BGN

BGN

BGN

BGN

BGN

BGN

BGN

school

UNOFF

VARIANT

mine UNOFF

locale

VARIANT

VARIANT

locale

locale

VARIANT

mine UNOFF Yavapai 342034N1121526W

reservoir BGN Yavapai 344540N1130226W

ppl

canal

park
Yavapai

Gila

Navajo

Yavapai

Apache

Santa Cruz

Gila

Gila

Yavapai

Greenlee

Coconino

Mohave

Yavapai

Mohave

Mohave

Coconino

Pima

Maricopa

Yuma

Pima

Pima

Maricopa

Yuma

Maricopa
334408 N1133150W

$320004 \mathrm{~N} 1121737 \mathrm{~W}$

$320004 N 1121737 \mathrm{~W}$

$332738 \mathrm{N1114132 \textrm {W }}$

$324305 \mathrm{~N} 1144206 \mathrm{~W}$

$332602 \mathrm{~N} 1120444 \mathrm{~W}$
SOURCE

COORDINATE

ELEV
FT

MAP NAME

Sheepsk in Wash

Happy Valley

Calderwood Butte

7348 Mica Mountain

2050 Currys Corner

Mica Mountain

Harbison Tank

1925 Harcuvar

Harcuvar Peak

Smith Peak

4618 Harcuvar Peak

Harcuvar

Date Creek Ranch SW

$330706 N 1090241 W$

Dix Creek

Dutton $\mathrm{Hill}$

Superior

Milkweed Canyon NW

4040 Patagonia

Jaycox Mtn

Dutchman Oraw

Whirlwind Rock

Hard Rocks

Hard Rocks

342212 N1113455W

Verde Hot Springs

Verde Hot Springs

Cane Springs Mtn

Limestone Canyon N

Brooklyn Peak

Cedar Lake Wash

Harshaw

Many Farms

Kayler Butte

$340051 N 1112434 \mathrm{~W}$

Gisela

Columbia

Florence Junction

Ash Peak

Sitgreaves Mtn

3235 Oatman

Behm Mesa

Davis Dam SE

Davis Dam SE

Hobble Tank

Tucson North

Woolsey Peak
Battle Flat

5666 Scratch Canyon

Yuma West

Phoenix 


\begin{tabular}{|c|c|c|c|c|c|c|c|}
\hline FEATURE NAME & $\begin{array}{l}\text { FEATURE } \\
\text { CLASS }\end{array}$ & STATUS & COUNTY & COORDINATE & $\begin{array}{l}\text { SOURCE } \\
\text { COORDINATE }\end{array}$ & $\begin{array}{c}\text { ELEV } \\
\text { FT }\end{array}$ & MAP NAME \\
\hline $\begin{array}{l}\text { Harmon Ranch } \\
\text { Harmon Tank } \\
\text { Harmony Villa } \\
\text { Harmonia Villa }\end{array}$ & $\begin{array}{l}\text { locale } \\
\text { reservoir } \\
\text { ppl }\end{array}$ & $\begin{array}{l}\text { UNOFF } \\
\text { BGN } \\
\text { BGN } \\
\text { VARIANT }\end{array}$ & $\begin{array}{l}\text { Cochise } \\
\text { Yavapai } \\
\text { Maricopa }\end{array}$ & $\begin{array}{l}314207 N 1095224 W \\
344900 N 1125936 W \\
33273 B N 1114132 W\end{array}$ & & & $\begin{array}{l}\text { Outl aw Mountain } \\
\text { Camp Wood } \\
\text { Buckhorn }\end{array}$ \\
\hline $\begin{array}{l}\text { Harold Bell Wright Park } \\
\text { Harolds Reservoir } \\
\text { Harolds Tank } \\
\text { Harold W Smith School } \\
\text { Harosoma } \\
\text { See Goldfield Mountains } \\
\text { Harosoma Mountains } \\
\text { See Goldfield Mountains } \\
\text { Harosoma Ridge } \\
\text { See Goldfield Mountains }\end{array}$ & $\begin{array}{l}\text { park } \\
\text { reservoir } \\
\text { reservoir } \\
\text { school } \\
\text { summit } \\
\text { summit } \\
\text { summit }\end{array}$ & $\begin{array}{l}\text { AOMIN } \\
\text { BGN } \\
\text { BGN } \\
\text { UNOFF } \\
\text { VARIANT } \\
\text { VARIANT } \\
\text { VARIANT }\end{array}$ & $\begin{array}{l}\text { Pima } \\
\text { Mohave } \\
\text { Yavapai } \\
\text { Maricopa } \\
\text { Maricopa } \\
\text { Maricopa } \\
\text { Maricopa }\end{array}$ & $\begin{array}{l}321345 \mathrm{~N} 1105120 \mathrm{~W} \\
364948 \mathrm{~N} 1130951 \mathrm{~W} \\
344632 \mathrm{~N} 1121307 \mathrm{~W} \\
333158 \mathrm{~N} 1121142 \mathrm{~W} \\
333112 \mathrm{~N} 1113046 \mathrm{~W} \\
333112 \mathrm{~N} 1113046 \mathrm{~W} \\
333112 \mathrm{~N} 1113046 \mathrm{~W}\end{array}$ & & & $\begin{array}{l}\text { Tucson East } \\
\text { White Pockets } \\
\text { Munds Draw } \\
\text { Glendale }\end{array}$ \\
\hline $\begin{array}{l}\text { Harper Canyon } \\
\text { Harper Mesa } \\
\text { Harper Tank } \\
\text { See Robbins Tank } \\
\text { Harper Tank } \\
\text { Harper Well } \\
\text { Harqua } \\
\text { Harquahala Mine } \\
\text { Harquahala Mountain } \\
\text { Harquahala Peak }\end{array}$ & $\begin{array}{l}\text { valley } \\
\text { summit } \\
\text { reservoir } \\
\text { reservoir } \\
\text { well } \\
\text { ppl } \\
\text { mine } \\
\text { summit }\end{array}$ & $\begin{array}{l}\text { BGN } \\
\text { BGN } \\
\text { VARIANT } \\
\text { BGN } 1981 \\
\text { UNOFF } \\
\text { BGN } \\
\text { UNOFF } \\
\text { BGN } \\
\text { VARIANT }\end{array}$ & $\begin{array}{l}\text { Yavapai } \\
\text { Greenlee } \\
\text { Yavapai } \\
\text { Yavapai } \\
\text { Coconino } \\
\text { Maricopa } \\
\text { Yuma } \\
\text { Yuma }\end{array}$ & $\begin{array}{l}341346 N 1124439 W \\
330653 N 1091508 \mathrm{~W} \\
344910 N 1130043 \mathrm{~W} \\
345005 \mathrm{~N} 1130237 \mathrm{~W} \\
351446 \mathrm{~N} 1114112 \mathrm{~W} \\
331435 \mathrm{~N} 1125954 \mathrm{~W} \\
334003 \mathrm{~N} 1133524 \mathrm{~W} \\
334840 \mathrm{~N} 1132046 \mathrm{~W}\end{array}$ & $341353 \mathrm{~N} 1124732 \mathrm{~W}$ & $\begin{array}{l}1080 \\
5681\end{array}$ & $\begin{array}{l}\text { Yarnell } \\
\text { Clifton } \\
\text { Scratch Canyon } \\
\text { Flagstaff West } \\
\text { Woolsey Peak } \\
\text { Harrisburg Valley } \\
\text { Harquahala Mtn }\end{array}$ \\
\hline $\begin{array}{l}\text { Harquahala Mountains } \\
\text { Hacquehila Mountains } \\
\text { Har-qua-halle Mountains } \\
\text { Huacahella Mountains } \\
\text { Penhatchapet Mountains } \\
\text { Harquahala Peak } \\
\text { See Harquahala Mountain } \\
\text { Harquahala Plain } \\
\text { Centennial Valley } \\
\text { Harqua Hala Plains } \\
\text { Harquahala Plains } \\
\text { Harquahala Valley }\end{array}$ & $\begin{array}{l}\text { summit } \\
\text { plain }\end{array}$ & $\begin{array}{l}\text { BGN } \\
\text { VARIANT } \\
\text { VARIANT } \\
\text { VARIANT } \\
\text { VARIANT } \\
\text { VARIANT } \\
\\
\text { BGN } 1964 \\
\text { VARIANT } \\
\text { VARIANT } \\
\text { VARIANT } \\
\text { VARIANT }\end{array}$ & $\begin{array}{l}\text { Yuma } \\
\text { Maricopa }\end{array}$ & $\begin{array}{l}334840 \mathrm{~N} 1132046 \mathrm{~W} \\
333611 \mathrm{~N} 1132033 \mathrm{~W}\end{array}$ & & & Courthouse Well \\
\hline $\begin{array}{l}\text { Harqua Hala Plains } \\
\text { See Harquahala Plain } \\
\text { Harquahala Plains } \\
\text { See Harquahala Plain } \\
\text { Harquahala Substation } \\
\text { Harquahala Valley } \\
\text { See Harquahala Plain } \\
\text { Harquahala Valley School } \\
\text { Har-qua-halle Mountains } \\
\text { See Harquahala Mountains }\end{array}$ & $\begin{array}{l}\text { plain } \\
\text { plain } \\
\text { locale } \\
\text { plain } \\
\text { school } \\
\text { range }\end{array}$ & $\begin{array}{l}\text { VARIANT } \\
\text { VARIANT } \\
\text { UNOFF } \\
\text { VARIANT } \\
\text { UNOFF } \\
\text { VARIANT }\end{array}$ & $\begin{array}{l}\text { Maricopa } \\
\text { Maricopa } \\
\text { Maricopa } \\
\text { Maricopa } \\
\text { Maricopa } \\
\text { Yuma }\end{array}$ & $\begin{array}{l}333611 N 1132033 W \\
333611 N 1132033 W \\
333115 N 1130730 W \\
333611 N 1132033 W \\
332614 N 1130952 W \\
334842 N 1132147 W\end{array}$ & & & Cortez Peak NW \\
\hline $\begin{array}{l}\text { Harquar Mountains } \\
\text { See Harcuvar Mountains } \\
\text { Harrahs Peak } \\
\text { See Boneyback Peak } \\
\text { Harrington Place } \\
\text { Harris } \\
\text { Harrisburg Cemetery } \\
\text { Harrisburg Valley } \\
\text { Harris Camp Canyon } \\
\text { Harris Camp Spring }\end{array}$ & $\begin{array}{l}\text { range } \\
\text { summit } \\
\text { locale } \\
\text { locale } \\
\text { cemetery } \\
\text { valley } \\
\text { valley } \\
\text { spring }\end{array}$ & $\begin{array}{l}\text { VARIANT } \\
\text { VARIANT } \\
\text { BGN } \\
\text { BGN } \\
\text { UNOFF } \\
\text { BGN } \\
\text { BGN } \\
\text { BGN }\end{array}$ & $\begin{array}{l}\text { La Paz } \\
\text { Gila } \\
\text { Pima } \\
\text { Mohave } \\
\text { La Paz } \\
\text { Yuma } \\
\text { Greenlee } \\
\text { Greenlee }\end{array}$ & $\begin{array}{l}335630 \mathrm{~N} 1133500 \mathrm{~W} \\
335142 \mathrm{~N} 1110953 \mathrm{~W} \\
320233 \mathrm{~N} 1103246 \mathrm{~W} \\
350813 \mathrm{~N} 1140459 \mathrm{~W} \\
334405 \mathrm{~N} 1133241 \mathrm{~W} \\
334335 \mathrm{~N} 1133033 \mathrm{~W} \\
325039 \mathrm{~N} 1091123 \mathrm{~W} \\
325012 \mathrm{~N} 1091629 \mathrm{~W}\end{array}$ & $\begin{array}{l}334550 \mathrm{~N} 1133509 \mathrm{~W} \\
325120 \mathrm{~N} 1091736 \mathrm{~W}\end{array}$ & & $\begin{array}{l}\text { Rincon Peak } \\
\text { Kingman } \\
\text { Harrisburg Valley } \\
\text { Harrisburg Valley } \\
\text { Sheldon } \\
\text { Ash Peak }\end{array}$ \\
\hline $\begin{array}{l}\text { Harris Cave } \\
\text { Harris Lake } \\
\text { Harris Lateral } \\
\text { Harris Mountain } \\
\text { Harrisonburg } \\
\quad \text { See Nords Ranch } \\
\text { Harrison Canyon } \\
\text { Harrison Canyon Dam } \\
\text { Harrison Creek } \\
\text { Harrison Mall }\end{array}$ & $\begin{array}{l}\text { cave } \\
\text { lake } \\
\text { canal } \\
\text { summit } \\
\text { locale } \\
\text { valley } \\
\text { dam } \\
\text { stream } \\
\text { locale }\end{array}$ & $\begin{array}{l}\text { BGN } \\
\text { BGN } \\
\text { BGN } \\
\text { BGN } \\
\text { VARIANT } \\
\text { BGN } \\
\text { UNOFF } \\
\text { BGN } \\
\text { UNOFF }\end{array}$ & $\begin{array}{l}\text { Apache } \\
\text { Apache } \\
\text { Yuma } \\
\text { Cochise } \\
\text { Yuma } \\
\text { Graham } \\
\text { Graham } \\
\text { Graham } \\
\text { Pima }\end{array}$ & $\begin{array}{l}341046 \mathrm{~N} 1093724 \mathrm{~W} \\
340853 \mathrm{~N} 1093731 \mathrm{~W} \\
323428 \mathrm{~N} 1144041 \mathrm{~W} \\
315939 \mathrm{~N} 1091116 \mathrm{~W} \\
\\
334408 \mathrm{~N} 1133150 \mathrm{~W} \\
323631 \mathrm{~N} 1100740 \mathrm{~W} \\
323412 \mathrm{~N} 1101448 \mathrm{~W} \\
323647 \mathrm{~N} 1100715 \mathrm{~W} \\
321325 \mathrm{~N} 1104725 \mathrm{~W}\end{array}$ & $\begin{array}{l}323423 \mathrm{~N} 1101459 \mathrm{~W} \\
323420 \mathrm{~N} 1101511 \mathrm{~W}\end{array}$ & $\begin{array}{l}B 685 \\
5649\end{array}$ & $\begin{array}{l}\text { Harrison Canyon } \\
\text { Harrison Canyon } \\
\text { Sierra Bonita Ranch } \\
\text { Tucson East }\end{array}$ \\
\hline $\begin{array}{l}\text { Harrison Tank } \\
\text { Harris Park } \\
\text { Harris Ranch } \\
\text { Harris Ranch } \\
\text { Harris Spring }\end{array}$ & $\begin{array}{l}\text { reservoir } \\
\text { flat } \\
\text { locale } \\
\text { locale } \\
\text { spring }\end{array}$ & $\begin{array}{l}\text { BGN } \\
\text { BGN } \\
\text { UNOFF } \\
\text { UNOFF } \\
\text { BGN }\end{array}$ & $\begin{array}{l}\text { Coconino } \\
\text { Coconino } \\
\text { Cochise } \\
\text { Pima } \\
\text { Yavapai }\end{array}$ & $\begin{array}{l}355029 \mathrm{~N} 1114407 \mathrm{~W} \\
343646 \mathrm{~N} 1112416 \mathrm{~W} \\
312440 \mathrm{~N} 1093449 \mathrm{~W} \\
315152 \mathrm{~N} 1111014 \mathrm{~W} \\
341421 \mathrm{~N} 1121417 \mathrm{~W}\end{array}$ & & & $\begin{array}{l}\text { Willows Camp } \\
\text { Calloway Butte } \\
\text { Douglas NE } \\
\text { Batamote Hills } \\
\text { Bumble Bee }\end{array}$ \\
\hline
\end{tabular}


NATIONAL GAZETTEER--ARIZONA 1986

\section{FEATURE NAME}

Harris Tank

Harris Tank

Harris Tank

Harris Wash

Harris Well

Harry Knight Spring

Harshaw

Harshaw Creek

Hart Canyon

Hartford Elementary School

Hartley Canyon

See Loy Canyon

Hartley Canyon

See Hart Well Canyon

Hartman Homestake Mines

Hartman Spring

Hartman Wash

Hart Mine

Hart Mine Wash

Hart Point

Hart Prairie

Hart Prairie Tank

Harts Butte

Hart Tank

Hart Tank

Hart Tank

Hart Well

Hartwell Canyon

See Hart Well Canyon

Hart We 11 Canyon Hartley Canyon Hartwell Canyon

Harvest Mission

Harvey Meadow

Harvey Mill Well

Harvey Mine

Harvey Spring

Harvey Tank

Harwood

Hasbidito Creek Hasbidi To Creek Hospitito Creek

Hasbidi To Creek

See Hasbidito Creek

Hasbidi To Spring

See Hasbidito Spring

Hasbidito Spring Hasbidi To Spring Hospitito Spring

Hasbidito Valley Hospitito Valley

Hashan Chuchg

Hashknife Tank

Has iamp

See Hassayampa River Has iamp River

See Hassayampa River

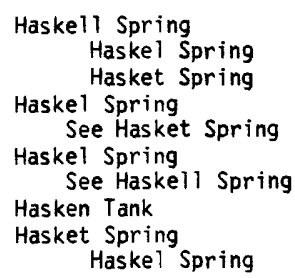

FEATURE

\begin{tabular}{ll}
\multicolumn{1}{c}{ CLASS } & STATUS \\
mine & UNOFF \\
reservoir & BGN \\
reservoir & BGN \\
stream & BGN \\
well & UNOFF \\
&
\end{tabular}

stream

valley

school

valley

valley

mine$$
\begin{aligned}
& \text { sp } \\
& \text { st } \\
& \text { mi } \\
& \text { st } \\
& \text { sum } \\
& \text { fl } \\
& \text { reser } \\
& \text { sum } \\
& \text { reser } \\
& \text { reser }
\end{aligned}
$$

BGN Maricopa 335907N1124628W

$\begin{array}{lll} & \text { MNOFF Yuma } & 331739 N 1143500 \mathrm{~W}\end{array}$

$\begin{array}{lll}\text { stream } B G N & \text { Yuma } & 331716 \mathrm{~N} 1143919 \mathrm{~W}\end{array}$

summit BGN Coconino 343235N1111057W

flat BGN 1933 Coconino 351959N1114429

$351849 \mathrm{~N} 1114429$

$315053 \mathrm{~N} 1104546 \mathrm{~W}$

Coconino 345311N1111042W

reservoir BGN Coconino 345945N1112455W

well UNOFF Mohave 344301N1134555W

valley VARIANT Yavapai 345436N1115540W

valley BGN 1971 Yavapai 345436 N1115540W

VARIANT
VARIANT

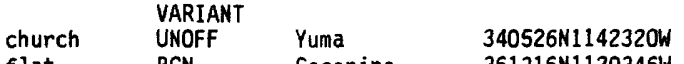

flat BGN Coconino 361316N1120346W

well UNOFF Gila 331852 N1104620W

mine UNOFF Gila 331838N1104630W

$\begin{array}{llll}\text { spring } & \text { BGN } & \text { Gila } & 331856 N 1104617 \mathrm{~W}\end{array}$

$331837 N 1104542$

locale $\quad$ BGN 1915 Apache 363625 N1093348W

VARIANT

VARIANT

stream VARIANT Apache 363625N1093348W

stream VARIANT

spring

Apache

$363615 N 1092403 \mathrm{~W}$

spring BGN 1915 Apache

$363615 \mathrm{~N} 1092403 \mathrm{~W}$

VARIANT

valley $\quad$ VARIANT

$\begin{array}{ll}\text { valley } & \text { BGN } 1915 \\ \text { VARIANT }\end{array}$

locale $B G N$

reservoir

BGN

VARIANT

stream

VARIANT

stream

spring

BGN 1976

VARIANT

VARIANT

VARIANT

spring

spring

reservoir

VARIANT

spring

BGN

BGN

VARIANT

Apache

$363713 N 1092757 W$

$344650 N 1094054 \mathrm{~W}$

Apache

Maricopa

331920N1124240W

Maricopa

$331920 \mathrm{~N} 1124240 \mathrm{~W}$

Yavapai

344409 N1120401W

Yavapai

$344359 N 1120501 \mathrm{~W}$

Yavapai

Mohave

Yavapai

344409 N1120401W

$352641 \mathrm{~N} 1133015 \mathrm{~W}$

$344359 \mathrm{~N} 1120501 \mathrm{~W}$

VARIANT

spring.

BGN

VARIANT
Yavapai Mohave
344409 N1120401W
$362342 \mathrm{~N} 1132329 \mathrm{~W}$
363445 N1091722W

\begin{tabular}{|c|c|c|}
\hline $\begin{array}{l}\text { SOURCE } \\
\text { COORDINATE }\end{array}$ & $\begin{array}{l}\text { ELEV } \\
\text { FT }\end{array}$ & MAP NAME \\
\hline $324819 \mathrm{~N} 1090649 \mathrm{~W}$ & 6764 & $\begin{array}{l}\text { Payson South } \\
\text { Call loway Butte } \\
\text { Apache Maid Mtn } \\
\text { Sheldon } \\
\text { Payson South }\end{array}$ \\
\hline $\begin{array}{l}312532 \mathrm{~N} 1104340 \mathrm{~W} \\
342539 \mathrm{~N} 1105857 \mathrm{~W}\end{array}$ & & $\begin{array}{l}\text { Copperopolis } \\
\text { Harshaw } \\
\text { Mt Hughes } \\
\text { Grama Draw } \\
\text { Chandler }\end{array}$ \\
\hline
\end{tabular}

Mt Lemmon

Mount Bigelow

Vulture Peak

Cibola SE

Cibola

Blue Ridge Reservoir Humphreys Peak

Humphreys Peak

1620 Helvetia

Chavez Mtn East

Chavez Mtn NW

Mormon Lake

Beecher Canyon

Loy Butte

Parker SW

Bright Angel Point

Pinal Peak

Pinal Peak

Pinal Peak

Pinal Peak

Imperial Reservoir

Little Round Rock
Round Rock

Round Rock

San Miguel

Milky Ranch

Cottonwood

Truxton

Cottonwood

Poverty Knoll 
FEATURE NAME

See Hassayampa River Hassamp River

See Hassayampa River Hass ayamp

See Hassayampa River Hassayampa

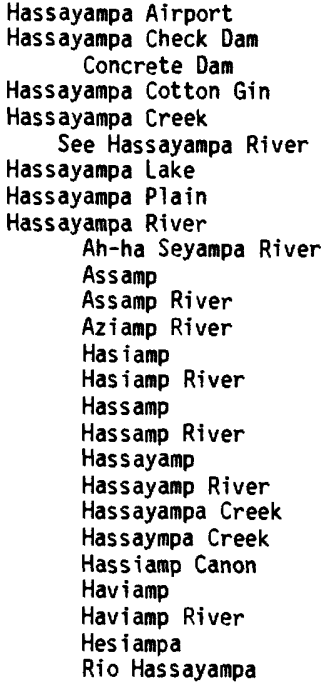

Haunted Canyon
FEATURE CLASS STATUS

COUNTY

strea

stream

stream

locale

airpor

dam

locale

stream reservoir

plain

stream

stream

stream

reservoir

locale

stream

spring

spring

pp)

well

reservoir

reservoir valley

locale

valley

reservoir

summit

reservoir

summit

reservoir

summit

summit

summit

reservoir

VARIANT

VARIANT

BGN

BGN

VARIANT

BGN

\section{BGN}

UNOFF

BGN

BGN

BGN

BGN

BGN
BGN

summit

reservoir

stream

spring

reservoir

summit

is land

area

dam

BGN

BGN

BGN

BGN

BGN

BGN

BGN 1932

VARIANT

VARIANT

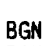

BGN
BGN

BGN

BGN

BGN

BGN

BGN

UNOFF

valley

BGN
Maricopa

Maricopa

Maricopa

Maricopa

Maricopa Yavapa i

Maricopa

Maricopa

Yavapai

Maricopa

Maricopa

VARIANT

DARIANT

ART

ARIANT
ARIANT

ARIANT

RIANT

ARIANT

RIANT

Yavapai

Maricopa

Maricopa

Coconino

Maricopa

Maricopa

Navajo

Navajo

Pinal

Apache

Coconino

Coconino

Navajo

Maricopa

Navajo

Coconino

Mohave

Mohave

Maricopa

Yavapai

Apache

Navajo

Coconino

Coconino

Coconino

Cochise

Gila

Gila

Gila

Navajo

Mohave

Mohave

Apache
$342040 \mathrm{N1123404 \textrm {W }}$

331920N1124240W

$331920 N 1124240 \mathrm{~W}$ $350926 \mathrm{~N} 1113439 \mathrm{~W}$ 334100 N1123800W

$331920 \mathrm{~N} 1124240 \mathrm{~W}$ $355902 \mathrm{~N} 1100351 \mathrm{~W}$

360054N1101900W

33173BN1110544W $354059 N 1093834 \mathrm{~W}$ $345154 N 1113937 \mathrm{~W}$ $365527 \mathrm{~N} 1122618 \mathrm{~W}$ $343045 N 1095514 \mathrm{~W}$ $333415 N 1120335 \mathrm{~W}$ $345118 N 1103205 \mathrm{~W}$ $364705 \mathrm{~N} 1122329 \mathrm{~W}$

363527 N1130343W $363458 \mathrm{N1130113 \textrm {W }}$ 323807 N1124430W

$343010 \mathrm{~N} 1115035 \mathrm{~W}$ $364243 \mathrm{N1093252W}$ $365927 \mathrm{~N} 1101549 \mathrm{~W}$ $360808 N 1120307 \mathrm{~W}$

$351222 N 1121537 \mathrm{~W}$

$360808 N 1120307 \mathrm{~W}$ $322020 \mathrm{~N} 1091032 \mathrm{~W}$ 335459 N1111833W $335453 \mathrm{~N} 1112155 \mathrm{~W}$ $340743 \mathrm{~N} 1110226 \mathrm{~W}$ $353052 \mathrm{N1} 101856 \mathrm{~W}$ $360154 \mathrm{N1} 140809 \mathrm{~W}$ $355000 \mathrm{~N} 1140625 \mathrm{~W}$ $343218 N 1094142 \mathrm{~W}$

SOURCE
COORDINATE

MAP NAME

849

1565 Daggs Tank Groom Creek

Arlington

Groom Creek Wildcat Well Hassayampa

Walnut Grove

Flagstaff East Daggs Tank

Low Mountain

Lt I Black Spot Mtn

342649N1095649W $345045 N 1103127 \mathrm{~W}$

6181 Cornfields Munds Mountain Shinarump Point Point of the Mtn

1285 Sunnys lope McCauley Sinks White Sage Flat

5933 Hat Knoll

Hat Knoll

2716 Hat Mountain

Camp Verde

5669 Dancing Rocks

Boot Mesa

5954 Bright Angel Point

McLellan Reservoir

$335525 N 1112052 \mathrm{~W}$

San Simon

Kayler Butte

Kayler Butte

Diamond Butte

Hauke Mesa

Hiller Mountains

Garnet Mtn 


\section{FEATURE NAME}

Haunted Canyon

Haunted Canyon Spring

Haunted Spring

Haupt Lateral

Hausman Spring

Havanaki

See Haivana Nakya

Havana Nakya

See Haivana Nakya

Havana Tank

Havash Lake

Havasu, Lake Havasu Lake Parker Dam Reservoir

Havasu Canyon

See Cataract Canyon

Havasu Canyon Cactus Canyon

Havasu Cove

Havasu Creek

See Cataract Creek

Havasu Creek

Cataract Creek

Havasu Falls

Havasu Lake

See Havasu, Lake

Havasu National Wildlife Refuge

Havasupai Elementary School

Havasupai Indian Reservation Havasupai Reservation

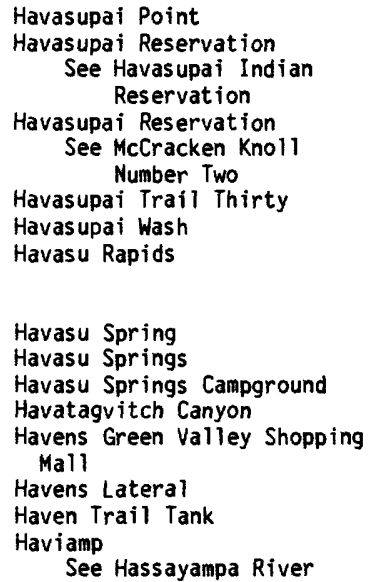

See Ash Creek

\section{FEATURE}

STATUS

COUNTY

COORDINATE

valley

spring

spring

canal

spring

ppl

pp1

reservoir

reservoir

reservoir

BGN 1906

BGN

BGN

BGN

VARIANT

VARIANT

Pinal

Gila

Yuma

Coconino

Pima

Pima

BGN Pima

BGN 1963 La Paz

VARIANT

VARIANT

VARIANT

valley

valley

bay

BGN 1964

BGN

Coconino

Coconino

Mohave

$361 \mathrm{~B} 28 \mathrm{~N} 1124540 \mathrm{~W}$

$342813 N 1142135 \mathrm{~W}$

VARIANT

stream

stream

falls

reservoir

park

school

reserve

BGN 1964

VARIANT

BGN 1932

VARIANT

Coconino

Coconino

Coconino

Mohave

ADMIN

UNOFF

UNOFF

VARIANT

Mohave

Coconino

cliff

BGN 1932

Coconino

VARIANT

reserve

summit

VARIANT

trail

stream

UNOFF

BGN

BGN

spring

spring

park

valley

BGN
BGN 1964

ADM IN

BGN

locale

UNOFF

canal

BGN

reservoir BGN

stream

VARIANT

Coconino

$61114 N 1122055 W$

361415 N112415OW

Coconino

$350844 \mathrm{~N} 1121125 \mathrm{~W}$

Coconino

Mohave

Mohave

Yuma

Coconino

La Paz

Coconino

Pima

Yuma

Gila

Maricopa

$361210 \mathrm{~N} 1124211 \mathrm{~W}$

$343016 \mathrm{~N} 1142147 \mathrm{~W}$

$361825 \mathrm{~N} 1124550 \mathrm{~W}$

$341738 \mathrm{~N} 1140726 \mathrm{~W}$ $341749 \mathrm{~N} 1140736 \mathrm{~W}$ $360753 \mathrm{~N} 1123641 \mathrm{~W}$ $315212 \mathrm{~N} 1105935 \mathrm{~W}$

$323524 N 1144101 \mathrm{~W}$ $333330 \mathrm{~N} 1105905 \mathrm{~W}$

331920N1124240W

VARIANT

stream

locale

locale

BGN

UNOFF

stream

BGN

VARIANT

valley

VARIANT

BGN

VARIANT

valley

BGN

BGN
UNOFF

VARIANT

valley

VARIANT

valley

valley

BGN 1962

VARIANT

VARIANT

VARIANT
Maricopa 331920N1124240W

Mohave 34480BN1141035W

Maricopa 332716N1115024W

Navajo

Pinal

353556N1102434W

$330907 N 1103330 \mathrm{~W}$

Mohave

Yavapa i

Graham

Graham

Graham

Graham

$344852 \mathrm{~N} 1132127 \mathrm{~W}$ $341913 \mathrm{~N} 1122033 \mathrm{~W}$

325004N1094908W

$324 B 30 N 1094745 \mathrm{~W}$

$325004 \mathrm{~N} 1094908 \mathrm{~W}$

$325440 N 1094912 \mathrm{~W}$ $361300 \mathrm{~N} 1124110 \mathrm{~W}$

$\begin{array}{cc}\text { SOURCE } & \text { ELEV } \\ \text { COORDINATE } & \text { FT }\end{array}$

MAP NAME

$361140 N 1120454 W$

Bright Angel Point

Haunted Canyon

Cutter

Yuma West

Parks

Vainom Kug

456 Gene Wash

448 Gene Wash

$361310 \mathrm{~N} 1124125 \mathrm{~W}$

$S$ B Point

Whitmore Point

$361300 \mathrm{~N} 1124110 \mathrm{~W}$

$S$ B Point

Havasu Falls

Lake Havasu City $\mathrm{N}$

Lake Havasu City $N$

Supai

Havasupai Point

Lake Havasu City $N$

$S$ B Point

Monkeys Head

Supai

Gene Wash

360625N1123055W Topocoba Hilltop

2900 Green Valley

Somerton

Salt River Peak

Yucca

1210 Mesa

$353538 N 1100842 W$

Egloffstein Butte

Coolidge Dam

$345045 N 1132737 \mathrm{~W}$

ilot Knob

324422N1095201W Thatcher

stream 
FEATURE NAME

Hawk Hollow Tank

Hawkins

Hawkins Butte

Hawkins Canyon

Hawkins Elementary School

Hawkins Railroad Station

Hawkins Tank

Hawk Peak

Hawk Peak Spring

Hawk Rock

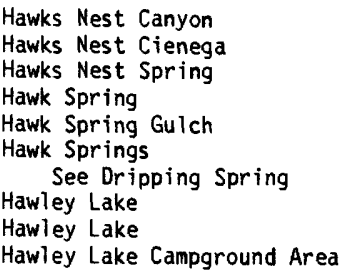

Hawks Nest Canyon

Hawks Nest Cienega

Hawks Nest Spring

Hawk Spring

Hawk Spring Gulch

Hawk Springs

See Dripping Spring

Hawley Lake

Hawley Lake

Hawley Lake Campground Area

Hawley Lake Post office

Hawthorne Elementary School

Hawthorne Interchange

Hay Butt

See Haystack Butte

Hay Butte

See Haystack Butte

Hay Canyon

Haycox Canyon

Haycox Mountain

Hay Dam

Hayden

Hayden

See Mesa

Hayden, Mount Hayden Peak

Hayden Canal

Hayden Commerce Center

Hayden Plaza East

Hayden Estates

See Windemere (subdivision)

Hayden High School Hayden Unif ied School

Hayden Junct ion

Hayden Lateral

Hayden Library

Hayden Park

Hayden Peak

Hayden Peak

Hayden Peak

See Hayden, Mount

Hayden Plaza East

See Hayden Commerce Center

Hayden Plaza Mesa Shopping

Center

Hayden Plaza North Shopping

Center

Hayden Plaza West Shopping

Center

Hayden Post Office

Hayden Railroad Station

Haydens Butte

See Tempe

Haydens Ferry

See Tempe

Haydens Mill

See Tempe

Hayden Swimming Pool and Park

Hayden Unified Schoo

Hayden Unified School

See Hayden High School

FEATURE
CLASS
reservoir
locale
summit
valley
school
building
reservoir
summit
spring
pillar

valley

spring

spring

valley

spring

reservoir

ppl

park

building

school

crossing

summit

summit

valley

valley

summit

pp 1

ppl

summit

canal

locale

ppl

locale

canal

building

park

summit

summit

summit

locale

locale

locale

locale

building

building

ppl

pp 1

ppl

park

school

school

\section{STATUS \\ COOROINATE}

BGN Graham

1932 Yavapai

1932 Coconino

UNOFF Maricopa

UNOFF Yavapai

1950 Coconino

BGN

Graham
Pinal

BGN

BGN

BGN

BGN

VARIANT

BGN

BGN

ADMIN

Greenlee

Apache

Navajo

Gila

Yavapai

Yuma

Apache

Apache

Apache

UNOFF

UNOFF

UNOFF

VARIAN

VARIANT

BGN

BGN

BGN

UNOFF

VARIANT

BGN 1932
VARIANT

8GN
BGN

VARIANT

VARIANT

Apache

Maricopa

Apache

Gila

Gila

Santa Cruz

Gila

Gila

Yavapai

Gila

Maricopa

Coconino

Maricopa

Maricopa

Maricopa

UNDFF

VARIANT

BGN

BGN

UNOFF

ADMIN

BGN

BGN

VARIANT

Gila

Pinal

Yuma

Gila

Maricopa

Pinal

Mohave

Coconino

VARIANT

UNOFF

Maricopa

Maricopa

Maricopa

Maricopa

UNOFF

UNOFF

UNOFF

Gila

VARIANT

VARIANT

Maricopa

Maricopa

VARIANT

Maricopa

ADMIN Gila

UNOFF

VARIANT

Gila

Gila
$324706 \times 1094957 \mathrm{~W}$

$341602 N 1125406 \mathrm{~W}$

$360444 N 1120003 W$

$334917 N 1095319 \mathrm{~W}$

$332610 \mathrm{~N} 1120144 \mathrm{~W}$

$341530 \mathrm{~N} 1125357 \mathrm{~W}$

353047 N1120709W

$324158 \mathrm{~N} 1095253 \mathrm{~W}$

$324146 \mathrm{~N} 1095342 \mathrm{~W}$

$332159 \mathrm{~N} 1113425 \mathrm{~W}$

$334258 N 1091601 W$

$334115 N 1093445 \mathrm{~W}$

364959 N1103620W

$331102 \mathrm{~N} 1103356 \mathrm{~W}$

$340512 N 1123259 \mathrm{~W}$

$333636 \mathrm{~N} 1140439 \mathrm{~W}$

$335936 \mathrm{~N} 1094529 \mathrm{~W}$

$335902 \mathrm{~N} 1094447 \mathrm{~W}$

$335915 \mathrm{~N} 1094526 \mathrm{~W}$

335847 N1094518W

$332537 \mathrm{~N} 1114753 \mathrm{~W}$

351837 N10g0621W

$334326 N 1103811 \mathrm{~W}$

$334326 \mathrm{~N} 1103811 \mathrm{~W}$

$313835 \mathrm{~N} 1103037 \mathrm{~W}$

$340701 \mathrm{Nl} 111608 \mathrm{~W}$

$340726 \mathrm{~N} 1111641 \mathrm{~W}$

$350700 \mathrm{~N} 1131444 \mathrm{~W}$

330017 N1104705W

$332520 \mathrm{~N} 1114919 \mathrm{~W}$

$361620 \mathrm{~N} 1115806 \mathrm{~W}$

$332546 N 1115744 \mathrm{~W}$

$332630 \mathrm{~N} 1115542 \mathrm{~W}$

$333155 N 1115412 W$

325935 N1104615W

$330035 N 1104853 \mathrm{~W}$

$323758 \mathrm{~N} 1144115 \mathrm{~W}$

330020 N1104703W

$332416 \mathrm{~N} 1120443 \mathrm{~W}$

$330222 \mathrm{~N} 1114$

$350452 \mathrm{~N} 1135415 \mathrm{~W}$

$361620 \mathrm{~N} 1115806 \mathrm{~W}$

$332630 \mathrm{~N} 1115542 \mathrm{~W}$

$332330 \mathrm{~N} 1115025 \mathrm{~W}$

$333557 \mathrm{N1120217W}$

$332935 \mathrm{~N} 1120741 \mathrm{~W}$

$330022 \mathrm{~N} 1104659 \mathrm{~W}$

$330040 N 1104929 \mathrm{~W}$

$332453 N 1115431 \mathrm{~W}$

$332453 \mathrm{~N} 1115431 \mathrm{~W}$

$332453 \mathrm{~N} 1115431 \mathrm{~W}$

$330020 \mathrm{~N} 1104700 \mathrm{~W}$

$325925 \mathrm{~N} 1104615 \mathrm{~W}$

325935N1104615W

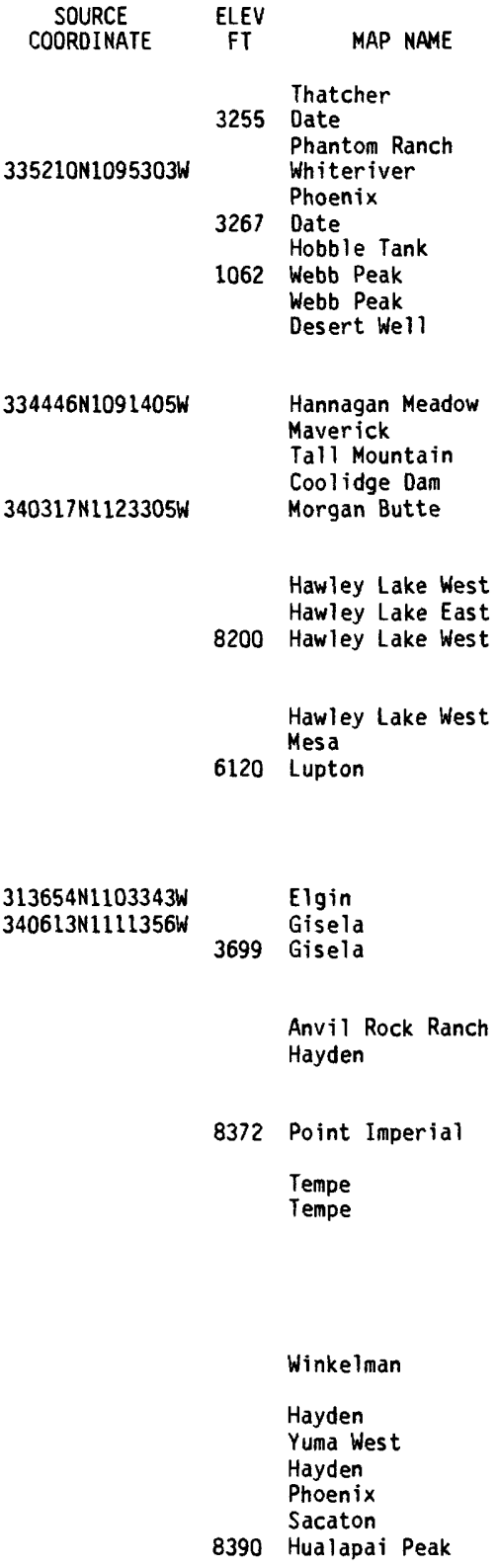

1460 Sunnys lope

Fowler

Hayden

Hayden
Hayden

Winkelman 


\begin{tabular}{|c|c|c|c|c|c|c|c|}
\hline FEATURE NAME & $\begin{array}{l}\text { FEATURE } \\
\text { CLASS }\end{array}$ & STATUS & COUNTY & COORDINATE & $\begin{array}{l}\text { SOURCE } \\
\text { COORDINATE }\end{array}$ & $\begin{array}{l}\text { ELEV } \\
\text { FT }\end{array}$ & MAP NAME \\
\hline $\begin{array}{l}\text { Haydon Ranch } \\
\text { Haydons Tank } \\
\text { Hayes Gulch } \\
\text { Hayes Hall } \\
\text { Hayes Mountains } \\
\text { Hayes Peak } \\
\text { Hayes Tank } \\
\text { Hayes Tank } \\
\text { Hay Fever Tank } \\
\text { Hayfield Draw }\end{array}$ & $\begin{array}{l}\text { locale } \\
\text { reservoir } \\
\text { valley } \\
\text { building } \\
\text { summit } \\
\text { summit } \\
\text { reservoir } \\
\text { reservoir } \\
\text { reservoir } \\
\text { valley }\end{array}$ & $\begin{array}{l}\text { UNOFF } \\
\text { BGN } \\
\text { BGN } \\
\text { UNOFF } \\
\text { BGN } \\
\text { BGN } \\
\text { BGN } \\
\text { BGN } \\
\text { BGN } \\
\text { BGN }\end{array}$ & $\begin{array}{l}\text { Pinal } \\
\text { Maricopa } \\
\text { Gila } \\
\text { Cochise } \\
\text { Gila } \\
\text { Yavapai } \\
\text { Gila } \\
\text { Gila } \\
\text { Mohave } \\
\text { Santa Cruz }\end{array}$ & $\begin{array}{l}325118 \mathrm{~N} 1105454 \mathrm{~W} \\
335931 \mathrm{~N} 1131104 \mathrm{~W} \\
332308 \mathrm{~N} 1104632 \mathrm{~W} \\
313357 \mathrm{~N} 1102042 \mathrm{~W} \\
331243 \mathrm{~N} 1103629 \mathrm{~W} \\
342835 \mathrm{~N} 1130751 \mathrm{~W} \\
332214 \mathrm{~N} 1104803 \mathrm{~W} \\
332412 \mathrm{~N} 1104122 \mathrm{~W} \\
350133 \mathrm{~N} 1132253 \mathrm{~W} \\
312016 \mathrm{~N} 1103538 \mathrm{~W}\end{array}$ & $312402 \mathrm{~N} 1104004 \mathrm{~W}$ & $\begin{array}{l}5010 \\
4100\end{array}$ & $\begin{array}{l}\text { Black Mountain } \\
\text { Aguila } \\
\text { Globe } \\
\text { Fort Huachuca } \\
\text { Coolidge Dam } \\
\text { Thorn Peak } \\
\text { Pinal Peak } \\
\text { Cammerman Wash } \\
\text { Penitentiary Mtn } \\
\text { Lochiel }\end{array}$ \\
\hline $\begin{array}{l}\text { Hayfield Draw } \\
\text { Hayfield Tank } \\
\text { Hay Flat Draw } \\
\text { See Railroad Wash } \\
\text { Hay Flat Draw } \\
\text { Hay Flat Tank } \\
\text { Hay Hollow } \\
\text { Hay Hollow Draw } \\
\text { Hay Hollow Wash } \\
\text { Hay Hook Ranch }\end{array}$ & $\begin{array}{l}\text { valley } \\
\text { reservoir } \\
\text { stream } \\
\text { valley } \\
\text { reservoir } \\
\text { valley } \\
\text { valley } \\
\text { stream } \\
\text { locale }\end{array}$ & $\begin{array}{l}\text { BGN } \\
\text { BGN } \\
\text { VARIANT } \\
\text { BGN } 1978 \\
\text { BGN } \\
\text { BGN } \\
\text { BGN } \\
\text { BGN } \\
\text { UNOFF }\end{array}$ & $\begin{array}{l}\text { Yavapai } \\
\text { Yavapai } \\
\text { Cochise } \\
\text { Cochise } \\
\text { Yavapai } \\
\text { Navajo } \\
\text { Navajo } \\
\text { Cochise } \\
\text { Pima }\end{array}$ & $\begin{array}{l}343829 \mathrm{~N} 1115554 \mathrm{~W} \\
343420 \mathrm{~N} 1120758 \mathrm{~W} \\
\\
322217 \mathrm{~N} 1093408 \mathrm{~W} \\
322043 \mathrm{~N} 1094327 \mathrm{~W} \\
342444 \mathrm{~N} 1123531 \mathrm{~W} \\
344135 \mathrm{~N} 1095208 \mathrm{~W} \\
344136 \mathrm{~N} 1095207 \mathrm{~W} \\
312050 \mathrm{~N} 1091354 \mathrm{~W} \\
315715 \mathrm{~N} 1113046 \mathrm{~W}\end{array}$ & $\begin{array}{l}321850 \mathrm{~N} 1094352 \mathrm{~W} \\
343253 \mathrm{~N} 1095744 \mathrm{~W} \\
342603 \mathrm{~N} 1095023 \mathrm{~W} \\
312532 \mathrm{~N} 1090604 \mathrm{~W}\end{array}$ & & $\begin{array}{l}\text { Railroad Pass } \\
\text { Wilhoit } \\
\text { Little Milky Ranch } \\
\text { Little Milky Ranch } \\
\text { W of Guadalupe Can } \\
\text { Kitt Peak }\end{array}$ \\
\hline $\begin{array}{l}\text { Hay Lake } \\
\text { Hay Lake } \\
\text { Hay Lake Dam } \\
\text { Hay Meadow } \\
\text { Hay Meadow Draw } \\
\text { Hay Meadow Draw Tank } \\
\text { Hay Meadow Tank } \\
\text { Hay Mountain } \\
\text { Haynes } \\
\text { See San Vicente }\end{array}$ & $\begin{array}{l}\text { lake } \\
\text { reservoir } \\
\text { dam } \\
\text { flat } \\
\text { valley } \\
\text { reservoir } \\
\text { reservoir } \\
\text { summit } \\
\text { locale }\end{array}$ & $\begin{array}{l}\text { BGN } \\
\text { BGN } \\
\text { UNOFF } \\
\text { BGN } \\
\text { BGN } \\
\text { BGN } \\
\text { BGN } \\
\text { BGN } \\
\text { VARIANT }\end{array}$ & $\begin{array}{l}\text { Apache } \\
\text { Coconino } \\
\text { Coconino } \\
\text { Apache } \\
\text { Coconino } \\
\text { Coconino } \\
\text { Coconino } \\
\text { Cochise } \\
\text { Pima }\end{array}$ & $\begin{array}{l}340012 \mathrm{~N} 1092556 \mathrm{~W} \\
344404 \mathrm{~N} 1111240 \mathrm{~W} \\
344403 \mathrm{~N} 1111240 \mathrm{~W} \\
335112 \mathrm{~N} 1094822 \mathrm{~W} \\
343728 \mathrm{~N} 1111233 \mathrm{~W} \\
343724 \mathrm{~N} 1111236 \mathrm{~W} \\
343646 \mathrm{~N} 1111213 \mathrm{~W} \\
313911 \mathrm{~N} 1095303 \mathrm{~W} \\
\\
320042 \mathrm{~N} 1113 \mathrm{~B} 11 \mathrm{~W}\end{array}$ & $343601 N 1111201 W$ & 9118 & $\begin{array}{l}\text { Greer } \\
\text { Hay Lake } \\
\text { Hay Lake } \\
\text { Corn Creek Plateau } \\
\text { Blue Ridge Reservoir } \\
\text { Blue Ridge Reservoir } \\
\text { Blue Ridge Reservoir } \\
\text { Hay Mountain }\end{array}$ \\
\hline $\begin{array}{l}\text { Haynes Farm } \\
\text { Haynes Shaft } \\
\text { Hayrock Ranch } \\
\text { Hays Ranch } \\
\text { Haystack } \\
\text { Haystack Butte } \\
\text { Hay Butt } \\
\text { Hay Butte }\end{array}$ & $\begin{array}{l}\text { locale } \\
\text { mine } \\
\text { locale } \\
\text { locale } \\
\text { summit } \\
\text { summit }\end{array}$ & $\begin{array}{l}\text { BGN } \\
\text { UNOFF } \\
\text { UNOFF } \\
\text { UNOFF } \\
\text { BGN } \\
\text { BGN } \\
\text { VARIANT } \\
\text { VARIANT }\end{array}$ & $\begin{array}{l}\text { Yuma } \\
\text { Yavapai } \\
\text { Apache } \\
\text { Yavapai } \\
\text { Cochise } \\
\text { Gila }\end{array}$ & $\begin{array}{l}335206 \mathrm{~N} 1135654 \mathrm{~W} \\
344522 \mathrm{~N} 1120751 \mathrm{~W} \\
341645 \mathrm{~N} 1092357 \mathrm{~W} \\
341647 \mathrm{~N} 1124323 \mathrm{~W} \\
320125 \mathrm{~N} 1091130 \mathrm{~W} \\
334326 \mathrm{~N} 1103811 \mathrm{~W}\end{array}$ & & $\begin{array}{l}4462 \\
4891 \\
5741\end{array}$ & $\begin{array}{l}\text { Utting } \\
\text { Munds Draw } \\
\text { Lyman Lake SW } \\
\text { Peeples Valley } \\
\text { Blue Mountain } \\
\text { Haystack Butte }\end{array}$ \\
\hline $\begin{array}{l}\text { Hays tack Butte } \\
\text { Hays tack Butte }\end{array}$ & $\begin{array}{l}\text { summit } \\
\text { summit }\end{array}$ & $\begin{array}{l}\text { BGN } \\
\text { BGN }\end{array}$ & $\begin{array}{l}\text { Gila } \\
\text { Navajo }\end{array}$ & $\begin{array}{l}335232 \mathrm{~N} 1111629 \mathrm{~W} \\
352058 \mathrm{~N} 1102202 \mathrm{~W}\end{array}$ & & $\begin{array}{l}2766 \\
6251\end{array}$ & $\begin{array}{l}\text { Kayler Butte } \\
\text { French Butte }\end{array}$ \\
\hline $\begin{array}{l}\text { Haystack Cienega } \\
\text { Haystack Creek }\end{array}$ & flat & $\begin{array}{l}\text { BGN } \\
\text { VARIANT }\end{array}$ & Apache & $340531 \mathrm{~N} 1094746 \mathrm{~W}$ & & & McNary \\
\hline $\begin{array}{l}\text { See Bronson Canyon } \\
\text { Haystack Island } \\
\text { Haystack Mountain } \\
\text { Haystack Mountain } \\
\text { Haystack Peak } \\
\text { Haystack Peak } \\
\text { Haystack Rock } \\
\text { Haystacks, The }\end{array}$ & $\begin{array}{l}\text { valley } \\
\text { island } \\
\text { summit } \\
\text { summit } \\
\text { summit } \\
\text { summit } \\
\text { summit } \\
\text { pillar }\end{array}$ & $\begin{array}{l}\text { BGN } \\
\text { BGN } \\
\text { BGN } \\
\text { BGN } \\
\text { BGN } \\
\text { BGN } \\
\text { BGN }\end{array}$ & $\begin{array}{l}\text { Gila } \\
\text { Gila } \\
\text { Mohave } \\
\text { Apache } \\
\text { Yuma } \\
\text { Yavapai } \\
\text { Coconino } \\
\text { Apache }\end{array}$ & $\begin{array}{l}334150 \mathrm{~N} 1104042 \mathrm{~W} \\
334147 \mathrm{~N} 1110745 \mathrm{~W} \\
315430 \mathrm{~N} 1102726 \mathrm{~W} \\
340536 \mathrm{~N} 1094847 \mathrm{~W} \\
334627 \mathrm{~N} 1140110 \mathrm{~W} \\
350344 \mathrm{~N} 1125 \mathrm{~B} 32 \mathrm{~W} \\
36583 \mathrm{BN} 1105241 \mathrm{~W} \\
345624 \mathrm{~N} 1094820 \mathrm{~W}\end{array}$ & & $\begin{array}{l}2190 \\
8036\end{array}$ & $\begin{array}{l}\text { Theo. Roosevelt Dam } \\
\text { Mescal } \\
\text { McNary } \\
\text { Ibex Peak } \\
\text { Turkey Canyon } \\
\text { Chaiyahi Flat } \\
\text { Adamana }\end{array}$ \\
\hline $\begin{array}{l}\text { Haystacks, The } \\
\text { Haystack Tank } \\
\text { Haystack Tank } \\
\text { Haystack Tank } \\
\text { Haystack Tank } \\
\text { Haystack Valley } \\
\text { Haywire Crater } \\
\text { Haywire Flat } \\
\text { Haywood Canyon } \\
\text { Haywood Spring }\end{array}$ & $\begin{array}{l}\text { summit } \\
\text { reservoir } \\
\text { reservoir } \\
\text { reservoir } \\
\text { reservoir } \\
\text { valley } \\
\text { crater } \\
\text { flat } \\
\text { valley } \\
\text { spring }\end{array}$ & $\begin{array}{l}\text { BGN } \\
\text { BGN } \\
\text { BGN } \\
\text { BGN } \\
\text { BGN } \\
\text { BGN } \\
\text { BGN } \\
\text { BGN } \\
\text { BGN } \\
\text { BGN }\end{array}$ & $\begin{array}{l}\text { Apache } \\
\text { Gila } \\
\text { Apache } \\
\text { Mohave } \\
\text { Yavapai } \\
\text { Pinal } \\
\text { Coconino } \\
\text { Coconino } \\
\text { Yavapai } \\
\text { Yavapai }\end{array}$ & $\begin{array}{l}353957 N 1090258 \mathrm{~W} \\
335301 \mathrm{~N} 1111520 \mathrm{~W} \\
340638 \mathrm{~N} 1094811 \mathrm{~W} \\
345013 \mathrm{~N} 1135846 \mathrm{~W} \\
350518 \mathrm{~N} 1125822 \mathrm{~W} \\
325056 \mathrm{~N} 1105905 \mathrm{~W} \\
352214 \mathrm{~N} 1112550 \mathrm{~W} \\
352331 \mathrm{N1} 112407 \mathrm{~W} \\
344155 \mathrm{~N} 1120933 \mathrm{~W} \\
344207 \mathrm{~N} 1120 \mathrm{~B} 3 \mathrm{~W}\end{array}$ & $\begin{array}{l}324906 \mathrm{~N} 1105649 \mathrm{~W} \\
344219 \mathrm{~N} 1120750 \mathrm{~W}\end{array}$ & & $\begin{array}{l}\text { Window Rock } \\
\text { Kayler Butte } \\
\text { McNary } \\
\text { Creamery Canyon } \\
\text { Turkey Canyon } \\
\text { Black Mountain } \\
\text { Sunset Crater East } \\
\text { Strawberry Crater } \\
\text { Hickey Mountain } \\
\text { Hickey Mountain }\end{array}$ \\
\hline $\begin{array}{l}\text { Hazard Tank } \\
\text { Hazel K Mine } \\
\text { Hazel Tank } \\
\text { Hazen Hole Tank } \\
\text { Hazen Tank } \\
\text { Hazen Tank } \\
\text { Hazen Well } \\
\text { Hazlett Hollow Campground } \\
\text { H Bar Ranch } \\
\text { Head, The }\end{array}$ & $\begin{array}{l}\text { reservoir } \\
\text { mine } \\
\text { reservoir } \\
\text { reservoir } \\
\text { reservoir } \\
\text { reservoir } \\
\text { well } \\
\text { park } \\
\text { locale } \\
\text { ridge }\end{array}$ & $\begin{array}{l}\text { BGN } \\
\text { UNOFF } \\
\text { BGN } \\
\text { BGN } \\
\text { BGN } \\
\text { BGN } \\
\text { UNOFF } \\
\text { ADMIN } \\
\text { UNOFF } \\
\text { BGN }\end{array}$ & $\begin{array}{l}\text { Navajo } \\
\text { Mohave } \\
\text { Coconino } \\
\text { Coconino } \\
\text { Maricopa } \\
\text { Mohave } \\
\text { Maricopa } \\
\text { Yavapai } \\
\text { Gila } \\
\text { Mohave }\end{array}$ & $\begin{array}{l}340954 \mathrm{~N} 1095206 \mathrm{~W} \\
352301 \mathrm{~N} 1140847 \mathrm{~W} \\
351732 \mathrm{~N} 1122907 \mathrm{~W} \\
355129 \mathrm{~N} 1124053 \mathrm{~W} \\
330900 \mathrm{~N} 1123339 \mathrm{~W} \\
352033 \mathrm{~N} 1132702 \mathrm{~W} \\
330719 \mathrm{~N} 1123454 \mathrm{~W} \\
341010 \mathrm{~N} 1121704 \mathrm{~W} \\
340708 \mathrm{~N} 1112141 \mathrm{~W} \\
360439 \mathrm{~N} 1141942 \mathrm{~W}\end{array}$ & & $\begin{array}{l}1098 \\
3200\end{array}$ & $\begin{array}{l}\text { Sponseller Mtn } \\
\text { Chloride } \\
\text { Fitzgerald Hill } \\
\text { Hazen Hole Tank } \\
\text { Margies Peak } \\
\text { Tuckayou Spring } \\
\text { Cotton Center SE } \\
\text { Crown King } \\
\text { Gisela } \\
\text { The Temple }\end{array}$ \\
\hline Head Canyon & valley & $\mathrm{BGN}$ & Graham & $325133 N 1093423 W$ & $325330 \mathrm{~N} 1093429 \mathrm{~W}$ & & San Jose \\
\hline
\end{tabular}




\begin{tabular}{|c|c|c|c|c|c|c|c|}
\hline FEATURE NAME & $\begin{array}{l}\text { FEATURE } \\
\text { CLASS }\end{array}$ & STATUS & COUNTY & COORDINATE & $\begin{array}{l}\text { SOURCE } \\
\text { COORDINATE }\end{array}$ & $\begin{array}{c}\text { ELEV } \\
\text { FT }\end{array}$ & MAP NAME \\
\hline $\begin{array}{l}\text { Head Center Mine } \\
\text { Header Tank } \\
\text { Headgate Rock } \\
\text { Headgate Rock Dam } \\
\text { Head of Aspen Creek Spring } \\
\text { Head of Black River Springs } \\
\text { Head of Canyon Tank } \\
\text { Head of Cottonwood Spring } \\
\text { Head-of-Day Mine Tanks }\end{array}$ & $\begin{array}{l}\text { mine } \\
\text { reservoir } \\
\text { summit } \\
\text { dam } \\
\text { spring } \\
\text { spring } \\
\text { reservoir } \\
\text { spring } \\
\text { reservoir }\end{array}$ & $\begin{array}{l}\text { UNOFF } \\
\text { BGN } \\
\text { BGN } \\
\text { UNOFF } \\
\text { BGN } \\
\text { BGN } \\
\text { BGN } \\
\text { BGN } \\
\text { BGN }\end{array}$ & $\begin{array}{l}\text { Graham } \\
\text { Gila } \\
\text { Yuma } \\
\text { Yuma } \\
\text { Yavapai } \\
\text { Apache } \\
\text { Yavapai } \\
\text { Maricopa } \\
\text { Graham }\end{array}$ & $\begin{array}{l}325841 \mathrm{~N} 1102020 \mathrm{~W} \\
340531 \mathrm{~N} 1110807 \mathrm{~W} \\
341007 \mathrm{~N} 1141635 \mathrm{~W} \\
341007 \mathrm{~N} 1141635 \mathrm{~W} \\
342955 \mathrm{~N} 1123233 \mathrm{~W} \\
335535 \mathrm{~N} 1092406 \mathrm{~W} \\
340541 \mathrm{~N} 1115245 \mathrm{~W} \\
335519 \mathrm{~N} 1115151 \mathrm{~W} \\
330813 \mathrm{~N} 1095302 \mathrm{~W}\end{array}$ & & & $\begin{array}{l}\text { Cobre Grande Mtn } \\
\text { Sheep Basin Mtn } \\
\text { Parker } \\
\text { Parker } \\
\text { Wilhoit } \\
\text { Big Lake North } \\
\text { Cooks Mesa } \\
\text { Humboldt Mtn } \\
\text { Gila Peak }\end{array}$ \\
\hline $\begin{array}{l}\text { Head of Hidden Pond } \\
\text { Head of New River Tank } \\
\text { Head of Rackensack Springs } \\
\text { Head of South Fork Spring } \\
\text { Headquarters } \\
\text { Headquarters Pasture Tank } \\
\text { Headquarter Spring } \\
\text { Headquarters Tank } \\
\text { Headquarters Tank } \\
\text { Headquarters Tank }\end{array}$ & $\begin{array}{l}\text { lake } \\
\text { reservoir } \\
\text { spring } \\
\text { spring } \\
\text { ppl } \\
\text { reservoir } \\
\text { spring } \\
\text { reservoir } \\
\text { reservoir } \\
\text { reservoir }\end{array}$ & $\begin{array}{l}\text { BGN } \\
\text { BGN } \\
\text { BGN } \\
\text { BGN } \\
\text { BGN } \\
\text { BGN } \\
\text { BGN } \\
\text { BGN } \\
\text { BGN } \\
\text { BGN }\end{array}$ & $\begin{array}{l}\text { Mohave } \\
\text { Yavapai } \\
\text { Maricopa } \\
\text { Apache } \\
\text { Navajo } \\
\text { Gila } \\
\text { Gila } \\
\text { Santa Cruz } \\
\text { Graham } \\
\text { Pinal }\end{array}$ & $\begin{array}{l}362423 \mathrm{~N} 1133528 \mathrm{~W} \\
340403 \mathrm{~N} 1115326 \mathrm{~W} \\
335418 \mathrm{~N} 1115139 \mathrm{~W} \\
335854 \mathrm{~N} 1092417 \mathrm{~W} \\
344851 \mathrm{~N} 1095151 \mathrm{~W} \\
335958 \mathrm{~N} 1110457 \mathrm{~W} \\
334425 \mathrm{~N} 1103839 \mathrm{~W} \\
312858 \mathrm{~N} 1103538 \mathrm{~W} \\
331641 \mathrm{~N} 1094918 \mathrm{~W} \\
332010 \mathrm{~N} 1110035 \mathrm{~W}\end{array}$ & & & $\begin{array}{l}\text { Poverty Spring } \\
\text { Cooks Mesa } \\
\text { Humboldt Mtn } \\
\text { Big Lake North } \\
\text { Agate House } \\
\text { Copper Mtn } \\
\text { Haystack Butte } \\
\text { Canelo Pass } \\
\text { Point of Pines West } \\
\text { Superior }\end{array}$ \\
\hline $\begin{array}{l}\text { Headquarters Tank } \\
\text { Headquarters Tank } \\
\text { Headquarters We11 } \\
\text { Headquarters Windmil11 } \\
\text { Headquarter Tank } \\
\text { Headquarter Tank } \\
\text { Headstart School } \\
\text { Headstart School } \\
\text { Head Tank } \\
\text { Head Trails Springs }\end{array}$ & $\begin{array}{l}\text { reservoir } \\
\text { reservoir } \\
\text { well } \\
\text { locale } \\
\text { reservoir } \\
\text { reservoir } \\
\text { school } \\
\text { school } \\
\text { reservoir } \\
\text { spring }\end{array}$ & $\begin{array}{l}\text { BGN } \\
\text { BGN } \\
\text { UNOFF } \\
\text { BGN } \\
\text { BGN } \\
\text { BGN } \\
\text { UNOFF } \\
\text { UNOFF } \\
\text { BGN } \\
\text { BGN }\end{array}$ & $\begin{array}{l}\text { Graham } \\
\text { Navajo } \\
\text { Gila } \\
\text { Cochise } \\
\text { Yuma } \\
\text { Yavapai } \\
\text { Coconino } \\
\text { Apache } \\
\text { Coconino } \\
\text { Pima }\end{array}$ & $\begin{array}{l}332147 \mathrm{~N} 1100208 \mathrm{~W} \\
342425 \mathrm{~N} 1102545 \mathrm{~W} \\
341311 \mathrm{~N} 1112756 \mathrm{~W} \\
315805 \mathrm{~N} 1091835 \mathrm{~W} \\
333332 \mathrm{~N} 1132214 \mathrm{~W} \\
342136 \mathrm{~N} 1114329 \mathrm{~W} \\
351738 \mathrm{~N} 1110017 \mathrm{~W} \\
363414 \mathrm{~N} 1091245 \mathrm{~W} \\
352511 \mathrm{~N} 1124839 \mathrm{~W} \\
320929 \mathrm{~N} 1103637 \mathrm{~W}\end{array}$ & & & $\begin{array}{l}\text { Ash Creek Ranch } \\
\text { Aripine } \\
\text { North Peak } \\
\text { Rustler Park } \\
\text { Courthouse Well } \\
\text { Verde Hot Springs } \\
\text { Grand Falls SE } \\
\text { Cove } \\
\text { Trinity Mtn } \\
\text { Mica Mountain }\end{array}$ \\
\hline $\begin{array}{l}\text { Heady-Ashburn Ranch } \\
\text { Heald Peak } \\
\quad \text { See Matthews Peak } \\
\text { Heap Place } \\
\text { Heard Museum } \\
\text { Heard School } \\
\text { Heard Scout Pueblo } \\
\text { Hearn Lateral } \\
\text { Hearst Mountain } \\
\text { Hearst Tanks }\end{array}$ & $\begin{array}{l}\text { locale } \\
\text { summit } \\
\text { locale } \\
\text { building } \\
\text { school } \\
\text { locale } \\
\text { canal } \\
\text { summit } \\
\text { reservoir }\end{array}$ & $\begin{array}{l}\text { UNOFF } \\
\text { VARIANT } \\
\text { BGN } \\
\text { UNOFF } \\
\text { UNOFF } \\
\text { BGN } \\
\text { BGN } \\
\text { BGN } \\
\text { BGN }\end{array}$ & $\begin{array}{l}\text { Santa Cruz } \\
\text { Apache } \\
\text { Apache } \\
\text { Maricopa } \\
\text { Maricopa } \\
\text { Maricopa } \\
\text { Yuma } \\
\text { Coconino } \\
\text { Coconino }\end{array}$ & $\begin{array}{l}312147 \mathrm{~N} 1103821 \mathrm{~W} \\
362151 \mathrm{~N} 1090912 \mathrm{~W} \\
343501 \mathrm{~N} 1092427 \mathrm{~W} \\
332817 \mathrm{~N} 1120418 \mathrm{~W} \\
332849 \mathrm{~N} 1120630 \mathrm{~W} \\
332141 \mathrm{~N} 1120227 \mathrm{~W} \\
323455 \mathrm{~N} 114435 \mathrm{~W} \\
351548 \mathrm{~N} 1121607 \mathrm{~W} \\
355841 \mathrm{~N} 1115855 \mathrm{~W}\end{array}$ & & 7226 & $\begin{array}{l}\text { Zion Reservoir } \\
\text { Phoenix } \\
\text { Phoenix } \\
\text { Lone Butte } \\
\text { Somerton } \\
\text { Hearst Mtn } \\
\text { Grandview Point }\end{array}$ \\
\hline $\begin{array}{l}\text { Hearthstone Park } \\
\text { Heart S Ranch } \\
\text { Heart Tank } \\
\quad \text { Pinto Tank } \\
\text { Heather Brae School } \\
\text { Heatherbrook (subdivision) } \\
\text { Heather Wash } \\
\quad \text { Prairie Wash } \\
\text { Heath Grave } \\
\text { Heath Tank Number One }\end{array}$ & $\begin{array}{l}\text { park } \\
\text { locale } \\
\text { reservoir } \\
\text { school } \\
\text { ppl } \\
\text { stream } \\
\text { cemetery } \\
\text { reservoir }\end{array}$ & $\begin{array}{l}\text { ADMIN } \\
\text { UNOFF } \\
\text { BGN } \\
\text { VARIANT } \\
\text { UNOFF } \\
\text { BGN } \\
\text { BGN } 1908 \\
\text { VARIANT } \\
\text { UNOFF } \\
\text { BGN }\end{array}$ & $\begin{array}{l}\text { Pima } \\
\text { Santa Cruz } \\
\text { Yuma } \\
\text { Maricopa } \\
\text { Maricopa } \\
\text { Coconino } \\
\text { Maricopa } \\
\text { Coconino }\end{array}$ & $\begin{array}{l}321118 \mathrm{~N} 1104812 \mathrm{~W} \\
314302 \mathrm{~N} 1103741 \mathrm{~W} \\
321600 \mathrm{~N} 1133308 \mathrm{~W} \\
\\
332952 \mathrm{~N} 1121240 \mathrm{~W} \\
332052 \mathrm{~N} 1115327 \mathrm{~W} \\
360149 \mathrm{~N} 1123119 \mathrm{~W} \\
\\
333001 \mathrm{~N} 1121908 \mathrm{~W} \\
343208 \mathrm{~N} 1112008 \mathrm{~W}\end{array}$ & $360547 \mathrm{~N} 1121741 \mathrm{~W}$ & 1190 & $\begin{array}{l}\text { Tucson East } \\
\text { Sonoita } \\
\text { Isla Pinta } \\
\text { Fowler } \\
\text { Guadalupe } \\
\text { Antelope Point } \\
\text { El Mirage } \\
\text { Long Valley }\end{array}$ \\
\hline $\begin{array}{l}\text { Heath Tank Number Two } \\
\text { Heaton } \\
\text { Maricopa } \\
\text { Maricopa Station } \\
\text { Maricopaville } \\
\text { Heaton Knolls } \\
\text { Heaton Reservoir } \\
\text { Heavy Boy Mine } \\
\text { Heavy Burn Tank } \\
\text { Heavy Weight Mine }\end{array}$ & $\begin{array}{l}\text { summit } \\
\text { reservoir } \\
\text { mine } \\
\text { reservoir } \\
\text { mine }\end{array}$ & $\begin{array}{l}\text { BGN } \\
\text { BGN } \\
\text { VARIANT } \\
\text { VARIANT } \\
\text { VARIANT } \\
\text { BGN } \\
\text { BGN } \\
\text { UNOFF } \\
\text { BGN } \\
\text { UNOFF }\end{array}$ & $\begin{array}{l}\text { Mohave } \\
\text { Mohave } \\
\text { Pima } \\
\text { Navajo } \\
\text { Pima }\end{array}$ & $\begin{array}{l}363321 \mathrm{~N} 1125547 \mathrm{~W} \\
363628 \mathrm{~N} 1125437 \mathrm{~W} \\
320335 \mathrm{~N} 1103738 \mathrm{~W} \\
340231 \mathrm{~N} 1100540 \mathrm{~W} \\
315147 \mathrm{~N} 1104635 \mathrm{~W}\end{array}$ & & & $\begin{array}{l}\text { Heaton Knolls } \\
\text { Heaton Knolls } \\
\text { Vail } \\
\text { Faught Ridge } \\
\text { Helvetia }\end{array}$ \\
\hline $\begin{array}{l}\text { Heber } \\
\text { Heber Job Corp Conservation } \\
\text { Center } \\
\text { Heber Ranger Station } \\
\text { Heber Road Tank } \\
\text { Heber Tank } \\
\text { Heber Trick Tank } \\
\text { Heckethorn Tank } \\
\text { Heckethorn Tank } \\
\text { Hecla Stone Corral }\end{array}$ & $\begin{array}{l}\text { ppl } \\
\text { building } \\
\text { locale } \\
\text { reservoir } \\
\text { reservoir } \\
\text { reservoir } \\
\text { reservoir } \\
\text { reservoir } \\
\text { locale }\end{array}$ & $\begin{array}{l}\text { BGN } \\
\text { UNOFF } \\
\text { UNOFF } \\
\text { BGN } \\
\text { BGN } \\
\text { BGN } \\
\text { BGN } \\
\text { BGN } \\
\text { BGN } \\
\text { VARIANT }\end{array}$ & $\begin{array}{l}\text { Navajo } \\
\text { Navajo } \\
\text { Navajo } \\
\text { Navajo } \\
\text { Graham } \\
\text { Navajo } \\
\text { Coconino } \\
\text { Coconino } \\
\text { Yavapai }\end{array}$ & $\begin{array}{l}342553 \mathrm{~N} 1103536 \mathrm{~W} \\
342522 \mathrm{~N} 1103915 \mathrm{~W} \\
342335 \mathrm{~N} 1103328 \mathrm{~W} \\
344524 \mathrm{~N} 1101354 \mathrm{~W} \\
325126 \mathrm{~N} 1092543 \mathrm{~W} \\
342510 \mathrm{~N} 1103332 \mathrm{~W} \\
350431 \mathrm{N1} 113851 \mathrm{~W} \\
353350 \mathrm{~N} 1113816 \mathrm{~W} \\
343217 \mathrm{N1} 120715 \mathrm{~W}\end{array}$ & & 6435 & $\begin{array}{l}\text { Heber } \\
\text { Hanks Draw } \\
\text { Heber } \\
\text { Porter Canyon } \\
\text { Tollgate Tank } \\
\text { Heber } \\
\text { Mountainaire } \\
\text { S P Mountain } \\
\text { Cherry }\end{array}$ \\
\hline Hecs Hole & bas in & BGN & Mohave & $363730 \mathrm{~N} 1140140 \mathrm{~W}$ & & & Hen Spring \\
\hline
\end{tabular}


NATIONAL GAZETTEER--ARIZONA 1986

\section{FEATURE NAME}

Hedges Well

Hedgpeth Hills

Hedgpeth $\mathrm{Hills}$

See Deem Hills

Hediendilla

Hedricks Canyon

Hee-A-Han Park (cemetery)

Hefty Tank

Heifer Branch Beaver Creek

Heifer Pasture Tank

Heifer Pasture Well

Heifer Spring

Heifer Tank

Heifer Tank

Heifer Tank

Heifer Tank

Heiffer Tank

Heintzelman Mine

Mina Colorado

Heiser Spring

Heiser Wash

Hela River

See Gila River

Helena

Helena Mine

Helena Railroad Station

Helens Dome

Helens Dome

Hel iograph Peak

Heliograph Ranger Lookout

Heliograph Spring

Hell Canyon

Hell Canyon

See Lawton Canyon

Hell Canyon

Hell Canyon

Helldive Spring

Hellgate Mountain

Hell Hole

Hellhole Bend

Hell Holes

See Hells Hole

Hell Hole Valley

Hellings Mill

See Phoenix

Hell Point

Hellsapopp in Well

Hells Canyon

Hells Canyon

Hells Canyon

Hells Canyon

Hells Canyon Spring

Hells Canyon Tank

Hells Canyon Tank

Hells Canyon Tank

Hells Oive Spring

Hells Gate

Hells Gate

Hells Gate Canyon

Moore Creek

Hells Gate Ridge

Hells Gate Trail

Hells Gate Trail Tank

Hells Half Acre

Hells Half Acre

Hells Half Acre

Hells Half Acre

Hells Half Acre Canyon

Hells Hip Pocket

Hells Hole

Hell Holes

\section{FEATURE}

STATUS

COUNTY

COORDINATE

well
summit

UNOFF

BGN
VARIANT

summit

locale

valley

cemetery

reservoir

BGA

BGN

UNOFF

BGN

reservoir

well

spring

reservoir

reservoir

reservoir

reservoir

mine

BGN
UNOFF
BGN
BGN
BGN
BGN
BGN
BGN
UNOFF
VARIANT

Maricopa

Maricopa

Maricopa

Pima

Mohave

Maricopa

Gila

Greenlee

Pinal

Yavapai

Apache

Santa Cruz

Apache

Gila

Coconino

Coconino

Pima

VARIANT

334108N1121021W

$334343 \mathrm{~N} 1120905 \mathrm{~W}$

$320400 \mathrm{~N} 1103500 \mathrm{~W}$

$365148 \mathrm{~N} 1135304 \mathrm{~W}$

$325701 \mathrm{~N} 1124253 \mathrm{~W}$

$332938 \mathrm{~N} 1104503 \mathrm{~W}$

$334419 N 1092031 \mathrm{~W}$

$324642 \mathrm{~N} 1111645 \mathrm{~W}$

342431 N1120055W

334659 N1091942W

$312345 \mathrm{~N} 1104030 \mathrm{~W}$

$333332 \mathrm{~N} 1094729 \mathrm{~W}$

$335549 \mathrm{~N} 1101047 \mathrm{~W}$

$352026 \mathrm{~N} 1123257 \mathrm{~W}$

$351033 \mathrm{~N} 1121553 \mathrm{~W}$

$314200 \mathrm{~N} 1111600 \mathrm{~W}$

$325953 \mathrm{~N} 1090341 \mathrm{~W}$

325442N1102710W

$332654 \mathrm{~N} 1120424 \mathrm{~W}$

$345453 \mathrm{~N} 1121705 \mathrm{~W}$

$345515 \mathrm{~N} 1090638 \mathrm{~W}$

$341331 \mathrm{~N} 1104641 \mathrm{~W}$

$354405 \mathrm{~N} 1135730 \mathrm{~W}$

$354548 \mathrm{~N} 1135652 \mathrm{~W}$

$335707 \mathrm{~N} 1120028 \mathrm{~W}$

$350453 \mathrm{~N} 1122414 \mathrm{~W}$

351751 N1132720W

$330032 \mathrm{~N} 1093803 \mathrm{~W}$

312910 N1110923W

321047 N1102535W

$341600 \mathrm{~N} 1110 \mathrm{~B} 21 \mathrm{~W}$

$320519 \mathrm{N1092059 \textrm {W }}$

$325403 \mathrm{~N} 1103257 \mathrm{~W}$

$342041 \mathrm{~N} 1111923 \mathrm{~W}$

$343447 \mathrm{~N} 1132512 \mathrm{~W}$

$325432 \mathrm{N1} 103301 \mathrm{~W}$

$333542 \mathrm{~N} 1112301 \mathrm{~W}$

$325953 \mathrm{~N} 1090341 \mathrm{~W}$ reservoir

\begin{tabular}{|c|c|c|c|}
\hline $\begin{array}{l}\text { spring } \\
\text { stream }\end{array}$ & $\begin{array}{l}\text { BGN } \\
\text { BGN } \\
\text { VARIANT }\end{array}$ & $\begin{array}{l}\text { Coconino } \\
\text { Coconino }\end{array}$ & $\begin{array}{l}353021 \mathrm{~N} 1112113 \mathrm{~W} \\
353142 \mathrm{~N} 1111921 \mathrm{~W}\end{array}$ \\
\hline $\begin{array}{l}\text { stream } \\
\text { locale } \\
\text { mine } \\
\text { building } \\
\text { summit } \\
\text { summit } \\
\text { summit }\end{array}$ & $\begin{array}{l}\text { BGN } \\
\text { UNOFF } \\
\text { UNOFF } \\
\text { BGN } \\
\text { BGN } \\
\text { BGN } 1932\end{array}$ & $\begin{array}{l}\text { Yuma } \\
\text { Maricopa } \\
\text { Pima } \\
\text { Maricopa } \\
\text { Cochise } \\
\text { Pima } \\
\text { Graham }\end{array}$ & $\begin{array}{l}324311 \mathrm{~N} 1143316 \mathrm{~W} \\
332122 \mathrm{~N} 1115634 \mathrm{~W} \\
315222 \mathrm{~N} 1104231 \mathrm{~W} \\
332052 \mathrm{~W} 1115645 \mathrm{~W} \\
320745 \mathrm{~N} 1092714 \mathrm{~W} \\
321259 \mathrm{~N} 1103341 \mathrm{~W} \\
323900 \mathrm{~N} 1095054 \mathrm{~W}\end{array}$ \\
\hline $\begin{array}{l}\text { locale } \\
\text { spring } \\
\text { gap }\end{array}$ & $\begin{array}{l}\text { UNOFF } \\
\text { BGN } \\
\text { BGN } \\
\text { VARIANT }\end{array}$ & $\begin{array}{l}\text { Graham } \\
\text { Graham } \\
\text { Yavapai }\end{array}$ & $\begin{array}{l}323900 \mathrm{~N} 1095054 \mathrm{~W} \\
323914 \mathrm{N1095121W} \\
335715 \mathrm{~W} 1122339 \mathrm{~W}\end{array}$ \\
\hline $\begin{array}{l}\text { valley } \\
\text { valley } \\
\text { valley } \\
\text { spring } \\
\text { summit } \\
\text { area }\end{array}$ & $\begin{array}{l}\text { BGN } \\
\text { BGN } 1977 \\
\text { BGN } \\
\text { BGN } \\
\text { BGN }\end{array}$ & $\begin{array}{l}\text { Maricopa } \\
\text { Yavapai } \\
\text { Yavapai } \\
\text { Graham } \\
\text { Yavapai } \\
\text { Pinal }\end{array}$ & $\begin{array}{l}\text { UNKNOWN } \\
340152 \mathrm{~N} 1114442 \mathrm{~W} \\
345505 \mathrm{~N} 1121640 \mathrm{~W} \\
324029 \mathrm{~N} 1094714 \mathrm{~W} \\
335757 \mathrm{~N} 1122454 \mathrm{~W} \\
325452 \mathrm{~N} 1102704 \mathrm{~W}\end{array}$ \\
\hline
\end{tabular}

330B21N1123854W

365157 N1135112W

334731 N1091756W

SOURCE

COOROINATE

ELEV

864 Cotton Center NW Hedgpeth Hills

Rincon Peak

Elbow Canyon

Gila Bend

Globe

Hannagan Meadow

Picacho Reservoir SE

Estler Peak

Buffalo Crossing

Harshaw

West Poker Mtn

Cedar Creek

Horse Trap Mesa

McLellan Reservoir

Cerro Colorado

353003N1112125W Wupatki SE

Guadalupe

Empire Ranch

Guadalupe

6376 Bowie Mtn North

Mica Mountain

1002 Mt Graham

1002 Mt Graham

Mt Graham

Garfias Mtn

$340133 \mathrm{~N} 1114621 \mathrm{~W}$

$350955 N 1121134 \mathrm{~W}$

Hell Point

Mt Graham

3339 Garfias Mtn

Booger Canyon

Hellhole Bend

$351542 N 1132557 \mathrm{~W}$

$354059 \mathrm{N1} 132430 \mathrm{~W}$

$342158 \mathrm{~N} 1111230 \mathrm{~W}$

$341340 \mathrm{~N} 1110626 \mathrm{~W}$

$340911 \mathrm{~N} 1110248 \mathrm{~W}$

$333610 N 1112127 \mathrm{~W}$
$341654 \mathrm{~N} 1104453 \mathrm{~W}$

$351842 \mathrm{~N} 1132756 \mathrm{~W}$

$353828 \mathrm{~N} 1132355 \mathrm{~W}$

$354636 \mathrm{~N} 1135709 \mathrm{~W}$

$325256 \mathrm{~N} 1103117 \mathrm{~W}$

$325547 N 1102613 W$

Booger Canyon

Hell Point

Barth We11

Parallel Canyon

Tuckayou Spring

Peach Springs NE

Music Mountains NW

Quartermaster Can SW

Daisy Mountain

Meath Spring

Tuckayou Spring

Bryce Mountain

Ruby

Happy Valley

Diamond Point

Oiamond Butte

Diamond Point

Diamond Butte

Cochise Head

Brandenburg Mtn

Payson North

Kaiser Spring

Brandenburg Mtn

Mormon Flat Dam 


\section{FEATURE NAME}

Hells Hole

Hells Hole

Hells Hole

Hells Hole

Hells Hole

Hells Hole

Hells Hole Canyon

Hells Hole Canyon

Hells Hole Creek

Hells Hole Peak

Hells Hole Spring

Hells Hole Tank

Hells Hollow

Hells Hollow

Hells Neck Ridge

Hells Pocket

Hells Tank

Hells Uncle Tank

Hells Well

Hell Tank

Hell Tank

Hellzapoppin Canyon

Hellzapopp in Creek

Helmet Peak

Helmet Peak Interchange

Helmwheel Ranch

Helvet ia

Helvetia Mine Camp Helvetia Mine

Helvetia Cemetery

Helvetia Mine

Helvetia Mine

See Helvetia

Helvetia Mine Camp

See Helvetia

Helvetia Spring

Shamrod Spring

Shamrod Springs

Helvetia Spring

See Shamrod Spring

Hemphill Spring

Henderson Cemetery

Henderson Flat

Henderson Mesa

Henderson Ranch

Henderson Ranch

Henders on Tank

Henderson Tank

Henderson Wash

Hendricks Gulch

Hendricks We11

Hen if in Ranch

Hen if in Well

Hennessy Buttes

Hennsey Tank

Henrie Tank

Henrietta Canyon

Henrietta Mine

Henrietta Spring

Henry Brown Tank

Henry Canyon

Henry Lateral

Henry Platt Springs

Henry School

Henry Slade Spring

Henry Spring

Henrys Tank

Henrys Tank

Henrys Well

See Cipriano Well

Henry Tank

\section{FEATURE}

bas in

bend

summit

valley

valley

valley

valley

valley

stream

summit

STATUS COUNTY

BGN
$B G$
$B G$
$B G$
$B G$
$B G$
$B G$
$B G$
$B G$
$B G$

Apache

Yavapai

Mohave

Gila

Gila

Graham

Greenlee

Graham

Greenlee

spring

reservoir

valley

valley

ridge

bas in

reservoir

reservoir

well

reservoir

\section{BGN}

BGN

BGN

BGN

$B G N$

$B G N$

BGN

BGN

Maricopa

Yavapai

Coconino

Mohave

Gila

Coconino

Coconino

Coconino

Yavapai

Gila

reservoir

valley

stream

summit

crossing

locale

locale

cemetery

\section{BGN}

BGN

BGN

UNOFF

UNOFF

BGN

VARIANT

VARIANT

cemetery UNOFF

Yavapai

Yavapa

Yavapai

Pima

Pima

Pinal

Pima

Pima

mine

UNOFF

VARIANT

locale

locale

spring

VARIANT

BGN 1982 Pima

VARIANT

VARIANT

VARIANT

spring

Pima

Pina

$315211 N 1104715 \mathrm{~W}$

cemetery

flat

summit

locale

locale

reservoir

reservoir

reservoir

valley

BGN
UNOF
$B G N$
BGN
UNOF
UNOF
BGN
BGN
BGN
BGN

well

locale

well

summit

reservoir

reservoir

valley

mine

spring

reservoir

BGN

UNOFF

Yavapai

Yavapai

Yavapai

Gila

Gila

Gila

Gila

Yavapai

Coch ise

Cochise

\section{UNOFF Pima}

UNOFF Mohave

UNOFF

BGN

BGN

$B G N$
$B G N$
$B G N$

UGN

BGN

Mohave

Navajo

Coconino

Coconino

Gila

Yavapai

Gila

Yavapai

valle

canal

spring

school

spring

spring

reservoir

reservoir

$B G N$
$B G N$

BGN

UNOFF

BGN

BGN

BGN

BGN

Cochise

Yuma

Apache

Pima

Apache

Navajo

Maricopa

Navajo

well

Pima

343311 N1120413W

$343152 \mathrm{~N} 1121340 \mathrm{~W}$

$345752 \mathrm{~N} 1120716 \mathrm{~W}$

$334437 \mathrm{~N} 1110946 \mathrm{~W}$

$331933 \mathrm{~N} 1105516 \mathrm{~W}$

$333233 \mathrm{~N} 1105912 \mathrm{~W}$

$333530 \mathrm{~N} 1110312 \mathrm{~W}$

$340 \mathrm{~B} 48 \mathrm{~N} 1125548 \mathrm{~W}$

$314624 \mathrm{~N} 1100252 \mathrm{~W}$

$312627 \mathrm{~N} 1095454 \mathrm{~W}$

$313547 N 1113945 \mathrm{~W}$

$353627 \mathrm{~N} 1134947 \mathrm{~W}$

$353627 \mathrm{~N} 1134944 \mathrm{~W}$

$350444 \mathrm{~N} 1100049 \mathrm{~W}$

345501 N1112538W

$364555 \mathrm{~N} 1122050 \mathrm{~W}$

$332 B 38 N 1104759 \mathrm{~W}$

$342741 \mathrm{~N} 1121726 \mathrm{~W}$

$332827 N 1104709 \mathrm{~W}$

350602 N1130355W

$315020 \mathrm{~N} 1095700 \mathrm{~W}$

$323056 \mathrm{~N} 1144607 \mathrm{~W}$

$342728 N 1091950$

$321343 \mathrm{~N} 1104750 \mathrm{~W}$

340411 N1091730W

340445N1103146

$334107 \mathrm{N1123927 \textrm {W }}$

$341924 \mathrm{~N} 1101115 \mathrm{~W}$

320005 N1130134W

$\begin{array}{cc}\text { SOURCE } & \text { ELEV } \\ \text { COORDINATE } & \text { FT }\end{array}$

MAP NAME

6048 West Poker Mtn

Crown King

Mount Logan

Copper Mtn

North Peak

Verde Hot Springs

$335134 \mathrm{~N} 1105940 \mathrm{~W}$

$341016 \mathrm{~N} 1113029 \mathrm{~W}$

$342010 \mathrm{~N} 1113611 \mathrm{~W}$

$324245 N 1095717 \mathrm{~W}$

$330134 N 1090447 \mathrm{~W}$

324246 N109571BW 


\section{FEATURE NAME}

Henry Tank

Henry Tank

Hensen Tank

Hensen Tank One

Heola Mine

Herberger Park Number Two

Herberger Park One

Herb Martyr Forest Camp

Hercules Mine

Hercules Mine

Herder Mountain

Hereford

Hereford Airstrip

Hereford Dairy Ranch

Herget Turquoise Mine

Heritage Court (subdivision)

Heritage Elementary School

Heritage Highlands

(subdivision)

Heritage North Ranch

(subdivision)

Heritage Park

Heritage Square

Heritage Terrace (subdivision)

Herman Mountain

Herman Spring

Hermitage Forest Camp

Hermit Bas in

Hermit Creek

Hermit Point

See Pima Point

Hermit Rapids

Hermits Home Mine

Hermits Rest

Hermit Trail

Hermosa Canyon

Hermosa $\mathrm{Hill}$

Hermosa Mine

Hermoso Park

Heron Point

Herrera School

Herring Mine

Hes iampa

See Hassayampa River

Hesnnann Spring

Hess Canyon

$$
\text { Hess Creek }
$$

Hess Creek

Hess Creek

See Hess Canyon

Hess Draw

Hess Flat

Hess Tank

Hess Wash

Hevener Lateral

Hewitt Canyon

Hewitt Ranch

Hewitt Ridge

Hewitt Station

Hewitt Tank

Hey Dog Tank

H Four Cemetery

$H$ Four Tank

Hibbard

Hibbard Interchange

Hibben Tank

Hibbin Tank

Hibernia Canyon

Hibernia Peak

Hickey Canyon

Hickey Mountain

\section{FEATURE
CLASS}

reservoir

reservoir

reservoir

mine UNOFF

park ADMIN

park

locale

mine

BGN

UNOFF

mine

summit

ppl

airport

locale

mine

ppl

schoo

ppl

STATUS COUNTY

COORDINATE

Gila

Gila

Gila

Yavapai

Maricopa

aricopa

Cochise

Yuma

UNOFF Mohave

BGN

BGN

ADMIN

UNOFF

UNOFF

UNOFF

BGN

Maricopa

Cochise

Cochise

Coch ise

Cochise

Maricopa

Maricopa

Maricopa

ppl

BGN

park

park

ppl

summit

spring

locale

bas in

stream

\section{ADNIN}

ADMIN

BGN

BGN

BGN

BGN

BGN 1906

BGN 1906

Maricopa

Maricopa

Maricopa

Maricopa

Pinal

Gila

Cochise

Coconino

Coconino

VARIANT

cliff

rapids

mine

locale

trail

valley

summit

mine

park

BGN 1932

Coconino

BGN Coconino

UNOFF Coconino

BGM

BGN

UNOFF

ADMIN

Santa Cruz

Santa Cruz

Santa Cruz

Maricopa

is 1 and

school

mine

stream

spring

valley

stream

valley

BGN

UNOFF Maricopa

VARIANT

Maricopa

BGN 1967 Givapa

VARIANT

BGN

Gila

VARIANT

Gila

valley

flat

reservoir

stream

canal

valley

locale

ridge

locale

reservoir

$\begin{array}{ll}\text { BGN } & \text { Navajo } \\ \text { BGN } & \text { Gila } \\ \text { BGN } & \text { Navajo } \\ \text { BGN } & \text { Navajo } \\ \text { BGN } & \text { Yuma } \\ \text { BGN } & \text { Pinal } \\ \text { UNOFF } & \text { Navajo } \\ \text { BGN } & \text { Pinal } \\ \text { BGN } & \text { Pinal } \\ \text { BGN } & \text { Navajo }\end{array}$

reservoir

cemetery

reservoir

locale

crossing

reservoir

reservoir

valley

summit

valley

BGN

UNOFF

$B G N$

BGN

BGN

BGN

BGN

BGN

summit

BGN

$344857 \mathrm{~N} 1120802 \mathrm{~W}$

$331731 \mathrm{~N} 1104450 \mathrm{~W}$

$331628 \mathrm{~N} 1104523 \mathrm{~W}$

$343205 \mathrm{~N} 1120544 \mathrm{~W}$

$333145 \mathrm{~N} 1120215 \mathrm{~W}$

$333351 \mathrm{N1120430 \textrm {W }}$

$315215 \mathrm{~N} 1091400 \mathrm{~W}$

$334614 \mathrm{~N} 1133259 \mathrm{~W}$

352519 N1141015W

$334455 \mathrm{~N} 1113308 \mathrm{~W}$

$312618 \mathrm{~N} 1100550 \mathrm{~W}$

$312501 N 1100802 \mathrm{~W}$

$312504 N 1100549 \mathrm{~W}$

$314631 N 1094923 \mathrm{~W}$

$333454 N 1115126 \mathrm{~W}$

$333430 \mathrm{~N} 1121025 \mathrm{~W}$

$333622 \mathrm{N1120442 \textrm {W }}$

333820 N1115555W

$332316 \mathrm{~N} 1114930 \mathrm{~W}$

$332659 \mathrm{~N} 1120358 \mathrm{~W}$

$333400 \mathrm{~N} 1115406 \mathrm{~W}$

$332632 \mathrm{~N} 1111738 \mathrm{~W}$

$342043 \mathrm{~N} 1110053 \mathrm{~W}$

$314553 \mathrm{~N} 1091943 \mathrm{~W}$

360445 N1121250W

$360557 \mathrm{~N} 1121232 \mathrm{~W}$

$360405 \mathrm{~N} 1121247 \mathrm{~W}$

SOURCE
COORDINATE

ELEV

MAP NAME

360427 N1121550W

\section{Young}

Munds Draw

Cutter

Pinal Peak

4640 Cherry

Sunnys lope

Sunnys lope

Portal Peak

Salome

Chloride

3693 Adams Mesa

Hereford

4276 Nicksville Hereford

Turquoise Mountain

1385 Sawik Mountain

Glendale

1360 Sunnys lope

1510 Currys Corner

Mesa

Phoenix

1330 Paradise Valley

4019 Weavers Needle

Promontory Butte

5870 Chiricahua Peak

Grand Canyon

Grand Canyon

Grand Canyon

Mt Hopkins

Grand Canyon

Grand Canyon

$312637 N 1104314 \mathrm{~W}$ 


FEATURE NAME
Hickory Mountain
Hickey Tanks
Hickiwan
Hikibon
Hikiro
Hikjorn
Hikuwan
Jiquibo
Kokuli
Milpitas
Perigua
Periqua
Piriqua
Tachitoa

$\begin{array}{ll}\text { FEATURE } & \\ \text { CLASS } & \text { STATUS } \\ & \\ \text { reservoir } & \text { VARIANT } \\ \text { ppI } & \text { BGN } \\ & \text { BGN 1941 } \\ & \text { VARIANT } \\ & \text { VARIANT } \\ & \text { VARIANT } \\ & \text { VARIANT } \\ & \text { VARIANT } \\ & \text { VARIANT } \\ & \text { VARIANT } \\ & \text { VARIANT } \\ & \text { VARIANT } \\ & \text { VARIANT } \\ & \text { VARIANT }\end{array}$

Hickiwan Peak

Hickiwan Valley Perigua Valley

Hickiwan Wash

Hickory Gulch

Hickory Mountain

See Hickey Mountain

Hickory Shadows II

See Wellington Court (subdivision)

$\begin{array}{llll}\text { summit } & \text { BGN } & \text { Pima } & 322124 N 1122802 \mathrm{~W} \\ \text { valley } & \text { BGN 1941 } & \text { Pima } & 321604 \mathrm{~N} 1122818 \mathrm{~W} \\ & \text { VARIANT } & & \\ \text { stream } & \text { BGN } & \text { Pima } & 321113 \mathrm{~N} 1122242 \mathrm{~W} \\ \text { valley } & \text { BGN } & \text { Greeniee } & 330705 \mathrm{~N} 1091 \mathrm{~B} 17 \mathrm{~W} \\ \text { summit } & \text { VARIANT } & \text { Yavapai } & 344200 \mathrm{~N} 1121110 \mathrm{~W} \\ \text { ppl } & \text { VARIANT } & & \\ & & \text { Maricopa } & 333535 \mathrm{~N} 1121155 \mathrm{~W}\end{array}$

$\begin{array}{ll}323203 N 1123408 \mathrm{~W} & \begin{array}{l}\text { Hickiwan } \\ \text { Hickiwan }\end{array} \\ 323204 \mathrm{~N} 1123408 \mathrm{~W} & \begin{array}{l}\text { Wof Wahak Hotrontk } \\ \text { Clifton }\end{array} \\ 330708 \mathrm{~N} 1091930 \mathrm{~W} & \\ \end{array}$

Hicks and Duncan Canyon

Hicks and Duncan Tank

Hicks Canyon

Hicks Ranch

Hicks School

Hicks Tank

Hicks Tank

Hicks Wash

Hicks Well

Hi Corbett Field

$\begin{array}{llll}\text { valley } & \text { BGN } & \text { Coconino } & 343022 N 1112413 \mathrm{~W} \\ \text { reservoir } & \text { BGN } & \text { Coconino } & 342925 \mathrm{~N} 1112554 \mathrm{~W} \\ \text { valley } & \text { BGN } & \text { Gila } & 332341 \text { N11052113W } \\ \text { locale } & \text { UNOFF } & \text { Greenlee } & 332107 N 1092930 \mathrm{~W} \\ \text { school } & \text { UNOFF } & \text { Yavapai } & 343421 \mathrm{~N} 112281 \mathrm{BW} \\ \text { reservoir } & \text { BGN } & \text { Greenlee } & 332053 \mathrm{~N} 1092427 \mathrm{~W} \\ \text { reservoir } & \text { 8GN } & \text { Gila } & 333924 N 1103208 \mathrm{~W} \\ \text { stream } & \text { BGN } & \text { Gila } & 333126 \mathrm{~N} 1105157 \mathrm{~W} \\ \text { well } & \text { UNOFF } & \text { Gila } & 333154 N 1105228 \mathrm{~W} \\ \text { park } & \text { AOMIN } & \text { Pima } & 331247 N 1105510 \mathrm{~W}\end{array}$

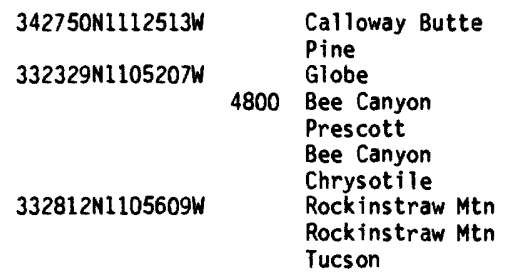

Hi Corbett School Hidden Cabin

Hidden Canyon

Hidden Canyon

Hidden Hills

Hidden Hollow

Hidden Hol low Tank

Hidden Lake

Hidden Lake

$\begin{array}{ll}\text { school } & \text { UNOFF } \\ \text { locale } & \text { UNOFF } \\ \text { locale } & \text { BGN } \\ \text { valley } & \text { BGN } \\ \text { valley } & \text { BGN } \\ \text { range } & \text { BGN } \\ \text { valley } & \text { BGN } \\ \text { reservoir } & \text { BGN } \\ \text { lake } & \text { BGN } \\ \text { lake } & \text { BGN }\end{array}$

Pima

$321202 \mathrm{~N} 1105152 \mathrm{~W}$ $332710 \mathrm{~N} 1121201 \mathrm{~W}$ $\begin{array}{ll}\text { Coconino } & 345924 N 1115411 \mathrm{~W} \\ \text { Yuma } & 332025 \mathrm{N1} 140510 \mathrm{~W}\end{array}$ $\begin{array}{ll}\text { Coconino } & 345924 N 1115411 \mathrm{~W} \\ \text { Yuma } & 332025 \mathrm{~N} 1140510 \mathrm{~W}\end{array}$

Mohave

Mohave

$362208 \mathrm{N1134021 \textrm {W }}$

$352143 \mathrm{~N} 1114936 \mathrm{~W}$

Apache

$340255 \mathrm{~N} 1092509 \mathrm{~W}$

SOURCE

ELEV
FT

MAP NAME

Hickey Mountain

2194 Hickiwan

Hidden Lake

Hidden Lake

Hidden Lake

Hidden Lake

Hidden Lake

Hidden Lake

Hidden Log Tank

Hidden Mines

Hidden Pasture

Hidden Rim

$\begin{array}{ll}\text { lake } & \text { BGN } \\ \text { lake } & \text { BGN } \\ \text { lake } & \text { BGN } \\ \text { lake } & \text { BGN } \\ \text { lake } & \text { BGN } \\ \text { reservoir } & \text { BGN } \\ \text { reservoir } & \text { BGN } \\ \text { mine } & \text { UNOFF } \\ \text { flat } & \text { BGN } \\ \text { cliff } & \text { BGN }\end{array}$

Navajo 341620N1103940W

Coconino 341947N1105035W

Nava jo 343454N1101442W

Apache 353451N1091039W

Mohave $362142 \mathrm{~N} 1133929 \mathrm{~W}$

Apache

Coconino 360738N1122750W

$363110 \mathrm{~N} 1134139 \mathrm{~W}$

$\begin{array}{ll}\text { Cochise } & 320709 \text { N1102536W } \\ \text { Mohave } & 362952 N 1134310 \mathrm{~W}\end{array}$

Hidden Smith Ravine Spring

spring

spring

Hidden Spring

Hidden Spring

Hidden Spring

Hidden Spring

Hidden Spring

Hidden Spring

Hidden Spring

Hidden Spring

Hidden Spring

Hidden Spring

Hidden Spring

Hidden Spring

Hidden Spring

Hidden Spring

Hidden Spring

Hidden Springs Mission

Hidden Tank

Hidden Tank

$\begin{array}{lll}\text { BGN } & \text { Yavapai } & 342857 \text { N1122248W } \\ \text { BGN } & \text { Pima } & 320401 \text { N1103312W } \\ \text { BGN } & \text { Graham } & 323515 N 1094958 W \\ \text { BGN } & \text { Pinal } & 331530 N 1110541 W \\ \text { BGN } & \text { Gila } & 335741 \text { N1101212W } \\ \text { BGN } & \text { Gila } & 335752 N 1110813 W \\ \text { BGN } & \text { Gila } & 341202 N 1112327 W \\ \text { BGN } & \text { Yavapai } & 341651 N 1115141 W \\ \text { BGN } & \text { Navajo } & 341724 N 1102302 W \\ \text { BGN } & \text { Navajo } & 341819 N 1103327 W \\ & & \\ & & \\ \text { BGN } & \text { Apache } & 342246 N 1092613 W \\ \text { BGN } & \text { Yavapai } & 343517 N 1124559 W \\ \text { BGN } & \text { Yavapai } & 345443 N 1130019 W \\ \text { BGN } & \text { Coconino } & 361131 N 1112307 W \\ \text { BGN } & \text { Mohave } & 362 B 12 N 1133741 W \\ \text { BGN } & \text { Apache } & 364052 N 1090927 W \\ \text { UNOFF } & \text { Coconino } & 361121 N 1112339 W \\ \text { BGN } & \text { Santa Cruz } & 312320 N 1111400 W \\ \text { BGN } & \text { Santa Cruz } & 313100 N 111034 B W\end{array}$

$332126 \mathrm{NI140423 \textrm {W }}$ $362333 \mathrm{NI} 133714 \mathrm{~W}$

351422 N1114302W
1040 Fowler

Loy Butte

Palm Canyon

Cane Springs SE

Mustang Point

Flagstaff West

Wing Mountain

Greer

Sponseller Mtn

Brookbank Point

$0 \mathrm{~W}$ Point

Second Knolls

Joe Woody Well

Mustang Point

Antelope Lake

Explorers Monument

St George Canyon

Galleta Flat West

Last Chance Canyon

Groom Creek

Rincon Peak

Stockton Pass

Superior

Cedar Creek

Picture Mtn

North Peak

Tule Mesa

Day Spring

Salado

Martin Mtn

Mount Hope

Willow Springs

Last Chance Canyon

Boiling Over Well

4820 Willow Springs

Ruby

Tubac 
NATIONAL GAZETTEER--ARIZONA 1986

FEATURE NAME

Hidden Tank

Hidden Tank

Hidden Tank

Hidden Tank

Hidden Tank

Hidden Tank

Hidden Tank

Hidden Tank

Hidden Tank

Hidden Tank

Hidden Tank

Hidden Tank

Hidden Tank

Hidden Tank

Hidden Tank

Hidden Tank

Hidden Tank

Hidden Tank

Hidden Tank

Hidden Tank

Hidden Treasure Mine

Hidden Treasure Mine

Hidden Treasure Mine

Hidden Tunnel Spring

Hidden Valley

Hidden Valley

Hidden Valley

Hidden Valley

Hidden Valley

Hidden Valley Airstrip

Hidden Valley Hills

Hidden Valley Interchange

Hidden Valley Ranch

Hidden Valley Spring

Hidden Valley Spring See Ide Valley Spring

Hidden Valley Tank

Hidden Valley Tanks

Hidden Wash

Hidden Water Spring

Hidden Well

Hidden Well

Hide Creek

Hide Creek Mountain

Hide Tank

Hieneken Tank

Hierogliphic Hills See Painted Rock Mountains

Hieroglyphic Canyon

Hieroglyphic Canyon

Hieroglyphic Mountains

Hieroglyphic Spring

Hieroglyphic Tanks

Hi Fuller Canyon

Fuller Canyon

Hi Fuller Spring

Fuller Spirng

Higgins $\mathrm{Hill}$

Higgins Spring

Higgins Tank

Highball Spring

High Blevens Spring

High Bliss Pond

High Creek

High Creek Spring

High Haven Ranch

High Henry Mine

Highjinks

Highjinks Mine

Highland Canal

See South Branch Highland Canal

\section{FEATURE}

CLASS

STATUS

COUNTY

COORDINATE

reservoir

reservoir

reservoir

reservoir

reservoir

reservoir

reservoir

reservoir

reservoir

reservoir

reservoir

BGN

Graham

323029N1092220W

BGN Pinal

BGN

BGN

BGN

BGN

BGN

BGN

reservoir

reservoir BGN

reservoir BGN

reservoir BGN

reservoir BGN

reservoir $B G N$

reservoir

reservoir

reservoir BGN

mine UNOFF

mine

spring

bas in

valley

valley

valley

valley

airport

summit

Mohave

BGN Yavapa

Yavapai

Pinal

Yuma

Maricopa

BGN $\quad$ Maricopa

ADMIN Pinal

Yuna

crossing UNOFF Pinal 325004N1120757W

locale UNOFF Pima 315127N1104242W

spring BGN Mohave 364333N1134425W

spring

reservoir

reservoir

valley

spring

well

BARIANT

BGN

BGN

BGN

Coconino

Yuma

Mohave

Maricopa

Pinal

we 11 UNOFF Gila

stream BGN Yavapai

summit

reservoir

reservoir

range

valley

valley

range

spring

reservoir

valley

spring

ridge

spring

reservoir

spring

spring

lake

strean

spring

loca

mine

locale

mine

canal

$345007 \mathrm{~N} 1125504 \mathrm{~W}$

$343805 \mathrm{~N} 1111120 \mathrm{~W}$

$345831 \mathrm{~N} 1120742 \mathrm{~W}$

325923N1130116W

$332356 \mathrm{~N} 1112535 \mathrm{~W}$

$341730 \mathrm{~N} 1113502 \mathrm{~W}$

$335346 \mathrm{~N} 1122433 \mathrm{~W}$

Gila

Maricopa

$\begin{array}{ll}\text { Pinal } & 332438 \mathrm{~N} 1112506 \mathrm{~W} \\ \text { Gila } & 341755 \mathrm{~N} 1113425 \mathrm{~W}\end{array}$

$342848 \mathrm{~N} 1111541 \mathrm{~W}$

Coconino

$342817 \mathrm{~N} 1111538 \mathrm{~W}$

Coconino

Cochise

Mohave

Coconino

Yavapai

$312626 \mathrm{~N} 1095525 \mathrm{~W}$

$345454 N 1134312 \mathrm{~W}$

$360315 \mathrm{~N} 1124906 \mathrm{~W}$

$342110 N 1115453 \mathrm{~W}$

Gila

Mohave

Graham

Pima

Yuma

Pina

UNOFF

BGN

UNOFF

VARIANT

Maricopa

$331821 \mathrm{~N} 1135834 \mathrm{~W}$

$323416 \mathrm{~N} 1104416 \mathrm{~W}$

$323412 N 1104417 \mathrm{~W}$ $\begin{array}{ll}\text { SOURCE } & \text { ELEV } \\ \text { COORDINATE } & \text { FT MAP NAME }\end{array}$

Whit lock Cienega

North of Oracle

Bee Canyon

New Water Mts

Star Well

Haystack Butte

Congress SW

Brookbank Point

Big Pug Tank

Heber

Mayer

Hay Lake

Scratch Canyon

Chavez Mtn West

Sedona

Gonzales Wash

May Tank Pocket

Chambers

Lockwood Canyon

Russell Spring

Socorro Peak

Cleator

Chloride

Battle Flat

Page Springs

Haley Hills

Hidden Valley

Lone Butte

Mount Nutt

Enid

Stone Cabin

1840 Antelope Peak

Empire Ranch

Mustang Knoll

Robbers Roost Canyon

Stone Cabin

Poverty Spring

Morman Flat Dan

North of Oracle

Chiricahua Butte

Seepage Mtn

7272 Camp Wood

Hay Lake

Perkinsville

$332453 \mathrm{~N} 1112404 \mathrm{~W}$

$342022 \mathrm{~N} 1113440 \mathrm{~W}$

Goldfield

Cane Springs Mtn

Garfias Mtn

Goldfield

Cane Springs Mtn

Kehl Ridge

Kehl Ridge

Bisbee

Pilgrim Wash

Higgins Tank

Dugas

Salt River Peak

Sullivan Draw South

Sierra Bonita Ranch

Bassett Peak

Empire Ranch

Kofa Butte

Campo Bonito

4992 Campo Bonito 
FEATURE NAME

FEATURE

Highland Canal

See North Branch Highline canal

Canal
Highland Canal

See Highline Canal

(historical)

Highland Park

Highland Park

Highland Terrace Mobile Home
Park canal

Highline Canal

High Line Canal

See South Branch Highland Canal

High Line Canal

See North Branch Highline Canal

Highline Canal (historical)

High Line Canal

Highland Canal

High Line Canal

See Highline Canal (historical)

Highline Substation

Highline Trail

High Lonesome Canyon

High Lonesome Spring

High Lonesome Tank

High Lonesome Well

High-Lonesome Windmill

High Lonesome Windmill

High Mesa

High Mountains

See Uinkaret Mountains

High Peak

See Graham, Mount

High Peak

High Peak Cienega

High Pig Tank

High Point Mountain

High Point Rock

High Saddle

High School Hill

High Spring

High Tank

High Tank

High Tank

High Tank

High Tank

High Tank

High Tank Nine

High Tank Number Two Spring

High Tanks

See Tinajas Altas

High Tank Six

Hightown

High View Point

See Hi View Point

High Wall Spring

Highwater Cienega

Highway Canyon

Highway Dam

Highway Drift Fence Tank

Highway Park

Highway Sixty Tank

Highway Spring

Highway Tank

Highway Tank

Highway Tank

canal

well

gap

falls

ppl

cliff

spring

park

\begin{tabular}{|c|c|c|c|}
\hline canal & VARIANT & Maricopa & $332202 \mathrm{~N} 1115722 \mathrm{~W}$ \\
\hline canal & VARIANT & Maricopa & $332927 \mathrm{~N} 1115301 \mathrm{~W}$ \\
\hline $\begin{array}{l}\mathrm{ppl} \\
\mathrm{ppl} \\
\text { locale }\end{array}$ & $\begin{array}{l}\text { BGN } \\
\text { BGN } \\
\text { UNOFF }\end{array}$ & $\begin{array}{l}\text { Cochise } \\
\text { Yavapai } \\
\text { Maricopa }\end{array}$ & $\begin{array}{l}312702 \mathrm{~N} 1095625 \mathrm{~W} \\
343333 \mathrm{~N} 1123406 \mathrm{~W} \\
333538 \mathrm{~N} 1120550 \mathrm{~W}\end{array}$ \\
\hline
\end{tabular}

VARIANT

canal

canal

ADMIN

ADMIN
BGN

Pima

Graham

Maricopa

$321331 \mathrm{N1105244W}$

$324810 \mathrm{N1094145W}$

$332123 N 1115723 W$

Maricopa

332202N1115722W

Maricopa

$332927 N 1115301 \mathrm{~W}$

VARIANT

VARIANT

VARIANT

local

trail

valley

spring

reservoir

locale

UNOFF
UNOFF
BGN
BGN
BGN
BGN
UNOFF

Maricopa

Maricopa

Gila

Cochise

Cochise

Cochise

Apache

Mohave

locale

summit

BGN

BGN

VARIANT

range

VARIANT

summit

summit

spring

summit $B G N$

pillar

summit

spring

reservoir

reservoir

reservoir

reservoir $B G$

reservoir $B G$

reservoir

reservoir

BGN

reservoir

Graham
Greenlee

Mohave

Graham

Yuma

Graham

Yavapai

Coconino

Coconino

Yavapai

Coconino

Yavapai

Pima

Pima

Greenlee

Yuma

Yuma

Coconino

Yuma

Yuma

Yuma

Yuma

Maricopa

VARIANT

Gila

Coconino $360231 \mathrm{N1123407 \textrm {W }}$

Graham 324210N1095259W

valley BGN Pima 314908N1103848W

$\begin{array}{llll}\text { dam } & \text { UNOFF } & \text { Santa Cruz } & 312602 N 1111013 \mathrm{~W} \\ \text { reservoir } & \text { BGN } & \text { Gila } & 335406 N 1102119 \mathrm{~W}\end{array}$

reservoir $B G$

park

$335406 \mathrm{~N} 1102119 \mathrm{~W}$

$340455 \mathrm{~N} 1101046 \mathrm{~W}$

Pinal

Navajo

Yavapai

Cochise

$342434 \mathrm{~N} 1131338 \mathrm{~W}$

$314603 \mathrm{N1} 102100 \mathrm{~W}$

spring

reservoir BGN
Pima

Pinal
$314834 \mathrm{N1} 104232 \mathrm{~W}$

$331609 \mathrm{N1111230W}$
Bisbee

6200 Iron Springs

1290 Sunnys lope

Tucs on

Safford

Tempe

Guadalupe

Diamond Point Pedregosa Mts West Swede Peak

Pedregosa Mts West

6639 High Lonesome Well

4538 Cedar Bas in

Sierra Bonita Ranch Dix Creek

Stone Cabin

Mt Graham

Casner Butte

Bodaway Mesa

5598 Tse Esgizii

Hackberry Mtn

7698 Williams South

Tule Mesa

Batamote Hills

Soza Canyon

Maple Peak

Livingston Hills

Livingston $\mathrm{Hill}$

Humphreys Peak

Livingston Hills

Owl Head

Livingston Hills

Guadalupe

Antelope Point Webb Peak

314943N1103922W

Empire Ranch

Ruby

Carrizo

Florence

Long Tom Canyon

Thorn Peak

McGrew Spring

Empire Ranch

Picketpost Mtn 
NATIONAL GAZETTEER--ARIZONA 1986

\section{FEATURE NAME}

Highway Tank

Highway Tank

Highway Tank

Highway Tank

Highway Tank

Highway Tank

Highway Tank

Highway Tank Dam

Highway Tanks

Highway Tanks

Highway Windmill

High White Valley

Higley

Higley Post Office

Higley School

Higley Substation

Higley Tank

See Higley Twin Tanks

Higley Twin Tanks
Higley Tank

Higway Tank

Hi Isle

Hi Jolly Monument

Hikibon

See Hickiwan

Hikiro

See Hickiwan

Hikjorn

See Hickiwan

Hikuwan

See Hickiwan

$\mathrm{Hi} 11$ and Hill Tank

Hill Cabin Tank

Hill Creek

See Mineral Creek

Hill Creek

Hill Oetention

Hillers Butte

Hill One

Hillside

Hillside Drain

Hillside Mine

Hillside Peak

Hills ide Railroad Station

Hillside Rocks

Hillside Spring

Hills ide Spring

Hillside Spring

Hillside Spring

Hillside Spring

Hillside Spring

Hillside Springs

Hillside Tank

Hi11 Tank

Hill Tank

Hill Tank

Hill Tank

Hillton Ranch

Hilltop (Site)

Hilltop

Hilltop Campground

Hilltop Mine

Hill Top Mine

Hilltop Ranch

Hilltop Tank

Hilitop Tank

Hill Top Tank

Hilltop Well

Hill Well

Hilton Mine

Hilton Wash
FEATURE

CLASS

STATUS

COUNTY

COORDINATE

reservoir BGN Gila 334229N1103220W

reservoir BGN Gila 334246 N1103039W

reservoir BGN Yavapai $342533 \mathrm{~N} 1121456 \mathrm{~W}$

reservoir BGN Coconino 343533N1111521

reservoir BGN Yavapai $343822 \mathrm{N1122145 \textrm {W }}$

reservoir BGN Coconino 343909N1104922W

Coconino 350412N1121231W

reservoir 8GN Apache 344318N1094635

reservoir $B G \mathrm{~N}$ 345520N1105021H

$\begin{array}{lll}\text { locale BGN } & \text { Yavapai } & 342249 N 1123847 \mathrm{~W}\end{array}$

$\begin{array}{llll}\text { valley } & \text { BGN } & \text { Apache } & 362028 \mathrm{~N} 1095556 \mathrm{~W} \\ \text { ppl } & \text { BGN } & \text { Maricopa } & 331826 \mathrm{~N} 1114313 \mathrm{~W} \\ \text { building } & \text { UNOFF } & \text { Maricopa } & 331823 \mathrm{~N} 1114317 \mathrm{~W} \\ \text { school } & \text { UNOFF } & \text { Maricopa } & 331837 \mathrm{~N} 1114258 \mathrm{~W} \\ \text { locale } & \text { UNOFF } & \text { Maricopa } & 331753 \mathrm{~N} 1114210 \mathrm{~W} \\ & \text { VARIANT } & & \\ \text { reservoir } & & \text { Mohave } & 363849 \mathrm{~N} 1131959 \mathrm{~W} \\ \text { reservoir } & \text { BGN } & \text { Mohave } & 363849 \mathrm{N1} 131959 \mathrm{~W} \\ & \text { VARIANT } & & \\ \text { reservoir } & \text { BGN } & \text { Navajo } & 345103 \mathrm{~N} 1095725 \mathrm{~W}\end{array}$

reservoir

BGN

$B G N$

locale $B$ e

pp

ppl

ppl

pp 1

BGN

stream

stream

reservoir

summit

summit

locale

stream

mine

summit

building

summit

spring

spring

spring

spring

spring

spring

spring

reservoir

reservoir

reservoir

reservoir

reservoir

locale

locale

ppl

park

\section{BGN}

Gila

BGN 1932 Coconino

BGN Coconino

BGN

BGN

Yavapai

Mohave

UNOFF
BGN
UNOFF
BGN
BGN
BGN
BGN
BGN
BGN
$8 G N$

Yavapai

Yavapai

Yavapai

Yavapai

Santa Cruz

Cochise

Graham

Apache

Apache

Mohave
Mohave

BGN

$B G N$
$B G N$

BGN

BGN

BGN

UNOFF

BGN

BGN

mine

mine

locale

reservoir

reservoir

reservoir

well

well

mine

stream

$\begin{array}{ll}\text { Mohave } & 354941 \mathrm{~N} 1135814 \mathrm{~W} \\ \text { Coconino } & 354053 \mathrm{~N} 1112403 \mathrm{~W} \\ \text { Cochise } & 314158 \mathrm{~N} 1091940 \mathrm{~W} \\ \text { Gila } & 341245 \mathrm{~N} 1112246 \mathrm{~W} \\ \text { Mohave } & 343347 \mathrm{~N} 113502 \mathrm{BW} \\ \text { Coconino } & 353345 \mathrm{~N} 112122 \mathrm{BW} \\ \text { Pima } & 315312 \mathrm{N1} 10375 \mathrm{~W} \\ \text { Cochise } & 315940 \mathrm{~N} 1091637 \mathrm{~W} \\ \text { Mohave } & 351229 \mathrm{~N} 1140127 \mathrm{~W} \\ \text { Yavapai } & 34303 \mathrm{BN} 1122254 \mathrm{~W} \\ & \\ & \\ \text { Cochise } & 315907 \mathrm{~N} 1091725 \mathrm{~W} \\ \text { Pinal } & 323400 \mathrm{~N} 1120614 \mathrm{~W} \\ \text { Gila } & 333708 \mathrm{~N} 1102357 \mathrm{~W} \\ \text { Graham } & 323114 \mathrm{~N} 1094324 \mathrm{~W} \\ \text { Yavapai } & 343603 \mathrm{~N} 1114412 \mathrm{~W} \\ \text { Coconino } & 351530 \mathrm{~N} 1122025 \mathrm{~W} \\ \text { Navajo } & 364600 \mathrm{~N} 1104039 \mathrm{~W} \\ \text { Gila } & 331432 \mathrm{~N} 1103057 \mathrm{~W} \\ \text { Pima } & 315245 \mathrm{~N} 1103724 \mathrm{~W} \\ \text { Pima } & 314559 \mathrm{~N} 110334 \mathrm{~W}\end{array}$

$314559 N 1103347 \mathrm{~W}$
341857 N1140835W

333953N1141408W

322208N1122829W

322208 N1122829W

32220BN1122829W

$322208 \mathrm{~N} 1122829 \mathrm{~W}$

321749 N1103845W

341048 N1111901W

$340958 \mathrm{~N} 1112535 \mathrm{~W}$

$341114 N 1112709 \mathrm{~W}$

$331225 \mathrm{~N} 1104032 \mathrm{~W}$

$350602 \mathrm{~N} 1120301 \mathrm{~W}$

$342506 \mathrm{~N} 1125459 \mathrm{~W}$

$343039 \mathrm{~N} 1142043 \mathrm{~W}$

343758 N1131235W

$342502 \mathrm{~N} 1125534 \mathrm{~W}$

$342502 \mathrm{~N} 1125458 \mathrm{~W}$

$343717 \mathrm{~N} 1131148 \mathrm{~W}$

$312436 \mathrm{~N} 1110810 \mathrm{~W}$

315344N1091649W

$330116 \mathrm{~N} 1101626 \mathrm{~W}$

$335712 \mathrm{~N} 1092126 \mathrm{~W}$

$344333 \mathrm{~N} 1132432 \mathrm{~W}$

352515 N11 $140648 \mathrm{~W}$
360830 N1120519w

\begin{tabular}{|c|c|c|}
\hline \multirow[t]{3}{*}{$\begin{array}{l}\text { SOURCE } \\
\text { COORDINATE }\end{array}$} & $\begin{array}{l}\text { ELEV } \\
\text { FT }\end{array}$ & MAP NAME \\
\hline & & Chrysotile \\
\hline & 5518 & $\begin{array}{l}\text { Chrysotile } \\
\text { Mayer } \\
\text { Long Valley } \\
\text { Prescott Valley N } \\
\text { Chevelon Butte } \\
\text { May Tank Pocket } \\
\text { Chrysotile } \\
\text { Adamana Three NE } \\
\text { Rock Station } \\
\text { Kirkland }\end{array}$ \\
\hline \multirow[t]{4}{*}{$361757 N 1095802 \mathrm{~W}$} & 1298 & $\begin{array}{l}\text { Tah Chee Wash } \\
\text { Higley } \\
\text { Higley } \\
\text { Higley } \\
\text { Higley }\end{array}$ \\
\hline & & $\begin{array}{l}\text { The Grandstand } \\
\text { Padilla Tank }\end{array}$ \\
\hline & & $\begin{array}{l}\text { Gene Wash } \\
\text { Quartzsite }\end{array}$ \\
\hline & & $\begin{array}{l}\text { Agua Caliente } \mathrm{Hill} \\
\text { Payson South }\end{array}$ \\
\hline $341035 \mathrm{N1112B26 \textrm {H }}$ & $\begin{array}{l}7170 \\
3853\end{array}$ & $\begin{array}{l}\text { North Peak } \\
\text { Mescal Warm Spring } \\
\text { Bright Angel Point } \\
\text { White Horse Lake } \\
\text { Hillside } \\
\text { Lake Havasu City N }\end{array}$ \\
\hline \multirow{3}{*}{$343144 N 1141825 W$} & 3853 & $\begin{array}{l}\text { Bozarth Mesa } \\
\text { Hillside } \\
\text { Hillside } \\
\text { Bagdad } \\
\text { Ruby } \\
\text { Rustler Park } \\
\text { Mt Turnball } \\
\text { Rudd Knoll } \\
\text { Elephant Mtn } \\
\text { Elements Canyon }\end{array}$ \\
\hline & & $\begin{array}{l}\text { Quartermaster Can SW } \\
\text { Gray Mountain } \\
\text { Apache } \\
\text { North Peak } \\
\text { Outch Flat SE } \\
\text { Howard Lake } \\
\text { Mount Fagan } \\
\text { Rustler Park } \\
\text { Kingman } \\
\text { Prescott }\end{array}$ \\
\hline & $\begin{array}{l}7182 \\
3173\end{array}$ & $\begin{array}{l}\text { Rustler Park } \\
\text { Kohatk } \\
\text { Cassadore Spring } \\
\text { Gillespie Mtn } \\
\text { Walker Mtn } \\
\text { Hearst Mtn } \\
\text { Oak Springs } \\
\text { Coolidge Dam } \\
\text { The Narrows } \\
\text { Spring Water Canyon }\end{array}$ \\
\hline
\end{tabular}


FEATURE

CLASS

STATUS
Himmel Park

Hindoo Amphitheater See Hindu Amphitheater

Hindu Amphitheater Hindoo Amphitheater

Hindu Canyon

Hine Airstrip

Hinkle Spring

Hinkle Spring Canyon

Hinton Canyon

Hinton Cemetery

Hinton Ranch

Hinton Spring

Hinton Springs

Hipbone Wash

Historic Railroad Avenue Park Hit

See Hitt Wash

Hitching Rack Well

Hitching Rock Well

Hitson Tank

Hitson Tank

Hit Tank

Hitt Spring Holloway Spring

Hitt Spring

See Holloway Spring

Hitt Wash

Hit Wash

Hitt Wash Well

Hitt Well

Hit Wash

See Hitt Wash

Hi View Mobile Home Park

Hi View Point

High View Point

Hiway Tank

Hiway Tank

Hiway Tank

Hi Windmill

HJH Ranch

$H$ Keeling School

H K Mesa

H K Ranch

$\mathrm{H}$ L Canyon

H L Canyon Eleven Trail

Hlohahle Point

See Lohali Point

Hlohah le Point

See Lohali Point

H L Saddle

$H$ Mine

Hoa Muerta

See Hoa Murk

Hoa Murk

Basket Burn

Hoa Muerta

Pozo Ben

Hoatson

Hobble Canyon

Hobble Mesa

Hobble Mountains

Hobble Natural Tank

Hobble Pond

Hobble Tank

Hobo Canyon

Hobo Spring

Hobo Tank

\begin{tabular}{|c|c|c|c|c|c|c|}
\hline park & $\begin{array}{l}\text { ADMIN } \\
\text { VARIANT }\end{array}$ & Pima & $321401 N 1105559 \mathrm{~W}$ & & & Tucson \\
\hline $\begin{array}{l}\text { bas in } \\
\text { bas in }\end{array}$ & $\begin{array}{l}\text { BGN } 1906 \\
\text { VARIANT }\end{array}$ & $\begin{array}{l}\text { Coconino } \\
\text { Coconino }\end{array}$ & $\begin{array}{l}361031 N 1121149 W \\
361031 N 1121149 W\end{array}$ & & & Shiva Temple \\
\hline $\begin{array}{l}\text { valley } \\
\text { airport } \\
\text { spring } \\
\text { valley } \\
\text { valley }\end{array}$ & $\begin{array}{l}\text { BGN } \\
\text { ADMIN } \\
\text { BGN } \\
\text { BGN } \\
\text { BGN }\end{array}$ & $\begin{array}{l}\text { Mohave } \\
\text { Pinal } \\
\text { Greenlee } \\
\text { Greenlee } \\
\text { Graham }\end{array}$ & $\begin{array}{l}354239 N 1133454 \mathrm{~W} \\
330253 \mathrm{~N} 1120127 \mathrm{~W} \\
333459 \mathrm{~N} 1090322 \mathrm{~W} \\
333635 \mathrm{~N} 1090432 \mathrm{~W} \\
330116 \mathrm{N1101649W}\end{array}$ & $\begin{array}{l}354156 \mathrm{~N} 1133002 \mathrm{~W} \\
333444 \mathrm{~N} 1090300 \mathrm{~W} \\
330200 \mathrm{~N} 1101 \mathrm{~B} 46 \mathrm{~W}\end{array}$ & 1189 & $\begin{array}{l}\text { Hindu Canyon } \\
\text { Maricopa } \\
\text { Blue } \\
\text { Blue } \\
\text { Mt Turnball }\end{array}$ \\
\hline $\begin{array}{l}\text { cemetery } \\
\text { locale } \\
\text { spring } \\
\text { spring } \\
\text { valley } \\
\text { park }\end{array}$ & $\begin{array}{l}\text { UNOFF } \\
\text { UNOFF } \\
\text { BGN } \\
\text { BGN } \\
\text { BGN } \\
\text { ADMIN } \\
\text { VARIANT }\end{array}$ & $\begin{array}{l}\text { Graham } \\
\text { Graham } \\
\text { Graham } \\
\text { Graham } \\
\text { Apache } \\
\text { Cochise }\end{array}$ & $\begin{array}{l}330344 \mathrm{~N} 1100238 \mathrm{~W} \\
325822 \mathrm{~N} 1101052 \mathrm{~W} \\
330114 \mathrm{~N} 1101726 \mathrm{~W} \\
330619 \mathrm{~N} 1101626 \mathrm{~W} \\
361556 \mathrm{~N} 1094246 \mathrm{~W} \\
321510 \mathrm{~N} 1094946 \mathrm{~W}\end{array}$ & $361801 \mathrm{~N} 1094808 \mathrm{~W}$ & & $\begin{array}{l}\text { Geronimo } \\
\text { Jackson Mtn } \\
\text { Mt Turnball } \\
\text { Mt Turnball } \\
\text { Many Farms SW } \\
\text { Willcox North }\end{array}$ \\
\hline $\begin{array}{l}\text { stream } \\
\text { well } \\
\text { well }\end{array}$ & $\begin{array}{l}\text { UNOFF } \\
\text { UNOFF }\end{array}$ & $\begin{array}{l}\text { Yavapai } \\
\text { Gila } \\
\text { Gila }\end{array}$ & $\begin{array}{l}344906 \mathrm{~N} 1123838 \mathrm{~W} \\
340931 \mathrm{~N} 1112042 \mathrm{~W} \\
340951 \mathrm{~N} 1112104 \mathrm{~W}\end{array}$ & & & $\begin{array}{l}\text { Payson South } \\
\text { Payson South }\end{array}$ \\
\hline $\begin{array}{l}\text { reservoir } \\
\text { reservoir } \\
\text { reservoir } \\
\text { spring }\end{array}$ & $\begin{array}{l}\text { BGN } \\
\text { BGN } \\
\text { BGN } \\
\text { BGN } 1964 \\
\text { VARIANT } \\
\text { VARIANT }\end{array}$ & $\begin{array}{l}\text { Coconino } \\
\text { Mohave } \\
\text { Pinal } \\
\text { Coconino }\end{array}$ & $\begin{array}{l}351906 \mathrm{~N} 1120440 \mathrm{~W} \\
362626 \mathrm{~N} 1124931 \mathrm{~W} \\
324359 \mathrm{~N} 1110322 \mathrm{~W} \\
350640 \mathrm{~N} 1120435 \mathrm{~W}\end{array}$ & & & $\begin{array}{l}\text { Sitgreaves Mtn } \\
\text { Hitson Tank } \\
\text { Chief Butte } \\
\text { White Horse Lake }\end{array}$ \\
\hline $\begin{array}{l}\text { spring } \\
\text { stream }\end{array}$ & $\begin{array}{l}\text { BGN } 1930 \\
\text { VARIANT } \\
\text { VARIANT }\end{array}$ & $\begin{array}{l}\text { Coconino } \\
\text { Yavapai }\end{array}$ & $\begin{array}{l}350642 \mathrm{~N} 1120515 \mathrm{~W} \\
344906 \mathrm{~N} 1123838 \mathrm{~W}\end{array}$ & $345104 \mathrm{~N} 1124842 \mathrm{~W}$ & & Simmons \\
\hline $\begin{array}{l}\text { well } \\
\text { well }\end{array}$ & $\begin{array}{l}\text { UNOFF } \\
\text { UNOFF } \\
\text { VARIANT }\end{array}$ & $\begin{array}{l}\text { Yavapai } \\
\text { Yavapai }\end{array}$ & $\begin{array}{l}344955 N 1124515 \mathrm{~W} \\
344947 \mathrm{~N} 1124339 \mathrm{~W}\end{array}$ & & 4728 & $\begin{array}{l}\text { Seepage Mtn } \\
\text { Simmons }\end{array}$ \\
\hline $\begin{array}{l}\text { stream } \\
\text { locale } \\
\text { cliff }\end{array}$ & $\begin{array}{l}\text { UNOFF } \\
\text { BGN } 1973 \\
\text { VARIANT }\end{array}$ & $\begin{array}{l}\text { Yavapai } \\
\text { Maricopa } \\
\text { Gila }\end{array}$ & $\begin{array}{l}344906 \mathrm{~N} 1123838 \mathrm{~W} \\
333533 \mathrm{~N} 1120549 \mathrm{~W} \\
342613 \mathrm{~N} 1111735 \mathrm{~W}\end{array}$ & & 1300 & $\begin{array}{l}\text { Sunnys lope } \\
\text { Keh1 Ridge }\end{array}$ \\
\hline $\begin{array}{l}\text { reservoir } \\
\text { reservoir } \\
\text { reservoir }\end{array}$ & $\begin{array}{l}\text { BGN } \\
\text { BGN } \\
\text { BGN }\end{array}$ & $\begin{array}{l}\text { Greenlee } \\
\text { Navajo } \\
\text { Coconino }\end{array}$ & $\begin{array}{l}331808 \mathrm{~N} 1092127 \mathrm{~W} \\
341359 \mathrm{~N} 1100353 \mathrm{~W} \\
353543 \mathrm{~N} 1105307 \mathrm{~W}\end{array}$ & & & $\begin{array}{l}\text { Pipestem Mtn } \\
\text { Show Low South } \\
\text { Grama Draw }\end{array}$ \\
\hline $\begin{array}{l}\text { locale } \\
\text { locale } \\
\text { school } \\
\text { summit } \\
\text { locale } \\
\text { valley } \\
\text { trail }\end{array}$ & $\begin{array}{l}\text { BGN } \\
\text { UNOFF } \\
\text { UNOFF } \\
\text { BGN } \\
\text { UNOFF } \\
\text { BGN } \\
\text { UNOFF } \\
\text { VARIANT }\end{array}$ & $\begin{array}{l}\text { Gila } \\
\text { Mohave } \\
\text { Pima } \\
\text { Yavapai } \\
\text { Yavapai } \\
\text { Greenlee } \\
\text { Greenlee }\end{array}$ & $\begin{array}{l}340745 \mathrm{~N} 1112244 \mathrm{~W} \\
351840 \mathrm{~N} 1142059 \mathrm{~W} \\
321528 \mathrm{~N} 1105750 \mathrm{~W} \\
340541 \mathrm{~N} 1114111 \mathrm{~W} \\
340547 \mathrm{~N} 111400 \mathrm{BW} \\
331636 \mathrm{~N} 1091520 \mathrm{~W} \\
331358 \mathrm{~N} 1092120 \mathrm{~W}\end{array}$ & 331257 N1092307W & 2360 & $\begin{array}{l}\text { North Peak } \\
\text { Grasshopper Junc SE } \\
\text { Tucson North } \\
\text { Chalk Mountain } \\
\text { Chalk Mountain } \\
\text { Pipestem Mtn } \\
\text { Mitchell }\end{array}$ \\
\hline cliff & VARIANT & Apache & $360851 \mathrm{~N} 1094901 \mathrm{~W}$ & & & \\
\hline cliff & & Apache & $360851 \mathrm{~N} 1094901 \mathrm{~W}$ & & & \\
\hline $\begin{array}{l}\text { gap } \\
\text { mine }\end{array}$ & $\begin{array}{l}\text { BGN } \\
\text { UNOFF } \\
\text { VARIANT }\end{array}$ & $\begin{array}{l}\text { Greenlee } \\
\text { Cochise }\end{array}$ & $\begin{array}{l}331259 \mathrm{~N} 1092252 \mathrm{~W} \\
314956 \mathrm{~N} 1102211 \mathrm{~W}\end{array}$ & & & $\begin{array}{l}\text { Coronado Mtn } \\
\text { McGrew Spring }\end{array}$ \\
\hline $\begin{array}{l}\text { locale } \\
\text { locale }\end{array}$ & $\begin{array}{l}\text { BGN } 1941 \\
\text { VARIANT } \\
\text { VARIANT } \\
\text { VARIANT } \\
\text { VARIANT }\end{array}$ & $\begin{array}{l}\text { Pima } \\
\text { Pima }\end{array}$ & $\begin{array}{l}321647 \mathrm{~N} 1124000 \mathrm{~W} \\
321647 \mathrm{~N} 1124000 \mathrm{~W}\end{array}$ & & & Sikort Chuapo \\
\hline mine & UNOFF & Cochise & $312538 \mathrm{~N} 1095402 \mathrm{~W}$ & & & Bisbee \\
\hline $\begin{array}{l}\text { valley } \\
\text { summit } \\
\text { summit } \\
\text { reservoir } \\
\text { lake } \\
\text { reservoir } \\
\text { valley }\end{array}$ & $\begin{array}{l}\text { BGN } \\
\text { BGN } \\
\text { BGN } \\
\text { BGN } \\
\text { BGN } \\
\text { BGN } \\
\text { BGN } \\
\text { VARIANT }\end{array}$ & $\begin{array}{l}\text { Mohave } \\
\text { Gila } \\
\text { Coconino } \\
\text { Coconino } \\
\text { Mohave } \\
\text { Coconino } \\
\text { Greeniee }\end{array}$ & $\begin{array}{l}363947 N 1134337 W \\
335744 N 1104628 W \\
353046 \mathrm{~N} 1120028 \mathrm{~W} \\
353030 \mathrm{~N} 1120105 \mathrm{~W} \\
363729 \mathrm{~N} 1133623 \mathrm{~W} \\
353043 \mathrm{~N} 1120201 \mathrm{~W} \\
332238 \mathrm{~N} 1091008 \mathrm{~W}\end{array}$ & $332154 \mathrm{~N} 1090607 \mathrm{~W}$ & $\begin{array}{l}5430 \\
7454\end{array}$ & $\begin{array}{l}\text { Mustang Knoll } \\
\text { Rock House } \\
\text { Hobble Tank } \\
\text { Hobble Tank } \\
\text { Sullivan Draw South } \\
\text { Hobble Tank } \\
\text { Dutch Blue Creek }\end{array}$ \\
\hline $\begin{array}{l}\text { spring } \\
\text { reservoir }\end{array}$ & $\begin{array}{l}\text { BGN } \\
B G N\end{array}$ & $\begin{array}{l}\text { Mohave } \\
\text { Coconino }\end{array}$ & $\begin{array}{l}344145 N 1132402 \mathrm{~W} \\
345438 \mathrm{~N} 1105416 \mathrm{~W}\end{array}$ & & & $\begin{array}{l}\text { Elephant Mtn } \\
\text { West Sunset Mtn }\end{array}$ \\
\hline
\end{tabular}


NATIONAL GAZETTEER--ARIZONA 1986

FEATURE CLASS
STATUS

COUNTY
COORDINATE

$\begin{array}{cc}\text { SOURCE } & \text { ELEV } \\ \text { COORDINATE } & \text { FT }\end{array}$

MAP NAME

Hobson Canyon

Hobson Mount

See Rawhide Mountain

Hochani Park

Hochderffer Hills

Hockderfer Trick Tank

Hocker Well

Hockey Puck Spring

Hock Spring

H 0 Davis Ranch

Hodges Tank

Hodgets Canyon

Hodgkins Gulch

Hackberry Gulch

Hodgkins Windmill

Hoemako Co-Operative Hospital

Ho-e Park

Hoe Tank

Hof fman Park

Hof fman Tank

Hoffman Tank

Hogan Cabin

Hogan Lake

Hogan Ridge

Hogan Ridge

Hogansaani Spring

Hogan Sa-ani Spring Hogan Say-ani Spring 0jo de Casa Spring

Hogan Sa-ani Spring See Hogansaani Spring

Hogansaani Wash

Hogan Say-ani Spring See Hogansaani Spring

Hogan Spring

Hogan Spring

Hogan Spring

Hogan Tank Number One

Hogan Tank Number Two

Hogan View Point

Hogan Well

Hogback Tank

Hog Bas in

Hog Bas in Tank

Hog Canyon

Hog Canyon

Hog Canyon

Hog Canyon

Hog Canyon

Hog Canyon

Hog Canyon

Hog Canyon

Hog Canyon

Hog Canyon

Hog Canyon

Hog Canyon

Hog Canyon Spring

Hog Canyon Spring

Hog Canyon Tank

Hog Canyon Tank

Hog Canyon Tank

Hog Canyon Wash

Hoge Ranch (site)

Hoggy John Tank

Hog Hill

Hog $\mathrm{Hill}$

$\mathrm{Hog} \mathrm{Hol}$

Hog Mountain

Hog Mountain

Hog Mountain Dam

Hog Mountain Dam Number Two

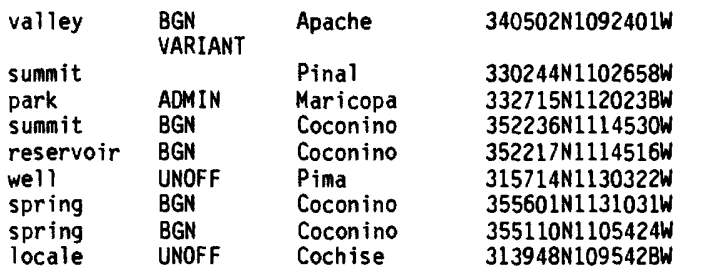

$352221 \mathrm{~N} 1132921 \mathrm{~W}$ 365038 N1133932W

$341435 \mathrm{~N} 1123323 \mathrm{~W}$

$341557 N 1123508 \mathrm{~W}$

$325243 \mathrm{~N} 1114419 \mathrm{~W}$

$332441 \mathrm{~N} 1120436 \mathrm{~W}$

$343557 N 1112052 \mathrm{~W}$

$321301 \mathrm{~N} 1105314 \mathrm{~W}$

351012 N1113653W

park ADM

reservoir

reservoir $B G$

resale $\quad B G$

ridge $\quad B G N$

ridge

spring

VARIANT
VARIANT
VARIANT
VARIANT

spring

stream

spring

spring

reservoir

reservoir

cliff

well

reservo in

reservo ir

valley

valley

valley

valley

valley

valley

valley

valley

valley

valley

valley

spring

spring

reservoir

reservoir

reservoir

BGN

VARIANT

BGN
BGN

BGN

BGN

BGN

UNOFF

BGN

BGN

BGN

$B G N$

BGN

BGN

BGN

BGN

BGN

BGN

BGN

BGN

BGN

BGN

BGN

BGN

$B G N$

BGN

$\begin{array}{lll}\text { stream } & \text { BGN } & \text { Graham } \\ \text { locale } & \text { UNOFF } & \text { Yuma } \\ \text { reservoir } & \text { BGN } & \text { Yavapai } \\ \text { summit } & \text { BGN } & \text { Yavapai } \\ \text { summit } & \text { BGN } & \text { Coconino } \\ \text { reservoir } & \text { BGN } & \text { Maricopa } \\ \text { summit } & \text { BGN } & \text { Gila } \\ \text { summit } & \text { BGN } & \text { Gila } \\ \text { dam } & \text { UNOFF } & \text { Gila } \\ \text { dam } & \text { UNOFF } & \text { Gila }\end{array}$

$323053 N 1095919 \mathrm{~W}$

$330319 N 1144015 \mathrm{~W}$

$350918 \mathrm{~N} 1131135$

$344147 \mathrm{~N} 1113521 \mathrm{~W}$

$350254 \mathrm{~N} 1115512 \mathrm{~W}$

$331301 \mathrm{~N} 1123754 \mathrm{~W}$

$331515 N 1103810$

$335020 N 1104905$

$331626 \mathrm{~N} 1103347 \mathrm{~W}$

$331625 N 1103344 \mathrm{~W}$

\begin{tabular}{|c|c|c|}
\hline \multirow[t]{2}{*}{$340342 \mathrm{~N} 1092230 \mathrm{~W}$} & & Greer \\
\hline & 9152 & $\begin{array}{l}\text { Phoenix } \\
\text { Kendrick Peak } \\
\text { Wing Mountain } \\
\text { Quitobaquito Springs } \\
\text { Hockey Puck Spring } \\
\text { Dinnebito Spring } \\
\text { Hay Mountain }\end{array}$ \\
\hline \multirow[t]{3}{*}{$\begin{array}{l}364827 \mathrm{~N} 1133652 \mathrm{~W} \\
341632 \mathrm{~N} 1123553 \mathrm{~W}\end{array}$} & & $\begin{array}{l}\text { Tuckayou Spring } \\
\text { Wolf Hole Mtn West } \\
\text { Wagoner }\end{array}$ \\
\hline & & $\begin{array}{l}\text { Walnut Grove } \\
\text { Casa Grande East } \\
\text { Phoenix } \\
\text { Long Valley } \\
\text { Tucson } \\
\text { Flagstaff East }\end{array}$ \\
\hline & & $\begin{array}{l}\text { Seligman East } \\
\text { Brooklyn Peak } \\
\text { Deep Lake } \\
\text { Cane Springs Mtn } \\
\text { Goldtooth } \\
\text { Hogansaani Spring }\end{array}$ \\
\hline
\end{tabular}

362949 N1113927W

Tatahatso Point

Brooklyn Peak

Iron Springs

Vulcans Throne

Brooklyn Peak

Brooklyn Peak

Goldtooth

Hogan Well

Hackberry Mtn

Arnold Mesa

Arnold Mesa

College Peaks

312635 N1092650W

313106 N1090529W

Guadalupe Spring

Sonoita

Stockton Pass

Fort Grant

Goldfield

Meddler Wash

$332510 N 1112432 \mathrm{~W}$

334459 N1105754W

Young

Oiamond Butte

Lake Montezuma

Lake Montezum

Skeleton Canyon

Gisela

Guadalupe Spring

Stockton Pass

Young

323522N1095113W Fort Grant

Picacho SW

Cross Mtn

6706 Apache Maid Mtn

Sycamore Point

Cotton Center NW

5757 Cutter

Sombrero Peak

Bucket Mtn

Bucket Mtn 
FEATURE
CLASS

STATUS

COUNTY

COORDINATE

Hog Mountain Spring

Hog Mountain Tanks

Hogpen Spring

Hog Ranch Tan

Hog Ranch Well

Hog Spring

Hog Spring

Hog Spring

Hog Spring

Hog Spring Canyon

Hog Spring Tank

Hog Spring Tank

Hogtail Canyon

See Hogtrail Canyon

Hogtail Saddle

See Hogtrail Saddle

Hog Tank

Hog Tank

Hog Tank

Hog Tank

Hog Tank

Hogtown

See Glenbar

Hogtrail Canyon Hogtail Canyon

Hogtrail Saddle

Hogtail Saddle

Hog Trough Spring

Hog Trough Tank

Hog Wallow Dam

Hog Wallow Lake

Hogwallow Spring

Hog Wash

Hohokam Elementary School

Ho Ho Kam Park

Hohokam-Pima Irrigation Sites

See Hohokam Pima National Monument

Hohokam Pima National Monument Hohokam-Pima Irrigation Sites

Park of the Four Waters

Snaketown

Hohokam Village (subdivision) Ho-Hos-Keli Wash

See Cottonwood Wash

Hoi Oidak

Hoka Tiki Mobile Village

Holaway School

Holbrook

Holbrook Airport

Holbrook City Hall

Holbrook High School

Holbrook Hospital

Holbrook Interchange

Holbrook Junior High School

Holbrook Library

Holbrook Plaza Shopping Center

Holbrook Post Office

Holbrook Railroad Station

Holbrook Ridge (historical)

Holdeman School

Holden Canyon

Holden Lake

Holden Spring

Holden Tank

Holden Tank

Holder Cabin

Holder Tank

Holder Tank

Holder Tank
$335016 N 1104955$

\begin{tabular}{|c|c|c|c|}
\hline $\begin{array}{l}\text { spring } \\
\text { reservoir } \\
\text { spring } \\
\text { reservoir } \\
\text { well } \\
\text { spring } \\
\text { spring } \\
\text { spring } \\
\text { spring } \\
\text { valley }\end{array}$ & $\begin{array}{l}\text { BGN } \\
\text { BGN } \\
\text { BGN } 1976 \\
\text { BGN } \\
\text { UNOFF } \\
\text { BGN } \\
\text { BGN } \\
\text { BGN } \\
\text { BGN } \\
\text { BGN }\end{array}$ & $\begin{array}{l}\text { Gila } \\
\text { Gila } \\
\text { Yavapai } \\
\text { Coconino } \\
\text { Yavapai } \\
\text { Graham } \\
\text { Apache } \\
\text { Yavapai } \\
\text { Yavapai } \\
\text { Navajo }\end{array}$ & $\begin{array}{l}335016 \mathrm{~N} 1104955 \mathrm{~W} \\
331626 \mathrm{N1103347W} \\
344551 \mathrm{~N} 1120603 \mathrm{~W} \\
354612 \mathrm{N11} 125955 \mathrm{~W} \\
341242 \mathrm{~N} 1125635 \mathrm{~W} \\
323102 \mathrm{~N} 1094514 \mathrm{~W} \\
341214 \mathrm{N1095024W} \\
343709 \mathrm{~N} 1124854 \mathrm{~W} \\
34385 \mathrm{~N} 1120751 \mathrm{~W} \\
341135 \mathrm{~N} 1101218 \mathrm{~W}\end{array}$ \\
\hline
\end{tabular}

valley BGN Navajo $341135 \mathrm{~N} 1101218 \mathrm{~W}$

reservoir BGN Apache $341228 \mathrm{~N} 1095025 \mathrm{~W}$

VARIANT

VARIANT

gap

reservoir

reservoir

reservoin

reservoir

BGN

BGN

$B G N$

BGN

reservoir BG

pp 1

valley

gap

spring

reservoir

dam

lake

spring

stream

park

park

park

\section{BGN
VARIANT}

BGN

VARIANT

BGN

VARIANT

BGN
BGN

UNOFF

Greenlee

BGN
BGN
BGN
UNOFF
ADMIN
VARIANT

ADMIN

VARIANT

VARIANT

VARIANT

pp

valley

locale

locale

school

ppl

airport

building

school

building

crossing

school

building

locale

building

building

ridge

school

valley

lake

spring

reservoir

reservoir

locale

reservoir

reservoir

reservoir
BGN

VARIANT

Maricopa

Apache

BGN

UNOFF

NN

ADMIN

UNOFF

UNOFF

UNOFF

UNOFF

UNOFF

UNOFF

UNOFF

UNOFF

BGN

UNOFF

$B G N$

$B G N$
$B G N$
$B G N$
$B G N$
$B G N$
$B G N$
$B G N$
$B G N$

Maricop

Pima

Navajo

Navajo

Navajo

Navajo

Navajo

Navajo

Navajo

Navajo

Navajo

Navajo

Navajo

Maricopa

Maricopa

Coconino

Yavapai

Coconino

Coconino

Yavapai

Gila

Yavapai
$345418 \mathrm{~N} 1100936 \mathrm{~W}$
$340830 \mathrm{~N} 1105309 \mathrm{~W}$
Greenlee

Graham

Gila

Gila

Gila

Yavapai

Graham

Greenlee

Greenlee

Gila

Gila

Apache

Apache

Greenlee

Navajo

Maricopa

Maricopa

Pinal

Pinal

332304N1092533W

$332440 \mathrm{~N} 1092123 \mathrm{~W}$

$323041 \mathrm{N1094242 \textrm {W }}$

$340343 \mathrm{~N} 1110249 \mathrm{~W}$

$340742 N 1105340 \mathrm{~W}$

344340 N1114237W

$325500 \mathrm{~N} 1095127 \mathrm{~W}$

332304N1092533W

332440 N1092123W

331523N110461 OW

$331521 \mathrm{~N} 1104621 \mathrm{~W}$

$335900 \mathrm{~N} 1092518 \mathrm{~W}$

$335857 \mathrm{~N} 1092536 \mathrm{~W}$

$332006 \mathrm{~N} 1090726 \mathrm{~W}$

$341737 \mathrm{~N} 1100540 \mathrm{~W}$

$332820 \mathrm{~N} 1115352 \mathrm{~W}$

332620 N1114944W

331100 N1115600W

331100 N1115600W

$341456 N 1100852 W$

Santa Cruz

Santa Cruz

$332626 \mathrm{~N} 1114910 \mathrm{~W}$

$360838 N 1093422 \mathrm{~W}$

321812 N1115217W

333409 N1121227W

$321616 \mathrm{~N} 1105652 \mathrm{~W}$

345408 N1100927W

345621

$345418 \mathrm{~N} 1100945 \mathrm{~W}$

345433N1100918W

345441 N1100924W

$345422 \mathrm{~N} 1100952 \mathrm{~W}$

345457 N1100918W

$345407 N 1100922 \mathrm{~W}$

345400 N11 $100927 \mathrm{~W}$

$334810 \mathrm{~N} 1112545 \mathrm{~W}$

$332435 \mathrm{~N} 1115730 \mathrm{~W}$

$312400 \mathrm{~N} 1111605 \mathrm{~W}$

312608 N1111706W

351553N1121451W

$343745 \mathrm{~N} 1124052 \mathrm{~W}$

SOURCE

COORDINATE

ELEV
FT

MAP NAME

$341235 N 1101702 W$

Sombrero Peak

Bucket Mtn

Clarkdale

Dike Tank

o'Neill Pass

Stockton Pass

Sponseller Mtn

Mart in Mtn

Hickey Mountain

Red Top Mtn

Limestone Canyon $\mathrm{N}$

Sponseller Mtn

Gillespie Mtn

Buzzard Roost Mesa

Oxbow Mtn

Oxbow Mtn

Casner Butte

Robinson Mesa

Rose Peak

Pinal Peak

Pinal Peak

Big Lake North

Big Lake North

Maple Peak

Show Low North

Tempe

Gila Butte NW 
FEATURE NAME

Holding Cienega Spring

Holding Pasture

Holding Pasture Tank

Holding Pen Tank

Holding Tank

Holdin Pasture Tank

Holdout Canyon

Holdout Creek

Holdout Mesa

Holdout Spring

Holdout Tank

Holdout Trail Sixty Nine

Holdup Canyon

Holdup Tank

Hold Up Tank

Hole, Lake

Lake Wilhelm

Hole, The

Hole, The

Hole, The

Hole, The

Hole Canyon

Hole Canyon Tank

Hole-in-Ground

Hole in Rock

Hole in Rock Valley

Hole in the Ground

Hole in the Ground

Hole in the Ground Canyon

Hole in the Ground Canyon

Hole in the Ground Tank

Hole in the Rock

Hole-in-the-Rock See Papago State Park

Hole in the Rock Hole-in-the-Rock

Hole-in-the-Rock

See Hole in the Rock

Hole-in-the-Rock Canyon

Hole in the Rock Tank

Hole in the Wall

Hole In The Wall Dropstructure

Hole-n-Wall Canyon

Hole-n-Wall Reservoir

Hole Reservoir

Hole Sappo Tank

Hole Spring

Hole Spring

Hole Spring

See Babes Hole Sprin

Holiday Palms Mobile Home Park

Holiday Park

Holiday Park School

Hol iday Spa Mobile Home Park

Holiday Village Mobile Home

Park

Holl laday Hot Springs

See Indian Hot Springs

Hol laday Ranch

Holladay School

Holl and Mine

Hollenback Point

Hollenbeck Point

Papago Point

Point Hollenbeck

Hollenbeck Point

See Hollenback Point

Holl ingshead Mountain

Hollingshead Point

Hollingshead Point Tank Hollingshead Point Tank Number One

\begin{tabular}{|c|c|c|c|}
\hline $\begin{array}{l}\text { FEATURE } \\
\text { CLASS }\end{array}$ & STATUS & COUNTY & COORDINATE \\
\hline $\begin{array}{l}\text { spring } \\
\text { area }\end{array}$ & $\begin{array}{l}\text { BGN } \\
\text { BGN }\end{array}$ & $\begin{array}{l}\text { Greenlee } \\
\text { Graham }\end{array}$ & $\begin{array}{l}331519 N 1091058 \mathrm{~W} \\
331423 \mathrm{~N} 1093100 \mathrm{~W}\end{array}$ \\
\hline $\begin{array}{l}\text { reservoir } \\
\text { reservoir } \\
\text { reservoir } \\
\text { reservoir } \\
\text { valley } \\
\text { stream } \\
\text { summit } \\
\text { spring } \\
\text { reservoir } \\
\text { trail }\end{array}$ & $\begin{array}{l}\text { BGN } \\
\text { BGN } \\
\text { BGN } \\
\text { BGN } \\
\text { BGN } \\
\text { BGN } \\
\text { BGN } \\
\text { BGN } \\
\text { BGN } \\
\text { UNOFF }\end{array}$ & $\begin{array}{l}\text { Navajo } \\
\text { Navajo } \\
\text { Gila } \\
\text { Yavapai } \\
\text { Graham } \\
\text { Graham } \\
\text { Graham } \\
\text { Graham } \\
\text { Graham } \\
\text { Graham }\end{array}$ & $\begin{array}{l}335902 \mathrm{~N} 1095458 \mathrm{~W} \\
340037 \mathrm{~N} 1102726 \mathrm{~W} \\
341407 \mathrm{~N} 1111029 \mathrm{~W} \\
342225 \mathrm{~N} 1115552 \mathrm{~W} \\
324844 \mathrm{~N} 1100458 \mathrm{~W} \\
325503 \mathrm{~N} 1101319 \mathrm{~W} \\
325439 \mathrm{~N} 1101241 \mathrm{~W} \\
323626 \mathrm{~N} 1101 \mathrm{~B} 44 \mathrm{~W} \\
324730 \mathrm{~N} 1100523 \mathrm{~W} \\
325512 \mathrm{~N} 1101755 \mathrm{~W}\end{array}$ \\
\hline $\begin{array}{l}\text { valley } \\
\text { reservoir } \\
\text { reservoir } \\
\text { lake }\end{array}$ & $\begin{array}{l}\text { BGN } \\
\text { BGN } \\
\text { BGN } \\
\text { BGN } 1973 \\
\text { VARIANT }\end{array}$ & $\begin{array}{l}\text { Graham } \\
\text { Gila } \\
\text { Coconino } \\
\text { Apache }\end{array}$ & $\begin{array}{l}325728 N 1100824 W \\
332854 N 1102757 W \\
350049 N 1113412 W \\
341525 N 1094443 W\end{array}$ \\
\hline $\begin{array}{l}\text { basin } \\
\text { bas in } \\
\text { bend } \\
\text { spring } \\
\text { valley }\end{array}$ & $\begin{array}{l}B G N \\
B G N \\
B G N \\
B G N \\
B G N\end{array}$ & $\begin{array}{l}\text { Mohave } \\
\text { Coconino } \\
\text { Yavapai } \\
\text { Greenlee } \\
\text { Gila }\end{array}$ & $\begin{array}{l}365037 N 1133057 \mathrm{~W} \\
365705 \mathrm{~N} 1114720 \mathrm{~W} \\
340748 \mathrm{~N} 1123438 \mathrm{~W} \\
331046 \mathrm{~N} 1090 \mathrm{~B} 5 \mathrm{~W} \\
335145 \mathrm{~N} 1103222 \mathrm{~W}\end{array}$ \\
\hline $\begin{array}{l}\text { reservoir } \\
\text { bas in } \\
\text { arch } \\
\text { valley } \\
\text { basin } \\
\text { basin } \\
\text { valley } \\
\text { valley } \\
\text { reservoir } \\
\text { arch }\end{array}$ & $\begin{array}{l}\text { BGN } \\
B G N \\
B G N \\
B G N \\
B G N \\
B G N \\
B G N \\
B G N \\
B G N \\
B G N\end{array}$ & $\begin{array}{l}\text { Gila } \\
\text { Coconino } \\
\text { Coconino } \\
\text { Navajo } \\
\text { Gila } \\
\text { Yavapai } \\
\text { Gila } \\
\text { Gila } \\
\text { Gila } \\
\text { Coconino }\end{array}$ & $\begin{array}{l}335333 \mathrm{~N} 1103307 \mathrm{~W} \\
342038 \mathrm{~N} 1105829 \mathrm{~W} \\
363413 \mathrm{~N} 1112437 \mathrm{~W} \\
362038 \mathrm{~N} 1100510 \mathrm{~W} \\
341055 \mathrm{~N} 1111512 \mathrm{~W} \\
344930 \mathrm{~N} 1130600 \mathrm{~W} \\
340921 \mathrm{~N} 1111056 \mathrm{~W} \\
341342 \mathrm{~N} 1111226 \mathrm{~W} \\
340846 \mathrm{~N} 1110916 \mathrm{~W} \\
365618 \mathrm{~N} 1115055 \mathrm{~W}\end{array}$ \\
\hline
\end{tabular}

$\begin{array}{lc}\text { SOURCE } & \text { ELEV } \\ \text { COORDINATE } & \text { FT }\end{array}$

MAP NAME

Fritz Canyon

Elevator Mtn

Alchesay Flat

Cibecue

McDonald Mtn

Dugas

324627N1100501W Tripp Canyon

325342N1101719W Jackson Mtn

Jackson Mtn

Bassett Peak

Tripp Canyon

Cobre Grande Mtn

325511N1100803W Jacks on Mtn

Natural Corra

Lower Lake Mary

Vernon

Wolf Hole Mtn East

Wrather Arch

Wagoner

Dix Creek

335403 N1103328

Mule Hoof Bend

Blue House Mtn

7569 Woods Canyon

5980 Dove Spring

Hole In Rock Valley

362104 N1100655W

Payson South

Scratch Canyon

McDonald Mtn

McDonald Mtn

McDonald Mtn

Wrather Arch

1425 Tempe

$362530 \mathrm{~N} 1121454 \mathrm{~W}$

$362705 \mathrm{~N} 1122054 \mathrm{~W}$

$331616 \mathrm{~N} 1104137 \mathrm{~W}$

$331243 \mathrm{~N} 1095610 \mathrm{~W}$

$364706 \mathrm{~N} 1132930 \mathrm{~W}$

331249 N1095650W

Quaking Aspen

Cutter

Gila Peak

Hole-N-Wall Canyon

$364834 \mathrm{~N} 1132725 \mathrm{~W}$

$364706 \mathrm{~N} 1132940 \mathrm{~W}$

$361900 \mathrm{~N} 1112958 \mathrm{~W}$

$355525 N 1122115 \mathrm{~W}$

$332827 \mathrm{~N} 1111256 \mathrm{~W}$

334838 N1110610W

Coconino

Maricopa

Gila

VARIANT

spring Coconino 350423N1115619W

locale UNOFF Maricopa 332432N1113739W

park ADMIN Maricopa $333014 N 1121212 \mathrm{~W}$

$364715 \mathrm{~N} 1132935 \mathrm{~W}$

Hole-N-Wall Canyon

Hole-N-Wall Canyon

The Gap

Metzger Tank

Iron Mountain

Armer Mountain

1535 Buckhorn

Glendale

Glendale

School UNOFF Maricopa 333002N1121203W

locale UNOFF Maricopa 333448 N1120255W

locale UNOFF Maricopa $332407 \mathrm{~N} 1115112 \mathrm{~W}$

VARIANT

ppl Graham 325954 N1095400W

school UNOFF Pima 321142N1105712W

mine UNOFF Santa Cruz 312214N1104142W

BGN 1985 Coconino

VARIANT

VARIANT

VARIANT

VARIANT

summit

VARIANT

Coconino

summit BGN Coconino

summit

reservoir

BGN

Coconino

360123N1115306W

$343851 \mathrm{N1112531 \textrm {W }}$

$343540 \mathrm{~N} 1114043 \mathrm{~W}$

BGN Yavapai 343538N1114020W

Tucs on

Duquesne

Cape Royal

7352 Happy Jack

Walker Mtn

Walker Mtn 


\section{FEATURE NAME}

Hollingshead Point Tank Number One

See Hollingshead Point Tank reservoir

Hollingshead Tank

Holl ingshead Tank

Hollow, The

Holloway Spring

See Hitt Spring

Holloway Spring
Hitt Spring

Holl loway Tank

Hollow Canyon

See Hawk Hollow Canyon

Hollow Place

Holly Park

See Country Club Annex Park

Holly Tank

Hollywood

Hollywood Bowl Tank

Hollywood Tank

Hollywood Well

Holmes Canyon

Holmes Creek

Holmes Elementary School

Holmes Spring

Hoit Overpass

Holy Cross Cemetery

Holy Grail Temple

Holy Hope Cemetery

Holy Joe Canyon

Holy Joe Pasture

Holy Joe Peak

Holy Joe Wash

Holy Moses Mine

Holy Oak Tank

Holyoke Wash

Home Creek

Home Ranch Tank

Homestake Mine

Homestead (subdivision)

Homestead Spring

Homestead Spring

Homestead Tank

Homestead Tank

Homestead Tank

Homestead Tank

Homestead Tank

Homestead Tank

Homestead Tank

See Pitts Homestead Tank

Homestead Tank

Homestead Windmill

Homestead Windmill

Home Tank

Home Tank

Home Tank Draw

Home Tank Number One

Home Tank Number Two

Honan Park Two

Honan Point

Hondo, Arroyo

Honey Bee Canyon

Honey Bee Tank

Honey Butte

Honey Butte Tank

Honey Butte Well

Honey Creek

Honey Creek Divide

Honeycutt Spring

\section{rese}

$$
\text { valley }
$$

pa

$$
\text { park }
$$

reservoir

ppl

reservoir

reservoir

well

\begin{tabular}{|c|c|c|c|}
\hline $\begin{array}{l}\text { reservoir } \\
\text { reservoir } \\
\text { valley }\end{array}$ & $\begin{array}{l}\text { BGN } \\
\text { BGN } \\
\text { BGN }\end{array}$ & $\begin{array}{l}\text { Yavapai } \\
\text { Coconino } \\
\text { Mohave }\end{array}$ & $\begin{array}{l}343547 N 1114140 \mathrm{~W} \\
344158 \mathrm{~N} 1112607 \mathrm{~W} \\
365444 \mathrm{~N} 1124547 \mathrm{~W}\end{array}$ \\
\hline $\begin{array}{l}\text { spring } \\
\text { spring }\end{array}$ & $\begin{array}{l}\text { BGN } 1964 \\
\text { VARIANT }\end{array}$ & $\begin{array}{l}\text { Coconino } \\
\text { Coconino }\end{array}$ & $\begin{array}{l}350640 \mathrm{~N} 1120435 \mathrm{~W} \\
350642 \mathrm{~N} 1120515 \mathrm{~W}\end{array}$ \\
\hline eservoir & $\begin{array}{l}\text { BGN } \\
\text { VARIANT }\end{array}$ & Coconino & $360610 \mathrm{~N} 1120505 \mathrm{~W}$ \\
\hline
\end{tabular}

valley

stream

$$
\begin{aligned}
& \text { sch } \\
& \text { spr } \\
& \text { cross } \\
& \text { cem } \\
& \text { sum } \\
& \text { cem } \\
& \text { val } \\
& \text { sum } \\
& \text { sum }
\end{aligned}
$$

$\begin{array}{llll}\text { stream } & \text { BGN } & \text { Pinal } & 324932 N 1103258 \mathrm{~W} \\ \text { mine } & \text { UNOFF } & \text { Mohave } & 350728 N 1140256 \mathrm{~W} \\ \text { reservoir } & \text { BGN } & \text { Navajo } & 342245 N 1101637 \mathrm{~W} \\ \text { stream } & \text { BGN } & \text { Graham } & 325507 N 1094805 \mathrm{~W} \\ \text { stream } & \text { BGN } & \text { Apache } & 33453 \mathrm{~N} 109224 \mathrm{~W} \\ \text { reservoir } & \text { BGN } & \text { Graham } & 323925 \mathrm{N1} 101625 \mathrm{~W} \\ \text { mine } & \text { UNOFF } & \text { Santa Cruz } & 312516 \mathrm{N1104428W} \\ \text { ppI } & \text { BGN } & \text { Maricopa } & 332720 N 1114554 \mathrm{~W} \\ \text { spring } & \text { BGN } & \text { Yavapai } & 340346 N 1115653 \mathrm{~W} \\ \text { spring } & \text { BGN } & \text { Coconino } & 345551 N 1112852 \mathrm{~W}\end{array}$

reservoir BGN Cochise 313710N1094757W reservoir BGN Cochise 314357 N1102010W reservoir BGN Pima 315155N1111034W reservoir BGN Yavapai 342400N1123507W reservoir $B G N$ $\begin{array}{llll}\text { reservoir } & \text { BGN } & \text { Navajo } & 34350 \mathrm{BN} 1102658 \mathrm{~W} \\ \text { reservoir } & \text { BGN } & \text { Coconino } & 344024 \mathrm{~N} 1111555 \mathrm{~W}\end{array}$ reservoir VARIANT Coconino 352145N1123316W

\begin{tabular}{|c|c|c|c|}
\hline $\begin{array}{l}\text { locale } \\
\text { reservoir } \\
\text { reservoir } \\
\text { valley } \\
\text { reservoir } \\
\text { reservoir } \\
\text { park } \\
\text { cliff } \\
\text { arroyo } \\
\text { valley }\end{array}$ & $\begin{array}{l}\text { BGN } \\
\text { BGN } \\
\text { BGN } \\
\text { BGN } \\
\text { BGN } \\
\text { BGN } \\
\text { ADMIN } \\
\text { BGN } 1906 \\
\text { BGN } \\
\text { BGN }\end{array}$ & $\begin{array}{l}\text { Yavapai } \\
\text { Coconino } \\
\text { Coconino } \\
\text { Coconino } \\
\text { Coconino } \\
\text { Coconino } \\
\text { Maricopa } \\
\text { Coconino } \\
\text { Pima } \\
\text { Pima }\end{array}$ & $\begin{array}{l}342535 \mathrm{~N} 1123958 \mathrm{~W} \\
350931 \mathrm{~N} 1114626 \mathrm{~W} \\
351115 \mathrm{~N} 1112943 \mathrm{~W} \\
343439 \mathrm{~N} 1113116 \mathrm{~W} \\
343642 \mathrm{~N} 1113043 \mathrm{~W} \\
343700 \mathrm{~N} 1113055 \mathrm{~W} \\
333419 \mathrm{~N} 1120555 \mathrm{~W} \\
360820 \mathrm{~N} 1115824 \mathrm{~W} \\
314251 \mathrm{~N} 1112841 \mathrm{~W} \\
322601 \mathrm{~N} 1105732 \mathrm{~W}\end{array}$ \\
\hline $\begin{array}{l}\text { reservoir } \\
\text { summit } \\
\text { reservoir } \\
\text { well } \\
\text { stream } \\
\text { ridge } \\
\text { spring }\end{array}$ & $\begin{array}{l}\text { BGN } \\
\text { BGN } 1937 \\
\text { BGN } \\
\text { UNOFF } \\
\text { BGN } \\
\text { BGN } \\
\text { BGN }\end{array}$ & $\begin{array}{l}\text { Yavapai } \\
\text { Gila } \\
\text { Gila } \\
\text { Gila } \\
\text { Gila } \\
\text { Gila } \\
\text { Pinal }\end{array}$ & $\begin{array}{l}344840 N 1121357 \mathrm{~W} \\
333815 N 1110637 \mathrm{~W} \\
333815 N 1110541 \mathrm{~W} \\
333749 \mathrm{~N} 1110627 \mathrm{~W} \\
335217 \mathrm{~N} 1105825 \mathrm{~W} \\
335126 \mathrm{~N} 1105813 \mathrm{~W} \\
332752 \mathrm{~N} 1111026 \mathrm{~W}\end{array}$ \\
\hline
\end{tabular}
reservoir BGN Coconino 360416N1122023W locale BGN Cochise 313612 N1094720W
Walker Mtn Happy Jack Moccas in

White Horse Lake

Davenport $\mathrm{Hill}$

Moenkopi

Greasewood Mountain Safford

San Carlos Esperanza Mill

2936 San Carlos Rover Peak $340916 \mathrm{~N} 1115255 \mathrm{~W}$ $340913 \mathrm{~N} 1115252 \mathrm{~W}$ Rover Peak

$324932 N 1103258 W$

\section{Mesa}

Weavers Needle Bowie

El Mirage

6703 King Arthur Castle

Tucson North

Holy Joe Peak

\begin{tabular}{|c|c|c|}
\hline \multicolumn{2}{|l|}{$324838 \mathrm{~N} 1103138 \mathrm{~W}$} & \multirow{2}{*}{$\begin{array}{l}\text { Holy Joe Peak } \\
\text { Kingman SE } \\
\text { Big Pug Tank } \\
\text { Pima } \\
\text { Big Lake South } \\
\text { Kennedy Peak } \\
\text { Harshaw } \\
\text { Mesa } \\
\text { Cooks Mesa } \\
\text { Mormon Lake }\end{array}$} \\
\hline $\begin{array}{l}325609 \mathrm{~N} 1094706 \mathrm{~W} \\
335157 \mathrm{~N} 1092538 \mathrm{~W}\end{array}$ & 1310 & \\
\hline & & $\begin{array}{l}\text { Gleeson SE } \\
\text { Huachuca City } \\
\text { Batamote Hills } \\
\text { Wilhoit } \\
\text { Zeniff } \\
\text { Turkey Mtn }\end{array}$ \\
\hline & 4220 & $\begin{array}{l}\text { Piute Point } \\
\text { Gleeson SE }\end{array}$ \\
\hline & & $\begin{array}{l}\text { Kirkland } \\
\text { Bellemont }\end{array}$ \\
\hline $343944 N 1113024 W$ & & $\begin{array}{l}\text { Buckhorn Mountain } \\
\text { Buckhorn Mountain } \\
\text { Buckhorn Mountain } \\
\text { Sunnys lope } \\
\text { Walhalla Plateau }\end{array}$ \\
\hline $\begin{array}{l}314341 \mathrm{~N} 1113351 \mathrm{~W} \\
322907 \mathrm{~N} 1105825 \mathrm{~W}\end{array}$ & & $\begin{array}{l}\text { Las Guijas } \\
\text { Oro Valley }\end{array}$ \\
\hline & & $\begin{array}{l}\text { Munds Draw } \\
\text { Windy } \mathrm{Hill} \\
\text { Windy } \mathrm{Hill} \\
\text { Windy } \mathrm{Hill}\end{array}$ \\
\hline $335132 N 1105734 W$ & & $\begin{array}{l}\text { Aztec Peak } \\
\text { Aztec Peak } \\
\text { Iron Mountain }\end{array}$ \\
\hline
\end{tabular}

4802 Holy Joe Peak

5415 Holy Joe Peak 


\section{FEATURE NAME}

Honeymoon Cabin

See Honeymoon Campground

Honeymoon Campground

Honeymoon Cabin

Honeymoon Ranch

Honeymoon Canyon

Honeymoon Ranch

See Honeymoon Campground

Honeymoon Seep

Honeymoon Spring

Honeymoon Tank

Honeymoon Trail

Honeymoon Trail (pack)

Honey Spring

Honga Springs

Honnas Ranch

Honor Is land Park

Hood Haf assienda

Hoodoo Knoll

Hoodoo Wash

Hoodoo Well

Hood Windmill

Hook and Line Ranch

Hooker Butte

Hooker Cabin

\section{Hooker Cienega}

Hooker Gap

Hooker Gap Charco Hooker Gap Water Hole

Hooker Gap Tank

Hooker Gap Water Hole

See Hooker Gap Charco

Hooker Gap Well

Hooker Gap Well

Hookers Gap Dan

Hookers Hot Springs

Hooker Tank

Hooker Tank

Hooker Tank

Hooker Well

Hook Tank

Hoop-em-up Tank

Hooper

Hooper Saddle

Hoopes Quarry

Hoosier Shaft

Hoot Owl Spring

Hoot Owl Tank

Hoover Dam

Boulder Dam

Hoover Dam Spring

Hoover Ditch

Hoovey Canyon

Green Canyon

Hurey Canyon

Huvey Canyon

Hop Canyon

Hop Canyon Tank

Hop Canyon Tank Dam

Hop Creek

Hope

Johannesberg

Hope, Mount

Hope Camp

Hopeful Tank

Hopeful Tank

Hope Wash

Mount Hope Wash

Hopewell Ranch

Hopewell Tunnel

Hopi Cultural Center

\section{FEATURE}

STATUS

COUNTY

COORDINATE

$\begin{array}{lc}\text { SOURCE } & \text { ELEV } \\ \text { COORDINATE } & \text { FT }\end{array}$

MAP NAME

park

VARIANT

park

ADMIN

VARIANT

$\begin{array}{ll}\text { valley } & \text { BGN } \\ & \text { VARIANT } \\ \text { park } & \\ \text { spring } & \text { BGN } \\ \text { spring } & \text { BGN } \\ \text { reservoir } & \text { BGN } \\ \text { trail } & \text { UNOFF } \\ \text { trail } & \text { UNOFF } \\ \text { spring } & \text { BGN } \\ \text { spring } & \text { BGN }\end{array}$

Navajo

Greenlee

Maricopa

Apache

Mohave

Mohave

Mohave

Navajo

Coconino

locale UNOFF

park

locale

summit

strean

well

locale

locale

summit

locale

ADMIN

BGN

BGN

BGN

UNOFF

BGN

UNOFF

BGN

BGN

flat BGN

gap BGN

reservoir BGN

reservoir

BGN

reservoir

well

well

dam

UNOFF

UNOFF

UNOFF

Pima

$343235 \mathrm{N11} 22847 \mathrm{~W}$

Cochise $313148 N 1092645 \mathrm{~W}$

Greenlee 334116N1092608W

Greenle

Yuma

$314154 \mathrm{~N} 1094523 \mathrm{~W}$

Pinal

Graham

$330900 \mathrm{~N} 11$

$322939 \mathrm{~N} 1100424 \mathrm{~W}$

$323103 N 1101915 W$

Graham 323402N1100400W

Graham

Graham

$331442 \mathrm{~N} 1095826 \mathrm{~W}$

$331557 N 1095828 \mathrm{~W}$

331717 N1100058W

Graham

Grahan

Grahan

Grahan

$331557 N 1095828 \mathrm{~W}$

$331531 \mathrm{~N} 1095957 \mathrm{~W}$

$331750 \mathrm{~N} 1100144 \mathrm{~W}$

$333224 \mathrm{~N} 1095744 \mathrm{~W}$

ppl BGN Cochise 322019N1101420W

reservoir BGN Graham 323341N1101525W

reservoir BGN Yavapai $342545 \mathrm{~N} 1120001 \mathrm{~W}$

reservoir BGN Yavapai $350903 \mathrm{~N} 1130355 \mathrm{~W}$

well UNOFF Yavapai 342538N1115947W

reservoir BGN Yavapai 341821 N1121413W

reservoir BGN Yavapai 342144N1114918W

locale BGN Yavapai 341558N1122256W

gap BGN Yavapai $341403 N 1122322 \mathrm{~W}$

mine UNOFF Gila 332651N1104930W

mine

reservoir

dam

spring

canal

valley

BGN

BGN

UNOFF

VARIANT

BGN

BGN 1960

VARIANT

VARIANT

VARIANT

Gila

Yavapai

Apache

Mohave

Yavapai

Maricopa

$332455 \mathrm{~N} 1104647 \mathrm{~W}$

$343019 \mathrm{~N} 1122330 \mathrm{~W}$

333556 N1095159W

$360058 \mathrm{~N} 1144414 \mathrm{~W}$

342351 N1125953W

$331524 \mathrm{~N} 1120912 \mathrm{~W}$

315702 N1092048W

3

$341345 N 1102425 W$

Humboldt Mtn

White Rock Wash

Quartermaster Can SW

Rock Canyon

Rock Canyon

Montezumas Chair

Vulcans Throne

Prescott

Pedregosa Mts West

332006 N1140154W

7945

Hoodoo Knob

Horn

Hoodoo Well

Outlaw Mountain

Coolidge Dam

4895 Reiley Peak

Bassett Peak

Sierra Bonita Ranch

Gila Peak

Tule Tubs

Ash Creek Ranch

5215 Tule Tubs

5050 Ash Creek Ranch

Elwood Canyon

Hookers Hot Springs

Bassett Peak

Estler Peak

Squaw Peak

Cleator

Tule Mesa

Battleship Butte

Minnehaha

Globe

Globe

Prescott

West Poker Mtn

Hoover Dam

Hillside

Laveen

Rustler Park
3660 Arivaca

Arnold Mesa

\begin{tabular}{|c|c|c|c|c|c|c|}
\hline $\begin{array}{l}\text { valley } \\
\text { reservoir } \\
\text { dam } \\
\text { stream } \\
\text { locale }\end{array}$ & $\begin{array}{l}\text { BGN } \\
\text { BGN } \\
\text { UNOFF } \\
\text { BGN } \\
\text { BGN } \\
\text { VARIANT }\end{array}$ & $\begin{array}{l}\text { Navajo } \\
\text { Navajo } \\
\text { Navajo } \\
\text { Yavapai } \\
\text { Yuma }\end{array}$ & $\begin{array}{l}340333 \mathrm{~N} 1101242 \mathrm{~W} \\
341352 \mathrm{~N} 1101016 \mathrm{~W} \\
341354 \mathrm{~N} 1101018 \mathrm{~W} \\
345200 \mathrm{~N} 1131730 \mathrm{~W} \\
334323 \mathrm{~N} 1134206 \mathrm{~W}\end{array}$ & $341418 \mathrm{~N} 1101032 \mathrm{~W}$ & 1531 & $\begin{array}{l}\text { Long Tom Canyon } \\
\text { Red Top Mtn } \\
\text { Red Top Mtn } \\
\text { Pilot Knob } \\
\text { Hope }\end{array}$ \\
\hline $\begin{array}{l}\text { Summit } \\
\text { locale } \\
\text { reservoir } \\
\text { reservoir }\end{array}$ & $\begin{array}{l}\text { BGN } \\
\text { BGN } \\
\text { BGN } \\
\text { BGN }\end{array}$ & $\begin{array}{l}\text { Yavapai } \\
\text { Pima } \\
\text { Gila } \\
\text { Gila }\end{array}$ & $\begin{array}{l}345622 \mathrm{~N} 1130635 \mathrm{~W} \\
320807 \mathrm{~N} 1103902 \mathrm{~W} \\
342306 \mathrm{~N} 1113232 \mathrm{~W} \\
342329 \mathrm{~N} 1113158 \mathrm{~W}\end{array}$ & & 7263 & $\begin{array}{l}\text { Mount Hope } \\
\text { Tanque Verde Peak } \\
\text { Strawberry } \\
\text { Strawberry }\end{array}$ \\
\hline valley & $\begin{array}{l}\text { BGN } 1979 \\
\text { VARIANT }\end{array}$ & Yavapai & $350040 \mathrm{~N} 1130622 \mathrm{~W}$ & $345730 \mathrm{~N} 1130500 \mathrm{~W}$ & & Anvil Rock \\
\hline $\begin{array}{l}\text { locale } \\
\text { tunnel } \\
\text { locale }\end{array}$ & $\begin{array}{l}\text { UNOFF } \\
\text { UNOFF } \\
\text { BGN }\end{array}$ & $\begin{array}{l}\text { Mohave } \\
\text { Yavapai } \\
\text { Navajo }\end{array}$ & $\begin{array}{l}344019 N 1133514 \mathrm{~W} \\
344602 \mathrm{~N} 1120635 \mathrm{~W} \\
355044 \mathrm{~N} 1103149 \mathrm{~W}\end{array}$ & & & $\begin{array}{l}\text { Wikieup } \\
\text { Clarkdale } \\
\text { Shongopovi }\end{array}$ \\
\hline
\end{tabular}




\begin{tabular}{|c|c|c|c|c|c|c|c|}
\hline FEATURE NAME & $\begin{array}{l}\text { FEATURE } \\
\text { CLASS }\end{array}$ & STATUS & COUNTY & COORDINATE & $\begin{array}{l}\text { SOURCE } \\
\text { COORDINATE }\end{array}$ & $\begin{array}{c}\text { ELEV } \\
\text { FT }\end{array}$ & MAP NAME \\
\hline $\begin{array}{l}\text { Hopi Elementary School } \\
\text { Hopi Indian Reservation } \\
\text { Hopi Reservation } \\
\text { Hopi Mission School } \\
\text { Hopi Point } \\
\text { Rowes } \\
\text { Rowes Point }\end{array}$ & $\begin{array}{l}\text { school } \\
\text { reserve } \\
\text { school } \\
\text { cliff }\end{array}$ & $\begin{array}{l}\text { UNOFF } \\
\text { UNOFF } \\
\text { VARIANT } \\
\text { UNOFF } \\
\text { BGN } 1906 \\
\text { VARIANT } \\
\text { VARIANT }\end{array}$ & $\begin{array}{l}\text { Maricopa } \\
\text { Navajo } \\
\text { Navajo } \\
\text { Coconino }\end{array}$ & $\begin{array}{l}332948 N 1115813 \mathrm{~W} \\
354700 \mathrm{~N} 1103010 \mathrm{~W} \\
355249 \mathrm{N1} 103625 \mathrm{~W} \\
360434 \mathrm{~N} 1120914 \mathrm{~W}\end{array}$ & & & $\begin{array}{l}\text { Tempe } \\
\text { Sun Altar } \\
\text { Oraibi } \\
\text { Grand Canyon }\end{array}$ \\
\hline $\begin{array}{l}\text { Hopi Reservation } \\
\text { See Hopi Indian Reservation } \\
\text { Hopi Reservoir } \\
\text { Hopi Reservoir Dam } \\
\text { See Pasture Canyon Dam } \\
\text { Hopi Spring } \\
\text { Hopi Trail Canyon } \\
\text { Hopi Tribal Offices (Polacca) } \\
\text { Hopi Tribal Offices } \\
\text { Hopi Tribe Picnic Area }\end{array}$ & $\begin{array}{l}\text { reserve } \\
\text { reservoir } \\
\text { dam } \\
\text { spring } \\
\text { valley } \\
\text { building } \\
\text { building } \\
\text { park }\end{array}$ & $\begin{array}{l}\text { VARIANT } \\
\text { BGN } \\
\text { VARIANT } \\
\text { BGN } \\
\text { BGN } \\
\text { UNOFF } \\
\text { UNOFF } \\
\text { ADMIN }\end{array}$ & $\begin{array}{l}\text { Navajo } \\
\text { Coconino } \\
\text { Coconino } \\
\text { Yavapai } \\
\text { Coconino } \\
\text { Navajo } \\
\text { Navajo } \\
\text { Navajo }\end{array}$ & $\begin{array}{l}354700 \mathrm{~N} 1103010 \mathrm{~W} \\
360730 \mathrm{~N} 1110730 \mathrm{~W} \\
360730 \mathrm{~N} 1110730 \mathrm{~W} \\
340717 \mathrm{~N} 1112906 \mathrm{~W} \\
355517 \mathrm{~N} 1112959 \mathrm{~W} \\
355012 \mathrm{~N} 1102250 \mathrm{~W} \\
355206 \mathrm{~N} 1103721 \mathrm{~W} \\
355227 \mathrm{~N} 1103602 \mathrm{~W}\end{array}$ & $355954 N 1112939 W$ & & $\begin{array}{l}\text { Mazatzal Peak } \\
\text { Coconino Point } \\
\text { Polacca } \\
\text { Shongopovi } \\
\text { Shongopovi }\end{array}$ \\
\hline $\begin{array}{l}\text { Hopi Wall } \\
\text { Hopkins, Mount } \\
\text { Hopkins Mountain } \\
\text { Hopkins Spring } \\
\text { Hop Mountain } \\
\text { Hop Spring } \\
\text { Horace Mann School } \\
\text { Horizon Park } \\
\text { Horn } \\
\text { Horn Cotton Gin }\end{array}$ & $\begin{array}{l}\text { cliff } \\
\text { summit } \\
\text { summit } \\
\text { spring } \\
\text { summit } \\
\text { spring } \\
\text { school } \\
\text { park } \\
\text { locale } \\
\text { locale }\end{array}$ & $\begin{array}{l}\text { BGN } \\
\text { BGN } \\
\text { BGN } \\
\text { BGN } \\
\text { BGN } \\
\text { BGN } \\
\text { UNOFF } \\
\text { ADMIN } \\
\text { BGN } \\
\text { BGN }\end{array}$ & $\begin{array}{l}\text { Coconino } \\
\text { Santa Cruz } \\
\text { Gila } \\
\text { Gila } \\
\text { Navajo } \\
\text { Navajo } \\
\text { Cochise } \\
\text { Maricopa } \\
\text { Yuma } \\
\text { Yuma }\end{array}$ & $\begin{array}{l}360411 N 1120939 W \\
314118 N 1105305 W \\
335109 N 1110043 W \\
335207 N 1110121 W \\
341006 N 1101011 W \\
341438 N 1101145 W \\
312632 N 1095511 W \\
333345 N 1120937 W \\
325641 N 1133009 W \\
325541 N 1133223 W\end{array}$ & & $\begin{array}{l}B 585 \\
6543 \\
68 B 2\end{array}$ & $\begin{array}{l}\text { Grand Canyon } \\
\text { Mt Hopkins } \\
\text { Armer Mountain } \\
\text { Armer Mountain } \\
\text { Red Top Mtn } \\
\text { Red Top Mtn } \\
\text { Bisbee } \\
\text { Glendale } \\
\text { Horn } \\
\text { Horn }\end{array}$ \\
\hline $\begin{array}{l}\text { Horn Creek } \\
\text { Horn Creek Rapids } \\
\text { Horner Cabin Spring } \\
\text { Horner Gulch } \\
\text { Horner Mountain } \\
\text { Horner Mountain Tank } \\
\text { Horney Tank } \\
\text { Horn Lateral } \\
\text { Horn Railroad Station } \\
\text { Horn Silver Mine }\end{array}$ & $\begin{array}{l}\text { stream } \\
\text { rapids } \\
\text { spring } \\
\text { valley } \\
\text { summit } \\
\text { reservoir } \\
\text { reservoir } \\
\text { canal } \\
\text { building } \\
\text { mine }\end{array}$ & $\begin{array}{l}\text { BGN } 1906 \\
\text { BGN } \\
\text { BGN } \\
\text { BGN } \\
\text { BGN } \\
\text { BGN } \\
\text { BGN } \\
\text { BGN } \\
\text { UNOFF } \\
\text { UNOFF }\end{array}$ & $\begin{array}{l}\text { Coconino } \\
\text { Coconino } \\
\text { Yavapai } \\
\text { Yavapai } \\
\text { Yavapai } \\
\text { Yavapai } \\
\text { Yavapai } \\
\text { Yuma } \\
\text { Yuma } \\
\text { Mohave }\end{array}$ & $\begin{array}{l}360556 N 1120803 W \\
360556 N 1120759 W \\
342432 N 1115234 W \\
342307 N 1120056 W \\
342420 N 1115211 W \\
342443 N 1115209 W \\
345741 N 1120830 W \\
323605 N 1144535 W \\
325640 N 1133007 W \\
354338 N 1142249 W\end{array}$ & $\begin{array}{l}360441 N 1120903 \mathrm{~W} \\
342456 \mathrm{~N} 1115053 \mathrm{~W}\end{array}$ & $5 \mathrm{~B} 81$ & $\begin{array}{l}\text { Grand Canyon } \\
\text { Grand Canyon } \\
\text { Arnold Mesa } \\
\text { Estler Peak } \\
\text { Horner Mtn } \\
\text { Horner Mtn } \\
\text { Perkinsville } \\
\text { Gadsden } \\
\text { Horn } \\
\text { White Hills West }\end{array}$ \\
\hline $\begin{array}{l}\text { Horn Spring } \\
\text { Horrell Creek } \\
\text { Horrell Ranch } \\
\text { Horrell Spring } \\
\text { Horrell Spring } \\
\text { Horrel Ranch } \\
\text { Horrel Well } \\
\text { Horse Bas in } \\
\text { Horse Basin Tanks } \\
\text { Horse Bone Flat }\end{array}$ & $\begin{array}{l}\text { spring } \\
\text { stream } \\
\text { locale } \\
\text { spring } \\
\text { spring } \\
\text { locale } \\
\text { well } \\
\text { basin } \\
\text { reservoir } \\
\text { flat }\end{array}$ & $\begin{array}{l}\text { BGN } \\
\text { BGN } \\
\text { UNOFF } \\
\text { BGN } \\
\text { BGN } \\
\text { UNOFF } \\
\text { UNOFF } \\
\text { BGN } \\
\text { BGN } \\
\text { BGN }\end{array}$ & $\begin{array}{l}\text { Graham } \\
\text { Maricopa } \\
\text { Gila } \\
\text { Gila } \\
\text { Gila } \\
\text { Gila } \\
\text { Gila } \\
\text { Gila } \\
\text { Graham } \\
\text { Gila }\end{array}$ & $\begin{array}{l}330431 \mathrm{~N} 1102209 \mathrm{~W} \\
332749 \mathrm{~N} 1110006 \mathrm{~W} \\
333453 \mathrm{~N} 1110103 \mathrm{~W} \\
332721 \mathrm{~N} 1105112 \mathrm{~W} \\
333330 \mathrm{~N} 1110429 \mathrm{~W} \\
332751 \mathrm{~N} 1105956 \mathrm{~W} \\
332721 \mathrm{~N} 1105102 \mathrm{~W} \\
332654 \mathrm{~N} 1105721 \mathrm{~W} \\
330519 \mathrm{~N} 1102516 \mathrm{~W} \\
335546 \mathrm{~N} 1101456 \mathrm{~W}\end{array}$ & $332938 \mathrm{~N} 1110445 \mathrm{~W}$ & 5061 & $\begin{array}{l}\text { Mt Turnball } \\
\text { Haunted Canyon } \\
\text { Two Bar Mtn } \\
\text { Globe } \\
\text { Two Bar Mtn } \\
\text { Inspiration } \\
\text { Globe } \\
\text { Inspiration } \\
\text { Rawhide Mtn } \\
\text { Cedar Creek }\end{array}$ \\
\hline $\begin{array}{l}\text { Horse Butte } \\
\text { Horsecamp } \\
\text { Horse Camp } \\
\text { Horse Camp } \\
\text { Horse Camp } \\
\text { Horse Camp } \\
\text { Horse Camp } \\
\text { Horse Camp Basin } \\
\text { Horsecamp Canyon } \\
\text { Horse Camp Canyon }\end{array}$ & $\begin{array}{l}\text { summit } \\
\text { locale } \\
\text { locale } \\
\text { locale } \\
\text { locale } \\
\text { locale } \\
\text { locale } \\
\text { basin } \\
\text { valley } \\
\text { valley }\end{array}$ & $\begin{array}{l}\text { BGN } \\
\text { BGN } \\
\text { BGN } \\
\text { BGN } \\
\text { BGN } \\
\text { BGN } \\
\text { BGN } \\
\text { BGN } \\
\text { BGN } \\
\text { BGN } 1975\end{array}$ & $\begin{array}{l}\text { Navajo } \\
\text { Graham } \\
\text { Graham } \\
\text { Pinal } \\
\text { Graham } \\
\text { Graham } \\
\text { Gila } \\
\text { Pinal } \\
\text { Graham } \\
\text { Pinal }\end{array}$ & $\begin{array}{l}353503 N 1101917 \mathrm{~W} \\
322657 \mathrm{~N} 1090848 \mathrm{~W} \\
324449 \mathrm{~N} 1095429 \mathrm{~W} \\
324555 \mathrm{~N} 1103026 \mathrm{~W} \\
330627 \mathrm{~N} 1093828 \mathrm{~W} \\
331327 \mathrm{~N} 1094859 \mathrm{~W} \\
335330 \mathrm{~N} 1105106 \mathrm{~W} \\
332722 \mathrm{~N} 1111752 \mathrm{~W} \\
322719 \mathrm{~N} 1091001 \mathrm{~W} \\
325507 \mathrm{~N} 1103056 \mathrm{~W}\end{array}$ & $\begin{array}{l}322609 \mathrm{~N} 1090752 \mathrm{~W} \\
325945 \mathrm{~N} 1102642 \mathrm{~W}\end{array}$ & 6667 & $\begin{array}{l}\text { Hauke Mesa } \\
\text { Orange Butte } \\
\text { Webb Peak } \\
\text { Holy Joe Peak } \\
\text { Bryce Mountain } \\
\text { Bonita Tank } \\
\text { Rock House } \\
\text { Weavers Needle } \\
\text { Orange Butte } \\
\text { Brandenburg Mtn }\end{array}$ \\
\hline $\begin{array}{l}\text { Horse Camp Canyon } \\
\text { Horse Camp Corral } \\
\text { Horse Camp Creek } \\
\text { Horse Camp Draw } \\
\text { Fish Creek }\end{array}$ & $\begin{array}{l}\text { valley } \\
\text { locale } \\
\text { stream } \\
\text { arroyo }\end{array}$ & $\begin{array}{l}\text { BGN } \\
\text { BGN } \\
\text { BGN } \\
\text { BGN } 1971 \\
\text { VARIANT }\end{array}$ & $\begin{array}{l}\text { Yavapai } \\
\text { Graham } \\
\text { Gila } \\
\text { Apache }\end{array}$ & $\begin{array}{l}341500 \mathrm{~N} 1114450 \mathrm{~W} \\
324308 \mathrm{~N} 1102053 \mathrm{~W} \\
335207 \mathrm{~N} 1105233 \mathrm{~W} \\
340314 \mathrm{~N} 1093356 \mathrm{~W}\end{array}$ & $\begin{array}{l}341737 \mathrm{~N} 1114704 \mathrm{~W} \\
335352 \mathrm{~N} 1104838 \mathrm{~W} \\
340313 \mathrm{~N} 1093356 \mathrm{~W}\end{array}$ & & $\begin{array}{l}\text { Verde Hot Springs } \\
\text { Kennedy Peak } \\
\text { Aztec Peak } \\
\text { Greens Peak }\end{array}$ \\
\hline $\begin{array}{l}\text { Horse Camp Mesa } \\
\text { Horse Camp Mesa Tank } \\
\text { Horse Camp Seep } \\
\text { Horse Camp Seep } \\
\text { Fuller Seep }\end{array}$ & $\begin{array}{l}\text { summit } \\
\text { reservoir } \\
\text { spring } \\
\text { spring }\end{array}$ & $\begin{array}{l}\text { BGN } \\
\text { BGN } \\
\text { BGN } \\
\text { BGN } \\
\text { VARIANT }\end{array}$ & $\begin{array}{l}\text { Navajo } \\
\text { Gila } \\
\text { Maricopa } \\
\text { Yavapai }\end{array}$ & $\begin{array}{l}340559 \mathrm{~N} 1104411 \mathrm{~W} \\
33530 \mathrm{BN} 1105207 \mathrm{~W} \\
33595 \mathrm{BN} 1112716 \mathrm{~W} \\
340646 \mathrm{~N} 1112929 \mathrm{~W}\end{array}$ & & 5875 & $\begin{array}{l}\text { Oak Creek Ranch } \\
\text { Rock House } \\
\text { Reno Pass } \\
\text { Mazatzal Peak }\end{array}$ \\
\hline $\begin{array}{l}\text { Horse Camp Spring } \\
\text { Horse Camp Spring } \\
\text { Horse Camp Spring } \\
\text { Horse Camp Spring }\end{array}$ & $\begin{array}{l}\text { spring } \\
\text { spring } \\
\text { spring } \\
\text { spring }\end{array}$ & $\begin{array}{l}\text { BGN } \\
\text { BGN } \\
\text { BGN } \\
\text { BGN }\end{array}$ & $\begin{array}{l}\text { Pima } \\
\text { Graham } \\
\text { Pinal } \\
\text { Gila }\end{array}$ & $\begin{array}{l}322241 \mathrm{~N} 1104053 \mathrm{~W} \\
324155 \mathrm{~N} 1102631 \mathrm{~W} \\
332744 \mathrm{~N} 1111737 \mathrm{~W} \\
333547 \mathrm{~N} 1102354 \mathrm{~W}\end{array}$ & & & $\begin{array}{l}\text { Mount Bigelow } \\
\text { Rhodes Peak } \\
\text { Weavers Needle } \\
\text { Cassadore Spring }\end{array}$ \\
\hline
\end{tabular}




\section{FEATURE NAME}

Horse Camp Tanks

Horse Canyon

Horse Canyon

Horse Canyon

Horse Canyon

Horse Canyon

Horse Canyon

Horse Canyon

Horse Canyon

Horse Canyon

Horse Canyon

Horse Canyon

Horse Canyon Ridge Tank

Horse Canyon Tank

Horse Canyon Tank

Horse Canyon Trail Number Two

hundred fifty four

Horse Canyon Trail Thirty-six
Horse Corral Point
Horse Creek
Horse Creek
Horse Creek
Horse Creek
See Cane Spring Canyon
Horse Creek Tank
Horse Crossing
Horse Crossing Trail

Horsefall Canyon

Horse Flat

Horse Flat Canyon

See Clay Tank Canyon

Horse Flat Canyon

Horse Flat Tank

Horsefoot Mountain

Horse Foot Ranch

Horse Foot Wash

Horsehead Spring

Horse Hill Hose Hill

Horse Hills

Horse Knoll

Horse Knoll Tank

Horse Knoll Tank

Horse Lake

Horse Lake

See Prime Lake

Horse Lake

Horse Lake

Horse Lake

Horse Lake

Horse Lake Tank

Horse Lookout Hil

Horsemens Park

See Scottsdale Horsemens Park

Horse Mesa

Horse Mesa

Vaquero Mesa

Horse Mesa

Horse Mesa

Horse Mesa

Horse Mesa

Horse Mesa

Horse Mesa Accomodation School

Horse Mesa Creek

Horse Mesa Dam

Horse Mesa Tank

Horse Mesa Tank

Horse Mesa Trap

Horse Mountain

See Morena Mountain

\section{FEATURE}

STATUS

COUNTY

COORDINATE

SOURCE

COORDINATE

ELEV

MAP NAME

\begin{tabular}{|c|c|c|c|}
\hline $\begin{array}{l}\text { reservoir } \\
\text { valley } \\
\text { valley } \\
\text { valley } \\
\text { valley } \\
\text { valley }\end{array}$ & $\begin{array}{l}B G N \\
B G N \\
B G N \\
B G N \\
B G N \\
B G N\end{array}$ & $\begin{array}{l}\text { Yavapai } \\
\text { Graham } \\
\text { Graham } \\
\text { Greenlee } \\
\text { Greenlee } \\
\text { Gila }\end{array}$ & $\begin{array}{l}344745 \mathrm{N1121156W} \\
323929 \mathrm{~N} 1102126 \mathrm{~W} \\
325718 \mathrm{~N} 1102535 \mathrm{~W} \\
33205711091054 \mathrm{~W} \\
333252 \mathrm{2} 1091153 \mathrm{~W} \\
335405 \mathrm{N1104430 \textrm {W }}\end{array}$ \\
\hline $\begin{array}{l}\text { valley } \\
\text { valley } \\
\text { valley } \\
\text { valley } \\
\text { valley } \\
\text { valley } \\
\text { reservoir } \\
\text { reservoir } \\
\text { reservoir } \\
\text { trail }\end{array}$ & $\begin{array}{l}\text { BGN } \\
B G N \\
B G N \\
B G N \\
B G N \\
B G N \\
B G N \\
B G N \\
B G N \\
\text { UNOFF }\end{array}$ & $\begin{array}{l}\text { Gila } \\
\text { Navajo } \\
\text { Navajo } \\
\text { Mohave } \\
\text { Coconino } \\
\text { Coconino } \\
\text { Greenlee } \\
\text { Graham } \\
\text { Gila } \\
\text { Graham }\end{array}$ & $\begin{array}{l}335552 \mathrm{~N} 1111757 \mathrm{~W} \\
342026 \mathrm{N1} 104024 \mathrm{~W} \\
345047 \mathrm{N1} 103219 \mathrm{~W} \\
350203 \mathrm{N1} 135756 \mathrm{~W} \\
363921 \mathrm{N1} 123421 \mathrm{~W} \\
365956 \mathrm{N1105612 \textrm {W }} \\
332001 \mathrm{N1} 1090942 \mathrm{~W} \\
323929 \mathrm{N1} 102109 \mathrm{~W} \\
335735 \mathrm{N1} 105028 \mathrm{~W} \\
323905 \mathrm{N1} 10200 \mathrm{~W}\end{array}$ \\
\hline
\end{tabular}

$\begin{array}{lll}\text { trail } & \text { UNOFF } & \text { Greenlee } \\ \text { cliff } & \text { BGN } & \text { Coconino } \\ \text { stream } & \text { BGN } & \text { Apache } \\ \text { stream } & \text { BGN } & \text { Yavapai } \\ \text { stream } & \text { BGN 1981 } & \text { Yavapai } \\ & \text { VARIANT } & \\ \text { valley } & & \text { Maricopa } \\ \text { reservoir } & \text { BGN } & \text { Yavapai } \\ \text { locale } & \text { BGN } & \text { Coconino } \\ \text { trail } & \text { UNOFF } & \text { Coconino }\end{array}$

$332000 \mathrm{~N} 1090715 \mathrm{~W}$ $361256 \mathrm{~N} 1105207 \mathrm{~W}$ $361256 \mathrm{N1105207 \textrm {W }}$ $334511 \mathrm{N1092152 \textrm {W }}$ $340440 \mathrm{~N} 1114218 \mathrm{~W}$

$333529 \mathrm{~N} 1112629 \mathrm{~W}$

$335607 \mathrm{N1122501 \textrm {W }}$

$343504 \mathrm{N1} 110747 \mathrm{~W}$

$343501 \mathrm{~N} 1110747 \mathrm{~W}$

$\begin{array}{llll}\text { valley } & \text { BGN } & \text { Cochise } & \text { 315811N1091916W } \\ \text { flat } & \text { BGN } & \text { Mohave } & \text { 355033N1135110W }\end{array}$

flat

valley

valley

reservoir

summit

locale

stream

spring

summit

summit

summit

reservoir

reservoir

lake

lake

lake

lake
lake
lake
reservoir
summit

BGN

Mohave

Mohave

BGN Mohave

BGN Cochise

UNOFF Pinal

Pinal

Greenlee

355141 N1133959w

$355309 \mathrm{~N} 1134250 \mathrm{~W}$

$355015 \mathrm{~N} 1135012 \mathrm{~N}$

$322452 \mathrm{~N} 1090556 \mathrm{~W}$

$324422 N 1105412 \mathrm{~W}$

324413 N1104910W

$332625 \mathrm{~N} 1091138 \mathrm{~W}$

$323834 N 1101934 \mathrm{~W}$

$32591 \mathrm{BN} 1102622 \mathrm{~W}$

331959 N1090547W

333418 N1091330W

335501 N1105158

$335741 N 1111302 \mathrm{~W}$

$341937 \mathrm{~N} 1104436 \mathrm{~W}$

$344756 \mathrm{~N} 1103036 \mathrm{~W}$

$350331 \mathrm{N1} 135403 \mathrm{~W}$

$363 \mathrm{~B} 24 \mathrm{~N} 1123215 \mathrm{~W}$

$370207 \mathrm{~N} 1105250 \mathrm{~W}$

351258 N1120048W

BGN
VARIANT

BGN Pinal 325502N1105115W

BGN Coconino 343752N1113008W

$343752 \mathrm{~N} 1113008 \mathrm{~W}$
$343715 \mathrm{~N} 1112946 \mathrm{~W}$

$343813 \mathrm{~N} 1113015 \mathrm{~W}$

BGN 1964

Coconino

$350355 N 1112752 \mathrm{~W}$

$350555 \mathrm{~N} 1113150 \mathrm{~W}$

350841 N1131959w

$351158 N 1115812 W$

$352834 \mathrm{N1120041 \textrm {W }}$

$353444 \mathrm{~N} 1123740 \mathrm{~W}$

$350352 \mathrm{~N} 1112752 \mathrm{~W}$

362B $45 \mathrm{~N} 1091734 \mathrm{~W}$

park

summit

summit

Maricopa

$333754 \mathrm{~N} 1115302 \mathrm{~W}$

$332754 \mathrm{~N} 1090550 \mathrm{~W}$

$333423 \mathrm{~N} 1111826 \mathrm{~W}$

BGN 1932 Greenlee VARIANT

summ

summit

summit

ppl

ppl

school

stream

dam

reservoir

reservoir

BGN

BGN Yavapai

BGN Maricopa

BGN Apache

UNOFF Maricopa

BGN Apache

UNOFF Maricopa

Yavapai

$335406 \mathrm{~N} 1094 \mathrm{~B} 43 \mathrm{~W}$

344738 N1114137W

364143 N1090242W

$333459 \mathrm{~N} 1112117 \mathrm{~W}$

$364218 \mathrm{~N} 1090245 \mathrm{~W}$

333458 N1112110W

$364121 \mathrm{~N} 1090219 \mathrm{~W}$

$333526 \mathrm{~N} 1112034 \mathrm{~W}$

$335101 \mathrm{N1} 102357 \mathrm{~W}$

$344739 \mathrm{~N} 1114126 \mathrm{~W}$

364540 N1090846W

$334932 \mathrm{N1092213 \textrm {W }}$

335609 N1122538

$340602 \mathrm{~N} 1113406 \mathrm{~W}$

Pillars of Hercules

Buffalo Crossing

Garfias Mtn

Chalk Mountain

Garfias Mtn

Blue Ridge Reservoir

Blue Ridge Reservoir

$315742 \mathrm{~N} 1091632 \mathrm{~W}$

Rustler Park

Horse Flat

355015N1135012W Devils Slide Rapids

Horse Flat

Engine Mtn

Fortified Mtn

324354N1105502W North of Oracle

7169 Davenport Hill

3947 Winkelman

6921 Apache Maid Mtn Calloway Butte Apache Maid Mtn Ashurst Lake

Fort Rock Ranch

6773 Garland Prairie Squaw Mtn

Bishop Lake

Ashurst Lake

6132 Bad Bug Butte

Alma Mesa

4112 Horse Mesa Dam

7884 Hawley Lake West

5284 Munds Mountain

Horse Mesa

Horse Mesa Dam

5640 Horse Mesa Horse Mesa Dam Horse Mesa

1891 Horse Mesa Dam

Beckers Butte

Munds Mountain

Hawley Lake West

bas in BGN Apache 335425N1094720W

$313543 \mathrm{~N} 1115236 \mathrm{~W}$ 


\section{FEATURE NAME}

Horse Mountain

Horse Mountain

Horse Mountain

See Bronco Butte

Horse Mountain

See Baker Mountain

Horse Mountain

Horse Mountain

Horse Mountain

Horse Mountain Spring

Horse Mountain Tank

Horse Mountain Tank

Horse Mountain Trail Number

Two Hundred Twelve

Horse Mountain Trick Tank

Horse Park

Horse Park Tank

Horse Pasture Canyon

Horse Pasture $\mathrm{Hill}$

Horse Pasture Recreation Area

Horse Pasture Spring

Horse Pasture Spring

Horse Pasture Spring

Horse Pasture Tank

Horse Pasture Tank

Horse Pasture Tank

Horse Pasture Tank

Horse Pasture Tank

Horse Pasture Tank

Horse Pasture Tank

Horse Pasture Tank

Horse Pasture Tank

Horse Pasture Tank

Horse Pasture Tank

Horse Pasture Tank

Horse Pasture Tank

Horse Pasture Tank

Horse Peak

Horse Ranch

Horse Ranch

Horse Range Mesa

Horse Reservoir

Horse Ridge

Horse Ridge

Horse Ridge

Horse Rock

\section{Horse Seep}

Horseshoe

See Quijotoa

Horseshoe, The

Horseshoe Bar

Horseshoe Bend

Horseshoe Bend Wash

Horseshoe Canyon

Horseshoe Canyon

Horseshoe Canyon

Horseshoe Cienega

Horseshoe Cienega

Horseshoe Cienega Lake

Horseshoe Cienega Lake

Campground

Horseshoe Cienega Lake Dam

Horseshoe Creek

Horseshoe Dam

Horseshoe Gulch

Horseshoe $\mathrm{Hill}$

Horseshoe Lake

Horseshoe Mesa

Horseshoe Mesa Caves

Horseshoe Mine
FEATURE

CLASS

STATUS COUNTY

COORDINATE

summ it

summit

summit

summit

summit

\section{BGN}

Graham

VARIANT

Greenlee

VARIANT

Maricopa

Gila

summit

summit

summit

spring

reservoir

reservoir

trail

reservoir

flat

\section{$B G N$}

BGN

BGN

BGN

BGN

$B G N$

UNOFF

Yavapa

Yavapa

Gila

Yavapai

Graham

Gila

BGN
BGN

Yavapa

Yavapai

Coconino

reservoir

valley

summit

park

spring

spring

spring

reservoir

reservoir

reservoir

BGN

BGN

BGN

ADMIN

BGN

BGN

BGN

Coconino

Navajo

Pima

Gila

Santa Cruz

Greenlee

Maricopa

Pima

Cochise

Graham

Pinal

reservoir

reservoir

reservoir

reservoir

reservoir

reservoir

reservoir

reservoir

reservoir

BGN
BGN
BGN
BGN
BGN
BGN
BGN
BGN
BGN
BGN

reservoir

summit

locale

locale

summit

reservoir

ridge

ridge

ridge

pillar

spring

locale

bas in

bend

bend

stream

valley

valley

valley

BGN

BGN

UNOFF

BGN

$B G N$

BGN

BGN

BGN

BGN

Gila

Maricopa

Maricopa

Yavapai

Coconino

Coconino

Navajo

Coconino

Coconino

Pina

Cochise

Pinal

Gila

Coconino

Graham

Pinal

Coconino

Coconino

BGN
VARIANT

Navajo

Pima

Coch ise

BGN

BGN

BGN

BGN

BGN

BGN

Gila

Gila

Greenlee

Yavapai

flat

swamp

reservoir

park

BGN
BGN
BGN

Apache

Greenlee

Apache

Apache

dam

stream

dam

valley

UNOFF

BGN

Apache

Apache

Maricopa

BGN 1963 Greenlee

BGN Coconino

lake

summit

BGN

Coconino

BGN 1906

BGN 1937

Coconino

cave

UNOFF
Coconino

Graham
$332926 \mathrm{~N} 1090615 \mathrm{~W}$

340233N1113927W

$324254 \mathrm{~N} 1102242 \mathrm{~W}$

344512 N1115018W

345804 N1113618W

$365944 N 1101335 \mathrm{~W}$

315119 N1111054W

$334441 N 1111336 \mathrm{~W}$

$312425 N 1111103 \mathrm{~W}$

$333250 \mathrm{N1092639 \textrm {W }}$

333431 N1112208W

$314053 \mathrm{~N} 1111122 \mathrm{~W}$

$333643 \mathrm{~N} 1102441 \mathrm{~W}$

$341514 N 1110451 \mathrm{~W}$

$342211 N 111501 B W$

343541N1113130W

$344153 \mathrm{NI} 103820 \mathrm{~W}$

$324234 N 1102221 W$

$325854 \mathrm{~N} 1102051 \mathrm{~W}$

333318 N1111615W

335032N1105619W

$341410 \mathrm{~N} 1122439 \mathrm{~W}$

$341505 \mathrm{~N} 1110146 \mathrm{~W}$

$341406 \mathrm{~N} 1122353 \mathrm{~W}$

$335644 \mathrm{~N} 1105503 \mathrm{~W}$

$341423 \mathrm{~N} 1122349 \mathrm{~W}$

$345815 \mathrm{~N} 1113628 \mathrm{~W}$

$314346 \mathrm{~N} 1091329 \mathrm{~W}$

$322920 \mathrm{~N} 1095025 \mathrm{~W}$

331908 N1110442W

$335718 \mathrm{~N} 1100705 \mathrm{~W}$

$335922 N 1130201 \mathrm{~W}$

$345143 \mathrm{~N} 1110539 \mathrm{~W}$

$350035 \mathrm{N1110042 \textrm {W }}$

$313543 \mathrm{~N} 1115235 \mathrm{~W}$

$315516 \mathrm{~N} 1100212 \mathrm{~W}$

$325926 \mathrm{~N} 1110026 \mathrm{~W}$ 
NATIONAL GAZETTEER--ARIZONA 1986

\begin{tabular}{|c|c|c|c|c|c|c|c|}
\hline FEATURE NAME & $\begin{array}{l}\text { FEATURE } \\
\text { CLASS }\end{array}$ & STATUS & COUNTY & COORDINATE & $\begin{array}{l}\text { SOURCE } \\
\text { COORDINATE }\end{array}$ & $\begin{array}{l}\text { ELEV } \\
\text { FT }\end{array}$ & MAP NAME \\
\hline $\begin{array}{l}\text { Horseshoe Mobile Home Park } \\
\text { Horseshoe Pass }\end{array}$ & locale & $\begin{array}{l}\text { UNOFF } \\
\text { VARIANT }\end{array}$ & Maricopa & 332448 N1115410W & & 1180 & Tempe \\
\hline $\begin{array}{l}\text { See Jack Wood Pass } \\
\text { Horseshoe Pass } \\
\text { Horseshoe Peak }\end{array}$ & $\underset{\text { gap }}{\text { gap }}$ & $\begin{array}{l}\text { BGN } 1959 \\
\text { VARIANT }\end{array}$ & $\begin{array}{l}\text { Cochise } \\
\text { Cochise }\end{array}$ & $\begin{array}{l}314500 \mathrm{~N} 1091045 \mathrm{~W} \\
314945 \mathrm{~N} 1091210 \mathrm{~W}\end{array}$ & & & Portal Peak \\
\hline See Sulphur Peak & summit & & Cochise & $314930 \mathrm{~N} 1091121 \mathrm{~W}$ & & & \\
\hline $\begin{array}{l}\text { Horseshoe Point } \\
\text { Horseshoe Ranch } \\
\text { Horseshoe Ranch } \\
\text { Horseshoe Rapids } \\
\text { Horseshoe Reservoir } \\
\text { Horseshoe Reservoir } \\
\text { Horseshoe Spring } \\
\text { Horseshoe Spring } \\
\text { Horseshoe Tank } \\
\text { Horseshoe Tank }\end{array}$ & $\begin{array}{l}\text { cape } \\
\text { locale } \\
\text { locale } \\
\text { rapids } \\
\text { reservoir } \\
\text { reservoir } \\
\text { spring } \\
\text { spring } \\
\text { reservoir } \\
\text { reservoir }\end{array}$ & $\begin{array}{l}\text { BGN } \\
\text { UNOFF } \\
\text { UNOFF } \\
\text { BGN } \\
\text { BGN } \\
\text { BGN } \\
\text { BGN } \\
\text { BGN } \\
\text { BGN } \\
\text { BGN }\end{array}$ & $\begin{array}{l}\text { Navajo } \\
\text { Cochise } \\
\text { Yavapai } \\
\text { Mohave } \\
\text { Maricopa } \\
\text { Coconino } \\
\text { Apache } \\
\text { Coconino } \\
\text { Pima } \\
\text { Pima }\end{array}$ & $\begin{array}{l}355140 \mathrm{~N} 1102549 \mathrm{~W} \\
322451 \mathrm{N1} 090427 \mathrm{~W} \\
341540 \mathrm{~N} 1120327 \mathrm{~W} \\
355502 \mathrm{~N} 1144226 \mathrm{~W} \\
335901 \mathrm{N11} 14229 \mathrm{~W} \\
362829 \mathrm{N111} 14605 \mathrm{~W} \\
340927 \mathrm{~N} 1091037 \mathrm{~W} \\
344655 \mathrm{N1} 112407 \mathrm{~W} \\
314146 \mathrm{N1111439W} \\
314815 \mathrm{~N} 1105608 \mathrm{~W}\end{array}$ & & 6132 & $\begin{array}{l}\text { Polacca } \\
\text { Engine Mtn } \\
\text { Cordes Junction } \\
\text { Ringbolt Rapids } \\
\text { Horseshoe Dam } \\
\text { Tatahatso Point } \\
\text { Coyote Hills } \\
\text { Hutch Mtn } \\
\text { Saucito Mtn } \\
\text { Green Valley }\end{array}$ \\
\hline $\begin{array}{l}\text { Horseshoe Tank } \\
\text { Horseshoe Tank } \\
\text { Horseshoe Tank } \\
\text { Horseshoe Tank } \\
\text { Horseshoe Tank } \\
\text { Horseshoe Tank } \\
\text { Horseshoe Tank } \\
\text { Horseshoe Tank } \\
\text { Horseshoe Tank Number Four } \\
\text { Horseshoe Tank Number One }\end{array}$ & $\begin{array}{l}\text { reservoir } \\
\text { reservoir } \\
\text { reservoir } \\
\text { reservoir } \\
\text { reservoir } \\
\text { reservoir } \\
\text { reservoir } \\
\text { reservoir } \\
\text { reservoir } \\
\text { reservoir }\end{array}$ & $\begin{array}{l}\text { BGN } \\
\text { BGN } \\
\text { BGN } \\
\text { BGN } \\
\text { BGN } \\
\text { BGN } \\
\text { BGN } \\
\text { BGN } \\
\text { BGN } \\
\text { BGN }\end{array}$ & $\begin{array}{l}\text { Navajo } \\
\text { Yavapai } \\
\text { Yavapai } \\
\text { Mohave } \\
\text { Coconino } \\
\text { Coconino } \\
\text { Coconino } \\
\text { Mohave } \\
\text { Cochise } \\
\text { Cochise }\end{array}$ & $\begin{array}{l}342615 N 1102402 \mathrm{~W} \\
344253 \mathrm{~N} 1124947 \mathrm{~W} \\
344805 \mathrm{~N} 1120911 \mathrm{~W} \\
345825 \mathrm{~N} 1132307 \mathrm{~W} \\
352015 \mathrm{~N} 1115248 \mathrm{~W} \\
352659 \mathrm{N1} 122046 \mathrm{~W} \\
352815 \mathrm{N1} 125131 \mathrm{~W} \\
360842 \mathrm{N1} 132911 \mathrm{~W} \\
314706 \mathrm{N1} 091005 \mathrm{~W} \\
314600 \mathrm{~N} 1090913 \mathrm{~W}\end{array}$ & & & $\begin{array}{l}\text { Aripine } \\
\text { Smith Mesa } \\
\text { Munds Draw } \\
\text { Gonzales Wash } \\
\text { Parks } \\
\text { Cataract Tank } \\
\text { Trinity Mtn } \\
\text { Yellow John Mtn } \\
\text { Portal Peak } \\
\text { Portal Peak }\end{array}$ \\
\hline $\begin{array}{l}\text { Horseshoe Tank Number Three } \\
\text { Horseshoe Tank Number Two } \\
\text { Horseshoe Well } \\
\text { Horse Spring } \\
\text { Horse Spring } \\
\text { Horse Spring } \\
\text { Horse Spring } \\
\text { Horse Spring } \\
\text { Horse Spring } \\
\text { Horse Spring }\end{array}$ & $\begin{array}{l}\text { reservoir } \\
\text { reservoir } \\
\text { well } \\
\text { spring } \\
\text { spring } \\
\text { spring } \\
\text { spring } \\
\text { spring } \\
\text { spring } \\
\text { spring }\end{array}$ & $\begin{array}{l}\text { BGN } \\
\text { BGN } \\
\text { UNOFF } \\
\text { BGN } \\
\text { BGN } \\
\text { BGN } \\
\text { BGN } \\
\text { BGN } \\
\text { BGN } \\
\text { BGN }\end{array}$ & $\begin{array}{l}\text { Cochise } \\
\text { Cochise } \\
\text { Pima } \\
\text { Gila } \\
\text { Apache } \\
\text { Yavapai } \\
\text { Gila } \\
\text { Yavapai } \\
\text { Yavapai } \\
\text { Navajo }\end{array}$ & $\begin{array}{l}314528 N 1090955 \mathrm{~W} \\
314512 \mathrm{~N} 1090924 \mathrm{~W} \\
313943 N 1115033 \mathrm{~W} \\
333452 \mathrm{N1} 104631 \mathrm{~W} \\
334726 \mathrm{~N} 1092103 \mathrm{~W} \\
335633 \mathrm{~N} 1122415 \mathrm{~W} \\
335930 \mathrm{N1} 102514 \mathrm{~W} \\
340227 \mathrm{N1} 122419 \mathrm{~W} \\
341516 \mathrm{~N} 1122429 \mathrm{~W} \\
353421 N 1101904 \mathrm{~W}\end{array}$ & & & $\begin{array}{l}\text { Portal Peak } \\
\text { Portal Peak } \\
\text { South Komelik } \\
\text { Rockinstraw Mtn } \\
\text { Buffalo Crossing } \\
\text { Garfias Mtn } \\
\text { Cibecue Peak } \\
\text { Copperopolis } \\
\text { Battleship Butte } \\
\text { Hauke Mesa }\end{array}$ \\
\hline $\begin{array}{l}\text { Horse Spring } \\
\text { Horse Spring } \\
\text { Horse Spring } \\
\text { Horse Spring Canyon } \\
\text { Horse Spring Point } \\
\text { Horse Springs } \\
\text { Horsespring Tank } \\
\text { Horse Tank } \\
\text { Horse Tank } \\
\text { Horse Tank }\end{array}$ & $\begin{array}{l}\text { spring } \\
\text { spring } \\
\text { spring } \\
\text { valley } \\
\text { cliff } \\
\text { spring } \\
\text { reservoir } \\
\text { reservoir } \\
\text { reservoir } \\
\text { reservoir }\end{array}$ & $\begin{array}{l}\text { BGN } \\
B G N \\
B G N \\
B G N \\
B G N \\
B G N \\
B G N \\
B G N \\
B G N \\
B G N\end{array}$ & $\begin{array}{l}\text { Navajo } \\
\text { Apache } \\
\text { Coconino } \\
\text { Mohave } \\
\text { Coconino } \\
\text { Greenlee } \\
\text { Coconino } \\
\text { Pima } \\
\text { Gila } \\
\text { Navajo }\end{array}$ & $\begin{array}{l}361113 \mathrm{~N} 1103435 \mathrm{~W} \\
361349 \mathrm{~N} 1090618 \mathrm{~W} \\
363902 \mathrm{N1} 123412 \mathrm{~W} \\
355926 \mathrm{~N} 1133102 \mathrm{~W} \\
363838 \mathrm{~N} 1123540 \mathrm{~W} \\
332044 \mathrm{~N} 1092435 \mathrm{~W} \\
363820 \mathrm{~N} 1123331 \mathrm{~W} \\
315034 \mathrm{~N} 1111137 \mathrm{~W} \\
332932 \mathrm{N1} 105240 \mathrm{~W} \\
333942 \mathrm{~N} 1095510 \mathrm{~W}\end{array}$ & $355705 \mathrm{~N} 1132930 \mathrm{~W}$ & & $\begin{array}{l}\text { Rocky Ridge NE } \\
\text { Upper Wheatfields } \\
\text { Guns ight Point } \\
\text { Amos Point } \\
\text { Gunsight Point } \\
\text { Bee Canyon } \\
\text { Gunsight Point } \\
\text { Batamote Hills } \\
\text { Inspiration } \\
\text { Bonito Prairie }\end{array}$ \\
\hline $\begin{array}{l}\text { Horse Tank } \\
\text { Horse Tank } \\
\text { Horse Tank } \\
\text { Horse Tank } \\
\text { Horse Tank } \\
\text { Horse Tank } \\
\text { Horse Tank } \\
\text { Horse Tank } \\
\text { Horse Tank } \\
\text { Horse Tank }\end{array}$ & $\begin{array}{l}\text { reservoir } \\
\text { reservoir } \\
\text { reservoir } \\
\text { reservoir } \\
\text { reservoir } \\
\text { reservoir } \\
\text { reservoir } \\
\text { reservoir } \\
\text { reservoir } \\
\text { reservoir }\end{array}$ & $\begin{array}{l}\text { BGN } \\
\text { BGN } \\
\text { BGN } \\
\text { BGN } \\
\text { BGN } \\
\text { BGN } \\
\text { BGN } \\
\text { BGN } \\
\text { BGN } \\
\text { BGN }\end{array}$ & $\begin{array}{l}\text { Gila } \\
\text { Navajo } \\
\text { Navajo } \\
\text { Coconino } \\
\text { Coconino } \\
\text { Yavapai } \\
\text { Coconino } \\
\text { Coconino } \\
\text { Coconino } \\
\text { Coconino }\end{array}$ & $\begin{array}{l}335713 N 1111420 \mathrm{~W} \\
340309 \mathrm{~N} 1101310 \mathrm{~W} \\
342011 \mathrm{~N} 1104147 \mathrm{~W} \\
342944 \mathrm{~N} 1105612 \mathrm{~W} \\
343121 \mathrm{~N} 1112531 \mathrm{~W} \\
344652 \mathrm{~N} 111400 \mathrm{WW} \\
351202 \mathrm{N1} 115851 \mathrm{~W} \\
351436 \mathrm{~N} 1122007 \mathrm{~W} \\
353208 \mathrm{N1} 121332 \mathrm{~W} \\
355030 \mathrm{N1} 114205 \mathrm{~W}\end{array}$ & & & $\begin{array}{l}\text { Picture Mtn } \\
\text { Long Tom Canyon } \\
\text { Brookbank Point } \\
\text { Porcupine Ridge } \\
\text { Calloway Butte } \\
\text { Munds Mountain } \\
\text { Garland Prairie } \\
\text { McLellan Reservoir } \\
\text { Howard Lake } \\
\text { Willows Camp }\end{array}$ \\
\hline $\begin{array}{l}\text { Horse Tank Creek } \\
\text { Horse Tank Number Two } \\
\text { Horse Tanks } \\
\text { Horse Tank Wash } \\
\text { See Horsetank Wash } \\
\text { Horsetank Wash } \\
\text { Horse Tank Wash }\end{array}$ & $\begin{array}{l}\text { stream } \\
\text { reservoir } \\
\text { reservoir } \\
\text { stream } \\
\text { stream }\end{array}$ & $\begin{array}{l}\text { BGN } \\
\text { BGN } \\
\text { BGN } \\
\text { VARIANT } \\
\text { BGN 1981 } \\
\text { VARIANT }\end{array}$ & $\begin{array}{l}\text { Gila } \\
\text { Gila } \\
\text { Yuma } \\
\text { Coconino } \\
\text { Coconino }\end{array}$ & $\begin{array}{l}335637 N 1105348 \mathrm{~W} \\
332922 \mathrm{~N} 1105219 \mathrm{~W} \\
331240 \mathrm{~N} 1141218 \mathrm{~W} \\
342933 \mathrm{~N} 1113108 \mathrm{~W} \\
342933 \mathrm{~N} 1113108 \mathrm{~W}\end{array}$ & $342838 \mathrm{~N} 1112728 \mathrm{~W}$ & & $\begin{array}{l}\text { McFadden Peak } \\
\text { Globe } \\
\text { Arch Tank }\end{array}$ \\
\hline $\begin{array}{l}\text { Horse The if Mesa } \\
\text { Horsethief Basin } \\
\text { Horsethief Basin Recreation } \\
\text { Area }\end{array}$ & $\begin{array}{l}\text { summit } \\
\text { bas in } \\
\text { park }\end{array}$ & $\begin{array}{l}\text { BGN } \\
\text { BGN } \\
\text { ADMIN }\end{array}$ & $\begin{array}{l}\text { Coconino } \\
\text { Yavapai } \\
\text { Yavapai }\end{array}$ & $\begin{array}{l}363827 \mathrm{~N} 1111124 \mathrm{~W} \\
340928 \mathrm{~N} 1121720 \mathrm{~W} \\
341020 \mathrm{~N} 1121647 \mathrm{~W}\end{array}$ & & 5994 & $\begin{array}{l}\text { Horsethief Mesa } \\
\text { Crown King } \\
\text { Crown King }\end{array}$ \\
\hline $\begin{array}{l}\text { Horsethief Bench } \\
\text { Horsethief Canyon } \\
\text { Horsethief Canyon } \\
\text { Horsethief Canyon }\end{array}$ & $\begin{array}{l}\text { bench } \\
\text { valley } \\
\text { valley } \\
\text { valley }\end{array}$ & $\begin{array}{l}\text { BGN } \\
B G N \\
B G N \\
B G N\end{array}$ & $\begin{array}{l}\text { Gila } \\
\text { Yavapai } \\
\text { Coconino } \\
\text { Mohave }\end{array}$ & $\begin{array}{l}341647 \mathrm{~N} 1112808 \mathrm{~W} \\
341243 \mathrm{~N} 1121758 \mathrm{~W} \\
352609 \mathrm{~N} 1115407 \mathrm{~W} \\
360005 \mathrm{~N} 1143956 \mathrm{~W}\end{array}$ & $\begin{array}{l}340942 \mathrm{~N} 1121848 \mathrm{~W} \\
352629 \mathrm{~N} 1115329 \mathrm{~W} \\
355932 \mathrm{~N} 1143823 \mathrm{~W}\end{array}$ & & $\begin{array}{l}\text { Buckhead Mesa } \\
\text { Crown King } \\
\text { Moritz Ridge } \\
\text { Hoover Dam }\end{array}$ \\
\hline
\end{tabular}


FEATURE NAME

\section{Horsethief Creek}

Horsethief Guard Station

Horsethief Lake

Horsethief Lookout Tower

Horsethief Tank

Horsethief Tank

Horse Track Canyon

Horse Trail Valley

Horse Trap Canyon

Horse Trap Canyon

Horse Trap Hill

Horse Trap Lake

Horse Trap Mesa

Horse Trap Sink

Horse Trap Tank

Horse Trap Tank

Horsetrap Tank

Horse Trough Spring

Horse Valley

Horse Valley

See Pine Valley

Horse Wash

Horse Wash Springs

Horse Water Tanks

Horton Campground

Horton Canyon

Horton Creek

Horton Creek

Horton Creek

Horton Creek Trai

Hortons Place

Horton Spring

Horton Tank

Horus Temple

Hosea Tank

Hose Hill

See Horse Hill

Hosey Mine

Hosey Tank

Hoshoni Park

Hoskininini Mesa

Hospital Flat

Hospital Flat

Hospital Flat Campground

Hospital Flat Recreation Area

Hospital Ridge

Hospital Tank

Hospitito Creek

See Hasbidito Creek

Hospitito Spring

See Hasbidito Spring

Hospitito Valley

See Hasbidito Valley

Hosteen Begay Well

Hosteen Tso Canyon Hosteen Tso Wash

Hosteen Tso Wash

Hosteen Tso Wash

See Hosteen Tso Canyon

Hostetter Tank

Hot Air Canyon

Hot Air Tank

Hot Air Trail Fifteen

Hotashonevo

See Charco de la Piedra

Hota Son Von

See Charco de la Piedra

Hotauta Amphitheater

Hotauta Canyon

Hot Boy Mine

\section{FEATURE}

stre

dam

locale

reservoir

tower

reservoir

STATUS

COUNTY

BGN Yavapa

UNOFF Yavapa

UNOFF Yavapai

BGN Yavapa

UNOFF Yavapai

Gila

reservoir

valley

valley

valley

valley

sumit

lake

summ it

reservoir

reservoir

\section{BGN}

BGN

BGN

BGN

$B G N$
$B G N$
$B G N$

BGN

BGN

$B G N$

reservoir reservoir

spring

bas in

BGN

BGN

BGN

Coconino

Apache

Navajo

Coconino

Coconino

Coconino

Coconino

Coconino

Coconino

Coconino

Coconino

Coconino

Mohave

Mohave

valley

stream

spring

reservoir

VARIANT

park

BGN

BGN

$B G N$

Mohave

Yavapai

Coconin

valley

stream

stream

stream

trail

locale

spring

reservoir

sumnit

ADMIN

Gila

BGN Gila

$B G N$

$B G N$

BGN
UNOFF

$B G N$

BGN

BGN

BGN 190

reservoir

BGN

Graham

Greenlee

Gila

Gila

Pinal

Gila

Gila

Coconino

Yavapai

VARIANT

summit

mine

reservoir

park

summit

flat

flat

park

park

UNOFF

ADMIN

BGN

BGN

BGN

ADM IN

Coconino

Santa Cruz

Yavapai

Maricopa

Navajo

Graham

Graham

Graham

ridge

reservoir

BGN

Coconino

Gila

Apache

stream

spring

VARIAN

valley

well

valley

VARIANT

Apache

Apache

UNOFF

BGN

VARIANT

Apache

stream $\quad B G$

valley

reservoir $B G$

valley $B G$

reservoir

trail

BGN

UNOFF

ppl

VARIANT

ppl

VARIANT

Apache

Apache

Coconino

Greenlee

Greenlee

Greenlee

Pima

Pima

basin BGN Coconino

valley BGN 1910 Coconino

mine

UNOFF

COORDINATE

$341333 \mathrm{~N} 1121708 \mathrm{~W}$ $340942 \mathrm{~N} 1121754 \mathrm{~W}$ $340940 \mathrm{~N} 1121730 \mathrm{~W}$ $340942 N 1121754 \mathrm{~W}$

340944 N1121310W

$341626 \mathrm{~N} 1112807 \mathrm{~W}$

360222N1121310W $360542 \mathrm{~N} 1091949 \mathrm{~W}$ $361730 \mathrm{~N} 1101906 \mathrm{~W}$ $342302 \mathrm{~N} 1105210 \mathrm{~W}$ $352852 \mathrm{~N} 1121203 \mathrm{~W}$ $352407 \mathrm{~N} 1120444 \mathrm{~W}$ 341925 N1105056 $352116 \mathrm{~N} 1123142 \mathrm{~W}$ $350631 \mathrm{~N} 1115118 \mathrm{~W}$ 344422 N1111857W

344847 N1113824W 345448 N1113045W 353300 N1133704W $360710 \mathrm{~N} 1133028 \mathrm{~W}$

$360623 \mathrm{~N} 1132659 \mathrm{~W}$ 344554 N1124139 $344440 \mathrm{~N} 1124543 \mathrm{~W}$ 353443 N1110326 $342021 \mathrm{~N} 1110539 \mathrm{~W}$

$341704 \mathrm{~N} 1112153 \mathrm{~W}$ $323002 \mathrm{~N} 1100328 \mathrm{~W}$ $334325 \mathrm{~N} 1091859 \mathrm{~W}$ $342024 \mathrm{~N} 1110541 \mathrm{~W}$ $342119 \mathrm{~N} 1110458 \mathrm{~W}$ 325240 N1103459W $342217 \mathrm{~N} 1110331 \mathrm{~W}$ 341611 N1112025 360756 N1121045 $344547 \mathrm{~N} 1130132 \mathrm{~W}$

$351258 \mathrm{~N} 1120048 \mathrm{~W}$ 313737 N1105038 $344322 \mathrm{~N} 1131823 \mathrm{~W}$ $333341 \mathrm{~N} 1120837 \mathrm{~W}$ $370200 \mathrm{~N} 1102400 \mathrm{~W}$ $323037 \mathrm{~N} 1092117 \mathrm{~W}$ $324003 N 1095235 \mathrm{~W}$ 323956 N1095227W $324021 \mathrm{~N} 1095240 \mathrm{~W}$

342610 N1110737W 
NATIONAL GAZETTEER--ARIZONA 1986

FEATURE NAME

Hotel Point

Hotel Spring

Hotevila

See Hotevilla

Hotevila Spring

See Hotevilla Spring

Hotevilla

See Hotevilla

Hotevilla

Hotevila

Hotevilla

Hoteville

Hotevilla Post Office

Hotevilla School

Hotevilla Spring Hotevila Spring

Hoteville

See Hotevilla

Hot Loop Tank

Hot Loop Trail

Hot Na Na Wash

Hoto Von Soto

See Charco de la Piedra

Hot Rock Canyon

See House Rock Wash

Hot Rock Mountain

Hot Rock Windmil

Hot Shot Headquarters

Hotshot Tank
Hot Spring
Hot Spring
Hot Spring
Hot Springs
Hot Springs
Hot Springs
See Hot Spring
Hot Springs Canyon
Prospect Creek

Hot Springs Canyon

Hot Springs Junction See Morristown

Hot Springs Tank

Hot Springs Wash

Hot Tamale Peak

Hot Tamale Wash

Hot Tank

Hot Well

Hot Well Draw

Houck

Houck Draw

Houck Interchange

Houck Railroad Station

Houden Mountain

See Houdon Mountain

Houdon Cabin

Houdon Mountain

Houden Mountain

Houdon Tank

Houghton Interchange

Houn' Dawg

See Stag Hound Butte

House Canyon

House Creek

Householder Pass

House Mine

Slate Mountain Mine

House Mine

House Mountain

House Mounta in Tank

House of Hands

House of Many Hands

\section{FEATURE}

CLASS

STATUS

COUNTY

COORDINATE

cape

pp

ppl

spring

ppl

pp

pp

building

school

spring

pp

reservoir

trail

stream

ppl

stream

summit

well

building

BGN

VARIANT

VARIANT

VARIANT

BGN 1967

VARIANT

VARIANT

VARIANT

UNOFF

UNOFF

BGN 1967

VARIANT

BGN

UNOFF

G

BGN

reservoir $B G$

spring $B G$

spring

BGN

BGN

BGN
VARIANT

BGN

spring

VARIANT

spring

valley

BGN

VARIANT

valley

BGN

ppl

VARIANT

reservoir BGN

stream BGN

summit BGN

stream BGN

reservoir BGN

well

valley

UNOFF

locale

BGN

BGN

crossing

building

UNOFF

UNOFF

summit

locale

BGN

BGN
BGN

VARIANT

reservoir BGN

crossing

UNOFF

VARIANT

summit

valley

strean

gap

mine

mine

summit

BGN

BGN

BGN

UNOFF

VARIANT

UNOFF

BGN

reservoir BGN

cave

BGN
BGN

VARIANT
Gila

Mohave

Navajo

Navajo

Navajo

Navajo

Navajo

Navajo

Navajo

Yavapa

Yavapai

Coconino

Pima

Coconino

Maricopa

Apache

Coconino

Pima

Greenlee

Yavapa i

Mohave

Greenlee

Mohave

Cochise

Greenlee

Maricopa

Graham

Graham

Pinal

Pinal

Coconino

Graham

Graham

Apache

Coconino

Apache

Apache

Gila

Gila

Gi la

Gila

$334040 \mathrm{~N} 1110932 \mathrm{~W}$

362151 N1124523W

$355540 \mathrm{~N} 1104020 \mathrm{~W}$

355543N1104026W

355540N1104020W

355540 N1104020W

355521 N1104004W

355518 N1103959W

$355543 \mathrm{~N} 1104026 \mathrm{~W}$

355540 N1104020W

$344631 \mathrm{~N} 1114308 \mathrm{~W}$

$344655 N 1114253 \mathrm{~W}$

$364047 \mathrm{N1114411W}$

321447 N1123615W

$364025 N 1114427 \mathrm{~W}$

$333502 \mathrm{~N} 1125251 \mathrm{~W}$

$360213 \mathrm{~N} 1091947 \mathrm{~W}$

$351713 N 1114327 W$

$322108 \mathrm{~N} 1124655 \mathrm{~W}$

$33044 \mathrm{BN} 1091809 \mathrm{~W}$

335909 N1122132W

35573BN1144329W

330252 N1092625W

355738N1144329W

321738 N1102223W

330247 N1092623W

$335124 N 1123721 \mathrm{~W}$

$330043 \mathrm{~N} 1095226 \mathrm{~W}$

$325920 N 1095430 \mathrm{~W}$

$331316 \mathrm{~N} 1105736 \mathrm{~W}$

$331310 \mathrm{~N} 1105935 \mathrm{~W}$

353359 N1115358

323940 N1091429W

$323333 \mathrm{~N} 1091737 \mathrm{~W}$

$351659 N 1091223 W$ $342905 \mathrm{~N} 1104551 \mathrm{~W}$

351657 N1091240W

$351626 N 1091253 \mathrm{~W}$

340551 N1110805W

$340623 \mathrm{~N} 1110515 \mathrm{~W}$

340551 N1110805W

$340620 N 1110747 \mathrm{~W}$

320341 N1104623W

UNKNOWN

Maricopa

Navajo

Gila

Mohave

Pinal

Gila

Yavapai

$363712 \mathrm{~N} 1102905 \mathrm{~W}$

$340920 \mathrm{~N} 1112503 \mathrm{~W}$

$355051 \mathrm{~N} 1143456 \mathrm{~W}$

$323036 \mathrm{~N} 1115301 \mathrm{~W}$

$340936 \mathrm{~N} 1112651 \mathrm{~W}$

344616 N1115111W

$344646 \mathrm{~N} 1114837 \mathrm{~W}$

$365401 \mathrm{~N} 1100952 \mathrm{~W}$

$\begin{array}{ll}\text { SOURCE } & \text { ELEV } \\ \text { COORDINATE } & \text { FT }\end{array}$

Theo. Roosevelt Oam $S$ B Point

Hotevilla

Hotevilla

Hotevilla

Hotevilla

Munds Mountain

Munds Mountain

Bitter Springs

$363433 \mathrm{~N} 1114005 \mathrm{~W}$

1993 Hot Rock Mtn

Spider Rock

Humphreys Peak

Ajo South

Clifton

Governors Peak

Ringbolt Rapids

Copperplate Gulch

321608N1101129w Soza Mesa

$330205 N 1092823 W$

Copperplate Gulch 
NATIONAL GAZETTEER--ARIZONA 1986

FEATURE NAME
House of Many Hands
See House of Hands
House of the Ghosts
(historical)
House Place Spring
House Ranch
House Rock
House Rock Canyon
House Rock Draw
See House Rock Wash
House Rock Rapids
House Rock Spring
House Rock Spring
House Rock Valley
House Rock Valley Buffalo Range
House Rock Wash
House Rock Oraw
Hot Rock Canyon

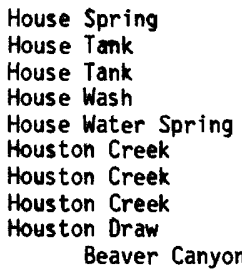

Houston Mesa

Houston Pocket

Hous ton Ranch

Hous ton Tank

Hoverrocker Ranch

Hovis Ranch

Howard Canyon

Howard Copper Mine

Howard Dam

Howard Draw

Howard $\mathrm{Hill}$

Howard Lake

Howard Mesa

Howard Mountain

Howard Peak

Howard Pocket

Howard Pocket Tank

Howard Pond

See Green Howard Tank

Howard Seep

Howard Seep Tank

Howard Silver Mine

Howard Spring

Howard Spring

Howards Tank

Howard Well (flowing)

Howard Well

Howe Lateral

Howell Canyon

Howell Mesa Cedar Mesa

Howell School

Howenst ine School

Howland Point

Howlands Butte, The

Hoxworth Springs

Hoyapi

See Giants Chair

Hoyer Memorial Campground

Hoyle Canyon

Hoyle Tank

H P Tank

H-Ranch
FEATURE
CLASS

STATUS

COUNTY

COORDINATE

\section{VARIANT}

cave
cliff

BGN 1917

Navajo

spring

locale

BGN

UNOFF

Maricopa

$B G N$

Gila

Graham

Coconino

valley

BGN

VARIANT

stream

rapids

spring

spring

valley

park

stream

BGN

BGN

BGN

BGN 1929

ADNIN

Coconino

VARIANT

VARIANT

spring
reservoir
reservoir
stream
spring
stream
stream
stream
valley

$\begin{array}{ll}\text { BGN } & \text { Gila } \\ \text { BGN } & \text { Cochise } \\ \text { BGN } & \text { Coconino } \\ \text { BGN } & \text { Pima } \\ \text { BGN } & \text { Yavapai } \\ \text { BGN 1974 } & \text { Gila } \\ \text { BGN } & \text { Gila } \\ \text { BGN } & \text { Yavapai } \\ \text { BGN } & \text { Coconino } \\ \text { VARIANT } & \end{array}$

$335754 \mathrm{~N} 1104703 \mathrm{~W}$ $322408 \mathrm{~N} 1100922 \mathrm{~W}$

$353330 \mathrm{~N} 1115422 \mathrm{~W}$

$322014 N 1113938 \mathrm{~W}$

340738 N1122922W

340732 N1111524W

$341002 \mathrm{~N} 1113448 \mathrm{~W}$

341655 N1114105W

$343228 N 1111133 \mathrm{~W}$

\begin{tabular}{|c|c|c|c|}
\hline $\begin{array}{l}\text { summit } \\
\text { basin } \\
\text { locale } \\
\text { reservoir } \\
\text { locale } \\
\text { locale } \\
\text { valley } \\
\text { mine } \\
\text { dam } \\
\text { valley }\end{array}$ & $\begin{array}{l}\text { BGN } \\
\text { BGN } \\
\text { UNOFF } \\
\text { BGN } \\
\text { UNOFF } \\
\text { UNOFF } \\
\text { BGN } \\
\text { UNOFF } \\
\text { UNOFF }\end{array}$ & $\begin{array}{l}\text { Gila } \\
\text { Gila } \\
\text { Santa Cruz } \\
\text { Cochise } \\
\text { Greenlee } \\
\text { Maricopa } \\
\text { Cochise } \\
\text { Yavapai } \\
\text { Graham }\end{array}$ & $\begin{array}{l}341633 \mathrm{~N} 1111816 \mathrm{~W} \\
340945 \mathrm{~N} 1111245 \mathrm{~W} \\
313439 \mathrm{N1} 103324 \mathrm{~W} \\
31351 \mathrm{~N} 1092308 \mathrm{~W} \\
325752 \mathrm{~N} 1090647 \mathrm{~W} \\
334355 \mathrm{~N} 1125459 \mathrm{~W} \\
32110111093453 \mathrm{~W} \\
341240 \mathrm{N1} 121135 \mathrm{~W} \\
325318 \mathrm{~N} 1094536 \mathrm{~W} \\
35062011113438 \mathrm{~W}\end{array}$ \\
\hline
\end{tabular}

valley

summi

lake

summit

summit

summit

bas in

reservoir

reservoir

spring

BGN Coconino

BGN Coconino

BGN Coconino

BGN

BGN Cochise

BGN Coconino

ARIAN

Coconino
Coconino

reservoir

mine

spring

spring

reservoir

well

well

cana!

valley

summit

BGN
UNOFF

BGN

BGN

BGN

UNOFF

UNOFF

BGN

BGN $\quad$ Cochise

VARIANT

Coconino

Yavapai

Coconino

Coconino

Yavapai

Graham

Yuma

Yuma

Cochise
Coconino

school

UNOFF

school

cape

summit

spring

pillar

park

valley

UNOFF

BGN

1932 Coconino

VARIANT

reservoir

ADMIN

BGN

BGN

reservoir

locale

BGN
UNOFF
$354730 \mathrm{~N} 1121626 \mathrm{~W}$

$353017 \mathrm{N1120946 \textrm {W }}$

$352849 \mathrm{N1120731W}$

$350201 N 1113748 \mathrm{~W}$

$321159 \mathrm{~N} 1093311 \mathrm{~W}$

$350208 \mathrm{~N} 1114826 \mathrm{~W}$

350208N1114820W

343928N1111320W

$352732 \mathrm{N1114431W}$

352733 N1114432W

341340 N1121241W

$345901 \mathrm{~N} 1113719 \mathrm{~W}$

353327 NI123543W

344733 N1120801W

$322620 \mathrm{NI} 1092046 \mathrm{~W}$

$325448 \mathrm{~N} 1132412 \mathrm{~W}$

$323930 \mathrm{~N} 1144202 \mathrm{~W}$

$321329 \mathrm{N1} 093226 \mathrm{~W}$

$355626 \mathrm{N1} 105133 \mathrm{~W}$

$321339 \mathrm{~N} 1105418 \mathrm{~W}$

$321258 \mathrm{~N} 1105604$

360929 N $1140422 \mathrm{~W}$

$360544 \mathrm{~N} 1120032 \mathrm{~W}$

$350225 N 1113427 \mathrm{~W}$

$354329 \mathrm{~N} 1103158 \mathrm{~W}$

$340202 \mathrm{N1092712W}$

342140N1104058W

$354633 \mathrm{~N} 1114224 \mathrm{~W}$

$350922 \mathrm{~N} 1130443 \mathrm{~W}$
342137 N1103919W
North Peak

Mt Turnbal

House Rock

House Rock

$364328 N 1120611 W$

Bitter Springs

Haunted Canyon

House Rock Spring SE

Bitter Springs

Buffalo Tanks

365030 N1120341W

Bitter Springs

Rock House

The Mesas

Ebert Mtn

Queens We11

Minnehaha

Pays on South

Cypress Butte

Verde Hot Springs

$341028 N 1113228 \mathrm{~N}$

342049 N1114743W

Blue Ridge Reservoir

$350241 N 1113812 W$

5350 Payson North

McDonald Mtn

O'Donnell Canyon

Pedregosa Mts West

Tillie Hall Peak

Belmont Mtn

Dos Cabezas

Bumble Bee

Pima

Lower Lake Mary

6071 Howard Hill Howard Lake

Howard Mesa

7654 Mountainaire

7502 Dos Cabezas

Dutton $\mathrm{Hil}$

Dutton $\mathrm{Hi} 11$

White Horse Hills

White Horse Hills

Bumble Bee

Mormon Mountain

Howard Spring

Munds Draw

3421 Martin Well

413 Aztec NW

Yuma West

Dos Cabezas

Howe 11 Mesa

Tucson

Tucson

Iceberg Canyon

5571 Phantom Ranch

Lower Lake Mary

342048 N1104215W

Greer

Brookbank Point

Brookbank Point

Willows Camp

Squaw Peak 
NATIONAL GAZETTEER--ARIZONA 1986

\begin{tabular}{|c|c|c|c|c|c|c|c|}
\hline FEATURE NAME & $\begin{array}{l}\text { FEATURE } \\
\text { CLASS }\end{array}$ & STATUS & COUNTY & COORDINATE & $\begin{array}{c}\text { SOURCE } \\
\text { COORDINATE }\end{array}$ & $\begin{array}{c}\text { ELEV } \\
\text { FT }\end{array}$ & MAP NAME \\
\hline $\begin{array}{l}\text { H Ranch Tank } \\
\text { H S Canyon } \\
\text { H Six Tank } \\
\text { H Six Well } \\
\text { H S Tank } \\
\text { Huacahella Mountains } \\
\text { See Harquahala Mountains } \\
\text { Huacavah } \\
\text { See Harcuvar Mountains }\end{array}$ & $\begin{array}{l}\text { reservoir } \\
\text { valley } \\
\text { reservoir } \\
\text { well } \\
\text { reservoir } \\
\text { range } \\
\text { range }\end{array}$ & $\begin{array}{l}\text { BGN } \\
\text { BGN } \\
\text { BGN } \\
\text { UNOFF } \\
\text { BGN } \\
\text { VARIANT } \\
\text { VARIANT }\end{array}$ & $\begin{array}{l}\text { Coconino } \\
\text { Yavapai } \\
\text { Santa Cruz } \\
\text { Santa Cruz } \\
\text { Coconino } \\
\text { Yuma } \\
\text { La Paz }\end{array}$ & $\begin{array}{l}352812 \mathrm{~N} 1123340 \mathrm{~W} \\
345616 \mathrm{~N} 1114833 \mathrm{~W} \\
312425 \mathrm{~N} 1110325 \mathrm{~W} \\
312413 \mathrm{~N} 1110340 \mathrm{~W} \\
343815 \mathrm{~N} 1112301 \mathrm{~W} \\
334842 \mathrm{~N} 1132147 \mathrm{~W} \\
335630 \mathrm{~N} 1133500 \mathrm{~W}\end{array}$ & $345633 \mathrm{~N} 1115022 \mathrm{~W}$ & & $\begin{array}{l}\text { Eagle Nest Mtn } \\
\text { Wilson Mountain } \\
\text { Pena Blanca Lake } \\
\text { Pena Blanca Lake } \\
\text { Happy Jack }\end{array}$ \\
\hline $\begin{array}{l}\text { Huacavah Mountains } \\
\text { See Harcuvar Mountains } \\
\text { Huachuca } \\
\text { See Camp Wallen } \\
\text { (historical) } \\
\text { Huachuca Canyon } \\
\text { Post Canyon } \\
\text { Huachuca City } \\
\text { Huachuca City School } \\
\text { Huachuca Mountains }\end{array}$ & $\begin{array}{l}\text { range } \\
\text { locale } \\
\text { valley } \\
\text { ppl } \\
\text { school } \\
\text { range }\end{array}$ & $\begin{array}{l}\text { BGN } 1959 \\
\text { VARIANT } \\
\text { BGN } \\
\text { UNOFF } \\
\text { BGN }\end{array}$ & $\begin{array}{l}\text { La Paz } \\
\text { Cochise } \\
\text { Cochise } \\
\text { Cochise } \\
\text { Cochise } \\
\text { Cochise }\end{array}$ & $\begin{array}{l}335630 \mathrm{~N} 1133500 \mathrm{~W} \\
313940 \mathrm{~N} 1101700 \mathrm{~W} \\
313822 \mathrm{~N} 1102019 \mathrm{~W} \\
313740 \mathrm{~N} 1102000 \mathrm{~W} \\
313756 \mathrm{~N} 1101956 \mathrm{~W} \\
312920 \mathrm{~N} 1102427 \mathrm{~W}\end{array}$ & $312913 \mathrm{~N} 1102324 \mathrm{~W}$ & & $\begin{array}{l}\text { Huachuca City } \\
\text { Huachuca City } \\
\text { Huachuca City } \\
\text { Huachuca Peak }\end{array}$ \\
\hline $\begin{array}{l}\text { Huachuca Peak } \\
\text { Huachuca Substation } \\
\text { Huachuca Tank } \\
\text { Huachuca Terrace } \\
\text { Huachuca Terrace Post Office } \\
\text { Huachuca Terrace School } \\
\text { Huaipai } \\
\text { See Walapai } \\
\text { Hual apai } \\
\text { See Mooney Falls }\end{array}$ & $\begin{array}{l}\text { summit } \\
\text { locale } \\
\text { reservoir } \\
\text { ppl } \\
\text { building } \\
\text { school } \\
\text { locale } \\
\text { falls }\end{array}$ & $\begin{array}{l}\text { BGN } \\
\text { UNOFF } \\
\text { BGN } \\
\text { BGN } \\
\text { UNOFF } \\
\text { UNOFF } \\
\text { VARIANT } \\
\text { VARIANT }\end{array}$ & $\begin{array}{l}\text { Cochise } \\
\text { Cochise } \\
\text { Santa Cruz } \\
\text { Cochise } \\
\text { Cochise } \\
\text { Cochise } \\
\text { Mohave } \\
\text { Coconino }\end{array}$ & $\begin{array}{l}312925 \mathrm{~N} 1102254 \mathrm{~W} \\
314137 \mathrm{N1102120 \textrm {W }} \\
312111 \mathrm{N1103016 \textrm {W }} \\
312348 \mathrm{~N} 1095528 \mathrm{~W} \\
312349 \mathrm{~N} 1095543 \mathrm{~W} \\
312337 \mathrm{~N} 1095532 \mathrm{~W} \\
352040 \mathrm{~N} 1135300 \mathrm{~W} \\
361546 \mathrm{~N} 1124224 \mathrm{~W}\end{array}$ & & 8410 & $\begin{array}{l}\text { Huachuca Peak } \\
\text { Huachuca City } \\
\text { Lochiel } \\
\text { Bisbee } \\
\text { Bisbee } \\
\text { Bisbee }\end{array}$ \\
\hline $\begin{array}{l}\text { Hualapai } \\
\text { See Walapai } \\
\text { Hualapai Bay } \\
\text { Hualpai Bay } \\
\text { Hualapai Canyon } \\
\text { Hualapai Canyon } \\
\text { Hualpai Canyon } \\
\text { Hualapai Falls } \\
\text { See Mooney Falls } \\
\text { Hualapai Hilltop }\end{array}$ & $\begin{array}{l}\text { locale } \\
\text { bay } \\
\text { valley } \\
\text { valley }\end{array}$ & $\begin{array}{l}\text { VARIANT } \\
\text { BGN } 1960 \\
\text { VARIANT } \\
\text { BGN } \\
\text { BGN 1960 } \\
\text { VARIANT } \\
\text { VARIANT } \\
\text { BGN }\end{array}$ & $\begin{array}{l}\text { Mohave } \\
\text { Mohave } \\
\text { Mohave } \\
\text { Coconino } \\
\text { Coconino } \\
\text { Coconino }\end{array}$ & $\begin{array}{l}352040 \mathrm{~N} 1135300 \mathrm{~W} \\
360130 \mathrm{~N} 1140745 \mathrm{~W} \\
351008 \mathrm{~N} 1135319 \mathrm{~W} \\
361305 \mathrm{~N} 1124130 \mathrm{~W} \\
361546 \mathrm{~N} 1124224 \mathrm{~W} \\
360944 \mathrm{~N} 1124231 \mathrm{~W}\end{array}$ & $\begin{array}{l}350713 \mathrm{~N} 1135157 \mathrm{~W} \\
360558 \mathrm{~N} 1124706 \mathrm{~W}\end{array}$ & & $\begin{array}{l}\text { Hiller Mountains } \\
\text { Rattlesnake Hill } \\
\text { Supai }\end{array}$ \\
\hline $\begin{array}{l}\text { Hualapai Indian Reservation } \\
\text { Hualpai Indian } \\
\text { Reservation } \\
\text { Hualpai Reservation } \\
\text { (Peach Springs) } \\
\text { Hualapai Reservation } \\
\text { Hualapai Indian Reserve } \\
\text { Hualapai Indian School Reserve } \\
\text { Hualapai Interchange } \\
\text { Hualapai Island } \\
\text { Hualpai Is land }\end{array}$ & $\begin{array}{l}\text { reserve } \\
\text { reserve } \\
\text { crossing } \\
\text { island }\end{array}$ & $\begin{array}{l}\text { UNOFF } \\
\text { VARIANT } \\
\text { VARIANT } \\
\text { VARIANT } \\
\text { UNDFF } \\
\text { UNDFF } \\
\text { UNOFF } \\
\text { BGN 1960 } \\
\text { VARIANT }\end{array}$ & $\begin{array}{l}\text { Mohave } \\
\text { Mohave } \\
\text { Mohave } \\
\text { Mohave }\end{array}$ & $\begin{array}{l}354000 \mathrm{~N} 1132400 \mathrm{~W} \\
\\
345506 \mathrm{~N} 1133720 \mathrm{~W} \\
352332 \mathrm{~N} 1133913 \mathrm{~W} \\
351152 \mathrm{~N} 113541 \mathrm{BW} \\
360157 \mathrm{~N} 114081 \mathrm{~W}\end{array}$ & & 4100 & $\begin{array}{l}\text { Tom Brown Canyon } \\
\text { Valentine } \\
\text { Rattlesnake Hill } \\
\text { Hiller Mountains }\end{array}$ \\
\hline $\begin{array}{l}\text { Hualapai Mountain } \\
\text { See Hualapai Peak } \\
\text { Hualapai Mountain County Park } \\
\text { Hualapai Mountains } \\
\text { Hualpai Mountains } \\
\text { Hualapai Peak } \\
\text { Hualapai Mountain } \\
\text { Hualpai Mountain } \\
\text { Hualpai Peak } \\
\text { Hualapai Reservation } \\
\text { See Hualapai Indian } \\
\text { Reservation }\end{array}$ & $\begin{array}{l}\text { summit } \\
\text { park } \\
\text { range } \\
\text { summit }\end{array}$ & $\begin{array}{l}\text { VARIANT } \\
\text { ADMIN } \\
\text { BGN } 1960 \\
\text { VARIANT } \\
\text { BGN } 1960 \\
\text { VARIANT } \\
\text { VARIANT } \\
\text { VARIANT } \\
\text { VARIANT }\end{array}$ & $\begin{array}{l}\text { Mohave } \\
\text { Mohave } \\
\text { Mohave } \\
\text { Mohave }\end{array}$ & $\begin{array}{l}350430 \mathrm{~N} 1135400 \mathrm{~W} \\
350521 \mathrm{~N} 1135351 \mathrm{~W} \\
345400 \mathrm{~N} 1135300 \mathrm{~W} \\
350430 \mathrm{~N} 1135400 \mathrm{~W}\end{array}$ & & 8417 & $\begin{array}{l}\text { Hualapai Peak } \\
\text { Wabayuma Peak } \\
\text { Hualapai Peak }\end{array}$ \\
\hline $\begin{array}{l}\text { Hualapai Reservoir } \\
\text { Hualapai Spring } \\
\text { Hualapai Spring } \\
\text { Hualapai Valley } \\
\text { Hualpai Valley } \\
\text { Hualapai Valley Joshua Trees } \\
\text { Hualapai Wash } \\
\text { Hualpai Wash } \\
\text { Hualapa Tank } \\
\text { Hualpai Wooney Falls } \\
\text { See Moon }\end{array}$ & $\begin{array}{l}\text { reservoir } \\
\text { spring } \\
\text { spring } \\
\text { valley } \\
\text { locale } \\
\text { stream } \\
\text { reservoir } \\
\text { falls }\end{array}$ & $\begin{array}{l}\text { BGN } \\
\text { BGN } \\
\text { BGN } \\
\text { BGN } \\
\text { VARIANT } \\
\text { BGN } \\
\text { BGN } 1960 \\
\text { VARIANT } \\
\text { BGN } \\
\text { VARIANT }\end{array}$ & $\begin{array}{l}\text { Mohave } \\
\text { Mohave } \\
\text { Coconino } \\
\text { Mohave } \\
\text { Mohave } \\
\text { Mohave } \\
\text { Coconino } \\
\text { Coconino }\end{array}$ & $\begin{array}{l}352649 \mathrm{~N} 1135400 \mathrm{~W} \\
350925 \mathrm{~N} 1135113 \mathrm{~W} \\
362526 \mathrm{~N} 1123248 \mathrm{~W} \\
351021 \mathrm{~N} 1135015 \mathrm{~W} \\
355730 \mathrm{~N} 1135500 \mathrm{~W} \\
360040 \mathrm{~N} 1140740 \mathrm{~W} \\
355905 \mathrm{~N} 1120435 \mathrm{~W} \\
361546 \mathrm{~N} 1124224 \mathrm{~W}\end{array}$ & $354708 \mathrm{~N} 1140803 \mathrm{~W}$ & & $\begin{array}{l}\text { Long Mountain } \\
\text { Hualapai Spring } \\
\text { Fishtail } \\
\text { Hualapai Spring } \\
\text { Grapevine Canyon } \\
\text { Hiller Mountains } \\
\text { Hualapai Tank }\end{array}$ \\
\hline
\end{tabular}


FEATURE CLASS STATUS COUNTY

COORDINATE

Hualpai

$$
\text { See Walapai }
$$

Hualpai Bay

See Hualapai Bay

Hualpai Canyon

See Hualapai Canyon

Hualpai Falls

See Mooney Falls

Hualpai Indian Reservation

See Hualapai Indian

Reservation

Hualpai Is land

See Hualapai Island

Hualpai Mountain

See Hualapai Peak

Hualpai Mountains

See Hualapai Mountains

Hualpai Peak

See Hualapai Peak

Hualpai Reservation (Peach

Springs)

See Hualapai Indian

Reservation

Hualpais Spring

See Pipeline Spring

Hualpais Spring

Hualpais Village (historical)

Hualpai Valley

See Hualapai Valley

Hualpai Wash

See Hualapai Wash

Hualpi

See Walpi

Huavabi Ranch

See Guevavi Mission

Hub, The (historical)

H U Bar Box

H U Bar Ranch Benton Rail H U Ranch

H U Bar Tank

Hubbard

See Kimball

Hubbard Cemetery
Hubbard Tank
Hubbard Tank
Hubbell Butte
Hubbell Hill
Hubbell Plateau
See Chuska Plateau
Hubbell Trading Post Nati
Historic Site
Hub Point

Huchberry Spring
See Hackberry Spring
Huck Ovi
Hudlow School
Hudson Park
Hudson Point
Hudson Ranch
Hudson School
Hudson Spring
Hueco, Cerro
Huerfano, The
Huerfano Butte
Huethawali, Mount
Huffer Spring
Huff Reservoir
Huff Tank
Huggins Peak

$\begin{array}{llll}\text { locale } & \text { VARIANT } & \text { Mohave } & 352040 \mathrm{~N} 1135300 \mathrm{~W} \\ \text { bay } & \text { VARIANT } & \text { Mohave } & 360130 \mathrm{~N} 1140745 \mathrm{~W} \\ \text { valley } & \text { VARIANT } & \text { Coconino } & 361305 \mathrm{~N} 1124130 \mathrm{~W} \\ \text { falls } & \text { VARIANT } & \text { Coconino } & 361546 \mathrm{~N} 1124224 \mathrm{~W} \\ \text { reserve } & \text { VARIANT } & \text { Coconino } & 354000 \mathrm{~N} 1132400 \mathrm{~W}\end{array}$

VARIANT

is 1 and

summit

range

summit

reserve

VARIANT

VARIANT

VARIANT

VARIANT

Mohave

Mohave

Mohave

Mohave

Coconino

VARIANT

spring

spring

locale

valley

stream

locale

locale

summit

bas in

locale

reservoir

locale

cemetery
reservoir reservoir

reservoir

summit

area

park

summit

BGN

VARIANT

VARIANT

VARIANT

Mohave

Coconino

Coconino

Mohave

Mohave

Navajo

VARIANT

BGN

BGN

UNOFF

VARIANT

VARIANT

BGN

VARIANT

Greenlee

Graham

UNOFF
BGN

BGN 1932 Coconino

BGN

Apache

Apache

ADMIN Apache

BGN

Navajo

VARIANT

spring

locale

schoo

park

cliff

locale

school

spring
summit

summit

summit

summit

spring

reservoir

reservoir

summit

$\begin{array}{lll} & \text { Graham } & 325823 N 1094025 \mathrm{~W} \\ \text { BGN } & \text { Navajo } & 355330 \mathrm{~N} 1104113 \mathrm{~W} \\ \text { UNOFF } & \text { Pima } & 321340 \mathrm{~N} 1105037 \mathrm{~W} \\ \text { AOMIN } & \text { Maricopa } & 332444 \mathrm{~N} 1115458 \mathrm{~W} \\ \text { BGN } & \text { Mohave } & 362430 \mathrm{~N} 1134409 \mathrm{~W} \\ \text { UNOFF } & \text { Santa Cruz } & 312655 \mathrm{~N} 1103759 \mathrm{~W} \\ \text { UNOFF } & \text { Maricopa } & 332328 N 1115458 \mathrm{~W} \\ \text { BGN } & \text { Gila } & 333506 \mathrm{~N} 1103956 \mathrm{~W} \\ \text { BGN } & \text { Apache } & 341858 \mathrm{~N} 1093315 \mathrm{~W} \\ & & \\ & & \\ \text { BGN } & \text { Pinal } & 323853 \mathrm{~N} 1111111 \mathrm{~W} \\ \text { BGN } & \text { Pima } & 315132 \mathrm{~N} 1104955 \mathrm{~W} \\ \text { BGN } 1932 & \text { Coconino } & 361214 \mathrm{~N} 1122256 \mathrm{~W} \\ \text { BGN } & \text { Coconino } & 342756 \mathrm{~N} 1112314 \mathrm{~W} \\ \text { BGN } & \text { Coconino } & 354701 \mathrm{~N} 1120354 \mathrm{~W} \\ \text { BGN } & \text { Coconino } & 354613 \mathrm{~N} 1120042 \mathrm{~W} \\ \text { BGN } & \text { Pinal } & 330409 \mathrm{~N} 1103236 \mathrm{~W}\end{array}$

344359 N1134927

$363400 \mathrm{~N} 1131200$

$363500 \mathrm{~N} 1131200 \mathrm{~W}$

351021N1135015W

360040N1140740W

354956N1102350W

312436N1105406W

$365529 N 1100521 \mathrm{~W}$

332520 N1091113W

$332458 \mathrm{~N} 1091115 \mathrm{~W}$

$332529 N 1091223 \mathrm{~W}$

325346 N1094629W

$325432 \mathrm{~N} 1094635 \mathrm{~W}$

$351146 \mathrm{~N} 1112956 \mathrm{~W}$

$351207 N 1125811 \mathrm{~W}$

$361114 N 1115357 \mathrm{~W}$

354240N1093339W

$360205 \mathrm{~N} 1093053 \mathrm{~W}$

$354235 \mathrm{~N} 1093327 \mathrm{~W}$

34162BN1101808W

Moriah Knoll

Moriah Knoll

5433 Mitten Buttes Dutch Blue Creek 4660 Dutch Blue Creek

Dutch Blue Creek

Pima

Winona

Purcell Canyon

6739 Walhalla Plateau Ganado

6333 Ganado

7149 Clay Springs

Hotevilla Tucson East Tempe

6688 Last Chance Canyon

5000 Harshaw

Tempe

Chrome Butte

6511 Cerro Hueco

2728 Durham Hills

4001 Helvetia

6275 Explorers Monument Pine

Red Butte

Red Butte

4356 Jerusalem Mtn 


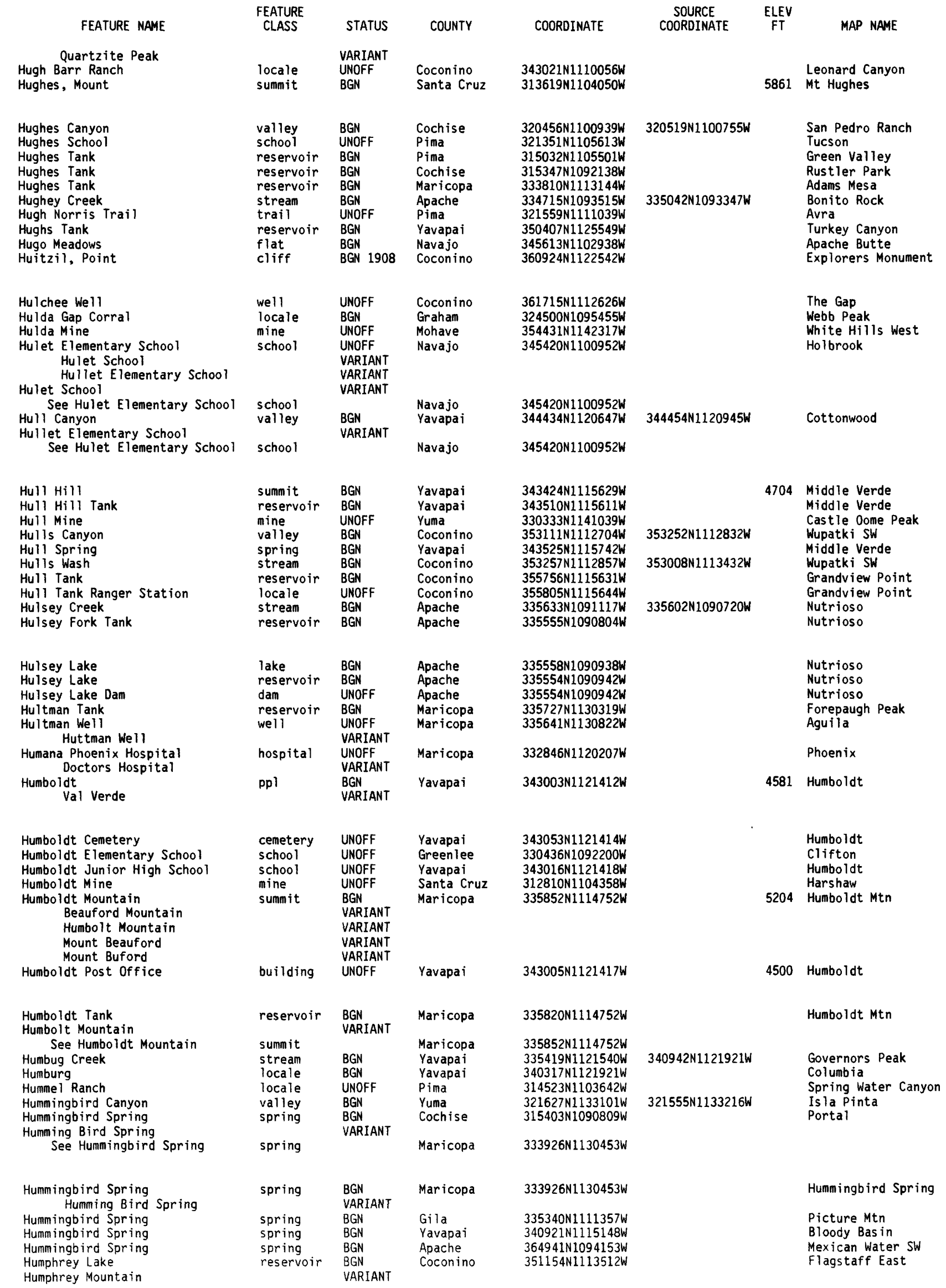




\begin{tabular}{|c|c|c|c|c|c|c|c|}
\hline FEATURE MAME & $\begin{array}{l}\text { FEATURE } \\
\text { CLASS }\end{array}$ & STATUS & COUNTY & COORDINATE & $\begin{array}{l}\text { SOURCE } \\
\text { COORDINATE }\end{array}$ & $\begin{array}{c}\text { ELEV } \\
\mathrm{FT}\end{array}$ & MAP NAME \\
\hline $\begin{array}{l}\text { See San Francisco Mountain } \\
\text { Humphreys Peak } \\
\text { See San Francisco Mountain }\end{array}$ & $\begin{array}{l}\text { summit } \\
\text { summit }\end{array}$ & VARIANT & $\begin{array}{l}\text { Coconino } \\
\text { Coconino }\end{array}$ & $\begin{array}{l}352027 \mathrm{~N} 1114057 \mathrm{~W} \\
352027 \mathrm{~N} 1114057 \mathrm{~W}\end{array}$ & & & \\
\hline $\begin{array}{l}\text { Humphreys Peak } \\
\text { San Francisco Peak } \\
\text { San Franciso Peak } \\
\text { Humphrey Tank } \\
\text { Humphrey Wash } \\
\text { Humpy Camp Well } \\
\text { Humpy Tank } \\
\text { Humpy Wash } \\
\text { Hundred and Fifty Mile Canyon } \\
\text { S B Canyon }\end{array}$ & $\begin{array}{l}\text { reservoir } \\
\text { stream } \\
\text { well } \\
\text { reservoir } \\
\text { stream } \\
\text { valley }\end{array}$ & $\begin{array}{l}\text { BGN } 1933 \\
\text { VARIANT } \\
\text { VARIANT } \\
\text { BGN } \\
\text { BGN } \\
\text { UNOFF } \\
\text { BGN } \\
\text { BGN } \\
\text { BGN } 1964 \\
\text { VARIANT }\end{array}$ & $\begin{array}{l}\text { Yavapai } \\
\text { Yavapai } \\
\text { Mavajo } \\
\text { Mavajo } \\
\text { Navajo } \\
\text { Mohave }\end{array}$ & $\begin{array}{l}344640 \mathrm{~N} 1124748 \mathrm{~W} \\
344814 \mathrm{N11} 124424 \mathrm{~W} \\
350604 \mathrm{N1102354 \textrm {W }} \\
350743 \mathrm{N1102139W} \\
350301 \mathrm{~N} 1102413 \mathrm{~W} \\
361220 \mathrm{N1} 12414 \mathrm{~W}\end{array}$ & $\begin{array}{l}344605 \mathrm{~N} 1124846 \mathrm{~W} \\
351434 \mathrm{~N} 1102049 \mathrm{~W} \\
362250 \mathrm{~N} 1124620 \mathrm{~W}\end{array}$ & 1263 & $\begin{array}{l}\text { Humphreys Peak } \\
\text { Seepage Mtn } \\
\text { Simmons } \\
\text { Humpy Camp Well } \\
\text { Rotten Bananas Butte } \\
\text { Humpy Camp Well } \\
\text { Havasu Falls }\end{array}$ \\
\hline $\begin{array}{l}\text { Hundred and Forty Mile Canyon } \\
\text { Hundred and Ninetyfour Mile } \\
\text { Canyon } \\
\text { Hundred and Ninetysix Mile } \\
\text { Creek } \\
\text { Hundred and Ninetythree Mile } \\
\text { Creek } \\
\text { Hundred and Ninetytwo Mile } \\
\text { Canyon } \\
\text { Hundred And Sixtyfour Mile } \\
\text { Canyon } \\
\text { See Tuckup Canyon }\end{array}$ & $\begin{array}{l}\text { valley } \\
\text { valley } \\
\text { stream } \\
\text { stream } \\
\text { valley }\end{array}$ & $\begin{array}{l}\text { BGN } 1932 \\
\text { BGN } \\
\text { BGN } \\
\text { BGN } \\
\text { BGN } \\
\text { VARIANT }\end{array}$ & $\begin{array}{l}\text { Coconino } \\
\text { Coconino } \\
\text { Coconino } \\
\text { Coconino } \\
\text { Coconino }\end{array}$ & $\begin{array}{l}362349 \mathrm{~N} 1123359 \mathrm{~W} \\
360522 \mathrm{~N} 1131539 \mathrm{~W} \\
360546 \mathrm{~N} 1131729 \mathrm{~W} \\
360523 \mathrm{~N} 1131356 \mathrm{~W} \\
360548 \mathrm{~N} 1131313 \mathrm{~W}\end{array}$ & $\begin{array}{l}362039 \mathrm{~N} 1123136 \mathrm{~W} \\
360224 \mathrm{~N} 1131628 \mathrm{~W} \\
360245 \mathrm{~N} 1131821 \mathrm{~W} \\
360141 \mathrm{~N} 1131659 \mathrm{~W} \\
360436 \mathrm{~N} 1131301 \mathrm{~W}\end{array}$ & & $\begin{array}{l}\text { Fishtail } \\
\text { Whitmore Point SE } \\
\text { Whitmore Point SE } \\
\text { Vulcans Throne SW } \\
\text { Vulcans Throne SW }\end{array}$ \\
\hline $\begin{array}{l}\text { Hundred and Sixtyfour Mile } \\
\text { Rapids } \\
\text { Hundred and Thirtyfive Mile } \\
\text { Rapids } \\
\text { Hundred and Thirtythree Mile } \\
\text { Creek } \\
\text { Hundred and Twentyeight Mile } \\
\text { Creek } \\
\text { Hundred and Twenty Mile Creek } \\
\text { Hundred and Twentyseven Mile } \\
\text { Creek }\end{array}$ & $\begin{array}{l}\text { rapids } \\
\text { rapids } \\
\text { stream } \\
\text { stream } \\
\text { stream } \\
\text { stream }\end{array}$ & $\begin{array}{l}\text { BGN } \\
\text { BGN } 1932 \\
\text { BGN } \\
\text { BGN } \\
\text { BGN } \\
\text { BGN }\end{array}$ & $\begin{array}{l}\text { Coconino } \\
\text { Coconino } \\
\text { Coconino } \\
\text { Coconino } \\
\text { Coconino } \\
\text { Coconino }\end{array}$ & $\begin{array}{l}361645 \mathrm{~N} 1125229 \mathrm{~W} \\
362241 \mathrm{~N} 1122900 \mathrm{~W} \\
362148 \mathrm{~N} 1122734 \mathrm{~W} \\
361835 \mathrm{N1} 122908 \mathrm{~W} \\
361422 \mathrm{~N} 1122819 \mathrm{~W} \\
361720 \mathrm{~N} 1122957 \mathrm{~W}\end{array}$ & $\begin{array}{l}362249 \mathrm{~N} 1122549 \mathrm{~W} \\
361735 \mathrm{~N} 1122506 \mathrm{~W} \\
361638 \mathrm{~N} 1122517 \mathrm{~W} \\
361709 \mathrm{~N} 1122633 \mathrm{~W}\end{array}$ & & $\begin{array}{l}\text { S B Point } \\
\text { Tapeats Amphitheater } \\
\text { Powell Plateau } \\
\text { Powell Plateau } \\
\text { Explorers Monument } \\
\text { Powell Plateau }\end{array}$ \\
\hline $\begin{array}{l}\text { Hundred and Twentytwo Mile } \\
\text { Creek } \\
\text { Hungry Valley } \\
\text { Hunsacker Wash } \\
\text { Hunsaker Tank } \\
\text { Hunt } \\
\text { Hunt Canyon } \\
\text { Hunt Canyon } \\
\text { Hunter Canyon } \\
\text { Hunter Creek } \\
\quad \text { Sharp Creek }\end{array}$ & $\begin{array}{l}\text { stream } \\
\text { basin } \\
\text { stream } \\
\text { reservoir } \\
\text { locale } \\
\text { valley } \\
\text { valley } \\
\text { valley } \\
\text { stream }\end{array}$ & $\begin{array}{l}\text { BGN } \\
\text { BGN } \\
\text { BGN } \\
\text { BGN } \\
\text { BGN } \\
\text { BGN } \\
\text { BGN } \\
\text { BGN } \\
\text { BGN } 1962 \\
\text { VARIANT }\end{array}$ & $\begin{array}{l}\text { Coconino } \\
\text { Mohave } \\
\text { Graham } \\
\text { Cochise } \\
\text { Apache } \\
\text { Cochise } \\
\text { Cochise } \\
\text { Cochise } \\
\text { Gila }\end{array}$ & $\begin{array}{l}361438 \mathrm{~N} 1123019 \mathrm{~W} \\
363417 \mathrm{N1140130 \textrm {W }} \\
325709 \mathrm{N1} 1095441 \mathrm{~W} \\
313517 \mathrm{N1092525 \textrm {W }} \\
343636 \mathrm{N1093737W} \\
313842 \mathrm{~W} 1092755 \mathrm{~W} \\
315954 \mathrm{N1091824W} \\
312425 \mathrm{~N} 1101413 \mathrm{~W} \\
341828 \mathrm{~N} 1110152 \mathrm{~W}\end{array}$ & $\begin{array}{l}325326 \mathrm{~N} 1095939 \mathrm{~W} \\
314023 \mathrm{~N} 1092048 \mathrm{~W} \\
315931 \mathrm{N1091822 \textrm {W }} \\
312330 \mathrm{N1} 101706 \mathrm{~W} \\
341807 \mathrm{N1} 105714 \mathrm{~W}\end{array}$ & 5433 & $\begin{array}{l}\text { Topocoba Hilltop } \\
\text { Virgin Peak } \\
\text { Eden } \\
\text { Pedregosa Mts West } \\
\text { Hunt } \\
\text { Bruno Peak } \\
\text { Rustler Park } \\
\text { Nicksville } \\
\text { Promontory Butte }\end{array}$ \\
\hline $\begin{array}{l}\text { Hunter Flat } \\
\text { Hunters Point } \\
\text { Hunters Point } \\
\text { Hunters Point } \\
\text { Hunters Point Boarding School } \\
\text { Hunters Point Campground } \\
\text { Hunters Point Pond } \\
\text { Hunters Point Spring } \\
\text { Hunters Point Trading Post } \\
\text { Hunter Spring }\end{array}$ & $\begin{array}{l}\text { flat } \\
\text { cliff } \\
\text { summit } \\
\text { ppl } \\
\text { school } \\
\text { park } \\
\text { reservoir } \\
\text { spring } \\
\text { locale } \\
\text { spring }\end{array}$ & $\begin{array}{l}\text { BGN } \\
\text { BGN } \\
\text { BGN } \\
\text { BGN } \\
\text { UNOFF } \\
\text { ADMIN } \\
\text { BGN } \\
\text { BGN } \\
\text { BGN } \\
\text { BGN }\end{array}$ & $\begin{array}{l}\text { Greenlee } \\
\text { Apache } \\
\text { Coconino } \\
\text { Apache } \\
\text { Apache } \\
\text { Apache } \\
\text { Apache } \\
\text { Apache } \\
\text { Apache } \\
\text { Cochise }\end{array}$ & $\begin{array}{l}324432 N 1090549 \mathrm{~W} \\
35332811090632 \mathrm{~W} \\
3549251104920 \mathrm{~W} \\
353252 \mathrm{~N} 1090616 \mathrm{~W} \\
353536 \mathrm{~N} 1090612 \mathrm{~W} \\
353602 \mathrm{~N} 1090621 \mathrm{~W} \\
353141 \mathrm{N1} 1090425 \mathrm{~W} \\
353351 \mathrm{~N} 1090606 \mathrm{~W} \\
353336 \mathrm{~N} 109055 \mathrm{~W} \\
312358 \mathrm{~N} 1101623 \mathrm{~W}\end{array}$ & & 6700 & $\begin{array}{l}\text { Duncan } \\
\text { Hunters Point } \\
\text { Padilla Mesa } \\
\text { Hunters Point } \\
\text { Hunters Point } \\
\text { Hunters Point } \\
\text { Hunters Point } \\
\text { Hunters Point } \\
\text { Hunters Point } \\
\text { Miller Peak }\end{array}$ \\
\hline $\begin{array}{l}\text { Hunter Tank } \\
\text { Hunting Tank } \\
\text { Hunting Tank } \\
\text { Huntington Square Shopping } \\
\text { Center } \\
\text { Hunt ley Tank } \\
\text { Hunt Park } \\
\text { Hunt Park } \\
\text { Hunt Ranch } \\
\text { Hunt Ranch }\end{array}$ & $\begin{array}{l}\text { reservoir } \\
\text { reservoir } \\
\text { reservoir } \\
\text { locale } \\
\text { reservoir } \\
\text { park } \\
\text { park } \\
\text { locale } \\
\text { locale }\end{array}$ & $\begin{array}{l}\text { BGN } \\
\text { BGN } \\
\text { BGN } \\
\text { UNOFF } \\
\text { BGN } \\
\text { ADMIN } \\
\text { ADMIN } \\
\text { UNOFF } \\
\text { UNOFF }\end{array}$ & $\begin{array}{l}\text { Yavapai } \\
\text { Cochise } \\
\text { Navajo } \\
\text { Cochise } \\
\text { Yavapai }\end{array}$ & $\begin{array}{l}343427 N 1111116 \mathrm{~W} \\
34370 \mathrm{BN} 1113818 \mathrm{~W} \\
344632 \mathrm{2} 1113416 \mathrm{~W} \\
332339 \mathrm{~N} 1115615 \mathrm{~W} \\
\\
345257 \mathrm{~N} 1115324 \mathrm{~W} \\
313842 \mathrm{~N} 1101959 \mathrm{~W} \\
345426 \mathrm{~N} 1100921 \mathrm{~W} \\
3138461101921 \mathrm{~W} \\
345515 \mathrm{~N} 1125237 \mathrm{~W}\end{array}$ & & & $\begin{array}{l}\text { Blue Ridge Reservoir } \\
\text { Walker Mtn } \\
\text { Stoneman Lake } \\
\text { Tempe } \\
\text { Loy Butte } \\
\text { Huachuca City } \\
\text { Holbrook } \\
\text { Huachuca City } \\
\text { Juniper Mts }\end{array}$ \\
\hline $\begin{array}{l}\text { Huntsman Spring } \\
\text { Hunts Mesa } \\
\text { Hunt Spring } \\
\text { Hunt Tank }\end{array}$ & $\begin{array}{l}\text { spring } \\
\text { summit } \\
\text { spring } \\
\text { reservoir }\end{array}$ & $\begin{array}{l}\text { BGN } \\
\text { BGN } \\
\text { BGN } \\
\text { BGN }\end{array}$ & $\begin{array}{l}\text { Pima } \\
\text { Navajo } \\
\text { Gila } \\
\text { Navajo }\end{array}$ & $\begin{array}{l}322537 \mathrm{~N} 1104530 \mathrm{~W} \\
365335 \mathrm{N1} 100416 \mathrm{~W} \\
334820 \mathrm{N1} 105328 \mathrm{~W} \\
342145 \mathrm{~N} 1101445 \mathrm{~W}\end{array}$ & & 6365 & $\begin{array}{l}\text { Mt Lemmon } \\
\text { Mitten Buttes } \\
\text { Aztec Peak } \\
\text { Pinedale }\end{array}$ \\
\hline
\end{tabular}


NATIONAL GAZETTEER--ARIZONA 1986

FEATURE NAME

Hunt Tank

Hunt Valley

Hupmobile Tank

Hurey Canyon

See Hoovey Canyon

Hurricane Cliffs

Hurricane Creek

Hurricane Dam

Hurricane Lake

Hurricane Lake Campground

Hurricane Wash

Main Run

Pierce Wash

Hurry Up Tank

Hutcherson Spring

Hutch Gulch

Hutch Gulch Creek

Hutchinson Tank

Hutch Mesa

Hutch Mountain

Mount Hutch

Hutch Springs

Hutch Tank

Hutch Tank

Hutch Tank

Hutch Tank

Huttman Wel1

See Hultman Well

Hutton Butte

Hutton Peak

Huvey Canyon

See Hoovey Canyon

Huxley Plateau

See Huxley Terrace

Huxley Terrace

Huxley Plateau

observation

Observation Plateau

H-V Ranch

$\mathrm{H}-\mathrm{V}$ Reservoir

Coyote Reservoir

$\mathrm{H} X$ Dam Hyde Cabin Spring
Hyde Spring

Hyde Creek Seep

Hyde Hill

Hyde Park (subdivision) Liberty Square

Hyde Park
Hyde Park Lodge
Hyder
Hyder Substation
Hyder Val ley
Hyder Well
Hyde Spring
Hyde Spring
See Hyde Cabin Spring
Hyde Spring

HYL Ranch

Hymn Book Spring

Hy Pond

H-2 Wash

\section{FEATURE}

CLASS

STATUS

COUNTY

valley

reservoir

BGN

BGN

BGN
VARIANT

valley

BGY

cliff

BGN

stream

dam

BGN Apache

reservoir

park

stream

BGN

BGN

Apache

Apache

VARIANT VARIANT

reservoir $B G N$

spring $B G M$

valley

BGN

Graham

Apache

Yavapa $i$

stream

summit

BGN 1981

BGN

BGN

BGN

spring

VARIANT
BGN

reservoir $B G N$

reservair $B G$

$B G N$

reservoir

VARIANT

well

summit

summit

valley VARIANT

BG 1932

BGN 1932
BGN

VARIANT

plateau

plateau

VARIANT

BGN 1908

VARIANT

VARIANT

Yavapai

Apache

Yavapai

Coconino

Yavapai

Yavapai

Yavapai

Coconino

Yavapai

Maricopa

Coconino

Pina 1

Cochise

Coconino

Coconino

VARIANT

$\begin{array}{ll}\text { locale } & \text { UNO } \\ \text { reservoir } & B G\end{array}$

UNOFF Apache

Apache

VARIANT

dam

spring

spring

summit

ppl

BGN

VARIANT

BGN

BGN

BGN

VARIANT

\begin{tabular}{|c|c|c|}
\hline $\begin{array}{l}\text { locale } \\
\text { ppl } \\
\text { ppl } \\
\text { locale } \\
\text { valley } \\
\text { well } \\
\text { spring }\end{array}$ & $\begin{array}{l}\text { BGN } \\
\text { BGN } \\
\text { BGN } \\
\text { UNOFF } \\
\text { BGN } 1965 \\
\text { UNOFF } \\
\text { BGN } \\
\text { VARIANT }\end{array}$ & $\begin{array}{l}\text { Coconino } \\
\text { Maricopa } \\
\text { Yuma } \\
\text { Maricopa } \\
\text { Yuma } \\
\text { Yuma } \\
\text { Gila }\end{array}$ \\
\hline $\begin{array}{l}\text { spring } \\
\text { spring }\end{array}$ & BGN & $\begin{array}{l}\text { Gila } \\
\text { Yavapai }\end{array}$ \\
\hline $\begin{array}{l}\text { locale } \\
\text { spring } \\
\text { reservoir } \\
\text { stream }\end{array}$ & $\begin{array}{l}\text { UNOFF } \\
\text { BGN } \\
\text { BGN } \\
\text { BGN }\end{array}$ & $\begin{array}{l}\text { Cochise } \\
\text { Gila } \\
\text { Mohave } \\
\text { Gila }\end{array}$ \\
\hline
\end{tabular}

$353114 N 1131208 \mathrm{~W}$

332751 N1115928W

$330059 \mathrm{~N} 1132053 \mathrm{~W}$

$330123 \mathrm{~N} 1131955 \mathrm{~W}$

$325901 \mathrm{N1131758 \textrm {W }}$

$330145 \mathrm{~N} 1132336 \mathrm{~W}$

$335254 \mathrm{N1} 112314 \mathrm{~W}$

$335327 \mathrm{~N} 1112421 \mathrm{~W}$

$345118 \mathrm{~N} 1124941 \mathrm{~K}$

$321017 N 1092644 \mathrm{~W}$

$335357 N 1111449 \mathrm{~W}$

$363112 \mathrm{~N} 1132908 \mathrm{~W}$

$333729 N 1105605 \mathrm{~W}$ $\begin{array}{cc}\text { SOURCE } & \text { ELEV } \\ \text { COORDINATE } & \text { FT NAP NAME }\end{array}$

343232M1093503W Camp Wood

Potter Mesa Tank

Harbison Tank

The Grandstand

335212N1093302W Bonito Rock

Bonito Rock

Bonito Rock

362359N1131810W $\begin{array}{ll}8960 & \begin{array}{l}\text { Bonito Rock } \\ \text { Yellowhorse Flat }\end{array}\end{array}$

Harrison Canyon

Whiting Knoll

341311N1115254W Bloody Bas in

341307N1115253W Bloody Bas in

Potter Mesa Tank

Brooklyn Peak

8532 Hutch Mtn

Brooklyn Peak

Brooklyn Peak

Brooklyn Peak

Jaycox Mtn

Turkey Canyon

6709 Walhalla Plateau

5615 Pinal Ranch

Havasupai Point

Loco Knoll

Loco Knol

Fisher Hills

Reno Pass

Seepage Mtn

7361 Davenport Hill

1440 Paradise Valley

Grand Canyon Caverns

1165 Tempe

Hyder

Hyder SE

$330904 N 1132319$

Agua Caliente

Baragan Mtn

Reno Pass

Seepage Mtn

Bowie Mtn North

Picture Mtn

Little Tanks

$333420 \mathrm{~N} 1105600 \mathrm{~W}$
Ibex Mountain

See Ice Cave
VARIANT

cave

Coconino

$352148 N 1113049 W$ 


\section{FEATURE NAME}

Thex Peak

Iceberg Canyon

Iceberg Ridge

Icebox Tank

Ice Box Tank

Ice Cave

Ibex Mountain

Ice Cream Cone Tank

Ice House Bend

Icehouse Canyon

See Kellner Canyon

Icehouse Canyon

Ice House Canyon

Ice House Canyon

See Icehouse Canyon

Ice Pond

Ida Canyon

Idaho Mine

Ida Peak

Ida Peak Spring

Idas Tank

Idazona Mines

Ideal Draw

Ideal Mine

Ide Valley

Ide Valley Spring

Hidden Valley Spring

Idle Hour Ranch

Idlewilde Forest Camp

I D Tank

I D Tank Number Two

I K Bar Well

Ike Clyde Tank

Ike Saddle

Ikes Backbone

Ike Smith Tank

Ike Spring

Ikes Spring

Ikes Tank

Ike Tank

Illa Tank

Illavar Wash

Imes School

Imlay Resort Tank

Immaculate Conception

Catholic School

Immaculate Heart Novitiate Immanuel Mission

See Emmanuel Mission

Immigrant Spring

IM Peak

Imperial, Point

Imperial Dam

Cocopah Damsite Number Three

Imperial Mobile Home Park

Imperial Mountain

Imperial National Wildlife

Refuge

Imperial Reservoir

Imperial Valley Cattle

Company Number One Airstrip

Imperial Well

Ina Road Interchange

Indain Tanks $\mathrm{Hill}$

See Indian Tank Hill

Independence Mine

Independent Spring

Indiana-Arizona Mine

Indian Bend Park

Indian Bend Park

\section{FEATURE}

STATUS

COUNTY

valley

ridge

BGN 1963 Yuma

reservoir

BGN

BGN

Mohave

Mohave
Cochise

reservoir

cave

reservoir

area

valley

valley

valley

lak

valley

mine

summit

spring

reservoir

mine

valley

mine

valley

spring

locale

locale

reservoir

reservoir

well

reservoir

gap

ridge

reservoir

spring

spring

reservoir

reservoir

reservoir

stream

school

reservoir

school

BGN Graham

BGN

BGN

VARIANT

BGN 1965 Gila

VARIANT

VARIANT

Gila

$\begin{array}{ll}\text { BGN } & \text { Coconino } \\ \text { BGN } & \text { Cochise } \\ \text { UNOFF } & \text { Mohave } \\ \text { BGN } & \text { Cochise } \\ \text { BGN } & \text { Cochise } \\ \text { BGN } & \text { Coconino } \\ \text { UNOFF } & \text { Maricopa } \\ \text { BGN } & \text { Cochise } \\ \text { UNOFF } & \text { Mohave } \\ \text { BGN } & \text { Mohave }\end{array}$

BGN

VARIANT

UNOFF

BGN

BGN

BGN

UNOFF

BGN

BGN

Mohave

Pima

Cochise

Apache

Apache

Gila

Gila

Yavapai

Yavapai

BGN

BGN 1932

BGN

BGN

BGN

BGN

UNOFF

UNOFF

Coconino

Yavapai

Coconino

Yavapai

Mohave

Maricopa

Mohave

Yuma

\begin{tabular}{|c|c|c|}
\hline church & $\begin{array}{l}\text { UNOFF } \\
\text { VARIANT }\end{array}$ & Pima \\
\hline $\begin{array}{l}\text { church } \\
\text { spring } \\
\text { summit } \\
\text { cliff } \\
\text { dam }\end{array}$ & $\begin{array}{l}\text { BGN } \\
\text { BGN } \\
\text { BGN } 1932 \\
\text { UNOFF } \\
\text { VARIANT }\end{array}$ & $\begin{array}{l}\text { Apache } \\
\text { Coconino } \\
\text { Yavapai } \\
\text { Coconino } \\
\text { Yuma }\end{array}$ \\
\hline locale & UNOFF & Maricopa \\
\hline $\begin{array}{l}\text { summit } \\
\text { park }\end{array}$ & $\begin{array}{l}\text { BGN } \\
\text { ADMIN }\end{array}$ & $\begin{array}{l}\text { Graham } \\
\text { Yuma }\end{array}$ \\
\hline $\begin{array}{l}\text { reservoir } \\
\text { airport }\end{array}$ & $\begin{array}{l}\text { BGN } \\
\text { ADMIN }\end{array}$ & $\begin{array}{l}\text { Yuma } \\
\text { Pima }\end{array}$ \\
\hline $\begin{array}{l}\text { well } \\
\text { crossing }\end{array}$ & $\begin{array}{l}\text { UNOFF } \\
\text { UNAFF } \\
\text { VARIANT }\end{array}$ & $\begin{array}{l}\text { Yuma } \\
\text { Pima } \\
\text { Apache }\end{array}$ \\
\hline $\begin{array}{l}\text { mine } \\
\text { spring } \\
\text { mine } \\
\text { park } \\
\text { park }\end{array}$ & $\begin{array}{l}\text { UNOFF } \\
\text { BGN } \\
\text { UNOFF } \\
\text { ADMIN } \\
\text { ADMIN }\end{array}$ & $\begin{array}{l}\text { Yavapai } \\
\text { Yavapai } \\
\text { Pima } \\
\text { Maricopa } \\
\text { Maricopa }\end{array}$ \\
\hline
\end{tabular}

321636 N1105004W

$364 \mathrm{BOBN} 1092348 \mathrm{~W}$

$342628 \mathrm{~N} 1111737 \mathrm{~W}$

341639 N1115208W

$361642 \mathrm{~N} 1115837 \mathrm{~W}$

$325259 \mathrm{~N} 1142748 \mathrm{~W}$

332448N1114630W

$325617 \mathrm{~N} 1102020 \mathrm{~W}$

$330427 N 1144052 \mathrm{~W}$

32525BN1142735W

$322800 \mathrm{~N} 1114458 \mathrm{~W}$

$324406 \mathrm{N1142600 \textrm {W }}$

$322015 N 1110356 \mathrm{~W}$

340542N1090746W

$335940 \mathrm{~N} 1123049 \mathrm{~W}$

342511 N1122909W

$322122 \mathrm{~N} 1112841 \mathrm{~W}$

332658 N1115458W

$333643 \mathrm{~N} 1120006 \mathrm{~W}$

\begin{tabular}{ccl} 
SOURCE & $\begin{array}{c}\text { ELEV } \\
\text { FT }\end{array}$ & \multicolumn{1}{c}{ MAP NAME } \\
361131N1140312W & $\begin{array}{l}\text { Ibex Peak } \\
\text { Iceberg Canyon } \\
\text { Iceberg Canyon } \\
\text { Portal Peak }\end{array}$ \\
& $\begin{array}{l}\text { The Mesas } \\
\text { Sunset Crater West } \\
\text { Cibecue } \\
\text { Needles }\end{array}$ \\
$331736 \mathrm{~N} 1105002 \mathrm{~W}$ & Globe
\end{tabular}

$\begin{array}{ll}312411 \text { N1101923W } & \begin{array}{l}\text { Williams South } \\ \text { Miller Peak } \\ \text { Cerbat }\end{array} \\ & \text { B496 } \\ & \begin{array}{l}\text { Rustler Park } \\ \text { Rustler Park } \\ \text { Calloway Butte }\end{array} \\ \text { Woolsey Peak } \\ \text { 321124N1093240W } & \begin{array}{l}\text { Pat Hills North } \\ \text { Buck Mountains } \\ \text { Mustang Knoll }\end{array}\end{array}$

Mustang Knoll

2B2B Jaynes

Portal

Corn Creek

5963 West Poker Mtn

Cassadore Spring

Beckers Butte

Verde Hot Springs

Verde Hot Springs

Piute Point

Pinyon Mtn

King Arthur Castle

Verde Hot Springs

White Horse Lake

$344644 N 1140304 \mathrm{~W}$

Sunrise Peak

Yucca

Glendale

Mustang Knoll

Yuma West

Sabino Canyon

Keh1 Ridge

5998 Tule Mesa

8803 Point Imperial

181 Imperial Reservoir

1260 Mesa

5590 Cobre Grande Mtn Picacho SW

181 Imperial Reservoir

1710 Gap Tank

1000 Fortuna

2200 Jaynes

Red Picacho

Groom Creek

Waterman Peak

Tempe

Sunnys lope 


\section{FEATURE MAME}

Indian Bend Schoo

Indian Bend Wash

Indian Bend Wash Greenbelt

Indian Bend Wasteway

Indian Bible Academy

Indian Butte

Indian Butte

Indian Butte

Indian Buttes

Indian Camp Canyon

Indian Camp Reservoir

Indian Camp Wash

Indian Camp Windmill

Indian Canyon

Indian Canyon

Indian Canyon

Indian Canyon

Indian Canyon

Indian Canyon

See Two Hundred and Ninemile Canyon

Indian Canyon

Indian Canyon

Indian Cave Spring

Indian Convalescent Home

Indian Corner Tank

Indian Creek

Indian Creek

Indian Creek

Indian Creek

See Nash Creek

Indian Creek

Indian Creek

Indian Creek

Indian Creek

See South Prong Sycamore Creek

Indian Creek

Indian Creek Campground

Indian Creek Ranch

Indian Creek Tank

Indian Delias Place

See Conley Points

Indian Farm Well

Indian Flat

Indian Flat

Indian Flat

Indian Flat Tank

Indian Flat Tank Number Two

Indian Flat Well

Indian Garden

Indian Gardens

Indian Gardens

Ind $i$ an Gardens

Indian Garden Well

Indian Grade Spring

Indian Head

Indian Head

Indian Head Mountain

Indian Head Mountain

Indian Health Station

Indian $\mathrm{Hill}$

Indian $\mathrm{Hill}$

Indian $\mathrm{Hil}$

Indian $\mathrm{Hill}$

Indian Hills Tank

Ind $i$ an Hollow

Indian Hollow Campground

Ind $i$ an Hollow-Thunder Springs

Trail Twenty-three

Indian Hollow Trick Tank

\section{FEATURE}

Chas

school

park

park

school

STATUS

COUNTY

UNOFF Maricopa

BGN Maricopa

ADMIN Maricopa

BGN

Maricopa

Yavapai

summit

summit

summit

valley

reservoir

stream

locale

valley

valley

BGN Pinal

BGN Maricopa

Gila

Maricopa

Gila

Gila

Pinal

Yavapai

Cochise

Pinal

valley

valley

valley

BGN
BGN
BGN

Yuma

Greenlee

Gila

valley

VARIANT

valley

valley

spring

BG

$B G N$

BGN

Mohave

hospital

UNOFF

Mohave

Greenlee

Maricopa

reservoir

BGN

stream

BGN

strean

stream

BGN

BGN
VARIANT

stream

stream

stream

stream

BGN

BGN

BGN

VARIANT

Graham 331707N1100320W

Cochise 312543N1091955W

Cochise 320044N1091713W

Greenlee

Gila

Gila 333903N1100526W

Yavapai 341027N1124348W

Yavapai

Yavapai

$341530 \mathrm{~N} 1120330 \mathrm{~W}$

$341842 \mathrm{~N} 1115308 \mathrm{~W}$

$\begin{array}{llll}\text { stream } & \text { BGN } & \text { Yavapai } & 342717 \text { N1122938W } \\ \text { park } & \text { ADMIN } & \text { Yavapai } & 342843 \mathrm{~N} 1122947 \mathrm{~W} \\ \text { locale } & \text { UNOFF } & \text { Yavapai } & 341814 \mathrm{N1115905 \textrm {W }} \\ \text { reservoir } & \text { BGN } & \text { Gila } & 334202 \mathrm{~N} 1100506 \mathrm{~W} \\ & \text { VARIANT } & & \\ \text { summit } & & \text { Gila } & 331719 \mathrm{N111} 2105 \mathrm{~W} \\ \text { well } & \text { UNOFF } & \text { Gila } & 340345 \mathrm{~N} 1111727 \mathrm{~W} \\ \text { flat } & \text { BGN } & \text { Gila } & 334200 \mathrm{~N} 1095945 \mathrm{~W} \\ \text { flat } & \text { BGN } & \text { Yavapai } & 343440 \mathrm{~N} 1113542 \mathrm{~W} \\ \text { flat } & \text { BGN } & \text { Coconino } & 352830 \mathrm{~N} 1113923 \mathrm{~W}\end{array}$

$342944 N 1123134 W$

reservoir BGN Navajo 334153N1095957W

reservoir BGN Yavapai 343435N1113606W

well UNOFF Navajo 334153N1095953W

basin BGN 1932 Coconino 360444N1120712W

area BGN Gila $\quad 341926$ N1110601W

$354721 \mathrm{~N} 1134028 \mathrm{~W}$

Coconino 345450N1114335W

Gila $\quad 333513 N 1103825 \mathrm{~W}$

$\begin{array}{ll}\text { Mohave } & 345431 \mathrm{~N} 1133456 \mathrm{~W} \\ \text { Pinal } & 323537 \mathrm{N1} 114416 \mathrm{~W}\end{array}$

$\begin{array}{lll}\text { spring } & B G N & \text { Mohave } \\ \text { summit } & B G N & \text { Pinal }\end{array}$

summit BGN Mohave

summit $8 \mathrm{GN} \quad$ Santa Cruz $313103 \mathrm{~N} 1104006 \mathrm{~W}$

summit BGN Pinal 325019N1103547W

Mohave $\quad 353217 \mathrm{~N} 1132512 \mathrm{~W}$

$343211 \mathrm{~N} 1122919 \mathrm{~W}$

$345341 N 1131053 \mathrm{~W}$

Yavapai 345408N1124749W

Coconino 350628N1120352W

Santa Cruz 313543N1110B23

Coconino $363007 N 1123526 \mathrm{~W}$

reservoir BGN Santa Crut

$362653 \mathrm{~N} 1121524 \mathrm{~W}$

$\begin{array}{llll}\text { park } & \text { ADMIN } & \text { Coconino } & 362745 \text { N1122903W } \\ \text { trail } & \text { UNOFF } & \text { Coconino } & 362310 \mathrm{~N} 1122729 \mathrm{~W}\end{array}$

reservoir $B G N$

Coconino

$362755 N 1122707 \mathrm{~W}$
Groom Creek

Groom Creek

Dugas

5715 Velasquez Butte

Gisela

Bonito Prairie

Buckhorn Mountain

White Horse Hills

unnys lope

Paradise Valley

Cottonwood

Ash Creek Rancl

Cochise Head

Harden Cienega

Velasquez Butte

Yarnell

Cordes Junction

5966 Bonito Prairie Buckhorn Mountain Bonito Prairie

Phantom Ranch

Promontory Butte

Spencer Canyon

Munds Park

Chrome Butte

Tom Brown Canyon

2209 Greene Reservoir

6151 Devils Hump

$\mathrm{Mt}$ Hughes

3294 Holy Joe Peak

Peach Spring

5710 Prescott

6180 Sunrise Peak

5786 Indian Peak

Murphy Peak

Jumpup Point

6320 Tapeats Amphitheater

Tapeats Amphitheater

Tapeats Amphitheater
White Horse Lake 


\begin{tabular}{|c|c|c|c|c|c|c|c|}
\hline FEATURE NAME & $\begin{array}{l}\text { FEATURE } \\
\text { CLASS }\end{array}$ & STATUS & COUNTY & COORDINATE & $\begin{array}{l}\text { SOURCE } \\
\text { COORDINATE }\end{array}$ & $\begin{array}{l}\text { ELEV } \\
\mathrm{FT}\end{array}$ & MAP NAME \\
\hline $\begin{array}{l}\text { Indian Hospital (Sells) } \\
\text { Indian Hot Springs } \\
\text { Indian Hot Springs } \\
\text { Holladay Hot Springs } \\
\text { Indian Kitchen } \\
\text { Indian Knoll }\end{array}$ & $\begin{array}{l}\text { hospital } \\
\text { spring } \\
\text { ppl } \\
\text { summit } \\
\text { summit }\end{array}$ & $\begin{array}{l}\text { UNOFF } \\
\text { BGN } \\
\text { BGN } \\
\text { VARIANT } \\
\text { BGN } \\
\text { BGN }\end{array}$ & $\begin{array}{l}\text { Pima } \\
\text { Graham } \\
\text { Graham } \\
\text { Pima } \\
\text { Mohave }\end{array}$ & $\begin{array}{l}315505 \text { N1115318W } \\
325958 \text { N1095355W } \\
325954 \text { N1095400W } \\
315705 N 1110554 \mathrm{~W} \\
364905 \mathrm{~N} 1124726 \mathrm{~W}\end{array}$ & & 3699 & $\begin{array}{l}\text { Sells West } \\
\text { Thatcher } \\
\text { Eden } \\
\text { Twin Buttes } \\
\text { Pipe Valley }\end{array}$ \\
\hline $\begin{array}{l}\text { Indian Lake } \\
\text { Indian Lake } \\
\text { Indian Lake Tank } \\
\text { Indian Lookout } \\
\text { Indian Mesa } \\
\text { Indian Mission Boarding School } \\
\text { Indian Moccasin } \\
\text { See Kaibab } \\
\text { Indian Moccas in } \\
\text { Indian Oasis } \\
\text { See Sells }\end{array}$ & $\begin{array}{l}\text { lake } \\
\text { lake } \\
\text { reservoir } \\
\text { summit } \\
\text { summit } \\
\text { school } \\
\text { ppl } \\
\text { ppl } \\
\text { ppl }\end{array}$ & $\begin{array}{l}\text { BGN } \\
\text { BGN } \\
\text { BGN } \\
\text { BGN } \\
\text { BGN } \\
\text { UNOFF } \\
\text { VARIANT } \\
\text { BGN } \\
\text { VARIANT }\end{array}$ & $\begin{array}{l}\text { Coconino } \\
\text { Coconino } \\
\text { Coconino } \\
\text { Gila } \\
\text { Yavapai } \\
\text { Navajo } \\
\text { Mohave } \\
\text { Mohave } \\
\text { Pima }\end{array}$ & $\begin{array}{l}350038 \mathrm{~N} 1112234 \mathrm{~W} \\
362333 \mathrm{~N} 1120735 \mathrm{~W} \\
350045 \mathrm{~N} 1112553 \mathrm{~W} \\
333556 \mathrm{N1102241W} \\
335754 \mathrm{N1121333W} \\
345 \mathrm{~B} 20 \mathrm{~N} 110035 \mathrm{~W} \\
365348 \mathrm{~N} 1124424 \mathrm{~W} \\
365350 \mathrm{~N} 1124430 \mathrm{~W} \\
315443 \mathrm{~N} 1115250 \mathrm{~W}\end{array}$ & & $\begin{array}{l}5977 \\
5300\end{array}$ & $\begin{array}{l}\text { Ashurst Lake } \\
\text { Kanabownits Spring } \\
\text { Ashurst Lake } \\
\text { Cassadore Spring } \\
\text { New River } \\
\text { Sun Valley }\end{array}$ \\
\hline $\begin{array}{l}\text { Indian Oasis School } \\
\text { Indian Pass } \\
\text { Indian Peak } \\
\text { Indian Peak } \\
\text { Indian Peak } \\
\text { See Little Granite Mountain } \\
\text { Indian Peak } \\
\text { See Indian Point } \\
\text { Indian Peak } \\
\text { Indian Peak Wash }\end{array}$ & $\begin{array}{l}\text { school } \\
\text { gap } \\
\text { summit } \\
\text { summit } \\
\text { summit } \\
\text { summit } \\
\text { summit } \\
\text { stream }\end{array}$ & $\begin{array}{l}\text { UNOFF } \\
\text { BGN } \\
\text { BGN } \\
\text { BGN } \\
\text { VARIANT } \\
\text { VARIANT } \\
\text { BGN } \\
\text { BGN }\end{array}$ & $\begin{array}{l}\text { Pima } \\
\text { Mohave } \\
\text { Greenlee } \\
\text { Greenlee } \\
\text { Maricopa } \\
\text { Maricopa } \\
\text { Yavapai } \\
\text { Mohave }\end{array}$ & $\begin{array}{l}314851 \mathrm{~N} 1114924 \mathrm{~W} \\
360406 \mathrm{~N} 1143812 \mathrm{~W} \\
333335 \mathrm{~N} 1091649 \mathrm{~W} \\
334600 \mathrm{~N} 1090639 \mathrm{~W} \\
334852 \mathrm{~N} 1113332 \mathrm{~W} \\
334858 \mathrm{~N} 1113202 \mathrm{~W} \\
345557 \mathrm{N11} 24 \mathrm{BBW} \\
342646 \mathrm{~N} 1141904 \mathrm{~W}\end{array}$ & $343103 \mathrm{~N} 1141413 \mathrm{~W}$ & 5455 & $\begin{array}{l}\text { Topawa } \\
\text { Hoover Dam } \\
\text { Strayhorse } \\
\text { Luna Lake }\end{array}$ \\
\hline $\begin{array}{l}\text { Indian Pine } \\
\text { Indian Point } \\
\text { Indian Point } \\
\text { See Little Granite Mountain } \\
\text { Indian Point } \\
\text { Indian Peak } \\
\text { Indian Point } \\
\text { See Indian Spring Peak } \\
\text { Indian Rapids } \\
\text { Indian Reserve } \\
\text { See Colorado River Indian } \\
\text { Reservation }\end{array}$ & $\begin{array}{l}\text { ppl } \\
\text { cliff } \\
\text { summit } \\
\text { summit }\end{array}$ & $\begin{array}{l}\text { BGN } \\
\text { BGN } \\
\text { VARIANT } \\
\text { BGN } 1965 \\
\text { VARIANT } \\
\text { VARIANT } \\
\text { BGN } \\
\text { VARIANT }\end{array}$ & $\begin{array}{l}\text { Navajo } \\
\text { Coconino } \\
\text { Maricopa } \\
\text { Maricopa }\end{array}$ & $\begin{array}{l}340448 \mathrm{~N} 1095417 \mathrm{~W} \\
345400 \mathrm{~N} 1114247 \mathrm{~W} \\
334852 \mathrm{~N} 1113332 \mathrm{~W} \\
334858 \mathrm{~N} 1113202 \mathrm{~W} \\
\\
335125 \mathrm{~N} 1113055 \mathrm{~W} \\
355351 \mathrm{~N} 1144143 \mathrm{~W} \\
334730 \mathrm{~N} 1142500 \mathrm{~W}\end{array}$ & & 3684 & $\begin{array}{l}\text { Maverick Mtn } \\
\text { Ringbolt Rapids }\end{array}$ \\
\hline $\begin{array}{l}\text { Indian Ridge Estates } \\
\text { Indian River Plaza } \\
\text { Indian Rock } \\
\text { Indian Rocks } \\
\text { Indian Rock Tank } \\
\text { Indian Ruin Tank } \\
\text { Indian School } \\
\text { Indian School Park } \\
\text { Indian School Station Post } \\
\text { Office }\end{array}$ & $\begin{array}{l}\text { ppl } \\
\text { locale } \\
\text { summit } \\
\text { summit } \\
\text { reservoir } \\
\text { reservoir } \\
\text { school } \\
\text { park } \\
\text { building }\end{array}$ & $\begin{array}{l}\text { BGN } \\
\text { BGN } \\
\text { BGN } \\
\text { BGN } \\
\text { BGN } \\
\text { BGN } \\
\text { UNOFF } \\
\text { AOMIN } \\
\text { UNOFF }\end{array}$ & $\begin{array}{l}\text { Pima } \\
\text { Maricopa } \\
\text { Navajo } \\
\text { Greenlee } \\
\text { Navajo } \\
\text { Yavapai } \\
\text { Maricopa } \\
\text { Maricopa } \\
\text { Maricopa }\end{array}$ & $\begin{array}{l}321516 \mathrm{~N} 1105032 \mathrm{~W} \\
332845 \mathrm{~N} 1115435 \mathrm{~W} \\
343503 \mathrm{~N} 1101737 \mathrm{~W} \\
324209 \mathrm{~N} 1091201 \mathrm{~W} \\
34347 \mathrm{N1101728W} \\
340207 \mathrm{~N} 1115023 \mathrm{~W} \\
332947 \mathrm{N1120412W} \\
332927 \mathrm{N11} 15435 \mathrm{~W} \\
333019 \mathrm{~N} 1120346 \mathrm{~W}\end{array}$ & & $\begin{array}{l}2520 \\
6005\end{array}$ & $\begin{array}{l}\text { Sabino Canyon } \\
\text { Tempe } \\
\text { Sheepskin Wash } \\
\text { Hot Well } \\
\text { Sheepsk in Wash } \\
\text { Rover Peak } \\
\text { Phoenix } \\
\text { Tempe } \\
\text { Sunnys lope }\end{array}$ \\
\hline $\begin{array}{l}\text { Indian Seeps Tank } \\
\text { Indian Spring } \\
\text { Indian Spring } \\
\text { Indian Spring } \\
\text { Indian Spring } \\
\text { Indian Spring } \\
\text { Indian Spring } \\
\text { Indian Springs } \\
\text { Indian Spring } \\
\text { Indian Spring }\end{array}$ & $\begin{array}{l}\text { locale } \\
\text { spring } \\
\text { spring } \\
\text { spring } \\
\text { spring } \\
\text { spring } \\
\text { spring } \\
\text { spring } \\
\text { spring }\end{array}$ & $\begin{array}{l}\text { BGN } \\
\text { BGN } \\
\text { BGN } \\
\text { BGN } \\
\text { BGN } \\
\text { BGN } \\
\text { BGN } \\
\text { VARIANT } \\
\text { BGN } \\
\text { BGN }\end{array}$ & $\begin{array}{l}\text { Coconino } \\
\text { Cochise } \\
\text { Graham } \\
\text { Graham } \\
\text { Pinal } \\
\text { Pinal } \\
\text { Gila } \\
\text { Gila } \\
\text { Gila }\end{array}$ & $\begin{array}{l}352152 \mathrm{~N} 1120528 \mathrm{~W} \\
322344 \mathrm{N1090637W} \\
324901 \mathrm{~N} 1100708 \mathrm{~W} \\
330303 \mathrm{~N} 1101335 \mathrm{~W} \\
331007 \mathrm{N1} 105824 \mathrm{~W} \\
331253 \mathrm{N1105609W} \\
331254 \mathrm{N1103448W} \\
331741 \mathrm{~N} 1104351 \mathrm{~W} \\
332605 \mathrm{N1103637W}\end{array}$ & & & $\begin{array}{l}\text { Williams North } \\
\text { Engine Mtn } \\
\text { Iripp Canyon } \\
\text { Beargrass Bas in } \\
\text { Hot Tamale Peak } \\
\text { Hot Tamale Peak } \\
\text { Coolidge Dam } \\
\text { Cutter } \\
\text { Dourine Canyon }\end{array}$ \\
\hline $\begin{array}{l}\text { Indian Spring } \\
\text { Indian Spring } \\
\text { Indian Spring } \\
\text { Indian Spring } \\
\text { Indian Spring } \\
\text { Indian Spring } \\
\text { Indian Spring } \\
\text { Indian Spring } \\
\text { Indian Spring } \\
\text { Indian Spring }\end{array}$ & $\begin{array}{l}\text { spring } \\
\text { spring } \\
\text { spring } \\
\text { spring } \\
\text { spring } \\
\text { spring } \\
\text { spring } \\
\text { spring } \\
\text { spring } \\
\text { spring }\end{array}$ & $\begin{array}{l}\text { BGN } \\
B G N \\
B G N \\
B G N \\
B G N \\
B G N \\
B G N \\
B G N \\
B G N \\
B G N\end{array}$ & $\begin{array}{l}\text { Maricopa } \\
\text { Graham } \\
\text { Gila } \\
\text { Maricopa } \\
\text { Maricopa } \\
\text { Maricopa } \\
\text { Yavapai } \\
\text { Navajo } \\
\text { Yavapai } \\
\text { Gila }\end{array}$ & 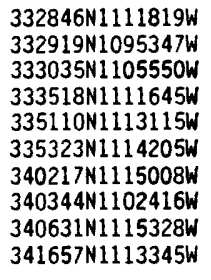 & & & $\begin{array}{l}\text { Weavers Needle } \\
\text { Natanes Mts NW } \\
\text { Salt River Peak } \\
\text { Horse Mesa Dam } \\
\text { Maverick Mtn } \\
\text { Horseshoe Dam } \\
\text { Rover Peak } \\
\text { Cibecue } \\
\text { Cooks Mesa } \\
\text { Cane Springs Mtn }\end{array}$ \\
\hline $\begin{array}{l}\text { Indian Spring } \\
\text { Indian Spring }\end{array}$ & $\begin{array}{l}\text { spring } \\
\text { spring }\end{array}$ & $\begin{array}{l}\text { BGN } \\
\text { BGN }\end{array}$ & $\begin{array}{l}\text { Navajo } \\
\text { Yavapai }\end{array}$ & $\begin{array}{l}34193 \mathrm{BN} 1101846 \mathrm{~W} \\
343441 \mathrm{~N} 1120026 \mathrm{~W}\end{array}$ & & & $\begin{array}{l}\text { Clay Springs } \\
\text { Cherry }\end{array}$ \\
\hline
\end{tabular}


NATIONAL GAZETTEER--ARIZONA 1986

\section{FEATURE NAME}

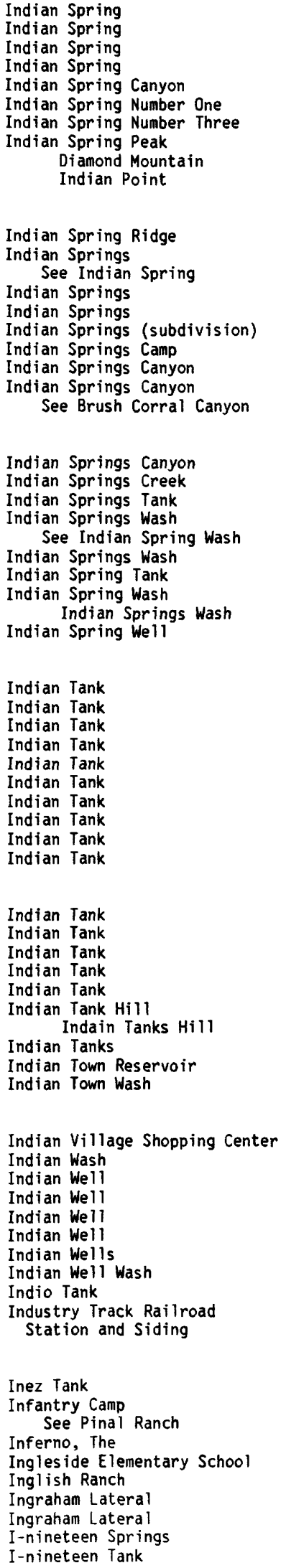

FEATURE
CLASS

spring

spring

spring

spring

valley

spring

spring

summit

ridge

spring

spring

spring

ppl

locale

valley

valley

valle

stream

reservoir

stream

stream

stream

well

reservoir

reservoir

reservoir

reservoir

reservoir

reservoir

reservoir

reservoir

reservoir

reservoir

reservoir

reservoir

reservoir

reservoir

reservoir

summit

reservoir

reservoir

stream

locale

stream

well

well

well

well

locale

reservoir

building
STATUS

$\begin{array}{ll}\text { BGN } & \text { Yavapai } \\ \text { BGN } & \text { Mohave } \\ \text { BGN } & \text { Mohave } \\ \text { BGN } & \text { Navajo } \\ \text { BGN } & \text { Gila } \\ \text { BGN } & \text { Maricopa } \\ \text { BGN } & \text { Yavapai } \\ \text { BGN 1965 } & \text { Maricopa } \\ \text { VARIANT } & \\ \text { VARIANT } & \end{array}$

BGN Gila

VARIANT

BGN

BGM Yavapa

BGN $\quad$ Yavapai

BGN Yavapai

VARIANT

Maricopa

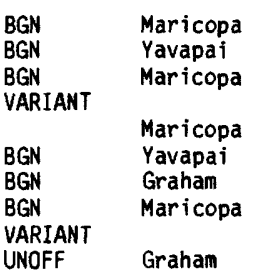

BGN Pima

BGN Maricopa

Maricopa
Apache

Apache

Yavapai

Coconino

Yavapai

Yavapai

Yavapai

Coconino

Coconino

Mohave

Coconino

Coconino

Coconino

Apache

ARIANT

BGN

BGN

Graham

Pima

Pima

$\begin{array}{lll}\text { reservoir } & \text { BGN } & \text { Santa Cruz } \\ \text { locale } & \text { VARIANT } & \text { Pinal } \\ \text { cliff } & \text { BGN } & \text { Coconino } \\ \text { school } & \text { UNOFF } & \text { Maricopa } \\ \text { locale } & \text { UNOFF } & \text { Pinal } \\ \text { canal } & \text { BGN } & \text { Yuma } \\ \text { canal } & \text { BGN } & \text { Yuma } \\ \text { spring } & \text { BGN } & \text { Gila } \\ \text { reservoir } & \text { BGN } & \text { Gila }\end{array}$

BGN Cochise
COORDINATE

$344415 N 1120456 \mathrm{~W}$ $345535 \mathrm{~N} 1132924 \mathrm{~W}$ $350243 N 1142022 \mathrm{~W}$ $354336 \mathrm{~N} 1101129 \mathrm{~W}$ $341631 \mathrm{~N} 1113354 \mathrm{~W}$ 332847 N1111806W $345307 \mathrm{N1124640 \textrm {W }}$ $335125 N 1113055 \mathrm{~W}$

341714N1113405W

$331254 \mathrm{~N} 1103448 \mathrm{~W}$ $341400 \mathrm{~N} 1122756 \mathrm{~W}$ $345320 \mathrm{~N} 1124543 \mathrm{~W}$ $333026 \mathrm{~N} 1121250 \mathrm{~W}$ $341355 \mathrm{~N} 1122804 \mathrm{~W}$ $322327 \mathrm{~N} 1090715 \mathrm{~W}$

334725 N1113019W

$334733 \mathrm{~N} 1113006 \mathrm{~W}$ $341359 \mathrm{~N} 1122920 \mathrm{~W}$ 334925 N1113022W

334826 N1113949W $345416 \mathrm{~N} 1124153 \mathrm{~W}$ 332828 N1095323W 334826 N1113949W 331919 N1100507W

$314309 \mathrm{~N} 1113615 \mathrm{~W}$ $334555 \mathrm{~N} 1124752 \mathrm{~W}$ $340606 \mathrm{~N} 1090722 \mathrm{~W}$ $344224 N 1093657 \mathrm{~W}$ 344741N1131630W $345955 \mathrm{N1} 120705 \mathrm{~W}$ $350423 \mathrm{~N} 1125340 \mathrm{~W}$ $350558 \mathrm{~N} 1123313 \mathrm{~W}$ 351647 N1131108W $352434 \mathrm{~N} 1122806 \mathrm{~W}$

$352910 \mathrm{~N} 1113947 \mathrm{~W}$ $352915 \mathrm{~N} 1132300 \mathrm{~W}$ $352955 \mathrm{~N} 1120018 \mathrm{~W}$ 353107 N1122550W $355523 \mathrm{N1} 120606 \mathrm{~W}$ $340542 \mathrm{~N} 1090746 \mathrm{~W}$

$322609 \mathrm{~N} 1091046 \mathrm{~W}$ $323033 N 1105942 W$ $323001 \mathrm{~N} 1105859 \mathrm{~W}$

323140 N1110210W

$332939 \mathrm{~N} 1120246 \mathrm{~W}$ $330022 \mathrm{~N} 1142945 \mathrm{~W}$ $323119 \mathrm{~N} 1131846 \mathrm{~W}$ $333113 N 1140505 \mathrm{~W}$ $345334 \mathrm{~N} 1124333 \mathrm{~W}$ $354219 \mathrm{~N} 1130209 \mathrm{~W}$ $352420 \mathrm{~N} 1100503 \mathrm{~W}$ 323049 N1105841W $321411 \mathrm{~N} 1112416 \mathrm{~W}$ $340124 N 1124855 \mathrm{~W}$

$312237 \mathrm{~N} 1102926 \mathrm{~W}$

$332052 \mathrm{~N} 1105934 \mathrm{~W}$ $360438 N 1120941 \mathrm{~W}$ $332918 \mathrm{~N} 1115750 \mathrm{~W}$ $324734 \mathrm{~N} 1105428 \mathrm{~W}$ $323200 \mathrm{~N} 1144639 \mathrm{~W}$ $323230 \mathrm{~N} 1144709 \mathrm{~W}$ $335654 \mathrm{~N} 1100544 \mathrm{~W}$ 335647 N1100553W

$323231 \mathrm{~N} 1110153 \mathrm{~W}$

\begin{tabular}{|c|c|c|}
\hline $\begin{array}{l}\text { SOURCE } \\
\text { COORDINATE }\end{array}$ & $\begin{array}{c}\text { ELEV } \\
\text { FT }\end{array}$ & MAP NAME \\
\hline $341728 N 1113343 W$ & 6023 & $\begin{array}{l}\text { Cottonwood } \\
\text { Gonzales Wash } \\
\text { Mount Mutt } \\
\text { Jadito Spring } \\
\text { Cane Springs Mtn } \\
\text { Weavers Needle } \\
\text { Indian Peaks } \\
\text { Maverick Mtn }\end{array}$ \\
\hline
\end{tabular}

Cane Springs Mtn

Minnehaha

Indian Peak

1100 Glendale

Minnehaha

322322N1090509W Engine Mtn

$\begin{array}{lll}\begin{array}{l}335105 N 1113142 \mathrm{~W} \\ \text { 341359N1122634W }\end{array} & \begin{array}{l}\text { Maverick Mtn } \\ \text { Minnehaha } \\ \text { Maverick Mtn }\end{array} \\ 345335 N 1124 \mathrm{~B} 27 \mathrm{~W} & 5911 & \begin{array}{l}\text { Limestone Peak } \\ \text { Natanes Mts NW } \\ \text { Bartlett Dam }\end{array} \\ 335323 \mathrm{~N} 1114205 \mathrm{~W} & 5140 \text { Ash Creek Ranch }\end{array}$

Mildred Peak

Vulture Mine

Loco Knoll

Stinking Springs Mtn

Pilot Knob

Sycamore Bas in

Turkey Canyon

Picacho Butte SE

Sugar loaf Peak

Stanford Tank

White Horse Hills

Cherokee Point

Squaw Mtn

Red Hill Ranch

6645 Tusayan East

Nelson Reservoir

Orange Butte

Oracle Junction

Oracle Juntion

Phoenix

Red Hill SW

Aguila Mts SE

Crystal Hill

4817 Limestone Peak

Crater Canyon

Indian Wells

Oracle Junction

La Tortuga Butte

2430 Flores

Huachuca Peak

Grand Canyon

Tempe

Black Mountain

Gadsden

Gadsden

Round Top Mtn

Round Top Mtn 
NATIONAL GAZETTEER--ARI ZONA 1986

\section{FEATURE NAME}

Initial Point

Inner Bas in

Interior Valley

Inscript ion Canyon

Inscription House Airport

Inscription House Ruin

Inscription House Ruin Spring

Inscription House Trading Post

Inscription Point

Inscription Rock

Inspiration

Inspiration Dam (abandoned)

Inspiration Main Shafts

Inspiration Point

Inspiration Point

Inspiration Post office

Inspiration Rock

Inspiration School

Inspiration Tailings Dam Number Four

Inspiration Tailings Dam

Number Four

Inspiration Tailings Dam

Number One

Inspiration Tailings Dam

Number Three

Inspiration Tailings Dam

Number Two

Inspiration Tunnel

Interchange One Hundred Fifty

Interchange One Hundred Fifty Four

Superstition Interchange

Interchange One Hundred Fifty

one

Interchange One Hundred Fifty

Seven

Interchange One Hundred Fifty Three

Interchange One Hundred Fifty Two

Interchange One Hundred
Fourteen

Interchange One Hundred Nine

Interchange One Hundred Ninety

Interchange One Hundred

Nintyfour

Florence Boulevard

Interchange

Interchange One Hundred Sixty

Interchange One Hundred Sixty Two

Interchange One Hundred Twelve Interchange One Hundred

Twenty One

Interchange Two Hundred Three Toltec Interchange

Interior Valley

See Inner Bas in

Interior Valley

International Smelter

In the Corner Tank

Iola Frans School

Iona Wash

Ione Marcus Gordon Memorial

Park

Iowa Camp Spring

Ioxikux

See Chiuli Shaik

Iramit

See Tatk Kam Vo

Ireland Shaft
FEATURE
CLASS

\section{CLASS}

STATUS

COUNTY

Maricopa

Coconino

bas in

valley

airport

locale

spring

locale

summit

pillar

ppl

UNOFF

mine

cliff

cliff

building

pillar

school

dam

dan

dan

dam

dam

dam

mine

crossing

crossing

crossing

crossing

UNOFF

Yavapai

Coconino

Coconino

Coconino

Coconino

Coconino

Mohave

Gila

BGN 1917

UNOFF

BGN

UNOFF

UNOFF

Gila

Gila

Cochise

Maricopa

Gila

Pima

Gila

Gila

crossing

UNOFF

crossing

UNOFF

crossing

UNOFF

crossing

UNOFF

Maricopa

332600 N1123525W

crossing

crossing

crossing

UNOFF

UNOFF

UNOFF

Maricopa

Pinal

Pinal

VARIANT

crossing

crossing

UNOFF

UNOFF

crossing

UNOFF

UNOFF

Maricopa

Maricopa

crossing

UNOFF

VARIANT

bas in

valley
locale

VARIAI

BGN
UNOFF

BGN

Coconino

Coconin

Gila

Graham

stream

cemetery

UNOFF

BGN

UNOFF

Pima

Maricop

Santa Cruz

334437 N1123400W

spring

BGN

locale

VARIANT

Coconino

Pima

VARIANT

UNOFF

COORDINATE

$332237 N 1121820$

$344620 \mathrm{~N} 1123540 \mathrm{~W}$

$365910 \mathrm{~N} 1104542 \mathrm{~W}$

$364013 N 1104910 \mathrm{~W}$

$363954 N 1104717 \mathrm{~W}$

$363905 N 1104537 \mathrm{~W}$

$353543 \mathrm{~N} 1111735 \mathrm{~W}$

$351111 \mathrm{~N} 1143358 \mathrm{~W}$

$332445 N 1105258 \mathrm{~W}$

$333425 \mathrm{~N} 1105403 \mathrm{~W}$

320001 N1091B39W

$334032 \mathrm{~N} 111100 \mathrm{BW}$

332446 N1105259W

$322552 N 1104537 \mathrm{~W}$

$332340 \mathrm{~N} 1105224 \mathrm{~W}$

$332500 \mathrm{~N} 1105030 \mathrm{~W}$

332600 N1105030W

$332500 \mathrm{~N} 1105135 \mathrm{~W}$

332455N1105030W

$332500 \mathrm{~N} 1105100 \mathrm{~W}$

332402 N1105308W

$332533 N 1120134 \mathrm{~W}$

$332321 \mathrm{N1115800 \textrm {W }}$

332438 N1115940W

$332056 \mathrm{~N} 1115816 \mathrm{~W}$

332440 N1115840W

$332622 N 1124037 \mathrm{~W}$

$325617 N 1114201 \mathrm{~W}$

325246 N1114010W

$331818 \mathrm{~N} 1115817 \mathrm{~W}$

331650 N1115800W

$332540 \mathrm{~N} 1123731 \mathrm{~W}$

324638 N1113708W

$352031 \mathrm{N1113906 \textrm {W }}$

$352149 N 1113716$

$332445 N 1105120 \mathrm{~W}$

$332359 N 1095913 \mathrm{~W}$

locale

mine
Pima

Gila
$332432 \mathrm{~N} 1115818 \mathrm{~W}$

$\begin{array}{ccc}\begin{array}{c}\text { SOURCE } \\ \text { COORDINATE }\end{array} & \text { ELEV } & \text { MAP NAME } \\ & & \begin{array}{l}\text { Tolleson } \\ \text { Humphreys Peak }\end{array} \\ 344558 \text { N1123526W } & \text { Sullivan Butte }\end{array}$

6777 Inscription Hse Ruin Inscription Hse Ruin Inscription Hse Ruin Inscription Hse Ruin

4405 Wupatki SE

Davis Dam

Inspiration

Salt River Peak

Inspiration

Cochise Head

3096 Theo. Roosevelt Dam

Inspiration

Mt Lemmon

Globe

Inspiration

Inspiration

Globe

Globe

Globe

Inspiration

Phoenix

Tempe

Tempe

Guada lupe

Tempe

Tempe

Valencia

Buckeye NW

1440 Casa Grande East

1427 Casa Grande East

Guadalupe

Guadalupe

Buckeye NW

Perryville

1520 Ninetysix Hills SW

351942N1114016W

Sunset Crater West

Globe

Natanes Mts NW

$335547 N 1123315 W$

Tucs on North

White Tank Mts NE

3920 Nogales

Mormon Lake

Globe 
FEATURE NAME

Irene Guich

Irene Spring

Irene Wash

Irene Well

Irene Well Wrene Windmill

Irene Windmill

See Irene Well

Irish Mag

Irishman Dam

Iris Spring

Iris Tank

Iris Tank

Iron Bell Ranch

Iron Canyon

Iron Canyon

Iron Canyon

Iron Canyon Spring

Iron Cap Shaft

Iron Dike

Iron Flat

Iron Flat Tank

Iron House Spring

Iron King Mine

Iron King Mine

Iron King Mine

Iron King Railroad Station

Iron Mine

Iron Mine Camp

Iron Mine Draw

Iron Mountain

Iron Mountain

Iron Mountain

Iron Mountain Spring

Iron Pipe

See Kui Tatk

Iron Pipe Village

See Kui Tatk

Ironside Hill Tank

Iron Spring

Iron Spring

Iron Spring

Iron Spring

Iron Spring

Iron Spring

Iron Spring

Iron Spring

Iron Spring Basin

Iron Springs

Iron Springs

Iron Springs

Iron Springs Post office

Iron Spring Wash

Iron Spring Wash

Iron Tank Well

Iron Tower

Iron Well

Ironwood Picnic Area

Ironwood Ranch

Ironwood School

Ironwood Spring

Ironwood Tank

Ironwood Tank

Ironwood Terrace (subdivision)

Ironwood Wash

Iroquois Wash

Irving Powerplant

Irving School

Irving Tank

Irvington Plaza Shopping Center
FEATURE

CLASS

STATUS

COUNTY

COORDINATE

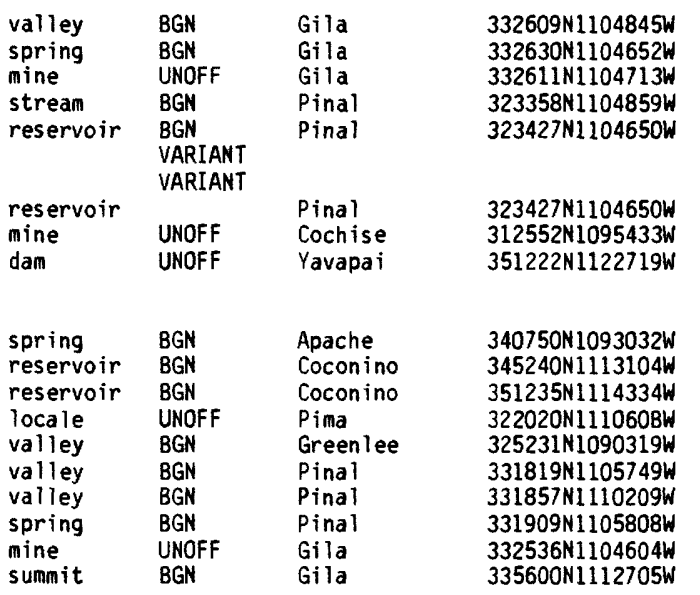

flat

BGN

spring $\quad B G$

mine UNOFF

mine

building

mine

locale

valley

UNOFF

NOFF

UNOFF

UNOFF

BGN

Coch ise

Pinal

Pinal

Yavapai

Yavapai

Yavapai

Yavapai

Navajo

Navajo

Coconino

summit

summit

spring

locale

locale

reservoir

spring

BGN

BGN

Pinal

Mohave

Pinal

VARIANT

Pima

Pima

BGN

BGN

spring

spring

spring

spring

spring

spring

bas in

spring

spring

BGN

BGN

BGN

BGN

BGN

BGN

BGN

BGN

BGN

ppl

stream

stream

well

summit

well

park

locale

school

BGN

UNOFF

BGN

BGN

BGN

BGN

UNOFF
ADMIN

ADMIN
UNOFF

UNOFF

spring

reservoir

reservoir

pp)

stream

strea

locale

school

reservoir

BGN

BGN

BGN

BGN

BGN

BGN
UNOFF

UNOFF

BGN

UNOFF

$\begin{array}{ll}\text { Cochise } & 315719 \mathrm{~N} 1091703 \mathrm{~W} \\ \text { Pima } & 322145 \mathrm{~N} 1103503 \mathrm{~W} \\ \text { Pima } & 322604 \mathrm{~N} 1103825 \mathrm{~W} \\ \text { Pima } & 322901 \mathrm{~N} 1105013 \mathrm{~W} \\ \text { Yavapai } & 340457 \mathrm{~N} 112315 \mathrm{~W} \\ \text { Yavapai } & 341214 \mathrm{~N} 1122221 \mathrm{~W} \\ \text { Mohave } & 354943 \mathrm{~N} 1135924 \mathrm{~W} \\ \text { Mohave } & 354925 \mathrm{~N} 1140105 \mathrm{~W} \\ \text { Graham } & 325959 \mathrm{~N} 109535 \mathrm{~W} \\ \text { Yavapai } & 343349 \mathrm{~N} 1123644 \mathrm{~W}\end{array}$

Yavapai

Yavapa

Yavapai

Mohave

Graham

Cochise

Yavapai

Pima

Yuma

Maricopa

Coconino

Pima

Navajo

Maricopa

Maricopa

Mohave

Gila

Maricopa

Yavapai

Pima
$321255 \mathrm{~N} 1102547 \mathrm{~W}$

$331924 N 1105912 \mathrm{~W}$

$332700 \mathrm{~N} 1110311 \mathrm{~W}$

$343003 \mathrm{~N} 1121524 \mathrm{~W}$

$344219 N 1120524 \mathrm{~W}$

$350603 \mathrm{~N} 1125240 \mathrm{~W}$

$343003 \mathrm{~N} 1121412 \mathrm{~W}$

$341044 \mathrm{~N} 1104431 \mathrm{~W}$

341022 N $1104419 W$

343611 N1112117W

$315243 \mathrm{~N} 1111502 \mathrm{~W}$

$332557 N 1111010 \mathrm{~W}$

$355048 \mathrm{~N} 1140049 \mathrm{~W}$

$332552 \mathrm{~N} 1110946 \mathrm{~W}$

$320218 N 1120450 \mathrm{~W}$

320218 N1120450W

$335424 N 1104930 \mathrm{~W}$

$314021 N 1105417 \mathrm{~W}$

$343505 \mathrm{~N} 1123409 \mathrm{~W}$

343507 N1123421

$343054 \mathrm{~N} 1130458 \mathrm{~W}$

$355237 \mathrm{~N} 1135856 \mathrm{~W}$

$324611 \mathrm{~N} 1100656 \mathrm{~W}$

$321300 \mathrm{~N} 1093626 \mathrm{~W}$

$350555 \mathrm{~N} 1125250 \mathrm{~W}$

$321156 \mathrm{~N} 1110753 \mathrm{~W}$

$324 B 14 N 1132952 \mathrm{~W}$

$333712 N 1120833 \mathrm{~W}$

$360526 \mathrm{~N} 1111014 \mathrm{~W}$ $315916 \mathrm{~N} 1112637 \mathrm{~W}$ $342134 \mathrm{~N} 1101015 \mathrm{~W}$

$333046 \mathrm{~N} 1121220 \mathrm{~W}$ $333956 \mathrm{~N} 1113532 \mathrm{~W}$ 342938 N1141B07W

$342414 \mathrm{~N} 1113701 \mathrm{~W}$

$332507 N 1114948 \mathrm{~W}$

$350318 \mathrm{~N} 1125104 \mathrm{~W}$

320947 N1105634W

$\begin{array}{cc}\text { SOURCE } & \text { ELEV } \\ \text { COORDINATE } & \text { FT MAP NAME }\end{array}$

332645N1104656W $\quad \begin{aligned} & \text { Globe } \\ & \text { Globe } \\ & \text { Globe } \\ & 323456 \text { N1104624W } \\ & \begin{array}{l}\text { Oracle } \\ \text { Oracle }\end{array}\end{aligned}$

Bisbee

Ash Fork

Whiting Knoll

Mormon Mountain

Flagstaff West

Jaynes

$\begin{array}{ll}325246 N 1090022 \mathrm{~W} & \text { Goat Camp Spring } \\ 332008 \mathrm{~N} 1105824 \mathrm{~W} & \text { Pinal Ranch }\end{array}$

$332024 N 1105827 \mathrm{~W}$ Superior

Pinal Ranch

Giobe

5027 Reno Pass

Happy Valley

Pinal Ranch

Haunted Canyon

Prescott Valley $S$

Cottonwood

Turkey Canyon

4500 Humbolt

Chediski Peak

Chediski Peak

$343430 \mathrm{~N} 1112021 \mathrm{~W}$

Long Valley

4820 Stevens Mtn

6056 Iron Mountain

6437 Garnet Mtn

Iron Mountain

Rock House

Mt Hopkins

Rustler Park

Piety $\mathrm{Hill}$

Mount Bigelow

Mt Lemmon

Morgan Butte

Crown King

Quartermaster Can SW

Garnet Mtn

Thatcher

Iron Springs

Iron Springs

5960 Iron Springs

Big Shipp Mtn

343506 N1130829W

354909N1140121W

Grapevine Canyon

5033 Tripp Canyon

7880 Dos Cabezas

Turkey Canyon

Brown Mtn

Aztec Hills

Glendale

Moenkopi

Palo Alto Ranch 


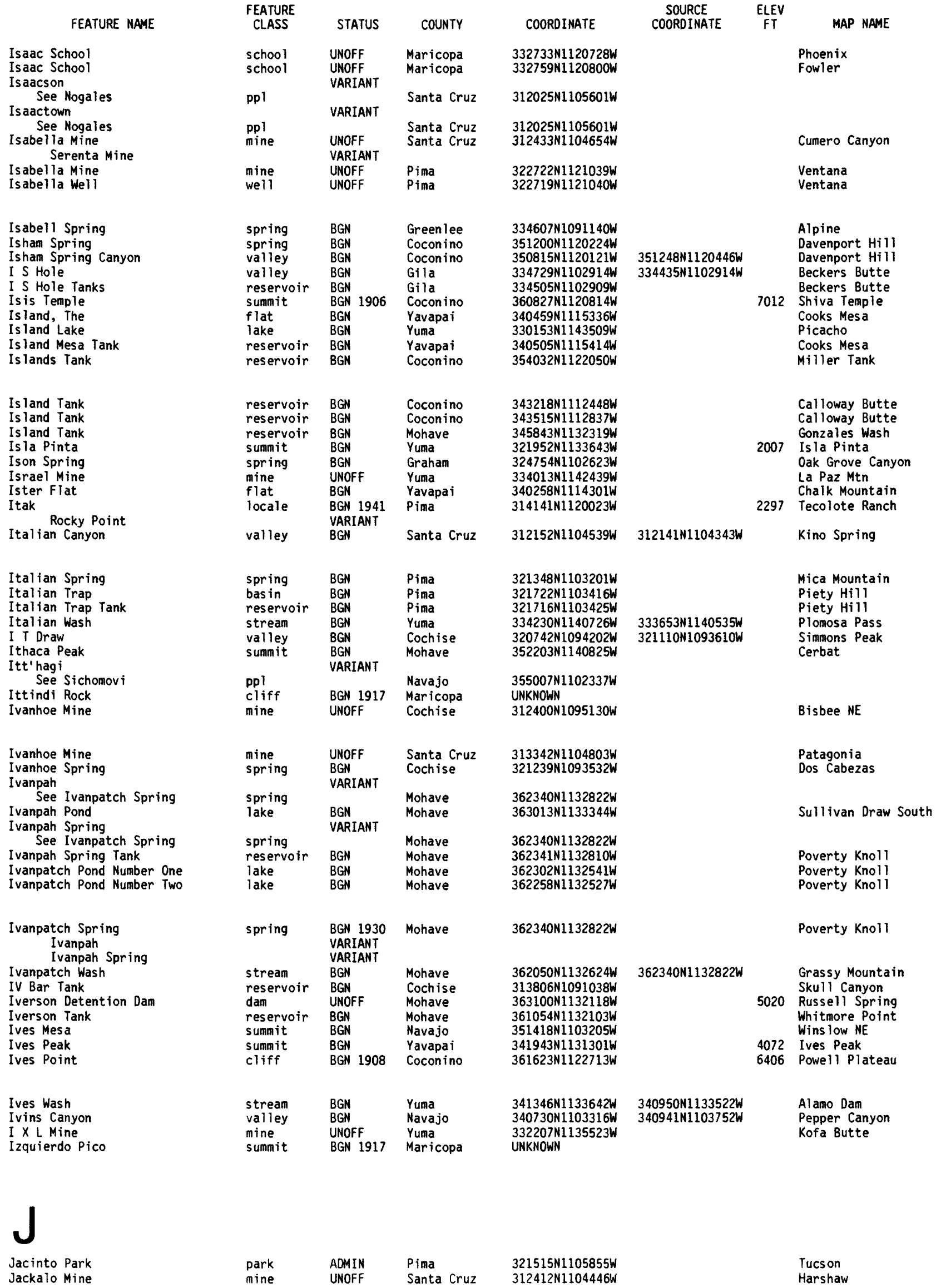




\section{FEATURE NAME}

Jack Ames Spring

See Jack Amos Spring

Jack Anos Spring

Jack Ames Spring

Jackass Basin
Jackass Canyon
Jackass Creek
Jackass Flat
Jackass Knoll
Jackass Spring
Jackass Tank
Jackass Tank
Jackass Tank
Jack Canyon-Mund Mountain
Fifty Five - Seventy Seven
Trail

Jack C William School
Mensendick Middle School

Jack Daniels Tank

Jack Doland Field

Jack Homer Spring

Jackie Dan

Jackies Pass

See Jakies Pass

Jackies Pass Spring

See Jakies Pass Spring

Jack in the Pulpit

Jack Jones Spring

Jackman Spring

Jackman Tank

Jackman Wash

Jackson Wash

Jack Mountain

Jack Mountain

Jack Pine Tank

Jackpot Mesa

Jackpot Mine

Jackpot Mine

Jackpot Spring

Jackrabbit

See Tat Momoli

Jack Rabbit

See Tat Momoli

Jackrabbit Canyon

Jackrabbit Fork

Jackrabbit House

Jackrabbit Mine

Jack Rabbit Mine

Jack Rabbit Mine

See Jackrabbit Mine

Jackrabbit Stadium

Jackrabbit Tank

Jack Rabbit Wash

See Tat Momoli Wash

Jackrabbit Wash

Dead Horse Wash

Jackrabbit Wash

Jackrabbit Wash

Jack Rabbit Well

See Tat Momoli

Jackrabbit Well

See Tat Momoli

Jacks Canyon

Brady Canyon

Rocky Gulch

Wet Beaver Creek

Jacks Canyon

Jacks Canyon

Salt Creek

\section{FEATURE \\ CLASS}

STATUS

COUNTY

COORDINATE

$340840 \mathrm{~N} 1100100 \mathrm{~W}$

$340840 \mathrm{~N} 1100100 \mathrm{~W}$

spring

VARIANT

BGN 1977 Navajo

VARIANT

bas in

valley

stream

flat

summit

spring

reservoir

reservoir

reservoir

trail

$\begin{array}{ll}\text { BGN } & \text { Yavapai } \\ \text { BGN } & \text { Navajo } \\ \text { BGN } & \text { Coconino } \\ \text { BGN } & \text { Coconino } \\ \text { BGN } & \text { Coconino } \\ \text { BGN } & \text { Yavapai } \\ \text { BGN } & \text { Gila } \\ \text { BGN } & \text { Yavapai } \\ \text { BGN } & \text { Coconino } \\ \text { UNOFF } & \text { Coconino }\end{array}$

$345414 N 1131356 \mathrm{~W}$

$364312 N 1103211 \mathrm{~W}$

$364621 N 1113918 \mathrm{~W}$

$350708 \mathrm{~N} 1121349 \mathrm{~W}$

$350737 \mathrm{N1} 121422 \mathrm{~W}$

$344100 \mathrm{~N} 1125707 \mathrm{~W}$

$341700 \mathrm{~N} 1111417 \mathrm{~W}$

$345144 \mathrm{~N} 1115355 \mathrm{~W}$

$350716 \mathrm{~N} 1121340 \mathrm{~W}$

$345000 \mathrm{~N} 1114205 \mathrm{~W}$

school

UNOFF Maricopa

reservoir

park

spring

dam

BGN

ADMIN

ADNIN
UGNOF

UNOFF

gap

VARIANT

spring

VARIANT

summit

spring

reservoir

stream

summit

summ it

reservoir

reservoir

BGN

BGN

BGN

BGN

VARIANT

BGN

BGN
BGN

summit

mine

mine

spring

locale

locale

valley

stream

BGN

UNOFF

UNOFF

BGN

VARIANT

VARIANT

BGN
BGN

locale

mine

BGN

UNOFF

VARIANT

mine

UNOFF

building

BGN

VARIANT

stream

stream

BGN 1978

stream

stream

locale

locale

valley

VARIANT

VARIANT

BGN

VARIANT

VARIANT

VARIANT

valley

valley
BGN Yavapai

VARIANT
Maricopa

Pinal

$333103 N 1121203 W$

$321715 N 1103918 \mathrm{~W}$

$365430 \mathrm{N11} 12710 \mathrm{~W}$

$361056 \mathrm{~N} 1112242 \mathrm{~W}$

$312706 \mathrm{~N} 1111148 \mathrm{~W}$

$341248 N 1122441 \mathrm{~W}$

$341300 \mathrm{~N} 1122455 \mathrm{~W}$

$324502 N 1123257 \mathrm{~W}$

$343941 \mathrm{~N} 112441 \mathrm{OW}$

$350252 \mathrm{~W} 1134949 \mathrm{~W}$

$355808 \mathrm{~N} 1115200 \mathrm{~W}$

$350207 \mathrm{~N} 1134652 \mathrm{~W}$

314132 N1105201W

$335123 \mathrm{~N} 1105851 \mathrm{~W}$

314405 N1113120W

343251 N1112838W

$325016 \mathrm{~N} 1091711 \mathrm{~W}$

$331632 \mathrm{~N} 1130015 \mathrm{~W}$

$344102 \mathrm{~N} 1142617 \mathrm{~W}$

$344057 \mathrm{N11} 142614 \mathrm{~W}$

323614 N1115140W

323614 N1115140W

$370315 \mathrm{~N} 1104211 \mathrm{~W}$

$370315 N 1104206 \mathrm{~W}$

323619 N1115343W

$323622 N 1115327 \mathrm{~W}$

$323622 \mathrm{~N} 1115327 \mathrm{~W}$

$332424 N 1114942 \mathrm{~W}$

$335945 \mathrm{~N} 1102509 \mathrm{~W}$

$323907 \mathrm{~N} 1114950 \mathrm{~W}$

333019N1124430W

$335055 N 1130521 \mathrm{~W}$

$334734 \mathrm{~N} 1125843 \mathrm{~W} \quad 334916 \mathrm{~N} 1130735 \mathrm{~W}$

$353846 \mathrm{~N} 1112006 \mathrm{~W} \quad 353654 \mathrm{~N} 1112925 \mathrm{~W}$

$323614 N 1115140 \mathrm{~W}$

Pinal

Coconino

$344101 \mathrm{N1113125W}$

$344613 N 1112606 \mathrm{~W}$

365646 N1104721W

$365645 N 1104721 \mathrm{~W}$

Navajo Begay

Navajo Begay

North Komelik

North Komelik

Mesa

Cibecue Peak

Wagner Wash Well

Wildcat Well

Wupatki NE

Apache Maid Mtn

$344440 \mathrm{~N} 1114555 \mathrm{~W} \quad 345140 \mathrm{~N} 1114220 \mathrm{~W}$ $345845 \mathrm{N1} 103905 \mathrm{~W} \quad 343801 \mathrm{N1111900W}$
Lake Montezuma
Clear Creek Res 


\begin{tabular}{|c|c|c|c|c|c|c|c|}
\hline FEATURE NAME & $\begin{array}{l}\text { FEATURE } \\
\text { CLASS }\end{array}$ & STATUS & COUNTY & COORDINATE & $\begin{array}{l}\text { SOURCE } \\
\text { COORDINATE }\end{array}$ & $\begin{array}{l}\text { ELEV } \\
\text { FT }\end{array}$ & MAP NAME \\
\hline $\begin{array}{l}\text { Jacks Canyon } \\
\text { Jacks Canyon Bridge } \\
\text { Jacks Canyon Tank } \\
\text { Jacks Gulch } \\
\text { Squaw Creek }\end{array}$ & $\begin{array}{l}\text { valley } \\
\text { bridge } \\
\text { reservoir } \\
\text { valley }\end{array}$ & $\begin{array}{l}\text { BGN } \\
\text { UNOFF } \\
\text { BGN } \\
\text { BGN } \\
\text { VARIANT }\end{array}$ & $\begin{array}{l}\text { Coconino } \\
\text { Navajo } \\
\text { Coconino } \\
\text { Yavapai }\end{array}$ & $\begin{array}{l}345900 \mathrm{~N} 1115940 \mathrm{~W} \\
345832 \mathrm{~N} 1103910 \mathrm{~W} \\
344827 \mathrm{~N} 1114203 \mathrm{~W} \\
340706 \mathrm{~N} 1115605 \mathrm{~W}\end{array}$ & $\begin{array}{l}350043 \mathrm{~N} 1120403 \mathrm{~W} \\
340950 \mathrm{~N} 1115402 \mathrm{~W}\end{array}$ & & $\begin{array}{l}\text { Loy Butte } \\
\text { Clear Creek Res } \\
\text { Munds Mountain } \\
\text { Cooks Mesa }\end{array}$ \\
\hline $\begin{array}{l}\text { Jack Shoe Ranch } \\
\text { Jack Smith Spring }\end{array}$ & $\begin{array}{l}\text { locale } \\
\text { spring }\end{array}$ & $\begin{array}{l}\text { UNOFF } \\
\text { BGN }\end{array}$ & $\begin{array}{l}\text { Gila } \\
\text { Coconino }\end{array}$ & $\begin{array}{l}334452 \mathrm{~N} 1110222 \mathrm{~W} \\
352042 \mathrm{~N} 1113848 \mathrm{~W}\end{array}$ & & & $\begin{array}{l}\text { Windy } \mathrm{Hill} \\
\text { Humphreys Peak }\end{array}$ \\
\hline $\begin{array}{l}\text { Jack Smith Spring Number Two } \\
\text { Jack Smith Tank } \\
\text { Jackson Box } \\
\text { Jackson Butte }\end{array}$ & $\begin{array}{l}\text { spring } \\
\text { reservoir } \\
\text { basin }\end{array}$ & $\begin{array}{l}\text { BGN } \\
\text { BGN } \\
\text { BGN } \\
\text { VARIANT }\end{array}$ & $\begin{array}{l}\text { Coconino } \\
\text { Coconino } \\
\text { Greenlee }\end{array}$ & $\begin{array}{l}352127 \mathrm{~N} 1113556 \mathrm{~W} \\
352228 \mathrm{~N} 1113420 \mathrm{~W} \\
334105 \mathrm{~N} 1090434 \mathrm{~W}\end{array}$ & & & $\begin{array}{l}\text { Sunset Crater West } \\
\text { Sunset Crater West } \\
\text { Maness Peak }\end{array}$ \\
\hline $\begin{array}{l}\text { See Lone Butte } \\
\text { Jackson Butte } \\
\text { Jackson Mountain }\end{array}$ & $\begin{array}{l}\text { summit } \\
\text { summit }\end{array}$ & $\begin{array}{l}\text { BGN } \\
\text { VARIANT }\end{array}$ & $\begin{array}{l}\text { Maricopa } \\
\text { Gila }\end{array}$ & $\begin{array}{l}331543 \mathrm{~N} 1120154 \mathrm{~W} \\
333733 \mathrm{N11} 103646 \mathrm{~W}\end{array}$ & & 6106 & Chrysotile \\
\hline $\begin{array}{l}\text { Jacks on Butte } \\
\text { Jackson Butte Recreation Area } \\
\text { Jackson Cabin }\end{array}$ & $\begin{array}{l}\text { summit } \\
\text { park } \\
\text { locale }\end{array}$ & $\begin{array}{l}\text { BGN } \\
\text { ADMIN } \\
\text { BGN }\end{array}$ & $\begin{array}{l}\text { Coconino } \\
\text { Gila } \\
\text { Graham }\end{array}$ & $\begin{array}{l}344520 \mathrm{~N} 1112659 \mathrm{~W} \\
333712 \mathrm{~N} 1103558 \mathrm{~W} \\
322822 \mathrm{~N} 1101826 \mathrm{~W}\end{array}$ & & $\begin{array}{l}7639 \\
4920\end{array}$ & $\begin{array}{l}\text { Hutch Mtn } \\
\text { Sevenmile Mts } \\
\text { Cherry Spring Peak }\end{array}$ \\
\hline $\begin{array}{l}\text { Jacks on Canyon } \\
\text { Jackson Canyon } \\
\text { Jackson Canyon } \\
\text { Jackson Canyon Spring } \\
\text { Jackson Creek } \\
\text { Jackson Hole Tank } \\
\text { Jackson Mine } \\
\text { Jackson Mountain } \\
\quad \text { Jackson Mountains } \\
\text { Jackson Mounta in } \\
\text { See Jackson Butte }\end{array}$ & $\begin{array}{l}\text { valley } \\
\text { valley } \\
\text { valley } \\
\text { spring } \\
\text { stream } \\
\text { reservoir } \\
\text { mine } \\
\text { summit }\end{array}$ & $\begin{array}{l}\text { BGN } \\
\text { BGN } \\
\text { BGN } \\
\text { BGN } \\
\text { BGN } \\
\text { BGN } \\
\text { UNOFF } \\
\text { BGN } \\
\text { VARIANT } \\
\text { VARIANT }\end{array}$ & $\begin{array}{l}\text { Graham } \\
\text { Greenlee } \\
\text { Mohave } \\
\text { Graham } \\
\text { Apache } \\
\text { Gila } \\
\text { Graham } \\
\text { Graham }\end{array}$ & $\begin{array}{l}322800 \mathrm{~N} 1101912 \mathrm{~W} \\
334112 \mathrm{~N} 1090443 \mathrm{~W} \\
355620 \mathrm{~N} 1134356 \mathrm{~W} \\
322900 \mathrm{~N} 1101736 \mathrm{~W} \\
334608 \mathrm{~N} 1090316 \mathrm{~W} \\
333809 \mathrm{~N} 1101126 \mathrm{~W} \\
322939 \mathrm{~N} 1101849 \mathrm{~W} \\
325454 \mathrm{~N} 1100806 \mathrm{~W} \\
333733 \mathrm{~N} 1103646 \mathrm{~W}\end{array}$ & $\begin{array}{l}322934 \mathrm{~N} 1101648 \mathrm{~W} \\
334055 \mathrm{~N} 1090340 \mathrm{~W} \\
355400 \mathrm{~N} 1134654 \mathrm{~W} \\
334 \mathrm{~B} 12 \mathrm{~N} 1090621 \mathrm{~W}\end{array}$ & 5890 & $\begin{array}{l}\text { Cherry Spring Peak } \\
\text { Maness Peak } \\
\text { Devils Slide Rapids } \\
\text { Cherry Spring Peak } \\
\text { Luna Lake } \\
\text { Forks Butte } \\
\text { Cherry Spring Peak } \\
\text { Jackson Mtn }\end{array}$ \\
\hline $\begin{array}{l}\text { Jackson Mountains } \\
\text { See Jackson Mountain } \\
\text { Jackson Park } \\
\text { Jackson Reservoir } \\
\text { Jackson School } \\
\text { Jackson Spring } \\
\text { Jackson Spring } \\
\text { Jackson Tank } \\
\text { Jackson Tank } \\
\text { Jackson Tank }\end{array}$ & $\begin{array}{l}\text { summit } \\
\text { flat } \\
\text { reservoir } \\
\text { school } \\
\text { spring } \\
\text { spring } \\
\text { reservoir } \\
\text { reservoir } \\
\text { reservoir }\end{array}$ & $\begin{array}{l}\text { VARIANT } \\
\text { BGN } \\
\text { BGN } \\
\text { UNOFF } \\
\text { BGN } \\
\text { BGN } \\
\text { BGN } \\
\text { BGN } \\
\text { BGN }\end{array}$ & $\begin{array}{l}\text { Graham } \\
\text { Coconino } \\
\text { Mohave } \\
\text { Maricopa } \\
\text { Graham } \\
\text { Apache } \\
\text { Gila } \\
\text { Apache } \\
\text { Gila }\end{array}$ & $\begin{array}{l}325454 \mathrm{~N} 1100 \mathrm{~B} 06 \mathrm{~W} \\
344602 \mathrm{~N} 1112755 \mathrm{~W} \\
363756 \mathrm{~N} 1124655 \mathrm{~W} \\
332643 \mathrm{~N} 1120603 \mathrm{~W} \\
325120 \mathrm{~N} 1102618 \mathrm{~W} \\
334841 \mathrm{~N} 1090658 \mathrm{~W} \\
333436 \mathrm{~N} 1105026 \mathrm{~W} \\
33481 \mathrm{BN} 1090627 \mathrm{~W} \\
341115 \mathrm{~N} 1111931 \mathrm{~W}\end{array}$ & & & $\begin{array}{l}\text { Hutch Mtn } \\
\text { Sunshine Ridge } \\
\text { Phoenix } \\
\text { Oak Grove Canyon } \\
\text { Luna Lake } \\
\text { Rock instraw Mtn } \\
\text { Luna Lake } \\
\text { Payson South }\end{array}$ \\
\hline $\begin{array}{l}\text { Jackson Tank } \\
\text { Jackson Tank } \\
\text { Jackson Tank } \\
\text { Jacksonville } \\
\text { See Nephi } \\
\text { Jackson Wash } \\
\text { See Timber Wash } \\
\text { Jackson Wash } \\
\text { See Jackman Wash } \\
\text { Jackson Well }\end{array}$ & $\begin{array}{l}\text { reservoir } \\
\text { reservoir } \\
\text { reservoir } \\
\text { locale } \\
\text { stream } \\
\text { stream } \\
\text { well }\end{array}$ & $\begin{array}{l}\text { BGN } \\
\text { BGN } \\
\text { BGN } \\
\text { VARIANT } \\
\text { VARIANT } \\
\text { VARIANT } \\
\text { UNOFF }\end{array}$ & $\begin{array}{l}\text { Coconino } \\
\text { Mohave } \\
\text { Mohave } \\
\text { Maricopa } \\
\text { Mohave } \\
\text { Mohave } \\
\text { Gila }\end{array}$ & $\begin{array}{l}355052 \mathrm{~N} 1121505 \mathrm{~W} \\
355349 \mathrm{~N} 1134746 \mathrm{~W} \\
364751 \mathrm{~N} 1131930 \mathrm{~W} \\
332500 \mathrm{~N} 1115330 \mathrm{~W} \\
350119 \mathrm{~N} 1134229 \mathrm{~W} \\
350207 \mathrm{~N} 1134652 \mathrm{~W} \\
333904 \mathrm{~N} 1105430 \mathrm{~W}\end{array}$ & & & $\begin{array}{l}\text { Howard } \mathrm{Hill} \\
\text { Quartermaster Canyon } \\
\text { Gyp Pocket }\end{array}$ \\
\hline $\begin{array}{l}\text { Jacks Point } \\
\text { Jacks Point Tank } \\
\text { Jack Spring } \\
\text { Jack Spring } \\
\text { Jack Spring } \\
\text { Jack Springs } \\
\text { Jacks Spring } \\
\text { Jacks Tank } \\
\text { Jacks Tank } \\
\text { Jacks Tank }\end{array}$ & $\begin{array}{l}\text { cliff } \\
\text { reservoir } \\
\text { spring } \\
\text { spring } \\
\text { spring } \\
\text { spring } \\
\text { spring } \\
\text { reservoir } \\
\text { reservoir } \\
\text { reservoir }\end{array}$ & $\begin{array}{l}\text { BGN } \\
\text { BGN } \\
\text { BGN } \\
\text { BGN } \\
\text { BGN } \\
\text { BGN } \\
\text { BGN } \\
\text { BGN } \\
B G N \\
\text { BGN }\end{array}$ & $\begin{array}{l}\text { Coconino } \\
\text { Coconino } \\
\text { Graham } \\
\text { Greenlee } \\
\text { Maricopa } \\
\text { Maricopa } \\
\text { Gila } \\
\text { Cochise } \\
\text { Graham } \\
\text { Yavapai }\end{array}$ & $\begin{array}{l}345013 \mathrm{~N} 1114140 \mathrm{~W} \\
345047 \mathrm{~N} 1114125 \mathrm{~W} \\
330453 \mathrm{~N} 1101740 \mathrm{~W} \\
334330 \mathrm{~N} 1090649 \mathrm{~W} \\
335601 \mathrm{~N} 1113609 \mathrm{~W} \\
335442 \mathrm{~N} 1115137 \mathrm{~W} \\
334130 \mathrm{~N} 1111933 \mathrm{~W} \\
314445 \mathrm{~N} 1091407 \mathrm{~W} \\
325640 \mathrm{~N} 1102645 \mathrm{~W} \\
342129 \mathrm{~N} 1115304 \mathrm{~W}\end{array}$ & & & $\begin{array}{l}\text { Munds Mountain } \\
\text { Munds Mountain } \\
\text { Mt Turnball } \\
\text { Maness Peak } \\
\text { Lion Mountain } \\
\text { Humboldt Mtn } \\
\text { Four Peaks } \\
\text { Apache } \\
\text { Booger Canyon } \\
\text { Dugas }\end{array}$ \\
\hline $\begin{array}{l}\text { Jacks Tank } \\
\text { Jack Stephens Tank } \\
\text { Jack Tank } \\
\text { Jack Tank } \\
\text { Jack Webb Tank } \\
\text { Jack Wood Canyon } \\
\text { Jack Wood Pass } \\
\text { Horseshoe Pass }\end{array}$ & $\begin{array}{l}\text { reservoir } \\
\text { reservoir } \\
\text { reservoir } \\
\text { reservoir } \\
\text { reservoir } \\
\text { valley } \\
\text { gap }\end{array}$ & $\begin{array}{l}\text { BGN } \\
\text { BGN } \\
\text { BGN } \\
\text { BGN } \\
\text { BGN } \\
\text { BGN } \\
\text { BGN } 1959 \\
\text { VARIANT }\end{array}$ & $\begin{array}{l}\text { Yavapai } \\
\text { Coconino } \\
\text { Santa Cruz } \\
\text { Coconino } \\
\text { Yavapai } \\
\text { Cochise } \\
\text { Cochise }\end{array}$ & $\begin{array}{l}350504 \mathrm{~N} 1125937 \mathrm{~W} \\
353519 \mathrm{~N} 1125245 \mathrm{~W} \\
312400 \mathrm{~N} 1103025 \mathrm{~W} \\
350652 \mathrm{~N} 1114755 \mathrm{~W} \\
351420 \mathrm{~N} 1131115 \mathrm{~W} \\
314210 \mathrm{~N} 1091001 \mathrm{~W} \\
314500 \mathrm{~N} 1091045 \mathrm{~W}\end{array}$ & $314547 \mathrm{~N} 1091246 \mathrm{~W}$ & 6061 & $\begin{array}{l}\text { Turkey Canyon } \\
\text { Rhodes Canyon } \\
\text { Canelo Pass } \\
\text { Dutton Hill } \\
\text { Cross Mtn } \\
\text { Apache } \\
\text { Portal Peak }\end{array}$ \\
\hline $\begin{array}{l}\text { Jack Wood Tank } \\
\text { Jacob Canyon }\end{array}$ & $\begin{array}{l}\text { reservoir } \\
\text { valley }\end{array}$ & $\begin{array}{l}\text { BGN } \\
\text { BGN }\end{array}$ & $\begin{array}{l}\text { Cochise } \\
\text { Coconino }\end{array}$ & $\begin{array}{l}314535 \mathrm{~N} 1091243 \mathrm{~W} \\
364843 \mathrm{~N} 1123551 \mathrm{~W}\end{array}$ & $364234 \mathrm{~N} 1121353 \mathrm{~W}$ & & $\begin{array}{l}\text { Portal Peak } \\
\text { Clear Water Spring }\end{array}$ \\
\hline $\begin{array}{l}\text { Jacob Canyon } \\
\text { Jacob C Fruchthendler } \\
\text { Elementary School }\end{array}$ & $\begin{array}{l}\text { valley } \\
\text { school }\end{array}$ & $\begin{array}{l}\text { BGN } \\
\text { UNOFF }\end{array}$ & $\begin{array}{l}\text { Coconino } \\
\text { Pima }\end{array}$ & $\begin{array}{l}365341 \mathrm{~N} 1123019 \mathrm{~W} \\
321605 \mathrm{~N} 1104957 \mathrm{~W}\end{array}$ & $365235 \mathrm{~N} 1122834 \mathrm{~W}$ & & $\begin{array}{l}\text { Fredonia } \\
\text { Sabino Canyon }\end{array}$ \\
\hline
\end{tabular}


NATIONAL GAZETTEER--ARIZONA 1986

FEATURE NAME
Fruchthendler School
Jacob Lake
Jacob Lake
Jacob Lake
Jacob Lake Camp
Jacobs Lake
Jacobs Lake Camp

Jacob Lake Camp

See Jacob Lake

Jacob Pools

See Jacobs Pool

Jacobs Lake

See Jacob Lake

Jacobs Lake Camp

See Jacob Lake

Jacobson Canyon

Jacobson Creek

Jacobs Park

Jacobs Pool

Jacob Pools

Jacobs Ranch

Jacobs Tank

Jacobs Tank

Jacobs Wash

Tanner Wash

Jacobs Well

Jacobs Well

Jacob Well

Jaco Well

Jacques Dam

Jaques Dan

Show Low Dam

Jacques Lake

See Show Low Lake

Jadi To

See Jadito Spring

Jadito

Jadito Station

Jadito Store

Jadito Trading Post

Jeddito

Jeddito Trading Post

Jadito Canyon

See Jadito Wash

Jadito Spring

Jadi To

Jadito Springs

Jeddito

Jeddito Spring

Jetto-to Spring

Jettyto Spring

Jetty-to Spring

Jadito Springs

See Jadito Spring

Jadito Station

See Jadito

Jadito Store

See Jadito

Jadito Trading Post

See Jadito

Jadito Wash

Corn Creek

Corn Wash

Jadito Canyon

Jeddito Wash

North Fork Corn Creek

North Jeddito Wash

Whe-yol-da-sah Wash

Jaeger Mine

Jagged Rock

Jagged Tooth Tank

Jagow Tank

Jagow Well

VARIANT

ppl

lake

pp 1

ppl

valley

strean

BGN

VARIANT

VARIANT

$\begin{array}{ll}\text { park } & \text { ADMIN } \\ \text { lake } & \text { BGN }\end{array}$

lake

locale

reservoir

reservoir

arroyo

well

BGN
VARIANT
UNOFF

VARIA
UNOFF
BGN
BGN

BGN
BGN

BGN

VARIANT
UNOFF

well UNOFF

Coconino

Coconino

Coconino

Graham

Apache

wel1 UNOFF

Well UNOFF

dam UNOFF

VARIANT

VARIANT

reservoir

VARIAST

spring

VARIANT

Navajo

BGN 1967
VARIANT

VARIANT

VARIANT

VARIANT

VARIANT

VARIANT

stream

spring

BGN 1967

VARIANT

VARIANT

VARIANT

VARIANT

VARIANT

VARIANT

VARIANT

VARIANT

spring

ppl

VARIANT

ppl

VARIANT

Navajo

VARIANT

ppl
stream

BGN 1967
VARIANT

VARIANT

VARIANT

VARIANT

VARIANT

VARIANT

VARIANT

mine

reservoir

reservoir

well

$\begin{array}{ll}\text { UNOFF } & \text { Pima } \\ \text { BGN } & \text { Navajo } \\ \text { BGN } & \text { Yavapai } \\ \text { BGN } & \text { Maricopa } \\ \text { UNOFF } & \text { Maricopa }\end{array}$

$\begin{array}{llll}\begin{array}{c}\text { FEATURE } \\ \text { CLASS }\end{array} & \text { STATUS } & \text { COUNTY } & \text { COORDINATE } \\ & & & \\ \text { lake } & \text { VARIANT } & & \\ \text { lake } & \text { BGN } & \text { Coconino } & 341916 \text { N1105024W } \\ \text { ppl } & \text { BGN } & \text { Coconino } & 364226 N 1121349 \mathrm{~W} \\ & \text { BGN 1941 } & \text { Coconino } & 36424 B N 1121256 \mathrm{~W} \\ & \text { VARIANT } & & \\ & \text { VARIANT } & & \\ & \text { VARIANT } & & \end{array}$

SOURCE COORDINATE

ELEV

AZ309

$364248 N 1121256 \mathrm{~W}$

364318 N1115415W

$364248 \mathrm{~N} 1121256 \mathrm{~W}$

Coconino 364248N1121256W

Graham 324054N1094606W

$324054 \mathrm{~N} 1094606 \mathrm{~W}$
$324445 \mathrm{~N} 109414 \mathrm{WW}$

323802N1094848W Mt Graham

$323807 \mathrm{~N} 1094846 \mathrm{~W}$

Artesia o w Point

Jacob Lake
7921 Jacob Lake
Pima 321605N1105916W

Coconino 364318N1115415W

Mohave 363231N1140112W

Yavapai 343745N1114002W

Apache 350137N1092413W

345609 N1101057W

$350318 \mathrm{~N} 1092318 \mathrm{~W}$

$363945 N 1135402 \mathrm{~W}$

$350228 \mathrm{~N} 1101211 \mathrm{~W}$

$341930 \mathrm{~N} 1105028 \mathrm{~W}$

Coconino

Maricopa

$341140 \mathrm{N1} 100018 \mathrm{~W}$

341140 N1100013W

$354218 N 1101317 \mathrm{~W}$

Navajo

354628 N1100810W

Coconino

352133N1105028W

$354218 \mathrm{~N} 1101317 \mathrm{~W}$

Navajo

354218 N1101317W

Navajo

354628 N1100810W

Navajo
354628N1100810W

$354628 \mathrm{~N} 1100810 \mathrm{~W}$

$352133 \mathrm{~N} 1105028 \mathrm{~W}$
Tucson North

5213 Emmett $\mathrm{Hill}$

Virgin Peak

Casner Butte

Navajo Springs

Holbrook

Navajo Springs

Jacobs Well

OW Point

Forth of July Butte

6542 Show Low South

Keams Canyon

Jadito Spring

Jadito Spring

Coconino

355430 N $1095630 \mathrm{~W}$

East of 01d Leupp
$350646 \mathrm{~N} 1101841 \mathrm{~W}$

$342336 \mathrm{~N} 1121142 \mathrm{~W}$

$331427 \mathrm{~N} 1125421 \mathrm{~W}$
315907 N1114B50W
$5322 \begin{aligned} & \text { Sells East } \\ & \text { Blairs Spring } \\ & \text { Mayer } \\ & \text { Woolsey Peak } \\ & \text { Tonopah }\end{aligned}$ 
NATIONAL GAZETTEER--ARIZONA 1986

\section{FEATURE NAME}

Jagway Valley

See Agway Valley

Jagwey Valley

See Agway valley

Jail Cave

Jake McCain Tank

Jakes Corner

Jakes Tank Canyon

Jake Tank

Jakies Pass

Jackies Pass

Jakies Pass Spring Jackies Pass Spring

Jalisco Canyon

Jalisco Dam

Jalisco Ridge

Jal isco Well

Jamaica Orain

James Bay

Janes Canyon

Janes C Thomas Park

James Pond

James Reservoir

James Tank

James Wash

James Wash

James Wel1

James Wel

James Well

James Well

Jamieson Tank

Jamison Mine

Jamison Tank

Jana Gordo Well

$\mathrm{J}$ and $\mathrm{M}$ Trailer Park

Janes 8utte

Jane Tank

Jane Wayland Child Guidance Center

Janice Tank

Janie Tank

Janis Canyon

Janis Spring

January Tank

Janus Crater

See Oouble Crater

Janus Spring

Janus Spring

See Espejo Spring

JAO Well

Japanese Slough Jap Slough

Japanese Tank

Japanese Valley

Jap Slough

See Japanese Slough

Jaquar Tank

Jaques 0am

See Jacques Oam

Jaques Mountain

Jaques Spring

Jaques Tank

Jaralosa Draw

Jarillas Spring

Jarillas Tank

Jarosoma Mountains

See Goldfield Mountains

Jarvis Dam

Jarvis Lake

Jarvis Ranch

Jarvis Wash

BGN Mohave

$344747 \mathrm{~N} 1091046 \mathrm{~W}$
FEATUR

CLASS

STATUS

COUNTY

COORDINATE

valley

valley

VARIANT

VARIANT

reservoir

reservoir

locale

valley

reservoir

gap

spring

valley

dam

ridge
well
canal
bay
valley
park
reservoir
reservoir
reservoir
stream

8GN

Mohave

Mohave

361827N1132933W

8GN

BGN

BGN

BGN

8GN

VARIANT

BGN

VARIANT

BGN

UNOFF

Greenlee

$330318 \mathrm{~N} 1091757 \mathrm{~W}$

Coconino 354023N1130335W

Gila 340038N1111907W

Gila

Yavapai

$335957 \mathrm{N1110420 \textrm {W }}$

$341247 N 1110114 \mathrm{~W}$

$341248 \mathrm{~N} 1122441 \mathrm{~W}$

Yavapai

$341300 \mathrm{~N} 1122455 \mathrm{~W}$

Santa Cruz

Pima

$313420 \mathrm{~N} 1111400 \mathrm{~W}$

$313133 N 1111244 \mathrm{~W}$

BGN Pima 313252N1111430W

UNOFF Pima

BGN Mohave

BGN Coconino

ADMIN Pima

Mohave

Mohave

Yavapai

Pima

$313347 \mathrm{~N} 1111356 \mathrm{~W}$

$342720 \mathrm{~N} 1141831 \mathrm{~W}$

$360744 N 1143547 \mathrm{~W}$

$350236 \mathrm{~N} 1114310 \mathrm{~W}$

$321112 \mathrm{~N} 1105547 \mathrm{~W}$

$362112 \mathrm{~N} 1132155 \mathrm{~W}$

$362257 N 1132345$

$344419 \mathrm{~N} 1121327 \mathrm{~W}$

$325227 \mathrm{~N} 1104729 \mathrm{~W}$

wel1

well

well

wel1

reservoir

mine

reservoir

well

locale

BGN

UNOFF

UNOFF

UNOFF

UNOFF

BGN

UNOFF

$8 \mathrm{GN}$

UNOFF

Pinal

Pima

Mohave

Yavapai

Pinal

Mohave

Mohave

Maricopa

Maricopa

$325227 \mathrm{~N} 1104729 \mathrm{~W}$

$315304 N 1115227 \mathrm{~W}$

32422BN1105601W

$343026 \mathrm{~N} 1122040 \mathrm{~W}$

$344405 \mathrm{~N} 1121413 \mathrm{~W}$

$325605 \mathrm{~N} 1112218 \mathrm{~W}$

$352010 \mathrm{~N} 1140759 \mathrm{~W}$

$354246 \mathrm{~N} 1135039 \mathrm{~W}$

$334143 \mathrm{~N} 1113100 \mathrm{~W}$

$332706 \mathrm{N1121522 \textrm {W }}$

summit

BGN Yavapai

reservoir

school

reservoir

reservoir

valley

spring

reservoir

crater

UNOFF

BGN

BGN

BGN

8GN

VARIANT

Coconino

Maricopa

345640 N1130035W

$352145 \mathrm{~N} 1123117 \mathrm{~W}$

$332646 \mathrm{~N} 1120600 \mathrm{~W}$

Coconino

Maricopa

Graham

Graham

Coconino

Coconino

$344033 \mathrm{N1} 111340 \mathrm{~W}$

$335817 \mathrm{N1} 130059 \mathrm{~W}$

$330616 \mathrm{~N} 1102546 \mathrm{~W}$

$330538 \mathrm{~N} 1102541 \mathrm{~W}$

$354041 \mathrm{~N} 1121831 \mathrm{~W}$

330439 N1102500W

$352034 \mathrm{~N} 1112649 \mathrm{~W}$

spring

spring

well

gut

reservoir

valley

gut

BGN

VARIANT

UNOFF

BGN

VARIANT

BGN

BGN

Coconino

Coconino

Coconino

Mohave

Santa Cruz

Santa Cruz

Mohave

355143N1112307W

$355832 \mathrm{~N} 1111922 \mathrm{~W}$

$350342 N 1113514$

345202N1143349h

$312700 \mathrm{~N} 1111610 \mathrm{~W}$

$312656 \mathrm{~N} 1111612 \mathrm{~W}$

345202N1143349W

reservoir BG

dam

BGN
VARIANT

summit $\quad B G N$

spring BGN

reservoir

valley

spring

reservoir

BGN

BGN

BGN

VARIANT

summit

Gila

Navajo

Navajo

Navajo

Navajo

Apache

Santa Cruz

Santa Cruz

Maricopa

$334235 N 1100954 \mathrm{~W}$

$341140 \mathrm{~N} 1100018 \mathrm{~W}$

341431 N1095339W

$341110 \mathrm{N1095620 \textrm {W }}$

$341417 \mathrm{~N} 1095234 \mathrm{~W}$

$313107 \mathrm{~N} 1112110 \mathrm{~W}$

312559 N1 $104830 \mathrm{~W}$

$333112 \mathrm{~N} 1113046 \mathrm{~W}$

dam UNOFF

reservoir $B G N$

locale UNOFF

Apache

Apache

Coconino

$335900 \mathrm{~N} 1091236 \mathrm{~W}$

$335900 \mathrm{~N} 1091236 \mathrm{~W}$

364642 N1115418W

$343324 \mathrm{~N} 1091110 \mathrm{~W}$

$\begin{array}{cc}\text { SOURCE } & \text { ELEV } \\ \text { COORDINATE } & \text { FT MAP NAME }\end{array}$

Clifton

Crater Canyon

Gisela 
FEATURE NAME

Jasper Canyon
Jasper Spring
Jasper Spring
Jasper Well
Javalina Canyon
Java Tank
Javel ina Canyon
Javel ina Dam
See Javilina Dam
Javelina Mountain
Javel ina Peak
Javel ina Peak
Javelina Spring
Javel ina Spring
Javelina Tank
Javel ina Tank
Javel ina Tank
Javel ina Tank
Javel ina Tank
Javel ina Wash
Javel ina Well
Javel ina Well
Javel in Canyon
Javilina Dam
Javel ina Dam
Jawbone Windnit

Jawbone Windmill

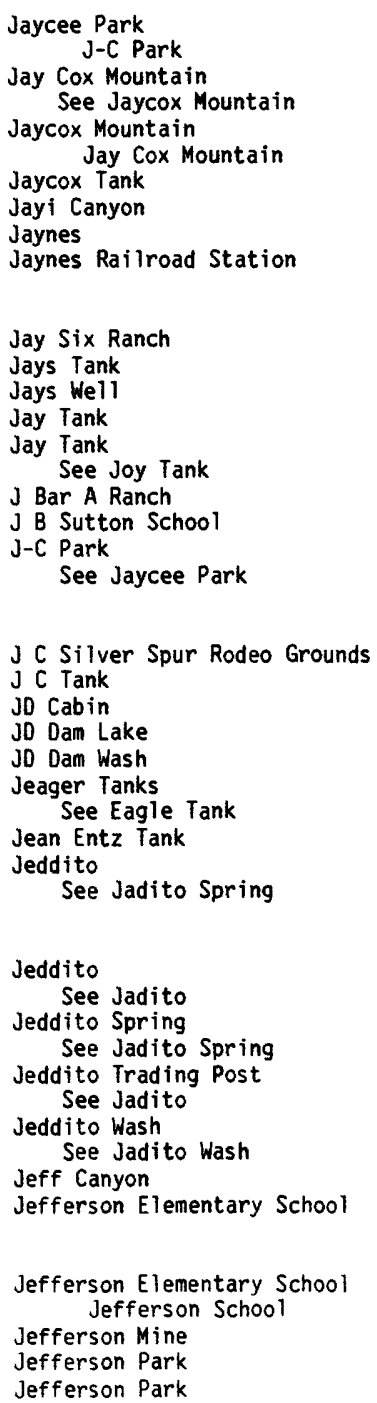

\begin{tabular}{|c|c|c|}
\hline $\begin{array}{l}\text { SOURCE } \\
\text { COORDINATE }\end{array}$ & $\begin{array}{c}\text { ELEV } \\
\text { FT }\end{array}$ & MAP NAME \\
\hline $332914 N 1104611 W$ & & $\begin{array}{l}\text { Globe } \\
\text { Owl Head } \\
\text { Globe } \\
\text { Globe } \\
\text { Brandenburg Mtn } \\
\text { Red Butte SW }\end{array}$ \\
\hline $322143 \mathrm{~N} 1100701 \mathrm{~W}$ & & Hookers Hot Springs \\
\hline & $\begin{array}{l}3912 \\
5592\end{array}$ & $\begin{array}{l}\text { Big Horn } \\
\text { Muskhog Mountain } \\
\text { Javelina Peak } \\
\text { Muskhog Mountain } \\
\text { Sombrero Peak } \\
\text { Three Points } \\
\text { Hat Mountain SW }\end{array}$ \\
\hline $313210 \mathrm{~N} 1110705 \mathrm{~W}$ & & $\begin{array}{l}\text { Picketpost Mtn } \\
\text { Carrizo } \\
\text { Bloody Basin } \\
\text { Black Mountain } \\
\text { Cumero Canyon } \\
\text { Big Horn } \\
\text { Tubac }\end{array}$ \\
\hline & & Walker Mtn \\
\hline
\end{tabular}

344950 N1111555W $344950 \mathrm{N1111555W}$

$344916 \mathrm{~N} 1111655 \mathrm{~W}$ $365025 \mathrm{~N} 1105900 \mathrm{~W}$ $321745 N 1110142 \mathrm{~W}$ $321745 \mathrm{~N} 1110143 \mathrm{~W}$

$315518 \mathrm{~N} 1102540 \mathrm{~W}$ $342408 \mathrm{~N} 1102440 \mathrm{~W}$ $343212 \mathrm{N1093849 \textrm {W }}$ $342829 N 1100311 \mathrm{~W}$

350418 N1114649W $314015 N 1092413 \mathrm{~W}$ $332734 N 1120730 \mathrm{~W}$ 332530 N1115658W

$324150 \mathrm{~N} 1143700 \mathrm{~W}$ 350951 N1121509W $350825 N 1120322 \mathrm{~W}$ $350353 N 1120137 \mathrm{~W}$ $350204 N 1120201 \mathrm{~W}$

323718 N1131938W 350625N1131741W

$354218 N 1101317 \mathrm{~W}$

$365425 N 1105602 W$

7431 Jaycox Mtn

Jaycox Mtn Chaiyahi Rim SW Jaynes Jaynes

Mescal

Aripine

Hunt

Taylor

Bruno Peak

Fowler

Yuma East

McLellan Reservoir 6640 Davenport $\mathrm{Hill}$ 6458 White Horse Lake White Horse Lake Devils Hump

Quartermaster Canyon
8uckhorn
Winslow
Patagonia
Tucson
Prescott




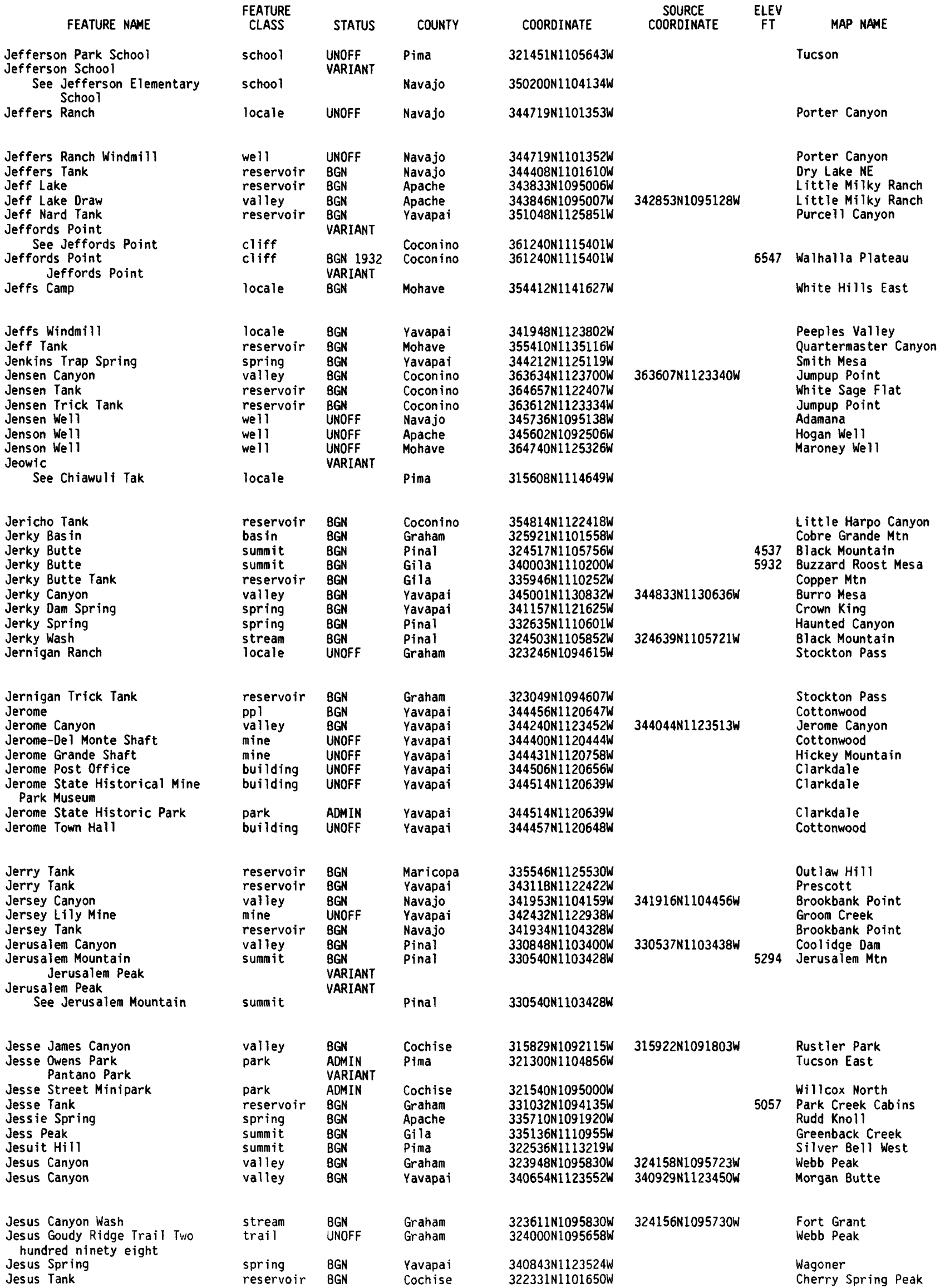


NATIONAL GAZETTEER--ARIZONA 1986

\section{FEATURE NAME}

Jesus Tank

Jesus Water

Jesus Tank

Jesus Water

See Jesus Tank

Jetto-to Spring

See Jadito Spring

Jettyto Spring

See Jadito Spring

Jetty-to Spring

See Jadito Spring

Jewell Hill

Jewell Park

See Buell Park

Jewell Well

Jewel Mine

Jewel Spring

J F Kennedy Elementary School

J F Kennedy School

J F Kennedy School

See J F Kenned Elementary School

$J$ F Ranch

$J$ F Ranch Trail

Jhus Canyon

Jhus Horse Saddle

Jicarilla Point

Jila River

See Gila River

Jim Adams Well

Jimana Inn

Jim Barth Tank

Jim Bennett Tank

Jim Camp Wash

Jim Creek

Jim Creek Spring

Jim Creek Trail Number Two

Hundred Thirty Five

Jim Creek Waterhole Spring

See Waterhole Spring

Jim Dam

Jim Dandy Tank

Jim Hart Memorial Monument

Jim Hop Tank

Jimmie King Number Nine Mine

Jimmie Luck Gulch

Jimmie Wash

Jimmy Land Tank

Jimmy Tank

Jim River Tank

Jim Roberts Draw

Jim Sam Butte

Jim Sam Tank

Jim Smith Tanks

Jimson Weed Canyon

Jimson Weed Wash

Jims Spring

Jims Tank

Jims Tank

Jims Tank

Jims Tank Number Two

Jims Well

Jim Thomas Wash

Jiquibo

See Hickiwan

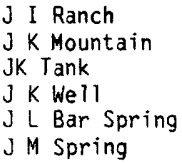

$J$ M Spring

$$
\begin{aligned}
& \text { FEATURE } \\
& \text { CLASS }
\end{aligned}
$$

STATUS

COUNTY

COORDINATE

$323948 N 1095814 W$

BGN 1975

BGN

VARIANT

reservoir

reservoir

Graham

Coconino

Graham

351104N1121803W

$323948 N 1095814 W$

spring

spring

spring

summit

flat

well

mine

spring

school

school

locale

trail

valley

VARIANT

VARIANT

Navajo

$354218 \mathrm{~N} 1101317 \mathrm{~W}$

$354218 N 1101317$

VARIANT

Navajo

Navajo

BGN

VARIANT

UNOFF

Apache

UNOFF

UNOFF

VARIANT

VARIANT

UNOFF

UNOFF

BGN

gap

BGN

BGN 1908

VARIAN

strean

well

locale

reservoir

reservoir

stream

stream

UNOFF

BGN

BGN

BGN

BGN

BGN

$\begin{array}{llll}\text { spring } & \text { BGN } & \text { Yavapai } & 340815 N 1121709 W \\ \text { trail } & \text { UNOFF } & \text { Yavapai } & 340815 N 1121626 \mathrm{~W}\end{array}$

VARIANT

spring

dam

reservoir

cemetery

reservoir

mine

\section{UNOFF}

BGN

UNOFF

BGN

UNOFF

Yavapai

$343730 \mathrm{~N} 1095614 \mathrm{~W}$

$333400 \mathrm{~N} 1114231 \mathrm{~W}$

$363102 \mathrm{~N} 1091639 \mathrm{~W}$

valley BGN Pinal 331040N1105922W

stream BGN Maricopa 334337N1124942W

reservoir BGN

345959 N1121246

reservoir BGN Coconino 352220N1122334W

valley BGN Gila 341944 N1111020W

summit

reservoir $B G$

valley BGN

valley

BGN

spring

reservoir $B G$

reservoir $B G N$

reservoir BGN

reservoir $B G N$

well UNOFF

stream

Gila

Gila

Yavapai

Apache

Apache

Maricopa

Yavapai

Coconino

Navajo

Yavapai

Yuma

ppl

VARIANT

Pima

$\begin{array}{llll}\text { locale } & \text { UNOFF } & \text { Pinal } & 332021 \mathrm{~N} 1110026 \mathrm{~W} \\ \text { summit } & \text { BGN } & \text { Pinal } & 332550 \mathrm{~N} 1110135 \mathrm{~W} \\ \text { reservoir } & \text { BGN } & \text { Coconino } & 345058 \mathrm{~N} 1112007 \mathrm{~W} \\ \text { well } & \text { UNOFF } & \text { Graham } & 330847 \mathrm{~N} 1101849 \mathrm{~W} \\ \text { spring } & \text { BGN } & \text { Yavapai } & 335929 \mathrm{~N} 1122951 \mathrm{~W} \\ \text { spring } & \text { BGN } & \text { Maricopa } & 335810 \mathrm{~N} 1114113 \mathrm{~W}\end{array}$

$340115 N 1110130 \mathrm{~W}$

352058 N $1131552 \mathrm{~W}$

361910 N1093100W

$362048 \mathrm{N1} 1093423 \mathrm{~W}$

$335119 N 1120045 \mathrm{~W}$

342724 N1114558

343456 N1111830W

$344041 \mathrm{~N} 1100508 \mathrm{~W}$

$342754 \mathrm{N111441 \textrm {BW }}$

$330025 \mathrm{~N} 1133104 \mathrm{~W}$

330029 N1105600W reservoir $B G N$ $\begin{array}{ll}\text { SOURCE } & \text { ELEV } \\ \text { COORDINATE } & \text { FT }\end{array}$

Webb Peak

McLellan Reservoir

4961 Inspiration

Black Mountain

Ibex Peak

Kanab Point

Superior

Iron Mountain

Iron Mounta in

Portal

$315753 \mathrm{~N} 1091633 \mathrm{~W}$

Rustler Park

Piute Point

Cave Creek

Mule Hoof Bend

Bylas

Purcell Canyon

Padilla Tank

Columbia

$345030 \mathrm{~N} 1094934 \mathrm{~W}$
$340930 \mathrm{~N} 1121554 \mathrm{~W}$

Crown King

Crown King

Cumero Canyon

Hay Hollow

Granite Reef Dan

Turkey Mtn

Mexican Cry Mesa

331106 N1105714W Hot Tamale Peak

335414N1125226W Star Well

Willow Mtn

Perkinsville

Fitzgerald Hill

342223N1110842W Diamond Point

340125N1110220W 5323 Buzzard Roost Mesa

$361703 N 1092628 \mathrm{~W}$

Blye Canyon SE

Many Farms

325712 N1105634W

Many Farms

New River SE

Horner Mtn

Long Valley

Tenmile Cedars

Hackberry Mtn

Palomas Mts East

Kearny

Superior

4490 Haunted Canyon

Jaycox Mtn

Dewey Flat

Garfias Mtn

Horseshoe Dam 


\section{FEATURE NAME}

Joanette Tank

Joanne Tank

Joaquin Canyon

Joaquin Creek

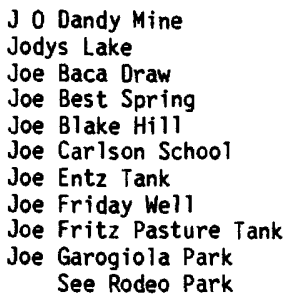

Joe Glenn Ranch

Joe Henry Memorial Park

Joe Lee Well

Joes Canyon Trail

Joes Gulch

Joes Hill

Joes Mud Hole

Joe Spring

Joes Ranch

Joes Reservoir

Joes Ridge
Joes Spring
Joes Tank
Joes Tank
Joes Tank
Joes Tank
Joes Tank
Joes Tank
Joes Wel1
Joe Tank
Joe Tank
Joe Tank
Joe Tank
Joe Tank
Joe Tank
Joe Tank Ridge
Joe Woody Wel1
Joeys Tank
Jog Tank
Jog Tank

\section{Johannesberg}

John Allen Park

John C Lincoln Hospital

Heliport

John C Page Park

John Daw Grave

John Daw Mesa

John Daw Well

John Etsitty Spring

John F Kennedy Middle School

John F Kennedy Park

John F Kennedy School

John F Long School

John Hall Cabin Tank

John Hall Tank

John Hands Picnic Ground

John Henry Tank

John Hunt Cabin

John Joe Well

John Kennedy Memorial Park

John Lee Tank

John Long Canyon

John L Wyatt Junior High School

John Moore Spring

John Moore Tank

\section{FEATURE}

CLASS

reservoir
reservoir
valley

stream

mine

lake

spring

summit

school

reservoir

well

reservoir

park

locale

park

well

trail

valley

summ it

lake

spring

locale

reservoir

ridge

spring

reservoir

reservoir

reservoir

reservoir

reservoir

reservoir

well

reservoir

UNOFF
BGN
BGN
BGN
BGN
UNOFF
BGN
UNOFF
BGN
VARIANT

Mohave

Apache

Yavapai

Mohave

Cochise

Yavapai

Apache

Greenlee

Pima

UNOFF
ADMIN
UNOFF
UNOFF
BGN
BGN
BGN
BGN
UNOFF
BGN

Cochise

Yuma

Coconino

Cochise

Yavapai

Yavapai

Coconino

Mohave

Coconino

Coconino

BGN
BGN

BGN

BGN

BGN

BGN

BGN

UNOFF

Yavapai

Gila

Yavapai

Yavapai

Yavapai

Coconino

Coconino

Yavapai

Apache

Cochise

reservoir

reservoir

reservoir

reservoir

reservoir

ridge

well

reservoir

reservoir

reservoir

BGN

BGN

BGN

BGN

BGN

BGN

BGN

BGN

$B G N$

Greenlee

Gila

Navajo

Coconino

Navajo

Apache

Coconino

Cochise

Cochise

VARIANT

locale

park

airport

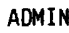

Yuma

Maricopa

Maricopa

park

cemetery

summit

well

spring

ADMIN

UNOFF

BGN

UNOFF

Coconino

Coconino

Coconino

Coconino

Coconino

school UNOFF

park

school

school

reservoir

reservoir

park

reservoir

locale

locale

ADMIN

UNOFF

UNOFF

BGN

BGN

ADMIN

BGN

BGN

BGN

cemetery

reservoir

valley

school

spring

UNOFF

BGN
BGN
UNOFF

UNOFF

$B G N$

reservoir $B G$
Maricopa

Pima

Gila

Maricopa

Apache

Navajo

Cochise

Yavapai

Navajo

Apache

Yuma

Yavapai

Cochise

Cochise

Gila

Gila
COORDINATE

$335820 \mathrm{N1130211 \textrm {W }}$

$344325 N 1111621 \mathrm{~W}$

$321556 \mathrm{~N} 1103611 \mathrm{~W}$

$312037 \mathrm{N1} 102227 \mathrm{~W}$

$335544 N 1130141 \mathrm{~W}$

$363402 N 1130847 \mathrm{~W}$

$340227 N 1092304 \mathrm{~W}$

$342852 N 1115640 \mathrm{~W}$

$365626 \mathrm{~N} 1132728 \mathrm{~W}$

$312048 \times 1093238 \mathrm{~W}$

$351625 \mathrm{~N} 1131547 \mathrm{~W}$

$354037 \mathrm{~N} 1094041 \mathrm{~W}$

$331732 N 1091056 \mathrm{~W}$

320942N1105755W

$313528 N 1092011 \mathrm{~W}$

$324340 \mathrm{~N} 1143855 \mathrm{~W}$

$361201 N 1111549 \mathrm{~W}$

$312111 N 1101815 \mathrm{~W}$

340711 N1121720W

$341051 N 1120443 \mathrm{~W}$

$363437 \mathrm{N1} 121240 \mathrm{~W}$

$360620 \mathrm{~N} 1134252 \mathrm{~W}$

$364917 \mathrm{N1114736 \textrm {W }}$

$365111 N 1120917 \mathrm{~W}$

$340739 \mathrm{N1121548 \textrm {W }}$

$340027 N 1104749 W$

$340726 \mathrm{N1121618 \textrm {W }}$

341142N1120517W

$343110 \mathrm{~N} 1121835 \mathrm{~W}$

$343406 \mathrm{~N} 1111805 \mathrm{~W}$

$343526 \mathrm{~N} 1111859 \mathrm{~W}$

345551 N1115602W

$354129 N 1093548 \mathrm{~W}$

$313813 N 1092219 W$

331742N1091923W

340435N1105732W

$341027 \mathrm{~N} 1111726 \mathrm{~W}$

341453N1100819W

$345958 \mathrm{~N} 1115433 \mathrm{~W}$

$341526 \mathrm{~N} 1100847 \mathrm{~W}$

353624N1091258W

$350030 \mathrm{N1113140 \textrm {W }}$

$313834 N 1095010 \mathrm{~W}$

$315022 N 1101955 \mathrm{~W}$

334323N1134206W

332105 N1114736W

333407 N1120412W

$365450 \mathrm{N11112720 \textrm {W }}$

$361932 \mathrm{~N} 1105130 \mathrm{~W}$

$362102 \mathrm{~N} 1105022 \mathrm{~W}$

$361932 N 1105159 \mathrm{~W}$

$360656 \mathrm{~N} 1111406 \mathrm{~W}$

$332303 \mathrm{N1120325 \textrm {W }}$

321048N1110030W

$335358 \mathrm{N1} 101016 \mathrm{~W}$

$333003 \mathrm{~N} 1121034 \mathrm{~W}$

$333744 N 1094605 \mathrm{~W}$

$340744 N 1100257 \mathrm{~W}$

$344435 \mathrm{~N} 1113801 \mathrm{~W}$

$343255 \mathrm{~N} 1101427 \mathrm{~W}$

$352229 \mathrm{~N} 1093633 \mathrm{~W}$

$324113 \mathrm{~N} 1143628 \mathrm{~W}$

344644 N1114938W

$314635 \mathrm{~N} 1092544 \mathrm{~W}$

$314241 \mathrm{N1} 100341 \mathrm{~W}$

$335030 \mathrm{~N} 1101845 \mathrm{~W}$

$334322 \mathrm{~N} 1101015 \mathrm{~W}$

\begin{tabular}{ccc} 
SOURCE & ELEV & \multicolumn{1}{c}{ MAP NAME } \\
321332N1103259W & FT & \multicolumn{1}{c}{$\begin{array}{l}\text { Forepaugh Peak } \\
\text { Turkey Mtn } \\
\text { Piety Hi11 } \\
\text { Montezuma Pass }\end{array}$} \\
& \\
& $\begin{array}{l}\text { Forepaugh Peak } \\
\text { Moriah Knol1 }\end{array}$ \\
& $\begin{array}{l}\text { Greer } \\
\text { Arnold Mesa } \\
\text { Yellowhorse Flat } \\
\text { Douglas }\end{array}$ \\
& $\begin{array}{l}\text { Devils Hump } \\
\text { Cornfields } \\
\text { Fritz Canyon }\end{array}$ \\
&
\end{tabular}

Pedregosa Mts East

Yuma West 


\section{FEATURE NAME}

John Moore Tank John Moore Tank Johnneys Tank John Nez Well

Johnnies Tank
Johnnie Tank
Johnny Bull Mine
Johnny Creek
Johnny Lyon Hills
Johnny Spring
Johnny Tank
Johnny Tank
John Q Thomas Elementary School
Johns Canyon

Johns Canyon
Johns Canyon Ridge
Johns Canyon Spring
John Schmutz Tank
Johns Dam
Johns Draw
Whe-Yol-Da-Sah Wash
South Fork Corn Creek
John Silver Spring Well
John Smith Wash
Johnson
Johnson Canyon
See Johnson Creek
Johnson Canyon
Johnson Canyon
Johnson Canyon
Johnson Corral Tank
Johnson Crater
Johnson Creek
Ash Creek
Ash Fork Draw
Ashfork Draw
Johnson Canyon
Partridge Creek
Pand

Johnson Creek

See Johnson Wash

Johnson Flat

Johnson Flat

Johnson Flat

Johnson Flat Spring

Johnson Flat Tank

Johnson Flat Tank

Johnson Lateral

Johns on Mine

Johnson Mine

Johnson Mountain

Johnson Peak

See Lime Peak

Johnson Peak

Johnson Point

Johns on Point

Johnson Ranch

Johnson Ranch

Johnson Reservoir

Johnson Road Interchange

Johnson Run

Johnson Run

Johnson School

Johnson Spring

Johnson Spring

Johnson Tank

Johnson Tank

Johnsonville

See Nephi

Johns on Wash

Johns on Wash

Johnson Creek
FEATURE
CLASS

STATUS

COUNTY $350121 N 1113211 \mathrm{~W}$

$\begin{array}{llll}\text { reservoir } & \text { BGN } & \text { Coconino } & 350121 N 1113211 \mathrm{~W} \\ \text { well } & \text { UNOFF } & \text { Apache } & 353237 \text { N1090523W }\end{array}$

reservoir BGM Yavapai 344337N1114750W reservoir BGN Navajo 340940N1100404W mine UNOFF Mohave 352440N1141104W stream BGN Graham 330039N1093316W summit BGN Cochise 320808N1101356W spring BGN Graham 330049N1093721W reservoir BGN Coconino 344943N1111809W reservoir BGN Coconino 353922N1115647W school UNOFF Coconino 351307N1113555W valley BGN Graham 324549N1100431W

valley BGN Greenlee 334419N1091938W ridge spring reservoir dam valley

locale valley

ppl

stream valley valley valley reservoir crater stream

BGN Greenlee

GGN Graham

BGN

UNOFF

BGN 1968 Navajo

VARIANT

VARIANT

BGN Apache

BGN Navajo

Navajo

BGN

VARIANT

Cochise

Coconino

BGN Cochise

BGN Greenlee

BGN 1975 Coconino

BGN Apache

BGN Coconino

BGN 1976 Coconino

VARIANT

VARIANT

VARIANT

VARIANT

VARIANT

VARIANT

stream
flat
flat
flat
spring
reservoir
reservoir
canal
mine

$\begin{array}{ll}\text { BGN } & \text { Coconino } \\ \text { BGN } & \text { Yavapai } \\ \text { BGN } & \text { Yavapai } \\ \text { BGN } & \text { Yavapai } \\ \text { BGN } & \text { Yavapai } \\ \text { BGN } & \text { Yavapai } \\ \text { BGN } & \text { Yuma } \\ \text { UNOFF } & \text { Cochise }\end{array}$

mine UNOFF Yavapai

summit

summit

summit

cliff

summit

locale

locale

reservoir

BAR

Yavapai

BGN 1932 Coconino

BGM 1969 Coconino

UNOFF Cochise

UNOFF Pima

BGN Coconino

crossing UNOFF Cochise

flat

stream

school

spring

spring

reservoir

reservoir

locale

BGN Coconino

UNOFF

$B G Y$

$B G N$

$B G N$

BGN

VARIANT

Yuma

Santa Cruz

Coconino

Yavapai

Coconino

Maricopa

stream

stream $\begin{array}{ll}\text { BGN } & \text { Yavapai } \\ \text { BGN } & \text { Coconino }\end{array}$

VARIANT
COOROINATE

335026 N1101944W $335340 \mathrm{~N} 1102136 \mathrm{~W}$ $353237 \mathrm{N1090523 \textrm {W }}$

SOURCE

COORDINATE

ELEV

MAP NAME

Carrizo SE

Carrizo

Lower Lake Mary

6584 Hunters Point

Lake Montezuma

Show Low South

Chloride

$330043 \mathrm{~N} 1093938 \mathrm{~W}$

Bonita Spring

Deepwell Ranch

Bonita Spring

Jaycox Mtn

Dog Knobs

Flagstaff East

324407 N1100233W

Tripp Canyon

334639 N1091617W

Hannagan Meadow

Blue Jay Peak

Buffalo Crossing

$334613 \mathrm{~N} 1091757 \mathrm{~W}$

$362345 \mathrm{~N} 1130311 \mathrm{~W}$

$324104 \mathrm{N1} 1094540 \mathrm{~W}$

$351900 \mathrm{N1103120 \textrm {W }}$

Mt Trumbull NE

Mt Graham

351630N1102500W Elephant Butte

351803 N1091522W

$363621 \mathrm{N1103805 \textrm {W }}$

$320611 \mathrm{N1100356 \textrm {W }}$

$363840 \mathrm{~N} 1103355 \mathrm{~W}$

6288 Burntwater Wash

$351217 \mathrm{~N} 1122857 \mathrm{~W}$

$313143 \mathrm{~N} 1095141 \mathrm{~W}$

$333806 \mathrm{~N} 1090539 \mathrm{~W}$

$351332 \mathrm{~N} 1122454 \mathrm{~W}$

$333032 \mathrm{~N} 1094618 \mathrm{~W}$

$351421 N 1122148 \mathrm{~W}$

$351217 \mathrm{~N} 1122857 \mathrm{~W}$

$334158 \mathrm{~N} 1085805 \mathrm{~W}$

$351430 \mathrm{~N} 1121917 \mathrm{~W}$

$351525 \mathrm{~N} 1121542 \mathrm{~W}$

Shonto

Dragoon

Glees on SE

Maness Peak

Ash Fork

6198 West Poker Mtn

McLe]lan Reservoir

Ash Fork
$365310 \mathrm{~N} 1123330 \mathrm{~W}$

$340911 \mathrm{N1122631 \textrm {W }}$

$342211 \mathrm{N1122741 \textrm {W }}$

$345450 \mathrm{~N} 1130955 \mathrm{~W}$

$340917 \mathrm{N1122700 \textrm {W }}$

$342213 \mathrm{~N} 1122754 \mathrm{~W}$

$345226 \mathrm{~N} 1131010 \mathrm{~W}$

$323428 \mathrm{NI} 144109 \mathrm{~W}$

$320638 \mathrm{~N} 1100348 \mathrm{~W}$

$341102 \mathrm{~N} 1124205 \mathrm{~W}$

$344756 \mathrm{~N} 1124851 \mathrm{~W}$

$320644 \mathrm{~N} 1100540 \mathrm{~W}$

$344927 \mathrm{~N} 1124527 \mathrm{~W}$

$360752 \mathrm{~N} 1120511 \mathrm{~W}$

$365150 \mathrm{N1} 113645 \mathrm{~W}$

$313535 \mathrm{~N} 1100417 \mathrm{~W}$

$315404 \mathrm{~N} 1104701 \mathrm{~W}$

$365650 \mathrm{~N} 1122109 \mathrm{~W}$

$320455 \mathrm{~N} 1100303 \mathrm{~W}$

$365517 \mathrm{~N} 1193245 \mathrm{~W}$

$365510 \mathrm{~N} 1123244 \mathrm{~W}$

$324219 N 1143801 \mathrm{~W}$

$313419 \mathrm{~N} 1104811 \mathrm{~W}$

$365925 \mathrm{N1121924 \textrm {W }}$

$345814 \mathrm{N1115355 \textrm {W }}$

$351504 \mathrm{N1114655 \textrm {W }}$

$332500 \mathrm{~N} 1115330 \mathrm{~W}$

342951 N1120158W 343256 N1120225W

$365310 \mathrm{~N} 1123330 \mathrm{~W} 371359 \mathrm{~N} 1122142 \mathrm{~W}$
Minnehaha

Battleship Butte

Sunrise Peak

Minnehaha

Batt leship 8utte

Burro Mesa

Somerton

Dragoon

Yarnell

5752 Seepage Mtn

Seepage Mtn

5295 Bright Angel Point

3806 Ferry Swale

Tombstone SE

3837 Corona De Tucson

Muggins Flat

Dragoon

Shinarump Point

Fredonia

Yuma West

Patagonia

Muggins Flat

Loy Butte

Wing Mountain

Estler Peak

Clear Water Spring 


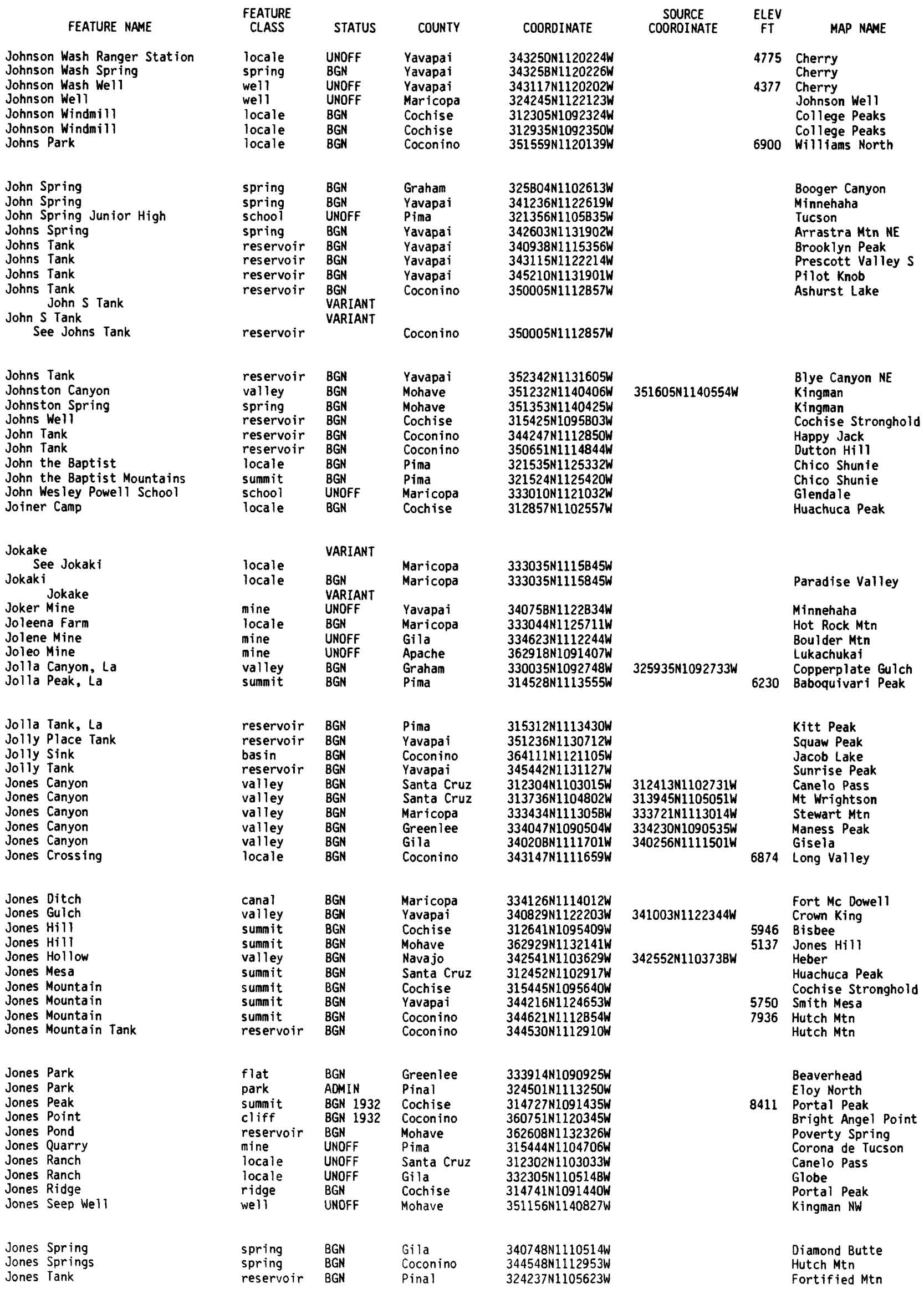




\section{FEATURE NAME}

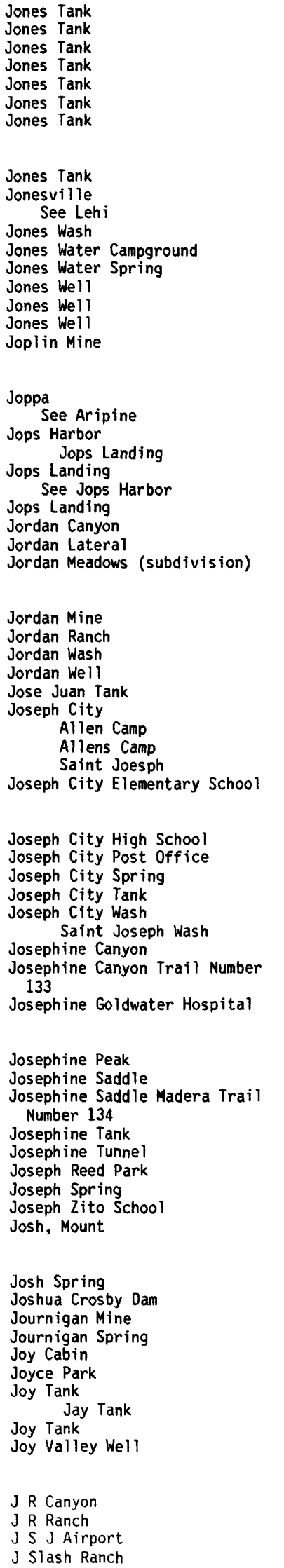

\begin{tabular}{|c|c|c|c|c|c|c|}
\hline $\begin{array}{l}\text { FEATURE } \\
\text { CLASS }\end{array}$ & STATUS & COUNTY & COORDINATE & $\begin{array}{l}\text { SOURCE } \\
\text { COORDINATE }\end{array}$ & $\begin{array}{c}\text { ELEV } \\
\text { FT }\end{array}$ & MAP NAME \\
\hline $\begin{array}{l}\text { reservoir } \\
\text { reservoir } \\
\text { reservoir } \\
\text { reservoir } \\
\text { reservoir } \\
\text { reservoir } \\
\text { reservoir }\end{array}$ & $\begin{array}{l}\text { BGN } \\
\text { BGN } \\
\text { BGN } \\
\text { BGN } \\
\text { BGN } \\
\text { BGN } \\
\text { BGN }\end{array}$ & $\begin{array}{l}\text { Maricopa } \\
\text { Yavapai } \\
\text { Yavapai } \\
\text { Coconino } \\
\text { Yavapai } \\
\text { Coconino } \\
\text { Coconino }\end{array}$ & $\begin{array}{l}333527 N 1125016 \mathrm{~W} \\
344117 \mathrm{N1115117W} \\
344155 \mathrm{~N} 1124622 \mathrm{~W} \\
345424 \mathrm{~N} 1113321 \mathrm{~W} \\
345637 \mathrm{~N} 1131124 \mathrm{~W} \\
352936 \mathrm{~N} 1124725 \mathrm{~W} \\
354838 \mathrm{~N} 1114018 \mathrm{~W}\end{array}$ & & & $\begin{array}{l}\text { Flatiron Mtn } \\
\text { Lake Montezuma } \\
\text { Smith Mesa } \\
\text { Mormon Mountain } \\
\text { Sunrise Peak } \\
\text { Trinity Mtn } \\
\text { Willows Camp }\end{array}$ \\
\hline reservoir & $\begin{array}{l}\text { BGN } \\
\text { VARIANT }\end{array}$ & Coconino & $360510 \mathrm{~N} 1124506 \mathrm{~W}$ & & & Higgins Tank \\
\hline $\begin{array}{l}\text { ppl } \\
\text { arroyo } \\
\text { park } \\
\text { spring } \\
\text { well } \\
\text { well } \\
\text { well } \\
\text { mine }\end{array}$ & $\begin{array}{l}\text { BGN } \\
\text { ADMIN } \\
\text { BGN } \\
\text { UNOFF } \\
\text { UNOFF } \\
\text { UNOFF } \\
\text { UNOFF }\end{array}$ & $\begin{array}{l}\text { Maricopa } \\
\text { Mohave } \\
\text { Gila } \\
\text { Pinal } \\
\text { Pinal } \\
\text { Maricopa } \\
\text { Mohave } \\
\text { Santa Cruz }\end{array}$ & $\begin{array}{l}332732 \mathrm{N1} 114846 \mathrm{~W} \\
343010 \mathrm{N1} 132809 \mathrm{~W} \\
333531 \mathrm{N1} 103832 \mathrm{~W} \\
332645 \mathrm{N1} 110320 \mathrm{~W} \\
324234 \mathrm{~N} 1105555 \mathrm{~W} \\
334848 \mathrm{N1} 125123 \mathrm{~W} \\
351132 \mathrm{~N} 1131336 \mathrm{~W} \\
313654 \mathrm{~N} 1105102 \mathrm{~W}\end{array}$ & $342823 N 1132927 \mathrm{~W}$ & 2663 & $\begin{array}{l}\text { Kaiser Spring } \\
\text { Chrome Butte } \\
\text { Haunted Canyon } \\
\text { Fortified Mtn } \\
\text { Vulture Mine } \\
\text { Kingman NW } \\
\text { Patagonia }\end{array}$ \\
\hline $\begin{array}{l}\text { locale } \\
\text { bay }\end{array}$ & $\begin{array}{l}\text { VARIANT } \\
\text { BGN } \\
\text { VARIANT } \\
\text { VARIANT }\end{array}$ & $\begin{array}{l}\text { Navajo } \\
\text { Mohave }\end{array}$ & 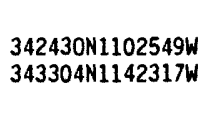 & & & Castle Rock \\
\hline $\begin{array}{l}\text { bay } \\
\text { locale } \\
\text { valley } \\
\text { canal } \\
\text { ppl }\end{array}$ & $\begin{array}{l}\text { BGN } \\
8 G N \\
B G N \\
B G N\end{array}$ & $\begin{array}{l}\text { Mohave } \\
\text { Mohave } \\
\text { Cochise } \\
\text { Yuma } \\
\text { Yavapai }\end{array}$ & $\begin{array}{l}343304 N 1142317 W \\
343238 N 114215 \mathrm{~W} \\
320102 \mathrm{~N} 1100313 \mathrm{~W} \\
324040 \mathrm{N1} 14384 \mathrm{~W} \\
343227 \mathrm{N1} 115155 \mathrm{~W}\end{array}$ & $315805 \mathrm{N1100009W}$ & $\begin{array}{l}600 \\
3040\end{array}$ & $\begin{array}{l}\text { Lake Havasu City } N \\
\text { Dragoon } \\
\text { Yuma West } \\
\text { Camp Verde }\end{array}$ \\
\hline $\begin{array}{l}\text { mine } \\
\text { locale } \\
\text { stream } \\
\text { well } \\
\text { reservoir } \\
\text { ppl }\end{array}$ & $\begin{array}{l}\text { UNOFF } \\
\text { UNOFF } \\
\text { BGN } \\
\text { UNOFF } \\
\text { BGN } \\
\text { BGN } \\
\text { VARIANT } \\
\text { VARIANT } \\
\text { VARIANT } \\
\text { UNOFF }\end{array}$ & $\begin{array}{l}\text { Mohave } \\
\text { Maricopa } \\
\text { Cochise } \\
\text { Yavapai } \\
\text { Pima } \\
\text { Navajo }\end{array}$ & $\begin{array}{l}351824 \mathrm{N11} 140538 \mathrm{~W} \\
330031 \mathrm{N1130820 \textrm {W }} \\
320102 \mathrm{N1} 100313 \mathrm{~W} \\
344636 \mathrm{N1} 124236 \mathrm{~W} \\
320513 \mathrm{N1130549W} \\
345721 \mathrm{N1} 10200 \mathrm{~W}\end{array}$ & $315805 \mathrm{N1} 100009 \mathrm{~W}$ & $\begin{array}{l}4690 \\
5023\end{array}$ & $\begin{array}{l}\text { Stockton Hill } \\
\text { Oatman Mountain } \\
\text { Dragoon } \\
\text { Simmons } \\
\text { Pozo Nuevo Well } \\
\text { Joseph City }\end{array}$ \\
\hline $\begin{array}{l}\text { school } \\
\text { building } \\
\text { spring } \\
\text { reservoir } \\
\text { stream }\end{array}$ & $\begin{array}{l}\text { UNOFF } \\
\text { UNOFF } \\
\text { BGN } \\
\text { BGN } \\
\text { BGN 1959 } \\
\text { VARIANT }\end{array}$ & $\begin{array}{l}\text { Navajo } \\
\text { Navajo } \\
\text { Navajo } \\
\text { Navajo } \\
\text { Navajo }\end{array}$ & $\begin{array}{l}345755 \mathrm{~N} 1101952 \mathrm{~W} \\
345720 \mathrm{N1} 102002 \mathrm{~W} \\
350023 \mathrm{N1101836 \textrm {W }} \\
350241 \mathrm{N1101810 \textrm {W }} \\
345657 \mathrm{N1102019W}\end{array}$ & $350413 N 1101207 \mathrm{~W}$ & 5000 & $\begin{array}{l}\text { Joseph City } \\
\text { Joseph City } \\
\text { Blairs Spring } \\
\text { Blairs Spring } \\
\text { Joseph City }\end{array}$ \\
\hline $\begin{array}{l}\text { valley } \\
\text { trail }\end{array}$ & $\begin{array}{l}\text { BGN } \\
\text { UNOFF }\end{array}$ & $\begin{array}{l}\text { Santa Cruz } \\
\text { Santa Cruz }\end{array}$ & $\begin{array}{l}313310 \mathrm{~N} 1110156 \mathrm{~W} \\
313547 \mathrm{N1} 105539 \mathrm{~W}\end{array}$ & $314121 \mathrm{N1} 105251 \mathrm{~W}$ & & $\begin{array}{l}\text { Tubac } \\
\text { San Cayetano Mts }\end{array}$ \\
\hline hospital & UNOFF & Navajo & $341436 \mathrm{~N} 1100310 \mathrm{~W}$ & & 6440 & Show Low South \\
\hline $\begin{array}{l}\text { summit } \\
\text { gap } \\
\text { trail }\end{array}$ & $\begin{array}{l}\text { BGN } \\
\text { BGN } \\
\text { UNOFF }\end{array}$ & $\begin{array}{l}\text { Santa Cruz } \\
\text { Santa Cruz } \\
\text { Santa Cruz }\end{array}$ & $\begin{array}{l}314051 \mathrm{N1105029W} \\
314137 \mathrm{N1} 105136 \mathrm{~W} \\
314305 \mathrm{~N} 1105246 \mathrm{~W}\end{array}$ & & $\begin{array}{l}8474 \\
7080\end{array}$ & $\begin{array}{l}\text { Mt Wrightson } \\
\text { Mt Wrightson } \\
\text { Mt Hopkins }\end{array}$ \\
\hline $\begin{array}{l}\text { reservoir } \\
\text { tunnel } \\
\text { park } \\
\text { spring } \\
\text { school } \\
\text { summit }\end{array}$ & $\begin{array}{l}\text { BGN } \\
\text { UNOFF } \\
\text { ADMIN } \\
\text { BGN } \\
\text { UNOFF } \\
\text { BGN }\end{array}$ & $\begin{array}{l}\text { Pima } \\
\text { Yavapai } \\
\text { Maricopa } \\
\text { Apache } \\
\text { Maricopa } \\
\text { Yavapai }\end{array}$ & $\begin{array}{l}321802 N 1103626 \mathrm{~W} \\
344558 \mathrm{~N} 1120449 \mathrm{~W} \\
332422 \mathrm{~N} 1114742 \mathrm{~W} \\
354046 \mathrm{~N} 1094613 \mathrm{~W} \\
332821 \mathrm{N1120925W} \\
343828 \mathrm{~N} 1124159 \mathrm{~W}\end{array}$ & & $\begin{array}{l}6317 \\
5964\end{array}$ & $\begin{array}{l}\text { Piety Hill } \\
\text { Clarkdale } \\
\text { Mesa } \\
\text { Steamboat Canyon } \\
\text { Fowler } \\
\text { Mt Josh }\end{array}$ \\
\hline $\begin{array}{l}\text { spring } \\
\text { dam } \\
\text { mine } \\
\text { spring } \\
\text { locale } \\
\text { park } \\
\text { reservoir }\end{array}$ & $\begin{array}{l}\text { BGN } \\
\text { UNOFF } \\
\text { UNOFF } \\
\text { BGN } \\
\text { BGN } \\
\text { ADMIN } \\
\text { BGN } \\
\text { VARIANT }\end{array}$ & $\begin{array}{l}\text { Yavapai } \\
\text { Mohave } \\
\text { Gila } \\
\text { Gila } \\
\text { Gila } \\
\text { Maricopa } \\
\text { Coconino }\end{array}$ & $\begin{array}{l}343758 \mathrm{~N} 1124112 \mathrm{~W} \\
362430 \mathrm{~N} 113143 \mathrm{~W} \\
334752 \mathrm{~N} 1110953 \mathrm{~W} \\
334750 \mathrm{~N} 1110956 \mathrm{~W} \\
340825 \mathrm{N1110202W} \\
332313 \mathrm{~N} 1115545 \mathrm{~W} \\
350418 \mathrm{~N} 1114649 \mathrm{~W}\end{array}$ & & & $\begin{array}{l}\text { Mt Josh } \\
\text { Mt Trumbul1 NW } \\
\text { Greenback Creek } \\
\text { Greenback Creek } \\
\text { Diamond Butte } \\
\text { Tempe } \\
\text { Dutton Hill }\end{array}$ \\
\hline $\begin{array}{l}\text { reservoir } \\
\text { well }\end{array}$ & $\begin{array}{l}\text { BGN } \\
\text { UNOFF }\end{array}$ & $\begin{array}{l}\text { Coconino } \\
\text { Graham }\end{array}$ & 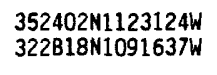 & & & $\begin{array}{l}\text { Eagle Nest Mtn } \\
\text { Mart in Well }\end{array}$ \\
\hline $\begin{array}{l}\text { valley } \\
\text { locale } \\
\text { airport } \\
\text { locale }\end{array}$ & $\begin{array}{l}\text { BGN } \\
\text { UNOFF } \\
\text { ADMIN } \\
\text { UNOFF }\end{array}$ & $\begin{array}{l}\text { Gila } \\
\text { Gila } \\
\text { Maricopa } \\
\text { Gila }\end{array}$ & $\begin{array}{l}335453 \mathrm{~N} 1110227 \mathrm{~W} \\
335444 \mathrm{N1110309 \textrm {W }} \\
332650 \mathrm{N1115045 \textrm {W }} \\
335830 \mathrm{N1110656 \textrm {W }}\end{array}$ & 335429 N1110407W & 1250 & $\begin{array}{l}\text { Copper Mtn } \\
\text { Copper Mtn } \\
\text { Mesa } \\
\text { Copper Mtn }\end{array}$ \\
\hline
\end{tabular}




\begin{tabular}{|c|c|c|c|c|c|c|c|}
\hline FEATURE NAME & $\begin{array}{l}\text { FEATURE } \\
\text { CLASS }\end{array}$ & STATUS & COUNTY & COORDINATE & $\begin{array}{l}\text { SOURCE } \\
\text { COORDINATE }\end{array}$ & $\begin{array}{c}\text { ELEV } \\
\text { FT }\end{array}$ & MAP NAME \\
\hline $\begin{array}{l}\text { JS Ranch } \\
\text { Juan Bautista de Anza High } \\
\text { School } \\
\text { Juan Encinas (historical) } \\
\text { Juan Garcia Mountain } \\
\text { Juan Hill }\end{array}$ & $\begin{array}{l}\text { locale } \\
\text { school } \\
\text { locale } \\
\text { summit } \\
\text { summit }\end{array}$ & $\begin{array}{l}\text { UNOFF } \\
\text { UNOFF } \\
\text { BGN } \\
\text { BGN } \\
\text { BGN }\end{array}$ & $\begin{array}{l}\text { Yavapai } \\
\text { Maricopa } \\
\text { Santa Cruz } \\
\text { Apache } \\
\text { Graham }\end{array}$ & $\begin{array}{l}340304 \mathrm{~N} 1113913 \mathrm{~W} \\
333010 \mathrm{~N} 1121514 \mathrm{~W} \\
312525 \mathrm{~N} 1111837 \mathrm{~W} \\
340910 \mathrm{~N} 1093901 \mathrm{~W} \\
324944 \mathrm{~N} 1100745 \mathrm{~W}\end{array}$ & & $\begin{array}{l}3880 \\
8804 \\
4965\end{array}$ & $\begin{array}{l}\text { Chalk Mountain } \\
\text { El Mirage } \\
\text { Bartlett Mtn } \\
\text { Boundary Butte } \\
\text { Buford Hill }\end{array}$ \\
\hline $\begin{array}{l}\text { Juan Tank Canyon } \\
\text { Juanuña Spring } \\
\text { Jubilee Mine } \\
\text { Jucqa-Va Spring } \\
\text { Judd Hollow } \\
\text { Judd Tank } \\
\text { Judge Oteys Tombstone } \\
\text { See Capitol Butte } \\
\text { Judia Canyon } \\
\text { Judson School }\end{array}$ & $\begin{array}{l}\text { valley } \\
\text { spring } \\
\text { mine } \\
\text { spring } \\
\text { valley } \\
\text { reservoir } \\
\text { summit } \\
\text { valley } \\
\text { school }\end{array}$ & $\begin{array}{l}\text { BGN } \\
\text { BGN } \\
\text { UNOFF } \\
\text { BGN } \\
\text { BGN } \\
\text { BGN } \\
\text { VARIANT } \\
\text { BGN } \\
\text { UNOFF }\end{array}$ & $\begin{array}{l}\text { Coconino } \\
\text { Cochise } \\
\text { Yavapai } \\
\text { Navajo } \\
\text { Coconino } \\
\text { Coconino } \\
\text { Yavapai } \\
\text { Graham } \\
\text { Maricopa }\end{array}$ & $\begin{array}{l}351707 \mathrm{~N} 1122325 \mathrm{~W} \\
320842 \mathrm{~N} 1102432 \mathrm{~W} \\
341857 \mathrm{N1} 121455 \mathrm{~W} \\
354849 \mathrm{~N} 1102954 \mathrm{~W} \\
365942 \mathrm{~N} 1114652 \mathrm{~W} \\
364456 \mathrm{N1} 122218 \mathrm{~W} \\
345310 \mathrm{~N} 1114822 \mathrm{~W} \\
324806 \mathrm{~N} 1093639 \mathrm{~W} \\
333211 \mathrm{~N} 1115607 \mathrm{~W}\end{array}$ & $370036 \mathrm{~N} 1114128 \mathrm{~W}$ & & $\begin{array}{l}\text { Fitzgerald Hill } \\
\text { Happy Valley } \\
\text { Cleator } \\
\text { Polacca } \\
\text { Wrather Arch } \\
\text { Warm Springs Canyon } \\
\text { San Jose } \\
\text { Paradise Valley }\end{array}$ \\
\hline $\begin{array}{l}\text { Judy Tank } \\
\text { Judy Tank } \\
\text { Judy Wash } \\
\text { Judy Wash Dam } \\
\text { See Judy Wash Retarding Dam } \\
\text { Judy Wash Retarding Dam } \\
\text { Judy Wash Dam }\end{array}$ & $\begin{array}{l}\text { reservoir } \\
\text { reservoir } \\
\text { arroyo } \\
\text { dam } \\
\text { dam }\end{array}$ & $\begin{array}{l}\text { BGN } \\
\text { BGN } \\
\text { BGN } \\
\text { VARIANT } \\
\text { UNOFF } \\
\text { VARIANT }\end{array}$ & $\begin{array}{l}\text { Santa Cruz } \\
\text { Coconino } \\
\text { Graham } \\
\text { Graham } \\
\text { Graham }\end{array}$ & $\begin{array}{l}312301 N 1102847 \mathrm{~W} \\
344427 \mathrm{N1111116W} \\
324818 \mathrm{~N} 1093648 \mathrm{~W} \\
\\
324818 \mathrm{~N} 1093648 \mathrm{~W} \\
324818 \mathrm{~N} 1093648 \mathrm{~W}\end{array}$ & $324612 \mathrm{~N} 1093050 \mathrm{~W}$ & & $\begin{array}{l}\text { Huachuca Peak } \\
\text { Hay Lake } \\
\text { San Jose }\end{array}$ \\
\hline $\begin{array}{l}\text { Julian Wash } \\
\text { Julia Randall School } \\
\text { Julia Tank } \\
\text { July } 4 \text { Butte } \\
\text { See Fourth of July Butte } \\
\text { Jumbo Pasture } \\
\text { Jumbo Tank } \\
\text { Jumbo Tank } \\
\text { Jumbo Wash } \\
\text { Jump Canyon }\end{array}$ & $\begin{array}{l}\text { stream } \\
\text { school } \\
\text { reservoir } \\
\text { summit } \\
\text { flat } \\
\text { reservoir } \\
\text { reservoir } \\
\text { valley } \\
\text { valley }\end{array}$ & $\begin{array}{l}\text { BGN } \\
\text { UNOFF } \\
\text { BGN } \\
\text { VARIANT } \\
\text { BGN } \\
\text { BGN } \\
\text { BGN } \\
\text { BGN } \\
\text { BGN }\end{array}$ & $\begin{array}{l}\text { Pima } \\
\text { Gila } \\
\text { Pima } \\
\text { Maricopa } \\
\text { Coconino } \\
\text { Coconino } \\
\text { Yavapai } \\
\text { Mohave } \\
\text { Mohave }\end{array}$ & $\begin{array}{l}321253 \mathrm{~N} 1105851 \mathrm{~W} \\
341403 \mathrm{~N} 1112033 \mathrm{~W} \\
314209 \mathrm{N1111819W} \\
\\
331620 \mathrm{~N} 1130650 \mathrm{~W} \\
343340 \mathrm{~N} 1111434 \mathrm{~W} \\
343344 \mathrm{~N} 1111441 \mathrm{~W} \\
351202 \mathrm{~N} 1123219 \mathrm{~W} \\
355203 \mathrm{~N} 1143946 \mathrm{~W} \\
363233 \mathrm{~N} 1134534 \mathrm{~W}\end{array}$ & $\begin{array}{l}354424 \mathrm{~N} 1143638 \mathrm{~W} \\
363316 \mathrm{~N} 1133852 \mathrm{~W}\end{array}$ & & $\begin{array}{l}\text { Blue Ridge Reservoir } \\
\text { Blue Ridge Reservoir } \\
\text { Cathedral Caves } \\
\text { Willow Beach } \\
\text { Cane Springs SE }\end{array}$ \\
\hline $\begin{array}{l}\text { Jumping Spring } \\
\text { Jumpoff, The } \\
\text { Jump-Off Canyon } \\
\text { Jumpoff Canyon } \\
\text { Jumpoff Hill } \\
\text { See Cochrane Hill } \\
\text { Jumpoff Ridge } \\
\text { Jump-off Spring } \\
\text { Jump-Off Spring } \\
\text { Jumpoff Spring }\end{array}$ & $\begin{array}{l}\text { spring } \\
\text { cliff } \\
\text { valley } \\
\text { valley } \\
\text { summit } \\
\text { ridge } \\
\text { spring } \\
\text { spring } \\
\text { spring }\end{array}$ & $\begin{array}{l}\text { BGN } \\
\text { BGN } \\
\text { BGN } \\
\text { BGN } \\
\text { VARIANT } \\
\text { BGN } \\
\text { BGN } \\
\text { BGN } \\
\text { BGN }\end{array}$ & $\begin{array}{l}\text { Coconino } \\
\text { Yuma } \\
\text { Gila } \\
\text { Navajo } \\
\text { Coconino } \\
\text { Navajo } \\
\text { Gila } \\
\text { Gila } \\
\text { Navajo }\end{array}$ & $\begin{array}{l}342936 \mathrm{~N} 1110424 \mathrm{~W} \\
341316 \mathrm{~N} 1140533 \mathrm{~W} \\
334046 \mathrm{~N} 1104547 \mathrm{~W} \\
340605 \mathrm{~N} 1102257 \mathrm{~W} \\
\\
351700 \mathrm{~N} 1112240 \mathrm{~W} \\
341227 \mathrm{~N} 1102117 \mathrm{~W} \\
333602 \mathrm{~N} 1105134 \mathrm{~W} \\
335733 \mathrm{~N} 1111150 \mathrm{~W} \\
341036 \mathrm{~N} 1102323 \mathrm{~W}\end{array}$ & $\begin{array}{l}334157 \mathrm{~N} 1104451 \mathrm{~W} \\
341354 \mathrm{~N} 1102012 \mathrm{~W}\end{array}$ & & $\begin{array}{l}\text { Limestone Canyon N } \\
\text { Rockinstraw Mtn } \\
\text { Picture Mtn } \\
\text { Bear Ridge }\end{array}$ \\
\hline $\begin{array}{l}\text { Jumpoff Tank } \\
\text { Jumpup Canyon } \\
\text { Jumpup Point } \\
\text { Jumpup Spring } \\
\text { Jump Up Tank } \\
\text { Jumpup Trick Tank } \\
\text { Junction Crater } \\
\text { Junction Interstate Nineteen } \\
\text { Interchange } \\
\text { Junction Over look }\end{array}$ & $\begin{array}{l}\text { reservoir } \\
\text { valley } \\
\text { cliff } \\
\text { spring } \\
\text { reservoir } \\
\text { reservoir } \\
\text { crater } \\
\text { crossing } \\
\text { locale }\end{array}$ & $\begin{array}{l}\text { BGN } \\
\text { BGN } \\
B G N \\
B G N \\
B G N \\
\text { BGN } \\
\text { BGN } \\
\text { UNOFF } \\
\text { BGN }\end{array}$ & $\begin{array}{l}\text { Navajo } \\
\text { Coconino } \\
\text { Coconino } \\
\text { Coconino } \\
\text { Greenlee } \\
\text { Coconino } \\
\text { Coconino } \\
\text { Pima } \\
\text { Apache }\end{array}$ & $\begin{array}{l}341352 \mathrm{N1} 102024 \mathrm{~W} \\
362914 \mathrm{N1} 123739 \mathrm{~W} \\
363150 \mathrm{N1} 123625 \mathrm{~W} \\
363436 \mathrm{N1} 123254 \mathrm{~W} \\
331956 \mathrm{N1091024W} \\
363442 \mathrm{N1123349W} \\
351735 \mathrm{~N} 1112000 \mathrm{~W} \\
321140 \mathrm{~N} 1105834 \mathrm{~W} \\
360814 \mathrm{~N} 1092932 \mathrm{~W}\end{array}$ & $363700 \mathrm{~N} 1122921 \mathrm{~W}$ & 6319 & $\begin{array}{l}\text { Limestone Canyon N } \\
\text { Kanab Point } \\
\text { Jumpup Point } \\
\text { Jumpup Point } \\
\text { Fritz Canyon } \\
\text { Jumpup Point } \\
\text { Merriam Crater } \\
\text { Tucson } \\
\text { Del Muerto }\end{array}$ \\
\hline $\begin{array}{l}\text { Junction Saddle } \\
\text { Junction State Route } \\
\text { Eightfour Interchange } \\
\text { Junction Tank } \\
\text { Junction Tank }\end{array}$ & $\begin{array}{l}\text { gap } \\
\text { crossing } \\
\text { reservoir } \\
\text { reservoir }\end{array}$ & $\begin{array}{l}\text { BGN } \\
\text { UNOFF } \\
\text { BGN } \\
\text { BGN }\end{array}$ & $\begin{array}{l}\text { Cochise } \\
\text { Pinal } \\
\text { Pinal } \\
\text { Apache }\end{array}$ & $\begin{array}{l}315059 \mathrm{~N} 1091719 \mathrm{~W} \\
324323 \mathrm{~N} 1113055 \mathrm{~W} \\
\\
331539 \mathrm{~N} 1111940 \mathrm{~W} \\
340707 \mathrm{~N} 1094107 \mathrm{~W}\end{array}$ & & 1595 & $\begin{array}{l}\text { Chiricahua Peak } \\
\text { Eloy South } \\
\text { Florence Junction } \\
\text { Horseshoe Cienega }\end{array}$ \\
\hline
\end{tabular}


MATIONAL GAZETTEER--ARIZONA 1986

\section{FEATURE NAME}

Junction Tank

Junction Tank

Junction Tank Number One

Junction Tanks

June Heaton Tank

June Spring

$$
\text { See Willow Spring }
$$

June Tank

Jungle Dam

Juniper

See Linden

Juniper 8ark Canyon

Juniper 8as in

Juniper Canyon MacDonald Canyon Macdonald Canyon

Juniper Dam

Juniper Flat See Juniper Flats

Juniper Flat

Juniper Flat

Juniper Flat

Juniper Flat

Juniper Flats Juniper Flat

Juniper Flat Tank

Juniper Flat Tank

Juniper Grove Wash

Juniper Gulch

See Charcoal Gulch

Juniper Heights

Juniper $\mathrm{Hill}$

Juniper Mesa

Juniper Mesa Tank

Juniper Mesa Tank

Juniper Mine

Juniper Mountain Bear Head Mountain

Juniper Mountains

Juniper Point

Juniper Ridge

Juniper Ridge

Juniper Ridge

Juniper Ridge Lookout Tower

Junipers, The

Juniper Spring

Juniper Spring
Sentinel Spring
Juniper Spring
Juniper Spring
Juniper Spring
Juniper Spring
Juniper Spring
Juniper Spring
Juniper Spring
Juniper Spring

Juniper Spring

Juniper Spring

Juniper Spring

Juniper Spring

Juniper Spring

Juniper Tank

Juniper Tank

Juniper Tank

Juniper Tank

Juniper Tank

Juniper Tank

Juniper Tank

Juniper Tank

Jun iper Tank

Juniper Tank
FEATURE

CLASS

STATUS

COUNTY

COORDINATE

$\begin{array}{llll}\text { reservoir } & \text { BGN } & \text { Coconino } & 350816 \mathrm{~N} 1115148 \mathrm{~W} \\ \text { reservoir } & \text { BGN } & \text { Mohave } & 352244 \mathrm{~N} 1142253 \mathrm{~W} \\ \text { reservoir } & \text { BGN } & \text { Gila } & 335715 \mathrm{~N} 1101438 \mathrm{~W} \\ \text { reservoir } & 8 \mathrm{BGN} & \text { Gila } & 335935 \mathrm{~N} 1101322 \mathrm{~W}\end{array}$

$\begin{array}{llll}\text { reservoir } & \text { BGN } & \text { Coconino } & 350816 \mathrm{~N} 1115148 \mathrm{~W} \\ \text { reservoir } & \text { BGN } & \text { Mohave } & 352244 \mathrm{~N} 1142253 \mathrm{~W} \\ \text { reservoir } & \text { BGN } & \text { Gila } & 335715 \mathrm{~N} 1101438 \mathrm{~W} \\ \text { reservoir } & 8 \mathrm{GN} & \text { Gila } & 335935 \mathrm{~N} 1101322 \mathrm{~W}\end{array}$

reservoir 8GN Gila $335935 \mathrm{~N} 1101322 \mathrm{~W}$

reservoir

VARIANT

spring

reservoir

dan

locale

valley

bas in

valley

BGN

UNOFF

VARIANT

BGN Navajo

BGN Pima

BGN 1965 Gila

VARIANT

VARIANT

$\begin{array}{llll}\text { dam } & \text { UNOFF } & \text { Graham } & 332248 \mathrm{~N} 1100630 \mathrm{~W} \\ & \text { VARIANT } & & \\ \text { flat } & & \text { Cochise } & 312904 \mathrm{~N} 1095800 \mathrm{~W} \\ \text { flat } & \text { BGN } & \text { Santa Cruz } & 313827 \mathrm{N1105102W} \\ \text { flat } & \text { BGN } & \text { Greenlee } & 331002 \mathrm{~N} 1092746 \mathrm{~W} \\ \text { flat } & \text { BGN } & \text { Gila } & 332600 \mathrm{~N} 1105652 \mathrm{~W} \\ \text { flat } & \text { BGN } & \text { Gila } & 335508 \mathrm{~N} 1105655 \mathrm{~W} \\ \text { flat } & \text { BGN } & \text { Cochise } & 312904 \mathrm{~N} 109580 \mathrm{~W} \\ & \text { VARIANT } & & \end{array}$

$361805 N 1125720 \mathrm{~W}$

363049 N1125544W

$343710 \mathrm{~N} 1094556 \mathrm{~W}$

341706 N1100923W

$354028 \mathrm{~N} 1090659 \mathrm{~W}$

$321101 \mathrm{~N} 1103831 \mathrm{~W}$

335152N1111604W

354131N1091037W

$335621 \mathrm{~N} 1111000 \mathrm{~W}$

335508 N1105653W

reservoir BGN

valley

BGN

BGN
VARIANT

valley

ppl

sumnit

summit

reservoir

mine

BGN

BGN

BGN

BGN

BGN
UNOFF

Gila

$\begin{array}{ll}\text { Coconino } & 343218 \mathrm{~N} 1113054 \mathrm{~W} \\ \text { Navajo } & 362400 \mathrm{~N} 1102358 \mathrm{~W}\end{array}$

Navajo

Yavapai

Yavapai

Yavapai

Yavapai

Greenlee

Yavapai

(3)

$343253 \mathrm{~N} 1115640 \mathrm{~W}$

$345637 \mathrm{~N} 1125333 \mathrm{~W}$

$331743 \mathrm{~N} 1090438 \mathrm{~W}$

$343544 N 1120545 \mathrm{~W}$

340956 N1122212W

summit BGN 1965 Gila

VARIANT

range BGN

sumnit $\quad B G N$

ridge

ridge

ridge

tower

woods

spring

spring

spring

spring

spring

spring

spring

spring

spring

spring

spring

spring

spring

spring

spring

reservoir

reservoir

reservoir

reservoir

reservoir

$B G N$
$B G N$
$B G N$

BGN

UNOFF

BGN

BGN

\section{Yavapai}

Navajo

Yavapai

Mavajo

Coconino

Navajo

Greenlee

Cochise

335625N1111020W

$350340 \mathrm{~N} 1125127 \mathrm{~W}$

341748 N1101105W

$341122 \mathrm{~N} 1121934 \mathrm{~W}$

$341543 N 1101201 \mathrm{~W}$

$352652 \mathrm{~N} 1115524 \mathrm{~W}$

$341610 \mathrm{~N} 1101125 \mathrm{~W}$

330637N1090437W

314509 N11 $02507 \mathrm{~W}$

$315007 N 1091636 \mathrm{~W}$

$8 G N$
VARIANT

Cochise

Graham

Graham

Gila

Green lee

Maricopa

Gila

Yavapai

Yavapai

$324209 \mathrm{N1102316 \textrm {W }}$

$325750 \mathrm{~N} 1102603 \mathrm{~W}$

$331304 N 1103429 \mathrm{~W}$

$332703 N 1092750 \mathrm{~W}$

$335142 \mathrm{~N} 1112328 \mathrm{~W}$

$335513 \mathrm{~N} 1111137 \mathrm{~W}$

$340826 \mathrm{~N} 1115307 \mathrm{~W}$

$341044 \mathrm{~N} 1122714 \mathrm{~W}$

341222N1124154W

$341329 \mathrm{~N} 1124246 \mathrm{~W}$

$342211 \mathrm{~N} 1122146 \mathrm{~W}$

$343601 N 1124303 \mathrm{~W}$

$345437 \mathrm{~N} 1131911 \mathrm{~W}$

$314527 \mathrm{~N} 1105247 \mathrm{~W}$

$322327 \mathrm{~N} 1100819 \mathrm{~W}$

$332205 N 1100609 \mathrm{~W}$

$334854 \mathrm{~N} 1100939 \mathrm{~W}$

335241M1105110W

reservoir

reservoir

reservoir

reservoir

reservoir
SOURCE

ELEV

MAP NAME

Bellemont

Grasshopper Junc NW

Cedar Creek

Cedar Creek

Hitson Tank

Heaton Knolls

Manuel Seep

Window Rock

Tanque Verde Peak

Tonto Bas in

Ash Creek ME

6200 Mt Wrightson

Coronado Mtn

Inspiration

McFadden Peak

Bisbee

McFadden Peak

Buckhorn Mountain

Great Spring

Prescott

5362 Middle Verde Juniper Mts

6398 Maple Peak

Cherry

Crown King

5888 Picture Mtn

Red Mountain

Pinedale

Crown King

Pinedale

Moritz Ridge

6998 Pinedale

Big Lue Mts

Apache Peak

Chiricahua Peak

Rhodes Peak

Booger Canyon

Coolidge Dam

Robinson Mesa

Boulder Mtn

Picture Mtn

Brooklyn Peak

Minnehaha

Yarnel

Yarnell

Battle Flat

Skull Valley

Mohon Peak

Green Valley

The Mesas

4877 Ash Creek Ranch

Cone Butte

Rock House

Young

Buzzard Roost Mesa

Columbia

Brooklyn Peak

Bloody Bas in 
FEATURE NAME

Juniper Tank

Juniper Tank

Juniper Tank

Juniper Tank

Juniper Tank

Juniper Tank

Jun iper Tank

Juniper Tank Dam

Juniper Tree Tank

Juniper Trick Tank

Juniper Trick Tank

Juniper Well

Juniper Well

Junniper Springs Two hundred

ninety five Trail

Juno Mine
Juno Temple
Ju Ot Te Park
Jupiter Canyon
Jupiter Mine
Jupiter Mine
Jupiter Mine
Jupiter Mine
Jupiter Point
See Tiyo Point

Jupiter Spring
Jupiter Temple
Jurko Ranch
J U Spring
Justine Spitalny School
Justins Windmill
J W Spendlove Reservoir
J W Tank
J $Z$ Rogers Spring

J W Tank

J Z Rogers Spring
FEATURE
CLASS

STATUS COUNTY

Navajo

reservoir

reservoir

reservoir

BGN

BGN

BGN

BGN

Gila

Yavapai

reservoir

reservoir

dam

reservoir

reservoir

reservoir $B G$

well UNOFF

well

trail

BGN
BGN
UNOFF
BGN
BGN
BGN
UNOFF
UNOFF
UNOFF

Coconino

Coconino

Santa Cruz

Cochise

Yavapai

Coconino

Santa Cruz

Coconino

Graham

$\begin{array}{lll}\text { mine } & \text { UNOFF } & \text { Mohave } \\ \text { summit } & \text { BGN 1906 } & \text { Coconino } \\ \text { park } & \text { ADMIN } & \text { Maricopa } \\ \text { valley } & \text { BGN } & \text { Pima } \\ \text { mine } & \text { UNOFF } & \text { Pima } \\ \text { mine } & \text { UNOFF } & \text { La Paz } \\ \text { mine } & \text { UNOFF } & \text { Mohave } \\ \text { mine } & \text { UNOFF } & \text { Mohave } \\ & \text { VARIANT } & \\ \text { cliff } & & \text { Coconino }\end{array}$

$352523 N 1141222 \mathrm{~W}$

$360900 \mathrm{~N} 1115329 \mathrm{~W}$

$332725 \mathrm{~N} 1120510 \mathrm{~W}$

$314326 \mathrm{N1113532 \textrm {W }}$

$314402 N 1113509 \mathrm{~W}$

$331712 \mathrm{N1143456 \textrm {W }}$

$343206 \mathrm{~N} 1141011 \mathrm{~W}$

$352341 \mathrm{~N} 1141024 \mathrm{~W}$

$361049 N 1120743 \mathrm{~W}$

spring

summit

spring

school

well

reservoir

reservoir

spring

$\begin{array}{ll}\text { BGN } & \text { Mohave } \\ \text { BGN 1906 } & \text { Coconino } \\ \text { UNOFF } & \text { Pima } \\ \text { BGN } & \text { Gila } \\ \text { UNOFF } & \text { Maricopa } \\ \text { UNOFF } & \text { Apache } \\ \text { BGN } & \text { Mohave } \\ \text { BGN } & \text { Coconino } \\ \text { BGN } & \text { Gila }\end{array}$

Gila
$343225 \mathrm{~N} 1141030 \mathrm{~W}$

$360804 N 1115322 \mathrm{~W}$

$322333 \mathrm{~N} 1110256 \mathrm{~W}$

$334037 N 1103943 \mathrm{~W}$

$332910 \mathrm{N1120925 \textrm {W }}$

$355955 N 1090318 \mathrm{~W}$

$363205 N 1131555 \mathrm{~W}$

$344302 \mathrm{N1112119 \textrm {W }}$

$334652 N 1105021 \mathrm{~W}$

$\begin{array}{cc}\text { SOURCE } & \text { ELEV } \\ \text { COORDINATE } & \text { FT }\end{array}$

MAP NAME

Red Top Mt

Pinedale

Buckhead Mesa

Page Springs

Hell Point

Moritz Ridge

Vulcans Throne SE

Pajarito Peak

Swede Peak

Jun iper Mts

East of $S$ P Mtn

Mt Wrightson

Kaibito

Kennedy Peak

Chloride

Walhalla Plateau

Phoenix

Mildred Peak

Mildred Peak

Cibola SE

Crossman Peak

Chloride

Crossman Peak

7081 Walhalla Plateau Ruelas Canyon

Haystack Butte Fowler

Buell Park

6058 Russell Spring

Turkey Mtn

Sombrero Peak

\section{$\mathrm{K}$}

KAAA-AM (Kingman)

KAET-TV (Phoenix)

KAFF-FM (Flagstaff)

KAIM-FM (Prescott)

KAIR-AM (Tucson)

KAPR-AM (Douglas)

KARZ-AM (Phoenix)

KARZ-AM (Phoenix)

KASA-AM (Phoenix

KATO-AM (Safford)

KAVV-FM (Sierra Vista)

KAVV-FM (Sierra Vista)

KAYN-FM (Nogales)

KAZM-AM (Sedona)

KBAS-AM (Bullhead City)

KBBC-FM (Lake Havasu City)

KBBC-FM (Lake Havasu City)

KBLU-AM (Yuma)

KBWA-AM (Will iams)

KBZB-AM (Bisbee)

KCCA-TV (Sierra Vista)

KCEE-AM (Tucson)

KCKY-AM (Coolidge)

KCKY-AM (Coolidge)

KCLS-AM (Flagstaff)

KCRJ-FM (Cottonwood)

KCUB-FM (Tuscon)

KCUZ-AM (Clifton)

KOAP-AM (Douglas)

KOAP-AM (Douglas)

\begin{tabular}{|c|c|c|c|}
\hline $\begin{array}{l}\text { tower } \\
\text { tower } \\
\text { tower } \\
\text { tower } \\
\text { tower } \\
\text { tower } \\
\text { tower } \\
\text { tower } \\
\text { tower } \\
\text { tower } \\
\text { tower }\end{array}$ & $\begin{array}{l}\text { UNOFF } \\
\text { UNOFF } \\
\text { UNOFF } \\
\text { UNOFF } \\
\text { UNOFF } \\
\text { UNOFF } \\
\text { UNOFF } \\
\text { UNOFF } \\
\text { UNOFF } \\
\text { UNOFF } \\
\text { UNOFF }\end{array}$ & $\begin{array}{l}\text { Mohave } \\
\text { Maricopa } \\
\text { Coconino } \\
\text { Yavapai } \\
\text { Pima } \\
\text { Cochise } \\
\text { Maricopa } \\
\text { Maricopa } \\
\text { Maricopa } \\
\text { Graham } \\
\text { Cochise }\end{array}$ & $\begin{array}{l}351127 N 1140105 \mathrm{~W} \\
331954 \mathrm{~N} 1120352 \mathrm{~W} \\
345807 \mathrm{~N} 1113024 \mathrm{~W} \\
343227 \mathrm{~N} 1122540 \mathrm{~W} \\
321456 \mathrm{~N} 1105529 \mathrm{~W} \\
312208 \mathrm{~N} 1093145 \mathrm{~W} \\
332923 \mathrm{~N} 1120825 \mathrm{~W} \\
333912 \mathrm{~N} 1115539 \mathrm{~W} \\
332236 \mathrm{~N} 1120525 \mathrm{~W} \\
324930 \mathrm{~N} 1094530 \mathrm{~W} \\
315513 \mathrm{~N} 1102208 \mathrm{~W}\end{array}$ \\
\hline $\begin{array}{l}\text { tower } \\
\text { tower } \\
\text { tower } \\
\text { tower } \\
\text { tower } \\
\text { tower } \\
\text { tower } \\
\text { tower } \\
\text { tower } \\
\text { tower }\end{array}$ & $\begin{array}{l}\text { UNOFF } \\
\text { UNOFF } \\
\text { UNOFF } \\
\text { UNOFF } \\
\text { UNOFF } \\
\text { UNOFF } \\
\text { UNOFF } \\
\text { UNOFF } \\
\text { UNOFF } \\
\text { UNOFF }\end{array}$ & $\begin{array}{l}\text { Cochise } \\
\text { Santa Cruz } \\
\text { Yavapai } \\
\text { Mohave } \\
\text { Mohave } \\
\text { Mohave } \\
\text { Yuma } \\
\text { Coconino } \\
\text { Cochise } \\
\text { Cochise }\end{array}$ & $\begin{array}{l}315520 \mathrm{~N} 1102235 \mathrm{~W} \\
312317 \mathrm{N1} 105538 \mathrm{~W} \\
345139 \mathrm{N1} 114910 \mathrm{~W} \\
350547 \mathrm{N1} 143404 \mathrm{~W} \\
342941 \mathrm{N1} 142059 \mathrm{~W} \\
343926 \mathrm{N1} 142042 \mathrm{~W} \\
324325 \mathrm{~N} 1143839 \mathrm{~W} \\
351538 \mathrm{N1} 121055 \mathrm{~W} \\
312517 \mathrm{N1} 1095313 \mathrm{~W} \\
312750 \mathrm{~N} 1101517 \mathrm{~W}\end{array}$ \\
\hline $\begin{array}{l}\text { tower } \\
\text { tower } \\
\text { tower } \\
\text { tower } \\
\text { tower } \\
\text { tower } \\
\text { tower } \\
\text { tower } \\
\text { tower }\end{array}$ & $\begin{array}{l}\text { UNOFF } \\
\text { UNOFF } \\
\text { UNOFF } \\
\text { UNOFF } \\
\text { UNOFF } \\
\text { UNOFF } \\
\text { UNOFF } \\
\text { UNOFF } \\
\text { UNOFF }\end{array}$ & $\begin{array}{l}\text { Pima } \\
\text { Pinal } \\
\text { Pinal } \\
\text { Coconino } \\
\text { Yavapai } \\
\text { Pima } \\
\text { Greenlee } \\
\text { Cochise } \\
\text { Cochise }\end{array}$ & $\begin{array}{l}321454 \mathrm{~N} 1110031 \mathrm{~W} \\
330025 \mathrm{~N} 1113254 \mathrm{~W} \\
330030 \mathrm{~N} 1113256 \mathrm{~W} \\
351126 \mathrm{~N} 1114009 \mathrm{~W} \\
344535 \mathrm{~N} 1120648 \mathrm{~W} \\
321637 \mathrm{~N} 1105850 \mathrm{~W} \\
330230 \mathrm{~N} 1091740 \mathrm{~W} \\
312106 \mathrm{~N} 1093348 \mathrm{~W} \\
312118 \mathrm{~N} 1093306 \mathrm{~W}\end{array}$ \\
\hline
\end{tabular}

Kingman

Lone Butte

Mormon Mountain

Prescott

Tucson

Douglas

Fowler

Currys Corner

Phoenix

Thatcher

Benson

Mesca

3960 Rio Rico

Sedona

Davis Dam SE

Lake Havasu City $S$

Franconia

Yuma West

Williams North

Bisbee

Miller Peak

Cat Mountain

Blackwater

Blackwater

Flagstaff West

Clarkdale

Tucson North

Clifton

Douglas

Douglas 
NATIONAL GAZETTEER--ARIZONA 1986

FEATURE NAME

KDJI-AM (Holbrook)

KDJI-AM (Holbrook)

KDJQ-AM (Mesa)

KDKB-FM (Mesa)

KENT-AN (Prescott)

KEZC-FM (Glendale)

KEZG-FM (Green Valley)

KEZG-FM (Green Valley)

KFBR-AM (Nogales)

KFLG-AM (Flagstaff)

KFLG-AY (Flagstaff)

KFLR-AM (Phoenix)

KFLR-AM (Phoenix)

$$
\text { KRI Z-AM }
$$

KFLT-AM (Tucson)

KFWJ-AM (Lake Havasu City)

KGUN-TV (Tucson)

KGUS-AM (Florence)

KHAC-AM (Window Rock)

KHEP-FM (Phoenix)

KHIL-AM (Willcox)

KHYT-AM (South Tucson)

KIAI-FM (Phoenix)

KIKO-AM (Miani)

KIKO-FM (Globe)

KIKX-AM (Tucson)

KIKX-AM (Tucson)

KINO-AM (Wins low)

KJJJ-AM (Phoenix)

KJJJ-FM (Glendale)

KJKJ-AM (Flagstaff)

KJOK-FM (Yuma)
KYOY-FM

KJOK-FM (Yuma)

KJYK-FM (Tucson)

KKAF-FM (Eloy)

KKAF-FM (Eloy)

KKLT-FM (Phoenix)

KKRK-FM (Douglas)

KLCF-AM (Clifton)

KLFF-AM (Glendale)

KLFF-AM (Glendale)

KLLE-AM (Marana)

KLPX-FM (Tucson)

KMCR-FM (Phoenix)

KMDX-FM (Parker)

KMDX-FM (Parker)

KMEO-AM (Phoenix)

KMEO-FM (Phoen ix)

KMLE-FM (Chandler)

KMOG-AM (Payson)

KNAU-FM (Flagstaff)

KNAU-FM (Flagstaff)

KNAZ-TV (Flagstaff)

KNCC-FM (Tsaile)

KNDE-FM (Tucson)

KNDE-FM (Tucson)

KNIX-AM (Tempe)

KNIX-FM (Phoenix)

XNNB-FM (Whiteriver)

KNNN-FM (Phoenix)

KNOT-AM (Prescott)

KNOT-FM (Prescott)

KNST-AM (Tucson)

KNST-AM (Tucson)

KNXV-TV (Phoenix)

KOLD-TV (Tucson)

KOOL-FM (Phoenix)

KOPA-AM (Scottsdale)

KOPO-FM (Marana)

KOPO-FM (Marana)

\section{FEATURE
CLASS}

tower

STATUS

COUNTY

Navajo

COORDINATE

$345355 \mathrm{~N} 1101130 \mathrm{~W}$

tower UNOFF Navajo 345422N1101128W

$\begin{array}{llll}\text { tower } & \text { UNOFF } & \text { Maricopa } & 332330 \mathrm{~N} 1115016 \mathrm{~W} \\ \text { tower } & \text { UNOFF } & \text { Maricopa } & 332004 \mathrm{~N} 1120336 \mathrm{~W}\end{array}$

tower UNOFF Yavapai $343242 \mathrm{~N} 1122646 \mathrm{~W}$

tower UNOFF Maricopa 333555N1120447W

tower UNOFF Pima $314736 \mathrm{~N} 1110218 \mathrm{~W}$

tower UNOFF Pima 315618N1105948W

tower UNOFF Santa Cruz 312109N1105543W

tower UNOFF Coconino 351126N1114037W

tower UNOFF Coconino 351202N1113650W

tower

tower

tower

tower

tower

tower

tower

tower

tower

tower

tower

tower

tower

tower

tower

tower

tower

tower

tower

tower

tower

tower

tower

tower

tower

tower

tower

tower

tower

tower

tower

tower

tower

tower

tower

tower

tower

tower

tower

tower

tower

tower

tower

tower

tower

tower

tower

tower

tower

tower

tower
tower

tower

tower

tower

tower

ower

tower

tower

tower

$\begin{array}{lll}\text { UNOFF } & \text { Maricopa } & 332605 N 1120640 \mathrm{~W} \\ \text { UNOFF } & \text { Maricopa } & 332609 \mathrm{~N} 1120635 \mathrm{~W} \\ \text { VARIANT } & & \\ \text { UNOFF } & \text { Pima } & 321207 N 1105648 \mathrm{~W} \\ \text { UNOFF } & \text { Mohave } & 342941 \mathrm{~N} 1142059 \mathrm{~W} \\ \text { UNOFF } & \text { Pima } & 322454 N 1104259 \mathrm{~W} \\ \text { UNOFF } & \text { Pinal } & 330050 \mathrm{~N} 1110038 \mathrm{~W} \\ \text { UNOFF } & \text { Apache } & 353841 \mathrm{N1090113W} \\ \text { UNOFF } & \text { Maricopa } & 331952 \mathrm{~N} 1120345 \mathrm{~W} \\ \text { UNOFF } & \text { Cochise } & 321600 \mathrm{~N} 1094958 \mathrm{~W}\end{array}$

$\begin{array}{lll}\text { UNOFF } & \text { Pima } & 321851 N 1105017 \mathrm{~W} \\ \text { UNOFF } & \text { Maricopa } & 331958 N 1120353 \mathrm{~W} \\ \text { UNOFF } & \text { Gila } & 332441 \times 1105017 \mathrm{~W} \\ \text { UNOFF } & \text { Gila } & 331720 \mathrm{~N} 1104945 \mathrm{~W} \\ \text { UNOFF } & \text { Pima } & 321736 \mathrm{~N} 1105340 \mathrm{~W} \\ \text { UNOFF } & \text { Pima } & 321736 \mathrm{~N} 1105341 \mathrm{~W} \\ \text { UNOFF } & \text { Navajo } & 350215 N 1104300 \mathrm{~W} \\ \text { UNOFF } & \text { Maricopa } & 333229 N 1120709 \mathrm{~W} \\ \text { UNOFF } & \text { Maricopa } & 333547 \mathrm{N1} 120529 \mathrm{~W} \\ \text { UNOFF } & \text { Coconino } & 351130 \mathrm{~N} 1113823 \mathrm{~W}\end{array}$

UNOFF
VARIANT
UNOFF
UNOFF
UNOFF
UNOFF
UNOFF
UNOFF
UNOFF
UNOFF

Yuma

Yuma

Yuma
Pima
Pinal

Pinal

Maricopa

Cochise

Greenlee

Maricopa

Maricopa

Pima

Pima

Maricopa

La Paz

La Paz

Maricopa

Maricopa

Maricopa

Gila

Coconino

Coconino

Coconino

Apache

Pima

Pima

Maricopa

Maricopa

Navajo

Maricopa

$323906 \mathrm{~N} 1143900 \mathrm{~W}$

$324255 N 1143855 \mathrm{~W}$

$321723 \mathrm{~N} 1110106 \mathrm{~W}$

$324451 \mathrm{~N} 1113311 \mathrm{~W}$

$325004 \mathrm{~N} 1113815 \mathrm{~W}$

$332000 \mathrm{~N} 1120348 \mathrm{~W}$

$312208 N 1093145 \mathrm{~W}$

$330240 \mathrm{~N} 1091742 \mathrm{~W}$

333027 N1121301W

$333030 \mathrm{~N} 1121303 \mathrm{~W}$

$322512 \mathrm{~N} 1110804 \mathrm{~W}$

$321723 \mathrm{~N} 1110106 \mathrm{~W}$

$331958 \mathrm{~N} 1120353 \mathrm{~W}$

$340722 \mathrm{N1141240 \textrm {W }}$

340849 N1 $141816 \mathrm{~W}$

332155 N1120630W

$333552 N 1120445$

$341600 N 1111854 \mathrm{~W}$

$345808 \mathrm{~N} 1113028 \mathrm{~W}$

$351121 \mathrm{~N} 1113925 \mathrm{~W}$

$345806 \mathrm{~N} 1113028 \mathrm{~W}$

$361745 \mathrm{~N} 1091213 \mathrm{~W}$

$320907 N 1105531 \mathrm{~W}$

321257 W1105654W

$332722 \mathrm{~N} 1115001 \mathrm{~W}$

$331958 N 1120353 \mathrm{~W}$

$334551 \mathrm{N1} 1095741 \mathrm{~W}$

332002N1120340W

$\begin{array}{ll}\text { Yavapai } & 343316 \mathrm{~N} 1122 \mathrm{~B} 10 \mathrm{~W} \\ \text { Yavapai } & 343429 \mathrm{~N} 1122845 \mathrm{~W} \\ \text { Pima } & 320313 \mathrm{~N} 1105647 \mathrm{~W} \\ \text { Pima } & 321204 \mathrm{~N} 1110102 \mathrm{~W} \\ \text { Maricopa } & 332000 \mathrm{~N} 1120346 \mathrm{~W} \\ \text { Pima } & 322456 \mathrm{~N} 1104250 \mathrm{~W} \\ \text { Maricopa } & 332002 \mathrm{~N} 1120342 \mathrm{~W} \\ \text { Maricopa } & 332900 \mathrm{~N} 1115625 \mathrm{~W} \\ \text { Pima } & 322320 \mathrm{~N} 111084 \mathrm{~W} \\ \text { Pima } & 322709 \mathrm{~N} 1110509 \mathrm{~W}\end{array}$

$\begin{array}{lc}\text { SOURCE } & \text { ELEV } \\ \text { COORDINATE } & \text { FT }\end{array}$

Holbrook

Holbrook

Mesa

Lone Butte

Prescott

Sunnys lope

Esperanza Mill

Sahaurita

3800 Nogales

Flagstaff West

Flagstaff East

Phoen ix

Phoenix

Tucson

Lake Havasu City S

Mount Bigelow

Florence

Window Rock

Lone Butte

Willcox North

Sabino Canyon

Lone Butte

Globe

Pinal Peak

Tucson North

Tucson North

Winslow

Sunnys lope

Sunnys lope

Flagstaff West

Yuma West

Yuma West

Jaynes

Eloy South

Casa Grande Mts

Lone Butte

Douglas

Clifton

Glendale

Glendale

Marana

Jaynes

Lone Butte

Black Peak

Parker

Lone Butte

Lone Butte

Sunnys lope

Payson North

Mormon Mountain

Flagstaff West

Mormon Mountain

Tsaile

Tucson

Tucson

Mesa

Lone Butte

Whiteriver

Lone Butte

Prescott

Prescott

Tucson SW

Cat Mountain

Lone Butte

Mount Bigelow

Lone Butte

Tempe

Marana

Ruelas Canyon 
FEATURE CLASS

STATUS

COUNTY

COORDINATE

SOURCE
COORDINATE

ELEV
FT

MAP NAME

KOY-AM (Phoenix)

KPAZ-TV (Phoenix)

KPGE-AM (Page)

KPHO-TV (Phoenix)

KPIN-AM (Casa Grande)

KPNX-TV (Mesa)

KPPR-AM (Globe)

KQEZ-FM (Coolidge)

KQYT-FM (Phoenix)

KRDS-AM (Tolleson)

KRFM-FM (Show Low)

KRHS-AM (Bullhead City)

KRHS-FM (Bullhead City)

KRIM-FM (Winslow)

KRIM-FM (Winslow)

KRIZ-AM

See KFLR-AM (Phoenix)

KRQQ-FM (TuCSON)

KRVZ-AM (Springerville)

KSAA-FM (Casa Grande)

KSAA-FM (Casa Grande)

KSML-AM (Globe)

KSOJ-FM (Flagstaff)

KSTM-FM (Apache Junction

KSUN-AM (Phoen $i x$ )

KSVA-AM (Sierra Vista)

KTAN-AM (Sierra Vista)

KTAR-AM (Phoenix)

KTAZ-FM (Sierra Vista)

KTBA-AM (Tuba City)

KTKT-AM (Tucson)

KTSP-TV (Phoenix)

KTTI-FM (Yuma)

KTUC-AM (Tucson)

KTUC-AM (Tucson)

KTVK-TV (Phoenix)

KTVW-TV (Phoenix)

KUAT-FM (TUCSOn)

KUAT-TV (Tucson)

KUKQ-AM (Tempe)

KUPD-FM (Tempe)

KUSK-TV (Prescott)

KUUK-AM (Wickenburg)

KVET-AM (Black Canyon City)

KVOA-TV (Tucson)

KVOI-AM (Tucson)

KVOI-AM (Oro Valley)

KVOY-AM (Yuma)

KVRD-AM (Cottonwood)

KVSL-AM (Show LOW)

KVVA-AM

KVWM-AM (Show Low)

KVWM-FM (Show Low)

KWAC-AM (Yuma)

KWAO-FM (Sun City)

KWCX-FM (Willcox)

KWFM-FM (Tucson)

KWLL-AM (Casa Grande)

KXAZ-FM (Page)

KXAZ-FM (Page)

KXEG-AM (Tolleson)

KXEW-AM (South Tucson)

KXKQ-FM (Safford)

KYCA-AM (Prescott)

KYOY-FM

See KJOK-FM (Yuma)

KZAZ-TV (Nogales)

KZKZ-AM (Flagstaff

KZMK-FM (Bisbee)

\begin{tabular}{|c|c|c|c|}
\hline $\begin{array}{l}\text { tower } \\
\text { tower } \\
\text { tower } \\
\text { tower } \\
\text { tower } \\
\text { tower } \\
\text { tower } \\
\text { tower } \\
\text { tower } \\
\text { tower }\end{array}$ & $\begin{array}{l}\text { UNOFF } \\
\text { UNOFF } \\
\text { UNOFF } \\
\text { UNOFF } \\
\text { UNOFF } \\
\text { UNOFF } \\
\text { UNOFF } \\
\text { UNOFF } \\
\text { UNOFF } \\
\text { UNOFF }\end{array}$ & $\begin{array}{l}\text { Maricopa } \\
\text { Maricopa } \\
\text { Coconino } \\
\text { Maricopa } \\
\text { Maricopa } \\
\text { Pinal } \\
\text { Maricopa } \\
\text { Gila } \\
\text { Pinal } \\
\text { Maricopa }\end{array}$ & $\begin{array}{l}332317 \mathrm{~N} 1120022 \mathrm{~W} \\
332002 \mathrm{~N} 1120342 \mathrm{~W} \\
365423 \mathrm{~N} 1112732 \mathrm{~W} \\
332002 \mathrm{~N} 1120343 \mathrm{~W} \\
332402 \mathrm{~N} 1120628 \mathrm{~W} \\
325149 \mathrm{~N} 1114354 \mathrm{~W} \\
331959 \mathrm{~N} 1120347 \mathrm{~W} \\
332251 \mathrm{~N} 1104525 \mathrm{~W} \\
330216 \mathrm{~N} 1113059 \mathrm{~W} \\
332006 \mathrm{~N} 1120339 \mathrm{~W}\end{array}$ \\
\hline $\begin{array}{l}\text { tower } \\
\text { tower } \\
\text { tower } \\
\text { tower } \\
\text { tower } \\
\text { tower }\end{array}$ & $\begin{array}{l}\text { UNOFF } \\
\text { UNOFF } \\
\text { UNOFF } \\
\text { UNOFF } \\
\text { UNOFF } \\
\text { UNOFF } \\
\text { VARIANT }\end{array}$ & $\begin{array}{l}\text { Maricopa } \\
\text { Navajo } \\
\text { Mohave } \\
\text { Mohave } \\
\text { Navajo } \\
\text { Navajo }\end{array}$ & $\begin{array}{l}332642 \mathrm{~N} 1121554 \mathrm{~W} \\
341220 \mathrm{~N} 1095626 \mathrm{~W} \\
350655 \mathrm{~N} 1143555 \mathrm{~W} \\
350655 \mathrm{~N} 1143555 \mathrm{~W} \\
350304 \mathrm{~N} 1104416 \mathrm{~W} \\
350822 \mathrm{~N} 1101027 \mathrm{~W}\end{array}$ \\
\hline $\begin{array}{l}\text { tower } \\
\text { tower } \\
\text { tower }\end{array}$ & $\begin{array}{l}\text { UNOFF } \\
\text { UNOFF }\end{array}$ & $\begin{array}{l}\text { Maricopa } \\
\text { Pima } \\
\text { Apache }\end{array}$ & $\begin{array}{l}332609 \mathrm{~N} 1120635 \mathrm{~W} \\
321321 \mathrm{~N} 1105815 \mathrm{~W} \\
340817 \mathrm{~N} 1091610 \mathrm{~W}\end{array}$ \\
\hline $\begin{array}{l}\text { tower } \\
\text { tower } \\
\text { tower } \\
\text { tower } \\
\text { tower } \\
\text { tower } \\
\text { tower } \\
\text { tower } \\
\text { tower } \\
\text { tower }\end{array}$ & $\begin{array}{l}\text { UNOFF } \\
\text { UNOFF } \\
\text { UNOFF } \\
\text { UNOFF } \\
\text { UNOFF } \\
\text { UNOFF } \\
\text { UNOFF } \\
\text { UNOFF } \\
\text { UNOFF } \\
\text { UNOFF }\end{array}$ & $\begin{array}{l}\text { Pinal } \\
\text { Pinal } \\
\text { Gila } \\
\text { Coconino } \\
\text { Pinal } \\
\text { Maricopa } \\
\text { Cochise } \\
\text { Cochise } \\
\text { Maricopa } \\
\text { Cochise }\end{array}$ & $\begin{array}{l}324926 \mathrm{~N} 1114208 \mathrm{~W} \\
325226 \mathrm{~N} 1114456 \mathrm{~W} \\
332251 \mathrm{~N} 1104525 \mathrm{~W} \\
345808 \mathrm{~N} 1113028 \mathrm{~W} \\
332454 \mathrm{~N} 1113253 \mathrm{~W} \\
332323 \mathrm{~N} 1115952 \mathrm{~W} \\
313253 \mathrm{~N} 1101454 \mathrm{~W} \\
313247 \mathrm{~N} 1101629 \mathrm{~W} \\
332844 \mathrm{~N} 1120006 \mathrm{~W} \\
313242 \mathrm{~N} 1101629 \mathrm{~W}\end{array}$ \\
\hline $\begin{array}{l}\text { tower } \\
\text { tower } \\
\text { tower } \\
\text { tower } \\
\text { tower } \\
\text { tower } \\
\text { tower } \\
\text { tower } \\
\text { tower } \\
\text { tower }\end{array}$ & $\begin{array}{l}\text { UNOFF } \\
\text { UNOFF } \\
\text { UNOFF } \\
\text { UNOFF } \\
\text { UNOFF } \\
\text { UNOFF } \\
\text { UNOFF } \\
\text { UNOFF } \\
\text { UNOFF } \\
\text { UNOFF }\end{array}$ & $\begin{array}{l}\text { Coconino } \\
\text { Pima } \\
\text { Maricopa } \\
\text { Yuma } \\
\text { Pima } \\
\text { Pima } \\
\text { Maricopa } \\
\text { Maricopa } \\
\text { Pima } \\
\text { Pima }\end{array}$ & $\begin{array}{l}360754 \mathrm{~N} 1111459 \mathrm{~W} \\
321519 \mathrm{~N} 1110031 \mathrm{~W} \\
332002 \mathrm{~N} 1120342 \mathrm{~W} \\
324242 \mathrm{~N} 1143858 \mathrm{~W} \\
320843 \mathrm{~N} 1105342 \mathrm{~W} \\
321157 \mathrm{~N} 1105654 \mathrm{~W} \\
332001 \mathrm{~N} 1120345 \mathrm{~W} \\
332000 \mathrm{~N} 1120346 \mathrm{~W} \\
322455 \mathrm{~N} 1104254 \mathrm{~W} \\
322455 \mathrm{~N} 1104254 \mathrm{~W}\end{array}$ \\
\hline $\begin{array}{l}\text { tower } \\
\text { tower } \\
\text { tower } \\
\text { tower } \\
\text { tower } \\
\text { tower } \\
\text { tower } \\
\text { tower } \\
\text { tower } \\
\text { tower }\end{array}$ & $\begin{array}{l}\text { UNOFF } \\
\text { UNOFF } \\
\text { UNOFF } \\
\text { UNOFF } \\
\text { UNOFF } \\
\text { UNOFF } \\
\text { UNOFF } \\
\text { UNOFF } \\
\text { UNOFF } \\
\text { UNOFF }\end{array}$ & $\begin{array}{l}\text { Maricopa } \\
\text { Maricopa } \\
\text { Yavapai } \\
\text { Maricopa } \\
\text { Yavapai } \\
\text { Pima } \\
\text { Pima } \\
\text { Pima } \\
\text { Yuma } \\
\text { Yavapai }\end{array}$ & $\begin{array}{l}332234 \mathrm{~N} 1115756 \mathrm{~W} \\
331957 \mathrm{~N} 1120353 \mathrm{~W} \\
344217 \mathrm{N1} 120655 \mathrm{~W} \\
335857 \mathrm{N1} 124420 \mathrm{~W} \\
340510 \mathrm{~N} 1120740 \mathrm{~W} \\
322456 \mathrm{~N} 1104249 \mathrm{~W} \\
321511 \mathrm{N1} 105744 \mathrm{~W} \\
322701 \mathrm{N11} 10339 \mathrm{~W} \\
323906 \mathrm{~N} 1143900 \mathrm{~W} \\
344315 \mathrm{~N} 1115955 \mathrm{~W}\end{array}$ \\
\hline $\begin{array}{l}\text { tower } \\
\text { tower } \\
\text { tower } \\
\text { tower } \\
\text { tower } \\
\text { tower } \\
\text { tower } \\
\text { tower } \\
\text { tower } \\
\text { tower }\end{array}$ & $\begin{array}{l}\text { UNOFF } \\
\text { UNOFF } \\
\text { UNOFF } \\
\text { UNOFF } \\
\text { UNOFF } \\
\text { UNOFF } \\
\text { UNOFF } \\
\text { UNOFF } \\
\text { UNOFF } \\
\text { UNOFF }\end{array}$ & $\begin{array}{l}\text { Navajo } \\
\text { Maricopa } \\
\text { Navajo } \\
\text { Navajo } \\
\text { Yuma } \\
\text { Maricopa } \\
\text { Cochise } \\
\text { Pima } \\
\text { Pinal } \\
\text { Coconino }\end{array}$ & $\begin{array}{l}341548 N 1100218 \mathrm{~W} \\
332411 \mathrm{N1} 120723 \mathrm{~W} \\
341314 \mathrm{N1} 100149 \mathrm{~W} \\
341314 \mathrm{~N} 1100149 \mathrm{~W} \\
324110 \mathrm{~N} 1142938 \mathrm{~W} \\
333606 \mathrm{~N} 1121730 \mathrm{~W} \\
321600 \mathrm{~N} 1094958 \mathrm{~W} \\
321511 \mathrm{N1} 105744 \mathrm{~W} \\
325609 \mathrm{N1} 114226 \mathrm{~W} \\
364642 \mathrm{~N} 1112546 \mathrm{~W}\end{array}$ \\
\hline $\begin{array}{l}\text { tower } \\
\text { tower } \\
\text { tower } \\
\text { tower } \\
\text { tower }\end{array}$ & $\begin{array}{l}\text { UNOFF } \\
\text { UNOFF } \\
\text { UNOFF } \\
\text { UNOFF } \\
\text { UNOFF } \\
\text { VARIANT }\end{array}$ & $\begin{array}{l}\text { Coconino } \\
\text { Maricopa } \\
\text { Pima } \\
\text { Graham } \\
\text { Yavapai }\end{array}$ & $\begin{array}{l}365423 \mathrm{~N} 1112732 \mathrm{~W} \\
332646 \mathrm{~N} 1121224 \mathrm{~W} \\
321146 \mathrm{~N} 1105902 \mathrm{~W} \\
324930 \mathrm{~N} 1094530 \mathrm{~W} \\
343303 \mathrm{~N} 1122745 \mathrm{~W}\end{array}$ \\
\hline $\begin{array}{l}\text { tower } \\
\text { tower } \\
\text { tower } \\
\text { tower }\end{array}$ & $\begin{array}{l}\text { UNOFF } \\
\text { UNOFF } \\
\text { UNOFF }\end{array}$ & $\begin{array}{l}\text { Yuma } \\
\text { Santa Cruz } \\
\text { Coconino } \\
\text { Cochise }\end{array}$ & $\begin{array}{l}324255 \mathrm{~N} 1143855 \mathrm{~W} \\
314218 \mathrm{~N} 1105526 \mathrm{~W} \\
351202 \mathrm{~N} 1113650 \mathrm{~W} \\
312852 \mathrm{~N} 1095730 \mathrm{~W}\end{array}$ \\
\hline
\end{tabular}

Phoenix

Lone Butte

Page

Lone Butte

Phoen ix

Casa Grande Mts

Lone Butte

Globe

Blackwater

Lone Butte

Tolleson

Lakes ide

Davis Dam SE

Davis Dam SE

Wins low

Turkey Track Butte

Tucson

Springerville

Casa Grande Mts

Casa Grande Mts

Globe

Mormon Mountain

Apache Junction

Tempe

Lewis Springs

Fort Huachuca

Phoen ix

Fort Huachuca

Tuba City

Jaynes

Lone Butte

Yuma West

Tucson

Tucson

Lone Butte

Lone Butte

Mount Bigelow

Mount Bigelow

Tempe

Lone Butte

Cottonwood

Wickenburg

Black Canyon City

Mount Bigelow

Tucson North

Ruelas Canyon

Yuma West

Cornville

Show Low North

Phoen ix

Show Low South

Show Low South

Fortuna

El Mirage

Willcox North

Tucson North

Casa Grande East

White Dome

Page

Fowler

Tucson

Thatcher

Prescott

5640 Mt Hopkins

Flagstaff East Bisbee 
NATIONAL GAZETTEER--ARIZONA 1986

FEATURE NAME

KZUL-AM (Parker)

KZZP-AM (Mesa)

KZZP-FM (Mesa)

KZZZ-FM (Kingman)

$K^{\prime} a i^{\prime} B i i^{\prime}$ To

See Kaibito

Kaaba Mine

See Kabba Mine

Kabba Mine

Kaaba Mine

Kabba Wash

Kabito

See Kaibito

Kabito Creek

See Kaibito Creek

Kabito Plateau

See Kaibito Plateau

Kabito Spring

See Kaibito Spring

Kachina Point

Kachina Points

Kachina School

Kahachi Miliuk

$\mathrm{Ka} \mathrm{Hill}$

Kaibab

Indian Moccas in

Kaibab Dam

Kaibab Elementary School

Kaibab Indian Reservation

Kaibab Paiute Reservation Kaibab-Paiute Reservation

Kaibab Lake

Kaibab Lake Campground

Kaibab Lodge

Kaibab National Forest

Kaibab Paiute Reservation See Kaibab Indian Reservation

Kaibab-Paiute Reservation See Kaibab Indian Reservation

Kaibab Plateau

Kaibab Spring

See Dutton Spring

Kaibab Trail

Kaibab Wash

Kaibeto

See Kaibito

Kaibi ito

See Kaibito

Kaibito

See Comar Spring

K-ai Bito

See Comar Spring

Kaibito

Kabito

Kaibeto

K'ai' Bii' To Kaibito

Kaibito Airport

Kaibito Boarding School

Kaibito Creek

Kabito Creek

Kaibito Wash

K-ai Bito Plateau See Kaibito Plateau

Kaibito Plateau

Kabito Plateau

K-ai Bito Plateau

Kai Peto Plateau

Kaipeto Plateau

K-ai Bito Spring
FEATURE

CLASS

STATUS

COUNTY

COOROINATE

tower UNOFF

tower UNOFF

pp)

mine

VARIANT

VARIANT

mine
mine

UNOFF

VARIANT

La Paz

Maricopa

Maricopa

Mohave

Coconino

$340914 \mathrm{~N} 1141715 \mathrm{~W}$

$332623 \mathrm{~N} 1115004 \mathrm{~W}$

332004 N1120335W

$351127 N 1140105 \mathrm{~W}$

Mohave

$363550 \mathrm{~N} 1110425 \mathrm{~W}$

$350532 N 1134321$

$350532 \mathrm{~N} 1134321 \mathrm{~W}$

stream BGN Mohave 350330N1133907

$363550 N 1110425 W$

ppl

stream

plain

spring

cliff

VARIANT

Coconino

365130 N111124BW

VARIANT

VARIANT

Coconino

362655 N1111710W

Coconino

$363554 \mathrm{N1110355 \textrm {W }}$

350504N1094715W

summit

school

locale

ppl

dam

school

reserve

BGN

Apache

BGN

UNOFF
BGN

BGN

BGN

VARIANT
UNOFF

UNOFF
UNOFF

BGN

VARIANT

VARIANT

Coconino

353407 N1105211W

Maricopa

Pima

Coconino

$333010 \mathrm{~N} 115915 \mathrm{~W}$

314 BO9N1114145W

351001 N1120031W

365348 N1124424W

Coconino

Maricopa

351706 N1120942W

$351706 \mathrm{~N} 1120942 \mathrm{~W}$

$365500 \mathrm{~N} 1124200 \mathrm{~W}$

reservoir $\quad B$

park

locale

BGN
ADMIN

BGN

VARIANT

reserve

VARIANT

reserve

Mohave

Coconino

$351704 \mathrm{~N} 1120942 \mathrm{~W}$

$351710 \mathrm{~N} 1120841 \mathrm{~W}$

$362450 \mathrm{~N} 1120758 \mathrm{~W}$

$355000 \mathrm{~N} 1120500 \mathrm{~W}$

Coconino

Coconino

Mohave

$365500 \mathrm{~N} 1124200 \mathrm{~W}$

Mohave

$365500 \mathrm{~N} 1124200 \mathrm{~W}$

plain

BGN 1974

Coconino

$\begin{array}{llll}\text { spring } & & \text { Coconino } & \text { UNKNOWN } \\ \text { trail } & \text { UNOFF } & \text { Coconino } & 360631 N 1120525 \mathrm{~W}\end{array}$

stream

BGN

VARIANT

ppl

ppl

VARIANT

Coconino

Coconino

$363550 \mathrm{~N} 1110425 \mathrm{~W}$

spring

Navajo

353151N1102456W

VARIANT

spring

pp 1

BGN 1968

VARIANT

VARIANT

VARIANT

VARIANT

airport

school

ADMIN

Coconino

Coconino

BGN 1968 Coconino

VARIANT

VARIANT

VARIANT

plain
plain

BGN 1968

VARIANT

VARIANT

VARIANT
Coconino 362655N1111710W

$362655 N 1111710 \mathrm{~W}$
(30N1110530W

$363453 \mathrm{~N} 1110532 \mathrm{~W}$

$365130 \mathrm{~N} 1111248 \mathrm{~W}$ tower UNOFF

$363500 \mathrm{~N} 1121000 \mathrm{~W}$ $\begin{array}{cc}\text { SOURCE } & \text { ELEV } \\ \text { COORDINATE } & \text { FT }\end{array}$

Parker

Mesa

Lone Butte

Kingman

Bottleneck Wash

350624 N113490BW

Bott leneck Wash

Kachina Point

Garces Mesas SE Paradise Valley Chiuli Shaik

72B7 Davenport Hil

Fredonia NW

6795 Williams North

Tempe

Moccas in

6795 Williams North Williams North Kanabownits Spring Red Butte

Telephone Hill

Phantom Ranch

Muggins Flat

$365412 \mathrm{~N} 1121552 \mathrm{~W}$

$363530 \mathrm{~N} 1105620 \mathrm{~W}$

6070 Kaibito

Kaibito

Cedar Tree Bench

Sitting Coyote Hill 
FEATURE NAME

See Kaibito Spring

Kaibito Spring

K-ai Bito Spring

Kabito Spring

Kai Peto Spring

Kaibito Springs

Kaipeto Spring

Kaibito Springs

See Kaibito Spring

Kaibito Wash

See Kaibito Creek

Kaihon Kug

old Quijotoa Well

Kailcheebito Spring

Kaipeto Plateau

See Kaibito Plateau

Kai Peto Plateau

See Kaibito Plateau

Kai Peto Spring

See Kaibito Spring

Kaipeto Spring

See Kaibito Spring

Kaiser Spring

Kaiser Spring Canyon

Kaiser Spring Wash

Kaiser Wash

Kaiser Wash Spring

Kaiser Waterhole

Kai Si Caude Well

Kai-Si-Kaid Well Number One

Kai-Si-Kaid Well Number Two

Kai Si Kato

Kai Si Kato

Kaitjimok

Kaka

See Gu Achi

Kaka Valley

Kaka Wash

Ka Kohl Hill

Ka Kotk Mountain

Kalbito Springs

Kamatuck

See Estrella, Sierra

Kambitch Reservoir

Kambitch Tank

Kana-a

See Kanaa Wash

Kana-a Creek

See Kanaa Wash

Kana-a Valley

See Kanaa Valley

Kanaa Valley

Kana-a Valley

Kanaa Wash

Kana a Wash

Kana-a

Kana-a Creek

Kana-a Wash

Kana a Wash

See Kanaa Wash

Kana-a Wash

See Kanaa Wash

Kanab Canyon

Kanab Creek

Kanab Mountains

See Kanab Plateau

Kanabownits Canyon

Kanabownits Lookout Tower

Kanabownits Spring

Kanab Plateau

Kanab Mountains CLASS

STATUS

COUNTY

spring

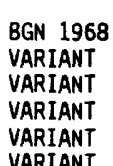

Coconine

Coconino

COORDINATE

SOURCE

COORDINATE ELEV

363554 N1110355W

$363554 N 1110355 W$

Kaibito

Vainom Kug

Sawmill

Apache 355613N1090819W

Coconino 362655N1111710W

Coconino

$362655 \mathrm{~N} 1111710 \mathrm{~W}$

VARIANT

spring

spring

spring

valley

arroyo

stream

spring

spring

well

well

well

spring

spring

ppl

ppl

valley

Coconino

363554 N1110355W

$365130 \mathrm{~N} 1111248 \mathrm{~W}$

VARIANT

VARIANT

VARIANT

VARIANT

BGN

$B G$

BGI

$B G N$

BGN

BGN

Coconino

Coconino

Mohave

Mohave

Mohave

Yuma

Mohave

Yuma

UNOFF

Navajo

Coconino

Coconino

Coconino

BGN

VARIANT

Coconino

Pima

BGN Maricopa

BGN Maricopa

Maricopa

summit

summit

spring

ridge

reservoir

reservoir

arroyo

BGN

BGN

Pima

Pima

Navajo

VARIANT

Pina1

Cochise

Cochise

VARIANT

Coconino

Coconino

363554N1110355W

$363554 N 1110355 \mathrm{~W}$

343559 N1132714W

$343338 N 1132944 \mathrm{~W}$

$343600 \mathrm{~N} 1132712 \mathrm{~W}$

$334637 N 1141927 \mathrm{~W}$

$345715 N 1133821 \mathrm{~W}$

$343928 N 1132402 W$

$343937 \mathrm{N1132353 \textrm {W }}$

$335052 N 1141917 \mathrm{~W}$

335038 N1141859W

360907 N1101609W

$363253 \mathrm{~N} 1112653 \mathrm{~W}$

$363247 N 1112658 \mathrm{~W}$

$361817 \mathrm{~N} 1104806 \mathrm{~W}$

$362428 \mathrm{N1} 104616 \mathrm{~W}$

$321925 \mathrm{~N} 1120226 \mathrm{~W}$

$323035 \mathrm{N1121857 \textrm {W }}$

$323405 N 1121211 \mathrm{~W}$

$323345 \mathrm{N11212} 2 \mathrm{WW}$

$323224 N 1122703 \mathrm{~W}$

$323212 \mathrm{N11} 22657 \mathrm{~W}$

$322149 \mathrm{N1113756 \textrm {W }}$

$320245 N 1120805$ W

353121 N1102538W

$331253 \mathrm{~N} 1121249 \mathrm{~W}$

$314520 \mathrm{N1} 091050 \mathrm{~W}$

$314434 \mathrm{~N} 1091103 \mathrm{~W}$

353412N1111629W

arroyo

VARIANT

$353412 \mathrm{~N} 1111629 \mathrm{~W}$

VARIANT

valley

valley

arroyo

BGN 1933

VARIANT

Coconin

Coconino

$353412 \mathrm{~N} 1111629 \mathrm{~W}$

$353412 \mathrm{~N} 1111629 \mathrm{~W}$

353412N1111629W

352145 N1112901W

VARIANT

VARIANT

VARIANT

VARIANT

VARIANT

arroyo

Coconino

$353412 \mathrm{~N} 1111629 \mathrm{~W}$

VARIANT

arroyo

valley

stream

BGN

BGN

VARIANT

plain

valley

tower

spring

BGN 1932

BGN 1932

VARIANT
Coconino

Coconino

Mohave

Mohave

Coconino

Coconino

Coconino

Mohave
353412 N1111629W

$362330 \mathrm{~N} 1123740 \mathrm{~W}$

362332 N1123745W

$36261 B N 1125253 \mathrm{~W}$

$361444 \mathrm{~N} 1121532 \mathrm{~W}$

$361726 N 1121240 \mathrm{~W}$

$361713 N 1121247 \mathrm{~W}$

$362618 \mathrm{N1125253 \textrm {W }}$
$362045 \mathrm{~N} 1120929 \mathrm{~W}$

$361935 N 1120754 W$
$372931 N 1122247 \mathrm{~W}$
Wupatki SE

Kaiser Spring

Kaiser Spring

Kaiser Spring

Moon Mtn SE

Pilgrim Wash

Moon Mtn SE

Coat Spring

Dove Spring

5855 Dove Spring

John Daw Mesa

Cow Springs

Kaka

Copperosity Hills

Copperosity Hills

Queens Well

Ben Nevis Mtn

Egloffstein Butte

Portal Peak

Apache

Wupatki SE
King Arthur Castle Kanab Point

Havasupai Point Kanabownits Spring Kanabownits Spring Hancock Knolls 
NATIONAL GAZETTEER--ARIZONA 1986

\section{FEATURE NAME}

Kanab Point

Kana Park

Kane

See Cane

Kane Cairn

See Cane Cairn

Kane Canyon

See Cane Canyon

Kane Corral

Kane Ranch

See Cane Ridge

Kane Spring

Kane Spring

Kane Spring

Kane Spring

Kane Spring

Kane Spring

See Cane Springs

Kane Spring Canyon Cane Spring Canyon Kane Springs Canyon

Kane Spring Mountain

Kane Spring Mountain

Kane Springs

Kane Springs

See Kanes Spring

Kane Springs

See Cane Springs

Kane Springs Canyon

See Kane Spring Canyon

Kane Springs Wash

See Cane Springs Wash

Kane Springs Wash

See Cone Wash

Kanes Spring

Kane Springs

Kane Trail

Kangaroo Headland

Kannally Ranch

Kannally Wash

Kans as Mine

Kansas Settlement

Kansas Substation

$K$ A Ranch

Karmella Mobile Home Park

Karrigan Peak

See Clara Peak

Karrigan Trading Post

Kartchner Substation

Kaska Badoya Well

Kasper Tunnel

Kast Ranch

Kate Tank

Katherine

Katherine Landing

Katherine Extension Mine

Katherine Landing See Katherine

Katherine Mine

Katherine Ranger Station

Katherine Wash

Kathy Tank

Kaufman Spring

Kaufman Tanks

Kavolik

Kavvaxiak

See Ko Vaya

Kawaika-A

Kay-Bee Mobile Villa
FEATURE

CLASS

STATUS

COUNTY

COORDINATE

$\begin{array}{lll}\text { cliff } & \text { BGN } & \text { Mohave } \\ \text { rapids } & \text { BGN 1932 Coconino }\end{array}$

park

VARIANT

locale

VARIANT

Coconino

$362326 \mathrm{N11} 23800 \mathrm{~W}$

$332659 \mathrm{~N} 1120239 \mathrm{~W}$

$363404 \mathrm{~N} 1120011$

local

VARIANT

valley

locale

BGN

Coconino

$363048 \mathrm{~N} 1115305 \mathrm{~W}$

Coconino

$363530 \mathrm{N11} 155805 \mathrm{~W}$

$363308 \mathrm{~N} 1120421 \mathrm{~W}$

locale

UNOFF

VARIANT

ridge

spring

spring

spring

spring

spring

BGN

BGN

BGN

BGN

VARIANT

spring

valley

BGN

VARIANT

VARIANT

summit

summit

spring

spring

spring

BGN

BGN

8GN

VARIANT

VARIANT

Santa Cruz

312928N1110330W

Coconino

Graham

Graham

Graham

Maricopa

Yavapai

Coconino

$363138 N 1120613 \mathrm{~W}$

$323148 N 1094801 \mathrm{~W}$

$325512 \mathrm{~N} 1100956 \mathrm{~W}$

$330925 \mathrm{~N} 1093716 \mathrm{~W}$

$332832 N 1111823$

363508 N1120240W

Pinal

Graham

Graham

Pinal

Pinal

Coconino

$330607 N 1105711 W$

323144 N1094835W

330911 N1093604W

330703N1105437W

331440 N1110425W

$363508 \mathrm{~N} 1120240 \mathrm{~W}$

VARIANT

valley

stream

VARIANT

Pinal

330607 N1105711W

valley

spring

trail

cliff

Mohave

BGN

VARIANT

UNOFF

Mohave

Pinal

Coconino

Coconino

locale

stream

mine

locale

locale

locale

locale

summit

locale

BGN

UNOFF

BGN

UNOFF

UNOFF

UNOFF

VARIANT

Pinal

Pinal

Santa Cruz

Cochise

Cochise

Maricopa

Maricopa

Yuma

Apache

locale UNOFF

well

tunnel

locale

reservoir

ppl

mine

UNOFF

UNOFF

UNOFF

8GN

BGN

UNOFF

VARIANT

ppl

mine UNOFF Mohave

locale

stream

reservoir

spring

reservoir

summit

UNOFF

$B G N$
$B G N$

BGN

$B G N$
$B G N$

BGN

ppl

locale

BGN

Cochise

Apache

Cochise

La Paz

Coconino

Mohave

Mohave

Mohave

Mohave

Mohave

Coconino

Coconino

Coconino

Pima

Pima

Navajo

locale UNOFF

Maricopa

$345446 \mathrm{~N} 1133726 \mathrm{~W}$

$345637 N 1134304 \mathrm{~W}$

$331440 \mathrm{~N} 1110425 \mathrm{~W}$

363341 N1120200W

362000 N1123648W

$323634 \mathrm{~N} 1104358 \mathrm{~W}$

$323839 \mathrm{~N} 1104139 \mathrm{~W}$

$312313 \mathrm{~N} 1104148 \mathrm{~W}$

$320354 \mathrm{~N} 1094544 \mathrm{~W}$

$320110 \mathrm{~N} 1094549 \mathrm{~W}$

$335802 \mathrm{~N} 1114132 \mathrm{~W}$

$332405 \mathrm{~N} 1115025 \mathrm{~W}$

$340950 \mathrm{~N} 1134840 \mathrm{~W}$

$353920 N 1090552 \mathrm{~W}$

$313400 \mathrm{~N} 1101833 \mathrm{~W}$

$353650 \mathrm{~N} 1093454 \mathrm{~W}$

$315916 \mathrm{~N} 1091709 \mathrm{~W}$

$334507 N 1134855 \mathrm{~W}$

$351811 \mathrm{~N} 1121740 \mathrm{~W}$

$351320 \mathrm{~N} 1143340 \mathrm{~W}$

351401 N1143125W
BGN 1932 Coconino

AOMIN Maricopa

$341131 \mathrm{~N} 1121639 \mathrm{~W}$

$\begin{array}{cc}\text { SOURCE } & \text { ELEV } \\ \text { COORDINATE } & \text { FT }\end{array}$

ELEV

AZ325

Kanab Point

Kanab Point

Phoenix

Pena Blanca Lake

Stockton Pass

Jackson Mtn

Elevator Mtn

Weavers Needle

Crown King

330841N1105430W Kearny

Stockton Pass

6698 Elevator Mtn

Kearny

Teapot Mountain

Cane 


\begin{tabular}{|c|c|c|c|c|c|c|c|}
\hline FEATURE NAME & $\begin{array}{l}\text { FEATURE } \\
\text { CLASS }\end{array}$ & STATUS & COUNTY & COORDINATE & $\begin{array}{l}\text { SOURCE } \\
\text { COORDINATE }\end{array}$ & $\begin{array}{c}\text { ELEV } \\
\text { FT }\end{array}$ & MAP NAME \\
\hline $\begin{array}{l}\text { Kayenta } \\
\text { See Tyende Mesa } \\
\text { Kayenta } \\
\text { Kayenta Airport } \\
\text { Kayenta Boarding School } \\
\text { Kayenta Creek } \\
\text { See Laguna Creek } \\
\text { Kayenta Elementary School } \\
\text { Kayenta Post Office }\end{array}$ & $\begin{array}{l}\text { summit } \\
\text { ppl } \\
\text { airport } \\
\text { school } \\
\text { stream } \\
\text { school } \\
\text { building }\end{array}$ & $\begin{array}{l}\text { VARIANT } \\
\text { BGN } \\
\text { AOMIN } \\
\text { UNOFF } \\
\text { VARIANT } \\
\text { UNOFF } \\
\text { UNOFF }\end{array}$ & $\begin{array}{l}\text { Navajo } \\
\text { Navajo } \\
\text { Navajo } \\
\text { Navajo } \\
\text { Apache } \\
\text { Navajo } \\
\text { Navajo }\end{array}$ & $\begin{array}{l}364759 \mathrm{~N} 1102004 \mathrm{~W} \\
364340 \mathrm{~N} 1101514 \mathrm{~W} \\
364635 \mathrm{~N} 1101410 \mathrm{~W} \\
364341 \mathrm{~N} 1101510 \mathrm{~W} \\
\\
365340 \mathrm{~N} 1094435 \mathrm{~W} \\
364350 \mathrm{~N} 1101526 \mathrm{~W} \\
364327 \mathrm{~N} 1101519 \mathrm{~W}\end{array}$ & & $\begin{array}{l}5641 \\
5710\end{array}$ & $\begin{array}{l}\text { Kayenta West } \\
\text { Kayenta East } \\
\text { Kayenta West } \\
\text { Kayenta West } \\
\text { Kayenta West }\end{array}$ \\
\hline $\begin{array}{l}\text { Kayenta Preschool } \\
\text { Kayfour Railroad Station } \\
\text { Kayler Butte } \\
\text { Kayler Spring } \\
\text { Kay Mine } \\
\text { Kay Tank } \\
\text { Kaytoggie Diversion Dam } \\
\text { Kaywood Wash } \\
\text { K Bar K Ranch } \\
\text { Kckel Spring }\end{array}$ & $\begin{array}{l}\text { school } \\
\text { building } \\
\text { summit } \\
\text { spring } \\
\text { mine } \\
\text { reservoir } \\
\text { dam } \\
\text { stream } \\
\text { locale } \\
\text { spring }\end{array}$ & $\begin{array}{l}\text { UNOFF } \\
\text { UNOFF } \\
\text { BGN } \\
\text { BGN } \\
\text { UNOFF } \\
\text { BGN } \\
\text { UNOFF } \\
\text { BGN } \\
\text { UNOFF } \\
\text { BGN }\end{array}$ & $\begin{array}{l}\text { Navajo } \\
\text { Yavapai } \\
\text { Gila } \\
\text { Gila } \\
\text { Yavapai } \\
\text { Yavapai } \\
\text { Navajo } \\
\text { Greenlee } \\
\text { Greenlee } \\
\text { Yavapai }\end{array}$ & $\begin{array}{l}364329 N 1101515 \mathrm{~W} \\
345340 \mathrm{~N} 1123219 \mathrm{~W} \\
335635 \mathrm{~N} 1111740 \mathrm{~W} \\
335634 \mathrm{~N} 1111805 \mathrm{~W} \\
340337 \mathrm{~N} 1120935 \mathrm{~W} \\
341035 \mathrm{~N} 1125909 \mathrm{~W} \\
335533 \mathrm{~N} 1095607 \mathrm{~W} \\
325142 \mathrm{~N} 1091050 \mathrm{~W} \\
333520 \mathrm{~N} 1090849 \mathrm{~W} \\
344935 \mathrm{~N} 1125200 \mathrm{~W}\end{array}$ & 325333 N1090419W & 2916 & $\begin{array}{l}\text { Kayenta West } \\
\text { Wineglass Ranch } \\
\text { Kayler Butte } \\
\text { Kayler Butte } \\
\text { Black Canyon City } \\
\text { O'Neill Pass } \\
\text { Alchesay Flat } \\
\text { Sheldon } \\
\text { Bear Mountain } \\
\text { Seepage Mtn }\end{array}$ \\
\hline $\begin{array}{l}\text { Keam } \\
\text { See Keams Canyon } \\
\text { Keam Canyon } \\
\text { See Keams Canyon } \\
\text { Keam Canyon } \\
\text { See Keams Canyon } \\
\text { Keams Canon } \\
\text { See Keams Canyon } \\
\text { Keams Canyon } \\
\text { Keam Canyon }\end{array}$ & $\begin{array}{l}\text { ppl } \\
\text { valley } \\
\text { ppl } \\
\text { ppl } \\
\text { valley }\end{array}$ & $\begin{array}{l}\text { VARIANT } \\
\text { VARIANT } \\
\text { VARIANT } \\
\text { VARIANT } \\
\text { BGN 1965 } \\
\text { VARIANT }\end{array}$ & $\begin{array}{l}\text { Navajo } \\
\text { Navajo } \\
\text { Navajo } \\
\text { Navajo } \\
\text { Navajo }\end{array}$ & $\begin{array}{l}354845 \mathrm{~N} 1101140 \mathrm{~W} \\
355010 \mathrm{~N} 1101415 \mathrm{~W} \\
354845 \mathrm{~N} 1101140 \mathrm{~W} \\
354845 \mathrm{~N} 1101140 \mathrm{~W} \\
355010 \mathrm{~N} 1101415 \mathrm{~W}\end{array}$ & $355300 \mathrm{~N} 1100430 \mathrm{~W}$ & & Keams Canyon \\
\hline $\begin{array}{l}\text { Keams Canyon } \\
\text { See Keams Canyon } \\
\text { Keams Canyon } \\
\text { Keam } \\
\text { Keam Canyon } \\
\text { Keams Canon } \\
\text { Keams Canyon } \\
\text { Peach Orchard Spring } \\
\text { Keams Canyon Boarding School } \\
\text { Keams Canyon Campground }\end{array}$ & $\begin{array}{l}\text { school } \\
\text { park }\end{array}$ & $\begin{array}{l}\text { VARIANT } \\
\text { BGN } 1915 \\
\text { VARIANT } \\
\text { VARIANT } \\
\text { VARIANT } \\
\text { VARIANT } \\
\text { VARIANT } \\
\text { UNOFF } \\
\text { ADMIN }\end{array}$ & $\begin{array}{l}\text { Navajo } \\
\text { Navajo }\end{array}$ & $\begin{array}{l}354837 N 1101123 W \\
354856 N 1101231 W\end{array}$ & & 6140 & $\begin{array}{l}\text { Keams Canyon } \\
\text { Keams Canyon }\end{array}$ \\
\hline $\begin{array}{l}\text { Keams Canyon Community Park } \\
\text { Keams Canyon Day School } \\
\text { Keams Canyon Post Office } \\
\text { Keams Canyon Road Interchange } \\
\text { Keams Canyon Wash } \\
\text { Keam Spring } \\
\text { Kearn Lake } \\
\text { Kearny } \\
\text { Kearny Airport } \\
\text { Keating Creek }\end{array}$ & $\begin{array}{l}\text { park } \\
\text { school } \\
\text { building } \\
\text { crossing } \\
\text { stream } \\
\text { spring } \\
\text { lake } \\
\text { ppl } \\
\text { airport } \\
\text { stream }\end{array}$ & $\begin{array}{l}\text { ADMIN } \\
\text { UNOFF } \\
\text { UNOFF } \\
\text { UNOFF } \\
\text { BGN } \\
\text { BGN } \\
\text { BGN } \\
\text { BGN } \\
\text { ADMIN } \\
\text { BGN }\end{array}$ & $\begin{array}{l}\text { Navajo } \\
\text { Navajo } \\
\text { Navajo } \\
\text { Navajo } \\
\text { Navajo } \\
\text { Gila } \\
\text { Apache } \\
\text { Pinal } \\
\text { Pinal } \\
\text { Cochise }\end{array}$ & $\begin{array}{l}354848 \mathrm{~N} 1101216 \mathrm{~W} \\
354835 \mathrm{~N} 1101121 \mathrm{~W} \\
354842 \mathrm{~N} 1101147 \mathrm{~W} \\
345825 \mathrm{~N} 1100515 \mathrm{~W} \\
354925 \mathrm{~N} 1102249 \mathrm{~W} \\
333207 \mathrm{~N} 1102559 \mathrm{~W} \\
343446 \mathrm{~N} 1091438 \mathrm{~W} \\
330325 \mathrm{~N} 1105436 \mathrm{~W} \\
330251 \mathrm{~N} 1105430 \mathrm{~W} \\
320441 \mathrm{~N} 1091039 \mathrm{~W}\end{array}$ & $\begin{array}{l}355016 \mathrm{~N} 1101400 \mathrm{~W} \\
320303 \mathrm{~N} 1091720 \mathrm{~W}\end{array}$ & 1828 & $\begin{array}{l}\text { Keams Canyon } \\
\text { Keams Canyon } \\
\text { Keams Canyon } \\
\text { Sun Valley } \\
\text { Polacca } \\
\text { Cassadore Spring } \\
\text { Kearn Lake } \\
\text { Kearny } \\
\text { Kearny } \\
\text { Blue Mountain }\end{array}$ \\
\hline $\begin{array}{l}\text { Keating Ridge } \\
\text { Keats Crossing (subdivision) } \\
\text { Keays Tank } \\
\text { KE Canyon } \\
\text { Keefer Hill } \\
\text { Keenan Camp } \\
\text { Keen School } \\
\text { Ke-en-ta } \\
\text { See Tyende Mesa } \\
\text { Ke-en-ta Creek } \\
\text { See Laguna Creek }\end{array}$ & $\begin{array}{l}\text { ridge } \\
\text { ppl } \\
\text { reservoir } \\
\text { valley } \\
\text { summit } \\
\text { locale } \\
\text { school } \\
\text { summit } \\
\text { stream }\end{array}$ & $\begin{array}{l}\text { BGN } \\
\text { BGN } \\
\text { BGN } \\
\text { BGN } \\
\text { BGN } \\
\text { BGN } \\
\text { UNOFF } \\
\text { VARIANT } \\
\text { VARIANT }\end{array}$ & $\begin{array}{l}\text { Navajo } \\
\text { Maricopa } \\
\text { Graham } \\
\text { Greenlee } \\
\text { Maricopa } \\
\text { Mohave } \\
\text { Pima } \\
\text { Navajo } \\
\text { Apache }\end{array}$ & $\begin{array}{l}341724 \mathrm{~N} 1102240 \mathrm{~W} \\
332236 \mathrm{~N} 1115143 \mathrm{~W} \\
331050 \mathrm{~N} 1094404 \mathrm{~W} \\
334424 \mathrm{~N} 1090537 \mathrm{~W} \\
334416 \mathrm{~N} 1121316 \mathrm{~W} \\
342323 \mathrm{~N} 1134612 \mathrm{~W} \\
321151 \mathrm{~N} 1105458 \mathrm{~W} \\
364759 \mathrm{~N} 1102004 \mathrm{~W} \\
\\
365340 \mathrm{~N} 1094435 \mathrm{~W}\end{array}$ & $334608 \mathrm{~N} 1090602 \mathrm{~W}$ & $\begin{array}{l}1210 \\
1696\end{array}$ & $\begin{array}{l}\text { Day Spring } \\
\text { Mesa } \\
\text { Park Creek Cabins } \\
\text { Maness Peak } \\
\text { Hedgpeth Hills } \\
\text { McCracken Peak } \\
\text { Tucson }\end{array}$ \\
\hline $\begin{array}{l}\text { Keesler Tank } \\
\text { See Kessler Tank } \\
\text { Keet Seel } \\
\text { See Keet Seel Ruin } \\
\text { Keet Seel Canyon } \\
\text { Keet Seel Ruin } \\
\text { Keet Seel } \\
\text { Khinitzel Ruin } \\
\text { Kiet Seel } \\
\text { Kietzeel } \\
\text { Kit siel } \\
\text { Kit sil } \\
\text { Kit Sil }\end{array}$ & $\begin{array}{l}\text { reservoir } \\
\text { locale } \\
\text { valley } \\
\text { locale }\end{array}$ & $\begin{array}{l}\text { VARIANT } \\
\text { VARIANT } \\
\text { BGN } \\
\text { BGN } \\
\text { VARIANT } \\
\text { VARIANT } \\
\text { VARIANT } \\
\text { VARIANT } \\
\text { VARIANT } \\
\text { VARIANT } \\
\text { VARIANT }\end{array}$ & $\begin{array}{l}\text { Coconino } \\
\text { Navajo } \\
\text { Navajo } \\
\text { Navajo }\end{array}$ & $\begin{array}{l}350852 N 1121922 \mathrm{~W} \\
364539 \mathrm{~N} 1102939 \mathrm{~W} \\
364153 \mathrm{~N} 1103019 \mathrm{~W} \\
364539 \mathrm{N1} 102939 \mathrm{~W}\end{array}$ & $364659 \mathrm{~N} 1102915 \mathrm{~W}$ & & $\begin{array}{l}\text { Betatakin Ruin } \\
\text { Keet Seel Ruin }\end{array}$ \\
\hline
\end{tabular}


Kits-il

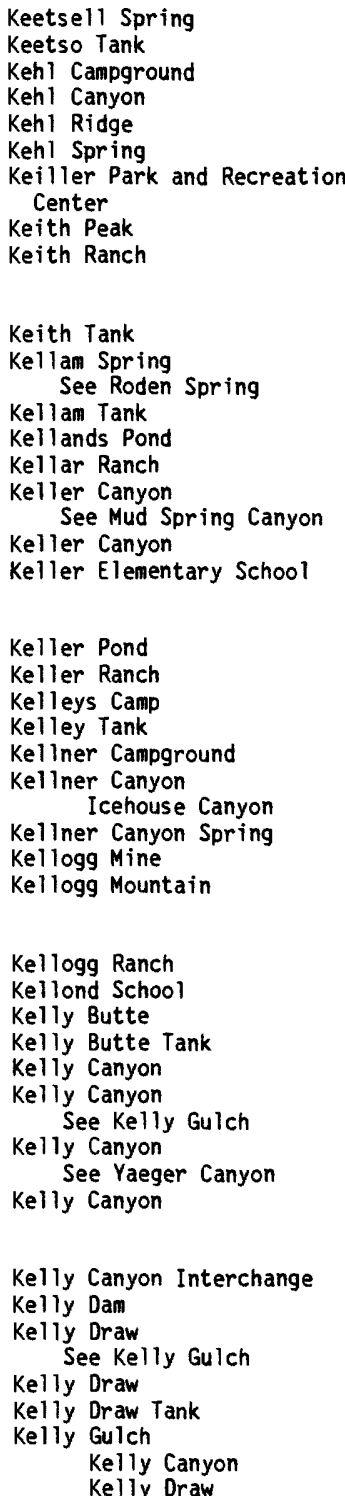

FEATURE
CLASS

STATUS

COUNTY

COORDIMATE

spring

reservoir

park

valley

ridge

spring

park

summit

locale

reservoir

spring

reservoir

reservoir

locale

valley

valley

school

$\begin{array}{lll}\text { reservoir } & \text { BGN } & \text { Mohave } \\ \text { locale } & \text { UNOFF } & \text { Cochise } \\ \text { locale } & \text { BGN } & \text { Pinal } \\ \text { reservoir } & \text { BGN } & \text { Coconino } \\ \text { park } & \text { AOMIN } & \text { Gila } \\ \text { valley } & \text { BGN 1965 } & \text { Gila } \\ & \text { VARIANT } & \\ \text { spring } & \text { BGN } & \text { Gila } \\ \text { mine } & \text { UNOFF } & \text { Yuma }\end{array}$

summ it

loca
sch
sum
res
val
vall
val
val

crossing

dam

valley

valley

reservoir

valley

bas in

cliff

spring

spring

reservoir

reservoir

reservoir

reservoir

valley

spring

$\begin{array}{lll}\text { locale } & \text { BGN } & \text { Pinal } \\ & \text { VARIANT } & \\ \text { VARIANT } & \\ \text { cemetery } & \text { UNOFF } & \text { Pinal } \\ \text { reservoir } & \text { BGN } & \text { Pima } \\ \text { locale } & \text { BGN } & \text { Mohave } \\ \text { locale } & \text { BGN } & \text { Yavapai } \\ \text { summit } & \text { BGN } & \text { Yavapai } \\ \text { locale } & \text { UNOFF } & \text { Cochise }\end{array}$

Graham

Coconino

Coconino

Mohave

Coconino

Cochise

Gila

Coconino

Coconino

Coconino

Mohave

Cochise

Coconino

BGN

VARIANT
$351558 \mathrm{~N} 1090709 \mathrm{~W}$

$354435 \mathrm{~N} 1113416 \mathrm{~W}$

$342608 \mathrm{~N} 1111857 \mathrm{~W}$

342911 N1111848W

$342724 \mathrm{~N} 1111912 \mathrm{~W}$

$342608 \mathrm{~N} 1111859 \mathrm{~W}$

$321539 \mathrm{N1} 1095031 \mathrm{~W}$

320655N1101315W

$320720 N 1101324 W$

350812N1113853W

$352501 \mathrm{~N} 1111725 \mathrm{~W}$

$350735 N 1113857 \mathrm{~W}$

$364327 N 1131601 \mathrm{~W}$

$314601 \mathrm{N1} 101338 \mathrm{~W}$

$332435 \mathrm{~N} 1090048 \mathrm{~W}$

$332442 \mathrm{N1085528 \textrm {W }}$

$332315 N 1114755 \mathrm{~W}$

$363205 N 1132151 \mathrm{~W}$

$313711 \mathrm{N1100645 \textrm {W }}$

$325751 \mathrm{M} 1104055 \mathrm{~W}$

$343726 \mathrm{~N} 1112152 \mathrm{~W}$

$332006 \mathrm{~N} 1104942 \mathrm{~W}$

$332135 \mathrm{~N} 1104710 \mathrm{~W}$

$331829 \mathrm{M} 1105020 \mathrm{~W}$

$333557 N 1141752 \mathrm{~W}$

322449N1104232W

$314005 \mathrm{~N} 1104018 \mathrm{~W}$

$321254 \mathrm{N1} 105059 \mathrm{~W}$

$334707 \mathrm{N1} 100640 \mathrm{~W}$

$334742 \mathrm{N1} 100831 \mathrm{~W}$

330358N1101909W

$331101 N 1102439 \mathrm{~W}$

Coconino

350250N1110403W

$350332 \mathrm{N1114259W}$

350307 N1114055W

360951 N1133229W

$331101 N 1102439 \mathrm{~W}$

$340151 \mathrm{~N} 1103657 \mathrm{~W}$

$340200 N 1103705 \mathrm{~W}$

$331101 \mathrm{N1} 102439 \mathrm{~W}$

350417 N1114200W

$355004 N 1132818 \mathrm{~W}$

$350340 \mathrm{~N} 1114118 \mathrm{~W}$

$312433 \mathrm{N1} 101556 \mathrm{~W}$

$330706 \mathrm{~N} 1104957 \mathrm{~W}$

$345138 \mathrm{N1113101 \textrm {W }}$

$350303 \mathrm{~N} 1113916 \mathrm{~W}$

$352508 \mathrm{~N} 1114214 \mathrm{~W}$

$355357 \times 1132532 \mathrm{~W}$

$321405 \mathrm{~N} 1101908 \mathrm{~W}$

$350432 \mathrm{N1115604 \textrm {W }}$

$330641 \times 1105822 W$

$330632 \mathrm{~N} 1105726 \mathrm{~W}$

$314619 \mathrm{~N} 1111258 \mathrm{~W}$

$353604 \mathrm{~N} 1142747 \mathrm{~W}$

$342604 \mathrm{~N} 1122708 \mathrm{~W}$

343919 N1120855W

$314535 \mathrm{~N} 1095318 \mathrm{~W}$ $\begin{array}{cc}\text { SOURCE } & \text { ELEV } \\ \text { COORDINATE } & \text { FT }\end{array}$

MAP NAME

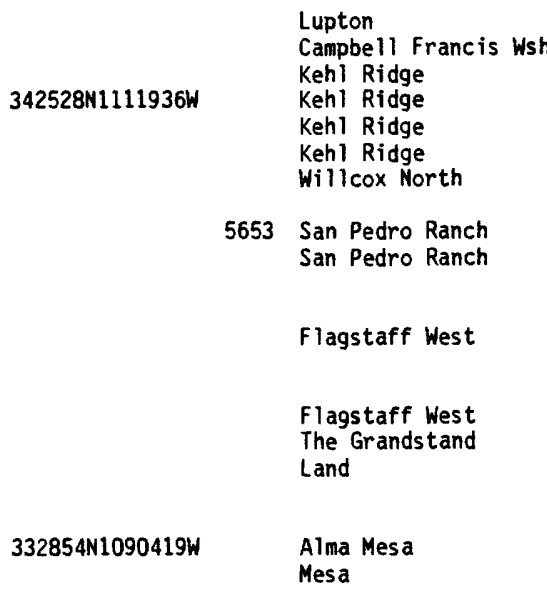

Russell Spring

Tombstone SE

Dudleyville

Long Valley

Pinal Peak

Pinal Peak

$331744 N 1105033$

Pinal Peak

Cunningham Mtn

Mount 8igelow

Sonoita

Tucson East

6130 Canyon Day

Cone Butte

330345N1101710w Mt Turnbuli

350201M1113837W Mountainaire

Mountainaire

Castle Peak

340219N1103727W Spotted Mountain

Spotted Mountain

San Carlos Reservoir

$330411 \mathrm{N1102027 \textrm {N }}$

Mountainaire

Travertine Rapids

Mountainaire

Miller Peak

Hayden

Stoneman Lake

Mountainaire

White Horse Hills

Price Point

321354N1101301W Wildhorse Mtn

Sycamore Point

Kearny

Kearny

Batamote Hills

Middle Water Spring Groom Creek

7088 Hickey Mountain Black Diamond Peak 


\section{FEATURE NAME}

Kendall Substation

Kenda II Tank

Kendrick Mountains

Kendrick Park

Kendrick Park Picnic Ground

Kendrick Peak Mount Kendrick

Kendrick Peak Trail

Kendrick Recreation Site

Kendrick Spring

Kendrick Spring

Kendrick Tank

Kendrick Tank

Kenilworth School

Kenilworth School

Ken Lindley Park

Kennecott Cooper Corporation

Hospital

Kennedy Cemetery

Kennedy Dam

Kennedy Falls Spring

Kennedy Falls Wash

Kennedy Park Creek

Kennedy Park Dam

Kennedy Pasture Spring

Kennedy Peak

Kennedy Ranch

Kennedy Ranch

Kennedy Spring

Kennedy Spring

Kennedy Tank

Kennedy Tank

Kennedy Well

Kennedy Windmill

Kenneth Tank

Kenny Tank

Kenny Well

Kensington (subdivision)

Kens Tank

Kens Tank

Kent Lateral

Kent Ranch

Kent Spring

Kent Spring Trail 156

Kentuck Mountain Kentucky Mountain

Kentucks Cabin

Kentucks Grave

Kentuck Spring

Kentuck Spring Campground

Kentucky Gulch

Kentucky Mountain See Kentuck Mountain

Kenworthy Ranch

Kenyon Ranch

Kenyon Station

Kinyon Station Murderers Grave Rancheria de San Diego

Kenyon Tank

Ke-opke See Shopishk

Kerley Valley
Kerrigan Peak

Kerwo

See Clara Peak

See Gu Vo

Kerwo Day School

Kerwo Well

Keseha Ranch
FEATURE
CLASS

STATUS COUNTY

COORDINATE

locale

UNOFF

Cochise

314451 N1095346W

reservoir

range

flat

park

summit

trail

park

spring

spring

BGN Navajo

BGN

BGN

ADMIN

BGN

VARIANT

UNOFF

ADMIN
BGN
BGN

BGN

Yavapai

Coconino

Coconino

Coconino

Coconino

Coconino

Gila

Coconino

reservoir BGN Coconino

reservoir

reservoir

school

schoo

park

BGN

UNOFF

UNOFF

ADMIN
UNOFF

Coconino

Pinal

Maricopa

Yavapai

Pinal

cemetery

dam

UNOFF

spring

UNOFF

Graham

Coconino

Graham

$\begin{array}{lll}\text { stream } & \text { BGN } & \text { Graham } \\ \text { stream } & \text { BGN } & \text { Pima } \\ \text { dam } & \text { UNOFF } & \text { Pima } \\ \text { spring } & \text { BGN } & \text { Pinal } \\ \text { summit } & \text { BGN } & \text { Graham } \\ \text { locale } & \text { UNOFF } & \text { Cochise } \\ \text { locale } & \text { UNOFF } & \text { Pinal } \\ \text { spring } & \text { 8GN } & \text { Santa Cruz } \\ \text { spring } & \text { BGN } & \text { Pinal } \\ \text { reservoir } & \text { BGN } & \text { Maricopa }\end{array}$

$342722 N 1103727 W$

$342640 \mathrm{~N} 1124743 \mathrm{~W}$

$352448 N 1114504 W$

$352530 \mathrm{~N} 1114525 \mathrm{~W}$

$352429 \mathrm{~N} 1115100 \mathrm{~W}$

$352410 \mathrm{~N} 1115104 \mathrm{~W}$

$352530 \mathrm{~N} 1114540 \mathrm{~W}$

$334709 \mathrm{~N} 1105040 \mathrm{~W}$

$352638 \mathrm{N1} 115021 \mathrm{~W}$

$352440 \mathrm{~N} 1114344 \mathrm{~W}$

$352525 \mathrm{~N} 1114857 \mathrm{~W}$

$325828 \mathrm{~N} 1112853 \mathrm{~W}$

$332744 \mathrm{~N} 1120449 \mathrm{~W}$

$343234 \mathrm{~N} 1122733 \mathrm{~W}$

$330333 \mathrm{N1} 105434 \mathrm{~W}$

$323827 N 1100921 \mathrm{~W}$

$350322 \mathrm{~N} 1115903 \mathrm{~W}$

$324553 \mathrm{~N} 1101051 \mathrm{~W}$

$324341 \mathrm{~N} 1101316 \mathrm{~W}$

$321048 \mathrm{~N} 1110002 \mathrm{~W}$

$321048 \mathrm{~N} 1110024 \mathrm{~W}$

$331546 \mathrm{~N} 1105739 \mathrm{~W}$

323B11N1101819W

312709 N1101353W

$332614 \mathrm{~N} 1110416 \mathrm{~W}$

$313019 \mathrm{~N} 1103825 \mathrm{~W}$

$332239 \mathrm{~N} 1110312 \mathrm{~W}$

$325451 \mathrm{~N} 1131232 \mathrm{~W}$

reservoir BGN Coconino 344419N1111601W

well

locale

reservoir

reservoir

well

ppl

reservoir

reservoir

UNOFF

BGN

BGN

UNOFF

BGN

VARIANT

BGN

Maricopa

Yavapai

Coconino

Santa Cruz

Pima

Maricopa

Coconino

Coconino

$344419 \mathrm{~N} 1111601 \mathrm{~W}$
$325252 \mathrm{~N} 1131239 \mathrm{~W}$

$342632 \mathrm{~N} 1123938 \mathrm{~W}$

$344028 \mathrm{~N} 1111714 \mathrm{~W}$

$312010 \mathrm{~N} 1103109 \mathrm{~W}$

$314722 \mathrm{~N} 1111124 \mathrm{~W}$

333700N1115825W

$324735 \mathrm{~N} 1101035 \mathrm{~W}$ $321051 N 1110024 \mathrm{~W}$

343943N1110859W

$344921 \mathrm{~N} 1112031 \mathrm{~W}$

canal

locale

spring

BGN

UNOFF

Yuma

$324220 \mathrm{~N} 1143838 \mathrm{~W}$

$361836 \mathrm{~N} 1130428 \mathrm{~W}$

$314245 \mathrm{~N} 1105122 \mathrm{~W}$

$314247 \mathrm{~N} 1105122 \mathrm{~W}$

335449 N1114700W

summit

locale

UNOFF

BGN

VARIANT

cemetery

UNOFF

BGN

Santa Cruz

Santa Cruz

Maricopa

Yavapai

Yavapai

Maricopa

$340805 \mathrm{~N} 1122140 \mathrm{~W}$

$340809 \mathrm{~N} 1122137 \mathrm{~W}$

$335442 \mathrm{~N} 1114910 \mathrm{~W}$

$341031 \mathrm{N1121635W}$

314414N1104343W

valley BGN Pima

summ it

locale

locale

locale

UNOFF

UNOFF

BGN

VARIANT

VARIANT

VARIANT

reservoir BGN

Santa Cruz

313639 N1110400W

$314510 \mathrm{~N} 1104537 \mathrm{~W}$

335449 N1114700W

Maricopa

Santa Cruz

$362721 \mathrm{N1131240 \textrm {W }}$

$313647 \mathrm{~N} 1110347 \mathrm{~W}$

330145 N1125540W

VARIANT

ppl

valley

BGN

Pinal

324317 N1114652W

summit VARIANT Yuma 340950N1134840W

ppl

school

UNOFF

UNOFF
UNOFF

UNOFF
Pima

Pima

Pima

Coconino
SOURCE
COORDINATE

ELEV
FT

MAP NAME

Outlaw Mountain

Heber

4199 Bismarck Mesa Kendrick Peak

Kendrick Peak

1041 Kendrick Peak

Kendrick Peak

7840 Kendrick Peak

Sombrero Peak

Kendrick Peak

White Horse Hills

Kendrick Peak

Valley Farms

Phoen ix

Prescott

Kearny

Eureka Ranch

Sycamore Point Buford $\mathrm{Hill}$

Eureka Ranch

Cat Mountain

2443 Cat Mountain Pinal Ranch

7549 Kennedy Peak 
FEATURE NAME

FEATURE

CLASS

STATUS

COUNTY

COORDINATE

$\begin{array}{cc}\text { SOURCE } & \text { ELEV } \\ \text { COORDINATE } & \text { FT }\end{array}$

MAP NAME

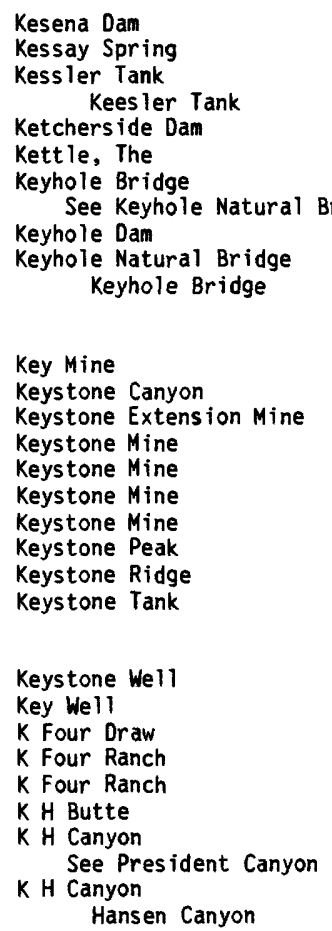

\begin{tabular}{|c|c|c|c|}
\hline $\begin{array}{l}\text { dam } \\
\text { spring } \\
\text { reservoir }\end{array}$ & $\begin{array}{l}\text { UNOFF } \\
\text { BGN } \\
\text { BGN } \\
\text { VARIANT }\end{array}$ & $\begin{array}{l}\text { Coconino } \\
\text { Apache } \\
\text { Coconino }\end{array}$ & $\begin{array}{l}353209 \mathrm{N1} 125314 \mathrm{~W} \\
340153 \mathrm{~N} 1093457 \mathrm{~W} \\
350852 \mathrm{~N} 1121922 \mathrm{~W}\end{array}$ \\
\hline $\begin{array}{l}\text { dam } \\
\text { bas in }\end{array}$ & $\begin{array}{l}\text { UNOFF } \\
\text { BGN } \\
\text { VARIANT }\end{array}$ & $\begin{array}{l}\text { Yuma } \\
\text { Coconino }\end{array}$ & $\begin{array}{l}330232 N 11405 \\
365608 \text { N11057 }\end{array}$ \\
\hline $\begin{array}{l}\operatorname{arch} \\
\operatorname{dam} \\
\operatorname{arch}\end{array}$ & $\begin{array}{l}\text { UNOFF } \\
\text { BGN } \\
\text { VARIANT }\end{array}$ & $\begin{array}{l}\text { Coconino } \\
\text { Mohave } \\
\text { Coconino }\end{array}$ & $\begin{array}{l}362248 N 11234 \\
361226 \times 11317 \\
362248 \times 11234\end{array}$ \\
\hline
\end{tabular}

\begin{tabular}{|c|c|c|c|}
\hline $\begin{array}{l}\text { mine } \\
\text { valley } \\
\text { mine } \\
\text { mine } \\
\text { mine } \\
\text { mine } \\
\text { mine } \\
\text { summit } \\
\text { ridge } \\
\text { reservoir }\end{array}$ & $\begin{array}{l}\text { UNOFF } \\
\text { BGN } \\
\text { UNOFF } \\
\text { UNOFF } \\
\text { UNOFF } \\
\text { UNOFF } \\
\text { UNOFF } \\
\text { BGN } \\
\text { BGN } \\
\text { BGN }\end{array}$ & $\begin{array}{l}\text { Mohave } \\
\text { Pinal } \\
\text { Mohave } \\
\text { Cochise } \\
\text { Yuma } \\
\text { Yavapai } \\
\text { Mohave } \\
\text { Pima } \\
\text { Gila } \\
\text { Pima }\end{array}$ & $\begin{array}{l}343124 \mathrm{~N} 1132220 \mathrm{~W} \\
330046 \mathrm{N1} 104914 \mathrm{~W} \\
352024 \mathrm{N1} 133707 \mathrm{~W} \\
320534 \mathrm{N1} 100330 \mathrm{~W} \\
330237 \mathrm{N1} 140104 \mathrm{~W} \\
340303 \mathrm{N1} 123437 \mathrm{~W} \\
352234 \mathrm{N1} 140907 \mathrm{~W} \\
315237 \mathrm{N1} 111252 \mathrm{~W} \\
335433 \mathrm{N1} 104358 \mathrm{~W} \\
315254 \mathrm{N1} 111244 \mathrm{~W}\end{array}$ \\
\hline
\end{tabular}

well UNOFF Apache 345509N1093125W

well UNOFF

valley

locale

locale

summit

valley

valley

GNOFF Gila

BGN

UNOFF

BGN

VARIANT

BGN 1975
VARIANT

VARIANT

locale

locale

locale

summit

valley

valley

dam

spring

reservoir

reservoir

valley

arroyo

valley

UNOFF

VARIANT

BGN 1932

VARIANT

BGN

VARIANT

Coconino

Yavapai

Coconino

Graham

Graham

Graham

Navajo

Graham

Pima

Coconino

Graham

Graham

BGN

$B G N$
$B G N$

BGN

VARIANT

BGN

BGN 1941

VARIANT

VARIANT

summi

reservoir

BGN 1941
VARIANT

VARIANT

VARIANT

locale

VARIANT

locale

locale

valley

UNOFF

VARIANT

Gila

Gila

Gila

Coconino

Mohave

Pinal

Graham

Graham

Navajo

Navajo

Santa Cruz

Pinal

VARIANT

valley

summit

reservoir

locale

locale

summit

$\begin{array}{ll}\text { VARIANT } & \text { Pinal } \\ \text { BGN } & \text { Graham } \\ \text { BGN } & \text { Coconino } \\ \text { BGN } & \text { Graa } \\ \text { VARIANT } & \\ \text { BGN 1931 } & \text { Pima }\end{array}$

323413N1102057W

323458 N1102031W

$364539 \mathrm{N1102939 \textrm {W }}$

$312627 \mathrm{~N} 1103517 \mathrm{~W}$

323252N11D2943W

$323252 \mathrm{~N} 1102943 \mathrm{~W}$

$323413 \mathrm{~N} 1102057 \mathrm{~W}$

$351306 \mathrm{~N} 1115631 \mathrm{~W}$

$324405 \mathrm{~N} 1134206 \mathrm{~W}$

$325346 \mathrm{~N} 1094629 \mathrm{~W}$
$332736 \mathrm{~N} 1102737 \mathrm{~W}$

352159 N1121538W $345543 \mathrm{~N} 1124832 \mathrm{~W}$

$352002 \mathrm{~N} 1121628 \mathrm{~W}$

$324238 \mathrm{~N} 1100504 \mathrm{~W}$

$323955 \mathrm{~N} 1100938 \mathrm{~W}$ $323955 \mathrm{~N} 1101000 \mathrm{~W}$

324347 N1100300W

$364539 \mathrm{~N} 1102939 \mathrm{~W}$ $324254 \mathrm{~N} 1100503 \mathrm{~W}$

$321000 \mathrm{~N} 1120730 \mathrm{~W}$ $361458 \mathrm{~N} 1115841 \mathrm{~W}$

$332655 \mathrm{~N} 1101033 \mathrm{~W}$ $332655 \mathrm{~N} 1101033 \mathrm{~W}$

$332937 \mathrm{~N} 1100505 \mathrm{~W}$ $331230 \mathrm{~N} 1103126 \mathrm{~W}$ $332938 \mathrm{~N} 1100507 \mathrm{~W}$ $315134 \mathrm{N1111109 \textrm {W }}$ 365100 N1114740W

$343142 \mathrm{~N} 1132816 \mathrm{~W}$ $323252 \mathrm{~N} 1102943 \mathrm{~W}$

$364858 \mathrm{~N} 1115039 \mathrm{~W}$

343022N1132B51W $323440 \mathrm{~N} 1101930 \mathrm{~W}$
Rhodes Canyon Greens Peak McLellan Reservoir

Slumgullion Pass Chaiyahi Flat

Whitmore Point Fishtail

\section{N1104834W}

Grayback Mts Hayden Valentine SE Dragoon Slumgullion Pass Morgan Butte Chloride

6206 Samaniego Peak Double Buttes Samaniego Peak

Ninemile Seep Natural Corral Hearst Mtn Indian Peak Hearst Mtn Blue Jay Peak

Eureka Ranch

Blue Jay Peak

Walhalla Plateau

Bronco Gulch

Ash Creek ME Coolidge Dam

5476 Ash Creek NE Batamote Hills The Big Knoll

Kaiser Spring Kielberg Canyon

Bassett Peak

Bassett Peak

Cane 10 Pass

Garland Prairie Mowhawk Mts NW Pima

7255 Oro Valley 
FEATURE CLASS
STATUS

COUNTY
COORDINATE

Kimball Peak

See Kimba11, Mount

Kimberly Peak

Kimble Canyon

Kimble Canyon Well

Kimble Ranch

Kimble Tank

Kinder Crossing

Kinder Crossing Trail

Kinder Draw

Kinder Spring

Kinder Tank

King Arthur Castle

King Benjamin Mine

King Benjamin Mine

King Canyon

King Canyon

See King Gulch

King Canyon

King Creek

King Crest

King Gulch

King Canyon

Kinght Canyon

See Wood Canyon

Kingler Spring

See Kinglet Spring

Kinglet Spring

Kingman Kingler Spring

Kingman Airfield

Kingman Airport

Mohave County Airport

Kingman City Hall

Kingman High School Kingman Union High School

Kingman Junior High School

Kingman Post Office

Kingman Railroad Station

Kingman Union High School See Kingman High School

Kingman Wash

Deadman Wash

King Memorial Center

King of Arizona Mine

King of Lead Mine

King Peak

King Ride

See Green Valley Hills

King Ridge

King Ridge Tank

Kingsbury Mountain

Kingsbury Spring

Kings Canyon

Kings Crown Peak

Kingsgate (subdivision)

King Solomon Gulch

King Solomon Mine

King Spring

Kings Ranch

Kingston Knolls Terrace

Kings Well

Kings Well

King Tank

King Tank

King Tank Number Three

King Tut Placer Mine

King Tutt Mesa (historical)

King Valley

King Well

King Well

summit
summit
valley
well
locale
reservoir
locale
trail
valley

VARIANT

Pima

BGN Yavapa

BGN Mohave

UNOFF

UNOFF

BGN

UNOFF Coconino

BGN

Coconino
Coconino

spring BGN Coconino 343032N1111B43W

reservoir

summit

mine

mine

valley

valley

valley

stream

summit

valley

valley

spring

spring

pp]

BGN

BGN 1908

UNOFF

UNOFF

BGN

VARIANT

$B G$

Coconino

Coconino

Yavapai

Yavapai

Pima

Yavapai

BGN

Greenlee

BGN 190B Coconino

BGN Greenlee

VARIANT

VARIANT

VARIANT

Greenlee

Pima
Pima

BGN 1981 Pima

VARIANT

BGN

Mohave

airport

airport

building

school

school

building

building

school

ADMIN Mohave

ADMIN Mohave

VARIANT

UNOFF

UNOFF

VARIANT

UNOFF

Mohave

Mohave

UNOFF

VARIANT

Mohave

Mohave

Mohave

valley

locale

mine

mine

summit

range

ridge

reservoir

BGN 1948 Mohave

VARIANT

summit

spring

valley

summit

ppl

valley

mine

spring

locale

ppl

well

well

reservoir

reservoir

reservoir

mine

summit

valley

well

well
BGN

UNOFF

UNOFF

BGN

VARIANT

BGN

Maricopa

Yuma

Cochise

Yavapai

Gila

Gila

BGN

BGN

BGN

BGN

BGN

UNOFF

BGN

UNOFF

BGN

Yavapai

Yavapa

Gila

Pinal

Maricopa

Yavapai

Yavapai

Yavapai

Pinal

Pima

UNOF
UNOF
BGN
BGN
BGN
UNOF
BGN
BGN
UNOF

BGN

UNOFF

BGN

UNOFF
Cochise

Gila

Yavapai

Coconino

Gila

Mohave

Yuma

Yuma

Maricopa
$322235 \mathrm{N1} 105246 \mathrm{~W}$

343436N1131244W

$344213 \mathrm{~N} 1132733 \mathrm{~W}$

$344216 \mathrm{~N} 1132710 \mathrm{~W}$

$314003 N 1090545 \mathrm{~W}$

$343359 \mathrm{~N} 1110832 \mathrm{~W}$

$343405 \mathrm{~N} 1110850 \mathrm{~W}$

$343240 \mathrm{NI} 111624 \mathrm{~W}$

$343223 \mathrm{N1111744 \textrm {W }}$

$361551 N 1121613 \mathrm{~W}$

$342652 \mathrm{~N} 1122328 \mathrm{~W}$

$342904 N 1122143 \mathrm{~W}$

$321454 N 1111031 \mathrm{~W}$

$330632 \mathrm{~N} 1092151 \mathrm{~W}$

$345246 \mathrm{N1121919W}$

330632N1092151W

$361639 \mathrm{N1122243W}$

$330632 \mathrm{N1092151W}$

$330901 N 109271 \mathrm{BW}$

$322647 N 1104643 \mathrm{~W}$

322647 N1104643W

$351122 \mathrm{N1140308 \textrm {W }}$

351330N1140035W

$351524 \mathrm{~N} 1135624 \mathrm{~W}$

$351124 N 1140310 \mathrm{~W}$

351129N1140326W

$351133 N 1140333 W$

$351123 \mathrm{~N} 1140307 \mathrm{~W}$

$351117 \mathrm{N1140307 \textrm {W }}$

$351129 \mathrm{~N} 1140326 \mathrm{~W}$

$360159 N 1144216 \mathrm{~W}$

$332355 N 1120301 \mathrm{~W}$

331609 N1135758W

$320229 N 1091831 \mathrm{~W}$

$343355 \mathrm{N1131347 \textrm {W }}$

$341348 \mathrm{~N} 1111011 \mathrm{~W}$

$341619 N 1110652 \mathrm{~W}$

$341606 \mathrm{~N} 1110646 \mathrm{~W}$

$342721 \mathrm{N1125539W}$

$342729 \mathrm{~N} 1125506 \mathrm{~W}$

332720 N1105002W

$331955 \mathrm{~N} 1110414 \mathrm{~W}$

$332250 N 1114740 \mathrm{~W}$

$340328 \mathrm{N1} 123938 \mathrm{~W}$

$340206 \mathrm{N1} 123524 \mathrm{~W}$

$345644 \mathrm{N1} 121936 \mathrm{~W}$

$332257 \mathrm{N111} 2600 \mathrm{~W}$
Greenlee 
FEATURE

CLASS

STATUS

COORDINATE

344852N1121759W $334853 \mathrm{~N} 1100314 \mathrm{~W}$ $335101 \mathrm{N1} 100325 \mathrm{~W}$

$334903 \mathrm{~N} 1100308 \mathrm{~W}$

$312312 \mathrm{N1} 101315 \mathrm{~W}$

Kinishba Tank

Kinjockity Ranch

Kin Lani

See Betatakin Ruin

Kin-li-Chee

See Kinlichee

Kinlichee

Kin-li-Chee

$\mathrm{Kin}-\mathrm{Li}$-Chee

Kin Li Chee

Kin-Li-Chee

See Kinlichee

Kin Li Chee

See Kinlichee

Kinlichee Chapter House

Kinlichee Creek

Ganado Wash

Kin-Li-Chee Creek

Kin Li Chee Creek

Kin-Li-Chee Creek

See Kinlichee Creek

Kin Li Chee Creek See Kinlichee Creek

Kinlichee School

Kinlichee Tribal Park

Kinnazzi Spring

Kinney Flat

Kinney Junction

Kinney Lookout

Kinney Mountain

Kinney Point

Kinney Tank

Kinney Well

Kinnikinick Campground

Kinnikinick Canyon

Kinnikinick Dam

Kinnikinick Lake

Kinnikinick Spring

Kinnison Wash

Kin ni taahll Well

Kino

Kino Community Hospital

Hel iport

Kino Junior High School

Kino Park

Kino Peak

Kino Plaza North Shopping

Center

Kino Post office

Kino Railroad Station

Kino Spring

Kino Springs
Kino Springs

Kino Springs Dan

Kino Springs Lake

Kinsey School

Kinsley Ranch

See Arivaca Junction

Kinsley Tank

Kinter

Kinusta Mesa

Kinyon Station

See Kenyon Station

Ki-ote-Te wash

See Coyote Wash

Kiowa Drain

Kiper Spring

Kirk Estates Subdivision Mini

$\begin{array}{ll}\text { well } & \text { UNOFF } \\ \text { locale } & \text { BGN } \\ \text { reservoir } & \text { BGN } \\ \text { well } & \text { UNOFF } \\ \text { locale } & \text { UNOFF } \\ & \text { VARIANT } \\ \text { locale } & \\ & \text { VARIANT } \\ \text { ppl } & \\ \text { ppl } & \text { BGN 1983 } \\ & \text { VARIANT } \\ & \text { VARIANT } \\ & \text { VARIANT }\end{array}$

Yavapai

Gila

Gila

Navajo

Apache

Apache

$364102 \mathrm{~N} 1103206 \mathrm{~W}$

$354522 \mathrm{~N} 1092530 \mathrm{~W}$

$354522 \mathrm{~N} 1092530 \mathrm{~W}$

\begin{tabular}{|c|c|}
\hline & VARIANT \\
\hline ppl & VARIANT \\
\hline $\begin{array}{l}\text { ppl } \\
\text { locale } \\
\text { stream }\end{array}$ & $\begin{array}{l}\text { BGN } \\
\text { BGN } 1983 \\
\text { VARIANT } \\
\text { VARIANT } \\
\text { VARIANT } \\
\text { VARIANT }\end{array}$ \\
\hline
\end{tabular}

Apache

$354428 \mathrm{~N} 1092940 \mathrm{~W}$

VARIANT

\begin{tabular}{|c|c|c|c|}
\hline $\begin{array}{l}\text { strean } \\
\text { school } \\
\text { park } \\
\text { spring } \\
\text { flat } \\
\text { locale } \\
\text { tower } \\
\text { summit } \\
\text { summit }\end{array}$ & $\begin{array}{l}\text { UNOFF } \\
\text { ADNIN } \\
\text { BGN } \\
\text { BGN } \\
\text { BGN } \\
\text { UNOFF } \\
\text { BGN } \\
\text { BGN }\end{array}$ & $\begin{array}{l}\text { Apache } \\
\text { Apache } \\
\text { Apache } \\
\text { Apache } \\
\text { Mohave } \\
\text { Apache } \\
\text { Apache } \\
\text { Navajo } \\
\text { Mohave }\end{array}$ & $\begin{array}{l}354428 \mathrm{~N} 1092940 \mathrm{~W} \\
354438 \mathrm{~N} 1092624 \mathrm{~W} \\
354505 \mathrm{~N} 1092500 \mathrm{~W} \\
352748 \mathrm{~N} 1092916 \mathrm{~W} \\
362151 \mathrm{~N} 1131836 \mathrm{~W} \\
335502 \mathrm{~N} 1094624 \mathrm{~W} \\
335240 \mathrm{~N} 1094524 \mathrm{~W} \\
340440 \mathrm{~N} 1095218 \mathrm{~W} \\
361840 \mathrm{~N} 1131706 \mathrm{~W}\end{array}$ \\
\hline $\begin{array}{l}\text { reservoir } \\
\text { well } \\
\text { park } \\
\text { valley } \\
\text { dam } \\
\text { reservoir } \\
\text { spring } \\
\text { arroyo } \\
\text { well } \\
\text { locale }\end{array}$ & $\begin{array}{l}\text { BGN } \\
\text { UNOFF } \\
\text { ADMIN } \\
\text { BGN } \\
\text { UNOFF } \\
\text { BGN } \\
\text { BGN } \\
\text { BGN } \\
\text { UNOFF } \\
\text { BGN }\end{array}$ & $\begin{array}{l}\text { Pima } \\
\text { Gila } \\
\text { Coconino } \\
\text { Coconino } \\
\text { Coconino } \\
\text { Coconino } \\
\text { Coconino } \\
\text { Pima } \\
\text { Navajo } \\
\text { Pima }\end{array}$ & $\begin{array}{l}315200 \mathrm{~N} 1105359 \mathrm{~W} \\
331932 \mathrm{~N} 1103619 \mathrm{~W} \\
345347 \mathrm{~N} 1111842 \mathrm{~W} \\
345306 \mathrm{~N} 1111255 \mathrm{~W} \\
345343 \mathrm{~N} 1111747 \mathrm{~W} \\
345343 \mathrm{~N} 1111747 \mathrm{~W} \\
345358 \mathrm{~N} 1111619 \mathrm{~W} \\
321112 \mathrm{~N} 1104906 \mathrm{~W} \\
361410 \mathrm{~N} 1103525 \mathrm{~W} \\
322005 \mathrm{~N} 1110341 \mathrm{~W}\end{array}$ \\
\hline
\end{tabular}

airport ADMIN Pima

School UNOFF Maricopa 332553N1114851W

park ADMIN Santa Cruz 312102N1105533W

summit BGN 1945 Pima 320635N1125717W

locale UNOFF Maricopa 333645N1120050W

building UNOFF Pima 321450N1105845W

building UNOFF Pima 321936N1110308W

spring BGN Cochise 313343N1102627W

VARIANT

locale

valley

stream

spring

park
VARIANT

BGN Navajo

ADMIN Maricopa
$343004 \mathrm{~N} 1142146 \mathrm{~W}$
SOURCE
COORDINATE

$\begin{array}{llll}\text { spring } & \text { BGN } & \text { Santa Cruz } & 312237 \text { N1105150W } \\ \text { ppl } & \text { BGN } & \text { Santa Cruz } & 312147 \text { N1104834W } \\ \text { dam } & \text { UNOFF } & \text { Santa Cruz } & 312237 \text { N1105154W } \\ \text { reservoir } & \text { 8GN } & \text { Santa Cruz } & 312237 \text { N1105154W } \\ \text { school } & \text { UNOFF } & \text { Coconino } & 351050 N 1113853 \mathrm{~W} \\ & \text { VARIANT } & & \\ \text { ppl } & & \text { Pima } & 314338 N 1110338 \mathrm{~W} \\ \text { reservoir } & \text { BGN } & \text { Pima } & 314438 N 1100544 \mathrm{~W} \\ \text { locale } & \text { BGN } & \text { Yuma } & 324526 \mathrm{N1142350W} \\ \text { summit } & \text { BGN } & \text { Apache } & 363934 \mathrm{~N} 1091756 \mathrm{~W}\end{array}$

BGN Cochise
$330145 N 1125540 \mathrm{~W}$

$352330 \mathrm{~N} 1104445 \mathrm{~W}$

$320309 N 1102339 \mathrm{~W}$

$332554 \mathrm{~N} 1114757 \mathrm{~W}$
King Canyon

Canyon Day

Canyon Day

Canyon Day

Nicksville

6600 Red Clay Wash

$354455 N 1091123 \mathrm{~W} \quad 6680 \begin{aligned} & \text { Kinlichee } \\ & \text { Kinlichee }\end{aligned}$

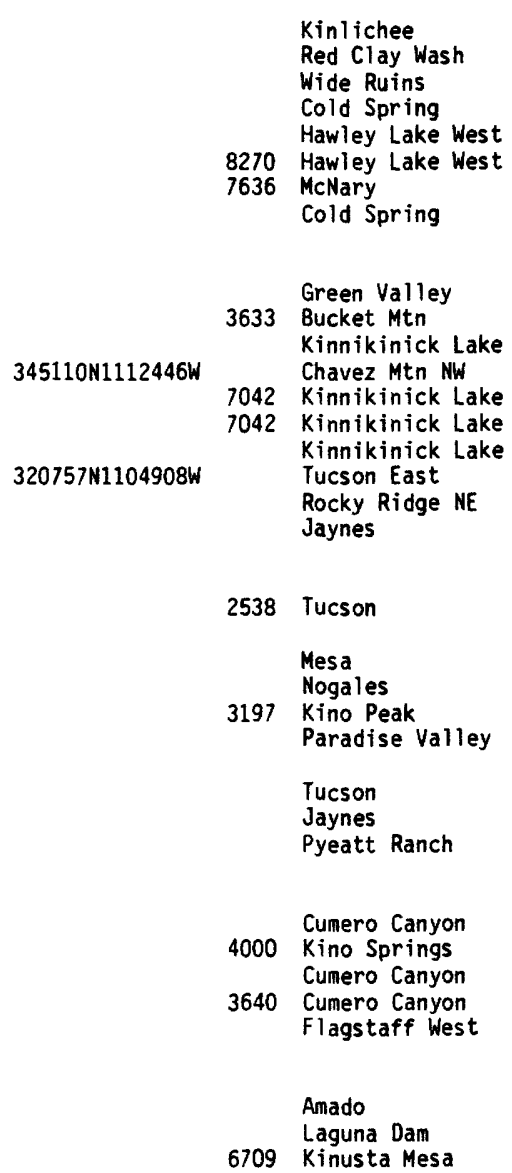

$343005 N 1141905 W$

Lake Havasu City $N$
Galleta Flat West

Mesa 


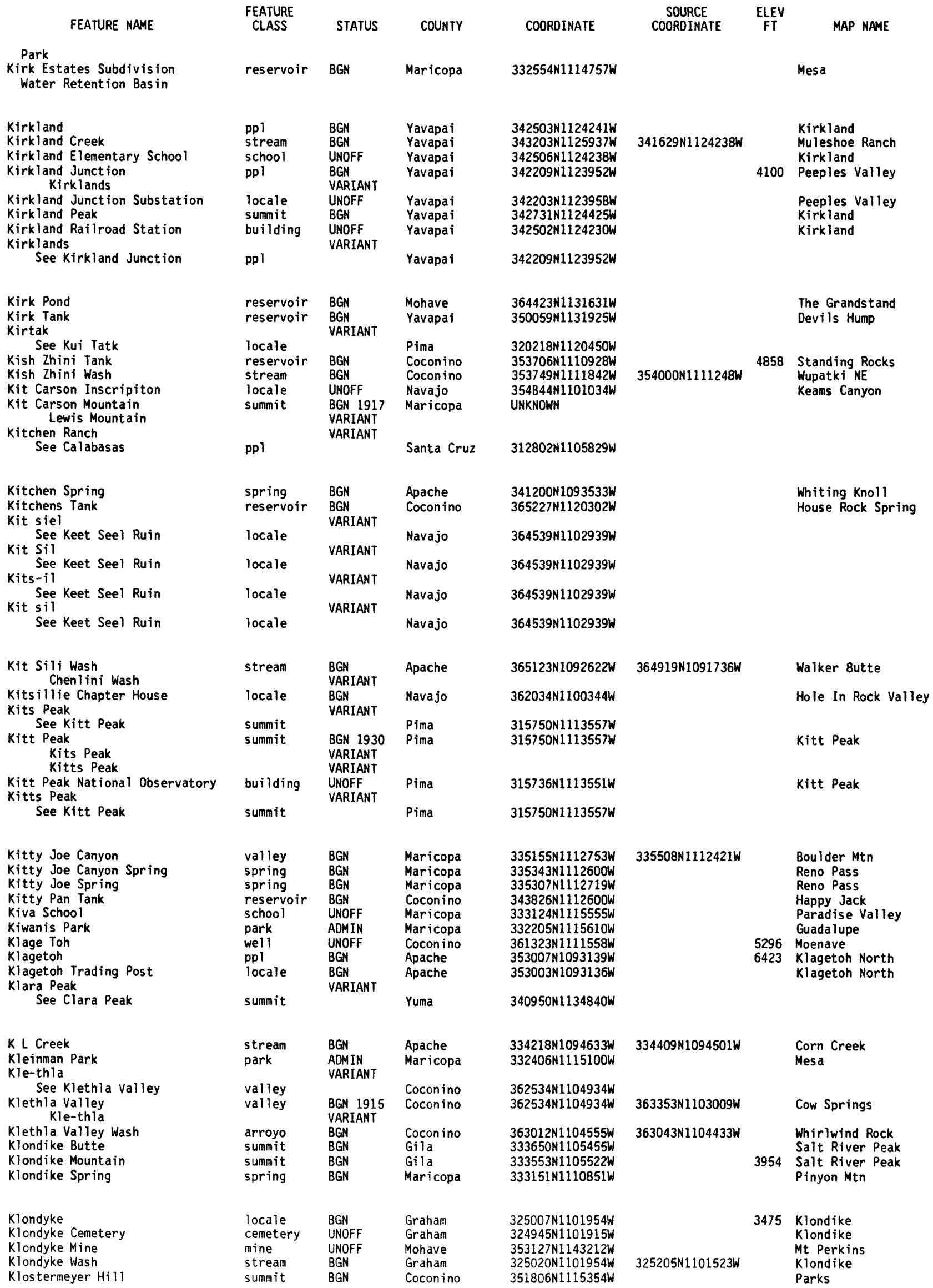


NATIONAL GAZETTEER--ARIZONA 1986

\begin{tabular}{|c|c|c|c|c|c|c|c|}
\hline FEATURE NAME & $\begin{array}{l}\text { FEATURE } \\
\text { CLASS }\end{array}$ & STATUS & COUNTY & COORDINATE & $\begin{array}{l}\text { SOURCE } \\
\text { COORDINATE }\end{array}$ & $\begin{array}{c}\text { ELEV } \\
\text { FT }\end{array}$ & MAP NAME \\
\hline $\begin{array}{l}\text { Klostermeyer Lake } \\
\text { Klostermeyer Spring } \\
\text { Klostermeyer Spring Tank } \\
\text { Klothos Temple } \\
\text { Clothopas Temple } \\
\text { Clothos Temple } \\
\text { Coronation Peak } \\
\text { Pagoda Mountain }\end{array}$ & $\begin{array}{l}\text { lake } \\
\text { spring } \\
\text { reservoir } \\
\text { summit }\end{array}$ & $\begin{array}{l}\text { BGN } \\
\text { BGN } \\
\text { BGN } \\
\text { BGN } \\
\text { VARIANT } \\
\text { VARIANT } \\
\text { VARIANT } \\
\text { VARIANT }\end{array}$ & $\begin{array}{l}\text { Coconino } \\
\text { Coconino } \\
\text { Coconino } \\
\text { Yuma }\end{array}$ & $\begin{array}{l}353114 \mathrm{~N} 1114414 \mathrm{~W} \\
351815 \mathrm{~N} 1115340 \mathrm{~W} \\
351815 \mathrm{~N} 1115340 \mathrm{~W} \\
324540 \mathrm{~N} 1141548 \mathrm{~W}\end{array}$ & & 1666 & $\begin{array}{l}\text { S P Mountain } \\
\text { Parks } \\
\text { Parks } \\
\text { Dome }\end{array}$ \\
\hline $\begin{array}{l}\text { KL Ranch } \\
\text { KM Mine } \\
\text { K M P Tank } \\
\text { Knabe Mine } \\
\text { Knape Ranch }\end{array}$ & $\begin{array}{l}\text { locale } \\
\text { mine } \\
\text { reservoir } \\
\text { mine }\end{array}$ & $\begin{array}{l}\text { UNOFF } \\
\text { UNOFF } \\
\text { BGN } \\
\text { UNOFF } \\
\text { VARIANT }\end{array}$ & $\begin{array}{l}\text { Apache } \\
\text { Gila } \\
\text { Graham } \\
\text { Maricopa }\end{array}$ & $\begin{array}{l}334227 \mathrm{N1} 1094637 \mathrm{~W} \\
334816 \mathrm{~N} 1102219 \mathrm{~W} \\
323332 \mathrm{~N} 1092706 \mathrm{~W} \\
334404 \mathrm{~N} 1131203 \mathrm{~W}\end{array}$ & & & $\begin{array}{l}\text { Corn Creek } \\
\text { Carrizo SE } \\
\text { Javelina Peak } \\
\text { Little Horn Peak }\end{array}$ \\
\hline $\begin{array}{l}\text { See Bear Spring Ranch } \\
\text { Knape Ranch } \\
\text { Knapp Gulch } \\
\text { Knife Edge Mesa Mine } \\
\text { Knight Canyon } \\
\text { Wood Canyon }\end{array}$ & $\begin{array}{l}\text { locale } \\
\text { locale } \\
\text { valley } \\
\text { mine } \\
\text { valley }\end{array}$ & $\begin{array}{l}\text { UNOFF } \\
\text { BGN } \\
\text { UNOFF } \\
\text { BGN 1964 } \\
\text { VARIANT }\end{array}$ & $\begin{array}{l}\text { Cochise } \\
\text { Cochise } \\
\text { Yavapai } \\
\text { Apache } \\
\text { Greenlee }\end{array}$ & $\begin{array}{l}320822 \mathrm{~N} 1092535 \mathrm{~W} \\
320823 \mathrm{~N} 1092535 \mathrm{~W} \\
342646 \mathrm{~N} 1122335 \mathrm{~W} \\
362907 \mathrm{~N} 1091444 \mathrm{~W} \\
330820 \mathrm{~N} 1092930 \mathrm{~W}\end{array}$ & $\begin{array}{l}342548 N 1122353 \mathrm{~W} \\
330743 N 1092508 \mathrm{~W}\end{array}$ & & $\begin{array}{l}\text { Bowie Mtn North } \\
\text { Groom Creek } \\
\text { Lukachukai } \\
\text { Coronado Mtn }\end{array}$ \\
\hline $\begin{array}{l}\text { Knight Creek } \\
\text { Knight Creek } \\
\text { Big Sandy Wash } \\
\text { Big Sandy River } \\
\text { Cottonwood Wash } \\
\text { Little Sandy Wash } \\
\text { Knight Creek Spring } \\
\text { Knight Hawk Mine } \\
\text { Knight Tank } \\
\text { Knipe Tank }\end{array}$ & $\begin{array}{l}\text { spring } \\
\text { mine } \\
\text { reservoir } \\
\text { reservoir }\end{array}$ & $\begin{array}{l}\text { BGN } 1963 \\
\text { BGN } \\
\text { VARIANT } \\
\text { VARIANT } \\
\text { VARIANT } \\
\text { VARIANT } \\
\text { BGN } \\
\text { UNOFF } \\
\text { BGN } \\
\text { BGN }\end{array}$ & $\begin{array}{l}\text { Mohave } \\
\text { Mohave } \\
\text { Yavapai } \\
\text { Coconino }\end{array}$ & $\begin{array}{l}350732 \mathrm{~N} 1132724 \mathrm{~W} \\
352031 \mathrm{N1140716 \textrm {W }} \\
340216 \mathrm{N1125339W} \\
350803 \mathrm{~N} 1112400 \mathrm{~W}\end{array}$ & $\begin{array}{l}330815 N 1092343 \mathrm{~W} \\
350542 \mathrm{~N} 1132352 \mathrm{~W}\end{array}$ & & $\begin{array}{l}\text { Bull Spring } \\
\text { Stockton Hill } \\
\text { Congress SW } \\
\text { Winona }\end{array}$ \\
\hline $\begin{array}{l}\text { Knob Hill } \\
\text { Knob Hill } \\
\text { Knob Hill Administrative Site } \\
\text { See Knob Hill Ranger } \\
\text { Station } \\
\text { Knob Hill Ranger Station } \\
\text { Knob Hill } \\
\text { Administrative Site }\end{array}$ & $\begin{array}{l}\text { summit } \\
\text { summit } \\
\text { locale } \\
\text { locale }\end{array}$ & $\begin{array}{l}\text { BGN } \\
\text { BGN } \\
\text { VARIANT }\end{array}$ & $\begin{array}{l}\text { Cochise } \\
\text { Cochise } \\
\text { Coconino } \\
\text { Coconino }\end{array}$ & $\begin{array}{l}312526 \mathrm{~N} 1095712 \mathrm{~W} \\
315520 \mathrm{~N} 1100333 \mathrm{~W} \\
351234 \mathrm{~N} 1113835 \mathrm{~W} \\
351234 \mathrm{~N} 1113835 \mathrm{~W}\end{array}$ & & 5105 & Flagstaff West \\
\hline $\begin{array}{l}\text { Knob Mountain } \\
\text { Knob Tank }\end{array}$ & $\begin{array}{l}\text { summit } \\
\text { reservoir }\end{array}$ & $\begin{array}{l}B G N \\
B G N\end{array}$ & $\begin{array}{l}\text { Gila } \\
\text { Graham }\end{array}$ & $\begin{array}{l}341005 \mathrm{~N} 1113120 \mathrm{~W} \\
323242 \mathrm{~N} 1101432 \mathrm{~W}\end{array}$ & & 6255 & $\begin{array}{l}\text { Cypress Butte } \\
\text { Harrison Canyon }\end{array}$ \\
\hline $\begin{array}{l}\text { Knob Tank } \\
\text { Knob Tank } \\
\text { Knob Tank } \\
\text { Knoell East (subdivision) } \\
\text { Knoell Mesa (subdivision) } \\
\text { Knoles Hole Spring } \\
\text { Knoll Dam } \\
\text { Knoll East Subdivision Mini } \\
\text { Park } \\
\text { Knoll East Subdivision Water } \\
\text { Retention Basin }\end{array}$ & $\begin{array}{l}\text { reservoir } \\
\text { reservoir } \\
\text { reservoir } \\
\text { ppl } \\
\text { pp 1 } \\
\text { spring } \\
\text { dam } \\
\text { park } \\
\text { reservoir }\end{array}$ & $\begin{array}{l}\text { BGN } \\
\text { BGN } \\
\text { BGN } \\
\text { BGN } \\
\text { BGN } \\
\text { BGN } \\
\text { UNOFF } \\
\text { ADMIN } \\
\text { BGN }\end{array}$ & $\begin{array}{l}\text { Yavapai } \\
\text { Yavapai } \\
\text { Yavapai } \\
\text { Maricopa } \\
\text { Maricopa } \\
\text { Gila } \\
\text { Coconino } \\
\text { Maricopa } \\
\text { Maricopa }\end{array}$ & $\begin{array}{l}343450 N 1113553 \mathrm{~W} \\
344125 \mathrm{~N} 1113712 \mathrm{~W} \\
345023 \mathrm{~N} 1124332 \mathrm{~W} \\
332238 \mathrm{~N} 1115311 \mathrm{~W} \\
332327 \mathrm{~N} 1114659 \mathrm{~W} \\
334941 \mathrm{~N} 1105452 \mathrm{~W} \\
342552 \mathrm{~N} 1110503 \mathrm{~W} \\
332126 \mathrm{~N} 1115239 \mathrm{~W} \\
332136 \mathrm{~N} 1115239 \mathrm{~W}\end{array}$ & & $\begin{array}{l}1200 \\
1240\end{array}$ & $\begin{array}{l}\text { Buckhorn Mountain } \\
\text { Apache Maid Mtn } \\
\text { Simmons } \\
\text { Tempe } \\
\text { Mesa } \\
\text { Aztec Peak } \\
\text { Knoll Lake } \\
\text { Guadalupe } \\
\text { Guadalupe }\end{array}$ \\
\hline $\begin{array}{l}\text { Knoll Lake } \\
\text { Knolls Lake } \\
\text { Knoll Lake Campground } \\
\text { Knoll Ridge } \\
\text { Knolls Ridge } \\
\text { Knolls Lake } \\
\text { See Knoll Lake } \\
\text { Knolls Ridge } \\
\text { See Knoll Ridge } \\
\text { Knoll Tank }\end{array}$ & $\begin{array}{l}\text { reservoir } \\
\text { park } \\
\text { ridge } \\
\text { reservoir } \\
\text { ridge } \\
\text { reservoir }\end{array}$ & $\begin{array}{l}\text { BGN } 1973 \\
\text { VARIANT } \\
\text { ADMIN } \\
\text { BGN } 1973 \\
\text { VARIANT } \\
\text { VARIANT } \\
\text { VARIANT } \\
\text { BGN }\end{array}$ & $\begin{array}{l}\text { Coconino } \\
\text { Coconino } \\
\text { Coconino } \\
\text { Coconino } \\
\text { Coconino } \\
\text { Coconino }\end{array}$ & $\begin{array}{l}342553 N 1110503 W \\
342539 N 1110531 W \\
342609 N 1110553 W \\
342553 N 1110503 W \\
342609 N 1110553 W \\
342703 N 1110511 W\end{array}$ & & & $\begin{array}{l}\text { Knoll Lake } \\
\text { Knoll Lake } \\
\text { Knoll Lake }\end{array}$ \\
\hline $\begin{array}{l}\text { Knoll Tank } \\
\text { Knothe Spring } \\
\text { Knox Elementary School } \\
\text { Kofa } \\
\text { Kofa Station } \\
\text { Kofa Butte } \\
\text { Mud Mountain } \\
\text { Kof a Cabin } \\
\text { Kofa Dam } \\
\text { Kofa Dam Wash }\end{array}$ & $\begin{array}{l}\text { reservoir } \\
\text { spring } \\
\text { school } \\
\text { locale } \\
\text { summit } \\
\text { building } \\
\text { dam } \\
\text { stream }\end{array}$ & $\begin{array}{l}\text { BGN } \\
\text { BGN } \\
\text { UNOFF } \\
\text { BGN } \\
\text { VARIANT } \\
\text { BGN } \\
\text { VARIANT } \\
\text { UNOFF } \\
\text { UNOFF } \\
\text { BGN }\end{array}$ & $\begin{array}{l}\text { Navajo } \\
\text { Graham } \\
\text { Maricopa } \\
\text { Yuma } \\
\text { Yuma } \\
\text { Yuma } \\
\text { Yuma } \\
\text { Yuma }\end{array}$ & $\begin{array}{l}344013 \mathrm{~N} 1095143 \mathrm{~W} \\
323330 \mathrm{~N} 1101958 \mathrm{~W} \\
331930 \mathrm{~N} 1115107 \mathrm{~W} \\
325255 \mathrm{~N} 1133845 \mathrm{~W} \\
331638 \mathrm{~N} 1135543 \mathrm{~W} \\
\\
333015 \mathrm{~N} 1135208 \mathrm{~W} \\
331740 \mathrm{~N} 1135528 \mathrm{~W} \\
331716 \mathrm{~N} 1135601 \mathrm{~W}\end{array}$ & $331750 \mathrm{~N} 1135445 \mathrm{~W}$ & 3247 & $\begin{array}{l}\text { Little Milky Ranch } \\
\text { Bassett Peak } \\
\text { Chandler } \\
\text { Kofa } \\
\text { Kofa Butte } \\
\text { New Water Well } \\
\text { Kofa Butte } \\
\text { Kofa Butte }\end{array}$ \\
\hline Kofa Deep Well & well & UNOFF & Yuma & $331316 \mathrm{~N} 1140004 \mathrm{~W}$ & & & Kofa Deep Well \\
\hline
\end{tabular}




\begin{tabular}{|c|c|c|c|c|c|c|c|}
\hline FEATURE NAME & $\begin{array}{l}\text { FEATURE } \\
\text { CLASS }\end{array}$ & STATUS & COUNTY & COORDINATE & $\begin{array}{l}\text { SOURCE } \\
\text { COORDINATE }\end{array}$ & $\underset{\text { ET }}{\text { ELEV }}$ & MAP NAME \\
\hline $\begin{array}{l}\text { Kofa Game Range } \\
\text { Kofa High School } \\
\text { Kofa Manganese Mine } \\
\text { Kofa Monument } \\
\text { Kofa Mountains } \\
\text { Kofa Range } \\
\text { S H Mountains } \\
\text { Short Horn Montains } \\
\text { SH Mountains }\end{array}$ & $\begin{array}{l}\text { park } \\
\text { school } \\
\text { mine } \\
\text { locale } \\
\text { summit }\end{array}$ & $\begin{array}{l}\text { ADMIN } \\
\text { UNOFF } \\
\text { UNOFF } \\
\text { BGN } \\
\text { BGN } 1963 \\
\text { VARIANT } \\
\text { VARIANT } \\
\text { VARIANT } \\
\text { VARIANT }\end{array}$ & $\begin{array}{l}\text { Yuma } \\
\text { Yuma } \\
\text { Yuma } \\
\text { Yuma } \\
\text { Yuma }\end{array}$ & $\begin{array}{l}331510 \mathrm{~N} 1140005 \mathrm{~W} \\
324024 \mathrm{N1} 143804 \mathrm{~W} \\
331537 \mathrm{N1} 135154 \mathrm{~W} \\
332540 \mathrm{~N} 1135502 \mathrm{~W} \\
331948 \mathrm{~N} 1135710 \mathrm{~W}\end{array}$ & & & $\begin{array}{l}\text { Palm Canyon } \\
\text { Yuma West } \\
\text { Hoodoo We11 } \\
\text { Owl Head } \\
\text { Kofa Butte }\end{array}$ \\
\hline $\begin{array}{l}\text { Kofa Queen Canyon } \\
\text { Kofa Queen Mine } \\
\text { Kofa Range } \\
\text { See Kofa Mountains } \\
\text { Kofa Station } \\
\text { See Kofa } \\
\text { Koger Tank } \\
\text { Kohatk } \\
\text { Cohota } \\
\text { Cojate } \\
\text { Cojela } \\
\text { Cojeta } \\
\text { Quajato } \\
\text { Quajote } \\
\text { Quojote }\end{array}$ & $\begin{array}{l}\text { valley } \\
\text { mine } \\
\text { summit } \\
\text { locale } \\
\text { reservoir } \\
\text { pp! }\end{array}$ & $\begin{array}{l}\text { BGN } \\
\text { UNOFF } \\
\text { VARIANT } \\
\text { VARIANT } \\
\text { BGN } \\
\text { BGN } \\
\text { VARIANT } \\
\text { VARIANT } \\
\text { VARIANT } \\
\text { VARIANT } \\
\text { VARIANT } \\
\text { VARIANT } \\
\text { VARIANT }\end{array}$ & $\begin{array}{l}\text { Yuma } \\
\text { Yuma } \\
\text { Yuma } \\
\text { Yuma } \\
\text { Coconino } \\
\text { Pinal }\end{array}$ & $\begin{array}{l}332318 \mathrm{~N} 1140604 \mathrm{~W} \\
332138 \mathrm{~N} 1140227 \mathrm{~W} \\
331948 \mathrm{~N} 1135710 \mathrm{~W} \\
325255 \mathrm{~N} 1133845 \mathrm{~W} \\
350040 \mathrm{~N} 111105 \mathrm{~W} \\
323442 \mathrm{~N} 1120018 \mathrm{~W}\end{array}$ & 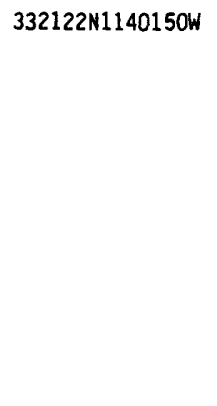 & 1639 & $\begin{array}{l}\text { Anderson Canyon } \\
\text { Kohatk }\end{array}$ \\
\hline $\begin{array}{l}\text { Kohatk Valley } \\
\text { Kohatk Wash } \\
\text { Quajote Wash } \\
\text { Santa Rosa Wash } \\
\text { Kohatk Well } \\
\text { Kohen Ranch } \\
\text { Kohi Kug } \\
\text { See Chiuli Shaik } \\
\text { Kohi Kug (site) } \\
\text { Koxikux } \\
\text { Kuit Vaya } \\
\text { Ventana }\end{array}$ & $\begin{array}{l}\text { valley } \\
\text { stream } \\
\text { well } \\
\text { locale } \\
\text { locale } \\
\text { locale }\end{array}$ & $\begin{array}{l}\text { BGN } \\
\text { BGN } 1941 \\
\text { VARIANT } \\
\text { VARIANT } \\
\text { UNOFF } \\
\text { UNOFF } \\
\text { VARIANT } \\
\text { BGN } 1941 \\
\text { VARIANT } \\
\text { VARIANT } \\
\text { VARIANT }\end{array}$ & $\begin{array}{l}\text { Pinal } \\
\text { Mohave } \\
\text { Pima } \\
\text { Pima }\end{array}$ & $\begin{array}{l}323539 \mathrm{~N} 1115959 \mathrm{~W} \\
341545 \mathrm{~N} 1140155 \mathrm{~W} \\
314943 \mathrm{~N} 1113846 \mathrm{~W} \\
315033 \mathrm{~N} 1113934 \mathrm{~W}\end{array}$ & $\begin{array}{l}323509 N 1121117 \mathrm{~W} \\
323648 \mathrm{~N} 1122310 \mathrm{~W}\end{array}$ & & $\begin{array}{l}\text { Kohatk } \\
\text { Vaiva Vo } \\
\begin{array}{l}\text { North Komelik } \\
\text { Monkeys Head }\end{array}\end{array}$ \\
\hline $\begin{array}{l}\text { Kohinoor Spring } \\
\text { Kohinoor Spring } \\
\text { See Coyote Spring } \\
\text { Kohls Ranch } \\
\text { Koht Kohi Hill } \\
\text { Kokopnyama } \\
\text { Koksumok } \\
\text { See Topawa } \\
\text { Kokuli } \\
\text { See Hickiwan }\end{array}$ & $\begin{array}{l}\text { spring } \\
\text { spring } \\
\text { ppl } 1 \\
\text { sumit } \\
\text { locale } \\
\text { ppl } \\
\text { ppl }\end{array}$ & $\begin{array}{l}\text { BGN } \\
\text { VARIANT } \\
\text { BGN } \\
\text { BGN } \\
\text { BGN } \\
\text { VARIANT } \\
\text { VARIANT }\end{array}$ & $\begin{array}{l}\text { Mohave } \\
\text { Mohave } \\
\text { Gila } \\
\text { Pima } \\
\text { Navajo } \\
\text { Pima } \\
\text { Pima }\end{array}$ & $\begin{array}{l}353618 \mathrm{~N} 1134909 \mathrm{~W} \\
353728 \mathrm{~N} 1134800 \mathrm{~W} \\
341931110537 \mathrm{~W} \\
322153 \mathrm{~N} 1113443 \mathrm{~W} \\
354649 \mathrm{~N} 1100736 \mathrm{~W} \\
314850 \mathrm{~N} 1114930 \mathrm{~W} \\
322208 \mathrm{~N} 1122829 \mathrm{~W}\end{array}$ & & 2781 & $\begin{array}{l}\text { Music Mountains SE } \\
\text { Promontory Butte } \\
\text { Koht Kohi Hill } \\
\text { Keams Canyon }\end{array}$ \\
\hline $\begin{array}{l}\text { Kolb Arch } \\
\text { Kolb Bridge } \\
\text { Kolb Bridge } \\
\text { See Kolb Arch } \\
\text { Kolipatvooka } \\
\text { See Gurli Put Vo } \\
\text { Koli-pat-vooka } \\
\text { See Gurli Put Vo } \\
\text { Komaktjiurt } \\
\text { See Quijotoa }\end{array}$ & $\begin{array}{l}\text { arch } \\
\text { locale } \\
\text { locale } \\
\text { locale }\end{array}$ & $\begin{array}{l}\text { BGN } 1977 \\
\text { VARIANT } \\
\text { VARIANT } \\
\text { VARIANT } \\
\text { VARIANT } \\
\text { VARIANT }\end{array}$ & $\begin{array}{l}\text { Coconino } \\
\text { Coconino } \\
\text { Pima } \\
\text { Pima } \\
\text { Pima }\end{array}$ & $\begin{array}{l}361704 \mathrm{~N} 1115805 \mathrm{~W} \\
361704 \mathrm{~N} 1115805 \mathrm{~W} \\
321214 \mathrm{~N} 1120108 \mathrm{~W} \\
321214 \mathrm{~N} 1120108 \mathrm{~W} \\
320738 \mathrm{~N} 1120815 \mathrm{~W}\end{array}$ & & & Point Imperial \\
\hline $\begin{array}{l}\text { Komakt juert } \\
\text { See Quijotoa } \\
\text { Komak Wuacho } \\
\text { Komalik } \\
\text { See Salina Springs } \\
\text { Komalik } \\
\text { See South Komelik } \\
\text { Komalik } \\
\text { See North Komelik } \\
\text { Komatke } \\
\text { See Estrella, Sierra }\end{array}$ & $\begin{array}{l}\text { locale } \\
\text { locale } \\
\text { spring } \\
\text { locale } \\
\text { pp1 } \\
\text { ridge }\end{array}$ & $\begin{array}{l}\text { VARIANT } \\
\text { BGN } \\
\text { VARIANT } \\
\text { VARIANT } \\
\text { VARIANT } \\
\text { VARIANT }\end{array}$ & $\begin{array}{l}\text { Pima } \\
\text { Pima } \\
\text { Apache } \\
\text { Pima } \\
\text { Pinal } \\
\text { Pinal }\end{array}$ & $\begin{array}{l}320738 N 1120815 \mathrm{~W} \\
321325 \mathrm{N1121946 \textrm {W }} \\
360139 \mathrm{~N} 1095221 \mathrm{~W} \\
314320 \mathrm{~N} 1114620 \mathrm{~W} \\
323028 \mathrm{~N} 1115645 \mathrm{~W} \\
331253 \mathrm{~N} 1121249 \mathrm{~W}\end{array}$ & & & Wahak Hotrontk \\
\hline $\begin{array}{l}\text { Komatke } \\
\text { See Gila Crossing } \\
\text { Komatke } \\
\text { Saint Johns } \\
\text { Saint Johns Mission } \\
\text { Kombaxia }\end{array}$ & $\begin{array}{l}\mathrm{ppl} \\
\mathrm{ppl}\end{array}$ & $\begin{array}{l}\text { VARIANT } \\
\text { BGN } \\
\text { VARIANT } \\
\text { VARIANT } \\
\text { VARIANT }\end{array}$ & $\begin{array}{l}\text { Maricopa } \\
\text { Maricopa }\end{array}$ & $\begin{array}{l}331636 \mathrm{~N} 1120958 \mathrm{~W} \\
331736 \mathrm{~N} 1121029 \mathrm{~W}\end{array}$ & & & Laveen \\
\hline
\end{tabular}


NATIONAL GAZETTEER--ARIZONA 1986

FEATURE NAME

lih

Komel in

See North Komelik

Kome lik

See South Komelik

Komel ik Mountain

Komelik Pass

Kom Kug

Kom Kug Windmill

Komlih

Salina Springs

Koml ih

See North Komelik

Komo Point

Komo Vaya

See Stoa Vaya (site)

om Vaya

See Stoa Vaya (site)

Kon $\mathrm{Vo}$

Coneva

Comova

Kom Vo Valley

Comovo Valley

Kon Tiki Mobile Home Park

Kookatsh

See Kuakatch

Kool Corner

Ko-opke

See Shopishk

Koopke

See Shopishk

Korn Canyon

Corn Canyon

Koroll Valley See Mohawk Valley

Korp Canyon

Koshopinot

See Ventana

Koson Vaya

Kots Kug

Stanford Ranch

Toros Ranch

Kots Kug Ranch

See Kots Kug Ranch

Kots Kug Ranch Kots Kug Ranch Stanford Ranch Toros Ranch

Ko Vaya

Cababi

Cahuabi

Cobabi Well

Kavvaxiak

Ko Vaya Hills

Cobabi Mountain

Cobabi Mountains

Covajea Mountains

Ko Vaya Wash

Koxikux

See Chiuli Shaik

Koxikux

See Kohi Kug (site)

KP Cienega

KP Cienega Campground

KP Creek

KP Mesa

KPNX TV Studio Heliport

K P Spring

CLASS

locale

spring

ppl

VARIANT

Apache

Pinal

COORDINATE

VARIANT

locale

summit

gap

locale

well

spring

ppl

cliff

locale

locale

ppl

valley

locale

ppl

locale

ppl

ppl

valley

BGN

$B G N$

BGN

VARIANT

VARIANT

Pima

Pima

Pima

Pima

Apache

Pinal

Coconino

Pima

VARIANT

Pima

BGN 1941 Pima

VARIANT

VARIANT

VARIANT

VARIANT

Pima

UNOFF

VARIANT

Maricopa

Pima

Yuma

VARIANT

Pinal

VARIANT

Pinal

BGN 1959 Cochise

VARIANT

VARIANT

valley

valley

ppl

spring

locale

BGN
VARIA

VARIANT

BGN 1941 Pima

VARIANT

VARIANT

VARIANT

locale

Pima

locale

BGN 1941 Pima

VARIANT

VARIANT

VARIANT

ppl

BGN 1941

VARIANT

VARIANT

VARIANT

VARIANT

summit BGN 1941

VARIANT

VARIANT

VARIANT

Pima

$320205 N 1115416 \mathrm{~W}$

$\begin{array}{llll}\text { stream } & \text { BGN } & \text { Pima } & 32124 B N 1120034\end{array}$

locale

locale

flat

park

stream

summit

airport

Pima

VARIANT

Greenlee

Greenlee

Greenlee

ADMI

BGN

BGN
ADMIN

Greenlee

Maricopa

spring

BGN
$321033 N 1121342 W$

$360139 N 1095221 \mathrm{~W}$

323028 N1115645

314940 N1121153W

$320335 \mathrm{~N} 1115803 \mathrm{~W}$

$312836 \mathrm{~N} 1095327 \mathrm{~W}$

Bisbee NE

$322758 \mathrm{~N} 1121433 \mathrm{~W}$

$314845 \mathrm{~N} 1121230 \mathrm{~W}$

$314940 \mathrm{~N} 1121153 \mathrm{~W}$

320437 N1115341W

1863 Santa Rosa Mts NW

1703 Santa Rosa Mts NW

Caponera Peak

Caponera Peak

Bright Angel Point

1773 Kom Vo

15828N1122134W Papago Farms

1210 Chandler

Laguna Dam

Huachuca Peak

Ko Vaya

Kots Kug Ranch

1368 Kots Kug Ranch

Ko Vaya

Ko Vaya

Navajo

$340845 N 1103304 W$
33345 $109212 \mathrm{~W}$

$333350 \mathrm{~N} 1091308 \mathrm{~W}$

$332740 \mathrm{~N} 1120430 \mathrm{~W}$

333429 N1092116W

Strayhorse

Bear Mountain

Bear Mountain

1327 Phoenix

Pepper Canyon
$333142 \mathrm{~N} 1091203 \mathrm{~W}$ 


\begin{tabular}{|c|c|c|c|c|c|c|c|}
\hline FEATURE NAME & $\begin{array}{l}\text { FEATURE } \\
\text { CLASS }\end{array}$ & STATUS & COUNTY & COORDINATE & $\begin{array}{l}\text { SOURCE } \\
\text { COORDINATE }\end{array}$ & $\begin{array}{c}\text { ELEV } \\
\text { FT }\end{array}$ & MAP NAME \\
\hline $\begin{array}{l}\text { K P Tank } \\
\text { KP Trail Seventy } \\
\text { Kram Ranch } \\
\text { See Cram Ranch } \\
\text { Krentz Ranch } \\
\text { Krishna Shrine } \\
\text { K Six Mountain } \\
\text { K-T Ranch } \\
\text { Kuakatch } \\
\text { Kookatsh } \\
\text { Pozo de Federico } \\
\text { Wall } \\
\text { Walls Well } \\
\text { Walls Wells }\end{array}$ & $\begin{array}{l}\text { reservoir } \\
\text { trail } \\
\text { locale } \\
\text { locale } \\
\text { summit } \\
\text { summit } \\
\text { locale } \\
\text { ppl }\end{array}$ & $\begin{array}{l}\text { BGN } \\
\text { UNOFF } \\
\text { VARIANT } \\
\text { UNOFF } \\
\text { BGN } 1906 \\
\text { BGN } \\
\text { UNOFF } \\
\text { BGN 1941 } \\
\text { VARIANT } \\
\text { VARIANT } \\
\text { VARIANT } \\
\text { VARIANT } \\
\text { VARIANT }\end{array}$ & $\begin{array}{l}\text { Greenlee } \\
\text { Greenlee } \\
\text { Coconino } \\
\text { Cochise } \\
\text { Coconino } \\
\text { Greenlee } \\
\text { Coconino } \\
\text { Pima }\end{array}$ & $\begin{array}{l}333437 \mathrm{~N} 1092109 \mathrm{~W} \\
333540 \mathrm{~N} 1091825 \mathrm{~W} \\
\\
363822 \mathrm{~N} 1115155 \mathrm{~W} \\
313850 \mathrm{~N} 1091803 \mathrm{~W} \\
360454 \mathrm{~N} 1115657 \mathrm{~W} \\
325943 \mathrm{~N} 1090742 \mathrm{~W} \\
344736 \mathrm{~N} 1112928 \mathrm{~W} \\
320815 \mathrm{~N} 1123944 \mathrm{~W}\end{array}$ & & $\begin{array}{l}6115 \\
2129\end{array}$ & $\begin{array}{l}\text { Swede Peak } \\
\text { Cape Royal } \\
\text { York } \\
\text { Hutch Mtn } \\
\text { Gunsight }\end{array}$ \\
\hline $\begin{array}{l}\text { Kuakatch Pass } \\
\text { Kuakatch Wash } \\
\text { Kuarchi } \\
\text { See Gu Achi } \\
\text { Kuatshi } \\
\text { See Gu Achi } \\
\text { Kuchapturela } \\
\text { See Walpi } \\
\text { Kuehn Well } \\
\text { Kuhne Hill }\end{array}$ & $\begin{array}{l}\text { gap } \\
\text { stream } \\
\text { ppl } \\
\text { ppl } \\
\text { locale } \\
\text { well } \\
\text { summit }\end{array}$ & $\begin{array}{l}\text { BGN } \\
\text { BGN } \\
\text { VARIANT } \\
\text { VARIANT } \\
\text { VARIANT } \\
\text { UNOFF } \\
\text { BGN } 1976\end{array}$ & $\begin{array}{l}\text { Pima } \\
\text { Pima } \\
\text { Pima } \\
\text { Pima } \\
\text { Navajo } \\
\text { Yuma } \\
\text { Yavapai }\end{array}$ & $\begin{array}{l}320752 \mathrm{~N} 1123919 \mathrm{~W} \\
321206 \mathrm{~N} 1125140 \mathrm{~W} \\
321925 \mathrm{~N} 1120226 \mathrm{~W} \\
321925 \mathrm{~N} 1120226 \mathrm{~W} \\
354956 \mathrm{~N} 1102350 \mathrm{~W} \\
333513 \mathrm{~N} 1141458 \mathrm{~W} \\
343101 \mathrm{~N} 1122850 \mathrm{~W}\end{array}$ & $320551 \mathrm{~N} 1123742 \mathrm{~W}$ & 5935 & $\begin{array}{l}\text { South of Quartzsite } \\
\text { Prescott }\end{array}$ \\
\hline $\begin{array}{l}\text { Kui Tatk } \\
\text { Iron Pipe } \\
\text { Iron Pipe Village } \\
\text { Kirtak } \\
\text { Kvitatk } \\
\text { Kuit Vaya } \\
\text { Kuit Vaya } \\
\text { See Kohi Kug (site) } \\
\text { Kuit Vaya Well } \\
\text { Kuke Chehedagi Tank }\end{array}$ & $\begin{array}{l}\text { locale } \\
\text { locale } \\
\text { well } \\
\text { reservoir }\end{array}$ & $\begin{array}{l}\text { BGN } 1941 \\
\text { VARIANT } \\
\text { VARIANT } \\
\text { VARIANT } \\
\text { VARIANT } \\
\text { BGN } \\
\text { VARIANT } \\
\text { UNOFF } \\
\text { BGN }\end{array}$ & $\begin{array}{l}\text { Pima } \\
\text { Pima } \\
\text { Pima } \\
\text { Pima }\end{array}$ & $\begin{array}{l}314042 \mathrm{~N} 1114049 \mathrm{~W} \\
315033 \mathrm{~N} 1113934 \mathrm{~W} \\
314043 \mathrm{~N} 1114050 \mathrm{~W} \\
315909 \mathrm{~N} 1120200 \mathrm{~W}\end{array}$ & & & $\begin{array}{l}\text { Aguirre Peak } \\
\text { Aguirre Peak } \\
\text { Gu Oidak }\end{array}$ \\
\hline $\begin{array}{l}\text { Kukomalik } \\
\text { See Salina Springs } \\
\text { Kukomalik } \\
\text { See North Komelik } \\
\text { Kunkachutz Wawasit } \\
\text { See Artesa } \\
\text { Kunde Knoll } \\
\text { Kunde Mountain } \\
\text { Kuoitak } \\
\text { See Gu Oidak }\end{array}$ & $\begin{array}{l}\text { spring } \\
\text { ppl } \\
\text { locale } \\
\text { summit } \\
\text { summit } \\
\text { ppl }\end{array}$ & $\begin{array}{l}\text { VARIANT } \\
\text { VARIANT } \\
\text { VARIANT } \\
\text { BGN } \\
\text { BGN } \\
\text { VARIANT }\end{array}$ & $\begin{array}{l}\text { Apache } \\
\text { Pinal } \\
\text { Pima } \\
\text { Coconino } \\
\text { Santa Cruz } \\
\text { Pima }\end{array}$ & $\begin{array}{l}360139 \mathrm{~N} 1095221 \mathrm{~W} \\
323028 \mathrm{~N} 1115645 \mathrm{~W} \\
315358 \mathrm{~N} 1115106 \mathrm{~W} \\
350756 \mathrm{~N} 1120930 \mathrm{~W} \\
313242 \mathrm{~N} 1104134 \mathrm{~W} \\
315518 \mathrm{~N} 1120234 \mathrm{~W}\end{array}$ & & $\begin{array}{l}7608 \\
5373\end{array}$ & $\begin{array}{l}\text { Williams South } \\
\text { Mt Hughes }\end{array}$ \\
\hline $\begin{array}{l}\text { Kupk } \\
\text { Kupk Copeka } \\
\text { See Shopishk } \\
\text { Kupke } \\
\text { See Shopishk } \\
\text { Kupk Hills } \\
\text { Cerro del Tecolote } \\
\text { Copeka Mountains } \\
\text { Copeke Mountain }\end{array}$ & $\begin{array}{l}\text { locale } \\
\text { ppl } \\
\text { ppl } \\
\text { summit }\end{array}$ & $\begin{array}{l}\text { BGN } 1941 \\
\text { VARIANT } \\
\text { VARIANT } \\
\text { VARIANT } \\
\text { BGN } 1941 \\
\text { VARIANT } \\
\text { VARIANT } \\
\text { VARIANT }\end{array}$ & $\begin{array}{l}\text { Pinal } \\
\text { Pinal } \\
\text { Pima }\end{array}$ & $\begin{array}{l}315525 \mathrm{~N} 1121247 \mathrm{~W} \\
324317 \mathrm{~N} 1114652 \mathrm{~W} \\
324317 \mathrm{~N} 1114652 \mathrm{~W} \\
315453 \mathrm{~N} 1121556 \mathrm{~W}\end{array}$ & & 1845 & Kom Vo \\
\hline $\begin{array}{l}\text { Kurtz Shaft } \\
\text { Kushs Mountain } \\
\text { Kuvo } \\
\text { See Gu Vo } \\
\text { Kuitak } \\
\text { See Vainom Kug } \\
\text { Kvitatk } \\
\text { See Kui Tatk } \\
\text { Kvitatk } \\
\text { See Vainom Kug }\end{array}$ & $\begin{array}{l}\text { tunnel } \\
\text { summit } \\
\text { ppl } \\
\text { locale } \\
\text { locale } \\
\text { locale }\end{array}$ & $\begin{array}{l}\text { UNOFF } \\
\text { BGN } \\
\text { VARIANT } \\
\text { VARIANT } \\
\text { VARIANT } \\
\text { VARIANT }\end{array}$ & $\begin{array}{l}\text { Pima } \\
\text { Gila } \\
\text { Pima } \\
\text { Pima } \\
\text { Pima } \\
\text { Pima }\end{array}$ & $\begin{array}{l}322519 \mathrm{~N} 1113221 \mathrm{~W} \\
341854 \mathrm{~N} 1110525 \mathrm{~W} \\
320356 \mathrm{~N} 1123336 \mathrm{~W} \\
320248 \mathrm{~N} 1120326 \mathrm{~W} \\
320218 \mathrm{~N} 1120450 \mathrm{~W} \\
320248 \mathrm{~N} 1120326 \mathrm{~W}\end{array}$ & & 5880 & $\begin{array}{l}\text { Silver Bell West } \\
\text { Promontory Butte }\end{array}$ \\
\hline $\begin{array}{l}\text { K V Tank } \\
\text { Kwagant Hollow } \\
\text { See Kwagunt Hollow } \\
\text { Kwagunt Butte } \\
\text { Kwagunt Canyon } \\
\text { Kwagunt Canyon } \\
\text { Kwagunt Creek } \\
\text { Kwagunt Hollow } \\
\text { Kwagant Hollow }\end{array}$ & $\begin{array}{l}\text { reservoir } \\
\text { valley } \\
\text { summit } \\
\text { valley } \\
\text { valley } \\
\text { stream } \\
\text { valley }\end{array}$ & $\begin{array}{l}\text { BGN } \\
\text { VARIANT } \\
\text { BGN } 1906 \\
\text { BGN } \\
\text { BGN } 1932 \\
\text { BGN } 1906 \\
\text { BGN } 1964 \\
\text { VARIANT }\end{array}$ & $\begin{array}{l}\text { Coconino } \\
\text { Coconino } \\
\text { Coconino } \\
\text { Coconino } \\
\text { Coconino } \\
\text { Coconino } \\
\text { Coconino }\end{array}$ & $\begin{array}{l}350945 \mathrm{~N} 1112328 \mathrm{~W} \\
363038 \mathrm{~N} 1123508 \mathrm{~W} \\
361352 \mathrm{~N} 1115036 \mathrm{~W} \\
361538 \mathrm{~N} 1114953 \mathrm{~W} \\
361545 \mathrm{~N} 1114935 \mathrm{~W} \\
361548 \mathrm{~N} 1114941 \mathrm{~W} \\
363038 \mathrm{~N} 1123508 \mathrm{~W}\end{array}$ & $\begin{array}{l}361227 \mathrm{~N} 1115643 \mathrm{~W} \\
361610 \mathrm{~N} 1115219 \mathrm{~W} \\
361227 \mathrm{~N} 1115643 \mathrm{~W} \\
363004 \mathrm{~N} 1122645 \mathrm{~W}\end{array}$ & 6377 & $\begin{array}{l}\text { Cape Solitude } \\
\text { Nankoweap Mesa } \\
\text { Nankoweap Mesa } \\
\text { Nankoweap Mesa } \\
\text { Jumpup Point }\end{array}$ \\
\hline
\end{tabular}




\section{FEATURE NAME}

Kwagunt Rapids

Kwagunt Trick Tank

$K X$ Ranch

KY Canyon

Kyeke Mine

KY Hills

Kyles Tank

Kyrene

See West Chandler

Kyrene

Kyrene Branch Cana

$$
\text { Western Canal }
$$

Kyrene Gin

Kyrene Steam Generating Plant

KY Tank

K4 Tank
Kydestia Spring

Kyrene del Norte School

\section{FEATURE}

CLASS

STATUS

COUNTY

rapids

BGN 1932

Coconino

COORDINATE

reservoir

locale

valley

spring

mine

summit

reservoir

locale

ppl

BGN
UNOFF
BGN
BGN
UNOFF
BGN
8GN
VARIANT

Coconino

Pina

Coconino

Navajo

Yavapai

Coconino Gila

Maricopa

BGN

Maricopa

cana $?$

BGN

VARIANT

school

locale

locale

reservoir

reservoir
UNOFF

BGN

UNOFF

BGN

BGN
Maricopa

Maricopa

Maricopa

Maricopa

Coconino

Coconino
$361551 N 1114943 W$

362847 N1122919W

$314044 N 1111218 \mathrm{~W}$

$352045 \mathrm{~N} 1122116 \mathrm{~W}$

$361947 \mathrm{~N} 1104017 \mathrm{~W}$

$343644 N 1131339 \mathrm{~W}$

$351941 \mathrm{~N} 1121843 \mathrm{~W}$

$333232 N 1105150 \mathrm{~W}$

$331819 \mathrm{~N} 1115642 \mathrm{~W}$

332005 N1115642W

$331944 N 1115638 \mathrm{~W}$

332129 N1115500W

331751 N1115739W

$332121 \mathrm{N1115608 \textrm {W }}$

352057 N1121940W

351959 N1121625W

\begin{tabular}{|c|c|c|}
\hline $\begin{array}{l}\text { SOURCE } \\
\text { COORDINATE }\end{array}$ & $\begin{array}{c}\text { ELEV } \\
\text { FT }\end{array}$ & $\begin{array}{c}\text { MAP NAME } \\
\text { Nankoweap Mesa }\end{array}$ \\
\hline $352110 \mathrm{~N} 1121839 \mathrm{~W}$ & 6769 & $\begin{array}{l}\text { Tapeats Amphitheater } \\
\text { Saucito Mtn } \\
\text { Hearst Mtn } \\
\text { Kydestea Spring } \\
\text { 8agdad } \\
\text { Hearst Mtn } \\
\text { Rockinstraw Mtn }\end{array}$ \\
\hline & $118 \mathrm{~B}$ & $\begin{array}{l}\text { Guadalupe } \\
\text { Guadalupe } \\
\text { Guadalupe } \\
\text { Guadalupe } \\
\text { Guadalupe } \\
\text { Hearst Mtn } \\
\text { Hearst Mtn }\end{array}$ \\
\hline
\end{tabular}

UNKNOWN

UNKNOWN

UNKNOWN

$333025 \mathrm{~N} 1112530 \mathrm{~W}$

$333135 \mathrm{~N} 1112514 \mathrm{~W}$

$333135 N 1112515$

$333135 \mathrm{~N} 1112515 \mathrm{~W}$

332B57N1112250W

$332612 \times 1111501 \mathrm{~W}$

$332612 N 1111500 \mathrm{~W}$

$332943 \mathrm{N1112333 \textrm {W }}$

Mormon Flat Dam

Mormon Flat Dam

Mormon Flat Dam

Mormon Flat Dam

Boulder Creek

La Barge Mountain

La Barge Mountain

LaBarge Spring

Labarge Spring Number Two

Labyrinth Bay

La Cañada Ranch

La Casa Trail Mobile Villa

La Casita Mobile Park

La Cebadilla Lake

Lacey Forks Canyon

Lacey Point

La Cholla Airpark

Lacy Airport

Ladder Tank

Ladder Tank

Ladd Tank

Ladrone Tank

Ladron Spring

Ladybug Peak

Ladybug Saddle

Lady Bug Trail Three Hundred

Twenty Nine

VARIANT

$332440 \mathrm{~N} 111240 \mathrm{OW}$

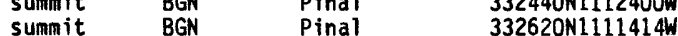

$332603 \mathrm{~N} 1111659 \mathrm{~W}$

$370002 \mathrm{~N} 1111825 \mathrm{~W}$

$315620 \mathrm{~N} 1111155 \mathrm{~W}$

$332458 \mathrm{~N} 1113520 \mathrm{~W}$

$332659 \mathrm{~N} 1114913 \mathrm{~W}$

$335731 \mathrm{~N} 1104724 \mathrm{~W}$

$350350 \mathrm{~N} 1094806 \mathrm{~W}$

$322648 \mathrm{~N} 1110008 \mathrm{~W}$

$\begin{array}{llll}\text { airport } & \text { ADMIN } & \text { Gila } & 341400 \mathrm{~N} 1112025 \mathrm{~W} \\ \text { reservoir } & \text { BGN } & \text { Yuna } & 330538 \mathrm{~N} 1141007 \mathrm{~W}\end{array}$

$\begin{array}{llll}\text { reservoir } & \text { BGN } & \text { Yuma } & 330538 \mathrm{~N} 1141007 \mathrm{~W} \\ \text { reservoir } & \text { BGN } & \text { Yavapai } & 342715 \mathrm{~N} 1114815 \mathrm{~W}\end{array}$

reservoir BGN Gila

reservoir BGN Grahan 325148N1100651W

spring BGN Greenlee 332746N1091012W

summit BGN 1932 Graham 323719N1094905W

gap BGN $\quad$ Graham 323724 N1094920

trail UNOFF Graham 323826N1094808

Lady Y U Ranch La Encarnacion
See Sacaton

Lafayette Parkway

Lafayette School

Lafayette School

Lafe Nelson School

La Fontana Heights

(subdivision)

La Fortuna Mine

See Fortuna Mine

$\begin{array}{llll}\text { locale } & \text { UNOFF } & \text { Mohave } & 350806 \text { N1135707W } \\ \text { ppl } & \text { VARIANT } & \text { Pinal } & 330436 \text { N1114419W } \\ \text { park } & \text { ADMIN } & \text { Maricopa } & 332943 N 1115602 \mathrm{~W} \\ \text { school } & \text { UNOFF } & \text { Maricopa } & 332909 \text { N1120120W } \\ \text { school } & \text { UNOFF } & \text { Maricopa } & 332918 \text { N1120121W } \\ \text { school } & \text { UNOFF } & \text { Graham } & 324936 \mathrm{~N} 1094308 \mathrm{~W} \\ \text { ppl } & \text { BGN } & \text { Maricopa } & 333047 \text { N1121240W }\end{array}$

VARIANT
5057 Goldfield

332644N1112000W

$321440 \mathrm{~N} 1114130 \mathrm{~W}$

$335808 N 1105036 \mathrm{~W}$

5077 Iron Mountain

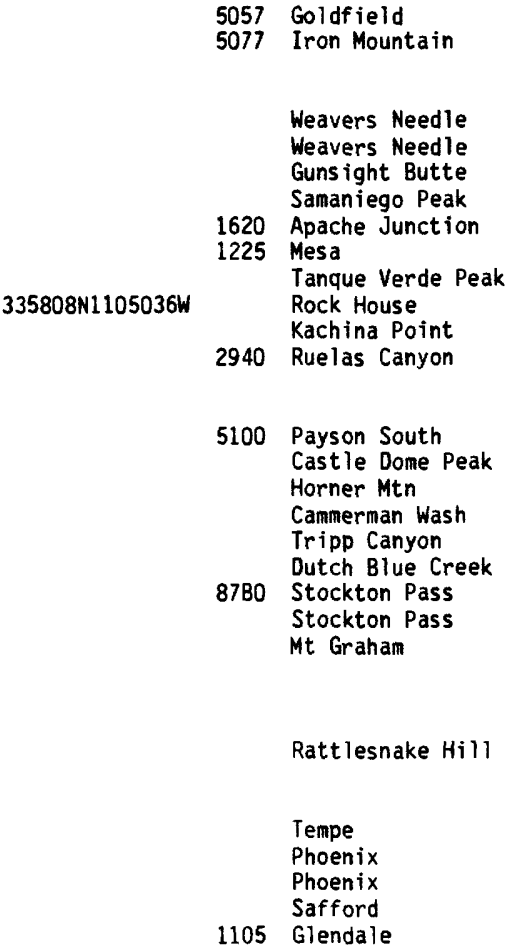

$323306 \mathrm{~N} 1141948 \mathrm{~W}$ 


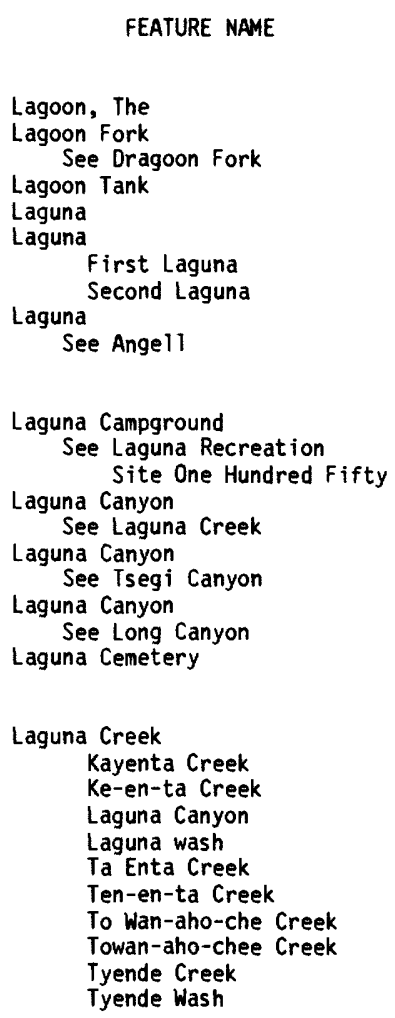

FEATURE CLASS

STATUS

COUNTY

stream
stream
reservoir
locale
$\mathrm{pp} 1$

locale

BGN

VARIANT

BGN

BGN

VARIANT

VARIANT

VARIANT

Coconino

VARIANT

park

strean

valley

valley

cemetery

stream

.

\begin{tabular}{|c|c|c|c|}
\hline $\begin{array}{l}\text { dam } \\
\text { lake } \\
\text { summit }\end{array}$ & $\begin{array}{l}\text { UNOFF } \\
\text { BGN } \\
\text { BGN } \\
\text { VARIANT }\end{array}$ & $\begin{array}{l}\text { Yuma } \\
\text { Coconino } \\
\text { Yuma }\end{array}$ & $\begin{array}{l}324923 \mathrm{~N} 1142936 \mathrm{~W} \\
355425 \mathrm{~N} 1130251 \mathrm{~W} \\
324704 \mathrm{~N} 1142646 \mathrm{~W}\end{array}$ \\
\hline park & ADMIN & Maricopa & $333155 N 1112451 \mathrm{~W}$ \\
\hline $\begin{array}{l}\text { reservoir } \\
\text { spring } \\
\text { school }\end{array}$ & $\begin{array}{l}\text { VARIANT } \\
\text { BGN } \\
\text { BGN } \\
\text { UNOFF }\end{array}$ & $\begin{array}{l}\text { La Paz } \\
\text { Apache } \\
\text { Pima }\end{array}$ & $\begin{array}{l}324923 \mathrm{~N} 1142936 \mathrm{~W} \\
342018 \mathrm{~N} 1094324 \mathrm{~W} \\
321755 \mathrm{~N} 1110145 \mathrm{~W}\end{array}$ \\
\hline $\begin{array}{l}\text { spring } \\
\text { valley }\end{array}$ & $\begin{array}{l}\text { BGN } \\
\text { BGN } \\
\text { VARIANT }\end{array}$ & $\begin{array}{l}\text { Pinal } \\
\text { Coconino }\end{array}$ & $\begin{array}{l}331405 \mathrm{~N} 1105640 \mathrm{~W} \\
355832 \mathrm{~N} 1130325 \mathrm{~W}\end{array}$ \\
\hline $\begin{array}{l}\text { stream } \\
\text { reservoir } \\
\text { school } \\
\text { locale } \\
\text { stream } \\
\text { reservoir } \\
\text { reservoir }\end{array}$ & $\begin{array}{l}\text { BGN } \\
\text { UNOFF } \\
\text { UNOFF } \\
\text { BGN } \\
\text { BGN } \\
\text { BGN }\end{array}$ & $\begin{array}{l}\text { Apache } \\
\text { Coconino } \\
\text { Maricopa } \\
\text { Pinal } \\
\text { Yuma } \\
\text { Pima } \\
\text { Pima }\end{array}$ & $\begin{array}{l}365340 \mathrm{~N} 1094435 \mathrm{~W} \\
350129 \mathrm{N1} 113449 \mathrm{~W} \\
332645 \mathrm{N1} 115511 \mathrm{~W} \\
325338 \mathrm{N1} 103411 \mathrm{~W} \\
321400 \mathrm{~N} 1135945 \mathrm{~W} \\
315441 \mathrm{~N} 1104127 \mathrm{~W} \\
321919 \mathrm{~N} 1103717 \mathrm{~W}\end{array}$ \\
\hline $\begin{array}{l}\text { reservoir } \\
\mathrm{ppl}\end{array}$ & $\begin{array}{l}\text { BGN } \\
\text { BGN }\end{array}$ & $\begin{array}{l}\text { Mohave } \\
\text { Maricopa }\end{array}$ & $\begin{array}{l}363409 \mathrm{~N} 1130311 \mathrm{~W} \\
333512 \mathrm{~N} 1120725 \mathrm{~W}\end{array}$ \\
\hline $\begin{array}{l}\text { reservoir } \\
\text { locale }\end{array}$ & $\begin{array}{l}\text { VARIANT } \\
\text { BGN } \\
\text { VARIANT } \\
\text { VARIANT } \\
\text { VARIANT } \\
\text { VARIANT }\end{array}$ & $\begin{array}{l}\text { Maricopa } \\
\text { Maricopa }\end{array}$ & $\begin{array}{l}335112 \mathrm{~N} 1121607 \mathrm{~W} \\
335019 \mathrm{~N} 1121558 \mathrm{~W}\end{array}$ \\
\hline flat & & Cochise & $320822 \mathrm{~N} 1095046 \mathrm{~W}$ \\
\hline locale & UNOFF & Maricopa & $332245 \mathrm{~N} 1115520 \mathrm{~W}$ \\
\hline $\begin{array}{l}\text { flat } \\
\text { ppl } \\
\text { airport } \\
\text { school } \\
\text { building } \\
\text { school } \\
\text { park } \\
\text { flat }\end{array}$ & $\begin{array}{l}\text { BGN } \\
\text { BGN } \\
\text { ADMIN } \\
\text { UNOFF } \\
\text { UNOFF } \\
\text { UNOFF } \\
\text { ADMIN } \\
\text { BGN }\end{array}$ & $\begin{array}{l}\text { Mohave } \\
\text { Mohave } \\
\text { Mohave } \\
\text { Mohave } \\
\text { Mohave } \\
\text { Mohave } \\
\text { Mohave } \\
\text { Pinal }\end{array}$ & $\begin{array}{l}360837 \mathrm{N11} 133129 \mathrm{~W} \\
342902 \mathrm{N11} 141918 \mathrm{~W} \\
342740 \mathrm{~N} 1142141 \mathrm{~W} \\
342939 \mathrm{N11} 11904 \mathrm{~W} \\
342843 \mathrm{N11} 142013 \mathrm{~W} \\
342 \mathrm{~B} 23 \mathrm{~N} 1141911 \mathrm{~W} \\
342609 \mathrm{N1} 141705 \mathrm{~W} \\
331220 \mathrm{~N} 1105959 \mathrm{~W}\end{array}$ \\
\hline
\end{tabular}

$345148 \mathrm{N1} 120439 \mathrm{~W}$

$351013 \mathrm{N1132030 \textrm {W }}$

$323514 N 1113743 \mathrm{~W}$

$324908 \mathrm{~N} 1142905 \mathrm{~W}$

351144N1111812W

Maricopa

$333155 N 1112451 W$

VARIANT

VARIANT

Apache

$365340 \mathrm{~N} 1094435 \mathrm{~W}$

VARIANT

Navajo

363903N1102554W

Navajo

364115 N1103042W

324806N1142944W

365340N1094435W

Apache

VARIANT

VARIANT

VARIANT

VARIANT

VARIANT

VARIANT

VARIANT

VARIANT

VARIANT

VARIANT

BGN

ADMIN $\begin{array}{ll}\text { SOURCE } & \text { ELEV } \\ \text { COORDINATE } & \text { FT MAP NAME }\end{array}$

325439N1132631W 325420N1132441W Aztec NW

$364100 \mathrm{~N} 1103030 \mathrm{~W}$

Laguna Dam

Mexican Water

Laguna Dam Prospect Point Laguna Dam

Mormon Flat Dam

Laguna Dam

Vernon

Jaynes

$355100 \times 1130304 \mathrm{~W}$

Hot Tamale Peak Prospect Point

Lower Lake Mary Tempe Brandenburg Mtn Sierra Lechuguilla Mount Fagan

$321510 N 1135642 \mathrm{~W}$ Piety Hill

Hat Knoll 1260 Sunnys lope

Baldy Mtn

Tempe

Castle Peak Lake Havasu City $S$ 483 Lake Havasu City S Lake Havasu City S Lake Havasu City $S$ Lake Havasu City $S$ Lake Havasu City S Hot Tamale Peak 
FEATURE

CLASS

STATUS

COORDINATE

SOURCE ELEV

FT MAP NAME

Lake Mary

See Upper Lake Mary

Lake Mary

See Lower Lake Mary

Lake Mary Boating Site

Lake Mary Meadows

Lake Mary Tank

See Mary, Lake

Lake Mary Valley

Clark Valley

Clarks Valley

Little Valley

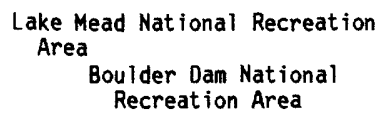

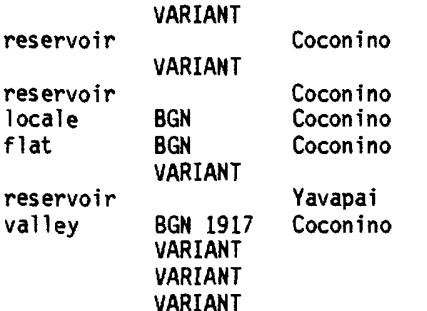

$350451 M 1113152 \mathrm{~W}$

$350645 N 1113457 \mathrm{~W}$ $350424 \mathrm{~N} 1113127 \mathrm{~W}$ $350524 N 1113505 W$

$345754 \mathrm{~N} 1130612 \mathrm{~W}$ $350902 \mathrm{~N} 1113556 \mathrm{~W}$

VARIANT

ADMIN

Mohave

VARIANT

mine

airport

UNOFF
ADMIN

BGN

Mohave

Mohave

Mohave

locale BGN

ppl

$\begin{array}{ll}\text { building } & \text { UN } \\ \text { summit } & \text { BG } \\ \text { summit } & B G \\ \text { reservoir } & B G \\ \text { ppl } & B G \\ \text { dam } & \text { UN } \\ \text { reservoir } & \text { BG } \\ \text { locale } & \text { BG } \\ \text { locale } & \text { BG } \\ \text { airport } & \text { AD }\end{array}$

UNOFF

BGN

BGN

$B G N$

BGN

BGN

ADMIN

Mohave

Yavapai

Yavapai

Apache

Coconino

Coconino

Navajo

Navajo

Coconino

Maricopa

Maricopa

Maricopa

park ADMIN Yavapai

park

is land

park

ridge

reservoir

mine

reservoir

BGN
VARIANT

ADMIN

BGN

UNOFF

VARIANT

Coconino

Coconino

Coconino

Navajo

Yavapai

Pinal

Navajo

VARIANT

reservoir

ppl

BGN

VARIANT

park ADMIN

dam UNOFF

park

dam

locale

reservoir

ADMIN

UNOFF

VARIANT

Navajo

Navajo

Navajo

Pima

Pima

Navajo

Navajo

reservoir

reservoir

reservoir

reservoir

reservoir

reservoir

bas in

school

ppl

BGN
BGN
BGN
BGN
BGN
BGN
BGN
UNOFF
VARIANT

Gila

Navajo

Coconino

Coconino

Mohave

Pinal

Mohave

Yavapai

Coconino

ppl

park

park

BGN 1966 Coconino

$\begin{array}{ll}\text { BGN } 1966 & \text { Coconino } \\ \text { ADMIN } & \text { Coconino }\end{array}$

$\begin{array}{ll}\text { ADMIN } & \text { Coconino } \\ \text { BGN } & \text { Coconino }\end{array}$

BGN

Coconino

school

stream
VARIANT

UNOFF

BGN
360056 N1144412W

$342019 N 1133726 \mathrm{~W}$

$353406 N 1141755$

$351325 N 1143325 \mathrm{~W}$

$343756 \mathrm{~N} 1114638 \mathrm{~W}$

$343756 \mathrm{N1114636 \textrm {W }}$

340928 N1094607W

$344722 \mathrm{~N} 1112952 \mathrm{~W}$

$344725 N 1113027 \mathrm{~W}$

340950 N $1095920 \mathrm{~W}$

$340942 \mathrm{~N} 1095836 \mathrm{~W}$

$343303 \mathrm{~N} 1112114 \mathrm{~W}$

$335200 \mathrm{~N} 112160 \mathrm{OW}$

335019 N1121558W

$334935 \mathrm{~N} 1121606 \mathrm{~W}$

$335403 \mathrm{~N} 1121607 \mathrm{~W}$ 350057 N1120155W

$365900 \mathrm{~N} 1112600 \mathrm{~W}$ 365800 N1111730 $340109 N 1100202 \mathrm{~W}$ $344706 \mathrm{~N} 1113329 \mathrm{~W}$ $323123 N 1115407 \mathrm{~W}$

$341140 \mathrm{~N} 1100013 \mathrm{~W}$

$341140 \mathrm{~N} 1100013 \mathrm{~W}$ $340916 \mathrm{~N} 1095822 \mathrm{~W}$

$340927 N 1095843 \mathrm{~W}$ $340930 \mathrm{~N} 1095854 \mathrm{~W}$ $321105 N 1104900 \mathrm{~N}$ $321112 \mathrm{N1104906 \textrm {W }}$

$340930 N 1095834 \mathrm{~W}$

340900N1095905W

$33440 \mathrm{BN} 1110826 \mathrm{~W}$ $340124 \mathrm{N1} 100600 \mathrm{~W}$ $350835 \mathrm{~N} 1114724 \mathrm{~W}$ $351115 \mathrm{~N} 1114826 \mathrm{~W}$ $353946 \mathrm{~N} 1140620 \mathrm{~W}$ $325417 \mathrm{~N} 1110416 \mathrm{~W}$ $362647 \mathrm{~N} 1130846 \mathrm{~W}$ $343528 \mathrm{~N} 1122003 \mathrm{~W}$

$345430 \mathrm{~N} 1112745 \mathrm{~W}$

$345433 \mathrm{~N} 1112647 \mathrm{~W}$

$350357 N 1112953 \mathrm{~W}$

$350358 N 1113004 \mathrm{~W}$

$312542 \mathrm{~N} 1102705 \mathrm{~W}$

$333523 \mathrm{~N} 1120728 \mathrm{~W}$

$333351 \mathrm{N1143059 \textrm {W }}$
351318 NI143346W

6840 Lower Lake Mary Lower Lake Mary

345920N1112814W Flagstaff East

Hoover Dam

Artillery Peak

3200 Dolan Springs

Davis Dam

Davis Dam

Lake Montezuma

Lake Montezuma

8501 Sponseller Mtn

Hutch Mtn

Stoneman Lake

6736 Lakeside

6696 Lakeside

Long Valley

Baldy Mtn

Baldy Mtn

Baldy Mtn

Governors Peak White Horse Lake

Wild Horse Mesa

Faught Ridge

Stoneman Lake

North Komelik

Lakes ide

6700 Lakeside

6707 Lakeside

Tucs on East

Tucs on East

6700 Lakeside

Georges Butte

Faught Ridge

Bel lemont

Bellemont

Red Lake

Ninetysix Hills NE

Mt Trumbull NW

Prescott Valley $S$

Mormon Lake

Ashurst Lake

Lower Lake Mary 
FEATURE NAME

Lake Well

Lake Wilhelm

See Hole, Lake

La Lesna

See Ak Komelik

LaLesna

See Ak Komelik

LaLoma Ranch

Lalo Peak

LaMadera Park

Lama Negra

See Agathla Peak

Lamar Reservoir

Lamb Camp

Lamberson and Riggs Ranch

Lamberson Ranch

Lamb Hotel

Lambing Camp Wash

Lambing Creek

Lambing Lake See Vail Lake

Lambs Lake

Lamb Spring

Lamb Spring

Lamb Tank

Lamb Tank

Lamb Well

Lame Deer Canyon

La Milagrosa-Aqua Caliente Trail

La Minta Dan

La Montana del Sur (trailer park )

La Moralita

$$
\text { See Stan Shuatuk }
$$

Lamova Spring

Lamphere Canyon

See Lanphier Canyon

Lampshire Canyon

Lampshire Tank

Lampshire Well

Lancaster

Lancaster Creek

Lancelot Point

and

Lander Spring

Landing Strip Tank

Landing Strip Tank

Landin Park

Landmark, The

Landmark Letter

Landmark Mountain

Landmark Tank

Landmark Wash

Landon Spring

Land Railroad Station

Landsman Camp

Landsman Spring

Land Tank

Lane Mountain

Lane Mountain Trail

Lane Spring

Lane Spring

Lane Tank

Lane Tank

Lane Tank

Lang Canyon

Lang Creek

Langes Run

See Langs Run

Langes Wash

\begin{tabular}{|c|c|c|c|}
\hline $\begin{array}{l}\text { FEATURE } \\
\text { CLASS }\end{array}$ & STATUS & COUNTY & COORDINATE \\
\hline well & $\begin{array}{l}\text { UNOFF } \\
\text { VARIANT }\end{array}$ & Coconino & $362459 N 1105123 \mathrm{~W}$ \\
\hline lake & & Apache & $341525 \mathrm{~N} 1094443 \mathrm{~W}$ \\
\hline locale & $\begin{array}{l}\text { VARIANT } \\
\text { VARIANT }\end{array}$ & Pima & $314304 \mathrm{~N} 1121202 \mathrm{~W}$ \\
\hline $\begin{array}{l}\text { locale } \\
\text { ppl } \\
\text { summit } \\
\text { park }\end{array}$ & $\begin{array}{l}\text { BGN } \\
\text { BGN } \\
\text { AOMIN } \\
\text { VARIANT }\end{array}$ & $\begin{array}{l}\text { Pima } \\
\text { Maricopa } \\
\text { Pima } \\
\text { Pima }\end{array}$ & $\begin{array}{l}314304 N 1121202 \mathrm{~W} \\
333048 \mathrm{~N} 1122131 \mathrm{~W} \\
313827 \mathrm{~N} 1113810 \mathrm{~W} \\
321533 \mathrm{~N} 1105551 \mathrm{~W}\end{array}$ \\
\hline $\begin{array}{l}\text { summit } \\
\text { reservoir }\end{array}$ & BGN & $\begin{array}{l}\text { Navajo } \\
\text { Mohave }\end{array}$ & $\begin{array}{l}364936 \mathrm{N1} 101330 \mathrm{~W} \\
362825 \mathrm{N1} 132807 \mathrm{~W}\end{array}$ \\
\hline $\begin{array}{l}\text { locale } \\
\text { locale } \\
\text { locale } \\
\text { building } \\
\text { stream } \\
\text { stream }\end{array}$ & $\begin{array}{l}8 G N \\
\text { UNOFF } \\
\text { UNOFF } \\
\text { UNOFF } \\
\text { BGN } \\
\text { BGN } \\
\text { VARIANT }\end{array}$ & $\begin{array}{l}\text { Graham } \\
\text { Cochise } \\
\text { Cochise } \\
\text { Graham } \\
\text { Pinal } \\
\text { Gila }\end{array}$ & $\begin{array}{l}325029 N 1101517 \mathrm{~W} \\
313523 \mathrm{~N} 1092851 \mathrm{~W} \\
320150 \mathrm{~N} 1092744 \mathrm{~W} \\
325000 \mathrm{~N} 1095307 \mathrm{~W} \\
325436 \mathrm{~N} 1110419 \mathrm{~W} \\
335115 \mathrm{~N} 1111758 \mathrm{~W}\end{array}$ \\
\hline $\begin{array}{l}\text { lake } \\
\text { lake } \\
\text { spring }\end{array}$ & $\begin{array}{l}\text { BGN } \\
8 G N\end{array}$ & $\begin{array}{l}\text { Coconino } \\
\text { Coconino } \\
\text { Yavapai }\end{array}$ & $\begin{array}{l}350525 \mathrm{~N} 1113045 \mathrm{~W} \\
364141 \mathrm{~N} 1121511 \mathrm{~W} \\
343702 \mathrm{~N} 1120500 \mathrm{~W}\end{array}$ \\
\hline $\begin{array}{l}\text { spring } \\
\text { reservoir } \\
\text { reservoir } \\
\text { well } \\
\text { valley } \\
\text { trail }\end{array}$ & $\begin{array}{l}8 G N \\
B G N \\
\text { BGN } \\
\text { UNOFF } \\
\text { BGN } \\
\text { UNOFF }\end{array}$ & $\begin{array}{l}\text { Navajo } \\
\text { Graham } \\
\text { Yavapai } \\
\text { Navajo } \\
\text { Apache } \\
\text { Pima }\end{array}$ & $\begin{array}{l}360921 \mathrm{~N} 1101038 \mathrm{~W} \\
324924 \mathrm{~N} 1095522 \mathrm{~W} \\
343403 \mathrm{~N} 1120611 \mathrm{~W} \\
354853 \mathrm{~N} 1100347 \mathrm{~W} \\
340047 \mathrm{~N} 1094357 \mathrm{~W} \\
321752 \mathrm{~N} 1104141 \mathrm{~W}\end{array}$ \\
\hline $\begin{array}{l}\text { dam } \\
\text { locale }\end{array}$ & $\begin{array}{l}\text { UNOFF } \\
\text { UNOFF }\end{array}$ & $\begin{array}{l}\text { Pima } \\
\text { Maricopa }\end{array}$ & $\begin{array}{l}313029 \mathrm{~N} 1112454 \mathrm{~W} \\
332220 \mathrm{~N} 1120403 \mathrm{~W}\end{array}$ \\
\hline
\end{tabular}

$\begin{array}{ccc}\begin{array}{c}\text { SOURCE } \\ \text { COORDINATE }\end{array} & \text { ELEV } & \\ & 5664 & \text { Cow Springs }\end{array}$

El Mirage

Aguirre Peak

Tucs on North

Poverty Knoll

Klondike

Pedregosa Mts West

Bowie Mtn South

Shingle Mill Mtn

Ninetys ix Hills NE

$325044 \mathrm{~N} 1105706 \mathrm{~W}$

$335630 \mathrm{~N} 1111027 \mathrm{~W}$

Tonto 8as in

Warm Springs Canyon Cherry

Pinon NW

Shingle Mill Mtn

Cherry

Lamb Well

335832N1094056W Horseshoe Cienega

Agua Caliente $\mathrm{Hill}$

Wilbur Canyon

1210 Lone Butte

\begin{tabular}{|c|c|c|c|}
\hline \multirow[b]{2}{*}{$\begin{array}{l}\text { locale } \\
\text { spring }\end{array}$} & \multicolumn{2}{|l|}{ VARIANT } & \multirow[b]{2}{*}{$\begin{array}{l}314756 \mathrm{~N} 1121759 \mathrm{~W} \\
354815 \mathrm{~N} 1102859 \mathrm{~W}\end{array}$} \\
\hline & $\begin{array}{l}\text { BGN } \\
\text { YARIANT }\end{array}$ & $\begin{array}{l}\text { Pima } \\
\text { Navajo }\end{array}$ & \\
\hline $\begin{array}{l}\text { valley } \\
\text { valley } \\
\text { reservoir } \\
\text { well } \\
\text { locale } \\
\text { stream }\end{array}$ & $\begin{array}{l}\text { BGN } \\
\text { BGN } \\
\text { UNOFF } \\
\text { BGN } \\
\text { BGN }\end{array}$ & $\begin{array}{l}\text { Greenlee } \\
\text { Santa Cruz } \\
\text { Santa Cruz } \\
\text { Santa Cruz } \\
\text { Yavapai } \\
\text { Yavapai }\end{array}$ & $\begin{array}{l}333539 N 1090751 \mathrm{~W} \\
313228 \mathrm{~N} 1103926 \mathrm{~W} \\
313149 \mathrm{~N} 1103614 \mathrm{~W} \\
313203 \mathrm{~N} 1103635 \mathrm{~W} \\
341849 \mathrm{~N} 1114253 \mathrm{~W} \\
341850 \mathrm{~N} 1134256 \mathrm{~W}\end{array}$ \\
\hline
\end{tabular}

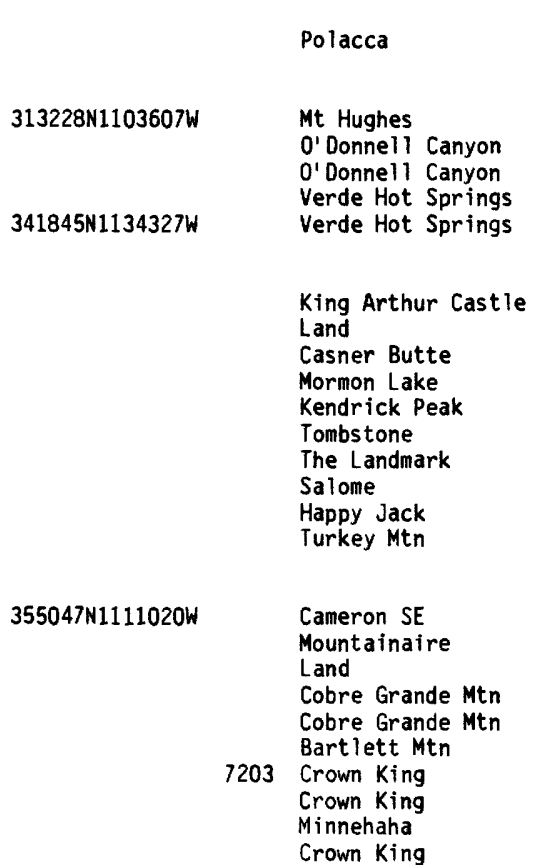

cliff BGN 1908 Coconino 361844N1121620W

locale BGN $\quad$ Cochise 315117 N1101343W

spring BGN Yavapai $343833 \mathrm{~N} 1114206 \mathrm{~W}$

reservoir BGN Coconino 345452N1112755W

reservoir BGN Coconino $352354 \mathrm{~N} 1114511 \mathrm{~W}$

park AOMIN Cochise 314221N1100312W

summit BGN

pillar BGN Yuma 334554N1133324W

summit BGN Coconino 344316N1112301W

reservoir BGN Coconino $\quad 344348$ N1112218W

$\begin{array}{llll}\text { valley } & \text { BGN } & \text { Coconino } & 354848 \text { N1112028W } \\ \text { spring } & \text { BGN } & \text { Coconino } & 350725 \text { N1114240W } \\ \text { building } & \text { UNOFF } & \text { Cochise } & 315115 N 1101342 \mathrm{~W} \\ \text { locale } & \text { BGN } & \text { Graham } & 325805 N 1101934 \mathrm{~W} \\ \text { spring } & \text { BGN } & \text { Graham } & 325806 \mathrm{~N} 1101933 \mathrm{~W} \\ \text { reservoir } & \text { BGN } & \text { Santa Cruz } & 312412 \mathrm{~N} 1111640 \mathrm{~W} \\ \text { summit } & \text { BGN } & \text { Yavapai } & 340912 \mathrm{~N} 1121909 \mathrm{~W} \\ \text { trail } & \text { UNOFF } & \text { Yavapai } & 340832 \mathrm{~N} 1121909 \mathrm{~W} \\ \text { spring } & \text { BGN } & \text { Yavapai } & 340737 \mathrm{N1122857W} \\ \text { spring } & \text { BGN } & \text { Yavapai } & 340814 \text { N1121927W }\end{array}$

reservoir BGN Graham 323241N1101329W

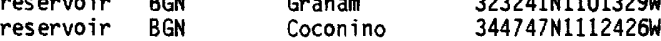

reservoir BGN Yavapai 344828N1130145W

valley BGN Yavapai 343933 N1121304W

$340356 \mathrm{~N} 1092716 \mathrm{~W}$

$344010 \mathrm{~N} 1120955 \mathrm{~W}$

Apache

$340323 \mathrm{~N} 1092917 \mathrm{~W}$

Mohave stream VARIANT

\footnotetext{
$364549 N 1130737 W$
} 
NATIONAL GAZETTEER--ARIZONA 1986

\section{FEATURE NAME}

See Langs Run

Lang Pond

Langs Run

Langes Run

Lang Valley

Langes Wash

Langston Black Canyon Tank

Langston Reservoir

Lang Tank

Lang Tank

Lang Valley

See Langs Run

Lann Tank

Lanphier Canyon Lamphere Canyon

Lantern Tank

La Osa Ranch

La Otra School

La Palma

LaPalma Corral

La Paz

See La Paz Well

La Paz Arroyo

La Paz County Yuma County

La Paz County Courthouse

La Paz Ferry

See Bradshaw Ferry (site)

La Paz Mountain

La Paz Mountains

See Dome Rock Mountains

La Paz Wash

Goodman Wash

La Paz Well

$$
\text { La Paz }
$$

Lapham

Pot Holes

Lapham Tank

La Placita Shopping Center See La Placita Village Shopping Center

La Placita Village Shopping Center

La Placita Shopping

Center

La Posa Plain Colorado Valley

La Posta Quemada Ranch

La Posta Quemado Canyon See Posta Quemada Canyon

La Pradera Park

See La Prudera Park

La Prudera Park

La Pradera Park

La Puerta Limita

See Marsh Pass

La Purisima Concepcion See Yuma

La Quitani Valley See Quituni Valley, La

La Quituni

See Ali Ak Chin

Large Whiskers Tank

Largo Creek

Largo Creek

See Carrizo Wash

Largo Mountain

Largo Tank

Largo Tank Number Two

Lariat Tra-Tel Trailer Court

Larimore (historical)

\section{FEATURE
CLASS}

STATUS

COUNTY

COORDINATE

strean
lake

BGN

Mohave

Mohave

Mohave

stream BGN

VARIANT

VARIANT

reservoir BGR

reservoir $B G N$

reservoir BGN

reservoir

VARIANT

stream

reservoir valley

reservoir

locale

school

ppl

locale

well

valley

civil

BGN
ADMIN

building

locale

summit

range

BGN

stream

well

UNOFF

locale BGN

reservoir BGN

locale

locale

\begin{tabular}{|c|c|}
\hline plain & BGN \\
\hline & VARIANT \\
\hline locale & $\begin{array}{l}\text { UNOFF } \\
\text { VARIANT }\end{array}$ \\
\hline valley & \\
\hline & VARIANT \\
\hline $\begin{array}{l}\text { park } \\
\text { park }\end{array}$ & ADNIN \\
\hline & $\begin{array}{l}\text { VARIANT } \\
\text { VARIANT }\end{array}$ \\
\hline
\end{tabular}

gap

ppl

valley

locale reservoi

stream

valley

summit

reservoir

reservoir

locale

locale
BGN

\section{BGN}

BGN

VARIANT

UNOFF

UNOFF

$B G N$

BGN

VARIANT

VARIANT

VARIANT

BGN 1960

VARIANT

VARIANT

VARIANT

UNOFF

VARIANT

VARIANT

VARIANT

VARIANT

BGN

BGN

VARIANT

Mohave

Mohave

Yavapai

Coconino

Mohave

Gila

Greenlee

Graham

Pinal

Maricopa

Pinal

Maricopa

Yuma

Yuma

La Paz

La Paz

La Paz

Yuma

Yuma

Yuma

Yuma

Yavapai

Maricopa

Pima

Pima

La Paz

$334400 \mathrm{~N} 1141000 \mathrm{~W}$

$320258 \mathrm{~N} 1103808 \mathrm{~W}$

320315 N1103800W

Pima

Maricopa

Maricopa

Navajo

Yuma

Pima

Pima

Coconino

Greenlee

Apache

BGN
BGN
BGN
UNOFF
BGN

Navajo

Navajo

Navajo

Maricopa

Santa Cruz

$363258 \mathrm{~N} 1130729 \mathrm{~W}$

$363605 N 1125924 \mathrm{~W}$

409N1130744W

$364549 N 1130737 \mathrm{~W}$

$335121 N 1111720 \mathrm{~W}$ $333539 N 1090751 \mathrm{~W}$

$325017 N 1101025 \mathrm{~W}$ $323242 \mathrm{~N} 1112545 \mathrm{~W}$ $332719 \mathrm{~N} 1120803 \mathrm{~W}$ $325245 \mathrm{~N} 1113052 \mathrm{~W}$ $325804 \mathrm{~N} 1123546 \mathrm{~W}$

$334045 N 1142832 W$

$333722 \mathrm{~N} 1142454 \mathrm{~W}$ 333730N1135230W

340845N1141720W

$333720 \mathrm{~N} 1143030 \mathrm{~W}$ $334137 \mathrm{N1} 142513 \mathrm{~W}$

$334127 N 1142011 W$ $334059 \mathrm{~N} 1142825 \mathrm{~W}$

$334045 N 1142832 W$

$341050 \mathrm{~N} 1122405 \mathrm{~W}$ $335525 \mathrm{~N} 1130857 \mathrm{~W}$

$321320 N_{1105825 W}$

$321320 \mathrm{N1105825W}$

$333211 \mathrm{~N} 1120839 \mathrm{~W}$

333211 N1120839W

$363906 \mathrm{~N} 1102546 \mathrm{~W}$

$324331 \mathrm{~N} 1143725 \mathrm{~W}$

315129 N1123224W

$354313 N 1113457 \mathrm{~W}$

$333515 \mathrm{~N} 1090828 \mathrm{~W}$

$343620 \mathrm{~N} 1092606 \mathrm{~W}$

$340526 \mathrm{~N} 1095141 \mathrm{~W}$

$340456 \mathrm{~N} 1095404 \mathrm{~W}$

$340517 N 1095252 \mathrm{~W}$

$332800 \mathrm{~N} 1115918 \mathrm{~W}$

313918 N1104243W
364549 N1130737W

$364316 \mathrm{~N} 1130716 \mathrm{~W}$

364549N1130737W 362359N1131517W

$333516 N 1142123 \mathrm{~W}$

$333950 \mathrm{~N} 1142338 \mathrm{~W}$

$315000 \mathrm{~N} 1123202 \mathrm{~W}$
Dome Rock Mts SW Gene Wash

Parker

1343 La Paz Mtn

La Paz Mtn

La Paz Mtn

Minnehaha

Aguila

2370 Tucson

AZ341

$\begin{array}{lc}\text { SOURCE } & \text { ELEV } \\ \text { COORDINATE } & \text { FT }\end{array}$

Heaton Kno

Behm Mesa

Flagstaff West

Tonto Bas in

Buford $\mathrm{Hill}$

Samaniego Hills

wier

Bosque

Quartzsite

3400 Vail

Glendale

Blue

7590 McNary

Indian Pine

Indian Pine

1170 Tempe

4550 Sonoita 
FEATURE NAME

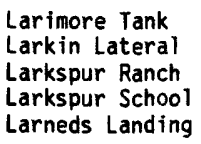

Las Palmaritas Park Las Ramadas Picnic Ground

Last Chance Canyon

Last Chance Knoll

Last Chance Mine

Last Chance Mine

Last Chance Mine

Last Chance Points

Last Chance Ranch

Last Chance Rapids

Last Chance Spring

Last Chance Tank

Last Chance Tank

Last Chance Tank

\section{FEATURE}

CLASS

STATUS

reservoir

canal

locale

school

locale

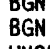

BGN

UNOFF

BGN

cliff

cliff

locale

stream

reservoir

spring

reservoir

valley

$\begin{array}{ll}\text { BGN } & \begin{array}{l}\text { Maricopa } \\ \text { Maricopa }\end{array} \\ \text { UNOFF } & \text { Maricopa } \\ \text { BGN } & \text { Yavapai } \\ \text { BGN } & \text { Coconino } \\ \text { BGN } & \text { Gila } \\ \text { BGN } & \text { Coconino } \\ \text { BGN } & \text { Mohave } \\ \text { BGN 1962 } & \text { Coconino } \\ \text { VARIANT } & \end{array}$

dam

valley

locale

ridge

reservoir

reservoir

reservoir

reservoir

ppl

summit

UNOFF
BGN
UNOFF
BGN
BGN
BGN
BGN
BGN
BGN
VARIANT

Mohave

Navajo

Graham

Coconino

Navajo

Coconino

Mohave

Mohave

Maricopa

Pima

VARIANT

summit

summit

locale

school

park

locale

locale

well

summit

locale

locale

VARIANT

UNOFF

UNOFF

VARIANT

ADMIN

BGN

VARIANT

Pima

Pima

Pima

Mohave

Pima

Pima

UNOFF

VARIANT

UNOFF

VARIANT

UNOFF

VARIANT

VARIANT

Pima

Pima

Pima

Santa Cruz

Santa Cruz

Santa Cruz

VARIANT

locale

reservoir

park

park

locale

school

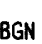

BGN
ADMIN

VARIANT

VARIANT

Pinal

Graham

Maricopa

Maricopa

UNOFF

VARIANT

Pima

Mohave

park

park

summit

mine

mine

mine

summit

locale

rapids

spring

reservoir

reservoir

reservoir

ADMIN Maricopa

ADMIN Maricopa

Mohave

Mohave

Santa Cruz

Yavapai

Coconino

Mohave

Cochise

Mohave

Gila

Pinal

Yavapai
COORDINATE

$363118 \mathrm{~N} 1130316 \mathrm{~W}$

$323058 \mathrm{~N} 1144725 \mathrm{~W}$

$332310 \mathrm{~N} 1113138 \mathrm{~W}$

$333606 \mathrm{~N} 1120144 \mathrm{~W}$

$341830 \mathrm{~N} 1140305 \mathrm{~W}$

UNKNOWN

UNKNOWH

$333704 \mathrm{~N} 1121724 \mathrm{~W}$

$340740 \mathrm{~N} 1120541 \mathrm{~W}$

$351239 \mathrm{~N} 1122417 \mathrm{~W}$

$341344 \mathrm{~N} 1112523 \mathrm{~W}$

$354053 \mathrm{~N} 1120459 \mathrm{~W}$

$364309 \mathrm{N1} 132$

$342308 \mathrm{N1} 104944 \mathrm{~W}$

341948 N1104928W

$353012 \mathrm{~N} 1141701 \mathrm{~W}$

$343553 \mathrm{~N} 1103422 \mathrm{~W}$

$322828 \mathrm{~N} 1100859 \mathrm{~W}$

$342315 N 1105121 \mathrm{~h}$

$343616 \mathrm{~N} 1103518 \mathrm{~W}$

$352526 \mathrm{~N} 1125359 \mathrm{~W}$

$364226 \mathrm{~N} 1133616 \mathrm{~W}$

$364835 \mathrm{~N} 1134441 \mathrm{~W}$

$332737 N 1114122 \mathrm{~W}$

$314335 \mathrm{~N} 1114910 \mathrm{~W}$

$342929 N 1104022 \mathrm{~W}$

Red Knoll

4811 The Mesas

Weimar Point

Red Knoll

Red Mesa

Sullivan Draw North

Wolf Hole Mtn West

1510 Buckhorn

$314335 \mathrm{~N} 1114910 \mathrm{~W}$

$314703 \mathrm{~N} 1113048 \mathrm{~W}$

$351137 \mathrm{~N} 1140332 \mathrm{~W}$

$320350 \mathrm{~N} 1103717 \mathrm{~W}$

$314013 \mathrm{~N} 1112253 \mathrm{~W}$

313921N1112244K

$314013 \mathrm{~N} 1112253 \mathrm{~W}$

$314007 \mathrm{~N} 1112246 \mathrm{~W}$

$313155 \mathrm{~N} 1103517 \mathrm{~W}$

$313106 \mathrm{~N} 1112103 \mathrm{~W}$

313106 N1112103W

$330943 \mathrm{~N} 1120500 \mathrm{~W}$

$331049 \mathrm{~N} 1095139 \mathrm{~W}$

$332044 \mathrm{~N} 1120438 \mathrm{~W}$

332044N1120438W

$314002 \mathrm{~N} 1113605 \mathrm{~W}$

351137N1140332W

$333635 N 1120822 \mathrm{~W}$

$332050 \mathrm{~N} 1120515 \mathrm{~W}$

$363115 N 1134157 \mathrm{~W}$

$362400 \mathrm{N1134248 \textrm {W }}$

$313604 \mathrm{~N} 1104819 \mathrm{~W}$

$341432 \mathrm{~N} 1121208 \mathrm{~W}$

$343412 \mathrm{~N} 1111958 \mathrm{~W}$

$362920 N 1134221 \mathrm{~W}$

$321413 N 1102556 \mathrm{~W}$

$355342 \mathrm{~N} 1134240 \mathrm{~W}$

$333308 \mathrm{~N} 1104305 \mathrm{~W}$

$324216 \mathrm{~N} 1105319 \mathrm{~W}$

$344605 \mathrm{~N} 1115829 \mathrm{~W}$

$350317 \mathrm{~N} 1093833 \mathrm{~W}$

Baboquivari Peak Kingman

3560 Rincon Peak Las Guijas

Las Guijas

Las Guijas

Arivaca

Bonita Tank Lone Butte

Mildred Peak

Glendale

St George Canyon

6758 Last Chance Canyon

Patagonia

Bumble Bee

Long Valley

Last Chance Canyon

Happy Valley

Devils Slide Rapids

Chrome Butte

Fortified Mtn 
NATIONAL GAZETTEER--ARIZONA 1986 FEATURE NAME

Last Chance Tank Last Chance Tank Last End Wash

Last Minute Well

Las Tres Bellotas See Tres Bellotas Well

Last Tank

Last Tank

Last Turn Hill

Las Vegas Ranch

Las Villas (subdivision)

Lateral B-2

La Terraza (subdivision)

Latimore Tank

La Tinaoca

See Tinajas Altas

Latino Americano Park

La Toma Crosscut Canal

(historical)

Latta Tank

Latter Day Saints Temple

Lattie Coor School

Laubs Mine

Lauffer Mountain See Buck Peak

Laugharn Elementary Schoo

Clifton Public School

Laughing Canyon

Laughing Jack Butte

Laundry Hill

Laundry Ridge

Laurel Canyon

Laurel Hole Spring

Laurel Spring

Laurel Spring

Laurel Spring

Laurel Spring

Lauzon Tank

Lava Butte

See Black Knob

Lava Butte

Lava Canyon

Chuar Canyon

Lava Canyon Rapids

Lava Cliff

Lava Cliff Rapids

Lava Creek

Chuar Creek

Lava Falls

Lava Falls Airport

Lava Falls Rapids

Vulcan Rapid

Vulcan Rapids

Lava Pinnacle

Lava Point

Lava River Cave

Lava Tank

Lava Tank

\section{Lava Wash}

Laveen

Laveen, Canal (historical)

Laveen Childrens Home

Laveen Post Office

Laveen School

Laveen South Branch, Canal (historical)

Lavender Open Pit Mine

La Ventana

See Window Mountain

Lavin Tank

Lawler Creek

\section{FEATURE}

CLASS

STATUS

reservoir

reservoir

valley

reservoir

well

BGN Coconino

BGN Navajo

VARIANT

Yavapa 1

Santa Cruz

COORDINATE

$352725 N 1131 B 08 W$

$353440 \mathrm{~N} 1130912 \mathrm{~W}$

$363747 N 1104200 \mathrm{~W}$

$350535 \mathrm{~N} 1131651 \mathrm{~W}$

$312822 N 1112134 \mathrm{~W}$

reservoir BGN Yavapai 343439N1114216W

reservoir BGN Coconino 350511N1120904W

summit BGN PinaT 331044N1110056W

locale UNOFF Yavapai 344901N1123806W

ppl

reservoir

Maricopa

Yuma

$323640 \mathrm{~N} 1143802 \mathrm{~W}$

332750 N1121117W

$340426 \mathrm{~N} 1115225 \mathrm{~W}$

Yuma

$321842 \mathrm{~N} 1140303 \mathrm{~W}$

\begin{tabular}{|c|c|c|c|}
\hline $\begin{array}{l}\text { park } \\
\text { canal }\end{array}$ & $\begin{array}{l}\text { ADMIN } \\
\text { BGN }\end{array}$ & $\begin{array}{l}\text { Yuma } \\
\text { Maricopa }\end{array}$ & $\begin{array}{l}324332 N 1143847 \mathrm{~W} \\
332606 \mathrm{~N} 1120032 \mathrm{~W}\end{array}$ \\
\hline $\begin{array}{l}\text { reservoir } \\
\text { church } \\
\text { school } \\
\text { nine }\end{array}$ & $\begin{array}{l}\text { BGN } \\
\text { UNOFF } \\
\text { UNOFF } \\
\text { UNOFF } \\
\text { VARIANT }\end{array}$ & $\begin{array}{l}\text { Cochise } \\
\text { Maricopa } \\
\text { Maricopa } \\
\text { Maricopa }\end{array}$ & $\begin{array}{l}314414 N 1091320 \mathrm{~W} \\
332445 \mathrm{~N} 1114908 \mathrm{~W} \\
332648 \mathrm{~N} 1122107 \mathrm{~W} \\
333937 \mathrm{~N} 1112124 \mathrm{~W}\end{array}$ \\
\hline immit & $\begin{array}{l}\text { UNOFF } \\
\text { VARIANT }\end{array}$ & $\begin{array}{l}\text { Gila } \\
\text { Greenlee }\end{array}$ & $\begin{array}{l}335412 N 1110405 \\
330236 N 1091734\end{array}$ \\
\hline
\end{tabular}

$365108 N 1102029 \mathrm{~W}$ $353157 \mathrm{N1133822 \textrm {W }}$

$312649 \times 1095522 \mathrm{~W}$

$313351 \mathrm{~N} 1102237 \mathrm{~W}$

$325105 \mathrm{~N} 1102044 \mathrm{~W}$

$340325 N 1115758 \mathrm{~W}$

333130 N1105624k

$342825 N 1125725 \mathrm{~W}$

343305N1131800W

$344032 \mathrm{~N} 1125529 \mathrm{~W}$

spring $B G N$

spring BGN Yavapa

reservoir $B G$

Coconino

360606 N1122344W

Coconino

summit

summit

valley

rapids

cliff

rapids

strean

VARIANT

BGN 1906 Coconino

BGN 1930 Coconino

VARIANT

BGN

BGN

Mohave

Mohave

GN 1930 Coconino

VARIANT

cliff

airport
falls

BGN

ADMIN

BGN

VARIANT

pillar BGN

summit

cave

reservoir $B G$

reservoir $B G$

stream $\quad B G N$

pp?

canal

building

building

school

canal

mine

BGN

UNOFF

UNOFF

UNOFF

BGN

Mohave

Coconino

Coconino

61217N1130447

361120 N1130530

$361151 N 1130459 \mathrm{~W}$

Coconino

Coconino

Coconino

Coconino

Coconino

$361224 N 1130335 \mathrm{~W}$

$54433 N 1113041 \mathrm{~W}$

$352032 N 1115007 \mathrm{~W}$

$352756 N 1114857 \mathrm{~W}$

$353654 N 1113529 \mathrm{~W}$

$354520 \mathrm{~N} 1113352 \mathrm{~W}$

$332146 \mathrm{~N} 1121007 \mathrm{~W}$

$332348 \mathrm{~N} 1120756 \mathrm{~W}$

$332240 N 1121403 \mathrm{~W}$

$332144 \mathrm{~N} 1121005 \mathrm{~W}$

332143N1121002W

332306 N1120846

$312555 \mathrm{~N} 1095355 \mathrm{~W}$

322127N1121434W

summit

UNOFF

Cochise

Pima

reservoir $B G N$

stream BGN

$352637 \mathrm{~N} 1113828 \mathrm{~W}$

$342137 \mathrm{N1} 125556 \mathrm{~W}$
BGM Yavapai

falls VARIANT
Coconino Yavapai
SOURCE

COORDINATE ELEV

MAP NAME

Blye Canyon NE Shonto NW

Devils Hump

Walker Mtn

May Tank Pocket

2881 Teapot Mountain Simmons

1290 Paradise Valley Somerton

1060 Fowler

Rover Peak

Yuma West

Phoenix

Apache

Mesa

Tolleson

Four Peaks

Clifton

365025N1101933W Tseyi-Hatsosi

6185 Milkweed Canyon SW

Bisbee

325448N1101809W Klondike

Klondike
Cooks Mesa

Salt River Peak

Hillside

Grayback Mts

Sheridan Mtn

Chamisa Tank

4242 Cape Solitude

Cape Solitude

$360846 \mathrm{~N} 1115033 \mathrm{~W}$

Cape Solitude

Spencer Canyon

Spencer Canyon

Cape Solitude

361206N1115520W

Vulcans Throne

1720 Vulcans Throne

Vulcans Throne

Vulcans Throne

Campbell Francis Wsh

Wing Mountain

Kendrick Peak

East of S P Mtn

$354222 N 1114426 \mathrm{~W}$

Coconino Point SE

1038 Laveen

Fowler

Fowler

Laveen

Laveen

Fowler

Bisbee 


\begin{tabular}{|c|c|c|c|c|c|c|c|}
\hline FEATURE NAME & $\begin{array}{l}\text { FEATURE } \\
\text { CLASS }\end{array}$ & STATUS & COUNTY & COORDINATE & $\begin{array}{c}\text { SOURCE } \\
\text { COORDINATE }\end{array}$ & $\begin{array}{c}\text { ELEV } \\
\text { FT }\end{array}$ & MAP NAME \\
\hline $\begin{array}{l}\text { Lawler Lateral } \\
\text { Lawler Peak } \\
\text { Lawler Spring } \\
\text { Lawless Tank } \\
\text { Lawrence Creek } \\
\text { Lawrence Crossing } \\
\text { Lawrence Park } \\
\text { Lawrence School } \\
\text { Anna Lawrence } \\
\text { Elementary School }\end{array}$ & $\begin{array}{l}\text { canal } \\
\text { summit } \\
\text { spring } \\
\text { reservoir } \\
\text { stream } \\
\text { locale } \\
\text { park } \\
\text { school }\end{array}$ & $\begin{array}{l}\text { BGN } \\
\text { BGN } \\
\text { BGN } \\
\text { BGN } \\
\text { BGN } \\
\text { BGN } \\
\text { ADMIN } \\
\text { UNOFF } \\
\text { VARIANT }\end{array}$ & $\begin{array}{l}\text { Yuma } \\
\text { Yavapai } \\
\text { Yavapai } \\
\text { Coconino } \\
\text { Gila } \\
\text { Yavapai } \\
\text { Maricopa } \\
\text { Pima }\end{array}$ & $\begin{array}{l}324201 \mathrm{~N} 1144033 \mathrm{~W} \\
343650 \mathrm{~N} 1131107 \mathrm{~W} \\
342406 \mathrm{~N} 1125758 \mathrm{~W} \\
350817 \mathrm{~N} 1121901 \mathrm{~W} \\
334047 \mathrm{~N} 1104824 \mathrm{~W} \\
343911 \mathrm{~N} 1114355 \mathrm{~W} \\
333211 \mathrm{~N} 1121129 \mathrm{~W} \\
320739 \mathrm{~N} 1110413 \mathrm{~W}\end{array}$ & $334122 N 1104653 W$ & & $\begin{array}{l}\text { Yuma West } \\
\text { Bagdad } \\
\text { Hills ide } \\
\text { McLellan Reservoir } \\
\text { Dagger Peak } \\
\text { Casner Butte } \\
\text { Glendale } \\
\text { Cat Mountain }\end{array}$ \\
\hline $\begin{array}{l}\text { Lawrence Spring } \\
\text { Laws Natural Tank } \\
\text { Lawson Canyon } \\
\text { Lawson Mine } \\
\text { Lawton Canyon } \\
\text { Hell Canyon } \\
\text { Devils Canyon } \\
\text { Canyon Diablo } \\
\text { Layton } \\
\text { See Safford }\end{array}$ & $\begin{array}{l}\text { spring } \\
\text { reservoir } \\
\text { valley } \\
\text { mine } \\
\text { valley }\end{array}$ & $\begin{array}{l}\text { BGN } \\
\text { BGN } \\
\text { BGN } \\
\text { UNOFF } \\
\text { BGN 1917 } \\
\text { VARIANT } \\
\text { VARIANT } \\
\text { VARIANT } \\
\text { VARIANT }\end{array}$ & $\begin{array}{l}\text { Yavapai } \\
\text { Coconino } \\
\text { Coconino } \\
\text { Coconino } \\
\text { Maricopa }\end{array}$ & $\begin{array}{l}341344 N 1123029 \mathrm{~W} \\
352540 \mathrm{~N} 1120409 \mathrm{~W} \\
363300 \mathrm{~N} 1123855 \mathrm{~W} \\
352129 \mathrm{~N} 1122630 \mathrm{~W} \\
\text { UNKNOWN }\end{array}$ & $363254 N 1123557 \mathrm{~W}$ & & $\begin{array}{l}\text { Wagoner } \\
\text { Howard Mesa } \\
\text { Grama Spring } \\
\text { Fitzgerald Hill }\end{array}$ \\
\hline $\begin{array}{l}\text { Layton Tank } \\
\text { Layton Tank } \\
\text { Layton Well } \\
\text { Lazarus Tanks } \\
\text { Lazona Trailer Court } \\
\text { Lazy Boy Mine } \\
\text { Lazy B Ranch Airstrip } \\
\text { Lazy Daze Mobile Home Park } \\
\text { Lazy D Trailer Ranch } \\
\text { Lazy J Ranch }\end{array}$ & $\begin{array}{l}\text { reservoir } \\
\text { reservoir } \\
\text { well } \\
\text { reservoir } \\
\text { locale } \\
\text { mine } \\
\text { airport } \\
\text { locale } \\
\text { locale } \\
\text { locale }\end{array}$ & $\begin{array}{l}\text { BGN } \\
\text { BGN } \\
\text { UNOFF } \\
\text { BGN } \\
\text { UNOFF } \\
\text { UNOFF } \\
\text { ADMIN } \\
\text { UNOFF } \\
\text { UNOFF } \\
\text { UNOFF }\end{array}$ & $\begin{array}{l}\text { Yavapai } \\
\text { Yavapai } \\
\text { Yuma } \\
\text { Yuma } \\
\text { Maricopa } \\
\text { Mohave } \\
\text { Greenlee } \\
\text { Maricopa } \\
\text { Maricopa } \\
\text { Cochise }\end{array}$ & $\begin{array}{l}335858 \mathrm{~N} 1122541 \mathrm{~W} \\
342816 \mathrm{~N} 1115329 \mathrm{~W} \\
325608 \mathrm{~N} 1132133 \mathrm{~W} \\
334223 \mathrm{~N} 1140420 \mathrm{~W} \\
332450 \mathrm{~N} 1114800 \mathrm{~W} \\
345858 \mathrm{~N} 1142252 \mathrm{~W} \\
323318 \mathrm{~N} 1090522 \mathrm{~W} \\
332708 \mathrm{~N} 1120859 \mathrm{~W} \\
332250 \mathrm{~N} 1120353 \mathrm{~W} \\
312340 \mathrm{~N} 1091216 \mathrm{~W}\end{array}$ & & $\begin{array}{l}428 \\
1240 \\
4135 \\
1360 \\
1160\end{array}$ & $\begin{array}{l}\text { Garfias Mtn } \\
\text { Arnold Mesa } \\
\text { Agua Caliente } \\
\text { Plomosa Pass } \\
\text { Mesa } \\
\text { Boundary Cone } \\
\text { Round Mtn } \\
\text { Fowler } \\
\text { Phoenix } \\
\text { Lazy J Ranch }\end{array}$ \\
\hline $\begin{array}{l}\text { Lazy J Trailer Lodge } \\
\text { Lazy KJ Ranch } \\
\text { Lazy RR Ranch } \\
\text { Lazy Tank } \\
\text { Lazy T-seven Ranch } \\
\text { Lazy Y Ranch } \\
\text { Lead-Dike Mine } \\
\text { Leaden Peak } \\
\text { See Zilbetod Peak } \\
\text { Lead Lily Shaft }\end{array}$ & $\begin{array}{l}\text { locale } \\
\text { locale } \\
\text { locale } \\
\text { reservoir } \\
\text { locale } \\
\text { locale } \\
\text { mine } \\
\text { summit } \\
\text { mine }\end{array}$ & $\begin{array}{l}\text { UNOFF } \\
\text { UNOFF } \\
\text { UNOFF } \\
\text { BGN } \\
\text { UNOFF } \\
\text { UNOFF } \\
\text { UNOFF } \\
\text { VARIANT } \\
\text { UNOFF }\end{array}$ & $\begin{array}{l}\text { Maricopa } \\
\text { Cochise } \\
\text { Santa Cruz } \\
\text { Coconino } \\
\text { Yavapai } \\
\text { Maricopa } \\
\text { Maricopa } \\
\text { Apache } \\
\text { Cochise }\end{array}$ & $\begin{array}{l}333228 N 1121155 \mathrm{~W} \\
312445 \mathrm{~N} 1094457 \mathrm{~W} \\
313624 \mathrm{~N} 1104355 \mathrm{~W} \\
351454 \mathrm{~N} 1121320 \mathrm{~W} \\
342949 \mathrm{~N} 1113425 \mathrm{~W} \\
332933 \mathrm{~N} 1125847 \mathrm{~W} \\
334623 \mathrm{~N} 1130249 \mathrm{~W} \\
\\
364830 \mathrm{~N} 1090944 \mathrm{~W} \\
315933 \mathrm{~N} 1091712 \mathrm{~W}\end{array}$ & & 1135 & $\begin{array}{l}\text { Glendale } \\
\text { Double Adobe } \\
\text { Mt Hughes } \\
\text { Williams South } \\
\text { Strawberry } \\
\text { Tonopah } \\
\text { Black Butte } \\
\text { Rustler Park }\end{array}$ \\
\hline $\begin{array}{l}\text { Lead Pill Mine } \\
\text { Lead Queen Mine } \\
\text { Lead Well } \\
\text { Leaf Hill } \\
\text { Leaky Tank } \\
\text { Leane Spring } \\
\text { See Leon Spring } \\
\text { Lease Windmill } \\
\text { Leatherwood Mine Group } \\
\text { Lea Tunnels }\end{array}$ & $\begin{array}{l}\text { mine } \\
\text { mine } \\
\text { well } \\
\text { summit } \\
\text { reservoir } \\
\text { spring } \\
\text { locale } \\
\text { mine } \\
\text { mine }\end{array}$ & $\begin{array}{l}\text { UNOFF } \\
\text { UNOFF } \\
\text { UNOFF } \\
\text { BGN } \\
\text { BGN } \\
\text { VARIANT } \\
\text { BGN } \\
\text { UNOFF } \\
\text { UNOFF }\end{array}$ & $\begin{array}{l}\text { Mohave } \\
\text { Santa Cruz } \\
\text { Yuma } \\
\text { Navajo } \\
\text { Gila } \\
\text { Santa Cruz } \\
\text { Cochise } \\
\text { Pima } \\
\text { Gila }\end{array}$ & $\begin{array}{l}342228 N 1134316 \mathrm{~W} \\
312902 \mathrm{~N} 1104307 \mathrm{~W} \\
334406 \mathrm{~N} 1141519 \mathrm{~W} \\
353432 \mathrm{~N} 1103023 \mathrm{~W} \\
340605 \mathrm{~N} 1110847 \mathrm{~W} \\
\\
312959 \mathrm{~N} 1110824 \mathrm{~W} \\
312534 \mathrm{~N} 1092853 \mathrm{~W} \\
322752 \mathrm{~N} 1104410 \mathrm{~W} \\
332432 \mathrm{~N} 1104548 \mathrm{~W}\end{array}$ & & 726 & $\begin{array}{l}\text { Rawhide Wash } \\
\text { Harshaw } \\
\text { Middle Camp Mtn } \\
\text { Tovar Mesa East } \\
\text { Sheep Bas in Mtn }\end{array}$ \\
\hline $\begin{array}{l}\text { Lebanon } \\
\text { Lebanon Hot Springs } \\
\text { Lebanon Cemetery } \\
\text { Lebanon Ditch } \\
\text { Lebanon Hot Springs } \\
\text { See Lebanon } \\
\text { Lebanon Reservoir Number One } \\
\text { Lebanon Reservoir Number Two } \\
\text { Lebanon Reservoir Number Two } \\
\text { Dam }\end{array}$ & $\begin{array}{l}\text { locale } \\
\text { cemetery } \\
\text { canal } \\
\text { locale } \\
\text { reservoir } \\
\text { reservoir } \\
\text { dam }\end{array}$ & $\begin{array}{l}\text { BGN } \\
\text { VARIANT } \\
\text { UNOFF } \\
\text { BGN } \\
\text { VARIANT } \\
\text { BGN } \\
\text { BGN } \\
\text { UNOFF }\end{array}$ & $\begin{array}{l}\text { Graham } \\
\text { Graham } \\
\text { Graham } \\
\text { Graham } \\
\text { Graham } \\
\text { Graham } \\
\text { Graham }\end{array}$ & $\begin{array}{l}324443 N 1094256 \mathrm{~W} \\
324542 N 1094357 \mathrm{~W} \\
324317 N 1094551 \mathrm{~W} \\
324443 N 1094256 \mathrm{~W} \\
324406 N 1094533 \mathrm{~W} \\
324438 N 1094441 \mathrm{~W} \\
324438 N 1094441 \mathrm{~W}\end{array}$ & & & $\begin{array}{l}\text { Artesia } \\
\text { Safford } \\
\text { Mt Graham }\end{array}$ \\
\hline $\begin{array}{l}\text { Le Barron Hill } \\
\text { Le Barron Tank } \\
\text { Lechee Da Si Kaid Spring } \\
\text { Leche-e Rock } \\
\text { Leche-e Wash } \\
\text { Lechequilla Peak } \\
\text { See Lechuguilla Peak } \\
\text { Lechgilla Mountains } \\
\text { See Tinajas Altas Mountains } \\
\text { Lechuguilla, Sierra de la } \\
\text { Lechuguilla Mountains } \\
\text { Mesa de Mal Pais } \\
\text { Mesas de Mal Pais }\end{array}$ & $\begin{array}{l}\text { summit } \\
\text { reservoir } \\
\text { spring } \\
\text { pillar } \\
\text { stream } \\
\text { summit } \\
\text { range } \\
\text { ridge }\end{array}$ & $\begin{array}{l}\text { BGN } \\
\text { BGN } \\
\text { BGN } \\
\text { BGN } \\
\text { BGN } \\
\text { VARIANT } \\
\text { VARIANT } \\
\text { BGN } \\
\text { VARIANT } \\
\text { VARIANT } \\
\text { VARIANT }\end{array}$ & $\begin{array}{l}\text { Coconino } \\
\text { Coconino } \\
\text { Coconino } \\
\text { Coconino } \\
\text { Coconino } \\
\text { Cochise } \\
\text { Yuma } \\
\text { Yuma }\end{array}$ & $\begin{array}{l}350730 N 1114657 \mathrm{~W} \\
351440 \mathrm{~N} 1114507 \mathrm{~W} \\
360851 \mathrm{N1110443W} \\
365149 \mathrm{~N} 1111832 \mathrm{~W} \\
362548 \mathrm{~N} 1114908 \mathrm{~W} \\
\\
321323 \mathrm{~N} 1102605 \mathrm{~W} \\
322135 \mathrm{~N} 1140616 \mathrm{~W} \\
321444 \mathrm{~N} 1135841 \mathrm{~W}\end{array}$ & $362330 \mathrm{~N} 1113905 \mathrm{~W}$ & 5900 & $\begin{array}{l}\text { Bellemont } \\
\text { Bellemont } \\
\text { Middle Mesa } \\
\text { Leche-e Rock } \\
\text { Tatahatso Point }\end{array}$ \\
\hline
\end{tabular}


FEATURE NANE

Tinajas Atlas Mountains

Lechuguilla Desert

Lechuguilla Mountains

See Lechuguilla, Sierra de la

Lechuguilla Peak Lechequilla Peak

Le Conte Plateau

Ledar Seep

Ledar Spring

Ledford Tank

Ledge Canyon

Ledge Canyon

Ledge Ruins

Ledge Spring

Ledge Spring

Ledge Tank

Lee Butte

Lee Cabin

Lee Canyon

See Tule Canyon

Lee Canyon

$$
\text { Tule Canyon }
$$

Lee Canyon

Lee Canyon

Lee Dam

Lee Dam

Lee Ferry

See Lees Ferry

Lee Howard Spring

Lee Johnson Spring

Lee Mountain

Lee Mountain

Lee Mountain

Lee Mountain Spring

Lee Mountain Tanks

Lee Park

See Bert Lee Park

Lees Ferry

See Marble Canyon

Lees Ferry

Lee Ferry

Lonely Dell

Lee Shaft

Lees Mine

Lee Spring

Lee Spring

Lee Tank

Lee Tank

Lee Tank

Lee Tank

Lee Valley Dam

Lee Valley Reservoir

Lee Well

Lefebre Canyon

See Le Fevre Canyon

Le Fevre Canyon Lefebre Canyon

Lefeure Ridge

Left Branch Long Hollow

Left Fork Honeysuckle Spring

Left Fork Markham Creek

Left Fork Markham Wash

West Fork Markham Wash

Left Fork Markham Wash See Left Fork Markham Creek

Left Fork Vock Canyon

Lefthand Canyon

Lefthand Canyon

Left Hand Canyon

Left Hand Moss Wash
FEATURE
CLASS

STATUS

COUNTY

plain

BGN

VARIANT

Yuma

Yuma

ridge

$\begin{array}{ll}\text { summit } & \text { BGN } \\ & \text { VARIANT }\end{array}$

plain

spring

spring

BGN 1908 Coconino

BGN
BGN
BGN

BGN

Cochise

Cochise

Graham

valley

valley

locale

spring

spring

reservoir

summit

locale

valley

BGN
BGN
BGN
BGN
BGN
BGN
BGN
BGN
VARIANT

Yavapai

Mohave

Apache

Graham

Mohave

Coconino

Coconino

Greenlee

Coconino

valley

BGN

valley
valley

valley

dam

dam

locale

spring

spring

summit

summit

summit

spring

reservoir

flat

ppl

locale

VARIANT

BGN Coconino

BGN 1932

UNOFF

UNOFF

VARIANT

Coconino

$\begin{array}{ll}\text { BGN } & \text { Cochise } \\ \text { BGN } & \text { Coconino }\end{array}$

BGN Pinal

$B G N$

BGN

$B G N$
$B G N$

VARIANT

Coconino

Navajo

Coconino

Navajo

Coconino

VARIANT

Coconino

Coconino

BAN 1905

VARIANT

mine UNOFF Santa Cruz

mine UNOFF

spring

spring

reservoir

reservoir

reservoir

reservoir

dam

reservoir

BGN

BGN

$B G N$
$B G N$

BGN

UNOFF

we11 UNOFF

valley

valley

ridge

valley

spring

stream

VARIANT

BGN

VARIANT

Coconino

BGN Graham

BGN Gila

BGN 1962 Graham

VARIAN

VARIANT

stream

valley

valley

valley

valley

stream

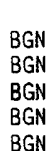

322505N1135857W

$321444 N 1135841 W$

321323N1102605W

$361028 \mathrm{~N} 1121918 \mathrm{~W}$

312808 N $1090422 \mathrm{~W}$

$312816 \mathrm{~N} 1090414 \mathrm{~W}$

$324112 N 1094434 \mathrm{~W}$

$350111 \mathrm{~N} 1131655 \mathrm{~W}$

$350527 \mathrm{~N} 1133717 \mathrm{~W}$

$360944 N 1092752 \mathrm{~W}$

$330316 N 1094717 \mathrm{~W}$

$350414 N 1133502 \mathrm{~W}$

$344030 \mathrm{~N} 1111926 \mathrm{~W}$

$345004 N 1113211 \mathrm{~W}$

333407 N1091040W

350036N1115826W

$350204 N 1120201 \mathrm{~W}$

$355805 N 1114124 \mathrm{~W}$

$361114 N 1123846 \mathrm{~W}$

$325630 \mathrm{~N} 1094954 \mathrm{~W}$

$353915 N 1114252 \mathrm{~W}$

$365203 N 1113540 \mathrm{~W}$

$312652 \mathrm{~N} 1090304 \mathrm{~W}$

$342628 \mathrm{~N} 1112053 \mathrm{~W}$

$330313 N 1104039 \mathrm{~W}$

$344922 N 1114259 \mathrm{~W}$

$350124 N 1101419 \mathrm{~W}$

$344819 N 1114247 \mathrm{~W}$

350044 N1101424W

345530N1113245W

$364856 N 1113813 \mathrm{~W}$

365203 N1113540W

$313616 \mathrm{~N} 1105035 \mathrm{~W}$

$330218 N 1104047 \mathrm{~W}$

$345009 \mathrm{~N} 1113315 \mathrm{~W}$

$345608 \mathrm{~N} 1125511 \mathrm{~W}$

$325005 N 1100801 \mathrm{~W}$

$332003 N 1092513 \mathrm{~W}$

$345332 \mathrm{~N} 1114059 \mathrm{~W}$

$345546 \mathrm{~N} 1113232 \mathrm{~W}$

$335630 \mathrm{~N} 1092954 \mathrm{~W}$

335628 N1093003W

354051 N1111645W

$365548 N 1122225 \mathrm{~W}$

$365548 N 1122225 \mathrm{~W}$

364659 N1121524W

324736 N1102025W

$333229 \mathrm{~N} 1104336 \mathrm{~W}$

$330337 \mathrm{~N} 1094715 \mathrm{~W}$

324535N1102145W

$330925 \mathrm{~N} 1095210 \mathrm{~W}$

$330337 N 1094715 \mathrm{~W}$

$352511 \mathrm{~N} 1140456 \mathrm{~W}$

$324034 \mathrm{~N} 1094334 \mathrm{~W}$

325019 N1095450W

$341826 \mathrm{~N} 1101535 \mathrm{~W}$

$345923 \mathrm{~N} 1134243 \mathrm{~W}$

$345856 \mathrm{~N} 1131651 \mathrm{~W}$
$350326 \mathrm{~N} 1133039 \mathrm{~W}$

$350634 N 1120644$

SOURCE
COORDINATE

ELEV

MAP NAME

White Horse Lake

Hellhole Bend

Supai

Pima

Additional Hill

Guadalupe Spring

Kehl Ridge

3786 Christmas

6592 Munds Mountain

5627 Lee Mountain

Munds Mountain

Lee Mountain

Ferry Swale

Patagonia

Christmas

Stoneman Lake

Juniper Mts

Buford Hill

Bee Canyon

Munds Park

Mormon Mountain

Big Lake North

9418 Mount Baldy

4458 Wupatki NE

Muggins Flat

Le Fevre Ridge

Klondike 


\section{FEATURE NAME}

Left Hand Spring

Left Hand Spring

Left Hand Spring

\section{Lefthand Tank \\ Lefthand Tank \\ Left Hand Tank \\ Left Prong Dix Creek Dix Creek}

Left Prong Fourmile Canyon

Legante Paseo (subdivision)

Legend City Amus ement Park

Legend Estates (subdivision)

Leghorn Mine

Legs, The

Legunita Wash

Lehi

Bottom City

Camp Utah

Jonesville

Utahville

Lehi Elementary School

Lehi South Branch, Canal

(historical)

Canal Nine

Lehi Substation

Lehman Mill

Lehman Mountain

Leinedecker Ranch

Leisure Canyon

Leisure Spring

Leisure Time Mobile Park

Leisure World (subivision)

Leivas Ranch

Le La Mine

Leland Butte

L-Eleven Spring

Lemmon, Mount

Lemmon Canyon Lemon Canyon

Lemmon Creek

Lemmon Park

Lemmon Rock Lookout

Lemmon Spring

Lemonade Spring

Lemonade Tank

Lemon Canyon

See Lemmon Canyon

Lemontree (subdivision)

Lems Spring Overpass

Lenang Park

Lengthy Canyon

Lengthy Canyon Trail

Eighty-nine

Lenoux Tank

Lenox Crater

Lenox Park

Lent Lateral

Leo Canyon

Leo Canyon Tank

Leonard Canyon

See East Leonard Canyon

Leonard Canyon

East Leonard Canyon

Leonard Point

Leon Canyon

Leone Canyon

Lion Canyon

Leone Canyon

See Leon Canyon

Leonor Hamble Junior High

School
FEATURE

STATUS

COUNTY

COORDINATE

spring

spring

$B G N$

$B G N$

spring

reservoir

reservoir

stream

valley

ppl

park

pp 1

mine

summit

strean

ppl

BGN

VARIANT

VARIANT

VARIANT

VARIANT

school

canal

UNOF

VARIANT

$\begin{array}{llll}\text { locale } & \text { UNOFF } & \text { Maricopa } & 332616 N 1114544 \mathrm{~W} \\ \text { locale } & \text { BGN } & \text { Yavapai } & 340545 N 1122742 \mathrm{~W} \\ \text { summit } & \text { BGN } & \text { Yavapai } & 340520 \mathrm{~N} 1122732 \mathrm{~W} \\ \text { locale } & \text { UNOFF } & \text { Cochise } & 312242 \mathrm{~N} 1100945 \mathrm{~W} \\ \text { valley } & \text { BGN } & \text { Gila } & 334749 \mathrm{N1104943W} \\ \text { spring } & \text { BGN } & \text { Gila } & 3348551104904 \mathrm{~W} \\ \text { locale } & \text { UNOFF } & \text { Maricopa } & 333339 N 1121230 \mathrm{~W} \\ \text { ppl } & \text { BGN } & \text { Maricopa } & 332404 N 1114121 \mathrm{~W} \\ \text { locale } & \text { UNOFF } & \text { Mohave } & 343203 N 1133357 \mathrm{~W} \\ \text { mine } & \text { UNOFF } & \text { Pinal } & 323409 N 112062 B \mathrm{~W}\end{array}$

summit

spring

valley

stream

flat

locale

spring

BGN
BGN
BGN

BGN Mohave

BGN 1939 Pima

VARIANT

BGN

BGN

BGN
BGN
BGN

BGN

reservoir $B G N$

valley

ppl

crossing

park

valley

trail

reservoir $B G N$

VARIANT

BGN

UNOFF

ADMIN
BGN

BGN
UNOFF

crater BGN

flat

canal

valley

reservoir

BGN

BGN

VARIANT

valley

valley

BGN 1973

VARIANT

BGN

cliff

valley

BGN 198

VARIANT

VARIANT

valley

UNOFF

332732 N1114846W

$331829 N 1090819 \mathrm{~W}$
Graham

330353 N1094730W

$341709 \mathrm{N1101642 \textrm {W }}$

$344200 \mathrm{~N} 1124351 \mathrm{~W}$

$324039 N 1094430 \mathrm{~W}$

$344122 N 1124346 \mathrm{~W}$

$345908 \mathrm{~N} 1134453 \mathrm{~W}$

$331110 N 1090923 \mathrm{~W}$

$324725 \mathrm{~N} 1102238 \mathrm{~W}$

$332217 N 1115154 \mathrm{~W}$

332649 N1115724W

$332802 \mathrm{~N} 1120911 \mathrm{~W}$

$343724 N 1120348 \mathrm{~W}$

$362202 N 1091540 \mathrm{~W}$

$313618 \mathrm{~N} 1113221 \mathrm{~W}$

Pima

Maricop

332637N1114756W

$332526 \mathrm{~N} 1115225 \mathrm{~W}$

$350127 N 1142538 \mathrm{~W}$

$334442 N 1100203 \mathrm{~W}$

$322635 \mathrm{~N} 1104716 \mathrm{~W}$

$322305 N 1104729 \mathrm{~W}$

$322304 \mathrm{~N} 1104729 \mathrm{~W}$

322616 N1104730

322605 N1104720

$322645 \mathrm{~N} 1104728 \mathrm{~W}$

Greenlee

Coconino

352802 N1130500W

Pima

Maricopa

Cochise

Maricopa

Greenlee

Greenlee

Coconino

$322305 N 1104729 \mathrm{~W}$

$332435 \mathrm{~N} 1114434 \mathrm{~W}$

313311 N1090805W

$332434 \mathrm{~N} 1120126 \mathrm{~W}$

$332920 \mathrm{~N} 1091642 \mathrm{~W}$

333008N $1091720 \mathrm{~W}$

352012 N1113435W

Coconino

Coconino

Yuma

Gila

Gila

Coconino

Coconino

Coconino

$352137 N 1113145 \mathrm{~W}$

$352035 \mathrm{~N} 1113348 \mathrm{~W}$

$323155 N 1144334 \mathrm{~W}$

$341315 \mathrm{~N} 1110445 \mathrm{~W}$

$341339 \mathrm{~N} 1110439 \mathrm{~W}$

$341354 N 1110326 \mathrm{~W}$

342800 N1110529W

343725 N1110222W

343727 N1110228W

342800 N1110529W

Santa Cruz

$312914 \mathrm{~N} 1110805 \mathrm{~W}$

$313142 \mathrm{~N} 1110849 \mathrm{~W}$

Santa Cruz

312914 N1110805W
325938 N1104611W

$313857 N 1113603 \mathrm{~W}$ $\begin{array}{cc}\text { SOURCE } & \text { ELEV } \\ \text { COORDINATE } & \text { FT MAP NAME }\end{array}$

Bryce Mountain

Clay Springs

Mount Josh

Artesia

Mt Josh

Pilgrim Wash

Dix Creek

$324218 \mathrm{~N} 1102527$

Oak Grove Canyon

1205 Chandler

Tempe

1075 Fowler

Cherry

6804 Red Cornfield Mesa Presumido Peak Mesa

Mesa

Mesa

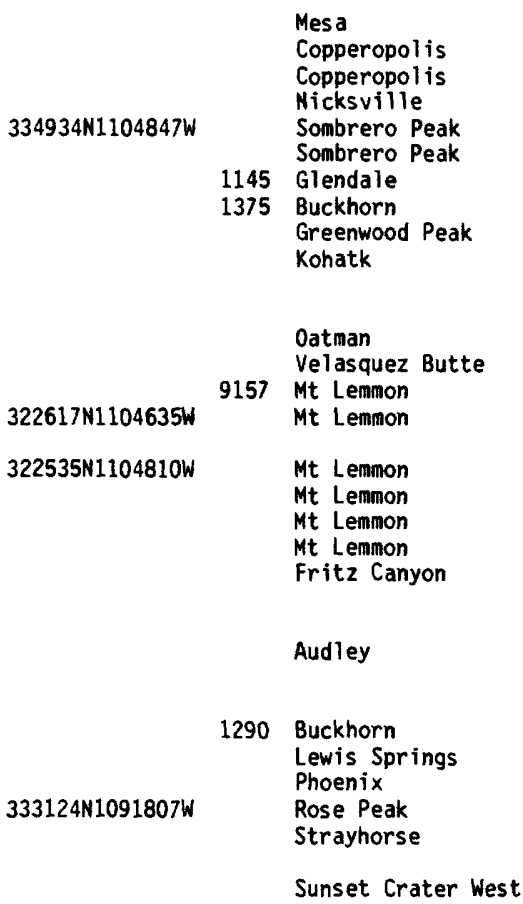

Sunset Crater West

Sunset Crater West

Somerton

Diamond Butte

Dianond Butte

Leonard Canyon

Leonard Canyon

Ruby

Winkelman 


\section{FEATURE NAME}

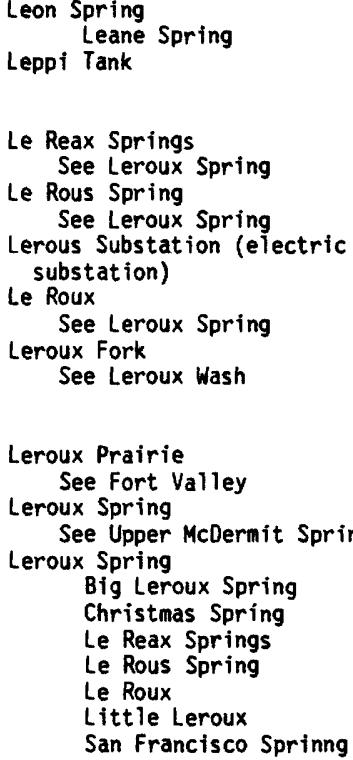

Lesna Peak, La

Lesna Peak, La

Lesna Spring

Lesslie Tank

Leupp

Leupp Boarding School

Leupp Corner

Leupp Lateral

Leupp Post Office

Leupp School

Leupp Traffic Interchange

Levais Wash

Leviathan Mine

Leviathan Mine

Levitt Tank

Lewis, Canal (historical)

Lewis and Pranty Creek Arrous Verde Arroyo Verde

Lewis and Pranty Creek

See Barranca Creek

Lewis Canyon

Lewis Canyon Campground

Lewis Creek

Lewis Kingman Park

Lewis Monument
FEATURE CLASS

spring

STATUS

COUNTY

COORDINATE

Santa Cruz

Yavapai

reservoir VARIANT

345024N1130625W

VARIANT

spring

spring

locale

VARIANT

Coconino

351736 N1114327W

UNOFF

Coconino

Navajo

$351736 \mathrm{~N} 1114327 \mathrm{~W}$

VARIANT

spring

stream

VARIANT

Coconino

$351736 N 1114327 \mathrm{~W}$

Navajo

345414N1102144W

VARIANT

valley

spring

spring

VARIANT

Coconino

Coconino

$351410 N 1114441 \mathrm{~W}$

BGN 1911

VARIANT

VARIANT

VARIANT

VARIANT

VARIANT

VARIANT

VARIANT

VARIANT

stream

stream

BGN 1915

VARIANT

VARIANT

VARIANT

VARIANT

stream

mine

UNOFF

UNOFF

Navajo

Santa Cruz

$345414 N 1101144$

313918 N1105220W

$321045 \mathrm{~N} 1093455 \mathrm{~W}$

VARIANT

summit
valley
stream
reservoir
reservoir
range

range

summit

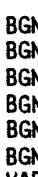

BGN

BGN

BGN

BGN

BGN 1979

VARIANT

VARIANT

Pima

Cochise

Cochise

Santa Cruz

Mohave

Pima

BGN

summit

sumnit

reservoir

ppl

schoo

locale

canal

building

school

BGN

BGN

BGN

UNOFF

BGN

BGN

UNOFF

UNOFF

\section{Pima}

Pima

Pima

Coconino

Coconino

Coconino

Coconino

Yuma

Coconino

Coconino

\section{crossing}

arroyo

mine

reservoir

canal

stream

UNOFF

BGN

UNOFF

UNOFF

8GN

BGN

BGN 1932

VARIANT

VARIANT

VARIANT

stream

Coconino

Mohave

Yavapai

Mohave

Pina

Maricopa

Maricopa

Maricopa

$333435 N 1112111 W$

$\begin{array}{lll}\text { valley } & \text { BGN } & \text { Navajo } \\ \text { park } & \text { ADMIN } & \text { Navajo } \\ \text { stream } & \text { BGN } & \text { Gila } \\ \text { park } & \text { ADMIN } & \text { Mohave } \\ \text { park } & \text { ADMIN } & \text { Cochise }\end{array}$

312949 NI112423

$313602 N 1093212 \mathrm{~W}$

313212 N1094013W

$312526 \mathrm{~N} 1103116 \mathrm{~W}$

$363221 \mathrm{~N} 1130325 \mathrm{~W}$

$314445 \mathrm{~N} 1121320 \mathrm{~W}$

$312949 \mathrm{~N} 1112423 \mathrm{~W}$

314443N1121323W

$314445 \mathrm{~N} 1121320 \mathrm{~W}$

312933N1112410W

350516 N1114712W

$351754 N 1110031 \mathrm{~K}$

$350427 \mathrm{~N} 1105126 \mathrm{~W}$

$335621 \mathrm{N1} 142441 \mathrm{~W}$

351641 N1105742W

351742N1110030W

350400 N1105005W

$343210 \mathrm{NI132803 \textrm {W }}$

$340958 \mathrm{NI} 124441 \mathrm{~W}$

$344950 \mathrm{~N} 1134735 \mathrm{~W}$

$315436 \mathrm{N1113321 \textrm {W }}$

$332552 \mathrm{~N} 1115051 \mathrm{~W}$

$333208 \mathrm{N11} 11815 \mathrm{~W}$

341657 N1101403W $341711 \mathrm{N1101416 \textrm {W }}$

$342048 \mathrm{~N} 1111155 \mathrm{~W}$

351204N1140130W

$313524 \mathrm{N1093029 \textrm {W }}$

$\begin{array}{lcl}\begin{array}{c}\text { SOURCE } \\ \text { COORDINATE }\end{array} & \text { ELEV } & \text { MAP NAME } \\ & \text { Ruby } \\ & \text { Scratch Canyon }\end{array}$

Holbrook

Humphreys Peak

351332N1095137W Holbrook

$313410 \mathrm{~N} 1092950 \mathrm{~W}$

Leslie Canyon

McNeal

Cane lo Pass

Hat Knoll

La Lesna Mts

4704 Cumero Mtn

2414 La Lesna Mts

La Lesna Mts

Cumero Mtn

Dutton Hill

Grand Falls SE

Grand Falls SE

Tucker Mes a

Poston

East of 01d Leupp

Grand Falls SE

$343010 N 1132956$

5019 Tucker Mesa

Kaiser Spring

Yarnell

Diamond Joe Peak

Kitt Peak

Mesa

333246N1111129W Horse Mesa Oam

$341629 N 1101611 W$
$34232 B N 1111058 W$$\quad \begin{aligned} & \text { Pinedale } \\ & \text { Pinedale } \\ & \text { Diamond Point } \\ & \text { Kingman } \\ & \text { Leslie Canyon }\end{aligned}$




\section{FEATURE NAME}

Lewis Mountain

See Kit Carson Mountain

Lewis Park

Lewis Ranch

Lewis Ranch

Lewis Spring

Lewis Springs

Fritz Springs

Lewis Tank

San Pedro Spring

Lewis Well

Lewis Wel1

Lew Tank

Lexington Place (subdivision)

Leyvas Canyon

L F Ranch

LF Tank

Libby Army Airfield/Sierra

Vista Muncipal Airport

Liberty

Altamount Toothaker Place

Liberty (siding)

Liberty Cemetery

Liberty Elementary School

Liberty Mine
Liberty Mine
Liberty Mobile Home Park
Liberty School
Liberty Square
See Hyde Park (subdivision)
Liberty Substation
Liberty Village (subdivision)
Library Park
Library Park

Libre Park

Lice $\mathrm{Hill}$

Lichee Sinil Spring

Licklog Tank

Lida Creek

See Lyda Creek

Liebres Tank

Liem Primary School

Lievres Tank

Light

Light Cemetery

Light Hall Well

Light-House Rock

See Lighthouse Rock

Light House Rock

See Lighthouse Rock

Lighthouse Rock

Light House Rock

Lighting Canyon

Lightning Mesa

Lightning Park

Lightning Ranch Airstrip

Lightning $R$ Ranch

Ligurta

$$
\text { Gila City }
$$

Li Haaditi ih Hil

Lii Haditiih Tank

Lilly Tank

Lily Hole Spring

\footnotetext{
Limbergh Spring

Lime Camp

Lime Creek

Lime Creek Spring

Lime $\mathrm{Hill}$
}

Lime Hills
FEATURE
CLASS

STATUS

COUNTY

COOROINATE

VARIANT

summit
park
local
local

ADMIN

UNOFF

UNOFF

spring

locale

BGN

BGN
VARIANT

reservoir

VARIANT

reser

well

reservoir

ppl

BGN

UNOFF

BGN
BGN

valley

BGN

locale

UNOFF

airport ADMIN

pp

BGN

locale BGN

cemetery UNOFF

school UNOFF

mine

mine

locale

school

ppl

locale

ppl

park

UNOFF

UNOFF

UNOFF
UNOFF

VARIANT

UNOFF

BGN

BGN
ADMIN

ADMIN

park

summit

spring

reservoir

ADMIN

BGN

BGN

stream

stream

reservoir BG

school

locale

BGN

UNOFF

BGN

cemetery

well

UNOFF
UNOFF

pillar

pillar

pillar

valley

VARIAN

VARIANT

BGN

VARIANT

VARIANT

summit

summit

airport

locale

locale

summit

reservoir

reservoir

BGN

Graham

BGN Green lee

BGN Apache

ADMIN

UNOFF

BGN

VARIANT

$B G N$

BGH

spring

$B G N$

spring

locale

stream

spring

summit

ridge

$\begin{array}{ll}\text { Maricopa } & \text { UNKNOWN } \\ \text { Maricopa } & 332610 N 1120310 W \\ \text { Santa Cruz } & 313228 \text { N1104303W }\end{array}$

Pinal $313228 \mathrm{~N} 1104303 \mathrm{~W}$

Graham 330234N110213BW

Cochise 313452N1100829W

Coconino 344918N1110945W

Pima 321414N1124439W

Navajo 351103N1102512W

Coconino 352123N1114304W

Maricopa 333815N1121200W

$314129 \mathrm{N1113658 \textrm {W }}$

Gila

Yavapai

$341338 N 1113044 \mathrm{~W}$

$341258 \mathrm{~N} 1122649 \mathrm{~W}$

$313500 \mathrm{~N} 1102000 \mathrm{~W}$

Maricopa

Maricopa

Maricopa

Maricopa

Pima

Mohave

Maricopa

Pima

Maricopa

Maricopa

Maricopa

Maricopa

Maricopa

Maricopa

Coconino

Apache

Cochise

Greenlee

Santa Cruz

Pima

Cochise

Cochise

Maricopa

Yuma

Yuma

Yuma

Apache

Santa Cruz

Yuma

Coconino

Coconino

Pima

Maricopa

BGH

BGN

BGN

BGN

BGN
Coconino

Graham

Maricopa

Yavapai

Pima

Mohave
332239N1122910W

$332352 \mathrm{~N} 1122901 \mathrm{~W}$

$332224 N 1122938 \mathrm{~W}$

332240N1122907W

314139N1111913W

$354115 \mathrm{N1143210 \textrm {W }}$

$334004 \mathrm{~N} 1120128 \mathrm{~W}$

320931N1105B17W

$333714 \mathrm{N1115800 \textrm {W }}$

$332445 N 1122958 \mathrm{~W}$

$332947 \mathrm{NI} 121634 \mathrm{~W}$

$332108 \mathrm{~N} 111472 \mathrm{BW}$

332651 N1120510W

$332912 \mathrm{~N} 1115743 \mathrm{~W}$

$361049 N 1110204 \mathrm{~W}$

$352818 N 1092742 \mathrm{~W}$

$314620 \mathrm{~N} 1091246 \mathrm{~W}$

330100 N1091023W

$314108 \mathrm{N1110B33W}$

$330247 \mathrm{N1091728 \textrm {W }}$

$315327 \mathrm{N1112946 \textrm {W }}$

$315422 \mathrm{~N} 1093434 \mathrm{~W}$

$315508 N 1093805 \mathrm{~W}$

333422N1124350W

330840 N1144104W

$330840 N 1144104 \mathrm{~W}$

$330840 \mathrm{N1144104 \textrm {W }}$

322711 N1091015W

$322523 N 1090908 \mathrm{~W}$

$330836 \mathrm{~N} 1090848 \mathrm{~W}$

$340510 \mathrm{~N} 1094249 \mathrm{~W}$

$322603 \mathrm{N1} 100600 \mathrm{~W}$

$313932 \mathrm{N1} 103039 \mathrm{~W}$

$324028 \mathrm{N1} 141739 \mathrm{~W}$

$353525 N 1110642 \mathrm{~W}$

$353528 \mathrm{N1} 110736 \mathrm{~W}$

$314544 \mathrm{N1} 112531 \mathrm{~W}$

$333036 \mathrm{~N} 1110415 \mathrm{~W}$

$350630 \mathrm{~N} 1114313 \mathrm{~W}$

$324842 \mathrm{~N} 1102648 \mathrm{~W}$

$335921 \mathrm{N1114413 \textrm {W }}$

$340531 N 1115331 \mathrm{~W}$

$321340 \mathrm{~N} 1125527 \mathrm{~W}$

$365545 \mathrm{~N} 1134336 \mathrm{~W}$

$\begin{array}{lc}\text { SOURCE } & \text { ELEV } \\ \text { COORDINATE } & \text { FT }\end{array}$

Phoenix

Mt Hughes

Brandenburg Mtn

Mt Turnball

Lewis Springs

Chavez Mtn West

Gunsight

5522 Standing Horse Mesa

Humphreys Peak 


\section{FEATURE NAME}

Lime Kiln Canyon

Lime Kiln Mine

Limekiln Wash

Lime Mountain

See Lime Peak

Lime Mountain

Lime Mountain

Lime Mountain Spring

Lime Peak

See Mae West Peaks

Lime Peak

Johnson Peak

Lime Spring

Lime Spring

Lime Spring

Lime Springs

Lime Spring Tank

See Seven Up Tank

Limestone Canyon

Limestone Canyon

See Limestone Gulch

Limestone Canyon

Limestone Canyon

Third Forest

Limestone Canyon

Limestone Canyon

Limestone Fire Station

Limestone Gulch imestone Canyon

Limest one Hills

Limestone Mountain

Limestone Mountain

Limestone Mountains

See Little Dragon Mountains

Limestone Pasture

Limestone Peak

Limestone Pocket

Limestone Quarry

Limestone Ranch

Limestone Reservoir

Limestone Ridge

Limestone Ridge

Limestone Ridge Tank Number One

Limestone Ridge Tank Number Two

Limestone Spring

Limestone Spring

Limestone Spring

Limestone Spring

Limestone Spring

Limestone Spring

Limestone Tank

Limestone Tank

Limestone Tank

Limestone Tank

Limestone Tank

Limestone Tank

Limestone Tank

Limes tone Tank

Limes tone Tank

Limestone Tank

Limestone Tank

Limestone Tank

Limestone Tank

Limestone Tank

Limestone Tank

Limestone Tanks

Limestone We11

Limestone We11

Lime Tank

Lime Tank

$$
\begin{gathered}
\text { FEATURE } \\
\text { CLASS }
\end{gathered}
$$

STATUS

COUNTY

COORDINATE

BGN Mohave

UNOFF Mohave

mine

summit

BGN

VARIANT

Yuma

Cochise

$364115 N 1140102 \mathrm{~W}$ $363737 \mathrm{N1} 135835 \mathrm{~W}$ $333451 N 1143103 \mathrm{~W}$

320644N1100540W

summit

BGN Maricopa 333213N1111048W

$\begin{array}{lll}\text { BGN } 1915 \text { Navajo } & 350700 N 1095500 \mathrm{~W} \\ \text { BGN } & \text { 333205N1111034W }\end{array}$

spring

VARIANT

summit

summit

BGN 1984 Cochise

Cochise

VARIANT

VARIANT

spring

BGN

Pinal

BGN 1977 Navajo

spring

spring

reservoir

valley

BGN

VARIANT

valley

valley

BGN

VARIANT

Greenle

BGN

VARIANT

Yavapai

Gila

Navajo

Graham

Navajo

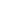

valley
valley
building
valley

BGN Coconino 343117N1110531W

BGN Yavapai 345856N1122257W

UNOFF Navajo 34104BN1101621W

BGN Greenlee 330422N1091747W

VARIANT

summit

BGN

summit

summit

$B G N$

VARIANT

summit

Gila

Cochise

Graham

Cochise

$341433 \mathrm{~N} 1113714 \mathrm{~W}$

$313958 \mathrm{~N} 1092038 \mathrm{~W}$

$330213 \mathrm{N1} 102017 \mathrm{~W}$

320500N1100730W

flat

summit
bas in
mine

mine

locale

reservoir

ridge

ridge

reservoir

reservoir

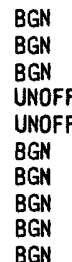

spring

spring

spring

spring

spring

spring

reservoir

reservoir $B G$

reservoir

reservoir $B G$

reservoir $B G N$

reservoir $B G N$

reservoir $B G$

reservoir $B G H$

reservoir $B G$

reservoir $B G$

reservoir $B G$

reservoir

reservoir $B G$

reservoir $B G N$

reservoir $B G N$

reservoir $B G$

well

reservoir

BGN

UNOFF

$B G N$

reservoir $B G N$
Coconino

Yavapai

Coconino

Gila

Coconino

Mohave

Navajo

Coconino

Navajo

Navajo

$34292 B N 1110645 \mathrm{~W}$

$345 B 39 \mathrm{~N} 1124401 \mathrm{~W}$

$350033 \mathrm{~N} 1120604 \mathrm{~W}$

$332443 \mathrm{~N} 1104650 \mathrm{~W}$

$342929 \mathrm{N1110705W}$

$363031 \mathrm{N1} 132437 \mathrm{~W}$

$340631 \mathrm{N1} 101449 \mathrm{~W}$

$340457 N 1101433 \mathrm{~W}$

$340340 \mathrm{~N} 1101514 \mathrm{~W}$

323834N1101551W $332450 \mathrm{~N} 1110306 \mathrm{~W}$

335405N1101B3OW

$341113 \mathrm{~N} 1101604 \mathrm{~W}$

$343058 \mathrm{~N} 1110317 \mathrm{~W}$

$352032 N 1132923 W$

$313415 N 1092515 \mathrm{~W}$

$314007 N 1092143 \mathrm{~W}$

$335238 \mathrm{~N} 1102129 \mathrm{~W}$

341654 N1112646W

Gila

Gila

Coconino

Yavapai

Coconino

Coconino

Coconino

Yavapai

Coconino

Yavapai

Coconino

Coconino

$342927 N 1110701 \mathrm{~W}$

$343526 \mathrm{~N} 1114918 \mathrm{~W}$

$343746 \mathrm{~N} 1111344 \mathrm{~W}$

343859 N1112225W

344931 N1110733W

$344937 N 1115913 \mathrm{~W}$

$345833 \mathrm{~N} 1110239 \mathrm{~W}$

$350603 \mathrm{~N} 1124 \mathrm{~B} 26 \mathrm{~W}$

$350915 \mathrm{~N} 1113717 \mathrm{~W}$

352BOON1123505W

Coconino

Coconino

Pima

Yavapai

Graham

Pinal
$362839 \mathrm{N1113802 \textrm {W }}$

$\begin{array}{cc}\text { SOURCE } & \text { ELEV } \\ \text { COORDINATE } & \text { FT }\end{array}$

\begin{tabular}{|c|c|}
\hline $363808 \mathrm{~N} 1140210 \mathrm{~W}$ & $\begin{array}{l}\text { Hen Spring } \\
\text { Jacobs Well } 1\end{array}$ \\
\hline $333259 N 1142442 W$ & Blythe \\
\hline
\end{tabular}

MAP NAME

3999 Pinyon Mtn

Lit Lithodendron Tank Pinyon Mtn

6644 Dragoon

Jerusalem Mtn

Whiteriver

Tule Mesa

Greenback Creek

325229N1101244W

Buford Hill

$341326 \mathrm{~N} 1101802 \mathrm{~W}$

$341739 \mathrm{~N} 1112627 \mathrm{~W}$

Limestone Canyon S

North Peak

$342846 \mathrm{~N} 1110726 \mathrm{~W}$ 35031 TN1123318W

$330716 \mathrm{N1091300 \textrm {W }}$

Leonard Canyon

Paulden

Limestone Canyon $M$

Clifton

Cypress Butte

Swede Peak

6687 Mt Turnball

Knoll Lake

5426 Limestone Peak

White Horse Lake

Globe

Knoll Lake

Little Tanks

Long Tom Canyon

Shinumo Altar

Long Tom Canyon

Limestone Canyon S

Kennedy Peak

Haunted Canyon 


\begin{tabular}{|c|c|c|c|c|c|c|c|}
\hline FEATURE NAME & $\begin{array}{l}\text { FEATURE } \\
\text { CLASS }\end{array}$ & STATUS & COUNTY & COORDINATE & $\begin{array}{l}\text { SOURCE } \\
\text { COORDINATE }\end{array}$ & $\begin{array}{c}\text { ELEV } \\
\text { FT }\end{array}$ & MAP NAME \\
\hline $\begin{array}{l}\text { Limpios Tank } \\
\text { Lincoln }\end{array}$ & reservoir & $\begin{array}{l}\text { BGM } \\
\text { VARIANT }\end{array}$ & Coconino & $345153 \mathrm{~N} 1113430 \mathrm{~W}$ & & & Stoneman Lake \\
\hline $\begin{array}{r}\text { See Rincon } \\
\text { Lincoln Canyon }\end{array}$ & $\begin{array}{l}\text { locale } \\
\text { valley }\end{array}$ & BGN & $\begin{array}{l}\text { Pima } \\
\text { Yavapai }\end{array}$ & $\begin{array}{l}320434 \mathrm{~N} 1115502 \mathrm{~W} \\
345455 \mathrm{~N} 1115543 \mathrm{~W}\end{array}$ & $345714 \mathrm{~N} 1115619 \mathrm{~W}$ & & Loy Butte \\
\hline $\begin{array}{l}\text { Lincoln Elementary School } \\
\text { Lincoln Elementary School } \\
\text { Lincoln Hospital } \\
\text { Lincoln Mine } \\
\text { Lincoln Plaza Shopping Center } \\
\text { Lincoln Ranch } \\
\text { Lincoln Regional Park } \\
\text { Lincoln School } \\
\text { Lincoln School } \\
\text { Lincoln School }\end{array}$ & $\begin{array}{l}\text { school } \\
\text { school } \\
\text { hospital } \\
\text { mine } \\
\text { locale } \\
\text { locale } \\
\text { park } \\
\text { school } \\
\text { school } \\
\text { school }\end{array}$ & $\begin{array}{l}\text { UNOFF } \\
\text { UNOFF } \\
\text { UNOFF } \\
\text { UNOFF } \\
\text { UNOFF } \\
\text { UNOFF } \\
\text { ADMIN } \\
\text { UNOFF } \\
\text { UNOFF } \\
\text { UNOFF }\end{array}$ & $\begin{array}{l}\text { Santa Cruz } \\
\text { Navajo } \\
\text { Maricopa } \\
\text { Yavapai } \\
\text { Maricopa } \\
\text { Yuma } \\
\text { Pima } \\
\text { Cochise } \\
\text { Maricopa } \\
\text { Maricopa }\end{array}$ & $\begin{array}{l}312038 \mathrm{~N} 1105540 \mathrm{~W} \\
350141 \mathrm{~N} 1104147 \mathrm{~W} \\
333409 \mathrm{~N} 1120413 \mathrm{~W} \\
341356 \mathrm{~N} 1121924 \mathrm{~W} \\
333150 \mathrm{~N} 1115534 \mathrm{~W} \\
341212 \mathrm{~N} 1134126 \mathrm{~W} \\
321018 \mathrm{~N} 1104840 \mathrm{~W} \\
312646 \mathrm{N1} 1095539 \mathrm{~W} \\
332441 \mathrm{N1114952W} \\
332610 \mathrm{~N} 1120332 \mathrm{~W}\end{array}$ & & 882 & $\begin{array}{l}\text { Nogales } \\
\text { Winslow } \\
\text { Sunnys lope } \\
\text { Crown King } \\
\text { Paradise Valley } \\
\text { Reid Valley } \\
\text { Tucson East } \\
\text { Bisbee } \\
\text { Mesa } \\
\text { Phoenix }\end{array}$ \\
\hline $\begin{array}{l}\text { Lincoln School } \\
\text { Lincoln Spring } \\
\text { Lincoln Tank } \\
\text { Lincoln Village Shopping } \\
\text { Center } \\
\text { Lincon }\end{array}$ & $\begin{array}{l}\text { school } \\
\text { spring } \\
\text { reservoir } \\
\text { locale }\end{array}$ & $\begin{array}{l}\text { UNOFF } \\
\text { BGN } \\
\text { BGN } \\
\text { UNOFF } \\
\text { VARIANT }\end{array}$ & $\begin{array}{l}\text { Yavapai } \\
\text { Gila } \\
\text { Navajo } \\
\text { Maricopa }\end{array}$ & $\begin{array}{l}343226 \mathrm{~N} 1122832 \mathrm{~W} \\
340229 \mathrm{~N} 1112401 \mathrm{~W} \\
341952 \mathrm{~N} 1102822 \mathrm{~W} \\
333145 \mathrm{~N} 1115534 \mathrm{~W}\end{array}$ & & & $\begin{array}{l}\text { Prescott } \\
\text { Mazatzal Peak } \\
\text { Day Spring } \\
\text { Paradise Valley }\end{array}$ \\
\hline $\begin{array}{l}\text { See Rincon } \\
\text { Linda Mine } \\
\text { Linda Vista, Rancho } \\
\text { Linda Vista Park }\end{array}$ & $\begin{array}{l}\text { locale } \\
\text { mine } \\
\text { locale } \\
\text { park }\end{array}$ & $\begin{array}{l}\text { UNOFF } \\
\text { UNOFF } \\
\text { ADNIN }\end{array}$ & $\begin{array}{l}\text { Pima } \\
\text { Maricopa } \\
\text { Pinal } \\
\text { Coconino }\end{array}$ & $\begin{array}{l}320434 \mathrm{~N} 1115502 \mathrm{~W} \\
335110 \mathrm{~N} 1131646 \mathrm{~W} \\
323608 \mathrm{~N} 1104738 \mathrm{~W} \\
351320 \mathrm{~N} 1113634 \mathrm{~W}\end{array}$ & & & $\begin{array}{l}\text { Harquahala Mtn } \\
\text { Oracle } \\
\text { Flagstaff East }\end{array}$ \\
\hline $\begin{array}{l}\text { Lindbergh Elementary School } \\
\text { Lindbergh Hill } \\
\text { Lindbergh Spring Roadside Park } \\
\text { Lindberg Tank } \\
\text { Lindberg Tank } \\
\text { Lindburg Tank } \\
\text { Linden } \\
\quad \text { Juniper } \\
\quad \text { Lindon } \\
\text { Linden Creek }\end{array}$ & $\begin{array}{l}\text { school } \\
\text { summit } \\
\text { park } \\
\text { reservoir } \\
\text { reservoir } \\
\text { reservoir } \\
\text { locale }\end{array}$ & $\begin{array}{l}\text { UNOFF } \\
\text { BGN } \\
\text { ADMIN } \\
\text { BGN } \\
\text { BGN } \\
\text { BGN } \\
\text { BGN } \\
\text { VARIANT } \\
\text { VARIANT } \\
\text { BGN } 1962\end{array}$ & $\begin{array}{l}\text { Maricopa } \\
\text { Coconino } \\
\text { Coconino } \\
\text { Pima } \\
\text { Yavapai } \\
\text { Yavapai } \\
\text { Navajo }\end{array}$ & $\begin{array}{l}332352 \mathrm{~N} 1114805 \mathrm{~W} \\
361745 \mathrm{~N} 1120454 \mathrm{~W} \\
350631 \mathrm{~N} 1114312 \mathrm{~W} \\
313902 \mathrm{~N} 1112646 \mathrm{~W} \\
350446 \mathrm{~N} 1125608 \mathrm{~W} \\
351830 \mathrm{~N} 1130237 \mathrm{~W} \\
341706 \mathrm{~N} 1100923 \mathrm{~W}\end{array}$ & $330000 \mathrm{~N} 1090515 \mathrm{~W}$ & & $\begin{array}{l}\text { Mesa } \\
\text { Little Park Lane } \\
\text { Mountainaire } \\
\text { Las Guijas } \\
\text { Turkey Canyon } \\
\text { Yampai SE } \\
\text { Pinedale }\end{array}$ \\
\hline $\begin{array}{l}\text { Linden Draw } \\
\text { Linden Wash } \\
\text { Readhead Wash } \\
\text { Linden Park Number Two } \\
\text { Linden Wash } \\
\text { See Linden Draw } \\
\text { Linden Wash } \\
\text { See Thistle Hollow } \\
\text { Linden Windmill } \\
\text { Lindon } \\
\text { See Linden }\end{array}$ & $\begin{array}{l}\text { park } \\
\text { valley } \\
\text { valley } \\
\text { locale } \\
\text { locale }\end{array}$ & $\begin{array}{l}\text { BGN } 1973 \\
\text { VARIANT } \\
\text { VARIANT } \\
\text { AOMIN } \\
\text { VARIANT } \\
\text { VARIANT } \\
\text { BGN } \\
\text { VARIANT }\end{array}$ & $\begin{array}{l}\text { Pima } \\
\text { Navajo } \\
\text { Navajo } \\
\text { Navajo } \\
\text { Navajo }\end{array}$ & $\begin{array}{l}342009 \mathrm{~N} 1100504 \mathrm{~W} \\
321302 \mathrm{~N} 1105342 \mathrm{~W} \\
342009 \mathrm{~N} 1100504 \mathrm{~W} \\
342258 \mathrm{~N} 1100633 \mathrm{~W} \\
342400 \mathrm{~N} 110085 \mathrm{~W} \\
341706 \mathrm{~N} 1100923 \mathrm{~W}\end{array}$ & $341413 \mathrm{~N} 1100926 \mathrm{~W}$ & 5889 & $\begin{array}{l}\text { Show Low North } \\
\text { Tucson }\end{array}$ \\
\hline $\begin{array}{l}\text { Lindo Park } \\
\text { Lindsey Canyon } \\
\text { Lindsey Grave } \\
\text { Lindsey Ranch } \\
\text { Lindsey Tank } \\
\text { Lindsey Tank } \\
\text { Line Boy Mine } \\
\text { Line Boy Spring } \\
\text { Line Camp Spring } \\
\text { Line City } \\
\text { See Nogales }\end{array}$ & $\begin{array}{l}\text { park } \\
\text { valley } \\
\text { cemetery } \\
\text { locale } \\
\text { reservoir } \\
\text { reservoir } \\
\text { mine } \\
\text { spring } \\
\text { spring } \\
\text { ppl }\end{array}$ & $\begin{array}{l}\text { ADMIN } \\
\text { BGN } \\
\text { UNOFF } \\
\text { UNOFF } \\
\text { BGN } \\
\text { BGN } \\
\text { UNOFF } \\
\text { BGN } \\
\text { BGN } \\
\text { VARIANT }\end{array}$ & $\begin{array}{l}\text { Maricopa } \\
\text { Graham } \\
\text { Graham } \\
\text { Cochise } \\
\text { Graham } \\
\text { Graham } \\
\text { Santa Cruz } \\
\text { Santa Cruz } \\
\text { Graham } \\
\text { Santa Cruz }\end{array}$ & $\begin{array}{l}332355 \mathrm{~N} 1120620 \mathrm{~W} \\
324235 \mathrm{~N} 1101144 \mathrm{~W} \\
324358 \mathrm{~N} 1100555 \mathrm{~W} \\
313811 \mathrm{~N} 1100835 \mathrm{~W} \\
324352 \mathrm{~N} 1100603 \mathrm{~W} \\
324412 \mathrm{~N} 1100544 \mathrm{~W} \\
312008 \mathrm{~N} 1104125 \mathrm{~W} \\
312010 \mathrm{~N} 1104124 \mathrm{~W} \\
330602 \mathrm{~N} 1094936 \mathrm{~W} \\
312025 \mathrm{~N} 1105601 \mathrm{~W}\end{array}$ & $324458 \mathrm{~N} 1100514 \mathrm{~W}$ & & $\begin{array}{l}\text { Phoenix } \\
\text { Eureka Ranch } \\
\text { Blue Jay Peak } \\
\text { Fairbank } \\
\text { Blue Jay Peak } \\
\text { Blue Jay Peak } \\
\text { Ouquesne } \\
\text { Ouquesne } \\
\text { Markham Creek }\end{array}$ \\
\hline $\begin{array}{l}\text { Line Cove } \\
\text { Lined Trees Windmill } \\
\text { Lines Canyon } \\
\text { Lines Tank } \\
\text { Line Tank } \\
\text { Section Corner Tank }\end{array}$ & $\begin{array}{l}\text { bay } \\
\text { well } \\
\text { valley } \\
\text { reservoir } \\
\text { reservoir }\end{array}$ & $\begin{array}{l}\text { BGN } \\
\text { UNOFF } \\
\text { BGN } \\
\text { BGN } \\
\text { BGN } \\
\text { VARIANT }\end{array}$ & $\begin{array}{l}\text { Mohave } \\
\text { Coconino } \\
\text { Graham } \\
\text { Greenlee } \\
\text { Pima }\end{array}$ & $\begin{array}{l}361142 \mathrm{~N} 1140237 \mathrm{~W} \\
363936 \mathrm{~N} 1110654 \mathrm{~W} \\
330017 \mathrm{~N} 1093246 \mathrm{~W} \\
325451 \mathrm{~N} 1092210 \mathrm{~W} \\
313817 \mathrm{~N} 1111048 \mathrm{~W}\end{array}$ & $330112 \mathrm{~N} 1093114 \mathrm{~W}$ & & $\begin{array}{l}\text { Iceberg Canyon } \\
\text { White Hill } \\
\text { Bonita Spring } \\
\text { Guthrie } \\
\text { Saucito Mtn }\end{array}$ \\
\hline $\begin{array}{l}\text { Line Tank } \\
\text { Line Tank } \\
\text { Line V Seven Ranch } \\
\text { Lineweaver School }\end{array}$ & $\begin{array}{l}\text { reservoir } \\
\text { reservoir } \\
\text { locale } \\
\text { school }\end{array}$ & $\begin{array}{l}\text { BGN } \\
\text { BGN } \\
\text { UNOFF } \\
\text { UNOFF }\end{array}$ & $\begin{array}{l}\text { Navajo } \\
\text { Coconino } \\
\text { Cochise } \\
\text { Pima }\end{array}$ & $\begin{array}{l}344854 \mathrm{~N} 1095953 \mathrm{~W} \\
351435 \mathrm{~N} 1114301 \mathrm{~W} \\
312748 \mathrm{~N} 1090659 \mathrm{~W} \\
321253 \mathrm{~N} 1105406 \mathrm{~W}\end{array}$ & & & $\begin{array}{l}\text { Padilla Tank } \\
\text { Flagstaff West } \\
\text { Guadalupe Spring } \\
\text { Tucson }\end{array}$ \\
\hline $\begin{array}{l}\text { Link Dart Tank } \\
\text { Link Point } \\
\text { Links Point (subdivision) } \\
\text { Link Spring } \\
\text { Linn Tank }\end{array}$ & $\begin{array}{l}\text { reservoir } \\
\text { summit } \\
\text { ppl } \\
\text { spring } \\
\text { reservoir }\end{array}$ & $\begin{array}{l}B G N \\
B G N \\
B G N \\
B G N \\
B G N\end{array}$ & $\begin{array}{l}\text { Coconino } \\
\text { Mohave } \\
\text { Maricopa } \\
\text { Mohave } \\
\text { Coconino }\end{array}$ & $\begin{array}{l}343641 \mathrm{~N} 1112536 \mathrm{~W} \\
363006 \mathrm{~N} 1134040 \mathrm{~W} \\
333536 \mathrm{~N} 1115 \mathrm{~B} 05 \mathrm{~W} \\
363027 \mathrm{~N} 1133952 \mathrm{~W} \\
344207 \mathrm{~N} 1111916 \mathrm{~W}\end{array}$ & & $\begin{array}{l}5775 \\
1380\end{array}$ & $\begin{array}{l}\text { Calloway Butte } \\
\text { St George Canyon } \\
\text { Paradise Valley } \\
\text { St George Canyon } \\
\text { Turkey Mtn }\end{array}$ \\
\hline
\end{tabular}




\begin{tabular}{|c|c|c|c|c|c|c|c|}
\hline FEATURE NAME & $\begin{array}{l}\text { FEATURE } \\
\text { CLASS }\end{array}$ & STATUS & COUNTY & COORDINATE & $\begin{array}{l}\text { SOURCE } \\
\text { COORDINATE }\end{array}$ & $\begin{array}{c}\text { ELEV } \\
\text { FT }\end{array}$ & MAP NAME \\
\hline $\begin{array}{l}\text { Linskey } \\
\text { See Wall } \\
\text { Lion Camp } \\
\text { Lion Canyon } \\
\text { See Leon Canyon }\end{array}$ & $\begin{array}{l}\text { locale } \\
\text { locale } \\
\text { valley }\end{array}$ & $\begin{array}{l}\text { VARIANT } \\
\text { BGN } \\
\text { VARIANT }\end{array}$ & $\begin{array}{l}\text { La Paz } \\
\text { Pinal } \\
\text { Santa Cruz }\end{array}$ & $\begin{array}{l}335945 N 1140927 \mathrm{~W} \\
325851 \mathrm{~N} 1103714 \mathrm{~W} \\
312914 \mathrm{~N} 1110805 \mathrm{~W}\end{array}$ & & & Brandenburg Mtn \\
\hline $\begin{array}{l}\text { Lion Canyon } \\
\text { Corral Creek } \\
\text { Lion Canyon } \\
\text { Lion Canyon } \\
\text { Weaver Creek }\end{array}$ & $\begin{array}{l}\text { valley } \\
\text { valley } \\
\text { valley }\end{array}$ & $\begin{array}{l}\text { BGN } 1965 \\
\text { VARIANT } \\
\text { BGN } \\
\text { BGN } 1972 \\
\text { VARIANT }\end{array}$ & $\begin{array}{l}\text { Gila } \\
\text { Yavapai } \\
\text { Yavapai }\end{array}$ & $\begin{array}{l}335839 \mathrm{~N} 1112252 \mathrm{~W} \\
340138 \mathrm{~N} 1115715 \mathrm{~W} \\
341014 \mathrm{~N} 1124148 \mathrm{~W}\end{array}$ & $\begin{array}{l}335913 \mathrm{~N} 1112412 \mathrm{~W} \\
340326 \mathrm{~N} 1115956 \mathrm{~W} \\
341243 \mathrm{~N} 1124019 \mathrm{~W}\end{array}$ & & $\begin{array}{l}\text { Reno Pass } \\
\text { Cooks Mesa } \\
\text { Yarnel1 }\end{array}$ \\
\hline $\begin{array}{l}\text { Lion Canyon } \\
\text { Lion Canyon Spring } \\
\text { Lion Hill } \\
\text { Lion Kill Spring } \\
\text { Lion Mine }\end{array}$ & $\begin{array}{l}\text { valley } \\
\text { spring } \\
\text { summit } \\
\text { spring } \\
\text { mine }\end{array}$ & $\begin{array}{l}\text { BGN } \\
\text { BGN } \\
\text { BGN } \\
\text { BGN } \\
\text { UNOFF }\end{array}$ & $\begin{array}{l}\text { Yavapai } \\
\text { Yavapai } \\
\text { Yuma } \\
\text { Mohave } \\
\text { Santa Cruz }\end{array}$ & $\begin{array}{l}351405 \mathrm{~N} 1125846 \mathrm{~W} \\
340238 \mathrm{~N} 1115912 \mathrm{~W} \\
341101 \mathrm{~N} 1141108 \mathrm{~W} \\
350810 \mathrm{~N} 1135210 \mathrm{~W} \\
312353 \mathrm{~N} 1105446 \mathrm{~W}\end{array}$ & $351415 N 1130157 \mathrm{~W}$ & & $\begin{array}{l}\text { Purcell Canyon } \\
\text { Cooks Mesa } \\
\text { Cross Roads } \\
\text { Hualapai Spring } \\
\text { Rio Rico }\end{array}$ \\
\hline $\begin{array}{l}\text { Lion Mountain } \\
\text { Lion Mountain } \\
\text { Lion Peak } \\
\text { Lion Rock } \\
\text { Lions Club Park } \\
\text { Lions Den Mine } \\
\text { Lion Spring } \\
\text { Lion Spring } \\
\text { Lion Spring } \\
\text { Lion Spring }\end{array}$ & $\begin{array}{l}\text { summit } \\
\text { summit } \\
\text { summit } \\
\text { summit } \\
\text { park } \\
\text { mine } \\
\text { spring } \\
\text { spring } \\
\text { spring } \\
\text { spring }\end{array}$ & $\begin{array}{l}\text { BGN } \\
\text { BGN } \\
\text { BGN } \\
\text { BGN } \\
\text { ADMIN } \\
\text { UNOFF } \\
\text { BGN } \\
\text { BGN } \\
\text { BGN } \\
\text { BGN }\end{array}$ & $\begin{array}{l}\text { Santa Cruz } \\
\text { Maricopa } \\
\text { Yavapai } \\
\text { Navajo } \\
\text { Yavapai } \\
\text { Maricopa } \\
\text { Pima } \\
\text { Maricopa } \\
\text { Gila } \\
\text { Yavapai }\end{array}$ & $\begin{array}{l}312730 \mathrm{~N} 1110514 \mathrm{~W} \\
335642 \mathrm{~N} 1113506 \mathrm{~W} \\
341049 \mathrm{~N} 1124151 \mathrm{~W} \\
364511 \mathrm{~N} 1101121 \mathrm{~W} \\
344440 \mathrm{~N} 1120131 \mathrm{~W} \\
334407 \mathrm{~N} 1131614 \mathrm{~W} \\
320517 \mathrm{~N} 1103327 \mathrm{~W} \\
333700 \mathrm{~N} 1111011 \mathrm{~W} \\
335519 \mathrm{~N} 1110635 \mathrm{~W} \\
340848 \mathrm{~N} 1121904 \mathrm{~W}\end{array}$ & & $\begin{array}{l}4600 \\
4608\end{array}$ & $\begin{array}{l}\text { Pena Blanca Lake } \\
\text { Lion Mountain } \\
\text { Yarnell } \\
\text { Agathla Peak } \\
\text { Cottonwood } \\
\text { Weldon Hill } \\
\text { Rincon Peak } \\
\text { Pinyon Mtn } \\
\text { Copper Mtn } \\
\text { Crown King }\end{array}$ \\
\hline $\begin{array}{l}\text { Lion Spring } \\
\text { Lion Spring } \\
\text { Lion Spring } \\
\text { Lion Spring } \\
\text { Lion Spring } \\
\text { Lion Spring Oraw } \\
\text { Lion Tank } \\
\text { Lion Tank } \\
\text { Lion Tank } \\
\text { Lipan Point }\end{array}$ & $\begin{array}{l}\text { spring } \\
\text { spring } \\
\text { spring } \\
\text { spring } \\
\text { spring } \\
\text { valley } \\
\text { reservoir } \\
\text { reservoir } \\
\text { reservoir } \\
\text { cliff }\end{array}$ & $\begin{array}{l}\text { BGN } \\
\text { BGN } \\
\text { BGN } \\
\text { BGN } \\
\text { BGN } \\
\text { BGN } \\
\text { BGN } \\
\text { BGN } \\
\text { BGN } \\
\text { BGN } 1906\end{array}$ & $\begin{array}{l}\text { Gila } \\
\text { Gila } \\
\text { Mohave } \\
\text { Mohave } \\
\text { Coconino } \\
\text { Gila } \\
\text { Apache } \\
\text { Mohave } \\
\text { Coconino } \\
\text { Coconino }\end{array}$ & $\begin{array}{l}341430 \mathrm{~N} 1111411 \mathrm{~W} \\
341525 \mathrm{~N} 1111250 \mathrm{~W} \\
343907 \mathrm{~N} 1132608 \mathrm{~W} \\
344030 \mathrm{~N} 1132029 \mathrm{~W} \\
350843 \mathrm{~N} 1113502 \mathrm{~W} \\
341419 \mathrm{~N} 1111433 \mathrm{~W} \\
340843 \mathrm{~N} 1095042 \mathrm{~W} \\
352259 \mathrm{~N} 113205 \mathrm{~W} \\
352559 \mathrm{~N} 1121627 \mathrm{~W} \\
360159 \mathrm{~N} 1115109 \mathrm{~W}\end{array}$ & 341749 N1111202W & & $\begin{array}{l}\text { McDonald Mtn } \\
\text { Diamond Point } \\
\text { Elephant Mtn } \\
\text { Negro Ed } \\
\text { Flagstaff East } \\
\text { McDonald Mtn } \\
\text { Sponseller Mtn } \\
\text { Blye Canyon NE } \\
\text { Cataract Tank } \\
\text { Desert View }\end{array}$ \\
\hline $\begin{array}{l}\text { Liquor Spring } \\
\text { Liquor Spring } \\
\text { Liscum } \\
\text { Lisitzky Subdivision } \\
\text { Litchfield } \\
\text { Litchfield } \\
\text { See Avondale } \\
\text { Litchfield } \\
\text { See Litchfield Park } \\
\text { Litchfield Airport }\end{array}$ & $\begin{array}{l}\text { spring } \\
\text { spring } \\
\text { locale } \\
\text { ppl } \\
\text { locale } \\
\text { ppl } \\
\text { ppl } \\
\text { airport }\end{array}$ & $\begin{array}{l}\text { BGN } \\
\text { BGN } \\
\text { BGN } \\
\text { BGN } \\
\text { BGN } \\
\text { VARIANT } \\
\text { VARIANT } \\
\text { ADMIN }\end{array}$ & $\begin{array}{l}\text { Gila } \\
\text { Gila } \\
\text { Maricopa } \\
\text { Navajo } \\
\text { Maricopa } \\
\text { Maricopa } \\
\text { Maricopa } \\
\text { Maricopa }\end{array}$ & $\begin{array}{l}332739 \mathrm{~N} 1104733 \mathrm{~W} \\
334312 \mathrm{~N} 1104950 \mathrm{~W} \\
335305 \mathrm{~N} 1115702 \mathrm{~W} \\
345541 \mathrm{~N} 1100809 \mathrm{~W} \\
332536 \mathrm{~N} 1122116 \mathrm{~W} \\
332608 \mathrm{~N} 1122056 \mathrm{~W} \\
332936 \mathrm{~N} 1122126 \mathrm{~W} \\
333005 \mathrm{~N} 1122210 \mathrm{~W}\end{array}$ & & $\begin{array}{l}2321 \\
5240\end{array}$ & $\begin{array}{l}\text { Globe } \\
\text { Dagger Peak } \\
\text { New River Mesa } \\
\text { Holbrook } \\
\text { Avondale }\end{array}$ \\
\hline $\begin{array}{l}\text { Litchfield Cemetery } \\
\text { Litchfield Junction } \\
\text { Litchfield Park } \\
\text { Litchfield } \\
\text { Litchton } \\
\text { Litchfield Park Dam } \\
\text { Litchfield Park Elementary } \\
\text { School } \\
\text { Litchfield Park Post Office } \\
\text { Litchfield Railroad Station }\end{array}$ & $\begin{array}{l}\text { cemetery } \\
\text { locale } \\
\text { ppl } \\
\text { dan } \\
\text { school } \\
\text { building } \\
\text { building }\end{array}$ & $\begin{array}{l}\text { UNOFF } \\
\text { BGN } \\
\text { BGN } \\
\text { VARIANT } \\
\text { VARIANT } \\
\text { UNOFF } \\
\text { UNOFF } \\
\text { UNOFF } \\
\text { UNOFF }\end{array}$ & $\begin{array}{l}\text { Maricopa } \\
\text { Maricopa } \\
\text { Maricopa } \\
\text { Maricopa }\end{array}$ & $\begin{array}{l}333106 N 1122054 W \\
332932 N 1122123 W \\
332938 N 1122127 W \\
332539 N 1122112 W\end{array}$ & & & $\begin{array}{l}\text { Avondale } \\
\text { Avondale } \\
\text { Avondale }\end{array}$ \\
\hline $\begin{array}{l}\text { Litchfield Siding } \\
\text { See MaMicken } \\
\text { Litchfield Substation } \\
\text { Litchton } \\
\text { See Litchfield Park } \\
\text { Lithodendron Creek } \\
\text { See Lithodendron Wash } \\
\text { Lithodendron Wash } \\
\text { Big Carrizo Wash } \\
\text { Carrizo Creek } \\
\text { Carrizo Wash } \\
\text { Lithodendron Creek }\end{array}$ & $\begin{array}{l}\text { locale } \\
\text { locale } \\
\text { ppl } \\
\text { stream } \\
\text { stream }\end{array}$ & $\begin{array}{l}\text { VARIANT } \\
\text { UNOFF } \\
\text { VARIANT } \\
\text { VARIANT } \\
\text { BGN } 1939 \\
\text { VARIANT } \\
\text { VARIANT } \\
\text { VARIANT } \\
\text { VARIANT }\end{array}$ & $\begin{array}{l}\text { Maricopa } \\
\text { Maricopa } \\
\text { Maricopa } \\
\text { Navajo } \\
\text { Navajo }\end{array}$ & $\begin{array}{l}332950 \mathrm{~N} 1122535 \mathrm{~W} \\
332933 \mathrm{~N} 1122043 \mathrm{~W} \\
332936 \mathrm{~N} 1122126 \mathrm{~W} \\
345816 \mathrm{~N} 1095650 \mathrm{~W} \\
345816 \mathrm{~N} 1095650 \mathrm{~W}\end{array}$ & $351144 \mathrm{~N} 1094344 \mathrm{~W}$ & & Carrizo Butte \\
\hline $\begin{array}{l}\text { Lithograph Spring } \\
\text { Little Acres } \\
\text { Little Ajo Mountains } \\
\text { Little Alamo Tank }\end{array}$ & $\begin{array}{l}\text { spring } \\
\text { ppl } \\
\text { summit } \\
\text { reservoir }\end{array}$ & $\begin{array}{l}\text { BGN } \\
\text { BGN } \\
B G N \\
\text { BGN }\end{array}$ & $\begin{array}{l}\text { Yavapai } \\
\text { Gila } \\
\text { Pima } \\
\text { Santa Cruz }\end{array}$ & $\begin{array}{l}342748 \mathrm{~N} 1115143 \mathrm{~W} \\
332341 \mathrm{~N} 1104913 \mathrm{~W} \\
322106 \mathrm{~N} 1125229 \mathrm{~W} \\
312155 \mathrm{~N} 1110108 \mathrm{~W}\end{array}$ & & 3412 & $\begin{array}{l}\text { Horner Mtn } \\
\text { Globe } \\
\text { Ajo South } \\
\text { Pajarito Peak }\end{array}$ \\
\hline
\end{tabular}




\begin{tabular}{|c|c|c|c|c|c|c|c|}
\hline FEATURE NAME & $\begin{array}{l}\text { FEATURE } \\
\text { CLASS }\end{array}$ & STATUS & COUNTY & COORDINATE & $\begin{array}{l}\text { SOURCE } \\
\text { COORDINATE }\end{array}$ & $\underset{\text { ELEV }}{\text { FT }}$ & MAP MAME \\
\hline $\begin{array}{l}\text { Little Alps } \\
\text { See Tehua Hills } \\
\text { Little Antelope Interchange } \\
\text { Little Antelope Tank } \\
\text { Little Antelope Tank } \\
\text { Little Arizona Spring }\end{array}$ & $\begin{array}{l}\text { range } \\
\text { crossing } \\
\text { reservoir } \\
\text { reservoir } \\
\text { spring }\end{array}$ & $\begin{array}{l}\text { VARIANT } \\
\text { UNOFF } \\
\text { BGN } \\
\text { BGN } \\
\text { BGN }\end{array}$ & $\begin{array}{l}\text { Coconino } \\
\text { Navajo } \\
\text { Coconino } \\
\text { Mohave }\end{array}$ & $\begin{array}{l}\text { UNKMOWN } \\
345444 \mathrm{~N} 1113825 \mathrm{~W} \\
344328 \mathrm{~N} 1104345 \mathrm{~W} \\
345348 \mathrm{~N} 1113816 \mathrm{~W} \\
362011 \mathrm{N1135806 \textrm {W }}\end{array}$ & & 6485 & $\begin{array}{l}\text { Munds Park } \\
\text { Potato Wash North } \\
\text { Munds Park } \\
\text { Gyp Hills }\end{array}$ \\
\hline $\begin{array}{l}\text { Little Artesian Well } \\
\text { Little Ash Creek } \\
\text { Little Ash Creek } \\
\text { Little Aso Tank } \\
\text { Little Baldy Tank } \\
\text { Little Bear Dam } \\
\text { See Shush Bezahze Dam } \\
\text { Little Bend } \\
\text { Little Big Hole Tank } \\
\text { Little Bighorn Peak } \\
\quad \text { Little Big Horn Peak }\end{array}$ & $\begin{array}{l}\text { well } \\
\text { stream } \\
\text { stream } \\
\text { reservoir } \\
\text { reservoir } \\
\text { dam } \\
\text { dend } \\
\text { reservoir } \\
\text { summit }\end{array}$ & $\begin{array}{l}\text { UNOFF } \\
\text { BGN } \\
\text { 8GN } \\
\text { BGN } \\
\text { BGN } \\
\text { VARIANT } \\
\text { BGN } \\
\text { BGN } \\
\text { BGN } \\
\text { VARIANT }\end{array}$ & $\begin{array}{l}\text { Graham } \\
\text { Pinal } \\
\text { Yavapai } \\
\text { Coconino } \\
\text { Coconino } \\
\text { Apache } \\
\text { Mohave } \\
\text { Gila } \\
\text { Maricopa }\end{array}$ & $\begin{array}{l}322545 \mathrm{~N} 1091936 \mathrm{~W} \\
330520 \mathrm{N1104056 \textrm {W }} \\
342045 \mathrm{~N} 1120415 \mathrm{~W} \\
352303 \mathrm{N1122818 \textrm {W }} \\
354054 \mathrm{N1} 123550 \mathrm{~W} \\
340342 \mathrm{N1} 1094412 \mathrm{~W} \\
364943 \mathrm{~N} 1135906 \mathrm{~W} \\
334245 \mathrm{N1} 102227 \mathrm{~W} \\
334400 \mathrm{~N} 1131200 \mathrm{~W}\end{array}$ & $\begin{array}{l}330520 \mathrm{~N} 1103825 \mathrm{~W} \\
342237 \mathrm{~N} 1120006 \mathrm{~W}\end{array}$ & 3473 & $\begin{array}{l}\text { Martin Well } \\
\text { Christmas } \\
\text { Cordes Junction } \\
\text { Stanford Tank } \\
\text { Tin House } \\
\text { Elbow Canyon } \\
\text { Popcorn Canyon } \\
\text { Little Horn Peak }\end{array}$ \\
\hline $\begin{array}{l}\text { Little Big Horn Peak } \\
\text { See Little Bighorn Peak } \\
\text { Little Big Horn Well } \\
\text { Little Bill Tank } \\
\text { Little Black Hills } \\
\text { Black Hills } \\
\text { Little Black Hill Tank } \\
\text { Little Black Hill Tank } \\
\text { Little Black Hill Tank } \\
\text { Little Black Mesa }\end{array}$ & $\begin{array}{l}\text { summit } \\
\text { well } \\
\text { reservoir } \\
\text { summit } \\
\text { reservoir } \\
\text { reservoir } \\
\text { reservoir } \\
\text { summit }\end{array}$ & $\begin{array}{l}\text { VARIANT } \\
\text { BGN } \\
\text { BGN } \\
\text { BGN } \\
\text { VARIANT } \\
\text { BGN } \\
\text { BGN } \\
\text { BGN } \\
\text { BGN } 1963\end{array}$ & $\begin{array}{l}\text { Maricopa } \\
\text { Maricopa } \\
\text { Coconino } \\
\text { Pinal } \\
\text { Yavapai } \\
\text { Yavapai } \\
\text { Coconino } \\
\text { Yavapai }\end{array}$ & 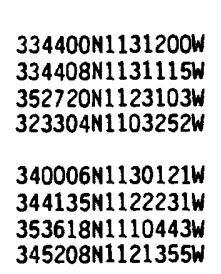 & & 3224 & $\begin{array}{l}\text { Little Horn Peak } \\
\text { Eagle Nest Mtn } \\
\text { Peppersauce Wash } \\
\text { Date Creek Ranch SE } \\
\text { Chino Valley South } \\
\text { White Water Tank } \\
\text { Munds Oraw }\end{array}$ \\
\hline $\begin{array}{l}\text { Little Black Mesa } \\
\text { Little 8lack Mountain } \\
\text { Little Black Mountain } \\
\text { Little Black Spot Mountain } \\
\text { Amusovi Mesa } \\
\text { Dahlizin Mesa } \\
\text { Dzil-le-sa-a Mesa } \\
\text { Ozilth-dazzi mesa } \\
\text { Zilh-in-sah Mesa } \\
\text { Zilh-le-sah Mesa } \\
\text { Zillesa Mesa } \\
\text { Zillesa Peak } \\
\text { Zilth-dush-jhini } \\
\text { Zil-yazi-zin-daah Mesa }\end{array}$ & $\begin{array}{l}\text { summit } \\
\text { summit } \\
\text { summit } \\
\text { summit }\end{array}$ & $\begin{array}{l}\text { BGN } \\
\text { BGN } \\
\text { BGN } \\
\text { BGN 1968 } \\
\text { VARIANT } \\
\text { VARIANT } \\
\text { VARIANT } \\
\text { VARIANT } \\
\text { VARIANT } \\
\text { VARIANT } \\
\text { VARIANT } \\
\text { VARIANT } \\
\text { VARIANT } \\
\text { VARIANT }\end{array}$ & $\begin{array}{l}\text { Coconino } \\
\text { Mohave } \\
\text { Mohave } \\
\text { Navajo }\end{array}$ & $\begin{array}{l}363108 \mathrm{~N} 1112156 \mathrm{~W} \\
341814 \mathrm{N1140012W} \\
365943 \mathrm{~W} 1132955 \mathrm{~W} \\
360457 \mathrm{N1101948W}\end{array}$ & & $\begin{array}{l}6400 \\
1849 \\
7001\end{array}$ & $\begin{array}{l}\text { Dove Spring SE } \\
\text { Monkeys Head } \\
\text { Yellowhorse Flat } \\
\text { Ltl Black Spot Mtn }\end{array}$ \\
\hline $\begin{array}{l}\text { Little Blue Box } \\
\text { Little Blue Creek } \\
\text { Blue Creek } \\
\text { Little Blue Creek Forty-one } \\
\text { Trail } \\
\text { Little Bly Tank } \\
\text { Little Bog Creek } \\
\text { Bog Creek } \\
\text { Little Boiling Spring } \\
\text { Little Bonito Creek } \\
\text { Bonita Creek } \\
\text { Bonito Creek } \\
\text { Corn Creek } \\
\text { Crooked Creek }\end{array}$ & $\begin{array}{l}\text { basin } \\
\text { stream } \\
\text { trail } \\
\text { reservoir } \\
\text { stream } \\
\text { spring } \\
\text { stream }\end{array}$ & $\begin{array}{l}\text { BGN } \\
\text { BGN } \\
\text { VARIANT } \\
\text { UNOFF } \\
\text { BGN } \\
\text { BGN } \\
\text { VARIANT } \\
\text { BGN } \\
\text { BGN 1970 } \\
\text { VARIANT } \\
\text { VARIANT } \\
\text { VARIANT } \\
\text { VARIANT }\end{array}$ & $\begin{array}{l}\text { Greenlee } \\
\text { Greenlee } \\
\text { Greenlee } \\
\text { Coconino } \\
\text { Apache } \\
\text { Graham } \\
\text { Apache }\end{array}$ & $\begin{array}{l}332413 \mathrm{~N} 1090926 \mathrm{~W} \\
332239 \mathrm{N1} 1091006 \mathrm{~W} \\
332904 \mathrm{~N} 1090500 \mathrm{~W} \\
344008 \mathrm{~N} 1110627 \mathrm{~W} \\
340337 \mathrm{N1} 1094329 \mathrm{~W} \\
330935 \mathrm{~N} 1093341 \mathrm{~W} \\
334130 \mathrm{~N} 1094715 \mathrm{~W}\end{array}$ & 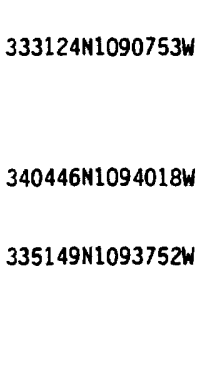 & & $\begin{array}{l}\text { Outch Blue Creek } \\
\text { Outch Blue Creek } \\
\text { Alma Mesa } \\
\text { Quayle Hill } \\
\text { Horseshoe Cienega } \\
\text { Elevator Mtn } \\
\text { Corn Creek }\end{array}$ \\
\hline $\begin{array}{l}\text { Little Boulder Canyon } \\
\text { Little Boulder Pond } \\
\text { Little Boul in Tank } \\
\text { Little Box Canyon Dam } \\
\text { Little Box Lake } \\
\text { Little Boy Creek } \\
\text { See Soldier Creek } \\
\text { Little Brewster Spring } \\
\text { Little Brushy } \\
\text { Little Brushy Mountain }\end{array}$ & $\begin{array}{l}\text { valley } \\
\text { lake } \\
\text { reservoir } \\
\text { dam } \\
\text { reservoir } \\
\text { stream } \\
\text { spring } \\
\text { summit } \\
\text { summit }\end{array}$ & $\begin{array}{l}\text { BGN } \\
\text { BGN } \\
\text { BGN } \\
\text { UNOFF } \\
\text { BGN } \\
\text { VARIANT } \\
\text { BGN } \\
\text { BGN } \\
\text { BGN }\end{array}$ & $\begin{array}{l}\text { Pinal } \\
\text { Mohave } \\
\text { Coconino } \\
\text { Pinal } \\
\text { Pinal } \\
\text { Apache } \\
\text { Gila } \\
\text { Apache } \\
\text { Apache }\end{array}$ & $\begin{array}{l}332742 \mathrm{~N} 1112326 \mathrm{~W} \\
362031 \mathrm{N1} 13202 \mathrm{~W} \\
352451 \mathrm{N1} 20216 \mathrm{~W} \\
331157 \mathrm{N1} 105948 \mathrm{~W} \\
331157 \mathrm{N110594BW} \\
340257 \mathrm{~N} 1094041 \mathrm{~W} \\
333343 \mathrm{~N} 1104620 \mathrm{~W} \\
34074 \mathrm{N1} 109494 \mathrm{~W} \\
335100 \mathrm{~N} 1094615 \mathrm{~W}\end{array}$ & $332634 \mathrm{~N} 1112351 \mathrm{~W}$ & $\begin{array}{l}2193 \\
2193\end{array}$ & $\begin{array}{l}\text { Goldfield } \\
\text { Cold Spring } \\
\text { Squaw Mtn } \\
\text { Hot Tamale Peak } \\
\text { Hot Tamale Peak }\end{array}$ \\
\hline $\begin{array}{l}\text { Little Brushy Spring } \\
\text { See Brushy Spring } \\
\text { Little Brushy Tank } \\
\text { Little Brushy Waterhole } \\
\text { Little Brushy Waterhole } \\
\text { See Little Brushy Tank } \\
\text { Little Buckhorn Creek } \\
\text { Little Buckhorn Tank }\end{array}$ & $\begin{array}{l}\text { reservoir } \\
\text { stream } \\
\text { reservoir }\end{array}$ & $\begin{array}{l}\text { VARIANT } \\
\text { BGN } \\
\text { VARIANT } \\
\text { VARIANT } \\
\text { BGN } \\
\text { BGN }\end{array}$ & $\begin{array}{l}\text { Graham } \\
\text { Yavapai } \\
\text { Greeniee }\end{array}$ & $\begin{array}{l}332412 \mathrm{~N} 1101744 \mathrm{~W} \\
340049 \mathrm{N1122858W} \\
331348 \mathrm{~N} 1090829 \mathrm{~W}\end{array}$ & 340158 N1123019W & 4060 & $\begin{array}{l}\text { Copperopol is } \\
\text { Dix Creek }\end{array}$ \\
\hline
\end{tabular}


NATIONAL GAZETTEER--ARIZONA 1986

\section{FEATURE NAME}

Little Buckhorn Tank

Little Buckskin Mountains

Little Buckskin Tank

Little Bull Canyon

Little Bull Tank

Little Bull Tank Number Two

Little Burro Spring

Little Burro Spring

See Burro Spring

Little Butte

Little Butte

Little Butte Mine

Little Butte Spring

Little Buttes Well

Little California Gulch See Seventys ix Gulch

Little California Gulch

Little Campaign Creek Apache Canyon

Little Canyon Park

Little Capitan Valley

Little Carrizo Wash See Little Lithodendron Wash

Little Casa Blanca Canyon

Little Cedar Knoll

Little Cedar Tank

Little Cherry Creek

Little Chevelon Tank

Little Chief Mine

Little Chino Valley Chino Valley

Little Christman Reservoir

Little Cinder Basin

Little Clayhole Reservoir

Little Clayhole Valley

Little Clayhole Wash

Little Colorado Plateau See Mogolion Plateau

Little Colorado River Chiquito

Collorado

Colorado

Colorado Chiquita

Colorado Chiquito

Flax

Flax River

Rio Colorado Chiquito

Rio de Lino

Tol-Chaco

Little Colorado River 8ridge

Little Colorado River Gorge

Little Colorado River Navajo

Tribal Park

Little Copper Creek

Little Copper Mountain Tank

Little Copper Spring See East Copper Spring

Little Cottonwood Canyon

Little Cottonwood Canyon

Little Cottonwood Canyon See Two Troughs Canyon

Little Cottonwood Spring

Little Cottonwood Tank

Little Cougar Canyon

Little Cowboy Windmil

Little Coyote Canyon

Little Coyote Canyon

Little Creek

Little Cypress Creek

Little Daisy Mine
FEATURE

STATUS

COUNTY

COORDINATE

reservoir

summit

BGN

$8 G N$

Coconino

Yuma

$354039 \mathrm{~N} 1114749 \mathrm{~W}$

$340643 \mathrm{~N} 1132926 \mathrm{~W}$

reservoir BGN Yavapai 342821N1113906W

valley

reservoir

reservoir

spring

BGN

BGN

BGN

VARIANT

spring

summit

mine

BGN

BGN

UNOFF

sprin

well

arroyo

valley

stream

park

valley

stream

BGN

UNOFF

VARIANT

BGN 1976 Cochise

VARIANT

ADMIN

BGN

VARIANT

Navajo

Grahan

Navajo

Gila

Yuma

Yuma

Gila

Gila

Cochise

Gila

Maricopa

Navajo

Mavajo

$344944 \mathrm{~N} 1103205 \mathrm{~W}$

$323155 \mathrm{~N} 1101316 \mathrm{~W}$

$354035 \mathrm{~N} 1103412 \mathrm{~W}$

$354155 \mathrm{N1} 104133 \mathrm{~W}$

$335812 \mathrm{~N} 1140350 \mathrm{~W}$

$335811 \mathrm{~N} 1140333 \mathrm{~W}$

$334242 N 1103930 \mathrm{~W}$

$333140 \mathrm{N1} 104028 \mathrm{~W}$

$321647 \mathrm{~N} 1093903 \mathrm{~W}$

$321637 \mathrm{N1093930 \textrm {W }}$

$333053 N 1120738 \mathrm{~W}$

$364929 \mathrm{N1100316 \textrm {W }}$

$345822 \mathrm{~N} 1095721 \mathrm{~W}$

valley

reservoir

stream

reservoir

mine

valley

reservoir

basin

BGN

BGN

BGN

UNOFF

BGN 1975

VARIANT

BGN

BGN

reservoir

valley

stream

BGN

BGN Mohave

VARIANT

plain

stream

BGN 189

BGN 1891

VARIANT

VARIANT

VARIANT

VARIANT

VARIANT

VARIANT

VARIANT

VARIAMT

VARIANT

\begin{tabular}{|c|c|c|}
\hline $\begin{array}{l}\text { bridge } \\
\text { valley } \\
\text { park }\end{array}$ & $\begin{array}{l}\text { UNOFF } \\
\text { BGN } \\
\text { ADMIN }\end{array}$ & $\begin{array}{l}\text { Apache } \\
\text { Coconino } \\
\text { Coconino }\end{array}$ \\
\hline $\begin{array}{l}\text { strean } \\
\text { reservoir }\end{array}$ & $\begin{array}{l}\text { BGN } \\
\text { 8GN } \\
\text { VARIANT }\end{array}$ & $\begin{array}{l}\text { Yavapai } \\
\text { Gila }\end{array}$ \\
\hline $\begin{array}{l}\text { pring } \\
\text { alley } \\
\text { alley }\end{array}$ & $\begin{array}{l}B G N \\
B G N\end{array}$ & $\begin{array}{l}\text { Yavapai } \\
\text { Graham } \\
\text { Graham }\end{array}$ \\
\hline
\end{tabular}

Santa Cruz

Coconino

Yavapai

Gila

Navajo

Yavapai

Mohave

Coconino

$313627 N 1104351 \mathrm{~W}$

36461 ON1122BO4W

$342121 N 1121455 \mathrm{~W}$

$335047 \mathrm{~N} 1110541 \mathrm{~W}$

$345507 \mathrm{~N} 1103326 \mathrm{~W}$

$321127 \mathrm{~N} 1123032 \mathrm{~W}$

$345020 \mathrm{~N} 1122700 \mathrm{~W}$

$362644 \mathrm{~N} 1132459 \mathrm{~W}$

$352001 N 1112754 \mathrm{~W}$

$363956 \mathrm{N1} 130443 \mathrm{~W}$

$364220 N 1130655 \mathrm{~W}$

$364249 N 1130734 \mathrm{~W}$

$353500 \mathrm{~N} 1113500 \mathrm{~N}$

$361128 \mathrm{~N} 1114811 \mathrm{~W}$

$343124 N 1094210 \mathrm{~W}$

361133 N1114752 $360400 \mathrm{~N} 1113500 \mathrm{~W}$

$342638 \mathrm{~N} 1123026 \mathrm{~W}$

335732 N1110501W

$342906 \mathrm{~N} 1123213 \mathrm{~W}$

$323149 N 1094639 \mathrm{~W}$

324905N1100511W
$334235 \mathrm{N1} 103952 \mathrm{~W}$

$333120 \mathrm{N1} 105937 \mathrm{~W}$

325040 N1100309

$352034 \times 1133349 \mathrm{~W}$

$345517 N 1130922 \mathrm{~W}$

340432 N1115025W

$355659 \mathrm{~N} 1110402 \mathrm{~W}$

$344303 \mathrm{~N} 1121233 \mathrm{~W}$

$361500 \mathrm{~N} 1124501 \mathrm{~W}$

$334942 \mathrm{~N} 1090427 \mathrm{~W}$

344641 N1130858W

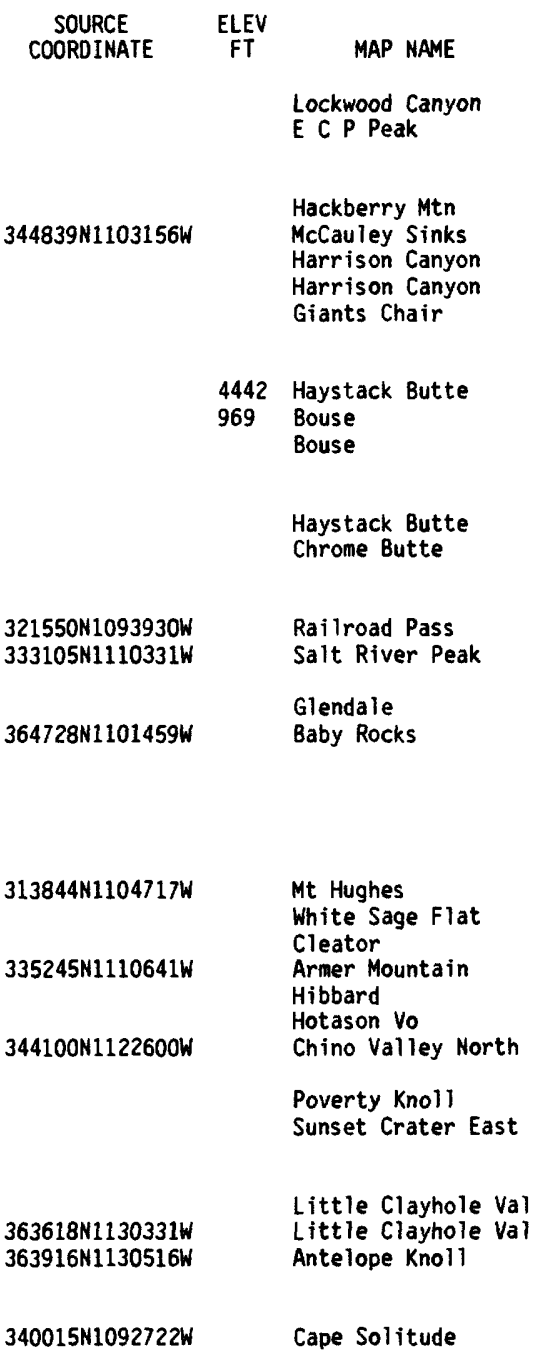

$355144 \mathrm{~N} 1112328 \mathrm{~W}$

Potter Mesa Tank

Cape Solitude

Blue Spring SE

$342807 N 1123141$

Wilhoit

Copper Mtn

$323000 \mathrm{~N} 1094602 \mathrm{~W}$

Stockton Pass

Tripp Canyon

Valentine SE

$340404 N 1115250 \mathrm{~W}$

Sunrise Peak

Appaloosa Ridge

$344323 \mathrm{N1} 121048 \mathrm{~W}$

$360428 N 1125151 \mathrm{~W}$

$335305 \mathrm{~N} 1090656 \mathrm{~W}$

Hickey Mountain

Supa $\mathbf{i}$

Luna Lake

Burro Mesa

Reno Pass 
FEATURE NAME

Little Daisy Tank

Little Dam North Tank

Little Deer Valley

Little Dianond Creek

Little Diamond Rim

Little Dogie Tank

Little Doubtful Canyon

Little Dragon

Little Dragon Mountains Limestone Mountains Little Dragoons

Little Dragoons

See Little Dragon Mountains

Little Draw Tank

Little Dry Canyon

Little Dry Lake

Little East Fork Spring

Little Eberling Tank

Little Elden Mountain

Little Elden Spring

Little Electric Well

Little Emigrant Canyon

Little E Tank

Little Eureka Spring

Little Field See Ali Oidak

Littlefield Beaverdam

Littlefield

See Beaver Dam

Little Field Is land

See Ali Oidak

Little Fish Canyon

Little Fortyfour Spring

Little Franks

Little Franks Well

Little Freeman Tank Ship Dam Tank

Little Gadwell Windmill

Little George Pond

Little George Reservoir

Little Giant Mine

Little Giant Spring

Little Gila Canal

Little Gila River

Little Goat Canyon

Little Golden Prospect

Little Gold Gulch

Little Grand Canyon Rancho

Little Granite Mountain

Indian Peak

Indian Point

Little Granite Mountain

Little Granite Mountain Trail

Number Thiry Seven

Little Grapevine Canyon

Little Grapevine Tank

Little Gray Hill

Little Grayhorse Canyon

Little Green Mine

Little Green Valley Little Valley

Little Gust James Wash

Little Hackberry Wash

Little Hackberry Well

Little Harpo Canyon

Little Harpo Tank

Little Harquahala Mountain

Little Hawk Spring

Little Haystack Mountain

Little Hells Gate

Little Hill Mines Airport

\section{FEATURE \\ CLASS}

STATUS

COUNTY

reservoir BGN

reservoir BGN

valley $B G N$

ridge

reservoir

valley

ridge

summit

summit

valley BGN

lake $B G N$

spring $B G N$

reservoir BGN

summit $B G N$

spring BGN

well

UNOFF

$\begin{array}{llll}\text { valley } & \text { BGN } & \text { Cochise } & \text { 320948N1092321W } \\ \text { reservoir } & \text { BGN } & \text { Coconino } & 353411 \text { N1125741W }\end{array}$

Cochise 322253 N1102014W

locale

VARIANT

$\mathrm{pp} 1$

BGN

VARIANT

locale

VARIANT

locale

VARIANT

valley

spring BGN

locale

reservoir

locale

lake

reservoir

mine

BGN

UNOFF

Cochise

Cochise

Cochise

Gila

Pima

Coconino

Coconino

Apache

Pima

Mohave

$321815 \mathrm{N1120130 \textrm {W }}$

$365314 N 1135544 \mathrm{~W}$

Mohave

365358N1135555W

Pima

Santa Cruz

Coconino

Graham

Graham

Coconino

VARIANT

BGN

BGN

BGN

BGN

Cochise

Mohave

Apache

Yuma

spring $\quad B G$

canal

stream

valley

mine

valley

locale

summit

BGN

BGN

BGN

UNOFF

BGN

UNOFF

BGN 1965

VARIANT

Apache

Pinal

Pinal

Maricopa

Yuma

Pinal

Maricopa

VARIANT

BGN

UNOFF

Yavapai

Yavapai

valley $B G N$

reservoir $B G N$

summit

valley

mine

BGN

BGN

BGN 1981

Maricopa

Maricopa

Coconino

Greenlee

Gila

valley VARIANT

$\begin{array}{lll}\text { stream } & \text { BGN } & \text { Pinal } \\ \text { stream } & \text { BGN } & \text { Yavapai } \\ \text { well } & \text { UNOFF } & \text { Yavapai } \\ \text { valley } & \text { BGN } & \text { Coconino } \\ \text { reservoir } & \text { BGN } & \text { Coconino } \\ \text { summit } & \text { BGN } & \text { Yuma } \\ \text { spring } & \text { BGN } & \text { Maricopa } \\ \text { summit } & \text { BGN } & \text { Apache } \\ \text { gap } & \text { BGN } & \text { Yavapai } \\ \text { airport } & \text { ADMIN } & \text { Pinal }\end{array}$

323714 N1103303W $343123 \mathrm{~N} 1120632 \mathrm{~W}$ $343342 \mathrm{~N} 1120541 \mathrm{~W}$ $354910 \mathrm{~N} 1122449 \mathrm{~W}$ $354945 \mathrm{N1122422}$ $334110 N 1133620$ $332819 \mathrm{~N} 1111736 \mathrm{~W}$ $340555 N 1094932 \mathrm{~W}$ $335847 N 1122345 \mathrm{~W}$ $335847 \mathrm{N1122345W}$
$323520 \mathrm{~N} 1105101 \mathrm{~W}$

$343633 \mathrm{~N} 1123426 \mathrm{~W}$

335958 N1115809W

335851N1115658

355719N1111354

$323118 \mathrm{~N} 1090341 \mathrm{~W}$

341640 N1110910

\begin{tabular}{|c|c|c|}
\hline $\begin{array}{l}\text { SOURCE } \\
\text { COORDINATE }\end{array}$ & $\begin{array}{c}\text { ELEV } \\
\text { FT }\end{array}$ & MAP NAME \\
\hline & & $\begin{array}{l}\text { Stoneman Lake } \\
\text { Fort Rock Ranch }\end{array}$ \\
\hline 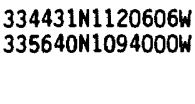 & & $\begin{array}{l}\text { Hedgpeth Hills } \\
\text { Hawley Lake West } \\
\text { Payson North } \\
\text { Oyayle Hill }\end{array}$ \\
\hline $322255 \mathrm{~N} 1090439 \mathrm{~W}$ & & $\begin{array}{l}\text { Doubtfull Canyon } \\
\text { Shiva Temple } \\
\text { Dragoon }\end{array}$ \\
\hline
\end{tabular}

$312736 \mathrm{N1095850 \textrm {W }}$

Hutch Mtn

Bisbee

Lower Lake Mary

Sombrero Peak

Ajo South

$901 B$ Sunset Crater West Sunset Crater West

Mesa Parada

$320756 N 1092403 W$

Bowie Mtn North

Rhodes Canyon

Cherry Spring Peak

Littlefield

$314345 N 1104536 \mathrm{~W} \quad$ Sonoita

Kehl Ridge

Orange Butte

Orange Butte

Eagle Nest Mtn

5142 Potter Mtn

Poverty Spring

Eagar

Cunningham Pass

Whiting Knoll

Sacaton

Blackwate

Iron Mountain

Osborne Well

$332800 \mathrm{N1111321 \textrm {W }}$

Christmas

New River

4214 Maverick Mtn

$322616 \mathrm{~N} 1090634 \mathrm{~W}$

7082 Iron Springs

Iron Springs

$335841 N 1115701 W$

New River Mesa

New River Mesa

5441 Goldtooth

Round Mtn

North Peak

Diamond Point

$324133 \mathrm{~N} 1102733 \mathrm{~W}$

343411 11120530W

Peppersauce Wash

Cherry

Cherry

354845N1122154W

Little Harpo Canyon Little Harpo Canyon Harrisburg Valley Weavers Needle

7730 McNary

Garfias Mtn

3850 Oracle 
FEATURE NAME

Little Hocter Tank

Little Hogan Well

Little Hog Hill Tank

Little Hole Tank

Little Hollow Place

Little Horner Tank

Little Horn Mountains

Little Horn Peak

Little Horn Well

Little Horse Park

Little Horse Park

Little Horse Tank

Little Horse Tank

Little Hull Tank

Little Hurricane Ridge

Little Hurricane Rim

Little Hutch Spring

Little Ice Cream Cone Hill

Little Indian Tank

Little Jeff Tank

Little Jesse James Canyon

Little Jim Tank

Little Jim Tank

Little Joe Draw

Little Joe Mine

Little Joe Spring

Little Joe Tank

Little Joe Tank

Little Johnny Mine

Little Joker Mine

Little Joker Spring

Little Jones Pond

Little Juan Tank

Little Kelley Tank

Little Kimble Mine

Little Knoll

Little KY Tank

Little Leroux

$$
\text { See Leroux Spring }
$$

Little Leroux Spring

Little Lime Creek

Little Lithodendron Tank

Little Lithodendron Wash Carrizo Wash Little Carrizo Wash

Little Lookout Spring Canyon See Little Lo Spring Canyon

Little Lo Spring Canyon

Little Lookout Spring Canyon

Lo Spring Canyon

Little Lo Tank

Little Maggie May See Cave Creek

Little Maggie May

Little Main Street Pond

Little Maud Mine

Little Meadows

Little Mesa

Little Mesa

Little Mesa

Little Mesa Redonda

Little Mesa Tank

Little Mesa Tanks

Little Mexican Spring

Little Mexican Spring Wash

Little Middle Mesa

Little Milky Wash

Little Miller Tank

Little Miller Tank

Little Moqui Spring

\section{FEATURE

CLASS

STATUS

COUNTY

COORDINATE

SOURCE

ELEV

MAP NAME

\begin{tabular}{|c|c|c|c|}
\hline $\begin{array}{l}\text { reservoir } \\
\text { well } \\
\text { reservoir } \\
\text { reservoir } \\
\text { basin } \\
\text { reservoir } \\
\text { summit } \\
\text { summit } \\
\text { well } \\
\text { flat }\end{array}$ & $\begin{array}{l}\text { BGN } \\
\text { UNOFF } \\
\text { BGN } \\
\text { BGN } \\
\text { BGN } \\
\text { BGN } \\
\text { BGN } \\
\text { BGN } \\
\text { UNOFF } \\
\text { BGN }\end{array}$ & $\begin{array}{l}\text { Coconino } \\
\text { Coconino } \\
\text { Yavapai } \\
\text { Coconino } \\
\text { Coconino } \\
\text { Yavapai } \\
\text { Yuma } \\
\text { Maricopa } \\
\text { Maricopa } \\
\text { Coconino }\end{array}$ & $\begin{array}{l}353639 \mathrm{~N} 1120434 \mathrm{~W} \\
361248 \mathrm{~N} 1111719 \mathrm{~W} \\
343743 \mathrm{~N} 1113602 \mathrm{~W} \\
343949 \mathrm{N11} 12244 \mathrm{~W} \\
355922 \mathrm{~N} 1110829 \mathrm{~W} \\
342400 \mathrm{~N} 1115320 \mathrm{~W} \\
332149 \mathrm{N1} 134107 \mathrm{~W} \\
334357 \mathrm{N1} 131051 \mathrm{~W} \\
334357 \mathrm{~N} 1131103 \mathrm{~W} \\
344945 \mathrm{~N} 1114612 \mathrm{~W}\end{array}$ \\
\hline $\begin{array}{l}\text { flat } \\
\text { reservoir } \\
\text { reservoir } \\
\text { reservoir } \\
\text { ridge } \\
\text { cliff } \\
\text { spring } \\
\text { summit } \\
\text { reservoir } \\
\text { reservoir }\end{array}$ & $\begin{array}{l}\text { BGN } \\
\text { BGN } \\
B G N \\
B G N \\
B G N \\
B G N \\
B G N \\
B G N \\
B G N \\
B G N\end{array}$ & $\begin{array}{l}\text { Coconino } \\
\text { Coconino } \\
\text { Coconino } \\
\text { Coconino } \\
\text { Mohave } \\
\text { Mohave } \\
\text { Yavapai } \\
\text { Apache } \\
\text { Navajo } \\
\text { Mohave }\end{array}$ & $\begin{array}{l}345712 \mathrm{~N} 1113523 \mathrm{~W} \\
345707 \mathrm{N1} 113525 \mathrm{~W} \\
351923 \mathrm{~N} 1114627 \mathrm{~W} \\
355817 \mathrm{~N} 1115511 \mathrm{~W} \\
363818 \mathrm{~N} 1125702 \mathrm{~W} \\
362929 \mathrm{N1} 132659 \mathrm{~W} \\
341158 \mathrm{~N} 1115421 \mathrm{~W} \\
362609 \mathrm{~N} 1095206 \mathrm{~W} \\
350304 \mathrm{~N} 1095918 \mathrm{~W} \\
355302 \mathrm{~N} 1135106 \mathrm{~W}\end{array}$ \\
\hline
\end{tabular}

valley BGN Cochise 315842N1092105W

reservoir BGN Coconino 360348N1123131W

reservoir BGN Coconino 360749N1122526W

valley BGN Mohave 363638N1133206W

mine UNOFF Yavapai 340306N1121759W

spring BGN Mohave 362208N1124509W

reservoir BGN Coconino 353007N1122015W

reservoir BGN Mohave 363353N1133156

mine UNOFF Pima 315546NL111727

mine UNOFF Santa Cruz 313826N1104814W

spring BGN Yavapai 340736N1122832W

lake BGN Mohave 362628N1133153W

reservoir BGN Yavapai 344821N1131210W

reservoir BGN Coconino 345944N1110832W

mine UNOFF

summit BGN 1979

reservoir BGN

VARIANT

spring

spring BGN Coconino

stream BGN Yavapai

reservoir BG

stream

Navajo

BGN 1974 Navajo

VARIANT

VARIANT

VARIANT

valley

valley

BGN

VARIANT

Coconino

Coconino

reservoir BG

stream

stream BGN 1968

reservoir

mine

flat

summit

summit

summit

summit

reservoir

reservoir

spring

stream

stream

reservoir

reservoir

spring
BGN

BGN
UNOFF
BGN

BGN

BGN

BGN

BGN
BGN
BGN
BGN
BGN
BGN
BGN
BGN
BGN
BGN
Coconino

Maricopa

Maricopa

Mohave

Mohave

Yavapai

Yavapai

Mohave

Apache

Mohave

Yavapai

Coconino

Coconino

Apache

Apache

Coconino

Coconino

Coconino
353110N1121530W

$333400 N 1120630 \mathrm{~W}$ $335830 \mathrm{~N} 1115200 \mathrm{~W}$ 363957 N1132654W $341038 \mathrm{N1112232 \textrm {W }}$ $350205 N 1141915 \mathrm{~W}$ $341940 \mathrm{N1114801 \textrm {W }}$ $342437 \mathrm{N1121826 \textrm {W }}$ $345634 \mathrm{N1} 132303 \mathrm{~W}$

$342819 \mathrm{N1095029W}$ $345645 \mathrm{N1} 132335 \mathrm{~W}$ 341948 N1114B10W $354335 \mathrm{~N} 1110746 \mathrm{~W}$ $354242 \mathrm{~N} 1111045 \mathrm{~W}$ $361114 \mathrm{~N} 1091842 \mathrm{~W}$ $344217 \mathrm{~N} 1095023 \mathrm{~W}$ $354206 \mathrm{~N} 1121806 \mathrm{~W}$ $354314 \mathrm{~N} 1120828 \mathrm{~W}$ $343513 \mathrm{~N} 1111212 \mathrm{~W}$
Hobble Tank

Moenave

Apache Maid Mtn

Happy Jack

Goldtooth

Arnold Mesa

Little Horn Peak

Little Horn Peak

Sedona

Mormon Mountain

Mormon Mountain

Wing Mountain

Grandview Point

Wild Band Pockets

Poverty Knoll

Brooklyn Peak

6195 Rough Rock

Lt 1 Lithodendron Tk

Quartermaster Canyon

315939 N1092006W

Rust ler Park

Antelope Point

Explorers Monument

$363024 N 1133205 \mathrm{~W}$

Sullivan Draw South

Columbia

$S$ B Point

Mixon Tank

Sullivan Draw South

Stevens Mtn

Mt Wrightson

Minnehaha

Poverty Spring

Burro Mesa

Chavez Mtn NW

Rawhide Wash

6433 Wrather Arch

Hearst Mtn

Humphreys Peak

Rover Peak

LtI Lithodendron Tk

Carrizo Butte

350555N1095555W

$340026 N 1115343 W$

$340043 N 1115335$

Humboldt Mtn

Dutchman Draw

North Peak

Mount Nutt

Tule Mesa

6502 Poland Junction

4802 Gonzales Wash

Mesa Redonda

Gonzales Wash

Tule Mesa

$354301 N 1110602 W$

Badger Spring

Badger Spring

Mummy Cave Ruins

Little Milky Ranch

Miller Tank

Valle Tank

Blue Ridge Reservoir
Cementosa Wash

Sycamore Point

5813 Mixon Tank 
FEATURE

CLASS

Little Mormon Lake

Mormon Lake

Little Mornon Tank

Little Mountain

Little Mountain

Little Mount Ord

Little Mud Spring

Little Mud Well

Little Nankoweap Canyon

Little Nankoweap Creek

Little Nelson Lake

Little Nogales Spring Nogales Spring

Little North Fork Tank

Little old Spring

Little Ortega Lake

$$
\text { Ortega Lake }
$$

Little Outfit Ranch

Little Page Tank

Little Park

\section{Little Park Lake}

Little Phil Tank

Little Picket Canyon

Little Pig Tank

Little Pimberton Tank

Little Pine Creek Well

Little Pine Flat

Little Pine Flat

Little Pine Hollow

Little Pineveta Tank

Little Pinto Canyon

Little Pipe Spring

Little Pipe Spring

Little Pivotrock Spring See Pivotrock Spring

Little Pleasant Valley

Little Pug Tank

Little Purcel1 Canyon

Little Purcell Tank

Little Purgatory Canyon

Little Quail Spring

Little Rabbit

Little Rainbow Valley Hall Valley Rainbow Valley

Little Rain Tank

Little Rain Tank

Little Ranch

Little Ranch Spring

Little Rattlesnake Tank

Little Red Hill Tank

Little Red Horse Wash

Little Red Lake (dry)

Little Redlands Tank

Little Red Tank

Little Reservoir

Little Reservoir

Little Rhoton Spring See Little Roden Spring

Little Rhoton Wash

See Little Roden Wash

Little Richmond Tank

Little Ridge, The

Little Righthand Canyon

Little Rincon Mountains

Little Robinson Canyon

Little Rock Creek

Little Rock Lake

Little Rock Tank

Little Rock Tank

Little Rocky Creek

stream

flat

lake

reservoir

valley

reservoir

reservoir

well

flat

flat

valley

reservoir

valley

spring

spring

spring

valley

reservoir

valley

reservoir

valley

spring

reservoir

valley

reservoir

reservoir

locale

spring

reservoir

reservoir

stream

lake

reservoir

reservoir

reservoir

reservoir

spring

stream

ridge

valley

summit

valley

stream

lake

reservoir

stream

lake
reservoir
summit
summit
summit
spring
well
valley
stream

BGN 1973 Navajo VARIANT

BGN

Maricopa

Maricopa

UNOFF Gila

BGN 1932 Coconino

BGN 1932

Coconino

\begin{tabular}{|c|c|c|c|}
\hline $\begin{array}{l}\text { lake } \\
\text { spring }\end{array}$ & $\begin{array}{l}\text { BGN } \\
\text { BGN } \\
\text { VARIANT }\end{array}$ & $\begin{array}{l}\text { Navajo } \\
\text { Pima }\end{array}$ & $\begin{array}{l}342318 \mathrm{~N} 1104222 \mathrm{~W} \\
315256 \mathrm{~N} 1102 \mathrm{~B} 35 \mathrm{~W}\end{array}$ \\
\hline $\begin{array}{l}\text { reservoir } \\
\text { spring } \\
\text { lake }\end{array}$ & $\begin{array}{l}\text { BGN } \\
\text { BGN } \\
\text { BGN } \\
\text { VARIANT }\end{array}$ & $\begin{array}{l}\text { Cochise } \\
\text { Yavapai } \\
\text { Apache }\end{array}$ & $\begin{array}{l}314719 \mathrm{~N} 1091030 \mathrm{~W} \\
345306 \mathrm{~N} 1125344 \mathrm{~W} \\
342248 \mathrm{~N} 1094006 \mathrm{~W}\end{array}$ \\
\hline $\begin{array}{l}\text { locale } \\
\text { reservoir } \\
\text { flat }\end{array}$ & $\begin{array}{l}\text { UNOFF } \\
\text { BGN } \\
\text { BGN }\end{array}$ & $\begin{array}{l}\text { Santa Cruz } \\
\text { Yavapai } \\
\text { Yavapai }\end{array}$ & $\begin{array}{l}312941 \mathrm{~N} 1103416 \mathrm{~W} \\
345623 \mathrm{~N} 1122211 \mathrm{~W} \\
344812 \mathrm{~N} 1114747 \mathrm{~W}\end{array}$ \\
\hline
\end{tabular}

BGN

BGN Coconino 361928N1120641W

$B G N$

BGN

BGN

UNOFF

BGN

BGN

BGN

BGN

\section{BG}

Coconino

Cochise

Yavapai

Yavapai

Yavapai

Maricopa

Coconino

Coconino

Yavapai

BGN

Gila

Gila

VARIANT

BGN
BGN
BGN

BGN

BGN

Coconino

Coconino

Navajo

Yavapai

Yavapai

Mohave

BGN

Yavapai

BGN 1975

VARIANT

VARIANT

BGN

BGN

UNOFF

BGN

Coconino

Gila

Gavapai

Yavapai

$351928 N 1120641 \mathrm{~W}$

35140BN1130451W

$344221 \mathrm{~N} 1114505 \mathrm{~W}$

$340104 N 1130457 W$

$344839 N 1124637 \mathrm{~W}$

$334732 N 111232$ OW

$350623 \mathrm{~N} 1120830 \mathrm{~W}$

$363429 \mathrm{~N} 1122704 \mathrm{~W}$

351436 N1123641W

332439 N1105539W

$333555 \mathrm{~N} 1104050 \mathrm{~W}$

$362627 \mathrm{~N} 1093815 \mathrm{~W}$

$342926 \mathrm{~N} 1112350 \mathrm{~W}$

$363030 N 1120703 \mathrm{~W}$

$342738 \mathrm{N1} 102007 \mathrm{~W}$

$350930 \mathrm{~N} 1130433 \mathrm{~W}$

$351025 \mathrm{~N} 1130225 \mathrm{~W}$

365449 N1 $134054 \mathrm{~W}$

$344837 \mathrm{~N} 1124912 \mathrm{~W}$

350858 N1095348W

$331030 \mathrm{~N} 1124230 \mathrm{~W}$

$351046 \mathrm{~N} 1122523 \mathrm{~W}$

$360046 \mathrm{~N} 1121751 \mathrm{~W}$

$331938 \mathrm{~N} 1105356 \mathrm{~W}$

$344419 \mathrm{~N} 1120601 \mathrm{~W}$

$34572 \mathrm{BN} 1121 \mathrm{~B} 56 \mathrm{~W}$

$353403 \mathrm{~N} 1122203 \mathrm{~W}$

$354759 \mathrm{~N} 1121141 \mathrm{~W}$

$353825 \mathrm{~N} 1125200 \mathrm{~W}$

$355106 \mathrm{~N} 1122928 \mathrm{~W}$

$322746 \mathrm{~N} 1101248 \mathrm{~W}$

$342918 \mathrm{~N} 1092142 \mathrm{~W}$

365655 N1122344W

Apache
Coconino

ARIANT

VARIANT

Coconino

$352700 \mathrm{~N} 1111657 \mathrm{~W}$

Coconino

352B35N1111415W

reservoir $\quad B$

reservoir

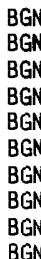

Gila

Coconino

Graham

Cochise

Mohave

Pina

Navajo

Pinal

Coconino

Graham

SOURCE
COORDINATE

MAP NAME

6343 Silver Springs

Chevelon Butte

Cane

Big Springs

6114 Reno Pass

Haunted Canyon

Rockinstraw Mtn

Nankoweap Mesa

361900 N1115500W

$361857 \mathrm{N1115503 \textrm {W }}$

Nankoweap Mesa

Hanks Draw

Mescal

Portal Peak

Juniper Mts

Concho Lake

Canelo Pass

Hell Point

Sedona

Little Park Lane

Squaw Peak

Bowie Mtn South

Lake Montezuma

Date Creek Ranch SE

Seepage Mtn

Boulder Mtn

May Tank Pocket

Sowats Spring

Cathedral Caves

$332356 \mathrm{~N} 1105644 \mathrm{~W}$

Inspiration

Chrome Butte

Windy Valley

$363026 \mathrm{~N} 1120746 \mathrm{~W}$

351050N1130240W

Cane

Big Pug Tank

Squaw Peak

Squaw Peak

Purgatory Canyon

Seepage Mtn

Pilot Rock

Cotton Center NW

Ash Fork

Piute Point 
NATIONAL GAZETTEER--ARIZONA 1986 FEATURE NAME

Little Rocky Tank

Little Roden Spring

Little Rhoton Spring

Little Roden Wash

Little Rhoton Wash

Little Rodgers Tanks

Little Rod Tank

Little Round Mountain

Round Mountain

Round Top Mountain

Little Round Rock

Little Round Top Mountain

Little Round Top Tank

Little RS Spring

Little Saddl

Little Salt Canyon

ittle Salt River Valley

(inundated)

Little Sam Moore Tank

Little San Domingo Mine

Little San Domingo Wash

Little Sand Tank

Little Sand Wash

Little Sand Wash

Little Sandy Spring

Little Sandy Wash

See Knight Creek

Little Santa Cruz Spring

Little Schultz Pond

Little Scott Tank

Little Seventy-seven Tank

Little Sevy Draw Pond

Little Shipp Mountain

Little Shipp Wash

Little Shirttail Mesa

Little Shonot Spring

Little Shot Mine

Little Sombrero Peak

Litt le Soto Tank

Little South Tank

Little Sowats Canyon

Little Sowats Spring

Little Spreade

Little Spring

Little Spring

Little Spring

Little Spring

Little Spring

Little Spring

Little Spring Stokes Spring

Little Spring

Little Spring

Little Spring

Little Spring

Little Spring Canyon

Little Springs Canyon

Little Springs Tank

Little Spring Tank

Little Spring Trick Tank

Little Squaw Creek

Little Squaw Mountain

Little Stanley Butte

Little Star Mountain

Little Steves Ranch

See Double Circle Ranch

Little Sullivan Tank

Little Summit (historical)

Little Sycamore Creek

\begin{abstract}
FEATURE
CLASS
\end{abstract}

STATUS

COUNTY

COORDINATE

$\begin{array}{lll}\text { reservoir } & \text { BGN } & \text { Coconino } \\ \text { spring } & \text { BGN } & \text { Coconino } \\ & \text { VARIANT } & \\ \text { stream } & \text { BGN } & \text { Coconino } \\ & \text { VARIANT } & \\ \text { reservoir } & \text { BGN } & \text { Coconino } \\ \text { reservoir } & \text { BGN } & \text { Coconino } \\ \text { summit } & \text { BGN 1971 } & \text { Yavapai } \\ & \text { VARIANT } & \\ & \text { VARIANT } & \end{array}$

VARIANT

summit
summit
reservoir
spring
gap
valley
valley
reservoir
mine

stream
reservoir
stream
stream
spring
stream
spring
reservoir
reservoir

reservoir
reservoir
summit
stream
summit
spring
mine
summit
reservoir
reservoir

BGN Navajo

BGN

Gila

Coconino

Navajo

Gila

Coconino

$\begin{array}{ll}\text { BGN } & \text { Coconino } \\ \text { UNOFF } & \text { Maricopa }\end{array}$

spring

reservoir

spring

spring

spring

spring

spring

spring

spring

spring

spring

spring

spring

locale

valley

valley

reservoir

reservoir

Pinal

Cochise

Graham

Graham

Apache

Navajo

Coconino

stream

stream

summit

summit

summit

locale

reservoir

summit

stream
SOURCE

COORDINATE

ELEV

MAP NAME

$344418 N 1112837 \mathrm{~W}$ $352700 \mathrm{~N} 1111657 \mathrm{~W}$

$352835 \mathrm{~N} 1111415 \mathrm{~W}$

$354052 \mathrm{~N} 1122850 \mathrm{~W}$

$351611 \mathrm{~N} 1121923 \mathrm{~W}$

$34580 \mathrm{BN} 1115006 \mathrm{~W}$

BGN Apache

$363129 N 1093248 \mathrm{~W}$

$335842 \mathrm{~N} 1095751 \mathrm{~W}$

$335747 \mathrm{~N} 1095722 \mathrm{~W}$

$331056 \mathrm{~N} 1104701 \mathrm{~W}$

$362722 \mathrm{N11} 22958 \mathrm{~W}$

$363848 \mathrm{~N} 1103718 \mathrm{~W}$

$334040 \mathrm{~N} 1110835 \mathrm{~W}$

$355934 \mathrm{~N} 1121536 \mathrm{~W}$

$335636 \mathrm{~N} 1123340 \mathrm{~W}$

$335108 \mathrm{N1123932W}$

$345817 \mathrm{NI} 120948 \mathrm{~W}$

$320126 \mathrm{N1} 092700 \mathrm{~W}$

$324555 \mathrm{~N} 1090910 \mathrm{~W}$

$313120 \mathrm{N1095657 \textrm {W }}$

345521 N1133734W

$343447 \mathrm{N1} 134227 \mathrm{~W}$

$362543 \mathrm{~N} 1132316 \mathrm{~W}$

$343139 \mathrm{N1102625 \textrm {W }}$

355549 N1114801W

$363239 \mathrm{~N} 1132924 \mathrm{~W}$

$342835 \mathrm{~N} 1130400 \mathrm{~W}$

$344728 \mathrm{~N} 1130705 \mathrm{~W}$

$363922 N 1102145 \mathrm{~W}$

$314158 \mathrm{~N} 1105141 \mathrm{~W}$

$335021 \mathrm{~N} 1104705 \mathrm{~W}$

$35232 B N 1130501 \mathrm{~W}$

$350457 N 1131315 \mathrm{~W}$

valley BGN Coconino 363148N1122716W

BGN Coconino

$363146 \mathrm{N1122728 \textrm {W }}$

$323513 \mathrm{~N} 1112113 \mathrm{~W}$

$315654 \mathrm{~N} 1100233 \mathrm{~W}$

$325624 \mathrm{~N} 1094835 \mathrm{~W}$

$330223 \mathrm{~N} 1094204 \mathrm{~W}$

$335652 \mathrm{~N} 1092239 \mathrm{~W}$

$340614 \mathrm{~N} 1101305 \mathrm{~W}$

$343543 N 1111337 \mathrm{~W}$

$351811 \mathrm{~N} 1115725 \mathrm{~W}$

35222BN1114330W

$361005 N 1101648 \mathrm{~W}$

$362039 \mathrm{N1} 130901 \mathrm{~W}$

363757 N1123545W

$343555 \mathrm{~N} 1111342 \mathrm{~W}$

$363800 \mathrm{N1} 123707 \mathrm{~W}$

342715 N1104556W

$343716 \mathrm{~N} 1111313 \mathrm{~W}$

$363700 \mathrm{~N} 1123250 \mathrm{~W}$

reservoir BGN Coconino 342647N1104654W
Maricopa

Coconino

Graham

$340115 \mathrm{N1} 120939 \mathrm{~W}$

$352318 \mathrm{N1} 120041 \mathrm{~W}$

$330141 \mathrm{~N} 1102309 \mathrm{~W}$

353B02N1102045W

332009 N1092935W

Greenlee

BGN 1917 Gila

$B G N$

Yavapai

$354149 \mathrm{~N} 1124457 \mathrm{~W}$

$332000 \mathrm{~N} 1104800 \mathrm{~W}$

$342140 \mathrm{~N} 1115848 \mathrm{~W}$
$363217 N 1122053 \mathrm{~W}$

6122 Little Round Rock

7128 Alchesay Flat

Alchesay Flat

El Capitan Mtn

364055N1103254W Betatakin Ruin

333710 N1105520W Theo. Roosevelt Dan

Metzger Tank

Red Picacho

335651N1123255W Wickenburg SW

Perkinsville

Bowie Mtn South

$\begin{array}{ll}320443 N 1092305 \mathrm{~W} & \text { Bowie Mt } \\ 324743 \mathrm{~N} 1090731 \mathrm{~W} & \text { Sheldon }\end{array}$

Potter Mtn

Groom Spring

Poverty Knoli

Zeniff

Deer Tank

Little Tanks

$343514 N 1130729 W$

4956 Big Shipp Mtn Malpais Mesa NE

5555 Scratch Canyon

Kayenta West

Mt Wrightson

Sombrero Peak

Audley

Anvil Rock Ranch

Sowats Spring

Sowats Spring

Red Rock

Knob Hill

Pima

Bryce Mountain

Big Lake North

Long Tom Canyon

Parks

Humphreys Peak

Coat Spring

Mount Logan

Gunsight Point

363704N1123140W Gunsight Point

Weimar Point

5779 Jumpup Point

$340408 N 1120014 W$

Weimar Point

Black Canyon City

Squaw Mtn

5488 Rawhide Mtn

6195 Star Mountain

Black Tank

Pinal Peak

342143N1115558W Dugas

Tapeats Amphitheater

Blue Ridge Reservoir

Blue Ridge Reservoir

Blue Ridge Reservoir 


\begin{tabular}{|c|c|c|c|c|c|c|c|}
\hline FEATURE NAME & $\begin{array}{l}\text { FEATURE } \\
\text { CLASS }\end{array}$ & STATUS & COUNTY & COORDINATE & $\begin{array}{l}\text { SOURCE } \\
\text { COORDINATE }\end{array}$ & $\begin{array}{c}\text { ELEV } \\
\text { FT }\end{array}$ & MAP NAME \\
\hline $\begin{array}{l}\text { Little Sycamore Spring } \\
\text { Little Sycamore Wash } \\
\text { Little Table Mountain } \\
\text { Little Table Top } \\
\text { Little Table Top } \\
\text { Mountains } \\
\text { Little Table Top Mountains } \\
\text { See Little Table Top } \\
\text { Little Tank } \\
\text { Little Tank }\end{array}$ & $\begin{array}{l}\text { summit } \\
\text { reservoir } \\
\text { reservoir }\end{array}$ & $\begin{array}{l}\text { BGN } \\
\text { BGN } \\
\text { BGN } \\
\text { BGN 1941 } \\
\text { VARIANT } \\
\text { VARIANT } \\
\text { BGN } \\
\text { BGN }\end{array}$ & $\begin{array}{l}\text { Graham } \\
\text { Yavapai } \\
\text { Pinal } \\
\text { Pinal }\end{array}$ & $\begin{array}{l}331111 \mathrm{~N} 1093516 \mathrm{~W} \\
343203 \mathrm{~N} 1130132 \mathrm{~W} \\
324755 \mathrm{~N} 1102925 \mathrm{~W} \\
324209 \mathrm{~N} 1120830 \mathrm{~W}\end{array}$ & $343620 \mathrm{~N} 1130810 \mathrm{~W}$ & & $\begin{array}{l}\text { Elevator Mtn } \\
\text { Big Shipp Mtn } \\
\text { Oak Grove Canyon } \\
\text { Little Table Top }\end{array}$ \\
\hline $\begin{array}{l}\text { Little Tank } \\
\text { Little Tank } \\
\text { Little Tank } \\
\text { Little Tank } \\
\text { Little Tank } \\
\text { Little Tanks } \\
\text { Little Thomas Wash } \\
\text { Little Thorne Spring } \\
\text { Little Tinaja Spring } \\
\text { Little Tom Moore Tank }\end{array}$ & $\begin{array}{l}\text { reservoir } \\
\text { reservoir } \\
\text { reservoir } \\
\text { reservoir } \\
\text { reservoir } \\
\text { reservoir } \\
\text { stream } \\
\text { spring } \\
\text { spring } \\
\text { reservoir }\end{array}$ & $\begin{array}{l}\text { BGN } \\
\text { BGN } \\
\text { BGN } \\
\text { BGN } \\
\text { BGN } \\
\text { BGN } \\
\text { BGN } \\
\text { BGN } \\
\text { BGN } \\
\text { BGN }\end{array}$ & $\begin{array}{l}\text { Greenlee } \\
\text { Mohave } \\
\text { Yavapai } \\
\text { Coconino } \\
\text { Coconino } \\
\text { Mohave } \\
\text { Pima } \\
\text { Mohave } \\
\text { Santa Cruz } \\
\text { Coconino }\end{array}$ & $\begin{array}{l}332234 \mathrm{~N} 1090407 \mathrm{~W} \\
343752 \mathrm{~N} 1134555 \mathrm{~W} \\
344323 \mathrm{~N} 1121048 \mathrm{~W} \\
352422 \mathrm{~N} 1115302 \mathrm{~W} \\
360013 \mathrm{~N} 1130444 \mathrm{~W} \\
363251 \mathrm{~N} 1132330 \mathrm{~W} \\
314415 \mathrm{~N} 1112518 \mathrm{~W} \\
351528 \mathrm{~N} 1142156 \mathrm{~W} \\
312523 \mathrm{~N} 1111230 \mathrm{~W} \\
355820 \mathrm{~N} 1121914 \mathrm{~W}\end{array}$ & $314424 \mathrm{~N} 1113244 \mathrm{~W}$ & & $\begin{array}{l}\text { Alma Mesa } \\
\text { Beecher Canyon } \\
\text { Hickey Mountain } \\
\text { Moritz Ridge } \\
\text { Vulcans Throne SE } \\
\text { Little Tanks } \\
\text { Las Guijas } \\
\text { Grasshopper Junc SE } \\
\text { Ruby } \\
\text { Metzger Tank }\end{array}$ \\
\hline $\begin{array}{l}\text { Littleton School } \\
\text { Little Tonto Tank } \\
\text { Little Toroweap Reservoir } \\
\text { Littletown } \\
\text { Littletown Park } \\
\text { Little Trap Spring } \\
\text { Little Trash Dam } \\
\text { Little Trash Dam Tank } \\
\text { Little Trough Creek } \\
\text { Little Trough Spring }\end{array}$ & $\begin{array}{l}\text { school } \\
\text { reservoir } \\
\text { reservoir } \\
\text { ppl } \\
\text { park } \\
\text { spring } \\
\text { dam } \\
\text { reservoir } \\
\text { stream } \\
\text { spring }\end{array}$ & $\begin{array}{l}\text { UNOFF } \\
\text { BGN } \\
\text { BGN } \\
\text { BGN } \\
\text { ADMIN } \\
\text { BGN } \\
\text { UNOFF } \\
\text { BGN } \\
\text { BGN } \\
\text { BGN }\end{array}$ & $\begin{array}{l}\text { Maricopa } \\
\text { Santa Cruz } \\
\text { Mohave } \\
\text { Pima } \\
\text { Pima } \\
\text { Gila } \\
\text { Coconino } \\
\text { Coconino } \\
\text { Gila } \\
\text { Gila }\end{array}$ & $\begin{array}{l}332604 \mathrm{~N} 1121826 \mathrm{~W} \\
312234 \mathrm{~N} 1111023 \mathrm{~W} \\
362721 \mathrm{~N} 1130228 \mathrm{~W} \\
320749 \mathrm{~N} 1105220 \mathrm{~W} \\
320805 \mathrm{~N} 1105223 \mathrm{~W} \\
335821 \mathrm{~N} 1100809 \mathrm{~W} \\
355701 \mathrm{~N} 1115255 \mathrm{~W} \\
355701 \mathrm{~N} 1115255 \mathrm{~W} \\
334655 \mathrm{~N} 1101904 \mathrm{~W} \\
334134 \mathrm{~N} 1102127 \mathrm{~W}\end{array}$ & $334008 \mathrm{~N} 1102118 \mathrm{~W}$ & & $\begin{array}{l}\text { Avondale } \\
\text { Ruby } \\
\text { Mt Trumbul1 NE } \\
\text { Tucson East } \\
\text { Tucson East } \\
\text { Cedar Creek } \\
\text { Grandview Point } \\
\text { Grandview Point } \\
\text { Carrizo SE } \\
\text { Popcorn Canyon }\end{array}$ \\
\hline $\begin{array}{l}\text { Little Trough Spring } \\
\text { Little Tucson } \\
\text { See Ali Chukson } \\
\text { Little Tule Tank } \\
\text { Little Tule Well } \\
\text { Tule Well }\end{array}$ & $\begin{array}{l}\text { spring } \\
\text { ppl } \\
\text { reservoir } \\
\text { well }\end{array}$ & $\begin{array}{l}\text { BGN } \\
\text { VARIANT } \\
\text { BGN } \\
\text { UNOFF } \\
\text { VARIANT }\end{array}$ & $\begin{array}{l}\text { Mohave } \\
\text { Pima } \\
\text { Pima } \\
\text { Pima }\end{array}$ & $\begin{array}{l}342704 \mathrm{~N} 1132156 \mathrm{~W} \\
315449 \mathrm{~N} 1114755 \mathrm{~W} \\
322140 \mathrm{~N} 1125557 \mathrm{~W} \\
322213 \mathrm{~N} 1125702 \mathrm{~W}\end{array}$ & & & $\begin{array}{l}\text { Chico Shunie } \\
\text { Chico Shunie }\end{array}$ \\
\hline $\begin{array}{l}\text { Little Turkey Creek } \\
\text { Little Turkey Tank } \\
\text { Little Tuscon } \\
\text { See Ali Chukson }\end{array}$ & $\begin{array}{l}\text { stream } \\
\text { reservoir } \\
\mathrm{ppl}\end{array}$ & $\begin{array}{l}\text { BGN } \\
\text { BGN } \\
\text { VARIANT }\end{array}$ & $\begin{array}{l}\text { Gila } \\
\text { Gila } \\
\text { Pima }\end{array}$ & $\begin{array}{l}335447 \mathrm{~N} 1110224 \mathrm{~W} \\
335518 \mathrm{~N} 111003 \mathrm{~W} \\
315449 \mathrm{~N} 1114755 \mathrm{~W}\end{array}$ & $335454 \mathrm{~N} 1105855 \mathrm{~W}$ & & $\begin{array}{l}\text { Copper Mtn } \\
\text { Copper Mtn }\end{array}$ \\
\hline $\begin{array}{l}\text { Little Valley } \\
\text { See Little Green Valley } \\
\text { Little Valley } \\
\text { See Lake Mary Valley } \\
\text { Little Valley } \\
\text { Little Valley Spring } \\
\text { Little Wagner Tank } \\
\text { Little Wallace Windmill } \\
\text { Little Walnut Canyon } \\
\text { Little Walnut Spring }\end{array}$ & $\begin{array}{l}\text { valley } \\
\text { valley } \\
\text { valley } \\
\text { spring } \\
\text { reservoir } \\
\text { locale } \\
\text { valley } \\
\text { spring }\end{array}$ & $\begin{array}{l}\text { VARIANT } \\
\text { VARIANT } \\
\text { BGN } 1917 \\
\text { BGN } \\
\text { BGN } \\
\text { BGN } \\
\text { BGN } \\
\text { BGN }\end{array}$ & $\begin{array}{l}\text { Gila } \\
\text { Coconino } \\
\text { Coconino } \\
\text { Apache } \\
\text { Coconino } \\
\text { Apache } \\
\text { Gila } \\
\text { Gila }\end{array}$ & $\begin{array}{l}341640 \mathrm{~N} 1110910 \mathrm{~W} \\
350902 \mathrm{~N} 1113556 \mathrm{~W} \\
364051 \mathrm{~N} 1113758 \mathrm{~W} \\
340219 \mathrm{~N} 1091922 \mathrm{~W} \\
354415 \mathrm{~N} 1121206 \mathrm{~W} \\
350545 \mathrm{~N} 1092559 \mathrm{~W} \\
340520 \mathrm{~N} 1110441 \mathrm{~W} \\
333733 \mathrm{~N} 1104215 \mathrm{~W}\end{array}$ & $340413 \mathrm{~N} 1110002 \mathrm{~W}$ & 5784 & $\begin{array}{l}\text { Bitter Springs } \\
\text { Eagar } \\
\text { Valle Tank } \\
\text { Navajo Springs } \\
\text { Buzzard Roost Mesa } \\
\text { Haystack Butte }\end{array}$ \\
\hline $\begin{array}{l}\text { Little Walnut Spring } \\
\text { Little Walnut Tank } \\
\text { Little Wash } \\
\text { Little Water } \\
\text { Little Water } \\
\text { Little Waterfall Well } \\
\text { Little Water Tank } \\
\text { Little Water Tank } \\
\text { Little Water Well } \\
\text { Little Water Well }\end{array}$ & $\begin{array}{l}\text { spring } \\
\text { reservoir } \\
\text { stream } \\
\text { area } \\
\text { lake } \\
\text { well } \\
\text { reservoir } \\
\text { reservoir } \\
\text { well } \\
\text { well }\end{array}$ & $\begin{array}{l}\text { BGN } \\
\text { BGN } \\
\text { BGN } \\
\text { BGN } \\
\text { BGN } \\
\text { UNOFF } \\
\text { BGN } \\
\text { BGN } \\
\text { UNOFF } \\
\text { UNOFF }\end{array}$ & $\begin{array}{l}\text { Yavapai } \\
\text { Gila } \\
\text { Coconino } \\
\text { Navajo } \\
\text { Navajo } \\
\text { Navajo } \\
\text { Coconino } \\
\text { Yavapai } \\
\text { Navajo } \\
\text { Coconino }\end{array}$ & $\begin{array}{l}343455 \mathrm{~N} 1120622 \mathrm{~W} \\
340449 \mathrm{~N} 1110109 \mathrm{~W} \\
355602 \mathrm{~N} 1110833 \mathrm{~W} \\
352649 \mathrm{~N} 1103413 \mathrm{~W} \\
362401 \mathrm{~N} 1101105 \mathrm{~W} \\
360700 \mathrm{~N} 1104144 \mathrm{~W} \\
344440 \mathrm{~N} 1112056 \mathrm{~W} \\
350249 \mathrm{~N} 1122913 \mathrm{~W} \\
360323 \mathrm{~N} 1100657 \mathrm{~W} \\
361432 \mathrm{~N} 1110936 \mathrm{~W}\end{array}$ & $355640 \mathrm{~N} 1110659 \mathrm{~W}$ & & $\begin{array}{l}\text { Cherry } \\
\text { Buzzard Roost Mesa } \\
\text { Goldtooth } \\
\text { Montezumas Chair } \\
\text { Cliff Rose Hill } \\
\text { Rocky Ridge SW } \\
\text { Turkey Mtn } \\
\text { Meath Spring } \\
\text { Whippoorwill Spring } \\
\text { Tuba City }\end{array}$ \\
\hline $\begin{array}{l}\text { Little Well } \\
\text { Little Well } \\
\text { Little Well } \\
\text { Little White Dam } \\
\text { Little White House Canyon } \\
\text { Little White House Ruins } \\
\text { Little White Tanks } \\
\text { Little Wild Bill Tank } \\
\text { Little Wildcat Canyon } \\
\text { Little Wildcat Canyon } \\
\text { See Wildcat Canyon }\end{array}$ & $\begin{array}{l}\text { well } \\
\text { well } \\
\text { well } \\
\text { dam } \\
\text { valley } \\
\text { locale } \\
\text { reservoir } \\
\text { reservoir } \\
\text { valley } \\
\text { valley }\end{array}$ & $\begin{array}{l}\text { UNOFF } \\
\text { UNOFF } \\
\text { UNOFF } \\
\text { UNOFF } \\
\text { BGN } \\
\text { BGN } \\
\text { BGN } \\
\text { BGN } \\
\text { BGN } 1962 \\
\text { VARIANT }\end{array}$ & $\begin{array}{l}\text { Gila } \\
\text { Apache } \\
\text { Coconino } \\
\text { Apache } \\
\text { Apache } \\
\text { Apache } \\
\text { Yuma } \\
\text { Coconino } \\
\text { Navajo }\end{array}$ & $\begin{array}{l}332 B 03 \mathrm{~N} 1110142 \mathrm{~W} \\
351152 \mathrm{~N} 1091301 \mathrm{~W} \\
355431 \mathrm{N1} 122021 \mathrm{~W} \\
360912 \mathrm{~N} 1091440 \mathrm{~W} \\
360725 \mathrm{~N} 1093135 \mathrm{~W} \\
360631 \mathrm{~N} 1093004 \mathrm{~W} \\
330826 \mathrm{~N} 1140635 \mathrm{~W} \\
353701 \mathrm{~N} 1120048 \mathrm{~W} \\
342358 \mathrm{~N} 1104424 \mathrm{~W}\end{array}$ & $360305 N 1092445 \mathrm{~W}$ & 1562 & $\begin{array}{l}\text { Haunted Canyon } \\
\text { Tolapai Spring } \\
\text { Metzger Tank } \\
\text { Lower Wheatfields } \\
\text { Ltl White Hse Ruins } \\
\text { Ltl White Hse Ruins } \\
\text { Kofa Deep Well } \\
\text { Hobble Tank } \\
\text { Hanks Draw }\end{array}$ \\
\hline
\end{tabular}


FEATURE NAME

Little Wildhorse Tank

Little Windmill

Little Wing Mountain

Little Wolf Creek

Little Wolf Pass

Little Wolf Spring

Little Wonder Tank

Little Woodcamp Spring

Little Woodcamp Spring

Little Wood Canyon

Little Wood Spring

Little Yaeger Canyon Little Yeager Canyon

Little Yeager Canyon See Yaeger Canyon

Little Yeager Canyon

See Little Yaeger Canyon

Liveoak Gulch

Liveoak Mine

Liveoak Shaft

Live Oak Tank

Live Oak Well

Livingston Hills

Livingston Lateral

Livingston Mine

Livingston Pass

See New Water Pass

Livingston Well

Lizard

Lizard Acres

Lizard Point

Lizard Rock

Lizard Spring

Lizard Spring (historical) Nash-bito

Lizard Spring

Lizard Wash

Lizard Wash

Lizzie Lee Mine Spring

Lloyds Tank

L L Ranch

Loading Chute Tank

Loafer Dam

Loafer Tank

Loaf Rock

Lobato Tank

Lobo Canyon

Lobo Pass

Lobo Peak

Lobo Tank
Lobo Tank
Lobo Well
Lochiel

Lochiel

See Lockett Lake

Lockett Lake

Locket Lake

Lockett Meadow Spring

Lockett Spring

Lockett Tank

Lockett Tank

Lockhart

See Love

Lockhart Well

Lockwood Canyon

Lockwood Draw

Lockwood Gulch

Lockwood Mesa

Lockwood Mesa Tank

Lockwood Park
FEATURE

CLASS

STATUS COUNTY

Coconino

Graham

Coconino

Yavapai

Mohave

Mohave

Graham

Gila

Gila

spring

spring

BGN

valley
spring
valley

BGN Cochise 320923N1091848W

BGN Cochise 320803N1091944W

BGN 1976 Yavapai

VARIANT

VARIANT

valley

valley

valley

mine

Yavapai

$343548 N 1121617 W$

Yavapai

BGN

Gila

UNOFF

Gila

mine

reservoir

well

summit

canal

gap

gap
well
locale

$\begin{array}{ll}\text { UNOFF } & \text { Gila } \\ \text { BGN } & \text { Navajo } \\ \text { UNOFF } & \text { Yavapai } \\ \text { BGN } & \text { Yuma } \\ \text { BGN } & \text { Yuma } \\ \text { UNOFF } & \text { Yuma } \\ \text { VARIANT } & \\ & \text { Yuma } \\ \text { UNOFF } & \text { Yuma } \\ \text { BGN } & \text { Maricopa }\end{array}$

332417 N1105426

34022BN1104316W

344608 N1125317W

$332902 \mathrm{~N} 114062 \mathrm{BW}$

$323936 \mathrm{~N} 1144250 \mathrm{~W}$

$333305 N 1140531 \mathrm{~W}$

333059 N1135622W

$333006 \mathrm{~N} 1140342 \mathrm{~W}$

333807 N1122040W

ppl

cape

summit

spring

spring

spring

stream

spring

$333851 \mathrm{~N} 1122016 \mathrm{~W}$

$365502 \mathrm{~N} 1133627 \mathrm{~W}$

$322252 \mathrm{~N} 1104151 \mathrm{~W}$

$341314 \mathrm{~N} 1115115 \mathrm{~W}$

$354500 \mathrm{~N} 109360 \mathrm{OW}$

$365545 \mathrm{~N} 1133627 \mathrm{~W}$

$362412 \mathrm{~N} 1091444 \mathrm{~W}$

$370055 N 1133615 \mathrm{~W}$

$340302 \mathrm{~N} 1121746 \mathrm{~W}$

reservoir BGN Yavapai 345231N1130558W

locale UNOFF Graham 323616N1093040W

reservoir BGN Coconino 345830N1112554W

dam UNOFF Graham 333226N1093410W

reservoir BGN Graham 333226N1093410W

summit BGN Mohave 351326N1143356h

reservoir BGN Coconino 353218N1114120W

valley BGN Santa Cruz 313342N1110906W

gap

BGN

BGN

Pima

315139 N1102735W

315049N1111228W

reservoir BGN Santa Cruz 312111N1110254W

reservoir BGN Santa Cruz $313313 \mathrm{~N} 1110826 \mathrm{~W}$

rel

BGN

Pima

$315057 \mathrm{~N} 1111241 \mathrm{~W}$

$312008 N 1103724 W$

lake

Santa Cruz

$355615 N 1115615 \mathrm{~W}$

$355615 N 1115615 \mathrm{~W}$

$352137 \mathrm{N1113712 \textrm {W }}$

$350855 \mathrm{~N} 1120907 \mathrm{~W}$

spring

reservoir

reservoir

BGN Maricopa

BGN

VARIANT

local

well

valley

arroyo

valley

summit

reservoir

UNOFF

BGN

BGN

BGN

$B G N$

flat BGN

Coconino

344738 N1110800W

$335108 \mathrm{~N} 1132754 \mathrm{~W}$

$340324 N 1091044 \mathrm{~W}$

$354059 \mathrm{~N} 1114346 \mathrm{~W}$

$343250 \mathrm{~N} 1110827 \mathrm{~W}$

$341522 \mathrm{~N} 1111615 \mathrm{~W}$

$340445 \mathrm{~N} 1115212 \mathrm{~W}$

$340435 \mathrm{~N} 1115124 \mathrm{~W}$ $\begin{array}{cc}\text { SOURCE } & \text { ELEV } \\ \text { COORDINATE } & \text { FT MAP NAME }\end{array}$

Miller Tank

Out law Mountain

Eureka Ranch

Wing Mountain

Battle Flat

$342432 \mathrm{~N} 1121905 \mathrm{~W}$

5404 Wolf Hole Mtn West

Woif Hole Mtn West

Klondike

Chrome Butte

Chrome Butte

$320735 N 1091931 \mathrm{~W}$

Little Wood Canyon

ittle Wood Canyon

344112N1120910W Hickey Mountain

332327N1105556W Inspiration

Inspiration

Inspiration

Oak Creek Ranch

Camp Wood

Livingston Hills

Yuma West

Crystal Hill

Crystal Hill

Calderwood Butte

Calderwood Butte

Lizard Point

7328 Mount Bigelow

Bloody Bas in

Ganado Mesa

Lizard Point

Lukachukai

Lizard Point

Columbia

Mount Hope

Tanque

Mormon Lake

Freezeout Mtn

Freezeout Mtn

Davis Dam

$S$ P Mountain

$313235 \mathrm{~N} 1110658 \mathrm{~W}$

Murphy Peak

Apache Peak

4951 Batamote Hills

Pajarito Peak

Murphy Peak

Batamote $\mathrm{Hi} 11 \mathrm{~s}$

Lochiel

Grandview Point

Sunset Crater West

Williams South

Hedgpeth $\mathrm{Hills}$

Campbell Francis Wsh

$354724 \mathrm{~N} 1115028 \mathrm{~W}$

$343047 \mathrm{N1} 110842 \mathrm{~W}$

341657N1111730W

7750

elson Reservoir

Additional $\mathrm{Hill}$

Blue Ridge Reservoir

Payson North

4198 Rover Peak

Rover Peak

Chavez Mtn West 
FEATURE NAME

Lockwood Spring

Lockwood Spring

Lockwood Spring

Lockwood Tank

Lockwood Tank

Loco Creek

Loco Knoll

Loco Knoll Number Three Tank

Loco Knolls

Loco Knoll Tank

Locomotive Peaks

See Locomotive Rock

Locomot ive Rock Locomotive Peaks

Loco Point

Loco Pool Spring

Loco Tank

Loco Twentynine Knoll Tank

Locust Canyon

Locust Canyon

Locust Point

Locust Spring

Locust Spring

Locust Spring

Locust Spring

Locust Tank

Lo Draw

Lofer Bench

Lofer Cienega

Lofer Cienega Creek

Lo flat Boggy Creek

Logan

See Quijotoa

Logan, Mount

Logan City

See Quijotoa

Logan Mine

Logan Mine Spring

Logan Mine Spring

Logan Wash

Log Cabin Spring

Log Cabin Spring

Log Cabin Tank

Log Canyon Tank

Log Corral Canyon

Log Corral Spring

Log Corral Wash

Logger Mountain

Loggers Tank

Logger Tank

Logging Camp Seep Tank

Log Landing Tank

Log Road Tank

Log Spring

Log Spring

Log Springs

Log Tank

Log Tank

Log Tank

Log Trough Canyon

Log Trough Spring

Log Well

Lohali Basin

Lohali Mesa

Lohali Point

Hlohahle Point

Lokasakad

ohah le Point

See Lokasakal Spring

Lokasakad Spring
FEATURE
CLASS

STATUS

COUNTY

spring

spring $B G N$

reservoir BGN

reservoir BGN

stream BGN

summit BGN

reservoir BGN

summit BGN

reservoir $B G N$

summit

summit

cape

spring

reservoir

valley

valley

cliff

spring

spring

spring

spring

reservoir

valley

bench

swamp

stream

BGN

flat

locale

summit

locale

mine

spring

spring

stream

spring

spring

reservoir

reservoir

valley

spring

stream

summ it reservoir $B G$ reservoir $B G$ reservoir $B G N$

reservoir $B G N$

spring $B G N$

spring

spring

reservoir

reservoir

BGN

BGN

$B G N$

BGN

BGN

BGN

BGN

BGN

VARIANT

VARIANT

BGN

VARIANT

UNOFF

$B G N$

\section{BGN}

BGN

BGN

$B G N$
$B G N$

BGN

BGN

BGN

BGN

BGN

BGN Navajo

Coconino

Coconino

Coconino

Navajo

Cochise

Mohave

Yavapai

Navajo

Coconino

reservoir

valley

spring

locale

basin

summit

cliff

spring
COORDINATE

343253 N1110828W 345828 N1112932W

50248N1115146W

344727 N1110805W

$354343 N 1114741 \mathrm{~W}$

$343657 N 1125542 \mathrm{~W}$

40028N1090606W

340121 N1090727

340253N1090709W

$340242 \mathrm{~N} 1090729 \mathrm{~W}$

$321930 \mathrm{~N} 1125210 \mathrm{~W}$

$321930 \mathrm{~N} 1125210 \mathrm{~W}$

$36473 B \mathrm{BN} 1123819 \mathrm{~W}$

343956 N1125538W

$343303 N 1115355$

$340319 \mathrm{~N} 1090622 \mathrm{~W}$

351445 N1111113W

$362344 \mathrm{~N} 1122159 \mathrm{~W}$

$362354 \mathrm{~N} 1122137 \mathrm{~W}$

$340113 N 1115249 \mathrm{~W}$

340450 N1102442W

$362401 \mathrm{~N} 1121707 \mathrm{~W}$

$365133 N 1134217 \mathrm{~W}$

$352123 N 1120334$

$352309 \mathrm{~N} 1121333 \mathrm{~W}$

$334556 \mathrm{~N} 1094207 \mathrm{~W}$

$334731 \mathrm{~N} 1093954 \mathrm{~W}$

$334705 N 1094135 W$

$352401 \mathrm{N1121350 \textrm {W }}$

320738 N1120815W

$362138 \mathrm{~N} 1131244 \mathrm{~W}$

$320738 N 1120815 \mathrm{~W}$

$343358 \mathrm{~N} 1120148 \mathrm{~W}$

$340843 \mathrm{~N} 1122534 \mathrm{~W}$

$343401 \mathrm{N1120147 \textrm {W }}$ 343149 N1124033W

$340949 \mathrm{~N} 1095706 \mathrm{~W}$

341014 N1122728

$351046 \mathrm{~N} 1113241 \mathrm{~W}$

$334235 \mathrm{~N} 1091148 \mathrm{~W}$

$334741 \mathrm{~N} 1113038 \mathrm{~W}$

$334741 \mathrm{~N} 1113044$

$334925 \mathrm{~N} 1113700 \mathrm{~W}$

$340636 \mathrm{~N} 1094800 \mathrm{~W}$

342011 N1102105W

$345149 \mathrm{~N} 1112409 \mathrm{~W}$

$345326 N 1112423 \mathrm{~W}$

350501 N1114219W

$340205 \mathrm{~N} 1100556 \mathrm{~W}$

$315010 \mathrm{~N} 1091150 \mathrm{~K}$

$361309 \mathrm{~N} 1133232 \mathrm{~W}$

$343607 \mathrm{~N} 1120426 \mathrm{~W}$

$335630 \mathrm{~N} 1095353 \mathrm{~W}$

$350844 \mathrm{~N} 1122000 \mathrm{~W}$

$352023 N 1120432 W$

$332856 \mathrm{~N} 1110908 \mathrm{~W}$

$332750 \mathrm{~N} 1110914 \mathrm{~W}$

$361321 \mathrm{~N} 1133240 \mathrm{~W}$

$360852 \mathrm{~N} 1095109$

$361053 \mathrm{~N} 1094945 \mathrm{~W}$

360851 N1094901W

360843 N1100900W

$352410 \mathrm{~N} 1100824 \mathrm{~W}$

$$
\begin{array}{lc}
\text { SOURCE } & \text { ELEV } \\
\text { COORDINATE } & \text { FT MAP NAME }
\end{array}
$$

Blue Ridge Reservoir Mormon Lake

Dutton Hill

Chavez Mtn West

Lockwood Canyon

344158N1130140W Muleshoe Ranch

9069 Loco Knoll

Loco Knoll

Loco Knoll

Loco Knoll

2107 Ajo South

Pipe Spring

Middle Verde

Loco Knoll

351349N1111355W Babbitt Wash

$362420 \mathrm{~N} 1121502 \mathrm{~W}$

Quaking Aspen

Quaking Aspen

Cooks Mesa

Cibecue

Quaking Aspen

Wolf Hole Mtn West

Sitgreaves Mtn

Howard Mesa

Marshall Butte

Marshall Butte

335026 N1093700W

Marshall Butte

Howard Mesa

7866 Mount Logan

Cherry

Minnehaha

Cherry

Skull valley

Lakes ide

Minnehaha

Flagstaff East

Beaverhead

334821N1113335W Maverick Mtn

Maverick Mtn

Maverick Mtn

$334825 \mathrm{~N} 1113341 \mathrm{~W}$

7898 McNary

Clay Springs

Hutch Mtn

Mormon Lake

Mountainaire 
NATIONAL GAZETTEER--ARIZONA 1986 FEATURE FEATURE NAME

CLASS

STATUS

COUNTY

COORDIMATE

SOURCE
COORDINATE

ELEV
FT

MAP NAME

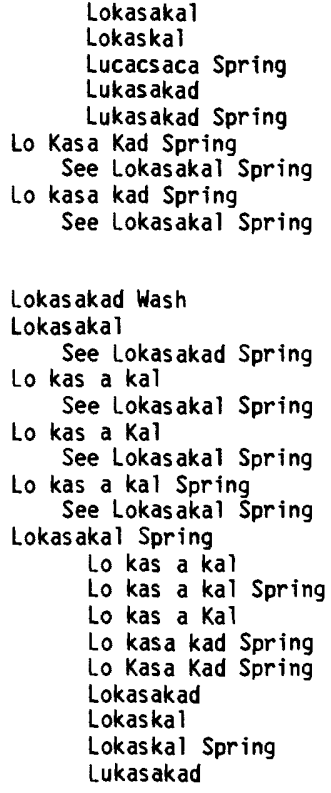

$\begin{array}{ll} & \text { VARIANT } \\ & \text { VARIANT } \\ & \text { VARIANT } \\ & \text { VARIANT } \\ & \text { VARIANT } \\ & \text { VARIANT } \\ \text { spring } & \\ \text { spring } & \text { VARIANT }\end{array}$

Navajo 360843N1100900W

Navajo 360843N1100900W

$\begin{array}{lll}\text { valley } & \text { BGN } & \text { Navajo } \\ \text { spring } & \text { VARIANT } & \\ \text { spring } & \text { VARIANT } & \text { Navajo } \\ \text { spring } & \text { VARIANT } & \text { Navajo } \\ \text { spring } & \text { VARIANT } & \text { Navajo } \\ \text { spring } & \text { BGN } & \text { Navajo } \\ & \text { VARIANT } & \\ & \text { VARIANT } & \\ & \text { VARIANT } & \\ & \text { VARIANT } & \\ & \text { VARIANT } & \\ & \text { VARIANT } & \\ & \text { VARIANT } \\ & \text { VARIANT } \\ & \text { VARIANT } & \end{array}$

$352050 \mathrm{N1100411W}$ $352410 \mathrm{~N} 1100824 \mathrm{~W}$

$360843 \mathrm{~N} 1100900 \mathrm{~W}$

360843N1100900W

360843N1100900W $360843 \mathrm{NI} 100900 \mathrm{~W}$

\section{N1101019W}

Five Buttes

Pinon NW

Kayenta West Rawhide Wash Tempe

\begin{tabular}{|c|c|c|c|}
\hline & VARIANT & & \multirow[b]{2}{*}{$\begin{array}{l}352410 \mathrm{~N} 1100824 \mathrm{~W} \\
360843 \mathrm{~N} 1100900 \mathrm{~W}\end{array}$} \\
\hline $\begin{array}{l}\text { spring } \\
\text { spring }\end{array}$ & VARIANT & $\begin{array}{l}\text { Navajo } \\
\text { Navajo }\end{array}$ & \\
\hline $\begin{array}{l}\text { spring } \\
\text { cliff } \\
\text { mine } \\
\text { school }\end{array}$ & $\begin{array}{l}\text { VARIANT } \\
\text { BGN } \\
\text { UNOFF } \\
\text { UNOFF } \\
\text { VARIANT }\end{array}$ & $\begin{array}{l}\text { Navajo } \\
\text { Navajo } \\
\text { Mohave } \\
\text { Maricopa }\end{array}$ & $\begin{array}{l}360843 \mathrm{~N} 1100900 \mathrm{~W} \\
363950 \mathrm{N1} 102056 \mathrm{~W} \\
342125 \mathrm{~N} 1134304 \mathrm{~W} \\
332926 \mathrm{~N} 1115540 \mathrm{~W}\end{array}$ \\
\hline school & & Maricopa & $332926 \mathrm{N1} 115545 \mathrm{~W}$ \\
\hline school & $\begin{array}{l}\text { UNOFF } \\
\text { VARIANT }\end{array}$ & Maricopa & $332926 \mathrm{~N} 1115545 \mathrm{~W}$ \\
\hline $\begin{array}{l}\text { school } \\
\text { summit } \\
\text { locale } \\
\text { ppl } \\
\text { park } \\
\text { park } \\
\text { school } \\
\text { reservoir }\end{array}$ & $\begin{array}{l}\text { UNOFF } \\
\text { BGN } \\
\text { BGN } \\
\text { BGN } \\
\text { ADMIN } \\
\text { ADMIN } \\
\text { UNOFF } \\
\text { BGN }\end{array}$ & $\begin{array}{l}\text { Maricopa } \\
\text { Pima } \\
\text { Coconino } \\
\text { Pima } \\
\text { Pima } \\
\text { Maricopa } \\
\text { Maricopa } \\
\text { Yavapai }\end{array}$ & $\begin{array}{l}332927 \mathrm{~N} 1115541 \mathrm{~W} \\
320657 \mathrm{~N} 1104016 \mathrm{~W} \\
353446 \mathrm{~N} 1112802 \mathrm{~W} \\
322653 \mathrm{~N} 1104516 \mathrm{~W} \\
322544 \mathrm{~N} 1104515 \mathrm{~W} \\
332637 \mathrm{~N} 1122106 \mathrm{~W} \\
332931 \mathrm{~N} 1120215 \mathrm{~W} \\
343041 \mathrm{~N} 1113552 \mathrm{~W}\end{array}$ \\
\hline $\begin{array}{l}\text { locale } \\
\text { summit } \\
\text { bridge } \\
\text { locale } \\
\text { sumnit }\end{array}$ & $\begin{array}{l}\text { UNOFF } \\
\text { BGN } \\
\text { UNOFF } \\
\text { UNOFF } \\
\text { BGN } \\
\text { VARIANT }\end{array}$ & $\begin{array}{l}\text { Maricopa } \\
\text { Pima } \\
\text { Mohave } \\
\text { Pima } \\
\text { Maricopa }\end{array}$ & $\begin{array}{l}333637 \mathrm{N11} 20900 \mathrm{~W} \\
322745 \mathrm{N1} 104341 \mathrm{~W} \\
342818 \mathrm{~N} 1142047 \mathrm{~W} \\
321437 \mathrm{N1} 10523 \mathrm{~W} \\
331543 \mathrm{~N} 1120154 \mathrm{~W}\end{array}$ \\
\hline $\begin{array}{l}\text { sumnit } \\
\text { ppl } \\
\text { summit } \\
\text { sumnit }\end{array}$ & $\begin{array}{l}\text { BGN } \\
B G N \\
B G N \\
B G N\end{array}$ & $\begin{array}{l}\text { Mohave } \\
\text { Maricopa } \\
\text { Graham } \\
\text { Navajo }\end{array}$ & $\begin{array}{l}365439 \mathrm{~N} 1125245 \mathrm{~W} \\
331357 \mathrm{~W} 1120247 \mathrm{~W} \\
325928 \mathrm{~N} 1102347 \mathrm{~W} \\
352759 \mathrm{~N} 1102154 \mathrm{~W}\end{array}$ \\
\hline $\begin{array}{l}\text { valley } \\
\text { spring } \\
\text { sumnit } \\
\text { reservoir } \\
\text { mine } \\
\text { mine } \\
\text { spring }\end{array}$ & $\begin{array}{l}\text { BGN } \\
\text { BGN } \\
\text { BGN } \\
\text { BGN } \\
\text { UNOFF } \\
\text { UNOFF } \\
\text { BGN } \\
\text { VARIANT }\end{array}$ & $\begin{array}{l}\text { Navajo } \\
\text { Navajo } \\
\text { Pima } \\
\text { Pima } \\
\text { Mohave } \\
\text { Mohave } \\
\text { Cochise }\end{array}$ & $\begin{array}{l}363857 N 1102704 \mathrm{~W} \\
352811 \mathrm{~N} 1102211 \mathrm{~W} \\
322521 \mathrm{~N} 1103523 \mathrm{~W} \\
322500 \mathrm{~N} 1103500 \mathrm{~W} \\
352347 \mathrm{~N} 1141041 \mathrm{~W} \\
355349 \mathrm{~N} 1140605 \mathrm{~W} \\
314939 \mathrm{~N} 1091619 \mathrm{~W}\end{array}$ \\
\hline $\begin{array}{l}\text { locale } \\
\text { summit }\end{array}$ & BGN & $\begin{array}{l}\text { Coconino } \\
\text { Navajo }\end{array}$ & $\begin{array}{l}365203 \mathrm{~N} 1113540 \mathrm{~W} \\
340117 \mathrm{~N} 1103056 \mathrm{~W}\end{array}$ \\
\hline $\begin{array}{l}\text { reservoir } \\
\text { summit } \\
\text { summit } \\
\text { summit }\end{array}$ & $\begin{array}{l}\text { BGN } \\
\text { BGN } \\
B G N \\
\text { BGN }\end{array}$ & $\begin{array}{l}\text { Navajo } \\
\text { Cochise } \\
\text { Maricopa } \\
\text { Yuma }\end{array}$ & $\begin{array}{l}340102 \mathrm{~N} 1103116 \mathrm{~W} \\
312430 \mathrm{~N} 1102346 \mathrm{~W} \\
333034 \mathrm{~N} 1113611 \mathrm{~W} \\
333625 \mathrm{~N} 1132759 \mathrm{~W}\end{array}$ \\
\hline
\end{tabular}




\begin{tabular}{|c|c|c|c|c|c|c|c|c|}
\hline & FEATURE NAME & $\begin{array}{l}\text { FEATURE } \\
\text { CLASS }\end{array}$ & STATUS & COUNTY & COORDINATE & $\begin{array}{l}\text { SOURCE } \\
\text { COORDINATE }\end{array}$ & $\begin{array}{l}\text { ELEV } \\
\text { FT }\end{array}$ & MAP NAME \\
\hline $\begin{array}{l}\text { Lone } \\
\text { Lone } \\
\text { Lone }\end{array}$ & $\begin{array}{l}\text { Mountain } \\
\text { Mountain } \\
\text { Mountain }\end{array}$ & $\begin{array}{l}\text { summit } \\
\text { summit }\end{array}$ & $\begin{array}{l}8 G N \\
\text { BGN } \\
\text { VARIANT }\end{array}$ & $\begin{array}{l}\text { Maricopa } \\
\text { Maricopa }\end{array}$ & $\begin{array}{l}334345 \mathrm{~N} 1113424 \mathrm{~W} \\
335041 \mathrm{~N} 1115233 \mathrm{~W}\end{array}$ & & 3222 & $\begin{array}{l}\text { Adams Mesa } \\
\text { Cave Creek }\end{array}$ \\
\hline $\begin{array}{l}\text { S } \\
\text { Lone } \\
\text { Lone }\end{array}$ & $\begin{array}{l}\text { See Long Mountain } \\
\text { Mountain } \\
\text { Mountain Canyon }\end{array}$ & $\begin{array}{l}\text { summit } \\
\text { summit } \\
\text { valley }\end{array}$ & $\begin{array}{l}B G N \\
B G N\end{array}$ & $\begin{array}{l}\text { Mohave } \\
\text { Mohave } \\
\text { Cochise }\end{array}$ & $\begin{array}{l}352417 \mathrm{N1135619W} \\
360800 \mathrm{~N} 1131901 \mathrm{~W} \\
312307 \mathrm{N1} 102148 \mathrm{~W}\end{array}$ & $312436 \mathrm{~N} 1102319 \mathrm{~W}$ & 4241 & $\begin{array}{l}\text { Whitmore Point } \\
\text { Miller Peak }\end{array}$ \\
\hline $\begin{array}{l}\text { Lone } \\
\text { Lone } \\
\text { Lone } \\
\text { Lone } \\
\text { Lone } \\
\text { Lone } \\
\text { Lone } \\
\text { Lone } \\
\text { Lone } \\
\text { Lone }\end{array}$ & $\begin{array}{l}\text { Mountain Ranch } \\
\text { Mountain Tank } \\
\text { Mountain Well } \\
\text { Pine Creek } \\
\text { Pine Dam } \\
\text { Pine Divide } \\
\text { Pine Saddle } \\
\text { Pine Saddle } \\
\text { Pine Spring } \\
\text { Pine Spring }\end{array}$ & $\begin{array}{l}\text { locale } \\
\text { reservoir } \\
\text { wel1 } \\
\text { stream } \\
\text { dam } \\
\text { ridge } \\
\text { gap } \\
\text { gap } \\
\text { spring } \\
\text { spring }\end{array}$ & $\begin{array}{l}\text { UNOFF } \\
\text { BGN } \\
\text { UNOFF } \\
\text { BGN } \\
\text { UNOFF } \\
\text { BGN } \\
\text { BGN } \\
\text { BGN } \\
\text { BGN } \\
\text { BGN }\end{array}$ & $\begin{array}{l}\text { Cochise } \\
\text { Yuma } \\
\text { Yuma } \\
\text { Apache } \\
\text { Navajo } \\
\text { Gila } \\
\text { Cochise } \\
\text { Maricopa } \\
\text { Graham } \\
\text { Gila }\end{array}$ & 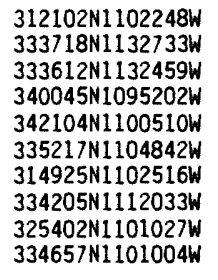 & $340012 \mathrm{~N} 1095013 \mathrm{~W}$ & & $\begin{array}{l}\text { Campini Mesa } \\
\text { Lone Mountain } \\
\text { Lone Mountain } \\
\text { McNary } \\
\text { Show Low North } \\
\text { Sombrero Peak } \\
\text { Apache Peak } \\
\text { Four Peaks } \\
\text { Jackson Mtn } \\
\text { Cone Butte }\end{array}$ \\
\hline $\begin{array}{l}\text { Lone } \\
\text { Lone } \\
\text { Lone } \\
\text { Lone } \\
\text { Lone } \\
\text { Lone } \\
\text { Lone } \\
\text { Lone } \\
\text { Lone } \\
\text { Lone }\end{array}$ & $\begin{array}{l}\text { Pine Spring } \\
\text { Pine Spring } \\
\text { Pine Tank } \\
\text { Pine Tank } \\
\text { Pine Tank } \\
\text { Pine Tank } \\
\text { Pine Tank } \\
\text { Pine Tank } \\
\text { Pine Tank Number One } \\
\text { Pine Tank Number Two }\end{array}$ & $\begin{array}{l}\text { spring } \\
\text { spring } \\
\text { reservoir } \\
\text { reservoir } \\
\text { reservoir } \\
\text { reservoir } \\
\text { reservoir } \\
\text { reservoir } \\
\text { reservoir } \\
\text { reservoir }\end{array}$ & $\begin{array}{l}B G N \\
B G N \\
B G N \\
B G N \\
B G N \\
B G N \\
B G N \\
B G N \\
B G N \\
B G N\end{array}$ & $\begin{array}{l}\text { Yavapai } \\
\text { Apache } \\
\text { Greenlee } \\
\text { Gila } \\
\text { Gila } \\
\text { Navajo } \\
\text { Coconino } \\
\text { Yavapai } \\
\text { Apache } \\
\text { Apache }\end{array}$ & $\begin{array}{l}342405 \mathrm{~N} 1123100 \mathrm{~W} \\
355120 \mathrm{N1095153 \textrm {W }} \\
331805 \mathrm{~N} 1090629 \mathrm{~W} \\
334252 \mathrm{N1095731W} \\
335232 \mathrm{~W} 1104845 \mathrm{~W} \\
340116 \mathrm{N1103011 \textrm {W }} \\
343218 \mathrm{N111301 \textrm {W }} \\
34453 \mathrm{NI} 113001 \mathrm{~W} \\
335931 \mathrm{~W} \\
335926 \mathrm{~N} 109005 \mathrm{~W} \\
\text { 335025W }\end{array}$ & & 7306 & $\begin{array}{l}\text { Wilhoit } \\
\text { Steamboat Rock } \\
\text { Maple Peak } \\
\text { Bonito Prairie } \\
\text { Rock House } \\
\text { Spotted Mountain } \\
\text { Buckhorn Mountain } \\
\text { Scratch Canyon } \\
\text { Hawley Lake West } \\
\text { Hawley Lake West }\end{array}$ \\
\hline $\begin{array}{l}\text { Lone } \\
\text { Lone } \\
\text { Lone } \\
\text { Lone } \\
\text { Lones } \\
\text { Lones } \\
\text { Lones } \\
\text { Lones } \\
\text { Lones } \\
\text { Lones }\end{array}$ & $\begin{array}{l}\text { Pine Trail } \\
\text { Rock } \\
\text { Rugged Tree Valley } \\
\text { Sharp Hill } \\
\text { some Knob Tank } \\
\text { some Lake } \\
\text { some Peak } \\
\text { some Pocket } \\
\text { some Pocket Tank } \\
\text { some Valley }\end{array}$ & $\begin{array}{l}\text { trail } \\
\text { island } \\
\text { valley } \\
\text { summit } \\
\text { reservoir } \\
\text { lake } \\
\text { summit } \\
\text { basin } \\
\text { reservoir } \\
\text { valley }\end{array}$ & $\begin{array}{l}\text { UNOFF } \\
\text { BGN } \\
\text { BGN } \\
\text { BGN } \\
\text { BGN } \\
\text { BGN } \\
\text { BGN } \\
\text { BGN } \\
\text { BGN } \\
\text { BGN }\end{array}$ & $\begin{array}{l}\text { Maricopa } \\
\text { Mohave } \\
\text { Navajo } \\
\text { Navajo } \\
\text { Coconino } \\
\text { Coconino } \\
\text { Yuma } \\
\text { Coconino } \\
\text { Coconino } \\
\text { Cochise }\end{array}$ & $\begin{array}{l}334224 \mathrm{~N} 1112102 \mathrm{~W} \\
355800 \mathrm{~N} 114445 \mathrm{~W} \\
361554 \mathrm{~N} 1101041 \mathrm{~W} \\
363346 \mathrm{~N} 1100232 \mathrm{~W} \\
353007 \mathrm{N1120340 \textrm {W }} \\
341703 \mathrm{N1105104 \textrm {W }} \\
332543 \mathrm{~N} 1140709 \mathrm{~W} \\
350015 \mathrm{~N} 112065 \mathrm{~W} \\
345921 \mathrm{~N} 112065 \mathrm{~W} \\
315555 \mathrm{~N} 1101448 \mathrm{~W}\end{array}$ & $315828 \mathrm{~N} 1101306 \mathrm{~W}$ & 2211 & $\begin{array}{l}\text { Four Peaks } \\
\text { Ringbolt Rapids } \\
\text { Toh NE Zhonnie Spr } \\
\text { Chilchinbito } \\
\text { Hobble Tank } \\
\text { O W Point } \\
\text { Livingston Hills } \\
\text { White Horse Lake } \\
\text { Sycamore Bas in } \\
\text { Saint David }\end{array}$ \\
\hline Lones & $\begin{array}{l}\text { some Valley } \\
\text { Chino Valley }\end{array}$ & & $\begin{array}{l}\text { BGN } 1975 \\
\text { VARIANT }\end{array}$ & Yavapai & $344645 \mathrm{~N} 1122220 \mathrm{~W}$ & $343850 \mathrm{~N} 1121835 \mathrm{~W}$ & & King Canyon \\
\hline $\begin{array}{l}\text { Lones } \\
\text { Lones } \\
\text { Lone } \\
\text { Lone } \\
\text { Lone } \\
\text { Lone } \\
\text { Lone } \\
\text { Lone }\end{array}$ & $\begin{array}{l}\text { some Valley } \\
\text { some Valley Pond } \\
\text { Star } \\
\text { Star Mine } \\
\text { Star Mine } \\
\text { Star Mountain } \\
\text { Star Wash } \\
\text { Sycamore Gulch }\end{array}$ & $\begin{array}{l}\text { valley } \\
\text { reservoir } \\
\text { ppl } \\
\text { mine } \\
\text { mine } \\
\text { summit } \\
\text { stream } \\
\text { valley }\end{array}$ & $\begin{array}{l}\text { BGN } \\
\text { BGN } \\
\text { BGN } \\
\text { UNOFF } \\
\text { UNOFF } \\
\text { BGN } \\
\text { BGN } \\
\text { BGN }\end{array}$ & $\begin{array}{l}\text { Mohave } \\
\text { Mohave } \\
\text { Graham } \\
\text { Cochise } \\
\text { Graham } \\
\text { Graham } \\
\text { Graham } \\
\text { Greenlee }\end{array}$ & $\begin{array}{l}363916 \mathrm{N1} 1131043 \mathrm{~W} \\
363843 \mathrm{~N} 1131041 \mathrm{~W} \\
324859 \mathrm{N1094050 \textrm {W }} \\
314959 \mathrm{N1} 102215 \mathrm{~W} \\
325527 \mathrm{N1} 1093722 \mathrm{~W} \\
32552 \mathrm{N1} 1093605 \mathrm{~W} \\
325044 \mathrm{N1} 109420 \mathrm{~W} \\
331050 \mathrm{~N} 1090938 \mathrm{~W}\end{array}$ & $\begin{array}{l}325617 N 1093654 \mathrm{~W} \\
330913 N 1090819 \mathrm{~W}\end{array}$ & & $\begin{array}{l}\text { Antelope Knoll } \\
\text { Antelope Knoll } \\
\text { Safford } \\
\text { McGrew Spring } \\
\text { Lone Star Mtn } \\
\text { Lone Star Mtn } \\
\text { Safford } \\
\text { Dix Creek }\end{array}$ \\
\hline $\begin{array}{l}\text { Lone } \\
\text { Lonet } \\
\text { Lone } \\
\text { Lone } \\
\text { Lone } \\
\text { Lone } \\
\text { Lone } \\
\text { Lone } \\
\text { Long } \\
\text { Long }\end{array}$ & $\begin{array}{l}\text { Tank } \\
\text { tree Canyon } \\
\text { Tree Mesa } \\
\text { Tree Pothole } \\
\text { Tree Road Overpass } \\
\text { Tree Tank } \\
\text { Tule Wash } \\
\text { Wolf Mine } \\
\text { Bend } \\
\text { Butte }\end{array}$ & $\begin{array}{l}\text { reservoir } \\
\text { valley } \\
\text { summit } \\
\text { lake } \\
\text { crossing } \\
\text { reservoir } \\
\text { stream } \\
\text { mine } \\
\text { bend } \\
\text { summit }\end{array}$ & $\begin{array}{l}\text { BGN } \\
\text { BGN } 1932 \\
\text { BGN } \\
\text { BGN } \\
\text { UNOFF } \\
\text { BGN } \\
\text { BGN } 1983 \\
\text { UNOFF } \\
\text { BGN } \\
\text { BGN }\end{array}$ & $\begin{array}{l}\text { Gila } \\
\text { Coconino } \\
\text { Greenlee } \\
\text { Coconino } \\
\text { Coconino } \\
\text { Coconino } \\
\text { Apache } \\
\text { Yavapai } \\
\text { La Paz } \\
\text { Navajo }\end{array}$ & $\begin{array}{l}334726 \mathrm{~N} 1101022 \mathrm{~W} \\
36044 \mathrm{~N} 112015 \mathrm{~W} \\
331452 \mathrm{~N} 1090929 \mathrm{~W} \\
355255 \mathrm{N1} 114735 \mathrm{~W} \\
351023 \mathrm{N1113852W} \\
353614 \mathrm{~N} 1113414 \mathrm{~W} \\
354428 \mathrm{~N} 1092940 \mathrm{~W} \\
335815 \mathrm{~N} 1123447 \mathrm{~W} \\
33180 \mathrm{~N} 114420 \mathrm{~W} \\
351518 \mathrm{N1} 101322 \mathrm{~W}\end{array}$ & $360358 \mathrm{N1120300 \textrm {W }}$ & 6453 & $\begin{array}{l}\text { Cone Butte } \\
\text { Phantom Ranch } \\
\text { Dix Creek } \\
\text { Deer Tank } \\
\text { Flagstaff West } \\
\text { East of S P Mtn } \\
\text { Kinlichee } \\
\text { Red Picacho } \\
\text { Cibola } \\
\text { Sunflower Butte }\end{array}$ \\
\hline $\begin{array}{l}\text { Long } \\
\text { Long } \\
\text { Long } \\
\text { Long } \\
\text { Long } \\
\text { Long } \\
\text { Long } \\
\text { Long } \\
\text { Long } \\
\text { Long }\end{array}$ & $\begin{array}{l}\text { Canyon } \\
\text { Canyon } \\
\text { Canyon } \\
\text { Canyon } \\
\text { Canyon } \\
\text { Canyon } \\
\text { Canyon } \\
\text { Canyon } \\
\text { Canyon } \\
\text { Canyon }\end{array}$ & $\begin{array}{l}\text { valley } \\
\text { valley } \\
\text { valley } \\
\text { valley } \\
\text { valley } \\
\text { valley } \\
\text { valley } \\
\text { valley } \\
\text { valley } \\
\text { valley }\end{array}$ & $\begin{array}{l}B G N \\
B G N \\
B G N \\
B G N \\
B G N \\
B G N \\
B G N \\
B G N \\
B G N \\
B G N\end{array}$ & $\begin{array}{l}\text { Cochise } \\
\text { Cochise } \\
\text { Gila } \\
\text { Green lee } \\
\text { Maricopa } \\
\text { Apache } \\
\text { Apache } \\
\text { Maricopa } \\
\text { Yavapai } \\
\text { Yavapai }\end{array}$ & $\begin{array}{l}321106 \mathrm{~N} 1092718 \mathrm{~W} \\
321646 \mathrm{N1} 109593 \mathrm{~W} \\
332352 \mathrm{~N} 1105208 \mathrm{~W} \\
332929 \mathrm{N1} 1090422 \mathrm{~W} \\
333554 \mathrm{~N} 1111946 \mathrm{~W} \\
334529 \mathrm{N1093915W} \\
335149 \mathrm{~N} 1091205 \mathrm{~W} \\
340001 \mathrm{N1115823W} \\
340339 \mathrm{~N} 1114916 \mathrm{~W} \\
344025 \mathrm{~N} 1113934 \mathrm{~W}\end{array}$ & $\begin{array}{l}321107 \mathrm{~N} 1092952 \mathrm{~W} \\
321806 \mathrm{N1} 100129 \mathrm{~W} \\
332320 \mathrm{~N} 1105135 \mathrm{~W} \\
332956 \mathrm{~N} 1090224 \mathrm{~W} \\
333940 \mathrm{~N} 1111936 \mathrm{~W} \\
334537 \mathrm{N1093448 \textrm {W }} \\
335248 \mathrm{~N} 1091251 \mathrm{~W} \\
340152 \mathrm{~N} 1115958 \mathrm{~W} \\
340627 \mathrm{~N} 1114810 \mathrm{~W} \\
343807 \mathrm{N1} 113244 \mathrm{~W}\end{array}$ & & $\begin{array}{l}\text { Bowie Mtn North } \\
\text { Square Mountain } \\
\text { Globe } \\
\text { Alma Mesa } \\
\text { Horse Mesa Dam } \\
\text { Marshall Butte } \\
\text { Alpine } \\
\text { Cooks Mesa } \\
\text { Rover Peak } \\
\text { Casner Butte }\end{array}$ \\
\hline $\begin{array}{l}\text { Long } \\
\text { Long } \\
\text { Long } \\
\text { Long }\end{array}$ & $\begin{array}{l}\text { Canyon } \\
\text { Canyon } \\
\text { Canyon } \\
\text { Canyon } \\
\text { Laguna Canyon }\end{array}$ & $\begin{array}{l}\text { valley } \\
\text { valley } \\
\text { valley } \\
\text { valley }\end{array}$ & $\begin{array}{l}\text { BGN } \\
\text { BGN } \\
\text { BGN } \\
\text { BGN } \\
\text { VARIANT }\end{array}$ & $\begin{array}{l}\text { Yavapai } \\
\text { Yavapai } \\
\text { Yavapai } \\
\text { Navajo }\end{array}$ & $\begin{array}{l}344529 \mathrm{~N} 1123909 \mathrm{~W} \\
345315 \mathrm{N1130234 \textrm {W }} \\
345328 \mathrm{N1115008 \textrm {W }} \\
364115 \mathrm{~N} 1103042 \mathrm{~W}\end{array}$ & $\begin{array}{l}343802 \mathrm{~N} 1123409 \mathrm{~W} \\
345439 \mathrm{N1} 125942 \mathrm{~W} \\
345644 \mathrm{N11} 15208 \mathrm{~W} \\
365046 \mathrm{N1} 102806 \mathrm{~W}\end{array}$ & & $\begin{array}{l}\text { Simmons } \\
\text { Mount Hope } \\
\text { Wilson Mountain } \\
\text { Betatak in Ruin }\end{array}$ \\
\hline
\end{tabular}




\section{FEATURE NAME}

Long Canyon

Long Canyon Fork Tank

Long Canyon Spring

Long Canyon Spring

Long Canyon Tank

Long Canyon Tank

Long Canyon Tank

Long Canyon Trail

Long Canyon Wash

Long Cienega

Long Creek

Long Creek

See Boucher Creek

Long Dike

Long Draw

Long Draw

Long Draw

Long Draw

Long Draw Well

Longfellow Elementary School

Plants ite School

Longfellow Ridge

Longfellow Ridge Spring

Longfellow School

Longfellow School

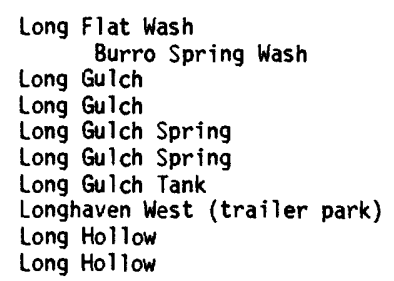

$$
\begin{aligned}
& \text { FEATURE } \\
& \text { CLASS } \\
& \text { valley } \\
& \text { reservoir } \\
& \text { spring } \\
& \text { spring } \\
& \text { reservoir } \\
& \\
& \text { reservoir } \\
& \text { reservoir } \\
& \text { trail } \\
& \text { valley } \\
& \text { flat } \\
& \text { stream } \\
& \text { stream } \\
& \text { levee } \\
& \text { valley } \\
& \\
& \text { valley } \\
& \text { valley } \\
& \text { valley } \\
& \text { well } \\
& \text { school } \\
& \text { ridge } \\
& \text { spring } \\
& \text { school } \\
& \text { school } \\
&
\end{aligned}
$$

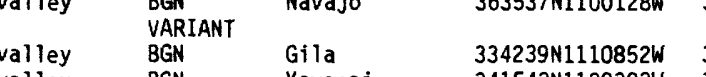$$
\text { valley BGN Yavapai } 341542 N 1120302 \mathrm{~W}
$$$$
\text { spring BGN Gila } 334345 N 1110750 \mathrm{~W}
$$$$
\text { spring BGN Yavapai 341632N1115908W }
$$$$
\text { reservoir BGN Yavapai }
$$$$
\begin{array}{llll}
\text { reservoir } & \text { BGN } & \text { Yavapai } & 341743 \mathrm{~N} 1115642 \mathrm{~W} \\
\text { locale } & \text { UNOFF } & \text { Maricopa } & 333026 \mathrm{N1121015W}
\end{array}
$$$$
\begin{array}{llll}
\text { locale UNOFF Maricopa } & 333026 \mathrm{~N} 1121015 \mathrm{~W}
\end{array}
$$$$
\begin{array}{llll}
\text { valley } & B G N & \text { Graham } & 324826 N 1101910 \mathrm{~W} \\
\text { valley } & B G N & \text { Navajo } & 342957 \text { N1102500W }
\end{array}
$$

$\begin{array}{llrr}\begin{array}{c}\text { FEATURE } \\ \text { CLASS }\end{array} & \text { STATUS } & \text { COUNTY } & \text { COORDINATE } \\ & & & \end{array}$

CLASS STATUS COUNTY COORDINATE

\begin{tabular}{l} 
BGN Coconino 364841N1105338W \\
\hline
\end{tabular} reservoir ppl BGN Maricopa 333604N1121153W rocale BGN Navajo 363719 N1102905W valley BGN Navajo 363756N1102700W locale UNOFF Apache 344801N1092426W valley BGN 1932 Coconino 355830N1120803W
Take

lake

lak

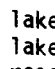

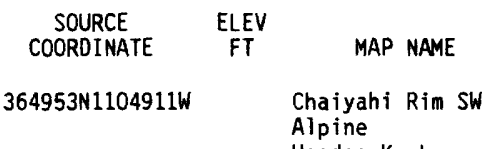




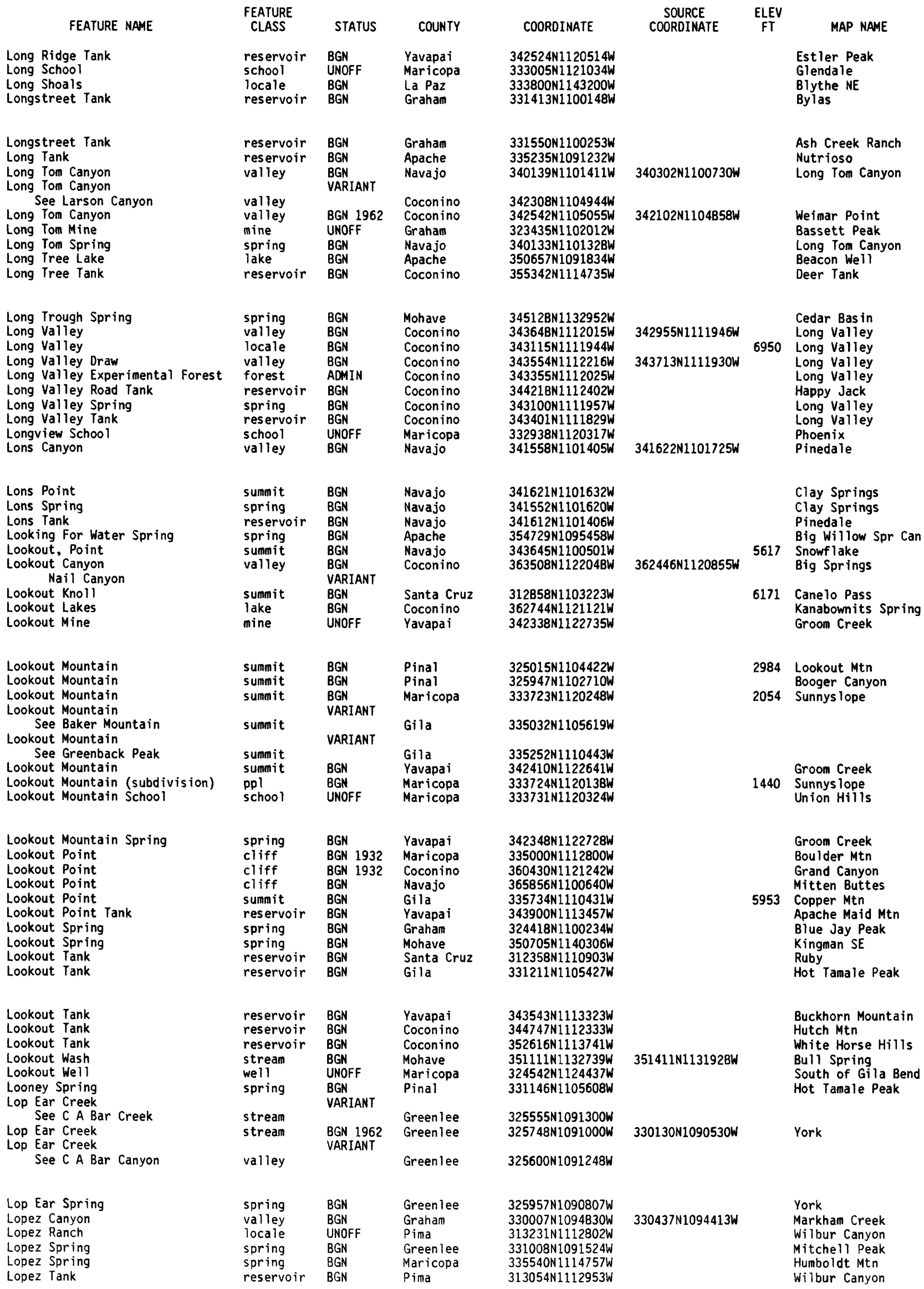


NATIONAL GAZETTEER--ARIZONA 1986

FEATURE NAME

Lopez Wash

Lopez Wash

Lopez Well

Lopez Wel1

Lopez Wells

Lopez Windmill

LO Pocket

LO Pocket Tank

Lords Ranch

Lorena Gulch

Lorin Farr Tank

Lorona Lateral

Lorta Railroad Station

Los Angeles Wash

Los Arcos Mall

Los Avispas Ranch

Los Burros

Los Burros Ranger Station

Los Camotes

$$
\text { See Shaotkam }
$$

Los Comates

See Shaotkam

Los Encinos Ranch

Los Girls Camp

Los Maderas (subdivision)

Los Niños Neighborhood Park

Los Niños School

os Nogales

See Nogales

Los Olivos Senior Center

Los Portales Mall

L O Spring

L 0 Spring

Lo Spring Canyon See Little Lo Spring Canyon Los Ranchitos School

Los Sierra Sauceba

See Sauceda Mountains

Los Sierra Sauceda

See Sauceda Mountains

Lost Acres Ranch

Lost Arrow Head Tank

Lost Bas in

Lost Cabin Mine

Lost Cabin Spring

Lost Cabin Wash

Lost Camp Canyon

Lost Camp Canyon Tank

Lost Camp Mountain

Lost Camp Mountain Tank

Lost Canyon

Lost Canyon

Lost Guich

Lost Canyon

Lost Canyon

Lost Canyon Tank

Lost Cienega

Lost Cow Tank

Lost Creek

Lost Creek Rapids

Lost Creek Reservoir

Lost Dog Canyon

Lost Dutch Canyon

Lost Dutchman Mobile Home Park

Lost Dutchman State Park

Lost Dutch Spring

Lost Eden

Lost Eden Tank

Lost Eden Tank

Los Tesoros (subdivision)
FEATURE

CLASS

STATUS

COUNTY

Pima

$\begin{array}{lll}\text { stream } & \text { BGN } & \text { Yuma } \\ \text { well } & \text { UNOFF } & \text { Pima } \\ \text { well } & \text { UNOFF } & \text { Pima }\end{array}$

$\begin{array}{lll}\text { stream } & \text { BGN } & \text { Yuma } \\ \text { well } & \text { UNOFF } & \text { Pima } \\ \text { well } & \text { UNOFF } & \text { Pima }\end{array}$

well

UNOF

we1

locale

reservoir

locale

valley

reservoir

canal

building UNOF

stream $\quad B G N$

UNOFF Pina

BGN Grahan

BGN Coconino

UNOFF Pima

Yavapai

Apache

Yuma

Cochise

Yuma

locale UNOFF

locale

locale

UNOFF

BGN

UNOFF

pp 1

ppl

VARIANT

locale

VARIANT

UNOFF

Maricopa

Pima

Apache

Apache

Pima

Pima

Pima

Graham

$\begin{array}{ll}\text { ppl } & \text { BGN } \\ \text { park } & \text { AOMIN } \\ \text { school } & \text { UNOFF } \\ & \text { VARIANT } \\ \text { ppl } & \\ \text { park } & \text { AOMIN } \\ \text { building } & \text { UNOFF } \\ \text { locale } & \text { UNOFF } \\ \text { spring } & \text { BGN } \\ \text { spring } & \text { BGN }\end{array}$

Maricopa

Pima

Pima

Santa Cruz

Maricopa

Maricopa

Maricopa

Yavapai

Coconino

VARIANT

school

VARIANT

range

VARIANT

range

locale

reservoir

bas in

\section{UNOFF
BGN}

BGN

mine

spring

stream

valley

reservoir

summit

reservoir

valley

valley

$\begin{array}{ll}\text { UNOFF } & \text { Pima } \\ \text { BGN } & \text { Mohave } \\ \text { BGN } & \text { Mohave } \\ \text { BGN } & \text { Gila } \\ \text { BGN } & \text { Gila } \\ \text { BGN } & \text { Gila } \\ \text { BGN } & \text { Gíla } \\ \text { BGN } & \text { Cochise } \\ \text { BGN } & \text { Gila } \\ \text { VARIANT } & \end{array}$

Coconino

Pima

Maricopa

Maricopa

Pima

Yavapai

Graham

Pima

Mhave

Gila

Gila

Gíla

VARIANT

valley

valley

reservoir

flat

reservoir

stream

rapids

reservoir

valley

valley

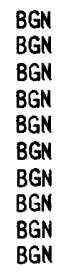

locale

park

spring

locale

reservoir

reservoir

pp

Coconino

Coconino

Coconino

Green lee

Coconino

Mohave

Mohave

Mohave

Santa Cruz

Maricopa

Maricopa

Pinal

Maricopa

Coconino

Coconino

Coconino

Maricopa
COORDINATE

$313523 \mathrm{~N} 1113006 \mathrm{~W}$ $331357 \mathrm{N1143904 \textrm {W }}$ $313108 \mathrm{N1113837 \textrm {W }}$ $313108 N 1113837 \mathrm{~W}$

$323953 \mathrm{~N} 1110211 \mathrm{~W}$

$330311 \mathrm{N1094504 \textrm {W }}$ $350552 \mathrm{~N} 1115627 \mathrm{~W}$ $350555 \mathrm{~N} 1115657 \mathrm{~W}$

$321913 \mathrm{~N} 1112624 \mathrm{~W}$

$341232 \mathrm{~N} 1121908 \mathrm{~W}$

$344602 \mathrm{~N} 1094934 \mathrm{~W}$

$323943 \mathrm{~N} 1144118 \mathrm{~W}$

$312344 \mathrm{~N} 1095300 \mathrm{~W}$

325854N1142750W

$332750 \mathrm{~N} 1115524 \mathrm{~W}$

$313031 N 1113520 \mathrm{~W}$

$340829 \mathrm{~N} 1094635 \mathrm{~W}$

$340826 \mathrm{~N} 1094636 \mathrm{~W}$

$314610 \mathrm{~N} 1122435 \mathrm{~W}$

314610 N1122435

$313611 \mathrm{~N} 1113604 \mathrm{~W}$

$324217 \mathrm{N1095505 \textrm {W }}$

332657 N1114700W

$320913 \mathrm{~N} 1105428 \mathrm{~W}$

320910 N1105427W

$312025 N 1105601 \mathrm{~W}$

$332952 \mathrm{~N} 1120110 \mathrm{~W}$

$332949 N 1120112 \mathrm{~W}$

$334934 \mathrm{~N} 1115521 \mathrm{~W}$

$344925 \mathrm{~N} 1125520 \mathrm{~W}$

$350911 \mathrm{~N} 1115900 \mathrm{~W}$

$335830 \mathrm{~N} 1115158 \mathrm{~W}$

$320813 \mathrm{~N} 1105625 \mathrm{~W}$

323556 N1123911W

$323556 \mathrm{~N} 1123911 \mathrm{~W}$

$321756 \mathrm{~N} 1112655 \mathrm{~W}$

$345647 \mathrm{~N} 1120320 \mathrm{~W}$

$333022 \mathrm{~N} 1094935 \mathrm{~W}$

315613 N1125038W

$352659 N 1142933 \mathrm{~W}$

$352119 \mathrm{~N} 1143528 \mathrm{~W}$

$341216 \mathrm{~N} 1110352 \mathrm{~W}$

341038 N $1110448 \mathrm{~W}$

$341203 \mathrm{~N} 1110446 \mathrm{~W}$

$341109 N 1110517 \mathrm{~W}$

320049 N1092052W

332613 N1105355W

$351342 \mathrm{~N} 1121026 \mathrm{~W}$ $363213 \mathrm{~N} 1121928 \mathrm{~W}$ 351357 N1121019W

333908 N1092000W

$351444 \mathrm{~N} 1121925 \mathrm{~W}$

355141 N113395B

$355147 \mathrm{~N} 1133957 \mathrm{~W}$

354501 N1135357W

$312913 \mathrm{~N} 1110514 \mathrm{~W}$

$332953 \mathrm{~N} 1111633 \mathrm{~W}$

$332502 \mathrm{~N} 1113556 \mathrm{~W}$

$332730 \mathrm{~N} 1112850 \mathrm{~W}$

$332929 \mathrm{~N} 1111627 \mathrm{~W}$

$343754 \mathrm{~N} 1111537 \mathrm{~W}$

$343720 \mathrm{~N} 1111645 \mathrm{~W}$

$343737 \mathrm{~N} 1111635 \mathrm{~W}$

331943 N1115444W

\begin{tabular}{|c|c|c|}
\hline $\begin{array}{l}\text { SOURCE } \\
\text { COORDINATE }\end{array}$ & $\begin{array}{c}\text { ELEV } \\
\text { FT }\end{array}$ & MAP NAME \\
\hline $\begin{array}{l}313127 \mathrm{N1112546 \textrm {W }} \\
331718 \mathrm{N1143312 \textrm {W }}\end{array}$ & $\begin{array}{l}3102 \\
3677\end{array}$ & $\begin{array}{l}\text { Presumido Peak } \\
\text { Picacho NW } \\
\text { Caponera Peak } \\
\text { Wilbur Canyon }\end{array}$ \\
\hline $330000 \mathrm{~N} 1142635 \mathrm{~W}$ & & $\begin{array}{l}\text { Chief 8utte } \\
\text { Markham Creek } \\
\text { Sycamore Point } \\
\text { Sycamore Point } \\
\text { Waterman Peak } \\
\text { Crown King } \\
\text { Agate House } \\
\text { Yuma West } \\
\text { Bisbee } \\
\text { Imperial Reservoir }\end{array}$ \\
\hline & $\begin{array}{l}3792 \\
7820\end{array}$ & $\begin{array}{l}\text { Tempe } \\
\text { Presumido Peak } \\
\text { Sponseller Mtn } \\
\text { Sponseller Mtn }\end{array}$ \\
\hline
\end{tabular}

Presumido Peak Webb Peak

1285 Mesa

Tucs on

Tucson

Phoenix

Phoenix

Cave Creek

Camp Wood

Garland Prairie

Tucson

Waterman Peak

Sycamore Bas in

West Poker Mtn

Lukeville

Grasshopper Junc NW

Spirit Mtn SE

Diamond Butte 


\section{FEATURE NAME}

Lost Gulch

See Skunk Gulch

Lost Gulch

Lost Gulch

See Lost Canyon

Lost Gun Point

Lost Horse Peak

Lost Horse Spring

Lost Horse Tank

Lost Knife Tank

Lost Lake

Lost Lake

Lost Lake

Lost Lake

Lost Lake

Lost Lake Tank

Lost Man Creek

Lost Man Tank

Lost Mountain

Lost Mule Creek

Lost Mule Tank

Lost Point

Lost Salt Canyon

Lost Salt Spring Number One

Lost Salt Spring Number Two

Lost Spring

Lost Spring

Lost Spring

Lost Spring

Lost Spring

Lost Spring

Lost Spring Gap

Lost Spring Mountain

Lost Spring Tank

Lost Spring Wash

Lost Tank

Lost Tank

Lost Tank

Lost Tank

Lost Tank

Lost Tank

Lost Tank

Lost Tank

Lost Tank

Lost Tank

Lost Tank

Lost Tank

Lost Tank

Lost Tank

Lost Tank

Lost Tank

Lost Tank

Lost Tank

Lost Tank

Lost Tank Canyon

Lost Tank Canyon

Lost Tank Ridge

Chediski Butte

Lost Wilson Mountain

Lott Lateral

Loudermilk Wash

Louis B Hazelton Memorial

Cemetery

\footnotetext{
Louis D'Or Shaft

Louis Hunt Tank

Louis Hunt Tank Draw

Louisiana Gulch

Greaterville Gulch

Louis Tank

Lounce Lookout

Louse Flat
}

\section{FEATURE}

CLASS

STATUS

COUNTY

COORDINATE

$332524 N 1105217 \mathrm{~W}$

valley

VARIANT

BGN

Gila

$332537 \mathrm{N1} 105257 \mathrm{~W}$

$332648 \mathrm{~N} 1105608 \mathrm{~W}$

Inspiration

VARIANT

valley
cliff
summit
spring
reservoir
reservoir
lake
lake
lake

Gila

BGN Navajo

BGN Maricor

Maricopa

Maricopa

Greenlee

Greenlee

Coconino

lake

lake

reservoir

stream

reservoir

summit

stream

reservoir

cliff

valley

BGN
$B G N$
$B G N$
$B G N$
$B G N$
$B G N$
$B G N$
$B G N$
$B G N$

Mohave

Coconino

Coconino

Mohave

Graham

Yavapai

Gila

Gila

Coconino

Gila

spring

spring

spring

spring

spring

spring

spring

spring

gap

summit

$B G=$
$B G=$
$B G$
$B G$
$B G N$
$B G N$
$B G=$
$B G N$
$B G N$
$B G N$

Gila

Gila

Graham

Apache

Coconino

Mohave

Mohave

Mohave

Coconino

Mohave

reservoir

stream

reservoir

reservoir

reservoir

reservoir

reservoir

reservoir

reservoir

BGN

BGN

BGN

BGN

BGN

BGN

BGN

BGN

Coconino

Coconino

Santa Cruz

Pima

Graham

Maricopa

Navajo

Gila

Gila

Gila

reservoir

reservoir

reservoir

reservoir

reservoir

reservoir

reservoir

reservoir

reservoir

reservoir

BGN

BGN

Navajo

Coconino

Coconino

Apache

Coconino

Yavapai

Coconino

Coconino

Coconino

Mohave

reservoir

valley

valley

ridge

summit

canal

stream

cemetery

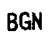

Coconino

Navajo

Navajo

Gila

Yavapai

Yuma

Maricopa

Maricopa

mine

mine

valley

valley

reservoir

park

flat

UNOFF

BGN

BGN

Gila

Navajo

Navajo

1959 Pima

BGN

Navajo

Yavapa

BGN

Gila

$332613 \mathrm{~N} 1105355 \mathrm{~W}$

353241 N1103202W

$324954 N 1121839 \mathrm{~W}$

$331940 \mathrm{~N} 1105745 \mathrm{~W}$

325029 N1121924W

340138 N1103935W

323347 N1090846W

$334024 N 1092208 \mathrm{~W}$

342334 N1110856W

344457 N1143054W

$350105 \mathrm{~N} 1115304 \mathrm{~W}$

345901 N1113459W

$354113 \mathrm{~N} 1132438 \mathrm{~W}$

$331930 \mathrm{~N} 1100933 \mathrm{~W}$

$345637 \mathrm{~N} 1115332 \mathrm{~W}$

$333603 \mathrm{~N} 1100552 \mathrm{~W}$

$333405 \mathrm{~N} 1100645 \mathrm{~W}$

$363148 \mathrm{~N} 1121856 \mathrm{~W}$

$341348 \mathrm{~N} 1105431 \mathrm{~W}$

341416 N1105350W

$341415 \mathrm{~N} 1105309 \mathrm{~W}$

$332338 \mathrm{~N} 1095227 \mathrm{~W}$

$334728 N 1092930 \mathrm{~W}$

$352817 \mathrm{~N} 1115252 \mathrm{~W}$

$360921 \mathrm{~N} 1132236 \mathrm{~W}$

$365213 \mathrm{~N} 1134717 \mathrm{~W}$

$365654 \mathrm{~N} 113031 \mathrm{WW}$

365957 N1122853W

$365733 \mathrm{~N} 1131012 \mathrm{~W}$

$352906 \mathrm{~N} 1115301 \mathrm{~W}$

$365748 \mathrm{~N} 1123134 \mathrm{~W}$

$312753 \mathrm{~N} 1110623 \mathrm{~W}$

320032 N1111859W

$323646 \mathrm{~N} 1092658 \mathrm{~W}$

$333706 \mathrm{~N} 1113553 \mathrm{~W}$

$340102 \mathrm{~N} 1102056 \mathrm{~W}$

$340647 \mathrm{~N} 1111226 \mathrm{~W}$

340824 N1104519W

$341143 \mathrm{~N} 1110105 \mathrm{~W}$

$341310 \mathrm{~N} 1100235 \mathrm{~W}$

$344846 \mathrm{~N} 1112104 \mathrm{~W}$

$344938 \mathrm{~N} 1112807 \mathrm{~W}$

$350020 \mathrm{~N} 1092705 \mathrm{~W}$

$351110 \mathrm{~N} 1122001 \mathrm{~W}$

$351604 \mathrm{~N} 1130153 \mathrm{~W}$

351807 N1122418W

352257 N1113555W

$352747 \mathrm{~N} 1124926 \mathrm{~W}$

$354647 \mathrm{~N} 1135121 \mathrm{~W}$

355341 N1120621W

$340855 \mathrm{~N} 1104408 \mathrm{~W}$

$344855 N 1102323 \mathrm{~W}$

$340835 \mathrm{~N} 1104604 \mathrm{~W}$

$340948 \mathrm{~N} 1104803 \mathrm{~W}$

$344200 \mathrm{~N} 1102551 \mathrm{~W}$

$345544 \mathrm{~N} 1114643 \mathrm{~W}$

$323400 \mathrm{~N} 1144507 \mathrm{~W}$

$330419 \mathrm{N1} 130412 \mathrm{~W}$

$332428 \mathrm{~N} 1123246 \mathrm{~W}$

$332657 \mathrm{~N} 1105225$

$343916 \mathrm{~N} 1100614 \mathrm{~W}$

$343907 N 1100535 \mathrm{~W}$

$314436 \mathrm{~N} 1104215 \mathrm{~W}$

$344051 N 1100744 W$

$314546 \mathrm{~N} 1104459 \mathrm{~W}$ 
NATIONAL GAZETTEER--ARIZONA 1986

\section{FEATURE NAME}

\author{
Louse Flat Tank \\ Louse Lake \\ Louse Tank Number One \\ Lous ley Hill \\ Lousy Canyon \\ Lousy Gulch \\ Lousy Tank \\ Lousy Tank \\ Louthan Tank \\ Love
}

Lockhart
Lovelace Tank

Love Lake
Lovers Leap
Loves Camp
Loves Mine
Lowboy Tank
Low Canyon Tank
Low Creek
Lowell

Lowe 11 Observatory

Lowells (historical)

Lowell School

Lowell School

Lowell School

Lowell Tank

Lowell Windmill

See Lower Hog Canyon

Lower Alamo Tank

Lower Arrieta Tank Lower Reata Tank

Lower Reata Water Tank

Lower Ash Creek Tank

Lower Ash Spring

Lower Badger Spring

Lower Badger Tank

Lower Bald Mountain Tank

Lower Barnhardt Tank

Lower Bas in

Lower Bas in

Lower Bas in

See Boulder Bas in

Lower Basin Spring

Lower Bas in Tank

Lower Bear Picnic Area

Lower Bear Spring

Lower Beecher Well

Lower Bellota Canyon Tank See Lower Bellota Tank

Lower Bellota Tank ower Bellota Canyon Tank

Lower Bell Tank

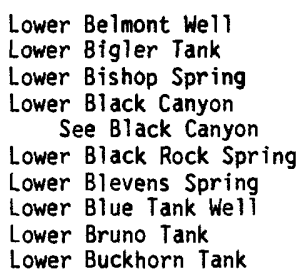

Lower Buck Spring

Lower Bull Canyon Tank

Lower Butcherknife Spring

Lower Camp Tank

Lower Camp Verde Indian

Reservation

Lower Carrizo Well

COORDINATE

$332430 \mathrm{~N} 1114835 \mathrm{~W}$

reservoir
FEATURE
CLASS

STATUS

COUNTY

$\begin{array}{llll}\text { reservoir } & \text { BGN } & \text { Gila } & 334740 N 1101426 \mathrm{~W} \\ \text { lake } & \text { BGN } & \text { Navajo } & 341203 \text { N1103623W }\end{array}$

reservoir BGN Gila $\quad 334949$ N1102027W

summit BGN Maricopa 334220N1114202W

valley BGN Yavapai 340849 N1120553W

valley BGN Gila $341118 N 1112228$

reservoir BGN Yavapai 340915N1120335

reservoir BGN Gila 341207N1112055W

reservoir BGN Gila 342244N1113729W

locale

reservoir

VARIANT

reservoir

mine

locale

mine

reservoir

reservoir

strean

ppl

building

Yuma

BGN

Yavapai

$335108 N 1132754 \mathrm{~W}$

344648N1131324W

Navajo

BGN

BGN

UNOFF

BGN

BGN

BGN

BGN
VARIANT

UNOFF

Cochise

Mohave

Mohave

Cochise

Greenlee

Graham

Cochise

Coconino

$342401 N 1100058 \mathrm{~W}$

$312520 \mathrm{~N} 1095552 \mathrm{~W}$

$341811 \mathrm{~N} 1133430 \mathrm{~W}$

$341936 \mathrm{N1133611 \textrm {W }}$

$313116 N 1090555 \mathrm{~W}$

$331707 \mathrm{~N} 1092028 \mathrm{~W}$

$323503 \mathrm{~N} 1101100 \mathrm{~W}$

312540 N1095335W

$323449 \mathrm{~N} 1101425 \mathrm{~W}$

351211N1113950W

locale BGN

school UNOFF

school

reservoir

locale

reservoir

reservoir

UNOFF

BGN

VARIANT

Santa Cruz

Cochise

Maricopa

Maricopa

Coconino

Cochise

BGN Santa Cruz

BGN 1978 Pima

VARIANT

VARIANT

reservoir

spring

spring

reservoir

reservoir

reservoir

bas in

bas in

basin

BGN

$B G N$
$B G N$
$B G N$

BGN

BGN
BGN
$B G N$

BGN

VARIANT

Pima

Goconino

Yavapai

Mohave

Gila

Mohave

Coconino

Mohave

$313150 N 1104613 \mathrm{~W}$

$312545 N 1095325 \%$

332608 N1120430W

351217 N1114107W

312444N1092335W

$312252 \mathrm{~N} 1110003 \mathrm{~W}$

$313032 N 1112447 \mathrm{~W}$

$315323 \mathrm{~N} 1111401 \mathrm{~W}$ $323047 \mathrm{~N} 1101521 \mathrm{~W}$

360246 N1105158W

$350545 N 1131058 \mathrm{~W}$

$350054 \mathrm{~N} 1132433 \mathrm{~W}$

$340551 N 1112201 \mathrm{~W}$

$345803 \mathrm{~N} 1132804 \mathrm{~W}$

$360257 N 1114322 \mathrm{~W}$

360630 N1144236W

spring BGN Mohave 345813N1132755W

reservoir BGN Coconino 355535N1114604W

park ADMIN Pima 32184BN1104750W

spring BGN Cochise 321522 N1093212W

well UNOFF Mohave 344058N1135116

reservoir

reservoir

VARIANT

BGN

VARIANT

Santa Cruz 312538N1110511W

Santa Cruz 31253BN1110511W

Gila

$340205 N 1104820 \mathrm{~W}$

well

spring

UNOFF Maricopa

BGN Navajo

Yavapai

VARIANT

valley

spring

spring

reservoir

reservoir

Mohave

BGN Gila

UNOFF Mohave

Cochise

Coconino

spring BGN Coconino

reservoir

spring

reservoir

BGN

8GN

BGN

BGN

well

UNOFF
Coconino 342641N1110811W

Gila 341357N1110454W

Gila 333932N1100108W

Yavapai 343326N1115111W

Apache

$343708 N 1091919 W$
Greenlee 331234N1092914W $\begin{array}{cc}\text { SOURCE } & \text { ELEV } \\ \text { COORDINATE } & \text { FT }\end{array}$

Cone Butte

Pepper Canyon

Carrizo SE

$340940 \mathrm{~N} 1120135 \mathrm{~W}$

2044 Fort MC Dowell

Joes $\mathrm{Hill}$

Payson South

Joes $\mathrm{Hill}$

Payson South

Strawberry

1971 Socorro Peak

Burro Mesa

Taylor

Bisbee

Artillery Peak

Artillery Peak

Skeleton Canyon

Pipestem Mtn

Harrison Canyon

Bisbee

Flagstaff West

4000 Patagonia

Bisbee

Mesa

Phoenix

Flagstaff West

Pena Blanca Lake

Wilbur Canyon

Samaniego Peak

Bassett Peak

Bat Spring

Anvil Rock Ranch

Penitentiary Mtn

Gisela

Gonzales Wash

Blue Spring

Gonzales Wash

Deer Tank

2800 Sabino Canyon

Luzena

Beecher Canyon

Pena Blanca Lake

Gentry Mtn

Hot Rock Mtn

Dry Lake NW

Tule Mesa

Cherry

Salt River Peak

Pilgrim Wash

Bruno Peak

Lockwood Canyon

Dane Canyon

Diamond Butte

Coronado Mtn

Velasquez Butte

Camp Verde

St Johns North 


\section{FEATURE NAME}

Lower Cedar Bench Tank Lower Cedar Tank

Lower Champaign Spring

Lower Cherum Spring

Lower Cienega Creek See Crooked Creek

Lower Coalfield Mine

Lower Coalson Spring

Lower Cornwall Well

Lower Corral

Lower Corral Canyon

Lower Corral Draw

Lower Corral Tank

Lower Corral Tank Number Two

Lower Corral Tanks

Lower Corral Tanks

Lower Cottonwood Tank

Lower CP Tank

Lower Crossing

Lower Cypress Spring

Lower Dam

Lower Dead Cow Spring

Lower Deadman Tank

Lower Delaney Tank

Lower Dillman Tank

Lower Division

See Boulder Bas in

Lower Dougherty Spring

Lower Dry Pasture Tank

Lower Firebox Tank

Lower Fishhook Canyon

Lower Fishhook Tank Number One

Lower Fishhook Tank Number Two

Lower Four Tank

Lower Fourth of July Spring

Lower French Gulch Windmili

Lower Goat Camp

Lower Goldwater Dam

Lower Goldwater Lake Goldwater Lake

Goldwater Lakes

Lower Grand Wash Cliffs

See Grand Wash Cliffs

Lower Grand Wash Ledge

See Grand Wash Cliffs

Lower Granite Gorge

Bridge Canyon

Granite Gorge of

Shivwits Division

Lower Granite Gorge

See Middle Granite Gorge

Lower Grapevine Spring

Lower Grass Flat Tank

Lower Hackberry Spring

Lower Hidden Spring

Lower Hilton Windmill

Lower H N Trough

Lower Hog Canyon Tank

Lower Hog Canyon Windmil Lowell Windmill

ower Holding Tank

Lower Holdout

Lower Hoot Ow1 Tank

Lower Horse Mesa Tank Number

Lower Hull Spring

Lower Hurricane Valley

Lower Hutcherson Spring

Lower Indian Spring

Lower Jack Tank

Lower Juan Miller Campground
FEATURE
CLASS

reservoir

reservoir BGN

spring

BGN

spring

stream

mine

spring

well

locale

valley

valley

reservoir

BGN

VARIANT

UNOFF

BGN

UNOFF

$B G N$

BGN

BGN

reservoir

reservoir

reservoir

reservoir

reservoir

reservoir

spring

dam

spring

reservoir

BGN

$B G N$
$B G N$
$B G N$
$B G N$

$B G N$

BGN

BGN

BGN

UNOFF

BGN

reservoir

reservoir

BGN

basin

spring

reservoir

reservoir

valley

reservoir

reservoir

reservoir

spring

locale

locale

dam

reservoir

VARIANT
VARIANT
VARIANT

cliff

BGN

BGN

$B G N$

BGN

UNOFF

BGN 1976

VARIANT

VARIANT

Mohave

COUNTY

COORDINATE

Yavapai

Coconino

Maricopa

$342250 \mathrm{~N} 1114730 \mathrm{~W}$

$351914 \mathrm{~N} 1122825 \mathrm{~W}$

332844N1110700W

Mohave

Apache

Pinal

Greenlee

Mohave

Gila

Yavapai

Gila

Gila

Yavapai

Yavapai

Navajo

Yavapai

Yavapa

Yavapa

Yavapai

Yavapai

Graham

Navajo

Coconino

Mohave

Yavapai

Yavapai

Navajo

Graham

Graham

Graham

Santa Cruz

Gila

Yavapai

Graham

Yavapai

Yavapai

$352353 N 1140649 \mathrm{~W}$

334708 N1094209W

$330420 \mathrm{~N} 1103511 \mathrm{~W}$

$331457 N 1090504 \mathrm{~W}$

$343652 \mathrm{~N} 1132209 \mathrm{~W}$

$341117 \mathrm{N1110800 \textrm {W }}$

334159 N1104450W

$344331 N 1130328 \mathrm{~W}$

341203 N1110813W

$341046 N 1110825 \mathrm{~W}$

$344415 \mathrm{~N} 1130311 \mathrm{~W}$

$350032 \mathrm{~N} 1124822 \mathrm{~W}$

$340832 \mathrm{~N} 1100735 \mathrm{~W}$

$340607 \mathrm{N1} 115041 \mathrm{~W}$

$344944 \mathrm{N1} 130241 \mathrm{~W}$

$344647 N 1134647 \mathrm{~W}$

$343431 \mathrm{~N} 1122106 \mathrm{~W}$

341221 N1121433W

$324614 \mathrm{N1} 094504 \mathrm{~W}$

$345237 N 1095448 \mathrm{~W}$

(3)

$360630 \mathrm{N1144236 \textrm {W }}$

$343650 \mathrm{N1} 125132 \mathrm{~W}$

$342225 \mathrm{~N} 1115935 \mathrm{~W}$

$335102 N 1095153 \mathrm{~W}$

331302 N1095918W

331155 N1095847W

331141 N1095859W

$312340 \mathrm{N1} 103854 \mathrm{~W}$

$334808 N 1103612 \mathrm{~W}$

$341624 N 1123441 \mathrm{~W}$

330246 N1101201W

$342954 \mathrm{~N} 1122724 \mathrm{~W}$

$342954 \mathrm{~N} 1122724 \mathrm{~W}$

363600 N1134600W

VARIANT

cliff

valley

BGN 1925

VARIANT

Mohave

Mohave

VARIANT

VARIANT

valley

spring.

reservoir

BGN

Coconino

Yavapai

Navajo

spring

spring
well

reservoir

reservoir

locale

reservoir

bas in

reservoir

BGN Yavapai

BGN Mohave

UNOFF Pima

Gila

BGN

BGN

BGN
VARIANT

BGN

BGN

$B G N$

reservoir BGN

BGN

spring

valley

spring

spring

reservoir

park
BGN

BGN

$B G N$
$B G N$

ADMIN
Greenlee

Cochise

Pinal

Graham

Apache

Gila

Coconino

Mohave

Apache

Mohave

Coconino

Greenlee

$\begin{array}{lc}\text { SOURCE } & \text { ELEV } \\ \text { COORDINATE } & \text { FT }\end{array}$

Horner Mtn

Fitzgerald Hill

Haunted Canyon

Elements Canyon

Jerusalem Mtn

Harden Cienega

Grayback Mts

McDonald Mtn 
NATIONAL GAZETTEER--ARIZONA 1986

\section{FEATURE NAME}

Lower Jumbo Mine

Lower Jump Springs

Lower Jumpup Spring

Lower Junction Dam

Lower Junct ion Tank

Lower Junction Tank Dam

Lower Kirkland Valley

Lower Knolls

Lower Laguna Tank

Lower lake

See Boulder Bas in

Lower Lake Lower Lake Mary
Lake Mary

Lower Lake Mary Dam

Lower Ledge Spring

Lower Limestone Tank

Lower Limestone Tank

Lower Little Park

Lower Lockwood Tank

Lower Log Road Campground

Lower Long Draw Tank

Lower Lyman Ditch

Lower Mc Cauley Tank

Lower McDermit Spring

Lower McGregor Spring

Lower McKinney Tank

Lower Martinez Tank

Lower Miami

Lower Middle Tank

Lower Moss Wash Well

Lower Mount Hope Spring

Lower Moyza Tank

See Suzy Q Tank

Lower Mud Spring Mud Spring

Lower Mud Tank

Lower Mule Creek Spring

Lower North Tank

Lower Oak Creek Windmill

Lower One Tank

Lower Paloma Dam

Lower Parson Well

Lower Pasture Tank

Lower Peach Springs

Lower Pesquiera Well See Lower Pesquira Well

Lower Pesquira Well Lower Pesquiera We11

Lower Pierce Tank

Lower Pigeon Spring

Lower Poquette Tank

Lower Providencia Tanks

Lower PV Trick Tank

Lower Racetrack Mesa Race Track Mesa

Lower Railroad Spring

Lower Ranch Well?

Lower Rattlesnake Tank

Lower Reata Tank

See Lower Arrieta Tank

Lower Reata Water Tank

See Lower Arrieta Tank

Lower Reservoir

Lower Ringtail Tank

Lower Rose Canyon Dam

Lower Rose Canyon Lake

Lower RR Tank

Lower Ruin

See Tonto (cliff dwellings)
FEATURE

CLASS

STATUS

COUNTY

COORDINATE

mine

spring

UNOFF

BGN

Yavapai

Mohave

spring

dam

reservoir

dam

valley

ridge

reservoir

basin

reservoir

BGN

UNOFF

BGN

BGN

BGN

BGN

VARIANT

reservoir

reservoir

Coconino

Graham

Graham

Gila

Yavapai

Navajo

Coconino

Mohave

Maricopa

BGN 1964

Coconino

Coconino

dam

spring

spring

reservoir

reservoir

flat

reservoir

park

$B G N$
$B G N$

BGN

BGN

BGN

BGN

Mohave

Mohave

Gila

Yavapai

Coconino

Coconino

Navajo

reservoir

canal

reservoir

spring

spring

reservoir

reservoir

ppl

reservoir

well

BGN Navajo

BGN Apache

Coconino

Coconino

Yavapai

Graham

Navajo

Gila

Yavapai

BGN

Mohave

spring

reservoir

spring

reservoir

spring

reservoir

locale

BGN

Yavapai

Pima

Gila

BGN

VARIANT

BGN

$B G N$

BGN

$B G N$
$B G N$

Gila

Yavapai

Mohave

Yavapai

Santa Cruz

dan

well

UNOFF
UNOFF

BGN

Santa Cruz

Mohave

Gila

spring BGN Mohave

well

well

reservoir

VARIANT

Santa Cruz

Santa Cruz

UNOFF

VARIANT

BGN

BGN

Navajo

Mohave

reservoir

reservoir

reservoir

summit

spring

well

reservoir

reservoir

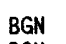

BGN

BGN

BGN

VARIANT

BGN

UNOFF

VARIANT

Maricopa

Santa Cruz

Gila

Gila

Pinal

Yavapai

Yavapai

Pima

VARIANT

reservoir reservoir

reservoir

dam

reservoir

reservoir

locale

BGN

Pima

Coconino

BGN Graham

UNOFF
$335728 \mathrm{~N} 1123410 \mathrm{~W}$

$363450 \mathrm{~N} 1134438 \mathrm{~W}$

$363215 \mathrm{~N} 1123505 \mathrm{~W}$

$332232 \mathrm{~N} 1101305 \mathrm{~W}$

$332232 N 1101305 \mathrm{~W}$

335936 N1101320W

$342626 \mathrm{~N} 1124634 \mathrm{~W}$

$344134 N 1100629 \mathrm{~W}$

$355523 \mathrm{~N} 1130235 \mathrm{~W}$

$360630 \mathrm{~N} 1144236 \mathrm{~W}$

$335015 N 1121611 \mathrm{~W}$

350645N1113457W

350645 N1113457W

$362843 N 1134121 \mathrm{~W}$

$350428 N 1133516 \mathrm{~W}$

$335210 \mathrm{~N} 1102236 \mathrm{~W}$

345932 N1122734W

$361827 N 1120633 \mathrm{~W}$

$354152 \mathrm{~N} 1114516 \mathrm{~W}$

335943 N $1095308 \mathrm{~W}$

$343110 \mathrm{~N} 1103022 \mathrm{~W}$

$343110 \mathrm{~N} 1092339 \mathrm{~W}$

351203 N1122049W

351529 N1115500W

$342545 \mathrm{~N} 1131835 \mathrm{~W}$

$330943 \mathrm{~N} 1100142 \mathrm{~W}$

$340559 \mathrm{~N} 1103707 \mathrm{~W}$

$332424 N 110511 \mathrm{BW}$

$342829 \mathrm{~N} 1121130 \mathrm{~W}$

$345935 \mathrm{~N} 1134219 \mathrm{~W}$

345631 N1130532W

$313830 \mathrm{~N} 1111210 \mathrm{~W}$

$333627 N 1104747 \mathrm{~W}$

$335108 \mathrm{~N} 1102813 \mathrm{~W}$

$342218 N 1121755$

$362250 N 1133849 \mathrm{~W}$

340831 N1122923W

$312150 \mathrm{~N} 1103915 \mathrm{~W}$

$312523 N 1104832 \mathrm{~W}$

$345758 \mathrm{~N} 1133041 \mathrm{~W}$

$334132 \mathrm{~N} 1095656 \mathrm{~W}$

$353533 N 1132621 \mathrm{~W}$

$312420 \mathrm{~N} 1105935 \mathrm{~W}$

$312420 \mathrm{~N} 1105935 \mathrm{~W}$

$343156 N 1102847 \mathrm{~W}$

$361800 \mathrm{~N} 1134112 \mathrm{~W}$

$334255 \mathrm{~N} 1125220 \mathrm{~W}$

$312245 \mathrm{~N} 1104902 \mathrm{~W}$

340747 N1105428W

$340942 \mathrm{~N} 1114028 \mathrm{~W}$

$331719 N 1110934 \mathrm{~W}$

$342655 N 1124024 \mathrm{~W}$

$344615 N 1113955 \mathrm{~W}$

$313032 \mathrm{~N} 1112447 \mathrm{~W}$ 
FEATURE NAME

Lower Rustler Spring

Lower Saginaw Reservoir Rock Reservoir

Lower Sahuarita Dam

Lower Salt House Tank

Lower Sandstone Tank

Lower San Luis Well

Lower Santan Church

Lower Sardina Well

Lower Sevenmile Well

Lower Sheep Spring

Lower Sierrita Well

Lower Simmons Peak

Lower Simmons Well

Lower Skeleton Tank

Lower Skinner Tank

Lower Slick Rock Spring

Lower Sparky Tank

Lower Spring

Lower Spring

Lower Spring Water Windmill

Lower Sullivan Tank

Lower Sycamore Tank

Lower Tailholt Tank

Lower Tank

Lower Tank

Lower Tank

Lower Tank

Lower Tank

Lower Tank

Lower Tank

Lower Tank

Lower Tank

Lower Thirteen Tank

Lower Thompson Mesa Tank

Lower Thompson Spring

Lower Till Iman

Lower Tincup Spring

Lower Tom Brown Well

Lower Triangle Tank

Lower Trick Tank

Lower Turkey Creek Spring Turkey Creek Spring

Lower Two Spring

Lower Two Tank

Lower Two Troughs Tank

Lower Wagner Tank

Lower Wakefield Spring

Lower Walkerfield Spring

Lower Hater

Lower Water Spring

Lower Well

Lower Wel

Lower Well

Lower Wheatfields

Lower Wildcat Tank

Lower Windmill

Lower Windy Tank

Lower Wolf Creek Campground

Lower Wood Camp Spring

Lowery Spring

See Lowrey Spring

Lowery We 11

Lowland Canal (historical)

Lowlander Tank

Lowman We1!

Low Mountain

Low Mountain

Low Mountain

Low Mountain

Low Mountain Airport
FEATURE

CLASS

STATUS COUNTY

spring

BGN

Cochise

COORDINATE

$315422 N 1091637 \mathrm{~W}$

$351430 \mathrm{~N} 112111 \mathrm{BW}$

$\begin{array}{ll}\text { reservoir } & \text { BGN } \\ & \text { VARIANT }\end{array}$

dam

reservoir

well

church

well

well

spring

UNOFF

Coconino

UNOFF

UNOFF

UNOFF

UNOFF

BGN

we 11

well

locale

reservoir

spring

reservoir

spring

spring

well 1

UNOFF

BGN

UNOFF

BGN

BGN

BGN

BGN

$B G N$

$B G N$

UNOFF

reservoir BGN

reservoir $B G$

reservoir $B G$

reservoir $B G$

reservoir BGN

reservoir BGN

reservoir BGN

reservoir

reservoir BGN

reservoir BGN

reservoir $\quad B G$

reservoir BG

reservoir $B G$

reservoir BGN

spring

locale

spring

well

reservoir

reservoir

spring

BGN 1982

spring

reservoir

reservoir

reservoir

spring

spring

spring

spring

well

well

locale

reservoir

locale

reservoir $B G$

park

spring

spring

wel

canal

reservoir

well

summit

summit

summit

$\mathrm{pp}$

airport
Pinal

Coconino

Cocon in

Pima

Pinal

Pima

Maricopa

$323215 N 1105905 \mathrm{~W}$

$360952 \mathrm{~N} 1133936 \mathrm{~W}$

$355044 \mathrm{~N} 1125010 \mathrm{~W}$

$31343 \mathrm{BN} 1112620 \mathrm{~W}$

$330846 \mathrm{~N} 1114630 \mathrm{~W}$

313639 N1110954W

$332525 \mathrm{~N} 1102851 \mathrm{~W}$

335541 N1113302W

Pima

Mohave

Mohave

Cochise

Yavapai

Yavapai

Gila

Pima

Mohave

Pima

$315459 N 1111321 \mathrm{~W}$

$345505 N 1132626$

$345526 \mathrm{~N} 1132641 \mathrm{~W}$

313542 N1090310W

341837 N1121523W

$343737 \mathrm{~N} 1120546 \mathrm{~W}$

$340413 N 1105 B 25 \mathrm{~W}$

$321218 \mathrm{~N} 1102823 \mathrm{~W}$

$360534 N 1133421 \mathrm{~W}$

$314808 \mathrm{~N} 1103323 \mathrm{~W}$

$363700 \mathrm{~N} 1133203 \mathrm{~W}$

Mohave

Graham

Yavapai

Pima

Cochise

Pinal

Yavapai

Navajo

Mohave

Navajo

Yavapai

Coconino

Santa Cruz

Gila

Coconino

Coconino

Coch ise

Mohave

Santa Cruz

$24111 \mathrm{~N} 1102055 \mathrm{~W}$

$344646 \mathrm{~N} 1124414 \mathrm{~W}$

313215 N111230BW

$314649 \mathrm{~N} 1102226 \mathrm{~W}$

$324541 \mathrm{~N} 1110705 \mathrm{~W}$

$341750 N 1122617 \mathrm{~W}$

$343001 N 1102315 \mathrm{~W}$

34331 BN11 $40127 \mathrm{~W}$

$343445 \mathrm{~N} 1100329 \mathrm{~W}$

$350102 \mathrm{~N} 1125840 \mathrm{~W}$

$351239 \mathrm{~N} 1112606 \mathrm{~W}$

$312052 \mathrm{~N} 110390 \mathrm{BW}$

$334820 \mathrm{~N} 1110347 \mathrm{~W}$

$361430 \mathrm{~N} 1120333 \mathrm{~W}$

$343742 \mathrm{~N} 1104745 \mathrm{~W}$

$312459 \mathrm{~N} 1092549 \mathrm{~W}$

345518 N1133052

$312055 \mathrm{~N} 1110346 \mathrm{~W}$

$343124 \mathrm{~N} 1102958 \mathrm{~W}$

$321023 \mathrm{~N} 1102853 \mathrm{~W}$

$362202 \mathrm{~N} 1121824 \mathrm{~W}$

$312202 N 1103847 \mathrm{~W}$

$324841 \mathrm{~N} 1100430 \mathrm{~W}$

$355921 \mathrm{N1} 121929 \mathrm{~W}$

$315150 \mathrm{N1102710 \textrm {W }}$

$315241 \mathrm{~N} 1102700 \mathrm{~W}$

$341812 \mathrm{~N} 1115910 \mathrm{~W}$

350722 N1132657W

321948 N1130109W

$333310 \mathrm{~N} 1104955 \mathrm{~W}$

$343246 \mathrm{~N} 1140109 \mathrm{~W}$

$361215 \mathrm{~N} 1090 \mathrm{BO} 7 \mathrm{~W}$

$344810 \mathrm{~N} 1121537 \mathrm{~W}$

$323122 N 1102937 \mathrm{~W}$

330551 N1093408W

$342714 N 1122734 \mathrm{~W}$

$333406 \mathrm{~N} 1103953 \mathrm{~W}$

365024N1114054W

$345954 \mathrm{~N} 1091414 \mathrm{~W}$

332920 N111531WW

$350419 N 1114115 \mathrm{~W}$

$341230 \mathrm{~N} 1125007 \mathrm{~W}$

$335651 \mathrm{~N} 1133056 \mathrm{~W}$

$355812 \mathrm{~N} 1100447 \mathrm{~W}$

$365005 \mathrm{~N} 1134336 \mathrm{~W}$

$355625 \mathrm{~N} 1100646 \mathrm{~W}$

$355655 \mathrm{~N} 1100715 \mathrm{~W}$

SOURCE
COORDV

MAP NAME

Rustler Park

Williams South

Oracle Junction

Snap Draw

Supai Camp SE

Wilbur Canyon

Gila Butte

Murphy Peak

2868 Natural Corral

Lion Mountain

Samaniego Peak

Gonzales Wash

Gonzales Wash

Skeleton Canyon

Battle Flat

Cottonwood

Young

Happy Valley

Mt Dellenbaugh

Spring Water Canyon

Sullivan Draw South

Kennedy Peak 
NATIONAL GAZETTEER--ARIZONA 1986

\section{FEATURE NAME}

Low Mountain Reservoir

Lowrey Spring

$$
\text { Lowery Spring }
$$

Lows Ranch

Low Tank

Low Valley

Loy Butte

Loy Butte Five

Loy Canyon

L P Cartley Canyon

L P Spring

L Tank

L Tank

L Tank

Lucacsaca Spring

See Lokasakad Spring

Lucifer Point

See Uncle Jim Point

Lucky Boy Mine

Lucky Boy Spring

Lucky Canyon

Lucky Canyon Windmill

Lucky Cuss Mine

Lucky Dam

Lucky Day Mine

Lucky Hills Stock Ranch

Lucky Jack

Lucky Ledge Mine

Lucky Mine

Lucky Mine

Lucky Spring

Lucky Spring

Lucky Spring Canyon

Lucky Strike Mine

Lucky Tank

Lucky Tank

Lucky Tank

Lucky Well

Lucson

See Tucson

Lucy Canyon

Lucy Peak

Ludden Mountain

Ludden Park

Lude 1 Wash See Sandridge Wash

Luding Siding

Luis Maria Baca Float Number Five

Luis Maria Baca Grant (float Number Three)

Lukachukai

Lukachukai Airport

Lukachukai Boarding School

Lukachukai Creek Lukachukai Wash

Lukachukai Mountains

Lukachukai Post office

Lukachukai Trading Post

Lukachukaj Wash

See Lukachukai Creek

Lukaigai Well

Lu Kai le gei Well

Lukai Spring

Lukai Wash

Lukasakad

See Lokasakad Spring

Lukasakad

See Lokasakal Spring

Lukasakad Spring
CLASS

STATUS

COUNTY

COORDINATE

$365018 N 1134248 W$

reservoir

BGN

Mohave

$365024 N 1114054 \mathrm{~W}$

spring

BGN 1969

local

reservoir BGN Coconino 345851N1112400W

basin BGN Coconino 363803N1111635W

summit BGN Yavapai 345635N1115550W

trail UNOFF Yavapai 345730 N1115521W

valley

$\begin{array}{lll} & \text { VARIANT } & \\ \text { BGN } & \text { Gila } & 341641 N 1113242 \mathrm{~W}\end{array}$

spring

reservoir

reservoir

reservoir

spring

cliff

mine

spring

valley

well

mine

dam

mine

locale

ridge

mine

mine

mine

spring

spring

valley

mine

reservoir

reservoir

reservoir

we 11

pp 1

BGN
BGN
BGN
BGN
VARIANT

Gila

Gila

Navajo

Coconino

341708 N1113250W

$333513 \mathrm{~N} 1100117 \mathrm{~W}$

$345230 \mathrm{N1} 103840 \mathrm{~W}$

$351114 N 1114826 \mathrm{~W}$

$352410 \mathrm{~N} 1100 \mathrm{~B} 24 \mathrm{~W}$

VARIANT

Navajo

Coconino

Mohave

Mohave

BGN

BGN

UNOFF

UNDFF

UNDFF

UNDFF

UNOFF

BGN

UNOFF

UNDFF

Yavapai

Yavapai

Maricopa

Yavapai

Maricopa

Cochise

Cochise

Santa Cruz

Maricopa

Yavapai

BGN
BGN
BGN
UNOFF
BGN
BGN
BGN
UNOFF
VARIANT

Yavapai

Yavapai

Yavapa

Gila

Yavapai

Coconino

Coconino

Mohave

Pima

valley

summit

summit

park

stream

locale

civil

civil

BGN
BGN

BGN

ADMIN

VARIANT

BGN

ADMIN

ADMIN

Mavajo

Yavapai

Maricopa

Maricopa

Mohave

Yuma

Yavapai

361248 N1120209W

352451 N1140857W

352512 N1140B58W

$343219 N 1115213 \mathrm{~W}$

$343152 \mathrm{~N} 1115320 \mathrm{~W}$

$33532 B N 1125714 \mathrm{~W}$

351811N1131943W

335317 N1124911W

$314246 \mathrm{~N} 1100453 \mathrm{~W}$

$312534 N 1095439 \mathrm{~W}$

314256N1105210W

$334331 \mathrm{N1131128 \textrm {W }}$

$340203 \mathrm{~N} 1121819 \mathrm{~W}$

$340221 \mathrm{~N} 1121521 \mathrm{~W}$

$340906 \mathrm{~N} 1122717 \mathrm{~W}$

$340233 \mathrm{~N} 1121422 \mathrm{~W}$

$335126 \mathrm{~N} 1105357 \mathrm{~W}$

$345505 \mathrm{~N} 1121820 \mathrm{~W}$

$351041 \mathrm{~N} 1112353 \mathrm{~W}$

$352739 N 1113500 \mathrm{~W}$

$360010 \mathrm{~N} 1140227 \mathrm{~W}$

$321318 N 1105533 W$

$340551 \mathrm{~N} 1100454 \mathrm{~W}$

$343444 N 1131311 \mathrm{~W}$

$334309 \mathrm{~N} 1121114 \mathrm{~W}$

333631 N1121918W

$365145 N 1131239 \mathrm{~W}$

324348 N1144013W

$345615 \mathrm{~N} 1130345 \mathrm{~W}$

313150N1105628W

Santa Cruz

$362501 \mathrm{~N} 1091341 \mathrm{~W}$

$362402 N 1091524 \mathrm{~W}$

362459 N1091345W

363B50N1093609W

362904 N1091211W

$362447 N 1091455 \mathrm{~W}$

362447 N1091455W

363850N1093609W

$354814 N 1092603 \mathrm{~W}$

$354927 N 1092515 \mathrm{~W}$

$353119 \mathrm{~N} 1102052 \mathrm{~W}$

$353002 \mathrm{~N} 1102413 \mathrm{~W}$

$352410 \mathrm{~N} 1100824 \mathrm{~W}$

spring

spring

Navajo

Navajo

VARIANT

SOURCE

COORDINATE

ELEV

MAP NAME

Wolf Hole Mtn West

Navajo Bridge

3720 Kino Springs

Sycamore Point

Many Ghosts Hill

5700 Loy Butte

Loy Butte

345524N1115500W

Page Springs

341756N1113313W

Cane Springs Mtn

Cane Springs Mtn

Georges Butte

Clear Creek Res

Bellemont

Chloride

Chloride

343028 N1115428W

Camp Verde

Middle Verde

Outlaw Hill

Blye Canyon SE

Vulture Peak

Tombs tone

Bisbee

Mt Wrightson

Little Horn Peak

Columbia

Columbia

Minnehaha

Black Canyon City

Aztec Peak

Hell Point

Winona

O'Leary Peak

Meadview Morth

340342N1100503

Faught Ridge

Bagdad

2197 Hedgpeth Hills

El Mirage

Yuna West

Mount Hope

San Cayetano Mts

Lukachukai

6433 Bad Bug Butte

Lukachukai

362556N1090921W

Dancing Rocks

Lukachukai 


\begin{tabular}{|c|c|c|c|c|c|c|c|}
\hline FEATURE NAME & $\begin{array}{l}\text { FEATURE } \\
\text { CLASS }\end{array}$ & STATUS & COUNTY & COORDINATE & $\begin{array}{l}\text { SOURCE } \\
\text { COORDINATE }\end{array}$ & $\begin{array}{c}\text { ELEV } \\
\text { FT }\end{array}$ & MAP NAME \\
\hline See Lokasakad Spring & spring & & Navajo & $352410 \mathrm{~N} 1100824 \mathrm{~W}$ & & & \\
\hline $\begin{array}{l}\text { Luke Mountain } \\
\text { Luke Mountain Tank } \\
\text { Luke School } \\
\text { Lukes Hoist Mine } \\
\text { Lukeville } \\
\text { Sonoita } \\
\text { Luke Wash } \\
\text { Luke Well } \\
\text { Lumpkin Tank } \\
\text { Lum Wash }\end{array}$ & $\begin{array}{l}\text { summit } \\
\text { reservoir } \\
\text { school } \\
\text { mine } \\
\text { ppl } \\
\text { stream } \\
\text { well } \\
\text { reservoir } \\
\text { stream }\end{array}$ & $\begin{array}{l}\text { BGN } \\
\text { BGN } \\
\text { UNOFF } \\
\text { UNOFF } \\
\text { BGN } \\
\text { VARIANT } \\
\text { BGN } \\
\text { UNOFF } \\
\text { BGN } \\
\text { BGN }\end{array}$ & $\begin{array}{l}\text { Coconino } \\
\text { Coconino } \\
\text { Maricopa } \\
\text { Yavapai } \\
\text { Pima } \\
\text { Maricopa } \\
\text { Maricopa } \\
\text { Coconino } \\
\text { Maricopa }\end{array}$ & $\begin{array}{l}344911 \mathrm{~N} 1113336 \mathrm{~W} \\
344831 \mathrm{~N} 1113428 \mathrm{~W} \\
333225 \mathrm{~N} 1122028 \mathrm{~W} \\
341054 \mathrm{~N} 1122014 \mathrm{~W} \\
315257 \mathrm{~N} 1124854 \mathrm{~W} \\
331911 \mathrm{~N} 1124549 \mathrm{~W} \\
331950 \mathrm{~N} 1130425 \mathrm{~W} \\
354404 \mathrm{~N} 1121632 \mathrm{~W} \\
332114 \mathrm{~N} 1122846 \mathrm{~W}\end{array}$ & $\begin{array}{l}332513 \mathrm{~N} 1124825 \mathrm{~W} \\
331853 \mathrm{~N} 1122345 \mathrm{~W}\end{array}$ & $\begin{array}{l}7008 \\
1410\end{array}$ & $\begin{array}{l}\text { Stoneman Lake } \\
\text { Stoneman Lake } \\
\text { El Mirage } \\
\text { Crown King } \\
\text { Lukeville } \\
\text { Arlington } \\
\text { Forth of July Butte } \\
\text { Miller Tank } \\
\text { Avondale SW }\end{array}$ \\
\hline $\begin{array}{l}\text { Luna Dam } \\
\text { Luna Lake } \\
\text { Luna Lake Campground } \\
\text { Lunan Mine } \\
\text { Lundell Tank } \\
\text { Lundgren Pond } \\
\text { Lund Pasture Tank } \\
\text { Lunn Tank } \\
\text { Lupe Well } \\
\text { Lupton }\end{array}$ & $\begin{array}{l}\text { dam } \\
\text { reservoir } \\
\text { park } \\
\text { mine } \\
\text { reservoir } \\
\text { lake } \\
\text { reservoir } \\
\text { reservoir } \\
\text { well } \\
\text { ppl }\end{array}$ & $\begin{array}{l}\text { UNOFF } \\
\text { BGN } \\
\text { ADNIN } \\
\text { UNOFF } \\
\text { BGN } \\
\text { BGN } \\
\text { BGN } \\
\text { BGN } \\
\text { UNOFF } \\
\text { BGN }\end{array}$ & $\begin{array}{l}\text { Apache } \\
\text { Apache } \\
\text { Apache } \\
\text { Yavapai } \\
\text { Mohave } \\
\text { Mohave } \\
\text { Gila } \\
\text { Gila } \\
\text { Santa Cruz } \\
\text { Apache }\end{array}$ & $\begin{array}{l}334936 \mathrm{~N} 1090454 \mathrm{~W} \\
334944 \mathrm{~N} 1090454 \mathrm{~W} \\
335010 \mathrm{~N} 1090432 \mathrm{~W} \\
340223 \mathrm{~N} 1121826 \mathrm{~W} \\
361246 \mathrm{~N} 1133717 \mathrm{~W} \\
361520 \mathrm{~N} 1134119 \mathrm{~W} \\
331713 \mathrm{~N} 1105434 \mathrm{~W} \\
331727 \mathrm{~N} 1105359 \mathrm{~W} \\
314029 \mathrm{~N} 1110232 \mathrm{~W} \\
352114 \mathrm{~N} 1090311 \mathrm{~W}\end{array}$ & & & $\begin{array}{l}\text { Luna Lake } \\
\text { Luna Lake } \\
\text { Luna Lake } \\
\text { Columbia } \\
\text { Cast le Peak } \\
\text { Mustang Point } \\
\text { Pinal Ranch } \\
\text { Pinal Ranch } \\
\text { Amado } \\
\text { Lupton }\end{array}$ \\
\hline $\begin{array}{l}\text { Lupton Chapter House } \\
\text { Lupton Interchange } \\
\text { Lust Tank } \\
\text { Lute Hart Tank } \\
\text { Lute Hart Tank } \\
\text { Luteky Tank } \\
\text { Luth Hart Tank } \\
\text { Lutz Canyon } \\
\text { Lutz Tunnel } \\
\text { Luzena } \\
\quad \text { Bowie Junction }\end{array}$ & $\begin{array}{l}\text { building } \\
\text { crossing } \\
\text { reservoir } \\
\text { reservoir } \\
\text { reservoir } \\
\text { reservoir } \\
\text { reservoir } \\
\text { valley } \\
\text { mine } \\
\text { locale }\end{array}$ & $\begin{array}{l}\text { UNOFF } \\
\text { UNOFF } \\
\text { BGN } \\
\text { BGN } \\
\text { BGN } \\
\text { BGN } \\
\text { BGN } \\
\text { BGN } \\
\text { UNOFF } \\
\text { BGN } \\
\text { VARIANT }\end{array}$ & $\begin{array}{l}\text { Apache } \\
\text { Apache } \\
\text { Coconino } \\
\text { Coconino } \\
\text { Coconino } \\
\text { Yavapai } \\
\text { Coconino } \\
\text { Cochise } \\
\text { Cochise } \\
\text { Cochise }\end{array}$ & $\begin{array}{l}352020 \mathrm{~N} 1090409 \mathrm{~W} \\
352128 \mathrm{~N} 1090305 \mathrm{~W} \\
343847 \mathrm{~N} 1111701 \mathrm{~W} \\
344744 \mathrm{~N} 1110720 \mathrm{~W} \\
350257 \mathrm{~N} 1110951 \mathrm{~W} \\
345916 \mathrm{~N} 1130249 \mathrm{~W} \\
344815 \mathrm{~N} 1111547 \mathrm{~W} \\
312240 \mathrm{~N} 1101613 \mathrm{~W} \\
312302 \mathrm{~N} 1101709 \mathrm{~W} \\
322117 \mathrm{~N} 1093734 \mathrm{~W}\end{array}$ & $312330 \mathrm{~N} 1101731 \mathrm{~W}$ & $\begin{array}{l}6200 \\
5765\end{array}$ & $\begin{array}{l}\text { Lupton } \\
\text { Lupton } \\
\text { Turkey Mtn } \\
\text { Chavez Mtn East } \\
\text { Anderson Canyon } \\
\text { Mount Hope } \\
\text { Jaycox Mtn } \\
\text { Miller Peak } \\
\text { Miller Peak } \\
\text { Luzena }\end{array}$ \\
\hline $\begin{array}{l}\text { Lyle Canyon Trail One Hundred } \\
\text { Twenty } \\
\text { Lyle Peak } \\
\text { Lyman Dam } \\
\text { Lyman Ditch } \\
\text { Lyman Lake } \\
\quad \text { Lyman Reservoir } \\
\text { Lyman Lake Marina } \\
\text { Lyman Lake State Park } \\
\text { Lyman Reservoir } \\
\text { See Lyman Lake }\end{array}$ & $\begin{array}{l}\text { trail } \\
\text { summit } \\
\text { dam } \\
\text { canal } \\
\text { reservoir } \\
\text { locale } \\
\text { park } \\
\text { reservoir }\end{array}$ & $\begin{array}{l}\text { UNOFF } \\
\text { BGN } \\
\text { UNOFF } \\
\text { BGN } \\
\text { BGN } \\
\text { VARIANT } \\
\text { BGN } \\
\text { ADMIN } \\
\text { VARIANT }\end{array}$ & $\begin{array}{l}\text { Cochise } \\
\text { Cochise } \\
\text { Apache } \\
\text { Apache } \\
\text { Apache } \\
\text { Apache } \\
\text { Apache } \\
\text { Apache }\end{array}$ & $\begin{array}{l}312750 \mathrm{~N} 1102520 \mathrm{~W} \\
312856 \mathrm{~N} 1102326 \mathrm{~W} \\
342154 \mathrm{~N} 1092300 \mathrm{~W} \\
342448 \mathrm{~N} 1092509 \mathrm{~W} \\
342125 \mathrm{~N} 1092123 \mathrm{~W} \\
342152 \mathrm{~N} 1092219 \mathrm{~W} \\
342147 \mathrm{~N} 1092227 \mathrm{~W} \\
342125 \mathrm{~N} 1092123 \mathrm{~W}\end{array}$ & & $597 \mathrm{~B}$ & $\begin{array}{l}\text { Huachuca Peak } \\
\text { Huachuca Peak } \\
\text { Lyman Lake SW } \\
\text { Salado } \\
\text { Lyman Lake } \\
\text { Lyman Lake } \\
\text { Lyman Lake }\end{array}$ \\
\hline $\begin{array}{l}\text { Lynn School } \\
\text { Lynn Tank } \\
\text { Lynx Campground } \\
\text { Lynx Creek } \\
\text { Lynx Creek Dam } \\
\text { Lynx Lake } \\
\text { Lynx Lake Dam } \\
\text { Lyon Latera1 } \\
\text { Lyons Canyon } \\
\text { Lyons Fork }\end{array}$ & $\begin{array}{l}\text { school } \\
\text { reservoir } \\
\text { park } \\
\text { stream } \\
\text { dam } \\
\text { reservoir } \\
\text { dam } \\
\text { canal } \\
\text { valley } \\
\text { stream }\end{array}$ & $\begin{array}{l}\text { UNOFF } \\
\text { BGN } \\
\text { ADMIN } \\
\text { BGN } \\
\text { UNOFF } \\
\text { BGN } \\
\text { UNOFF } \\
\text { BGN } \\
\text { BGN } \\
\text { BGN }\end{array}$ & $\begin{array}{l}\text { Pima } \\
\text { Coconino } \\
\text { Yavapai } \\
\text { Yavapai } \\
\text { Yavapai } \\
\text { Yavapai } \\
\text { Yavapai } \\
\text { Yuma } \\
\text { Gila } \\
\text { Pinal }\end{array}$ & $\begin{array}{l}321035 \mathrm{~N} 1105948 \mathrm{~W} \\
365404 \mathrm{~N} 1114723 \mathrm{~W} \\
343104 \mathrm{~N} 1122325 \mathrm{~W} \\
343251 \mathrm{~N} 1121444 \mathrm{~W} \\
34342 \mathrm{BN} 1122100 \mathrm{~W} \\
343118 \mathrm{~N} 1122312 \mathrm{~W} \\
34311 \mathrm{BN} 1122312 \mathrm{~W} \\
323150 \mathrm{~N} 1144727 \mathrm{~W} \\
331636 \mathrm{~N} 1105756 \mathrm{~W} \\
331535 \mathrm{~N} 1105 \mathrm{~B} 11 \mathrm{~W}\end{array}$ & $\begin{array}{l}342659 \mathrm{~N} 1122453 \mathrm{~W} \\
331817 \mathrm{~N} 1105230 \mathrm{~W} \\
331817 \mathrm{~N} 1105552 \mathrm{~W}\end{array}$ & 5229 & $\begin{array}{l}\text { Tucson } \\
\text { Wrather Arch } \\
\text { Prescott } \\
\text { Humboldt } \\
\text { Prescott Valley } \mathrm{S} \\
\text { Prescott } \\
\text { Prescott } \\
\text { Gadsden } \\
\text { Pinal Ranch } \\
\text { Pinal Ranch }\end{array}$ \\
\hline $\begin{array}{l}\text { Lyons Fork Spring } \\
\text { Lyons Point } \\
\text { Lyon Spring } \\
\text { Lyon Spring Number One } \\
\text { Lyons School } \\
\text { Lan Lyons School } \\
\text { Lytle Spring }\end{array}$ & $\begin{array}{l}\text { spring } \\
\text { cliff } \\
\text { spring } \\
\text { spring } \\
\text { school } \\
\text { spring }\end{array}$ & $\begin{array}{l}\text { BGN } \\
\text { BGN } \\
\text { BGN } \\
\text { BGN } \\
\text { UNOFF } \\
\text { VARIANT } \\
\text { BGN }\end{array}$ & $\begin{array}{l}\text { Gila } \\
\text { Mohave } \\
\text { Yavapai } \\
\text { Yavapai } \\
\text { Pima } \\
\text { Mohave }\end{array}$ & $\begin{array}{l}331737 \mathrm{~N} 1105551 \mathrm{~W} \\
365739 \mathrm{~N} 1125316 \mathrm{~W} \\
343430 \mathrm{~N} 1120106 \mathrm{~W} \\
343415 \mathrm{~N} 1120045 \mathrm{~W} \\
321016 \mathrm{~N} 1104946 \mathrm{~W} \\
365509 \mathrm{~N} 1131101 \mathrm{~W}\end{array}$ & & & $\begin{array}{l}\text { Pinal Ranch } \\
\text { Colorado City } \\
\text { Cherry } \\
\text { Cherry } \\
\text { Tucson East } \\
\text { Lost Spring Mtn We }\end{array}$ \\
\hline
\end{tabular}


FEATURE CLASS

STATUS

COUNTY

COOROINATE

SOURCE

COORDINATE FT

MAP NAME

Mable Pond

McAfee Place Unit Two Mini Park

McAfee Place Unit Two Water

Retention Bas in

McAllister Range

MCAllister Spring

McAll ister Wash

McBeth Spring McKeth Spring

McBride Spring

McBride Tank

MCBridge Canyon

McBryde Reservoir

McCafferty Canyon

McCamant Hills

McCann Spring Tank

McCarrell Memorial Cemetery

McCarroll Interchange

McCarty Draw

Clear Creek Canyon Miller Creek

McCarty Draw

See Miller Canyon

McCarty Ridge

McCarty Tank

McCauley Sinks

McCleary Canyon

McCleary Peak

McClellan

See Supai

McClellan Mine

McClellans Wash

See McClellan Wash

$\mathrm{McClellan}$ Tanks

McClellan Wash McClellans Wash

McClellan Wash

McClellan Wash

McClendon Tank

$\mathrm{McCleve}$ Canyon

McCleve Tank

McClintock Oraw

$\mathrm{McCl}$ intock High School

McClintock Manor (subdivision)

McClintock Ridge

McClintock Spring

McCloud Mountains

McCloud Spring

McClure Canyon

McClure Lake

McClure Spring

McClure Tank

McConnico

McCormacks Well

McCormick Canyon

McCormick Park

Northeast D McCormick Park

McCormick Railroad Park

McCormick Ranch

McCormick Spring

McCormick Wash

McCoy Bridge

McCracken Knoll Number One lake BGM

AOMIN Mohave

BGN

Maricopa

$362916 \mathrm{~N} 1132249 \mathrm{~W}$

$332355 \mathrm{~N} 1114800 \mathrm{~W}$

$332355 \mathrm{~N} 1114800 \mathrm{~W}$

range BGN Yavapai 341248N1122930W

spring BGN Yavapi 341241N1123037W

BGN 1981 Santa Cruz 314124N1105128W

spring BGN Greenlee 331352N1092033W

reservoir BGN Gila 335840N111043BW

valley BGN Greenlee 333001N1092806W

reservoir BGN

valley BGN Pima 313612N1112154W

$\begin{array}{ll}\text { ridge } & \text { BGN } \\ \text { reservoir } & \text { BGN } \\ \text { cemetery } & \text { UNOFF } \\ \text { crossing } & \text { UNOFF } \\ \text { valley } & \text { BGN 1966 } \\ & \text { VARIANT } \\ & \text { VARIANT } \\ & \text { VARIANT }\end{array}$

valley Coconino 343259N1111417W

ridge BGN $\quad \begin{array}{ll}\text { Coconino } & 343259 N 1111417 \mathrm{~W} \\ & \end{array}$

reservoir BGN Pinal 324230N1105835W

basin BGN Navajo 344756 N1103515W

valley BGN $\quad$ Pima $315041 \mathrm{N1104310 \textrm {W }}$

summit BGN 1930 Pima 314341N1105050W

Coconino 35134BN1121411W

mine UNOFF Mohave 351B00N1140600W

VARIANT

reservoir

BGN

Pinal

Coconino

$324547 \mathrm{~N} 1113053 \mathrm{~W}$

$362729 \mathrm{~N} 1113451 \mathrm{~W}$

stream

stream

stream

reservoir

valley

reservoir

valley

school

pp 1

BGN
VARIANT
BGN
BGN
BGN
BGN
BGN
BGN
UNOFF
BGN

Pinal

Pinal

Pinal

Cochise

Navajo

Mavajo

Coconino

Maricopa

Maricopa

$324547 \mathrm{~N} 1113053 \mathrm{~W}$

$325524 \mathrm{N1113034 \textrm {W }}$

$330305 \mathrm{~N} 1113956 \mathrm{~W}$

$313511 \mathrm{~N} 1095634 \mathrm{~W}$

$341426 \mathrm{~N} 1101427 \mathrm{~W}$

$341350 \mathrm{~N} 1101538 \mathrm{~W}$

343003 N1110B39W

$332350 \mathrm{~N} 1115423 \mathrm{~W}$

$332322 \mathrm{~N} 1115417 \mathrm{~W}$

\section{ridge}

spring

summit

spring

valley

lake

spring

reservoir

locale

well

BGN Coconino

$342755 \mathrm{~N} 1111005 \mathrm{~W}$

$342924 N 1110909 \mathrm{~W}$

342545N1125742W

342619 N1125B2BW

$312817 \mathrm{~N} 1102117 \mathrm{~W}$

$343527 \mathrm{~N} 1111644 \mathrm{~W}$

312B28N1102219W

$345653 \mathrm{~N} 1121801 \mathrm{~W}$

$350838 \mathrm{~N} 1140534 \mathrm{~W}$

$333005 \mathrm{~N} 1140219 \mathrm{~W}$

valley $B G N \quad$ Cochise $321204 N 1102429 W$

$321540 \mathrm{~N} 1105400 \mathrm{~W}$

$333215 \mathrm{~N} 1115521 \mathrm{~W}$

333309 N1115405W

$340853 \mathrm{~N} 1094622 \mathrm{~W}$

$332418 \mathrm{~N} 110470 \mathrm{WW}$

$340247 \mathrm{~N} 1094340 \mathrm{~W}$

$350853 \mathrm{~N} 1121147 \mathrm{~W}$

Apache

Gila

Coconino
Poverty Knoll

Mesa

Mesa

Minnehaha

Wagoner

331532 N1142707W $\quad \begin{aligned} & \text { Red Hill SW } \\ & \text { Mt Wrightson }\end{aligned}$

Mitchell Peak

Copper Mtn

Baldy Bill Point

Antelope Knoll

$313801 \mathrm{~N} 1112148 \mathrm{~W} \quad$ Arivaca

McCauley Sinks

Adams Mesa

Chambers

343047 N1111620w $5700 \begin{aligned} & \text { Chambers } \\ & \text { Blue Ridge Reservoir }\end{aligned}$

Long Valley

Fortified Mtn

McCauley Sinks

Empire Ranch

Mt Wrightson

Stockton $\mathrm{Hill}$

Cedar Ridge

Eloy North

Coolidge

Sacaton

Potter Mtn

Red Top Mtn

Limestone Canyon $N$

Blue Ridge Reservoir

Tempe

1190 Tempe

Dane Canyon

Dane Canyon

Hillside

Hillside

Miller Peak

Long Valley

Miller Peak

Hell Point

Kingman

Crystal Hill

321043N1102318W Happy Valley

Tucson North

Paradise Valley

1300 Paradise Valley

Sponseller Mtn

$332514 N 1104555 \mathrm{~W}$

$$
\text { Globe }
$$


McCracken Knoll Number Three Mccracken Knoll Number Two

UNOFF
BGN
VARIANT
BGN
VARIANT
AOMIN
BGN
UNOFF
BGN

valley lake

spring

\section{BGN}

BGN

VARIANT

valley

valley

valley

strean

flat

VARIANT

Ben Gila

BGN Navajo

BGN Apache

BGN

summit

reservoir

park

bas in

locale

spring

reservoir

flat

reservoir

spring

BGN

ADMIN

BGN

UNOFF

BGN

BGN

BGN

VARIANT

spring BGN 1969

stream

DPI VARIANT

summit BGN

VARIANT

$\begin{array}{ll}\text { park } & \text { AOMIN } \\ \text { VARIANT }\end{array}$

summit

McDowell Mountain Regional Park McDowell Mountains

McDowell Mountains

McDowell Pass

McDowell Peak

$$
\text { Mount McDowell }
$$

McDowell Tank

McDowell Trailer Village

McE Thaney Tank

McE lheny Tank

McEnary Tunnel

McEuen Cemetery

McEwen Trap Spring

McFadden Creek

McFadden Horse Mountain

McFadden Peak

\begin{tabular}{|c|c|c|}
\hline $\begin{array}{l}\text { park } \\
\text { range } \\
\text { summit }\end{array}$ & $\begin{array}{l}\text { AOMIN } \\
\text { BGN } \\
\text { BGN }\end{array}$ & $\begin{array}{l}\text { Maricopa } \\
\text { Maricopa }\end{array}$ \\
\hline $\begin{array}{l}\text { gap } \\
\text { summit }\end{array}$ & $\begin{array}{l}\text { BGN } \\
\text { BGN } \\
\text { VARIANT } \\
\text { VARIANT }\end{array}$ & $\begin{array}{l}\text { Maricopa } \\
\text { Maricopa }\end{array}$ \\
\hline $\begin{array}{l}\text { locale } \\
\text { locale } \\
\text { building }\end{array}$ & $\begin{array}{l}\text { UNOFF } \\
\text { UNOFF } \\
\text { UNOFF }\end{array}$ & $\begin{array}{l}\text { Maricopa } \\
\text { Maricopa } \\
\text { Maricopa }\end{array}$ \\
\hline $\begin{array}{l}\text { reservoir } \\
\text { locale } \\
\text { reservoir } \\
\text { reservoir } \\
\text { tunnel } \\
\text { cemetery } \\
\text { spring } \\
\text { stream } \\
\text { summit } \\
\text { summit }\end{array}$ & $\begin{array}{l}\text { BGN } \\
\text { UNOFF } \\
\text { BGN } \\
\text { BGN } \\
\text { UNOFF } \\
\text { UNOFF } \\
\text { BGN } \\
\text { BGN } \\
\text { BGN } \\
\text { BGN }\end{array}$ & $\begin{array}{l}\text { Maricopa } \\
\text { Maricopa } \\
\text { Yavapai } \\
\text { Yavapai } \\
\text { Graham } \\
\text { Graham } \\
\text { Graham } \\
\text { Gila } \\
\text { Gila } \\
\text { Gila }\end{array}$ \\
\hline
\end{tabular}

$350840 \mathrm{N1121050 \textrm {W }}$

$342629 \mathrm{N1134630 \textrm {W }}$

$352742 \mathrm{~N} 1124656 \mathrm{~W}$

$325301 \mathrm{N1123554 \textrm {W }}$

$350206 N 1094132 \mathrm{~W}$

$341542 \mathrm{~N} 1124337 \mathrm{~W}$

363511N1131906W

$363511 \mathrm{N1131906 \textrm {W }}$

323517 N1144601W

$345120 \mathrm{~N} 1120649 \mathrm{~W}$

$313435 \mathrm{N1102955 \textrm {W }}$

$343937 \mathrm{N111} 10300 \mathrm{~W}$

$351415 \mathrm{~N} 1115631 \mathrm{~W}$

$345912 \mathrm{N1111807 \textrm {W }}$

35160BN1115446W

335152N1111604W

$335152 \mathrm{~N} 1111604 \mathrm{~W}$

$345427 \mathrm{~N} 1102443 \mathrm{~W}$

$333715 \mathrm{N1093420 \textrm {W }}$

$361448 \mathrm{~N} 1133417 \mathrm{~W}$

340B1ON1111104W

$340752 \mathrm{~N} 1111100 \mathrm{~W}$

$321730 N 1104721 \mathrm{~W}$

$340827 \mathrm{~N} 1111307 \mathrm{~W}$

312614 N1090622W

$345451 \mathrm{~N} 1102447 \mathrm{~W}$

$333833 \mathrm{~N} 1093356 \mathrm{~W}$

$351242 \mathrm{~N} 1120404 \mathrm{~W}$

$351327 \mathrm{N1} 120301 \mathrm{~W}$

350752N1120659W

350752N1120659W

330801N1103543W

333B12N1114026W

$333226 \mathrm{~N} 1114134 \mathrm{~W}$

Maricopa

Maricopa

$332800 \mathrm{~N} 1115458 \mathrm{~W}$

$333226 \mathrm{~N} 1114134 \mathrm{~W}$

$334102 \mathrm{~N} 1114318 \mathrm{~W}$

$334100 \mathrm{~N} 1115130 \mathrm{~W}$

$333943 \mathrm{N11} 14841 \mathrm{~W}$

$333348 \mathrm{~N} 1114250 \mathrm{~W}$

$333936 \mathrm{~N} 1114903 \mathrm{~W}$

332757 N1115907W

332800 N1121010W

332755 N1120126W

333556 N1113739W 332756 N1120027W $344925 \mathrm{~N} 1125820 \mathrm{~W}$ $344756 \mathrm{~N} 1130903 \mathrm{~W}$ $324633 \mathrm{~N} 1095200 \mathrm{~W}$ $330016 \mathrm{~N} 1095449 \mathrm{~W}$
$331145 \mathrm{~N} 109363 \mathrm{~W}$ $335225 \mathrm{~N} 1105847 \mathrm{~W}$ $335248 \mathrm{~N} 1105635 \mathrm{~W}$ $335436 \mathrm{~N} 1105755 \mathrm{~W}$
343017 N1134532W
Williams South Williams South Williams South

2304 Williams South Mccracken Peak Dutch Flat SE

3524 McCracken Peak

Trinity Mtn

Bosque

Pinta

Peeples Valley

Russell Spring

100 Gadsden

Clarkdale

Pyeatt Ranch

Quayle Hill

351652N1115459W

Garland Prairie Kinnikinick Lake Parks

$344658 \mathrm{~N} 1102606 \mathrm{~W}$ $333948 N 1093426 \mathrm{~W}$

Apache Butte Freezeout Mtn Castle Peak

5621 McDonald Mtn McDonald Mtn Sabino Canyon McDonald Mtn Guadalupe Spring Apache Butte Maverick Davenport $\mathrm{Hill}$ Davenport Hill

Davenport Hill

$330713 \mathrm{~N} 1103713 \mathrm{~W}$

Coolidge Dam

2830 Granite Reef Dam Tempe

Fort Mc Dowell

4034 McDowell Peak McDowell Peak Granite Reef Dam 4034 McDowell Peak

Tempe

Fowler

Phoenix

Granite Reef Dam Phoenix

Camp Wood

Burro Mesa

Thatcher

Fort Thomas

Elevator Mtn

$335403 N 1105646 \mathrm{~W}$ 
FEATURE CLASS

McFadden Peak Lookout McFall Crags

McFarland Canyon

McFarland Spring

McGarrys Wash

McGee Mountain

McGee Ranch

McGee School

McGee Wash

McGee Well

McGee Windmill

McGinnel Spring

McGraw School

McGrew Spring

MCGuffie Mine

McGuire Crossing

MacGuire Park

McGuireville

McGuireville Interchange

Machan School

McHat Tank

Mcheffy Butte

McHood Park

McInturf Spring

McInturf Trick Tank

McIntyre Canyon

McIntyre Tank

McIntyre Wel

Mckay Peak

See McKays Peak

McKay Reservoir

McKays Peak

McKay Peak

McKay Spring

McKay Tank

McKell ips Lake Park

Mackelprange Wash

See Mackelprang Wash

Mackel Prange Wash

See Mackelprang Wash

Mackelprang Spring

Mackel Prang Wash

See Mackelprang Wash

Mackelprang Wash

Cottonwood Wash

Macket Pang Wash

Mackel Prange Wash

Mackel Prang Wash

Mackelprange Wash

Salt Well Wash

McKemy Junior High School

Mackenize Wash

See Mackenzie Wash

McKenney Spring

Mackenzie Creek

Copper Wash

Mackenzie Wash

McKenzie Peak

Mackenzie Ranch

McKenzie Ranch

Mackenzie Tank

McKenzie Tank

Mackenzie Wash Copper Creek Mackenize Wash

Mackenzie Wash

See Mackenzie Creek

Mckeon Ranch

McKeth Spring

See McBeth Spring

valley

valley

schoo

tream

spring

stream

stream

locale

spring

$\begin{array}{llll}\text { tower } & \text { UNOFF } & \text { Gila } & 335437 \text { N1105755 } \\ \text { cliff } & \text { BGN } & \text { Pima } & 322133 \text { N1104748 } \\ \text { valley } & \text { BGN } & \text { Maricopa } & 335734 \text { N1112921 } \\ \text { spring } & \text { BGN } & \text { Coconino } & 342838 N 1111144 \\ \text { stream } & \text { BGN } & \text { Mohave } & 350649 N 1133832 \\ \text { summit } & \text { BGN } & \text { Gila } & 334022 N 1104714 \\ \text { locale } & \text { UNOFF } & \text { Pima } & 315339 N 1111051 \\ \text { school } & \text { UNOFF } & \text { Pina } & 315341 N 1111049 \\ \text { valley } & \text { BGN } & \text { Mohave } & 350010 N 1132602 \\ \text { well } & \text { UNOFF } & \text { Pima } & 315116 N 1110930 \\ & & & \\ & & & \\ \text { locale } & \text { BGN } & \text { Graham } & 323618 N 1100836 \\ \text { spring } & \text { BGN } & \text { Pinal } & 332019 N 1110713 \\ \text { school } & \text { UNOFF } & \text { Yuma } & 324107 N 1143653 \\ \text { spring } & \text { BGN } & \text { Cochise } & 315104 N 1102123 \\ \text { mine } & \text { UNOFF } & \text { Mohave } & 341547 N 1134119 \\ \text { locale } & \text { BGN } & \text { Coconino } & 342719 N 1110112 \\ \text { park } & \text { AOMIN } & \text { Maricopa } & 335750 N 1124423 \\ \text { ppl } & \text { BGN } & \text { Yavapai } & 343817 N 1114859 \\ \text { crossing } & \text { UNOFF } & \text { Yavapai } & 343822 N 1114900 \\ \text { school } & \text { UNOFF } & \text { Maricopa } & 332837 N 1120205 \\ & & & \end{array}$

reservoir BGN Coconino 351605N1120205W

summit BGN Mohave 345509N1142357W

park ADMIN Navajo 345806N1103838W

spring BGN Gila 341051N1105420W

reservoir BGN Gila $341018 \mathrm{N1105540 \textrm {W }}$

valley BGN Yavapai 350838N1124227W

reservoir BGN Yavapai 351439 N1124304W

well UNOFF Yuma

summit VARIANT Apache 335834N1094752W

reservoir BGN Apache 340127N1091344W

summit BGN Apache 335834N1094752

$\begin{array}{llll} & \text { VARIANT } & & \\ \text { spring } & \text { BGN } & \text { Apache } & 341135 \mathrm{~N} 1094333 \mathrm{~W}\end{array}$

reservoir BGN Pima 313619N1112829W

park ADMIN Maricopa 332717N1115445W

valley VARIANT Navajo 350858N1101642W

valley VARIANT Navajo 350858N1101642W

spring BGN Navajo 351438N1101630W

VARIANT

Navajo

VARIANT

VARIANT

VARIANT

VARIANT

VARIANT

VARIANT

UNOFF

VARIANT

$B G N$

BGN

VARIANT

VARIANT

summit BGN

locale UNOFF

locale UNOFF

reservoir

BGN

BGN

VARIANT

VARIANT

VARIANT

UNOFF

VARIANT
Maricopa

Mohave

Gila

Mohave

Coch ise

Cochise

Pima

Cochise

Cochise

Mohave

Mohave

Greenlee

Santa Cruz
350858 N1101642W

$340405 \mathrm{~N} 1105516 \mathrm{~W}$

$345302 \mathrm{~N} 1135710 \mathrm{~W}$

$322155 N 1090842 W$

$320421 \mathrm{~N} 1102657 \mathrm{~W}$

323011 N1110559W

$320457 \mathrm{~N} 1102640 \mathrm{~W}$

$321521 \mathrm{~N} 1090534 \mathrm{~W}$

344937N1140958W

$345302 N 1135710 \mathrm{~W}$

324953N1091103W $\begin{array}{cc}\text { SOURCE } & \text { ELEV } \\ \text { COORDINATE } & \text { FT }\end{array}$

MAP NAME

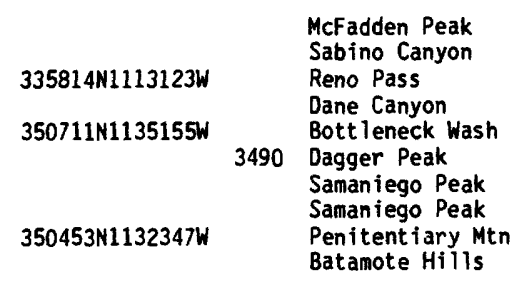

Harrison Canyon

Superior

Yuma East

McGrew Spring

Rawhide Wash

Knoll Lake

Wickenburg

Lake Montezuma

Lake Montezuma

Phoenix

Sitgreaves Mtn

2300 Boundary Cone

Clear Creek Res

Dxbow Mtn

Oxbow Mtn

$351605 N 1124339$

Picacho Butte

Picacho Butte

2095 Webber Canyon

Nelson Reservoir

9175 Hawley Lake West

Boundary Butte

Wilbur Canyon

Tempe

Rotten Bananas Butte

350858 N1101642W

$351517 \times 1101632$

Rotten Bananas Butte

Tempe

345732 N1135519W

Young

Wabayuma Peak

345302 N1135710W

$314124 N 1105128 \mathrm{~W}$ 


\section{FEATURE NAME}

Macket Pang Wash See Mackelprang Wash Mackey Canyon

Mackey Tank

McKibbins Pond

McKinley School

McKinney Canyon

McKinney Cemetery

McKinney Dam

McKinney Dam

McKinney Mountain

McKinney Spring

McKinney Tank

McKinney Tank

McKinnon Point

$$
\text { See Widforss Point }
$$

Mckinzie Mine

McKitrick Creek See McKittrick Creek

Mckittrick Creek McKitrick Creek

Mackl in Well

Macks Crossing

Macks Tank

Macks Tank Number One

Macks Tank Number Two

Mack Tank

Mack Wel1

McLellan Dan

McLellan Reservoir

McLellan Siding Tank

McLendon Peak

MacLennan School

McMath Solar Telescope

McMicken

Litchfield Siding

Mcricken Dan

McMicken Dam Outlet Channel

McMillan Mesa Switzer Mesa

McMillan Mine

McMillanville Town Well

McMillen Wash

McMillianvill

McMullen Valley Grace Valley

McMullen Valley

See Aguila Valley

McNalley Tank

McNary

McNary Annex School

McNary Ditch

McNary Elementary School

McNary High School

McNary Place

McNary Railroad Station

McNary Siphon

McNary Tank

McNeal

McNeal Generating Plant

McNeal Post Office

McNealy Spring

See McNelty Spring

McNeil Tank

McNelty Spring McNealy Spring

McPhaul Bridge

McPherson Canal

McPhers on Pass

McPherson Tank

McPherson Wash

\section{FEATURE}

CLASS

STATUS

COUNTY

COORDINATE

SOURCE

COORDINATE

ELEV

MAP NAME

Valley VARIANT Navajo 350858N1101642W

$\begin{array}{llll}\text { valley } & & \text { Navajo } & 350858 \mathrm{~N} 1101642 \mathrm{~W} \\ \text { valley } & B G N & \text { Cochise } & 315946 \mathrm{~N} 1091501 \mathrm{~W}\end{array}$

reservoir BGN Cochise 315822N1091705W

lake BGN Greenlee 334056N1092814W

school UNOFF Maricopa 332721N1120359W

valley BGN Graham 330632N1100325W

cemetery UNOFF Pinal 324219N1104345

dam UNOFF Pinal 324219N1104345

dam UNOFF Graham 331145N1095946W

$315813 N 1091559 W$

summit $\quad B G$

spring $B G$

reservoir $B G$

reservoir BGN

cliff

mine

UNOFF

VARIANT

strean

BGN

VARIANT

Graham

Pinal

Gila

Coconino

$331031 N 1100014 \mathrm{~W}$

$325932 \mathrm{~N} 1102818 \mathrm{~W}$

$340508 N 1105337 \mathrm{~W}$

$352856 \mathrm{~N} 1113941 \mathrm{~W}$

Coconino 361046N1120458w

Yavapai 340703N1122859W

Greenlee $\quad 333047 N 1091234 \mathrm{~W}$

333047 N1091234W

$333343 \mathrm{~N} 1091710 \mathrm{~W}$

4587 Byl

Booger Canyon

Young

White Horse Hills

Copperopolis

Bear Mountain

we

UNOFF

Gila

Coconino

Coconino

Yavapai

Yavapai

Yavapai

Graham

Coconino

Coconino

dam

$B G N$

UNOFF

reservoir $B G$

reservoir $B G H$

Coconino

$334832 \mathrm{~N} 1100037 \mathrm{~W}$

$343706 \mathrm{~N} 1110531 \mathrm{~W}$

$343646 \mathrm{~N} 1112111 \mathrm{~W}$

$343132 \mathrm{~N} 1113452 \mathrm{~W}$

$343111 \mathrm{N1113510 \textrm {W }}$

$345734 N 1121705 W$

$325500 \mathrm{~N} 1095036 \mathrm{~W}$

$351318 \mathrm{~N} 1121712 \mathrm{~W}$

$351314 N 1121711$

$351323 N 1121752$

summit BGN 1980 Yavapai 341832N1131107W

school UNOFF Maricopa 335806N1124404W

building UNOFF Pima 315730N1113542W

locale BGN Maricopa 332950N1122535W

canal BGN

Maricopa 334119N1122520W

ppl BGN 1984 Maricopa 333315N1121505W

$\begin{array}{lll} & \text { VARIANT mine } & \\ \text { UNOFF } & 322318 N 1135439 \mathrm{~W}\end{array}$

well UNOFF Gila 333345 N1104027W

stream BGN Gila 332327 N1104639N

locale BGN $\quad$ Gila $\quad 333326 N 1104045 \mathrm{~W}$

valley BGN 1964 Yuma 334348N1133719W

VARIANT

VARIANT

valley

ppl

BGN

Maricopa

$335906 \mathrm{~N} 1125344 \mathrm{~W}$

$314629 \mathrm{~N} 1102906 \mathrm{~W}$

$340425 N 1095123 \mathrm{~W}$

$340435 N 1095115 \mathrm{~W}$

$340328 \mathrm{~N} 1094421 \mathrm{~W}$

$340431 N 1095118 \mathrm{~W}$

$340428 \mathrm{~N} 1095118 \mathrm{~W}$

$341746 \mathrm{~N} 1122925 \mathrm{~W}$

$340419 \mathrm{~N} 1095023 \mathrm{~W}$

$342906 N 1123658$

$340502 \mathrm{~N} 1095130 \mathrm{~W}$

$313604 \mathrm{~N} 1094010 \mathrm{~W}$

$313133 \mathrm{~N} 1094148 \mathrm{~W}$

$313602 \mathrm{~N} 1094009 \mathrm{~W}$

342044N1122849W

$341459 \mathrm{~N} 1100533 \mathrm{~W}$

$342044 \mathrm{~N} 1122849 \mathrm{~W}$

$324534 N 1142514 \mathrm{~W}$

$324633 \mathrm{~N} 1143030 \mathrm{~W}$

$330732 \mathrm{~N} 1140958 \mathrm{~W}$

$330621 N 1140858 \mathrm{~W}$

$330915 \mathrm{~N} 1140812 \mathrm{~W}$
$332426 \mathrm{~N} 1104456 \mathrm{~W}$

$335520 \mathrm{~N} 1132322 \mathrm{~W}$

\section{Chrome}

Chrome Butte

Harrisburg Valley

Canyon Day

6260 Leonard Canyon Long Valley

Buckhorn Mountain Buckhorn Mountain Sheridan Mtn Pina

15 McLellan Reservoir McLellan Reservoir

4091 Malpais Mesa SW Wickenburg Kitt Peak Perryville

1354 McMicken Dam McMicken Dam

7200 El Mirage

Buck Peak

Apache Peak

7316 McNary

McNary

Horseshoe Cienega McNary

McNary

Battleship Butte McNary Wilhoit

7297 McNary

4169 McNeal

4079 McNeal

McNeal

Show Low South Battleship Butte

Laguna Dam

Bard

Arch Tank

Castle Dome Peak

330622 N1140857W 


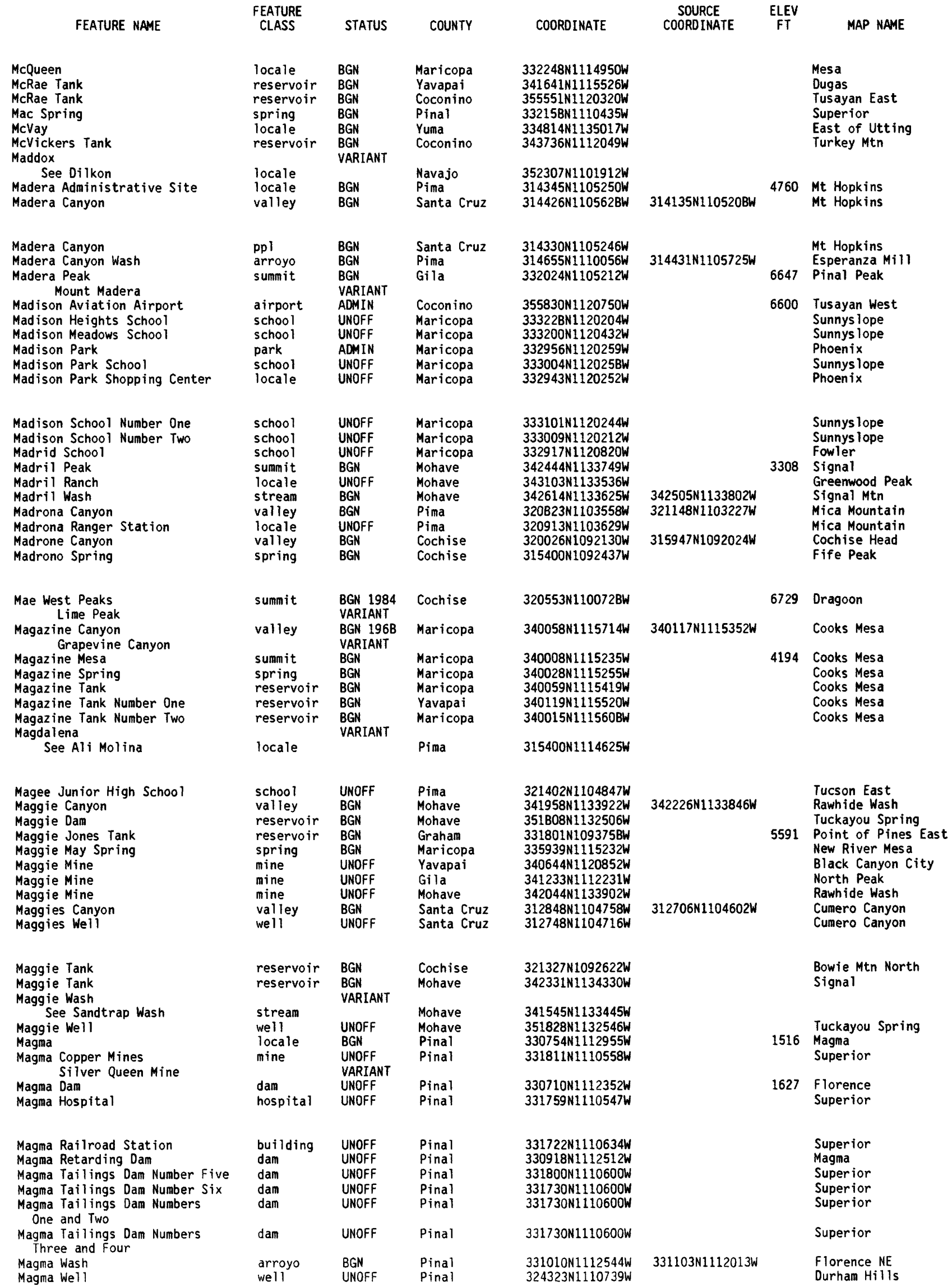




\section{FEATURE NAME}

Magna Mine

Magnes ium Queen Mines

Magnesium Springs

Magnetic Mesa

Magnet Tank

Magnum Springs Ranger Station

Mahala Tank

Mahan Mountain

Mahan Park

Mahan Park Tank

Mahan Ranch

Mahan Spring

Mahan Tank

Mahan Tank

Mahan Tank

Ma-ha Tuak Park

Ma Ha Tuak Range

Maha Well

Maho, Lake

Mahone Peak

$$
\text { See Mohon Peak }
$$

Mahoney Ridge

Mahoney Wash

Mai Dagi

Maidenhead Canyon

Maid Tank

Maijtoh

Mailbox Canyon

Mailbox Mesa

Mailbox Well

Mail Carrier Spring

Mail Creek

Mail Station Draw

Mail Trail Tank Mumber Two

Main Camp Well

Main Canal

Main Canyon

Main Canyon Tank

Main Drain

Main Drain Extension

Maine

Maine

See Parks

Maine Mine

Main Lateral

Main Outlet Drain

Main Outlet Drain

Main Run

See Hurricane Wash

Main Spring

Main Spring

Main Street Valley

Main Tank

Maish

See Marsh Railroad Station

Maish

See Marsh (historical)

Maishpvaxia

See Maish Vaya

Maish-vaxia

See Maish Vaya

Maish Vaya

Covered Well

Covered Wells

Maish-vaxia

Maishpvaxia

Maispvaxia

Pozo Tapado

Maispvaxia

West Wells

See Maish Vaya
CLASS

mine
mine
spring
summit
reservoir
locale
reservoir
summit
flat
reservoir

STATUS

COUNTY

COORDIMATE

324337 N1102841W

$324341 \mathrm{~N} 1114706 \mathrm{~W}$

$325958 \mathrm{~N} 1095355 \mathrm{~W}$

$353407 \mathrm{~N} 1112839 \mathrm{~W}$

$340525 \mathrm{~N} 1105309 \mathrm{~W}$

$363745 \mathrm{N1} 121550 \mathrm{~W}$

$351002 \mathrm{~N} 1122120 \mathrm{~W}$

$344654 N 1112351 \mathrm{~W}$

$343737 \mathrm{N1} 112233 \mathrm{~W}$

$343731 \mathrm{N1112203 \textrm {W }}$

locale UNOFF Coconino 344658 N1112332W

spring BGN Coconino $344733 \mathrm{N11112415 \textrm {W }}$

reservoir BGN Coconino 344622N1112249W

reservoir BGN Coconino

reservoir BGM

well

BGN

UNOFF

BGM

VARIANT

summit

Maricopa

Navajo

Navajo

Yavapai

ridge

stream

valley

reservoir

spring

valley

summit

well

spring

BGN
BGN
BGN
BGN
BGN
BGN
BGN
BGN
UNOFF
BGN

Yavapai

Yavapai

Apache

Yavapai

Coconino

Coconino

Graham

Gila

Graham

Apache

$\begin{array}{ll}\text { stream } & \text { B } \\ \text { valley } & \text { B } \\ \text { reservoir } & B \\ \text { well } & \text { U } \\ \text { canal } & \text { B } \\ \text { valley } & \text { B } \\ \text { reservoir } & \text { B } \\ \text { canal } & \text { B } \\ \text { canal } & \text { B } \\ \text { locale } & B\end{array}$

BGN
BGN
BGN
UNOFF
BGN
BGN
BGN
BGN
BGN
BGN

Gila

Apache

Yavapai

Maricopa

Yuma

Mavajo

Gila

Yuma

Yuma

Coconino

VARIANT

ppl

mine

canal

canal

canal

UNOFF

BGN

BGN

VARIANT

stream

spring

$B G$

BGN

BGN

reservoir BGM

building

VARIANT

locale

pp 1

pp

VARIANT

VARIANT

ppl

BGN 1941
VARIANT
VARIANT
VARIANT
VARIANT
VARIANT
VARIANT
VARIANT
VARIANT

$p p$

Pima

$353958 \mathrm{~N} 1102036 \mathrm{~W}$

354837 N1101010W

345656N1131754W

$341704 \mathrm{~N} 1123714 \mathrm{~W}$

$340417 \mathrm{N1123503 \textrm {W }}$

353748N1094337W

$341522 \mathrm{~N} 1122539 \mathrm{~W}$

$344412 \mathrm{~N} 1113240 \mathrm{~W}$

$362259 \mathrm{N1} 105040 \mathrm{~W}$

$324044 N 1102141 \mathrm{~W}$

$340536 \mathrm{~N} 1110324 \mathrm{~W}$

$324025 \mathrm{~N} 1102328 \mathrm{~W}$

$354102 \mathrm{~N} 1093849 \mathrm{~W}$

$342504 \mathrm{N1111547 \textrm {W }}$

$343315 \mathrm{~N} 1094100 \mathrm{~W}$

$342607 \mathrm{N1} 113533 \mathrm{~W}$

$330014 \mathrm{~N} 1131628 \mathrm{~W}$

$340135 \mathrm{~N} 1142100 \mathrm{~W}$

$341611 \mathrm{N1} 101358 \mathrm{~W}$

$335207 \mathrm{~N} 1102411 \mathrm{~W}$

$323624 \mathrm{~N} 1144335$

$324205 \mathrm{~N} 1144251 \mathrm{~W}$

$351511 \mathrm{~N} 1115616 \mathrm{~W}$

$331324 \mathrm{N1092328 \textrm {W }}$

$332155 \mathrm{N1} 105420 \mathrm{~W}$

364713 M1132910W

$312739 \mathrm{N1091823 \textrm {W }}$

$320049 N 1103514 W$

$320100 \mathrm{N1103514W}$

321001 N1120736W

$321001 \mathrm{~N} 1120736 \mathrm{~W}$

$321001 N 1120736 \mathrm{~W}$ $\begin{array}{cc}\text { SOURCE } & \text { ELEV } \\ \text { COORDINATE } & \text { FT MAP NAME }\end{array}$

Rhodes Peak Silver Reef Mts

Thatcher

Wupatki SW

Young

Warm Springs Canyon

MCLellan Reservoir

B270 Hutch Mtn

Happy Jack

Turkey Mtn

Hutch Mtn

Hutch Mtn

Hutch Mtn

Hutch Mtn

Markham Dam

Lone Butte

Lone Butte

Star Mountain

$340333 \mathrm{M} 1123441 \mathrm{~W}$

$353821 \mathrm{N1} 094356 \mathrm{~W}$

$341434 \mathrm{N1122449 \textrm {W }}$

$323916 \mathrm{~N} 1102416 \mathrm{~W}$

$342635 \mathrm{~N} 1111618 \mathrm{~W}$ $342707 \mathrm{~N} 1094100 \mathrm{~W}$

Hunt

463

Hyder

341311N1101629W Parker SE

Beckers Butte

Somerton

Yuma West

Parks

Harshaw

Somerton

Fortuna

Yuma West

Coronado Mtn

Pinal Ranch

$363436 \mathrm{~N} 1132516 \mathrm{~W}$

Hole-n-wall Canyon

Cinder $\mathrm{Hill}$

2521 Maish Vaya 
NATIONAL GAZETTEER--ARIZONA 1986

FEATURE
CLASS

STATUS

COUNTY

COORDINATE

SOURCE
COORDINATE

ELEV

MAP NAME

Maitio Spring

See Maito
Maito
Coyote Springs
Coyote Water
Maitio Spring
Mai to Spring
Maito Spring
Mayeto
Mai to Spring
See Maito

Maito Spring

Maivayi

Jayi

Moi Vaya

Moivavi

Mueykava

Majalcas Ranch

Majorie Wash

Makgum Havoka

Makumivooka

Makumivooka

See Makgum Havoka

Malapai Cliffs

See Malpais Cliffs

Malapais Hills

See Malpais Hills

Malapais Mountain

Malapais Tank

Malapai Tank

Malapai Tank

Malapai Tank

Malay Canyon

Malay Creek

Malay Gap

Malay Spring

Malay Tank

Malay Tank

Malco Mine

Malgosa Canyon

Malgosa Creek

Malgosa Crest

Malibu Drain

Malicious Gap

Malipai Windmil

Mallory Detention Dan

Mallory Draw

Mallory Shaft

Mallory Spring

Malloy Latera?

Malony (historical)

Malpais Canyon

Malpais Cliffs

Malapai Cliffs

Malpais Flattop Mesa

Malpais Hill

Malpais $\mathrm{Hill}$

Malpais Hill

Malpais $\mathrm{Hill}$

Malpais Hills

Malapais Hills

Malpais Hills

See Santan Mountains

Malpais Mesa

Malpais Mesa

Malpais Mountain

Malpa is Mountain

See Glassford $\mathrm{Hill}$

Malpais Spring

Malpais Spring

Malpais Spring

$\begin{array}{llll}\text { spring } & \text { VARIANT } & \text { Apache } & 361615 N 1094250 \mathrm{~W} \\ \text { spring } & \text { BGN 1971 } & \begin{array}{l}\text { Apache } \\ \text { VARIANT } \\ \text { VARIANT }\end{array} & 361615 \text { N1094250W } \\ & \begin{array}{l}\text { VARIANT } \\ \text { VARIANT }\end{array} & & \\ & \text { VARIANT } & & \\ & \text { VARIANT } & & \\ & \text { VARIANT } & & \\ \text { spring } & & \text { Apache } & 361615 \mathrm{~N} 1094250 \mathrm{~W}\end{array}$

spring

locale

VARIANT

BGN

VARIANT

VARIANT
VARIANT

VARIANT

locale

arroyo

UNOFF

BGN

BGN 1941

VARIANT

Cochise

Apache

Maricopa

$361615 N 1094250 \mathrm{~W}$

323348 N1122729W

$321700 \mathrm{N1102145 \textrm {W }}$ $315905 \mathrm{~N} 1110457 \mathrm{~W}$ $321629 N 1115737 \mathrm{~W}$

VARIANT

locale

cliff

VARIANT

VARIANT

summit

summit

well

reservoir

reservoir

BGN

UNOFF

BGN

reservoir

valley

strean

gap.

spring

reservoir
reservoir

mine

valley

stream

BGN Coconino

BGN

BGN

$B G N$

BGN

BGN

BGN 1927 Coconino

BGN 1927 Coconino

summit

stream

gap

locale

dan

valley

mine

spring

canal

locale

BGN 1906 Coconino 361451N1115033W

BGN Mohave 342943N1142027W

BGN Gila

BGN Yavapai

UNOFF

BGN

UNOFF

$B G N$

BGN

BGN

valley

cliff

summit

summit

summit

summit

summit

summit

BGN

BGN 191

BGN

BGN

$B G N$

BGN

BGN

BGN

Graham

Gila

Apache

Yuma

Santa Cruz

$335531 \mathrm{~N} 1110643 \mathrm{~W}$

$341829 \mathrm{~N} 1123910 \mathrm{~W}$

$330225 \mathrm{~N} 1100040 \mathrm{~W}$

$342054 \mathrm{~N} 1092816 \mathrm{~W}$

$332528 N 1104717 \mathrm{~W}$

$341221 N 1093328 \mathrm{~W}$

341221N1093328W

$313045 \mathrm{~N} 1104659 \mathrm{~W}$

VARIANT

summit

summit

summit

summit

summit

spring

spring
Maricopa

Maricopa

Mohave

Pima

Maricopa

Pinal

Yavapai

Pinal

334240N1113900W $334200 \mathrm{~N} 1112500 \mathrm{~W}$

$354734 N 1144027 \mathrm{~W}$

$322848 N 1113347 \mathrm{~W}$

$324231 \mathrm{N1130437 \textrm {W }}$

$325445 \mathrm{N1} 104420 \mathrm{~W}$

$340614 N 1121735 \mathrm{~W}$

$330808 \mathrm{~N} 1114007 \mathrm{~W}$

Pinal

Yavapai

Navajo

Greenlee

Yavapai

Greenlee

Apache
$330828 \mathrm{~N} 1114050 \mathrm{~W}$

$341957 \mathrm{~N} 1130600 \mathrm{~W}$

$352039 \mathrm{~N} 1100844 \mathrm{~W}$

330917N1092004W

$343522 \mathrm{~N} 1122253 \mathrm{~W}$

$331407 \mathrm{~N} 1091444 \mathrm{~W}$

340449 N1112908W

$342436 \mathrm{~N} 1093327 \mathrm{~W}$
4229 Weavers Needle

Hot Well

Velasquez Butte

Show Low North

Hutch Mtn

Dos Cabezas

Freezeout Mtn

Freezeout Mtn

Greasewood Mountain

Baldy Bill Point

Freezeout Mtn

Burnt Mill Ranch

$\begin{array}{ll}361306 N 1115207 W & \text { Cape Solitude } \\ 361306 N 1115207 W & \text { Cape Solitude }\end{array}$

$342957 \mathrm{N1142020 \textrm {W }}$

5584 Cape Solitude

Lake Havasu City S

Copper Mtn

Peeples Valley

$341038 N 1093334 \mathrm{~W}$

Geronimo

Globe

Whiting Knoll

Gadsden

3960 Patagonia

334353N1113425W Fort Mc Dowell

Mine Mountain

2682 Silver Bell West

856 Malpais Hill

2492 Dudleyville

5632 Columbia

2496 Chandler Heights

2996 Malpais Mes

6413 Sunflower Butte

6981 Mitchell Peak

Dix Creek

Mazatzal Peak

Concho
Lyman Lake SW

2771 Willow Beach
Many Farms SW

Moi Vaya

Soza Mesa

Twin Buttes

Santa Rosa Mts SW 
FEATURE CLASS
COUNTY

$\begin{array}{lll}\text { spring } & \text { BGN } & \text { Navajo } \\ \text { reservoir } & \text { BGN } & \text { Cochise } \\ \text { reservoir } & \text { BGN } & \text { Yavapai } \\ \text { reservoir } & \text { BGN } & \text { Yavapai } \\ \text { reservoir } & \text { BGN } & \text { Coconino } \\ \text { reservoir } & \text { BGN } & \text { Coconino } \\ \text { reservoir } & \text { BGN } & \text { Coconino } \\ \text { reservoir } & \text { BGN } & \text { Gila } \\ \text { locale } & \text { ADNIN } & \text { Pima } \\ & \text { VARIANT } & \\ \text { ridge } & & \text { Pima }\end{array}$

VARIANT

Mamatotk Peak

$$
\text { See Bailey Peak }
$$

Mamie Creek

Mamie Creek

$$
\text { See Coyote Creek }
$$

Mammon Mine

Mammoth

Shuitz

Mammoth Camp

See Mammoth Mine

Mammoth Copper Corporation
Hospital
Mammoth Elementary School
Mammoth Incline
Mammoth Mine
Mammoth Mine
Mammoth Camp
Old Mammoth Mine
Shultz Mine
Mammoth Mine

Mammoth Mine

Mammoth Softball Field Park
Mammoth Spar Mine
Mammoth Valley View Cemetery
Mammoth Wash
Mammoth Wash
Mammoth Wash
Mamtotk Peak
See Chupan Mountain
Manakacha Point
$\quad$ Mannikaja Point
Manataba Park
Manazana
See Mishongnovi
Mand M Pond
Maness Mountain
Maness Peak
Manganese Mesa
See Black Mesa
Manganese Mine
Mangas Mountain (historical)

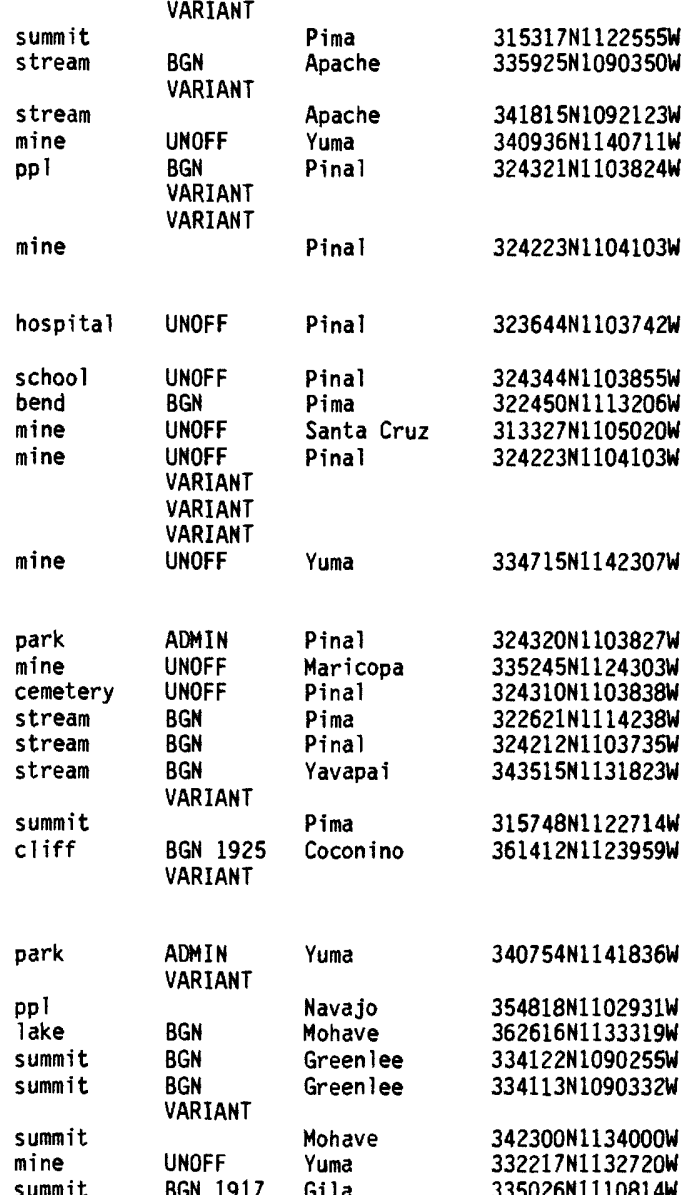

Mangas Mountain

See Three Sisters Mountain Mangrum Spring

Mangum Canyon

Mangum Springs

Mangum Springs

Manhasset Mart Shopping Center

Man Head

See Duckbill

Man Head

Manila

Mani ia Canyon

Manila Mine

Manila Wash

Manitou $\mathrm{Hill}$

Manitowoc Min

Maniyville

$$
\text { See Willow Springs Ranch }
$$

Mannerhe im Tank

\begin{tabular}{|c|c|c|c|}
\hline & VARIANT & & \\
\hline $\begin{array}{l}\text { summit } \\
\text { spring } \\
\text { valley } \\
\text { spring } \\
\text { locale } \\
\text { locale }\end{array}$ & $\begin{array}{l}\text { BGN } \\
\text { BGN } \\
\text { BGN } \\
\text { BGN } \\
\text { UNOFF } \\
\text { VARIANT }\end{array}$ & $\begin{array}{l}\text { Gila } \\
\text { Greenlee } \\
\text { Coconino } \\
\text { Coconino } \\
\text { Coconino } \\
\text { Maricopa }\end{array}$ & $\begin{array}{l}335026 \mathrm{~N} 1110814 \mathrm{~W} \\
333051 \mathrm{N1} 1090914 \mathrm{~W} \\
363737 \mathrm{~N} 1122047 \mathrm{~W} \\
363713 \mathrm{~N} 1122012 \mathrm{~W} \\
363734 \mathrm{N1} 122055 \mathrm{~W} \\
332938 \mathrm{N1120050W}\end{array}$ \\
\hline $\begin{array}{l}\text { summit } \\
\text { summit }\end{array}$ & BGN 1982 & $\begin{array}{l}\text { Pima } \\
\text { Pima }\end{array}$ & $\begin{array}{l}320230 \mathrm{~N} 1103243 \mathrm{~W} \\
321227 \mathrm{~N} 1103233 \mathrm{~W}\end{array}$ \\
\hline $\begin{array}{l}\text { locale } \\
\text { valley } \\
\text { mine } \\
\text { stream } \\
\text { summit } \\
\text { mine }\end{array}$ & $\begin{array}{l}\text { BGN } \\
\text { BGN } \\
\text { UNOFF } \\
\text { BGN } \\
\text { BGN } \\
\text { UNOFF } \\
\text { VARIANT }\end{array}$ & $\begin{array}{l}\text { Navajo } \\
\text { Cochise } \\
\text { Cochise } \\
\text { Navajo } \\
\text { Gila } \\
\text { Mohave }\end{array}$ & $\begin{array}{l}345754 \mathrm{~N} 1102446 \mathrm{~W} \\
31345 \mathrm{BN} 1102811 \mathrm{~W} \\
313323 \mathrm{~N} 1102645 \mathrm{~W} \\
345750 \mathrm{~N} 1102426 \mathrm{~W} \\
332250 \mathrm{~N} 1105816 \mathrm{~W} \\
342758 \mathrm{~N} 1140941 \mathrm{~W}\end{array}$ \\
\hline $\begin{array}{l}\text { locale } \\
\text { reservoir }\end{array}$ & BGN & $\begin{array}{l}\text { Pinal } \\
\text { Navajo }\end{array}$ & $\begin{array}{l}324254 \mathrm{~N} 1105227 \mathrm{~W} \\
341746 \mathrm{~N} 1095231 \mathrm{~W}\end{array}$ \\
\hline
\end{tabular}

Mannikaja Point

summit BGN 1917 Gila 335026 N1110814W

Five Buttes Paramore Crater Page Springs Sunrise Peak Wing Mountain Mount Floyd Additional $\mathrm{Hill}$

\begin{tabular}{|c|c|}
\hline $335715 \mathrm{~N} 1090700 \mathrm{~W}$ & Escudilla Mtn \\
\hline & $\begin{array}{l}\text { Osborne Well } \\
\text { Mammoth }\end{array}$ \\
\hline
\end{tabular}
San Carlos Avra

Campo Bonito

Mammoth

Silver Bell West Patagonia Mammoth

Moon Mtn

Mammoth Wickenburg Mammoth Gap Tank Mammoth

Grayback Mts $323838 \mathrm{~N} 1104350 \mathrm{~W}$ 343342N1131446W

Supai

Parker

Poverty Spring

Maness Peak Maness Peak

Nottbusch Butte 5444 Greenback Creek

Bear Mountain Warm Springs Canyon Big Springs Warm Springs Canyon Phoenix

8434 Mica Mountain 313227 N1102705W

4958 Apache Butte Pyeatt Ranch Pyeatt Ranch Apache Butte 350211 N1101849W 4216 Inspiration Standard Wash

Silver Springs 
NATIONAL GAZETTEER--ARIZONA 1986

\section{FEATURE NAME}

See Manakacha Point

Manning Camp

Manning Tank

Mann Latera

Manny Gonzales Park

Mansfield Canyon

Mansfield Group

Mansfield Junior High School

Mansfield Park

Manson Mesa

Mansunita

Manterola Tank

Mantkin Spring

Manuel Seep

Manuel Seep Draw

Manuels Well

Manuels Well

See Siovi Shuatak

Manuel Wash

Manu Temple

Many Bobcats Hill

Many Cherry Canyon

Many Coyote Mesa

Many Farms

Many Farms Boarding School

Many Farms Child Development Center

Many Farms Dam

Many Farms Elementary School

Many Farms High School

Many Farms Lake

Many Farms Lake Campground

Many Farms Public School

Many Farms Spring

Many Farms Trading Post

Many Ghosts Hill

Many Greasewood Valley

Many Ladders Trail

Many Owl Canyon

Many Sheep Valley

Many Skull Spring

Many Skulls Trail

Manzana Mountain

See Manzanita Mountain

Manzanita Campground

Manzanita Canyon

Manzanita Creek

Manzanita Creek

Manzanita Mine

Manzanita Mountain

Manzana Mountain

Manzanita Park

See Manzanita Winston Reynolds Park

Manzanita Park

Manzanita Point

Manzanita School

Manzanita School

Manzanita Spring

Manzanita Spring

Manzanita Spring

Manzanita Tank

Manzanita Tank

Manzanita Winston Reynolds Park

Manzoro Manzanita Park

Manzo School

Maos Trail

Mapes Tank

Maple Camp

Maple Canyon

\section{FEATURE}

CLASS

STATUS

cliff

$\begin{array}{ll}\text { locale } & \text { BGN } \\ \text { reservoir } & \text { BGN } \\ \text { canal } & \text { BGN } \\ \text { park } & \text { ADMIN } \\ \text { valley } & \text { BGN } \\ \text { mine } & \text { UNOFF } \\ \text { school } & \text { UNOFF } \\ \text { park } & \text { ADMIN } \\ \text { summit } & \text { BGN }\end{array}$

COORDINATE

361412 N1123959W

locale

BGN

reservoir

spring

spring

valley

locale

locale

arroyo

summit

summit

BGN

BGN
BGN
BGN

BGN

VARIANT

BGN

BGN 1906

Pima

Greenlee

Yuma

Cochise

Santa Cruz

Santa Cruz

Pima

Pima

Coconino

Santa Cruz

$321234 \mathrm{~N} 1103312 \mathrm{~W}$

$331925 \mathrm{~N} 1091021 \mathrm{~W}$

$323242 \mathrm{N1144701 \textrm {W }}$

$321535 \mathrm{~N} 1095005 \mathrm{~W}$

$313658 \mathrm{~N} 1104737 \mathrm{~W}$

$313708 \mathrm{~N} 1104802 \mathrm{~W}$

$321338 \mathrm{~N} 1105705 \mathrm{~W}$

$321453 \mathrm{~N} 1105800 \mathrm{~W}$

$365438 \mathrm{~N} 1112718 \mathrm{~W}$

$312300 \mathrm{~N} 1103700 \mathrm{~W}$

Coconino 351032N1115719W

Gila 341026N1112251W

Apache 343029N1094554W

Apache

Pima

Pima

Mohave

BGN

Coconino
Navajo

valley $B G N \quad$ Apache

summit

ppl

school

BGN

BGN

Apache

Apache

Apache

school UNOFF Apache

dam

UNOFF Apache

school

UNOFF

Apache

Apache

Apache

reservoir BGN

schoo

spring

locale

summit

valley

trail

valley

valley

spring

trail

\section{ADMIN \\ UNOFF}

BGN

BGN
$B G N$
$B G N$

UNOFF

BGN

BGN

Apache

Apache

Apache

Apache

Coconino

Navajo

Apache

Coconino

Navajo

Navajo

UNOFF

summit

park

valley

stream

stream

mine

summit

VARIANT

ADNI

BGN

BGN 1932

UNOFF

Apache

Santa Cruz

Coconino

Yavapai

Yavapai

Coconino

Mohave

VARIANT

Santa Cruz

VARIANT

park

Pima

park
cliff

cliff

school

spring

spring

spring

ADMIN Maricopa

BGN 1932 Coconino

UNOFF Maricopa

UNOFF

BGN

BGN

Mohave

Santa Cruz

$343640 \mathrm{~N} 1094338 \mathrm{~W}$

$315700 \mathrm{~N} 1123800 \mathrm{~W}$

$315703 N 1123551 \mathrm{~W}$

$343318 \mathrm{~N} 1132132 \mathrm{~W}$

361000 N1120502W

360417 N1103034W

$361019 N 1092429 \mathrm{~W}$

$362101 \mathrm{~N} 1091611 \mathrm{~W}$

$362110 \mathrm{~N} 1093702 \mathrm{~W}$

362158 N1093740W

$362115 N 1093717 \mathrm{~W}$

362148 N1093630W

$362157 \mathrm{~N} 1093739 \mathrm{~W}$

$362222 \mathrm{~N} 1093729 \mathrm{~W}$

$362125 \mathrm{~N} 1093544 \mathrm{~W}$

$362030 \mathrm{N1093634W}$

$362054 N 1093705 W$

$362155 \mathrm{~N} 1093300 \mathrm{~W}$

362111 N1093704W

$363835 N 1111900 \mathrm{~W}$

361B01N1101816W

$360 B 59 N 1092533 \mathrm{~W}$

$361730 \mathrm{~N} 1104937 \mathrm{~W}$

$361206 \mathrm{~N} 1102556 \mathrm{~W}$

363039N1101033W

$361300 \mathrm{~N} 1092232 \mathrm{~W}$

$312310 \mathrm{~N} 1111145 \mathrm{~W}$

$345611 \mathrm{~N} 1114439 \mathrm{~W}$

340711 N1115924W

$343131 \mathrm{~N} 1122841 \mathrm{~W}$

$361106 \mathrm{~N} 1120153 \mathrm{~W}$

352354 N1141041W

$312310 N 1111145 \mathrm{~W}$

$340535 \mathrm{~N} 1115941 \mathrm{~W}$

$343028 \mathrm{N11} 23048 \mathrm{~W}$

$361223 \mathrm{~N} 1120018 \mathrm{~W}$

$362208 \mathrm{~N} 1101246 \mathrm{~W}$

361733N1104723W

$362112 \mathrm{~N} 1102636 \mathrm{~W}$

BGN

reservoir

reservoir

park

BGN

BGN

Yavapai

320926N1110119W

$332415 \mathrm{~N} 1120753 \mathrm{~W}$

$361044 \mathrm{N1} 120130 \mathrm{~W}$

$333335 \mathrm{~N} 1120832 \mathrm{~W}$

$351253 \mathrm{~N} 1140100 \mathrm{~W}$

$312231 \mathrm{~N} 1111215 \mathrm{~W}$

$324400 \mathrm{~N} 1100108 \mathrm{~W}$

$343727 \mathrm{N1} 120452 \mathrm{~W}$

$324624 \mathrm{~N} 1102420 \mathrm{~W}$

$350332 \mathrm{~N} 1122943 \mathrm{~W}$

$320926 \mathrm{~N} 1110119 \mathrm{~W}$

$320241 N 1095813 \mathrm{~W}$

$321403 \mathrm{~N} 1105940 \mathrm{~W}$

$360750 \mathrm{~N} 1092904 \mathrm{~W}$

$351445 \mathrm{~N} 1130017 \mathrm{~W}$

$315050 \mathrm{~N} 1091150 \mathrm{~W}$

332146 N1091033W

$313813 \mathrm{~N} 1105104 \mathrm{~W}$

$\begin{array}{cc}\text { SOURCE } & \text { ELEV } \\ \text { COORDINATE } & \text { FT MAP NAME }\end{array}$

Mica Mountain

Fritz Canyon

Gadsden

Willcox North

Patagonia

Patagonia

Tucson

Tucson 
FEATURE CLASS
COUNTY

valley
valley
summit
reservoir
spring
spring
spring
spring
spring
spring

BGN 1979
BGN
BGN
BGN
BGN
BGN
BGN
BGN
BGN
BGN

Mohave
Gila
Greenlee
Mohave
Graham
Graham
Greenlee
Maricopa
Greenlee
Gila

spring

Maple Spring

Maple Spring

Maple Spring Tank

Maple Tank

Maques Place

Marana

Marana (siding)

Marana Airpark Marana Airport

Marana Air Park Interchange

Marana Airport

See Marana Airpark

Marana Auxillary Landing Field Edsfield

Marana Elementary School

Marana High School

Marana Interchange

Marana Junior High School

Marana Park

Marana Post Office

Marana Railroad Station

Marana Sheriffs Office

Marble Canon

See Marble Canyon

Marble Canyon

Marble Canyon

Marble Canon

Marble Gorge

Marble Canyon

Lees Ferry

Marble Canyon Airport

Marble Canyon Lodge

Marble Canyon National Monument

Marble Flats

Marble Gorge

See Marble Canyon

Marble Hill

See White Horse Hills

Marble Hills

See White Horse Hills

Marble Lateral

Marble Mine

Marble Mountain

See White Horse Hills

Marble Peak

Marble Quarry

Marble Spring

Marble Viewpoint

Marcelle Canyon

Marcelle Spring

Marchant Tank

Marcos de Niza High School

Marcos Monument

See Explorers Monument

Marcos Terrace

$$
\text { Coronado Plateau }
$$

Marcou Crater

See Stewart Crater

Marcou Mesa

Mreek

See Markham Wash
Greenlee 332221N1090525W

Greenlee 325833N1092157W

$322612 N 1111329$

$322730 \mathrm{~N} 1111229 \mathrm{~W}$

323038N1111938W

$323024 N 1111606 \mathrm{~W}$

crossing VARIANT

Pinal

VARIANT

airport

airport

school

schoo

crossing

school

building

building

building

valley

valley

ppl

ADMIN

VARIANT

UNOFF

UNOFF

UNOFF

UNOFF

ADMIN

Pinal

Pinal

Pima

Pima

Pima

Pima

Pima

UNOFF Pima

UNOFF

Pima

Coconino

$\begin{array}{ll}\text { BGN } & \text { Cochise } \\ \text { BGN } 1960 & \text { Coconino }\end{array}$

VARIANT

VARIANT

Coconino

VARIANT

airport

building

park

ADMIN

UNOFF

ADMIN

BGN 1932

valley

ARIANT

summit

VARIANT

summit

VARIANT

Coconino

Coconino

Coconino

Coconino

Coconino

Coconino

Coconino

323038 N1111938

$343945 \mathrm{~N} 1112911 \mathrm{~W}$

$322717 N 1111229 \mathrm{~W}$

$322708 \times 1111220 \mathrm{~W}$

$322743 N 1111257 \mathrm{~W}$

$322714 N 1111229 \mathrm{~W}$

$322653 \mathrm{~N} 1111220 \mathrm{~W}$

$322734 N 1111405 \mathrm{~W}$

$322725 N 1111227 \mathrm{~W}$

$322735 \mathrm{~N} 1111402 \mathrm{~W}$

$361130 \mathrm{~N} 1114800 \mathrm{~W}$

320751 N1092211

$361130 \mathrm{~N} 1114800 \mathrm{~W}$

$364856 N 1113813 W$

$364845 N 1113845 \mathrm{~W}$

$364858 \mathrm{N1113815 \textrm {W }}$

$363520 N 1114610 \mathrm{~W}$

$361357 N 1120417$ W

361130 N1114800W

$352322 N 1114213 \mathrm{~W}$

352322N1114213W

canal

mine

BGN

UNOFF

VARIANT

summit

summit

mine

spring

locale

valley

spring

BGN

UNOFF

BGN

BGN

BGN

BGN

reservoir

BGN

school

UNOFF

summit

VARIANT

bench

BGN 190

VARIANT

VARIANT

crater

summit

BGN

VARIANT

Yuma

Yavapai

324220 N1143952W

$341417 N 1114914 \mathrm{~W}$

Coconino

Pima

Cochise

Apache

Coconino

Maricopa

Yavapai

$352322 \mathrm{~N} 1114213 \mathrm{~W}$

$322813 \mathrm{~N} 1104432 \mathrm{~W}$

$320653 \mathrm{~N} 1092411 \mathrm{~W}$

$335846 \mathrm{~N} 1092734 \mathrm{~W}$

$362400 \mathrm{~N} 1120337 \mathrm{~W}$

$340004 \mathrm{~N} 1115142 \mathrm{~W}$

340106 N1115053

Mohave

Maricopa

$363755 N 1131612 \mathrm{~W}$

332159 N1115504W

Coconino

$361221 N 1122642 \mathrm{~W}$

361317 N1122609W

$352140 \mathrm{~N} 1112413 \mathrm{~W}$

$350352 \mathrm{~N} 1101315 \mathrm{~W}$

Navajo

325617 N1095317W
340137 N1115026W

$\begin{array}{cc}\text { SOURCE } & \text { ELEV } \\ \text { COORDINATE } & \text { FT }\end{array}$

$364837 N 1134036$
$340015 N 1112730$

Mazatzal Peak

8294 Maple Peak

Wolf Hole Mtn West

Bassett Peak

Mt Turnbull

Coronado Mtn

Pinyon Mtn

Blue

Mazatzal Peak

Dutton $\mathrm{Hill}$

Wolf Hole Mtn West

Strawberry

Maple Peak

Guthrie

Marana

Marana

1891 Red Rock

1940 Red Rock

Newman Peak

Marana

Marana

Marana

Marana

Marana

Marana

Marana

Marana

$320654 \mathrm{~N} 1092444 \mathrm{~W}$

$365130 \mathrm{~N} 111360 \mathrm{OH}$

Little Wood Canyon

Cape Solitude

4000 Navajo Bridge

3603 Navajo Bridge

Navajo Bridge

North Canyon Point Bright Angel Point

Yuma West

Bloody Bas in

7670 Mount Bigelow

Bowie Mtn South

Big Lake North

Dog Point

Rover Peak

Rover Peak

The Grandstand

Guadalupe

Explorers Monument

Lee Mountain 
FEATURE

CLASS
STATUS

COUNTY
COORDINATE

$330145 N 1094745 \mathrm{~W}$

344411N1120140W

344400N1120144W

$330443 \mathrm{~N} 1092153 \mathrm{~W}$

$\begin{array}{llll}\text { Ppl } & & \text { Greenlee } & 330443 N 1092153 \mathrm{~W} \\ \text { reservoir } & \text { BGN } & \text { Navajo } & 334054 N 1095917 \mathrm{~W} \\ \text { spring } & \text { BGN } & \text { Gila } & 334945 N 1101044 \mathrm{~W}\end{array}$

$\begin{array}{llll}\text { ppl } & & \text { Greenlee } & 330443 N 1092153 \mathrm{~W} \\ \text { reservoir } & \text { BGN } & \text { Navajo } & 334054 \mathrm{~N} 1095917 \mathrm{~W} \\ \text { spring } & \text { BGN } & \text { Gila } & 334945 \mathrm{~N} 1101044 \mathrm{~W}\end{array}$

Mare Springs

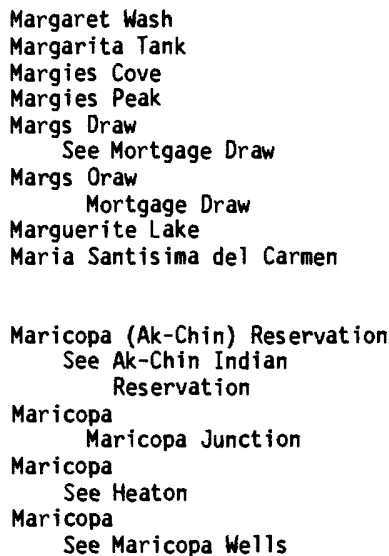

Maricopa County General Hospital

Maricopa County Highway Department

Maricopa County Jail Annex

Maricopa County Juvenile Detention Home

Maricopa County Municipal Water Conservation District Number One

Maricopa County Veterninary Center

Maricopa General Hospital

Hel iport

Maricopa High School

Maricopa Indian Res ervation See Ak-Chin Indian Reservation

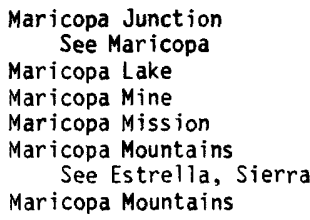

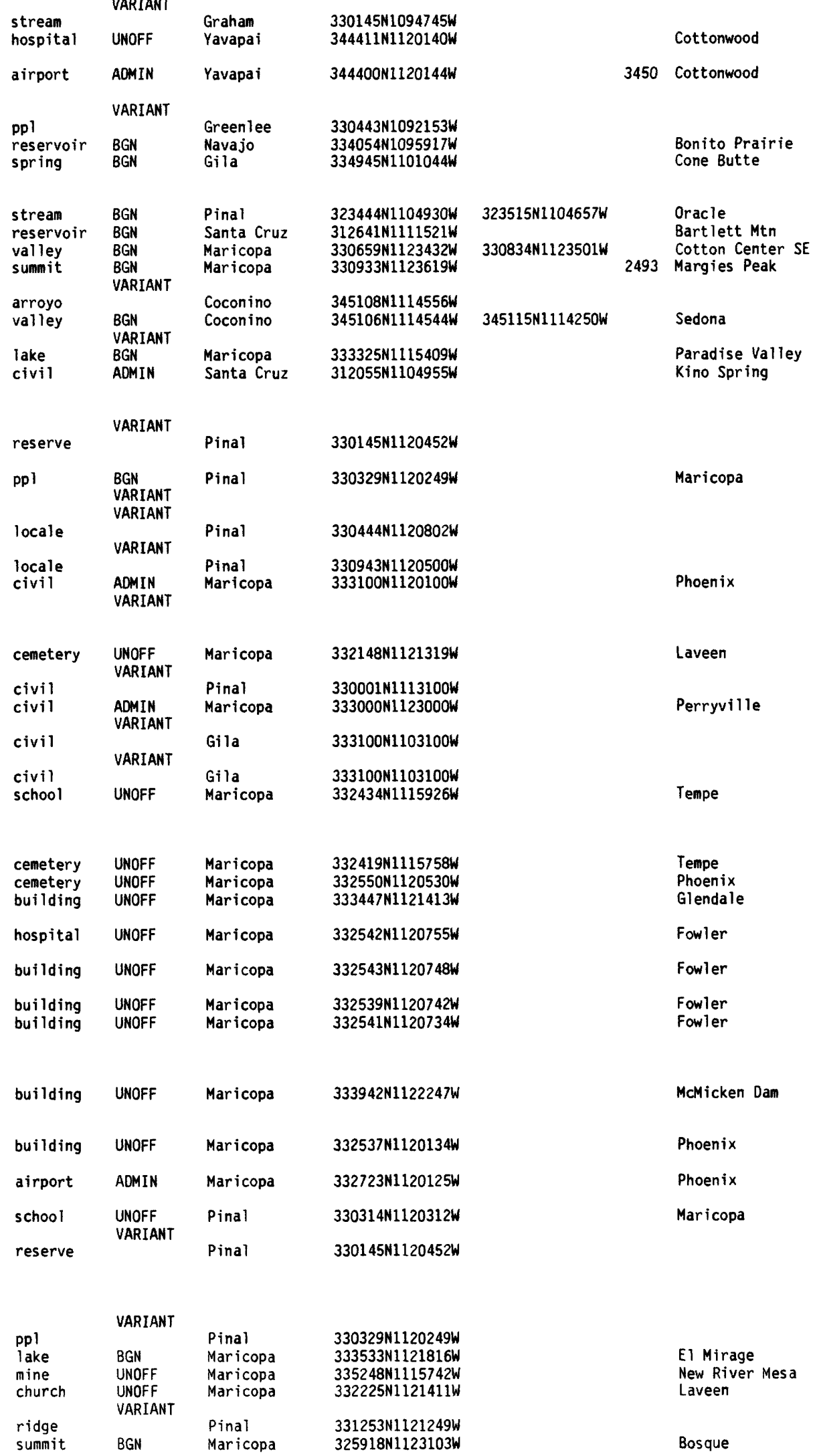




\section{FEATURE NAME}

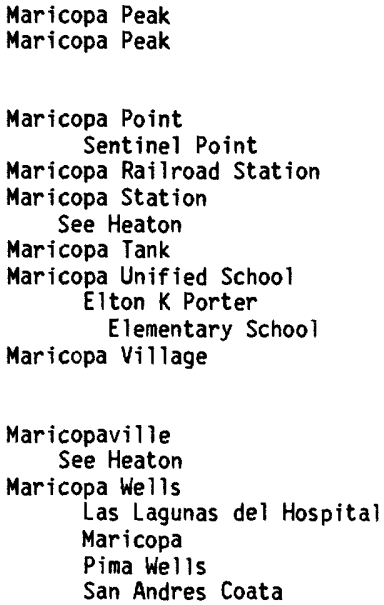

\section{FEATURE
CLASS}

STATUS

COUNTY

COORDINATE

summit
summit

\section{BGN}

BGN

Maricopa

Maricopa

cliff

building

locale

reservoir

school

\section{BGN 1906}

VARIANT

UNOFF VARIANT

pp1

BGN

UNOFF

VARIANT

BGN

Coconino

Pinal

Pinal

Maricopa

Pinal

Maricopa

VARIANT

locale

locale

\section{BGN}

VARIANT

VARIANT

VARIANT

valley

valley

VARIAN

BGN

BGN

stream

stream $B G$

park

stream

reservoir

mine

locale

building

$$
\text { ADMI }
$$$$
\text { BARIANT }
$$

VARI

BGN

UNOFF

VARIANT

Pinal

Pinal

Pima

Graham

Graham

Graham

Graham

Graham

Pima

Pima

Maricopa

Maricopa

VARIANT

pp
ca
bu
loca
val
capp
sp

ppl
canal

building

locale

valley

cape

spring

valley

park

park

valley

stream

dam

arroyo

stream

stream

stream
well

reservoir

reservoir

reservoir

mine

BGN
UNOFF
VARIANT
UNOFF
BGN
BGN 1932
BGN
BGN

Maricopa

Maricopa

Maricopa

Maricopa

Apache

Maricopa

BGN

BGN

ADMIN

ADMIN

BGN

$B G N$

BGN 1962

VARIANT

VARIANT

UNOFF

Maricopa

Santa Cruz

Maricopa

Maricopa

Greenlee

Pima

Graham

Coconino

Yavapai

$\begin{array}{lll}\text { reservoir } & \text { BGN } & \text { Apache } \\ \text { stream } & \text { VARIANT } & \begin{array}{l}\text { Graham } \\ \text { pp 1 }\end{array} \\ \text { BGN } & \text { Maricopa } \\ \text { ppl } & \text { BGN } & \text { Maricopa } \\ \text { ppl } & \text { BGN } & \text { Maricopa }\end{array}$

Graham VARIAN

VARIANT

Graham

UNOFF

BGN

BGN

$B G N$

Yavapa $i$

Apache

Graham

Yavapai

$330145 \mathrm{~N} 1094745 \mathrm{~W}$

$351703 \mathrm{N1130712W}$

$350933 \mathrm{~N} 1093906 \mathrm{~W}$

$325722 \mathrm{N1093504 \textrm {W }}$

$345529 \mathrm{~N} 1121234 \mathrm{~W}$

$342750 \mathrm{~N} 1122242 \mathrm{~W}$

350846 N1093932W

325617 N1095317W

$333540 \mathrm{~N} 1121029 \mathrm{~W}$

332141 N1115111W

332651N1115544W
324508 N1122244W 331930 N1120821W

$360412 \mathrm{~N} 1120844 \mathrm{~W}$

$330325 \mathrm{~N} 1120253 \mathrm{~W}$

$330444 \mathrm{~N} 1120802 \mathrm{~W}$

$334655 \mathrm{N1121216 \textrm {W }}$

$330315 \mathrm{~N} 1120257 \mathrm{~W}$

$332217 N 1121413 W$

$330444 \mathrm{~N} 1120802 \mathrm{~W}$

$330943 \mathrm{~N} 112050 \mathrm{WW}$

$324529 \mathrm{~N} 1102658 \mathrm{~W}$ $324426 \mathrm{~N} 1094241 \mathrm{~W}$

$324627 N 1094053 \mathrm{~W}$

$324630 \mathrm{~N} 1094050 \mathrm{~W}$
$324203 \mathrm{~N} 1094712 \mathrm{~W}$

$324627 \mathrm{N1094053 \textrm {W }}$

312B51N1112922W

$315653 \mathrm{~N} 1125052 \mathrm{~W}$

$333452 \mathrm{~N} 1120714 \mathrm{~W}$

333608N1121703W

$333551 \mathrm{N1121616 \textrm {W }}$

$334153 \mathrm{~N} 1121729 \mathrm{~W}$

333608N1121703W

$333544 \mathrm{~N} 1121647 \mathrm{~W}$ $343443 \mathrm{~N} 1091426 \mathrm{~W}$ $361739 \mathrm{N1115537 \textrm {W }}$ $335621 \mathrm{N1113107 \textrm {W }}$ 335620 N111311BW

$343044 N 1091656 \mathrm{~W}$

$312211 N 1105602 \mathrm{~W}$ 333254 N1120738W 332908 N1121045W $330612 \mathrm{~N} 1092027 \mathrm{~W}$ $322728 \mathrm{~N} 1102814 \mathrm{~W}$ 330145 N1094745W

$354249 \mathrm{N1122715W}$ $351526 \mathrm{~N} 1131042 \mathrm{~W}$

$351450 N 1130404 \mathrm{~W}$

$325617 N 1095317 \mathrm{~W}$

$330143 N 1094743 W$

$324410 \mathrm{~N} 1102529 \mathrm{~W}$

$311843 N 1110145 \mathrm{~W}$

$322652 \mathrm{~N} 1102258 \mathrm{~W}$ 330340 N1094713W

$\begin{array}{cc}\text { SOURCE } & \text { ELEV } \\ \text { COORDINATE } & \text { FT }\end{array}$

MAP NAME

4084 Big Horn

Laveen

Grand Canyon

Maricopa

Biscuit Flat

Maricopa

Laveen

Pima Butte

0ak Grove Canyon Artesia

$\begin{array}{rll}323940 \text { N1095148W } & \begin{array}{l}\text { Safford } \\ \text { Mt Graham } \\ \text { Safford }\end{array} \\ 324007 \text { N1095145W } & \begin{array}{l}\text { Cumero Mtn } \\ \text { Lukeville }\end{array} \\ 1250 & \begin{array}{l}\text { Sunnyslope } \\ \text { Sull }\end{array}\end{array}$

6373

Calderwood Butte E1 Mirage

El Mirage Kearn Lake Point Imperial Lion Mountain Lion Mountain

Nogales Glendale Fowler 


\section{FEATURE NAME}

Marlow Mesa

Marlow Mesa

Marlow Mesa Tank

Marmee Mine

Marmonier Ditch

Maroga Canyon

Maroney Gulch

Maroney Well

Maroon Crater

Maroon Mountain

Marquetta Pass

See Marquitta Pass

Marquette Mine

Marquitta Mine

Marquitta Pass

Marsh

Marquetta Pass

Marsh (historical) Maish

Marsh Airstrip

Marshall Butte

Marshall Flat Tank

Marshall Gulch

Marshall Gulch Picnic Area

Marshall Lake

Marshall Mesa Tank

Marshall Mountain

Marshall Peak

Marshall Ranch

Marshall Ridge

Marshalls (historical)

Marshall Saddle

Marshall School

Marshall School

Marshall Tank

Marshall Tank

Marshall Tank

Marshall Tank

Marsha11 Tank

Marshall Well

Marsh Creek

Marsh Creek Ranch

Marsh Creek Tank

Mars Hill

Marsh Pass

La Puerta Limita

Marsh Railroad Station Maish

Marsh Valley

Marteen Tank

Martin, Mount

Martina Mountain

Martin Canyon

Martin Canyon

Martin Canyon

Martin Canyon Tank

Martin Creek

Mart in Dam

Martin Dam Draw

Martinez Canyon

Martinez Canyon

Martinez Creek

Martinez Draw

White Horse Draw

Martinez Gulch

Martinez Hill

Berger Butte

Martinez Mountain

Sahuarita Butte

Sahuarito Butt

Sahurito Peak
FEATURE

CLASS

STATUS

COUNTY

COORDINATE

SOURCE COORDINATE

ELEV
FT

MAP NAME

summit BGN Yavapai 342215N1115537W

summit BGN Yavapai 342316N1115523W

reservoir BGN Yavapai 342250N1115448W

mine UNOFF Santa Cruz 312333N1110827W

canal BGN Maricopa 332404N1120412W

valley BGN Graham 325322N1102413W

$\begin{array}{llll}\text { valley } & \text { BGN } & \text { Yavapai } & 343444 N 1131228 W \\ \text { well } & \text { UNOFF } & \text { Mohave } & 365042 N 1125456 \mathrm{~W}\end{array}$

summit

BGH

Coconino

VARIANT

$\begin{array}{llll}\text { gap } & \text { Yuma } & 334027 N 1141857 \mathrm{~W} \\ \text { mine } & \text { UNOFF } & \text { Cochise } & 312133 \text { N1094738W }\end{array}$

$\begin{array}{lll}\text { mine UNOFF Cochise } & 312133 \text { N1094738W }\end{array}$

Yuma

mine UNOFF Yuma 333955N114181BW

gap

locale

locale

BGN
VARIANT

$\begin{array}{ll}\text { Pima } & \text { 320048N1103513W } \\ \text { Pima } & \text { 320100N1103514W }\end{array}$

airport $\begin{aligned} & \text { VARIANT } \\ & \text { ADIN Maricopa 332805N1122404W }\end{aligned}$

summit BGN Apache 335007N1094159W

reservoir BGN Apache 341230N1094922W

valley BGN Pima 322540N1104518W

park ADMIN Pima 322544N1104515W

lake BGN Coconino 350709N1113203W

reservoir BGN Coconino 350710N1113342W

summit BGN Apache 341248N1094951W

summit BGN Pima 322525N1104600W

locale UNOFF Mohave 362611N1131225W

ridge BGN Cochise 313324N1102324W

locale BGN Santa Cruz 313100N1105200W

$\begin{array}{llll}\text { gap } & \text { BGN } & \text { Pima } & \text { 322553N1104630W } \\ \text { school } & \text { UNOFF } & \text { Pima } & \text { 321154N1104755W }\end{array}$

school UNOFF Coconino 351227N1113903W

reservoir BGN Apache 341256N1094924W

reservoir BGN Yavapai 345332N1115223W

reservoir BGN Navajo 350635N1102542W

reservoir BGN Coconino 353533N1122510

$353540 \mathrm{~N} 1135534 \mathrm{~W}$

well UNOFF Navajo 350545N1102112W

stream BGN Gila 341135N1110236W

locale UNOFF Gila 340941N1110123W

reservoir BGN Gila 341017N1110045W

summit BGN Coconino 351208N1113947W

gap BGN Navajo 363906N1102546W

building UNOFF Pima 320049N1103514W

basin $B$ ARIANT Pinal 332751N1112152W

$\begin{array}{llll}\text { basin } & B G N & \text { Pinal } & 332751 \text { N1112152W } \\ \text { reservoir } & B G N & \text { Coconino } & 352615 N 1120023 W\end{array}$

summit BGN Cochise 312559N1095622W

summit BGN 1977 Pima 320332N1112648W

valley $B G N$ Graham 323331N1095202W

valley

valley

reservoir

stream

dam

valley

valley

valley

strean

valley

BGN Pinal

BGN Yavapai

BGN Yavapai

$B G N$

$B G N$

$B G N$

$B G N$

BGN 1983

VARIANT

Coconino

Coconino

Graham

Pinal

Yavapai

Apache

valley

BGN

Yuma

VARIANT

VARIANT

VARIANT

VARIANT

VARIANT
$365042 \mathrm{~N} 1125456 \mathrm{~W}$

$351827 \mathrm{~N} 1112131 \mathrm{~W}$

$345636 \mathrm{~N} 1115026 \mathrm{~W}$

$334027 N 1141857 \mathrm{~W}$

$320048 \mathrm{~N} 1103513 \mathrm{~W}$

$330615 \mathrm{~N} 1103120 \mathrm{~W}$

$344446 \mathrm{~N} 1121312 \mathrm{~W}$

$344332 \mathrm{~N} 1121009 \mathrm{~W}$

$341309 \mathrm{~N} 1125521 \mathrm{~W}$

$352410 \mathrm{~N} 1122328 \mathrm{~W}$

$352340 \mathrm{~N} 1122301 \mathrm{~W}$

$325346 \mathrm{~N} 1102444 \mathrm{~W}$

$330640 \mathrm{~N} 1111242 \mathrm{~W}$

$340215 \mathrm{N1124720 \textrm {W }}$

$343329 \mathrm{~N} 1094709 \mathrm{~W}$

$340916 \mathrm{~N} 1105616 \mathrm{~W}$

4581 Jugas

4740 Arnold Mesa

Arnold Mesa

Ruby

Phoenix

325440N1102306W Booger Canyon

Bagdad

Maroney Well

Merriam Crater

6666 Wilson Mountain

Bisbee SE

Middle Camp Mtn

Middle Camp Mtn

Rincon Peak

3560 Rincon Peak

1018 Perryville

Marshall Butte

Sponseller Mtn

$322552 N 1104615 W$

Mt Lemmon

Mt Lemmon

7112 Lower Lake Mary

Lower Lake Mary

7703 Sponseller Mtn

$8300 \mathrm{Mt}$ Lemmon

Mt Trumbull NW

Pyeatt Ranch

Patagonia

Mt Lemmon

Tucson East

Flagstaff West

Sponseller Mtn

Wilson Mountain

Humpy Camp Well

Red Hill Ranch

Music Mountains SW

Blairs Spring

Diamond Butte

Diamond Butte

Diamond Butte

Flagstaff West

Marsh Pass

Rincon Peak

Weavers Needle

Squaw Mtn

7093 Bisbee

4042 San Pedro

$323341 N 1095118 \mathrm{~W}$

Stockton Pass

$330345 N 1102901 \mathrm{~W}$

Jerusalem Mtn

Hickey Mountain

Hickey Mountain

O' Neill

Stanford Tank

Stanford Tank

Booger Canyon

North Butte

Flores

Manuel Seep

$333939 N 1142418 \mathrm{~W}$ $320623 N 1105915 \mathrm{~W}$

333943N1142307W

La Paz Mtn

2854 Tucson SW 
FEATURE NAME

Martinez Lake

Martinez Lake

Martinez Mine

Martinez Mine

Martinez Mountain

See Martinez $\mathrm{Hill}$

Martinez Mountain

Martinez Ranch

Martinez Ranch

Martinez Ranch

Martinez Spring

Martinez Tank

Martinez Tank

Martinez Wash

See Cumaro Wash

Martinez Wash

Martinez Wash

Martinez Wash

Martinez Well

Martinez Well

Martinez Well

Martin Latera1

Mart in Luther Dam

Mart in Luther King Junior

School

Mart in Luther Tank

Mart in Mine

Martin Mountain

Mart in Mountain Tank

Mart in Peak

Martin Ranch Airstrip

Martin School

Martin Spring

Martin Spring

Martin Spring

Martin Tank

Mart in Tank

Martin Wash

Mart in Well (flowing)

Mart in Well

Mart in Wel

Marvin Tank

Mary, Lake Lake Mary Tank

Mary, Lake

Mary A Canyon

Mary E Dill School

Mary E Ranch

Mary G Mine

Mary Kane Canyon

Maryland Avenue School

Maryland Knoll

Maryland West Mobile Home Park

Marys Lake Spring

Marys Tank

Marys Tank

Marys Tank

Marysville

Maysville

Maryville

Rowes Station

Marysville $\mathrm{Hill}$

Mary Tank

Maryvale

Maryvale Community Hospital

See Maryvale Samaritan Hospital

Maryvale High School

Maryvale Mal1

Maryvale Park

Maryvale Play Lot

\section{FEATURE
CLASS}

STATUS

COUNTY

COORDINATE

lake

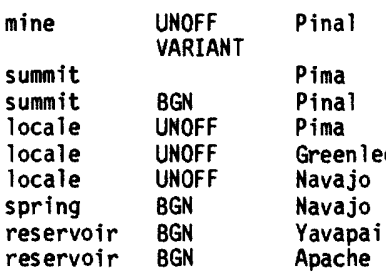

$331005 N 1110916 \mathrm{~W}$

320623N1105915W

324831 N1103443W

$315314 \mathrm{~N} 1104006 \mathrm{~W}$

$331219 N 1090934 \mathrm{~W}$

$340400 \mathrm{~N} 1103633 \mathrm{~W}$

$352627 N 1095900 \mathrm{~W}$

$340530 \mathrm{~N} 1124748 \mathrm{~W}$

$342812 \mathrm{~N} 1094858 \mathrm{~W}$

VARIANT

stream

stream

stream

stream

well

well

well

canal

BGN 1975

BGN

UNOFF

UNOFF

UNOFF

BGN

UNOFF

Pima

Graham

Maricopa

Pima

Pina1

Yuma

Yuma

Gila

school

UNOFF

Maricopa

reservoir

mine

summit

reservoir

summit

airport

school

spring

BGN

UNOFF

BGN
BGN
BGN

BGN

UNOFF

GGN

spring

spring $\quad B G$

reservoir $B G N$

reservoir

stream BGN

well

well

well

reservoir

reservoir

UNOFF

UNOFF

BGM

BGM

VARIANT

Gila

Apache

Yavapai

Yavapai

Yuma

Pinal

Pina

Maricopa

315909 N1102950W

$320135 \mathrm{~N} 1102840 \mathrm{~W}$

330256 N1093427W

335955 N1124438

$314035 \mathrm{~N} 1112326 \mathrm{~W}$

$331005 \mathrm{~N} 1110916 \mathrm{~W}$

$333933 \mathrm{~N} 1142341 \mathrm{~N}$

323918 N1144000W

333912N1101712

$332415 N 1120155 \mathrm{~W}$

333912 N1101712W

$365224 N 1091718 \mathrm{~W}$

$343124 N 1124620 \mathrm{~W}$

$343215 \mathrm{~N} 1124920 \mathrm{~W}$

$333945 N 1133524 \mathrm{~W}$

$323115 N 1105635 \mathrm{~W}$

$321411 \mathrm{~N} 1105826 \mathrm{~W}$

335751 N1112738W

Yavapai 340936N1123601W

341007 N1111556

Gila

Gila

Graham

Graham

Graham

Gila

Coconino

Yavapai

$340748 \mathrm{~N} 1105630 \mathrm{~W}$

$341055 \mathrm{~N} 1111027 \mathrm{~W}$

$323021 \mathrm{~N} 1095644 \mathrm{~W}$

$322601 N 1092046 \mathrm{~W}$

$323313 N 1095232$

331907 N1104019W

$351353 \mathrm{~N} 1114757 \mathrm{~W}$

345754 N1130612W

323341 N1095128W

reservoir

\section{BGN}

school
locale

mine

valley

school

summit

locale

spring

reservoir

reservoir $B G$

reservoir

locale

BGN

VARIANT

VARIANT
VARIANT

VARIANT

summit

reservoir $\quad B G$

pp)

BGN

Gila

Coconino

Coconino
Cochise

Maricopa

Pima

Santa Cruz

Maricopa

Mohave

Maricopa

Apache

Coconino

Coconino

Mohave

Maricopa

$343323 \mathrm{~N} 1111839 \mathrm{~W}$

$343710 \mathrm{~N} 1111804 \mathrm{~W}$

332847 N11 $15000 \mathrm{~W}$

$341239 \mathrm{~N} 1112309 \mathrm{~W}$

$350620 \mathrm{~N} 1114758 \mathrm{~W}$

$333007 \mathrm{N1} 121037 \mathrm{~W}$

VARIANT

hospita

Maricopa

333012 N1121010W

school UNOFF

locale UNOFF

UNOFF
ADNIN

ADMIN
Maricopa

Maricopa

Maricopa

Maricopa
$332920 \mathrm{N1121102W}$

$332953 \mathrm{~N} 1121015 \mathrm{~W}$

$333004 \mathrm{N1} 121010 \mathrm{~W}$

$332907 \mathrm{~N} 1121155 \mathrm{~W}$

$\begin{array}{cc}\text { SOURCE } & \text { ELEV } \\ \text { COORDINATE } & \text { FT }\end{array}$

Silver Springs Imperial Reservoir Lukeville

Mineral Mtn

3661 Holy Joe Peak

4092 Mount Fagan

Dix Creek

Spotted Mountain

Greasewood Spring

Flores

Mesa Redonda

$\begin{array}{ll}320418 N 1102923 W & \begin{array}{l}\text { Galleta Flat West } \\ \text { 330100N1093952W }\end{array} \\ 340215 N 1124720 \mathrm{~W} & \begin{array}{l}\text { Bonita Spring } \\ \text { Wickenburg } \\ \text { Las Guijas } \\ \text { Mineral Mtn } \\ \text { La Paz Mtn } \\ \text { Yuma West } \\ \text { Popcorn Canyon }\end{array}\end{array}$

Phoenix

5523 Popcorn Canyon Toh Chin Lini Mesa

6433 Martin Mtn Martin Mtn

2333 Harrisburg Valley

3280 Oracle Junction

Tucson

Reno Pass

Wagoner

Payson South

Oxbow Mtn

McDonald Mtn

Fort Grant

Mart in We 11

4884 Fort Grant 


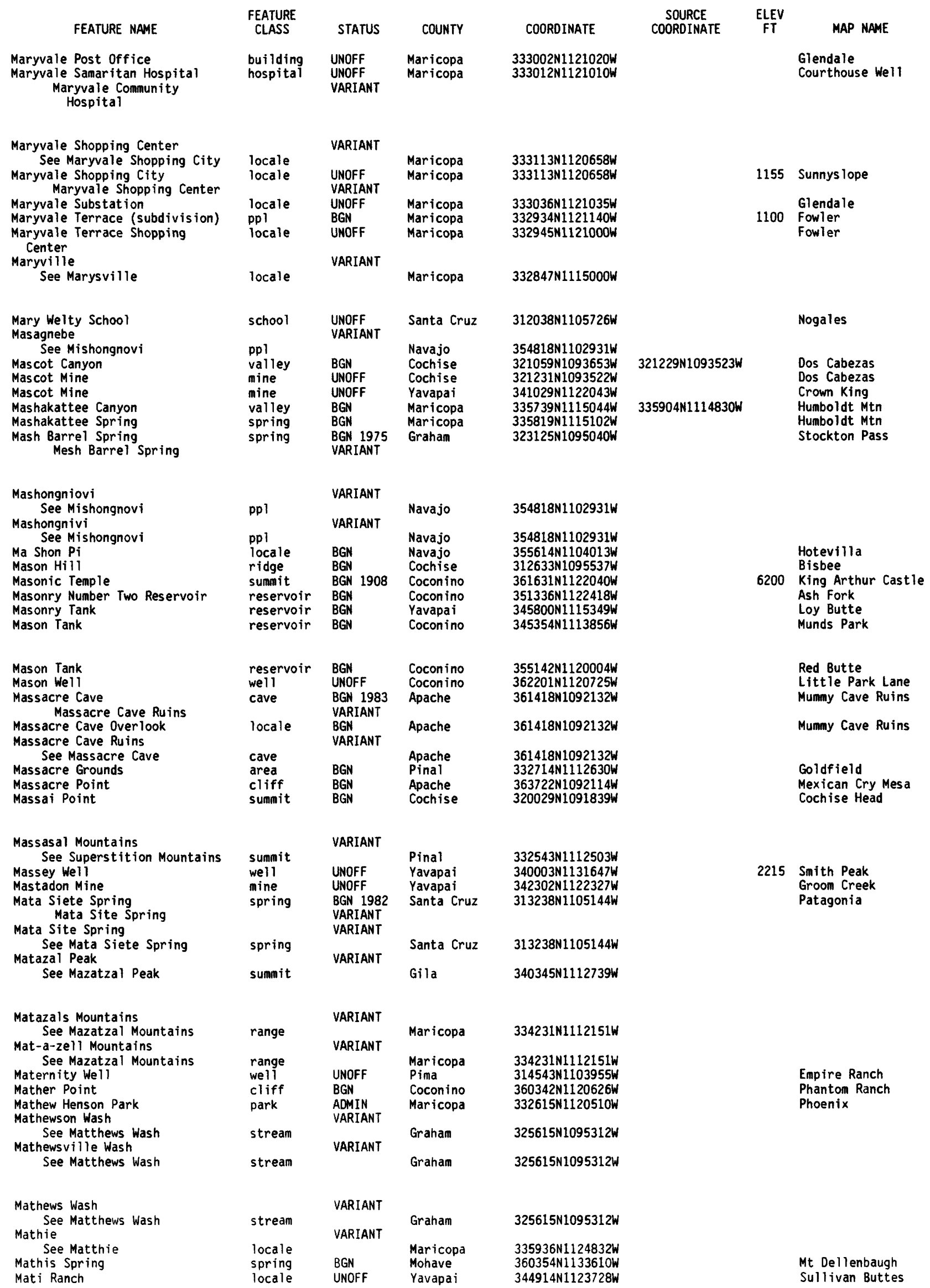




\begin{tabular}{|c|c|c|c|c|c|c|c|}
\hline FEATURE NAME & $\begin{array}{l}\text { FEATURE } \\
\text { CLASS }\end{array}$ & STATUS & COUNTY & COORDINATE & $\begin{array}{l}\text { SOURCE } \\
\text { COORDINATE }\end{array}$ & $\begin{array}{l}\text { ELEV } \\
\text { FT }\end{array}$ & MAP NAME \\
\hline $\begin{array}{l}\text { Matkatameeba Canyon } \\
\text { See Matkatamiba Canyon } \\
\text { Matkatamiba Canyon } \\
\text { Matkatameeba Canyon }\end{array}$ & $\begin{array}{l}\text { valley } \\
\text { valley }\end{array}$ & $\begin{array}{l}\text { VARIANT } \\
\text { BGN } 1925 \\
\text { VARIANT }\end{array}$ & $\begin{array}{l}\text { Coconino } \\
\text { Coconino }\end{array}$ & $\begin{array}{l}362033 \mathrm{~N} 1124016 \mathrm{~W} \\
362033 \mathrm{~N} 1124016 \mathrm{~W}\end{array}$ & $361529 N 1123441 \mathrm{~W}$ & & Havasu Falls \\
\hline $\begin{array}{l}\text { Matkatamiba Mesa } \\
\text { Matkatamiba Rapids } \\
\quad \text { Natkatameeba Rapids } \\
\text { Matson Tank } \\
\text { Matterhorn } \\
\text { Matthews Peak } \\
\text { Heald Peak } \\
\text { Matthewsville } \\
\text { See Glenbar } \\
\text { Matthews Wash } \\
\text { Mathewson Wash } \\
\text { Mathews ille Wash } \\
\text { Mathews Wash }\end{array}$ & $\begin{array}{l}\text { summit } \\
\text { rapids } \\
\text { reservoir } \\
\text { summit } \\
\text { summit } \\
\text { ppl } \\
\text { stream }\end{array}$ & $\begin{array}{l}\text { BGN } 1932 \\
\text { BGN } 1925 \\
\text { VARIANT } \\
\text { BGN } \\
\text { BGN } \\
\text { BGN } 1915 \\
\text { VARIANT } \\
\text { VARIANT } \\
\text { BGN } 1962 \\
\text { VARIANT } \\
\text { VARIANT } \\
\text { VARIANT }\end{array}$ & $\begin{array}{l}\text { Coconino } \\
\text { Coconino } \\
\text { Coconino } \\
\text { Coconino } \\
\text { Apache }\end{array}$ & $\begin{array}{l}361920 \mathrm{~N} 1124135 \mathrm{~W} \\
362039 \mathrm{~N} 1124018 \mathrm{~W} \\
351323 \mathrm{~N} 1114101 \mathrm{~W} \\
350319 \mathrm{~N} 1121713 \mathrm{~W} \\
362151 \mathrm{~N} 1090912 \mathrm{~W} \\
\\
325500 \mathrm{~N} 1095127 \mathrm{~W} \\
325615 \mathrm{~N} 1095312 \mathrm{~W}\end{array}$ & $324950 \mathrm{~N} 1100220 \mathrm{~W}$ & $\begin{array}{l}6422 \\
9512\end{array}$ & $\begin{array}{l}\text { Havasu Falls } \\
\text { Havasu Falls } \\
\text { Flagstaff West } \\
\text { Matterhorn } \\
\text { Tsaile }\end{array}$ \\
\hline $\begin{array}{l}\text { Matthie } \\
\qquad \text { Mathie } \\
\text { Matthie Tank } \\
\text { Mattie Canyon } \\
\text { Mattress Cienega } \\
\text { Mattys Fork } \\
\text { Maud Hill } \\
\text { Mauldin Airstrip } \\
\text { Maureen Lake } \\
\text { Maurice C Cash School }\end{array}$ & $\begin{array}{l}\text { locale } \\
\text { reservoir } \\
\text { valley } \\
\text { flat } \\
\text { stream } \\
\text { summit } \\
\text { airport } \\
\text { reservoir } \\
\text { school }\end{array}$ & $\begin{array}{l}\text { BGN } \\
\text { VARIANT } \\
\text { BGN } \\
\text { BGN } \\
\text { BGN } \\
\text { BGN } \\
\text { BGN } \\
\text { ADMIN } \\
\text { BGN } \\
\text { UNOFF }\end{array}$ & $\begin{array}{l}\text { Maricopa } \\
\text { Maricopa } \\
\text { Pima } \\
\text { Apache } \\
\text { Maricopa } \\
\text { Cochise } \\
\text { Maricopa } \\
\text { Coconino } \\
\text { Maricopa }\end{array}$ & $\begin{array}{l}335936 \mathrm{~N} 1124832 \mathrm{~W} \\
335934 \mathrm{~N} 1124904 \mathrm{~W} \\
315020 \mathrm{~N} 1103413 \mathrm{~W} \\
340539 \mathrm{~N} 1093932 \mathrm{~W} \\
335736 \mathrm{~N} 1115621 \mathrm{~W} \\
314425 \mathrm{~N} 1094830 \mathrm{~W} \\
332855 \mathrm{~N} 1130005 \mathrm{~W} \\
351118 \mathrm{~N} 1113500 \mathrm{~W} \\
332355 \mathrm{~N} 1120823 \mathrm{~W}\end{array}$ & $\begin{array}{l}314806 \mathrm{~N} 1103037 \mathrm{~W} \\
335623 \mathrm{~N} 1115319 \mathrm{~W}\end{array}$ & $\begin{array}{l}5082 \\
1180\end{array}$ & $\begin{array}{l}\text { Vulture Peak } \\
\text { Vulture Peak } \\
\text { Spring Water Canyon } \\
\text { Horseshoe Cienega } \\
\text { New River Mesa } \\
\text { Outlaw Mountain } \\
\text { Saddle Mtn } \\
\text { Flagstaff East } \\
\text { Fowler }\end{array}$ \\
\hline $\begin{array}{l}\text { Mauv Canyon } \\
\text { See Muav Canyon } \\
\text { Maverick } \\
\text { Maverick Bas in } \\
\text { Maverick Bas in } \\
\text { Maverick Bas in } \\
\text { Maverick Bas in } \\
\text { Maverick Bas in Tank } \\
\text { Maverick Butte } \\
\text { Maverick Butte }\end{array}$ & $\begin{array}{l}\text { valley } \\
\text { locale } \\
\text { bas in } \\
\text { bas in } \\
\text { bas in } \\
\text { valley } \\
\text { reservoir } \\
\text { summit } \\
\text { summit }\end{array}$ & $\begin{array}{l}\text { VARIANT } \\
\text { BGN } \\
\text { BGN } \\
\text { BGN } \\
\text { BGN } \\
\text { BGN } \\
\text { BGN } \\
\text { BGN } \\
\text { BGN }\end{array}$ & $\begin{array}{l}\text { Coconino } \\
\text { Apache } \\
\text { Greenlee } \\
\text { Yavapai } \\
\text { Yavapai } \\
\text { Gila } \\
\text { Yavapai } \\
\text { Maricopa } \\
\text { Yavapai }\end{array}$ & $\begin{array}{l}361629 N 1121932 \mathrm{~W} \\
334434 \mathrm{~N} 1093248 \mathrm{~W} \\
330215 \mathrm{~N} 1090410 \mathrm{~W} \\
340713 \mathrm{~N} 1113105 \mathrm{~W} \\
343326 \mathrm{~N} 1113500 \mathrm{~W} \\
335301 \mathrm{~N} 1111021 \mathrm{~W} \\
343320 \mathrm{~N} 1113520 \mathrm{~W} \\
335639 \mathrm{~N} 1114727 \mathrm{~W} \\
344017 \mathrm{~N} 1113809 \mathrm{~W}\end{array}$ & $335544 \mathrm{~N} 1110931 \mathrm{~W}$ & $\begin{array}{l}4870 \\
5495\end{array}$ & $\begin{array}{l}\text { Maverick } \\
\text { Big Lue Mts } \\
\text { Table Mountain } \\
\text { Buckhorn Mountain } \\
\text { Picture Mtn } \\
\text { Buckhorn Mountain } \\
\text { Humboldt Mtn } \\
\text { Casner Butte }\end{array}$ \\
\hline \begin{tabular}{l} 
Maverick Butte \\
Maverick Camp \\
Maverick Canyon \\
Maverick Canyon \\
\multicolumn{1}{c}{ Canyon del Muerto } \\
Del Muerto \\
Maverick Canyon \\
Maverick Canyon Corral \\
Maverick Cienega \\
Maverick Flat
\end{tabular} & $\begin{array}{l}\text { valley } \\
\text { locale } \\
\text { swamp } \\
\text { flat }\end{array}$ & $\begin{array}{l}\text { BGN } \\
\text { BGN } \\
\text { BGN } \\
\text { BGN } \\
\text { VARIANT } \\
\text { VARIANT } \\
\text { BGN } \\
\text { BGN } \\
\text { BGN } \\
\text { BGN }\end{array}$ & $\begin{array}{l}\text { Coconino } \\
\text { Graham } \\
\text { Apache } \\
\text { Gila }\end{array}$ & $\begin{array}{l}342828 \mathrm{~N} 1111050 \mathrm{~W} \\
331402 \mathrm{~N} 1093746 \mathrm{~W} \\
335547 \mathrm{~N} 1094415 \mathrm{~W} \\
341553 \mathrm{~N} 1112603 \mathrm{~W}\end{array}$ & $\begin{array}{l}320601 \mathrm{~N} 1092254 \mathrm{~W} \\
331328 \mathrm{~N} 1093645 \mathrm{~W} \\
342705 \mathrm{~N} 1111126 \mathrm{~W}\end{array}$ & 7650 & $\begin{array}{l}\text { White Horse Hills } \\
\text { Iron Mountain } \\
\text { Cochise Head } \\
\text { Park Creek Cabins } \\
\text { Dane Canyon } \\
\text { Park Creek Cabins } \\
\text { Hawley Lake East } \\
\text { Buckhead Mesa }\end{array}$ \\
\hline $\begin{array}{l}\text { Maverick Flat Tank } \\
\text { Maverick Gap Spring } \\
\text { Maverick Hill } \\
\text { Maverick Lake } \\
\text { Maverick Mountain } \\
\text { Maverick Mountain } \\
\text { Maverick Mountain } \\
\text { Maverick Mountain } \\
\text { Maverick Mountain } \\
\text { Maverick Mountain }\end{array}$ & $\begin{array}{l}\text { reservoir } \\
\text { spring } \\
\text { summit } \\
\text { lake } \\
\text { summit } \\
\text { summit } \\
\text { summit } \\
\text { summit } \\
\text { summit } \\
\text { summit }\end{array}$ & $\begin{array}{l}\text { BGN } \\
B G N \\
B G N \\
B G N \\
B G N \\
B G N \\
B G N \\
B G N \\
B G N \\
B G N\end{array}$ & $\begin{array}{l}\text { Gila } \\
\text { Yavapai } \\
\text { Greenlee } \\
\text { Apache } \\
\text { Cochise } \\
\text { Graham } \\
\text { Graham } \\
\text { Apache } \\
\text { Maricopa } \\
\text { Yavapai }\end{array}$ & $\begin{array}{l}341546 \mathrm{~N} 1112603 \mathrm{~W} \\
343742 \mathrm{~N} 1120402 \mathrm{~W} \\
330136 \mathrm{~N} 1090326 \mathrm{~W} \\
333842 \mathrm{~N} 1094040 \mathrm{~W} \\
321546 \mathrm{~N} 109352 \mathrm{WW} \\
323540 \mathrm{~N} 1094750 \mathrm{~W} \\
324214 \mathrm{~N} 1102520 \mathrm{~W} \\
333730 \mathrm{~N} 1094110 \mathrm{~W} \\
335037 \mathrm{N11} 13248 \mathrm{~W} \\
342544 \mathrm{~N} 1122826 \mathrm{~W}\end{array}$ & & $\begin{array}{l}7488 \\
6091 \\
7122 \\
7003 \\
8088 \\
4604 \\
7443\end{array}$ & $\begin{array}{l}\text { Buckhead Mesa } \\
\text { Cottonwood } \\
\text { Big Lue Mts } \\
\text { Odart Mtn } \\
\text { Luzena } \\
\text { Stockton Pass } \\
\text { Rhodes Peak } \\
\text { Maverick SW } \\
\text { Maverick Mtn } \\
\text { Groom Creek }\end{array}$ \\
\hline $\begin{array}{l}\text { Maverick Mountain Wash } \\
\text { Maverick Peak } \\
\text { Maverick Spring } \\
\text { Maverick Spring } \\
\text { Maverick Spring } \\
\text { Maverick Spring } \\
\text { Maverick Spring } \\
\text { Maverick Spring } \\
\text { Maverick Spring } \\
\text { Maverick Spring }\end{array}$ & $\begin{array}{l}\text { stream } \\
\text { summit } \\
\text { spring } \\
\text { spring } \\
\text { spring } \\
\text { spring } \\
\text { spring } \\
\text { spring } \\
\text { spring } \\
\text { spring }\end{array}$ & $\begin{array}{l}\text { BGN } \\
\text { BGN } \\
\text { BGN } \\
\text { BGN } \\
\text { BGN } \\
\text { BGN } \\
\text { BGN } \\
\text { BGN } \\
\text { BGN } \\
\text { BGN }\end{array}$ & $\begin{array}{l}\text { Maricopa } \\
\text { Cochise } \\
\text { Pima } \\
\text { Greenlee } \\
\text { Graham } \\
\text { Gila } \\
\text { Gila } \\
\text { Greeniee } \\
\text { Gila } \\
\text { Maricopa }\end{array}$ & $\begin{array}{l}335141 N 1113539 \mathrm{~W} \\
320110 \mathrm{~N} 1091623 \mathrm{~W} \\
322351 N 1104005 \mathrm{~W} \\
331334 \mathrm{~N} 1090734 \mathrm{~W} \\
331453 \mathrm{~N} 1093555 \mathrm{~W} \\
331616 \mathrm{~N} 1104638 \mathrm{~W} \\
331809 \mathrm{~N} 1105145 \mathrm{~W} \\
333336 \mathrm{~N} 1092753 \mathrm{~W} \\
334117 \mathrm{~N} 1101119 \mathrm{~W} \\
334956 \mathrm{~N} 1113211 \mathrm{~W}\end{array}$ & $334932 N 1113241 W$ & 1290 & $\begin{array}{l}\text { Maverick Mtn } \\
\text { Cochise Head } \\
\text { Mount Bigelow } \\
\text { Dix Creek } \\
\text { Elevator Mtn } \\
\text { Pinal Peak } \\
\text { Pinal Peak } \\
\text { Baldy Bill Point } \\
\text { Forks Butte } \\
\text { Maverick Mtn }\end{array}$ \\
\hline $\begin{array}{l}\text { Maverick Spring } \\
\text { Maverick Spring Canyon } \\
\text { Maverick Springs Canyon } \\
\text { Maverick Springs Canyon }\end{array}$ & $\begin{array}{l}\text { spring } \\
\text { valley }\end{array}$ & $\begin{array}{l}\text { BGN } \\
\text { BGN } \\
\text { VARIANT } \\
\text { VARIANT }\end{array}$ & $\begin{array}{l}\text { Yavapai } \\
\text { Maricopa }\end{array}$ & $\begin{array}{l}340702 \mathrm{~N} 1113108 \mathrm{~W} \\
334 \mathrm{~B} 58 \mathrm{~N} 1113139 \mathrm{~W}\end{array}$ & $335040 \mathrm{~N} 1113226 \mathrm{~W}$ & & $\begin{array}{l}\text { Table Mountain } \\
\text { Maverick Mtn }\end{array}$ \\
\hline
\end{tabular}




\section{FEATURE NAME}

See Maverick Spring Canyon Maverick Tank

Maverick Tank

Maverick Tank

Maverick Tank

Maverick Tank

Maverick Tank

Maverick Tank

Maverick Well

Maverick Well

Maveric Tank

Mavis Wash

Maxey

See Fort Thomas

Maxey Lateral

Maxie Tank

Max Seep

Max Tank

Maxwell Junior High School

Maxwell Lake (historical)

Maxwell Park

Maxwell Spring

Maxwell Tank

Maxwell Tank

Maxwe 11 Tank

Maxwell Tank

Mayall Telescope (158 Inch)

Mayberry Spring

Maybe Tank

May Day Peak

Mayencopi

$$
\text { See Moenkopi }
$$

Mayer

Mayer Elementary School

Mayer High School

Mayer Post Office

Mayes Tank

Mayeto

See Maito

Mayfair Plaza Shopping Center Mayfair Shopping Center

Mayfield Canyon

Mayfield Spring

Mayflower Spring

Mayflower Tank

Mayf lower Terrace (subdivision)

Maynard Tank

Mays Gap

Mays Gap Tunnel Spring

See Tunnel Spring

Mays Gap Well

Mays Hills

Mays Tank

Maysville

See Marysville

Mays Wash

Mayswell Canyon

Mayswell Peak

May Tank

May Tank

May Tank Canyon

May Tank Pocket

Mayvaxi

See Maivayi

Mazatzal Divide

Mazatzal Divide Trail

Mazatzal Divide 23

Mazatzal Mountains

Matazals Mountains

Mat-a-zell Mountains

Mazatzal Mountains

$\begin{array}{lll} & & \\ \text { sGN } & \text { Pima } & 314524 \text { N1113505W }\end{array}$

school BGN Santa Cruz 312341N1103219W

$\begin{array}{llll}\text { school } & \text { UNOFF } & \text { Pima } & \text { 321332N1110136W } \\ \text { lake } & \text { BGN 1954 } & \text { Maricopa } & 333250 N 1113945 W\end{array}$

$\begin{array}{llll}\text { flat } & \text { BGN } 1954 \text { Maricopa } & 333250 N 1113945 W \\ & \text { Coconino } & 343550 \text { N1112434W }\end{array}$

$\begin{array}{lll}\text { spring BGN Coconino } & 351658 \text { N1114746W }\end{array}$

$$
\begin{aligned}
& \text { FEATURE } \\
& \text { CLASS } \\
& \text { valley } \\
& \text { reservoir } \\
& \text { reservoir } \\
& \text { reservoir } \\
& \text { reservoir } \\
& \text { reservoir } \\
& \\
& \text { reservoir } \\
& \text { reservoir } \\
& \text { well } \\
& \text { well } \\
& \text { reservoir } \\
& \text { stream } \\
& \text { ppl } \\
& \text { canal } \\
& \text { reservoir } \\
&
\end{aligned}
$$$$
\text { reservoir }
$$$$
\text { summit }
$$

\section{ppl}

$\mathrm{pp} 1$

school

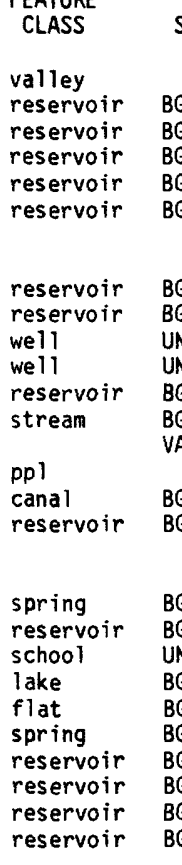


NATIONAL GAZETTEER--ARIZONA 1986

\section{FEATURE NAME}

Mazatzal Range

Maz-at-zark Mountains

Mazatzal Mountains

See Mazatzal Mountains

Mazatzal Peak

Matazal Peak

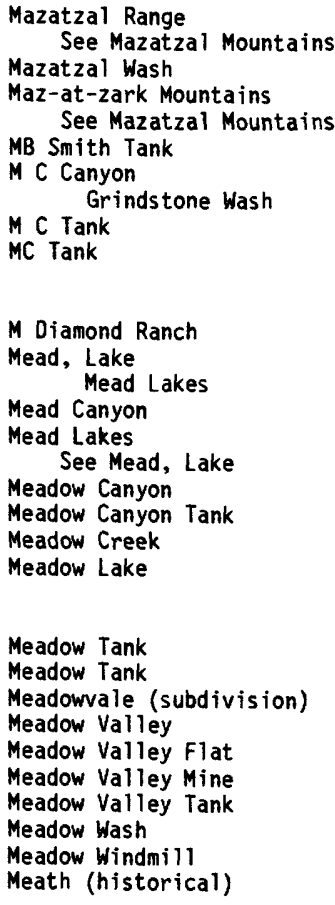

\section{FEATURE}

CLASS

STATUS

COUNTY

VARIANT

VARIANT

VARIANT

range

summit

BGN 1947 VARIANT

Maricop

VARIANT

range
stream
range
reservoir
valley

reservoir

locale

reservoir

valley

reservoir valley reservoir stream

lake

BGN
VARIA

VARIANT

BGN

BGN 1977

VARIANT

BGN

BGN

UNOFF

BGN 1948

VARIANT

BGN

VARIANT

$B G N$
$B G N$
$B G N$

BGN

reservoir

reservoir

ppl

valley

flat

mine

reservoir

strean

locale

ppl

dam

building

spring

reservoir

stream

cape

cape

well

well

BGN
BGN
BGN
BGN
BGN
UNOFF
BGN
BGN
BGN
BGN

$\begin{array}{ll}\text { Maricopa } & 334231 N 1112151 W \\ \text { Yavapai } & 340150 N 1113358 W\end{array}$

Maricopa

Coconino

Yavapai

Coconino

Coconino

Yavapai

Mohave

Gila

Mohave

Coconino

Coconino

Mohave

Yavapai

Coconino

Coconino

Maricopa

Santa Cruz

Santa Cruz

Santa Cruz

Sarita Cruz

Apache

Yavapai

Yavapai

UNOFF
UNOFF
BGN
BGN
BGN
BGN
BGN
BGN
UNOFF

UNOFF
BGN
BGN
BGN
BGN
BGN
BGN
UNOFF
UNOFF

Yavapai

Yavapai

Yavapai

Coconino

Yavapai

Navajo

Gila

Gila

Gila

Pima

park
summit

well

stream

valley

spring

spring

locale

locale

AOMIN
BGN
UNOFF
BGN
BGN 1935
BGN
BGN
UNOFF
UNOFF
BGN

Pima

Gila

Maricopa

Gila

Coconino

Yavapa $i$

Maricopa

Mohave

Pinal

Mohave

spring

reservoir

dam UNOFF

reservoir $B G N$

gap

well

VARIANT

BGN 1959

VARIANT

Mohave

Coconino

Coconino

Coconino

Coconino

Pima
Pima

UNOFF

Pima

VARIANT

locale

locale

VARIANT

Mohave

344306 N1142911W

VARIANT
334231N1112151W

345041 N1112514h

$345532 \mathrm{~N} 1121632 \mathrm{~W}$

$345840 \mathrm{~N} 1121539 \mathrm{~W}$

$350653 \mathrm{~N} 1121258 \mathrm{~W}$

$343657 N 1114303 W$

$360056 \mathrm{~N} 1144413 \mathrm{~W}$

332120N1105645W

$360056 N 1144413 \mathrm{~W}$

$343339 N 1113131 \mathrm{~W}$

$343120 \mathrm{~N} 1113059 \mathrm{~W}$

$350133 \mathrm{N1141306 \textrm {k }}$

$350803 \mathrm{~N} 1131943 \mathrm{~W}$

343042N1112B44W

$344815 \mathrm{~N} 1112404 \mathrm{~W}$

332605 N1114628W

$312803 \mathrm{N1} 103743 \mathrm{~W}$

$312854 \mathrm{N1103820 \textrm {W }}$

$313037 \mathrm{N1} 103504 \mathrm{~W}$

$313017 N 11035244$

$344805 \mathrm{~N} 1090630 \mathrm{~W}$

$341753 \mathrm{~N} 1124328 \mathrm{~W}$

$350724 N 1122648 \mathrm{~W}$

350741 N1122734W

$350720 \mathrm{N1122655W}$

$350451 \mathrm{N1122622 \textrm {W }}$

$351002 \mathrm{N1} 122413 \mathrm{~W}$

$350259 N 1122445 \mathrm{~W}$

$333736 \mathrm{N1105725 \textrm {W }}$

$333841 \mathrm{N1} 105735 \mathrm{~W}$

$334048 \mathrm{~N} 1105452 \mathrm{~W}$

$314039 \mathrm{~N} 1111449 \mathrm{~W}$

$321430 \mathrm{~N} 1105608 \mathrm{~W}$

$334730 \mathrm{~N} 1104208 \mathrm{~W}$

$331342 \mathrm{~N} 1131019 \mathrm{~W}$

$334610 \mathrm{N1104021 \textrm {W }}$

$343551 \mathrm{N1} 120517 \mathrm{~W}$

$334800 \mathrm{~N} 1112347 \mathrm{~W}$

$343801 \mathrm{~N} 1133418 \mathrm{~W}$

$323212 \mathrm{~N} 1112149 \mathrm{~W}$

$364038 \mathrm{~N} 1124411 \mathrm{~W}$

$365413 N 1124922 \mathrm{~W}$

$355432 \mathrm{~N} 1120306 \mathrm{~W}$

$344434 \mathrm{~N} 1110837 \mathrm{~W}$

$345023 \mathrm{~N} 1110639 \mathrm{~W}$

$345021 \mathrm{~N} 1110639 \mathrm{~W}$

$314556 \mathrm{~N} 1104746 \mathrm{~W}$

$314556 \mathrm{~N} 1104746 \mathrm{~W}$

314551N110541BW
$355242 \mathrm{~N} 1102402 \mathrm{~W}$ reservoir

SOORDINATE ELEV

MAP NAME

340205N1112944W Table Mountain

Hutch Mtn

Hell Point

Hell Point

May Tank Pocket

Walker Mtn

1221 Hoover Dam

331949N1105507W Pinal Ranch

$343004 N 1112753 \mathrm{~W}$

Buckhorn Mountain

Buckhorn Mountain

Kingman SW

Fort Rock Ranch

Calloway Butte

Hutch Mtn

1280 Mesa

Harshaw

Harshaw

O' Donnell Canyon

O' Donnell Canyon

354733N1091128W Fort Defiance

Peeples Valley

Meath Spring 
NATIONAL GAZETTEER--ARIZONA 1986

\begin{tabular}{|c|c|c|c|c|c|c|c|}
\hline FEATURE NAME & $\begin{array}{l}\text { FEATURE } \\
\text { CLASS }\end{array}$ & STATUS & COUNTY & COORDINATE & $\begin{array}{l}\text { SOURCE } \\
\text { COORDINATE }\end{array}$ & $\begin{array}{l}\text { ELEV } \\
\text { FT }\end{array}$ & MAP NAME \\
\hline $\begin{array}{l}\text { See Topock } \\
\text { Melloy Spring } \\
\text { Melrose Shopping Center } \\
\text { Melvin E Sine School } \\
\text { Memorial Airfield } \\
\text { Goodyear Air Force } \\
\text { Auxillary Field }\end{array}$ & $\begin{array}{l}\text { locale } \\
\text { spring } \\
\text { locale } \\
\text { school } \\
\text { airport }\end{array}$ & $\begin{array}{l}\text { BGN } \\
\text { UNOFF } \\
\text { UNOFF } \\
\text { ADMIN } \\
\text { VARIANT }\end{array}$ & $\begin{array}{l}\text { Mohave } \\
\text { Gila } \\
\text { Maricopa } \\
\text { Maricopa } \\
\text { Maricopa }\end{array}$ & $\begin{array}{l}344306 \mathrm{~N} 1142911 \mathrm{~W} \\
331505 \mathrm{~N} 1105345 \mathrm{~W} \\
332955 \mathrm{~N} 1120458 \mathrm{~W} \\
333246 \mathrm{~N} 1120940 \mathrm{~W} \\
331430 \mathrm{~N} 1115400 \mathrm{~W}\end{array}$ & & 1179 & $\begin{array}{l}\text { Pinal Ranch } \\
\text { Phoenix } \\
\text { Glendale } \\
\text { Gila Butte NW }\end{array}$ \\
\hline $\begin{array}{l}\text { Menorial Hospital } \\
\quad \text { See Phoenix Memorial } \\
\text { Hospital } \\
\text { Menorial Hospital Heliport } \\
\text { Menorial Park } \\
\text { Memory Lawn Cemetery } \\
\text { Menagers Lake } \\
\text { Mencius Temple } \\
\text { Mendoza Canyon } \\
\text { Mendoza Wash }\end{array}$ & $\begin{array}{l}\text { hospital } \\
\text { airport } \\
\text { cemetery } \\
\text { cemetery } \\
\text { lake } \\
\text { summit } \\
\text { valley } \\
\text { stream }\end{array}$ & $\begin{array}{l}\text { ADNIN } \\
\text { UNOFF } \\
\text { UNOFF } \\
\text { BGN } \\
\text { BGN } 1906 \\
\text { BGN } \\
\text { BGN }\end{array}$ & $\begin{array}{l}\text { Maricopa } \\
\text { Maricopa } \\
\text { Yavapai } \\
\text { Maricopa } \\
\text { Pima } \\
\text { Coconino } \\
\text { Pima } \\
\text { Pima }\end{array}$ & $\begin{array}{l}332608 \mathrm{~N} 1120452 \mathrm{~W} \\
332601 \mathrm{~N} 1120452 \mathrm{~W} \\
343240 \mathrm{~N} 1122711 \mathrm{~W} \\
332718 \mathrm{~N} 1120657 \mathrm{~W} \\
314915 \mathrm{~N} 1123223 \mathrm{~W} \\
361029 \mathrm{~N} 1121345 \mathrm{~W} \\
315841 \mathrm{~N} 1112843 \mathrm{~W} \\
320431 \mathrm{~N} 1112019 \mathrm{~W}\end{array}$ & $\begin{array}{l}315848 N 1113159 \mathrm{~W} \\
315848 \mathrm{N1} 113159 \mathrm{~W}\end{array}$ & $\begin{array}{l}1068 \\
1742 \\
6997\end{array}$ & $\begin{array}{l}\text { Phoenix } \\
\text { Prescott } \\
\text { Phoenix } \\
\text { Menagers Lake } \\
\text { Shiva Temple } \\
\text { Palo Alto Ranch } \\
\text { Three Points }\end{array}$ \\
\hline $\begin{array}{l}\text { Menefee Windmill } \\
\text { Menlo Park } \\
\text { Menlo Park School } \\
\text { Menlo Plaza Shopping Center } \\
\text { Mennonite Mission } \\
\text { Mensendick Middle School } \\
\quad \text { See Jack C William School } \\
\text { Mercer Ranch } \\
\text { Mercer Spring } \\
\text { Mercer Tunnel Spring }\end{array}$ & $\begin{array}{l}\text { locale } \\
\text { park } \\
\text { school } \\
\text { locale } \\
\text { school } \\
\text { school } \\
\text { locale } \\
\text { spring } \\
\text { spring }\end{array}$ & $\begin{array}{l}\text { BGN } \\
\text { ADMIN } \\
\text { UNOFF } \\
\text { UNOFF } \\
\text { UNOFF } \\
\text { VARIANT } \\
\text { UNOFF } \\
\text { BGN } \\
\text { BGN }\end{array}$ & $\begin{array}{l}\text { Cochise } \\
\text { Pima } \\
\text { Pima } \\
\text { Pima } \\
\text { Navajo } \\
\text { Maricopa } \\
\text { Pinal } \\
\text { Pima } \\
\text { Gila }\end{array}$ & $\begin{array}{l}312311 \mathrm{~N} 1102705 \mathrm{~W} \\
321335 \mathrm{~N} 1105922 \mathrm{~W} \\
321331 \mathrm{~N} 1105926 \mathrm{~W} \\
321341 \mathrm{~N} 1105925 \mathrm{~W} \\
352905 \mathrm{~N} 1095229 \mathrm{~W} \\
333103 \mathrm{~N} 1121203 \mathrm{~W} \\
324345 \mathrm{~N} 1102739 \mathrm{~W} \\
322010 \mathrm{~N} 1104208 \mathrm{~W} \\
331955 \mathrm{~N} 1105757 \mathrm{~W}\end{array}$ & & 2340 & $\begin{array}{l}\text { Huachuca Peak } \\
\text { Tucson } \\
\text { Tucs on } \\
\text { Tucs on } \\
\text { Arrowhead Butte NE } \\
\text { Rhodes Peak } \\
\text { Agua Caliente Hi1l } \\
\text { Pinal Ranch }\end{array}$ \\
\hline $\begin{array}{l}\text { Merchant Tank } \\
\text { Mercuria Mine } \\
\text { Mercury Mine School } \\
\text { Mercy Tank } \\
\text { Meridian Butte } \\
\quad \text { Rooster Mesa } \\
\text { Meridiancheri Mobile Home Park } \\
\text { Merit Spring } \\
\text { Meritt Butte } \\
\quad \text { See Merrick Butte }\end{array}$ & $\begin{array}{l}\text { reservoir } \\
\text { mine } \\
\text { school } \\
\text { reservoir } \\
\text { summit } \\
\text { locale } \\
\text { spring } \\
\text { summit }\end{array}$ & $\begin{array}{l}\text { BGN } \\
\text { UNOFF } \\
\text { UNOFF } \\
\text { BGN } \\
\text { BGN } 1960 \\
\text { VARIANT } \\
\text { UNOFF } \\
\text { BGN } \\
\text { VARIANT }\end{array}$ & $\begin{array}{l}\text { Coconino } \\
\text { Gila } \\
\text { Maricopa } \\
\text { Pima } \\
\text { Navajo } \\
\text { Maricopa } \\
\text { Mohave } \\
\text { Navajo }\end{array}$ & $\begin{array}{l}351052 N 1122327 W \\
335826 \mathrm{~N} 1112614 \mathrm{~W} \\
333426 \mathrm{~N} 1120133 \mathrm{~W} \\
315346 \mathrm{~N} 1113108 \mathrm{~W} \\
365405 \mathrm{~N} 1100000 \mathrm{~W} \\
\\
332515 \mathrm{~N} 1113450 \mathrm{~W} \\
352141 \mathrm{~N} 1140414 \mathrm{~W} \\
365850 \mathrm{~N} 1100507 \mathrm{~W}\end{array}$ & & $\begin{array}{l}6430 \\
1650\end{array}$ & $\begin{array}{l}\text { Ash Fork } \\
\text { Reno Pass } \\
\text { Sunnys lope } \\
\text { Kitt Peak } \\
\text { Mitten Buttes } \\
\text { Apache Junction } \\
\text { Stockton Hill }\end{array}$ \\
\hline $\begin{array}{l}\text { Meriwhitica Canyon } \\
\text { Meriwhitica Springs } \\
\text { Meriwhitica Tank } \\
\text { Merle Findlay Tank } \\
\text { Merlin Abyss } \\
\text { Merlo Mine } \\
\text { Merlyn Lake } \\
\text { Meryln Tank } \\
\text { Merriam Crater } \\
\text { See Merriam Mountain }\end{array}$ & $\begin{array}{l}\text { valley } \\
\text { spring } \\
\text { reservoir } \\
\text { reservoir } \\
\text { valley } \\
\text { mine } \\
\text { lake }\end{array}$ & $\begin{array}{l}\text { BGN } \\
\text { BGN } \\
\text { BGN } \\
\text { BGN } \\
\text { BGN } 1908 \\
\text { UNOFF } \\
\text { BGN } \\
\text { VARIANT } \\
\text { VARIANT }\end{array}$ & $\begin{array}{l}\text { Mohave } \\
\text { Mohave } \\
\text { Mohave } \\
\text { Mohave } \\
\text { Coconino } \\
\text { Mohave } \\
\text { Apache } \\
\text { Coconino }\end{array}$ & $\begin{array}{l}354748 N 1133918 \mathrm{~W} \\
354711 N 1134031 \mathrm{~W} \\
354501 N 1134211 \mathrm{~W} \\
362800 \mathrm{~N} 1124818 \mathrm{~W} \\
361631 \mathrm{~N} 1121729 \mathrm{~W} \\
350143 \mathrm{~N} 1135157 \mathrm{~W} \\
335555 \mathrm{~N} 1092512 \mathrm{~W} \\
352011 \mathrm{~N} 1111720 \mathrm{~W}\end{array}$ & $\begin{array}{l}354029 N 1134957 \mathrm{~W} \\
361933 \mathrm{~N} 1121832 \mathrm{~W}\end{array}$ & 2655 & $\begin{array}{l}\text { Spencer Canyon } \\
\text { Spencer Canyon } \\
\text { Spencer Canyon } \\
\text { Hitson Tank } \\
\text { King Arthur Castle } \\
\text { Dean Peak } \\
\text { Big Lake North }\end{array}$ \\
\hline $\begin{array}{l}\text { Merriam Mountain } \\
\text { Merriam Crater } \\
\text { Merrick Butte } \\
\text { Meritt Butte } \\
\text { Merrill Crater } \\
\text { Merrill Creek } \\
\text { See Merrill Wash } \\
\text { Merrill Peak } \\
\text { Merrill Wash } \\
\text { Merril Wash } \\
\text { Merrill Creek }\end{array}$ & $\begin{array}{l}\text { summit } \\
\text { summit } \\
\text { summit } \\
\text { stream } \\
\text { summit } \\
\text { stream }\end{array}$ & $\begin{array}{l}\text { BGN } 1931 \\
\text { VARIANT } \\
\text { BGN } \\
\text { VARIANT } \\
\text { BGN 1931 } \\
\text { VARIANT } \\
\text { BGN } 1950 \\
\text { BGN } \\
\text { VARIANT } \\
\text { VARIANT }\end{array}$ & $\begin{array}{l}\text { Coconino } \\
\text { Navajo } \\
\text { Coconino } \\
\text { Graham } \\
\text { Graham } \\
\text { Graham }\end{array}$ & $\begin{array}{l}352011 \mathrm{~N} 1111720 \mathrm{~W} \\
365850 \mathrm{~N} 1100507 \mathrm{~W} \\
351326 \mathrm{~N} 1111618 \mathrm{~W} \\
325050 \mathrm{~N} 1095258 \mathrm{~W} \\
324215 \mathrm{~N} 1095735 \mathrm{~W} \\
325050 \mathrm{~N} 1095258 \mathrm{~W}\end{array}$ & $324830 \mathrm{~N} 1095222 \mathrm{~W}$ & 6595 & $\begin{array}{l}\text { Merriam Crater } \\
\text { Mitten Buttes } \\
\text { Angell }\end{array}$ \\
\hline $\begin{array}{l}\text { Merril Wash } \\
\text { See Merrill Wash } \\
\text { Merrilyn Dam } \\
\text { Merrit Pass } \\
\text { See Merritt Pass } \\
\text { Merritt Canyon } \\
\text { Merritt Draw } \\
\text { Merritt Pass } \\
\quad \text { Merrit Pass } \\
\text { Merritt Spring }\end{array}$ & $\begin{array}{l}\text { stream } \\
\text { dam } \\
\text { gap } \\
\text { valley } \\
\text { valley } \\
\text { gap } \\
\text { spring }\end{array}$ & $\begin{array}{l}\text { VARIANT } \\
\text { UNOFF } \\
\text { VARIANT } \\
\text { BGN } \\
\text { BGN } \\
\text { BGN } \\
\text { VARIANT } \\
\text { BGN }\end{array}$ & $\begin{array}{l}\text { Graham } \\
\text { Apache } \\
\text { Yavapai } \\
\text { Cochise } \\
\text { Coconino } \\
\text { Yavapai }\end{array}$ & $\begin{array}{l}325050 \mathrm{~N} 1095258 \mathrm{~W} \\
343330 \mathrm{~N} 1094809 \mathrm{~W} \\
340626 \mathrm{~N} 1125924 \mathrm{~W} \\
312532 \mathrm{~N} 1102715 \mathrm{~W} \\
342939 \mathrm{~N} 1110955 \mathrm{~W} \\
340626 \mathrm{~N} 1125924 \mathrm{~W} \\
342716 \mathrm{~N} 1111055 \mathrm{~W}\end{array}$ & $\begin{array}{l}312758 \mathrm{~N} 1102402 \mathrm{~W} \\
342642 \mathrm{N1} 111136 \mathrm{~W}\end{array}$ & & $\begin{array}{l}\text { Huachuca Peak } \\
\text { Dane Canyon } \\
\text { Congress SW } \\
\text { Dane Canyon }\end{array}$ \\
\hline $\begin{array}{l}\text { Merry-Go-Round } \\
\text { Mervin Tank } \\
\text { Meryln Tank }\end{array}$ & $\begin{array}{l}\text { summit } \\
\text { reservoir }\end{array}$ & $\begin{array}{l}\text { BGN } \\
\text { BGN } \\
\text { VARIANT }\end{array}$ & $\begin{array}{l}\text { Coconino } \\
\text { Coconino }\end{array}$ & $\begin{array}{l}345229 \mathrm{~N} 1114227 \mathrm{~W} \\
344219 \mathrm{~N} 1112452 \mathrm{~W}\end{array}$ & & & $\begin{array}{l}\text { Munds Mountain } \\
\text { Happy Jack }\end{array}$ \\
\hline
\end{tabular}




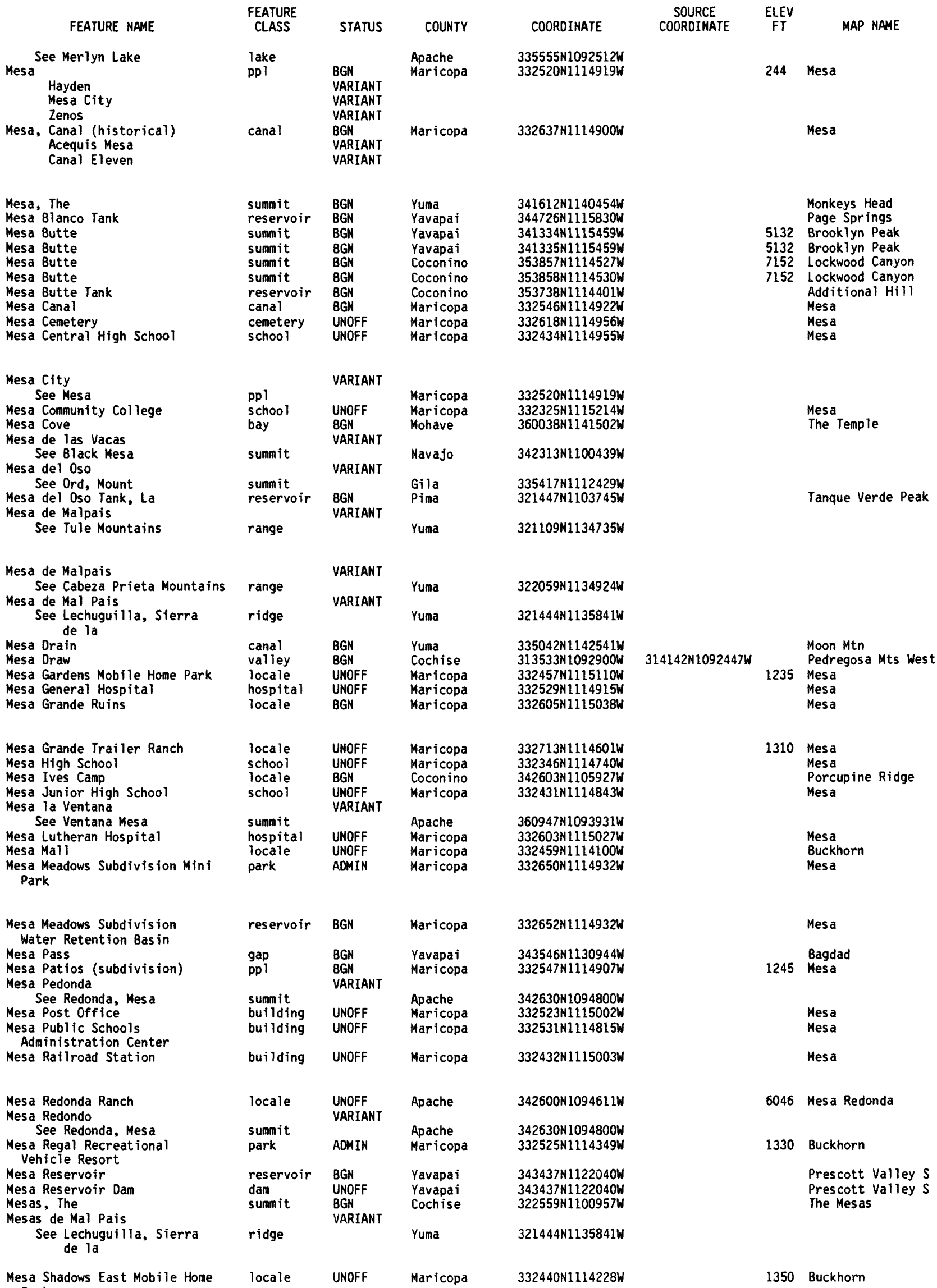


NATIONAL GAZETTEER--ARIZONA 1986

FEATURE NAME

Mesa Shadows Mobile Home Park Mesa Side Tank

Mesa Spring

Mesa Substation

Mesa Tank

Mesa Tank

Mesa Tank

Mesa Tank

Mesa Tank

Mesa Tank

Mesa Tank

Mesa Tank

Mesa Tank

Mesa Tank

Mesa Tank

Mesa Tank

Mesa Tank

Mesa Tank

Mesa Tank

Mesa Tank

Mesa Tank

Mesa Tank

Mes a Tank

Mesa Tank

Mesa Tank

Mes a Tank

Mesa Tank

Mesa Tank

Mesa Tank, La

Mesa Tank Number Two

Mesa Tanks

Mesa Tierra Number Three

Subdivision Mini Park

Mesa Tierra Number Three

Subdivision Water Retetion Basin

Mesa Trail Valley

Mesa Trail Wash

Mesa Travelodge Mobile Home Park

Mesa Verde Estates

(subdivision)

Mesa Village Park

Park

Mesa Villas Number Two Water Retention Basin

Mesa Wash

Mesa Wash

Mesa Well

Mesa Well

Mesa Well

Mesa Well

Mesa Windmill

Mescal

Mescal Arroyo

Mescal Canyon

Mescal Creek

Mescal Creek

Mescal Creek

Mescal Dam

Mescalero Point

Mescal Gulch

Mescal Interchange

Mescal Mountain

Mescal Mountain

Mescal Mountains

$$
\text { Mescal Range }
$$

Mescal Peak

Mescal Pit

FEATURE
CLASS

STATUS

COUNTY

COORDINATE

local

spring

locale

reservoir

reservoir

reservoir

reservoir

reservoir

reservoir BGN

reservoir BGN

reservoir BGN

reservoir $B G N$

reservoir $B G$

reservoir $B G$

reservoir $B G$

reservoir BGI

reservoir

Pinal

Greenlee

Pina

Greenlee

Greenlee

Greenlee

Gila

Gila

Gila

Gila

reservoir $B G N$

reservoir BGN

reservoir BGN Coconino

reservoir $B G N$

we11

well

well

well

locale

valley

valley

stream

UNOFF

UNOFF

UNOFF

BGA

BGN

BGN

$B G N$

BGN

Gila

Apache

ridge

BGN

VARIANT

Gila

$\begin{array}{lll}\text { UNOFF } & \text { Maricopa } & 332440 N 1114303 W \\ \text { BGN } & \text { Santa Cruz } & 312754 N 1110354 W \\ \text { BGN } & \text { Coconino } & 360943 N 1112155 W \\ \text { UNOFF } & \text { Maricopa } & 332523 N 1114810 W \\ \text { BGN } & \text { Santa Cruz } & 312425 N 1110950 W \\ \text { BGN } & \text { Santa Cruz } & 312454 N 1111000 W \\ \text { BGN } & \text { Santa Cruz } & 313426 N 1102911 W \\ \text { BGN } & \text { Cochise } & 321025 N 1101159 W\end{array}$

$321025 N 1101159 \mathrm{~W}$

reservoir BGN Yavapai 341852N1121201W

reservoir BGN Gila 342238N1113327W

reservoir BGN Yavapai 342953N1114803W

reservoir BGN Coconino 343840N1112722W

345141 N1115620W

reservoir BGN Coconino 352252N1122036W

reservoir BGN Coconino 353045N1120911W

reservoir BGN Gila

reservoir BGN Santa Cruz 314034N1104418W

park ADMIN Maricopa $332302 N 1114714 \mathrm{~W}$

reservoir BGN Maricopa 332255N1114714W

valley BGN Navajo 362825N1101003W

valley BGN Navajo 363350N1100600W

locale UNOFF Maricopa 332333N1115008W

ppl BGN Yavapai 343505N1115134W

$\begin{array}{lll}\text { park } & \text { ADMIN Pima } & \text { 321243N1105212W }\end{array}$

park ADMIN Maricopa 332510N1114645W

reservoir BGN Maricopa 332510N1114645W

stream BGN $19 B 0$ Pinal 324238N1115520W

stream BGN Navajo 345755N1102009W

well UNOFF Pima 322830N1103526W

$345656 \mathrm{~N} 1092124 \mathrm{~W}$

$353512 \mathrm{~N} 1112620 \mathrm{~W}$

$\begin{array}{ll}\text { Graham } & 324222 \mathrm{~N} 1101021 \mathrm{~W} \\ \text { Cochise } & 315924 \mathrm{N1} 102605 \mathrm{~W}\end{array}$

Cochise 315923N1103355W

$321344 \mathrm{~N} 1093900 \mathrm{~W}$

Cochise 314405N1102101W

$\begin{array}{llll}\text { stream } & \text { BGN } & \text { Gila } & 330833 N 1103745 W\end{array}$

stream BGN Yavapai 341535N1123617W

UNOFF Gila 331000N1104330W

cliff BGN 1908 Coconino 360604N1121719W

valley BGN Yavapai 344524N1120148W

crossing UNOFF Cochise 315746N1102603W

summit BGN Graham 331036N1093642W

sumpit BGN Yavapai 345434N1115018W

$331010 \mathrm{~N} 1104245 \mathrm{~W}$

summit BGN Graham 324607N1102436W

locale BGN Graham $\quad 33012 B N 1101445 W$
SOURCE

COORDINATE

ELEV
FT

MAP NAME

AZ393

Pena Blanca Lake

Moenave

Mesa

Ruby

Ruby

Pyeatt Ranch

Deepwell Ranch

Durham Hills

Guthrie

Mineral Mtn

Bee Canyon

Pipester Mtn

Alma Mesa

Sombrero Peak

Kayler Butte

Mazatzal Peak

Oiamond Butte

Cleator

Dugas

Walnut Grove

Strawberry

Horner Mtn

Happy Jack

Hay Lake

Page Springs

Cedar Bas in

Cataract Tank

Howard Lake

Diamond Butte

Sonoita

Mesa

Mesa

$362914 N 1100919 W$

$363101 \mathrm{N1} 101031 \mathrm{~W}$

Cliff Rose Hill

Chilchinbito

205 Mesa

Tucson East

Mesa

Mesa

Vaiva Vo

Joseph City

Buehman Canyon

Kayler Butte

Fairchild Well

Wupatki SW

Eureka Ranch

Mescal

The Narrows

Simmons Peak

Huachuca City

$331114 N 1104433 \mathrm{~W}$

Mescal Warm Spring

Walnut Grove

Mescal Warm Spring

Piute Point

Clarkdale

Mescal

344229 N1120830

6740 Elevator Mtn

Wilson Mountain

Mescal Warm Spring

5648 Oak Grove Canyon

Beargrass Bas in
3120 Camp Verde 
FEATURE NAME

Mescal Pit Catchment Basin Mescal Pit Spring

Mescal Pit Tank

Mescal Range

See Mescal Mountains

Mescal Ridge

Mescal Ridge Tank

Mescal Ridge Tank Number One

Mescal Spring

Mescal Spring

Mescal Spring

Mescal Spring

Mescal Spring

Mescal Tank

Mescal Tank

Mescal Tank

Mescal Tank

Mescal Tank

Mescal Tank

Mescal Warm Spring

Mese la Oso

See Ord, Mount

Mesh Barrel Spring

See Mash Barrel Spring

Mesqual

See Hali Murk

Mesquit

See Continental

Mesquit

See Hali Murk

Mesquite Canyon

Mesquite Canyon Spring

Mesquite Creek

Mesquite Flat

Mesquite Flat

Mezquite Flat

Mesquite Flat Spring

Mesquite Gray Well

See Anita Well

Mesquite Gray Well

Mesquite Jim Well

Mesquite Mountain

Mesquite Mountains Mamatotk Mountains

Mesquite Seep

Mesquite Spring

Mesquite Spring

Mesquite Spring

Mesquite Spring

Mesquite Springs Campground

Mesquite Spring Tank

Mesquite Tank

Mesquite Tank

Mesquite Tank

Mesquite Tank

Mesquite Tank

Mesquite Tank

Mesquite Tank

Mesquite Tanks

Mesquite Thicket Spring

Mesquite Wash

Mesquite We11

Mesquite Well

Mesquite Well

Mesquite Well

Mesquite Windmill

Metall ic Accident Mine

Metate Dar

Metate Mine

Metate Peak

Metate Spring

\section{FEATURE}

CLASS

STATUS

spring

reservoir

ridge

ridge

reservoir

reservoir $B G$

spring

spring

spring

reservoir

reservoir

reservoir

reservoir

reservoir

reservoir

spring

summit

spring

locale

pp 1

BGN
BGN
BGN
VARIANT

BGN

BGN
BGN

$B G N$

BGN
BGN
BGN
BGN
BGN
BGN
BGN
BGN
BGN
BGN

\section{.}

BGN

VARIANT

VARIANT

VARIANT

VARIANT

Pima

VARIANT

locale

valley

spring

stream

flat

flat

spring

well

BGN

BGN

BGN 1932

BGN

BGN 1932

VARIANT

BGN

VARIANT

wel

well

ridge

spring

spring

spring

spring

spring

park

reservoir

reservoir

reservoir

reservoir

reservoir

reservoir

reservoir

reservoir

reservoir

UNOFF

UNOFF

BGN

BGN 1964

VARIAN

BGN

BGN

BGN

BGN

BGN

spring

stream

well

well

well

locale

local

mine

mine

BGN

BGN

BGN

BGN

BGN

BGN

BGN

BGN

UNOFF

UNOFF

UNOFF

UNOF

BGN

UNOFF

UNOFF

Pima

Pima

Pima

Maricopa

Greenlee

Maricopa

Pina

Santa Cruz

Santa Cruz

Yuma

Yuma

ma

Santa Cruz

Maricopa

Yavapai

Mohave

Mohave

Maricopa

Cochise

Cochise

Maricopa

Maricopa

Maricopa

Gila

Yavapai

Pima

UNOFF

Mohave

Maricopa

Pima

Maricopa

Graham

La Paz

Cochise

Mohave

Gila

Gila

summit

BGN

BGN

spring

Graham

\section{ADMIN}

COORDINATE

$334952 \mathrm{~N} 1102457 \mathrm{~W}$

$333056 \mathrm{~N} 1111920 \mathrm{~W}$

340405N1115722W

$331010 \mathrm{~N} 1104245 \mathrm{~W}$

$341546 \mathrm{~N} 1110455 \mathrm{~W}$

$341621 \mathrm{N1110357 \textrm {W }}$

$341631 \mathrm{~N} 1110406 \mathrm{~W}$

$314440 \mathrm{~N} 1102538 \mathrm{~W}$

$315639 \mathrm{N1} 103624 \mathrm{~W}$

$330141 \mathrm{~N} 1101540 \mathrm{~W}$

$331019 N 1093748 \mathrm{~W}$

$344340 \mathrm{~N} 1120757 \mathrm{~W}$

$325207 N 1102640 \mathrm{~W}$

$331148 N 1104019 \mathrm{~W}$

$335125 N 1101935 \mathrm{~W}$

342553 N I114255

344348 N1120825W

$351134 N 1121711 \mathrm{~W}$

$330917 N 1103813 \mathrm{~W}$

335417 N1112429W

323125N1095040W

$320004 N 1121737 \mathrm{~W}$

315108 N1105827W

$320004 N 1121737 \mathrm{~W}$

$320931 \mathrm{~N} 1102703 \mathrm{~W}$

$321044 \mathrm{~N} 1102818 \mathrm{~W}$

333148 N1112256W

330957 N $1090959 \mathrm{~W}$

$333219 N 1112235 \mathrm{~W}$

322441 N110372OW

313606 N1110615W

$313614 \mathrm{~N} 1110617 \mathrm{~W}$

$325835 \mathrm{~N} 1134744 \mathrm{~W}$

$335931 N 1141659 W$

$315334 \mathrm{~N} 1122641 \mathrm{~W}$

$313005 \mathrm{~N} 1110601 \mathrm{~W}$

$334350 \mathrm{~N} 1113252 \mathrm{~W}$

$342248 \mathrm{~N} 1114627 \mathrm{~W}$

$342912 \mathrm{~N} 1114603 \mathrm{~W}$

$354013 N 1132517 \mathrm{~W}$

$354016 \mathrm{~N} 1132516 \mathrm{~W}$

$334413 N 1113432 \mathrm{~W}$

$313859 N 1094904 \mathrm{~W}$

$314530 \mathrm{~N} 1102138 \mathrm{~W}$

$333716 \mathrm{N1131724 \textrm {W }}$

$334402 \mathrm{~N} 1124643 \mathrm{~W}$

$334731 \mathrm{~N} 1120043 \mathrm{~W}$

$335157 \mathrm{~N} 1102030 \mathrm{~W}$

$314813 \mathrm{~N} 1111017 \mathrm{~W}$

$350745 \mathrm{~N} 1133300 \mathrm{~W}$

$334351 \mathrm{~N} 1113051 \mathrm{~W}$

$322556 \mathrm{~N} 1112917 \mathrm{~W}$

$324920 \mathrm{~N} 1122808 \mathrm{~W}$

325240 N1100222W

$334614 \mathrm{~N} 1133649 \mathrm{~W}$

$314145 \mathrm{~N} 1095650 \mathrm{~W}$

$352255 \mathrm{~N} 1140923 \mathrm{~W}$

$332344 \mathrm{~N} 1103555 \mathrm{~W}$

$332442 \mathrm{~N} 1103620 \mathrm{~W}$ 
NATIONAL GAZETTEER--ARIZONA 1986

FEATURE NAME

Metate Tank
Metate Tank
Metate Tank
Metate Tank
Metcalf (site)
Metcalf Cemetery
Meteor City
Meteor Crater
Barringer Crater
Coon Butte
Coon Mountain
Crater Mound
Crater Mountain
Frank ins Hole
Meteor Mountain
Meteorite Mountain

Meteor Crater Interchange

Meteor Crater Ranch

Meteor Crater Rest Area

Meteorite Mountain See Meteor Crater

Meteor Mountain See Meteor Crater

Meteor Tank

Methodist Camp

Methodist Creek

Methodist Mesa

Methodist Mesa Tank

Methodist Mountain See Salome Mountain

Methodist Mountain

Metias Tank

Metote Pit Tank

Metrocenter Shopping Center

Metuck Springs

Metuck Tank

Metzger Tank
Metz Tank
Metz Tank
Metz Tank
M E Wash
Mexican Canyon
Mexican Canyon
Mexican Canyon
Mexican Consulate
Mexican Cry Mesa
Mexican Cry Mine
Mexican Dam
Mexican Gulch
Mexican Hat Mountain
Mexican Hay Lake
Mexican Hay Lake Dam
Mexican Hollow
Mexican Hollow Wash
Mexican Jack Tank
Mexican Joe Tank
Mexican Lake
Mexican Mine Canyon
Mexican-Nest Tank
Mexican Pocket
Mexican Rest Peak
Mexican Rest Spring
Mexican Saddle (historical)
Mexican Seep
Mexican Sink
Mexican Spring
Mexican Spring
Mexican Tank
Mexican Tank
Mexican Tank
Mexican Tank
Mexican Tank
Mexican Tank

FEATURE
CLASS

STATUS

COUNTY

COORDINATE

reservoir reservoir

reservoir

reservoir

locale

cemetery

locale

crater

BGN

BGN

BGN

BGN

UNOFF

BGN

BGN 1946

VARIANT

VARIANT

VARIANT

VARIANT

VARIANT

VARIANT

VARIANT

VARIANT

\section{N1103156W}

Gila 332345N1103554W

Yavapai $\quad 342835 \mathrm{~N} 1120413 \mathrm{~W}$

Coconino 350818N1121227W

Greenlee $\quad 330641$ N1092156W

$330238 N 1091840 \mathrm{~W}$

$350540 \mathrm{~N} 1105605 \mathrm{~W}$

Coconino 350141N1110121W$$
\text { cra }
$$

\begin{tabular}{|c|c|c|c|}
\hline $\begin{array}{l}\text { crossing } \\
\text { locale } \\
\text { park }\end{array}$ & $\begin{array}{l}\text { UNOFF } \\
\text { UNOFF } \\
\text { ADIN } \\
\text { VARIANT }\end{array}$ & $\begin{array}{l}\text { Coconino } \\
\text { Coconino } \\
\text { Coconino }\end{array}$ & $\begin{array}{l}350636 \mathrm{~N} 1110148 \mathrm{~W} \\
350126 \mathrm{~N} 1105921 \mathrm{~W} \\
350611 \mathrm{~N} 1105929 \mathrm{~W}\end{array}$ \\
\hline ater & VARIANT & Coconino & $350141 \mathrm{~N} 1110121 \mathrm{~W}$ \\
\hline $\begin{array}{l}\text { ater } \\
\text { servoir } \\
\text { cale } \\
\text { ream }\end{array}$ & $\begin{array}{l}\text { BGN } \\
\text { BGN } \\
\text { BGN }\end{array}$ & $\begin{array}{l}\text { Coconino } \\
\text { Gila } \\
\text { Cochise } \\
\text { Gila }\end{array}$ & $\begin{array}{l}350141 \mathrm{~N} 1110121 \mathrm{~W} \\
341209 \mathrm{~N} 1113633 \mathrm{~W} \\
315555 \mathrm{~N} 1091910 \mathrm{~W} \\
334440 \mathrm{~N} 1111122 \mathrm{~W}\end{array}$ \\
\hline
\end{tabular}

$\begin{array}{lll}\text { sumit } & \text { BGN } & \text { Gila }\end{array}$

reservoir BGN Gila 334612N1111120W

summit VARIANT Gila 334756N1110737W

summit BGN 1965 Gila 334809N1110905W

reservoir BGN Apache 343851N1094427W

reservoir BGN Yavapai 344328N1125642W

locale UNOFF Maricopa 333429N1120716W

spring BGN Mohave 353849 N1132256W

reservoir BGN $\quad$ Coconino $\quad 353734$ N1131751W

reservoir BGN Coconino 355837N1121652W

reservoir BGN Coconino 350748N1114927W

reservoir BGN Coconino $350759 N 1114926 \mathrm{~W}$

reservoir BGN Coconino 350929N1114931W

valley BGN Maricopa 334828N1122805W

valley BGN Cochise 312831N1095009W

valley BGN Graham 324912N1095910W

valley BGN Gila 340625 N1105720W

$\begin{array}{llll}\text { building UNOFF } & \text { Cochise } & 312038 N 1093312 \mathrm{~W} \\ \text { summit } & B G N & \text { Apache } & 363350 N 1091709 \mathrm{~W}\end{array}$

$\begin{array}{llll}\text { dam } & \text { UNOFF } & \text { Apache } & 363302 N 1091835 \mathrm{~W} \\ \text { UNOFF } & \text { Yavapai } & 350722 \mathrm{~N} 1123206 \mathrm{~W}\end{array}$

valley BGN Yavapai $341135 \mathrm{N1120942 \textrm {W }}$

summit BGN Cochise $\quad 314812$ N1094830W

reservoir BGN

dam

valley

stream

reservoir

Apache

Apache

BGN Navajo

BGN Navajo

reservoir $B G N$

lake BGN Navajo

valley

reservoir

bas in

summit

spring

summit

spring

flat

spring

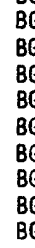

Gila

Yavapai

Coconino

Navajo

Navajo

1917 Gila

BGN Yavapai

Yavapai

Coconino

spring

reservoir

reservoir

reservoir

reservoir

reservoir

reservoir
SOURCE

COORDINATE

ELEV
FT

MAP NAME

Piety $\mathrm{Hill}$

Dourine Canyon

Estler Peak

Williams South

Clifton

Clifton

5034 Tucker Mesa SW

5123 Meteor Crater
Meteor Crater

Tucker Mesa SW

Tucker Mesa SW

Cypress Butte

Rust ler Park

Theo. Roosevelt Dam

Greenback Creek

Greenback Creek

5050 Greenback Creek Potter Mesa Tank Sheridan Mtn

1235 Sunnys lope

Peach Springs Canyon

Peach Springs NE

Metzger Tank

Bellemont

Bellemont

Bellemont

Hieroglyphic Mts SW

Bisbee NE

Shingle Mill Mtn

Young

Douglas

Mexican Cry Mesa

Mexican Cry Mesa

Picacho Butte SE

$340204 N 1092151 \mathrm{~W}$

$340206 N 1092500 \mathrm{~W}$

344423N1095909W

344422N1095909w

$360853 N 1122939 \mathrm{~W}$

340013 N1125244W

$342223 \mathrm{~N} 1095917 \mathrm{~W}$

$332850 \mathrm{~N} 1104906 \mathrm{~W}$

$344800 \mathrm{~N} 1130429 \mathrm{~W}$

$350204 \mathrm{~N} 1114328 \mathrm{~W}$

$351332 N 1101335 \mathrm{~W}$

351312 N1101313W

UNKNOWN

344718 N1120523W

$365035 \mathrm{~N} 1115305 \mathrm{~W}$

$321149 \mathrm{N1} 1093219 \mathrm{~W}$

$363340 N 1092355 \mathrm{~W}$

$324831 \mathrm{~N} 1095934 \mathrm{~W}$

$332600 \mathrm{~N} 1105616 \mathrm{~W}$

$340702 \mathrm{~N} 1105643 \mathrm{~W}$

$344718 \mathrm{~N} 1120515 \mathrm{~W}$

$345837 \mathrm{~N} 1121250 \mathrm{~W}$

350727 N1123157W
Bumble Bee

Turquoise Mountain

$341310 N 1121013 W$

8890

Eagar

Hay Hollow

Hay Hollow

Explorers Monument

Congress SW

$332944 N 110472 B$

Silver Springs

Globe

Scratch Canyon

Mountainaire

6156 Turkey Track Butte

Clarkdale

The Big Knoll

Dos Cabezas

Round Rock

Shingle Mill Mtn

Inspiration

Oxbow Mtn

Clarkdale

Perkinsville

Picacho Butte SE
Turkey Track Butte 


\begin{tabular}{|c|c|c|c|c|c|c|c|}
\hline FEATURE NAME & $\begin{array}{l}\text { FEATURE } \\
\text { CLASS }\end{array}$ & STATUS & COUNTY & COORDINATE & $\begin{array}{l}\text { SOURCE } \\
\text { COORDINATE }\end{array}$ & $\begin{array}{l}\text { ELEV } \\
\text { FT }\end{array}$ & MAP NAME \\
\hline $\begin{array}{l}\text { Mexican Tank } \\
\text { Mexican Tank } \\
\text { Mexican Tank } \\
\text { Rickys Tank }\end{array}$ & $\begin{array}{l}\text { reservoir } \\
\text { reservoir } \\
\text { locale }\end{array}$ & $\begin{array}{l}\text { BGN } \\
\text { BGN } \\
\text { BGN } \\
\text { VARIANT }\end{array}$ & $\begin{array}{l}\text { Coconino } \\
\text { Coconino } \\
\text { Cochise }\end{array}$ & $\begin{array}{l}353 \mathrm{~B} 53 \mathrm{~N} 1125320 \mathrm{~W} \\
355643 \mathrm{~N} 1130805 \mathrm{~W} \\
313256 \mathrm{~N} 109043 \mathrm{BW}\end{array}$ & & & $\begin{array}{l}\text { Tin House } \\
\text { Hockey Puck Spring } \\
\text { Skeleton Canyon }\end{array}$ \\
\hline $\begin{array}{l}\text { Mexican Tank } \\
\text { See Rickys Tank } \\
\text { Mexican Town } \\
\text { Mexican Water } \\
\text { Mexican Water Recreation Area } \\
\text { Mexican Water Trading Post } \\
\text { Meyer Park } \\
\text { Meyer School } \\
\text { Meyers School } \\
\text { Meyer Wash }\end{array}$ & $\begin{array}{l}\text { locale } \\
\text { ppl } \\
\text { locale } \\
\text { park } \\
\text { locale } \\
\text { park } \\
\text { school } \\
\text { school } \\
\text { stream }\end{array}$ & $\begin{array}{l}\text { VARIANT } \\
\text { BGN } \\
\text { BGN } \\
\text { ADMIN } \\
\text { BGN } \\
\text { ADMIN } \\
\text { UNOFF } \\
\text { UNOFF } \\
\text { BGN }\end{array}$ & $\begin{array}{l}\text { Cochise } \\
\text { Pima } \\
\text { Apache } \\
\text { Apache } \\
\text { Apache } \\
\text { Maricopa } \\
\text { Maricopa } \\
\text { Pima } \\
\text { Pinal }\end{array}$ & $\begin{array}{l}313322 \mathrm{~N} 1090436 \mathrm{~W} \\
322205 \mathrm{~N} 1125147 \mathrm{~W} \\
365801 \mathrm{~N} 1093814 \mathrm{~W} \\
365523 \mathrm{~N} 1093632 \mathrm{~W} \\
365527 \mathrm{~N} 1093611 \mathrm{~W} \\
332400 \mathrm{~N} 1115448 \mathrm{~W} \\
332405 \mathrm{~N} 1115450 \mathrm{~W} \\
321212 \mathrm{~N} 1105322 \mathrm{~W} \\
325439 \mathrm{~N} 1104856 \mathrm{~W}\end{array}$ & $325303 \mathrm{~N} 1105221 \mathrm{~W}$ & 4920 & $\begin{array}{l}\text { Ajo South } \\
\text { Mexican Water } \\
\text { Walker Creek Res } \\
\text { Walker Creek Res } \\
\text { Tempe } \\
\text { Tempe } \\
\text { Tucson } \\
\text { Winkelman }\end{array}$ \\
\hline $\begin{array}{l}\text { Mezquite Flat } \\
\text { See Mesquite Flat } \\
\text { M F Ranch } \\
\text { M H Tank } \\
\text { Miami } \\
\text { Miami Concentrator } \\
\text { Miami Flat } \\
\text { Miami Gardens } \\
\text { Miami High School } \\
\text { Miami-Inspiration Hospital }\end{array}$ & $\begin{array}{l}\text { flat } \\
\text { locale } \\
\text { reservoir } \\
\text { ppl } \\
\text { locale } \\
\text { flat } \\
\text { ppl } \\
\text { school } \\
\text { hospital }\end{array}$ & $\begin{array}{l}\text { VARIANT } \\
\text { UNOFF } \\
8 G N \\
\text { BGN } \\
\text { UNOFF } \\
\text { BGN } \\
\text { BGN } \\
\text { UNOFF } \\
\text { UNOFF }\end{array}$ & $\begin{array}{l}\text { Maricopa } \\
\text { Gila } \\
\text { Navajo } \\
\text { Gila } \\
\text { Gila } \\
\text { Gila } \\
\text { Gila } \\
\text { Gila } \\
\text { Gila }\end{array}$ & $\begin{array}{l}333219 \mathrm{~N} 1112235 \mathrm{~W} \\
332031 \mathrm{~N} 1105607 \mathrm{~W} \\
340332 \mathrm{~N} 1103048 \mathrm{~W} \\
332357 \mathrm{~N} 1105205 \mathrm{~W} \\
332417 \mathrm{~N} 1105218 \mathrm{~W} \\
332651 \mathrm{~N} 1104952 \mathrm{~W} \\
332437 \mathrm{~N} 1104940 \mathrm{~W} \\
332437 \mathrm{~N} 1105002 \mathrm{~W} \\
332420 \mathrm{~N} 1104932 \mathrm{~W}\end{array}$ & & $\begin{array}{l}4508 \\
3411 \\
3275\end{array}$ & $\begin{array}{l}\text { Pinal Ranch } \\
\text { Spotted Mountain } \\
\text { Globe } \\
\text { Globe } \\
\text { Globe } \\
\text { Globe } \\
\text { Globe } \\
\text { Globe }\end{array}$ \\
\hline $\begin{array}{l}\text { Miami Post Office } \\
\text { Miami Railroad Station } \\
\text { Miami Tailings Dam Number Two } \\
\text { Miami Tailings Pond } \\
\text { Miami Wash } \\
\text { Mica Giant Mine } \\
\text { Mica Meadow } \\
\text { Mica Mine } \\
\text { Mica Mine } \\
\text { Mica Mountain }\end{array}$ & $\begin{array}{l}\text { building } \\
\text { building } \\
\text { dam } \\
\text { reservoir } \\
\text { stream } \\
\text { mine } \\
\text { flat } \\
\text { mine } \\
\text { mine } \\
\text { summit }\end{array}$ & $\begin{array}{l}\text { UNOFF } \\
\text { UNOFF } \\
\text { UNOFF } \\
\text { BGN } \\
\text { BGN } \\
\text { UNOFF } \\
\text { BGN } \\
\text { UNOFF } \\
\text { UNOFF } \\
\text { BGN }\end{array}$ & $\begin{array}{l}\text { Gila } \\
\text { Gila } \\
\text { Gila } \\
\text { Gila } \\
\text { Gila } \\
\text { Mohave } \\
\text { Pima } \\
\text { Pima } \\
\text { Yuma } \\
\text { Pima }\end{array}$ & $\begin{array}{l}332401 \mathrm{~N} 1105156 \mathrm{~W} \\
332354 \mathrm{~N} 1105205 \mathrm{~W} \\
332412 \mathrm{~N} 1105150 \mathrm{~W} \\
332427 \mathrm{~N} 1105150 \mathrm{~W} \\
332703 \mathrm{~N} 1105012 \mathrm{~W} \\
350214 \mathrm{~N} 1135059 \mathrm{~W} \\
321248 \mathrm{~N} 110322 \mathrm{~W} \\
321940 \mathrm{~N} 1125740 \mathrm{~W} \\
323259 \mathrm{~N} 1141840 \mathrm{~W} \\
321315 \mathrm{~N} 1103233 \mathrm{~W}\end{array}$ & $332452 \mathrm{~N} 1105002 \mathrm{~W}$ & 8666 & $\begin{array}{l}\text { Globe } \\
\text { Globe } \\
\text { Globe } \\
\text { Globe } \\
\text { Globe } \\
\text { Dean Peak } \\
\text { Mica Mountain } \\
\text { Chico Shunie } \\
\text { Fortuna Mine } \\
\text { Mica Mountain }\end{array}$ \\
\hline $\begin{array}{l}\text { Mica Tank } \\
\text { Michaelbach Tank } \\
\text { See Micheibach Tank } \\
\text { Michelbach Ranch } \\
\text { Michelbach Tank } \\
\text { Michaelbach Tank } \\
\text { Michelbach Tank } \\
\text { Michigan Lake } \\
\text { Michigan Palms Mobile Home Park } \\
\text { Michigan Tank }\end{array}$ & $\begin{array}{l}\text { reservoir } \\
\text { reservoir } \\
\text { locale } \\
\text { reservoir } \\
\text { reservoir } \\
\text { lake } \\
\text { locale } \\
\text { reservoir }\end{array}$ & $\begin{array}{l}\text { BGN } \\
\text { VARIANT } \\
\text { UNOFF } \\
\text { BGN } \\
\text { VARIANT } \\
\text { BGN } \\
\text { BGN } \\
\text { UNOFF } \\
\text { BGN }\end{array}$ & $\begin{array}{l}\text { Pima } \\
\text { Coconino } \\
\text { Coconino } \\
\text { Coconino } \\
\text { Coconino } \\
\text { Apache } \\
\text { Maricopa } \\
\text { Coconino }\end{array}$ & $\begin{array}{l}321314 \mathrm{~N} 1103950 \mathrm{~W} \\
352014 \mathrm{~N} 1114534 \mathrm{~W} \\
351945 \mathrm{~N} 1114451 \mathrm{~W} \\
352014 \mathrm{~N} 1114534 \mathrm{~W} \\
\\
353820 \mathrm{~N} 1113821 \mathrm{~W} \\
350702 \mathrm{~N} 1091825 \mathrm{~W} \\
333911 \mathrm{~N} 1120201 \mathrm{~W} \\
355122 \mathrm{~N} 1114846 \mathrm{~W}\end{array}$ & & 1460 & $\begin{array}{l}\text { Humphreys Peak } \\
\text { Wing Mountain } \\
\text { Additional Hill } \\
\text { Beacon Well } \\
\text { Union Hills } \\
\text { Peterson Flat }\end{array}$ \\
\hline $\begin{array}{l}\text { Michigan Trailer Park } \\
\text { Mickey Rye Well } \\
\text { Mickle Tank } \\
\text { Midas Mine } \\
\text { Middle Alamo } \\
\text { Middle Basin } \\
\text { See Virgin Basin } \\
\text { Middle Camp Mountain } \\
\text { Middle Canyon } \\
\text { Middle Canyon }\end{array}$ & $\begin{array}{l}\text { locale } \\
\text { well } \\
\text { reservoir } \\
\text { mine } \\
\text { reservoir } \\
\text { basin } \\
\text { summit } \\
\text { valley } \\
\text { valley }\end{array}$ & $\begin{array}{l}\text { UNOFF } \\
\text { UNOFF } \\
\text { BGN } \\
\text { UNOFF } \\
\text { BGN } \\
\text { VARIANT } \\
\text { BGN } \\
\text { BGN } \\
\text { BGN }\end{array}$ & $\begin{array}{l}\text { Maricopa } \\
\text { Pima } \\
\text { Coconino } \\
\text { Yuma } \\
\text { Santa Cruz } \\
\text { Mohave } \\
\text { Yuma } \\
\text { Santa Cruz } \\
\text { Cochise }\end{array}$ & $\begin{array}{l}332917 N 1120736 \mathrm{~W} \\
315903 \mathrm{~N} 1110852 \mathrm{~W} \\
351009 \mathrm{~N} 1115438 \mathrm{~W} \\
332609 \mathrm{~N} 113575 \mathrm{~W} \\
312251 \mathrm{~N} 1110028 \mathrm{~W} \\
\\
360718 \mathrm{~N} 1142645 \mathrm{~W} \\
334032 \mathrm{~N} 1142010 \mathrm{~W} \\
313126 \mathrm{~N} 1103152 \mathrm{~W} \\
314801 \mathrm{~N} 1101621 \mathrm{~W}\end{array}$ & $\begin{array}{l}312 B 39 \mathrm{~N} 1103115 \mathrm{~W} \\
315050 \mathrm{~N} 1102415 \mathrm{~W}\end{array}$ & 1110 & $\begin{array}{l}\text { Fowler } \\
\text { Samaniego Peak } \\
\text { Garland Prairie } \\
\text { Owl Head } \\
\text { Pena Blanca Lake }\end{array}$ \\
\hline $\begin{array}{l}\text { Middle Canyon } \\
\text { Middle Canyon } \\
\text { Middle Canyon } \\
\text { Middle Canyon Tank } \\
\text { Middle Canyon Wash } \\
\text { Middle Cedar Creek } \\
\text { Middle Cottonwood Tank } \\
\text { Middle Crossing Tank } \\
\text { Middle Division } \\
\text { See Virgin Basin }\end{array}$ & $\begin{array}{l}\text { valley } \\
\text { valley } \\
\text { valley } \\
\text { reservoir } \\
\text { stream } \\
\text { stream } \\
\text { reservoir } \\
\text { reservoir } \\
\text { basin }\end{array}$ & $\begin{array}{l}\text { BGN } \\
\text { BGN } \\
\text { BGN } \\
\text { BGN } \\
\text { BGN } \\
\text { BGN } \\
\text { BGN } \\
\text { BGN } \\
\text { VARIANT }\end{array}$ & $\begin{array}{l}\text { Pima } \\
\text { Navajo } \\
\text { Mohave } \\
\text { Pima } \\
\text { Cochise } \\
\text { Gila } \\
\text { Navajo } \\
\text { Coconino } \\
\text { Mohave }\end{array}$ & $\begin{array}{l}314809 \mathrm{~N} 1103633 \mathrm{~W} \\
340753 \mathrm{~N} 1101249 \mathrm{~W} \\
364127 \mathrm{~N} 1140214 \mathrm{~W} \\
321503 \mathrm{~N} 1102735 \mathrm{~W} \\
314800 \mathrm{~N} 1101622 \mathrm{~W} \\
335446 \mathrm{~N} 1100918 \mathrm{~W} \\
341127 \mathrm{~N} 1100917 \mathrm{~W} \\
350745 \mathrm{~N} 1121841 \mathrm{~W} \\
360718 \mathrm{~N} 1142645 \mathrm{~W}\end{array}$ & $\begin{array}{l}314845 \mathrm{~N} 1103904 \mathrm{~W} \\
341022 \mathrm{~N} 1101539 \mathrm{~W} \\
363936 \mathrm{~N} 1140247 \mathrm{~W} \\
315050 \mathrm{~N} 1102415 \mathrm{~W} \\
340333 \mathrm{~N} 1100414 \mathrm{~W}\end{array}$ & & $\begin{array}{l}\text { Spring Water Canyon } \\
\text { Red Top Mtn } \\
\text { Hen Spring } \\
\text { Soza Canyon } \\
\text { McGrew Spring } \\
\text { Cedar Creek } \\
\text { Red Top Mtn } \\
\text { McLellan Reservoir }\end{array}$ \\
\hline $\begin{array}{l}\text { Middle Fishhook Canyon } \\
\text { Middle Fork } \\
\text { See Middle Prong Creek } \\
\text { Middle Fork Brookbank Canyon } \\
\text { Middle Fork Bucksk in Wash } \\
\text { Middle Fork Goodwin Canyon } \\
\text { Middle Goodwin Creek }\end{array}$ & $\begin{array}{l}\text { valley } \\
\text { stream } \\
\text { valley } \\
\text { stream } \\
\text { valley }\end{array}$ & $\begin{array}{l}\text { BGN } \\
\text { BGN } \\
\text { BGN } \\
\text { VARIANT }\end{array}$ & $\begin{array}{l}\text { Graham } \\
\text { Greenlee } \\
\text { Navajo } \\
\text { Navajo } \\
\text { Graham }\end{array}$ & $\begin{array}{l}331352 \mathrm{~N} 1095850 \mathrm{~W} \\
332633 \mathrm{~N} 1092925 \mathrm{~W} \\
342159 \mathrm{~N} 1104217 \mathrm{~W} \\
341946 \mathrm{~N} 1103509 \mathrm{~W} \\
330024 \mathrm{~N} 1101426 \mathrm{~W}\end{array}$ & $\begin{array}{l}342036 \mathrm{~N} 1104301 \mathrm{~W} \\
341804 \mathrm{~N} 1103610 \mathrm{~W} \\
325847 \mathrm{~N} 1101858 \mathrm{~W}\end{array}$ & & $\begin{array}{l}\text { Brookbank Point } \\
\text { Outlaw Draw } \\
\text { Beargrass Bas in }\end{array}$ \\
\hline
\end{tabular}




\begin{tabular}{|c|c|c|c|c|c|c|c|}
\hline FEATURE NAME & $\begin{array}{l}\text { FEATURE } \\
\text { CLASS }\end{array}$ & STATUS & COUNTY & COORDINATE & $\begin{array}{l}\text { SOURCE } \\
\text { COORDINATE }\end{array}$ & $\begin{array}{c}\text { ELEV } \\
\text { FT }\end{array}$ & MAP NAME \\
\hline $\begin{array}{l}\text { Middle Goodwin Wash } \\
\text { Middle Fork Larson Draw } \\
\text { Middle Fork Palamino Canyon }\end{array}$ & $\begin{array}{l}\text { valley } \\
\text { valley }\end{array}$ & $\begin{array}{l}\text { VARIANT } \\
\text { BGN } \\
\text { BGN }\end{array}$ & $\begin{array}{l}\text { Navajo } \\
\text { Coconino }\end{array}$ & $\begin{array}{l}343334 \mathrm{~N} 1103655 \mathrm{~W} \\
342210 \mathrm{~N} 1105419 \mathrm{~W}\end{array}$ & $\begin{array}{l}343117 \mathrm{N1103749W} \\
342150 \mathrm{~W} 1105615 \mathrm{~W}\end{array}$ & & $\begin{array}{l}\text { Red Knoll } \\
\text { Woods Canyon }\end{array}$ \\
\hline $\begin{array}{l}\text { Middle Fork Rocky Draw } \\
\text { Middle Fork Spring } \\
\text { Middle Fork Squaw Creek } \\
\text { Middle Fork Tank } \\
\text { Middle Fork Tank } \\
\text { Middle Fork Tank } \\
\text { Middle Fork West Fork Black } \\
\text { Canyon } \\
\text { Middle Fork Willis Canyon } \\
\text { Middle Goodwin Creek } \\
\text { See Middle Fork Goodwin } \\
\text { Canyon }\end{array}$ & $\begin{array}{l}\text { valley } \\
\text { spring } \\
\text { stream } \\
\text { reservoir } \\
\text { reservoir } \\
\text { reservoir } \\
\text { valley } \\
\text { valley } \\
\text { valley }\end{array}$ & $\begin{array}{l}\text { BGN } \\
\text { BGN } \\
\text { BGN } \\
\text { BGN } \\
\text { BGN } \\
\text { BGN } \\
\text { BGN } \\
\text { BGN } \\
\text { VARIANT }\end{array}$ & $\begin{array}{l}\text { Navajo } \\
\text { Yavapai } \\
\text { Yavapai } \\
\text { Yavapai } \\
\text { Navajo } \\
\text { Navajo } \\
\text { Navajo } \\
\text { Coconino } \\
\text { Graham }\end{array}$ & $\begin{array}{l}342123 \mathrm{~N} 1103536 \mathrm{~W} \\
341005 \mathrm{~N} 1115429 \mathrm{~W} \\
340726 \mathrm{~N} 1115734 \mathrm{~W} \\
341021 \mathrm{~N} 1115358 \mathrm{~W} \\
341820 \mathrm{~N} 1103549 \mathrm{~W} \\
342117 \mathrm{~N} 1104159 \mathrm{~W} \\
341953 \mathrm{~N} 1104200 \mathrm{~W} \\
\\
365034 \mathrm{~N} 1121356 \mathrm{~W} \\
330024 \mathrm{~N} 1101426 \mathrm{~W}\end{array}$ & $\begin{array}{l}341751 \mathrm{~N} 1104351 \mathrm{~W} \\
364959 \mathrm{~N} 1121329 \mathrm{~W}\end{array}$ & & $\begin{array}{l}\text { Dutlaw Draw } \\
\text { 8rooklyn Peak } \\
\text { Cooks Mesa } \\
\text { Brooklyn Peak } \\
\text { Outlaw Draw } \\
\text { Brookbank Point } \\
\text { Brookbank Point } \\
\text { House Rock Spring SW }\end{array}$ \\
\hline $\begin{array}{l}\text { Middle Granite Gorge } \\
\text { Lower Granite Gorge }\end{array}$ & valley & $\begin{array}{l}\text { BGN } 1925 \\
\text { VARIANT }\end{array}$ & Coconino & $362205 N 1122753 W$ & $361553 N 1123145 W$ & & Powell Plateau \\
\hline $\begin{array}{l}\text { Middle Hill } \\
\text { Middle Kehl Canyon } \\
\text { Middle Knoll } \\
\text { Middle Lake }\end{array}$ & $\begin{array}{l}\text { summit } \\
\text { valley } \\
\text { summit }\end{array}$ & $\begin{array}{l}\text { BGN } \\
\text { BGN } \\
\text { BGN } 1979 \\
\text { VARIANT }\end{array}$ & $\begin{array}{l}\text { Coconino } \\
\text { Coconino } \\
\text { Coconino }\end{array}$ & $\begin{array}{l}355026 \mathrm{~N} 1113855 \mathrm{~W} \\
342717 \mathrm{~N} 1111838 \mathrm{~W} \\
365200 \mathrm{~N} 1115042 \mathrm{~W}\end{array}$ & $342610 \mathrm{~N} 1111929 \mathrm{~W}$ & 6640 & $\begin{array}{l}\text { Willows Camp } \\
\text { Kehl Ridge } \\
\text { The Big Knoll }\end{array}$ \\
\hline See Virgin Basin & bas in & & Mohave & $360718 N 1142645 W$ & & & \\
\hline $\begin{array}{l}\text { Middle Leonard Canyon } \\
\text { Middle Lyman Ditch } \\
\text { Middlemarch Canyon } \\
\text { Middlemarch Pass } \\
\text { Middle Pass }\end{array}$ & $\begin{array}{l}\text { valley } \\
\text { canal } \\
\text { valley } \\
\text { gap }\end{array}$ & $\begin{array}{l}\text { BGN } \\
\text { BGN } \\
\text { BGN } \\
\text { BGN } 1978 \\
\text { VARIANT }\end{array}$ & $\begin{array}{l}\text { Coconino } \\
\text { Apache } \\
\text { Cochise } \\
\text { Cochise }\end{array}$ & $\begin{array}{l}342617 N 1110646 \mathrm{~W} \\
342952 \mathrm{~N} 1092348 \mathrm{~W} \\
315214 \mathrm{~N} 1095542 \mathrm{~W} \\
315200 \mathrm{~N} 1095712 \mathrm{~W}\end{array}$ & $\begin{array}{l}342335 \mathrm{~N} 1110826 \mathrm{~W} \\
315345 \mathrm{~N} 1095724 \mathrm{~W}\end{array}$ & 5680 & $\begin{array}{l}\text { Knoll Lake } \\
\text { Salado } \\
\text { Black Diamond Peak } \\
\text { Black Diamond Peak }\end{array}$ \\
\hline $\begin{array}{l}\text { Middle Mesa } \\
\text { Middle Mesa } \\
\text { Middle Mesa }\end{array}$ & $\begin{array}{l}\text { summit } \\
\text { summit }\end{array}$ & $\begin{array}{l}\text { BGN } \\
\text { BGN } \\
\text { VARIANT }\end{array}$ & $\begin{array}{l}\text { Coconino } \\
\text { Apache }\end{array}$ & $\begin{array}{l}353428 N 1112815 W \\
360828 N 1091840 W\end{array}$ & & 7203 & $\begin{array}{l}\text { Wupatki SW } \\
\text { Mummy Cave Ruins }\end{array}$ \\
\hline $\begin{array}{l}\text { Middle Mesa Tank } \\
\text { Middle Mesa Tank } \\
\text { Middle Mohave Wash } \\
\text { Middle Moss Wash Well } \\
\text { Middle Mountain } \\
\text { Middle Mountain } \\
\text { Middle Mountain } \\
\text { Middle Mountain } \\
\text { Middle Mountains } \\
\text { Middle Mountain Tank }\end{array}$ & $\begin{array}{l}\text { reservoir } \\
\text { reservoir } \\
\text { stream } \\
\text { we11 } \\
\text { summit } \\
\text { summit } \\
\text { summit } \\
\text { summit } \\
\text { ridge } \\
\text { reservoir }\end{array}$ & $\begin{array}{l}\text { BGN } \\
\text { BGN } \\
\text { BGN } \\
\text { UNOFF } \\
\text { BGN } \\
\text { BGN } \\
\text { BGN } \\
\text { BGN } \\
\text { BGN } \\
\text { BGN }\end{array}$ & $\begin{array}{l}\text { Yavapai } \\
\text { Yavapai } \\
\text { Mohave } \\
\text { Mohave } \\
\text { Pinal } \\
\text { Maricopa } \\
\text { Greenlee } \\
\text { Gila } \\
\text { Yuma } \\
\text { Pinal }\end{array}$ & $\begin{array}{l}341934 \mathrm{~N} 1121221 \mathrm{~W} \\
342256 \mathrm{~N} 1115555 \mathrm{~W} \\
342450 \mathrm{~N} 1140132 \mathrm{~W} \\
345953 \mathrm{~N} 1134435 \mathrm{~W} \\
325310 \mathrm{~N} 1111212 \mathrm{~W} \\
334459 \mathrm{~N} 1120754 \mathrm{~W} \\
334626 \mathrm{~N} 1091556 \mathrm{~W} \\
335650 \mathrm{~N} 1110300 \mathrm{~W} \\
330151 \mathrm{~N} 1141944 \mathrm{~W} \\
325332 \mathrm{~N} 1111215 \mathrm{~W}\end{array}$ & $343051 N 1140418 \mathrm{~W}$ & 5954 & $\begin{array}{l}\text { Cleator } \\
\text { Arnold Mesa } \\
\text { Mohave Springs } \\
\text { Pilgrim Wash } \\
\text { Ninetysix Hills NW } \\
\text { Hedgpeth Hills } \\
\text { Buffalo Crossing } \\
\text { Copper Mtn } \\
\text { Middle Mts North } \\
\text { Ninetysix Hills NW }\end{array}$ \\
\hline $\begin{array}{l}\text { Middle Mountain Tank } \\
\text { Middle Oak Point } \\
\text { Middle Pass } \\
\text { See Middlemarch Pass } \\
\text { Middle Pasture Tank } \\
\text { Middle Point Tank } \\
\text { Middle Polecat Canyon } \\
\text { Middle Polles Tank } \\
\text { Middle Pond } \\
\text { Middle Prong Creek } \\
\text { Eagle Creek } \\
\text { Middle Fork }\end{array}$ & $\begin{array}{l}\text { reservoir } \\
\text { cliff } \\
\text { gap } \\
\text { reservoir } \\
\text { reservoir } \\
\text { valley } \\
\text { reservoir } \\
\text { reservoir } \\
\text { stream }\end{array}$ & $\begin{array}{l}\text { BGN } \\
\text { BGN } \\
\text { VARIANT } \\
\text { BGN } \\
\text { BGN } \\
\text { BGN } \\
\text { BGN } \\
\text { BGN } \\
\text { BGN } \\
\text { VARIANT } \\
\text { VARIANT }\end{array}$ & $\begin{array}{l}\text { Apache } \\
\text { Coconino } \\
\text { Cochise } \\
\text { Gila } \\
\text { Graham } \\
\text { Cochise } \\
\text { Gila } \\
\text { Mohave } \\
\text { Greenlee }\end{array}$ & $\begin{array}{l}334734 N 1091652 \mathrm{~W} \\
363938 \mathrm{~N} 1121853 \mathrm{~W} \\
315200 \mathrm{~N} 1095712 \mathrm{~W} \\
334300 \mathrm{~N} 1102808 \mathrm{~W} \\
325239 \mathrm{~N} 1100327 \mathrm{~W} \\
321616 \mathrm{~N} 1093824 \mathrm{~W} \\
341512 \mathrm{~N} 1113145 \mathrm{~W} \\
362926 \mathrm{~N} 1132845 \mathrm{~W} \\
332633 \mathrm{~N} 1092925 \mathrm{~W}\end{array}$ & $\begin{array}{l}321438 \mathrm{~N} 1093739 \mathrm{~W} \\
332825 \mathrm{~N} 1093550 \mathrm{~W}\end{array}$ & & $\begin{array}{l}\text { Brushy Canyon } \\
\text { Telegraph Wash } \\
\text { Railroad Pass } \\
\text { Cane Springs Mtn } \\
\text { Poverty Knoll } \\
\text { Robinson Mesa }\end{array}$ \\
\hline $\begin{array}{l}\text { Middle Prong Spring } \\
\text { Middle Prong Spring } \\
\text { Middle Prong Tank } \\
\text { Middle Red Creek } \\
\text { Monroe Canyon } \\
\text { Red Creek } \\
\text { Middle Reservoir } \\
\text { Middle Sardina Dam } \\
\text { Middle School } \\
\text { Middle Schroeder Butte }\end{array}$ & $\begin{array}{l}\text { spring } \\
\text { spring } \\
\text { reservoir } \\
\text { stream }\end{array}$ & $\begin{array}{l}\text { BGN } \\
\text { BGN } \\
\text { BGN } \\
\text { BGN } \\
\text { VARIANT } \\
\text { VARIANT } \\
\text { BGN } \\
\text { BGN } \\
\text { UNOFF } \\
\text { BGN }\end{array}$ & $\begin{array}{l}\text { Coconino } \\
\text { Santa Cruz } \\
\text { Gila } \\
\text { Yavapai }\end{array}$ & $\begin{array}{l}330131 N 1101234 \mathrm{~W} \\
334942 \mathrm{~N} 1092243 \mathrm{~W} \\
332102 \mathrm{~N} 1092254 \mathrm{~W} \\
341016 \mathrm{~N} 1114521 \mathrm{~W}\end{array}$ & $341554 N 1114601 \mathrm{~W}$ & 3964 & $\begin{array}{l}\text { Beargrass Basin } \\
\text { Big Lake South } \\
\text { Bee Canyon } \\
\text { Bloody Basin }\end{array}$ \\
\hline $\begin{array}{l}\text { Middle Sevenmile Tank } \\
\text { Middle Spring } \\
\text { Middle Spring } \\
\text { Middle Spring }\end{array}$ & $\begin{array}{l}\text { reservoir } \\
\text { spring } \\
\text { spring } \\
\text { spring }\end{array}$ & $\begin{array}{l}\text { BGN } \\
\text { BGN } \\
\text { BGN } \\
\text { BGN }\end{array}$ & $\begin{array}{l}\text { Navajo } \\
\text { Gila } \\
\text { Navajo } \\
\text { Coconino }\end{array}$ & $\begin{array}{l}334545 N 1095557 \mathrm{~W} \\
335745 \mathrm{~N} 1105151 \mathrm{~W} \\
352919 \mathrm{~N} 1100858 \mathrm{~W} \\
354205 \mathrm{~N} 1111004 \mathrm{~W}\end{array}$ & & & $\begin{array}{l}\text { Whiteriver } \\
\text { Rock House } \\
\text { Na Ah Tee Canyon } \\
\text { Badger Spring }\end{array}$ \\
\hline
\end{tabular}


FEATURE NAME

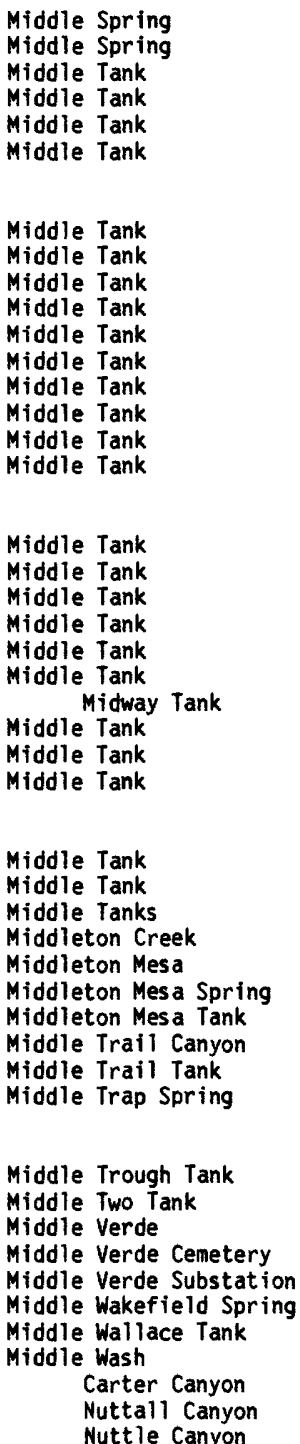

Middle Water

Middle Water Canyon

Middlewater Creek

Middle Water Spring

Middle Water Spring

Middle Water Spring

Middle Water Tank

Middlewater Windmil

Middle Well

Middle Well

Middle Wel

Middle Wel

Middle Well

Middle Wide Mes a

Middle Windmill

Cerro Montosa

Sierra Montosa

Sierra Montoso

Sierra Montrosa

Sierra Montrose

Middle Windmill

Middle Witch Canyon

Midel A Tank

Midgely Bridge Picnic Area

\section{FEATURE}

CLASS

STATUS

spring

reservoir

reservoir

reservoir

reservoir

reservoir $B G$

reservoir $B G$

reservoir BGN

reservoir $B G$

reservoir $B G$

reservoir $8 G$

reservoir BGN

reservoir $B G$

reservoir

reservoir BG

reservoir BGN

reservoir 8GN

reservoir $B G N$

reservoir

reservoir

reservoir

reservoir

BGN

reservoir 8

reservoir $B G$

reservoir BG

stream

summit

spring

reservoir

valley

reservoir

spring

reservoir

reservoir

ppl

cemetery

locale

spring

reservoir

strean

$\begin{array}{lll}\text { MGN } & \text { Mohave } & 360855 N 1132011 \mathrm{~W} \\ \text { Mohave } & 363204 N 1140231 \mathrm{~W} \\ \text { BN } & \text { Pima } & 314123 N 1112807 \mathrm{~W} \\ \text { BGN } & \text { Pima } & 314128 N 1113257 \mathrm{~W} \\ \text { CGN } & \text { Cochise } & 314644 N 1102337 \mathrm{~W} \\ \text { PGN } & \text { Pima } & 320421 \mathrm{~N} 1112500 \mathrm{~W}\end{array}$

Graham

Pinal

Pinal

Maricopa

Greenlee

Pinal

Gila

Navajo

Navajo

Navajo

Yavapai

Coconino

Yavapai

Navajo

Apache

Apache

Navajo

Apache

Mohave

Coconino

Mohave

Maricopa

Yavapai

Gila

Gila

Gila

Apache

Yavapai

Gila

Mohave

Santa Cruz

Yavapai

Yavapai

Yavapai

Cochise

Apache

BGN

BGN

BGN 1962 Graham

VARIANT

VARIANT

VARIANT

spring

valley

stream

spring

spring

spring

reservoir

locale

well

well

BGN
BGN
8GN
BGN
BGN
BGN
BGN
BGN
UNOFF
UNOFF

$322730 \mathrm{~N} 1100930 \mathrm{~W}$

$324608 \mathrm{NL} 110326 \mathrm{~W}$

$325813 \mathrm{~N} 1110441 \mathrm{~W}$

$330007 \mathrm{~N} 1122041 \mathrm{~W}$

$330757 N 1090727 \mathrm{~W}$

331307 N1111959W

$335748 \mathrm{~N} 1105115 \mathrm{~W}$

$341840 \mathrm{~N} 1103530 \mathrm{~W}$

$342353 \mathrm{~N} 1101721 \mathrm{~W}$

$342445 \mathrm{~N} 1102300 \mathrm{~W}$

$342940 \mathrm{~N} 1123932 \mathrm{~W}$

$343104 \mathrm{~N} 1112223 \mathrm{~W}$

$343205 \mathrm{~N} 1124818 \mathrm{~W}$

$344152 \mathrm{~N} 1102758 \mathrm{~W}$

$344253 \mathrm{~N} 1094830 \mathrm{~W}$

$344743 \mathrm{~N} 1094109 \mathrm{~W}$

$345641 \mathrm{~N} 1095304 \mathrm{~W}$

$351053 \mathrm{~N} 1091525 \mathrm{~W}$

$352441 \mathrm{~N} 1142352 \mathrm{~W}$

$352901 \mathrm{~N} 1124923 \mathrm{~W}$

$364924 \mathrm{~N} 1133633 \mathrm{~W}$

$334523 \mathrm{~N} 1120935 \mathrm{~W}$

$341620 \mathrm{~N} 1121614 \mathrm{~W}$

$340106 \mathrm{~N} 1104851 \mathrm{~W}$

$335905 \mathrm{~N} 1104943 \mathrm{~W}$

$340025 \mathrm{~N} 1104857 \mathrm{~W}$

$361525 \mathrm{~N} 1092024 \mathrm{~W}$

$345527 \mathrm{~N} 1121853 \mathrm{~W}$

334852N1105040W

$362728 \mathrm{~N} 1133006 \mathrm{~W}$

$312239 \mathrm{~N} 1103904 \mathrm{~W}$

$343712 \mathrm{~N} 1115327 \mathrm{~W}$

$343752 \mathrm{~N} 1115308 \mathrm{~W}$

$344048 \mathrm{~N} 1120008 \mathrm{~W}$

$315225 \mathrm{~N} 1102635 \mathrm{~W}$

$345115 \mathrm{~N} 1094450 \mathrm{~W}$

325013 N1095550W
Yavapa

Yavapai

Yavapai

Gila

Mohave

Mohave

Coconino

Yavapai

Yuma

Apache

341858 N1115710W $344654 \mathrm{~N} 1131215 \mathrm{~W}$ $342128 N 1123337 W$ $334417 N 1112014 \mathrm{~W}$ $350702 \mathrm{N1} 132542 \mathrm{~W}$ $353528 \mathrm{~N} 1142810 \mathrm{~W}$ $353708 \mathrm{~N} 1123402 \mathrm{~W}$ $330422 \mathrm{~N} 1135322 \mathrm{~W}$

$342110 \mathrm{~N} 1090458 \mathrm{~W}$

Apache

Yavapai

Apache

Apache

Pima $342124 \mathrm{~N} 1123336 \mathrm{~W}$
344738 N1094126W

$350238 \mathrm{~N} 1125617 \mathrm{~W}$

350951 N1091430W

$362439 \mathrm{~N} 1091748 \mathrm{~W}$

$320819 \mathrm{~N} 1112243 \mathrm{~W}$

\section{we}

wel 1

well

locale

UNOFF
UNOFF
UNOFF
BGN
BGN
VARIANT
VARIANT
VARIANT
VARIANT
VARIANT

locale

valley

reservoir

park
BGN

BGN 1976

ADMIN $\begin{array}{cc}\text { SOURCE } & \text { ELEV } \\ \text { COORDINATE } & \text { FT }\end{array}$

MAP NAME

Whitmore Point

Virgin Peak

Las Guijas

Mildred Peak

Apache Peak

San Pedro

Greasewood Mountain

Ninetys ix Hills SE

Ninetysix Hills NE

Mobile

Hardin Cienega

Florence NE

Rock House

Out law Draw

Big Pug Tank

Aripine

Kirkland

Long Valley

Martin Mtn

Dry Lake NW

Adamana Three ME

Milky Ranch

Carrizo Butte

Sanders

Grasshopper Junc NW

Trinity Mtn

Wolf Hole Mtn East

Biscuit Flat

$341636 N 1121743 W$

Battle Flat

5792 Gentry Mtn

Rock House

Gentry Mtn

361718 N1091822W

Red Cornfield Mesa

Hell Point

Rock House

Poverty Spring

Harshaw

3168 Middle Verde

Cornville

Cottonwood

Apache Peak

Milky Ranch

324738 N1095817W

Shingle Mill Mtn
$345113 \mathrm{~N} 1131227 \mathrm{~W}$

$342253 \mathrm{~N} 1123016 \mathrm{~W}$

Dugas

Burro Mesa

Walnut Grove

Four Peaks

Penitentiary Mtn

Middle Water Spring

Howard Spring

Walnut Grove

Engesser Pass SW

The Rincon

5499 Milky Ranch

5890 Turkey Canyon

Tolapai Spring

Bad Bug Butte

La Tortuga Butte 
NATIONAL GAZETTEER--ARIZONA 1986

\begin{tabular}{|c|c|c|c|c|c|c|c|}
\hline FEATURE NAME & $\begin{array}{l}\text { FEATURE } \\
\text { CLASS }\end{array}$ & STATUS & COUNTY & COORDINATE & $\begin{array}{l}\text { SOURCE } \\
\text { COORDINATE }\end{array}$ & $\begin{array}{c}\text { ELEV } \\
\text { FT }\end{array}$ & MAP NAME \\
\hline $\begin{array}{l}\quad \text { Picnic Four Area } \\
\text { Midges Court (trailer park) } \\
\text { Midget Draw } \\
\text { Midget Mine } \\
\text { Midgley Bridge } \\
\text { Midland City }\end{array}$ & $\begin{array}{l}\text { locale } \\
\text { valley } \\
\text { mine } \\
\text { bridge } \\
\text { ppl }\end{array}$ & $\begin{array}{l}\text { VARIANT } \\
\text { UNOFF } \\
\text { BGN } \\
\text { UNOFF } \\
\text { UNOFF } \\
\text { BGN }\end{array}$ & $\begin{array}{l}\text { Maricopa } \\
\text { Gila } \\
\text { Gila } \\
\text { Coconino } \\
\text { Gila }\end{array}$ & $\begin{array}{l}333052 \mathrm{~N} 1120919 \mathrm{~W} \\
340715 \mathrm{~N} 1112219 \mathrm{~W} \\
340949 \mathrm{~N} 1112131 \mathrm{~W} \\
345307 \mathrm{~N} 1114430 \mathrm{~W} \\
332443 \mathrm{~N} 1104925 \mathrm{~W}\end{array}$ & $340947 \mathrm{~N} 1112137 \mathrm{~W}$ & 1140 & $\begin{array}{l}\text { Glendale } \\
\text { Gise1a } \\
\text { Payson South } \\
\text { Munds Park } \\
\text { Globe }\end{array}$ \\
\hline $\begin{array}{l}\text { Midland School } \\
\text { Midnight Canyon } \\
\text { Midnight Canyon } \\
\text { Midnight Creek } \\
\text { Midnight Dam } \\
\text { Midnight Mesa } \\
\text { Midnight Mine } \\
\text { Midnight Mine } \\
\text { Midnight Owl Mine } \\
\text { Midnight Tank }\end{array}$ & $\begin{array}{l}\text { school } \\
\text { valley } \\
\text { valley } \\
\text { stream } \\
\text { dam } \\
\text { summit } \\
\text { mine } \\
\text { mine } \\
\text { mine } \\
\text { reservoir }\end{array}$ & $\begin{array}{l}\text { UNOFF } \\
\text { BGN } \\
\text { BGN } \\
\text { BGN } \\
\text { UNOFF } \\
\text { BGN } \\
\text { UNOFF } \\
\text { UNOFF } \\
\text { UNOFF } \\
\text { BGN }\end{array}$ & $\begin{array}{l}\text { Gila } \\
\text { Graham } \\
\text { Graham } \\
\text { Graham } \\
\text { Graham } \\
\text { Yavapai } \\
\text { Mohave } \\
\text { Mohave } \\
\text { Yavapai } \\
\text { Graham }\end{array}$ & $\begin{array}{l}332432 \mathrm{~N} 1104920 \mathrm{~W} \\
325302 \mathrm{~N} 1092834 \mathrm{~W} \\
330043 \mathrm{~N} 1093305 \mathrm{~W} \\
330532 \mathrm{~N} 1093401 \mathrm{~W} \\
330600 \mathrm{~N} 1093130 \mathrm{~W} \\
340742 \mathrm{~N} 1113419 \mathrm{~W} \\
350223 \mathrm{~N} 1142523 \mathrm{~W} \\
352332 \mathrm{~N} 1141106 \mathrm{~W} \\
335957 \mathrm{~N} 1123048 \mathrm{~W} \\
330624 \mathrm{~N} 1093210 \mathrm{~W}\end{array}$ & $\begin{array}{l}325217 N 1092352 W \\
330306 \mathrm{~N} 1093125 \mathrm{~W} \\
330403 \mathrm{~N} 1093048 \mathrm{~W}\end{array}$ & 4844 & $\begin{array}{l}\text { Globe } \\
\text { Gila Box } \\
\text { Bonita Spring } \\
\text { Bonita Spring } \\
\text { Bonita Spring } \\
\text { Cypress Butte } \\
\text { Oatman } \\
\text { Chloride } \\
\text { Red Picacho } \\
\text { Bonita Spring }\end{array}$ \\
\hline $\begin{array}{l}\text { Midnite Mine } \\
\text { Midnite Spring } \\
\text { Midnite Test Mine } \\
\text { Midtown Shopping Center } \\
\text { Midway } \\
\text { Midway } \\
\text { Midway Canyon } \\
\text { Midway Dam } \\
\text { Midway Detention Dam } \\
\quad \text { See Midway Retention Dam }\end{array}$ & $\begin{array}{l}\text { mine } \\
\text { spring } \\
\text { mine } \\
\text { locale } \\
\text { locale } \\
\text { locale } \\
\text { valley } \\
\text { dam } \\
\text { dam }\end{array}$ & $\begin{array}{l}\text { UNOFF } \\
\text { BGN } \\
\text { UNOFF } \\
\text { UNOFF } \\
\text { BGN } \\
\text { BGN } \\
\text { BGN } \\
\text { UNOFF } \\
\text { VARIANT }\end{array}$ & $\begin{array}{l}\text { Pima } \\
\text { Yavapai } \\
\text { Yavapai } \\
\text { Coconino } \\
\text { Maricopa } \\
\text { Yuma } \\
\text { Cochise } \\
\text { Santa Cruz } \\
\text { Graham }\end{array}$ & $\begin{array}{l}315848 N 1115132 \mathrm{~W} \\
342843 \mathrm{~N} 1122412 \mathrm{~W} \\
342833 \mathrm{~N} 1122417 \mathrm{~W} \\
351305 \mathrm{~N} 1113719 \mathrm{~W} \\
323801 \mathrm{N1125116W} \\
340414 \mathrm{~N} 1135309 \mathrm{~W} \\
322350 \mathrm{~N} 1090810 \mathrm{~W} \\
312705 \mathrm{~N} 1111033 \mathrm{~W} \\
\\
330200 \mathrm{~N} 1095948 \mathrm{~W}\end{array}$ & $322508 N 1090625 \mathrm{~W}$ & $\begin{array}{l}6960 \\
1169 \\
1451\end{array}$ & $\begin{array}{l}\text { Sells East } \\
\text { Groom Creek } \\
\text { Groom Creek } \\
\text { Flagstaff East } \\
\text { Midway } \\
\text { Powerline Well } \\
\text { Orange butte } \\
\text { Ruby }\end{array}$ \\
\hline $\begin{array}{l}\text { Midway Number One Tank } \\
\text { Midway Number Two Tank } \\
\text { Midway Peak } \\
\text { Midway Retention Dam } \\
\text { Midway Detention Dam } \\
\text { Midway Station } \\
\text { Midway Tank } \\
\text { Midway Tank } \\
\text { Midway Tank } \\
\text { Midway Tank }\end{array}$ & $\begin{array}{l}\text { reservoir } \\
\text { reservoir } \\
\text { summit } \\
\text { dam } \\
\text { locale } \\
\text { reservoir } \\
\text { reservoir } \\
\text { reservoir } \\
\text { reservoir }\end{array}$ & $\begin{array}{l}\text { BGN } \\
\text { BGN } \\
\text { BGN } \\
\text { UNOFF } \\
\text { VARIANT } \\
\text { BGN } \\
\text { BGN } \\
\text { BGN } \\
\text { BGN } \\
\text { BGN }\end{array}$ & $\begin{array}{l}\text { Coconino } \\
\text { Coconino } \\
\text { Cochise } \\
\text { Graham } \\
\text { Maricopa } \\
\text { Pina } \\
\text { Graham } \\
\text { Gila } \\
\text { Mohave }\end{array}$ & $\begin{array}{l}360307 N 1122049 \mathrm{~W} \\
360343 \mathrm{~N} 1122050 \mathrm{~W} \\
322411 \mathrm{~N} 1090840 \mathrm{~W} \\
330200 \mathrm{~N} 1095948 \mathrm{~W} \\
\\
325326 \mathrm{~N} 1130332 \mathrm{~W} \\
313327 \mathrm{~N} 1111233 \mathrm{~W} \\
331148 \mathrm{~N} 1100122 \mathrm{~W} \\
335807 \mathrm{~N} 1112105 \mathrm{~W} \\
342532 \mathrm{~N} 1140344 \mathrm{~W}\end{array}$ & & 5551 & $\begin{array}{l}\text { Piute Point } \\
\text { Piute Point } \\
\text { Orange Butte } \\
\text { Markham Creek } \\
\text { Sentinel NE } \\
\text { Murphy Peak } \\
\text { Bylas } \\
\text { Kayler Butte } \\
\text { Mohave Springs }\end{array}$ \\
\hline $\begin{array}{l}\text { Midway Tank } \\
\text { Midway Tank } \\
\text { See Middle Tank } \\
\text { Midway Tank } \\
\text { Midway Tank } \\
\text { Midway Tank } \\
\text { Midway Wash } \\
\text { Midway Well } \\
\text { Mid Well } \\
\text { Miguel, Mount }\end{array}$ & $\begin{array}{l}\text { reservoir } \\
\text { reservoir } \\
\text { reservoir } \\
\text { reservoir } \\
\text { reservoir } \\
\text { stream } \\
\text { well } \\
\text { well } \\
\text { summit }\end{array}$ & $\begin{array}{l}\text { BGN } \\
\text { VARIANT } \\
\text { BGN } \\
\text { BGN } \\
\text { BGN } \\
\text { BGN } \\
\text { UNOFF } \\
\text { UNOFF } \\
\text { BGN }\end{array}$ & $\begin{array}{l}\text { Yavapai } \\
\text { Apache } \\
\text { Yavapai } \\
\text { Yavapai } \\
\text { Coconino } \\
\text { Maricopa } \\
\text { Pima } \\
\text { Yuma } \\
\text { Pima }\end{array}$ & $\begin{array}{l}343946 \mathrm{~N} 1122144 \mathrm{~W} \\
344743 \mathrm{~N} 1094109 \mathrm{~W} \\
345236 \mathrm{~N} 1121550 \mathrm{~W} \\
345953 \mathrm{~N} 1131516 \mathrm{~W} \\
355025 \mathrm{~N} 1124501 \mathrm{~W} \\
324331 \mathrm{N1} 130124 \mathrm{~W} \\
313324 \mathrm{N1} 111249 \mathrm{~W} \\
332031 \mathrm{~N} 1135841 \mathrm{~W} \\
322018 \mathrm{~N} 1104938 \mathrm{~W}\end{array}$ & $323334 \mathrm{~N} 1124056 \mathrm{~W}$ & & $\begin{array}{l}\text { Hell Point } \\
\text { Mohon Peak } \\
\text { Supai Camp SE } \\
\text { Malpais Hill } \\
\text { Murphy Peak } \\
\text { Kofa Butte } \\
\text { Sabino Canyon }\end{array}$ \\
\hline $\begin{array}{l}\text { Mikes Cabin } \\
\text { Mike Spring } \\
\text { Mikes Spring } \\
\quad \text { See Butler Spring } \\
\text { Mikes Tank } \\
\text { Mikes Tank } \\
\text { Mikes Tank } \\
\text { Mike Tank } \\
\text { Milagrosa Canyon, La } \\
\text { Milagro Well }\end{array}$ & $\begin{array}{l}\text { locale } \\
\text { spring } \\
\text { spring } \\
\text { reservoir } \\
\text { reservoir } \\
\text { reservoir } \\
\text { reservoir } \\
\text { valley } \\
\text { well }\end{array}$ & $\begin{array}{l}\text { BGN } \\
\text { BGN } \\
\text { VARIANT } \\
\text { BGN } \\
\text { BGN } \\
\text { BGN } \\
\text { BGN } \\
\text { BGN } \\
\text { UNOFF }\end{array}$ & $\begin{array}{l}\text { Yavapai } \\
\text { Navajo } \\
\text { Yavapai } \\
\text { Navajo } \\
\text { Navajo } \\
\text { Yavapai } \\
\text { Coconino } \\
\text { Pima } \\
\text { Pima }\end{array}$ & $\begin{array}{l}341703 \mathrm{~N} 1115048 \mathrm{~W} \\
353028 \mathrm{~N} 1100221 \mathrm{~W} \\
341539 \mathrm{~N} 1122600 \mathrm{~W} \\
342753 \mathrm{~N} 1102724 \mathrm{~W} \\
343239 \mathrm{N1} 101951 \mathrm{~W} \\
344917 \mathrm{N1} 130309 \mathrm{~W} \\
352305 \mathrm{~N} 1123007 \mathrm{~W} \\
321753 \mathrm{N1} 104248 \mathrm{~W} \\
315533 \mathrm{~N} 1113013 \mathrm{~W}\end{array}$ & $322051 N 1103941 \mathrm{~W}$ & 3444 & $\begin{array}{l}\text { Aripine } \\
\text { Sheepskin Wash } \\
\text { Scratch Canyon } \\
\text { Eagle Nest Mtn } \\
\text { Agua Caliente Hill } \\
\text { Kitt Peak }\end{array}$ \\
\hline $\begin{array}{l}\text { Mildred Mine } \\
\text { Mildred Mine } \\
\text { Mildred Peak } \\
\text { Mildren Mine } \\
\text { Mile-and-a-half Lake } \\
\text { Miles Manor } \\
\text { Miles School } \\
\text { Mile-Wide Mine } \\
\text { Milholland Creek } \\
\text { See Mulholland Wash }\end{array}$ & $\begin{array}{l}\text { mine } \\
\text { mine } \\
\text { summit } \\
\text { mine } \\
\text { lake } \\
\text { ppl } \\
\text { school } \\
\text { mine } \\
\text { arroyo }\end{array}$ & $\begin{array}{l}\text { UNOFF } \\
\text { UNOFF } \\
\text { BGN } \\
\text { UNOFF } \\
\text { BGN } \\
\text { BGN } \\
\text { UNOFF } \\
\text { UNOFF } \\
\text { VARIANT }\end{array}$ & $\begin{array}{l}\text { Pima } \\
\text { Apache } \\
\text { Pima } \\
\text { Pima } \\
\text { Coconino } \\
\text { Cochise } \\
\text { Pina } \\
\text { Pima } \\
\text { Yavapai }\end{array}$ & $\begin{array}{l}320219 \mathrm{~N} 1115545 \mathrm{~W} \\
364214 \mathrm{~N} 1091705 \mathrm{~W} \\
314247 \mathrm{~N} 1113533 \mathrm{~W} \\
320217 \mathrm{~N} 1115544 \mathrm{~W} \\
363700 \mathrm{~N} 1121307 \mathrm{~W} \\
313330 \mathrm{N1} 102021 \mathrm{~W} \\
321315 \mathrm{~N} 1105659 \mathrm{~W} \\
321548 \mathrm{~N} 1110920 \mathrm{~W} \\
343635 \mathrm{~N} 1131628 \mathrm{~W}\end{array}$ & & 5567 & $\begin{array}{l}\text { Ko Vaya } \\
\text { Kinusta Mesa } \\
\text { Mildred Peak } \\
\text { Ko Vaya } \\
\text { Telephone Hill } \\
\text { Fort Huachuca } \\
\text { Tucson } \\
\text { Avra }\end{array}$ \\
\hline $\begin{array}{l}\text { Military Hill } \\
\text { Military Plaza Park } \\
\text { Military Sinkhole } \\
\text { Military Tank } \\
\text { Milk Creek }\end{array}$ & $\begin{array}{l}\text { summit } \\
\text { park } \\
\text { basin } \\
\text { reservoir } \\
\text { stream }\end{array}$ & $\begin{array}{l}\text { BGN } \\
\text { ADMIN } \\
\text { BGN } \\
\text { BGN } \\
\text { BGN }\end{array}$ & $\begin{array}{l}\text { Cochise } \\
\text { Pima } \\
\text { Coconino } \\
\text { Graham } \\
\text { Apache }\end{array}$ & $\begin{array}{l}314100 \mathrm{~N} 1100405 \mathrm{~W} \\
321307 \mathrm{~N} 1105807 \mathrm{~W} \\
341840 \mathrm{~N} 1105529 \mathrm{~W} \\
331614 \mathrm{~N} 1100529 \mathrm{~W} \\
333941 \mathrm{N1} 1093045 \mathrm{~W}\end{array}$ & $334204 N 1093106 \mathrm{~W}$ & & $\begin{array}{l}\text { Tombstone } \\
\text { Tucs on } \\
\text { Woods Canyon } \\
\text { Ash Creek Ranch } \\
\text { Maverick }\end{array}$ \\
\hline
\end{tabular}




\section{FEATURE NAME}

Milk Creek

Milk Creek

Milk Creek

Milk Ranch

Milk Ranch

Milk Ranch Creek

Milk Ranch Point

Milk Ranch Spring

Milk Ranch Tank

Milkwater

Milkweed Canyon

Milkweed Spring

Milky House

Milky Tank

Milky Tank

Milky Wash

Milky Wash Bridge

Milky Way Tank

Mill Canyon

Mill Canyon

Mill City

See Phoenix

Mi11 Creek Mineral Creek

Mill Creek Spring

Mill Creek Well

Miller Canyon

Miller Canyon

$$
\text { Grenego Canyon }
$$

McCarty Draw

Miller Canyon

Miller Canyon Recreation Area

Miller Creek

Miller Creek

Miller Creek

See McCarty Draw

Miller Dam Tank

Miller Flat

Miller Hill

Miller Lateral

Miller Mines

Miller Mountain

Miller Mountain

Miller Peak

Miller Peak Trail

Miller Peak Trail

See Crest Trail Number

One Hundred Three

Miller Plaza Shopping Center Miller Ranch

Miller Ranch

Miller Reservoir

Cullings Well

Cullins Well

Miller Ridge

Millers Cave

Miller School

Miller Seep Tank

Millers Pocket

Miller Spring

Miller Spring

Miller Spring

Miller Spring

Miller Spring

Miller Spring

Miller Spring

Miller Spring

Millers Windmill

Miller Tank

Miller Tank

Miller Tank
FEATURE
CLASS

stream
stream
stream
locale
locale

STATUS COUNTY

BGN Apache

BGN 1932 Coconino

UNOFF Pinal

UNOFF Yavapai

stream
cliff
spring
reservoir
locale
valley
spring
locale
reservoir
reservoir

$B G N$
$B G N$
$B G N$
$B G N$
$B G N$
$B G N$
$B G N$
$B G N$
$B G N$
$B G N$

stream BGN

bridge

valley

valley

UNOFF

BGN

BGN

BGN

ppl

stream

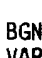

spring

BGN

BGN

well

UNOFF

valley

BGN

BGN 1966

VARIANT

valley BGN

park

BGN

ADMIN

BGN

VARIANT

stream

valley

reservoir

flat

ridge

canal

mine

summit

summit

summit

trail

trail

\section{$B G N$}

$B G N$

BGN

UNOFF

$B G N$

BGN

BGN

UNOFF

VARIANT

locale
locale

locale

reservoir

UNOFF

UNOFF

UNOF

BGN
VARIANT

VARIANT

ridge $\quad B G N$

school UNOFF

reservoir

UNOFF
BGN

basin

reservoir

spring
spring

spring

spring

spring

spring

spring

locale

$B G N$

BGN

BGN

$B G N$

$B G N$

$B G N$

$B G N$

BGN

BGN

reservoir

$\begin{array}{ll}\text { reservoir } & B G N \\ \text { reservoir } & B G N\end{array}$
Pinal

Coconino

Apache

Navajo

Apache

Mohave

Mohave

Apache

Apache

Apache

Navajo

Apache

Maricopa

Pima

Maricopa

Maricopa

Pinal

Gila

Gila

Coconino

Cochise

Cochise

Yavapai

Yavapai

Coconino

Yavapai

Pima

Cochise

Yuma

Maricopa

Mohave

Yavapai

Cochise

Cochise

Cochise

COORDINATE

335634N1091118W

$341422 \mathrm{~N} 1123254 \mathrm{~W}$

$361224 \mathrm{~N} 1120935 \mathrm{~W}$

$332153 N 1111554 \mathrm{~W}$

$340659 \mathrm{~N} 1121712 \mathrm{~W}$

$332215 \mathrm{~N} 1111709 \mathrm{~W}$

$342352 \mathrm{~N} 1112444 \mathrm{~W}$

334900 N1091242W

$340209 \mathrm{~N} 1095505 \mathrm{~W}$

$360310 \mathrm{~N} 1090636 \mathrm{~W}$

$354322 \mathrm{~N} 1133656 \mathrm{~W}$

$353707 \mathrm{N1134220 \textrm {W }}$

344639 N1094341W

$344222 \mathrm{~N} 1095026 \mathrm{~W}$

344844 N1093541W

344219 N1095223W

$344540 \mathrm{~N} 1094742 \mathrm{~W}$

334806 N1121130W

$314748 \mathrm{~N} 1104625 \mathrm{~W}$

335953N1115144W

$332654 \mathrm{~N} 1120424 \mathrm{~W}$

$331450 \mathrm{~N} 1105640 \mathrm{~W}$

331706 N1105021W

$331524 \mathrm{~N} 1105416 \mathrm{~W}$

$320903 \mathrm{~N} 1102845 \mathrm{~W}$

$343259 \mathrm{~N} 1111417 \mathrm{~W}$

343300 N1111420W

$312453 \mathrm{~N} 1101633 \mathrm{~W}$

341629 N1124239W

343249 N1122808W

$343209 \mathrm{~N} 1111445 \mathrm{~W}$

$344740 \mathrm{~N} 1123345 \mathrm{~W}$

$320843 \mathrm{~N} 1102836 \mathrm{~W}$

$312648 \mathrm{~N} 1095455 \mathrm{~W}$

$323944 N 1144221 \mathrm{~W}$

332906 N1111657W

$341904 N 1134203 \mathrm{~W}$

$343143 \mathrm{~N} 1131204 \mathrm{~W}$

$312334 \mathrm{~N} 1101732 \mathrm{~W}$

$312333 \mathrm{~N} 1101754 \mathrm{~W}$

312404N1101834W

Maricopa

Apache

Mohave

Yuma

Coconino

Apache

Mohave

Coconino

Coconino

Coconino

Santa Cruz

Cochise

Graham

Gila

Pinal

Greenlee

Apache

Yavapa 1

Navajo

Yavapai

Yavapai

SOURCE
COORDINATE

335620N1090648W Nutrioso

$361715 \mathrm{~N} 1120733 \mathrm{~W}$ Shiva Temple

Shiva Temple

Columbia

$332242 N 1111531 W$

Florence Junction

Pine

Alpine

Indian Pine

Sonsela Buttes

353351N1134358W Hindu Canyon

Milkweed Canyon SW

Milky Ranch

Little Milky Ranch

Seven Springs

Little Milky Ranch

Adamana Three NE

Biscuit flat

Helvetia

Humboldt Mtn

$331700 \mathrm{~N} 1105004 \mathrm{~W}$

Hot Tamale Peak

Pinal Peak

Pinal Ranch 
NATIONAL GAZETTEER--ARIZONA 1986

\section{FEATURE NAME}

Miller Tank

Miller Tank

Miller Tank

Miller Tank

Miller Tank

Miller Valley

Miller Valley Post office

Miller Valley School

Miller Wash

Miller Wash

Miller Wash

Miller Wash Reservoir

Miller Wash Tank

Miller Water Tank

Miller Well

Miller Windmill

Millet Swale

Millet Swale Dam

Millet Swale Reservoir

Milligan Creek

Milligan Knoll

Saffel Knoll

Saffell Knoll

Milligan Lake

Milligan Peak

Milligan Valley

Million Hills

Million Hills Wash

Mill Park

Mill Park Tank

Mill Point Tank

Mills Canyon

Mills Cove Area

Millsite Canyon

Millsite Canyon

Mill Spring

Mills Quarry

Mills Ranch

Mills Ridge Tank

Mills Tank

Milltown (site)

Mill Wash

Milos Butte

Milpa Tank

Milpitas See Hickiwan

Milton Mine

Milton Ray Tank

Mimbreno Point

Mimsh Wahia

Mina Colorado See Heintzelman Mine

Mine Canyon

Mine Canyon

Mine Canyon

Mine Mountain

Mine Mountain Spring

Mineral Butte

Mineral Canyon

Mineral City

See Ehrenberg

Mineral Creek

Rio San Francisco

Mineral Creek

See Mill Creek

Mineral Creek

See Rye Creek

Mineral Creek

Hill Creek

Rye Creek

Mineral Creek
FEATURE

CLASS

STATUS

COUNTY

COORDINATE

351305 N1125743W

$353805 \mathrm{~N} 1122317 \mathrm{~W}$

$3538050 \mathrm{~N} 1141219 \mathrm{~W}$

$354231 \mathrm{N1120812 \textrm {W }}$

354231 N1121829w

$343311 \mathrm{N1} 122831 \mathrm{~W}$

$343310 \mathrm{~N} 122844 \mathrm{~W}$

ppl BGN Coconino

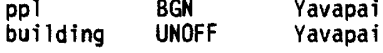

$\begin{array}{ll}\text { school } & \text { UN } \\ \text { stream } & B G M \\ \text { stream } & B G N \\ \text { stream } & B G \\ \text { reservoir } & B G \\ \text { reservoir } & B G \\ \text { reservoir } & B G \\ \text { well } & \text { UN } \\ \text { locale } & B G \\ \text { strean } & B G \\ & \end{array}$

UNOFF Yavapai 343328N1122855W

BGN Pinal

Yavapai

Coconino

Coconino

Coconino

Coconino

Yuma
Yavapai

Navajo

dam

reservoir

stream

sumbit

lake

summit

valley

summit

valley

flat

reservoir

reservoir

valley

bay

valley

valley

spring

mine

locale

reservoir

reservo
locale

stream
summit

reservoir

pp1

mine UNOFF

$\begin{array}{ll}\text { UNOFF } & \text { Navajo } \\ \text { BGN } & \text { Navajo } \\ \text { BGN } & \text { Apache } \\ \text { BGN 1971 } & \text { Apache } \\ \text { VARIANT } & \\ \text { VARIANT } & \\ \text { BGN } & \text { Greenlee } \\ \text { BGN } & \text { Greenlee } \\ \text { BGN } & \text { Apache } \\ \text { BGN } & \text { Mohave }\end{array}$

BGN Mohave

BGN Coconino

$B G N$

$B G N$
$B G N$
$B G N$

BGN

BGN

$B G N$

UNOFF

Yavapai

Gila

Gila

Cochise

Pinal

Gila

Coconino

UNOFF Graham

BGN Gila

BGN

Graham

Mohave

Maricopa

Pima

BGN

VARIANT

Pima

reservoir

cliff

spring

BGN

BGN Maricopa

BGN 1908 Coconino

BGN

VARIANT

mine

valley

valley

valley
summit

spring

BGN

BGN 1985

BGN

BGN

Pina

Pima

Cochise

Graham

Gila

Maricopa

Maricopa

summit

valley

BGN

ppl
stream

BGN 190

VARIANT

Pinal

Coconino

Yuma

BGN

VARIANT

VARIANT

stream

stream

VARIANT

Pinal

Gila

stream

BGN

VARIANT

VARIANT

stream

$324402 \mathrm{~N} 1110125 \mathrm{~W}$

$340905 \mathrm{~N} 1131719 \mathrm{~W}$

$354020 \mathrm{N1122033 \textrm {W }}$

$353252 \mathrm{~N} 1120014 \mathrm{~W}$

$352330 \mathrm{~N} 1115801 \mathrm{~W}$

345155N1113200W

$340641 \mathrm{~N} 1131951 \mathrm{~W}$

$340 B 49 \mathrm{N1} 122525 \mathrm{~W}$

$342551 \mathrm{~N} 1100357 \mathrm{~W}$

$342550 \mathrm{~N} 1100227 \mathrm{~W}$

$342550 \mathrm{N1} 100227 \mathrm{~W}$

340151 N1091406W

$340223 \mathrm{~N} 1091640 \mathrm{~W}$

$33432 \mathrm{BN} 1090408 \mathrm{~W}$

$334251 \mathrm{~N} 1090515 \mathrm{~W}$

$340137 \mathrm{~N} 1091627 \mathrm{~W}$

$361451 \mathrm{N1140247 \textrm {W }}$

$361239 \mathrm{~N} 1140246 \mathrm{~W}$ $350609 \mathrm{~N} 1114838 \mathrm{~W}$ $350619 N 1114756 \mathrm{~W}$

342908 N1115752W

$334205 N 1111056 \mathrm{~W}$

$334140 \mathrm{~N} 1111023 \mathrm{~W}$

$322322 \mathrm{~N} 1090147 \mathrm{~W}$

$332003 \mathrm{~N} 1111353 \mathrm{~W}$

332952 N1104308

$350223 N 1121703 \mathrm{~W}$

$323721 N 1095939 \mathrm{~W}$

$334110 \mathrm{~N} 1111231 \mathrm{~W}$

$324113 \mathrm{~N} 1100805 \mathrm{~W}$

$345528 \mathrm{~N} 1143116 \mathrm{~W}$

$333923 N 1124625 \mathrm{~W}$

$345438 \mathrm{~N} 1113259 \mathrm{~W}$

$31381 B N 1113152 \mathrm{~W}$

$322208 \mathrm{~N} 1122829 \mathrm{~W}$

$315807 N 1125323 \mathrm{~W}$

$335545 \mathrm{~N} 1131123 \mathrm{~W}$

$360511 \mathrm{~N} 1121644 \mathrm{~W}$

$315740 \mathrm{~N} 1115416 \mathrm{~W}$

$314200 \mathrm{~N} 1111600 \mathrm{~W}$

$314434 \mathrm{~N} 1102439 \mathrm{~W}$

$330036 \mathrm{~N} 1101137 \mathrm{~W}$

$340302 \mathrm{~N} 1110420 \mathrm{~W}$

$334227 \mathrm{~N} 1112510 \mathrm{~W}$

$334155 \mathrm{~N} 1112540 \mathrm{~W}$

$335258 \mathrm{~N} 1125053 \mathrm{~W}$

$324556 \mathrm{~N} 1105819 \mathrm{~W}$

$340439 \mathrm{~N} 1131950 \mathrm{~W}$

352908N1115714W

$342431 N 1094917 \mathrm{~W}$

Minnehaha
Taylor

5714 Taylor

$340059 N 1091834 \mathrm{~W}$

8800 Nelson Reservoir

8800 Eagar

Maness Peak

8132 Maness Peak

340044N1091716W Eagar

Iceberg Canyon

$361501 N 1135945 W$

Iceberg Canyon

Dutton $\mathrm{Hil}$

Dutton $\mathrm{Hill}$

Arnold Mesa

334016N1111610W Theo. Roosevelt Dam

Theo. Roosevelt Dam

Engine Mtn

Picketpost Mtn

Cammerman Wash

Matterhorn

Fort Grant

Georges Butte

Eureka Ranch

Needles NE

Star Well

7528 Mormon Mountain

Mildred Peak

West of Lukeville

Aguila

6605 Piute Point

Sells West

$314641 \mathrm{~N} 110255 \mathrm{BW}$

$330254 N 1101412 \mathrm{~W}$

$340245 \mathrm{~N} 1110337 \mathrm{~W}$

Mustang Mountains

Beargrass Bas in

Buzzard Roost Mesa

5162 Mine Mountain

Mine Mountain 


\begin{tabular}{|c|c|c|c|c|c|c|c|}
\hline FEATURE NAME & $\begin{array}{l}\text { FEATURE } \\
\text { CLASS }\end{array}$ & STATUS & COUNTY & COORDINATE & $\begin{array}{l}\text { SOURCE } \\
\text { COORDINATE }\end{array}$ & $\begin{array}{c}\text { ELEV } \\
\text { FT }\end{array}$ & MAP NAME \\
\hline $\begin{array}{l}\text { Mineral Oraw } \\
\text { Mineral Creek } \\
\text { Mineral Creek } \\
\text { Mineral Creek Arch Dam } \\
\text { Mineral Creek Dam Tank } \\
\text { Mineral Creek Diversion Dam }\end{array}$ & $\begin{array}{l}\text { strean } \\
\text { strean } \\
\text { dam } \\
\text { reservoir } \\
\text { dam }\end{array}$ & $\begin{array}{l}\text { VARIANT } \\
\text { BGN } 1973 \\
\text { BGN } \\
\text { UNOFF } \\
\text { BGN } \\
\text { UNOFF }\end{array}$ & $\begin{array}{l}\text { Apache } \\
\text { Yavapai } \\
\text { Pinal } \\
\text { Yavapai } \\
\text { Pinal }\end{array}$ & $\begin{array}{l}342253 \mathrm{~N} 1093951 \mathrm{~W} \\
343453 \mathrm{~N} 1131241 \mathrm{~W} \\
331248 \mathrm{~N} 1105948 \mathrm{~W} \\
342013 \mathrm{~N} 1121550 \mathrm{~W} \\
331118 \mathrm{~N} 1105948 \mathrm{~W}\end{array}$ & $\begin{array}{l}340815 \mathrm{~N} 1093550 \mathrm{~W} \\
343327 \mathrm{~N} 1131223 \mathrm{~W}\end{array}$ & & $\begin{array}{l}\text { Concho Lake } \\
\text { 8agdad } \\
\text { Hot Tanale Peak } \\
\text { 8att le Flat } \\
\text { Hot Tamale Peak }\end{array}$ \\
\hline $\begin{array}{l}\text { See Mineral Creek } \\
\text { Mineral Hill } \\
\text { Mineral Hill } \\
\text { Mineral Hill Mine } \\
\text { Mineral Hill Mines } \\
\text { Mineral Hill Tank } \\
\text { Mineral Lake } \\
\text { Mineral Mountain }\end{array}$ & $\begin{array}{l}\text { strean } \\
\text { summit } \\
\text { summit } \\
\text { mine } \\
\text { mine } \\
\text { reservoir } \\
\text { lake } \\
\text { summit }\end{array}$ & $\begin{array}{l}\text { BGN } \\
\text { BGN } \\
\text { UNOFF } \\
\text { UNOFF } \\
\text { BGN } \\
\text { BGN } \\
\text { BGN }\end{array}$ & $\begin{array}{l}\text { Yavapai } \\
\text { Pima } \\
\text { Yuma } \\
\text { Pima } \\
\text { Yuma } \\
\text { Gila } \\
\text { Coconino } \\
\text { Pinal }\end{array}$ & $\begin{array}{l}341740 \mathrm{~N} 1121334 \mathrm{~W} \\
315912 \mathrm{~N} 1110450 \mathrm{~W} \\
341343 \mathrm{~N} 1140056 \mathrm{~W} \\
315912 \mathrm{~N} 1110515 \mathrm{~W} \\
341358 \mathrm{~N} 1140031 \mathrm{~W} \\
342045 \mathrm{~N} 1113615 \mathrm{~W} \\
351344 \mathrm{~N} 1120136 \mathrm{~W} \\
331024 \mathrm{~N} 1111409 \mathrm{~W}\end{array}$ & & 3750 & $\begin{array}{l}\text { Twin Buttes } \\
\text { Osborne Well } \\
\text { Twin Buttes } \\
\text { Osborne Well } \\
\text { Cane Springs Mtn } \\
\text { Davenport Hill } \\
\text { Mineral Mtn }\end{array}$ \\
\hline $\begin{array}{l}\text { Mineral Park } \\
\text { Mineral Park } \\
\text { Mineral Park Cemetery } \\
\text { Mineral Peak } \\
\text { Mineral Spring } \\
\text { Mineral Springs } \\
\text { Mineral Tank } \\
\text { Mineral Wash } \\
\text { Miner Flat } \\
\text { Mine Road Spring }\end{array}$ & $\begin{array}{l}\text { locale } \\
\text { locale } \\
\text { cemetery } \\
\text { summit } \\
\text { spring } \\
\text { spring } \\
\text { reservoir } \\
\text { strean } \\
\text { flat } \\
\text { spring }\end{array}$ & $\begin{array}{l}\text { BGN } \\
\text { BGN } \\
\text { UNOFF } \\
\text { BGN } \\
\text { BGN } \\
\text { BGN } \\
\text { BGN } \\
\text { BGN } \\
\text { BGN } \\
\text { BGN }\end{array}$ & $\begin{array}{l}\text { Cochise } \\
\text { Mohave } \\
\text { Mohave } \\
\text { Yavapai } \\
\text { Gila } \\
\text { Apache } \\
\text { Gila } \\
\text { Yuma } \\
\text { Navajo } \\
\text { Gila }\end{array}$ & $\begin{array}{l}321401 \mathrm{~N} 1093723 \mathrm{~W} \\
352215 \mathrm{~N} 1140908 \mathrm{~W} \\
352212 \mathrm{~N} 1140851 \mathrm{~W} \\
343312 \mathrm{~N} 1131241 \mathrm{~W} \\
341027 \mathrm{~N} 1112742 \mathrm{~W} \\
340939 \mathrm{~N} 1093631 \mathrm{~W} \\
335832 \mathrm{~N} 1105130 \mathrm{~W} \\
341518 \mathrm{~N} 1140034 \mathrm{~W} \\
335859 \mathrm{~N} 1095504 \mathrm{~W} \\
341250 \mathrm{~N} 1113021 \mathrm{~W}\end{array}$ & $340946 \mathrm{~N} 1140002 \mathrm{~W}$ & & $\begin{array}{l}\text { Dos Cabezas } \\
\text { Cerbat } \\
\text { Cerbat } \\
\text { Bagdad } \\
\text { North Peak } \\
\text { Whiting Knoll } \\
\text { Rock House } \\
\text { Monkeys Head } \\
\text { Alchesay Flat } \\
\text { Cypress Butte }\end{array}$ \\
\hline $\begin{array}{l}\text { Miners Canyon } \\
\text { Miners Gulch } \\
\text { Miners Needle } \\
\text { Miners Summit } \\
\text { Miners Tank } \\
\text { Miners Trail } \\
\text { Mine Shaft Spring } \\
\text { Mineshaft Spring } \\
\text { Mineshaft Spring } \\
\text { Minesha Point Spring }\end{array}$ & $\begin{array}{l}\text { valley } \\
\text { valley } \\
\text { summit } \\
\text { sumnit } \\
\text { reservoir } \\
\text { trail } \\
\text { spring } \\
\text { spring } \\
\text { spring }\end{array}$ & $\begin{array}{l}\text { BGN } \\
\text { BGN } \\
\text { BGN } \\
\text { BGN } \\
\text { BGN } \\
\text { UNOFF } \\
\text { BGN } \\
\text { BGN } \\
\text { BGN } 1975 \\
\text { VARIANT }\end{array}$ & $\begin{array}{l}\text { Pinal } \\
\text { Navajo } \\
\text { Pinal } \\
\text { Pinal } \\
\text { Yavapai } \\
\text { Pinal } \\
\text { Santa Cruz } \\
\text { Graham } \\
\text { Graham }\end{array}$ & $\begin{array}{l}332353 \mathrm{~N} 1111858 \mathrm{~W} \\
341115 \mathrm{~N} 1104437 \mathrm{~W} \\
332431 \mathrm{~N} 1111918 \mathrm{~W} \\
332453 \mathrm{~N} 1111933 \mathrm{~W} \\
342045 \mathrm{~N} 1123252 \mathrm{~W} \\
332425 \mathrm{~N} 1111851 \mathrm{~W} \\
312211 \mathrm{~N} 1110619 \mathrm{~W} \\
324344 \mathrm{~N} 1100505 \mathrm{~W} \\
325750 \mathrm{~N} 1101639 \mathrm{~W}\end{array}$ & $\begin{array}{l}332452 \mathrm{~N} 1111900 \mathrm{~W} \\
341143 \mathrm{~N} 1104344 \mathrm{~W}\end{array}$ & $\begin{array}{l}3648 \\
3516\end{array}$ & $\begin{array}{l}\text { Weavers Needle } \\
\text { Chediski Peak } \\
\text { Weavers Needle } \\
\text { Weavers Needle } \\
\text { Walnut Grove } \\
\text { Weavers Needle } \\
\text { Pajarito Peak } \\
\text { Blue Jay Peak } \\
\text { Cobre Grande Mtn }\end{array}$ \\
\hline $\begin{array}{l}\text { Mineshaft Well } \\
\text { Mine Shaft Windmill } \\
\text { Minesha Point Spring } \\
\text { See Mineshaft Spring } \\
\text { Mine Spring } \\
\text { Mine Spring } \\
\text { Mine Tank } \\
\text { Mine Tank } \\
\text { Mine Tank } \\
\text { Mine Tank }\end{array}$ & $\begin{array}{l}\text { well } \\
\text { locale } \\
\text { spring } \\
\text { spring } \\
\text { spring } \\
\text { reservoir } \\
\text { reservoir } \\
\text { reservoir } \\
\text { reservoir }\end{array}$ & $\begin{array}{l}\text { UNOFF } \\
\text { BGN } \\
\text { VARIANT } \\
\text { BGN } \\
\text { BGN } \\
\text { BGN } \\
\text { BGN } \\
\text { BGN } \\
\text { BGN }\end{array}$ & $\begin{array}{l}\text { Graham } \\
\text { Pinal } \\
\text { Graham } \\
\text { Yavapai } \\
\text { Mohave } \\
\text { Santa Cruz } \\
\text { Pima } \\
\text { Gila } \\
\text { Maricopa }\end{array}$ & $\begin{array}{l}324005 \mathrm{~N} 1094607 \mathrm{~W} \\
325640 \mathrm{~N} 1111049 \mathrm{~W} \\
325750 \mathrm{~N} 1101639 \mathrm{~W} \\
342903 \mathrm{~N} 1115106 \mathrm{~W} \\
352100 \mathrm{~N} 113455 \mathrm{BW} \\
313506 \mathrm{~N} 1105051 \mathrm{~W} \\
315553 \mathrm{~N} 1104203 \mathrm{~W} \\
334908 \mathrm{~N} 1102135 \mathrm{~W} \\
335532 \mathrm{~N} 1125421 \mathrm{~W}\end{array}$ & & & $\begin{array}{l}\text { Horner Mtn } \\
\text { Peacock Peak } \\
\text { Patagonia } \\
\text { Mount Fagan } \\
\text { Carrizo SE } \\
\text { Outlaw Hill }\end{array}$ \\
\hline $\begin{array}{l}\text { Mine Tank } \\
\text { Mine Tank } \\
\text { Mine Tank } \\
\text { Mine Tank Number Two } \\
\text { Mineta Ridge } \\
\text { Mine Well } \\
\text { Mine Windmill } \\
\text { Ming Spur } \\
\text { See Fortuna } \\
\text { Mings Ranch }\end{array}$ & $\begin{array}{l}\text { reservoir } \\
\text { reservoir } \\
\text { reservoir } \\
\text { reservoir } \\
\text { ridge } \\
\text { well } \\
\text { well } \\
\text { locale } \\
\text { locale }\end{array}$ & $\begin{array}{l}\text { BGN } \\
\text { BGN } \\
\text { BGN } \\
\text { BGN } \\
\text { BGN } \\
\text { UNOFF } \\
\text { UNOFF } \\
\text { VARIANT } \\
\text { UNOFF }\end{array}$ & $\begin{array}{l}\text { Gila } \\
\text { Yavapai } \\
\text { Coconino } \\
\text { Gila } \\
\text { Pima } \\
\text { Pinal } \\
\text { Graham } \\
\text { Yuma } \\
\text { Pinal }\end{array}$ & $\begin{array}{l}340157 \mathrm{~N} 1110412 \mathrm{~W} \\
342654 \mathrm{~N} 1125739 \mathrm{~W} \\
343610 \mathrm{~N} 1111951 \mathrm{~W} \\
334940 \mathrm{~N} 1102057 \mathrm{~W} \\
321920 \mathrm{~N} 1102936 \mathrm{~W} \\
324316 \mathrm{~N} 1110514 \mathrm{~W} \\
324347 \mathrm{~N} 1100653 \mathrm{~W} \\
324126 \mathrm{~N} 1142708 \mathrm{~W} \\
330128 \mathrm{~N} 1103206 \mathrm{~W}\end{array}$ & & 3840 & $\begin{array}{l}\text { Buzzard Roost Mesa } \\
\text { Hillside } \\
\text { Long Valley } \\
\text { Carrizo SE } \\
\text { Soza Canyon } \\
\text { Chief Butte } \\
\text { Blue Jay Peak }\end{array}$ \\
\hline $\begin{array}{l}\text { Mingus Lake } \\
\text { Mingus Mountain } \\
\quad \text { Mingus Mountains } \\
\text { Mingus Mountain Campground } \\
\text { Mingus Mountains } \\
\text { See Mingus Mountain } \\
\text { Mingus Springs Ranch } \\
\text { Mingus Substation } \\
\text { Mingus Union High School } \\
\text { Mining Mountain }\end{array}$ & $\begin{array}{l}\text { lake } \\
\text { sumnit } \\
\text { park } \\
\text { summit } \\
\text { locale } \\
\text { locale } \\
\text { school } \\
\text { summit }\end{array}$ & $\begin{array}{l}\text { BGN } \\
\text { BGN } \\
\text { VARIANT } \\
\text { ADMIN } \\
\text { VARIANT } \\
\text { UNOFF } \\
\text { UNOFF } \\
\text { UNOFF } \\
\text { BGN }\end{array}$ & $\begin{array}{l}\text { Yavapai } \\
\text { Yavapai } \\
\text { Yavapai } \\
\text { Yavapai } \\
\text { Yavapai } \\
\text { Yavapai } \\
\text { Yavapai } \\
\text { Pinal }\end{array}$ & $\begin{array}{l}344149 \mathrm{~N} 1120745 \mathrm{~W} \\
344138 \mathrm{~N} 1120737 \mathrm{~W} \\
344134 \mathrm{~N} 1120708 \mathrm{~W} \\
344138 \mathrm{~N} 1120737 \mathrm{~W} \\
343853 \mathrm{~N} 1120914 \mathrm{~W} \\
344254 \mathrm{~N} 1120930 \mathrm{~W} \\
344300 \mathrm{~N} 1120016 \mathrm{~W} \\
325122 \mathrm{~N} 1103439 \mathrm{~W}\end{array}$ & & 3949 & $\begin{array}{l}\text { Hickey Mountain } \\
\text { Hickey Mountain } \\
\text { Cottonwood } \\
\text { Holy Joe Peak }\end{array}$ \\
\hline $\begin{array}{l}\text { Minnehaha } \\
\text { Minnehaha Creek } \\
\text { Minnehaha Flat } \\
\text { Minnehaha Spring } \\
\text { Minnehaha Spring }\end{array}$ & $\begin{array}{l}\text { locale } \\
\text { stream } \\
\text { flat } \\
\text { spring }\end{array}$ & $\begin{array}{l}\text { BGN } \\
\text { BGN } \\
\text { BGN } \\
\text { BGN } \\
\text { VARIANT }\end{array}$ & $\begin{array}{l}\text { Yavapai } \\
\text { Yavapai } \\
\text { Yavapai } \\
\text { Yavapai }\end{array}$ & $\begin{array}{l}340948 \mathrm{~N} 1122424 \mathrm{~W} \\
341154 \mathrm{~N} 1123224 \mathrm{~W} \\
341102 \mathrm{~N} 1122406 \mathrm{~W} \\
34110 \mathrm{~N} 1122402 \mathrm{~W}\end{array}$ & $341034 \mathrm{~N} 1122501 \mathrm{~W}$ & & $\begin{array}{l}\text { Minnehaha } \\
\text { Wagoner } \\
\text { Minnehaha } \\
\text { Minnehaha }\end{array}$ \\
\hline
\end{tabular}


NATIONAL GAZETTEER--ARIZONA 1986

FEATURE NAME

See Rabbit Spring

Minnehaha Spring

Minnehaha Waters

Minnesota Court (trailer park)

Minnesota Mine

Minnie Nash Spring

Minor, Canal (historical)

Canal Fourteen Lower Branch

Minoto Ranch

Mint

Mint Mine

Mint Shaft

Mint Spring

Mint Spring

Mint Spring

Mint Tank

Mint Wash

Miracle Mile Exchange

Miracle Valley

Miracle Valley

Mirador (subdivision)

Mirasol Park

Mirror Mountain

See Glassford Hill

Misenhimer Draw

Misery Spring

Misery Well

Misery Well

Mi-shong-i-nivi

See Mishongnovi

Mi-Shong-i-nivi

See Mishongnovi

Mishonginivi

See Mishongnovi

Mishongnovi

Beunaventura

Manazana

Mas agnebe

Mashongniovi

Mashongnivi

Mi-shong-i-nivi

Mi-Shong-i-nivi

Mishonginivi

Tseitsokit

Missile Tank

Mission Manor School

Mission Manor Shopping Center

Mission Mine

Mission Monterey (subdivision)

Mission Park

Mission Park

Mission Ridge Park

Mission Santos Angeles de Guevavi

See Guevavi Mission locale (historical)

Missions Tailings Dam Number

$$
\text { Two }
$$

Mission Tailings Dam Number One

Mission Valley (subdivison)

Mission View School

Miss issippi Wash

Missouri Bill $\mathrm{Hill}$

Missouri Bill Tank

Mistake Mine

Mistake Peak

Mistake Tank

Mitchell Butte

Mitchell Cabin Spring

FEATURE
CLASS

STATUS COUNTY

COORDINATE

spring

spring

falls

mine

locale

mine

spring

canal

locale

locale

mine

mine

spring

spring

spring

reservoir

stream

ppl

airport

ppl

park

summit

Yavapai

BGN

UNOFF

UNOFF

Yavapai

Yavapai

Mohave

VARIANT

UNOFF Yavapai

UNOFF Mohave

UNOFF Yavapai

BGN

Gavapa
Gila

BGN Yavapai

$B G N$

BGN

BGN

UNOFF

BGN
ADMIN

BGN

ADMIN

Coconino

Coconino

Yavapai

Pima

Cochise

Cochise

Maricopa

Pima

Yavapai

valley

spring

BGN

BGN

UNOFF

pp 1

VARIANT

VARIANT

pp1

VARIANT

ppl

ppl

BGN

VARIANT

VARIANT

VARIANT

VARIANT

VARIANT

VARIANT

VARIAMT

VARIANT

VARIANT

reservoir

school

locale

mine

ppl

park

park

park

BGN

UNOFF

UNOFF

BGN

ADMIN

ADMIN

ADMIN

VARIANT

Cochise

Yavapai

Navajo

Navajo

Navajo

Navajo

Pima

Pima

Pima

Pima

Maricopa

Pima

Maricopa

Pima

Santa Cruz

dam

UNOFF

Pima

Yavapai

Gila

Yavapai

Navajo
$341154 \mathrm{~N} 1122828 \mathrm{~W}$

$341202 \mathrm{~N} 1122846 \mathrm{~W}$

$341207 N 1122519 \mathrm{~W}$

$352412 \mathrm{~N} 1141028 \mathrm{~W}$

$332705 \mathrm{~N} 1115805 \mathrm{~W}$

UNOFF Santa Cruz 312317N1104558W

BGN Cochise 321534N1094001W

BGN Maricopa 332830N1115026W

BGN Yavapai

$341411 N 1123237 W$

$344210 \mathrm{~N} 1123418 \mathrm{~W}$

$352001 \mathrm{N1140742 \textrm {W }}$

$342745 \mathrm{~N} 1123644 \mathrm{~W}$

$333143 \mathrm{~N} 1104540 \mathrm{~W}$

$343828 N 1123132 \mathrm{~W}$

$345151 \mathrm{~N} 1112433 \mathrm{~W}$

$345156 \mathrm{~N} 1112439 \mathrm{~W}$

$344906 \mathrm{~N} 1123753 \mathrm{~W}$

$321536 \mathrm{~N} 1110007 \mathrm{~W}$

$312245 \mathrm{~N} 1100910 \mathrm{~W}$

$312224 \mathrm{~N} 1100925 \mathrm{~W}$

$333440 \mathrm{~N} 1115150 \mathrm{~W}$

$321200 \mathrm{~N} 1105711 \mathrm{~W}$

$343522 \mathrm{~N} 1122253 \mathrm{~W}$

321844 N1094100W

$340840 \mathrm{~N} 1122152 \mathrm{~W}$

$342917 \mathrm{~N} 1134417 \mathrm{~W}$

$350244 \mathrm{~N} 1133522 \mathrm{~W}$

354818N1102931W

$354818 N 1102931 W$

$354818 \mathrm{~N} 1102931 \mathrm{~W}$

$354818 N 1102931 \mathrm{~W}$

$315730 \mathrm{~N} 1104002 \mathrm{~W}$

$320831 \mathrm{N1} 105850 \mathrm{~W}$

$320804 \mathrm{~N} 1105757 \mathrm{~W}$

$315930 \mathrm{~N} 1110345 \mathrm{~W}$

$333426 \mathrm{~N} 1115200 \mathrm{~W}$

$320839 \mathrm{~N} 1105845 \mathrm{~W}$

$333413 \mathrm{~N} 1120932 \mathrm{~W}$

$320732 \mathrm{~N} 1110159 \mathrm{~W}$

312436 N1105406W

$315900 \mathrm{~N} 1110400 \mathrm{~W}$

$315900 \mathrm{~N} 1110400 \mathrm{~W}$

$332109 \mathrm{~N} 1115105 \mathrm{~W}$

$321130 \mathrm{N1105817W}$

$341414 \mathrm{~N} 1134336 \mathrm{~W}$

$353125 \mathrm{~N} 1114242 \mathrm{~W}$

$353051 \mathrm{~N} 1114317 \mathrm{~W}$

$340250 \mathrm{NI} 124321 \mathrm{~W}$

$335503 \mathrm{~N} 1110957 \mathrm{~W}$

343102 N1115954W

$365836 \mathrm{N1} 100907 \mathrm{~W}$

$330425 \mathrm{N1} 101914 \mathrm{~W}$
$321745 N 1094203 \mathrm{~W}$

Railroad Pass

Crown King

2371 Signal

Aust in Peak

Polacca

$\begin{array}{lcl}\text { SOURCE } & \text { ELEV } \\ \text { COORDINATE } & \text { FT }\end{array}$

Minnehaha

Chloride

1200 Tempe

Cumero Canyon

Wagoner

Mount Josh

Wilhoit

Rockinstraw Mtn

Hutch Mtn

Hutch Mtn

Jaynes

Nicksville

Hereford SW

370 Sawik Mountain

Tucson

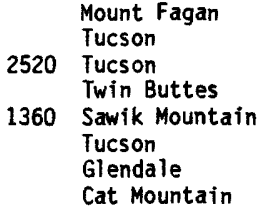

Twin Buttes

Twin Buttes

1205 Chandler

Tucs on

341711N1134313W Reid Valley

7431 S P Mountain

$S$ P Mountain

Sam Powell Peak

5930 Picture Mtn

Middle Verde Mystery Valley Mt Turnbull
Jerome Canyon 
FEATURE NAME

Mitchell Canyon

Mitchell Canyon

Mitchell Lodge

Mitchell Mesa

Mitchell Park

Mitchell Peak

Mitchell School

Mitchell School

Mitchell School

Mitchell Spring

Mitchell Spring

Mitchell Tank

Mitche11 Tank

Mitchell Wash

Mitchell Well

Mitchell Windmill

Mitten Peak

See Pilot Rock

Mitten Peak

Pilot Rock

Mittry Lake

Rabbit Mountain

Mittry Lake Refuge

Mixon Tank

M K Tank

M K Windmill

ML Windmill

Moa Ave

See Moenave

Moa Ave Settlement

See Moenave

Moa Ave Spring (historical) Moehavi

Moenave

Moen $A b$

Moana Ranch

Moana Tank
M O Best Park

Mobile

Mobile Elementary School

Mobile Haven Park

Mobile Railroad Station

Mobile Valley

Mobile Well

Mocass in Post Office

Moccas in

Moccas in Canyon

Moccas in Mountains

Moccas in Spring

Mocho Canyon

Mocho Spring

Moch-Ovi

Mociac Mountain

See Mokaac Mountain

Mociac Wash

See Mokaac Wash

Mociac Well

Mockingbird Hill

Mockingbird Mine

Mockingbird Pass

Mockingbird Wash

Mockingbird Wash

Model A Tank

Model Creek

Modest Lateral

Modoc Mountain

Modred Abyss

Moe Ave

See Moenave

Moehavi

See Moa Ave Spring

(historical)

\section{FEATURE}

CLASS

STATUS

COUNTY

COORDINATE

valley

valley

locale

summit

park

summit

school

BGN

BGN

BGN

BGN

ADM IN

BGN

school

UNOFF

school

spring

spring

reservoir

reservoir

stream

well

locale

UNOFF

$B G N$

BGN

BGN

BGN

UNOFF

BGN

pillar

VARIANT

summit

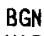

BGN

VARIANT

reservoir

park

reservoir

reservoir

locale

locale

BGN

ADMIN

BGN

BGN

BGN

pp 1

Graham

Graham

Maricopa

Navajo

Pima

Greenlee
Santa Cruz

Maricopa

Maricopa

Graham

Yavapai

Pima

Maricopa

Yavapai

Pima

Navajo

Navajo

Navajo

Yuma

Yuma

Coconino

Coconino

Graham

Yavapai

Coconino

VARIANT

pp 1

spring

VGY 1915

Coconino

Coconino

VARIANT

VARIANT

VARIANT

locale UNOFF Yavapa

reservoir BGN Yavapa

park ADMIN Maricopa

ADMIN

Maricopa

school

local

building

valley

well

building

ppl

valley

summit

spring

UNOFF

UNOFF

UNOFF

BGN

UNOFF

UNOFF

BGN

BGM

BGN

BGN

Maricopa

Coconino

Maricopa

Maricopa

Maricopa

Mohave

Mohave

Mohave

Mohave

Mohave

valley

BGN

Yavapai

spring

BGN

Yavapai

cliff

BAN

summit

arroyo

locale

summit

VARIANT

Mohave

BGN

Mohave

UNOFF

Maricopa

Mohave

gap

stream
stream

stream

stream

canal

summit

valley

pp1

BGN

BGN Mohave

BGN Maricopa

BGN Yavapai

Yuma

BGN

BGN 1908

VARIANT

Greenlee
Coconino

Coconino

322916 N1101920W $330513 \mathrm{~N} 1102124 \mathrm{~W}$ $332206 \mathrm{~N} 1120157 \mathrm{~W}$ $365820 \mathrm{~N} 1100637 \mathrm{~W}$ $321520 \mathrm{~N} 1105715 \mathrm{~W}$

$331310 \mathrm{~N} 1092204 \mathrm{~W}$

$312052 \mathrm{N1} 105617 \mathrm{~W}$

$332515 \mathrm{~N} 1115652 \mathrm{~W}$

$332800 \mathrm{~N} 1120849 \mathrm{~W}$

$323012 \mathrm{~N} 1101814 \mathrm{~W}$

335457 N1121943W

313958 N1113130W

$333821 \mathrm{~N} 1124934 \mathrm{~W}$

$335723 N 1123404 W$

$313907 N 1111831 \mathrm{~W}$

344223N1104250W

$35090 \mathrm{BN} 1095234 \mathrm{~W}$

350741 N1100305W

324907 N1142916W

$325110 \mathrm{~N} 1142705 \mathrm{~W}$

$353119 \mathrm{N1121946 \textrm {W }}$

$352256 \mathrm{~N} 1122317 \mathrm{~W}$

$323802 \mathrm{~N} 1100920 \mathrm{~W}$

$340906 \mathrm{~N} 1122820 \mathrm{~W}$

360819 N1112012W

$360819 \mathrm{~N} 1112012 \mathrm{~W}$

$361200 \mathrm{~N} 1111700 \mathrm{~W}$

$344110 \mathrm{~N} 1124030 \mathrm{~W}$

$344222 \mathrm{~N} 1124214 \mathrm{~W}$

$332732 \mathrm{~N} 1120412 \mathrm{~W}$

$330319 N 1121616 \mathrm{~W}$

$330323 \mathrm{~N} 1121612 \mathrm{~W}$

$351325 \mathrm{~N} 1113518 \mathrm{~W}$

$330313 \mathrm{~N} 1121640 \mathrm{~W}$

$330329 \mathrm{~N} 1121516 \mathrm{~W}$

$330200 \mathrm{~N} 1121706 \mathrm{~W}$

$365432 \mathrm{~N} 1124530 \mathrm{~W}$

$365434 \mathrm{~N} 1124529 \mathrm{~W}$

$365430 \mathrm{~N} 1124550 \mathrm{~W}$

$365752 \mathrm{~N} 1124715 \mathrm{~W}$

$365436 \mathrm{~N} 1124543 \mathrm{~W}$

341149 N1123622W

$341224 \mathrm{~N} 1123755 \mathrm{~W}$
VARIANT

spring
Coconino 


\begin{tabular}{|c|c|c|c|c|c|c|c|}
\hline FEATURE NAME & $\begin{array}{l}\text { FEATURE } \\
\text { CLASS }\end{array}$ & STATUS & COUNTY & COORDINATE & $\begin{array}{l}\text { SOURCE } \\
\text { COORDINATE }\end{array}$ & $\begin{array}{c}\text { ELEV } \\
\text { FT }\end{array}$ & MAP NAME \\
\hline $\begin{array}{l}\text { Moehavi } \\
\text { See Moenave } \\
\text { Moen Abi } \\
\text { See Moa Ave Spring } \\
\text { (historical) } \\
\text { Moen Abi } \\
\text { See Moenave }\end{array}$ & $\begin{array}{l}\text { ppl } \\
\text { spring }\end{array}$ & $\begin{array}{l}\text { VARIANT } \\
\text { VARIANT } \\
\text { VARIANT }\end{array}$ & $\begin{array}{l}\text { Coconino } \\
\text { Coconino }\end{array}$ & $\begin{array}{l}360819 \mathrm{~N} 1112012 \mathrm{~W} \\
361200 \mathrm{~N} 1111700 \mathrm{~W} \\
360819 \mathrm{~N} 1112012 \mathrm{~W}\end{array}$ & & & \\
\hline $\begin{array}{l}\text { Moenave } \\
\text { See Moa Ave Spring } \\
\text { (historical) } \\
\text { Moenave } \\
\text { Moa Ave } \\
\text { Moa Ave Settlement } \\
\text { Moe Ave } \\
\text { Moehavi } \\
\text { Moen Abi } \\
\text { Moenave Canyon }\end{array}$ & $\begin{array}{l}\text { spring } \\
\text { ppl }\end{array}$ & $\begin{array}{l}\text { BGN } 1971 \\
\text { VARIANT } \\
\text { VARIANT } \\
\text { VARIANT } \\
\text { VARIANT } \\
\text { VARIANT } \\
\text { BGN }\end{array}$ & $\begin{array}{l}\text { Coconino } \\
\text { Coconino }\end{array}$ & $\begin{array}{l}361200 \mathrm{~N} 1111700 \mathrm{~W} \\
360819 \mathrm{~N} 1112012 \mathrm{~W} \\
360822 \mathrm{~N} 1112016 \mathrm{~W}\end{array}$ & $360910 \mathrm{~N} 1111940 \mathrm{~W}$ & 4794 & $\begin{array}{l}\text { Moenave } \\
\text { Moenave }\end{array}$ \\
\hline $\begin{array}{l}\text { Moencopie } \\
\text { See Moenkopi } \\
\text { Moencopie Wash } \\
\text { See Moenkopi } \\
\text { Moenkapi } \\
\text { See Moenkopi } \\
\text { Moenkopi } \\
\text { Concaba } \\
\text { Mayencopi } \\
\text { Moencopie } \\
\text { Moencopie Wash } \\
\text { Moenkapi } \\
\text { Muencovi } \\
\text { Ranchera de los Gandules } \\
\text { Rancherio de los Guadelas } \\
\text { Tennehleto Spring }\end{array}$ & $\begin{array}{l}\mathrm{ppl} \\
\mathrm{ppl} \\
\mathrm{ppl} \\
\mathrm{ppl}\end{array}$ & $\begin{array}{l}\text { VARIANT } \\
\text { VARIANT } \\
\text { VARIANT } \\
\text { BGN } 1915 \\
\text { VARIANT } \\
\text { VARIANT } \\
\text { VARIANT } \\
\text { VARIANT } \\
\text { VARIANT } \\
\text { VARIANT } \\
\text { VARIANT } \\
\text { VARIANT } \\
\text { VARIANT }\end{array}$ & $\begin{array}{l}\text { Coconino } \\
\text { Coconino } \\
\text { Coconino } \\
\text { Coconino }\end{array}$ & $\begin{array}{l}360640 \mathrm{~N} 1111318 \mathrm{~W} \\
360640 \mathrm{~N} 1111318 \mathrm{~W} \\
360640 \mathrm{~N} 1111318 \mathrm{~W} \\
360640 \mathrm{~N} 1111318 \mathrm{~W}\end{array}$ & & 4777 & Moenkopi \\
\hline $\begin{array}{l}\text { Moenkopi Canyon } \\
\text { See Biko Hodo Klizg } \\
\text { Moenkopi Canyon } \\
\text { See Blue Canyon } \\
\text { Moenkopi Creek } \\
\text { See Biko Hodo Klizg } \\
\text { Moenkopi Elementary School } \\
\text { Moenkopi Plateau } \\
\text { Moeur Park } \\
\text { Moff it Canyon }\end{array}$ & $\begin{array}{l}\text { valley } \\
\text { valley } \\
\text { valley } \\
\text { school } \\
\text { plain } \\
\text { park } \\
\text { valley }\end{array}$ & $\begin{array}{l}\text { VARIANT } \\
\text { VARIANT } \\
\text { VARIANT } \\
\text { UNOFF } \\
\text { BGN } \\
\text { ADMIN } \\
\text { BGN }\end{array}$ & $\begin{array}{l}\text { Coconino } \\
\text { Coconino } \\
\text { Coconino } \\
\text { Coconino } \\
\text { Coconino } \\
\text { Maricopa } \\
\text { Yavapai }\end{array}$ & $\begin{array}{l}355325 \mathrm{~N} 1112641 \mathrm{~W} \\
361027 \mathrm{~N} 1105254 \mathrm{~W} \\
355325 \mathrm{~N} 1112641 \mathrm{~W} \\
360636 \mathrm{~N} 1111313 \mathrm{~W} \\
355707 \mathrm{~N} 1110420 \mathrm{~W} \\
332615 \mathrm{~N} 1115628 \mathrm{~W} \\
345911 \mathrm{~N} 1131255 \mathrm{~W}\end{array}$ & $345706 \mathrm{~N} 1131557 \mathrm{~W}$ & & $\begin{array}{l}\text { Moenkopi } \\
\text { Appaloosa Ridge } \\
\text { Tempe } \\
\text { Sunrise Peak }\end{array}$ \\
\hline $\begin{array}{l}\text { Moffit Tank } \\
\text { Mogollon Escarpment } \\
\text { See Mogollon Rim } \\
\text { Mogollon Mesa } \\
\text { See Mogollon Plateau } \\
\text { Mogollon Mesa } \\
\text { Mogollon Mountains } \\
\text { See Mogollon Rim } \\
\text { Mogollon Plateau } \\
\text { Coconino Plateau } \\
\text { Colorado Plateau } \\
\text { Little Colorado Plateau } \\
\text { Mogollon Mesa } \\
\text { Plateau of Arizona }\end{array}$ & $\begin{array}{l}\text { reservoir } \\
\text { cliff } \\
\text { plain } \\
\text { summit } \\
\text { cliff } \\
\text { plain }\end{array}$ & $\begin{array}{l}\text { BGN } \\
\text { VARIANT } \\
\text { VARIANT } \\
\text { BGN } \\
\text { VARIANT } \\
\text { BGN } 1974 \\
\text { VARIANT } \\
\text { VARIANT } \\
\text { VARIANT } \\
\text { VARIANT } \\
\text { VARIANT }\end{array}$ & $\begin{array}{l}\text { Pinal } \\
\text { Coconino } \\
\text { Coconino } \\
\text { Yavapai } \\
\text { Coconino } \\
\text { Coconino }\end{array}$ & $\begin{array}{l}324 \mathrm{~B} 07 \mathrm{~N} 1103329 \mathrm{~W} \\
341501 \mathrm{~N} 1104501 \mathrm{~W} \\
353500 \mathrm{~N} 1113500 \mathrm{~W} \\
342 \mathrm{~B} 38 \mathrm{~N} 1113552 \mathrm{~W} \\
341501 \mathrm{~N} 1104501 \mathrm{~W} \\
353500 \mathrm{~N} 1113500 \mathrm{~W}\end{array}$ & & 5900 & $\begin{array}{l}\text { Strawberry } \\
\text { S P Mountain }\end{array}$ \\
\hline $\begin{array}{l}\text { Mogollon Rim } \\
\text { Mogollon Escarpment } \\
\text { Mogollon Mountains } \\
\text { Rim of Tonto Basin } \\
\text { The Rim } \\
\text { Tonto Basin Rim } \\
\text { Tonto Rim } \\
\text { Mogul Draw } \\
\text { Mohave, Lake } \\
\text { Mohave Canyon }\end{array}$ & $\begin{array}{l}\text { valley } \\
\text { reservoir } \\
\text { valley }\end{array}$ & $\begin{array}{l}\text { BGN } 1985 \\
\text { VARIANT } \\
\text { VARIANT } \\
\text { VARIANT } \\
\text { VARIANT } \\
\text { VARIANT } \\
\text { VARIANT } \\
\text { BGN } \\
\text { BGN } \\
\text { BGN }\end{array}$ & $\begin{array}{l}\text { Cochise } \\
\text { Mohave } \\
\text { Mohave }\end{array}$ & $\begin{array}{l}320532 N 1093454 \mathrm{~W} \\
351157 \mathrm{~N} 1143413 \mathrm{~W} \\
343636 \mathrm{~N} 1142506 \mathrm{~W}\end{array}$ & $\begin{array}{l}321053 N 1093154 \mathrm{~W} \\
344057 N 1142738 \mathrm{~W}\end{array}$ & & $\begin{array}{l}\text { Pat Hills North } \\
\text { Davis Dam } \\
\text { Castle Rock }\end{array}$ \\
\hline $\begin{array}{l}\text { Mohave City } \\
\text { See Mojave City } \\
\text { Mohave County } \\
\text { Mojave County } \\
\text { Mohave County Airport }\end{array}$ & $\begin{array}{l}\text { locale } \\
\text { civil }\end{array}$ & $\begin{array}{l}\text { VARIANT } \\
\text { BGN } 1949 \\
\text { VARIANT } \\
\text { VARIANT }\end{array}$ & $\begin{array}{l}\text { Mohave } \\
\text { Mohave }\end{array}$ & $\begin{array}{l}350240 \mathrm{~N} 1143720 \mathrm{~W} \\
360500 \mathrm{~N} 1134600 \mathrm{~W}\end{array}$ & & & Bat Cave \\
\hline
\end{tabular}




\begin{tabular}{|c|c|c|c|c|c|c|c|}
\hline FEATURE NAME & $\begin{array}{l}\text { FEATURE } \\
\text { CLASS }\end{array}$ & STATUS & COUNTY & COOROINATE & $\begin{array}{l}\text { SOURCE } \\
\text { COOROINATE }\end{array}$ & $\begin{array}{c}\text { ELEV } \\
\text { FT }\end{array}$ & MAP NAME \\
\hline $\begin{array}{l}\text { See Kingman Airport } \\
\text { Mohave County Courthouse } \\
\text { Mohave County Fairgrounds } \\
\text { Mohave County General } \\
\text { Hospital Airfield }\end{array}$ & $\begin{array}{l}\text { airport } \\
\text { building } \\
\text { park } \\
\text { airport }\end{array}$ & $\begin{array}{l}\text { UNOFF } \\
\text { ADMIN } \\
\text { ADMIN }\end{array}$ & $\begin{array}{l}\text { Mohave } \\
\text { Mohave } \\
\text { Mohave } \\
\text { Mohave }\end{array}$ & $\begin{array}{l}351524 \mathrm{~N} 1135624 \mathrm{~W} \\
351133 \mathrm{~N} 1140307 \mathrm{~W} \\
351247 \mathrm{~N} 1140134 \mathrm{~W} \\
351310 \mathrm{~N} 1140225 \mathrm{~W}\end{array}$ & & 3430 & $\begin{array}{l}\text { Kingman } \\
\text { Kingman } \\
\text { Kingman }\end{array}$ \\
\hline $\begin{array}{l}\text { Mohave County Hospital } \\
\text { Mohave Creek } \\
\text { See Mohave Wash } \\
\text { Mohave Crossing } \\
\text { Mohave Elementary School } \\
\text { See Mohave Valley School } \\
\text { Mohave High School } \\
\text { Mohave Mine } \\
\text { Mohave Mountains } \\
\text { Bill Williams Mountains } \\
\text { Chemehuevi Mountains } \\
\text { Chemehuevis Mountains } \\
\text { Chimhuevis Mountains } \\
\text { Mohave Range } \\
\text { Sierra de San Ildefonso }\end{array}$ & $\begin{array}{l}\text { hospital } \\
\text { stream } \\
\text { locale } \\
\text { school } \\
\text { school } \\
\text { mine } \\
\text { range }\end{array}$ & $\begin{array}{l}\text { UNOFF } \\
\text { VARIANT } \\
\text { BGN } \\
\text { VARIANT } \\
\text { UNOFF } \\
\text { UNOFF } \\
\text { BGN 1964 } \\
\text { VARIANT } \\
\text { VARIANT } \\
\text { VARIANT } \\
\text { VARIANT } \\
\text { VARIANT } \\
\text { VARIANT }\end{array}$ & $\begin{array}{l}\text { Mohave } \\
\text { Mohave } \\
\text { Mohave } \\
\text { Mohave } \\
\text { Mohave } \\
\text { Mohave } \\
\text { Mohave }\end{array}$ & $\begin{array}{l}351247 \mathrm{~N} 1140223 \mathrm{~W} \\
341528 \mathrm{~N} 1135856 \mathrm{~W} \\
352000 \mathrm{~N} 1143517 \mathrm{~W} \\
\\
345440 \mathrm{~N} 1143600 \mathrm{~W} \\
350620 \mathrm{~N} 1143559 \mathrm{~W} \\
354026 \mathrm{~N} 1143158 \mathrm{~W} \\
343818 \mathrm{~N} 1142314 \mathrm{~W}\end{array}$ & & & $\begin{array}{l}\text { Spirit Mtn SE } \\
\text { Davis Oan SE } \\
\text { Mohave Mine } \\
\text { Topock }\end{array}$ \\
\hline $\begin{array}{l}\text { Mohave Peak } \\
\text { Mohave Point } \\
\text { Mohave Range } \\
\quad \text { See Mohave Mountains } \\
\text { Mohave Rock } \\
\text { Mohave School } \\
\text { Mohave Springs } \\
\text { Mohave Springs Mesa } \\
\text { Mohave Tank } \\
\text { Mohave Tanks }\end{array}$ & $\begin{array}{l}\text { summit } \\
\text { cliff } \\
\text { range } \\
\text { island } \\
\text { school } \\
\text { spring } \\
\text { summit } \\
\text { reservoir } \\
\text { reservoir }\end{array}$ & $\begin{array}{l}\text { BGN } \\
\text { BGN } 1906 \\
\text { VARIANT } \\
\text { BGN } \\
\text { UNOFF } \\
\text { BGN } \\
\text { BGN } \\
\text { BGN } \\
\text { BGN }\end{array}$ & $\begin{array}{l}\text { Yuma } \\
\text { Coconino } \\
\text { Mohave } \\
\text { Mohave } \\
\text { Maricopa } \\
\text { Mohave } \\
\text { Mohave } \\
\text { Mohave } \\
\text { Yuma }\end{array}$ & $\begin{array}{l}331636 \mathrm{~N} 1142927 \mathrm{~W} \\
360420 \mathrm{~N} 1120955 \mathrm{~W} \\
343 \mathrm{~B} 18 \mathrm{~N} 1142314 \mathrm{~W} \\
343646 \mathrm{~N} 114252 \mathrm{WW} \\
333102 \mathrm{~N} 1115347 \mathrm{~W} \\
342657 \mathrm{~N} 1140502 \mathrm{~W} \\
342702 \mathrm{~N} 1140422 \mathrm{~W} \\
342535 \mathrm{~N} 1140120 \mathrm{~W} \\
332259 \mathrm{~N} 1142638 \mathrm{~W}\end{array}$ & & $\begin{array}{l}2771 \\
6974\end{array}$ & $\begin{array}{l}\text { Mohave Peak } \\
\text { Grand Canyon } \\
\text { Castle Rock } \\
\text { Paradise Valley } \\
\text { Mohave Springs } \\
\text { Mohave Springs } \\
\text { Mohave Springs } \\
\text { North Trigo Peaks }\end{array}$ \\
\hline $\begin{array}{l}\text { Mohave Valley } \\
\text { Mojave Valley } \\
\text { Mohave Valley Post office } \\
\text { Mohave Valley School } \\
\text { Mohave Elementary School } \\
\text { Mohave Wash } \\
\text { Mohave Wash } \\
\text { Mohave Creek } \\
\text { Mohawk } \\
\quad \text { Chrytoval }\end{array}$ & $\begin{array}{l}\text { valley } \\
\text { building } \\
\text { school } \\
\text { stream } \\
\text { stream } \\
\text { locale }\end{array}$ & $\begin{array}{l}\text { BGN } \\
\text { VARIANT } \\
\text { UNOFF } \\
\text { UNOFF } \\
\text { VARIANT } \\
\text { BGN } \\
\text { BGN } \\
\text { VARIANT } \\
\text { BGN } \\
\text { VARIANT }\end{array}$ & $\begin{array}{l}\text { Mohave } \\
\text { Mohave } \\
\text { Mohave } \\
\text { Yuma } \\
\text { Mohave } \\
\text { Yuma }\end{array}$ & $\begin{array}{l}350710 \mathrm{~N} 1143715 \mathrm{~W} \\
345540 \mathrm{~N} 1143551 \mathrm{~W} \\
345440 \mathrm{~N} 1143600 \mathrm{~W} \\
332929 \mathrm{~N} 1143445 \mathrm{~W} \\
341528 \mathrm{~N} 1135856 \mathrm{~W} \\
324336 \mathrm{~N} 1134516 \mathrm{~W}\end{array}$ & $\begin{array}{l}331556 \mathrm{~N} 1141850 \mathrm{~W} \\
343319 \mathrm{~N} 1140126 \mathrm{~W}\end{array}$ & 475 & $\begin{array}{l}\text { Davis Dam SE } \\
\text { Needles NE } \\
\text { Needles NE } \\
\text { Mule Wash } \\
\text { Castaneda Hills SW } \\
\text { Mohawk }\end{array}$ \\
\hline $\begin{array}{l}\text { Mohawk Canal } \\
\text { Mohawk Canyon } \\
\text { Gateway Canyon } \\
\text { Mohawk Creek } \\
\text { Mohawk Gap } \\
\text { See Mohawk Pass } \\
\text { Mohawk Inn } \\
\text { See Ow? } \\
\text { Mohawk Interchange } \\
\text { Mohawk Mine }\end{array}$ & $\begin{array}{l}\text { canal } \\
\text { valley } \\
\text { stream } \\
\text { gap } \\
\text { ppl } \\
\text { crossing } \\
\text { mine }\end{array}$ & $\begin{array}{l}\text { BGN } \\
\text { BGN } \\
\text { VARIANT } \\
\text { BGN } \\
\text { VARIANT } \\
\text { VARIANT } \\
\text { UNOFF } \\
\text { UNOFF }\end{array}$ & $\begin{array}{l}\text { Yuma } \\
\text { Coconino } \\
\text { Coconino } \\
\text { Yuma } \\
\text { Yuma } \\
\text { Yuma } \\
\text { Santa Cruz }\end{array}$ & $\begin{array}{l}324210 \mathrm{~N} 1135758 \mathrm{~W} \\
361353 \mathrm{~N} 1125755 \mathrm{~W} \\
361402 \mathrm{~N} 1125749 \mathrm{~W} \\
324345 \mathrm{~N} 1134425 \mathrm{~W} \\
\\
324319 \mathrm{~N} 1134729 \mathrm{~W} \\
324342 \mathrm{~N} 1134309 \mathrm{~W} \\
313433 \mathrm{~N} 1105014 \mathrm{~W}\end{array}$ & $\begin{array}{l}355745 \mathrm{~N} 1130257 \mathrm{~W} \\
355530 \mathrm{~N} 1130417 \mathrm{~W}\end{array}$ & & $\begin{array}{l}\text { Tacna } \\
\text { Gateway Rapids } \\
\text { Gateway Rapids }\end{array}$ \\
\hline $\begin{array}{l}\text { Mohawk Mine } \\
\text { Mohawk Mine } \\
\text { Mohawk Mine } \\
\text { Mohawk Mountain } \\
\text { See Mohawk Peak } \\
\text { Mohawk Mountains } \\
\text { Big Horn Mountains } \\
\text { Mohawk Range } \\
\text { Mohawk Mountains } \\
\text { See Bryan Mountains }\end{array}$ & $\begin{array}{l}\text { mine } \\
\text { mine } \\
\text { mine } \\
\text { summit } \\
\text { range }\end{array}$ & $\begin{array}{l}\text { UNOFF } \\
\text { UNOFF } \\
\text { UNOFF } \\
\text { VARIANT } \\
\text { BGN } \\
\text { VARIANT } \\
\text { VARIANT } \\
\text { VARIANT }\end{array}$ & $\begin{array}{l}\text { Pinal } \\
\text { Yavapai } \\
\text { Mohave } \\
\text { Yuma } \\
\text { Yuma }\end{array}$ & $\begin{array}{l}324215 \mathrm{~N} 1104052 \mathrm{~W} \\
341559 \mathrm{~N} 1122153 \mathrm{~W} \\
351914 \mathrm{~N} 1140801 \mathrm{~W} \\
323522 \mathrm{~N} 1143850 \mathrm{~W} \\
323526 \mathrm{~N} 1133 \mathrm{~B} 49 \mathrm{~W}\end{array}$ & & & $\begin{array}{l}\text { Mammoth } \\
\text { Battle Flat } \\
\text { Cerbat }\end{array}$ \\
\hline $\begin{array}{l}\text { Mohawk Papago Well Road (Jeep) } \\
\text { Mohawk Pass } \\
\text { Mohawk Gap } \\
\text { Mohawk Peak } \\
\text { Mohawk Mountain } \\
\text { Mohawk Range } \\
\text { See Mohawk Mountains } \\
\text { Mohawk Valley } \\
\text { Koroll Valley } \\
\text { Mohawk Valley School }\end{array}$ & $\begin{array}{l}\text { trail } \\
\text { gap } \\
\text { summit }\end{array}$ & $\begin{array}{l}\text { UNOFF } \\
\text { BGN } \\
\text { VARIANT } \\
\text { BGN } \\
\text { VARIANT } \\
\text { VARIANT } \\
\text { BGN } \\
\text { VARIANT } \\
\text { UNOFF }\end{array}$ & $\begin{array}{l}\text { Yuma } \\
\text { Yuma } \\
\text { Yuma }\end{array}$ & $\begin{array}{l}323526 \mathrm{~N} 1133849 \mathrm{~W} \\
324110 \mathrm{~N} 1141136 \mathrm{~W} \\
324507 \mathrm{~N} 1135808 \mathrm{~W}\end{array}$ & $320914 \mathrm{~N} 1131711 \mathrm{~W}$ & 2775 & $\begin{array}{l}\text { Mohawk Mts SW } \\
\text { Mohawk Mts NW } \\
\text { Mowhawk Mts SW }\end{array}$ \\
\hline Mohawk Wash & stream & BGN & Yuma & $323123 \mathrm{~N} 1134132 \mathrm{~W}$ & $321918 \mathrm{~N} 1133856 \mathrm{~W}$ & & Mohawk Mts SW \\
\hline
\end{tabular}




\section{FEATURE NAME}

Mohawk Wash

Mohawk 6.3 Lateral

Mohawk 6.9 Lateral

Mohawk 7.9 Lateral

Mohawk 8.5 Lateral

Mohawk 9.1 Latera

Mohawk 9.B Lateral

Mohon Camp

Mohon Canyon

Mohone Peak

See Mohon Peak

Mohon Mountains

Aztec Mountains

Mohon Peak

Mahone Peak

Mohone Peak

Mohon Spring

Mohon Tank

Moivavi

See Maivayi

Moi Vaya

$$
\text { See Maivayi }
$$

Mojave City Mohave City

Mojave County See Mohave County

Mojave Valley

See Mohave Valley

Mojohave Ridge

Mojonera Canyon

Mojonera Well

Mokaac Mountain

Mociac Mountain

MokeAk Mountain

Mo-Ke-ock Mountain

Mo-Ke-ok Mountain

Mokiac Mountain

Mokiah Mountain

Mo-Ki-ok Mountain

Moqueak Mountain

Mokaac Reservoir

Mokaac Spring

Mokaac Wash

Mociac Wash

MoKeAk Wash

Mo-Ke-oK Wash

Mo-Ke-ok Wash

Mokiac Wash

Mokiah Wash

Mo-Ki-OK Wash

Moqueak Wash

MoKeAk Mountain

See Mokaac Mountain

MoKeAk Wash

See Mokaac Wash

Mo-Ke-ock Mountain

See Mokaac Mountain

Mo-Ke-ok Mountain

See Mokaac Mountain

Mo-Ke-oK Wash

See Mokaac Wash

Mo-Ke-ok Wash

See Mokaac Wash

Mokiac Mountain

See Mokaac Mountain

Mokiac Wash

See Mokaac Wash

Mokiah Mountain

See Mokaac Mountain

Mokiah Wash

See Mokaac Wash

$\begin{array}{ll}\begin{array}{c}\text { FEATURE } \\ \text { CLASS }\end{array} & \text { S } \\ \text { stream } & \text { BG } \\ \text { canal } & B G N \\ \text { canal } & B G \\ \text { canal } & B G \\ \text { canal } & B G \\ \text { canal } & B G \\ \text { canal } & B G N \\ \text { locale } & B G \\ \text { valley } & B G N\end{array}$

STATUS

COUNTY

Yuma
Yuma
Yuma
Yuma
Yuma
Yuma
Yuma
Yavapai
Mohave

COORDINATE

$324356 \mathrm{~N} 1135526 \mathrm{~W}$

$323910 \mathrm{~N} 1140708 \mathrm{~W}$

$323922 \mathrm{~N} 1140606 \mathrm{~W}$

$323924 \mathrm{~N} 1140524 \mathrm{~W}$

$323923 \mathrm{~N} 1140453 \mathrm{~W}$

$323946 \mathrm{~N} 1140423 \mathrm{~W}$

$324016 N 1140106 \mathrm{~W}$

345B26N1131B05W

$350036 \mathrm{~N} 1132206 \mathrm{~W}$

$355706 \mathrm{~N} 1131 \mathrm{~B} 07 \mathrm{~W}$

345656 N1131754W

$345648 \mathrm{~N} 1131745 \mathrm{~W}$

345656N1131754W

345830 N1131804W

$350223 \mathrm{~N} 1132204 \mathrm{~W}$

Yavapa

Maricopa

32334BN1122729W

locale

locale

locale

VARIANT

BGN $1 B 90$

VARIANT

VARIANT

civil VARIANT

valley

ridge
valley

Mohave

$350710 N 1143715$

Santa Cruz 312142N1110715W

Santa Cruz 312620N1112120W

well UNOFF Santa Cruz 312751N1111909W

sumnit BGN 1979 Mohave 365321 N1133747W

BARIANT

VARIANT

VARIANT

VARIANT

VARIANT

VARIANT

VARIANT

VARIANT

reservoir

spring

arroyo

BGN

BGN 1979

Mohave

Mohave

Mohave

VARIANT

VARIANT

VARIANT

VARIANT

VARIANT

VARIANT

VARIANT

VARIANT

VARIANT

summit

VARIANT

arroyo

summit

summit

arroyo

VARIANT

VARIANT

VARIANT

Mohave

Mohave

Mohave

Mohave

Mohave

$365726 N 1133247 \mathrm{~W}$

$36535 \mathrm{BN} 1133452 \mathrm{~W}$

$370000 \mathrm{~N} 1133530 \mathrm{~W}$

365352N1133423W

Lizard Point

Lizard Point

Lizard Point
541 Davis Dam SE

Bart lett Mtn 5189 Purgatory Canyon arroyo

summ it

arroyo

summit

arroyo
VARIANT

VARIANT

VARIANT

VARIANT

VARIANT

Mohave

$370000 \mathrm{~N} 1133530 \mathrm{~W}$

Mohave

$365321 N 1133747 \mathrm{~W}$

Mohave

370000 N1133530W

Mohave

$365321 \mathrm{~N} 1133747 \mathrm{~W}$

Mohave 


\section{FEATURE NAME}

Mo-Ki-ok Mountain

See Mokaac Mountain

Mo-Ki-Ok Wash

See Mokaac Wash

Molina Basin

Mol ina Lateral

Molina Spring

Molinitos

See Stan Shuatuk

Molino Bas in

Molino Bas in Campground

Molino Canyon

Molino Tank, El

Molinton

See Stan Shuatuk

Mollen Well

Mollie Davenport Mine

Mollies Nipple

Molly Ann Draw

Molly Ann Tank

Molonitos

See Stan Shuatuk

Momo Park

Monadnock Amphitheater Monadnock Canyon

Monadnock Canyon

See Monadnock Amphitheater

Monarch Mine

Monarch Mine

Monarch Wash

MonDak Mobile Home Park

Money Metal Shaft

Monfort Park

Monitor Mine

Monk Draw

$$
\text { Wood Canyon }
$$

Monk Draw

See Wood Canyon

Monkey Canyon

Monkey Cove

Monkey Rock

Monkeys Head Conic Peak

Monkey Spring

Monkey Springs

Monkey Spring

Monkey Spring

Monkey Springs

See Monkey Spring

Monkey Tank

Monkey Tank

Monk Ranch

Monk Tank

Monreal Well (dry)

Monroe Canyon

See Middle Red Creek

Monroe Canyon

Monroe Canyon Windmill

Monroe Lateral

Monroe School

Montague Spring

Montague We11

Montana Dam

Montana del Sur

See Burgundy $\mathrm{Hi} 1$ (subdivision)

Montana Mine

Montana Mountain

Montana Peak

Montana Ranch

Montana Wash

\section{FEATURE}

CLASS

STATUS

COUNTY

COORDINATE

$365321 N 1133747 \mathrm{~W}$

summit

arroyo

bas in

canal

spring

locale

bas in

VARIANT

VARIANT

BGN

BGN

BGN

VARIANT

BGN

park

valley

reservoir

ADMIN

BGN

VARIANT

locale

well

mine

summit

valley

reservoir

UNOFF

UNOFF

BGN

BGN

BGN
BGN

locale

loca

park
basin

VARIANT

as in

bas in

mine

mine

stream

locale

mine

park

mine

valley

valley

valley

bay

summit

summit

spring

spring

spring

spring

reservoir BGN

ADMIN

BGN 1910

VARIANT

VARIANT

UNOFF

UNOFF

BGN

UNOFF

UNOFF

ADMIN

UNOFF

BGN

VARIANT

VARIANT

BGN

$B G N$

BGN

BGN

VARIANT

BGN

VARIANT

BGN

VARIANT

reservoir

locale

reservoir

well

BGN

UNOF

UNOFF

VARIANT

stream

valley

locale

canal

school

BGN

BGN

UNOFF

Mohave

Mohave

Apache

Yuma

Apache

Pima

Pima

Pima

Pima

Pinal

Pima

Pima

Maricopa

Mohave

Coconino

Coconino

Pina

Maricopa

Coconino

$332345 \mathrm{~N} 1120445 \mathrm{~W}$

$361220 \mathrm{~N} 1121745 \mathrm{~W}$

Coconino

$361220 N 1121745 \mathrm{~W}$

Yavapa

Yavapai

Maricopa

$335913 \mathrm{~N} 1123536 \mathrm{~W}$

$343720 \mathrm{~N} 1120124 \mathrm{~W}$

$335502 \mathrm{~N} 1124036 \mathrm{~W}$

Maricopa

$332510 \mathrm{N1114458 \textrm {W }}$

Gila

Maricopa

Pinal

Cochise

$332629 N 1105452 \mathrm{~W}$

$333425 N 1120341 \mathrm{~W}$

$331303 \mathrm{~N} 1105711 \mathrm{~W}$

$322129 \mathrm{~N} 1093704 \mathrm{~W}$

Cochise

Santa Cruz

$322323 N 1094229 \mathrm{~W}$

Mohave

313734N1104242W

Mohave

Yuma

Santa Cruz

$355021 \mathrm{N1144151 \textrm {W }}$

$341602 N 1140658 \mathrm{~W}$

Graham

$313803 N 1104212 W$

Maricopa

Santa Cruz

$325812 N 1101653 \mathrm{~W}$

$333050 \mathrm{~N} 1110705 \mathrm{~W}$

$313803 N 1104212 \mathrm{~W}$

Cochise

$315726 \mathrm{~N} 1091805 \mathrm{~W}$

Yavapai

Cochise

Graham

Yuma

Yavapai

Yavapai

Yavapai

Yuma

Maricopa

spring BGN Gila $\quad 334355 N 1104902 W$

dam

UNOFF

Gila

pp1

VARIANT

$312647 \mathrm{~N} 1111259 \mathrm{~W}$

mine UNOFF

summit

summit

locale

UNOFF

BGN
BGN
UNOFF

$332148 \mathrm{~N} 1115835 \mathrm{~W}$

Santa Cruz

$312731 \mathrm{N1111415 \textrm {W }}$

$332417 N 1110913 \mathrm{~W}$

$312636 \mathrm{~N} 1111338 \mathrm{~W}$

313238 N1111623W

stream $\quad B G N$
Santa Cruz

Pima

Mohave

Nelson Reservoir Somerton

Nelson Reservoir

Agua Caliente Hill

$322223 N 1103942$

4760 Agua Caliente $\mathrm{Hill}$

Agua Caliente Hill

Florence NE

Stevens Mtn

Little Horn Peak

$353940 N 1120105$

5551 Whitmore Point SE 


\section{FEATURE NAME}

Montana Wash

See Silver Creek Wash

Montano Ranch

Montara (subdivision)

Montazona Mine

Montazona Pass

Montclair Terrace (subdivision)

Montebello School

Monte Carlo Interchange

Montecito Mobile Home Estates

Monte Cristo Mine

Monte Cristo Mine

Monte Cristo Mine

Monte Cristo Substation

Monte de la Expuma

See Superstition Mountain

Monterey Mine

Monterey Park

Monterey Park School

Monterey Village Shopping

Center

Montes Spring

Monte Vista Peak

Monte Vista Peak Lookout

Monte Vista School

Montezuma

Montezuma, Lake

Montezuma Airport

Montezuma Canal

Montezuma Canyon

Montezuma Castle Mational

Monument

Montezuma Cave

Montezuma Head

Montezuma Head

See Montezumas Head

Montezuma Head

Face Mountain

Montezumas Head

Montezuma Lake
Montezuma Mine
Montezuma Mine
Montezuma Pass
Montezuma Peak
Ash Peak
Bercich Peak
Montezuma Peak
Montezuma Point
Wal lapai Point
Montezuma Ranch
Montezumas Chair
Montezuma School
Montezumas Head
Montezuma Head
Montezumas Head
See Montezuma Head
Montezuma Sleeping
Montezuma Tank
Montezuma Tank
Montezuma Well
Montezuma Well
Montgomery Road Interchange
Montgomery Stadium
Montgomery Substation
Montlure Camp
Montosa Bas in
Montosa Canyon
Montosa Canyon
Montosa Mine
Montoso, Cerro
Montoya Tank

FEATURE
CLASS

STATUS

COUNTY

COOROINATE

stream
locale

local

mine

gap

school

crossing

VARIANT

UNOF

BGN

BGN

BGN

UNOFF

UNOFF

locale UNOFF

mine

mine

mine

locale

UNOFF
UNOFF
UNOFF

UNOFF

VARIANT

summit

mine

park

UNOFF

ADMIN

school

UNOFF

locale

UNOFF

Mohave

Pina

Maricopa

Pima

Pima

Maricopa

Maricopa

Coconino

Maricopa

Yavapai

Yavapai

Yavapai

Yavapai

Pinal

Maricopa

Maricopa

Maricopa

spring

summit

tower

school

locale

lake

airport

canal

BGN

Pima

Gila

Cochise

Cochise

Maricopa

Maricopa

Yavapai

Yavapai

Graham

valley $B G N \quad$ Cochise

park ADMIN Yavapai

cave BGN Pina

summit

BGN 1945 Pima VARIANT

summit

summit

BGN

VARIANT

VARIANT

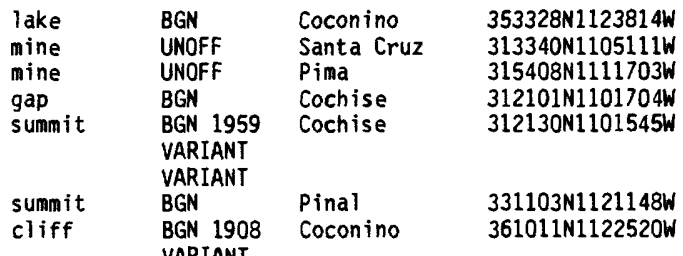

summit BGN $\quad$ Navajo $\quad 352640$ N1103028W

school UNOFF Yavapai 344057N1120003W

summit BGN Pinal 330801N1120934W

VARIANT

VARIANT

summit

summit

reservoir BGN

reservoir

11

well

crossing UNOF

locale $B G M$

locale UNOFF

locale

bas in

valley

valley

BGN

BGN
BGN

BGN

Maricopa

Yavapai

Coconino

$330915 \mathrm{~N} 1131240 \mathrm{~W}$

$331454 \mathrm{~N} 1121440 \mathrm{~W}$

$344052 \mathrm{~N} 1120058 \mathrm{~W}$

$351304 \mathrm{~N} 1115602 \mathrm{~W}$

mine

UNOFF

Santa Cruz

Yavapa $i$

Pinal

Maricopa

Maricopa

Apache

Santa Cruz

Santa Cruz

Cochise

Santa Cruz

$313351 N 1105113 W$

343857 N1114506W

$324741 \mathrm{N1} 115135 \mathrm{~W}$

$332714 \mathrm{~N} 1120345 \mathrm{~W}$

333638 N1120050W

$335934 \mathrm{~N} 1092709 \mathrm{~W}$

$314040 \mathrm{~N} 1105558 \mathrm{~W}$

$314123 \mathrm{~N} 1110239 \mathrm{~W}$

$315115 \mathrm{N1} 103022 \mathrm{~W}$

$314007 \mathrm{~N} 1105545 \mathrm{~W}$

$\begin{array}{llll}\text { summit } & \text { BGN 1971 } & \text { Apache } & 341506 \text { N1093505W } \\ \text { reservoir } & \text { BGN } & \text { Santa Cruz } & 312419 \text { N1110750W }\end{array}$ $\begin{array}{lll}\text { SOURCE } & \text { ELEV } \\ \text { COORDINATE } & \text { FT }\end{array}$

Cerro Colorado

1200 Glenda le Drew Spring Well

Ventana

1450 Currys Corner Sunnys lope Ash Fork

1190 Tempe

Morgan Butte

Weaver Peak

Groom Creek

Morgan Butte

Harquahala Mtn

Phoenix

Phoenix

2540 Tucson East

Chrome Butte

9357 Chiricahua Peak

9357 Chiricahua Peak

Phoenix

Oatman Mountain

Lake Montezuma

3370 Camp Verde

Safford

$312201 \mathrm{~N} 1101700 \mathrm{~W}$

Bob Thompson Peak

Lake Montezuma

Chiuli Shaik

3634 Mount Ajo

Yel. Medicine Butte

Bishop Lake

Patagonia

Stevens Mtn

Montezuma Pass

7676 Montezuma Pass

4354 Montezuma Peak

Explorers Monument

Bob Thompson Peak

6689 Montezumas Chair

Cottonwood

Montezuma Peak

Montezuma Peak

Cottonwood

Garland Prairie

Patagonia

Lake Montezuma

1368 Chuichu

Phoenix

Sunnys lope

8700 Big Lake North

Mt Hopkins

314106 N1105344W 314944 N1102439W

Spring Water Canyon

Mt Hopkins

8438 Cerro Hueco

Ruby 
FEATURE NAME

Montoya Tank

Montrose Canyon

Montys Tank

Monument Bluff

Monument Canyon

Monument Canyon

Monument Canyon

See Glen Canyon

Monument Canyon Wash

Monument Creek

Monument Creek Rapid

See Granite Rapids

Monument $\mathrm{Hill}$

Monument $\mathrm{Hill}$

Monument Mesa Tank

Monument Mountain

Monument Mountains

See Buckskin Mountains

Monument Number One Annex

Monument Number Two Tunnel

Monument Number 1 Tunnel

Monument Peak

Monument Point

Monument Point

Monument Rock

$$
\text { See Spider Rock }
$$

Monument Section Thirty Two Tank

Monument Spring
Monument Tank
Monument Tank
Monument Tank
Monument Tank
Monument Tanks
Monument Valley
The Land of Time
Room Enough
Monument Valley High

Monument Valley Navajo
Park
Monument Wash
Monument Wash Tank
Monusva Spring Well
Monzingo Ranch
Moody Point
Moody Spring
Moody Tank
Moon, Valley of the

Moon Anchor Mine
Moon Canyon
Moon Crater
Moon Creek
Mooney Canyon
Mooney Falls
Hualapai
Hualapai Falls
Hualpai
Hualpai Falls

Mooney Mountain

Mooney Tank

Mooney Trail

Moon $\mathrm{Hill}$

Moonlight Bay Reservoir

Moonlight Creek

See 01 jeto Wash

Moonlight Wash

See 01 jeto Wash

Moon Mountain

Moon Mountain

Moon Mountain School

Moon Mountain Shopping Center
FEATURE

CLASS

STATUS COUNTY

reservoir

valley

reservoir

summit

valley

valley

valley

BGN

$B G N$
$B G N$
$B G N$

BGN

BGN

VARIANT

arroyo

stream

$\begin{array}{ll}\text { BGN } & \text { Apache } \\ \text { BGN } 1906 & \text { Coconino }\end{array}$ VARIANT

rapids

summit

summit

reservoir

BGN

BGN

summit

BGN

range

VARIANT

$\begin{array}{ll}\text { mine } & \text { UNOFF } \\ \text { mine } & \text { BGN } \\ \text { mine } & \text { BGN } \\ \text { summit } & \text { BGN } \\ \text { cliff } & \text { BGN } \\ \text { cliff } & \text { BGN } \\ & \text { VARIANT } \\ \text { pillar } & \\ \text { reservoir } & \text { BGN }\end{array}$

Coconino Maricopa

Navajo

Yavapai

Maricopa

La Paz

Navajo

Apache

Navajo

Gila

Coconino

Coconino

Apache

Yavapai

$342303 \mathrm{N1121712W}$

$\begin{array}{llll}\text { spring } & \text { BGN } & \text { Gila } & 333906 \mathrm{~N} 1104038 \mathrm{~W} \\ \text { reservoir } & \text { BGN } & \text { Santa Cruz } & 312012 \mathrm{~N} 1110423 \mathrm{~W} \\ \text { reservoir } & \text { BGN } & \text { Santa Cruz } & 312259 \mathrm{~N} 1111003 \mathrm{~W} \\ \text { reservoir } & \text { BGN } & \text { Graham } & 33152 \mathrm{BN} 1101209 \mathrm{~W} \\ \text { reservoir } & \text { BGN } & \text { Coconino } & 351104 \mathrm{N1113116 \textrm {W }} \\ \text { reservoir } & \text { BGN } & \text { Coconino } & 344350 \mathrm{N1112906 \textrm {W }} \\ \text { basin } & \text { BGN 1915 } & \text { Apache } & 365657 \mathrm{~N} 1095524 \mathrm{~W}\end{array}$

basin BGN 1915 Coconino

VARIANT

school UNOFF

Navajo

park

ADMIN

stream

we

well

locale

summit

reservoir

bas in

\section{BGN}

BGN

UNOFF

UNOFF

BGN

BGN

BGN

BGN

mine

valley

crater

stream

valley

falls

UNOFF
BGN
BGN
BGN
BGN
BGN 1925
VARIANT
VARIANT
VARIANT
VARIANT

Navajo

Coconino

Coconino

Navajo

Grahan

Gila

Maricopa

Graham

Pima

Maricopa

Cochise

Coconino

Apache

Yavapai

Coconino

VARIANT

$365657 \mathrm{~N} 1095524 \mathrm{~W}$

$364342 \mathrm{~N} 1101437 \mathrm{~W}$

$365500 \mathrm{~N} 1000500 \mathrm{~W}$

$354320 \mathrm{~N} 1122627 \mathrm{~W}$

$353257 \mathrm{N1} 123143 \mathrm{~W}$

355303 N1104119W

$322539 \mathrm{~N} 1095836 \mathrm{~W}$

$334827 \mathrm{~N} 1105226 \mathrm{~W}$

$331007 \mathrm{~N} 1125013 \mathrm{~W}$

$325135 \mathrm{N1092103 \textrm {W }}$

$320540 \mathrm{~N} 1103037 \mathrm{~W}$

$333832 \mathrm{~N} 1130048 \mathrm{~W}$

$312655 \mathrm{~N} 1095538 \mathrm{~W}$

352032 N1112258W

$33543 \mathrm{BN} 1094418 \mathrm{~W}$

$345446 \mathrm{N1} 11565 \mathrm{BW}$

361546 N1124224W
312702 N1095516W

$335412 N 1093915 \mathrm{~W}$

$345900 \mathrm{~N} 1115459 \mathrm{~W}$

\begin{tabular}{|c|c|c|}
\hline $\begin{array}{l}\text { SOURCE } \\
\text { COORDINATE }\end{array}$ & $\begin{array}{l}\text { ELEV } \\
\text { FT }\end{array}$ & MAP NAME \\
\hline $\begin{array}{l}332554 \mathrm{~N} 1112650 \mathrm{~W} \\
360001 \mathrm{~N} 1091213 \mathrm{~W}\end{array}$ & 1009 & $\begin{array}{l}\text { Flagstaff West } \\
\text { Oro Valley } \\
\text { Turkey Mtn } \\
\text { Monument Bluff } \\
\text { Goldfield } \\
\text { Spider Rock }\end{array}$ \\
\hline $\begin{array}{l}360001 \mathrm{~N} 1091213 \mathrm{~W} \\
360334 \mathrm{~N} 1121022 \mathrm{~W}\end{array}$ & & $\begin{array}{l}\text { Spider Rock } \\
\text { Grand Canyon }\end{array}$ \\
\hline & & $\begin{array}{l}\text { Avondale } \\
\text { Flattop Hill } \\
\text { Rover Peak } \\
\text { Cooks Mesa }\end{array}$ \\
\hline
\end{tabular}

Mystery Valley

Rooster Rock

Mystery Valley

5092 Payson South

Monument Point

Tapeats Amphitheater

Poland Junction

Haystack Butte

Pajarito Peak

Ruby

Branaman Spring

Flagstaff East

Happy Jack

Rooster Rock

Kayenta East

Mitten Buttes

352649 N1123254W

Markham Dam

Howard Spring

Hotevilla

W of Greasewood Mtn

Sombrero Peak

Spring Mtn

Ash Peak

Rincon Peak

Hummingbird Spring Bisbee

6491 Sunset Crater East

Hawley Lake East

Loy Butte

Havasu Falls

\begin{tabular}{|c|c|c|c|}
\hline $\begin{array}{l}\text { summit } \\
\text { reservoir } \\
\text { trail } \\
\text { summit } \\
\text { reservoir }\end{array}$ & $\begin{array}{l}\text { BGN } \\
\text { BGN } \\
\text { UNOFF } \\
\text { BGN } \\
\text { BGN } \\
\text { VARIANT }\end{array}$ & $\begin{array}{l}\text { Coconino } \\
\text { Coconino } \\
\text { Yavapai } \\
\text { Maricopa } \\
\text { Coconino }\end{array}$ & $\begin{array}{l}350831 \mathrm{~N} 1115417 \mathrm{~W} \\
350453 \mathrm{~N} 1115316 \mathrm{~W} \\
345527 \mathrm{~N} 1115659 \mathrm{~W} \\
333644 \mathrm{~N} 1120517 \mathrm{~W} \\
345238 \mathrm{~N} 1104647 \mathrm{~W}\end{array}$ \\
\hline stream & VARIANT & Navajo & $371710 \mathrm{~N} 1101735 \mathrm{~W}$ \\
\hline $\begin{array}{l}\text { stream } \\
\text { summit }\end{array}$ & $B G N$ & $\begin{array}{l}\text { Navajo } \\
\text { Maricopa }\end{array}$ & $\begin{array}{l}371710 \mathrm{~N} 1101735 \mathrm{~W} \\
333716 \mathrm{N11} 120535 \mathrm{~W}\end{array}$ \\
\hline $\begin{array}{l}\text { summit } \\
\text { school } \\
\text { locale }\end{array}$ & $\begin{array}{l}\text { BGN } \\
\text { UNOFF } \\
\text { UNOFF }\end{array}$ & $\begin{array}{l}\text { Yuma } \\
\text { Maricopa } \\
\text { Maricopa }\end{array}$ & $\begin{array}{l}335022 \mathrm{N11} 142506 \mathrm{~W} \\
333625 \mathrm{N1} 120555 \mathrm{~W} \\
333733 \mathrm{N1} 120557 \mathrm{~W}\end{array}$ \\
\hline
\end{tabular}

7406 Garland Prairie Sycamore Point Loy Butte

1678 Sunnys lop Rock Station

1458 Sunnys lope

Moon Mtn

Sunnys lope

Union Hills 


\section{FEATURE NAME}

Moonshine Canyon

Moonshine Canyon

Moonshine Creek

Moonshine Draw

See West Moonshine Draw

Moonshine Draw

Moonshine Gulch

Moonshine Gulch

Moonshine Hill

Moonshine Park

Moonshine Park

Moonshine Ridge

Moonshiner Spring

Moonshine Spring

Moonshine Spring

Moonshine Spring

Moonshine Spring Number Three

Moonshine Spring Number Two

Moonshine Springs

Moonshine Tank

Moon Valley

Moon Valley Canyon

$$
\text { (subdivision) }
$$

Moon Valley High School

Moon Valley Mobile Home Estates

Moon Valley Park

Moon Valley Plaza Shopping

Center

Moonville Creek

Moore Canyon

Moore Canyon

Moore Creek

Moore Creek

$$
\text { See Ellison Creek }
$$

Moore Creek

See Hells Gate Canyon

Moore Gulch

Moore Mine

Moore Mine

Moore Mountain

Moore Mountain Tank

Moore Ranch

Moore Ranch

Moore Ranch

Moore Spring

Moores Spring

Moore Tank

Moore Tank

Moore Tank

Moore Tank

Moore Tank

Moore Wash

Moore Well

Moore Well

Moore Well

Moose Wel

Moovalya Lake

Moqueak Mountain

See Mokaac Mountain

Moqueak Wash Moqui

See Mokaac Wash

Moqui

Moqui

Moqui Draw

Moqui Lookout Tower

Moqui Pueblos

Moqui Ranch

Moqui

Moqwi
FEATURE
CLASS

STATUS

COUNTY

BGN
BGN
BGN
VARIANT

Greenlee

valley

valley

valley

valley

valley

BGN 1973 Coconino

BGN Yuma

valle

summit

flat

flat

ridge

spring

spring

spring

spring

spring

BGN $\quad$ Gi

BGN

BGN

BGN

BGN

BGN

BGN

$B G N$

BGN

Gila

Greenlee

Apache

Mohave

Yavapai

Yavapai

Coconino

Mohave

Yavapai

spring

spring

valley

pp 1

BGN

BGN

BGN

BGN

school

locale

park

UNOFF

UNOFF

UNOFF
ADMIN

UNOFF

Yavapai

Yavapai

Gila

Maricopa

Maricopa

Maricopa

Maricopa

Maricopa

Maricopa

strea

valley

valley

stream

tream

valley

valley

mine

BGN

BGN

BGN

Yavapai

Cochise

Navajo

Gila

VARIANT

Gila

VARIANT

BGN

Gila

Maricopa

UNOFF

mine

summit.

reservoir

locale

locale

locale

spring

spring

reservoir

reservoir

UNOFF

BGN

BGN

UNOFF

UNOFF

UNOFF

BGN

BGN

$B G N$

BGN

reservoir $B G N$

reservoir $B G$

reservoir $B G$

stream BGN

well UNOFF

well

well

reservoir

UNOFF

UNOFF

BGN

VARIANT

summit

VARIANT

arroyo

VARIANT

locale

ppl

locale

valley

tower

locale
locale

BGN

BGN

BGN

UNOFF

BGN

UNOFF

VARIANT

VARIANT

Cochise

Gila

Gila

Cochise

Greenlee

Gila

Greenlee

Yavapai

Cochise

Greenlee

Greenlee

Coconino

Coconino

Gila

Maricopa

Maricopa

Coconino

Coconino

Yuma

Mohave

Mohave

Coconino

Coconino

Coconino

Coconino

Coconino

COORDINATE

$333124 \mathrm{~N} 1091225 \mathrm{~W}$

$344133 \mathrm{~N} 1125455 \mathrm{~W}$

324050N1095426W

342905 N1110B35W

$342916 \mathrm{~N} 1110843 \mathrm{~W}$

$331610 \mathrm{~N} 1135058 \mathrm{~W}$

335023N110480BW

$332503 \mathrm{~N} 1105230 \mathrm{~W}$

$333659 \mathrm{~N} 1091507 \mathrm{~W}$

$340724 N 1094134 \mathrm{~W}$

364752N1125041W

$341226 \mathrm{~N} 1123553 \mathrm{~W}$

$342753 \mathrm{~N} 1131213 \mathrm{~W}$

$342839 \mathrm{~N} 1110823 \mathrm{~W}$

$364654 \mathrm{~N} 1125047 \mathrm{~W}$

$344100 \mathrm{~N} 1125508 \mathrm{~W}$

344133N1125504W

$344143 \mathrm{~N} 1125628 \mathrm{~W}$

$335012 \mathrm{~N} 1104751 \mathrm{~W}$

333B50N1120518W

$333815 N 1120451 \mathrm{~W}$

$333545 \mathrm{~N} 1120810 \mathrm{~W}$

$333833 N 1120314 W$

$333735 \mathrm{~N} 1120448 \mathrm{~W}$

333630 N1120358W

$342625 \mathrm{~N} 1124646 \mathrm{~W}$ $312620 \mathrm{~N} 1095945 \mathrm{~W}$

$342009 \mathrm{~N} 1102241 \mathrm{~W}$

$342046 \mathrm{N1} 1111248 \mathrm{~W}$

$342109 \mathrm{N1111646 \textrm {W }}$

34215BN1111230W

340049 N1120944W $313720 \mathrm{~N} 1112509 \mathrm{~W}$

$320656 \mathrm{~N} 1100359 \mathrm{~W}$

$340945 \mathrm{~N} 1112240 \mathrm{~W}$

$334005 \mathrm{N1} 100703 \mathrm{~W}$

$31451 \mathrm{BN} 1093042 \mathrm{~W}$

331B11N1092910W

$335246 \mathrm{~N} 1112107 \mathrm{~W}$

$332320 \mathrm{~N} 1090250 \mathrm{~W}$

$342024 N 1123607 \mathrm{~W}$

$312945 \mathrm{~N} 1091 \mathrm{~B} 33$

33183BN1092922W

331943N1092359W

$351728 \mathrm{N1} 114 \mathrm{~B} 53 \mathrm{~W}$

$354157 \mathrm{~N} 1122258 \mathrm{~W}$

340B43N1112303W

$334416 \mathrm{~N} 1114727 \mathrm{~W}$

33593BN1120609W

$345635 \mathrm{M} 1113156 \mathrm{~W}$

$351037 \mathrm{N1} 120301 \mathrm{~W}$

$341007 \mathrm{N1141635 \textrm {W }}$

$365321 N 1133747$ 
FEATURE NAME

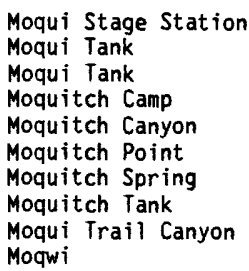

Morgan Flat

Morgan $\mathrm{Hill}$

Morgan Mine

Morgan Mountain

Morgans Ferry

Morgan Spring

Morgan Spring

Morgan Springs Well

See Morgan Spring Well

Morgan Spring Hell

Morgan Springs Well Morgan Wel1

Morgan Tank

Morgan Tank

Morgan Tank

Morgan Tank

Morgantown

Morgan Wash

Morgan Wash

See Morgan City Wash

Morgan Wash

See Morgan Spring Well

\section{FEATURE}

CLASS

STATUS

COUNTY

COORDINATE

local

reservoir

reservoir

locale

valley

cliff

spring

reservoir

valley

locale

pp 1

stream

locale

spring

well

stream

dam

summit

BGN
BGN
BGN
BGN
BGN
BGN
BGN
BGN
BGN
VARIANT

Coconino

Coconino

Coconino

Coconino

Coconino

Coconino

Coconino

Coconino

Coconino

\section{BGN}

BGN

BGN

BGN

BGN 1906

UNOFF

UNOF

BGN

UNOFF

BGN 1941

VARIAN

VARIANT

VARIANT

VARIANT

VARIANT

VARIAN

VARIANT

Maricopa

Cochise

Santa Cruz

Graham

Gila

Pima

Yuma

Pima

Ping

on ino

.

ppl

valley

valley

school

spring

mine

building

summ it

\section{BGN}

VARIANT

BGN

BGN

UNOFF

VARIANT

UNOFF

UNOFF

VARIANT

Greenlee

Greenlee

Greenlee

Greenlee

Greenlee

Greenlee

Greenlee

Pima

VARIANT

summit

airport

summit

valley

mine

stream

well

reservoir

POMIM

BGN

BGN

UNOFF

BGN

VARIANT

UNOFF

BGN

Pima

Yavapai

Apache

Maricopa

Maricopa

Maricopa

Navajo

flat

summit

mine

summit

locale

spring

spring

locale

locale

BGN Navajo

BGN Coconino

BGN

BGN

BGN

BGN

Navajo

Cochise

Yavapai

BGN

Apache

Apache

VARIANT

VARIANT

reservoir

reservoir

reservoir

reservoir

ppl

stream

BGN
BGN
BGN

BGN

BGN

BGN

VARIANT

stream

stream

locale
Navajo

Coconino

Coconino

La Paz

Maricopa

Navajo

Apache
$354713 N 1115242 \mathrm{~W}$ 343658 N1110835W 360419 N1123131W $363 \mathrm{~B} 19 \mathrm{~N} 1122030 \mathrm{~W}$ $363823 \mathrm{~N} 1122040 \mathrm{~W}$ $363740 \mathrm{~N} 1121914 \mathrm{~W}$ $363759 N 1121932 \mathrm{~W}$ $36474 \mathrm{BN} 1115 \mathrm{~B} 19 \mathrm{~W}$ $360448 \mathrm{~N} 1123527 \mathrm{~W}$ $343654 N 1110837 \mathrm{~W}$

333903 N1120B07W $312659 \mathrm{~N} 1095628 \mathrm{~W}$

312055 N1105040W $324920 \mathrm{~N} 1101407 \mathrm{~W}$ $360020 N 1115525 \mathrm{~W}$ $332812 \mathrm{~N} 1104804 \mathrm{~W}$ $313804 N 1112822 \mathrm{~W}$ $324220 \mathrm{~N} 1144342 \mathrm{~W}$ $313543 \mathrm{~N} 1115236 \mathrm{~W}$
$330443 N 1092153 W$

$330042 N 1091937 \mathrm{~W}$

$330405 N 1092052 W$

$330436 \mathrm{~N} 1092154 \mathrm{~W}$

$325823 \mathrm{~N} 1092059 \mathrm{~W}$

$330526 \mathrm{~N} 1092158 \mathrm{~W}$

330304 N1091937W

$313543 \mathrm{~N} 1115236 \mathrm{~W}$

313543 N1115236W $\begin{array}{cc}\text { SOURCE } & \text { ELEV } \\ \text { COORDINATE } & \text { FT MAP NAME }\end{array}$

Harbison Tank Blue Ridge Reservoir Antelope Point

$363227 \mathrm{~N} 1121038 \mathrm{~W} \quad$ Warm Springs Canyon Warm Springs Canyon Warm Springs Canyon Warm Springs Canyon One Toe Ridge

360440N1123058W Antelope Point

1315 Hedgpeth Hills Bisbee

Kino Springs Buford Hill

Cape Royal

Globe

$314223 N 1113628 W$

Las Guijas

Yuma West

4342 San August in 
NATIONAL GAZETTEER--ARIZONA 1986

FEATURE NAME

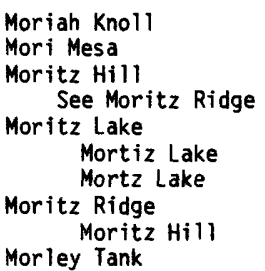

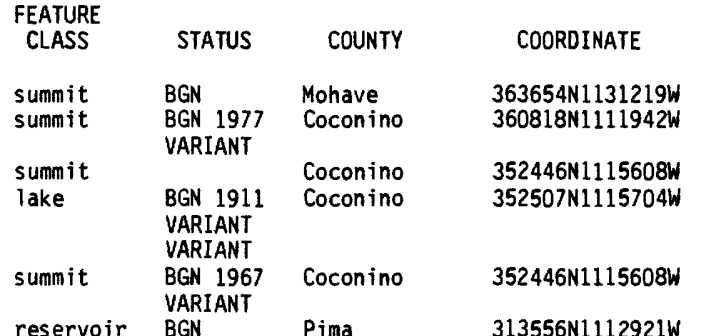

\begin{tabular}{lcl}
$\begin{array}{l}\text { SOURCE } \\
\text { COOROINATE }\end{array}$ & ELEV & \multicolumn{1}{c}{ MAP NAME } \\
6133 & $\begin{array}{l}\text { Moriah Knoll } \\
5112\end{array}$ \\
& Moenave \\
& Moritz Ridge \\
7656 & Moritz Ridge \\
& Wilbur Canyon
\end{tabular}

VARIANT

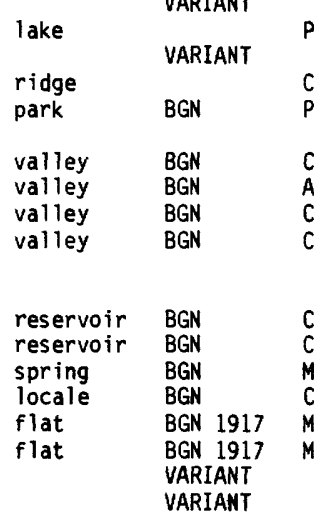

Pima

Coconino

$313252 \mathrm{~N} 1113109 \mathrm{~W}$

$363330 \mathrm{~N} 1112000 \mathrm{~W}$ $325501 \mathrm{~N} 1114524 \mathrm{~W}$

$315205 N 109222 \mathrm{BW}$ $333246 \mathrm{~N} 1095048 \mathrm{~W}$

Cochise Apache

Coconino

Coconino

$345229 \mathrm{~N} 1114518 \mathrm{~W}$

$350711 \mathrm{~N} 1111812 \mathrm{~W}$

$350248 \mathrm{~N} 1112625 \mathrm{~W}$

Coconino Coconino Maricopa Coconino

Maricopa

Maricopa

flat

Maricopa $350508 \mathrm{~N} 1112342 \mathrm{~W}$ $332933 \mathrm{~N} 1110421 \mathrm{~W}$ $343701 \mathrm{N1} 104713 \mathrm{~W}$ $333001 \mathrm{N1112700 \textrm {W }}$ $333225 \mathrm{~N} 1112615 \mathrm{~W}$

$333225 N 1112615 \mathrm{~W}$

$\begin{array}{ll}\text { dam } & \text { UNOFF } \\ \text { mine } & \text { UNOFF } \\ \text { spring } & \text { BGN } \\ \text { summit } & \text { BGN } \\ \text { lake } & \text { BGN } \\ & \text { VARIANT } \\ & \text { VARIANT }\end{array}$

lake

pp 1

BGN 1966 VARIANT

$\begin{array}{lll}\text { tower } & \text { UNOFF } & \text { Coconino } \\ \text { valley } & \text { BGN 1917 } & \text { Coconino } \\ & \text { VARIANT } & \\ & \text { VARIANT } & \\ \text { summit } & \text { BGN } & \text { Coconino } \\ \text { reservoir } & \text { BGN } & \text { Coconino } \\ \text { reservoir } & \text { BGN } & \text { Yavapai } \\ \text { basin } & \text { BGN } & \text { Yavapai } \\ \text { reservoir } & \text { BGN } & \text { Yavapai } \\ \text { locale } & \text { UNOFF } & \text { Coconino }\end{array}$

$345312 \mathrm{~N} 1112538 \mathrm{~W}$ $345643 \mathrm{~N} 1112707 \mathrm{~W}$

$345805 \mathrm{~N} 1113033 \mathrm{~W}$ $345756 \mathrm{~N} 1113026 \mathrm{~W}$ $351425 \mathrm{~N} 1125253 \mathrm{~W}$ $345305 \mathrm{~N} 1120812 \mathrm{~W}$ $345056 \mathrm{~N} 1120808 \mathrm{~W}$ $345432 \mathrm{~N} 1112618 \mathrm{~W}$

\begin{tabular}{|c|c|c|c|}
\hline & VARIANT & & \\
\hline $\begin{array}{l}\text { ridge } \\
\text { ridge }\end{array}$ & $\begin{array}{l}\text { BGN } \\
\text { VARIANT } \\
\text { VARIANT }\end{array}$ & $\begin{array}{l}\text { Coconino } \\
\text { Coconino }\end{array}$ & $\begin{array}{l}363330 \mathrm{~N} 1112000 \mathrm{~W} \\
363330 \mathrm{~N} 1112000 \mathrm{~W}\end{array}$ \\
\hline trail & UNOFF & Cochise & $315020 \mathrm{~N} 1091 \mathrm{~B} 30 \mathrm{~W}$ \\
\hline $\begin{array}{l}\text { spring } \\
\text { spring } \\
\text { spring }\end{array}$ & $\begin{array}{l}\text { BGN } \\
\text { BGN } \\
\text { BGN }\end{array}$ & $\begin{array}{l}\text { Cochise } \\
\text { Pima } \\
\text { Gila }\end{array}$ & $\begin{array}{l}315123 N 1091917 \mathrm{~W} \\
322207 \mathrm{~N} 1105020 \mathrm{~W} \\
334721 \mathrm{~N} 1103215 \mathrm{~W}\end{array}$ \\
\hline reservoir & $\begin{array}{l}B G N \\
B G N\end{array}$ & Graham & $331103 N 1095942 W$ \\
\hline $\begin{array}{l}\text { reservoir } \\
\text { reservoir }\end{array}$ & $\begin{array}{l}\text { BGN } \\
B G N\end{array}$ & $\begin{array}{l}\text { Pima } \\
\text { Pinal }\end{array}$ & $\begin{array}{l}314203 \mathrm{~N} 1113011 \mathrm{~W} \\
331407 \mathrm{~N} 1112056 \mathrm{~W}\end{array}$ \\
\hline reservoir & BGN & Gila & $334152 \mathrm{~N} 1102641 \mathrm{~W}$ \\
\hline reservoir & BGN & Gila & $334222 \mathrm{~N} 1110330 \mathrm{~W}$ \\
\hline reservoir & BGN & Yavapai & $340520 \mathrm{~N} 1115528 \mathrm{~W}$ \\
\hline reservoir & BGN & Yavapai & $340648 \mathrm{~N} 1121756 \mathrm{~W}$ \\
\hline reservoir & BGN & Coconino & $343940 \mathrm{~N} 1104553 \mathrm{~W}$ \\
\hline reservoir & $B G N$ & Coconino & $350544 \mathrm{~N} 1112138 \mathrm{~W}$ \\
\hline
\end{tabular}

reservoir $B G N$

Cochise
$315050 N 1091746 \mathrm{~W}$ $333253 \mathrm{~N} 1094531 \mathrm{~W}$ $345504 \mathrm{~N} 1114524 \mathrm{~W}$ $350105 \mathrm{~N} 1112618 \mathrm{~W}$

Casa Grande West

Chiricahua Peak

West Poker Mtn

Sedona

Elliott Canyon

Ashurst Lake

Ashurst Lake

Haunted Canyon

Chevelon Crossing

Mormon Flat

Mormon Flat Dam

1610 Mormon Flat Dam Cave Creek Lion Mountain

6431 Concho Lake

Presumido Peak

Mormon Lake

Mormon Lake

345637N1112912W 7107 Mormon Lake

8456 Mormon Mountain Mormon Mountain Purcell Canyon

Perkinsville

Munds Draw

Mormon Lake

6470 Dove Spring SE

Chiricahua Peak

Chiricahua Peak Sabino Canyon Mule Hoof Bend

Gila Peak

Cinder $\mathrm{Hill}$ Mildred Peak Florence NE

Brushy Canyon

Windy $\mathrm{Hill}$

Cooks Mesa

Columbia

Chevelon Butte

6371 Elliott Canyon

Lazy J Ranch 
FEATURE NAME

Mormon Tea Flat

Mormon Trail Historical Marker

Mormon Well

Mormon Well

Morning Dove Spring

Morning Glory Mine

Morning Mine

Morningside Park

Morning Star Mine

Morning Star Mine

Morning Star Mine

Morris Day Gap

Morris K Udall Regional Park

Morrison Creek Coyote Creek

Morris Tank

Morris Tank

Morris Tank

Morristown

Hot Springs Junction

Vulture Siding

Morristown Overpass

Morristown Schoo

Morris Windmill

Morro Tank

Morse Canyon

See Turkey Creek

Morse Canyon

Morse Creek

Morse Canyon

See Ward Canyon

Morse Canyon Campground

Morse Creek

See Morse Canyon

Mortensens

See Pinedale

Mortensen Wash

Mortenson Wash

Morterson Wash

Mortensen Wash

Mortensen Wash

See Dodson Wash

Mortenson

See Pinedale

Mortenson Wash

See Mortensen Wash

Morterson Wash

See Mortensen Wash

Morterson Wash

See Dodson Wash

Mortgage Draw

Margs Draw

Mortgage Draw

See Margs Draw

Mortgage Spring

Mortiz Lake

See Moritz Lake

Morton Canyon Wash

Morton Dam

Morton Lake

Morton Tanks

Mortz Lake

See Moritz Lake

Morus Spring

Mosca Tank

Moscow Peak

Mosely Park

Mosquito Lake

Mossback Mine

Mossback Wash

Moss Lake

Moss Mine

Moss Spring

\section{FEATURE
CLASS}

STATUS

COUNTY

flat $\quad B G$

park ADMIN

well UNOFF

Well UNOFF

spring $B G N$

mine

park

UNOFF

UNOFF

UNOFF

mine UNOFF

mine UNOFF

gap BGN

park

stream

reservoir

reservoir

reservoir

pp 1

BGN

ALM 1983

VARIANT

BGN

BGN

BGN

VARIANT

VARIANT

Coconino

Pinal

Coconino

Mohave

Coconino

Santa Cruz

Santa Cruz

Maricopa

Pima

Maricopa

Maricopa

Greenlee

Pina

Apache

Pinal

Navajo

Navajo

Maricopa

crossing

school

UNOFF

UNOFF

BGN

reservoir $B G$

VARIANT

strean

valley

BGN 1960

VARIANT

valley

VARIANT

Maricopa

Maricopa

Navajo

Pima

Coch ise

Cochise

Cochise

Cochise

park

valley

pp 1

arroyo

VARIANT

VARIANT

Cochise

Navajo

BGN 1973 Navajo

VARIANT

VARIANT

arroyo

BGN

VARIANT

stream

Navajo

Navajo

VARIANT

ppl

Navajo

Navajo

Navajo

arroyo

VARIANT

strean

VARIAN

arroyo

BGN

VARIANT

Navajo

Coconino

VARIANT

valley

BGN

$\begin{array}{ll}\text { spring } & \text { BGN } \\ & \text { VARIANT }\end{array}$

lake

arroyo

dam

BGN

BGN
UNOFF

BGN

reservoir $B G$

VARIANT

lake

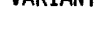

Coconino

Coconino

Coconino

Coconino

Coconino

Coconino

Coconino

Coconino

$\begin{array}{ll}\text { spring } & \text { BGN } \\ \text { reservoir } & \text { BGN } \\ \text { summit } & \text { BGN } \\ \text { park } & \text { ADMIN } \\ \text { lake } & \text { BGN } \\ \text { mine } & \text { UNOFF } \\ \text { stream } & \text { BGN } \\ \text { lake } & \text { BGN } \\ \text { mine } & \text { UNOFF } \\ \text { spring } & \text { BGN }\end{array}$

Pima

Pima

Yavapai

Pinal

Coconino

Mohave

Mohave

Coconino

Mohave

Coconino
COOROINATE

$355215 N 1113609 \mathrm{~W}$

$323905 \mathrm{~N} 1112349 \mathrm{~W}$

361711 N1105728W

365844 N1135937W

363658 N1122052W

$312545 \mathrm{~N} 1104335 \mathrm{~W}$

312241 N1110533W

$333852 N 1120613 \mathrm{~W}$

314537 N1104544W

333818 N1125450W

$335708 \mathrm{~N} 1123422 \mathrm{~W}$

331851 N1090706W

$321445 N 1105011 \mathrm{~W}$

$335925 \mathrm{~N} 1090350 \mathrm{~W}$

$323242 N 1113702 \mathrm{~W}$

$343543 \mathrm{~N} 1101814 \mathrm{~W}$

$343620 \mathrm{~N} 1102907 \mathrm{~W}$

$335124 N 1123721 \mathrm{~W}$

$335035 N 1123641 \mathrm{~W}$

$335118 N 1123717 \mathrm{~W}$

$343542 N 1101750 \mathrm{~W}$

315102 N1111747W

315956 N1094903W

$315150 N 1092018 \mathrm{~W}$

$315150 N 1092018 \mathrm{~W}$

315114 N1091940W

$315150 \mathrm{~N} 1092018 \mathrm{~W}$

$341827 N 1101503 \mathrm{~W}$

341913 N1101321W

342751N1101018

342758 N1100858

$341827 N 1101503 \mathrm{~W}$

341913N1101321W

341913N1101321W

$342758 \mathrm{~N} 1100858 \mathrm{~W}$

$345108 \mathrm{~N} 1114556 \mathrm{~W}$

345106 N1114544W

$350214 N 1114232 \mathrm{~W}$

352507 N1115704W

$345247 N 1111505$

$345330 \mathrm{~N} 1111730 \mathrm{~W}$

$345330 \mathrm{~N} 1111730 \mathrm{~W}$

$345329 N 1111337 \mathrm{~W}$

352507N1115704W

$322555 \mathrm{~N} 1104005 \mathrm{~W}$ $314316 \mathrm{~N} 1112610 \mathrm{~W}$

342411 N1122343W

$325229 \mathrm{~N} 1114414 \mathrm{~W}$

$341731 \mathrm{~N} 1105143 \mathrm{~W}$

$350548 \mathrm{~N} 1142432 \mathrm{~W}$

$350455 \mathrm{~N} 1142637 \mathrm{~W}$

$341652 \mathrm{~N} 1105156 \mathrm{~W}$

$350600 \mathrm{~N} 1142649 \mathrm{~W}$

$360341 \mathrm{~N} 1130146 \mathrm{~W}$

SOURCE
COORDINATE

MAP NAME

Coconino Point SE

Newman Peak

Tonalea

Littlefield

Big Springs

Harshaw

Pena Blanca Lake

Union Hills

Helvetia

Belmont Mtn

Red Picacho

6743 Maple Peak

Tucson East

Escudilla Mtn

Friendly Corners

Sheepskin Wash

Zeniff

Wittmann

Wittmann 
FEATURE NAME

Moss Tank

Mother Hubbard Canyon

Mothers Canyon

Mott Spring

Mound Canyon

See Glen Canyon

Mound Mountain

Mountain, Point of the

Mountain, Point of the

\begin{tabular}{|c|}
\hline $\begin{array}{l}\text { Mountainaire } \\
\text { Mountain Gate Mobile Home Park } \\
\text { Mountain King Mine } \\
\text { Mountain Lion Canyon } \\
\text { Mountain Lion Canyon } \\
\text { Mountain Lion Spring } \\
\text { Mountain Meadow } \\
\text { Mountain Meadows Memorial } \\
\text { Gardens } \\
\text { Mountain Ranch Trail Number Ter }\end{array}$ \\
\hline $\begin{array}{l}\text { Mountain Shadows Mobile Homes } \\
\text { Park } \\
\text { Mountain Sheep Spring } \\
\text { Mountain Sheep Spring } \\
\text { Mountain Sheep Wash } \\
\text { Mountains ide Spring } \\
\text { Mountain Spring } \\
\text { Mountain Spring } \\
\text { Mountain Spring } \\
\text { Mountain Spring }\end{array}$ \\
\hline $\begin{array}{l}\text { Mountain Spring } \\
\text { Mountain Spring } \\
\text { Mountain Spring } \\
\text { Mountain Spring Canyon } \\
\text { See Posta Quemada Canyon } \\
\text { Mountain Springs } \\
\text { Mountain Spring Wash } \\
\text { Mountain States Telephone and } \\
\text { Telegraph Company Tower } \\
\text { Mountaintop Tank }\end{array}$ \\
\hline $\begin{array}{l}\text { Mountain View } \\
\text { Genega de los Pinas } \\
\text { Mountain View Cemetery } \\
\text { Mountain View Cemetery } \\
\text { Mountain View Cemetery } \\
\text { Mountain View Cemetery } \\
\text { Mountain View Estates } \\
\text { (subdivision) } \\
\text { Mountain View High School } \\
\text { Mountain View Meadows } \\
\text { (subdivision) }\end{array}$ \\
\hline
\end{tabular}

Mountain View Mobile Home Park

Mountain View Overpass

Mountain View Park

Mountain View Park

Mountain View Park

Mountain View Park

Mountain View Pioneer Hospital

See Valley View Community Hospital

Mountain View Pioneer Hospital

Mountain View School

Mountain View Tank

Mountain View Tank

Mountain View Trailer Court

Mountain Vista (subdivision)

Mountain Well (dry)

Mount Babuquiburi

$$
\text { See Baboquivari Peak }
$$

Mount Baldy

See BaIdy Peak

FEATURE

CLASS

STATUS

COUNTY

COORDINATE

SOURCE ELEV

MAP NAME

\begin{tabular}{|c|c|c|c|}
\hline $\begin{array}{l}\text { summit } \\
\text { stream } \\
\text { valley } \\
\text { valley } \\
\text { spring }\end{array}$ & $\begin{array}{l}\text { BGN } \\
\text { BGN } \\
\text { BGN } \\
\text { BGN } \\
\text { BGN } \\
\text { VARIANT }\end{array}$ & $\begin{array}{l}\text { Coconino } \\
\text { Mohave } \\
\text { Greenlee } \\
\text { Graham } \\
\text { Graham }\end{array}$ & $\begin{array}{l}351723 \mathrm{~N} 1120441 \mathrm{~W} \\
345931 \mathrm{~N} 1133925 \mathrm{~W} \\
334336 \mathrm{~N} 1090250 \mathrm{~W} \\
323444 \mathrm{~N} 1095308 \mathrm{~W} \\
32333 \mathrm{BN} 1101 \mathrm{~B} 44 \mathrm{~W}\end{array}$ \\
\hline $\begin{array}{l}\text { valley } \\
\text { summit } \\
\text { cliff } \\
\text { cliff }\end{array}$ & $\begin{array}{l}\text { BGN } \\
B G N \\
B G N\end{array}$ & $\begin{array}{l}\text { Coconino } \\
\text { Maricopa } \\
\text { Apache } \\
\text { Navajo }\end{array}$ & $\begin{array}{l}365155 N 1113457 \mathrm{~W} \\
332821 \mathrm{~N} 1110 \mathrm{~B} 14 \mathrm{~W} \\
340250 \mathrm{~N} 1091947 \mathrm{~W} \\
343143 \mathrm{~N} 1095446 \mathrm{~W}\end{array}$ \\
\hline
\end{tabular}

ppl

locale

mine

valley

spring

locale

cemetery

trail

locale

spring

spring

valley

spring

spring

spring

spring

spring

spring

spring

spring

valley

spring

stream

tower

reservoir

BGN

UNOFF

UNOFF

BGN

BGN

BGN

UNOFF

UNOFF

UNOFF

BGN

Mohave

BGN Mohave

BGN Navajo

BGN Pinal

BGN Maricopa

Maricopa

Maricopa

BGM Yavapai

BGN Yavapai

BGN

VARIANT

Mohave

Pima

BGN Yavapai

BGN Yavapai

UNOFF

Maricopa

Cochise

cemetery

cemetery

cemetery

cemetery

pp I BGN

school

ppl

locale

crossing

park

park

park

park

hospital

hospital

school

reservoir

reservoir

locale

pp!

well

summit

summ it
BGN Pima

UNOFF Pinal

Mohave

Coconino

Yavapai

UNOFF

BGN

Maricopa

Maricopa

UNOFF

UNOFF

ADMI

ADMIN

AOMIN

ADMIN

VARIANT

Maricopa

Pima

Maricopa

Maricopa

Maricopa

Coconino

Maricopa

UNOFF

UNOFF

BGN

BGN

UNOF

BGN

VARIANT

VARIANT
Maricopa

Maricopa

Pima

Maricopa

Maricopa

Maricopa

Pima

Apache
350308 N1135402W $334553 \mathrm{~N} 1090353 \mathrm{~W}$ $323543 \mathrm{~N} 1095103 \mathrm{~W}$

$350507 N 1113955 \mathrm{~W}$

$332137 \mathrm{~N} 1120520 \mathrm{~W}$

$314625 \mathrm{~N} 1104710 \mathrm{~W}$

$334021 \mathrm{N1094554 \textrm {W }}$

340729 N1104307W

$334406 \mathrm{~N} 1102732 \mathrm{~W}$

$341922 \mathrm{~N} 1110020 \mathrm{~W}$

$341139 \mathrm{~N} 1111855 \mathrm{~W}$

341759 N1114427W

334125N1120714W

$363123 N 1123402 \mathrm{~W}$

$365237 N 1134627 \mathrm{~W}$

$365633 \mathrm{~N} 1134815 \mathrm{~W}$

$352821 \mathrm{~N} 1101926 \mathrm{~W}$

$332612 \mathrm{~N} 1111011 \mathrm{~W}$

$332938 \mathrm{~N} 1110445 \mathrm{~W}$

334019N1114915W

$334436 \mathrm{~N} 1112335 \mathrm{~W}$

$340603 \mathrm{~N} 1113418 \mathrm{~W}$

$343254 \mathrm{~N} 1131314 \mathrm{~W}$

353734K1141953W

$320315 N 1103800 \mathrm{~W}$

$340529 \mathrm{~N} 1122206 \mathrm{~W}$

$342756 \mathrm{~N} 1131335 \mathrm{~W}$

$332000 \mathrm{~N} 1120348 \mathrm{~W}$

314730N1090754W

320009 N1104052W

325002 N1114358W

$33245 B N 1113937 \mathrm{~W}$

$351203 \mathrm{~N} 1140203 \mathrm{~W}$

351447 N1121215W

$343215 \mathrm{~N} 1115015 \mathrm{~W}$

332620 N111462OW

$333322 \mathrm{~N} 1121115 \mathrm{~W}$

332839 N1115435W

$320025 \mathrm{~N} 1104124 \mathrm{~W}$

332528 N1122109W

$333411 \mathrm{~N} 1115348 \mathrm{~W}$

$333437 \mathrm{~N} 1120450 \mathrm{~W}$

$351232 \mathrm{~N} 1113857 \mathrm{~W}$

333543N1121807W

$333544 N 1121805 W$

333432 N1120528W

315918 N1103943W

$324548 \mathrm{~N} 1104542 \mathrm{~W}$

$333425 \mathrm{~N} 1120529 \mathrm{~W}$

333837 N1120104W

$330 \mathrm{~B} 41 \mathrm{~N} 1123453 \mathrm{~W}$

$314616 \mathrm{~N} 1113542 \mathrm{~W}$

335422 N1093344W

\section{$343254 N 1131314 N$}

$334309 \mathrm{~N} 1093940 \mathrm{~W}$

$340813 N 1104343 \mathrm{~W}$

$364944 N 1134507 \mathrm{~W}$
Eagar
Point of the Mtn

Mountainaire

1190 Lone Butte

Helvetia

Corn Creek

Oak Creek Ranch

Brushy Canyon

5970 Promontory Butte

Payson South

Verde Hot Springs

1390 Union Hills

Jumpup Point

Mtn Sheep Spring

Mtn Sheep Spring

Dilkon

Iron Mountain

Haunted Canyon

McDowell Peak

Mine Mountain

Table Mountain

Bagdad

White Hills East

Columbia

Thorn Peak

Lone Butte

Portal Peak

Vail

Casa Grande Mts

Buckhorn

Kingman

Williams South

3080 Camp Verde

Mesa

1160 Glendale

1220 Tempe

Vail

Tolleson

Paradise Valley

Sunnys lope

Flagstaff West

El Mirage

Sunnys lope

Mount Fagan

Putnam Wash

1240 Sunnys lope

1450 Union Hills

1174 Margies Peak 
FEATURE CLASS

\section{STATUS}

COUNTY
COORDINATE

Mount Baldy Primitive Area See Mount Baldy Wilderness Mount Baldy Wilderness Mount Baldy Primitive Area

Mount Beauchamp See Willow Mountain summit See Humboldt Mountain summit Mount Buford See Humboldt Mountain summit

Mount Carmel School

See Elden Mountain

Mount Elden Little League Field

Mount Elden School

Mount Elliott Spring

Mounterest Ranch

Mount Fagan Ranch

Mount Fraguita See Fraguita Peak

park
park
summit
summit
summit
school
summit
park
school
spring
locale
locale

summit

VARIANT

ADMIN

VARIANT

Apache

Apache

VARIANT

VARIANT

VARIANT

Graham

Maricopa

Maricopa

UNOFF

VARIANT

ADMIN

ADMIN

UNDFF
BGN
UNDFF

UNOFF

VARIANT

Maricopa

Coconino

Coconino

Coconino

Yavapai

Pinal

Pima

Santa Cruz
Mount Beauford

Mount Elden

Mount Francis Trail Forty Eight Mount Graham

See Pinaleno Mountains

Mount Graham Mill Site

Mount Graham Sawmill

Mount Hope

See Fort Rock Ranch

Mount Hope Tank

Mount Hope Wash

See Hope Wash

Mount Humphrey See San Francisco Mountain

Mount Hutch

See Hutch Mountain

Mount Kendrick

See Kendrick Peak

Mount Lemmon

See Summerhaven

Mount Lemmon Post Office

Mount Lemmon Ski Valley

Mount Lion Tank

Mount McDowell See McDowell Peak

Mount Madera

See Madera Peak

Mount Ochoa

See Pyramid Peak

Mount Ord Lookout Tower

Mount Ord Irough Spring

Mount Peale

See Peeley, Mount

Mount Peele See Peeley, Mount

Mount Pele

See Peeley, Mount

Mount Rayburne

Mount Roddick

See Fraguita Peak

Mount Seneca Howland

See Navajo Mountain

Mount Sitgreaves

See Sitgreaves Mountain

Mount Trumbull

Mount Trumbul1 (historical

P. 0.)

Mount Union Family Picnic

Ground

Mount Union Mine

Mount Union Recreational Area

Mount Wado

trail

range

locale

locale

locale

reservoir

valley

summit

summit

summit

ppl

building

locale

summit

summit

summit

tower

spring

summit

summit

summit

summit

summit

summit

summit

locale

locale

park

mine

park
335852 N1114752W

332526N1115603W

$351441 \mathrm{~N} 1113617 \mathrm{~W}$

$351219 \mathrm{~N} 1113659 \mathrm{~W}$

$351239 \mathrm{~N} 1113655 \mathrm{~W}$

$342822 \mathrm{~N} 1121922 \mathrm{~W}$

$325148 \mathrm{N1} 103603 \mathrm{~W}$

$315532 \mathrm{~N} 1104530 \mathrm{~W}$

313025 N1111955W

UNOFF

VARIANT

Yavapai

342B10N1123154W

$323827 N 1095035 \mathrm{~W}$

324307 N1095416W

$324510 \mathrm{~N} 1095248 \mathrm{~W}$

$350848 \mathrm{~N} 1131937 \mathrm{~W}$

$345454 \mathrm{~N} 1130637 \mathrm{~W}$

350040N1130622W

Yavapai

VARIANT

reservoir

VARIANT

VARIANT

VARIANT

UNOFF

BGN

VARIANT

Coconino

352027 N1114057W

Coconino

Coconino

Pima

Pima

Pima

Coconino

Maricopa

Gila

Maricopa

Maricopa

Gila

Gila

VARIANT

VARIANT
Gila

Gila

Graham

Santa Cruz

Coconino

Coconino

Mohave

Mohave

Yavapai

Yavapai

Yavapai
344807 N1112322W

352429N1115100W

322619 N1104533W

$322640 \mathrm{~N} 1104536 \mathrm{~W}$

322708 N1104700W

350030 N1113723W

332024N1105212W

334449N1121049W

335418 N1112431W

335457 N1112400W

340007 N1112911W

340007 N1112911W

$340007 \mathrm{~N} 1112911 \mathrm{~W}$

$322940 \mathrm{~N} 1091306 \mathrm{~W}$

$313025 N 1111955 \mathrm{~W}$

370200N1105210W

352032N1120020W

362443 N1131929W

362444 N1131030W

$342454 \mathrm{~N} 1122408 \mathrm{~W}$

$342414 \mathrm{~N} 1122452 \mathrm{~W}$

$342457 \mathrm{~N} 1122408 \mathrm{~W}$
$333936 \mathrm{~N} 1114903 \mathrm{~W}$
SOURCE

ELEV
FT

MAP NAME
Tempe

Flagstaff East

Flagstaff East

Poland Junction

Holy Joe Peak

Corona De Tucson

Withoit

Webb Peak

Shingle Mill Mtn

Mount Hope

Mt Lemmon

Mt Lemmon

Lower Lake Mary

Reno Pass

Reno Pass

4680 Orange $8 u t t$

5329 Jones $\mathrm{Hill}$

Jones $\mathrm{Hi} 11$

Groom Creek

Groom Creek Groom Creek 
NATIONAL GAZETTEER--ARIZONA 1986

\begin{tabular}{|c|c|c|c|c|c|c|c|}
\hline FEATURE NAME & $\begin{array}{l}\text { FEATURE } \\
\text { CLASS }\end{array}$ & STATUS & COUNTY & COORDINATE & $\begin{array}{l}\text { SOURCE } \\
\text { COORDINATE }\end{array}$ & $\begin{array}{c}\text { ELEV } \\
\text { FT }\end{array}$ & MAP NAME \\
\hline $\begin{array}{l}\text { See Wodo, Mount } \\
\text { Mount Wing } \\
\text { See Wing Mountain }\end{array}$ & $\begin{array}{l}\text { summit } \\
\text { summit }\end{array}$ & VARIANT & $\begin{array}{l}\text { Coconino } \\
\text { Coconino }\end{array}$ & $\begin{array}{l}361219 N 1123857 \mathrm{~W} \\
351625 N 1114659 \mathrm{~W}\end{array}$ & & & \\
\hline $\begin{array}{l}\text { Mowing Machine Spring } \\
\text { Mowry Mine } \\
\text { Mowry Wash } \\
\text { Moyza Canyon } \\
\text { Moyza Ranch } \\
\text { Moyza Tank } \\
\text { Moyza Well } \\
\text { MR Ranch } \\
\text { MT Ranch } \\
\text { Muav Canyon } \\
\text { Mauv Canyon }\end{array}$ & $\begin{array}{l}\text { spring } \\
\text { mine } \\
\text { stream } \\
\text { valley } \\
\text { locale } \\
\text { reservoir } \\
\text { well } \\
\text { locale } \\
\text { locale } \\
\text { valley }\end{array}$ & $\begin{array}{l}\text { BGN } \\
\text { UNOFF } \\
\text { BGN } \\
\text { BGN } \\
\text { UNOFF } \\
\text { BGN } \\
\text { UNOFF } \\
\text { UNOFF } \\
\text { UNOFF } \\
\text { BGN 1932 } \\
\text { VARIANT }\end{array}$ & $\begin{array}{l}\text { Pinal } \\
\text { Santa Cruz } \\
\text { Santa Cruz } \\
\text { Pima } \\
\text { Pima } \\
\text { Pima } \\
\text { Pima } \\
\text { Pima } \\
\text { Yavapai } \\
\text { Coconino }\end{array}$ & $\begin{array}{l}332510 \mathrm{~N} 1110159 \mathrm{~W} \\
312542 \mathrm{~N} 1104211 \mathrm{~W} \\
312716 \mathrm{~N} 1103514 \mathrm{~W} \\
313857 \mathrm{~N} 1111136 \mathrm{~W} \\
313934 \mathrm{~N} 1111338 \mathrm{~W} \\
313640 \mathrm{~N} 1111132 \mathrm{~W} \\
313624 \mathrm{~N} 1111121 \mathrm{~W} \\
321615 \mathrm{~N} 1104233 \mathrm{~W} \\
341938 \mathrm{~N} 1114506 \mathrm{~W} \\
361629 \mathrm{~N} 1121932 \mathrm{~W}\end{array}$ & $\begin{array}{l}312525 \mathrm{~N} 1104335 \mathrm{~W} \\
313424 \mathrm{~N} 1110923 \mathrm{~W} \\
362003 \mathrm{~N} 1122102 \mathrm{~W}\end{array}$ & 2900 & $\begin{array}{l}\text { Haunted Canyon } \\
\text { Harshaw } \\
\text { Canelo Pass } \\
\text { Saucito Mtn } \\
\text { Saucito Mtn } \\
\text { Murphy Peak } \\
\text { Murphy Peak } \\
\text { Agua Caliente Hill } \\
\text { Tule Mesa } \\
\text { King Arthur Castle }\end{array}$ \\
\hline $\begin{array}{l}\text { Muddy Creek } \\
\text { See Muddy Wash } \\
\text { Muddy Creek } \\
\text { Muddy Wash } \\
\text { Muddy Mil1 } \\
\text { Muddy Tank } \\
\text { Muddy Tank } \\
\text { Muddy Tank } \\
\text { Muddy Tank Ravine } \\
\text { Muddy Wash } \\
\text { Muddy Creek }\end{array}$ & $\begin{array}{l}\text { stream } \\
\text { stream } \\
\text { well } \\
\text { reservoir } \\
\text { reservoir } \\
\text { reservoir } \\
\text { valley } \\
\text { stream }\end{array}$ & $\begin{array}{l}\text { VARIANT } \\
\text { BGN } 1979 \\
\text { VARIANT } \\
\text { UNOFF } \\
\text { BGN } \\
\text { BGN } \\
\text { BGN } \\
\text { BGN } \\
\text { BGN } 1979 \\
\text { VARIANT }\end{array}$ & $\begin{array}{l}\text { Yavapai } \\
\text { Yavapai } \\
\text { Yavapai } \\
\text { Pinal } \\
\text { Greenlee } \\
\text { Coconino } \\
\text { Pinal } \\
\text { Yavapai }\end{array}$ & $\begin{array}{l}350040 \mathrm{~N} 1130622 \mathrm{~W} \\
350657 \mathrm{~N} 1131130 \mathrm{~W} \\
\\
345935 \mathrm{~N} 113042 \mathrm{BW} \\
323842 \mathrm{~N} 1105732 \mathrm{~W} \\
333741 \mathrm{~N} 1090307 \mathrm{~W} \\
352959 \mathrm{~N} 1111112 \mathrm{~W} \\
323852 \mathrm{~N} 1105808 \mathrm{~W} \\
350040 \mathrm{~N} 1130622 \mathrm{~W}\end{array}$ & $\begin{array}{l}323852 \mathrm{~N} 1105522 \mathrm{~W} \\
345620 \mathrm{~N} 1125825 \mathrm{~W}\end{array}$ & 5582 & $\begin{array}{l}\text { Anvil Rock Ranch } \\
\text { Mount Hope } \\
\text { Fortified Mtn } \\
\text { Maness Peak } \\
\text { Grand Falls } \\
\text { Fortified Mtn } \\
\text { Anvil Rock }\end{array}$ \\
\hline $\begin{array}{l}\text { Muddy Wash } \\
\text { See Muddy Creek } \\
\text { Mudersbach Mine } \\
\text { Mudersbach Well } \\
\text { Mud Hen Tank } \\
\text { Mudhole Mine } \\
\text { Mud Hole Tank } \\
\text { Mudhole Tank } \\
\text { Mudhole Tank } \\
\text { Mud Hollow }\end{array}$ & $\begin{array}{l}\text { stream } \\
\text { mine } \\
\text { well } \\
\text { reservoir } \\
\text { mine } \\
\text { reservoir } \\
\text { reservoir } \\
\text { reservoir } \\
\text { valley }\end{array}$ & $\begin{array}{l}\text { VARIANT } \\
\text { UNOFF } \\
\text { UNOFF } \\
\text { BGN } \\
\text { UNOFF } \\
\text { BGN } \\
\text { BGN } \\
\text { BGN } \\
\text { BGN }\end{array}$ & $\begin{array}{l}\text { Yavapai } \\
\text { Yuma } \\
\text { Coconino } \\
\text { Coconino } \\
\text { Yavapai } \\
\text { Graham } \\
\text { Graham } \\
\text { Mohave } \\
\text { Graham }\end{array}$ & $\begin{array}{l}350657 N 1131130 \mathrm{~W} \\
33481 \mathrm{BN} 1140338 \mathrm{~W} \\
352407 N 1114744 \mathrm{~W} \\
353035 \mathrm{~N} 1114121 \mathrm{~W} \\
342710 \mathrm{~N} 1122256 \mathrm{~W} \\
323752 \mathrm{~N} 1091923 \mathrm{~W} \\
333223 \mathrm{~N} 1095438 \mathrm{~W} \\
363635 \mathrm{~N} 1132524 \mathrm{~W} \\
325201 \mathrm{~N} 1094954 \mathrm{~W}\end{array}$ & $324945 N 1095152 \mathrm{~W}$ & 7911 & $\begin{array}{l}\text { Ibex Peak } \\
\text { Kendrick Peak } \\
\text { S P Mountain } \\
\text { Groom Creek } \\
\text { Whitlock Mts NE } \\
\text { Elwood Canyon } \\
\text { Little Tanks } \\
\text { Thatcher }\end{array}$ \\
\hline $\begin{array}{l}\text { Mud Hollow } \\
\text { Mud Hollow Tank } \\
\text { Mud Ketch Tank } \\
\text { Mud Lake } \\
\text { Mud Lake } \\
\text { Mud Lake } \\
\text { Mud Lake Tank } \\
\text { Mud Lake Tank } \\
\text { Mud Mountain } \\
\text { See Kofa Butte }\end{array}$ & $\begin{array}{l}\text { valley } \\
\text { reservoir } \\
\text { reservoir } \\
\text { lake } \\
\text { lake } \\
\text { lake } \\
\text { reservoir } \\
\text { reservoir } \\
\text { summit }\end{array}$ & $\begin{array}{l}\text { BGN } \\
\text { BGN } \\
\text { BGN } \\
\text { BGN } \\
\text { BGN } \\
\text { BGN } \\
\text { BGN } \\
\text { BGN } \\
\text { VARIANT }\end{array}$ & $\begin{array}{l}\text { Graham } \\
\text { Graham } \\
\text { Coconino } \\
\text { Coconino } \\
\text { Coconino } \\
\text { Coconino } \\
\text { Coconino } \\
\text { Coconino } \\
\text { Yuma }\end{array}$ & $\begin{array}{l}325318 N 1094917 \mathrm{~W} \\
325145 N 1095021 \mathrm{~W} \\
351828 \mathrm{~N} 1121916 \mathrm{~W} \\
345522 \mathrm{~N} 1112117 \mathrm{~W} \\
350323 N 1105419 \mathrm{~W} \\
363807 \mathrm{~N} 1121735 \mathrm{~W} \\
343824 N 1111926 \mathrm{~W} \\
345509 \mathrm{~N} 1112131 \mathrm{~W} \\
331638 \mathrm{~N} 1135543 \mathrm{~W}\end{array}$ & $325254 N 1094927 \mathrm{~W}$ & & $\begin{array}{l}\text { Pima } \\
\text { Thatcher } \\
\text { Hearst Mtn } \\
\text { Kinnikinick Lake } \\
\text { Tucker Mesa SW } \\
\text { Warm Springs Canyon } \\
\text { Turkey Mtn } \\
\text { Kinnikinick Lake }\end{array}$ \\
\hline $\begin{array}{l}\text { Mud Mountain } \\
\text { Mud Number One Tank } \\
\text { Mud Seep } \\
\text { Mud Seep Tank } \\
\text { Mud Spring } \\
\text { Mud Spring } \\
\text { Mud Spring } \\
\text { See Mud Springs } \\
\text { Mud Spring } \\
\text { Mud Spring }\end{array}$ & $\begin{array}{l}\text { summit } \\
\text { reservoir } \\
\text { spring } \\
\text { reservoir } \\
\text { spring } \\
\text { spring } \\
\text { spring } \\
\text { spring } \\
\text { spring }\end{array}$ & $\begin{array}{l}\text { BGN } \\
\text { BGN } \\
\text { BGN } \\
\text { BGN } \\
\text { BGN } \\
\text { BGN } \\
\text { VARIANT } \\
\text { BGN } \\
\text { BGN }\end{array}$ & $\begin{array}{l}\text { Mohave } \\
\text { Yavapai } \\
\text { Yavapai } \\
\text { Coconino } \\
\text { Cochise } \\
\text { Cochise } \\
\text { Cochise } \\
\text { Pima } \\
\text { Pima }\end{array}$ & $\begin{array}{l}364032 \mathrm{~N} 1134704 \mathrm{~W} \\
342904 \mathrm{~N} 1113447 \mathrm{~W} \\
342455 \mathrm{~N} 1113703 \mathrm{~W} \\
350647 \mathrm{~N} 1120744 \mathrm{~W} \\
312341 \mathrm{~N} 1102314 \mathrm{~W} \\
312632 \mathrm{~N} 1102330 \mathrm{~W} \\
\\
313110 \mathrm{~N} 1092948 \mathrm{~W} \\
314530 \mathrm{~N} 1103104 \mathrm{~W} \\
322257 \mathrm{~N} 1104419 \mathrm{~W}\end{array}$ & & 5796 & $\begin{array}{l}\text { Cane Springs } \\
\text { Strawberry } \\
\text { Strawberry } \\
\text { May Tank Pocket } \\
\text { Huachuca Peak } \\
\text { Huachuca Peak }\end{array}$ \\
\hline $\begin{array}{l}\text { Mud Spring } \\
\text { Mud Spring } \\
\text { Mud Spring } \\
\text { Mud Spring } \\
\text { Mud Spring }\end{array}$ & $\begin{array}{l}\text { spring } \\
\text { spring } \\
\text { spring } \\
\text { spring } \\
\text { spring }\end{array}$ & $\begin{array}{l}\text { BGN } \\
\text { BGN } 1975 \\
\text { BGN } \\
\text { BGN } \\
\text { BGN }\end{array}$ & $\begin{array}{l}\text { Graham } \\
\text { Graham } \\
\text { Graham } \\
\text { Graham } \\
\text { Pinal }\end{array}$ & $\begin{array}{l}323946 N 1101807 \mathrm{~W} \\
324459 \mathrm{~N} 1102222 \mathrm{~W} \\
325425 \mathrm{~N} 1101159 \mathrm{~W} \\
325604 \mathrm{~N} 1094817 \mathrm{~W} \\
330 \mathrm{~B} 13 \mathrm{~N} 1103126 \mathrm{~W}\end{array}$ & & & $\begin{array}{l}\text { Kennedy Peak } \\
\text { Kennedy Peak } \\
\text { Jackson Mtn } \\
\text { Pima } \\
\text { Coolidge Dam }\end{array}$ \\
\hline
\end{tabular}


FEATURE NAME

Mud Spring

Mud Spring

Mud Spring

Mud Spring

Mud Spring

Mud Spring

Mud Spring

Mud Spring

Mud Spring

Mud Spring

Mud Spring

See Lower Mud Spring

Mud Spring

Mud Spring

Mud Spring

Mud Spring

Mud Spring

Mud Spring

Mud Spring

Mud Spring

Mud Spring

Mud Spring

Mud Spring

Mud Spring

Mud Spring

Mud Spring

Mud Spring

Mud Spring

Mud Spring

Mud Spring

Mud Spring

Mud Spring

Mud Spring

Mud Spring

Mud Spring

Mud Spring

Mud Spring

Mud Spring

Mud Spring

Mud Spring

Mud Spring

Mud Spring

Mud Spring

Mud Spring

Mud Spring

Mud Spring

Mud Spring Canyon

Mud Spring Canyon

Mud Spring Canyon

Keller Canyon

Mud Springs Canyon

Mud Spring Canyon

Mud Spring Canyon

Mud Spring Canyon

Mud Spring Creek

Mud Springs Creek

Mud Spring Oraw

See Mud Springs Oraw

Mud Spring Mesa

Mud Springs Mesa

Mud Spring Mesa

Mud Springs

Mud Spring

Mud Springs

Mud Springs

Mud Springs

Mud Springs

Mud Springs

Bear Creek Spring

Mud Springs

Mud Springs
FEATURE

spring

spring

spring

spring

spring

spring

spring

spring

spring

spring

spring

spring

spring

spring

spring

spring

pring

spring

spring

spring

spring

spring

spring

spring

spring

spring

spring

spring

spring

spring

spring

spring

spring

spring

spring

spring

spring

spring

spring

spring

spring

spring

spring

spring

valley

valley

valley

valley

valley

valley

stream

STATUS

COUNTY

COORDINATE

$331128 N 1104228$

$331324 N 1092328 \mathrm{~W}$

331335N1092038W

331659 N1090911W

Greenlee

Greenlee

Greenle

$331801 N 1105829 \mathrm{~W}$

BGN Pinal

BGN Gil

BGN Gila

Gila

Gila

BGN Greenlee

VARIANT

BGN Gila

BGN Mache

BGN Gila

BGN 1967 Gi

BGN Gila

BGN Gila

BGN Yavapai

BGN Apache

BGN Gila

Yavapai

Yavapai

Apache

Navajo

$332156 \mathrm{N1105112W}$

$333040 \mathrm{~N} 1110305 \mathrm{~W}$

$333130 \mathrm{~N} 1104247 \mathrm{~W}$

$333547 N 1101634 W$

$333600 \mathrm{~N} 1091436 \mathrm{~W}$

$333627 N 1104747 \mathrm{~W}$

$333639 N 1094301 \mathrm{~W}$

$334205 \mathrm{~N} 1112139 \mathrm{~W}$

$334830 \mathrm{N1105549 \textrm {W }}$

$335127 \mathrm{~N} 1102716 \mathrm{~W}$

$335435 N 1110659 \mathrm{~W}$

$335539 \mathrm{N1101244 \textrm {W }}$

$335722 \mathrm{N1121905W}$

$335931 N 1090648 \mathrm{~W}$

$340051 N 1111 B 55$

$341021 \mathrm{~N} 1121441 \mathrm{~W}$

$341114 N 1115149 \mathrm{~W}$

$341338 \mathrm{N11018}$

BGN Navajo 341338N1101826W

$\begin{array}{lll}\text { BGN } & \text { Gila } & 341338 N 1111812 W \\ \text { BGN } & \text { Yavapai } & 341436 \text { N1123335W } \\ \text { BGN } & \text { Gila } & 341513 \text { N1111107W } \\ \text { BGN } & \text { Yavapai } & 341628 N 1115037 \text { W } \\ \text { BGN } & \text { Yavapai } & 341703 N 1115332 W \\ \text { BGN } & \text { Yavapai } & 341740 N 1114348 W \\ \text { BGN } & \text { Apache } & 342154 N 1092847 W \\ \text { BGN } 1973 & \text { Coconino } & 342754 N 1111 B 48 W \\ \text { BGN } & \text { Yavapai } & 344303 N 1125146 W \\ \text { BGN } & \text { Mohave } & 344346 N 1135156 W\end{array}$

$\begin{array}{lll}\text { BGN } & \text { Yavapai } & 344652 N 1124934 W \\ \text { BGN } & \text { Yavapai } & 345510 N 1131542 W \\ \text { BGN } & \text { Coconino } & 345734 N 1113236 \mathrm{~W} \\ \text { BGN } & \text { Yavapai } & 345815 \text { N1125426W } \\ \text { BGN } & \text { Mohave } & 350827 N 1132713 \mathrm{~W} \\ \text { BGN } & \text { Mohave } & 351839 N 1142056 \mathrm{~W} \\ \text { BGN } & \text { Mohave } & 351919 \text { N1134705W } \\ \text { BGN } & \text { Mohave } & 353606 N 1141804 \mathrm{~W} \\ \text { BGN } & \text { Mohave } & 355051 \text { N1135915W } \\ \text { BGN } & \text { Mohave } & 361204 N 1132622 \mathrm{~W}\end{array}$

BGN Mohave 364145N1134644W

BGN Pima $\quad 314619 N 1103439 \mathrm{~W}$

BGN Pinal 324932N110325BW

Greenlee 332435N1090048w

VARIANT

VARIANT

BGN

BGN

BGN

Maricopa

Navajo

Yavapai

BGN 1981 Yavapai

VARIANT

VARIANT

valley

summit

summit

spring

spring

spring

spring

spring

spring

spring

spring
BGN
VARIANT

BGN

BGN 1959

VARIANT

BGN

BGN

BGN

Cochis

Graham

Greenlee

Cochise

Cochise

Graham

Graham

BGN
BGN
VARIANT
BGN

BGN

Greenlee

Yuma

Greenlee

Maricopa
$322538 N 1100710 \mathrm{~W}$
$333216 \mathrm{~N} 1111513 \mathrm{~W}$

$333437 \mathrm{~N} 1095829 \mathrm{~W}$

$345340 \mathrm{~N} 1131523 \mathrm{~W}$

$341035 \mathrm{~N} 1115036 \mathrm{~W}$

$333001 \mathrm{K1111401 \textrm {W }}$ $333530 \mathrm{~N} 1095648 \mathrm{~W}$

$345550 \mathrm{~N} 1131637 \mathrm{~W}$

$341056 \mathrm{~N} 1115339 \mathrm{~W}$

$\begin{array}{ll}\text { SOURCE } & \text { ELEV } \\ \text { COORDINATE } & F T\end{array}$

Mescal Warm Spring

Coronado Mtn

Mitchell Peak

Fritz Canyon

Pinal Ranch

Pinal Peak

Two Bar Mtn

Chrome Butte

Sontag Creek

Bear Mountain

Maverick SW

Four Peaks

Aztec Peak

Beckers Butte

Copper Mtn

Cedar Creek

Governors Peak

Escudilla Mtn

Gisela

Bumble Bee

Bloody Bas in

Sponseller Mtn

imestone Canyon $N$

Payson South

Wagoner

Diamond Point

Tule Mesa

Dugas

Verde Hot Springs

Lyman Lake SW

Kehl Ridge

Smith Mes

Beecher Canyon

Seepage Mtn

Mohon Peak

Mormon Mountain

Juniper Mts

Bull Spring

Grasshopper Junc SE

Peacock Peak

Dolan Springs

Quartermaster Can SW

Yellow John Mtn

Cane Springs

Spring Water Canyon

Holy Joe Peak

Alma Mesa

Horse Mesa Dam

Elwood Canyon

Mohon Peak

Bloody Bas in

Jackson Mtn

6152 Alma Mesa

Pedregosa Mts West 


\section{FEATURE NAME}

Mud Springs

Mud Springs

Mud Springs

Mud Springs Canyon

Mud Springs Canyon

Mud Springs Canyon

Mud Springs Canyon

Mud Springs Canyon

See Mud Spring Canyon

Mud Springs Creek

See Mud Spring Creek

Mud Springs Draw Mud Spring Draw

Mud Springs Draw

Mud Springs Knoll

Mud Springs Mesa See Mud Spring Mesa

Mud Springs Ranch

Mud Springs Tank

Mud Springs Tank Number One

Mud Springs Tank Number Two

Mud Springs Trail Forty-nine

Mud Springs Underpass

Mud Springs Wash

Mud Spring Tank

Mud Spring Tank

Mud Tank

Mud Tank

Mud Tank

Mud Tank

Mud Tank

Mud Tank

Mud Tank

Mud Tank

Mud Tank

Mud Tank

Mud Tank

Mud Tank

Mud Tank

Mud Tank

Mud Tank

Mud Tank

Mud Tank

Mud Tank

Mud Tank Draw

See Mud Tanks Draw

Mud Tank Number Two

Mud Tanks Draw

Mud Tank Draw

Mud Tanks Mesa

Mud Tanks Trail Fifty

Mud Tank Wash

Muencovi

See Moenkopi

Muerto, Canyon del An-e' et segh

Canyon Trigo

Del Muerto Canyon

Mueykava

See Maivayi

Muggins Flat

Muggins Mesa

Muggins Mountains

Muggins Peak

Muggins Placers Mine

Muggins Wash

Muggs Castle Tank

Mug Tank

Muik Vaya

Mu-koon-tu-weap

\section{FEATURE}

spring

spring

spring

valley

valley

STATUS COUNTY

COORDINATE

BGN
BGN
BGN
BGN
BGN

valley

valley

valley

stream

valley

valley

summit

Yavapai

Coconino

Apache

Cochise

Green lee

$340414 N 1120725 \mathrm{~W}$

$350658 \mathrm{~N} 1121100 \mathrm{~W}$

$360341 N 1093252 \mathrm{~W}$

322858 N1100305W

$331627 N 1091135 \mathrm{~W}$

BGN Greenlee

BGN

Gila

$332225 N 1092931 W$ $332251 N 1105005 \mathrm{~W}$

$332711 \mathrm{N1092527W}$

$332040 \mathrm{~N} 1105217 \mathrm{~W}$

$332435 N 1090048 \mathrm{~W}$

VARIANT

Greenlee

Yavapai

BGN 1959 Cochise

VARIANT

BGN

Gila

BGN

Graham

$31035 \mathrm{~N} 1115036 \mathrm{~W}$

312900 N1093430W

$334701 N 1104021 \mathrm{~W}$

$324800 \mathrm{~N} 1095012 \mathrm{~W}$

313335 N1092600W

334834 N1104119W

VARIANT

summit

locale

reservoir

reservoir

reservoir

trai]

crossing

stream

reservoir

BGN

BGN

UNOFF

UNOFF

BGN

BGN

Graham

Graham

Greenlee

Greenlee

Greenlee

Yavapai

Gila

Navajo

reservoir

reservoir

reservoir

reservoir

reservoir

reservoir

reservoir

reservoir

reservoir

reservoir

BGN Coconino

BGN Santa Cruz

Pima

Pima

Graham

Apache

Gila

$335152 \mathrm{~N} 1102651 \mathrm{~W}$

Gila 340400N1104924W

$325450 \mathrm{~N} 1101215 \mathrm{~W}$

$313052 \mathrm{~N} 1092844 \mathrm{~W}$

$324803 \mathrm{N1095022W}$

$332353 \mathrm{~N} 1092610 \mathrm{~W}$

$332432 \mathrm{~N} 1092713 \mathrm{~W}$

$332500 \mathrm{~N} 1092656 \mathrm{~W}$

$340355 \mathrm{N1120831W}$

$333815 \mathrm{~N} 1104806 \mathrm{~W}$

$333545 \mathrm{~N} 1095741 \mathrm{~W}$

Navajo

reservoir

reservoir

reservoir

reservoir

reservoir

reservoir

reservoir

reservoir

reservoir

reservoir

BGN Navajo

Navajo

Yavapai

Yavapai

Coconino

Coconino

Coconino

Mohave

Mohave

Coconino

345733N1113237W

$312210 \mathrm{~N} 1110338 \mathrm{~W}$

$314301 N 1111151 \mathrm{~W}$

$321 \mathrm{~B} 20 \mathrm{~N} 1104125 \mathrm{~W}$

$323737 \mathrm{N1091}$

$333627 \mathrm{N1} 094258 \mathrm{~W}$

$340450 \mathrm{~N} 1103902 \mathrm{~W}$

$341005 \mathrm{~N} 1100402 \mathrm{~W}$

$342913 \mathrm{~N} 1104032 \mathrm{~W}$

$342936 \mathrm{~N} 1113455 \mathrm{~W}$

$344858 \mathrm{~N} 1124236 \mathrm{~W}$

$345218 N 1110519 \mathrm{~W}$

$345734 N 1113739 \mathrm{~W}$

$352434 \mathrm{~N} 1124154 \mathrm{~W}$

$352818 N 1133423 \mathrm{~W}$

$353034 \mathrm{~N} 1133313 \mathrm{~W}$

$353331 N 1121042 \mathrm{~W}$

VARIANT

valley

reservoir

valley

summit

trail

stream

pp1

valley

BGN

Yavapai

Yavapa

BGN 1981 Yavapai

VARIANT

BGN

Yavapai

Yavapai

VARIANT

Coconino

BGN 1915 Apache

VARIANT

VARIANT

VARIANT

VARIANT

locale

flat

bench

range

summit

BGN

BGN

BGN

Maricopa

Coconino

Yuma

Yuma

Yuma

mine

stream

reservoir

reservoir

area

$\begin{array}{ll}\text { BGN } & \text { Yuma } \\ \text { BGN } & \text { Coconino } \\ \text { BGN } & \text { Graham } \\ \text { BGN } & \text { Pima } \\ \text { VARIANT } & \end{array}$

$342602 N 1113343 \mathrm{~W}$

$343004 \mathrm{~N} 1113431 \mathrm{~W}$

$342602 N 1113343 \mathrm{~W}$

$342856 N 1113737 \mathrm{~W}$

$342937 N 1113803 \mathrm{~W}$

345233N1123639W

$360640 \mathrm{~N} 1111318 \mathrm{~W}$

$360835 N 1092920$

323348 N1122729W

$365814 N 1122045 \mathrm{~W}$

$324744 \mathrm{~N} 1142000 \mathrm{~W}$

$324442 \mathrm{~N} 1141209 \mathrm{~W}$

$324443 N 1141503 W$

$324630 \mathrm{~N} 1141447 \mathrm{~W}$

$324321 \mathrm{N1141652W}$

$354946 \mathrm{~N} 1114353 \mathrm{~W}$

$325019 \mathrm{N1} 1092855 \mathrm{~W}$

$322740 \mathrm{~N} 1121234 \mathrm{~W}$
$343157 N 1113512 W$

$\begin{array}{cc}\text { SOURCE } & \text { ELEV } \\ \text { COORDINATE } & \text { FT }\end{array}$

MAP NAME

Squaw Creek Mesa

May Tank Pocket

[t] White Hse Ruins

Reiley Peak 
FEATURE NAME

See Toroweap Valley

Mulberry Canyon

Mulberry Canyon

Mulberry Canyon

Mulberry Drain

Mulberry Spring

Mulberry Spring

Mulberry Spring

Mulberry Spring

Mulberry Tank

Mulberry Tank

Mulberry Wash

Mulberry Wash

Mulcarie Tank

Mulden Spring See Muldoon Spring

Muldoon Canyon

Muldoon Gulch

Muldoon Spring Mulden Spring

Muldoon Tank

Mule Camp Spring

Mule Canyon

Mule Canyon

Mule Corral Canyon

Mule Creek

Mule Crossing

Mule Deer Tank

Mule Deer Tank

Mule Ears

Mule Gulch Mule Pass Gulch

Mule Gulch

See Tombstone Canyon

Mule Hoof Bend

Mule Hoof Canyon

Mule Mountain Ranch

Mule Mountains

Mule Pass Mountain

Mule Park

Mule Pass Mountains

Mule Pass

Puerta del las Mulas

Mule Pass Gulch

See Mule Gulch

Mule Pass Gulch

See Tombstone Canyon

Mule Pass Mountain

See Mule Mountains

Mule Pass Mountains

See Mule Mountains

Mule Pass Tunnel

Mule Point

Mule Point Pond

Mule Ridge

Mule Shoe Bend

Mule Shoe Bend

Muleshoe Canyon

Muleshoe Ranch

Muleshoe Ranch

Mule Shoe Tank

Mule Shoe Tank

Muleshoe Tank

Muleshoe Tank

Mule Spring

Mule Spring

Mule Spring Point

Mule Tank

Mule Tank

Mule Tank

Mule Wash
FEATURE

CLASS

STATUS

COUNTY

COORDINATE

$\begin{array}{ll}\text { valley } & \\ \text { valley } & \text { BGN } \\ \text { valley } & B G N \\ \text { valley } & B G N \\ & \\ \text { stream } & \text { BGN } \\ \text { spring } & B G N \\ \text { spring } & B G N \\ \text { spring } & B G N \\ \text { spring } & B G N \\ \text { reservoir } & B G N \\ \text { reservoir } & B G N \\ \text { stream } & B G N \\ \text { stream } & B G N \\ \text { reservoir } & B G N\end{array}$

VARIANT

spring

valley

valley
spring

reservoir

spring

valley

valley

valley

strean

locale

reservoir

reservoir

summit

valley

valley

BGN

BGN 1976

VARIANT

BGN

BGN

BGN

BGN

BGN

BGN

SGN

(

BGN 1960

VARIANT

VARIANT

bend

valley

locale

range

flat

gap

BGN

BGN

UNOFF

BGN 1903

VARIANT

VARIANT

VARIANT

VARIANT

valley

VARIANT

valley

range

range

tunnel

cliff

reservoir

ridge

bend

bend

valley

locale

locale

reservoir

reservoir

reservoir

reservoir $B G$

spring $B G N$

spring $B G N$

cliff

reservoir $B G$

reservoir

reservoir

stream $\begin{array}{ll}\text { Mohave } & 361229 \mathrm{~N} 1130524 \mathrm{~W} \\ \text { Cochise } & 313721 \mathrm{N1091751W}\end{array}$

$315206 \mathrm{~N} 1113645$

Mohave

Pima

Pinal

Yavapai

Mohave

Pima

Yavapai

Pima

Pina1

Yavapai

Yavapai

Yavapai

Yavapai

Yavapai

Yavapai

Yavapai

Yavapai

Apache

Apache

Gila

Coconino

Pima

Pima

Cochise

Cochise

$315253 \mathrm{~N} 1104028 \mathrm{~W}$

$342738 \mathrm{~N} 1142003 \mathrm{~W}$

315309 N1104236W

$324404 \mathrm{~N} 1102959 \mathrm{~W}$

$340136 \mathrm{~N} 1121840 \mathrm{~W}$

$353643 \mathrm{~N} 1132409 \mathrm{~W}$

$315245 \mathrm{~N} 1104059 \mathrm{~W}$

343023 N1120344W

$314928 \mathrm{~N} 1113918 \mathrm{~W}$

$324038 \mathrm{~N} 1103627 \mathrm{~W}$

$343440 \mathrm{~N} 1114124 \mathrm{~W}$

$315313 \mathrm{~N} 1113604 \mathrm{~W}$

$324418 \mathrm{~N} 1102804 \mathrm{~W}$

341510 N1121822W

$345240 N 1122134 \mathrm{~W}$

$341542 \mathrm{~N} 1121713 \mathrm{~W}$

$341510 N 1121822 \mathrm{~W}$

$344938 \mathrm{~N} 1122129 \mathrm{~W}$

$343141 N 1123718$

$342119 \mathrm{N1121801 \textrm {W }}$

$360706 \mathrm{~N} 1091701 \mathrm{~W}$

333421 N1095209W

$341633 \mathrm{~N} 1104756 \mathrm{~W}$

342727 N1110001W

321416 N1103711W

$321421 \mathrm{N1} 103733 \mathrm{~W}$

$322917 \mathrm{~N} 1104823 \mathrm{~W}$

$312632 \mathrm{N1} 095000 \mathrm{~W}$

$312632 N 1095507 \mathrm{~W}$

Gila

Gila

Cochise

Coconino

Cochise

$334740 \mathrm{~N} 1103101 \mathrm{~W}$

$334729 \mathrm{~N} 1103115 \mathrm{~W}$

$312823 N 1095827 \mathrm{~W}$

$312639 \mathrm{~N} 1095143 \mathrm{~W}$

$344530 \mathrm{~N} 1112532 \mathrm{~W}$

$312730 \mathrm{~N} 1095632 \mathrm{~W}$

$312632 \mathrm{~N} 1095000 \mathrm{~W}$

Cochise

Cochise

$312632 \mathrm{~N} 1095507 \mathrm{~W}$

312639 N1095143W

$312639 \mathrm{~N} 1095143 \mathrm{~W}$

$312730 \mathrm{~N} 1095630 \mathrm{~W}$

$361717 \mathrm{N1} 132009 \mathrm{~W}$

$361836 \mathrm{~N} 1132008 \mathrm{~W}$

Cochise

Mohave

Mohave

Santa Cruz

$312536 \mathrm{~N} 1111306 \mathrm{~W}$

Yavapai

Coconino

Graham

Cochise

Yavapai

Pima

Pima

Coconino

Coconino

Yavapai

$341142 \mathrm{~N} 1114218 \mathrm{~W}$

$355554 \mathrm{~N} 1114148 \mathrm{~W}$

$323005 \mathrm{~N} 1101927 \mathrm{~W}$

$322020 \mathrm{~N} 1101411 \mathrm{~W}$

$343149 \mathrm{~N} 1125853 \mathrm{~W}$

$313142 \mathrm{~N} 1111940 \mathrm{~W}$

$321952 \mathrm{~N} 1115605 \mathrm{~W}$

$345631 \mathrm{~N} 1110023 \mathrm{~W}$

$351820 \mathrm{~N} 1121409 \mathrm{~W}$

$341050 \mathrm{~N} 1115137 \mathrm{~W}$

$341935 N 1104642 W$

$341801 \mathrm{~N} 1104711 \mathrm{~W}$

$334234 N 1100538 \mathrm{~W}$

$341914 \mathrm{~N} 1104631 \mathrm{~W}$

$353225 \mathrm{~N} 1121337 \mathrm{~W}$

$332639 \mathrm{~N} 1143716 \mathrm{~W}$

$313754 N 1091952 \mathrm{~W}$

$315313 \mathrm{~N} 1113604 \mathrm{~W}$

342755 N1141943W

344941 N1122051

$341417 \mathrm{~N} 1121914 \mathrm{~W}$

$333351 N 1094756 \mathrm{~W}$

$341900 \mathrm{~N} 1104527 \mathrm{~W}$

$312544 N 1095328 \mathrm{~W}$

$\begin{array}{cc}\text { SOURCE } & \text { ELEV } \\ \text { COORDINATE } & \text { FT }\end{array}$

MAP NAME

Pedregosa Mts East

Baboquivari Peak

Empire Ranch

Lake Havasu City S Mount Fagan

Rhodes Peak

Columbia

Peach Springs

Mount Fagan

Cherry

Chiuli Shaik

Clark Ranch

Walker Mtn

Hell Point

Battle Flat

Battle Flat

King Canyon

Iron Springs

Battle Flat

Spider Rock

2091 
NATIONAL GAZETTEER--ARIZONA 1986

\section{FEATURE NAME}

Mule Hell

Muley Mountain

Mulgullo Point

Mulholland Bas in

Mulholland Creek See Mulholland Wash

Mulholland Tank

Mulholland Wash

Milholl and Creek Mulholland Creek

Mulkins Ranch

Mullen

See Topock

Mullen Mesa

Mullens Cut

Mullen Spring

Mullen Wash

Mullen Hell Mullen Wells

Mullen Hells

See Mullen Hell

Mullican Canyon Mulligan Canyon

Mullican Place Tank

Mullican Ranch

Mullican Tank

Mullican Tank Number One

Mullican Tank Number Two

Mulligan Canyon

See Mullican Canyon

Mulligan Peak

Mullin Spring

Munmy Cave

Mummy House

Mummy Cave Overlook

Mumny Cave Ruins

Mummy House

See Mummy Cave

Mummy Mounta in

Munmiy Mountain Observatory

Munds Canyon

Munds Canyon

Munds Draw

Munds Mountain

\section{Munds Park}

Munds Park

Munds Park Interchange

Munds Park Rest Area

Christenson Rest Area

Munds Park Substation

Munds Spring

Munds Tank

Munds Tank

Munds Tank

Munds Tank Number One

Munds Tank Number Two

Munds Wel1

Munro Reservoir

Munsonville

$$
\text { See San Jose }
$$

Mural Hil1

Murderers Grave

See Kenyon Station

Murdock Elementary School East Plantsite School

Murdock Meighborhood Center Murk Kui Wash

Murphey School

See Catalina Foothills School

Murphy Canyon

valley $B G N$

$315550 \mathrm{~N} 1121102$

\section{FEATURE}

\section{well}

summit

cliff

UNOFF
BGN
BGN 1925
BGN

COUNTY

\section{Graham}

Mohave

Coconino

Yavapai

$331642 \mathrm{N1101245 \textrm {W }}$

$361522 \mathrm{~N} 1123948 \mathrm{H}$

$343534 N 1131427 \mathrm{H}$

VARIANT

arroyo

reservoir

arroyo

locale

locale

summit

BGN

Yavapai

BGN

VARIANT

VARIANT

UNOFF

VARIANT

Cochise

BGN

Mohave

Yavapai

344306 $1142911 \mathrm{~W}$

$\begin{array}{llll}\text { gap } & \text { BGN } & \text { Maricopa } & 331937 \text { N1125923W } \\ \text { spring } & B G N & \text { Yavapai } & 343830 N 1123914 W\end{array}$

stream BGN Yavapai 340047N1114316

well UNOFF Maricopa 331957N1130113k

VARIANT

well

valley

BGN

VARIANT

reservoir

BGN

Maricopa

Yavapai

331957N1130113k

$344336 \mathrm{~N} 1114046 \mathrm{~W}$

$344415 \mathrm{~N} 1113610 \mathrm{~W}$

local

reservoir

reservoir

reservoir

UNOFF

BGN

BGN

BGN

VARIANT

valley

summit

spring

cave

BGN

BGN

BGN 1959

Green le

Pinal

VARIANT

$\begin{array}{llll}\text { locale } & \text { BGN } & \text { Apache } & 361340 \mathrm{N1092125W} \\ \text { locale } & \text { BGN } 1983 & \begin{array}{l}\text { Apache } \\ \text { A61357N1092120W }\end{array}\end{array}$

$345334 N 1121245$ W

$345130 \mathrm{~N} 1114238 \mathrm{~W}$

summit

BGN Coconino 345631N1113926W

ppl BGN Coconino 345644N1113822W

crossing UNOFF Coconino 345632N1113910W

locale BGN Coconino 345712N1114014H

locale UARIANT Coconino 345612N1113901H

$345514 N 1113415 \mathrm{~W}$

Coconino

reservoir BGN Coconino 345645N1113631K

reservoir BGN Mohave 351822N1132228W

reservoir BGN Yavapai 344951N1121150N

$\begin{array}{llll}\text { reservoir } & \text { BGN } & \text { Yavapa } & \text { 344951N1121150N } \\ \text { reservoir } & \text { BGM } & \text { Yavapai } & 344758 \text { N1121252W }\end{array}$

$\begin{array}{llll}\text { reservoir BGM } & \text { Yavapa } & 344758 \text { N1121252W } \\ \text { well } & \text { UNOFF } & \text { Mohave } & \text { 351811N1132228W }\end{array}$

reservoir BGN Gila 341355N1111751W

ppl

spl

VARIANT

locale

school

BGN

VARIANT

Graham

Cochise

$324912 \mathrm{~N} 1093529 \mathrm{~W}$

$312705 \mathrm{~N} 1095303 \mathrm{~W}$

UNOFF

Maricopa

VARIANT

locale

stream

UMOFF Coconino

BGN

VARIANT

Pima

school

valley

BGN

COORDINATE

$344043 \mathrm{~N} 1132250 \mathrm{~W}$

340117N1114111H

$344306 \mathrm{N1113334 \textrm {W }}$

$344416 \mathrm{~N} 1113620 \mathrm{~W}$

$344224 \mathrm{~N} 1113353 \mathrm{~W}$

$344224 \mathrm{~N} 1113000 \mathrm{~W}$

$344217 \mathrm{N1112926 \textrm {W }}$

$344336 \mathrm{~N} 1114046 \mathrm{~W}$

$330419 N 1091555 \mathrm{~W}$

$332637 \mathrm{N1111408 \textrm {W }}$

$361350 \mathrm{~N} 1092120$

361350 N1092120W

$333237 \mathrm{N1115735W}$

333319N1115742W

$345442 \mathrm{N11} 14331 \mathrm{~W}$

$351730 N 1132432 \mathrm{~W}$

$330145 \mathrm{~N} 1125540 \mathrm{H}$

SOURCE

ELEV

MAP NAME

3447 Branaman Spring

4808 Elephant Mtn

Havasu Falls

Bagdad

Hutch Mtn

Grayback Mts

Little Wood Canyon

Chalk Mountain

Gillespie

Mt Josh

Chalk Mountain

Columbus Peak

Casner Butte

Apache Maid Mtn

Apache Maid Mtn Apache Maid Mtn Apache Maid Mtn Happy Jack

5612 Clifton

Iron Mountain Mummy Cave Ruins

Mummy Cave Ruins Mummy Cave Ruins

2260 Paradise Valley Paradise Valley Munds Park

$\begin{array}{ll}351 B 02 N 1132240 \mathrm{~W} & \text { Tuckayou Spring } \\ 344607 \mathrm{~N} 1121518 \mathrm{~W} & \text { Perkinsville }\end{array}$

$\begin{array}{ll}351 B 02 N 1132240 \mathrm{~W} & \text { Tuckayou Sprin } \\ 344607 \mathrm{~N} 1121518 \mathrm{~W} & \text { Perkinsville }\end{array}$

6834 Munds Mountain

Munds Park

Munds Park

Munds Park

Munds Park

Munds Park

Mormon Mountain

Munds Mountain

Mormon Mountain

Blye Canyon SE

Munds Draw

Munds Draw

Blye Canyon SE

Payson South

6502 Bisbee

Clifton

$351135 \mathrm{~N} 1113850 \mathrm{~W}$

$321715 \mathrm{~N} 1105623 \mathrm{~W}$

$315550 \mathrm{~N} 1115711 \mathrm{~W}$

68B0 Flagstaff West

Kupk

Murphy Peak 


\section{FEATURE NAME}

Murphy Johnson Tank

Murphy Park

Murphy Peak

Murphy Ranch

Murphy Ranch

Murphy Ranch Mountain

Murphy School

Murphy School Number Two

Murphy School Three

Murphy Spring

Murphy Spring

Murphy Tank

Murphy Tank

Murphy Wash

Murphy Well

Murphy Well

Murphy Wel1

Murray Bas in

Murrays Lake

Murray Tank

Murray Wash

Museum of Northern Arizona

Mushroom Reef

Music Canyon

See Trap Canyon

Music Canyon

Music Canyon Spring

Music Mountain

Music Mountain Mine

Music Mountains

Musk Hog Canyon

Musk Hog Canyon

Musk Hog Canyon Spring

Muskhog Mountain

Muskhog Spring

Musk Hog Spring

Musk Hog Spring

Muskhog Tank

Muskhog Water

Mustang $\mathrm{Hi} 1$ ls

Mustang Knoll

Mustang Mountains

Mustang Park Tank

Mustang Peak

Mustang Point

Mustang Pond

Mustang Reservoir

Mustang Ridge

Mustang Spring

Mustang Spring

Mustang Tank

Mustang Tank

Myberg Bas in

Myers Mine

Myers Tank

Myres Mine

Myron Pond

Myrtle Lake

Myrt le Park

Myrtle Point

Myrtle Tank

Myrtle Trail

Mystery Castle

Mystery Spring

Mystery Valley Valley of Mystery

Mystic Spring

Mystic Spring Platea

See Spencer Terrace

M-Z Bar Ranch

\section{FEATURE \\ CLASS}

reservoir park

summit

locale

STATUS

COUNTY

BGN

ADMIN

BGN

Coconino

Maricopa

Santa Cruz

$\begin{array}{llll}\text { locale } & \text { UNOFF } & \text { Gila } & 334925 \mathrm{~N} 1105414 \mathrm{~W} \\ \text { summit } & \text { BGN } & \text { Gila } & 332903 \mathrm{~N} 1105600 \mathrm{~W} \\ \text { school } & \text { UNOFF } & \text { Maricopa } & 332612 \mathrm{~N} 1120656 \mathrm{~W} \\ \text { school } & \text { UNOFF } & \text { Maricopa } & 332653 \mathrm{~N} 1120735 \mathrm{~W} \\ \text { school } & \text { UNOFF } & \text { Maricopa } & 332547 \mathrm{N1120611W} \\ \text { spring } & \text { BGN } & \text { Gila } & 332939 \mathrm{~N} 1105547 \mathrm{~W} \\ \text { spring } & \text { BGN } & \text { Yavapai } & 343943 \mathrm{~N} 1125104 \mathrm{~W} \\ \text { reservoir } & \text { BGN } & \text { Cochise } & 314650 \mathrm{~N} 1100500 \mathrm{~W} \\ \text { reservoir } & \text { BGN } & \text { Gila } & 334930 \mathrm{~N} 1105405 \mathrm{~W} \\ \text { stream } & \text { BGN } & \text { Gila } & 332850 \mathrm{~N} 1105306 \mathrm{~W}\end{array}$

we

well

locale

basin

reservoir

stream

building

bar

valley

UNOFF

BGN

BGN

BGN

BGN

BGN
UNOFF

BGN 1948

VARIANT

Pima

Greenlee

Apache

Apache

Coconino

Coconino

Gila

Coconino

Mohave

Pinal

$\begin{array}{llll}\text { valley } & \text { BGN } 1969 & \text { Pinal } & 332705 \mathrm{~N} 1112022 \mathrm{~W} \\ \text { spring } & \text { BGN } & \text { Pinal } & 332707 N 1112015 \mathrm{~W} \\ \text { summit } & \text { BGN } & \text { Pinal } & 332719 \mathrm{N1111B} 42 \mathrm{~W} \\ \text { mine } & \text { UNOFF } & \text { Mohave } & 353832 \mathrm{~N} 1135442 \mathrm{~W} \\ \text { range } & \text { BGN } & \text { Mohave } & 353921 \mathrm{N1135011W} \\ \text { valley } & \text { BGN } & \text { Graham } & 330034 \mathrm{~N} 1101619 \mathrm{~W} \\ \text { valley } & \text { BGN } & \text { Pinal } & 332350 \mathrm{~N} 1111502 \mathrm{~W} \\ \text { spring } & \text { BGN } & \text { Graham } & 330134 \mathrm{~N} 1101641 \mathrm{~W} \\ \text { summit } & \text { BGN } & \text { Cochise } & 322126 \mathrm{~N} 1100530 \mathrm{~W} \\ \text { spring } & \text { BGN } & \text { Cochise } & 321406 \mathrm{~N} 1094002 \mathrm{~W}\end{array}$

$\begin{array}{llll}\text { spring } & \text { BGN } & \text { Pinal } & 330451 N 1102950 \mathrm{~W} \\ \text { spring } & \text { BGN } & \text { Maricopa } & 332922 \mathrm{~N} 1110401 \mathrm{~W}\end{array}$

$\begin{array}{llll}\text { spring } & \text { BGN } & \text { Maricopa } & 332922 \mathrm{~N} 1110401 \mathrm{~W} \\ \text { reservoir } & \text { BGN } & \text { Maricopa } & 333512 \mathrm{~N} 1111019 \mathrm{~W}\end{array}$

spring BGN Gila $\quad 332126 \mathrm{~N} 1105156 \mathrm{~W}$

summit BGN Yavapai 341247N1115010W

summit BGN 1979 Mohave 364336N1133936W

summit BGN Santa Cruz 314056N1102812W

reservoir BGN Coconino 350052N1113509W

summit BGN Santa Cruz 314136N1102833W

cliff BGN Mohave 361515N1134413W

reservoir BGN Mohave 364506N1134115W

reservoir BGN Mohave

ridge BGN

spring BGN Mohave

spring BGN Mohave

reservoir BGN Yavapai

reservoir

bas in

mine

reservoir

$B G N$

UNOFF

Coconin

Gila

Yavapai

Yavapai

reservoir

lake

park

cliff

reservoir

trail

building

spring

bas in

UNOFF
BGN
BGN
ADMIN
BGN
BGN
UNOFF
UNOFF
BGN
BGN

Pinal

Mohave

Coconino

Maricopa

Gila

Yavapai

Gila

Maricopa

Gila

Navajo

spring

BGN 1932

Coconino

bench VARIAN

locale

360846 N1130111W

$332130 \mathrm{N1120345 \textrm {W }}$
COORDINATE

$353649 \mathrm{~N} 1124701 \mathrm{~W}$

$333443 \mathrm{~N} 1121250 \mathrm{~W}$

$313106 \mathrm{~N} 1110949 \mathrm{~W}$

$315633 \mathrm{~N} 1103642 \mathrm{~W}$

$313240 \mathrm{~N} 1111003 \mathrm{~W}$

$324622 \mathrm{~N} 1091428 \mathrm{~W}$

$351729 \mathrm{~N} 1091526 \mathrm{~W}$

$340502 \mathrm{~N} 1091448 \mathrm{~W}$

$363753 N 1121032 \mathrm{~W}$

$351838 \mathrm{~N} 1122952 \mathrm{~W}$

$333050 \mathrm{~N} 1105148 \mathrm{~W}$

$351406 \mathrm{~N} 1113941 \mathrm{~K}$

360532N1142002W

332607N1111908W

$332719 N 1111911 W$

$361231 N 1122322 \mathrm{~W}$

SOURCE
COORDINATE

ELEV
FT

MAP NAME

6271 Big Bud Tank Glendale

5329 Murphy Peak

The Narrows

Aztec Peak

4389 Inspiration

Phoenix

Fowler

Phoenix

Inspiration

Smith Mesa

Haberstock Hill

Aztec Peak

332928 N1105409W

Inspiration

Murphy Peak

Sheldon

Burntwater Wash

Nelson Reservoir

Jacob Lake

Fitzgerald Hill

Rockinstraw Mtn

Flagstaff West

The Temple

$330237 N 1101748$

$332303 \mathrm{~N} 11$

$335116 \mathrm{~N} 1104244 \mathrm{~W}$

$364412 N 1134211 \mathrm{~W}$

$365142 N 1134247 \mathrm{~W}$

$341222 \mathrm{~N} 1114958 \mathrm{~W}$

$332622 \mathrm{~N} 1105519 \mathrm{~W}$

$340920 \mathrm{~N} 1124243 \mathrm{~W}$

$341016 \mathrm{~N} 1131056 \mathrm{~W}$

$331053 N 1111132 W$

$363956 \mathrm{~N} 1133441 \mathrm{~W}$

$342405 \mathrm{~N} 1110928 \mathrm{~W}$

$333244 \mathrm{~N} 1121036 \mathrm{~W}$

$342227 N 1110841 \mathrm{~W}$

$342615 \mathrm{~N} 1114215 \mathrm{~W}$

$342404 \mathrm{~N} 1111046 \mathrm{~W}$

$334656 \mathrm{~N} 1105918 \mathrm{~W}$

$365431 \mathrm{~N} 110111 \mathrm{OW}$

$361300 \mathrm{~N} 1122317 \mathrm{~W}$
$322223 \mathrm{N1110950 \textrm {W }}$
Weavers Needle

4311 Weavers Needle

Music Mountains NW

6646 Music Mountains NE

Mt Turnball

Weavers Needle

Mt Turnbull

7424 Muskhog Mountain Simmons Peak

Rawhide Mtn Haunted Canyon Pinyon Mtn

Bloody Bas in

6101 Mustang Knoll Mustang Mountains

6317 Mustang Mountains Mustang Point

Wolf Hole Mtn West Poverty Spring

Picacho Colorado

Mustang Knoll

Wolf Hole Mtn West

Bloody Bas in

6408 Vulcans Throne

Inspiration

Yarnell

Date Creek Ranch NW

Mineral Mtn

Sullivan Draw North

7782 Dane Canyon

Glendale

Diamond Point

Hackberry Mtn

Dane Canyon

Lone Butte

Aztec Peak

Mystery Valley

Explorers Monument

Avra Weavers Needle Lower Lake Mary 
NATIONAL GAZETTEER--ARIZONA 1986

COORDINATE

$\begin{array}{cc}\text { SOURCE } & \text { ELEV } \\ \text { COORDINATE } & \text { FT }\end{array}$

MAP NAME

$N$

Na Ah Tee

Na-Ah-Tee Canyon

Na-at-tee Canyon

Na-a-tih Trading Post

Naahtee Canyon

See Na Ah Tee Canyon

Na Ah Tee Canyon

Na-ettee

Naahtee Canyon

Ma-Ah-Tee Canyon See Ma Ah Tee

Na Ah Tee Canyon Spring

$\mathrm{Na}$ Ah Tee Wash

Naakai N Daachaahi Wash

$\mathrm{Na-a}$-tih Trading Post

See $\mathrm{Na}$ Ah Tee

Na-at-tee Canyon

Naches

See Natches

Nachi Kulik

Naco

Naco Hills

Naco Post Office

Nadaburg

See Wittmann

Nadaburg School

Na Des Bah Well

Naegel in Canyon

Naegel in Rim

Naegel in Rim Tank

Naegelin Spring Canyon

Naegle Tank

Naegle Well

$\mathrm{Na}$-ettee

See Na Ah Tee Canyon

Nagel Logging Camp

Nagiller Ranch

Nagiller Tank

Nagiller Tank

Nagiller Tank

Nagles Crossing

Nahche Mountain

See Boneyback Peak

Nail Canyon

See Lookout Canyon

Nail Canyon

Nail Creek

Nail Point

Nail Ranch

Naji Point

Najo Spring

akai Canyon

See Nokai Canyon

Nakai Creek

See Nokai Creek

Nakai Mesa

See Nokai Mesa

Nakai Yazzie Spring

Nakia Canyon

See Nokai Canyon

Nakia Creek

See Nokai Creek

Nakia Mesa

See Nokai Mesa

$\begin{array}{ll}\text { locale } & \text { BGN } \\ & \text { VARIANT } \\ & \text { VARIANT } \\ & \text { VARIANT } \\ & \text { VARIANT }\end{array}$

valley

VARIANT

$\begin{array}{ll}\text { valley } & \text { BGN } \\ & \text { VARIANT } \\ & \text { VARIANT } \\ & \text { VARIANT }\end{array}$

locale

spring

valley

valley

locale

BGN

BGN

BGN

VARIANT

$352918 N 1100709 W$

Navajo

352918N1100709W

$352949 N 1101111 W$

Indian Wells

Navajo 352925N1100838W

Navajo 352948N1101012W

Mavajo 352823N1100422W

Apache

Navajo

$354342 N 1093023 \mathrm{~W}$

$352918 \mathrm{~N} 1100709 \mathrm{~W}$ $354110 \mathrm{N1093024W}$

Na Ah Tee Canyon

Indian Wells

Kinlichee

VARIANT

locale

locale

summit

ppl

summit

building

pp 1

VARIANT
BGN
BGN
BGN
UNOFF
VARIAN

Navajo

352925N1100838W

Graham

Pima

Cochise

Cochise

Cochise

Maricopa

31239N1101758W

$313600 \mathrm{~N} 1114228 \mathrm{~W}$

$312007 \mathrm{~N} 1095651 \mathrm{~W}$

$312344 N 1095845 \mathrm{~W}$

$312008 \mathrm{~N} 1095645 \mathrm{~W}$

$334635 \mathrm{~N} 1123140 \mathrm{~W}$

school UNOFF Maricopa 334653N1123128W

locale BGN Apache 353717N1092412W

$\begin{array}{llll}\text { valley } & \text { BGN } & \text { Gila } & 341406 N 1105557 \mathrm{~W}\end{array}$

cliff $B G N \quad$ Gila $\quad 341237$ N1105159W

reservoir BGN Gila 341234N1105130W

valley BGN Gila 341009 N1105359W

reservoir BGN Apache 341030N1094428

well UNOFF Cochise 315346N1102230W

valley

VARIANT

Navajo

$352918 \mathrm{~N} 1100709 \mathrm{~W}$

\begin{tabular}{|c|c|c|c|}
\hline $\begin{array}{l}\text { locale } \\
\text { locale } \\
\text { reservoir } \\
\text { reservoir } \\
\text { reservoir } \\
\text { locale }\end{array}$ & $\begin{array}{l}\text { BGN } \\
\text { UNOFF } \\
\text { BGN } \\
\text { BGN } \\
\text { BGN } \\
\text { BGN }\end{array}$ & $\begin{array}{l}\text { Coconino } \\
\text { Coconino } \\
\text { Coconino } \\
\text { Coconino } \\
\text { Coconino } \\
\text { Mohave }\end{array}$ & $\begin{array}{l}342737 \mathrm{~N} 1105428 \mathrm{~W} \\
353346 \mathrm{~N} 1115956 \mathrm{~W} \\
350939 \mathrm{~N} 1121927 \mathrm{~W} \\
355213 \mathrm{~N} 1120445 \mathrm{~W} \\
360044 \mathrm{~N} 1122739 \mathrm{~W} \\
365150 \mathrm{~N} 1123444 \mathrm{~W}\end{array}$ \\
\hline & VARIANT & Gila & $35142 N 1110$ \\
\hline & & Coconino & $363508 N 1122$ \\
\hline
\end{tabular}

$\begin{array}{llll}\text { valley } & \text { BGN } & \text { Coconino } & 364233 \mathrm{~N} 1122233 \mathrm{~W} \\ \text { stream } & \text { BGN } & \text { Gila } & 333730 \mathrm{~N} 1105319 \mathrm{~W} \\ \text { cliff } & \text { BGN } & \text { Coconino } & 363742 \mathrm{~N} 1122010 \mathrm{~W} \\ \text { locale } & \text { UNOFF } & \text { Gila } & 340745 \mathrm{~N} 1104813 \mathrm{~W} \\ \text { cliff } & \text { BGN 1906 } & \text { Coconino } & 361020 \mathrm{N1115528 \textrm {W }} \\ \text { reservoir } & \text { BGN } & \text { Cochise } & 315003 \mathrm{~N} 1095420 \mathrm{~W} \\ \text { valley } & \text { VARIANT } & \text { Navajo } & 371236 \mathrm{~N} 1103340 \mathrm{~W} \\ \text { stream } & \text { VARIANT } & & \\ & & \text { San Juan (UT) } & 371236 \mathrm{~N} 1103340 \mathrm{~W}\end{array}$

summit

VARIANT

spring

valley

stream

summit

$\begin{array}{lll}\text { BGN } & \text { Navajo } & 365827 \text { N1102850W } \\ \text { VARIANT } & \text { Navajo } & 360820 \text { N1104028W } \\ \text { VARIANT } & \text { Navajo } & 371236 \text { N1103340W } \\ \text { VARIANT } & \text { San Juan (UT) } & 371236 \text { N1103340W } \\ & \text { Navajo } & 365827 \text { N1102850W }\end{array}$

341250 N1104936

341131 N1105400

3096 Caponera Peak

Naco

8 isbee

Naco

Wittmann

7006 Tudecoz Spring Oxbow Mtn

Parallel Canyon

Parallel Canyon

Oxbow Mtn

Boundary Butte

Benson

7120 Porcupine Ridge

Ebert Mtn

McLellan Reservoir

Red Butte

Chamisa Tank

Clear Water Spring

$363508 \mathrm{~N} 1122047 \mathrm{~W}$ $333629 \mathrm{~N} 1105215 \mathrm{~W}$

Toothpick Ridge

Salt River Peak

Warm Springs Canyon

Parallel Canyon

Walhalla Plateau

Black Diamond Peak

Rocky Ridge NW 
NATIONAL GAZETTEER--ARIZONA 1986

\section{FEATURE NAME}

Nalakihu Ruin

Naltazan Well

Naltazen Dam

Naltazen Dam Number One

Nan Dahs Taan Mesa

Nankoweap Butte

Nankoweap Canyon

Nankoweap Creek

Nankoweap Mesa

Nankoweap Rapids

Nan Lyons School

See Lyons School

Nantac Rim

Nantac Trail

Nantes Mountains

See Natanes Plateau

Nantes Mountains

See Natanes Mountains

Napoleons Tomb

Nappa Spring

Narcho Santos

Nariska

Nariz, Sierra de la Mariz Mountains

Nariz Mountains

See Ajo Range

Nariz Mountains

See Nariz, Sierra de la

Narragansett Mine

Narrow Creek Spring

Narrow Gauge Tank

Narrows, The

Narrows, The

Narrows, The

Narrows, The

Narrows. The

Narrows, The

Narrows, The

Narrows, The

Narrows Tank

Narrows Tank

Narrow Tank

Narrow Wash

Nash-bito

See Lizard Spring (historical)

Nash Canyon

Nash Creek

Indian Creek

South Fork Nash Creek

Nash Creek Dam

Nash Creek Reservoir

Nashklini Creek

See Nazlini Creek

Nashlini Creek

See Mazlini Creek

Nash Pasture Tank

Nash Point

Nash School

$$
\text { E C Nash School }
$$

Nas ib Karam Park

Naslini

See Nazlini

Natanabah Well

Natanes Butte

See Chiricahua Butte

Natanes Creek

Natanes Mountain

See Natanes Plateau

Natanes Mountains

Nantes Mountains
FEATURE
CLASS

STATUS

locale

BGN

COOROINATE

Coconino

353358N1112812W

wel

dam

summit

summit

valley

stream

summit

rapids

school

UNOFF

UNOFF

UNOFF

BGN 1932

BGN 1927

BGN 1932

BGN 1927

BGN 1932

VARIANT

Gila

Gila

Gila

Navajo

Coconino

Coconino

Coconino

Coconino

Coconino

Pima

cliff

trail

BGN

UNOFF

VARIANT

plain

summit

is land

spring

locale

locale

summit

VARIANT

BGN 1948

Graham

BGN Pima

BGN Pinal

range

summit

mine

spring

reservoir

gap

BGN 194

Pima

VARIANT

VARIANT Pima

Pima

UNOFF

BGN

BGN

Pima

Apache

Pima

gap

gap

gap

gap

gap

valley

reservoir

reservoir

reservoir

BGN

BGN

$B G N$

$B G N$

BGN

$B G N$
$B G N$
$B G N$

$B G N$

BGM

valley $\quad B G N$

spring

VARIANT

Cochise

Graha

Gila

Coconino

Coconino

Gila

Mohave

Gila

Yavapai

Graham

331214 N1104114W

332141 N1102910W

$331800 \mathrm{NL} 104030 \mathrm{~W}$

$335127 \mathrm{N1095829 \textrm {W }}$

361547 N1115259W

$361817 N 1115128 \mathrm{~W}$

361817 N1115128W

$361633 \mathrm{~N} 1115134 \mathrm{~W}$

361817 N1115117W

321016 N1104946W

$331822 \mathrm{~N} 1094744 \mathrm{~W}$

$331749 \mathrm{N1094405 \textrm {W }}$

$333205 N 1095617 \mathrm{~W}$

332421 N1095524W

$360709 \mathrm{N1142127 \textrm {W }}$

$342118 \mathrm{~N} 1110111 \mathrm{~W}$

$320843 \mathrm{~N} 1120828 \mathrm{~W}$

$323016 \mathrm{~N} 1111546 \mathrm{~W}$

314742N1123216W

$320240 \mathrm{~N} 1124104 \mathrm{~W}$

$314742 \mathrm{~N} 1123216 \mathrm{~W}$

$315045 \mathrm{NL104535 \textrm {W }}$

362447 N1090409W

$344612 \mathrm{~N} 1121307 \mathrm{~W}$

$315328 \mathrm{N1103247 \textrm {W }}$

$320735 N 1101725 \mathrm{~W}$

$330144 N 1094744 \mathrm{~W}$

$340734 \mathrm{N1111507W}$

$351402 \mathrm{~N} 1114004 \mathrm{~W}$

$361735 \mathrm{~N} 1104953 \mathrm{~W}$

$342137 N 1112656 \mathrm{~W}$

$365508 \mathrm{N1} 135147 \mathrm{~W}$

$332203 \mathrm{N1103417 \textrm {W }}$

$341049 \mathrm{N1} 115423 \mathrm{~W}$

$323128 \mathrm{N1} 101434 \mathrm{~W}$

Coconino

$361527 N 1105643 \mathrm{~W}$

354500 N1093600W

valley

BGN

Apache

stream

BGN

Navajo

VARIANT

BGN

Navajo

Navajo

VARIANT

stream

VARIAN

stream

reservoir

summit

school

BGN

BGN

UNOFF

park

ADMIN

pp 1

VARIANT

Apache

Apache

Gila

Coconino

Pima

Santa Cruz

Apache

Coconino

we11

UNOFF

VARIANT

summit

stream

$B G N$

VARIANT

plain

summit

BGN

VARIANT

$\begin{array}{ccc}\text { SOURCE } & \text { ELEV } \\ \text { COORDINATE } & \text { FT MAP NAME }\end{array}$

Wupatki SW

Mescal Warm Spring

San Carlos

Cutter

6268 Whiteriver

5430 Point Imperial

361633N1115408W Nankoweap Mesa

361419N1115842W Nankoweap Mesa

6242 Nankoweap Mesa

Nankoweap Mesa

Point of Pines West

Point of Pines East

The Temple

Promontory Butte

Maish Vaya

1950 Friendly Corners

2688 Menagers Lake

Helvetia

Roof Butte

Munds Draw

The Narrows

Wildhorse Mtn

Markham Creek

Payson South

Flagstaff West

John Daw Mesa

$342151 \mathrm{~N} 1112648 \mathrm{~W}$

$365501 \mathrm{N1} 134958 \mathrm{~W}$

Tead a

Mtn Sheep Spring 
NATIONAL GAZETTEER--ARIZONA 1986

\section{FEATURE
CLASS}

Natanes Peak

See Chiricahua Butte

Natanes Plateau Nantes Mountains Natanes Mountains

Natch Canyon

Natches

Naches

Natchez Mountain

See Boneyback Peak

Natchi Point

See Uncle Jim Point

Nates Canyon

Nates Tank

National Canyon Cataract Canyon

National Park Service

Training Center National Park Service Training School

National Park Service

Training School

See National Park Service Training Center

National Tank

Nativity School

latkatameeba Rapids See Matkatamiba Rapids

Natoni Wel

Nat Tank

Natural Arch

Natural Arch

Natural Arch

Natural Arch

Natural Arch

Natural Bridge See Tonto Natural Bridge

Natural Bridge

Natural Bridge Canyon

Natural Corral

Natural Corral Creek Oak Creek

Natural Corral Creek

See Cassadore Creek

Natural Corral Mesa

Natural Corral Spring

Natural Corrals Wash

Natural Tank

Natural Tank

Natural Tank

Natural Tank

Natural Tank

Natural Tank

Natural Tank

Natural Tank

Natural Tank

Natural Tank

Natural Tanks

Natural Well

Natural Window

Navaho

See Navajo

Navaho Country

See Navajo Country

Navaho County

See Navajo County

Navaho Creek

See Navajo Creek

Navaho Reservation

See Navajo Indian

Reservation
CLASS

STATUS

COUNTY

COORDINATE

SOURCE

COORDINATE

ELEV
FT

VARIANT

summit

Gila

$333341 N 1100742 W$

BGN

VARIANT

VARIANT

valley

BGN

$B G N$

VARIANT

VARIANT

summit

VARIANT

cliff

Graham

$333205 N 1095617 W$

Coconino

$360958 \mathrm{~N} 1115420 \mathrm{~W}$

$331239 \mathrm{~N} 1101758 \mathrm{~W}$

$361152 N 1115611$

Gila

$335142 \mathrm{~N} 1110953 \mathrm{~W}$

Coconino

$361248 \mathrm{~N} 1120209 \mathrm{~W}$

valley BGN Mohave 363556N1124949W

reservoir BGN Mohave 363319N1125135W

valley BGN Coconino 361524N1125329W

VARIANT

school UNOFF

Coconino

$360259 \mathrm{~N} 1120756 \mathrm{~W}$

VARIANT

VARIANT

school

Coconino

360259N1120756W

\begin{tabular}{|c|c|c|c|}
\hline $\begin{array}{l}\text { reservoir } \\
\text { school }\end{array}$ & $\begin{array}{l}\text { BGN } \\
\text { UNOFF }\end{array}$ & $\begin{array}{l}\text { Coconino } \\
\text { Coconino }\end{array}$ & $\begin{array}{l}355810 N 1125612 \mathrm{~W} \\
351205 \mathrm{~N} 1113854 \mathrm{~W}\end{array}$ \\
\hline $\begin{array}{l}\text { rapids } \\
\text { well } \\
\text { reservoir } \\
\text { arch } \\
\text { arch } \\
\text { arch }\end{array}$ & $\begin{array}{l}\text { UNOFF } \\
\text { BGN } \\
\text { BGN } \\
\text { BGN } \\
\text { BGN } \\
\text { BGN }\end{array}$ & $\begin{array}{l}\text { Coconino } \\
\text { Coconino } \\
\text { Coconino } \\
\text { Yuma } \\
\text { Mohave } \\
\text { Navajo } \\
\text { Navajo }\end{array}$ & $\begin{array}{l}362039 \mathrm{~N} 1124018 \mathrm{~W} \\
353345 \mathrm{~N} 1110750 \mathrm{~W} \\
350426 \mathrm{~N} 1121315 \mathrm{~W} \\
340946 \mathrm{~N} 1135117 \mathrm{~W} \\
361551 \mathrm{N1125503W} \\
364545 \mathrm{~N} 1100822 \mathrm{~W} \\
365357 \mathrm{~N} 1101007 \mathrm{~W}\end{array}$ \\
\hline
\end{tabular}

365729N1095240W

arch

arch

valley

locale

stream

BGN

VARIANT

BGN

BGN

BGN

BGN

VARIANT

stream

VARIANT

Apache

Gila

Mohave

Apache

Gila

Gila

Gila

summit

BGN

spring

strean

reservoir

reservoir

reservoir

reservoir

reservoir

reservoir

Graham

Mohave

Yuma

Gila

Gila

Yavapai

Coconino

Coconino

reservoir BGN Yavapai

reservoir $B G N$

reservoir

reservoir

well

arch

BGN

BGN
UNOFF

BGN

VARIANT

pp 1

VARIANT

Coconino

Coconino

Cochise

Gila

Coconino

Apache

Navajo

341914N1112721W

$355235 \mathrm{~N} 1131908 \mathrm{~W}$

$354228 \mathrm{~N} 1090554 \mathrm{~W}$

332826 N1102538W

$332404 N 1102440 \mathrm{~W}$

$354320 \mathrm{~N} 1091005 \mathrm{~W}$

332904 N1102452W

$332904 N 1102452 W$

$332630 \mathrm{~N} 1102642 \mathrm{~W}$

330854N1095730W

$344353 N 1133632 W$

$323937 N 1132107 \mathrm{~W}$

$332505 N 1102634 \mathrm{k}$

$340400 N 1105403 \mathrm{~W}$

$342745 N 1113419 \mathrm{~W}$

$343424 N 1111609 \mathrm{~W}$

344240N1110852W

$344624 \mathrm{~N} 1112709 \mathrm{~W}$

$344648 \mathrm{~N} 1114037 \mathrm{~W}$

$344730 \mathrm{~N} 1111037 \mathrm{~W}$

355646 N1130118W

$313808 \mathrm{~N} 1090451 \mathrm{~W}$

$334305 N 1104520$

$365402 \mathrm{~N} 1105928 \mathrm{~W}$

$350727 N 1093215 \mathrm{~W}$

area

VARIANT

civil

VARIANT

stream

VARIAN

Navajo

Coconino

$365615 \mathrm{~N} 1104845 \mathrm{~W}$

reserve

344411 N1134356
363206N1125212W

Robinson Canyon Robinson Canyon

Grand Canyon

355330N1125340W $\quad \begin{aligned} & \text { Robinson Canyon } \\ & \text { Fern Glen Canyon } \\ & \text { Grand Canyon }\end{aligned}$

National Tank

Flagstaff West

Standing Rocks

May Tank Pocket

Swansea

Fern Glen Canyon

Agathla Peak

Mystery Valley

Rooster Rock

Granite Park

Window Rock

Natural Corral

Natural Corral

Natural Corral

Gila Peak

Wikieup

Aguila Mts ME

Natural Corral

Young

Strawberry

Long Valley

Hay Lake

Hutch Mtn

Munds Mountain

Chavez Mtn West

Prospect Point

Skull Canyon

Dagger Peak

Chaiyahi Flat 


\begin{tabular}{|c|c|c|c|c|c|c|c|}
\hline FEATURE NAME & $\begin{array}{l}\text { FEATURE } \\
\text { CLASS }\end{array}$ & STATUS & COUNTY & COORDINATE & $\begin{array}{l}\text { SOURCE } \\
\text { COORDINATE }\end{array}$ & $\begin{array}{l}\text { ELEV } \\
\text { FT }\end{array}$ & MAP NAME \\
\hline $\begin{array}{l}\text { Navaho Spring } \\
\text { See Navajo Spring } \\
\text { Navajo } \\
\text { Navaho } \\
\text { Navajoe }\end{array}$ & $\begin{array}{l}\text { spring } \\
\text { ppl }\end{array}$ & $\begin{array}{l}\text { VARIANT } \\
\text { BGN } 1906 \\
\text { VARIANT } \\
\text { VARIANT }\end{array}$ & $\begin{array}{l}\text { Coconino } \\
\text { Apache }\end{array}$ & $\begin{array}{l}364555 \mathrm{~N} 1113602 \mathrm{~W} \\
350727 \mathrm{~N} 1093215 \mathrm{~W}\end{array}$ & & & Navajo South \\
\hline $\begin{array}{l}\text { Navajo Bill Spring } \\
\text { Navajo Bill Tank } \\
\text { Navajo Bridge } \\
\text { Grand Canyon Bridge } \\
\text { Navajo Canyon } \\
\text { Navajo Community Center } \\
\text { Navajo Community College } \\
\text { Navajo Community College } \\
\text { Navajo Compressor Station } \\
\text { Navajo Country } \\
\text { Navaho Country }\end{array}$ & $\begin{array}{l}\text { spring } \\
\text { reservoir } \\
\text { bridge } \\
\text { valley } \\
\text { building } \\
\text { school } \\
\text { school } \\
\text { locale } \\
\text { area }\end{array}$ & $\begin{array}{l}\text { BGN } \\
\text { BGN } \\
\text { UNOFF } \\
\text { VARIANT } \\
\text { BGN } 1963 \\
\text { UNOFF } \\
\text { UNOFF } \\
\text { UNOFF } \\
\text { UNOFF } \\
\text { BGN } \\
\text { VARIANT }\end{array}$ & $\begin{array}{l}\text { Gila } \\
\text { Gila } \\
\text { Coconino } \\
\text { Coconino } \\
\text { Apache } \\
\text { Apache } \\
\text { Apache } \\
\text { Apache } \\
\text { Navajo }\end{array}$ & $\begin{array}{l}334332 \mathrm{~N} 1100702 \mathrm{~W} \\
334443 \mathrm{~N} 1100812 \mathrm{~W} \\
364904 \mathrm{~N} 1113751 \mathrm{~W} \\
\\
365831 \mathrm{~N} 1112315 \mathrm{~W} \\
351707 \mathrm{~N} 1091242 \mathrm{~W} \\
361736 \mathrm{~N} 1091257 \mathrm{~W} \\
362216 \mathrm{~N} 1093732 \mathrm{~W} \\
353312 \mathrm{~N} 1094331 \mathrm{~W} \\
360001 \mathrm{~N} 1100001 \mathrm{~W}\end{array}$ & $364045 \mathrm{~N} 1104947 \mathrm{~W}$ & $\begin{array}{l}6000 \\
7070\end{array}$ & $\begin{array}{l}\text { Velasquez Butte } \\
\text { Forks Butte } \\
\text { Navajo Bridge } \\
\text { Page } \\
\text { Houck } \\
\text { Tsaile } \\
\text { Many Farms SW } \\
\text { Sunrise Springs } \\
\text { Whippoorwill Spring }\end{array}$ \\
\hline $\begin{array}{c}\text { Navajo County } \\
\text { Apache County } \\
\text { Navaho County } \\
\text { Navajoe County } \\
\text { Navajo County Fairgrounds } \\
\text { Navajo Creek } \\
\text { Navaho Creek } \\
\text { Navajoe Creek } \\
\text { Navajoe } \\
\text { See Navajo }\end{array}$ & $\begin{array}{l}\text { locale } \\
\text { stream }\end{array}$ & $\begin{array}{l}\text { BGN } 1906 \\
\text { VARIANT } \\
\text { VARIANT } \\
\text { VARIANT } \\
\text { BGN } \\
\text { BGN } 1906 \\
\text { VARIANT } \\
\text { VARIANT } \\
\text { VARIANT }\end{array}$ & $\begin{array}{l}\text { Mavajo } \\
\text { Coconino }\end{array}$ & $\begin{array}{l}345407 \mathrm{~N} 1100910 \mathrm{~W} \\
365826 \mathrm{~N} 1112320 \mathrm{~W}\end{array}$ & $363626 \mathrm{~N} 1104818 \mathrm{~W}$ & & Tall Mountain NW \\
\hline $\begin{array}{l}\text { Navajoe County } \\
\text { See Navajo County } \\
\text { Navajoe Creek } \\
\text { See Navajo Creek } \\
\text { Navajoe Reservation } \\
\text { See Navajo Reservation } \\
\text { Navajoe Spring } \\
\text { See Navajo Spring } \\
\text { Navajo Falls } \\
\text { Navajo Fortress }\end{array}$ & $\begin{array}{l}\text { civil } \\
\text { stream } \\
\text { reserve } \\
\text { spring } \\
\text { falls } \\
\text { summit }\end{array}$ & $\begin{array}{l}\text { VARIANT } \\
\text { VARIANT } \\
\text { VARIANT } \\
\text { VARIANT } \\
\text { BGN } 1932 \\
\text { BGN }\end{array}$ & $\begin{array}{l}\text { Navajo } \\
\text { Coconino } \\
\text { Apache } \\
\text { Coconino } \\
\text { Coconino } \\
\text { Apache }\end{array}$ & $\begin{array}{l}365615 \mathrm{~N} 1104845 \mathrm{~W} \\
365826 \mathrm{~N} 1112320 \mathrm{~W} \\
354501 \mathrm{~N} 1094459 \mathrm{~W} \\
\\
364555 \mathrm{~N} 1113602 \mathrm{~W} \\
361458 \mathrm{~N} 1124151 \mathrm{~W} \\
360924 \mathrm{~N} 1092602 \mathrm{~W}\end{array}$ & & 6483 & $\begin{array}{l}\text { Supai } \\
\text { Del Muerto }\end{array}$ \\
\hline $\begin{array}{l}\text { Navajo Gospel Mission } \\
\text { Navajo-Hopi Joint Use Area } \\
\text { Navajo Indian Reservation } \\
\text { Western Navaho } \\
\text { Reservation } \\
\text { Navaho Reservation } \\
\text { Piute Indian Reservation } \\
\text { Navajo Interchange } \\
\text { Navajo Interchange } \\
\text { Navajo John Well }\end{array}$ & $\begin{array}{l}\text { crossing } \\
\text { crossing } \\
\text { well }\end{array}$ & $\begin{array}{l}\text { UNOFF } \\
\text { BGN } \\
\text { BGN } 1906 \\
\text { VARIANT } \\
\text { VARIANT } \\
\text { VARIANT } \\
\text { UNOFF } \\
\text { UNOFF } \\
\text { UNOFF }\end{array}$ & $\begin{array}{l}\text { Apache } \\
\text { Coconino } \\
\text { Coconino }\end{array}$ & $\begin{array}{l}360210 \mathrm{~N} 1103032 \mathrm{~W} \\
353500 \mathrm{~N} 1102000 \mathrm{~W} \\
363001 \mathrm{~N} 1090001 \mathrm{~W}\end{array}$ & & 5676 & $\begin{array}{l}\text { Rocky Ridge SE } \\
\text { Hauke Mesa } \\
\text { Red Valley }\end{array}$ \\
\hline $\begin{array}{l}\text { Navajo Lookout Dam } \\
\text { Navajo Lutheran Missions } \\
\text { Navajo Mission } \\
\text { Navajo Mission School } \\
\text { Navajo Mountain } \\
\text { Mount Seneca Howland } \\
\text { Sierra Panoche } \\
\text { Navajo Mountain Mission } \\
\text { Navajo National Monument } \\
\text { Navajo National Monument } \\
\text { Campground }\end{array}$ & $\begin{array}{l}\text { dam } \\
\text { church } \\
\text { church } \\
\text { school } \\
\text { summit }\end{array}$ & $\begin{array}{l}\text { UNOFF } \\
\text { UNOFF } \\
\text { UNOFF } \\
\text { UNOFF } \\
\text { BGN } \\
\text { VARIANT } \\
\text { VARIANT } \\
\text { UNOFF } \\
\text { ADMIN } \\
\text { ADMIN }\end{array}$ & $\begin{array}{l}\text { Navajo } \\
\text { Apache } \\
\text { Apache } \\
\text { Navajo } \\
\text { Coconino }\end{array}$ & $\begin{array}{l}353718 \mathrm{~N} 1103316 \mathrm{~W} \\
365418 \mathrm{~N} 1090614 \mathrm{~W} \\
353529 \mathrm{~N} 1090608 \mathrm{~W} \\
345306 \mathrm{~N} 1101136 \mathrm{~W} \\
370200 \mathrm{~N} 1105210 \mathrm{~W} \\
\\
365605 \mathrm{~N} 1104632 \mathrm{~W} \\
364111 \mathrm{~N} 1103209 \mathrm{~W} \\
364112 \mathrm{~N} 1103229 \mathrm{~W}\end{array}$ & & 1038 & $\begin{array}{l}\text { Tovar Mesa East } \\
\text { Teec Nos Pos } \\
\text { Hunters Point } \\
\text { Holbrook } \\
\text { Navajo Begay } \\
\\
\text { Chaiyahi Rim NE } \\
\text { Betatak in Ruin } \\
\text { Betatakin Ruin }\end{array}$ \\
\hline $\begin{array}{l}\text { Navajo National Monument } \\
\text { Headquarters } \\
\text { Navajo Number Five Airstrip } \\
\text { Navajo Number Four Airstrip } \\
\text { Navajo Park } \\
\text { Navajo Point } \\
\text { Navajo Point } \\
\text { Navajo Point } \\
\text { See Desert View Point } \\
\text { Navajo Point } \\
\text { See Desert View }\end{array}$ & $\begin{array}{l}\text { building } \\
\text { airport } \\
\text { airport } \\
\text { park } \\
\text { cliff } \\
\text { cliff } \\
\text { summit } \\
\text { locale }\end{array}$ & $\begin{array}{l}\text { UNOFF } \\
\text { ADMIN } \\
\text { ADMIN } \\
\text { ADMIN } \\
\text { BGN } \\
\text { BGN } \\
\text { VARIANT } \\
\text { VARIANT }\end{array}$ & $\begin{array}{l}\text { Navajo } \\
\text { Apache } \\
\text { Apache } \\
\text { Pima } \\
\text { Graham } \\
\text { Coconino } \\
\text { Coconino } \\
\text { Coconino }\end{array}$ & $\begin{array}{l}364042 \mathrm{~N} 1103225 \mathrm{~W} \\
345312 \mathrm{~N} 1092536 \mathrm{~W} \\
345442 \mathrm{~N} 1093830 \mathrm{~W} \\
321559 \mathrm{~N} 1105733 \mathrm{~W} \\
330917 \mathrm{~N} 1100750 \mathrm{~W} \\
360242 \mathrm{~N} 1114930 \mathrm{~W} \\
360230 \mathrm{~N} 1114926 \mathrm{~W} \\
360234 \mathrm{~N} 1114933 \mathrm{~W}\end{array}$ & & $\begin{array}{l}6440 \\
5800\end{array}$ & $\begin{array}{l}\text { Betatakin Ruin } \\
\text { Hogan Well } \\
\text { Adamana One Nw } \\
\text { Tucson North } \\
\text { Calva } \\
\text { Desert View }\end{array}$ \\
\hline $\begin{array}{l}\text { Navajo Pond } \\
\text { Navajo Reservation } \\
\text { Navajoe Reservation }\end{array}$ & $\begin{array}{l}\text { reservoir } \\
\text { reserve }\end{array}$ & $\begin{array}{l}\text { BGN } \\
\text { BGN } 1906 \\
\text { VARIANT }\end{array}$ & $\begin{array}{l}\text { Mohave } \\
\text { Apache }\end{array}$ & $\begin{array}{l}364234 N 1131811 W \\
354501 N 1094459 W\end{array}$ & & & $\begin{array}{l}\text { The Grandstand } \\
\text { Ganado Mesa SW }\end{array}$ \\
\hline
\end{tabular}


NATIONAL GAZETTEER--ARIZONA 1986

\section{FEATURE NAME}

Navajo School

Navajo Spring

Navajo Spring

Navaho Spring

Navajoe Spring

Navajo Springs

Navajo Springs

Navajo Stand Rock

Navajo Station

Navajo Trail

Navajo Tribal Fairground

Navajo Tribal Headquarters

Navajo Tribal Museum and Zoo Tse Bonito Museum

Navajo Tribe Ranch Headquarters Navapache Hospital

Navato Pit Tank

Naviska

Nawt Vaya

Agua la Vara

Agua la Varia

Agua Lavaria

Alamo

Not Vaya

Nawt Vaya Well

Naylor Junior High School

Nazlini

Naslini

Nazlini Trading Post

Nazlini Airport

Nazlini Canyon

Nazl ini Creek

Nashlini Creek

Nashklini Creek

Nazlini Creek

See Nazlini Wash

Nazlini Trading Post See Nazlini

Nazlini Trading Post

Nazlini Wash Chinle Wash Nazlini Creek

Nazlini Wash

See Chinle Wash

N B Ranch

Ndishchii Naati

Neagle Ranch

Neal Butler Park

Neal Cabin

Neal Canyon

Neale Mesa

Neal Mountain

Neal Mountain Tank

Neal Mountain Tank

Neal Spring

Neal Spring Sandwash Spring

Nea1 Spring

Neal Spring

Neal Tank

Neal Tank Number Two

Nealy Well

Neatherl in Latera

Neboyias Water Well

Ned Lake

Needed Tank

Needed Tank

Nee De Mise Betoh

Need le, The

Needle, The$$
\begin{aligned}
& \text { FEATURE } \\
& \text { CLASS } \\
& \text { school } \\
& \text { spring } \\
& \text { spring } \\
& \text { spring } \\
& \text { spring } \\
& \text { pillar } \\
& \text { locale } \\
& \text { trail } \\
& \text { park } \\
& \text { building } \\
& \text { locale } \\
& \text { building } \\
& \text { hospital } \\
& \text { reservoir }
\end{aligned}
$$$$
\text { locale }
$$$$
\text { STATUS COUNTY COOROINATE }
$$

(n)

well

school

ppl

(a)
VARIANT VARIANT VARIANT UNOFF UNOFF BGN

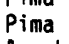

Apache VARIANT

\begin{tabular}{|c|c|c|c|c|c|c|}
\hline $\begin{array}{l}\text { airport } \\
\text { valley } \\
\text { stream }\end{array}$ & $\begin{array}{l}\text { ADMIN } \\
\text { BGN } \\
\text { BGN } 1983 \\
\text { VARIANT } \\
\text { VARIANT } \\
\text { VARIANT }\end{array}$ & $\begin{array}{l}\text { Apache } \\
\text { Apache } \\
\text { Apache }\end{array}$ & 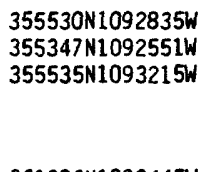 & $\begin{array}{l}355549 N 1092147 \mathrm{~W} \\
355928 \mathrm{~N} 1091837 \mathrm{~W}\end{array}$ & 6180 & $\begin{array}{l}\text { Nazlini } \\
\text { Nazlini } \\
\text { Beautiful val Well }\end{array}$ \\
\hline stream & VARIANT & Apache & $361206 N 1093445 W$ & & & \\
\hline $\begin{array}{l}\text { ppl } \\
\text { locale }\end{array}$ & BGN & $\begin{array}{l}\text { Apache } \\
\text { Apache }\end{array}$ & $\begin{array}{l}355347 \mathrm{N1} 1092653 \mathrm{~W} \\
355347 \mathrm{~N} 1092656 \mathrm{~W}\end{array}$ & & & Nazlini \\
\hline stream & $\begin{array}{l}\text { BGN } 1983 \\
\text { VARIANT } \\
\text { VARIANT } \\
\text { VARIANT }\end{array}$ & Apache & $361206 N 1093445 \mathrm{~W}$ & $355935 \mathrm{~N} 1093215 \mathrm{~W}$ & & Chinle $4 \mathrm{NE}$ \\
\hline $\begin{array}{l}\text { stream } \\
\text { locale } \\
\text { area } \\
\text { locale } \\
\text { park } \\
\text { locale }\end{array}$ & $\begin{array}{l}\text { UNOFF } \\
\text { BGN } \\
\text { UNOFF } \\
\text { ADMIN } \\
\text { BGN }\end{array}$ & $\begin{array}{l}\text { Apache } \\
\text { Gila } \\
\text { Apache } \\
\text { Apache } \\
\text { Mohave } \\
\text { Gila }\end{array}$ & $\begin{array}{l}365340 \mathrm{~N} 1094435 \mathrm{~W} \\
341319 \mathrm{N1} 112916 \mathrm{~W} \\
361202 \mathrm{N1091630W} \\
341024 \mathrm{N1} 094421 \mathrm{~W} \\
351610 \mathrm{N1} 140036 \mathrm{~W} \\
341315 \mathrm{N1111035W}\end{array}$ & & 3362 & $\begin{array}{l}\text { North Peak } \\
\text { Mummy Cave Ruins } \\
\text { Boundary Butte } \\
\text { Stockton Hill } \\
\text { McOonald Mtn }\end{array}$ \\
\hline $\begin{array}{l}\text { valley } \\
\text { summit } \\
\text { summit } \\
\text { reservoir } \\
\text { reservoir } \\
\text { spring } \\
\text { spring }\end{array}$ & $\begin{array}{l}\text { BGN } \\
\text { BGN } \\
\text { BGN } \\
\text { BGN } \\
\text { BGN } \\
\text { BGN } \\
\text { BGN } 1974 \\
\text { VARIANT }\end{array}$ & $\begin{array}{l}\text { Gila } \\
\text { Mohave } \\
\text { Gila } \\
\text { Gila } \\
\text { Gila } \\
\text { Gila } \\
\text { Gila }\end{array}$ & $\begin{array}{l}340627 \mathrm{N1111610 \textrm {W }} \\
344040 \mathrm{N1} 132752 \mathrm{~W} \\
340638 \mathrm{~N} 1111335 \mathrm{~W} \\
340534 \mathrm{~N} 1111250 \mathrm{~W} \\
340614 \mathrm{N1} 111258 \mathrm{~W} \\
340616 \mathrm{~N} 1111503 \mathrm{~W} \\
340807 \mathrm{N1} 111853 \mathrm{~W}\end{array}$ & $340612 \mathrm{~N} 1111434 \mathrm{~W}$ & $\begin{array}{l}4992 \\
5432\end{array}$ & $\begin{array}{l}\text { Gisela } \\
\text { Elephant Mtn } \\
\text { Sheep Bas in Mtn } \\
\text { Sheep Bas in Mtn } \\
\text { Sheep Bas in Mtn } \\
\text { Gisela } \\
\text { Payson South }\end{array}$ \\
\hline $\begin{array}{l}\text { spring } \\
\text { spring }\end{array}$ & $\begin{array}{l}\text { BGN } \\
\text { BGN } 1932\end{array}$ & $\begin{array}{l}\text { Apache } \\
\text { Coconino }\end{array}$ & $\begin{array}{l}341139 \mathrm{~N} 1093620 \mathrm{~W} \\
361525 \mathrm{N1} 120006 \mathrm{~W}\end{array}$ & & & $\begin{array}{l}\text { Whiting Knoll } \\
\text { Little Park Lane }\end{array}$ \\
\hline $\begin{array}{l}\text { mine } \\
\text { reservoir } \\
\text { reservoir } \\
\text { well } \\
\text { canal } \\
\text { well } \\
\text { lake } \\
\text { reservoir } \\
\text { reservoir } \\
\text { spring }\end{array}$ & $\begin{array}{l}\text { UNOFF } \\
\text { BGN } \\
\text { BGN } \\
\text { UNOFF } \\
\text { BGN } \\
\text { UNOFF } \\
\text { BGN } \\
\text { BGN } \\
\text { BGN } \\
\text { BGN }\end{array}$ & $\begin{array}{l}\text { Gila } \\
\text { Gila } \\
\text { Gila } \\
\text { Mohave } \\
\text { Yuma } \\
\text { Apache } \\
\text { Navajo } \\
\text { Gila } \\
\text { Yavapai } \\
\text { Coconino }\end{array}$ & $\begin{array}{l}340849 \mathrm{~N} 1111628 \mathrm{~W} \\
341653 \mathrm{N1111222W} \\
340630 \mathrm{~N} 1111321 \mathrm{~W} \\
354114 \mathrm{N1141701W} \\
323308 \mathrm{~N} 1144530 \mathrm{~W} \\
360654 \mathrm{~N} 1092539 \mathrm{~W} \\
341719 \mathrm{N1} 100319 \mathrm{~W} \\
340737 \mathrm{N1110734W} \\
342748 \mathrm{~N} 1113758 \mathrm{~W} \\
361358 \mathrm{~N} 1105923 \mathrm{~W}\end{array}$ & & & $\begin{array}{l}\text { Payson South } \\
\text { Diamond Point } \\
\text { Sheep Bas in Mtn } \\
\text { White Hills East } \\
\text { Gadsden } \\
\text { Three Turkey Canyon } \\
\text { Show Low North } \\
\text { McDonald Mtn } \\
\text { Hackberry Mtn } \\
\text { Begashibito Canyon }\end{array}$ \\
\hline $\begin{array}{l}\text { pillar } \\
\text { pillar }\end{array}$ & $\begin{array}{l}\text { BGN } \\
\text { BGN }\end{array}$ & $\begin{array}{l}\text { Yuma } \\
\text { Yavapai }\end{array}$ & $\begin{array}{l}334044 \mathrm{~N} 1133314 \mathrm{~W} \\
340658 \mathrm{~N} 1123730 \mathrm{~W}\end{array}$ & & & $\begin{array}{l}\text { Harrisburg Valley } \\
\text { Sam Powell Peak }\end{array}$ \\
\hline
\end{tabular}

Paradise Valley Mormon Lake Ferry Swale

Navajo Springs Ferry Swale

Square Butte

$363158 \mathrm{~N} 1105740 \mathrm{~W}$ $331757 \mathrm{N1112340 \textrm {W }}$ $364753 \mathrm{~N} 1131335 \mathrm{~W}$ 353928 N1090400W $354042 \mathrm{N1O90248 \textrm {W }}$ $350243 \mathrm{~N} 1091217 \mathrm{~W}$ $341210 \mathrm{~N} 1100102 \mathrm{~W}$ $334257 \mathrm{N1} 095645 \mathrm{~W}$

$322933 \mathrm{~N} 1111516 \mathrm{~W}$ $320159 \mathrm{N1112918 \textrm {W }}$

$321055 \mathrm{~N} 1115105 \mathrm{~W}$ $321209 \mathrm{N1} 105356 \mathrm{~W}$ 355347 N1092653W

2402 Sil Nakya Tucs on Nazlini Superstition Mts SW White Pockets Window Rock Window Rock Deep Lake

6580 Show Low South Bonito Prairie

1944 West of Marana San Pedro

Sam Powell Peak 
FEATURE NAME

Needle, The

Needle Canyon

Needle Canyon

Needle Creek

Needle Mountain

Needle Peak

Need le Rock

Needle Rock

Needles

See Topock
Needles
See Powell (historical)
Needles, The
Needles Eye
See Coolidge Dam
Needles Eye
The Needle
Needles Eye

Needles Eye
Needle Trail
Needle Valley
Needmore Tank
Needmore Wash
Need Tank
Neely Spring
Neeye Mine
Neff
Negrita Tank, La

Negro, Cerro

Negro Ben Peak

Negro Ben Spring

Negro Canyon Nigger Canyon

Negro Canyon

Negro Canyon

Negro Ed

Negro Ed Spring

Negro Flat

Negro Flat Tank North Tank

Negrohead

Negro Head Spring Nergo Spring

Negro Henry Canyon

Negro Knob

Negro Spring

Negro Spring

Negro Tank

Negro Tank

Negro Tank

Negro Wash

Nigger Wash

Negro Well

Neighborhood Canyon

Neighborhood Cemetery

Neighbor Spring

Neilson Spring

Neil V Christensen Elementary School

Nellie-Meda Mine

Nellie Mine

Nells Tank

$\mathrm{Nelson}$

Nelson

Nelson Canyon

Nelson Cemetery

$\mathrm{Ne}$ ison Dam

Nelson Drain

Nelson Lake

Nelson Lake Point

\section{FEATURE}

CLASS

pillar

valley

stream

summit

summit

summit

summit

locale

locale
pillar

dam

gap

gap

summit

trail

valley

reservoir

stream

reservoir

spring

mine

locale

reservoir

summit

summit

spring

valley

valley

valley

summit

spring

flat

reservoir

summit

summit

spring

valley

summit

spring

spring

reservoir

reservoir

reservoir

stream

well

valley

cemetery

spring

spring

schoo

mine

mine

reservoir

locale

ppl

valley

cemetery

dam

stream

lake

cliff
STATUS

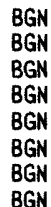

$B G N$
$B G N$
$B G N$
$B G N$
$B G N$
$B G N$
$B G N$
$B G N$

VARIANT

VARIANT

BGN

VARIANT

BGN

VARIANT

BGN

BGN
UNOFF
BGN
BGN
BGN
BGN
BGN
UNOFF
BGN
BGN

BGN
BGN
BGN
BGN
VARIANT
BGN
BGN
BGN
BGN
BGN

BGN 1975

BGN

BGN

BGN

VARIANT

BGN Pinal

BGN Apache

GGN Graham

\section{BGN}

BGN

BGN

BGN 1965
VARIANT

VARIANT
UNOFF

BGN

UNOFF

BGN

BGN

UNOFF

UNOFF

UNOFF

BGN

BGN

BGN

BGN 1979

BGN 1979
UNOFF

UNOFF

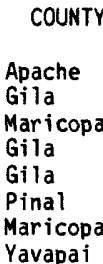

Mohave

Mohave

Mohave

Gila

Greenlee

Pinal

Yuma

Pinal

Pima

Coconino
Coconino

Yavapai

Cochise

Mohave

Cochise

Coconino

Pima

Yavapai

Yavapai

Santa Cruz

Graham

Greenlee

Mohave

Mohave

Maricopa

Mohave

Mohave

Apache

Santa Cruz

Cochise

Coconino

Gila

Gila

Maricopa

Cochise

Santa Cruz

Apache

Coconino

Yavapai

Mohave

Coconino

Pima

Yavapai

Yavapa

Yavapai
Apache

BGN
BGN

BGN
Mohave

Coconino

Gila
COORDINATE

$362320 \mathrm{~N} 1095451 \mathrm{~W}$

$332409 \mathrm{~N} 1105520 \mathrm{~W}$

$332816 \mathrm{~N} 1112327 \mathrm{~W}$

$332226 N 1105451 \mathrm{~W}$

$332322 \mathrm{~N} 1105555 \mathrm{~W}$

$324618 \mathrm{~N} 1120018 \mathrm{~W}$

334627 N111394 ${ }^{\circ}$

$342611 \mathrm{N1114116 \textrm {W }}$

$344306 N 1142911 W$

$344306 \mathrm{~N} 1142911 \mathrm{~W}$

$344034 \mathrm{~N} 1142613 \mathrm{~W}$

$331029 N 1103138 \mathrm{~W}$

$330300 \mathrm{~N} 1090529 \mathrm{~W}$

330810 N1103514W

$331649 N 1143343 \mathrm{~W}$

$332615 N 1112154 \mathrm{~W}$

$321532 \mathrm{~N} 1123651 \mathrm{~W}$

$354048 \mathrm{~N} 1114257 \mathrm{~W}$

$354830 \mathrm{~N} 1113044 \mathrm{~W}$

$344854 N 1115906 \mathrm{~W}$

$314922 \mathrm{~N} 1095343 \mathrm{~W}$

$341912 \mathrm{~N} 1133249 \mathrm{~W}$

$312 B 45 N 1095845 \mathrm{~W}$

$345429 \mathrm{~N} 1112933 \mathrm{~W}$

321724N1113613W

$342214 N 1131449 W$

$342333 \mathrm{~N} 1131510 \mathrm{~W}$

$313235 \mathrm{~N} 1110230 \mathrm{~W}$

$323137 N 1101857 \mathrm{~W}$

$325651 \mathrm{~N} 1091649 \mathrm{~W}$

$343855 \mathrm{~N} 1132103 \mathrm{~W}$

$343 B 32 \mathrm{~N} 1132003 \mathrm{~W}$

$344739 N 1115501 \mathrm{~W}$

330517 N1121525W

$350315 \mathrm{~N} 1142425 \mathrm{~W}$

$362414 \mathrm{~N} 1135636 \mathrm{~W}$

$332214 N 1111213 \mathrm{~W}$

324957 N1102940W

$341226 \mathrm{~N} 1093648 \mathrm{~W}$

$323227 \mathrm{~N} 1101749 \mathrm{~W}$

$341128 N 1093641 W$

$313016 \mathrm{~N} 1110455 \mathrm{~W}$

$322423 \mathrm{~N} 1101000 \mathrm{~W}$

$352811 \mathrm{N1120309W}$

$333005 \mathrm{~N} 1105135 \mathrm{~W}$

$333105 \mathrm{~N} 1104820 \mathrm{~W}$

$332226 \mathrm{~N} 1120202 \mathrm{~W}$

$320006 \mathrm{~N} 1092418 \mathrm{~W}$

$312415 \mathrm{~N} 1102810 \mathrm{~W}$

$341752 \mathrm{~N} 1092124 \mathrm{~W}$

351333N1113503W

$340125 \mathrm{~N} 1130740 \mathrm{~W}$

$345754 \mathrm{N1} 142412 \mathrm{~W}$

$343256 \mathrm{~N} 1111848 \mathrm{~W}$

$322544 \mathrm{~N} 1111608 \mathrm{~W}$

353051 N1131910W

$353045 N 1131950 \mathrm{~W}$

353107 N1131840W

$340335 \mathrm{~N} 1091137 \mathrm{~W}$

$342858 \mathrm{~N} 1141854 \mathrm{~W}$

$341913 \mathrm{N1} 104503 \mathrm{~W}$

341741 N1104642W

\begin{tabular}{ccc}
$\begin{array}{c}\text { SOURCE } \\
\text { COORDINATE }\end{array}$ & $\begin{array}{c}\text { ELEV } \\
\text { FT }\end{array}$ & \multicolumn{1}{c}{ MAP NAME } \\
$332325 \mathrm{~N} 1105609 \mathrm{~W}$ & & $\begin{array}{l}\text { Rough Rock NW } \\
\text { Inspiration }\end{array}$ \\
$332537 \mathrm{~N} 1112126 \mathrm{~W}$ & & $\begin{array}{l}\text { Goldfield } \\
\text { Pinal Ranch }\end{array}$ \\
$332312 \mathrm{~N} 110560 \mathrm{~W}$ & 5058 & $\begin{array}{l}\text { Inspiration } \\
\text { Indian Butte } \\
\text { Bart lett Dam } \\
\text { Hackberry Mtn }\end{array}$
\end{tabular}

Topock

Big Lue Mts

Coolidge Dam

Cibola SE

Weavers Needle

Gakolik Mts

Additional Hill

Coconino Point SE

Page Springs

Black Diamond Peak

Artillery Peak

Bisbee 


\section{FEATURE NAME}

Nelson Mes

Nelson Mine

Nelson Place Spring

Nelson Railroad Station

Nels on Ranch

Nelson Reservoir

Nelson Reservoir Campground

Nelson Spring

Nelson Tank

Nelson Tank

Nelson Tank

Nelson Tank

Nelson Tank

Nelson Tank

Nelson Tanks

Nelson Trail Number One

Hundred Fifty Nine

Neison Well

Nelson Well

Nemo Spring

Nephi

Johnsonville Jacksonville

Neptune Wash

Nergo Spring

See Negro Head Spring

Nesbitt Spring

Neskahi Wash

NE Spring

Nestor, Mount

Nestors

See Tatk Kam Vo

Nest Well

Nesuftanga

Nettle Tank

Never Go Dry Tank

Nevershine

Neversweat Ridge

Neville Rapids

See Seventy-Five Mile

evills Rapids

Seventyfive Mile Rapids

Nevitt Park

Nevitt School

New Automobile Tank

Newberry Butte

Newberry Mesa

Newberry Point

New Cedar Drift Fence Tank

New Colorado Mine

New Cornelia Branch Hospital

New Cornelia Min

New Cornelia Tailings Dam

New Corral Spring

New Creek

New Daggs Tank

New Deal Mine

New Dent and Sayer Tank

New England Mine

New Era Mine Dump

Newfield

Newguard Well

Newhall Well

New Harpo Tank

New Home Mobile Park

New Hope

New Hope Trailer Park

New Horizons (subdivision)

New Jersey Mine

New Jersey Mine
FEATURE

CLASS

STATUS

COUNTY

COORDINATE

$\begin{array}{llll}\text { summit } & \text { BGN } & \text { Yavapai } & 343647 \text { N1130829W } \\ \text { mine } & \text { UNOFF } & \text { Maricopa } & 335320 \mathrm{~N} 1115030 \mathrm{~W} \\ \text { spring } & \text { BGN } & \text { Yavapai } & 341912 \mathrm{N1114946 \textrm {W }} \\ \text { building } & \text { UNOFF } & \text { Yavapai } & 353055 \mathrm{~N} 1131919 \mathrm{~W} \\ \text { locale } & \text { UNOFF } & \text { Pinal } & 323055 \mathrm{~N} 1105538 \mathrm{~W} \\ \text { reservoir } & \text { BGN } & \text { Apache } & 340335 \mathrm{~N} 1091139 \mathrm{~W} \\ \text { park } & \text { ADMIN } & \text { Apache } & 340258 \mathrm{~N} 1091123 \mathrm{~W}\end{array}$

park $\quad$ ADMIN Apache $\quad 340258$ N1091123W

spring BGN Mohave 345543N1133201W

reservoir BGN $\quad$ Yavapai $\quad 341341$ N1125644W

reservoir BGN

reservoir BGN Mohave 352604N1132722W

reservoir BGN

$353130 \mathrm{~N} 1133107 \mathrm{~W}$

reservoir BGN Coconino 35373BN1124309W

reservoir BGN Navajo 342723N1103903W

trail UNOFF Yavapai 341730N1114852W

well UNOFF Pinal 324113N1104627W

well UNOFF Gila

spring BGN Yavapai 342923N1121918

locale BGN Maricopa 332500N1115330W

VARIANT

VARIANT

stream BGN

VARIANT

Mohave

39304241421504

Pinal 332214N1111213W

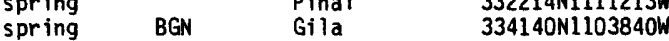

stream BGN Navajo 371129N1104008W

spring BGN Coconino 351655N1115911W

summit BGN Coconino 345353N1113020W

locale

well

locale

reservoir

reservoir

summit

VARIANT

Navajo

$B G N$

BGN

Navajo

354649N1100826W

$312856 N 1104815 W$
$334715 N 1105248 W$
$361432 N 1135157 W$

ridge BGN Yuma 330239N1134750W

$360310 \mathrm{~N} 1115405 \mathrm{~W}$

rapids

VARIANT

rapids

BGN

park

school

reservoir

summit

ADMIN

UNOFF

BGN

BGN 1906

Coconino

$360313 \mathrm{~N} 1115410 \mathrm{~W}$

Coconino

Maricopa

Maricopa

Coconino

$332310 \mathrm{~N} 1115900 \mathrm{~W}$

$332315 \mathrm{~N} 1115902 \mathrm{~W}$

$354644 \mathrm{~N} 1115804 \mathrm{~N}$

$360344 N 1115819$

summit BGN Coconino $352541 \mathrm{M} 1105548 \mathrm{M}$

cliff BGN 1908 Coconino 361B06N1122510W

reservoir BGN Gila $334839 N 1101247 \mathrm{~W}$

mine UNOFF Pima 314030N1111831W

$322205 \mathrm{~N} 1125150 \mathrm{~W}$

UMOFF

dam UNOFF

spring BGN

stream BGN

reservoir $B G N$

UNOFF

reservoir $B G M$

mine UNOFF

mine UNOFF

locale

well

well

reservoir

locale

ppl

BGN

UNOFF

BGN

BGN

$\begin{array}{ll}\text { locale } & \text { UNOFF } \\ \text { ppl } & \text { BGN } \\ \text { mine } & \text { UNOFF } \\ \text { mine } & \text { UNOFF }\end{array}$

Maricopa

Maricopa

Yavapai

Mohave

$322200 \mathrm{~N} 1125030 \mathrm{~W}$

$334044 \mathrm{~N} 1103659 \mathrm{~W}$

$333415 \mathrm{~N} 1102742 \mathrm{~W}$

$352446 \mathrm{~N} 1141002 \mathrm{~W}$

$354638 \mathrm{~N} 1114818 \mathrm{~W}$

$341850 \mathrm{~N} 1134226 \mathrm{~W}$

342705 N1122047W

$313251 \mathrm{~N} 1114358 \mathrm{~W}$

$351340 \mathrm{~N} 1141255 \mathrm{~W}$

$341135 \mathrm{~N} 1125302 \mathrm{~W}$

$355010 \mathrm{~N} 1122401 \mathrm{~W}$

33305BN1120654W

$333750 \mathrm{N1} 134601 \mathrm{~W}$

$332446 \mathrm{~N} 1114209 \mathrm{~W}$

$332129 \mathrm{~N} 1115057 \mathrm{~W}$

$341043 \mathrm{~N} 1122030 \mathrm{~W}$

$352503 \mathrm{~N} 1141027 \mathrm{~W}$

\begin{tabular}{ccc}
$\begin{array}{c}\text { SOURCE } \\
\text { COORDINATE }\end{array}$ & $\begin{array}{c}\text { ELEV } \\
\text { FT }\end{array}$ & \multicolumn{1}{c}{ MAP NAME } \\
& 4422 & $\begin{array}{l}\text { Bagdad } \\
\text { Humboldt Mtn } \\
\text { Tule Mesa } \\
\text { Nelson } \\
\text { Oracle Junction } \\
\text { Nelson Reservoir }\end{array}$ \\
& 7412 Nelson
\end{tabular}

Nelson Reservoir

Tom Brown Canyon

O'Neill Pass

Prescott Valley $\mathrm{N}$

Cherokee Point

Blye Canyon NE

Milkweed Canyon SE

Black Tank

Hanks Draw

Tule Mesa

North of Oracle

3033 Bucket Mtn

Poland Junction

1190 Tempe

343147 N1141B36W

Lake Havasu City N

Haystack Butte

365940 N1103500W

No Mans Mesa South

Parks

7713 Mormon Mountain

534 Montezumas Chair

Keams Canyon

Cumero Canyon

Aztec Peak

Snap Canyon East

Neversweat Ridge

Cape Royal

Tempe

Tempe

Harbison Tank

5104 Cape Royal

Newberry Mesa

Powell Plateau

Cone Butte

Cerro Colorado

Ajo South

Ajo South

Ajo South

Chrysotile

$333806 \mathrm{~N} 1102645 \mathrm{~W}$

ssadore Spring

Daggs Tank
Chloride

Peterson Flat

Rawhide Wash

Poland Junction

Caponera Peak

Kingman NW

O'Neill Pass

Little Harpo Canyon

1150 Sunnyslope

Vicksburg

Buckhorn

1205 Chandler

Crown King

Chloride 
FEATURE NAME

New Lewis Tank

New Limestone Tank

New London Mine

Newman Canyon

Newman $\mathrm{Hill}$

Newman Park

Newman Park Interchange

Newman Peak

Newman Peak Ranch Airstrip

Newman Point

Newman Spring

Newman Tank

Newman Tank

Newman Tank

Newman Tank

Newman Tank

Newman Tank

New Moon Mine

New Mud Tank

New Olea Well

New Ore Mine

New Park Well

New Pasture Tank

New Pasture Well

New Peter Lockett Tank

New Post

See Camp Wallen (historical)

New Ranch Tank

New Reservoir

See Slade Reservoir

New River

Skunk Creek

New River

Duppa Station

Newriver

iver

New River Interchange

New River Mesa

New River Mountains

New River School

New River Substation

New River Tank

New Round Tank

New Savoy Mine

Newspaper Rock

New Spring

New Spring

New Standard Mine

New Synder Tank

New Tacna

See Tanque Aloma

New Tank

New Tank

New Tank

New Tank

New Tank

New Tank

New Tank

New Tank

New Tank

New Tank

New Tank

New Tank

New Tank

New Tank

New Tank

New Tank

New Tank

New Tank

\section{FEATURE}

CLASS
reservoir
reservoir
mine
valley
summit
flat

STATUS

COUNTY

BGN

UNOFF

BGN

$B G N$
$B G N$

Coconino

Yavapai

Mohave

Coconino

Coconino

Coconino

crossing

summit

a irport

summit

spring

reservoir

reservoir

reservoir $B G$

reservoir $B G$

reservoir $B G$

reservoir $B$

mine

UNOFF
BGN
ADMIN

ADMIN
BGN

$B G N$

$B G N$

GN

BGN

N

Coconino

Pinal

Pinal

Navajo

Coconino

Navajo

Coconino

Coconino

Coconino

Coconino

COORDINATE

355441 N1115244

351747 N1131622W

$351720 \mathrm{N1} 140845 \mathrm{~W}$

$350330 \mathrm{~N} 1112917 \mathrm{~W}$

$352341 \mathrm{~N} 1115231 \mathrm{~W}$

$35011 B N 1114058 \mathrm{~W}$

350107 N1114103W

324308 N1112359

$324410 \mathrm{~N} 1112646 \mathrm{~W}$

341945 N1102310W

$352417 N 1115149 \mathrm{~W}$

$341954 \mathrm{~N} 1102255 \mathrm{~W}$

345859 N1113408W

$350041 \mathrm{~N} 1114059 \mathrm{~W}$

$350235 \mathrm{~N} 1113021 \mathrm{~W}$

$352358 \mathrm{~N} 1115234 \mathrm{~W}$

reservoir

well UNOFF

well

reservoir

well

reservoir

locale

OFF

GN

UNOFF

UNOFF

BGN

UNOFF

BGN

VARIANT

Coconino

Mohave

Mohave

Mohave

Pima

Maricopa

Graham

Graham

Yavapai

Cochise

$360549 N 1123032 \mathrm{~W}$

$352250 \mathrm{~N} 1140900 \mathrm{~W}$

$353102 \mathrm{~N} 1133405 \mathrm{~W}$

$34305 B N 1132224 \mathrm{~W}$

$322732 \mathrm{~N} 1120759 \mathrm{~W}$

$332030 \mathrm{~N} 1125610 \mathrm{~W}$

$322713 \mathrm{~N} 1092452 \mathrm{~W}$

$322608 N 1092521 \mathrm{~W}$

$351306 \mathrm{~N} 1124309 \mathrm{~W}$

313940N1 101700W

reservoir $B G$

reservoir

BARIAN

stream

ppl

BGN

VARIANT

BGN

VARIANT

VARIANT

VARIANT

ppl

crossing

summit

range

school

locale

reservoir

reservoir

mine

pillar

spring

UNOFF

BGN

BGN

UNOFF

UNOFF

BGN
BGN
UNOFF

UNOFF

$B G N$

BGN

spring $B G N$

mine UNOFF

$\begin{array}{ll}\text { reservoir } & \text { BGN } \\ & \text { VARIANT }\end{array}$

ppl

reservoir $B G N$

reservoir BGN

reservoir $B G N$

reservoir $B G$

reservoir $B G N$

reservoir $B G N$

reservoir $B G N$

reservoir $B G M$

reservoir $B G$

reservoir $B G$

reservoir $B G N$

reservoir $8 G$

reservoir $B G N$

reservoir $B G N$

reservoir $B G N$

reservoir $B G N$

reservoir $B G$

reservoir BGN
Coconino

$351253 \mathrm{~N} 1120424 \mathrm{~W}$

$335944 \mathrm{N1092010 \textrm {W }}$

$333053 \mathrm{~N} 1121812 \mathrm{~W}$

Maricopa

Maricopa

335457N1120807W

Maricopa

335457 N1 120807W

Maricopa

Maricopa

Maricopa

Maricopa

Maricopa

Maricopa

Navajo

Yavapai

Apache

Pinal

Mohave

Yuma

Coconino

Yuma

Santa Cruz

Cochise

Pima

Pima

Graham

Graham

Pinal

Greenlee

Maricopa

Gila

Maricopa

Navajo

Coconino

Navajo

Coconino

Coconino

Coconino

Coconino

$345139 N 1110115 \mathrm{~W}$

$353405 \mathrm{~N} 1122610 \mathrm{~W}$

SOURCE
COORDINATE

Grandview Point

Blye Canyon SE

Cerbat

345900N1113125W Ashurst Lake

8503 Moritz Ridge

Mountainaire

Mountainaire

4506 Newman Peak

1642 Newman Peak

Day Spring

Kendrick Peak

Oay Spring

Mormon Mountain

Mountainaire

Lower Lake Mary

Moritz Ridge

Antelope Point

Chloride

Milkweed Canyon SE

Grayback Mts 
NATIONAL GAZETTEER--ARIZONA 1986

FEATURE NAME

New Tank

New Tank

New Tank

New Tank

New Tennessee Mine

Newt Lewis Tank

Newton Butte

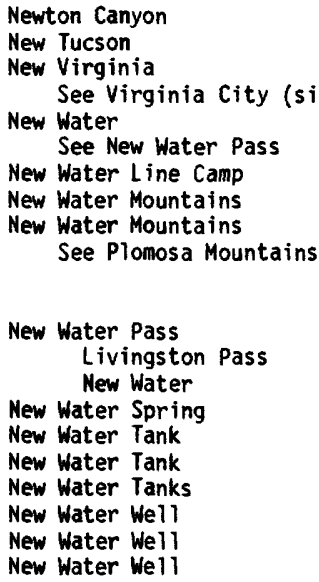

Newton Canyon

New Tucson

New Virginia

water

See New Water Pass

New Water Line Camp

New Water Mountains

New Water Mountains

See Plomosa Mountains

New Water Pass

Livingston Pass

New Water

New Water Spring

New Water Tank

New Water Tank

New Water Tanks

New Water Well

New Water Wel

New Water Well

See Virginia City (site)

New Water Well

New Water Windmill

New Well

New Well

New Well

New We]

New Well

New We]1

New Well Windmill

New Windaill

New Windmi 11

New Windmil

New Windmill

New World Park

New Wright Monument

New Year Mine

New Years Cabin Spring

New York Mine

New York Mine

Neyezee Well

Nez Spring

N Five Spring

Niagara Creek

ic-doit-soe

See Wildcat Peak

Nic do it soe

See Wildcat Peak

Nichols Wel

Nickals Tank

Nick and Mora Tank

Nicks Camp Canyon

Nicksville

Nigger Canyon

See Negro Canyon

Nigger Wash

See Negro Wash

Night Hawk

Night Hawk Spring

Nigh Trap Tank

Night Trap Tank

Nig Well Number Two

Niña-Niños

Nina Pond

Nina Well

FEATURE
CLASS
reservoir
reservoir
reservoir
reservoir
mine
reservoir
summit

STATUS

COUNTY

Coconino

BGN

BGN

BGN

BGN

UNOFF

BGN

BGN 1906

Coconino

Coconino

Mohave

Coconino

Coconino

\begin{tabular}{|c|c|c|c|}
\hline $\begin{array}{l}\text { valley } \\
\text { ppl }\end{array}$ & $\begin{array}{l}\text { BGN } \\
\text { BGN } \\
\text { VARIANT }\end{array}$ & $\begin{array}{l}\text { Cochise } \\
\text { Pima }\end{array}$ & $\begin{array}{l}320027 \mathrm{~N} 1092221 \mathrm{~W} \\
315838 \mathrm{~N} 1104214 \mathrm{~W}\end{array}$ \\
\hline locale & VARIANT & Mohave & $342810 \mathrm{~N} 1133735 \mathrm{~W}$ \\
\hline $\begin{array}{l}\text { gap } \\
\text { locale } \\
\text { range }\end{array}$ & $\begin{array}{l}\text { BGN } \\
\text { BGN } \\
\text { VARIANT }\end{array}$ & $\begin{array}{l}\text { Yuma } \\
\text { Yavapai } \\
\text { Yuma }\end{array}$ & $\begin{array}{l}333059 N 1135622 \mathrm{~W} \\
350402 \mathrm{~N} 1130119 \mathrm{~W} \\
333144 \mathrm{~N} 1135445 \mathrm{~W}\end{array}$ \\
\hline ange & & Yuma & $334200 \mathrm{~N} 1140300 \mathrm{~W}$ \\
\hline ap & $\begin{array}{l}\text { BGN } \\
\text { VARIANT } \\
\text { VARIANT }\end{array}$ & Yuma & $333059 \mathrm{NI1} 135622 \mathrm{~W}$ \\
\hline $\begin{array}{l}\text { spring } \\
\text { reservoir } \\
\text { reservoir } \\
\text { reservoir } \\
\text { well } \\
\text { well } \\
\text { well }\end{array}$ & $\begin{array}{l}\text { BGN } \\
\text { BGN } \\
\text { BGN } \\
\text { BGN } \\
\text { UNOFF } \\
\text { UNOFF } \\
\text { UNOFF }\end{array}$ & $\begin{array}{l}\text { Mohave } \\
\text { Mohave } \\
\text { Mohave } \\
\text { Yavapai } \\
\text { Yuma } \\
\text { Gila } \\
\text { Mohave }\end{array}$ & $\begin{array}{l}355 B 07 N 1135618 \mathrm{~W} \\
355750 \mathrm{~N} 1135030 \mathrm{~W} \\
355837 \mathrm{~N} 1135705 \mathrm{~W} \\
350207 \mathrm{~N} 1125903 \mathrm{~W} \\
333036 \mathrm{~N} 1135212 \mathrm{~W} \\
333332 \mathrm{~N} 1104659 \mathrm{~W} \\
350139 \mathrm{~N} 1133650 \mathrm{~W}\end{array}$ \\
\hline
\end{tabular}

well UNOFF

$\begin{array}{ll}\text { well } & \text { UNOFF } \\ \text { locale } & \text { BGN } \\ \text { well } & \text { UNOFF } \\ \text { well } & \text { UNOFF } \\ \text { well } & \text { UNOFF } \\ \text { well } & \text { UNOFF } \\ \text { well } & \text { UNOFF } \\ \text { well } & \text { UNOFF } \\ \text { well } & \text { UNOFF } \\ \text { locale } & \text { BGN }\end{array}$

Mohave

Yavapai

Santa Cruz

Santa Cruz

Cochise

Mohave

Navajo

Yavapa

Cochise

$\begin{array}{ll}\text { locale } & \text { BGN } \\ \text { locale } & \text { BGN } \\ \text { locale } & \text { BGN } \\ \text { park } & \text { ADMIN } \\ \text { park } & \text { ADMIN } \\ \text { mine } & \text { UNOFF } \\ \text { spring } & \text { BGN } \\ \text { mine } & \text { UNOFF } \\ \text { mine } & \text { UNOFF } \\ \text { well } & \text { UNOFF }\end{array}$

Cochise

Yavapai

Yavapai

Maricopa

Graham

Gila

Mohave

Santa Cruz

Santa Cruz

Apache

$350847 \mathrm{~N} 1132620 \mathrm{~W}$

$350136 \mathrm{~N} 1125919 \mathrm{~W}$

313338 N1 103630W

$313926 \mathrm{~N} 1110514 \mathrm{~W}$

$322024 N 1092147 \mathrm{~W}$

$343836 \mathrm{~N} 1134931 \mathrm{~W}$

$350432 \mathrm{~N} 1102240 \mathrm{~W}$

$351902 \mathrm{N1} 131302 \mathrm{~W}$

$314255 \mathrm{~N} 1111103 \mathrm{~W}$

$312412 \mathrm{~N} 1092701 \mathrm{~W}$

$313837 \mathrm{~N} 1094717 \mathrm{~W}$

$341252 \mathrm{NI} 120121 \mathrm{~W}$

$342300 \mathrm{~N} 1123944 \mathrm{~W}$

$333351 N 1120952 W$

$324539 \mathrm{~N} 1092622 \mathrm{~W}$

$330340 N 1104635 \mathrm{~W}$

$350353 \mathrm{~N} 1135204 \mathrm{~W}$

$312257 \mathrm{NI} 104147 \mathrm{~W}$

$313137 N 1103637 \mathrm{~W}$

$355846 \mathrm{~N} 1091744 \mathrm{~W}$

spring BGN Coconino 360345N1105543W

spring BGN Navajo 340040N1102808

stream BGN Yavapai 343606NI131338W

VARIANT Coconino

summit

summit

well

VARIANT

reservoir $B G$

$\begin{array}{ll}\text { valley } & \text { BG } \\ \text { ppl } & \text { BGN }\end{array}$

valley

stream

mine

spring

reservoir

reservoir BGN

well UNOFF

park

reservoir $B G N$

well

BGN
Coconino

Yavapai

Mohave

Navajo

$362232 N 1110214$

$345455 \mathrm{~N} 1115634 \mathrm{~W}$

363414 N1131106

343609 N1095707W

$341800 \mathrm{~N} 1102000 \mathrm{~W}$

Navajo
Cochise

Santa Cruz

313235N1110230W

Gila

Cochise

Maricopa

$312456 \mathrm{~N} 1095449 \mathrm{~W}$

$332815 \mathrm{~N} 1111703 \mathrm{~K}$

$340934 \mathrm{~N} 1114830 \mathrm{~W}$

Graham

$331929 \mathrm{~N} 1093150 \mathrm{~W}$

Gila

Maricopa

Mohave

331957 N1104220W

$363706 \mathrm{~N} 1132800 \mathrm{~W}$

344737 N1103359W
$312618 \mathrm{~N} 1101454 \mathrm{~W}$

$332620 \mathrm{~N} 1120518 \mathrm{~W}$

\begin{tabular}{|c|c|c|}
\hline $\begin{array}{l}\text { SOURCE } \\
\text { COORDINATE }\end{array}$ & $\begin{array}{l}\text { ELEV } \\
\text { FT }\end{array}$ & MAP NAME \\
\hline & 5912 & $\begin{array}{l}\text { Mixon Tank } \\
\text { Gray Mountain } \\
\text { Driftwood Canyon } \\
\text { Piute Point } \\
\text { Chloride } \\
\text { Grandview Point } \\
\text { Phantom Ranch }\end{array}$ \\
\hline $315931 \mathrm{N1092114W}$ & 3520 & $\begin{array}{l}\text { Cochise Head } \\
\text { Mount Fagan }\end{array}$ \\
\hline & 5730 & $\begin{array}{l}\text { Anvil Rock } \\
\text { New Water Mts }\end{array}$ \\
\hline
\end{tabular}

1960 New Water Mts

Grapevine Canyon

Quartermaster Canyon

Grapevine Canyon

Turkey Canyon

New Water Well

Rockinstraw Mtn

Austin Peak

Bull Spring

6152 Turkey Canyon

O'Donnell Canyon

Amado

Olga

Beecher Canyon

5064 Humpy Camp Well

5413 Sugarloaf Peak

Saucito Mtn

College Peaks

4292 Outlaw Mountain

Joes $\mathrm{Hill}$

Kirkland

Glendale

Tollgate Tank

Hayden

Dean Peak

Harshaw

O'Donnell Canyon

White Rock Wash

Bat Canyon

Cibecue

Bagdad

Loy Butte

Moriah Knoll

Point of the Mtn

Clay Springs

Nicksville

Bisbee

Weavers Needle

Bloody Bas in

5782 Willow Mtn SE

3496 Cutter

Phoenix

Little Tanks

McCauley Sinks 
FEATURE NAME

Nine and a Half Mile Tank

Ninemile

Ninemile Corral

Ninemi le Creek

Ninemile Creek

Nine Mile Dam

Ninemile Draw

Ninemile Peak

Ninemile Ranch

Ninemile Seep

Nine Mile Station

See Fortuna

Ninemile Tank

Ninemile Tank

Ninemile Wash

Ninemile Well

Nine Tank

Nineteen R, Lateral

Nineteen R-37, Lateral

Nineteen R-37-24, Lateral

Ninetyfour Mile Creek

Ninetyone Mile Creek

Ninetys ix Hills

Ninetys ix Ranch

Ninetysix Spring

Nininger Tank

Nippers, The

Nipple Butte

Barrel Butte

Nira Tank

Nishduitso

See Wildcat Peak

Nits in Canyon

$N$ I Windmill

Nixon Ranger Station

Nixon Spring

Nizhoni Point

N Lazy H Ranch

N1 Tank

Noah

$$
\text { Fillibuster Camp }
$$

N O Bar Mesa

N O Bar Mesa Tank

N $O$ Bar Mesa Tank Number Two

N O Bar Ranch

Noble Draw Tank

Noble Mountain

$\mathrm{N}-\mathrm{O}$ Canyon

Nodman Canyon

Noe Canal

Nogales

Dos Nogales

Is aacson

Is aactown

Line City

Los Nogales

Villa Rivas

Nogales Canyon

Nogales High School

Nogales International Airport

Nogales International Waste

Water Treatment Plant

Nogales Spring

Nogales Spring

See Little Nogales Spring

Nogales Substation

Nogales Wash

Nogalito Spring

No Good Tank

Noipa Kam

\section{FEATURE
CLASS}

STATUS

COUNTY

$\begin{array}{ll}\text { reservoir } & \text { BGN } \\ \text { area } & B G N \\ \text { locale } & B G N \\ \text { stream } & B G N \\ \text { stream } & \text { BGN } \\ \text { dam } & \text { UNOFF }\end{array}$

Yavapai

Graham

Navajo

Cochise

Graham

Graham

valley

summi

locale

spring

locale

reservoir

reservoir

stream

well

reservoir

canal

canal

canal

stream

stream

summit

locale

spring

reservoir

BGN
BGN
UNOFF
BGN
VARIANT
BGN
BGN
BGN
UNOFF

Navajo

Pima

Cochise

Apache

Yuma

Graham

Yavapai

Apache

Maricopa

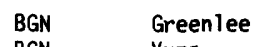

Yuma

Yuma

Yuma

Coconino

Pinal

Pinal

Pinal

Mohave

\begin{tabular}{|c|c|c|c|}
\hline $\begin{array}{l}\text { summit } \\
\text { summit }\end{array}$ & $\begin{array}{l}\text { BGN } \\
\text { BGN } \\
\text { VARIANT }\end{array}$ & $\begin{array}{l}\text { Cochise } \\
\text { Navajo }\end{array}$ & $\begin{array}{l}320044 \mathrm{~N} 1091311 \mathrm{~W} \\
353247 \mathrm{~N} 1102459 \mathrm{~W}\end{array}$ \\
\hline reservoir & $\begin{array}{l}\text { BGN } \\
\text { VARIANT }\end{array}$ & Yavapai & $344217 N 1113731 \mathrm{~W}$ \\
\hline $\begin{array}{l}\text { summit } \\
\text { valley } \\
\text { locale } \\
\text { locale } \\
\text { spring }\end{array}$ & $\begin{array}{l}\text { BGN } \\
\text { BGN } \\
\text { UNOFF } \\
\text { BGN }\end{array}$ & $\begin{array}{l}\text { Coconino } \\
\text { Coconino } \\
\text { Cochise } \\
\text { Mohave } \\
\text { Mohave }\end{array}$ & $\begin{array}{l}362232 N 1110214 W \\
364005 N 1104924 W \\
313702 N 1095304 W \\
362322 N 1130907 W \\
362408 N 1130845 W\end{array}$ \\
\hline
\end{tabular}

cliff $\quad B G N$

locale

reservoir

locale

summit

reservoir

reservoir

locale

BGN

UNOFF

BGN

VARIANT

VARIANT

BGN

BGN

BGN

UNOFF

reservoir

summit

valley

valley

canal

pp

BGN
BGN
BGN
BGN
BGN
BGN
VARIANT
VARIANT
VARIANT
VARIANT
VARIANT
VARIANT

Apache

Pima

Grahan

Yuma

Greenlee

Greenlee

Greenlee

Greenlee

350410 N1094739W

$320652 \mathrm{~N} 1104126 \mathrm{~W}$
$325533 \mathrm{~N} 1101714 \mathrm{~W}$

$324105 \mathrm{~N} 1140117 \mathrm{~W}$

$331639 N 1092212 \mathrm{~W}$

$331741 \mathrm{~N} 1092313 \mathrm{~W}$

$331711 \mathrm{~N} 1092213 \mathrm{~W}$

$331731 \mathrm{~N} 1092423 \mathrm{~W}$

Apache

Apache

Cochise

Mohave

Yuma

Santa Cruz

$335256 \mathrm{~N} 1091114 \mathrm{~W}$

335300 N1091245W

$321932 \mathrm{~N} 1101315 \mathrm{~W}$

$352916 \mathrm{~N} 1140646 \mathrm{~W}$

$323031 \mathrm{N1144}$

$312025 N 1105601 \mathrm{~W}$ $\begin{array}{cc}\text { SOURCE } & \text { ELEV } \\ \text { COORDINATE } & \text { FT }\end{array}$

MAP NAME

Hackberry Mtn

Elevator Mtn

Second Knolls

Bowie Mtn North

Tule Tubs

321247 N1092953h

$331232 N 1095536 \mathrm{~W}$

Gila Peak

343701 N1100900N

Flattop Hil

2560 Hotason Vo

Bowie Mtn North

Ninemile Seep

Gila Peak

Walker Mtn

Adamana

South of Gila Bend

Maple Peak

Parker SW

Parker SW

Parker SW

Grand Canyon

Grand Canyon

Ninetysix Hills NE

Ninetys ix Hills SE

Haunted Canyon

Hitson Tank

5523 Blue Mountain

6557 Egloffstein Butte

Casner Butte

$363917 N 1104704 W$

Inscription Hse Ruin

4494 Potter Mtn

Mt Trumbull NW

Mt Trumbull NW

Kachina Point

Vail

Cobre Grande Mtn

Wellton Mesa

6333 Pipestem Mtn

Bee Canyon

Pipestem Mtn

Bee Canyon

Alpine

Nutrioso

$322354 N 1101122 \mathrm{~W}$

$352944 \mathrm{~N} 1141033 \mathrm{~W}$

Hookers Hot Springs

Elements Canyon

Gadsden

Nogales

\begin{tabular}{|c|c|c|c|}
\hline $\begin{array}{l}\text { valley } \\
\text { school } \\
\text { airport } \\
\text { locale }\end{array}$ & $\begin{array}{l}\text { BGN } \\
\text { UNOFF } \\
\text { ADMIN } \\
\text { UNOFF }\end{array}$ & $\begin{array}{l}\text { Pima } \\
\text { Santa Cruz } \\
\text { Santa Cruz } \\
\text { Santa Cruz }\end{array}$ & $\begin{array}{l}314854 \mathrm{~N} 1113354 \mathrm{~W} \\
312030 \mathrm{~N} 1105626 \mathrm{~W} \\
312502 \mathrm{~N} 1105055 \mathrm{~W} \\
312703 \mathrm{~N} 1105747 \mathrm{~W}\end{array}$ \\
\hline spring & $\begin{array}{l}\text { BGN } \\
\text { VARIANT }\end{array}$ & Mohave & $315249 \mathrm{~N} 1102807 \mathrm{~W}$ \\
\hline $\begin{array}{l}\text { spring } \\
\text { locale } \\
\text { stream }\end{array}$ & $\begin{array}{l}\text { UNOFF } \\
\text { BGN }\end{array}$ & $\begin{array}{l}\text { Pima } \\
\text { Pima } \\
\text { Santa Cruz }\end{array}$ & $\begin{array}{l}315256 \mathrm{~N} 1102835 \mathrm{~W} \\
320310 \mathrm{~N} 1105128 \mathrm{~W} \\
312407 \mathrm{~N} 1105711 \mathrm{~W}\end{array}$ \\
\hline $\begin{array}{l}\text { spring } \\
\text { reservoir } \\
\text { locale }\end{array}$ & $\begin{array}{l}\text { BGN } \\
\text { BGN } \\
B G N\end{array}$ & $\begin{array}{l}\text { Santa Cruz } \\
\text { Coconino } \\
\text { Pima }\end{array}$ & $\begin{array}{l}312557 \mathrm{~N} 1111700 \mathrm{~W} \\
344011 \mathrm{~N} 1112611 \mathrm{~W} \\
321706 \mathrm{~N} 1120853 \mathrm{~W}\end{array}$ \\
\hline
\end{tabular}

$314746 \mathrm{~N} 1113421 \mathrm{~W}$

Baboquivari Peak

Nogales

Cumero Canyon

Rio Rico

Mescal

Tucson SE

Rio Rico

Bartlett Mtn

Happy Jack

2107 Window Mtn 
NATIONAL GAZETTEER--ARIZONA 1986 FEATURE NAME

Noipa Kan Hills

Nokai Canyon

Nakai Canyon

Nakia Canyon

Nokai Creek

Nakai Creek

Nakia Creek

Nokai Mesa

Nakai Mesa

Nakia Mesa

Nokaito Bench

Nolan Creek

Nolan Ranch

Nolan Ranch

Nolan Tank

Nolan Tank

Noli

See Nolic

Noli

See Picacho
Noli
See San Luis
Nolia
See Nolic
Nolia Tank
Nolic
Desert Well
Noll
Nolia
Noolik
Noria
Norlic

No Mans Land (historical)
No Mans Land
See Diana Temple
Nommel Place
No Name Creek
No Name Reservoir
No Nane Spring
No Name Tank
No Name Tank
No Name Tank
No Name Tank
No Nane Wash
No Name Wash
No Name Wash Dan
Nonesuch Rocks
Nonesuch Spring
Noolik
See Nolic
Noonan Canyon
Noon Camp
See Noonville (site)

Noon Creek

Noon Creek Campground

Noon Creek Picnic Grounds

Noon Creek Ridge

Noon Creek Trai

Noon Tank

Noonville (site)

Noon Camp

Nords Ranch

Centennial

Hargua Hala

Harrisonburg

Noria

See Nolic

Norlic

See Nolic

Normal Junction

Norma Mines

Norman Spring

Norman Spring
VARIANT

locale

locale

mine

spring

spring
VARIANT

BGN

UNOFF

BGN

BGN
Pima

Pima

Maricopa

Mohave

Navajo

Navajo
320207 N1115707W

320207 N1115707W

$332439 N 1115453 \mathrm{~W}$

$354402 \mathrm{~N} 1142242 \mathrm{~W}$

$334446 \mathrm{~N} 1095438 \mathrm{~W}$

$334739 \mathrm{~N} 1095352 \mathrm{~W}$

FEATURE
CLASS

sunnit

valley

stream

summit

BGN 1961

Navajo

VARIANT

bench

stream

locale

locale

reservoir

reservoir

locale

BGN 1971

$B G N$

UNOFF

UNOFF

BGN

BGN

VARIANT

Apache

Greenlee

Cochise

Cochise

Greenlee

Yavapai

Pima

COORDINATE

$321810 \mathrm{~N} 1120728 \mathrm{~W}$

$371236 \mathrm{~N} 1103340 \mathrm{~W}$

$371236 \mathrm{~N} 1103340 \mathrm{~W} \quad 364800 \mathrm{~N} 1103200 \mathrm{~W}$

(36)

365827 N1102850W

$365933 \mathrm{~N} 1093420 \mathrm{~W}$

$333922 \mathrm{~N} 1090526 \mathrm{~W}$

$320036 \mathrm{~N} 1091137 \mathrm{~W}$

320708 N1090930W

$334112 \mathrm{~N} 1090253 \mathrm{~W}$

345310 N1115443W

320207N1115707W

VARIANT

locale

VARIANT

Pima

320327 N1115650W

locale

locale

reservoir

locale

VARIANT

VARIANT

Pima

Pima

BGN

BGN 1977 Pima

VARIANT

VARIANT

VARIANT

VARIANT

VARIANT

VARIANT

320449N1115716W

320207 N1115707W

$320141 N 1120002 \mathrm{~W}$

$320207 N 1115707 \mathrm{~W}$

$334133 N 1085942 \mathrm{~W}$

SOURCE COORDINATE

ELEV
FT

MAP NAME

AZ433

2440 Gu Achi

No Mans Mesa South

Tall Mountain

Big Point

Walker Creek Res

Maness Peak

Blue Mountain

Vanar NW

Maness Peak

Loy Butte

Vainom Kug

Ko Vaya

summit
summit
locale
stream
reservoir
spring
reservoir
reservoir
reservoir

BGN 1917

VARIANT

BGN

BGN

BGN
$B G N$
$B G N$

BGN

BGN

BGN

reservoir

stream

stream

dam

ridge

spring

locale

valley

locale

BGN

$B G N$

UNOFF

BGN

BGN

VARIANT

BGN

VARIANT

Coconino

Yuma

Apache

Grahan

Gila

Graham

Apache

Gila

Coconino

Graham

Graham

Graham

Gila

Gila

Pima

Cochise

Santa Cruz

UNKNOWN

360619 N1121653W

$330456 \mathrm{~N} 1144111 \mathrm{~W}$

340218 N1094615

$324718 \mathrm{~N} 1094606 \mathrm{~W}$

$333937 \mathrm{N1} 103922 \mathrm{~W}$

$330955 N 1100159 \mathrm{~W}$

$340047 \mathrm{N1} 1094306 \mathrm{~W}$

$340048 \mathrm{~N} 1110131 \mathrm{~W}$

$345348 N 1110731 \mathrm{~W}$

$324842 \mathrm{~N} 1095055 \mathrm{~W}$

$324951 \mathrm{N1} 094508 \mathrm{~W}$

324718 N109400OW

$333220 \mathrm{N1110126 \textrm {W }}$

$333300 \mathrm{~N} 1110150 \mathrm{~W}$

$320207 N 1115707 \mathrm{~W}$

$315406 \mathrm{~N} 1095450 \mathrm{~W}$

$312320 \mathrm{~N} 1110530 \mathrm{~W}$

stream $\quad B G$

$\begin{array}{llll}\text { stream } & \text { BGN } & \text { Graham } & 324008 \text { N1094703W } \\ \text { park } & \text { ADMIN } & \text { Graham } & 324004 N 1094747 \mathrm{~W}\end{array}$

park

park $\quad$ ADMN

trail UNOFF

reservoir

locale

locale

BGN

BGN

VARIANT

UNOFF
VARIANT

VARIANT

VARIANT

Graham

Graham

Graham

Pima

Santa Cruz

Yuma

$324004 \mathrm{~N} 1094747 \mathrm{~W}$

$324002 N 1094750 \mathrm{~W}$

$323917 N 1094943 \mathrm{~W}$

$323926 N 1094922 \mathrm{~W}$

$313143 \mathrm{~N} 1111106 \mathrm{~W}$

$312320 \mathrm{~N} 1110530 \mathrm{~W}$

$334408 \mathrm{~N} 1133150 \mathrm{~W}$

$325155 N 1094724 W$

324452N1094746W

Thatcher

Thatcher

Safford

Two Bar Mtn

Two Bar Mtn

315416N1095710W Cochise Stronghold

$323924 \mathrm{~N} 1095044 \mathrm{~W}$

Mt Graham

Mt Graham

Mt Graham

Mt Graham

Mt Graham

Murphy Peak

3880 Pena Blanca Lake

Harrisburg Valley
Tempe

White $\mathrm{Hill}$ ls West

Bonito Prairie

Whiteriver 


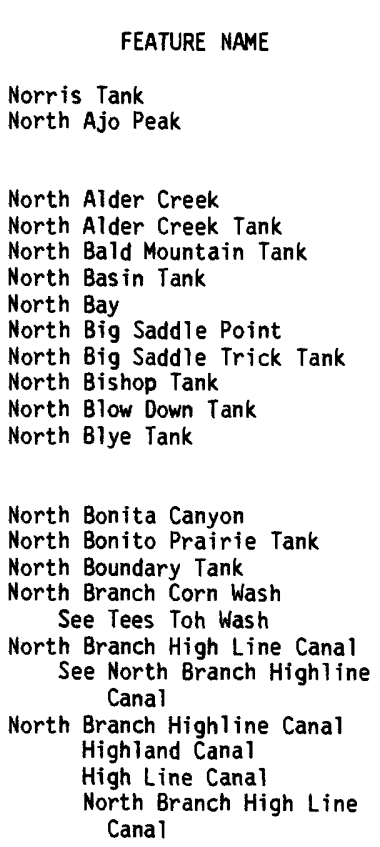

\section{FEATURE}

STATUS

COUNTY

COORDINATE

reservoir summit

\section{$B G N$}

BGN

Coconino

Pima

stream
reservoir
reservoir
reservoir
bay
cape
reservoir
reservoir
reservoir
reservoir

BGN Gila

$B G N$

$B G N$
$B G N$ BGI

$B G$ $B G N$
$B G N$
$B G N$ BGN

reservoir

valley

reservoir

reservoir

stream

cana 1

canal

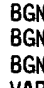

$B G N$

BGN VARIANT

VARIANT

Gila

Yavapai

Pima

Mohave

Coconino

Coconino

Yavapai

Coconino

Mohave

Cochise

Gila

Navajo

Navajo

Maricopa

BGN

VARIANT

VARIANT

VARIANT

Maricopa

BGN

VARIANT

valley

valley

reservoir reservoir

stream

reservoir

spring

summit

summit

reservoir

reservoir

reservoir

canal

valley

valley

valley

strean

cape

spring

trail

stream

reservoir

locale

hospital

BGN 1960

VARIANT

BGN

BGN 1976

$B G N$

BGN

BGN

BGN

BGN

BGN

BGN

VARIANT

BGN

BGN

BGN

BGN

BGN

UNOF

BGN

BGN

UNOFF

$\begin{array}{lll}\text { summit } & \text { BGN } & \text { Cochise } \\ & \text { VARIANT } & \text { Pima } \\ \text { range } & & \text { Gila } \\ \text { reservoir } & \text { BGN } & \text { Greenlee } \\ \text { stream } & \text { BGN } & \text { Coconino } \\ \text { stream } & \text { BGN } & \text { Pima } \\ \text { reservoir } & \text { BGN } & \text { Gila } \\ \text { dam } & \text { UNOFF } & \text { Yuma } \\ \text { canal } & \text { BGN } & \\ & \text { VARIANT } & \text { Pima } \\ \text { park } & & \\ & & \\ & & \\ \text { building } & \text { UNOFF } & \text { Maricopa } \\ \text { reservoir } & \text { BGN } & \text { Navajo } \\ \text { reservoir } & \text { BGN } & \text { Coconino } \\ \text { reservoir } & \text { BGN } & \text { Santa Cruz } \\ \text { dam } & \text { UNOFF } & \text { Pima }\end{array}$

312750 N1092528W

$320714 N 1114758 \mathrm{~W}$ $335154 N 1105121 \mathrm{~W}$ $331 B 15 N 1092405 \mathrm{~W}$ $363750 \mathrm{~N} 1114545 \mathrm{~W}$ $322305 \mathrm{~N} 1125029 \mathrm{~W}$

332912 N1103718W

$323858 \mathrm{~N} 1144318 \mathrm{~W}$

321540 N1105400W

$332942 \mathrm{~N} 1120152 \mathrm{~W}$ $342312 \mathrm{~N} 1101049 \mathrm{~W}$ $353124 \mathrm{~N} 1120231 \mathrm{~W}$

$312341 N 1103804 \mathrm{~W}$

$313233 \mathrm{~N} 1112533 \mathrm{~W}$

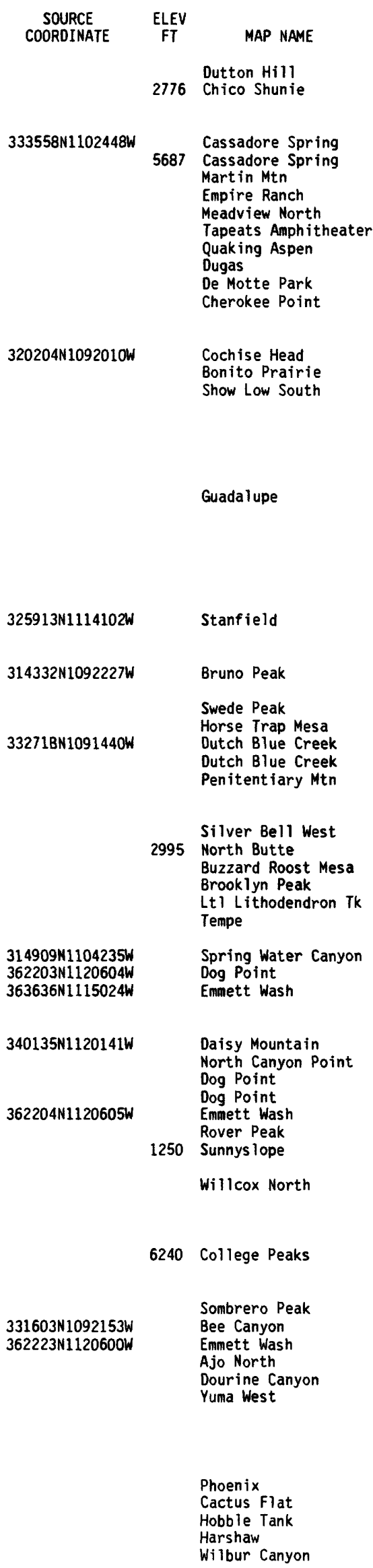


FEATURE NAME

North End Dam Tank

Northern Cochise Community

Hospital

Northern Mine

Northern Village Shopping Center

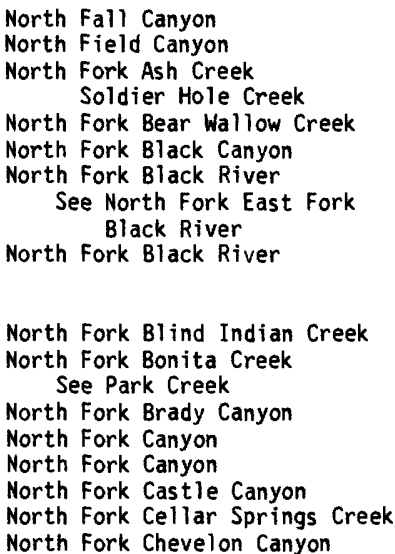

North Fork East River

$$
\text { See North Fork East Fork }
$$

North Fork of Grand River See Colorado River

North Fork of White River See North Fork White River

North Fork Palomino Canyon North Fork Chevelon Canyon

North Fork Parker Creek

North Fork Pipestem Canyon See Pipestem Canyon

North Fork Robinson Wash

\begin{tabular}{llll}
$\begin{array}{l}\text { FEATURE } \\
\text { CLASS }\end{array}$ & STATUS & \multicolumn{1}{c}{ COUNTY } & COORDINATE \\
$\begin{array}{l}\text { reservoir } \\
\text { hospital }\end{array}$ & $\begin{array}{l}\text { BGN } \\
\text { UNOFF }\end{array}$ & $\begin{array}{l}\text { Pima } \\
\text { Cochise }\end{array}$ & $313232 \mathrm{~N} 1112532 \mathrm{~W}$ \\
mine & UNOFF & YUma & $321620 \mathrm{~N} 1095000 \mathrm{~W}$ \\
locale & UNOFF & Maricopa & $333313 \mathrm{~N} 1120631 \mathrm{~W}$
\end{tabular}

SOURCE
COORDINATE

MAP NAME

Wilbur Canyon Willcox North

Wellton Hills Sunnys lope

Chloride Kennedy Peak Ash Creek Ranch

valley

BGN Mohave

BGN 1975 Graham

$323920 \mathrm{~N} 1102157 \mathrm{~W}$

$332122 \mathrm{~N} 1100025 \mathrm{~W}$

$352718 \mathrm{~N} 1141002 \mathrm{~W}$

$323900 N 1102358$

$332212 \mathrm{~N} 1095222 \overline{\mathrm{W}}$

$333554 \mathrm{~N} 1092652 \mathrm{~W}$

$333436 \mathrm{~N} 1092206 \mathrm{~W}$

stream

VARIAN

Greenlee $342150 \mathrm{~N} 1103912 \mathrm{~W}$ $342221 \mathrm{~N} 1104048 \mathrm{~W}$

Baldy Bill Point Brookbank Point

334900N1091BO3W

stream VARIANT

stream

Apache

BGN

Apache

$335515 \mathrm{~N} 1092305 \mathrm{~W}$

$335754 \mathrm{~N} 1092522 \mathrm{~W}$

Big Lake North

stream

BGN Yavapai

341654 N1122409W

$341906 \mathrm{~N} 1122324 \mathrm{~W}$

$330727 \mathrm{~N} 1093916 \mathrm{~W}$ $340308 \mathrm{~N} 1110631 \mathrm{~W}$ 314651 N1090853W $361818 \mathrm{~N} 1134732 \mathrm{~W}$ $363505 \mathrm{~N} 1122012 \mathrm{~W}$

$341323 \mathrm{~N} 1122901 \mathrm{~W}$ $342214 \mathrm{~N} 1105317 \mathrm{~W}$

$340250 \mathrm{~N} 1110815 \mathrm{~W}$

$314908 \mathrm{~N} 1090846 \mathrm{~W}$ $362009 \mathrm{~N} 113435 \mathrm{BW}$ 363427N1121553W $341353 \mathrm{~N} 1122445 \mathrm{~W}$

Coconino $341323 \mathrm{~N} 1122901 \mathrm{~W} \quad 341353 \mathrm{~N} 1122445 \mathrm{~W}$

stream

valley

BGN Yavapai

BGN 1962 Coconino

VARIANT

valley

Coconino

$342214 \mathrm{~N} 1105402 \mathrm{~W}$

VARIANT

valley

stream

stream

stream

stream

BGN

Coconino

$342215 \mathrm{~N} 1105312 \mathrm{~W}$

$324145 \mathrm{~N} 1102818 \mathrm{~W}$

$335119 \mathrm{~N} 1105031 \mathrm{~W}$

$324312 \mathrm{~N} 1102710 \mathrm{~W}$ $335320 \mathrm{N1} 104817 \mathrm{~W}$

Rhodes Peak Sombrero Peak

VARIANT Coconino 352133N110502BW

VARIANT

Navajo

$352941 \mathrm{~N} 1103449 \mathrm{~W}$

stream

stream

stream

valley

stream

BGN

BGN

Yavapai

Yavapai

Apache

BGN 1975 Graham

VARIANT

BGN

Apache

$341534 \mathrm{~N} 1125450 \mathrm{~W}$ $340626 \mathrm{~N} 1113121 \mathrm{~W}$ $335524 \mathrm{~N} 1094137 \mathrm{~W}$

$32371 B N 1101918 \mathrm{~W}$

341429 N1124739W $340747 \mathrm{~N} 1112906 \mathrm{~W}$ $335554 \mathrm{N1} 1093922 \mathrm{~W}$

$323820 \mathrm{~N} 1101753 \mathrm{~W}$

334900 N1091803W

335755 N1092510W

Date

Table Mountain Hawley Lake East Bassett Peak

Strayhorse
VARIANT

VARIANT

VARIANT

VARIANT

stream

valley

valley

valley

valley

valley

stream

BGN
$B G N$
$B G N$
$B G N$
$B G N$

Apache

Graham

Cochise

Yavapai

Coconino

Coconino

VARIANT

Apache

VARIANT

stream

stream

valley

stream

valley

stream
VARIANT

BGN VARIANT

BGN VARIANT

Yuma

Navajo Coconino

Gila

Graham

Mohave
$334900 \mathrm{~N} 1091803 \mathrm{~W}$

$330024 \mathrm{~N} 1101426 \mathrm{~W}$ $315806 \mathrm{~N} 1091829 \mathrm{~W}$ $343720 N 1113604 \mathrm{~W}$ $363814 \mathrm{~N} 1122014 \mathrm{~W}$ $364031 \mathrm{~N} 1122024 \mathrm{~W}$

$330408 \mathrm{N1101653 \textrm {W }}$ $315926 \mathrm{~N} 1091717 \mathrm{~W}$ $343837 N 1113332 \mathrm{~W}$ $363817 \mathrm{N1121750 \textrm {W }}$ $363826 \mathrm{N1} 121656 \mathrm{~W}$

334900 N $1091803 \mathrm{~W}$

$315400 \mathrm{~N} 1145700 \mathrm{~W}$

334728 N1095941W $342214 N 1105402 \mathrm{~W}$

$334752 \mathrm{~N} 1105801 \mathrm{~W}$

$324118 \mathrm{~N} 1102140 \mathrm{~W}$

362800
$342149 \mathrm{~N} 1105614 \mathrm{~W}$

$334825 N 1105703 W$

Woods Canyon

Aztec Peak

Hitson Tank
Beargrass Bas in Rustler Park Buckhorn Mountain Warm Springs Canyon Warm Springs Canyon 


North Fork Rock Canyon
North Fork Rock Creek
North Fork Rucker Canyon
North Fork Salt River
See White River
North Fork Sharp Hollow
North Fork Spring
North Fork Squaw Creek
North Fork Tank
North Fork Tank
North Fork Walnut Creek
North Fork Well
North Fork White River
North Fork of White River
Shake Creek
Snake Creek White River
North Fork White River
See Snake Creek

See Snake Creek

North Fork Will is Canyon

North Fourteen Tank

Northgate Shopping Center

North Gate Wel

North Georgia Mine

North Gila Drain

North Gila East Main Canal

North Gila Valley

North Hackberry Mine

North Headquarters Tank

North Headquarters Wash North Highline Lateral Canal

North Hole

North Hole Spring

North Horse Flat Tank

North Howl and Cove

North Ike Tank

See North Keesler Tank

North Iron Gate Tank

North Jeddito Wash

See Jadito Wash

North Junior High School

North Kees ler Tank

North Ike Tank

North Kinnikinick Tank

North Kinnikinick Tank

North Konelik

Gu Komelik

Komal ik

Komel ih

Komlih

Kukomalik

North Laguna Tank

Northland Pioneer College

North Lewis Center

North Mammoth

North Mesa

North Mill Well

North Mine Spring

North Mingus Trail Number One Hundred Six
FEATURE NAME

North Gila Main Canal

North Hoodoo Well

North Mesa Tank

FEATURE
CLASS

STATUS COUNTY

valley
stream
valley
stream
valley
spring
stream

BGN Coconino

BGN Yavapai

BGN Cochise

VARIANT

BGN Gila

BGN Yavapai

BGN

Yavapai

reservoir

Pinal

reservoir

stream

well

BGN

Yavapai

Yavapai

Yavapai

Navajo

BGN 1971

VARIANT

VARIANT

VARIANT

stream

VARIAN

valley

BGN

Apache

reservoir

locale

well

mine

canal

canal

canal

valley

mine

reservoir

BGN

UNOFF

UNOFF

BGN

BGN

BGN

UNOFF

Santa Cruz

Pima

Navajo

Mohave

Yuma

Yuma

Yuma

Yuma

Mohave

Graham

stream

canal

bas in

spring

well

reservoir

bay

BGN Graham

BGN

UGNOFF

UNOF

BGN

VARIANT

reservoir reservoir

BGN

Maricopa

Yavapai

Yavapai

Yuma

Mohave

Mohave

Coconino

Yavapai

VARIANT

strean

reservoir

reservoir

reservoir

ppl

UNOFF

Coconino

P Pinal

BGN 1977 Coconino

BGN

Coconino

BGN Coconino

BGN 1978 Pinal

VARIANT

VARIANT

VARIANT

VARIANT

VARIANT

$\begin{array}{llll}\text { reservoir } & \text { BGN } & \text { Coconino } & 355918 N 1130413 \mathrm{~W} \\ \text { school } & \text { UNOFF } & \text { Navajo } & 345524 N 1090817 \mathrm{~W} \\ \text { building } & \text { UNOFF } & \text { Maricopa } & 332523 N 1114944 \mathrm{~W} \\ \text { ppl } & \text { BGN } & \text { Pinal } & 324401 N 1103 \mathrm{~B} 47 \mathrm{~W} \\ \text { summit } & \text { BGN } & \text { Coconino } & 353512 \mathrm{~N} 1112609 \mathrm{~W} \\ \text { reservoir } & \text { BGN } & \text { Apache } & 345001 \mathrm{~N} 1094351 \mathrm{~W} \\ \text { well } & \text { UNOFF } & \text { Apache } & 350804 N 1094038 \mathrm{~W} \\ \text { spring } & \text { BGN } & \text { Yavapai } & 342916 \mathrm{N1115114W} \\ \text { trai1 } & \text { UNOFF } & \text { Yavapai } & 344255 \mathrm{~N} 1120937 \mathrm{~W}\end{array}$

summit

BGN

Mountain Sunnys lope Mountain

North Mountain

North Mountain

North Mountain Flood

Detention Dam Number Three

North Mounta in Flood

Detention Dam Number Two A

North Mountain Hospital

\section{summ}

summit

VARIANT

VARIANT

dan

BGN

UGN

Maricopa

Apache

dam UNOFF

hospital
Maricopa

Maricopa
$344005 \mathrm{~N} 1093415 \mathrm{~W}$
COORDINATE

340008 N $1093448 \mathrm{~W}$

$365034 \mathrm{~N} 1121356 \mathrm{~W}$

312104 N1103953W

$321502 \mathrm{~N} 1105432 \mathrm{~W}$

$342319 N 1095347 \mathrm{~W}$

$352454 \mathrm{~N} 1141038 \mathrm{~W}$

$324642 \mathrm{~N} 1143011 \mathrm{~W}$

$324831 \mathrm{~N} 1142935 \mathrm{~W}$

$324632 \mathrm{~N} 1143006 \mathrm{~W}$

$324302 \mathrm{~N} 1143259 \mathrm{~W}$

352137 N1134643W

$324715 N 1092821 W$

$324855 N 1142924 W$

324727 N1093020W

$332227 \mathrm{~N} 112015 \mathrm{BW}$

$342903 \mathrm{~N} 1115248 \mathrm{~W}$

$342845 \mathrm{~N} 1115301 \mathrm{~W}$

$332156 \mathrm{~N} 1135146 \mathrm{~W}$

$355116 N 1135053 \mathrm{~W}$

$360959 \mathrm{~N} 1140415 \mathrm{~W}$

$351347 \mathrm{~N} 1121940 \mathrm{~W}$

$352641 \mathrm{~N} 1131656 \mathrm{~W}$

324859 N1092018W

$352133 \mathrm{~N} 1105028 \mathrm{~W}$

$325317 \mathrm{~N} 1114517 \mathrm{~W}$

$351347 \mathrm{~N} 1121940 \mathrm{~W}$

$345415 N 1111905 \mathrm{~W}$

$333507 \mathrm{~N} 1120418 \mathrm{~W}$

$\begin{array}{lc}\text { SOURCE } & \text { ELEV } \\ \text { COORDINATE } & \text { FT }\end{array}$

MAP NAME

363742N1120628W House Rock

$340807 \mathrm{N1121424 \textrm {W } \quad \text { Bumble Bee }}$

314921N1091917W Chiricahua Peak

342306N1103959W Hanks Draw

Battleship Butte

Joes $\mathrm{Hill}$

Superior

345606M1125755H Brooklyn Peak

Juniper Mts

2952 Grayback Mts

340008 N1093448W Whiteriver

365014N1121151W House Rock Spring SW

Duquesne

2440 Tucson North

Mesa Redonda NW

Chloride

Bard

Laguna Dam

Bard

Yuma East

Peacock Peak

Tollgate Tank

San Jose

Lone Butte

Arnold Mesa

Arnold Mesa

Hoodoo Well

Horse Flat

Iceberg Canyon

B1ye Canyon NE

Casa Grande West

100 McLellan Reservoir

Kinnikinick Lake

Kinnikinick Lake

1606 North Komelik

Prospect Point

Holbrook

Mesa

Mammoth

Wupatki SW

Milky Ranch

North Mill Well

Horner Mtn

Hickey Mountain

2104 Sunnys lope

$335932 \mathrm{~N} 1120416 \mathrm{~W}$

333618 N1120318W

$333536 \mathrm{~N} 1120418 \mathrm{~W}$

333448 N1120414W
382B Daisy Mountain

5998 Stinking Springs Mtn

Sunnys lope

Sunn, slope

Sunnys lope 
NATIONAL GAZETTEER--ARIZONA 1986 FEATURE NAME

North Mountain Park

North Oak Creek

North Oak Points

North OW Point

North Park

North Park

North Park Plaza Shopping Center

North Park Plaza Shopping Center

North Pass

North Pass Spring

North Pass Tank Number One

North Pass Tank Number Two

North Pasture Spring

North Pasture Spring

North Pasture Tank

North Pat Mesa Tank

North Peak

North Peak Trail

North Phoenix High School

North Pine Creek

Pine Creek

North Pinta Tank

North Plowbeam Tank

orth Ranch II

See Kensington (subdivision)

North Red Creek

North Red Hill

North Rim

Bright Angel Point

North Rim Entrance Station

North Rim Inn

North Rim Lookout Tower

North Rim Tank

North Saddle Mountain

North School

North Senator Tank

North Sheba Crater

North Side Canal

North Side Mountains

See Uinkaret Mountains

North Side Mountains

See Yon Dot Mountains

North Six Tank

North Slick Rock Tank

North Split Tank

North Spring

North Spring

North Spring

North Star Mine

North Star Mine

$$
\text { Polaris }
$$

North Star Peak

North Star Wash

North Star We11

North Sycamore Creek

North Tailholt Tank

North Tank

North Tank

North Tank

North Tank

North Tank

North Tank

North Tank

North Tank

North Tank

North Tank

$$
\text { Northwest Tank }
$$

FEATURE
CLASS

STATUS

COUNTY

COOROINATE

Maricopa

$\begin{array}{ll}\text { park } & \text { ADMIN } \\ \text { stream } & \text { BGN } \\ \text { summit } & \text { BGN } \\ \text { cliff } & \text { BGN } \\ \text { park } & \text { ADMIN } \\ \text { park } & \text { AOMIN } \\ \text { locale } & \text { UNOFF }\end{array}$

locale

UNOFF

Graham

Coconino

Gila

Pinal

Pinal

Navajo

333507 N1120418W

$323202 \mathrm{~N} 1101041 \mathrm{~W}$

$364028 \mathrm{~N} 1121832 \mathrm{~W}$

$341718 \mathrm{~N} 1104916 \mathrm{~W}$

$324551 \mathrm{N1113356 \textrm {W }}$

325907 N1113110W

$331919 N 1115031 \mathrm{~W}$

350227 N1104050W

gap

spring

reservoir

reservoir

spring

spring

reservoir

reservoir $B G$

summit BGN

trai1 UNOFF

school

stream

reservoir

reservoir

ppl

UNOFF Maricopa

BGN

VARIANT

BGN

BGN
VARIANT

stream
summit

local

locale

local

tower

reservoir

sumait

school

reservoir

crater

canal BGN

range

summit

reservoir

reservoir

reservoir

spring

spring

spring

mine

mine

summit

strean

well

reservoir

reservoir

BGN
$B G N$

Yavapai

Yuma

Gila

Maricopa

Yavapai

Coconino

$314059 \mathrm{~N} 1113757 \mathrm{~W}$

$340818 \mathrm{~N} 1115148 \mathrm{~W}$

$340841 \mathrm{~N} 1115143 \mathrm{~W}$

$340932 \mathrm{~N} 1115138 \mathrm{~W}$

$340803 \mathrm{~N} 1115146 \mathrm{~W}$

$343810 \mathrm{~N} 1124442 \mathrm{~W}$

$353536 \mathrm{~N} 1114827 \mathrm{~W}$

$331441 N 1091312 \mathrm{~W}$

$340903 \mathrm{N1} 112 \mathrm{~B} 38 \mathrm{~W}$

$341000 \mathrm{~N} 1112825 \mathrm{~W}$

$332842 \mathrm{~N} 1120328 \mathrm{~W}$

341621 NI122341W

322127 N1133801W

$342101 N 1113525 \mathrm{~W}$

$333700 \mathrm{~N} 1115825 \mathrm{~W}$

$341056 \mathrm{~N} 1114532 \mathrm{~W}$ $363229 \mathrm{~N} 1113636 \mathrm{~W}$

361238 N1120338W

$362005 \mathrm{~N} 1120655 \mathrm{~W}$

$361220 \mathrm{N1} 120320 \mathrm{~W}$

361950 N1120603W

$344156 \mathrm{~N} 1113702 \mathrm{~W}$

$313115 \mathrm{~N} 1104042 \mathrm{~W}$

$325850 \mathrm{~N} 1113119 \mathrm{~W}$

$355040 \mathrm{~N} 1141758 \mathrm{~W}$

351843N1111624W

$330250 N 1112744 \mathrm{~W}$

361911 N1131045W

$361850 \mathrm{N1113715 \textrm {W }}$

$312546 \mathrm{~N} 110381 \mathrm{BW}$

$324724 N 1092035 \mathrm{~W}$

$350014 N 1130222 \mathrm{~W}$

$335411 N 1091641 \mathrm{~W}$

340531 N1093255W

Apache

62326N1124157W

$324930 \mathrm{~N} 1112030 \mathrm{~W}$

$331749 \mathrm{~N} 1135809 \mathrm{~W}$

$320627 \mathrm{~N} 1102524 \mathrm{~W}$

$331515 N 1135845 \mathrm{~W}$

$331520 \mathrm{~N} 1135917 \mathrm{~W}$

$342243 \mathrm{~N} 1111701 \mathrm{~W}$

$344545 \mathrm{~N} 1124643 \mathrm{~W}$

$312140 \mathrm{~N} 1103955 \mathrm{~W}$

reservoir BGN Pima 314423N1112930W

Cochise 314731N1092508W

reservoir BGN Pima $314841 \mathrm{N1112351 \textrm {W }}$

reservoir BGN $\quad$ Pima $315013 N 1112858 \mathrm{~W}$

reservoir BGN Pima 315347N1112557W

Graham 323857N1101501W

reservoir BGN Graham 325133N1092348W

reservoir

BGN 1975 Graham

VARIANT
$331848 \mathrm{~N} 1135736 \mathrm{~W}$

$\begin{array}{cc}\text { SOURCE } & \text { ELEV } \\ \text { COORDINATE } & \text { FT MAP NAME }\end{array}$

Sunnys lope

Harrison Canyon

Warm Springs Canyon

$0 \mathrm{~W}$ Point

Eloy North

Coolidge

Chandler

Winslow

Aguirre Peak

Bloody Bas in

Bloody Bas in

Bloody Bas in

Bloody Basin

Mt Josh

Chapel Mtn

Big Lue Mts

7449 North Peak

North Peak

$341414 N 1122204 W$

Phoenix

Battleship Butte

Christmas Pass

Cane Springs Mtn

Bloody Bas in

Cedar Tree Hills

Bright Angel Point

Little Park Lane

8340 Bright Angel Point

9165 Little Park Lane

Apache Maid Mtn

5434 Mt Hughes

Coolidge

Senator Mtn

6407 Merriam Crater

Florence

Harshaw

Ash Peak

Anvil Rock

Rudd Knoll

Greens Peak

Kanab Point

Picacho Reservoir SE

Kofa Butte

6041 Galleta Flat West

Kofa Butte

Kofa Butte

Kehl Ridge

Seepage Mtn

Duquesne

Las Guijas

Stanford Canyon

Portal Peak

Fresno Wash

Fresno Wash

Palo Alto Ranch

Kennedy Peak

Tollgate Tank

Mobile 


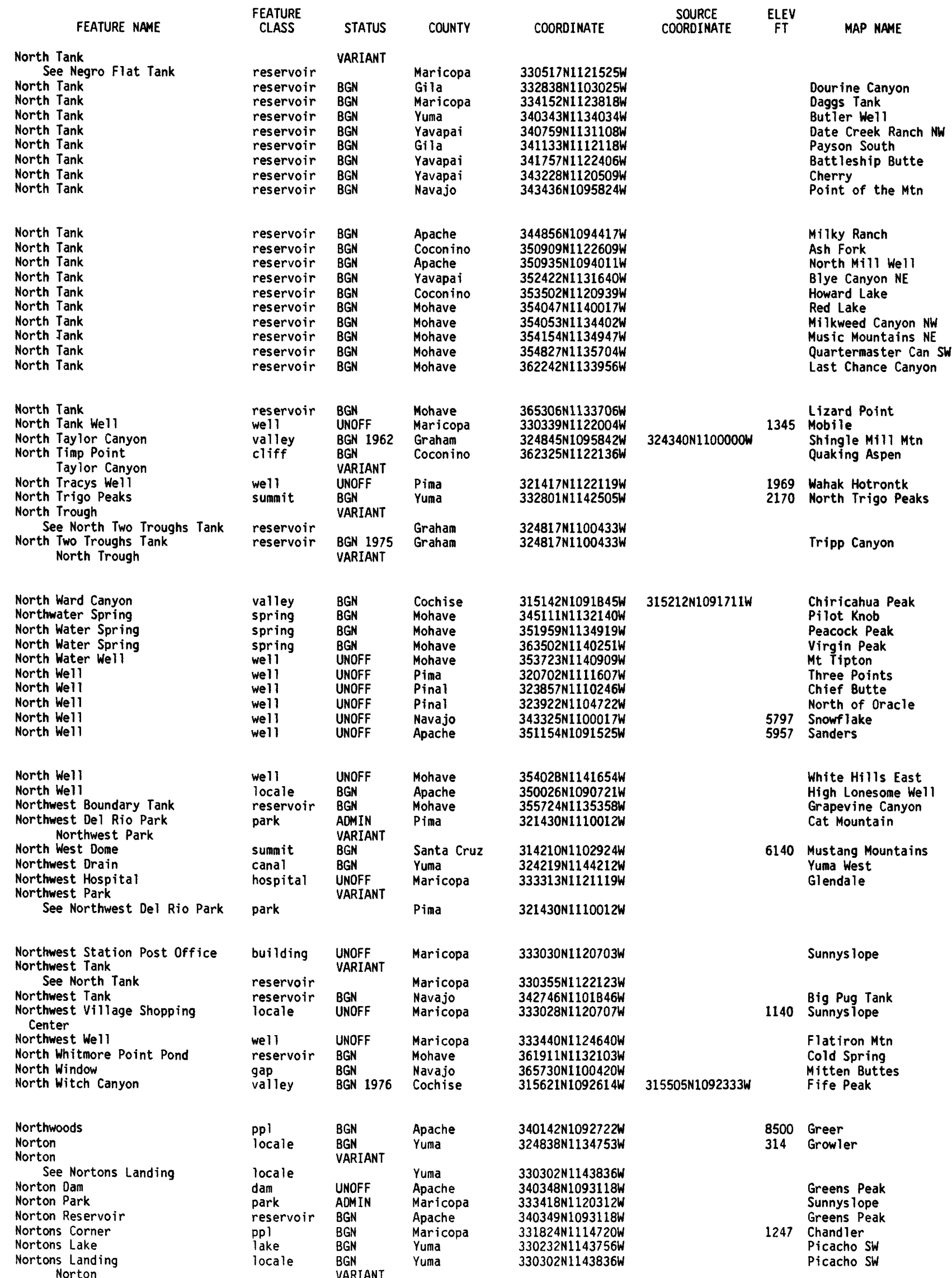




\begin{tabular}{|c|c|c|c|c|c|c|c|}
\hline FEATURE NAME & $\begin{array}{c}\text { FEATURE } \\
\text { CLASS }\end{array}$ & STATUS & COUNTY & COORDINATE & $\begin{array}{l}\text { SOURCE } \\
\text { COORDINATE }\end{array}$ & $\begin{array}{c}\text { ELEV } \\
\text { FT }\end{array}$ & MAP NAME \\
\hline $\begin{array}{l}\text { Norton Spring } \\
\text { Norton Spring } \\
\text { Norton Tank } \\
\text { Norton Tank } \\
\text { Norton Water Tank } \\
\text { N-O Spring } \\
\text { No Tank } \\
\text { No Trail Mesa } \\
\text { Not-tahn-de-lit } \\
\text { See Burnt Corn Spring }\end{array}$ & $\begin{array}{l}\text { spring } \\
\text { spring } \\
\text { reservoir } \\
\text { reservoir } \\
\text { reservoir } \\
\text { spring } \\
\text { reservoir } \\
\text { summit } \\
\text { spring }\end{array}$ & $\begin{array}{l}\text { BGN } \\
\text { BGN } \\
\text { BGN } \\
\text { BGN } \\
\text { BGN } \\
\text { BGN } \\
\text { BGN } \\
\text { BGN } \\
\text { VARIANT }\end{array}$ & $\begin{array}{l}\text { Graham } \\
\text { Graham } \\
\text { Yuma } \\
\text { Yavapai } \\
\text { Yavapai } \\
\text { Cochise } \\
\text { Greenlee } \\
\text { Coconino } \\
\text { Navajo }\end{array}$ & $\begin{array}{l}324347 \mathrm{~N} 1102638 \mathrm{~W} \\
325029 \mathrm{~N} 1101043 \mathrm{~W} \\
325733 \mathrm{N1135240 \textrm {W }} \\
352357 \mathrm{N1} 130339 \mathrm{~W} \\
350822 \mathrm{~N} 1125831 \mathrm{~W} \\
321945 \mathrm{~N} 1101339 \mathrm{~W} \\
331513 \mathrm{~N} 1091303 \mathrm{~W} \\
355120 \mathrm{~N} 1104731 \mathrm{~W} \\
360758 \mathrm{~N} 1100714 \mathrm{~W}\end{array}$ & & 6110 & $\begin{array}{l}\text { Rhodes Peak } \\
\text { Buford Hill } \\
\text { North of Roll } \\
\text { Audley } \\
\text { Purcell Canyon } \\
\text { Hookers Hot Springs } \\
\text { Fritz Canyon } \\
\text { Padilla Mesa }\end{array}$ \\
\hline $\begin{array}{l}\text { Nottahndelit Spring } \\
\text { See Burnt Corn Spring } \\
\text { Not Tak Tank } \\
\text { Nottbusch Butte } \\
\text { Nottbush Butte } \\
\text { Nottbusch Mine } \\
\text { Nottbusch Valley } \\
\text { Nottbusch Wash } \\
\text { Nottbush Butte } \\
\text { See Nottbusch Butte }\end{array}$ & $\begin{array}{l}\text { spring } \\
\text { reservoir } \\
\text { summit } \\
\text { mine } \\
\text { valley } \\
\text { stream } \\
\text { summit }\end{array}$ & $\begin{array}{l}\text { VARIANT } \\
\text { BGN } \\
\text { BGN } 1963 \\
\text { VARIANT } \\
\text { UNOFF } \\
\text { BGN } \\
\text { BGN } \\
\text { VARIANT }\end{array}$ & $\begin{array}{l}\text { Navajo } \\
\text { Pima } \\
\text { Yuma } \\
\text { Yuma } \\
\text { Yuma } \\
\text { Maricopa } \\
\text { Yuma }\end{array}$ & $\begin{array}{l}360758 \mathrm{~N} 1100714 \mathrm{~W} \\
315251 \mathrm{N1} 120717 \mathrm{~W} \\
331944 \mathrm{~N} 1132500 \mathrm{~W} \\
330433 \mathrm{~N} 1134635 \mathrm{~W} \\
331700 \mathrm{~N} 1132500 \mathrm{~W} \\
325901 \mathrm{~N} 1131 \mathrm{~B} 39 \mathrm{~W} \\
331944 \mathrm{~N} 1132500 \mathrm{~W}\end{array}$ & $\begin{array}{l}322230 \mathrm{~N} 1133130 \mathrm{~W} \\
331515 \mathrm{~N} 1132508 \mathrm{~W}\end{array}$ & 2184 & $\begin{array}{l}\text { Gu Oidak } \\
\text { Nottbusch Butte } \\
\text { Neversweat Ridge } \\
\text { Nottbusch Butte } \\
\text { Agua Caliente }\end{array}$ \\
\hline $\begin{array}{l}\text { Not Vaya } \\
\text { See Nawt Vaya } \\
\text { Novinger Butte } \\
\text { Novio Spring } \\
\text { No Water Tank } \\
\text { No Way Spring } \\
\text { N Tank } \\
\text { Nuestro Park } \\
\text { Nueve Park } \\
\text { Nugent Lateral }\end{array}$ & $\begin{array}{l}\text { locale } \\
\text { summit } \\
\text { spring } \\
\text { reservoir } \\
\text { spring } \\
\text { reservoir } \\
\text { park } \\
\text { park } \\
\text { canal }\end{array}$ & $\begin{array}{l}\text { VARIANT } \\
\text { BGN } 1932 \\
\text { BGN } \\
\text { BGN } \\
\text { BGN } \\
\text { BGN } \\
\text { ADMIN } \\
\text { ADNIN } \\
\text { BGN }\end{array}$ & $\begin{array}{l}\text { Pima } \\
\text { Coconino } \\
\text { Pima } \\
\text { Coconino } \\
\text { Graham } \\
\text { Navajo } \\
\text { Maricopa } \\
\text { Maricopa } \\
\text { Yuma }\end{array}$ & $\begin{array}{l}320159 \mathrm{~N} 111291 \mathrm{BW} \\
361516 \mathrm{~N} 1115631 \mathrm{~W} \\
322533 \mathrm{~N} 1104309 \mathrm{~W} \\
353343 \mathrm{~N} 1110754 \mathrm{~W} \\
331906 \mathrm{~N} 1100757 \mathrm{~W} \\
341051 \mathrm{~N} 1100207 \mathrm{~W} \\
332601 \mathrm{~N} 1120341 \mathrm{~W} \\
33241 \mathrm{BN} 1120330 \mathrm{~W} \\
323917 \mathrm{~N} 1143 \mathrm{~B} 5 \mathrm{WW}\end{array}$ & & & $\begin{array}{l}\text { Point Imperial } \\
\text { Mount Bigelow } \\
\text { Standing Rocks } \\
\text { Branaman Spring } \\
\text { Show Low South } \\
\text { Phoen ix } \\
\text { Phoenix } \\
\text { Yuma West }\end{array}$ \\
\hline $\begin{array}{l}\text { Nugents Pass } \\
\text { Nugget Canyon } \\
\text { Nugget Canyon } \\
\text { Nugget Mesa } \\
\text { Nugget Mine } \\
\text { Nugget Mountain } \\
\text { Nugget Wash } \\
\text { Nugget Wash } \\
\text { Nugget Wash Spring } \\
\text { Numas i to Canyon } \\
\text { See Potato Canyon }\end{array}$ & $\begin{array}{l}\text { gap } \\
\text { valley } \\
\text { valley } \\
\text { summit } \\
\text { mine } \\
\text { summit } \\
\text { stream } \\
\text { stream } \\
\text { spring } \\
\text { valley }\end{array}$ & $\begin{array}{l}\text { BGN } \\
\text { BGN } \\
\text { BGN } \\
\text { BGN } \\
\text { UNOFF } \\
\text { BGN } \\
\text { BGN } \\
\text { BGN } \\
\text { BGN } \\
\text { VARIANT }\end{array}$ & $\begin{array}{l}\text { Cochise } \\
\text { Pina } \\
\text { Pinal } \\
\text { Gila } \\
\text { Pinal } \\
\text { Gila } \\
\text { Yuma } \\
\text { Gila } \\
\text { Gila } \\
\text { Coconino }\end{array}$ & $\begin{array}{l}321100 \mathrm{~N} 1100600 \mathrm{~W} \\
323218 \mathrm{~N} 1104110 \mathrm{~W} \\
323221 \mathrm{~N} 1104111 \mathrm{~W} \\
333111 \mathrm{~N} 1104622 \mathrm{~W} \\
324248 \mathrm{~N} 1114832 \mathrm{~W} \\
332943 \mathrm{~N} 1104617 \mathrm{~W} \\
324608 \mathrm{~N} 1141755 \mathrm{~W} \\
332807 \mathrm{~N} 1105030 \mathrm{~W} \\
333010 \mathrm{~N} 1104657 \mathrm{~W} \\
364251 \mathrm{~N} 1105143 \mathrm{~W}\end{array}$ & $\begin{array}{l}323037 \mathrm{~N} 1104428 \mathrm{~W} \\
323037 \mathrm{~N} 1104425 \mathrm{~W} \\
324724 \mathrm{~N} 1141820 \mathrm{~W} \\
333126 \mathrm{~N} 1104436 \mathrm{~W}\end{array}$ & 5147 & $\begin{array}{l}\text { Steele Hills } \\
\text { Campo Bonito } \\
\text { Campo Bonito } \\
\text { Rockinstraw Mtn } \\
\text { Silver Reef Mts } \\
\text { Globe } \\
\text { Dome } \\
\text { Globe } \\
\text { Rockinstraw Mtn }\end{array}$ \\
\hline $\begin{array}{l}\text { Number Eleven Tank } \\
\text { Number Fifteen, Tank } \\
\text { Number Five, Tank } \\
\text { Number Five, Tank } \\
\text { Number Five, Tank } \\
\text { Number Five, Well } \\
\text { Number Five, Wel1 } \\
\text { Number Five, Wel1 } \\
\text { Number Five Trough } \\
\text { Number Five Trough }\end{array}$ & $\begin{array}{l}\text { reservoir } \\
\text { reservoir } \\
\text { reservoir } \\
\text { reservoir } \\
\text { reservoir } \\
\text { well } \\
\text { well } \\
\text { well } \\
\text { reservoir } \\
\text { reservoir }\end{array}$ & $\begin{array}{l}\text { BGN } \\
\text { BGN } \\
\text { BGN } \\
\text { BGN } \\
\text { BGN } \\
\text { UNOFF } \\
\text { UNOFF } \\
\text { UNOFF } \\
\text { BGN } \\
\text { BGN }\end{array}$ & $\begin{array}{l}\text { Coconino } \\
\text { Coconino } \\
\text { Pima } \\
\text { Greenlee } \\
\text { Yavapai } \\
\text { Apache } \\
\text { Yavapai } \\
\text { Yavapai } \\
\text { Mohave } \\
\text { Mohave }\end{array}$ & $\begin{array}{l}355126 \mathrm{~N} 1124105 \mathrm{~W} \\
355 \mathrm{~B} 18 \mathrm{~N} 1124936 \mathrm{~W} \\
315019 \mathrm{~N} 1112851 \mathrm{~W} \\
323303 \mathrm{~N} 1091029 \mathrm{~W} \\
340427 \mathrm{~N} 1115137 \mathrm{~W} \\
345703 \mathrm{~N} 1093016 \mathrm{~W} \\
350343 \mathrm{~N} 1131530 \mathrm{~W} \\
351941 \mathrm{~N} 1130 \mathrm{~B} 05 \mathrm{~W} \\
345059 \mathrm{~N} 1140305 \mathrm{~W} \\
350411 \mathrm{~N} 1140411 \mathrm{~W}\end{array}$ & & & $\begin{array}{l}\text { Hazen Hole Tank } \\
\text { Supai Camp } \\
\text { Fresno Wash } \\
\text { Whitlock Peak } \\
\text { Rover Peak } \\
\text { Ninemile Seep } \\
\text { Devils Hump } \\
\text { Sugarloaf Peak } \\
\text { Yucca SE } \\
\text { Kingman SE }\end{array}$ \\
\hline $\begin{array}{l}\text { Number Five Trough } \\
\text { Number Four, Lake } \\
\text { Number Four, Tank } \\
\text { Number Four, Tank } \\
\text { Number Four, Tank } \\
\text { Number Four, Tank } \\
\text { Number Four, Well } \\
\text { Number Four, Well } \\
\text { Number Four, Well } \\
\text { Number Four, Well }\end{array}$ & $\begin{array}{l}\text { reservoir } \\
\text { lake } \\
\text { reservoir } \\
\text { reservoir } \\
\text { reservoir } \\
\text { reservoir } \\
\text { well } \\
\text { well } \\
\text { well } \\
\text { well }\end{array}$ & $\begin{array}{l}\text { BGN } \\
\text { BGN } \\
\text { BGN } \\
\text { BGN } \\
\text { BGN } \\
\text { BGN } \\
\text { UNOFF } \\
\text { UNOFF } \\
\text { UNOFF } \\
\text { UNOFF }\end{array}$ & $\begin{array}{l}\text { Mohave } \\
\text { Coconino } \\
\text { Pima } \\
\text { Greenlee } \\
\text { Coconino } \\
\text { Coconino } \\
\text { Navajo } \\
\text { Yavapai } \\
\text { Yavapai } \\
\text { Coconino }\end{array}$ & $\begin{array}{l}351724 \mathrm{~N} 1131334 \mathrm{~W} \\
342410 \mathrm{~N} 1110616 \mathrm{~W} \\
315 \mathrm{~B} 48 \mathrm{~N} 1111929 \mathrm{~W} \\
323126 \mathrm{~N} 1091131 \mathrm{~W} \\
353011 \mathrm{~N} 1113533 \mathrm{~W} \\
355709 \mathrm{~N} 1124555 \mathrm{~W} \\
345032 \mathrm{~N} 1103520 \mathrm{~W} \\
350426 \mathrm{~N} 1131203 \mathrm{~W} \\
350542 \mathrm{~N} 1130402 \mathrm{~W} \\
363309 \mathrm{~N} 1112355 \mathrm{~W}\end{array}$ & & $\begin{array}{l}5871 \\
5362\end{array}$ & $\begin{array}{l}\text { Cerbat } \\
\text { Knoll Lake } \\
\text { Stevens Mtn } \\
\text { Whitlock Peak } \\
\text { East of S P Mtn } \\
\text { Supai Camp } \\
\text { McCauley Sinks } \\
\text { Anvil Rock Ranch } \\
\text { Anvil Rock } \\
\text { Dove Spring }\end{array}$ \\
\hline $\begin{array}{l}\text { Number Four and One-Half, Tank } \\
\text { Number Four Tank } \\
\text { Number Fourteen, Tank } \\
\text { Number Four Trough } \\
\text { Number Nine Tank } \\
\text { Number One, Lake } \\
\text { Number One, Tank } \\
\text { Number One, Tank } \\
\text { Number One, Tank } \\
\text { Number One, Tank }\end{array}$ & $\begin{array}{l}\text { reservoir } \\
\text { reservoir } \\
\text { reservoir } \\
\text { reservoir } \\
\text { reservoir } \\
\text { lake } \\
\text { reservoir } \\
\text { reservoir } \\
\text { reservoir } \\
\text { reservoir }\end{array}$ & $\begin{array}{l}\text { BGN } \\
B G N \\
B G N \\
B G N \\
B G N \\
B G N \\
B G N \\
B G N \\
B G N \\
B G N\end{array}$ & $\begin{array}{l}\text { Coconino } \\
\text { Coconino } \\
\text { Coconino } \\
\text { Mohave } \\
\text { Coconino } \\
\text { Coconino } \\
\text { Pima } \\
\text { Greenlee } \\
\text { Pinal } \\
\text { Yavapai }\end{array}$ & $\begin{array}{l}355819 \mathrm{~N} 1124353 \mathrm{~W} \\
353840 \mathrm{~N} 1121110 \mathrm{~W} \\
355609 \mathrm{~N} 1124925 \mathrm{~W} \\
345129 \mathrm{~N} 1140115 \mathrm{~W} \\
354837 \mathrm{~N} 1124436 \mathrm{~W} \\
35032 \mathrm{BN} 1113631 \mathrm{~W} \\
314640 \mathrm{~N} 1112851 \mathrm{~W} \\
323604 \mathrm{~N} 109101 \mathrm{WW} \\
325622 \mathrm{~N} 1111229 \mathrm{~W} \\
344310 \mathrm{~N} 1124012 \mathrm{~W}\end{array}$ & & & $\begin{array}{l}\text { Hualapai Tank } \\
\text { Valle Tank } \\
\text { Supai Camp } \\
\text { Yucca SE } \\
\text { Hazen Hole Tank } \\
\text { Lower Lake Mary } \\
\text { Fresno Wash } \\
\text { Whitlock Peak } \\
\text { Ninetysix Hills NW } \\
\text { Mt Josh }\end{array}$ \\
\hline
\end{tabular}


FEATURE

Number One, Tank Number One, Tank Number One, Tank

Number One, Tank

Number One, Well

Number One, Well

Number One, Well

Number One Dam

Number One Dirt Tank

Number One Trough Tank

Number Seventy-nine, Lateral

Number Six, Well

Number Ten Tank

Number Ten Tank

Number Thirteen, Tank

Number Thirteen and One-Half, Tank

Number Thirtys ix Tank

Number Thirty-two, Tank

Number Thirtytwo, Tank

Number Three, Tank

Number Three, Tank

Number Three, Tank

Number Three, Tank

Number Three, Well

Number Three, Well

Number Three, Well

Number Three, Well

Number Three Dirt Tank

Number Three Tank

Number Three Tanks

Number Three Trough

Number Twelve Tank

Number Twenty, Tank

Number Twenty One, Well

Number Twentytwo, Tank

Number Two, Tank

Number Two, Tank

Number Two, Tank

Number Two, Tank

Number Two, Tank

Number Two, Tank

Number Two, Well

Number Two Dirt Tank

Number Two Tank

Number Two Tank

Number Two Tanks

Number Two Trough

Nunn Tank

Nurusse

Nut Dam

See Nutrioso Dam

Nut Fall Canyon

See Nuttall Canyon

Nutrioso

Nutrioso Creek

Nutrioso Dam

Nut Dam

Nutrioso Reservoir

Nutt, Mount

Battleship Mountain Nutt Mountain

Nuttall Canyon

See Middle Wash

Nuttall Canyon

Nut Fall Canyon

Nuttle Canyon

Nutter Pond

uttles Canyon

Nutter Reservoir

Nutter Tank

Nuttle Canyon

CLASS

cana 1

well

well

well

well

well

well

well

summit

dam

valley

ppl

strean

dam

summit

stream

valley
STATUS

COUNTY

COORDINATE

$\begin{array}{ll}\text { reservoir } & \text { BGN } \\ \text { reservoir } & \text { BGN } \\ \text { reservoir } & \text { BGN } \\ \text { reservoir } & \text { BGN } \\ \text { well } & \text { UNOFF } \\ \text { well } & \text { UNOFF } \\ \text { well } & \text { UNOFF } \\ \text { dam } & \text { UNOFF } \\ \text { reservoir } & \text { BGN } \\ \text { reservoir } & \text { BGN }\end{array}$

8GN

reservoir

reservoir

reservoir

reservoir

reservoir

reservoir

reservoir

UNOFF Yavapai

$B G N$

BGN

BGN

BGN

reservoir

reservoir

reservoir

reservoir

$\begin{array}{ll}\text { reservoir } & B G M \\ \text { reservoir } & B G M\end{array}$

\section{BGN}

BGN

BGN

UNOFF

UNOFF

UNOFF

UNOFF

reservoir

reservoir

reservoir

reservoir

reservoir

reservoir

reservoir

reservoir

reservoir

BGM

BGN
BGN
BGN
BGN
UNOF
BGN
BGN
BGN
BGN
BGN

reservoir reservoir

reservoir

reservoir

reservoir

reservoir

reservoir

reservoir

BGN
BGN
UNOF
BGN
BGN
BGN
BGN
BGN
BGN
BGN

VARIANT

reservoir

VARIANT

BGN

BGN

UNOFF

VARIANT

BGN

BGN

VARIANT

VARIANT

VARIANT

reservoir

reservoir

reservoir
BGN 1962
VARIANT

VARIANT

BGN

BGN

BGN

VARIANT
Yavapai

Coconino

Coconino

Coconino

Pima

Yavapai

Coconino

Gila

Pinal

Coconino

Coconino

Yavapai

Pima

Pima

Coconino

Coconino

Coconino

Coconino

Maricopa

Navajo

Yavapai

Coconino

Pinal

Pinal

Santa Cruz

Mohave

Coconino

Coconino

Yavapai

Pinal

Pima

Yavapai

Coconino

Yavapai

Coconino

Coconino

Coconino

Pinal

Santa Cruz

Greenlee

Mohave

Mohave

Yavapai

Coconino

Apache

$344311 N 1124012 W$

345738 N1111210W

353531 N1124929W

$353943 \mathrm{~N} 1122130 \mathrm{~W}$

$322728 N 1125022 \mathrm{~W}$

$350826 \mathrm{~N} 1131718 \mathrm{~W}$

$362337 N 1112501 \mathrm{~W}$

340807 N1110822W

$324038 N 1105154 \mathrm{~N}$

$353505 N 1141704 \mathrm{~W}$

$340012 N 1142425 \mathrm{~W}$

35809N1130731W

351819 N1123525W

355008 N1124239W

$355316 \mathrm{~N} 1112321 \mathrm{~W}$

$355340 \mathrm{~N} 1123247 \mathrm{~W}$

$340455 \mathrm{~N} 1124339 \mathrm{~W}$

$315945 \mathrm{~N} 1112004 \mathrm{~W}$

315949N1112007W

345507 N1111106W

$353226 \mathrm{~N} 1124730 \mathrm{~W}$

$353959 \mathrm{~N} 1122518 \mathrm{~W}$

$355342 \mathrm{N11} 24740 \mathrm{~W}$

$323136 \mathrm{~N} 1125521 \mathrm{~W}$

$344832 \mathrm{~N} 1103720 \mathrm{~W}$

$350520 N 1131032 \mathrm{~W}$

$363214 N 1112535 W$

$323715 N 1105130 \mathrm{~W}$

$323520 \mathrm{~N} 1112208 \mathrm{~W}$

312547 N1103912W

$344946 \mathrm{~N} 1140105 \mathrm{~W}$

$355218 N 1123816 \mathrm{~W}$

$355821 \mathrm{~N} 1124200 \mathrm{~W}$

$350303 \mathrm{~N} 1130056 \mathrm{~W}$

$325833 \mathrm{~N} 1111217 \mathrm{~W}$

$314730 \mathrm{~N} 1112922 \mathrm{~W}$

$343223 N 1113428 \mathrm{~W}$

$345602 \mathrm{~N} 1111122 \mathrm{~W}$

$351410 \mathrm{~N} 1124123 \mathrm{~W}$

$353333 \mathrm{~N} 1124819 \mathrm{~W}$

$353935 \mathrm{~N} 1122320 \mathrm{~W}$

$362824 N 1112451 \mathrm{~W}$

323926 N1105150W

$312527 \mathrm{N1} 104118 \mathrm{~W}$

$331452 N 1091225 \mathrm{~W}$

$352213 \mathrm{~N} 1132202 \mathrm{~W}$

$345055 \mathrm{~N} 1140051 \mathrm{~W}$

$345146 \mathrm{~N} 1121552 \mathrm{~W}$

365033 N1111838W

335706 N1091248W

$324740 N 1095815 \mathrm{~W}$

$335711 N 1091231 \mathrm{~W}$

$340903 N 1091735 \mathrm{~W}$

335706 N1091248W

335708 N1091257W

350516 N1142110W

$335335 N 1090941 W$

Apache

Apache

Mohave

Graham

325013 N1095550W

$324740 \mathrm{~N} 1095815 \mathrm{~W}$

364659 N1132042W

$362641 \mathrm{N1132808 \textrm {W }}$

363040 N1133534W

$\begin{array}{cc}\text { SOURCE } & \text { ELEV } \\ \text { COORDINATE } & \text { FT }\end{array}$

Mt Josh

Chavez Mtn NW

6089 Big Bud Tank

Miller Tank 
FEATURE NAME

CLASS

See Middle Wash

stream

Nuttle Canyon

See Nuttall Canyon valley

Nuttles Canyon

See Nuttall Canyon

Nutt Mountain

See Nutt, Mount

Nuvat-i-kyan-bi

See San Francisco Mountain

Nyce Cabin

Nyce Lake

Nyerwi $\mathrm{Ki}$

See San Luis

locale
STATUS

COUNTY

COORDINATE

325013 N1095550W

$\begin{array}{ll}\text { VARIANT } & \text { Graham } \\ \text { VARIANT } & \text { Graham } \\ \text { VARIANT } & \text { Mohave } \\ \text { BGN } & \begin{array}{l}\text { Coconino } \\ \text { BGN }\end{array} \\ \text { Nache } \\ \end{array}$

VARIANT

Pima

$320449 \mathrm{~N} 1115716 \mathrm{~W}$ $\begin{array}{lc}\text { SOURCE } & \text { ELEV } \\ \text { COORDINATE } & \text { FT MAP NAME }\end{array}$

Corn Creek Plateau

Chediski Peak
O'Brien Gulch

$O^{\prime}$ Brien Mine

O'Carroll Canyon

O' Connell Spring

O'Connell Tank

O'Dell Tank

O'Donnell Canyon

O'Donnell Canyon

See Post Canyon

O'Grady Canyon

O' Haco Cabins

Ohaca Cabins

O'Haco Lookout Tower

O'Haco Tank

O' Haco Tank

O'Haco Tank

O'Keefe Spring

O' Keefe Tank

O'Leary Canyon

O' Leary Peak

O' Neal Park

O'Neil Hills

See Agua Dulce Mountains

O'Neil Hills

See O'Neill Hills

O'Neill Butte

$O^{\prime}$ Neill Crater

O'Neill Hills

See Agua Dulce Mountains

O' Neill Hills

O'Neil Hills

$0^{\prime}$ Neils Hills

O'Neill Pass

O'Neill Point

See Yavapai Point

O'Neills Grave

O'Neill Spring

O'Neill Spring

O'Neil Spring

Oneil Spring

O'Neil Pass

$\mathrm{O}^{\prime} \mathrm{Neils} \mathrm{Hills}$

See O'Neill Hills

O'Neil Spring

$0^{\prime} \mathrm{Ne}$ il Spring

See O'Neill Spring

O'Neil Tank

Oak Butte

Oak Canyon

Oak Canyon

\begin{tabular}{|c|c|c|c|c|c|c|}
\hline $\begin{array}{l}\text { valley } \\
\text { mine } \\
\text { valley } \\
\text { spring } \\
\text { reservoir } \\
\text { reservoir } \\
\text { valley } \\
\text { valley }\end{array}$ & $\begin{array}{l}\text { BGN } \\
\text { UNOFF } \\
\text { BGN } \\
\text { BGN } \\
\text { BGN } \\
\text { BGN } \\
\text { BGN } 1959 \\
\text { VARIANT }\end{array}$ & $\begin{array}{l}\text { Yavapai } \\
\text { Mohave } \\
\text { Pinal } \\
\text { Maricopa } \\
\text { Coconino } \\
\text { Coconino } \\
\text { Santa Cruz } \\
\text { Santa Cruz }\end{array}$ & $\begin{array}{l}340600 \mathrm{~N} 1123349 \mathrm{~W} \\
351757 \mathrm{~N} 1140 \mathrm{~B} 01 \mathrm{~W} \\
330109 \mathrm{~N} 1104433 \mathrm{~W} \\
333420 \mathrm{~N} 1111606 \mathrm{~W} \\
360022 \mathrm{~N} 1121441 \mathrm{~W} \\
353943 \mathrm{~N} 1114342 \mathrm{~W} \\
13750 \mathrm{~N} 1102810 \mathrm{~W} \\
313520 \mathrm{~N} 1103015 \mathrm{~W}\end{array}$ & $\begin{array}{l}340355 \mathrm{~N} 1123326 \mathrm{~W} \\
330404 \mathrm{~N} 1104657 \mathrm{~W}\end{array}$ & & $\begin{array}{l}\text { Morgan Butte } \\
\text { Cerbat } \\
\text { Christmas } \\
\text { Mesa } \\
\text { Grand Canyon } \\
\text { Additional Hill } \\
\text { Mustang Mountains }\end{array}$ \\
\hline $\begin{array}{l}\text { valley } \\
\text { locale }\end{array}$ & $\begin{array}{l}\text { BGN } \\
\text { BGN } \\
\text { VARIANT }\end{array}$ & $\begin{array}{l}\text { Pinal } \\
\text { Coconino }\end{array}$ & $\begin{array}{l}332724 N 1112411 \mathrm{~W} \\
342914 \mathrm{~N} 1110243 \mathrm{~W}\end{array}$ & $332626 \mathrm{~N} 1112515 \mathrm{~W}$ & & $\begin{array}{l}\text { Goldfield } \\
\text { Knoll Lake }\end{array}$ \\
\hline $\begin{array}{l}\text { tower } \\
\text { reservoir } \\
\text { reservoir } \\
\text { reservoir } \\
\text { spring } \\
\text { reservoir } \\
\text { valley }\end{array}$ & $\begin{array}{l}\text { UNOFF } \\
\text { BGN } \\
\text { BGN } \\
\text { BGN } \\
\text { BGN } \\
\text { BGN } \\
\text { BGN }\end{array}$ & $\begin{array}{l}\text { Coconino } \\
\text { Maricopa } \\
\text { Maricopa } \\
\text { Coconino } \\
\text { Cochise } \\
\text { Cochise } \\
\text { Santa Cruz }\end{array}$ & $\begin{array}{l}342627 \mathrm{~N} 1110427 \mathrm{~W} \\
335456 \mathrm{~N} 1125053 \mathrm{~W} \\
335921 \mathrm{~N} 1125324 \mathrm{~W} \\
344102 \mathrm{~N} 1105718 \mathrm{~W} \\
314634 \mathrm{~N} 1092431 \mathrm{~W} \\
314540 \mathrm{~N} 1092355 \mathrm{~W} \\
313654 \mathrm{~N} 1103342 \mathrm{~W}\end{array}$ & $313509 \mathrm{~N} 1103855 \mathrm{~W}$ & 7640 & $\begin{array}{l}\text { Knoll Lake } \\
\text { Vulture Peak } \\
\text { Outlaw Hill } \\
\text { Hamilton Crossing } \\
\text { Stanford Canyon } \\
\text { Stanford Canyon } \\
\text { O'Donnell Canyon }\end{array}$ \\
\hline $\begin{array}{l}\text { summit } \\
\text { park }\end{array}$ & $\begin{array}{l}\text { BGN } 1931 \\
\text { ADMIN } \\
\text { VARIANT }\end{array}$ & $\begin{array}{l}\text { Coconino } \\
\text { Maricopa }\end{array}$ & $\begin{array}{l}352406 \mathrm{~N} 1113132 \mathrm{~W} \\
333103 \mathrm{~N} 1121150 \mathrm{~W}\end{array}$ & & 8916 & $\begin{array}{l}\text { O' Leary Peak } \\
\text { Glendale }\end{array}$ \\
\hline summit & VARIANT & Pima & $320320 \mathrm{~N} 1131157 \mathrm{~W}$ & & & \\
\hline $\begin{array}{l}\text { Summit } \\
\text { summit } \\
\text { crater }\end{array}$ & $\begin{array}{l}\text { BGN } 1964 \\
\text { BGN } \\
\text { VARIANT }\end{array}$ & $\begin{array}{l}\text { Yuma } \\
\text { Coconino } \\
\text { Coconino }\end{array}$ & $\begin{array}{l}320537 \mathrm{~N} 1132135 \mathrm{~W} \\
360417 \mathrm{~N} 1120523 \mathrm{~W} \\
35151 \mathrm{BN} 1112742 \mathrm{~W}\end{array}$ & & 6072 & $\begin{array}{l}\text { Phantom Ranch } \\
\text { Sunset Crater East }\end{array}$ \\
\hline summit & & Pima & $320320 \mathrm{~N} 1131157 \mathrm{~W}$ & & & \\
\hline summit & $\begin{array}{l}\text { BGN } 1965 \\
\text { VARIANT } \\
\text { VARIANT }\end{array}$ & Yuma & $320537 \mathrm{~N} 1132135 \mathrm{~W}$ & & & O'Neill Hills \\
\hline gap & $\begin{array}{l}\text { BGN } \\
\text { VARIANT }\end{array}$ & Yuma & $320550 \mathrm{~N} 1132121 \mathrm{~W}$ & & & O'Neill Hills \\
\hline $\begin{array}{l}\text { cliff } \\
\text { cemetery } \\
\text { spring } \\
\text { spring }\end{array}$ & $\begin{array}{l}\text { UNOFF } \\
\text { BGN } \\
\text { BGN } 1932 \\
\text { VARIANT } \\
\text { VARIANT }\end{array}$ & $\begin{array}{l}\text { Coconino } \\
\text { Yuma } \\
\text { Coconino } \\
\text { Coconino }\end{array}$ & $\begin{array}{l}360400 \mathrm{~N} 1120703 \mathrm{~W} \\
320551 \mathrm{~N} 1132110 \mathrm{~W} \\
350602 \mathrm{~N} 1114113 \mathrm{~W} \\
360101 \mathrm{~N} 1115842 \mathrm{~W}\end{array}$ & & & $\begin{array}{l}\text { O'Neill Hills } \\
\text { Mountainaire } \\
\text { Cape Royal }\end{array}$ \\
\hline gap & $\begin{array}{l}\text { BGN } \\
\text { VARIANT }\end{array}$ & Yavapai & $341342 \mathrm{~N} 1125753 \mathrm{~W}$ & & & O'Neill Pass \\
\hline $\begin{array}{l}\text { summit } \\
\text { spring }\end{array}$ & $\begin{array}{l}\text { BGN } \\
\text { VARIANT }\end{array}$ & $\begin{array}{l}\text { Yuma } \\
\text { Maricopa }\end{array}$ & $\begin{array}{l}320537 \mathrm{~N} 1132135 \mathrm{~W} \\
335141 \mathrm{~N} 1112915 \mathrm{~W}\end{array}$ & & & Boulder Mtn \\
\hline $\begin{array}{l}\text { spring } \\
\text { reservoir } \\
\text { summit } \\
\text { valley } \\
\text { valley }\end{array}$ & $\begin{array}{l}\text { BGN } \\
\text { BGN } \\
B G N \\
\text { BGN }\end{array}$ & $\begin{array}{l}\text { Coconino } \\
\text { Maricopa } \\
\text { Graham } \\
\text { Greenlee } \\
\text { Greenlee }\end{array}$ & $\begin{array}{l}360101 \mathrm{~N} 1115842 \mathrm{~W} \\
335103 \mathrm{~N} 1112811 \mathrm{~W} \\
324950 \mathrm{~N} 1101224 \mathrm{~W} \\
325742 \mathrm{~N} 1092001 \mathrm{~W} \\
330803 \mathrm{~N} 1091134 \mathrm{~W}\end{array}$ & $\begin{array}{l}325423 \mathrm{~N} 1092014 \mathrm{~W} \\
330806 \mathrm{~N} 1091311 \mathrm{~W}\end{array}$ & & $\begin{array}{l}\text { Boulder Mtn } \\
\text { Buford } \mathrm{Hill} \\
\text { Guthrie } \\
\text { Dix Creek }\end{array}$ \\
\hline
\end{tabular}


FEATURE NAME

Oak Canyon
Oak Canyon
Oak Canyon Tank
Oak Creek
Oak Creek
Oak Creek
Oak Creek
Oak Creek
Oak Creek
See Natural Corral Creek
Oak Creek
Oak Creek
Oak Creek
Oak Creek
Oak Creek
Oak Creek
Oak Creek
Oak Creek
See Pumphouse Wash
Oak Creek
Oak Creek
Oak Creek Atrport
See Sedona Airport
Oak Creek Canyon
Oak Creek Canyon Natural Area
Oak Creek Dam
Oak Creek Ditch
Oak Creek Mountain
Oak Creek Ranch
Oak Creek Ranch

Oak Creek School

Oak Creek Spring

Oak Creek Tank

Oak Creek Tank

Oak Creek Vista Campground

Oak Creek Well

Oakdale Tank

Oak Dam

Oak Draw

Oak Oraw Water Well

Oaker Spring

Oakes Tank

Oak Flat

Oak Flat

Oak Flat Campground

Oak Flat Spring

Oak Flat Spring

Oak Flat Tank

Oak Grove

Oak Grove Canyon

Oak Grove Canyon
Oak Grove Spring
Oak Grove Tank
Oak Grove Tank
Oak Grove Tank
Oak Grove Tank
Oak Hill
Oak Hill
Oak Hill
Oak Hill

Oak Hill Draw

Oak Hill Tank

Oak Hill Tank Number One

Oakhurst (subdivision)

Oakie Hole

Oakie Spring

Oak Knoll Village

Oakland Mine

Oak Ranch

Oak Ridge

See Oak Springs
FEATURE CLASS

STATUS

valley

valley

reservoir

stream

stream

stream

stream

BGN
BGN
BGN
BGN
BGN
BGN
BGN
BGN
VARIANT

stream

stream

stream

stream

strean

stream

stream

stream

stream

BGN

BGN

BGN

BGN 1965

$B G N$

BGN

BGN 1964

VARIANT

locale

BGN

BGN

airport

valley

park

canal

locale

locale

locale

VARIANT

BGN

ADMIN

UNOFF

BGN

BGN

UNOFF

UNOFF

school
spring
reservoir
reservoir
park
well
reservoir
dam
valley
well

UNOFF Yavapai

BGN

BGN

BGN

ADNIN

UNOFF

BGN

UNOFF

spring
reservoir

rlat

flat

park

spring

spring

reservoir

locale

valley

UNOFF

valley

spring

reservoir

reservoir

reservoir

summit

summit

summit

BGN

BGN

BGN

BGN
BGN
BGN

BGN

BGN

valley

reservoir

reservoir

ppl

reservoir

spring

ppl

mine

locale

locale
COUNTY

Yuma

Coconino

Graham

Cochise

Graham

Graham

Pinal

Gila

Greenlee

Gila

Gila

Gila

Yavapai

Yavapai

Coconino

Apache

Yavapai

Yavapai

Coconino

Coconino

Graham

Yavapai

Apache

Gila

Navajo

Yavapai

Gila

Gila

Yavapai

Pima

Graham

Graham

Graham

Gila

Mohave

Graham

Pinal

Pinal

Pinal

Gila

Navajo

Mohave

Cochise

Graham

COORDINATE

$332531 \mathrm{~N} 1140348 \mathrm{~W}$

364009 N1122053W

$323214 \mathrm{~N} 1094223 \mathrm{~W}$

$320235 \mathrm{~N} 1091329 \mathrm{~W}$

$323358 \mathrm{~N} 1100400 \mathrm{~W}$

$324533 \mathrm{~N} 1101406 \mathrm{~W}$

$330321 \mathrm{~N} 1093602 \mathrm{~W}$

$331612 \mathrm{~N} 1110136 \mathrm{~W}$

332404 N1102440W

$332638 \mathrm{~N} 1091101 \mathrm{~W}$

$332904 \mathrm{N1} 102453 \mathrm{~W}$

$334253 \mathrm{~N} 1105310 \mathrm{~W}$

$334921 \mathrm{~N} 1111651 \mathrm{~W}$

335719 N1104132W

$340916 \mathrm{~N} 1123157 \mathrm{~W}$

$344040 \mathrm{~N} 1115630 \mathrm{~W}$

$350126 \mathrm{~N} 1114407 \mathrm{~W}$

$354850 \mathrm{~N} 1091834 \mathrm{~W}$

$344645 \mathrm{~N} 1114545 \mathrm{~W}$

$345054 \mathrm{~N} 1114715 \mathrm{~W}$

$345445 N 1114334 \mathrm{~W}$

$350009 \mathrm{~N} 1114611 \mathrm{~W}$

$323152 \mathrm{~N} 1101427 \mathrm{~W}$

$344432 \mathrm{~N} 1115325 \mathrm{~W}$

$355109 \mathrm{~N} 1091713 \mathrm{~W}$

$335250 \mathrm{~N} 1111109 \mathrm{~W}$

340252 N $1104225 \mathrm{~W}$

$344422 \mathrm{~N} 1115409 \mathrm{~W}$

$340835 \mathrm{~N} 1122814 \mathrm{~W}$

$333322 \mathrm{~N} 1102334 \mathrm{~W}$

$334440 \mathrm{~N} 1105440 \mathrm{~W}$

$350153 \mathrm{~N} 1114401 \mathrm{~W}$

340949 N1122613W

$314610 \mathrm{~N} 1104309 \mathrm{~W}$

$331742 \mathrm{~N} 1095000 \mathrm{~W}$

$324035 \mathrm{~N} 1093256 \mathrm{~W}$

$323248 \mathrm{~N} 1094236 \mathrm{~W}$

$335304 \mathrm{~N} 1111047 \mathrm{~W}$

$352043 \mathrm{~N} 1132257 \mathrm{~W}$

$324436 \mathrm{~N} 1095257 \mathrm{~W}$

$331829 \mathrm{~N} 1110247 \mathrm{~W}$

$331827 \mathrm{~N} 1110234 \mathrm{~W}$

$332616 \mathrm{~N} 1110611 \mathrm{~W}$

$334250 \mathrm{~N} 1111816 \mathrm{~W}$

$340205 \mathrm{~N} 1104$

$360910 \mathrm{~N} 1133459 \mathrm{~W}$

$322238 \mathrm{~N} 1100151 \mathrm{~W}$

$325152 \mathrm{~N} 1102543 \mathrm{~W}$

$313353 \mathrm{~N} 1103947 \mathrm{~W}$

$330734 \mathrm{~N} 1094257 \mathrm{~W}$

$343444 \mathrm{~N} 1112927 \mathrm{~W}$

$344553 \mathrm{~N} 1113207 \mathrm{~W}$

$345049 \mathrm{~N} 1113323 \mathrm{~W}$

$343230 \mathrm{~N} 1113414 \mathrm{~W}$

$343843 \mathrm{~N} 1113330 \mathrm{~W}$

$344002 \mathrm{~N} 1111814 \mathrm{~W}$

$351534 \mathrm{~N} 1120045 \mathrm{~W}$

Coconino

Yavapa i

Coconino

Yavapai

Maricopa

Coconino

Gila

Yavapai

Yuma

Cochise

Apache

$\begin{array}{cc}\text { SOURCE } & \text { ELEV } \\ \text { COORDINATE } & \text { FT }\end{array}$

MAP NAME

$332411 \mathrm{~N} 1140336 \mathrm{~W} \quad$ Livingston Hills

363908N1121724W Warm Springs Canyon

Gillespie Mtn

Blue Mountain

Sierra Bonita Ranch

Buford $\mathrm{Hill}$

Bonita Spring

Superior

332717 N1091627W

$333411 \mathrm{~N} 1102235 \mathrm{~W}$

$334616 \mathrm{~N} 1105541 \mathrm{~W}$

$335538 \mathrm{~N} 1110805 \mathrm{~W}$

$340749 \mathrm{~N} 1103906 \mathrm{~W}$

$340930 \mathrm{~N} 1122453 \mathrm{~W}$

$350135 \mathrm{~N} 1114410 \mathrm{~W}$

$355032 \mathrm{~N} 1091810 \mathrm{~W}$

Dutch Blue Creek

Natural Corral

Meddler Wash

Tonto Bas in

Double Buttes

Wagoner

Cornville

Oak Creek Mtn

065 Sedona

350245N1114522W Munds Park

Dutton $\mathrm{Hill}$

Harrison Canyon

Cornville

7936 Oak Creek Mtn

Picture Mtn

Oak Creek Ranch

Cornville

Minnehaha

Cassadore Spring

Meddler Wash

Mountainaire

4657 Minnehaha

Empire Ranch

Point of Pines West

$323105 N 1094451 W$

Artesia NE

Gillespie Mtn

Picture Mtn

Tuckayou Spring

Webb Peak

Superior 
FEATURE NAME

Oak Ridge Wash

Oak Spring

Oak Spring

Oak Spring

Oak Spring

Oak Spring

Oak Spring

Oak Spring

Oak Spring

Oak Spring

Oak Spring

Oak Spring

Oak Spring

Oak Spring

Oak Spring

Oak Spring

See Gold Tooth Smith Spring

Oak Spring

Oak Spring

Oak Spring

Oak Spring

Oak Spring

Oak Spring

Oak Spring

Oak Spring

Oak Spring

Oak Spring

Oak Spring

Oak Spring

Oak Spring

Oak Spring

Oak Spring

Oak Spring

Oak Spring

Oak Spring Canyon

Oak Spring Canyon

Oak Spring Canyon

Oak Spring Canyon

See Bear Canyon

Oak Spring Draw

See Cave Draw

Oak Spring Draw

Oak Spring Draw Tank

Oak Spring Number Two

Oak Springs

Oak Springs

Oak Ridge

Oak Springs Canyon

Oak Spring Tank

Oak Spring Tank

Oak Spring Valley

Oak Spring Wash

Oak Street School

Oak Tank

Oak Tank

Oak Tank

Oak Tank

Oak Tank

Oak Tank

Oak Thicket Ranch

Oak Thicket Spring

Oak Tree Canyon

Oak Tree Windmill

Oak Trough Tank

Oak Wash

Dak Wells

Oakwood Estates Subdivision Mini Park

Oakwood Estates Subdivision

Water Retention Basin
FEATURE
CLASS

STATUS

COUNTY

COORDINATE

$\begin{array}{cc}\text { SOURCE } & \text { ELEV } \\ \text { COORDINATE } & \text { FT }\end{array}$

MAP NAME

\begin{tabular}{|c|c|c|c|}
\hline $\begin{array}{l}\text { valley } \\
\text { spring } \\
\text { spring } \\
\text { spring } \\
\text { spring } \\
\text { spring } \\
\text { spring } \\
\text { spring } \\
\text { spring } \\
\text { spring }\end{array}$ & $\begin{array}{l}\text { BGN } \\
\text { BGN } \\
B G N \\
\text { BGN } \\
\text { BGN } \\
\text { BGN } \\
\text { BGN } \\
\text { BGN } \\
\text { BGN } \\
\text { BGN }\end{array}$ & $\begin{array}{l}\text { Apache } \\
\text { Cochise } \\
\text { Graham } \\
\text { Graham } \\
\text { Graham } \\
\text { Graham } \\
\text { Graham } \\
\text { Greenlee } \\
\text { Pinal } \\
\text { Pinal }\end{array}$ & $\begin{array}{l}352515 N 1093012 \mathrm{~W} \\
312153 \mathrm{~N} 1101747 \mathrm{~W} \\
324023 \mathrm{~N} 1101731 \mathrm{~W} \\
324535 \mathrm{~N} 1102339 \mathrm{~W} \\
325758 \mathrm{~N} 1102541 \mathrm{~W} \\
330125 \mathrm{~N} 1102204 \mathrm{~W} \\
330636 \mathrm{~N} 1101528 \mathrm{~W} \\
331633 \mathrm{~N} 1090618 \mathrm{~W} \\
332252 \mathrm{~N} 1110645 \mathrm{~W} \\
332734 \mathrm{~N} 1110400 \mathrm{~W}\end{array}$ \\
\hline
\end{tabular}

\section{$353021 N 1092017 \mathrm{~W}$}

Klagetoh South

Montezuma Pass

Kennedy Peak

Oak Grove Canyon

Booger Canyon

Mt Turnball

Mt Turnball

Maple Peak

Haunted Canyon

Haunted Canyon

Chrome Butte

Cassadore Spring

Sombrero Peak

Greenback Creek

Kayler Butte

Reno Pass

Gisela

Boundary Butte

Buckhead Mesa

Cottonwood

Cedar Bas in

Seepage Mtn

Flagstaff East

Kingman

Uranium Spring

Beeshsikad Spring

Spider Rock

Sonsela Buttes

Warm Springs Canyon Horse Mesa

Wolf Hole Mtn East

Wolf Hole Mtn West

Holy Joe Peak

$325008 \mathrm{~N} 1103052 \mathrm{~W}$

Kayler Butte

Buckhead Mesa valley Gila $\quad 335625$ N1111930W

BGN 1974

VARIANT Gila

valley

valiey

Gila

valley

reservoir

spring

spring

locale

valley

reservoir

reservoir

valley

valley

school

reservoir

reservoir

reservoir

reservoir $B G N$

reservoir

reservoir

locale

BGN
BGN
BGN
BGN
BGN
YARIANT
BGN
BGN
BGN
BGN

Gila

Greenlee

Navajo

Greenlee

Gila

Navajo

Apache

\section{BGN Apache}

UNOFF

BGN

BGN

$B G N$

BGN

BGN

UNOFF

Gila

Pima

Santa Cruz

Greenlee

Apache

Coconino

Yavapai

Coconino

Cochise

$\begin{array}{llll}\text { spring } & \text { BGN } & \text { Gila } & 341302 N 1113115 \mathrm{~W} \\ \text { valley } & \text { BGN } & \text { Pima } & 314828 N 1103537 \mathrm{~W} \\ \text { well } & \text { UNOFF } & \text { Pima } & 314818 \mathrm{~N} 1104104 \mathrm{~W} \\ \text { reservoir } & \text { BGN } & \text { Graham } & 330151 \text { N1093935W } \\ \text { stream } & \text { BGN } & \text { Yavapai } & 344313 \mathrm{~N} 1120001 \mathrm{~W} \\ \text { locale } & \text { BGN 1932 } & \text { Pinal } & 324720 \mathrm{~N} 1105613 \mathrm{~W} \\ \text { park } & \text { ADMIN } & \text { Maricopa } & 332615 \mathrm{~N} 1114758 \mathrm{~W} \\ & & & \\ \text { reservoir } & \text { BGN } & \text { Maricopa } & 332615 N 1114758 \mathrm{~W}\end{array}$

$341810 N 1111224 \mathrm{~W}$

$341908 \mathrm{~N} 1111211 \mathrm{~W}$

$331536 \mathrm{~N} 1090642 \mathrm{~W}$

$365207 \mathrm{~N} 1103836 \mathrm{~W}$

$352832 \mathrm{~N} 1090737 \mathrm{~W}$

$331529 \mathrm{~N} 1090654 \mathrm{~W}$

$331339 \mathrm{~N} 1105047 \mathrm{~W}$

$340658 \mathrm{~N} 1104059 \mathrm{~W}$

352609 N1090739W

$364307 \mathrm{~N} 1090016 \mathrm{~W}$

332425 N1105023W

$312751 \mathrm{N1112206 \textrm {W }}$

$312950 \mathrm{~N} 1111052 \mathrm{~W}$

$331704 \mathrm{~N} 1092453 \mathrm{~W}$

$333421 N 1094533 \mathrm{~W}$

$345155 N 1114103 \mathrm{~W}$

$345555 \mathrm{~N} 1131010 \mathrm{~W}$

$355959 \mathrm{~N} 1131002 \mathrm{~W}$

$312730 \mathrm{~N} 1095708 \mathrm{~W}$

331757 N1090601W.

$352911 \mathrm{~N} 1090751 \mathrm{~W}$

364459 N1090302W

Globe

Bartlett Mtn

Ruby

Bee Canyon

6332 West Poker Mtn

Munds Mountain

Sunrise Peak

Hockey Puck Spring

$B$ isbee

$314835 N 1104348 \mathrm{~W}$

Cypress Butte

Spring Water Canyon

Empire Ranch

Bryce Mountain

$\begin{array}{lll}344154 N 1120656 \mathrm{~W} & & \begin{array}{l}\text { Cottonwood } \\ \text { Black Mountain }\end{array}\end{array}$

Iron Mountain

Mesa 
FEATURE

CLASS

Oas is Community Park Oas is Ranch

Oatman Flat

Oatman Grave

Oatman Mountain

Oatman Post Office

Oatman Southern Mine

Oatman Syndicate Mine

Oat Spring

Oat Tank

O Bar 0 Canyon
0-Bar-0 Ranch
0 Bar 0 Tank
0 B Draw
Obed Meadow
Obi Canyon
Obi Point
Observation

See Huxley Terrace

Observation Plateau

See Huxley Terrace

observatory Mesa

Obsidian Tank

0 B Wel

See $0 \operatorname{coti} 110$

Occident Mine

Ochete Creek

See Pacheta Creek

Ochoa, Mount

Ochoa Point

Ochoa School

Ocotillo

Ocatilla

Ocotillo

Ocotillo Branch Library

Ocotillo Interchange

Ocotillo Mine Group

Ocotillo Power Plant

Ocotillo School

Ocotillo Tank

Ocotillo Tank

Octagon Butte

Octave

Octave Mine

Odart Cienega

Odart Mountain

Odart Ranch

Oddfellows-Peterson Park Peterson Park

Odell Dam
Odell Lake
Odell Well
Odle Ranch
O D Ridge
Ogilvie Well
Ogle Well
Ohaca Cabins
See O'Haco Cabins
Oike Tank
See Dike Tank
Oil Well Canyon
Oil Well Tank
Oit Ihuk
Ojero Mine (historical)
Ojo Blanco Spring
Ojo Blanco Spring
Ojo Bonito Tank
Ojo de Casa Spring
See Hogansaani Spring
Ojo de los Coyotes

plateau

dam

well

locale

ridge

well

well

locale

valley

locale

mine

spring

spring

spring

$\begin{array}{llll}\text { park } & \text { ADMIN } & \text { Maricopa } & 332420 \mathrm{~N} 1113556 \mathrm{~W} \\ \text { locale } & \text { UNOFF } & \text { Pima } & 322328 \mathrm{~N} 1110451 \mathrm{~W} \\ \text { ppl } & \text { BGN } & \text { Mohave } & 350135 \mathrm{~N} 1142258 \mathrm{~W} \\ \text { flat } & \text { BGN } & \text { Maricopa } & 330009 \mathrm{N1130915 \textrm {W }} \\ \text { cemetery } & \text { UNOFF } & \text { Maricopa } & 330015 \mathrm{~N} 1130920 \mathrm{~W} \\ \text { summit } & \text { BGN } & \text { Maricopa } & 330331 \mathrm{~N} 1130839 \mathrm{~W} \\ \text { building } & \text { UNOFF } & \text { Mohave } & 350135 \mathrm{N1142259W} \\ \text { mine } & \text { UNOFF } & \text { Mohave } & 345823 \mathrm{~N} 1142543 \mathrm{~W} \\ \text { mine } & \text { UNOFF } & \text { Mohave } & 345825 \mathrm{~N} 1142502 \mathrm{~W} \\ \text { spring } & \text { BGN } & \text { Navajo } & 365204 \mathrm{~N} 1103616 \mathrm{~W}\end{array}$

reservoir BGN Coconino 350508N1120803W

valley

locale UNOFF Graham 322927N1094925W

reservoir BGN Graham 323027N1094803W

valley BGN Cochise $320631 \mathrm{~N} 1094141 \mathrm{~W}$

swamp BGN Navajo

BGN 1906 Coconino

VARIANT

Coconino

$360928 \mathrm{~N} 1120043 \mathrm{~W}$

$361245 N 1122219 \mathrm{~W}$

VARIANT

\begin{tabular}{|c|c|c|c|}
\hline \multirow[b]{2}{*}{$\begin{array}{l}\text { plateau } \\
\text { summit } \\
\text { reservoir } \\
\text { well }\end{array}$} & \multicolumn{2}{|l|}{ VARIANT } & \multirow[b]{2}{*}{$\begin{array}{l}361245 N 1122219 \mathrm{~W} \\
351300 \mathrm{~N} 1114137 \mathrm{~W} \\
352111 \mathrm{~N} 1115518 \mathrm{~W} \\
343751 \mathrm{~N} 1095442 \mathrm{~W}\end{array}$} \\
\hline & $\begin{array}{l}\text { BGN } \\
\text { BGN } \\
\text { UNOFF } \\
\text { YARIANT }\end{array}$ & $\begin{array}{l}\text { Coconino } \\
\text { Coconino } \\
\text { Coconino } \\
\text { Navajo }\end{array}$ & \\
\hline $\begin{array}{l}\text { b } \\
\text { ine }\end{array}$ & & Maricopa & $331437 \mathrm{N1115128 \textrm {W }}$ \\
\hline ream & VARIANT & $\begin{array}{l}\text { Mohave } \\
\text { Apache }\end{array}$ & $333845 \mathrm{~N} 1093102 \mathrm{~W}$ \\
\hline
\end{tabular}

summit BGN Maricopa 334513N1120947W

cliff BGN 1932 Coconino 360614N1115141W

school UNOFF Pima 321212N1105811W

pp) BGN Maricopa 331437N1115128W

building UNOFF Maricopa

$332348 \mathrm{~N} 1135745 \mathrm{~W}$

building UNOFF Maricopa 332533N1115449W

school UNOFF Maricopa 333202N1120741W

reservoir BGN Santa Cruz 313838N1105919W

reservoir BGN Yavapai 345248N1120325W

summit BGN Coconino 365530N1105959W

locale BGN Yavapai $340830 \mathrm{~N} 1124121 \mathrm{~W}$

mine UNOFF Yavapai 340838 N1124224W

flat BGN Apache 334328N1093634W

summit BGN Apache 334343N1093852W

locale UNOFF Apache 334400N1093624W

park ADMIN Maricopa 332336N1115740W

reservoir

reservoir

UNOFF

BGN

UNOFF

UNOFF

BGN

UNOFF

UNOFF

VARIANT

VARIANT

Coconino

Coconino

Maricopa

Mohave

Apache

Coconino

Pinal

Coconino

Coconino

reservoir

reservoir$$
\text { BGN }
$$

BGN
BGN
BGN
UNOFF
BGN
BGN
BGN
VARIANT

Pima

Pima

Pima

Pima

Pima

Pima

Apache

Apache
$345600 \mathrm{~N} 1113758 \mathrm{~W}$

$345600 \mathrm{~N} 1113757 \mathrm{~W}$

$335233 \mathrm{~N} 1120117 \mathrm{~W}$

$350513 N 1134900 \mathrm{~W}$

$335307 N 1092312 \mathrm{~W}$

$350218 \mathrm{~N} 1105552 \mathrm{~W}$

323444N1110403W

342914 N1110243W

354921N1125410W

314527 N1103454W

$314544 \mathrm{~N} 1103553 \mathrm{~W}$

$321 B 56 \mathrm{~N} 1121442 \mathrm{~W}$

$314405 \mathrm{~N} 1105000 \mathrm{~W}$

$315336 \mathrm{~N} 1104250 \mathrm{~W}$

$341443 \mathrm{~N} 1094348 \mathrm{~W}$

365116 N1093115W
$315355 \mathrm{~N} 1104239 \mathrm{~W}$
SOURCE
COORDINATE

MAP NAME

Apache Junction

Ruelas Canyon

Oatman

Oatman Mountain

Oatman Mountain

1732 Oatman Mountain

Oatman

Boundary Cone

Boundary Cone

Tall Mountain

May Tank Pocket

W of Greasewood Mtn

4957 Greasewood Mountain

Stockton Pass

321043N1093543W Dos Cabezas SW

Joseph City

361024 N1120010W

Bright Angel Point

7928 Bright Angel Point

Flagstaff West

Parks

Hay Hollow

White Hills West

$1 B 44$ Biscuit Flat Desert View

Tucs on

1206 Gila Butte

Cleator

Phoenix

Benson

Owl Head

1240 Tempe

Glendale

Mt Hopkins

Sycamore Bas in

6700 Chaiyahi Flat

3400 Yarnell

Yarnell

Maverick

8525 Odart Mtn

Maverick

Tempe

6749 Munds Park

Munds Park

Daisy Mountain

Dean Peak

Big Lake North

5182 Tucker Mesa SW

Tortolita Mts
314509 N1103248W

Spring Water Canyon Spring Water Canyon

Window Mtn

Mt Wrightson

Mount Fagan

Mount Fagan

Boundary Butte 
NATIONAL GAZETTEER--ARIZONA 1986

FEATURE NAME

See Pan Tak

Ojo Gato Spring

Ojos

See Sunshine

Ok Ditch

Okemah Park

Okie Well

Oklahoma Flat

Oklahoma Flat Draw

Oklahoma Mine

OK Mine

OK Notch

OK Ranch

OK Tank

OK Wel1

Olaf Knolls

Olberg

Olberg Trading Post

old Alamo Mine Camp

0ld Automobile Tank

Old Baldy

See Wrightson, Mount

01d Baldy

01d Baidy

0ld Bas in

0ld Bextrum Mine

old Bisbee High School

0ld Bisbee West

01d Bonnie Tunne

old Callett Tank

old Camp

old Camp Canyon

01d Camp Farm

01d Camp Grant

See Fort Grant (State Industrial School

01d Camp Spring

01d Camp Tank

01d Camp Wash

old Camp Well

old Camp Well

01d Caves Crater

Cave Hill

Doney $\mathrm{Hill}$

Sheep Hill

01d Cemetery

old City Cemetery

old City Park (Bisbee)

old Cofer Headquarters

old Colter Ranch

old Columbine

old Comanche Mine

01d Corral Cienega

old Cow Springs Trading Post

old Cross Cut Canal

01d Dandrea Ranch

01d Deer Creek

See Deer Creek

01d Oent and Sayer Tank

old Dick Mine

01d Dick Mine

0ld Dirt Tank

Old Dominion Library

01d Dominion Shaft

01d East Side Tank

01d Farm Spring

01d Finch Ranch

0ld Forester Tank

old Forester Well

0ld Fort

See Gila Bend

\section{FEATURE \\ CLASS}

STATUS

COUNTY

Pima

$\begin{array}{ll}\text { spring } & \text { BGN } \\ \text { locale } & \text { VARIANT } \\ \text { canal } & \text { BGN } \\ \text { park } & \text { ADMIN } \\ \text { well } & \text { UNOFF } \\ \text { flat } & \text { BGN } \\ \text { valley } & \text { BGN } \\ \text { mine } & \text { UNOFF } \\ \text { mine } & \text { UNOFF }\end{array}$

Apache

Coconino

Yavapai

Maricopa

Maricopa

Navajo

Navajo

Pinal

Cochise

gap

locale

wel

summit

locale

building

locale

reservoir

summ it

BGN

UNOFF

BGN

UNOFF

BGN

BGN

UNOFF

BGN

VARIANT

Cochise

Cochise

Yavapai

Coconino

Mohave

Pinal

Pinal

Yuma

Coconino

Santa Cruz

summit $\quad B G$

summit

sumin

bas in

building

mine

mine

reservoir

locale

valley

BGN

BGN

BGN

UNOFF

UNOFF

UNOFF

BGN

BGN

BGN

locale BGN

VARIANT

spring BGN

reservoir $B G$

stream

well

well

BGN

UNOFF

UNOFF

BGN

VARIANT

VARIANT

VARIANT

Santa Cruz

Gila

Mohave

Santa Cruz

Cochise

Cochise

Mohave

Greenlee

Graham

Graham

Yavapai

Graham

Yavapai

Mavajo

Maricopa

Maricopa

Mohave

Coconino

cemetery

UNOFF

UNOFF

cemetery

park

building

locale

ppl

flat

locale

cana 1

ADMIN
UNOFF

UNOFF
UNOFF

BGN

UNOFF

UNOFF

BGN

BGN

Graham

Maricopa

Cochise

Mohave

Apache

Graham

Mohave

Apache

Coconino

Maricopa

locale UNOFF

VARIANT

stream
reservoir $B G N$

mine UNOFF

mine

mine UNOFF

reservoir

building

mine

reservoir

Yavapai

Pinal

Coconino

Pima

Yavapai

Pima

Gila

Gila

Yavapai

spring

locale

reservoir

well

BGN 1959

BGN

UNOFF

Coconino

Pinal

Pima

Pima

ppl

Maricopa
COORDINATE 320042N1113353W

341450 N1093345W

350726 N1110151W

343820 N1115525W

$332450 N 1115951 \mathrm{~W}$

323406N1130814W

$342346 \mathrm{~N} 110325 \mathrm{WW}$

$342648 \mathrm{~N} 1102929 \mathrm{~W}$

$330949 N 1111432 \mathrm{~W}$

320549 N1100340W

$314537 N 1095245 \mathrm{~W}$

314446 N1092653W

$345352 \mathrm{~N} 1114948 \mathrm{~W}$

$361343 N 1111955$

$362750 N 1135048 \mathrm{~W}$

$330532 N 1114108 \mathrm{~W}$

$330535 \mathrm{~N} 1114114 \mathrm{~W}$

$332415 N 1135745 \mathrm{~W}$

355140N1115927W

314146N1105052W

$314200 \mathrm{~N} 1105100 \mathrm{~W}$

$331337 \mathrm{N1104754W}$

354841 N1140818W

$312215 \mathrm{~N} 1110631 \mathrm{~W}$

$312634 \mathrm{~N} 1095459 \mathrm{~W}$

$312454 N 1095559 \mathrm{~W}$

$355316 N 1131926 \mathrm{~W}$

$330432 N 1090442 W$

$322831 N 1091112 \mathrm{~W}$

$323025 \mathrm{~N} 1091343 \mathrm{~W}$

344311N1124322W

$323722 \mathrm{~N} 1095643 \mathrm{~W}$

344257N1124405W

$335122 N 1095230 \mathrm{~W}$

333047 N1125438W

$334118 N 1130121 \mathrm{~W}$

345922 N1135849

$351648 \mathrm{~N} 1113135 \mathrm{~W}$

$325120 \mathrm{N1094745W}$

$332643 \mathrm{~N} 1120522 \mathrm{~W}$

312636 N1095449W

$344823 N 1132118 \mathrm{~W}$

$340146 N 1093531 \mathrm{~W}$

$324226 N 1095432 \mathrm{~W}$

$352316 N 1141114 \mathrm{~W}$

$340359 N 1094309 \mathrm{~W}$

$62448 N 1105036 \mathrm{~W}$

332805N1115840W

$342433 N_{1122245 W}$

$325424 N 110275 \mathrm{BW}$

$354523 \mathrm{~N} 1114648 \mathrm{~W}$

$315127 \mathrm{N1104642 \textrm {W }}$

$343253 N 1131315 \mathrm{~W}$

$322553 \mathrm{~N} 1103432 \mathrm{~W}$

$332424 \mathrm{~N} 1104728 \mathrm{~W}$

332449 N1104719W

$342510 \mathrm{~N} 1120153 \mathrm{~W}$

$363601 \mathrm{N1104903 \textrm {W }}$

324721 N1105232W

$313216 \mathrm{~N} 1112445 \mathrm{~W}$

$313225 \mathrm{~N} 1112438 \mathrm{~W}$

325652N1124258W 


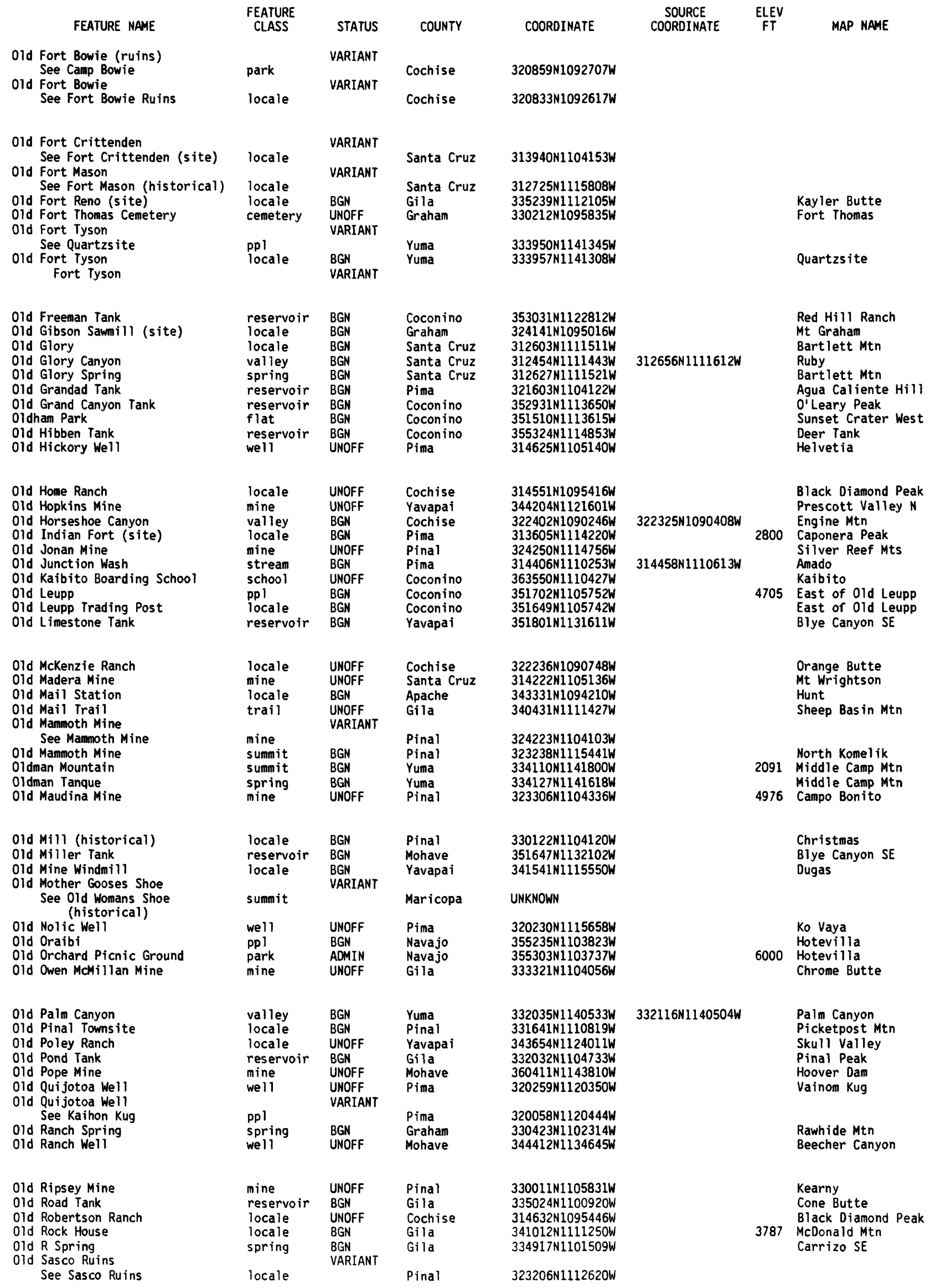


NATIONAL GAZETTEER--ARIZONA 1986 FEATURE NAME

01d Sawmill Spring

old Scott Tank

old Second Mesa School (site)

01d Senator Mill (historical)

old Seventynine Tank

old Shongopavi (site)

old Smith Mine

old Smokey Mountain

old Sopori School

old Stage Station

old Summit Springs

old Tank

01d Tank

01d Tanner Trai

Old Taylor Tank Dam

old Trails (site)

Old Trails Highway Interchange

old Trails Park

old Tucson

old Two Guns Ruin

old Verde Canal

old Well

old Well Corral

Old West Boulder Canyon

01d West Estates Retention

Bas in

old West Valley Subdivision

Mini Park

01d West Valley Subdivision

Water Retention Bas in

01d Womans Shoe (historical)

old Mother Gooses Shoe

old Wright Monument

0ld Zorilla Ranch
Olea Ranch
Oleary Bas in
Oley Tank
Olga
Olga Detention Dam
Olga Overpass
Olga Railroad Station
Olgato Creek
See Oljeto Wash
Olin Tank
Oliva
See Bradshaw Ferry (site)
Olive
See Olive City (historical)
Olive City (historical)
Olive
Bradshaws Ferry

olive City

See Bradshaw Ferry (site)

Olive Mine

Olive Plaza Shopping Center

01 iver Knoll

oliver Spring

Oliver Spring Canyon

Oliver Tank

01 iver Tank

Oliver Trail Spring

olivette Mine

Olive Village Shopping Center

01 ive West (subdivision)

01 ja Creek See 01 jeto Wash

01 jato Creek See 01 jeto Wash

01 jeto Creek See 01 jeto Wash

01 je To Creek

\section{FEATURE}

STATUS

COUNTY

$\begin{array}{llll}\text { spring } & \text { BGN } & \text { Cochise } & 312517 N 1101746 \mathrm{~W} \\ \text { reservoir } & \text { BGN } & \text { Navajo } & 341242 \mathrm{~N} 1100342 \mathrm{~W}\end{array}$

school UNOFF Navajo $354758 \mathrm{~N} 1103112 \mathrm{~W}$

locale BGN Mohave 360045N1141425W

reservoir BGN $\quad$ Yavapai $\quad 344952$ N1115111W

ppl BGN $\quad$ Navajo 354816 N1103111K

mine UNOFF Maricopa 334822N1124015W

summit BGN $\quad$ Yuma $\quad 332028 \mathrm{~N} 1140245 \mathrm{~W}$

spring

reservoir

BGN

BGN

BGN

Pima

Graham

Graham

$331835 \times 1092632 \mathrm{~W}$

trail UNOFF

locale BGN

crossing UNOFF

park

locale

locale

canal

well

locale

valley

reservoir

park

reservoir

summit

park

UNOFF

BGN

BGN

BGN

UNOFF

BGN

Coconino

Pima

Mohave

Mohave

Mohave

Pima

Coconino

Maricopa

Yavapai

Pima

Pinal

Maricopa

$323011 N 1113720 \mathrm{~W}$

park $\quad$ ADRI

locale UNOFF

ocale

locale
basin

reservoir

locale

dam

crossing

building

stream

\section{UNOFF}

BGN

BGN

BGN

UNOFF

UNOFF

UNOFF

VARIANT

reservoir

BGN

VARIANT

locale

ppl

ppl

locale

locale

mine

locale

summit

spring

valley

reservoir

reservoir

spring BGN

mine UNOFF

locale UNOFF

VARIANT

BGN

VARIANT

VARIANT

VARIANT

La Paz

UNOFF Santa Cruz

UNOFF

BGN

$B G N$

GN

Coconino

Coconino

Graham

Pima

Maricopa

pp1 BGN

stream

VARIANT

Maricopa

Navajo

VARIANT

stream

VARIANT

stream

VARIANT
Navajo

Navajo
345523N1111434W dam UNOFF
COORDINATE

$341115 N 1094935 \mathrm{~W}$

$360418 N 1114952 \mathrm{~W}$

$321553 N 1103900 \mathrm{~W}$

$350038 N 1142314 \mathrm{~W}$

345453N1140907W

$351108 N 1140307 \mathrm{~W}$

$321305 \mathrm{~N} 1110746 \mathrm{~W}$

$350659 \mathrm{~N} 1110544 \mathrm{~W}$

$333820 \mathrm{~N} 1115430 \mathrm{~W}$

$351633 \mathrm{N1131401 \textrm {W }}$

$332630 \mathrm{~N} 1112421 \mathrm{~W}$

332045N1114812W

332652N1114946W

332652N1114946W

UNKNOWN

$333720 N 1143030 \mathrm{~W}$

$\begin{array}{lc}\text { SOURCE } & \text { ELEV } \\ \text { COORDINATE } & \text { FT MAP NAME }\end{array}$

Miller Peak

Show Low South

Shongopovi

850 Hiller Mountains

Sedona

Shongopovi

Wickenburg SW

Palm Canyon

3380 Saucito Mtn

3504 Whitlock Cienega

Natanes Mts NW

Bee Canyon

Sponseller Mtn

Desert View

Agua Caliente Hill

Oatman

Yucca NH

Kingman

Brown Mtn

Tucker Mesa SW

Currys Corner

5290 Sugarloaf Peak

1790 Friendly Corners

$332619 N 1112617 W$

Goldfield

Chandler

Mesa

Mesa

Tollgate Tank

Guthrie

Arrastra Mtn NE

Strawberry Crater

Burro Mesa

Olga

olga

olga

olga

Chavez Mtn NW

$333720 \mathrm{~N} 1143030 \mathrm{~W}$

$333640 \mathrm{~N} 1143130 \mathrm{~W}$

$333640 N 1143130 \mathrm{~W}$

Blythe

$312508 \mathrm{~N} 1104216 \mathrm{~W}$

$333405 N 1121105 W$

$330342 N 1095046 \mathrm{~W}$

330411 N1095019W

$330100 \mathrm{N1} 1095410 \mathrm{~W}$

$352905 \mathrm{~N} 1123501 \mathrm{~W}$

35342 IN1121419W

$330528 \mathrm{N1094932 \textrm {W }}$

$315745 \mathrm{N1110545W}$

333358 N1120910W

$330405 N 1095001 \mathrm{~W}$

Glendale

4805 Markham Creek

Markham Creek

Fort Thomas

Eagle Nest Mtn

Howard Lake

Markham Creek

Twin Buttes

Giendale

1150 Glendale 


\begin{tabular}{|c|c|c|c|c|c|c|c|}
\hline FEATURE NAME & $\begin{array}{l}\text { FEATURE } \\
\text { CLASS }\end{array}$ & STATUS & COUNTY & COORDINATE & $\begin{array}{l}\text { SOURCE } \\
\text { COORDINATE }\end{array}$ & $\begin{array}{l}\text { ELEV } \\
\text { FT }\end{array}$ & MAP NAME \\
\hline $\begin{array}{l}\text { See } 01 \text { jeto Wash } \\
\text { O1jetoh Wash } \\
\text { See Oljeto Wash }\end{array}$ & $\begin{array}{l}\text { stream } \\
\text { stream }\end{array}$ & VARIANT & $\begin{array}{l}\text { Navajo } \\
\text { Navajo }\end{array}$ & $\begin{array}{l}371710 \mathrm{~N} 1101735 \mathrm{~W} \\
371710 \mathrm{~N} 1101735 \mathrm{~W}\end{array}$ & & & \\
\hline $\begin{array}{l}\text { 01jeto Wash } \\
\text { Moonlight Creek } \\
\text { Moonl ight Wash } \\
01 \text { gato Creek } \\
01 \text { ja Creek } \\
01 \text { jato Creek } \\
01 \text { je To Creek } \\
01 \text { jeto Creek } \\
01 \text { jetoh Wash } \\
\text { 011igar Tank }\end{array}$ & reservoir & $\begin{array}{l}\text { BGN } \\
\text { VARIANT } \\
\text { VARIANT } \\
\text { VARIANT } \\
\text { VARIANT } \\
\text { VARIANT } \\
\text { VARIANT } \\
\text { VARIANT } \\
\text { VARIANT } \\
\text { BGN }\end{array}$ & Navajo & $371710 \mathrm{~N} 1101735 \mathrm{~W}$ & $365212 N 1101953 \mathrm{~W}$ & & McFadden Peak \\
\hline $\begin{array}{l}\text { Olney Well Oraw } \\
\text { 010 Canyon } \\
010 \text { Mesa } \\
\text { 01sen Wash } \\
\text { O1son Canyon } \\
\text { See Aulson Canyon } \\
\text { 01son Well } \\
\text { Omega Mine } \\
\text { Omni Range Radio Facility } \\
\text { One, Lake }\end{array}$ & $\begin{array}{l}\text { valley } \\
\text { valley } \\
\text { summit } \\
\text { stream } \\
\text { valley } \\
\text { well } \\
\text { mine } \\
\text { tower } \\
\text { lake }\end{array}$ & $\begin{array}{l}\text { BGN } \\
\text { BGN } 1925 \\
\text { BGN } \\
\text { BGN } \\
\text { VARIANT } \\
\text { UNOFF } \\
\text { UNOFF } \\
\text { UNOFF } \\
\text { BGN }\end{array}$ & $\begin{array}{l}\text { Greenlee } \\
\text { Coconino } \\
\text { Coconino } \\
\text { Pinal } \\
\text { Mohave } \\
\text { Graham } \\
\text { Pima } \\
\text { Pima } \\
\text { Coconino }\end{array}$ & $\begin{array}{l}323225 \mathrm{~N} 1090219 \mathrm{~W} \\
362214 \mathrm{~N} 1123853 \mathrm{~W} \\
362232 \mathrm{~N} 1123540 \mathrm{~W} \\
324107 \mathrm{~N} 1110659 \mathrm{~W} \\
\\
365537 \mathrm{~N} 1123656 \mathrm{~W} \\
324305 \mathrm{~N} 1093527 \mathrm{~W} \\
315122 \mathrm{N1104609W} \\
320721 \mathrm{N1104912 \textrm {W }} \\
341801 \mathrm{N1105310 \textrm {W }}\end{array}$ & $\begin{array}{l}323031 N 1090538 \mathrm{~W} \\
361955 \mathrm{~N} 1123341 \mathrm{~W} \\
324215 \mathrm{~N} 1105827 \mathrm{~W}\end{array}$ & 4543 & $\begin{array}{l}\text { Artesia NE } \\
\text { Helvetia } \\
\text { Tucson SE } \\
\text { Woods Canyon }\end{array}$ \\
\hline $\begin{array}{l}\text { One Cottonwood Canyon } \\
\text { One Eleven Detention Dam } \\
\text { One Horn Canyon } \\
\text { One Horn Tank } \\
\text { One Hundred and One Spring } \\
\text { One Hundred Eighty Three Mile } \\
\text { Airport } \\
\text { One Hundred Eleven Ranch } \\
\text { One Hundred Five, Tank } \\
\text { One Hundred Thirteen, Tank }\end{array}$ & $\begin{array}{l}\text { valley } \\
\text { dam } \\
\text { valley } \\
\text { reservoir } \\
\text { spring } \\
\text { airport } \\
\text { locale } \\
\text { reservoir } \\
\text { reservoir }\end{array}$ & $\begin{array}{l}\text { BGN } \\
\text { UNOFF } \\
\text { BGN } \\
\text { BGN } \\
\text { BGN } \\
\text { ADMIN } \\
\text { UNOFF } \\
\text { BGN } \\
\text { BGN }\end{array}$ & $\begin{array}{l}\text { Navajo } \\
\text { Graham } \\
\text { Greenlee } \\
\text { Greenlee } \\
\text { Coconino } \\
\text { Coconino } \\
\text { Graham } \\
\text { Pima } \\
\text { Pima }\end{array}$ & $\begin{array}{l}355332 \mathrm{~N} 1101814 \mathrm{~W} \\
324254 \mathrm{~N} 1092736 \mathrm{~W} \\
331644 \mathrm{~N} 1090216 \mathrm{~W} \\
331806 \mathrm{~N} 1090315 \mathrm{~W} \\
342916 \mathrm{~N} 1112107 \mathrm{~W} \\
360630 \mathrm{~N} 1131245 \mathrm{~W} \\
\\
324305 \mathrm{~N} 1092833 \mathrm{~W} \\
322140 \mathrm{~N} 1113410 \mathrm{~W} \\
321546 \mathrm{~N} 1113728 \mathrm{~W}\end{array}$ & $\begin{array}{l}355835 N 1101521 W \\
331825 N 1090323 W\end{array}$ & 1705 & $\begin{array}{l}\text { Wepo Village } \\
\text { Dry Mtn } \\
\text { Maple Peak } \\
\text { Maple Peak } \\
\text { Kehl Ridge } \\
\text { Vulcans Throne SW } \\
\text { Dry Mountain } \\
\text { Koht Kohl Hill } \\
\text { Koht Kohl Hill }\end{array}$ \\
\hline $\begin{array}{l}\text { One Hundred Three Mesa } \\
\text { Oneil Spring } \\
\text { See O'Neill Spring } \\
\text { One Mile } \\
\text { One Mile Spring } \\
\text { One Mile Tanks } \\
\text { One More Day Tank } \\
\text { One Mountain } \\
\text { One Toe Ridge } \\
\text { Onetto Spring }\end{array}$ & $\begin{array}{l}\text { summit } \\
\text { spring } \\
\text { locale } \\
\text { spring } \\
\text { reservoir } \\
\text { reservoir } \\
\text { summit } \\
\text { ridge } \\
\text { spring }\end{array}$ & $\begin{array}{l}\text { BGN } \\
\text { VARIANT } \\
\text { BGN } \\
\text { BGN } \\
\text { BGN } \\
\text { BGN } \\
\text { BGN } \\
\text { BGN } \\
\text { BGN }\end{array}$ & $\begin{array}{l}\text { Cochise } \\
\text { Coconino } \\
\text { Coconino } \\
\text { Coconino } \\
\text { Navajo } \\
\text { Yavapai } \\
\text { Maricopa } \\
\text { Coconino } \\
\text { Mohave }\end{array}$ & $\begin{array}{l}312024 \mathrm{~N} 1102018 \mathrm{~W} \\
360101 N 1115842 \mathrm{~W} \\
36481 \mathrm{BN} 1120313 \mathrm{~W} \\
364827 \mathrm{N1} 120314 \mathrm{~W} \\
340527 \mathrm{~N} 1103758 \mathrm{~W} \\
350448 \mathrm{~N} 1131433 \mathrm{~W} \\
333035 \mathrm{~N} 1113610 \mathrm{~W} \\
364613 \mathrm{~N} 1115505 \mathrm{~W} \\
350242 \mathrm{~N} 1142149 \mathrm{~W}\end{array}$ & & $\begin{array}{l}6030 \\
2809\end{array}$ & $\begin{array}{l}\text { Montezuma Pass } \\
\text { House Rock Spring SE } \\
\text { House Rock Spring } \\
\text { Oak Creek Ranch } \\
\text { Anvil Rock Ranch } \\
\text { Stewart Mtn } \\
\text { One Toe Ridge } \\
\text { Mount Nutt }\end{array}$ \\
\hline $\begin{array}{l}\text { One V Well } \\
\text { One Way Pass } \\
\text { One Windmill Well } \\
\text { Oniel Park } \\
\text { Onion Creek } \\
\text { Onion Mountain } \\
\text { Onion Saddle } \\
\text { Onion Spring } \\
\text { Onion Spring } \\
\text { Onyx Bridge }\end{array}$ & $\begin{array}{l}\text { we l1 } \\
\text { gap } \\
\text { well } \\
\text { park } \\
\text { stream } \\
\text { summit } \\
\text { gap } \\
\text { spring } \\
\text { spring } \\
\text { arch }\end{array}$ & $\begin{array}{l}\text { UNOFF } \\
\text { BGN } \\
\text { UNOFF } \\
\text { ADMIN } \\
\text { BGN } \\
\text { BGN } \\
\text { BGN } \\
\text { BGN } \\
\text { BGN } \\
\text { BGN }\end{array}$ & $\begin{array}{l}\text { Graham } \\
\text { Mohave } \\
\text { Apache } \\
\text { Pinal } \\
\text { Cochise } \\
\text { Yavapai } \\
\text { Cochise } \\
\text { Cochise } \\
\text { Navajo } \\
\text { Apache }\end{array}$ & $\begin{array}{l}331108 \mathrm{~N} 1094146 \mathrm{~W} \\
363507 \mathrm{N1} 133813 \mathrm{~W} \\
351147 \mathrm{N1091951 \textrm {W }} \\
325340 \mathrm{~N} 1114454 \mathrm{~W} \\
315538 \mathrm{~N} 1091317 \mathrm{~W} \\
343333 \mathrm{~N} 1120128 \mathrm{~W} \\
315600 \mathrm{~N} 1091546 \mathrm{~W} \\
315603 \mathrm{~N} 1091524 \mathrm{~W} \\
355952 \mathrm{~N} 1102907 \mathrm{~W} \\
350640 \mathrm{~N} 1094718 \mathrm{~W}\end{array}$ & 315557 N1091538W & 5725 & $\begin{array}{l}\text { Park Creek Cabins } \\
\text { St George Canyon } \\
\text { Sanders } \\
\text { Casa Grande East } \\
\text { Portal } \\
\text { Cherry } \\
\text { Rustler Park } \\
\text { Rustler Park } \\
\text { Onion Spring } \\
\text { Kachina Point }\end{array}$ \\
\hline $\begin{array}{l}\text { Onyx Cave } \\
\text { Onyx Tank } \\
\text { Oo-Kut } \\
\text { See Blackwater } \\
\text { O0 Tank } \\
\text { Opansoitak } \\
\text { See Gila Bend } \\
\text { Opasoitac } \\
\text { See Gila Bend } \\
\text { Open Draw }\end{array}$ & $\begin{array}{l}\text { cave } \\
\text { reservoir } \\
\text { ppl } \\
\text { reservoir } \\
\text { ppl } \\
\text { ppl } \\
\text { valley }\end{array}$ & $\begin{array}{l}\text { BGN } \\
\text { BGN } \\
\text { VARIANT } \\
\text { BGN } \\
\text { VARIANT } \\
\text { VARIANT }\end{array}$ & $\begin{array}{l}\text { Santa Cruz } \\
\text { Coconino } \\
\text { Pinal } \\
\text { Yavapai } \\
\text { Maricopa } \\
\text { Maricopa } \\
\text { Apache }\end{array}$ & $\begin{array}{l}314303 \mathrm{~N} 1104611 \mathrm{~W} \\
350950 \mathrm{~N} 1112714 \mathrm{~W} \\
330152 \mathrm{~N} 1113455 \mathrm{~W} \\
350813 \mathrm{~N} 1125122 \mathrm{~W} \\
325652 \mathrm{~N} 1124258 \mathrm{~W} \\
325652 \mathrm{~N} 1124258 \mathrm{~W} \\
334951 \mathrm{~N} 1091820 \mathrm{~W}\end{array}$ & $335044 \mathrm{~N} 1092142 \mathrm{~W}$ & & $\begin{array}{l}\text { Mt Wrightson } \\
\text { Winona }\end{array}$ \\
\hline $\begin{array}{l}\text { Open Draw } \\
\text { Open Draw Spring } \\
\text { Open Draw Tank } \\
\text { Open Draw Tank } \\
\text { Ophir Gulch } \\
\quad \text { Greaterville Gulch } \\
\text { Opportunity Hall Special School } \\
\text { Oquer Canyon }\end{array}$ & $\begin{array}{l}\text { valley } \\
\text { spring } \\
\text { reservoir } \\
\text { reservoir } \\
\text { valley }\end{array}$ & $\begin{array}{l}\text { BGN } \\
\text { BGN } \\
\text { BGN } \\
\text { BGN } \\
\text { BGN } \\
\text { VARIANT } \\
\text { UNOFF } \\
\text { BGN }\end{array}$ & $\begin{array}{l}\text { Coconino } \\
\text { Apache } \\
\text { Greenlee } \\
\text { Coconino } \\
\text { Pima }\end{array}$ & $\begin{array}{l}342709 \mathrm{~N} 1110204 \mathrm{~W} \\
335037 \mathrm{~N} 1092034 \mathrm{~W} \\
331723 \mathrm{~N} 1092706 \mathrm{~W} \\
344712 \mathrm{~N} 1111523 \mathrm{~W} \\
314408 \mathrm{~N} 1104030 \mathrm{~W}\end{array}$ & 314541 N1104650W & & $\begin{array}{l}\text { Knol1 Lake } \\
\text { Buffalo Crossing } \\
\text { Bee Canyon } \\
\text { Jaycox Mtn } \\
\text { Sonoita }\end{array}$ \\
\hline
\end{tabular}




\begin{tabular}{|c|c|c|c|c|c|c|c|}
\hline FEATURE NAME & $\begin{array}{l}\text { FEATURE } \\
\text { CLASS }\end{array}$ & STATUS & COUNTY & COORDINATE & $\begin{array}{l}\text { SOURCE } \\
\text { COORDINATE }\end{array}$ & $\begin{array}{c}\text { ELEV } \\
\text { FT }\end{array}$ & MAP NAME \\
\hline $\begin{array}{l}\text { Oquer Lake } \\
\text { Oquer Point }\end{array}$ & $\begin{array}{l}\text { lake } \\
\text { cliff }\end{array}$ & $\begin{array}{l}\text { BGN } \\
\text { BGN }\end{array}$ & $\begin{array}{l}\text { Coconino } \\
\text { Coconino }\end{array}$ & $\begin{array}{l}363001 \mathrm{~N} 1121322 \mathrm{~W} \\
363239 \mathrm{~N} 1121859 \mathrm{~W}\end{array}$ & & & $\begin{array}{l}\text { Telephone } \mathrm{Hill} \\
\text { Big Springs }\end{array}$ \\
\hline $\begin{array}{l}\text { Ora Acres } \\
\text { Orabi } \\
\text { See Oraibi } \\
\text { Oracle } \\
\text { Oracle Elementary School } \\
\text { Oracle Foothills Estates } \\
\text { Oracle Hill } \\
\text { Oracle Junction } \\
\text { Oracle Microwave Station } \\
\text { Oracle Middle School }\end{array}$ & $\begin{array}{l}\text { airport } \\
\text { ppl } \\
\text { ppl } \\
\text { school } \\
\text { ppl } \\
\text { summit } \\
\text { locale } \\
\text { tower } \\
\text { school }\end{array}$ & $\begin{array}{l}\text { ADMIN } \\
\text { VARIANT } \\
\text { BGN } \\
\text { UNOFF } \\
\text { BGN } \\
\text { BGN } \\
\text { BGN } \\
\text { UNOFF } \\
\text { UNOFF }\end{array}$ & $\begin{array}{l}\text { La Paz } \\
\text { Navajo } \\
\text { Pinal } \\
\text { Pinal } \\
\text { Pina } \\
\text { Pinal } \\
\text { Pinal } \\
\text { Pinal } \\
\text { Pinal }\end{array}$ & $\begin{array}{l}334057 N 1141242 \mathrm{~W} \\
355231 \mathrm{~N} 1103711 \mathrm{~W} \\
323639 \mathrm{~N} 1104613 \mathrm{~W} \\
323630 \mathrm{~N} 1104535 \mathrm{~W} \\
321759 \mathrm{~N} 1105710 \mathrm{~W} \\
323511 \mathrm{~N} 1104629 \mathrm{~W} \\
323318 \mathrm{~N} 1105558 \mathrm{~W} \\
324541 \mathrm{~N} 1105601 \mathrm{~W} \\
323657 \mathrm{~N} 1104745 \mathrm{~W}\end{array}$ & & $\begin{array}{l}4513 \\
2440 \\
3308\end{array}$ & $\begin{array}{l}\text { Oracle } \\
\text { Oracle } \\
\text { Tucson North } \\
\text { Oracle } \\
\text { Oracle Junction } \\
\text { Black Mountain } \\
\text { Oracle }\end{array}$ \\
\hline $\begin{array}{l}\text { Oracle Park } \\
\text { Oracle Place Shopping Center } \\
\text { Oracle Ranger Station } \\
\text { Oracle Ridge } \\
\text { Oracle Ridge Plaza Shopping } \\
\text { Center } \\
\text { Oracle Substation } \\
\text { Oracle Turbine Station } \\
\text { Oraiba } \\
\text { See Oraibi }\end{array}$ & $\begin{array}{l}\text { park } \\
\text { locale } \\
\text { locale } \\
\text { ridge } \\
\text { locale } \\
\text { locale } \\
\text { locale } \\
\text { ppl }\end{array}$ & $\begin{array}{l}\text { ADMIN } \\
\text { UNOFF } \\
\text { UNOFF } \\
\text { BGN } \\
\text { UNOFF } \\
\text { UNOFF } \\
\text { UNOFF } \\
\text { VARIANT }\end{array}$ & $\begin{array}{l}\text { Pinal } \\
\text { Pima } \\
\text { Pinal } \\
\text { Pima } \\
\text { Pima }\end{array}$ & $\begin{array}{l}323621 N 1104614 W \\
322011 N 1105835 W \\
323558 N 1104708 W \\
323016 N 1104441 W \\
321714 N 1105844 W \\
323603 N 1105855 W \\
323721 N 1104519 W \\
355231 N 1103711 W\end{array}$ & & $\begin{array}{l}2540 \\
7494 \\
2300\end{array}$ & $\begin{array}{l}\text { Oracle } \\
\text { Tucson North } \\
\text { Oracle } \\
\text { Campo Bonito } \\
\text { Tucson North } \\
\text { Oracle Junction } \\
\text { Oracle }\end{array}$ \\
\hline $\begin{array}{l}\text { Oraibi } \\
\text { Orabi } \\
\text { Oraiba } \\
\text { Oraybe } \\
\text { Oraibi Butte } \\
\text { Oraibi Community Building } \\
\text { Oraibi Day School } \\
\text { Oraibi Mesa } \\
\text { Third Mesa } \\
\text { Oraibi Mesa } \\
\text { See Third Mesa }\end{array}$ & $\begin{array}{l}\text { summit } \\
\text { building } \\
\text { school } \\
\text { summit }\end{array}$ & $\begin{array}{l}\text { BGN } 1915 \\
\text { VARIANT } \\
\text { VARIANT } \\
\text { VARIANT } \\
\text { BGN } \\
\text { UNOFF } \\
\text { UNOFF } \\
\text { BGN } 1952 \\
\text { VARIANT } \\
\text { VARIANT }\end{array}$ & $\begin{array}{l}\text { Navajo } \\
\text { Navajo } \\
\text { Navajo } \\
\text { Navajo }\end{array}$ & $\begin{array}{l}355249 \mathrm{~N} 1104249 \mathrm{~W} \\
355229 \mathrm{~N} 1103716 \mathrm{~W} \\
355235 \mathrm{~N} 1103649 \mathrm{~W} \\
355423 \mathrm{~N} 1104154 \mathrm{~W} \\
\\
355610 \mathrm{~N} 1103851 \mathrm{~W}\end{array}$ & & $\begin{array}{l}6567 \\
6571\end{array}$ & $\begin{array}{l}\text { Hotevilla } \\
\text { Shongopovi } \\
\text { Oraibi } \\
\text { Hotevilla }\end{array}$ \\
\hline $\begin{array}{l}\text { Orange Grove Junior High School } \\
\text { Orange Tank } \\
\text { Orangetree (subdivision) } \\
\text { Orangetree Estates } \\
\text { (subdivision) } \\
\text { Orange Tree Shopping Center } \\
\text { Orangewood School } \\
\text { Orangewood Village Mobilehome } \\
\text { Park } \\
\text { Oras Well } \\
\text { See Oros Well }\end{array}$ & $\begin{array}{l}\text { school } \\
\text { reservoir } \\
\text { ppl } \\
\text { ppl } \\
\text { locale } \\
\text { school } \\
\text { locale }\end{array}$ & $\begin{array}{l}\text { UNOFF } \\
\text { BGN } \\
\text { BGN } \\
\text { BGN } \\
\text { UNOFF } \\
\text { UNOFF } \\
\text { UNOFF } \\
\text { VARIANT }\end{array}$ & $\begin{array}{l}\text { Pima } \\
\text { Coconino } \\
\text { Maricopa } \\
\text { Maricopa } \\
\text { Maricopa } \\
\text { Maricopa } \\
\text { Maricopa }\end{array}$ & $\begin{array}{l}32192 \mathrm{BN} 1105634 \mathrm{~W} \\
350902 \mathrm{~N} 1112204 \mathrm{~W} \\
332013 \mathrm{~N} 1115340 \mathrm{~W} \\
333511 \mathrm{~N} 1115751 \mathrm{~W} \\
\\
332945 \mathrm{~N} 1115353 \mathrm{~W} \\
333244 \mathrm{~N} 1120554 \mathrm{~W} \\
333924 \mathrm{~N} 1120706 \mathrm{~W} \\
313902 \mathrm{~N} 1111936 \mathrm{~W}\end{array}$ & & $\begin{array}{l}1190 \\
1370\end{array}$ & $\begin{array}{l}\text { Tucson North } \\
\text { Angell } \\
\text { Guadalupe } \\
\text { Paradise Valley } \\
\text { Tempe } \\
\text { Sunnys lope } \\
\text { Union Hills }\end{array}$ \\
\hline $\begin{array}{l}\text { Oraybe } \\
\text { See Oraibi } \\
\text { Orchard Draw } \\
\text { Orchard Spring } \\
\text { Orchard Tank } \\
\text { Ord, Mount } \\
\text { Mesa del Oso } \\
\text { Mese la Oso } \\
\text { Ord, Mount } \\
\text { Ord Creek }\end{array}$ & $\begin{array}{l}\text { ppl } \\
\text { valley } \\
\text { spring } \\
\text { reservoir } \\
\text { summit }\end{array}$ & $\begin{array}{l}\text { VARIANT } \\
\text { BGN } \\
\text { BGN } \\
\text { BGN } \\
\text { BGN } \\
\text { VARIANT } \\
\text { VARIANT } \\
\text { BGN } \\
\text { BGN }\end{array}$ & $\begin{array}{l}\text { Navajo } \\
\text { Yavapai } \\
\text { Pima } \\
\text { Gila } \\
\text { Gila }\end{array}$ & $\begin{array}{l}355231 N 1103711 W \\
345339 N 1121104 W \\
322745 N 1104405 W \\
341323 N 1112143 W \\
335417 N 1112429 W\end{array}$ & $335505 \mathrm{~N} 1093515 \mathrm{~W}$ & 7128 & $\begin{array}{l}\text { Perkinsville } \\
\text { Mount Bigelow } \\
\text { Payson South } \\
\text { Reno Pass }\end{array}$ \\
\hline $\begin{array}{l}\text { Orderville Canyon } \\
\text { Ord Mine } \\
\text { Ordy Tank } \\
\text { Oregon Trail Mobile Hone Park } \\
\text { Orejana Canyon } \\
\quad \text { Orejano Canyon } \\
\text { Orejana Canyon }\end{array}$ & $\begin{array}{l}\text { valley } \\
\text { mine } \\
\text { reservoir } \\
\text { locale } \\
\text { valley } \\
\text { valley }\end{array}$ & $\begin{array}{l}\text { BGN } \\
\text { UNOFF } \\
\text { BGN } \\
\text { UNOFF } \\
\text { BGN } \\
\text { VARIANT } \\
\text { BGN }\end{array}$ & $\begin{array}{l}\text { Coconino } \\
\text { Gila } \\
\text { Gila } \\
\text { Maricopa } \\
\text { Greenlee }\end{array}$ & $\begin{array}{l}365326 \mathrm{~N} 1120845 \mathrm{~W} \\
335726 \mathrm{~N} 1112352 \mathrm{~W} \\
331052 \mathrm{~N} 1105248 \mathrm{~W} \\
333328 \mathrm{~N} 1120652 \mathrm{~W} \\
331045 \mathrm{~N} 1091435 \mathrm{~W} \\
345501 \mathrm{~N} 1131544 \mathrm{~W}\end{array}$ & $\begin{array}{l}363817 \mathrm{~N} 1121004 \mathrm{~W} \\
331343 \mathrm{~N} 1091544 \mathrm{~W} \\
345550 \mathrm{~N} 1131700 \mathrm{~W}\end{array}$ & 1210 & $\begin{array}{l}\text { Buck Pasture Canyon } \\
\text { Reno Pass } \\
\text { Hot Tamale Peak } \\
\text { Sunnys lope } \\
\text { Dix Creek } \\
\text { Mohon Peak }\end{array}$ \\
\hline
\end{tabular}




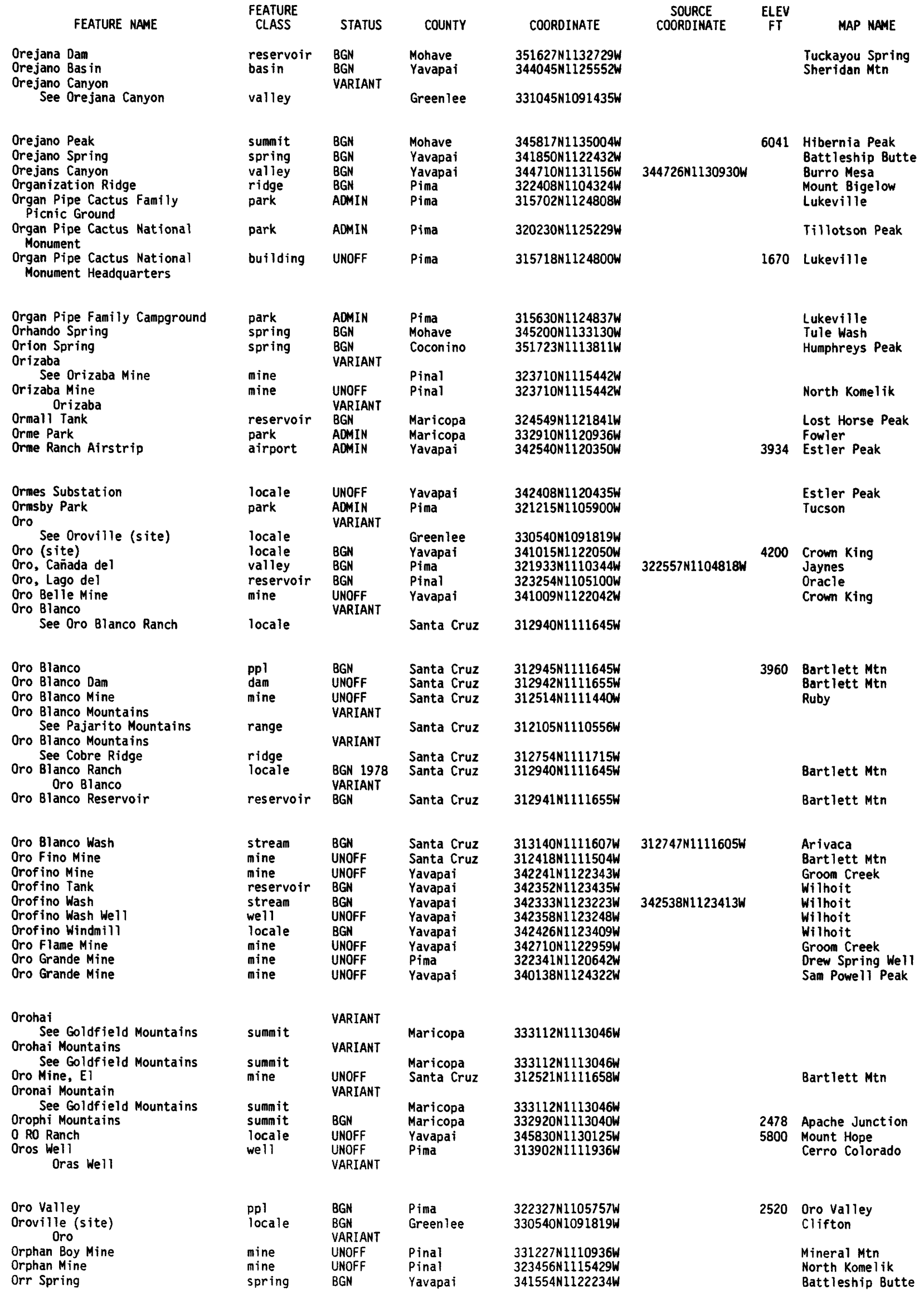




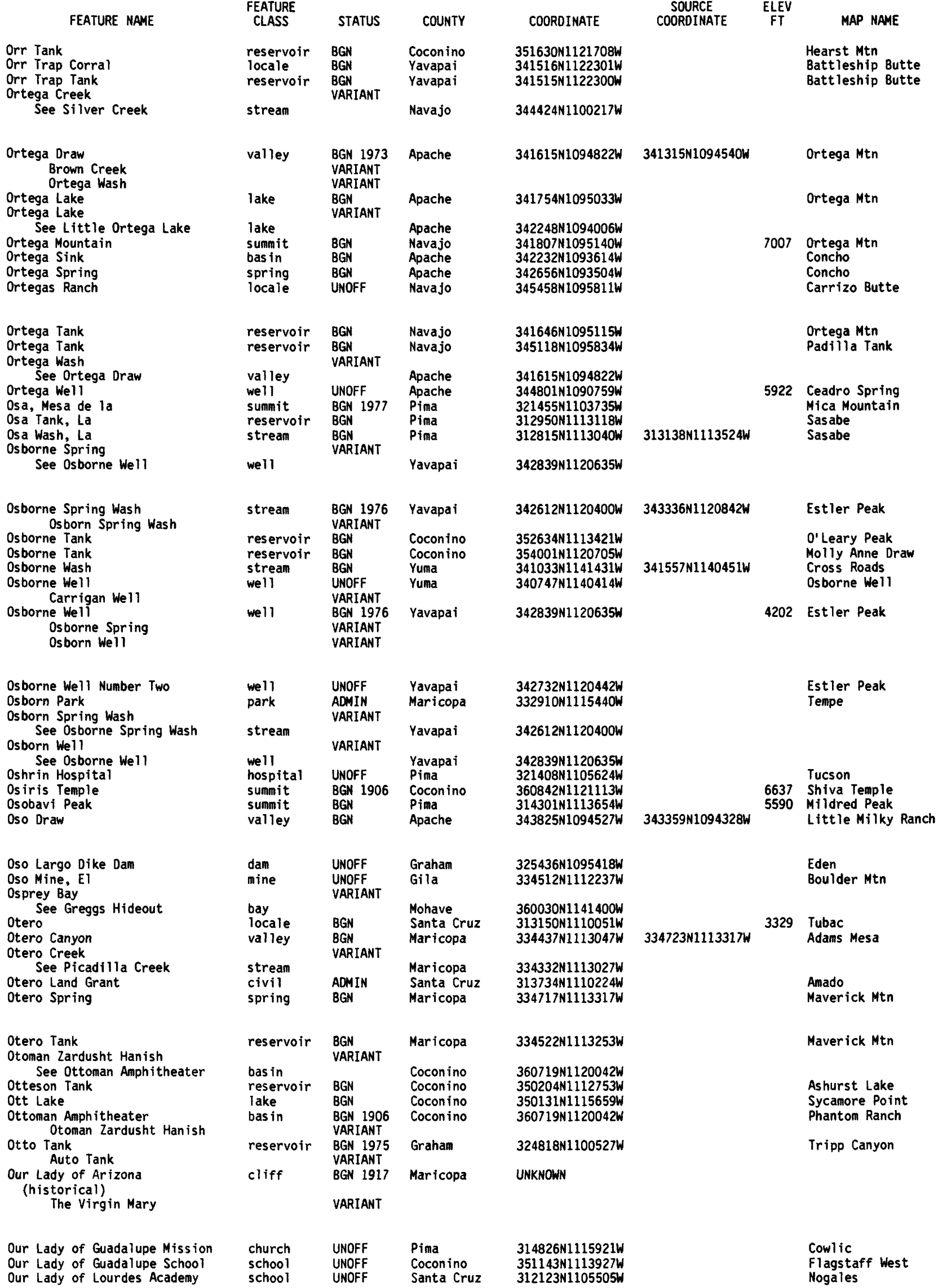




\section{FEATURE NAME}

Our Lady of Lourdes Mission Our Lady of Mount Carmel School Our Lady of Perpetual Help School

Oury Park Coury Park

Outlaw Draw

Out law Mountain

Out law Mountain

Outlaw Seep

Out law Spring

Out law Tank

Out law Windaill

Out let Canyon

Out let Neck

Out let Spring

Outs ide Tank

Out West Trailer Park

Overgaard

Overgaard Airport

Overgaard Post Office

Overgaard Tank

Overland Mine

Overland Trail (subdivision)

Overlook Picnic Area

Sabino Canyon Picnic Area

Over look Ridge Gardner Reservoir

Oversite Canyon

Oversite Trail One Hundred

Twelve

Overton Canyon

Owen Dam

Owens Mine

Owens Tank

Owens Tank

Ow1

Mohawk Inn

Owi Box Canyon

Owi Canyon

Owl Canyon

Owl Creek

Owl Hat Point

Owl Head

Owlhead

Owl Head Buttes

Owl Head Dam

Owl Hoot Windmill

owl Nest

Owl Nest Canyon

Owl Rock

Owl Rocks

Owls Cap

Owls Nest Mountain

Owl Spring

Owl Spring

Owl Spring

Owl Spring Mesa

Ow1 Spring Valley

Owl Tank

Owl Tank

Ow1 Valley

Owl Wash

Owl Wash

Owl Well

OW Point

OW Ranch

Owyhee Wel1

Oxbow Gulch

\begin{tabular}{|c|c|c|c|}
\hline $\begin{array}{l}\text { FEATURE } \\
\text { CLASS }\end{array}$ & STATUS & COUNTY & COORDINATE \\
\hline $\begin{array}{l}\text { church } \\
\text { school } \\
\text { school }\end{array}$ & $\begin{array}{l}\text { UNOFF } \\
\text { UNOFF } \\
\text { UNOFF }\end{array}$ & $\begin{array}{l}\text { Pima } \\
\text { Maricopa } \\
\text { Maricopa }\end{array}$ & $\begin{array}{l}315346 N 1114704 \mathrm{~W} \\
332417 N 1115527 \mathrm{~W} \\
333244 N 1121312 \mathrm{~W}\end{array}$ \\
\hline park & $\begin{array}{l}\text { ADMIN } \\
\text { VARIANT }\end{array}$ & Pima & $321348 N 1105851 \mathrm{~W}$ \\
\hline $\begin{array}{l}\text { valley } \\
\text { summit } \\
\text { summit } \\
\text { summit } \\
\text { spring } \\
\text { spring } \\
\text { reservoir } \\
\text { locale } \\
\text { valley } \\
\text { ridge }\end{array}$ & $\begin{array}{l}\text { BGN } \\
\text { BGN } \\
8 G N \\
\text { BGN } \\
\text { BGN } \\
\text { BGN } \\
\text { BGN } \\
\text { BGN } \\
\text { BGN } 1906 \\
\text { BGN }\end{array}$ & $\begin{array}{l}\text { Navajo } \\
\text { Maricopa } \\
\text { Cochise } \\
\text { Cochise } \\
\text { Navajo } \\
\text { Cochise } \\
\text { Maricopa } \\
\text { Cochise } \\
\text { Coconino } \\
\text { Apache }\end{array}$ & $\begin{array}{l}341807 N 1103155 \mathrm{~W} \\
335416 \mathrm{N1125903W} \\
312954 \mathrm{~N} 1090439 \mathrm{~W} \\
314058 \mathrm{~N} 1095043 \mathrm{~W} \\
341805 \mathrm{~N} 1103147 \mathrm{~W} \\
320510 \mathrm{~N} 1091632 \mathrm{~W} \\
335334 \mathrm{N1125838W} \\
314052 \mathrm{~N} 1095059 \mathrm{~W} \\
360935 \mathrm{N1} 120810 \mathrm{~W} \\
355453 \mathrm{~N} 1090301 \mathrm{~W}\end{array}$ \\
\hline
\end{tabular}

$\begin{array}{llll}\text { spring } & \text { BGN 1906 } & \text { Coconino } & 361340 \text { N1120605W } \\ \text { reservoir } & \text { BGN } & \text { Coconino } & 343443 N 1113010 \mathrm{~W} \\ \text { locale } & \text { UNOFF } & \text { Maricopa } & 332703 \text { N1120741W } \\ \text { pp1 } & \text { BGN } & \text { Navajo } & 342327 N 1103309 W \\ \text { airport } & \text { AOMIN } & \text { Navajo } & 342352 N 1103150 W \\ \text { building } & \text { UNOFF } & \text { Navajo } & 342320 N 1103312 W \\ \text { reservoir } & \text { BGN } & \text { Navajo } & 342219 \text { N1103304W } \\ \text { mine } & \text { UNOFF } & \text { Gila } & 330258 \text { N1104842W } \\ \text { pp1 } & \text { BGN } & \text { Maricopa } & 333920 \text { N1120936W } \\ \text { park } & \text { AOMIN } & \text { Pima } & 321850 \text { N1104842W }\end{array}$

\begin{tabular}{|c|c|c|c|}
\hline $\begin{array}{l}\text { ridge } \\
\text { lake }\end{array}$ & $\begin{array}{l}\text { BGN } \\
\text { BGN } \\
\text { VARIANT }\end{array}$ & $\begin{array}{l}\text { Cochise } \\
\text { Mohave }\end{array}$ & $\begin{array}{l}320850 N 1092620 \mathrm{~W} \\
362056 \mathrm{~N} 1133731 \mathrm{~W}\end{array}$ \\
\hline $\begin{array}{l}\text { valley } \\
\text { trail }\end{array}$ & $\begin{array}{l}\text { BGN } \\
\text { UNOFF }\end{array}$ & $\begin{array}{l}\text { Cochise } \\
\text { Cochise }\end{array}$ & $\begin{array}{l}312307 N 1101854 \mathrm{~W} \\
312342 \mathrm{~N} 1101855 \mathrm{~W}\end{array}$ \\
\hline $\begin{array}{l}\text { valley } \\
\text { dam } \\
\text { mine } \\
\text { reservoir }\end{array}$ & $\begin{array}{l}\text { BGN } \\
\text { UNOFF } \\
\text { UNOFF } \\
\text { BGN }\end{array}$ & $\begin{array}{l}\text { Cochise } \\
\text { Coconino } \\
\text { Mohave } \\
\text { Navajo }\end{array}$ & $\begin{array}{l}320357 \mathrm{~N} 1091903 \mathrm{~W} \\
353959 \mathrm{N1} 12571 \mathrm{BW} \\
355052 \mathrm{N1} 14155 \mathrm{BW} \\
342041 \mathrm{N1} 101349 \mathrm{~W}\end{array}$ \\
\hline
\end{tabular}

$\begin{array}{llll}\text { reservoir } & \text { BGN } & \text { Navajo } & 342648 N 1102931 \mathrm{~W} \\ \text { ppl } & \text { BGN } & \text { Yuma } & 324319 N 1134729 \mathrm{~W}\end{array}$

\section{valley}

valley

valley

stream

summit

summit.

locale

summit
dam
locale
summit
valley
summit
cliff
summit
summit
spring

VARIANT
BGN

BGN

BGN

BGN

BGN

$B G N$
$B G N$

Navajo

Graham

Greenlee 325753N1091814W

Cochise 31403BN1090544W

Apache 355707N1095705W

Yuna

Pinal

$\begin{array}{lll}\text { BGN } & \text { Pinal } & 323550 N 1110722 W \\ \text { UNOFF } & \text { Yuma } & 332615 N 1135501 W \\ \text { BGN } & \text { Cochise } & 313207 N 109545 W \\ \text { BGN } & \text { Apache } & 362115 N 1092631 W \\ \text { BGN } & \text { Apache } & 362230 N 1092536 W \\ \text { BGN } & \text { Navajo } & 364914 N 1101457 W \\ \text { BGN } & \text { Yavapai } & 344339 N 1124554 W \\ \text { BGN } & \text { Coconino } & 360143 N 1111337 W \\ \text { BGN } & \text { Pima } & 32940 N 1115535 W \\ \text { BGN } & \text { Gila } & 335653 N 1101058 W\end{array}$

$355707 \mathrm{N1095705W}$

$332632 N 1135455 \mathrm{~W}$
$334200 \mathrm{~N} 1110600 \mathrm{~W}$

$341842 \mathrm{~N} 1103042 \mathrm{~W}$

$1537 N 1120623$

\begin{tabular}{|c|c|c|}
\hline \multirow[t]{3}{*}{$\begin{array}{c}\text { SOURCE } \\
\text { COORDINATE }\end{array}$} & $\begin{array}{c}\text { ELEV } \\
\text { FT }\end{array}$ & MAP NAME \\
\hline & 2627 & $\begin{array}{l}\text { Sells East } \\
\text { Tempe } \\
\text { Glendale }\end{array}$ \\
\hline & & Tucson \\
\hline \multirow[t]{4}{*}{$41842 \mathrm{~N} 1103042 \mathrm{~W}$} & 3052 & Outlaw Draw \\
\hline & 2936 & Guadalupe Spring \\
\hline & 5069 & $\begin{array}{l}\text { Outlaw Mountain } \\
\text { Outlaw Oraw } \\
\text { Cochise Head } \\
\text { Outlaw Hill }\end{array}$ \\
\hline & & Out law Mounta in \\
\hline \multirow{4}{*}{$61537 \mathrm{~N} 1120623 \mathrm{~W}$} & & $\begin{array}{l}\text { Shiva Temple } \\
\text { Buell Park }\end{array}$ \\
\hline & & $\begin{array}{l}\text { Bright Angel Point } \\
\text { Buckhorn Mtn }\end{array}$ \\
\hline & 1064 & $\begin{array}{l}\text { Fowler } \\
\text { Heber } \\
\text { Heber } \\
\text { Heber } \\
\text { Out law Draw } \\
\text { Hayden }\end{array}$ \\
\hline & $\begin{array}{l}1300 \\
2720\end{array}$ & Hedgpeth Hills \\
\hline
\end{tabular}

spring BGN Navajo 352532N1100704W

spring BGN Navajo 363519N1100953W

summit

valley

reservoir

reservoir

valley

stream

stream

well

BGN

$B G N$

$B G N$

$B G N$

$B G N$

BGN

BGN

Navajo

Navajo

363816N1100949W

Coconino 355152N1120523W

Navajo 361650N1102506W

Graham 323403N1093053W

Yuma

Navajo

$324436 \mathrm{N1134844 \textrm {W }}$

summit

locale

well

$B G N$

UNOFF

valley
Coconino

Gila

Apache

Gila
341635N1104938W

341647 N110480OW

340711 N1112210W

(3)

$320342 \mathrm{~N} 1091759 \mathrm{~W}$

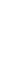

$3551291101511 \mathrm{~W}$

$322957 N 1094458 \mathrm{~W}$

$330143 \mathrm{~N} 1091616 \mathrm{~W}$

313948 N1090041W

Bowie Mtn North

Mustang Point

Miller Peak

Miller Peak

Cochise Head

Rose Well Camp West

Senator Mtn

Pinedale

Aripine

Mohawk

Sun Altar

Monk Draw

Guthrie

Skull Canyon

Beeshsikad Spring

Owl Head

Chief Butte

Tortolita Mts

Owl Head

5126 Potter Mtn

6142 Tall Tree Mesa

361917 N1092243W

Tall Tree Mesa

6547 Agath la Peak

5250 Smith Mesa

Moenkopi

Santa Rosa Mts NW

Cedar Creek

Indian Wells

Owl Spring

Owl Spring

Kayenta East

Belmont Mtn

Red Butte

Owl Valley

Tanque

Mohawk

Owl Valley

0 W Point

0 W Point

Kearn Lake

$341015 \mathrm{~N} 1112119 \mathrm{~W}$ 
FEATURE NAME

Oxbow Hill

Ox Yoke Mountain

Oxbow Mine

Oxbow Mountain

Oxbow Mountain Tank

Oxbow Spring

Oxbow Tank

Oxbow Tank

Oxbow Tank

Oxbow Tank

Ox Bow Trail Number One

Hundred Sixty Three

Ox Frame Canyon

Ox Frame Tank

Oxhide Mine Spring

Oxide Pit

Oxtail Draw

Oxtail Tank

Ox Wash

Ox Yoke Mountain

See Oxbow $\mathrm{Hill}$

Oza Butte

Oz Yoke Spring
Oxford Plaza Shopping Center

\begin{tabular}{|c|c|c|c|}
\hline $\begin{array}{c}\text { FEATURE } \\
\text { CLASS }\end{array}$ & STATUS & COUNTY & COORDINATE \\
\hline summit & $\begin{array}{l}\text { BGN } 1974 \\
\text { VARIANT }\end{array}$ & Gila & $341007 \mathrm{~N} 1112020 \mathrm{~W}$ \\
\hline $\begin{array}{l}\text { mine } \\
\text { summit } \\
\text { reservoir } \\
\text { spring }\end{array}$ & $\begin{array}{l}\text { UNOFF } \\
\text { BGN } \\
\text { BGN } \\
\text { BGN }\end{array}$ & $\begin{array}{l}\text { Gila } \\
\text { Gila } \\
\text { Gila } \\
\text { Yavapai }\end{array}$ & $\begin{array}{l}341006 \mathrm{~N} 1112114 \mathrm{~W} \\
341345 \mathrm{~N} 1105945 \mathrm{~W} \\
341325 \mathrm{~N} 1105933 \mathrm{~W} \\
344208 \mathrm{~N} 1120354 \mathrm{~W}\end{array}$ \\
\hline $\begin{array}{l}\text { reservoir } \\
\text { reservoir } \\
\text { reservoir } \\
\text { reservoir } \\
\text { trail }\end{array}$ & $\begin{array}{l}\text { BGN } \\
\text { BGN } \\
\text { BGN } \\
\text { BGN } \\
\text { UNOFF }\end{array}$ & $\begin{array}{l}\text { Gila } \\
\text { Gila } \\
\text { Gila } \\
\text { Yavapai } \\
\text { Yavapai }\end{array}$ & $\begin{array}{l}341022 \mathrm{~N} 1112018 \mathrm{~W} \\
341314 \mathrm{~N} 1110013 \mathrm{~W} \\
341319 \mathrm{~N} 1105955 \mathrm{~W} \\
342303 \mathrm{~N} 1115022 \mathrm{~W} \\
342338 \mathrm{~N} 1115000 \mathrm{~W}\end{array}$ \\
\hline $\begin{array}{l}\text { locale } \\
\text { valley } \\
\text { reservoir } \\
\text { spring }\end{array}$ & $\begin{array}{l}\text { UNOFF } \\
\text { BGN } \\
\text { BGN } \\
\text { BGN }\end{array}$ & $\begin{array}{l}\text { Pima } \\
\text { Pima } \\
\text { Pima } \\
\text { Gila }\end{array}$ & $\begin{array}{l}321227 \mathrm{~N} 1105223 \mathrm{~W} \\
315110 \mathrm{~N} 1111210 \mathrm{~W} \\
315255 \mathrm{~N} 1111159 \mathrm{~W} \\
332235 \mathrm{~N} 1105517 \mathrm{~W}\end{array}$ \\
\hline $\begin{array}{l}\text { basin } \\
\text { valley } \\
\text { reservoir } \\
\text { stream }\end{array}$ & $\begin{array}{l}\text { BGN } \\
\text { BGN } \\
\text { BGN } \\
\text { BGN } \\
\text { VARIANT }\end{array}$ & $\begin{array}{l}\text { Pima } \\
\text { Yavapai } \\
\text { Yavapai } \\
\text { Maricopa }\end{array}$ & $\begin{array}{l}322352 \mathrm{~N} 1113008 \mathrm{~W} \\
343042 \mathrm{~N} 1115940 \mathrm{~W} \\
343313 \mathrm{~N} 1115737 \mathrm{~W} \\
335232 \mathrm{~N} 1123924 \mathrm{~W}\end{array}$ \\
\hline $\begin{array}{l}\text { summit } \\
\text { summit } \\
\text { spring }\end{array}$ & $\begin{array}{l}\text { BGN } 1906 \\
\text { BGN }\end{array}$ & $\begin{array}{l}\text { Gila } \\
\text { Coconino } \\
\text { Mohave }\end{array}$ & $\begin{array}{l}341007 \mathrm{~N} 1112020 \mathrm{~W} \\
361058 \mathrm{~N} 1120400 \mathrm{~W} \\
344339 \mathrm{~N} 1134759 \mathrm{~W}\end{array}$ \\
\hline
\end{tabular}

spring BGN Mohave 344339N1134759W

\begin{tabular}{|c|c|c|}
\hline \multirow[t]{4}{*}{$\begin{array}{l}\text { SOURCE } \\
\text { COORDINATE }\end{array}$} & $\begin{array}{c}\text { ELEV } \\
\text { FT }\end{array}$ & MAP NAME \\
\hline & 4887 & Payson South \\
\hline & 6448 & $\begin{array}{l}\text { Payson South } \\
\text { Oxbow Mtn } \\
\text { Oxbow Mtn } \\
\text { Cottonwood }\end{array}$ \\
\hline & & $\begin{array}{l}\text { Payson South } \\
\text { Diamond Butte } \\
\text { Oxbow Mtn } \\
\text { Horner Mtn } \\
\text { Horner Mtn }\end{array}$ \\
\hline $315319 N 1111225 \mathrm{~W}$ & 2580 & $\begin{array}{l}\text { Tucson East } \\
\text { Batamote Hills } \\
\text { Samaniego Peak } \\
\text { Inspiration }\end{array}$ \\
\hline $\begin{array}{l}343355 N 1115734 W \\
335639 N 1123452 W\end{array}$ & & $\begin{array}{l}\text { Silver Bell West } \\
\text { Middle Verde } \\
\text { Middle Verde } \\
\text { Wickenburg }\end{array}$ \\
\hline & 8065 & $\begin{array}{l}\text { Bright Angel Point } \\
\text { Beecher Canyon }\end{array}$ \\
\hline
\end{tabular}

$322932 \mathrm{~N} 1103708 \mathrm{~W}$

$331125 N 1095942 W$

Buehman Canyon

Gila Peak

$344115 \mathrm{~N} 1105017 \mathrm{~W}$

Pump Ranch Tank

Chukut Kuk

Seven Springs

Luna Lake

Tempe

Tempe

Telegraph Wash

Beargrass Basin Galleta Flat East Galleta Flat East
Maverick

$320036 \mathrm{~N} 1102507 \mathrm{~W}$

$335218 \mathrm{~N} 1093202 \mathrm{~W}$

Bonito Rock

Bonito Rock

8200 Bonito Rock

Pacheta Lake Campground

Pachete Creek See Pacheta Creek

Pacheto Creek

See Pacheta Creek

Pacific Canyon

Pacific Mine

Pacific Mobile Manor

Paciñimo

See Pisinimo

Pacinimo

See Pis inimo

Packard Elementary Schoo

Packard Mesa

Packard Ranch

Packards

See Punkin Center

Packard Spring
$334619 N 1093230 \mathrm{~W}$

$334624 N 1093205 \mathrm{~W}$

stream BGN Apache 333845N1093102W

VARIANT

dam UNOFF

reservoir BGN Apache

Apache

Apache

333845 N1093102W

$333845 \mathrm{~N} 1093102 \mathrm{~W}$

$331549 N 1110453 \mathrm{~W}$

$340755 \mathrm{~N} 1122234 \mathrm{~W}$

$332458 \mathrm{~N} 1113704 \mathrm{~W}$

$320206 N 1121852 \mathrm{~W}$

ppl

Pima

VARIANT

ppl

UNOFF

school

summit

$B G N$

UGN

VARIANT

pp1

BGN
Pima

$335216 \mathrm{~N} 1111846 \mathrm{~W}$

$345324 N 1120531 \mathrm{~W}$

$345155 N 1120432 \mathrm{~W}$

$335220 \mathrm{~N} 1111845 \mathrm{~W}$

$335130 \mathrm{~N} 1112102 \mathrm{~W}$

\section{N1110417W Superior Minnehaha 1560 Apache Junction}

Tonto Bas in Sycamore Bas in Clarkdale

Tonto Bas in 


\section{FEATURE NAME}

Packard Stadium (baseball)

Packard Tank

Packard Trail Nmber Sixty Six

Packard Trail Tank

Packard Wash

Packer

Packer Tank

Packeto Creek

See Pacheta Creek

Packing Horse Creek

Packing Horse Creek

See Pineasco Creek

Pack Rat Hill

Pack Rat Spring

Pack Rat Well

Packsaddle Campground

Packsaddle Mountain

Packsaddle Mountain

Packsaddle Tank

Packwood Canyon

Packwood Mountain Packwood Peak

Packwood Peak

See Packwood Mountain

Packwood Springs

Paddit We11

Paddock Ranch

Paddock Spring

Paddock Well

Paddy Butte

Paddy Cienega

Paddy Creek

Paddy Creek

Paddy Fork Tank

Paddy Lynch Windmill

Paddys River

Paddys River Two hundred

ninety three Trail

Padelford Wash

Padilla Mesa

Padilla Tank

Padre Canyon Canyon Padre

Padre Reservoir

Padre Reservoir Pan Reservoir

Padres Mesa

Padre Tank

Pad Wo' o Tank

Page

Page Elementary School

Page Flat

Page Flat Tank

Page High School

Page Municipal Airport

Page Ranch

Page Springs

Page Springs State Fish

Cultural Station

Page Substation

Page Tank

See Page Water Storage Tank

Page Wash

Page Water Storage Tank Page Tank

Pagoda Mall

Pagoda Mountain

See Klothos Temple

Paguekwash Point

Fishtail Point

Paquequash Point
CLASS

STATUS

COUNTY

COORDINATE

local

BGN

reservoir $B G$

Maricopa

trai

reservoir

stream

locale

reservoir

stream

stream

UNOFF

BGN

BGN

BGN

VARIANT

stream

BGN

VARIANT

summit

spring

wel1

park

summ it

summit

reservoir

valley

$\begin{array}{ll}\text { BGN } & \text { Pima } \\ \text { BGN } & \text { Navajo } \\ \text { UNOFF } & \text { Yavapai } \\ \text { ADMIN } & \text { Mohave } \\ \text { BGN } & \text { Cochise } \\ \text { BGN } & \text { Mohave } \\ \text { BGN } & \text { Graham } \\ \text { BGN } & \text { Graham } \\ \text { BGN } & \text { Graham } \\ \text { VARIANT } & \end{array}$

summit

spring

well

locale

spring

well

summit

flat

stream

VARIANT

BGN
UNOFF
UNOFF
BGN
UNOFF
BGN
BGN
BGN

Graham

Graham

Maricopa

Yavapai

Yavapai

Coconino

Apache

Apache

Apache

strean

reservoir

locale

strean

trail

BGN

BGN

BGN

stream

summit

reservoir

valley

BGN

BGN 1915

BGN

BGN 1964

reservoir

reservoir

BGN

BGN

summit

reservoir

ppl

school

flat

reservoir

Apache

$B G N$

UNOFF

BGN

BGN

schoo

airport

locale

ppl

locale

UNOFF

ADMIN

UNOFF

BGN

BGN

locale

UNOFF

VARIANT

reservoir

stream

BGN

reservoir $\quad B G$

locale

VARIANT

UNOFF

VARIANT

summit

cliff

Coconino

Yavapai
BGN 1925

VARIANT

VARIANT

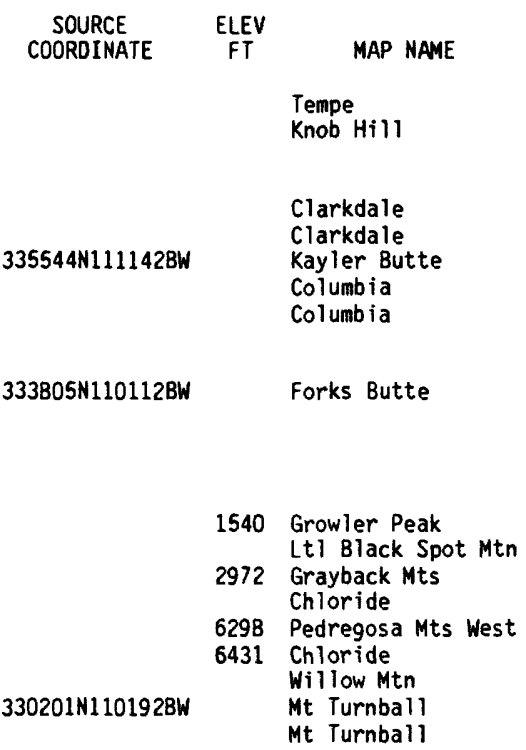

$330242 \mathrm{~N} 1101938 \mathrm{~W}$

$330305 N 1102107 \mathrm{~W}$

$32404 B N 1131041 \mathrm{~W}$

$344729 \mathrm{~N} 1125548 \mathrm{~W}$

344721 N1125550w

354203 N1111534W

$333830 \mathrm{~N} 1093616 \mathrm{~W}$

333930N1093651W

333509 N1093841

335446 N1091018

$335536 \mathrm{~N} 1090755 \mathrm{~W}$

$324106 \mathrm{~N} 1101120 \mathrm{~W}$

324239 N1101220W

$323734 \mathrm{~N} 1101549 \mathrm{~W}$

$334148 \mathrm{~N} 1122030 \mathrm{~W}$

$354705 \mathrm{~N} 1104721 \mathrm{~W}$

344549 N1095357

$351300 \mathrm{~N} 1110630 \mathrm{~W}$

351751 N1124840W

$351802 N 1124 B 54 W$

351605 N1093226W

$350358 \mathrm{~N} 1112215 \mathrm{~W}$

320909 N1115724W

$365431 \mathrm{N1112822W}$

$365445 \mathrm{~N} 1112730 \mathrm{~W}$

$345546 \mathrm{~N} 1122111 \mathrm{~W}$

$345636 \mathrm{~N} 1122141 \mathrm{~W}$

$365447 \mathrm{~N} 1112728 \mathrm{~W}$

$365529 \mathrm{~N} 1112649 \mathrm{~W}$

$313105 N 1102725 \mathrm{~W}$

344603N1115334W

$344547 \mathrm{~N} 1115321 \mathrm{~W}$

365417 N1112832W

354540 N1115850W

$345611 \mathrm{~N} 1121834 \mathrm{~W}$

354540 N1115850W

345726 N1122436W

Mt Turnball

South of Sentinel

5896 Camp Wood

Camp Wood

4290 Wupatki NE

8010 Maverick

Maverick

$334023 N 1093517 \mathrm{~W}$

Maverick SW

335329 N1090704W

Nutrioso

$323518 N 1101702 \mathrm{~W}$

4072 Eureka Ranch

Eureka Ranch

Kennedy Peak

$334931 N 1122227 \mathrm{~W}$

Calderwood Butte

Padilla Mesa

Padilla Tank

$350130 \mathrm{~N} 1112253 \mathrm{~W}$

Canyon Diablo

Seligman East

Seligman East

Dipping Water Well

Elliott Canyon

Sand Wells

Page

Page

Hell Point

Hell Point

Page

4310 Page

Pyeatt Ranch

Page Springs

Page Springs

Page

Hell Point

Harbison Tank

1150 Sunnys lope

$324540 \mathrm{~N} 1141548 \mathrm{~W}$

$362224 \mathrm{~N} 1124023 \mathrm{~W}$

565B Havasu Falls 
NATIONAL GAZETTEER--ARIZONA 1986

\section{FEATURE NAME}

Pahreah Canyon

See Paria Canyon

Pahreah Plateau

See Paria Plateau

Pahreah River

See Paria River

Pahrea River

See Paria River

Pah-Roose River See Virgin River

Pah Ute Canyon

See Piute Canyon

Pah-ute Canyon

See Piute Canyon

Pahute Canyon

See Piute Canyon

Paige Canyon

Paige Creek

Paige Well

Pain in the Back Canyon

Painted Bluffs

Painted Cave Ranch

Painted Cliffs

Painted Desert

El Desierto Pintado

Painted Desert Interchange

Painted Desert Vista Picnic

Area

Painted Rock Dam

Painted Rock Historic Park

Painted Rock Interchange

Painted Rock Mountains

Hierogliphic Hills

Picture Rocks

Sierra Escritas Piedras

Pintadas

Sierra Pinta Sierra

Sibupuc

Painted Rock Reservoir

Painted Rock Reservoir

Painted Tank Number One

Painted Tank Number Two

Paint Pots

Paint Rock

Rasberry Peak

Paint Rock Prairie

Pair o' Dice Cienega

Paradise Cienega

Pair O' Dice Ranch

Paisano Canyon

Paisano Wash

Paiute Canyon

$$
\text { See Piute Canyon }
$$

Paiute Elementary School

Paiute Park

Paiute Point

Paiute Point

See Piute Point

Paiute Primitive Area

Paiute Trail Point

Paiute Trail Wash

Pajarita Mo See Pajarito Mountains

Pajarito

See Pajarito Peak

Pajarito Mountains

Arizona Mountains

Bear Valley Mountains

Oro Blanco Mountains

Pajarita Mountains

Pajaritos Mountains

Sierra de Los Pajaritos

Sierra del Pajarito

$\begin{array}{llll}\begin{array}{c}\text { FEATURE } \\ \text { CLASS }\end{array} & \text { STATUS } & \text { COUNTY } & \text { COORDINATE } \\ \text { valley } & \text { VARIANT } & \text { Coconino } & 365201 \mathrm{~N} 1113525 \mathrm{~W} \\ & & & \\ \text { plain } & \text { VARIANT } & \text { Coconino } & 364856 \mathrm{N1115627 \textrm {W }} \\ \text { stream } & \text { VARIANT } & \text { Coconino } & 365131 \mathrm{N1113600 \textrm {W }} \\ \text { stream } & \text { VARIANT } & \text { Coconino } & 365131 \mathrm{~N} 1113600 \mathrm{~W} \\ \text { stream } & \text { VARIANT } & \text { Mohave } & 360818 \mathrm{~N} 1142531 \mathrm{~W} \\ \text { valley } & \text { VARIANT } & \text { Navajo } & 371100 \mathrm{~N} 1104230 \mathrm{~W}\end{array}$

VARIANT

valley

valley

valley

stream

well

valley

summit

locale

cliff

plain

crossing

park

dam

ADMIN

UNOFF

range

BGN

VARIANT

VARIANT

VARIANT

VARIANT

$\begin{array}{llll}\text { reservoir } & \text { BGN } & \text { Maricopa } & 330423 N 1130040 \mathrm{~W} \\ \text { reservoir } & \text { BGN } & \text { Maricopa } & 330423 N 1130040 \mathrm{~W} \\ \text { reservoir } & \text { BGN } & \text { Yavapai } & 343450 \mathrm{~N} 1113431 \mathrm{~W} \\ \text { reservoir } & \text { BGN } & \text { Yavapai } & 343438 \mathrm{~N} 1113436 \mathrm{~W} \\ \text { summit } & \text { BGN 1948 } & \text { Mohave } & 360244 \mathrm{~N} 1144206 \mathrm{~W} \\ \text { summit } & \text { BGN 1985 } & \text { Cochise } & 314956 \mathrm{~N} 1091758 \mathrm{~W} \\ & \text { VARIANT } & & \\ \text { flat } & \text { BGN } & \text { Greenlee } & 332904 N 1091105 \mathrm{~W} \\ \text { flat } & \text { BGN } & \text { Apache } & 334106 \mathrm{~N} 1093051 \mathrm{~W}\end{array}$

locale UNOFF Apache 334127N1093106W

$\begin{array}{llll}\text { valley } & \text { BGN } & \text { Pinal } & 325451 N 1102854 W \\ \text { stream } & B G N & \text { Pinal } & 325449 N 1111944 W\end{array}$

VARIANT

valley
school UNOFF

$\begin{array}{ll}\text { school } & \text { UNOFF } \\ \text { park } & \text { ADNIN }\end{array}$

cape BGN

liff VARIANT

park ADMIN

cliff $B G N$

valley $B G N$

range

summit

range

VARIANT

BGN

VARIANT

VARIANT

VARIANT

VARIANT

VARIANT

VARIANT

VARIANT
Navajo 371100N1104230W

Maricopa 332915N1115629W

Maricopa $332904 N 1115627 \mathrm{~W}$

$361151 \mathrm{N1140012 \textrm {W }}$

Coconino 360704N1121930W

Mohave

Coconino

Coconino

$365000 \mathrm{~N} 1135000 \mathrm{~W}$

$354624 \mathrm{~N} 1110838 \mathrm{~W}$

$354311 N 1111114 W$

Santa Cruz

$312105 \mathrm{~N} 1110556 \mathrm{~W}$

Santa Cruz

$312138 \mathrm{~N} 1110511 \mathrm{~W}$

$312105 \mathrm{~N} 1110556 \mathrm{~W}$ $\begin{array}{ccc}\text { SOURCE } & \text { ELEV } \\ \text { CODRDINATE } & \text { FT MAP NAME }\end{array}$

$371100 \mathrm{~N} 1104230 \mathrm{~W}$

$371100 \mathrm{~N} 1104230 \mathrm{~W}$

$321703 \mathrm{~N} 1102246 \mathrm{~W}$

$321703 \mathrm{~N} 1102246 \mathrm{~W}$

$320821 \mathrm{N1102B31 \textrm {W }}$

$362203 \mathrm{~N} 1100047 \mathrm{~W}$

$\begin{array}{ll}\text { Greenlee } & 331017 \mathrm{~N} 1092440 \mathrm{~W} \\ \text { Pinal } & 353000 \mathrm{~N} 1110500 \mathrm{~W}\end{array}$

$333552 \mathrm{~N} 1111842 \mathrm{~W}$

$353001 \mathrm{N1} 100500 \mathrm{~W}$

$340338 \mathrm{N1094648 \textrm {W }}$

$352326 \mathrm{~N} 1112553 \mathrm{~W}$

$330423 \mathrm{~N} 1130040 \mathrm{~W}$

$330122 \mathrm{~N} 1130249 \mathrm{~W}$

$325439 \mathrm{~N} 1125730 \mathrm{~W}$

$325923 \mathrm{~N} 1130116 \mathrm{~W}$
Soza Canyon

Soza Canyon

4147 Happy Valley

Hole In Rock Valley

7185 Coronado Mtn

Brandenburg Mtn

Horse Mesa Dam

White Cone

Kachina Point

Strawberry Crater

Dendora Valley

Dendora Valley

Theba

Sentinel NE
Dendora Valley

Dendora Valley Buckhorn Mountain Buckhorn Mountain Hoover Dam

9375 Chiricahua Peak

Dutch Blue Creek Maverick

Maverick

325742N1102621W Booger Canyon $325326 \mathrm{N1110612W}$ Cactus Forest

Tempe

Tempe

Iceberg Canyon

Mount Bangs

The Landmark

Badger Spring

$354655 N 1110513 W$

Pajarito Peak 
A2456

FEATURE NAME
NATIONAL GAZETTEER--ARIZONA 1986

FEATURE
CLASS

CLASS

STATUS

COUNTY

COORDINATE

SOURCE
COORDINATE

MAP NAME

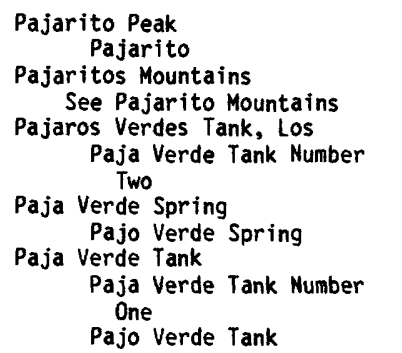

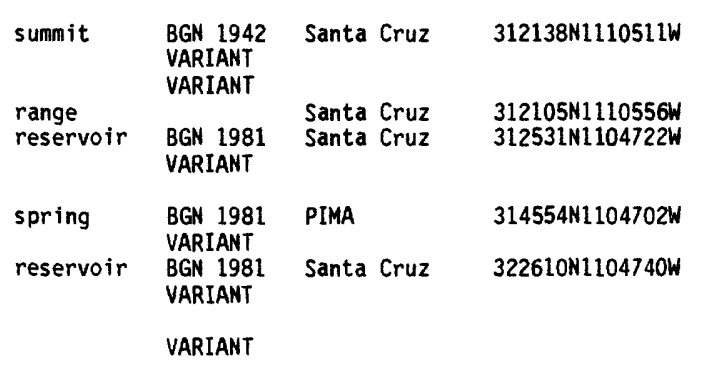

Paja Verde Tank Number One See Paja Verde Tank

Paja Verde Tank Number Two

See Pajaros Verdes Tank, Los

Pajonal Tank

Pajo Verde Spring See Paja Verde Spring

Pajo Verde Tank

See Paja Verde Tank

Pakoon Springs

Pakoon Tank

Pakoon Wash

Palace Canyon

Palace Peak

Palace Station

Palaco Canyon

See Peck Canyon

Palaco canyon

See Peck Canyon

Palamino Canyon

See Palomino Canyon

Palisade Canyon

Pal is ade Creek

Palisade Ranger Station

Palisade Rock

Palis ades Creek

Palisades of Fish Creek Canyon See Bronze, Walls of

Palisades of the Desert

Palisade Spring

Palma Park

Palmaritas (subdivision)

Palmas del Sol (trailer park)

Palmas Royale (subdivision)

Palm Canyon Fish Tail Canyon

Paimcroft School

Palmdale School

Palmerita Ranch

Palmer Mine

Paimer Park

Paimer Ranch

Palmer Spring

Palmer Wash

Palmer Well

Palm Gardens Mobile Home Manor

Palm Glen Shopping Center

Paim Grove Shopping Center

Paim Lake

Palm Lakes Village (trailer park)

Palm Lane School

Palm Shadows Mobile Home Park

Palm Springs

Palms Trailer Park

Palintree Wash

Palm Village Shopping Center

\section{reservoir \\ reservoir \\ reservoir \\ spring \\ reservoir

spring
reservoir
valley
valley
summit
locale
valley
valley

VARIANT

VARIANT

Santa Cruz

Santa Cruz

Pima

BGN

VARIANT

VARIANT

PIMA

Santa Cruz

$B G N$
$B G N$
$B G N$

BGN

BGN

BGN

BGN

VARIANT

VARIANT

(1)

valley

valley

stream
locale

pillar

stream

cliff

cliff

spring

park

locale

ppl

valiey

school

school

locale

mine

park

spring

spring

stream
well

locale

locale

locale

lake

locale

school

locale

ppl

locale

stream

locale

VARIANT

Mohave

Mohave

Greenlee

Greenlee

Yavapai

Santa Cruz

Santa Cruz

BGN

ADMIN

BGN

UNOFF

BGN

BGN

VARIANT

UNOFF

UNOFF

UNOFF

Pima

Maricopa

Maricopa

Maricopa

Maricopa

Yuma

Yuma

Maricopa

Yuma

UNOFF

ADNIN

BGN

BGN

UNOFF

UNOFF

UNOFF

BGN

UNOFF

Pinal

Maricopa

Graham

Maricopa

Pinal

Pinal

Maricopa

Maricopa

Maricopa

Maricopa

Maricopa

UNOFF

UNOFF

$B G N$

UNOFF

BGN

UNOFF

Maricopa

Maricopa

Pinal

Maricopa

Mohave

Maricopa

$\begin{array}{lll} & \text { Coconino } & 342215 N 1105312 \mathrm{~W} \\ \text { BGN } & \text { Pima } & 322201 \mathrm{~N} 1104610 \mathrm{~W} \\ \text { BGN } & \text { Apache } & 360755 \mathrm{~N} 109080 \mathrm{~W} \\ \text { UNOFF } & \text { Pima } & 322439 \mathrm{~N} 1104251 \mathrm{~W} \\ \text { BGN } & \text { Pima } & 322444 \mathrm{N1} 104247 \mathrm{~W} \\ \text { BGN 1932 } & \text { Coconino } & 360820 \mathrm{~N} 1114848 \mathrm{~W} \\ \text { VARIANT } & & \\ & \text { Maricopa } & \text { UNKNOWN } \\ \text { BGN 1906 } & \text { Coconino } & 360618 \mathrm{~N} 1114729 \mathrm{~W}\end{array}$

$313040 \mathrm{~N} 1110050 \mathrm{~W}$
$313040 \mathrm{~N} 1110050 \mathrm{~W}$

$362456 N 1135724 \mathrm{~W}$

$362346 \mathrm{~N} 1135651 \mathrm{~W}$

$330754 \mathrm{~N} 1091713 \mathrm{~W}$

$330135 N 1090623 \mathrm{~W}$

$342236 \mathrm{N1122432 \textrm {W }}$

360618 N1114729W

$322433 \mathrm{~N} 1104331 \mathrm{~W}$ $333400 \mathrm{~N} 1120327 \mathrm{~W}$ $333332 N 1120755 \mathrm{~W}$ $332703 \mathrm{~N} 1114146 \mathrm{~W}$ $333325 \mathrm{~N} 1120500 \mathrm{~W}$ $332134 \mathrm{~N} 1140620 \mathrm{~W}$

$324027 N 1143743 W$ $332415 \mathrm{~N} 1120056 \mathrm{~W}$ 341751 N1132518W

$332653 \mathrm{~N} 1112811 \mathrm{~W}$ $332304 \mathrm{~N} 1115606 \mathrm{~W}$ $322347 \mathrm{~N} 1095056 \mathrm{~W}$ $335347 \mathrm{~N} 1112734 \mathrm{~W}$ $324622 \mathrm{~N} 1104738 \mathrm{~W}$ $324534 \mathrm{~N} 1105144 \mathrm{~W}$ $332447 N 1114605 \mathrm{~W}$ $333223 \mathrm{~N} 1120805 \mathrm{~W}$ $332944 \mathrm{~N} 1115940 \mathrm{~W}$ 335558N1124128W

$333807 N 1120030 \mathrm{~W}$
$332812 \mathrm{~N} 1121148 \mathrm{~W}$ $333238 N 1121012 \mathrm{~W}$ $332417 \mathrm{~N} 1113216 \mathrm{~W}$ 332759 N1120215W $343046 \mathrm{~N} 1141837 \mathrm{~W}$ 332533 N1115720W
$363204 N 1140230 \mathrm{~W}$

$322430 \mathrm{N1104308W}$

$361056 \mathrm{~N} 1090552 \mathrm{~W}$

360734 N1114720W

$332130 N 1140512 \mathrm{~W}$
$362453 \mathrm{~N} 1135720 \mathrm{~W}$ $330826 \mathrm{~N} 1091814 \mathrm{~W}$

5236 Pajarito Peak

Cumero Canyon

HELVETIA

Cumero Canyon

Fresno Wash

Lower Wheatfields

Mount Bigelow

Mount Bigelow

Cape Solitude

Desert View

Mount Bigelow

Sunnys lope

1210 Glendale

1470 Buckhorn

1210 Sunnys lope

Palm Canyon

Yuma West

Phoenix

Palmerita Ranch

Goldfield

Tempe

4416 Greasewood Mountain

Reno Pass

324554 N1105224W

Putnam

1260 Mesa

Glendale

Tempe

Wickenburg

1450 Union Hills

Fowler Apache Junction

$343135 N 1141638 \mathrm{~W}$
1170 GIendale
1110 Phoenix

Lake Havasu City N

Tempe 
NATIONAL GAZETTEER--ARIZONA 1986

FEATURE NAME

Palo Alto Ranch

Palo Christi School

Palo Ferro Ranch

Palo Fiero Tank

Paloma, Cañada de la Canada De La Potoma

Paloma Prospect

Palomas

Doanville

Palomas Mountains

Palomas Mountains

See Plomosa Mountains

Palomas Plain

Paloma Spring

Palomas Spring

Palomas Tank

Palomas Wash

Paloma Wash

Paloma Well

Palominas

Palominas Elementary School

Palominas Post Office

Palomino Canyon North Fork Chevelon Canyon Palamino Canyon

Palomino Draw

Palomino Lake

Palomino Mountain

Palomino Peak

Palomino School

Palomino Tank

Palomino Tank

Palo Prado Interchange

Palo Verde

Palo Verde Branch Library

Palo Verde Camp

Palo Verde Dam

Palo Verde High School

Palo Verde Hills

Palo Verde Intake

Palo Verde Interchange

Palo Verde Mine

Palo Verde Mine

Palo Verde Mobile Home and

Recreational Vehicle Park

Palo Verde Mobile Manor

Palo Verde Mountains

Palo Verde Nuclear Generating

Station

Palo Verde Overpass

Palo Verde Park

Palo Verde Park

Palo Verde Park

Palo Verde Park

Palo Verde Picnic Area and

Campground

Palo Verde Plaza Shopping

Center

Palo Verde Ranch

Palo Verde Recreation Site 147

Palo Verde School

Palo Verde School

Palo Verde Stand

Palo Verde Substation

Palo Verde Tank

Palo Verde Tank

Palo Verde Tank

Palo Verde Wash

Palpais Point

See Chezhindeza Mes a
FEATURE

CLASS

locale

school

STATUS

COUNTY

COORDINATE

315257 N1112343W

$351135 \mathrm{~N} 1140301 \mathrm{~W}$

$\begin{array}{llll}\text { locale } & \text { UNOFF } & \text { Pima } & 322409 \mathrm{~N} 1110147 \mathrm{~W} \\ \text { reservoir } & \text { BGN } & \text { Maricopa } & 333812 \mathrm{~N} 1113047 \mathrm{~W}\end{array}$

valley BGN Santa Cruz 312347N1105213W

mine UNOFF

locale $8 \mathrm{GN}$

VARIANT

Yuma 325432N1132850W

range

BGN

VARIANT

plain

spring

spring

reservoir

stream

strean

well

locale

school

building

8GN 1965 Yuma

BGN Santa Cruz

valle

8GN 1963

VARIANT

VARIANT

valley

lake

summit

summ it

school

BGN 1962

8GN

JNOFF

reservoir

BGN

reservoir

crossing UNOFF

Ppl 8 GN

building UNOFF

locale

dam

school UNOFF

summit

locale BGN

crossing UNOFF

mine UNDFF

mine UNOFF

locale

ridge

UNOFF

BGN

locale

park

ADMIN

park

park

park

locale

locale

park

school

schoo

ppl

reservoir

reservoir

reservoir

stream

ADMIN
ADMIN

ADMIN

ADMIN

UNOFF

UNOFF

ADMIN

UNOFF

summit
Cochise

Santa Cruz

Cochise

Mohave

Santa Cruz

Cochise

Cochise

Cochise

Coconino

Cocon

$342218 \mathrm{~N} 1140326 \mathrm{~W}$

330052N1133803

$334200 \mathrm{~N} 1140300 \mathrm{~W}$

331632 N1133950W

$312442 \mathrm{~N} 1103057 \mathrm{~W}$

$321341 \mathrm{~N} 1101524 \mathrm{~W}$

$312811 \mathrm{~N} 1111652 \mathrm{~W}$

$321242 N 1101853 \mathrm{~W}$

$341850 \mathrm{~N} 1135842 \mathrm{~W}$

$312510 \mathrm{~N} 1104924 \mathrm{~W}$

$312247 \mathrm{~N} 1100704 \mathrm{~W}$

312249 N1100720W

$312246 \mathrm{~N} 1100715 \mathrm{~W}$

350128 N $1132041 \mathrm{~W}$

$342123 N 1105433 \mathrm{~W}$

$332719 N 1112317 \mathrm{~W}$

345949 N1131811W

$333755 N 1120108 \mathrm{~W}$

$340633 \mathrm{~N} 1104431 \mathrm{~W}$

Navajo

Yavapai

Santa Cruz

Maricopa

Maricopa

Pina

Yuma

Pima

Maricopa

Yuma

Pima

313140 N1110125W

$332053 \mathrm{~N} 1124036 \mathrm{~W}$

$333007 \mathrm{~N} 1121008 \mathrm{~W}$

$321158 \mathrm{~N} 1130358 \mathrm{~W}$

$334358 \mathrm{~N} 1143036 \mathrm{~W}$

$321220 \mathrm{~N} 1105041 \mathrm{~W}$

$332457 N 1125603$

$334408 \mathrm{~N} 1143040 \mathrm{~W}$

$320943 \mathrm{~N} 1105500 \mathrm{~W}$

Maricopa 332750N1130039W

Mohave 344150N1141041W

Maricopa $\quad 332923 \mathrm{~N} 1125608 \mathrm{~W}$

Maricopa 332751N1115925W

Pinal 330148N1121027W

Maricopa 332330N1125150W

Pima

$321125 \mathrm{N1} 105454 \mathrm{~W}$

$321256 \mathrm{~N} 1105046 \mathrm{~W}$

331856N1115048W

$332130 \mathrm{~N} 1115225 \mathrm{~W}$

$\begin{array}{ll}\text { Maricopa } & 332600 \mathrm{~N} 1114000 \mathrm{~W} \\ \text { Pima } & 321305 \mathrm{~N} 1110822 \mathrm{~W}\end{array}$

$\begin{array}{ll}\text { Maricopa } & 332600 \mathrm{~N} 1114000 \mathrm{~W} \\ \text { Pima } & 321305 \mathrm{~N} 1110822 \mathrm{~W}\end{array}$

Pima

Pinal

$321224 \mathrm{~N} 1105025 \mathrm{~W}$

$323640 \mathrm{~N} 1110232 \mathrm{~W}$

$333205 \mathrm{~N} 1112545 \mathrm{~W}$

$332056 \mathrm{~N} 1124036 \mathrm{~W}$

Maricopa

Maricopa

Pima

Maricopa

Graham

Maricopa

Maricopa

Mohave

Apache
$333248 N 1120833 \mathrm{~W}$

$322011 N 1120156 \mathrm{~W}$

$332243 \mathrm{~N} 1124034 \mathrm{~W}$

$331154 \mathrm{~N} 1100007 \mathrm{~W}$

$334526 \mathrm{~N} 1115754 \mathrm{~W}$

$334913 \mathrm{~N} 1120958 \mathrm{~W}$

$342918 N 1142127 \mathrm{~W}$

365138 N1091520W locale UNOFF

crossing UNOFF

$342215 N 1105312 W$

345954N1131911W

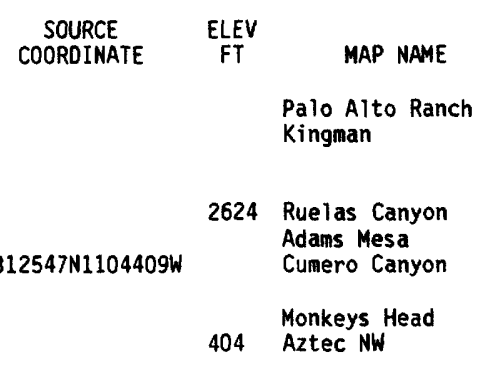

Palomas Mts West

Cementosa Wash

Canelo Pass

Wildhorse Mtn

Bartlett Mtn

Wildhorse Mtn

Castaneda $\mathrm{Hills} \mathrm{SW}$

Cumero Canyon

Hereford

Hereford

Hereford

Woods Canyon

Devils Hump

Woods Canyon

Goldfield

Union Hills

Oak Creek Ranch

Mohon Peak

Tubac

Hassayampa

Glendale

Palo Verde Camp

Blythe NE

Tucson East

Tonopah

Blythe NE

2575 Tucson

Saddle Mtn

Buck Mountains

1110 Tonopah

1165 Tempe

Enid

Wintersburg

Tucson

Tucson East

Chandler

Chandler

Buckhorn 


\begin{tabular}{|c|c|c|c|c|c|c|c|}
\hline FEATURE NAME & $\begin{array}{l}\text { FEATURE } \\
\text { CLASS }\end{array}$ & STATUS & COUNTY & COORDINATE & $\begin{array}{l}\text { SOURCE } \\
\text { COORDINATE }\end{array}$ & $\begin{array}{l}\text { ELEV } \\
\text { FT }\end{array}$ & MAP NAME \\
\hline Pambo Tank & reservoir & BGN & Yavapai & $342514 \mathrm{~N} 1114145 \mathrm{~W}$ & & & Hackberry Mtn \\
\hline $\begin{array}{l}\text { Panameta Point } \\
\text { Panameta Terrace } \\
\text { Pancho Spring } \\
\text { Pancho Spring } \\
\text { Pancho Spring } \\
\text { Pancho Tank } \\
\text { Pancrazi Latera1 } \\
\text { Pan Dam } \\
\text { P and E Junction } \\
\text { Pan Nepodk }\end{array}$ & $\begin{array}{l}\text { cliff } \\
\text { bench } \\
\text { reservoir } \\
\text { spring } \\
\text { spring } \\
\text { reservoir } \\
\text { canal } \\
\text { dam } \\
\text { locale } \\
\text { summit }\end{array}$ & $\begin{array}{l}\text { BGN } 1925 \\
\text { BGN } 1932 \\
\text { BGN } \\
\text { BGN } \\
\text { BGN } \\
\text { BGN } \\
\text { BGN } \\
\text { UNOFF } \\
\text { BGN } \\
\text { BGN }\end{array}$ & $\begin{array}{l}\text { Coconino } \\
\text { Coconino } \\
\text { Apache } \\
\text { Gila } \\
\text { Apache } \\
\text { Graham } \\
\text { Yuma } \\
\text { Yavapai } \\
\text { Yavapai } \\
\text { Pima }\end{array}$ & $\begin{array}{l}361913 \mathrm{~N} 1123713 \mathrm{~W} \\
361847 \mathrm{N1123B13W} \\
341133 \mathrm{~W} 1094305 \mathrm{~W} \\
334001 \mathrm{~N} 1103852 \mathrm{~W} \\
341132 \mathrm{~W} 1094309 \mathrm{~W} \\
322709 \mathrm{~N} 1101040 \mathrm{~W} \\
323758 \mathrm{~N} 114395 \mathrm{~W} \\
351803 \mathrm{~N} 112485 \mathrm{~W} \\
343622 \mathrm{~W} 1122414 \mathrm{~W} \\
315906 \mathrm{~N} 1115640 \mathrm{~W}\end{array}$ & & $\begin{array}{l}5340 \\
2911\end{array}$ & $\begin{array}{l}\text { Fossil Bay } \\
\text { Havasu Falls } \\
\text { Boundary Butte } \\
\text { Haystack Butte } \\
\text { Boundary Butte } \\
\text { Greasewood Mountair } \\
\text { Yuma West } \\
\text { Seligman East } \\
\text { Prescott } \\
\text { Sells West }\end{array}$ \\
\hline $\begin{array}{l}\text { Panoche Creek } \\
\text { See Trilby Wash } \\
\text { Pan Quemado } \\
\text { Pan Quemado } \\
\text { Pan Reservoir } \\
\text { See Padre Reservoir }\end{array}$ & $\begin{array}{l}\text { stream } \\
\text { summit } \\
\text { summit }\end{array}$ & $\begin{array}{l}\text { VARIANT } \\
\text { BGN } \\
\text { BGN } \\
\text { VARIANT }\end{array}$ & $\begin{array}{l}\text { Maricopa } \\
\text { Pima } \\
\text { Pinal }\end{array}$ & 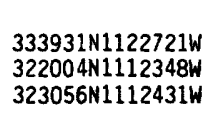 & & 2480 & $\begin{array}{l}\text { Waterman Peak } \\
\text { Friendly Corners }\end{array}$ \\
\hline $\begin{array}{l}\text { See Padre Reservoir } \\
\text { Pan Tak } \\
\text { Cajote Spring } \\
\text { Coyote } \\
\text { Coyote Indian Village } \\
\text { Coyote Spring } \\
\text { Coyote Village } \\
\text { Coyotes Spring } \\
\text { 0jo de los Coyotes } \\
\text { Pantak }\end{array}$ & $\begin{array}{l}\text { reservoir } \\
\text { locale }\end{array}$ & $\begin{array}{l}\text { BGN } 1941 \\
\text { VARIANT } \\
\text { VARIANT } \\
\text { VARIANT } \\
\text { VARIANT } \\
\text { VARIANT } \\
\text { VARIANT } \\
\text { VARIANT } \\
\text { VARIANT }\end{array}$ & $\begin{array}{l}\text { Yavapai } \\
\text { Pima }\end{array}$ & $\begin{array}{l}351 \mathrm{~B} 02 \mathrm{~N} 1124 \mathrm{~B} 54 \mathrm{~W} \\
320042 \mathrm{~N} 1113353 \mathrm{~W}\end{array}$ & & & Pan Tak \\
\hline $\begin{array}{l}\text { Pantak } \\
\text { See Pan Tak } \\
\text { Pan Tak Pass } \\
\text { Alisa Pass } \\
\text { Aliso Pass } \\
\text { Aliza Pass }\end{array}$ & $\begin{array}{l}\text { locale } \\
\text { gap }\end{array}$ & $\begin{array}{l}\text { VARIANT } \\
\text { BGN } 1941 \\
\text { VARIANT } \\
\text { VARIANT } \\
\text { VARIANT }\end{array}$ & $\begin{array}{l}\text { Pima } \\
\text { Pima }\end{array}$ & $\begin{array}{l}320042 \mathrm{~N} 1113353 \mathrm{~W} \\
315823 \mathrm{~N} 1113307 \mathrm{~W}\end{array}$ & & & Kitt Peak \\
\hline $\begin{array}{l}\text { Pan Tak Wash } \\
\text { Pan Tank } \\
\text { Pan Tank } \\
\text { Pantano }\end{array}$ & $\begin{array}{l}\text { stream } \\
\text { reservoir } \\
\text { reservoir } \\
\text { locale }\end{array}$ & $\begin{array}{l}\text { BGN } \\
\text { BGN } \\
\text { BGN } \\
\text { BGN }\end{array}$ & $\begin{array}{l}\text { Pima } \\
\text { Pima } \\
\text { Yavapai } \\
\text { Pima }\end{array}$ & $\begin{array}{l}320541 \mathrm{N1113158W} \\
315545 \mathrm{~N} 1120359 \mathrm{~W} \\
351752 \mathrm{~N} 1125010 \mathrm{~W} \\
315958 \mathrm{~N} 1103446 \mathrm{~W}\end{array}$ & $315840 \mathrm{~N} 1113342 \mathrm{~W}$ & & $\begin{array}{l}\text { Pan Tak } \\
\text { Gu Oidak } \\
\text { Sel igman East } \\
\text { The Narrows }\end{array}$ \\
\hline $\begin{array}{l}\text { Pantano Park } \\
\text { See Jesse Owens Park } \\
\text { Pantano Parkview Shopping }\end{array}$ & $\begin{array}{l}\text { park } \\
\text { locale }\end{array}$ & $\begin{array}{l}\text { VARIANT } \\
\text { UNOFF }\end{array}$ & $\begin{array}{l}\text { Pima } \\
\text { Pima }\end{array}$ & $\begin{array}{l}321300 \mathrm{~N} 1104856 \mathrm{~W} \\
321216 \mathrm{~N} 1104912 \mathrm{~W}\end{array}$ & & 2630 & Tucson East \\
\hline $\begin{array}{l}\text { Pantano Plaza Shopping Center } \\
\text { Pantano Railroad Station } \\
\text { Pantano Substation } \\
\text { Pantano Underpass } \\
\text { Pantano Wash } \\
\text { Panther Butte }\end{array}$ & $\begin{array}{l}\text { locale } \\
\text { building } \\
\text { locale } \\
\text { crossing } \\
\text { stream } \\
\text { summit }\end{array}$ & $\begin{array}{l}\text { UNOFF } \\
\text { UNOFF } \\
\text { UNOFF } \\
\text { UNOFF } \\
\text { BGN } \\
\text { BGN }\end{array}$ & $\begin{array}{l}\text { Pima } \\
\text { Pima } \\
\text { Pima } \\
\text { Pima } \\
\text { Pima } \\
\text { Pinal }\end{array}$ & $\begin{array}{l}321219 N 1104915 \mathrm{~W} \\
315959 \mathrm{N1} 103452 \mathrm{~W} \\
315752 \mathrm{N1103411W} \\
315907 \mathrm{N1103352W} \\
321607 \mathrm{N1105230W} \\
323924 \mathrm{N1110150W}\end{array}$ & $320216 \mathrm{~N} 1104053 \mathrm{~W}$ & 2625 & $\begin{array}{l}\text { Tucson East } \\
\text { The Narrows } \\
\text { The Narrows } \\
\text { The Narrows } \\
\text { Sabino Canyon } \\
\text { Chief Butte }\end{array}$ \\
\hline $\begin{array}{l}\text { Panther Creek } \\
\text { Panther Gulch } \\
\text { Panther Mountain } \\
\text { Panther Peak } \\
\text { Panther Point } \\
\text { Panther Spring } \\
\text { Panther Spring } \\
\text { Pan Wash } \\
\text { Panya Point } \\
\text { Panya Tank }\end{array}$ & $\begin{array}{l}\text { stream } \\
\text { valley } \\
\text { summit } \\
\text { summit } \\
\text { ridge } \\
\text { spring } \\
\text { spring } \\
\text { stream } \\
\text { cliff } \\
\text { reservoir }\end{array}$ & $\begin{array}{l}B G N \\
B G N \\
B G N \\
B G N \\
B G N \\
B G N \\
B G N \\
B G N \\
B G N=1925 \\
B G N\end{array}$ & $\begin{array}{l}\text { Greenlee } \\
\text { Gila } \\
\text { Gila } \\
\text { Pima } \\
\text { Mohave } \\
\text { Gila } \\
\text { Yavapai } \\
\text { Pima } \\
\text { Coconino } \\
\text { Coconino }\end{array}$ & $\begin{array}{l}333434 \mathrm{~N} 1091225 \mathrm{~W} \\
335133 \mathrm{N1110811W} \\
334859 \mathrm{~N} 1110811 \mathrm{~W} \\
322045 \mathrm{~N} 1110952 \mathrm{~W} \\
345941 \mathrm{N1132021 \textrm {W }} \\
3349211110758 \mathrm{~W} \\
3452221125530 \mathrm{~W} \\
315809 \mathrm{~N} 112045 \mathrm{~W} \\
361110 \mathrm{~N} 1124021 \mathrm{~W} \\
360818 \mathrm{~N} 1124035 \mathrm{~W}\end{array}$ & $\begin{array}{l}333532 \mathrm{~N} 1091417 \mathrm{~W} \\
334917 \mathrm{N1110815 \textrm {W }}\end{array}$ & $\begin{array}{l}3435 \\
4935\end{array}$ & $\begin{array}{l}\text { Bear Mountain } \\
\text { Greenback Creek } \\
\text { Greenback Creek } \\
\text { Avra } \\
\text { Mohon Peak } \\
\text { Greenback Creek } \\
\text { Camp Wood } \\
\text { Gu Oidak } \\
\text { Supai } \\
\text { Supai }\end{array}$ \\
\hline $\begin{array}{l}\text { Papago } \\
\text { Papago Bass Hatchery } \\
\text { Papago Butte } \\
\text { Papago Buttes } \\
\text { Red Buttes }\end{array}$ & $\begin{array}{l}\text { locale } \\
\text { locale } \\
\text { summit } \\
\text { summit }\end{array}$ & $\begin{array}{l}\text { BGN } \\
\text { UNOFF } \\
\text { BGN } \\
\text { BGN } 1917 \\
\text { VARIANT }\end{array}$ & $\begin{array}{l}\text { Maricopa } \\
\text { Maricopa } \\
\text { Pinal } \\
\text { Maricopa }\end{array}$ & $\begin{array}{l}330615 N 1130818 \mathrm{~W} \\
332721 \mathrm{~N} 1115644 \mathrm{~W} \\
325948 \mathrm{~N} 1120828 \mathrm{~W} \\
332735 \mathrm{~N} 1115655 \mathrm{~W}\end{array}$ & & 2079 & $\begin{array}{l}\text { Oatman Mountain } \\
\text { Tempe } \\
\text { Haley Hills } \\
\text { Tempe }\end{array}$ \\
\hline $\begin{array}{l}\text { Papago Canyon } \\
\text { Papago Creek } \\
\text { Papago Farms } \\
\text { Papago Gin } \\
\text { Papago Indian Agency } \\
\text { Sells Papago Indian } \\
\text { Agency }\end{array}$ & $\begin{array}{l}\text { valley } \\
\text { stream } \\
\text { ppl } \\
\text { locale } \\
\text { building }\end{array}$ & $\begin{array}{l}\text { BGN } \\
\text { BGN } 1932 \\
\text { BGN } \\
\text { 8GN } \\
\text { UNOFF } \\
\text { VARIANT }\end{array}$ & $\begin{array}{l}\text { Pima } \\
\text { Coconino } \\
\text { Pima } \\
\text { Pinal } \\
\text { Pima }\end{array}$ & $\begin{array}{l}315158 \mathrm{~N} 1104205 \mathrm{~W} \\
360246 \mathrm{~N} 1115427 \mathrm{~W} \\
314709 \mathrm{~N} 1121830 \mathrm{~W} \\
330136 \mathrm{~N} 111594 \mathrm{BW} \\
315443 \mathrm{~N} 1115256 \mathrm{~W}\end{array}$ & $\begin{array}{l}315327 \mathrm{~N} 1104324 \mathrm{~W} \\
360041 \mathrm{~N} 1115318 \mathrm{~W}\end{array}$ & & $\begin{array}{l}\text { Empire Ranch } \\
\text { Cape Royal } \\
\text { Papago Farms } \\
\text { Sacaton Butte } \\
\text { Sells West }\end{array}$ \\
\hline $\begin{array}{c}\text { Papago Indian Chief Mine } \\
\text { Papago Indian Reservation } \\
\text { Papago Reservation }\end{array}$ & $\begin{array}{l}\text { mine } \\
\text { reserve }\end{array}$ & $\begin{array}{l}\text { UNOFF } \\
\text { BGN } \\
\text { VARIANT }\end{array}$ & $\begin{array}{l}\text { Maricopa } \\
\text { Pima }\end{array}$ & $\begin{array}{l}324612 \mathrm{~N} 1122957 \mathrm{~W} \\
320 \mathrm{~B} 00 \mathrm{~N} 1120500 \mathrm{~W}\end{array}$ & & & $\begin{array}{l}\text { Big Horn } \\
\text { Gurli Put vo }\end{array}$ \\
\hline
\end{tabular}


NATIONAL GAZETTEER--ARIZONA 1986

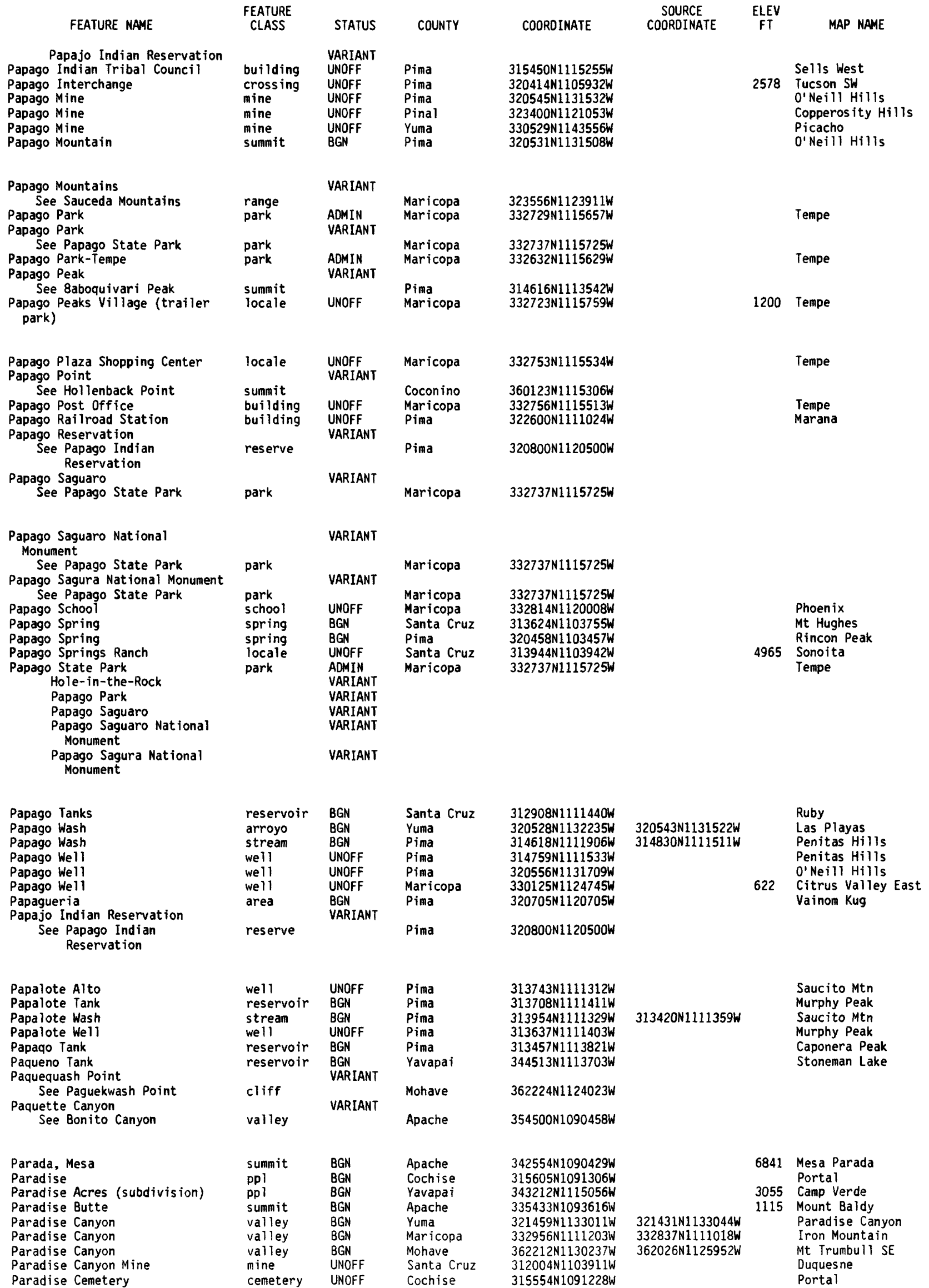




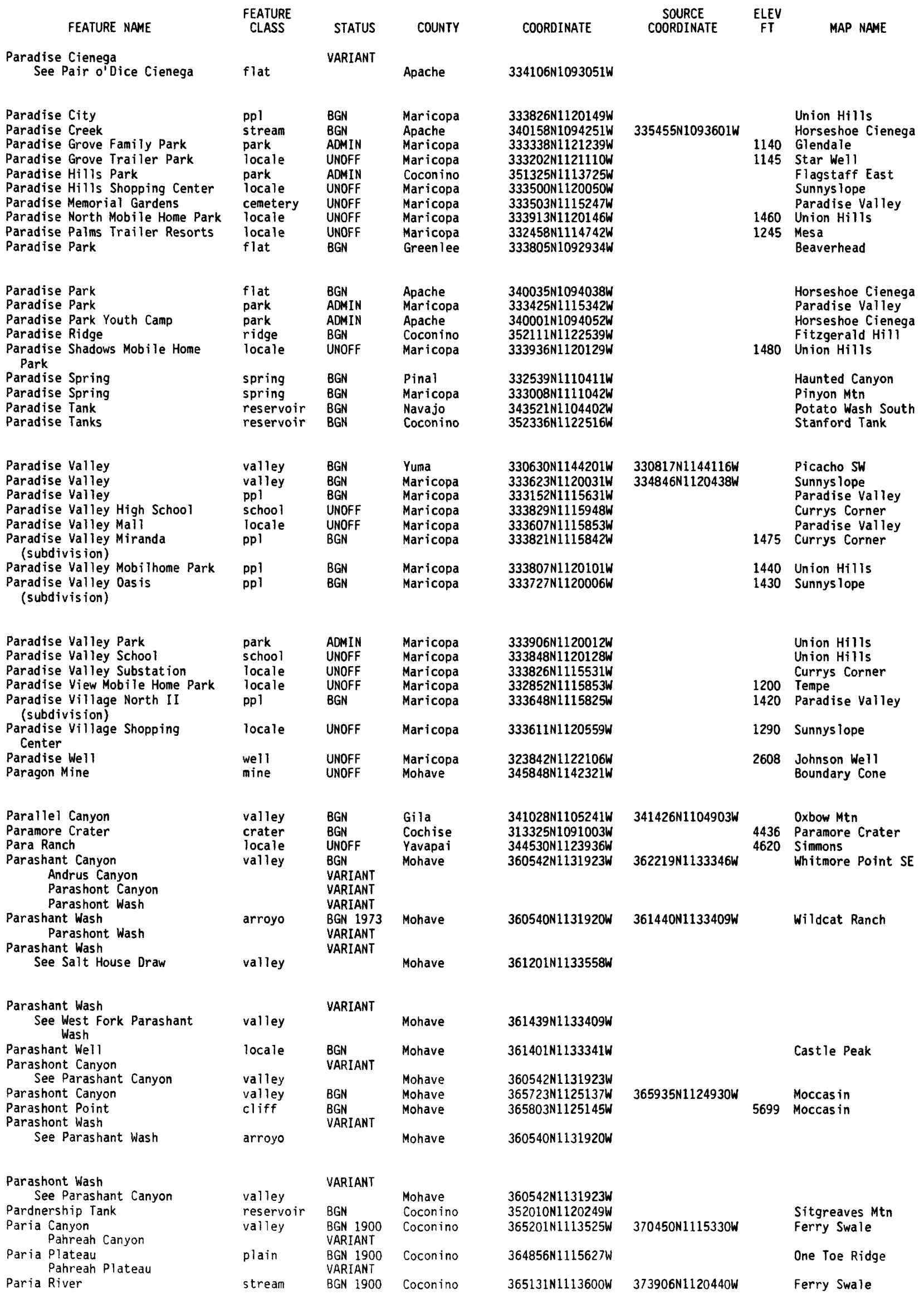


NATIONAL GAZETTEER--ARIZONA 1986 FEATURE NAME

Pa-ria River Pahrea River Pahreah River Rio Santa Teresa Ute Creek

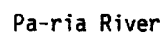

FEATURE CLASS STATUS COUNTY

VARIANT VARIANT VARIANT VARIANT VARIANT

VARIANT

$\begin{array}{ll}\text { stream } & \\ \text { valley } & B G \\ \text { cliff } & B G \\ \text { spring } & B G\end{array}$

$\begin{array}{ll}\text { ppl } & \\ \text { flat } & B G N \\ \text { flat } & B G N\end{array}$

$\begin{array}{ll}\text { flat } & B G N \\ \text { flat } & B G N\end{array}$

crossing UNOFF

$\begin{array}{ll}\text { crossing } & \text { UNOFF } \\ \text { valley } & B G N\end{array}$

locale UNOFF

stream

stream

stream

strean

locale

reservoir

BGN
VARIANT

BGN

BGN

$B G N$

BGN

$B G N$

school

School
ppl
valley

valley

dam

reservoir

UNOFF

BGN

BGN 1959

BGN

UNOFF

BGN VARIANT

park

$\begin{array}{lll}\text { school } & \text { UNOFF } & \text { Santa Cr } \\ \text { building } & \text { UNOFF } & \text { La Paz } \\ \text { stream } & \text { BGN } & \text { Gila } \\ \text { locale } & \text { UNOFF } & \text { Gila } \\ \text { dam } & \text { UNOFF } & \text { Yuma } \\ & \text { VARIANT } & \\ \text { reservoir } & & \text { Mohave } \\ \text { valley } & \text { BGN } & \text { Apache } \\ \text { school } & \text { UNOFF } & \text { La Paz } \\ \text { hospital } & \text { UNOFF } & \text { La Paz }\end{array}$

summit

BGN

locale BGN

airport $A D M I N$

reservoir BGN

gap

building

locale

locale

park

spring

BGN

UNOFF

UNOFF

UNOFF

ADMIN

BGN

reservoir $B G M$

reservoir BG

valley BGN

stream

well

locale

locale

school

locale

park

UNOFF

UNOFF

UNOFF

UNOFF

UNOFF

VARIANT

park ADMIN

pp 1
ADMIN
BGN
VARIANT VARIANT
Yavapai

Yavapai

La Paz

Navajo

Pinal

La Paz

Cochise

Santa Cruz

La Paz

Yavapai

Gila

Mohave

Yuma

Pinal

Maricopa

Maricopa

Pima

Maricopa

Maricopa

Pinal

$365131 \mathrm{N1113600 \textrm {W }}$ $362430 \mathrm{~N} 1122327 \mathrm{~W}$ 362522 N1122239w $362448 \mathrm{~N} 1121859 \mathrm{~V}$

$351538 \mathrm{~N} 1115653 \mathrm{~W}$ $340855 \mathrm{~N} 1112952 \mathrm{~W}$ $341425 \mathrm{~N} 1123650 \mathrm{~W}$ 343431 N1111614W

$321100 \mathrm{~N} 1105720 \mathrm{~W}$ $321814 \mathrm{~N} 1093713 \mathrm{~W}$ $332904 \mathrm{N1120430 \textrm {W }}$ 330727 N1093916W

$335204 N 1111 B 26 \mathrm{~W}$ $335334 \mathrm{~N} 1110221 \mathrm{~W}$ $341307 \mathrm{N1123347 \textrm {W }}$ $331145 \mathrm{M} 1093750 \mathrm{~W}$ 335408 N1105950W

$345418 \mathrm{~N} 1100901 \mathrm{~W}$ $340900 \mathrm{N114171B}$ $311900 \mathrm{~N} 1103600 \mathrm{~W}$ $323 B 15 N 111043 B W$ $312537 \mathrm{~N} 1102717 \mathrm{~W}$ $312537 N 1102717 \mathrm{~W}$

312542N1102705K

$312220 \mathrm{~N} 1103122 \mathrm{~W}$ $340849 \mathrm{N1141737 \textrm {W }}$ $334322 \mathrm{~N} 1110037 \mathrm{~W}$ $334748 \mathrm{~N} 1105809 \mathrm{~W}$ $341748 \mathrm{N1140819 \textrm {W }}$

$341747 \mathrm{N1140B2O \textrm {W }}$ $350511 N 1092053 \mathrm{~W}$ $340 \mathrm{B3} 3 \mathrm{~N} 1141716 \mathrm{~W}$ $340 B 11 N 1141703 \mathrm{~W}$ $341805 \mathrm{~N} 1124143 \mathrm{~W}$ $340903 N 1141614 \mathrm{~W}$ $342203 N 1102438 \mathrm{~W}$ 332730 N111245B $340 B 47 \mathrm{~N} 1141716 \mathrm{~W}$ $312649 \mathrm{~N} 1102650 \mathrm{~W}$ 340916 N1141655W 345057 N1125014W

$332006 \mathrm{~N} 1104716 \mathrm{~W}$ $364535 \mathrm{~N} 1132052 \mathrm{~W}$ 333639 N1143106W $323701 \mathrm{N1111520 \textrm {W }}$ $332228 \mathrm{~N} 1130520 \mathrm{~W}$

$333032 \mathrm{~N} 1120538 \mathrm{~W}$ 321309 N1105154 $333958 \mathrm{~N} 1120 \mathrm{BO} \mathrm{W}$

$33291 B N 1120452 \mathrm{~W}$

$331100 \mathrm{~N} 1115600 \mathrm{~W}$

Maricopa

$332432 \mathrm{~N} 1114210 \mathrm{~W}$ $351538 \mathrm{~N} 1115653 \mathrm{~W}$
341817 N1124139W $313438 \mathrm{~N} 1103557 \mathrm{~W}$

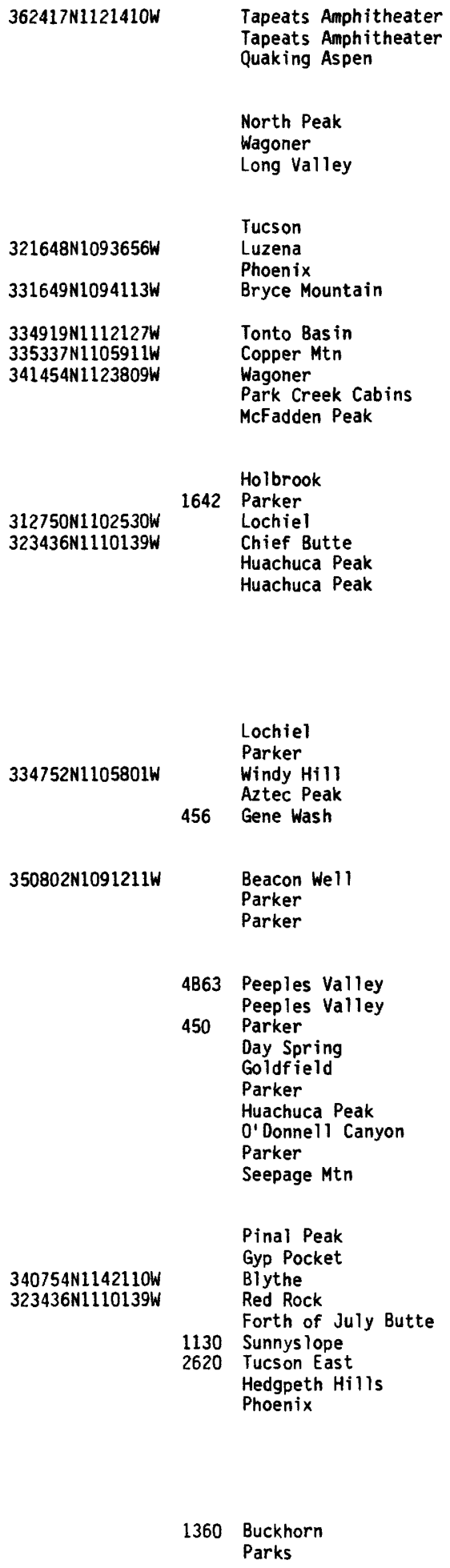




\begin{tabular}{|c|c|c|c|c|c|c|c|}
\hline FEATURE NAME & $\begin{array}{l}\text { FEATURE } \\
\text { CLASS }\end{array}$ & STATUS & COUNTY & COORDINATE & $\begin{array}{l}\text { SOURCE } \\
\text { COORDINATE }\end{array}$ & $\begin{array}{c}\text { ELEV } \\
\text { FT }\end{array}$ & MAP NAME \\
\hline $\begin{array}{l}\text { Park Scottsdale Shopping Center } \\
\text { Parkside (subdivision) } \\
\text { Parks Interchange } \\
\text { Parks Lake } \\
\text { Park Spring } \\
\text { Park Spring }\end{array}$ & $\begin{array}{l}\text { locale } \\
\text { ppl } \\
\text { crossing } \\
\text { reservoir } \\
\text { spring } \\
\text { spring }\end{array}$ & $\begin{array}{l}\text { UNOFF } \\
\text { BGN } \\
\text { UNOFF } \\
\text { BGN } \\
\text { BGN } \\
\text { BGN }\end{array}$ & $\begin{array}{l}\text { Maricopa } \\
\text { Maricopa } \\
\text { Coconino } \\
\text { Graham } \\
\text { Maricopa } \\
\text { Gila }\end{array}$ & $\begin{array}{l}333121 \mathrm{~N} 1115355 \mathrm{~W} \\
332100 \mathrm{~N} 1115915 \mathrm{~W} \\
351520 \mathrm{~N} 1115618 \mathrm{~W} \\
323328 \mathrm{~N} 1091809 \mathrm{~W} \\
332922 \mathrm{~N} 1111118 \mathrm{~W} \\
335200 \mathrm{~N} 1111826 \mathrm{~W}\end{array}$ & & $\begin{array}{l}1300 \\
7100\end{array}$ & $\begin{array}{l}\text { Paradise Valley } \\
\text { Guadalupe } \\
\text { Parks } \\
\text { Whitlock Cienega } \\
\text { Iron Mountain } \\
\text { Tonto Bas in }\end{array}$ \\
\hline $\begin{array}{l}\text { Park Tank } \\
\text { Park Tank } \\
\text { Park Tank } \\
\text { Park Tank } \\
\text { Park Tank } \\
\text { Park Tank } \\
\text { Park Valley } \\
\text { Parkview Estates (subdivision) } \\
\text { Parkview Hospital } \\
\text { See Yuma Regional Medical } \\
\text { Center }\end{array}$ & $\begin{array}{l}\text { reservoir } \\
\text { reservoir } \\
\text { reservoir } \\
\text { reservoir } \\
\text { reservoir } \\
\text { reservoir } \\
\text { valley } \\
\text { ppl } \\
\text { hospital }\end{array}$ & $\begin{array}{l}\text { BGN } \\
\text { BGN } \\
\text { BGN } \\
\text { BGN } \\
\text { BGN } \\
\text { BGN } \\
\text { BGN } \\
\text { BGN } \\
\text { VARIANT }\end{array}$ & $\begin{array}{l}\text { Cochise } \\
\text { Pima } \\
\text { Gila } \\
\text { Coconino } \\
\text { Coconino } \\
\text { Coconino } \\
\text { Yuma } \\
\text { Maricopa } \\
\text { Yuma }\end{array}$ & $\begin{array}{l}313511 N 1090346 \mathrm{~W} \\
321626 \mathrm{~N} 1103244 \mathrm{~W} \\
342245 \mathrm{~N} 1111918 \mathrm{~W} \\
344731 \mathrm{N1} 112918 \mathrm{~W} \\
345329 \mathrm{N1} 113110 \mathrm{~W} \\
355338 \mathrm{~N} 1130649 \mathrm{~W} \\
325405 \mathrm{~N} 1132422 \mathrm{~W} \\
334212 \mathrm{~N} 1120954 \mathrm{~W} \\
\\
324058 \mathrm{~N} 1143800 \mathrm{~W}\end{array}$ & $325131 \mathrm{~N} 1132109 \mathrm{~W}$ & $\begin{array}{l}6635 \\
1400\end{array}$ & $\begin{array}{l}\text { Skeleton Canyon } \\
\text { Piety Hill } \\
\text { Kehl Ridge } \\
\text { Hutch Mtn } \\
\text { Mormon Mountain } \\
\text { Prospect Point } \\
\text { Aztec NW } \\
\text { Hedgpeth Hills }\end{array}$ \\
\hline $\begin{array}{l}\text { Parkview Mesa (subdivision) } \\
\text { Parkview North (subdivision) } \\
\text { Parkview Park } \\
\text { Parkview Village Mobile Home } \\
\text { and Recreational Vehicle Park } \\
\text { Parkway Special School } \\
\text { Park Well } \\
\text { Park Well } \\
\text { Park Well } \\
\text { Parkwood (subdivision) }\end{array}$ & $\begin{array}{l}\text { ppl } \\
\text { ppl } \\
\text { park } \\
\text { locale } \\
\text { school } \\
\text { well } \\
\text { well } \\
\text { well } \\
\text { ppl }\end{array}$ & $\begin{array}{l}\text { BGN } \\
\text { BGN } \\
\text { ADMIN } \\
\text { UNOFF } \\
\text { UNOFF } \\
\text { UNOFF } \\
\text { UNOFF } \\
\text { UNOFF } \\
\text { BGN }\end{array}$ & $\begin{array}{l}\text { Maricopa } \\
\text { Maricopa } \\
\text { Pima } \\
\text { Maricopa } \\
\text { Maricopa } \\
\text { Gila } \\
\text { Navajo } \\
\text { Navajo } \\
\text { Maricopa }\end{array}$ & $\begin{array}{l}332250 \mathrm{~N} 1115036 \mathrm{~W} \\
333815 \mathrm{~N} 1120855 \mathrm{~W} \\
321213 \mathrm{~N} 1105449 \mathrm{~W} \\
332704 \mathrm{~N} 1115757 \mathrm{~W} \\
\\
332400 \mathrm{~N} 1114735 \mathrm{~W} \\
332928 \mathrm{~N} 1104204 \mathrm{~W} \\
342755 \mathrm{~N} 1100544 \mathrm{~W} \\
342933 \mathrm{~N} 1102635 \mathrm{~W} \\
332842 \mathrm{~N} 1120913 \mathrm{~W}\end{array}$ & & $\begin{array}{l}1210 \\
1290 \\
1200\end{array}$ & $\begin{array}{l}\text { Mesa } \\
\text { Hedgpeth Hills } \\
\text { Tucson } \\
\text { Tempe } \\
\text { Mesa } \\
\text { Cammerman Wash } \\
\text { Taylor } \\
\text { Aripine } \\
\text { Fowler }\end{array}$ \\
\hline $\begin{array}{l}\text { Parquasito Verde Park } \\
\text { Parque Vista Estates } \\
\text { (subdivision) } \\
\text { Parra Tank } \\
\text { Parrette Well } \\
\text { Parrish Creek } \\
\text { Parsee Hill } \\
\text { See Poston Butte } \\
\text { Parsnip Spring } \\
\text { Parsons Canyon } \\
\text { Wire Corral Draw }\end{array}$ & $\begin{array}{l}\text { park } \\
\text { ppl } \\
\text { reservoir } \\
\text { well } \\
\text { stream } \\
\text { summit } \\
\text { spring } \\
\text { valley }\end{array}$ & $\begin{array}{l}\text { ADMIN } \\
\text { BGN } \\
\text { BGN } \\
\text { UNOFF } \\
\text { BGN } \\
\text { VARIANT } \\
\text { BGN } \\
\text { BGN 1975 } \\
\text { VARIANT }\end{array}$ & $\begin{array}{l}\text { Maricopa } \\
\text { Maricopa } \\
\text { Pima } \\
\text { Maricopa } \\
\text { Navajo } \\
\text { Pinal } \\
\text { Gila } \\
\text { Pinal }\end{array}$ & $\begin{array}{l}332107 \mathrm{~N} 1114731 \mathrm{~W} \\
333920 \mathrm{~N} 1120042 \mathrm{~W} \\
321348 \mathrm{~N} 1130858 \mathrm{~W} \\
334 \mathrm{~B} 48 \mathrm{~N} 1115330 \mathrm{~W} \\
364327 \mathrm{~N} 1101846 \mathrm{~W} \\
\\
330318 \mathrm{~N} 1112429 \mathrm{~W} \\
342601 \mathrm{~N} 1112551 \mathrm{~W} \\
325410 \mathrm{~N} 1102742 \mathrm{~W}\end{array}$ & $364624 N 1102523 W$ & 1480 & $\begin{array}{l}\text { Chandler } \\
\text { Union Hills } \\
\text { N of Agua Dulce Mts } \\
\text { Cave Creek } \\
\text { Kayenta West }\end{array}$ \\
\hline $\begin{array}{l}\text { Parsons Grove } \\
\text { Parsons Spring } \\
\text { Summers Spring } \\
\text { Parsons Tank } \\
\text { Partnership Tank } \\
\text { Partnership Tank } \\
\text { Partnership Well } \\
\text { Partnership Well } \\
\text { Partridge (historical) } \\
\text { Partridge Canyon } \\
\text { See Ton Lockett Draw }\end{array}$ & $\begin{array}{l}\text { locale } \\
\text { spring } \\
\text { reservoir } \\
\text { reservoir } \\
\text { reservoir } \\
\text { well } \\
\text { well } \\
\text { locale } \\
\text { valley }\end{array}$ & $\begin{array}{l}\text { BGN } \\
\text { BGN } \\
\text { VARIANT } \\
\text { BGN } \\
\text { BGN } \\
\text { BGN } \\
\text { UNOFF } \\
\text { UNOFF } \\
\text { BGN } \\
\text { VARIANT }\end{array}$ & $\begin{array}{l}\text { Pinal } \\
\text { Yavapai } \\
\text { Yavapai } \\
\text { Yavapai } \\
\text { Navajo } \\
\text { Navajo } \\
\text { Navajo } \\
\text { Santa Cruz } \\
\text { Yavapai }\end{array}$ & $\begin{array}{l}324928 \mathrm{~N} 1102832 \mathrm{~W} \\
345413 \mathrm{~N} 1120349 \mathrm{~W} \\
343045 \mathrm{~N} 1114037 \mathrm{~W} \\
342708 \mathrm{~N} 1113844 \mathrm{~W} \\
342800 \mathrm{~N} 1103010 \mathrm{~W} \\
343555 \mathrm{~N} 1100006 \mathrm{~W} \\
345750 \mathrm{~N} 1095533 \mathrm{~W} \\
312847 \mathrm{~N} 1111629 \mathrm{~W} \\
\\
351226 \mathrm{~N} 1123602 \mathrm{~W}\end{array}$ & & $\begin{array}{l}5690 \\
4120\end{array}$ & $\begin{array}{l}\text { Oak Grove Canyon } \\
\text { Sycamore Basin } \\
\text { Walker Mtn } \\
\text { Hackberry Mtn } \\
\text { Heber } \\
\text { Snowflake } \\
\text { Carrizo Butte } \\
\text { Bartlett Mtn }\end{array}$ \\
\hline $\begin{array}{l}\text { Partridge Creek } \\
\text { Partridge Wash } \\
\text { Partridge Creek } \\
\text { See Johnson Creek } \\
\text { Partridge Creek } \\
\text { See Ash Fork Draw } \\
\text { Partridge Wash } \\
\text { See Partridge Creek } \\
\text { Parvin Lateral } \\
\text { Pasadera Mountain }\end{array}$ & $\begin{array}{l}\text { stream } \\
\text { valley } \\
\text { stream } \\
\text { canal } \\
\text { summit }\end{array}$ & $\begin{array}{l}\text { BGN } 1975 \\
\text { VARIANT } \\
\text { VARIANT } \\
\text { VARIANT } \\
\text { VARIANT } \\
\text { BGN } \\
\text { BGN } 1911\end{array}$ & $\begin{array}{l}\text { Yavapai } \\
\text { Coconino } \\
\text { Yavapai } \\
\text { Yavapai } \\
\text { Yuma } \\
\text { Gila }\end{array}$ & $\begin{array}{l}351217 N 1122857 \mathrm{~W} \\
351204 \mathrm{~N} 1123223 \mathrm{~W} \\
350659 \mathrm{~N} 1124347 \mathrm{~W} \\
323203 \mathrm{~N} 1144709 \mathrm{~W} \\
331253 \mathrm{~N} 1105001 \mathrm{~W}\end{array}$ & $352617 N 1124347 \mathrm{~W}$ & & $\begin{array}{l}\text { Gadsden } \\
\text { El Capitan Mtn }\end{array}$ \\
\hline $\begin{array}{l}\text { Pasa Robles Well } \\
\text { Pascua Yaqui Indian Village } \\
\text { Pascua-Yaqui Reservation } \\
\text { Pascua-Yaqui Reservation } \\
\text { See Pascua Yaqui Indian } \\
\text { Village } \\
\text { Pason Dam Draw } \\
\text { See Polson Dam Draw } \\
\text { Pass Mountain } \\
\text { See Baragan Mountain }\end{array}$ & $\begin{array}{l}\text { valley } \\
\text { summit }\end{array}$ & $\begin{array}{l}\text { UNOFF } \\
\text { BGN } \\
\text { VARIANT } \\
\text { VARIANT }\end{array}$ & $\begin{array}{l}\text { Mohave } \\
\text { Pima } \\
\text { Pima } \\
\text { Coconino } \\
\text { Yuma }\end{array}$ & $\begin{array}{l}350603 \mathrm{~N} 1132242 \mathrm{~W} \\
321454 \mathrm{~N} 1105901 \mathrm{~W} \\
321454 \mathrm{~N} 1105901 \mathrm{~W} \\
352137 \mathrm{~N} 1122210 \mathrm{~W} \\
330538 \mathrm{~N} 1132659 \mathrm{~W}\end{array}$ & & & $\begin{array}{l}\text { Penitentiary Mtn } \\
\text { Tucson }\end{array}$ \\
\hline $\begin{array}{l}\text { Pass Mountain } \\
\text { See Turtleback Mountain }\end{array}$ & summit & ARIANT & Yuma & $330823 \mathrm{~N} 113234 \mathrm{IW}$ & & & \\
\hline
\end{tabular}


NATIONAL GAZETTEER--ARIZONA 1986

\section{FEATURE MAME}

Pass Mountains

Pass Mountains

See Pass Mountain

Pass Tank

Pass Tank

Pastora Peak

Pastore Tank

\section{Pasture Canyon}

Pasture Canyon

Pasture Canyon Dam Hopi Reservoir Dam

Pasture Canyon Reservoir

Pasture Five Charco

Pasture Number Three Tank

Pasture Spring Cane Spring

Pasture Spring

See Cane Spring

Pasture Spring

Pasture Tank

Pasture Tank

Pasture Tank

Pasture Tank

Pasture Tank

Pasture Tank

Pasture Tank

Pasture Tank

Pasture Tank Number One

Pasture Tank Number One

Pasture Three Tank Pasture Three Tanks

Pasture Three Tanks See Pasture Three Tank

Pasture Wash

Pasture Wash Ranger Station

Pasture Wash Tank

Pasture Well

Pasture Well

Patagonia

Patagonia Lake

Patagonia Lake State Park

Patagonia Mountains

Patagonia Ranger Station

Patagonia-Sonoita Creek

Sanctuary

See San Jose de Sonoita

Patagonia Union High School

Patch Tank

Pat Cienega

Pat Creek

Pat Duke Tank

Paterson Spring

Pate Spring

Pat Hills

Pat Hughes Tank

Paticho Lake

Patio

Pat Knoll

Pat Knoll Guard Station

Pat Mountain

Pat Mullen Mountain

Pat Mullen Spring

Patrick, Canal (historical) Second Canal System

Patrick Lower Branch, Canal

(historical)

Second Canal Systen

Patrick Park

Patriot Square
FEATURE

CLASS

STATUS

COUNTY

COORDINATE

$332909 N 1113547 \mathrm{~W}$

summit

8GN

VARIANT

summit

Maricopa

Maricopa

Cochise

reservoir BGM

reservoir $\quad B G$

summit $B G N$

reservoir BGN

valle

valle

dam

BGN

BGN

UNOFF

VARIANT

reservoir BGN

reservoir $B G$

reservoir

spring

BGN

BGH

spring

Yavapai

Apache

Yavapai

Coconino

Coconino

Coconino

Coconino

Graham

Yavapai

Gila

Gila

$332909 N 1113547 W$

$320919 N 1092838 \mathrm{~W}$

$345517 N 1121324 \mathrm{~W}$

$364725 \mathrm{N1090950 \textrm {W }}$

$342808 \mathrm{~N} 1131050 \mathrm{~W}$

$360646 \mathrm{~N} 1111307 \mathrm{~W}$

$364253 \mathrm{~N} 1120235 \mathrm{~W}$

$360730 \mathrm{~N} 1110730 \mathrm{~W}$

$360811 N 1111254 \mathrm{~W}$

$332032 \mathrm{~N} 1095555 \mathrm{~W}$

345015 N1125906W

$335343 \mathrm{~N} 1110955 \mathrm{~W}$

$335408 N 1111023 W$

spring

$8 \mathrm{GN}$

reservoir BGN

ir BGN

reservoir $B G M$

reservoir BGN

reservoir BGN

reservoir $B G N$

reservoir $B G N$

reservoir BGM

reservoir BGN

VARIANT

VARIANT

reservoir

stream

locale

UNOFF

reservoir BGN

well

UNOFF

ppl BGN

lake $\quad B G N$

park

summit

locale

ADMIN
BGN

BGN

VARIANT

Coconino

Pima

Greenlee 332457N1091328W

Gila 335423N1101211W

Apache 340218N1093505W

Gila 340624N1110356

Gila 341406N1112332W

Coconino 343438N1113029W

Gila 334014N1100055W

Gila

Yavapai

$335417 \mathrm{N1101219 \textrm {W }}$

$350145 \mathrm{~N} 1130220 \mathrm{~W}$

Yavapai

Coconino

Coconino

Coconino

Santa Cruz

Yavapai

$350145 \mathrm{~N} 1130220 \mathrm{~W}$

$360800 \mathrm{~N} 1123630 \mathrm{~W}$

$360815 \mathrm{~N} 1122344 \mathrm{~W}$

$360544 \mathrm{~N} 1122640 \mathrm{~W}$

$312853 \mathrm{~N} 1104854 \mathrm{~W}$

$344122 N 1120210 \mathrm{~W}$

Santa Cruz

Santa Cruz

Santa Cruz

$313222 \mathrm{M} 1104520 \mathrm{~W}$

$312935 \mathrm{~N} 1105209 \mathrm{~W}$

$312930 \mathrm{~N} 1105058 \mathrm{~W}$

$312456 \mathrm{~N} 1104347 \mathrm{~W}$

$313245 \mathrm{~N} 1104451 \mathrm{~W}$

civil

school

reservoir

UNOFF

Santa Cruz

$312746 \mathrm{~N} 1105818 \mathrm{~W}$

$313246 \mathrm{~N} 1104443 \mathrm{~W}$

$345221 \mathrm{~N} 1112725 \mathrm{~W}$

flat

stream

reservoir

spring

spring

summit

reservoir

reservoir

locale

summit

BGN
BGN
BGN
BGN
BGN
BGN
BGN
BGN
BGN
BGN

Apache

Greenlee

Coconino

Coconino

Apache

Cochise

Apache

Navajo

Yuma

Apache

$334436 \mathrm{~N} 1093455 \mathrm{~W}$

$331303 \mathrm{~N} 1091143 \mathrm{~W}$

$345013 \mathrm{~N} 1110450 \mathrm{~W}$

350918 N1114828W

$340908 \mathrm{~N} 1093649 \mathrm{~W}$

$320100 N 1093651 \mathrm{~W}$

$344 \mathrm{~B} 11 \mathrm{~N} 1093648 \mathrm{~W}$

341711 N1100759

$324313 N 1143704 \mathrm{~W}$

$335753 \mathrm{~N} 1091934 \mathrm{~W}$

locale

UNOFF Apache

BGN

summit

summit

spring

canal

canal

BGN

VARIANT

BGN

Greenlee

Greenlee

Navajo

Navajo

Maricopa

Maricopa

$335824 \mathrm{~N} 1091901 \mathrm{~W}$

$331508 \mathrm{~N} 1091136 \mathrm{~W}$

331501 N1091425W

$340914 \mathrm{~N} 1095302 \mathrm{~W}$

$340928 \mathrm{~N} 1095247 \mathrm{~W}$

332634 N1120225W

$332625 N_{11} 20304 \mathrm{~W}$

VARIANT

ppl BGN Maricopa

Maricopa
$332337 \mathrm{~N} 1120112 \mathrm{~W}$

$332652 \mathrm{N1120425W}$
VARIANT

well UNOFF

$\begin{array}{cc}\text { SOURCE } & \text { ELEV } \\ \text { COORDINATE } & \text { FT MAP NAME }\end{array}$

3312 Apache Junction

Bowie Mtn North

Perkinsville

9412 Pastora Peak

Thorn Peak

361048N1111148W Moenkopi

House Rock

Tuba City

4882 Tuba City

Tule Tubs

Camp Wood

Picture Mtn

Quaking Aspen

Bartlett Mtn

Bylas

Dutch Blue Creek

Cedar Creek

Greens Peak

Buzzard Roost Mesa

North Peak

Buckhorn Mountain 


\begin{tabular}{|c|c|c|c|c|c|c|c|}
\hline FEATURE NAME & $\begin{array}{l}\text { FEATURE } \\
\text { CLASS }\end{array}$ & STATUS & COUNTY & COORDINATE & $\begin{array}{l}\text { SOURCE } \\
\text { COORDINATE }\end{array}$ & $\begin{array}{c}\text { ELEV } \\
\text { FT }\end{array}$ & MAP NAME \\
\hline $\begin{array}{l}\text { Block } 77 \text { (park) } \\
\text { Pat Scott Canyon } \\
\text { Pat Scott Peak } \\
\text { Pat Scott Spring } \\
\text { Pat Spring } \\
\text { Pats Shoe Spring } \\
\text { Pat Tank } \\
\text { Pat Tank }\end{array}$ & $\begin{array}{l}\text { valley } \\
\text { summit } \\
\text { spring } \\
\text { spring } \\
\text { spring } \\
\text { reservoir } \\
\text { reservoir }\end{array}$ & $\begin{array}{l}\text { VARIANT } \\
\text { BGN } \\
\text { BGN } \\
\text { BGN } \\
\text { BGN } \\
\text { BGN } \\
\text { BGN } \\
\text { BGN }\end{array}$ & $\begin{array}{l}\text { Cochise } \\
\text { Cochise } \\
\text { Cochise } \\
\text { Coconino } \\
\text { Maricopa } \\
\text { Coconino } \\
\text { Coconino }\end{array}$ & $\begin{array}{l}312526 \mathrm{~N} 1101937 \mathrm{~W} \\
312545 \mathrm{~N} 1102045 \mathrm{~W} \\
312556 \mathrm{N1} 102031 \mathrm{~W} \\
352333 \mathrm{~N} 1114120 \mathrm{~W} \\
335430 \mathrm{~N} 1113603 \mathrm{~W} \\
350340 \mathrm{~N} 1121120 \mathrm{~W} \\
352307 \mathrm{~N} 1114138 \mathrm{~W}\end{array}$ & $312534 \mathrm{~N} 1102048 \mathrm{~W}$ & & $\begin{array}{l}\text { Miller Peak } \\
\text { Miller Peak } \\
\text { Miller Peak } \\
\text { White Horse Hills } \\
\text { Lion Mountain } \\
\text { May Tank Pocket } \\
\text { White Horse Hills }\end{array}$ \\
\hline $\begin{array}{l}\text { Pat Tank } \\
\text { Patterdell Pines Convent } \\
\text { Patterson Corral } \\
\text { Patterson Lateral } \\
\text { Patterson Ravine } \\
\text { Patterson School } \\
\text { Patterson Spring } \\
\text { Patterson Spring } \\
\text { Patterson Spring } \\
\text { Patterson Spring }\end{array}$ & $\begin{array}{l}\text { reservoir } \\
\text { church } \\
\text { locale } \\
\text { canal } \\
\text { valley } \\
\text { school } \\
\text { spring } \\
\text { spring } \\
\text { spring } \\
\text { spring }\end{array}$ & $\begin{array}{l}\text { BGN } \\
\text { UNOFF } \\
\text { BGN } \\
\text { BGN } \\
\text { BGN } \\
\text { UNOFF } \\
\text { BGN } \\
\text { BGN } \\
\text { BGN } \\
\text { BGN }\end{array}$ & $\begin{array}{l}\text { Coconino } \\
\text { Yavapai } \\
\text { Mohave } \\
\text { Yuma } \\
\text { Pinal } \\
\text { Maricopa } \\
\text { Graham } \\
\text { Gila } \\
\text { Gila } \\
\text { Apache }\end{array}$ & $\begin{array}{l}352325 \mathrm{~N} 1114120 \mathrm{~W} \\
342825 \mathrm{~N} 1122739 \mathrm{~W} \\
355135 \mathrm{~N} 1140355 \mathrm{~W} \\
324010 \mathrm{~N} 1143840 \mathrm{~W} \\
323906 \mathrm{~N} 1105408 \mathrm{~W} \\
332150 \mathrm{~N} 1114546 \mathrm{~W} \\
322907 \mathrm{~N} 1102204 \mathrm{~W} \\
331829 \mathrm{~N} 1105559 \mathrm{~W} \\
331851 \mathrm{~N} 1105534 \mathrm{~W} \\
340809 \mathrm{~N} 1093238 \mathrm{~W}\end{array}$ & $323940 N 1105234 \mathrm{~W}$ & 4500 & $\begin{array}{l}\text { White Horse Hills } \\
\text { Groom Creek } \\
\text { Garnet Mtn } \\
\text { Yuma West } \\
\text { Fortified Mtn } \\
\text { Chandler } \\
\text { Cherry Spring Peak } \\
\text { Pinal Ranch } \\
\text { Pinal Ranch } \\
\text { Whiting Knoll }\end{array}$ \\
\hline $\begin{array}{l}\text { Patterson Spring } \\
\text { Patterson Tank } \\
\text { Patterson Tank } \\
\text { Patterson Tank } \\
\text { Patterson Tank } \\
\text { Patterson Tank } \\
\text { Patterson Wash } \\
\text { Patterson Well } \\
\text { Pattie Butte } \\
\text { Patton Spring }\end{array}$ & $\begin{array}{l}\text { spring } \\
\text { reservoir } \\
\text { reservoir } \\
\text { reservoir } \\
\text { reservoir } \\
\text { reservoir } \\
\text { stream } \\
\text { well } \\
\text { summit } \\
\text { spring }\end{array}$ & $\begin{array}{l}\text { BGN } \\
\text { BGN } \\
\text { BGN } \\
\text { BGN } \\
\text { BGN } \\
\text { BGN } \\
\text { BGN } \\
\text { UNOFF } \\
\text { BGN } 1932 \\
\text { BGN }\end{array}$ & $\begin{array}{l}\text { Yavapai } \\
\text { Cochise } \\
\text { Pima } \\
\text { Pinal } \\
\text { Maricopa } \\
\text { Apache } \\
\text { Graham } \\
\text { Mohave } \\
\text { Coconino } \\
\text { Coconino }\end{array}$ & $\begin{array}{l}341342 \mathrm{~N} 1122321 \mathrm{~W} \\
313332 \mathrm{~N} 1090407 \mathrm{~W} \\
314343 \mathrm{~N} 1110528 \mathrm{~W} \\
323938 \mathrm{~N} 1105308 \mathrm{~W} \\
331546 \mathrm{~N} 1125702 \mathrm{~W} \\
343146 \mathrm{~N} 1094242 \mathrm{~W} \\
325518 \mathrm{~N} 1095208 \mathrm{~W} \\
355117 \mathrm{~N} 1140306 \mathrm{~W} \\
360417 \mathrm{~N} 1120319 \mathrm{~W} \\
342650 \mathrm{~N} 1112153 \mathrm{~W}\end{array}$ & $325151 N 1095258 \mathrm{~W}$ & 5306 & $\begin{array}{l}\text { Minnehaha } \\
\text { Skeleton Canyon } \\
\text { Amado } \\
\text { Fort ified Mtn } \\
\text { Gillespie } \\
\text { Hunt } \\
\text { Pima } \\
\text { Garnet Mtn } \\
\text { Phantom Ranch } \\
\text { Kehl Ridge }\end{array}$ \\
\hline $\begin{array}{l}\text { Patton Spring Draw } \\
\text { Pat Will iams Spring } \\
\text { Pauitue Well } \\
\text { Paulcell Place } \\
\text { Paulden } \\
\text { Pauline Canyon } \\
\text { Pauline Mine } \\
\text { Pauline Well } \\
\text { Paul Moore Tank } \\
\text { Paul Spur }\end{array}$ & $\begin{array}{l}\text { valley } \\
\text { spring } \\
\text { well } \\
\text { locale } \\
\text { ppl } \\
\text { valley } \\
\text { mine } \\
\text { well } \\
\text { reservoir } \\
\text { ppl }\end{array}$ & $\begin{array}{l}\text { BGN } \\
\text { BGN } \\
\text { UNOFF } \\
\text { BGN } \\
\text { BGN } \\
\text { BGN } \\
\text { UNOFF } \\
\text { UNOFF } \\
\text { BGN } \\
\text { BGN }\end{array}$ & $\begin{array}{l}\text { Gila } \\
\text { Navajo } \\
\text { Coconino } \\
\text { Apache } \\
\text { Yavapai } \\
\text { Santa Cruz } \\
\text { Pima } \\
\text { Santa Cruz } \\
\text { Coconino } \\
\text { Cochise }\end{array}$ & $\begin{array}{l}342531 N 1112207 \mathrm{~W} \\
362650 \mathrm{~N} 1104041 \mathrm{~W} \\
361146 \mathrm{N1111} 131 \mathrm{~W} \\
345743 \mathrm{~N} 1094931 \mathrm{~W} \\
345308 \mathrm{~N} 1122803 \mathrm{~W} \\
313125 \mathrm{N1} 103151 \mathrm{~W} \\
315529 \mathrm{N1} 104150 \mathrm{~W} \\
313008 \mathrm{~N} 1103102 \mathrm{~W} \\
353747 \mathrm{N1123106 \textrm {W }} \\
312158 \mathrm{~N} 1094402 \mathrm{~W}\end{array}$ & $342712 \mathrm{~N} 1112223 \mathrm{~W}$ & 5286 & $\begin{array}{l}\text { Kehl Ridge } \\
\text { Black Mesa Wash NW } \\
\text { Moenave } \\
\text { Adamana } \\
\text { Paulden } \\
\text { O'Donnell Canyon } \\
\text { Mount Fagan } \\
\text { O'Donnell Canyon } \\
\text { Tin House } \\
\text { Paul Spur }\end{array}$ \\
\hline $\begin{array}{l}\text { Paul Tank } \\
\text { Pavo Kug (historical) } \\
\text { Pavo Kug Wash } \\
\text { Pavo Kug Wash }\end{array}$ & $\begin{array}{l}\text { reservoir } \\
\text { locale } \\
\text { stream }\end{array}$ & $\begin{array}{l}\text { BGN } \\
\text { BGN } \\
\text { BGN } 1977 \\
\text { VARIANT }\end{array}$ & $\begin{array}{l}\text { Gila } \\
\text { Pima } \\
\text { Pima }\end{array}$ & $\begin{array}{l}335940 \mathrm{~N} 1105802 \mathrm{~W} \\
315927 \mathrm{~N} 1114016 \mathrm{~W} \\
315945 \mathrm{~N} 1114112 \mathrm{~W}\end{array}$ & $315645 \mathrm{~N} 111380 \mathrm{OW}$ & & $\begin{array}{l}\text { McFadden Peak } \\
\text { San Juan Spring } \\
\text { San Juan Spring }\end{array}$ \\
\hline $\begin{array}{l}\text { See Anegan Wash } \\
\text { Paws Pocket } \\
\text { Paxton Place } \\
\text { Paya Point } \\
\text { Pay Dirt Spring } \\
\text { Paymaster Canyon }\end{array}$ & $\begin{array}{l}\text { stream } \\
\text { basin } \\
\text { locale } \\
\text { cliff } \\
\text { spring } \\
\text { valley }\end{array}$ & $\begin{array}{l}\text { BGN } \\
\text { BGN } \\
\text { BGN } 1925 \\
\text { BGN } \\
\text { BGN } 1962\end{array}$ & $\begin{array}{l}\text { Pima } \\
\text { Mohave } \\
\text { Yavapai } \\
\text { Coconino } \\
\text { Yavapai } \\
\text { Graham }\end{array}$ & $\begin{array}{l}321059 \mathrm{~N} 1114007 \mathrm{~W} \\
361255 \mathrm{~N} 1131300 \mathrm{~W} \\
341020 \mathrm{~N} 1122902 \mathrm{~W} \\
361823 \mathrm{~N} 1123648 \mathrm{~W} \\
340948 \mathrm{~N} 1122435 \mathrm{~W} \\
331025 \mathrm{~N} 1095155 \mathrm{~W}\end{array}$ & 330850 N1095320W & & $\begin{array}{l}\text { Whitmore Rapids } \\
\text { Minnehaha } \\
\text { Fossil Bay } \\
\text { Minnehaha } \\
\text { Bonita Tank }\end{array}$ \\
\hline $\begin{array}{l}\text { Paymaster Dam } \\
\text { Paymaster Mine } \\
\text { Paymaster Mine } \\
\text { Paymaster Mine } \\
\text { Paymaster Spring } \\
\text { Paymaster Tank } \\
\text { Paymaster Wash } \\
\text { Payne Tank } \\
\text { Pay Rock Mine } \\
\text { Payroll Mine }\end{array}$ & $\begin{array}{l}\text { dam } \\
\text { mine } \\
\text { mine } \\
\text { mine } \\
\text { spring } \\
\text { reservoir } \\
\text { stream } \\
\text { reservoir } \\
\text { mine } \\
\text { mine }\end{array}$ & $\begin{array}{l}\text { UNOFF } \\
\text { UNOFF } \\
\text { UNOFF } \\
\text { UNOFF } \\
\text { BGN } \\
\text { BGN } \\
\text { BGN } 1962 \\
\text { BGN } \\
\text { UNOFF } \\
\text { UNOFF }\end{array}$ & $\begin{array}{l}\text { Graham } \\
\text { Santa Cruz } \\
\text { Pima } \\
\text { Mohave } \\
\text { Santa Cruz } \\
\text { Graham } \\
\text { Graham } \\
\text { Coconino } \\
\text { Gila } \\
\text { Mohave }\end{array}$ & $\begin{array}{l}331210 \mathrm{~N} 1095112 \mathrm{~W} \\
312449 \mathrm{~N} 1104427 \mathrm{~W} \\
315648 \mathrm{~N} 1110715 \mathrm{~W} \\
351902 \mathrm{~N} 1140 \mathrm{~B} 13 \mathrm{~W} \\
312439 \mathrm{~N} 1104217 \mathrm{~W} \\
331212 \mathrm{~N} 1095120 \mathrm{~W} \\
331215 \mathrm{~N} 1094840 \mathrm{~W} \\
344129 \mathrm{~N} 111025 \mathrm{~W} \\
341238 \mathrm{~N} 1112203 \mathrm{~W} \\
352452 \mathrm{~N} 1141025 \mathrm{~W}\end{array}$ & $330848 \mathrm{~N} 1095319 \mathrm{~W}$ & 5070 & $\begin{array}{l}\text { Bonita Tank } \\
\text { Harshaw } \\
\text { Twin Buttes } \\
\text { Cerbat } \\
\text { Harshaw } \\
\text { Bonita Tank } \\
\text { Bonita Tank } \\
\text { Quayle Hill } \\
\text { Payson South } \\
\text { Chloride }\end{array}$ \\
\hline $\begin{array}{l}\text { Payson } \\
\text { Payson Airport } \\
\quad \text { Birch Mesa Airport } \\
\text { Payson Cemetery } \\
\text { Payson Fire Station } \\
\text { Payson High School } \\
\text { Payson Hospital } \\
\text { Payson Indian Reservation } \\
\text { Tonto-Apache Reservation } \\
\text { Payson Junior High School }\end{array}$ & $\begin{array}{l}\text { ppl } \\
\text { airport } \\
\text { cemetery } \\
\text { building } \\
\text { school } \\
\text { hospital } \\
\text { reserve } \\
\text { school }\end{array}$ & $\begin{array}{l}\text { BGN } \\
\text { ADMIN } \\
\text { VARIANT } \\
\text { UNOFF } \\
\text { UNOFF } \\
\text { UNOFF } \\
\text { UNOFF } \\
\text { BGN } \\
\text { VARIANT } \\
\text { UNOFF }\end{array}$ & $\begin{array}{l}\text { Gila } \\
\text { Gila } \\
\text { Gila } \\
\text { Gila } \\
\text { Gila } \\
\text { Gila } \\
\text { Gila } \\
\text { Gila }\end{array}$ & $\begin{array}{l}341351 N 1111928 \mathrm{~W} \\
341524 \mathrm{~N} 1112020 \mathrm{~W} \\
341409 \mathrm{~N} 1112120 \mathrm{~W} \\
341351 \mathrm{~N} 1111950 \mathrm{~W} \\
341412 \mathrm{~N} 1111955 \mathrm{~W} \\
341349 \mathrm{~N} 1111916 \mathrm{~W} \\
341317 \mathrm{~N} 1111940 \mathrm{~W} \\
341411 \mathrm{~N} 1111949 \mathrm{~W}\end{array}$ & & $\begin{array}{l}4887 \\
5156\end{array}$ & $\begin{array}{l}\text { Pays on South } \\
\text { Pays on North } \\
\text { Payson South } \\
\text { Payson South } \\
\text { Payson South } \\
\text { Payson South } \\
\text { Payson South } \\
\text { Payson South }\end{array}$ \\
\hline $\begin{array}{l}\text { Payson Post Office } \\
\text { Payson Ranger Station } \\
\text { Payson Rodeo Grounds }\end{array}$ & $\begin{array}{l}\text { building } \\
\text { locale } \\
\text { park }\end{array}$ & $\begin{array}{l}\text { UNOFF } \\
\text { UNOFF } \\
\text { AOMIN }\end{array}$ & $\begin{array}{l}\text { Gila } \\
\text { Gila } \\
\text { Gila }\end{array}$ & $\begin{array}{l}341352 \mathrm{~N} 1112009 \mathrm{~W} \\
341431 \mathrm{~N} 1111820 \mathrm{~W} \\
341441 \mathrm{~N} 1111955 \mathrm{~W}\end{array}$ & & 5000 & $\begin{array}{l}\text { Payson South } \\
\text { Payson South } \\
\text { Payson South }\end{array}$ \\
\hline
\end{tabular}


NATIONAL GAZETTEER--ARIZONA 1986

\section{FEATURE NAME}

Paz, Parque de

P Bar Camp

P Bar Lake

P B Creek

P B Ranch

P B Spring

Peabody Coal Company Airstrip

Peaceful Valley Memorial Park

Peaceful Valley Ranch

Peace Tank

Peach Canyon

Peaches Spring

Peaches Tank

Peach Flat

Peach Flat Tank

Peach Hollow Tank

Peach Orchard Spring Barkdol Spring

Peach Orchard Spring See Keams Canyon

Peach $\mathrm{Pu}$

Peach Spring

Peach Spring

Peach Spring

See Peach Springs

Peach Spring

Peach Spring

Peach Springs

Peach Spring

Peach Springs

Peach Springs Airport

Peach Springs Canyon

Peach Springs Post Office

Peach Springs Railroad Station

Peach Springs Wash

Peach Tank

Peach Tank

Peach Tree Spring

Peach Tree Tank

Peach Tree Tank

Peach Tree Tank

Peachville Mountain

Peachville Tank

Peachville Wash

Peach Wash

Peacock Canyon

Peacock Mountains

Peacock Peak

Peacock Spring

Peacock Spring

See Dewey Mahone Spring

Peacock Village (subdivision)

Peacock Wash

Peak Spring

Pearce

Sun Sites

Pearce Canyon

Pierce Canyon

Pearce Cemetery

Pearce Elementary School

Pearce Ferry

$$
\text { Colorado Crossing }
$$

Pierce Ferry

Pearce Mountain See Pierce Mountain

Pearce Post Office

Pearce Ranch

Pearce Tank

Pearce Well

Pearl Handle Pit
FEATURE
CLASS

STATUS

COUNTY

COOROINATE

$332705 \mathrm{~N} 1122030 \mathrm{~W}$

$341942 \mathrm{~N} 1122918 \mathrm{~W}$

park

lake

stream

locale

spring

ADNIN
BGN
BGN
BGN
UNOFF
BGN

Maricopa

Yavapai

Greenlee

Gila

Gila

Gila

airport

ADMIN

Navajo

cemetery

locale

UNOFF

reservoir BGN

spring $B G N$

flat

reservoir BG

reservoir $B G N$

spring

BGN

BGN 1974

Coconino

Graham

Gila

Coconino

Navajo

Yavapai

Gila

Gila

Gila

Gila

VARIANT

ppl

locale

spring

spring

spring

spring

spring

spring

BGN
BGN

Navajo

Pima

Graham

VARIANT

Mohave

$B G N$

BGN

Navajo

Navajo

VARIANT

pp)

BG

airpor

valley

building

building

stream

reservoir BG

spring BGN

reservoir BGN

reservoir BGN

reservoir BGN

summit BGN

reservoir BGN

stream BGN

stream BGN

valley $B G N$

spring

BGN

BGN

BGN

Mohave

Mohave

Mohave

Mohave

Mohave

Mohave

Gila

Yavapai

Cochise

Graham

Greenlee

Gila

Pinal

Pinal

Pinal

Coconino

Pinal

Mohave

Mohave

Pinal

VARIANT

spring

ppl

arroyo

spring

ppl

valley

cemetery

$B G N$

BGN

BGN

VARIANT

Mohave

Maricopa

Mohave

Gila

Cochise

1973 Mohave

UNOFF

Cochise

school

UNOFF

Cochise

local

BGN 197

VARIANT

VARIANT

summi

BGN

VARIANT

Cochise

Apache

building

UNOFF

UNOFF

Cochise

Navajo

Navajo

we 1

UNOFF

Navajo

Pinal
333839 N1091605W

335532N110542OW

$335612 \mathrm{~N} 1105532 \mathrm{~W}$

335612 N1105540W

$363102 \mathrm{~N} 1102326 \mathrm{~W}$

351154N1113355W

324411 N1101254W

$340825 \mathrm{~N} 1111908 \mathrm{~W}$

$364953 \mathrm{~N} 1104911 \mathrm{~W}$

360138 N1100037W

$342822 \mathrm{~N} 1114341 \mathrm{~W}$

$335150 \mathrm{~N} 1104846 \mathrm{~W}$

$335215 \mathrm{~N} 1104928 \mathrm{~W}$

$335945 \mathrm{~N} 1110349 \mathrm{~W}$

$341245 \mathrm{~N} 1112134 \mathrm{k}$

$354845 \mathrm{~N} 1101140 \mathrm{~W}$ $324328 \mathrm{~N} 1102305 \mathrm{~W}$

324749 N1102841W

$353444 N 1132552 W$

$362846 \mathrm{~N} 1103707 \mathrm{~W}$

364325 N1103220W

353444 N1132552W

$353145 \mathrm{~N} 1132529 \mathrm{~W}$

$353235 \mathrm{~N} 1132450 \mathrm{~W}$

$354532 \mathrm{~N} 1132137 \mathrm{~W}$

$353144 \mathrm{~N} 1132534 \mathrm{~W}$

$353145 N 1132533 \mathrm{~W}$

$354532 \mathrm{~N} 1132137 \mathrm{~W}$

$335432 \mathrm{~N} 1101250 \mathrm{~W}$

$341443 \mathrm{~N} 1114404 \mathrm{~W}$

$315312 \mathrm{~N} 1091148 \mathrm{~W}$

$324354 \mathrm{~N} 1102206 \mathrm{~W}$

325311 N1091622W

$335625 \mathrm{~N} 1102016 \mathrm{~W}$

$332050 \mathrm{~N} 1110634 \mathrm{~W}$

$332100 \mathrm{~N} 1110658 \mathrm{~W}$

$331939 \mathrm{NI} 110603 \mathrm{~W}$

$364846 \mathrm{~N} 1111304 \mathrm{~W}$

332059 N1111435W

$351859 \mathrm{~N} 1134630 \mathrm{~W}$

$351816 \mathrm{~N} 1134619 \mathrm{~W}$

332148N1111516h

$353021 N 1133741 \mathrm{~W}$ 333845 N1121420W $350826 \mathrm{~N} 1133824 \mathrm{~W}$ $332831 \mathrm{~N} 1105733 \mathrm{~W}$ 315418 N1094912W

360839 N1135812W

315428 N1094945W

$315405 \mathrm{~N} 1094925 \mathrm{~W}$

$360700 \mathrm{~N} 1140000 \mathrm{~W}$

$315400 N 1094858 W$

$340836 \mathrm{~N} 1094423 \mathrm{~W}$

$315610 N 1094945 \mathrm{~W}$

$341850 N 1100707 \mathrm{~W}$

343649 N1101611W

$341546 \mathrm{~N} 1101 \mathrm{~B} 59 \mathrm{~W}$

$331026 \mathrm{~N} 1105931 \mathrm{~W}$ $320339 \mathrm{~N} 1121859 \mathrm{~W}$ valley BGN

\begin{tabular}{|c|c|c|}
\hline $\begin{array}{c}\text { SOURCE } \\
\text { COORDINATE }\end{array}$ & $\begin{array}{l}\text { ELEV } \\
\text { FT }\end{array}$ & MAP NAME \\
\hline $335655 \mathrm{~N} 1105743 \mathrm{~W}$ & & $\begin{array}{l}\text { Tolleson } \\
\text { Batt leship Butte } \\
\text { Hannagan Meadow } \\
\text { McFadden Peak } \\
\text { McFadden Peak } \\
\text { McFadden Peak } \\
\text { Long House Valley }\end{array}$ \\
\hline $364812 \mathrm{~N} 1104314 \mathrm{~W}$ & 3864 & $\begin{array}{l}\text { Flagstaff East } \\
\text { Eureka Ranch } \\
\text { Payson South } \\
\text { Chaiyahi Rim SE } \\
\text { Whippoorwill Spring } \\
\text { Hackberry Mtn } \\
\text { Sombrero Peak } \\
\text { Sombrero Peak } \\
\text { Copper Mtn } \\
\text { Payson South }\end{array}$ \\
\hline & & $\begin{array}{l}\text { Pisinimo } \\
\text { Rhodes Peak } \\
\text { Oak Grove Canyon }\end{array}$ \\
\hline & & $\begin{array}{l}\text { Black Mesa Wash NE } \\
\text { Betatakin Ruin } \\
\text { Peach Springs }\end{array}$ \\
\hline $\begin{array}{l}353626 \mathrm{~N} 1132715 \mathrm{~W} \\
35330 \mathrm{BN} 1132353 \mathrm{~W}\end{array}$ & 4800 & $\begin{array}{l}\text { Peach Springs } \\
\text { Peach Springs } \\
\text { Oiamond Peak } \\
\text { Peach Springs } \\
\text { Peach Springs } \\
\text { Diamond Peak } \\
\text { Cedar Creek } \\
\text { Wet Bottom Mesa } \\
\text { Portal } \\
\text { Kennedy Peak }\end{array}$ \\
\hline $\begin{array}{l}332107 \mathrm{~N} 1110538 \mathrm{~W} \\
364230 \mathrm{~N} 1111449 \mathrm{~W} \\
332148 \mathrm{~N} 1111522 \mathrm{~W}\end{array}$ & $\begin{array}{l}5990 \\
6292\end{array}$ & $\begin{array}{l}\text { Guthrie } \\
\text { Carrizo } \\
\text { Superior } \\
\text { Superior } \\
\text { Superior } \\
\text { Cedar Tree Bench } \\
\text { Picketpost Mtn } \\
\text { Peacock Peak } \\
\text { Peacock Peak } \\
\text { Florence Junction }\end{array}$ \\
\hline
\end{tabular}

$\begin{array}{ll}351221 N 1134701 W & 1210 \begin{array}{l}\text { Hedgpeth Hills } \\ \text { Tin Mountain NW } \\ \text { Inspiration } \\ \text { Pearce }\end{array} \\ \text { 360810N1134812W } & \begin{array}{l}\text { Snap Canyon West } \\ \text { Pearce }\end{array} \\ & \begin{array}{l}\text { Pearce } \\ \text { Meadview North }\end{array} \\ & \begin{array}{l}\text { Pearce } \\ \text { Pearce } \\ \text { Show Low North } \\ \text { Sheeps in Wash }\end{array} \\ & \begin{array}{l}\text { Clay Springs } \\ \text { Hot Tamale Peak }\end{array}\end{array}$


FEATURE NAME

Pearl Harbor Storage Tank

Pearl Harbor Tank

Pearl Mine

Pearl Wash

Pearly Creek

See Perley Creek

Pearson Falls Wash

Pearson Falls Wash

See Red Canyon

Pearson Spring

Pearsons Spring

Pear Tank

Peasoup Creek

Peavine Tank

Pecan Grove School

Pecan Grove Trailer Park

Pechan, Mount

Pechan Camp

Peck Basin

Peck Canyon

Palaco canyon

Palaco Canyon

Peck Canyon

Peck Canyon

Peck Canyon Interchange

Peck Mine

Pecks (histoical)

Pecks Lake

Pecks Point Tank Number One

Pecks Point Tank Number Three

Pecks Point Tank Number Two

Peck Spring

Peck Spring

Peck Wash

Big Spring

Big Springs Wash

Peck Well

Bryce Wash

Pedia Tank

Pedregosa Mountains Pedrogrosa Mountains Swisshelm Mountains

Pedrogrosa Mountains

See Pedregosa Mountains

Peeley, Mount

Mount Peale

Mount Peele

Mount Pele

Peeples Creek

Peeples Valley

Peeples Valley

Peoples Ranch

Peeples Valley Pioneer Cemetery

Peeples Valley School

Peepstem Canyon

Peerless Mine

Peet Spring

Peewee Tank

Peg Leg Well

Pegrin Well

Pela Seca Spring

Pelon, Cerro

Peloncilla Range

See Peloncillo Mountains

Peloncillo Mountains

Black Hills

Black Mountains

Guadalupe Mountains

Peloncilla Range

Peloucillo Range
FEATURE

CLASS

STATUS

reservoir

reservoir

mine

valley

stream

stream

valley

spring

spring

reservoir

reservoir

school

locale

summit

locale

bas in

valley

valley

valley

vall

crossing UNOF

mine

locale

reservoir

reservoir

reservoir

reservoir

spring

spring

stream

we 1

well

reservoir

range

range

range

summit

VARIANT

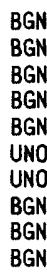

BGN

BGN

UNOFF

UNOFF

BGN

VARIANT

VARIANT

UNOFF

UNOF

BGN
BGN

BGN

BGN

BGN

BGN

BGN

BGN 1962
VARIANT

VARIANT

VARIANT

UNOFF

BGN

BGN 198

VARIANT

VARIANT

VARIANT

BGN
BGN
UNOFF
$8 G N$
VARIANT
BGN
VARIANT

BGN 1930 Santa Cruz

VARIANT

BGN Pima

Yavapai

Santa Cruz

Yavapai

Santa Cruz

Yavapai

Coconino

Coconino

Coconino

Pima

Yavapai

Graham

Santa Cruz

312858N1110700W

Pinal

Cochise

BGN 1973

VARIANT

VARIANT

VARIANT

Cochis

Gila

tream

valley

pp

cemetery

school

valley

spring

reservoir

BGN Yavapai

BGN Yavapai

BGN Yavapai

VARIANT

UNOFF

UNOFF

UNOFF

BGN

BGN

\section{we}

well
well
spring

spring
summit

range

range

$353853 \mathrm{~N} 1115210 \mathrm{~W}$ 353858 N1115019W

$324400 \mathrm{~N} 1104415 \mathrm{~W}$

324536 N1103945W

$342121 \mathrm{N1111416 \textrm {W }}$

$345031 \mathrm{~N} 1133738 \mathrm{~W}$

$345321 N 1132945 W$

$351645 \mathrm{~N} 1114822 \mathrm{~W}$

$322426 N 1103632 \mathrm{~W}$

$315343 \mathrm{~N} 1105900 \mathrm{~W}$

$335126 \mathrm{~N} 1093427 \mathrm{~W}$

345753N1122551W

$324257 \mathrm{~N} 1143843 \mathrm{~W}$

332916 N1120657W

$335849 \mathrm{~N} 1123231 \mathrm{~W}$

322623N1104020W

$313040 \mathrm{~N} 1110050 \mathrm{~W}$

$322928 \mathrm{~N} 1102940 \mathrm{~W}$

341813 N1121909W

$313022 \mathrm{~N} 1110029 \mathrm{~W}$

$341616 \mathrm{~N} 1121841 \mathrm{~W}$

$312144 N 1105040 \mathrm{~W}$

$344624 \mathrm{~N} 1120221 \mathrm{~W}$

$343504 \mathrm{~N} 1112244 \mathrm{~W}$

$343433 \mathrm{~N} 1112229 \mathrm{~W}$

$343525 \mathrm{~N} 1112124 \mathrm{~W}$

322857 N1103300

$325506 \mathrm{~N} 1095000 \mathrm{~W}$

$324757 N 1111738 \mathrm{~W}$

$313612 N 1092326 \mathrm{~W}$

$313612 \mathrm{~N} 1092326 \mathrm{~W}$

$340007 N 1112911 \mathrm{~W}$

$342038 \mathrm{~N} 1131510 \mathrm{~W}$

341744 N1124248W 341608 N1124335W

$341651 \mathrm{~N} 1124316 \mathrm{~W}$

$341702 \mathrm{~N} 1124316 \mathrm{~W}$

$324132 \mathrm{~N} 1102306 \mathrm{~W}$

$345915 \mathrm{~N} 1142348 \mathrm{~W}$

Mohave

Yavapai

$343810 \mathrm{~N} 1112202 \mathrm{~W}$

$\begin{array}{ll}\text { Pinal } & 330245 N 1110353 \mathrm{~W} \\ \text { Maricopa } & 334542 \mathrm{~N} 1131005 \mathrm{~W}\end{array}$

$\begin{array}{ll}\text { Pinal } & 330245 N 1110353 \mathrm{~W} \\ \text { Maricopa } & 334542 \mathrm{~N} 1131005 \mathrm{~W}\end{array}$

Pinal 323140N1104346W

Graham 323523N1091236W

Graham

$323523 \mathrm{~N} 1091236 \mathrm{~W}$
UNOFF
UNOFF

BGN

BGN

BGN 1985

BGN 198

VARIANT

VARIANT

VARIANT

VARIANT
COORDINATE

$322835 N 1103418 \mathrm{~W}$

341344 N1122001W

Redington

Battle Flat

Tubac

Battle Flat

3760 Kino Springs

3332 Clarkdale

Calloway Butte

Long Valley

Long Valley

Buehman Canyon

Battle Flat

$330200 \mathrm{~N} 1094200 \mathrm{~W}$

Pima

Pena Blanca Lake

Picacho Reservoir SE

6541 Pedregosa Mts West

7030 Mazatzal Peak

$342335 \mathrm{~N} 1131755 \mathrm{~W}$

$341506 \mathrm{N1124418 \textrm {W }}$

$323950 \mathrm{~N} 1102500 \mathrm{~W}$

Santa Cruz 313713N1110452W

Arrastra Mtn SE

Peeples Valley

Peeples Valley 


\section{FEATURE NAME}

Pelon Spring

Peloucillo Range

See Peloncillo Mountains

Pelveler Chimney Spring

See Peveler Chimney Spring

Pemberton Ranch

Pemberton Tank

Pemberton Tank

Pena Blanca Arroyo

See Sanos Tee Wash

Pena Blanca Canyon

See Peña Blanca Canyon

Peña Blanca Canyon

Atascoso Cañon

Pena Blanca Canyon

Pino Blanco Canyon

Piño Blanco Canyon

Pena Blanca Creek

See Sanos Tee Wash

Peña Blanca Lake

Peña Blanca Spring

Peña Blanca Trail Number

Forty-one

Pena Blanka Creek See Sanos Tee Wash

Penasca Canyon

See Peñasco Canyon

Peñasco Canyon

Penasca Canyon

Pensaco Canyon

Peñasco Dam

Peñasco Tank

Pendergast School

Pendleton Mesa

Pen Hatch A Pet Mountains See Gila Bend Mountains

Penhatchapet Mountains See Harquahala Mountains

Peninsula Windmil

Penitas $\mathrm{Hill}$

See Peñitas Hills

Peñitas Hills

$$
\text { Penitas Hill }
$$

Peñitas Wash

Penitent iary Mountain

Penitentiary Spring

Penitentiary Tanks

Penns Pocket

See Pen Pocket

Penn Valley

Penn Valley Dam

Penny Claim

Pen Pocket

Ambush Water Pocket

Penrod Penns Pocket

See Pinetop

Penrod Burn

Penrod Cabin

Penrod Flat

Penrod Mountain

Penrod Tank

Penrod Tank

Penrod Tank

Pensaco Canyon

See Peñasco Canyon

Pensfield Place (subdivision)

Pen Tank

Pen Tank

Penzance

Peoples Canyon
FEATURE
CLASS

STATUS COUNTY

spring

range

BGN

Pima

Graham

spring

locale

reservoir

reservoir

arroyo

VARIANT

UNOFF

BGN
BGN

VARIANT

Gila

Maricopa

Yavapai

Yavapai

Apache

VARIANT

valley
valley

BGN 1942

VARIANT

VARIANT

VARIANT

VARIANT

VARIANT

arroyo

reservoir

BGN

spring

trail

BGN

UNOFF

VARIANT

arroyo

valley

valley

VARIANT

BGN

VARIANT

VARIANT

dam

reservoir

school

summit

BGN
BGN

UNOFF

BGN

VARIANT

range

range

well

summit

VARIANT

UNOFF

VARIANT

Santa Cruz

Santa Cruz

Pena Blanca Lake

Apache 362915N1083418W

Santa Cruz 312433N1110505W

Santa Cruz 312319N1110530W

Apache

Santa Cruz

Santa Cruz 312303N1111002W

Santa Cruz 314024N1110812W

Maricopa 332927N1121518W

Gila 335804N1105247W

Maricopa $\quad 331321 \times 1130214 \mathrm{~W}$

Yuma

Apache

Pima

summit

BGN

stream

summit

spring

reservoir

VARIANT

BGN

$B G N$

$B G N$

BGN
BGN

VARIANT

reservoir

valley

BGN

dam

mine

reservoir

UNOFF

BGN 1974

VARIANT
VARIANT

VARIANT

ppl

area

locale

flat

BGN

BGN

BGN

summ it

BGN

reservoir $B G$

reservoir $B G M$

reservoir BGN

valley

VARIANT

valley

reservoir $B G N$

reservoir

locale

valley
Pima

Pima

Mohave

Mohave

Mohave

Mohave

Mohave

Mohave

Pima

Mohave

$314525 \mathrm{~N} 1111752 \mathrm{~W}$

$314746 \mathrm{~N} 1112408 \mathrm{~W}$

$350628 \mathrm{~N} 1132902 \mathrm{~W}$

$350646 \mathrm{~N} 1132805 \mathrm{~W}$

$350633 \mathrm{~N} 1132725 \mathrm{~W}$

$360416 \mathrm{~N} 113272 \mathrm{BW}$

$361300 \mathrm{~N} 1133107 \mathrm{~W}$

361318 N1133124W

$360416 \mathrm{~N} 1132728 \mathrm{~W}$

Navajo

Apache

Navajo

Apache

Apache

Apache

Navajo

Apache

Santa Cruz

Maricopa

Coconino

Coconino

Navajo

Yavapai

$340733 N 1095613 \mathrm{~W}$

340538 N $1094310 \mathrm{~W}$

$340340 N 1095832 \mathrm{~W}$

$340444 \mathrm{~N} 1094342 \mathrm{~W}$

$340458 \mathrm{~N} 1094438 \mathrm{~W}$

340607 N1094638W

$341323 N 1095103 \mathrm{~W}$

341518 N1095010W

$312422 \mathrm{~N} 1111142 \mathrm{~W}$

$333526 \mathrm{~N} 1121220 \mathrm{~W}$

$345427 \mathrm{~N} 1113038 \mathrm{~W}$

$351832 \mathrm{N1} 121242 \mathrm{~W}$

$345419 \mathrm{N1} 101515 \mathrm{~W}$

342037 N1131509W
COORDINATE

$312501 N 1110442 W$

$312242 N 1110608 \mathrm{~W}$

$312429 \mathrm{~N} 1110558 \mathrm{~W}$

$362915 N 1083418 \mathrm{~W}$

312422N1111142W

$312422 N 1111142 \mathrm{~W}$

$312233 \times 1110919 W$

Ruby

$334842 N 1132147 \mathrm{~W}$

$360742 N 1092202 \mathrm{~W}$

314525 N1111752W

321846 N1112630W

$\begin{array}{lcr}\text { SOURCE } & \text { ELEV } & \\ \text { COORDINATE } & \text { FT } & \text { MAP NAME } \\ & & \text { Soza Canyon }\end{array}$

Fort Mc Dowe11

Mt Josh

Sullivan Buttes

3832 Pena B1anca Lake

Pena Blanca Lake Pena Blanca Lake

Ruby

Saucito Mtn

Avondale

5334 McFadden Peak

Mummy Cave Ruins

Penitas Hills

$314824 N 1111402 W$

Fresno Wash

5301 Penitentiary Mtn

Penitentiary Mtn

Penitentiary Mtn

Castle Peak

Waterman Peak

Whitmore Point SW

Horseshoe Cienega

Indian Pine

Horseshoe Cienega

8433 Horseshoe Cienega

McNary

Sponseller Mtn

Ortega Mtn

1175 Glendale

Mormon Mountain

Williams North

Joseph City

Arrastra Mtn SE
361055N1133022W Castle Peak 


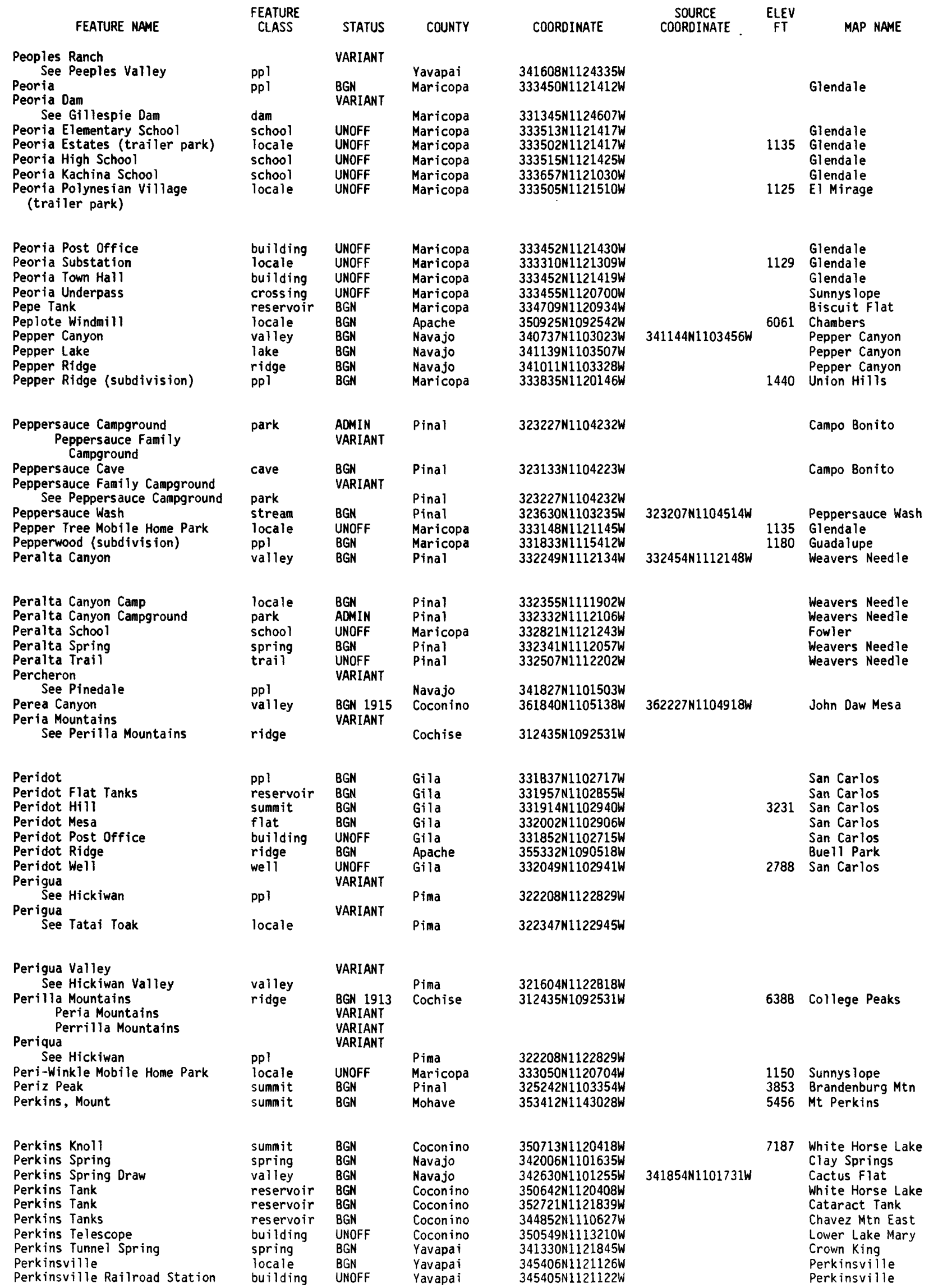


FEATURE
CLASS

STATUS

COUNTY

COORDINATE

SOURCE
COORDINATE

ELEV

MAP NAME

Perley Creek

See Bonita Creek

Perley Creek

Pearly Creek

Perlite Mine

Perlite Spring

Pero Bonito Mine

Peroxide Well

Perphery Gate

Perrilla Mountains

See Perilla Mountains

$\begin{array}{ll}\text { stream } & \text { VARIANT } \\ \text { stream } & \text { BGN } \\ & \text { VARIANT } \\ \text { mine } & \text { UNOFF } \\ \text { spring } & \text { BGN } \\ \text { mine } & \text { UNOFF } \\ \text { well } & \text { UNOFF } \\ \text { dam } & \text { BGN } \\ & \text { VARIANT }\end{array}$

Gila

342056N1111421W

Pinal 331617N1110745W

Pinal 331920N1110955W

Yavapai 340314N1121828W

Maricopa 332607N1124545W

La Paz 330900N1144100W

Cochise $\quad 312435 N 1092531 \mathrm{~W}$

Perrin Dan Rock Dam

Perrin Dan

Perrin Draw

Perrin Tank

Perrin Tank

Perry Creek

Perry Lake

Perry Mesa

Perry Mesa Tank

Perry Park

Perry Spring

Perry Tank Canyon

Perryville

Perryville Substation

Perry Windmill

Pescadero Mountain

Pescadero Wash

Pesch Canal

Peshlakai Point

Peshlaki Spring

Pesqueira Canyon Pesquiera Canyon

Pesqueira Wash

Pesqueria Wash

Pesquiera Wash

Pesqueria Wash

See Pesqueira Wash

Pesquiera Canyon

See Pesqueira Canyon

Pesquiera Tank

Pesquiera Wash

See Pesqueira Wash

Pesthouse Tank

Petal Hills

Pete Cobb Spring

Pete Kitchens Museun

Pete Kitchens Ranch

El Potrero

Revanton

Saxon Dairy

Saxons Dairy Ranch

Saxton

Pete Moore Spring

Pete Mountain

Petes Mountain

Pete Number One Tank

Peter Deswood Well

Peter Lockett Canyon

Peter Lockett Tank

Petermans Station (historical)

Peters Canyon

Peters Corner

dam

dam

valley

(

reservoir $B G$

reservoir $B G$

stream BGN

lake BGN

summit $B G N$

reservoir BGN

park ADMIN

spring $\quad B G$

valley

ppl

locale

locale

summit

strean

canal

summit

Maricopa

Apache

Yavapai

Maricopa

Maricopa

Yavapai

Pima

Pima

Yuma

BGN 1977

Coconino

spring
valley

BGN

Coconino

BGN 1984 Santa Cruz

VARIANT

stream BGN 19B4

VARIANT

VARIANT

Pima

VARIANT

stream

VARIANT

valley

Pima

Santa Cruz

reservoir BGN

VARIANT

stream

summit $\quad B G$

spring $B G N$

building UNOFF

locale

UNOFF

VARIANT

VARIANT

VARIANT

VARIANT

VARIANT

Santa Cruz

312212 N1110203W

Pima

Yavapai

Coconino

Gila

Santa Cruz

Santa Cruz

313905 N1112016k

343639 N1114228W

$364112 \mathrm{~N} 1113830 \mathrm{~W}$

$335302 N 1101235 \mathrm{~W}$

$12400 \mathrm{~N} 1105725 \mathrm{~W}$

$312416 \mathrm{~N} 1105709 \mathrm{~W}$

$334210 \mathrm{~N} 1092915 \mathrm{~N}$

$341215 \mathrm{~N} 1120533 \mathrm{~W}$

$332513 N 1122845$

1125N1120243W

$321310 \mathrm{~N} 1112833 \mathrm{~W}$

$323723 N 1144507 \mathrm{~W}$

352957 N1112122W

$313905 \mathrm{~N} 1112016 \mathrm{~W}$

$312103 N 1110342 W$

Rio Rico

313722 N1111958W

Cerro Colorado

Pajarito Peak

Walker Mtn

Bitter Springs

Cedar Creek

Rio Rico

3610 Rio Rico

spring BGN Cochise 312705N1095840W

summit BGN 1983 Santa Cruz 314227N1105343W

reservoir BGN Coconino 352504N1113935W

well UNOFF Apache 363013N1092219W

reservoir BGN Yavapai 351242 N1124254W

locale BGN Yuma 334600Ni135000W

Maricopa 333126N1112232W

locale $\quad B G N$

locale $\quad B G N \quad G i l a$

valley BGM

spring BGN

reservoir $B G$

flat $B G N$

summit $\quad B G N$

summit $\quad B G N$

ppl

BGN
$325233 N 1120253 \mathrm{~W}$

Gila 340108N1110021W

340149N1110120W

$340103 \mathrm{~N} 1110026$

Navajo 342148N1101233

Graham 324227N1095545W

Pinal 332748N1111937W

Gila

$334338 \mathrm{~N} 1111423 \mathrm{~W}$

332237 N1115725
Bisbee

7661 Mt Hopkins

White Horse Hills

5586 Mexican Cry Mesa

Picacho Butte

Picacho Butte

Salome

$332758 \mathrm{~N} 1111750 \mathrm{~W}$

Mormon Flat Dam

1380 Antelope Peak NE

$340004 N 1105752 W$

Buzzard Roost Mesa Buzzard Roost Mesa Buzzard Roost Mesa Pinedale Webb Peak

3765 Weavers Needle

3314 Theo. Roosevelt Dam

1200 Tempe 


\begin{tabular}{|c|c|c|c|c|c|c|c|}
\hline FEATURE NAME & $\begin{array}{l}\text { FEATURE } \\
\text { CLASS }\end{array}$ & STATUS & COUNTY & COORDINATE & $\begin{array}{l}\text { SOURCE } \\
\text { COORDINATE }\end{array}$ & $\underset{\mathrm{FT}}{\mathrm{ELEV}}$ & MAP NAME \\
\hline $\begin{array}{l}\text { Peterson } \\
\text { Peterson Flat }\end{array}$ & $\begin{array}{l}\text { locale } \\
\text { flat }\end{array}$ & $\begin{array}{l}B G N \\
B G N\end{array}$ & $\begin{array}{l}\text { Maricopa } \\
\text { Coconino }\end{array}$ & $\begin{array}{l}\text { 332242N1115634W } \\
\text { 355023N1114750W }\end{array}$ & & & $\begin{array}{l}\text { Tempe } \\
\text { Peterson Flat }\end{array}$ \\
\hline $\begin{array}{l}\text { Peterson Park } \\
\quad \text { See Oddfel lows-Peterson } \\
\quad \text { Park } \\
\text { Peterson Peak } \\
\text { Peterson Ranch } \\
\text { Peterson Ranch } \\
\text { Peterson Seepage } \\
\text { Peterson Spring } \\
\text { Peterson Tank } \\
\text { Peterson Tank }\end{array}$ & $\begin{array}{l}\text { park } \\
\text { summit } \\
\text { locale } \\
\text { locale } \\
\text { reservoir } \\
\text { spring } \\
\text { reservoir } \\
\text { reservoir }\end{array}$ & $\begin{array}{l}\text { BGN } \\
\text { UNOFF } \\
\text { UNOFF } \\
\text { BGN } \\
\text { BGN } \\
\text { BGN } \\
\text { BGN }\end{array}$ & $\begin{array}{l}\text { Maricopa } \\
\text { Cochise } \\
\text { Cochise } \\
\text { Gila } \\
\text { Coconino } \\
\text { Navajo } \\
\text { Navajo } \\
\text { Navajo }\end{array}$ & $\begin{array}{l}332336 \mathrm{~N} 1115740 \mathrm{~W} \\
312838 \mathrm{~N} 1102348 \mathrm{~W} \\
312726 \mathrm{~N} 1102352 \mathrm{~W} \\
334857 \mathrm{~N} 1105510 \mathrm{~W} \\
350055 \mathrm{~N} 1113659 \mathrm{~W} \\
34095 \mathrm{~N} 1095711 \mathrm{~W} \\
341005 \mathrm{~N} 1095728 \mathrm{~W} \\
341531 \mathrm{~N} 1101354 \mathrm{~W}\end{array}$ & & & $\begin{array}{l}\text { Huachuca Peak } \\
\text { Huachuca Peak } \\
\text { Aztec Peak } \\
\text { Lower Lake Mary } \\
\text { Lakes ide } \\
\text { Lakeside } \\
\text { Pinedale }\end{array}$ \\
\hline $\begin{array}{l}\text { Peterson Tank } \\
\text { Peterson Tanks } \\
\text { Peterson Wash } \\
\text { Peters Pocket } \\
\text { Peter Spring } \\
\text { Peters Spring } \\
\text { Peters Tank } \\
\text { Peters Tank } \\
\text { Peters Trai1 } \\
\text { Peters Wash }\end{array}$ & $\begin{array}{l}\text { reservoir } \\
\text { reservoir } \\
\text { stream } \\
\text { lake } \\
\text { spring } \\
\text { spring } \\
\text { reservoir } \\
\text { reservoir } \\
\text { trail } \\
\text { stream }\end{array}$ & $\begin{array}{l}\text { BGN } \\
B G N \\
B G N \\
B G N \\
B G N \\
B G N \\
B G N \\
B G N \\
\text { UNOFF } \\
B G N\end{array}$ & $\begin{array}{l}\text { Coconino } \\
\text { Coconino } \\
\text { Graham } \\
\text { Mohave } \\
\text { Yavapai } \\
\text { Yavapai } \\
\text { Greenlee } \\
\text { Coconino } \\
\text { Maricopa } \\
\text { Pinal }\end{array}$ & $\begin{array}{l}354213 \mathrm{~N} 1112859 \mathrm{~W} \\
35501811114708 \mathrm{~W} \\
325139 \mathrm{~N} 1094313 \mathrm{~W} \\
360503 \mathrm{N1132903 \textrm {W }} \\
341259 \mathrm{N1} 122556 \mathrm{~W} \\
343046 \mathrm{N1120607W} \\
332917 \mathrm{N1092040 \textrm {W }} \\
351628 \mathrm{N1122018W} \\
3328221111831 \mathrm{~W} \\
323149 \mathrm{~N} 1102945 \mathrm{~W}\end{array}$ & $325948 \mathrm{~N} 1093917 \mathrm{~W}$ & & $\begin{array}{l}\text { Gray Mountain } \\
\text { Peterson Flat } \\
\text { San Jose } \\
\text { Whitmore Point SW } \\
\text { Minnehaha } \\
\text { Cherry } \\
\text { Rose Peak } \\
\text { Hearst Mtn } \\
\text { Weavers Needle } \\
\text { Kielberg Canyon }\end{array}$ \\
\hline $\begin{array}{l}\text { Peters Well } \\
\text { Petes Cabin Mesa } \\
\text { Pete Smith Peak } \\
\text { See Sinkhole Pond } \\
\text { Pete Smith Peak } \\
\text { See Smith Peak } \\
\text { Petes Mountain } \\
\text { See Pete Mountain } \\
\text { Pete Spring } \\
\text { Petes Retreat Pond }\end{array}$ & $\begin{array}{l}\text { well } \\
\text { summit } \\
\text { lake } \\
\text { summit } \\
\text { summit } \\
\text { spring } \\
\text { lake }\end{array}$ & $\begin{array}{l}\text { UNOFF } \\
\text { BGN } \\
\text { VARIANT } \\
\text { VARIANT } \\
\text { VARIANT } \\
\text { BGN } \\
\text { BGN }\end{array}$ & $\begin{array}{l}\text { Pinal } \\
\text { Gila } \\
\text { Mohave } \\
\text { Yuma } \\
\text { Santa Cruz } \\
\text { Apache } \\
\text { Navajo }\end{array}$ & $\begin{array}{l}323234 \mathrm{~N} 1102702 \mathrm{~W} \\
341330 \mathrm{~N} 1114125 \mathrm{~W} \\
362921 \mathrm{~N} 1132419 \mathrm{~W} \\
340354 \mathrm{~N} 1132118 \mathrm{~W} \\
\\
314227 \mathrm{~N} 1105343 \mathrm{~W} \\
354840 \mathrm{~N} 1095858 \mathrm{~W} \\
340927 \mathrm{N1} 100012 \mathrm{~W}\end{array}$ & & & $\begin{array}{l}\text { Big Willow Spr Can } \\
\text { Show Low South }\end{array}$ \\
\hline $\begin{array}{l}\text { Petes Tank } \\
\text { Petes Tank } \\
\text { Petes Tank } \\
\text { Petes Tank } \\
\text { Petes Wash } \\
\text { Petes We11 } \\
\text { Pete Tank } \\
\text { Pete Tank } \\
\text { Pete Tank } \\
\text { Petrie Railroad Station }\end{array}$ & $\begin{array}{l}\text { reservoir } \\
\text { reservoir } \\
\text { reservoir } \\
\text { reservoir } \\
\text { stream } \\
\text { well } \\
\text { reservoir } \\
\text { reservoir } \\
\text { reservoir } \\
\text { building }\end{array}$ & $\begin{array}{l}\text { BGN } \\
\text { BGN } \\
\text { BGN } \\
\text { BGN } \\
\text { BGN } \\
\text { UNOFF } \\
\text { BGN } \\
\text { BGN } \\
\text { BGN } \\
\text { UNOFF }\end{array}$ & $\begin{array}{l}\text { Coconino } \\
\text { Coconino } \\
\text { Yavapai } \\
\text { Navajo } \\
\text { Yuma } \\
\text { Yuma } \\
\text { Santa Cruz } \\
\text { Gila } \\
\text { Coconino } \\
\text { Pima }\end{array}$ & 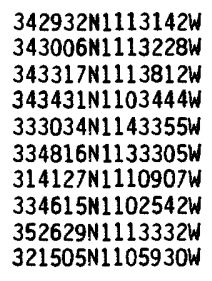 & $332609 \mathrm{~N} 1142424 \mathrm{~W}$ & 1840 & $\begin{array}{l}\text { Strawberry } \\
\text { Buckhorn Mountain } \\
\text { Walker Mtn } \\
\text { Red Knoll } \\
\text { Blythe } \\
\text { Salome } \\
\text { Saucito Mtn } \\
\text { Beckers Butte } \\
\text { O'Leary Peak } \\
\text { Tucson North }\end{array}$ \\
\hline $\begin{array}{l}\text { Petrified Creek } \\
\text { Petrified Forest } \\
\text { Petrified Forest National } \\
\text { Monument } \\
\text { See Petrified Forest }\end{array}$ & $\begin{array}{l}\text { stream } \\
\text { area }\end{array}$ & $\begin{array}{l}\text { BGN } \\
\text { BGN } \\
\text { VARIANT }\end{array}$ & $\begin{array}{l}\text { Navajo } \\
\text { Apache } \\
\text { Navajo }\end{array}$ & $\begin{array}{l}340524 \mathrm{~N} 1100045 \mathrm{~W} \\
355432 \mathrm{~N} 1093447 \mathrm{~W} \\
350001 \mathrm{~N} 1094800 \mathrm{~W}\end{array}$ & $340716 \mathrm{~N} 1095848 \mathrm{~W}$ & & $\begin{array}{l}\text { Faught Ridge } \\
\text { Beautiful Val Well }\end{array}$ \\
\hline $\begin{array}{l}\text { Petrified Forest National Park } \\
\text { Petrified Forest } \\
\text { National Monument } \\
\text { Petrified Forest Overpass }\end{array}$ & park & $\begin{array}{l}\text { ADMIN } \\
\text { VARIANT }\end{array}$ & Navajo & $350001 \mathrm{~N} 1094800 \mathrm{~W}$ & & & Petrified Forest \\
\hline Petrified Forest Overpass & crossing & UNOFF & Apache & $350252 \mathrm{~N} 1094808 \mathrm{~W}$ & & & Kachina Point \\
\hline $\begin{array}{l}\text { Petrified Forest Tank } \\
\text { Petrified Tank } \\
\text { Petroglyphs Tank } \\
\text { Petroglyph Wash } \\
\text { Pet Tank } \\
\text { Petterson Tank } \\
\text { Pettis Ranch } \\
\text { Petty Knoll } \\
\text { Peveler Chimney Spring } \\
\quad \text { Pelveler Chimney Spring }\end{array}$ & $\begin{array}{l}\text { reservoir } \\
\text { reservoir } \\
\text { reservoir } \\
\text { valley } \\
\text { reservoir } \\
\text { reservoir } \\
\text { locale } \\
\text { summit } \\
\text { spring }\end{array}$ & $\begin{array}{l}\text { BGN } \\
\text { BGN } \\
\text { BGN } \\
\text { BGN } \\
\text { BGN } \\
\text { BGN } \\
\text { UNOFF } \\
\text { BGN } \\
\text { BGN 1974 } \\
\text { VARIANT }\end{array}$ & $\begin{array}{l}\text { Navajo } \\
\text { Navajo } \\
\text { Coconino } \\
\text { Mohave } \\
\text { Yavapai } \\
\text { Maricopa } \\
\text { Navajo } \\
\text { Mohave } \\
\text { Gila }\end{array}$ & $\begin{array}{l}345034 \mathrm{~N} 1095142 \mathrm{~W} \\
340620 \mathrm{~N} 1100015 \mathrm{~W} \\
355758 \mathrm{~N} 1114024 \mathrm{~W} \\
360539 \mathrm{N1143009W} \\
352051 \mathrm{~N} 1130109 \mathrm{~W} \\
331550 \mathrm{~N} 1125705 \mathrm{~W} \\
340013 \mathrm{N1} 1095239 \mathrm{~W} \\
362010 \mathrm{~N} 1131023 \mathrm{~W} \\
341011 \mathrm{N11} 10623 \mathrm{~W}\end{array}$ & $360203 \mathrm{~N} 1143724 \mathrm{~W}$ & 6436 & $\begin{array}{l}\text { Agate House } \\
\text { Faught Ridge } \\
\text { Hellhole Bend } \\
\text { Petroglyph Wash } \\
\text { Yampai SE } \\
\text { Gillespie } \\
\text { Indian Pine } \\
\text { Mount Logan } \\
\text { Diamond Butte }\end{array}$ \\
\hline $\begin{array}{l}\text { Peyron Ranch } \\
\text { Peyron Tank } \\
\text { Pfau Spring } \\
\text { PFE Yard (railroad) } \\
\text { Phantom Canyon } \\
\text { Phantom Creek } \\
\text { West Fork Bright Angel } \\
\text { Creek } \\
\text { West Fork Phantom Creek }\end{array}$ & $\begin{array}{l}\text { locale } \\
\text { reservoir } \\
\text { spring } \\
\text { locale } \\
\text { valley } \\
\text { stream }\end{array}$ & $\begin{array}{l}\text { UNOFF } \\
\text { BGN } \\
\text { BGN } \\
\text { BGN } \\
\text { BGN } \\
\text { BGN 1906 } \\
\text { VARIANT } \\
\text { VARIANT }\end{array}$ & $\begin{array}{l}\text { Pima } \\
\text { Pima } \\
\text { Yavapai } \\
\text { Pima } \\
\text { Coconino } \\
\text { Coconino }\end{array}$ & $\begin{array}{l}315147 \mathrm{~N} 1111556 \mathrm{~W} \\
315634 \mathrm{~N} 1111014 \mathrm{~W} \\
343621 \mathrm{N1120012 \textrm {W }} \\
321200 \mathrm{N1105600 \textrm {W }} \\
360658 \mathrm{N1120510 \textrm {W }} \\
360658 \mathrm{N1120513 \textrm {W }}\end{array}$ & $\begin{array}{l}361238 \mathrm{N1120630 \textrm {W }} \\
361234 \mathrm{N1} 120717 \mathrm{~W}\end{array}$ & & $\begin{array}{l}\text { Penitas Hills } \\
\text { Samaniego Peak } \\
\text { Cherry } \\
\text { Tucson } \\
\text { Phantom Ranch } \\
\text { Phantom Ranch }\end{array}$ \\
\hline
\end{tabular}




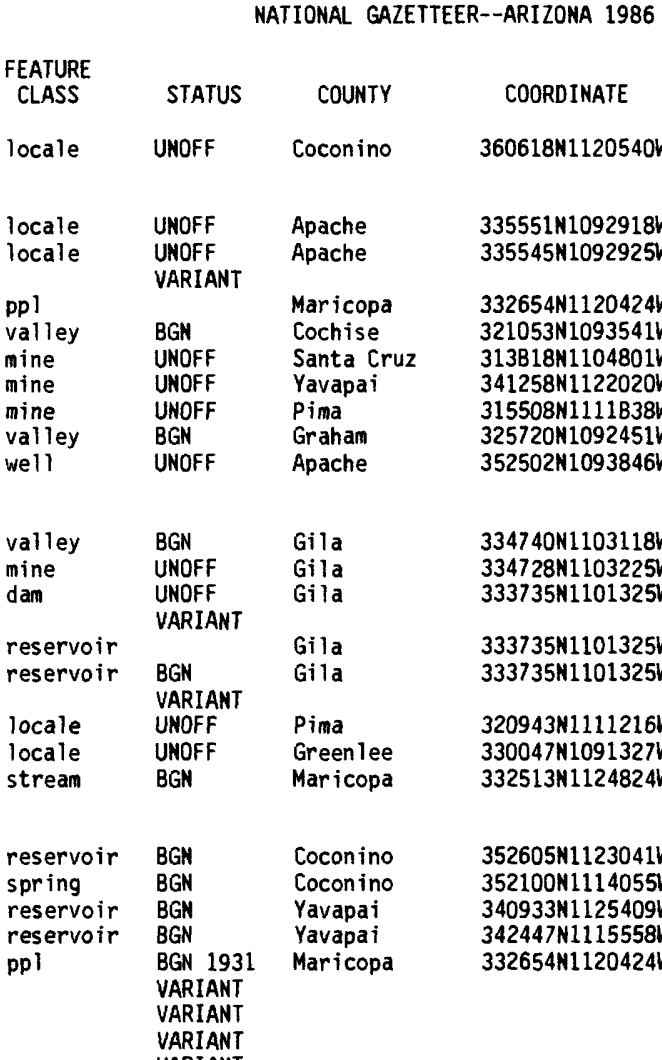

\section{FEATURE NAME}

Phantom Ranch

Phelps Fire Station

Phelps Ranch

Phenix

See Phoenix

Philadelphia Canyon

Philadelphia Mine

Philadelphia Mine

Philimena Mine

Phillip Canyon

Phillip Joe Well

Phillips Canyon

Phillips Mine

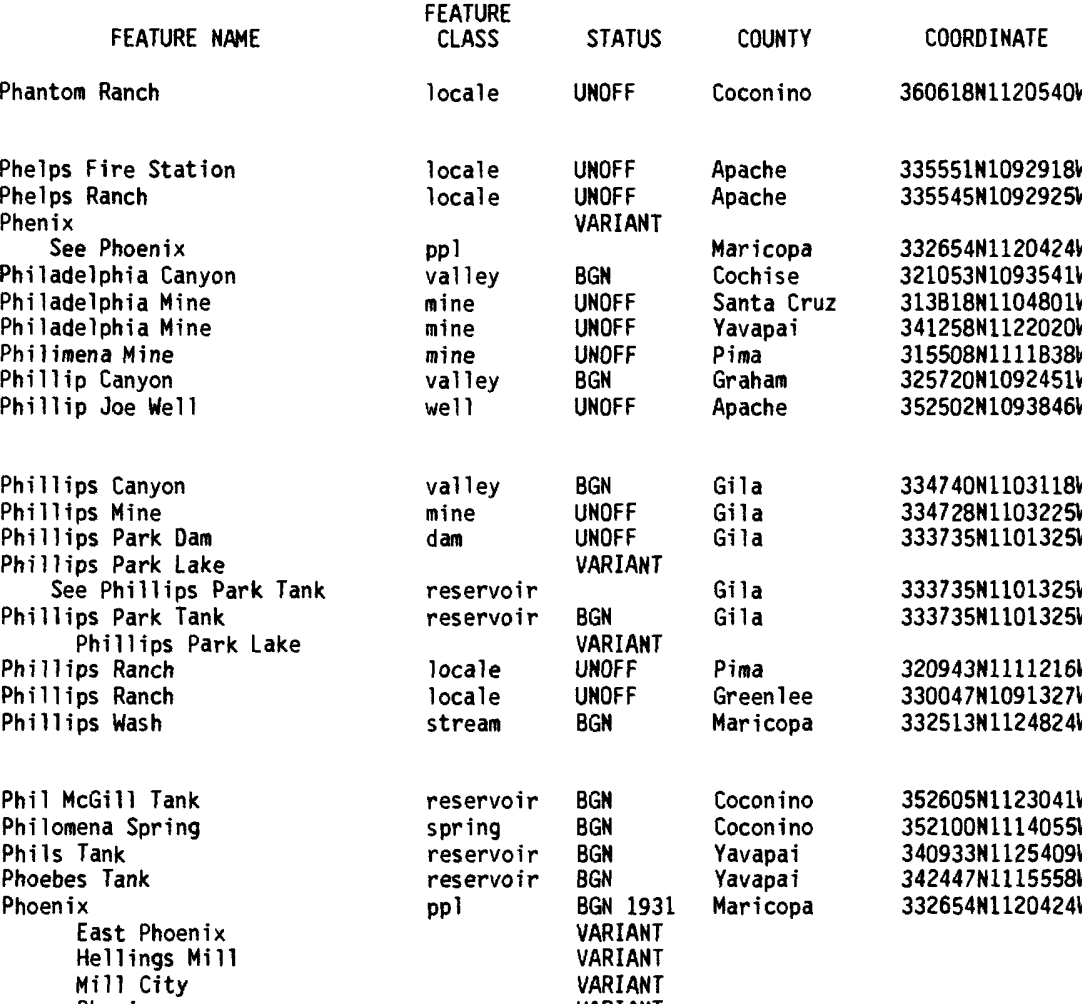

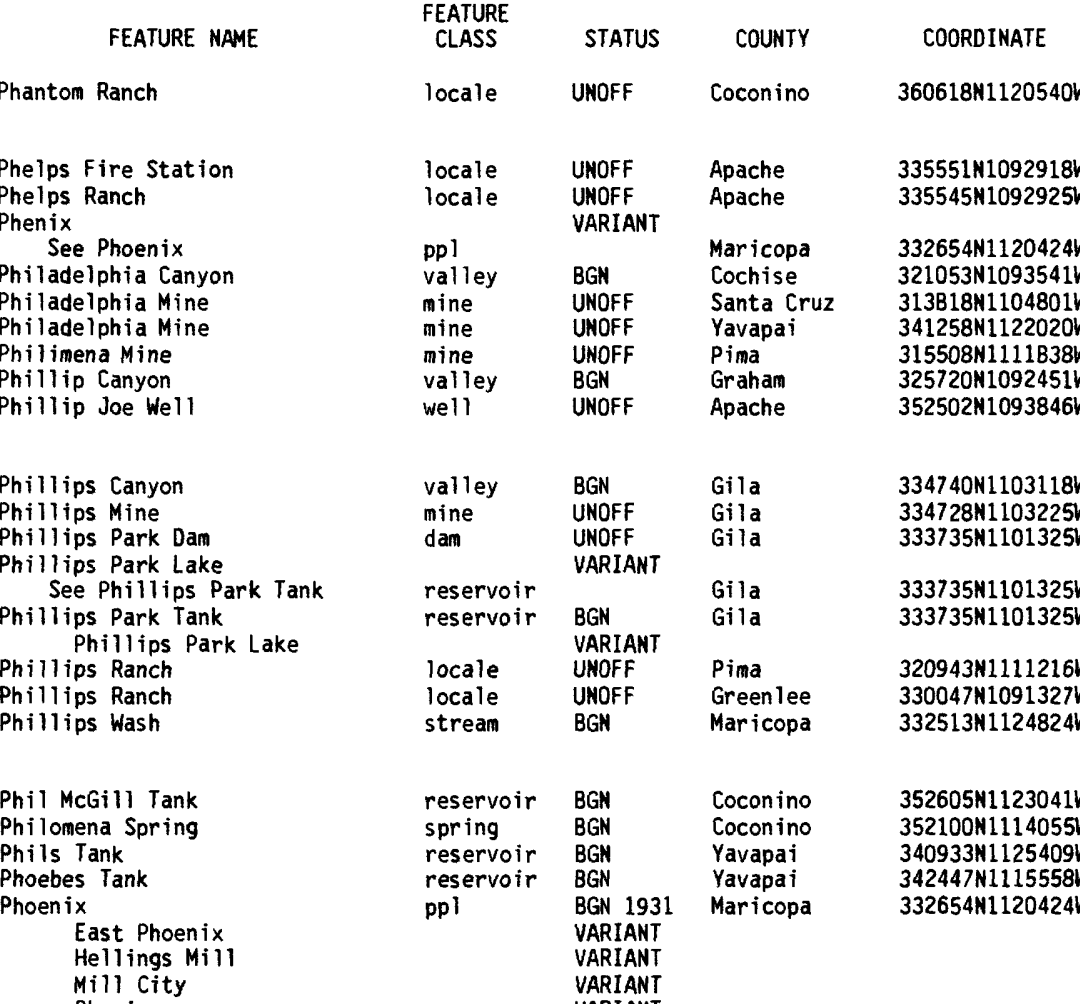

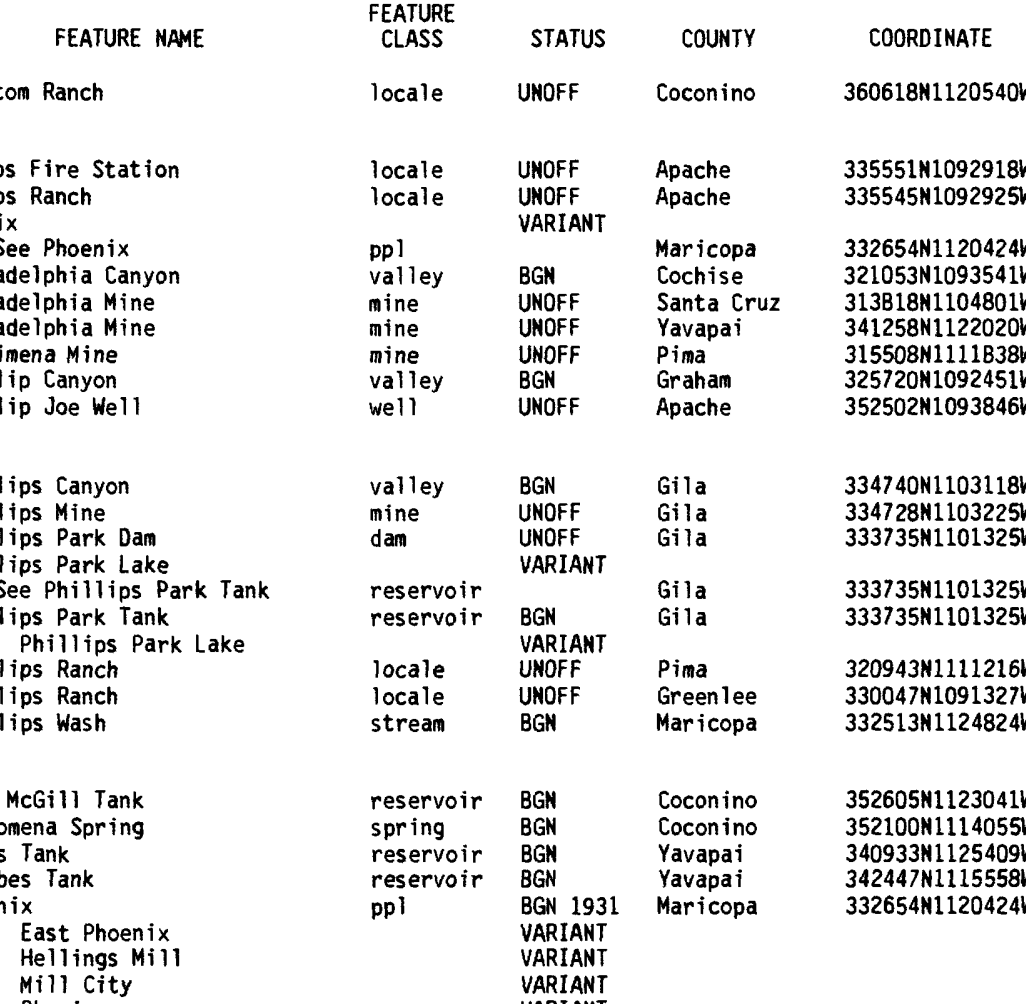

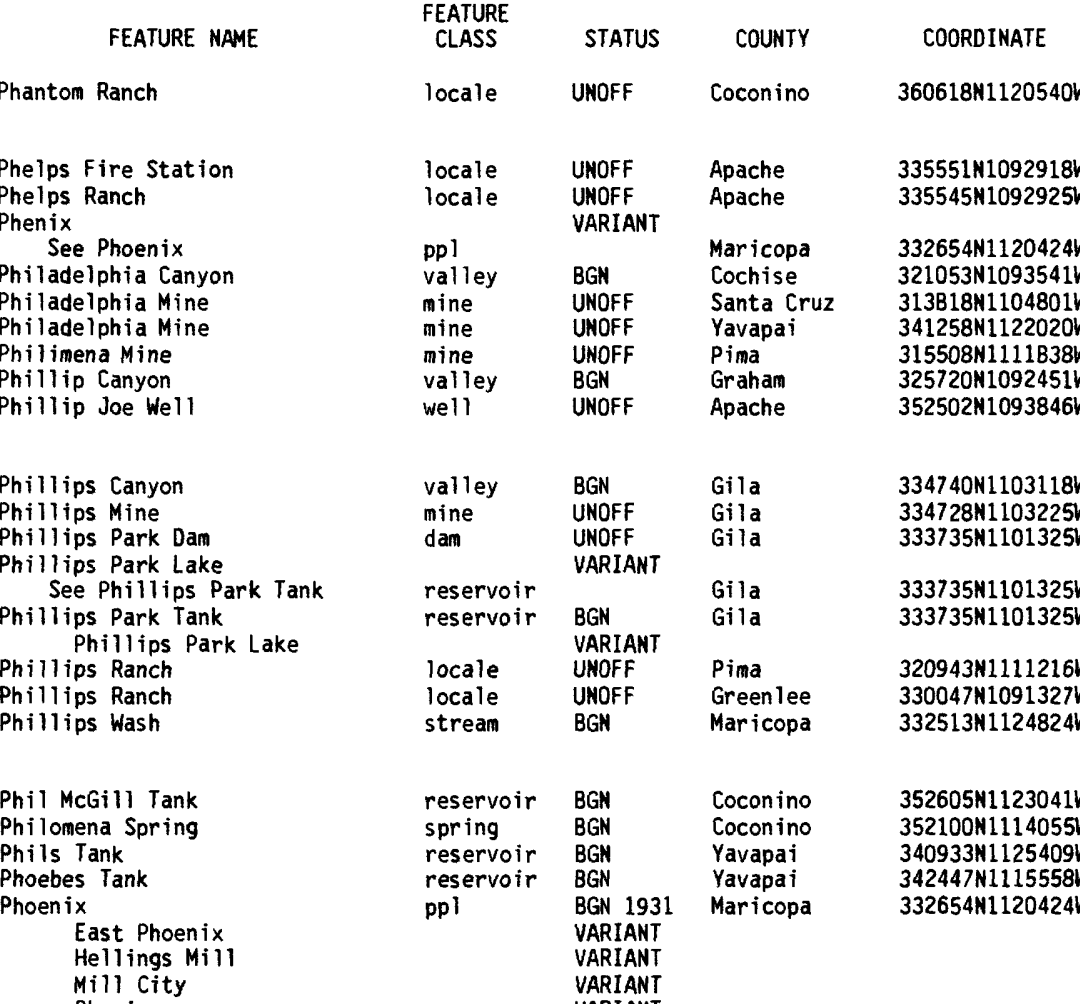

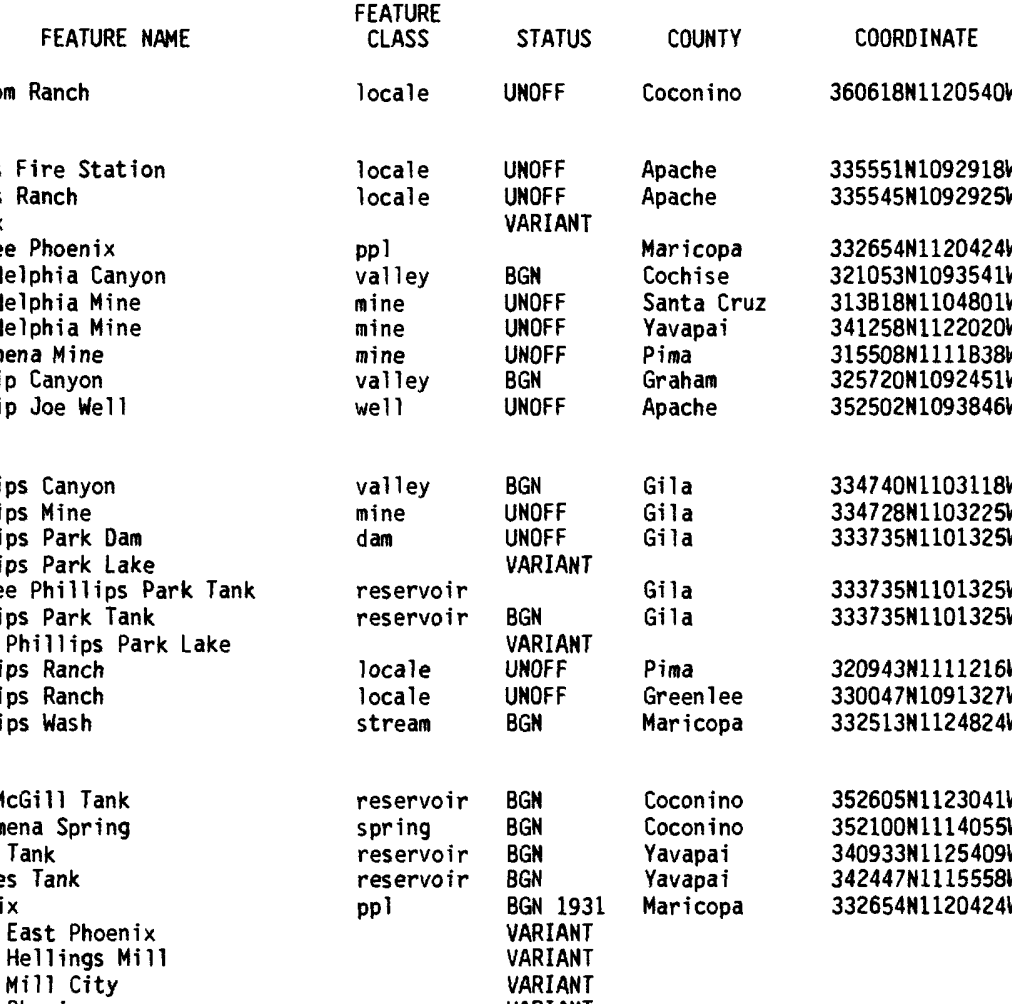

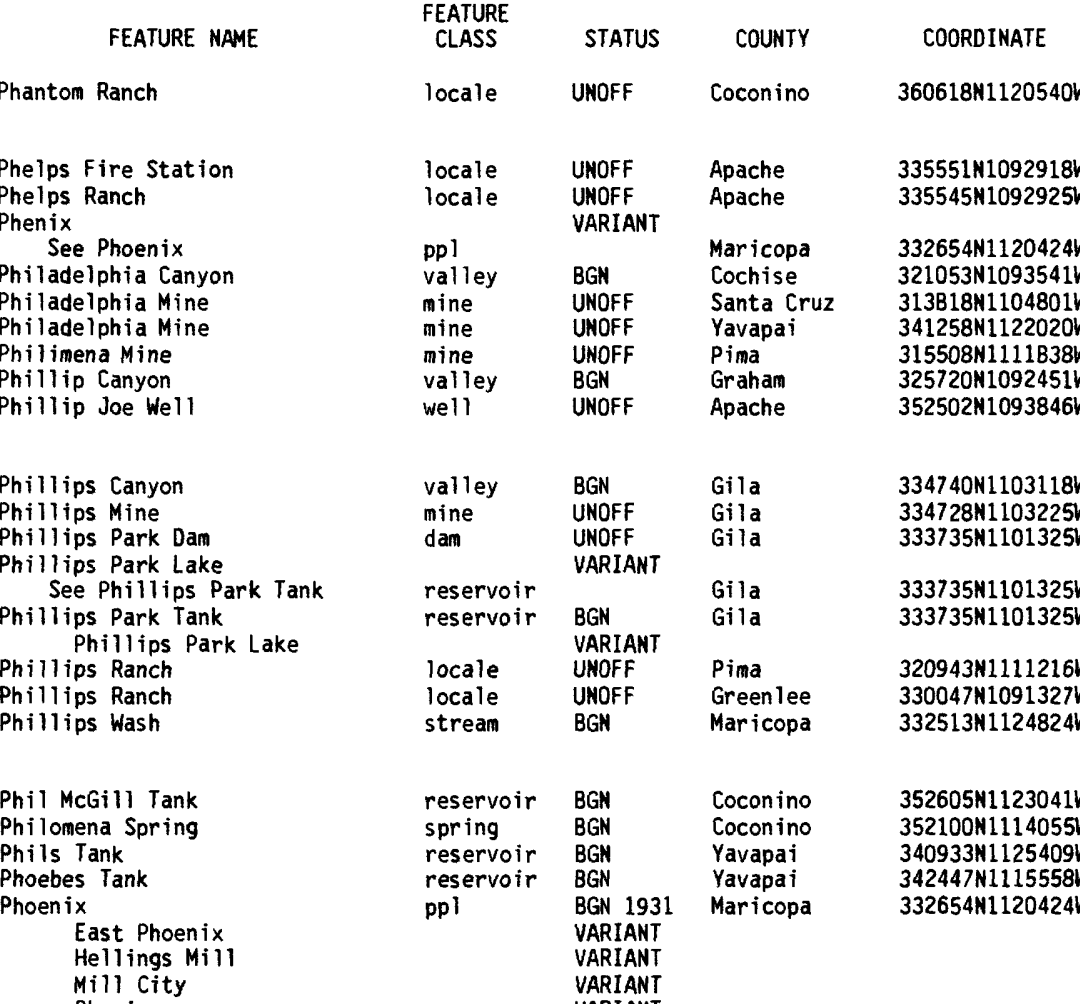

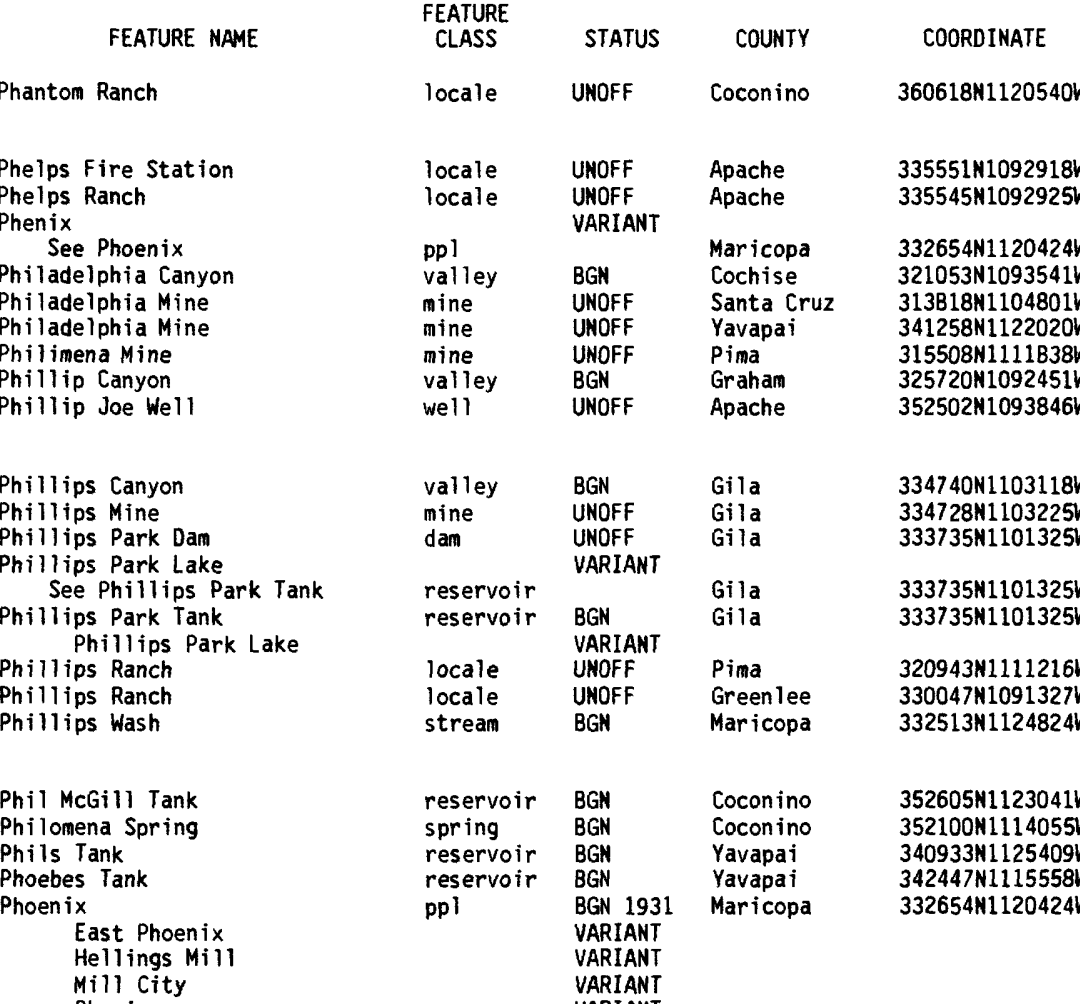

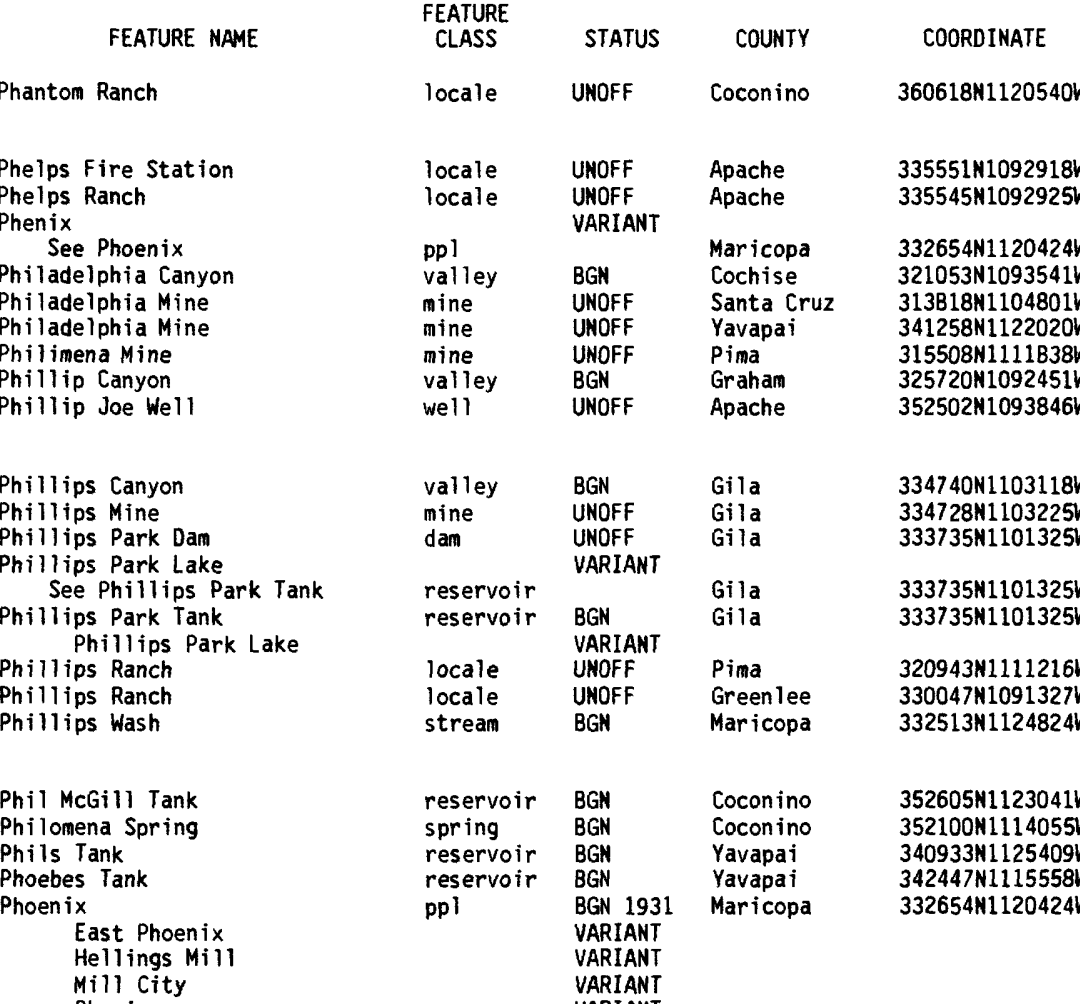

Phil McGill Tank

Philomena Spring

Phils Tank

Phoebes Tank

Phoen ix

East Phoenix

Hellings Mill

Mill City

Phenix

Pumpkinsville

Salt River

Smiths Station

Smith Station

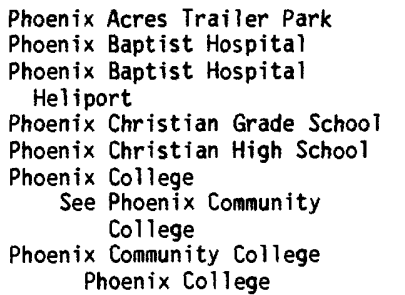

Phoenix Community Hospital

Phoenix Community Service

Center

Phoenix Deer Valley Municipal Airport

Deer Valley Airport

Phoenix District Airport

Phoen ix Filter Plant

Phoen ix General Hospital

Phoenix Giants Baseball Park See Phoenix Municipal Stadium

Phoenix Gun Club

Phoenix International Raceway

Phoenix Junior College

Phoenix Junior College

(Camelback Extension)

Phoenix Junior College

(Glendale Extension)

Phoenix Litchfield Municipal

Airport

Phoenix Medical Center

Phoenix Menorial Hospital Memorial Hospital

Phoenix Memorial Park

Phoenix Mine

$$
\begin{aligned}
& \text { FEATUR } \\
& \text { CLASS } \\
& \text { locale } \\
& \text { locale } \\
& \text { locale } \\
& \text { ppl } \\
& \text { valley } \\
& \text { mine } \\
& \text { mine } \\
& \text { mine } \\
& \text { valley } \\
& \text { well } \\
& \\
& \text { valley } \\
& \text { mine } \\
& \text { dam } \\
& \text { reservo } \\
& \text { reservoir } \\
& \text { locale } \\
& \text { locale } \\
& \text { stream } \\
& \\
& \text { reservor } \\
& \text { spring } \\
& \text { reservoir } \\
& \text { reservo } \\
& \text { ppl }
\end{aligned}
$$

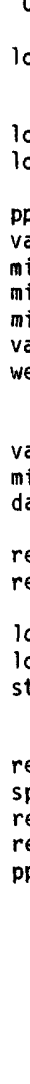$$
\text { UNOFF Maricopa 332628N1120814W }
$$

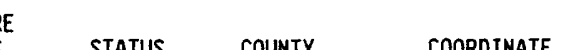

CLASS STATUS

school UNOFF Maricopa

school UNOFF Maricopa

school

hossital

building UNOFF

airport

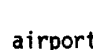

hospital

locale

school

hospital

cemet
mine airport ADMIN Maricopa

school

locale

locale

locale

school

school

airport

airpor

hospital

333123M1120814

$333129 \mathrm{N1120603 \textrm {W }}$

$332941 N 1120548 \mathrm{~W}$

332857 N1120515W

Maricopa

UNOFF Maricopa

VARIANT

MOFF

ANIM

ADMIN

VARIANT

ADMIN

UNOFF

VARIANT

Maricopa

Maricopa

Maricopa

Maricopa

Maricopa

Maricopa

Maricopa

UNOFF

UNOFF

UNOFF

UNOFF

Maricopa

Maricopa

Maricopa

Maricopa

Maricopa

Maricopa

ADMIN

$\begin{array}{ll}\text { UNOFF } & \text { Maricopa } \\ \text { VARIANT } & \\ \text { UNOFF } & \text { Maricopa } \\ \text { UNOFF } & \text { Maricopa }\end{array}$

332832N1120128W
$332113 \mathrm{~N} 1120503 \mathrm{~W}$ 332219 N1121900W

$333155 \mathrm{~N} 1120547 \mathrm{~W}$

332547 N1122150W

$332945 \mathrm{~N} 1120253 \mathrm{~W}$

332608N1120452W

$334011 \mathrm{~N} 1120435 \mathrm{~W}$ 335306 N1115700W $332857 \mathrm{N11} 20513 \mathrm{~W}$ $333035 \mathrm{~N} 1120252 \mathrm{~W}$ 9360 Big Lake North
Big Lake North

\begin{tabular}{|ll} 
321152N1093503W & $\begin{array}{l}\text { Dos Cabezas } \\
\text { Mt Wrightson } \\
\text { Crown King } \\
\text { Stevens Mtn }\end{array}$ \\
325909N1092719W & $\begin{array}{l}\text { Gila Box } \\
\text { Boggy Lake We11 }\end{array}$
\end{tabular}

334733N1103346W Mule Hoof Bend Mule Hoof Bend Forks Butte

5649 Forks Butte

Brown Mtn Rátt lesnake Spring Wintersburg

Eagle Nest Mtn Humphreys Peak 0 'Neill Pass Arnold Mesa Phoenix

1060 Fowler Sunnys lope

1174 Sunnys lope

Phoenix

Phoenix

Phoenix

Sunnys lope

Phoenix

1475 Union Hills

1050 Fowler Granite Reef Dam

Phoenix

Lone Butte

Avondale SE

Phoenix

Sunnys lope

Sunnys lope

968 


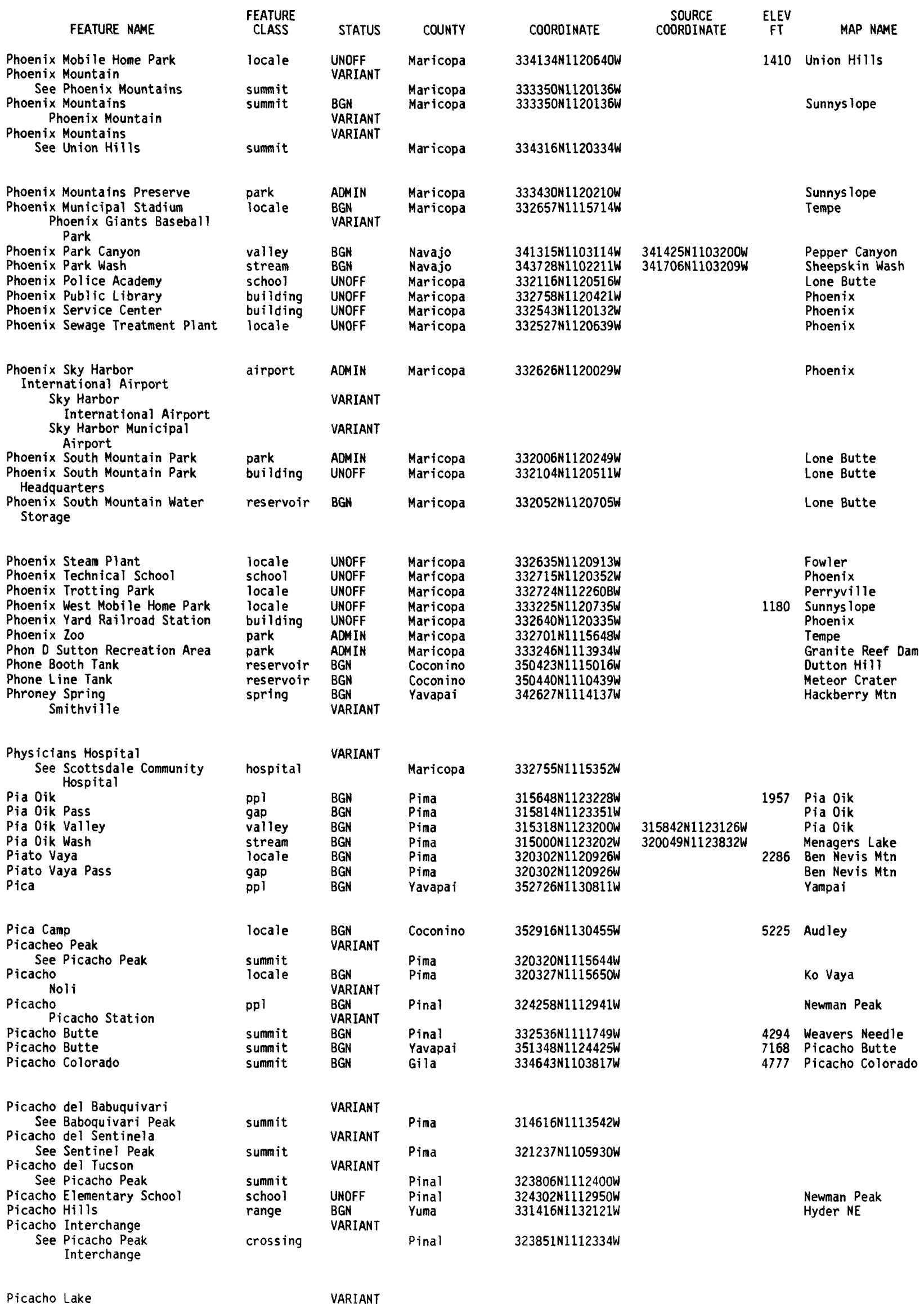


FEATURE NAME

See Picacho Reservoir Picacho Mine

Picacho Mountains

Picacho Overpass Picacho Railroad Overpass

Picacho Pass

Picacho Peak Picacheo Peak

Picacho Peak

Cerro de Tacca

Picacho del Tucson

Taceo

Tcacca Picacho Peak Interchange
Picacho Interchange

Picacho Peak State Park

Picacho Railroad Overpass See Picacho Overpass

Picacho Railroad Station

Picacho Reservoir

$$
\text { Picacho Lake }
$$

Picacho Reservoir Dam

Picacho Station

See Picacho

Picacho View Mine

Picacho Wash

Picaclo Peak Nature Trail

Picadilla Creek

$$
\text { Otero Creek }
$$
Picodica Creek

Pica Railroad Station

Pick and Drill Mine

Picket Canyon

Picket Corral Tank

Picket Corral Tank

Picket Mill Well

Picket Park

Picket Pen Tank

Picket Post See Picketpost Inn

Picket Post

See Pinal Ranch

Picket Post Creek

See Queen Creek

Picketpost Inn

Picket Post

Pinal

Pinal City

Picketpost Mountain

Pickett Corral

Pickett Junior High Schoo

Pickett Lake

Picket Trail Dugout

Pickhandle Hills

Picnic Creek

Picnic Four Area

See Midgely Bridge Picnic Area

Picnic Hill

Picnic Spring

Picnic Spring

Picnic Tank

Picnic Tank

Picnic Tank

Pico del Babuquivari See Baboquivari Peak

Pico Derecho Mountain

Picodica Creek

See Picadilla Creek

Picture Mountain Rock Mountain

Picture Rock

Picture Rocks reservoir

STATUS

COUNTY

Pinal

Pima

Pinal

Pinal

Pinal

Pima

Pinal

summit

BGI

VARIANT

VARIANT

VARIANT

VARIANT

$\begin{array}{llll}\text { crossing } & \begin{array}{l}\text { UNOFF } \\ \text { VARIANT }\end{array} & \text { Pinal } & 323851 N 1112334 \mathrm{~W} \\ \text { park } & \begin{array}{l}\text { ADMIN } \\ \text { VARIANT }\end{array} & \text { Pinal } & 343755 \mathrm{~N} 1112414 \mathrm{~W} \\ \text { crossing } & & \text { Pinal } & 324336 \mathrm{~N} 1113055 \mathrm{~W} \\ \text { building } & \text { UNOFF } & \text { Pinal } & 324258 \mathrm{~N} 1112919 \mathrm{~W} \\ \text { reservoir } & \begin{array}{l}\text { BGN } \\ \text { VARIANT }\end{array} & \text { Pinal } & 325104 \mathrm{~N} 1112920 \mathrm{~W} \\ \text { dam } & \text { UNOFF } & \text { Pinal } & 325100 \mathrm{~N} 1112924 \mathrm{~W} \\ \text { ppl } & \text { VARIANT } & \text { Pinal } & 324258 \mathrm{~N} 1112941 \mathrm{~W}\end{array}$

mine UNOFF Yavapai $\quad 335745 \mathrm{~N} 1123350 \mathrm{~W}$

stream BGN Maricopa 334125N1122527W

park ADMIN Pinal 323916N1112522W

stream BGN 1965 Maricopa 334332N1113027W

VARIANT

VARIANT

building UNOF

mine UNOFF

valley $B G N$

reservoir $B G N$

reservoir $B G$

we 11

flat

reservoir

UNOFF

BGN

BGN

VARIANT

locale

VARIANT

locale

stream

VARIANT

Yavapai

Yavapai

Cochise

Graham

$352731 \mathrm{~N} 1130807 \mathrm{~W}$

$342832 \mathrm{~N} 1120957 \mathrm{~W}$

$320119 \mathrm{~N} 1092428 \mathrm{~W}$

$331903 \mathrm{~N} 1093929 \mathrm{~W}$

Yavapai 340451N1115708W

331442N1111005W

Cochise $\quad 320137 \mathrm{N1092139W}$

Gila 341017N1111108W

Pinal

Pinal

Maricopa

331647N1110903W

332052N1105934W

331548 N1114015W

locale

BGN

VARIANT

VARIANT

VARIANT

summit $B G N$

locale

school

lake

reservoir

BGN

UNOFF

BGN

range

BGN 1966

Pinal

331647 N1110903W

Pinal

Yavapai

Pima

Coconino

Graham

Cochise

stream

BGN

park

VARIANT

summit

spring

spring

reservoir

reservoir

reservoir

BGN
BGN
BGN
BGN
BGN
BGN

Apache

Coconino

345306 N1114431W

Apache

Apache

Yavapai

Apache

Yavapai

Coconino

VARIANT

summit

summit

stream

summit

basin
BGN 1917

Pima
Gila

VARIANT

Maricopa

BGN 1965

VARIANT

BGN

VARIANT
331524 N1110925W

$350916 \mathrm{N1130932 \textrm {W }}$

$321259 \mathrm{~N} 1105014 \mathrm{~W}$

340559 N1091353h

$340540 \mathrm{~N} 1091426 \mathrm{~W}$

$340941 \mathrm{~N} 1114954 \mathrm{~W}$

$340625 \mathrm{~N} 1091228 \mathrm{~W}$

340945 N1115344W

$344804 \mathrm{~N} 1112717 \mathrm{~W}$

$334332 \mathrm{~N} 1113027 \mathrm{~W}$

$335545 \mathrm{~N} 1110947 \mathrm{~W}$

Mohave 343729N1142600W
SOURCE COORDINATE

ELEV
FT

MAP NAME

Ko Vaya

Picacho Reservoir SE

1600 Vaiva Vu

Picacho Pass

Ko Vaya

3370 Newman Peak

1790 Newman Peak

Newman Peak

Newman Peak

1505 Picacho Reservoir

Picacho Reservoir

Red Picacho

McMicken Dam

Newman Peak

334455N1112310W Adams Mesa

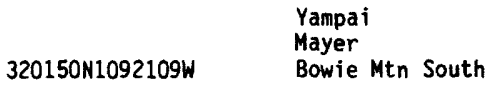

5752 Point of Pines East

Cooks Mesa

Mineral Mtn

Cochise Head

McDonald Mtn

Picketpost Mtn

$312325 \mathrm{~N} 1090700 \mathrm{~W}$

$340234 \mathrm{~N} 1091638 \mathrm{~W}$

Coyote Hills

Nelson Reservoir

Nelson Reservoir

Bloody Bas in

Nelson Reservoir

Brooklyn Peak

Hutch Mtn

6451 Picture Mtn
Castle Rock 


\begin{tabular}{|c|c|c|c|c|c|c|c|}
\hline FEATURE NAME & $\begin{array}{l}\text { FEATURE } \\
\text { CLASS }\end{array}$ & STATUS & COUNTY & COORDINATE & $\begin{array}{l}\text { SOURCE } \\
\text { COORDINATE }\end{array}$ & $\begin{array}{l}\text { ELEV } \\
\text { FT }\end{array}$ & MAP NAME \\
\hline See Painted Rock Mountains & range & & Maricopa & $325923 \mathrm{~N} 1130116 \mathrm{~W}$ & & & \\
\hline $\begin{array}{l}\text { Picture Rocks } \\
\text { Picture Rocks } \\
\text { Pidgeon Spring } \\
\text { Pidgeon Tank } \\
\text { Piebald Gulch } \\
\text { Piebald Well } \\
\text { Piedmont } \\
\text { Piedmont Well } \\
\text { Piedomont Railroad Station } \\
\text { Piedra }\end{array}$ & $\begin{array}{l}\text { summit } \\
\text { summit } \\
\text { spring } \\
\text { reservoir } \\
\text { valley } \\
\text { well } \\
\text { locale } \\
\text { well } \\
\text { building } \\
\text { locale }\end{array}$ & $\begin{array}{l}\text { BGN } \\
\text { BGN } \\
\text { BGN } \\
\text { BGN } \\
\text { BGN } \\
\text { UNOFF } \\
\text { BGN } \\
\text { UNOFF } \\
\text { UNOFF } \\
\text { BGN }\end{array}$ & $\begin{array}{l}\text { Pima } \\
\text { Pinal } \\
\text { Pima } \\
\text { Pima } \\
\text { Gila } \\
\text { Gila } \\
\text { Yavapai } \\
\text { Yavapai } \\
\text { Yavapai } \\
\text { Maricopa }\end{array}$ & $\begin{array}{l}321924 N 1110735 \mathrm{~W} \\
330026 \mathrm{~N} 1111727 \mathrm{~W} \\
322645 \mathrm{~N} 1104625 \mathrm{~W} \\
322 \mathrm{~B} 5 \mathrm{~N} 110435 \mathrm{~W} \\
332 \mathrm{~B} 09 \mathrm{~N} 1105401 \mathrm{~W} \\
332720 \mathrm{~N} 1105414 \mathrm{~W} \\
341420 \mathrm{~N} 1125149 \mathrm{~W} \\
341219 \mathrm{~N} 1115636 \mathrm{~W} \\
341420 \mathrm{~N} 1125147 \mathrm{~W} \\
325417 \mathrm{~N} 1125905 \mathrm{~W}\end{array}$ & $33270 \mathrm{BN} 1105436 \mathrm{~W}$ & $\begin{array}{l}2883 \\
1937 \\
\\
\\
3326\end{array}$ & $\begin{array}{l}\text { Avra } \\
\text { Florence SE } \\
\text { Mt Lemmon } \\
\text { Mount Bigelow } \\
\text { Inspiration } \\
\text { Inspiration } \\
\text { Congress } \\
\text { Brooklyn Peak } \\
\text { Congress } \\
\text { Theba }\end{array}$ \\
\hline $\begin{array}{l}\text { Piedra, Tanque } \\
\text { Piedragosa Tanks } \\
\text { Piedras Grandes Picnic Ground } \\
\text { Pieper Hatchery Spring } \\
\text { Pieper Tank } \\
\text { Pieper Tank } \\
\text { Pieper Tank } \\
\text { Pierce Airport } \\
\text { Pierce Canyon } \\
\quad \text { See Pearce Canyon }\end{array}$ & $\begin{array}{l}\text { reservoir } \\
\text { reservoir } \\
\text { park } \\
\text { spring } \\
\text { reservoir } \\
\text { reservoir } \\
\text { reservoir } \\
\text { airport } \\
\text { valley }\end{array}$ & $\begin{array}{l}\text { BGN } \\
\text { BGN } \\
\text { ADMIN } \\
\text { BGN } \\
\text { BGN } \\
\text { BGN } \\
\text { BGN } \\
\text { ADMIN } \\
\text { VARIANT }\end{array}$ & $\begin{array}{l}\text { Coconino } \\
\text { Santa Cruz } \\
\text { Maricopa } \\
\text { Gila } \\
\text { Coconino } \\
\text { Coconino } \\
\text { Coconino } \\
\text { Maricopa } \\
\text { Mohave }\end{array}$ & $\begin{array}{l}351805 \mathrm{~N} 112051 \mathrm{BW} \\
312031 \mathrm{~N} 1104734 \mathrm{~W} \\
332044 \mathrm{~N} 1120437 \mathrm{~W} \\
342601 \mathrm{~N} 1111527 \mathrm{~W} \\
344046 \mathrm{~N} 1110936 \mathrm{~W} \\
345132 \mathrm{~N} 1110311 \mathrm{~W} \\
345836 \mathrm{~N} 1110008 \mathrm{~W} \\
332200 \mathrm{~N} 1123705 \mathrm{~W} \\
360 \mathrm{~B} 39 \mathrm{~N} 1135812 \mathrm{~W}\end{array}$ & & & $\begin{array}{l}\text { Willians North } \\
\text { Kino Springs } \\
\text { Lone Butte } \\
\text { Kehl Ridge } \\
\text { Hay Lake } \\
\text { Chavez Mtn East } \\
\text { Chavez Mtn NE } \\
\text { Buckeye }\end{array}$ \\
\hline $\begin{array}{l}\text { Pierce Creek } \\
\text { See Fort Pearce Wash } \\
\text { Pierce Ferry } \\
\text { See Pearce Ferry } \\
\text { Pierce Ferry Boat Anchorage } \\
\text { Pierce Mountain } \\
\quad \text { Pearce Mountain } \\
\text { Pierce Park } \\
\text { Pierce Seep } \\
\text { Pierce Spring }\end{array}$ & $\begin{array}{l}\text { stream } \\
\text { locale } \\
\text { harbor } \\
\text { summit } \\
\text { park } \\
\text { spring } \\
\text { spring }\end{array}$ & $\begin{array}{l}\text { VARIANT } \\
\text { VARIANT } \\
\text { BGN } \\
\text { BGN } \\
\text { VARIANT } \\
\text { ADNIN } \\
\text { BGN } \\
\text { BGN }\end{array}$ & $\begin{array}{l}\text { Mohave } \\
\text { Mohave } \\
\text { Mohave } \\
\text { Apache } \\
\text { Maricopa } \\
\text { Navajo } \\
\text { Apache }\end{array}$ & $\begin{array}{l}370430 \mathrm{~N} 1133433 \mathrm{~W} \\
360700 \mathrm{~N} 1140000 \mathrm{~W} \\
360658 \mathrm{~N} 1140008 \mathrm{~W} \\
340836 \mathrm{~N} 1094423 \mathrm{~W} \\
332815 \mathrm{~N} 1115900 \mathrm{~W} \\
342341 \mathrm{N1} 103114 \mathrm{~W} \\
340836 \mathrm{~N} 1094424 \mathrm{~W}\end{array}$ & & & $\begin{array}{l}\text { Meadview North } \\
\text { Boundary Butte } \\
\text { Tempe } \\
\text { Heber } \\
\text { Boundary Butte }\end{array}$ \\
\hline $\begin{array}{l}\text { Pierce Tank } \\
\text { Pierce Tank } \\
\text { Pierce Wash } \\
\text { Pierce Wash } \\
\text { See Hurricane Wash } \\
\text { Pierce Wash } \\
\text { See Fort Pearce Wash } \\
\text { Pierce Wash } \\
\text { Pierce Wash Tank } \\
\text { Pierce Wash Tank }\end{array}$ & $\begin{array}{l}\text { reservoir } \\
\text { reservoir } \\
\text { stream } \\
\text { stream } \\
\text { stream } \\
\text { valley } \\
\text { reservoir } \\
\text { reservoir }\end{array}$ & $\begin{array}{l}\text { BGN } \\
\text { BGN } \\
\text { BGN } \\
\text { VARIANT } \\
\text { VARIANT } \\
\text { BGN } \\
\text { BGN } \\
\text { BGN }\end{array}$ & $\begin{array}{l}\text { Navajo } \\
\text { Coconino } \\
\text { Navajo }\end{array}$ & $\begin{array}{l}342740 \mathrm{~N} 1102917 \mathrm{~W} \\
344959 \mathrm{~N} 1112446 \mathrm{~W} \\
343601 \mathrm{~N} 1103302 \mathrm{~W} \\
370018 \mathrm{~N} 1132248 \mathrm{~W} \\
370430 \mathrm{~N} 1133433 \mathrm{~W} \\
360705 \mathrm{~N} 1140009 \mathrm{~W} \\
342833 \mathrm{~N} 1102914 \mathrm{~W} \\
343558 \mathrm{~N} 1103231 \mathrm{~W}\end{array}$ & $360602 \mathrm{~N} 1140317 \mathrm{~W}$ & & $\begin{array}{l}\text { Meadview North } \\
\text { Aripine } \\
\text { Red Knoll }\end{array}$ \\
\hline $\begin{array}{l}\text { Pierre Tank } \\
\text { Piety Hill } \\
\text { Pigeon Canyon } \\
\text { Pigeon Canyon } \\
\text { Pigeon Creek } \\
\text { Pigeon Creek } \\
\text { Pigeon Creek } \\
\text { Pigeon Pockets } \\
\text { Pigeon Point } \\
\text { Pigeon Spring }\end{array}$ & $\begin{array}{l}\text { reservoir } \\
\text { summit } \\
\text { valley } \\
\text { valley } \\
\text { stream } \\
\text { stream } \\
\text { stream } \\
\text { basin } \\
\text { cliff } \\
\text { spring }\end{array}$ & $\begin{array}{l}\text { BGN } \\
\text { BGN } \\
\text { BGN } \\
\text { BGN } \\
\text { BGN } \\
\text { BGN } \\
\text { BGN } \\
\text { BGN } \\
\text { BGN } \\
\text { BGN }\end{array}$ & $\begin{array}{l}\text { Coconino } \\
\text { Pima } \\
\text { Mohave } \\
\text { Coconino } \\
\text { Greenlee } \\
\text { Gila } \\
\text { Yavapai } \\
\text { Coconino } \\
\text { Coconino } \\
\text { Gila }\end{array}$ & $\begin{array}{l}352945 \mathrm{~N} 1113334 \mathrm{~W} \\
322110 \mathrm{~N} 1103247 \mathrm{~W} \\
361724 \mathrm{~N} 1135013 \mathrm{~W} \\
364325 \mathrm{~N} 1123031 \mathrm{~W} \\
331607 \mathrm{~N} 1091142 \mathrm{~W} \\
340414 \mathrm{~N} 1111026 \mathrm{~W} \\
341804 \mathrm{~N} 1114209 \mathrm{~W} \\
362824 \mathrm{~N} 1120057 \mathrm{~W} \\
364322 \mathrm{~N} 1123256 \mathrm{~W} \\
334245 \mathrm{~N} 1112001 \mathrm{~W}\end{array}$ & $\begin{array}{l}361720 \mathrm{~N} 1133649 \mathrm{~W} \\
364516 \mathrm{~N} 1122633 \mathrm{~W} \\
331356 \mathrm{~N} 1092310 \mathrm{~W} \\
340032 \mathrm{~N} 1111125 \mathrm{~W} \\
341803 \mathrm{~N} 1114453 \mathrm{~W}\end{array}$ & 4714 & $\begin{array}{l}\text { O'Leary Peak } \\
\text { Piety Hill } \\
\text { Grand Gulch Bench } \\
\text { Gunsight Point } \\
\text { Fritz Canyon } \\
\text { Sheep Bas in Mtn } \\
\text { Verde Hot Springs } \\
\text { Dog Point } \\
\text { Guns ight Point } \\
\text { Four Peaks }\end{array}$ \\
\hline $\begin{array}{l}\text { Pigeon Spring } \\
\text { Pigeon Spring } \\
\text { Pigeon Spring } \\
\text { Pigeon Spring } \\
\text { Pigeon Spring } \\
\text { Pigeon Spring } \\
\text { Pigeon Spring Number Two } \\
\text { Pigeon Spring Well } \\
\text { Pigeon Tank } \\
\text { Pigeon Tank }\end{array}$ & $\begin{array}{l}\text { spring } \\
\text { spring } \\
\text { spring } \\
\text { spring } \\
\text { spring } \\
\text { spring } \\
\text { spring } \\
\text { well } \\
\text { mine } \\
\text { reservoir }\end{array}$ & $\begin{array}{l}\text { BGN } \\
\text { BGN } \\
\text { BGN } \\
\text { BGN } \\
\text { BGN } \\
\text { BGN } \\
\text { BGN } \\
\text { UNOFF } \\
\text { UNOFF } \\
\text { BGN }\end{array}$ & $\begin{array}{l}\text { Gila } \\
\text { Yavapai } \\
\text { Apache } \\
\text { Navajo } \\
\text { Apache } \\
\text { Coconino } \\
\text { Apache } \\
\text { Gila } \\
\text { Gila } \\
\text { Santa Cruz }\end{array}$ & $\begin{array}{l}340010 \mathrm{~N} 1112639 \mathrm{~W} \\
342936 \mathrm{~N} 1123238 \mathrm{~W} \\
352417 \mathrm{~N} 1092959 \mathrm{~W} \\
360559 \mathrm{N1} 101904 \mathrm{~W} \\
363629 \mathrm{N1} 1092435 \mathrm{~W} \\
364325 \mathrm{~N} 1123034 \mathrm{~W} \\
35243 \mathrm{BN} 1092947 \mathrm{~W} \\
333515 \mathrm{~N} 1103107 \mathrm{~W} \\
340210 \mathrm{N1} 111156 \mathrm{~W} \\
312323 \mathrm{~N} 1103 \mathrm{~B} 35 \mathrm{~W}\end{array}$ & & 4093 & $\begin{array}{l}\text { Mazatzal Peak } \\
\text { Wilhoit } \\
\text { Wide Ruins } \\
\text { Ltl Black Spot Mtn } \\
\text { Round Rock } \\
\text { Gunsight Point } \\
\text { Wide Ruins } \\
\text { Sevenmile Mts } \\
\text { Sheep Bas in Mtn } \\
\text { Harshaw }\end{array}$ \\
\hline $\begin{array}{l}\text { Pigeon Tank } \\
\text { Pigeon Tank } \\
\text { Pigeon Tank } \\
\text { Pigeon Wash } \\
\text { Piggie Tank } \\
\text { Pigg Spring } \\
\text { See Pig Spring } \\
\text { Pigman Tank } \\
\text { Pig Pen Spring } \\
\text { Pig Pen Tank }\end{array}$ & $\begin{array}{l}\text { reservoir } \\
\text { reservoir } \\
\text { reservoir } \\
\text { valley } \\
\text { reservoir } \\
\text { spring } \\
\text { reservoir } \\
\text { spring } \\
\text { reservoir }\end{array}$ & $\begin{array}{l}\text { BGN } \\
\text { BGN } \\
\text { BGN } \\
\text { BGN } \\
\text { BGN } \\
\text { VARIANT }\end{array}$ & $\begin{array}{l}\text { Gila } \\
\text { Mohave } \\
\text { Coconino } \\
\text { Mohave } \\
\text { Gila } \\
\text { Gila } \\
\text { Coconino } \\
\text { Greenlee } \\
\text { Navajo }\end{array}$ & $\begin{array}{l}333626 \mathrm{~N} 1103409 \mathrm{~W} \\
361731 \mathrm{~N} 1133645 \mathrm{~W} \\
364405 \mathrm{~N} 1122858 \mathrm{~W} \\
36135 \mathrm{BN} 1135959 \mathrm{~W} \\
335505 \mathrm{~N} 1101302 \mathrm{~W} \\
\\
341320 \mathrm{~N} 1112535 \mathrm{~W} \\
343149 \mathrm{~N} 1111512 \mathrm{~W} \\
330023 \mathrm{~N} 1090343 \mathrm{~W} \\
342421 \mathrm{~N} 1102940 \mathrm{~W}\end{array}$ & $361724 \mathrm{~N} 1135013 \mathrm{~W}$ & & $\begin{array}{l}\text { Sevenmile Mts } \\
\text { Wildcat Ranch } \\
\text { Toothpick Ridge } \\
\text { Snap Canyon West } \\
\text { Cedar Creek }\end{array}$ \\
\hline
\end{tabular}


NATIONAL GAZETTEER--ARIZONA 1986 FEATURE NAME

Pig Spring

Pig Spring
Pigg Spring
Pig Trough Tank
Pikes Peak
Pila Cerro Well
Pilar River
See Virgin River
Pilar Tank, El

Pilas Well, Los

Pilcher Hill

Pile of Sticks

Pilgrim Playground

Pilgrim Wash

Algrim Wash

Pilgrim Wash Well

Pillars of Hercules

Pillow, The

Pillow Mountain

Pillow Mountain

Pillow Ridge

Pill Tank Number One

Pill Two Tank

Piloleno Mountain See Pinaleno Mountains

Pilot Knob

Pilot Knob

Pilot Knob Basin

Pilot Knob Spring

Pilot Knob Tank

Pilot Rock

Pilot Rock

$$
\text { Mitten Peak }
$$

Pilot Rock

See Mitten Peak

Pima (railroad station)

Pima

Pima Agency

See Sacato

Pima Air Museum

Pima and Maricopa Indian

Reservation

See Ak-Chin Indian Reservation

Pima Butte

Pima Canyon

Pima Canyon

Pima Cenetery

Pima Central School

Pima City Hall

Pima College East Campus

Pima Community College

Pima County

See Santa Cruz County

Pima County

See Cochise County

Pima County

Pima County

See Pinal County

Pima County

See Graham County

Pima County Fairgrounds

Pima County General Hospital

Pina County Rodeo Grounds

Pima County Sheriffs Office (Ajo)

Pima Elementary School

Pima Elementary School

Pima Fire Station

Pima Gap

Pima Gap Tank

FEATURE

CLASS

STATUS

COUNTY

COORDINATE

spring

reservoir

summit

well

BGN 1974 Gila

VARIANT

BGN Maricopa

$314054 N 1104607 \mathrm{~W}$

$343048 N 1090927 \mathrm{~W}$

reservoir BGN Santa Cruz

stream BGN Mohave 345531N1134031W

Well VARIANT

pillar

cape

summit

UNOFF

Mohave

Coconino

Apache

Apache

Coconino

$360919 N 1105019 \mathrm{~W}$

$362526 \mathrm{~N} 1091656 \mathrm{~W}$

range

VARIANT

summit

summit

bas in

spring

reservoir

Gila

BGN

BGN

$B G N$

Yavapai

Yavapai

Yavapai

Gila

pillar

BGN

pillar

BGN Mohave

Navajo

VARIANT

VARIANT

summit

locale

ppl

BG

Navajo

Pima

BGN Graham

pp 1

VARIANT

building

UNOFF

Pinal

Pima

VARIANT

summit

valley

valley

cemetery

school

building

school

school

civil

civil

civil

civil

civil

BGN

$B G N$

BGN

UNOFF

UNOFF

Pinal

Pinal

Pima

Maricopa

Graham

$341525 \mathrm{~N} 1112731 \mathrm{~W}$

345049 N1131623W

$345120 N 1131616$

315958 N1105702

Santa Cruz

Pima
$323203 \mathrm{N1104730W}$ $341320 \mathrm{~N} 1112535 \mathrm{~W}$

BGN Yavapai

$314750 \mathrm{~N} 1111437 \mathrm{~W}$

$360818 N 1142531 \mathrm{~W}$

well UNOFF Apache

$\begin{array}{llll}\text { summit } & \text { BGN } & \text { Maricopa } & 334233 \mathrm{~N} 1121143 \mathrm{~W} \\ \text { summit } & \text { BGN } & \text { Coconino } & 364609 \mathrm{~N} 1110347 \mathrm{~W}\end{array}$

locale UNOFF Coconino 345743N1112852W

$345328 N 1134311 \mathrm{~W}$

$355542 \mathrm{~N} 1092326 \mathrm{~W}$

361447 N1113632W

ridge $\quad$ BGN $\quad$ Navajo $\quad 353034$ N1103344W

Coconino 345936N1111125W

reservoir BGN Coconino 350012N1111010W

$323827 N 1095035 \mathrm{~W}$

$345119 \mathrm{~N} 1131530 \mathrm{~W}$

$341515 N 1112735 \mathrm{~W}$

$342443 N 1141719 \mathrm{~W}$

$350908 N 1095234 \mathrm{~W}$

350741 N1100305W

$325346 N 1094937 \mathrm{~W}$

330436 N1114419W

$320700 \mathrm{~N} 1105129 \mathrm{~W}$

$330145 N 1120452 W$

$330848 N 1120119 \mathrm{~W}$ $322115 \mathrm{~N} 1105617 \mathrm{~W}$

$332236 \mathrm{~N} 1115812 \mathrm{~W}$ $325253 \mathrm{~N} 1095013 \mathrm{~W}$ $330451 \mathrm{N1114421 \textrm {W }}$

$325348 \times 1094937 \mathrm{~W}$

$322257 \mathrm{~N} 1105316 \mathrm{~W}$ $332113 \mathrm{~N} 1120125 \mathrm{~W}$

1677

7 Pima Butte

Tucson North

Tempe

Pima

Sacaton

2850 Pima

Tucson East

Cat Mountain

$320954 N 1104902 W$

$313100 N 1110001 W$

$315555 N 1094430 \mathrm{~W}$

$320001 N 1120010 \mathrm{~W}$

$330001 \mathrm{N1113100 \textrm {W }}$

330100N1100100W

park ADMIN Pima 320242N1104703W

hospital UNOFF Pima 321120N1105810W

park ADMIN Pima 320955N1105750W

building UNOFF Pima 322300N1125125W

School UNOFF Graham 325337N1094934W

school UNOFF Maricopa 332918N1115400W

building UNOFF Graham 325342N1094337W

gap BGN Graham 330250N1094250W $\begin{array}{cc}\text { SOURCE } & \text { ELEV } \\ \text { COORDINATE } & \text { FT }\end{array}$

Tovar Mesa East

Chavez Mtn NW

Buckhead Mesa

Pilot Knob

Pilot Knob

Buckhead Mesa

Lake Havasu City S

660 Sahaurita

Tucson SE
Vainom Kug

\begin{tabular}{|c|c|}
\hline 3040 & $\begin{array}{l}\text { Tucson SE } \\
\text { Tucson } \\
\text { Tucson } \\
\text { Ajo North }\end{array}$ \\
\hline & $\begin{array}{l}\text { Pima } \\
\text { Tempe }\end{array}$ \\
\hline & $\begin{array}{l}\text { Pima } \\
\text { Bryce Mountain }\end{array}$ \\
\hline
\end{tabular}

5481 Bryce Mountain 


\begin{tabular}{|c|c|c|c|c|c|c|c|}
\hline FEATURE NAME & $\begin{array}{l}\text { FEATURE } \\
\text { CLASS }\end{array}$ & STATUS & COUNTY & COORDINATE & $\begin{array}{l}\text { SOURCE } \\
\text { COOROINATE }\end{array}$ & $\begin{array}{l}\text { ELEV } \\
\text { FT }\end{array}$ & MAP NAME \\
\hline $\begin{array}{l}\text { Pima High School } \\
\text { Pima Hospital } \\
\text { Pima Lateral } \\
\text { Pima Mine } \\
\text { Pima Mine Interchange } \\
\text { Pima Park } \\
\text { Pima Point } \\
\text { Hermit Point } \\
\text { Seri Point } \\
\text { Pima Post Office }\end{array}$ & $\begin{array}{l}\text { school } \\
\text { hospital } \\
\text { canal } \\
\text { mine } \\
\text { crossing } \\
\text { park } \\
\text { cliff } \\
\text { building }\end{array}$ & $\begin{array}{l}\text { UNOFF } \\
\text { UNOFF } \\
\text { BGN } \\
\text { UNOFF } \\
\text { UNOFF } \\
\text { ADMIN } \\
\text { BGN } 1906 \\
\text { VARIANT } \\
\text { VARIANT } \\
\text { UNOFF }\end{array}$ & $\begin{array}{l}\text { Graham } \\
\text { Pinal } \\
\text { Pinal } \\
\text { Pima } \\
\text { Pima } \\
\text { Maricopa } \\
\text { Coconino }\end{array}$ & $\begin{array}{l}325335 \mathrm{~N} 1094930 \mathrm{~W} \\
330457 \mathrm{~N} 1114504 \mathrm{~W} \\
325934 \mathrm{~N} 1113227 \mathrm{~W} \\
315856 \mathrm{~N} 1110347 \mathrm{~W} \\
320005 \mathrm{~N} 1105930 \mathrm{~W} \\
332855 \mathrm{~N} 1115342 \mathrm{~W} \\
360419 \mathrm{N1} 121158 \mathrm{~W}\end{array}$ & & 2850 & $\begin{array}{l}\text { Pima } \\
\text { Gila Butte SE } \\
\text { Coolidge } \\
\text { Twin Buttes } \\
\text { Tucson SW } \\
\text { Tempe } \\
\text { Grand Canyon }\end{array}$ \\
\hline $\begin{array}{l}\text { Pima Public Library } \\
\text { Pima Railroad Station } \\
\text { Pima Saddle } \\
\text { Pima Spring } \\
\text { Pima Spur } \\
\text { Pima Substation } \\
\text { Pima Villages } \\
\text { See Casa Blanca } \\
\text { Pima Wash } \\
\text { Pima Wash }\end{array}$ & $\begin{array}{l}\text { building } \\
\text { building } \\
\text { gap } \\
\text { spring } \\
\text { locale } \\
\text { locale } \\
\text { ppl } \\
\text { stream } \\
\text { stream }\end{array}$ & $\begin{array}{l}\text { UNOFF } \\
\text { UNOFF } \\
\text { BGN } \\
\text { BGN } \\
\text { BGN } \\
\text { UNOFF } \\
\text { VARIANT } \\
\text { BGN } \\
\text { BGN }\end{array}$ & $\begin{array}{l}\text { Graham } \\
\text { Graham } \\
\text { Pima } \\
\text { Pima } \\
\text { Pima } \\
\text { Maricopa } \\
\text { Pinal } \\
\text { Pima } \\
\text { Mohave }\end{array}$ & $\begin{array}{l}325344 N 1094337 \mathrm{~W} \\
325325 N 1094917 \mathrm{~W} \\
322259 \mathrm{N1} 105306 \mathrm{~W} \\
322255 \mathrm{~N} 1105325 \mathrm{~W} \\
320003 \mathrm{~N} 1110015 \mathrm{~W} \\
332847 \mathrm{~N} 1122530 \mathrm{~W} \\
\\
330713 \mathrm{~N} 1115315 \mathrm{~W} \\
321740 \mathrm{~N} 1105852 \mathrm{~W} \\
342743 \mathrm{~N} 1142024 \mathrm{~W}\end{array}$ & $\begin{array}{l}322257 N 1105316 \mathrm{~W} \\
342743 \mathrm{~N} 1142024 \mathrm{~W}\end{array}$ & $\begin{array}{l}2850 \\
2850 \\
2838\end{array}$ & $\begin{array}{l}\text { Pima } \\
\text { Pima } \\
\text { Oro Valley } \\
\text { Oro Valley } \\
\text { San Xavier Mission } \\
\text { Perryville } \\
\text { Tucson North } \\
\text { Lake Havasu City } s\end{array}$ \\
\hline $\begin{array}{l}\text { Pima Well } \\
\text { Pima Wells } \\
\text { See Maricopa Wells } \\
\text { Pimberton Tank } \\
\text { Pimeria Alta } \\
\text { Pimeria Alta } \\
\text { See Cochise County } \\
\text { Pimeria Well } \\
\text { Pimoria Well } \\
\text { Pimoria Well } \\
\text { See Pimeria Well }\end{array}$ & $\begin{array}{l}\text { well } \\
\text { locale } \\
\text { reservoir } \\
\text { area } \\
\text { civil } \\
\text { well } \\
\text { well }\end{array}$ & $\begin{array}{l}\text { UNOFF } \\
\text { VARIANT } \\
\text { BGN } \\
\text { BGN } \\
\text { VARIANT } \\
\text { UNOFF } \\
\text { VARIANT } \\
\text { VARIANT }\end{array}$ & $\begin{array}{l}\text { Graham } \\
\text { Pinal } \\
\text { Yavapai } \\
\text { Pima } \\
\text { Cochise } \\
\text { Yuma }\end{array}$ & $\begin{array}{l}325037 N 1095425 \mathrm{~W} \\
330943 \mathrm{~N} 1120500 \mathrm{~W} \\
344259 \mathrm{N1124019W} \\
320700 \mathrm{~N} 1120700 \mathrm{~W} \\
315555 \mathrm{~N} 1094430 \mathrm{~W} \\
324245 \mathrm{~N} 1133631 \mathrm{~W} \\
324245 \mathrm{~N} 1133631 \mathrm{~W}\end{array}$ & & 367 & $\begin{array}{l}\text { Mt Josh } \\
\text { Vainom Kug }\end{array}$ \\
\hline $\begin{array}{l}\text { Pinacate Lava Flow } \\
\text { Pinacate Valley } \\
\text { Pinal } \\
\text { See Picketpost Inn } \\
\text { Pinal } \\
\text { Pinal Camp } \\
\text { See Pinal Ranch } \\
\text { Pinal City } \\
\text { See Picketpost Inn } \\
\text { Pinal County } \\
\text { Maricopa County } \\
\text { Pima County }\end{array}$ & $\begin{array}{l}\text { lava } \\
\text { basin } \\
\text { locale } \\
\text { locale } \\
\text { locale } \\
\text { locale } \\
\text { civil }\end{array}$ & $\begin{array}{l}\text { BGN } \\
\text { BGN } \\
\text { VARIANT } \\
\text { BGN } \\
\text { VARIANT } \\
\text { VARIANT } \\
\text { AOMIN } \\
\text { VARIANT } \\
\text { VARIANT }\end{array}$ & $\begin{array}{l}\text { Yuma } \\
\text { Yuma } \\
\text { Pinal } \\
\text { Gila } \\
\text { Pinal } \\
\text { Pinal } \\
\text { Pinal }\end{array}$ & $\begin{array}{l}320643 \mathrm{~N} 1132921 \mathrm{~W} \\
320750 \mathrm{~N} 1133100 \mathrm{~W} \\
331647 \mathrm{~N} 1110903 \mathrm{~W} \\
332234 \mathrm{~N} 1104511 \mathrm{~W} \\
332052 \mathrm{~N} 1105934 \mathrm{~W} \\
331647 \mathrm{~N} 1110903 \mathrm{~W} \\
330001 \mathrm{~N} 1113100 \mathrm{~W}\end{array}$ & & 3719 & $\begin{array}{l}\text { Las Playas } \\
\text { Monument Bluff }\end{array}$ \\
\hline $\begin{array}{l}\text { Pinal County } \\
\text { See Gila County } \\
\text { Pinal County Fairgrounds } \\
\text { Pinal County Parkway Rest Area } \\
\text { Pinal County West Park } \\
\text { Pinal Creek } \\
\text { Pinal Dusters Airstrip } \\
\text { Pinaleno Mountains } \\
\text { Graham Mountain } \\
\text { Graham Mountains } \\
\text { Mount Graham } \\
\text { Piloleno Mountain } \\
\text { Pinal Leno } \\
\text { Pinal-Llano Mountains } \\
\text { Pinaleno Range } \\
\text { Pinalino Mountains } \\
\text { Pino-Leno Mountains } \\
\text { Sierra Bonita Mountains }\end{array}$ & $\begin{array}{l}\text { civil } \\
\text { park } \\
\text { locale } \\
\text { park } \\
\text { stream } \\
\text { airport } \\
\text { range }\end{array}$ & $\begin{array}{l}\text { VARIANT } \\
\text { AOMIN } \\
\text { BGN } \\
\text { AOMIN } \\
\text { BGN } 1917 \\
\text { AOMIN } \\
\text { BGN } 1950 \\
\text { VARIANT } \\
\text { VARIANT } \\
\text { VARIANT } \\
\text { VARIANT } \\
\text { VARIANT } \\
\text { VARIANT } \\
\text { VARIANT } \\
\text { VARIANT } \\
\text { VARIANT } \\
\text { VARIANT }\end{array}$ & $\begin{array}{l}\text { Gila } \\
\text { Pinal } \\
\text { Pinal } \\
\text { Pinal } \\
\text { Gila } \\
\text { Pinal } \\
\text { Graham }\end{array}$ & $\begin{array}{l}333100 \mathrm{~N} 1103100 \mathrm{~W} \\
325220 \mathrm{~N} 1113408 \mathrm{~W} \\
323510 \mathrm{~N} 1105640 \mathrm{~W} \\
325015 \mathrm{~N} 1120646 \mathrm{~W} \\
333710 \mathrm{~N} 1105459 \mathrm{~W} \\
330041 \mathrm{~N} 1120257 \mathrm{~W} \\
323827 \mathrm{~N} 1095035 \mathrm{~W}\end{array}$ & $331613 N 1104802 \mathrm{~W}$ & 1193 & $\begin{array}{l}\text { Eloy North } \\
\text { Oracle Junction } \\
\text { Indian Butte } \\
\text { Salt River Peak } \\
\text { Maricopa } \\
\text { Mt Graham }\end{array}$ \\
\hline $\begin{array}{l}\text { Pinaleno Range } \\
\text { See Pinaleno Mountains } \\
\text { Pinal General Hospital } \\
\text { Pinal ino Mountains } \\
\text { See Pinaleno Mountains } \\
\text { Pinal Leno } \\
\text { See Pinaleno Mountains } \\
\text { Pinal-Llano Mountains } \\
\text { See Pinaleno Mountains } \\
\text { Pinal Mountain }\end{array}$ & $\begin{array}{l}\text { range } \\
\text { hospital } \\
\text { range } \\
\text { range } \\
\text { range }\end{array}$ & $\begin{array}{l}\text { VARIANT } \\
\text { UNOFF } \\
\text { VARIANT } \\
\text { VARIANT } \\
\text { VARIANT } \\
\text { VARIANT }\end{array}$ & $\begin{array}{l}\text { Graham } \\
\text { Pinal } \\
\text { Graham } \\
\text { Graham } \\
\text { Graham }\end{array}$ & $\begin{array}{l}323827 N 1095035 \mathrm{~W} \\
330136 \mathrm{~N} 1112334 \mathrm{~W} \\
323827 \mathrm{~N} 1095035 \mathrm{~W} \\
323827 \mathrm{~N} 1095035 \mathrm{~W} \\
323827 \mathrm{~N} 1095035 \mathrm{~W}\end{array}$ & & & Florence \\
\hline
\end{tabular}


FEATURE NAME

See Pinal Peak

Pinal Mountains

See Coronado Mountains (historical)

Pinal Mountains

Pinal Pass

Pinal Peak

Pinal Mountain

Pinal Pioneer Parkway Rest Area

Pinal Point

Pinal Ranch

Camp Pinal

Infantry Camp

Picket Post

Pinal Camp

Pinal Ranger Station

Pinal Recreation Area

Pinal Well

Piña Sopori Ranch

Pinaveta

$$
\text { Pinevita }
$$

Pinchot Guard Station

Pinchot Springs

Pine

Pineair Ranch

See Frasers Ranch

Pineasco Creek Packing Horse Creek

Pineasco Spring

Pine Butte

Pine Mountain

Pine Canyon

Pine Canyon

Pine Canyon

Pine Canyon

Pine Canyon

Pine Canyon

See Spencer Canyon

Pine Canyon

Pine Canyon

Pine Canyon

Pine Canyon

Pine Canyon

Pine Canyon

Pine Canyon

Pine Canyon

\section{Pine Canyon Dam \\ Pine Canyon Tank \\ Pine Canyon Well \\ Pine Creek \\ Pine Creek \\ Pinon Creek \\ Pinyon Creek \\ Reevis Creek \\ Pine Creek}

Camp Creek

Pine Creek

Pine Creek

Pine Creek

Pine Creek

Pine Creek

See North Pine Creek

Pine Creek

Pine Creek

Pine Creek

Pine Creek

Pine Creek Dam

Pine Creek Seeps

Pine Creek Spring

Pine Creek Tank

Pine Creek Trail Number
FEATURE

CLASS

STATUS COUNTY

Gila

COORDINATE

331656 N1104914W

summit

VARIANT

summ it

gap

summit

locale

cliff

locale

BGN 1965

Maricopa

UNKNOWN

BGN

VARIANT

BGN

BGN 1906

UNOFF

VARIANT

VARIANT

VARIANT

VARIANT

Gila

Gila

Gila

Pinal

Coconino

Pinal

UNOFF

locale

park

well

locale

locale

locale

spring

pp 1

locale

AOMIN

UNOFF

UNOFF

BGN

VARIANT

UNOFF

BGN

BGN

VARIANT

Gila

Gila

Gila

Santa Cruz

Yavapai

Coconino

Coconino

Gila

Maricopa

$\begin{array}{ll}\text { stream } & \text { BGN } \\ & \text { VARIANT }\end{array}$

spring

summit

valley

valley

valley

valley

valley

$B G N$

VARIANT

BGN

$B G N$

BGN

BGN

BGN

VARIANT

valley

valley
valley

valley
valley

valley

valley

valley

valley

valley

BGN

BGN

BGN

BGN

BGN

BGN
BGN

Gila

Gila

Maricopa

Santa Cruz

Cochise

Cochise

Pima

Cochise

dam

dam UNOFF

well

stream

stream

BGN

BGN

Pima

Gila

Yavapai

Yavapai

Yavapai

Coconino

Mohave

Apache

Coconino

Cochise

Apache

BGN 1965 Maricopa

VARIANT

VARIANT

$\begin{array}{ll} & \text { VARIANT } \\ \text { stream } & \text { BGN } \\ & \text { VARIANT }\end{array}$

Maricopa

322309 N1104453W

$332310 \mathrm{N1092452 \textrm {W }}$

$342319 \mathrm{~N} 1112710 \mathrm{~W}$

$344335 \mathrm{~N} 1125400 \mathrm{~W}$

$345330 \mathrm{~N} 1130510 \mathrm{~W}$

$350100 \mathrm{~N} 1131618 \mathrm{~W}$

$353400 \mathrm{~N} 1125735 \mathrm{~W}$

$353440 \mathrm{~N} 1141426 \mathrm{~W}$

$35362 \mathrm{BN} 1092343 \mathrm{~W}$

$353434 N 1125854 \mathrm{~W}$

$322314 \mathrm{N1} 100915 \mathrm{~W}$

$353507 N 1092131 \mathrm{~W}$

$320134 N 1092828 \mathrm{~W}$

333611 N1111310W

315407 N1091704W

$332852 \mathrm{~N} 1110750 \mathrm{~W}$

334532 N1113015W 334803 N1112333W

$332352 \mathrm{~N} 1092209 \mathrm{~W}$

$342708 \mathrm{~N} 1112257 \mathrm{~W}$ $344900 \mathrm{~N} 1125550 \mathrm{~W}$

$345640 \mathrm{~N} 1131726 \mathrm{~W}$

$353537 \mathrm{~N} 1125955 \mathrm{~W}$

$353517 \mathrm{~N} 1141202 \mathrm{~W}$

$353509 \mathrm{~N} 1091846 \mathrm{~W}$

BGN

stre

stream

stream

stream

stream

stream

BGN
BGN

$B G N$

BGN

VARIANT

BGN Yavapai

BGN Yavapai

Yavapai

Navajo

Yavapa

stream

BGN

dan

sam

UNOFF

$\begin{array}{ll}\text { spring } & B G N \\ \text { spring } & B G N \\ \text { reservoir } & B G N \\ \text { trail } & \text { UNOFF }\end{array}$

trail UNOFF

Yavapai
Yavapai
Yavapai
Greenlee
Yavapai

$335912 \mathrm{~N} 1094912 \mathrm{~W}$

$340947 \mathrm{~N} 1105822 \mathrm{~W} \quad 341215 \mathrm{~N} 1105449 \mathrm{~W}$

$341132 \mathrm{~N} 1122423 \mathrm{~W} \quad 341303 \mathrm{~N} 1122204 \mathrm{~W}$

$341319 \mathrm{~N} 1112929 \mathrm{~W}$

$342708 \mathrm{~N} 1112257 \mathrm{~W}$

$341621 N 1122341 \mathrm{~W}$

$341942 \mathrm{~N} 1122005 \mathrm{~W}$

$342356 \mathrm{~N} 1122152 \mathrm{~W}$

$344758 \mathrm{~N} 1125356 \mathrm{~W}$

Greenlee
Yavapai

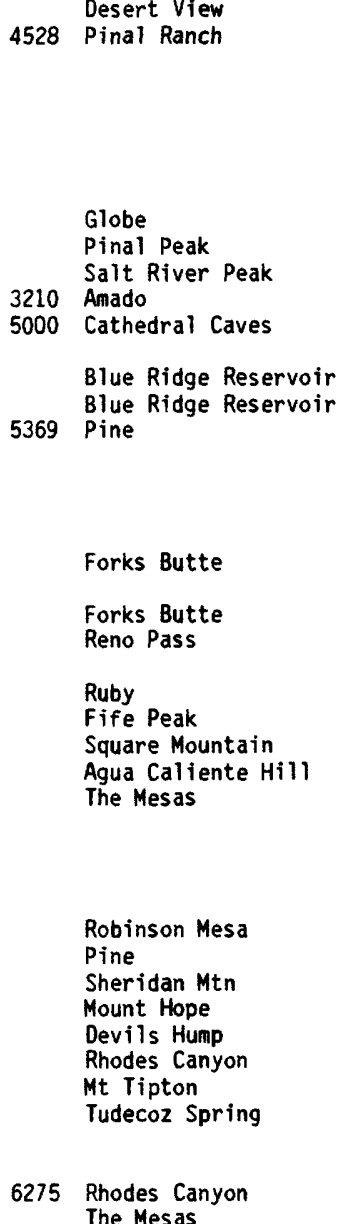

Pinal Peak

Pinal Peak

7848 Pinal Peak

2050 Cactus Forest

127 Antelope Lake

Bowie Mtn South

Pinyon Mtn

Maverick Mtn

Alchesay Flat

Oxbow Mtn

Minnehaha

North Peak

Battle Flat

Simmons

Scratch Canyon

Wineglass Ranch

Scratch Canyon 


\begin{tabular}{|c|c|c|c|c|c|c|c|}
\hline FEATURE NAME & $\begin{array}{l}\text { FEATURE } \\
\text { CLASS }\end{array}$ & STATUS & COUNTY & COORDINATE & $\begin{array}{l}\text { SOURCE } \\
\text { COORDINATE }\end{array}$ & $\begin{array}{l}\text { ELEV } \\
\text { FT }\end{array}$ & MAP NAME \\
\hline $\begin{array}{l}\text { Two-hundred Eighty-nine } \\
\text { Pine Creek Wash } \\
\text { Pine Creek Well } \\
\text { Pinecrest Park } \\
\text { Pinecrest Plaza Shopping Center }\end{array}$ & $\begin{array}{l}\text { stream } \\
\text { well } \\
\text { park } \\
\text { locale }\end{array}$ & $\begin{array}{l}\text { 8GN } \\
\text { UNOFF } \\
\text { ADMIN } \\
\text { UNOFF }\end{array}$ & $\begin{array}{l}\text { Coconino } \\
\text { Gila } \\
\text { Pima } \\
\text { Pima }\end{array}$ & $\begin{array}{l}351940 \mathrm{~N} 1121156 \mathrm{~W} \\
341007 \mathrm{~N} 1105646 \mathrm{~W} \\
321422 \mathrm{~N} 1105316 \mathrm{~W} \\
321410 \mathrm{~N} 1105316 \mathrm{~W}\end{array}$ & $351654 N 1121248 W$ & 2500 & $\begin{array}{l}\text { Williams North } \\
\text { Oxbow Mtn } \\
\text { Tucson } \\
\text { Tucson }\end{array}$ \\
\hline 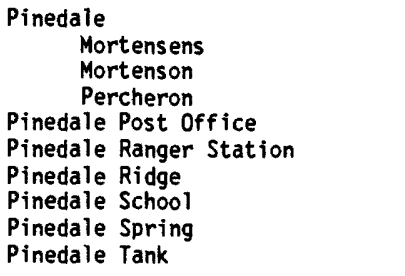 & $\begin{array}{l}\text { building } \\
\text { locale } \\
\text { ridge } \\
\text { school } \\
\text { spring } \\
\text { reservoir }\end{array}$ & $\begin{array}{l}\text { BGN } \\
\text { VARIANT } \\
\text { VARIANT } \\
\text { VARIANT } \\
\text { UNOFF } \\
\text { UNOFF } \\
\text { BGN } \\
\text { UNOFF } \\
\text { BGN } \\
\text { BGN }\end{array}$ & $\begin{array}{l}\text { Navajo } \\
\text { Navajo } \\
\text { Navajo } \\
\text { Navajo } \\
\text { Navajo } \\
\text { Navajo }\end{array}$ & $\begin{array}{l}341823 \mathrm{~N} 1101456 \mathrm{~W} \\
341817 \mathrm{~N} 1101442 \mathrm{~W} \\
341756 \mathrm{~N} 1101759 \mathrm{~W} \\
341816 \mathrm{~N} 1101453 \mathrm{~W} \\
341800 \mathrm{~N} 1101414 \mathrm{~W} \\
341918 \mathrm{~N} 1101627 \mathrm{~W}\end{array}$ & & $\begin{array}{l}6400 \\
6400\end{array}$ & $\begin{array}{l}\text { Clay Springs } \\
\text { Pinedale } \\
\text { Pinedale } \\
\text { Clay Springs } \\
\text { Pinedale } \\
\text { Pinedale } \\
\text { Clay Springs }\end{array}$ \\
\hline $\begin{array}{l}\text { Pine Flat Tank } \\
\text { Pine Flat Tank } \\
\text { Pine Flat Tank } \\
\text { Pine Flat Tank } \\
\text { Pine Flat Tank } \\
\text { Pine Flat Tank } \\
\text { Pine Flat Trail } \\
\text { Pine Flat We11 } \\
\text { Pine Grove Campground } \\
\text { Pine Grove Hill }\end{array}$ & $\begin{array}{l}\text { reservoir } \\
\text { reservoir } \\
\text { reservoir } \\
\text { reservoir } \\
\text { reservoir } \\
\text { reservoir } \\
\text { trail } \\
\text { well } \\
\text { park } \\
\text { summit }\end{array}$ & $\begin{array}{l}\text { BGN } \\
\text { BGN } \\
\text { BGN } \\
\text { BGN } \\
\text { BGN } \\
\text { BGN } \\
\text { UNOFF } \\
\text { UNOFF } \\
\text { ADMIN } \\
\text { BGN }\end{array}$ & $\begin{array}{l}\text { Graham } \\
\text { Gila } \\
\text { Gila } \\
\text { Yavapai } \\
\text { Yavapai } \\
\text { Coconino } \\
\text { Yavapai } \\
\text { Mohave } \\
\text { Coconino } \\
\text { Coconino }\end{array}$ & $\begin{array}{l}332021 \mathrm{~N} 1093800 \mathrm{~W} \\
334022 \mathrm{~N} 1100359 \mathrm{~W} \\
335855 \mathrm{~N} 1110347 \mathrm{~W} \\
344442 \mathrm{~N} 1125955 \mathrm{~W} \\
345857 \mathrm{~N} 1125249 \mathrm{~W} \\
350218 \mathrm{~N} 112082 \mathrm{~W} \\
341846 \mathrm{~N} 1115026 \mathrm{~W} \\
344023 \mathrm{~N} 1132116 \mathrm{~W} \\
350143 \mathrm{~N} 1112712 \mathrm{~W} \\
345930 \mathrm{~N} 1112823 \mathrm{~W}\end{array}$ & & $\begin{array}{l}5983 \\
4320 \\
7278\end{array}$ & $\begin{array}{l}\text { Point of Pines East } \\
\text { Velasquez Butte } \\
\text { Copper Mtn } \\
\text { Sheridan Mtn } \\
\text { Juniper Mts } \\
\text { May Tank Pocket } \\
\text { Tule Mesa } \\
\text { Negro Ed } \\
\text { Ashurst Lake } \\
\text { Mormon Lake }\end{array}$ \\
\hline $\begin{array}{l}\text { Pine Grove Number One Tank } \\
\text { Pine Grove Number Two Tank } \\
\text { Pine Gulch } \\
\text { Pine Hill } \\
\text { Pine Hill } \\
\text { Pine Hollow } \\
\text { Pine Hollow Canyon } \\
\text { Pine Hollow Trick Tank } \\
\text { Pine Lake } \\
\text { Pine Lake }\end{array}$ & $\begin{array}{l}\text { reservoir } \\
\text { reservoir } \\
\text { valley } \\
\text { summit } \\
\text { summit } \\
\text { valley } \\
\text { valley } \\
\text { reservoir } \\
\text { lake } \\
\text { lake }\end{array}$ & $\begin{array}{l}\text { BGN } \\
\text { BGN } \\
\text { BGN } \\
\text { BGN } \\
\text { BGN } \\
\text { BGN } \\
\text { BGN } \\
\text { BGN } \\
\text { BGN } \\
\text { BGN }\end{array}$ & $\begin{array}{l}\text { Coconino } \\
\text { Coconino } \\
\text { Cochise } \\
\text { Coconino } \\
\text { Coconino } \\
\text { Coconino } \\
\text { Coconino } \\
\text { Coconino } \\
\text { Apache } \\
\text { Coconino }\end{array}$ & $\begin{array}{l}345933 \mathrm{~N} 1112858 \mathrm{~W} \\
345959 \mathrm{~N} 1112949 \mathrm{~W} \\
314154 \mathrm{~N} 1092001 \mathrm{~W} \\
345602 \mathrm{~N} 1112141 \mathrm{~W} \\
351351 \mathrm{N1120345W} \\
363451 \mathrm{~N} 1123245 \mathrm{~W} \\
370048 \mathrm{~N} 1120213 \mathrm{~W} \\
363509 \mathrm{~N} 1122434 \mathrm{~W} \\
342310 \mathrm{~N} 1094629 \mathrm{~W} \\
345535 \mathrm{~N} 1112217 \mathrm{~W}\end{array}$ & $\begin{array}{l}314336 \mathrm{~N} 1091845 \mathrm{~W} \\
363322 \mathrm{~N} 1122045 \mathrm{~W} \\
365811 \mathrm{~N} 1120630 \mathrm{~W}\end{array}$ & 7332 & $\begin{array}{l}\text { Mormon Lake } \\
\text { Mormon Lake } \\
\text { Swede Peak } \\
\text { Kinnikinick Lake } \\
\text { Davenport Hill } \\
\text { Jumpup Point } \\
\text { Pine Hollow Canyon } \\
\text { Sowats Spring } \\
\text { Mesa Redonda } \\
\text { Kinnikinick Lake }\end{array}$ \\
\hline $\begin{array}{l}\text { Pine Lake } \\
\text { Pine Lake } \\
\text { Pine Lake Tank } \\
\text { Pine Log Tank } \\
\text { Pine Mountain } \\
\quad \text { Black Mountains }\end{array}$ & $\begin{array}{l}\text { lake } \\
\text { reservoir } \\
\text { reservoir } \\
\text { reservoir } \\
\text { summit }\end{array}$ & $\begin{array}{l}\text { BGN } \\
\text { BGN } \\
\text { BGN } \\
\text { BGN } \\
\text { BGN } \\
\text { VARIANT }\end{array}$ & $\begin{array}{l}\text { Mohave } \\
\text { Navajo } \\
\text { Coconino } \\
\text { Greenlee } \\
\text { Maricopa }\end{array}$ & $\begin{array}{l}350521 N 1135205 W \\
340645 N 1095550 W \\
345538 N 1112214 W \\
332154 N 1091527 W \\
334456 N 1112401 W\end{array}$ & & 6236 & $\begin{array}{l}\text { Dean Peak } \\
\text { Indian Pine } \\
\text { Kinnikinick Lake } \\
\text { Pipes tem Mtn } \\
\text { Mine Mountain }\end{array}$ \\
\hline $\begin{array}{l}\text { Pine Mountain } \\
\text { Pine Mountain } \\
\text { Pine Mountain } \\
\text { See Pine Butte }\end{array}$ & $\begin{array}{l}\text { summit } \\
\text { summit } \\
\text { summit }\end{array}$ & $\begin{array}{l}\text { BGN } \\
\text { BGN } \\
\text { VARIANT }\end{array}$ & $\begin{array}{l}\text { Gila } \\
\text { Gila } \\
\text { Maricopa }\end{array}$ & $\begin{array}{l}335702 \mathrm{~N} 1105916 \mathrm{~W} \\
335843 \mathrm{~N} 1110818 \mathrm{~W} \\
335913 \mathrm{~N} 1112607 \mathrm{~W}\end{array}$ & & $\begin{array}{l}6704 \\
6028\end{array}$ & $\begin{array}{l}\text { McFadden Peak } \\
\text { Picture Mtn }\end{array}$ \\
\hline $\begin{array}{l}\text { Pine Mountain } \\
\text { Pine Mountain } \\
\text { Pine Mountain } \\
\text { Pine Mountain Mine } \\
\text { Pine Mountain Mine } \\
\text { Pine Mountains } \\
\text { See Uinkaret Mountains } \\
\text { Pine Mountain Tank } \\
\text { Pine Mountain Tank } \\
\text { Pine Mountain Trail }\end{array}$ & $\begin{array}{l}\text { summit } \\
\text { summit } \\
\text { summit } \\
\text { mine } \\
\text { mine } \\
\text { range } \\
\text { reservoir } \\
\text { reservoir } \\
\text { trail }\end{array}$ & $\begin{array}{l}\text { BGN } \\
\text { BGN } \\
\text { BGN } \\
\text { UNOFF } \\
\text { UNOFF } \\
\text { VARIANT } \\
\text { BGN } \\
\text { BGN } \\
\text { UNOFF }\end{array}$ & $\begin{array}{l}\text { Yavapai } \\
\text { Yavapai } \\
\text { Coconino } \\
\text { Maricopa } \\
\text { Yavapai } \\
\text { Mohave } \\
\text { Gila } \\
\text { Coconino } \\
\text { Maricopa }\end{array}$ & $\begin{array}{l}341750 \mathrm{~N} 1114706 \mathrm{~W} \\
342011 \mathrm{~N} 1122400 \mathrm{~W} \\
344533 \mathrm{~N} 1112042 \mathrm{~W} \\
335845 \mathrm{~N} 1112653 \mathrm{~W} \\
342716 \mathrm{~N} 1122325 \mathrm{~W} \\
\\
361911 \mathrm{~N} 1131045 \mathrm{~W} \\
335819 \mathrm{~N} 1110241 \mathrm{~W} \\
350155 \mathrm{~N} 1121021 \mathrm{~W} \\
334549 \mathrm{~N} 1112324 \mathrm{~W}\end{array}$ & & $\begin{array}{l}6814 \\
7996\end{array}$ & $\begin{array}{l}\text { Tule Mesa } \\
\text { Battleship Butte } \\
\text { Jaycox Mtn } \\
\text { Reno Pass } \\
\text { Groom Creek }\end{array}$ \\
\hline $\begin{array}{l}\text { Pine Park } \\
\text { Pine Park Canyon } \\
\quad \text { See Beaver Dam Wash } \\
\text { Pine Peak } \\
\text { Pine Pond } \\
\text { Pine Post Office }\end{array}$ & $\begin{array}{l}\text { flat } \\
\text { valley } \\
\text { summit } \\
\text { lake } \\
\text { building }\end{array}$ & $\begin{array}{l}\text { BGN } \\
\text { VARIANT } \\
\text { BGN } \\
\text { BGN } \\
\text { UNOFF }\end{array}$ & $\begin{array}{l}\text { Cochise } \\
\text { Mohave } \\
\text { Mohave } \\
\text { Mohave } \\
\text { Gila }\end{array}$ & $\begin{array}{l}312907 \mathrm{~N} 110232 \mathrm{BW} \\
365342 \mathrm{~N} 1135510 \mathrm{~W} \\
345227 \mathrm{~N} 1135122 \mathrm{~W} \\
361624 \mathrm{~N} 1132520 \mathrm{~W} \\
342312 \mathrm{~N} 1112716 \mathrm{~W}\end{array}$ & & 7225 & $\begin{array}{l}\text { Diamond Joe Peak } \\
\text { Grassy Mountain } \\
\text { Pine }\end{array}$ \\
\hline
\end{tabular}


NATIONAL GAZETTEER--ARIZONA 1986

\begin{tabular}{|c|c|c|c|c|c|c|c|}
\hline FEATURE NAME & $\begin{array}{l}\text { FEATURE } \\
\text { CLASS }\end{array}$ & STATUS & COUNTY & COORDINATE & $\begin{array}{c}\text { SOURCE } \\
\text { COORDINATE }\end{array}$ & $\begin{array}{l}\text { ELEV } \\
\text { FT }\end{array}$ & MAP NAME \\
\hline $\begin{array}{l}\text { Pine Ranger Station } \\
\text { Pine Reservoir } \\
\text { Pine Ridge } \\
\text { Pine Ridge }\end{array}$ & $\begin{array}{l}\text { locale } \\
\text { reservoir } \\
\text { ridge } \\
\text { ridge }\end{array}$ & $\begin{array}{l}\text { UNOFF } \\
\text { BGN } \\
\text { BGN } \\
\text { BGN }\end{array}$ & $\begin{array}{l}\text { Gila } \\
\text { Coconino } \\
\text { Cochise } \\
\text { Gila }\end{array}$ & $\begin{array}{l}342251 \mathrm{~N} 1112706 \mathrm{~W} \\
363244 \mathrm{~N} 1114202 \mathrm{~W} \\
322354 \mathrm{~N} 1100954 \mathrm{~W} \\
342034 \mathrm{~N} 1112849 \mathrm{~W}\end{array}$ & & & $\begin{array}{l}\text { Pine } \\
\text { Tanner Well } \\
\text { The Mes as } \\
\text { Buckhead Mesa }\end{array}$ \\
\hline $\begin{array}{l}\text { Pine Ridge } \\
\text { Pine Ridge } \\
\text { See Boulder Mountain } \\
\text { Pine Ridge Tank } \\
\text { Pine Ridge Tank } \\
\text { Pine Ridge Tank } \\
\text { Pine Ridge Tank } \\
\text { Pine Ridge Two Tank } \\
\text { Pinery Canyon } \\
\text { Pinery Canyon Campground }\end{array}$ & $\begin{array}{l}\text { ridge } \\
\text { summit } \\
\text { reservoir } \\
\text { reservoir } \\
\text { reservoir } \\
\text { reservoir } \\
\text { reservoir } \\
\text { valley } \\
\text { park }\end{array}$ & $\begin{array}{l}\text { BGN } \\
\text { VARIANT } \\
\text { BGN } \\
\text { BGN } \\
\text { BGN } \\
\text { BGN } \\
\text { BGN } \\
\text { BGN } \\
\text { ADMIN }\end{array}$ & $\begin{array}{l}\text { Coconino } \\
\text { Maricopa } \\
\text { Gila } \\
\text { Coconino } \\
\text { Coconino } \\
\text { Coconino } \\
\text { Coconino } \\
\text { Cochise } \\
\text { Cochise }\end{array}$ & $\begin{array}{l}350224 \mathrm{~N} 1120904 \mathrm{~W} \\
334813 \mathrm{~N} 1112531 \mathrm{~W} \\
342157 \mathrm{~N} 1112946 \mathrm{~W} \\
343825 \mathrm{~N} 1112930 \mathrm{~W} \\
343927 \mathrm{~N} 1113056 \mathrm{~W} \\
344459 \mathrm{~N} 1111914 \mathrm{~W} \\
343912 \mathrm{~N} 1112903 \mathrm{~W} \\
315853 \mathrm{~N} 1092216 \mathrm{~W} \\
315559 \mathrm{~N} 1091614 \mathrm{~W}\end{array}$ & $315517 \mathrm{~N} 1091542 \mathrm{~W}$ & & $\begin{array}{l}\text { Buckhead Mesa } \\
\text { Happy Jack } \\
\text { Apache Maid Mtn } \\
\text { Turkey Mtn } \\
\text { Happy Jack } \\
\text { Rustler Park } \\
\text { Rustler Park }\end{array}$ \\
\hline $\begin{array}{l}\text { Pinery Creek } \\
\text { Pine School } \\
\text { Pine Seep } \\
\text { Pine Spring } \\
\text { Pine Spring } \\
\text { Pine Spring } \\
\text { Pine Spring } \\
\text { Pine Spring } \\
\text { Pine Spring } \\
\text { Pine Spring }\end{array}$ & $\begin{array}{l}\text { stream } \\
\text { school } \\
\text { spring } \\
\text { reservoir } \\
\text { spring } \\
\text { spring } \\
\text { spring } \\
\text { spring } \\
\text { spring } \\
\text { spring }\end{array}$ & $\begin{array}{l}\text { BGN } \\
\text { UNOFF } \\
\text { BGN } \\
\text { BGN } \\
\text { BGN } \\
\text { BGN } \\
\text { BGN } \\
\text { BGN } \\
\text { BGN } \\
\text { BGN }\end{array}$ & $\begin{array}{l}\text { Cochise } \\
\text { Gila } \\
\text { Yavapai } \\
\text { Apache } \\
\text { Cochise } \\
\text { Greenlee } \\
\text { Gila } \\
\text { Navajo } \\
\text { Gila } \\
\text { Gila }\end{array}$ & $\begin{array}{l}320115 \mathrm{~N} 1093250 \mathrm{~W} \\
342316 \mathrm{~N} 1112716 \mathrm{~W} \\
345009 \mathrm{~N} 1125141 \mathrm{~W} \\
341017 \mathrm{~N} 1094055 \mathrm{~W} \\
315444 \mathrm{~N} 1091807 \mathrm{~W} \\
331239 \mathrm{~N} 1091731 \mathrm{~W} \\
335858 \mathrm{~N} 1102659 \mathrm{~W} \\
340226 \mathrm{~N} 1102702 \mathrm{~W} \\
340452 \mathrm{~N} 1104906 \mathrm{~W} \\
340524 \mathrm{~N} 1105000 \mathrm{~W}\end{array}$ & $315525 \mathrm{~N} 1091548 \mathrm{~W}$ & & $\begin{array}{l}\text { Pat Hills North } \\
\text { Pine } \\
\text { Seepage Mtn } \\
\text { Boundary Butte } \\
\text { Rustler Park } \\
\text { Mitchell Peak } \\
\text { Cibecue Peak } \\
\text { Cibecue } \\
\text { Gentry Mtn } \\
\text { Gentry Mtn }\end{array}$ \\
\hline $\begin{array}{l}\text { Pine Spring } \\
\text { Pine Spring } \\
\text { Pine Spring } \\
\text { See Dandy Wire Spring } \\
\text { Pine Spring } \\
\text { Pine Spring } \\
\text { Pine Spring } \\
\text { Pine Spring } \\
\text { Pine Spring } \\
\text { Pine Spring }\end{array}$ & $\begin{array}{l}\text { spring } \\
\text { spring } \\
\text { spring } \\
\text { spring } \\
\text { spring } \\
\text { spring } \\
\text { spring } \\
\text { spring } \\
\text { spring }\end{array}$ & $\begin{array}{l}\text { BGN } \\
\text { BGN } \\
\text { VARIANT } \\
\text { BGN } \\
\text { BGN } \\
\text { BGN } \\
\text { BGN } \\
\text { BGN } \\
\text { BGN }\end{array}$ & $\begin{array}{l}\text { Yavapai } \\
\text { Apache } \\
\text { Yavapai } \\
\text { Yavapai } \\
\text { Yavapai } \\
\text { Yavapai } \\
\text { Yavapai } \\
\text { Gila } \\
\text { Yavapai }\end{array}$ & $\begin{array}{l}340931 \mathrm{~N} 1122039 \mathrm{~W} \\
341015 \mathrm{~N} 1094056 \mathrm{~W} \\
341539 \mathrm{~N} 1122508 \mathrm{~W} \\
341548 \mathrm{~N} 1122546 \mathrm{~W} \\
341613 \mathrm{~N} 1122507 \mathrm{~W} \\
341832 \mathrm{~N} 1114739 \mathrm{~W} \\
342005 \mathrm{~N} 1122327 \mathrm{~W} \\
342242 \mathrm{~N} 1112320 \mathrm{~W} \\
343642 \mathrm{~N} 1120834 \mathrm{~W}\end{array}$ & & & $\begin{array}{l}\text { Battleship Butte } \\
\text { Battleship Butte } \\
\text { Tule Mesa } \\
\text { Battleship Butte } \\
\text { Pine } \\
\text { Humboldt }\end{array}$ \\
\hline $\begin{array}{l}\text { Pine Spring } \\
\text { Pine Spring } \\
\text { Pine Spring } \\
\text { Pine Spring } \\
\text { Pine Spring } \\
\text { Pine Spring } \\
\text { Pine Spring } \\
\text { Pine Spring Canyon } \\
\text { Pine Spring Draw Tank } \\
\text { Pine Springs }\end{array}$ & $\begin{array}{l}\text { spring } \\
\text { spring } \\
\text { spring } \\
\text { spring } \\
\text { spring } \\
\text { spring } \\
\text { spring } \\
\text { valley } \\
\text { reservoir } \\
\text { spring }\end{array}$ & $\begin{array}{l}\text { BGN } \\
\text { BGN } \\
\text { BGN } \\
\text { BGN } \\
\text { BGN } \\
\text { BGN } \\
\text { BGN } \\
\text { BGN } \\
\text { BGN } \\
\text { BGN }\end{array}$ & $\begin{array}{l}\text { Yavapai } \\
\text { Coconino } \\
\text { Yavapai } \\
\text { Coconino } \\
\text { Navajo } \\
\text { Navajo } \\
\text { Mohave } \\
\text { Navajo } \\
\text { Yavapai } \\
\text { Apache }\end{array}$ & $\begin{array}{l}344518 \mathrm{~N} 1125344 \mathrm{~W} \\
344628 \mathrm{~N} 1112104 \mathrm{~W} \\
345812 \mathrm{~N} 1125349 \mathrm{~W} \\
355012 \mathrm{~N} 1130552 \mathrm{~W} \\
361347 \mathrm{~N} 1100053 \mathrm{~W} \\
363701 \mathrm{~N} 1102015 \mathrm{~W} \\
365737 \mathrm{~N} 1123907 \mathrm{~W} \\
361228 \mathrm{~N} 1100250 \mathrm{~W} \\
350105 \mathrm{~N} 1124718 \mathrm{~W} \\
344118 \mathrm{~N} 1090608 \mathrm{~W}\end{array}$ & $361447 \mathrm{~N} 1100018 \mathrm{~W}$ & & $\begin{array}{l}\text { Camp Wood } \\
\text { Jaycox Mtn } \\
\text { Juniper Mts } \\
\text { Frazier Wells } \\
\text { Burnt Corn Spring } \\
\text { Marsh Pass SE } \\
\text { Kaibab } \\
\text { Burnt Corn Spring } \\
\text { Red Mountain } \\
\text { Valle Bonito NE }\end{array}$ \\
\hline $\begin{array}{l}\text { Pine Springs } \\
\text { See Pine Springs Ranch } \\
\text { Pine Springs } \\
\text { Pine Springs Airport } \\
\text { Pine Springs Interchange } \\
\text { See Devil Dog Interchange } \\
\text { Pine Springs Ranch } \\
\text { Pine Springs } \\
\text { Pine Springs Wash } \\
\text { Pine Springs Wash }\end{array}$ & $\begin{array}{l}\text { locale } \\
\text { ppl } \\
\text { airport } \\
\text { crossing } \\
\text { locale } \\
\text { stream } \\
\text { valley }\end{array}$ & $\begin{array}{l}\text { VARIANT } \\
\text { BGN } \\
\text { ADMIN } \\
\text { VARIANT } \\
\text { BGN 1977 } \\
\text { VARIANT } \\
\text { BGN } \\
\text { BGN }\end{array}$ & $\begin{array}{l}\text { Coconino } \\
\text { Apache } \\
\text { Apache } \\
\text { Coconino } \\
\text { Coconino } \\
\text { Apache } \\
\text { Apache }\end{array}$ & $\begin{array}{l}351245 N 1121645 \mathrm{~W} \\
352419 \mathrm{~N} 1091646 \mathrm{~W} \\
352403 \mathrm{~N} 1091631 \mathrm{~W} \\
\\
351313 \mathrm{~N} 1121634 \mathrm{~W} \\
351245 \mathrm{~N} 1121645 \mathrm{~W} \\
\\
344324 \mathrm{~N} 1091506 \mathrm{~W} \\
355942 \mathrm{~N} 1093807 \mathrm{~W}\end{array}$ & $\begin{array}{l}343627 N 1090129 \mathrm{~W} \\
355111 \mathrm{~N} 1095105 \mathrm{~W}\end{array}$ & 6930 & $\begin{array}{l}\text { Pine Springs } \\
\text { Pine Springs } \\
\text { McLellan Reservoir } \\
\text { Schnebly Well } \\
\text { Tolani }\end{array}$ \\
\hline $\begin{array}{l}\text { Pine Springs Well } \\
\text { Pine Springs Well } \\
\text { Pine Spring Tank } \\
\text { Pine Spring Tank } \\
\text { Pine Tank } \\
\text { Pine Tank } \\
\text { Pine Tank } \\
\text { Pine Tank } \\
\text { Pine Tank } \\
\text { Pine Tank }\end{array}$ & $\begin{array}{l}\text { well } \\
\text { well } \\
\text { reservoir } \\
\text { reservoir } \\
\text { reservoir } \\
\text { reservoir } \\
\text { reservoir } \\
\text { reservoir } \\
\text { reservoir } \\
\text { reservoir }\end{array}$ & $\begin{array}{l}\text { UNOFF } \\
\text { UNOFF } \\
\text { BGN } \\
\text { BGN } \\
\text { BGN } \\
\text { BGN } \\
\text { BGN } \\
\text { BGN } \\
\text { BGN } \\
\text { BGN }\end{array}$ & $\begin{array}{l}\text { Apache } \\
\text { Apache } \\
\text { Greenlee } \\
\text { Coconino } \\
\text { Cochise } \\
\text { Greenlee } \\
\text { Gila } \\
\text { Gila } \\
\text { Navajo } \\
\text { Navajo }\end{array}$ & $\begin{array}{l}343916 N 1090407 \mathrm{~W} \\
352430 \mathrm{~N} 1091544 \mathrm{~W} \\
332222 \mathrm{~N} 1092402 \mathrm{~W} \\
344627 \mathrm{~N} 1112102 \mathrm{~W} \\
321735 \mathrm{~N} 1095918 \mathrm{~W} \\
332137 \mathrm{~N} 1090404 \mathrm{~W} \\
334020 \mathrm{~N} 1103515 \mathrm{~W} \\
335251 \mathrm{N1} 100429 \mathrm{~W} \\
341809 \mathrm{~N} 1101346 \mathrm{~W} \\
342540 \mathrm{~N} 1102133 \mathrm{~W}\end{array}$ & & 6915 & $\begin{array}{l}\text { Valle Bonito NE } \\
\text { Pine Springs } \\
\text { Bee Canyon } \\
\text { Jaycox Mtn } \\
\text { Square Mountain } \\
\text { Maple Peak } \\
\text { Chrysotile } \\
\text { Round Top Mtn } \\
\text { Pinedale } \\
\text { Big Pug Tank }\end{array}$ \\
\hline $\begin{array}{l}\text { Pine Tank } \\
\text { Pine Tank } \\
\text { Pine Tank } \\
\text { Pine Tank } \\
\text { Pine Tank } \\
\text { Pine Tank } \\
\text { Pine Tank }\end{array}$ & $\begin{array}{l}\text { reservoir } \\
\text { reservoir } \\
\text { reservoir } \\
\text { reservoir } \\
\text { reservoir } \\
\text { reservoir } \\
\text { reservoir }\end{array}$ & $\begin{array}{l}\text { BGN } \\
B G N \\
B G N \\
B G N \\
B G N \\
B G N \\
B G N\end{array}$ & $\begin{array}{l}\text { Yavapai } \\
\text { Coconino } \\
\text { Coconino } \\
\text { Yavapai } \\
\text { Coconino } \\
\text { Coconino } \\
\text { Coconino }\end{array}$ & $\begin{array}{l}342711 \mathrm{~N} 1113633 \mathrm{~W} \\
344651 \mathrm{~N} 1111717 \mathrm{~W} \\
344837 \mathrm{~N} 1113635 \mathrm{~W} \\
345 \mathrm{~B} 48 \mathrm{~N} 1114705 \mathrm{~W} \\
350253 \mathrm{~N} 1112110 \mathrm{~W} \\
351431 \mathrm{~N} 1120355 \mathrm{~W} \\
351733 \mathrm{~N} 1121222 \mathrm{~W}\end{array}$ & & & $\begin{array}{l}\text { Strawberry } \\
\text { Jaycox Mtn } \\
\text { Stoneman Lake } \\
\text { Wilson Mountain } \\
\text { Elliott Canyon } \\
\text { Davenport Hill } \\
\text { Williams North }\end{array}$ \\
\hline
\end{tabular}




\begin{tabular}{|c|c|c|c|c|c|c|c|}
\hline FEATURE NAME & $\begin{array}{l}\text { FEATURE } \\
\text { CLASS }\end{array}$ & STATUS & COUNTY & COORDINATE & $\begin{array}{l}\text { SOURCE } \\
\text { COORDINATE }\end{array}$ & $\begin{array}{l}\text { ELEV } \\
\text { FT }\end{array}$ & MAP NAME \\
\hline $\begin{array}{l}\text { Pine Tank } \\
\text { Pine Tank Canyon } \\
\text { Pine Thicket Tank }\end{array}$ & $\begin{array}{l}\text { reservoir } \\
\text { valley } \\
\text { reservoir }\end{array}$ & $\begin{array}{l}\text { BGN } \\
B G N \\
B G N\end{array}$ & $\begin{array}{l}\text { Coconino } \\
\text { Yavapai } \\
\text { Gila }\end{array}$ & $\begin{array}{l}355036 \mathrm{~N} 1130628 \mathrm{~W} \\
344705 \mathrm{~N} 1114108 \mathrm{~W} \\
341524 \mathrm{~N} 1110903 \mathrm{~W}\end{array}$ & $344915 N 1113542 W$ & & $\begin{array}{l}\text { Frazier Wells } \\
\text { Munds Mountain } \\
\text { Diamond Point }\end{array}$ \\
\hline $\begin{array}{l}\text { Pinetop } \\
\text { Penrod } \\
\text { Pinetop Mountain } \\
\text { Pinetop Mountain } \\
\text { Pinetop Mountain Tank } \\
\text { Pinetop Post Office } \\
\text { Pinetop Springs } \\
\text { Pinetop Tank } \\
\text { Pine Tree Canyon } \\
\text { Pine Tree Pockets }\end{array}$ & $\begin{array}{l}\text { ppl } \\
\text { summit } \\
\text { summit } \\
\text { reservoir } \\
\text { building } \\
\text { spring } \\
\text { reservoir } \\
\text { valley } \\
\text { basin }\end{array}$ & $\begin{array}{l}\text { BGN } \\
\text { VARIANT } \\
\text { BGN } \\
\text { BGN } \\
\text { BGN } \\
\text { UNOFF } \\
\text { BGN } \\
\text { BGN } \\
\text { BGN } \\
\text { BGN }\end{array}$ & $\begin{array}{l}\text { Navajo } \\
\text { Navajo } \\
\text { Yavapai } \\
\text { Navajo } \\
\text { Navajo } \\
\text { Navajo } \\
\text { Yavapai } \\
\text { Apache } \\
\text { Coconino }\end{array}$ & $\begin{array}{l}340733 \mathrm{~N} 1095613 \mathrm{~W} \\
340628 \mathrm{~N} 1095616 \mathrm{~W} \\
345042 \mathrm{~N} 1125600 \mathrm{~W} \\
340608 \mathrm{~N} 1095612 \mathrm{~W} \\
340729 \mathrm{~N} 1095612 \mathrm{~W} \\
340724 \mathrm{~N} 1095456 \mathrm{~W} \\
345118 \mathrm{~N} 1125550 \mathrm{~W} \\
361517 \mathrm{~N} 1092042 \mathrm{~W} \\
365034 \mathrm{~N} 1115729 \mathrm{~W}\end{array}$ & $361632 \mathrm{~N} 1092059 \mathrm{~W}$ & $\begin{array}{l}6959 \\
7385 \\
6900\end{array}$ & $\begin{array}{l}\text { Lakeside } \\
\text { Indian Pine } \\
\text { Camp Wood } \\
\text { Indian Pine } \\
\text { Indian Pine } \\
\text { Indian Pine } \\
\text { Camp Wood } \\
\text { Red Cornfield Mesa } \\
\text { One Toe Ridge }\end{array}$ \\
\hline $\begin{array}{l}\text { Pine Tree Reservoir } \\
\text { Pine Tree Tank } \\
\text { Pine Tree Valley } \\
\text { Pine Tree Wash } \\
\text { Pine Valley } \\
\text { Horse Valley } \\
\text { Pineveta Interchange } \\
\text { See Crookton Interchange } \\
\text { Pineveta Tank } \\
\text { Pineveta Wash }\end{array}$ & $\begin{array}{l}\text { reservoir } \\
\text { reservoir } \\
\text { valley } \\
\text { valley } \\
\text { valley } \\
\\
\text { crossing } \\
\text { reservoir } \\
\text { stream }\end{array}$ & $\begin{array}{l}\text { BGN } \\
\text { BGN } \\
\text { BGN } \\
\text { BGN } \\
\text { BGN } \\
\text { VARIANT } \\
\text { VARIANT } \\
\text { BGN } \\
\text { BGN }\end{array}$ & $\begin{array}{l}\text { Coconino } \\
\text { Gila } \\
\text { Navajo } \\
\text { Navajo } \\
\text { Mohave }\end{array}$ & $\begin{array}{l}361821 \mathrm{~N} 1113238 \mathrm{~W} \\
334034 \mathrm{~N} 1103410 \mathrm{~W} \\
362059 \mathrm{~N} 1100236 \mathrm{~W} \\
362500 \mathrm{~N} 1100618 \mathrm{~W} \\
360623 \mathrm{~N} 1132659 \mathrm{~W}\end{array}$ & $\begin{array}{l}361802 \mathrm{~N} 1100216 \mathrm{~W} \\
362725 \mathrm{~N} 1100449 \mathrm{~W} \\
360714 \mathrm{~N} 1132717 \mathrm{~W}\end{array}$ & & $\begin{array}{l}\text { Bodaway Mesa } \\
\text { Chrysotile } \\
\text { Hole In Rock Valley } \\
\text { Chilchinbito Canyon } \\
\text { Whitmore Point SW }\end{array}$ \\
\hline $\begin{array}{l}\text { Pinevita } \\
\text { See Pinaveta } \\
\text { Pine Wash } \\
\text { Pine Water Spring } \\
\text { Pine Well } \\
\text { Pine Wells } \\
\text { Piney Hill } \\
\text { Piney Hill Creek } \\
\text { Piney Hill Wash } \\
\text { Piney Hill Wash } \\
\text { See Piney Hill Creek }\end{array}$ & $\begin{array}{l}\text { locale } \\
\text { stream } \\
\text { spring } \\
\text { locale } \\
\text { well } \\
\text { summit } \\
\text { stream }\end{array}$ & $\begin{array}{l}\text { VARIANT } \\
\text { 8GN } \\
\text { 8GN } \\
\text { BGN } \\
\text { UNOFF } \\
\text { BGN } \\
\text { BGN } \\
\text { VARIANT } \\
\text { VARIANT }\end{array}$ & $\begin{array}{l}\text { Yavapai } \\
\text { Apache } \\
\text { Apache } \\
\text { Mohave } \\
\text { Apache } \\
\text { Apache } \\
\text { Apache }\end{array}$ & $\begin{array}{l}351338 \mathrm{~N} 1123420 \mathrm{~W} \\
364256 \mathrm{~N} 1090441 \mathrm{~W} \\
363133 \mathrm{~N} 1091150 \mathrm{~W} \\
360938 \mathrm{~N} 1133121 \mathrm{~W} \\
354603 \mathrm{~N} 1094612 \mathrm{~W} \\
354541 \mathrm{~N} 1091005 \mathrm{~W} \\
354543 \mathrm{~N} 1090550 \mathrm{~W} \\
354543 \mathrm{~N} 1090550 \mathrm{~W}\end{array}$ & $354514 \mathrm{~N} 1091009 \mathrm{~W}$ & $\begin{array}{l}6613 \\
8102\end{array}$ & $\begin{array}{l}\text { Horse Mesa } \\
\text { Cove } \\
\text { Castle Peak } \\
\text { Steamboat Rock } \\
\text { Piney Hill } \\
\text { Fort Defiance }\end{array}$ \\
\hline $\begin{array}{l}\text { Piney Hill Wash } \\
\text { Pineyon (historical) } \\
\text { Pinon } \\
\text { Pin Head Knoll } \\
\text { Pinion Tank } \\
\text { Pink Arrow } \\
\text { Pink Cliffs } \\
\text { Pinkham Mine } \\
\text { Pinkhead Gulch } \\
\text { Pinkley Peak }\end{array}$ & $\begin{array}{l}\text { valley } \\
\text { locale } \\
\text { summit } \\
\text { reservoir } \\
\text { locale } \\
\text { cliff } \\
\text { mine } \\
\text { valley } \\
\text { summit }\end{array}$ & $\begin{array}{l}\text { BGN } \\
\text { BGN } \\
\text { VARIANT } \\
\text { BGN } \\
\text { BGN } \\
\text { BGN } \\
\text { BGN } \\
\text { UNOFF } \\
\text { BGN } \\
\text { BGN } 1945\end{array}$ & $\begin{array}{l}\text { Apache } \\
\text { Apache } \\
\text { Navajo } \\
\text { Coconino } \\
\text { Navajo } \\
\text { Navajo } \\
\text { Mohave } \\
\text { Greenlee } \\
\text { Pima }\end{array}$ & $\begin{array}{l}354542 \mathrm{~N} 1090548 \mathrm{~W} \\
\text { UNKNOWN } \\
343014 \mathrm{~N} 1100626 \mathrm{~W} \\
360429 \mathrm{~N} 1130349 \mathrm{~W} \\
354637 \mathrm{~N} 1100924 \mathrm{~W} \\
343811 \mathrm{~N} 1102106 \mathrm{~W} \\
352324 \mathrm{~N} 1141051 \mathrm{~W} \\
330416 \mathrm{~N} 1092356 \mathrm{~W} \\
320016 \mathrm{~N} 1125126 \mathrm{~W}\end{array}$ & $330610 N 1092333 W$ & 3145 & $\begin{array}{l}\text { Snowf lake } \\
\text { Vulcans Throne SE } \\
\text { Keams Canyon } \\
\text { Dry Lake NE } \\
\text { Chloride } \\
\text { Copperplate Gulch } \\
\text { Tillotson Peak }\end{array}$ \\
\hline $\begin{array}{l}\text { Pink Tank } \\
\text { Pinky Canyon } \\
\text { Pinky Tank } \\
\text { Pinnacle Crater } \\
\text { Pinnacle Mountain } \\
\quad \text { See Pinnacle Peak } \\
\text { Pinnacle Paradise (subdivision) } \\
\text { Pinnacle Peak } \\
\text { Pinnacle Peak } \\
\text { Pinnacle Mountain }\end{array}$ & $\begin{array}{l}\text { reservoir } \\
\text { valley } \\
\text { reservoir } \\
\text { crater } \\
\text { summit } \\
\text { ppl } \\
\text { summit } \\
\text { summit }\end{array}$ & $\begin{array}{l}\text { BGN } \\
\text { BGN } \\
\text { BGN } \\
\text { BGN } \\
\text { VARIANT } \\
\text { BGN } \\
\text { 8GN } \\
\text { BGN } 1966 \\
\text { VARIANT }\end{array}$ & $\begin{array}{l}\text { Pina } \\
\text { Yavapai } \\
\text { Yavapai } \\
\text { Coconino } \\
\text { Maricopa } \\
\text { Maricopa } \\
\text { Pima } \\
\text { Maricopa }\end{array}$ & $\begin{array}{l}322555 \mathrm{~N} 1103125 \mathrm{~W} \\
344415 \mathrm{~N} 1131436 \mathrm{~W} \\
344508 \mathrm{~N} 1131752 \mathrm{~W} \\
351945 \mathrm{~N} 1112855 \mathrm{~W} \\
334337 \mathrm{~N} 1115150 \mathrm{~W} \\
334205 \mathrm{~N} 1115338 \mathrm{~W} \\
322107 \mathrm{~N} 1125255 \mathrm{~W} \\
334337 \mathrm{~N} 1115150 \mathrm{~W}\end{array}$ & $343503 \mathrm{~N} 1131743 \mathrm{~W}$ & $\begin{array}{l}1280 \\
3170\end{array}$ & $\begin{array}{l}\text { Buehman Canyon } \\
\text { Bozarth Meza } \\
\text { Pilot Knob } \\
\text { Sunset Crater East }\end{array}$ \\
\hline $\begin{array}{l}\text { Pinnacle Peak Country Club } \\
\text { Estates (subdivision) }\end{array}$ & $\mathrm{ppl}$ & BGN & Maricopa & 334113 N1115338W & & 1870 & Currys Corner \\
\hline $\begin{array}{l}\text { Pinnacle Peak Estates I } \\
\text { (subdivision) }\end{array}$ & ppl & BGN & Maricopa & 334227 N1115420W & & 1970 & Currys Corner \\
\hline $\begin{array}{l}\text { Pinnacle Peak Estates II } \\
\text { (subdivision) }\end{array}$ & $\mathrm{ppl}$ & BGN & Maricopa & $334122 \mathrm{~N} 1115420 \mathrm{~W}$ & & 1850 & Currys Corner \\
\hline $\begin{array}{l}\text { Pinnacle Peak Estates III } \\
\text { (subdivision) }\end{array}$ & $\mathrm{ppl}$ & BGN & Maricopa & $334237 N 1115348 \mathrm{~W}$ & & 2030 & Currys Corner \\
\hline $\begin{array}{l}\text { Pinnacle Peak Heights } \\
\text { (subdivision) }\end{array}$ & $\mathrm{ppl}$ & BGN & Maricopa & 334144 N1115150W & & 2140 & McDowe 11 Peak \\
\hline $\begin{array}{l}\text { Pinnacle Peak Heights IV } \\
\text { (subdivision) }\end{array}$ & ppl & BGN & Maricopa & $334156 N 1115152 \mathrm{~W}$ & & 2200 & McDowe11 Peak \\
\hline $\begin{array}{l}\text { Pinnacle Peak Heights V-VI } \\
\text { (subdivision) }\end{array}$ & $\mathrm{ppl}$ & $B G N$ & Maricopa & $334130 \mathrm{~N} 1115150 \mathrm{~W}$ & & 2100 & Mc0owe1l Peak \\
\hline $\begin{array}{l}\text { Pinnacle Peak Interchange } \\
\text { Pinnacle Peak Shadows }\end{array}$ & $\begin{array}{l}\text { crossing } \\
\text { ppl }\end{array}$ & $\begin{array}{l}\text { UNOFF } \\
\text { BGN }\end{array}$ & $\begin{array}{l}\text { Maricopa } \\
\text { Maricopa }\end{array}$ & $\begin{array}{l}334200 \mathrm{~N} 1120650 \mathrm{~W} \\
334146 \mathrm{~N} 1115245 \mathrm{~W}\end{array}$ & & 2050 & $\begin{array}{l}\text { Union Hills } \\
\text { Currys Corner }\end{array}$ \\
\hline
\end{tabular}


NATIONAL GAZETTEER--ARIZONA 1986

\section{FEATURE NAME}

Pinnacle Peak Substation

Pinnacle Peak Village

Pinnacle Ridge

\section{Pinnacle Ridge Big Ridge \\ Pinnacle Rock \\ Pinnacles, The \\ Pinnacle Valley \\ Pinnacle Valley Well \\ Pino, Canyon de la Canyon de la Pino \\ Pino Blanco Canyon}

See Peña Blanca Canyon

FEATURE

CLAS

STATUS

COUNTY

COORDINATE

local
ppl

ppl
ridge

UNOFF

BGN

Maricopa

Maricopa

Graham

$334201 N 1115611 \mathrm{~W}$

$334200 \mathrm{~N} 1115404 \mathrm{~W}$

$325217 \mathrm{~N} 1101336 \mathrm{~W}$

ridge

pillar

ridge

reservoir

valley

well

valley

BGN 1979

365009 N1115444W

BGN

BGN

BGN
BGN
UNOFF

UNOFF

BGN 1977

VARIANT

valley

Coconino

Graham

Coconino

Coconino

Coconino

Pima

Santa Cruz

365709 N1111622W

$324414 N 1095219 \mathrm{~W}$

$354946 \mathrm{~N} 1130914 \mathrm{~W}$

$364911 N 1115344 \mathrm{~W}$

$364914 N 1115221 \mathrm{~W}$

$321544 \mathrm{~N} 1103742 \mathrm{~W}$

$312501 N 1110442 W$

Piño Blanco Canyon See Peña Blanca Canyon

Piño Blanco Ranch

Pino-Leno Mountains See Pinaleno Mountains Pinon See Pineyon (historical)

Pinon Boarding School

Piñon Camp

Pinon Creek

See Pine Creek

Pinon Landing Strip

Piñon Mountain Tank

Pinon Post Office

Pinon Rodeo Grounds

Pinon Spring

Piñon Spring

Pinon Tank

Piñon Tank

Piñon Tank Number One

Piñon Tank Number Two

Pinon Trading Post

Pinos, Playas de los

Pinta

Pinta, Sierra

Pintado Point

Pinta Playa

Pinta Road Interchange

Pintas, Point of the

Pinta Sands

Pinto Cow Canyon

Pinto Creek

See Rock Creek

Pinto Creek

See West Fork Pinto Creek

Pinto Creek

Pinto Creek Well

Pinto Lake

Pinto Mesa

Pinto Mesa Spring

Pinto Mesa Tank

Pinto Mesa Tank

Pinto Peak

Pinto Shaft

Pinto Spring

Pinto Spring

Pinto Spring

Pinto Spring Trough

Pinto Tank

Pinto Tank See Heart Tank

Pinto Tank

Pinto Valley Tailings Dam

Number One

Pinto Valley Tailings Dam

Number Three

\section{VARIANT}

valley

locale

range

locale

ppl

school

locale

VARIANT

UNOFF

VARIANT

VARIANT

BGN

UNOFF

BGN

Pima

Graham

Apache

Navajo

Navajo

Pinal

VARIANT

stream

airport

reservoir

building

park

spring

spring

reservoir

reservoir

ADMIN

BGN

UNOFF

ADNIN

BGN

BGN

BGN

BGN

Maricopa

Navajo

Greenlee

Navajo

Navajo

Cochise

Grahan

Apache

reservoir BGN

reservoir

locale

flat

locale

range

cliff

flat

crossing

sumnit

BGN

BGN

BGN

$B G N$

BGN

BGN

UNOFF

BGN

Greenlee

Greenlee

Navajo

Greenlee

Apache

Yuma

Apache

Yuma

Apache

Yuma

area BGN Yuma

valley

BGN

VARIANT

stream

stream

stream

well

lake

ridge

VARIANT

BGN 1965 Pinal

BGN

$$
\text { Gila }
$$

Coconino

Yavapai

spring

reservoir

reservoir

summit

mine

spring

spring

reservoir

reservoir

BGN
BGN
BGN
BGN
UNOFF
BGN
BGN
BGN
BGN
BGN

Yavapai

Gila

Yavapai

Pinal

Gila

Pima

Greenlee

Pinal

Pinal

Santa Cruz

$333611 N 1111310 \mathrm{~W}$

360603N1101333W

$360559 N 1101340 \mathrm{~W}$

$315155 \mathrm{~N} 1095845 \mathrm{~W}$

351215 N1112B1OW

$341433 \mathrm{~N} 1094954 \mathrm{~W}$

$331056 \mathrm{~N} 1091027 \mathrm{~W}$

$331135 N 1091058 \mathrm{~W}$

$360601 N 1101333 \mathrm{~W}$

$322806 \mathrm{~N} 1090259 \mathrm{~W}$

$350456 \mathrm{~N} 1093748 \mathrm{~W}$

321547 N1133232

$350452 \mathrm{~N} 1094803 \mathrm{~W}$

320909 N1132944

$350529 N 1093826 \mathrm{~W}$

322459 N1133932W

$320908 \mathrm{~N} 1133254 \mathrm{~W}$

$340652 \mathrm{~N} 1115920 \mathrm{~W}$

332617 N1110427W

$332731 \mathrm{N1110018 \textrm {W }}$

$333820 \mathrm{~N} 1105955 \mathrm{~W}$

$333455 \mathrm{~N} 1105948 \mathrm{~W}$

$342039 \mathrm{N1105027 \textrm {W }}$

$343225 N 1115625 \mathrm{~W}$

$343222 N 1115528 \mathrm{~W}$

333650 N1105918W

$343233 \mathrm{~N} 1115700 \mathrm{~W}$

$332743 \mathrm{~N} 1110706 \mathrm{~W}$

$332306 \mathrm{~N} 1105853 \mathrm{~W}$

$322459 N 1103825 \mathrm{~W}$

$330934 \mathrm{~N} 1092515 \mathrm{~W}$

$332626 \mathrm{~N} 1110349 \mathrm{~W}$

332706 N1110903W

313249 N1103525W

VARIANT

reservoir

reservoir

dam

Yuma

BGN

UNOFF

Gila

dam

UNOFF
Santa Cruz

UNOFF Gila

$360528 \mathrm{~N} 1101358 \mathrm{~W}$

$332107 \mathrm{~N} 1091346 \mathrm{~W}$

$330457 N 1102245 \mathrm{~W}$

SOURCE

COOROINATE

ELEV
FT

MAP NAME

Currys Corner

1940 Currys Corner 


\begin{tabular}{|c|c|c|c|c|c|c|c|}
\hline FEATURE NAME & $\begin{array}{l}\text { FEATURE } \\
\text { CLASS }\end{array}$ & STATUS & COUNTY & COOROINATE & $\begin{array}{l}\text { SOURCE } \\
\text { COORDINATE }\end{array}$ & $\begin{array}{c}\text { ELEV } \\
\text { FT }\end{array}$ & MAP NAME \\
\hline $\begin{array}{l}\text { Pinto Valley Tailings Dam } \\
\text { Number Two } \\
\text { Pinyon Creek } \\
\text { See Pine Creek }\end{array}$ & stream & $\begin{array}{l}\text { UNOFF } \\
\text { VARIANT }\end{array}$ & Maricopa & $332430 \mathrm{~N} 1105900 \mathrm{~W}$ & & & Inspiration \\
\hline $\begin{array}{l}\text { Pinyon Knob } \\
\text { Pinyon Mountain } \\
\text { Pinyon Tank } \\
\text { Pioneer } \\
\text { Pioneer Acres (subdivision) } \\
\text { Pioneer Bas in } \\
\text { Pioneer Cemetery } \\
\text { Pioneer Creek } \\
\text { Pioneer Elementary School } \\
\text { Pioneer Estates (subdivision) }\end{array}$ & $\begin{array}{l}\text { summit } \\
\text { summit } \\
\text { reservoir } \\
\text { ppl } \\
\text { pp } 1 \\
\text { basin } \\
\text { cemetery } \\
\text { stream } \\
\text { school } \\
\text { ppl }\end{array}$ & $\begin{array}{l}\text { BGN } \\
\text { BGN } 1965 \\
\text { BGN } \\
\text { BGN } \\
\text { BGN } \\
\text { BGN } \\
\text { UNOFF } \\
\text { BGN } \\
\text { UNOFF } \\
\text { BGN }\end{array}$ & $\begin{array}{l}\text { Greenlee } \\
\text { Maricopa } \\
\text { Gila } \\
\text { Yuma } \\
\text { Yavapai } \\
\text { Gila } \\
\text { Maricopa } \\
\text { Gila } \\
\text { Maricopa } \\
\text { Maricopa }\end{array}$ & $\begin{array}{l}332848 \mathrm{~N} 1090310 \mathrm{~W} \\
333542 \mathrm{~N} 1110810 \mathrm{~W} \\
334905 \mathrm{~N} 1100746 \mathrm{~W} \\
334131 \mathrm{~N} 1135340 \mathrm{~W} \\
343335 \mathrm{~N} 1115035 \mathrm{~W} \\
331509 \mathrm{~N} 1104940 \mathrm{~W} \\
325548 \mathrm{~N} 1124305 \mathrm{~W} \\
331148 \mathrm{~N} 1104905 \mathrm{~W} \\
333710 \mathrm{~N} 1121140 \mathrm{~W} \\
333 \mathrm{~B} 15 \mathrm{~N} 1121015 \mathrm{~W}\end{array}$ & $331628 N 1104843 W$ & $\begin{array}{l}5268 \\
3100\end{array}$ & $\begin{array}{l}\text { Alma Mesa } \\
\text { Pinyon Mtn } \\
\text { Cone Butte } \\
\text { Bear Hills } \\
\text { Camp Verde } \\
\text { Pinal Peak } \\
\text { Gila Bend } \\
\text { El Capitan Mtn } \\
\text { Glendale } \\
\text { Hedgpeth Hills }\end{array}$ \\
\hline $\begin{array}{l}\text { Pioneer Interchange } \\
\text { Pioneer Mine } \\
\text { Pioneer Mine } \\
\text { Pioneer Mountain } \\
\text { Pioneer Park } \\
\text { Pioneer Pass } \\
\text { Pioneer Pass Campground } \\
\text { Pioneer School } \\
\text { Pioneers Historical Museum } \\
\text { Pioneer Village II } \\
\text { (subdivision) }\end{array}$ & $\begin{array}{l}\text { crossing } \\
\text { mine } \\
\text { mine } \\
\text { summit } \\
\text { park } \\
\text { gap } \\
\text { park } \\
\text { school } \\
\text { building } \\
\text { ppl }\end{array}$ & $\begin{array}{l}\text { UNOFF } \\
\text { UNOFF } \\
\text { UNOFF } \\
\text { BGN } \\
\text { ADMIN } \\
\text { BGN } \\
\text { ADMIN } \\
\text { UNDFF } \\
\text { UNOFF } \\
\text { BGN }\end{array}$ & $\begin{array}{l}\text { Maricopa } \\
\text { Gila } \\
\text { Mohave } \\
\text { Gila } \\
\text { Maricopa } \\
\text { Gila } \\
\text { Gila } \\
\text { Apache } \\
\text { Coconino } \\
\text { Maricopa }\end{array}$ & $\begin{array}{l}334911 \mathrm{~N} 1120827 \mathrm{~W} \\
331404 \mathrm{~N} 1105014 \mathrm{~W} \\
350107 \mathrm{~N} 1142425 \mathrm{~W} \\
331449 \mathrm{~N} 1105037 \mathrm{~W} \\
332501 \mathrm{~N} 1114907 \mathrm{~W} \\
331612 \mathrm{~N} 1104804 \mathrm{~W} \\
331650 \mathrm{~N} 1104746 \mathrm{~W} \\
343022 \mathrm{~N} 1092206 \mathrm{~W} \\
351325 \mathrm{~N} 1113916 \mathrm{~W} \\
333445 \mathrm{~N} 1121238 \mathrm{~W}\end{array}$ & & $\begin{array}{l}5986 \\
6156\end{array}$ & $\begin{array}{l}\text { Biscuit Flat } \\
\text { El Capitan Mtn } \\
\text { Oatman } \\
\text { El Capitan Mtn } \\
\text { Mesa } \\
\text { Pinal Peak } \\
\text { Pinal Peak } \\
\text { St Johns North } \\
\text { Flagstaff West } \\
\text { Glendale }\end{array}$ \\
\hline $\begin{array}{l}\text { Pipe Creek } \\
\text { Pipeline Canyon } \\
\text { Pipeline Canyon } \\
\text { Pipeline Canyon } \\
\text { Pipeline Canyon } \\
\text { Pipeline Pond } \\
\text { Pipeline Spring } \\
\text { Pipeline Spring } \\
\text { Pipeline Spring } \\
\text { Hualpais Spring }\end{array}$ & $\begin{array}{l}\text { stream } \\
\text { valley } \\
\text { valley } \\
\text { valley } \\
\text { valley } \\
\text { lake } \\
\text { spring } \\
\text { spring } \\
\text { spring }\end{array}$ & $\begin{array}{l}\text { BGN } 1932 \\
\text { BGN } \\
\text { BGN } \\
\text { BGN } \\
\text { BGN } \\
\text { BGN } \\
\text { BGN } \\
\text { BGN } \\
\text { BGN } \\
\text { VARIANT }\end{array}$ & $\begin{array}{l}\text { Coconino } \\
\text { Graham } \\
\text { Maricopa } \\
\text { Yavapai } \\
\text { Yavapai } \\
\text { Mohave } \\
\text { Pima } \\
\text { Yavapai } \\
\text { Mohave }\end{array}$ & $\begin{array}{l}360558 \mathrm{~N} 1120640 \mathrm{~W} \\
324537 \mathrm{~N} 1102646 \mathrm{~W} \\
335318 \mathrm{~N} 1121735 \mathrm{~W} \\
340840 \mathrm{~N} 1122157 \mathrm{~W} \\
342254 \mathrm{~N} 1121918 \mathrm{~W} \\
362633 \mathrm{~N} 1133001 \mathrm{~W} \\
322519 \mathrm{~N} 1103643 \mathrm{~W} \\
342346 \mathrm{N1} 122004 \mathrm{~W} \\
344359 \mathrm{~N} 1134927 \mathrm{~W}\end{array}$ & $\begin{array}{l}360315 N 1120529 W \\
324428 N 1102524 W \\
335336 N 1122153 W \\
340928 N 1122014 W \\
342356 N 1122013 W\end{array}$ & & $\begin{array}{l}\text { Phantom Ranch } \\
\text { Oak Grove Canyon } \\
\text { Governors Peak } \\
\text { Crown King } \\
\text { Poland Junction } \\
\text { Poverty Spring } \\
\text { Buehman Canyon } \\
\text { Poland Junction } \\
\text { Beecher Canyon }\end{array}$ \\
\hline $\begin{array}{l}\text { Pipeline Tank } \\
\text { Pipeline Tank } \\
\text { Pipeline Tank } \\
\text { Pipeline Tank } \\
\text { Pipeline Tank } \\
\text { Pipeline Tank } \\
\text { Pipeline Tank } \\
\text { Pipeline Tank } \\
\text { Pipeline Tank } \\
\text { Piper Gulch }\end{array}$ & $\begin{array}{l}\text { reservoir } \\
\text { reservoir } \\
\text { reservoir } \\
\text { reservoir } \\
\text { reservoir } \\
\text { reservoir } \\
\text { reservoir } \\
\text { reservoir } \\
\text { reservoir } \\
\text { valley }\end{array}$ & $\begin{array}{l}\text { BGN } \\
B G N \\
B G N \\
B G N \\
B G N \\
B G N \\
B G N \\
B G N \\
B G N \\
B G N\end{array}$ & $\begin{array}{l}\text { Graham } \\
\text { Mohave } \\
\text { Yavapai } \\
\text { Coconino } \\
\text { Coconino } \\
\text { Coconino } \\
\text { Yavapai } \\
\text { Coconino } \\
\text { Coconino } \\
\text { Santa Cruz }\end{array}$ & $\begin{array}{l}324726 \mathrm{~N} 1100448 \mathrm{~W} \\
345342 \mathrm{~N} 1132513 \mathrm{~W} \\
350556 \mathrm{~N} 1122453 \mathrm{~W} \\
351519 \mathrm{~N} 1114700 \mathrm{~W} \\
351811 \mathrm{~N} 1121006 \mathrm{~W} \\
351827 \mathrm{~N} 1120450 \mathrm{~W} \\
351837 \mathrm{~N} 1130728 \mathrm{~W} \\
351848 \mathrm{N1} 120620 \mathrm{~W} \\
352959 \mathrm{~N} 1121703 \mathrm{~W} \\
313707 \mathrm{~N} 1104822 \mathrm{~W}\end{array}$ & $313800 N 1105021 W$ & & $\begin{array}{l}\text { Tripp Canyon } \\
\text { Gonzales Wash } \\
\text { Meath Spring } \\
\text { Wing Mountain } \\
\text { Williams North } \\
\text { Sitgreaves Mtn } \\
\text { Yampai SE } \\
\text { Sitgreaves Mtn } \\
\text { Cataract Tank } \\
\text { Patagonia }\end{array}$ \\
\hline $\begin{array}{l}\text { Piper Springs } \\
\text { Piper Springs Wash } \\
\text { Piper Tank } \\
\text { Pipe Spring } \\
\text { Pipe Spring National Monument } \\
\text { Pipe Springs National } \\
\text { Monument } \\
\text { Yell low Rock Spring } \\
\text { National Monument } \\
\text { Yellow Rocksprings } \\
\text { National Monument }\end{array}$ & $\begin{array}{l}\text { spring } \\
\text { stream } \\
\text { reservoir } \\
\text { spring } \\
\text { park }\end{array}$ & $\begin{array}{l}\text { BGN } \\
\text { BGN } \\
\text { BGN } \\
\text { BGN } \\
\text { ADMIN } \\
\text { VARIANT } \\
\text { VARIANT } \\
\text { VARIANT }\end{array}$ & $\begin{array}{l}\text { Pinal } \\
\text { Pinal } \\
\text { Coconino } \\
\text { Coconino } \\
\text { Mohave }\end{array}$ & $\begin{array}{l}325900 \mathrm{~N} 1104334 \mathrm{~W} \\
325753 \mathrm{~N} 1104515 \mathrm{~W} \\
351220 \mathrm{~N} 1112033 \mathrm{~W} \\
360423 \mathrm{~N} 1120608 \mathrm{~W} \\
365143 \mathrm{~N} 1124411 \mathrm{~W}\end{array}$ & $325917 N 1104216 \mathrm{~W}$ & & $\begin{array}{l}\text { Dudleyville } \\
\text { Winkelman } \\
\text { Angell } \\
\text { Phantom Ranch } \\
\text { Pipe Spring }\end{array}$ \\
\hline $\begin{array}{c}\text { Pipe Springs National Monument } \\
\text { See Pipe Spring National } \\
\text { Monument }\end{array}$ & park & VARIANT & Mohave & $365143 \mathrm{~N} 1124411 \mathrm{~W}$ & & & \\
\hline $\begin{array}{l}\text { Pipestem Canyon } \\
\text { North Fork Pipestem } \\
\text { Canyon }\end{array}$ & valley & $\begin{array}{l}\text { BGN } 1975 \\
\text { VARIANT }\end{array}$ & Graham & $324118 \mathrm{~N} 1102140 \mathrm{~W}$ & $324205 \mathrm{~N} 1102541 \mathrm{~W}$ & & Kennedy Peak \\
\hline $\begin{array}{l}\text { Pipestem Canyon } \\
\text { Pipestem Creek } \\
\text { Pipes tem Mountain } \\
\text { Pipestem Mountain Tank }\end{array}$ & $\begin{array}{l}\text { valley } \\
\text { stream } \\
\text { summit } \\
\text { reservoir }\end{array}$ & $\begin{array}{l}\text { BGN } \\
\text { BGN } \\
\text { BGN } \\
\text { BGN }\end{array}$ & $\begin{array}{l}\text { Greenlee } \\
\text { Greenlee } \\
\text { Greenlee } \\
\text { Greenlee }\end{array}$ & $\begin{array}{l}331803 \mathrm{~N} 1091706 \mathrm{~W} \\
331803 \mathrm{~N} 1091706 \mathrm{~W} \\
332205 \mathrm{~N} 1091916 \mathrm{~W} \\
332152 \mathrm{~N} 1091841 \mathrm{~W}\end{array}$ & $\begin{array}{l}332359 N 1092004 \mathrm{~W} \\
332359 \mathrm{~N} 1092004 \mathrm{~W}\end{array}$ & 7212 & $\begin{array}{l}\text { Pipestem Mtn } \\
\text { Pipestem Mtn } \\
\text { Pipestem Mtn } \\
\text { Pipestem Mtn }\end{array}$ \\
\hline $\begin{array}{l}\text { Pipe Tank } \\
\text { Pipe Tank Number Two } \\
\text { Pipe Valley } \\
\text { Pipe Valley Wash } \\
\text { Pipyak }\end{array}$ & $\begin{array}{l}\text { reservoir } \\
\text { reservoir } \\
\text { valley } \\
\text { stream } \\
\text { locale }\end{array}$ & $\begin{array}{l}\text { BGN } \\
B G N \\
B G N \\
B G N \\
B G N\end{array}$ & $\begin{array}{l}\text { Yavapai } \\
\text { Yavapai } \\
\text { Mohave } \\
\text { Mohave } \\
\text { Pima }\end{array}$ & $\begin{array}{l}341332 \mathrm{~N} 1120349 \mathrm{~W} \\
341253 \mathrm{~N} 1120401 \mathrm{~W} \\
364743 \mathrm{~N} 1124322 \mathrm{~W} \\
364700 \mathrm{~N} 1124213 \mathrm{~W} \\
321849 \mathrm{~N} 1114720 \mathrm{~W}\end{array}$ & $\begin{array}{l}365100 \mathrm{~N} 1125418 \mathrm{~W} \\
365508 \mathrm{~N} 1124908 \mathrm{~W}\end{array}$ & & $\begin{array}{l}\text { Joes Hill } \\
\text { Joes Hill } \\
\text { Pipe Spring } \\
\text { Pipe Spring } \\
\text { Santa Rosa Mts SE }\end{array}$ \\
\hline
\end{tabular}


NATIONAL GAZETTEER--ARIZONA 1986

\section{FEATURE NAME}

Pipyak Valley

Piriqua

See Hickiwan

Pirtleville

Pirtleville School

Pis inemo See Pisinimo

Pisinimo

Pacinimo

Paciñimo

Pis inemo Pisin Mo

Pisinimo School

Pisinimo Valley

See Quijotoa Valley

Pisinimo Wash

Pis in Mo See Pisinimo

Piskorski Canyon See Peck Canyon

Pisto Hill

Pistola Peak See Grey Peak

Pistol Butte

Pistol Creek

Pistol Creek

Pistol Saddle Tank

Pistor Junior High School

Pitahaya Canyon

Pitchfork Canyon

Pitchfork Canyon Wash

Pitchfork Tank

Pitchfork Tank

Pit Hole Tank

Pitman Valley

Pit Number Two Tank

Pitoikam

Fresnal

Fresnal Well

Pitoi Kam

Pitoikam Ranch

Pitoi Kam

See Pitoikam

Pitoikam Ranch

See Pitoikam

Pitsebytso

See Bitsihuitsos Butte

Pitsehytso

See Bitsihuitsos Butte

Pit Spring

Pit Tank

Pit Tank

Pit Tank

Pit Tank

Pit Tank

Pit Tank

Pit Tank Number One

Pit Tank Number Two

Pittman Elementary School

Pittman Interchange

Pittsburg Mine

Pittsburg Point

Pittsburg Tonto Mine

Pitts Homestead Tank Homestead Tank

Pitts Tank

Pitt Tank

Pius Draw

Pius Farm Draw

Pius Spring

Pius Tank
FEATURE

CLASS

STATUS

COUNTY

valley

pp 1

schoo

BGN

VARIANT

BGN

UNOFF

Pima

Pima

Cochise

Cochise

VARIANT

pp1
pp1

\section{BGN 194}

VARIANT

VARIANT

VARIANT

VARIANT

schoo

Pima

$320218 N 1121900 \mathrm{~W}$

$315828 N 1122134 W$

valley

Pima

st

ppl

valley

summit

summit

summit

stream

BGN

VARIANT

Pima

Pima

Santa Cruz

Pima

BGN

VARIANT

Greenlee

Apache

Graham

strean

reservoir

school

valley

valley

stream

reservoir

reservoir

reservoir $B G H$

valley $B G N$

reservoir

locale

\section{BGN}

BGN 194

VARIANT

VARIANT

VARIANT

VARIANT

VARIANT

locale

VARIANT

locale

Apache

Yavapai

Pima

Pima

Graham

Graham

Coconino

Coconino

Gila

Coconino

Coconino

Pima

Pima

Pima

314840N1114044W

and

VARIANT

summ $i$

summit

spring

reservoir

reservoir

reservoir

reservoir

reservoir

reservoir

reservoir

reservoir

school

crossing

mine

is land

mine

VARIANT

BGN

BGN

BGN

$B G N$

BGN
BGN

\section{Apache}

Apache

Apache

Gila

Navajo

Coconino

Apache

Coconino

BGN

BGN

BGN
UNOFF

UNOFF

UNOFF

BGN

UNOFF

8GN 1976

Coconino

Navajo

Navajo

Navajo

Coconino

Mohave

Mohave

Gila

Coconino

VARIANT

reservoir

reservoir

valley

BGN

BGN

BGN

reservoir BGN

COORDINATE

322007N1114635W

N1122829W

$312138 \mathrm{~N} 1093405 \mathrm{~W}$

$320206 \mathrm{~N} 1121852 \mathrm{~W}$

$320206 \mathrm{~N} 1121852 \mathrm{~W}$

$320031 N 1122128 \mathrm{~W}$

320206 N1121852W

$320352 \mathrm{~N} 1103848 \mathrm{~W}$

$331346 \mathrm{~N} 1092429 \mathrm{~W}$

$335719 N 1094616 \mathrm{~W}$

330755 N1092950W

$335639 \mathrm{~N} 1094637 \mathrm{~W}$

341458 N1114538W $320910 \mathrm{~N} 1110135 \mathrm{~W}$ $320708 \mathrm{~N} 1124245 \mathrm{~W}$ $323603 \mathrm{~N} 1095308 \mathrm{~W}$ $323525 \mathrm{~N} 1095707 \mathrm{~W}$ $343910 \mathrm{~N} 1112340 \mathrm{~W}$ $350104 \mathrm{~N} 1105703 \mathrm{~W}$ $334333 \mathrm{~N} 1100334 \mathrm{~W}$

351338 N1115859W

$350330 \mathrm{~N} 1113130 \mathrm{~W}$

$314840 \mathrm{~N} 1114044 \mathrm{~W}$

314840N1114044W

$362453 N 1094952 \mathrm{~W}$

$362453 N 1094952 \mathrm{~W}$ $340942 \mathrm{~N} 1094454 \mathrm{~W}$ $335820 \mathrm{~N} 1101903 \mathrm{~W}$ $335950 \mathrm{~N} 1095432 \mathrm{~W}$ $343048 N 1104747 \mathrm{~W}$ $343739 N 1094547 \mathrm{~W}$ $345200 \mathrm{~N} 1112603 \mathrm{~W}$

$351741 \mathrm{~N} 1120729 \mathrm{~W}$ $340458 \mathrm{~N} 1095306 \mathrm{~W}$ $340459 \mathrm{~N} 1095234 \mathrm{~W}$ $345420 \mathrm{~N} 1101000 \mathrm{~W}$ $343113 \mathrm{~N} 1141402 \mathrm{~W}$ $342737 \mathrm{~N} 1142136 \mathrm{~W}$ $340000 \mathrm{~N} 1111740 \mathrm{~W}$ $352145 \mathrm{~N} 1123316 \mathrm{~W}$

Yavapai

Coconino

Coconino

Coconino

Coconino

Coconino $343045 \mathrm{~N} 1110018 \mathrm{~W}$ reservoir
1895 Pisinimo

$313040 \mathrm{~N} 1110050 \mathrm{~W}$ $351552 \mathrm{~N} 1120301 \mathrm{~W}$
$340315 \mathrm{~N} 1125154 \mathrm{~W}$ $353315 \mathrm{~N} 1121802 \mathrm{~W}$ $343013 \mathrm{~N} 1110235 \mathrm{~W}$ $343305 \mathrm{~N} 1110001 \mathrm{~W}$ $343028 \mathrm{~N} 1105955 \mathrm{~N}$
Douglas

Douglas

Pisinimo

320524N1121333W Pisinimo

Vail

$\begin{array}{cc}\text { SOURCE } & \text { ELEV } \\ \text { COORDINATE } & \text { FT MAP NAME }\end{array}$

$321301 N 1114743 \mathrm{~W} \quad$ Santa Rosa Mts SE Coronado Mtn 
AZ484

\section{FEATURE NAME}

Piute Canyon

Pah Ute Canyon

Pah-ute Canyon

Pahute Canyon

Paiute Canyon

Piute Canyon Creek

See Piute Creek

Piute Creek

Piute Canyon Creek

Piute Indian Reservation

See Navajo Indian Reservation

Piute Mesa

Piute Point

Paiute Point

Pi Va Hon Kia Pi

Pivot Rock Canyon

Pivot Rock Spring

See Pivotrock Spring

Pivotrock Spring

Little Pivotrock Spring

Pivot Rock Spring

Placer Gulch

Placerita

Placerita Gulch

Placeritas Creek

Placerito Canyon

Placeritos Wash

Placer Peak

Placer Tank

Plain Tank

Plain Tank Flat

Plain View Peak Plainview Point

Plainview Point See Plain View Peak

Plancha Mountain

Plane Rock

Planet

Planet Mine

Planet Peak

Planet Ranch

Eagle Landing

Planet Saturn Mine

Plantation Tank

Plantsite

Plantsite School
See Longfellow Elementary
School
Plata Mine, La

Plata Railroad Station

Plateau of Arizona

See Mogollon Plateau

Plateau of Arizona

See Coconino Plateau

Plateau Point

Plat inum Tanks

Plato Well, La

Platten Tank

Platts Windmill

Platt Well

Platt Well

Playa de los Pimas See Willcox Playa

Playa Margarita Park

Playas, Las

Playboy Tank

Playground Jerome Family

Picknicking Ground

The Playground Picnic Ground

NATIONAL GAZETTEER--ARIZONA 1986

FEATURE

CLASS

valley

valley

DA

stream

stream

BGN

reserve

summit

cliff

locale

valley

spring

spring

valley

locale

valley

stream

valley

summit

reservoir

reservoir

flat

summit

summit

sumit

summit

summit
locale

mine

summit

mine

mine

rese
ppl

school

mine

building

plain

plain

BGN

BGN
UNOFF

BGN

UNOFF

VARIANT

UNOFF

UNOF
BGN
BGN

VARIANT

reservoir

well

reservoir

locale

well

well

flat

park

flat

reservoir

park

UNOFF

UNOFF

VARIANT

VARIANT

BGN 1932

Coconino

Coconino

BGN

UNOFF

BGN

BGN

UNOFF

UNOFF

VARIANT

ADMIN

BGN

BGN

ADMIN

VARIANT

Apache

Navajo

Coconino

Coconino

Yavapai

Pima

Pina

Mohave

Mohave

Graham

Graham
San Juan (UT) 371055N1104235W

San Juan (UT) 371055 N1104235W

$363001 N 1090001 \mathrm{~W}$

$365807 \mathrm{~N} 1103809 \mathrm{~W}$

$360704 \mathrm{~N} 1121930 \mathrm{~W}$

Navajo 355322N1104156W

Coconino $343017 \mathrm{N1112452 \textrm {W }}$

$342926 \mathrm{~N} 1112350 \mathrm{~W}$

$342926 \mathrm{~N} 1112350 \mathrm{~W}$

$330711 N 1092104 \mathrm{~W}$

$\begin{array}{ll}\text { Greenlee } & 330711 \mathrm{~N} 1092104 \mathrm{~W} \\ \text { Yavapai } & 341609 \mathrm{~N} 1123843 \mathrm{~W}\end{array}$

Yavapai $341802 N 1123655 W$

$342547 N 1131318 \mathrm{~W}$

$313124 N 1112059 \mathrm{~W}$

$314044 \mathrm{~N} 1113054 \mathrm{~W}$

$315248 N 1111219 \mathrm{~W}$

$313846 \mathrm{~N} 1112052 \mathrm{~W}$

$353915 \mathrm{~N} 1133253 \mathrm{~W}$

$353808 \mathrm{~N} 1133130 \mathrm{~W}$

$324134 \mathrm{~N} 1095151 \mathrm{~W}$

$324134 N 1095151 W$

$\begin{array}{ll}\text { Mohave } & 341924 \mathrm{~N} 1133637 \mathrm{~W} \\ \text { Apache } & 363930 \mathrm{~N} 1094004 \mathrm{~W} \\ \text { Yuma } & 341451 \mathrm{~N} 1135751 \mathrm{~W} \\ \text { Yuma } & 341434 \mathrm{~N} 1135750 \mathrm{~W} \\ \text { Yuma } & 341001 \mathrm{N1135851 \textrm {W }} \\ \text { Yuma } & 341444 \mathrm{~N} 1135702 \mathrm{~W} \\ & \\ \text { Yavapai } & 341146 \mathrm{~N} 1124639 \mathrm{~W} \\ \text { Coconino } & 344128 \mathrm{~N} 1111218 \mathrm{~W} \\ \text { Greenlee } & 330323 \mathrm{~N} 1091955 \mathrm{~W}\end{array}$

330833N1092003W

$341632 N 1123904 \mathrm{~W}$

$342415 N 1132035 \mathrm{~W}$

$313145 \mathrm{~N} 1112202 \mathrm{~W}$

$314213 \mathrm{~N} 1113624 \mathrm{~W}$

\section{0}

Arivaca

Mildred Peak

Tall Mountain NW

Piute Point

Hotevilla

Calloway Butte

Pine

Clifton

Peeples Valley

Walnut Grove

Cerro Colorado

Hindu Canyon

Hindu Canyon

1037 Mt Graham

Artillery Peak

5621 Rock Point

Planet

Planet

3141 Planet

Planet

3640 Congress

Hay Lake

Clifton

O'Donnell Canyon Ruelas Canyon

Phantom Ranch

Antelope Point

O'Donnell Canyon

Ebert Mtn

Schnebly Well

Platt Well

Apache $\quad 344217$ N1091919W

Maricopa $\quad 324049$ N1123332W

Maricopa 325451N1123722W

973

Bosque

Fowler

Las Playas

Yellow John Mtn

Hickey Mountain 


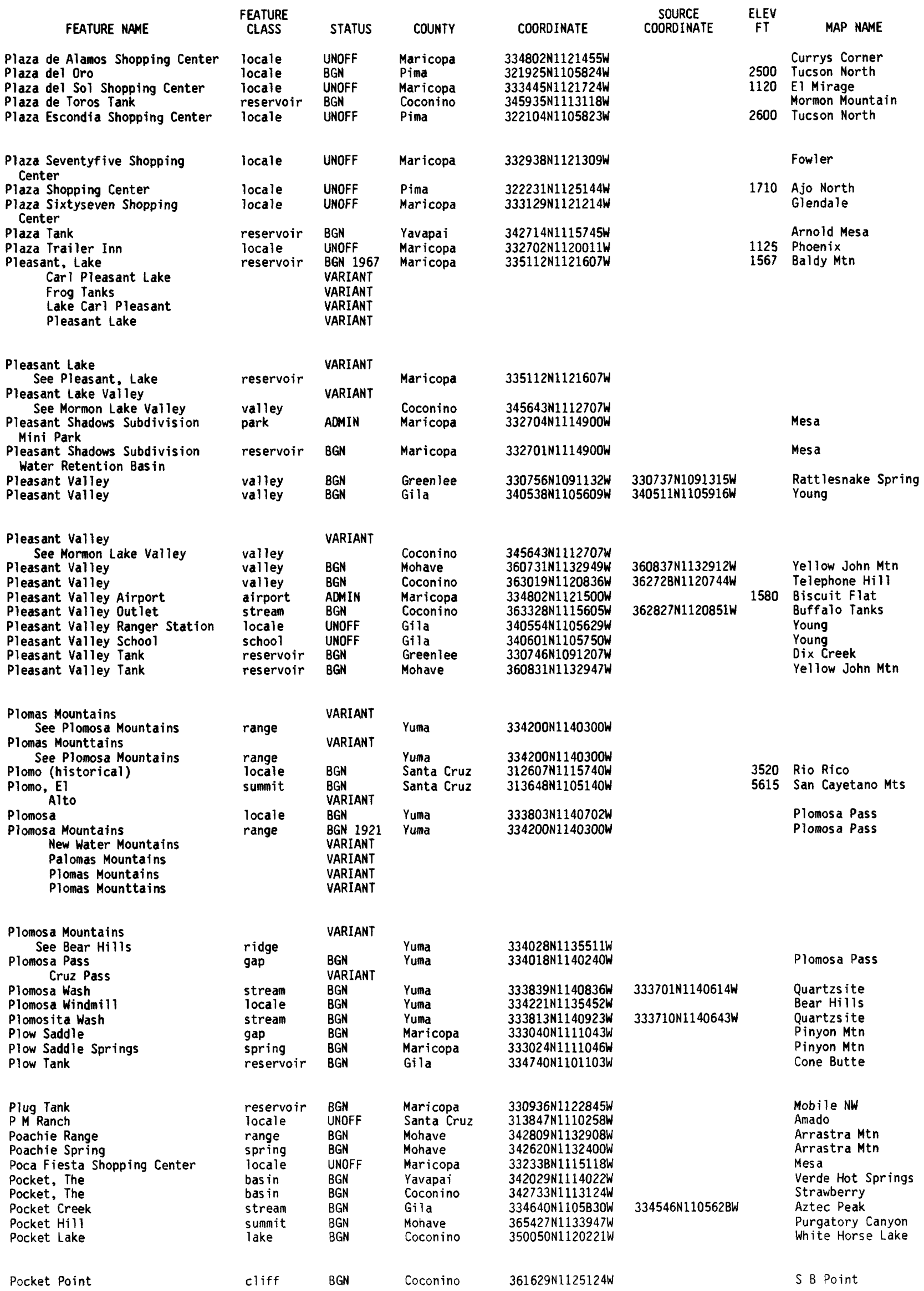




\section{FEATURE NAME}

Pocket Point Tank

Pocket Spring

Pocket Tank

Pocket Tank

Pocket Tank

Pocket Tank

Pocomate Springs

Pocum Cove

Pocum Tank

Pocum Wash

Grand Wash

Poer Spring

Pogue

See Black Knob

Point, The

Point, The

Pointer Spring

Point Hollenbeck

See Hollenback Point

Point of Mountain Spring

Point of Pines (historical)

Point of Pines

Point of Pines Charco

Point of Pines Creek

Point of Pines Dam

Point of Pines Lake

Point of Rocks

Point of Rock Spring

Point Spring

Point Sublime Trail

Point Tank

Point Tank

Point Tank

Point Tawa

$$
\text { See Tawa Point }
$$

Poison Canyon

Poison Creek

Poison Dam Draw See Polson Dam Draw

Poison Ivy Canyon

Poison Ivy Spring

Poison Spring

Poison Spring

Poison Spring

Poison Springs Wash

Poison Well

Poker Canyon

Poker Gap Creek

Poker Mountain

Poker Mountain Tank

Poker Mountain Tank Number Two Polaca

$$
\text { See Polacca }
$$

Polacca

Polaca

Polacca Airport

Polacca Creek

See Polacca Wash

Polacca Creek

See Burnt Corn Wash

Polacca Day School

Polacca Post Office

Polacca Trading Post

Polacca Wash

Burnt Corn Wash

Corn Creek

First Mesa Wash

Oraibi Wash

Polacca Creek

Polacca Wash

See Burnt Corn Wash
FEATURE

STATUS

COUNTY

reservoir

spring

reservoir

reservoir

reservoir

spring

BGN

VARIANT

valle

BGN

reservoir

valley

BGN

BGN

VARIANT

spring

VARIANT

summit

cape

cape

spring

BGN

BGN

VARIANT

summit

local

ppl

reservoir

stream

dam

reservoir

locale

spring

spring

BGN
BGN
BGN
BGN
BGN
UNOF
BGN
BGN
BGN
BGN

trail

reservoir

reservoir

reservoir

UNOFF

BGN
BGN
BGN

VARIANT

cliff

valley

stream

BGN

BGN

VARIANT

valley

Coconino

Gila

Gila

Gila

Yavapai

Yavapai

Coconino

Mohave

Mohave

Mohave

Cochise

Coconino

Apache

Coconino

Pinal

Coconino

Apache

Graham

Graham

Graham

Graham

Graham

Graham

Maricopa

Gila

Mohave

Coconino

Gila

Gila

Coconino

Apache

Gila

Yavapai

Coconino

COORDINATE

$342726 \mathrm{N1113142W}$

$340745 N 1111159 \mathrm{~W}$

$340757 N 1111202 \mathrm{~W}$

$340922 \mathrm{~N} 1111246 \mathrm{~W}$

$345228 \mathrm{~N} 1120809 \mathrm{~W}$

$350210 \mathrm{~N} 1131656 \mathrm{~W}$

$354920 \mathrm{N11} 30939 \mathrm{~W}$

364312 N1134619W

$364546 N 1132841 \mathrm{~W}$

$363215 N 1134638 \mathrm{~W}$

$322322 \mathrm{~N} 1100726 \mathrm{~W}$

$355901 \mathrm{~N} 1112748 \mathrm{~W}$

$41951 N 1090308 \mathrm{~N}$

$353 \mathrm{~B} 26 \mathrm{~N} 1113646 \mathrm{~W}$

332719 N1110930W

360123 N1115306W

$340255 \mathrm{~N} 1091939 \mathrm{~W}$

$332110 N 1094435 \mathrm{~W}$

$332157 N 1094503 \mathrm{~W}$

$332216 N 1094402 W$

$332255 \mathrm{~N} 1094036 \mathrm{~W}$

$332200 \mathrm{~N} 1094730 \mathrm{~W}$

$332202 N 1094741 \mathrm{~W}$

$325938 \mathrm{~N} 1124526 \mathrm{~W}$

$335855 \mathrm{N1112035 \textrm {W }}$

$365518 \mathrm{~N} 1124322 \mathrm{~W}$

$361544 N 1121106 \mathrm{~W}$

$341823 \mathrm{~N} 1112334 \mathrm{~W}$

$341951 \mathrm{N11} 12759 \mathrm{~W}$

343202N1112525W

$350450 N 1094659 \mathrm{~W}$

$342332 \mathrm{~N} 1112135 \mathrm{~W}$

340909 N1121033W

$352137 N 1122210$

valley

spring

spring

spring

spring

stream

well

valley

strean

summit

BGN

$B G N$

BGN

BGN

BGN

BGN

UNOFF

BGN

BGN

Apache

Navajo

Gila

Gila

Coconino

Gila

Maricopa

Apache

Apache

Apache

$361457 N 1091735 \mathrm{~W}$

$340404 \mathrm{N1} 102329 \mathrm{~N}$

$333424 N 1105658$

$342457 N 1112032 \mathrm{~W}$

$350802 \mathrm{~N} 1115827 \mathrm{~W}$

333706 N1105723W

$331353 \mathrm{~N} 1124936 \mathrm{~W}$

$333336 \mathrm{~N} 1095159 \mathrm{~W}$

$333059 N 1094912 \mathrm{~W}$

$333301 N 1094512 \mathrm{~W}$

reservoir $B G$

reservoir BGN

ppl

ppl

VARIAN

airport

VARIANT

ADMIN

VARIANT

stream

VARIANT

stream

Apache

$333114 \mathrm{N1094709 \textrm {W }}$

333140 N1094638

$355012 \mathrm{~N} 1102251 \mathrm{~W}$

$355012 N 1102251 \mathrm{~W}$

354730N1102521W

352133N1105028W

Coconino

schoo

building

locale

UNOFF

UNOFF

BGN

BGN

BGN 1967

VARIANT

VARIANT

VARIANT

VARIANT

VARIANT

VARIANT
355908 N $1100835 \mathrm{~W}$

Navajo

Navajo

Navajo

Navajo

Coconino

354950 N1102317W

$355015 \mathrm{~N} 1102249 \mathrm{~W}$

$355026 \mathrm{~N} 1102217 \mathrm{~W}$

$352133 \mathrm{~N} 1105028 \mathrm{~W}$

Navajo

$\begin{array}{cc}\text { SOURCE } & \text { ELEV } \\ \text { COORDINATE } & \text { FT }\end{array}$

MAP NAME 


\section{FEATURE NAME}

Polacca Wash

See Donkey Spring Canyon

Poland Creek

Poland Junction

Poland Junction Substation

Poland-Walker Tunnel

Polaris

See North Star Mine

Polar is Mine

Polaris Mountain Summit Peak

Pole Bridge Canyon

Pole Bridge Canyon Natural Area

Pole Bridge Trail Two Hundred

Sixtyfour

Pole Camp Canyon

Polecat Canyon

Polecat Canyon

Polecat Wash

Pole Corral Spring

Pole Corral Tank

Pole Hollow Canyon

Pole Hollow Spring

Pole Knoll

Pole Spring

Slate Spring

Pole Spring

Pole Spring

Poley Ranch

Polk Well

Pollack Tank

Pollack Well

Polles Mesa

Polles Tank Number Two

Pollocks Substation

Pollock Well

Pollux Temple

Polo Tank

Polo Village

Polson Dam

Polson Dam Draw

Pason Dam Draw

Poison Dam Draw

Polson Tank
Polson Tank
Polvo
Pomerene
Pomerene Canal
Pomerene Elementary School
Pomeroy Tanks
Pomono Mine
Poncho Tank
Pond Canyon
See Walla Valley

Ponderosa Campground

Ponderosa Group Camp

Ponderosa Park

Ponderosa Pine Spring

Ponderosa Plaza Shopping Center

Ponderosa Recreation Center

Pond Tank

Po $\mathrm{Ni} \mathrm{Vi}$

Pontatoc Canyon

Alamo Canyon Number One

$$
\begin{aligned}
& \text { Pontatock Mine } \\
& \text { See Pontatoc Mine } \\
& \text { Pontatoc Mine } \\
& \text { Pontatock Mine } \\
& \text { Pontatoc Ridge } \\
& \text { Pontatoo Ridge } \\
& \text { Pontatoo Ridge }
\end{aligned}
$$

See Pontatoc Ridge
FEATURE

STATUS

COUNTY

COORDINATE

SOURCE

ELEV
FT

MAP NAME

$61019 N 1100319 W$ $341420 \mathrm{~N} 1121255 \mathrm{~W}$ $342703 \mathrm{~N} 1121607 \mathrm{~W}$ $342711 \mathrm{~N} 1121616 \mathrm{~W}$ $342615 \mathrm{~N} 1122159 \mathrm{~W}$

$341110 \mathrm{~N} 1122037 \mathrm{~W}$ Bumble Bee

4897 Poland Junction Pol and Junction Poland Junct ion

35809 $351912 \mathrm{~N} 1140725 \mathrm{~W}$ $331830 \mathrm{~N} 1135850 \mathrm{~W}$

Stockton Hill

3624 Kofa Butte

$315141 \mathrm{N1092014 \textrm {W }}$ $315100 \mathrm{~N} 109202 \mathrm{~W}$ 315107 N1092020W

$342007 \mathrm{~N} 1122929 \mathrm{~W}$ $321727 \mathrm{N1093815 \textrm {W }}$ $322005 \mathrm{~N} 1101208 \mathrm{~W}$ $325227 \mathrm{~N} 1105010 \mathrm{~W}$ $353446 \mathrm{~N} 1134552 \mathrm{~W}$ $333041 \mathrm{~N} 1100014 \mathrm{~W}$

\section{N1092023W Chiricahua Peak Portal Peak Chiricahua Peak \\ $342215 \mathrm{~N} 1123012 \mathrm{~W}$ $321616 N 1093824 \mathrm{~W}$ $322131 \mathrm{~N} 1100639 \mathrm{~W}$ $325305 \mathrm{~N} 1105143 \mathrm{~W}$ \\ Battleship Butte \\ Railroad Pass \\ Hookers Hot Springs \\ Putnam Wash \\ Music Mountains SE \\ 5917 Georges Butte}

$341246 \mathrm{~N} 1112757 \mathrm{~W}$

$341115 \mathrm{~N} 1112709 \mathrm{~W}$ $340234 \mathrm{N1093043 \textrm {W }}$ $342052 \mathrm{~N} 1123015 \mathrm{~W}$

$343603 \mathrm{~N} 1123321 \mathrm{~W}$

$344803 N 1124649 \mathrm{~W}$ $343652 \mathrm{~N} 1123953 \mathrm{~W}$ $332525 \mathrm{~N} 1103328 \mathrm{~W}$

$344955 \mathrm{~N} 1110223 \mathrm{~W}$

locale UNOFF Yavapai

well

reservoir BGN Goconino

well UNOFF Maricopa

sumit BGN Gila

$341627 \mathrm{~N} 1113252 \mathrm{~N}$

$350400 \mathrm{~N} 1123816 \mathrm{~W}$

$335448 \mathrm{~N} 1131542 \mathrm{~W}$

$360714 \mathrm{~N} 1121807 \mathrm{~W}$

$325144 N 1110924 W$

$321423 \mathrm{~N} 1105651 \mathrm{~W}$

$352049 \mathrm{N1122135W}$

$\begin{array}{llll} & & & \\ \text { valley } & \text { BGN } 1983 & \text { Coconino } & 352049 \mathrm{~N} 1122135 \mathrm{~W} \\ \end{array}$

$341044 \mathrm{~N} 1112652 \mathrm{~W}$

North Peak

North Peak

9793 Greens Peak

Walnut Grove

Iron Springs

Seepage Mtn

4830 Skull Valley

3154 Dourine Canyon

Chavez Mtn East

Gladden

4263 Cane Springs Mtn Cane Springs Mtn

South Butte

Gladden

6249 Piute Point

Ninetysix Hills SW

Tucson

Coconino

VARIANT

VARIANT

reservoir

ppl

ppl

canal

school

reservoir

mine

reservoir

BGN

BGN

BGN

BGN

UNOFF

(

BGN

UNOFF

valley

VARIANT

Navajo

Coconino

Pima

Cochise

Cochise

Cochise

Coconino

Coch ise

Graham

Coconino

park ADMIN Gila 341756N1110650W

locale BGN Gila 341800 N1110700W

$342817 \mathrm{N1} 122912 \mathrm{~W}$

$\begin{array}{lll}\text { spring } B G N & \text { Navajo } & 360706 N 1101912 W\end{array}$

locale UNOFF Navajo 340736N1095635W

park ADMIN Coconino 351247N1113655W

2553 Tucson
351908N1122127W

$341642 \mathrm{~N} 1101027 \mathrm{~W}$

$352050 \mathrm{~N} 1122135 \mathrm{~W}$

$321113 N 1105431 \mathrm{~W}$

$315958 \mathrm{~N} 1101708 \mathrm{~W}$

$315814 N 1101559 \mathrm{~W}$

$315955 \mathrm{~N} 1101709 \mathrm{~W}$

$350907 \mathrm{~N} 1120146 \mathrm{~W}$

$312717 N 1101955 \mathrm{~W}$

$325510 \mathrm{~N} 1101751 \mathrm{~W}$

$361345 \mathrm{~N} 1121400 \mathrm{~W}$

$365011 N 1133955 \mathrm{~W}$

$355253 \mathrm{~N} 1104248 \mathrm{~W}$

$322018 \mathrm{~N} 1105415 \mathrm{~W}$

$322144 N 1105237 W$

Hearst Mtn

Pinedale

Hearst Mtn

3542 Benson

Benson

Davenport Hill

Miller Peak

Cobre Grande Mtn

Promontory Butte

5680 Promontory But te

Groom Creek

Lt1 Black Spot Mtn Lakeside

6900 Flagstaff East Wolf Hole Mtn West Hotevilla

Tucson North

Tucson North

321956 N1105352W

$321956 \mathrm{~N} 1105352 \mathrm{~W}$

$322040 \mathrm{~N} 1105310 \mathrm{~W}$

Tucson North 


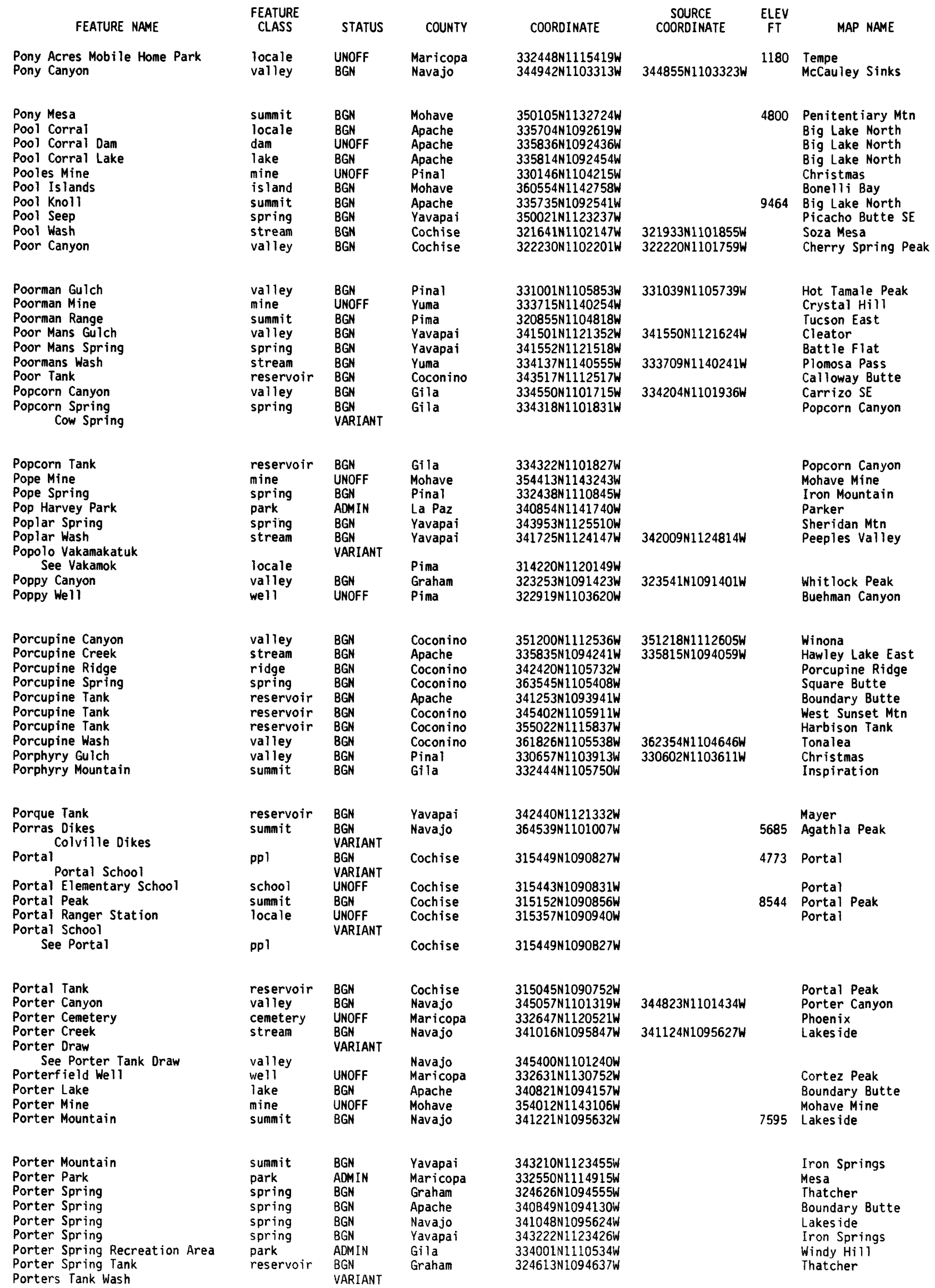




\begin{tabular}{|c|c|c|c|c|c|c|c|}
\hline FEATURE NAME & $\begin{array}{l}\text { FEATURE } \\
\text { CLASS }\end{array}$ & STATUS & COUNTY & COORDINATE & $\begin{array}{l}\text { SOURCE } \\
\text { COORDINATE }\end{array}$ & $\underset{\mathrm{FT}}{\mathrm{ELEV}}$ & MAP NAME \\
\hline See Porter Tank Draw & valley & & Navajo & $345400 \mathrm{~N} 1101240 \mathrm{~W}$ & & & \\
\hline $\begin{array}{l}\text { Porter Tank } \\
\text { Porter Tank } \\
\text { Porter Tank Oraw } \\
\text { Porter Draw } \\
\text { Porters Tank Wash } \\
\text { Porter Wash } \\
\text { Porter Well } \\
\text { Portland Mine } \\
\text { Portland Ridge } \\
\text { Portl land Wash } \\
\quad \text { Granite Wash }\end{array}$ & $\begin{array}{l}\text { reservoir } \\
\text { reservoir } \\
\text { valley } \\
\text { stream } \\
\text { well } \\
\text { mine } \\
\text { ridge } \\
\text { stream }\end{array}$ & $\begin{array}{l}\text { BGN } \\
\text { BGN } \\
\text { BGN } \\
\text { VARIANT } \\
\text { VARIANT } \\
\text { BGN } \\
\text { UNOFF } \\
\text { UNOFF } \\
\text { BGN } \\
\text { BGN } \\
\text { VARIANT }\end{array}$ & $\begin{array}{l}\text { Graham } \\
\text { Navajo } \\
\text { Mohave } \\
\text { Pima } \\
\text { Mohave }\end{array}$ & $\begin{array}{l}330418 N 1095918 W \\
345102 N 1101329 W \\
352250 N 1143004 W \\
322342 N 1112952 W \\
352103 N 1143138 W\end{array}$ & $\begin{array}{l}330706 N 1095442 \mathrm{~W} \\
352324 \mathrm{~N} 1142934 \mathrm{~W}\end{array}$ & & $\begin{array}{l}\text { Lakes ide } \\
\text { Brookbank Point } \\
\text { Holbrook } \\
\text { Gila Peak } \\
\text { Porter Canyon } \\
\text { Spirit Mtn NE } \\
\text { Silver Bell East } \\
\text { Spirit Mtn SE }\end{array}$ \\
\hline $\begin{array}{l}\text { Porto Rico Canyon } \\
\text { Portoritas Tank } \\
\text { Porvenir Tank } \\
\text { Posa Plain, La } \\
\text { Posas Plain } \\
\quad \text { Posas Valley } \\
\text { Posas } \\
\text { See Quartzsite } \\
\text { Posas Plain } \\
\text { See Posa Plain, La }\end{array}$ & $\begin{array}{l}\text { valley } \\
\text { reservoir } \\
\text { reservoir } \\
\text { plain }\end{array}$ & $\begin{array}{l}\text { BGN } \\
\text { BGN } \\
\text { BGN } \\
\text { BGN } 1963 \\
\text { VARIANT } \\
\text { VARIANT } \\
\text { VARIANT } \\
\text { VARIANT }\end{array}$ & $\begin{array}{l}\text { Gila } \\
\text { Pima } \\
\text { Pinal } \\
\text { La Paz }\end{array}$ & $\begin{array}{l}332414 \mathrm{~N} 1105100 \mathrm{~W} \\
321447 \mathrm{~N} 1103743 \mathrm{~W} \\
323117 \mathrm{~N} 1113822 \mathrm{~W} \\
333557 \mathrm{~N} 1141051 \mathrm{~W}\end{array}$ & $332359 N 1105054 \mathrm{~W}$ & & $\begin{array}{l}\text { Globe } \\
\text { Tanque Verde Peak } \\
\text { Greene Reservoir } \\
\text { South of Quartzsite }\end{array}$ \\
\hline $\begin{array}{l}\text { Posas Valley } \\
\text { See Posa Plain, La } \\
\text { Poso Blanco } \\
\text { See Stoa Vaya (site) } \\
\text { Posos Gulch, Los } \\
\text { Posos Gulch, Los } \\
\text { Posos Tank, Los } \\
\text { Possum Tank } \\
\text { Posta Quemada Canyon } \\
\text { La Posta Quemado Canyon } \\
\text { Mountain Spring Canyon }\end{array}$ & $\begin{array}{l}\text { plain } \\
\text { locale } \\
\text { valley } \\
\text { valley } \\
\text { reservoir } \\
\text { reservoir } \\
\text { valley }\end{array}$ & $\begin{array}{l}\text { VARIANT } \\
\text { VARIANT } \\
\text { BGN } \\
\text { BGN } \\
\text { BGN } \\
\text { BGN } \\
\text { BGN } \\
\text { VARIANT } \\
\text { VARIANT }\end{array}$ & $\begin{array}{l}\text { La Paz } \\
\text { Pima } \\
\text { Pima } \\
\text { Pima } \\
\text { Pima } \\
\text { Yavapai } \\
\text { Pima }\end{array}$ & $\begin{array}{l}333557 \mathrm{~N} 1141051 \mathrm{~W} \\
321033 \mathrm{~N} 1121342 \mathrm{~W} \\
314703 \mathrm{~N} 1103655 \mathrm{~W} \\
314704 \mathrm{~N} 1103658 \mathrm{~W} \\
314624 \mathrm{N1} 104128 \mathrm{~W} \\
341142 \mathrm{~N} 1130158 \mathrm{~W} \\
320315 \mathrm{~N} 1103800 \mathrm{~W}\end{array}$ & $\begin{array}{l}314616 \mathrm{~N} 1104446 \mathrm{~W} \\
314609 \mathrm{~N} 1104402 \mathrm{~W} \\
320654 \mathrm{~N} 1103124 \mathrm{~W}\end{array}$ & & $\begin{array}{l}\text { Spring Water Canyon } \\
\text { Spring Water Canyon } \\
\text { Empire Ranch } \\
\text { Date Creek Ranch } \\
\text { Vail }\end{array}$ \\
\hline $\begin{array}{l}\text { Post Canyon } \\
\quad 0^{\prime} \text { Donnell Canyon } \\
\text { Post Canyon } \\
\text { See Huachuca Canyon } \\
\text { Post Creek } \\
\text { Posten Butte } \\
\text { See Poston Butte } \\
\text { Posten Railroad Station } \\
\text { See Poston Railroad Station } \\
\text { Post Lake }\end{array}$ & $\begin{array}{l}\text { valley } \\
\text { stream } \\
\text { summit } \\
\text { building } \\
\text { lake }\end{array}$ & $\begin{array}{l}\text { BGN } 1959 \\
\text { VARIANT } \\
\text { VARIANT } \\
\text { BGN } \\
\text { VARIANT } \\
\text { VARIANT } \\
\text { BGN }\end{array}$ & $\begin{array}{l}\text { Cochise } \\
\text { Graham } \\
\text { Pinal } \\
\text { Pinal } \\
\text { Coconino }\end{array}$ & $\begin{array}{l}313520 \mathrm{~N} 1103015 \mathrm{~W} \\
313822 \mathrm{~N} 1102019 \mathrm{~W} \\
324003 \mathrm{~N} 1095458 \mathrm{~W} \\
330318 \mathrm{~N} 1112429 \mathrm{~W} \\
330122 \mathrm{~N} 1113108 \mathrm{~W} \\
350135 \mathrm{~N} 1112523 \mathrm{~W}\end{array}$ & $324146 \mathrm{~N} 1095341 \mathrm{~W}$ & & O'Donnell Canyon \\
\hline $\begin{array}{l}\text { Post le Ranch } \\
\quad \text { See Del Rio } \\
\text { Postmaster Spring } \\
\text { Post Office Canyon } \\
\text { Post Office Farms } \\
\text { Post Office Spring } \\
\text { Post Office Tank } \\
\text { Post Office Tank } \\
\text { Post Office Tank } \\
\text { Poston }\end{array}$ & $\begin{array}{l}\text { locale } \\
\text { spring } \\
\text { valley } \\
\text { bend } \\
\text { spring } \\
\text { reservoir } \\
\text { reservoir } \\
\text { reservoir } \\
\text { locale }\end{array}$ & $\begin{array}{l}\text { VARIANT } \\
\text { BGN } \\
\text { BGN } \\
\text { BGN } \\
\text { BGN } \\
\text { BGN } \\
\text { BGN } \\
\text { BGN } \\
\text { BGN }\end{array}$ & $\begin{array}{l}\text { Yavapai } \\
\text { Yavapai } \\
\text { Navajo } \\
\text { Navajo } \\
\text { Graham } \\
\text { Gila } \\
\text { Navajo } \\
\text { Mohave } \\
\text { Pinal }\end{array}$ & $\begin{array}{l}344923 N 1122634 \mathrm{~W} \\
342659 \mathrm{~N} 1122044 \mathrm{~W} \\
335812 \mathrm{~N} 1095523 \mathrm{~W} \\
335733 \mathrm{~N} 1095501 \mathrm{~W} \\
330208 \mathrm{~N} 1102144 \mathrm{~W} \\
334405 \mathrm{~N} 1102258 \mathrm{~W} \\
335807 \mathrm{~N} 1095535 \mathrm{~W} \\
363642 \mathrm{~N} 1133806 \mathrm{~W} \\
330200 \mathrm{~N} 1113130 \mathrm{~W}\end{array}$ & $340102 \mathrm{~N} 1095816 \mathrm{~W}$ & & $\begin{array}{l}\text { Poland Junction } \\
\text { Alchesay Flat } \\
\text { Alchesay Flat } \\
\text { Mt Turnball } \\
\text { Brushy Canyon } \\
\text { Alchesay Flat } \\
\text { St George Canyon } \\
\text { Blackwater }\end{array}$ \\
\hline $\begin{array}{l}\text { Poston } \\
\text { Poston Butte } \\
\text { Parsee Hill } \\
\text { Posten Butte } \\
\text { Postons Butte } \\
\text { Postons Folly } \\
\text { Primrose Hill } \\
\text { Stiles Hill } \\
\text { Poston Butte } \\
\text { Poston Junior High School }\end{array}$ & $\begin{array}{l}\text { ppl } \\
\text { summit }\end{array}$ & $\begin{array}{l}\text { BGN } \\
\text { BGN } \\
\text { VARIANT } \\
\text { VARIANT } \\
\text { VARIANT } \\
\text { VARIANT } \\
\text { VARIANT } \\
\text { VARIANT } \\
\text { BGN } 1932 \\
\text { UNOFF }\end{array}$ & $\begin{array}{l}\text { Coconino } \\
\text { Maricopa }\end{array}$ & $\begin{array}{l}361045 N 1115406 \mathrm{~W} \\
332543 \mathrm{~N} 1114639 \mathrm{~W}\end{array}$ & & 1748 & $\begin{array}{l}\text { Walhalla Plateau } \\
\text { Mesa }\end{array}$ \\
\hline $\begin{array}{l}\text { Poston Railroad Station } \\
\text { Posten Railroad Station } \\
\text { Postons Butte } \\
\text { See Poston Butte } \\
\text { Poston School } \\
\text { Postons Folly } \\
\text { See Poston Butte } \\
\text { Poston Two }\end{array}$ & $\begin{array}{l}\text { summit } \\
\text { school } \\
\text { summit } \\
\text { locale }\end{array}$ & $\begin{array}{l}\text { UNOFF } \\
\text { VARIANT } \\
\text { VARIANT } \\
\text { UNOFF } \\
\text { VARIANT }\end{array}$ & $\begin{array}{l}\text { Pinal } \\
\text { Yuma } \\
\text { Pinal } \\
\text { Yuma }\end{array}$ & $\begin{array}{l}330318 \mathrm{~N} 1112429 \mathrm{~W} \\
335630 \mathrm{~N} 1142600 \mathrm{~W} \\
330318 \mathrm{~N} 1112429 \mathrm{~W} \\
335646 \mathrm{~N} 1142515 \mathrm{~W}\end{array}$ & & & B1ackwater \\
\hline
\end{tabular}




\section{FEATURE NAME}

Post Ranch

Post School

Post Well

Potato Butte

Potato Canyon

Numasito Canyon
Potatoe Lake

See Potato Lake

Potato Field Draw

Potato Garden Valley

Potato Hill

Potato Lake

Potatoe Lake

Potato Lake

Potato Lake Draw

Potato Lake Tank

Potato Patch

Potato Patch

Potato Patch

Potato Patch

Potato Patch

Potato Patch

Potato Patch

Potato Patch

Potato Patch Draw

Potato Patch Draw

Potato Patch Recreational Area

Potato Patch Tank

Potato Patch Tank

Potato Tank

Potato Tank

Potato Tank

Potato Valley

Potato Wash

Pothole

Pothole

Pothole Canyon

Pothole Canyon

Pot Hole Peak

Pothole Point

Pot Hole Reservoir

See Pothole Reservoir

Pothole Reservoir

Pot Hole Reservoir

Potholes

Pot Holes

See La Paz Well

Pothole Spring

Pothole Spring

Pot Hole Tank

Pot Hole Tank

Pot Hole Tank

Pot Hole Tank

Pothole Tank

Pothole Tank

Pot Hole Tank

Pothole Tank

Pothole Tank Number Four

Pothole Tank Number One

Pothole Tank Number Three

Potnero Well

Potrero Canyon

Potrero Creek

Pottebaum Tank

Potter Airfield

See Potters Field

Potter Canyon

Potter Lateral

Potter Lateral

Potter Mesa

Potter Mesa Tank
FEATURE

CLASS

locale
school

STATUS

COUNTY

UNOFF

Cochise

Yuma

well

summit

valley

UNOFF

BGN

BGN

VARIANT

lake

valley

valley

summit

lake

BGN
$B G N$
$B G N$
BGN
VARIAN

Santa Cruz

Gila

Coconino

Coconino

Navajo

Navajo

Coconino

Coconino

lake

valley

reservoir $B G$

area BGN

area

area

area

flat

flat

locale

BGN
$B G N$
$B G N$
$B G N$
$B G N$
$B G N$
$B G N$
$B G N$
$B G N$
$B G N$

locale

valley

valley

park

reservoir

reservoir

reservoir

reservoir

reservoir

bas in

Coconino

Coconino

Navajo

Coconino

Mohave

Maricopa

Apache

Yavapai

stream

bas in

lake

valley

valley

summit

cliff

reservoir

reservoir

BGN Yavapai

$B G N$

BGN

ADMIN
BGN
BGN

BGN

$B G N$

BGN

BGN

BGN

BGN

$B G N$

BGN

$B G N$

BGN

VARIANT

BGN

VARIANT

reservoir

$B G N$

VARIANT

well

spring

spring

reservoir

reservoir

reservoir

reservoir

reservoir

BGN

BGN

BGN

BGN

BGN

$B G N$

reservoir

reservoir $B G$

reservoir BGI

reservoir BGI

reservoir $B G$

reservoir BG

well

valley

stream

UNOFF

reservoir

BGN

BGN

Navajo

Coconino

Yavapai

Coconino

Coconino

Coconino

Coconino

Coconino

Mohave

Navajo

Greenlee

Navajo

Cochise

Coconino

Cochise

Coconino

Mohave

Mohave

Coconino

Yuma

Graham

Yavapai

Cochise

Navajo

Yavapa

Gila

Coconino

Yavapai

Yavapai

Coconino

Yavapai

Yavapai

Yavapai

Santa Cruz

Santa Cruz

Santa Cruz

Maricopa

VARIANT

$\begin{array}{ll}\text { airport } & \\ \text { valley } & B G N \\ \text { cana? } & B G N \\ \text { cana? } & B G N \\ \text { summit } & B G N \\ \text { reservoir } & B G N\end{array}$

Pinal

Mohave

Yuma

Yuma

Apache

Apache

COORDINATE

$315346 \mathrm{~N} 1102115 \mathrm{~W}$

$324304 \mathrm{N1143728W}$

$313307 N 1103442 \mathrm{~W}$

$340520 \mathrm{~N} 1110030 \mathrm{~W}$

$364251 \mathrm{N1105143 \textrm {W }}$

$342744 N 1112043 \mathrm{~W}$

$343256 \mathrm{~N} 1104124 \mathrm{~W}$

$362608 \mathrm{~N} 1101139 \mathrm{~W}$

$352934 \mathrm{~N} 1115630 \mathrm{~N}$

$342744 \mathrm{~N} 1112043 \mathrm{~W}$

350316 N1112407W $342758 \mathrm{~N} 1112018 \mathrm{~W}$

332510 $12420 \mathrm{~W}$

332519N1105520

$342700 \mathrm{~N} 1104702 \mathrm{~W}$

$350526 \mathrm{~N} 1135422 \mathrm{~W}$

$335702 \mathrm{~N} 1113107 \mathrm{~W}$

$340837 \mathrm{~N} 1093548 \mathrm{~W}$

342548 N1122448W

$344239 \mathrm{N1120916 \textrm {W }}$ $342138 \mathrm{N1103531 \textrm {W }}$ 342751 N1104602W

$344154 N 1120747 \mathrm{~W}$

$342653 N 1104733 \mathrm{~W}$

344929 N1113037W

$342737 \mathrm{~N} 1104635 \mathrm{~W}$

$352258 \mathrm{~N} 1114152 \mathrm{~W}$

$352927 N 1115437 \mathrm{~W}$

$362406 \mathrm{~N} 1131229 \mathrm{~W}$

$344519 N 1103915 \mathrm{~W}$ 325554 N1091557W

$343110 \mathrm{~N} 1101328 \mathrm{~W}$

$314636 \mathrm{~N} 1090937 \mathrm{~W}$

$355209 \mathrm{~N} 1113304 \mathrm{~W}$

$314824 \mathrm{~N} 1090836 \mathrm{~W}$

360851 N1123644W

$363212 \mathrm{~N} 1132626 \mathrm{~W}$

$363212 \mathrm{~N} 1132626 \mathrm{~W}$

355009N1120040W

$334045 N 1142832 \mathrm{~W}$

$330024 N 1093640 \mathrm{~W}$

$344036 \mathrm{~N} 1125017 \mathrm{~W}$

$314812 \mathrm{~N} 1090930 \mathrm{~W}$

$341155 N 1100458 \mathrm{~W}$

$341757 N 1115342 \mathrm{~W}$

$342206 N 1112205 \mathrm{~W}$

$343143 \mathrm{~N} 1112349 \mathrm{~W}$

$345418 \mathrm{~N} 1121646 \mathrm{~W}$

$345425 \mathrm{N1125526 \textrm {W }}$

$355155 \mathrm{~N} 1131041 \mathrm{~W}$

340130 N1115422W

$340522 \mathrm{N1} 115456 \mathrm{~W}$

$340141 \mathrm{~N} 1115351 \mathrm{~W}$

$312237 \mathrm{~N} 1105834 \mathrm{~W}$

312651 N1105751V

$312706 \mathrm{~N} 1105741 \mathrm{~W}$ 


\section{FEATURE NAME}

Potter Mountain

Potter Place

Potter Place Draw

Potters Airfield See Potters Field

Potters Field Potter Airfield Potters Airfield

Potters Hole

Potters Wash

Potter Tank

Potter Hell

Potter Windmill

Pottery Hill

Pottery Point

Potts Canyon

Potts Mountain

Potts Tank

Potts Tank

Pouquette Dan

Pouquette $\mathrm{Hill}$

Pouquette Homestead Tank

Pouquette Tank

Pouquette Tank

Pouquette Tank

Pouquette Tank

Pouquette Tank

Pour off Canyon

Pouroff Tank

Pour-off Tank, The

Poverty Draw

Poverty Flat

Poverty Flat

Poverty Flat

Poverty Flat Tank

Poverty Knoll Solitaire Butte

Poverty Mountain

Poverty Spring

Poverty Spring

Poverty Spring

Powderhouse Canyon

Powder Puff Landing Strip

Powell

Powell (historical)

Mellen

Needles

Red Crossing

Red Rock

Powell

The Needles

Powell

Topock

Powe 11, Lake

Escalante Lake

Glen Canyon Reservoir

Powell Estates Subdivision Mini Park

Powell Estates Subdivision Water Retention Bas in

Powell Junior High School

Powe11 Lake See Topock Marsh

Powell Peak

Powell Plateau

Powells Plateau

Powell Point

Powell Railroad Station

Powell School

Powells Monument

Powells Plateau

$$
\begin{aligned}
& \text { FEATURE } \\
& \text { CLASS }
\end{aligned}
$$

STATUS

COUNTY

COOROINATE

313049 N1095432W

summit

locale

valley

BGN

Apache

44847N1093918W

$\begin{array}{lll}\text { VARIANT } & \text { Pinal } & 325226 N 1115733 \mathrm{~W} \\ \begin{array}{l}\text { ADMIN } \\ \text { VARIANT }\end{array} & \text { Pinal } & 325226 \mathrm{~N} 1115733 \mathrm{~W} \\ \text { VARIANT } & & \\ \text { BGN } & \text { Coconino } & 355732 \mathrm{N1} 125559 \mathrm{~W} \\ \text { BGN } & \text { Pinal } & 331317 N 1105926 \mathrm{~W} \\ \text { BGN } & \text { Apache } & 344616 N 1093946 \mathrm{~W} \\ \text { UNOFF } & \text { Apache } & 344840 N 1093919 \mathrm{~W} \\ \text { BGN } & \text { Apache } & 344429 N 1093832 \mathrm{~W}\end{array}$

airport

airport

reservoir

stream

reservoir

well

locale

summit

summit

valley

summit

reservoir

reservoir

dam

summit

reservoir

reservoir

BGN Coconino

BGN Gila

Pinal

Mohave

Mohave

Coconino

Coconino

Coconino

Coconino

Maricopa

reservoir

reservoir

reservoir

reservoir

valley

reservoir

valley

flat

flat

flat

reservoir

summit

summit

spring

spring

spring

valley

airport

mine

locale

UNOFF

BGN

VARIANT

VARIANT

VARIANT

VARIANT

VARIANT

VARIANT

locale

locale

BGN

Mohave

Coconino

Coconino

Coconino

Coconino

Navajo

Coconino

Yavapai

Coconino

Cochise

Pinal

Coconino

Maricopa

Mohave

Mohave

Gila

Coconino

Mohave

Mohave

Apache

Cochise

Mohave

reservoir

BGN 1959

VARIANT

$\begin{array}{ll} & \text { VARIANT } \\ \text { park AOMIM }\end{array}$

Maricopa

$353457 N 1110104 \mathrm{~W}$

$334559 \mathrm{N1} 104831 \mathrm{~W}$

$331724 N 1111127 \mathrm{~W}$

$342215 N 1134348 \mathrm{~W}$

$342014 N 1134428 \mathrm{~W}$

$351813 \mathrm{~N} 1123725 \mathrm{~W}$

$353722 \mathrm{~N} 1122702 \mathrm{~W}$

351751 N1120619W

$351153 N 1120654$

335442N1124830W

$351737 \mathrm{~N} 1120704 \mathrm{~W}$

$352636 \mathrm{~N} 1122744 \mathrm{~W}$

$353010 \mathrm{~N} 1122332 \mathrm{~W}$

$353438 \mathrm{~N} 1121630 \mathrm{~W}$

$344335 \mathrm{N1} 102519 \mathrm{~W}$

$345216 N 1112241 \mathrm{~W}$

$345928 \mathrm{~N} 1130611 \mathrm{~W}$

$342914 \mathrm{~N} 1111850 \mathrm{~W}$

$312933 N 1092724 \mathrm{~W}$

$330734 N 1103442 W$

342827 N1111958W

$325822 N 1121325 \mathrm{~W}$

$362737 N 1132625 \mathrm{~W}$

$362411 N 1132954 \mathrm{~W}$

$333612 N 1103611 \mathrm{~W}$

$342909 \mathrm{~N} 1111946 \mathrm{~W}$

$362356 \mathrm{~N} 1133250 \mathrm{~W}$

$351112 \mathrm{~N} 1140215 \mathrm{~W}$

$343727 \mathrm{~N} 1093940 \mathrm{~W}$

$312535 \mathrm{N1095501 \textrm {W }}$

$344306 \mathrm{~N} 1142911 \mathrm{~W}$

$351207 N 1140248 W$

SOURCE
COORDINAT

ELEV

MAP NAME

$\begin{array}{lll}6535 & \begin{array}{l}\text { Potter Mtn } \\ \text { Milky Ranch } \\ \text { Milky Ranch }\end{array}\end{array}$

$342904 N 1111954$

1309 Double Peak

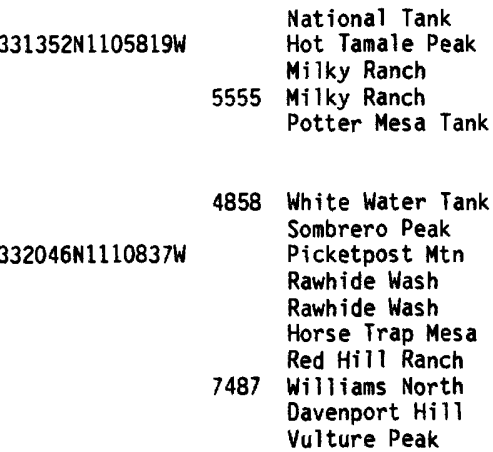

Sitgreaves Mtn

Stanford Tank

Red Hill Ranch

Mixon Tank

Dry Lake NW

Hutch Mtn

Mount Hope

Kehl Ridge

College Peaks

Coolidge Dam

Kehl Ridge

Haley Hills

6347 Poverty Knol1

6791 Poverty Knoll

Sevenmile Mts

Kehl Ridge

Poverty Spring

Kingman

5418 Hunt

Bisbee

Topock

$344306 \mathrm{~N} 1142911 \mathrm{~W}$

$344414 N 1142234 \mathrm{~W}$

365610 N1112900W

332350 N1115050W

swamp

summ it

plain

BGN

BGN 1932

VARIANT

cliff BGN 1937

building UNOFF

chool

UNOF

BGN

VARIANT
$332350 \mathrm{~N} 1115052 \mathrm{~W}$

332357 N1115059W

$344635 N 1143049 \mathrm{~W}$

Maricopa

Maricopa

Mohave

Mohave

Coconino

$344039 \mathrm{~N} 1142324 \mathrm{~W}$

$361751 \mathrm{~N} 1122337 \mathrm{~W}$

$360429 \mathrm{~N} 1120905 \mathrm{~W}$

$344414 N 1142236 \mathrm{~W}$

$333009 \mathrm{~N} 1121031 \mathrm{~W}$

Mohave

Maricopa

$365053 \mathrm{~N} 1114045 \mathrm{~W}$

ank

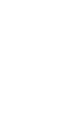

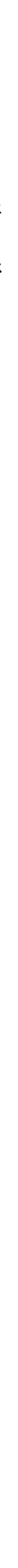




\begin{tabular}{|c|c|c|c|c|c|c|c|}
\hline FEATURE NAME & $\begin{array}{l}\text { FEATURE } \\
\text { CLASS }\end{array}$ & STATUS & COUNTY & COORDINATE & $\begin{array}{l}\text { SOURCE } \\
\text { COORDINATE }\end{array}$ & $\begin{array}{l}\text { ELEV } \\
\text { FT }\end{array}$ & MAP NAME \\
\hline $\begin{array}{l}\text { See Powell Plateau } \\
\text { Powell Spring }\end{array}$ & $\begin{array}{l}\text { plain } \\
\text { spring }\end{array}$ & BGN 1976 & $\begin{array}{l}\text { Coconino } \\
\text { Yavapai }\end{array}$ & $\begin{array}{l}361751 N 1122337 \mathrm{~W} \\
343454 \mathrm{~N} 1120445 \mathrm{~W}\end{array}$ & & & Cherry \\
\hline $\begin{array}{l}\text { Powell Spring } \\
\text { Powell Springs Campground } \\
\text { Power Canal } \\
\text { Powerl ine Oam } \\
\text { Powerl ine Pass } \\
\text { Power Line Reservoir } \\
\text { Power Line Tank } \\
\text { Powerl ine Tank } \\
\text { Power Line Tank } \\
\text { Powerl ine Tank }\end{array}$ & $\begin{array}{l}\text { spring } \\
\text { park } \\
\text { canal } \\
\text { dam } \\
\text { gap } \\
\text { reservoir } \\
\text { reservoir } \\
\text { reservoir } \\
\text { reservoir } \\
\text { reservoir }\end{array}$ & $\begin{array}{l}\text { BGN } 1932 \\
\text { ADNIN } \\
\text { BGN } \\
\text { UNOFF } \\
\text { BGN } 1980 \\
\text { BGN } \\
\text { BGN } \\
\text { BGN } \\
\text { BGN } \\
\text { BGN }\end{array}$ & $\begin{array}{l}\text { Coconino } \\
\text { Yavapai } \\
\text { Gila } \\
\text { Pinal } \\
\text { Graham } \\
\text { Pinal } \\
\text { Pinal } \\
\text { Maricopa } \\
\text { Gila } \\
\text { Yavapai }\end{array}$ & $\begin{array}{l}362045 \mathrm{~N} 1122126 \mathrm{~W} \\
343441 \mathrm{~N} 1120411 \mathrm{~W} \\
333713 \mathrm{~N} 1105751 \mathrm{~W} \\
332154 \mathrm{~N} 1113254 \mathrm{~W} \\
323736 \mathrm{~N} 1092429 \mathrm{~W} \\
323303 \mathrm{~N} 1105810 \mathrm{~W} \\
323702 \mathrm{~N} 1105952 \mathrm{~W} \\
333952 \mathrm{~N} 1124839 \mathrm{~W} \\
341257 \mathrm{~N} 1111333 \mathrm{~W} \\
341914 \mathrm{~N} 1121432 \mathrm{~W}\end{array}$ & & 4640 & $\begin{array}{l}\text { King Arthur Castle } \\
\text { Cherry } \\
\text { Salt River Peak } \\
\text { Desert Well } \\
\text { Ory Mtn } \\
\text { Oracle Junction } \\
\text { Oracle Junction } \\
\text { Star Well } \\
\text { McDonald Mtn } \\
\text { Cleator }\end{array}$ \\
\hline $\begin{array}{l}\text { Powerline Tank } \\
\text { Powerl ine Tank } \\
\text { Powerl ine Tank } \\
\text { Power Line Tank } \\
\text { Powerl ine Tank } \\
\text { Power Line Tank } \\
\text { Powerl ine Trick Tank } \\
\text { Power Line Wash } \\
\text { Powerl ine Wash } \\
\text { Power Line Well }\end{array}$ & $\begin{array}{l}\text { reservoir } \\
\text { reservoir } \\
\text { reservoir } \\
\text { reservoir } \\
\text { reservoir } \\
\text { reservoir } \\
\text { reservoir } \\
\text { stream } \\
\text { stream } \\
\text { well }\end{array}$ & $\begin{array}{l}\text { BGN } \\
\text { BGN } \\
\text { BGN } \\
\text { BGN } \\
\text { BGN } \\
\text { BGN } \\
\text { BGN } \\
\text { BGN } \\
\text { BGN } \\
\text { UNOFF }\end{array}$ & $\begin{array}{l}\text { Navajo } \\
\text { Yavapai } \\
\text { Coconino } \\
\text { Coconino } \\
\text { Yavapai } \\
\text { Coconino } \\
\text { Coconino } \\
\text { Pinal } \\
\text { Maricopa } \\
\text { Maricopa }\end{array}$ & $\begin{array}{l}344211 \mathrm{~N} 1095416 \mathrm{~W} \\
344247 \mathrm{~N} 1120931 \mathrm{~W} \\
344803 \mathrm{~N} 1112153 \mathrm{~W} \\
345501 \mathrm{~N} 1112235 \mathrm{~W} \\
350312 \mathrm{~N} 1125935 \mathrm{~W} \\
350841 \mathrm{~N} 1115921 \mathrm{~W} \\
351114 \mathrm{~N} 1112545 \mathrm{~W} \\
323908 \mathrm{~N} 1110208 \mathrm{~W} \\
333837 \mathrm{~N} 1124635 \mathrm{~W} \\
333640 \mathrm{~N} 1124403 \mathrm{~W}\end{array}$ & $\begin{array}{l}323606 \mathrm{~N} 1110018 \mathrm{~W} \\
335321 \mathrm{~N} 1125457 \mathrm{~W}\end{array}$ & 6311 & $\begin{array}{l}\text { Hay Hollow } \\
\text { Hickey Mountain } \\
\text { Jaycox Mtn } \\
\text { Mormon Lake } \\
\text { Turkey Canyon } \\
\text { Garland Prairie } \\
\text { Winona } \\
\text { Chief Butte } \\
\text { Star Well } \\
\text { Wagner Wash Well }\end{array}$ \\
\hline $\begin{array}{l}\text { Powerline We } 11 \\
\text { Powers Butte } \\
\text { Powers Butte Farms } \\
\text { Powers Canyon } \\
\text { Powers Garden } \\
\text { Powers Garden Ninety Six Trail } \\
\text { Powers Garden Spring } \\
\text { Powers Gulch } \\
\text { Powers Hill } \\
\text { Powers Mine }\end{array}$ & $\begin{array}{l}\text { well } \\
\text { summit } \\
\text { locale } \\
\text { valley } \\
\text { locale } \\
\text { trail } \\
\text { spring } \\
\text { valley } \\
\text { summit } \\
\text { mine }\end{array}$ & $\begin{array}{l}\text { UNOFF } \\
\text { BGN } \\
\text { BGN } \\
\text { BGN } \\
\text { BGN } \\
\text { UNOFF } \\
\text { BGN } \\
\text { BGN } \\
\text { BGN } 1975 \\
\text { UNOFF }\end{array}$ & $\begin{array}{l}\text { Yuma } \\
\text { Maricopa } \\
\text { Maricopa } \\
\text { Cochise } \\
\text { Graham } \\
\text { Graham } \\
\text { Graham } \\
\text { Pinal } \\
\text { Graham } \\
\text { Graham }\end{array}$ & $\begin{array}{l}340420 \mathrm{~N} 1135312 \mathrm{~W} \\
331824 \mathrm{~N} 1124403 \mathrm{~W} \\
331748 \mathrm{~N} 1124446 \mathrm{~W} \\
321534 \mathrm{~N} 1090545 \mathrm{~W} \\
323913 \mathrm{~N} 1102132 \mathrm{~W} \\
323820 \mathrm{~N} 1102122 \mathrm{~W} \\
323857 \mathrm{~N} 1102131 \mathrm{~W} \\
332359 \mathrm{N1} 110034 \mathrm{~W} \\
324153 \mathrm{~N} 1102037 \mathrm{~W} \\
323534 \mathrm{~N} 1102038 \mathrm{~W}\end{array}$ & $\begin{array}{l}322005 N 1090328 \mathrm{~W} \\
332121 \mathrm{~N} 1105907 \mathrm{~W}\end{array}$ & $\begin{array}{l}1294 \\
791\end{array}$ & $\begin{array}{l}\text { Powerline Well } \\
\text { Hassayampa } \\
\text { Hassayampa } \\
\text { Doubtful Canyon } \\
\text { Kennedy Peak } \\
\text { Kennedy Peak } \\
\text { Kennedy Peak } \\
\text { Haunted Canyon } \\
\text { Kennedy Peak } \\
\text { Bassett Peak }\end{array}$ \\
\hline $\begin{array}{l}\text { Power Tank } \\
\text { Power Tank } \\
\text { Power Tank } \\
\text { Poyer Tank } \\
\text { Poyner Water } \\
\text { Pozito Well } \\
\text { Pozo } \\
\text { Pozo Ben } \\
\text { See Hoa Murk } \\
\text { Pozo Blanco } \\
\text { See Stoa Vaya (site) }\end{array}$ & $\begin{array}{l}\text { reservoir } \\
\text { reservoir } \\
\text { reservoir } \\
\text { reservoir } \\
\text { reservoir } \\
\text { well } \\
\text { ppl } \\
\text { locale } \\
\text { locale }\end{array}$ & $\begin{array}{l}\text { BGN } \\
\text { BGN } \\
\text { BGN } \\
\text { BGN } \\
\text { BGN } \\
\text { UNOFF } \\
\text { BGN } \\
\text { VARIANT } \\
\text { VARIANT }\end{array}$ & $\begin{array}{l}\text { Coconino } \\
\text { Coconino } \\
\text { Coconino } \\
\text { Navajo } \\
\text { Maricopa } \\
\text { Pima } \\
\text { Maricopa } \\
\text { Pima } \\
\text { Pima }\end{array}$ & $\begin{array}{l}344430 \mathrm{~N} 1112229 \mathrm{~W} \\
350101 \mathrm{~N} 1115453 \mathrm{~W} \\
351053 \mathrm{~N} 1120906 \mathrm{~W} \\
343718 \mathrm{~N} 1103008 \mathrm{~W} \\
330447 \mathrm{~N} 1123741 \mathrm{~W} \\
315401 \mathrm{~N} 1113443 \mathrm{~W} \\
331637 \mathrm{~N} 1115026 \mathrm{~W} \\
321647 \mathrm{~N} 1124000 \mathrm{~W} \\
321033 \mathrm{~N} 1121342 \mathrm{~W}\end{array}$ & & 1216 & $\begin{array}{l}\text { Turkey Mtn } \\
\text { Sycamore Point } \\
\text { Williams South } \\
\text { Red Knoll } \\
\text { Cotton Center } \\
\text { Kitt Peak } \\
\text { Chandler }\end{array}$ \\
\hline $\begin{array}{l}\text { Pozo Colorado } \\
\text { See Chiulikam } \\
\text { Pozo de Federico } \\
\text { See Kuakatch } \\
\text { Pozo Hondo Tank } \\
\text { Pozo Hondo Wash } \\
\text { Pozo Nuevo Ranch } \\
\text { Pozo Nuevo Tank } \\
\text { Pozo Nuevo Well } \\
\text { Pozo Ondo } \\
\text { See Ventana }\end{array}$ & $\begin{array}{l}\text { locale } \\
\text { ppl } \\
\text { reservoir } \\
\text { stream } \\
\text { locale } \\
\text { reservoir } \\
\text { well } \\
\text { ppl }\end{array}$ & $\begin{array}{l}\text { VARIANT } \\
\text { VARIANT } \\
\text { BGN } \\
\text { BGN } \\
\text { UNOFF } \\
\text { BGN } \\
\text { UNOFF } \\
\text { VARIANT }\end{array}$ & $\begin{array}{l}\text { Maricopa } \\
\text { Pima } \\
\text { Pima } \\
\text { Pima } \\
\text { Pima } \\
\text { Pima } \\
\text { Pima } \\
\text { Pima }\end{array}$ & $\begin{array}{l}323428 N 1123131 \mathrm{~W} \\
320815 \mathrm{~N} 1123944 \mathrm{~W} \\
314511 \mathrm{~N} 1112719 \mathrm{~W} \\
313728 \mathrm{~N} 1112910 \mathrm{~W} \\
314642 \mathrm{~N} 1112417 \mathrm{~W} \\
314652 \mathrm{~N} 112451 \mathrm{~W} \\
320101 \mathrm{~N} 1130200 \mathrm{~W} \\
322758 \mathrm{~N} 1121433 \mathrm{~W}\end{array}$ & $314027 N 1113751 \mathrm{~W}$ & & $\begin{array}{l}\text { Fresno Wash } \\
\text { Wilbur Canyon } \\
\text { Fresno Wash } \\
\text { Fresno Wash } \\
\text { Pozo Nuevo Well }\end{array}$ \\
\hline $\begin{array}{l}\text { Pozo Redondo } \\
\text { See Sikort Chuapo } \\
\text { Pozo Redondo Mountains } \\
\text { See Sikort Chuapo Mountains } \\
\text { Pozo Redondo Mountains } \\
\text { Guns ight Mountains } \\
\text { Gunsight Range }\end{array}$ & $\begin{array}{l}\text { locale } \\
\text { range } \\
\text { summit }\end{array}$ & $\begin{array}{l}\text { VARIANT } \\
\text { VARIANT } \\
\text { BGN } 1941 \\
\text { VARIANT } \\
\text { VARIANT }\end{array}$ & $\begin{array}{l}\text { Pima } \\
\text { Pima } \\
\text { Pima }\end{array}$ & $\begin{array}{l}321855 \mathrm{~N} 1124016 \mathrm{~W} \\
322150 \mathrm{~N} 1123717 \mathrm{~W} \\
321841 \mathrm{~N} 1124152 \mathrm{~W}\end{array}$ & & & Sikort Chuapo \\
\hline $\begin{array}{l}\text { Pozo Redondo Valley } \\
\text { Pozo Salado } \\
\text { Pozo Salado Well }\end{array}$ & $\begin{array}{l}\text { valley } \\
\text { reservoir } \\
\text { well }\end{array}$ & $\begin{array}{l}\text { BGN } 1941 \\
\text { BGN } \\
\text { UNOFF }\end{array}$ & $\begin{array}{l}\text { Pima } \\
\text { Pima } \\
\text { Pima }\end{array}$ & $\begin{array}{l}322217 \mathrm{~N} 1124136 \mathrm{~W} \\
322410 \mathrm{~N} 1125622 \mathrm{~W} \\
315534 \mathrm{~N} 1125622 \mathrm{~W}\end{array}$ & $321333 \mathrm{~N} 1123923 \mathrm{~W}$ & & $\begin{array}{l}\text { Sikort Chuapo } \\
\text { Childs Mtn } \\
\text { West of Lukeville }\end{array}$ \\
\hline $\begin{array}{l}\text { Pozo Tapado } \\
\text { See Maish Vaya } \\
\text { Pozo Verde Mount } \\
\text { See Pozo Verde Mountains } \\
\text { Pozo Verde Mountain } \\
\text { See Pozo Verde Mountains } \\
\text { Pozo Verde Mountains }\end{array}$ & $\begin{array}{l}\text { ppl } \\
\text { summit } \\
\text { summit }\end{array}$ & $\begin{array}{l}\text { VARIANT } \\
\text { VARIANT } \\
\text { VARIANT } \\
\text { VARIANT }\end{array}$ & $\begin{array}{l}\text { Pima } \\
\text { Pima } \\
\text { Pima }\end{array}$ & $\begin{array}{l}321001 \mathrm{~N} 1120736 \mathrm{~W} \\
313130 \mathrm{~N} 1113600 \mathrm{~W} \\
313130 \mathrm{~N} 1113600 \mathrm{~W}\end{array}$ & & & \\
\hline
\end{tabular}


NATIONAL GAZETTEER--ARIZONA 1986

FEATURE NAME
See Baboquivari Mountains
Pozo Verde Mountains
Pozo Verde Mount
Pozo Verde Mountain
Sierra del Pozo Verde
Sierra Verde
Pragaatzo

See Bekihatso

Pra ga at zo Lake See Bekihatso

Prahaatzo

See Bekihatso

Prairie Dog Tank

Prairie Dog Tank

Prairie Dog Tank

\section{Prairie Pit Tank}

Prairie Tank

Prairie Wash

See Heather Wash

Prairie Wash

$P$ Ranch

P Ranch Canyon

Pratt

See Lake Carl Pleasant

Pratt Canyon

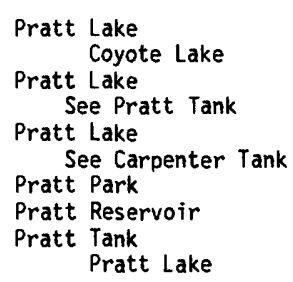

pp 1

lake

lake

lake

reservoir reservoir reservoir

BGN

VARIANT

Maricopa

Apache

VARIANT

reservoir reservoir

stream

stream

locale

valley

locale

valley

lake

lake

reservoir

flat

reservoir

lake

reservoir reservoir summit

valley

valley

spring

gap

bend

spring

well

gap

gap

gap

gap

ppl

school

school

school

airport

forest

school

building

building

locale

reservoir

locale

locale
VARIANT

BGN

BGN

BGN

BGN

BGN
VARIANT

BGN 1932

UNOFF

BGN

VARIANT

BGN

BGN

VARIANT

VARIANT

VARIANT

BGN

BGN

VARIANT

VARIANT

Apache

Apache

Coconino

Coconino

Coconino

Navajo

Yavapai

Coconino

Coconino

Graham

Graham

Maricopa

Coconino

Apache

Coconino

Coconino

Coconino

Coconino

Coconino

BGN

BGN

BGN

BGN

VARIANT

BGN

BGN

BGN

VARIANT

VARIANT

VARIANT

VARIANT

Coconino

Coconino

Maricopa

Graham

Gila

Graham

Pima

Yuma

Pima

Pima

Pima

Pima

Pima

Pima

BGN

UNOFF

UNOFF

UNOFF

VARIANT

ADM IN

VARIANT

UNOFF

UNOFF

Yavapai

Yavapai

Yavapai

Yavapai

Yavapai

Yavapai

Yavapai

Yavapai

UNOFF

BGN

UNOFF
Yavapai

Yavapai

Yavapai

Yavapai

Yavapai
$331853 \mathrm{~N} 1115700 \mathrm{~W}$

$360007 N 1093833 \mathrm{~W}$

$360007 N 1093833 W$

360007 N1093833W

$344334 \mathrm{~N} 1111512 \mathrm{~W}$

$345705 \mathrm{~N} 1105017 \mathrm{~W}$

351908N1120907

333723 N1095532W

$350800 \mathrm{~N} 1122536 \mathrm{~W}$

$360317 N 1122959 \mathrm{~W}$

$323849 \mathrm{~N} 1094306 \mathrm{~W}$

$323858 \mathrm{~N} 1094305 \mathrm{~W}$

335019N1121558W

$363101 \mathrm{N1} 121908 \mathrm{~W}$

$340132 N 1090415 \mathrm{~W}$

344941 N1111308W

344936 N1111409W

344715N1112719W

365613 N1122639W

344941N1111308W

$344936 \mathrm{N1111409 \textrm {W }}$

$344943 \mathrm{NI} 111310 \mathrm{~W}$

$333108 \mathrm{~N} 1115813 \mathrm{~W}$

$341614 N 1111012 \mathrm{~W}$

325532N1101032W

$313350 \mathrm{~N} 1113611 \mathrm{~W}$

$325800 \mathrm{~N} 1142959 \mathrm{~W}$

$321750 \mathrm{~N} 1103707 \mathrm{~W}$

315836 N1115159W

$313350 \mathrm{~N} 1113611 \mathrm{~W}$

$313350 N 1113611 W$

$313350 N 1113611 \mathrm{~W}$

313350N1113611W

$343224 \mathrm{~N} 1122804 \mathrm{~W}$

$343702 \mathrm{~N} 1122702 \mathrm{~W}$

$343347 \mathrm{~N} 1122835 \mathrm{~W}$

343215N1122815

$343905 \mathrm{N1} 122514 \mathrm{~W}$

$343500 \mathrm{~N} 1123600 \mathrm{~W}$

$343229 \mathrm{~N} 1121555 \mathrm{~W}$

343223N1122807W

$343211 \mathrm{~N} 1122807 \mathrm{~W}$

$343125 \mathrm{~N} 1123046 \mathrm{~W}$

$343234 \mathrm{~N} 1122930 \mathrm{~W}$

$343245 \mathrm{~N} 1122816 \mathrm{~W}$
$343243 N 1122804 \mathrm{~W}$
$360149 \mathrm{~N} 1123119 \mathrm{~W}$

325602 N1101055W

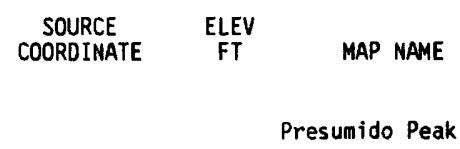

Turkey Mtn Rock Station Williams North

Elwood Canyon Ash Fork

360624N1122003W Chamisa Tank

Artesia

Artesia

362946N1121753W Big Springs

7990 Loco Knoll 


\begin{tabular}{|c|c|c|c|c|c|c|c|}
\hline FEATURE NAME & $\begin{array}{l}\text { FEATURE } \\
\text { CLASS }\end{array}$ & STATUS & COUNTY & COORDINATE & $\begin{array}{l}\text { SOURCE } \\
\text { COORDINATE }\end{array}$ & $\underset{\text { FT }}{\text { ELEV }}$ & MAP NAME \\
\hline $\begin{array}{l}\text { Prescott Substation } \\
\text { Prescott Valley } \\
\text { Prescott Valley Airport } \\
\text { Prescott Valley Community } \\
\text { Center Park }\end{array}$ & $\begin{array}{l}\text { locale } \\
\text { ppl } \\
\text { airport } \\
\text { park }\end{array}$ & $\begin{array}{l}\text { UNOFF } \\
\text { BGN } \\
\text { ADMIN } \\
\text { ADMIN }\end{array}$ & $\begin{array}{l}\text { Yavapai } \\
\text { Yavapai } \\
\text { Yavapai } \\
\text { Yavapai }\end{array}$ & $\begin{array}{l}343610 \mathrm{~N} 1122714 \mathrm{~W} \\
343636 \mathrm{N1121854 \textrm {W }} \\
343500 \mathrm{N1} 121750 \mathrm{~W} \\
343639 \mathrm{N1} 121805 \mathrm{~W}\end{array}$ & & 5016 & $\begin{array}{l}\text { Prescott } \\
\text { Prescott Valley } S \\
\text { Prescott Valley } S \\
\text { Prescott Valley } S\end{array}$ \\
\hline $\begin{array}{l}\text { Prescott Valley Plaza } \\
\text { Shopping Center }\end{array}$ & locale & UNOFF & Yavapai & $343512 \mathrm{~N} 1121912 \mathrm{~W}$ & & & Prescott Valley S \\
\hline $\begin{array}{l}\text { Prescott Valley Recreation Area } \\
\text { Prescott Valley Town Park } \\
\text { Prescott Valley Town Park }\end{array}$ & park & $\begin{array}{l}\text { ADMIN } \\
\text { VARIANT } \\
\text { VARIANT }\end{array}$ & Yavapai & $343607 \mathrm{~N} 1121856 \mathrm{~W}$ & & & Prescott Valley S \\
\hline $\begin{array}{l}\text { See Prescott Valley } \\
\text { Recreation Area }\end{array}$ & park & & Yavapai & $343607 \mathrm{~N} 1121856 \mathrm{~W}$ & & & \\
\hline & valley & $\begin{array}{l}\text { BGN } 1975 \\
\text { VARIANT }\end{array}$ & Graham & $323955 \mathrm{~N} 1100938 \mathrm{~W}$ & $324304 \mathrm{~N} 1100300 \mathrm{~W}$ & & Eureka Ranch \\
\hline President Harding Rapids & rapids & $B G N$ & Coconino & $362317 \mathrm{~N} 1115049 \mathrm{~W}$ & & & Tatahatso Point \\
\hline $\begin{array}{l}\text { President Mine } \\
\text { Presley Tank } \\
\text { Press Tank } \\
\text { Preston Hills (subdivision) } \\
\text { Bent Tree }\end{array}$ & $\begin{array}{l}\text { mine } \\
\text { reservoir } \\
\text { reservoir } \\
\text { ppl }\end{array}$ & $\begin{array}{l}\text { UNOFF } \\
\text { BGN } \\
\text { BGN } \\
\text { BGN } \\
\text { VARIANT }\end{array}$ & $\begin{array}{l}\text { Graham } \\
\text { Coconino } \\
\text { Coconino } \\
\text { Maricopa }\end{array}$ & $\begin{array}{l}324345 \mathrm{~N} 1100520 \mathrm{~W} \\
352646 \mathrm{N1123833 \textrm {W }} \\
365413 \mathrm{~N} 1120250 \mathrm{~W} \\
333505 \mathrm{N1115200 \textrm {W }}\end{array}$ & & 1380 & $\begin{array}{l}\text { Blue Jay Peak } \\
\text { Mount Floyd } \\
\text { Coyote Buttes } \\
\text { Sawik Mountain }\end{array}$ \\
\hline $\begin{array}{l}\text { Preston Mesa } \\
\text { Preston Wel1 } \\
\text { Preston Wel1 } \\
\text { Presumido Canyon } \\
\text { Presumido Pass } \\
\text { Preciena Canyon } \\
\text { Presciendo Canon } \\
\text { Prescimida Pass } \\
\text { Prescimide Pass } \\
\text { Prescimido Pass }\end{array}$ & $\begin{array}{l}\text { summit } \\
\text { well } \\
\text { well } \\
\text { valley } \\
\text { gap }\end{array}$ & $\begin{array}{l}\text { BGN } \\
\text { UNOFF } \\
\text { UNOFF } \\
\text { BGN } \\
\text { BGN 1941 } \\
\text { VARIANT } \\
\text { VARIANT } \\
\text { VARIANT } \\
\text { VARIANT } \\
\text { VARIANT }\end{array}$ & $\begin{array}{l}\text { Coconino } \\
\text { Pinal } \\
\text { Coconino } \\
\text { Pima } \\
\text { Pima }\end{array}$ & $\begin{array}{l}362207 \mathrm{~N} 1111215 \mathrm{~W} \\
332101 \mathrm{N1111130 \textrm {W }} \\
361932 \mathrm{N111210OW} \\
313105 \mathrm{N1113850 \textrm {W }} \\
313350 \mathrm{N1113611 \textrm {W }}\end{array}$ & $313342 \mathrm{~N} 1113609 \mathrm{~W}$ & 6830 & $\begin{array}{l}\text { Preston Mesa South } \\
\text { Picketpost Mtn } \\
\text { Preston We11 } \\
\text { Caponera Peak } \\
\text { Presumido Peak }\end{array}$ \\
\hline $\begin{array}{l}\text { Presumido Peak } \\
\text { Presumido Ranch } \\
\text { Presumido Store } \\
\text { Price } \\
\text { Price Canyon } \\
\text { Price Canyon } \\
\text { Price Canyon Trail Two } \\
\text { Hundred Twentyfour }\end{array}$ & $\begin{array}{l}\text { summit } \\
\text { locale } \\
\text { locale } \\
\text { locale } \\
\text { valley } \\
\text { valley } \\
\text { trail }\end{array}$ & $\begin{array}{l}\text { BGN } \\
\text { UNOFF } \\
\text { BGN } \\
\text { BGN } \\
\text { BGN } \\
\text { BGN } \\
\text { UNOFF }\end{array}$ & $\begin{array}{l}\text { Pima } \\
\text { Pima } \\
\text { Pima } \\
\text { Pinal } \\
\text { Cochise } \\
\text { Mohave } \\
\text { Cochise }\end{array}$ & $\begin{array}{l}313401 N 1113713 \mathrm{~W} \\
313236 \mathrm{N1113557W} \\
313142 \mathrm{N1113720W} \\
330544 \mathrm{~N} 111354 \mathrm{~W} \\
314119 \mathrm{~N} 1091352 \mathrm{~W} \\
355653 \mathrm{~N} 1132523 \mathrm{~W} \\
314647 \mathrm{N1091510W}\end{array}$ & $\begin{array}{l}314907 N 1091543 \mathrm{~W} \\
355932 \mathrm{N1132714W}\end{array}$ & $\begin{array}{l}4806 \\
3295\end{array}$ & $\begin{array}{l}\text { Presumido Peak } \\
\text { Presumido Peak } \\
\text { Presumido Peak } \\
\text { North Butte } \\
\text { Apache } \\
\text { Price Point } \\
\text { Chiricahua Peak }\end{array}$ \\
\hline $\begin{array}{l}\text { Priceless Mine } \\
\text { Price Pocket }\end{array}$ & $\begin{array}{l}\text { mine } \\
\text { spring }\end{array}$ & $\begin{array}{l}\text { UNOFF } \\
\text { BGN }\end{array}$ & $\begin{array}{l}\text { Mohave } \\
\text { Mohave }\end{array}$ & $\begin{array}{l}341850 \mathrm{~N} 1133418 \mathrm{~W} \\
355921 \mathrm{N1132717W}\end{array}$ & & & $\begin{array}{l}\text { Artillery Peak } \\
\text { Price Point }\end{array}$ \\
\hline $\begin{array}{l}\text { Price Point } \\
\text { Price Railroad Station } \\
\text { Price Shake Pine Gulch Trail } \\
\text { 235-236 }\end{array}$ & $\begin{array}{l}\text { summit } \\
\text { building } \\
\text { trail }\end{array}$ & $\begin{array}{l}\text { BGN } \\
\text { UNDFF } \\
\text { UNOFF }\end{array}$ & $\begin{array}{l}\text { Mohave } \\
\text { Pinal } \\
\text { Cochise }\end{array}$ & $\begin{array}{l}355911 \text { N1132524W } \\
330557 \mathrm{N1111429W} \\
314410 \mathrm{~N} 1091745 \mathrm{~W}\end{array}$ & & 6588 & $\begin{array}{l}\text { Price Point } \\
\text { North Butte } \\
\text { Swede Peak }\end{array}$ \\
\hline $\begin{array}{l}\text { Price Spring } \\
\text { Price Tank } \\
\text { Pride Mine } \\
\text { Pride Mine } \\
\text { Pride Ranch } \\
\text { Pride Well }\end{array}$ & $\begin{array}{l}\text { spring } \\
\text { reservoir } \\
\text { mine } \\
\text { mine } \\
\text { locale } \\
\text { well }\end{array}$ & $\begin{array}{l}\text { BGN } \\
\text { BGN } \\
\text { UNOFF } \\
\text { UNOFF } \\
\text { UNOFF } \\
\text { UNOFF }\end{array}$ & $\begin{array}{l}\text { Cochise } \\
\text { Gila } \\
\text { Santa Cruz } \\
\text { Yuma } \\
\text { Cochise } \\
\text { Cochise }\end{array}$ & $\begin{array}{l}314615 \mathrm{~N} 1091535 \mathrm{~W} \\
333538 \mathrm{~N} 1104930 \mathrm{~W} \\
312303 \mathrm{~N} 1104159 \mathrm{~W} \\
340918 \mathrm{~N} 1140216 \mathrm{~W} \\
322418 \mathrm{~N} 1101616 \mathrm{~W} \\
322418 \mathrm{~N} 1101618 \mathrm{~W}\end{array}$ & & & $\begin{array}{l}\text { Chiricahua Peak } \\
\text { Rockinstraw Mtn } \\
\text { Harshaw } \\
\text { Osborne Well } \\
\text { Cherry Spring Peak } \\
\text { Cherry Spring Peak }\end{array}$ \\
\hline $\begin{array}{l}\text { Pridham Canyon } \\
\text { Pridham Creek } \\
\text { Priebe Creek } \\
\text { Priebe Creek Tank } \\
\text { Priest Draw } \\
\text { Priest Tank } \\
\text { Prieta, Sierra } \\
\quad \text { Granite Range } \\
\text { San Prieto } \\
\text { Prieta, Sierra }\end{array}$ & $\begin{array}{l}\text { valley } \\
\text { stream } \\
\text { stream } \\
\text { reservoir } \\
\text { valley } \\
\text { reservoir } \\
\text { range }\end{array}$ & $\begin{array}{l}\text { BGN } \\
\text { BGN } \\
\text { BGN } \\
\text { BGN } \\
\text { BGN } \\
\text { BGN } \\
\text { BGN } \\
\text { VARIANT } \\
\text { VARIANT } \\
\text { BGN }\end{array}$ & $\begin{array}{l}\text { Cochise } \\
\text { Cochise } \\
\text { Gila } \\
\text { Gila } \\
\text { Coconino } \\
\text { Coconino } \\
\text { Yavapai }\end{array}$ & $\begin{array}{l}314832 N 1092614 \mathrm{~W} \\
315100 \mathrm{~N} 1093406 \mathrm{~W} \\
334412 \mathrm{N1100659W} \\
334355 \mathrm{~N} 1100449 \mathrm{~W} \\
350453 \mathrm{~N} 1113611 \mathrm{~W} \\
350407 \mathrm{N1113803W} \\
343126 \mathrm{N1123411W}\end{array}$ & $\begin{array}{l}314855 \mathrm{~N} 1092239 \mathrm{~W} \\
314842 \mathrm{N1092234W} \\
334409 \mathrm{~N} 1100243 \mathrm{~W} \\
350306 \mathrm{~N} 1113848 \mathrm{~W}\end{array}$ & & $\begin{array}{l}\text { Stanford Canyon } \\
\text { Squaretop Hills East } \\
\text { Velasquez Butte } \\
\text { Velasquez Butte } \\
\text { Lower Lake Mary } \\
\text { Mountainaire } \\
\text { Iron Springs }\end{array}$ \\
\hline & ridge & $B G N$ & Yavapai & 343118 N1123410W & & & Iron Springs \\
\hline $\begin{array}{l}\text { Prieta, Sierra } \\
\text { Prietai } \\
\text { Prieta Peak } \\
\quad \text { Prieto Peak } \\
\text { Sierra Prieta }\end{array}$ & $\begin{array}{l}\text { summit } \\
\text { summit } \\
\text { summit }\end{array}$ & $\begin{array}{l}\text { BGN } \\
\text { BGN } \\
\text { BGN } 1941 \\
\text { VARIANT } \\
\text { VARIANT }\end{array}$ & $\begin{array}{l}\text { Yuma } \\
\text { Yavapai } \\
\text { Pinal }\end{array}$ & $\begin{array}{l}324243 \mathrm{~N} 1143704 \mathrm{~W} \\
343430 \mathrm{~N} 1123335 \mathrm{~W} \\
323244 \mathrm{~N} 1115319 \mathrm{~W}\end{array}$ & & $\begin{array}{l}298 \\
6254 \\
3332\end{array}$ & $\begin{array}{l}\text { Yuma East } \\
\text { Iron Springs } \\
\text { North Komelik }\end{array}$ \\
\hline $\begin{array}{l}\text { Prieto, Cerro } \\
\text { Prieto, Cerro } \\
\text { Prieto Creek } \\
\text { See Eagle Creek } \\
\text { Prieto Peak } \\
\text { See Prieta Peak }\end{array}$ & $\begin{array}{l}\text { summit } \\
\text { summit } \\
\text { stream } \\
\text { summit }\end{array}$ & $\begin{array}{l}\text { BGN } \\
\text { BGN } \\
\text { VARIANT }\end{array}$ & $\begin{array}{l}\text { Pima } \\
\text { Pinal } \\
\text { Greenlee } \\
\text { Pinal }\end{array}$ & $\begin{array}{l}314201 N 1113443 \mathrm{~W} \\
323124 \mathrm{~N} 1112531 \mathrm{~W} \\
325736 \mathrm{~N} 1092420 \mathrm{~W} \\
323244 \mathrm{~N} 1115319 \mathrm{~W}\end{array}$ & & 4646 & $\begin{array}{l}\text { Mildred Peak } \\
\text { Samaniego Hills }\end{array}$ \\
\hline
\end{tabular}


NATIONAL GAZETTEER--ARIZONA 1986

\section{FEATURE NAME}

Prieto Plateau

Primavera School

Prime Canyon

Prime Lake

Horse Lake

Primeria Well

Primero Branch, Canal

(historical)

Primrose $\mathrm{Hill}$

See Poston Butte

Primrose Spring

Prince Albert Mine

Prince Charming Spring

Prince George Mine

Prince Mall

Prince Mine

Prince School

Princess Mine

Princess Pat Mine

Prince Tank

Pringle Pump

Pringle Wash

Pringle Well

Prison Hill

Procopio Spring

Proctor $\mathrm{Hill}$

Proctor Ranch

Proctor Spring

Proctor Wash

Profanity Ridge

Profanity Tank

Professor Creek

Progress Plaza Shopping Center

Prominent Point

Promontory Butte

Promontory Lookout Tower

Pronghorn Ranch

Pronghorn Tank

Prong Lake

Prospect Canyon

Prospect Canyon

Prospect Creek

See Hot Springs Canyon

Prospect Draw

Prospect Point

Prospect Ridge

Prospect Spring

Prospect Tank

Prospect Tank

Prospect Tank

Prospect Valley

Prosperity Mine

Prosperity Tank

Prosperity Tank

Proto Canyon

Provedencia Canyo

See Providencia Canyon

Providencia Canyon

Provedencia Canyon

Providencia Hill

Providencia Well

Province of Tusayan

See Tusayan

Province Tusayan

See Tusayan

Prudence Park

See Stefan Gollob Park

Prude Ranch

Pruneville Well

Pryce Canyon

Pryce Lake
STATUS COUNTY

plain

valley

lake

well

canal

summit

BGN

BGN

Greenlee

Yavapai

Apache

BGN 1964 Coconino

VARIANT

UNOFF

Yuma

Maricopa

COORDINATE

$331305 \mathrm{~N} 1091925 \mathrm{~W}$ $343133 N 1122951 \mathrm{~W}$

$334705 \mathrm{~N} 1091012 \mathrm{~W}$

$350555 \mathrm{~N} 1113150 \mathrm{~W}$

$324244 N 1133631 W$

$332155 \mathrm{~N} 1121335 \mathrm{~W}$

VARIANT

Pinal

$330318 N 1112429 W$

spring $\quad B G N$

mine UNOFF Mohave $354401 \mathrm{N1142307 \textrm {W }}$

$\begin{array}{llll}\text { spring } B G N & \text { Gila } & 332604 N 1105442 W\end{array}$

mine UNOFF Mohave 351852N1140552W

locale UNOFF Pima 321622N1105934W

mine UNOFF Maricopa 334638N1122154W

school UNOFF Pima 321620 N1105807W

mine UNOFF Yuma 330622N1143502W

mine UNOFF Graham 325957N1102128W

reservoir BGN Navajo 343436N1102003W

locale BGN Gila $\quad 333342 N 1105325 \mathrm{~W}$

stream BGN Gila $\quad 334412 N 1104830 \mathrm{~W}$

well

sumpit

spring

summit

spring

stream

ridge

UNOFF

BGN

Yuma

Gila

Pima

UNOFF Pima

BGN Pima

BGN 1979 Pima

BGN Apache

reservoir

BGN Apache

locale

cliff

cliff

tower

locale

reservoir

lake

valley

BGN

UNOFF

Maricopa

Pima

Coconino

Coconino

Coconino

Coconino

Coconino

Pinal

valley

BGN

valley

valley

ridge

spring

reservoir

reservoir $\quad B G N$

reservoir $B G$

mine

BGN

reservoir $B G N$

reservoir $B G$

valley $B G N$

valley

VARIANT

valley

summit

BGN

VARIANT

well

area

area

park

locale

well

valley

UNOFF

VARIANT

Coconino

Cochise

Greenlee

Coconino

Coconino

Apache

Coch ise

Greenlee

$334436 \mathrm{~N} 1104631 \mathrm{~W}$

$324341 \mathrm{N1143652 \textrm {W }}$

333239 N1104740W

320953N1113803W

$314444 N 1105414 \mathrm{~W}$

$314838 N 1104752 W$

$314313 \mathrm{~N} 1110800 \mathrm{~W}$

$335601 \mathrm{N1} 1090659 \mathrm{~W}$

$335510 N 1090727 \mathrm{~W}$

$340208 \mathrm{~N} 1114836 \mathrm{~W}$

$332610 \mathrm{~N} 1120456 \mathrm{~W}$

$322152 \mathrm{N1105431W}$

$342044 \mathrm{~N} 1110247 \mathrm{~W}$

$342237 N 1110118 \mathrm{~W}$

$351944 \mathrm{~N} 1121112 \mathrm{~W}$

$351822 \mathrm{N1121330 \textrm {W }}$

$352942 \mathrm{~N} 1115147 \mathrm{~W}$

$324524 \mathrm{N1} 103000 \mathrm{~W}$

$361150 \mathrm{~N} 1130454 \mathrm{~W}$

$321738 \mathrm{~N} 1102223 \mathrm{~W}$

$331116 \mathrm{~N} 1090612 \mathrm{~W}$

$355635 \mathrm{~N} 1130700 \mathrm{~W}$

$355851 \mathrm{~N} 1130615 \mathrm{~W}$

$344920 N 1092154 \mathrm{~W}$

$312915 \mathrm{~N} 1090333 \mathrm{~W}$

$331318 N 1090348 \mathrm{~W}$

355329N1130933W

$334512 N 1104423 W$

Sombrero Peak

White Hills West

Inspiration

Stockton Hill

2300 Tucson North

Baldy Mtn

Tucson North

Picacho

Cobre Grande Mtn

Sheepsk in Wash

2800 Salt River Peak

Dagger Peak

Dagger Peak

Yuma East

Rockinstraw Mtn

2604 Black Hills

Mt Hopkins

Helvetia

315042N1111212W Saucito Mtn

Escudilla Mtn

$340324 N 1114619 \mathrm{~W}$

Escudilla Mtn

Rover Peak

Phoen ix

Tucson North

Promontory Butte

Knoll Lake

Williams North

Williams North

Kendrick Peak

324539N1102954W Oak Grove Canyon

$361044 N 1130448$

Vulcans Throne

Harden Cienega

7112 Prospect Point

Prospect Point

Prospect Spring

Guadalupe Spring

Hardin Cienega

Hockey Puck Spring

Vulcans Throne

Twin Buttes

Meteor Crater

Campbell Francis Wsh

$315726 \mathrm{~N} 1110604 \mathrm{~W}$

354139N1113201W

Santa Cruz 312314N1105226W

Santa Cruz 312239N1104845W

Santa Cruz 312239 N1104845W

Pima

$315500 \mathrm{~N} 1111806 \mathrm{~W}$

$312117 N 1105407 \mathrm{~W}$

Cumero Canyon

Cumero Canyon

3996 Stevens Mtn

Cumero Canyon

Navajo 354505N1103600W

Navajo 354505N1103600W

Pima 321255N1104949W

Graham 323937N1101612W

Graham $323937 N 1101612 \mathrm{~W}$

Navajo $\quad 341102 \mathrm{~N} 1103539 \mathrm{~W}$

Navajo

$341216 N 1103517 W$

$312334 N 1104251 W$

lake

BGN 


\begin{tabular}{|c|c|c|c|c|c|c|c|}
\hline FEATURE NAME & $\begin{array}{l}\text { FEATURE } \\
\text { CLASS }\end{array}$ & STATUS & COUNTY & COORDINATE & $\begin{array}{c}\text { SOURCE } \\
\text { COORDINATE }\end{array}$ & $\begin{array}{l}\text { ELEV } \\
\text { FT }\end{array}$ & MAP NAME \\
\hline $\begin{array}{l}\text { P Six Ranch } \\
\text { P S Knoll } \\
\text { P S Knoll Forest Camp } \\
\text { P S Knoll Lookout Tower } \\
\text { P S Ranch } \\
\text { P S Spring Tank } \\
\text { P T Coe School } \\
\text { Public Health Agency Hospital } \\
\text { Puebla Viejo } \\
\quad \text { See Pueblo Viejo } \\
\quad \text { (historical) }\end{array}$ & $\begin{array}{l}\text { locale } \\
\text { summit } \\
\text { locale } \\
\text { tower } \\
\text { locale } \\
\text { reservoir } \\
\text { school } \\
\text { hospital } \\
\text { locale }\end{array}$ & $\begin{array}{l}\text { UNOFF } \\
\text { BGN } \\
\text { BGN } \\
\text { UNOFF } \\
\text { UNOFF } \\
\text { BGN } \\
\text { UNOFF } \\
\text { UNOFF } \\
\text { VARIANT }\end{array}$ & $\begin{array}{l}\text { Apache } \\
\text { Apache } \\
\text { Apache } \\
\text { Apache } \\
\text { Apache } \\
\text { Apache } \\
\text { Maricopa } \\
\text { La Paz } \\
\text { Graham }\end{array}$ & $\begin{array}{l}334300 \mathrm{~N} 1095230 \mathrm{~W} \\
334516 \mathrm{~N} 1092351 \mathrm{~W} \\
334528 \mathrm{~N} 1092223 \mathrm{~W} \\
334517 \mathrm{~N} 1092351 \mathrm{~W} \\
334551 \mathrm{~N} 1092245 \mathrm{~W} \\
333717 \mathrm{~N} 1094248 \mathrm{~W} \\
332840 \mathrm{~N} 1120827 \mathrm{~W} \\
340848 \mathrm{~N} 114181 \mathrm{~W} \\
\\
325000 \mathrm{~N} 1093400 \mathrm{~W}\end{array}$ & & 8045 & $\begin{array}{l}\text { Bonito Prairie } \\
\text { Big Lake South } \\
\text { Buffalo Crossing } \\
\text { Big Lake South } \\
\text { Big Lake South } \\
\text { Maverick SW } \\
\text { Fowler } \\
\text { Parker }\end{array}$ \\
\hline $\begin{array}{l}\text { Pueblo Canyon } \\
\text { Pueblo Colorado } \\
\text { See Puebio Colorado Valley } \\
\text { Pueblo Colorado } \\
\text { See Ganado } \\
\text { Pueblo Colorado River } \\
\text { See Pueblo Colorado Wash } \\
\text { Pueblo Colorado Valley } \\
\text { Pueblo Colorado } \\
\text { Pueblo Colorado Wash } \\
\text { Cornfields Wash } \\
\text { Ganado Wash } \\
\text { Pueblo Colorado River } \\
\text { Twin Buttes Wash }\end{array}$ & $\begin{array}{l}\text { valley } \\
\text { valley } \\
\text { ppl } \\
\text { arroyo } \\
\text { valley } \\
\text { arroyo }\end{array}$ & $\begin{array}{l}\text { BGN } \\
\text { VARIANT } \\
\text { VARIANT } \\
\text { VARIANT } \\
\text { BGN } 1915 \\
\text { VARIANT } \\
\text { BGN } 1974 \\
\text { VARIANT } \\
\text { VARIANT } \\
\text { VARIANT } \\
\text { VARIANT }\end{array}$ & $\begin{array}{l}\text { Gila } \\
\text { Navajo } \\
\text { Apache } \\
\text { Navajo } \\
\text { Navajo } \\
\text { Navajo }\end{array}$ & $\begin{array}{l}335022 \mathrm{~N} 1105136 \mathrm{~W} \\
351855 \mathrm{~N} 1095959 \mathrm{~W} \\
354241 \mathrm{~N} 1093229 \mathrm{~W} \\
351620 \mathrm{~N} 1100850 \mathrm{~W} \\
351855 \mathrm{~N} 1095959 \mathrm{~W} \\
351620 \mathrm{~N} 1100850 \mathrm{~W}\end{array}$ & $\begin{array}{l}354413 N 1092933 W \\
354413 N 1092933 W\end{array}$ & & Sunflower Butte \\
\hline $\begin{array}{l}\text { Pueblo Colorado Wash } \\
\text { See Cottonwood Wash } \\
\text { Pueblo de la Concepcion } \\
\text { See Yuma } \\
\text { Pueblo Elementary School } \\
\text { Pueblo Ganado } \\
\text { See Ganado } \\
\text { Pueblo Gardens } \\
\text { Pueblo Gardens School } \\
\text { Pueblo Grande (ruin) }\end{array}$ & $\begin{array}{l}\text { stream } \\
\text { ppl } \\
\text { school } \\
\text { ppl } \\
\text { ppl } \\
\text { school } \\
\text { locale }\end{array}$ & $\begin{array}{l}\text { VARIANT } \\
\text { VARIANT } \\
\text { UNOFF } \\
\text { VARIANT } \\
\text { BGN } \\
\text { UNOFF } \\
\text { BGN }\end{array}$ & $\begin{array}{l}\text { Navajo } \\
\text { Yuma } \\
\text { Maricopa } \\
\text { Apache } \\
\text { Pima } \\
\text { Pima } \\
\text { Maricopa }\end{array}$ & $\begin{array}{l}350010 \mathrm{~N} 1103915 \mathrm{~W} \\
324331 \mathrm{~N} 1143725 \mathrm{~W} \\
333134 \mathrm{~N} 1115422 \mathrm{~W} \\
\\
354241 \mathrm{~N} 1093229 \mathrm{~W} \\
321146 \mathrm{~N} 1105619 \mathrm{~W} \\
321145 \mathrm{~N} 1105615 \mathrm{~W} \\
332644 \mathrm{~N} 1115900 \mathrm{~W}\end{array}$ & & 2490 & $\begin{array}{l}\text { Tucson } \\
\text { Tucson } \\
\text { Tempe }\end{array}$ \\
\hline $\begin{array}{l}\text { Pueblo Grande Museum } \\
\text { Pueblo Grande Park } \\
\text { Pueblo High School } \\
\text { Pueblo Mine } \\
\text { Pueblo Plaza Shopping Center } \\
\text { Pueblo Plaza Shopping Center } \\
\text { Pueblo Sereno Mobile Home Park } \\
\text { Pueblo Trick Tank } \\
\text { Pueblo Viejo (historical) } \\
\text { Puebla Viejo }\end{array}$ & $\begin{array}{l}\text { building } \\
\text { park } \\
\text { school } \\
\text { mine } \\
\text { locale } \\
\text { locale } \\
\text { locale } \\
\text { reservoir } \\
\text { locale }\end{array}$ & $\begin{array}{l}\text { UNOFF } \\
\text { ADMIN } \\
\text { UNOFF } \\
\text { UNOFF } \\
\text { UNOFF } \\
\text { UNOFF } \\
\text { UNOFF } \\
\text { BGN } \\
\text { BGN } \\
\text { VARIANT }\end{array}$ & $\begin{array}{l}\text { Maricopa } \\
\text { Pima } \\
\text { Pima } \\
\text { Gila } \\
\text { Pima } \\
\text { Maricopa } \\
\text { Maricopa } \\
\text { Coconino } \\
\text { Graham }\end{array}$ & $\begin{array}{l}332644 \mathrm{~N} 1115902 \mathrm{~W} \\
321135 \mathrm{~N} 1105601 \mathrm{~W} \\
321058 \mathrm{~N} 1105842 \mathrm{~W} \\
335114 \mathrm{~N} 1105359 \mathrm{~W} \\
321221 \mathrm{N1} 105647 \mathrm{~W} \\
333452 \mathrm{~N} 1121528 \mathrm{~W} \\
332712 \mathrm{~N} 1115406 \mathrm{~W} \\
343350 \mathrm{~N} 1104605 \mathrm{~W} \\
325000 \mathrm{~N} 1093400 \mathrm{~W}\end{array}$ & & $\begin{array}{l}2455 \\
1120 \\
1190\end{array}$ & $\begin{array}{l}\text { Tempe } \\
\text { Tucson } \\
\text { Tucson } \\
\text { Aztec Peak } \\
\text { Tucs on } \\
\text { El Mirage } \\
\text { Tempe } \\
\text { Chevelon Crossing } \\
\text { Tanque }\end{array}$ \\
\hline $\begin{array}{l}\text { Puente, Arroyo del } \\
\text { Puerco Elementary School } \\
\text { Puerco Ridge } \\
\text { Puerco River } \\
\text { Rio Puerco } \\
\text { Rio Puerco del Oriente } \\
\text { Rio Puerco del Ouest } \\
\text { Rio Puerco of the West } \\
\text { The Perky } \\
\text { Puerco Tank }\end{array}$ & $\begin{array}{l}\text { valley } \\
\text { school } \\
\text { ridge } \\
\text { stream }\end{array}$ & $\begin{array}{l}\text { BGN } \\
\text { UNOFF } \\
\text { BGN } \\
\text { BGN } 1974 \\
\text { VARIANT } \\
\text { VARIANT } \\
\text { VARIANT } \\
\text { VARIANT } \\
\text { VARIANT } \\
\text { BGN }\end{array}$ & $\begin{array}{l}\text { Pima } \\
\text { Apache } \\
\text { Apache } \\
\text { Navajo }\end{array}$ & $\begin{array}{l}314036 \mathrm{~N} 1113505 \mathrm{~W} \\
351305 \mathrm{~N} 1091955 \mathrm{~W} \\
345433 \mathrm{~N} 1093333 \mathrm{~W} \\
345459 \mathrm{~N} 1100526 \mathrm{~W}\end{array}$ & $\begin{array}{l}314134 \mathrm{~N} 1113619 \mathrm{~W} \\
353433 \mathrm{~N} 1081050 \mathrm{~W}\end{array}$ & & $\begin{array}{l}\text { Mildred Peak } \\
\text { Sanders } \\
\text { Ninemile Seep } \\
\text { Sun Valley }\end{array}$ \\
\hline $\begin{array}{l}\text { Puerta del las Mulas } \\
\text { See Mule Pass } \\
\text { Puerto Blanco Drive } \\
\text { Puerto Blanco Mountains } \\
\text { Bates Well Mountains } \\
\text { Dripping Spring Mountains } \\
\text { Puerto Blanco Mountains } \\
\text { See Bates Mountains } \\
\text { Puerto Blanco Pass } \\
\text { Puerto Canyon }\end{array}$ & $\begin{array}{l}\text { summit } \\
\text { gap } \\
\text { valley }\end{array}$ & $\begin{array}{l}\text { VARIANT } \\
\text { UNOFF } \\
\text { BGN } 1945 \\
\text { VARIANT } \\
\text { VARIANT } \\
\text { VARIANT } \\
\text { BGN } \\
\text { BGN }\end{array}$ & $\begin{array}{l}\text { Pima } \\
\text { Pima } \\
\text { Santa Cruz }\end{array}$ & $\begin{array}{l}320630 \mathrm{~N} 1125700 \mathrm{~W} \\
320125 \mathrm{~N} 1125332 \mathrm{~W} \\
313800 \mathrm{~N} 1110332 \mathrm{~W}\end{array}$ & $313609 \mathrm{~N} 1110805 \mathrm{~W}$ & & $\begin{array}{l}\text { Turquoise Mountain } \\
\text { Tillotson Peak }\end{array}$ \\
\hline $\begin{array}{l}\text { Puerto Cielo } \\
\text { Puertocito } \\
\text { Puertocito Wash } \\
\text { Altar Wash } \\
\text { Puerto de Bucareli } \\
\text { See Grand Canyon } \\
\text { Puerto del Dado } \\
\text { See Apache Pass }\end{array}$ & $\begin{array}{l}\text { airport } \\
\text { locale } \\
\text { stream }\end{array}$ & $\begin{array}{l}\text { ADMIN } \\
\text { BGN } \\
\text { BGN } 1979 \\
\text { VARIANT } \\
\text { VARIANT } \\
\text { VARIANT }\end{array}$ & $\begin{array}{l}\text { Cochise } \\
\text { Pima } \\
\text { Pima }\end{array}$ & $\begin{array}{l}360646 \mathrm{~N} 1135943 \mathrm{~W} \\
320906 \mathrm{~N} 1092852 \mathrm{~W}\end{array}$ & $313233 \mathrm{~N} 1112602 \mathrm{~W}$ & 3980 & $\begin{array}{l}\text { Douglas NE } \\
\text { Wilbur Canyon } \\
\text { Las Guijas }\end{array}$ \\
\hline
\end{tabular}


NATIONAL GAZETTEER--ARIZONA 1986

\section{FEATURE NAME}

Puerto Park

Puerto Spring

Pugh Knoll

Pugh Knoll Tank

Pulcifer Creek

Supolvre Creek

Pullian Airport

Pulpit Rock

Pump Canyon

Pumphouse

See Vainom Kug

Pump House Wash

See Pumphouse Wash

Pumphouse Wash

Oak Creek

Pump House Wash

Pumping Station Tank

Pumpkin Center

See Punk in Center

Pumpk in Center

Pumpk in Flower Butte

See Sunf lower Butte

Pumpkin Knoll

Pumpk in Lake

Pumpk in Patch

See Vulture

Pumpkinsville

See Phoenix

Pumpkin Tank

Pump Mine Wash

Pump Mine Well

Pump Ranch Tank Sims Tank

Pump Ranch Tank See Sims Tank

Pump Station Dam

Pump Station Spring

Pump Tank

Pump Well

Pumroy Canyon

Punk in Center

Packards

Pumpkin Center

Tonto Bas in

Tontobas in

Punk in Center Landing Strip

Punkin Center Post Office

Punk Tank

Punk Tank

Punta del Agua

Purcell Canyon

Purcell Cienega

Purcell Draw

Purcell Tank

Purcell Tank

Purcell Tank

Purcell Tank

Purcell Well

Purdy

Purebred Spring

Purgatory Canyon

Purgatory Tank

Puro Railroad Station

Purple Hill Tank

Purple Pansy Mine

Purple Sage Mobile Home Park

Pusch Peak

Pusch Ridge

Pusch Ridge Wilderness

Pusher Canyon

\section{FEATURE}

STATUS

COUNTY

COORDINATE

park

spring

ADMIN

BGN

\begin{tabular}{|c|c|c|}
\hline $\begin{array}{l}\text { summit } \\
\text { reservoir } \\
\text { stream }\end{array}$ & $\begin{array}{l}\text { BGN } \\
\text { BGN } \\
\text { BGN } 1939\end{array}$ & $\begin{array}{l}\text { Mohave } \\
\text { Mohave } \\
\text { Apache }\end{array}$ \\
\hline $\begin{array}{l}\text { airport } \\
\text { summit } \\
\text { valley } \\
\text { canal }\end{array}$ & $\begin{array}{l}\text { ADMIN } \\
\text { BGN } \\
\text { BGN } \\
\text { BGN } \\
\text { VARIANT }\end{array}$ & $\begin{array}{l}\text { Coconino } \\
\text { Mohave } \\
\text { Pima } \\
\text { Yuma }\end{array}$ \\
\hline local & & Pima \\
\hline
\end{tabular}

VARIANT

stream

stream

reservoir

ppl

locale

summit

summit

lake

locale

ppl

reservoir

stream

well

reservoir

BGN 1964

VARIANT

VARIANT

BGN

VARIANT

BGN

VARIANT

Coconino

Coconino

Graham

Gila

Coconino

Navajo

BGN

BGN

VARIANT

VARIANT

BGN

BGN

UNOFF

BARIANT

VARIANT

reservoir

dam

spring

reservoir

well

valley

ppl

UNOFF

BGN

BGN

UNOFF

BGN

BGN 1965

VARIANT

VARIANT

airport ADMIN Gila

building

reservoir

locale

valley

swamp

valley

reservoir

reservoir

UNOF

$B G N$

BGN

BGN

$B G N$

BGN

BGN

$B G N$
$B G N$

reservoir

reservoir

well

locale

spring

valley

reservoir

building

reservoir

mine

\section{BGN}

BGN
UNDFF

BGN

BGN

BGN

BGN

UNOFF

BGN
UNOFF

locale

summit

ridge

park

valley

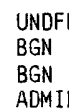

UNDFF
BGN
BGN
AOMIN
BGN
Coconino

Graham

Pinal

Yavapai

Maricopa

Greenlee

Gila

Coconino

Maricopa

Maricopa

aricopa

aricopa

conino

ia

Santa Cruz

Coconino

Pima

Yavapai

Apache

Navajo

Maricopa

Maricopa

Navajo

Navajo

Apache

Greenlee

Yavapai

Mohave

Yavapai

Yavapai

Apache

Maricopa

Maricopa

Pima

Pima

Pima

Navajo
$344904 N 1104911 \mathrm{~W}$

$332230 \mathrm{~N} 1094130 \mathrm{~W}$

$332022 N 1110347 \mathrm{~W}$

345628 N1123116\%

$332054 \mathrm{~N} 1130254 \mathrm{~W}$

$325750 \mathrm{~N} 1091832 \mathrm{~W}$

$335220 \mathrm{~N} 1111845 \mathrm{~W}$

$\begin{array}{ll}325433 N 1091851 \mathrm{~W} & \text { Forth of JuTh } \\ & \text { Guthrie } \\ & \text { Tonto Bas in }\end{array}$

$335120 \mathrm{~N} 1111830 \mathrm{~W}$

$335222 N 1111847 \mathrm{~W}$

$312120 \mathrm{~N} 1110135 \mathrm{~W}$

$352140 \mathrm{~N} 1122900 \mathrm{~W}$

$315700 \mathrm{~N} 1110600 \mathrm{~W}$

$351126 \mathrm{~N} 1125654 \mathrm{~W}$

$335432 \mathrm{~N} 1093122 \mathrm{~W}$

343257 N1104124W

$334741 \mathrm{N1120305 \textrm {W }}$

$335028 \mathrm{~N} 1121005 \mathrm{~W}$

$343312 \mathrm{~N} 1104124 \mathrm{~W}$

$343411 \mathrm{~N} 1102702 \mathrm{~W}$

$343421 \mathrm{~N} 1091225 \mathrm{~W}$

$324329 N 1090558 \mathrm{~W}$

$341449 \mathrm{~N} 1122741 \mathrm{~W}$

$365824 \mathrm{~N} 1134233 \mathrm{~W}$

$344238 \mathrm{~N} 1113909 \mathrm{~W}$

$345015 \mathrm{~N} 1122630 \mathrm{~W}$

$344345 N 1094603 \mathrm{~W}$

$334556 \mathrm{~N} 1130738 \mathrm{~W}$

$333221 \mathrm{~N} 1121155 \mathrm{~W}$

$322219 \mathrm{~N} 1105618 \mathrm{~W}$

$32224 \mathrm{DN} 1105526 \mathrm{~W}$

$322200 \mathrm{~N} 1104900 \mathrm{~W}$

$334800 \mathrm{~N} 10956 \mathrm{DBW}$ Superior

Tonto Bas in

Tonto Bas in

Tonto Bas in

Pajarito Peak

Twin Buttes

351128N1125954W Purcell Canyon

Mount Baldy

342722N1104154W Potato Wash South

New River SE

Biscuit Flat

Zeniff

Kearn Lake

3655 Duncan

Minnehaha

365337 N1134441W

Casner Butte

$\begin{array}{lc}\text { SOURCE } & \text { ELEV } \\ \text { COORDINATE } & \text { FT }\end{array}$

Lone Butte

Amado

$\begin{array}{lll}340919 N 1094020 \mathrm{~W} & & \begin{array}{l}\text { Hat Knoll } \\ \text { Boundary Butte }\end{array} \\ 315341 \mathrm{~N} 1103615 \mathrm{~W} & 6672 & \begin{array}{l}\text { Flagstaff West } \\ \text { Topock } \\ \text { The Narrows } \\ \text { Parker SE }\end{array}\end{array}$

350739N1113937W Mountainaire

6017 Stove Canyon

Moritz Ridge

7490 Moritz Ridge

Pepper Canyon

Moritz Ridge

Tiger Well

Tiger Well

Pump Ranch Tank

Point of Pines East

Wineglass Ranch

Forth of July Butte

Fitzgerald $\mathrm{Hill}$

Potato Wash South

Purgatory Canyon 


\begin{tabular}{|c|c|c|c|c|c|c|c|}
\hline FEATURE NAME & $\begin{array}{l}\text { FEATURE } \\
\text { CLASS }\end{array}$ & STATUS & COUNTY & COORDINATE & $\begin{array}{l}\text { SOURCE } \\
\text { COORDINATE }\end{array}$ & $\begin{array}{c}\text { ELEV } \\
\text { FT }\end{array}$ & MAP NAME \\
\hline $\begin{array}{l}\text { Pussy Tank } \\
\text { Putesoi Canyon } \\
\text { Putman Spring } \\
\text { Putman Wash } \\
\text { Putnam Spring }\end{array}$ & $\begin{array}{l}\text { reservoir } \\
\text { valley } \\
\text { spring } \\
\text { stream } \\
\text { spring }\end{array}$ & $\begin{array}{l}\text { BGN } \\
\text { BGN } 1925 \\
\text { BGN } \\
\text { BGN } \\
\text { BGN }\end{array}$ & $\begin{array}{l}\text { Navajo } \\
\text { Coconino } \\
\text { Mohave } \\
\text { Mohave } \\
\text { Pinal }\end{array}$ & $\begin{array}{l}334442 N 1095929 \mathrm{~W} \\
361142 \mathrm{~N} 1123948 \mathrm{~W} \\
352844 \mathrm{~N} 1141358 \mathrm{~W} \\
353047 \mathrm{N1142222W} \\
324930 \mathrm{~N} 1104509 \mathrm{~W}\end{array}$ & $\begin{array}{l}361418 N 1123258 \mathrm{~W} \\
352917 N 1141200 \mathrm{~W}\end{array}$ & & $\begin{array}{l}\text { Bonito Prairie } \\
\text { Supai } \\
\text { Chloride } \\
\text { Dolan Springs } \\
\text { Putnam Wash }\end{array}$ \\
\hline $\begin{array}{l}\text { Putnam Wash } \\
\text { Putney Flat } \\
\text { Puzzles Mountains } \\
\text { See Tank Mountains } \\
\text { PW Tank } \\
\text { Pyeatt Cave } \\
\text { Pyeatt Draw } \\
\text { Pyeatt Ranch } \\
\text { Pyeatt Tank } \\
\text { Pyeatt Tank }\end{array}$ & $\begin{array}{l}\text { stream } \\
\text { flat } \\
\text { ridge } \\
\text { reservoir } \\
\text { cave } \\
\text { valley } \\
\text { locale } \\
\text { reservoir } \\
\text { reservoir }\end{array}$ & $\begin{array}{l}\text { BGN } \\
\text { BGN } \\
\text { VARIANT } \\
\text { BGN } \\
\text { BGN } \\
\text { BGN } \\
\text { UNOFF } \\
\text { BGN } \\
\text { BGN }\end{array}$ & $\begin{array}{l}\text { Pinal } \\
\text { Coconino } \\
\text { Yuma } \\
\text { Coconino } \\
\text { Cochise } \\
\text { Gila } \\
\text { Cochise } \\
\text { Cochise } \\
\text { Coconino }\end{array}$ & $\begin{array}{l}325018 \mathrm{~N} 1104300 \mathrm{~W} \\
350921 \mathrm{~N} 1122528 \mathrm{~W} \\
330937 \mathrm{~N} 1134142 \mathrm{~W} \\
344129 \mathrm{~N} 1111450 \mathrm{~W} \\
313307 \mathrm{~N} 1102646 \mathrm{~W} \\
342049 \mathrm{~N} 1111458 \mathrm{~W} \\
313329 \mathrm{~N} 1102717 \mathrm{~W} \\
313327 \mathrm{~N} 1102725 \mathrm{~W} \\
344807 \mathrm{~N} 1110246 \mathrm{~W}\end{array}$ & $341827 N 1110929 \mathrm{~W}$ & 6984 & $\begin{array}{l}\text { Hay Lake } \\
\text { Pyeatt Ranch } \\
\text { Diamond Point } \\
\text { Pyeatt Ranch } \\
\text { Pyeatt Ranch } \\
\text { Chavez Mtn East }\end{array}$ \\
\hline $\begin{array}{l}\text { Pyle Ranch } \\
\text { Pymn Canyon } \\
\text { Pymn Canyon Pond } \\
\quad \text { Whipple Reservoir } \\
\text { Pyramid Butte } \\
\text { Pyramid Mountain } \\
\text { Pyramid Canyon } \\
\text { Pyramid Canyon } \\
\text { Pyramid Mountain } \\
\text { See Pyramid Butte }\end{array}$ & $\begin{array}{l}\text { locale } \\
\text { valley } \\
\text { lake } \\
\text { summit } \\
\text { valley } \\
\text { valley } \\
\text { summit }\end{array}$ & $\begin{array}{l}\text { UNOFF } \\
\text { BGN } \\
\text { BGN } \\
\text { VARIANT } \\
\text { BGN } \\
\text { VARIANT } \\
\text { BGN } \\
\text { BGN } \\
\text { VARIANT }\end{array}$ & $\begin{array}{l}\text { Gila } \\
\text { Mohave } \\
\text { Mohave } \\
\text { Navajo } \\
\text { Mohave } \\
\text { Coconino } \\
\text { Navajo }\end{array}$ & $\begin{array}{l}342216 \mathrm{~N} 1111027 \mathrm{~W} \\
361756 \mathrm{~N} 1132300 \mathrm{~W} \\
361708 \mathrm{~N} 1132546 \mathrm{~W} \\
352143 \mathrm{~N} 1102809 \mathrm{~W} \\
351207 \mathrm{~N} 1143422 \mathrm{~W} \\
365016 \mathrm{~N} 1104856 \mathrm{~W} \\
352143 \mathrm{~N} 1102809 \mathrm{~W}\end{array}$ & $\begin{array}{l}351704 N 1143536 \mathrm{~W} \\
365152 \mathrm{~N} 1104453 \mathrm{~W}\end{array}$ & 6263 & $\begin{array}{l}\text { Diamond Point } \\
\text { Grassy Mountain } \\
\text { Grassy Mountain } \\
\text { Chimney Butte } \\
\text { Spirit Mtn SE } \\
\text { Chaiyahi Rim SE }\end{array}$ \\
\hline $\begin{array}{l}\text { Pyramid Peak } \\
\text { Pyramid Peak } \\
\text { Mount Ochoa } \\
\text { Pyramid Peak } \\
\text { Pyramid Rock } \\
\text { Pyramids, The } \\
\text { P-Y Tank } \\
\text { PZ Ranch }\end{array}$ & $\begin{array}{l}\text { summit } \\
\text { summit } \\
\text { summit } \\
\text { is land } \\
\text { summit } \\
\text { reservoir } \\
\text { locale }\end{array}$ & $\begin{array}{l}\text { BGN } \\
\text { BGN } \\
\text { VARIANT } \\
\text { BGN } \\
\text { BGN } \\
\text { BGN } \\
\text { BGN } \\
\text { UNOFF }\end{array}$ & $\begin{array}{l}\text { Yuma } \\
\text { Maricopa } \\
\text { Maricopa } \\
\text { Mohave } \\
\text { Navajo } \\
\text { Pima } \\
\text { Pinal }\end{array}$ & $\begin{array}{l}334057 \mathrm{~N} 1134100 \mathrm{~W} \\
334449 \mathrm{~N} 1121049 \mathrm{~W} \\
\\
335300 \mathrm{~N} 1120356 \mathrm{~W} \\
351348 \mathrm{~N} 1133406 \mathrm{~W} \\
341016 \mathrm{~N} 1104421 \mathrm{~W} \\
314805 \mathrm{~N} 1112824 \mathrm{~W} \\
325217 \mathrm{~N} 1104250 \mathrm{~W}\end{array}$ & & $\begin{array}{l}2140 \\
2269 \\
2614 \\
5923 \\
2120\end{array}$ & $\begin{array}{l}\text { Hope } \\
\text { Hedgpeth Hills } \\
\text { Daisy Mountain } \\
\text { Davis Dam } \\
\text { Chediski Peak } \\
\text { Fresno Wash } \\
\text { Lookout Mtn }\end{array}$ \\
\hline $\begin{array}{l}\text { Q Ranch } \\
\text { Quaijotoa Mountains } \\
\quad \text { See Brownell Mountains }\end{array}$ & $\begin{array}{l}\text { locale } \\
\text { summit }\end{array}$ & $\begin{array}{l}\text { UNOFF } \\
\text { VARIANT }\end{array}$ & $\begin{array}{l}\text { Gila } \\
\text { Pima }\end{array}$ & $\begin{array}{l}340317 \mathrm{~N} 1104833 \mathrm{~W} \\
321208 \mathrm{~N} 1120912 \mathrm{~W}\end{array}$ & & 5536 & Gentry Mtn \\
\hline $\begin{array}{l}\text { Quail Canyon } \\
\text { Quail Canyon } \\
\text { Quail Country Place } \\
\text { (subdivision) } \\
\text { Quail Draw } \\
\text { Quail Draw Reservoir } \\
\text { Quail Flat } \\
\text { Quail Hill } \\
\text { Quail Lane (subdivision) } \\
\text { Quail Mesa Airport }\end{array}$ & $\begin{array}{l}\text { valley } \\
\text { valley } \\
\text { ppl } \\
\text { valley } \\
\text { reservoir } \\
\text { flat } \\
\text { summit } \\
\text { ppl } \\
\text { airport }\end{array}$ & $\begin{array}{l}\text { BGN } \\
\text { BGN } \\
\text { BGN } \\
\text { BGN } \\
\text { BGN } \\
\text { BGN } \\
\text { BGN } \\
\text { BGN } \\
\text { ADMIN }\end{array}$ & $\begin{array}{l}\text { Gila } \\
\text { Mohave } \\
\text { Maricopa } \\
\text { Mohave } \\
\text { Mohave } \\
\text { Mohave } \\
\text { Mohave } \\
\text { Maricopa } \\
\text { La Paz }\end{array}$ & $\begin{array}{l}332448 \mathrm{~N} 1104750 \mathrm{~W} \\
365351 \mathrm{N1133422W} \\
333905 \mathrm{~N} 1120412 \mathrm{~W} \\
\\
365553 \mathrm{~N} 1132806 \mathrm{~W} \\
365015 \mathrm{~N} 1133300 \mathrm{~W} \\
365011 \mathrm{~N} 1133308 \mathrm{~W} \\
364942 \mathrm{~N} 1133401 \mathrm{~W} \\
333500 \mathrm{~N} 1121142 \mathrm{~W} \\
334440 \mathrm{~N} 1142835 \mathrm{~W}\end{array}$ & $\begin{array}{l}332422 \mathrm{N1104813W} \\
365003 \mathrm{~W} 1133547 \mathrm{~W} \\
364807 \mathrm{N1} 133337 \mathrm{~W}\end{array}$ & $\begin{array}{l}1180 \\
290\end{array}$ & $\begin{array}{l}\text { Globe } \\
\text { Lizard Point } \\
\text { Union Hills } \\
\text { Yellowhorse Flat } \\
\text { Wolf Hole Mtn East } \\
\text { Wolf Hole Mtn East } \\
\text { Wolf Hole Mtn East } \\
\text { Glendale } \\
\text { La Paz Mtn }\end{array}$ \\
\hline $\begin{array}{l}\text { Quail Mesa Dam } \\
\text { Quail Mesa Tank } \\
\text { Quail Place (subdivision) } \\
\text { Quail Spring } \\
\\
\text { Quail Warm Spring } \\
\text { Quail Spring } \\
\text { Quail Spring } \\
\text { Quail Spring } \\
\text { Quail Spring }\end{array}$ & $\begin{array}{l}\text { dam } \\
\text { reservoir } \\
\text { ppl } \\
\text { spring } \\
\text { spring } \\
\text { spring } \\
\text { spring } \\
\text { spring } \\
\text { spring }\end{array}$ & $\begin{array}{l}\text { UNOFF } \\
\text { BGN } \\
\text { BGN } \\
\text { BGN } \\
\text { VARIANT } \\
\text { BGN } \\
\text { BGN } \\
\text { BGN } \\
\text { BGN } \\
\text { BGN }\end{array}$ & $\begin{array}{l}\text { Gila } \\
\text { Gila } \\
\text { Maricopa } \\
\text { Graham } \\
\text { Graham } \\
\text { Greenlee } \\
\text { Pinal } \\
\text { Gila } \\
\text { Maricopa }\end{array}$ & $\begin{array}{l}332540 \mathrm{~N} 1103018 \mathrm{~W} \\
332540 \mathrm{~N} 1103019 \mathrm{~W} \\
332047 \mathrm{~N} 1115220 \mathrm{~W} \\
330315 \mathrm{~N} 1093330 \mathrm{~W} \\
\\
330935 \mathrm{~N} 1102418 \mathrm{~W} \\
330946 \mathrm{~N} 1091752 \mathrm{~W} \\
332057 \mathrm{~N} 1111433 \mathrm{~W} \\
334900 \mathrm{~N} 1104837 \mathrm{~W} \\
335453 \mathrm{~N} 1120220 \mathrm{~W}\end{array}$ & & $\begin{array}{l}3025 \\
3025 \\
1995\end{array}$ & $\begin{array}{l}\text { Dourine Canyon } \\
\text { Dourine Canyon } \\
\text { Chandler } \\
\text { Bonita Spring } \\
\text { San Carlos Reservoir } \\
\text { Mitchell Peak } \\
\text { Picketpost Mtn } \\
\text { Sombrero Peak } \\
\text { Daisy Mountain }\end{array}$ \\
\hline $\begin{array}{l}\text { Quail Spring } \\
\text { Quail Spring } \\
\text { Quail Spring } \\
\text { Quail Spring } \\
\text { Quail Spring } \\
\text { Quail Spring } \\
\text { Quail Spring } \\
\text { Quail Spring }\end{array}$ & $\begin{array}{l}\text { spring } \\
\text { spring } \\
\text { spring } \\
\text { spring } \\
\text { spring } \\
\text { spring } \\
\text { spring } \\
\text { spring }\end{array}$ & $\begin{array}{l}\text { BGN } \\
\text { BGN } \\
\text { BGN } \\
\text { BGN } \\
\text { BGN } \\
\text { BGN } \\
\text { BGN } \\
\text { BGN }\end{array}$ & $\begin{array}{l}\text { Yavapai } \\
\text { Yavapai } \\
\text { Yavapai } \\
\text { Yavapai } \\
\text { Yavapai } \\
\text { Coconino } \\
\text { Mohave } \\
\text { Mohave }\end{array}$ & $\begin{array}{l}341556 \mathrm{~N} 1121428 \mathrm{~W} \\
342223 \mathrm{~N} 1114127 \mathrm{~W} \\
342245 \mathrm{~N} 1122630 \mathrm{~W} \\
342728 \mathrm{~N} 1125658 \mathrm{~W} \\
342838 \mathrm{~N} 1131202 \mathrm{~W} \\
343156 \mathrm{~N} 1110957 \mathrm{~W} \\
352939 \mathrm{~N} 1141638 \mathrm{~W} \\
364956 \mathrm{~N} 1133451 \mathrm{~W}\end{array}$ & & & $\begin{array}{l}\text { Cleator } \\
\text { Verde Hot Springs } \\
\text { Groom Creek } \\
\text { Hills ide } \\
\text { Thorn Peak } \\
\text { Blue Ridge Reservoir } \\
\text { Grasshopper Junction } \\
\text { Wolf Hole Mtn East }\end{array}$ \\
\hline
\end{tabular}


NATIONAL GAZETTEER--ARIZONA 1986

\section{FEATURE NAME}

Quail Spring Canyon

Quail Springs

Quail Springs Wash

Quail Spring Wash

Quail Spring Wash

Quail Tank

Quail Tank

Quail Tank

Quail Tank

Quail Tank

Quail Tank

Quail Tank

Quail Trick Tank

Quail Valley (subdivision)

Quail Wash

Quajata Creek

See Greene Wash

Quajato

See Kohatk

Quajote

See Kohatk

Quajote Wash

See Kohatk Wash

Quajote Wash

See Greene Wash

Quajoto Wash

See Greene Wash

Quakie Patch Spring

Quakie Tank

Quaking Aspen

Quaking Aspen Canyon

Quaking Aspen Canyon

Quaking Aspen Spring

Quaking Aspen Tank

Quaking Asp Spring

Quality Hill

Quantrell Mine

Quarry Canyon

Quarry Reservoir

Quarry Sink

Quarry Tank

Quarry Tank

Quarry Tank

Quarter Circle Bar Tank

Quarter Circle J Ranch

Landing Strip

Quarter Circle U Ranch

Quarter Circle U Trail

Quarter Circle V Bar Ranch

Quarter Circle $X \times$ Ranch

Quarter Circle $x \times$ Ranch

Quarter Corner Tank

Quartermaster Canyon

Quartermaster Springs

Quartermaster View Point

Quarter Pond

Quarter Tank

Quartite Peak

Quartsite

See Quartzsite

Quartsite Canyon

See Quartzite Canyon

Quartsite Peak

See Quartzite Peak

Quartsite Tank

Quartz Hill

Quartz Hill Spring

Quartzite

See Quartzsite

Quartzite Canyon

See Bonito Creek
FEATURE
CLASS

STATUS

COUNTY

valley

spring

BGN
BGN

Gila

Yavapai

strean

stream

valley

reservoir

reservoir

reservoir $B G$

reservoir $B G$

reservoir

reservoir

reservoir

BGN
$B G N$
$B G N$
$B G N$
$B G N$
$B G N$
$B G N$
$B G N$
$B G N$
$B G N$

Gila

Yavapai

Maricopa

Gila

Maricopa

Yavapai

Yavapai

Yavapai

Coconino

Mohave

reservoir

ppl

stream

BGN

GN

Yavapai

Maricopa

Maricopa

stream

ppl

Pinal

Pina $]$

Pinal

ppl

stream

VARIANT

VARIANT

Pinal

VARIANT

strea

stream

spring

reservoir

locale

valley

valley

spring

reservoir

spring

summit

mine

valley

reservoir

reservoir

reservoir

reservoir

reservoir

VARIANT

Pinal

BGN Pinal

BGN Coconino

Coconino

1966 Coconino

BGN 1966 Coconino

$\begin{array}{ll}\text { BGN } & \text { Coconino } \\ \text { BGN } & \text { Coconino }\end{array}$

reservoir $B G N$

airport ADMIM

locale

trail

locale

locale

locale

reservoir

valley

BGN

BGN

BGN

BGN

BGN

BGN

BGN
BGN
$B G N$

Coconino

Mohave

Cochise

Santa Cruz

Cochise

Graham

Coconino

Yavapai

Yavapai

Coconino

Coconino

Yavapai

UNOFF

UNOFF

UNOFF

UNOFF

UNOFF

BGN

Pinal

Pinal

Yavapai

Coconino

Coconino

Coconino

Mohave

spring BGN Mohave

locale

lake

reservoir

summit

$B G N$

BGN

BGN

BGN

pp 1

valley

VARIANT

summit

VARIANT

Mohave

Mohave

Coconino

Gila

Yuma

Gila

Gila

reservoir

summit

spring

BGN

Gila

Graham

ppl

BGN 1975

Graham

Yuma

stream

VARIANT

Apache
COORDINATE

$334755 \mathrm{N1} 104848 \mathrm{~W}$ $344011 \mathrm{~N} 1120259 \mathrm{~W}$

333546 N1105953W $342837 \mathrm{~N} 1130343 \mathrm{~W}$

$330759 \mathrm{~N} 1130405 \mathrm{~W}$

$335023 \mathrm{~N} 1102016 \mathrm{~W}$

$335628 \mathrm{~N} 1125602 \mathrm{~W}$

$342029 N 1115223 \mathrm{~W}$

$342153 \mathrm{M1114100 \textrm {W }}$

$343039 \mathrm{N1122041 \textrm {W }}$

$344315 \mathrm{~N} 1110356 \mathrm{~W}$

$353458 \mathrm{~N} 1133906 \mathrm{~W}$

$343237 N 1114413 \mathrm{~W}$

$333742 \mathrm{N1} 115845 \mathrm{~W}$

330757N1130403W

325352N1115644W

323442N1120018W

$323442 N 1120018 W$

$323809 N 1115517 W$

$325352 \mathrm{~N} 1115644 \mathrm{~W}$

$325352 \mathrm{~N} 1115644 \mathrm{~W}$

$340950 \mathrm{~N} 1094244 \mathrm{~W}$

$352117 N 1115612 \mathrm{~W}$

$362240 N 1121615 \mathrm{~W}$

342756 N1112017W

$362211 \mathrm{N1122041 \textrm {W }}$

$362243 N 1121654 W$

$365021 \mathrm{~N} 1114640 \mathrm{~W}$

$364750 \mathrm{N1} 134807 \mathrm{~W}$

$312625 \mathrm{~N} 1095515 \mathrm{~W}$

$314235 \mathrm{~N} 1105526 \mathrm{~W}$

$312633 \mathrm{~N} 1095525 \mathrm{~W}$

$325825 \mathrm{~N} 1095840 \mathrm{~W}$

350610 N1114334W

$345224 \mathrm{N1} 120135 \mathrm{~W}$

$350823 \mathrm{N1} 122020 \mathrm{~W}$

352236 N1124957W

$344609 \mathrm{~N} 1111831 \mathrm{~W}$

$343032 \mathrm{N1} 124045 \mathrm{~W}$

$332258 \mathrm{N1112020 \textrm {W }}$

$332647 \mathrm{~N} 1112305 \mathrm{~W}$

$342602 \mathrm{N1} 120411 \mathrm{~W}$

$351027 \mathrm{~N} 1121555 \mathrm{~W}$

$351208 \mathrm{~N} 1122243 \mathrm{~W}$

$345143 \mathrm{~N} 1111919 \mathrm{~W}$

$355802 N 1134531 \mathrm{~W}$

$355732 N 1134555 \mathrm{~W}$

$355803 \mathrm{~N} 1134653 \mathrm{~W}$

$362635 \mathrm{~N} 1133302 \mathrm{~W}$

$345728 \mathrm{N1112317 \textrm {W }}$

332B11N1104436W

$333950 \mathrm{~N} 1141345 \mathrm{~W}$

$332720 \mathrm{~N} 1104320 \mathrm{~W}$

$332812 \mathrm{~N} 1104436 \mathrm{~W}$

$332910 \mathrm{~N} 1104548 \mathrm{~W}$

$325053 \mathrm{~N} 1101537 \mathrm{~W}$

$325054 \mathrm{~N} 1101605 \mathrm{~W}$

333950 N1141345W

$354400 \mathrm{~N} 1090412 \mathrm{~W}$

$\begin{array}{ccc}\begin{array}{c}\text { SOURCE } \\ \text { COORDIMATE }\end{array} & \begin{array}{c}\text { ELEV } \\ \text { FT }\end{array} & \text { MAP NAME } \\ 335010 \text { N1104850W } & & \begin{array}{l}\text { Sombrero Peak } \\ \text { Cottonwood }\end{array}\end{array}$

$333432 N 1105734 \mathrm{~W}$

$342553 \mathrm{~N} 1125723 \mathrm{~W}$ 


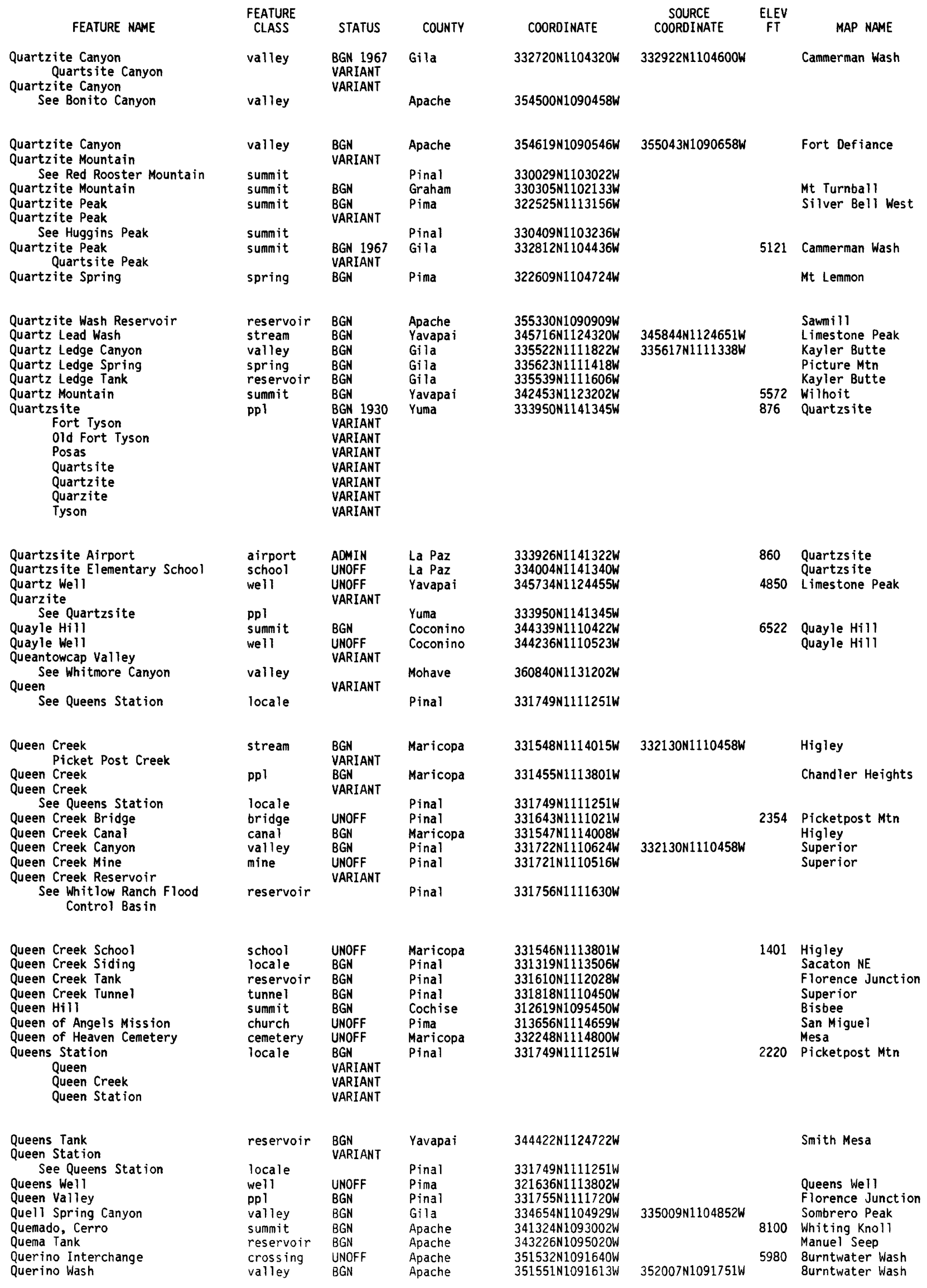


FEATURE
CLASS

Questa Spring

Quetzal, Point

Quiburi Mission

Quickwater Spring

Quien Sabe

See Quien Sabe Peak

Quien Sabe Creek

Quien Sabe Draw

Quien Sabe Mine

Quien Sabe Peak

Quien Sabe

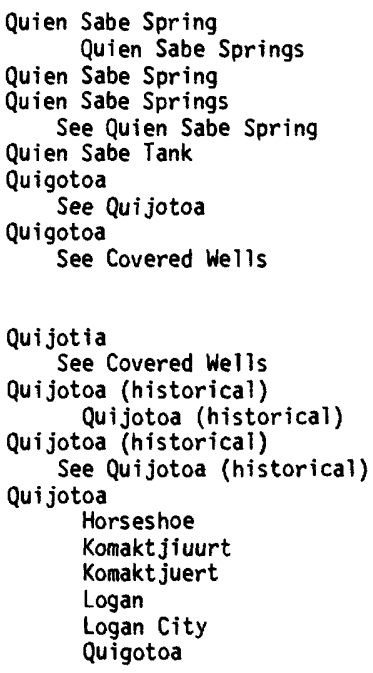

locale

\begin{tabular}{|c|c|c|c|}
\hline $\begin{array}{l}\text { spring } \\
\text { cliff } \\
\text { church } \\
\text { spring }\end{array}$ & $\begin{array}{l}\text { BGN } \\
\text { BGN } 1908 \\
\text { UNOFF } \\
\text { BGN } \\
\text { VARIANT }\end{array}$ & $\begin{array}{l}\text { Pima } \\
\text { Coconino } \\
\text { Cochise } \\
\text { Mohave }\end{array}$ & $\begin{array}{l}315002 \mathrm{~N} 1104117 \mathrm{~W} \\
361048 \mathrm{~N} 1122828 \mathrm{~W} \\
314503 \mathrm{~N} 1101205 \mathrm{~W} \\
365142 \mathrm{~N} 1123449 \mathrm{~W}\end{array}$ \\
\hline $\begin{array}{l}\text { summit } \\
\text { strean } \\
\text { valley } \\
\text { mine } \\
\text { summit }\end{array}$ & $\begin{array}{l}\text { BGN } \\
\text { BGN } \\
\text { UNOFF } \\
\text { BGN } 1965 \\
\text { VARTANT }\end{array}$ & $\begin{array}{l}\text { Maricopa } \\
\text { Maricopa } \\
\text { Coconino } \\
\text { Maricopa } \\
\text { Maricopa }\end{array}$ & $\begin{array}{l}335610 \mathrm{~N} 1115248 \mathrm{~W} \\
335754 \mathrm{~N} 1115305 \mathrm{~W} \\
343106 \mathrm{~N} 1111211 \mathrm{~W} \\
335700 \mathrm{~N} 1115235 \mathrm{~W} \\
335610 \mathrm{~N} 1115248 \mathrm{~W}\end{array}$ \\
\hline
\end{tabular}

$\begin{array}{lc}\text { SOURCE } & \text { ELEV } \\ \text { COORDINATE } & \text { FT }\end{array}$

MAP NAME

\begin{tabular}{|c|c|c|}
\hline & & $\begin{array}{l}\text { Empire Ranch } \\
\text { Explorers Monument } \\
\text { Land } \\
\text { Clear Water Spring }\end{array}$ \\
\hline \multirow[t]{5}{*}{$\begin{array}{l}335616 \mathrm{~N} 1115209 \mathrm{~W} \\
342915 \mathrm{~N} 1111305 \mathrm{~W}\end{array}$} & $\begin{array}{l}4040 \\
4884\end{array}$ & $\begin{array}{l}\text { New River Mesa } \\
\text { Blue Ridge Reservoir } \\
\text { New River Mesa } \\
\text { New River Mesa }\end{array}$ \\
\hline & & $\begin{array}{l}\text { New River Mesa } \\
\text { Blue Ridge Reservoir }\end{array}$ \\
\hline & & Kino Springs \\
\hline & 2800 & Ben Nevis Mtn \\
\hline & & Maish Vaya \\
\hline
\end{tabular}

$320420 \mathrm{~N} 1120830 \mathrm{~W}$

$320738 \mathrm{~N} 1120815 \mathrm{~W}$

$335650 \mathrm{~N} 1115248 \mathrm{~K}$

343017 N1111238W

$335650 \mathrm{~N} 1115248 \mathrm{~W}$

$312108 \mathrm{~N} 1105137 \mathrm{~W}$

$320738 N 1120815 W$

$321000 \mathrm{~N} 1120730 \mathrm{~W}$

VARIANT

BGN

VARIANT

Pima

Pima

VARIANT

VARIANT

VARIANT

VARIANT

VARIANT

VARIANT

VARIANT

VARIAN

Pima

321000 N1120730W

325352N1115644W

$320416 \mathrm{~N} 1120846 \mathrm{~W}$

320651 N1 $120853 \mathrm{~W}$

$321031 \mathrm{N1121014 \textrm {W }}$

$320930 \mathrm{~N} 1120637 \mathrm{~W}$

$315828 N 1122134 \mathrm{~W}$

$322601 \times 1121632$

Ben Nevis Mtn Ben Nevis Mtn Maish Vaya Gurli Put Vo

Kom Vo

322351N1115855W

$320945 N 1121015 W$

Santa Rosa Mts SW

$320248 \mathrm{~N} 1120326 \mathrm{~W}$

$320851 \mathrm{~N} 1092805 \mathrm{~W}$

$325915 \mathrm{~N} 1124530 \mathrm{~W}$

$340823 \mathrm{~N} 1115412 \mathrm{~W}$

324138 N1122803W

Bowie Mtn North

Smurr

Brooklyn Peak

Yavapai

$315744 \mathrm{~N} 1113651 \mathrm{~W}$

Kitt Peak

VARIANT

VARIANT

VARIANT

321522N1113621W

Koht Kohl Hill

$315744 N 1113651 W$

$315744 N 1113651 \mathrm{~W}$

$325016 \mathrm{~N} 1101642 \mathrm{~W}$

$351626 \mathrm{~N} 1125856 \mathrm{~W}$

Klandik

Seligman West

$315744 N 1113651 W$

315624N1130100W

$315843 \mathrm{~N} 1130203 \mathrm{~W}$

$315624 \mathrm{~N} 1130100 \mathrm{~W}$ 
AZ502

FEATURE NAME

Quitobaquito Hills

Agua Dulce Mountains

Quitobaquita Mountains Quito Baquito Hills

Quito Baquito Mountains

Quitovaquito Mountains

Quito Baquito Hills

See Quitobaquito Hills

Quito Baquito Mountains See Quitobaquito Hills

Quitobaquito Springs

Quitovaquita

See Quitobaquito

Quitovaquito Mountains See Quitobaquito Hills Quituni Valley, La

La Quitani Valley

Quivero

Quivero Railroad Station

Quojote

See Kohatk
NATIONAL GAZETTEER--ARIZONA 1986$$
\text { FEATURE }
$$$$
\text { CLASS }
$$$$
\text { STATUS }
$$$$
\text { BGN } 1965 \text { Pima }
$$$$
\text { VARIANT }
$$$$
\text { VARIANT }
$$$$
\text { VARIANT }
$$$$
\text { VARIANT }
$$$$
\text { VARIANT }
$$

summit

VARIANT

VARIANT

sumnit

spring

locale

summit

valley

locale building

ppl

$$
\text { Pima }
$$

Pima

BGN

VARIANT

VARIANT

BGN 1941 VARIANT

BGN UNOFF VARIANT

Coconino Coconino

Pinal$$
\text { COUNTY }
$$

COORDINATE

315843N1130203W

315843N1130203W

$315843 N 11302036$ 315640N1130101W

315624N1130100W

315843N1130203W $315000 \mathrm{N1} 123202 \mathrm{~W}$

Pima
Pima

$353157 N 1121124 \mathrm{~W}$ $353207 \mathrm{N1} 121018 \mathrm{~W}$

$323442 N 1120018 \mathrm{~W}$
Ra, Tower of

Rabaho

See Covered Wells Rabbit

See Rabbit Ranch

Rabbit Bill Tank

Rabbit Brush Well

Rabbit Canyon

Rabbit Hollow Tank

Rabbit Is land

Rabbit Lake

Rabbit Mountain See Mitten Peak

Rabbit Ranch Rabbit

Rabbit Spring

Minnehaha Spring

Rabbit Spring

Rabbit Tank

Rabbit Tank

Rabbit Trap Corral

Rabbit Valley

Rabbit Water

Race Horse Cienega

Racetrack Knoll

Race Track Mesa

See Lower Racetrack Mesa

Race Track Mesa

See Upper Racetrack Mesa

Race Track Tank

Racetrack Tank

Racetrack Tank

Racetrack Tank

Racetrack Wash

Racetrack Well

Racetrack Windmi 11

Rackensack Canyon Rackensack Gulch

Rackensack Gulch

See Rackensack Canyon

Rackensack Spring

Radar Hill

Radio Hill

\begin{tabular}{|c|c|c|c|c|c|c|}
\hline pillar & $\begin{array}{l}\text { BGN } 1906 \\
\text { VARIANT }\end{array}$ & Coconino & $360827 N 1121211 \mathrm{~W}$ & & 6076 & Shiva Temple \\
\hline locale & VARIANT & Pima & $321000 \mathrm{~N} 1120730 \mathrm{~W}$ & & & \\
\hline $\begin{array}{l}\text { locale } \\
\text { reservoir } \\
\text { well } \\
\text { valley } \\
\text { reservoir } \\
\text { island }\end{array}$ & $\begin{array}{l}\text { BGN } \\
\text { UNDFF } \\
\text { BGN } \\
\text { BGN } \\
\text { BGN }\end{array}$ & $\begin{array}{l}\text { Pinal } \\
\text { Coconino } \\
\text { Coconino } \\
\text { Coconino } \\
\text { Yavapai } \\
\text { Gila }\end{array}$ & $\begin{array}{l}325018 N 1105301 \mathrm{~W} \\
351019 N 1121935 \mathrm{~W} \\
361109 N 1111302 \mathrm{~W} \\
353607 N 1114535 \mathrm{~W} \\
345024 \mathrm{~N} 1131930 \mathrm{~W} \\
334149 \mathrm{~N} 1110849 \mathrm{~W}\end{array}$ & $353623 \mathrm{~N} 1115152 \mathrm{~W}$ & & $\begin{array}{l}\text { McLellan Reservoir } \\
\text { Tuba City } \\
\text { Lockwood Canyon } \\
\text { Pilot Knob } \\
\text { Theo. Roosevelt Dam }\end{array}$ \\
\hline reservoir & $\begin{array}{l}\text { BGN } \\
\text { VARIANT }\end{array}$ & Coconino & $352757 N 1115727 \mathrm{~W}$ & & & Moritz Ridge \\
\hline $\begin{array}{l}\text { summit } \\
\text { locale }\end{array}$ & $\begin{array}{l}\text { UNOFF } \\
\text { VARIANT }\end{array}$ & $\begin{array}{l}\text { Mavajo } \\
\text { Pinal }\end{array}$ & $\begin{array}{l}350741 \mathrm{~N} 1100305 \mathrm{~W} \\
325018 \mathrm{~N} 1105301 \mathrm{~W}\end{array}$ & & & Black Mountain \\
\hline spring & $\begin{array}{l}\text { BGN } \\
\text { VARIANT }\end{array}$ & Yavapai & $341154 \mathrm{~N} 1122828 \mathrm{~W}$ & & & Minnehaha \\
\hline $\begin{array}{l}\text { spring } \\
\text { reservoir } \\
\text { reservoir }\end{array}$ & $\begin{array}{l}\text { BGN } \\
\text { BGN } \\
\text { BGN }\end{array}$ & $\begin{array}{l}\text { Navajo } \\
\text { Navajo } \\
\text { Coconino }\end{array}$ & $\begin{array}{l}353138 \mathrm{~N} 1100314 \mathrm{~W} \\
350750 \mathrm{~N} 1095248 \mathrm{~W} \\
353633 \mathrm{~N} 1114620 \mathrm{~W}\end{array}$ & & & $\begin{array}{l}\text { White Cone } \\
\text { Pilot Rock } \\
\text { Chapel Mtn }\end{array}$ \\
\hline $\begin{array}{l}\text { locale } \\
\text { valley } \\
\text { reservoir } \\
\text { swamp } \\
\text { summit }\end{array}$ & $\begin{array}{l}\text { BGN } \\
\text { BGN } \\
\text { BGN } \\
\text { BGN } \\
\text { BGN } \\
\text { VARIANT }\end{array}$ & $\begin{array}{l}\text { Graham } \\
\text { Navajo } \\
\text { Apache } \\
\text { Apache } \\
\text { Coconino }\end{array}$ & $\begin{array}{l}331247 N 1093752 \mathrm{~W} \\
361912 \mathrm{N1} 101717 \mathrm{~W} \\
361143 \mathrm{~N} 1092503 \mathrm{~W} \\
334926 \mathrm{~N} 1093005 \mathrm{~W} \\
362856 \mathrm{~N} 1123520 \mathrm{~W}\end{array}$ & $362031 N 1101645 \mathrm{~W}$ & 4884 & $\begin{array}{l}\text { Park Creek Cabins } \\
\text { Red Slide Peak } \\
\text { Del Muerto } \\
\text { Bonito Rock } \\
\text { Fishtail }\end{array}$ \\
\hline summit & VARIANT & Gila & $340942 \mathrm{~N} 1114028 \mathrm{~W}$ & & & \\
\hline $\begin{array}{l}\text { summit } \\
\text { reservoir }\end{array}$ & BGN & $\begin{array}{l}\text { Gila } \\
\text { Pima }\end{array}$ & $\begin{array}{l}341034 \mathrm{N1} 113750 \mathrm{~W} \\
321823 \mathrm{N1} 103716 \mathrm{~W}\end{array}$ & & & Piety Hill \\
\hline $\begin{array}{l}\text { reservoir } \\
\text { reservoir } \\
\text { reservoir } \\
\text { stream } \\
\text { well } \\
\text { locale } \\
\text { valley }\end{array}$ & $\begin{array}{l}\text { BGN } \\
\text { BGN } \\
\text { BGN } \\
\text { BGN } \\
\text { UNOFF } \\
\text { BGN } \\
\text { BGN } \\
\text { VARIANT } \\
\text { VARIANT }\end{array}$ & $\begin{array}{l}\text { Gila } \\
\text { Coconino } \\
\text { Coconino } \\
\text { Yavapai } \\
\text { Yavapai } \\
\text { Yavapai } \\
\text { Maricopa }\end{array}$ & $\begin{array}{l}341605 \mathrm{~N} 1111902 \mathrm{~W} \\
345148 \mathrm{~N} 1113222 \mathrm{~W} \\
350925 \mathrm{~N} 1122032 \mathrm{~W} \\
342917 \mathrm{N1} 120252 \mathrm{~W} \\
343114 \mathrm{~N} 1120334 \mathrm{~W} \\
343149 \mathrm{~N} 1120300 \mathrm{~W} \\
335407 \mathrm{~N} 1114852 \mathrm{~W}\end{array}$ & $\begin{array}{l}343335 N 1120350 \mathrm{~W} \\
335357 \mathrm{~N} 1115155 \mathrm{~W}\end{array}$ & $\begin{array}{l}4452 \\
4520\end{array}$ & $\begin{array}{l}\text { Payson Morth } \\
\text { Stoneman Lake } \\
\text { McLellan Reservoir } \\
\text { Estler Peak } \\
\text { Cherry } \\
\text { Cherry } \\
\text { Humboldt Mtn }\end{array}$ \\
\hline valley & & Maricopa & $335407 N 1114852 \mathrm{~W}$ & & & \\
\hline $\begin{array}{l}\text { spring } \\
\text { summit } \\
\text { summit }\end{array}$ & $\begin{array}{l}\text { BGN } \\
B G N \\
B G N\end{array}$ & $\begin{array}{l}\text { Maricopa } \\
\text { Yuma } \\
\text { Coconino }\end{array}$ & $\begin{array}{l}335405 \mathrm{~N} 1115108 \mathrm{~W} \\
324101 \mathrm{N1} 140305 \mathrm{~W} \\
351848 \mathrm{~N} 1120350 \mathrm{~W}\end{array}$ & & $\begin{array}{l}443 \\
7215\end{array}$ & $\begin{array}{l}\text { Humboldt Mtn } \\
\text { Wellton Mesa } \\
\text { Williams North }\end{array}$ \\
\hline
\end{tabular}
Canyon

ilot Knob

Moritz Ridge

White Cone

Pilot Rock

ark Creek Cabins Red Slide Peak

7215 Williams North
Black Mountain
SOURCE
COORDINATE

Quitobaquito Springs

Quitobaquito Springs

Menagers Lake

Howard Lake Howard Lake 
NATIONAL GAZETTEER--ARIZONA 1986

\section{FEATURE NAME}

Radio Ridge

Radiun

Radiun Hot Springs

Rad Water

Rafael Draw

Rafael Tank

Rafter M Bar Tank

Rafter Tank

Rag Canyon

Ragged Top

Ragged Top Mountain

Rags Canyon

Rail End Canyon

Rail H U Ranch

See H U Bar Ranch

Rai) N Ranch

Railroad Canyon

Railroad Dam Santa Fe Dam

Railroad Draw

Railroad Draw

Railroad Draw Tank

Railroad Draw Tanks

Railroad Embankment

Railroad Embankment Reservoir

Railroad Fill Tank

Railroad Number One Tank

Railroad Number Two Tank

Railroad Pass Rail Road Pass

Rail Road Pass

See Railroad Pass

Railroad Pass Rail Road Pass

Rail Road Pass

See Railroad Pass

Railroad Spring

Rail Road Spring

See Cool Spring

Railroad Spring

Railroad Tank

Railroad Tank

Railroad Tank

Railroad Tank

Railroad Tank

Railroad Tank

Railroad Tank

Railroad Wash

Hay Flat Draw

Railroad Wash

Railroad Well

Rail X Ranch

Rainbow Bridge National

Monument

Rainbow Campground

Rainbow End Wash

Rainbow Forest

Rainbow Forest

See Giant Logs

Rainbow Lake

Lakeside Reservoir

Rainbow Lake Campground

Ra inbow Lodge

Rainbow Lodge Spring

Rainbow Mine

Rainbow Mine

Rainbow Mines

Rainbow Plateau

Rainbow Plateau

Rainbow Spring

Rainbow Spring

BGN Graham
FEATURE
CLASS

STATUS COUNTY

COORDINATE

$322633 N 1104632 W$

$332701 \mathrm{~N} 1104926 \mathrm{~W}$

$324425 N 1140408$

$330630 \mathrm{~N} 1123822 \mathrm{~W}$

$345324 N 1120822$

$\begin{array}{llll}\text { reservoir } & B G N & \text { Yavapai } & 345618 N 1120902 \mathrm{~W} \\ \text { reservoir } & \text { BGN } & \text { Yavapai } & 351053 \mathrm{~N} 1124109 \mathrm{~W}\end{array}$

$\begin{array}{llll}\text { reservoir } & B G N & \text { Yavapai } & 345618 N 1120902 \mathrm{~W} \\ \text { reservoir } & \text { BGN } & \text { Yavapai } & 351053 \mathrm{~N} 1124109 \mathrm{~W}\end{array}$

reservoir BGN Yavapai 342953N1113434W

Mohave 345111M1132139W

summit

valley

valley

locale

locale

valley

dam

valley

valley

reservoir

reservoir

dam

reservoir

reservoir

reservoir

reservoir

gap

gap

gap
pass

VARIAN

pass

spring

VARIANT

Pima

Gila

$335430 \mathrm{~N} 1102112$

$335947 \mathrm{N1122240 \textrm {W }}$

VARIANT

Greenlee

Pima

332458 N1091115

$323010 N 1105307 \mathrm{~W}$

$323010 \mathrm{~N} 1105307 \mathrm{~W}$

BGN Yavapai

$351436 \mathrm{~N} 1121106 \mathrm{~W}$

UNOFF
VARIANT

BGN Yavapa

$B G N$

BGN

UNOFF

BGN

BGN

Coconino

Coconino

Yavapai

Coconino

Yavapai

Yavapa

Yavapai

Coconino

BGN

Coconino

Cochise

Cochise

Mohave

Mohave

Coconino

$345214 N 1120617 \mathrm{~W}$

$350613 N 1115522 \mathrm{~W}$

345658 N1120736

350459 N1115332W

351912 N1125348

$351912 \mathrm{~N} 1125348$

$350143 \mathrm{~N} 1122822 \mathrm{~W}$

$351215 N 1112807 \mathrm{~W}$

$351206 \mathrm{~N} 1112808 \mathrm{~W}$

$322038 \mathrm{N1094435 \textrm {W }}$

$322038 N 1094435$

$351117 \mathrm{N1140302W}$

351117 N1140302W

$345229 \mathrm{~N} 1112701 \mathrm{~W}$

VARIANT

spring

spring

reservoir

reservoir

reservoir

reservoir

reservoir

reservoir

$B G N$
$B G N$
$B G N$
$B G N$
$B G N$
$B G N$
$B G N$
$B G N$

Mohave

Coconino

Maricopa

Navajo

Yavapai

Coconino

Coconino

Coconino

Coconino

$\begin{array}{ll}\text { stream } & \text { BGN } 1978 \text { Cochise } \\ & \text { VARIANT }\end{array}$

stream

well

locale

park

park

stream

area

VARIA
BGN
UNOFF

UNOFF

Cochise

Greenlee

Yavapai

Santa Cruz

Coconino

$350807 \mathrm{~N} 1115732 \mathrm{~W}$

335858 N1125910W

$342131 \mathrm{~N} 1101125 \mathrm{~W}$

$345814 N 1122601 \mathrm{~W}$

$350135 N 1112822 \mathrm{~W}$

$350926 \mathrm{~N} 1115158 \mathrm{~W}$

351850 N1113355

353456 N1121054W

322217 N1093408W

$324144 N 1090408 \mathrm{~W}$

$342921 N 1124111 \mathrm{~W}$

313749 N1104241W

$365959 N 1105747 \mathrm{~W}$

$335226 \mathrm{~N} 1092443 \mathrm{~W}$

$323404 \mathrm{~N} 1105527 \mathrm{~W}$

344840 N1095230W

$323620 \mathrm{~N} 1104756 \mathrm{~W}$

Pinal

Navajo

VARIANT

area

reservoir

Navajo

Navajo

BGN 1964

park ADMIN Navajo

locale BGN Coconino

spring

mine

mine

locale

BGN

UNOFF

UNOFF

Coconino

Maricopa

Mohave

$344900 \mathrm{~N} 1095155 \mathrm{~W}$

$340900 \mathrm{~N} 1095905 \mathrm{~W}$

$340832 \mathrm{~N} 1095847 \mathrm{~W}$

$365945 \mathrm{~N} 1105332 \mathrm{~W}$

$370007 N 1105325 \mathrm{~W}$

$334303 \mathrm{~N} 1131915 \mathrm{~W}$

$352448 \mathrm{~N} 1140921 \mathrm{~W}$

341937 N1104610W

plain

plain

spring

spring

$361840 \mathrm{~N} 1121906 \mathrm{~W}$

$365714 \mathrm{~N} 1111240 \mathrm{~W}$

$341442 \mathrm{~N} 1122005 \mathrm{~W}$

$353324 \mathrm{~N} 1101330 \mathrm{~W}$

$345943 \mathrm{~N} 1120802 \mathrm{~W}$

$350514 N 1115210 \mathrm{~W}$

Mt Lemmon

3255 Globe

305 Wellton Mesa

Cotton Center

Perkinsville

Perkinsville

Picacho Butte

345457N1131911W Strawberry

Pilot Knob

3907 Silver Bell East

6213 Carrizo

340037 N1122218W Garfias Mtn

325207 N1092746W Gila Box

351833N1124735W Oracle Junction

Purcell Canyon

Williams South

Clarkdale

Sycamore Point

Perkinsville

Sycamore Point

Seligman West

Seligman West

Meath Spring

Winona

Winona

Railroad Pass

3300 Kingman

Hutch Mtn

Garland Prairie

Out law Hill

Pinedale

Paulden

Ashurst Lake

Bellemont

Sunset Crater West

Howard Lake

Luzena 


\section{FEATURE NAME}

Rainbow Tank

Rainbow Tank

Rainbow Valley See Little Rainbow Valley

Rainbow Valley

Rainbow Valley

Rainbow Valley Substation

Rainbow Wash

Rainbow Well

Rain God Mesa

Sastanha Mesa

Sastonho Mesa

Rain Mountain

Rain Tank

Rain Tank Flat

Rain Tank Wash

Raintree (subdivision)

Raintree Luxury Homes

(subdivision)

Rain Valley

Rain Valley Ranch

Rainville Ranch

Rainville Wash

Rainy Spring

Raleigh Well

Ralphs Hill

See Tanque Aloma

Ralphs Mill

See Tanque Alona

Ralph Spring

Ralphs Spring

Ralph Tank

Ralston Tank

Ramanote Canyon

Ramanote Peak

Ramanote Wells

Rama Shrine

Ramo Shrine

Rambler Mobile Park

Rambling Rons Mobile Hone Park

Rambo Creek

See Ramboz Wash

Rambo Ranch

Rambo Tank

Rambo Wash

See Ramboz Wash

Ramboz Peak

Ramboz Spring

Ramboz Wash

\section{Aliso Creek}

Rambo Creek

Rambo Wash

Ram Butte

Ramer Tank

Ramhead Tank

Ramhead Wash

Ramona Mine

Ramon Esquerra Ranch

Ramon Tank

Ramon Tank

Ramon Tank

Ramo Shrine

See Rama Shrine

Ramp, The

Ramp, The

Rampart Cave

Ramps Canyon

Ramsey

Ramsey Canyon

Ramsey Mine

\begin{tabular}{|c|c|c|}
\hline $\begin{array}{l}\text { FEATURE } \\
\text { CLASS }\end{array}$ & STATUS & COUNTY \\
\hline $\begin{array}{l}\text { reservoir } \\
\text { reservoir }\end{array}$ & $\begin{array}{l}\text { BGN } \\
\text { BGN } \\
\text { VARIANT }\end{array}$ & $\begin{array}{l}\text { Coconino } \\
\text { Coconino }\end{array}$ \\
\hline $\begin{array}{l}\text { valley } \\
\text { valley } \\
\text { ppl }\end{array}$ & $\begin{array}{l}\text { BGN } 1975 \\
\text { BGN }\end{array}$ & $\begin{array}{l}\text { Maricopa } \\
\text { Maricopa } \\
\text { Maricopa }\end{array}$ \\
\hline $\begin{array}{l}\text { locale } \\
\text { stream } \\
\text { well } \\
\text { summit }\end{array}$ & $\begin{array}{l}\text { UNOFF } \\
\text { BGN } \\
\text { UNOFF } \\
\text { BGN } \\
\text { VARIANT } \\
\text { VARIANT }\end{array}$ & $\begin{array}{l}\text { Maricopa } \\
\text { Maricopa } \\
\text { Graham } \\
\text { Navajo }\end{array}$ \\
\hline $\begin{array}{l}\text { summit } \\
\text { reservoir } \\
\text { flat } \\
\text { stream }\end{array}$ & $\begin{array}{l}\text { BGN } \\
\text { BGN } \\
\text { BGN } \\
\text { BGN }\end{array}$ & $\begin{array}{l}\text { Apache } \\
\text { Coconino } \\
\text { Coconino } \\
\text { Coconino }\end{array}$ \\
\hline $\begin{array}{l}\mathrm{ppl} \\
\mathrm{ppl}\end{array}$ & $\begin{array}{l}\text { BGN } \\
\text { BGN }\end{array}$ & $\begin{array}{l}\text { Maricopa } \\
\text { Maricopa }\end{array}$ \\
\hline $\begin{array}{l}\text { valley } \\
\text { locale } \\
\text { locale } \\
\text { stream } \\
\text { spring } \\
\text { well } \\
\text { ppl }\end{array}$ & $\begin{array}{l}\text { BGN } \\
\text { UNOFF } \\
\text { UNOFF } \\
\text { BGN } \\
\text { BGN } \\
\text { UNOFF } \\
\text { VARIANT }\end{array}$ & $\begin{array}{l}\text { Santa Cruz } \\
\text { Santa Cruz } \\
\text { Greenlee } \\
\text { Greenlee } \\
\text { Maricopa } \\
\text { Maricopa } \\
\text { Yuma }\end{array}$ \\
\hline
\end{tabular}

COORDINATE

$354011 \mathrm{~N} 1123458 \mathrm{~W}$

354129 N1115516W

$331030 \mathrm{~N} 1124230 \mathrm{~W}$

$331700 \mathrm{~N} 1123230 \mathrm{~W}$

$331355 \mathrm{~N} 1122311 \mathrm{~W}$

$331303 \mathrm{~N} 1122535 \mathrm{~W}$

331049 N1124250W

$330751 \mathrm{~N} 1093728 \mathrm{~W}$

$365632 \mathrm{~N} 1100425 \mathrm{~W}$

$361616 \mathrm{~N} 1095852 \mathrm{~W}$

$355618 N 1120937 \mathrm{~W}$

$352146 \mathrm{~N} 1115314 \mathrm{~W}$

$355136 \mathrm{~N} 1121839 \mathrm{~W}$

$332010 \mathrm{~N} 1115431 \mathrm{~W}$

$331953 \mathrm{~N} 1115546 \mathrm{~W}$

314107 N1102345W

$314236 \mathrm{~N} 1102727 \mathrm{~W}$

$323809 \mathrm{~N} 1090352 \mathrm{~W}$

$324233 \mathrm{~N} 1090521 \mathrm{~W}$

$333420 \mathrm{~N} 1111300 \mathrm{~W}$

$324658 \mathrm{~N} 1122628 \mathrm{~W}$

$324150 \mathrm{~N} 1135725 \mathrm{~W}$

VARIANT

ppl

spring

spring

reservoir

reservoir

valley

summit

well

summit

locale

locale

stream

locale

reservoir

stream

summit

spring

stream

(1)

well

summit

reservoir

reservoir

valley

mine

locale

reservoir

reservoir

reservoir

summit

cliff

summit

cave

valley

locale

valley

mine

$\begin{array}{ll}\text { BGN } & \text { Yuma } \\ \text { BGN } & \text { Yavapai } \\ \text { BGN } & \text { Yavapai } \\ \text { BGN } & \text { Yanta Cruz } \\ \text { BGN } & \text { Santa Cruz } \\ \text { BGN } & \text { Santa Cruz } \\ \text { UNOFF } & \text { Santa Cruz } \\ \text { BGN 1906 } & \text { Coconino }\end{array}$

$324150 \mathrm{~N} 1135725 \mathrm{~W}$

$345524 \mathrm{~N} 1130010 \mathrm{~W}$

$340926 \mathrm{~N} 1122824 \mathrm{~W}$

$313338 \mathrm{~N} 1103347 \mathrm{~W}$

$343235 N 1114458 \mathrm{~W}$

$312914 \mathrm{~N} 1110435 \mathrm{~W}$

$312654 N 1110741 \mathrm{~W}$

$312826 \mathrm{~N} 1110435 \mathrm{~W}$

360442N1115523W

VARIANT

UNOFF

UNOFF

VARIANT

UNOFF

BGN

VARIANT

BGN

BGN

Maricopa

Maricopa

Gila

Cochise

Coconino

Gila

Gila

Gila

BGN 1968

Gila

VARIANT

VARIANT

UNOFF Gila

BGN Navajo

$B G N$

BGN

BGN Navajo

UNOFF Mohave

BGN

BGN

VARIANT

$B E N$

BGN

BGN 1948

BGN

Pima

Yavapai

Coconino

Coconino

Navajo

Navajo

Mohave

Maricopa

BGN Cochise

$\begin{array}{ll}\text { BGN } & \text { Cochise } \\ \text { UNOFF } & \text { Yuma }\end{array}$

$341141 \mathrm{N1104751W}$
332450N1113751W

$333134 N 1120951 W$

$332110 \mathrm{~N} 1103847 \mathrm{~W}$

$312800 \mathrm{~N} 1101426 \mathrm{~W}$

$353712 \mathrm{~N} 1122120 \mathrm{~W}$

$332110 \mathrm{~N} 1103847 \mathrm{~W}$

$332742 \mathrm{~N} 1104650 \mathrm{~W}$

332739 N1104614W

$332110 \mathrm{~N} 1103847 \mathrm{~W}$

$332751 \mathrm{~N} 1104643 \mathrm{~W}$

$332750 \mathrm{~N} 1104605 \mathrm{~W}$

$351714 \mathrm{~N} 1101214 \mathrm{~W}$

$360852 \mathrm{N1} 100852 \mathrm{~W}$

$360806 \mathrm{~N} 1100444 \mathrm{~W}$

$323508 N 1115352 \mathrm{~W}$

$341519 \mathrm{~N} 1140015 \mathrm{~W}$

$321058 \mathrm{~N} 1111714 \mathrm{~W}$

$335757 \mathrm{~N} 1122419 \mathrm{~W}$

$351253 \mathrm{~N} 1115917 \mathrm{~W}$

$360442 \mathrm{~N} 1115523 \mathrm{~W}$

$365720 \mathrm{N1102148W}$

$365524 \mathrm{N1} 102505 \mathrm{~W}$

$360556 \mathrm{N1} 135557 \mathrm{~W}$

$335930 \mathrm{~N} 1115139 \mathrm{~W}$

$312645 \mathrm{N1} 101839 \mathrm{~W}$

$312745 \mathrm{~N} 1101720 \mathrm{~W}$

$333744 \mathrm{~N} 1135841 \mathrm{~W}$

$361304 N 1095844 W$ $\begin{array}{ll}\text { SOURCE } & \text { ELEV } \\ \text { COORDINATE } & \text { FT MAP NAME }\end{array}$

Tin House

Dog Knobs

330500N1121730W Buckeye

Mobile NW

Mobile NW

Cotton Center NW

4997 Elevator Mtn

5921 Mitten Buttes

7799 Tah Chee Wash

Tusayan West

7485 Parks

Howard Hill

1185 Guadalupe

1180 Guadalupe

$314338 N 1102945 \mathrm{~W}$

Mustang Mountains Mustang Mountains

Duncan

Duncan

Pinyon Mtn

Big Horn

$312535 N 1110845 \mathrm{~W}$

Mount Hope

Minnehaha

O'Donnell Canyon

Walker Mtn

6047 Ruby

Pena Blanca Lake

6411 Cape Royal

1530 Buckhorn

1150 Glendale

Nicksville

Mixon Tank

5086 Globe

Globe

Cutter

Globe

Sunflower Butte Parallel Canyon

Burnt Corn Spring

Burnt Corn Spring

North Komelik

Monkeys Head

Cocoraque Butte

Garf ias Mtn

Garland Prairie

Boot Mesa

6529 Big Point

Columbine Falls

Humboldt Mtn

Miller Peak

Miller Peak

Bear Hills 


\section{FEATURE NAME}

Ramsey Peak

Ramsey Slide

Ramsey Slide Tank

Ramsey Tank

Ramsey Tank

Ramsey Well

Ramsgate

\section{Ramsgate Spring}

Ramsgate Well

Ram Spring

Rams Shopping Center

Ram Valley

Ranch Creek

See Tulapai Creek

Ranch Creek

Gilson Wash

Tulapai Creek

Ranchera de los Gandules
See Moenkopi
Rancheria de San Diego
See Kenyon Station
Rancheria Spring
Rancherio de los Guadelas
See Moenkopi
Rancho de Arboleda
(subdivision)
Rancho de Chandler
(subdivision)

Rancho del Cielo
Rancho del Lago
Rancho del Rio
Rancho de Martinez
Rancho Encanto (subdivision)
Rancho Encanto Plaza Shopping
Center
Rancho Grande Park
Rancho Hermoso (trailer park)
Rancho Mobile Estates

$\begin{array}{llll}\text { ppl } & \text { VARIANT } & \text { Coconino } & 360640 \mathrm{~N} 1111318 \mathrm{~W} \\ \text { locale } & \text { VARIANT } & \text { Maricopa } & 330145 \mathrm{~N} 1125540 \mathrm{~W} \\ \text { spring } & \text { BGN } & \text { Pinal } & 323215 \mathrm{~N} 1105003 \mathrm{~W} \\ \text { ppl } & \text { VARIANT } & \text { Coconino } & 360640 \mathrm{~N} 1111318 \mathrm{~W} \\ \text { ppl } & \text { BGN } & \text { Maricopa } & 332725 N 1114650 \mathrm{~W} \\ \text { ppl } & \text { BGN } & \text { Maricopa } & 331720 \mathrm{~N} 1114910 \mathrm{~W}\end{array}$

FEATURE
CLASS

STATUS

COUNTY

COORDINATE

$\begin{array}{llll}\text { we11 } & \text { UNOFF } & \text { Pima } & 314713 \mathrm{~N} 1102941 \mathrm{~W} \\ \text { locale } & \text { BGN } & \text { Yavapai } & 343445 \mathrm{~N} 1123736 \mathrm{~W}\end{array}$

$\begin{array}{llll}\text { we11 } & \text { UNOFF } & \text { Pima } & 314713 \mathrm{~N} 1102941 \mathrm{~W} \\ \text { locale } & \text { BGN } & \text { Yavapai } & 343445 \mathrm{~N} 1123736 \mathrm{~W}\end{array}$

spring BGN Yavapai 343501N1123718W

UNOFF Yavapai

locale UNOFF Pima 321554 N1105448W

valley BGN Maricopa 335112N1112703W

stream Gila 331403N1104050W

stream BGN 1970 Gila 332110 N1103847W

VARIANT

VARIANT

locale

locale

civil

ppl

locale

park

locale

locale

UNOFF
UNDFF
UNOFF
AOMIN
BGN
UNOFF
AOMIN
UNOFF
UNOFF

stream

$B G N$

locale

airport

ppl

airport

ocale

ppl

airport

UNOFF

ADMIN

BGN

UNOFF

BGN

ADMIN

Rancho Seco Tank

Rancho Tempe Family and Adult

Mobile Home Park

Rancho Viejo Tank

Rancho Vista Estates

Ranch Tank

Randall Water Tank

$R$ and $H$ Mine

Randolph

Randolph Airport

See Sarita Airport Randolph Canyon
Fraser Canyon

Randolph Park

Randolph Railroad Station

Randolph Spring

Ranegras Plain Hanegras Plain Ranegras Plains

Ranegras Plains

See Ranegras Plain

Range Line Dam

Ranger Draw

\begin{tabular}{|c|c|c|c|c|c|}
\hline $\begin{array}{l}\text { reservoir } \\
\text { locale }\end{array}$ & $\begin{array}{l}\text { BGN } \\
\text { UNOFF }\end{array}$ & $\begin{array}{l}\text { Pima } \\
\text { Maricopa }\end{array}$ & $\begin{array}{l}314234 \mathrm{~N} 1112041 \mathrm{~W} \\
332302 \mathrm{~N} 1115728 \mathrm{~W}\end{array}$ & 1185 & $\begin{array}{l}\text { Cerro Colorado } \\
\text { Tempe }\end{array}$ \\
\hline $\begin{array}{l}\text { reservoir } \\
\text { ppl } \\
\text { reservoir } \\
\text { reservoir } \\
\text { mine } \\
\text { ppl }\end{array}$ & $\begin{array}{l}\text { BGN } \\
\text { BGN } \\
\text { BGN } \\
\text { BGN } \\
\text { UNOFF } \\
\text { BGN } \\
\text { VARIANT }\end{array}$ & $\begin{array}{l}\text { Coconino } \\
\text { Yavapai } \\
\text { Pima } \\
\text { Coconino } \\
\text { Yavapai } \\
\text { Pinal }\end{array}$ & $\begin{array}{l}351119 N 1120618 \mathrm{~W} \\
343123 \mathrm{~N} 1123031 \mathrm{~W} \\
315333 \mathrm{~N} 1111112 \mathrm{~W} \\
355528 \mathrm{~N} 1120805 \mathrm{~W} \\
341330 \mathrm{~N} 1121257 \mathrm{~W} \\
325501 \mathrm{~N} 1113051 \mathrm{~W}\end{array}$ & & $\begin{array}{l}\text { Davenport Hill } \\
\text { Iron Springs } \\
\text { Samaniego Peak } \\
\text { Tusayan West } \\
\text { Bumble Bee } \\
\text { Coolidge }\end{array}$ \\
\hline airport & & Pinal & $325608 \mathrm{~N} 1112902 \mathrm{~W}$ & & \\
\hline valley & $\begin{array}{l}\text { BGN } \\
\text { VARIANT }\end{array}$ & Pinal & $332332 \mathrm{~N} 1111652 \mathrm{~W}$ & $332517 \mathrm{~N} 1111040 \mathrm{~W}$ & Weavers Needle \\
\hline $\begin{array}{l}\text { park } \\
\text { building } \\
\text { spring } \\
\text { plain }\end{array}$ & $\begin{array}{l}\text { ADMIN } \\
\text { UNOFF } \\
\text { BGN } \\
\text { BGN } 1964 \\
\text { VARIANT } \\
\text { VARIANT } \\
\text { VARIANT }\end{array}$ & $\begin{array}{l}\text { Pima } \\
\text { Pinal } \\
\text { Pinal } \\
\text { Yuma }\end{array}$ & $\begin{array}{l}321238 \mathrm{~N} 1105519 \mathrm{~W} \\
325423 \mathrm{~N} 1113035 \mathrm{~W} \\
332511 \mathrm{~N} 1111420 \mathrm{~W} \\
333916 \mathrm{~N} 1134835 \mathrm{~W}\end{array}$ & & $\begin{array}{l}\text { Tucson } \\
\text { Coolidge } \\
\text { Iron Mountain } \\
\text { Vicksburg }\end{array}$ \\
\hline plain & & Yuma & $333916 \mathrm{~N} 1134835 \mathrm{~W}$ & & \\
\hline $\begin{array}{l}\text { dam } \\
\text { valley }\end{array}$ & $\begin{array}{l}\text { UNOFF } \\
\text { BGN }\end{array}$ & $\begin{array}{l}\text { Santa Cruz } \\
\text { Navajo }\end{array}$ & $\begin{array}{l}312353 \mathrm{~N} 1110912 \mathrm{~W} \\
342445 \mathrm{~N} 1103643 \mathrm{~W}\end{array}$ & $342213 N 1103744 \mathrm{~W}$ & $\begin{array}{l}\text { Ruby } \\
\text { Heber }\end{array}$ \\
\hline
\end{tabular}

Heber
$312559 N 1102003 \mathrm{~W}$ $345409 \mathrm{~N} 1095455 \mathrm{~W}$ 345350N1095433W $314819 \mathrm{N1102034 \textrm {W }}$ $342950 \mathrm{N1121111 \textrm {W }}$

Miller Peak Carrizo Butte Carrizo Butte McGrew Spring Mayer

Apache Peak

5092 Skull Valley

Iron Springs Iron Springs Sunflower Butte

335051N1112338W $\begin{array}{ll}2400 & \begin{array}{l}\text { Tucson North } \\ \text { Boulder Mtn }\end{array}\end{array}$

331440N1104747W Cutter

Oracle

1300 Mesa

1220 Chandler

Rincon Peak

Vail

Hereford

Tucson SW

1310 Hedgpeth Hills Union Hills

Casa Grande East

1130 Phoenix

1155 Phoenix

$331655 N 1110408 \mathrm{~W}$

Superior

$332525 \mathrm{~N} 1115803 \mathrm{~W}$

$343907 N 1114246 \mathrm{~W}$

$333600 \mathrm{~N} 1120102 \mathrm{~W}$

$312105 N 1094415 \mathrm{~W}$

$313236 \mathrm{~N} 1110227 \mathrm{~W}$

Santa Cruz $333813 N 1115931 \mathrm{~W}$

$\begin{array}{ll}\text { Maricopa } & 333813 N 1115931 \mathrm{~W} \\ \text { Maricopa } & 335600 N 1124700 \mathrm{~W}\end{array}$

1140 Tempe

3904 Casner Butte

1420 Sunnys lope

4240 Paul Spur

Tubac

1460 Currys Corner

2510 Vulture Peak 
FEATURE NAME

Ranger Guard Station

Ranger Pass

Ranger Pass Trick Tank

Ranger Spring

Ranger Station Spring

Ranger Tank

Ranger Tank

Ranieri Tank

Rankin

Rankin Ranch

Rank in Tank

Rapid Number One Hundred Eight See Browns Riffle

Rapid Number $10 B$

See Browns Riffle

Rapid Transit Mine

Rare Metals

Rarick Canyon

Rarick Tank

Rasberry Peak

See Paint Rock

Rascoe Tank

Rasmussen Mine

Raso

Raspberry Bas in

Raspberry Creek

Raspberry Peak

Raspberry Peak

Raspberry Ridge

Raspberry Spring

Raspberry Trai1 Thirty-five

Raster Wash

Ratliff Spring

Rattler Mine

Rattle Rock Saddle

Ratt lesnake Basin

Ratt lesnake Bas in

Rattlesnake Bluff

Rattlesnake Burn

Rattlesnake Canyon

Ratt lesnake Canyon

Ratt lesnake Canyon

Ratt lesnake Canyon

Rattlesnake Canyon

Rattlesnake Canyon

Ratt lesnake Canyon

Ratt lesnake Canyon

Ratt lesnake Canyon

Ratt lesnake Canyon

Rattlesnake Canyon

Rattlesnake Canyon

Ratt lesnake Canyon

Ratt lesnake Canyon

Rattlesnake Crater

Ratt lesnake Creek

Rattlesnake Creek

See Strayhorse Creek

Rattlesnake Dam

Ratt lesnake Draw

Rattlesnake Gap

Rattlesnake Gap Camp

Rattlesnake Hill

Ratt lesnake $\mathrm{HI} 1 \mathrm{I}$

Rattlesnake Lake

Rattlesnake Mesa

Ratt lesnake Mes a

Ratt lesnake Mine

Rattlesnake Mine

Rattlesnake Pass

Rattlesnake Pasture Tank

Rattlesnake Peak
FEATURE
CLASS

local

gap

reservoir

spring

spring

reservoir

reservoir

reservoir $B G$

locale

reservoir

UNOFF

BGN

VARIANT

rapids

VARIANT

rapids

mine

ppl

UNOFF

val iey

BGN

reservoir

BGN

VARIANT

summit

BGN

reservoir

mine

locale

bas in

stream

sumnit

summit

UNOFF

BGN

BGN

BGN

BGN 1985

BGN

ridge

spring

trail

valley

spring

mine

gap.

bas in

summit

BGN

$B G N$

UNOFF

BGN

BGN

UNOFF

BGN

BGN

BGN

BGN

area

valley

valley

valley

valley

valley

valley

valley

BGN

BGN

BGN

BGN

BGN

BGN

BGN

$B G N$

BGN

valley

valley

valley

valley

valley

crater

stream

stream
dam

BGN

BGN

BGN 1932

BGN
BGN

BGN

VARIANT

UNOFF

Cochise

Coconino

Greenlee

Mohave

Cochise

Cochise

Greenlee
Gila

Coconino

Santa Cruz

Cochise

Cochise

Pima

Graham

Greenlee

Pinal

$325944 N 1103749 \mathrm{~W}$

Gila 340859N1112112W

$340904 N 1121154 \mathrm{~W}$

$342525 \mathrm{N1121010 \textrm {W }}$

$344553 \mathrm{~N} 1114248 \mathrm{~W}$

$36110 \mathrm{BN} 1123 \mathrm{B5} 6 \mathrm{~W}$

$362933 N 1133926 \mathrm{~W}$

$351332 \mathrm{N1} 111958 \mathrm{~W}$

$324752 \mathrm{~N} 1101717 \mathrm{~W}$

Coconino

Graham

Greenlee

$332902 N 1091211 \mathrm{~W}$

Santa Cruz 313225N1103241W

valley $B G$

gap

locale

summit

summit

lake

summit

sumnit

mine

mine

BGN

BGN

BGN

BGN

BGN

BGN

$B G N$

UNOFF

UNOFF

Navajo

Greenlee

Greenlee

Apache

Mohave

Green lee

Graham

Coconino

Gila

Apache

gap

BGN

reservoir $B G N$

Pima

Green lee

Cochise

SOURCE

ELEV

MAP NAME

Camp Wood

Sowats Spring

Sowats Spring

Humboldt Mtn

Patagonia

Quayle $\mathrm{Hill}$

Tusayan West

New River SE

2783 Tucson East

Reid Valley

Sycamore Point

Crown King

Tuba City

Casner Butte

Stoneman Lake

Diamond Butte

O' Neill Hills

4371 Willcox North

Strayhorse

$333330 \mathrm{~N} 1091848 \mathrm{~W}$

Bear Mountain

9420 Chiricahua Peak

8318 Strayhorse

Chiricahua Peak

Humphreys Peak

Strayhorse

Kaiser Spring

Fife Peak

Hot Tamale Peak

Rustler Park

Dudleyvill

Strayhorse

4535 Sheep Bas in Mtn

7066 Loy Butte

Mt Hopkins

Rustler Park

$314222 N 1105332 \mathrm{~W}$

$315352 \mathrm{~N} 1091736 \mathrm{~W}$

$322138 \mathrm{~N} 1100555 \mathrm{~W}$

$322155 N 1104809 \mathrm{~W}$

$323932 \mathrm{N1} 102131 \mathrm{~W}$

$330528 \mathrm{~N} 1090956 \mathrm{~W}$

$330048 \mathrm{~N} 1103409 \mathrm{~W}$

$331845 \mathrm{~N} 1090430 \mathrm{~W}$

341037 N1112039W

$340842 \mathrm{~N} 1121304 \mathrm{~W}$

$342916 \mathrm{~N} 1121141 \mathrm{~W}$

$344855 \mathrm{~N} 1112955 \mathrm{~W}$

$361057 N 1123427 \mathrm{~W}$

$362308 \mathrm{~N} 1134224 \mathrm{~W}$

$323538 N 1101752 \mathrm{~W}$ 
FEATURE NAME

Rattlesnake Peak Rattlesnake

Ratt lesnake Point

Rattlesnake Point

Rattlesnake Point

Rattlesnake Reservoir

Rattlesnake Spring

Ratt lesnake Spring

Rattlesnake Spring

Rattlesnake Spring

Rattlesnake Spring

Rattlesnake Spring

Rattlesnake Spring

Rattlesnake Spring

Rattlesnake Spring

Rattlesnake Spring

Rattlesnake Spring

Ratt lesnake Spring

Rattlesnake Spring

Rattlesnake Tank

Rattlesnake Tank

Rattlesnake Tank

Ratt lesnake Tank

Ratt lesnake Tank

Ratt lesnake Tank

Rattlesnake Tank

Rattlesnake Tank

Rattlesnake Tank

Ratt lesnake Tank

Ratt lesnake Tank

Rattlesnake Tank

Ratt lesnake Tank

Rattlesnake Wash

Rattlesnake Well

Ratt lesnake Windmil

Raven Butte

Raven Butte Tank

Ravens Roost

Rawcon Tank

See Bawcom Tank

Rawhide Canyon

Rawhide Mine

Rawhide Mountain

Hobson Mountain

Spion Kop

Rawhide Mountains

Rawhide Wash

Rawley Mine
Raw Tank
Ray
Ray Cowden Tank
Ray District Elementary School
See Ray Unified District
Elementary School
Ray District High School
Ray Junction
Ray Junction
See Kelvin

Rayment Wash

$$
\text { See Reymert Wash }
$$

Raymert

See Reymert

Ray Mine

Raymond Lake

Raymond Park

Raymond Tank

Raymond Tank

Raymond Tank

Raymond W Bliss Army Hospital

Ray Place

Ray Schnepf Ranch Airstrip

\section{FEATURE \\ CLASS}

STATUS

COUNTY

COORDINATE

summit

summit

cliff

cliff

summit

reservoir

spring

BGN
$B G N$
$B G N$
$B G N$
$B G N$
$B G N$
$B G N$

spring

spring

spring

spring

spring

spring

spring

spring

spring

spring

spring

spring

reservoir

reservoir

reservoir

reservoir

reservoir

reservoir

reservoir

reservoir

BGN Graha

reservoir

reservoir

reservoir

reservoir

reservoir

stream

well

locale

summit

reservoir

BGN Yavapai

BGN Apache

BGN 1977 Yavapa

UNOFF Pima

BGN Yuma

summit

reservoir

valley

mine

summit

BGN

VARIANT

BGN

Maricopa

UNOFF Mohave

BGN 1922 Pinal

VARIANT

VARIANT

range $B G N$ Mohave

stream

mine

UNOFF Maricopa

reservoir

$\mathrm{ppl}$

spring

school

school

locale

locale

BGN

BGN

VARIANT

UNOFF Pinal

UGN

VARIAN

VARIANT

stream

locale

mine

mine

park

reservoir

reservoir

reservoir

VARTANT

UNOFF Pinal

BGN Coconino

AOMIN Coconino

BGN Coconino

BGN

$B G N$

hospital

locale

UNOFF

BGN

ADM IN
Cochise

Pima

Cochise

Apache

Navajo

Mohave

Graham

Greenlee

Greenlee

Greenlee

Pinal

Gila

Navajo

Yavapai

Yavapai

Mohave

Mohave

Santa Cruz

Cochise

Pinal

Graham

Greenlee

Greenlee

Navajo

Navajo

Yavapai

Yavapai

Coconino

Yuma

Coconino

Pinal

Mohave
Mohave

Apache

Apache

Mohave

Pinal

Pinal

Pinal

Pinal

$315433 \mathrm{~N} 1091842 \mathrm{~W}$ 322155 N1104837W 320907 N1091840W 334008 N1093053W $342025 \mathrm{~N} 1101812 \mathrm{~W}$ $363450 \mathrm{~N} 1132614 \mathrm{~W}$ 312534 N1102153W

323636N1102059W 330439 N1091010W 331418 N1100308W $331829 \mathrm{N1} 090417 \mathrm{~W}$ $331947 N 1091252 \mathrm{~W}$ $332151 \mathrm{~N} 1111434 \mathrm{~W}$ 335741 N1111420W $340030 \mathrm{~N} 1100058 \mathrm{~W}$ 343057 N112241 4W

$354603 \mathrm{~N} 1140115 \mathrm{~W}$ 362754 N1134033W $312402 \mathrm{~N} 1110946 \mathrm{~W}$ $313415 \mathrm{~N} 1095108 \mathrm{~W}$ $324015 \mathrm{~N} 1105236 \mathrm{~W}$ $325547 \mathrm{N1093446 \textrm {W }}$ $330607 \mathrm{~N} 1091005 \mathrm{~W}$ 333040 N1091910W 342307 N1101423W $343648 \mathrm{N1} 102014 \mathrm{~W}$

$344612 \mathrm{~N} 1113815 \mathrm{~W}$

$345209 N 1102217 \mathrm{~W}$ $350008 \mathrm{N1122005 \textrm {W }}$ 350542 N1121944W $345624 \mathrm{N1121844 \textrm {W }}$ $315840 \mathrm{~N} 1114832 \mathrm{~W}$ $350105 N 1092241 \mathrm{~W}$ $322416 \mathrm{~N} 1140634 \mathrm{~W}$ 322419 N1140710W

332756N1113801W

344245N1111308W $331425 \mathrm{N1110012 \textrm {W }}$ $341755 \mathrm{~N} 1133934 \mathrm{~W}$ 330244 N1102658W

$341621 \mathrm{N1134220 \textrm {W }}$ $341719 \mathrm{N1133710 \textrm {W }}$

341948 N1134230W

330257N1130159W

$334729 \mathrm{N1091204 \textrm {W }}$

$331100 \mathrm{~N} 1105949 \mathrm{~W}$

$350233 \mathrm{N1132527 \textrm {W }}$

330346 N1105433W

$330352 \mathrm{N1105443 \textrm {W }}$

$330625 \mathrm{N1} 105745 \mathrm{~W}$

$330641 \mathrm{~N} 1105822 \mathrm{~W}$

Coconino

Coconino

331734N1111208W

$331347 \mathrm{~N} 1111231 \mathrm{~W}$ $331039 \mathrm{N1} 105645 \mathrm{~W}$ $352432 \mathrm{~N} 1115730 \mathrm{~W}$ $350530 \mathrm{~N} 1114325 \mathrm{~W}$ $345450 \mathrm{~N} 1111723 \mathrm{~W}$ $351527 \mathrm{N1115108 \textrm {W }}$ 353919 N1114628W

Cochise Mohave Maricopa

SOURCE
COORDINATE

ELEV

MAP NAME

7914 Rustler Park

6653 Sabino Canyon Little Wood Canyon Maverick

Clay Springs

Little Tanks

Miller Peak

Bassett Peak

5373 Rattlesnake Spring

Bylas

Maple Peak

Fritz Canyon 


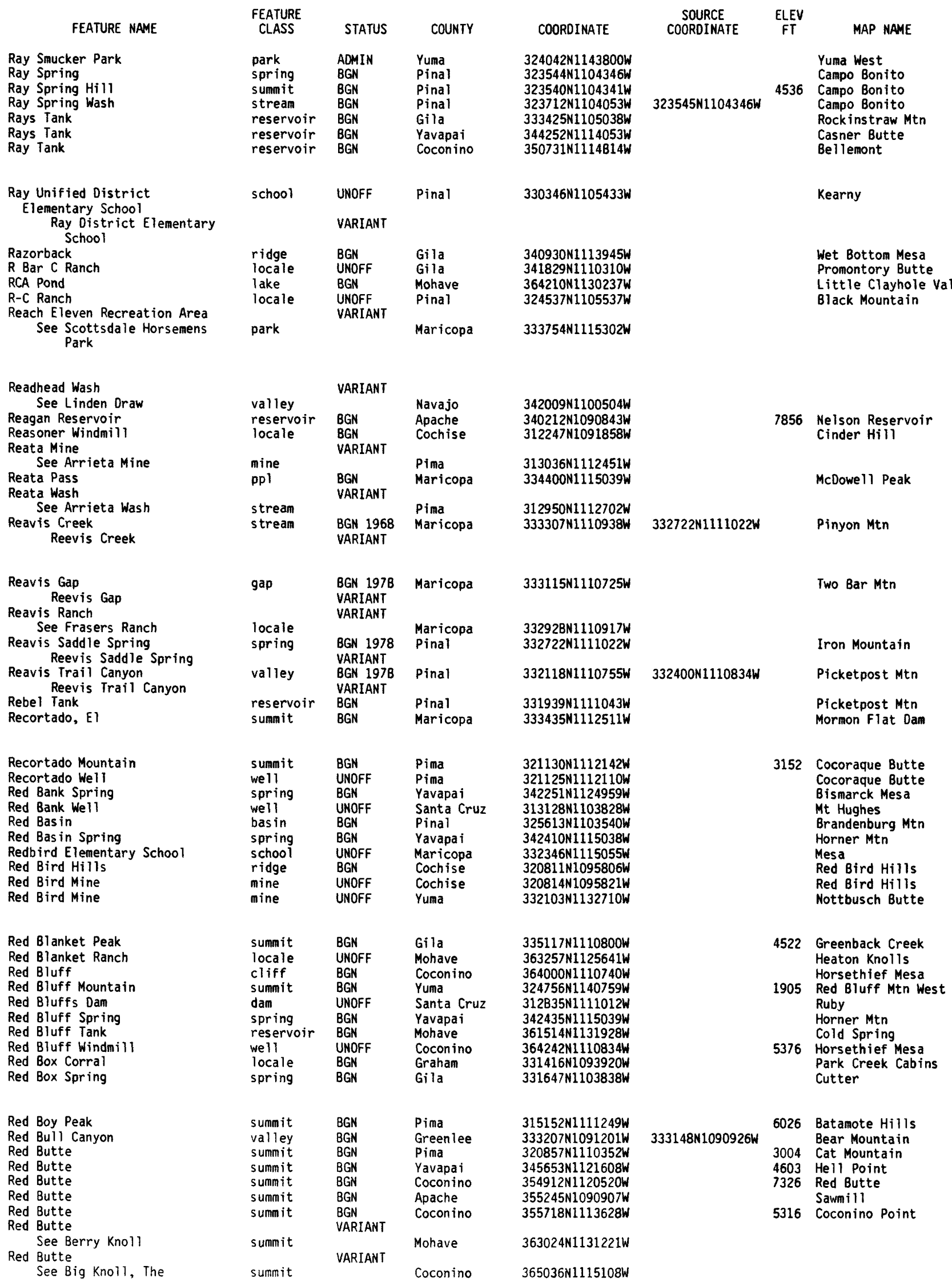


NATIONAL GAZETTEER--ARIZONA 1986

\begin{tabular}{|c|c|c|c|c|c|c|c|c|}
\hline & FEATURE NAME & $\begin{array}{l}\text { FEATURE } \\
\text { CLASS }\end{array}$ & STATUS & COUNTY & COORDINATE & $\begin{array}{c}\text { SOURCE } \\
\text { COORDINATE }\end{array}$ & $\begin{array}{l}\text { ELEV } \\
\text { FT }\end{array}$ & MAP NAME \\
\hline $\begin{array}{l}\text { Red } \\
\text { Red } \\
\text { Red } \\
\text { Red } \\
\text { Red } \\
\text { Red } \\
\text { Red }\end{array}$ & $\begin{array}{l}\text { See Red Knolls } \\
\text { Buttes } \\
\text { See Papago Buttes } \\
\text { Butte Tank } \\
\text { Cabin } \\
\text { Canyon } \\
\text { Canyon } \\
\text { Canyon } \\
\text { Canyon } \\
\text { Pearson Falls Wash }\end{array}$ & $\begin{array}{l}\text { summit } \\
\text { summit } \\
\text { reservoir } \\
\text { locale } \\
\text { valley } \\
\text { valley } \\
\text { valley } \\
\text { valley }\end{array}$ & $\begin{array}{l}\text { VARIANT } \\
\text { BGN } \\
\text { BGN } \\
\text { BGN } \\
\text { BGN } \\
\text { BGN } \\
\text { BGN } \\
\text { VARIANT }\end{array}$ & $\begin{array}{l}\text { Coconino } \\
\text { Maricopa } \\
\text { Coconino } \\
\text { Apache } \\
\text { Greenlee } \\
\text { Gila } \\
\text { Yavapai } \\
\text { Mohave }\end{array}$ & $\begin{array}{l}365221 \mathrm{~N} 1115016 \mathrm{~W} \\
332735 \mathrm{~N} 1115655 \mathrm{~W} \\
354817 \mathrm{~N} 1120540 \mathrm{~W} \\
341157 \mathrm{~N} 1093628 \mathrm{~W} \\
330229 \mathrm{~N} 1091634 \mathrm{~W} \\
335452 \mathrm{~N} 1101542 \mathrm{~W} \\
344620 \mathrm{~N} 1131549 \mathrm{~W} \\
345321 \mathrm{~N} 1132945 \mathrm{~W}\end{array}$ & $\begin{array}{l}330351 \mathrm{~N} 1091637 \mathrm{~W} \\
335707 \mathrm{~N} 1101130 \mathrm{~W} \\
345002 \mathrm{~N} 1131602 \mathrm{~W} \\
345321 \mathrm{~N} 1132915 \mathrm{~W}\end{array}$ & & $\begin{array}{l}\text { Red Butte } \\
\text { Whiting Knoll } \\
\text { Clifton } \\
\text { Carrizo } \\
\text { Pilot Knob } \\
\text { Tule Wash }\end{array}$ \\
\hline $\begin{array}{l}\text { Red } \\
\text { Red } \\
\text { Red } \\
\text { Red } \\
\text { Red } \\
\text { Red } \\
\text { Red } \\
\text { Red } \\
\text { Red } \\
\text { Red }\end{array}$ & $\begin{array}{l}\text { Canyon } \\
\text { Canyon } \\
\text { Canyon Ranch } \\
\text { Canyon Spring } \\
\text { Canyon Spring } \\
\text { Canyon Tank } \\
\text { Canyon Tank } \\
\text { Canyon Tank } \\
\text { Canyon Tank Number Two } \\
\text { Cheek Butte }\end{array}$ & $\begin{array}{l}\text { valley } \\
\text { valley } \\
\text { locale } \\
\text { spring } \\
\text { spring } \\
\text { reservoir } \\
\text { reservoir } \\
\text { reservoir } \\
\text { reservoir } \\
\text { summit }\end{array}$ & $\begin{array}{l}\text { BGN } \\
\text { BGN } 1906 \\
\text { UNOFF } \\
\text { BGN } \\
\text { BGN } \\
\text { BGN } \\
\text { BGN } \\
\text { BGN } \\
\text { BGN } \\
\text { BGN }\end{array}$ & $\begin{array}{l}\text { Yavapai } \\
\text { Coconino } \\
\text { Yavapai } \\
\text { Gila } \\
\text { Mohave } \\
\text { Navajo } \\
\text { Navajo } \\
\text { Yavapai } \\
\text { Gila } \\
\text { Navajo }\end{array}$ & $\begin{array}{l}345449 \mathrm{~N} 1115359 \mathrm{~W} \\
360237 \mathrm{~N} 1115515 \mathrm{~W} \\
345458 \mathrm{~N} 1115405 \mathrm{~W} \\
335558 \mathrm{~N} 1101222 \mathrm{~W} \\
345153 \mathrm{~N} 1132940 \mathrm{~W} \\
340016 \mathrm{~N} 1102433 \mathrm{~W} \\
340312 \mathrm{~N} 1103351 \mathrm{~W} \\
344933 \mathrm{~N} 1131602 \mathrm{~W} \\
335606 \mathrm{~N} 1101353 \mathrm{~W} \\
352006 \mathrm{~N} 1102339 \mathrm{~W}\end{array}$ & $\begin{array}{l}345519 N 1115307 \mathrm{~W} \\
355944 \mathrm{~N} 1115625 \mathrm{~W}\end{array}$ & 6495 & $\begin{array}{l}\text { Loy Butte } \\
\text { Cape Royal } \\
\text { Loy Butte } \\
\text { Cedar Creek } \\
\text { Cedar Bas in } \\
\text { Cibecue } \\
\text { Spotted Mountain. } \\
\text { Pilot Knob } \\
\text { Cedar Creek } \\
\text { Chimney Butte }\end{array}$ \\
\hline $\begin{array}{l}\text { Red } \\
\text { Red } \\
\text { Red } \\
\text { Red } \\
\text { Red } \\
\text { Red } \\
\text { Red } \\
\text { Red } \\
\text { Red } \\
\text { Red }\end{array}$ & $\begin{array}{l}\text { Cheek Spring } \\
\text { Chief Mine } \\
\text { Chief Mine } \\
\text { Clay Dam } \\
\text { Clay Mesa } \\
\text { Clay Mesa } \\
\text { Clay Ridge } \\
\text { Clay Spring } \\
\text { Clay Spring } \\
\text { Clay Trail }\end{array}$ & $\begin{array}{l}\text { spring } \\
\text { mine } \\
\text { mine } \\
\text { dam } \\
\text { summit } \\
\text { summit } \\
\text { ridge } \\
\text { spring } \\
\text { spring } \\
\text { trail }\end{array}$ & $\begin{array}{l}\text { BGN } \\
\text { UNOFF } \\
\text { UNOFF } \\
\text { UNOFF } \\
\text { BGN } \\
\text { BGN } \\
\text { BGN } \\
\text { BGN } \\
\text { BGN } \\
\text { UNOFF }\end{array}$ & $\begin{array}{l}\text { Navajo } \\
\text { Pinal } \\
\text { Pinal } \\
\text { Navajo } \\
\text { Navajo } \\
\text { Apache } \\
\text { Coconino } \\
\text { Yavapai } \\
\text { Coconino } \\
\text { Apache }\end{array}$ & $\begin{array}{l}351958 \mathrm{~N} 1102346 \mathrm{~W} \\
323413 \mathrm{~N} 1120727 \mathrm{~W} \\
323516 \mathrm{~N} 1115340 \mathrm{~W} \\
353338 \mathrm{~N} 1103041 \mathrm{~W} \\
352842 \mathrm{~N} 1100230 \mathrm{~W} \\
363227 \mathrm{~N} 1092703 \mathrm{~W} \\
363238 \mathrm{~N} 1110542 \mathrm{~N} \\
340728 \mathrm{~N} 1122631 \mathrm{~W} \\
355210 \mathrm{~N} 1104616 \mathrm{~W} \\
360816 \mathrm{~N} 1091741 \mathrm{~W}\end{array}$ & & $\begin{array}{l}5519 \\
6211\end{array}$ & $\begin{array}{l}\text { Chimney Butte } \\
\text { Kohatk } \\
\text { North Komelik } \\
\text { Tovar Mesa East } \\
\text { Indian Wells } \\
\text { Round Rock } \\
\text { Kaibito } \\
\text { Copperopolis } \\
\text { Padilla Mesa } \\
\text { Mummy Cave Ruins }\end{array}$ \\
\hline $\begin{array}{l}\text { Red } \\
\text { Red } \\
\text { Red } \\
\text { Red } \\
\text { Red } \\
\text { Red } \\
\text { Red } \\
\text { Red } \\
\text { Red } \\
\text { Red }\end{array}$ & $\begin{array}{l}\text { Clay Wash } \\
\text { Cliff } \\
\text { Cliff Spring } \\
\text { Cloud Mine } \\
\text { Cloud Mine } \\
\text { Cloud Wash } \\
\text { Cloud Wash } \\
\text { Cornfield Mesa } \\
\text { Corral } \\
\text { Creek }\end{array}$ & $\begin{array}{l}\text { arroyo } \\
\text { cliff } \\
\text { spring } \\
\text { mine } \\
\text { mine } \\
\text { stream } \\
\text { stream } \\
\text { summit } \\
\text { locale } \\
\text { stream }\end{array}$ & $\begin{array}{l}\text { BGN } \\
\text { BGN } \\
\text { BGN } \\
\text { UNOFF } \\
\text { UNOFF } \\
\text { BGN } \\
\text { BGN } \\
\text { BGN } \\
\text { BGN } \\
\text { BGN }\end{array}$ & $\begin{array}{l}\text { Apache } \\
\text { Maricopa } \\
\text { Mohave } \\
\text { Yuma } \\
\text { Maricopa } \\
\text { Yuma } \\
\text { Maricopa } \\
\text { Apache } \\
\text { Graham } \\
\text { Yavapai }\end{array}$ & $\begin{array}{l}354616 \mathrm{~N} 1092514 \mathrm{~W} \\
334942 \mathrm{~N} 1123948 \mathrm{~W} \\
365906 \mathrm{~N} 1124118 \mathrm{~W} \\
330601 \mathrm{~N} 1143556 \mathrm{~W} \\
335018 \mathrm{~N} 1125039 \mathrm{~W} \\
330350 \mathrm{~N} 1143855 \mathrm{~W} \\
335005 \mathrm{~N} 1125019 \mathrm{~W} \\
362022 \mathrm{~N} 1091546 \mathrm{~W} \\
323446 \mathrm{~N} 1100638 \mathrm{~W} \\
340025 \mathrm{~N} 1122022 \mathrm{~W}\end{array}$ & $\begin{array}{l}354836 \mathrm{~N} 1092307 \mathrm{~W} \\
330752 \mathrm{~N} 1143525 \mathrm{~W} \\
335139 \mathrm{~N} 1125110 \mathrm{~W} \\
340214 \mathrm{~N} 1122352 \mathrm{~W}\end{array}$ & & $\begin{array}{l}\text { Red Clay Wash } \\
\text { Wickenburg SW } \\
\text { Kaibab } \\
\text { Picacho } \\
\text { Vulture Mine } \\
\text { Picacho SW } \\
\text { Vulture Mine } \\
\text { Red Cornfield Mesa } \\
\text { Sierra Bonita Ranch } \\
\text { Columbia }\end{array}$ \\
\hline $\begin{array}{l}\text { Red } \\
\text { Red } \\
\text { Red } \\
\text { Red } \\
\text { Red }\end{array}$ & $\begin{array}{l}\text { Creek } \\
\text { Grove Creek } \\
\text { Soda Spring Creek } \\
\text { Soda Springs Creek } \\
\text { Creek } \\
\text { See Middle Red Creek } \\
\text { Creek Spring } \\
\text { Crossing } \\
\text { See Powell (historical) } \\
\text { Crossing } \\
\text { See Topock }\end{array}$ & $\begin{array}{l}\text { stream } \\
\text { spring } \\
\text { locale } \\
\text { locale }\end{array}$ & $\begin{array}{l}\text { BGN } 1968 \\
\text { VARIANT } \\
\text { VARIANT } \\
\text { VARIANT } \\
\text { VARIANT } \\
\text { BGN } \\
\text { VARIANT } \\
\text { VARIANT }\end{array}$ & $\begin{array}{l}\text { Yavapai } \\
\text { Yavapai } \\
\text { Mohave } \\
\text { Mohave }\end{array}$ & $\begin{array}{l}341016 \mathrm{~N} 1114521 \mathrm{~W} \\
341355 \mathrm{~N} 1114831 \mathrm{~W} \\
344306 \mathrm{~N} 1142911 \mathrm{~W} \\
344306 \mathrm{~N} 1142911 \mathrm{~W}\end{array}$ & $341550 \mathrm{~N} 1114930 \mathrm{~W}$ & & Wet Bottom Mesa \\
\hline $\begin{array}{l}\text { Red } \\
\text { Redd } \\
\text { (s } \\
\text { Redd } \\
\text { Red } \\
\text { Red } \\
\text { Red }\end{array}$ & $\begin{array}{l}\text { Cross Mine } \\
\text { Idells Ranch Acres } \\
\text { subdivision) } \\
\text { Iden Park } \\
\text { Dike Pond } \\
\text { Dirt Tank } \\
\text { Field Canyon } \\
\text { See West Divide Two } \\
\text { Hundred Eighty-nine } \\
\text { field Canyon }\end{array}$ & $\begin{array}{l}\text { mine } \\
\text { ppl } \\
\text { park } \\
\text { lake } \\
\text { reservoir } \\
\text { trail } \\
\text { valley }\end{array}$ & $\begin{array}{l}\text { UNOFF } \\
\text { BGN } \\
\text { ADMIN } \\
\text { BGN } \\
\text { BGN } \\
\text { VARIANT }\end{array}$ & $\begin{array}{l}\text { Yuma } \\
\text { Yavapai } \\
\text { Maricopa } \\
\text { Coconino } \\
\text { Coconino } \\
\text { Graham } \\
\text { Pima }\end{array}$ & $\begin{array}{l}324014 \mathrm{~N} 1134149 \mathrm{~W} \\
343420 \mathrm{~N} 1115145 \mathrm{~W} \\
332127 \mathrm{~N} 1115507 \mathrm{~W} \\
355218 \mathrm{~N} 1122229 \mathrm{~W} \\
364419 \mathrm{~N} 1110005 \mathrm{~W} \\
323033 \mathrm{~N} 1101922 \mathrm{~W} \\
322540 \mathrm{~N} 1102900 \mathrm{~W}\end{array}$ & $323513 \mathrm{~N} 1101708 \mathrm{~N}$ & 3100 & $\begin{array}{l}\text { Mowhawk Mts NW } \\
\text { Camp Verde } \\
\text { Guadalupe } \\
\text { Howard Hill } \\
\text { White Hill }\end{array}$ \\
\hline $\begin{array}{l}\text { Red } \\
\text { Red } \\
\text { Red } \\
\text { Red } \\
\text { Red } \\
\text { Red } \\
\text { Red } \\
\text { Red } \\
\text { Red } \\
\text { Red }\end{array}$ & $\begin{array}{l}\text { Flat } \\
\text { Flat } \\
\text { Flat Pond } \\
\text { Flat Tank } \\
\text { Flat Tank } \\
\text { Hat Tank } \\
\text { Hill } \\
\text { Hill } \\
\text { Hill } \\
\mathrm{Hill}\end{array}$ & $\begin{array}{l}\text { flat } \\
\text { flat } \\
\text { reservoir } \\
\text { reservoir } \\
\text { reservoir } \\
\text { reservoir } \\
\text { summit } \\
\text { summit } \\
\text { summit } \\
\text { summit }\end{array}$ & $\begin{array}{l}\text { BGN } \\
B G N \\
B G N \\
B G N \\
B G N \\
B G N \\
B G N \\
B G N \\
B G N \\
B G N\end{array}$ & $\begin{array}{l}\text { Gila } \\
\text { Yavapai } \\
\text { Mohave } \\
\text { Coconino } \\
\text { Yavapai } \\
\text { Yavapai } \\
\text { Santa Cruz } \\
\text { Cochise } \\
\text { Pima } \\
\text { Pinal }\end{array}$ & $\begin{array}{l}332539 \mathrm{~N} 1105741 \mathrm{~W} \\
345056 \mathrm{~N} 1120943 \mathrm{~W} \\
363919 \mathrm{~N} 1131728 \mathrm{~W} \\
344837 \mathrm{~N} 1110849 \mathrm{~W} \\
345046 \mathrm{~N} 1121010 \mathrm{~W} \\
350213 \mathrm{~N} 1123157 \mathrm{~W} \\
312401 \mathrm{~N} 1104414 \mathrm{~W} \\
313410 \mathrm{~N} 1091453 \mathrm{~W} \\
322607 \mathrm{~N} 1112451 \mathrm{~W} \\
324144 \mathrm{~N} 1104111 \mathrm{~W}\end{array}$ & & 1702 & $\begin{array}{l}\text { Inspiration } \\
\text { Munds Draw } \\
\text { The Grandstand } \\
\text { Chavez Mtn West } \\
\text { Munds Draw } \\
\text { Picacho Butte SE } \\
\text { Harshaw } \\
\text { Paramore Crater } \\
\text { Silver Bell East } \\
\text { Mammoth }\end{array}$ \\
\hline
\end{tabular}




\section{FEATURE NAME}

Red $\mathrm{Hi} 1$

Red Hil

Red Hill

Red Hill

Red Hill

Red $\mathrm{Hil}$

Red Hil

Red $\mathrm{Hill}$

Red $\mathrm{Hi} 11$

Red $\mathrm{Hill}$

Red $\mathrm{Hill}$

Red $\mathrm{Hill}$

Red $\mathrm{Hill}$

Red Hil

Red $\mathrm{Hil}$

Red Hill Landing Strip

Red Hill Pass

Red Hill Ranch

Red Hills

Red Hills

Red Hills

Red Hills

Red Hills

Red Hills

Red Hills

Red Hills

Red Hills

Red Hills

Red Hills Canyon

Red Hills Corral

Red Hills Information Center

Red Hills Trail

Red Hill Tank

Red Hill Tank

Red Hill Tank

Red Hill Tank

Red Hill Tank

Red Hill Tank

Red Hill Tank

Red Hill Tank

Red Hill Tank

Red Hill Tank

Red Hill Tank

Red Hill Tank

Red Hill Tank

Red Hill Tank

Red Hill Windmill

Red Hole

Red Horn Canyon

Red Horn Spring

Red Horse Spring

Red Horse Tank

Red Horse Tank

Red Horse Wash

Red House Bas in

Red House Well

Redington

Red Knob

Red Knob Tank

Red Knob Wells

Red Knoll

Red Knoll

Red Knoll

Red Knoll Canyon

Red Knoll Flat

Red Knoll Flat Tank

Red Knolls

Red Knolls

Red Butte

Red Knolls Amphitheater

Red Knoll Tank
FEATURE
CLASS

summit
summit
summit
summit
summit
summit
summit
summit
summit
summit

STATUS COUNTY

COORDINATE

$\begin{array}{ll}\text { BGN } & \text { Greenlee } \\ \text { BGN } & \text { Yuma } \\ \text { BGN } & \text { Navajo } \\ \text { BGN } & \text { Yavapai } \\ \text { BGN } & \text { Yavapai } \\ \text { BGN } & \text { Coconino } \\ \text { BGN } & \text { Navajo } \\ \text { BGN } & \text { Yavapai } \\ \text { BGN } & \text { Coconino } \\ \text { BGN } & \text { Coconino }\end{array}$

sumnit

summit

sumpit

summit

summit

airport

gap

locale

ridge

$\begin{array}{ll}\text { BGN } & \text { Coconino } \\ \text { BGN } & \text { Coconino } \\ \text { BGN } & \text { Coconino } \\ \text { BGN } & \text { Apache } \\ \text { BGN } & \text { Coconino } \\ \text { ADNIN } & \text { Coconino } \\ \text { BGN 1917 } & \text { Gila } \\ \text { UNOFF } & \text { Coconino } \\ \text { BGN } & \text { Navajo } \\ \text { BGN } & \text { Pima }\end{array}$

$215 \mathrm{~N} 1113628 \mathrm{~W}$

$353856 \mathrm{~N} 1120151 \mathrm{~W}$

$355141 \mathrm{N1113833 \textrm {W }}$

355923N1094534W

$362204 \mathrm{N1113455 \textrm {W }}$

$344105 \mathrm{~N} 1110048 \mathrm{~W}$

$332700 \mathrm{~N} 1105000 \mathrm{~W}$

$353255 \mathrm{~N} 1122448 \mathrm{~W}$

$345015 \mathrm{~N} 1103243 \mathrm{~W}$

$321512 \mathrm{~N} 1111047 \mathrm{~W}$

summit BGN Graham 330645N1095538W

summit

summit

summit

summit

summit

valley

locale

$\begin{array}{ll}\text { BGN } & \text { Graham } \\ \text { BGN } & \text { Pinal } \\ \text { BGN } & \text { Maricopa } \\ \text { BGN } & \text { Yuma } \\ \text { BGN } & \text { Greenlee } \\ \text { BGN 1974 } & \text { Gila } \\ \text { BGN } & \text { Yavapai } \\ \text { BGN } & \text { Apache } \\ \text { BGN } & \text { Yavapai } \\ \text { BGN } & \text { Gila }\end{array}$

$331142 \mathrm{~N} 1110010 \mathrm{~W}$

$332821 \mathrm{N1112248 \textrm {W }}$

$334011 \mathrm{N1132300 \textrm {W }}$

$334053 \mathrm{~N} 1090840 \mathrm{~W}$

340902 N1111534W

$340905 \mathrm{~N} 1113804 \mathrm{~W}$

$352616 \mathrm{~N} 1092731 \mathrm{~W}$

$342946 \mathrm{~N} 1124830 \mathrm{~W}$

340954 N1111551W

building

trail

reservoir

reservoir

reservoir

reservoir

reservoir

reservoir

reservoir

reservoir

UNOFF Pima

UNOFF Maricopa

BGN

BGN
BGN
BGN

BGN

Cochise

Gila

Gila

Gila

Yavapai

Yavapai

Coconino

$321514 N 1111141 \mathrm{~W}$

$332834 \mathrm{~N} 1112247 \mathrm{~W}$

$313422 \mathrm{~N} 1111153 \mathrm{~W}$

$314157 N 1091425 \mathrm{~W}$

$334814 \mathrm{~N} 1101349 \mathrm{~W}$

$335842 \mathrm{~N} 1130536 \mathrm{~W}$

$342043 N 1112551 \mathrm{~W}$

343649 N1113433W

$343830 N 1123615 W$

$344118 N 1110041 \mathrm{~W}$

reservoir

reservoir

reservoir

reservoir

reservoir

reservoir

locale

bas in

valley

spring

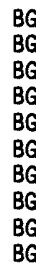

Navajo

Yavapai

Yavapai

Yavapai

Coconino

Coconino

Apache

Yavapai

Mohave

Mohave

spring

reservoir

reservoir

valley

bas in

well

ppl

summit

reservoir

well

BGN Yavapai

Yavapai

Coconino

Coconino

Coconino

Apache

Pima

Mohave

Mohave

Mohave

summit

summit

summit

valley

flat

reservoir

summit

summit

bas in

BGN Gila

BGN Navajo

$B G N$

$B G N$

BGN

$B G N$
$B G N$
$B G N$

Coconino

Navajo

Graham

1979 Coconino

VARIANT

Graham

$344552 \mathrm{~N} 1104314 \mathrm{~W}$

$344652 \mathrm{~N} 1113555 \mathrm{~W}$

$350 \mathrm{~B} 07 \mathrm{N1131644 \textrm {W }}$

351242N1124850W

$353317 \mathrm{N1120939W}$

$355126 \mathrm{~N} 1113820 \mathrm{~W}$

$355548 N 1094647 \mathrm{~W}$

$340625 \mathrm{~N} 1115833 \mathrm{~W}$

$351959 \mathrm{N1133100 \textrm {W }}$

$351951 \mathrm{N1} 133126 \mathrm{~W}$

$343516 \mathrm{~N} 1120118 \mathrm{~W}$

$354804 \mathrm{N1} 121239 \mathrm{~W}$

$355222 \mathrm{N1115350 \textrm {W }}$

$354412 \mathrm{~N} 1121631 \mathrm{~W}$

$353120 \mathrm{~N} 1112833 \mathrm{~W}$

$362937 N 1093613 \mathrm{~W}$

$322539 N 1102933 \mathrm{~W}$

$343721 \mathrm{N1132406 \textrm {W }}$

343650 N1132352W

343715 N1132449W

335849 N1101307W

$343139 \mathrm{~N} 1103512 \mathrm{~W}$

$350622 \mathrm{~N} 1120231 \mathrm{~W}$

$325801 N 1093243 \mathrm{~W}$

$343220 \mathrm{~N} 1103430 \mathrm{~W}$

$343211 \mathrm{N1103435 \textrm {W }}$

$325642 \mathrm{~N} 1095626 \mathrm{~W}$

$365221 \mathrm{~N} 1115016 \mathrm{~W}$

325735 N1095639W

reservoir

BGN

Gila

$335834 N 1101441 W$

$\begin{array}{cc}\text { SOURCE } & \text { ELEV } \\ \text { COORDINATE } & \text { FT MAP NAME }\end{array}$

4680 Rattlesnake Spring

1507 Red Hill

5672 Snowf lake

6181 Buckhorn Mountain

5552 Jerome Canyon

6562 Quayle $\mathrm{Hill}$ Relic Point

6338 Stoneman Lake Sycamore Point

7751 Moritz Ridge

7219 East of S P Mtn

Molly Anne Draw

Willows Camp

Steamboat Rock NE

Bodaway Mesa

Quayle Hill

Globe

Red Hill Ranch

McCauley Sinks

Avra

Fort Thomas

Teapot Mountain

2769 Goldfield

Socorro Mine

Beaverhead

Pays on South

Wet Botton Mesa

6705 Wide Ruins

Bismarck Mesa

4600 Payson South

Avra

Goldfield

Murphy Peak

Apache

Cone Butte

Forepaugh Peak

Buckhead Mesa

Buckhorn Mountain 
NATIONAL GAZETTEER--ARIZONA 1986

FEATURE NAME

Red Knoll Tank

Red Knoll Well

Red Lake

Red Lake

Red Lake

Red Lake

Red Lake

Red Lake

Red Lake

Red Lake

Red Lake

Red Lake

Red Lake

Red Lake

Red Lake Trading Post

Tonalea Post office

Red Lake Chapter House

Red Lake Dan

Red Lake Draw

Red Lake Flat

Red Lake Siding

Red Lake Tank

Red Lake Tank

Red Lake Tank

Red Lake Tank

Red Lake Tank

Red Lake Tank

Red Lake Trading Post

Red Lake Trading Post

See Red Lake

Red Lake Valley

Red Lake Valley

Red Lake Wash

Red Lake Well

Redlands Ranch

Redman Cave

Redman Mesa

Redman Mesa Tank

Red Mesa

Red Mes a

Red Mesa

Red Mesa

Red Mesa

Red Mesa

Red Mesa Canyon

Red Mesa Day School

Red Mesa Reservoir

Red Metal Canyon

Red Metal Spring

Red Metal Tank

Redmond Flat

Redmond Mountain

Redmond Tank

Redmond Wash

Redmond Well

Red Mountain

Red Mountain

Red Mountain

Red Mountain

Red Mountain

See Turt leback Mountain

Red Mountain

Red Mountain

Red Mountain

Red Mountain

Red Mountain

Red Mountain

Red Mountain

Red Mountain

Red Mountain Mine

Red Mountain Ranch

\section{FEATURE}

CLASS

STATUS

COUNTY

COORDINATE

reservoir
well
flat
flat
lake
lake
lake
lake
lake

BGN

UNOFF

BGN

$B G N$

BGN

BGN

BGN

lake

reservoir $B G$

reservoir $B G$

ppI BGN

ppl BGN

VARIANT

building UNOFF

valley $B G N$

flat

locale

reservoir

reservoir

reservoir $B C N$

reservoir $B G$

reservoir $B G$

locale BGN

pp

Mavajo

Navajo

Mohave

Coconino

Yavapa

Coconino

Apache

Apache

Yavapai

Coconino

Coconino

Apache

Coconino

Coconino

Apache

Apache

Yavapai

$343216 N 1103522 \mathrm{~W}$

$343240 \mathrm{~N} 1103400 \mathrm{~W}$

$354023 \mathrm{~N} 1140401 \mathrm{~V}$

$361905 N 1105537 \mathrm{~W}$

344402N1131949W

$344714 \mathrm{~N} 1111057 \mathrm{~W}$

$345408 \mathrm{~N} 1093537 \mathrm{~W}$

$350036 \mathrm{~N} 1091040 \mathrm{~W}$

$351222 \mathrm{~N} 1130358 \mathrm{~N}$

$352234 N 1120930 \mathrm{~W}$

353829 N1124955W

$355540 \mathrm{~N} 1090221 \mathrm{~W}$

$352245 N 1120935 \mathrm{~W}$

361921 N1105655W

$355425 \mathrm{~N} 1090256 \mathrm{~W}$

$355500 \mathrm{~N} 1090200 \mathrm{~W}$

$350857 \mathrm{~N} 1130633 \mathrm{~W}$

$351325 \mathrm{~N} 1130428 \mathrm{~W}$

$352250 \mathrm{~N} 1120942 \mathrm{~W}$

$343054 \mathrm{~N} 1101637 \mathrm{~W}$

$345145 N 1093719 \mathrm{~W}$

$351105 \mathrm{~N} 1130408 \mathrm{~W}$

$353812 \mathrm{~N} 1125020 \mathrm{~W}$

$354037 \mathrm{~N} 1113336 \mathrm{~W}$

$354715 \mathrm{~N} 1122940 \mathrm{~W}$

361907 N1105618W

361921 N1105655W

Coconino

$\begin{array}{llll}\text { basin } & \text { BGN } & \text { Coconino } & 362436 N 1105610 \mathrm{~W} \\ \text { valley } & \text { BGN } & \text { Coconino } & 352228 N 1120951 \mathrm{~W}\end{array}$

stream

well

locale

locale

summit

reservoir

summit

summit

$B G N$

BGN 1964

UNOFF

BGN

BGN

BGN

BGN

BGN

summit

summit

summit

locale

valley

school

reservoir

valley

spring

reservoir

\section{BGN}

BGN

BGN

$B G N$

BGN
UNOFF
BGN

BGN

BGN

Coconino

Yavapai

Coconino

Gila

Gila

Gila

Apache

Apache

$353345 N 1121600 \mathrm{~W}$

$351253 \mathrm{~N} 1130341 \mathrm{~W}$

$354824 N 1122557 \mathrm{~W}$

$341114 N 1104659 \mathrm{~W}$

335608 N1110154W

$360924 \mathrm{~N} 1093726 \mathrm{~W}$

$363315 N 1092157 \mathrm{~W}$

Coconino

Coconino

Apache

Apache

Apache

Apache

Coconino

Gila

Gila

Gila

363836N1113241W $364338 \mathrm{N1112729 \textrm {W }}$ $365936 \mathrm{~N} 1092034 \mathrm{~K}$

365947 N1092206W $363212 \mathrm{~N} 1092110$

365739 N1092143W

$363740 \mathrm{~N} 1113232 \mathrm{~W}$

341114 N1113532W

341143 N1113339W

$341240 N 1113327 \mathrm{~W}$

flat BGN Gila 333939N1105000W

$\begin{array}{lll}\text { summit } \quad B G N & \text { Gila } & 333619 N 1105127 W\end{array}$

reservoir BGN Gila 333650N1105110W

stream BGN Gila 333844N1105117W

sumnit

summit

summit

UNOFF

BGN

$B G N$

$B G N$

Gila

$333708 \mathrm{~N} 1105000 \mathrm{~W}$

$312429 N 1095729 \mathrm{~W}$

$313015 N 1104305 \mathrm{~W}$

$320530 \mathrm{~N} 1092400 \mathrm{~W}$

$330808 \times 1092631 \mathrm{~W}$

VARIANT

summit

Greenlee

Yuma

$330823 N 1132341 W$

summit

summit

summit

summit

summit

summit

summit

summit

mine

locale
BGN

BGN
BGN
BGN
BGN
BGN
BGN
BGN
BGN
UNOFF
UNOFF

Greenlee

Maricopa

Maricopa

Yavapai

Yuma

Yavapai

Yavapai

Coconino

Pinal

Maricopa
$332657 \mathrm{~N} 1091650 \mathrm{~W}$

$334706 \mathrm{~N} 1113120 \mathrm{~W}$

$335928 N 1120117 \mathrm{~W}$

340647 N1115815W

$34502 \mathrm{BN} 1124725 \mathrm{~W}$

350109 N1125201W

$353123 \mathrm{~N} 1115229 \mathrm{~W}$

330749 N1110800W

$332901 \mathrm{~N} 1114032 \mathrm{~W}$ dam UNOFF

reservoir $B G$

$335545 \mathrm{N11} 10144 \mathrm{~W}$

\begin{tabular}{|c|c|c|}
\hline \multirow[t]{3}{*}{$\begin{array}{l}\text { SOURCE } \\
\text { COORDINATE }\end{array}$} & $\begin{array}{c}\text { ELEV } \\
\text { FT }\end{array}$ & MAP NAME \\
\hline & 5436 & $\begin{array}{l}\text { Red Knoll } \\
\text { Red Knoll } \\
\text { Red Lake } \\
\text { Tonalea } \\
\text { Negro Ed } \\
\text { Chavez Mtn West } \\
\text { Ninemile Seep } \\
\text { Deep Lake } \\
\text { Squaw Peak }\end{array}$ \\
\hline & & $\begin{array}{l}\text { Howard Mesa } \\
\text { Rose We } 11 \text { Camp East } \\
\text { Buell Park } \\
\text { Howard Mesa } \\
\text { Tonalea }\end{array}$ \\
\hline \multirow[t]{2}{*}{$351057 \mathrm{~N} 1130422 \mathrm{~W}$} & & $\begin{array}{l}\text { Buell Park } \\
\text { Buell Park } \\
\text { Squaw Peak }\end{array}$ \\
\hline & & $\begin{array}{l}\text { Squaw Peak } \\
\text { Howard Mesa } \\
\text { Sheepsk in Wash } \\
\text { Seven Springs } \\
\text { Squaw Peak } \\
\text { Rose Well Camp East } \\
\text { Campbell Francis Wsh } \\
\text { Little Harpo Canyon } \\
\text { Tonalea }\end{array}$ \\
\hline
\end{tabular}

$\begin{array}{lrl}351857 N 1120231 W & \begin{array}{l}\text { White Mesa Arch } \\ \text { Williams North } \\ \text { 351B36N1120615W }\end{array} \\ & 5678 \begin{array}{l}\text { Mixon Tank } \\ \text { Squaw Peak } \\ \text { Little Harpo Canyon } \\ \text { Parallel Canyon } \\ \text { Copper Mtn } \\ \text { Copper Mtn }\end{array} \\ & 5853 \text { Chinle } \\ 6095\end{array}$

Explosive Rock

6240 Dead Monkey Ridge 
FEATURE NAME

Red Mountain Spring

Red Mountain Tank

Red Mountain Tanks

Red Mountain Twenty-five Trail

Red Needle

Redonda, Mesa

Mesa Pedonda

Mesa Redondo

Redondo Mes a

Redondo Mesa

See Redonda, Mesa

Redondo Ranch

Redondo Ruins (Butterfield

Stage Station)

Redondo Tank

Redondo Wash

Red Peak

Red Peak Valley

Red Picacho

Red Pocket

Red Pocket Tanks

Red Point

Red Point

Red Point

Red Point

Red Point

Red Point

Red Point

Red Point Hills

Red Point Mesa

Red Point Spring

Red Point Tank

Red Point Tank

Red Point Tank Dam

Red Point Wash

Red Pond

Red Pond

Red Raspberry Tank

Red Raven Wash

Red Reservoir

Red Ridge

Red Ridge

Red River Tank

Redrock

Red Rock

Red Rock

Red Rock

Red Rock

Redrock

See Red Rock

Red Rock

Redrock

Red Rock

$$
\text { See Powell (historica1) }
$$

Rock

See Topock

Red Rock

Red Rock

Red Valley

Red Rock Boarding School

Red Rock Campground

Redrock Canyon

Red Rock Canyon

Redrock Canyon

See Carruthers Canyon

Red Rock Canyon

Red Rock Cliff

Redrock Creek

Red Rock Dam

Red Rock Elementary School

Red Rock Gate

Red Rock Gulch
FEATURE

$\begin{array}{ll}\text { spring } & \text { BGN } \\ \text { reservoir } & \text { BGN } \\ \text { reservoir } & \text { BGN } \\ \text { trail } & \text { UNOFF } \\ \text { pillar } & \text { BGN } \\ \text { summit } & \text { BGN 1966 } \\ & \text { VARIANT } \\ & \text { VARIANT } \\ & \text { VARIANT } \\ & \text { VARIANT }\end{array}$

summit

Apache

342630 N1094800W

\begin{tabular}{|c|c|c|c|}
\hline $\begin{array}{l}\text { locale } \\
\text { locale }\end{array}$ & $\begin{array}{l}\text { UNOFF } \\
\text { BGN }\end{array}$ & $\begin{array}{l}\text { Pima } \\
\text { Yuma }\end{array}$ & $\begin{array}{l}315225 \mathrm{~N} 1113249 \mathrm{~W} \\
324428 \mathrm{~N} 1142920 \mathrm{~W}\end{array}$ \\
\hline $\begin{array}{l}\text { reservoir } \\
\text { stream } \\
\text { summit } \\
\text { valley } \\
\text { summit } \\
\text { basin } \\
\text { reservoir }\end{array}$ & $\begin{array}{l}\text { BGN } \\
B G N \\
B G N \\
B G N \\
B G N \\
B G N \\
B G N\end{array}$ & $\begin{array}{l}\text { Santa Cruz } \\
\text { Pima } \\
\text { Apache } \\
\text { Navajo } \\
\text { Yavapai } \\
\text { Coconino } \\
\text { Mohave }\end{array}$ & $\begin{array}{l}314051 \mathrm{~N} 1110810 \mathrm{~W} \\
315209 \mathrm{~N} 1113010 \mathrm{~W} \\
362655 \mathrm{~N} 1095553 \mathrm{~W} \\
362542 \mathrm{~N} 1102544 \mathrm{~W} \\
335745 \mathrm{~N} 1123049 \mathrm{~W} \\
365323 \mathrm{~N} 1115846 \mathrm{~W} \\
363709 \mathrm{~N} 1135940 \mathrm{~W}\end{array}$ \\
\hline
\end{tabular}

354209 N1093328W $360318 \mathrm{~N} 1134116 \mathrm{~W}$ $363445 \mathrm{~N} 1120931 \mathrm{~W}$

cliff

cliff
cliff

cliff

summit

summit

summit

summit

summit

BGN

BGN

BGN

$B G N$

BGN

BGN

BGN

BGN

BGN

Apache

Mohave

Coconino

Coconino

Maricopa

Navajo

Apache

Coconino

Apache

Gila

reservoir $B G N$

reservoir

dam

valley

lake

reservoir

reservoir $B G$

stream

reservoir $B G N$

ridge

BGN

UNOFF

$B G N$

BGN

BGN

$B G N$
$B G N$
$B G N$

Gila

Yavapai

Navajo

Mohave

Mohave

Coconino

Yuma

Coconino

Pima

$364235 \mathrm{~N} 1113851 \mathrm{~W}$

$323226 \mathrm{~N} 1131748 \mathrm{~W}$

$362246 \mathrm{~N} 1100442 \mathrm{~W}$

$364628 \mathrm{~N} 1095626 \mathrm{~W}$

$361347 \mathrm{~N} 1113220 \mathrm{~W}$

364238 N1095728W

$335259 \mathrm{~N} 1101441 \mathrm{~W}$

$331530 \mathrm{~N} 1105453 \mathrm{~W}$

$345118 \mathrm{~N} 1121426 \mathrm{~W}$

$345117 \mathrm{~N} 1121426 \mathrm{~W}$

$362242 \mathrm{~N} 1100422 \mathrm{~W}$

$361928 N 1133204 \mathrm{~W}$

$362524 N 1132439 \mathrm{~W}$

$345803 \mathrm{~N} 1113243 \mathrm{~W}$

$330528 \mathrm{~N} 1132838 \mathrm{~W}$

$361630 \mathrm{~N} 1114518 \mathrm{~W}$

$322750 \mathrm{~N} 1104558 \mathrm{~W}$

summit

reservoir

pillar

pillar

pillar

summit

summit

locale

locale

BGN

BGN

$B G N$
$B G N$

BGN

BGN

BGN

VARIANT

Yavapai

Yavapai

Cochise

Maricopa

Mohave

Gila

Apache

Pinal

BGN 1964 Pinal

VARIANT

VARIANT

locale

locale

locale

ppl

school

park

valley

valley

VARIANT

Mohave

BGN
$B G N$

VARIANT

UNOFF

ADMIN

BGN

Mohave

Yavapai

Apache

Apache

Yavapai

340248 N1115807W

$340241 \mathrm{~N} 1115759 \mathrm{~W}$

$321005 \mathrm{~N} 1102307 \mathrm{~W}$

$330356 \mathrm{~N} 1124313 \mathrm{~W}$

$342151 \mathrm{~N} 1141229 \mathrm{~W}$

$335736 \mathrm{~N} 1112639 \mathrm{~W}$

363347 N1090444W

323434N1111930W

$323434 \mathrm{~N} 1111930 \mathrm{~W}$

$332246 \mathrm{~N} 1140038 \mathrm{~W}$

Santa Cruz

$344306 \mathrm{~N} 1142911 \mathrm{~W}$

$344306 \mathrm{~N} 1142911 \mathrm{~W}$

$344932 \mathrm{~N} 1114857 \mathrm{~W}$

$363616 \mathrm{~N} 1090336 \mathrm{~W}$

$363554 \mathrm{~N} 1090327 \mathrm{~W}$

$344930 \mathrm{~N} 1114818 \mathrm{~W}$

$313234 \mathrm{~N} 1104406 \mathrm{~W}$

$314539 \times 1091942$

valley

valley

cliff

stream

dam

schoo]

bend

valley
BGN

VARIANT

Cochise

BGN

BGN

BGN

UNOFF

UNOFF

$B G N$

BGN
Cochise

Maricopa

Coconino

Cochise

Yuma

La Paz
Yavapai
$321817 N 1101147 \mathrm{~W}$

$330322 \mathrm{~N} 1124226 \mathrm{~W}$

$354532 \mathrm{~N} 1110657 \mathrm{~W}$

332440 N1135219W

$323425 \mathrm{~N} 1111944 \mathrm{~W}$

330200 N1143400W

$341742 \mathrm{~N} 1120114 \mathrm{~W}$
320931N1101756W

SOURCE
COORDINATE

Payson South Chapel Mtn

Red Mountain

Rose Peak

5664 Snake Butte

6830 Mesa Redonda

315308N1113508W Saucito Mtn Baboquivari Peak

6242 Rough Rock NW

Great Spring

Red Picacho

Poverty Flat

Red Pockets

Ganado

Tincanebitts Point

Telephone Hill

Bitter Springs

1183 Aguila Mts SE

Chilchinbito Canyon

Red Point

Pillow Mtn

Red Point Mesa

Cedar Creek

Pinal Ranch

Munds Draw

Munds Draw

Chilchinbito Canyon

Wildcat Ranch

Poverty Knoll

Mormon Mountain

Baragan Mtn 


\begin{tabular}{|c|c|c|c|c|c|c|c|}
\hline FEATURE NAME & $\begin{array}{l}\text { FEATURE } \\
\text { CLASS }\end{array}$ & STATUS & COUNTY & COORDINATE & $\begin{array}{l}\text { SOURCE } \\
\text { COORDIMATE }\end{array}$ & $\begin{array}{c}\text { ELEV } \\
\text { FT }\end{array}$ & MAP NAME \\
\hline $\begin{array}{l}\text { Red Rock Hill } \\
\text { Red Rock Interchange } \\
\text { Red Rock Knoll } \\
\text { Red Rock Mine } \\
\text { Red Rock Mine } \\
\text { Red Rock Mine } \\
\text { Red Rock Picnic Area } \\
\text { Red Rock Railroad Station } \\
\text { Redrock Ranch } \\
\text { Red Rock Reservoir }\end{array}$ & $\begin{array}{l}\text { summit } \\
\text { crossing } \\
\text { summit } \\
\text { mine } \\
\text { mine } \\
\text { mine } \\
\text { park } \\
\text { building } \\
\text { locale } \\
\text { reservoir }\end{array}$ & $\begin{array}{l}\text { BGN } \\
\text { UNOFF } \\
\text { BGN } \\
\text { UNOFF } \\
\text { UNOFF } \\
\text { UNOFF } \\
\text { ADMIN } \\
\text { UNOFF } \\
\text { UNOFF } \\
\text { BGN }\end{array}$ & $\begin{array}{l}\text { Mavajo } \\
\text { Pinal } \\
\text { Mohave } \\
\text { Pinal } \\
\text { Gila } \\
\text { Yavapai } \\
\text { Santa Cruz } \\
\text { Pinal } \\
\text { Santa Cruz } \\
\text { La Paz }\end{array}$ & $\begin{array}{l}364117 \mathrm{~N} 1101337 \mathrm{~W} \\
323423 \mathrm{~N} 1111919 \mathrm{~W} \\
362244 \mathrm{~N} 1134312 \mathrm{~W} \\
324645 \mathrm{~N} 1111130 \mathrm{~W} \\
331718 \mathrm{~N} 1105637 \mathrm{~W} \\
342650 \mathrm{~N} 1121935 \mathrm{~W} \\
312358 \mathrm{~N} 111050 \mathrm{~W} \\
323437 \mathrm{~N} 1111927 \mathrm{~W} \\
313226 \mathrm{~N} 1104009 \mathrm{~W} \\
332441 \mathrm{~N} 1135219 \mathrm{~W}\end{array}$ & & 3840 & $\begin{array}{l}\text { Kayenta East } \\
\text { Red Rock } \\
\text { Last Chance Canyon } \\
\text { Ninetysix Hills SW } \\
\text { Pinal Ranch } \\
\text { Poland Junction } \\
\text { Pena Blanca Lake } \\
\text { Red Rock } \\
\text { Mt Hughes } \\
\text { Valencia }\end{array}$ \\
\hline $\begin{array}{l}\text { Red Rock Rim } \\
\text { Red Rock School } \\
\text { Red Rock Spring } \\
\text { Red Rock Spring } \\
\text { Red Rock Spring } \\
\text { Red Rock Spring } \\
\text { Red Rock Spring } \\
\text { Red Rock Spring } \\
\text { Red Rock Spring } \\
\text { Red Rock Spring }\end{array}$ & $\begin{array}{l}\text { cliff } \\
\text { school } \\
\text { spring } \\
\text { spring } \\
\text { spring } \\
\text { spring } \\
\text { spring } \\
\text { spring } \\
\text { spring } \\
\text { spring }\end{array}$ & $\begin{array}{l}\text { BGN } \\
\text { UNOFF } \\
\text { BGM } \\
\text { BGM } \\
\text { BGN } \\
\text { BGN } \\
\text { BGN } \\
\text { BGN } \\
\text { BGN } \\
\text { BGN }\end{array}$ & $\begin{array}{l}\text { Apache } \\
\text { Apache } \\
\text { Maricopa } \\
\text { Gila } \\
\text { Navajo } \\
\text { Yavapai } \\
\text { Navajo } \\
\text { Gila } \\
\text { Mohave } \\
\text { Mohave }\end{array}$ & $\begin{array}{l}360912 \mathrm{~N} 1094205 \mathrm{~W} \\
363553 \mathrm{~N} 1090327 \mathrm{~W} \\
332805 \mathrm{N1} 11035 \mathrm{~W} \\
335627 \mathrm{~N} 1111005 \mathrm{~W} \\
340047 \mathrm{~N} 1102606 \mathrm{~W} \\
341327 \mathrm{N1} 115129 \mathrm{~W} \\
341712 \mathrm{N1} 102030 \mathrm{~W} \\
342215 \mathrm{~N} 1112403 \mathrm{~W} \\
351504 \mathrm{~N} 1142225 \mathrm{~W} \\
360001 \mathrm{N1} 133901 \mathrm{~W}\end{array}$ & & & $\begin{array}{l}\text { Ventana Mesa } \\
\text { Red Valley } \\
\text { Haunted Canyon } \\
\text { Picture Mtn } \\
\text { Cibecue } \\
\text { Bloody Basin } \\
\text { Clay Springs } \\
\text { Buckhead Mesa } \\
\text { Grasshopper Junc SE } \\
\text { Tincanebitts Point }\end{array}$ \\
\hline $\begin{array}{l}\text { Red Rock Spring } \\
\text { Redrock Spring Well } \\
\text { Red Rock Tank } \\
\text { Red Rock Tank } \\
\text { Redrock Tank } \\
\text { Red Rock Tank } \\
\text { Red Rock Tank } \\
\text { Red Rock Tank } \\
\text { Red Rock Tank } \\
\text { Red Rock Tank }\end{array}$ & $\begin{array}{l}\text { spring } \\
\text { well } \\
\text { reservoir } \\
\text { reservoir } \\
\text { reservoir } \\
\text { reservoir } \\
\text { reservoir } \\
\text { reservoir } \\
\text { reservoir } \\
\text { reservoir }\end{array}$ & $\begin{array}{l}\text { BGN } \\
\text { UNOFF } \\
\text { BGN } \\
\text { BGN } \\
\text { BGN } \\
\text { BGN } \\
\text { BGN } \\
\text { BGN } \\
\text { BGN } \\
\text { BGN }\end{array}$ & $\begin{array}{l}\text { Mohave } \\
\text { Coconino } \\
\text { Santa Cruz } \\
\text { Cochise } \\
\text { Cochise } \\
\text { Graham } \\
\text { Gila } \\
\text { Gila } \\
\text { Apache } \\
\text { Yavapai }\end{array}$ & $\begin{array}{l}363303 \mathrm{~N} 1140124 \mathrm{~W} \\
353752 \mathrm{~N} 1105227 \mathrm{~W} \\
312940 \mathrm{~N} 1110957 \mathrm{~W} \\
314512 \mathrm{~N} 1091303 \mathrm{~W} \\
320936 \mathrm{~N} 1102346 \mathrm{~W} \\
332402 \mathrm{~N} 1101207 \mathrm{~W} \\
333025 \mathrm{~N} 1103257 \mathrm{~W} \\
342132 \mathrm{~N} 1112324 \mathrm{~W} \\
342627 \mathrm{~N} 1095033 \mathrm{~W} \\
350842 \mathrm{~N} 1123242 \mathrm{~W}\end{array}$ & & & $\begin{array}{l}\text { Virgin Peak } \\
\text { Garces Mesas ME } \\
\text { Ruby } \\
\text { Portal Peak } \\
\text { Happy Valley } \\
\text { Bronco Gulch } \\
\text { Sevenmile Mts } \\
\text { Buckhead Mesa } \\
\text { Mesa Redonda } \\
\text { Cathedral Caves }\end{array}$ \\
\hline $\begin{array}{l}\text { Red Rock Tank } \\
\text { Red Rock Tank } \\
\text { Red Rock Trading Post } \\
\text { Red Rock Vall ley } \\
\text { Red Rock Valley } \\
\text { Redrock Valley } \\
\text { Red Rock Wash } \\
\text { Red Rock Well } \\
\text { Red Rooster Mountain } \\
\text { Quartzite Mountain }\end{array}$ & $\begin{array}{l}\text { reservoir } \\
\text { reservoir } \\
\text { locale } \\
\text { basin } \\
\text { basin } \\
\text { valley } \\
\text { valley } \\
\text { well } \\
\text { summit }\end{array}$ & $\begin{array}{l}\text { BGN } \\
\text { BGN } \\
\text { BGN } \\
\text { BGN } \\
\text { BGN } \\
\text { BGN } 1915 \\
\text { BGN } \\
\text { UNOFF } \\
\text { BGN 1970 } \\
\text { VARIANT }\end{array}$ & $\begin{array}{l}\text { Mohave } \\
\text { Coconino } \\
\text { Apache } \\
\text { Apache } \\
\text { Apache } \\
\text { Apache } \\
\text { Apache } \\
\text { Gila } \\
\text { Pinal }\end{array}$ & $\begin{array}{l}352418 \mathrm{~N} 1132124 \mathrm{~W} \\
353444 \mathrm{~N} 1120012 \mathrm{~W} \\
363614 \mathrm{~N} 1090339 \mathrm{~W} \\
363509 \mathrm{~N} 1090313 \mathrm{~W} \\
364113 \mathrm{~N} 1090324 \mathrm{~W} \\
364210 \mathrm{N1090824W} \\
363625 \mathrm{~N} 1090351 \mathrm{~W} \\
333039 \mathrm{~N} 1103154 \mathrm{~W} \\
330029 \mathrm{~N} 1103022 \mathrm{~W}\end{array}$ & 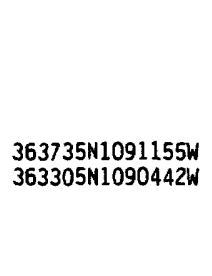 & $\begin{array}{l}3661 \\
487 B\end{array}$ & $\begin{array}{l}\text { Blye Canyon NE } \\
\text { Hobble Tank } \\
\text { Red Valley } \\
\text { Red Valley } \\
\text { Horse Mesa } \\
\text { Boiling Over Well } \\
\text { Red Valley } \\
\text { Sevenmile Mts } \\
\text { Jerusalem Mtn }\end{array}$ \\
\hline $\begin{array}{l}\text { Red Rooster Spring } \\
\text { Red Rover Mine } \\
\text { Red Saddle Tank } \\
\text { Red Sands } \\
\text { Red Seep Spring } \\
\text { Red Seep Spring } \\
\text { Red Slide Peak } \\
\text { Red Slide Peak Wash } \\
\text { Red Spot Spring } \\
\text { Red Spring }\end{array}$ & $\begin{array}{l}\text { spring } \\
\text { mine } \\
\text { reservoir } \\
\text { flat } \\
\text { spring } \\
\text { spring } \\
\text { summit } \\
\text { valley } \\
\text { spring } \\
\text { spring }\end{array}$ & $\begin{array}{l}\text { BGN } \\
\text { UNOFF } \\
\text { BGN } \\
\text { BGN } \\
\text { BGN } \\
\text { BGN } \\
\text { BGN } \\
\text { BGN } \\
\text { BGN } \\
\text { BGN } 1979\end{array}$ & $\begin{array}{l}\text { Pinal } \\
\text { Maricopa } \\
\text { Gila } \\
\text { Mohave } \\
\text { Graham } \\
\text { Yavapai } \\
\text { Navajo } \\
\text { Navajo } \\
\text { Coconino } \\
\text { Santa Cruz }\end{array}$ & $\begin{array}{l}330002 \mathrm{~N} 1102749 \mathrm{~W} \\
340038 \mathrm{~N} 1115042 \mathrm{~W} \\
341527 \mathrm{~N} 1113109 \mathrm{~W} \\
365601 \mathrm{~N} 1123314 \mathrm{~W} \\
331425 \mathrm{~N} 1094310 \mathrm{~W} \\
344327 \mathrm{~N} 1120838 \mathrm{~W} \\
361946 \mathrm{~N} 1102136 \mathrm{~W} \\
361931 \mathrm{N1} 102141 \mathrm{~W} \\
363647 \mathrm{~N} 1105127 \mathrm{~W} \\
313601 \mathrm{~N} 1110909 \mathrm{~W}\end{array}$ & $362005 N 1102317 \mathrm{~W}$ & 6841 & $\begin{array}{l}\text { Rawhide Mtn } \\
\text { Rover Peak } \\
\text { Cane Springs Mtn } \\
\text { Fredonia } \\
\text { Park Creek Cabins } \\
\text { Hickey Mountain } \\
\text { Red Slide Peak } \\
\text { Red Slide Peak } \\
\text { Whirlwind Rock } \\
\text { Murphy Peak }\end{array}$ \\
\hline $\begin{array}{l}\text { Red Spring } \\
\text { Red Spring } \\
\text { Upper Peach Spring }\end{array}$ & $\begin{array}{l}\text { spring } \\
\text { spring }\end{array}$ & $\begin{array}{l}\text { BGN } \\
\text { BGN } \\
\text { VARIANT }\end{array}$ & $\begin{array}{l}\text { Gila } \\
\text { Mohave }\end{array}$ & $\begin{array}{l}335358 \mathrm{~N} 1101353 \mathrm{~W} \\
353332 \mathrm{~N} 1132518 \mathrm{~W}\end{array}$ & & & $\begin{array}{l}\text { Cedar Creek } \\
\text { Peach Springs }\end{array}$ \\
\hline $\begin{array}{l}\text { Red Spring } \\
\text { Red Spring Pass } \\
\text { Red Spring Tank } \\
\text { Reds Tank } \\
\text { Red Star Mine } \\
\text { Redtail Dam Tank } \\
\text { Red Tail Ranch }\end{array}$ & $\begin{array}{l}\text { spring } \\
\text { gap } \\
\text { reservoir } \\
\text { reservoir } \\
\text { mine } \\
\text { reservoir } \\
\text { locale }\end{array}$ & $\begin{array}{l}\text { BGN } \\
\text { BGN } 1978 \\
\text { BGN } \\
\text { BGN } \\
\text { UNOFF } \\
\text { BGN } \\
\text { UNOFF }\end{array}$ & $\begin{array}{l}\text { Coconino } \\
\text { Santa Cruz } \\
\text { Santa Cruz } \\
\text { Pinal } \\
\text { Yavapai } \\
\text { Graham } \\
\text { Cochise }\end{array}$ & $\begin{array}{l}360412 \mathrm{~N} 1130129 \mathrm{~W} \\
313609 \mathrm{~N} 1110900 \mathrm{~W} \\
313632 \mathrm{~N} 1110836 \mathrm{~W} \\
325348 \mathrm{~N} 1112054 \mathrm{~W} \\
340209 \mathrm{~N} 1121757 \mathrm{~W} \\
322636 \mathrm{~N} 1094608 \mathrm{~W} \\
322347 \mathrm{~N} 1094823 \mathrm{~W}\end{array}$ & 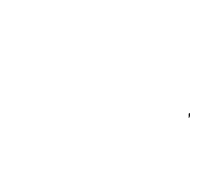 & 4000 & $\begin{array}{l}\text { Vulcans Throne SE } \\
\text { Murphy Peak } \\
\text { Murphy Peak } \\
\text { Cactus Forest } \\
\text { Columbia } \\
\text { Greasewood Mountain } \\
\text { Willcox North }\end{array}$ \\
\hline $\begin{array}{l}\text { Red Tail Substation } \\
\text { Redtail Tank } \\
\text { Red Tail Tank } \\
\text { Red Tank } \\
\text { Red Tank } \\
\text { Red Tank } \\
\text { Red Tank } \\
\text { Red Tank } \\
\text { Red Tank } \\
\text { Red Tank }\end{array}$ & $\begin{array}{l}\text { locale } \\
\text { reservoir } \\
\text { reservoir } \\
\text { reservoir } \\
\text { reservoir } \\
\text { reservoir } \\
\text { reservoir } \\
\text { reservoir } \\
\text { reservoir } \\
\text { reservoir }\end{array}$ & $\begin{array}{l}\text { UNOFF } \\
\text { BGN } \\
\text { BGN } \\
\text { BGN } \\
\text { BGN } \\
\text { BGN } \\
\text { BGN } \\
\text { BGN } \\
\text { BGN } \\
\text { BGN }\end{array}$ & $\begin{array}{l}\text { Cochise } \\
\text { Pima } \\
\text { Greenlee } \\
\text { Santa Cruz } \\
\text { Pima } \\
\text { Cochise } \\
\text { Cochise } \\
\text { Pima } \\
\text { Pima } \\
\text { Greenlee }\end{array}$ & $\begin{array}{l}322027 \mathrm{~N} 1094540 \mathrm{~W} \\
321451 \mathrm{~N} 1130958 \mathrm{~W} \\
333027 \mathrm{~N} 1092 \mathrm{~B} 05 \mathrm{~W} \\
314011 \mathrm{~N} 1110734 \mathrm{~W} \\
314814 \mathrm{~N} 1112926 \mathrm{~W} \\
320836 \mathrm{~N} 1102535 \mathrm{~W} \\
321119 \mathrm{~N} 1092726 \mathrm{~W} \\
322132 \mathrm{~N} 1103122 \mathrm{~W} \\
322 \mathrm{~B} 42 \mathrm{~N} 1103617 \mathrm{~W} \\
330937 \mathrm{~N} 1090822 \mathrm{~W}\end{array}$ & & & $\begin{array}{l}\text { Willcox North } \\
\text { N of Agua Oulce Mts } \\
\text { Baldy Bill Point } \\
\text { Saucito Mtn } \\
\text { Fresno Wash } \\
\text { Happy Vall ley } \\
\text { Bowie Mtn North } \\
\text { Piety Hill } \\
\text { Buehman Canyon } \\
\text { Dix Creek }\end{array}$ \\
\hline
\end{tabular}


FEATURE NAME

Red Tank

Red Tank

Red Tank

Red Tank

Red Tank

Red Tank

Red Tank

Red Tank

Red Tank

Red Tank

Red Tank

Red Tank

Red Tank

Red Tank

Red Tank

Red Tank

Red Tank

Red Tank

Red Tank

Red Tank

Red Tank Canyon

See Right Prong Dix Creek

Red Tank Canyon

Red Tank Draw

Red Tank Number One

Red Tanks

Red Tanks

Red Tank

Red Tanks Canyon

Red Tanks Divide

Red Tanks Pond

See Red Tank Well

Red Tanks Spring

Red Tanks Trail

Red Tanks Well

Red Tank Well

Red Tanks Pond

Red Tank Well

Red Top Mine

Red Top Mountain

Red Top Mountain

Red Tree Spring

Redus Canyon

Red Valley

Red Valley

$$
\text { Black Creek Valley }
$$

See Red Rock

Redwall Canyon

Red Wash

Redwater Tank

Red Water Wash

Red Whiskers Spring

Red Willow Canyon

Red Willow Spring

Red Willow Spring

Red Willow Spring

Red Wing Well

Redwood Gardens Mobile Home Park

Red Wood Spring

Reed Bas in

Reeder Tank

Reed Gulch

Reed Lake Tank

Reed Park

Reeds Camp

Reed Spring

Reeds Reservoir

Reeds Water

Reeds Winter Camp

Reed Tank
FEATURE

CLASS

STATUS

COUNTY

COORDINATE

reservoir

reservoir

reservoir

reservoir

reservoir

reservoir

reservoir

reservoir

reservoir

BGN
BGN

BGN

BGN

BGN

BGN

BGN

BGN

BGN

reservoir BGN

reservoir BGM

reservoir

reservoir $B G N$

reservoir BGI

reservoir BGN

reservoir BGN

reservoir $B G H$

reservoir

reservoir

BGN

$\begin{array}{ll}\text { Graham } & 331325 \mathrm{~N} 1100103 \mathrm{~W} \\ \text { Gila } & 335347 \mathrm{~N} 1101344 \mathrm{~W} \\ \text { Gila } & 335917 \mathrm{N1} 101417 \mathrm{~W} \\ \text { Apache } & 343611 \mathrm{N1093057 \textrm {W }} \\ \text { Coconino } & 344049 \mathrm{N1104916 \textrm {W }} \\ \text { Coconino } & 344108 \mathrm{~N} 1110242 \mathrm{~W} \\ \text { Navajo } & 344308 \mathrm{~N} 1102742 \mathrm{~W} \\ \text { Apache } & 344522 \mathrm{~N} 1093235 \mathrm{~W} \\ \text { Navajo } & 344653 \mathrm{~N} 1104141 \mathrm{~W} \\ \text { Coconino } & 344908 \mathrm{~N} 1110602 \mathrm{~W}\end{array}$

Coconino

$344908 \mathrm{N1} 110602 \mathrm{~W}$

Apache 344918N1094134W

Yavapai 345453N1125646W

Coconino 351731M1122320W

Coconino 352140N1120812W

Coconino 352237N1115409W

Coconino 352824N1121759W

Mohave 353604N1133801W

Coconino 354159N1121147W

Coconing

coconino

$354630 \mathrm{~N} 1114142 \mathrm{~W}$

$355008 \mathrm{N1} 130351 \mathrm{~W}$

stream VARIANT

valley

valley

reservoir

reservoir

reservoir

reservoir

valley

gap

BG

Greenlee

Greenlee

Yavapai

Gila

Santa Cruz

Navajo

Coconino

Pinal

Pinal

VARIANT

well

spring

trail

well

well

well

mine

summit

summit

spring

valley

valley

ppl

valley

stream

BGN

UNOFF

UNOFF

UNOFF

VARIANT

UNOFF

BGN

Maricopa

Graham

Pinal

Pima

Maricopa

Gila

Mohave

Yuma

BGN
BGN
BGN
BGN

Mavajo

Apache

Cochise

1959 Apache

VARIANT

VARIANT

reservoir

BGN 1908

Apache

Coconino

Apache

Navajo

valley

spring

valley

spring

spring

spring

well

locale

BGN

BGN

Apache

Gila

Apache

Gila

Mohave

Mavajo

Cochise

Maricopa

spring

BGN

Pinal

bas in

reservoir

valley $\quad B G$

park ADMIN

locale

spring

reservoir

well

locale

BGN

BGN

BGN

UNOFF

reservoir BGN

Pinal

Coconino

Gila

Coconino

Maricopa

Pinal

Coconino

Mohave

Pinal

Coconino

$331110 N 1090923 \mathrm{~W}$

$330918 \mathrm{~N} 1091004 \mathrm{~W}$

343901N1114450W

335309N1101410W

$313245 N 1103405 W$

314

$345044 \mathrm{~N} 1105812 \mathrm{~W}$

$332402 \mathrm{~N} 1111533 \mathrm{~W}$

$332536 \mathrm{~N} 1111619 \mathrm{~W}$

332549 N1111538W

$331750 \mathrm{N1125140 \textrm {W }}$

325B32N1093032W

$332520 \mathrm{N1111610 \textrm {W }}$

$315 B 55 N 1125023 \mathrm{~W}$

331750 N1125140W

$333558 N 1101027 \mathrm{~W}$

$342207 \mathrm{N1134348 \textrm {W }}$

$323442 \mathrm{~N} 1141748 \mathrm{~W}$

$341018 \mathrm{N1101040 \textrm {W }}$

$362600 \mathrm{N1095421 \textrm {W }}$

$322357 N 1101345 \mathrm{~W}$

$355456 \mathrm{~N} 1090146 \mathrm{~W}$

$322605 \mathrm{~N} 1101459 \mathrm{~W}$

$360115 \mathrm{~N} 1090312 \mathrm{~W}$

363616 N1090336W

$361620 \mathrm{N1121926 \textrm {W }}$

365317 N1 OB5434W

$342927 \mathrm{N1} 103622 \mathrm{~W}$

$361716 \mathrm{~N} 1121812 \mathrm{~W}$ $362919 N 1090323 \mathrm{~W}$

$362522 N 1093457 W$

$331428 \mathrm{~N} 1103804 \mathrm{~W}$

$361523 \mathrm{~N} 1095125 \mathrm{~W}$

$335833 \mathrm{~N} 1100107 \mathrm{~W}$

$354455 \mathrm{~N} 1141600 \mathrm{~W}$

361907 N1 103250W

$320640 \mathrm{~N} 1092734 \mathrm{~W}$

$332445 \mathrm{~N} 1115246 \mathrm{~W}$

332744M1111143W

$330324 N 1103643 \mathrm{~W}$

$351407 N 1120549 \mathrm{~W}$

$335 B 43 N 1111848 \mathrm{~W}$

$345912 \mathrm{~N} 1112603 \mathrm{~W}$

$332422 \mathrm{~N} 1114742 \mathrm{~W}$

$332410 \mathrm{~N} 1111646 \mathrm{~W}$

$362348 \mathrm{~N} 1104812 \mathrm{~W}$

$365854 \mathrm{~N} 1131102 \mathrm{~W}$

$332337 \mathrm{~N} 1111652 \mathrm{~W}$

$351650 \mathrm{~N} 1122102 \mathrm{~W}$

351348 N1121605W
$362807 N 1093137 W$

361546 N1094900W

335942 N1112113W

Bylas

Cedar Creek

Cedar Creek

Stinking Springs 
NATIONAL GAZETTEER--ARIZONA 1986 FEATURE NAME

Reed Tank

Reed Valley

Reed Well

Reed Windmil1

Reedy Bend

Reef Basin Sixty Eight Trail

Reef Mine

Reef of Rock

Reef Ridge

Reef Rock

Reef Tank

Rees Canyon

See Reese Canyon

Reese Canyon Rees Canyon

Reese Ranch

Reese Ranch

Reese Tank

Reese Tanks

Rees Peak

Reeves Creek

Reeves Ranch

Reeves Tank

Reeves Tank

Reeve Tank

See Reserve Tank

Reevis Creek

See Reavis Creek

Reevis Creek

See Pine Creek

Reevis Gap

See Reavis Gap

Reevis Grave

Reevis Ranch

See Frasers Ranch

Reevis Saddle Spring

See Reavis Saddle Spring

Reevis Trail

Reevis Trail

Reevis Trail Canyon

See Reavis Trail Canyon

Reference Point Creek

Reference Point Rapids

Refuge Rock

Regal Canyon

Regal Mine

Register Tank

Reg Tank

Reidhead Tank

Reid Valley

Reiley Canyon

Reiley Creek

Reiley $\mathrm{Hill}$

Reiley Peak

Reiley Tank

Riley Tank

Reilly, Mount

Reimer Draw

Reimer Peak

Reimer Spring

Reimer Tank

Reina Cleri Seminary

Reliable Mine

Relic Point

Renaissance (subdivision)

Rendezvous Park

Renee Spring

Renegade Mine

Renegade Mine

Reneke Knoll

Reneke Tank
FEATU

reservoir
valley
well
locale
bend
trail
mine
ridge
ridge

ridge

summit

reservoir

valley

valley

locale

locale

reservoir

reservoir

STATUS COUNTY

$\begin{array}{ll}\text { BGN } & \text { Coconino } \\ \text { BGN } & \text { Navajo }\end{array}$

UNOFF La Paz

BGN

BGN

BGN

BGN

BGN

BGN

VARIANT

UNOFF

UNOFF

BGN

summit

BGN

stream

reservoir

reservoir

reservoir

stream

UGN

BGN
BGN

VARIANT

VARIANT

VARIANT

VARIANT

gap

cemetery

UNOFF

VARIANT

locale

spring

trail

valley

VARIANT

UNOFF

UNOFF

VARIANT

stream

rapids

ridge

valley

mine

reservoir

reservoir

reservoir

valley

valley

BGN
BGN
BGN
BGN
UNOFF
BGN
BGN
BGN
BGN
BGN

stream

summit

summit

reservoir

BGN

summit

valley

summit

spring

reservoir

school UNOFF

mine

cliff

ppl

park ADMI

spring

mine

mine

summit

reservoir
Yuma

Graham

Cochise

Pima

Gila

Pima

Graham

Coconino

Coconino

Pinal

Gila

Apache

Coconino

Coconino

Cochise

Cochise

Cochise

Coconino

Pima

Maricopa

Maricopa

Maricopa

Pinal

Maricopa

Pinal

Pina

Pinal

Pinal

Mohave

Mohave

Apache

Gila

Gila

Graham

Gila

Navajo

Yuma

Cochise

Graham

Graham

Cochise

Cochise

Cochise

Yavapai

Yavapai

Yavapai

Yavapai

COOROINATE

$355826 \mathrm{~N} 1120720 \mathrm{~W}$

$362900 \mathrm{~N} 1102017 \mathrm{~W}$

$335743 \mathrm{~N} 1132704 \mathrm{~W}$

$361740 \mathrm{~N} 1102053 \mathrm{~W}$

$325000 \mathrm{~N} 1142800 \mathrm{~W}$

$325500 \mathrm{~N} 1101823 \mathrm{~W}$

$312537 \mathrm{N1} 101716 \mathrm{~W}$

322744 N1104646W

340446 N1111245W

$321252 \mathrm{~N} 1103157 \mathrm{~W}$

$325422 N 1101 B 08 W$

352611 N1113750W

$352611 \mathrm{~N} 1113750 \mathrm{~W}$

$325016 \mathrm{~N} 1103445 \mathrm{~W}$

$330510 \mathrm{~N} 1104242 \mathrm{~W}$

345806 N1093723W

$352333 \mathrm{~N} 1114007 \mathrm{~W}$

$352121 \mathrm{~N} 1113904 \mathrm{~W}$

$314251 N 1100227 \mathrm{~W}$

$314300 \mathrm{~N} 1095902 \mathrm{~W}$

$314244 \mathrm{~N} 1095755 \mathrm{~W}$

$350410 \mathrm{~N} 1112012 \mathrm{~W}$

321641 N1103958W

333307 N1110938W

333611N1111310W

$333115 N 1110725 \mathrm{~W}$

$332642 \mathrm{~N} 1111038 \mathrm{~W}$

$332928 N 1110917 \mathrm{~W}$

$332722 \mathrm{~N} 1111022 \mathrm{~W}$

$332409 \mathrm{~N} 1110913 \mathrm{~W}$

332707 N1111020W

332118 N1110755W

355309 N1134250W

$355314 N 1134244 \mathrm{~W}$

$360735 \mathrm{~N} 1092712 \mathrm{~W}$

$334921 N 1103629 \mathrm{~W}$

$334904 \mathrm{~N} 1103544 \mathrm{~W}$

$324941 \mathrm{N1} 100802 \mathrm{~W}$

$335945 \mathrm{~N} 1105802 \mathrm{~W}$

$342747 N 1102535 \mathrm{~W}$

$341233 \mathrm{~N} 1134049 \mathrm{~W}$

$322536 \mathrm{~N} 1100441 \mathrm{~W}$

$322642 \mathrm{~N} 1100057 \mathrm{~W}$

$322627 \mathrm{~N} 1100350 \mathrm{~W}$

$322319 \mathrm{~N} 1100626 \mathrm{~W}$

$322320 \mathrm{~N} 1100730 \mathrm{~W}$

$312522 \mathrm{~N} 1095502 \mathrm{~W}$

$342411 N 1115943 \mathrm{~W}$

342711 N1115908W

342657 N1115834W

342805 N1115846W

Pima

Pinal

Navajo

Maricopa

Maricopa

Graham

Yuma

Maricopa

Coconino

Coconino
$321213 N 1104811 \mathrm{~W}$

$324507 \mathrm{~N} 1102922 \mathrm{~W}$

$344943 \mathrm{~N} 1104628 \mathrm{~W}$

332106 N1115525W

$332512 N 1114943 \mathrm{~W}$

$323649 N 1101434 \mathrm{~W}$

$333201 \mathrm{~N} 1140251 \mathrm{~W}$

$335335 \mathrm{~N} 1124911 \mathrm{~W}$

$351347 \mathrm{~N} 1120841 \mathrm{~W}$

$352631 \mathrm{~N} 112292 \mathrm{OW}$

\begin{tabular}{|c|c|c|}
\hline $\begin{array}{l}\text { SOURCE } \\
\text { COORDINATE }\end{array}$ & $\begin{array}{c}\text { ELEV } \\
\text { FT }\end{array}$ & MAP NAME \\
\hline $362814 N 1101355 \mathrm{~W}$ & 6596 & $\begin{array}{l}\text { Tusayan East } \\
\text { Yucca Hill } \\
\text { Webber Canyon } \\
\text { Red Slide Peak } \\
\text { Laguna Dam } \\
\text { Cobre Grande Mtn } \\
\text { Miller Peak } \\
\text { Mt Leimmon } \\
\text { Sheep Basin Mtn }\end{array}$ \\
\hline & 8372 & $\begin{array}{l}\text { Mica Mountain } \\
\text { Cobre Grande Mtn }\end{array}$ \\
\hline $352113 \mathrm{~N} 1113950 \mathrm{~W}$ & & $\begin{array}{l}\text { White Horse Hills } \\
\text { Holy Joe Peak } \\
\text { Christmas } \\
\text { Ninemile Seep } \\
\text { White Horse Hills }\end{array}$ \\
\hline $314447 N 1095502 \mathrm{~W}$ & 6346 & $\begin{array}{l}\text { Humphreys Peak } \\
\text { Tombstone } \\
\text { Hay Mountain } \\
\text { Hay Mountain } \\
\text { Elliott Canyon }\end{array}$ \\
\hline
\end{tabular}

Iron Mountain

Iron Mountain

Iron Mountain

354842N1135850W

$334729 N 1103359 W$

$341222 N 1134227 \mathrm{~W}$

$322219 N 1100500 \mathrm{~W}$

322217 N1100457W

Reiley Peak 
FEATURE NAME

Renner Mine

Renner We11

Reno Canyon

Reno Creek

Reno Pass

Reno Spring

Repecita Tank

Replacing Cover Spring

Represo Tank

Represso, El Cerrito de

Represso de Lamita, E1

Republic Mine

Republic Mine

Rescue Canyon

Rescue Rock Mesa

Rescue Spring

Research Ranch Headquarters

Reservation Creek

Reservation Dam

Reservation Flat

Reservation Lake

Reservation Lake Campgrounds

Reservation Ranch

Reservation Ranch

Reservation Spring

Reservation Tank

Reservation Tank

Reservation Tank

Reservation Tank

Reservation Tank

Reservation Tank

Reservation Tank

Reservation Tank Number Two

Reservation Well

Reserve Tank

Reeve Tank

Reserve Tank

Reservoir Canyon

Reservoir Number One

Reservoir Number Three

Reservoir Number Two

Reservoir Tank

Resnal

See Chiuli Shaik

Resolution Mine (abandoned)

Resource Pond

Res Tank

Resta Well

Res thaven Cemetery

Res thaven Cemetery

Rest Haven Memorial Gardens

Resting Cattle Valley

Retort Oven

Reuell Jarvis Tank

Revanton

See Pete Kitchens Ranch

Reventon

See Arivaca Junction

Reward Mine

Rex Ranch

Rex We11

Reymert

Raymert

Reymert Mine

Reymert Wash

Rayment Wash

Reymert Well

Reynolds Canyon

Reynolds Creek

Reynolds Creek Ranger Station

Reynolds Ranch

\section{FEATURE \\ CLASS}

STATUS COUNTY

mine

well

valley

stream

gap

reservoir

spring

reservoir

UNOF
UNOF
BGN
BGN
BGN
BGN
BGN
BGN
BGN
BGN

Yuma

Yuma

Yavapa

Gila

Gila

Pinal

Navajo

Pinal

Pima

$\begin{array}{llll}\text { reservoir } & \text { BGN } & \text { Pima } & 321748 N 1112320 \mathrm{~W} \\ \text { mine } & \text { UNOFF } & \text { Cochise } & 320604 \mathrm{~N} 1100353 \mathrm{~W} \\ \text { mine } & \text { UNOFF } & \text { Yuma } & 333754 \text { N1135556W } \\ \text { valley } & \text { BGN } & \text { Gila } & 332628 N 1104747 \mathrm{~W} \\ \text { summit } & \text { BGN } & \text { Apache } & 363455 N 1092053 \mathrm{~W} \\ \text { spring } & \text { BGN } & \text { Gila } & 332717 N 1104651 \mathrm{~W} \\ \text { building } & \text { UNOFF } & \text { Santa Cruz } & 313526 \mathrm{N1103022W} \\ \text { stream } & \text { BGN } & \text { Apache } & 334143 N 1092826 \mathrm{~W} \\ \text { dam } & \text { UNOFF } & \text { Apache } & 335024 N 1093000 \mathrm{~W} \\ \text { flat } & \text { BGN } & \text { Apache } & 340717 N 1094618 \mathrm{~W}\end{array}$

reservoir

park

locale

locale

spring

reservoir

reservoir

reservoir

reservoir

reservoir $B G$

BGN
ADNIN
UNOFF
UNOFF
BGN
BGN
BGN
BGN
BGN
BGN

Apache

Apache

Apache

Apache

Apache

Pima

Gila

Gila

Gila

Apache

reservoir $B G$

reservoir

reservoir

well

reservoir

reservoir

valley

reservoir $B G$

reservoir

reservoir

reservoir $B G$

locale

mine

take

reservoir

well

cemetery

cemetery

$B G N$
$B G N$
$B G N$

Coconino

Mohave

Gila

Coconino

NAFF

VARIANT

Pima

Coconino

Graham

Coconino

Coconino

$335025 N 1093010 \mathrm{~W}$

$335020 \mathrm{~N} 1093013 \mathrm{~W}$

$335016 N 1093059 \mathrm{~W}$

$335024 N 1092943 \mathrm{~W}$

$340734 N 1094612 W$

$320559 \mathrm{~N} 1112646 \mathrm{~W}$

334009 N1103214W

$334545 N 1103157 \mathrm{~W}$

$340355 \mathrm{~N} 1104700 \mathrm{~W}$

$340733 \mathrm{~N} 1094718 \mathrm{~W}$

$350910 \mathrm{~N} 1111129 \mathrm{~W}$ 355707 N1135418 $332806 \mathrm{~N} 1104219 \mathrm{~W}$

$350816 \mathrm{~N} 1110926 \mathrm{~W}$

321641 N1103958W

345448 N1111326W

$322552 \mathrm{~N} 1094815 \mathrm{~W}$

$351303 N 1115007 \mathrm{~W}$

$351323 N 1115047 \mathrm{~W}$

cemetery UNOFF

valley

bas in

reservoir

local

ppl

ppl

mine

locale

well

locale

mine

stream

well

valley

stream
locale

locale
Coconino

Apache

Pima

Yuma

Mohave

Graham

Pima

Maricopa

Maricopa

$351316 N 1115037 \mathrm{~W}$

$335107 N 1092314 W$

314943 N1113846W

$332225 \mathrm{~N} 1134520 \mathrm{~W}$

$364225 N 1130050 \mathrm{~W}$

322733 N1094650W

313041 N1112435W

$332340 \mathrm{~N} 1115916$

$333308 \mathrm{~N} 1121135 \mathrm{~W}$

$325136 \mathrm{~N} 1094205 \mathrm{~W}$ $362412 N 1101631 \mathrm{~W}$

$341128 N 1135511 \mathrm{~W}$

344833 N1093452W

312416 N1105709W

314338 N1110338W

$323602 \mathrm{~N} 1120235 \mathrm{~W}$

$314205 \mathrm{~N} 1110246 \mathrm{~W}$

$314202 \mathrm{~N} 1110238 \mathrm{~W}$

$331347 N 1111231 \mathrm{~W}$

331441 N1111204W

$331734 \mathrm{~N} 1111208 \mathrm{~W}$

$331528 \mathrm{~N} 1111218 \mathrm{~W}$

$332414 \mathrm{~N} 1105100 \mathrm{~W}$

$335219 N 1105833 \mathrm{~W}$

333052 N1091230W

Gila

Gila

Greenlee
$335218 \mathrm{~N} 1110013 \mathrm{~W}$
$322840 N 1094703 \mathrm{~W}$

\begin{tabular}{|c|c|c|}
\hline $\begin{array}{l}\text { SOURCE } \\
\text { COORDINATE }\end{array}$ & $\begin{array}{l}\text { ELEV } \\
\text { FT }\end{array}$ & MAP NAME \\
\hline \multirow{3}{*}{$\begin{array}{l}342309 \mathrm{~N} 1115330 \mathrm{~W} \\
335409 \mathrm{~N} 1112427 \mathrm{~W}\end{array}$} & & $\begin{array}{l}\text { Mowhawk } \\
\text { Mesquite Jim Well }\end{array}$ \\
\hline & & $\begin{array}{l}\text { Dugas } \\
\text { Tonto Bas in }\end{array}$ \\
\hline & 2399 & $\begin{array}{l}\text { Reno Pass } \\
\text { Baldy Bill Point } \\
\text { Picacho Reservoir SE } \\
\text { Pinon NW } \\
\text { Oracle Junction } \\
\text { Waterman Peak }\end{array}$ \\
\hline \multirow[t]{2}{*}{$332716 \mathrm{~N} 1104628 \mathrm{~W}$} & & $\begin{array}{l}\text { Waterman Peak } \\
\text { Dragoon } \\
\text { Bear Hills } \\
\text { Globe }\end{array}$ \\
\hline & 6794 & $\begin{array}{l}\text { Mexican Cry Mesa } \\
\text { Globe }\end{array}$ \\
\hline \multirow[t]{3}{*}{$335330 \mathrm{~N} 1093253 \mathrm{~W}$} & 4800 & $\begin{array}{l}0^{\prime} \text { Donnell Canyon } \\
\text { Hoodoo Knob } \\
\text { Bonito Rock } \\
\text { McNary }\end{array}$ \\
\hline & 8960 & $\begin{array}{l}\text { Bonito Rock } \\
\text { Bonito Rock } \\
\text { Bonito Rock } \\
\text { Big Lake South } \\
\text { Sponseller Mtn } \\
\text { San Pedro } \\
\text { Chrysotile } \\
\text { Mule Hoof Bend } \\
\text { Gentry Mtn } \\
\text { Sponseller Mtn }\end{array}$ \\
\hline & 5634 & $\begin{array}{l}\text { Babbitt Wash } \\
\text { Grapevine Canyon } \\
\text { Cammerman Wash } \\
\text { Babbitt Wash } \\
\text { Agua Caliente } \mathrm{Hill}\end{array}$ \\
\hline \multirow[t]{3}{*}{$322840 \mathrm{~N} 1094703 \mathrm{~W}$} & & $\begin{array}{l}\text { Chavez Mtn NW } \\
\text { Greasewood Mountain } \\
\text { Bellemont } \\
\text { Bellemont }\end{array}$ \\
\hline & & $\begin{array}{l}\text { Bell lemont } \\
\text { Big Lake South }\end{array}$ \\
\hline & & $\begin{array}{l}\text { Hoodoo Well } \\
\text { Little Clayhole Val } \\
\text { Greasewood Mountain } \\
\text { Wilbur Canyon } \\
\text { Tempe } \\
\text { Glendale }\end{array}$ \\
\hline \multirow[t]{3}{*}{$362454 N 1101217 \mathrm{~W}$} & & $\begin{array}{l}\text { Safford } \\
\text { Yucca Hill } \\
\text { Planet } \\
\text { Seven Springs }\end{array}$ \\
\hline & & $\begin{array}{l}\text { Kohatk } \\
\text { Amado }\end{array}$ \\
\hline & & $\begin{array}{l}\text { Amado } \\
\text { Mineral Mtn }\end{array}$ \\
\hline 331408 N1111149W & & $\begin{array}{l}\text { Mineral Mtn } \\
\text { Picketpost Mtn }\end{array}$ \\
\hline $\begin{array}{l}332358 \mathrm{~N} 1105054 \mathrm{~W} \\
335038 \mathrm{~N} 1105420 \mathrm{~W}\end{array}$ & & $\begin{array}{l}\text { Picketpost Mtn } \\
\text { Globe } \\
\text { Armer Mountain } \\
\text { Aztec Peak }\end{array}$ \\
\hline
\end{tabular}

Bonito Rock

Big Lake South

San Pedro

Mule Hoof Bend

Gentry Mtn

Babbitt Wash

Agua Caliente $\mathrm{Hill}$

Greasewood Mountain

Bellemont

Bellemont

Hoodoo Well

Greasewood Mountair

bur Canyon

Yucca Hill

Planet 


\section{FEATURE NAME}

Reynolds School

Reynolds Trailer Court

R-fourteen Ranch

Rhem Tunnel

Rhine Canyon

Rhine Ridge

Rhodes Canyon

Rhodes Canyon

Rhodes Canyon Dam

Rhodes Peak

Rhodes Ranch

Rhodes Ranch

See Cibola

Rhodes Tank

Rhoton Crater

See Roden Crater

Rhoton Spring

See Roden Spring

Rhyolite Canyon

Rhyolite Peak

Rhyolite Spring

Ribbon Falls

Rice Gulch

Yellowjacket Gulch

Rice Hollow

Rice Hollow Trick Tank

Rice Peak

Rice Peak

Rice Public Schoo

Rice Seeps

Rice Spring

Rice Substation

Rice Tank

Rice Water Canyon

Richard C Miller School

Richardson Cabin

Richards Ranch

Richey Schoo

Rich Gulch

Rich Hill

Richinbar Mine

Richmond Bas in

Richmond Mountain

Richmond Spring

Richville

Ricketts Mine

Rick Tank

Rickys Tank

See Mexican Tank

Rickys Tank

Mexican Tank

Rico Mine

Riddle Tank

Riddle Tank

Riddle Windmill

Ridenour Mine

Rider Canyon

Rider Point

Ridgegate (subdivision)

Ridges Spring

Ridge Tank

Ridge Tank

Ridge Tank

Ridge Tank

Ridge Tank

Ridge Tank

Ridge Tank

Ridge Tank

Ridge Tank

Ridge Tank

Ridge Tank Number One
FEATURE

locale

locale

reservoir

crater

spring

valley

\begin{tabular}{ll} 
STATUS & \multicolumn{1}{c}{ COUNTY } \\
UNOFF & Pima \\
UNOFF & Maricopa \\
UNOFF & Gila \\
UNOFF & Cochise \\
BGN & Navajo \\
BGN & Navajo \\
BGN & Graham \\
BGN & Coconino \\
UNOFF & Coconino
\end{tabular}

COORDINATE

$321103 \mathrm{~N} 1104958 \mathrm{~W}$

$332450 \mathrm{~N} 1115345 \mathrm{~W}$

$335157 \mathrm{~N} 1101210 \mathrm{~W}$

$315936 \mathrm{~N} 1091638 \mathrm{~W}$

$341444 \mathrm{~N} 1102515 \mathrm{~W}$

$341648 \mathrm{~N} 1102522 \mathrm{~W}$

$323036 \mathrm{~N} 1102916 \mathrm{~W}$

$353047 N 1130045 \mathrm{~W}$

$353240 \mathrm{~N} 1125805 \mathrm{~W}$

$323939 N 1102457 \mathrm{~W}$

$324029 \mathrm{~N} 1102741 \mathrm{~W}$

$331859 \mathrm{~N} 1143951 \mathrm{~W}$

350838N1120636W

$352531 \mathrm{~N} 1111530 \mathrm{~W}$

Coconino

$352501 \mathrm{~N} 1111725 \mathrm{~W}$

$320021 \mathrm{~N} 1092117 \mathrm{~W}$

summit $\quad B G N \quad$ Graham 324817N1091830W

spring BGN Mohave 351752N1142503W

falls $\quad$ BGN 1906 Coconino $360932 \mathrm{N1120317 \textrm {W }}$

valley BGN 1968 Yavapai 342503N1115529W

valley BGN Coconino 362BI4N1122752W

reservoir BGN Coconino 362920N1122649W

summit BGN Pima $323042 \mathrm{~N} 1104458 \mathrm{~W}$

summit $\quad$ BGN $\quad$ Yavapai $341742 N 1115527$ W

school UNOFF Gila 332122N1102708W

spring BGN Navajo 342418N1102810W

spring BGN Yavapai 342514N1115422W

locale UNOFF Maricopa 332330N1114819W

reservoir BGN Coconino 344520 N1110856W

valley BGN Pinal 331715N1111050W

school UNOFF Maricopa 333353N1120605W

locale BGN Greenlee 333333N1091129W

locale UNOFF Cochise 312728N1101624W

school UNOFF Pima 321454N1105856W

valley BGN Yavapai 335755 N1121725W

summit BGN Yavapai 341020N1124241W

mine UNOFF Yavapai 341204N1120607W

$33315 \mathrm{BN} 1104530 \mathrm{~W}$

summit BGN Gila $333103 \mathrm{~N} 1104246 \mathrm{~W}$

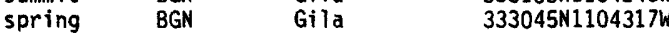

locale BGN Apache 341710N1092117W

mine UNOFF Cochise 315101N1102140W

reservoir BGN Yavapai 344419N1121117W

ocale VARIANT

Cochise

$313256 \mathrm{~N} 1090438 \mathrm{~W}$

$\begin{array}{ll}\text { locale } & \text { BGN } \\ & \text { VARIANT } \\ \text { mine } & \text { UNOFF } \\ \text { reservoir } & \text { BGN } \\ \text { reservoir } & \text { BGN } \\ \text { locale } & \text { BGN } \\ \text { mine } & \text { UNOFF } \\ \text { valley } & \text { BGN } \\ \text { cliff } & \text { BGN } \\ \text { ppl } & \text { BGN }\end{array}$

Cochise

Mohave

Cochise

Navajo

Pinal

Coconino

Coconino

Coconino

Maricopa

$313322 \mathrm{~N} 1090436 \mathrm{~W}$

$352050 \mathrm{~N} 1140651 \mathrm{~W}$

$313428 \mathrm{N1092104 \textrm {W }}$

$343017 \mathrm{~N} 1095447 \mathrm{~W}$

$323215 N 1110432 \mathrm{~W}$

$360559 \mathrm{~N} 1131026 \mathrm{~W}$

$364026 \mathrm{~N} 1114427 \mathrm{~W}$

$364007 \mathrm{~N} 1114446 \mathrm{~W}$

$333654 \mathrm{~N} 1120344 \mathrm{~W}$

spring BGN Yavapai

reservoir BGN Santa Cruz

reservoir $B G N$

reservoir $B G N$

reservoir $B G N$

reservoir $B G$

reservoir $B G$

reservoir $B G N$

reservoir $B G$

reservoir $B G N$

reservoir BGN

reservoir $B G$

$341009 \mathrm{~N} 1122916 \mathrm{~W}$

$312322 \mathrm{~N} 1110901 \mathrm{~W}$

$312407 \mathrm{~N} 1104050 \mathrm{~W}$

$315019 N 1110940 \mathrm{~W}$

Greenlee $331446 N 1090812 \mathrm{~W}$

Pima

Gila 334746N1105230W

Gila 340604N1105411W

Navajo 342120N1103702W

$343027 N 1120611 \mathrm{~W}$

$335011 \mathrm{~N} 1101541 \mathrm{~W}$
SOURCE

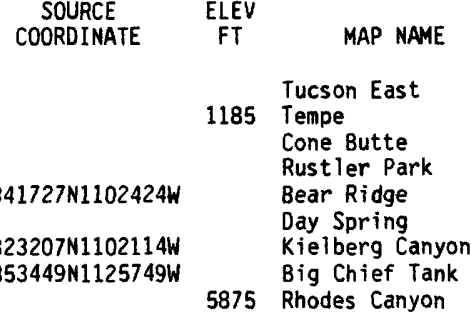

7123 Rhodes Peak

Rhodes Peak

Davenport Hill

315930N1091B09W Cochise Head

Ash Peak

Burns Spring

Bright Angel Point

Arnold Mesa

342540N1115332W

Tapeats Amphitheater

Tapeats Amphitheater

7575 Campo Bonito

5221 Dugas

San Carlos

Aripine

Arnold Mesa

Mesa

Chavez Mtn West

331914N1110840W Picketpost Mtn

Sunnys lope

5560 Bear Mountain

Miller Peak

Tucson

335914N1121659W Governors Peak

5340 Yarnell

Joes Hill

Rockinstraw Mtn

5836 Chrome Butte

Chrome Butte

Lyman Lake

McGrew Spring

Hickey Mountain

Skeleton Canyon

Stockton $\mathrm{Hill}$

Pedregosa Mts East

Point of the Mtn

Tortolita Mts

Vulcans Throne SW

$363848 \mathrm{~N} 1114859 \mathrm{~W}$

Bitter Springs

Bitter Springs

1380 Sunnys lope

Gila $\quad 342036 N 1112818 \mathrm{~W}$
Minnehaha

Ruby

Harshaw

Batamote Hills

Dix Creek

Mitchell Peak

Aztec Peak

Young

Buckhead Mesa

Outlaw Draw

Cherry

Carrizo SE 


\begin{tabular}{|c|c|c|c|c|c|c|c|}
\hline FEATURE NAME & $\begin{array}{l}\text { FEATURE } \\
\text { CLASS }\end{array}$ & STATUS & COUNTY & COORDINATE & $\begin{array}{l}\text { SOURCE } \\
\text { COORDINATE }\end{array}$ & $\begin{array}{l}\text { ELEV } \\
\text { FT }\end{array}$ & MAP NAME \\
\hline $\begin{array}{l}\text { Ridge Tanks } \\
\text { Ridge Top Tank } \\
\text { Rieder Tunnel } \\
\text { Riggle Tank } \\
\text { Riggs Canyon } \\
\text { Riggs Canyon } \\
\text { Riggs Cemetery } \\
\text { Riggs Creek }\end{array}$ & $\begin{array}{l}\text { reservoir } \\
\text { reservoir } \\
\text { mine } \\
\text { reservoir } \\
\text { valley } \\
\text { valley } \\
\text { cemetery } \\
\text { stream }\end{array}$ & $\begin{array}{l}\text { 8GN } \\
\text { BGN } \\
\text { UNOFF } \\
\text { BGN } \\
\text { BGN } \\
\text { BGN } \\
\text { UNOFF } \\
\text { BGN }\end{array}$ & $\begin{array}{l}\text { Coconino } \\
\text { Apache } \\
\text { Cochise } \\
\text { Yavapai } \\
\text { Coconino } \\
\text { Mohave } \\
\text { Cochise } \\
\text { Apache }\end{array}$ & $\begin{array}{l}344311 \mathrm{~N} 1112939 \mathrm{~W} \\
334741 \mathrm{~N} 1091735 \mathrm{~W} \\
315922 \mathrm{~N} 1091559 \mathrm{~W} \\
342316 \mathrm{~N} 1123453 \mathrm{~W} \\
363337 \mathrm{~N} 1121946 \mathrm{~W} \\
365540 \mathrm{~N} 1123651 \mathrm{~W} \\
320140 \mathrm{~N} 1092743 \mathrm{~W} \\
340030 \mathrm{~N} 1091135 \mathrm{~W}\end{array}$ & $\begin{array}{l}363238 \mathrm{~N} 1121619 \mathrm{~W} \\
36573 \mathrm{BN} 1123711 \mathrm{~W} \\
335802 \mathrm{~N} 1091720 \mathrm{~W}\end{array}$ & & $\begin{array}{l}\text { Happy Jack } \\
\text { Buffalo Crossing } \\
\text { Rustler Park } \\
\text { Wilhoit } \\
\text { Big Springs } \\
\text { Fredonia } \\
\text { Bowie Mtn South } \\
\text { Nelson Reservoir }\end{array}$ \\
\hline $\begin{array}{l}\text { Riggs Creek Dam } \\
\text { Riggs Creek Reservoir } \\
\text { Riggs Flat } \\
\text { Riggs Flat Campground } \\
\text { Riggs Flat Dam } \\
\text { Riggs Flat Recreation Area } \\
\text { Riggs Home Ranch } \\
\text { Riggs Lake } \\
\text { Riggs Mesa } \\
\text { Riggs Mountain }\end{array}$ & $\begin{array}{l}\text { dam } \\
\text { reservoir } \\
\text { flat } \\
\text { park } \\
\text { dam } \\
\text { park } \\
\text { locale } \\
\text { reservoir } \\
\text { summit } \\
\text { summit }\end{array}$ & $\begin{array}{l}\text { UNOFF } \\
\text { BGN } \\
\text { BGN } \\
\text { ADMIN } \\
\text { UNOFF } \\
\text { ADMIN } \\
\text { UNOFF } \\
\text { BGN } \\
\text { BGN } \\
\text { BGN } 1954\end{array}$ & $\begin{array}{l}\text { Apache } \\
\text { Apache } \\
\text { Mohave } \\
\text { Graham } \\
\text { Graham } \\
\text { Graham } \\
\text { Cochise } \\
\text { Graham } \\
\text { Graham } \\
\text { Cochise }\end{array}$ & $\begin{array}{l}335936 \mathrm{~N} 1091348 \mathrm{~W} \\
335935 \mathrm{~N} 109135 \mathrm{~W} \\
365345 \mathrm{~N} 1123622 \mathrm{~W} \\
324229 \mathrm{~N} 1095742 \mathrm{~W} \\
324148 \mathrm{~N} 1095748 \mathrm{~W} \\
324228 \mathrm{~N} 1095744 \mathrm{~W} \\
320105 \mathrm{~N} 1092611 \mathrm{~W} \\
324230 \mathrm{~N} 1095754 \mathrm{~W} \\
324700 \mathrm{~N} 109465 \mathrm{~W} \\
320100 \mathrm{~N} 1092130 \mathrm{~W}\end{array}$ & & 6165 & $\begin{array}{l}\text { Nutrioso } \\
\text { Nutrioso } \\
\text { Fredonia } \\
\text { Webb Peak } \\
\text { Webb Peak } \\
\text { Webb Peak } \\
\text { Bowie Mtn South } \\
\text { Webb Peak } \\
\text { Thatcher } \\
\text { Cochise Head }\end{array}$ \\
\hline $\begin{array}{l}\text { Riggs Point } \\
\text { Riggs Reservoir } \\
\text { Riggs Reservoir Dam } \\
\text { Riggs Seep } \\
\text { Riggs Spring } \\
\text { Riggs Spring } \\
\text { Riggs Spring } \\
\text { Riggs Tank } \\
\text { Right Branch Long Hollow } \\
\text { Right Fork Foote Creek }\end{array}$ & $\begin{array}{l}\text { cliff } \\
\text { reservoir } \\
\text { dam } \\
\text { spring } \\
\text { spring } \\
\text { spring } \\
\text { spring } \\
\text { reservoir } \\
\text { valley } \\
\text { stream }\end{array}$ & $\begin{array}{l}\text { BGN } \\
\text { BGN } \\
\text { UNOFF } \\
\text { BGN } \\
\text { BGN } \\
\text { BGN } \\
\text { BGN } \\
\text { BGN } \\
\text { BGN } \\
\text { BGN }\end{array}$ & $\begin{array}{l}\text { Coconino } \\
\text { Graham } \\
\text { Graham } \\
\text { Cochise } \\
\text { Cochise } \\
\text { Coconino } \\
\text { Mohave } \\
\text { Cochise } \\
\text { Graham } \\
\text { Greenlee }\end{array}$ & $\begin{array}{l}363323 N 1121918 \mathrm{~W} \\
324701 N 1094633 \mathrm{~W} \\
32471 \mathrm{BN} 1094600 \mathrm{~W} \\
321904 \mathrm{~N} 1101421 \mathrm{~W} \\
315809 \mathrm{N1092048 \textrm {W }} \\
363342 \mathrm{N1} 121936 \mathrm{~W} \\
365658 \mathrm{~N} 1123730 \mathrm{~W} \\
315559 \mathrm{~N} 1092456 \mathrm{~W} \\
324724 \mathrm{N1} 102106 \mathrm{~W} \\
333819 \mathrm{~N} 1090917 \mathrm{~W}\end{array}$ & $\begin{array}{l}324643 N 1102150 \mathrm{~W} \\
334102 \mathrm{~N} 1091218 \mathrm{~W}\end{array}$ & & $\begin{array}{l}\text { Big Springs } \\
\text { Thatcher } \\
\text { Thatcher } \\
\text { Hookers Hot Springs } \\
\text { Rustler Park } \\
\text { Big Springs } \\
\text { Fredonia } \\
\text { Fife Peak } \\
\text { Klondike } \\
\text { Beaverhead }\end{array}$ \\
\hline $\begin{array}{l}\text { Right Fork Honeysuckle Spring } \\
\text { Right Fork Markham Creek } \\
\text { Right Fork Markham Wash } \\
\text { Right Fork Markham Wash } \\
\text { See Right Fork Markham } \\
\text { Creek }\end{array}$ & $\begin{array}{l}\text { spring } \\
\text { stream }\end{array}$ & $\begin{array}{l}\text { BGN } \\
\text { BGN } 1962 \\
\text { VARIANT } \\
\text { VARIANT }\end{array}$ & $\begin{array}{l}\text { Gila } \\
\text { Graham }\end{array}$ & $\begin{array}{l}333247 N 1104331 W \\
330337 N 1094715 W\end{array}$ & $330718 \mathrm{~N} 1094618 \mathrm{~W}$ & & $\begin{array}{l}\text { Chrome Butte } \\
\text { Markham Creek }\end{array}$ \\
\hline $\begin{array}{l}\text { Right Fork Water Canyon } \\
\text { Righthand Canyon } \\
\text { Right Hand Canyon } \\
\text { Right Hand Canyon }\end{array}$ & $\begin{array}{l}\text { valley } \\
\text { valley } \\
\text { valley } \\
\text { valley }\end{array}$ & $\begin{array}{l}\text { BGN } \\
\text { BGN } 1975 \\
\text { BGN } \\
\text { BGN }\end{array}$ & $\begin{array}{l}\text { Navajo } \\
\text { Graham } \\
\text { Navajo } \\
\text { Navajo }\end{array}$ & $\begin{array}{l}341455 \mathrm{~N} 1101603 \mathrm{~W} \\
323508 \mathrm{~N} 1094436 \mathrm{~W} \\
335221 \mathrm{~N} 1095609 \mathrm{~W} \\
341813 \mathrm{~N} 1101638 \mathrm{~W}\end{array}$ & $\begin{array}{l}341617 \mathrm{~N} 1101807 \mathrm{~W} \\
323630 \mathrm{~N} 1094755 \mathrm{~W} \\
335124 \mathrm{~N} 1095318 \mathrm{~W} \\
341637 \mathrm{~N} 1101740 \mathrm{~W}\end{array}$ & & $\begin{array}{l}\text { Limestone Canyon N } \\
\text { Gillespie Mtn } \\
\text { Whiteriver } \\
\text { Clay Springs }\end{array}$ \\
\hline $\begin{array}{l}\text { Right Hand Canyon } \\
\text { Righthand Dam } \\
\text { Right Hand Draw } \\
\text { Fool Hollow }\end{array}$ & $\begin{array}{l}\text { valley } \\
\text { dam } \\
\text { valley }\end{array}$ & $\begin{array}{l}\text { BGN } 1980 \\
\text { UNOFF } \\
\text { BGN } 1964 \\
\text { VARIANT }\end{array}$ & $\begin{array}{l}\text { Yavapai } \\
\text { Graham } \\
\text { Navajo }\end{array}$ & $\begin{array}{l}345348 \mathrm{~N} 1131503 \mathrm{~W} \\
323504 \mathrm{~N} 1094536 \mathrm{~W} \\
341526 \mathrm{~N} 1100408 \mathrm{~W}\end{array}$ & $\begin{array}{l}345652 \mathrm{~N} 1131628 \mathrm{~W} \\
341239 \mathrm{~N} 1100640 \mathrm{~W}\end{array}$ & & $\begin{array}{l}\text { Sunrise Peak } \\
\text { Stockton Pass } \\
\text { Show Low North }\end{array}$ \\
\hline $\begin{array}{l}\text { Righthand Spring } \\
\text { Right Hand Tank } \\
\text { Right Prong Dix Creek } \\
\text { Dix Creek } \\
\text { Red Tank Canyon } \\
\text { Right Prong Fourmile Canyon }\end{array}$ & $\begin{array}{l}\text { spring } \\
\text { reservoir } \\
\text { stream }\end{array}$ & $\begin{array}{l}\text { BGN } \\
8 G N \\
\text { BGN } \\
\text { VARIANT } \\
\text { VARIANT } \\
\text { BGN }\end{array}$ & $\begin{array}{l}\text { Graham } \\
\text { Navajo } \\
\text { Greenlee }\end{array}$ & $\begin{array}{l}323531 N 1094633 \mathrm{~W} \\
341247 \mathrm{~N} 1100544 \mathrm{~W} \\
331110 \mathrm{~N} 1090923 \mathrm{~W}\end{array}$ & $\begin{array}{l}330546 \mathrm{~N} 1091035 \mathrm{~W} \\
324704 \mathrm{~N} 1102736 \mathrm{~W}\end{array}$ & & $\begin{array}{l}\text { Stockton Pass } \\
\text { Show Low South } \\
\text { Dix Creek } \\
\text { Oak Grove Canyon }\end{array}$ \\
\hline $\begin{array}{l}\text { Right Prong Fourmile Creek } \\
\text { Riley Barracks } \\
\text { Riley Saddle } \\
\text { Rileys El Encinar } \\
\text { Riley Spring } \\
\text { Riley Tank } \\
\text { See Reiley Tank } \\
\text { Riley Tank } \\
\text { Riley Well } \\
\text { Rillito }\end{array}$ & $\begin{array}{l}\text { stream } \\
\text { building } \\
\text { gap } \\
\text { locale } \\
\text { spring } \\
\text { reservoir } \\
\text { reservoir } \\
\text { well } \\
\text { ppl }\end{array}$ & $\begin{array}{l}\text { BGN } \\
\text { UNOFF } \\
\text { BGN } \\
\text { BGN } \\
\text { BGN } \\
\text { VARIANT } \\
\text { BGN } \\
\text { UNOFF } \\
\text { BGN }\end{array}$ & $\begin{array}{l}\text { Graham } \\
\text { Cochise } \\
\text { Santa Cruz } \\
\text { Cochise } \\
\text { Cochise } \\
\text { Cochise } \\
\text { Navajo } \\
\text { Gila } \\
\text { Pima }\end{array}$ & $\begin{array}{l}324725 \mathrm{~N} 1102248 \mathrm{~W} \\
313325 \mathrm{~N} 1102125 \mathrm{~W} \\
314114 \mathrm{~N} 1105044 \mathrm{~W} \\
312923 \mathrm{~N} 1095920 \mathrm{~W} \\
321735 \mathrm{~N} 1093710 \mathrm{~W} \\
\\
322320 \mathrm{~N} 1100730 \mathrm{~W} \\
343437 \mathrm{~N} 1100404 \mathrm{~W} \\
333127 \mathrm{~N} 1104720 \mathrm{~W} \\
322453 \mathrm{~N} 1110920 \mathrm{~W}\end{array}$ & $324704 N 1102730 \mathrm{~W}$ & 7920 & $\begin{array}{l}\text { Oak Grove Canyon } \\
\text { Fort Huachuca } \\
\text { Mt Wrightson } \\
\text { Bisbee } \\
\text { Luzena }\end{array}$ \\
\hline $\begin{array}{l}\text { Rillito Creek } \\
\text { See Rillito River } \\
\text { Rillito Park and Racetrack } \\
\text { Rillito Railroad Station } \\
\text { Rillito River } \\
\text { Rillito Creek } \\
\text { Rillito Wash } \\
\text { Rita Creek } \\
\text { Rollito Creek } \\
\text { Rillito Vista Park }\end{array}$ & $\begin{array}{l}\text { stream } \\
\text { park } \\
\text { building } \\
\text { stream }\end{array}$ & $\begin{array}{l}\text { VARIANT } \\
\text { ADMIN } \\
\text { UNOFF } \\
\text { BGN 1984 } \\
\text { VARIANT } \\
\text { VARIANT } \\
\text { VARIANT } \\
\text { VARIANT } \\
\text { ADMIN }\end{array}$ & $\begin{array}{l}\text { Pima } \\
\text { Pima } \\
\text { Pima } \\
\text { Pima }\end{array}$ & $\begin{array}{l}321849 \mathrm{~N} 1110316 \mathrm{~W} \\
321724 \mathrm{~N} 1105714 \mathrm{~W} \\
322444 \mathrm{~N} 1110842 \mathrm{~W} \\
321849 \mathrm{~N} 1110316 \mathrm{~W}\end{array}$ & $321607 N 1105229 \mathrm{~W}$ & & $\begin{array}{l}\text { Tucson North } \\
\text { Marana } \\
\text { Jaynes }\end{array}$ \\
\hline $\begin{array}{l}\text { Rillito Wash } \\
\text { See Rillito River } \\
\text { Rim-Moody Point Trail }\end{array}$ & $\begin{array}{l}\text { stream } \\
\text { trail }\end{array}$ & $\begin{array}{l}\text { VARIANT } \\
\text { UNOFF }\end{array}$ & $\begin{array}{l}\text { Pima } \\
\text { Gila }\end{array}$ & $\begin{array}{l}321849 \mathrm{~N} 1110316 \mathrm{~W} \\
334815 \mathrm{~N} 1105222 \mathrm{~W}\end{array}$ & & & Sombrero Peak \\
\hline
\end{tabular}




\section{FEATURE NAME}

Rimay Jims

Rimmy Jim Tank

Rim of Green Valley

Rim of Tonto Bas in

See Mogollon Rim

Rim Pit Tank

Rim Pond

Rim Rock

Rim Rock

Rimrock

Rimrock Airport

Rimrock Post Office

Rim Rock Ranch

Rimrock Ranch

Rimrock Tank

Rim Tank

Rim Tank

Rim Tank
Rim Tank
Rim Tank
Rim Tank
Rim Tank
Rim Tank Bas in
Rincon
$\quad$ Lincoln
Lincon

Rincon, The

Rincon, The

Rincon, The

Rinconada

$$
\text { See Gila Bend }
$$

Rinconada Spring

Rincon Bas in

Rincon Bas in

Rincon Canyon

Rincon Creek

Rincon Dam

Rincon High School

Rincon Mine

Rincon Mountains

Sierra Colorado

Sierra El Rincon Tanque Verde Mountains

Rincon Pass

$$
\begin{aligned}
& \text { E1 Rincon } \\
& \text { Cape Horn }
\end{aligned}
$$

Rincon Peak

Rincon Ranch

Rincon Ranch

Rincon Sanitorium

Rincon School

Rincon Spring

Rincon Spring

Rincon Spring

Rincon Tank

Rincon Tank

Rincon Tank

Rincon Tank

Rincon Tank

Rincon Tank

Rincon Tank

Rincon Tank

Rincon Tank

Rincon Tank

Rincon Valley

Rincon We11

Rincon Wells

Rinehart Tank

Rinehart Tank

Ringbolt Rapids

$$
\begin{aligned}
& \text { FEATURE } \\
& \text { CLASS }
\end{aligned}
$$

STATUS

COUNTY

COORDINATE

$350636 \mathrm{~N} 1110149 \mathrm{~W}$

$354258 \mathrm{N1112819 \textrm {W }}$

$341407 N 1111122 \mathrm{~W}$

$341501 N 1104501 \mathrm{~W}$

$\begin{array}{llll}\text { reservoir } & B G N & \text { Gila } & 334825 N 1101947 \mathrm{~W} \\ \text { reservoir } & \text { BGN } & \text { Mohave } & 363952 N 1132945 \mathrm{~W}\end{array}$

$\begin{array}{llll}\text { reservoir } & B G N & \text { Gila } & 334825 N 1101947 \mathrm{~W} \\ \text { reservoir } & \text { BGN } & \text { Mohave } & 363952 N 1132945 \mathrm{~W}\end{array}$

summit BGN Graham 330629N1094526W

summit BGN Coconino 352447N1124628

locale BGN Yavapai 343902N1114442W

airport ADMIN Yavapai 343903N1114715W

building UNOFF Yavapai 343833N1114736W

locale UNOFF Cochise 312746N1100031W

locale UNOFF Yavapai 343856N1114611W

$345439 \mathrm{~N} 1131338 \mathrm{~W}$

$\begin{array}{llll}\text { reservoir } & \text { BGN } & \text { Gila } & 335053 N 1100916 \mathrm{~W} \\ \text { reservoir } & \text { BGN } & \text { Gila } & 341138 \text { 11 }\end{array}$

reservoir BGN Coconino 343255N1113254W

$344119 N 1113508 \mathrm{~W}$

reservoir BGN Apache 344410N1094044W

reservoir BGN Apache 344953N1093209W

reservoir BGN Navajo 350331N1095457

basin BGN Coconino 343242N1113253W

locale BGN 1977 Pima 320434N1115502W

bas in BGN Pinal 330913N1110641W

$\begin{array}{llll}\text { basin } & \text { BGN } & \text { Yavapai } & \text { 340152N1115251W } \\ \text { basin } & \text { BGN } & \text { Yavapai } & \text { 343519N1130335W }\end{array}$

$\begin{array}{llll}\text { basin } & B G N & \text { Yavapai } & 343519 N 1130335 \mathrm{~W} \\ \text { cliff } & B G N & \text { Apache } & 34174 \mathrm{BN} 1090318 \mathrm{~W}\end{array}$

ppl VARIANT Maricopa 325652N112425BW

$\begin{array}{llll}\text { ppl } & & \text { Maricopa } & 325652 \text { N112425BW } \\ \text { spring } & B G N & \text { Pima } & 321755 N 1103855 W\end{array}$

$\begin{array}{llll}\text { spring } & \text { BGN } & \text { Pima } & 321755 N 1103855 \mathrm{~W} \\ \text { basin } & B G N & \text { Yavapai } & 335850 N 1122910 \mathrm{~W}\end{array}$

basin BGN Navajo 350843N1103650W

valley BGN Graham 324524N1094501W

stream BGN Pima

$\begin{array}{llll}\text { dam } & \text { UNOFF } & \text { Graham } & \text { 323602N1101417W } \\ \text { school } & \text { UNOFF } & \text { Pima } & 321339 N 1105317 \mathrm{~W} \\ \text { mine } & \text { UNOFF } & \text { Yavapai } & 341042 \text { N1124459W } \\ \text { ridge } & \text { BGN 1976 } & \text { Pima } & 320755 N 1103108 W\end{array}$

ridge BGN 1976 Pima 320755N1103108W

VARIANT
VARIANT

gap

BGN 1917

VARIANT

\begin{tabular}{|c|c|c|c|}
\hline $\begin{array}{l}\text { summit } \\
\text { locale } \\
\text { locale } \\
\text { hospital } \\
\text { school } \\
\text { spring } \\
\text { spring } \\
\text { spring } \\
\text { reservoir } \\
\text { reservoir }\end{array}$ & $\begin{array}{l}\text { BGN } \\
\text { UNOFF } \\
\text { UNOFF } \\
\text { UNOFF } \\
\text { UNOFF } \\
\text { BGN } \\
\text { BGN } \\
\text { BGN } \\
\text { BGN } \\
\text { BGN }\end{array}$ & $\begin{array}{l}\text { Pima } \\
\text { Pinal } \\
\text { Navajo } \\
\text { Pima } \\
\text { Yavapai } \\
\text { Graham } \\
\text { Yavapai } \\
\text { Yavapai } \\
\text { Pima } \\
\text { Pima }\end{array}$ & 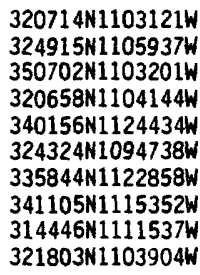 \\
\hline $\begin{array}{l}\text { reservoir } \\
\text { reservoir } \\
\text { reservoir } \\
\text { reservoir } \\
\text { reservoir } \\
\text { reservoir } \\
\text { reservoir } \\
\text { reservoir } \\
\text { valley } \\
\text { well }\end{array}$ & $\begin{array}{l}\text { BGN } \\
\text { BGN } \\
\text { BGN } \\
\text { BGN } \\
\text { BGN } \\
\text { BGN } \\
\text { BGN } \\
\text { BGN } \\
\text { BGN } \\
\text { UNOFF }\end{array}$ & $\begin{array}{l}\text { Pinal } \\
\text { Apache } \\
\text { Maricopa } \\
\text { Yavapai } \\
\text { Yavapai } \\
\text { Yavapai } \\
\text { Mohave } \\
\text { Coconino } \\
\text { Pima } \\
\text { Apache }\end{array}$ & $\begin{array}{l}325946 \mathrm{~N} 1111329 \mathrm{~W} \\
334737 \mathrm{N1} 1091116 \mathrm{~W} \\
335007 \mathrm{N1} 112852 \mathrm{~W} \\
340126 \mathrm{N1115216 \textrm {W }} \\
340339 \mathrm{N1} 130139 \mathrm{~W} \\
344455 \mathrm{N1} 124945 \mathrm{~W} \\
352305 \mathrm{N1} 132642 \mathrm{~W} \\
353830 \mathrm{N1123423W} \\
320510 \mathrm{N1} 104241 \mathrm{~W} \\
344205 \mathrm{~N} 1090929 \mathrm{~W}\end{array}$ \\
\hline $\begin{array}{l}\text { well } \\
\text { reservoir } \\
\text { reservoir } \\
\text { rapids }\end{array}$ & $\begin{array}{l}\text { UNOFF } \\
\text { BGN } \\
\text { BGN } \\
\text { BGN }\end{array}$ & $\begin{array}{l}\text { Mohave } \\
\text { Gila } \\
\text { Coconino } \\
\text { Mohave }\end{array}$ & $\begin{array}{l}343817 \mathrm{~N} 1132715 \mathrm{~W} \\
345 \mathrm{~B} 55 \mathrm{~N} 110575 \mathrm{~W} \\
350558 \mathrm{~N} 1115242 \mathrm{~W} \\
355740 \mathrm{~N} 1144343 \mathrm{~W}\end{array}$ \\
\hline
\end{tabular}

VARIANT

Maricopa

UNKNOWN

\begin{tabular}{lcl}
$\begin{array}{c}\text { SOURCE } \\
\text { COORDINATE }\end{array}$ & $\begin{array}{c}\text { ELEV } \\
\text { FT }\end{array}$ & \multicolumn{1}{c}{ MAP NAME } \\
53733 & $\begin{array}{l}\text { Meteor Crater } \\
\text { Gray Mountain } \\
\text { McDonald Mtn }\end{array}$ \\
& \\
& $\begin{array}{l}\text { Carrizo SE } \\
\text { Dutchman Draw }\end{array}$ \\
5774 & $\begin{array}{l}\text { Markham Creek } \\
\text { Trinity Mtn }\end{array}$ \\
& Casner Butte \\
3575 & $\begin{array}{l}\text { Lake Montezuma } \\
\text { Lake Montezuma } \\
\text { Hereford } \\
\text { Lake Montezuma } \\
\text { Sunrise Peak } \\
\text { Cone Butte } \\
\text { Oxbow Mtn }\end{array}$ \\
&
\end{tabular}

Buckhorn Mountain

Apache Maid Mtn

Potter Mesa Tank

Seven Springs

Lt I Lithodendron Tk

Buckhorn Mountain

25B6 Ko Vaya

Teapot Mountain

Cooks Mesa

Big Shipp Mtn

The Rincon

Agua Caliente Hill

Garfias Mtn

Wins low NE

Thatcher

$32424 \mathrm{BN} 1094900 \mathrm{~W}$

Tanque Verde Peak

Harrison Canyon

Tucson

Yarnell

Mica Mountain
$320846 N 1103355 \mathrm{~W}$
8482 Rincon Peak Black Mountain Rincon Ranch Vail Sam Powell Peak Mt Graham

Garfias Mtn Brooklyn Peak Cerro Colorado Agua Caliente Hill

2178 Ninetysix Hills NW Alpine

Boulder Mtn

Rover Peak

Date Creek Ranch SE

Smith Mesa

Cherokee Point

Tin House

Vail

Valle Bonito

3140 Elephant Mtn McFadden Peak Sycamore Point Ringbolt Rapids 


\section{FEATURE NAME}

Ringcone Tank

Ring Cone Tank

Ringtail Canyon

Ring Tank

Rio Arivapa

See Aravaipa Creek

Rio Asuncion See Salt River

Rio Azul

See Gila River

Rio Azul

See Bonita Creek

Rio Azul

See Blue River

Rio Azul

See Verde River

Rio Azul Rapids

Rio Azulrio de Lasrio See Salt River

Rio Bonita

See Bonita Creek

Rio Colorado Chiquito

See Little Colorado River

Cornez

See Sikort Chuapo Wash

Rio Cornez

See Tenmile Wash

Rio Cornez Wash

Rio Cornez Wash

See Tenmile Wash

Rio de Chelly

See Chinle Wash

Rio de Flag Bridge

Rio de Flag Trick Tank

Rio de la Asuncion See Salt River

Rio de la Iara

See Dead Wash

Rio de las Balsas See Gila River

Rio de las Balsas

See Salt River

Rio de la Xara

See Dead Wash

Rio de Lino

See Little Colorado River

Rio del los Apostoles See Gila River

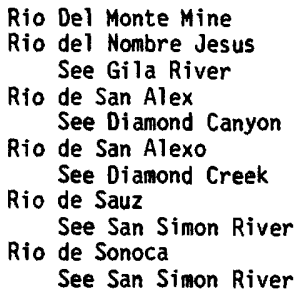

Rio Lower Branch, Canal (historical)

Rio Pilar

See Virgin River

\section{FEATURE
CLASS}

STATUS

COUNTY

COORDINATE

reservoir

valley

reservoir

stream

BGN Yavapai

$B G N$

VARIANT

Graham

Pinal

324B57N1095347W

$344707 N 1130557 \mathrm{~W}$

324133N1102205W

$345153 \mathrm{~N} 1115014 \mathrm{~W}$

$325021 N 1104251 \mathrm{~W}$

VARIANT

stream

stream

stream

stream

stream

rapids

stream

stream

stream

stream

stream

arroyo

stream

stream

bridge

well

stream

stream

VARIANT

Maricopa

$332252 \mathrm{~N} 1121844 \mathrm{~W}$

VARIANT

VARIANT

Yuma

Graham

324311N1143316W

VARIANT

Greenlee

$325336 \mathrm{~N} 1092840 \mathrm{~W}$

VARIANT

Maricopa

331233N1091128W

BGN 1917

VARIANT

Maricopa

Maricopa

UNKNOWN

VARIANT

VARIANT

VARIANT

Graham

332252N1121844W

Coconino

$325336 \mathrm{N1092840 \textrm {W }}$

VARIANT

Pima

Yuma

BGN

VARIANT

Pima

VARIANT

Yuma

UNOFF

UNOFF

VARIANT

VARIANT

Apache

Coconino

Coconino

Maricopa

Apache

VARIANT

stream

stream

stream

stream

stream

mine

stream

valley

stream

stream

stream

VARIANT

Yuma

Maricopa

VARIANT

VARIANT

VARIANT

Coconino

Yuma

UNOFF

VARIANT

VARIANT

VARIANT

VARIANT

VARIANT

and

stream

VARIAN

VARIANT

stream

stream

stream

canal

VARIANT

VARIANT

BGN

Yuma

Yuma

Mohave

Mohave

Graham

Graham

Graham

Mohave

Yuma

Maricopa

Maricopa

VARIANT

$324311 \mathrm{N1143316 \textrm {W }}$
SOURCE
COORDINATE

Shingle Mill Mtn

324223N1102247W $\quad \begin{aligned} & \text { Scratch Canyon } \\ & \text { Kennedy Peak }\end{aligned}$ Sedona
Ajo North

$325213 N 1132833 \mathrm{~W}$

$365340 \mathrm{~N} 1094435 \mathrm{~W}$

$351103 \mathrm{N1113756 \textrm {W }}$

$351604 \mathrm{N1112101 \textrm {W }}$

$332252 \mathrm{~N} 1121844 \mathrm{~W}$

345859N1094727W

32431 1N1143316W

332252N1121B44W

345859 N1094727W

36112BN1114811W

324311N1143316W

$334242 N 1133541 \mathrm{~W}$

$354600 \mathrm{~N} 1132216 \mathrm{~W}$

354558N1132222W

$324953 \mathrm{~N} 1093855 \mathrm{~W}$

$324953 \mathrm{~N} 1093855 \mathrm{~W}$

324953N1093855W

$360818 N 1142531 \mathrm{~W}$

324311 N1143316W

$331920 \mathrm{~N} 1124240 \mathrm{~W}$

$332510 \mathrm{N1120950 \textrm {W }}$

Fowler
Flagstaff West Merrian Crater

Harrisburg Valley

stream 
NATIONAL GAZETTEER--ARIZONA 1986

\section{FEATURE NAME}

Rio Prieto

See Eagle Creek

Rio Prieto

See San Francisco River

Rio Puerco

See Puerco River

Rio Puerco del Oriente

See Puerco River

Rio Puerco del Ouest

See Puerco River

Rio Puerco of the West See Puerco River

Riordan

Riordan Overpass

Riordan Railroad Station

Rio Rico

Rio Rico Airstrip

Rio Rico Calabasas Interchange

FEATURE

CLASS

STATUS

COUNTY

COORDINATE

Greenlee

325736N1092420W

strean

VARIANT

VARIANT

VARIANT

stream

Apache

325832N1092218W

Navajo

Navajo

345459M1100526W

stream

VARIANT

VARIANT

Rio Salado

See Salt River

Rio Salado Industrial

Recreation Park

Rio San Carlos

See San Carlos River

Rio San Domingo

See San Simon River

Rio San Francisco

See Mineral Creek

Rio San Pedro

See San Pedro River

Rio Santa Cruz

See Santa Cruz River

Rio Santa Maria See Santa Maria River

Rio Santa Teresa

See Paria River

Rio Sauz

See San Simon River

Rioso Reservoir

Rio Suez

See San Simon River

Rio Tank

Rio Tenmile Wash

See Tenmile Wash

Rio Verde

See Verde River

Rio Verde

Rio Verde Well

Rio Virgen

See Virgin River

Rio Vista Mine

Rio Vista School

Ripper Spring

Ripper Spring Canyon

Ripper Tank

Rip Rap Tank

Ripsey Hill

Ripsey Ranch

Ripsey Spring

Ripsey Wash

Rip Spring

Rip Van Winkle Mine

Rita Creek

See Rillito River

Rita Interchange

Ritchey Peak

Rittenhouse

Rittenhouse Dam

Rittenhouse Substation

Ritter Butte

Ritter Creek
VARIANT

stream

locale

crossing

building

pp1

airport

crossing

strea

park

VARIANT

ADMIN

VARIANT

strean

stream

stream

VARIANT

VARIANT

Navajo

Navajo

Coconino

Coconino

Coconino

Santa Cruz

Santa Cruz

Santa Cruz

Maricopa

Maricopa

$332252 \mathrm{N1121844W}$

$332452 \mathrm{N1} 12030 \mathrm{WW}$

331156N1102437W

Graham

Pinal

324953N1093855W

330612 N1105828W

VARIANT

stream

VARIANT

stream

stream

stream

stream

reservoir

stream

reservoir

stream

stream

ppl

well

VARIAN

VARIANT

VARIANT

Pinal

Pinal

Mohave

Coconino

Graham

Apache

VARIANT

BGN

VARIANT

VARIANT

Maricopa

Maricopa

Maricopa

VARIANT

stream

mine

school

spring

valley

reservoir

reservoir

summit

locale

UNOFF

UNOFF

$B G N$

BGN

BGN

BGN

BGN

Mohave

Yuma

Maricopa

Gila

Gila

Gila

Navajo

Pinal

Pinal

spring

stream

spring

mine

BGN Pinal

BGN Gila

UNOFF Mohave

stream

crossing

summit

iocale

dam

VARIANT

Pima

UNOFF

BGN

$B G N$

UNOFF

Pima

Pima

Maricopa

Pinal

locale

UNOFF

BGN

BGN
Maricopa

Coconino

Yavapai
$351133 \mathrm{N1114411 \textrm {W }}$

$351141 \mathrm{N1114414 \textrm {W }}$

$351148 \mathrm{N1114446 \textrm {W }}$

7N1105833W

$7110034 \mathrm{~W}$

$360818 N 1142531 \mathrm{~W}$ $332439 \mathrm{~N} 1120405 \mathrm{~W}$ $332741 \mathrm{~N} 11 \mathrm{O}$ $341419 \mathrm{~N} 1110523 \mathrm{~W}$ $335235 \mathrm{N1} 095248 \mathrm{~W}$ $325940 N 1105800 \mathrm{~W}$ $325724 N 1105833 \mathrm{~W}$

$330142 N 1105841 W$

$330607 \mathrm{~N} 1110032 \mathrm{~W}$

$332914 N 1105509 \mathrm{~W}$

$321 B 49 N 1110316 \mathrm{~W}$

320454 N1104B19W

$315206 \mathrm{~N} 1111058 \mathrm{~W}$

$331524 N 1113804 \mathrm{~W}$

$331618 \mathrm{~N} 1113000 \mathrm{~W}$

$331454 \mathrm{N1113822W}$

$350035 \mathrm{~N} 1114243 \mathrm{~W}$

342137 N1125556W
BGN Pinal 332758 N1105953W

$\begin{array}{ccc}\text { SOURCE } & \text { ELEV } \\ \text { COORDINATE } & \text { FT MAP NAME }\end{array}$

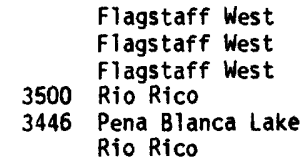

Phoenix

Nutrioso

Valle Tank

1610 Fort MCDowell Adams Mesa

$332735 \mathrm{N1105707W}$

Cross Roads

Phoenix

Inspiration

Inspiration

Diamond Butte

Alches ay Flat

3920 Crozier Peak

Crozier Peak

$325923 N 1105915 W$

Kearny

Grayback

Inspiration

White Hills West

Tucson SE

Batamote Hills

1402 Higley

Desert Well 


\begin{tabular}{|c|c|c|c|c|c|c|c|}
\hline FEATURE NAME & $\begin{array}{l}\text { FEATURE } \\
\text { CLASS }\end{array}$ & STATUS & COUNTY & COORDINATE & $\begin{array}{l}\text { SOURCE } \\
\text { COORDINATE }\end{array}$ & $\begin{array}{c}\text { ELEV } \\
\text { FT }\end{array}$ & MAP NAME \\
\hline $\begin{array}{l}\text { Ritter Dam } \\
\text { Ritter Mountain } \\
\text { Ritter Peak } \\
\text { Ritter School } \\
\text { Ritter Spring } \\
\text { Ritter Tank } \\
\text { Ritter Tank }\end{array}$ & $\begin{array}{l}\text { dam } \\
\text { summit } \\
\text { summit } \\
\text { school } \\
\text { spring } \\
\text { reservoir } \\
\text { reservoir }\end{array}$ & $\begin{array}{l}\text { UNOFF } \\
\text { BGN } \\
\text { BGN } \\
\text { UNOFF } \\
\text { BGN } \\
\text { BGN } \\
\text { BGN }\end{array}$ & $\begin{array}{l}\text { Yavapai } \\
\text { Coconino } \\
\text { Yavapai } \\
\text { Maricopa } \\
\text { Coconino } \\
\text { Yavapai } \\
\text { Coconino }\end{array}$ & 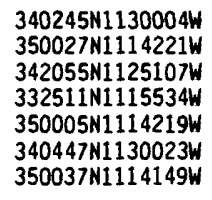 & & $\begin{array}{l}5688 \\
6790\end{array}$ & $\begin{array}{l}\text { Date Creek Ranch SE } \\
\text { Mountainaire } \\
\text { Weaver Peak } \\
\text { Tempe } \\
\text { Mountainaire } \\
\text { Date Creek Ranch SE } \\
\text { Mountainaire }\end{array}$ \\
\hline $\begin{array}{l}\text { River Colderan Ranch } \\
\text { River de Flag }\end{array}$ & locale & $\begin{array}{l}\text { UNOFF } \\
\text { VARIANT }\end{array}$ & Graham & $324230 \mathrm{~N} 1101219 \mathrm{~W}$ & & & Eureka Ranch \\
\hline $\begin{array}{l}\text { See Flag, Rio de } \\
\text { River Island } \\
\text { River Number One Dam } \\
\text { River of the Rafts }\end{array}$ & $\begin{array}{l}\text { stream } \\
\text { island } \\
\text { dam }\end{array}$ & $\begin{array}{l}\text { BGN } \\
\text { UNOFF } \\
\text { VARIANT }\end{array}$ & $\begin{array}{l}\text { Coconino } \\
\text { Mohave } \\
\text { Apache }\end{array}$ & $\begin{array}{l}351430 \mathrm{~N} 1112500 \mathrm{~W} \\
343928 \mathrm{N1142658 \textrm {W }} \\
335618 \mathrm{~N} 1092936 \mathrm{~W}\end{array}$ & & & $\begin{array}{l}\text { Topock } \\
\text { Big Lake North }\end{array}$ \\
\hline $\begin{array}{l}\quad \text { See Salt River } \\
\text { River Reservoir } \\
\text { River Reservoir } \\
\text { River Reservoir Dan }\end{array}$ & $\begin{array}{l}\text { stream } \\
\text { reservoir } \\
\text { reservoir } \\
\text { dam }\end{array}$ & $\begin{array}{l}\text { BGN } \\
\text { BGN } \\
\text { UNOFF }\end{array}$ & $\begin{array}{l}\text { Maricopa } \\
\text { Apache } \\
\text { Apache } \\
\text { Apache }\end{array}$ & 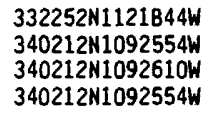 & & 8221 & $\begin{array}{l}\text { Greer } \\
\text { Greer } \\
\text { Greer }\end{array}$ \\
\hline $\begin{array}{l}\text { River Reservoir Number Three } \\
\text { Dam }\end{array}$ & dam & UNOFF & Apache & $340212 \mathrm{~N} 1092612 \mathrm{~W}$ & & & Greer \\
\hline $\begin{array}{l}\text { Riverside } \\
\text { Riverside }\end{array}$ & ppl 1 & $\begin{array}{l}\text { BGN } \\
\text { VARIANT }\end{array}$ & Pinal & $330619 \mathrm{~N} 1105726 \mathrm{~W}$ & & & Kearny \\
\hline $\begin{array}{l}\quad \text { See Kelvin } \\
\text { Riverside Park } \\
\text { Riverside Park } \\
\text { Riverside Recreation Site } \\
\text { Riverside School } \\
\text { River Tank }\end{array}$ & $\begin{array}{l}\text { locale } \\
\text { park } \\
\text { park } \\
\text { park } \\
\text { school } \\
\text { reservoir }\end{array}$ & $\begin{array}{l}\text { ADMIN } \\
\text { ADMIN } \\
\text { ADMIN } \\
\text { UNOFF } \\
\text { BGN }\end{array}$ & $\begin{array}{l}\text { Pinal } \\
\text { Yuma } \\
\text { Maricopa } \\
\text { Maricopa } \\
\text { Maricopa } \\
\text { Graham }\end{array}$ & $\begin{array}{l}330641 \mathrm{N1} 1105822 \mathrm{~W} \\
324332 \mathrm{~N} 1143643 \mathrm{~W} \\
33253 \mathrm{N1} 1120358 \mathrm{~W} \\
334851 \mathrm{N1} 113840 \mathrm{~W} \\
332604 \mathrm{N1121011W} \\
325328 \mathrm{~N} 1092621 \mathrm{~W}\end{array}$ & & & $\begin{array}{l}\text { Yuma East } \\
\text { Phoenix } \\
\text { Bartlett Dam } \\
\text { Fowler } \\
\text { Gila Box }\end{array}$ \\
\hline $\begin{array}{l}\text { River Tank } \\
\text { River Trail } \\
\text { Riverview Park } \\
\text { River Windmill } \\
\text { River Windmill } \\
\text { Riviera } \\
\text { Riviera Mobile Home Park } \\
\text { Riviera Plaza Shopping Center } \\
\text { Riviera Post Office } \\
\text { Roach Wash }\end{array}$ & $\begin{array}{l}\text { reservoir } \\
\text { trai1 } \\
\text { park } \\
\text { locale } \\
\text { locale } \\
\text { ppl } \\
\text { locale } \\
\text { locale } \\
\text { building } \\
\text { stream }\end{array}$ & $\begin{array}{l}\text { BGN } \\
\text { UNOFF } \\
\text { ADMIN } \\
\text { BGN } \\
\text { BGN } \\
\text { BGN } \\
\text { UNOFF } \\
\text { UNOFF } \\
\text { UNOFF } \\
\text { BGN }\end{array}$ & $\begin{array}{l}\text { Yavapai } \\
\text { Coconino } \\
\text { Pima } \\
\text { Cochise } \\
\text { Navajo } \\
\text { Mohave } \\
\text { Maricopa } \\
\text { Maricopa } \\
\text { Mohave } \\
\text { Pinal }\end{array}$ & $\begin{array}{l}342715 \mathrm{~N} 1130938 \mathrm{~W} \\
360554 \mathrm{N1} 120603 \mathrm{~W} \\
321435 \mathrm{~N} 1105928 \mathrm{~W} \\
314316 \mathrm{~N} 1095042 \mathrm{~W} \\
3508411092844 \mathrm{~W} \\
350603 \mathrm{~N} 1143714 \mathrm{~W} \\
3327151115432 \mathrm{~W} \\
332525 \mathrm{N1} 114712 \mathrm{~W} \\
350540 \mathrm{N1} 143746 \mathrm{~W} \\
325719 \mathrm{N1} 104516 \mathrm{~W}\end{array}$ & $325839 \mathrm{~N} 1103938 \mathrm{~W}$ & $\begin{array}{l}5692 \\
1200\end{array}$ & $\begin{array}{l}\text { Thorn Peak } \\
\text { Phantom Ranch } \\
\text { rucson } \\
\text { Out law Mountain } \\
\text { Chambers } \\
\text { Davis Dam SE } \\
\text { Tempe } \\
\text { Mesa } \\
\text { Mt Manchester } \\
\text { Winkelman }\end{array}$ \\
\hline $\begin{array}{l}\text { Roadbed Tank } \\
\text { Road Camp Windmill } \\
\text { Road Canyon } \\
\text { Road Canyon } \\
\text { Road Canyon } \\
\text { Road Canyon } \\
\text { Road Canyon } \\
\text { Road Canyon } \\
\text { Road Canyon Dam } \\
\text { Road Canyon Tank }\end{array}$ & $\begin{array}{l}\text { reservoir } \\
\text { locale } \\
\text { valley } \\
\text { valley } \\
\text { valley } \\
\text { valley } \\
\text { valley } \\
\text { valley } \\
\text { dam } \\
\text { reservoir }\end{array}$ & $\begin{array}{l}B G N \\
B G N \\
B G N \\
B G N \\
B G N \\
B G N \\
B G N \\
B G N \\
\text { UNOFF } \\
B G N\end{array}$ & $\begin{array}{l}\text { Coconino } \\
\text { Yavapai } \\
\text { Cochise } \\
\text { Pinal } \\
\text { Graham } \\
\text { Yavapai } \\
\text { Mohave } \\
\text { Mohave } \\
\text { Yavapai } \\
\text { Yavapai }\end{array}$ & 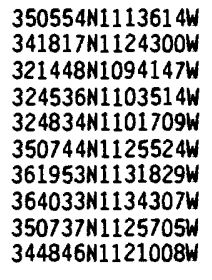 & $\begin{array}{l}321518 \mathrm{N109} 4054 \mathrm{~W} \\
324638 \mathrm{~N} 1102949 \mathrm{~W} \\
324852 \mathrm{~N} 1101409 \mathrm{~W} \\
3507341125955 \mathrm{~W} \\
361929 \mathrm{N1132026 \textrm {W }} \\
364150 \mathrm{N11} 134025 \mathrm{~W}\end{array}$ & & $\begin{array}{l}\text { Lower Lake Mary } \\
\text { Peeples Valley } \\
\text { Simmons Peak } \\
\text { Holy Joe Peak } \\
\text { Klondike } \\
\text { Turkey Canyon } \\
\text { Cold Spring } \\
\text { Mustang Knoll } \\
\text { Purcell Canyon } \\
\text { Munds Draw }\end{array}$ \\
\hline $\begin{array}{l}\text { Road Canyon Tank } \\
\text { Road Canyon Well } \\
\text { Roades Ranch (historical) } \\
\text { Road Hollow } \\
\text { Road Hollow Point } \\
\text { Road Junction Windmill } \\
\text { Road Pond } \\
\text { Road Pond } \\
\text { Road Pond } \\
\text { Road Reservoir }\end{array}$ & $\begin{array}{l}\text { reservoir } \\
\text { well } \\
\text { locale } \\
\text { valley } \\
\text { cliff } \\
\text { locale } \\
\text { reservoir } \\
\text { reservoir } \\
\text { reservoir } \\
\text { reservoir }\end{array}$ & $\begin{array}{l}\text { BGN } \\
\text { UNOFF } \\
\text { BGN } \\
\text { BGN } \\
\text { BGN } \\
\text { BGN } \\
\text { BGN } \\
\text { BGN } \\
\text { BGN } \\
\text { BGN }\end{array}$ & $\begin{array}{l}\text { Yavapai } \\
\text { Santa Cruz } \\
\text { Pima } \\
\text { Coconino } \\
\text { Coconino } \\
\text { Maricopa } \\
\text { Mohave } \\
\text { Mohave } \\
\text { Mohave } \\
\text { Mohave }\end{array}$ & $\begin{array}{l}350738 \mathrm{N1125701W} \\
312857 \mathrm{~W} 1111952 \mathrm{~W} \\
314700 \mathrm{~N} 111030 \mathrm{~W} \\
362725 \mathrm{~N} 1122112 \mathrm{~W} \\
362752 \mathrm{N1121921W} \\
340037 \mathrm{~W} 1115711 \mathrm{~W} \\
362945 \mathrm{~N} 113243 \mathrm{~W} \\
363004 \mathrm{N1} 13243 \mathrm{~W} \\
365305 \mathrm{~N} 1130536 \mathrm{~W} \\
363749 \mathrm{N1} 130429 \mathrm{~W}\end{array}$ & $362821 N 1121607 \mathrm{~W}$ & 3130 & $\begin{array}{l}\text { Purcell Canyon } \\
\text { Bartlett Mtn } \\
\text { Haberstock Hill } \\
\text { Quaking Aspen } \\
\text { Quaking Aspen } \\
\text { Cooks Mesa } \\
\text { Poverty Knoll } \\
\text { Little Tanks } \\
\text { Lost Spring Mtn East } \\
\text { Little Clayhole Val }\end{array}$ \\
\hline $\begin{array}{l}\text { Road Ridge } \\
\text { Roadrunner Mobile Home Park } \\
\text { Roadrunner Mountain } \\
\text { Roadrunner Park } \\
\text { Roadrunner Rapids } \\
\text { Two Hundred And } \\
\text { Seventeenmile Canyon } \\
\text { Rapids } \\
\text { Two Hundred And } \\
\text { Seventeenmile Rapids }\end{array}$ & $\begin{array}{l}\text { ridge } \\
\text { locale } \\
\text { summit } \\
\text { park } \\
\text { rapids }\end{array}$ & $\begin{array}{l}\text { BGN } \\
\text { UNOFF } \\
\text { BGN } \\
\text { ADMIN } \\
\text { BGN } \\
\text { VARIANT }\end{array}$ & $\begin{array}{l}\text { Gila } \\
\text { Maricopa } \\
\text { Pima } \\
\text { Maricopa } \\
\text { Mohave }\end{array}$ & $\begin{array}{l}341855 \mathrm{~N} 1113535 \mathrm{~W} \\
332405 \mathrm{~N} 1120430 \mathrm{~W} \\
322240 \mathrm{N11} 22943 \mathrm{~W} \\
333556 \mathrm{N11} 20021 \mathrm{~W} \\
355141 \mathrm{N11} 131840 \mathrm{~W}\end{array}$ & & 1080 & $\begin{array}{l}\text { Cane Springs Mtn } \\
\text { Phoenix } \\
\text { Cimarron Peak } \\
\text { Sunnys lope } \\
\text { Diamond Peak }\end{array}$ \\
\hline $\begin{array}{c}\text { Roadrunner School } \\
\text { Roadrunner School } \\
\text { Cholla School } \\
\text { Roadrunner Tank }\end{array}$ & $\begin{array}{l}\text { school } \\
\text { school } \\
\text { reservoir }\end{array}$ & $\begin{array}{l}\text { UNOFF } \\
\text { UNOFF } \\
\text { VARIANT } \\
\text { BGN }\end{array}$ & $\begin{array}{l}\text { Maricopa } \\
\text { Maricopa }\end{array}$ & $\begin{array}{l}333301 \mathrm{N1120846 \textrm {W }} \\
333527 \mathrm{N1} 120010 \mathrm{~W} \\
334210 \mathrm{~N} 1105835 \mathrm{~W}\end{array}$ & & & $\begin{array}{l}\text { Glendale } \\
\text { Sunnys lope } \\
\text { Meddler Wash }\end{array}$ \\
\hline
\end{tabular}


FEATURE NAME

Roadside Mine

Roadside Picnic Area Milepost Two Hundred Ninety

Roadside Spring

Roads ide Table Milepost Three Hundred Twentyseven

Roadside Table Milepost Two Hundred Ninetythree

Roadside Tank

Roads ide Tank

Roadside Tank

Roadside Tank

Roadside Tank

Roadside Tank

Roadside Tank

Roadside Tank

Roadside Tank

Roads ide Tank

Roadside Well

Road Tank

Road Tank

Road Tank

Road Tank

Road Tank

Road Tank

Road Tank

Road Tank

Road Tank

Road Tank

Road Tank

Road Tank

Road Tank

Road Tank

Road Tank

Road Tank

Road Tank

Road Tank

Road Tank

Roan Cow Canyon

Roaring Rapids

Roaring Rapids

Roaring Springs

Roaring Springs Campground

Roaring Springs Canyon

Roath Ranch

Robbers Roost

Robbers Roost

Robbers Roost

Robbers Roost Canyon

Robbers Roost Canyon

Robbers Roost Mountain

Robbers Roost Spring

Robbers Roost Spring

Robbers Roost Tank

Robbers Roost Tank

Robber Tank

Robbins Butte

Roberts Butte

Robbins Butte State Game

Management Unit

Robbins Tank Harper Tank

Robert E Tank

Roberts Butte

See Robbins Butte

Roberts Camp

Roberts Draw Tank

Roberts Mesa

Robertson Hollow

Robertson Wash

Roberts Ranch

\section{FEATURE}

mine

STATUS

COUNTY

COORDINATE

UNOFF

Pima

spring

ADMIN

Gila

Yavapai

locale BGN Gila $\quad 334830$ N1100734W

334729 N1103010W

$341642 \mathrm{~N} 1114311 \mathrm{~W}$

\begin{tabular}{|c|c|c|c|}
\hline ocale & BGN & Gila & $334745 \mathrm{~N} 1103002 \mathrm{~W}$ \\
\hline $\begin{array}{l}\text { reservoir } \\
\text { reservoir } \\
\text { reservoir } \\
\text { reservoir } \\
\text { reservoir } \\
\text { reservoir } \\
\text { reservoir } \\
\text { reservoir }\end{array}$ & $\begin{array}{l}\text { BGN } \\
B G N \\
B G N \\
B G N \\
B G N \\
B G N \\
B G N \\
B G N\end{array}$ & $\begin{array}{l}\text { Santa Cruz } \\
\text { Apache } \\
\text { Yavapai } \\
\text { Mohave } \\
\text { Coconino } \\
\text { Coconino } \\
\text { Yavapai } \\
\text { Coconino }\end{array}$ & $\begin{array}{l}312735 \mathrm{~N} 1111207 \mathrm{~W} \\
335152 \mathrm{~N} 1091250 \mathrm{~W} \\
341013 \mathrm{~N} 1114835 \mathrm{~W} \\
343738 \mathrm{~N} 1135005 \mathrm{~W} \\
344300 \mathrm{~N} 1112559 \mathrm{~W} \\
344624 \mathrm{~N} 1110953 \mathrm{~W} \\
344653 \mathrm{~N} 1130333 \mathrm{~W} \\
345251 \mathrm{~N} 1112830 \mathrm{~W}\end{array}$ \\
\hline $\begin{array}{l}\text { reservoir } \\
\text { reservoir } \\
\text { well } \\
\text { reservoir } \\
\text { reservoir } \\
\text { reservoir } \\
\text { reservoir } \\
\text { reservoir } \\
\text { reservoir } \\
\text { reservoir }\end{array}$ & $\begin{array}{l}\text { BGN } \\
\text { BGN } \\
\text { UNOFF } \\
\text { 8GN } \\
\text { BGN } \\
\text { BGN } \\
\text { BGN } \\
\text { BGN } \\
\text { BGN } \\
\text { BGN }\end{array}$ & $\begin{array}{l}\text { Yavapai } \\
\text { Mohave } \\
\text { Santa Cruz } \\
\text { Santa Cruz } \\
\text { Cochise } \\
\text { Cochise } \\
\text { Gila } \\
\text { Yuma } \\
\text { Greenlee } \\
\text { Maricopa }\end{array}$ & $\begin{array}{l}345621 \mathrm{~N} 1130405 \mathrm{~W} \\
352237 \mathrm{~N} 1132125 \mathrm{~W} \\
313344 \mathrm{~N} 1102910 \mathrm{~W} \\
312756 \mathrm{~N} 1111527 \mathrm{~W} \\
314032 \mathrm{~N} 1094901 \mathrm{~W} \\
314211 \mathrm{~N} 1102201 \mathrm{~W} \\
331700 \mathrm{~N} 1105236 \mathrm{~W} \\
332047 \mathrm{N1} 132921 \mathrm{~W} \\
332330 \mathrm{~N} 1092917 \mathrm{~W} \\
334419 \mathrm{~N} 1123837 \mathrm{~W}\end{array}$ \\
\hline
\end{tabular}

reservoir BGN Gila

reservoir BGN Navajo

reservoir BGN Navajo

reservoir BGN Yavapa

reservoir BGN Yavapai

reservoir BGN

reservoir

reservoir $B G$

reservoir $B G$

reservoir BGN

reservoir

reservoir

valley

rapids

rapids

park

valley

locale

summit

locale

locale

valley

valley

summit

spring

reservoir

reservoir $B G$

reservoir $B G$

park

BGN 1959 Maricopa

park

VARIANT

Yavapai

Coconino

Apache

Yavapai

Yavapai

Coconino

Coconino

Greenlee

Mohave

Mohave

Mohave

Coconino

$\begin{array}{ll}\text { ADMIN } & \text { Coconino } \\ \text { BGN 1932 } & \text { Coconino } \\ \text { UNOFF } & \text { Sant a ruz }\end{array}$

UNOFF Santa Cru

BGN

Yavapai

reservoir BGN 1981 Yavapai VARIANT

reservoir $B G N$

Yavapa

summit

locale

BGN

Maricopa

Yavapai

reservoir $B G N$

summit

valley

stream

locale

\section{BGN Gila}

BGN

$B G N$

UNDFF
Gila

Apache

Cochise

Navajo
335521N1101136W

$341749 \mathrm{~N} 1101127 \mathrm{~W}$

$342201 N 1102158 \mathrm{~W}$

$342205 N 1115058 \mathrm{~W}$

342547 N1114811

$342950 \mathrm{~N} 1113549 \mathrm{~W}$

343509 N1112839W

$343603 N 1094902 W$

$344328 \mathrm{~N} 1113339 \mathrm{~W}$

$344519 \mathrm{~N} 1120909 \mathrm{~W}$

352709 N1113930W

$360029 \mathrm{N1121218 \textrm {N }}$

$331617 N 1090819 \mathrm{~W}$

$354700 \mathrm{~N} 1144200 \mathrm{~W}$

$355035 \mathrm{~N} 1144209 \mathrm{~W}$

$361142 \mathrm{~N} 1120206 \mathrm{~W}$

361147 N1120218W

$361135 \mathrm{~N} 1120200 \mathrm{~W}$

$313222 N 1103148 \mathrm{~W}$

345548 N1115802W

$345131 N 1113749 \mathrm{w}$

353938 N1130908W

$335918 \mathrm{~N} 1115946 \mathrm{~W}$

353907 N1131144k

$340134 \mathrm{~N} 1110815 \mathrm{~W}$

35906 N1115927

$361648 \mathrm{~N} 1120518 \mathrm{~W}$

345551 N1115747

$353929 \mathrm{N1} 130910 \mathrm{~W}$

353522 N1122000W

$331915 N 1124015$

331857 N1123948W

$344910 N 1130043 \mathrm{~W}$

345009 N1121550W

$331915 \mathrm{~N} 1124015 \mathrm{~W}$

$340604 \mathrm{~N} 1123153 \mathrm{~W}$

$342006 \mathrm{~N} 1111003 \mathrm{~W}$

$342148 \mathrm{~N} 1110837 \mathrm{~W}$

$340538 \mathrm{~N} 1091701 \mathrm{~W}$

$314622 \mathrm{~N} 1100257 \mathrm{~W}$

335948 N1095411W

\begin{tabular}{lcl}
$\begin{array}{c}\text { SOURCE } \\
\text { COORDINATE }\end{array}$ & ELEV & \multicolumn{1}{c}{ MAP NAME } \\
& & $\begin{array}{l}\text { Pan Tak } \\
\text { Mule Hoof Bend } \\
\text { Verde Hot Springs } \\
\end{array}$ \\
5045 & $\begin{array}{l}\text { Cone Butte }\end{array}$
\end{tabular}

3420 Mule Hoof Bend

Ruby

Alpine

Bloody Bas in

Beecher Canyon

Happy Jack

Chavez Mtn West

Scratch Canyon

Mormon Lake

Mount Hope

Blye Canyon NE

Pyeatt Ranch

Bartlett Mtn

Out law Mountain

Huachuca City

Pinal Ranch

Nottbusch Butte

Robinson Mes a

Daggs Tank

Cedar Creek

Pinedale

Clay Springs

Tule Mesa

Horner Mtn

Strawberry

Calloway Butte

Manuel Seep

Apache Maid Mtn

Munds Draw

White Horse Hills

Grand Canyon

Fritz Canyon

Willow Beach

Willow Beach

Bright Angel Point

361516 N1120120N

5200

Bright Angel Point
Bright Angel Point

5065 O'Donnell Canyon

5110 Loy Butte

$335628 \mathrm{N1115909 \textrm {W }}$

Munds Mountain

Robbers Roost Canyon

New River Mesa

Robbers Roost Canyon

5870 Sheep Bas in Mtn

New River Mesa

Little Park Lane

Loy Butte

Robbers Roost Canyon

Mixon Tank

1179 Hass ayampa

Hass ayampa

Scratch Canyon

King Canyon

Morgan Butte

Diamond Point

$340442 N 1091611 \mathrm{~W}$

6686 Diamond Point

Eagar

Haberstock $\mathrm{Hill}$

Alchesay Flat 
FEATURE NAME

Roberts Ranch

Roberts School

Roberts Well

Robert Tank

Robidoux Airport See Valle Airport

Robin Landing Field

Robinson Canyon

Robinson Canyon

Robinson Crate

Robinson Ditch

Robinson Flat

Robinson Mesa

Robinson Mesa Twenty-seven

Trail

Robinson Mountain

Robinson Reservoir

Robinson Spring

Robinson Spring

Robinson Spring

Robins on Tank

Robinson Tank

Robinson Trail Crossing

Robinson Wash

Robin Tank

Robison School

Roblas Butte

Roblas Canyon Robles Canyon

Roblas Well

Roble Canyon

Robles Canyon See Roblas Canyon

Robles Junction Robles Ranch

Robles Pass

Roble Spring

Robles Ranch

See Robles Junction

Robles Wash, Los

Robles Well

Rob Roy Mine

Rob Roy We 11

Robs Well

Rock, Point

Rock, Spring on the

Rock Basin Spring

Rock Bas in Tank

Rock Bottom Tank

Rock Bottom Tank

Rock Butte

See Rock Peak

Rock Butte

Rock Candy Mountain Mine

Rock Canyon

Rock Canyon

See Ventana Canyon

Rock Canyon

Rock Canyon

Rock Canyon

Rock Canyon

Rock Canyon

Rock Canyon

Rock Canyon

Rock Canyon

Rock Canyon Point

Rock Canyon Reservoir

Rock Canyon Reservoir

Rock Canyon Spring

Rock Canyon Trail Two Hundred

Fiftynine
FEATURE

$\begin{array}{ll}\text { locale } & \text { UNOFF } \\ \text { school } & \text { UNOFF } \\ \text { well } & \text { UNOFF } \\ \text { reservoir } & \text { BGN } \\ \text { airport } & \text { VARIANT }\end{array}$

COORDINATE

Apache

Pima

Maricopa

Coconino

airport

Coconino

\begin{tabular}{|c|c|c|c|}
\hline $\begin{array}{l}\text { airport } \\
\text { valley } \\
\text { valley } \\
\text { crater } \\
\text { canal } \\
\text { flat } \\
\text { summit } \\
\text { trail }\end{array}$ & $\begin{array}{l}\text { ADMIN } \\
\text { BGN } \\
\text { BGN } \\
\text { BGN } 1931 \\
\text { BGN } \\
\text { BGN } \\
\text { BGN } \\
\text { UNOFF }\end{array}$ & $\begin{array}{l}\text { Yavapai } \\
\text { Greenlee } \\
\text { Mohave } \\
\text { Coconino } \\
\text { Graham } \\
\text { Graham } \\
\text { Greenlee } \\
\text { Greenlee }\end{array}$ & $\begin{array}{l}344440 \mathrm{~N} 1122640 \mathrm{~W} \\
332852 \mathrm{~N} 1092823 \mathrm{~W} \\
363456 \mathrm{~N} 1124844 \mathrm{~W} \\
352334 \mathrm{~N} 1113248 \mathrm{~W} \\
324657 \mathrm{~N} 1094739 \mathrm{~W} \\
324901 \mathrm{~N} 1094607 \mathrm{~W} \\
332905 \mathrm{~N} 1092726 \mathrm{~W} \\
332837 \mathrm{~N} 1092500 \mathrm{~W}\end{array}$ \\
\hline immit & BGN & oconino & $352310 \mathrm{~N} 1113237 \mathrm{~W}$ \\
\hline
\end{tabular}

summit

BGN

Coconino

reservoir

spring

spring

spring

reservoir

reservoir

locale

stream

reservoir

schoo

BGN

BGN

BGN

BGN

$B G N$

BGN

BGN

BGN

UNOFF

Mohave

Pima

Pima

Apache

Yavapai

Mohave

Navajo

Mohave

Yuma

Pima

summit

valley

well

valley

BGN

BGN

VARIANT

UNOFF

BGN

VARIANT

valley

locale

BGN

gap

VARIANT

gap

spring

locale

strea
well

well

wel

well

summit

spring

Pinal

Pinal

Pinal

Cochise

Pinal

Pima

Pima

Cochise

Pima

BNY

BGN

UNOFF

UNOFF

UNOFF

BGN

BGN

spring

BGN

reservoir $B G$

reservoir BGN

summit

summit

mine

valley

valley

VARIANT

BGN

UNOFF

BGN

VARIANT

Pinal

Pima

Yuma

Yuma

Greenlee

Mohave

Coconino

Greenlee

Mohave

Coconino

Apache

Pinal

Yavapai

Santa Cruz

Cochise

Pina

valley

valley

valley

valley

valley

valley

valley

cliff

reservoir

BGN

BGN

BGN

BGN

$B G N$

BGN

BGN

BGN

BGN

Gila

Gila

Coconino

Coconino

Coconino

Mohave

Coconino

Coconino

reservoir $B G N$

spring $B G N$
363004N1124905W

$314454 \mathrm{~N} 1105017 \mathrm{~W}$

$314506 \mathrm{~N} 1105021 \mathrm{~W}$

340048 N1091008W

$345339 \mathrm{~N} 1115302 \mathrm{~W}$

$362927 \mathrm{~N} 1124909 \mathrm{~W}$

$342134 \mathrm{~N} 1100524 \mathrm{~W}$

$363456 \mathrm{~N} 1124844 \mathrm{~W}$

$331012 \mathrm{~N} 1141331 \mathrm{~W}$

$321247 \mathrm{~N} 1105551 \mathrm{~W}$

331946 N1111337W

$331839 N 1111354 \mathrm{~W}$

331939N1111304W

$321754 \mathrm{~N} 1102348 \mathrm{~W}$

$331 B 39 N 1111354 \mathrm{~W}$

320438 N1111840W

$321035 N 1110253 \mathrm{~W}$

$321610 \mathrm{~N} 1102651 \mathrm{~W}$

$320438 \mathrm{~N} 1111840 \mathrm{~W}$

$323350 \mathrm{~N} 1112601 \mathrm{~W}$

$321038 \mathrm{~N} 1111437 \mathrm{~W}$

$331621 N 1135749 \mathrm{~W}$

$331710 \mathrm{N1135B05 \textrm {N }}$

$365303 \mathrm{N1} 130031 \mathrm{~W}$

$355740 \mathrm{~N} 1111422 \mathrm{~W}$

$331302 \mathrm{~N} 1090748 \mathrm{~W}$

$361633 \mathrm{N1} 131949 \mathrm{~W}$

$344221 \mathrm{~N} 1112130 \mathrm{~W}$

$330806 \mathrm{~N} 1113838 \mathrm{~W}$

$345936 \mathrm{~N} 1122637 \mathrm{~W}$

$314253 N 1104931 \mathrm{~W}$

$315404 \mathrm{~N} 1092701 \mathrm{~W}$

$322001 \mathrm{~N} 1105122 \mathrm{~W}$

$334927 N 1103704 \mathrm{~W}$ $341624 \mathrm{~N} 1112920 \mathrm{~W}$ $352623 \mathrm{N1132747 \textrm {W }}$ $364035 \mathrm{~N} 1115630 \mathrm{~W}$ $364203 \mathrm{~N} 1123355 \mathrm{~W}$ $364545 \mathrm{~N} 1123646 \mathrm{~W}$ 365807 N1121850W 365B31N1131B56W $364455 N 1123622 W$ $364645 \mathrm{~N} 1123434 \mathrm{~W}$

365342 N1120848W $335230 \mathrm{~N} 1101837 \mathrm{~W}$ $315350 \mathrm{~N} 1092000 \mathrm{~W}$
$350619 N 1093757 \mathrm{~W}$
Coconino

Gila

Cochise

$\begin{array}{ccc}\text { SOURCE } & \text { ELEV } & \\ \text { COORDINATE } & \text { FT } & \text { MAP NAME } \\ & & \text { Tolapai Spring } \\ & \text { Tucson } \\ & \text { Flatiron Mtn } \\ & \text { Cataract Tank }\end{array}$

4772 Chino Valley South

332657 N1092649W 4772 Robinson Mesa

363027 N1124905W Robinson Canyon

7342 O'Leary Peak

Thatcher

6224 Robinson Mesa Robinson Mesa

7911 O'Leary Peak

Robinson Canyon

Mt Wrightson

Helvetia

Nelson Reservoir

Loy Butte

Hitson Tank

$362433 \mathrm{~N} 1124246 \mathrm{~W}$

Show Low North

Robinson Canyon

Arch Tank

Tucson 


\section{FEATURE NAME}

Rock Corral Bench

Rock Corral Canyon

Rock Corral Peak

See Tumacacori Peak

Rock Corral Ranch

Rock Corral Spring

Rock Creek

Rock Creek

Pinto Creek

Rock Creek

Rock Creek

Rock Creek

Rock Creek

Turkey Creek

Rock Creek

Rock Creek
Rock Creek
Rock Creek
See Bill Arp Creek
Rock Creek
Rock Creek
Rock Creek
Rock Creek
Rock Creek Picnic Area
Rock Creek Ranch

Rock Creek Spring

Rock Creek Spring

Rock Creek Station

Rock Crossing

Rock Crossing Campground

Rock Crossing Reservoir

Rock Crossing Trail

Rock Crossing Windmill

Rock Dam

Rock Dam

See Perrin Dam

Rock Dike Tank

Rockfell low Dome

Rock Gap

Rock Gap, The

Rock Gap Valley

Rock Gate Detention

Rock Head

Rock Hill

Rockhole Pocket Reservoir

Rock Hole Spring

Rock Holes Tank

Rock Hole Tank

Rock Hole Tank

Rock Hole Tank

Rock Hole Tank

Rock Horse Creek

See Rock House Creek

Rock House

Rock House

Rock House

Rock House

Rock House

Rock House

Rockhouse, The

Rock House Butte

Rockhouse Cabin

Rockhouse Canyon

Rock House Canyon

Rockhouse Canyon

Rock House Canyon Rock Tank Canyon

Rockhouse Creek

See Rock House Creek

Rock House Creek
FEATURE

CLASS

bench

valley

summit

locale

spring

stream

stream

stream

stream

stream

stream

stream

stream

stream

stream

stream

stream

stream

stream

stream

park

locale

STATUS

COUNTY

COORDINATE

BGN Coconino

VARIANT

Santa Cruz

BGN Santa Cruz

BGN Cochise

BGN Pinal

BGN Pinal

VARIANT

BGN

BGN

Apache

Yavapa

BGN 1931 Navajo

$B G N$

BGN

VARIANT

BGN

$B G N$
$B G N$
$B G N$

BGN

BGN

UNOFF

spring

spring

ocale

locale

park

reservoir

trail

wel

dan

dan

BGN
BGN
BGN
BGN
ADMIN
BGN
UNOFF
UNOFF
UNOFF
VARIANT

reservoir $B G$

summit $B G$

valley

reservoir

summit

summit

reservoir

spring

reservoir

reservoir BGN

reservoir BGN

reservoir BGN

reservoir $B G N$

stream

locale

locale

locale

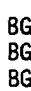

locale

locale

locale

pillar

summit

locale

valley

valley

valley

valley

BGN

BGN

BGN

BGN

BGN

$B G N$

GN

GN

Yavapai

Gila

Yavapai

Gila

Navajo

Mohave

Mohave

Apache

Cochise

Yavapai

Mohave

Apache

Mohave

Coconino

Mohave

Coconino

Apache

Pima

Coconino

Coconino

Cochise

Navajo

Apache

Coconino

Yavapai

Mohave

Gila

Maricopa

Coconino

Coconino

Coconino

Yavapai

Gila

Graham

Pinal

Maricopa

BGN Gila

BGN Coconino

Yavapai

Yavapai

Gila

Mohave

Cochise

Greenlee

Pinal

Gila

ARIANT

VARIANT

stream
stream

Gila

$362441 \mathrm{~N} 1113953 \mathrm{~W}$

$313323 \mathrm{~N} 1110256 \mathrm{~W}$

$313414 \mathrm{~N} 1110502 \mathrm{~W}$

$313250 \mathrm{~N} 1110306 \mathrm{~W}$

$313315 \mathrm{~N} 1110452 \mathrm{~W}$

315319 N1092956W

$332617 N 1110427 \mathrm{~W}$

334348 N1113040W

$334924 N 1094850 \mathrm{~W}$

340337 N1122635W

$340343 \mathrm{~N} 1110405 \mathrm{~W}$

$340548 N 1104423 \mathrm{~W}$

$340816 \mathrm{~N} 1112317 \mathrm{~W}$

(3)

$341345 \mathrm{~N} 113045 \mathrm{~W}$

$345316 \mathrm{~N} 1141027 \mathrm{~W}$

$365823 \mathrm{~N} 1131843 \mathrm{~W}$

$334930 \mathrm{~N} 1094831 \mathrm{~W}$

312947 N $1095944 \mathrm{~W}$

$340343 \mathrm{~N} 1122653 \mathrm{~W}$

$345710 \mathrm{~N} 1140035 \mathrm{~W}$

$334922 N 1094837 \mathrm{~W}$

$364334 \mathrm{~N} 113202 \mathrm{BW}$

$364336 \mathrm{~N} 1132032 \mathrm{~W}$

$343238 \mathrm{~N} 1111225 \mathrm{~W}$

$343916 \mathrm{~N} 1094052 \mathrm{~W}$

321131 N1112220W

$351430 \mathrm{~N} 1121118 \mathrm{~W}$

$345648 \mathrm{~N} 1113126 \mathrm{~W}$

$315534 \mathrm{~N} 1095837 \mathrm{~W}$

$363520 \mathrm{~N} 1101317 \mathrm{~W}$

$363511 \mathrm{N1092915 \textrm {W }}$

$361757 \mathrm{~N} 1100829 \mathrm{~W}$

$331309 \mathrm{~N} 1104100 \mathrm{~W}$

$354045 \mathrm{~N} 1110140 \mathrm{~W}$

$364901 \mathrm{~N} 1131303 \mathrm{~W}$

$333304 \mathrm{~N} 1104416 \mathrm{~W}$

334609 N1125958W

$344104 \mathrm{~N} 1112948 \mathrm{~W}$

$345240 \mathrm{~N} 1113233 \mathrm{~W}$

$350434 N 1114741 \mathrm{~W}$

$350526 \mathrm{~N} 1125830 \mathrm{~W}$

$335745 N 1104211 W$

$324002 N 1093444 \mathrm{~W}$

$324352 \mathrm{~N} 1105923 \mathrm{~W}$

$332903 \mathrm{~N} 1113117 \mathrm{~W}$

$335610 \mathrm{~N} 1104802 \mathrm{~W}$

$351524 \mathrm{N1111620 \textrm {W }}$

$352929 N 1131205 \mathrm{~W}$

$340309 \mathrm{~N} 1122636 \mathrm{~W}$

$342635 \mathrm{~N} 1134610 \mathrm{~W}$

$322346 \mathrm{~N} 1101322 \mathrm{~W}$

$330434 \mathrm{~N} 1092006 \mathrm{~W}$

$330909 \mathrm{N1} 103257 \mathrm{~W}$

335748 N1104210W

$330443 N 1104121 \mathrm{~W}$

$340742 \mathrm{~N} 1121037 \mathrm{~W}$

$340658 \mathrm{~N} 1112803 \mathrm{~W}$

$342146 N 1113203 \mathrm{~W}$

$344622 \mathrm{~N} 1103430 \mathrm{~W}$

$345930 \mathrm{~N} 1140004 \mathrm{~W}$

$365828 \mathrm{~N} 1131620 \mathrm{~W}$

$343345 \mathrm{~N} 1111256 \mathrm{~W}$

$340537 \mathrm{~N} 1122048 \mathrm{~W}$

$322326 \mathrm{~N} 1100654 \mathrm{~W}$

330558 N1092025W

$330706 N 1103035$

$335625 \mathrm{~N} 1105100 \mathrm{~W}$

$335745 \mathrm{~N} 1104211 \mathrm{~W}$

$335745 N 1104211 W$

335622N1105108W

Double Buttes 


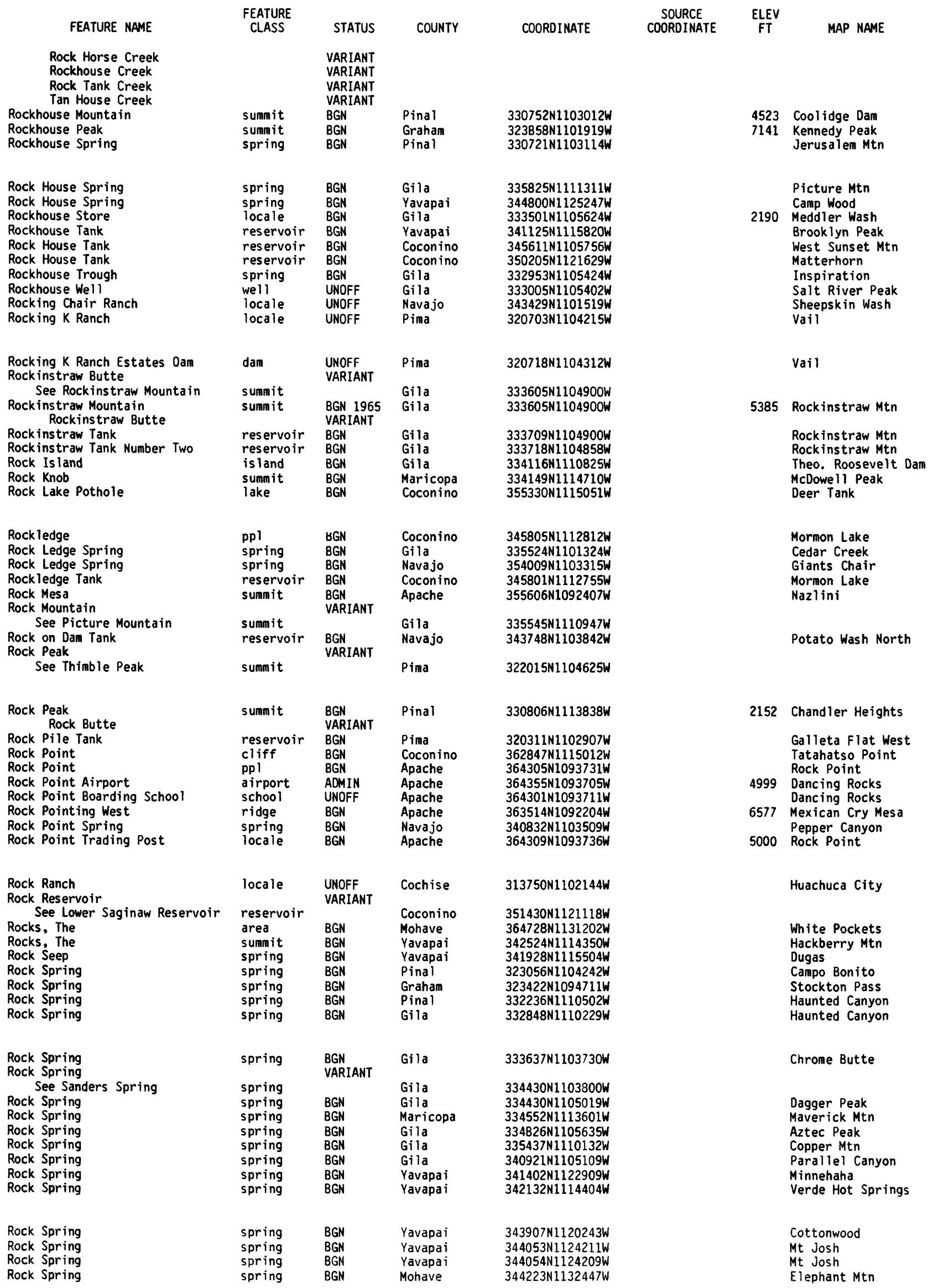




\section{FEATURE NAME}

Rock Spring

Rock Spring

Rock Spring

Rock Spring

Rock Spring

Rock Spring Canyon

Rock Spring Draw

Rock Spring Draw Tank

Rock Springs

Rock Springs Butte

Rock Springs Interchange

Rock Springs Substation

Rock Spring Tank

Rock Spring Well

Rock Station

Rock Tank

Rock Tank

Rock Tank

Rock Tank

Rock Tank

Rock Tank

Rock Tank

Rock Tank

Rock Tank

Rock Tank

Rock Tank

Rock Tank

Rock Tank

Rock Tank

Rock Tank

Rock Tank

Rock Tank

Rock Tank

Rock Tank

Rock Tank

Rock Tank

Rock Tank

Rock Tank

Rock Tank

Rock Tank

Rock Tank

Rock Tank

Rock Tank

Rock Tank

Rock Tank

Rock Tank

Rock Tank

Rock Tank

Rock Tank

Rock Tank

Rock Tank Canyon

Rock Tank Canyon

Rock Tank Canyon

See Rock House Canyon

Rock Tank Canyon

Rock Tank Canyon

Rock Tank Creek

See Rock House Creek

Rock Tank Dam

Rock Tanks

Rock Tanks

Rock Tanks

Rock Tanks Spring

Rock Top

Rock Top Spring

Rock Top Wash

Rock Trick Tank

Rockwall Gulch

Rockwall Spring

Rock Water Spring

Rock We11
FEATURE

STATUS COUNTY

COORDINATE

spring

spring

spring

spring

valley

$B G N$

BGN Mohave

Mahave

Coconino

$B G N$

Cochise

$\begin{array}{ll}\text { valley } & \text { BGN } \\ \text { reservoir } & \text { BGN } \\ \text { locale } & \text { BGN } \\ \text { summit } & \text { BGN } \\ \text { crossing } & \text { UNOFF } \\ \text { locale } & \text { UNOFF } \\ \text { reservoir } & \text { BGN } \\ \text { well } & \text { UNOFF } \\ \text { locale } & \text { BGN } \\ \text { reservoir } & \text { BGN }\end{array}$

Yavapai

Yavapai

Yavapai

Gila

Yavapai

Yavapai

Yavapai

Gila

Coconino

Santa Cruz

reservoir reservoir reservoir

reservoir

reservoir

reservoir

reservoir

reservoir

reservoir

reservoir

\section{$B G N$}

$B G N$

$B G N$

$B G N$

$B G N$

$B G N$

$B G N$

$B G N$

$B G N$

Pima

Pima

Cochise

Pima

Cochise

Pima

Cochise

Graham

Yuma

reservoir

reservoir

reservoir

reservoir

reservo

reservoir

reservoir

reservoir

reservoir

$B G N$
$B G N$
$B G N$
$B G N$
$B G N$
$B G N$
$B G N$
$B G N$
$B G N$
$B G N$

Graham

Pinal

Graham

Pinal

Maricopa

Maricopa

Maricopa

Gila

Yavapai

Yavapai

reservoir

reservoir

reservoir

reservoir

reservoir

reservoir

reservoir

reservoir

reservoir

reservoir

reservoir

reservoir

reservoir

reservoir

valley

valley

valley

valley

valley

BGN Navajo

BGN Yavapai

Coconino

Coconino

Navajo

Mohave

Apache

Coconino

Coconino

Coconino

BGN Mohave.

BGN

BGN

BGN

BGN

VARIANT

Yavapai

Coconino

Coconino

Greenlee

Gila

Gila

BGN Yavapai

BGN Navajo

VARIANT

stream

reservoir

reservoir

reservoir

spring

summit

spring

valley

reservoir

valley

spring

spring

well

$351210 \mathrm{N1122236 \textrm {H }}$

BGN Yavapa
$344948 \mathrm{~N} 1124740 \mathrm{~W}$

$345200 \mathrm{N1125426 \textrm {W }}$

354437 N1141639W

$363831 N 1102224 \mathrm{~W}$

364059 N1123423W

$313235 \mathrm{N1102037 \textrm {W }}$

342151 N1115549W

$342201 N 1115401 \mathrm{~W}$

$340256 \mathrm{~N} 1120852 \mathrm{~W}$

$333621 \mathrm{N1103705 \textrm {W }}$

$340313 N 1120845 \mathrm{~W}$

$340307 \mathrm{N1120856 \textrm {W }}$

$342058 \mathrm{N1114414 \textrm {W }}$

$333832 \mathrm{~N} 1103504 \mathrm{~W}$

$345513 N 1104812 \mathrm{~W}$

$312326 \mathrm{N1110325 \textrm {W }}$

$312959 \mathrm{N1112715 \textrm {W }}$

$313503 \mathrm{N1112743 \textrm {W }}$

$313511 \mathrm{N1112410 \textrm {W }}$

$313949 \mathrm{N1095026 \textrm {W }}$

314105 N1111326

$315319 N 1092512 \mathrm{~W}$

$322334 \mathrm{N1} 103708 \mathrm{~W}$

322421 N1100950

$323550 \mathrm{N1} 094440 \mathrm{~W}$

$324007 N 1132223 \mathrm{~W}$

$324042 N 1092813 \mathrm{~W}$

$325348 \mathrm{~N} 1110637 \mathrm{~W}$

325628 N1093513

$325953 N 1110626 \mathrm{~W}$

334407 N1120028W

334532N1115236W

$334612 \mathrm{N11} 12344 \mathrm{~W}$

$342104 N 1113157 \mathrm{~W}$

$342534 N 1114354 \mathrm{~W}$

$342804 N 1131002 \mathrm{~W}$

$343136 \mathrm{N1095611 \textrm {W }}$

$343227 \mathrm{N1113528 \textrm {W }}$

$343455 \mathrm{N1112931 \textrm {W }}$

$345634 \mathrm{N1114212 \textrm {W }}$

$345710 \mathrm{N1095300 \textrm {W }}$

$345809 \mathrm{N1} 132108 \mathrm{~W}$

$345827 N 1093550$

$350345 \mathrm{~N} 1121435 \mathrm{~W}$

$351607 N 1120053 \mathrm{~W}$

$352552 \mathrm{N1132630 \textrm {W }}$

$352807 \mathrm{N1131126 \textrm {W }}$

$353110 \mathrm{N1114201 \textrm {W }}$

$353132 \mathrm{N11} 20357 \mathrm{~W}$

$331842 \mathrm{N1090821 \textrm {W }}$

$332139 \mathrm{N1105019 \textrm {W }}$

$335748 \mathrm{N1104210 \textrm {N }}$

$344102 \mathrm{N1131022 \textrm {W }}$

$345126 \mathrm{N1103201 \textrm {W }}$

Gila 335745N1104211W

UNOFF Navajo 345054N1103258W

BGN Gila 332109N1105055W

BGN Navajo 341441N1095505W

3602

$\begin{array}{ll}\text { Coconino } & 360249 \mathrm{~N} 1122528 \mathrm{~W} \\ \text { Gila } & 340948 \mathrm{~N} 1105201 \mathrm{~W}\end{array}$

$\begin{array}{ll}\text { Gila } & 340948 \mathrm{~N} 1105201 \mathrm{~W} \\ \text { Coconino } & 345100 \mathrm{~N} 1113246 \mathrm{~W}\end{array}$

Coconino 345109N1113251W

Apache $355517 \mathrm{~N} 1092309 \mathrm{~W}$

355340 N1091810W

$\begin{array}{lll}\text { BGN } & \text { Coconino } & 343650 \mathrm{~N} 1105829 \mathrm{~W} \\ \text { BGN } & \text { Yavapai } & 340236 \mathrm{N1} 121828 \mathrm{~W}\end{array}$

340401 N1121810W

$312424 \mathrm{N1110532 \textrm {N }}$

$324321 \mathrm{N1} 1092155 \mathrm{~W}$

$\begin{array}{ccc}\text { SOURCE } & \text { ELEV } \\ \text { COORDINATE } & \text { FT MAP NAME }\end{array}$

Seepage Mtn

Camp Wood

White $\mathrm{Hill}$ s East

Kayenta West

Gunsight Point

313057 N1102253W Fort Huachuca

$342158 \mathrm{N1115313W \quad \text {Dugas }}$

Dugas

2021 Black Canyon City

5362 Sevenmile Mts 
FEATURE NAME

Rock Window

Rocky Arroyo

Rocky Bas in Tank Number One

Rocky Bas in Tank Number Two

Rocky Bottom Tank

\section{Rocky Boy Peak \\ Rocky Canyon \\ Rocky Creek \\ Rocky Creek \\ See Rocky Gulch \\ Rocky Dobl in Spring \\ Rocky Draw \\ Rocky Dublin Spring \\ Rocky Doblin Spring \\ Rocky Flat \\ Rocky Ford Mine \\ Rocky Gulch \\ Rocky Gulch \\ Rocky Creek \\ Rocky Gulch \\ See Jacks Canyon \\ Rocky Gulch \\ Rocky John Canyon \\ York Creek

Rocky Junction
Rocky Park Tank
Rocky Point
Rocky Point
Rocky Point
Rocky Point
Rocky Point
See Itak
Rocky Point
Rocky Point Junction
See Why

See Rocky Dublin Spring

Rocky Point Recreation Area

Rocky Point Tank

Rocky Rapids

Rocky Ridge

Rocky Ridge

Rocky Ridge Airport

Rocky Ridge School

Rocky Spring

Rocky Spring

Rocky Spring Mine

Rocky Tank

Rocky Tank

Rocky Tank

Rocky Tank

Rocky Tank

Rocky Tank

Rocky Top

Rocky Top

Roco Roja, Rancho

Roden Crater

Rodin Crater

Rhoton Crater

Roden Spring

Kellam Spring

Rhoton Spring

Rodeo Flat

Rodeo Flat Spring

Rodeo Flat Tank

Rodeo Ground Corral

Rodeo Park

Rodeo Tank

$$
\text { Joe Garogiola Park }
$$

Rodeo Tank

Rodger Creek

Rodgers Oraw
FEATURE
CLASS

STATUS

COUNTY

COORDINATE

arch

valley

reservoir

reservoir

reservoir

BGN
BGN
$B G N$
BGN

Apache

Navajo

Navajo

Navajo

Coconino

$363720 N 1093337 \mathrm{~W}$

$342120 N 1095953 \mathrm{~W}$

$333711 \mathrm{N1095736 \textrm {W }}$

$333643 \mathrm{N1095859 \textrm {W }}$

$344924 N 1112202 \mathrm{~W}$

summit

valley

stream

valley

spring

valley

spring

BGN Yavapai 341856N1124807W

BGN Cochise 322022N1100132W

BGN Gila 333405N1102802W

VARIANT

VARIANT

Gila

$332602 \mathrm{~N} 1101850 \mathrm{~W}$

BGN Gila

BGN Navajo

BGN 1965 Gila

VARIANT

mine

valley

BGN

UNOFF

BGN

VARIANT

VARIANT

valley

valley

valley

BGN

BGN 1962

VARIANT

Graham

Gila

Gila

$335411 \mathrm{N1111446 \textrm {W }}$

$335411 \mathrm{~N} 1111446 \mathrm{~W}$

$325740 \mathrm{~N} 1094810 \mathrm{~W}$

$341202 \mathrm{~N} 1112216 \mathrm{~W}$

$332602 \mathrm{~N} 1101850 \mathrm{~W}$

Coconino

Coconino

$344101 \mathrm{~N} 1113125 \mathrm{~W}$

$344339 \mathrm{N1113149 \textrm {W }}$

325330 N1091210W

$344556 N 1112848 \mathrm{~W}$

$332839 N 1101454 \mathrm{~W}$

$345016 \mathrm{~N} 1113521 \mathrm{~W}$

$360125 N 1140851 \mathrm{~W}$

reservoir

cape

cliff

pillar

summit

locale

locale

ppl

BGN

BGN 1983 Mohave

BGN Pima

BGN Maricopa

BGN Pima

VARIANT

BGN

VARIANT

Pima

Maricopa

$321034 \mathrm{~N} 1112119 \mathrm{~W}$

$330142 N 1130713 W$

$314110 \mathrm{~N} 1115924 \mathrm{~W}$

314141 N1120023W

$323201 \mathrm{N1125051 \textrm {W }}$

Pima

321607 N1124417W

park

reservoir

rapids

cliff

ridge

airport

school

spring

spring

mine

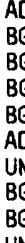

Coconino

Pima

Mohave

Coconino

Navajo

Navajo

Navajo

Gavajo

Yavapai

Apache

reservoir

reservoir

reservoir

reservoir

reservoir

reservoir

summit

summit

locale

crater

BGN

BGN

BGN

BGN
$B G N$

BGN

UNOFF

BGN

VARIANT

Greenlee

Greenlee

Gila

Gila

Gila

Yavapai

Graham

Graham

Yavapai

Coconino

$342010 N 1105655 \mathrm{~W}$

$321038 \mathrm{~N} 1112109 \mathrm{~W}$

$355400 \mathrm{~N} 1144200 \mathrm{~W}$

$350530 \mathrm{N1120751W}$

$360647 \mathrm{~N} 1103614 \mathrm{~W}$

$360419 \mathrm{N1103533 \textrm {W }}$

$331 B 09 N 1103819 \mathrm{~W}$

$342133 \times 1121840 \mathrm{~W}$

$363140 N 1090315 \mathrm{~W}$

$325211 N 1091519 \mathrm{~W}$

$332226 \mathrm{~N} 1091518 \mathrm{~W}$

$332941 N 1101241 \mathrm{~W}$

$333248 N 1104955 \mathrm{~W}$

$335545 N 1102058 \mathrm{~W}$

$345046 \mathrm{~N} 1124436 \mathrm{~W}$

$325613 N 1101451 \mathrm{~W}$

$325619 N 1101503 \mathrm{~W}$

$343843 \mathrm{~N} 1114238 \mathrm{~W}$

$352531 \mathrm{N1} 111530 \mathrm{~W}$

$352501 N 1111725 \mathrm{~W}$

spring

BGN

VARIANT

VARIANT

flat

spring.

reservoir

locale

park

BGN

$B G N$

BGN

VARIANT

reservoir

BGN

Coconino

$342559 N 1114821 \mathrm{~W}$

reservoir

stream

BGN

BGN
$342523 \mathrm{~N} 1114827 \mathrm{~W}$

$342608 \mathrm{~N} 1114 \mathrm{Bl}$ TW

395348 N1090858W

$320942 \mathrm{~N} 1105755 \mathrm{~W}$

315433N1112210W

Pima

Yavapai

Yavapai

Apac

$332208 \mathrm{~N} 1095953 \mathrm{~W}$

$335100 \mathrm{~N} 1120506 \mathrm{~W}$

354539 N1124301W
SOURCE
COORDINATE

ELEV

MAP NAME
Little Round Rock
Silver Springs
5759 Elwood Canyon
Elwood Canyon
Jaycox Mtn

6210 Weaver Peak

333826N1102635W $\quad \begin{aligned} & \text { Muskhog Mountain } \\ & \text { Cassadore Spring }\end{aligned}$

341749N1103816W Outlaw Draw

Picture Mtn

Pima

Payson South

$\begin{array}{ll}330702 N 1092005 \mathrm{~W} & \text { Clifton } \\ 333640 \mathrm{~N} 1101147 \mathrm{~W} & \text { Sontag Mesa }\end{array}$

Apache Maid Mtn

York 
NATIONAL GAZETTEER--ARIZONA 1986

FEATURE MAME

Rodgers Tank

See Rogers Tank

Rodgers Tank

Rodgers Tank

Rodger Tank

Rodin Crater

See Roden Crater

Rodolfo Wash

Rods Winter Camp Tank

Rod Tank

Roes ley Park

Rogers Canyon

Rogers Canyon

Rogers Canyon Spring

Rogers Cemetery

Rogers Dam

Rogers Lake

Rogers Lake

Rogers Lake

Rogers Reservoir

Rogers Reservoir Dam

Rogers School

Rogers Spring

Rogers Tank Rodgers Tank

Rogers Troughs

Rogers Well

Rogers Well

Rohr Ranch

Rok

See Rok Siding

Rok Siding

Rok

Roland Pond

Roll

Rolle School

Rolling Hills Cemetery

Rolling Hills Country Club

Estates

Rolling Hills Shopping Center

Roll in W Mobile Home Ranch

Rollito Creek

See Rillito River

Roll Ranch

Rolls, The

Romaines Field

See Hoa Murk

Romero Canyon

Romero Creek

Romero Pass

Romero Ranch

Romero Spring

Romero Wash

Romero Wash

Romero Well

Romo Well

Ronnys Tank

Roof Butte

Roosevelt

Roosevelt Canal

Roosevelt Conservation District Eastern Auxilary Canal

Roosevelt Canal

Roosevelt Irrigation

District Canal

Roosevelt Conservation District See Rooseveit Canal

FEATURE
CLASS

STATUS

COUNTY

COORDINATE

SOURCE

COOROIMATE

ELEV

MAP NAME

$\begin{array}{ll}\text { reservoir } & \text { VARIANT } \\ \text { reservoir } & \text { BGN } \\ \text { reservoir } & \text { BGN } \\ \text { reservoir } & \text { BGN } \\ \text { crater } & \text { VARIANT }\end{array}$

Yavapai 344946N1120125W

Coconino 351637N1121859W

Coconino 354110N1124925W

Mohave 355456N1132711W

Coconino

352531N1111530W

arroyo BGN 1966 Pima 315845N1110445W

reservoir BGN Coconino 351349N1122254W

reservoir BGN Coconino 351105N1121545W

park

valley

valley

spring

cemetery UNOFF Graham 325325N1095023W

centery UMOFF

flat BGN

Graham

Apache

Apache

$335636 \mathrm{N1091612 \textrm {W }}$

$343520 \mathrm{~N} 1093424 \mathrm{~W}$

lake BGM Coconino 350908N1114708W

reservoir BGN Graham 325246M1095053W

reservoir BGN Apache 335636N1091612

dam UNOFF Graham 325248N1095048W

school UNOFF Pima

$332536 \times 1111013 \mathrm{~W}$

reservoir BGN 1976 Yavapai 344946N1120125W

locale $\quad$ BARIANT

Pinal

332533N1111021W

well UNOFF Maricopa 334628N1131341W

well UNOFF Apache 343157N1094842W

locale UNOFF Mohave 343329N1133424W

locale VARIANT Yavapai 350250N1122354k

locale BGN Yavapai 350250N1122354W

school UMOFF Yuma 324041N1143535W

cemetery UNOFF Yavapai 343904N1122550W

ppl BGN Pima

locale UNOFF Pima 321134N1105030W

locale UNOFF Maricopa 333847N1120227W

stream

locale

area

locale

VARIANT

UNOFF

BGN

VARIANT

Pima 321849N1110316 W

Cochise 315830N1092914W

333738N1112950W

$321647 N 1124000 \mathrm{~W}$

valley
stream

gap

locale

spring

strean

stream

well

well

BGN
BGN
BGN
UNOFF
BGN
BGN
BGN
UNOFF
UNOFF
BGN

Pima

$\begin{array}{ll}\text { Pima } & 322556 \mathrm{~N} 1105314 \mathrm{~W} \\ \text { Apache } & 335356 \mathrm{M} 1090102 \mathrm{~W}\end{array}$

Apache

Pima

Pinal

Apache

Pina

Pinal

Pima

Maricopa

Coconino

$322356 \mathrm{~N} 1104950 \mathrm{~W}$

$325552 \mathrm{~N} 1105131 \mathrm{~W}$

$342614 N 1092728 \mathrm{~W}$

$321938 \mathrm{~N} 1113014 \mathrm{~W}$

$325838 \mathrm{~N} 1104702 \mathrm{~W}$

$321840 \mathrm{~N} 111300 \mathrm{BW}$

$333943 \mathrm{N1113640 \textrm {W }}$

$343121 \mathrm{~N} 1111741 \mathrm{~W}$

summit BGN Apache 362741N1090544W

Gila

$362741 N 1090544 W$

$331634 \mathrm{~N} 1114251 \mathrm{~W}$

VARIANT

VARIANT

BGN

VARIANT

Maricopa

$332838 \mathrm{~N} 1121648 \mathrm{~W}$

VARIANT

Maricopa

331634 N1114251W

VARIANT

Roosevelt Dam
Hearst Mtn

Rose Well Camp East Price Point

\begin{tabular}{|c|c|c|}
\hline $\begin{array}{l}332446 \mathrm{~N} 1110940 \mathrm{~W} \\
351623 \mathrm{~N} 1121847 \mathrm{~W}\end{array}$ & & $\begin{array}{l}\text { Twin Buttes } \\
\text { Ash Fork } \\
\text { McLellan Reservoir } \\
\text { Phoenix } \\
\text { Iron Mountain } \\
\text { Hearst Mtn } \\
\text { Iron Mountain } \\
\text { Pima } \\
\text { Rudd Knoll } \\
\text { Stinking Springs }\end{array}$ \\
\hline & 7256 & $\begin{array}{l}\text { Bellemont } \\
\text { Stinking Springs } \\
\text { Pima } \\
\text { Rudd Knoll } \\
\text { Pima } \\
\text { Tucson East } \\
\text { Iron Mountain } \\
\text { Clarkdale }\end{array}$ \\
\hline
\end{tabular}

Tiger Well

Manuel Seep

Greenwood Peak

Meath Spring

Yuma East

Chino Valley South

2675 Tucs on East

2680 Tucson East

1430 Union Hills

Fife Peak

Mine Mountain

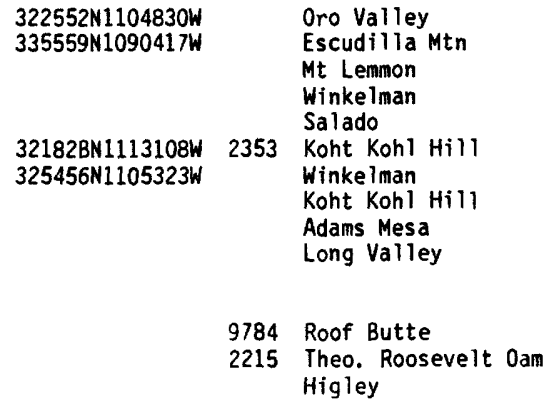

Avondale
Poverty Knoll

See Theodore Roosevelt Dam

dam

Gila

$334018 N 1110939 W$ 


\begin{tabular}{|c|c|c|c|c|c|c|c|}
\hline FEATURE NAME & $\begin{array}{l}\text { FEATURE } \\
\text { CLASS }\end{array}$ & STATUS & COUNTY & COOROINATE & $\begin{array}{l}\text { SOURCE } \\
\text { COORDINATE }\end{array}$ & $\begin{array}{l}\text { ELEV } \\
\text { FT }\end{array}$ & MAP NAME \\
\hline $\begin{array}{c}\text { Roosevelt Elementary School } \\
\text { Roosevelt School }\end{array}$ & school & $\begin{array}{l}\text { UNOFF } \\
\text { VARIANT }\end{array}$ & Pinal & $331741 N 1110557 \mathrm{~W}$ & & & Superior \\
\hline $\begin{array}{l}\text { Roosevelt Elementary School } \\
\text { Roosevelt Elementary School } \\
\text { Roosevelt Irrigation District } \\
\text { Canal }\end{array}$ & $\begin{array}{l}\text { school } \\
\text { school }\end{array}$ & $\begin{array}{l}\text { UNOFF } \\
\text { UNOFF } \\
\text { VARIANT }\end{array}$ & $\begin{array}{l}\text { Maricopa } \\
\text { Navajo }\end{array}$ & $\begin{array}{l}332358 N 1115252 W \\
350100 N 1104148 W\end{array}$ & & & $\begin{array}{l}\text { Tempe } \\
\text { Winslow }\end{array}$ \\
\hline $\begin{array}{l}\text { See Rooseveit Canal } \\
\text { Roosevelt Lake } \\
\text { See Theodore Roosevelt Lake }\end{array}$ & $\begin{array}{l}\text { canal } \\
\text { reservoir }\end{array}$ & VARIANT & $\begin{array}{l}\text { Maricopa } \\
\text { Gila }\end{array}$ & $\begin{array}{l}332838 N 1121648 W \\
334018 N 1110938 W\end{array}$ & & & \\
\hline $\begin{array}{l}\text { Roosevelt Lake Wildlife Area } \\
\text { Roosevelt Mine } \\
\text { Roosevelt Park } \\
\text { Roosevelt Ranger Station } \\
\text { Roosevelt Reservoir }\end{array}$ & $\begin{array}{l}\text { park } \\
\text { mine } \\
\text { park } \\
\text { locale }\end{array}$ & $\begin{array}{l}\text { ADMIN } \\
\text { UNOFF } \\
\text { ADMIN } \\
\text { UNOFF } \\
\text { VARIANT }\end{array}$ & $\begin{array}{l}\text { Gila } \\
\text { Yavapai } \\
\text { Maricopa } \\
\text { Gila }\end{array}$ & $\begin{array}{l}334420 \mathrm{~N} 1111125 \mathrm{~W} \\
341448 \mathrm{~N} 1121216 \mathrm{~W} \\
332702 \mathrm{~N} 1120436 \mathrm{~W} \\
334007 \mathrm{~N} 1110740 \mathrm{~W}\end{array}$ & & 2160 & $\begin{array}{l}\text { Theo. Roosevelt Dam } \\
\text { Bumble Bee } \\
\text { Phoenix } \\
\text { Theo. Roosevelt Dar }\end{array}$ \\
\hline $\begin{array}{l}\text { See Theodore Roosevelt Lake } \\
\text { Roosevelt School } \\
\text { Roosevelt School } \\
\text { Roosevelt School }\end{array}$ & $\begin{array}{l}\text { reservoir } \\
\text { school } \\
\text { school }\end{array}$ & $\begin{array}{l}\text { UNOFF } \\
\text { UNOFF } \\
\text { VARIANT }\end{array}$ & $\begin{array}{l}\text { Gila } \\
\text { Pima } \\
\text { Yuma }\end{array}$ & $\begin{array}{l}334018 N 1110938 \mathrm{~W} \\
321415 \mathrm{~N} 1105823 \mathrm{~W} \\
324305 \mathrm{~N} 1143731 \mathrm{~W}\end{array}$ & & & $\begin{array}{l}\text { Tucson } \\
\text { Yuma West }\end{array}$ \\
\hline $\begin{array}{l}\text { See Roosevelt Elementary } \\
\text { School }\end{array}$ & school & & Pinal & $331741 \mathrm{~N} 1110557 \mathrm{~W}$ & & & \\
\hline $\begin{array}{l}\text { Roosevelt School } \\
\text { Roosevelt Tank } \\
\text { Roosevelt Tank } \\
\text { Roosevelt Tank } \\
\text { Roostercomb } \\
\text { Rooster Mesa }\end{array}$ & $\begin{array}{l}\text { school } \\
\text { reservoir } \\
\text { reservoir } \\
\text { reservoir } \\
\text { summit }\end{array}$ & $\begin{array}{l}\text { UNOFF } \\
\text { BGN } \\
\text { BGN } \\
\text { BGN } \\
\text { BGN } \\
\text { VARIANT }\end{array}$ & $\begin{array}{l}\text { Maricopa } \\
\text { Cochise } \\
\text { Maricopa } \\
\text { Coconino } \\
\text { Cochise }\end{array}$ & $\begin{array}{l}332330 \mathrm{~N} 1120356 \mathrm{~W} \\
320923 \mathrm{~N} 1091933 \mathrm{~W} \\
334326 \mathrm{~N} 1123745 \mathrm{~W} \\
345633 \mathrm{~N} 1110755 \mathrm{~W} \\
321741 \mathrm{~N} 1090526 \mathrm{~W}\end{array}$ & & & $\begin{array}{l}\text { Phoenix } \\
\text { Little Wood Canyon } \\
\text { Daggs Tank } \\
\text { Chavez Mtn NW } \\
\text { Doubtful Canyon }\end{array}$ \\
\hline $\begin{array}{l}\quad \text { See Meridian Butte } \\
\text { Rooster Rock } \\
\text { Roper Dam } \\
\text { Roper Lake }\end{array}$ & $\begin{array}{l}\text { summit } \\
\text { summit } \\
\text { dam } \\
\text { lake }\end{array}$ & $\begin{array}{l}\text { BGN } \\
\text { UNOFF } \\
\text { BGN }\end{array}$ & $\begin{array}{l}\text { Navajo } \\
\text { Apache } \\
\text { Graham } \\
\text { Graham }\end{array}$ & $\begin{array}{l}365405 \mathrm{~N} 1100000 \mathrm{~W} \\
365457 \mathrm{~N} 1095906 \mathrm{~W} \\
324518 \mathrm{~N} 1094206 \mathrm{~W} \\
324518 \mathrm{~N} 1094206 \mathrm{~W}\end{array}$ & & 5984 & $\begin{array}{l}\text { Rooster Rock } \\
\text { Safford } \\
\text { Safford }\end{array}$ \\
\hline $\begin{array}{l}\text { Roper Tank } \\
\text { Roque Tank } \\
\text { Rosalie Mine } \\
\text { Rosalie Mine Trail Number Eight } \\
\text { Rosalie Spring } \\
\text { Rosalie Tank } \\
\text { Rosario Mine } \\
\text { Rosas Park } \\
\text { Rosebud } \\
\text { Rosebud Tank }\end{array}$ & $\begin{array}{l}\text { reservoir } \\
\text { reservoir } \\
\text { mine } \\
\text { trail } \\
\text { spring } \\
\text { reservoir } \\
\text { mine } \\
\text { reservoir } \\
\text { locale } \\
\text { reservoir }\end{array}$ & $\begin{array}{l}\text { BGN } \\
\text { BGN } \\
\text { UNOFF } \\
\text { UNOFF } \\
\text { BGN } \\
\text { BGN } \\
\text { UNOFF } \\
\text { BGN } \\
\text { BGN } \\
\text { BGN }\end{array}$ & $\begin{array}{l}\text { Yavapai } \\
\text { Coconino } \\
\text { Yavapai } \\
\text { Yavapai } \\
\text { Yavapai } \\
\text { Yavapai } \\
\text { Santa Cruz } \\
\text { Pinal } \\
\text { Apache } \\
\text { Coconino }\end{array}$ & $\begin{array}{l}345440 \mathrm{~N} 1122346 \mathrm{~W} \\
345614 \mathrm{~N} 1112313 \mathrm{~W} \\
341108 \mathrm{~N} 1115711 \mathrm{~W} \\
340624 \mathrm{~N} 1115430 \mathrm{~W} \\
341041 \mathrm{N1115648W} \\
341043 \mathrm{~N} 1115656 \mathrm{~W} \\
313534 \mathrm{~N} 1105028 \mathrm{~W} \\
323639 \mathrm{N1} 112247 \mathrm{~W} \\
340002 \mathrm{~N} 1091600 \mathrm{~W} \\
354942 \mathrm{~N} 1123251 \mathrm{~W}\end{array}$ & & & $\begin{array}{l}\text { Paulden } \\
\text { Mormon Lake } \\
\text { Brooklyn Peak } \\
\text { Cooks Mesa } \\
\text { Brooklyn Peak } \\
\text { 8rooklyn Peak } \\
\text { Patagonia } \\
\text { Samaniego Hillss } \\
\text { Eagar } \\
\text { Rosebud Tank }\end{array}$ \\
\hline $\begin{array}{l}\text { Rose Canyon } \\
\text { Rose Canyon } \\
\text { Rose Canyon Campground } \\
\text { Rose Canyon Lake } \\
\text { Rose Creek } \\
\text { Rose Creek Lodge } \\
\text { Rose Creek Spring } \\
\text { Rosedale Cenetery } \\
\text { Rosedale Heights } \\
\text { Rose Garden Place (subdivision) }\end{array}$ & $\begin{array}{l}\text { valley } \\
\text { valley } \\
\text { park } \\
\text { reservoir } \\
\text { strean } \\
\text { locale } \\
\text { spring } \\
\text { cemetery } \\
\text { ppl } \\
\text { ppl }\end{array}$ & $\begin{array}{l}\text { BGN } \\
\text { BGN } \\
\text { ADMIN } \\
\text { BGN } \\
\text { BGN } \\
\text { BGN } \\
\text { BGN } \\
\text { UNOFF } \\
\text { BGN } \\
\text { BGN }\end{array}$ & $\begin{array}{l}\text { Pima } \\
\text { Cochise } \\
\text { Pima } \\
\text { Pima } \\
\text { Gila } \\
\text { Gila } \\
\text { Gila } \\
\text { Maricopa } \\
\text { Navajo } \\
\text { Maricopa }\end{array}$ & $\begin{array}{l}322308 \mathrm{~N} 1104302 \mathrm{~W} \\
322448 \mathrm{~N} 1100256 \mathrm{~W} \\
322335 \mathrm{~N} 1104214 \mathrm{~W} \\
322315 \mathrm{~N} 1104240 \mathrm{~W} \\
335046 \mathrm{~N} 1105853 \mathrm{~W} \\
335003 \mathrm{~N} 1105839 \mathrm{~W} \\
334918 \mathrm{~N} 1105900 \mathrm{~W} \\
332647 \mathrm{~N} 1120524 \mathrm{~W} \\
345433 \mathrm{~N} 1100910 \mathrm{~W} \\
334005 \mathrm{~N} 1120655 \mathrm{~W}\end{array}$ & $\begin{array}{l}322356 N 1104131 \mathrm{~W} \\
322345 \mathrm{~N} 1100410 \mathrm{~W} \\
334839 \mathrm{~N} 1105953 \mathrm{~W}\end{array}$ & $\begin{array}{l}6933 \\
5391\end{array}$ & $\begin{array}{l}\text { Mount Bigelow } \\
\text { Reiley Peak } \\
\text { Mount Bigelow } \\
\text { Mount Bigelow } \\
\text { Aztec Peak } \\
\text { Aztec Peak } \\
\text { Aztec Peak } \\
\text { Phoenix } \\
\text { Holbrook } \\
\text { Union Hills }\end{array}$ \\
\hline $\begin{array}{l}\text { Rose Garden Place III } \\
\text { (subdivision) } \\
\text { Rose Garden Spring } \\
\text { Rose Garden Tank } \\
\text { Rose Lane Junior High School } \\
\text { Roselane Park } \\
\text { Rose Lane Trailer Park } \\
\text { Rose Lateral } \\
\text { Rose Linda School } \\
\text { Rosemary Lodge }\end{array}$ & $\begin{array}{l}\text { ppl } \\
\text { spring } \\
\text { reservoir } \\
\text { school } \\
\text { park } \\
\text { locale } \\
\text { canal } \\
\text { school } \\
\text { locale }\end{array}$ & $\begin{array}{l}\text { BGN } \\
\text { BGN } \\
\text { BGN } \\
\text { UNOFF } \\
\text { ADMIN } \\
\text { UNOFF } \\
\text { BGN } \\
\text { UNOFF } \\
\text { BGN }\end{array}$ & $\begin{array}{l}\text { Maricopa } \\
\text { Graham } \\
\text { Gila } \\
\text { Maricopa } \\
\text { Maricopa } \\
\text { Maricopa } \\
\text { Yuma } \\
\text { Maricopa } \\
\text { Maricopa }\end{array}$ & $\begin{array}{l}334012 \mathrm{~N} 1120637 \mathrm{~W} \\
331228 \mathrm{~N} 1093947 \mathrm{~W} \\
333625 \mathrm{~N} 1102329 \mathrm{~W} \\
333136 \mathrm{~N} 1120323 \mathrm{~W} \\
333141 \mathrm{N1} 120956 \mathrm{~W} \\
332655 \mathrm{~N} 1120730 \mathrm{~W} \\
324153 \mathrm{~N} 1143952 \mathrm{~W} \\
332414 \mathrm{N1} 120322 \mathrm{~W} \\
332138 \mathrm{~N} 1120235 \mathrm{~W}\end{array}$ & & 1390 & $\begin{array}{l}\text { Union Hills } \\
\text { Park Creek Cabins } \\
\text { Cassadore Spring } \\
\text { Sunnys lope } \\
\text { Glendale } \\
\text { Fowler } \\
\text { Yuma West } \\
\text { Phoenix } \\
\text { Lone Butte }\end{array}$ \\
\hline $\begin{array}{l}\text { Rosemary Tank } \\
\text { Rosemont Camp } \\
\text { Rosemont Junction } \\
\text { Rosemont Springs } \\
\text { Rose Peak } \\
\text { Rose Peak } \\
\text { Rose Point } \\
\text { Rose School } \\
\text { Rose Spring } \\
\text { Rose Spring }\end{array}$ & $\begin{array}{l}\text { reservoir } \\
\text { ppl } \\
\text { locale } \\
\text { spring } \\
\text { summit } \\
\text { summit } \\
\text { cliff } \\
\text { school } \\
\text { spring } \\
\text { spring }\end{array}$ & $\begin{array}{l}\text { BGN } \\
\text { BGN } \\
\text { BGN } \\
\text { BGN } \\
\text { BGN } \\
\text { BGN } \\
\text { BGN 190B } \\
\text { UNOFF } \\
\text { BGN } \\
\text { BGN }\end{array}$ & $\begin{array}{l}\text { Santa Cruz } \\
\text { Pima } \\
\text { Pima } \\
\text { Pima } \\
\text { Pima } \\
\text { Greenlee } \\
\text { Coconino } \\
\text { Pima } \\
\text { Greenlee } \\
\text { Coconino }\end{array}$ & $\begin{array}{l}312326 \mathrm{~N} 1103133 \mathrm{~W} \\
314930 \mathrm{~N} 1104403 \mathrm{~W} \\
315003 \mathrm{~N} 1104356 \mathrm{~W} \\
314942 \mathrm{~N} 1104417 \mathrm{~W} \\
322253 \mathrm{~N} 1104310 \mathrm{~W} \\
332623 \mathrm{~N} 1092213 \mathrm{~W} \\
361928 \mathrm{~N} 1122021 \mathrm{~W} \\
321016 \mathrm{~N} 1105843 \mathrm{~W} \\
333457 \mathrm{~N} 1093000 \mathrm{~W} \\
361330 \mathrm{~N} 1112353 \mathrm{~W}\end{array}$ & & $\begin{array}{l}4820 \\
4790 \\
7299 \\
8786 \\
7567\end{array}$ & $\begin{array}{l}\text { Cane lo Pass } \\
\text { Empire Ranch } \\
\text { Empire Ranch } \\
\text { Empire Ranch } \\
\text { Mount Bigelow } \\
\text { Rose Peak } \\
\text { King Arthur Castle } \\
\text { Tucson } \\
\text { Baldy Bill Point } \\
\text { Willow Springs }\end{array}$ \\
\hline Rose Tank & reservoir & $B G N$ & Yavapai & $344840 \mathrm{~N} 1130635 \mathrm{~W}$ & & & Scratch Canyon \\
\hline
\end{tabular}


NATIONAL GAZETTEER--ARIZONA 1986

\section{FEATURE NAME}

Rose Tank

Rose Tank

Rose Terrace Trailer Park

Rose Tree Ranch

Rose Well Camp

Rosewood Point

Rosey Creek

Rosey Creek Campground

Rosilda Spring

Rosilda Spring Canyon

Roskruge Junior High School

Roskruge Mountains

Roskruge Mountains

See Silver Bell Mountains

Ross Airport

Ross Draw

Ross Spring

Ross Spring

Ross Spring

Ross Tank

Rosy Canyon

Rotary Park

Rotary Park

Roten Cabin

Rotenhouse We 11

Rotten Bananas Butte

Rotten Spring

Rotten Spring

Rouch We11

Rough Canyon

Rough Canyon

Rough Canyon

Rough Canyon Tank

Rough House Tank

Rough Mountain

Rough Mountain

Rough Point Wells

Rough Ridge Tank

Rough Rock

Rough Rock

Rough Rock Airstrip

Rough Rock Demonstration School

Rough Rock Point

Rough Rock Spring

Rough Rock Spring

Rough Rock Trail Canyon

Rough Rock Well

Round Butte

Round Butte

See Round Top

Round Butte

Round Butte

Round Butte Spring

Round Cienega

Round Corral

Round Corral

Round $\mathrm{Hill}$

Round $\mathrm{Hil}$

Round $\mathrm{HiTl}$

See Bald Mountain

Round Hill Tank

Round Is land (historical)

Round Mounta in

Round Mountain

Round Mountain

Round Mounta in

Round Mounta in

Round Mountain

Round Mountain

Round Mountain

See Little Round Mountain
FEATURE

CLASS

STATUS

COUNTY

COORDINATE

reservoir

locale

locale

locale

cliff

stream

park

spring

BGN

BGN

UNOFF

UNOFF

BGN

BGN

ADMIN

BGN

Yavapai

Coconino

Maricopa

Santa Cruz

Coconino

Pima

Apache

Apache

valley

school

BGN Coconino

UNOFF

range

BGN 1974 Pima

VARIANT

summit

airport

valley

spring

spring

spring

BGN

BGN

BGN

reservoir

valley

park

park

locale

well

summit

spring

well

BGN

BGN
ADMIN

ADMIN

BGN

UNOFF

BGN

$B G N$

$B G N$

UNOFF

Pima

Maricopa

Navajo

Yavapai

Yavapai

Coconino

Gila

Mohave

Maricopa

Maricopa

Graham

Apache

Navajo

Navajo

Navajo

Mohave

valle

valley

valley

reservoir

reservoir

sumnit

well

reservoir

pillar

BGN Cochise

Maricopa

Gila

Coconino

Cochise

Cochise

Coconing

Greenlee

BGN

BGN

ppl

airport

chool

cliff

spring

spring

valley

well

sunnit

sumnit

\section{BGN Apache}

ADMIN Apache

UNOFF Apache

BGN

BGN

BGN

$B G N$

UNOFF

BGN

VARIANT

Coconino

Navajo

Apache

Apache

Navajo

Maricopa

Pinal

summit

BGN Maricopa

Navajo

Navajo

Apache

Cochise

Yavapa

Pima

locale

locale

sumnit

summit

summit

Yavapa

Yavapai

reservoir $B G N$

is lan

sumait

summit

summit

summit

summit

summit

summit

summit
BGN Cochise

$350913 N 1131708 W$

$354804 N 1125449 \mathrm{~W}$

$333053 \mathrm{~N} 1120918 \mathrm{~N}$

$314025 \mathrm{~N} 1102950 \mathrm{~W}$

$354431 N 1125219 \mathrm{~W}$

$322124 N 1105512$

$340228 \mathrm{~N} 1092722 \mathrm{~W}$

$340230 \mathrm{~N} 1092741 \mathrm{~W}$

$351031 \mathrm{~N} 1120343 \mathrm{~W}$

$350905 \mathrm{~N} 1120145 \mathrm{~W}$

$321343 \mathrm{~N} 1105746 \mathrm{~W}$

$321321 \mathrm{~N} 1112524 \mathrm{~W}$

$322451 \mathrm{~N} 1112953 \mathrm{~W}$

$332449 \mathrm{~N} 1115044 \mathrm{~W}$

$342324 \mathrm{~N} 1103240 \mathrm{~W}$

$341517 N 1122837 \mathrm{~W}$

341639 N1122833W

$351216 N 1120107 \mathrm{~W}$

$341810 \mathrm{~N} 1113546 \mathrm{~W}$

$365750 \mathrm{~N} 1125220 \mathrm{~W}$

$322313 N 1115357 \mathrm{~W}$

$332357 N 1115007 \mathrm{~W}$

$325704 \mathrm{~N} 1101530 \mathrm{~W}$

$350936 N 1092302 \mathrm{~W}$

$351351 \mathrm{N1} 101946 \mathrm{~W}$

$340019 \mathrm{~N} 1102136 \mathrm{~W}$

$340941 \mathrm{~N} 1104202 \mathrm{~W}$

$365048 \mathrm{~N} 1125146 \mathrm{~W}$

313008 N1102709W

321803 N1093516W

332916 N1111249

$333005 N 1104545 \mathrm{~W}$

355118 N1114304

$320605 N 1092019 W$

$321428 N 1093246 \mathrm{~W}$

$361327 \mathrm{~N} 1112008 \mathrm{~W}$

$331958 \mathrm{~N} 1092257 \mathrm{~W}$

362641 N1091619W

$362426 \mathrm{N1095220 \textrm {W }}$

$362400 \mathrm{~N} 1095200 \mathrm{~W}$

$362427 \mathrm{~N} 1095137 \mathrm{~W}$

360108 N1104643W

$360236 \mathrm{~N} 1101852 \mathrm{~W}$

361157 N1092438W

$362043 \mathrm{~N} 1095424 \mathrm{~W}$

$360211 \mathrm{N1} 101907 \mathrm{~W}$

$324716 \mathrm{~N} 1123005 \mathrm{~W}$

$331216 \mathrm{~N} 1114308 \mathrm{~W}$

334701N1113650W

$351959 N 1100147 \mathrm{~W}$

$351935 \mathrm{~N} 1100056 \mathrm{~W}$

$335234 N 1092243$

$315331 \mathrm{N1} 102527 \mathrm{~W}$

$341444 \mathrm{~N} 1114554 \mathrm{~W}$

$313700 \mathrm{~N} 1112927 \mathrm{~W}$

342917 N1121212

$345243 \mathrm{~N} 1125056 \mathrm{~W}$

$313730 \mathrm{~N} 1112906 \mathrm{~W}$

353400 N114400OW

$323220 \mathrm{~N} 1090557 \mathrm{~W}$

$334546 \mathrm{~N} 1110150 \mathrm{~W}$ 


\section{FEATURE NAME}

Round Mountain

Round Mountain

Round Mountain Dam Number Two

Round Mountain Draw

Round Mountain Spring

Round Mountain Tank

Round Mountain Tank

Round Mountain Tank

Round Mountain Well

Round Park

Round Peak

See Round Rock

Round Pond

Round Rock

Round Rock

Round Peak

Round Rock Butte

Tsenakahn

Tsenakahn Butte

Tse nakani

Tsenakani

Round Rock

Round Roc

Bisdot ' $^{\prime}$ is desaki

Round Rock Store

Tsenakaahn

Tsenakahn

Round Rock Butte

See Round Rock

Round Rock Dam

Round Rock Day School

Round Rock Lake

Round Rock Reservoir

Round Rock Store

See Round Rock

Round Rock Trading Post

Round Spring

Round Tank

Round Tank

Round Tank Well

Round the Mountain Spring

Round the Mountain Trail

Round Top

Round Butte

Round Top

Round Top Butte

See Round Top Mountain

Round Top

Round Top

Round Top Butte

See Round Top

Round Top Mesa Campground

Round Top Mountain

Round Top

Round Top Mountain

See Little Round Mountain

Round Top Mountain

Round Top Mountain Lookout

Round Top Ridge

Round Top Trading Post

Round Top Wash

\section{Roundtree Canyon \\ Round Tree Canyon \\ Round Tree Canyon}

See Roundtree Canyon

Roundtree Spring

Roundup Bas in

Roundup Bas in Tank

Roundup Grounds Canyon

Roundup Hil

Roundup Park
FEATURE
CLASS

STATUS

COUNTY

summit

summit

dam

valley

spring

reservoir

reservoir

reservoir

well

gap

$\begin{array}{ll}\text { BGN } & \text { Coconino } \\ \text { BGN } & \text { Coconino } \\ \text { UNOFF } & \text { Greenlee } \\ \text { BGN } & \text { Green lee } \\ \text { BGN } & \text { Yavapai } \\ \text { BGN } & \text { Graham } \\ \text { BGN } & \text { Yavapai } \\ \text { BGN } & \text { Coconino } \\ \text { UNOFF } & \text { Yavapai } \\ \text { BGN } & \text { Cochise }\end{array}$

COORDINATE

350407 N1120508

$352647 N 1124347 \mathrm{~W}$

$323234 N 1090518 \mathrm{~W}$

323441N1090222W

$341101 N 1123846 \mathrm{~W}$

$323131 \mathrm{~N} 1094354 \mathrm{~W}$

$344333 \mathrm{~N} 1113653 \mathrm{~W}$

$350421 \mathrm{~N} 1120558 \mathrm{~W}$

$343052 \mathrm{~N} 1131525 \mathrm{~W}$

315206N1091703W

VARIANT

summit

reservoir

pillar

summit

BGN

Apache

Coconino

BGN 1915 Apache

VARIANT

VARIANT

VARIANT

VARIANT

VARIANT

summit
locale

BGN

Coconino

VARIANT

VARIANT

VARIANT

VARIANT

VARIANT

summit

dam

school

UNOFF

UNOFF

reservoir

reservoir

locale

locale

spring

reservoir

reservoir

well

spring

BGN

BGN

BGN

BGN

BGN

UNOFF

$B G N$

trail

summit

UNOFF

BGN

VARIANT

VARIANT

VARIANT

summit

summit

summit

BGN

BGN

VARIANT

summit

park

summit

ADM

BGN
VARIANT

VARIANT

summit

summit

tower

ridge

locale

arroyo

BGN

UNOFF

8GN

BGN

BGN

valley

BGN 1968 Yavapaj

VARIANT

VARIANT

valley

spring

bas in

reservoir

valley

summit

BGN

$B G N$

BGN

BGN

BGN

$B G N$
Mohave

Apache

$363009 \mathrm{~N} 109331 \mathrm{WW}$

$364208 N 1132005 \mathrm{~W}$

$360709 \mathrm{~N} 1110636 \mathrm{~W}$

$363009 \mathrm{N1093311 \textrm {W }}$

365807 N1105610W

$363047 \mathrm{~N} 1092822 \mathrm{~W}$

363009 N1093311W

$362948 \mathrm{~N} 1092906 \mathrm{~W}$

363050 N1092823W

$362948 \mathrm{~N} 1092906 \mathrm{~W}$

$362914 \mathrm{~N} 1092709 \mathrm{~W}$

363047 N1092822W

363047 N1092B2OW

$340553 N 1115654 \mathrm{~W}$

$331332 \mathrm{~N} 1123755 \mathrm{~W}$

$340544 \mathrm{~N} 1111221 \mathrm{~W}$

$340740 \mathrm{~N} 1131909 \mathrm{~W}$

$324226 \mathrm{~N} 1094923 \mathrm{~W}$

$324125 N 1094847 \mathrm{~W}$

$331216 \mathrm{~N} 1114308 \mathrm{~W}$

$335600 \mathrm{~N} 1100034 \mathrm{~W}$

$352605 \mathrm{~N} 1102926 \mathrm{~W}$

$354328 N 1093318 \mathrm{~W}$

$331216 N 1114308 \mathrm{~W}$

$365510 \mathrm{~N} 1094600 \mathrm{~W}$

$335600 \mathrm{~N} 1100034 \mathrm{~W}$

345808 N1115006W

345811 N1114745W

$335600 \mathrm{~N} 1100033 \mathrm{~W}$

$362805 \mathrm{~N} 1093333 \mathrm{~W}$

$354301 \mathrm{N1093149 \textrm {W }}$

$335647 \mathrm{~N} 1095542 \mathrm{~W}$

340906 N1114817W

Yavapai

$340906 \mathrm{~N} 1114817 \mathrm{~W}$

$340618 N 1115157 \mathrm{~W}$

$343827 \mathrm{~N} 1113607 \mathrm{~W}$

$343842 \mathrm{~N} 1113619 \mathrm{~W}$

$325927 \mathrm{~N} 1101340 \mathrm{~W}$

$333743 \mathrm{~N} 1110107 \mathrm{~W}$

Gila

Coconino
SOURCE
COORDINATE

ELEV

MAP NAME

214 White Horse Lake

7098 Mount Floyd

Round Mtn

Round Mtn

Yarnell

Gillespie Mtn

Apache Maid Mtn

White Horse Lake

3516 Grayback Mts

Chiricahua Peak

The Grandstand

5042 Tuba City SE

6288 Little Round Rock

6022 Chaiyahi Flat

5350 Round Rock

Fire Dance Mesa Round Rock

Fire Dance Mesa Fire Dance Mesa

5346 Round Rock Cooks Mesa Cotton Center NW Sheep Bas in Mtn Smith Peak NE Mt Graham

Mt Graham

1509 Chandler Heights

6666 Shonto Butte Ganado

5160 Garnet Ridge

7189 Round Top Mtn

6127 Wilson Mountain Round Top Mtn Many Farms NE

335824 N1095759W

6400 Ganado Alchesay Flat

340600 N1115150W

Bloody Basin

Rover Peak Apache Maid Mtn Apache Maid Mtn

$330041 N 1101332 \mathrm{~W}$ Jackson Mtn

2511 Windy Hill Hutch Mtn 


\section{FEATURE NAME}

Roundup Park

Roundup Park Spring

Roundup Park Tank

Roundup Picnic Ground

Roundup Tank

Round Valley

See Muddy Canyon

Round Valley

Round Valley

Round Valley

Round Valley

Round Valley

Round Valley

Round Valley

Round Valley

Round Valley

See Kid Pen Valley

Round Valley

Round Valley High School

Round Valley Interchange

Round Valley Ranch

Round Valley Spring

Round Valley Tank

Round Valley Tank

Round Valley Trading Post

Round Valley Wash

Roundy Creek

Roundy Creek

See Tanner Wash

Roundy Crossing

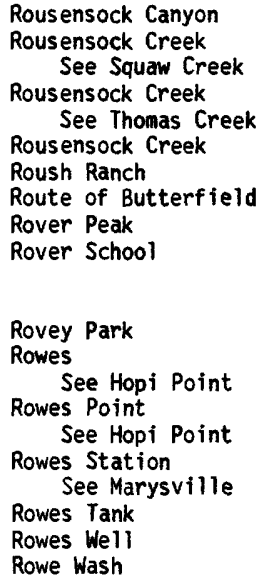

Rover Peak

Rover School

Rovey Park

Rowes

See Hopi Point

Rowes Point

See Hopi Point

Rowes Station

See Marysville

Rowes Tank

Rowes Well

Rowe Wash

Route of Butterfield Stage

Rowe Well Picnic Area

Rowlan Tank

Rowood

Row Water Canyon

Row Water Spring

Royal Arch

Royal Arch Creek

Royal Arches

Royal Blue Mine

Royal Estates West

(subdivision)

Royal Flush Mine

Royal Glen Mobile Hone Park

Royal Paim Park

Royal Palm School

Royal Palms of Mesa Shopping$$
\text { Center }
$$

Royal Paim Travel Trailer and

Mobile Home Park

Royal Palm Village (trailer park )

\section{FEATURE \\ CLASS}

STATUS

COUNTY

COORDINATE

$344942 \mathrm{~N} 1113053 \mathrm{~W}$

flat

spring

park ADMIN Santa Cruz

VARIANT

arroyo

bas in

valley

\section{BGN}

BGN

valley

valley

valley

valley

valley

valley

valley

crossing

BGN

BGN

$B G N$

BGN

VARIANT

$B G N$

UNOFF

Coconino

Yavapai

Gila

Cochise

Maricopa

Apache

Gila

Apache

Mhave

Mohave

Coconino

Coconino

Apache

Mohave

locale

spring

reservoir

reservoir

locale

stream

stream

strean

locale

UNOFF Mohave

BGN Yavapai

$B G N$

$B G N$

BGN

BGN

VARIANT

Gila.

Coconino

Navajo

Yavapai

Coconino

BGN

Navajo

valley BGN Greenlee

stream

VARIANT

Greenlee

VARIANT

stream

stream

locale

trail

summit

school

BGN

UNOFF

UNOFF

BGN

UNOFF

park

ADMIN

cliff

VARIANT

cliff

VARIANT

VARIANT

locale

reservoir

well

BGN

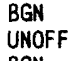

Greenlee

Greenlee

Cochise

Yuma

Yavapai

Maricopa

stream

$B G N$

Maricopa

Coconino

Coconino

Maricopa

Coconino

Coconino

Maricopa

reservoir

locale

valley

spring

arch

stream

arch

mine

ppl

$\begin{array}{ll}\text { ADMIN } & \text { Coconino } \\ \text { BGN } & \text { Coconino } \\ \text { BGN } & \text { Pima } \\ \text { BGN } & \text { Mohave } \\ \text { BGN } & \text { Mohave } \\ \text { BGN } & \text { Yuma } \\ \text { BGN 1908 } & \text { Coconino } \\ \text { BGN } & \text { Coconino } \\ \text { UNOFF } & \text { Santa Cruz } \\ \text { BGN } & \text { Maricopa }\end{array}$

$360153 \mathrm{~N} 1121024 \mathrm{~W}$ 345657 N1105258W

$322206 \mathrm{~N} 1125043 \mathrm{~W}$

350221 1133909W

$350240 \mathrm{N1} 133429 \mathrm{~W}$

$332358 \mathrm{~N} 1133949 \mathrm{~W}$

361151 N1122658W

$362354 \mathrm{~N} 1115324 \mathrm{~W}$

$313619 \mathrm{~N} 1105139 \mathrm{~W}$

$333630 \mathrm{N1121120 \textrm {W }}$

$\begin{array}{llll}\text { mine } & \text { UNOFF } & \text { Gila } & 341006 \text { N1111625W } \\ \text { locale } & \text { UNOFF } & \text { Maricopa } & 333235 N 1120907 W \\ \text { park } & \text { AOMIN } & \text { Maricopa } & 333327 N 1120521 W \\ \text { school } & \text { UNOFF } & \text { Maricopa } & 333344 N 1120557 W \\ \text { locale } & \text { UNOFF } & \text { Maricopa } & 332702 \text { N1114811W } \\ \text { locale } & \text { UNOFF } & \text { Maricopa } & 333412 \text { N1120606W } \\ \text { locale } & \text { UNOFF } & \text { Maricopa } & 332445 \text { N1114448W }\end{array}$

SOURCE
COORDINATE

ELEV

MAP NAME

Stoneman Lake

Hutch Mtn

Hutch Mtn

5480 Mt Wrightson

Munds Park

Georges Butte

Portal

334900N1112B50W Maverick Mtn

340625N1091439W Eagar

$341205 N 1111854 \mathrm{~W} \quad$ Payson South

Concho Lake

Creanery Canyon

$344812 \mathrm{~N} 1135500 \mathrm{~W}$

$350533 \mathrm{~N} 1133855 \mathrm{~W}$

Bottleneck Wash

$364728 N 1121143 W$

Buck Pasture Canyon

Eagar

Tin Mountain NW

Bottleneck Wash

Seepage Mtn

Georges Butte

Valle Tank

6340 Pinon

$345234 N 1125137 \mathrm{~W}$ Seepage Mtn

363440 N1114020W North Canyon Point

Show Low North

$332614 \mathrm{~N} 1092124 \mathrm{~W}$

Dutch Blue Creek

$332614 N 1092124 \mathrm{~W}$

Dutch Blue Creek

Portal Peak

Ligurta

5279 Rover Peak

Guadalupe

Glendale

$360929 N 1122748 \mathrm{~W}$

6675 Grand Canyon

Grand Canyon

$335202 \mathrm{~N} 1115401 \mathrm{~W}$

Cave Creek

Grand Canyon

West Sunset Mtn

1714 Ajo South

Bottleneck Wash

Aust in Peak

Coyote Peak

Explorers Monument

Buffalo Ranch

Patagonia

1210 Glendale

Payson South

1175 Glendale

Sunnys lope

1210 Sunnys lope

Mesa

1225 Sunnys lope

1285 Buckhorn 


\begin{tabular}{|c|c|c|c|c|c|c|c|}
\hline FEATURE NAME & $\begin{array}{l}\text { FEATURE } \\
\text { CLASS }\end{array}$ & STATUS & COUNTY & COORDINATE & $\begin{array}{l}\text { SOURCE } \\
\text { COORDINATE }\end{array}$ & $\begin{array}{l}\text { ELEV } \\
\text { FT }\end{array}$ & MAP NAME \\
\hline $\begin{array}{l}\text { Royal Palo Verde Shopping } \\
\text { Center }\end{array}$ & locale & UNOFF & Maricopa & $333305 N 1120327 \mathrm{~W}$ & & 1250 & Sunnys lope \\
\hline $\begin{array}{l}\text { Roy Canyon } \\
\text { Roys Pond } \\
\text { Roy Spring }\end{array}$ & $\begin{array}{l}\text { valley } \\
\text { lake }\end{array}$ & $\begin{array}{l}\text { BGN } \\
\text { BGN } \\
\text { VARIANT }\end{array}$ & $\begin{array}{l}\text { Graham } \\
\text { Mohave }\end{array}$ & $\begin{array}{l}325617 N 1092602 \mathrm{~W} \\
362223 \mathrm{~N} 1131948 \mathrm{~W}\end{array}$ & $325834 N 1092708 \mathrm{~W}$ & & $\begin{array}{l}\text { Gila Box } \\
\text { Cold Spring }\end{array}$ \\
\hline $\begin{array}{l}\text { See Willow Spring } \\
\text { Roy Spring } \\
\text { Roys Tank } \\
\text { Roy Tank } \\
\text { Roy Tank }\end{array}$ & $\begin{array}{l}\text { spring } \\
\text { spring } \\
\text { reservoir } \\
\text { reservoir } \\
\text { reservoir }\end{array}$ & $\begin{array}{l}\text { BGN } \\
\text { BGN } \\
\text { BGN } \\
\text { BGN }\end{array}$ & $\begin{array}{l}\text { Gila } \\
\text { Yavapai } \\
\text { Pinal } \\
\text { Graham } \\
\text { Coconino }\end{array}$ & $\begin{array}{l}340907 \mathrm{~N} 1111700 \mathrm{~W} \\
342645 \mathrm{~N} 1121507 \mathrm{~W} \\
323532 \mathrm{~N} 1105029 \mathrm{~W} \\
324434 \mathrm{~N} 1102220 \mathrm{~W} \\
350358 \mathrm{~N} 1122001 \mathrm{~W}\end{array}$ & & & $\begin{array}{l}\text { Poland Junction } \\
\text { Oracle } \\
\text { Kennedy Peak } \\
\text { Matterhorn }\end{array}$ \\
\hline $\begin{array}{l}\text { RRR Ranch } \\
\text { RR Tank } \\
\text { R-seven Spring } \\
\text { R Seven Tank } \\
\text { R S Hill } \\
\text { RS Spring } \\
\text { R S Tank } \\
\text { Rubble Dam } \\
\text { Rubble Dam Three } \\
\text { Rubble Number One Dam }\end{array}$ & $\begin{array}{l}\text { locale } \\
\text { reservoir } \\
\text { spring } \\
\text { reservoir } \\
\text { summit } \\
\text { spring } \\
\text { reservoir } \\
\text { dam } \\
\text { dam } \\
\text { dam }\end{array}$ & $\begin{array}{l}\text { UNOFF } \\
\text { BGN } \\
\text { BGN } \\
\text { BGN } \\
\text { BGN } \\
\text { BGN } \\
\text { BGN } \\
\text { UNOFF } \\
\text { UNOFF } \\
\text { UNOFF }\end{array}$ & $\begin{array}{l}\text { Pinal } \\
\text { Yavapai } \\
\text { Gila } \\
\text { Coconino } \\
\text { Coconino } \\
\text { Gila } \\
\text { Coconino } \\
\text { Graham } \\
\text { Graham } \\
\text { Graham }\end{array}$ & $\begin{array}{l}332224 N 1112541 \mathrm{~W} \\
342200 \mathrm{~N} 1121225 \mathrm{~W} \\
335453 \mathrm{~N} 1100654 \mathrm{~W} \\
355010 \mathrm{~N} 1120829 \mathrm{~W} \\
352138 \mathrm{~N} 1115756 \mathrm{~W} \\
331058 \mathrm{~N} 1104624 \mathrm{~W} \\
352156 \mathrm{~N} 1115825 \mathrm{~W} \\
330555 \mathrm{~N} 1093153 \mathrm{~W} \\
330315 \mathrm{~N} 1093604 \mathrm{~W} \\
330440 \mathrm{~N} 1094050 \mathrm{~W}\end{array}$ & & 8063 & $\begin{array}{l}\text { Superstition Mts SW } \\
\text { Cleator } \\
\text { Round Top Mtn } \\
\text { Red Butte SW } \\
\text { Parks } \\
\text { El Capitan Mtn } \\
\text { Parks } \\
\text { Bonita Spring } \\
\text { Bonita Spring } \\
\text { Bryce Mountain }\end{array}$ \\
\hline $\begin{array}{l}\text { Rubel Ranch } \\
\text { See X Bar One Ranch } \\
\text { Rubel Ranch Landing Strip } \\
\text { See X Bar One Ranch } \\
\text { Airstrip }\end{array}$ & $\begin{array}{l}\text { locale } \\
\text { airport }\end{array}$ & $\begin{array}{l}\text { VARIANT } \\
\text { VARIANT }\end{array}$ & $\begin{array}{l}\text { Yavapai } \\
\text { Yavapai }\end{array}$ & $\begin{array}{l}352233 \mathrm{~N} 1131812 \mathrm{~W} \\
352251 \mathrm{~N} 1131 \mathrm{BOOW}\end{array}$ & & & \\
\hline $\begin{array}{l}\text { Ruby } \\
\text { Ruby Canyon } \\
\text { Ruby Interchange } \\
\text { Ruby Lakes } \\
\text { Ruby Mine }\end{array}$ & $\begin{array}{l}\text { ppl } \\
\text { valley } \\
\text { crossing } \\
\text { lake } \\
\text { mine }\end{array}$ & $\begin{array}{l}\text { BGN } \\
\text { BGN } 1908 \\
\text { UNOFF } \\
\text { BGN } \\
\text { UNOFF }\end{array}$ & $\begin{array}{l}\text { Santa Cruz } \\
\text { Coconino } \\
\text { Santa Cruz } \\
\text { Santa Cruz } \\
\text { Yuma }\end{array}$ & $\begin{array}{l}312740 \mathrm{~N} 1111413 \mathrm{~W} \\
361119 \mathrm{N1} 121858 \mathrm{~W} \\
312558 \mathrm{~N} 1105751 \mathrm{~W} \\
31262 \mathrm{BN} 1111419 \mathrm{~W} \\
324509 \mathrm{~N} 1134503 \mathrm{~W}\end{array}$ & $360910 \mathrm{~N} 1122112 \mathrm{~W}$ & 3940 & $\begin{array}{l}\text { Ruby } \\
\text { Havasupai Point } \\
\text { Rio Rico } \\
\text { Ruby } \\
\text { Growler }\end{array}$ \\
\hline $\begin{array}{l}\text { Ruby Peak } \\
\text { Ruby-Star Ranch } \\
\text { Ruby Tank }\end{array}$ & $\begin{array}{l}\text { summit } \\
\text { locale }\end{array}$ & $\begin{array}{l}\text { BGN } \\
\text { UNOFF } \\
\text { VARIANT }\end{array}$ & $\begin{array}{l}\text { Santa Cruz } \\
\text { Pima }\end{array}$ & $\begin{array}{l}312832 N 1111347 \mathrm{~W} \\
315519 \mathrm{~N} 1110511 \mathrm{~W}\end{array}$ & & 5051 & $\begin{array}{l}\text { Ruby } \\
\text { Twin 8uttes }\end{array}$ \\
\hline $\begin{array}{l}\text { See Boulder Tank } \\
\text { Ruby Tank } \\
\text { Ruby Trail Dam } \\
\text { Ruby Wash } \\
\text { Rucker Canyon } \\
\text { White River Canyon } \\
\text { White Water Canyon }\end{array}$ & $\begin{array}{l}\text { reservoir } \\
\text { reservoir } \\
\text { dam } \\
\text { stream } \\
\text { valley }\end{array}$ & $\begin{array}{l}\text { BGN } \\
\text { UNOFF } \\
\text { BGN } \\
\text { BGN } 1959 \\
\text { VARIANT } \\
\text { VARIANT }\end{array}$ & $\begin{array}{l}\text { Santa Cruz } \\
\text { Santa Cruz } \\
\text { Santa Cruz } \\
\text { Yavapai } \\
\text { Cochise }\end{array}$ & $\begin{array}{l}312 B 13 N 1111225 \mathrm{~W} \\
312 B 17 N 1111222 \mathrm{~W} \\
312656 N 1111227 \mathrm{~W} \\
340046 \mathrm{~N} 1122904 \mathrm{~W} \\
314510 \mathrm{~N} 1092545 \mathrm{~W}\end{array}$ & $\begin{array}{l}335923 \mathrm{~N} 1123030 \mathrm{~W} \\
315029 \mathrm{~N} 1091753 \mathrm{~W}\end{array}$ & & $\begin{array}{l}\text { Ruby } \\
\text { Ruby } \\
\text { Copperopol is } \\
\text { Stanford Canyon }\end{array}$ \\
\hline $\begin{array}{l}\text { Rucker Canyon Dam } \\
\text { Rucker Canyon Ranch } \\
\text { Hampe Ranch } \\
\text { Rucker Canyon Trail Two } \\
\text { Hundred Twentytwo }\end{array}$ & $\begin{array}{l}\text { dam } \\
\text { locale } \\
\text { trail }\end{array}$ & $\begin{array}{l}\text { UNOFF } \\
\text { UNOFF } \\
\text { VARIANT } \\
\text { UNOFF }\end{array}$ & $\begin{array}{l}\text { Cochise } \\
\text { Cochise } \\
\text { Cochise }\end{array}$ & $\begin{array}{l}314648 \mathrm{~N} 1091836 \mathrm{~W} \\
314512 \mathrm{~N} 1092125 \mathrm{~W} \\
314730 \mathrm{~N} 1091630 \mathrm{~W}\end{array}$ & & & $\begin{array}{l}\text { Chiricahua Peak } \\
\text { Chiricahua Peak } \\
\text { Chiricahua Peak }\end{array}$ \\
\hline $\begin{array}{l}\text { Rucker Cemetery } \\
\text { Rucker Forest Camp } \\
\text { Rucker Lake } \\
\text { Rucker Lake Campground } \\
\text { Rucker Ranger Station }\end{array}$ & $\begin{array}{l}\text { cemetery } \\
\text { locale } \\
\text { reservoir } \\
\text { park } \\
\text { locale }\end{array}$ & $\begin{array}{l}\text { UNOFF } \\
\text { BGN } \\
\text { BGN } \\
\text { ADMIN } \\
\text { UNOFF }\end{array}$ & $\begin{array}{l}\text { Cochise } \\
\text { Cochise } \\
\text { Cochise } \\
\text { Cochise } \\
\text { Cochise }\end{array}$ & $\begin{array}{l}314403 N 1092918 \mathrm{~W} \\
314705 N 1091812 \mathrm{~W} \\
314641 N 1091833 \mathrm{~W} \\
314644 N 1091825 \mathrm{~W} \\
314556 \mathrm{~N} 1092055 \mathrm{~W}\end{array}$ & & & $\begin{array}{l}\text { Bruno Peak } \\
\text { Chiricahua Peak } \\
\text { Chiricahua Peak } \\
\text { Chiricahua Peak } \\
\text { Chiricahua Peak }\end{array}$ \\
\hline $\begin{array}{l}\text { Rucker Raspberry Ridge Irail } \\
\text { Two Hundred Twentyeight }\end{array}$ & trail & UNOFF & Cochise & $314828 \mathrm{~N} 1091700 \mathrm{~W}$ & & & Chiricahua Peak \\
\hline $\begin{array}{l}\text { Rucker School } \\
\text { Rucker Tank } \\
\text { Rucker Tank } \\
\text { Rucker Tank } \\
\text { Rudd Creek } \\
\text { Rudd Knoll Spring } \\
\text { Rudd Knoll Spring } \\
\text { Rudd Reservoir }\end{array}$ & $\begin{array}{l}\text { school } \\
\text { reservoir } \\
\text { reservoir } \\
\text { reservoir } \\
\text { stream } \\
\text { spring } \\
\text { spring } \\
\text { reservoir }\end{array}$ & $\begin{array}{l}\text { UNOFF } \\
\text { BGN } \\
\text { BGN } \\
\text { BGN } \\
\text { BGN } \\
\text { BGN } \\
\text { BGN } \\
\text { BGN }\end{array}$ & $\begin{array}{l}\text { Cochise } \\
\text { Pima } \\
\text { Mohave } \\
\text { Mohave } \\
\text { Apache } \\
\text { Apache } \\
\text { Apache } \\
\text { Apache }\end{array}$ & $\begin{array}{l}314437 N 1092848 \mathrm{~W} \\
315747 \mathrm{~N} 1112710 \mathrm{~W} \\
351022 \mathrm{~N} 1132232 \mathrm{~W} \\
352520 \mathrm{~N} 1132233 \mathrm{~W} \\
340411 \mathrm{~N} 1091155 \mathrm{~W} \\
335848 \mathrm{~N} 1092149 \mathrm{~W} \\
335902 \mathrm{~N} 1092138 \mathrm{~W} \\
335902 \mathrm{~N} 1092113 \mathrm{~W}\end{array}$ & 335929 N1091919W & & $\begin{array}{l}\text { Bruno Peak } \\
\text { Palo Alto Ranch } \\
\text { Bull Spring } \\
\text { Cherokee Point } \\
\text { Nelson Reservoir } \\
\text { Rudd Knoll } \\
\text { Rudd Knoll } \\
\text { Rudd Knoll }\end{array}$ \\
\hline $\begin{array}{l}\text { Rudds Tank } \\
\text { Rudy Pass } \\
\text { Rudys Tank } \\
\text { Ruelas Canyon } \\
\text { Ruelas Spring } \\
\text { Ruelas Spring Number Four } \\
\text { Ruelas } 4 \\
\text { Ruelas Spring } 4 \\
\text { Ruelas Spring Number Four } \\
\text { See Ruelas Spring }\end{array}$ & $\begin{array}{l}\text { reservoir } \\
\text { gap } \\
\text { reservoir } \\
\text { valley } \\
\text { spring }\end{array}$ & $\begin{array}{l}\text { BGN } \\
\text { BGN } \\
\text { BGN } \\
\text { BGN } \\
\text { BGN } 1982 \\
\text { VARIANT } \\
\text { VARIANT } \\
\text { VARIANT } \\
\text { VARIANT } \\
\text { VARIANT }\end{array}$ & $\begin{array}{l}\text { Coconino } \\
\text { Yavapai } \\
\text { Pima } \\
\text { Pima } \\
\text { Pima }\end{array}$ & $\begin{array}{l}351413 N 1114442 \mathrm{~W} \\
340334 \mathrm{~N} 1131030 \mathrm{~W} \\
321609 \mathrm{~N} 1104029 \mathrm{~W} \\
322742 \mathrm{~N} 1110412 \mathrm{~W} \\
314937 \mathrm{~N} 1104727 \mathrm{~W}\end{array}$ & $322954 N 1110145 \mathrm{~W}$ & & $\begin{array}{l}\text { Flagstaff West } \\
\text { Date Creek Ranch SW } \\
\text { Agua Caliente Hill } \\
\text { Ruelas Canyon } \\
\text { Helvetia }\end{array}$ \\
\hline
\end{tabular}


NATIONAL GAZETTEER--ARIZONA 1986

\section{FEATURE NAME}

Ruelas Spring Number Two and$$
\text { Three }
$$

Ruelas Spring 4

$$
\begin{aligned}
& \text { See Ruelas Spring } \\
& \text { Ruelas } 4
\end{aligned}
$$

See Ruelas Spring

Ruesch Spring

Rugged Mesa

Rugged Mesa
Rugged Well

Ruin Bas in

Ruin $\mathrm{Hill}$

Ruin Mountain

Ruin Point Tank

Ruins Point

Ruin Springs

Ruins Ridge

Ruins Spring

Ruins Tank

Ruins Tank

Ruins Tank Number Two

Ruins Wash

Ruin Tank

Ruin Tank

Ruin Tank

Ruin Tank

Ruiz Canyon

Rumsey Park

Runner Tank

Rupe Tank

Rupley Wash

Rupley Well

Rural Schoo

Rush Place Windmill

Rush Spring

Russell Gulch

Russell Gulch Tank

Russell Hill

Russell Point

Russell Quarry

Russell Reservoir

Russell Spring

Russell Spring

Russell Spring

Russe11 Tank

Russelliville (historical)

Russellville Peak

Russell Wash

Russell Wash

Russian Molokan Cemetery

Russian Well

Rustler Canyon

Rustler Gulch

Rustler Park

Rustler Park

Rust ler Park Campground

Rustler Park Canyon

Rustlers Canyon

See Cold Creek

Rustlers Canyon

Rustlers Spring

Rusty Shovel

See Vakamok

Rusty Tank

Rusty Tank

Rusty Tank

Rusty Tank Number Two

Ruth Cowden Well

Ruth Fisher Elementary School

Ruth Mine

FEATURE
CLASS

STATUS COUNTY

COORDINATE

315040 N1104625W

$314937 N 1104727 \mathrm{~W}$

spring

VARIANT

spring

$\begin{array}{llll}\text { spring } & \text { BGN } & \text { Mohave } & 365349 N 1131909 \mathrm{~W} \\ \text { ridge } & \text { BGN } & \text { Yavapai } & 341400 \mathrm{~N} 1115303 \mathrm{~W}\end{array}$

summit BGN Yavapai 341403N1114527W

well UNOFF Yavapai

basin GGN Gila 332913N1105408W

summit BGN Navajo 361350N1103118

summit BGN Coconino 350500N1120051W

reservoir BGN Yavapai 341009N1114926W

cliff BGN Navajo 355704N1103324W

spring BGN Navajo 340803N1100541W

ridge BGN Apache 353614N1094317

spring BGN Navajo 355118N1103130W

reservoir BGN Gila $334936 N 1100305$

reservoir BGN Yavapai 345228 N1125235W

reservoir BGN Gila $\quad 334941$ N1100235W

Apache 353550N1094418W

reservoir BGN Pinal 323313N11049436

reservoir BGN Yavapai 344212N1114041

reservoir BGN Yavapai $350231 N 1122556 \mathrm{~W}$

reservoir BGN Coconino 350435N1120034W

stream BGN Apache 354457N1092246W

valley BGN Gila $\quad 332320 \mathrm{~N} 1104648 \mathrm{~W}$

park

reservoir

ADMIN

Gila

Yavapai

$341420 \mathrm{~N} 1112000 \mathrm{~N}$

$343106 \mathrm{~N} 1114040 \mathrm{~W}$

reservoir BGN Coconino 351949N1120416W

stream BGN Mohave 342802N1133727W

$\begin{array}{llll}\text { stream } & \text { BGN } & \text { Mohave } & 342802 \text { N1133727W } \\ \text { wel1 } & \text { UNOFF } & \text { Mohave } & 342742 \text { N1134108W }\end{array}$

school UNOFF Maricopa

locale BGN Yavapai

spring BGN Yavapa

valley BGN Gila

reservoir BGN Gila

summit BGN

summit BGN

Yavapai

Navajo

mine

reservoir

spring

spring

spring

reservoir

locale

summit

stream

UNOFF

BGN

BGN

$B G N$

$B G N$

BGN

BGN 1965

GN

stream

Coconino

Apache

Santa Cruz

Yavapai

Yohave

Coconino

Cochise

Cochise

Yavapai

Coconino

342742N1134108W

$341634 N 1123636 \mathrm{~W}$

$341036 \mathrm{~N} 1122331 \mathrm{~W}$

$332449 \mathrm{~N} 1104937 \mathrm{~W}$

332149 N1104828:

34372 BN1114507W

341923N1102051W

$352442 \mathrm{~N} 1123117 \mathrm{~W}$

$335926 \mathrm{~N} 1091955 \mathrm{~W}$

$312034 N 1110209 \mathrm{~W}$

$343711 \mathrm{N1114540 \textrm {W }}$

$363108 \mathrm{~N} 1131920 \mathrm{~W}$

$355219 \mathrm{~N} 1115242 \mathrm{~W}$

$320500 \mathrm{~N} 1100400 \mathrm{~W}$

$320510 \mathrm{~N} 110070 \mathrm{BW}$

$343753 \mathrm{~N} 1114720 \mathrm{~W}$

35472BN111525Bh

cemetery UNOFF Maricopa 333151N1121308W

well UNOFF Yavapai 342720N1120844W

valley BGN Cochise $\quad 313858$ N1091846W

valley BGN Pinal 331125N1105944W

flat

flat

park

valley

BGN

BGN

VARIANT

315412 N1091630

$330315 N 1101904 \mathrm{~N}$

315420 N1091645

$330410 \mathrm{~N} 1102027 \mathrm{~W}$

stream

Greenlee

325630 N1091427W

valley

spring

BGN 1962 Greenlee

BGN Greenlee

$330100 N 1091030 \mathrm{~W}$

$330341 N 1090744 \mathrm{~W}$

$314220 \mathrm{~N} 1120149 \mathrm{~W}$

$314617 N 1092403 \mathrm{~W}$

$350324 N 1132537 \mathrm{~W}$ $\begin{array}{cc}\text { SOURCE } & \text { ELEV } \\ \text { COORDINATE } & \text { FT MAP NAME }\end{array}$

Helvetia

Rock Canyon

Brooklyn Peak

4390 Bloody Bas in

4363 Brooklyn Peak

Inspiration

Rocky Ridge NE

6721 White Horse Lake

Bloody Basin

Oraibi

Show Low South

6284 Sunrise Springs

Shongopovi

Canyon Day

Camp Wood

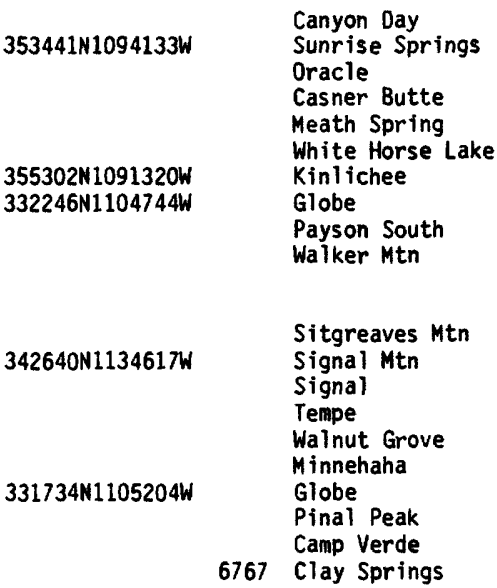

Eagle Nest Mtn

Rudd Knoll

Pajarito Peak

Camp Verde

Russell Spring

Harbison Tank

Dragoon

$343542 N 1114423$

6616 Dragoon

Lake Montezuma

Harbison Tank

$313938 N 1092103 \mathrm{~W}$

Glendale

Mayer

Swede Peak

Hot Tamale Peak

Rust ler Park

Mt Turnball

8409 Rustler Park

330229 N1101837W
$341232 N 1114758 \mathrm{~W}$

$355115 N 1120221 \mathrm{~W}$

$340948 \mathrm{~N} 1114615 \mathrm{~W}$

$332931 \mathrm{~N} 1125213 \mathrm{~W}$

res Cochise

reservoir BGN

reservoir BGN

we 11

UNOFF

UNOFF

Maricopa

UNOFF Yavapai

$342759 N 1122914 W$
$330445 N 1090655 \mathrm{~W}$

Rattlesnake Spring

Rattlesnake Spring

Stanford Canyon

Bloody Bas in

Red Butte

Bloody Bas in

Penitentiary Mtn

Wintersburg

Groom Creek 
NATIONAL GAZETTEER--ARIZONA 1986

\section{FEATURE NAME}

Ruths Tank

Ruth Tank

Ryal Canyon

Ryal Spring

Ryan

Ryan Detention Dam

Ryan Draw

Ryan field

Ryan Ranch

Ryan Ranch

Ryan Tank

Ryan Tank

Ryan Trick Tanks

Rybery Tank

Rye

Rye Creek

Mineral Creek

Creek

Rye Creek Tank

Rye Creek Well

Ryland Creek

\section{FEATURE}

CLASS

STATUS

reservoir

reservoir

valley

spring

locale

dam

valley

airport

locale

locale

reservoir

reservoir

reservoir

reservoir

locale

strean

strear

reservoir

wel1

stream
Coconino

See Mineral Creek

$\begin{array}{ll}\text { BGN } & \text { Coconino } \\ \text { BGN } & \text { Gila } \\ \text { BGN } & \text { Yavapai } \\ \text { BGN } & \text { Yavapai } \\ \text { BGN } & \text { Coconino } \\ \text { VARIANT } & \\ \text { UNOFF } & \text { Graham } \\ \text { BGN } & \text { Graham } \\ \text { ADMIN } & \text { Pima }\end{array}$

UNOFF

UNOFF

$B G N$

$B G N$

BGN

BGN

BGN

VARIANT

VARIAN

Apache
Coconino
Maricopa
Navajo
Navajo
Coconino
Gila
Gila

Gila

BGN

UNOFF

BGN
Gila

Gila

Yavapai
COORDINATE

344509 N1111514W 340758 N1105938W

$343148 \mathrm{~N} 1115203 \mathrm{~W}$

343030 N1115400W 364118 N1122055W $323027 \mathrm{~N} 1092642 \mathrm{~W}$ $320830 \mathrm{~N} 1111021 \mathrm{~W}$

$340042 N 1093928 \mathrm{~W}$ $342212 \mathrm{~N} 1104904 \mathrm{~W}$

$334505 N 1113431 \mathrm{~W}$

334501M1104422h

$351154 \mathrm{~N} 1115459 \mathrm{~W}$

340634N1112111W

340140 N1111705W

340958 N1112535W

$340821 \mathrm{~N} 1112406 \mathrm{~W}$

$340440 \mathrm{~N} 1112035 \mathrm{~W}$

$340517 \mathrm{~N} 1122631 \mathrm{~W}$
322940N1092649W

343551N1104440W

\begin{tabular}{|c|c|c|}
\hline $\begin{array}{l}\text { SOURCE } \\
\text { COORDINATE }\end{array}$ & $\begin{array}{c}\text { ELEV } \\
\text { FT }\end{array}$ & MAP NAME \\
\hline $343023 \mathrm{~N} 1115414 \mathrm{~W}$ & & $\begin{array}{l}\text { Jaycox Mtn } \\
\text { Oxbow Mtn } \\
\text { Camp Verde } \\
\text { Middle Verde } \\
\text { Warm Springs Canyon }\end{array}$ \\
\hline $322414 \mathrm{~N} 1093127 \mathrm{~W}$ & 2415 & $\begin{array}{l}\text { Ryan Draw } \\
\text { Javel ina Peak } \\
\text { Brown Mtn }\end{array}$ \\
\hline $341154 \mathrm{~N} 1112531 \mathrm{~W}$ & & $\begin{array}{l}\text { Horseshoe Cienega } \\
0 \text { W Point } \\
\text { Maverick Mtn } \\
\text { Potato Wash South } \\
\text { Potato Wash South } \\
\text { Garland Prairie } \\
\text { Gisela } \\
\text { Gisela }\end{array}$ \\
\hline $340901 \mathrm{N1} 122432 \mathrm{~W}$ & & $\begin{array}{l}\text { North Peak } \\
\text { Gisela } \\
\text { Copperopolis }\end{array}$ \\
\hline
\end{tabular}

$360746 \mathrm{~N} 1101850 \mathrm{~W}$ $315157 N 1112722 \mathrm{~W}$ $321920 \mathrm{~N} 1104833 \mathrm{~W}$

$321850 \mathrm{~N} 1104842 \mathrm{~W}$ $321540 \mathrm{~N} 1104928 \mathrm{~W}$ $321756 \mathrm{~N} 1104715 \mathrm{~W}$

$321756 \mathrm{~N} 1104715 \mathrm{~W}$ $321855 \mathrm{~N} 1104839 \mathrm{~W}$ $322005 \mathrm{~N} 1104700 \mathrm{~W}$

$322254 \mathrm{~N} 1110632 \mathrm{~W}$

$321839 \mathrm{~N} 1104904 \mathrm{~W}$ $321840 \mathrm{~N} 1104904 \mathrm{~W}$

building UNOFF Pima

park ADMIN Pima

stream BGN Pima

well UNOFF

Cochise

$315157 N 1112722 W$

$315308 \mathrm{~N} 1102149 \mathrm{~W}$

$314905 N 1113433 \mathrm{~W}$

$351333 N 1095136 \mathrm{~W}$

$\begin{array}{llll}\text { valley } & B G N & \text { Navajo } & 351333 N 1095136 \mathrm{~W} \\ \text { lake } & \text { BGN } & \text { Mohave } & 362747 \text { N1133315W }\end{array}$

locale UNOFF lochise 320939 N1093558W

$352624 N 1093814 W$

$314905 \mathrm{~N} 1113433 \mathrm{~W}$

Coat Spring

Fresno Wash

Sabino Canyon

321922N1104835W Sabino Canyon

Sabino Canyon

Sabino Canyon

Sabino Canyon

Sabino Canyon

Ruelas Canyon

Sabino Canyon

2730 Sabino Canyon

Pinal $331038 N 1120448 \mathrm{~W}$

BGN

VARIANT

VARIAN

VARIANT Sacaton

Sacaton Section

Sacaton Station

locale

Pinal

$323417 N 1103058 \mathrm{~W}$

Sacaton

E1 Tusonimo

La Encarnacion

Pima Agency

San Juan Capistrano

Soacson

Tucsonimon

Tusonimo

Uturitu

vturituc

Zacatone Camp

Sacaton Ball Field Park

Sacaton Butte

Sacaton Cemetery

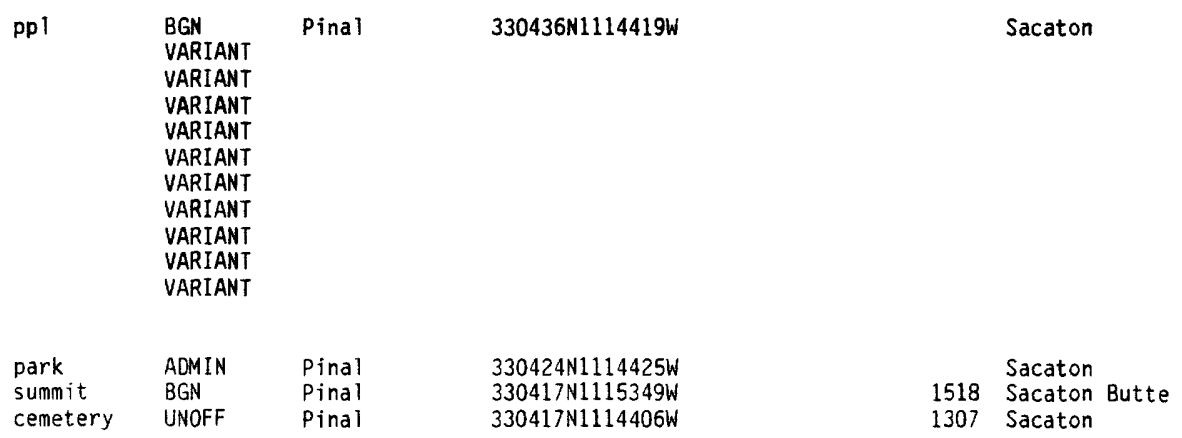

Fresno Wash

Benson

Chinde Mesa

Poverty Spring

Dos Cabezas

Pima Butte

1307 Sacaton 
NATIONAL GAZETTEER--ARIZONA 1986 FEATURE NAME

Sacaton Community Church Sacaton Dam

Sacaton Fairgrounds

Sacaton Flats

Sacaton Flats

Sacaton Flats Community Center

Sacaton Mountain

See Sacaton Mountains

Sacaton Mountains

Sacaton Mountain

Sacaton Peak

Sacaton Public School

Sacaton Ranch Sacaton

Sacaton Section

See Sacate

Sacaton Spring

Sacaton Station

See Sacate

Sacaton Tank

Sacaton Tank

Sacaton Wash Sacatan Wash

Sacaton Wash

Sacket Tank

Sack Tongue Tank

Sacramento Hill

Sacramento Range

See Black Mountains

Sacramento Valley

Sacramento Wash

Trout Creek

Sacred Heart Cemetery

Sacred Heart School

Sacred Heart Schoo

Sacred Mountain

Sacred Mountain Trading Post

Saddle

Saddleback

Saddle Back Mountain

See Saddle Mountain

Saddleback Mounta in

See Saddle Mountain

Saddl eback Mounta in

Saddle Butte

Saddle Butte

Saddle Canyon

Saddle Canyon

Saddle Canyon

Saddle Corral

Saddle Crater

Saddle Gap

Saddlehorn Ranch (subdivision)

Saddle Horn Rock

Saddle Horse Canyon

Saddle Horse Oraw

Saddle Horse Spring

Saddle Horse Tank

Saddle Horse Tank

Saddle Horse Tank

Saddle Mountain

See Boundary Ridge

Saddle Mountain

Saddle Mountain

Saddle Mountain

Saddle Back Mountain

Saddle Mountain

Saddleback Mountain

Saddle Mountain

Saddle Mountain

Saddle Mountain

$343237 N 1122824 \mathrm{~W}$
FEATURE
CLASS

STATUS

COUNTY

COOROINATE

church UNOFF Pinal 330458N1114421

UNOFF $\quad$ 353818N1141546

park ADMIN Pinal 330433N1114435W

flat BGN Maricopa 331114N1131710

locale BGN Pinal 330412N1114004

building UNOFF Pinal 330359N1114008

VARIANT

Pinal

$330051 N 1114912 W$

\begin{tabular}{|c|c|c|c|}
\hline summit & $\begin{array}{l}\text { BGN } \\
\text { VARIANT }\end{array}$ & Pinal & $330051 \mathrm{~N} 1114912 \mathrm{~W}$ \\
\hline $\begin{array}{l}\text { summit } \\
\text { school } \\
\text { locale }\end{array}$ & $\begin{array}{l}\text { BGN } \\
\text { UNOFF } \\
\text { UNOFF } \\
\text { VARIANT } \\
\text { VARIANT }\end{array}$ & $\begin{array}{l}\text { Pinal } \\
\text { Pinal } \\
\text { Pinal }\end{array}$ & $\begin{array}{l}330011 \mathrm{~N} 1114026 \mathrm{~W} \\
330445 \mathrm{~N} 1114527 \mathrm{~W} \\
323417 \mathrm{~N} 1103058 \mathrm{~W}\end{array}$ \\
\hline $\begin{array}{l}\text { locale } \\
\text { spring }\end{array}$ & $\begin{array}{l}\text { BGN } \\
\text { VARIANT }\end{array}$ & $\begin{array}{l}\text { Pinal } \\
\text { Mohave }\end{array}$ & $\begin{array}{l}331038 N 1120448 W \\
353658 N 1141801 W\end{array}$ \\
\hline locale & & Pinal & $331038 \mathrm{~N} 1120448 \mathrm{~W}$ \\
\hline
\end{tabular}

reservoir BGN Cochise 314810N1101646W

reservoir BGN Navajo 343308 N1101930W

stream BGN Cochise 314816N1013200W

VARIANT

$\begin{array}{lll} & \text { BGN } & \text { Graham } 2308 N 1095039\end{array}$

reservoir BGN Navajo 342221N1102208

reservoir BGN Cochise 313438N1095951

summit BGN Cochise 312610N1095422W

range Mohave 352814N1143038W

valley BGN Mohave

stream BGN

cemetery

school

school

summit

locale

summit

VARIANT

UNOFF

UNOFF

UNOFF

$8 G N$

BGN

BGN

Mohave

Cochise

Santa Cruz

Yavapai

Yavapai

Coconino

Maricopa

Pima

VARIANT

summit

summit

summit

summit

summit

valley

valley

valley

locale

crater

gap

pillar

valley

valley

valley
spring

reservoir $B G$

reservoir BGN

ridge

summit

summit

summit

summit

VARIANT

BGN

BGN

BGN

BGN

Pinal

Maricopa

Maricopa

Yavapai

Navajo

Pinal

Coconino

Coconino

UNOFF Gila

8GN

BGN

BGN

BGN

BGN

BGN

GN

GN

Coconino

Cochise

Maricopa

Coconino

Mohave

Apache

Mohave

Apache

Coconino

344853 N1140935W

344349N1142914W

312154 N1093439W

$312016 N 1105624 \mathrm{~W}$

$343927 N 1114226 \mathrm{~W}$

$352718 \mathrm{~N} 1113345 \mathrm{~W}$

$330928 \mathrm{~N} 1130446 \mathrm{~W}$

$321930 \mathrm{~N} 1104727 \mathrm{~W}$

$325925 \mathrm{~N} 1104016 \mathrm{~W}$

$332600 \mathrm{~N} 1130230 \mathrm{~W}$ $334908 \mathrm{~N} 1122009 \mathrm{~W}$ $344942 \mathrm{~N} 1123402 \mathrm{~W}$ $352913 \mathrm{~N} 1102414 \mathrm{~W}$ $324920 \mathrm{~N} 1102943 \mathrm{~W}$ $362201 \mathrm{~N} 1115324 \mathrm{~W}$

$362235 \mathrm{~N} 1122257 \mathrm{~W}$

$341835 \mathrm{~N} 1113149 \mathrm{~W}$

351719 N1111130W

$312316 \mathrm{~N} 1092604 \mathrm{~W}$ 333828 N1121116W

355548 N1113752W

$361322 \mathrm{N1130237 \textrm {W }}$

$350031 \mathrm{N1094319 \textrm {W }}$

$361345 N 1130319 \mathrm{~W}$

$350019 N 1093943 \mathrm{~W}$

350853N1115037W

$324 B 41 N 1103012 \mathrm{~W}$

$355605 N 1114502 \mathrm{~W}$

$361924 \mathrm{~N} 1115514 \mathrm{~W}$

$312918 N 1103945 \mathrm{~W}$

summit

summ it
$322646 \mathrm{~N} 1101305 \mathrm{~W}$

$325925 \mathrm{~N} 1104016 \mathrm{~W}$

332600N1130230w

335732 N1113115W

$B G N$

BGN

VARIANT

BGN 1963

BGN

Maricopa

$352610 \mathrm{~N} 1114402 \mathrm{~W}$

361844 N1115700W
$361410 \mathrm{~N} 1130325 \mathrm{~W}$ $350050 \mathrm{~N} 1093333 \mathrm{~W}$

$361 B 35 N 1115817 \mathrm{~W}$

$362029 \mathrm{~N} 1122126 \mathrm{~W}$

$\begin{array}{cc}\text { SOURCE } & \text { ELEV } \\ \text { COORDINATE } & \text { FT }\end{array}$

Sacaton

White Hills East

Sacaton

Hyder NE

Sacaton

Sacaton

Gila Butte SE

2755 Sacaton

Gila Butte SE

Peppersauce Wash

Dolan Springs

McGrew Spring

Sheepskin Wash

Land

Greasewood Mountain

Clay Springs

4634 Potter Mtn

Bisbee

\begin{tabular}{|c|c|c|}
\hline $\begin{array}{l}352534 \mathrm{~N} 1141237 \mathrm{~W} \\
352534 \mathrm{~N} 1141237 \mathrm{~W}\end{array}$ & & $\begin{array}{l}\text { Yucca } \\
\text { Topock }\end{array}$ \\
\hline & $\begin{array}{l}4123 \\
4409\end{array}$ & $\begin{array}{l}\text { Douglas } \\
\text { Nogales } \\
\text { Prescott } \\
\text { Casner Butte } \\
\text { O'Leary Peak } \\
\text { Quail Spring Wash } \\
\text { Sabino Canyon }\end{array}$ \\
\hline
\end{tabular}

2372 Baldy Mtn

5690 Sullivan Buttes

6449 Shonto Butte

Oak Grove Canyon

Point Imperial

Tapeats Amphitheater

Cane Springs Mtn

6232 Merriam Crater

College Peaks

1250 Hedgpeth Hills

Hellhole Bend

Vulcans Throne

Pinta

Vulcans Throne

Pinta

Bellemont

Deer Tank

5809 Harshaw

6167 The Mesas

4240 Dudleyville

3037 Saddle Mtn

6335 Lion Mountain

8864 White Horse $\mathrm{Hills}$

8424 Point Imperial 


\begin{tabular}{|c|c|c|c|c|c|c|c|}
\hline FEATURE MAME & $\begin{array}{l}\text { FEATURE } \\
\text { CLASS }\end{array}$ & STATUS & COUNTY & COORDINATE & $\begin{array}{l}\text { SOURCE } \\
\text { COORDINATE }\end{array}$ & $\begin{array}{c}\text { ELEV } \\
\text { FT }\end{array}$ & MAP NAME \\
\hline $\begin{array}{l}\text { Saddle Mountain Spring } \\
\text { Saddle Mountain Tank } \\
\text { Saddle Mountain Tank } \\
\text { Saddle Ridge } \\
\text { Saddle Ridge } \\
\text { Saddle Ridge Pasture } \\
\text { Saddle Ridge Pasture Tank } \\
\text { Saddle Ridge Tank }\end{array}$ & $\begin{array}{l}\text { spring } \\
\text { reservoir } \\
\text { reservoir } \\
\text { ridge } \\
\text { ridge } \\
\text { flat } \\
\text { reservoir } \\
\text { reservoir }\end{array}$ & $\begin{array}{l}\text { BGN } \\
B G N \\
B G N \\
B G N \\
B G N \\
B G N \\
B G N \\
B G N\end{array}$ & $\begin{array}{l}\text { Maricopa } \\
\text { Santa Cruz } \\
\text { Graham } \\
\text { Gila } \\
\text { Coconino } \\
\text { Gila } \\
\text { Gila } \\
\text { Gila }\end{array}$ & $\begin{array}{l}335704 \mathrm{~N} 1113155 \mathrm{~W} \\
313028 \mathrm{N1103836 \textrm {W }} \\
322607 \mathrm{N1101146 \textrm {W }} \\
341907 \mathrm{N1113207 \textrm {W }} \\
355620 \mathrm{N1111257W} \\
342049 \mathrm{~W} 113256 \mathrm{~W} \\
342104 \mathrm{N1113309 \textrm {W }} \\
342007 \mathrm{N1113241 \textrm {W }}\end{array}$ & & & $\begin{array}{l}\text { Lion Mountain } \\
\text { Mt Hughes } \\
\text { The Mesas } \\
\text { Cane Springs Mtn } \\
\text { Goldtooth } \\
\text { Cane Springs Mtn } \\
\text { Cane Springs Mtn } \\
\text { Cane Springs Mtn }\end{array}$ \\
\hline $\begin{array}{l}\text { Saddle Rock } \\
\text { Saddle Tank } \\
\text { Saddle Tank } \\
\text { Saddle Tank } \\
\text { Saddle Tank } \\
\text { Saddle Tank } \\
\text { Saddle Tank } \\
\text { Saddle Tank } \\
\text { Saddle Tank } \\
\text { Saddle Tanks }\end{array}$ & $\begin{array}{l}\text { summit } \\
\text { reservoir } \\
\text { reservoir } \\
\text { reservoir } \\
\text { reservoir } \\
\text { reservoir } \\
\text { reservoir } \\
\text { reservoir } \\
\text { reservoir } \\
\text { reservoir }\end{array}$ & $\begin{array}{l}\text { BGN } \\
\text { BGN } \\
\text { BGN } \\
\text { BGN } \\
B G N \\
\text { BGN } \\
\text { BGN } \\
\text { BGN } \\
\text { BGN } \\
\text { BGN }\end{array}$ & $\begin{array}{l}\text { Pinal } \\
\text { Santa Cruz } \\
\text { Graham } \\
\text { Graham } \\
\text { Gila } \\
\text { Gila } \\
\text { Yavapai } \\
\text { Yavapai } \\
\text { Coconino } \\
\text { Greenlee }\end{array}$ & $\begin{array}{l}332748 \mathrm{~N} 1113101 \mathrm{~W} \\
312541 \mathrm{N11} 10933 \mathrm{~W} \\
322816 \mathrm{N1101157W} \\
323157 \mathrm{N1094415W} \\
335250 \mathrm{~N} 1102814 \mathrm{~W} \\
341455 \mathrm{N1112337W} \\
3420391115132 \mathrm{~W} \\
343945 \mathrm{~N} 1124913 \mathrm{~W} \\
351620 \mathrm{N1} 115539 \mathrm{~W} \\
325423 \mathrm{~N} 1092036 \mathrm{~W}\end{array}$ & & 2405 & $\begin{array}{l}\text { Apache Junction } \\
\text { Ruby } \\
\text { The Mesas } \\
\text { Gillespie Mtn } \\
\text { Cibecue Peak } \\
\text { North Peak } \\
\text { Tule Mesa } \\
\text { Smith Mesa } \\
\text { Parks } \\
\text { Guthrie }\end{array}$ \\
\hline $\begin{array}{l}\text { Sadies Peak } \\
\text { Saeltso Springs } \\
\text { See Setsiltso Springs } \\
\text { Saffel Canyon } \\
\text { See Saffell Canyon } \\
\text { Saffel Knoll } \\
\text { See Milligan Knoll } \\
\text { Saffel Knoll } \\
\text { See Saffell Knoll } \\
\text { Saffell Canyon } \\
\text { Saffel Canyon }\end{array}$ & $\begin{array}{l}\text { summit } \\
\text { spring } \\
\text { valley } \\
\text { summit } \\
\text { summit } \\
\text { valley }\end{array}$ & $\begin{array}{l}\text { BGN } \\
\text { VARIANT } \\
\text { VARIANT } \\
\text { VARIANT } \\
\text { VARIANT } \\
\text { BGN } \\
\text { VARIANT }\end{array}$ & $\begin{array}{l}\text { Yavapai } \\
\text { Apache } \\
\text { Apache } \\
\text { Apache } \\
\text { Apache } \\
\text { Apache }\end{array}$ & $\begin{array}{l}342708 \mathrm{~N} 1125452 \mathrm{~W} \\
364343 \mathrm{~N} 1094004 \mathrm{~W} \\
340403 \mathrm{~N} 1091730 \mathrm{~W} \\
340223 \mathrm{~N} 1091640 \mathrm{~W} \\
340350 \mathrm{~N} 1091653 \mathrm{~W} \\
340403 \mathrm{~N} 1091730 \mathrm{~W}\end{array}$ & $340346 \mathrm{~N} 1091642 \mathrm{~W}$ & & Hillside \\
\hline $\begin{array}{l}\text { Saffell Knoll } \\
\text { See Milligan Knoll } \\
\text { Saffell Knoll } \\
\text { Saffel Knoll } \\
\text { Saffell Spring } \\
\text { Saffel Spring } \\
\text { Saffel Spring } \\
\text { See Saffell Spring } \\
\text { Safford } \\
\text { Layton } \\
\text { Stafford }\end{array}$ & $\begin{array}{l}\text { summit } \\
\text { summit } \\
\text { spring } \\
\text { spring } \\
\text { ppl }\end{array}$ & $\begin{array}{l}\text { VARIANT } \\
\text { BGN } 1971 \\
\text { VARIANT } \\
\text { BGN } \\
\text { VARIANT } \\
\text { VARIANT } \\
\text { BGN } \\
\text { VARIANT } \\
\text { VARIANT }\end{array}$ & $\begin{array}{l}\text { Apache } \\
\text { Apache } \\
\text { Apache } \\
\text { Apache } \\
\text { Graham }\end{array}$ & $\begin{array}{l}340223 \mathrm{~N} 1091640 \mathrm{~W} \\
340350 \mathrm{~N} 1091653 \mathrm{~W} \\
340303 \mathrm{~N} 1091617 \mathrm{~W} \\
\\
340303 \mathrm{~N} 109161 \mathrm{~W} \\
325002 \mathrm{~N} 1094225 \mathrm{~W}\end{array}$ & & 7794 & $\begin{array}{l}\text { Eagar } \\
\text { Eagar } \\
\text { Safford }\end{array}$ \\
\hline $\begin{array}{l}\text { Safford Cemetery } \\
\text { Safford City Hall } \\
\text { Safford Fire Department } \\
\text { Safford High School } \\
\text { Safford Inn Hospital } \\
\text { Safford Interchange } \\
\text { Safford Junior High School } \\
\text { Safford Junior High School } \\
\text { Safford Morence Trail } \\
\text { Safford Municipal Airport }\end{array}$ & $\begin{array}{l}\text { cemetery } \\
\text { building } \\
\text { building } \\
\text { school } \\
\text { building } \\
\text { crossing } \\
\text { school } \\
\text { school } \\
\text { trail } \\
\text { airport }\end{array}$ & $\begin{array}{l}\text { UNOFF } \\
\text { UNOFF } \\
\text { UNOFF } \\
\text { UNOFF } \\
\text { UNOFF } \\
\text { UNOFF } \\
\text { UNOFF } \\
\text { UNOFF } \\
\text { UNOFF } \\
\text { ADMIN }\end{array}$ & $\begin{array}{l}\text { Graham } \\
\text { Graham } \\
\text { Graham } \\
\text { Graham } \\
\text { Graham } \\
\text { Cochise } \\
\text { Pima } \\
\text { Graham } \\
\text { Graham } \\
\text { Graham }\end{array}$ & $\begin{array}{l}324816 \mathrm{~N} 1094239 \mathrm{~W} \\
32495 \mathrm{~N} \mathrm{N1094255 \textrm {W }} \\
32495 \mathrm{~N} 1094253 \mathrm{~W} \\
324944 \mathrm{~N} 1094320 \mathrm{~W} \\
324945 \mathrm{~N} 1094237 \mathrm{~W} \\
322131 \mathrm{~N} 1094052 \mathrm{~W} \\
321305 \mathrm{~N} 1105757 \mathrm{~W} \\
324941 \mathrm{~N} 1094250 \mathrm{~W} \\
325853 \mathrm{~N} 1094020 \mathrm{~W} \\
32511 \mathrm{N1} 1093805 \mathrm{~W}\end{array}$ & & $\begin{array}{l}2920 \\
2920 \\
2920\end{array}$ & $\begin{array}{l}\text { Safford } \\
\text { Safford } \\
\text { Safford } \\
\text { Safford } \\
\text { Safford } \\
\text { Railroad Pass } \\
\text { Tucson } \\
\text { Safford } \\
\text { Weber Peak } \\
\text { Safford }\end{array}$ \\
\hline $\begin{array}{l}\text { Safford Peak } \\
\text { Safford Post office } \\
\text { Safford Public Library } \\
\text { Safford Railroad Station } \\
\text { Safford Valley } \\
\text { Safford Valley }\end{array}$ & $\begin{array}{l}\text { summit } \\
\text { building } \\
\text { building } \\
\text { building } \\
\text { valley }\end{array}$ & $\begin{array}{l}\text { BGN } \\
\text { UNOFF } \\
\text { UNOFF } \\
\text { UNOFF } \\
\text { BGN } \\
\text { VARIANT }\end{array}$ & $\begin{array}{l}\text { Pima } \\
\text { Graham } \\
\text { Graham } \\
\text { Graham } \\
\text { Graham }\end{array}$ & $\begin{array}{l}322043 \mathrm{~N} 1110858 \mathrm{~W} \\
325002 \mathrm{~N} 1094240 \mathrm{~W} \\
324947 \mathrm{~N} 1094257 \mathrm{~W} \\
324950 \mathrm{~N} 1094241 \mathrm{~W} \\
325400 \mathrm{~N} 1094700 \mathrm{~W}\end{array}$ & & $\begin{array}{l}3563 \\
2920 \\
2920 \\
2920\end{array}$ & $\begin{array}{l}\text { Avra } \\
\text { Safford } \\
\text { Safford } \\
\text { Safford } \\
\text { Pima }\end{array}$ \\
\hline $\begin{array}{l}\text { See Gila Valley } \\
\text { Saffron Valley } \\
\text { Sag Creek } \\
\text { Sagebrush Canyon }\end{array}$ & $\begin{array}{l}\text { valley } \\
\text { valley } \\
\text { stream } \\
\text { valley }\end{array}$ & $\begin{array}{l}\text { BGN } 1908 \\
\text { BGN } \\
\text { BGN }\end{array}$ & $\begin{array}{l}\text { Graham } \\
\text { Coconino } \\
\text { Gila } \\
\text { Apache }\end{array}$ & $\begin{array}{l}331100 \mathrm{~N} 1101300 \mathrm{~W} \\
361927 \mathrm{N1122058 \textrm {W }} \\
332712 \mathrm{~N} 1101959 \mathrm{~W} \\
361719 \mathrm{N1} 1095039 \mathrm{~W}\end{array}$ & $\begin{array}{l}362002 \mathrm{N1} 121710 \mathrm{~W} \\
332955 \mathrm{N1} 101523 \mathrm{~W} \\
361 \mathrm{~B} 57 \mathrm{N1} 1094941 \mathrm{~W}\end{array}$ & & $\begin{array}{l}\text { King Arthur Castle } \\
\text { Sontag Mesa } \\
\text { Sweathouse Peak }\end{array}$ \\
\hline $\begin{array}{l}\text { Sagebrush Dam } \\
\text { Sage Brush Point } \\
\text { Sagebrush Spring } \\
\text { Sagebrush Wash } \\
\text { Sagebrush Well } \\
\text { Sagebrush Well } \\
\text { Sage Orain } \\
\text { Sa-gee-ka Butte } \\
\text { See Segeke Butte } \\
\text { Sage Flat Reservoir }\end{array}$ & $\begin{array}{l}\text { dam } \\
\text { cape } \\
\text { spring } \\
\text { valley } \\
\text { well } \\
\text { well } \\
\text { stream } \\
\text { summit } \\
\text { reservoir }\end{array}$ & $\begin{array}{l}\text { UNOFF } \\
\text { BGN } \\
\text { BGN } \\
\text { BGN } \\
\text { UNOFF } \\
\text { UNOFF } \\
\text { BGN } \\
\text { VARIANT } \\
\text { BGN }\end{array}$ & $\begin{array}{l}\text { Apache } \\
\text { Coconino } \\
\text { Apache } \\
\text { Navajo } \\
\text { Navajo } \\
\text { Navajo } \\
\text { Mohave } \\
\text { Navajo } \\
\text { Mohave }\end{array}$ & $\begin{array}{l}360948 \times 1091703 \mathrm{~W} \\
360735 \mathrm{~N} 1123517 \mathrm{~W} \\
351643 \mathrm{~N} 1090424 \mathrm{~W} \\
362411 \mathrm{N1} 102306 \mathrm{~W} \\
360320 \mathrm{~N} 1101020 \mathrm{~W} \\
362405 \mathrm{~N} 1102311 \mathrm{~W} \\
343046 \mathrm{~N} 1141814 \mathrm{~W} \\
364717 \mathrm{~N} 1101618 \mathrm{~W} \\
361214 \mathrm{~N} 1131005 \mathrm{~W}\end{array}$ & $\begin{array}{l}362451 N 1101953 \mathrm{~W} \\
343101 N 1141753 \mathrm{~W}\end{array}$ & & $\begin{array}{l}\text { Mummy Cave Ruins } \\
\text { Topocoba Hilltop } \\
\text { Lupton } \\
\text { Great Spring } \\
\text { Pinon } \\
\text { Great Spring } \\
\text { Lake Havasu City N }\end{array}$ \\
\hline House Wash & stream & BGN & Apache & $354505 \mathrm{~N} 1092548 \mathrm{~W}$ & $355123 \mathrm{~N} 1091743 \mathrm{~W}$ & & Red Clay Wash \\
\hline
\end{tabular}


FEATURE NAME

Sage Memorial Hospital
Sage Peak
Sage Tank
Sage Tank
Sage Valley
Sagewood (subdivision)
Sagewood Spring
Saginaw
Saginaw
Saginaw Hill
Saginaw Reservoirs
Saginaw Sink
Sagi ot Sosi Canyon
See Tseyi-Hatsosi Canyon
Sagittarius Ridge
Saguaro (historical)
Sahauro
Sahura
Sahuaro

Saguaro Airport

Saguaro del Norte Recreation Area

Saguaro Gap

Saguaro Gap Well

Saguaro High School

Saguaro Lake

Sahuaro Lake Stewart Mountain Lake

Saguaro Mine

Saguaro Mational Monument

(Tucson Mountain Section)

Saguaro Mational Monument

East Unit

Saguaro Power Plant

Saguaro School

Saguaro Slope Ranch

Saguaro Tank

Saguaro Tank

Saguaro Tank

Saguaro Vista Shopping Center

Saguaro Well

Sagy at Sosi Canyon

See Tseyi-Hatsosi Canyon

Sahara Mobtle Home Park

Sahauro

See Saguaro (historical)

$S$ A Hill

Sahkoo Park

Sahotsaidbeazhe Canyon

See Dennehotso Canyon

Sa Hot soid be azhe Canyon See Dennehotso Canyon

Sahotsoid Beazhe Canyon

See Dennehotso Canyon

Sah Tah Mine

Sahuarita

Sahuartto

Saurita

Sahuarita Butte

See Martinez HIll

Sahuarita Elementary School

Sahuarita Heights

Sahuarita High School

Sahuarita Junior High School

Sahuarita Post Office

Sahuarita Railroad Station

Sahuarita Wash

Sahuarito

See Sahuarita

Sahuarito Butte

See Martinez Hill

\begin{tabular}{|c|c|c|c|}
\hline $\begin{array}{l}\text { FEATURE } \\
\text { CLASS }\end{array}$ & STATUS & COUNTY & COORDINATE \\
\hline $\begin{array}{l}\text { hospital } \\
\text { summit } \\
\text { reservoir } \\
\text { reservoir } \\
\text { valley } \\
\text { ppl } \\
\text { spring } \\
\text { mine } \\
\text { ppl }\end{array}$ & $\begin{array}{l}\text { UNOFF } \\
\text { BGN } 1932 \\
\text { BGN } \\
\text { BGN } \\
\text { BGN } \\
\text { BGN } \\
\text { BGN } \\
\text { UNOFF } \\
\text { BGN }\end{array}$ & $\begin{array}{l}\text { Apache } \\
\text { Cochise } \\
\text { Coconino } \\
\text { Coconino } \\
\text { Navajo } \\
\text { Maricopa } \\
\text { Apache } \\
\text { Cochise } \\
\text { Cochise }\end{array}$ & $\begin{array}{l}354237 N 1093235 \mathrm{~W} \\
314659 \mathrm{~N} 1091555 \mathrm{~W} \\
354942 \mathrm{N1} 130000 \mathrm{~W} \\
355133 \mathrm{~N} 1120731 \mathrm{~W} \\
365121 \mathrm{N1} 103706 \mathrm{~W} \\
332317 \mathrm{~N} 1115010 \mathrm{~W} \\
353619 \mathrm{~N} 1093245 \mathrm{~W} \\
312547 \mathrm{N1} 1095243 \mathrm{~W} \\
312545 \mathrm{~N} 1095258 \mathrm{~W}\end{array}$ \\
\hline $\begin{array}{l}\text { summit } \\
\text { reservoir } \\
\text { reservoir }\end{array}$ & $\begin{array}{l}\text { BGN } \\
\text { BGN } \\
\text { BGN } \\
\text { VARIANT }\end{array}$ & $\begin{array}{l}\text { Pima } \\
\text { Coconino } \\
\text { Coconino }\end{array}$ & $\begin{array}{l}320826 \mathrm{~N} 1110437 \mathrm{~W} \\
351427 \mathrm{~N} 1121118 \mathrm{~W} \\
350441 \mathrm{~N} 1114023 \mathrm{~W}\end{array}$ \\
\hline $\begin{array}{l}\text { valley } \\
\text { ridge } \\
\text { locale }\end{array}$ & $\begin{array}{l}\text { BGN } 1908 \\
\text { BGN } 1917 \\
\text { VARIANT } \\
\text { VARIANT } \\
\text { VARIANT }\end{array}$ & $\begin{array}{l}\text { Navajo } \\
\text { Coconino } \\
\text { Pima }\end{array}$ & $\begin{array}{l}365212 \mathrm{~N} 1101952 \mathrm{~W} \\
361224 \mathrm{~N} 1121636 \mathrm{~W} \\
322700 \mathrm{~N} 1113300 \mathrm{~W}\end{array}$ \\
\hline
\end{tabular}

$\begin{array}{cc}\text { SOURCE } & \text { ELEV } \\ \text { COORDINATE } & \mathrm{FT}\end{array}$

$364823 N 1103740 \mathrm{~W}$

Ganado

Chiricahua Peak

Frazier Wells

Red Butte SW

Tall Mountain

1210 Mesa

Klagetoh North

Bisbee

Bisbee

2832 Cat Mountain

Williams South

Mountainaire

Havasupa i Point

Silver Bell West

\begin{tabular}{|c|c|c|c|}
\hline $\begin{array}{l}\text { airport } \\
\text { park }\end{array}$ & $\begin{array}{l}\text { ADMIN } \\
\text { ADMIN }\end{array}$ & $\begin{array}{l}\text { Maricopa } \\
\text { Maricopa }\end{array}$ & $\begin{array}{l}332654 N 1120100 W \\
333436 N 1113201 W\end{array}$ \\
\hline $\begin{array}{l}\text { gap } \\
\text { well } \\
\text { school } \\
\text { reservoir }\end{array}$ & $\begin{array}{l}\text { BGN } \\
\text { UNOFF } \\
\text { UNOFF } \\
\text { BGN } 1965 \\
\text { VARIANT } \\
\text { VARIANT }\end{array}$ & $\begin{array}{l}\text { Pima } \\
\text { Pima } \\
\text { Maricopa } \\
\text { Maricopa }\end{array}$ & $\begin{array}{l}321735 N 1131511 W \\
321707 N 1131331 W \\
333138 N 1115421 W \\
333356 N 1113210 \mathrm{~W}\end{array}$ \\
\hline mine & UNOFF & Gila & $334853 \mathrm{~N} 1111022 \mathrm{~W}$ \\
\hline park & ADMIN & Pima & $321643 \mathrm{~N} 1111055 \mathrm{~W}$ \\
\hline park & ADMIN & Pima & $321000 \mathrm{~N} 1103500 \mathrm{~W}$ \\
\hline $\begin{array}{l}\text { locale } \\
\text { school } \\
\text { locale } \\
\text { reservoir } \\
\text { reservoir } \\
\text { reservoir }\end{array}$ & $\begin{array}{l}\text { UNOFF } \\
\text { UNOFF } \\
\text { UNOFF } \\
\text { BGN } \\
\text { BGN } \\
\text { BGN }\end{array}$ & $\begin{array}{l}\text { Pinal } \\
\text { Pinal } \\
\text { Pinal } \\
\text { Pina } \\
\text { Yuna } \\
\text { Maricopa }\end{array}$ & $\begin{array}{l}323310 \mathrm{~N} 1111745 \mathrm{~W} \\
325326 \mathrm{N1} 114512 \mathrm{~W} \\
332511 \mathrm{N1} 112839 \mathrm{~W} \\
313536 \mathrm{N1} 113831 \mathrm{~W} \\
330607 \mathrm{N1} 140755 \mathrm{~W} \\
334802 \mathrm{~N} 1121212 \mathrm{~W}\end{array}$ \\
\hline
\end{tabular}

Phoenix

Stewart Mtn

Granite Mts South

Saguaro Gap Well

Paradise Valley

1506 Stewart Mtn

Greenback Creek

Avra

Mica Mountain

Red Rock

Casa Grande West

Goldfield

Caponera Peak

Castle Dome Peak

Biscuit Flat

2580 Tucson East

Mount Triplet

1175 Glendale

4822 Battle Flat

Currys Corner

341855N112161

$333755 \mathrm{~N} 1115546 \mathrm{~W}$

365338N1094435W

valley

ADMIN

VARIANT

Apache

VARIANT

valley

Apache

$365338 N 1094435 \mathrm{~W}$

$365338 \mathrm{~N} 1094435 \mathrm{~W}$

365219 N1091723

315727 N1105718W

Toh Chin Lini Mesa

mine

UNOFF

Apache

Pina

VARIANT

VARIANT

VARIANT

summit

Pima

$320623 N 1105915 \mathrm{~W}$

School UNOFF Pima 315744N1105656W

$315700 N 1105529 \mathrm{~W}$

315737 N11 $105834 \mathrm{~W}$

$315733 N 1105852 \mathrm{~W}$

$315726 N 1105722 \mathrm{~W}$

$315744 \mathrm{~N} 1105716 \mathrm{~W}$

$322823 \mathrm{~N} 1105555 \mathrm{~W}$

$320623 N 1105915 \mathrm{~W}$
Sahaurita

2780 Sahaurita

Sahaurita

Sahaurita

Sahaurita

Sahaurita

Oro valley pp 1

summit
VARIANT
$323336 \mathrm{~N} 1110110 \mathrm{~W}$
2702 Sahuarita 


\begin{tabular}{|c|c|c|c|c|c|c|c|}
\hline FEATURE NAME & $\begin{array}{l}\text { FEATURE } \\
\text { CLASS }\end{array}$ & STATUS & COUNTY & COORDINATE & $\begin{array}{l}\text { SOURCE } \\
\text { COORDINATE }\end{array}$ & $\begin{array}{c}\text { ELEV } \\
\text { FT }\end{array}$ & MAP NAME \\
\hline $\begin{array}{l}\text { Sahuaro } \\
\text { See Saguaro (historical) } \\
\text { Sahuaro High School } \\
\text { Sahuaro Lake } \\
\text { See Saguaro Lake } \\
\text { Sahuaro Ranch } \\
\text { Sahuaro School } \\
\text { Sahuaro School } \\
\text { Sahuaro Tank } \\
\text { Sahura } \\
\text { See Saguaro (historical) }\end{array}$ & $\begin{array}{l}\text { locale } \\
\text { school } \\
\text { reservoir } \\
\text { locale } \\
\text { school } \\
\text { school } \\
\text { reservoir } \\
\text { locale }\end{array}$ & $\begin{array}{l}\text { VARIANT } \\
\text { UNOFF } \\
\text { VARIANT } \\
\text { UNOFF } \\
\text { UNOFF } \\
\text { UNOFF } \\
\text { BGN } \\
\text { VARIANT }\end{array}$ & $\begin{array}{l}\text { Pima } \\
\text { Pima } \\
\text { Maricopa } \\
\text { Pima } \\
\text { Pima } \\
\text { Maricopa } \\
\text { Yavapai } \\
\text { Pima }\end{array}$ & $\begin{array}{l}322700 \mathrm{~N} 1113300 \mathrm{~W} \\
321332 \mathrm{~N} 1104822 \mathrm{~W} \\
333356 \mathrm{~N} 1113210 \mathrm{~W} \\
322029 \mathrm{~N} 1110659 \mathrm{~W} \\
321425 \mathrm{~N} 1110507 \mathrm{~W} \\
333611 \mathrm{~N} 1120742 \mathrm{~W} \\
340937 \mathrm{~N} 1114738 \mathrm{~W} \\
322700 \mathrm{~N} 1113300 \mathrm{~W}\end{array}$ & & & $\begin{array}{l}\text { Tucson East } \\
\text { Jaynes } \\
\text { Cat Mountain } \\
\text { Glendale } \\
\text { Bloody Bas in }\end{array}$ \\
\hline $\begin{array}{l}\text { Sahurito Peak } \\
\text { See Martinez Hill } \\
\text { Sahwick Mountain } \\
\text { See Sawik Mountain } \\
\text { Sah-wik Mountain } \\
\text { See Sawik Mountain } \\
\text { Saint Agatha Campground } \\
\text { Saint Agatha Mission } \\
\text { Saint Agnes School } \\
\text { Saint Ambrose School }\end{array}$ & $\begin{array}{l}\text { summit } \\
\text { summit } \\
\text { summit } \\
\text { park } \\
\text { church } \\
\text { school } \\
\text { school }\end{array}$ & $\begin{array}{l}\text { VARIANT } \\
\text { VARIANT } \\
\text { VARIANT } \\
\text { ADMIN } \\
\text { UNOFF } \\
\text { UNOFF } \\
\text { UNOFF }\end{array}$ & $\begin{array}{l}\text { Pima } \\
\text { Maricopa } \\
\text { Maricopa } \\
\text { Yavapai } \\
\text { Pima } \\
\text { Maricopa } \\
\text { Pima }\end{array}$ & $\begin{array}{l}320623 N 1105915 W \\
333212 N 1114538 W \\
333212 N 1114538 W \\
342908 N 1123011 W \\
321317 N 1114901 W \\
332824 N 1120148 W \\
321306 N 1105608 W\end{array}$ & & & $\begin{array}{l}\text { Wilhoit } \\
\text { Sil Nakya } \\
\text { Phoenix } \\
\text { Tucson }\end{array}$ \\
\hline $\begin{array}{l}\text { Saint Ann Cemetery } \\
\text { Saint Ann Church } \\
\text { Saint Anselm Mission } \\
\text { Saint Anthony Mine } \\
\text { Saint Anthony Spring } \\
\text { Saint Bernardo } \\
\text { See Awatobi (site) } \\
\text { Saint Catherines Church } \\
\text { Saint Christopher Mine } \\
\text { Saint Clair, Lake }\end{array}$ & $\begin{array}{l}\text { cemetery } \\
\text { church } \\
\text { church } \\
\text { mine } \\
\text { spring } \\
\text { locale } \\
\text { church } \\
\text { mine } \\
\text { reservoir }\end{array}$ & $\begin{array}{l}\text { UNOFF } \\
\text { UNOFF } \\
\text { UNOFF } \\
\text { UNOFF } \\
\text { BGN } \\
\text { VARIANT } \\
\text { UNOFF } \\
\text { UNOFF } \\
\text { BGN }\end{array}$ & $\begin{array}{l}\text { Pinal } \\
\text { Apache } \\
\text { Apache } \\
\text { Yavapai } \\
\text { Yavapai } \\
\text { Navajo } \\
\text { Pinal } \\
\text { Santa Cruz } \\
\text { Pinal }\end{array}$ & $\begin{array}{l}330727 \mathrm{~N} 1114423 \mathrm{~W} \\
361700 \mathrm{~N} 1091046 \mathrm{~W} \\
351710 \mathrm{~N} 1090935 \mathrm{~W} \\
335822 \mathrm{~N} 1122724 \mathrm{~W} \\
335823 \mathrm{~N} 1122716 \mathrm{~W} \\
\\
354331 \mathrm{~N} 1101639 \mathrm{~W} \\
331338 \mathrm{~N} 1121014 \mathrm{~W} \\
312853 \mathrm{~N} 1111713 \mathrm{~W} \\
323903 \mathrm{~N} 1115612 \mathrm{~W}\end{array}$ & & 6100 & $\begin{array}{l}\text { Sacaton } \\
\text { Tsaile } \\
\text { Houck } \\
\text { Garfias Mtn } \\
\text { Garfias Mtn } \\
\text { Montezuma Peak } \\
\text { Bartlett Mtn } \\
\text { Vaiva Vu }\end{array}$ \\
\hline $\begin{array}{l}\text { Saint Claire Mountain } \\
\text { See Saint Clair Mountain } \\
\text { Saint Claire Peak } \\
\text { See Saint Clair Peak } \\
\text { Saint Claire Spring } \\
\text { See Saint Clair Spring } \\
\text { Saint Clair Mountain } \\
\text { Saint Claire Mountain } \\
\text { Saint Clair Peak } \\
\text { Saint Claire Peak }\end{array}$ & $\begin{array}{l}\text { summit } \\
\text { summit } \\
\text { spring } \\
\text { summit } \\
\text { summit }\end{array}$ & $\begin{array}{l}\text { VARIANT } \\
\text { VARIANT } \\
\text { VARIANT } \\
\text { BGN } \\
\text { VARIANT } \\
\text { BGN } \\
\text { VARIANT }\end{array}$ & $\begin{array}{l}\text { Maricopa } \\
\text { Maricopa } \\
\text { Maricopa } \\
\text { Maricopa } \\
\text { Maricopa }\end{array}$ & $\begin{array}{l}335523 \mathrm{~N} 1114328 \mathrm{~W} \\
335352 \mathrm{~N} 1114340 \mathrm{~W} \\
335517 \mathrm{~N} 1114355 \mathrm{~W} \\
335523 \mathrm{~N} 1114328 \mathrm{~W} \\
335352 \mathrm{~N} 1114340 \mathrm{~W}\end{array}$ & & $\begin{array}{l}3252 \\
4230\end{array}$ & $\begin{array}{l}\text { Horseshoe Dam } \\
\text { Horseshoe Dam }\end{array}$ \\
\hline $\begin{array}{l}\text { Saint Clair Spring } \\
\text { Saint Claire Spring } \\
\text { Saint Cyril School } \\
\text { Saint David } \\
\text { Saint David Cemetery } \\
\text { Saint David Ditch } \\
\text { Saint David Elementary School } \\
\text { Saint David High School } \\
\text { Saint David Post Office } \\
\text { Saint Oavid Substation }\end{array}$ & $\begin{array}{l}\text { spring } \\
\text { school } \\
\text { ppl } \\
\text { cemetery } \\
\text { canal } \\
\text { school } \\
\text { school } \\
\text { building } \\
\text { locale }\end{array}$ & $\begin{array}{l}\text { BGN } \\
\text { VARIANT } \\
\text { UNOFF } \\
\text { BGN } \\
\text { UNOFF } \\
\text { BGN } \\
\text { UNOFF } \\
\text { UNOFF } \\
\text { UNOFF } \\
\text { UNOFF }\end{array}$ & $\begin{array}{l}\text { Maricopa } \\
\text { Pima } \\
\text { Cochise } \\
\text { Cochise } \\
\text { Cochise } \\
\text { Cochise } \\
\text { Cochise } \\
\text { Cochise } \\
\text { Cochise }\end{array}$ & $\begin{array}{l}335517 \mathrm{~N} 1114355 \mathrm{~W} \\
321438 \mathrm{~N} 1105326 \mathrm{~W} \\
315415 \mathrm{~N} 1101249 \mathrm{~W} \\
315159 \mathrm{~N} 1101218 \mathrm{~W} \\
315023 \mathrm{~N} 1101224 \mathrm{~W} \\
315421 \mathrm{~N} 1101310 \mathrm{~W} \\
315421 \mathrm{~N} 1101307 \mathrm{~W} \\
315419 \mathrm{~N} 1101324 \mathrm{~W} \\
315243 \mathrm{~N} 1101417 \mathrm{~W}\end{array}$ & & & $\begin{array}{l}\text { Horseshoe Dam } \\
\text { Tucson } \\
\text { Saint David } \\
\text { Land } \\
\text { Land } \\
\text { Saint David } \\
\text { Saint David } \\
\text { Saint David } \\
\text { Saint David }\end{array}$ \\
\hline $\begin{array}{l}\text { Saint Francis Borgia Church } \\
\text { Saint Francis Cemetery } \\
\text { Saint Francis Mission } \\
\text { Saint Francis Mission } \\
\text { Saint Francis School } \\
\text { Saint Francis Xavier Grade } \\
\text { School } \\
\text { Saint Francois Xavier du Bac } \\
\text { See San Xavier del Bac } \\
\text { Mission }\end{array}$ & $\begin{array}{l}\text { church } \\
\text { cemetery } \\
\text { church } \\
\text { church } \\
\text { school } \\
\text { school }\end{array}$ & $\begin{array}{l}\text { UNOFF } \\
\text { UNOFF } \\
\text { UNOFF } \\
\text { UNOFF } \\
\text { UNOFF } \\
\text { UNOFF } \\
\text { VARIANT }\end{array}$ & $\begin{array}{l}\text { Pinal } \\
\text { Maricopa } \\
\text { Pima } \\
\text { Pinal } \\
\text { Yuma } \\
\text { Maricopa }\end{array}$ & $\begin{array}{l}330822 \mathrm{~N} 1115911 \mathrm{~W} \\
332824 \mathrm{~N} 1115826 \mathrm{~W} \\
315519 \mathrm{~N} 1121250 \mathrm{~W} \\
330152 \mathrm{~N} 1120430 \mathrm{~W} \\
324140 \mathrm{~N} 1143736 \mathrm{~W} \\
333021 \mathrm{~N} 1120408 \mathrm{~W} \\
320626 \mathrm{~N} 1110024 \mathrm{~W}\end{array}$ & & 1845 & $\begin{array}{l}\text { Gila Butte NW } \\
\text { Tempe } \\
\text { Kupk } \\
\text { Maricopa } \\
\text { Yuma West } \\
\text { Sunnys lope }\end{array}$ \\
\hline $\begin{array}{l}\text { Saint George Canyon } \\
\text { Saint George Tank } \\
\text { Saint Gregory School } \\
\text { Saint Isabel Mission } \\
\text { Saint James Camp } \\
\text { Saint James Range } \\
\text { See Black Mountains } \\
\text { Saint Joe Canyon } \\
\text { Saint Joe Ridge } \\
\text { Saint Joesph } \\
\text { See Joseph City }\end{array}$ & $\begin{array}{l}\text { valley } \\
\text { reservoir } \\
\text { school } \\
\text { school } \\
\text { locale } \\
\text { range } \\
\text { valley } \\
\text { ridge } \\
\text { ppl }\end{array}$ & $\begin{array}{l}\text { BGN } \\
\text { BGN } \\
\text { UNOFF } \\
\text { UNOFF } \\
\text { BGN } \\
\text { VARIANT } \\
\text { BGN } \\
\text { BGN } \\
\text { VARIANT }\end{array}$ & $\begin{array}{l}\text { Mohave } \\
\text { Pima } \\
\text { Maricopa } \\
\text { Apache } \\
\text { Yavapai } \\
\text { Mohave } \\
\text { Coconino } \\
\text { Coconino } \\
\text { Navajo }\end{array}$ & $\begin{array}{l}363108 \mathrm{~N} 1134015 \mathrm{~W} \\
315842 \mathrm{~N} 1112516 \mathrm{~W} \\
332910 \mathrm{~N} 1120555 \mathrm{~W} \\
362506 \mathrm{~N} 1091350 \mathrm{~W} \\
343049 \mathrm{~N} 1123120 \mathrm{~W} \\
\\
352814 \mathrm{~N} 1143038 \mathrm{~W} \\
342536 \mathrm{~N} 1104539 \mathrm{~W} \\
342250 \mathrm{~N} 1104624 \mathrm{~W} \\
345721 \mathrm{~N} 1102000 \mathrm{~W}\end{array}$ & $363316 \mathrm{~N} 1133952 \mathrm{~W}$ & 6020 & $\begin{array}{l}\text { St George Canyon } \\
\text { Palo Alto Ranch } \\
\text { Phoenix } \\
\text { Lukachukai } \\
\text { Iron Springs }\end{array}$ \\
\hline
\end{tabular}


NATIONAL GAZETTEER--ARIZONA 1986 FEATURE NAME

$$
\begin{gathered}
\text { FEATURE } \\
\text { CLASS }
\end{gathered}
$$

STATUS

COUNTY

\begin{tabular}{|c|c|c|c|}
\hline spring & BGN & Coconino & $342048 \mathrm{~N} 1104735 \mathrm{~W}$ \\
\hline pp1 & VARTANT & Apache & $343021 N 1092137 \mathrm{~W}$ \\
\hline church & VARIANT & Maricopa & $331725 \mathrm{~N} 1121021 \mathrm{~W}$ \\
\hline $\begin{array}{l}\text { ppl } \\
\text { ppl }\end{array}$ & $\begin{array}{l}\text { BGN } \\
\text { VARIANT }\end{array}$ & $\begin{array}{l}\text { Maricopa } \\
\text { Apache }\end{array}$ & $\begin{array}{l}331736 \mathrm{~N} 1121029 \mathrm{~W} \\
343021 \mathrm{~N} 1092137 \mathrm{~W}\end{array}$ \\
\hline ana 1 & $\mathrm{BGN}$ & Maricopa & $332329 N 1121934 \mathrm{~W}$ \\
\hline
\end{tabular}

COORDINATE

Saint Johns Chapel See Saint Johns Indian School

Saint Johns City Park

Saint Johns Creek

Saint Johns High School

Saint Johns Indian School Saint Johns Chapel

Saint Johns Mine

Saint Johns Mission Saint Johns

Saint Johns Mission See Konatke

Saint Johns Municipal Airport

Saint Johns School

Saint Johns Stake Welfare Ranch

Saint Johns Tank

Saint John Tank

Saint Joseph Hospital

Saint Josephs Academy

Saint Josephs Catholic School

Saint Josephs Hospital

Saint Josephs Hospital Helistop

Saint Josephs Reservoir

Saint Josephs School

Saint Joseph Wash

See Joseph City Wash

Saint Joseph Youth Camp

Saint Jude Well

Saint Louis Mine

Saint Louis Mine

Saint Lukes Hospital

Saint Lukes in the Desert

Hospital

Saint Marks School

Saint Mary/Basha Elementary School

See Basha Elementary School

Saint Mary Schoo

Saint Marys Dan

Saint Marys Elementary School

Saint Marys Heliport

Saint Marys High School

Saint Marys Hospital

Saint Marys Lake

Saint Marys Road Interchange

Saint Mathews Mountain

See Saint Matthews Mountain

Saint Matthews Mountain

Saint Mathews Mountain

Saint Matthews School

Saint Michaels

Saint Michaels Church

See Saint Michaels Indian School

Saint Michaels Elementary

School

See Saint Michaels Indian School

Saint Michaels Indian School Saint Michaels Church

Saint Michaels
VARIANT

school

park

stream

school

school

mine

church

\section{ADMIN}

BGN

UNOFF

UNOFF

UNOFF

BGN

VARIANT

Maricopa

$331724 N 1121022 W$

Apache

Gila

Apache

Yavapai

Maricopa

VARIANT

airpl

airport

school

reservoir

reservoir

hospital

school

school

airport ADMIN

reservoir

school

BGN

VARIANT

stream

locale

well

mine

UNOFF

UNOFF

UNOFF

UNOFF

hospita

hospital

UNOFF

UNOFF

school

UNOFF

VARIANT

school

school

dam

school

UNOFF

UNOFF

UNOFF

\section{airport}

school

hospita

lake

crossing

ADMIN

UNOFF

UNOFF

BGN

UNOFF

VARIANT

summit

summ it

school

BGN 1977

VARIANT

UNOFF

ppl

BGN

VARIANT

school

VARIANT

school

school

$$
\text { UNOF }
$$

VARIANT

VARIANT

Apache 343939N1092110W

Apache 335912N1092005

Pima 315544N11131416
Maricopa 331736N1121029W

Apache 343115N1092245W

Pima 321043N1105840W

Gila 341036N1112139W

Gila 333030N1104422W

Gima $321336 N 1105116 W$

$\begin{array}{ll}\text { Pima } & 321336 \mathrm{~N} 1105116 \mathrm{~W} \\ \text { Pima } & 321339 \mathrm{~N} 1105057 \mathrm{~W}\end{array}$

Navajo 350207N1104145

Maricopa 332852N1120444W

$321309 N 1105225$

Navajo 345657N1102019W

Coconino 345645N1112932W

Santa Cruz 313836N1104807W

Mohave 351815N1140726W

Maricopa 332714N1120230W

Pima 321428N1105740W

Maricopa 332720N1120100W

Maricopa $331850 N 1115047 \mathrm{~W}$

Mohave 351129N1140312W

Apache 335936N1091916W

Maricopa 332702N1120408W

Pima 321335N1105956W

Maricopa 332709N1120411W

Pima 321337N1110001W

Apache 335936N1091916W

Pima 321345N1105854W

Yavapai 344603N1121513W

$344603 \mathrm{~N} 1121513 \mathrm{~W}$

$332707 N 1120611 \mathrm{~W}$

Maricopa

$353841 N 1090542 W$

353845 N1090545W

Apache

Apache

353845N1090545W

Apache

$353845 \mathrm{~N} 1090545 \mathrm{~W}$
Maricopa 332852N1120448W
SOURCE

COORDINATE

ELEV
FT

MAP NAME

OW Point

5686 St Johns North

Avondale

St Johns North

North Peak

St Johns North

Laveen

Cleator

Laveen

5732 Zion Reservoir Tucson

Schnebly Well

Payson South

Chrome Butte

Tucs on East

Tucson East

Winslow

Phoenix

1107 Phoenix

Rudd Knoll

Tucson East

Mormon Lake

3577 Kitt Peak

Mt Wrightson

Stockton Hill

Phoenix

Tucson

Phoenix

Kingman

Rudd Knoll

Phoenix

2345 Tucs on

Phoenix

Cat Mountain

Rudd Knol1

Tucson

6307 King Canyon

Phoenix

Window Rock

Window Rock 
AZ542

FEATURE NAME

Elementary School

Saint Michaels Mission

Saint Michaels Post Office

Saint Patrick Mine

Saint Patrick School

Saint Peter

See Wellton

Saint Peters Done

Saint Peters Mission School

Saint Simon and Jude School

Saints Peter and Paul School

Saint Theresa Mine

Saint Theresa Mission

Saint Theresa School

Saint Thomas School

Saint Vincent de Paul School

Sa-jini

See Black Rock Butte

Sajini Butte

See Black Pinnacle

Salada

See Salt River

Salada, Laguna

Salado

Salido

Salado Springs

Salah-Kai Mesa

See Balakai Mesa

Salahkai Mesa

See Balakai Mesa

Salahkai Point

See Balakai Point

Sa La kai Mesa

See Balakai Mesa

Salano School

Sala Ranch

Salaratus Draw

Salaratus Pond

Salazar Cemetery

Salceda Mountains See Sauceda Mountains

Salcedo Tank

Salcedo Well

Salcilla

See Chiulikam

Salcita Spring

Salec

See Tsaile

Salero Mine

Salero Mountain

Salero Ranch

Saletso Springs

See Setsiitso Springs

Salida Gulch

Salida Spring

Salida Tank

Salido

See Salado

Salina

Salina Springs

Salinas Springs

Sal inas

$$
\text { Tselani }
$$

See Salt River

Salina Springs Gukome lik

Komal ik

Komel ih

Koml in

Kukomal ik

Salina Springs
FEATURE

CLASS

STATUS

NATIONAL GAZETTEER--ARIZONA 1986

COUNTY COORDINATE

SOURCE
COOROINATE

MAP NAME

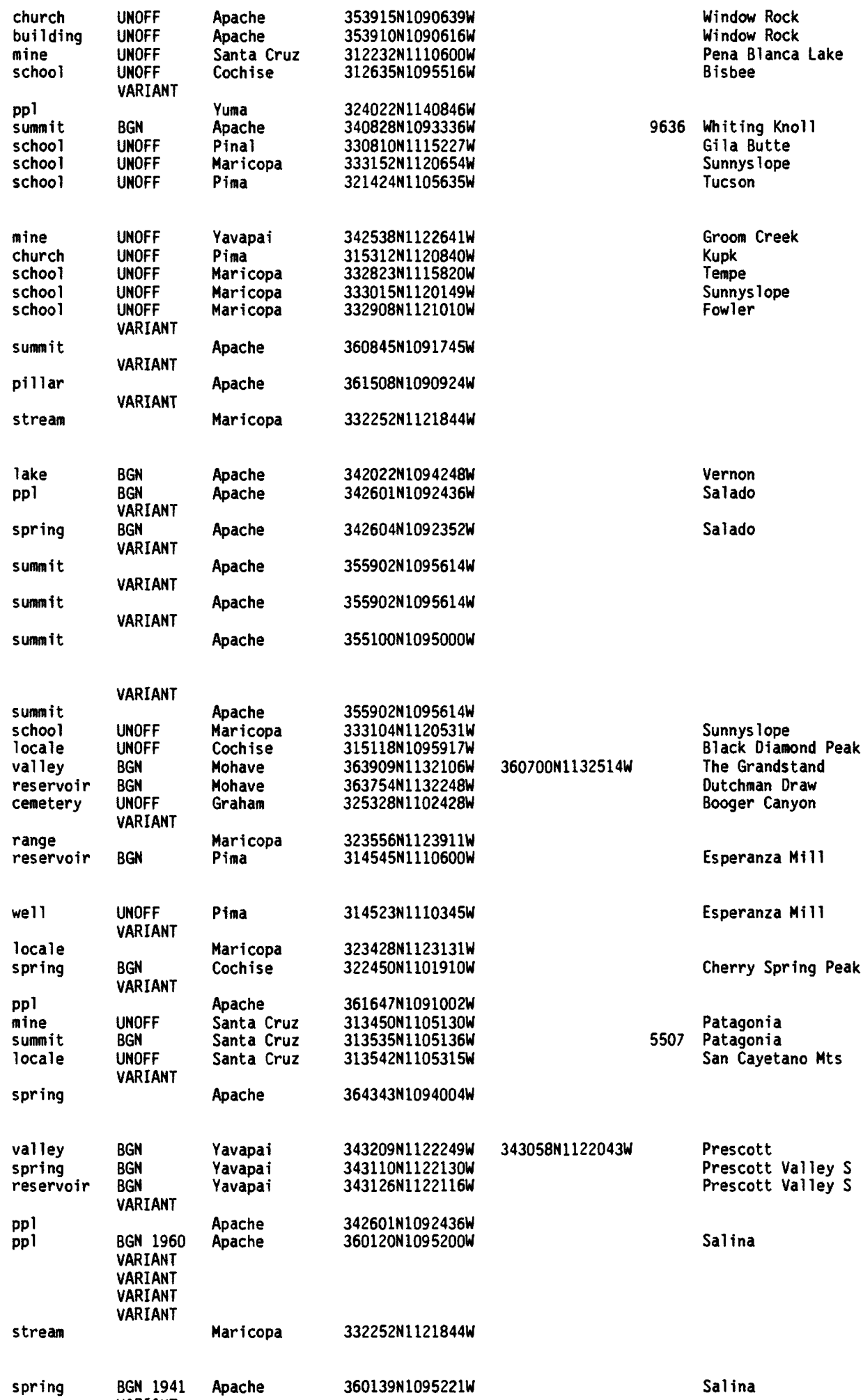

BARIANT

VARIANT

VARIANT

VARIANT

VARIANT

VARIANT 
NATIONAL GAZETTEER--ARIZONA 1986

\section{FEATURE NAME}

See Salina

Salinas Springs

See Salina

Salk Elementary School

Salltso Springs

See Setsiltso Springs

Sally May Canyon

See Sally May Wash

Sallymay Creek

See Salome Creek

Sally May Creek

See Salome Creek

Sally May Spring

Sally May Tank

Sally May Tank See Towel Tank

Sally May Wash Sally May Canyon Salome Canyon Salome Creek

Salmon Lake

Salmon Lake Bas in

Salmon Lake Butte

Salmon Lake Spring

Salmon Lake Tank

Salome

Salome Airport

Salome Canyon See Sally May Wash

Salome Creek

Sally May Creek Sallymay Creek

Salome Creek

See Sally May Wash

Salome Elementary School

Salome Emergency Airfield

Salome High School

Salome Mountain

Methodist Mountain

Salome Mountains

Salome Mountains

See Salome Mountain

Salome Peak

Salome Railroad Station

Salome Sheriffs Office

Salome Wash

Saloon Canyon

Saloon Canyon

Salponite High School

Salt Bas in

Salt Box Spring

Salt Box Tank

Salt Box Tank

Salt Canyon

Salt Creek

Salt Creek

Salt Creek

Salt Creek

Salt Creek

Salt Creek

Salt Creek

See Jacks Canyon

Salt Creek Camp

Salt Creek Ranch Headquarters

Salt Creek Rapids

Salt Creek Tank

Salt Creek Tank

Salt Creek Tank

Salt Ground Canyon

Salt Ground Tank

Salt Ground Tank
FEATUR

CLASS

ppl

ppl

school

spring

stream

stream

stream

spring

reservoir

reservoir

stream

$\begin{array}{ll} & \text { VARIANT } \\ & \text { VARIANT } \\ \text { lake } & \text { BGN } \\ \text { bas in } & \text { BGN } \\ \text { summit } & \text { BGN }\end{array}$

Coconino

Coconino

Coconino

343037 N1113225W

343112 N1113256W

$343048 \mathrm{~N} 1113236 \mathrm{~W}$

reservoir BGN Yavapai 343105N1113312W

ppl BGN Yuma 334652N1133650W

airport ADMIN La Paz 334625N1133710W

strean

stream

VARIANT

BGN 1937

VARIANT

VARIANT

VARIANT

stream

schoo

airport

school

summit

UNOFF

ADMIN
UNOFF

BGN 1965

VARIANT

VARIANT

VARIANT

summit

summit

BGN

UNOFF

building

stream

valley

valley

school

bas in

spring

reservoir

reservoir

valley

UNOFF

BGN

BGN

BGN

UNOFF

BGN

BGN

$B G N$

$B G N$

BGN

stream $\quad B G$

stream $B G$

stream

stream

stream

stream

valley

locale

building

BGN

BGN

BGN

BGN 1906

VARIANT

Yavapai 342314N1113919W

Gila 334156N1110536W

Yavapai

$342314 N 1113919 W$

Navajo

BGN

rapids

reservoir BGN

reservoir $B G N$

reservoir $B G N$

valley BGN

reservoir $B G N$

reservoir $B G N$
La Paz

La Paz

Yuma

Gila

Gila

Yuma

a Paz

La Paz

Yuma

Pinal

Navajo

Pima

Greenlee

Grahar

Greenlee

Graham

Gila

Graham

Graham

Navajo

Mohave

Mohave

Coconino

Yavajo

Graham

$334656 \mathrm{N1} 133709 \mathrm{~W}$

$334630 \mathrm{~N} 1133610 \mathrm{~W}$

334756N1110737W

$334756 N 1110737 \mathrm{~W}$

$335023 \mathrm{~N} 1134240 \mathrm{~W}$

$334655 \mathrm{~N} 1133653 \mathrm{~W}$

334649 N1133640W

334603 N1133502W

$324501 \mathrm{NL} 102923 \mathrm{~W}$

$342216 N 1103842 \mathrm{~W}$

$321520 \mathrm{~N} 1105652 \mathrm{~W}$

33242BN1090832W

$332043 N 1101125 \mathrm{~W}$

$331655 N 1091623 \mathrm{~W}$

$332043 \mathrm{~N} 1101102 \mathrm{~W}$

$341301 N 1110423 \mathrm{~W}$

$330745 \mathrm{~N} 1100616 \mathrm{~W}$

$331215 \mathrm{~N} 1101903 \mathrm{~W}$

340418 N1102928W

$343843 \mathrm{~N} 1131655 \mathrm{~W}$

355549 N1134244W

$360555 \mathrm{~N} 1121008 \mathrm{~W}$

$345845 N 1103905 \mathrm{~W}$

$343912 \mathrm{N1131754W}$

$332155 \mathrm{N1101529 \textrm {W }}$

$\begin{array}{ll}\text { Coconino } & 360558 \mathrm{~N} 1121009 \mathrm{~W} \\ \text { Graham } & 332115 \mathrm{~N} 1101648 \mathrm{~W}\end{array}$

$\begin{array}{ll}\text { Graham } & 332115 \mathrm{~N} 1101648 \mathrm{~W} \\ \text { Navajo } & 340719 \mathrm{~N} 1103316 \mathrm{~W}\end{array}$

Yavapai 34421BN1131801W

Greenlee

Greenlee

$331511 \mathrm{~N} 1090335 \mathrm{~W}$
$333440 \mathrm{~N} 1133508 \mathrm{~W}$

331302 N1091133W

331431 N1090953 spring BGN Yavapai 343717N1120458W $\begin{array}{lcl}\text { SOURCE } & \text { ELEV } \\ \text { COORDINATE } & \text { FT }\end{array}$

Buckhorn

Hackberry Mtn

Hackberry Mtn

Hackberry Mtn

Buckhorn Mountain

Buckhorn Mountain

6448 Buckhorn Mountain

Buckhorn Mountain

1877 Salome

Salome

$335427 N 1110247 \mathrm{~W}$

Windy Hill

Salome

1346 Hope SW

Salome

5426 Greenback Creek

$334603 N 1133943 \mathrm{~W}$

$324653 \mathrm{~N} 1102830 \mathrm{~W}$

$342255 \mathrm{~N} 1104006 \mathrm{~W}$

3991 Harcuvar

Salome

Salome

Salome

Oak Grove Canyon

Brookbank Point

Tucson North

Dutch Blue Creek

Branaman Spring

Pipestem Mtn

Branaman Spring

341458 N1110200W

Oi amond Butte

$331400 \mathrm{N1100232 \textrm {W }}$

331931 NI 100835W

$341126 \mathrm{~N} 1103944 \mathrm{~W}$

$344044 N 1132218 \mathrm{~W}$

$355816 \mathrm{NL} 133852 \mathrm{~W}$

$360423 \mathrm{~N} 1120938 \mathrm{~W}$

Bylas

Dewey Flat

Cibecue

Negro Ed

Oevils Slide Rapids

Grand Canyon

Negro Ed

Mount Triplet

Grand Canyon

Mount Triplet

Spotted Mountain

Negro Ed

Dix Creek

Dix Creek

Maple Peak 


\section{FEATURE NAME}

Salt Gulch

Salt Gulch Tank

Salt House

Salt House Creek

Salt House Draw

Parashant Wash

Salt House Eighteen Trail

Salt House Lake

Salt House Tank

Saltire Mountains

See Galiuro Mountains

Salt Lick Canyon

Salt Log Canyon

Salt Mine Substation

Salt Mountain

Salt Mountain

See Superstition Mountains

Salto Canyon del

Salton Tanks

Salt Peak Tank

Salt Point

Salt Pond

Salt Reservoir

Salt River

Assumption
Assuption
Black River
Blau Fluss
Blue River
Rio de la Asuncion
Rio de las Balsas
Rio Asuncion
Rio Azulrio de Lasrio
Rio Salado
River of the Rafts
Salada
Salinas

Salt River

See Black River

Salt River

See Phoenix

Saltriver

See Salt River

Salt River

Saltriver

Salt River Post Office

Salt River Bird Reservation

Salt River Canyon

Salt River Draw

Salt River Indian Day School

Salt River Indian Reservation

Salt River Reservation

Sa1t River Mountains

See South Mountains

Salt River Mountains

Salt River Peak

Salt River Post Office

See Salt River

Salt River Power Operations Department

Sa1t River Power Plant

Salt River Range

See South Mountains

Salt River Reservation

See Sa1t River Indian

Reservation

Salt River Reservation Clinic

Salt River Rim Tank

Salt River Tank

Salt River Valley

Salt Seeps

\section{FEATURE \\ CLASS}

STATUS

COUNTY

reservoir BGN

locale

BGN

BGN

Gila

Greenlee

stream

valley

trail

lake

reservoir

range

valley

valley

BGN

BGN 1973 Mohave

VARIANT

UNOFF

$B G N$

BGN

VARIANT

$B G N$

BGN

Greenlee

Apache

Apache

Graham

Gila

Gila

locale

summ it

summit

valley

reservoir

reservoir

cliff

reservoir

reservoir

UNOFF

Yavapai

Graham

VARIANT

BGN

BGN

BGN

$B G N$

$B G N$
$B G N$

stream

BGN

VARIANT

VARIANT

VARIANT

VARIANT

VARIANT

VARIAMT

VARIANT

VARIANT

VARIANT

VARIANT

VARIANT

VARIANT

VARIANT

Pinal

Pima

Yuma

Gila

Mavajo

Mohave

Coconino

Maricopa

$332252 \mathrm{~N} 1121844 \mathrm{~W}$

COORDINATE

$334522 \mathrm{N1I} 11208 \mathrm{~W}$
$334700 \mathrm{NII} 11156 \mathrm{~W}$

$333248 \mathrm{~N} 1092125 \mathrm{~W}$

333002 N1092440W

$361201 N 1133558 \mathrm{~W}$

$333250 \mathrm{~N} 1092028 \mathrm{~W}$

$335705 \mathrm{~N} 1092012 \mathrm{~W}$

333902N1093550W

$323600 \mathrm{~N} 1102100 \mathrm{~W}$

$341355 \mathrm{~N} 1110524 \mathrm{~W}$

335807 N1110326W

$353250 \mathrm{~N} 1115228 \mathrm{~W}$

$331529 N 1101932 \mathrm{~W}$

$332543 N 1112503 \mathrm{~W}$

$321510 \mathrm{~N} 1104031 \mathrm{~W}$

325639 NII $40040 \mathrm{~W}$

333311 N1105458W

$361455 \mathrm{~N} 1102627 \mathrm{~W}$

$363416 \mathrm{~N} 1132032 \mathrm{~W}$

$362712 \mathrm{N1113917W}$

092126h

$360815 \mathrm{N1} 134048 \mathrm{~W}$

SOURCE
COORDINATE

MAP NAME

$334754 N 1111047 \mathrm{~W}$

Greenback Creek

Greenback Creek

Strayhorse

Baldy Bill Point

Castle Peak

Strayhorse

Rudd Knoll

Maverick

341605N1110827W Diamond Butte

335813N1110019W Copper Mtn

Middle Verde

3450 Mount Triplet

$321821 N 1103645 W$

Agua Caliente Hill

Salton Tanks

Salt River Peak

6644 Big Mountain Dam

Russell Spring

Shinumo Altar

Avondale

Mesa

Windy $\mathrm{Hill}$

park

Gila

334000N1110350W

Salt River Peak

$333710 \mathrm{~N} 1105520 \mathrm{~W}$

$334952 N 1103422$

$332 \mathrm{BOON} 1115147 \mathrm{~W}$

$333100 \mathrm{NI11} 14600 \mathrm{~W}$

$334420 \mathrm{N1101330 \textrm {W }}$

$340704 \mathrm{~N} 1103659 \mathrm{~W}$

Maricopa

Maricopa

BGN

VARIANT

Maricopa

331944 N1120439W

$333418 \mathrm{~N} 1105536 \mathrm{~W}$

$333250 \mathrm{~N} 1105453 \mathrm{~W}$

summit BGN 1917 Gila

VARIANT

Maricopa

332800 NI11 $15148 \mathrm{~W}$

ppl

building

UNOFF

Maricopa

332646 NI115705W

$332901 \mathrm{~N} 1115624 \mathrm{~W}$

331944N1120439W

ridge

UNOFF

VARIANT

Maricopa

Maricopa

$333100 N 1114600 \mathrm{~W}$

reserve

VARIAN

Maricopa

332B08N111515BW

$334910 \mathrm{~N} 1102919 \mathrm{~W}$

$351926 \mathrm{~N} 1123108 \mathrm{~W}$

$332252 \mathrm{N1} 121844 \mathrm{~W}$

$350624 \mathrm{~N} 1092706 \mathrm{~W}$
Mule Hoof Bend

Mesa

Sawik Mountain

4208 Salt River Peak 4857 Salt River Peak

Tempe

Tempe

Mesa

Beckers Butte

Horse Trap Mesa

Navajo Springs 


\section{FEATURE NAME}

Salt Seeps

Salt Seeps Wash

Cottonwood Wash

Salt Shed Dam

Salt Shed Tank

Salt Spring

Salt Spring

\author{
Salt Spring \\ Salt Spring \\ Salt Spring \\ Salt Spring \\ Salt Spring Bay \\ Salt Springs \\ Salt Spring Wash \\ Salt Tank \\ Salt Tank \\ Salt Tank \\ See Salt Well Tank
}

Salt Trail Canyon

Salt Trap Spring

Salt Trap Tank

Salt Trap Tank

Salt Water Cone

Salt Water Ridge

Salt Water Seep

Salt Water Spring

Salt Water valley

Salt Water Valley

Salt Water Wash

Saltwater Wash

Salt Weed Bench

Salt Well

Salt Well

Salt Well

Salt Well

Salt Well

Sait Well

Salt Well Tank

Salt Well Tank

Salt Tank

Salt Well Wash

See Mackelprang Wash

Salty Tank

Salty Tank

Salty Water Windmill

Salvation Army Camp Wood

Salvation Peak

Samaniego Hills

Samaniego Peak

Samaniego Peak

Samaniego Ridge

Samaniego Ridge Seven

Samaniego Spring

Sam Canyon

Sam Canyon

Sam Canyon Tank

Sam Green Tank

Sam Hale Reservoir

Sam Moore Tank

Samoa Mine

Sample Mine

Sample Wash

Sam Powell Peak

Sampson Tank

Sampson Well

Samps on Well

Sampson Windmill

Sams Butte

Sams Butte Tank

Sams Dam Tank

Samse 1 Mines
FEATURE

CLASS

STATUS COUNTY

COORDINATE

spring

valley

dam

reservoir

spring

spring

spring

spring

spring

spring

bay.

spring

stream

reservoir

reservoir

BGN 1974 Navajo

VARIANT

UNOFF Graham

UNOFF

BGN

BGN

Graham

Graham

Graham

BGN Mohave

BGN

BGN

BGN

BGN

BGN

BGN

BGN

VARIANT

Mohave

Mohave

Apache

Mohave

Gila

Mohave

Navajo

Navajo

reservoir

Navajo

valley

$\begin{array}{ll}\text { BGN } & \text { Coconino } \\ \text { BGN } & \text { Navajo } \\ \text { BGN } & \text { Graham } \\ \text { BGN } & \text { Navajo } \\ \text { BGN } & \text { Apache } \\ \text { BGN } & \text { Navajo } \\ \text { BGN } & \text { Navajo } \\ \text { BGN } & \text { Navajo } \\ \text { BGN } & \text { Navajo } \\ \text { BGN } & \text { Navajo }\end{array}$

361106N1114228W

(100406W

$325741 \mathrm{~N} 1093400 \mathrm{~W}$

335359 N1095730W

$362650 \mathrm{~N} 1092708 \mathrm{~W}$

$362259 \mathrm{~N} 1101333 \mathrm{~W}$

$351317 N 1102144 \mathrm{~W}$

$361301 N 1100151 \mathrm{~W}$

$361755 N 1102007 \mathrm{~W}$

$362233 \mathrm{~N} 1101340 \mathrm{~W}$

valley

valley

stream

valley

bench

well

wel

well

we 11

wel1

reservoir

BGN

BGN

BGN

UNOFF

UNOFF

UNOFF

UNOFF

UNOFF

Coconino

Coconino

Coconino

Pima

Apache

Navajo

Coconino

Coconino

Apache

reservoir

BGN

VARIANT

Navajo

VARIANT

valley

reservoir

reservoir

locale

park

summit

summit

$B G N$

$B G N$
$B G N$

BGN
AOMIN

ADMIN

$B G N$

summit

summit

ridge

trail

spring

valley

valley

reservoir

reservoir

reservoir

BGN
BGN
BGN
UNOFF
BGN
BGN
BGN
BGN
BGN
BGN

Navajo

Santa Cruz

Graham

Coconino

Pinal

Yavapa

Pinal

$364342 N 1114134 W$ $353947 \mathrm{~N} 1105631 \mathrm{~W}$

364258 N1113947W

$314803 N 1122717 \mathrm{~W}$

$322303 N 1131138 \mathrm{~W}$

344321 N1093940W

$345031 \mathrm{~N} 1095800 \mathrm{~W}$

351623 N1111620W

$354133 N 1105215 \mathrm{~W}$

$344328 N 1093936 \mathrm{~W}$

345038 N1095732W

350858 N1101642W

$312749 \mathrm{~N} 1111116 \mathrm{~W}$

$325152 \mathrm{~N} 1101701 \mathrm{~W}$

$355031 \mathrm{~N} 1110200 \mathrm{~W}$

$323224 \mathrm{~N} 1104242 \mathrm{~W}$

335847 N1122204W

323037 N1112546W

Pima

Pima

Pima

Pima

Pima

Graham

Gila

Navajo

Gila

Apache

reservoir BG

mine

mine

stream

summit

well

well
locale

summit

UNOFF

UNOFF

UNOF
BGN
BGN

BGN

UNOFF

UNOFF

BGN

Coconino

Mohave

Pinal

Pinal

Yavapai

Yavapai

Yavapai

Grahan

Coconino

reservoir $B G N$

reservoir BGN

mine

BGN

Coconine

Yavapa

Gila

$315440 \mathrm{~N} 1111200 \mathrm{~W}$

$322810 \mathrm{~N} 1104902 \mathrm{~W}$

$322916 \mathrm{~N} 1104824 \mathrm{~W}$

$322726 \mathrm{~N} 1104853 \mathrm{~W}$

$322655 \mathrm{~N} 1105020 \mathrm{~W}$

$331400 \mathrm{~N} 1100232 \mathrm{~W}$

$335954 N 1103718 \mathrm{~W}$

$340120 \mathrm{~N} 1103817 \mathrm{~W}$

$335045 \mathrm{~N} 1100736 \mathrm{~W}$

$335756 N 1092917 \mathrm{~W}$

$360215 N 1121751 \mathrm{~W}$

$\begin{array}{cc}\text { SOURCE } & \text { ELEV } \\ \text { COORDINATE } & \text { FT }\end{array}$

MAP NAME

$\begin{array}{ll} & \text { Mitten Peak } \\ 351600 \mathrm{~N} 1100400 \mathrm{~W} & \text { Turkey Track Butte }\end{array}$

Point of Pines East

6023 Point of Pines East

Geronimo

Mount Triplet

Senator Mtn NE

Sonsela Buttes

Wildcat Ranch

Walker Butte

Hiller Mountains

$355322 \mathrm{~N} 1141556 \mathrm{~W}$

Cedar Creek

Garnet Mtn NW

Faught Ridge

Out law Oraw

361933N1101914W

$362304 \mathrm{~N} 1101232 \mathrm{~W}$

$363930 N 1113859 \mathrm{~W}$

$354411 \mathrm{N1} 104945 \mathrm{~W}$

$331557 N 1100111 \mathrm{~W}$

$340231 N 1103908 \mathrm{~W}$ 


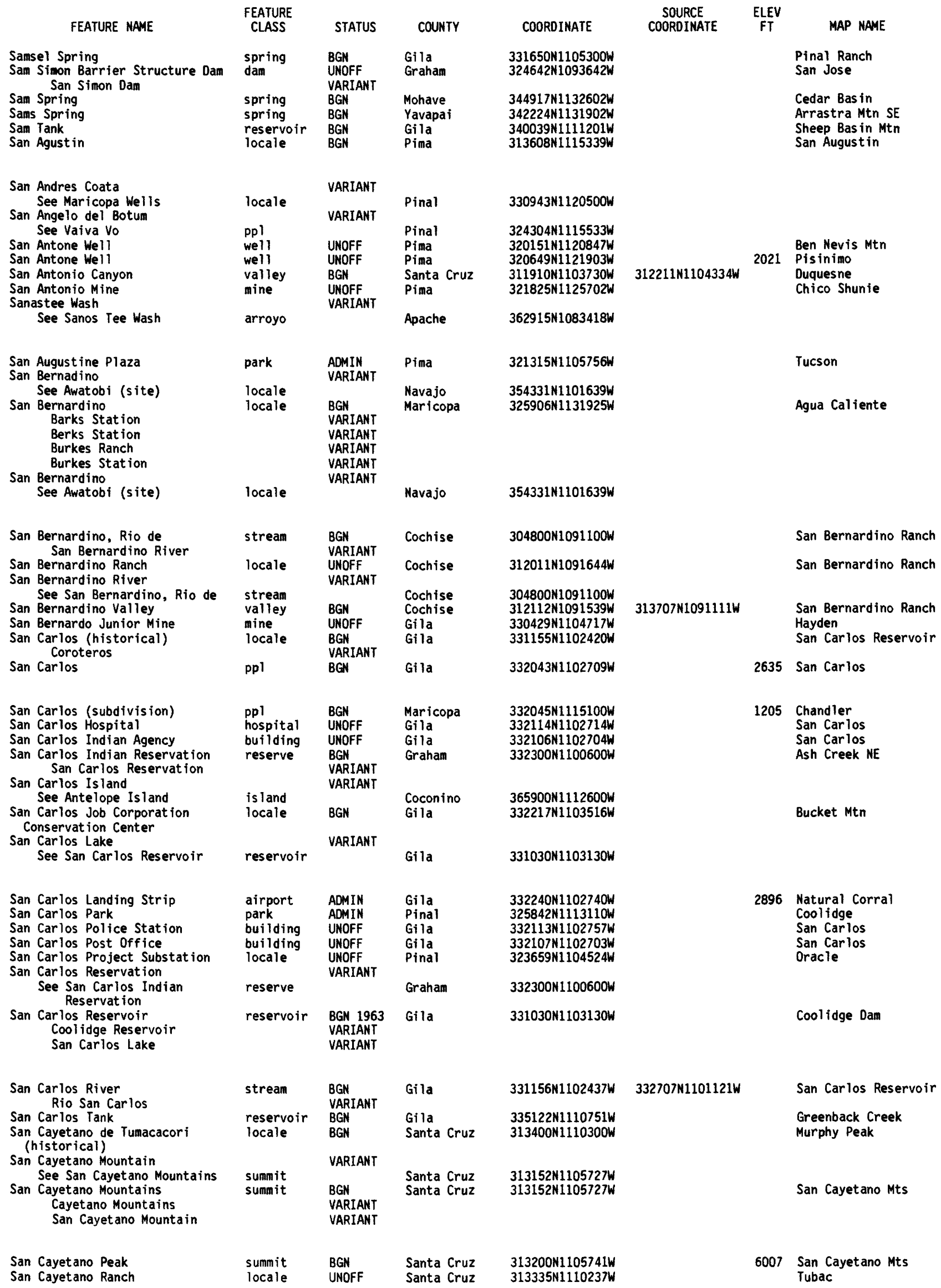


NATIONAL GAZETTEER--ARIZONA 1986

\begin{tabular}{|c|c|c|c|c|c|c|c|}
\hline FEATURE NAME & $\begin{array}{l}\text { FEATURE } \\
\text { CLASS }\end{array}$ & STATUS & COUNTY & COORDIMATE & $\begin{array}{l}\text { SOURCE } \\
\text { COORDINATE }\end{array}$ & $\begin{array}{c}\text { ELEV } \\
\text { FT }\end{array}$ & MAP MAME \\
\hline $\begin{array}{l}\text { Sanchez } \\
\text { Sanchez Monument } \\
\text { San Clemente Shopping Center } \\
\text { San Cosme Del Tucson }\end{array}$ & $\begin{array}{l}\text { ppl } \\
\text { park } \\
\text { locale }\end{array}$ & $\begin{array}{l}\text { BGN } \\
\text { ADMIN } \\
\text { UNOFF } \\
\text { VARIANT }\end{array}$ & $\begin{array}{l}\text { Graham } \\
\text { Graham } \\
\text { Pima }\end{array}$ & $\begin{array}{l}325210 \mathrm{~N} 1093232 \mathrm{~W} \\
325045 \mathrm{~N} 1093338 \mathrm{~W} \\
321317 \mathrm{~N} 1105431 \mathrm{~W}\end{array}$ & & 2520 & $\begin{array}{l}\text { San Jose } \\
\text { San Jose } \\
\text { Tucson }\end{array}$ \\
\hline $\begin{array}{l}\text { See Tucson } \\
\text { San Cristobal Valley } \\
\text { San Cristobal Wash } \\
\text { San Cristobas Wash } \\
\text { See Growler Wash }\end{array}$ & $\begin{array}{l}\text { ppl } \\
\text { valley } \\
\text { stream } \\
\text { stream }\end{array}$ & $\begin{array}{l}\text { BGN } \\
\text { BGN } \\
\text { VARIANT }\end{array}$ & $\begin{array}{l}\text { Pima } \\
\text { Yuma } \\
\text { Yuma } \\
\text { Yuma }\end{array}$ & $\begin{array}{l}321318 \mathrm{~N} 1105533 \mathrm{~W} \\
324720 \mathrm{~N} 1134435 \mathrm{~W} \\
324707 \mathrm{~N} 1134431 \mathrm{~W} \\
323233 \mathrm{~N} 1132550 \mathrm{~W}\end{array}$ & $\begin{array}{l}321200 \mathrm{~N} 1131607 \mathrm{~W} \\
315943 \mathrm{~N} 1130221 \mathrm{~W}\end{array}$ & & $\begin{array}{l}\text { Texas Hill } \\
\text { Texas Hill }\end{array}$ \\
\hline $\begin{array}{l}\text { Sanctuary Ridge } \\
\text { Sandalwood (subdivision) } \\
\text { Sand Canyon } \\
\text { Sand Canyon } \\
\text { Sand Cone Springs } \\
\text { Sand Cove } \\
\text { Sand Creek }\end{array}$ & $\begin{array}{l}\text { summit } \\
\text { ppl } \\
\text { valley } \\
\text { valley } \\
\text { spring } \\
\text { valley }\end{array}$ & $\begin{array}{l}\text { BGN } 1917 \\
\text { BGN } \\
\text { BGN } \\
\text { BGN } \\
\text { BGN } \\
\text { BGN } \\
\text { VARIANT }\end{array}$ & $\begin{array}{l}\text { Maricopa } \\
\text { Maricopa } \\
\text { Santa Cruz } \\
\text { Coconino } \\
\text { Apache } \\
\text { Mohave }\end{array}$ & $\begin{array}{l}\text { UNKNOWN } \\
333742 \mathrm{~N} 1115952 \mathrm{~W} \\
312955 \mathrm{~N} 1104910 \mathrm{~W} \\
364711 \mathrm{~N} 1105010 \mathrm{~W} \\
362003 \mathrm{~N} 1093412 \mathrm{~W} \\
364018 \mathrm{~N} 1134915 \mathrm{~W}\end{array}$ & $\begin{array}{l}312817 \mathrm{~N} 1104814 \mathrm{~W} \\
364732 \mathrm{~N} 1104728 \mathrm{~W} \\
364409 \mathrm{~N} 1134919 \mathrm{~W}\end{array}$ & 1440 & $\begin{array}{l}\text { Currys Corner } \\
\text { Cumero Canyon } \\
\text { Chaiyahi Rim SE } \\
\text { Many Farms } \\
\text { Cane Springs }\end{array}$ \\
\hline $\begin{array}{l}\text { See Sandstone Wash } \\
\text { Sand Creek } \\
\text { Sand Creek }\end{array}$ & $\begin{array}{l}\text { arroyo } \\
\text { strean } \\
\text { strean }\end{array}$ & $\begin{array}{l}\text { BGN } \\
\text { BGN }\end{array}$ & $\begin{array}{l}\text { Coconino } \\
\text { Apache } \\
\text { Yavapai }\end{array}$ & $\begin{array}{l}354554 \mathrm{~N} 1124144 \mathrm{~W} \\
340240 \mathrm{~N} 1094709 \mathrm{~W} \\
340409 \mathrm{~N} 1121958 \mathrm{~W}\end{array}$ & $\begin{array}{l}335902 \mathrm{~N} 1094114 \mathrm{~W} \\
340703 \mathrm{~N} 1122339 \mathrm{~W}\end{array}$ & & $\begin{array}{l}\text { McNary } \\
\text { Columbia }\end{array}$ \\
\hline $\begin{array}{l}\text { Sand Creek } \\
\text { Sand Creek } \\
\text { Sand Creek }\end{array}$ & $\begin{array}{l}\text { strean } \\
\text { strean }\end{array}$ & $\begin{array}{l}\text { BGN } \\
\text { BGN } \\
\text { VARIANT }\end{array}$ & $\begin{array}{l}\text { Coconino } \\
\text { Coconino }\end{array}$ & $\begin{array}{l}354258 \mathrm{~N} 1123637 \mathrm{~W} \\
354800 \mathrm{~N} 1124249 \mathrm{~W}\end{array}$ & $\begin{array}{l}354841 N 1125318 W \\
355722 N 1124808 W\end{array}$ & & $\begin{array}{l}\text { Tin House } \\
\text { Hazen Hole Tank }\end{array}$ \\
\hline $\begin{array}{c}\text { See Aubrey Landing } \\
\text { (historical) }\end{array}$ & locale & & Mohave & $341800 \mathrm{~N} 1140436 \mathrm{~W}$ & & & \\
\hline $\begin{array}{l}\text { Sand Draw } \\
\text { Sand Draw Tank } \\
\text { Sanders } \\
\text { Sanders Airport } \\
\text { Sanders Interchange }\end{array}$ & $\begin{array}{l}\text { valley } \\
\text { reservoir } \\
\text { ppl } \\
\text { airport } \\
\text { crossing }\end{array}$ & $\begin{array}{l}\text { BGN } \\
\text { BGN } \\
\text { BGN } \\
\text { ADMIN } \\
\text { UNOFF }\end{array}$ & $\begin{array}{l}\text { Coconino } \\
\text { Coconino } \\
\text { Apache } \\
\text { Maricopa } \\
\text { Apache }\end{array}$ & $\begin{array}{l}344556 \mathrm{~N} 1105142 \mathrm{~W} \\
343534 \mathrm{~N} 1105312 \mathrm{~W} \\
351259 \mathrm{~N} 1091959 \mathrm{~W} \\
332100 \mathrm{~N} 1115740 \mathrm{~W} \\
351256 \mathrm{~N} 1091957 \mathrm{~W}\end{array}$ & $343456 \mathrm{~N} 1105423 \mathrm{~W}$ & $\begin{array}{l}5865 \\
1224 \\
5865\end{array}$ & $\begin{array}{l}\text { Pump Ranch Tank } \\
\text { Grama Draw } \\
\text { Sanders } \\
\text { Guadalupe } \\
\text { Sanders }\end{array}$ \\
\hline $\begin{array}{l}\text { Sanders Mesa } \\
\text { Sanderson Pass } \\
\text { Sanders Peak } \\
\text { Sanders Post Office } \\
\text { Sanders Rangeline Cabin } \\
\text { Sanders Spring } \\
\quad \text { Bluff Spring }\end{array}$ & $\begin{array}{l}\text { summit } \\
\text { gap } \\
\text { summit } \\
\text { building } \\
\text { locale } \\
\text { spring }\end{array}$ & $\begin{array}{l}\text { BGN } \\
\text { BGN } \\
\text { BGN } \\
\text { UNOFF } \\
\text { BGN } \\
\text { BGN } \\
\text { VARIANT }\end{array}$ & $\begin{array}{l}\text { Yavapai } \\
\text { Coconino } \\
\text { Cochise } \\
\text { Apache } \\
\text { Graham } \\
\text { Gila }\end{array}$ & $\begin{array}{l}343521 \mathrm{~N} 1131039 \mathrm{~W} \\
352021 \mathrm{~N} 1115643 \mathrm{~W} \\
315134 \mathrm{~N} 1091551 \mathrm{~W} \\
351252 \mathrm{~N} 1092013 \mathrm{~W} \\
330616 \mathrm{~N} 1102546 \mathrm{~W} \\
334345 \mathrm{~N} 1103711 \mathrm{~W}\end{array}$ & & & $\begin{array}{l}\text { Bagdad } \\
\text { Parks } \\
\text { Chiricahua Peak } \\
\text { Sanders } \\
\text { Rawhide Mtn } \\
\text { Chrysotile }\end{array}$ \\
\hline $\begin{array}{l}\text { Sanders Spring } \\
\text { Rock Spring } \\
\text { Sanders Wash }\end{array}$ & $\begin{array}{l}\text { spring } \\
\text { stream }\end{array}$ & $\begin{array}{l}\text { BGN } \\
\text { VARIANT } \\
\text { BGN }\end{array}$ & $\begin{array}{l}\text { Gila } \\
\text { Greenlee }\end{array}$ & $\begin{array}{l}334430 \mathrm{~N} 1103800 \mathrm{~W} \\
324932 \mathrm{~N} 1091022 \mathrm{~W}\end{array}$ & $325145 N 1090545 \mathrm{~W}$ & & $\begin{array}{l}\text { Haystack Butte } \\
\text { Sheldon }\end{array}$ \\
\hline $\begin{array}{l}\text { S and E Tank } \\
\text { Sandeval Draw } \\
\text { See Sandoval Draw } \\
\text { Sand Flat } \\
\text { Sand Flat Tank } \\
\text { Sand Flat Tank } \\
\text { Sand Hill Crack } \\
\text { Sandhill Crack } \\
\text { Sandhill Crack } \\
\text { See Sand Hill Crack }\end{array}$ & $\begin{array}{l}\text { reservoir } \\
\text { valley } \\
\text { flat } \\
\text { reservoir } \\
\text { reservoir } \\
\text { gap }\end{array}$ & $\begin{array}{l}\text { BGN } \\
\text { VARIANT } \\
\text { BGN } \\
\text { BGN } \\
\text { BGN } \\
\text { BGN } \\
\text { VARIANT } \\
\text { VARIANT }\end{array}$ & $\begin{array}{l}\text { Graham } \\
\text { Navajo } \\
\text { Coconino } \\
\text { Yavapai } \\
\text { Mohave } \\
\text { Coconino }\end{array}$ & $\begin{array}{l}332210 \mathrm{~N} 1095255 \mathrm{~W} \\
343830 \mathrm{~N} 1094813 \mathrm{~W} \\
34583 \mathrm{BN} 1121042 \mathrm{~W} \\
345811 \mathrm{~N} 1121048 \mathrm{~W} \\
361646 \mathrm{~N} 1132022 \mathrm{~W} \\
364355 \mathrm{~N} 1115309 \mathrm{~W} \\
364355 \mathrm{~N} 1115309 \mathrm{~W}\end{array}$ & & & $\begin{array}{l}\text { Perkinsville } \\
\text { Perkinsville } \\
\text { Cold Spring } \\
\text { Emmett Hill }\end{array}$ \\
\hline $\begin{array}{l}\text { Sandhill Ranch Airport } \\
\text { Sand Hills } \\
\text { Sand Hills } \\
\text { Sand Hill Spring } \\
\text { Sand Hollow Wash } \\
\text { Sandia Wash } \\
\text { San Dionisio } \\
\text { See Yuma } \\
\text { San Dionisio } \\
\text { See San Dionysio } \\
\text { (historical) }\end{array}$ & $\begin{array}{l}\text { airport } \\
\text { range } \\
\text { summit } \\
\text { spring } \\
\text { stream } \\
\text { strean } \\
\text { ppl } \\
\text { ppl }\end{array}$ & $\begin{array}{l}\text { ADMIN } \\
\text { BGN } \\
\text { BGN } \\
\text { BGN } \\
\text { BGN } \\
\text { BGN } \\
\text { VARIANT } \\
\text { VARIANT }\end{array}$ & $\begin{array}{l}\text { Coconino } \\
\text { Coconino } \\
\text { Navajo } \\
\text { Navajo } \\
\text { Mohave } \\
\text { Greenlee } \\
\text { Yuma } \\
\text { Yuma }\end{array}$ & $\begin{array}{l}365600 \mathrm{~N} 1115800 \mathrm{~W} \\
364948 \mathrm{~N} 1115650 \mathrm{~W} \\
355305 \mathrm{~N} 1102049 \mathrm{~W} \\
355325 \mathrm{~N} 1102050 \mathrm{~W} \\
364901 \mathrm{~N} 1135936 \mathrm{~W} \\
324712 \mathrm{~N} 1090945 \mathrm{~W} \\
324331 \mathrm{~N} 1143725 \mathrm{~W} \\
324505 \mathrm{~N} 1143400 \mathrm{~W}\end{array}$ & $\begin{array}{l}370509 \mathrm{~N} 1140704 \mathrm{~W} \\
324736 \mathrm{~N} 1090809 \mathrm{~W}\end{array}$ & 5865 & $\begin{array}{l}\text { Poverty Flat } \\
\text { One Toe Ridge } \\
\text { Wepo Village } \\
\text { Wepo Village } \\
\text { Elbow Canyon } \\
\text { Sheldon }\end{array}$ \\
\hline $\begin{array}{l}\text { San Dionysio } \\
\text { See Yuma } \\
\text { San Dionysio (historical) } \\
\text { San Dionisio } \\
\text { Sand Mill } \\
\text { San Domingo Gulch } \\
\text { See San Domingo Wash } \\
\text { San Domingo Peak } \\
\text { San Domingo Wash } \\
\text { San Domingo Gulch } \\
\text { Santo Domingo Gulch } \\
\text { Santo Domingo Wash }\end{array}$ & $\begin{array}{l}\text { ppl } \\
\text { ppl } \\
\text { locale } \\
\text { stream } \\
\text { summit } \\
\text { stream }\end{array}$ & $\begin{array}{l}\text { VARIANT } \\
\text { BGN } \\
\text { VARIANT } \\
\text { BGN } \\
\text { BGN } \\
\text { VARIANT } \\
\text { VARIANT } \\
\text { VARIANT }\end{array}$ & $\begin{array}{l}\text { Yuma } \\
\text { Yuma } \\
\text { Yavapai } \\
\text { Maricopa } \\
\text { Maricopa } \\
\text { Maricopa }\end{array}$ & $\begin{array}{l}324331 \mathrm{~N} 1143725 \mathrm{~W} \\
324505 \mathrm{~N} 1143400 \mathrm{~W} \\
340440 \mathrm{~N} 1124436 \mathrm{~W} \\
335313 \mathrm{~N} 1123942 \mathrm{~W} \\
335541 \mathrm{N1} 123752 \mathrm{~W} \\
335313 \mathrm{~N} 1123942 \mathrm{~W}\end{array}$ & $340038 \mathrm{~N} 1123259 \mathrm{~W}$ & 2714 & $\begin{array}{l}\text { Bard } \\
\text { Sam Powell Peak }\end{array}$ \\
\hline
\end{tabular}


FEATURE NAME

Sandoval Draw Sandeval Draw

Sandow Hill

Sandpiper Park

Desert Springs Park

Sand Point

Sandridge Wash

Ludel Wash

Sandrock Canyon

Sandrock Draw Tank

Sandrock Pasture

Sandrock Spring

Sandrock Tank

Sands Draw

Sands Draw Detention Dam

Sand Seeps

Sand Spring

Sand Spring

Sand Spring

Sand Spring

Sand Spring

Sand Spring

Sand Spring

Sand Spring

Sand Spring

Sand Spring

Sand Spring

Sand Spring

Sand Spring

Sand Spring

Sand Springs

Sand Springs

Dinnebito Trading Post

Sand Springs

Sand Springs Mesa

Sands Ranch

Sandstone Camp

Sandstone Canyon

Sandstone Spring

Sands tone Tank

Sands tone Tank

Sands tone Tank

Sandstone Wash

Sand Creek

Sands Well

Sands West Camp

Sand Tank

Sand Tank

Sand Tank

Sand Tank

Sand Tank

Sand Tank

Sand Tank

Sand Tank

Sand Tank

Sand Tank

Sand Tank

Sand Tank

Sand Tank

Sand Tank Canyon

Sand Tank Mountains

Saucedo Mountains

Sand Tank Wash

Sand Tank Well

Sand Trap Tank

Sand Trap Tank

Sand Trap Wash

See Sandtrap Wash

Sandtrap Wash

Maggie Wash

Sand Trap Wash
FEATURE

CLASS

STATUS

COUNTY

COORDINATE

$343830 \mathrm{~N} 1094813 \mathrm{~W}$

valley

BGN 1983

Navajo

Pinal

summit

park

AOMIN
VARIANT

cliff

stream

BGN

BGN

VARIANT

valley

BGN

reservoir

$B G N$

Mohave

Gila

Coconino

$343102 \mathrm{~N} 1113027 \mathrm{~W}$

flat BGN Coconino 343003N1113159W

spring BGN Yavapai 341513 N1121535W

reservoir BGN Coconino 343049N1113147W

valley BGN Graham 323007N1092013W

dam

spring

spring

spring

spring

spring

UNOFF

BGN

BGN

BGN

BGN

BGN

Graham

Coconino

Navajo

Apache

Navajo

Mavajo

spring

spring

spring

spring

spring

spring

spring

spring

spring

spring

BGN

BGN

BGN

BGN

BGN

BGN

BGN

BGN

spring

pp

BG

locale

summit

locale

locale

valley

spring

Coconino

Navajo

Navajo

Apache

Navajo

Apache

Navajo

Mohave

Mohave

Mohave

reservoir

reservoir

reservoir

arroyo

well

locale

reservoir

reservoir

reservoir

reservoir

reservoir

reservoir

reservoir

reservoir

reservoir

reservoir

reservoir

reservoir

reservoir

BGN
BGN
VARIANT
VARIANT

BGN

$B G N$

UNOFF

BGN

BGN

Navajo

Coconino

$322934 \mathrm{~N} 1092302 \mathrm{~W}$

$345841 \mathrm{~N} 1120321 \mathrm{~W}$

$351815 \mathrm{~N} 1100324$

353025 N1093139W

354357 N1100958W

355458 N1102113W

$361010 N 1105544 \mathrm{~W}$

361227 N1103947W

$362431 \mathrm{~N} 1102510 \mathrm{~W}$

$362558 \mathrm{~N} 1095324 \mathrm{~W}$

$362920 \mathrm{~N} 1103625 \mathrm{~W}$

$363720 \mathrm{N1090431 \textrm {W }}$

$363750 \mathrm{~N} 1104207 \mathrm{~W}$

364229 N1134709h

$365336 \mathrm{~N} 1123944 \mathrm{~W}$

365645 N1132141

Apache

Coconino

Cochise

Yavapai

Coconino

Maricopa

BGN

BGN

BGN 198

VARIANT

UNOFF

BGN

BGN

BGN

BGN

Coconino

Coconino

Coconino

Coconino

Graham

Pima

Cochise

Pima

Graham

$B G N$

BGN

BGN

$B G N$

BGN

$B G N$

BGN

BGN

valley

summit

BGN

Graham

Graham

Apache

Apache

Navajo

Apache

Navajo

Navajo

Coconino

strean

well

reservoir

reservoir

stream

stream

1941 Maricopa

UNOF

$B G N$

BGN

VARIANT

BGN 1967

VARIANT

VARIANT

$\begin{array}{lc}\text { SOURCE } & \text { ELEV } \\ \text { COORDINATE } & \text { FT }\end{array}$

MAP NAME

Little Milky Ranch

Teapot Mountain Paradise Valley

Grama Draw

$365032 N 1125423 W$

White Pockets

343037 N1112901W

Strawberry

Buckhorn Mountain

Buckhorn Mtn

Battle Flat

Buckhorn Mountain

$322926 \mathrm{~N} 1091150 \mathrm{~W}$

Whit lock Cienega

Ryan Draw

Sycamore Bas in

Five Buttes

6417 Klagetoh North

6166 Jadito Spring

Wepo Village

Begashibito Canyon

Rocky Ridge NW 


\section{FEATURE}

STATUS

COUNTY
COOROINATE

$\begin{array}{ll}\text { well } & \text { UNOFF } \\ \text { stream } & \text { BGN 1962 } \\ & \text { VARIANT } \\ \text { stream } & \text { BGN } \\ \text { stream } & \text { BGN } \\ \text { stream } & \text { BGN } \\ \text { stream } & \text { BGN } \\ \text { stream } & \text { BGN } \\ \text { locale } & \text { BGN } \\ \text { spring } & \text { BGN }\end{array}$

\section{Sand Wash Spring}

andwash Spring

See Neal Spring

Sand Wash Spring Number Two

Sand Well

Sand Well

Sand Wells Chot Vaya

Sandwood Drain

Sandy Bob Canyon

Sandy Bob Springs Windnil

Sandy Bob Tank

Sandy Bob Windmi 1

Sandy Canyon Wash

Sandy Hill Well

Sandy Point

Sandy Saddle

Sandy Tank

Sandy Tank

Sandy Tank

Double Tank

Sanencheck Rock

See Saneneheck Rock

Sanenecheck Rock

See Saneneheck Rock

Saneneheck Rock

Sa-ne-ne-heck Rock

Sanencheck Rock

Sanenecheck Rock

Sanenehec Rock

Thief Rock

Sa-ne-ne-heck Rock

See Saneneheck Rock

Sanenehec Rock

See Saneneheck Rock

Saner Spring

San Fancisco Wash

See Flag, Rio de

San Felipe de Jesus Guevavi

See Guevavi Mission (historical)

Sanford

See Adamsville

Sanford Butte

Sanford Canyon

Sanford Ranch

See Circle 2 Ranch

Sanfords (historical)

San Francisco Canal North

Branch

San Francisco Canal South

Branch

San Francisco del Adid

See Gu Achi

San Francisco Mine

San Francisco Mountain

Fire Mountains

Humphrey Mountain

Humphreys Peak

Mount Humphrey

Nuvat-i-kyan-bi

BGN Gila spring BGN 1974 Gila 340734N1111712 VARIANT

spring

spring

well

well

well

stream

valley

locale BGN Cochise

reservoir BGN

locale

stream

well

cape

gap

reservoir

reservoir

reservoir

BGN

UNOFF Yavapa

UNOFF Navajo

BGN 1977

VARIANT

BGN

Pima

Mohave

Cochise

Cochise
Cochise

Mohave

$\begin{array}{ll}\text { BGN } & \text { Mohave } \\ \text { UNOFF } & \text { Apache }\end{array}$

BGN 1948

Gila

Santa Cruz

Santa Cruz

VARIAN

VARIANT

summit

VARIANT

summit

summ it

BGN

VARIANT

VARIANT

VARIANT

VARIANT

VARIANT

VARIANT

summit

VARIANT

summit

spring

stream

locale

BGN

VARIANT

VARIANT

Navajo

Navajo

Cochise

Coconino

Santa Cruz

313120 N1095819W

313209 N1095946W

$313110 \mathrm{~N} 1095957 \mathrm{~W}$

$365210 N 1123443 \mathrm{~W}$

$360017 \mathrm{~N} 1093341 \mathrm{~W}$

$360641 \mathrm{~N} 1140608 \mathrm{~W}$

$340611 \mathrm{~N} 1112841 \mathrm{~W}$

$312319 \mathrm{~N} 1104752 \mathrm{~W}$

$312634 N 1111145 \mathrm{~W}$

313836 N1110944k

$365817 N 1124725 W$

Navajo

363208N1103810W

363208 N1103810W

363208 N1103810W

$343034 N 1141958 W$

313009 N1095705W

Potter Mtn
Potter Mtn

Clear Water Spring

Lt 1 White Hse Ruins

Meadview North

Mazatzal Peak

Cumero Canyon

Ruby

Saucito Mtn

6656 Shonto

Swede Peak

VARIANT

locale

summit

valley

locale

locale

canal

canal

BGN

VARIANT

Santa Cruz 312956N1104845W

BGN Santa Cruz 312950N1105031W

BGN Maricopa 332432N1120212W

BGN

VARIANT

pp

mine

UNOFF

Pima

Mohave

VARIANT

VARIANT

VARIANT

VARIANT

VARIANT
Maricopa

332337 N1120122W

Santa Cruz 313024N1104848W

$315137 N 1103428 \mathrm{~W}$

$315304 N 1103707$

4695 Patagonia Spring Water Canyon Phoenix

Phoenix
Pinal 330046N1112629W

3800 Cumero Canyon
Beecher Canyon 1229 Humphreys Peak 


\section{FEATURE NAME}

San Francisco Mountains

San Francisco Peak

San Francisco Peaks

Virgin Snow

San Francisco Mountain Plateau See San Francisco Plateau

San Francisco Mountains

San Francisco Mountains

See San Francisco Mountain

San Francisco Peak

See San Francisco Mountain

San Francisco Peak

See Humphreys Peak

San Francisco Peaks

See San Francisco Mountain

San Francisco Peaks Natural

Area

San Francisco Plateau

Colorado Plateau

San Francisco Mountain Plateau

San Francisco Plateau

See Coconino Plateau

San Francisco River

Frisco River

Rio Prieto

San Francisco Sprinng

See Leroux Spring

San Francisco Volcanic Field

San Francisco Wash

San Francisco Wash

See Wainut Creek

San Francisco Xavier

San Franciso Peak

See Humphreys Peak

San Gabriel (subdivision)

San Gregorio

See Donnelly Ranch

Sanguinetti Field

Sanguinetti Memorial Park

San Ignacio de la Canoa

San Ignacio del Babocomari

San Ignacio Ranch

San Joaquin Well

San Jose

Munsonville

San Jose, Rancho
San Jose Canal
San Jose Cemetery
San Jose de Sonoita
Patagonia-Sonoita Creek
Sanctuary

San Jose Wash

San Juan

See San Juan Spring

San Juan Canyon

\section{San Juan Capistrano}

See Sacaton

San Juan de las Boguillas y

Nogales

San Juan Drain

San Juan Flat

$$
\text { Don Juan Flat }
$$

San Juan Hill

San Juan Lake

San Juan Mine

San Juan Park

San Juan Pass

San Juan Plaza Shopping Center

San Juan Ranch

San Juan Spring

\section{FEATURE
CLASS}

STATUS

COUNTY

COORDINATE

VARIANT

VARIANT

VARIAN

VARIANT

plain

summit

VARIANT

sumnit

sumnit

summit

sumn it

BGN

VARIANT

VARIANT

VARIANT

VARIANT

park

ADMIN

plain

VARIANT

VARIANT

VARIANT

plain

stream

BGN 1962

VARIANT

VARIANT Apache 325832N1092218W

VARIANT

spring

lava

stream

stream

church

summit

ppl

BGN

BGN

VARIANT

UNOFF

VARIANT

BGN

VARIANT

locale

park

cemetery

civil

civil

locale
well

ppl

\section{ADMIN \\ UNOFF \\ ADMIN \\ ADMIN \\ UNOFF \\ UNOFF}

BGN

loca

canal

cemetery

civil

UNOFF

BGN

UNOFF

ADMIN

VARIANT

stream $B G N$

locale

VARIANT

valley

BGN

VARIANT

ppl

stream

flat

summit

lake

mine

park

gap

locale

locale

spring

Coconino

Green lee

Coconino

Coconino

Coconino

Coconino

Coconino

Coconino

35211N1114137W

$353000 \mathrm{~N} 1122500 \mathrm{~W}$

Coconino

Coconino

Coconino

Coconino

Maricopa

Coconino

Maricopa

Pinal

Yuma

Yuma

Pima

Cochise

Pima

Pima

Graham

Cochise

Graham

Graham

Santa Cruz

Graham

Pima

Pima

ADMIN

Pinal

BGN Mohave

BGN 1971

VARIANT

BGN

BGN

UNOFF

Apache

Pima

Apache

Graham

ADMIN

BGN

UNOFF

UNOFF

BGN
Pima

Pima

Pima

Pima

Pima
$351736 \mathrm{~N} 1114327 \mathrm{~W}$

353712N1113718W

$351412 \mathrm{~N} 1111041 \mathrm{~W}$

$351441 \mathrm{N1112509 \textrm {W }}$

$332216 \mathrm{~N} 1120105 \mathrm{~W}$

352047 N1114040W

333858N1120911W

$330213 N 1110913 \mathrm{~W}$

$324315 \mathrm{~N} 1143802 \mathrm{~W}$

$324112 \mathrm{~N} 1143737 \mathrm{~W}$

$314926 \mathrm{N1} 105945 \mathrm{~W}$

$313833 \mathrm{~N} 1102547 \mathrm{~W}$

$320 B 54 N 1113439 \mathrm{~W}$

$321326 \mathrm{~N} 1111318 \mathrm{~W}$

$324912 \mathrm{~N} 1093529 \mathrm{~W}$

312043 N1094448W

$324933 \mathrm{~N} 1093455 \mathrm{~W}$

$324910 \mathrm{N1093520 \textrm {W }}$

$312746 \mathrm{~N} 1105818 \mathrm{~W}$

$324905 \mathrm{~N} 1093530 \mathrm{~W}$

$315524 N 1114021$

$315522 \mathrm{~N} 1114023 \mathrm{~W}$

$330436 \mathrm{~N} 1114419 \mathrm{~W}$

$314157 N 1101113 \mathrm{~W}$

$343011 \mathrm{~N} 1142014 \mathrm{~W}$

$340815 \mathrm{~N} 1094010 \mathrm{~W}$

$320541 \mathrm{N1102848 \textrm {W }}$

$340832 N 1094023 \mathrm{~W}$

$325650 \mathrm{~N} 1093901 \mathrm{~W}$

$321204 \mathrm{~N} 1110034 \mathrm{~W}$

$315551 \mathrm{N1} 113712 \mathrm{~W}$

$321503 \mathrm{~N} 1105739 \mathrm{~W}$

$315013 \mathrm{~N} 1111600 \mathrm{~W}$

$320527 \mathrm{~N} 1102801 \mathrm{~W}$

$\begin{array}{ll}\text { SOURCE } & \text { ELEV } \\ \text { COORDINATE } & \text { FT }\end{array}$

Maness Peak

Humphreys Peak

Red Hill Ranch

335302N1091204W Guthrie

East of S P Mtn Babbitt Wash

Lone Butte

1300 Hedgpeth Hills

Yuma West

Yuma West

Green Valley

Mustang Mountains

2408 San Ignacio Ranch

Brown Mtn

San Jose

Paul Spur

San Jose

3027 San Jos

Rio Rico

$324923 N 1092404$

San Jose

$315649 N 1113851 \mathrm{~W}$

San Juan Spring

Fairbank

343033N1141838W

Lake Havasu City N

Boundary Butte

5269 Galleta Flat West Boundary Butte Weber Peak

Cat Mountain

Kitt Peak 


\section{FEATURE NAME}

San Juan Spring

San Juan

San Juan Tank

San Juan Tank

San Juan Tanks

San Juan Trail

San Juan Wash

San Juan Wash

San Juan Well

San Lorenzo

See Sil Nakya

San Lorenzo Well

See Sil Nakya

San Lucy Village

San Luis

Cobabi

Noli

Nyerwi $\mathbf{K i}$

San Luis

San Luis

San Luis Dam

San Luis Guebavi

See Guevavi Mission (historical)

San Luis Mine

San Luis Mountains

San Luis Wash

San Luis Wash

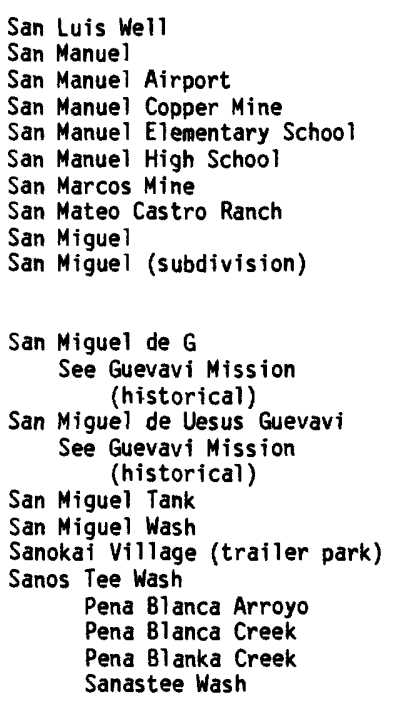

Sano Tank Mountains

San Pablo

$$
\text { See Tempe }
$$

San Pablo

San Pueblo

San Pablo Mountains

See Laguna Mountains

San Patricio Tank

San Paulo Village Park

San Pedro (historical)

San Pedro

San Pedro Well

Viopoli

Viopuli

San Pedro

See Wellton

San Pedro Ranch

San Pedro River

Rio San Pedro

San Pedro Spring

See Lewis Springs

\section{FEATURE}

STATUS

COUNTY

COORDIMATE

locale

reservoir

reservoir

reservoir

BGN
VARIANT
BGN

BGN

BGN

Pina

Pima

Apache

trail

stream

stream

well

UNOFF

BGN

BGN

UNOFF

VARIANT

ppl

pp 1

$\mathrm{pp} 1$

locale

VARIANT

BGN

BGN 194

VARIANT

VARIANT

p

dam

locale

mine

summit

stream

BGN

BGN

UNOFF

Pima

Pima

Pima

Pima

Maricopa

Pina

VARIANT

stream

UNOFF

BGN

BGN 1979 Pima

BGN Pima

wel

Dpl UNOFF

airport

mine

school

school

mine

locale

locale

ppl

BGN

ADMIN

UNOFF

UNOFF

UNOFF

UNOFF

UNOFF

BGN

$B G N$
$B G N$

Pima

Yuma

Pima

Santa Cruz

Pima

Pima

Jocale

VARIANT

locale

reservoir

stream $B G N$

locale

arroyo

UNOFF

BGN

VARIANT

VARIANT

VARIANT

VARIANT

Pima

Pinal

Pinal

Pinal

Pinal

Pinal

Yuma

Pinal

Pima

Maricopa

Santa Cruz

312436 N1105406W

Santa Cruz

$312436 \mathrm{N1} 105406 \mathrm{~W}$ summit $\quad B G N$

pp 1

locale

VARIANT

BGN

VARIANT

VARIANT

Stumm it

reservoir

park

locale

BGN

ADMIN

Maricopa

Maricopa

Maricopa

Yuma

Pima

Pima

Cochise pp 1

pp

VARIANT

VARIANT

VARIANT

VARIANT

ppl

locale

UNOFF

BGN

VARIANT

VARIANT

Pina

Yuma

locale

Cochise $\quad 313452 \mathrm{N1100829W}$
SOURCE
COORDINATE

MAP NAME

San Juan Spring

Penitas Hills

Three Points

Boundary Butte

Cat Mountain

$\begin{array}{lll}315108 \text { N1111427W } & \begin{array}{l}\text { Fresno Wash } \\ \text { 315649N1113852W }\end{array} \\ & \text { Sells East } \\ \text { The52 } & \text { Three Points }\end{array}$

$\begin{array}{lll}315108 \text { N1111427W } & \begin{array}{l}\text { Fresno Wash } \\ \text { 315649N1113852W }\end{array} \\ & \text { Sells East } \\ \text { The52 } & \text { Three Points }\end{array}$

702 Gila Bend

Ko Vaya

Gu Achi

See Gadsden

Wilbur Canyon

Wilbur Canyon

Wilbur Canyon

Las Guijas

$313031 \mathrm{N1112309 \textrm {W }}$

Kupk

320440N1115500W

Wilbur Canyon

Campo Bonito

3275 Mammoth

Manmoth

Manmoth

Campo Bonito

Socorro Peak

Florence Junction

2477 San Miguel

1220 Glendale
Pina

Pima

Maricopa

$313633 \mathrm{~N} 1114632 \mathrm{~W}$

$314815 \mathrm{~N} 1112830 \mathrm{~W}$

$331400 \mathrm{~N} 1114015 \mathrm{~W}$

Apache

$\begin{array}{ll}\text { Cochise } & 320149 N 1100910 \mathrm{~W} \\ \text { Pinal } & 325904 \mathrm{~N} 1104656 \mathrm{~W}\end{array}$

314756N1113140W San Miguel

1390 Chandler Heights

Tsaile Butte
Moi Vaya

Tempe

Cocoraque Butte

Hereford

San Pedro

San Pedro Ranch Winkeiman
Tucson East 
FEATURE

CLASS
STATUS

COUNTY

San Pedro Tank

San Pedro Valley

San Pedro Vista

San Pedro Well

See San Pedro

San Prieto

See Prieta, Sierra

San Pueblo

See San Pablo

Sanrace Cliff Dwellings

San Rafael (historical)

San Rafael

San Rafael de la Zanja

San Rafael del Valle

San Rafael del Valle

San Rafael Valley

San Rafael Well

San Rafael Well

San Rafale de Guevavi

See Guevavi Mission (historical)

San Ramon Mine

San Raphae

See Guevavi Mission (historical)

San Salvador Dam

San Salvador Reservoir

San Seraf in

Ak Chin

Akchin

Aktjin

San Simon

See Wahak Hotrontk

San Simon

San Simon Creek

See San Simon River

San Simon Dam

See Sam Simon Barrier

Structure Dam

San Simon Dam Drop Structure The Fan

San Simon Elementary School
San Simon Head
San Simon High School
San Simon Indian Village
See Wahak Hotrontk
Sans imon Mine
San Simon Peak
San Simon Post Office
San Simon Railroad Station
San Simon River
Rio de Sauz
Rio de Sonoca
Rio de Suanca
Rio San Domingo
Rio Sauz
Rio Suez
San Simon Creek
San Simon Wash
Sauz River
Solomonville Wash
Suauca

San Simon Stream

San Simon Substation

San Simon Valley See Qui jotoa Valley

San Simon valley

San Simon Wash

Vanori Wash

San Simon Wash

See San Simon River

San Simon Well

$\begin{array}{llll}\begin{array}{l}\text { reservoir } \\ \text { valley }\end{array} & \text { BGM } & \text { Pima } & 315624 N 1112836 \mathrm{~W} \\ \text { locale } & \text { BGN } & \text { Cochise } & 321422 \mathrm{~N} 1101947 \mathrm{~W} \\ & \text { VARIANT } & \text { Pima } & 322403 \mathrm{~N} 1104127 \mathrm{~W} \\ \text { ppl } & & \text { Pima } & 320500 \mathrm{~N} 1112915 \mathrm{~W} \\ \text { range } & \text { VARIANT } & & \\ & & \text { Yavapai } & 343126 \mathrm{~N} 1123411 \mathrm{~W} \\ \text { locale } & \text { VARIANT } & & \\ \text { loca le } & & \text { Maricopa } & 332541 \mathrm{~N} 1115636 \mathrm{~W}\end{array}$

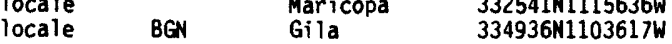

locale BGN Santa Cruz 312712N1103543W

locale BGN Pima 314414N1120125W

civil ADMIN Santa Cruz 312408N1103433W

civil ADNIN Cochise 312715N1100649W

civil ADMIN Cochise 313332 M1100834W

valley BGN Santa Cruz 312300N1103500W

well

$314314 N 1120158 \mathrm{~W}$

$315013 \mathrm{~N} 1112718 \mathrm{~W}$

locale

VARIANT

Pima

Santa Cruz

$312436 \mathrm{~N} 1105406 \mathrm{~W}$

mine

UNOFF

VARIANT

Santa Cruz

313705N1105126W

$312436 \mathrm{~N} 1105406 \mathrm{~W}$

locale

UNOFF

dam

reservoir

ppl

BGN

Santa Cruz

$335854 M 1091942 W$

Apache

Apache

Pima

VARIANT

VARIANT

VARIANT

VARIANT

pp1
pp1

stream

dan

dam

BGN 1941

Pima

Cochise

Graham

Grahan

Graham

UNOFF

VARIANT

school

sumnit

UNOFF

BGN
UNOFF

VARIANT

ppl

mine.

summit

building

building

stream

UNOFF

BGN

UNOFF

UNOFF

BGN

VARIANT

VARIANT

VARIANT

VARIANT

VARIANT

VARIANT

VARIANT

VARIANT

VARIANT

VARIANT

VARIANT

Cochise

Cochise

Cochise

Pima

Santa Cruz

Grahan

Cochise

Cochise

Graham
$321058 \mathrm{~N} 1122154 \mathrm{~W}$

$321604 \mathrm{~N} 1091337 \mathrm{~W}$

$324642 \mathrm{~N} 1093642 \mathrm{~W}$

322718 N1092200W

$321600 \mathrm{~N} 1091325 \mathrm{~W}$

$320421 \mathrm{N1091507 \textrm {W }}$

$321600 \mathrm{~N} 109132 \mathrm{WW}$

$321058 \mathrm{~N} 1122154 \mathrm{~W}$

$313209 \mathrm{~N} 1104147 \mathrm{~W}$

$322545 \mathrm{~N} 1091035 \mathrm{~W}$

$321605 \mathrm{~N} 1091340 \mathrm{~W}$

$321604 \mathrm{~N} 1091330 \mathrm{~W}$

$324953 \mathrm{~N} 1093855 \mathrm{~W}$
$324953 \mathrm{~N} 1093855 \mathrm{~W}$ $\begin{array}{cc}\text { SOURCE } & \text { ELEV } \\ \text { COORDINATE } & \text { FT MAP NAME }\end{array}$

Palo Alto Ranch

Wildhorse Mtn

Mount Bigelow

Mule Hoof Bend

4890 Canelo Pass

2178 Tecolote Ranch

Canelo Pass

Hereford

Lewis Springs

Lochiel

2211 Tecolote Ranch

3160 Fresno Wash

Patagonia

Rudd Knoll

Rudd Knoll

1848 Gu Achi

3612 San Simon

Mart in Well

San Simon

Cochise Head

San Simon

Mt Hughes

5325 Orange Butte

San Simon

320000 N1090125W San Simon

\begin{tabular}{|c|c|c|c|c|c|}
\hline $\begin{array}{l}\text { stream } \\
\text { locale }\end{array}$ & $\begin{array}{l}\text { BGN } \\
\text { UNOFF } \\
\text { VARIANT }\end{array}$ & $\begin{array}{l}\text { Graham } \\
\text { Cochise }\end{array}$ & $\begin{array}{l}324604 \mathrm{~N} 1102238 \mathrm{~W} \\
321530 \mathrm{~N} 1091035 \mathrm{~W}\end{array}$ & $324216 \mathrm{~N} 1102543 \mathrm{~W}$ & $\begin{array}{l}\text { Oak Grove Canyon } \\
\text { San Simon }\end{array}$ \\
\hline $\begin{array}{l}\text { valley } \\
\text { valley } \\
\text { stream }\end{array}$ & $\begin{array}{l}\text { BGN } \\
\text { BGN } \\
\text { VARIANT } \\
\text { VARIANT }\end{array}$ & $\begin{array}{l}\text { Pima } \\
\text { Graham } \\
\text { Pima }\end{array}$ & $\begin{array}{l}315828 \mathrm{~N} 1122134 \mathrm{~W} \\
324800 \mathrm{~N} 1094000 \mathrm{~W} \\
314621 \mathrm{~N} 1122449 \mathrm{~W}\end{array}$ & $\begin{array}{l}313800 \mathrm{~N} 1091200 \mathrm{~W} \\
322524 \mathrm{~N} 1121410 \mathrm{~W}\end{array}$ & $\begin{array}{l}\text { Rodeo } \\
\text { Bailey Peak }\end{array}$ \\
\hline $\begin{array}{l}\text { stream } \\
\text { well }\end{array}$ & UNOFF & $\begin{array}{l}\text { Graham } \\
\text { Pima }\end{array}$ & $\begin{array}{l}324953 \mathrm{~N} 1093855 \mathrm{~W} \\
321055 \mathrm{~N} 1122208 \mathrm{~W}\end{array}$ & & Wahak Hotrontk \\
\hline
\end{tabular}


NATIONAL GAZETTEER--ARIZONA 1986 FEATURE NAME

San Simon y Judas

See Gila Bend

San Solano Mission

Santa Ana

See Santan

Santa Atascoso Mountains

See Tumacacori Mountains

Santa Atoscos Mountains See Tumacacori Mountains

Santa Catalina Mountains

Sierra de la Saint Catarina

Santa Catalina Natural Area

Santa Clara River See Virgin River

Santa Clara School

Santa Claus

Santa Cruz

See Haivana Nakya

Santa Cruz

Santa Cruz

Santa Cruz Canyon

Santa Cruz County Pima County Cochise County

Santa Cruz Ditch

Santa Cruz Flats

Santa Cruz Mine

Santa Cruz Park

Santa Cruz River Rio Santa Cruz Santa Cruz Wash

Santa Cruz River See Greene Wash

Santa Cruz River Park

Santa Cruz School

Santa Cruz Spring

Santa Cruz Valley

Santa Cruz Valley High Schoo

Santa Cruz Wash

Santa Cruz Was

See Santa Cruz River

Santa Cruz Wash

Santa Fe Airport See Ash Fork Landing Strip

Santa Fe Dam

Santa Fe Dam

See Railroad Dam

Santa Fe Ranch

Santa Fe Reservoir

Santa Fe Spring

Santa Fe Tank

Santa Fe Tank Feed Trough

Santa Fe Well

Santa Fe Well

Santa Fe Wells

Santag Creek

See Sontag Creek

Santa Grande Mobile Home Park

Santa Lucia

Santa Lucia Ranch

Santa Margarita Ranch

Santa Margarita Tank

Santa Margarita Wash

Santa Maria

Santa Maria (subdivision)

Santa Maria del Agua Cal iente See Agua Caliente

Santa Maria Mine

Santa Maria Mountains

Santa Maria Ranch

FEATURE

CLASS

STATUS

COUNTY

COORDINATE

VARIANT

ppl

church

locale

range

range

range

UNOFF

VARIANT

VARIANT

Maricopa

Pinal

Santa Cruz

VARIANT

Santa Cruz

BGN

Pima

VARIANT

park

stream

school

locale

ppl

locale

locale

valley

civil

ADMIN

VARIANT

VARIANT

canal

flat

mine

park

stream

BGN

BGN

UNOFF

ADMIN

BGN

VARIANT

VARIANT

VARIANT

strea

park

schoo

spring

valley

school

arroyo

stream

ADMIN

UNOFF

BGN

BGN

UNOFF

BGN

VARIANT

Pinal

Pina

Pina

Pinal

Pinal

stream

airport

dam

dam

locale

reservoir

spring

reservoir

BGN

VARIANT

Maricopa

Yavapai

UNOFF

VARIANT

UNOFF

BGN

BGN
BGN

reservoir

BGN 1976

VARIANT
UNOFF

we11

well

UNOFF

UNOFF

VARIANT

stream

locale

locale

UNOFF

BGN

UNOFF

locale

reservoir

strean
ppl

pp 1

locale

mine

range

locale
SOURCE

COORDINATE

ELEV
FT

MAP NAME

$325652 \mathrm{~N} 1124258 \mathrm{~W}$

314850N1114921W

$331033 N 1114755 W$

$313327 \mathrm{~N} 1110713 \mathrm{~W}$

$313327 N 1110713 \mathrm{~W}$

$322549 \mathrm{~N} 1104217 \mathrm{~W}$

$321411 \mathrm{~N} 1105903 \mathrm{~W}$

Santa Cruz 312316N1105217W

Mohave 343453N1134240W

$331358 \mathrm{~N} 1120835 \mathrm{~W}$

Santa Cruz 313153N1104233W

Pima 321241N1105911W

$324152 \mathrm{~N} 1113302 \mathrm{~W}$

$312955 N 1103526 \mathrm{~W}$

$343453 \mathrm{~N} 1134240 \mathrm{~W}$

$321138 \mathrm{~N} 1105903 \mathrm{~W}$

$330050 \mathrm{~N} 1115719 \mathrm{~W}$

$324152 \mathrm{~N} 1113302 \mathrm{~W}$
UNOFF Pima 314037N1113459W

BGN Pima 315636N111305iW

BGN Pima

BGN Maricopa

BGN Maricopa

VARIANT

UNOFF

BGN

UNOFF
Maricopa

La Paz.

Yavapai

Yavapai
$314104 \mathrm{~N} 1112633 \mathrm{~W}$

$332522 \mathrm{~N} 1121212 \mathrm{~W}$

$333442 \mathrm{~N} 1121012 \mathrm{~W}$

325907 N1131925W

$341148 \mathrm{~N} 1133824 \mathrm{~W}$

$345203 \mathrm{~N} 1125325 \mathrm{~W}$

$342241 \mathrm{~N} 1131059 \mathrm{~W}$
$331552 N 1121127 \mathrm{~N}$

$351355 \mathrm{~N} 1122910 \mathrm{~W}$ $350958 \mathrm{~N} 1112 \mathrm{~B} 30 \mathrm{~W}$

$51436 \mathrm{~N} 1121106 \mathrm{~W}$ $31242 B N 1105335 \mathrm{~W}$ $351433 \mathrm{~N} 1121110 \mathrm{~W}$ $345852 \mathrm{N1} 140018 \mathrm{~W}$ $351354 \mathrm{N1} 122619 \mathrm{~W}$

$352208 N 1123516 \mathrm{~W}$

$341750 \mathrm{~N} 1093412 \mathrm{~W}$ $351502 \mathrm{~N} 1122654 \mathrm{~W}$

$351613 \mathrm{~N} 1125730 \mathrm{~W}$

$333019 N 1102007 \mathrm{~W}$ $333057 \mathrm{N1} 120914 \mathrm{~W}$ $320402 \mathrm{~N} 1115656 \mathrm{~W}$

$314011 \mathrm{N1111247W}$
Topawa

Mount Bigelow

Mt Lemmon

Tucson

Cerbat

Ko Vaya

Montezuma Peak

Mitchell Peak

Tubac

Montezuma Peak

Eloy South

Mt Hughes

Tucs on

Eloy South

Tucson

Cumero Canyon

Groom Spring

Tucson

Eloy North

324632N1114626W Sacaton Butte

324736N1114606W Laveen

Winona

3600 Rio Rico

Williams South

Yucca NE

Ash Fork

Horse Trap Mesa

7028 Cerro Hueco

Fitzgerald $\mathrm{Hill}$

Seligman West

1145 Glendale

Ko Vaya

Saucito Mtn

Mildred Peak

Kitt Peak

$314036 \mathrm{~N} 1113505 \mathrm{~W}$

Las Guijas

1015 Fowler

1200 Glendale

Reid Valley

7272 Juniper Mts

Thorn Peak 
NATIONAL GAZETTEER--ARIZONA 1986

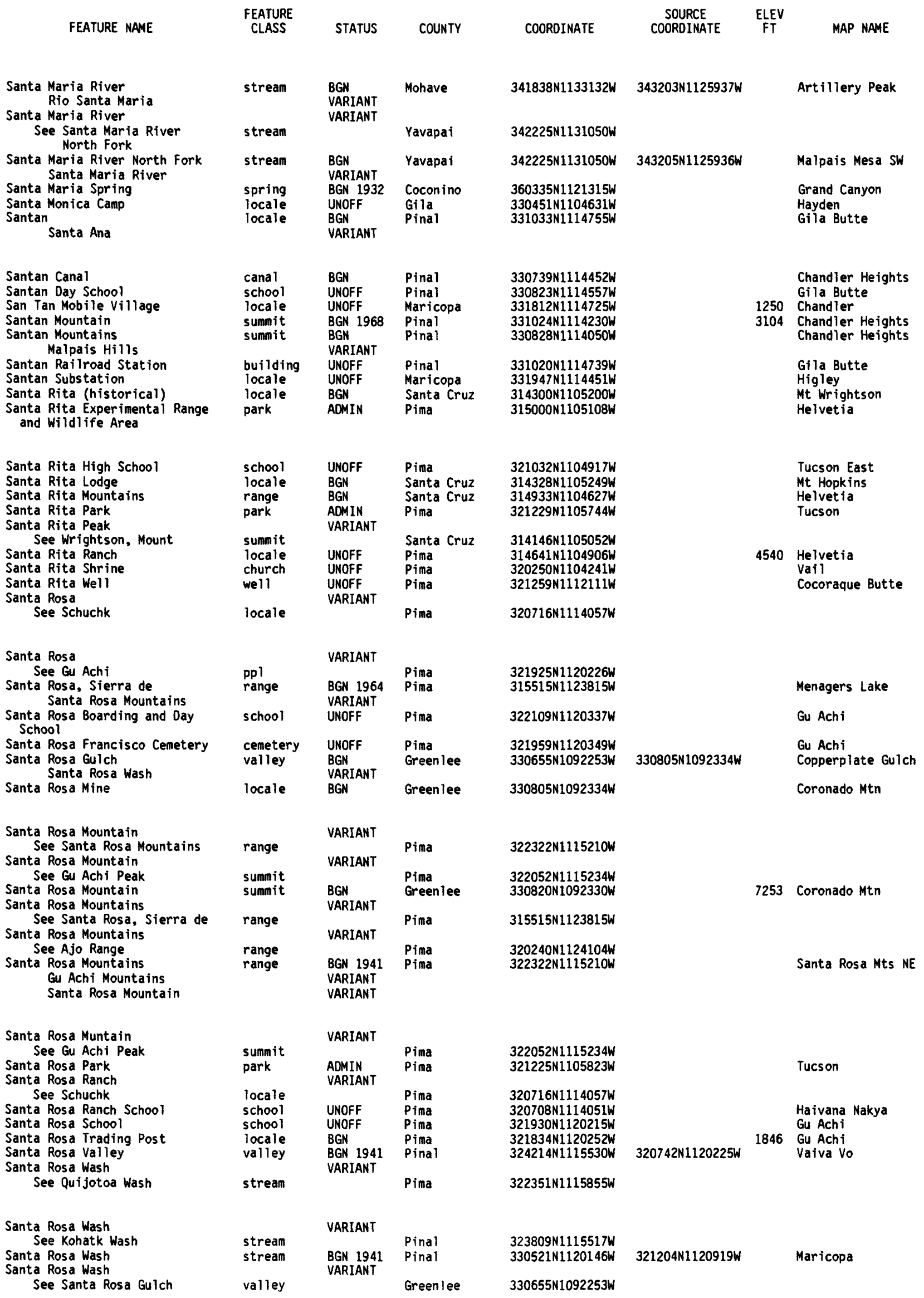


NATIONAL GAZETTEER--ARIZONA 1986

\section{FEATURE NAME}

Santa Rosa Well

See Gu Achi

Santa Teresa Mountains

Turnbull Mountains

Santa Teresa Well

Santiago (subdivision)

Santi Vaya

See Viason Chin

Santo Domingo Gulch

See San Domingo Wash

Santo Domingo Wash

See San Domingo Wash

San Tomos Well

Santo Niño Mine

Santos Angeles

See Guevavi Mission

(historical)

Santos Apostoles San Simon y Judas

See Gila Bend

Santo Tomas (subdivision)

Sanup Plateau

Sanur Plateau

See Shivwits Plateau

San Vicente

Haynes

San Vicente Wash

San Xavier

San Xavier del Bac

See San Xavier del Bac Mission

San Xavier del Bac Mission Saint Francois Xavier du Bac

San Xavier del Bac

San Xavier Indian Reservation

San Xavier Interchange

San Xavier Mine

San Xavier Plaza Shopping

Center

San Ysidro

See Haivana Makya

Sapano Vaya

Sapori Wash

See Sopori Wash

Sapo Tank

Sapphire Canyon

Sarah Oening Canyon
Sarah Jane Tank
Sarah Marley School
Saranake
See Sil Nakya
Sardina Canyon
Sardina Dam
Sardina Dam
Sardina Peak
Sardina Well
Sardine Creek
Sardine Falls
Sardine Saddle
Sargent Well
Sarita Airport
Randolph Airport
Sasabe
Sasabe, Arroyo del
Sasabe Flat
See Altar Valley
Sasco
See Sasco Ruins
Sasco Cemetery
Sasco Ruins

\section{FEATURE}

CLASS

STATUS

COUNTY

COORDINATE

locale

VARIANT

stream

VARIANT

Pima

stream

we11

mine

locale

VARIANT

Maricopa

UNOFF

VARTAMT

Maricopa

Pima

Santa Cruz

Santa Cruz

VARIANT

pp 1

ppl

plain

plain
locale

stream

BGI
BGI
VAR

Maricopa

Maricopa

Mohave

VARIANT

Mohave

Pima

BGN

VARIANT

Pima

pp 1

BGN

church

VARIANT

Pima

Pima

church

UNOFF

Pima

VARIANT

Pina

VARIANT

crossing UNOF

Pima

Pima

mine

locale

UNOFF

UNOFF

Pima

VARIANT

ppl

locale

BGN
VARIANT

stream

reservoir

valley

$B G N$

BGN 1908

valley
reservoir

reservoir
school

BGN

BGN

UMOFF

pp 1

valley

dam

dam

summit

BGN

UNOFF

UNOFF

BGN

Pima

Pima

Santa Cruz

Pima

Coconino

Cochise

Coconino

cochise

Pima

Pima

Santa Cruz

Santa Cruz

$320228 N 1113813$

gap

well

airport

ppl

valley

$B G N$

BGN

Greenlee

Pinal

VARIANT

valley

BGN

VARIANT

Pima

Pima

Pima

VARIANT

locale

cemetery

UNOFF

Pinal

Pinal
SOURCE

COORDINATE

ELEV
FT

MAP NAME

$\begin{array}{llll}\text { Pp1 } & & \text { Pima } & \text { 321925N1120226W } \\ \text { range } & \text { BGN } 1966 & \text { Graham } & 325340 N 1101133 \mathrm{~W}\end{array}$

Well VARIANT UNOFF Pima 320052N1111959W

pp1 BGN Maricopa 333715N1115825W

320055N1121723W

335313N1123942W

$335313 \mathrm{~N} 1123942 \mathrm{~W}$

$320928 \mathrm{N1} 120211 \mathrm{~W}$

$312140 \mathrm{~N} 1104303 \mathrm{~W}$

312436N1105406W

$325652 \mathrm{~N} 1124258 \mathrm{~W}$

$333254 N 1115457 \mathrm{~W}$

$360350 \mathrm{~N} 1134306 \mathrm{~W}$

362500 N1133001W

$320042 \mathrm{N1113811W}$

315825 N1110540W

$320626 \mathrm{~N} 1110024 \mathrm{~W}$

320626 N1110024W

$320300 \mathrm{N1110500 \textrm {W }}$

$320624 \mathrm{N1105932 \textrm {W }}$

315817 N1110523W

$321036 \mathrm{N1110007 \textrm {W }}$

$320024 \mathrm{N1114247 \textrm {W }}$

313549 N1113944W

$314326 \mathrm{N1110230 \textrm {W }}$

$313320 \mathrm{N1111932 \textrm {W }}$

$360843 \mathrm{~N} 1121728 \mathrm{~W}$

$320004 \mathrm{~N} 1091944 \mathrm{~W}$

$344647 \mathrm{N1111608 \textrm {W }}$

$312027 \mathrm{N1} 1093259 \mathrm{~W}$

321318N1114857W

$314052 \mathrm{~N} 1111210 \mathrm{~W}$

$313427 N 1110905 \mathrm{~W}$

$313732 \mathrm{~N} 1111012 \mathrm{~W}$

$313525 N 1110717 \mathrm{~W}$

313426 N1110904W

stream BGN Greenlee 331042N1091448W

$331130 \mathrm{~N} 1091631 \mathrm{~W}$

$331227 \mathrm{N1092237 \textrm {W }}$

$325608 \mathrm{~N} 1112902 \mathrm{~W}$

312919 N1113229W

$312700 \mathrm{~N} 1113100 \mathrm{~W}$

320753N1111638W
Jackson Mtn

Three Points

1430 Paradise Valley

Gurli Put Vo

Duquesne

1300 Paradise Valley

Tincanebitts Point

Haivana Nakya

Haivana Makya

Twin Buttes

San Xavier Mission

San Xavier Mission

2505 Tucson SW

Twin Buttes

2430 Cat Mountain

Caponera Peak

Arivaca

360621N1121923W Havasupai Point

315931N1091844W Cochise Head

Jaycox Mtn

Douglas

313401N1110701W Saucito Mtn

Murphy Peak

Saucito Mtn

5606 Tubac

Murphy Peak

$331237 N 1092227 \mathrm{~W}$

Dix Creek

Mitchell Peak

Coronado Mtn

North of Oracle

1464 Valley Farms

Sasabe

Sasabe

Friendly Corners 


\begin{tabular}{|c|c|c|c|c|c|c|c|}
\hline FEATURE NAME & $\begin{array}{l}\text { FEATURE } \\
\text { CLASS }\end{array}$ & STATUS & COUNTY & COORDINATE & $\begin{array}{l}\text { SOURCE } \\
\text { COORDINATE }\end{array}$ & $\begin{array}{l}\text { ELEV } \\
\text { FT }\end{array}$ & MAP NAME \\
\hline $\begin{array}{l}\text { Old Sasco Ruins } \\
\text { Sasco } \\
\text { Sasco Tank } \\
\text { Sase Nasket } \\
\text { Sastanha Mesa } \\
\text { See Rain God Mesa }\end{array}$ & $\begin{array}{l}\text { reservoir } \\
\text { bench } \\
\text { summit }\end{array}$ & $\begin{array}{l}\text { VARIANT } \\
\text { VARIANT } \\
\text { BGN } \\
\text { BGN } \\
\text { VARIANT }\end{array}$ & $\begin{array}{l}\text { Pinal } \\
\text { Coconino } \\
\text { Navajo }\end{array}$ & $\begin{array}{l}323133 \mathrm{~N} 1112735 \mathrm{~W} \\
362138 \mathrm{~N} 1115129 \mathrm{~W} \\
365632 \mathrm{~N} 1100425 \mathrm{~W}\end{array}$ & & & $\begin{array}{l}\text { Friendly Corners } \\
\text { Nankoweap Mesa }\end{array}$ \\
\hline $\begin{array}{l}\text { Sastonho Mesa } \\
\text { See Rain God Mesa } \\
\text { Satan Butte } \\
\text { S A Tank } \\
\text { Satathite Mountain } \\
\text { Satchin Cliff } \\
\text { Sattell Knoll Substation } \\
\text { Sauceda } \\
\text { See Chiulikam } \\
\text { Sauceda Mountains } \\
\text { Los Sierra Sauceba } \\
\text { Los Sierra Sauceda } \\
\text { Papago Mountains } \\
\text { Salceda Mountains } \\
\text { Saucedo Mountains } \\
\text { Saucita Mountains }\end{array}$ & $\begin{array}{l}\text { summit } \\
\text { summit } \\
\text { reservoir } \\
\text { summit } \\
\text { cliff } \\
\text { locale } \\
\text { locale } \\
\text { range }\end{array}$ & $\begin{array}{l}\text { VARIANT } \\
\text { BGN } \\
\text { BGN } \\
\text { BGN } \\
\text { BGN } 1917 \\
\text { UNOFF } \\
\text { VARIANT } \\
\text { BGN } 1941 \\
\text { VARIANT } \\
\text { VARIANT } \\
\text { VARIANT } \\
\text { VARIANT } \\
\text { VARIANT } \\
\text { VARIANT }\end{array}$ & $\begin{array}{l}\text { Navajo } \\
\text { Navajo } \\
\text { Yavapai } \\
\text { Pinal } \\
\text { Maricopa } \\
\text { Apache } \\
\text { Maricopa } \\
\text { Maricopa }\end{array}$ & $\begin{array}{l}365632 \mathrm{~N} 1100425 \mathrm{~W} \\
353156 \mathrm{N1095524 \textrm {W }} \\
341854 \mathrm{N1121602W} \\
325046 \mathrm{~N} 1103512 \mathrm{~W} \\
\text { UNKNOWN } \\
340348 \mathrm{~N} 1091642 \mathrm{~W} \\
323428 \mathrm{~N} 1123131 \mathrm{~W} \\
323556 \mathrm{~N} 112391 \mathrm{~W}\end{array}$ & & $\begin{array}{l}6332 \\
3672\end{array}$ & $\begin{array}{l}\text { Satan Butte } \\
\text { Battle Flat } \\
\text { Holy Joe Peak } \\
\text { Eagar } \\
\text { Hat Mountain SW }\end{array}$ \\
\hline $\begin{array}{l}\text { Sauceda Wash } \\
\text { Sauceda Well } \\
\text { See Chiulikam } \\
\text { Saucedo Mountains } \\
\text { See Sauceda Mountains } \\
\text { Saucedo Mountains } \\
\text { See Sand Tank Mountains } \\
\text { Saucida } \\
\text { See Chiulikam } \\
\text { Saucita } \\
\text { See Chiulikam }\end{array}$ & $\begin{array}{l}\text { stream } \\
\text { locale } \\
\text { range } \\
\text { summit } \\
\text { locale } \\
\text { locale }\end{array}$ & $\begin{array}{l}\text { BGN } \\
\text { VARIANT } \\
\text { VARIANT } \\
\text { VARIANT } \\
\text { VARIANT } \\
\text { VARIANT }\end{array}$ & $\begin{array}{l}\text { Maricopa } \\
\text { Maricopa } \\
\text { Maricopa } \\
\text { Maricopa } \\
\text { Maricopa } \\
\text { Maricopa }\end{array}$ & $\begin{array}{l}325910 \mathrm{~N} 1124632 \mathrm{~W} \\
323428 \mathrm{~N} 1123131 \mathrm{~W} \\
323556 \mathrm{~N} 112391 \mathrm{~W} \\
324328 \mathrm{~N} 1122638 \mathrm{~W} \\
323428 \mathrm{~N} 1123131 \mathrm{~W} \\
323428 \mathrm{~N} 1123131 \mathrm{~W}\end{array}$ & $323241 \mathrm{~N} 122731 \mathrm{~W}$ & & Smurr \\
\hline $\begin{array}{l}\text { Saucita Mountains } \\
\text { See Sauceda Mountains } \\
\text { Saucita Tank } \\
\text { Saucito Tank } \\
\text { Saucito } \\
\text { See Chiulikam } \\
\text { Saucito Canyon } \\
\text { Saucito Mountain } \\
\text { Saucito Mountain } \\
\text { Saucito Spring }\end{array}$ & $\begin{array}{l}\text { locale } \\
\text { valley } \\
\text { summit } \\
\text { summit } \\
\text { spring }\end{array}$ & $\begin{array}{l}\text { VARIANT } \\
\text { BGN } \\
\text { VARIANT } \\
\text { VARIANT } \\
\text { BGN } \\
\text { BGN } \\
\text { BGN } \\
\text { BGN }\end{array}$ & $\begin{array}{l}\text { Maricopa } \\
\text { Santa Cruz } \\
\text { Maricopa } \\
\text { Pima } \\
\text { Santa Cruz } \\
\text { Pima Cruz } \\
\text { Santa Cruz }\end{array}$ & $\begin{array}{l}323556 \mathrm{~N} 1123911 \mathrm{~W} \\
312637 \mathrm{~N} 1111747 \mathrm{~W} \\
\\
323428 \mathrm{~N} 1123131 \mathrm{~W} \\
321720 \mathrm{~N} 1102711 \mathrm{~W} \\
313930 \mathrm{~N} 1110825 \mathrm{~W} \\
31546 \mathrm{~N} 1113346 \mathrm{~W} \\
312520 \mathrm{~N} 1111821 \mathrm{~W}\end{array}$ & 321609 N1102754W & $\begin{array}{l}4528 \\
5014\end{array}$ & $\begin{array}{l}\text { Bartlett Mtn } \\
\text { Soza Canyon } \\
\text { Saucito Mtn } \\
\text { Kitt Peak } \\
\text { Bartlett Mtn }\end{array}$ \\
\hline $\begin{array}{l}\text { Saucito Spring } \\
\text { Saucito Spring } \\
\text { Saucito Tank } \\
\text { See Saucita Tank } \\
\text { Saucito Wash } \\
\text { Saucito Wash } \\
\text { Saucito Well } \\
\text { Saul Point } \\
\text { Sauls } \\
\text { Sauls } \\
\text { See Saul Point }\end{array}$ & $\begin{array}{l}\text { spring } \\
\text { spring } \\
\text { reservoir } \\
\text { stream } \\
\text { stream } \\
\text { well } \\
\text { summit } \\
\text { summit }\end{array}$ & $\begin{array}{l}\text { BGN } \\
\text { BGN } \\
\text { VARIANT } \\
\text { BGN } \\
\text { BGN } \\
\text { UNOFF } \\
\text { BGN } \\
\text { VARIANT } \\
\text { VARIANT }\end{array}$ & $\begin{array}{l}\text { Santa Cruz } \\
\text { Pima } \\
\text { Santa Cruz } \\
\text { Pima } \\
\text { Pima } \\
\text { Santa Cruz } \\
\text { Navajo } \\
\text { Navajo }\end{array}$ & $\begin{array}{l}312642 \mathrm{~N} 1111724 \mathrm{~W} \\
314407 \mathrm{~N} 1111641 \mathrm{~W} \\
312637 \mathrm{~N} 1111747 \mathrm{~W} \\
314214 \mathrm{N1111026 \textrm {W }} \\
315145 \mathrm{~N} 1112635 \mathrm{~W} \\
313906 \mathrm{~N} 1110856 \mathrm{~W} \\
341958 \mathrm{~N} 1102131 \mathrm{~W} \\
341958 \mathrm{~N} 1102131 \mathrm{~W}\end{array}$ & $\begin{array}{l}313900 \mathrm{~N} 1110744 \mathrm{~W} \\
315441 \mathrm{N1113336 \textrm {W }}\end{array}$ & & $\begin{array}{l}\text { Bartlett Mtn } \\
\text { Cerro Colorado } \\
\text { Saucito Mtn } \\
\text { Fresno Wash } \\
\text { Saucito Mtn } \\
\text { Clay Springs }\end{array}$ \\
\hline $\begin{array}{l}\text { Saulsbury Canyon } \\
\text { Saulsbury Canyon Trail Two } \\
\text { Hundred Sixtythree } \\
\text { Saulsbury Saddle } \\
\text { Saunders Canyon } \\
\text { Saunders Spring } \\
\text { Saunders Tank } \\
\text { Saurita } \\
\text { See Sahuarita } \\
\text { Sausaulito Creek }\end{array}$ & $\begin{array}{l}\text { valley } \\
\text { trail } \\
\text { gap } \\
\text { valley } \\
\text { spring } \\
\text { reservoir } \\
\text { ppl } \\
\text { stream }\end{array}$ & $\begin{array}{l}\text { BGN } \\
\text { UNOFF } \\
\text { BGN } \\
\text { BGN } \\
\text { BGN } \\
\text { BGN } \\
\text { VARIANT } \\
\text { BGN }\end{array}$ & $\begin{array}{l}\text { Cochise } \\
\text { Cochise } \\
\text { Cochise } \\
\text { Gila } \\
\text { Gila } \\
\text { Navajo }\end{array}$ & $\begin{array}{l}315152 \mathrm{~N} 1091953 \mathrm{~W} \\
315245 \mathrm{~N} 1091835 \mathrm{~W} \\
\\
315305 \mathrm{~N} 1091850 \mathrm{~W} \\
341037 \mathrm{N1} 105355 \mathrm{~W} \\
341104 \mathrm{N1} 105335 \mathrm{~W} \\
344929 \mathrm{~N} 1102026 \mathrm{~W} \\
315727 \mathrm{~N} 1105718 \mathrm{~W} \\
322530 \mathrm{~N} 1105707 \mathrm{~W}\end{array}$ & $341146 N 1105323 \mathrm{~W}$ & & $\begin{array}{l}\text { Chiricahua Peak } \\
\text { Rustler Park } \\
\text { Rustler Park } \\
\text { Oxbow Mtn } \\
\text { Oxbow Mtn } \\
\text { Saunders Draw }\end{array}$ \\
\hline $\begin{array}{l}\text { Sauz River } \\
\text { See San Simon River } \\
\text { Savage Dam } \\
\text { Savage Tunnel Spring } \\
\text { Savage Well } \\
\text { Savanic Mine } \\
\text { Savoita Spring } \\
\text { Savoy Mine } \\
\text { Saw Buck Mountain }\end{array}$ & $\begin{array}{l}\text { stream } \\
\text { dam } \\
\text { spring } \\
\text { well } \\
\text { mine } \\
\text { spring } \\
\text { mine }\end{array}$ & $\begin{array}{l}\text { VARIANT } \\
\text { UNOFF } \\
\text { BGN } \\
\text { UNOFF } \\
\text { UNOFF } \\
\text { BGN } \\
\text { UNOFF } \\
\text { VARIANT }\end{array}$ & $\begin{array}{l}\text { Graham } \\
\text { Graham } \\
\text { Gila } \\
\text { Coconino } \\
\text { Mohave } \\
\text { Santa Cruz } \\
\text { Yavapai }\end{array}$ & $\begin{array}{l}324953 \mathrm{~N} 1093855 \mathrm{~W} \\
324718 \mathrm{~N} 1094606 \mathrm{~W} \\
332053 \mathrm{~N} 1105722 \mathrm{~W} \\
353522 \mathrm{~N} 1112226 \mathrm{~W} \\
361617 \mathrm{N1134801 \textrm {W }} \\
312820 \mathrm{~N} 1111400 \mathrm{~W} \\
341044 \mathrm{~N} 1122019 \mathrm{~W}\end{array}$ & & 5062 & $\begin{array}{l}\text { Thatcher } \\
\text { Pinal Ranch } \\
\text { Wupatki SE } \\
\text { Grand Gulch Bench } \\
\text { Ruby } \\
\text { Crown King }\end{array}$ \\
\hline
\end{tabular}




\begin{tabular}{|c|c|c|c|c|c|c|c|}
\hline FEATURE NAME & $\begin{array}{l}\text { FEATURE } \\
\text { CLASS }\end{array}$ & STATUS & COUNTY & COORDINATE & $\begin{array}{l}\text { SOURCE } \\
\text { COOROINATE }\end{array}$ & $\begin{array}{l}\text { ELEV } \\
\text { FT }\end{array}$ & MAP NAME \\
\hline See Sawbuck Mountain & summit & & Graham & $332843 \mathrm{~N} 1094016 \mathrm{~W}$ & & & \\
\hline $\begin{array}{l}\text { Sawbuck Mountain } \\
\text { Saw Buck Mountain } \\
\text { Sawbuck Tank } \\
\text { Sawed Off Mountain } \\
\text { Sawik Mountain } \\
\text { Granite Reef Mountain } \\
\text { Sahwick Mountain } \\
\text { Sah-wik Mountain } \\
\text { Sheldon Mountain } \\
\text { Sawlog Tank }\end{array}$ & $\begin{array}{l}\text { summit } \\
\text { reservoir } \\
\text { summit } \\
\text { summit }\end{array}$ & $\begin{array}{l}\text { BGN } \\
\text { VARIANT } \\
\text { BGN } \\
\text { BGN } \\
\text { BGN } 1917 \\
\text { VARIANT } \\
\text { VARIANT } \\
\text { VARIANT } \\
\text { VARIANT } \\
\text { BGN }\end{array}$ & $\begin{array}{l}\text { Graham } \\
\text { Graham } \\
\text { Greenlee } \\
\text { Maricopa }\end{array}$ & $\begin{array}{l}332843 \mathrm{~N} 1094016 \mathrm{~W} \\
332816 \mathrm{~N} 1094005 \mathrm{~W} \\
333425 \mathrm{~N} 1091540 \mathrm{~W} \\
333212 \mathrm{~N} 1114538 \mathrm{~W}\end{array}$ & & $\begin{array}{l}6861 \\
6415 \\
2131\end{array}$ & $\begin{array}{l}\text { Sawbuck Mtn } \\
\text { Sawbuck Mtn } \\
\text { Strayhorse } \\
\text { Sawik Mountain }\end{array}$ \\
\hline $\begin{array}{l}\text { Sawlog Tank } \\
\text { Sawlog Tank Number One } \\
\text { Sawlog Tank Number Two } \\
\text { Sawmill } \\
\text { Sawmill } \\
\text { Sawmill Canyon } \\
\text { Sawmill Canyon } \\
\text { See East Sawmill Canyon } \\
\text { Saw Mill Canyon } \\
\text { See West Sawmill Canyon }\end{array}$ & $\begin{array}{l}\text { reservoir } \\
\text { reservoir } \\
\text { reservoir } \\
\text { locale } \\
\text { ppl } \\
\text { valley } \\
\text { valley } \\
\text { valley }\end{array}$ & $\begin{array}{l}\text { BGN } \\
\text { BGN } \\
\text { BGN } \\
\text { BGN } \\
\text { BGN } \\
\text { BGN } \\
\text { VARIANT } \\
\text { VARIANT }\end{array}$ & $\begin{array}{l}\text { Coconino } \\
\text { Yavapai } \\
\text { Yavapai } \\
\text { Gila } \\
\text { Apache } \\
\text { Cochise } \\
\text { Pima } \\
\text { Pima }\end{array}$ & $\begin{array}{l}350533 \mathrm{~N} 1120218 \mathrm{~W} \\
343007 \mathrm{~N} 1113806 \mathrm{~W} \\
343022 \mathrm{~N} 1113824 \mathrm{~W} \\
333705 \mathrm{~N} 1102345 \mathrm{~W} \\
355409 \mathrm{~N} 1090955 \mathrm{~W} \\
312712 \mathrm{~N} 1102233 \mathrm{~W} \\
314333 \mathrm{~N} 1104938 \mathrm{~W} \\
314653 \mathrm{~N} 1105053 \mathrm{~W}\end{array}$ & $312626 \mathrm{~N} 1102057 \mathrm{~W}$ & 5680 & $\begin{array}{l}\text { White Horse Lake } \\
\text { Walker Mtn } \\
\text { Walker Mtn } \\
\text { Cassadore Spring } \\
\text { Sawmill } \\
\text { Huachuca Peak }\end{array}$ \\
\hline $\begin{array}{l}\text { Sawmill Canyon } \\
\text { See West Sawmill Canyon } \\
\text { Sawmill Canyon } \\
\text { Sawmill Canyon } \\
\text { Sawmill Canyon } \\
\text { Sawmill Canyon } \\
\text { Sawmill Creek } \\
\text { Saw Mill Creek } \\
\text { Sawmill Canyon } \\
\text { Sawmill Canyon Tank }\end{array}$ & $\begin{array}{l}\text { valley } \\
\text { valley } \\
\text { valley } \\
\text { valley } \\
\text { valley }\end{array}$ & $\begin{array}{l}\text { VARIANT } \\
\text { BGN } \\
\text { BGN } \\
\text { 8GN } \\
\text { BGN } \\
\text { VARIANT } \\
\text { VARIANT } \\
\text { BGN } \\
\text { BGN }\end{array}$ & $\begin{array}{l}\text { Pima } \\
\text { Graham } \\
\text { Graham } \\
\text { Greenlee } \\
\text { Gila }\end{array}$ & $\begin{array}{l}314653 \mathrm{~N} 1105053 \mathrm{~W} \\
324627 \mathrm{N1} 100342 \mathrm{~W} \\
333414 \mathrm{~N} 1095640 \mathrm{~W} \\
333441 \mathrm{~N} 1091022 \mathrm{~W} \\
334751 \mathrm{~N} 1102819 \mathrm{~W} \\
\\
350950 \mathrm{~N} 1140339 \mathrm{~W} \\
314330 \mathrm{~N} 1104634 \mathrm{~W}\end{array}$ & $\begin{array}{l}324438 N 1100155 \mathrm{~W} \\
332919 \mathrm{~N} 1095409 \mathrm{~W} \\
333217 \mathrm{~N} 1090834 \mathrm{~W} \\
333725 \mathrm{~N} 1102430 \mathrm{~W} \\
350559 \mathrm{~N} 1135306 \mathrm{~W}\end{array}$ & & $\begin{array}{l}\text { Tripp Canyon } \\
\text { Elwood Canyon } \\
\text { Bear Mountain } \\
\text { Beckers Butte } \\
\text { Kingman } \\
\text { Mt Wrightson }\end{array}$ \\
\hline $\begin{array}{l}\text { Sawmill Canyon Trail } 146 \\
\text { Sawmill Canyon Wash } \\
\text { Sawmill Canyon Well } \\
\text { Sawmill Creek } \\
\text { See Squaw Creek } \\
\text { Sawmill Creek } \\
\text { Sawmill Creek } \\
\text { Saw Mill Creek } \\
\text { Saw Mill Creek } \\
\text { See Sawmill Creek }\end{array}$ & $\begin{array}{l}\text { trail } \\
\text { arroyo } \\
\text { well } \\
\text { stream } \\
\text { stream } \\
\text { stream } \\
\text { stream }\end{array}$ & $\begin{array}{l}\text { UNOFF } \\
\text { BGN } \\
\text { UNOFF } \\
\text { VARIANT } \\
\text { BGN } \\
\text { BGN } \\
\text { VARIANT } \\
\text { VARIANT }\end{array}$ & $\begin{array}{l}\text { Santa Cruz } \\
\text { Pima } \\
\text { Pima } \\
\text { Graham } \\
\text { Graham } \\
\text { Gila } \\
\text { Gila }\end{array}$ & $\begin{array}{l}314300 \mathrm{~N} 110470 \mathrm{~W} \\
315140 \mathrm{~N} 1105820 \mathrm{~W} \\
314549 \mathrm{~N} 1104938 \mathrm{~W} \\
332829 \mathrm{~N} 1095320 \mathrm{~W} \\
333413 \mathrm{~N} 1095641 \mathrm{~W} \\
334751 \mathrm{~N} 1102820 \mathrm{~W} \\
334751 \mathrm{~N} 1102820 \mathrm{~W}\end{array}$ & $\begin{array}{l}332432 \mathrm{~N} 1095529 \mathrm{~W} \\
333453 \mathrm{~N} 1102315 \mathrm{~W}\end{array}$ & & $\begin{array}{l}\text { Mt Wrightson } \\
\text { Green Valley } \\
\text { Helvetia }\end{array}$ \\
\hline $\begin{array}{l}\text { Saw Mill Creek } \\
\text { See Sawmill Canyon } \\
\text { Sawmill Creek } \\
\text { See Sawmill Canyon } \\
\text { Sawmill Dam } \\
\text { Sawmill Flat } \\
\text { Sawmill Gulch } \\
\text { Sawmill Hills } \\
\text { Sawmill Mountains } \\
\text { Sawmill Point }\end{array}$ & $\begin{array}{l}\text { valley } \\
\text { valley } \\
\text { dam } \\
\text { flat } \\
\text { valley } \\
\text { ridge } \\
\text { range } \\
\text { cliff }\end{array}$ & $\begin{array}{l}\text { VARIANT } \\
\text { VARIANT } \\
\text { UNOFF } \\
\text { BGN } \\
\text { BGN } \\
\text { BGN } \\
\text { BGN } \\
\text { BGN }\end{array}$ & $\begin{array}{l}\text { Gila } \\
\text { Gila } \\
\text { Gila } \\
\text { Yavapai } \\
\text { Yavapai } \\
\text { Coconino } \\
\text { Mohave } \\
\text { Coconino }\end{array}$ & $\begin{array}{l}334751 \mathrm{~N} 1102819 \mathrm{~W} \\
334751 \mathrm{N1} 102819 \mathrm{~W} \\
333725 \mathrm{~N} 1102413 \mathrm{~W} \\
345505 \mathrm{~N} 1130500 \mathrm{~W} \\
342954 \mathrm{~N} 1122342 \mathrm{~W} \\
345026 \mathrm{~N} 1111950 \mathrm{~W} \\
362222 \mathrm{N1} 131327 \mathrm{~W} \\
363247 \mathrm{N1122357W}\end{array}$ & $342843 \mathrm{~N} 1122414 \mathrm{~W}$ & & $\begin{array}{l}\text { Cassadore Spring } \\
\text { Mount Hope } \\
\text { Groom Creek } \\
\text { Jaycox Mtn } \\
\text { Mount Logan } \\
\text { Sowats Spring }\end{array}$ \\
\hline $\begin{array}{ll}\text { Sawmill } & \text { Post office } \\
\text { Sawmill } & \text { Spring } \\
\text { Sawmill } & \text { Spring } \\
\text { Sawmill } & \text { Spring } \\
\text { Sawmill } & \text { Spring } \\
\text { Sawmill } & \text { Spring } \\
\text { Sawmill } & \text { Spring } \\
\text { Sawmill } & \text { Spring } \\
\text { Sawmill } & \text { Spring } \\
\text { Sawmill } & \text { Springs }\end{array}$ & $\begin{array}{l}\text { building } \\
\text { spring } \\
\text { spring } \\
\text { spring } \\
\text { spring } \\
\text { spring } \\
\text { spring } \\
\text { spring } \\
\text { spring } \\
\text { spring }\end{array}$ & $\begin{array}{l}\text { UNOFF } \\
\text { BGN } \\
\text { BGN } \\
\text { BGN } 1975 \\
\text { BGN } \\
\text { BGN } \\
\text { BGN } \\
\text { BGN } \\
\text { BGN } \\
\text { BGN }\end{array}$ & $\begin{array}{l}\text { Apache } \\
\text { Cochise } \\
\text { Pima } \\
\text { Graham } \\
\text { Greenlee } \\
\text { Apache } \\
\text { Apache } \\
\text { Apache } \\
\text { Coconino } \\
\text { Coconino }\end{array}$ & $\begin{array}{l}355402 \mathrm{~N} 1090953 \mathrm{~W} \\
312619 \mathrm{~N} 1102117 \mathrm{~W} \\
314347 \mathrm{~N} 1104915 \mathrm{~W} \\
324518 \mathrm{~N} 1100245 \mathrm{~W} \\
331217 \mathrm{~N} 1092301 \mathrm{~W} \\
335 \mathrm{~B} 3 \mathrm{BN} 1090315 \mathrm{~W} \\
340354 \mathrm{~N} 1092115 \mathrm{~W} \\
340903 \mathrm{~N} 1093545 \mathrm{~W} \\
351717 \mathrm{~N} 1115732 \mathrm{~W} \\
345014 \mathrm{~N} 1112234 \mathrm{~W}\end{array}$ & & & $\begin{array}{l}\text { Sawmill } \\
\text { Miller Peak } \\
\text { Mt Wrightson } \\
\text { Tripp Canyon } \\
\text { Coronado Mtn } \\
\text { Escudilla Mtn } \\
\text { Eagar } \\
\text { Whiting Knoll } \\
\text { Parks } \\
\text { Hutch Mtn }\end{array}$ \\
\hline $\begin{array}{l}\text { Sawmill Tank } \\
\text { Sawmill Tank } \\
\text { Sawmill Tank } \\
\text { Sawmill Tank } \\
\text { Sawmill Tank } \\
\text { Sawmill Tank } \\
\text { Sawmill Tank Number One } \\
\text { Sawmill Tank Number Two } \\
\text { Sawmill Tanks } \\
\text { Sawmill Trading Post }\end{array}$ & $\begin{array}{l}\text { reservoir } \\
\text { reservoir } \\
\text { reservoir } \\
\text { reservoir } \\
\text { reservoir } \\
\text { reservoir } \\
\text { reservoir } \\
\text { reservoir } \\
\text { reservoir } \\
\text { locale }\end{array}$ & $\begin{array}{l}\text { BGN } \\
\text { BGN } \\
\text { BGN } \\
\text { BGN } \\
\text { BGN } \\
\text { BGN } \\
\text { BGN } \\
\text { BGN } \\
\text { BGN } \\
\text { BGN }\end{array}$ & $\begin{array}{l}\text { Gila } \\
\text { Coconino } \\
\text { Yavapai } \\
\text { Coconino } \\
\text { Coconino } \\
\text { Mohave } \\
\text { Gila } \\
\text { Gila } \\
\text { Coconino } \\
\text { Apache }\end{array}$ & $\begin{array}{l}333728 \mathrm{~N} 1102412 \mathrm{~W} \\
343626 \mathrm{~N} 1111057 \mathrm{~W} \\
344820 \mathrm{~N} 1124932 \mathrm{~W} \\
350 \mathrm{~B} 25 \mathrm{~N} 1115349 \mathrm{~W} \\
351727 \mathrm{~N} 1115730 \mathrm{~W} \\
362252 \mathrm{~N} 1131244 \mathrm{~W} \\
331705 \mathrm{~N} 1102941 \mathrm{~W} \\
331727 \mathrm{~N} 1102930 \mathrm{~W} \\
345013 \mathrm{~N} 1112226 \mathrm{~W} \\
355403 \mathrm{~N} 1090953 \mathrm{~W}\end{array}$ & & 5636 & $\begin{array}{l}\text { Cassadore Spring } \\
\text { Blue Ridge Reservoir } \\
\text { Seepage Mtn } \\
\text { Garland Prairie } \\
\text { Parks } \\
\text { Mt Trumbul1 NW } \\
\text { San Carlos } \\
\text { San Carlos } \\
\text { Jaycox Mtn } \\
\text { Sawmill }\end{array}$ \\
\hline
\end{tabular}




\section{FEATURE}

CLASS

STATUS

COUNTY

COORDINATE

\section{arroyo}

Sawmill Wash

Sawmill Water Storage Tank Sawtooth See Sawtooth Peak

Sawtooth Mountain Farrar Peak

Ferra Peak

Sawtooth Mountain

Sawtooth Mountains

Sawtooth Peak
Sawtooth
Sawtooth Ridge
Sawtooth School
Sawtooth Tank
Sawtooth Tank
Sawtooth Tank Number Two
Sawyer Tank
Saxon Dairy
See Pete Kitchens Ranch

Saxons Dairy Ranch

See Pete Kitchens Ranch
Saxton

See Pete Kitchens Ranch

Sayer Spring

Sayre Tank
Sazini Butt

See Black Rock Butte

$S$ B Canyon

See Hundred and Fifty Mile Canyon

\section{S B Mountain \\ $S$ B Point \\ Scaddan Mountain \\ Scaddan Wash \\ Scales School \\ Scanlon Ferry \\ See Greggs Ferry (submerged ruin) \\ Scanton Spring \\ Scanlon Tunnel \\ Scanion Wash Scanton Wash \\ Scanion Wash \\ Scanion Well \\ Scanton Wash \\ See Scanlon Wash \\ $s$ Canyon \\ $S$ Canyon \\ South Canyon}

Scarb Hill

Scarborough Tank Number One Scarborough Tank Number Two Scarface Mountain

Scarlet Spring

Scar Tank

Scattered Willow Wash

Scatter Wash

Scelly Creek

See Skully Creek

Schafers Tank

Schaffer Wash

See Shaffer Wash

Scheelite Canyon

Scheelite Ridge

Schellbach Butte

Schell Canyon

Schell Gulch

Schell Spring

Schenectady Mine

Scherer Canyon

strean

stream

stream
valley

valley

summit

summit

spring

stream

stream

ridge

summit

valley

valley

spring

mine

valley
Apache

\begin{tabular}{|c|c|c|c|}
\hline $\begin{array}{l}\text { arroyo } \\
\text { stream } \\
\text { reservoir }\end{array}$ & $\begin{array}{l}\text { BGN } \\
\text { BGN } \\
\text { BGN } \\
\text { VARIANT }\end{array}$ & $\begin{array}{l}\text { Apache } \\
\text { Coconino } \\
\text { Graham }\end{array}$ & $\begin{array}{l}355030 \mathrm{~N} 1090700 \mathrm{~W} \\
344815 \mathrm{~N} 111133 \mathrm{~W} \\
324630 \mathrm{~N} 1100402 \mathrm{~W}\end{array}$ \\
\hline $\begin{array}{l}\text { summit } \\
\text { summit }\end{array}$ & $\begin{array}{l}\text { BGN } \\
\text { VARIANT } \\
\text { VARIANT }\end{array}$ & $\begin{array}{l}\text { Coconino } \\
\text { Yuma }\end{array}$ & $\begin{array}{l}351040 \mathrm{~N} 1122152 \mathrm{~W} \\
333647 \mathrm{~N} 1142128 \mathrm{~W}\end{array}$ \\
\hline $\begin{array}{l}\text { summit } \\
\text { range }\end{array}$ & $\begin{array}{l}\text { BGN } \\
\text { BGN }\end{array}$ & $\begin{array}{l}\text { Gila } \\
\text { Pinal }\end{array}$ & $\begin{array}{l}334903 \mathrm{~N} 1100524 \mathrm{~W} \\
323723 \mathrm{~N} 1114434 \mathrm{~W}\end{array}$ \\
\hline summit & $\begin{array}{l}\text { BGN } 1977 \\
\text { VARIANT }\end{array}$ & Coconino & $351040 \mathrm{~N} 1122152 \mathrm{~W}$ \\
\hline $\begin{array}{l}\text { ridge } \\
\text { school } \\
\text { reservoir } \\
\text { reservoir } \\
\text { reservoir } \\
\text { reservoir }\end{array}$ & $\begin{array}{l}\text { BGN } \\
\text { UNOFF } \\
\text { BGN } \\
\text { BGN } \\
\text { BGN } \\
\text { BGN } \\
\text { VARIANT }\end{array}$ & $\begin{array}{l}\text { Pinal } \\
\text { Pinal } \\
\text { Gila } \\
\text { Coconino } \\
\text { Gila } \\
\text { Yavapai }\end{array}$ & 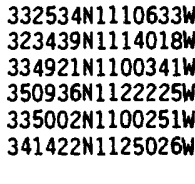 \\
\hline locale & & Santa Cruz & $312416 \mathrm{~N} 1105709 \mathrm{~W}$ \\
\hline locale & $\begin{array}{l}\text { VARIANT } \\
\text { VARIANT }\end{array}$ & Santa Cruz & $312416 \mathrm{~N} 1105709 \mathrm{~W}$ \\
\hline $\begin{array}{l}\text { locale } \\
\text { spring } \\
\text { reservoir }\end{array}$ & $\begin{array}{l}\text { BGN } \\
\text { BGN } \\
\text { VARIANT }\end{array}$ & $\begin{array}{l}\text { Santa Cruz } \\
\text { Yavapai } \\
\text { Coconino }\end{array}$ & $\begin{array}{l}312416 \mathrm{~N} 1105709 \mathrm{~W} \\
340246 \mathrm{~N} 1123625 \mathrm{~W} \\
352207 \mathrm{N1115116 \textrm {W }}\end{array}$ \\
\hline $\begin{array}{l}\text { summit } \\
\text { valley }\end{array}$ & ARIANT & $\begin{array}{l}\text { Apache } \\
\text { Mohave }\end{array}$ & $\begin{array}{l}360845 \mathrm{~N} 1091745 \mathrm{~W} \\
361220 \mathrm{~N} 1124140 \mathrm{~W}\end{array}$ \\
\hline
\end{tabular}

summit BGN Maricopa 335316N1113455W

cliff BGN Mohave 361828N1125003W

$333902 N 1140610 \mathrm{H}$

stream BGN Yuma 333938N1140854W

school UNOFF Maricopa 332530N1115649W

locale Mohave

spring BGN Pinal

mine UNOFF Gila

stream BGN 1975 Pinal

VARIANT

VARIAIT
BGN
UNOFF

VARIANT

BGN

BGN

VARIANT

BGN

reservoir BGN

reservoir $B G N$

$\begin{array}{ll}\text { spring } & B G N \\ \text { reservoir } & B G N\end{array}$

stream $B G N$

stream BGN VARIANT

reservoir

BGN

VARIANT

valley
Gila

Pinal

Graham

Greenlee

Coconino

360420N1140727W

324317 N1102920W

332944N11057344

324038N1103345W

$332959 \mathrm{~N} 1105854 \mathrm{~W}$

$333020 \mathrm{~N} 1105624 \mathrm{~W}$

324038 N1103345W

$324139 \mathrm{~N} 1094755 \mathrm{~W}$

$333549 \mathrm{~N} 1090715 \mathrm{~W}$

352724N1120118W

Gila

Gila

Gila

Coconino

Apache

Maricopa

Greenlee

Coconino

332714 N1104410W

332749 N1104310

$321227 \mathrm{~N} 1125606 \mathrm{~W}$

$340525 \mathrm{~N} 1105453 \mathrm{~W}$

350650 N1 120628W

$354454 \mathrm{N1} 1092020 \mathrm{~W}$

$333948 \mathrm{~N} 1120947 \mathrm{~W}$

325600 N1091005

$353056 \mathrm{N1} 124250 \mathrm{~W}$

314214 N1112610W $312801 \mathrm{~N} 1102123 \mathrm{~W}$ $312755 \mathrm{~N} 1101859 \mathrm{~W}$ $360852 \mathrm{~N} 1120640 \mathrm{~W}$ $333525 \mathrm{N1} 1092647 \mathrm{~W}$ $334031 \mathrm{~N} 1110255 \mathrm{~W}$

344658 N1112302W

$352520 \mathrm{~N} 1141058 \mathrm{~W}$

$312935 \mathrm{~N} 1095332 \mathrm{~W}$
SOURCE
COORDINATE

MAP NAME

$\begin{aligned} 355004 N 1090711 \mathrm{~W} & \begin{array}{l}\text { Fort Defiance } \\ \text { Chavez Mtn West } \\ \text { Tripp Canyon }\end{array} \\ 2990 \text { Cunningham Mtn } & \text { Cand12249W } \\ 6577 & \begin{array}{l}\text { Canyon Day } \\ \text { Greene Reservoir }\end{array} \\ 6185 & \begin{array}{l}\text { McLellan Reservoir } \\ \text { Haunted Canyon } \\ \text { Greene Reservoir } \\ \text { Canyon Day } \\ \text { McLellan Reservoir } \\ \text { Canyon Day } \\ \text { Congress }\end{array}\end{aligned}$

Morgan Butte Wing Mountain

333806 N1140538W

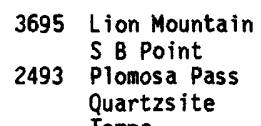

Rhodes Peak

Inspiration

Clark Ranch

Inspiration Salt River Peak

$324237 N 1094955 \mathrm{~W}$

$333346 \mathrm{~N} 1090455 \mathrm{~W}$

Mt Graham

Blue

Squaw Mtn

Cammerman Wash Cammerman Wash

2546 Bates Well

Young

$354745 N 1091215 \mathrm{~W}$

$334244 \mathrm{N1} 120335 \mathrm{~W}$

White Horse Lake

East of Kinlichee

Hedgpeth $\mathrm{Hills}$

Bishop Lake

$\begin{array}{ll}\text { 312607N1102026W } & \begin{array}{l}\text { Miller Peak } \\ \text { Miller Peak } \\ \text { Bright Angel Point }\end{array} \\ \text { 333447N1092810W } & \begin{array}{l}\text { Baldy Bill Point } \\ \text { Windy Hill } \\ \text { Hutch Mtn } \\ \text { 334815N1110009W }\end{array} \\ \text { Chloride } \\ \text { Bisbee }\end{array}$




\section{FEATURE NAME}

Dixie Canyon

Shearer Canyon

Scheurnan Mountain

Scheurman Mountain Tank Schili Creek

See Tsaile Creek

Schlechts Butte

Schmidt Telescope

Schmutz Ranch

Schmutz Spring

Schnebly Hill

Schnebly Hill Vista

Schnebly Number Two Tank

Schnebly Tank

Schnebly Well

Schneider Canyon

Schoenholzer Canyon

Schoens Crossing

Scholefield Canyon

Scholefield Spring

Schook Toahk

See Slate Mountains

School Canyon

School Canyon

School Hill

School House Canyon See Greaser Wash

School House Canyon

Schoolhouse Canyon

Schoolhouse Draw

Schoolhouse Draw

Schoolhouse Gulch

Schoolhouse Point

Schoolhouse Point Recreation

Schoolhouse Spring

Schoolhouse Tank

Schoolhouse Tank

Schoolhouse Tank

Schoolhouse Tank

Schoolhouse Tank

Schoolhouse Wash

School Section Pond

School Section Tank

Schreck Tank

Schroeder Tank

Schroeder Tank

Schroeder Tank

Schroeder Tank

Schuchk

Santa Rosa

Santa Rosa Ranch

Schuchk Ka Wuacho Awotarm

Schuchk Ka Wuacho Awotam

$$
\text { See Schuchk }
$$

Schuchuli

Gunsight

Gunsight Ranch

Gunsight Well

Sialatuk

Schuk Cowlik

Schultz Creek

Schultze Ranch

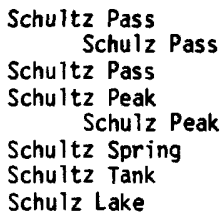

Schulz Lake

FEATURE
CLASS

STATUS

COUNTY

COORDINATE

SOURCE

COORDINATE

ELEV

MAP NAME

VARIANT

VARIANT

\begin{tabular}{|c|c|c|c|}
\hline $\begin{array}{l}\text { ummit } \\
\text { ummit }\end{array}$ & $\begin{array}{l}\text { BGN } \\
\text { BGN }\end{array}$ & $\begin{array}{l}\text { Yavapai } \\
\text { Yavapai }\end{array}$ & $\begin{array}{l}345035 \mathrm{~N} 1115007 \mathrm{~W} \\
345012 \mathrm{~N} 1115007 \mathrm{~W}\end{array}$ \\
\hline $\begin{array}{l}\text { rean } \\
\text { Immit } \\
\text { lilding } \\
\text { cale } \\
\text { oring } \\
\text { omnit } \\
\text { cale }\end{array}$ & $\begin{array}{l}\text { BGN } \\
\text { UNOFF } \\
\text { UNOFF } \\
\text { BGN } \\
\text { BGN } \\
\text { BGN }\end{array}$ & $\begin{array}{l}\text { Apache } \\
\text { Maricopa } \\
\text { Pina } \\
\text { Mohave } \\
\text { Mohave } \\
\text { Coconino } \\
\text { Coconino }\end{array}$ & $\begin{array}{l}361646 \mathrm{~N} 1091143 \mathrm{~W} \\
333030 \mathrm{~N} 1114117 \mathrm{~W} \\
315739 \mathrm{~N} 1113556 \mathrm{~W} \\
362205 \mathrm{~N} 1130233 \mathrm{~W} \\
362143 \mathrm{~N} 1125508 \mathrm{~W} \\
345255 \mathrm{~N} 1114032 \mathrm{~W} \\
345323 \mathrm{~N} 1114209 \mathrm{~W}\end{array}$ \\
\hline
\end{tabular}

reservoir BGN Coconino 345255N1114138W

reservoir BGN Coconino $345248 N 1114206 \mathrm{~W}$

well UNOFF Apache 344258N1091538W

valley BGN Pinal $\quad 330151$ N1104844W

valley BGN Pinal $\quad 323902 N 1102911 \mathrm{~W}$

locale BGN Navajo 342435N1100658W

spring

range

BGN Navajo

BGN Pima

VARIANT

valley

valley

strean

Cochise

Santa Cruz

Cochise

stream
valley

valley

valley

valley

valley

BGN

VARIANT

BGN

BGN

BGN

BGI

Greenlee

summit BGN

$\begin{array}{ll}\text { park } & \text { BGN } \\ \text { park } & \text { ADMIN }\end{array}$

spring

reservoir

reservoir

reservoir

reservoir

reservoir

stream

BGN

BGN

BGN

BGN

BGN

BGN

BGN

reservoir

reservoir

reservoir

reservoir

reservoir

reservoir

reservoir

locale

BGN

BGN

BGN

BGN
BGN

BGN

BGN

BGN 1941
VARIANT

VARIANT

VARIANT

VARIANT

locale

pp ?

BGN 1941

Pima

Mohave
Gila

Gila

Gila

Gila

Coconino

Gila

Mohave

VARIANT

VARIANT
VARIANT

VARIANT

summit $B G N$

BGN

Pima

stream
locale

UNOFF

$\begin{array}{ll}\text { gap } & \text { BGN } 1933 \\ \text { VARIANT }\end{array}$

gap

summit BGN 1933

spring

VARIANT

BGM

reservoir BGN
Pinal

$315124 N 1104202 \mathrm{~W}$

315153N1104300W

$323203 \mathrm{~N} 1115259 \mathrm{~W}$

Greenlee

Gila

Cochise

Coconino

Yavapai

Gila

Mohave

Yavapai

Yavapai

Coconino

Coconino

Yavapai

Pina

Coconino

320002 N1122209W

$332227 \mathrm{~N} 1105456 \mathrm{~W}$

$312010 N 1102525 \mathrm{~W}$

$313218 \mathrm{~N} 1104459 \mathrm{~W}$

$325445 N 1091203 \mathrm{~W}$

$333743 \mathrm{~N} 1090547 \mathrm{~W}$

$341545 \mathrm{~N} 1111512 \mathrm{~W}$

$312744 N 1100027 \mathrm{~W}$

$350546 \mathrm{~N} 1114100 \mathrm{~W}$

$343020 \mathrm{N1122837 \textrm {W }}$

$333921 N 1110046 \mathrm{~W}$

$333900 N 1110034 \mathrm{~W}$

$350506 \mathrm{~N} 1133033 \mathrm{~W}$

$332133 \mathrm{~N} 1104632 \mathrm{~W}$

$333604 \mathrm{~N} 1110449 \mathrm{~W}$

$335021 N 1111301 \mathrm{~W}$

$341902 N 1110655 \mathrm{~W}$

$352106 \mathrm{~N} 1120559 \mathrm{~W}$

$333932 \mathrm{~N} 1110350 \mathrm{~W}$

$363906 \mathrm{~N} 1133326 \mathrm{~W}$

$362826 \mathrm{~N} 1125710 \mathrm{~W}$

$343155 N 1122221 \mathrm{~W}$

$343457 N 1114636 \mathrm{~W}$

$344203 \mathrm{N1112201 \textrm {W }}$

$344703 \mathrm{~N} 1112726 \mathrm{~W}$

$320716 \mathrm{N1114057 \textrm {W }}$

$320716 N 1114057 \mathrm{~W}$

$321320 \mathrm{N1} 124115 \mathrm{~W}$

$330424 N 1104733 \mathrm{~W}$

$324133 \mathrm{~N} 1102555 \mathrm{~W}$

$315130 N 1104444 \mathrm{~W}$

4899 Sedona

Sedona

1798 Granite Reef Dam Kitt Peak

Mt Trumbul1 SE

Fern Glen Canyon

6646 Munds Park

Munds Park

Munds Park

Munds Park

Schnebly Well

Hayden

Rhodes Peak

Taylor

Empire Ranch

Empire Ranch

312337N1102500W Campini Mesa

313029N1104339W Mt Hughes

Bisbee

$333804 N 1090608 \mathrm{~W}$

$341653 N 1111324 \mathrm{~W}$

$312808 \mathrm{~N} 1095938 \mathrm{~W}$

$350657 \mathrm{~N} 1113718 \mathrm{w}$

342934N1122727W

Maness Peak

Payson North

Hereford

Mountainaire

Prescott

Windy $\mathrm{Hill}$

Windy $\mathrm{Hill}$

Aust in Peak

Pinal Peak

2856 Two Bar Mtn

Greenback Creek

Promontory Butte

Sitgreaves Mtn

$333539 N 1110631 W$

Windy $\mathrm{Hill}$

Sullivan Draw North

Hancock Knolls

Prescott Valley $S$

Camp Verde

Turkey Mtn

Hutch Mtn

Red Mountain

1972 Gunsight

$351705 N 1113753 W$

$351616 N 1113707 W$

2098 Pisinimo

Flagstaff West

Pinal Ranch

Humphreys Peak

Coconino 351939N1115B06W

$351856 \mathrm{~N} 1113751 \mathrm{~W}$

361B24N1132407W $\begin{array}{ll}\text { Mohave } & 361 B 24 N 1132407 \mathrm{~W} \\ \text { Coconino } & 351707 N 1113731 \mathrm{~W}\end{array}$

$\begin{array}{ll}\text { Mohave } & 361 \mathrm{~B} 24 \mathrm{~N} 1132407 \mathrm{~W} \\ \text { Coconino } & 351707 \mathrm{~N} 1113731 \mathrm{~W} \\ \text { Coconino } & 351138 \mathrm{~N} 1120026 \mathrm{~W}\end{array}$

Coconino
Haivana Nakya 


\begin{tabular}{|c|c|c|c|c|c|c|c|}
\hline FEATURE NAME & $\begin{array}{l}\text { FEATURE } \\
\text { CLASS }\end{array}$ & STATUS & COUNTY & COORDINATE & $\begin{array}{l}\text { SOURCE } \\
\text { COORDINATE }\end{array}$ & $\underset{\mathrm{FT}}{\mathrm{ELEV}}$ & MAP NAME \\
\hline $\begin{array}{l}\text { Schulz Pass } \\
\text { See Schultz Pass }\end{array}$ & gap & VARIANT & Coconino & $351705 \mathrm{~N} 1113753 \mathrm{~W}$ & & & \\
\hline $\begin{array}{l}\text { Schulz Peak } \\
\text { See Schultz Peak } \\
\text { Schumaker Spring } \\
\text { Schumaller School } \\
\text { Schuster Spring } \\
\text { Schuster Spring } \\
\text { Schutz Lateral } \\
\text { Schuylkill Mine } \\
\text { Schwanbeck Tank } \\
\text { Scissor Tank }\end{array}$ & $\begin{array}{l}\text { summit } \\
\text { spring } \\
\text { school } \\
\text { spring } \\
\text { spring } \\
\text { canal } \\
\text { mine } \\
\text { reservoir } \\
\text { reservoir }\end{array}$ & $\begin{array}{l}\text { VARIANT } \\
\text { BGN } \\
\text { UNOFF } \\
\text { BGN } \\
\text { BGN } \\
\text { BGN } \\
\text { UNOFF } \\
\text { BGN } \\
\text { BGN }\end{array}$ & $\begin{array}{l}\text { Coconino } \\
\text { Santa Cruz } \\
\text { Pima } \\
\text { Apache } \\
\text { Apache } \\
\text { Yuma } \\
\text { Mohave } \\
\text { Yavapai } \\
\text { Yavapai }\end{array}$ & $\begin{array}{l}351856 \mathrm{~N} 1113751 \mathrm{~W} \\
312409 \mathrm{~N} 1111345 \mathrm{~W} \\
321340 \mathrm{~N} 1104910 \mathrm{~W} \\
340918 \mathrm{~N} 1092843 \mathrm{~W} \\
34285 \mathrm{~N} 1093001 \mathrm{~W} \\
323309 \mathrm{~N} 1144608 \mathrm{~W} \\
352509 \mathrm{~N} 1141109 \mathrm{~W} \\
345752 \mathrm{~N} 1121801 \mathrm{~W} \\
344754 \mathrm{N1} 123551 \mathrm{~W}\end{array}$ & & & $\begin{array}{l}\text { Ruby } \\
\text { Tucson East } \\
\text { Springerville NW } \\
\text { Concho } \\
\text { Gadsden } \\
\text { Chloride } \\
\text { Hell Point } \\
\text { Sullivan Buttes }\end{array}$ \\
\hline $\begin{array}{l}\text { Scorpion Ridge } \\
\text { Scotia Canyon } \\
\text { Bodie Wash }\end{array}$ & $\begin{array}{l}\text { ridge } \\
\text { valiey }\end{array}$ & $\begin{array}{l}\text { BGN } 1908 \\
\text { BGN } 1959 \\
\text { VARIANT }\end{array}$ & $\begin{array}{l}\text { Coconino } \\
\text { Cochise }\end{array}$ & $\begin{array}{l}361022 \mathrm{~N} 1121644 \mathrm{~W} \\
312500 \mathrm{N1} 102550 \mathrm{~W}\end{array}$ & $312745 \mathrm{N1102345W}$ & 5836 & $\begin{array}{l}\text { Havasupai Point } \\
\text { Huachuca Peak }\end{array}$ \\
\hline $\begin{array}{l}\text { Scott Cabin } \\
\text { Scott Canyon } \\
\text { Scott Dam } \\
\text { Scott Libby Elementary School } \\
\text { Scott Mine } \\
\text { Scott Mountain } \\
\text { Scott Point }\end{array}$ & $\begin{array}{l}\text { locale } \\
\text { valley } \\
\text { dam } \\
\text { school } \\
\text { mine } \\
\text { summit } \\
\text { summit }\end{array}$ & $\begin{array}{l}\text { BGN } \\
\text { BGN } \\
\text { UNOFF } \\
\text { UNOFF } \\
\text { UNOFF } \\
\text { BGN } \\
\text { BGN }\end{array}$ & $\begin{array}{l}\text { Navajo } \\
\text { Mohave } \\
\text { Navajo } \\
\text { Maricopa } \\
\text { Maricopa } \\
\text { Pinal } \\
\text { Navajo }\end{array}$ & $\begin{array}{l}341300 N 1102624 \mathrm{~W} \\
365725 \mathrm{~N} 1125359 \mathrm{~W} \\
341018 \mathrm{~N} 1095736 \mathrm{~W} \\
33283 \mathrm{~N} 1122742 \mathrm{~W} \\
334052 \mathrm{~N} 1125836 \mathrm{~W} \\
331143 \mathrm{~N} 1105707 \mathrm{~W} \\
341632 \mathrm{~N} 1102008 \mathrm{~W}\end{array}$ & $365812 N 1125332 \mathrm{~W}$ & $\begin{array}{l}6715 \\
5096 \\
6975\end{array}$ & $\begin{array}{l}\text { Bear Ridge } \\
\text { Colorado City } \\
\text { Lakeside } \\
\text { Perryvile } \\
\text { Belmont Mtn } \\
\text { Hot Tamale Peak } \\
\text { Clay Springs }\end{array}$ \\
\hline $\begin{array}{l}\text { Scott Reservoir } \\
\text { Scott Ridge } \\
\text { Scotts Basin } \\
\text { Scottsdale } \\
\text { Scottsdale, Canal (historical) } \\
\text { Canai Fourteen } \\
\text { Scottsdale Ballpark }\end{array}$ & $\begin{array}{l}\text { reservoir } \\
\text { ridge } \\
\text { basin } \\
\text { ppl } \\
\text { canal }\end{array}$ & $\begin{array}{l}\text { BGN } \\
\text { BGN } \\
\text { BGN } \\
\text { BGN } \\
\text { BGN } \\
\text { VARIANT } \\
\text { VARIANT }\end{array}$ & $\begin{array}{l}\text { Navajo } \\
\text { Navajo } \\
\text { Yavapai } \\
\text { Maricopa } \\
\text { Maricopa }\end{array}$ & $\begin{array}{l}341023 N 1095738 W \\
341619 N 1101917 W \\
343606 N 1125721 W \\
333033 N 1115354 W \\
332841 N 1115351 W\end{array}$ & & 6715 & $\begin{array}{l}\text { Lakeside } \\
\text { Clay Springs } \\
\text { Muleshoe Ranch } \\
\text { Paradise Valley } \\
\text { Tempe }\end{array}$ \\
\hline $\begin{array}{c}\text { See Scottsdale Stadium } \\
\text { Scottsdale Community College } \\
\text { Scottsdale Community Hospital } \\
\text { Physicians Hospital }\end{array}$ & $\begin{array}{l}\text { building } \\
\text { school } \\
\text { hospital }\end{array}$ & $\begin{array}{l}\text { UNOFF } \\
\text { UNOFF } \\
\text { VARIANT }\end{array}$ & $\begin{array}{l}\text { Maricopa } \\
\text { Maricopa } \\
\text { Maricopa }\end{array}$ & 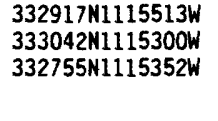 & & & $\begin{array}{l}\text { Paradise Valley } \\
\text { Tempe }\end{array}$ \\
\hline $\begin{array}{l}\text { Scottsdale East Shopping Center } \\
\text { Scottsdale Fashion Square } \\
\text { Shopping Center }\end{array}$ & $\begin{array}{l}\text { locale } \\
\text { locale }\end{array}$ & $\begin{array}{l}\text { UNOFF } \\
\text { UNOFF }\end{array}$ & $\begin{array}{l}\text { Maricopa } \\
\text { Maricopa }\end{array}$ & $\begin{array}{l}332728 \mathrm{~N} 1115726 \mathrm{~W} \\
333014 \mathrm{~N} 1115540 \mathrm{~W}\end{array}$ & & & $\begin{array}{l}\text { Tempe } \\
\text { Paradise Valley }\end{array}$ \\
\hline $\begin{array}{l}\text { Scottsdale High School } \\
\text { Scottsdale Horsemens Park } \\
\text { Cholla Park } \\
\text { Horsemens Park } \\
\text { Reach Eleven Recreation } \\
\text { Area }\end{array}$ & $\begin{array}{l}\text { school } \\
\text { park }\end{array}$ & $\begin{array}{l}\text { UNOFF } \\
\text { AOMIN } \\
\text { VARIANT } \\
\text { VARIANT } \\
\text { VARIANT }\end{array}$ & $\begin{array}{l}\text { Maricopa } \\
\text { Maricopa }\end{array}$ & $\begin{array}{l}332945 \mathrm{~N} 1115520 \mathrm{~W} \\
333754 \mathrm{N1115302W}\end{array}$ & & & $\begin{array}{l}\text { Tempe } \\
\text { Currys Corner }\end{array}$ \\
\hline Scottsdale Mall & locale & UNOFF & Maricopa & $332935 \mathrm{N1115520 \textrm {W }}$ & & & Tempe \\
\hline $\begin{array}{c}\text { Scottsdale Memorial Hospital } \\
\text { Baptist Hospital of } \\
\text { Scottsdale }\end{array}$ & hospital & $\begin{array}{l}\text { UNOFF } \\
\text { VARIANT }\end{array}$ & Maricopa & 332917 N1115520W & & & Tempe \\
\hline $\begin{array}{l}\text { Scottsdale Mobile Home Park } \\
\text { Scottsdale Municipal Airport } \\
\text { Scottsdale Oak Plaza Shopping } \\
\text { Center }\end{array}$ & $\begin{array}{l}\text { locale } \\
\text { airport } \\
\text { locale }\end{array}$ & $\begin{array}{l}\text { UNOFF } \\
\text { ADMIN } \\
\text { UNOFF }\end{array}$ & $\begin{array}{l}\text { Maricopa } \\
\text { Maricopa } \\
\text { Maricopa }\end{array}$ & $\begin{array}{l}332712 N 1115457 W \\
333709 N 1115449 \mathrm{~W} \\
332828 \mathrm{N1115545W}\end{array}$ & & $\begin{array}{l}1200 \\
1478\end{array}$ & $\begin{array}{l}\text { Tempe } \\
\text { Paradise Valley } \\
\text { Tempe }\end{array}$ \\
\hline $\begin{array}{l}\text { Scottsdale Plaza Shopping } \\
\text { Center }\end{array}$ & locale & UNOFF & Maricopa & $332819 N 1115529 \mathrm{~W}$ & & & Tempe \\
\hline Scottsdale Post Office & building & UNOFF & Maricopa & $332916 N 1115525 \mathrm{~W}$ & & & Tempe \\
\hline $\begin{array}{l}\text { Scottsdale Ranch } \\
\text { Scottsdale Regional Shopping } \\
\text { Center }\end{array}$ & $\begin{array}{l}\text { ppl } \\
\text { locale }\end{array}$ & $\begin{array}{l}\text { BGN } \\
\text { UNOFF }\end{array}$ & $\begin{array}{l}\text { Maricopa } \\
\text { Maricopa }\end{array}$ & $\begin{array}{l}333430 \mathrm{~N} 1115127 \mathrm{~W} \\
332800 \mathrm{~N} 1115527 \mathrm{~W}\end{array}$ & & 1370 & $\begin{array}{l}\text { Sawik Mountain } \\
\text { Tempe }\end{array}$ \\
\hline $\begin{array}{l}\text { Scottsdale Shopping Center } \\
\text { Scottsdale Stadium } \\
\text { Scottsdale Ballpark }\end{array}$ & $\begin{array}{l}\text { locale } \\
\text { building }\end{array}$ & $\begin{array}{l}\text { UNOFF } \\
\text { UNOFF } \\
\text { VARIANT }\end{array}$ & $\begin{array}{l}\text { Maricopa } \\
\text { Maricopa }\end{array}$ & $\begin{array}{l}333004 N 1115504 \mathrm{~W} \\
332917 N 1115513 \mathrm{~W}\end{array}$ & & & $\begin{array}{l}\text { Paradise Valley } \\
\text { Tempe }\end{array}$ \\
\hline $\begin{array}{l}\text { Scottsdale Trailer Corral } \\
\text { Scottsdale Village Shopping } \\
\text { Center }\end{array}$ & $\begin{array}{l}\text { locale } \\
\text { locale }\end{array}$ & $\begin{array}{l}\text { UNOFF } \\
\text { UNOFF }\end{array}$ & $\begin{array}{l}\text { Maricopa } \\
\text { Maricopa }\end{array}$ & 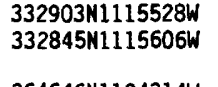 & & 1240 & $\begin{array}{l}\text { Tempe } \\
\text { Tempe }\end{array}$ \\
\hline Scotts Hole & bas in & BGN & Mohave & $364646 \mathrm{~N} 1124314 \mathrm{~W}$ & & & Pipe Spring \\
\hline $\begin{array}{l}\text { Scotts Knob } \\
\text { Scotts Point } \\
\text { Scott Spring } \\
\text { Scott Spring } \\
\text { Scotts Tank } \\
\text { Scotts Well } \\
\text { Scotts Well } \\
\text { Scott Tank }\end{array}$ & $\begin{array}{l}\text { summit } \\
\text { cliff } \\
\text { spring } \\
\text { spring } \\
\text { reservoir } \\
\text { well } \\
\text { well } \\
\text { reservoir }\end{array}$ & $\begin{array}{l}\text { BGN } \\
\text { BGN } \\
\text { BGN } \\
\text { BGN } \\
\text { BGN } \\
\text { UNOFF } \\
\text { UNOFF } \\
\text { BGN }\end{array}$ & $\begin{array}{l}\text { Pima } \\
\text { Mohave } \\
\text { Coconino } \\
\text { Apache } \\
\text { Coconino } \\
\text { Mohave } \\
\text { Mohave } \\
\text { Navajo }\end{array}$ & $\begin{array}{l}321414 N 1104033 \mathrm{~W} \\
365748 N 1125357 \mathrm{~W} \\
350134 N 1114314 \mathrm{~W} \\
361542 \mathrm{N1094116W} \\
343610 \mathrm{~N} 1112352 \mathrm{~W} \\
343337 \mathrm{N1} 141012 \mathrm{~W} \\
343410 \mathrm{N1} 141120 \mathrm{~W} \\
341145 \mathrm{~N} 1100050 \mathrm{~W}\end{array}$ & & 2915 & $\begin{array}{l}\text { Tanque Verde Peak } \\
\text { Colorado City } \\
\text { Mountainaire } \\
\text { Many Farms SW } \\
\text { Calloway Butte } \\
\text { Crossman Peak } \\
\text { Crossman Peak } \\
\text { Show Low South }\end{array}$ \\
\hline
\end{tabular}




\section{FEATURE NAME}

Scott Tank

Scott Tank

Scott Tank

Scott Wash

Scott Well

Scotty Spring

Scotty Spring Mine

Scout Tank

Scraper Knoll

Scratch Canyon

Screen Tank

Screwbean Spring

Scribner Gulch

Warsaw Gulch

Scrub Point

SCS Tank

SCS Tank

S C Townhouse Mobile Home

Estates

Scylla Butte

See Cottonwood Canyon

Seachi Canyon

Seacrist Junior High

Sea Lark Drain

Seal Mountain

Seal Mountain Trail

Seaman Wash

Sea Ranger Drain

Sears Kay Ranch

Sears Park

Sears Point

Sears Tank

Seasonal Springs

Seaton Spring

Seba Dalkai

Seba Dalkaj Wash

See Tees Toh Wash

Sebra Tank

Secelid Tank

Sechrist School

Seco, Arroyo

Seco, Rancho

Secody Well

Secondary Tank

Second Aspen Canyon

See Patrick Lower Branch. Canal (historical)

Second Canal System

See Patrick, Cana

(historical)

Second Canal System

See Turney, Canal (historical)

Second Canal System

See Bueno Lower Branch, Canal (historical)

Second Flat Mesa

Second Forest

See Crystal Forest

Second Hollow

Second Hollow Spring

Second Hollow Tank

Second Knoll

Second Knolls

Second Knoll Tank

Second Laguna

$$
\text { See Laguna }
$$

Second Mesa

Second Mesa

\section{FEATURE \\ CLASS}

STATUS

COUNTY

COORDINATE

reservoir

reservoir BGN

reservoir

stream

well

spring

mine

reservoir

summit

reservoir

spring

valley

summit

reservoir

reservoir

locale

summit

valley$$
\text { BGN } 1908
$$

Navajo

Coconino

343013N1102230W

$350623 \mathrm{~N} 1114832 \mathrm{~W}$

Coconino 355529N1115457W

Navajo $343602 N 1102237 \mathrm{~W}$

Yavapai

Yavapai

Gila

Apache

Yavapai

Coconino

Mohave

$332957 \mathrm{NI} 140317 \mathrm{~W}$

$342629 \mathrm{~N} 1122940 \mathrm{~W}$

$342625 \mathrm{~N} 1122852 \mathrm{~W}$

$341544 \mathrm{~N} 1110439 \mathrm{~W}$

$341510 \mathrm{~N} 1091814 \mathrm{~W}$

$345027 \mathrm{~N} 1130732 \mathrm{~W}$

$345334 \mathrm{~N} 111292 \mathrm{OW}$

$342856 \mathrm{~N} 1141225 \mathrm{~W}$

312353N1111450W

$341833 \mathrm{~N} 1101825 \mathrm{~W}$

$331452 N 1094719 \mathrm{~W}$

$351716 \mathrm{~N} 1122130 \mathrm{~W}$

$333437 \mathrm{~N} 1121614 \mathrm{~W}$

$360804 N 1121531 \mathrm{~W}$

$355943 \mathrm{~N} 1093205 \mathrm{~W}$

$\begin{array}{llll}\text { valley } & \text { BGN } & \text { Apache } & 360024 N 1092954 \mathrm{~W} \\ \text { school } & \text { UNOFF } & \text { Pima } & 321055 \mathrm{~N} 1104623 \mathrm{~W} \\ \text { stream } & \text { BGN } & \text { Mohave } & 342707 \mathrm{NI} 141934 \mathrm{~W} \\ \text { summit } & \text { BGN } & \text { Yavapai } & 340915 \mathrm{~N} 1123332 \mathrm{~W} \\ \text { trail } & \text { UNOFF } & \text { Yavapai } & 341032 \mathrm{~N} 1123330 \mathrm{~W} \\ \text { stream } & \text { BGN } & \text { Coconino } & 365 \mathrm{~B} 53 \mathrm{~N} 1121652 \mathrm{~W} \\ \text { canal } & \text { BGN } & \text { Mohave } & 342708 \mathrm{~N} 1141934 \mathrm{~W} \\ \text { locale } & \text { UNOFF } & \text { Maricopa } & 335306 \mathrm{~N} 1114815 \mathrm{~W} \\ \text { park } & \text { ADMIN } & \text { Pima } & 321303 \mathrm{~N} 1105202 \mathrm{~W} \\ \text { cliff } & \text { BGN } & \text { Yuma } & 325557 \mathrm{~N} 1132228 \mathrm{~W}\end{array}$

\begin{tabular}{ll}
$360133 \mathrm{~N} 1092531 \mathrm{~W}$ & \multicolumn{1}{|c|}{$\begin{array}{l}\text { Three Turkey Canyon } \\
\text { Tucson East } \\
\text { Lake Havasu City S }\end{array}$} \\
$370651 \mathrm{~N} 1121320 \mathrm{~W}$ & $5120 \begin{array}{l}\text { Wagoner } \\
\text { Wagoner }\end{array}$ \\
$\begin{array}{l}\text { Muggins Flat } \\
\text { Lake Havasu City S } \\
\text { Humboldt Mtn } \\
\text { Tucson East } \\
\text { Agua Caliente }\end{array}$
\end{tabular}

reservoir BGN Coconino 345007N1111434W

$\begin{array}{lll}\text { spring } & \text { Coconino } & 345007 N 1111434 W \\ \text { spring } & \text { Gila } & 335123 N 1101110 \mathrm{~W}\end{array}$

$\begin{array}{llll}\text { spring } & \text { BGN } & \text { Gila } & 335123 N 1101110 \mathrm{~W} \\ \text { spring } & \text { BGN } & \text { Yavapai } & 342330 \mathrm{NI} 122133 \mathrm{~W}\end{array}$

schoo1 UNOFF Navajo 352959N110265IW

stream VARIANT Navajo 352941N1103449W

reservoir BGN Yavapai 345629NIII5707W

$\begin{array}{llll}\text { reservoir } & \text { BGN } & \text { Yavapai } & 345629 N 1115707 \mathrm{~W} \\ \text { reservoir } & \text { BGN } & \text { Coconino } & 352526 \text { NIII }\end{array}$

school UNOFF Coconino 351322 N1113910W

stream BGN Pima 314512 N1112438W

locale UNOFF Pima 314105N1111739W

well UNOFF Coconino 361329N1111856W

reservoir BGN Greenlee 332004N1092533W

valley BGN Apache 361726N1095156W

canal VARIANT Maricopa

$332625 \mathrm{~N} 1120304 \mathrm{~W}$

cana 1

VARIANT

Maricopa

$332634 N 1120225 \mathrm{~W}$

VARIANT

cana

$332829 N 1120407 \mathrm{~W}$

VARIANT

canal

summit

area

valley

BGN

VARIANT

$332931 \mathrm{N1120540 \textrm {W }}$

$353425 \mathrm{~N} 1101239 \mathrm{~W}$

$345200 \mathrm{~N} 1094704 \mathrm{~W}$ $340311 \mathrm{~N} 1095935 \mathrm{~W}$

$\begin{array}{lll}\text { spring } & \text { BGN } & \text { Navajo } \\ \text { reservoir } & \text { BGN } & \text { Navajo } \\ \text { summit } & \text { BGN } & \text { Navajo } \\ \text { summit } & \text { BGN } & \text { Navajo } \\ \text { reservoir } & \text { BGN } & \text { Navajo } \\ & \text { VARIANT } & \\ \text { pp1 } & & \text { Yuma } \\ \text { summit } & \text { BGN } & \text { Navajo } \\ \text { ppl } & \text { BGN } & \text { Navajo }\end{array}$

$340239 \mathrm{~N} 1095809 \mathrm{~W}$

$340236 \mathrm{~N} 1095820 \mathrm{~W}$

$341508 \mathrm{~N} 1095622 \mathrm{~W}$

$343631 \mathrm{~N} 1101222 \mathrm{~W}$

341530 N1095650W

$324908 \mathrm{~N} 1142905 \mathrm{~W}$

$355343 \mathrm{~N} 1103012 \mathrm{~W}$

$354736 \mathrm{~N} 1103016 \mathrm{~W}$

\begin{tabular}{|c|c|c|}
\hline $\begin{array}{l}\text { SOURCE } \\
\text { COORDINATE }\end{array}$ & $\begin{array}{c}\text { ELEV } \\
\text { FT }\end{array}$ & $\begin{array}{l}\text { MAP NAME } \\
\text { Sheepskin Wash } \\
\text { Dutton Hill }\end{array}$ \\
\hline $44841 N 1130442 W$ & 7215 & $\begin{array}{l}\text { Grandview Point } \\
\text { Zeniff } \\
\text { Livingston Hills } \\
\text { Groom Creek } \\
\text { Groom Creek } \\
\text { Promontory Butte } \\
\text { Lyman Lake } \\
\text { Burro Mesa } \\
\text { Mormon Lake } \\
\text { Standard Wash }\end{array}$ \\
\hline $2457 \mathrm{~N} 1111545 \mathrm{~W}$ & 1112 & $\begin{array}{l}\text { Ruby } \\
\text { Clay Springs } \\
\text { Bonita Tank } \\
\text { Hearst Mtn } \\
\text { El Mirage }\end{array}$ \\
\hline & & Havasupai Point \\
\hline
\end{tabular}

Chavez Mtn West

Cone Butte

Poland Junction

Egloffstein Butte

Loy Butte

Kendrick Peak

Flagstaff West

314014 N1111822W

Fresno Wash

Cerro Colorado

5308 Moenave

Bee Canyon

361945N1094957W Sweathouse Peak 
FEATURE NAME

Second Mesa Campground

Second Mesa Day School

Second Mesa Post Office

Second Reservoir

Second Trail Canyon

Second Water Canyon

Second Water Spring

Second Water Trail

Seco Tank

Secret Cabin

Secret Canyon

Secret Mountain

Secret Pass

Secret Pass Canyon

Secret Pass Spring

Secret Pass Wash

Secret Pasture

Secret Pocket

Secret Tank

Secret Tank

Section Corner Tank

See Line Tank

Section Corner Tank

Section Eighteen Tank

Section Eighteen Tank

Section Eight Well

Section Eleven Tank

Section Eleven Tank

Section Eleven We1l

Section Fifteen Tank

Section Fifteen Windmil1

Section Five Tank

Section Five Tank

Section Five Tank

Section Five Tank

Section Five Tank

Section Four Tank

Section Fourteen Well

Section House Spring

Section Line Tank

Section Nine Tank

Section Nineteen Well

Section Nine Well

Section One Tank

Section One Well

Section Seventeen Tank

Section Seven Wel1

Section Six Tank

Section Sixteen Hill

Section Sixteen Tank

Section Tank

Section Tank

Section Ten Tank

Section Ten Tank

Section Ten Tank

Section Thirteen Tank

Section Thirteen Tank

Section Thirteen Well

Section Thirty-four Tank

Section Thirty-four Tank

Section Thirty Spring

Section Thirty Tank

Section Thirty Tank

Section Thirty Tank

Section Thirty-three Number

One Tank

Section Thirty-three Number

Two Tank

Section Thirty-three Spring

Section Thirty-three Tank

\section{FEATURE}

park

STATUS

COUNTY

COORDINATE

$345042 \mathrm{~N} 1103138 \mathrm{~W}$

School UNOFF Navajo 354735N1103020W

building UNOFF Navajo 354731 N1102942W

reservoir BGN Coconino 362309N1113746W

valley BGN Graham 324647N1101850W

valley BGN Maricopa 332945N1112434W

trail

reservoir

locale

valley

UNOFF Maricopa

$332941 \mathrm{~N} 1112433 \mathrm{~W}$

$332938 \mathrm{~N} 1112510 \mathrm{~W}$

$314249 \mathrm{~N} 1112326 \mathrm{~W}$

$345751 \mathrm{~N} 1115354 \mathrm{~W}$

$345548 \mathrm{~N} 1114824 \mathrm{~W}$

Yavapai

summit

gap

valley

spring

stream

flat

basin

reservoir

reservoir

reservoir

BGN
BGN
BGN
BGN
BGN
BGN
BGN
BGN
BGN
VARIANT

Yavapai

Mohave

Mohave

Mohave

Mohave

Pina

Coconino

Coconino

Coconino

$345802 \mathrm{~N} 1115322 \mathrm{~W}$

$350852 \mathrm{~N} 1142155 \mathrm{~W}$

350758 N1143358W

$350829 \mathrm{~N} 1142430 \mathrm{~W}$

$350132 \mathrm{~N} 1141255 \mathrm{~W}$

$320732 \mathrm{~N} 1102833 \mathrm{~W}$

$350031 \mathrm{N1121011W}$

$350009 \mathrm{~N} 1115356 \mathrm{~W}$

350048 N1121012W

Pima

313817 N1111048W

reservoir reservoir

reservoir

well

BGM

BGN

BGN
UNOFF

reservoir

well

reservoir

locale

reservoir

BGN

UNOFF

UNO

BGN

BGN

reservoir

reservoir

reservoir

reservoir

reservoir

wel

spring

reservoir

reservoir

well

$\begin{array}{ll}\text { Yavapai } & 343403 \mathrm{~N} 1114247 \mathrm{~W} \\ \text { Navajo } & 343602 \mathrm{~N} 1102236 \mathrm{~W} \\ \text { Yavapai } & 350149 \mathrm{~N} 1125012 \mathrm{~W} \\ \text { Mohave } & 351830 \mathrm{~N} 1132142 \mathrm{~W} \\ \text { Navajo } & 341121 \mathrm{~N} 1095847 \mathrm{~W} \\ \text { Navajo } & 343151 \mathrm{N1} 103058 \mathrm{~W} \\ \text { Santa Cruz } & 313647 \mathrm{~N} 1110503 \mathrm{~W} \\ \text { Yavapai } & 350733 \mathrm{~N} 1125333 \mathrm{~W} \\ \text { Yavapai } & 342818 \mathrm{~N} 1123927 \mathrm{~W} \\ \text { Navajo } & 341734 \mathrm{~N} 1100143 \mathrm{~W}\end{array}$

BGN Navajo

BGN

$B G N$

BGN

UNOFF

BGN

$B G N$

BGN

UNOFF

well

UNOFF Yavapai

reservoir

reservoir

reservoir

well

reservoir

summit

reservoir

reservoir

reservoir

BG

$B G N$

$B G N$

UNOFF

BGN

BGN

BGN

reservoir

reservoir

reservoir

reservoir

reservoir

reservoir

well

reservoir

reservoir

spring

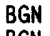

BGN

BGN

BGN

BGN

BGN

UNOFF

BGN
$B G N$
$B G N$

reservoir

reservoir

reservoir

reservoir

BGN

$B G N$
$B G N$
$B G N$

BGN

reservoir

BGN

spring

reservoir BGN
Coconino

Coconino

Yavapai

Apache

Cochise

Yavapai

Apache

Yavapai

Yavapai

Yavapa

Coconino

Coconino

Coconino

Coconino

Coconino

$341803 \mathrm{~N} 1095525 \mathrm{~W}$

$343152 \mathrm{~N} 1113144 \mathrm{~W}$

$343746 \mathrm{~N} 1105318 \mathrm{~W}$

$350323 \mathrm{~N} 1124900 \mathrm{~W}$

$343612 \mathrm{~N} 1094740 \mathrm{~W}$

$320226 \mathrm{~N} 1101625 \mathrm{~W}$

$344551 \mathrm{~N} 1120826 \mathrm{~W}$

$335132 \mathrm{~N} 1090723 \mathrm{~W}$

$343206 \mathrm{~N} 1103931 \mathrm{~W}$

$350235 \mathrm{~N} 1125427 \mathrm{~W}$

$345839 \mathrm{~N} 1112408 \mathrm{~W}$

$352430 \mathrm{~N} 1131111 \mathrm{~W}$

$350711 \mathrm{~N} 1124823 \mathrm{~W}$

$350750 \mathrm{~N} 1124958 \mathrm{~W}$

$345758 \mathrm{~N} 1112251 \mathrm{~W}$

$352238 \mathrm{~N} 1115823 \mathrm{~W}$

$343057 \mathrm{N1104526 \textrm {W }}$

$350707 N 11139$

$342954 \mathrm{~N} 1104651 \mathrm{~W}$

Yavapai

Navajo

Yavapai

Coconino

Yavapai

Yavapai

Yavapa

Navajo

Navajo

Yavapai

351340N1131125W

$341152 \mathrm{~N} 1095944 \mathrm{~W}$

$350227 \mathrm{~N} 1124705 \mathrm{~W}$

$352320 \mathrm{~N} 1115716 \mathrm{~W}$

343857 N1123744W

$350227 N 1125113 \mathrm{~W}$

350657 N1125117W

$341325 \mathrm{~N} 1095923 \mathrm{~W}$

$342837 \mathrm{~N} 1103140 \mathrm{~W}$

$344930 \mathrm{~N} 1124949 \mathrm{~W}$

Apache

Navajo

Navajo

Navajo

Navajo

Coconino

Navajo
$345530 \mathrm{~N} 1124312 \mathrm{~W}$

$\begin{array}{cc}\text { SOURCE } & \text { ELEV } \\ \text { COORDINATE } & \text { FT }\end{array}$

MAP NAME

Shongopovi

Shongopovi

Polacca

Shinumo Altar

324534N1102112W Klondike

$332840 \mathrm{~N} 1112429 \mathrm{~W}$ Goldfield 


\begin{tabular}{|c|c|c|c|c|c|c|c|c|}
\hline & FEATURE NAME & $\begin{array}{l}\text { FEATURE } \\
\text { CLASS }\end{array}$ & STATUS & COUNTY & COORDINATE & $\begin{array}{l}\text { SOURCE } \\
\text { COORDINATE }\end{array}$ & $\begin{array}{l}\text { ELEV } \\
\text { FT }\end{array}$ & MAP NAME \\
\hline Section & Thirtythree Tank & reservoir & BGN & Yavapai & $345915 \mathrm{~N} 1125406 \mathrm{~W}$ & & & Juniper Mts \\
\hline $\begin{array}{l}\text { Section } \\
\text { Section } \\
\text { Section } \\
\text { Section } \\
\text { Section } \\
\text { Section } \\
\text { Section } \\
\text { Section } \\
\text { Section } \\
\text { Section }\end{array}$ & $\begin{array}{l}\text { Thirty Windmill } \\
\text { Twelve Spring } \\
\text { Twelve Tank } \\
\text { Twelve Tank } \\
\text { Twenty-eight Tank } \\
\text { Twentyfive Tank } \\
\text { Twentyfive Tank } \\
\text { Twenty-four Tank } \\
\text { Twentyfour Tank } \\
\text { Twenty-four Tank }\end{array}$ & $\begin{array}{l}\text { locale } \\
\text { spring } \\
\text { reservoir } \\
\text { reservoir } \\
\text { reservoir } \\
\text { reservoir } \\
\text { reservoir } \\
\text { reservoir } \\
\text { reservoir } \\
\text { reservoir }\end{array}$ & $\begin{array}{l}\text { BGN } \\
\text { BGN } \\
\text { BGN } \\
\text { BGN } \\
\text { BGN } \\
\text { BGN } \\
\text { BGN } \\
\text { BGN } \\
\text { BGN } \\
\text { BGN }\end{array}$ & $\begin{array}{l}\text { Cochise } \\
\text { Yavapai } \\
\text { Navajo } \\
\text { Coconino } \\
\text { Graham } \\
\text { Apache } \\
\text { Yavapai } \\
\text { Navajo } \\
\text { Coconino } \\
\text { Coconino }\end{array}$ & $\begin{array}{l}315024 \mathrm{~N} 1100831 \mathrm{~W} \\
343115 \mathrm{~N} 1122523 \mathrm{~W} \\
343638 \mathrm{~N} 1104158 \mathrm{~W} \\
345159 \mathrm{~N} 1111736 \mathrm{~W} \\
324755 \mathrm{~N} 1100626 \mathrm{~W} \\
341400 \mathrm{~N} 1094530 \mathrm{~W} \\
345957 \mathrm{~N} 1125105 \mathrm{~W} \\
343018 \mathrm{~N} 1104236 \mathrm{~W} \\
350553 \mathrm{~N} 1114256 \mathrm{~W} \\
353201 \mathrm{~N} 1114830 \mathrm{~W}\end{array}$ & & 4198 & $\begin{array}{l}\text { Land } \\
\text { Prescott } \\
\text { Potato Wash South } \\
\text { Jaycox Mtn } \\
\text { Tripp Canyon } \\
\text { Sponseller Mtn } \\
\text { Indian Peaks } \\
\text { Potato Wash South } \\
\text { Mountainaire } \\
\text { Chapel Mtn }\end{array}$ \\
\hline $\begin{array}{l}\text { Section } \\
\text { Section } \\
\text { Section } \\
\text { Section } \\
\text { Section } \\
\text { Section } \\
\text { Section } \\
\text { Section } \\
\text { Section } \\
\text { Section }\end{array}$ & $\begin{array}{l}\text { Twentynine Reservoir } \\
\text { Twenty Nine Tank } \\
\text { Twentyn ine Well } \\
\text { Twentyone Tank } \\
\text { Twentyone Tank } \\
\text { Twenty-one Tank } \\
\text { Twenty-seven Tank } \\
\text { Twenty-s ix Tank } \\
\text { Twenty Tank } \\
\text { Twenty Tank }\end{array}$ & $\begin{array}{l}\text { reservoir } \\
\text { reservoir } \\
\text { well } \\
\text { reservoir } \\
\text { reservoir } \\
\text { reservoir } \\
\text { reservoir } \\
\text { reservoir } \\
\text { reservoir } \\
\text { reservoir }\end{array}$ & $\begin{array}{l}\text { BGN } \\
\text { BGN } \\
\text { UNOFF } \\
\text { BGN } \\
\text { BGN } \\
\text { BGN } \\
\text { BGN } \\
\text { BGN } \\
\text { BGN } \\
\text { BGN }\end{array}$ & $\begin{array}{l}\text { Navajo } \\
\text { Yavapai } \\
\text { Yavapai } \\
\text { Apache } \\
\text { Navajo } \\
\text { Navajo } \\
\text { Navajo } \\
\text { Coconino } \\
\text { Apache } \\
\text { Coconino }\end{array}$ & $\begin{array}{l}341915 \mathrm{~N} 1100225 \mathrm{~W} \\
344405 \mathrm{~N} 1125456 \mathrm{~W} \\
350551 \mathrm{~N} 1124915 \mathrm{~W} \\
341455 \mathrm{~N} 1094753 \mathrm{~W} \\
343026 \mathrm{~N} 1103250 \mathrm{~W} \\
343504 \mathrm{~N} 1103936 \mathrm{~W} \\
342420 \mathrm{~N} 1101820 \mathrm{~W} \\
344507 \mathrm{~N} 1112821 \mathrm{~W} \\
340937 \mathrm{N1} 1094329 \mathrm{~W} \\
343027 \mathrm{~N} 1104612 \mathrm{~W}\end{array}$ & & & $\begin{array}{l}\text { Show Low North } \\
\text { Sheridan Mtn } \\
\text { Red Mountain } \\
\text { Sponseller Mtn } \\
\text { Red Knoll } \\
\text { Potato Wash South } \\
\text { Big Pug Tank } \\
\text { Hutch Mtn } \\
\text { Boundary Butte } \\
\text { Chevelon Crossing }\end{array}$ \\
\hline $\begin{array}{l}\text { Section } \\
\text { Section } \\
\text { Section } \\
\text { Section } \\
\text { Section } \\
\text { Section } \\
\text { Section } \\
\text { Section } \\
\text { Secucito } \\
\text { Secundin }\end{array}$ & $\begin{array}{l}\text { Twenty Tank } \\
\text { Twentythree Tank } \\
\text { Twenty-three Tank } \\
\text { Twentytwo Tank } \\
\text { Two Dam Tank } \\
\text { Two Tank } \\
\text { Two Tank } \\
\text { Wel1 } \\
\text { o Spring } \\
\text { no }\end{array}$ & $\begin{array}{l}\text { reservoir } \\
\text { reservoir } \\
\text { reservoir } \\
\text { reservoir } \\
\text { reservoir } \\
\text { reservoir } \\
\text { reservoir } \\
\text { well } \\
\text { spring } \\
\text { locale }\end{array}$ & $\begin{array}{l}\text { BGN } \\
\text { BGN } \\
\text { BGN } \\
\text { BGN } \\
\text { BGN } \\
\text { BGN } \\
\text { BGN } \\
\text { UNOFF } \\
\text { BGN } \\
\text { BGN }\end{array}$ & $\begin{array}{l}\text { Navajo } \\
\text { Navajo } \\
\text { Yavapai } \\
\text { Coconino } \\
\text { Yavapai } \\
\text { Navajo } \\
\text { Coconino } \\
\text { Pima } \\
\text { Maricopa } \\
\text { Pima }\end{array}$ & $\begin{array}{l}343501 N 1095552 \mathrm{~W} \\
342957 \mathrm{N1} 103056 \mathrm{~W} \\
344520 \mathrm{~N} 1125112 \mathrm{~W} \\
351053 \mathrm{~N} 1122226 \mathrm{~W} \\
344757 \mathrm{N1123312W} \\
341240 \mathrm{~N} 1095209 \mathrm{~W} \\
351 \mathrm{~B} 22 \mathrm{~N} 1122122 \mathrm{~W} \\
315141 \mathrm{~N} 1111821 \mathrm{~W} \\
333643 \mathrm{~N} 1112524 \mathrm{~W} \\
314138 \mathrm{~N} 1112632 \mathrm{~W}\end{array}$ & & & $\begin{array}{l}\text { Point of the Mtn } \\
\text { Heber } \\
\text { Seepage Mtn } \\
\text { McLellan Reservoir } \\
\text { Sullivan Buttes } \\
\text { Sponseller Mtn } \\
\text { Hearst Mtn } \\
\text { Penitas Hills } \\
\text { Mormon Flat Dam } \\
\text { Las Guijas }\end{array}$ \\
\hline $\begin{array}{l}\text { Secundin } \\
\text { Security } \\
\text { Sedal Ca } \\
\text { Sedge Sp } \\
\text { Sediment } \\
\text { Sedona } \\
\text { Sedona A } \\
\text { Oa } \\
\text { Sedona I } \\
\text { Sedona M }\end{array}$ & $\begin{array}{l}\text { no Well } \\
\text { y Acres (subdivision) } \\
\text { anyon } \\
\text { pring } \\
\text { tation Tank } \\
\text { Airport } \\
\text { ak Creek Airport } \\
\text { Interchange } \\
\text { Memorial Park }\end{array}$ & $\begin{array}{l}\text { well } \\
\text { ppl } \\
\text { valley } \\
\text { spring } \\
\text { reservoir } \\
\text { ppl } \\
\text { airport } \\
\text { crossing } \\
\text { cemetery }\end{array}$ & $\begin{array}{l}\text { UNOFF } \\
\text { BGN } \\
\text { BGN } \\
\text { BGN } \\
\text { BGN } \\
\text { BGN } \\
\text { ADMIN } \\
\text { VARIANT } \\
\text { UNOFF } \\
\text { UNOFF }\end{array}$ & $\begin{array}{l}\text { Pima } \\
\text { Yavapai } \\
\text { Gila } \\
\text { Coconino } \\
\text { Coconino } \\
\text { Coconino } \\
\text { Yavapai } \\
\text { Yavapai } \\
\text { Coconino }\end{array}$ & $\begin{array}{l}314140 \mathrm{~N} 1112642 \mathrm{~W} \\
343303 \mathrm{~N} 1115150 \mathrm{~W} \\
334050 \mathrm{~N} 1104100 \mathrm{~W} \\
345408 \mathrm{~N} 1112514 \mathrm{~W} \\
350937 \mathrm{~N} 1114253 \mathrm{~W} \\
345211 \mathrm{N1114537 \textrm {W }} \\
345054 \mathrm{~N} 1114715 \mathrm{~W} \\
344125 \mathrm{~N} 1114434 \mathrm{~W} \\
345036 \mathrm{~N} 1114551 \mathrm{~W}\end{array}$ & $333739 \mathrm{~N} 1103654 \mathrm{~W}$ & 4827 & $\begin{array}{l}\text { Las Guijas } \\
\text { Camp Verde } \\
\text { Haystack Butte } \\
\text { Mormon Lake } \\
\text { Flagstaff West } \\
\text { Sedona } \\
\text { Sedona } \\
\text { Casner Butte } \\
\text { Sedona }\end{array}$ \\
\hline $\begin{array}{r}\text { Sedona R } \\
\text { Sedona S } \\
\text { See Cany } \\
\text { Seed Hil } \\
\text { Seegmill } \\
\text { Seegmill } \\
\text { Se } \\
\text { Seegmill } \\
\text { Seegmill } \\
\text { Seegmull } \\
\text { See }\end{array}$ & $\begin{array}{l}\text { Ranger Station } \\
\text { School } \\
\text { yon } \\
\text { II } \\
\text { ler Canyon } \\
\text { ler Mountain } \\
\text { eegmuller Mountain } \\
\text { ler Point } \\
\text { ler Spring } \\
\text { ler Mountain } \\
\text { Seegmiller Mountain }\end{array}$ & $\begin{array}{l}\text { locale } \\
\text { school } \\
\text { valley } \\
\text { summit } \\
\text { valley } \\
\text { summit } \\
\text { cliff } \\
\text { spring } \\
\text { summit }\end{array}$ & $\begin{array}{l}\text { UNOFF } \\
\text { UNOFF } \\
\text { BGN } \\
\text { BGN } \\
\text { BGN } \\
\text { BGN } 1979 \\
\text { VARIANT } \\
\text { BGN } \\
\text { BGN } \\
\text { VARIANT }\end{array}$ & $\begin{array}{l}\text { Coconino } \\
\text { Coconino } \\
\text { Gila } \\
\text { Navajo } \\
\text { Coconino } \\
\text { Mohave } \\
\text { Coconino } \\
\text { Mohave } \\
\text { Mohave }\end{array}$ & $\begin{array}{l}345052 \mathrm{~N} 1114556 \mathrm{~W} \\
345147 \mathrm{~N} 1114558 \mathrm{~W} \\
341833 \mathrm{~N} 1110152 \mathrm{~W} \\
353656 \mathrm{N1} 103008 \mathrm{~W} \\
363809 \mathrm{N1115702W} \\
364917 \mathrm{N1} 133113 \mathrm{~W} \\
363720 \mathrm{~N} 1120225 \mathrm{~W} \\
365143 \mathrm{N1} 132940 \mathrm{~W} \\
364917 \mathrm{~N} 1133113 \mathrm{~W}\end{array}$ & $\begin{array}{l}342221 N 1110111 \mathrm{~W} \\
363606 \mathrm{~N} 1120335 \mathrm{~W}\end{array}$ & $\begin{array}{l}5715 \\
6043\end{array}$ & $\begin{array}{l}\text { Sedona } \\
\text { Sedona } \\
\text { Promontory Butte } \\
\text { Tovar Mesa East } \\
\text { Enmett Hill } \\
\text { Hole-n-wall Canyon } \\
\text { Cane } \\
\text { Hole-N-Wall Canyon }\end{array}$ \\
\hline $\begin{array}{l}\text { Seeley T } \\
\text { Seely Ta } \\
\text { Seepage } \\
\text { Seepage } \\
\text { Seepage } \\
\text { Seep Spr } \\
\text { Seep Spr } \\
\text { Seep Spr } \\
\text { Seep Spr } \\
\text { Seep Spr }\end{array}$ & $\begin{array}{l}\text { Tank } \\
\text { ank } \\
\text { Canyon } \\
\text { Mountain } \\
\text { Tank } \\
\text { ring } \\
\text { ring } \\
\text { ring } \\
\text { ring } \\
\text { ring }\end{array}$ & $\begin{array}{l}\text { reservoir } \\
\text { reservoir } \\
\text { valley } \\
\text { summit } \\
\text { reservoir } \\
\text { spring } \\
\text { spring } \\
\text { spring } \\
\text { spring } \\
\text { spring }\end{array}$ & $\begin{array}{l}\text { BGN } \\
\text { BGN } \\
B G N \\
\text { BGN } \\
\text { BGN } \\
\text { BGN } \\
B G N \\
\text { BGN } \\
\text { BGN } \\
\text { BGN }\end{array}$ & $\begin{array}{l}\text { Coconino } \\
\text { Graham } \\
\text { Yavapai } \\
\text { Yavapai } \\
\text { Yavapai } \\
\text { Pinal } \\
\text { Greenlee } \\
\text { Maricopa } \\
\text { Navajo } \\
\text { Yavapai }\end{array}$ & $\begin{array}{l}355612 N 1114707 \mathrm{~W} \\
323643 \mathrm{~N} 1092255 \mathrm{~W} \\
344447 \mathrm{~N} 1124501 \mathrm{~W} \\
344543 \mathrm{~N} 1124905 \mathrm{~W} \\
344510 \mathrm{~N} 1124857 \mathrm{~W} \\
331129 \mathrm{~N} 1110810 \mathrm{~W} \\
331348 \mathrm{~N} 1090917 \mathrm{~W} \\
334935 \mathrm{~N} 1131659 \mathrm{~W} \\
340946 \mathrm{~N} 1100529 \mathrm{~W} \\
342213 \mathrm{~N} 1123038 \mathrm{~W}\end{array}$ & $344532 \mathrm{~N} 1124930 \mathrm{~W}$ & & $\begin{array}{l}\text { Deer Tank } \\
\text { Javelina Peak } \\
\text { Smith Mesa } \\
\text { Seepage Mtn } \\
\text { Seepage Mtn } \\
\text { Mineral Mtn } \\
\text { Dix Creek } \\
\text { Harquahala Mtn } \\
\text { Show Low South } \\
\text { Walnut Grove }\end{array}$ \\
\hline $\begin{array}{l}\text { Seep Spr } \\
\text { Seep Spr } \\
\text { Seep Spr } \\
\text { Seep Spr } \\
\text { Seep Spr } \\
\text { Seep Spr } \\
\text { Seep Spr } \\
\text { Seep Tan } \\
\text { Seep Tan }\end{array}$ & $\begin{array}{l}\text { ring } \\
\text { ring } \\
\text { ring } \\
\text { ring Canyon } \\
\text { ring Canyon } \\
\text { ring Canyon } \\
\text { ring Mountain } \\
\text { nk } \\
\text { nk }\end{array}$ & $\begin{array}{l}\text { spring } \\
\text { spring } \\
\text { spring } \\
\text { valley } \\
\text { valley } \\
\text { valley } \\
\text { summit } \\
\text { reservoir } \\
\text { reservoir }\end{array}$ & $\begin{array}{l}\text { BGN } \\
\text { BGN } 1908 \\
\text { BGN } \\
\text { BGN } \\
\text { BGN } \\
\text { BGN } \\
\text { BGN } \\
\text { BGN } \\
\text { BGN }\end{array}$ & $\begin{array}{l}\text { Yavapai } \\
\text { Coconino } \\
\text { Mohave } \\
\text { Greenlee } \\
\text { Gila } \\
\text { Mohave } \\
\text { Greenlee } \\
\text { Greenlee } \\
\text { Coconino }\end{array}$ & $\begin{array}{l}344455 \mathrm{~N} 1125820 \mathrm{~W} \\
361051 \mathrm{~N} 1122356 \mathrm{~W} \\
365203 \mathrm{~N} 1133019 \mathrm{~W} \\
33051 \mathrm{~N} 1090515 \mathrm{~W} \\
332551 \mathrm{~N} 1105721 \mathrm{~W} \\
365307 \mathrm{~N} 1133050 \mathrm{~W} \\
331420 \mathrm{~N} 1090755 \mathrm{~W} \\
331834 \mathrm{~N} 1092428 \mathrm{~W} \\
345133 \mathrm{~N} 1113259 \mathrm{~W}\end{array}$ & $\begin{array}{l}330508 \mathrm{N1090651W} \\
332634 \mathrm{~N} 1105703 \mathrm{~W} \\
364936 \mathrm{~N} 1133027 \mathrm{~W}\end{array}$ & 6241 & $\begin{array}{l}\text { Sheridan Mtn } \\
\text { Explorers Monument } \\
\text { Wolf Hole Mtn East } \\
\text { Big Lue Mts } \\
\text { Inspiration } \\
\text { Lizard Point } \\
\text { Dix Creek } \\
\text { Bee Canyon } \\
\text { Stoneman Lake }\end{array}$ \\
\hline
\end{tabular}


NATIONAL GAZETTEER--ARIZONA 1986

FEATURE NAME

Seep Tank

See Spring

Segahatosi Canyon See Tseyi-Hatsos i Canyon

Segeke Butte Half Dome Sa-gee-ka Butte Se-gi-ke Butte

Segetoa Spring

$$
\text { See Tsegito Spring }
$$

Segetoa Spring

See Tsegito Spring

Segi Ho Cho Mesa

Se-gi-ke Butte

See Segeke Butte

Segi Mesas

$$
\text { Tsegi Mesas }
$$

Segito Canyon

Sego Tank

Sehili

Sehili Tsehili

See Tsaile

Seiber Point

Sei Betoh

Sei Be Toh

Seibold Ranch

Sei Haasgaii Wash

Seklagaidesa Canyon See Tseligaideeza Canyon Selba Dalkai Spring

Seligman

Seligman Airport

Seligman Canyon

Seligman Dam

Seligman Elementary and High School

Seligman Interchange

Seligman Junction Substation

Seligman Post office

Seligman Railroad Station

Seligman Substation

Selleh Park

Seller Spring

Sellers Tank

Sells

Indian Oas is

Sells Airport

Sells Consolidated School

Sells Papago Indian Agency See Papago Indian Agency

Sells Valley

Sells Wash

See Gu Oidak Wash

Sells Wash

Big Fields Wash

Gu Oidak Wash

Selman Tank

Semen Cistern

Seminole Park

Senate Mine

Senator Mine

Senator Mine

Senator Morgan Mine

Senator Mountain

Seneca Lake

Seneca Lake Dam

Senita Basin

Senita Pass

Senita School$$
\begin{aligned}
& \text { FEATUR } \\
& \text { CLASS }
\end{aligned}
$$$$
\text { STATUS }
$$

reservoir

BGN

Yavapai

COORDINATE

$345622 \mathrm{~N} 1125822 \mathrm{~W}$

spring

BGN

VARIANT

valley

Gila

Navajo

VARIANT

VARIANT

VARIANT

spring

VARIANT

spring

VARIANT

Apache

Apache

Apache

summit

summit

summit

BGN VARIANT

valley

reservoir

locale

ppl

BGN 1915

VARIANT

BGN

BGN

BGN

VARIANT

VARIAN

cliff

spring
well

locale

stream

valley

spring

ppl

airport

BGN 1932

BGI

$361425 \mathrm{~N} 1111629 \mathrm{~W}$

UNOFF Santa Cruz 313306N1104235W

VARIANT

BGN

$B G N$

ADMIN

valle

dam

BGN

UNOFF

UNOFF

crossing UNOFF

locale UNOFF

building UNOFF

building UNOFF

locale UNOFF

park

ADNIN

$\begin{array}{ll}\text { spring } & \text { B } \\ \text { reservoir } & B \\ \text { ppl } & \text { B }\end{array}$

airport

BGN

BGN

VARIANT

school UNOFF

UNOFF

building

valley

BGN

VARIANT

arroyo

Coconino

$353942 \mathrm{~N} 1110905 \mathrm{~W}$

Apache

Navajo

Yavapai

Yavapai

Yavapai

Yavapai

Yavapai

Yavapai

Yavapai

Yavapai

Yavapai

Yavapai

Maricopa

Coconino

Coconino

Pima

Pima

Pima

Pima

Pima

Pima

stream

BGN 1964 Pima

VARIANT

VARIANT

reservoir BGN

well UNOFF

park

mine

mine

mine

mine

UNOFF

ADMIN
UNOFF

UNOFF

UNOFF

UNOFF

Coconino

Mohave

Pima

Yavapai

Yavapai

Mohave

Pima

summit

locale

lake

dam

bas in

gap

school

$\begin{array}{lll}\text { BGN } & \text { Mohave } & 355011 N 1141901 \mathrm{~W} \\ \text { BGN } & \text { Gila } & 334524 \mathrm{~N} 1103044 \mathrm{~W} \\ \text { BGN } & \text { Gila } & 334549 \mathrm{~N} 1103000 \mathrm{~W} \\ \text { UNOFF } & \text { Gila } & 334548 \mathrm{N1} 103030 \mathrm{~W} \\ \text { BGN } & \text { Pima } & 315737 \mathrm{N1} 125126 \mathrm{~W} \\ \text { BGN } & \text { Pima } & 315711 \mathrm{N1} 125120 \mathrm{~W} \\ \text { UNOFF } & \text { Maricopa } & 333452 \mathrm{~N} 1120837 \mathrm{~W}\end{array}$

$353500 \mathrm{~N} 1102415 \mathrm{~W}$

$351932 \mathrm{~N} 1125236 \mathrm{~W}$

$344229 \mathrm{N1} 131012 \mathrm{~W}$

351923N1125320W

$355924 N 1111446 \mathrm{~W}$

$353201 \mathrm{N1} 124056 \mathrm{~W}$

315443N1115250W

$315558 \mathrm{~N} 1115337 \mathrm{~W}$

$315448 \mathrm{~N} 1115252 \mathrm{~W}$

$315443 \mathrm{~N} 1115256 \mathrm{~W}$

$315153 \mathrm{~N} 1115916 \mathrm{~W}$

$315530 \mathrm{~N} 1120925 \mathrm{~W}$

$315552 \mathrm{~N} 1121120 \mathrm{~W}$

353109 N1121043W

365734 N1124B16W

321349 N1105957W

$341209 N_{1125133 \mathrm{~W}}$

$342458 \mathrm{~N} 1122440 \mathrm{~W}$

$354904 \mathrm{~N} 1141716 \mathrm{~W}$

$315310 \mathrm{~N} 1110438 \mathrm{~W}$ $\begin{array}{cc}\text { SOURCE } & \text { ELEV } \\ \text { COORDINATE } & \text { FT }\end{array}$

6197 Juniper Mts

Promontory Butte

6800 Tseyi-Hatsosi

6754 Kinusta Mesa

Boot Mesas

Chaiyahi Rim SE

Parks

Point Imperial Whippoorwill Spring

5302 Moenave

Mt Hughes

Badger Spring

Egloffstein Butte

Seligman West

5237 Seligman West

$344525 N 1130957 W$

Bozarth Mesa

Seligman West

Seligman East

Seligman East

Cathedral Caves

Seligman West

Seligman West

Seligman East

Tempe

$315621 \mathrm{~N} 1114700 \mathrm{~W}$

Goldtooth

Bishop Lake

Sells West

2409 Sells West

Sells West

315650 N1113950W

Kupk

Moccas in

Tucson

Congress

7600 Groom Creek

Senator Mtn

Twin Buttes

5127 Senator Mtn

Mule Hoof Bend

Mule Hoof Bend

Mule Hoof Bend

Lukeville

Lukeville

Glendale 


\section{FEATURE NAME}

Senita Tank

Sentinel

Sentinel Butte
Maricopa

325130N1131245W

Cochise 314849 N1091430W

Pima 321237N1105930W

Coconino

Coconino

Cochise

\begin{tabular}{|c|c|c|c|}
\hline $\begin{array}{l}\text { stream } \\
\text { summit } \\
\text { valley } \\
\text { rapids } \\
\text { stream }\end{array}$ & $\begin{array}{l}\text { BGN } \\
\text { BGN } \\
\text { BGN } \\
\text { BGN } \\
\text { BGN } 1939 \\
\text { VARIANT } \\
\text { VARIANT }\end{array}$ & $\begin{array}{l}\text { Maricopa } \\
\text { Apache } \\
\text { Mohave } \\
\text { Mohave } \\
\text { Apache }\end{array}$ & 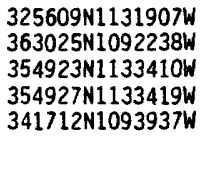 \\
\hline & & & $341712 N 109393$ \\
\hline
\end{tabular}

locale
locale
building
reservoir
locale
park
locale
reservoir

VARIANT

BGN

UNOFF

BGN

$B G N$

ADMIN

BGN

VARIANT

mine

Pima
Maricopa
Maricopa
Coconino
Coconino
Maricopa
Coconino
Coconino
Santa Cru

314005 N1120723W

$331358 \mathrm{~N} 1115011 \mathrm{~W}$

$331342 \mathrm{~N} 1115007 \mathrm{~W}$

$352234 N 1115301 \mathrm{~W}$

$351422 \mathrm{~N} 1121621 \mathrm{~W}$

$333622 \mathrm{~N} 1115728 \mathrm{~W}$

$351420 \mathrm{~N} 1121647 \mathrm{~W}$

351451 N1121540W

VARIANT

cliff

valley
rapids

reservoir

valley

locale

summit

summit

reservoir

school

spring

spring

BGN 1908

BGN 1932

BGN

VARIANT

VARIANT

BGN

Coconino

Coconino

Coconino

Coconino

Cochise

Pima

Apache

BGN 1906

Coconino

Navajo

UNOFF

VARIANT

VARIANT

VARIANT

VARIANT

VARIANT

VARIANT

VARIANT

VARIANT

pillar reservoir

$\begin{array}{lll}\text { BGN } & \text { Coconino } & 363633 \text { N1105522W } \\ \text { BGN } & \text { Navajo } & 343140 \mathrm{~N} 1102116 \mathrm{~W}\end{array}$

360419 N1121158 361220 N1121947W $361232 \mathrm{~N} 1121945 \mathrm{~W}$ $350253 \mathrm{~N} 1113806 \mathrm{~W}$

$321502 \mathrm{~N} 1095919 \mathrm{~W}$

$314756 \mathrm{N1121759 \textrm {W }}$ $341438 N 1094217 \mathrm{~W}$

360715N1121040W

$343140 \mathrm{~N} 1102116 \mathrm{~W}$

331824 N1115009W

$364343 \mathrm{~N} 1094004 \mathrm{~W}$ $364343 \mathrm{~N} 1094004 \mathrm{~W}$
Maricopa 325133N1131239w

312433N1104654W
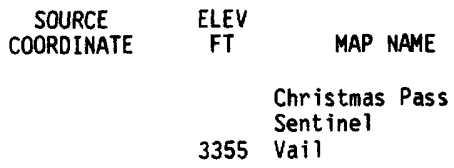

1077 Sentinel Peak Tucson

Agua Caliente

Page

\begin{tabular}{|c|c|c|}
\hline 113153 & & ente \\
\hline & & Separation Canyon \\
\hline
\end{tabular}

1214 Gila Butte Gila Butte Moritz Ridge McLellan Reservoir Paradise Valley McLellan Reservoir McLellan Reservoir

$361124 N 1122118 \mathrm{~W}$

Havasupai Point Havasupai Point Mountainaire

7444 Boundary Butte

6026 Grand Canyon

Chandler

Rock Point

Square Butte Sheepskin Wash 
FEATURE NAME

Seucito Canyon

Seven, Canal (historical)

Canal Viejo

Seven, Tank

Seven Anchor Spring

Seven Anchor Tank

Seven Bar Hill

Seven Cataracts

Seven Cross A Ranch

Seven Cross Tank

Seven Dash Ranch

Seven Gelding Tank

Seven Hundred Well

Seven Knolls

Seven Knolls Bench

Seven Knolls Bench Reservoir

Seven Lower Branch, Canal

(historical)

Canal Cottonwood

\section{Sevenmile}

Sevenmile Camp

Sevenmile Canyon

Sevenmile Canyon

Sevenmile Cemetery

Sevenmile Creek

Sevenmile Creek

See Sevenmile Wash

Seven Mile Dan

Sevenmile Dam

Sevenmile Draw

See Sevenmile Wash

Seven Mile Draw

See Sevenmile Wash

Sevenmile Draw

Sevenmile Gulch

Sevenmile Mountain

Sevenmile Mountains

Sevenmile Peak

Sevenmi le Rim

Sevenmile School

Sevenmile Spring

Sevenmile Spring

Sevenmile Tank

Sevenmile Tank

Sevenmile Tank

Sevenmile Tank

Sevenmile Tank

Sevenmile Tank

Sevenmile Tank

Sevenmile Tank Dam

Sevenmile Wash

Sevenmile Creek

Seven Mile Draw

Sevenmile Draw

Sycamore Creek

Seven Mile Well

Sevenmile Windmi11

Seven Palms Mobile Home Estates

Seven Pines Tank

Seven Ranch Tank

Seven Springs

Seven Springs

Seven Springs

Seven Springs

Seven Springs Draw

Seven Springs Picnic Grounds

Seven Springs Ranch

Seven Springs Wash

Seven Springs Wash

Surprise Creek
FEATURE
CLASS

valley

canal

reservoir

spring

reservoir $B G$

sumin it

falls

locale

reservoir

locale

reservoir

well

summit

reservoir

canal

STATUS

COUNTY

BGN Maricopa

BGN

VARIANT

BGN Coconino

Coconino

Coconino

Coconino

Pina

Greenlee

Graham

Cochise

Coconino

Mohave

Mohave

Mohave

Maricopa

VARIANT

locale

locale

valley

valley

cenetery

stream

stream

dam

dam

BGN

BGN

BGN

UNOFF

BGN

VARIANT

UNOFF

UNOFF

VARIANT

stream

stream

valley

valley

summit

summit

summit

cliff

school

spring

spring

reservoir

reservoir

reservoir

reservoir

reservoir

reservoir

reservoir

dam
stream

UNOFF
BGN 1967

VARIANT

BGN

$B G N$

BGN

BGN

$B G N$

BGN

UNOF
BGN
BGN
BGN
BGN
BGN
BGN
BGN
BGN
BGN

BGN

we 11

local

locale

reservoir

BGN 1967
VARIANT

VARIANT

VARIANT

VARIANT

UNOFF

BGN

BGN
UNOFF

BGN

Navajo

Gila

Navajo

Gila

Gila

Graham

Navajo

334707 N1095722W

333257 N1103638W 334739 N1095730W $340207 N 1110232 \mathrm{~W}$ $334656 \mathrm{~N} 1095722 \mathrm{~W}$ 331439 N1095010W

$332210 \mathrm{~N} 1102632 \mathrm{~W}$

$331242 N 1095335 \mathrm{~W}$

343609 N1100613W

Gila

Gila

Navajo

Yavapai

Maricopa

Gila

Maricopa

Navajo

$332210 \mathrm{~N} 1102632 \mathrm{~W}$

$332210 \mathrm{N1102632 \textrm {W }}$

$343726 \mathrm{~N} 1100421 \mathrm{~W}$

$343130 N 1122308$

330912 N1121509W

$333413 N 1103423 \mathrm{~W}$

$335545 N 1130300$

334549N1095801W

Navajo

Navajo

Yavapai

Graham

Gila

Gila

Navajo

Coconino

Yavapai

Coconino

$334721 \mathrm{~N} 1095759 \mathrm{~W}$

$334406 \mathrm{~N} 1095508 \mathrm{~W}$

$343049 \mathrm{~N} 1122411 \mathrm{~W}$

$331236 \mathrm{~N} 1095340 \mathrm{~W}$

$333215 \mathrm{~N} 1103651 \mathrm{~W}$

$334324 N 1095532 \mathrm{~W}$

$334656 \mathrm{~N} 1095654 \mathrm{~W}$

$342640 \mathrm{~N} 1112804 \mathrm{~W}$

$343040 \mathrm{~N} 1122420 \mathrm{~W}$

$360618 \mathrm{N1122121 \textrm {W }}$

Navajo

Gila

$334655 \mathrm{~N} 1095654 \mathrm{~W}$

$332210 N 1102632 \mathrm{~W}$

Gila

Navajo

Maricopa

$333433 \mathrm{~N} 1103826 \mathrm{~W}$

$34355 \mathrm{BN} 110094 \mathrm{BW}$

$333833 \mathrm{~N} 1120352 \mathrm{~W}$

$352806 \mathrm{~N} 1120220 \mathrm{~W}$

reservoir $B G N$

$\begin{array}{ll}\text { spring } & B G N \\ \text { spring } & B G N\end{array}$

spring

spring

spring

valley

park

locale

strean

stream

BGN

BGN

BGN

AOMIN

UNOFF

BGN

BGN

VARIANT

Coconino

Maricopa

Apache

Apache

Mohave

Apache

Maricopa

Mohave

Maricopa

$352550 \mathrm{~N} 1123557 \mathrm{~W}$

$335744 N 1115054 \mathrm{~W}$

$335751 N 1092153 \mathrm{~W}$

$344645 N 1093019 \mathrm{~W}$

$361750 \mathrm{~N} 1135910 \mathrm{~W}$

$335620 \mathrm{N109234}$ ?

$33575 B N 11151454$ 361752N1135909W

335759 N1115151W

344229 N1094014W

$335808 N 1092131 W$

335508 N1114956W

344641N1093024W

\begin{tabular}{ccc}
$\begin{array}{c}\text { SOURCE } \\
\text { COORDINATE }\end{array}$ & ELEV & \multicolumn{1}{c}{ MAP NAME } \\
333701N1112500W & & $\begin{array}{l}\text { Mormon Flat Dam } \\
\text { Phoen ix }\end{array}$ \\
& & $\begin{array}{l}\text { O'Leary Peak } \\
\text { Hutch Mtn }\end{array}$ \\
& & $\begin{array}{l}\text { Parks } \\
\text { Davenport Hill }\end{array}$
\end{tabular}

Agua Caliente $\mathrm{Hill}$

Robinson Mesa

Shingle Mill Mtn

Steele Hills

Jaycox Mtn 


\section{FEATURE NAME}

Seven Tank

Seventeen Mile Ranch

Seventeen Tank

Seventeen Tank

Seventeen Windmill

Seventh Day Adventist School

Seventyfive Mile Creek

Seventy-Five Mile Rapids Neville Rapids

Seventyfive Mile Rapids

See Nevills Rapids

Seventyfour Plains

Seventynine Mine

Seventyseven Tank

Seventysix Gulch Little California Gulch 76 Gulch

Seventys ix Mine

Seventysix Ranch

Seventy Six Ranch

Seventysix Spring

Seventy Wash

Seven Up Pasture Tank

Seven Up Ranch

Seven Up Spring

Seven Up Tank Lime Spring Tank

Seven $V$ Ranch

Seven VT Draw

Seven $X$ Tank

Severin Canyon Servant Draw

Sevier Flat

Sevier Tank

Sevilla School

Sevy Draw

Sevy Draw Reservoir Number One

Sevy Draw Reservoir Number Two

Sewell School

Sewer Canyon

Sewer Number One Tank

Sewer Number Two Tank

Sexton Canyon

Sezhini Butte

See Black Rock Butte

Shaantoh Spring

See Shato Spring

Shaatkam

See Shaotkan

Shack Spring

Shack Tank

Shaded Spring

Sha Donde Tank

Shadow Canyon

Shadow Cave

Shadow Hills (subdivision)

Shadow Mountain

Shadow Mountain

See Black Knob

Shadow Mountain (subdivision)

Shadow Mountain School

Shadow Mountain Village

Scottsdale (trailer park)

Shadow Mountain Wel

Shadow Ridge II (subdivision)

Shadow Rim Camp

Shady De11

Shady Grove Mobile and

Recreational Vehicle Park

Shady Ranch Trailer Lodge

Shady Rest Mobile Home Park

\section{FEATURE}

CLASS

reservoir

locale

reservoir

reservoir

locale

school

stream

rapids

STATUS

COUNTY

COORDINATE

BGN Yavapai

UNOFF Mohave

BGN Yavapai

Coconin

UNOFF Apache

BGN 1932 Coconino

BGN Coconino

VARIANT

VARIANT

rapids

plain

mine

reservoir

arroyo

mine

locale

local

spring

reservoir

locale

spring

reservoir

locale

valley

reservoir

valley

flat

reservoir

school

valley

reservoir

reservoir

school

BGN

UNOFF

BGN

Coconino

BGN 1976 Cochise

VARIANT

VARIANT

UNOFF Yavapai

UNOFF

Graham

UNOFF Gila

BGN Cochise

UNOFF

BGN Yavapai

BGN 1977 Navajo

VARIANT

UNOFF Yavapai

BGN Cochise

BGN Pima

BGN Cochise

BGN Coconino

BGN Coconino

UNOFF Maricopa

Pima

valley

reservoir

reservoir

valley

BGN

BGN

VARIANT

summit

spring

VARIANT

VARIANT

ppl

spring

reservoir

spring

reservoir

pp1

cave

pp1

summit

summit

BGN

BGN

BGN

BGN

BGN

BGN

VARIANT

Yavapai

Coconino

Coconino

Greenlee

Apache

Navajo

Pima

Mohave

Gila

Navajo

Coconino

Maricopa

Coconino

Maricopa

Coconino

Coconino

ppl

school

BGN

UNOFF

Maricopa

locale

UNOFF

Maricopa

Maricopa

wel

UNOFF

Coconino

ppl

locale

bas in

locale

BGN

BGN

UNOFF

Maricopa

Gila

Yavapai

Maricopa

locale

UNOFF

Maricopa Maricopa

$351358 N 1131237$

$344341 \mathrm{~N} 1135506 \mathrm{~W}$

$344202 \mathrm{~N} 1115629 \mathrm{~W}$ $355400 \mathrm{~N} 1120508 \mathrm{~W}$ $351247 N 1091710 \mathrm{~W}$ 344438 N1120100W $360326 N 1115348 \mathrm{~N}$ $360310 \mathrm{~N} 1115405 \mathrm{~W}$

$360313 M 1115410 \mathrm{~W}$

$351902 \mathrm{N1131000 \textrm {W }}$

$330352 \mathrm{~N} 1104848 \mathrm{~W}$

$355647 \mathrm{~N} 1114917 \mathrm{~W}$

321647 N1093903W

$340312 \mathrm{~N} 1121517 \mathrm{~W}$

$340158 \mathrm{~N} 1111723 \mathrm{~W}$

$321558 N 1093917 \mathrm{~W}$

$334322 \mathrm{~N} 1142709 \mathrm{~W}$

$345010 \mathrm{~N} 1130136 \mathrm{~W}$

$344904 N 1125759 \mathrm{~W}$

$344852 N 1125750 \mathrm{~W}$

$334546 \mathrm{~N} 1095458 \mathrm{~W}$

$344614 N 1124009 \mathrm{~W}$

320637 N1093638W

$313936 \mathrm{~N} 1113410 \mathrm{~W}$

$321502 \mathrm{~N} 1095919 \mathrm{~W}$

$351146 \mathrm{N1120946 \textrm {W }}$

$351150 \mathrm{~N} 1120940 \mathrm{~W}$

$333058 \mathrm{~N} 1120826 \mathrm{~W}$

$363834 N 1132644 \mathrm{~W}$

$363411 N 1132922 \mathrm{~W}$

$363454 N 1132914 \mathrm{~W}$

$321338 \mathrm{~N} 1105158 \mathrm{~W}$

$350044 N 1131649 W$

$360110 \mathrm{~N} 1121131 \mathrm{~W}$

$360115 \mathrm{~N} 1121128 \mathrm{~W}$

$324930 \mathrm{~N} 1091101 \mathrm{~W}$

$360845 \mathrm{~N} 1091745 \mathrm{~W}$

363632N1103822W

314610N1122435W

$350808 \mathrm{~N} 1135702 \mathrm{~W}$

$334530 \mathrm{~N} 1105203 \mathrm{~W}$

$354904 N 1103123 \mathrm{~W}$

$344130 \mathrm{~N} 1111005 \mathrm{~W}$

$333911 \mathrm{N1120716 \textrm {W }}$

SOURCE

ELEV
FT

MAP NAME

Cross Mtn

Dutch Flat NW

Cornville

Tusayan East

5898 Sanders

Cottonwood

Cape Royal

Cape Royal

Sugarloaf Peak

Hayden

Deer Tank

Railroad Pass

Columbia

Blue Jay Peak

321048 N1093436W

321818 N1100249W

$363240 N 1133124 \mathrm{~W}$

324939N1091559w 
MATIONAL GAZETTEER--ARIZONA 1986

\section{FEATURE NAME}

Shaefers Treasure Mine

Shafer Ranch

Shaffer Camp

Shaffer Ranch

Shaffer Spring

Shaffer Wash

Schaffer Wash

Shake Canyon

See Shake Gulch

Shake Creek

See North Fork White River

Shake Creek

See Snake Creek

Shake Gulch

Shake Canyon

Shake Pile Tank

Shake Ridge

Shake Ridge Tank

Shake Spring

Shake Spring

Shake Spring

Shake Tree Canyon

Shake Tree Trail

Shalako

Shale Rock Pond

Shaler Plateau

Shale Tank

Shale Tank

Shallow Rapids

Shanrock Mine

Shamrock Mobile Home Park

Shamrock Shaft

Shamrock Tank

Shamrod Spring

See Helvetia Spring

Shamrod Spring

See Chavez Spring

Shamrod Spring

Helvetia Spring

Shamrod Springs

Shamrod Springs

See Helvetia Spring

Shamrod Springs

See Chavez Spring

Shamrod Springs

See Shamrod Spring

Shanetoh Spring

Shangri La Ranch

Shanley Spring

Shanley Tank

Shanley Tank

Shannon Bas in

Shannon Campground

Shannon Gulch

Shannon Mine

Shannon Mountain

Shannon Park

Shannon Recreation Area

Shanto

See Shonto

Shanto Canyon

See Shato Canyon

Shanto Plateau

See Shonto Plateau

Shan-to Spring

See Shato Spring

Shanto Spring

See Shato Spring

Shanto Stream

See Shonto Wash

Shanto Trading Post

\section{FEATURE}

CLASS

mine

locale

locale

locale

spring

stream

valley

STATUS

COUNTY

COORDINATE

UNOFF

UNOFF

UNOFF

BGN

BGN

VARIANT

VARIANT

Mohave
Cochise
Pima

$320943 \mathrm{N1} 092459 \mathrm{~W}$

Santa Cruz 312339N1104114W

Mohave 350219N1142121W

Pina

Cochise

314214N1112610W

$314045 N 1091900 \mathrm{~W}$

VARIANT

stream

stream

valley

reservoir

ridge

reservoir

spring

VARIA

Navajo

Apache

BGN 1959 Cochise

VARIANT

BGM

BGH

$B G N$

Gila

Gila

Gila

Cochise

spring

spring

valley

trail

summit

reservoir

plain

reservoir

reservoir

rapids

BGN
BGN
BGN
UNOFF
BGN
BGN
BGN
BGN
BGN
BGN

Graham

Gila

Gila

Gila

UNOFF

BGN

190B Coconino

Coconin

Apache

BGN Coconino

mine UNOFF

locale

mine

reservoir

UNOFF

UNOFF
UNOFF

UWOFF

VARIANT

spring

spring

spring

VARIANT

BGN 1982

VARIANT

VARIANT

Mohave

Yuma

Maricopa

Greenlee

Yavapai

Pima

Pima

VARIANT

spring

spring

spring

spring

locale

spring

reservoir

VARIA

VARIANT

Pima

Pima

BGN

UNOFF

BGM

BGN

Pima

Navajo

Maricopa

Mohave

Mohave

reservoir

bas in

park

valley

mine

summit

park

park

ppl

BGN

ADMIN

BGN

UNOFF

BGN

ADMIM

ADMIN

VARIANT

Mohave

Mohave

Graham

Gila

Mohave

Greenlee

Graham

Graham

Navajo

VARIANT

valley

plain

VARIANT

Coconino

Navajo

Navajo

Navajo

Coconino

valley

VARIANT

VARIANT
334728N1095941W

340008 N1093448W $314045 \mathrm{~N} 1091900 \mathrm{~W}$

342318N1113535W $340356 \mathrm{~N} 1112452 \mathrm{~W}$

$340405 \mathrm{~N} 1112451 \mathrm{~W}$

$320117 \mathrm{N1092019W}$

$323604 N 1095032 \mathrm{~W}$

$334203 \mathrm{~N} 1111909 \mathrm{~W}$

$340307 \mathrm{~N} 1112439 \mathrm{~W}$

$340404 \mathrm{~N} 1112616 \mathrm{~W}$

$353301 \mathrm{N1} 103620 \mathrm{~W}$

$363902 N 1132010 \mathrm{~W}$

360916 N1121914W

333443N1094959W

$355244 \mathrm{N1120415 \textrm {N }}$

$355155 \mathrm{~N} 1144012 \mathrm{~W}$

$334045 N 1135334 \mathrm{~W}$

$333209 \mathrm{~N} 1121428 \mathrm{~W}$

$324532 \mathrm{N1091508 \textrm {W }}$

$340642 \mathrm{~N} 1121440 \mathrm{~W}$

315205N1104639W

$315205 \mathrm{~N} 1104647 \mathrm{~W}$

$315211 \mathrm{N1104715W}$

340344N1112700W

$315205 N 1104639 \mathrm{~W}$

$315205 N 1104647 \mathrm{~W}$

$315211 \mathrm{N1104715 \textrm {W }}$

353253N1101728W

$335316 \mathrm{N1120445W}$

$355250 N 1132123 \mathrm{~W}$

355948 N1132720W

363626 N1131013W

343857 N1133849W

$323926 \mathrm{~N} 109512 \mathrm{BW}$

$342034 \mathrm{N1112146 \textrm {W }}$

$341947 \mathrm{N1} 134009 \mathrm{~W}$

$330659 \mathrm{~N} 1092141 \mathrm{~W}$

323927 N1095130W

$323932 N 1095127 \mathrm{~W}$

363540 N1103830W

$362452 \mathrm{~N} 1105050 \mathrm{~W}$

364141 N1103945W

363632N1103822W

363632N1103822W

362452N1105050W

31445BN1091647W

Swede Peak

Strawberry

Mazatzal Peak

Mazatzal Peak

Cochise Head

Stockton Pass

Four Peaks

Mazatzal Peak

Mazatzal Peak

Tovar Mesa East

The Grandstand

Havasupai Point 


\section{FEATURE NAME}

See Shonto

Shanub Point

Shaot Kam

See Shaotkan

Shaotkam

Canote

Comate

Comote

Comot

Los Camotes

Los Comates

Shaatkam

Shaot Kam

Sha-pah-1a

See Shipolovi

Sha-pah-lah-lwee

See Shipolovi

Shariot Hall Museum

Sharp Butte

Sharp Creek

Sharp Creek

Sharp Creek

See Hunter Creek

Sharp Hollo

Sharp Hollow Tank

Sharp Hollow Trick Tank

Sharp Peak

Shato

See Shonto

Shato Canyon

See Shonto Wash

Shato Canyon

Shanto Canyon

Shato Creek

See Shonto Wash

Shato Plateau

See Shonto Plateau

Sha to Spring

See Shato Spring

Sha-to Spring

See Shato Spring

Shato Spring

Shaantoh Spring

Shanto Spring

Shan-to Spring

Sha to Spring

Sha-to Spring

Sunnyside Spring

Shato Stream (historical)

Shato Stream

See Shonto Wash

Shattuck

Shaw Butte

See North Mountain

Shaw Butte

Shaw Butte Microwave Relay

Station

Shaw Butte School

Shaw Canyon

Shawmut

Shaw Peak

Shaw Peak Trail Two Hundred

Fiftyone

Shaw Substation

Shaw Tank

Shaw Well

Shea Middle School

Shea Plaza Shopping Center
FEATURE
CLASS

STATUS

COUNTY

clif

$\mathrm{ppl}$
$\mathrm{ppl}$

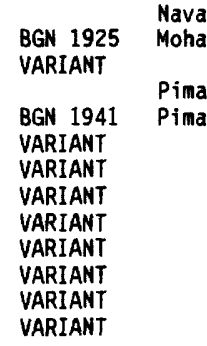

ppl

ppl

building

summit

strean

stream

stream

VARIANT

VARIANT

UNOFF

BGN

BGN

BGN

VARIANT

Navajo

Mavajo

Yavapai

Navajo

Apache

Gila

Gila

valley

reservoir

reservoir

summit

ppl

valley

valley

BGN Navajo

BGN Navajo

BGN Mavajo

VARIANT

VARIANT

Navajo

Coconino

Coconino

VARIANT

VARIANT

valley

plain

spring

spring

spring

VARIANT

VARIANT

VARIANT

BGN 1915

VARIANT

VARIANT

VARIANT

VARIANT

VARIANT

VARIANT

VARIANT

valley

mine

summit

sumnit

summit
tower

school

BGN 1915 VARIANT

UNOFF

VARIANT

BGN

UNOFF

UNOFF

valley

locale

summit

trail

BGN

BGN

BGN

UNOFF

Shearer Canyon

See Scherer Canyon

Shea Scottsdale Shopping Center

Shea Spring locale

reservoir

well

school

locale

UNOFF Maricopa 333510N1120551W

BGN Yavapai 341956N1123152

UNOFF Cochise 320116N1093431W

UNOFF Maricopa 333509N1120121

$333451 \mathrm{~N} 1120047 \mathrm{~W}$

VARIANT

valley

locale

spring

Maricopa

Cochise

Maricopa

Yavapai

$312935 N 1095332$

$344647 \mathrm{N1} 120117 \mathrm{~W}$
Coconino 362452N1105050W

Navajo

$364141 N 1103945 W$

$362452 \mathrm{M} 1105050 \mathrm{~W}$

$362452 \mathrm{~N} 1105050 \mathrm{~W}$

$312556 N 1095513 \mathrm{~W}$

$333507 N 1120418 \mathrm{~W}$

$333537 \mathrm{~N} 112050 \mathrm{WW}$

$333553 M 1120615$

$320241 \mathrm{~N} 1103513 \mathrm{~W}$

$325949 N 1123011 \mathrm{~W}$

$315802 \mathrm{~N} 1091639$

Maricopa

Cochise
COOROINATE

$363540 \mathrm{~N} 1103830 \mathrm{~W}$

$\begin{array}{cc}\text { SOURCE } & \text { ELEV } \\ \text { COORDINATE } & \text { FT MAP NAME }\end{array}$

Kanab Point

1680 Bailey Peak

Prescott

5725 Turkey Track Butte

Maverick SW

Woods Canyon

$333519 N 1094257$

$342005 N 1105858 \mathrm{~W}$

342322N1103916W Heber

Hanks Draw

Hanks Draw

3683 San Pedro

364123N1103404W Cow Springs

Shonto

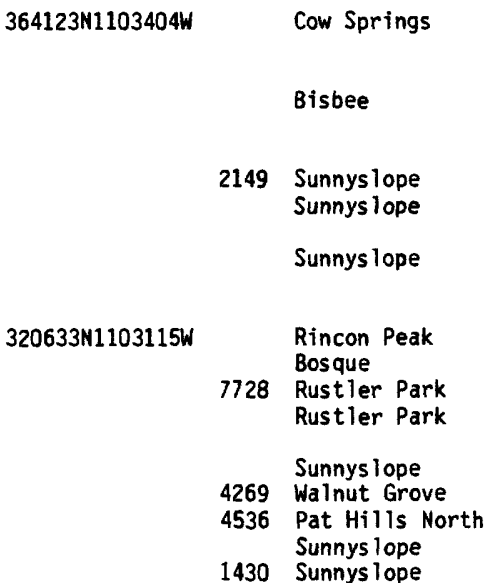

364123N1103404W Cow Springs

Bisbee

2149 Sunnys lope Sunnys lope

Sunnys lope

320633N1103115W Rincon Peak

Bosque

7728 Rustler Park

Rustler Park

Sunnys lope

4269 Walnut Grove

4536 Pat Hills North Sunnys lope

1430 Sunnys lope

Paradise Valley
Clarkdale 


\begin{tabular}{|c|c|c|c|c|c|c|c|}
\hline FEATURE MAME & $\begin{array}{l}\text { FEATURE } \\
\text { CLASS }\end{array}$ & STATUS & COUNTY & COORDINATE & $\begin{array}{l}\text { SOURCE } \\
\text { COORDINATE }\end{array}$ & $\begin{array}{c}\text { ELEV } \\
\text { FT }\end{array}$ & MAP NAME \\
\hline $\begin{array}{l}\text { Sheavwitz Plateau } \\
\text { See Shivwits Plateau } \\
\text { Shea Water } \\
\text { Sheba Mine } \\
\text { Sheba Temple } \\
\text { She-be-ku } \\
\text { See Cibecue }\end{array}$ & $\begin{array}{l}\text { plain } \\
\text { spring } \\
\text { mine } \\
\text { summit } \\
\text { ppl }\end{array}$ & $\begin{array}{l}\text { VARIANT } \\
\text { BGN } \\
\text { UNOFF } \\
\text { BGN } 1906 \\
\text { VARIANT }\end{array}$ & $\begin{array}{l}\text { Mohave } \\
\text { Yavapai } \\
\text { Yuma } \\
\text { Coconino } \\
\text { Navajo }\end{array}$ & $\begin{array}{l}362500 \mathrm{~N} 1133001 \mathrm{~W} \\
343530 \mathrm{N1124125 \textrm {W }} \\
335254 \mathrm{N1} 133 \mathrm{~B} 3 \mathrm{~W} \\
360338 \mathrm{N1115546 \textrm {W }} \\
\\
340241 \mathrm{~N} 1102905 \mathrm{~W}\end{array}$ & & & $\begin{array}{l}\text { Skull Valley } \\
\text { Harcuvar Peak } \\
\text { Cape Royal }\end{array}$ \\
\hline $\begin{array}{l}\text { Shed Tank } \\
\text { Shed Valley } \\
\text { Shed Valley Tank } \\
\text { Sheehy Canyon } \\
\text { Sheehys (historical) } \\
\text { Sheehy Spring } \\
\text { Sheep Basin } \\
\text { Sheep Basin Mountain } \\
\text { Sheep Bridge } \\
\text { Sheep Bridge }\end{array}$ & $\begin{array}{l}\text { reservoir } \\
\text { valley } \\
\text { reservoir } \\
\text { valley } \\
\text { locale } \\
\text { spring } \\
\text { basin } \\
\text { sumati } \\
\text { bridge } \\
\text { bridge }\end{array}$ & $\begin{array}{l}\text { BGN } \\
\text { BGN } \\
\text { BGN } \\
\text { BGN } 1960 \\
\text { BGN } \\
\text { BGN } \\
\text { BGN } \\
\text { BGN } \\
\text { UNOFF } \\
\text { UNOFF }\end{array}$ & $\begin{array}{l}\text { Yavapai } \\
\text { Coconino } \\
\text { Coconino } \\
\text { Santa Cruz } \\
\text { Santa Cruz } \\
\text { Santa Cruz } \\
\text { Cochise } \\
\text { Gila } \\
\text { Maricopa } \\
\text { Yavapai }\end{array}$ & $\begin{array}{l}344523 \mathrm{~N} 1121116 \mathrm{~W} \\
365200 \mathrm{N11} 11253 \mathrm{~W} \\
365030 \mathrm{N1114333 \textrm {W }} \\
314050 \mathrm{N1110338W} \\
312158 \mathrm{~N} 1103456 \mathrm{~W} \\
312204 \mathrm{N1103441 \textrm {W }} \\
320312 \mathrm{N1100721 \textrm {W }} \\
3401471111241 \mathrm{~W} \\
333319 \mathrm{N1113511 \textrm {W }} \\
340439 \mathrm{N1114227 \textrm {W }}\end{array}$ & $\begin{array}{l}364934 N 1114418 W \\
314029 N 1105837 W\end{array}$ & $\begin{array}{l}4650 \\
6263\end{array}$ & $\begin{array}{l}\text { Munds Draw } \\
\text { Navajo Bridge } \\
\text { The Big Knoll } \\
\text { Amado } \\
\text { Lochiel } \\
\text { Lochiel } \\
\text { Dragoon } \\
\text { Sheep Basin Mtn } \\
\text { Stewart Mtn } \\
\text { Chalk Mountain }\end{array}$ \\
\hline $\begin{array}{l}\text { Sheep Butte } \\
\text { Sheep Camp } \\
\text { Sheep Camp } \\
\text { Sheep Camp Spring } \\
\text { Sheep Camp Spring } \\
\text { Sheepcamp Spring } \\
\text { Sheep Camp Springs } \\
\text { Sheep Camp Tank } \\
\text { Sheep Camp Wash } \\
\text { Sheep Canyon } \\
\text { See Sheep Wash }\end{array}$ & $\begin{array}{l}\text { summit } \\
\text { locale } \\
\text { locale } \\
\text { spring } \\
\text { spring } \\
\text { spring } \\
\text { spring } \\
\text { reservoir } \\
\text { stream } \\
\text { stream }\end{array}$ & $\begin{array}{l}\text { BGN } \\
B G N \\
B G N \\
B G N \\
B G N \\
B G N \\
B G N \\
\text { BGN } \\
\text { BGN } \\
\text { VARIANT }\end{array}$ & $\begin{array}{l}\text { Navajo } \\
\text { Graham } \\
\text { Maricopa } \\
\text { Pinal } \\
\text { Apache } \\
\text { Mohave } \\
\text { Yavapai } \\
\text { Yavapai } \\
\text { Graham } \\
\text { Graham }\end{array}$ & 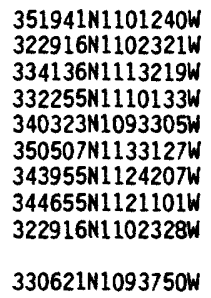 & $322656 \mathrm{~N} 1102046 \mathrm{~W}$ & 6444 & $\begin{array}{l}\text { Sunf lower Butte } \\
\text { Redington } \\
\text { Adams Mesa } \\
\text { Haunted Canyon } \\
\text { Greens Peak } \\
\text { Aust in Peak } \\
\text { Mt Josh } \\
\text { Munds Draw } \\
\text { Redington }\end{array}$ \\
\hline $\begin{array}{l}\text { Sheep Canyon } \\
\text { Sheep Canyon Spring } \\
\text { Sheep Canyon Spring } \\
\text { Sheep Cienega } \\
\text { Sheep Cienega } \\
\text { Sheep Corral Spring } \\
\text { Sheep Corral Tank } \\
\text { Sheep Creek } \\
\text { Sheep Creek } \\
\text { Sheep Creek Cabin }\end{array}$ & $\begin{array}{l}\text { valley } \\
\text { spring } \\
\text { spring } \\
\text { flat } \\
\text { swamp } \\
\text { spring } \\
\text { reservoir } \\
\text { stream } \\
\text { stream } \\
\text { locale }\end{array}$ & $\begin{array}{l}B G N \\
B G N \\
B G N \\
B G N \\
B G N \\
B G N \\
B G N \\
B G N \\
B G N \\
B G N\end{array}$ & $\begin{array}{l}\text { Cochise } \\
\text { Cochise } \\
\text { Yavapai } \\
\text { Apache } \\
\text { Apache } \\
\text { Gila } \\
\text { Yavapai } \\
\text { Maricopa } \\
\text { Yavapai } \\
\text { Yavapai }\end{array}$ & 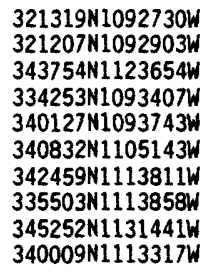 & $\begin{array}{l}340030 \mathrm{~N} 1113009 \mathrm{~W} \\
345304 \mathrm{N1131106 \textrm {W }}\end{array}$ & & $\begin{array}{l}\text { Bowie Mtn North } \\
\text { Bowie Mtn North } \\
\text { Jerome Canyon } \\
\text { Maverick } \\
\text { Horseshoe Cienega } \\
\text { Parallel Canyon } \\
\text { Hackberry Mtn } \\
\text { Horseshoe Dam } \\
\text { Sunrise Peak } \\
\text { Table Mountain }\end{array}$ \\
\hline $\begin{array}{l}\text { Sheep Creek Seep } \\
\text { Sheep Crossing/Baldy } \\
\text { Ninetyfour Irail } \\
\text { Sheep Cross ing Campground } \\
\text { Sheep Oip Canyon } \\
\text { Sheep Oip Creek } \\
\text { Sheep Dip Well } \\
\text { Sheep Gulch } \\
\text { Sheep Gulch } \\
\text { Sheep Gulch Spring }\end{array}$ & $\begin{array}{l}\text { spring } \\
\text { trail } \\
\text { park } \\
\text { valley } \\
\text { stream } \\
\text { well } \\
\text { valley } \\
\text { valley } \\
\text { spring }\end{array}$ & $\begin{array}{l}\text { BGN } \\
\text { UNOFF } \\
\text { AOMIN } \\
\text { BGN } \\
\text { BGN } \\
\text { UNOFF } \\
\text { BGN } \\
\text { BGN } \\
\text { BGN }\end{array}$ & $\begin{array}{l}\text { Maricopa } \\
\text { Apache } \\
\text { Apache } \\
\text { Apache } \\
\text { Apache } \\
\text { Navajo } \\
\text { Yavapai } \\
\text { Yavapai } \\
\text { Yavapai }\end{array}$ & $\begin{array}{l}335942 \mathrm{~N} 1113254 \mathrm{~W} \\
335608 \mathrm{~N} 1093230 \mathrm{~W} \\
\\
335735 \mathrm{~N} 1093021 \mathrm{~W} \\
361709 \mathrm{~N} 1093214 \mathrm{~W} \\
362037 \mathrm{N1093431W} \\
362151 \mathrm{~W} 1102049 \mathrm{~W} \\
341130 \mathrm{~N} 1120941 \mathrm{~W} \\
341703 \mathrm{~N} 1120302 \mathrm{~W} \\
341031 \mathrm{N1120835W}\end{array}$ & $\begin{array}{l}361643 \mathrm{~N} 1092532 \mathrm{~W} \\
361725 \mathrm{~N} 1091908 \mathrm{~W} \\
341019 \mathrm{~N} 1120812 \mathrm{~W} \\
341911 \mathrm{~N} 1120131 \mathrm{~W}\end{array}$ & & $\begin{array}{l}\text { Lion Mountain } \\
\text { Mount Baldy } \\
\text { Mount Baldy } \\
\text { Many Farms } \\
\text { Many Farms } \\
\text { Red Slide Peak } \\
\text { Bumble Bee } \\
\text { Cordes Junction } \\
\text { Bumble Bee }\end{array}$ \\
\hline $\begin{array}{l}\text { Sheephead Canyon } \\
\text { See Sheepshead Canyon } \\
\text { Sheep Hill } \\
\text { See Old Caves Crater } \\
\text { Sheep Hill } \\
\text { Sheep Hill } \\
\text { Sheep Hill Tank } \\
\text { Sheep Mesa } \\
\text { Black Mesa } \\
\text { Sheep Mesa } \\
\text { See Black Mesa }\end{array}$ & $\begin{array}{l}\text { valley } \\
\text { crater } \\
\text { summit } \\
\text { summit } \\
\text { reservoir } \\
\text { summit }\end{array}$ & $\begin{array}{l}\text { VARIANT } \\
\text { VARIANT } \\
\text { BGN } \\
\text { BGN } \\
\text { BGN } 1965 \\
\text { BGN } 1955 \\
\text { VARIANT } \\
\text { VARIANT }\end{array}$ & $\begin{array}{l}\text { Yavapai } \\
\text { Coconino } \\
\text { Coconino } \\
\text { Coconino } \\
\text { Coconino } \\
\text { Maricopa } \\
\text { Maricopa }\end{array}$ & $\begin{array}{l}344356 \mathrm{~N} 1115528 \mathrm{~W} \\
351648 \mathrm{~N} 1113135 \mathrm{~W} \\
351410 \mathrm{~N} 1113346 \mathrm{~W} \\
352919 \mathrm{N1115902W} \\
351316 \mathrm{~W} 1113109 \mathrm{~W} \\
334302 \mathrm{~N} 1113402 \mathrm{~W} \\
\\
334337 \mathrm{N1} 113522 \mathrm{~W}\end{array}$ & & $\begin{array}{l}7263 \\
3132\end{array}$ & $\begin{array}{l}\text { Flagstaff East } \\
\text { Moritz Ridge } \\
\text { Flagstaff East } \\
\text { Adams Mesa }\end{array}$ \\
\hline $\begin{array}{l}\text { Sheep Mine } \\
\text { Sheep Mine } \\
\text { Sheep Mountain } \\
\text { Sheep Mountain } \\
\text { Sheep Mountain } \\
\text { Sheep Mountain } \\
\text { Sheep Mountain } \\
\text { Sheep Mountain } \\
\text { Sheep Mountain } \\
\text { Sheep Mountain Spring }\end{array}$ & $\begin{array}{l}\text { mine } \\
\text { mine } \\
\text { summit } \\
\text { summit } \\
\text { summit } \\
\text { summit } \\
\text { summit } \\
\text { summit } \\
\text { summit } \\
\text { spring }\end{array}$ & $\begin{array}{l}\text { UNOFF } \\
\text { UNOFF } \\
\text { BGN } \\
\text { BGN } \\
B G N \\
\text { BGN } \\
B G N \\
\text { BGN } \\
\text { BGN } \\
\text { BGN }\end{array}$ & $\begin{array}{l}\text { Yuma } \\
\text { Yuna } \\
\text { Pima } \\
\text { Yuma } \\
\text { Maricopa } \\
\text { Maricopa } \\
\text { Maricopa } \\
\text { Yavapai } \\
\text { Coconino } \\
\text { Pinal }\end{array}$ & $\begin{array}{l}325441 \mathrm{N1135949W} \\
341357 \mathrm{~W} 1140012 \mathrm{~W} \\
320658 \mathrm{~N} 1131310 \mathrm{~W} \\
323158 \mathrm{~N} 1141401 \mathrm{~W} \\
330642 \mathrm{~N} 1123148 \mathrm{~W} \\
333523 \mathrm{~N} 1112350 \mathrm{~W} \\
3359251113034 \mathrm{~W} \\
340307 \mathrm{~N} 1122309 \mathrm{~W} \\
361736 \mathrm{N1113603W} \\
332651 \mathrm{~N} 1111850 \mathrm{~W}\end{array}$ & & $\begin{array}{l}1977 \\
3156 \\
3567 \\
6996 \\
0432\end{array}$ & $\begin{array}{l}\text { North of Roll } \\
\text { Osborne Well } \\
\text { Agua Dulce Mts } \\
\text { Wellton Hills } \\
\text { Cotton Center SE } \\
\text { Mormon Flat Dam } \\
\text { Lion Mountain } \\
\text { Copperopolis } \\
\text { Bodaway Mesa } \\
\text { Weavers Meedle }\end{array}$ \\
\hline $\begin{array}{l}\text { Sheep Mounts We } 11 \\
\text { Sheep Peak }\end{array}$ & $\begin{array}{l}\text { we } 11 \\
\text { summit }\end{array}$ & $\begin{array}{l}\text { UNOFF } \\
\text { 8GN }\end{array}$ & $\begin{array}{l}\text { Mohave } \\
\text { Pima }\end{array}$ & $\begin{array}{l}342616 \mathrm{~N} 1135010 \mathrm{~W} \\
322416 \mathrm{~N} 1130720 \mathrm{~W}\end{array}$ & & 2217 & $\begin{array}{l}\text { McCracken Peak } \\
\text { Growler Peak }\end{array}$ \\
\hline
\end{tabular}


NATIONAL GAZETTEER--ARIZONA 1986

\section{FEATURE NAME}

Sheep Pelt Well

Sheep Pockets Reservoir

Sheep Pockets Trough

Sheep Point

Sheep Point Canyon

Sheep Ranch Canyon

Sheep Ranch Tank

Sheep Saddle

Sheepshead

Sheepshead Canyon Sheephead Canyon

Sheepshead Mountain

Sheepshead Tank

Sheepskin Spring

Sheepskin Tank

Sheepsk in Wash

Sheep Spring

Sheep Springs

Sheep Spring

Sheep Spring

Sheep Spring

Sheep Spring

Sheep Spring

Sheep Spring

Sheep Spring

Sheep Spring

Sheep Spring Point

Sheep Springs

See Sheep Spring

Sheep Springs Dan

Sheep Spring Tank

Sheep Tank

Sheep Tank

Sheep Tank

Sheep Tank

Sheep Tank

Sheep Tank

Sheep Tank

Sheep Tank

Sheep Tank

Sheep Tank

Sheep Tank

Sheep Tank Draw

Sheep Tank Mine

Sheep Tank Well (historical)

Sheeptrail Tank

Sheep Wash

Sheep Wash

Sheep Wash

Sheep Canyon

Sheep Wash

Sheep Wash

Sheep Wash

Sheep Wash Tank

Sheer Wall Rapids

Sheffield Place (subdivision)

Sheidon

Sheldon Elementary School

Sheldon Mine

Sheldon Mountain

Sheldon Mountain

See Sawik Mountain

Sheldon Mountain

See McDowel1 Peak

Sheldon Wash

See Ash Peak Canyon

Shelf Tank

Shellenberger Canyon

Shelley

Shelley Draw

Shell Mountain

\section{FEATURE \\ CLASS}

well

reservoir

reservoir

cliff

valley

valley

reservoir

gap

summit

valley

summit

reservoir

spring

reservoir

stream

sprin

spring

spring

spring

spring

spring

spring

spring

cape

spring

dam

reservoir

reservoir

reservoir

reservoir

reservoir

reservoir

reservoir

reservoir

reservoir

reservoir

reservoir

valley

mine

mine

well

reservoir

stream

stream

strea

stream

stream

reservoir

rapids

ppl

locale

school

mine

summit

summit

VARIAI

s umm it

VARIANT

valley

valley

reservoir BGN

valley $B G N$

locale $B G N$

summit $\quad B G N$

VARIANT
STATUS

COUNTY

Coconino

Mohave

Mohave

Apache

Apache

Coconino

Greenlee

$\begin{array}{ll}\text { BGN } & \text { Cochise } \\ \text { BGN 1970 } & \text { Yavapai }\end{array}$

Yavapai

Yavapa

Navajo

Navajo

Navajo

Apache
Santa Cruz

COOROINATE

$361257 \mathrm{~N} 1111815 \mathrm{~W}$

$363630 \mathrm{~N} 1131630 \mathrm{~W}$

$361308 \mathrm{~N} 1092115 \mathrm{~W}$

$361255 \mathrm{~N} 1092141 \mathrm{~W}$

$312722 \mathrm{~N} 1103512 \mathrm{~W}$

$353014 N 1125245 \mathrm{~W}$

$332840 \mathrm{~N} 1092229 \mathrm{~W}$

$315217 \mathrm{~N} 1095933 \mathrm{~W}$

$344356 \mathrm{~N} 111552 \mathrm{BW}$

$344408 \mathrm{~N} 1115528 \mathrm{~W}$

34472BN1115700W

$362436 \mathrm{~N} 1103833 \mathrm{~W}$

343439N1102107W

$343607 N 1102119 W$

$340313 N 1093356$ W

$340817 N 1121246 \mathrm{~W}$

$342904 \mathrm{N1120204 \textrm {W }}$

$343801 \mathrm{~N} 1123708 \mathrm{~W}$

345458 N1113211W

$351913 \mathrm{~N} 1101452 \mathrm{~W}$

$355102 \mathrm{N1} 134915 \mathrm{~W}$

$355232 \mathrm{~N} 1102157 \mathrm{~W}$

$341803 \mathrm{~N} 1104756 \mathrm{~W}$

340313N1093356W

Apache

Apache

Apache

Pima

Graham

Yuma

Gila

Coconino

Yavapai

Coconino

Coconino

Coconino

Coconino

Coconino

Coconino

Yuma

Yuma

Yavapai

Cochise

Graham

Graham

\section{BGN Greenlee}

Gila

Coconino

Greenlee

Coconino

Maricopa

Greenlee

Navajo

Yavapai

Greenlee

$340224 N 1093200 \mathrm{~W}$

$340258 \mathrm{~N} 1093414 \mathrm{~W}$

$322709 \mathrm{~N} 1130622 \mathrm{~W}$

$324613 N 1094805 \mathrm{~W}$

$332212 \mathrm{~N} 1134350 \mathrm{~W}$

$335432 \mathrm{~N} 1111635 \mathrm{~W}$

$344035 \mathrm{~N} 1112312 \mathrm{~W}$

$345322 N 1131212$

$350443 \mathrm{~N} 1121257 \mathrm{~W}$

350826 N1115522W

$353124 N 1115752 W$

360333 N1121915W

344002 N1112123W

$332225 N 1134521 \mathrm{~W}$

$332020 \mathrm{~N} 1134516 \mathrm{~W}$

$344645 \mathrm{~N} 1113758 \mathrm{~W}$

$324244 N 1101217$

330621N1093750W

$331706 \mathrm{~N} 1092954 \mathrm{~W}$

$334501 N 1104833 \mathrm{~W}$

$331745 \mathrm{~N} 1092732 \mathrm{~W}$

$364153 N 1114244 \mathrm{~W}$

$332915 \mathrm{~N} 1121510 \mathrm{~W}$

$324853 N 1091018$

$345409 \mathrm{~N} 1100935 \mathrm{~W}$

$342653 \mathrm{N1} 122345 \mathrm{~W}$

$324825 \mathrm{~N} 1091453 \mathrm{~W}$

Maricopa

333212 N1114538N

Maricopa

333936NI114903W

$324830 \mathrm{N1091045 \textrm {W }}$

$\begin{array}{ll}\text { Greenlee } & 324830 N 1091045 \mathrm{~W} \\ \text { Navajo } & 343052 \mathrm{~N} 1095913 \mathrm{~W} \\ \text { Pima } & 314807 \mathrm{N110303BW}\end{array}$

Pima

Yavapai

$341135 \mathrm{~N} 1122422 \mathrm{~W}$

$342314 N 1103809 \mathrm{~W}$

$340540 N 1104813 \mathrm{~W}$
$363650 \mathrm{~N} 1131551 \mathrm{~W}$

$341956 N 1104745 \mathrm{~W}$

$354445 \mathrm{~N} 1120828 \mathrm{~N}$

$315840 \mathrm{~N} 1101537 \mathrm{~W}$

361005 N1113924W

\begin{tabular}{|c|c|c|}
\hline $\begin{array}{l}\text { SOURCE } \\
\text { COORDINATE }\end{array}$ & $\begin{array}{c}\text { ELEV } \\
\text { FT }\end{array}$ & MAP NAME \\
\hline $\begin{array}{l}361244 N 1092019 \mathrm{~W} \\
312955 \mathrm{~N} 1103526 \mathrm{~W}\end{array}$ & 5299 & $\begin{array}{l}\text { Moenave } \\
\text { Russell Spring } \\
\text { Russell Spring } \\
\text { Mummy Cave Ruins } \\
\text { Mummy Cave Ruins } \\
\text { Canelo Pass } \\
\text { Rhodes Canyon } \\
\text { Rose Peak }\end{array}$ \\
\hline $344820 \mathrm{~N} 1115717 \mathrm{~W}$ & & $\begin{array}{l}\text { Black Diamond Peak } \\
\text { Cornville }\end{array}$ \\
\hline $343136 \mathrm{~N} 1101936 \mathrm{~W}$ & & $\begin{array}{l}\text { Cornville } \\
\text { Page Springs } \\
\text { Black Mesa Wash NW } \\
\text { Sheepskin Wash } \\
\text { Sheepskin Wash } \\
\text { Greens Peak }\end{array}$ \\
\hline & & $\begin{array}{l}\text { Bumble Bee } \\
0 \mathrm{~W} \text { Point } \\
\text { Estler Peak } \\
\text { Jerome Canyon } \\
\text { Mormon Mountain } \\
\text { Sunflower Butte } \\
\text { Horse Flat } \\
\text { Wepo Village } \\
0 \mathrm{~W} \text { Point }\end{array}$ \\
\hline
\end{tabular}

Greens Peak

Greens Peak

Growler Peak

Thatcher

Cementosa Wash

Kayler Butte

Happy Jack

Sunrise Peak

May Tank Pocket

Garland Prairie

Ebert Mtn

Valle Tank

Piute Point

Turkey Mtn

Hoodoo Well

Hoodoo Well

Munds Mountain

Benson

Eureka Ranch

$24548 \mathrm{~N} 1100758$

$330330 \mathrm{~N} 1094028 \mathrm{~N}$

Bryce Mountain

$332424 \mathrm{~N} 1092115 \mathrm{~W}$

$334751 \mathrm{N1104446 \textrm {W }}$ 


\section{FEATURE NAME}

Shell Rock Tank

Shell Tank

Shelter Cove

Shelton Tank

Sheppard Wash

Sheppard Windmill

Sheridan Hills

See Sheridan Mountains

Sheridan Lake (dry) Southern Mountain

Sheridan Mountains

Cimarron Mountains Sheridan Hills Sheridan Range

Sheridan Mountains See Cimarron Mountains Sheridan Range

See Sheridan Mountains

Sheridan Tank

Sheriffs Draw

Sheriffs Mesa

Sheriffs Posse Arena

Sheriffs Posse Rodeo and

Roping Area

Sher lock Draw

Sher lock Draw Tank Number One

Sher lock Draw Tank Number Two

Sher lock Tank
Shell Mountain Tank

Sheridan Mountain

\section{FEATURE}

STATUS

COUNTY

Center

Sherwood Park

Sherwood Post office

Sherwood Shopping Center

Sheuy Well

Shevion

See Chevelon Creek

Shevlon Creek

See Chet Tank

Shevlons Butte

See Chevelon Butte

Sheza Butte

Shibel1, Mount

Shields Lateral

Shilchin Bito Canyon See Chilchinbito Canyon

Shiloh Canyon (subdivision)

Shilo Tank

Shi-mo-pavi

See Shongopov

Shi-mo-pavi Spring

See Shongopovi Spring

Shimopovi

See Shongopovi

Shimopovi Spring

See Shongopovi Spring

Shinarump $\mathrm{Cl}$ iff

Shin-ar-ump Cliffs

Shin-ar-ump Cliffs

See Shinarump Cliffs

Shinarump Point

Shiner Ranch

Shiner Tank

Shingle Canyon reservoir

reservoir

reservoir

bay

reservoir

stream

locale

summit

BGN

BGN

BGN

BGN

BGN

BGN

VARIANT

lake

summit

BGN

BGN

VARIANT

BGN 1941

VARIANT

VARIANT

VARIANT

VARIANT

summit

summit

VARIANT

Pima

Pima

reservoir

valley

summit

building

park

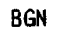

$B G N$

BGN

UNOFF

ADMIN

valley

reservoir

reservoir

reservoir

BGN

BGN

BGN
BGN

park

spring

spring

arroyo

ppl

locale

locale

park

building

ADMIN

$B G N$
$B G N$

BGN

BGN

UNOFF

Gila 340505N1104736W

Yavapai 350246N1122015W

Navajo 342547N1102813W

Mohave $\quad 360456 \mathrm{~N} 1144250 \mathrm{~W}$

Mohave 344704N1132302W

Yavapai 342056N1123942W

Yavapai

Pima

$342136 \mathrm{~N} 1123833 \mathrm{~W}$

$322356 \mathrm{~N} 1120607 \mathrm{~W}$

Yavapai

Yavapai

Pima

$343952 \mathrm{~N} 1125400 \mathrm{~W}$

$344202 N 1125249 \mathrm{~W}$

$322356 \mathrm{~N} 1120607 \mathrm{~W}$

$322821 N 1120905 \mathrm{~W}$

$322356 \mathrm{~N} 1120607 \mathrm{~W}$

Yavapai 344119N1125209W

Pima 314236N1111049W

Pina

Cochise

Graham

$314328 \mathrm{~N} 1111128 \mathrm{~W}$

$321517 \mathrm{~N} 1095055 \mathrm{~W}$

$324952 \mathrm{~N} 1094540 \mathrm{~W}$

Apache

Apache

Apache

Apache

$340350 \mathrm{~N} 1093515 \mathrm{~W}$

$340457 \mathrm{~N} 1093433 \mathrm{~W}$

$340345 \mathrm{~N} 1093445 \mathrm{~W}$

$340351 \mathrm{N1093501 \textrm {W }}$

Maricopa

Graham

Yavapai

Yavapai

Coconino

Coconino

Maricopa

ADMIN Maricopa

$332625 N 1120613 \mathrm{~W}$

$331052 \mathrm{~N} 1101934 \mathrm{~W}$

$345621 \mathrm{N1} 130130 \mathrm{~W}$

345416 N1130455W

$351426 \mathrm{~N} 1120239 \mathrm{~W}$

$351058 \mathrm{~N} 1113940 \mathrm{~W}$

$332452 \mathrm{~N} 1114820 \mathrm{~W}$

$332315 N 1114844 \mathrm{~W}$

$332443 \mathrm{N1114814W}$

well

UNOFF

UNOFF

VARIANT

stream

VARIANT

reservoir

VARIANT

summit

BGN

summit $\quad B G N$

cana

BGN

valley

ppl

reservoir $B G$

ppl

spring

ppl

Maricopa

Santa Cruz

$332849 \mathrm{~N} 1115734 \mathrm{~W}$

$313236 \mathrm{~N} 1105604 \mathrm{~W}$

Navajo

345704N1103118W

Pinal

325640N1102833W

Coconino

Navajo

Santa Cruz

344133N1105053W

Navajo

Maricopa

Coconino

Navajo

Navajo

Navajo

VARIANT

spring

cliff

BGN

VARIANT

VARIANT

clif

cliff

locale
reservoir

BGN

UNOFF

BGN

BGN
Navajo

Coconino

Coconino

Coconino

Coconino

Coconino

Navajo

\begin{tabular}{|c|c|c|}
\hline $\begin{array}{l}\text { SOURCE } \\
\text { COORDINATE }\end{array}$ & $\begin{array}{c}\text { ELEV } \\
\text { FT }\end{array}$ & MAP NAME \\
\hline $342458 \mathrm{~N} 1123449 \mathrm{~W}$ & & $\begin{array}{l}\text { Gentry Mtn } \\
\text { Matterhorn } \\
\text { Aripine } \\
\text { Hoover Dam } \\
\text { Cedar Bas in } \\
\text { Peeples Valley } \\
\text { Peeples Valley }\end{array}$ \\
\hline
\end{tabular}

Sheridan Mtn

6199 Sheridan Mtn

Drew Spring Well
$344138 N 1100743 W$

$313030 \mathrm{~N} 1105736 \mathrm{~W}$

323512N1144340W

$363125 N 100248 \mathrm{~W}$

$333505 N 1115044 \mathrm{~W}$

$354626 \mathrm{~N} 1122648 \mathrm{~W}$

354820N1103138W

$354830 \mathrm{~N} 1103145 \mathrm{~W}$

354820N1103138W

5727 Flattop Hill

5146 San Cayetano Mts

Somerton

1410 Sawik Mountain Little Harpo Canyon

$354 B 30 N 1103145 W$ $365855 \mathrm{~N} 1122548 \mathrm{~W}$

$365855 \mathrm{~N} 1122548 \mathrm{~W}$ $365924 \mathrm{~N} 1122949 \mathrm{~W}$

$351105 \mathrm{~N} 1120826 \mathrm{~W}$

$351043 \mathrm{~N} 1120819 \mathrm{~W}$

341800 N1102143W
Shinarump Point

Shinarump Point

Williams South

Williams South

Clay Springs 
NATIONAL GAZETTEER--ARIZONA 1986

\section{FEATURE NAME}

Shingle Canyon

Shingle Canyo

See Cottonwood Canyon

Shingle Mill Canyon

Shingle Mill Mesa Thirty Five

$$
\text { Trail }
$$

Shingle Mill Mountain

Shingle Spring

Shinuma Altar

See Shinumo Altar

Shinumo Altar

Shinuma Altar

Shinumo Amphitheater

Shinumo Creek

Shinumo Creek

See Big Spring Canyon

Shinumo Rapids

Shinumo Wash

Shi-paui-i-luvi

See Shipolovi

Shi-pau-i-luvi

See Shipolovi

Shipaulavi

See Shipolovi

Shipaulov

See Shipolovi

Ship Dam Tank

See Little Freeman Tank

Shipley Tank

Shipley We1l

Shipley Well
Shipolia
See Shipolovi
Shipolovi
Ah-le-la
Ahela
Ci-pau-lo-vi
Sha-pah-la
Sha-pah-lah-lwee
Shi-paui-i-luvi
Shi-pau-i-luvi
Shipaulavi
Shipaulovi
Shipolia
Shipowlawe
Sipaulovi

Shipolovi Community Building

Shipowlawe

See Shipolovi

Shipping Pasture Tank

Shipping Pasture Tank

Shipping Pasture Tank

Shipping Pasture Tank

Shipping Tank

Shipp Ranch

Ship Rock

Shiprock

Shipyard Tank

Shira Temple

Shirley Well

Shirttail Hills

Shirttail Mesa

Shirttail Spring

Shiva Temple

Shivers Trap Spring

Shivwits Plateau Sanur Plateau

Sheavwitz Plateau

Shiwits Plateau

Shiwitz Plateau

Shiwits Plateau

See Shivwits Plateau

Shiwitz Plateau
FEATURE

CLASS

STATUS

COUNTY

COORDINATE

350143N1141247W

valle

valley

valley

BGN

VARIANT

trail

summit

spring

summit

BGN

Mohave

Mohave

Graham

Graham

BGN

BGN

Graham

Navajo

Coconino

350616 N1140035W

$324733 \mathrm{~N} 1095312 \mathrm{~W}$

324627 N1095428W

$324534 N 1095457 \mathrm{~W}$

$341707 \mathrm{~N} 1102231 \mathrm{~W}$

362600 N1114253W

summit BGN

bas in

BGN

$362600 N 1114253 \mathrm{~W}$

strean

BGN 1932

VARIANT

valley

rapids

stream

ppl

BGN 1932

BGN

VARIANT

Coconino

$361732 \mathrm{~N} 1121423 \mathrm{~W}$

Coconino

361412 N1122058W

Coconino

Coconino

Coconino

Navajo

361905 N1121530W

$361416 \mathrm{~N} 1122112 \mathrm{~W}$

363148 N1114958W

$354830 \mathrm{~N} 1102944 \mathrm{~W}$

VARIANT

pp 1

Navajo

354830N1102944W

ppl

VARIANT

pp 1

Navajo

354830N1102944W

Navajo

354830N1102944W

reservoir reservoir well

Coconino

$353021 \mathrm{~N} 1123140 \mathrm{~W}$

VARIANT

UGN

wel

UNOFF VARIANT

ppl

ppl

BGN

VARIANT

VARIANT

VARIANT

VARIANT

VARIANT

VARIANT

VARIANT

VARIANT

VARIANT

VARIANT

VARIANT

VARIANT

bu

building UNOFF

VARIANT

reservoir

reservoir

reservoir

reservoir

reservoir

locale

is land

Yavapai

$352320 \mathrm{~N} 1132259 \mathrm{~W}$

$342055 N 1122444 \mathrm{~W}$

Mohave

$353136 N 1132225 \mathrm{~W}$

354B3ON1102944W

$354830 \mathrm{~N} 1102944 \mathrm{~W}$

Navajo

Navajo

BGN

BGN

BGN

BGN

UNOFF

summit

reservoir

summit

well 1

summit

summit

spring

summit

spring

plain

BGN

BGN 1906

UNOFF

BGN

BGN

BGN

BGN 1906

BGN

BGN

BGN 1974

VARIANT

VARIANT

VARIANT

VARIANT

VARIANT

plain

VARIANT
Mohave

$362500 \mathrm{~N} 1133001 \mathrm{~W}$
54830 N1102944W $340024 N 1110035 \mathrm{~W}$

$344605 \mathrm{~N} 1112635 \mathrm{~W}$

$350220 N 1093834 \mathrm{~W}$

352947 N1133131W

$343732 \mathrm{~N} 1114236 \mathrm{~W}$

$\begin{array}{ll}\text { Mohave } & 343155 \mathrm{~N} 1132732 \mathrm{~W} \\ \text { Maricopa } & 333348 \mathrm{~N} 1112947 \mathrm{~W}\end{array}$

Yavapai 342036N1131107W

$340235 N 1093551 \mathrm{~W}$

UNKNOWN

$314145 \mathrm{~N} 1111723 \mathrm{~W}$

$335315 \mathrm{~N} 1122409 \mathrm{~W}$

344641 N1131025W

$360952 N 1120937 \mathrm{~W}$

\begin{tabular}{|c|c|c|}
\hline $\begin{array}{l}\text { SOURCE } \\
\text { COORDINATE }\end{array}$ & $\begin{array}{c}\text { ELEV } \\
\text { FT }\end{array}$ & MAP NAME \\
\hline $350637 \mathrm{~N} 1135713 \mathrm{~W}$ & & Kingman SW \\
\hline 324407 N1095358W & & $\begin{array}{l}\text { Shingle Mill Mtn } \\
\text { Shingle Mill Mtn }\end{array}$ \\
\hline & 6323 & $\begin{array}{l}\text { Shingle Mill Mtn } \\
\text { Day Spring }\end{array}$ \\
\hline & 6520 & Shinumo Altar \\
\hline $361906 \mathrm{~N} 1121544 \mathrm{~W}$ & & $\begin{array}{l}\text { Kanabownits Spring } \\
\text { Havasupai Point }\end{array}$ \\
\hline $362739 \mathrm{~N} 1113627 \mathrm{~W}$ & & $\begin{array}{l}\text { Havasupai Point } \\
\text { North Canyon Point }\end{array}$ \\
\hline
\end{tabular}

Cherokee Point Battleship Butte

Nelson

Polacca

Polacca

$\begin{array}{ll}\text { Yavapai } & 344545 \mathrm{~N} 1125510 \mathrm{~W} \\ \text { Mohave } & 362500 \mathrm{~N} 1133001 \mathrm{~W}\end{array}$

$\begin{array}{ll}\text { Yavapai } & 344545 \mathrm{~N} 1125510 \mathrm{~W} \\ \text { Mohave } & 362500 \mathrm{~N} 1133001 \mathrm{~W}\end{array}$ 


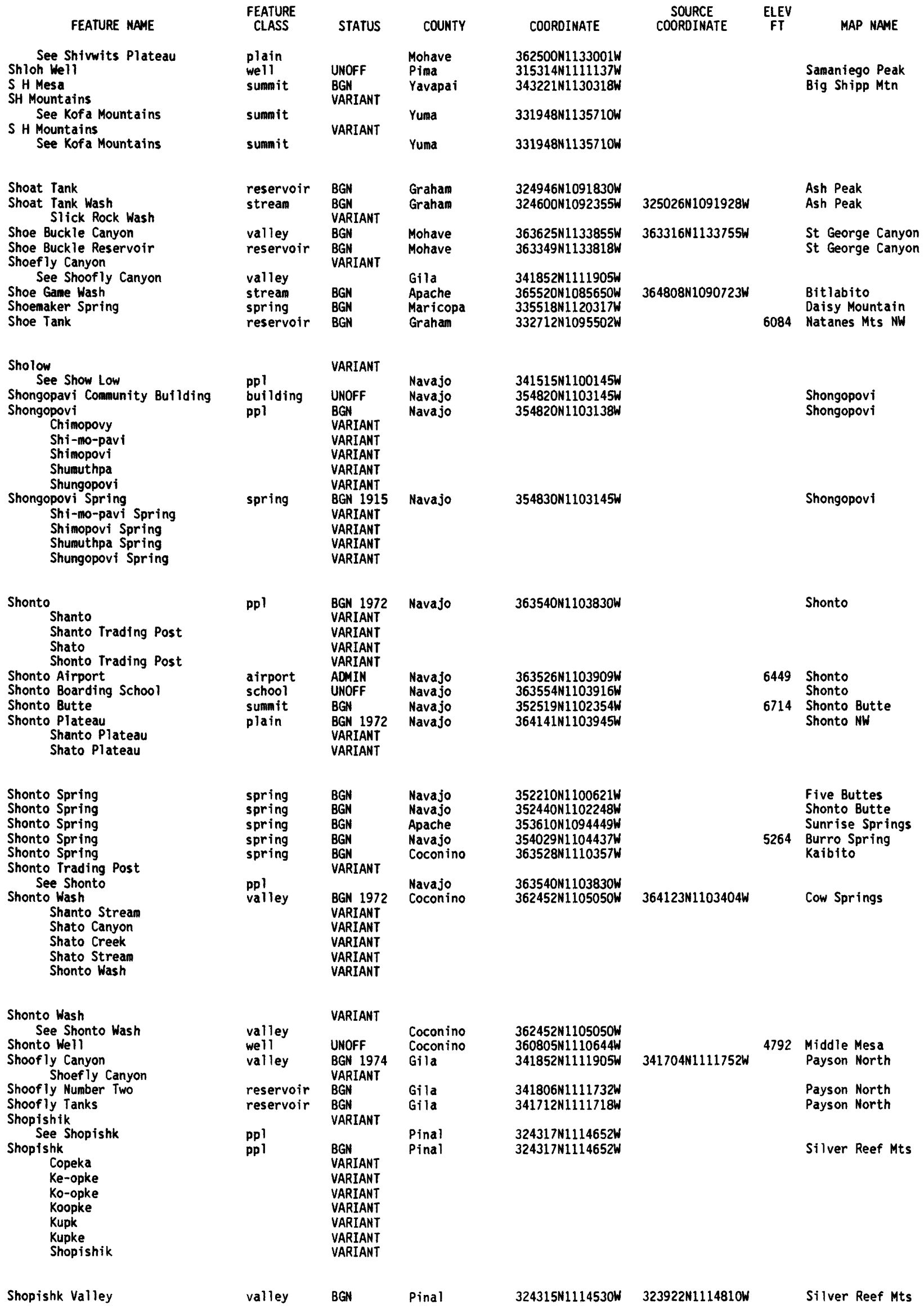




\begin{tabular}{|c|c|c|c|c|c|c|c|}
\hline FEATURE NAME & $\begin{array}{l}\text { FEATURE } \\
\text { CLASS }\end{array}$ & STATUS & COUNTY & COORDINATE & $\begin{array}{l}\text { SOURCE } \\
\text { COORDINATE }\end{array}$ & $\begin{array}{c}\text { ELEV } \\
\text { FT }\end{array}$ & MAP NAME \\
\hline $\begin{array}{l}\text { Short Chops } \\
\text { Short Creek } \\
\text { Short Creek } \\
\text { Short Creek } \\
\text { See Fort Pearce Wash } \\
\text { Short Creek } \\
\text { See Cane Beds } \\
\text { Short Creek } \\
\text { See Colorado City }\end{array}$ & $\begin{array}{l}\text { valley } \\
\text { strean } \\
\text { streain } \\
\text { strean } \\
\text { locale } \\
\text { ppl }\end{array}$ & $\begin{array}{l}\text { BGN } \\
\text { BGN } \\
\text { BGN } 1979 \\
\text { VARIANT } \\
\text { VARIANT } \\
\text { VARIANT }\end{array}$ & $\begin{array}{l}\text { Gila } \\
\text { Yavapai } \\
\text { Mohave } \\
\text { Mohave } \\
\text { Mohave } \\
\text { Mohave }\end{array}$ & $\begin{array}{l}334842 N 1105011 W \\
345514 N 1131820 \mathrm{~W} \\
365825 \mathrm{~N} 1131610 \mathrm{~W} \\
370430 \mathrm{~N} 1133433 \mathrm{~W} \\
365647 \mathrm{~N} 1125337 \mathrm{~W} \\
365925 \mathrm{~N} 1125830 \mathrm{~W}\end{array}$ & $\begin{array}{l}335010 N 1104915 W \\
345434 N 1131732 W \\
370425 N 1125553 W\end{array}$ & & $\begin{array}{l}\text { Sombrero Peak } \\
\text { Mohon Peak } \\
\text { Rock Canyon }\end{array}$ \\
\hline $\begin{array}{l}\text { Short Creek, Lakes of } \\
\text { Short Creek Reservoir Number } \\
\text { Two } \\
\text { Short Creek Reservoir Number } \\
\text { Two Dam } \\
\text { Short Creek Souths ide Number } \\
\text { Two } \\
\text { Short Creek Souths ide Number } \\
\text { Two Dam } \\
\text { Short Creek Tank }\end{array}$ & $\begin{array}{l}\text { lake } \\
\text { reservoir } \\
\text { dan } \\
\text { reservoir } \\
\text { dan } \\
\text { reservoir }\end{array}$ & $\begin{array}{l}\text { BGN } \\
\text { UNOFF } \\
\text { UNOFF } \\
\text { UNOFF } \\
\text { UNOFF }\end{array}$ & $\begin{array}{l}\text { Mohave } \\
\text { Mohave } \\
\text { Mohave } \\
\text { Mohave } \\
\text { Mohave }\end{array}$ & $\begin{array}{l}365646 \mathrm{~N} 1130010 \mathrm{~W} \\
365930 \mathrm{~N} 1125800 \mathrm{~W} \\
365930 \mathrm{~N} 1125800 \mathrm{~W} \\
365930 \mathrm{~N} 1125800 \mathrm{~W} \\
365930 \mathrm{~N} 1125800 \mathrm{~W} \\
351336 \mathrm{~N} 1130216 \mathrm{~W}\end{array}$ & & 5829 & $\begin{array}{l}\text { Lost Spring Mtn East } \\
\text { Colorado City } \\
\text { Colorado City } \\
\text { Colorado City } \\
\text { Colorado City } \\
\text { Squaw Peak }\end{array}$ \\
\hline $\begin{array}{l}\text { Short Grass Canyon } \\
\text { Shorthair Well } \\
\text { Short Horn Montains } \\
\text { See Kofa Mountains } \\
\text { Shorty Canp Spring } \\
\text { Shorty Davis Tank } \\
\text { Shortys Canyon } \\
\text { Shortys Well } \\
\text { Shorty Tank } \\
\text { Shorty Tank }\end{array}$ & $\begin{array}{l}\text { valley } \\
\text { well } \\
\text { sumit } \\
\text { spring } \\
\text { reservoir } \\
\text { valley } \\
\text { well } \\
\text { reservoir } \\
\text { reservoir }\end{array}$ & $\begin{array}{l}\text { BGN } \\
\text { UNOFF } \\
\text { VARIANT } \\
\text { BGN } \\
\text { BGN } \\
\text { BGN } \\
\text { UNOFF } \\
\text { BGN } \\
\text { BGN }\end{array}$ & $\begin{array}{l}\text { Apache } \\
\text { Apache } \\
\text { Yuna } \\
\text { Gila } \\
\text { Yavapai } \\
\text { Yavapai } \\
\text { Grahan } \\
\text { Gila } \\
\text { Yavapai }\end{array}$ & $\begin{array}{l}365826 \mathrm{~N} 1094058 \mathrm{~W} \\
365809 \mathrm{~N} 1090545 \mathrm{~W} \\
331948 \mathrm{~N} 1135710 \mathrm{~W} \\
333952 \mathrm{N1} 103800 \mathrm{~W} \\
351154 \mathrm{~N} 1130935 \mathrm{~W} \\
340519 \mathrm{N1} 121456 \mathrm{~W} \\
330912 \mathrm{~N} 1094642 \mathrm{~W} \\
334143 \mathrm{~N} 1102433 \mathrm{~W} \\
351831 \mathrm{~N} 1125825 \mathrm{~W}\end{array}$ & 365948 N1093848W & & $\begin{array}{l}\text { Haystack Butte } \\
\text { Cross Mtn } \\
\text { Black Canyon City } \\
\text { Bonita Tank } \\
\text { Brushy Canyon } \\
\text { Seligman West }\end{array}$ \\
\hline $\begin{array}{l}\text { Shoshone Park } \\
\text { Shoshone Point } \\
\text { Crenation Point } \\
\text { Shot Up Tank } \\
\text { Shot Up Well } \\
\text { Shovel Spring } \\
\text { Shower Point Campground } \\
\text { Shower Spring } \\
\text { Show Low } \\
\text { Sholow }\end{array}$ & $\begin{array}{l}\text { park } \\
\text { cliff } \\
\text { reservoir } \\
\text { well } \\
\text { spring } \\
\text { park } \\
\text { spring } \\
\text { ppl }\end{array}$ & $\begin{array}{l}\text { ADMIN } \\
\text { BGN } 1906 \\
\text { VARIANT } \\
\text { BGN } \\
\text { UNOFF } \\
\text { BGN } \\
\text { ADMIN } \\
\text { BGN } \\
\text { BGN } 1933 \\
\text { VARIANT }\end{array}$ & $\begin{array}{l}\text { Maricopa } \\
\text { Coconino } \\
\text { Mohave } \\
\text { Mohave } \\
\text { Pina } \\
\text { Pima } \\
\text { Gila } \\
\text { Navajo }\end{array}$ & $\begin{array}{l}333235 N 1115410 \mathrm{~W} \\
360241 \mathrm{~N} 1120332 \mathrm{~W} \\
\\
343606 \mathrm{~N} 1140247 \mathrm{~W} \\
343902 \mathrm{~N} 1140431 \mathrm{~W} \\
322638 \mathrm{~N} 1104852 \mathrm{~W} \\
322429 \mathrm{N1} 104314 \mathrm{~W} \\
335157 \mathrm{~N} 1101300 \mathrm{~W} \\
341515 \mathrm{~N} 1100145 \mathrm{~W}\end{array}$ & & $\begin{array}{l}1819 \\
7800 \\
6347\end{array}$ & $\begin{array}{l}\text { Paradise Valley } \\
\text { Phanton Ranch } \\
\text { Buck Mountains SE } \\
\text { Buck Mountains NE } \\
\text { Mt Lemmon } \\
\text { Mount Bigelow } \\
\text { Cone Butte } \\
\text { Show Low North }\end{array}$ \\
\hline $\begin{array}{l}\text { Show Low City Park } \\
\text { Showlow Creek } \\
\text { See Wainut Creek } \\
\text { Show Low Creek } \\
\text { See Walnut Creek } \\
\text { Showlow Creek } \\
\text { See Show Low Creek } \\
\text { Show Low Creek } \\
\text { Showlow Creek } \\
\text { Showlow Creek } \\
\text { See Silver Creek }\end{array}$ & $\begin{array}{l}\text { park } \\
\text { stream } \\
\text { stream } \\
\text { stream } \\
\text { strean }\end{array}$ & $\begin{array}{l}\text { ADMIN } \\
\text { VARIANT } \\
\text { VARIANT } \\
\text { VARIANT } \\
\text { BGN } 1950 \\
\text { VARIANT } \\
\text { VARIANT }\end{array}$ & $\begin{array}{l}\text { Navajo } \\
\text { Navajo } \\
\text { Navajo } \\
\text { Navajo } \\
\text { Navajo } \\
\text { Navajo }\end{array}$ & $\begin{array}{l}341442 \mathrm{~N} 1100325 \mathrm{~W} \\
340950 \mathrm{~N} 1095848 \mathrm{~W} \\
340950 \mathrm{~N} 1095848 \mathrm{~W} \\
342530 \mathrm{~N} 1100400 \mathrm{~W} \\
342530 \mathrm{~N} 1100400 \mathrm{~W} \\
344424 \mathrm{~N} 1100217 \mathrm{~W}\end{array}$ & 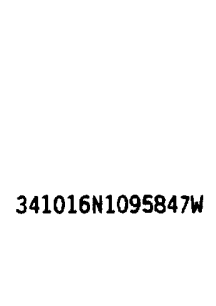 & & Show Low South \\
\hline $\begin{array}{l}\text { Show Low Creek Bridge } \\
\text { Show Low Dan } \\
\text { See Jacques Dam } \\
\text { Show Low Elementary School } \\
\text { Show Low High School } \\
\text { Show Low Junior High School } \\
\text { Show Low Lake } \\
\text { Jacques Lake } \\
\text { Lake Showlow } \\
\text { Lake Show Low }\end{array}$ & $\begin{array}{l}\text { bridge } \\
\text { dan } \\
\text { school } \\
\text { school } \\
\text { school } \\
\text { reservoir }\end{array}$ & $\begin{array}{l}\text { UNOFF } \\
\text { VARIANT } \\
\text { UNOFF } \\
\text { UNOFF } \\
\text { UNOFF } \\
\text { BGN } \\
\text { VARIANT } \\
\text { VARIANT } \\
\text { VARIANT }\end{array}$ & $\begin{array}{l}\text { Navajo } \\
\text { Navajo } \\
\text { Navajo } \\
\text { Navajo } \\
\text { Navajo } \\
\text { Navajo }\end{array}$ & $\begin{array}{l}342507 N 1100504 \mathrm{~W} \\
341140 \mathrm{~N} 1100018 \mathrm{~W} \\
341502 N 1100200 \mathrm{~W} \\
341529 \mathrm{~N} 1100247 \mathrm{~W} \\
341457 \mathrm{~N} 1100200 \mathrm{~W} \\
341140 \mathrm{~N} 1100013 \mathrm{~W}\end{array}$ & & $\begin{array}{l}6300 \\
6542\end{array}$ & $\begin{array}{l}\text { Show Low North } \\
\text { Show Low North } \\
\text { Show Low South } \\
\text { Show Low South }\end{array}$ \\
\hline $\begin{array}{l}\text { Show Low Library } \\
\text { Show Low Municipal Airport } \\
\text { Show Low Post Office } \\
\text { Show Low Town Hal1 } \\
\text { Show Low Well } \\
\text { Show Pockets Tank } \\
\text { S H Peak } \\
\text { S H Ranch } \\
\text { Shroder Tank } \\
\text { Shrug Nakya } \\
\text { See Wolfley H } 111\end{array}$ & $\begin{array}{l}\text { building } \\
\text { airport } \\
\text { building } \\
\text { building } \\
\text { well } \\
\text { reservoir } \\
\text { suanit } \\
\text { locale } \\
\text { reservoir } \\
\text { summit }\end{array}$ & $\begin{array}{l}\text { UNOFF } \\
\text { ADNIN } \\
\text { UNOFF } \\
\text { UNOFF } \\
\text { UNOFF } \\
\text { BGN } \\
\text { BGN } \\
\text { UNOFF } \\
\text { BGN } \\
\text { VARIANT }\end{array}$ & $\begin{array}{l}\text { Navajo } \\
\text { Navajo } \\
\text { Navajo } \\
\text { Navajo } \\
\text { Navajo } \\
\text { Mohave } \\
\text { Yavapai } \\
\text { Yavapai } \\
\text { Yavapai } \\
\text { Pima }\end{array}$ & $\begin{array}{l}341459 \mathrm{~N} 1100208 \mathrm{~W} \\
341555 \mathrm{~N} 1095955 \mathrm{~W} \\
341512 \mathrm{~N} 1100202 \mathrm{~W} \\
341511 \mathrm{~N} 1100208 \mathrm{~W} \\
341855 \mathrm{~N} 1100030 \mathrm{~W} \\
361122 \mathrm{~N} 1132027 \mathrm{~W} \\
345928 \mathrm{~N} 1131640 \mathrm{~W} \\
343235 \mathrm{~N} 1130406 \mathrm{~W} \\
343946 \mathrm{~N} 1123659 \mathrm{~W} \\
\\
313821 \mathrm{~N} 1120020 \mathrm{~W}\end{array}$ & & $\begin{array}{l}6400 \\
6411 \\
6300 \\
6300 \\
6400\end{array}$ & $\begin{array}{l}\text { Show Low South } \\
\text { Silver Springs } \\
\text { Show Low North } \\
\text { Show Low North } \\
\text { Show Low North } \\
\text { Whitmore Point } \\
\text { Mohon Peak } \\
\text { Big Shipp Mtn } \\
\text { Jerome Canyon }\end{array}$ \\
\hline
\end{tabular}


FEATURE NAME

Shucking Tank

Shuffs Tank

Shulte Spring

Shults Spring

Shultz

See Mammoth

Shultz Mine

See Mammoth Mine

Shultz Spring

Shumay

See Shumway

Shumuthpa

See Shongopovi

Shumuthpa Spring

Shumway

Shongopovi Spring$$
\text { Shumay }
$$

Shumway Butte

Shumway Cemetery

Shumway Tank

Shungopovi

See Shongopovi

Shungopovi Spring

See Shongopovi Spring

Shurtlett Spring

Shush Be Tou

Shush Be Tou Campgrounds

Shush Be Tou Dam

$$
\text { Big Bear Dam }
$$

Shush Bezahze

Shush Bezahze Campgrounds

Shush Bezahze Dam Little 8ear Dam

Shute Road Well

Shute Spring

See Shute Springs

Shute Springs Shute Spring

Shute Springs Creek

Shute Tank

Shute Tank Number Two

Shuunakia

See Ak Komelik

Shylock Mine

Sialatuk

Siby 1

See Schuchuli

Sibyl Interchange

Sibyl Railroad Station

Sichimovi

See Sichomovi

Sichomivi

See Sichomovi

Si-chom-ivi

See Sichomovi

Sichomovi

Itt'hagi

Sichimovi

Si-chom-ivi

Sichomivi

Siclehema

See Sikul Himatk

Side Hill Claim

Sidehill Spring

Sidehill Tank

Side Mountain

Side Oat Tank

Side Rock Campground

Side Rock Well

Sides Knoll

Sides Lake

Sid Simpson Spring

\section{FEATURE}

CLASS

STATUS

reservoir $B$

reservoir BGM

spring $B G$

$\begin{array}{ll}\text { spring } & \text { BGN } \\ & \text { VARIANT }\end{array}$

ppl

mine

spring

ppl

VARIANT

BGN

VARIANT

VARIANT

pp

spring

pp1

summit

reservoir

ppl

VARIANT

BGN

VARIANT

BGN

UNOFF

BGN
VARIANT

VARIANT

spring

spring

reservoir

park

dam

reservoir

park

dam

BGN

BGN

ADMIN

UNOFF

VARIANT

BGN

ADMIN

UNOFF

VARIANT

well

UNOFF

spring

spring

stream

reservoir

reservoir

VARIANT

BGN

VARIANT

BGN

BGN
$8 G N$

VARIANT

locale

UNOFF

ppl

VARIAN

crossing

building

BGN

UNOFF

UNOFF

VARIANT

pp 1

VARIANT

ppl

Navajo

Yavapal

Apache

Apache

Apache

Apache

Apache

Apache

Gila

Gila

Gila

Gila

Pima

Gila

Pima

Yavapai

Pima

Cochise

Cochise

Cochise

Navajo

Navajo

VARIANT

ppl
ppl

BGN

Navajo

Navajo

VARIANT

VARIANT

VARIAN

VARIANT

VARIANT

pp $]$

min

spring

reservoir

summit

reservoir

park

well

summit
lake

sprin

Pima

UNOFF Cochise

Apache

Gila

Coconino

Gila

Apache

Apache

Pima
COORDINATE

352541 N1124128W

344629 N1112511W

$335557 N 1115605 \mathrm{~W}$

$361037 \mathrm{~N} 1131806 \mathrm{~W}$

$324321 \mathrm{N1103824W}$

324223N1104103W

$324123 N 1104245 W$

342422 N110042OW

$354820 \mathrm{~N} 1103138 \mathrm{~W}$

$354830 \mathrm{~N} 1103145 \mathrm{~W}$

$342422 \mathrm{~N} 1100420 \mathrm{~W}$

$342331 \mathrm{~N} 1100418 \mathrm{~W}$

$342428 \mathrm{~N} 1100457 \mathrm{~W}$

$342403 N 1102542 \mathrm{~W}$

$354820 \mathrm{~N} 1103138 \mathrm{~W}$

$354830 \mathrm{~N} 1103145 \mathrm{~W}$

341254 N1121929W

340344N1094405W

$340347 N 1094355 \mathrm{~W}$

$340330 \mathrm{N1O}$ 0933OW

$340334 \mathrm{N1094326 \textrm {W }}$

$340321 \mathrm{N1094325W}$

$340342 \mathrm{~N} 1094412 \mathrm{~W}$

$333524 N 1105002 W$

$333535 \mathrm{~N} 1105238 \mathrm{~W}$

$333535 \mathrm{N1} 105238 \mathrm{~W}$

333717 N1105424W

$313749 \mathrm{N1113319 \textrm {W }}$

$333441 \mathrm{N1} 105140 \mathrm{~W}$

314304N1121202W

$343719 N 1121104 \mathrm{~W}$

$321320 \mathrm{~N} 1124115 \mathrm{~W}$

$315706 \mathrm{~N} 1101136 \mathrm{~W}$

$315933 N 1101032 \mathrm{~W}$

$315710 N 1101031 \mathrm{~W}$

355007 N1102337W

$355007 \mathrm{~N} 1102337 \mathrm{~W}$

$355007 \mathrm{N1102337 \textrm {W }}$

$355007 \mathrm{~N} 1102337 \mathrm{~W}$

Coconino

Coconino

320654 N1120206W

$314659 N 1094942 W$

$335708 \mathrm{~N} 1105218 \mathrm{~W}$

$334730 \mathrm{~N} 1101536 \mathrm{~W}$

$345812 \mathrm{~N} 1114500 \mathrm{~W}$

$361505 \mathrm{~N} 1105 \mathrm{~B} 37 \mathrm{~W}$

$342046 \mathrm{~N} 1094637 \mathrm{~W}$

$342021 \mathrm{~N} 1094705 \mathrm{~W}$

$315414 \mathrm{N1111145 \textrm {W }}$
SOURCE ELEV

MAP NAME

Mount Floyd

Hutch Mtn

New River Mesa

Whitmore Point

Mamnoth

Taylor

6117 Taylor

Taylor

Aripine

Crown King

7808 Horseshoe Cienega

7820 Horseshoe Cienega

Horseshoe Cienega

7898 Horseshoe Cieneg

7900 Horseshoe Cienega

Horseshoe Cienega

Rockinstraw Mtn

Salt River Peak

$333602 N 1105117$

Salt River Peak

Mildred Peak

Rockinstraw Mtn

Humboldt

Saint David

Saint David

Saint David

Polacca

$364935 \mathrm{~N} 1091013 \mathrm{~W}$

355439 N1113645W

urquoise Mountain

Pastora Peak

Rock House 
NATIONAL GAZETTEER--ARIZONA 1986

FEATURE MAME

Siegfried Pyre

Siemond Ranch

Sierra Ancha Experimental

Forest

Sierra Ancha Mountains

See Ancha, Sierra

Sierra Ancha Wilderness Area

Sierra Apache

See Apache Peaks

Sierra Arida

\section{Sierra Arteza}

See Artesa Mountains

Sierra Atascosa

See Tumacacori Mountains

Sierra Babququvari

See Baboquivari Mountains

Sierra Blanca, Lake

Sierra Blanca Canyon

Sierra 81 anca Dan

Sierra Blanca Mountains

See Blanca, Sierra

Sierra Blanca Spring

Sierra Blanco

See Blanca, Sierra

Sierra Bonita Mountains See Pinaleno Mountains

Sierra Bonita Ranch

Sierra Canyon

Sierra Colorado

See Rincon Mountains

Sierra de

See Guadalupe Mountains

Sierra de la Cabeza Prieta See Cabeza Prieta Mountains

Sierra de la Espuma

See Superstition Mountains

Sierra de la Frente Negna

See Sentinel Peak

Sierra de la Gila

See Gila Mountains

Sierra del Ajo

See Ajo Range

Sierra del Ajo

See Ajo, Mount

Sierra de la Naril

See Ajo Range

Sierra de la Nariz

See Ajo Range

Sierra de la Saint Catarina

See Santa Catalina

Mountains

Sierra de las Animas

See Animas Mountain, Las

Sierra de la Santa Cruz

See Canelo Hills

Sierra de la Tinaja

See Tinajas Altas Mountains

Sierra de la Union

See Morena Mountain

Sierra de la Union Mountains

See Morena Mountain

Sierra del Babuquibari

See Baboquivari Mountains

Sierra del la Morena

See Morena Mountain

Sierra de Los Pajaritos

See Pajarito Mountains

Sierra del Pajarito

See Pajarito Mountains

Sierra del Pozo Verde

See Pozo Verde Mountains
FEATURE

CLASS

STATUS

COUNTY

\begin{tabular}{|c|c|c|c|}
\hline $\begin{array}{l}\text { summit } \\
\text { locale } \\
\text { forest }\end{array}$ & $\begin{array}{l}\text { BGN } 1906 \\
\text { UNOFF } \\
\text { ADMIN }\end{array}$ & $\begin{array}{l}\text { Coconino } \\
\text { Pima } \\
\text { Gila }\end{array}$ & $\begin{array}{l}361148 \mathrm{~N} 1115426 \mathrm{~W} \\
315729 \mathrm{N1} 103131 \mathrm{~W} \\
334715 \mathrm{~N} 1105742 \mathrm{~W}\end{array}$ \\
\hline & VARIANT & & \\
\hline $\begin{array}{l}\text { range } \\
\text { park }\end{array}$ & $\begin{array}{l}\text { ADMIN } \\
\text { VARIANT }\end{array}$ & $\begin{array}{l}\text { Gila } \\
\text { Gila }\end{array}$ & $\begin{array}{l}335727 \mathrm{N1111110W} \\
334918 \mathrm{~N} 1105240 \mathrm{~W}\end{array}$ \\
\hline $\begin{array}{l}\text { Summit } \\
\text { ridge }\end{array}$ & BGN & $\begin{array}{l}\text { Gila } \\
\text { Yuma }\end{array}$ & $\begin{array}{l}333226 N 1104431 \mathrm{~W} \\
321308 \mathrm{~N} 1134021 \mathrm{~W}\end{array}$ \\
\hline
\end{tabular}

ridge

VARIANT

summit

range

range

lake

valley

dam

summit

spring

summit

range

locale

valley

ridge

range

VARIANT

VARIANT

BGN

UNOFF

VARIANT

Pima

Santa Cruz

Pima

Apache

Cochise

Apache

Pima

BGN

VARIANT

VARIANT

UNOFF

BGN

VARIANT

VARIANT

range

range

summit

sumait

range

range

sument

range

range

range

summit

VARIANT

VARIANT

VARIANT

VARIANT

VARIANT

Cochise

Pima

Graham

Graham

Santa Cruz

Pima

Cochise

Yuma

Pinal

Pima

Yuma

Pima

VARIANT

VARIANT

Pina

Pina

VARIANT

VARIANT

Pima

Pima

VARIAN

summit

range

sumnit

summit

range

VARIANT

VARIANT

VARIANT

VARIANT

VARIANT

Pima

Santa Cruz

Yuma

Pima

Pima

Pima

VARIANT

sumbit

VARIAN

range

range

summit
VARIANT

VARIANT
Pima

Santa Cruz

Santa Cruz

Pima
312000 N1090300W

$322059 N 1134924 \mathrm{~W}$

332543N1112503W

321237 N1105930W

$323430 \mathrm{~N} 1141833 \mathrm{~W}$

320240N1124104W

$320136 \mathrm{N1124124W}$

320240 N1124104W

320240 N1124104W

314335N1114910W

$313155 N 1103517 \mathrm{~W}$

322135N1140616W

313543 N1115236W

313543N1115236W

314723N1113510W

313543N1115236W

$312105 \mathrm{~N} 1110556 \mathrm{~W}$

$312105 \mathrm{~N} 1110556 \mathrm{~W}$

313130N1113600W
$322549 N 1104217 \mathrm{~W}$
COORDINATE

315039 N1115246W

SOURCE
COORDINATE
FT MAP NAME

7914 Walhalla Plateau The Narrows

Aztec Peak

Aztec Peak

Sierra Arida

313327N1110713W

314723N1113510W

$335230 \mathrm{~N} 1091607 \mathrm{~W}$

$321642 \mathrm{~N} 1102120 \mathrm{~W}$

$335230 \mathrm{~N} 1091612 \mathrm{~W}$

8435 Rudd Knoll

Soza Mesa

Rudd Knoll

$321245 N 1121437 \mathrm{~W}$

$321926 \mathrm{N1101800 \textrm {W }}$

Soza Mesa

$321245 N 1121437$

$323827 N 1095035 \mathrm{~W}$

$323037 \mathrm{N1} 100223 \mathrm{~W}$

$312508 \mathrm{N1112118 \textrm {W }}$

$312752 N 1111814 W$

Sierra Bonita Ranch Bartlett Mtn 


\begin{tabular}{|c|c|c|c|c|}
\hline FEATURE NAME & $\begin{array}{l}\text { FEATURE } \\
\text { CLASS }\end{array}$ & STATUS & COUNTY & COORDINATE \\
\hline $\begin{array}{l}\text { Sierra del Tule } \\
\text { See Tule Mountains }\end{array}$ & range & VARIANT & Yuma & $321109 \mathrm{N1} 134735 \mathrm{~W}$ \\
\hline $\begin{array}{l}\text { Sierra del Tule } \\
\text { See Cabeza Prieta Mountains } \\
\text { Sierra de Morenzo } \\
\text { See Morena Mountain } \\
\text { Sierra de San Ildefonso } \\
\text { See Mohave Mountains } \\
\text { Sierra de San Joseph de Cumars } \\
\text { See Estrella, Sierra } \\
\text { Sierra de San Pedro } \\
\text { See Dome Rock Mountains }\end{array}$ & $\begin{array}{l}\text { range } \\
\text { summit } \\
\text { range } \\
\text { ridge } \\
\text { range }\end{array}$ & $\begin{array}{l}\text { VARIANT } \\
\text { VARIANT } \\
\text { VARIANT } \\
\text { VARIANT } \\
\text { VARIANT }\end{array}$ & $\begin{array}{l}\text { Yuma } \\
\text { Pima } \\
\text { Mohave } \\
\text { Pinal } \\
\text { Yuma }\end{array}$ & $\begin{array}{l}322059 \mathrm{~N} 1134924 \mathrm{~W} \\
313543 \mathrm{~N} 1115236 \mathrm{~W} \\
343818 \mathrm{~N} 1142314 \mathrm{~W} \\
331253 \mathrm{~N} 1121249 \mathrm{~W} \\
334127 \mathrm{~N} 1142011 \mathrm{~W}\end{array}$ \\
\hline $\begin{array}{l}\text { Sierra de Santa Rosa } \\
\text { See Ajo Range } \\
\text { Sierra de Santiago } \\
\text { See Black Mountains } \\
\text { Sierra det Babuqibari } \\
\text { See Baboquivari Mountains } \\
\text { Sierra El Rincon } \\
\text { See Rincon Mountains } \\
\text { Sierra Escritas Piedras } \\
\text { Pintadas } \\
\text { See Painted Rock Mountains }\end{array}$ & $\begin{array}{l}\text { range } \\
\text { range } \\
\text { range } \\
\text { ridge }\end{array}$ & $\begin{array}{l}\text { VARIANT } \\
\text { VARIANT } \\
\text { VARIANT } \\
\text { VARIANT } \\
\text { VARIANT }\end{array}$ & $\begin{array}{l}\text { Pima } \\
\text { Mohave } \\
\text { Pima } \\
\text { Pima }\end{array}$ & $\begin{array}{l}320240 \mathrm{~N} 1124104 \mathrm{~W} \\
352814 \mathrm{~N} 1143038 \mathrm{~W} \\
314723 \mathrm{~N} 1113510 \mathrm{~W} \\
320755 \mathrm{~N} 1103108 \mathrm{~W}\end{array}$ \\
\hline $\begin{array}{l}\text { Sierra Galiuro Mountains } \\
\text { See Galiuro Mountains } \\
\text { Sierra las Animas } \\
\text { See Animas Mountain, Las } \\
\text { Sierra Montosa } \\
\text { See Middle Windmill } \\
\text { Sierra Montoso } \\
\text { See Middle Windmil1 } \\
\text { Sierra Montrosa } \\
\text { See Middle Windmil11 }\end{array}$ & $\begin{array}{l}\text { range } \\
\text { summit } \\
\text { locale } \\
\text { locale } \\
\text { locale }\end{array}$ & $\begin{array}{l}\text { VARIANT } \\
\text { VARIANT } \\
\text { VARIANT } \\
\text { VARIANT }\end{array}$ & $\begin{array}{l}\text { Grahan } \\
\text { Pima } \\
\text { Pima } \\
\text { Pima } \\
\text { Pima }\end{array}$ & $\begin{array}{l}323600 \mathrm{~N} 1102100 \mathrm{~W} \\
314335 \mathrm{~N} 1114910 \mathrm{~W} \\
320819 \mathrm{~N} 1112243 \mathrm{~W} \\
320819 \mathrm{~N} 1112243 \mathrm{~W} \\
320819 \mathrm{~N} 1112243 \mathrm{~W}\end{array}$ \\
\hline $\begin{array}{l}\text { Sierra Montrose } \\
\text { See Middle Windmill } \\
\text { Sierra Mo-Quin-To-Ora } \\
\text { See Done Rock Mountains } \\
\text { Sierra Moreno } \\
\text { See Morena Mountain } \\
\text { Sierra Panoche } \\
\text { See Navajo Mountain } \\
\text { Sierra Pinta Sierra Sibupuc } \\
\text { See Painted Rock Mountains }\end{array}$ & $\begin{array}{l}\text { locale } \\
\text { range } \\
\text { summit } \\
\text { sumit } \\
\text { range }\end{array}$ & $\begin{array}{l}\text { VARIANT } \\
\text { VARIANT } \\
\text { VARIANT } \\
\text { VARIANT } \\
\text { VARIANT }\end{array}$ & $\begin{array}{l}\text { Pima } \\
\text { Yuma } \\
\text { Pima } \\
\text { Coconino } \\
\text { Maricopa }\end{array}$ & $\begin{array}{l}320819 N 1112243 \mathrm{~W} \\
334127 \mathrm{~N} 1142011 \mathrm{~W} \\
313543 \mathrm{~N} 1115236 \mathrm{~W} \\
370200 \mathrm{~N} 1105210 \mathrm{~W} \\
325923 \mathrm{~N} 1130116 \mathrm{~W}\end{array}$ \\
\hline $\begin{array}{l}\text { Sierra Plaza Subdivision } \\
\text { Sierra Prieta } \\
\text { See Slate Mountains } \\
\text { Sierra Prieta } \\
\text { See Prieta Peak } \\
\text { Sierra Prieta Crest Trail } \\
\text { Nmber Two Hundred Sixty Four } \\
\text { Sierra Prieta Overlook } \\
\text { Sierra Sonoita } \\
\text { See Sonoyta Mountains }\end{array}$ & $\begin{array}{l}\mathrm{ppl} \\
\text { range } \\
\text { summit } \\
\text { trail } \\
\text { locale } \\
\text { range }\end{array}$ & $\begin{array}{l}\text { BGN } \\
\text { VARIANT } \\
\text { VARIANT } \\
\text { UNOFF } \\
\text { BGN } \\
\text { VARIANT }\end{array}$ & $\begin{array}{l}\text { Navajo } \\
\text { Pinal } \\
\text { Pinal } \\
\text { Yavapai } \\
\text { Yavapai } \\
\text { Pima }\end{array}$ & $\begin{array}{l}345438 N 1100954 \mathrm{~W} \\
323203 N 1115259 \mathrm{~W} \\
323244 N 1115319 \mathrm{~W} \\
343129 \mathrm{N1} 123405 \mathrm{~W} \\
343018 \mathrm{~N} 1123317 \mathrm{~W} \\
315508 N 1125057 \mathrm{~W}\end{array}$ \\
\hline $\begin{array}{l}\text { Sierra Spring } \\
\text { Sierra Tanks } \\
\text { Sierra Tordilla We } 11 \\
\text { Sierra Tortilato } \\
\text { See Tortilla Mountains } \\
\text { Sierra Tortillata } \\
\text { See Tortilla Mountains } \\
\text { Sierra Tortolita } \\
\text { See Tortolita Mountains } \\
\text { Sierra Verde } \\
\text { See Pozo Verde Mountains }\end{array}$ & $\begin{array}{l}\text { spring } \\
\text { reservoir } \\
\text { well } \\
\text { range } \\
\text { range } \\
\text { range } \\
\text { summit }\end{array}$ & $\begin{array}{l}\text { BGN } \\
\text { BGN } \\
\text { UNOFF } \\
\text { VARIANT } \\
\text { VARIANT } \\
\text { VARIANT } \\
\text { VARIANT }\end{array}$ & $\begin{array}{l}\text { Santa Cruz } \\
\text { Santa Cruz } \\
\text { Santa Cruz } \\
\text { Pinal } \\
\text { Pinal } \\
\text { Pima } \\
\text { Pima }\end{array}$ & $\begin{array}{l}312720 \mathrm{~N} 1111804 \mathrm{~W} \\
312606 \mathrm{~N} 1112002 \mathrm{~W} \\
312024 \mathrm{~N} 1104547 \mathrm{~W} \\
325626 \mathrm{~N} 1105625 \mathrm{~W} \\
325626 \mathrm{~N} 1105625 \mathrm{~W} \\
322925 \mathrm{~N} 1110340 \mathrm{~W} \\
313130 \mathrm{~N} 1113600 \mathrm{~W}\end{array}$ \\
\hline $\begin{array}{l}\text { Sierra Vista } \\
\text { Sierra Vista City Park } \\
\text { Sierra Vista Community Hospital } \\
\text { Sierra Vista Estates } \\
\text { (subdivision) } \\
\text { Sierra Vista Junior High School } \\
\text { Sierra Vista Ranch }\end{array}$ & $\begin{array}{l}\text { ppl } \\
\text { park } \\
\text { hospital } \\
\text { ppl }\end{array}$ & $\begin{array}{l}\text { BGN } \\
\text { ADMIN } \\
\text { UNOFF } \\
\text { BGN }\end{array}$ & $\begin{array}{l}\text { Cochise } \\
\text { Cochise } \\
\text { Cochise } \\
\text { Cochise }\end{array}$ & $\begin{array}{l}313316 \mathrm{~N} 1101811 \mathrm{~W} \\
313321 \mathrm{~W} 1101555 \mathrm{~W} \\
313305 \mathrm{~N} 1101616 \mathrm{~W} \\
312900 \mathrm{~N} 1101515 \mathrm{~W}\end{array}$ \\
\hline
\end{tabular}

5200 Holbrook

Iron Springs Iron Springs

Bartlett Mtn Bartlett Mtn Kino Springs
Fort Huachuca Fort Huachuca Fort Huachuca Miller Peak

Fort Huachuca Presumido Peak 
NATIONAL GAZETTEER--ARIZONA 1986

FEATURE NAME

Sierra Vista School

Sierra Well

Sierrita Mill

Sierrita Mine East Pit

Sierrita Mine West Pit

Sierrita Mountains

Tinajota Mountains

Sierrita Prieta

See Slate Mountains

Sierrita Tailings Dam

Sierrita Tank

Sierrita Wel

Sif Vaya

$$
\begin{aligned}
& \text { Bitters Well } \\
& \text { Bitter Well } \\
& \text { Bitter Wells } \\
& \text { Sivvaxia }
\end{aligned}
$$

Signal

Signal

See Swansea

Signal Butte

Signal Butt

Signal Butte Substation

Signal Canyon

Signal Hill

Signal Hill

Signal Hill

Signal Hill

Signal Mountain

Signal Mountain

Signal Mountain

Signal Mountains

See Coronado Mountains (historical)

Signal Peak

Signal Peak

Signal Peak

Signal Peak

Signal Peak Lookout Tower

Signal Village

Sikort Chuapo

Pozo Redondo Sikorttjuupo

Sikort Chuapo Mountains Pozo Redondo Mountains

Sikort Chuapo Wash Rio Cornez

Sikorttjuupo

See Sikort Chuapo

Sikulhamakt

See Sikul Himatk

Sikulhamatk

See Sikul Himatk

sikulhimat

See Sikul Himatk

Sikul Himatk

Siclehema

Sikulhamakt

Sikulhamatk

Sikulhimat

Vaheja

Sikul Himatk Tank

Sikul Himatk Wash

Silent Bas in

$\mathrm{Si}$ ih-Tus ayan

See Fluted Rock

Silimok

See Sil Murk (Papago)

Silinakik

See Sil Nakya

Sil Murk (Papago)

$$
\text { Silimok }
$$

FEATURE

CLASS

STATUS

COUNTY

COORDINATE

schoo

well

UNOFF
UNOFF

UNOFF

Maricopa

Santa Cruz

$333941 \mathrm{N1121107 \textrm {W }}$

$312558 \mathrm{N1112001}$

$315225 \mathrm{~N} 1110627 \mathrm{~W}$

mine UNOFF Pima 315210N1110729W

mine UNOFF Pima $315232 \mathrm{~N} 1110836 \mathrm{~W}$

range BGN Pima 315240N1111140W

VARIANT

range

reservoir

well

UGN

UNOFF

BGN

VARIANT

VARIANT

VARIANT

VARIANT

\section{Pinal}

Pima

Pima

Pima

Pinal

$323203 \mathrm{~N} 1115259 \mathrm{~W}$

315100 N1110300

320059 N1111552W

315043 N1111442W

$323705 \mathrm{~N} 112065 \mathrm{~W}$

VARIANT

locale

locale

summit

summit

locale

valley

summit

summit

summit

BGN

BGN

BGN

UNOFF

BGN

BGN

BGN

summit

summit

summit

BGN 1932

BGN

BGN

BGN

VARIANT

summit

summit
summit

BGN

BGN

BGN

summit BGN

tower UNOFF

pp1

locale

BGN

VARIANT

VARIANT

$\begin{array}{ll}\text { range } & \text { BGN } 1941 \\ & \text { VARIANT }\end{array}$

stream

VARIANT

BGN
VARIANT

VARIANT

VARIANT

ppl

ppl

ppl

BGN 1941 Pima

VARIANT

VARIANT

VARIANT

VARIANT

VARIANT

reservoir

\section{stream}

BGN

BGN

bas in

VARIANT

summi

VARIANT

ppl

pp1

VARIANT

ppl

$332521 N 1113635 \mathrm{~W}$
$322150 N 1123717 \mathrm{~W}$
Yuma

Mohave

Yuma

Maricopa

Maricopa

Mohave

Cochise

Pima

Coconino

Coconino

Maricopa

Pinal

Mohave

Maricopa

Pinal

Pinal

Gila

Yuma

Gila

Cochise

Pima

Pima

Pima

Pima

$321855 \mathrm{~N} 1124016 \mathrm{~W}$

Pima

320654 N1120206W

Pima

320654N1120206W

Pima

$341012 \mathrm{~N} 1135043 \mathrm{~W}$

342827 N1133759W

(25009N1135147W

342449 N1133431W

$314125 N 1095342 W$

321732N1111226W

$361013 \mathrm{~N} 1122126 \mathrm{~W}$

$331228 N 1125713 \mathrm{~W}$

332040N1105955W

UNKNOWN

$324304 \mathrm{~N} 1104440 \mathrm{~W}$

325741 N1113931W

$331735 N 1105007 \mathrm{~W}$

$332133 \mathrm{~N} 1140455 \mathrm{~W}$

$331735 \mathrm{~N} 1105007 \mathrm{~W}$

$313300 \mathrm{~N} 1102120 \mathrm{~W}$

$321855 \mathrm{~N} 1124016 \mathrm{~W}$

$322715 \mathrm{~N} 1124947 \mathrm{~W}$

320900 N1123520W

$320654 \mathrm{N1} 120206 \mathrm{~W}$

$320654 \mathrm{N1} 120206 \mathrm{~W}$

$342702 N 1133657 W$

614 Growler

1717 Apache Junction Apache Junction Signal Mtn

5164 Hay Mountain Avra

7444 Williams South

6773 Havasupai Point

2182 Woolsey Peak

4829 Pinal Ranch

2351 Signal Mtn

4364 Mammoth

2282 Casa Crande East

7812 Pinal Peak

Palm Canyon

1357 Pinal Ranch

Fort Huachuca

1904 Sikort Chuapo

Gakokik Mts

Ajo North

2147 Vainom Kug

$320718 N 1120235 \mathrm{~W}$

$320312 N 1120345$

$343941 \mathrm{~N} 1130323 \mathrm{~W}$

320702 N1120241W

Vainom Kug

Vainom Kug

Behm Mesa

Apache $\quad 355309$ N1091454W

Maricopa

$325900 \mathrm{~N} 1124340 \mathrm{~W}$

Pima

32131BN1114857W

$325900 \mathrm{~N} 1124340 \mathrm{~W}$

\section{F}

979

Batamote Hills

Bart eth Hills Esperanza Mill .

Samaniego Peak Samaniego Peak 
FEATURE NAME

Sil Nakya

Beebhak

San Lorenzo

San Lorenzo We 1

Saranake

Seranake

Silinakik

Sil Nakya

See Bibyak

Sil Nakya Hills

Sil Nakya Pass

Sil Nakya Valley

Sil Nakya Wash

Silo Tank

Silted Tank

Silt Tank

Silt Tank

Silva (historical)

Silverado Ridge

Silverado Wash

Silver Age Mine

Silver Bas in

Silver Bas in Creek

Silver Bear

Silver Bear Gulch

Silver Bell

Silverbell

Silverbell

See Silver Bell

Silverbell

$$
\text { Silver Bell }
$$

Silver Bell

See Silverbell

Silver Bell Cemetery

silver Belle

See Silver Bell

Silver Bell Mine

Silverbell Mountains

See Silver Bell Mountains

Silver Bell Mountains Roskruge Mountains Silverbell Mountains Waterman Mountains

Silverbell Number One Dam

Silverbell Number Two Dam

Silver Bell Peak

Silver Bell Post office

Silverbell Regional Park

Silver Bell Tailing Dam

Silver Bell Tailings Pond

Silver Bell Trailer Park

Silver Bell Wash

Silver Belt Shaft

Silver Butte

Silver Butte Spring

Silver Camp Canyon

Silver Camp Divide

Silver Cave

Silver Christmas Mine

\section{Silver Clip Claim}

See Clip Mine

Silver Coin Mine

Silver Cord Mine

Silver Creek

Silver Creek

Silver Creek

Silver Creek

Silver Creek

See Slide Creek

\section{FEATURE}

CLASS

ppl

STATUS

COUNTY

COORDINATE

$321318 N 1114857 W$

VARIANT

VARIANT

VARIANT

VARIANT

VARIANT

VARIANT

VARIANT

VARIANT

locale

summit

gap

valley

stream

reservoir

reservoir

reservoir

reservoir

locale

ridge

BGN $1941 \quad P$ im

Pina

321510N1115510W

BGN

BGN

BGN

BGN

BGN

BGN

BGN

stream $\quad B G$

bas in

strean

mine

valley

ppl

BGN Pinal

UNOFF Mohave

BGN

BGN

BGN

JNOF

BGN

Cochise

Greenle

Cochise

VARIANT

VARIANT

VARIANT

ppl

locale

BGN 1961

Pima

loca

cemetery

ppl

mine

summit

VARIANT

VARIANT

UNOFF

VARIANT

UNOFF

VARIANT

sumnit

BGN

VARIANT

VARIANT

dam UARIANT

dam

summ

building

park

UNOFF

BGN

BGN
UNOFF

UNOFF

ADMIN

dam

BGN

reservoir

locale

stream

mine

summit

spring

valley

gap
cave
mine

mine

UNOFF

BGN

UNOFF

BGN

BGN

BGN

BGN

BGN

UNOFF

Pima

Pima

Pima

Pima

Pina

Pima

Maricopa

Pima

Gila

Gila

Gila

Cochise

Cochise

Santa Cruz

$321325 \mathrm{~N} 1114947 \mathrm{~W}$

$330319 N 1092239 \mathrm{~W}$

Yavapai

VARIANT

mine

mine

mine

stream

stream

stream

stream

stream

$\begin{array}{lll} & \text { La Paz } & 330813 N 1143455 \mathrm{~W} \\ \text { UNOFF } & \text { Pima } & 313754 N 1112145 \mathrm{~W} \\ \text { UNOFF } & \text { Yavapai } & 341517 N 1121217 \mathrm{~W} \\ \text { BGN } & \text { Cochise } & 311900 \mathrm{~N} 1091630 \mathrm{~W} \\ \text { BGN } & \text { Cochise } & 315523 \mathrm{~N} 1090741 \mathrm{~W} \\ \text { BGN } & \text { Gila } & 330656 N 1104712 \mathrm{~W} \\ \text { BGN } & \text { Greenlee } & 330939 N 1091603 \mathrm{~W} \\ \text { VARIANT } & & \\ & \text { Apache } & 340250 N 1094800 \mathrm{~W}\end{array}$

$333015 \mathrm{~N} 1120345 \mathrm{~W}$

$335255 \mathrm{~N} 1101116 \mathrm{~W}$

315444N1091213W $\begin{array}{ll}\text { SOURCE } & \text { ELEV } \\ \text { COORDINATE } & \text { FT MAP NAME }\end{array}$

2211 Sil Nakya
$322300 \mathrm{~N} 1113000 \mathrm{~W}$

$322550 N 1113215 \mathrm{~W}$

$321347 N 1114807 \mathrm{~W}$

$321323 N 1114854 \mathrm{~W}$

$3225471115722 \mathrm{~W}$

$334954 N 1095600 \mathrm{~W}$

345859 N $1111333 \mathrm{~K}$

$353856 \mathrm{~N} 1134646 \mathrm{~W}$

$312936 N 1105944 \mathrm{~W}$

332013N1110453W

$332001 N 1110543 \mathrm{~W}$

$352423 \mathrm{~N} 1141104 \mathrm{~W}$

$330003 \mathrm{~N} 1092040 \mathrm{~W}$
$312551 \mathrm{~N} 1095444 \mathrm{~W}$

$312558 N 1095439 \mathrm{~W}$

$322300 \mathrm{~N} 1113000 \mathrm{~W}$

$312524 N 1095455 \mathrm{~W}$

\begin{tabular}{|c|c|c|}
\hline $\begin{array}{l}321121 \mathrm{~N} 1114709 \mathrm{~W} \\
320813 \mathrm{~N} 1114828 \mathrm{~W}\end{array}$ & 3375 & $\begin{array}{l}\text { Sil Nakya } \\
\text { Sil Nakya } \\
\text { Sil Nakya } \\
\text { Santa Rosa Mts NW } \\
\text { Cinder Hill } \\
\text { Whiteriver } \\
\text { Chavez Mtn NW } \\
\text { Music Mountains NE } \\
\text { Rio Rico } \\
\text { Superior }\end{array}$ \\
\hline $\begin{array}{l}332008 \mathrm{~N} 1110506 \mathrm{~W} \\
330359 \mathrm{~N} 1092242 \mathrm{~W} \\
312524 \mathrm{~N} 1095455 \mathrm{~W}\end{array}$ & & $\begin{array}{l}\text { Superior } \\
\text { Chloride } \\
\text { Copperplate Gulch } \\
\text { Clifton } \\
\text { Bisbee } \\
\text { Bisbee }\end{array}$ \\
\hline & 2639 & Silver Bell East \\
\hline
\end{tabular}

Silver Bell West

Silver Bell West

Mineral Mtn

Silver Bell East

Silver Bell East

$322330 \mathrm{N1112BOOW}$

$322236 \mathrm{~N} 1112730 \mathrm{~W}$

$322430 \mathrm{~N} 1112930 \mathrm{~W}$

$322304 \mathrm{~N} 1113005 \mathrm{~W}$

$321710 \mathrm{~N} 1110200 \mathrm{~W}$

$322300 N 1112854 \mathrm{~W}$

$322653 N 1113402 \mathrm{~W}$

$332843 \mathrm{~K} 1105304 \mathrm{~W}$

$335323 N 1101141 \mathrm{~W}$

$321312 N 1094005 \mathrm{~W}$

$321417 N 1093843 W$

313730 N1104733W

$341418 \mathrm{~N} 1121542 \mathrm{~W}$

$322518 N 1113038 W$

$321414 N 1093844$

Silver Bell East

4261 Silver Bell East

Silver Bell West

Jaynes

Silver Bell East

Silver Bell East

1130 Sunnys lope

Silver Bell West

6132 Cedar Creek

Cedar Creek

Simmons Peak

Simmons Peak

Mt Wrightson

Crown King

$313157 N 1092401 \mathrm{~W}$

$331612 \mathrm{~N} 1104752 \mathrm{~W}$

$331015 N 1091949 \mathrm{~W}$
Cerro Colorado

Cleator

San Bernardino Ranch

Portal

Hayden

Mitchell Peak 
NATIONAL GAZETTEER--ARIZONA 1986

FEATURE NAME

Silver Creek

Silver Creek

Silver Creek

See Brown Creek

Silver Creek

Ortega Creek

Showlow Creek

Silver Creek

Silver Creek

See Bright Angel Creek

Silver Creek

Silver Creek Mine

Silver Creek Reservoir See White Mountain Lake

Silver Creek Spring

Silver Creek Spring

See Silver Springs

Silver Creek Spring

Silver Creek Tank

Silver Creek Wash

Montana Wash

Silver Crown Mine

Silver Cut Meadows

Silver Dime Mine

Silver Dollar Mine

Silver Dollar Spring

Silvergate II (subdivision)

Silvergate Trails (subdivision)

Silver $\mathrm{Hill}$

Silver Hill

Silver Hill Mine

Silver Hill Mine

Silver King Mine

Silver King Mine

Silver King Mine

Silver King Wash

Silver King Windmill

Silver Lake

See White Mountain Lake

Silver Mountain

Silver Mountain

Silver Peak

Silver Peak

Silver Prince Mine

Silver Prince Mine

Silver Queen Mine

Silver Queen Mine

See Magma Copper Mines

Silver Queen Mine

Silver Reef Mine

Silver Reef Mountains

See Tat Momoli Mountains

Silver Reef Mountains

Silver Reef Pass

Silver Reef Valley

Silver Reef Wash

Silverrona Spring

Silver Shield Mine

Silver Spray Spring

See Grimes Spring

Silver Spring

Silver Spring

Silver Spring Gulch

Silver Springs

Clark And Kinneys Spring

Silver Creek Spring

Silver Spruce Mine

Silver Spur Ranch (trailer park)

Silver Spur Spring

Silver Spur village (trailer park)
FEATURE

CLASS

STATUS

COUNTY

COORDINATE

stream

stream

stream

stream

stream

ppl
mine

reservoir

spring

spring

spring

reservoir

stream

mine

flat

mine

mine

spring

ppl

$\mathrm{ppl}$

summit

summit

mine

mine

mine

mine

mine

we 11

reservoir

summit

summit

summit

summit

mine

mine

mine

mine

mine

summit

summit

gap

stream

spring

mine

spring

spring

spring

valley

spring

BGN

VARIANT

VARIANT

mine UNOFF

spring

BGN
UNOFF
340744N1122135W

341447 N1120338

$341951 \mathrm{N1095527 \textrm {W }}$

Yavapai

Yavapai

Navajo

Navajo

Mohave

Coconino

Navajo

Gila

Navajo

Yavapai

Navajo

Mohave

Yavapai

Mohave

ARIANT

UNOFF
BGN
UNOFF
UNOFF
BGN
BGN
BGN
BGN
BGN
UNOFF

Yavapai

Mohave

Gila

Yavapai

Yavapai

Maricopa

Maricopa

Pima

Mohave

Pima

Pima

Santa Cruz 313946 N1105144W

Pinal 331949N1110519W

Pinal

Pinal

Navajo

Yavapai

Mohave

Cochise

Cochise

Coch ise

Yuma

Pinal

Pinal

Yuma

Pinal

Pinal

BGN

BGN

BGN

UNOFF

VARIANT

BGN

G

$344424 N 1100217 \mathrm{~W}$

$324120 N 1115202$
350733 N11 143452W

360555 N1120532W

$342024 \mathrm{~N} 1095656 \mathrm{~W}$

$331255 \mathrm{~N} 1104817 \mathrm{~W}$

$342156 \mathrm{~N} 1095923 \mathrm{~W}$

341611 N1115239W

$341952 \mathrm{~N} 1095527 \mathrm{~W}$

$350436 \mathrm{~N} 1142541 \mathrm{~W}$

$341611 N 1115651 \mathrm{~W}$

$350734 N 1143449 \mathrm{~W}$

$341900 \mathrm{~N} 1123555 \mathrm{~W}$

$351900 N 1143001 \mathrm{~W}$

$331218 \mathrm{~N} 110480 \mathrm{BW}$

$340752 \mathrm{~N} 1122549 \mathrm{~W}$

$340800 \mathrm{~N} 1122554 \mathrm{~W}$

$332025 \mathrm{~N} 1115224 \mathrm{~W}$

$331942 N 1115241 \mathrm{~W}$

$314114 \mathrm{~N} 1112006 \mathrm{~W}$

$352427 \mathrm{N1} 141209 \mathrm{~W}$

$31411 B N 1112018 \mathrm{~W}$

41334N1112143W

331642 N1110926

$331914 N 1110642 W$

$342156 \mathrm{N1095923 \textrm {W }}$

$340748 \mathrm{~N} 1122421 \mathrm{~W}$

$351756 \mathrm{~N} 1140632 \mathrm{~W}$

$315416 \mathrm{~N} 1091148 \mathrm{~W}$

321449 N1093952W

$315815 N 1091748 \mathrm{~W}$

$330440 \mathrm{~N} 1134714 \mathrm{~W}$

325407 N1105357W

$331811 N 1110558 \mathrm{~W}$

$334554 \mathrm{~N} 1132442 \mathrm{~W}$

$324243 \mathrm{~N} 1114903 \mathrm{~W}$

323957 N1115323W

$324228 \mathrm{~N} 1114816 \mathrm{~W}$

324148 N1115101K

$324339 \mathrm{~N} 111513 \mathrm{~W}$

$332102 \mathrm{~N} 1110603 \mathrm{~W}$

313911 N1111659W

$341238 \mathrm{~N} 1112338 \mathrm{~W}$

315258 N1102800

$344210 \mathrm{~N} 1120554 \mathrm{~W}$

34431BN1120205W

341952 N1095527W

$342426 \mathrm{~N} 1122557 \mathrm{~W}$

$332500 \mathrm{~N} 1113745 \mathrm{~W}$

$320030 N 1092133 \mathrm{~W}$

$332512 \mathrm{~N} 1113738 \mathrm{~W}$ locale UNOFF

$\begin{array}{cc}\text { SOURCE } & \text { ELEV } \\ \text { COORDINATE } & \text { FT MAP NAME }\end{array}$

340846N1122344W Crown King

$341632 \mathrm{~N} 1115156 \mathrm{~W}$ Joes $\mathrm{Hill}$

341951N1095527W Tenmile Cedars

350242N1142150W Davis Dam

2atman

Davis Dam

$350243 N 1142149$

6100 Silver Springs

El Capitan Mtn

Dugas

Wainut Grove

Spirit Mtn SE

El Capitan Mtn

Minnehaha

Minnehaha

1995 Chandler

1195 Guadalupe

3790 Cerro Colorado

4123 Chloride

Cerro Colorado

Waterman Peak

Mt Wrightson

Superior

Payson South

$332109 \mathrm{~N} 1110507 \mathrm{~W}$

Picketpost Mtn

Superior

6144 Minnehaha

Stockton $\mathrm{Hill}$

7975 Portal

Simmons Peak

Rustler Park

Neversweat Ridge

Crozier Peak

Socorro Peak

Silver Reef Mts

Silver Reef Mts

Silver Reef Mts

Silver Reef Mts

Silver Reef Mts

$324014 N 1114830 \mathrm{~W}$

Superior 


\begin{tabular}{|c|c|c|c|c|c|c|c|}
\hline FEATURE NAME & $\begin{array}{l}\text { FEATURE } \\
\text { CLASS }\end{array}$ & STATUS & COUNTY & COORDINATE & $\begin{array}{c}\text { SOURCE } \\
\text { COORDINATE }\end{array}$ & $\begin{array}{l}\text { ELEV } \\
\text { FT }\end{array}$ & MAP NAME \\
\hline $\begin{array}{l}\text { Silverstrike Mine } \\
\text { Silverstrike Spring } \\
\text { Silver Tank } \\
\text { Silver Tank } \\
\text { Silvertip Mine } \\
\text { Silynarki } \\
\text { See Sil Nakya } \\
\text { Simis School } \\
\text { Simmons (site) } \\
\text { Simmons Gulch }\end{array}$ & $\begin{array}{l}\text { mine } \\
\text { spring } \\
\text { reservoir } \\
\text { reservoir } \\
\text { mine } \\
\text { ppl } \\
\text { school } \\
\text { locale } \\
\text { valley }\end{array}$ & $\begin{array}{l}\text { UNOFF } \\
\text { BGN } \\
\text { BGN } \\
\text { BGN } \\
\text { UNOFF } \\
\text { VARIANT } \\
\text { UNOFF } \\
\text { BGN } \\
\text { BGN }\end{array}$ & $\begin{array}{l}\text { Cochise } \\
\text { Cochise } \\
\text { Cochise } \\
\text { Pima } \\
\text { Cochise } \\
\text { Pima } \\
\text { Maricopa } \\
\text { Yavapai } \\
\text { Mohave }\end{array}$ & $\begin{array}{l}321057 N 1092935 \mathrm{~W} \\
321044 \mathrm{~N} 1092926 \mathrm{~W} \\
315517 \mathrm{~N} 1091036 \mathrm{~W} \\
315734 \mathrm{~N} 1103652 \mathrm{~W} \\
312853 \mathrm{~N} 1090318 \mathrm{~W} \\
\\
321318 \mathrm{~N} 111485 \mathrm{~W} \\
333232 \mathrm{~N} 1120341 \mathrm{~W} \\
344853 \mathrm{~N} 1123800 \mathrm{~W} \\
345656 \mathrm{~N} 113245 \mathrm{~W}\end{array}$ & $345525 \mathrm{N1132914W}$ & 4549 & $\begin{array}{l}\text { Bowie Mtn North } \\
\text { Bowie Mtn North } \\
\text { Portal } \\
\text { The Narrows } \\
\text { Guadalupe Spring } \\
\text { Sunnys lope } \\
\text { Simmons } \\
\text { Gonzales Wash }\end{array}$ \\
\hline $\begin{array}{l}\text { Simmons Peak } \\
\text { Simmons Peak } \\
\text { Simmons Spring } \\
\text { Simmons Spring } \\
\text { Simon Springs } \\
\text { Simonton Flat } \\
\text { Simpson Cabins } \\
\text { Simpson Creek } \\
\text { See Crystal Creek } \\
\text { Simpson Lake }\end{array}$ & $\begin{array}{l}\text { summit } \\
\text { summit } \\
\text { spring } \\
\text { spring } \\
\text { spring } \\
\text { flat } \\
\text { locale } \\
\text { stream } \\
\text { reservoir }\end{array}$ & $\begin{array}{l}8 G N \\
\text { BGN } \\
\text { BGN } \\
\text { BGN } \\
\text { BGN } \\
\text { BGN } \\
\text { UNOFF } \\
\text { VARIANT } \\
\text { BGN }\end{array}$ & $\begin{array}{l}\text { Cochise } \\
\text { Yavapai } \\
\text { Greenlee } \\
\text { Mohave } \\
\text { Graham } \\
\text { Gila } \\
\text { Gila } \\
\text { Apache } \\
\text { Gila }\end{array}$ & $\begin{array}{l}321435 \mathrm{~N} 1093740 \mathrm{~W} \\
345032 \mathrm{~N} 1123411 \mathrm{~W} \\
331907 \mathrm{N1} 092802 \mathrm{~W} \\
345552 \mathrm{~N} 1132554 \mathrm{~W} \\
325505 \mathrm{~N} 1095338 \mathrm{~W} \\
341242 \mathrm{~N} 1112730 \mathrm{~W} \\
332852 \mathrm{~N} 1104824 \mathrm{~W} \\
360452 \mathrm{~N} 1090856 \mathrm{~W} \\
331935 \mathrm{~N} 1105419 \mathrm{~W}\end{array}$ & & $\begin{array}{l}7398 \\
5757\end{array}$ & $\begin{array}{l}\text { Simmons Peak } \\
\text { Sullivan Buttes } \\
\text { Bee Canyon } \\
\text { Gonzales Wash } \\
\text { Eden } \\
\text { North Peak } \\
\text { Globe }\end{array}$ \\
\hline $\begin{array}{l}\text { Simpson Ranch } \\
\text { Simpson School } \\
\text { Simpson Spring } \\
\text { Simpson Spring } \\
\text { Simpson Tank } \\
\text { Sims Pond } \\
\text { Sims Reservoir } \\
\text { Sims Tank } \\
\text { See Pump Ranch Tank } \\
\text { Sims Tank } \\
\text { Pump Ranch Tank }\end{array}$ & $\begin{array}{l}\text { locale } \\
\text { school } \\
\text { spring } \\
\text { spring } \\
\text { reservoir } \\
\text { lake } \\
\text { reservoir } \\
\text { reservoir } \\
\text { reservoir }\end{array}$ & $\begin{array}{l}\text { UNOFF } \\
\text { UNOFF } \\
\text { BGN } \\
\text { BGN } \\
\text { BGN } \\
\text { BGN } \\
\text { BGN } \\
\text { VARIANT } \\
\text { BGN } \\
\text { VARIANT }\end{array}$ & $\begin{array}{l}\text { Apache } \\
\text { Maricopa } \\
\text { Pima } \\
\text { Gila } \\
\text { Pima } \\
\text { Mohave } \\
\text { Mohave } \\
\text { Coconino } \\
\text { Coconino }\end{array}$ & $\begin{array}{l}340057 N 1090249 \mathrm{~W} \\
333058 \mathrm{N1120628W} \\
314703 \mathrm{~N} 1102749 \mathrm{~W} \\
332847 \mathrm{N1} 104847 \mathrm{~W} \\
315443 \mathrm{N1} 104314 \mathrm{~W} \\
362332 \mathrm{N1133254W} \\
363954 \mathrm{N1} 12545 \mathrm{~W} \\
\\
344714 \mathrm{~N} 1105152 \mathrm{~W} \\
344904 \mathrm{~N} 1104911 \mathrm{~W}\end{array}$ & & 7800 & $\begin{array}{l}\text { Loco Knoll } \\
\text { Sunnys lope } \\
\text { Apache Peak } \\
\text { Globe } \\
\text { Mount Fagan } \\
\text { Poverty Spring } \\
\text { Wild 8and Pockets }\end{array}$ \\
\hline $\begin{array}{l}\text { Sin Agua Tank } \\
\text { Sinagua Valley } \\
\text { Sin City } \\
\text { Sinclair Tank } \\
\text { Sinclair Wash } \\
\text { Sin Fin Mine } \\
\text { Singing Spur Mobile Park } \\
\text { Singing Wind Ranch } \\
\text { Single Standard Mine } \\
\text { Sinita Tank }\end{array}$ & $\begin{array}{l}\text { reservoir } \\
\text { valley } \\
\text { locale } \\
\text { reservoir } \\
\text { stream } \\
\text { mine } \\
\text { locale } \\
\text { locale } \\
\text { mine } \\
\text { reservoir }\end{array}$ & $\begin{array}{l}\text { BGN } \\
\text { BGN } 1971 \\
\text { BGN } \\
\text { BGN } \\
\text { BGN } \\
\text { UNOFF } \\
\text { UNOFF } \\
\text { UNOFF } \\
\text { UNOFF } \\
\text { BGN }\end{array}$ & $\begin{array}{l}\text { Coconino } \\
\text { Coconino } \\
\text { Maricopa } \\
\text { Coconino } \\
\text { Coconino } \\
\text { Graham } \\
\text { Maricopa } \\
\text { Cochise } \\
\text { Gila } \\
\text { Yuma }\end{array}$ & $\begin{array}{l}344830 \mathrm{~N} 1112155 \mathrm{~W} \\
352553 \mathrm{~N} 1113449 \mathrm{~W} \\
332500 \mathrm{~N} 1115521 \mathrm{~W} \\
350935 \mathrm{~N} 1114130 \mathrm{~W} \\
351112 \mathrm{~N} 1113802 \mathrm{~W} \\
325841 \mathrm{~N} 1102024 \mathrm{~W} \\
333010 \mathrm{~N} 112020 \mathrm{~W} \\
320051 \mathrm{~N} 1101843 \mathrm{~W} \\
341148 \mathrm{~N} 1112209 \mathrm{~W} \\
321300 \mathrm{~N} 1134047 \mathrm{~W}\end{array}$ & $\begin{array}{l}352357 \mathrm{~N} 1113531 \mathrm{~W} \\
350839 \mathrm{~N} 1114436 \mathrm{~W}\end{array}$ & $\begin{array}{l}1170 \\
1160\end{array}$ & $\begin{array}{l}\text { Jaycox Mtn } \\
\text { O'Leary Peak } \\
\text { Tempe } \\
\text { Flagstaff West } \\
\text { Flagstaff West } \\
\text { Cobre Grande Mtn } \\
\text { Sunnys lope } \\
\text { Galleta Flat East } \\
\text { Payson South } \\
\text { Sierra Arida }\end{array}$ \\
\hline $\begin{array}{l}\text { Sink Hole Number One Tank } \\
\text { Sinkhole Pond } \\
\text { Sinkhole Pond } \\
\text { Pete Smith Peak } \\
\text { Sinkhole Pond } \\
\text { Sinkhole Reservoir } \\
\text { Sink Hole Reservoir } \\
\text { Sink Hole Reservoir } \\
\text { See Sinkhole Reservoir } \\
\text { Sinkhole Tank }\end{array}$ & $\begin{array}{l}\text { reservoir } \\
\text { lake } \\
\text { lake } \\
\text { reservoir } \\
\text { reservoir }\end{array}$ & $\begin{array}{l}\text { BGN } \\
\text { BGN } \\
\text { BGN } \\
\text { VARIANT } \\
\text { BGN } \\
\text { BGN } \\
\text { VARIANT } \\
\text { VARIANT } \\
\text { BGN }\end{array}$ & $\begin{array}{l}\text { Coconino } \\
\text { Mohave } \\
\text { Mohave } \\
\text { Mohave } \\
\text { Mohave }\end{array}$ & $\begin{array}{l}343123 \mathrm{~N} 1111849 \mathrm{~W} \\
361623 \mathrm{~N} 1131751 \mathrm{~W} \\
362921 \mathrm{~N} 1132419 \mathrm{~W} \\
364235 \mathrm{~N} 1133440 \mathrm{~W} \\
363651 \mathrm{~N} 1132229 \mathrm{~W} \\
\\
363651 \mathrm{~N} 1132229 \mathrm{~W} \\
342112 \mathrm{~N} 1114449 \mathrm{~W}\end{array}$ & & & $\begin{array}{l}\text { Long Valley } \\
\text { Cold Spring } \\
\text { Poverty Knoll } \\
\text { Sullivan Draw North } \\
\text { Russell Spring }\end{array}$ \\
\hline $\begin{array}{l}\text { Sinkhole Tank } \\
\text { Sinkhole Tank } \\
\text { Sink Hole Tank } \\
\text { Sinkhole Tank } \\
\text { Sinkhole Tank } \\
\text { Sinkhole Tank } \\
\text { Sinking Ship } \\
\text { Sinking Ship Butte } \\
\text { The Battleship } \\
\text { The Battleship Iowa } \\
\text { The Three Castles } \\
\text { Three Castles }\end{array}$ & $\begin{array}{l}\text { reservoir } \\
\text { reservoir } \\
\text { reservoir } \\
\text { reservoir } \\
\text { reservoir } \\
\text { reservoir } \\
\text { summit }\end{array}$ & $\begin{array}{l}\text { BGN } \\
\text { BGN } \\
\text { BGN } \\
\text { BGN } \\
\text { BGN } \\
\text { BGN } \\
\text { BGN } 1932 \\
\text { VARIANT } \\
\text { VARIANT } \\
\text { VARIANT } \\
\text { VARIANT } \\
\text { VARIANT }\end{array}$ & $\begin{array}{l}\text { Navajo } \\
\text { Coconino } \\
\text { Coconino } \\
\text { Coconino } \\
\text { Coconino } \\
\text { Yavapai } \\
\text { Coconino }\end{array}$ & $\begin{array}{l}343131 \mathrm{~N} 1102741 \mathrm{~W} \\
343751 \mathrm{~N} 1110559 \mathrm{~W} \\
343818 \mathrm{~N} 1112429 \mathrm{~W} \\
350050 \mathrm{~N} 1113029 \mathrm{~W} \\
350454 \mathrm{~N} 1111002 \mathrm{~W} \\
351721 \mathrm{~N} 1124732 \mathrm{~W} \\
355925 \mathrm{~N} 1115729 \mathrm{~W}\end{array}$ & & 7344 & $\begin{array}{l}\text { Zeniff } \\
\text { Quayle Hill } \\
\text { Happy Jack } \\
\text { Lower Lake Mary } \\
\text { Anderson Canyon } \\
\text { Seligman East } \\
\text { Grandview Point }\end{array}$ \\
\hline $\begin{array}{l}\text { Sinking Ship Butte } \\
\text { See Sinking Ship } \\
\text { Sinks, The } \\
\text { Sinks, The } \\
\text { Sink Tank } \\
\text { Sink Valley } \\
\text { Sinoski Mine } \\
\text { Sinyala, Mount }\end{array}$ & $\begin{array}{l}\text { summit } \\
\text { area } \\
\text { basin } \\
\text { reservoir } \\
\text { valley } \\
\text { mine } \\
\text { summit }\end{array}$ & $\begin{array}{l}\text { VARIANT } \\
\text { BGN } \\
\text { BGN } \\
\text { BGN } \\
\text { BGN } \\
\text { UNOFF } \\
\text { BGN } 1925\end{array}$ & $\begin{array}{l}\text { Coconino } \\
\text { Yavapai } \\
\text { Navajo } \\
\text { Coconino } \\
\text { Mohave } \\
\text { Yavapai } \\
\text { Coconino }\end{array}$ & $\begin{array}{l}355925 N 1115729 W \\
345617 N 1124436 \mathrm{~W} \\
343336 \mathrm{~N} 1101413 \mathrm{~W} \\
355440 \mathrm{~N} 1125444 \mathrm{~W} \\
362616 \mathrm{~N} 1131231 \mathrm{~W} \\
340745 \mathrm{~N} 1123921 \mathrm{~W} \\
361759 \mathrm{~N} 1124218 \mathrm{~W}\end{array}$ & $362809 N 1131220 \mathrm{~W}$ & 5434 & $\begin{array}{l}\text { Limestone Peak } \\
\text { Second Knolls } \\
\text { National Tank } \\
\text { Mt Trumbull NW } \\
\text { Yarnell } \\
\text { Havasu Falls }\end{array}$ \\
\hline
\end{tabular}


NATIONAL GAZETTEER--ARIZONA 1986

\begin{tabular}{|c|c|c|c|c|c|c|c|}
\hline FEATURE NAME & $\begin{array}{l}\text { FEATURE } \\
\text { CLASS }\end{array}$ & STATUS & COUNTY & COORDINATE & $\begin{array}{l}\text { SOURCE } \\
\text { COORDINATE }\end{array}$ & $\begin{array}{l}\text { ELEV } \\
\text { FT }\end{array}$ & MAP NAME \\
\hline $\begin{array}{l}\text { Sinyala Canyon } \\
\text { Sinyala Canyon } \\
\text { See Sinyala, Mount }\end{array}$ & summit & $\begin{array}{l}\text { VARIANT } \\
\text { VARIANT }\end{array}$ & Coconino & $361759 \mathrm{~N} 1124218 \mathrm{~W}$ & & & \\
\hline $\begin{array}{l}\text { Sinyala Canyon } \\
\text { Sinyala Mesa } \\
\text { Sinyala Rapids } \\
\text { Sinyala Tank } \\
\text { Sinyella Spring } \\
\text { Siovi Shuatak } \\
\text { Cochiba Well } \\
\text { Coch ibo } \\
\text { Cochibo Well } \\
\text { Cochivo } \\
\text { Con Quien } \\
\text { Coons Can Well } \\
\text { Manuels Well } \\
\text { Sweetwater }\end{array}$ & $\begin{array}{l}\text { valley } \\
\text { summit } \\
\text { rapids } \\
\text { reservoir } \\
\text { spring } \\
\text { locale }\end{array}$ & $\begin{array}{l}\text { BGN } 1932 \\
\text { BGN } 1932 \\
\text { BGN } 1932 \\
\text { BGN } \\
\text { BGN } \\
\text { BGN } 1941 \\
\text { VARIANT } \\
\text { VARIANT } \\
\text { VARIANT } \\
\text { VARIANT } \\
\text { VARIANT } \\
\text { VARIANT } \\
\text { VARIANT } \\
\text { VARIANT }\end{array}$ & $\begin{array}{l}\text { Coconino } \\
\text { Coconino } \\
\text { Coconino } \\
\text { Coconino } \\
\text { Coconino } \\
\text { Pima }\end{array}$ & $\begin{array}{l}361916 \mathrm{~N} 1124308 \mathrm{~W} \\
361753 \mathrm{~N} 1124246 \mathrm{~W} \\
361909 \mathrm{~N} 1124322 \mathrm{~W} \\
360409 \mathrm{~N} 1123150 \mathrm{~W} \\
355656 \mathrm{~N} 1123130 \mathrm{~W} \\
315703 \mathrm{~N} 1123551 \mathrm{~W}\end{array}$ & $361708 \mathrm{~N} 1123930 \mathrm{~W}$ & & $\begin{array}{l}\text { Havasu Falls } \\
\text { Havasu Falls } \\
\text { Havasu Falls } \\
\text { Antelope Point } \\
\text { Baldy Basin } \\
\text { Pia Oik }\end{array}$ \\
\hline $\begin{array}{l}\text { Siovi Shuatak } \\
\text { See Sweetwater } \\
\text { Siovi Shuatak Pass } \\
\text { Siovi Shuatak Wash } \\
\text { Sipaulovi } \\
\text { See Shipolovi } \\
\text { Siphon Basin } \\
\text { Siphon Canyon } \\
\text { Siphon Canyon } \\
\text { Siphon Draw }\end{array}$ & $\begin{array}{l}\text { locale } \\
\text { gap } \\
\text { stream } \\
\text { ppl } \\
\text { basin } \\
\text { valley } \\
\text { valley } \\
\text { valley }\end{array}$ & $\begin{array}{l}\text { VARIANT } \\
\text { BGN } \\
\text { BGN } \\
\text { VARIANT } \\
\text { BGN } \\
\text { BGN } \\
\text { BGN } \\
\text { BGN }\end{array}$ & $\begin{array}{l}\text { Pinal } \\
\text { Pima } \\
\text { Pima } \\
\text { Navajo } \\
\text { Gila } \\
\text { Cochise } \\
\text { Cochise } \\
\text { Pinal }\end{array}$ & $\begin{array}{l}330755 N 1115024 W \\
315805 N 1123710 W \\
315120 N 1123254 W \\
\\
354830 N 1102944 W \\
332832 N 1105300 W \\
320959 N 1092627 W \\
321051 N 1093051 W \\
332107 N 1113425 W\end{array}$ & $\begin{array}{l}320740 \mathrm{~N} 1092641 \mathrm{~W} \\
321148 \mathrm{~N} 1093023 \mathrm{~W} \\
332620 \mathrm{~N} 1112710 \mathrm{~W}\end{array}$ & & $\begin{array}{l}\text { Inspiration } \\
\text { Bowie Mtn North } \\
\text { Dos Cabezas } \\
\text { Desert Well }\end{array}$ \\
\hline $\begin{array}{l}\text { Siphon Well } \\
\text { Siple Tank } \\
\text { Sitgreaves Mountain } \\
\quad \text { Mount Sitgreaves } \\
\text { Sitgreaves Peak } \\
\text { Sitgreaves National Forest } \\
\text { Sitgreaves Pass } \\
\text { Sitgreaves Peak } \\
\text { See Sitgreaves Mountain } \\
\text { Sitgreaves School }\end{array}$ & $\begin{array}{l}\text { well } \\
\text { reservoir } \\
\text { summit } \\
\text { forest } \\
\text { gap } \\
\text { summit } \\
\text { school }\end{array}$ & $\begin{array}{l}\text { UNOFF } \\
\text { BGN } \\
\text { BGN } \\
\text { VARIANT } \\
\text { VARIANT } \\
\text { ADMIN } \\
\text { BGN } \\
\text { VARIANT } \\
\text { UNOFF }\end{array}$ & $\begin{array}{l}\text { Navajo } \\
\text { Mohave } \\
\text { Coconino } \\
\text { Navajo }\end{array}$ & $\begin{array}{l}313555 \mathrm{~N} 1105209 \mathrm{~W} \\
353939 \mathrm{~N} 1133249 \mathrm{~W} \\
352032 \mathrm{~N} 1120020 \mathrm{~W} \\
\\
342500 \mathrm{~N} 1103001 \mathrm{~W} \\
350245 \mathrm{~N} 1142135 \mathrm{~W} \\
352032 \mathrm{~N} 1120020 \mathrm{~W} \\
342321 \mathrm{~N} 1103308 \mathrm{~W}\end{array}$ & & 9388 & $\begin{array}{l}\text { Patagonia } \\
\text { Hindu Canyon } \\
\text { Sitgreaves Mtn } \\
\text { Out law Oraw } \\
\text { Mount Nutt } \\
\text { Heber }\end{array}$ \\
\hline $\begin{array}{l}\text { Sitgreaves School } \\
\text { Sitting Bull Mine } \\
\text { Sitting Coyote Hill } \\
\text { Sitting Coyote Mesa } \\
\text { Sitting Coyote Windmill } \\
\text { Sitting Giant Rock Wash } \\
\text { Sitting Lizard Rock } \\
\text { Sitting Rock } \\
\text { Sivili Chuchg } \\
\text { Siviuni } \\
\text { See Sichomovi }\end{array}$ & $\begin{array}{l}\text { school } \\
\text { mine } \\
\text { summit } \\
\text { summit } \\
\text { well } \\
\text { valley } \\
\text { pillar } \\
\text { pillar } \\
\text { locale } \\
\text { ppl }\end{array}$ & $\begin{array}{l}\text { UNOFF } \\
\text { UNOFF } \\
\text { BGN } \\
\text { BGN } \\
\text { UNOFF } \\
\text { BGN } \\
\text { BGN } \\
\text { BGN } \\
\text { BGN } \\
\text { VARIANT }\end{array}$ & $\begin{array}{l}\text { Navajo } \\
\text { Yavapai } \\
\text { Coconino } \\
\text { Apache } \\
\text { Coconino } \\
\text { Apache } \\
\text { Coconino } \\
\text { Apache } \\
\text { Pima } \\
\text { Navajo }\end{array}$ & $\begin{array}{l}342538 N 1103544 \mathrm{~W} \\
343723 \mathrm{~N} 1120343 \mathrm{~W} \\
362455 \mathrm{~N} 1111607 \mathrm{~W} \\
362914 \mathrm{~N} 1092213 \mathrm{~W} \\
362417 \mathrm{N1111634W} \\
361733 \mathrm{~N} 1095533 \mathrm{~W} \\
363800 \mathrm{~N} 1111042 \mathrm{~W} \\
360846 \mathrm{~N} 1094947 \mathrm{~W} \\
314439 \mathrm{N1} 120936 \mathrm{~W} \\
355007 \mathrm{~N} 1102337 \mathrm{~W}\end{array}$ & $361614 N 1095735 W$ & $\begin{array}{l}5648 \\
7428\end{array}$ & $\begin{array}{l}\text { Heber } \\
\text { Cherry } \\
\text { Sitting Coyote Hill } \\
\text { Bad Bug Butte } \\
\text { Sitting Coyote Hill } \\
\text { Tah Chee Wash } \\
\text { Horseth ief Mesa } \\
\text { Lohali Point } \\
\text { La Lesna Mts }\end{array}$ \\
\hline $\begin{array}{l}\text { Sivvaxia } \\
\text { See Sif Vaya } \\
\text { Six, Canal (historical) } \\
\text { Canal del Rio } \\
\text { Canal Rio } \\
\text { Canal Tolleson } \\
\text { Six, Tank } \\
\text { Six Bar Hole } \\
\text { Six Bar Mesa Tank } \\
\text { Six Bar Ranch }\end{array}$ & $\begin{array}{l}\text { reservoir } \\
\text { basin } \\
\text { reservoir } \\
\text { locale }\end{array}$ & $\begin{array}{l}\text { VARIANT } \\
\text { BGN } \\
\text { VARIANT } \\
\text { VARIANT } \\
\text { VARIANT } \\
\text { BGN } \\
\text { BGN } \\
\text { BGN } \\
\text { UNOFF }\end{array}$ & $\begin{array}{l}\text { Coconino } \\
\text { Yavapai } \\
\text { Yavapai } \\
\text { Yavapai }\end{array}$ & $\begin{array}{l}352317 \mathrm{N1} 113555 \mathrm{~W} \\
340624 \mathrm{N1} 115610 \mathrm{~W} \\
340740 \mathrm{~N} 1115416 \mathrm{~W} \\
340750 \mathrm{~N} 1115503 \mathrm{~W}\end{array}$ & & 7430 & $\begin{array}{l}\text { O'Leary Peak } \\
\text { Cooks Mesa } \\
\text { Brooklyn Peak } \\
\text { Brooklyn Peak }\end{array}$ \\
\hline $\begin{array}{l}\text { Six Bar Ridge } \\
\text { Six Mile Crossing } \\
\text { Sixmile Draw } \\
\text { Sixmile Gap } \\
\text { Sixmile Hill } \\
\text { Sixmile Spring } \\
\text { Sixmile Tank } \\
\text { Sixmile Well } \\
\text { Sixmile Well } \\
\text { Sixmile Windmill }\end{array}$ & $\begin{array}{l}\text { ridge } \\
\text { locale } \\
\text { valley } \\
\text { valley } \\
\text { summit } \\
\text { spring } \\
\text { reservoir } \\
\text { well } \\
\text { well } \\
\text { locale }\end{array}$ & $\begin{array}{l}\text { BGN } \\
\text { BGN } \\
\text { BGN } \\
\text { BGN } \\
\text { BGN } \\
\text { BGN } \\
\text { BGN } \\
\text { UNOFF } \\
\text { UNOFF } \\
\text { BGN }\end{array}$ & $\begin{array}{l}\text { Yavapai } \\
\text { Mohave } \\
\text { Navajo } \\
\text { Mohave } \\
\text { Cochise } \\
\text { Mohave } \\
\text { Graham } \\
\text { Graham } \\
\text { Yuma } \\
\text { Navajo }\end{array}$ & $\begin{array}{l}340736 \mathrm{N1115338W} \\
343340 \mathrm{~N} 1132104 \mathrm{~W} \\
343506 \mathrm{N1} 100636 \mathrm{~W} \\
365741 \mathrm{N1123454W} \\
315335 \mathrm{N1} 094959 \mathrm{~W} \\
365746 \mathrm{N1123430W} \\
331506 \mathrm{~N} 1102509 \mathrm{~W} \\
322643 \mathrm{N1} 1095942 \mathrm{~W} \\
335 \mathrm{~B} 5 \mathrm{N1} 140413 \mathrm{~W} \\
343411 \mathrm{~N} 1100959 \mathrm{~W}\end{array}$ & $\begin{array}{l}343330 \mathrm{~N} 1100958 \mathrm{~W} \\
365844 \mathrm{~N} 1123448 \mathrm{~W}\end{array}$ & 4898 & $\begin{array}{l}\text { Brooklyn Peak } \\
\text { Grayback Mts } \\
\text { Snowflake } \\
\text { Fredonia } \\
\text { Pearce } \\
\text { Fredonia } \\
\text { San Carlos } \\
\text { W of Greasewood Mtn } \\
\text { Bouse } \\
\text { Second Knolls }\end{array}$ \\
\hline
\end{tabular}




\begin{tabular}{|c|c|c|c|c|c|c|c|}
\hline FEATURE NAME & $\begin{array}{l}\text { FEATURE } \\
\text { CLASS }\end{array}$ & STATUS & COUNTY & COORDINATE & $\begin{array}{l}\text { SOURCE } \\
\text { COORDINATE }\end{array}$ & $\begin{array}{c}\text { ELEV } \\
\text { FT }\end{array}$ & MAP NAME \\
\hline $\begin{array}{l}\text { Six Shooter Canyon } \\
\text { See Sixshooter Canyon } \\
\text { Six Shooter Canyon } \\
\text { See Sixshooter Canyon } \\
\text { Sixshooter Canyon } \\
\text { Six Shooter Canyon } \\
\text { Six-shooter Canyon }\end{array}$ & $\begin{array}{l}\text { valley } \\
\text { valley } \\
\text { valley }\end{array}$ & $\begin{array}{l}\text { VARIANT } \\
\text { VARIANT } \\
\text { BGN } 1965 \\
\text { VARIANT } \\
\text { VARIANT }\end{array}$ & $\begin{array}{l}\text { Greenlee } \\
\text { Gila } \\
\text { Gila }\end{array}$ & $\begin{array}{l}330821 \mathrm{N1} 1090731 \mathrm{~W} \\
332252 \mathrm{~N} 1104610 \mathrm{~W} \\
332252 \mathrm{N1104610 \textrm {W }}\end{array}$ & $331731 \mathrm{N1104956 \textrm {W }}$ & & Globe \\
\hline $\begin{array}{l}\text { Six-shooter Canyon } \\
\text { See Sixshooter Canyon } \\
\text { Sixshooter Gap } \\
\text { Sixshooter Tank } \\
\text { Six-shooter Tank } \\
\text { Sixshooter Tank } \\
\text { Six Tank } \\
\text { Sixteenmile Tank } \\
\text { Sixteen Tank } \\
\text { Sixteen Tank }\end{array}$ & $\begin{array}{l}\text { valley } \\
\text { gap } \\
\text { reservoir } \\
\text { reservoir } \\
\text { reservoir } \\
\text { reservoir } \\
\text { reservoir } \\
\text { reservoir } \\
\text { reservoir }\end{array}$ & $\begin{array}{l}\text { VARIANT } \\
\text { BGN } \\
\text { BGN } \\
\text { BGN } \\
\text { BGN } \\
\text { BGN } \\
\text { BGN } \\
\text { BGN } \\
\text { BGN }\end{array}$ & $\begin{array}{l}\text { Gila } \\
\text { Greenlee } \\
\text { Greenlee } \\
\text { Maricopa } \\
\text { Coconino } \\
\text { Yavapai } \\
\text { Navajo } \\
\text { Yavapai } \\
\text { Coconino }\end{array}$ & 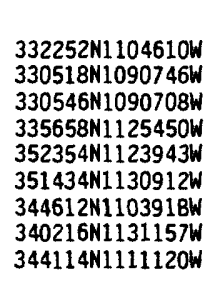 & & & $\begin{array}{l}\text { Rattlesnake Spring } \\
\text { Rattlesnake Spring } \\
\text { Outlaw Hill } \\
\text { Mount Floyd } \\
\text { Cross Mtn } \\
\text { Relic Point } \\
\text { Oate Creek Ranch SW } \\
\text { Hay Lake }\end{array}$ \\
\hline $\begin{array}{l}\text { Sixteen To One Mine } \\
\text { Sixth Avenue Interchange } \\
\text { Sixtymile Canyon } \\
\text { Sixtymile Creek } \\
\text { Sixtymile Rapids } \\
\text { Sixtyone Tank } \\
\text { Sixtysix Peak } \\
\text { Sixty Six Ranch } \\
\text { Sixty Six Ranch } \\
\text { Sixtythree Mine }\end{array}$ & $\begin{array}{l}\text { mine } \\
\text { crossing } \\
\text { valley } \\
\text { stream } \\
\text { rapids } \\
\text { reservoir } \\
\text { sumit } \\
\text { locile } \\
\text { locale } \\
\text { mine }\end{array}$ & $\begin{array}{l}\text { UNOFF } \\
\text { UNOFF } \\
\text { BGN } \\
\text { BGN } 1927 \\
\text { BGN } \\
\text { BGN } \\
\text { BGN } \\
\text { UNOFF } \\
\text { UNOFF } \\
\text { UNOFF }\end{array}$ & $\begin{array}{l}\text { Graham } \\
\text { Pima } \\
\text { Coconino } \\
\text { Coconino } \\
\text { Coconino } \\
\text { Coconino } \\
\text { Graham } \\
\text { Pinal } \\
\text { Gila } \\
\text { Mohave }\end{array}$ & 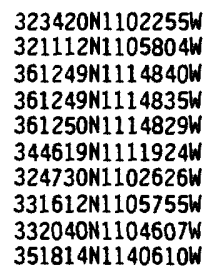 & $\begin{array}{l}361238 \mathrm{~N} 1115211 \mathrm{~W} \\
361238 \mathrm{~N} 1115211 \mathrm{~W}\end{array}$ & $\begin{array}{l}5634 \\
2894\end{array}$ & $\begin{array}{l}\text { Kielberg Canyon } \\
\text { Tucson } \\
\text { Cape Solitude } \\
\text { Cape Solitude } \\
\text { Cape Solitude } \\
\text { Jaycox Mtn } \\
\text { Oak Grove Canyon } \\
\text { Pinal Ranch } \\
\text { Pinal Peak } \\
\text { Stockton Hill }\end{array}$ \\
\hline $\begin{array}{l}\text { Sixtythree Tank } \\
\text { Sixtytwo Tank } \\
\text { Sixty Two Tank } \\
\text { Sizer Knoll } \\
\text { Skeleton Bone Tank } \\
\text { Skeleton Canyon } \\
\text { Skeleton Canyon } \\
\text { Skeleton Canyon } \\
\text { Skeleton Cave } \\
\text { See Browns Cave }\end{array}$ & $\begin{array}{l}\text { reservoir } \\
\text { reservoir } \\
\text { reservoir } \\
\text { summit } \\
\text { reservoir } \\
\text { valley } \\
\text { valley } \\
\text { valley } \\
\text { cave }\end{array}$ & $\begin{array}{l}\text { BGN } \\
\text { BGN } \\
\text { BGN } \\
\text { BGN } \\
\text { BGN } \\
\text { BGN } \\
\text { BGN } \\
\text { BGN } \\
\text { VARIANT }\end{array}$ & $\begin{array}{l}\text { Coconino } \\
\text { Coconino } \\
\text { Coconino } \\
\text { Apache } \\
\text { Yavapai } \\
\text { Cochise } \\
\text { Pinal } \\
\text { Greeniee } \\
\text { Maricopa }\end{array}$ & $\begin{array}{l}344049 \mathrm{N1111735W} \\
344950 \mathrm{N1112149 \textrm {W }} \\
3549061121154 \mathrm{~W} \\
340045 \mathrm{N1} 1092541 \mathrm{~W} \\
345027 \mathrm{N1115923W} \\
313539 \mathrm{~N} 1090406 \mathrm{~W} \\
325051 \mathrm{N1} 103444 \mathrm{~W} \\
331626 \mathrm{~N} 1090452 \mathrm{~W} \\
\\
333637 \mathrm{~N} 1111907 \mathrm{~W}\end{array}$ & $\begin{array}{l}313320 \mathrm{~N} 1085818 \mathrm{~W} \\
325031 \mathrm{N1} 103218 \mathrm{~W} \\
331742 \mathrm{~N} 1090454 \mathrm{~W}\end{array}$ & 9424 & $\begin{array}{l}\text { Turkey Mtn } \\
\text { Jaycox Mtn } \\
\text { Red Butte SW } \\
\text { Greer } \\
\text { Page Springs } \\
\text { Skeleton Canyon } \\
\text { Holy Joe Peak } \\
\text { Maple Peak }\end{array}$ \\
\hline $\begin{array}{l}\text { Skeleton Mesa } \\
\text { Skeleton Park Tank } \\
\text { Skeleton Ridge } \\
\text { Skeleton Tank } \\
\text { Skeleton Tank } \\
\text { Skeleton Tank } \\
\text { Skiddy Canyon } \\
\text { Skiddy Ridge } \\
\text { Skiddy Tank } \\
\text { Skid Tank }\end{array}$ & $\begin{array}{l}\text { summit } \\
\text { reservoir } \\
\text { ridge } \\
\text { reservoir } \\
\text { reservoir } \\
\text { reservoir } \\
\text { valley } \\
\text { ridge } \\
\text { reservoir } \\
\text { reservoir }\end{array}$ & $\begin{array}{l}\text { BGN } \\
\text { BGN } \\
B G N \\
B G N \\
B G N \\
\text { BGN } \\
B G N \\
8 G N \\
\text { BGN } \\
\text { BGN }\end{array}$ & $\begin{array}{l}\text { Navajo } \\
\text { Coconino } \\
\text { Yavapai } \\
\text { Cochise } \\
\text { Grahan } \\
\text { Gila } \\
\text { Navajo } \\
\text { Navajo } \\
\text { Navajo } \\
\text { Gila }\end{array}$ & $\begin{array}{l}364435 \mathrm{~N} 1102559 \mathrm{~W} \\
345349 \mathrm{N1113816 \textrm {W }} \\
341729 \mathrm{N111} 14526 \mathrm{~W} \\
313150 \mathrm{N1} 109040 \mathrm{~W} \\
331009 \mathrm{N1} 1093755 \mathrm{~W} \\
335144 \mathrm{N1} 102213 \mathrm{~W} \\
340749 \mathrm{N1} 100614 \mathrm{~W} \\
341018 \mathrm{N1} 100440 \mathrm{~W} \\
341042 \mathrm{N1} 100439 \mathrm{~W} \\
335842 \mathrm{N1} 105055 \mathrm{~W}\end{array}$ & $341234 \mathrm{~N} 1100512 \mathrm{~W}$ & & $\begin{array}{l}\text { Marsh Pass } \\
\text { Munds Park } \\
\text { Tule Mesa } \\
\text { Skeleton Canyon } \\
\text { Park Creek Cabins } \\
\text { Carrizo SE } \\
\text { Show Low South } \\
\text { Show Low South } \\
\text { Show Low South } \\
\text { Rock House }\end{array}$ \\
\hline $\begin{array}{l}\text { Skiff School } \\
\text { Ski Hi Retreat Tank } \\
\text { Skinner Pasture Tank } \\
\text { West Skinner Tank }\end{array}$ & $\begin{array}{l}\text { school } \\
\text { reservoir } \\
\text { reservoir }\end{array}$ & $\begin{array}{l}\text { UNOFF } \\
\text { BGN } \\
\text { BGN } 1979 \\
\text { VARIANT }\end{array}$ & $\begin{array}{l}\text { Maricopa } \\
\text { Navajo } \\
\text { Coconino }\end{array}$ & $\begin{array}{l}332552 \mathrm{~N} 1120235 \mathrm{~W} \\
340940 \mathrm{N1} 1095318 \mathrm{~W} \\
355415 \mathrm{~N} 111593 \mathrm{~W}\end{array}$ & & & $\begin{array}{l}\text { Phoenix } \\
\text { Lakeside } \\
\text { Grandview Point }\end{array}$ \\
\hline $\begin{array}{l}\text { Skinner Ridge } \\
\text { Skinner Tank } \\
\text { Skinner Tank } \\
\text { Skinner Village } \\
\text { See Troy } \\
\text { Skinnerville } \\
\text { See Troy }\end{array}$ & $\begin{array}{l}\text { ridge } \\
\text { reservoir } \\
\text { reservoir } \\
\text { locale } \\
\text { locale }\end{array}$ & $\begin{array}{l}\text { BGN } \\
\text { BGN } \\
\text { BGN } \\
\text { VARIANT } \\
\text { VARIANT }\end{array}$ & $\begin{array}{l}\text { Coconino } \\
\text { Yavapai } \\
\text { Coconino } \\
\text { Pinal } \\
\text { Pinal }\end{array}$ & 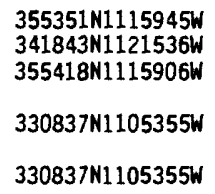 & & & $\begin{array}{l}\text { Grandview Point } \\
\text { Battle Flat } \\
\text { Grandview Point }\end{array}$ \\
\hline $\begin{array}{l}\text { Skinny Mesa } \\
\text { Skipper Tank } \\
\text { Skoksonak } \\
\text { Skousen Tank } \\
\text { Skull Cave } \\
\text { Skull Cave } \\
\text { See Browns Cave } \\
\text { Skull Mesa } \\
\text { Skull Spring } \\
\text { Skull Valley }\end{array}$ & $\begin{array}{l}\text { summit } \\
\text { reservoir } \\
\text { locale } \\
\text { reservoir } \\
\text { cave } \\
\text { cave } \\
\text { summit } \\
\text { spring } \\
\text { valley }\end{array}$ & $\begin{array}{l}\text { BGN } \\
\text { BGN } \\
B G N \\
B G N \\
\text { BGN } \\
\text { VARIANT } \\
\text { BGN } \\
\text { BGN } \\
\text { BGN } 1979\end{array}$ & $\begin{array}{l}\text { Apache } \\
\text { Mohave } \\
\text { Pima } \\
\text { Coconino } \\
\text { Maricopa } \\
\text { Maricopa } \\
\text { Maricopa } \\
\text { Greenlee } \\
\text { Yavapai }\end{array}$ & $\begin{array}{l}365209 N 1094439 \mathrm{~W} \\
35435111142125 \mathrm{~W} \\
3217441113213 \mathrm{~W} \\
355208 \mathrm{N111} 2032 \mathrm{~W} \\
333507 \mathrm{N1112238W} \\
333637 \mathrm{~W} 1111907 \mathrm{~W} \\
335533 \mathrm{N1115452 \textrm {W }} \\
3346141091719 \mathrm{~W} \\
342710 \mathrm{~N} 1124140 \mathrm{~W}\end{array}$ & $343310 \mathrm{~N} 1124000 \mathrm{~W}$ & 5235 & $\begin{array}{l}\text { Mexican Water SW } \\
\text { White Hills East } \\
\text { Koht Kohl Hill } \\
\text { Peterson Flat } \\
\text { Mormon Flat Dam }\end{array}$ \\
\hline $\begin{array}{l}\text { Sku11 Valley } \\
\text { See Coughran Canyon } \\
\text { Skull Valley }\end{array}$ & $\begin{array}{l}\text { valley } \\
\text { ppl }\end{array}$ & $\begin{array}{l}\text { VARIANT } \\
\text { BGN }\end{array}$ & $\begin{array}{l}\text { Yavapai } \\
\text { Yavapai }\end{array}$ & $\begin{array}{l}343010 \mathrm{~N} 1124143 \mathrm{~W} \\
343019 \mathrm{~N} 1124105 \mathrm{~W}\end{array}$ & & & Skull Valley \\
\hline
\end{tabular}


NATIONAL GAZETTEER--ARIZONA 1986

FEATURE NAME

Skull Valley Cemetery

Sku1l Valley Elementary School

Skull Valley Railroad Station

Skull Valley Ranch School

Skull Valley Wash

Skull Valley Wash

See Coughran Canyon

Skully Creek

C A Bar Canyon

Cottonwood Creek

Scelly Creek

Skunk Bas in

Skunk Camp Wash

Skunk Canyon

Skunk Canyon

See Skunk Gulch

Skunk Canyon

Skunk Canyon

Skunk Canyon

Skunk Canyon

Skunk Canyon

Skunk Canyon Spring

Skunk Canyon Spring

Skunk Creek

See New River

Skunk Creek

Cottonwood Creek

Skunk Creek Tank

Skunk Flat

Skunk Gulch

$$
\text { Lost Gulch }
$$

Skunk Canyon

Skunk Ridge

Skunk Spring

Skunk Spring

Skunk Spring

West Skinner Tank

Skunk Tank

Skunk Tank Canyon

Skunk Tank Canyon

Skunk Tank Ridge

Sky, Arch in the

Sky Harbor International

Airport

See Phoenix Sky Harbor International Airport

Sky Harbor Municipal Airport

See Phoenix Sky Harbor

International Airport

Sky Hi Pioneer Airport

Skyline Bel Aire Estates

Skyl ine Heights (subdivision)

Skyline Interchange

Sky Ridge Mobile Homes

Sky Y Camp

Slade Ranch

Slade Reservoir

Cahon Reservoir

New Reservoir

Slash S Ranch

Slash Well

Slate Creek

slate Creek

slate Creek

slate Creek

Slate Lakes

Slate Lakes Cave

Slate Mountain

Slate Mountain Mine

See House Mine

Slate Mountains
FEATURE

CLASS

cemetery

school

building

school

stream

valley

strean

VARIANT

VARIANT
VARIANT

VARIANT

bas in

stream

valley

valley

valley

BGN

BGN

BGN

VARIANT

BGN

Gila

Graham

Gila

Gila

valley

valley

valley

valley

pring

spring

stream

stream

BGN Mavajo

BGN Yavapai

BGN Mohave

BGN Coconino

Graham

BGN Mohave

VARIANT

BGN

VARIANT

Maricopa

Maricopa

reservoir

flat

valley

Apache

VARIANT

VARIANT

ridge

spring

spring

spring

BGN

BGN

$B G N$

BGN

VARIANT

aricopa

Santa Cruz

Gila

Navajo

reservoir

valley

valley

ridge

arch

$\begin{array}{ll}\text { BGN } & \text { Maricopa } \\ \text { BGN } & \text { Maricopa } \\ \text { BGN } & \text { Gila }\end{array}$

BGN 1956 Coconino

VARIANT

airport

Maricopa

VARIANT

airport

VARIANT

Maricopa

airport

ppl

BGM

crossing BGN

locale UNOFF

locale

locale

reservoir

BGN

UNOFF

BGN 1971 Apache

VARIANT

Maricopa

Pima

Maricopa

Cochise

Maricopa

Yavapai

loca

well

stream

stream

stream

stream

lake

cave

summit

mine

UNOFF

UNOF

BGN

BGN

1932 Coconino

BGN Coconino

BGN

BGN

VARIANT

Coconino

Coconino

Pinal

range

BGN 1941 Pinal
333658 N1121437W
COOROINATE

343151 N1124108

343006 N1124010W

$342952 \mathrm{~N} 1124111 \mathrm{~W}$

$342825 \mathrm{~N} 1124126 \mathrm{~W}$

$342417 N 1124357 W$

343010 N1124143W

325600 N1091005W

325940 N1090500W

335739 N1115502W

$331004 N 1105305 \mathrm{~W}$

$332421 N 1095926 \mathrm{~W}$

$332524 N 1105217 W$

332609 N1105347W

$340838 \mathrm{~N} 1102140 \mathrm{~W}$

$342753 N 1131342$

345540 N1132423W

$350902 \mathrm{~N} 1113557 \mathrm{~W}$

332548 N1095938W

345442 N1132537W

$333053 \mathrm{~N} 1121812 \mathrm{~W}$

$335718 \mathrm{N1120308W}$

334910 N1120637W

$335932 N 1090600 \mathrm{~W}$

$332524 N 1105217 \mathrm{~W}$

335652 N1115420W

$312910 \mathrm{~N} 1111809 \mathrm{~W}$

332647 N1105408

354503N1101159W

$335730 N 1115421 W$

$335800 \mathrm{~N} 1115455 \mathrm{~W}$

$335935 \mathrm{~N} 1111017 \mathrm{~W}$

$340111 \mathrm{N1110956}$

$365400 \mathrm{~N} 1105930 \mathrm{~W}$

332626 N1120029W

$332626 N 1120029 \mathrm{~W}$

$334018 \mathrm{~N} 1120006 \mathrm{~W}$

$321913 \mathrm{~N} 1105320 \mathrm{~W}$

$333252 \mathrm{~N} 1120244 \mathrm{~W}$

$332220 \mathrm{~N} 1120400 \mathrm{~W}$

$342740 \mathrm{~N} 1122647 \mathrm{~W}$

$335937 N 1093114 W$

335944 N1092010

$331205 N 1105504 \mathrm{~W}$

$324454 \mathrm{~N} 1110046 \mathrm{~W}$

$335623 \mathrm{~N} 1111825 \mathrm{~W}$

340307 N1120945W

$342010 \mathrm{~N} 1122931 \mathrm{~W}$

360806 N1121442W

$352845 N 1114819 \mathrm{~W}$

352731 N1114858W

$352940 \mathrm{~N} 1115031 \mathrm{~W}$

$323036 \mathrm{~N} 1115301 \mathrm{~W}$

323203 N1115259W

341159 N1102151W

$43313 N 1131427 \mathrm{~W}$

345353N1132722\%

350757 N1114024k

332703 N1105411W

$335631 N 1115327 \mathrm{~W}$

AZ585

\begin{tabular}{|c|c|c|}
\hline $\begin{array}{l}\text { SOURCE } \\
\text { COORDINATE }\end{array}$ & $\begin{array}{c}\text { ELEV } \\
\text { FT }\end{array}$ & MAP NAME \\
\hline $342959 \mathrm{~N} 1124129 \mathrm{~W}$ & 4168 & $\begin{array}{l}\text { Skull Valley } \\
\text { Skull Valley } \\
\text { Kirkland } \\
\text { Kirkland } \\
\text { Kirkland }\end{array}$ \\
\hline $325940 \mathrm{~N} 1090500 \mathrm{~W}$ & & York \\
\hline $\begin{array}{l}331342 N 1105048 \mathrm{~W} \\
332646 \mathrm{~N} 1100134 \mathrm{~W}\end{array}$ & & $\begin{array}{l}\text { New River Mesa } \\
\text { Hot Tamale Peak } \\
\text { Natanes Mts NW }\end{array}$ \\
\hline $332704 N 1105412 \mathrm{~W}$ & & Inspiration \\
\hline
\end{tabular}

Limestone Canyon $N$

Thorn Peak

Gonzales Wash

Flagstaff East

Natanes Mts NW

Gonzales Wash

Glendale

New River SE

Escudilla Mtn

Globe

New River Mesa

Bartlett Mtn

Inspiration

Keams Canyon

New River Mesa

New River Mesa

Picture Mtn

Sheep Bas in Mtn

Chaiyahi Flat

1560 Union Hills

2880 Tucson North

1270 Sunnys lope Mescal

1220 Lone Butte

Groom Creek 


\begin{tabular}{|c|c|c|c|c|c|c|c|}
\hline FEATURE NAME & $\begin{array}{l}\text { FEATURE } \\
\text { CLASS }\end{array}$ & STATUS & COUNTY & COORDINATE & $\begin{array}{l}\text { SOURCE } \\
\text { COORDINATE }\end{array}$ & $\begin{array}{c}\text { ELEV } \\
\text { FT }\end{array}$ & MAP NAME \\
\hline $\begin{array}{l}\text { Black Ranger } \\
\text { Schook Toahk } \\
\text { Sierra Prieta } \\
\text { Sierrita Prieta } \\
\text { Slate Mountain Well Seventy-one } \\
\text { Slate Spring } \\
\text { See Pole Spring } \\
\text { Slate Spring } \\
\text { Slate Tank }\end{array}$ & $\begin{array}{l}\text { well } \\
\text { spring } \\
\text { spring } \\
\text { reservoir }\end{array}$ & $\begin{array}{l}\text { VARIANT } \\
\text { VARIANT } \\
\text { VARIANT } \\
\text { VARIANT } \\
\text { UNOFF } \\
\text { VARIANT } \\
\text { BGN } \\
\text { BGN }\end{array}$ & $\begin{array}{l}\text { Pima } \\
\text { Yavapai } \\
\text { Yavapai } \\
\text { Yavapai }\end{array}$ & $\begin{array}{l}322950 \mathrm{~N} 1114913 \mathrm{~W} \\
342052 \mathrm{~N} 1123015 \mathrm{~W} \\
342121 \mathrm{N1122933 \textrm {W }} \\
342649 \mathrm{~N} 1113459 \mathrm{~W}\end{array}$ & & 1664 & $\begin{array}{l}\text { Santa Rosa Mts NE } \\
\text { Battleship Butte } \\
\text { Strawberry }\end{array}$ \\
\hline $\begin{array}{l}\text { Slate Hell } \\
\text { Slats Tank } \\
\text { Slaughter Camp } \\
\text { Slaughter Draw } \\
\text { Slaughterhouse Canyon } \\
\text { Slaughterhouse Gulch } \\
\text { Slaughter House Spring } \\
\text { See Slaughterhouse Spring } \\
\text { Slaughterhouse Spring } \\
\text { Slaughter House Spring }\end{array}$ & $\begin{array}{l}\text { well } \\
\text { reservoir } \\
\text { locale } \\
\text { valley } \\
\text { valley } \\
\text { valley } \\
\text { spring } \\
\text { spring }\end{array}$ & $\begin{array}{l}\text { UNOFF } \\
\text { BGN } \\
\text { BGN } \\
\text { BGN } \\
\text { BGN } \\
\text { BGN } \\
\text { VARIANT } \\
\text { BGN } 1976 \\
\text { VARIANT }\end{array}$ & $\begin{array}{l}\text { Coconino } \\
\text { Mohave } \\
\text { Graham } \\
\text { Greenlee } \\
\text { Mohave } \\
\text { Yavapai } \\
\text { Yavapai } \\
\text { Yavapai }\end{array}$ & $\begin{array}{l}352824 N 1115013 \mathrm{~W} \\
352814 N 1134040 \mathrm{~W} \\
330916 \mathrm{N1} 1094740 \mathrm{~W} \\
333856 \mathrm{~N} 1092302 \mathrm{~W} \\
351051 \mathrm{~N} 1140152 \mathrm{~W} \\
343345 \mathrm{~N} 1122634 \mathrm{~W} \\
\\
344531 \mathrm{N1120611W} \\
344531 \mathrm{~W} 1120611 \mathrm{~W}\end{array}$ & $\begin{array}{l}333658 N 1092334 \mathrm{~W} \\
351033 \mathrm{~N} 1135918 \mathrm{~W} \\
343206 \mathrm{~N} 1122520 \mathrm{~W}\end{array}$ & 7387 & $\begin{array}{l}\text { Kendrick Peak } \\
\text { Valentine } \\
\text { Bonita Tank } \\
\text { Hoodoo Knob } \\
\text { Kingman } \\
\text { Prescott }\end{array}$ \\
\hline $\begin{array}{l}\text { Slaughter House Wash } \\
\text { Slaughter Mountain } \\
\text { Slaughter Tank } \\
\text { Slaughter Tank } \\
\text { Slavin Gulch } \\
\text { Slavin Wash } \\
\text { Slavin Well } \\
\text { Sleepers Bend } \\
\text { Sleeping Beauty } \\
\text { See Sleeping Beauty Peak }\end{array}$ & $\begin{array}{l}\text { stream } \\
\text { summit } \\
\text { reservoir } \\
\text { locale } \\
\text { valley } \\
\text { stream } \\
\text { well } \\
\text { bend } \\
\text { summit }\end{array}$ & $\begin{array}{l}\text { BGN } \\
\text { BGN } \\
\text { BGN } \\
\text { BGN } \\
\text { BGN } \\
\text { BGN } \\
\text { UNOFF } \\
\text { BGN } \\
\text { VARIANT }\end{array}$ & $\begin{array}{l}\text { Cochise } \\
\text { Graham } \\
\text { Mohave } \\
\text { Gila } \\
\text { Cochise } \\
\text { Cochise } \\
\text { Cochise } \\
\text { Yuma } \\
\text { Gila }\end{array}$ & $\begin{array}{l}313813 N 1102116 \mathrm{~W} \\
330727 \mathrm{~N} 1094600 \mathrm{~W} \\
344457 \mathrm{N1} 132238 \mathrm{~W} \\
342331 \mathrm{N1113700 \textrm {W }} \\
315240 \mathrm{~N} 1100138 \mathrm{~W} \\
315227 \mathrm{N1101305W} \\
315212 \mathrm{~N} 1100431 \mathrm{~W} \\
330100 \mathrm{~N} 1143200 \mathrm{~W} \\
332708 \mathrm{~N} 1105310 \mathrm{~W}\end{array}$ & $\begin{array}{l}313315 N 1102411 \mathrm{~W} \\
315446 \mathrm{~N} 1095935 \mathrm{~W} \\
315435 \mathrm{~N} 1095947 \mathrm{~W}\end{array}$ & 4592 & $\begin{array}{l}\text { Huachuca City } \\
\text { Markham Creek } \\
\text { Elephant Mtn } \\
\text { Strawberry } \\
\text { Knob Hill } \\
\text { Land } \\
\text { Haberstock Hill } \\
\text { Picacho }\end{array}$ \\
\hline $\begin{array}{l}\text { Sleeping Beauty Mountain } \\
\text { Sleeping Beauty Mountain } \\
\text { See Sleeping Beauty Peak } \\
\text { Sleeping Beauty Peak } \\
\text { sleeping Beauty } \\
\text { Sleeping Beauty Mountain } \\
\text { Sleeping Beauty Spring } \\
\text { Sleeping Beauty Tank } \\
\text { Sleeping Duck } \\
\text { Sleepy Hill Windmill }\end{array}$ & $\begin{array}{l}\text { spring } \\
\text { reservoir } \\
\text { flat } \\
\text { locale }\end{array}$ & $\begin{array}{l}\text { BGN } \\
\text { VARIANT } \\
\text { BGN } \\
\text { VARIANT } \\
\text { VARIANT } \\
\text { BGN } \\
\text { BGN } \\
\text { BGN } \\
\text { BGN }\end{array}$ & $\begin{array}{l}\text { Gila } \\
\text { Gila } \\
\text { Apache } \\
\text { Coconino }\end{array}$ & $\begin{array}{l}331222 \mathrm{~N} 1110142 \mathrm{~W} \\
332708 \mathrm{~N} 1105310 \mathrm{~W} \\
332708 \mathrm{~N} 1105310 \mathrm{~W} \\
\\
332804 \mathrm{~N} 1105421 \mathrm{~W} \\
332800 \mathrm{~N} 1105224 \mathrm{~W} \\
360854 \mathrm{~N} 1093049 \mathrm{~W} \\
360442 \mathrm{~N} 1105729 \mathrm{~W}\end{array}$ & & 5482 & $\begin{array}{l}\text { Inspiration } \\
\text { Inspiration } \\
\text { Globe } \\
\text { Chinle } \\
\text { Bat Canyon }\end{array}$ \\
\hline $\begin{array}{l}\text { Sleepy Hollow Trailer Village } \\
\text { Sleepy Hollow Windmill } \\
\text { Slick Rock } \\
\text { Slick Rock Basin } \\
\text { slick Rock Detention Dam } \\
\text { Slick Rock Spring } \\
\text { Slick Rock Spring } \\
\text { Slick Rock Spring } \\
\text { Slick Rock Tank } \\
\text { Slick Rock Tank }\end{array}$ & $\begin{array}{l}\text { locale } \\
\text { locale } \\
\text { cliff } \\
\text { basin } \\
\text { dam } \\
\text { spring } \\
\text { spring } \\
\text { spring } \\
\text { reservoir } \\
\text { reservoir }\end{array}$ & $\begin{array}{l}\text { UNOFF } \\
\text { BGN } \\
\text { BGN } \\
\text { BGN } \\
\text { UNOFF } \\
\text { BGN } \\
\text { BGN } \\
\text { BGN } \\
\text { BGN } \\
\text { BGN }\end{array}$ & $\begin{array}{l}\text { Maricopa } \\
\text { Apache } \\
\text { Graham } \\
\text { Graham } \\
\text { Graham } \\
\text { Graham } \\
\text { Gila } \\
\text { Yavapai } \\
\text { Pima } \\
\text { Yavapai }\end{array}$ & $\begin{array}{l}332401 \mathrm{~N} 1120424 \mathrm{~W} \\
350047 \mathrm{~N} 1092912 \mathrm{~W} \\
324337 \mathrm{~N} 1095341 \mathrm{~W} \\
324605 \mathrm{~N} 1092133 \mathrm{~W} \\
324342 \mathrm{~N} 1092836 \mathrm{~W} \\
324240 \mathrm{~N} 1094802 \mathrm{~W} \\
334611 \mathrm{~N} 1103620 \mathrm{~W} \\
343750 \mathrm{~N} 1120542 \mathrm{~W} \\
312928 \mathrm{~N} 1112617 \mathrm{~W} \\
342328 \mathrm{~N} 1121820 \mathrm{~W}\end{array}$ & & 1080 & $\begin{array}{l}\text { Phoenix } \\
\text { Navajo Springs } \\
\text { Webb Peak } \\
\text { Ash Peak } \\
\text { Dry Mtn } \\
\text { Mt Graham } \\
\text { Mule Hoof Bend } \\
\text { Cottonwood } \\
\text { Cumero Mtn } \\
\text { Poland Junction }\end{array}$ \\
\hline $\begin{array}{l}\text { Slick Rock Tank } \\
\text { Slick Rock Wash } \\
\text { Slick Rock Wash } \\
\text { See Shoat Tank Wash } \\
\text { Slick Rock Wash } \\
\text { Slide Canyon } \\
\text { Slide Cove } \\
\text { Slide Creek } \\
\text { Silver Creek } \\
\text { Slide Mountain }\end{array}$ & $\begin{array}{l}\text { reservoir } \\
\text { stream } \\
\text { stream } \\
\text { valley } \\
\text { valley } \\
\text { bay } \\
\text { stream } \\
\text { summit }\end{array}$ & $\begin{array}{l}\text { BGN } \\
\text { BGN } \\
\text { VARIANT } \\
\text { BGN } \\
\text { BGN } \\
\text { BGN } 1983 \\
\text { BGN } 1964 \\
\text { VARIANT } \\
\text { BGN }\end{array}$ & $\begin{array}{l}\text { Mohave } \\
\text { Graham } \\
\text { Graham } \\
\text { Apache } \\
\text { Coconino } \\
\text { Mohave } \\
\text { Apache } \\
\text { Mohave }\end{array}$ & $\begin{array}{l}361106 \mathrm{~N} 1132029 \mathrm{~W} \\
324308 \mathrm{~N} 1093229 \mathrm{~W} \\
\\
324600 \mathrm{~N} 1092355 \mathrm{~W} \\
354356 \mathrm{~N} 1090402 \mathrm{~W} \\
363926 \mathrm{~N} 1123613 \mathrm{~W} \\
360045 \mathrm{~N} 1141250 \mathrm{~W} \\
340250 \mathrm{~N} 1094800 \mathrm{~W} \\
361937 \mathrm{~N} 1131008 \mathrm{~W}\end{array}$ & $\begin{array}{l}324642 \mathrm{~N} 1092252 \mathrm{~W} \\
354636 \mathrm{~N} 1085639 \mathrm{~W} \\
363519 \mathrm{~N} 1122136 \mathrm{~W} \\
340214 \mathrm{~N} 1094740 \mathrm{~W}\end{array}$ & 7586 & $\begin{array}{l}\text { Window Rock } \\
\text { Gunsight Point } \\
\text { Hiller Mountains } \\
\text { McNary } \\
\text { Mount Logan }\end{array}$ \\
\hline $\begin{array}{l}\text { Slide Point } \\
\text { Slide Rock Swim Area } \\
\text { slide Spring } \\
\text { slide Spring } \\
\text { slide Tank } \\
\text { Sliding Rock Overlook } \\
\text { Sliding Rock Ruins } \\
\text { Sliding Rocks Valley } \\
\text { Sliker Hill } \\
\text { Sliker Tank }\end{array}$ & $\begin{array}{l}\text { cape } \\
\text { park } \\
\text { spring } \\
\text { spring } \\
\text { reservoir } \\
\text { locale } \\
\text { locale } \\
\text { valley } \\
\text { summit } \\
\text { reservoir }\end{array}$ & $\begin{array}{l}\text { BGN } \\
\text { ADNIN } \\
\text { BGN } \\
\text { BGN } \\
\text { BGN } \\
\text { BGN } \\
\text { BGN } \\
\text { BGN } \\
\text { BGN } \\
\text { BGN }\end{array}$ & $\begin{array}{l}\text { Coconino } \\
\text { Coconino } \\
\text { Gila } \\
\text { Coconino } \\
\text { Coconino } \\
\text { Apache } \\
\text { Apache } \\
\text { Navajo } \\
\text { Coconino } \\
\text { Coconino }\end{array}$ & $\begin{array}{l}363929 N 1123247 \mathrm{~W} \\
345650 \mathrm{~N} 1114512 \mathrm{~W} \\
340829 \mathrm{~N} 1105409 \mathrm{~W} \\
363928 \mathrm{~N} 1123345 \mathrm{~W} \\
363921 \mathrm{~N} 1122804 \mathrm{~W} \\
360654 \mathrm{~N} 1092614 \mathrm{~W} \\
360718 \mathrm{~N} 1092604 \mathrm{~W} \\
361556 \mathrm{~N} 1100946 \mathrm{~W} \\
350853 \mathrm{~N} 1115037 \mathrm{~W} \\
350737 \mathrm{~N} 1115055 \mathrm{~W}\end{array}$ & $361435 \mathrm{~N} 1100742 \mathrm{~W}$ & 7555 & $\begin{array}{l}\text { Gunsight Point } \\
\text { Wilson Mountain } \\
\text { Oxbow Mtn } \\
\text { Gunsight Point } \\
\text { Toothpick Ridge } \\
\text { Three Turkey Canyon } \\
\text { Three Turkey Canyon } \\
\text { Toh NE Zhonnie Spr } \\
\text { Bellemont } \\
\text { Bellemont }\end{array}$ \\
\hline $\begin{array}{l}\text { Slim Canyon } \\
\text { Slim Jim Canyon }\end{array}$ & $\begin{array}{l}\text { valley } \\
\text { valley }\end{array}$ & $\begin{array}{l}\text { BGN } \\
\text { BGN }\end{array}$ & $\begin{array}{l}\text { Apache } \\
\text { Coconino }\end{array}$ & $\begin{array}{l}361050 \mathrm{~N} 1093306 \mathrm{~W} \\
342701 \mathrm{~N} 1105007 \mathrm{~W}\end{array}$ & $\begin{array}{l}361257 \mathrm{~N} 1092552 \mathrm{~W} \\
342400 \mathrm{~N} 1104849 \mathrm{~W}\end{array}$ & & $\begin{array}{l}\text { Chinle } \\
\text { Weimar Point }\end{array}$ \\
\hline
\end{tabular}




\section{FEATURE NAME}

Slin Jim Creek

Slim Jim Ridge

Slims Spring

slims Tank

Slim Tank

Slinkard Spring

Slippery Well

slit Rock

Sloan Creek

Sloan Ranch

Slovan Well

Slumgullion Pass

Slurry Pond Number One

Slurry Pond Number One Dan

Small Butte

Small Canyon

Small Creek Wel

Small Hill Reservoir

Small 0il Well Tank

Small Point

Small Salt Well Tank

Small Tank

Small Tank

Small Tank

Small Tank

Small Tank

Small Twin Canyon

Small White Mesa

Small White Mesa flat

Small Wide Mesa

Smelter Canyon

Smelter Hill

Smelter Hill

Smelter Town

Smelter Wash

Smiley Tank

Smiling Tiger Ranch

Smith and Evans Tank

Smith Butte

Smith Butte

Smith Butte

See Flat Top Butte

Smith Cabin

Smith Canyon

Smith Canyon

Smith Canyon

Smith Canyon

See South Smith Canyon

Smith Canyon

Smith Canyon

Smith Canyon

Smith Cienega

Smith Creek

Smith Detention Dan

Smith Elementary School

See Colnez Smith School

Smith Gulch

Smith $\mathrm{Hill}$

Smith Lake

Smith Mesa

Smith Mesa Tank

$$
\text { Smith Tank }
$$

Smith Mill (site) Smiths Mill

Smith Mine

Smith Park

Smith Peak

Pete Smith Peak

Smith Ranch

Smith Ranch (historical)

Smith Ravine

\section{FEATURE}

STATUS

COUNTY

COORDINATE

$\begin{array}{ll}\text { stream } & \text { BGN } \\ \text { ridge } & B G N \\ \text { spring } & B G N \\ \text { reservoir } & B G N \\ \text { reservoir } & \text { BGN } \\ \text { spring } & \text { BGN } \\ \text { weli } & \text { UNOFF } \\ \text { arch } & \text { BGN }\end{array}$

Yavapai

Coconino

Apache

Yavapai

Coconino

Gila

Cochise

Pima

$\begin{array}{ll}\text { stream } & \text { BGN } \\ \text { locale } & \text { UNOFF } \\ \text { well } & \text { UNOFF } \\ \text { gap } & \text { BGN } \\ \text { reservoir } & \text { 8GN } \\ \text { dam } & \text { UNOFF } \\ \text { summit } & \text { BGN } \\ \text { valley } & \text { BGN } \\ \text { well } & \text { UNOFF } \\ \text { reservoir } & \text { BGN }\end{array}$

Gila

Maricopa

Yuma

Yavapai

Yavapai

Coconino

Apache

Apache

Pinal

reservoir

cliff

reservoir

reservoir $B G$

reservoir

reservoir

valley

summit

$B G N$
$B G N$
$B G N$
$B G N$
$B G N$
$B G N$
$B G N$
$B G N$
$B G N$
$B G N$

Navajo

Coconino

Apache

Greenlee

Yavapai

Coconino

Coconino

Mohave

Apache

Navajo

flat

summit

valley

summit

summit

locale

reservoir

locale

reservoir

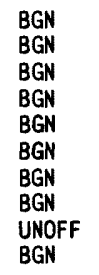

Navajo

Apache

Gila

Greenlee

Yavapai

Pinal

Pinal

Coconino

Cochise

Yavapaj

\begin{tabular}{|c|c|c|c|}
\hline $\begin{array}{l}\text { summit } \\
\text { summit }\end{array}$ & $\begin{array}{l}\text { BGN } \\
B G N\end{array}$ & $\begin{array}{l}\text { Coconino } \\
\text { Yavapai }\end{array}$ & $\begin{array}{l}350111 \mathrm{~N} 1114130 \mathrm{~W} \\
350943 \mathrm{~N} 1123722 \mathrm{~W}\end{array}$ \\
\hline $\begin{array}{l}\text { summit } \\
\text { locale } \\
\text { valley } \\
\text { valley } \\
\text { valley }\end{array}$ & $\begin{array}{l}\text { BGN } \\
\text { BGN } \\
\text { BGN } \\
\text { BGN }\end{array}$ & $\begin{array}{l}\text { Navajo } \\
\text { Greenlee } \\
\text { Santa Cruz } \\
\text { Santa Cruz } \\
\text { Cochise }\end{array}$ & $\begin{array}{l}351102 \mathrm{~N} 1101855 \mathrm{~W} \\
332937 \mathrm{N1} 1091236 \mathrm{~W} \\
313449 \mathrm{~N} 1104341 \mathrm{~W} \\
314243 \mathrm{~N} 1103539 \mathrm{~W} \\
321522 \mathrm{~N} 1094437 \mathrm{~W}\end{array}$ \\
\hline & SIAN & Greenlee & $330417 N 10927$ \\
\hline
\end{tabular}

valley

valley

valley

valley

flat

stream

dam

school

valley

summit

\section{BGN}

BGN

BGN

BGN

BGN

VARIANT

BGN

BGN

lake

summit

reservoir

locale

mine

park

summit

locale

locale

valley

$340457 \mathrm{~N} 1123654 \mathrm{~W}$

$342444 N 1105011 \mathrm{~W}$

$351710 \mathrm{~N} 1090333 \mathrm{~W}$

340209 N1121603W

$333124 \mathrm{~N} 1104436 \mathrm{~W}$

$320027 \mathrm{N1} 1094759 \mathrm{~W}$

$314920 \mathrm{NI} 123640 \mathrm{~W}$

335834N1104237W

313549 N1090410W

$323328 \mathrm{N1125114 \textrm {W }}$

$330215 \mathrm{N1140521 \textrm {K }}$

$351718 \mathrm{~N} 1130036 \mathrm{~W}$

351718 N1130036W

$364943 \mathrm{~N} 1110950 \mathrm{~W}$

$363545 \mathrm{~N} 1092030 \mathrm{~W}$

$362612 \mathrm{~N} 1091315 \mathrm{~W}$

$323327 N 1105832 \mathrm{~W}$

344118 N1102345W

$362256 \mathrm{N1114957 \textrm {W }}$

$344317 N 1094137 \mathrm{~W}$

$331456 \mathrm{N1092817 \textrm {W }}$

342001 N1121627W

$344555 \mathrm{~N} 1110503 \mathrm{~W}$

$350309 \mathrm{N1} 114813 \mathrm{~W}$

$354735 \mathrm{~N} 1135029 \mathrm{~W}$

$360447 \mathrm{~N} 1091819 \mathrm{~W}$

$363550 \mathrm{~N} 1100605 \mathrm{~W}$

$363630 \mathrm{~N} 1100653 \mathrm{~W}$

$362318 \mathrm{~N} 1091818 \mathrm{~W}$

332314N1105306W

330127 N1091818W

$342823 N 1122209 \mathrm{~W}$

$331728 \mathrm{~N} 1111635 \mathrm{~W}$

$324053 \mathrm{~N} 1103640 \mathrm{~W}$

$355243 \mathrm{N111} 3820 \mathrm{~W}$

$312251 \mathrm{N1} 101026 \mathrm{~W}$

$350443 N 1130143 \mathrm{~W}$

Greenlee

Greenlee

Coconino

Yavapai

Apache

Apache

Graham

Cochise

Santa Cruz

Cochise

$331754 \mathrm{N1092506 \textrm {W }}$

$342517 \mathrm{N1} 104525 \mathrm{~W}$

$343755 \mathrm{N1} 125331 \mathrm{~W}$

$335628 \mathrm{~N} 1093508 \mathrm{~N}$

$340002 \mathrm{~N} 1093703 \mathrm{~W}$

$325145 \mathrm{~N} 1094228 \mathrm{~W}$

$313310 \mathrm{~N} 1102003 \mathrm{~W}$

$313254 \mathrm{N1104647 \textrm {W }}$

315131N1100121W

$351911 \mathrm{N1121409W}$

$344313 \mathrm{~N} 1125106 \mathrm{~W}$

344423N1124940W

$334821 \mathrm{N1124014 \textrm {W }}$

322854N1140010W

$332628 \mathrm{~N} 1120846 \mathrm{~W}$

$340354 \mathrm{N1132118 \textrm {W }}$

$\begin{array}{lll}\text { ADMIN } & \text { Maricopa } & 332628 \mathrm{~N} 1120846 \mathrm{~W} \\ \text { BGN } & \text { Yuma } & 340354 \text { N1132118W }\end{array}$

VARIANT

\section{UNOFF}

BGN

SOURCE
COORDINATE

MAP NAME

340249 N1123311W

Morgan Butte

Weimar Point

Lupton

Columbia

East of S P Mtn

Chrome Butte

Sulphur Spring

Menagers Lake

340116N1104800W Double Buttes

Skeleton Canyon

Deadman Gap

Slumgullion Pass

Yampai SE

Yampai SE

5354 Cedar Tree Bench

Mexican Cry Mesa

Lukachukai

Oracle Junction

Dry Lake NW

Tatahatso Point

Potter Mesa Tank

Coronado Mtn

Batt le Flat

Chavez Mtn East

Dutton Hill

Horse Flat

Spider Rock

Chilchinbito

Chilchinbito

Bad Bug Butte

$332143 N 1105237 \mathrm{~W}$

Inspiration

3784 Clifton

Poland Junction

Florence Junction

$323406 \mathrm{~N} 1104416 \mathrm{~W}$

Clark Ranch

Hellhole Bend

Nicksville

Anvil Rock

7245 Mountainaire

Cathedral Caves

$313721 N 1104621 \mathrm{~W}$

$314246 \mathrm{N110424}$

321657 N1094310

5000 Dutch Blue Creek

Mt Hughes

Elgin 


\section{FEATURE NAME}

Smith Ravine Spring

Smith Ridge

Smith Ridge

Smith School

Smiths Mill

See Smith Mill (site)

Smithsonian Astrophysical observatory

Smith Spring
Smith Spring
Smiths Station
See Phoenix
Smith Station
See Phoenix
Smith Tank
Smith Tank
Smith Tank
See Smith Mesa Tank

Smith Tank

Smith Tank

Smith Tank

Smith Tank

Smith Tank

Smith Tank

Smith Tank

Smith Tanks

smithville

See Phroney Spring

Smithville Canal

Smith Wash

Smith Wash

Smith Wash

Smith Wash

Smith Well

Smith We11

Smitty Spring

Smoke Hole Tank

Smoke Rise Park

Smoke Signal

Smoke Signal Point

Smoke Signal Spring

Smoketree El lementary School

Smoke Tree Wash

Smoketree Was

Smokey Tank

Smoki Museum

Smoky Hollow

Smoky Hollow Tank

Smooth Butte

Smooth Knoll

Smoot Lake

Smuggler Canyon

Smuggler Mine

Smugglers Canyon

Smurr

Snafu Tank

Snag Spring

Snake Butte

Snake Creek

Snake Creek

North Fork white River Shake Creek

Snake Creek Tank Number One

Snake Creek White River

See North Fork White River

Snake Den Point

Snake Draw

Snake Flat

Snake Gulch

Snake Number Two Dam

Snake Pond
FEATURE
CLASS

STATUS

COUNTY

COORDINATE

spring

ridge

ridge

school

BGN

BGN

BGN

VARIANT

locale

UNOFF

Yavapai

Navajo

Coconino

Pima

building

UNOFF

Maricopa

Santa Cruz

$342836 \mathrm{~N} 1122336 \mathrm{~W}$

$342042 \mathrm{~N} 1102252 \mathrm{~W}$

342246 N1104537W

$321054 \mathrm{N1105207 \textrm {W }}$

$334821 \mathrm{~N} 1124014 \mathrm{~W}$

$314110 \mathrm{N1} 105245 \mathrm{~W}$

\begin{tabular}{|c|c|c|c|}
\hline $\begin{array}{l}\text { spring } \\
\text { spring }\end{array}$ & $\begin{array}{l}\mathrm{BGN} \\
\mathrm{BGN}\end{array}$ & $\begin{array}{l}\text { Greenlee } \\
\text { Coconino }\end{array}$ & 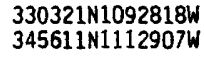 \\
\hline $\mathrm{ppl}$ & YADTANT & Maricopa & $332654 \mathrm{~N} 1120424 \mathrm{~W}$ \\
\hline $\begin{array}{l}\text { ppl } \\
\text { reservoir } \\
\text { reservoir }\end{array}$ & $\begin{array}{l}\text { BGN } \\
\text { BGN } \\
\text { SARTANT }\end{array}$ & $\begin{array}{l}\text { Maricopa } \\
\text { Cochise } \\
\text { Navajo }\end{array}$ & $\begin{array}{l}332654 \mathrm{~N} 1120424 \mathrm{~W} \\
313138 \mathrm{N1} 090517 \mathrm{~W} \\
343004 \mathrm{N1} 102458 \mathrm{~W}\end{array}$ \\
\hline reservoir & & Yavapaf & $344423 N 1124940 \mathrm{~W}$ \\
\hline $\begin{array}{l}\text { reservoir } \\
\text { reservoir } \\
\text { reservoir } \\
\text { reservoir } \\
\text { reservoir } \\
\text { reservoir } \\
\text { reservoir } \\
\text { reservoir }\end{array}$ & $\begin{array}{l}\text { BGN } \\
B G N \\
B G N \\
B G N \\
B G N \\
\text { BGN } \\
\text { BGN } \\
\text { BGN } \\
\text { VARIANT }\end{array}$ & $\begin{array}{l}\text { Coconino } \\
\text { Coconino } \\
\text { Coconino } \\
\text { Coconino } \\
\text { Coconino } \\
\text { Mohave } \\
\text { Mohave } \\
\text { Coconino }\end{array}$ & $\begin{array}{l}345609 \mathrm{~N} 1112838 \mathrm{~W} \\
35131711128023 \mathrm{~W} \\
351615 \mathrm{N11} 121244 \mathrm{~W} \\
352548 \mathrm{N1115757W} \\
354944 \mathrm{N1} 114152 \mathrm{~W} \\
355231 \mathrm{N1135112W} \\
363523 \mathrm{~W} 1131412 \mathrm{~W} \\
352520 \mathrm{N1124315W}\end{array}$ \\
\hline
\end{tabular}

spring

canal

stream

stream

stream

stream

well

well

spring

reservoir

park

ppi

cliff

spring

schoo

stream

reservoir

building

valley

reservoir

BGN

$B G N$

BGN

BGN

BGN

UNOFF

UNOFF

BGN

BGN

ADMIN

$342627 N 1114137 \mathrm{~W}$

$325210 N 1094604 \mathrm{~W}$

$314822 \mathrm{~N} 1100645 \mathrm{~W}$

$322042 \mathrm{~N} 109404 \mathrm{WW}$

330000 N1104934

333858 N11 40BO6W

$315118 \mathrm{N1100107 \textrm {W }}$

$332853 \mathrm{~N} 1102730 \mathrm{~W}$

$315524 \mathrm{~N} 1103019 \mathrm{~W}$

$361601 N 1105102 \mathrm{~W}$

$351409 \mathrm{N1113413 \textrm {W }}$

$355848 \mathrm{~N} 1100240 \mathrm{~W}$

$355958 \mathrm{~N} 1100059 \mathrm{~W}$

360039 N1100144W

$342907 N 1141914 \mathrm{~W}$

$322100 \mathrm{N1134032 \textrm {W }}$

$342937 \mathrm{N11} 141839 \mathrm{~W}$

$345933 N 1121215 \mathrm{~W}$

$343236 \mathrm{~N} 1122729 \mathrm{~W}$

$341253 \mathrm{~N} 1110541 \mathrm{~W}$

$341106 \mathrm{N1110551 \textrm {W }}$

Summit BGN Navajo 352209N1095848

summit BGN Apache, 341913 N1093946 W

lake BGN Coconino 352815N1120648W

valley BGN Greenlee 325945N1092041W

mine UNOFF Greenlee 325938N1092048W

valley BGN P12930N1113615W

locale BGN Maricopa 325543N1124914W

reservoir BGN Coconino 343708N1112038W

$\begin{array}{llll}\text { spring BGN Yavapai 344657N1125436 } & \end{array}$

summit BGN Navajo 353824N1102634W

stream BGN Greenlee 334031N1092855W

stream BGN 1971 Apache 340008N1093448W

VARIANT

reservoir BGN

VARIANT

stream

cliff

valley

BGN

Apache

Navajo

Apache

Coconino

$340028 \mathrm{~N} 1093423 \mathrm{~W}$

$334728 \mathrm{~N} 1095941 \mathrm{~W}$

362607 N1091548W

$343040 \mathrm{~N} 1112119 \mathrm{~W}$

$354928 N 1093633 \mathrm{~W}$

$\begin{array}{lll}\text { valley } & \text { BGN } & \text { Coconino } \\ \text { dam } & \text { UNOFF } & \text { Coconino } \\ \text { reservoir } & \text { BGN } & \text { Mohave }\end{array}$

363830 N1123725W

$344754 \mathrm{~N} 1111706 \mathrm{~W}$

$365126 \mathrm{N1130809 \textrm {W }}$

\begin{tabular}{|c|c|c|}
\hline \multirow[t]{3}{*}{$\begin{array}{l}\text { SOURCE } \\
\text { COORDIMATE }\end{array}$} & $\begin{array}{c}\text { ELEV } \\
\text { FT }\end{array}$ & MAP NAME \\
\hline & & $\begin{array}{l}\text { Groom Creek } \\
\text { Day Spring } \\
\text { Weimar Point } \\
\text { Tucson East }\end{array}$ \\
\hline & & Mt Hopkins \\
\hline
\end{tabular}

Copperplate Gulch Mormon Lake

Skeleton Canyon Zeniff

Mormon Lake

Flagstaff East Willi ams North Moritz Ridge Willows Camp

Quartermaster Canyon Moriah Knoll Mount Floyd

\begin{tabular}{|c|c|c|}
\hline 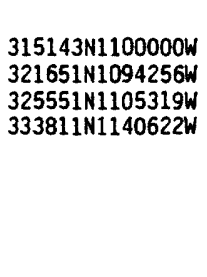 & $\begin{array}{l}4916 \\
3337 \\
5941\end{array}$ & $\begin{array}{l}\text { Thatcher } \\
\text { Haberstock Hill } \\
\text { RaiTroad Pass } \\
\text { Winkelman } \\
\text { Quartzsite } \\
\text { Haberstock Hill } \\
\text { Natural Corral } \\
\text { The Narrows } \\
\text { John Daw Mesa } \\
\text { Flagstaff East }\end{array}$ \\
\hline & & $\begin{array}{l}\text { Low Mountain } \\
\text { Low Mountain } \\
\text { Whippoorwill Spring } \\
\text { Lake Havasu City } 5\end{array}$ \\
\hline 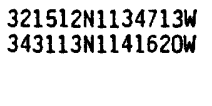 & & $\begin{array}{l}\text { Christmas Pass } \\
\text { Lake Havasu City S } \\
\text { Perkinsville }\end{array}$ \\
\hline \multirow[t]{2}{*}{$341053 \mathrm{~N} 1110529 \mathrm{~W}$} & & $\begin{array}{l}\text { Diamond Butte } \\
\text { Diamond Butte }\end{array}$ \\
\hline & 6961 & $\begin{array}{l}\text { Arrowhead Butte } \\
\text { Vernon } \\
\text { Squaw Mtn }\end{array}$ \\
\hline 325937 N1091951W & & $\begin{array}{l}\text { Guthrie } \\
\text { Guthrie }\end{array}$ \\
\hline $313038 N 1113614 \mathrm{~W}$ & 728 & $\begin{array}{l}\text { Presumido Peak } \\
\text { Smurr } \\
\text { Long Valley } \\
\text { Camp Wood }\end{array}$ \\
\hline & & \\
\hline \multirow[t]{2}{*}{$\begin{array}{l}333716 \mathrm{~N} 1092609 \mathrm{~W} \\
340036 \mathrm{N1} 1093346 \mathrm{~W}\end{array}$} & & $\begin{array}{l}\text { Hoodoo Knob } \\
\text { Greens Peak }\end{array}$ \\
\hline & & Greens Peak \\
\hline $342927 N 1111951 \mathrm{~W}$ & & $\begin{array}{l}\text { Bad Bug Butte } \\
\text { Long Valley } \\
\text { Ganado Mesa }\end{array}$ \\
\hline 364249 N1121858W & & $\begin{array}{l}\text { Gunsight Point } \\
\text { Jaycox Mtn } \\
\text { White Pockets }\end{array}$ \\
\hline
\end{tabular}




\section{FEATURE NAME}

Snake Ridge
Snake Ridge
Snake Ridge
Snake Ridge Tank
Snake Spring
Snake Springs
Snake Springs Rest Area

Snake Spring Wash
Snake Tank
Snake Tank
Snake Tank
Snake Tank Number One
Snake Tank Number Two
Snaketown
See Hohokam Pima National
Snaketown
Snumt
Snake Track Tank
Snap Canyon
Snap Draw
Snap Point
Snap Seep Tank
Snap Spring
Snap Tank
Snare Canyon
Snipe Hollow
Snipe Lake
Snodgrass Tank
Snowball Mine
Snowbird Canyon
Snowbird Spring
Snowdrift Mine
Snowflake
Snowf lake Elementary School
Snowflake Junior High School
Snowflake Municipal Airport
Snowf lake Taylor Elementary
School

FEATURE
CLASS

ridge

ridge

ridge

reservoir

spring

spring

park

stream

reservoir

reservoir

reservoir

reservoir

reservoir

park

locale

reservoir

valley

valley

cliff

reservoir

spring

reservoir

valley

valley

lake

reservoir

mine

valley

spring

mine

$\mathrm{ppl}$

school

school

airport

school

flat

park

summit

summit

trail

stream

ridge

spring

spring

See Pocomate Springs
STATUS

COUNTY

Greenlee

Navajo

Coconino

Coconino

Apache

Apache

Apache

BGN
BGN
BGN
BGN
BGN
BGN
VARIANT

Mohave

Pima

Greenlee

Coconino

Coconino

Coconino

Pinal

Pina1

Yavapai

Mohave

Mohave

Mohave

Coconino

Mohave

Mohave

Greenlee

Coconino

Coconino

Maricopa

Maricopa

Navajo

Navajo

Yavapai

Navajo

Navajo

Navajo

Navajo

Navajo

UNOFF

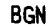

ADMIN

BGN

UNOFF

BGN

BGN

BGN
VARIANT

Graham

Graham

Mohave

Cochise

Cochise

Apache

Gila

Coconino

Coconino

stream

summit

reservoir

reservoir

reservoir

reservoir

summit

summit

mine

BGN

BGN
BGN
BGN

BGN

BGN

BGN

BGN

BGN 1977

UNOFF

Apache

Gila

Gila

Navajo

Gila

Cochise

Pima

Coconino

Pima

mine

reservoir

reservoir

well

well

UNOFF

BGN

BGN

UGN

UNOFF

VARIANT

summit

ppl

valley

VARIANT

BGN

Mohave

Pinal

Coconino

Pina

Yuma

Coconino

Pinal

Greenlee

Mohave

Yavapai

Coconino
COORDINATE

330933N1091130W $340657 \mathrm{~N} 1101106 \mathrm{~W}$ $343616 \mathrm{~N} 1112803 \mathrm{~W}$ $343543 N 1112 B 54 \mathrm{~W}$ $340010 N 1093359 \mathrm{~W}$ $354535 \mathrm{~N} 1093647 \mathrm{~W}$ $355210 \mathrm{~N} 1093548 \mathrm{~W}$

$343139 \mathrm{~N} 1132735 \mathrm{~W}$ 313143 N1112910 $334026 \mathrm{~N} 1092627 \mathrm{~W}$ $343350 \mathrm{~N} 1112751 \mathrm{~W}$ $344802 \mathrm{~N} 1111740 \mathrm{~W}$ $344751 \mathrm{N1111659 \textrm {W }}$

$331100 \mathrm{~N} 1115600 \mathrm{~W}$

$331059 N 1115508 \mathrm{~W}$

$341750 \mathrm{~N} 1121604 \mathrm{~W}$ 360910 N1135810W $361146 \mathrm{N1133622 \textrm {W }}$ $361023 \mathrm{~N} 1134759 \mathrm{~W}$ $345623 N 1113041 \mathrm{~W}$ $361035 \mathrm{~N} 1134449 \mathrm{~W}$ 3610351134449 $332217 N 1085905 \mathrm{~W}$ $363407 \mathrm{~N} 1121328 \mathrm{~W}$ 363153 N1121229W

$334632 \mathrm{~N} 1121257 \mathrm{~W}$ $334433 \mathrm{N1} 131902 \mathrm{~W}$ $354743 N 1101531 \mathrm{~W}$ $354817 \mathrm{~N} 1101330 \mathrm{~W}$ $342544 N 1122316 \mathrm{~W}$ $343048 \mathrm{~N} 1100440 \mathrm{~W}$ $343026 N 1100450 \mathrm{~W}$ $342926 \mathrm{~N} 1100454$ $343247 \mathrm{N1} 100634 \mathrm{~W}$ $342750 N 1100507 \mathrm{~W}$

323912 N1095150W 323913 N1095148W $350338 \mathrm{NI} 133016 \mathrm{~W}$ $315020 \mathrm{N1} 1091604 \mathrm{~W}$ 315107 N1091326W 335811 N1093955W $341546 \mathrm{~N} 1105816 \mathrm{~W}$ $351956 \mathrm{~N} 1114011 \mathrm{~W}$

$354920 \mathrm{~N} 1130939 \mathrm{~W}$

$335801 N 1093943 \mathrm{~W}$ 341357 N1112336W $341316 \mathrm{~N} 1112306 \mathrm{~W}$ $340308 \mathrm{~N} 1095538 \mathrm{~W}$ $340420 \mathrm{~N} 1105605 \mathrm{~W}$ $314009 \mathrm{~N} 1090810 \mathrm{~W}$ $320929 \mathrm{~N} 1110649 \mathrm{~W}$ $351210 \mathrm{~N} 1121838 \mathrm{~W}$

$314359 \mathrm{~N} 1104543 \mathrm{~W}$

$361005 N 1134339 \mathrm{~W}$ $360950 \mathrm{N1134235W}$

$332012 \mathrm{~N} 1090546$

$362940 \mathrm{~N} 1121027 \mathrm{~W}$

Biscuit Flat

$354803 \mathrm{~N} 1101316 \mathrm{~W}$

Weldon $\mathrm{Hill}$

Sun Altar

Keams Canyon

Groom Creek

Snowf lake

Snowf lake

Taylor

Snowflake

Taylor

Mt Graham

Mt Graham

5879 Austin Peak Chiricahua Peak Portal Peak

335838 N1093920W Hawley Lake East

Woods Canyon

Humphreys Peak

$335827 N 1093903 W$

5158 Hawley Lake East

North Peak

Indian Pine

Young

Apache

2624 Cat Mountain

6968 McLellan Reservoir

Mt Wrightson

Granite Park

North of Oracle

McLellan Reservoir

North of Oracle

Palomas Mts East

32403N110493W

$351210 N 1121838 \mathrm{~W}$

$330436 \mathrm{~N} 1114419 \mathrm{~W}$

$330052 \mathrm{~N} 1091456 \mathrm{~W}$

330446 N1091319W

Rattlesnake Spring

$350519 \mathrm{~N} 1134904 \mathrm{~W}$

$340535 \mathrm{~N} 1120909 \mathrm{~W}$

$350705 \mathrm{~N} 1135152 \mathrm{~W}$

$340627 \mathrm{~N} 1121333 \mathrm{~W}$

$364649 \mathrm{~N} 1114615 \mathrm{~W}$
Dean Peak

Black Canyon City

Bitter Springs 


\section{FEATURE NAME}

Soap Creek Number One Tank Soap Creek Number Two Tank Soap Creek Pasture

Soap Creek Pasture

See Black Valley

Soap Creek Rapids

Soap Creek Trail

Soapweed Tank

$S O B$ Canyon

Sob Canyon

See S O B Canyon

Sockdolager Rapids

Socorra Mine

Socorro Peak

Soda Canyon

Soda Springs Gulch

Soda Lake

See Willcox Playa

Soda Lake

Soda Lake

Soda Spring

Soda Spring

Soda Spring

Soda Spring

Soda Spring

Soda Spring Creek

See Red Creek

Soda Spring Creek

See Soda Springs Creek

Soda Spring Number One

Soda Spring Number Two

Soda Spring Ranch

Soda Springs

Soda Springs Creek

See Red Creek

Soda Springs Creek Soda Spring Creek

Soda Springs Guich See Soda Canyon

Soda Water Spring

Sohu Park

Solano, Rancho

Solano Park

Solano School

Solano Wash

Solano Well

Soldado Tank

Soldier Annex Canal

Soldier Annex Dam

Soldier Annex Lake

Soldier Basin

Soldier Butte

Soldier Camp

Soldier Camp

Soldier Camp

Soldier Camp Creek

Soldier Creek

Soldier Camp Mountain

Soldier Camp Trail

Soldier Camp Wash

Soldier Camp Wash

See Bladder Canyon

Soldier Canyon

Soldier Creek

Soldier Creek

Soldier Creek

Soldier Creek

Little Boy Creek

Soldier Creek

See Soldier Camp Creek
FEATURE

CLASS

STATUS

COUNTY

COORDINATE

reservoir

reservoir

flat

BGN

BGN

Coconino

Coconino

Coconino

valley

rapids

VARIANT

trail

BGN Coconino

UNOFF Coconino

reservoir

valley

BGN

BGN
VARIANT

VARIANT

valley

rapids

mine

summit

valley

BGN 1932 Coconino

UNOFF Yuma

BGN Yuma

BGN Gila

VARIANT

VARIANT

flat

reservoir

spring

spring

spring

spring

spring

stream

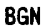

BGN

BGN

$B G N$

BGN

BGN

BGN

VARIANT

Graham

Yavapai

Yuma

Yavapai

Cochise

Apache

Apache

Gila

Gila

Yavapai

Yavapai

VARIANT

stream

spring

spring

locale

spring

stream

stream

BGN

BGN

UNOFF

BGN

VARIANT

BGN 1968

VARIANT

Yavapai

Yavapai

Yavapai

Yavapai

Maricopa

Yavapai

Yavapai

VARIANT

valley

spring

park

locale

park

school

stream

well

reservoir

BGN

ADMIN

UNOFF

ADMIN

UNOFF

UNOFF

BGN

dam

reservoir

basin

summit

ppl

locale

locale

stream

BGN

UNOFF

BGN

$B G N$
$B G N$

BGN

BGN

BGN 1981

VARIANT

Gila

Grahan

Maricopa

Maricopa

Maricopa

Maricopa

Pina

Pima

Pima

Coconino

Coconino

Coconino

Santa Cruz

Apache

Pima

Maricopa

Gila

Gila

summit

BGN

UNOFF

Gila

BGY

Maricopa

VARIANT

valley

valley

stream

stream

stream

stream

BGN

BGN

BGN

BGN

VARIANT

Gila

Pima

Coch ise

Graham

Gila

Apache

VARIANT

$365234 \mathrm{~N} 1114510 \mathrm{~W}$

$365222 \mathrm{N1} 114528 \mathrm{~W}$

$364741 \mathrm{N1114640 \textrm {W }}$

365545N1115755W

$364415 \mathrm{~N} 1114132 \mathrm{~W}$

364357 N1114610W

$324224 N 1091700 \mathrm{~W}$

$344924 N 1120354 \mathrm{~W}$

344924N1120354W

360246 N1115708W

$334441 N 1132813 \mathrm{~W}$

$334534 N 1132716$

$331117 \mathrm{N1103114W}$

$320822 \mathrm{N1095046 \textrm {W }}$

343547 N1093617W

$343603 \mathrm{~N} 1093615 \mathrm{~W}$

$324600 \mathrm{~N} 1102234 \mathrm{~W}$

$331227 \mathrm{~N} 1103205 \mathrm{~W}$

$334952 \mathrm{~N} 1101709 \mathrm{~W}$

$343845 \mathrm{~N} 1114428 \mathrm{~W}$

344912N1130905W

340954N1143112W

$341227 \mathrm{~N} 1114829 \mathrm{~W}$

$341422 \mathrm{N1114906 \textrm {W }}$

$341355 \mathrm{~N} 1114939 \mathrm{~W}$

$343 \mathrm{~B} 52 \mathrm{~N} 1114426 \mathrm{~W}$

$335628 \mathrm{~N} 1120627 \mathrm{~W}$

340954N1143112W

$341227 \mathrm{~N} 1114829 \mathrm{~W}$

$331117 N 1103114$

$325841 \mathrm{N1} 101549 \mathrm{~W}$

$332703 \mathrm{~N} 1120221 \mathrm{~W}$

$323400 \mathrm{~N} 1105052 \mathrm{~W}$

$333105 N 1120545 \mathrm{~W}$

$341525 N 1115015 W$

Stinking Springs

Stinking Springs

Oak Grove Canyon

Coolidge Dam

Carrizo SE

Casner Butte

Burro Mesa

Bloody Basin

Bloody Basin

Casner Butte

Daisy Mountain

Bloody Basin 


\section{fEATURE NAME}

Soldier Creek Campground Soldier Creek Recreation Area

Soldier Hole Creek

Soldier Hole Creek

See North Fork Ash Creek

Soldier Hole Spring

Soldier Hole Tank

Soldier Lake

\section{Soldier Lake Tank \\ Soldier Mesa \\ Soldier Mesa Tank \\ Soldier Pass \\ Soldier Spring \\ Soldier Spring \\ Soldiers Tank \\ Soldier Trail \\ Soldier Trail Tank \\ Soldier Wash}

Soldier Well

Soldier Well

Soldier Well Tank

Soleng Shopping Center

Solitaire Butte See Poverty Knoll

Solitude, Cape

Solitude Gulch

Solitude Gulch Tank

Solitude Tailings Dam

Solitude Tailings Pond Solomon

Solomonville Solomonsville

Solomon Butte

Solomon Elementary School See Solomon School

Solomon Pass

Solomonville Pass

Solomon Post Office

Solomon School
Solomon Elementary School
Solomon Siding
Solomonsville
See Solomon
Solomonsville Cemetery
Solomon Temple
Solomonville
See Solomon
Solomonville Pass
See Solomon Pass

Solomonville Wash See San Simon River

Solo Peak

Solo Spring Solo Springs

Solo Springs

See Solo Spring

Sol Ray Spring

See Sol Rhea Spring

Sol Rhea Saddie

Sol Rhea Spring
Sol Ray Spring

Sols Wash

Sols Wash Tank

Sombrero Butte

Sombrero Butte

See Sombrero Peak

Sombrero Butte

Sombrero Butte Tank

Sombrero Peak Sombrero Butte
FEATURE
CLASS

STATUS

COUNTY

COORDINATE$$
\text { park }
$$

ADMIN

stream

stream

spring

reservoir

reservoir

reservoir

summit

reservoir

gap

spring

spring

reservoir

trail

reservoir

stream

well
well
reservoir
locale

summit

cliff

valley

reservoir

dam

reservoir

pp I

summit

school

gap

building

school

locale BG

VARIA

pp1

cemetery

summit

ppl

gap

VARIANT

UNOFF

BGN

VARIANT

VARIANT

strean

summit

spring

VARIANT

BGN

BGN

VARIANT

VARIANT

spring

spring

gap

VARIANT

BGN

spring

stream

reservoir

summit

summit

locale

reservoir

summit

$p p 1$

BGN
Graham 324156N1095511W

Graham 324153N1095513

Graham 331958N1095722W

Graham

Graham

Graham

Coconino

$332122 \mathrm{~N} 1100025 \mathrm{~W}$

$332304 \mathrm{~N} 1095556 \mathrm{~W}$

$332041 \mathrm{Ni} 095656 \mathrm{~W}$

344738N1111357W

Pima 322533N1104441W

Coconino 343019Ni112930W

Coconino 343027N1112933W

Yavapai 345415N1114727W

Apache 334242N1090936 W

Apache 340435N1093625

Y332118N1134203W

Coconino 343410Nillo3i6

Coconino 343837 N1110122

Coconino

$345145 \mathrm{~N} 1114548 \mathrm{~W}$

$315434 \mathrm{~N} 1112316 \mathrm{~W}$

$362812 \mathrm{N1101031 \textrm {W }}$

$315753 N 1112155$

$32114111105801 \mathrm{~W}$

362737 N1132625W

$361049 \mathrm{N1114758 \textrm {W }}$

$332245 \mathrm{~N} 1105008 \mathrm{~W}$

$332220 \mathrm{N1} 105039 \mathrm{~W}$

$332320 \mathrm{N1104950 \textrm {W }}$

$332330 \mathrm{N1104945 \textrm {W }}$

324845 N1093800W

343420N1103140W

$324850 \mathrm{N1093755 \textrm {W }}$

325515N1093445W

$324850 \mathrm{N1} 093750 \mathrm{~W}$

324850N1093755W

324808N1093839w

324845 N1093800 W

324808 N1093721W

360326N1115453W

324845N1093800W

325515N1093445W

Graham

Graham

Pima

Yavapai

$324953 N 1093855 \mathrm{~W}$

$323012 N 1114023$

$335705 N 1121557 \mathrm{~W}$

Yavapa

335705N1121557W

$323007 N 1102155$

$322930 \mathrm{~N} 1102138 \mathrm{~W}$

$323007 N 1102155 \mathrm{~W}$

$335821 N 1124339 \mathrm{~W}$

$340331 \mathrm{N1} 125459 \mathrm{~N}$

$324249 N 1102907 \mathrm{~W}$

$335050 \mathrm{~N} 1104655 \mathrm{~W}$

$324334 \mathrm{~N} 1102854 \mathrm{~W}$

$335130 N 1104703 \mathrm{~W}$

$335050 \mathrm{~N} 1104655 \mathrm{~W}$ $\begin{array}{cc}\text { SOURCE } & \text { ELEV } \\ \text { COORDINATE } & \text { FT MAP NAME }\end{array}$

\begin{tabular}{|c|c|c|}
\hline $32057 N 1095245 \mathrm{~W}$ & & $\begin{array}{l}\text { Webb Peak } \\
\text { Webb Peak } \\
\text { Natanes Mts NW }\end{array}$ \\
\hline & $\begin{array}{l}5076 \\
6778\end{array}$ & $\begin{array}{l}\text { Natanes Mts NW } \\
\text { Tule Tubs } \\
\text { Chavez Mtn West }\end{array}$ \\
\hline $407 \mathrm{~N} 1114736 \mathrm{~W}$ & & $\begin{array}{l}\text { Mount Bigelow } \\
\text { Calloway Butte } \\
\text { Calloway Butte } \\
\text { Wilson Mountain } \\
\text { Hoodoo Knob } \\
\text { Greens Peak } \\
\text { Cementosa Wash } \\
\text { Leonard Canyon } \\
\text { Quayle Hill } \\
\text { Sedona }\end{array}$ \\
\hline
\end{tabular}

Palo Alto Ranch

7090 Cliff Rose Hill Stevens Mtn

2430 Tucson

$332052 \mathrm{~N} 1105037 \mathrm{~W}$

Cape Solitude

Globe

Pinal Peak

Globe

Globe

Safford

6189 Red Knoll

Lone Star Mtn

2600 Safford

Safford

Safford

San Jose

5070 Cape Royal

2947 Greene Reservoir Governors Peak

Cherry Spring Peak

Bassett Peak

Wickenburg

Congress SW

Rhodes Peak

Rhodes Peak

Sombrero Peak

6436 Sombrero Peak

Somerton 
NATIONAL GAZETTEER--ARIZONA 1986

FEATURE NAME

Algodones Land Grant Somerton Airport

Somerton Canal

Somerton City Hall

Somerton Elementary School

Somerton Lateral

Somerton Laterai Wasteway

Somerton Park

Somerton Post Office

Somerton Siding

Sonny Tank

Benny Tank

Sonoita

Bunny Tank

Sonoyta

Sonoita

See Lukeville

Sonoita Creek

Sonoita Valley

Sonoyta Creek

Sonoita District Number

Twenty-Fiver School

Sonoita Mountains

See Sonoyta Mountains

Sonoita Range

See Sonoyta Mountains

Sonoita valley

See Sonoita Creek

Sonoita Valley

See Sonoyta Valley

Sonora

Sonora Desert

See Sonoran Desert

Sonora $\mathrm{Hill}$

Sonoran Desert

Carson Plains

Sonora Desert

Desierto Grande

Desierto de Altar

Sonora Town

Sonoyta

See Sonoita

Sonoyta Creek

See Sonoita Creek

Sonoyta Mountain

See Sonoyta Mountains Sonoyta Mountains

Sierra Sonoita

Sonoita Mountains

Sonoita Range

Sonoyta Mountain

Sonoyta Valley Sonoita Valley

Sonrisa Park

Sonsaia

See Sonsela Buttes

Sonsela Buttes

Sonsala

Sonsela Mountain

Sonsella Buttes

Sonsola

So Sela

Sosela Buttes

Sosile

Sonse la Mountain

See Sonsela Buttes

Sonsella Buttes

See Sonsela Buttes

Sonsola

Soe Sonsela Buttes

Sontag Creek

See Bear Creek

Sontag Creek
FEATURE

CLASS

STATUS

COUNTY

VARIANT

airpor

canal

building

school

canal

cana?

park

building

BGN

UNOFF

UNOFF

BGN

ADMIN

ADMIN

locale

reservoir

BGN

VARIANT

VARIANT

locale
BAN 1941
VARIANT

VARIANT

pp 1

BGN 1941

VARIANT

VARIANT

school UNOFF

Santa Cruz

314050N1103920W

range

VARIANT

range

VARIANT

range

stream

VARIANT

Pima

315508N1125057W

Pina

312741 N1105843W

VARIANT

Santa Cruz

Pima

ppl

BGN

VARIANT

plain

summit

BGN

BGN

VARIANT

VARIANT

VARIANT

VARIANT

Maricopa

VARIANT

locale

stream

VARIANT

VARIANT

range

range

BGN 1941

VARIANT

VARIANT

VARIANT

VARIANT

valley

BGN 1941 Pima

park

VARIANT

summit

ADMIN

VARIANT

summit

BGN 1915

VARIANT

VARIANT

VARIANT

VARIANT

VARIANT

VARIANT

VARIANT

VARIANT

summit

summit

summit

stream

stream

$315508 \mathrm{N1125057 \textrm {W }}$

VARIANT

Apache

360603N1090606W

VARIANT

Apache

360603N1090606W

VARIANT

Apache

$360603 \mathrm{~N} 1090606 \mathrm{~W}$

BGN

Gila
Gila
$360603 \mathrm{~N} 1090606 \mathrm{~W}$
315508N1125057W

315233N1124735W
Santa Cruz

Pima

Pima

312741N1105843W

315508N1125057W

Lukeville

Maricopa

315233N1124735W

$333613 \mathrm{~N} 1115813 \mathrm{~W}$

$360603 \mathrm{~N} 1090606 \mathrm{~W}$

315321 N1123709W

Lukeville

Paradise Valley

8887 Sonsela 8uttes

Apache

Lukeville
Paradise valley
Sonsela 8uttes

Santa Cruz 314046N1103917W
332007N1114720W

Hot Tamale Peak

Gila Bend

Chandler
Somerton

Somerton

Somerton

Somerton

Gadsden

ajarito Peak

4880 Sonoita

Hot Tamale Peak 
NATIONAL GAZETTEER--ARIZONA 1986

FEATURE NAME

Santag Creek

Sontag Mes

Sopori

See Sopori Ranch

Sopori Ranch Sopori

Sopori School

Sopori Wash

Sapori Wash

Sore Fingers

Sorenson Lake

Sore Spring

Soreye Tank

Sorghum Canyon

Sorghum $\mathrm{Hil}$

Sorin Camp

Sorrel Horse Canyon

Sorrel Horse Mes

So Sela

See Sonsela Buttes

Sosela Buttes Sosile

See Sonsela Buttes

See Sonsela Buttes

Soto Dam

Soto Dan Tank

Soto Peak

Soto Peak

See Gunsight Mountain

Sotos Crossing (historical)

Soto Tank

Soto Tank

Soto Wash

Sourdough Well

Sourgrass Flat

Sourgrass Flat Windmill

Sour Water Canyon

Sour Water Spring

Sour Water Wash

Sour Water Wash

South American Point

South Bald Mountain Tank

South Bay

South Beaver School

South Benches Spring

South Benches Tank

South Big Saddle Point

South Big Spring Big Spring

South Big Spring Canyon

See Big Spring Canyon

South Bisbee

South Blow Down Tank

South Blye Tank

South Branch Highl and Canal Highland Canal High Line Canal

South Brunner Canyon

See South Bruno Canyon

South Bruno Canyon

Brunner Canyon

South Brunner Canyon

South Burnt Corral Point

South Butte

South Butte

South Buzzard Roost Mesa Tank

South Cactus Tank

South Campbell Tank

South Camp Well

South Canyon
FEATURE

CLASS

STATUS

COUNTY

COORDINATE

VARIANT

\begin{tabular}{|c|c|c|c|}
\hline summ it & $\begin{array}{l}\text { BGN } \\
\text { VARIANT }\end{array}$ & Gila & $332935 \mathrm{~N} 1102057 \mathrm{~W}$ \\
\hline $\begin{array}{l}\text { locale } \\
\text { locale }\end{array}$ & $\begin{array}{l}\text { UNOFF } \\
\text { VARIANT }\end{array}$ & $\begin{array}{l}\text { Santa Cruz } \\
\text { Santa Cruz }\end{array}$ & $\begin{array}{l}314326 \mathrm{~N} 1110706 \mathrm{~W} \\
314326 \mathrm{~N} 1110706 \mathrm{~W}\end{array}$ \\
\hline $\begin{array}{l}\text { school } \\
\text { stream }\end{array}$ & $\begin{array}{l}\text { UNOFF } \\
\text { BGN } \\
\text { VARIANT }\end{array}$ & $\begin{array}{l}\text { Pima } \\
\text { Santa Cruz }\end{array}$ & $\begin{array}{l}314210 \mathrm{~N} 1111110 \mathrm{~W} \\
314326 \mathrm{~N} 1110230 \mathrm{~W}\end{array}$ \\
\hline $\begin{array}{l}\text { locale } \\
\text { summit }\end{array}$ & $\begin{array}{l}\text { UNOFF } \\
\text { BGN }\end{array}$ & $\begin{array}{l}\text { Cochise } \\
\text { Yuma }\end{array}$ & $\begin{array}{l}312221 \mathrm{~N} 1100336 \mathrm{~W} \\
333810 \mathrm{~N} 1133026 \mathrm{~W}\end{array}$ \\
\hline $\begin{array}{l}\text { lake } \\
\text { spring } \\
\text { reservoir } \\
\text { valley } \\
\text { summit } \\
\text { locale } \\
\text { valley } \\
\text { summit } \\
\text { summit }\end{array}$ & $\begin{array}{l}\text { BGN } \\
\text { BGN } \\
\text { BGN } \\
\text { BGN } \\
\text { BGN } \\
\text { BGN } \\
\text { BGN } \\
\text { BGN }\end{array}$ & $\begin{array}{l}\text { Apache } \\
\text { Gila } \\
\text { Coconino } \\
\text { Gila } \\
\text { Gila } \\
\text { Cochise } \\
\text { Gila } \\
\text { Apache }\end{array}$ & $\begin{array}{l}343411 \mathrm{~N} 1092219 \mathrm{~W} \\
334606 \mathrm{~N} 1100710 \mathrm{~W} \\
352107 \mathrm{~N} 1115651 \mathrm{~W} \\
340925 \mathrm{~N} 1111616 \mathrm{~W} \\
341006 \mathrm{~N} 1111652 \mathrm{~W} \\
315317 \mathrm{~N} 1095808 \mathrm{~W} \\
340155 \mathrm{~N} 1110928 \mathrm{~W} \\
345642 \mathrm{~N} 1093924 \mathrm{~W}\end{array}$ \\
\hline
\end{tabular}

summit

summit

dam

reservoir

summit

summit

locale

VARIANT

Apache

UNOFF

BGN

BGN

VARIANT

BGN

reservoir BGN

reservoir

stream

well

flat

locale

valley

spring

stream

stream

cape

bay

school

spring

reservo

spring

valley

BGN

UNOFF

BGN

BGN

BGN

BGN

(I)

BGN
BGN

BGN

BGN

BGN

UNOFF

BGN

$B G N$

$B G N$

BGN 1932

VARIANT

ppl

reservoir $B G$

reservoir $B G$

canal

valley

valley

cliff

summit

summit

reservoir

reservoir

reservoir

well

Yavapai

Yavapai

Pima

Pima

Santa Cruz

360603 N1090606W

$360603 \mathrm{~N} 1090606 \mathrm{~W}$

$352236 \mathrm{~N} 1130410 \mathrm{~W}$

$352236 \mathrm{~N} 1130410 \mathrm{~W}$

$315642 \mathrm{~N} 1111350 \mathrm{~W}$

$315746 \mathrm{~N} 1111428 \mathrm{~W}$

$313750 \mathrm{~N} 1110208 \mathrm{~W}$

Santa Cruz 312223N1111005W

Pima 315615N1111404W

Pima 320234N1112055

Coconino 362154N1120507W

Yavapai 341713N1123933W

Yavapai 341720N1123929w

Coconino 362345N1105300W

Coconino $363227 \mathrm{N1} 105640 \mathrm{~W}$

Yavapai 343008N1120306W

Coconino

$362341 \mathrm{~N} 1105239 \mathrm{~W}$

Mohave

Yavapai

Mohave

Coconino

Yavapai

Yavapai

Coconino

Coconino

$361052 \mathrm{~N} 1140041 \mathrm{~W}$

$343319 \mathrm{N1124811 \textrm {W }}$

$360617 N 1140558 \mathrm{~W}$

$351130 \mathrm{N1113905 \textrm {W }}$

$343900 \mathrm{~N} 1125047 \mathrm{~W}$

$343833 \mathrm{~N} 1125132 \mathrm{~W}$

$362614 N 1122313 \mathrm{~W}$

Coconino

361905 N1121530W

$312501 N 1095411 \mathrm{~W}$

$362317 N 1120939 W$

$352728 N 1132514 \mathrm{~W}$

$332123 N 1115723 \mathrm{~W}$

$314233 N 1092514 \mathrm{~W}$

$314233 \mathrm{~N} 1092514 \mathrm{~W}$

$362812 \mathrm{~N} 1122419 \mathrm{~W}$

$330456 \mathrm{NI} 11139 \mathrm{~W}$

$350601 N 1123922 \mathrm{~W}$

$340046 \mathrm{~N} 1110348$

$334455 N 1110845 \mathrm{~W}$

$341022 N 1115941 \mathrm{~W}$

$345524 \mathrm{~N} 1093330 \mathrm{~W}$ reservoir

$361906 \mathrm{~N} 1121537 \mathrm{~W}$

315638N1111318W

363314 NI105436W

$343255 N 1120352 \mathrm{~W}$

363455 N1105549W

Audley

Audley

4527 Samaniego Peak

3180 Amado

Alamo Spring

Samaniego Peak

Three Points

Little Park Lane

Peeples Valley

Peeples Valley

White Mesa Arch

Square Butte

Cherry

White Mesa Arch

Iceberg Canyon

Martin Mtn

Meadview North

Flagstaff West

Smith Mesa

Smith Mesa

Tapeats Amphitheater

King Arthur Castle

Bisbee

De Motte Park

Cherokee Point

Guadalupe

314110 N 1092230W

Bruno Peak

Tapeats Amphitheater

2848 North Butte

South Butte

Buzzard Roost Mesa

Georges Butte

Brooklyn Peak

Ninemile Seep 
FEATURE NAME

See S Canyon

South Canyon

South Canyon Dam Tank

South Canyon Point

South Canyon Spring

South Canyon Tank

South Central Post Office

South Cienega Creek

South Cienega Spring

South Collge Peak

South Comobabi Mountains

Comobavi Mountains

South Comobavi Mountains

South Comobavi Mountains

See South Comobabi Mountains

South Copper Fork Tank

South Cove

South Cove

South Dam Tailings Pond

South Daniels Gulch Spring

South Deer Flat Tank

South Drain

Southeast Orain

Southeast Mesa

Southeast Station Post Office

Southeast Tank

Southeast Tank

South Entrance Station

Southern Acres Mobile Home Park

Southern Arizona Mental

Health Center

Southern Arizona School for

Boys

Southern Belle Mine

Southern Canal

Southern Cross Mine

Southern Mountain

See Sheridan Mountain

Southern Paims Shopping Center

Southern Palms Trailer Park

Southern Substation

Southern Tank

South Extension Canal

\section{South Field Canyon Field Canyon}

South Field Canyon Tank

South Fork

See South Fork Cave Creek

South Fork Ash Canyon

South Fork Ash Creek

South Fork Ash Creek

South Fork Bear Wal low Creek

South Fork Big Spring Canyon

South Fork Bonito Creek

South Fork Buford Canyon

South Fork Campground

South Fork Canyon

South Fork Canyon

South Fork Canyon Trail Two

Hundred Fortythree

South Fork Castle Canyon

South Fork Cave Creek South Fork

South Fork Cave Creek See Cave Creek

South Fork Cellar Springs Creek Cellar Spring Creek Cellar Springs Creek

South Fork Clark wash

South Fork Cooper Forks

FEATURE
CLASS

STATUS

COUNTY

valley

valley

BGN

Greenlee

reservoir

cliff

spring

reservoir

building

strean

spring

summit

range

BGN

BGN

$B G N$

UNOFF

BGN

BGN

BGN

BGN

VARIANT

VARIANT

VARIANT

range

reservoir

bay

reservoir

spring

reservoir

canal

canal

summit

building

reservoir

reservoir

locale

hospital

school

school

mine

canal

mine

summit

locale

locale

locale

reservoir

cana 1

valley

reservoir

BGN 197

VARIANT

stream

valley

stream

stream

stream

valley

stream

valley

park

valley

valley

trail

valley

stream

VARIANT

BEN

BGN

BGN

BGN

BGN

BGN

BGN

ADNIN

BGN

BGN

UNOFF

BGN

BGN 1959

VARIANT

Graham

Coconino

Graham

Maricopa

Graham

Graham

Cochise

Pima

Pima

Gila

Mohave

Mohave

Pima

Yavapai

Maricopa

Yuma

Yuma

Yavapai

Maricopa

Coconino

Coconino

Coconin

Maricopa

Pima

Pima

Pinal

Maricopa

Yuma

Yavapai

Maricopa

Maricopa

Maricopa

Graham

Maricopa

Graham

Graham

Cochise

Cochise

Graham

Graham

Green lee

Coconino

Apache

Graham

Apache

Cochise

Yavapai

Cochise

Coconino

Cochise

VARIANT

stream

stream

BGN 1972

Cochise

VARIANT

VARIANT

BGN

BGN

Pinal

Gila

stream
COORDINATE

333549 N1090715W 363011N1115128W

$324143 \mathrm{~N} 1094804 \mathrm{~W}$

$362913 N 1115159 \mathrm{~W}$

362017 N1120209W

$324220 \mathrm{~N} 1102527 \mathrm{~W}$

$332333 \mathrm{~N} 1120400 \mathrm{~W}$

$331558 N 1093430 \mathrm{~W}$

$331538 N 1093734 \mathrm{~W}$

$312718 \mathrm{~N} 1092516 \mathrm{~W}$

320026 N1115223W

$320026 \mathrm{~N} 1115223 \mathrm{~W}$

$335122 \mathrm{~N} 1104940 \mathrm{~W}$

$360522 \mathrm{~N} 1140550 \mathrm{~W}$

$360526 \mathrm{~N} 1140550 \mathrm{~W}$

$322236 \mathrm{~N} 1125036 \mathrm{~W}$

$342404 N 1121752 \mathrm{~W}$

$335713 N 1114803 \mathrm{~W}$

$323254 \mathrm{~N} 1144712 \mathrm{~W}$

323456 N1144147W

344850 N1131853W

$332552 \mathrm{~N} 1120241 \mathrm{~W}$

$345124 N 1112356$

354759 N1125704W

$360221 \mathrm{~N} 1120716 \mathrm{~W}$

$332336 \mathrm{~N} 1120023 \mathrm{~W}$

$321338 \mathrm{~N} 1105649 \mathrm{~W}$

$321814 N 1104843 W$

$323307 N 1104408 \mathrm{~W}$

$332920 \mathrm{~N} 1114332 \mathrm{~W}$

$334642 \mathrm{~N} 1140209 \mathrm{~W}$

$344202 \mathrm{~N} 1125249 \mathrm{~W}$

$332342 \mathrm{~N} 1115440 \mathrm{~W}$

$332333 \mathrm{~N} 1114954 \mathrm{~W}$

$332333 \mathrm{~N} 1120931 \mathrm{~W}$

$323023 \mathrm{~N} 1101310 \mathrm{~W}$

$332223 \mathrm{~N} 1122854 \mathrm{~W}$

$323928 \mathrm{~N} 1102135 \mathrm{~W}$

$323807 N 1102242 \mathrm{~W}$

$315305 \mathrm{~N} 1091030 \mathrm{~W}$

$312240 \mathrm{~N} 1101508 \mathrm{~W}$

$323011 \mathrm{~N} 1101109 \mathrm{~W}$

$332122 \mathrm{~N} 1100025 \mathrm{~W}$

$333554 N 1092652$

362042N1121144W

$354530 \mathrm{~N} 1090600 \mathrm{~W}$

$324945 \mathrm{~N} 1101546 \mathrm{~W}$

$340444 N 1092443 \mathrm{~W}$

$321648 N 1100431 \mathrm{~W}$

340726 N1115733W

$315000 \mathrm{~N} 1091145 \mathrm{~W}$

$363340 \mathrm{~N} 112163 \mathrm{OW}$

315305N1091030W

stream

SOURCE

COORDINATE

ELEV
FT

MAP NAME

$362026 \mathrm{~N} 1120243 \mathrm{~W} \quad$ North Canyon Point

$331249 N 1093541 W$

Mt Grahan

Tatahatso Point

Little Park Lane

Rhodes Peak

Phoenix 
NATIONAL GAZETTEER--ARIZONA 1986

\section{FEATURE NAME}

South Fork Corn Creek

See Johns Draw

South Fork Corn Wash

See Coyote Wash

South Fork Creek

See South Fork Squaw Creek

South Fork Date Creek

South Fork Deadman Creek

South Fork Deer Creek

Deer Creek

South Fork Deer Lake Canyon

South Fork Forest Camp

South Fork Goodwin Canyon

South Fork Keating Creek

South Fork Little Colorado

River

South Fork Middle Canyon

South Fork Moquitch Canyon

South Fork Mud Spring Creek South Fork Mud Springs Creek

South Fork Mud Springs Creek See South Fork Mud Spring Creek

South Fork Nash Creek See Nash Creek

South Fork Oak Canyon

South Fork Parker Creek

South Fork Rock Canyon

South Fork Rock Creek

South Fork Salt River See Black River

South Fork Santa Maria River

South Fork Sheep Creek

South Fork Skeleton Canyon

South Fork Soap Creek

South Fork Spring

South Fork Spring Creek

South Fork Squaw Creek South Fork Creek

South Fork Sycamore Creek See South Prong Sycamore Creek

South Fork Tank

South Fork Tank

South Fork Walnut Creek

South Fork Will is Canyon

South Fork Wood Canyon

South Fort

South Fourteen Tank South Tank

Southgate Mall

Southgate Shopping Center

Southgate Shopping Center

South Georgia Mine

South Gila Ditch

South Gila Valley

South Gila Valley Main Canal

South Goodwin Spring

South Goodwin Tank

South Headquarters Tank

South Highline Lateral Canal

South Hole

South Hole Spring

South Horse Mountain Tank

South Howland Cove

South Iron Gate Tank

South Komelik

Comely
Komalik

Komalik
FEATUR

$\begin{array}{cccc}\text { CLASS } & \text { STATUS } & \text { COUNTY } & \text { COORDINATE } \\ & \text { VARIANT } & & \\ \text { valley } & \text { VARIANT } & \text { Navajo } & 351900 \mathrm{~N} 1103120 \mathrm{~W} \\ \text { valley } & & \text { Navajo } & 352330 \mathrm{~N} 1104445 \mathrm{~W}\end{array}$

VARIANT

stream

strean

strean

strean

valley

locale

valley

stream

stream

valley

valley

stream

strean

BGN
BGN
BGN
VARI
BGN
BGN
BGN
BGN

BGN

BGN

VARIANT

Yavapai

VARIANT

strean

valley

valley

stream

stream

stream

valley

stream

spring

stream

stream

stream

reservoir $B G N$

reservoir

stream

valley

valley

locale

reservoir

locale

locale

locale

mine

canal

valley

canal

spring

reservoir

reservoir

canal

bas in

spring

reservoir

bay

reservoir

locale $334751 \mathrm{N1} 105801 \mathrm{~W}$ $332430 \mathrm{N1} 115017 \mathrm{~W}$ $352612 \mathrm{~N} 1131635 \mathrm{~W}$
BGN

BGN

BGN

BGN

VARIANT

Gila

BGN

BGN

BGN

BGN

BGN

VARIANT

VARIANT

Gila

Coconino

Gila

Coconino

Gila

Maricopa

Cochise

Coconino

Graham

Yavapai

Yavapai

Yavapai

Gila

BGN
BGN
BGN
BGN
BGN
BGN
VARIANT
UNOFF
UNOFF
UNOFF

Yavapai

Yavapai

Coconino

Coch ise

Yavapa

Santa Cruz

Yuma

Pima

Maricopa

UNOFF

BGN

BGN

BGN

BGN

BGN

BGN

BGN

Mohave

Yuma

Yuma

Yuma

Graham

Graham

Graham

Maricopa

Yavapai

Yavapai

BGN

BGN

BGN

Gila

Mohave

Yavapai

VARIANT

VARIANT

VARIANT
$340711 N 1115731 \mathrm{~W}$ $341534 \mathrm{N1} 125451 \mathrm{~W}$ $340546 \mathrm{~N} 1113156 \mathrm{~W}$ $340255 \mathrm{~N} 1112233 \mathrm{~W}$

$342248 \mathrm{~N} 1105414 \mathrm{~W}$ $315203 \mathrm{~N} 1091117 \mathrm{~W}$ $325810 \mathrm{~N} 1101142 \mathrm{~W}$

$320234 \mathrm{~N} 1091438 \mathrm{~W}$

$340521 N 1092457 W$

314956 N1102300 $363802 N 1122004$ $341033 \mathrm{~N} 1115123 \mathrm{~W}$

$314929 N 1102429 \mathrm{~W}$

$363526 \mathrm{~N} 1121700 \mathrm{~W}$

$340931 \mathrm{N1115333 \textrm {W }}$

341033N1115123W

333839 N1100618W $363953 N 1121924$ $363906 \mathrm{N11} 20205 \mathrm{~W}$ $340742 \mathrm{~N} 1121116 \mathrm{~W}$

334420 N1101330W $342210 \mathrm{~N} 1131102 \mathrm{~W}$ 335549 N1113742W

$313539 N 1090406 \mathrm{~W}$ $364412 N 1114319 \mathrm{~W}$ 325750N1101242W $341042 \mathrm{~N} 1123455 \mathrm{~W}$ $340711 \mathrm{N1115731 \textrm {W }}$

341842 N1115308W

340206 N1112259W

$345410 \mathrm{~N} 1125656 \mathrm{~W}$ $345531 \mathrm{N1} 125412 \mathrm{~W}$ $365035 \mathrm{~N} 1121356 \mathrm{~W}$ $320627 \mathrm{N1} 091803 \mathrm{~W}$ $340848 \mathrm{~N} 1121559 \mathrm{~W}$ $31202 \mathrm{BN1} 103930 \mathrm{~W}$

$324020 \mathrm{~N} 1143731 \mathrm{~W}$ 321109 N1105810W

$345322 \mathrm{~N} 1125827 \mathrm{~W}$ $364733 \mathrm{~N} 1121322 \mathrm{~W}$ $320434 \mathrm{~N} 1091759 \mathrm{~W}$

352449 N1141032W $325547 \mathrm{~N} 1132110 \mathrm{~W}$

$324333 \mathrm{~N} 1143602 \mathrm{~W}$

$324058 \mathrm{~N} 1143142 \mathrm{~W}$ $325721 \mathrm{N1101403 \textrm {W }}$ $335730 \mathrm{~N} 1101352 \mathrm{~W}$ $332118 \mathrm{~N} 1100114 \mathrm{~W}$ $332025 \mathrm{~N} 1115739 \mathrm{~W}$ $342714 \mathrm{~N} 1115250 \mathrm{~W}$ $342702 \mathrm{~N} 1115248 \mathrm{~W}$

$324404 N 1142551 W$

$341438 N 1110144 \mathrm{~W}$ $360912 \mathrm{~N} 1140436 \mathrm{~W}$ 314320 N1114620W

363759 N1121703W $334826 \mathrm{~N} 1105635 \mathrm{~W}$ $363313 N 1120914 W$

$342450 \mathrm{N1} 125926 \mathrm{~W}$

$335509 \mathrm{~N} 1113207 \mathrm{~W}$

$313022 \mathrm{~N} 1090426 \mathrm{~W}$ $364126 \mathrm{~N} 1115045 \mathrm{~W}$ 340932 N1123652W $340413 \mathrm{~N} 1115826 \mathrm{~W}$

Bitter Canyon Bitter Springs Jackson Mtn

Wagoner

Cooks Mesa

Mazatzal Peak

Juniper Mts

Juniper Mts

House Rock Spring SW

Cochise Head

6591 Crown King

Duquesne

Yuma East

2445 Tucson

Mesa

Chloride

Agua Caliente

Yuma East

Yuma East

Jackson Mtn 
FEATURE NAME

South Lawn Memorial Cemetery

South McBryde Pond

South Mendoza Wash

South Mesa

South Mesa

South Mesa Tank

South Moccas in Wash

South Mountain

South Mountain

South Mountain

South Mountain High School

South Mountains

Salt River Mountains

Salt River Range

South Mountain Trailer Park

South Negro Canyon

South Nine Section Tank

South Nutter Reservoir

South Oak Creek

South Oak Points

South of Bar T Tank

South Pass

South Pass Spring

South Pasture Tank

South Pasture Tank

South Peoples Spring

South Phoenix

South Phoenix Adult Center

South Plaza Shopping Center

South Pocket

South Pocket Tank

South Prong Sycamore Creek

Indian Creek

South Fork Sycamore Creek

South Red Hill

South Rim

South Rim Campgrounds

South Rock Tank

South Santan

South School

South School

South Senator Tank

South Sheba Crater

South Shooter Flat Tank

South Shore Campground

South Side Canal

Southside Canal

Southside District Hospital

South Slick Rock Tank

South Smith Canyon

Smith Canyon

South Spruce Ridge

South Squirrel Spring

South Stock Pen Tank

South Summit Tank

South Tailholt Tank

South Tank

$$
\text { See South Fourteen Tank }
$$

South Tank

South Tank

South Tank

South Tank

South Tank

South Tank

South Tank

South Tank

South Tank

South Tank

South Tank

South Tank

South Tank
FEATURE
CLASS

STATUS

COUNTY

COORDINATE

cemetery
reservoir

UNOFF

Pima

reservo

BN

summit

BGN

summit

reservoir

stream

summit

summit

summit

school

ridge

BGN

BGN

BGN

BGN

BGN

BGN

BGN 1964
VARIANT

VARIANT

locale

valley

reservoir

reservoir

stream

summit

gap

spring

UNO
$B G N$
BGN
$B G N$
$B G N$
$B G N$
$B G N$
$B G N$
$B G N$
$B G$

Maricop

reservoir

reservoir

spring

pp

building

locale

bas in

reservoir

strean

NOFF
$B G N$
$B G N$
$B G N$
$B G N$
$B G N$
$B G N$
$B G N$
$B G N$

Graham

BGN Yavapai

BG Yarai

UNOFF Maricopa

UNOFF

UNOF

$B G N$

BGN

1968 Yavapai

VARIANT

VARIANT

summit
cliff
park
reservoir
locale
school
school
reservoir
crater
reservoir

BGN
BGN
ADMIN
BGN
BGN
UNOFF
UNOFF
BGN
BGN
BGN

park ADMIN

canal

hospital

reservoir

valley

ridge

spring

ADMIN
BGN
BGN

UNOFF

BGN

BGN 1964

VARIANT

BGN

$B G N$
$B G N$

reservoir

reservoir

reservoir

BGN

reservoir

reservoir

reservoir

reservoir

reservoir

reservoir

reservoir

BGN

BGN

BGN

BGN

BGN

BGN

reservoir

BGN

reservoir $B G N$

reservoir BGM

reservoir $B G$

reservoir BGV

reservoir
Mohave

Yavapai

Coconino

Yavapai

Mohave

Apache

Maricopa

Maricopa

Navajo

Mohave

Graham

Coconino

Gila

Cochise

Cochise

Yavapai

Maricop

Maricopa

Yavapai

Yavapai

Coconino

Coconino

Pima

Coconino

Pinal

Pinal

Pinal

Mohave

Coconino

Greenlee

Apache

Pinal

Pinal

Maricopa

Grahan

Greenlee

Yavapai

Greenlee

Greenlee

Graham

Yavapai

$320908 \mathrm{~N} 1105658 \mathrm{~W}$

$363938 \mathrm{~N} 1130800 \mathrm{~W}$

$320340 \mathrm{~N} 1112122 \mathrm{~W}$

$344221 \mathrm{~N} 1125635 \mathrm{~W}$

$353332 \mathrm{~N} 1112840 \mathrm{~W}$

$344328 \mathrm{~N} 1125816 \mathrm{~W}$

$365217 \mathrm{N1} 124156 \mathrm{~W}$

$315958 \mathrm{~N} 1120849 \mathrm{~W}$

$334554 \mathrm{~N} 1133324 \mathrm{~W}$

$343736 \mathrm{~N} 1093326 \mathrm{~W}$

$332348 \mathrm{~N} 1120343 \mathrm{~W}$

$331944 N 1120439 \mathrm{~W}$

$332210 \mathrm{~N} 1120425 \mathrm{~W}$

$323139 \mathrm{~N} 1101846 \mathrm{~W}$

343841 N1101718

$362525 \mathrm{~N} 1132658 \mathrm{~W}$

$323202 \mathrm{~N} 1101040 \mathrm{~W}$

$363843 \mathrm{~N} 1121941 \mathrm{~W}$

340309 N1112142W

$314704 N 1095305 \mathrm{~W}$

$314705 \mathrm{~N} 1095313 \mathrm{~W}$

$342418 \mathrm{~N} 1114751 \mathrm{~W}$

$342930 \mathrm{~N} 1115716 \mathrm{~W}$

$342234 N 1131614 W$

$332424 \mathrm{~N} 1120422 \mathrm{~W}$

$332320 \mathrm{~N} 1120411 \mathrm{~W}$

$332329 \mathrm{~N} 1120425 \mathrm{~W}$

345811 N1115108

$345822 \mathrm{~N} 1115031 \mathrm{~W}$

$341842 \mathrm{~N} 1115308 \mathrm{~W}$

$341820 \mathrm{~N} 1114926 \mathrm{~W}$

362957 N1113530W

$355905 \mathrm{N1} 115802 \mathrm{~W}$

32231 ON1104154W

$363737 \mathrm{~N} 112055 \mathrm{OW}$

$330703 \mathrm{~N} 1114444 \mathrm{~W}$

$325219 N 1114525 \mathrm{~W}$

$325834 \mathrm{~N} 1113114 \mathrm{~W}$

$351801 \mathrm{~N} 1111521 \mathrm{~W}$

$332352 \mathrm{~N} 1090456 \mathrm{~W}$

$361616 \mathrm{~N} 1091129 \mathrm{~W}$

$325832 \mathrm{~N} 1113637 \mathrm{~W}$

$330105 N 1113811 \mathrm{~W}$

332453N111 4932W

$324617 N 1092103 \mathrm{~W}$

$330417 N 1092710 \mathrm{~W}$

342709 N1122459W

$333225 \mathrm{~N} 1092630 \mathrm{~N}$

$325932 N 1091625 \mathrm{~W}$

332351N1101418W

$344515 \mathrm{~N} 1124631 \mathrm{~W}$

Santa Cruz 312028N1103930

$313902 \mathrm{~N} 1095129 \mathrm{~W}$

314702 N1105449W

$315056 \mathrm{~N} 1111000 \mathrm{~W}$

$\begin{array}{ll}\text { Graham } & 323320 \mathrm{~N} 1094245 \mathrm{~W} \\ \text { Pinal } & 324501 \mathrm{~N} 1110342 \mathrm{~W}\end{array}$

$\begin{array}{ll}\text { Graham } & 323320 \mathrm{~N} 1094245 \mathrm{~W} \\ \text { Pinal } & 324501 \mathrm{~N} 1110342 \mathrm{~W}\end{array}$

Gila

Maricopa

Maricopa

Navajo

Yavapai

Yavapai

Apache

Mohave

\begin{tabular}{|c|c|c|}
\hline $\begin{array}{l}\text { SOURCE } \\
\text { COORDINATE }\end{array}$ & $\begin{array}{l}\text { ELEV } \\
\text { FT }\end{array}$ & MAP NAME \\
\hline $15824 \mathrm{~N} 1113153 \mathrm{~W}$ & & $\begin{array}{l}\text { Tucs on } \\
\text { Antelope Knoll } \\
\text { Three Points }\end{array}$ \\
\hline $65335 \mathrm{~N} 1124828 \mathrm{~W}$ & 5521 & $\begin{array}{l}\text { Sheridan Mtn } \\
\text { Wupatki SW } \\
\text { Sheridan Mtn } \\
\text { Pipe Spring } \\
\text { Kupk }\end{array}$ \\
\hline & $\begin{array}{l}2311 \\
6060\end{array}$ & $\begin{array}{l}\text { Salome } \\
\text { Stinking Springs Mtn } \\
\text { Phoenix } \\
\text { Lone Butte }\end{array}$ \\
\hline
\end{tabular}

1220 Hassayampa

Bassett Peak

Dry Lake NE 
FEATURE NAME

South Tank

South Tank

South Taylor Canyon

South Taylor Spring

South Taylor Wash

South Taylor Wash

See Grant Draw

South Trigo Peaks

South Tucson

South Vekol Well

South Walnut Spring

South Well

South Well

South Well

See Vaya chin

Southwest Archeological Center

Southwestern Bible Bapt ist

College

See Southwestern College

Southwestern College Southwestern Bible Baptist College

Southwestern Research Station Southwest Gas Site Mini Park Southwest Indian School

Southwest Lateral

Southwest Poultry Experiment

Station

Southwest Tank

South Windail1

South Wing Tank

South Witch Canyon

Witch Canyon

Sowats Canyon

Sowats Point

Sowats Spring

Sowats Trick Tank

Soza Canyon

Soza Mesa

Soza Ranch

Soza Wash

Spades Tank

Spains Well (dry)

Spanish Trail

Spannabone Lake (dry)

Sparkplug Tank

Sparks Tank

Sparky Spring

Spar Mine

Spar Tank

Spaulding Draw

Spaulding Spring

Spaulding Tank

Spaulding Well

$S$ P Crater

Speaks Spring

Spearhead Mesa

Spear Ranch

Spear Ranch

Spear-R Spring

Spears Lake (dry)

Specter Canyon

See Specter Chasm

Specter Chasm

$$
\text { Specter Canyon }
$$

Specter Rapids

Specter Terrace

Speeds Tank

Speedway Boulevard Interchange

Speedway Greasewood Park
FEATURE

STATUS COUNTY

COORDINATE

$\begin{array}{llll}\text { reservoir BGN } & \text { Coconino } & 354909 \mathrm{~N} 1121321 \mathrm{~W} \\ \text { reservoir } & \mathrm{BGN} & \text { Mohave } & 364703 \mathrm{~N} 1133713 \mathrm{~W}\end{array}$

valley $B G N$

323926 N1100110W

$\begin{array}{llll}\text { spring } & \text { BGN } & \text { Graham } & 324136 N 1100104 W \\ \text { stream } & \text { BGN } 1975 & \text { Graham } & 323322 N 1095955 W\end{array}$

$\begin{array}{llll}\text { valley } & & \text { Graham } & 323123 \mathrm{~N} 1100140 \mathrm{~W} \\ \text { summit } & \text { BGN } & \text { Yuma } & 332514 \mathrm{~N} 1142151 \mathrm{~W} \\ \text { ppl } & \text { BGN } & \text { Pima } & 321158 \mathrm{~N} 1105804 \mathrm{~W}\end{array}$

$\begin{array}{llll}\text { valley } & & \text { Graham } & 323123 \mathrm{~N} 1100140 \mathrm{~W} \\ \text { summit } & \text { BGN } & \text { Yuma } & 332514 \mathrm{~N} 1142151 \mathrm{~W} \\ \text { ppl } & \text { BGN } & \text { Pima } & 321158 \mathrm{~N} 1105804 \mathrm{~W}\end{array}$

$\begin{array}{llll}\text { ppl } & \text { BGN } & \text { Pima } & 321158 \text { N1105804W } \\ \text { well } & \text { UNOFF } & \text { Maricopa } & 324415 \mathrm{~N} 1121350 \mathrm{~W}\end{array}$

spring $\quad B G N \quad$ Gila

well UMOFF Mavajo 350509N1102203W

well UNOFF Mohave 353034N1142921W

$322050 \mathrm{~N} 1121934 \mathrm{~W}$

$332153 \mathrm{~N} 1104601 \mathrm{~W}$

ppl Pima

building

UNOFF
VARIANT

school

school

UNOFF

VARIANT

Maricopa

Maricopa

$333546 \mathrm{~N} 1120117 \mathrm{~W}$

$333546 \mathrm{~N} 1120117 \mathrm{~W}$

\begin{tabular}{|c|c|}
\hline $\begin{array}{l}\text { building } \\
\text { park } \\
\text { school } \\
\text { canal } \\
\text { locale }\end{array}$ & $\begin{array}{l}\text { UNOFF } \\
\text { ADMIN } \\
\text { UNOFF } \\
\text { BGN } \\
\text { UNOFF }\end{array}$ \\
\hline $\begin{array}{l}\text { reservoir } \\
\text { locale } \\
\text { reservoir } \\
\text { valley }\end{array}$ & $\begin{array}{l}\text { BGN } \\
\text { BGN } \\
\text { BGN } \\
\text { BGN } 1976 \\
\text { VARIANT }\end{array}$ \\
\hline
\end{tabular}

$352315 \mathrm{~N} 1114908 \mathrm{~W}$

$315621 \mathrm{~N} 1092614 \mathrm{~W}$

stream BGN Cochise

reservoir BGN Yavapai

trail UNOFF Apache

lake BGN

reservoir $B G$

reservoir

spring

mine

reservoir

valley

spring

reservoir

Mohave

Maricopa

Maricopo
Gila

Graham

Graham

Coconino

Coconino

Coconino

well

crater

spring

locale

locale

spring

flat

valley

UNOFF

Coconino

Cochise

Navajo

Cochise

Mohave

Gila

BGN

VARIANT

Coconino

BGN 1908

VARIANT

rapids $\quad$ BGN 1932

BGN 1932 Coconino

reservoir

crossing

BGN

ADMIN
Coconino

Coconino

Yavapai

Pima
$315257 \mathrm{N1091212 \textrm {W }}$

$324510 \mathrm{~N} 111330 \mathrm{BW}$

$333648 \mathrm{~N} 1121257 \mathrm{~W}$

$323319 N 1144522 \mathrm{~W}$

$333121 \mathrm{~N} 1121045 \mathrm{~W}$

$313954 \mathrm{~N} 1095128 \mathrm{~W}$

$351538 \mathrm{~N} 1114741 \mathrm{~W}$

315426 N10923466

$363112 \mathrm{~N} 1123443 \mathrm{~W}$

$363034 \mathrm{N1} 123216 \mathrm{~W}$

$363139 \mathrm{~N} 1122716 \mathrm{~W}$

$362954 \mathrm{~N} 1122932 \mathrm{~W}$

$322137 \mathrm{N1} 102607 \mathrm{~W}$

$322117 \mathrm{~N} 1101930 \mathrm{~W}$

$322108 \mathrm{~N} 1102527 \mathrm{~W}$

$322135 \mathrm{~N} 1102557 \mathrm{~W}$

$344417 \mathrm{~N} 1124715 \mathrm{~W}$

$323725 \mathrm{N1} 133057 \mathrm{~W}$

$361419 N 1091857 \mathrm{~W}$

350017 N1143633W

$314120 \mathrm{~N} 1111313 \mathrm{~W}$

$335445 \mathrm{~N} 1113132 \mathrm{~W}$

$340155 \mathrm{~N} 1105821 \mathrm{~W}$

$325632 \mathrm{~N} 1100815 \mathrm{~W}$

$323410 \mathrm{~N} 1094402 \mathrm{~W}$

$343133 \mathrm{~N} 1110238 \mathrm{~W}$

$343014 \mathrm{~N} 1110205 \mathrm{~W}$

$343018 \mathrm{~N} 1110202 \mathrm{~W}$

$320247 N 1111759 \mathrm{~W}$

$353456 \mathrm{~N} 1113752 \mathrm{~W}$

321242N1093809W

$365722 \mathrm{~N} 1100250 \mathrm{~W}$

322123N1102529W

$354546 \mathrm{~N} 1141736 \mathrm{~W}$

$335645 \mathrm{~N} 1101940 \mathrm{~W}$

$345544 \mathrm{~N} 1143621 \mathrm{~W}$

$361854 N 1122847 \mathrm{~W}$

$363114 N 1122701 W$

321854 N1102833W

322344 N1101838W

Portal

Eloy North

Glendale

Gadsden

Glendale

Kendrick Peak

4642 Outlaw Mountain

Wing Mountain

Fife Peak

Jumpup Point

Jumpup Point

Sowats Spring

Tapeats Amphitheater

Soza Canyon

Soza Mesa

Soza Canyon

Smith Mesa

Mohawk Mts SE

Mummy Cave Ruins

Davis Dam SE

Saucito Mtn

Lion Mountain

Young

Jackson Mtn

Gillespie Mtn

342859 N1110155W

eonard Canyon

Leonard Canyon

Leonard Canyon

Three Points

$S$ P Mountain

Simmons Peak

5984 Mitten Buttes

3041 Soza Canyon

Senator Mtn

Carrizo

Needles NE

$361854 N 1122847 W$

$361855 \mathrm{~N} 1123050 \mathrm{~W}$

Powell Plateau

$361854 \mathrm{~N} 1122836 \mathrm{~W}$

$361821 \mathrm{~N} 1122730 \mathrm{~W}$

344731 N1114321W

$321409 \mathrm{~N} 110590 \mathrm{OW}$

$321350 \mathrm{~N} 1110125 \mathrm{~W}$
Powell Plateau

Powell Plateau

Munds Mountain

2330 Tucson

Cat Mountain 
FEATURE NAME

Speedway Post Office

Spence Creek

Spence Creek Spring

Spencer Canyon

Pine Canyon

Spencer Canyon

Spencer Canyon Campground

Spencer Creek

Spencer Knol

Spencer Peak

Spencer Plateau

See Spencer Terrace

Spencer Spring

Spencer Spring

Spencer Spring Creek

Spencer Springs

Spencers Well

Spencer Tank

Spencer Terrace

Mystic Spring Platea

Spencer Plateau

Spencer Well

Spence Spring

Spence Spring

Spendlove Tank

Spenser Wash

$S$ P Hill

Spider Ranch

Spider Rock

Monument Rock

The Captains

The Monuments

Spider Rock Overlook

Spider Spring

Spider Spring

Spider Tank

Spider Web Ranch

Spike E Hills

Spillway Beaverhead Lodge

Spine, The

Spion Kop

See Rawhide Mountain

Spitz Hill

Spitz Spring

Spitz Spring Overpass

Spitz Spring Underpass

Splashing Water Canyon

Split Rock

Split Rock Canyon

Split Tank

Split Tank

Split Tank

Split Tank

\section{Split Tank}

Split Tank

$S P$ Mountain

Sponseller

Sponseller Lake

Sponseller Mountain

Sponseller Tank

Spoonseller Tank

Spook Canyon

Spook Hill

Spook Hill Dam

Spook Hill Recreation Area

Spooks Knoll Reservoir

Spook Tank

Spoonhead, Mount

Spoonhead Butte

Spoonhead Butte

See Spoonhead, Mount
FEATURE

CLASS

STATUS COUNTY

building UNOFF Pima

stream BGN Yavapai

spring BGN Yavapai

valley

\section{BGN}

VARIANT

valley

park

stream

summit

summit

bench

spring

BGN

ADMIN

BGN

BGN

BGN

VARIANT

BGN

spring

stream

spring

locale

reservoir

bench

we 1

spring

$B G N$

BGN

BGN

BGN

BGN 1908

VARIANT

VARIANT

spring

reservoir

stream

summ it

locale

pillar

$\begin{array}{ll} & \text { VARIANT } \\ \text { locale } & \text { VARIANT }\end{array}$

locale

spring

spring

reservoir

locale

range

locale

ridge

summit

summit

BGN

BGN

BGN

BGN

BGN 1959

VARIANT

BGN

BGN

BGN

BGN

BGN

BGN

BGN

VARIANT

BGN

spring

BGN Coconino

crossing UNOFF

valley

valley

summit

reservoir

reservoir

reservoir

reservoir

UNOFF

BGN
BGN
BGN

BGN

BGN

BGN
BGN

reservoir

reservoir

sumnit

locale

lake

summit

reservoir

valley

summit

BGN

BGN

BGN

BGN

BGN

VARIANT

BGN

BGN

dam

UNOFF

park

reservoir

reservoir

summit

ADMIN

BGN

BGN

BGN 1925

VARIANT

summ it

VARIANT
Pima

Mohave

Pima

Yavapai

Mohave

Pima

Coconino

Pinal

Coconino

Yavapai

Pinal

Mohave

Apache

Mohave

Coconino

Navajo

Apache

Yavapai

Mohave

Yuma

Apache

Apache

COORDINATE

$321412 \mathrm{N1105512W}$

$343401 \mathrm{N1} 123159 \mathrm{~W}$

$343419 N 1123248 \mathrm{~W}$

$322309 N 1104453 \mathrm{~W}$

354926N1133849W

$322500 \mathrm{N1104424 \textrm {W }}$

$344620 \mathrm{N1131549 \textrm {W }}$

$363224 N 1130645 W$

$322514 N 1104435 \mathrm{~W}$

$361300 \mathrm{~N} 1122317 \mathrm{~W}$

$332432 \mathrm{NII} 10829 \mathrm{~W}$

343354N1123203W

332620N1110610W

$354659 \mathrm{N1133900 \textrm {W }}$

$351543 N 1091345 \mathrm{~W}$

360109 N1132648W

$361300 \mathrm{~N} 1122317 \mathrm{~W}$

351301 N1100623W

$335644 \mathrm{~N} 1092455 \mathrm{~W}$

342209 N1122428W

$364437 N 1131358 \mathrm{~W}$

$341347 \mathrm{~N} 1133427 \mathrm{~W}$

$350032 \mathrm{~N} 1121725 \mathrm{~W}$

$344142 \mathrm{NI124621W}$

$360630 \mathrm{~N} 1092100 \mathrm{~W}$

$360618 N 1092115 \mathrm{~W}$

$344120 \mathrm{~N} 1124620 \mathrm{~W}$

$355026 \mathrm{~N} 1102344 \mathrm{~W}$

$344018 \mathrm{N1124523W}$

$353948 \mathrm{~N} 1112945 \mathrm{~W}$

321B21N1094904W

$334145 \mathrm{~N} 1091240 \mathrm{~W}$

$330740 \mathrm{~N} 1110238 \mathrm{~W}$

$330244 N 1102658 \mathrm{~W}$

$351605 \mathrm{~N} 1115929 \mathrm{~W}$

$351539 N 1115827 \mathrm{~W}$

$351452 \mathrm{~N} 1115840 \mathrm{~W}$

$351453 \mathrm{~N} 1115842 \mathrm{~W}$

$363745 \mathrm{~N} 1092102 \mathrm{~W}$

$320024 \mathrm{~N} 1091451 \mathrm{~W}$

$313303 \mathrm{~N} 1102244 \mathrm{~W}$

$312121 \mathrm{N11} 10009 \mathrm{~W}$

$312810 \mathrm{~N} 1110508 \mathrm{~W}$

$322758 \mathrm{~N} 1103623 \mathrm{~W}$

$331943 \mathrm{~N} 1092507 \mathrm{~W}$

344212 N1113919W

344527 N1112248W

$353456 \mathrm{~N} 1113743 \mathrm{~W}$

$341147 N 1095312 \mathrm{~W}$

$341410 \mathrm{~N} 1095042 \mathrm{~W}$

$341423 \mathrm{~N} 1095133 \mathrm{~W}$

$342915 \mathrm{~N} 1103815 \mathrm{~W}$

322B33N1141711W

$332850 \mathrm{NL1} 14032 \mathrm{~W}$

$332718 \mathrm{NI114036 \textrm {W }}$

$332634 \mathrm{N1} 113928 \mathrm{~W}$

$364845 \mathrm{N11} 23035 \mathrm{~W}$

322859 N1141648W

$361115 \mathrm{~N} 1123658 \mathrm{~W}$

Yuma

Coconino

Coconino

$361115 N 1123658 W$

\begin{tabular}{|c|c|c|}
\hline $\begin{array}{l}\text { SOURCE } \\
\text { COORDINATE }\end{array}$ & $\begin{array}{l}\text { ELEV } \\
\text { FT }\end{array}$ & MAP NAME \\
\hline $343541 \mathrm{~N} 1123412 \mathrm{~W}$ & & $\begin{array}{l}\text { Tucson } \\
\text { Iron Springs } \\
\text { Iron Springs }\end{array}$ \\
\hline $322500 \mathrm{~N} 1104427 \mathrm{~W}$ & & Mount Bigelow \\
\hline $\begin{array}{l}354017 N 1133355 W \\
345059 N 1131425 W\end{array}$ & $\begin{array}{l}7860 \\
6073\end{array}$ & $\begin{array}{l}\text { Spencer Canyon } \\
\text { Mount Bigelow } \\
\text { Pilot Knob } \\
\text { Hat Knoll } \\
\text { Mount Bigel ow }\end{array}$ \\
\hline & & Iron Mountain \\
\hline $332440 \mathrm{~N} 1110929 \mathrm{~W}$ & 6034 & $\begin{array}{l}\text { Iron Springs } \\
\text { Haunted Canyon } \\
\text { Spencer Canyon } \\
\text { Houck } \\
\text { Whitmore Point SW } \\
\text { Explorers Monument }\end{array}$ \\
\hline & 5420 & $\begin{array}{l}\text { Mitten Peak } \\
\text { Big Lake North }\end{array}$ \\
\hline
\end{tabular}

Batt leship Butte

Antelope Knoll

Alamo Dam

4997 Matterhorn

5212 Smith Mesa

Spider Rock

Spider Rock

Smith Mesa 
NATIONAL GAZETTEER--ARIZONA 1986

Spoonseller Tank

See Sponseller Tank

Spoon Tank

Spot Interchange

Spotted Mountain

Spotted Mountain Tank

Spout Spring

Spreader Dike

Spring, The

Spring Beach Spring

Spring Branch

Spring Canyon

Spring Canyon

Spring Canyon

Frye Canyon

Hawk Hollow Canyon

Spring Canyon

Spring Canyon

Spring Canyon

Spring Canyon

Spring Canyon

Spring Canyon

See Wild Cherry Canyon

Spring Canyon

Wild Cherry Canyon

Spring Canyon Dam Tank

Spring Canyon Tank

Spring Canyon Tank

Spring Canyon Tank

Spring Cove

Spring Creek

Spring Creek

Spring Creek

Spring Creek

Spring Creek

Spring Creek

Fontana Creek

Spring Creek

Spring Creek

Spring Creek

See Yellow Jacket Creek

Spring Creek

Spring Creek

Walker Creek

Spring Creek

Spring Creek

See Arnold Canyon

Spring Creek Flat Tank

Spring Creek Mine

Spring Creek Ranch

Spring Ditch

Springer Mountain

Springerville

Springerville-Eagar Municipal

Airport

Springfield Elementary School

Springfield Mine

Springfield Tank

Springfield Tank

Spring Gulch

See Arnold Canyon

Spring Gulch

Spring Junior High School

Spring Mine

Spring Mountain

Spring Peak

Spring Ridge

Spring Ridge

Springs Forest Service Station

Spring Tank

Spring Tank
FEATURE

CLASS

reservoir

STATUS

COUNTY

COORDINATE

VARIANT

reservoir

crossing

summit

reservoir

spring

dam

spring

stream

valley

valley

valley

valley

valley

valley

valley

valley

valley

BGN Gila

UNOFF Yuma

BGN Mavajo

Navajo

UNOFF Yavapai

BGN Mohave

BGN Coconino

Gila

Cochise

BGN Graham

BGN 1962 Graham

VARIANT

VARIANT

BGN Graham

BGN

BGN

Mohave

BGN Mohave

VARIANT

valley

reservoir

reservoir

reservoir

reservoir

bay

stream

stream

stream

BGN 1959 Apache

VARIANT

BGN

BGN

BGN

BGH

BGN

BGN

BGN

stream

stream

BGN Gila

BGN Yavapai

BGN 1932 Gila

VARIANT

stream

stream

stream

stream

stream

BGN

VARIANT

BGN

BGN

BGN
VARIANT

Yavapai

Gila

Yavapai

Yavapai

Yavapai

stream BGN Yavapai

VARIANT

valley

reservoir

mine

locale

canal

summit

ppl

airport

BGN

UNOFF

BGN

BGN
BGN

ADMIN

Yavapa

Yavapai
Gila

Gila

Gila

Yavapai

Mavajo

Apache

Apache

school UNOFF Apache

mine

reservoir

UNOFF

BGN

VARIANT

valley

valley

school

mine

BGN 1968

UNOFF

UNOFF

BGN

Yavapai

Yavapai

Yavapai

Yavapai

Yavapai

Pima

summit

\section{(1)}

summit $\quad B G$

ridge $\quad B G$

ridge BGN

building

reservoir

BGN

BGN
Maricopa

Yavapai

Navajo

Navajo

Yavapai

Navajo

Yavapai
$342915 N 1103815 W$

$335013 \mathrm{N1102227 \textrm {W }}$

32500BN1132124W

$340033 \mathrm{N1} 103635 \mathrm{~W}$

$340114 N 1103600 \mathrm{~W}$

$334950 N 1091112 \mathrm{~W}$

$350400 \mathrm{~N} 1124755 \mathrm{~W}$

$342815 \mathrm{~N} 1133809 \mathrm{~W}$

$345630 \mathrm{~N} 1112919 \mathrm{~W}$

331544 N1104113

$312655 \mathrm{~N} 1095548 \mathrm{~W}$

$324026 \mathrm{~N} 1094332 \mathrm{~W}$

$324830 \mathrm{~N} 1094745 \mathrm{~W}$

$325043 \mathrm{~N} 110200 \mathrm{BW}$

$325316 \mathrm{~N} 1092947 \mathrm{~W}$

$331555 \mathrm{~N} 1090900 \mathrm{~W}$

$360105 \mathrm{~N} 1140957 \mathrm{~W}$

360108 N1132102W

360630 N1092515W

360700N1092630W

$323855 \mathrm{~N} 1094526 \mathrm{~W}$

$325137 \mathrm{N1101804 \textrm {W }}$

$325642 \mathrm{~N} 1093247 \mathrm{~W}$

$35051123045 \mathrm{~W}$

$360127 \mathrm{N1140945 \textrm {W }}$

$312559 \mathrm{~N} 1100604 \mathrm{~W}$

$325821 N 1095324 \mathrm{~W}$

333649 N1110007W

$335835 \mathrm{~N} 1102903 \mathrm{~W}$

$340556 \mathrm{~N} 1122740 \mathrm{~W}$

$341120 \mathrm{~N} 1123305 \mathrm{~W}$ 341B40N1110355W

315N1120115W

$343516 \mathrm{~N} 1131209 \mathrm{~W}$

$343738 \mathrm{N1113934 \textrm {W }}$

$344438 N 11154511$

$342446 \mathrm{N1115743 \textrm {W }}$

$334020 \mathrm{N1105812 \textrm {W }}$

$340437 N 1110432 \mathrm{~W}$

$340152 \mathrm{~N} 1110235 \mathrm{~W}$

$344520 \mathrm{~N} 1115322 \mathrm{~W}$

340851 N1095652W

$340 \mathrm{~B} 00 \mathrm{N1091707 \textrm {W }}$

340800 N1091845W

340756 N1091622W

$341228 N 1122205 \mathrm{~W}$

$343935 \mathrm{N1} 123139 \mathrm{~W}$

$344202 N 1123703 \mathrm{~W}$

$342446 \mathrm{~N} 1115743 \mathrm{~W}$

$342450 \mathrm{~N} 1115615 \mathrm{~W}$

$321357 \mathrm{~N} 1105835 \mathrm{~W}$

341712 N1132443W

$330953 \mathrm{~N} 1125001 \mathrm{~W}$

$340654 \mathrm{~N} 1103511 \mathrm{~W}$

$350043 \mathrm{Nl} 101825 \mathrm{~W}$

$343603 \mathrm{~N} 1124100 \mathrm{~W}$

$340339 \mathrm{~N} 1103717 \mathrm{~W}$

$341321 \mathrm{N1} 115724 \mathrm{~W}$

$360612 N 109265 \mathrm{~W}$

$312727 N 1095839 \mathrm{~W}$

$325851 \mathrm{N1095128 \textrm {W }}$

$333154 \mathrm{~N} 1110100 \mathrm{~W}$

$340921 \mathrm{N1103854 \textrm {h }}$

$340722 N 1122758 \mathrm{~W}$

335858N1110201W

341008 N1123952W

34203BN1110300W

343514N1131100W

343531 M1113451W

$345907 N 1115611 W$

$342615 N 1115345 W$ 
FEATURE NAME

Spring Tank

Spring Tank

Spring Tank

Spring Tank

Spring Tank

Spring Tank

Spring Tank

Spring Trail Spring

Spring Valley

Spring Valley

Spring Valley

Spring Valley Guard Station

Spring Valley Knolls

Spring Valley Tank

Spring Valley Wash

Spring Wash

Spring Wash

See Cane Springs Wash

Spring Water Canyon

Sproul, The

Spruce Brook

See Tsaile Creek

Spruce Canyon

Spruce Canyon Spring

Spruce Creek Spring

Sprucedale

Espero

Spruce Mountain

Spruce Mountain

Spruce Mountain Lookout

Family Picnic Area

Spruce Spring

Spruce Spring

Spruce Tank

Spruce Tank

Sprung Spring

$S$ P Tank

$S$ P Tank

Spud Creek

Spud Hill

Spud Mountain

Spud Patch Tank

Spud Rock

Spud Rock Cabin (site)

Spud Rock Spring

Spundulic Mine

Spur Cross

Spurlock

Spur lock Tank

Spur Tank

Spur Tank

Spur Tank

Squabble Mine

Square Butte

Square Mountain

Square Butte

Square Butte Spring

Square Butte Wash

Square Mountain

Square Mountain

See Square Butte

Square Pond

Square Tank

Square Tank

Squaretop Hills

Squaw Bas in Tank

Squaw Beach

Squaw Butte

See Squaw Peak

Squaw Butte

See Squaw Peak
FEATURE
CLASS

STATUS

COUNTY

reservoir

reservoir

reservoir

Yavapai

Navajo

Yavapai

Apache

reservoir $B G N$

reservoir

reservoir

spring

valley

valley

locale

locale

summit

reservoir

Coconino

Coconino

Coconino

Graham

Yavapai

Coconino

Yavapai

Coconino

Coconino

Coconino

stream

stream

stream

valley

crater

stream

valley

spring

BGN

VARIANT

BG

BGN

VARIANT

spring

locale

summit

summit

park

spring

spring

reservoir

BG

BGN

ARIANT

BGN

BGN
ADMIN

Coconino

Yavapai

Mohave

Pima

Coconino

Apache

Yavapa

Yavapai

BGN

BGN

Greenle

Apache

Yavapai

Yavapai

Apache

Apache

Greenlee

reservoir

spring

reservoir

reservoir

stream

summit

summit

reservoir

summit

locale

Coconino

Santa Cru

Coconino

Coconino

Apache

Coconino

1963 Yavapai

Apache

Pima

Pima

spring

mine

locale

locale

reservoir

reservoir

reservoir

reservoir

mine

summit

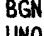

UNOFF

BGN

BGN

BGN

BGN

BGN
UNOFF

BGN

VARIANT

Pima

Pinal

Greenlee

Gila

Navajo

Gila

Yavapai

Coconino

Pima

Greenlee

summit

spring

valley

summit

summit

reservoir

reservoir

reservoir

summit

BGN

BGN

BGN

Coconino

Coconino

Coconino

Cochise

VARIANT

Greenlee

Mohave

Pima

Pima

Cochise

reservoir

beach

BGN

Gila

summit

VARIANT

summit

VARIANT

Mohave

Gila

Gila

COORDINATE

$341408 \mathrm{~N} 1125706 \mathrm{~W}$

$342436 \mathrm{~N} 1101406 \mathrm{~W}$

343127 N1120518W

344353N1093613W

$344634 \mathrm{~N} 1112038 \mathrm{~W}$

$351557 N 1115122 W$

352643 N1115018W

$325823 \mathrm{~N} 1101907 \mathrm{~W}$

$335523 \mathrm{~N} 1122142 \mathrm{~W}$

$352304 \mathrm{~N} 1115745 \mathrm{~W}$

$342042 \mathrm{~N} 1120930 \mathrm{~W}$

$352126 \mathrm{~N} 1115723 \mathrm{~W}$

$352051 \mathrm{N11} 15605 \mathrm{~W}$

$352042 \mathrm{~N} 1115741 \mathrm{~W}$

353741 N1121550W

340657N1114253W

345446 N1133726W

314838 N1103458W

$352012 N 1111829 \mathrm{~W}$

361646 N1091143W

$343359 \mathrm{~N} 1123828 \mathrm{~W}$

343317 N1123542W

$343420 \mathrm{~N} 1123249 \mathrm{~W}$

334425 N1091935W

$335553 N 1093 B 20 \mathrm{~W}$

$342747 \mathrm{N1122410 \textrm {W }}$

342744 N1122410W

$335410 \mathrm{~N} 1092920 \mathrm{~W}$

$335753 \mathrm{~N} 1092846 \mathrm{~W}$

333839 N1091750W

$344905 N 1112241 \mathrm{~W}$

$314147 \mathrm{N1105136 \textrm {W }}$

$350049 \mathrm{~N} 1121714 \mathrm{~W}$

353625 N1114020W

$334027 N 1093142 \mathrm{~W}$

$352911 \mathrm{~N} 1115626 \mathrm{~W}$

$343004 N 1121618 \mathrm{~W}$

$340053 N 1092857 \mathrm{~W}$

$321312 \mathrm{~N} 1103300 \mathrm{~W}$

$321208 \mathrm{~N} 1103206 \mathrm{~W}$

$321215 N 1103154 \mathrm{~W}$

$323535 \mathrm{~N} 1120434 \mathrm{~W}$

$331100 \mathrm{~N} 1092726 \mathrm{~W}$

$340854 \mathrm{~N} 1110154 \mathrm{~W}$

$350331 N 1100502 W$

$333918 \mathrm{~N} 1102550 \mathrm{~W}$

$345825 \mathrm{~N} 1124919 \mathrm{~W}$

345912 N1112509W

$321914 N 1112731 \mathrm{~W}$

$330320 \mathrm{~N} 1092108 \mathrm{~W}$

363616 N1105533W

$363609 \mathrm{~N} 1105604 \mathrm{~W}$

$363855 \mathrm{~N} 1105715 \mathrm{~W}$

$321818 N 1095837 \mathrm{~W}$

$330320 \mathrm{~N} 1092108 \mathrm{~W}$

$364212 N 1132005 \mathrm{~W}$

$314348 \mathrm{~N} 1111915 \mathrm{~W}$

$314912 N 1112207 \mathrm{~W}$

314919 N1093628W 
NATIONAL GAZETTEER--ARIZONA 1986

FEATURE NAME

Squaw Butte

Squaw Tit

Squaw Canyon

Squaw Canyon

Squaw Canyon

Squaw Canyon

Squaw Canyon Well

Squaw Coxcombs

Squaw Creek

Squaw Creek

Squaw Creek

Rousensock Creek

Squaw Creek

Sawmill Creek

Squaw Creek

Squaw Creek

Squaw Creek

Squaw Creek

See Bottle Canyon

Squaw Creek

See Jacks Gulch

Squaw Creek Mesa

Squaw Creek Tank

Squaw Creek Tank

Squaw Dance Valley

Squaw Dress Ridge

Squaw Flat

Squaw Flat

Squaw Flat Spring

Squaw Gulch

Squaw Lake

Squaw Mesa

Squaw Mesa

Squaw Mountain

Squaw Mountain

Squaw Mountain

Squaw Nest Mountain

Squaw Peak

Squaw Peak

Squaw Peak

Squaw Peak

Squaw Butte

Squaw Peak

Squaw Butte

Squaw Peak

Squaw Peak

Squaw Peak

Squaw Peak

Squaw Peak

Squaw Peak Canyon

Squaw Peak Filtration Plant

Squaw Peak Mine

Squaw Peak Park

Squaw Peak School

Squaw Peak Tank

Squaw Peak Tank

Squaw Peak Terrace (trailer parks)

Squaw Pockets

Squaw Pocket We 11

Squaw Saddle

Squaw Spring

Squaw Spring

Squaw Spring

Squaw Springs

Squaw Tank

Squaw Tank

Squaw Tank

Squaw Tank

Squaw Tank

Squaw Tank
FEATURE
CLASS

STATUS COUNTY

COORDINATE

$341622 \mathrm{~N} 1114140 \mathrm{~W}$

summit

valley

valley

BGN
VARIANT
BGN

Yavapai

Graham

Maricopa

$331055 \mathrm{~N} 1102604 \mathrm{~W}$

$332824 \mathrm{N1} 112145 \mathrm{~W}$

valley

valley

well

summit

stream

stream

stream

stream

\section{BGN}

BGN

UNOFF

1975 Graham

BGN Graham

BGN Greenlee

VARIANT

BGN

Graham

$362329 N 11218021$

$362502 \mathrm{~N} 1135337 \mathrm{~W}$

330918 N1102640W

$352623 \mathrm{~N} 1120218 \mathrm{~W}$

$324 B 13 N 1101803 \mathrm{~W}$

$330155 \mathrm{~N} 1101453 \mathrm{~W}$

332320N1091120W

332829 N1095320W

SOURCE

COORDINATE

ELEV

MAP NAME

4330 Verde Hot Springs

$330313 N 1102141 W$

332859 N1112117h

San Carlos Reservoir Weavers Needle

$362354 N 1121412$ $362239 \mathrm{~N} 1134405 \mathrm{~W}$

Quaking Aspen

Pakoon Springs

2658 San Carlos Reservoir

7186 Squaw Mtn

$330258 \mathrm{~N} 1101423 \mathrm{~W}$

$332458 \mathrm{~N} 1092123 \mathrm{~W}$

Klondike

Beargrass Bas in

Dutch Blue Creek

Natanes Mts NW

strean

BGN Apache

stream

stream

$\begin{array}{ll}\text { BGN } & \text { Yavapai } \\ \text { BGN } & \text { Yavapai }\end{array}$

$334540 \mathrm{N1093906 \textrm {W }}$

$340510 \mathrm{N1120641 \textrm {W }} 340645 \mathrm{N1} 115323 \mathrm{~W}$

Marshall Butte
Squaw Creek Mes

Verde Hot Springs

valley

VARIANT

Graham

$324530 \mathrm{~N} 1101900 \mathrm{~W}$

valley

summit BGN

VARIANT

reservoir $B G N$

Yavapai

$340706 \mathrm{~N} 1115605 \mathrm{~W}$

$332542 \mathrm{~N} 1095336 \mathrm{~W}$

$341650 \mathrm{~N} 1114237 \mathrm{~W}$

valley BGN Navajo $\quad 362243 \mathrm{~N} 1101141 \mathrm{~W}$

ridge $\quad B G N$

flat BGN 1917 Maricopa 333752N1111200W

flat BGN 1917 Maricopa 335816N1113137W

spring BGN Maricopa 335814N1113105W

valley BGN Santa Cruz 313047N1104759W

reservoir BGN Apache 350059N1091358W

flat $\quad$ BGN $\quad$ Yavapai $335818 \mathrm{~N} 1122058 \mathrm{~W}$

summit BGN Gila 340036 N1105725W

summit $\quad$ BGN $\quad$ Cochise $314023 N 1090957 \mathrm{~W}$

summit $\quad$ BGN $\quad$ Yavapai 340445 N1115907W

summit BGN Coconino 352523N1120045W

summit

pillar

summit

summit

summit

summit

BGN

BGN

$B G N$

BGN

BGN

VARIANT

BGN

Gila

$352523 \mathrm{~N} 1120045 \mathrm{~W}$

$340842 \mathrm{~N} 1111409 \mathrm{~W}$

$332023 \mathrm{~N} 1140201 \mathrm{~W}$

$333250 \mathrm{~N} 1120112 \mathrm{~W}$

$333352 \mathrm{~N} 1105144 \mathrm{~W}$

Maricopa

Gila

Gila

340037 N1105725W

362345N1101145W

313649 N1105051W

3545 Squaw Creek Mesa

Natanes Mts NW

Verde Hot Springs

Cliff Rose Hill

5533 Carrizo

Theo. Roosevelt Dan

Lion Mountain

Lion Mountain

Patagonia

Deep Lake

Governors Peak

Young

5280 Apache

5905 Cooks Mesa

7942 Squaw Mtn

4501 McDonald Mtn

4416 Palm Canyon

5761 Patagonia

2608 Sunnys lop

4786 Rockinstraw Mtn

6623 Young

summit BGN Yuma 340958N1135700W

sumnit BGN Yavapai 342522N1124636W

$342810 \mathrm{~N} 1115229 \mathrm{~W}$

Yavapai $\quad 351255 \mathrm{~N} 1130606 \mathrm{~W}$

$355344 \mathrm{~N} 1142533 \mathrm{~W}$

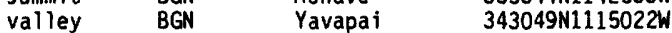

locale UNOFF Maricopa 333149N1120142W

mine UNOFF Yavapai 342856 N1115125W

park ADMIN Maricopa 333248N1120113W

school UNOFF Maricopa 333019N1120030W

reservoir BGN Yavapai $\quad 342744 \mathrm{~N} 1115344 \mathrm{~W}$

reservoir BGN Yavapai 343030N1115103W

$332945 \mathrm{~N} 1120053 \mathrm{~W}$

reservoir BGN Mohave 362234N1134427W

well UNOFF Mohave 352838N1142956W

Graham 324333N1101920W

spring BGN

$\begin{array}{llll}\text { spring } & \text { BGN } & \text { Gila } & 331651 N 1104858 \mathrm{~W} \\ \text { spring } & \text { BGN } & \text { Coconino } & 362342 \mathrm{~N} 1121706 \mathrm{~W}\end{array}$

spring BGN Apache 350805N1092539W

reservoir BGN Graham 324502N1102050W

reservoir BGN Graham 325043N1095914W

reservoir BGN Gila $340030 \mathrm{N1105632W}$

reservoir BGN Navajo 343510N1103555W

reservoir BGN Coconino 350647N1112226W

reservoir BGN Mohave 362150N1134540W
Planet

4178 Bismarck Mes

6525 Horner Mtn

6700 Squaw Peak

342B47N1115331W

Camp Verde

Sunnys lope

Horner Mtn

Sunnys lope

Sunnys lope

Arnold Mesa

Camp Verde

1180 Phoenix

Last Chance Canyon

Grasshopper Junc NW

Kennedy Peak

Rawhide Mtn

Pinal Peak

Quaking Aspen

Chambers

Shingle Mill Mtn

Young

Red Knol

Elliott Canyon

Grand Gulch Bench 


\begin{tabular}{|c|c|c|c|c|c|c|c|}
\hline FEATURE NAME & $\begin{array}{l}\text { FEATURE } \\
\text { CLASS }\end{array}$ & STATUS & COUNTY & COORDINATE & $\begin{array}{l}\text { SOURCE } \\
\text { COORDINATE }\end{array}$ & $\begin{array}{l}\text { ELEV } \\
\text { FT }\end{array}$ & MAP NAME \\
\hline $\begin{array}{l}\text { Squaw Tanks } \\
\text { Squaw Tit } \\
\text { Squaw Tit } \\
\text { See Squaw Butte }\end{array}$ & $\begin{array}{l}\text { reservoir } \\
\text { summit } \\
\text { summit }\end{array}$ & $\begin{array}{l}\text { BGN } \\
\text { BGN } \\
\text { VARIANT }\end{array}$ & $\begin{array}{l}\text { Yuma } \\
\text { Maricopa } \\
\text { Yavapai }\end{array}$ & $\begin{array}{l}332013 \mathrm{~N} 1140051 \mathrm{~W} \\
324039 \mathrm{~N} 1122237 \mathrm{~W} \\
341622 \mathrm{~N} 1114140 \mathrm{~W}\end{array}$ & & 4021 & $\begin{array}{l}\text { Palm Canyon } \\
\text { Kaka NW }\end{array}$ \\
\hline $\begin{array}{l}\text { Squaw Tit } \\
\text { See Thimble Mountain } \\
\text { Squaw Tits } \\
\text { Squaw Hash } \\
\text { Squirrel Canyon } \\
\text { Squirrel Spring } \\
\text { Squirrel Tank } \\
\text { Squirrel Tank } \\
\text { Srerra Babuquivari } \\
\text { See Baboquivari Mountains }\end{array}$ & $\begin{array}{l}\text { summit } \\
\text { summit } \\
\text { stream } \\
\text { valley } \\
\text { spring } \\
\text { reservoir } \\
\text { reservoir } \\
\text { range }\end{array}$ & $\begin{array}{l}\text { VARIANT } \\
\text { BGN } \\
\text { BGN } \\
\text { BGN } \\
\text { BGN } \\
\text { BGN } \\
\text { BGN } \\
\text { VARIANT }\end{array}$ & $\begin{array}{l}\text { Mohave } \\
\text { Maricopa } \\
\text { Navajo } \\
\text { Greenlee } \\
\text { Apache } \\
\text { Greenlee } \\
\text { Gila } \\
\text { Pima }\end{array}$ & $\begin{array}{l}350241 \mathrm{~N} 1141812 \mathrm{~W} \\
325055 \mathrm{~N} 1122831 \mathrm{~W} \\
343840 \mathrm{~N} 1103413 \mathrm{~W} \\
333049 \mathrm{~N} 1092804 \mathrm{~W} \\
340227 \mathrm{~N} 1092732 \mathrm{~W} \\
333137 \mathrm{~N} 1092655 \mathrm{~W} \\
334103 \mathrm{~N} 1100143 \mathrm{~W} \\
314723 \mathrm{~N} 1113510 \mathrm{~W}\end{array}$ & $\begin{array}{l}343359 \text { N1103750W } \\
333416 \mathrm{~N} 1092434 \mathrm{~W}\end{array}$ & 2478 & $\begin{array}{l}\text { Big Horn } \\
\text { Potato Wash NE } \\
\text { Baldy Bill Point } \\
\text { Greer } \\
\text { Baldy Bill Point } \\
\text { Velasquez Butte }\end{array}$ \\
\hline $\begin{array}{l}\text { S R P Trick Tank } \\
\text { Stacey Lake } \\
\text { Stacy Ranch } \\
\text { Stacy Spring } \\
\text { Stafford } \\
\quad \text { See Safford } \\
\text { Stagecoach Pass } \\
\text { Stagecoach Trailer Park } \\
\text { Stage Station } \\
\text { Stage Tank }\end{array}$ & $\begin{array}{l}\text { reservoir } \\
\text { lake } \\
\text { locale } \\
\text { spring } \\
\text { ppl } \\
\text { gap } \\
\text { locale } \\
\text { locale } \\
\text { reservoir }\end{array}$ & $\begin{array}{l}\text { BGN } \\
\text { BGN } \\
\text { UNOFF } \\
\text { BGN } \\
\text { VARIANT } \\
\text { BGN } \\
\text { UNOFF } \\
\text { BGN } \\
\text { BGN }\end{array}$ & $\begin{array}{l}\text { Yavapai } \\
\text { Santa Cruz } \\
\text { Greenlee } \\
\text { Greenlee } \\
\text { Graham } \\
\text { Yuma } \\
\text { Maricopa } \\
\text { Coconino } \\
\text { Coconino }\end{array}$ & $\begin{array}{l}345737 \mathrm{~N} 1122223 \mathrm{~W} \\
312236 \mathrm{~N} 1105118 \mathrm{~W} \\
331606 \mathrm{~N} 1091053 \mathrm{~W} \\
331900 \mathrm{~N} 1090523 \mathrm{~W} \\
\\
325002 \mathrm{~N} 1094225 \mathrm{~W} \\
331828 \mathrm{~N} 1140554 \mathrm{~W} \\
332708 \mathrm{~N} 1120856 \mathrm{~W} \\
350545 \mathrm{~N} 1121610 \mathrm{~W} \\
350544 \mathrm{~N} 1121607 \mathrm{~W}\end{array}$ & & 1058 & $\begin{array}{l}\text { Hell Point } \\
\text { Cumero Canyon } \\
\text { Fritz Canyon } \\
\text { Maple Peak }\end{array}$ \\
\hline $\begin{array}{l}\text { Stagg Ranch } \\
\text { Stagg Tank } \\
\text { Stag Hound Butte } \\
\text { Houn' Dawg } \\
\text { Stago Canyon } \\
\text { Stairway Canyon } \\
\text { Stake Tank } \\
\text { Stallion Tank } \\
\text { Stamps Spring } \\
\text { Stamps Hell } \\
\text { Stanp Well }\end{array}$ & $\begin{array}{l}\text { locale } \\
\text { reservoir } \\
\text { summit } \\
\text { valley } \\
\text { valley } \\
\text { reservoir } \\
\text { reservoir } \\
\text { spring } \\
\text { well }\end{array}$ & $\begin{array}{l}\text { UNOFF } \\
\text { BGN } \\
\text { BGN } 1917 \\
\text { VARIANT } \\
\text { BGN } \\
\text { BGN } \\
\text { BGN } \\
\text { BGN } \\
\text { BGN } \\
\text { UNOFF } \\
\text { VARIANT }\end{array}$ & $\begin{array}{l}\text { Cochise } \\
\text { Coconino } \\
\text { Maricopa } \\
\text { Navajo } \\
\text { Mohave } \\
\text { Gila } \\
\text { Graham } \\
\text { Apache } \\
\text { Maricopa }\end{array}$ & $\begin{array}{l}312734 N 1100519 \mathrm{~W} \\
352645 \mathrm{~N} 1113512 \mathrm{~W} \\
\text { UNKNOWN } \\
334748 \mathrm{~N} 1095712 \mathrm{~W} \\
361418 \mathrm{~N} 1125742 \mathrm{~W} \\
335726 \mathrm{~N} 1101247 \mathrm{~W} \\
332718 \mathrm{~N} 1094659 \mathrm{~W} \\
341508 \mathrm{~N} 1091119 \mathrm{~W} \\
324826 \mathrm{~N} 1130733 \mathrm{~W}\end{array}$ & $\begin{array}{l}335112 \mathrm{~N} 1095521 \mathrm{~W} \\
361625 \mathrm{~N} 1125748 \mathrm{~W}\end{array}$ & $\begin{array}{l}5355 \\
608 B\end{array}$ & $\begin{array}{l}\text { Whiteriver } \\
\text { Gateway Rapids } \\
\text { Cedar Creek } \\
\text { Stove Canyon } \\
\text { Voigt Ranch } \\
\text { Aztec SE }\end{array}$ \\
\hline $\begin{array}{l}\text { Stamps Well } \\
\text { Stamp Well } \\
\text { See Stamps Well } \\
\text { Stanberry Ranch } \\
\text { Standard (site) } \\
\text { Standard Gulch } \\
\text { Standard Mine } \\
\text { Standard Mineral Mine } \\
\text { Standard Tungsten Mine } \\
\text { Standard Wash }\end{array}$ & $\begin{array}{l}\text { well } \\
\text { well } \\
\text { locale } \\
\text { locale } \\
\text { valley } \\
\text { mine } \\
\text { mine } \\
\text { mine } \\
\text { stream }\end{array}$ & $\begin{array}{l}\text { UNOFF } \\
\text { VARIANT } \\
\text { UNOFF } \\
\text { BGN } \\
\text { BGN } \\
\text { UNOFF } \\
\text { UNOFF } \\
\text { UNOFF } \\
\text { BGN }\end{array}$ & $\begin{array}{l}\text { Maricopa } \\
\text { Maricopa } \\
\text { Graham } \\
\text { Navajo } \\
\text { Greenlee } \\
\text { Yavapai } \\
\text { Mohave } \\
\text { Cochise } \\
\text { Mohave }\end{array}$ & $\begin{array}{l}324839 \mathrm{~N} 1130729 \mathrm{~W} \\
324826 \mathrm{~N} 1130733 \mathrm{~W} \\
323917 \mathrm{~N} 1095957 \mathrm{~W} \\
341555 \mathrm{~N} 1101407 \mathrm{~W} \\
330556 \mathrm{~N} 1092140 \mathrm{~W} \\
341046 \mathrm{~N} 1122205 \mathrm{~W} \\
350633 \mathrm{~N} 1134841 \mathrm{~W} \\
315147 \mathrm{~N} 1095719 \mathrm{~W} \\
342225 \mathrm{~N} 1141322 \mathrm{~W}\end{array}$ & $\begin{array}{l}330649 N 1092033 \mathrm{~W} \\
343205 \mathrm{N1} 140744 \mathrm{~W}\end{array}$ & 6498 & $\begin{array}{l}\text { Webb Peak } \\
\text { Pinedale } \\
\text { Clifton } \\
\text { Crown King } \\
\text { Dean Peak } \\
\text { Black Diamond Peak } \\
\text { Gene Wash }\end{array}$ \\
\hline $\begin{array}{l}\text { Standing Bar Tank } \\
\text { Standing Cow Ruins } \\
\text { Standing Horse Mesa } \\
\text { Standing Redrock Creek } \\
\text { Standing Red Rock Creek } \\
\text { Standing Red Rock Creek } \\
\text { See Standing Redrock Creek } \\
\text { Standing Rock } \\
\text { Standing Rock } \\
\text { Standing Rock }\end{array}$ & $\begin{array}{l}\text { reservoir } \\
\text { locale } \\
\text { summit } \\
\text { stream }\end{array}$ & $\begin{array}{l}\text { BGN } \\
\text { BGN } \\
\text { BGN } \\
\text { BGN } 1915 \\
\text { VARIANT } \\
\text { VARIANT } \\
\text { BGN } \\
\text { BGN } \\
\text { BGN }\end{array}$ & $\begin{array}{l}\text { Apache } \\
\text { Coconino } \\
\text { Apache } \\
\text { Apache }\end{array}$ & $\begin{array}{l}321343 N 1115734 W \\
360945 N 1092516 W \\
351043 \mathrm{~W} 1102414 W \\
363630 N 1090350 \mathrm{~W} \\
\\
363630 \mathrm{~N} 1090350 \mathrm{~W} \\
361424 N 1111322 \mathrm{~W} \\
361013 \mathrm{~N} 1092458 \mathrm{~W} \\
363459 \mathrm{~N} 1092905 \mathrm{~W}\end{array}$ & $362902 N 1090958 \mathrm{~W}$ & $\begin{array}{l}5379 \\
6089\end{array}$ & $\begin{array}{l}\text { Sand Wells } \\
\text { Del Muerto } \\
\text { Standing Horse Mesa } \\
\text { Red Valley }\end{array}$ \\
\hline $\begin{array}{l}\text { Standing Rock Catchment Bas in } \\
\text { Standing Rocks } \\
\text { Standing Rocks } \\
\text { Standing Rock Tank } \\
\text { Standing Rock Well } \\
\text { Standing Tree } \\
\text { See Blackwater } \\
\text { Stands bury Ranch } \\
\text { Stanfield } \\
\text { Summerland } \\
\text { Table Top }\end{array}$ & $\begin{array}{l}\text { reservoir } \\
\text { pillar } \\
\text { pillar } \\
\text { reservoir } \\
\text { well } \\
\text { ppl } \\
\text { locale } \\
\text { ppl }\end{array}$ & $\begin{array}{l}\text { BGN } \\
\text { BGN } \\
\text { BGN } \\
\text { BGN } \\
\text { UNOFF } \\
\text { VARIANT } \\
\text { UNOFF } \\
\text { BGN } \\
\text { VARIANT } \\
\text { VARIANT }\end{array}$ & $\begin{array}{l}\text { Gila } \\
\text { Navajo } \\
\text { Coconino } \\
\text { Gila } \\
\text { Coconino } \\
\text { Pinal } \\
\text { Graham } \\
\text { Pinal }\end{array}$ & $\begin{array}{l}331217 N 1103517 \mathrm{~W} \\
351237 \mathrm{~N} 1101514 \mathrm{~W} \\
353333 \mathrm{~N} 1111357 \mathrm{~W} \\
334648 \mathrm{~N} 1100603 \mathrm{~W} \\
361420 \mathrm{~N} 1111339 \mathrm{~W} \\
\\
330152 \mathrm{~N} 1113455 \mathrm{~W} \\
323422 \mathrm{~N} 1100522 \mathrm{~W} \\
325257 \mathrm{~N} 1115741 \mathrm{~W}\end{array}$ & & 5552 & $\begin{array}{l}\text { Coolidge Dam } \\
\text { Rotten Bananas Butte } \\
\text { Standing Rocks } \\
\text { Canyon Day } \\
\text { Tuba City }\end{array}$ \\
\hline $\begin{array}{l}\text { Stanfield Road Interchange } \\
\text { Stanfield School } \\
\text { Stanford Canyon } \\
\text { Stanford Creek } \\
\text { Stanford Ranch }\end{array}$ & $\begin{array}{l}\text { crossing } \\
\text { school } \\
\text { valley } \\
\text { stream }\end{array}$ & $\begin{array}{l}\text { UNOFF } \\
\text { UNOFF } \\
\text { BGN } \\
\text { BGN } \\
\text { VARIANT }\end{array}$ & $\begin{array}{l}\text { Pinal } \\
\text { Pinal } \\
\text { Cochise } \\
\text { Cochise }\end{array}$ & $\begin{array}{l}324942 \mathrm{~N} 1115746 \mathrm{~W} \\
325232 \mathrm{~N} 1115744 \mathrm{~W} \\
314946 \mathrm{~N} 1092712 \mathrm{~W} \\
315057 \mathrm{~N} 1093341 \mathrm{~W}\end{array}$ & $\begin{array}{l}314932 \mathrm{~N} 1092214 \mathrm{~W} \\
314936 \mathrm{~N} 1092232 \mathrm{~W}\end{array}$ & & $\begin{array}{l}\text { Double Peak } \\
\text { Stanfield } \\
\text { Stanford Canyon } \\
\text { Squaretop Hills East }\end{array}$ \\
\hline
\end{tabular}


NATIONAL GAZETTEER--ARIZONA 1986

FEATURE NAME

See Kots Kug

Stanford

See Kots Kug Ranch

Stanford Ranch

Stanford Spring

Stanford Tank

Stanley Butte

Stansberry Number Four Tank

Stansberry Number Three Tank

Stan Shuatuk

Cervant is We11

La Moralita

Molinitos

Molinton

Molonitos

Serventi Well

Stan Tank

Stanton

Antelope Valley

Uicer Gulch

Stanton Point

Stanvix Hall

See Stanwix

Stanwix

See Stoval

Stanwix

Stanvix Hall

Stanwixs Station

The Dutchmans

Stanwix Flats
Sentine Plain

Stanwixs Station

See Stanwix

Stapley Hall Special School

Stapley Park

Star Creek

Star Flat

Stargo

Stargo Gulch

Apache Gulch

Stark

Stark Overpass

Stark Railroad Station

Starkweather Tank

Stark Well

Starlight Canyon Straight Canyon

Starlight Mine

Starlight Mine

Starlight Park

Starlight Park School

Starlight Wel

Starline Elementary School

Starlite Trailer Park

Star Mountain

Star Peak Springs

Star Plaza Shopping Center

Star Ranch (abandoned)

Starting of the Water Spring

Starting Water Wash

Star Valley

Star Valley

Starvation Canyon

Starvation Flat

Starvation Point

Starvation Tank

Starve Out Well

Star Wash

Star Well

State Land Tank

Stateline Dam
FEATURE

CLASS

locale

locale

locale

spring

reservoir

summit

reservoir

reservoir

locale

COUNTY

Pima

VARIANT

BGN

Apache

BGN Coconino

BGN Graham

Graham

Graham

BGN 1941 Pima

VARIANT

VARIANT

VARIANT

VARIANT

VARIANT

VARIANT

locale
locale

BGN

VARIANT

VARIANT

BGN 1925 Coconino 361841N1123052W

Gila

$342407 N 1113022 \mathrm{~W}$

$340955 N 1124343 \mathrm{~W}$

Maricopa

VARIANT

BGN

VARIANT

VARIANT

VARIANT

$\begin{array}{ll}\text { flat } & \text { BGN } \\ & \text { VARIANT } \\ & \text { VARIANT } \\ \text { locale } & \end{array}$

Maricopa

$325204 N 1131915 \mathrm{~W}$

Maricopa

Maricopa

Maricopa

Apache

$\begin{array}{lll}\text { flat } & \text { BGN } & \text { Pinal } \\ \text { ppl } & \text { BGN } & \text { Greenlee } \\ \text { valley } & \text { BGN 1964 } & \text { Greenlee }\end{array}$

$\begin{array}{lll}\text { flat } & \text { BGN } & \text { Pinal } \\ \text { ppl } & \text { BGN } & \text { Greenlee } \\ \text { valley } & \text { BGN 1964 } & \text { Greenlee }\end{array}$

valley

BGN 1964

locale BGN

building UNOFF

reservoir BGN

well

valley

UNOFF

BGN 1977
VARIANT

mine UNOFF

$\begin{array}{ll}\text { mine } & \text { UNOFF } \\ \text { park } & \text { AOMIN }\end{array}$

school UNOFF

well

school

locale

summit

spring

locale

locale

spring

stream

UNOFF

UNOFF

UNOFF

BGN

BGN

UNOFF

UNOF

BGN

BGN

$\begin{array}{ll}\text { valley } & \text { BGN } \\ \text { ppl } & \text { BGN } \\ \text { valley } & \text { BGN } \\ \text { flat } & \text { BGN } \\ \text { cliff } & \text { BGN } \\ \text { locale } & \text { BGN } \\ \text { well } & \text { UNOFF } \\ \text { stream } & \text { BGN } \\ \text { well } & \text { UNOFF } \\ \text { reservoir } & \text { BGN }\end{array}$

Cochise

Cochise

Cochise

Coconino

Cochise

Yavapai

Graham

Yavapai

Maricopa

Maricopa

Graham

Mohave

Maricopa

Navajo

Apache

Maricopa

Cochise

Navajo

Coconino

Gila

Gila

Cochise

Graham

Mohave

Cochise

Graham

Maricopa

Maricopa

Yavapai

dam

UNOFF

Green lee $324507 \mathrm{~N} 1105252 \mathrm{~W}$

342404 N1122427W crossing UNOFF
$325023 \mathrm{~N} 1131920 \mathrm{~W}$

$332532 \mathrm{~N} 1114803 \mathrm{~W}$ $332433 N 1114913 \mathrm{~W}$

$335518 N 1094149 \mathrm{~W}$

$330404 N 1092134 \mathrm{~W}$

$330255 \mathrm{~N} 1092055 \mathrm{~W}$

312217 N1100210W

$312250 \mathrm{~N} 1100257 \mathrm{~W}$

$312213 \mathrm{~N} 1100202 \mathrm{~W}$

$354138 \mathrm{~N} 1130818 \mathrm{~W}$

$312215 \mathrm{~N} 1100239 \mathrm{~W}$

$342334 \mathrm{N1} 122502 \mathrm{~W}$

$330532 N 1102150 \mathrm{~W}$

$332916 N 1121337 \mathrm{~W}$

332916 N1121346W

$330826 \mathrm{~N} 1102456 \mathrm{~W}$

$342904 \mathrm{~N} 1141745 \mathrm{~W}$

332700 N1115930W

$353751 N 1101811 \mathrm{~W}$

$360537 N 1090325 \mathrm{~W}$

$332944 N 1121214$

320207 N1092832W

$363320 \mathrm{~N} 1104435 \mathrm{~W}$

$364550 \mathrm{~N} 1110905 \mathrm{~W}$

$341414 N 1111433 \mathrm{~W}$

$341518 \mathrm{~N} 1111528 \mathrm{~W}$

$313502 \mathrm{~N} 1090726 \mathrm{~W}$

$323115 N 1092834 \mathrm{~W}$

$365906 \mathrm{~N} 1134157 \mathrm{~W}$

$323235 N 1090615$

$323143 N 1092843 \mathrm{~W}$

333640 N1124650W

333819 N1124644W

$343409 \mathrm{~N} 2115315 \mathrm{~W}$

323146 N1090258W

342450 N1122430W
$335013 N 1124820$

$\begin{array}{lc}\text { SOURCE } & \text { ELEV } \\ \text { COORDINATE } & \text { FT }\end{array}$

Rodeo

Luna Lake

Stanford Tank

7029 Mt Turnball

Webb Peak

Blue Jay Peak

Papago Farms

Strawberry

Yarnell

Fossil Bay

554 Aztec SE

Aztec SE

\begin{tabular}{ll} 
3esa \\
335457N1094111W & $\begin{array}{l}\text { Mesa } \\
\text { Hawley Lake East } \\
\text { Black Mountain } \\
\text { Clifton } \\
\text { Clifton }\end{array}$ \\
\hline 330415N1092204W & Cla
\end{tabular}

Stark

Hereford

Stark

Robbers Roost Canyon

Stark

Groom Creek

Mt Turnbail

Groom Creek

Fowler

Fowler

San Carlos Reservoir

ake Havasu City

1140 Tempe

6474 Star Mountain

Sonsela Butte

Fowler

Bowie Mtn South

Shonto

363908N1105516W Cedar Tree Bench

341452N1111454W McDonald Mtn

Payson North

Skeleton Canyon

Javelina Peak

Purgatory Canyon

Skeleton Canyon

3359 Javelina Peak

Flatiron Mtn

Star Well

Middle Verde

Round Mtn 
FEATURE NAME

State Line Reservoir

State Line Reservoir

Stateline Tank

Stateline Tank

State of Texas Mine

State Tank

Station Tank

Station Tank

Statonic

See Stotonic

Stead Flat

Steam

Steamboat

See Steamboat Canyon

Steamboat Canyon

Steamboat Canyon Steamboat

Steamboat Trading Post

Steamboat Canyon Trading Post

Steamboat Cove

Steamboat Mountain

Steamboat Mountain

Steamboat Rock Submarine Rock

Steamboat Rock

Steamboat Rock

Steamboat Rock

Steamboat Spring

Steamboat Tank

Steamboat Tank

Steamboat Trading Post

See Steamboat Canyon

Steamboat Wash

Steamboat Wash

Steam Pump

See Vainom Kug

Steam Pump Ranch

Steam Pump Village

See Vainom Kug

Steel Crater

Steel Dam

Steel Dam Reservoir

Steele Canyon

Steele Hills

Steele Ranch

Steele School

Steele Tank

Steel Rim Tank

Steel Tank

Steel Tank

Steel Trough Spring

Steel Woods Windmill

Steep Canyon Tank

Steeple Canyon

Steeplechase (subdivision)

Steeple Creek

Steeple Mesa

Steeple Mesa Seventy-Three

Trail

Steep Tank

Steep Tank

Steer Dam

Steer Mountain

Steer Pasture Spring

Steer Pasture Tank

Steer Pasture Tank

Steer Pasture Tank

Steer Pasture Tank

Steer Pasture Well

Steer Ridge
FEATURE

CLASS

STATUS

COUNTY

$\begin{array}{ll}\text { reservoir } & B G N \\ \text { reservoir } & B G N \\ \text { reservoir } & B G N \\ \text { reservoir } & \text { BGN } \\ \text { mine } & \text { UNOFF } \\ \text { reservoir } & \text { BGN } \\ \text { reservoir } & \text { BGN } \\ \text { reservoir } & \text { BGN } \\ & \text { VARIANT } \\ \text { ppl } & \end{array}$

Mohave

Mohave

Greenlee

Green lee

Cochise

Pima

Coconino

Coconino

Pinal

COORDINATE

$365831 \mathrm{~N} 1134036 \mathrm{~W}$

$365854 \mathrm{~N} 1133309 \mathrm{~W}$

$332707 N 1090250 \mathrm{~W}$

$333657 \mathrm{N1090259 \textrm {W }}$

$312102 \mathrm{~N} 1101620 \mathrm{~W}$

$313410 \mathrm{~N} 1112835 \mathrm{~W}$

$350559 N 1121602 \mathrm{~W}$

351522N1120203W

330929N1114755W

flat BGN Gila 332554 N1104839W

locale BGN Yuma 324340N1144200W

ppl

valley

Apache

$\mathrm{pp} 1$

ppl

BGN 1915 Apache

BGN Apache

VARIANT

VARIANT

BGN

BGN

Apache

Mohave

sumit $B G N$ Pinal

$362155 \mathrm{~N} 1122354 \mathrm{~W}$

is land BGN 1917 Gila

Villar VARIANT

summit $B G N$

summit $B G N$

spring BGN

reservoir $B G N$

reservoir

$B G N$

VARIANT

ppl

strean

valley

locale

locale

locale

reservoir

BGN

BGN

VARIANT

UNOFF

VARIANT

Mohave

Coconino

Apache

Yavapai

Yavapai

Coconino

354453 N1095100W

354440 N1095229W

354453N1095100W

$354448 N 1095130 \mathrm{~W}$

342351 N1141509W

$334050 N 1110503 \mathrm{~W}$

$342412 N 1141533 \mathrm{~W}$

$345321 N 1114503 \mathrm{~W}$

$354519 N 1095011 \mathrm{~W}$

$341343 N 1122625 \mathrm{~W}$

$344726 N 1131811 \mathrm{~W}$

$345314 N 1114455 \mathrm{~W}$

dam

reservoir

valley

ridge

locale

school

reservoir

reservoir

reservoir

reservoir

BGN

UNOFF

BGN

BGN

BGN
UNOFF

UNOFF

BGN

BGN

$B G N$
$B G N$

spring

locale

reservoir

valley

ppl

stream

summit

trail

BGN Pima

BGN Cochise

BGN

BGN

BGN

Maricopa

Greenlee

Greenlee

Greenlee

reservoir

reservoir

dam

summit

spring

reservoir

reservoir

reservoir

reservoir

well

ridge

spring
BGN Greenlee

BGN

UNOFF

BGN

BGN

BGN
BGN
$B G N$

BGN

UNOFF

BGN

Apache

Gila

Gila

Gila

Pima

Graham

Graham

Gila

Navajo

BGN
$354453 \mathrm{N1095100 \textrm {W }}$

$330252 \mathrm{~N} 1105352 \mathrm{~W}$

$352434 \mathrm{N1} 095319 \mathrm{~W}$

$320248 \mathrm{~N} 1120326 \mathrm{~W}$

322418 N1105701W

$320248 \mathrm{~N} 1120326 \mathrm{~W}$

351337 N1122516h

351332N1122455W

$351330 \mathrm{~N} 1122454 \mathrm{~W}$

$312831 N 1095416 \mathrm{~W}$

$321106 \mathrm{~N} 1100114 \mathrm{~W}$

321047 N1095707W

$321244 \mathrm{~N} 1104846 \mathrm{~W}$

$333030 \mathrm{~N} 1100233 \mathrm{~W}$

$354105 \mathrm{~N} 1120330 \mathrm{~W}$

$321306 \mathrm{~N} 1104034 \mathrm{~W}$

$354444 N 1134431 W$

$321419 N 1102831 \mathrm{~W}$

312121 N1091811K

$331634 \mathrm{~N} 1090356 \mathrm{~W}$

333637 N1090628W

$333841 \mathrm{~N} 1120725 \mathrm{~W}$

$333326 \mathrm{N1091129 \textrm {W }}$

333427 N1091320W

$333545 \mathrm{~N} 1091430 \mathrm{~W}$

$332132 \mathrm{~N} 1090336 \mathrm{~W}$

SOURCE

COORDINATE

ELEV
FT

MAP NAME

Purgatory Canyon

Lizard Point

Alma Mesa

Blue

Montezuma Pass

3574 Wilbur Canyon

Matterhorn

Williams North

Globe

Yuma West

354637 N1094748W

Steamboat Canyon

Steamboat Canyon

6380 Steamboat Canyon

Lake Havasu City S

3373 Hayden

7422 Powell Plateau

Windy $\mathrm{Hill}$

Lake Havasu City S

Wilson Mountain

Steamboat Rock

Minnehaha

Pilot Knob

Munds Park

$\begin{array}{lll}\text { 330753N1105153W } & \begin{array}{l}\text { Kearny } \\ \text { Greasewood Spring }\end{array} \\ & 2585 \text { Oro Valley }\end{array}$

Ash Fork

Ash Fork

Ash Fork

Bisbee

Steele Hills Red Bird Hills

Tucson East

5905 Georges Butte

Molly Anne Draw

Tanque Verde Peak

Milkweed Canyon NW 


\section{FEATURE NAME}

Steer Spring Canyon

Steer Springs

Steer Springs Canyon

Steer Tank

Steer Tank

Steer Tank

Steer Tank

Steer Unit Tank Steer Unit Twenty Three Tank

Steer Unit Twenty Three Tank See Steer Unit Tank

Stef an Gollob Park

Prudence Park

Stegal Tank

Stehr Lake

Stehr Lake Dam

Stehr Tank

Steiger Tank

Stellar Airpark

\section{Stephen Aisle}

Estevan

Stephen Butte

Stephen Park
Stephenson Ranch

Stephens Well

Stephens We 1

Steppe Mine

Sterling Canyon

Sterling Canyon

Sterling Canyon Tank

Sterling Spring

Stermer Ridge

Stermer Tank

Sterrett Mesa

Stetonic

See Stotonic

Stetson Plaza Shopping Center

Stevans Tank Evans Tank

Stevens Canyon

Stevens Gorge

Stevens Mine

Stevens Mountain

Stevenson Canyon

Stevenson Elementary School

Stevenson Lateral

Stevenson Schoo

Stevenson School

Stevens Ranch

Stevens Ranch

Stevens Ranch

Stevens Spring

Stevens Tank

Stevens Tank

Stevens Tank

Stevens Wash

Steve Tank

Steward Observatory

Stewards Tank

Steward Substation

Stewart Canyon

Stewart Cliffs

Stewart Crater Marcou Crater

Stewart Creek

Stewart Dam

Stewart Oam Tank

Stewart Forest Camp

Stewart Mountain

Stewart Mountain Dam

\section{FEATURE}

valley

spring

valley

reservoir

reservoir

reservoir

reservoir

reservoir

STATUS

COUNTY

BGN
$B G N$
$B G N$
$B G N$
$B G N$
$B G N$
$B G N$
$B G N$
VARIAII

Mavajo

Graham

Grahan

Gila

Gila

Apache

Coconino

Apache

VARIANT

VARIANT

park

reservoir

reservoir

dam

reservoir

reservoir

airport

gap

summit

park

locale

well

well

mine

valley

valley

reservoir $B G$

spring

ridge

reservoir

summit

$\mathrm{pp} 1$

jocale

reservoir

ADMIN

VARIANT

BGN Gila

BGN Yavapai $342225 \mathrm{~N} 1114022 \mathrm{~W}$

$331753 \mathrm{N1115454 \textrm {W }}$

361252N1122715W

353733N1101121W

$332535 \mathrm{N1120302 \textrm {W }}$

$320001 \mathrm{N1} 092609 \mathrm{~W}$

$344436 \mathrm{~N} 1124045 \mathrm{~W}$

$344436 \mathrm{~N} 1124045 \mathrm{~W}$

$320100 \mathrm{~N} 1115445 \mathrm{~W}$

$345613 \mathrm{N1} 114743 \mathrm{~W}$

$350128 \mathrm{N1114409 \textrm {W }}$

$B G N$

Pima

Coconino

Coconino

Coconino

Coconino

Navajo

Navajo

Apache

ARIANT

Pinal

UNOFF Maricopa

BGN 1977 Coconino VARIANT

valley

valley

mine

summit

valley

school

canal

school

school

locale

\section{BGN}

BGN

UNOFF

BGN

BGN

UNOFF

BGN

UNOFF

UNOFF

UNOFF

local

locale

spring

reservoir

reservoir

reservoir

stream

reservoir

building

reservoir

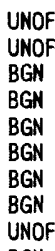

UNOFF
BGN
BGN
BGN
BGN
BGN
BGN
UNOFF
BGN

Santa Cruz

Gila

Greenlee

Pina

Pima

Maricopa

Yuma

Cochise

Maricopa

Santa Cruz

$350232 N 1114621 \mathrm{~W}$

$350130 \mathrm{N1114422W}$

$342307 \mathrm{NL1} 103708 \mathrm{~W}$

$342046 \mathrm{~N} 1103804 \mathrm{~W}$

$355435 \mathrm{~N} 1090626 \mathrm{~W}$

$330929 N 1114755 \mathrm{~W}$

$332954 \mathrm{~N} 1115539 \mathrm{~W}$

$351115 \mathrm{~N} 1121618 \mathrm{~W}$

313338 N110440IW

$332223 \mathrm{N1105241 \textrm {W }}$

$330805 N 1092133 \mathrm{~W}$

$315433 \mathrm{~N} 1111808 \mathrm{~W}$

$315123 \mathrm{~N} 1103434 \mathrm{~W}$

$332412 \mathrm{~N} 1113728 \mathrm{~W}$

323243 N1144320W

$312045 N 1093131 \mathrm{~W}$

$332548 \mathrm{NI} 120318 \mathrm{~W}$

$313405 \mathrm{~N} 1104432 \mathrm{~W}$

locale

valley

cliff

crater

UNOFF

BGN

BGN 1971

VARIANT

stream BGN

reservoir

UNOFF

BGN

BGN

Pima

Apache

Yavapai

Apache

Coconino

Coconino

Pima

Gila

Yavapai

$315418 \mathrm{~N} 1111717 \mathrm{~W}$

$341523 \mathrm{~N} 1094606 \mathrm{~W}$

$345548 \mathrm{~N} 1131951 \mathrm{~W}$

$341455 N 1094613 \mathrm{~W}$

$344617 \mathrm{~N} 1112825 \mathrm{~W}$

$353155 \mathrm{N1} 115112 \mathrm{~W}$

$315737 \mathrm{~N} 1112332 \mathrm{~W}$

$340850 \mathrm{~N} 1105915 \mathrm{~W}$

$315744 \mathrm{NL} 113559 \mathrm{~W}$

$343605 \mathrm{~N} 1114901 \mathrm{~W}$

315359N1111553K

Cochise

Greenlee

Mohave

Coconino

Gila

Yavapai

Yavapai

Cochise

Maricopa

$322022 \mathrm{~N} 1095330 \mathrm{~W}$

$323542 \mathrm{~N} 1090959 \mathrm{~W}$

$36070 B N 1143200 \mathrm{~W}$

$352140 \mathrm{~N} 1112413 \mathrm{~W}$

$341333 \mathrm{~N} 1111435 \mathrm{~W}$

$345124 N 1124319 W$

$345124 N 1124319 \mathrm{~W}$

$315310 \mathrm{~N} 1091015 \mathrm{~W}$

$333455 \mathrm{~N} 1113325 \mathrm{~W}$

dam UNOFF Maricopa

SOURCE
COORDINATE

$331439 N 1100045 \mathrm{~W}$

$345542 \mathrm{N1114557 \textrm {W }}$

$350245 \mathrm{~N} 1114639 \mathrm{~W}$

ELEV

MAP NAME

341500N1102227W Bear Ridge

Bylas

Bylas

3162 Dourine Canyon

Haystack Butte

Horseshoe Cienega

Turkey Mtn

Escudilla Mtn

Tucson East

Pinal Peak

3724 Verde Hot Springs

Verde Hot Springs

Verde Hot Springs

Fitzgerald $\mathrm{Hill}$

1175 Guadalupe 


\begin{tabular}{|c|c|c|c|c|c|c|c|}
\hline FEATURE NAME & $\begin{array}{l}\text { FEATURE } \\
\text { CLASS }\end{array}$ & STATUS & COUNTY & COORDINATE & $\begin{array}{l}\text { SOURCE } \\
\text { COORDINATE }\end{array}$ & $\begin{array}{l}\text { ELEV } \\
\text { FT }\end{array}$ & MAP NAME \\
\hline $\begin{array}{l}\text { Stewart Mountain Lake } \\
\quad \text { See Saguaro Lake } \\
\text { Stewart Mountain Trailer Park } \\
\text { Stewart Park } \\
\text { Stewart Pocket } \\
\text { Stewart Ranch } \\
\text { Stewart Spring } \\
\text { Stewart Springs } \\
\text { Stewart Springs } \\
\text { See Stewart Spring }\end{array}$ & $\begin{array}{l}\text { reservoir } \\
\text { locale } \\
\text { park } \\
\text { basin } \\
\text { locale } \\
\text { spring } \\
\text { spring }\end{array}$ & $\begin{array}{l}\text { VARIANT } \\
\text { UNOFF } \\
\text { AOMIN } \\
\text { BGN } \\
\text { UNOFF } \\
\text { BGN 1983 } \\
\text { VARIANT } \\
\text { VARIANT }\end{array}$ & $\begin{array}{l}\text { Maricopa } \\
\text { Maricopa } \\
\text { Maricopa } \\
\text { Gila } \\
\text { Cochise } \\
\text { Coconino }\end{array}$ & $\begin{array}{l}333356 \mathrm{~N} 1113210 \mathrm{~W} \\
332458 \mathrm{~N} 1113741 \mathrm{~W} \\
332420 \mathrm{~N} 1115008 \mathrm{~W} \\
341319 \mathrm{~N} 1111612 \mathrm{~W} \\
312931 \mathrm{~N} 1093200 \mathrm{~W} \\
350623 \mathrm{~N} 1120924 \mathrm{~W} \\
350623 \mathrm{~N} 1120924 \mathrm{~W}\end{array}$ & & 1540 & $\begin{array}{l}\text { Buckhorn } \\
\text { Mesa } \\
\text { Payson South } \\
\text { Douglas NE } \\
\text { May Tank Pocket }\end{array}$ \\
\hline $\begin{array}{l}\text { Stewart Tank } \\
\text { Stewart Tank } \\
\text { Stewart Tank } \\
\text { Stidham Ranch } \\
\text { Stiles } \\
\text { See Dilkon } \\
\text { Stiles Hill } \\
\text { See Poston Butte } \\
\text { Still Canyon } \\
\text { Still Canyon Tank }\end{array}$ & $\begin{array}{l}\text { reservoir } \\
\text { reservoir } \\
\text { reservoir } \\
\text { locale } \\
\text { locale } \\
\text { summit } \\
\text { valley } \\
\text { reservoir }\end{array}$ & $\begin{array}{l}\text { BGN } \\
\text { BGN } \\
\text { BGN } \\
\text { UNOFF } \\
\text { VARIANT } \\
\text { VARIANT } \\
\text { BGN } \\
\text { BGN }\end{array}$ & $\begin{array}{l}\text { Gila } \\
\text { Navajo } \\
\text { Coconino } \\
\text { Cochise } \\
\text { Navajo } \\
\text { Pinal } \\
\text { Greenlee } \\
\text { Gila }\end{array}$ & $\begin{array}{l}341239 N 1111757 \mathrm{~W} \\
341248 \mathrm{~N} 1095244 \mathrm{~W} \\
344415 \mathrm{~N} 1105514 \mathrm{~W} \\
315355 \mathrm{~N} 1090302 \mathrm{~W} \\
\\
352307 \mathrm{~N} 1101912 \mathrm{~W} \\
\\
330318 \mathrm{~N} 1112429 \mathrm{~W} \\
333157 \mathrm{~N} 1091200 \mathrm{~W} \\
341439 \mathrm{~N} 1110911 \mathrm{~W}\end{array}$ & 333147 N1091106W & & $\begin{array}{l}\text { Payson South } \\
\text { Lakeside } \\
\text { Hamilton Crossing } \\
\text { Portal NE }\end{array}$ \\
\hline $\begin{array}{l}\text { Still Spring } \\
\text { Still Tank } \\
\text { Stina Canyon } \\
\text { Stina Point } \\
\text { Stinkbug Spring } \\
\text { Stinking Spring } \\
\text { Stinking Springs } \\
\text { Stinking Springs Mountain } \\
\text { Stinking Spring Tank } \\
\text { Stink Seep Number One }\end{array}$ & $\begin{array}{l}\text { spring } \\
\text { reservoir } \\
\text { valley } \\
\text { cliff } \\
\text { spring } \\
\text { spring } \\
\text { spring } \\
\text { summit } \\
\text { reservoir } \\
\text { spring }\end{array}$ & $\begin{array}{l}\text { BGN } \\
\text { BGN } \\
\text { BGN } 1932 \\
\text { BGN } \\
\text { BGN } \\
\text { BGN } \\
\text { BGN } \\
\text { BGN } \\
\text { BGN } \\
\text { BGN }\end{array}$ & $\begin{array}{l}\text { Greenlee } \\
\text { Coconino } \\
\text { Coconino } \\
\text { Coconino } \\
\text { Navajo } \\
\text { Gila } \\
\text { Apache } \\
\text { Apache } \\
\text { Gila } \\
\text { Apache }\end{array}$ & $\begin{array}{l}333158 \mathrm{~N} 1091138 \mathrm{~W} \\
343502 \mathrm{~N} 1111404 \mathrm{~W} \\
362237 \mathrm{~N} 1122255 \mathrm{~W} \\
362220 \mathrm{~N} 1122027 \mathrm{~W} \\
354 \mathrm{~B} 12 \mathrm{~N} 1103158 \mathrm{~W} \\
335537 \mathrm{~N} 1100929 \mathrm{~W} \\
343726 \mathrm{~N} 1093434 \mathrm{~W} \\
343736 \mathrm{~N} 1093327 \mathrm{~W} \\
335524 \mathrm{~N} 1101043 \mathrm{~W} \\
343332 \mathrm{~N} 1094705 \mathrm{~W}\end{array}$ & $362253 \mathrm{~N} 1121800 \mathrm{~W}$ & 5346 & $\begin{array}{l}\text { Bear Mountain } \\
\text { Blue Ridge Reservoir } \\
\text { Tapeats Amphitheater } \\
\text { King Arthur Castle } \\
\text { Shongopovi } \\
\text { Cedar Creek } \\
\text { Stinking Springs } \\
\text { Stinking Springs Mtn } \\
\text { Cedar Creek } \\
\text { Manuel Seep }\end{array}$ \\
\hline $\begin{array}{l}\text { Stink Seep Number Two } \\
\text { Stinson Mountain } \\
\text { Stinson Peak } \\
\text { Stinson School } \\
\text { See Dorothy Stinson } \\
\text { Elementary School }\end{array}$ & $\begin{array}{l}\text { spring } \\
\text { summit } \\
\text { summit } \\
\text { school }\end{array}$ & $\begin{array}{l}\text { BGN } \\
\text { BGN } \\
\text { BGN } \\
\text { VARIANT }\end{array}$ & $\begin{array}{l}\text { Apache } \\
\text { Yavapai } \\
\text { Maricopa } \\
\text { Graham }\end{array}$ & $\begin{array}{l}34340 B N 1094649 \mathrm{~W} \\
344720 \mathrm{~N} 1125427 \mathrm{~W} \\
323043 \mathrm{~N} 1123417 \mathrm{~W} \\
\\
324854 \mathrm{~N} 1094254 \mathrm{~W}\end{array}$ & & 6411 & $\begin{array}{l}\text { Manuel Seep } \\
\text { Camp Wood } \\
\text { Tom Thumb }\end{array}$ \\
\hline $\begin{array}{l}\text { Stinson Tank } \\
\text { Stinson Wash } \\
\text { Stinson Wash } \\
\text { Stoag Tontk Well }\end{array}$ & $\begin{array}{l}\text { reservoir } \\
\text { stream } \\
\text { stream } \\
\text { well }\end{array}$ & $\begin{array}{l}\text { BGN } \\
\text { BGN } \\
\text { BGN } \\
\text { UNOFF }\end{array}$ & $\begin{array}{l}\text { Yavapai } \\
\text { Navajo } \\
\text { Yavapai } \\
\text { Pima }\end{array}$ & $\begin{array}{l}344733 \mathrm{~N} 1125442 \mathrm{~W} \\
342143 \mathrm{~N} 1101954 \mathrm{~W} \\
344631 \mathrm{~N} 1125242 \mathrm{~W} \\
314945 \mathrm{~N} 1122220 \mathrm{~W}\end{array}$ & $\begin{array}{l}341837 N 1102357 \mathrm{~W} \\
344729 \mathrm{N1125359W}\end{array}$ & & $\begin{array}{l}\text { Camp Wood } \\
\text { Clay Springs } \\
\text { Camp Wood } \\
\text { Papago Farms }\end{array}$ \\
\hline $\begin{array}{l}\text { Stoapit } \\
\text { See Stoa Pitk } \\
\text { Stoa Pitk } \\
\text { Stoapit } \\
\text { Toapit } \\
\text { Toatipk } \\
\text { Stoa Vaya (site) } \\
\text { Komo Vaya } \\
\text { Kombaxia } \\
\text { Kom Vaya } \\
\text { Poso Blanco } \\
\text { Pozo Blanco }\end{array}$ & $\begin{array}{l}\mathrm{ppl} \\
\mathrm{ppl}\end{array}$ & $\begin{array}{l}\text { VARIANT } \\
\text { BGN } 1941 \\
\text { VARIANT } \\
\text { VARIANT } \\
\text { VARIANT } \\
\text { BGN 1941 } \\
\text { VARIANT } \\
\text { VARIANT } \\
\text { VARIANT } \\
\text { VARIANT } \\
\text { VARIANT }\end{array}$ & $\begin{array}{l}\text { Pima } \\
\text { Pima }\end{array}$ & $\begin{array}{l}322906 \mathrm{~N} 1123058 \mathrm{~W} \\
322906 \mathrm{~N} 1123058 \mathrm{~W}\end{array}$ & & 2403 & Maish Vaya \\
\hline $\begin{array}{l}\text { Stock Driveway Reservoir } \\
\text { Stockham } \\
\text { Stockham Railroad Station } \\
\text { Stockman Spring } \\
\text { Stockman Station } \\
\text { Stockman Station } \\
\text { Stock Number Two Tank } \\
\text { Stock Pen Canyon } \\
\text { Stock Pen Tank } \\
\text { Stock Pond }\end{array}$ & $\begin{array}{l}\text { reservoir } \\
\text { ppl } \\
\text { building } \\
\text { spring } \\
\text { locale } \\
\text { locale } \\
\text { reservoir } \\
\text { valley } \\
\text { reservoir } \\
\text { lake }\end{array}$ & $\begin{array}{l}\text { BGN } \\
\text { BGN } \\
\text { UNOFF } \\
\text { BGN } \\
\text { BGN } \\
\text { BGN } \\
\text { BGN } \\
\text { BGN } \\
\text { BGN } \\
\text { BGN }\end{array}$ & $\begin{array}{l}\text { Mohave } \\
\text { Pima } \\
\text { Pima } \\
\text { Gila } \\
\text { Gila } \\
\text { Gila } \\
\text { Greenlee } \\
\text { Greenlee } \\
\text { Greenlee } \\
\text { Mohave }\end{array}$ & $\begin{array}{l}364044 \mathrm{~N} 1133932 \mathrm{~W} \\
321627 \mathrm{~N} 1110025 \mathrm{~W} \\
321625 \mathrm{~N} 1110036 \mathrm{~W} \\
335457 \mathrm{~N} 1101136 \mathrm{~W} \\
334608 \mathrm{~N} 1100144 \mathrm{~W} \\
335535 \mathrm{~N} 1101141 \mathrm{~W} \\
331850 \mathrm{~N} 1092118 \mathrm{~W} \\
325815 \mathrm{~N} 1091626 \mathrm{~W} \\
325933 \mathrm{~N} 1091625 \mathrm{~W} \\
365341 \mathrm{~N} 1124313 \mathrm{~W}\end{array}$ & $325922 \mathrm{~N} 1091605 \mathrm{~W}$ & & $\begin{array}{l}\text { Mustang Knoll } \\
\text { Jaynes } \\
\text { Jaynes } \\
\text { Cedar Creek } \\
\text { Canyon Day } \\
\text { Cedar Creek } \\
\text { Pipestem Mtn } \\
\text { Guthrie } \\
\text { Guthrie } \\
\text { Kaibab }\end{array}$ \\
\hline $\begin{array}{l}\text { Stockpond Tank } \\
\text { Stocks Canyon } \\
\text { Stock Tank Number Three } \\
\text { Stockton } \\
\text { Stockton Draw } \\
\text { Stockton Gap } \\
\text { Stockton Hill } \\
\text { Stockton Hill } \\
\text { Stockton Mine } \\
\text { Stockton Pass } \\
\text { Eagle Pass }\end{array}$ & $\begin{array}{l}\text { reservoir } \\
\text { valley } \\
\text { reservoir } \\
\text { locale } \\
\text { valley } \\
\text { gap } \\
\text { summit } \\
\text { summit } \\
\text { mine } \\
\text { gap }\end{array}$ & $\begin{array}{l}\text { BGN } \\
\text { BGN } \\
\text { BGN } \\
\text { BGN } \\
\text { BGN } \\
\text { BGN } \\
\text { BGN } \\
\text { BGN } \\
\text { UNOFF } \\
\text { BGN } \\
\text { VARIANT }\end{array}$ & $\begin{array}{l}\text { Graham } \\
\text { Greenlee } \\
\text { Greenlee } \\
\text { Mohave } \\
\text { Cochise } \\
\text { Greenlee } \\
\text { Cochise } \\
\text { Mohave } \\
\text { Mohave } \\
\text { Graham }\end{array}$ & $\begin{array}{l}324937 \mathrm{~N} 1095750 \mathrm{~W} \\
323847 \mathrm{~N} 1090429 \mathrm{~W} \\
331826 \mathrm{~N} 1092045 \mathrm{~W} \\
351834 \mathrm{~N} 1140521 \mathrm{~W} \\
313844 \mathrm{~N} 1095339 \mathrm{~W} \\
330411 \mathrm{~N} 1090612 \mathrm{~W} \\
314234 \mathrm{~N} 1095607 \mathrm{~W} \\
352004 \mathrm{~N} 1140656 \mathrm{~W} \\
351838 \mathrm{~N} 1140522 \mathrm{~W} \\
323529 \mathrm{~N} 1095115 \mathrm{~W}\end{array}$ & $\begin{array}{l}323720 \mathrm{~N} 1091152 \mathrm{~W} \\
314532 \mathrm{~N} 1095255 \mathrm{~W}\end{array}$ & $\begin{array}{l}5593 \\
5938 \\
5650\end{array}$ & $\begin{array}{l}\text { Shingle Mill Mtn } \\
\text { Duncan } \\
\text { Pipestem Mtn } \\
\text { Stockton Hill } \\
\text { Hay Mountain } \\
\text { Big Lue Mts } \\
\text { Hay Mountain } \\
\text { Stockton Hill } \\
\text { Stockton Hill } \\
\text { Stockton Pass }\end{array}$ \\
\hline
\end{tabular}




\begin{tabular}{|c|c|c|c|c|c|c|c|}
\hline FEATURE NAME & $\begin{array}{l}\text { FEATURE } \\
\text { CLASS }\end{array}$ & STATUS & COUNTY & COORDINATE & $\begin{array}{l}\text { SOURCE } \\
\text { COORDINATE }\end{array}$ & $\begin{array}{c}\text { ELEV } \\
\text { FT }\end{array}$ & MAP NAME \\
\hline $\begin{array}{l}\text { Stockton Pass Campground } \\
\text { Stockton Pass Dam } \\
\text { Stockton Pass Wash } \\
\text { Cienega Wash } \\
\text { Gillespie Wash } \\
\text { Stockton Wash } \\
\text { Stockton Wash Dam } \\
\text { See Stockton Wash } \\
\text { Retarding Dam } \\
\text { Stockton Wash Retarding Dam } \\
\text { Stockton Wash Dam }\end{array}$ & $\begin{array}{l}\begin{array}{l}\text { park } \\
\text { dam } \\
\text { stream }\end{array} \\
\text { stream } \\
\text { dam } \\
\text { dam }\end{array}$ & $\begin{array}{l}\text { ADMIN } \\
\text { UNOFF } \\
\text { BGN } \\
\text { VARIANT } \\
\text { VARIANT } \\
\text { BGN } \\
\text { VARIANT }\end{array}$ & $\begin{array}{l}\text { Graham } \\
\text { Graham } \\
\text { Grahan }\end{array}$ & $\begin{array}{l}324755 N 1094108 \mathrm{~W} \\
324718 N 1094142 \mathrm{~W} \\
324718 \mathrm{~N} 1094142 \mathrm{~W}\end{array}$ & $\begin{array}{l}323600 \mathrm{~N} 1095030 \mathrm{~W} \\
323855 \mathrm{~N} 1094330 \mathrm{~W}\end{array}$ & 5650 & $\begin{array}{l}\text { Stockton Pass } \\
\text { Safford } \\
\text { Artesia } \\
\text { Safford }\end{array}$ \\
\hline $\begin{array}{l}\text { Stockton Well } \\
\text { Stockyard Tank } \\
\text { Stoddard Mine } \\
\text { Stoddard Ranch } \\
\text { Stoddard Spring } \\
\text { Stofella Lateral } \\
\text { Stokes Spring } \\
\text { See Little Spring } \\
\text { Stokes Well } \\
\text { Stolen Tank }\end{array}$ & $\begin{array}{l}\text { well } \\
\text { reservoir } \\
\text { mine } \\
\text { locale } \\
\text { spring } \\
\text { canal } \\
\text { spring } \\
\text { well } \\
\text { reservoir }\end{array}$ & $\begin{array}{l}\text { UNOFF } \\
\text { BGN } \\
\text { UNOFF } \\
\text { UNOFF } \\
\text { BGN } \\
\text { BGN } \\
\text { VARIANT } \\
\text { UNOFF } \\
\text { BGN }\end{array}$ & $\begin{array}{l}\text { Gila } \\
\text { Yavapai } \\
\text { Yavapai } \\
\text { Pima } \\
\text { Yavapai } \\
\text { Yuma } \\
\text { Coconino } \\
\text { Mohave } \\
\text { Navajo }\end{array}$ & $\begin{array}{l}331203 \mathrm{~N} 1103444 \mathrm{~W} \\
340009 \mathrm{~N} 1125422 \mathrm{~W} \\
342503 \mathrm{~N} 1121114 \mathrm{~W} \\
314411 \mathrm{N1} 103736 \mathrm{~W} \\
342519 \mathrm{N1} 121103 \mathrm{~W} \\
323850 \mathrm{~N} 1143902 \mathrm{~W} \\
\\
352228 \mathrm{~N} 1114330 \mathrm{~W} \\
350131 \mathrm{N1} 134823 \mathrm{~W} \\
342942 \mathrm{~N} 1103616 \mathrm{~W}\end{array}$ & & 2472 & $\begin{array}{l}\text { Coolidge Dam } \\
\text { Congress SW } \\
\text { Mayer } \\
\text { Sonoita } \\
\text { Mayer } \\
\text { Yuma West } \\
\text { Dean Peak } \\
\text { Heber }\end{array}$ \\
\hline $\begin{array}{l}\text { Stolen Tank Number Two } \\
\text { Stone Cabin } \\
\text { Stone Cabin Box Spring } \\
\text { Stone Cabin Canyon } \\
\text { See Florida Canyon } \\
\text { Stone Cabin Canyon } \\
\text { Stone Cabin Dam } \\
\text { Stone Cabin Gap Wash } \\
\text { Stone Cabin Mountain } \\
\text { Stone Cabin Spring }\end{array}$ & $\begin{array}{l}\text { reservoir } \\
\text { locale } \\
\text { spring } \\
\text { valley } \\
\text { valley } \\
\text { dam } \\
\text { valley } \\
\text { sumnit } \\
\text { spring }\end{array}$ & $\begin{array}{l}\text { BGN } \\
\text { BGN } \\
\text { BGN } \\
\text { VARIANT } \\
\text { BGN } \\
\text { UNOFF } \\
\text { BGN } \\
\text { BGN } \\
\text { BGN }\end{array}$ & $\begin{array}{l}\text { Navajo } \\
\text { Yuma } \\
\text { Gila } \\
\text { Pima } \\
\text { Pinal } \\
\text { Cochise } \\
\text { Yuma } \\
\text { Gila } \\
\text { Graham }\end{array}$ & $\begin{array}{l}343041 N 1103538 \mathrm{~W} \\
331557 N 1141423 \mathrm{~W} \\
331348 \mathrm{~N} 1105255 \mathrm{~W} \\
\\
31462 \mathrm{BN} 1105202 \mathrm{~W} \\
325330 \mathrm{~N} 1102943 \mathrm{~W} \\
322336 \mathrm{~N} 1101729 \mathrm{~W} \\
330625 \mathrm{~N} 1132612 \mathrm{~W} \\
331421 \mathrm{N1105052W} \\
322816 \mathrm{~N} 1102200 \mathrm{~W}\end{array}$ & 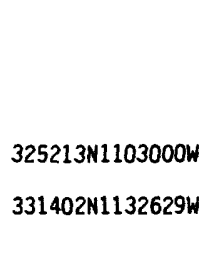 & & $\begin{array}{l}\text { Red Knoll } \\
\text { Stone Cabin } \\
\text { Hot Tamale Peak } \\
\text { Booger Canyon } \\
\text { Cherry Spring Peak } \\
\text { Baragan Mtn } \\
\text { E1 Capitan Mtn } \\
\text { Cherry Spring Peak }\end{array}$ \\
\hline $\begin{array}{l}\text { Stone Cabin Spring } \\
\text { Stone Cabin Wash } \\
\text { Stone Camp Spring } \\
\text { Stone Corral } \\
\text { See Hecla } \\
\text { Stone Corral Canyon } \\
\text { Stone Corral Spring } \\
\text { Stone Corral Springs } \\
\text { Stone Creek } \\
\text { Stone Creek }\end{array}$ & $\begin{array}{l}\text { spring } \\
\text { stream } \\
\text { spring } \\
\text { locale } \\
\text { valley } \\
\text { spring } \\
\text { spring } \\
\text { stream } \\
\text { stream }\end{array}$ & $\begin{array}{l}\text { BGN } \\
\text { BGN } \\
\text { BGN } \\
\text { VARIANT } \\
\text { BGN } \\
\text { BGN } \\
\text { BGN } \\
\text { BGN } \\
\text { BGN } 1932\end{array}$ & $\begin{array}{l}\text { Gila } \\
\text { Gila } \\
\text { Yavapai } \\
\text { Yavapai } \\
\text { Yavapai } \\
\text { Mohave } \\
\text { Yavapai } \\
\text { Apache } \\
\text { Coconino }\end{array}$ & $\begin{array}{l}331348 N 1105254 \mathrm{~W} \\
331036 \mathrm{~N} 1105354 \mathrm{~W} \\
340703 \mathrm{~N} 1115105 \mathrm{~W} \\
\\
343217 \mathrm{~N} 1120715 \mathrm{~W} \\
344034 \mathrm{~N} 1131126 \mathrm{~W} \\
352700 \mathrm{~N} 1134324 \mathrm{~W} \\
344123 \mathrm{~N} 1131944 \mathrm{~W} \\
334955 \mathrm{~N} 1090140 \mathrm{~W} \\
362048 \mathrm{~N} 1122713 \mathrm{~W}\end{array}$ & $\begin{array}{l}344353 N 1130623 W \\
335437 N 1090457 W \\
362145 N 1122359 W\end{array}$ & & $\begin{array}{l}\text { Bozarth Mesa } \\
\text { Valentine } \\
\text { Negro Ed } \\
\text { Luna Lake } \\
\text { Powell Plateau }\end{array}$ \\
\hline $\begin{array}{l}\text { Stone Dam } \\
\text { Stonegate Crossing } \\
\text { (subdivision) } \\
\text { Stone Hoe, Canal (historical) } \\
\text { Stone House } \\
\text { Stone House } \\
\text { Stone House Wash } \\
\text { Stone Lake } \\
\text { Bishop Lake } \\
\text { Stoneman Lake }\end{array}$ & $\begin{array}{l}\text { dam } \\
\text { ppl } \\
\text { canal } \\
\text { locale } \\
\text { locale } \\
\text { stream } \\
\text { lake } \\
\text { lake }\end{array}$ & $\begin{array}{l}\text { UNOFF } \\
\text { BGN } \\
\text { BGN } \\
\text { BGN } \\
\text { BGN } \\
\text { BGN } \\
\text { BGN } 1976 \\
\text { VARIANT } \\
\text { BGN }\end{array}$ & $\begin{array}{l}\text { Coconino } \\
\text { Maricopa } \\
\text { Maricopa } \\
\text { Pima } \\
\text { Navajo } \\
\text { Coconino } \\
\text { Coconino } \\
\text { Coconino }\end{array}$ & $\begin{array}{l}351338 \mathrm{~N} 1122420 \mathrm{~W} \\
331955 \mathrm{~N} 1115013 \mathrm{~W} \\
332900 \mathrm{~N} 1115245 \mathrm{~W} \\
321828 \mathrm{~N} 1104755 \mathrm{~W} \\
344422 \mathrm{~N} 1103343 \mathrm{~W} \\
353018 \mathrm{N1} 111450 \mathrm{~W} \\
352810 \mathrm{~N} 1123815 \mathrm{~W} \\
344646 \mathrm{~N} 1113105 \mathrm{~W}\end{array}$ & $352 B 24 N 1111617 \mathrm{~W}$ & 6717 & $\begin{array}{l}\text { Ash Fork } \\
\text { Chandler } \\
\text { Tempe } \\
\text { Sabino Canyon } \\
\text { Potato Wash NE } \\
\text { Standing Rocks } \\
\text { Mount Floyd } \\
\text { Stoneman Lake }\end{array}$ \\
\hline $\begin{array}{l}\text { Stoneman Lake } \\
\text { Stoneman Lake Interchange } \\
\text { Stone Mountain } \\
\text { Stone Park } \\
\text { Stone Peak } \\
\text { Stone Ridge } \\
\text { Stone Tank } \\
\text { Stone Tank } \\
\text { Stoney Mountain Park } \\
\text { Stontonyak } \\
\quad \text { See Stotonic }\end{array}$ & $\begin{array}{l}\text { ppi } \\
\text { crossing } \\
\text { pillar } \\
\text { park } \\
\text { summit } \\
\text { ridge } \\
\text { reservoir } \\
\text { well } \\
\text { park } \\
\text { ppl }\end{array}$ & $\begin{array}{l}\text { BGN } \\
\text { UNOFF } \\
\text { BGN } \\
\text { ADMIN } \\
\text { BGN } \\
\text { BGN } \\
\text { BGN } \\
\text { UNOFF } \\
\text { ADMIN } \\
\text { VARIANT }\end{array}$ & $\begin{array}{l}\text { Coconino } \\
\text { Yavapai } \\
\text { Maricopa } \\
\text { Maricopa } \\
\text { Pima } \\
\text { Cochise } \\
\text { Gila } \\
\text { Cochise } \\
\text { Maricopa } \\
\text { Pinal }\end{array}$ & $\begin{array}{l}344653 \mathrm{~N} 1113043 \mathrm{~W} \\
344552 \mathrm{~N} 1113921 \mathrm{~W} \\
332759 \mathrm{~N} 1113814 \mathrm{~W} \\
335813 \mathrm{~N} 1124338 \mathrm{~W} \\
322740 \mathrm{~N} 1115200 \mathrm{~W} \\
313015 \mathrm{~N} 1102041 \mathrm{~W} \\
340126 \mathrm{~N} 1105200 \mathrm{~W} \\
320115 \mathrm{~N} 1101751 \mathrm{~W} \\
333516 \mathrm{~N} 1120230 \mathrm{~W} \\
330929 \mathrm{~N} 1114755 \mathrm{~W}\end{array}$ & & $\begin{array}{l}5325 \\
1921 \\
1950\end{array}$ & $\begin{array}{l}\text { Stoneman Lake } \\
\text { Munds Mountain } \\
\text { Buckhorn } \\
\text { Wickenburg } \\
\text { Santa Rosa Hts NE } \\
\text { Fort Huachuca } \\
\text { Gentry Mtn } \\
\text { Galleta Flat East } \\
\text { Sunnys lope }\end{array}$ \\
\hline $\begin{array}{l}\text { Stony Mountain Villas } \\
\text { (subdivision) } \\
\text { Stonys Cabin } \\
\text { Stopes Tank } \\
\text { Stop Trail Spring } \\
\text { Storey Road Underpass } \\
\text { Storm Canyon } \\
\text { Storm Canyon Spring } \\
\text { Storm Canyon Well }\end{array}$ & $\begin{array}{l}\text { ppl } \\
\text { locale } \\
\text { reservoir } \\
\text { spring } \\
\text { crossing } \\
\text { valley } \\
\text { spring } \\
\text { well }\end{array}$ & $\begin{array}{l}\text { BGN } \\
\text { BGN } \\
\text { BGN } \\
\text { UNOFF } \\
\text { BGN } \\
\text { BGN } \\
\text { UNOFF }\end{array}$ & $\begin{array}{l}\text { Maricopa } \\
\text { Coconino } \\
\text { Pima } \\
\text { Apache } \\
\text { Pinal } \\
\text { Gila } \\
\text { Gila } \\
\text { Gila }\end{array}$ & $\begin{array}{l}333524 \mathrm{~N} 1120150 \mathrm{~W} \\
354220 \mathrm{~N} 1130212 \mathrm{~W} \\
313522 \mathrm{~N} 1111756 \mathrm{~W} \\
365006 \mathrm{~N} 1091319 \mathrm{~W} \\
325338 \mathrm{~N} 1114110 \mathrm{~W} \\
333 \mathrm{~B} 00 \mathrm{~N} 1104647 \mathrm{~W} \\
333609 \mathrm{~N} 1104324 \mathrm{~W} \\
333755 \mathrm{~N} 1104535 \mathrm{~W}\end{array}$ & $333523 \mathrm{~N} 1104357 \mathrm{~W}$ & $\begin{array}{l}1470 \\
5694\end{array}$ & $\begin{array}{l}\text { Sunnys lope } \\
\text { Crater Canyon } \\
\text { Arivaca } \\
\text { Pastora Peak } \\
\text { Casa Grande East } \\
\text { Dagger Peak } \\
\text { Chrome Butte } \\
\text { Dagger Peak }\end{array}$ \\
\hline
\end{tabular}




\begin{tabular}{|c|c|c|c|c|c|c|c|}
\hline FEATURE NAME & $\begin{array}{l}\text { FEATURE } \\
\text { CLASS }\end{array}$ & STATUS & COUNTY & COORDINATE & $\begin{array}{l}\text { SOURCE } \\
\text { COORDINATE }\end{array}$ & $\begin{array}{l}\text { ELEV } \\
\text { FT }\end{array}$ & MAP NAME \\
\hline Storm Seep & spring & BGN & Yavapai & $350106 N 1123052 W$ & & & Picacho Butte SE \\
\hline $\begin{array}{l}\text { Story Mine } \\
\text { Stotonic } \\
\text { Statonic } \\
\text { Stetonic } \\
\text { Stontonyak } \\
\text { Stotonik } \\
\text { Stotonyak } \\
\text { Stotonik } \\
\text { See Stotonic } \\
\text { Stotonyak }\end{array}$ & $\begin{array}{l}\text { ppl } \\
\text { locale }\end{array}$ & $\begin{array}{l}\text { UNOFF } \\
\text { BGN 1941 } \\
\text { VARIANT } \\
\text { VARIANT } \\
\text { VARIANT } \\
\text { VARIANT } \\
\text { VARIANT } \\
\text { VARIANT } \\
\text { BGN } 1941\end{array}$ & $\begin{array}{l}\text { Maricopa } \\
\text { Pinal }\end{array}$ & $\begin{array}{l}335741 N 1113019 \mathrm{~W} \\
330929 \mathrm{~N} 1114755 \mathrm{~W}\end{array}$ & & 1230 & $\begin{array}{l}\text { Lion Mountain } \\
\text { Gila Butte }\end{array}$ \\
\hline $\begin{array}{l}\text { Stotonyak } \\
\quad \text { See Stotonic } \\
\text { Stotz Canyon } \\
\text { Stout Cemetery } \\
\text { Stouts Well } \\
\text { Stout Well } \\
\text { Stoval Christvale } \\
\text { Christoval } \\
\text { Chrystoval } \\
\text { Crystoval } \\
\text { Grinnell Station } \\
\text { Stanwix } \\
\text { Texas Hill }\end{array}$ & $\begin{array}{l}\text { ppl } \\
\text { valley } \\
\text { cemetery } \\
\text { well } \\
\text { well } \\
\text { locale }\end{array}$ & $\begin{array}{l}\text { VARIANT } \\
\text { BGN } \\
\text { UNOFF } \\
\text { UNOFF } \\
\text { UNOFF } \\
\text { BGN } \\
\text { VARIANT } \\
\text { VARIANT } \\
\text { VARIANT } \\
\text { VARIANT } \\
\text { VARIANT } \\
\text { VARIANT }\end{array}$ & $\begin{array}{l}\text { Pinal } \\
\text { Navajo } \\
\text { Maricopa } \\
\text { Mohave } \\
\text { Maricopa } \\
\text { Yuma }\end{array}$ & $\begin{array}{l}330929 \mathrm{~N} 1114755 \mathrm{~W} \\
341900 \mathrm{~N} 1104320 \mathrm{~W} \\
325449 \mathrm{~N} 1124427 \mathrm{~W} \\
343523 \mathrm{~N} 1134738 \mathrm{~W} \\
330144 \mathrm{~N} 1125256 \mathrm{~W} \\
324554 \mathrm{~N} 1133717 \mathrm{~W}\end{array}$ & $341845 \mathrm{~N} 1104500 \mathrm{~W}$ & $\begin{array}{l}3069 \\
400\end{array}$ & $\begin{array}{l}\text { Brookbank Point } \\
\text { Gila Bend } \\
\text { Dutch Flat SE } \\
\text { Citrus Valley West } \\
\text { Dateland }\end{array}$ \\
\hline $\begin{array}{l}\text { Stoval Airfield } \\
\text { Stove Canyon } \\
\text { Stove Canyon } \\
\text { Stove Canyon Spring } \\
\text { Stove Spring } \\
\text { Stove Spring } \\
\text { Stove Spring Canyon } \\
\text { Stove Tank } \\
\text { Stove Tank } \\
\text { Stove Wash }\end{array}$ & $\begin{array}{l}\text { airport } \\
\text { valley } \\
\text { valley } \\
\text { spring } \\
\text { spring } \\
\text { spring } \\
\text { valley } \\
\text { reservoir } \\
\text { reservoir } \\
\text { stream }\end{array}$ & $\begin{array}{l}\text { ADMIN } \\
\text { BGN } \\
\text { BGN } \\
\text { BGN } \\
\text { BGN } \\
\text { BGN } \\
\text { BGN } \\
\text { BGN } \\
\text { BGN } \\
\text { BGN }\end{array}$ & $\begin{array}{l}\text { Yuma } \\
\text { Greenlee } \\
\text { Graham } \\
\text { Graham } \\
\text { Graham } \\
\text { Yavapai } \\
\text { Mohave } \\
\text { Greenlee } \\
\text { Graham } \\
\text { Greenlee }\end{array}$ & $\begin{array}{l}324420 \mathrm{~N} 1133732 \mathrm{~W} \\
330339 \mathrm{~N} 1092755 \mathrm{~W} \\
332903 \mathrm{~N} 1094845 \mathrm{~W} \\
332808 \mathrm{~N} 1095025 \mathrm{~W} \\
332730 \mathrm{~N} 1095016 \mathrm{~W} \\
340940 \mathrm{~N} 1123913 \mathrm{~W} \\
344411 \mathrm{~N} 1134356 \mathrm{~W} \\
331210 \mathrm{~N} 1092423 \mathrm{~W} \\
332914 \mathrm{~N} 1095045 \mathrm{~W} \\
325118 \mathrm{~N} 1091108 \mathrm{~W}\end{array}$ & $\begin{array}{l}330400 \mathrm{~N} 1092933 \mathrm{~W} \\
332500 \mathrm{~N} 1095029 \mathrm{~W} \\
344244 \mathrm{~N} 1134706 \mathrm{~W} \\
325158 \mathrm{~N} 1090834 \mathrm{~W}\end{array}$ & 6061 & $\begin{array}{l}\text { Mowhawk Mts NE } \\
\text { Copperplate Gulch } \\
\text { Stove Canyon } \\
\text { Stove Canyon } \\
\text { Stove Canyon } \\
\text { Yarnell } \\
\text { Aubrey Peak } \\
\text { Coronado Mtn } \\
\text { Stove Canyon } \\
\text { Sheldon }\end{array}$ \\
\hline $\begin{array}{l}\text { Stowe Gulch } \\
\text { Stowe Knoll } \\
\text { Stowe Spring } \\
\text { Stowe Tank } \\
\text { Stradding Well } \\
\text { Straddle Spring } \\
\text { Straddling Lake } \\
\text { Straddling Spring } \\
\text { Straham Tank } \\
\text { Strahan Spring }\end{array}$ & $\begin{array}{l}\text { valley } \\
\text { summit } \\
\text { spring } \\
\text { reservoir } \\
\text { locale } \\
\text { spring } \\
\text { lake } \\
\text { spring } \\
\text { reservoir } \\
\text { spring }\end{array}$ & $\begin{array}{l}\text { BGN } \\
\text { BGN } \\
\text { BGN } \\
\text { BGN } \\
\text { BGN } \\
\text { BGN } \\
\text { BGN } \\
\text { BGN } \\
\text { BGN } \\
\text { BGN }\end{array}$ & $\begin{array}{l}\text { Graham } \\
\text { Graham } \\
\text { Graham } \\
\text { Graham } \\
\text { Apache } \\
\text { Graham } \\
\text { Apache } \\
\text { Apache } \\
\text { Yavapai } \\
\text { Coconino }\end{array}$ & $\begin{array}{l}325211 \mathrm{~N} 1102200 \mathrm{~W} \\
324706 \mathrm{~N} 1095727 \mathrm{~W} \\
325604 \mathrm{~N} 1102117 \mathrm{~W} \\
324 \mathrm{~B} 23 \mathrm{~N} 1094706 \mathrm{~W} \\
350624 \mathrm{~N} 1090414 \mathrm{~W} \\
331214 \mathrm{~N} 1100249 \mathrm{~W} \\
341902 \mathrm{~N} 1092618 \mathrm{~W} \\
341907 \mathrm{~N} 1092625 \mathrm{~W} \\
344744 \mathrm{~N} 1120725 \mathrm{~W} \\
350456 \mathrm{~N} 1115525 \mathrm{~W}\end{array}$ & $325705 N 1101802 \mathrm{~W}$. & 6652 & $\begin{array}{l}\text { Klondike } \\
\text { Shingle Mill Mtn } \\
\text { Cobre Grande Mtn } \\
\text { Thatcher } \\
\text { High Lonesome Well } \\
\text { Bylas } \\
\text { Lyman Lake SW } \\
\text { Lyman Lake SW } \\
\text { Clarkdale } \\
\text { Sycamore Point }\end{array}$ \\
\hline $\begin{array}{l}\text { Straight Canyon } \\
\quad \text { See Starlight Canyon } \\
\text { Straight Canyon } \\
\text { Straight Ridge } \\
\text { Stratton Camp Spring } \\
\text { Stratton Canyon } \\
\text { Stratton Mine } \\
\text { Stratton Saddle } \\
\text { Strattons Camp (historical) } \\
\text { Stratton Wash }\end{array}$ & $\begin{array}{l}\text { valley } \\
\text { valley } \\
\text { ridge } \\
\text { spring } \\
\text { valley } \\
\text { mine } \\
\text { gap } \\
\text { locale } \\
\text { stream }\end{array}$ & $\begin{array}{l}\text { VARIANT } \\
\text { BGN } 1906 \\
\text { BGN } \\
\text { BGN } \\
\text { BGN } \\
\text { UNOFF } \\
\text { BGN } \\
\text { BGN } \\
\text { BGN }\end{array}$ & $\begin{array}{l}\text { Yavapai } \\
\text { Coconino } \\
\text { Navajo } \\
\text { Pima } \\
\text { Pima } \\
\text { Pima } \\
\text { Pima } \\
\text { Pima } \\
\text { Pinal }\end{array}$ & $\begin{array}{l}342334 \mathrm{~N} 1122502 \mathrm{~W} \\
360531 \mathrm{~N} 1114102 \mathrm{~W} \\
341905 \mathrm{~N} 1102420 \mathrm{~W} \\
322755 \mathrm{~N} 1104441 \mathrm{~W} \\
322930 \mathrm{~N} 1103939 \mathrm{~W} \\
322756 \mathrm{~N} 1104436 \mathrm{~W} \\
332758 \mathrm{~N} 1104511 \mathrm{~W} \\
322803 \mathrm{~N} 1104440 \mathrm{~W} \\
323340 \mathrm{~N} 1103028 \mathrm{~W}\end{array}$ & $\begin{array}{l}360306 \mathrm{~N} 1114832 \mathrm{~W} \\
322848 \mathrm{~N} 1104446 \mathrm{~W}\end{array}$ & 6700 & $\begin{array}{l}\text { Blue Spring } \\
\text { Day Spring } \\
\text { Mount Bigelow } \\
\text { Campo Bonito } \\
\text { Mount Bigelow } \\
\text { Mt Lemmon } \\
\text { Mount Bigelow } \\
\text { Peppersauce Wash }\end{array}$ \\
\hline $\begin{array}{l}\text { Strawberry } \\
\text { Strawberry Canyon } \\
\text { Strawberry Crater } \\
\text { Strawberry Creek } \\
\text { Strawberry Hollow } \\
\text { Strawberry Mountain } \\
\text { Strawberry Spring } \\
\text { Strawberry Valley } \\
\text { Strayhorse } \\
\text { Stray Horse Campground }\end{array}$ & $\begin{array}{l}\text { ppl } \\
\text { valley } \\
\text { crater } \\
\text { stream } \\
\text { valley } \\
\text { summit } \\
\text { spring } \\
\text { basin } \\
\text { locale } \\
\text { park }\end{array}$ & $\begin{array}{l}\text { BGN } \\
\text { BGN } \\
\text { BGN } \\
\text { BGN } \\
\text { BGN } \\
\text { BGN } \\
\text { BGN } \\
\text { BGN } \\
\text { BGN } \\
\text { ADMIN }\end{array}$ & $\begin{array}{l}\text { Gila } \\
\text { Gila } \\
\text { Coconino } \\
\text { Gila } \\
\text { Gila } \\
\text { Gila } \\
\text { Yavapai } \\
\text { Gila } \\
\text { Greenlee } \\
\text { Greenlee }\end{array}$ & $\begin{array}{l}342428 \mathrm{~N} 1112934 \mathrm{~W} \\
342440 \mathrm{~N} 1112919 \mathrm{~W} \\
352632 \mathrm{~N} 1112810 \mathrm{~W} \\
342325 \mathrm{~N} 1113312 \mathrm{~W} \\
342257 \mathrm{N1} 112724 \mathrm{~W} \\
342257 \mathrm{~N} 1112919 \mathrm{~W} \\
343750 \mathrm{~N} 1120831 \mathrm{~W} \\
342423 \mathrm{~N} 1112945 \mathrm{~W} \\
333302 \mathrm{~N} 1091903 \mathrm{~W} \\
333301 \mathrm{~N} 1091903 \mathrm{~W}\end{array}$ & $\begin{array}{l}342634 \mathrm{~N} 1112747 \mathrm{~W} \\
342335 \mathrm{~N} 1112903 \mathrm{~W} \\
342421 \mathrm{~N} 1112854 \mathrm{~W}\end{array}$ & 7560 & $\begin{array}{l}\text { Pine } \\
\text { Pine } \\
\text { Strawberry Crater } \\
\text { Strawberry } \\
\text { Pine } \\
\text { Pine } \\
\text { Hickey Mountain } \\
\text { Pine } \\
\text { Strayhorse } \\
\text { Strayhorse }\end{array}$ \\
\hline $\begin{array}{l}\text { Stray Horse Canyon Trail Twenty } \\
\text { Strayhorse Creek } \\
\text { Rattlesnake Creek } \\
\text { Stray Horse Creek } \\
\text { Stray Horse Creek } \\
\text { See Strayhorse Creek } \\
\text { Strayhorse Divide }\end{array}$ & $\begin{array}{l}\text { trail } \\
\text { stream }\end{array}$ & $\begin{array}{l}\text { UNOFF } \\
\text { BGN } \\
\text { VARIANT } \\
\text { VARIANT } \\
\text { VARIANT } \\
\text { BGN }\end{array}$ & $\begin{array}{l}\text { Green lee } \\
\text { Greenlee }\end{array}$ & $\begin{array}{l}332902 N 1091211 \mathrm{~W} \\
332922 \mathrm{~N} 1092034 \mathrm{~W}\end{array}$ & $332632 \mathrm{~N} 1092136 \mathrm{~W}$ & & $\begin{array}{l}\text { Dutch Blue Creek } \\
\text { Dutch Blue Creek }\end{array}$ \\
\hline
\end{tabular}


NATIONAL GAZETTEER--ARIZONA 1986

FEATURE NAME

Strayhorse Spring
Strickland Spring

Strickland Tank

Strickland Wash

Stringfield

Stringfield Springs

Stringfield Tank

Stringfield Well

Stringtown

See Alma

Stringtown Wash

Strofiost Flat

Stronghold Canyon

See Stronghold Canyon West

Stronghold Canyon East Cochise Stronghold Canyon East

Stronghold Canyon West Stronghold Canyon

Stubb Gulch

See Stubbs Gulch

Stubbs Gulch

Stubb Gulch

Stubbs Tank

Stubbs Tank Stubb Tank

Stubb Tank

$$
\text { See Stubbs Tank }
$$

Stub Number One

Stub Number Two

Stud Horse Butte

Studhorse Seep

Stud Horse Tank

Stump Canyon

Stump Spring

Stump Spring

Stump Tank

Stump Tank

Sturdevant Point

Stutter Spring

Stutz Hell

Suappoa, Mount

See San Simon River

Subia Ranch

Sublime, Point

Submarine Rock

See Steamboat Rock

Substitute Tank

Sucker Gulch

Sudder Park

Suei Va Spring

Su Eltso Springs

See Setsiltso Springs

Sue Mine

Sueno Park

Sues Tank

Sues Tank

Suffering Gulch

Suffering Wash

Suffolk Hills School

Sufrido Tank

Sugarbowl Tank

Sugar Loaf

See Sugarloaf Mountain

Sugarloaf

Sugarloaf

Sugarloaf

Sugar loaf

Sugar loaf

See Sugarloaf Peak
FEATURE

CLASS

STATUS

COUNTY

COORDINATE

$\begin{array}{llll}\text { spring } & \text { BGN } & \text { Greenlee } & 332638 N 1092130 \mathrm{~W} \\ \text { Spring } & \text { BGN } & \text { Yavapai } & 344045 N 1124048 \mathrm{~W}\end{array}$

stream BGN Yavapai 344541N1123943W

spring

BGN Yavapai

reservoir BGN Yavapai

Yavapai

Maricopa

Yavapai

locale

stream

flat

valley

$B G N$

VARIANT

Yavapai

Cochise

valley

BGN

VARIANT

valley

BGN 1976

VARIANT

VARIAN

valley
valley

reservoir BARIANT

Yavapai

Cochise

BGN 1979

VARIANT

VARIANT

reservoir

canal

canal

summit

spring

reservoir $B G$

valley $B G N$

BGN

BGN

BGN

$B G N$

BGN

BGN

Yavapai

Yavapai

Yuma

Yuma

Yavapai

Graham

Yavapai

Cochise

spring $B G N$ Apache

spring BGN Yavapai

reservoir BGN Yavapai

reservoir $B G N$

cliff

spring

well

summit

BGN 1932

Coconino

Coconino

Gila

Yuma

Maricopa

stream

Graham

locale

UNOFF

cape BGN 1906

VARIANT

is land

reservoir

valley

park

spring

spring

BGN

BGN

VARIANT

mine

mine

reservoir

reservoir

valley

stream

school

reservoir

reservoir

summit

UNOFF

ADMIN

BGN

BGN

BGN

BGN

UNOFF

BGN

BGN

VARIANT

Greenlee

Coconino

Gila

Gila

Maricopa

Navajo

Apache

Yuma

Maricopa

Coconino

Coconino

Pinal

Pima

Pima

Cochise

$34142 \mathrm{~N} 1123321 \mathrm{~W}$

$350341 \mathrm{N1122740 \textrm {W }}$

$343425 \mathrm{NI} 123447$

332448N1115119W

$344933 \mathrm{~N} 1125200 \mathrm{~W}$

$344308 N 1130245 \mathrm{~W}$

315235N1101057W

$315709 N 1095641 \mathrm{~W}$

315354N1095721W

$315235 \mathrm{~N} 1101057 \mathrm{~W}$

$315535 N 1095848 \mathrm{~W}$

344421 N1130113W $344421 N 1130113 \mathrm{~W}$

$322207 N 1100052 W$

$344630 \mathrm{~N} 1125830 \mathrm{~W}$

344430 N1130130W

$344430 \mathrm{~N} 1130130 \mathrm{~W}$

$323529 \mathrm{~N} 1144116 \mathrm{~W}$

$323448 \mathrm{~N} 1144034 \mathrm{~W}$

$351454 N 1124038 \mathrm{~W}$

$330528 \mathrm{~N} 1094638 \mathrm{~W}$

$344438 N 1114758 \mathrm{~W}$

$312416 N 1101357 \mathrm{~W}$

335718 N1091825W

$341031 \mathrm{~N} 1123904 \mathrm{~W}$

341827 N1121505W

$351249 \mathrm{~N} 1121633 \mathrm{~W}$

$360752 \mathrm{NI} 120610 \mathrm{~W}$

$333239 \mathrm{~N} 1104135 \mathrm{~W}$

$333952 \mathrm{~N} 1134858 \mathrm{~W}$

331958 N1120359W

324953N1093855W

$325758 \mathrm{~N} 1091956 \mathrm{~W}$

$361154 N 1121501 \mathrm{~W}$

$334050 N 1110503 \mathrm{~W}$

$333639 \mathrm{~N} 1110324 \mathrm{~W}$

$314502 N 1104415 \mathrm{~W}$

$332213 N 1115508 \mathrm{~W}$

$354851 \mathrm{~N} 1103144 \mathrm{~W}$

$364343 N 1094004 \mathrm{~W}$

$341135 \mathrm{~N} 1141240 \mathrm{~W}$

$332819 \mathrm{N1} 120910 \mathrm{~W}$

$344402 \mathrm{~N} 1113156 \mathrm{~W}$

$344405 \mathrm{~N} 1113046 \mathrm{~W}$

$324245 \mathrm{~N} 1105547 \mathrm{~W}$

$324231 \mathrm{~N} 1110844 \mathrm{~W}$

$322108 \mathrm{~N} 1105741 \mathrm{~W}$

313359 N1112643W

$350316 \mathrm{~N} 1135104 \mathrm{~W}$

$320051 N 1091927 \mathrm{~W}$

summit

summit

summit

BGN

BGN

Yuma

Coconino

Navajo

Yavapai

VARIANT

summ it

Coconino

343839 N1124159W

$\begin{array}{cc}\text { SOURCE } & \text { ELEV } \\ \text { COORDINATE } & \text { FT }\end{array}$

MAP NAME

Rose Peak

Mount Josh

Mount Josh

Simmons

Mount Josh

Iron Springs

Meath Spring

Iron Springs

Seepage Mtn

Behm Mesa

Cochise Stronghold

Saint David

Scratch Canyon

Muskhog Mountain

Behm Mesa

Somerton

Somerto

5733 Picacho Butte

Markham Creek

Lake Montezuma

312318 N1101626W Nicksville

Rudd Knoll

Yarnel1

Batt le Flat

McLellan Reservoir 
FEATURE NAME

Sugarloaf Butte Sugarloaf Mountain Sugarloaf Hill

Sugarloaf Mountain Sugar Loaf

Sugarloaf Mountain
Sugarloaf Mountain
Sugarloaf Mountain
See Sugarloaf Butte
Sugarloaf Mountain
Sugarloaf Mountain
Sugarloaf Mountain
Sugarloaf Mountain
Sugarloaf Mountain
Sugarloaf Mountain

Sugarloaf Mountain
Sugarloaf Peak
Sugarloaf Peak
Sugarloaf
Sugarloaf Peak
Sugarloaf Tank
Sugarloaf Tank
Sugarloaf Tank
Sugarloaf Tank Number One
Sugarloaf Tank Number Two

Sugarloaf Tank Mumber Two

Sugar Pond

Suicide Canyon

Suicide Point

Suicide Ridge

Suicide Ridge

Suicide Spring

Suicide Tank

Suicide Tank

Suicide Tank

Suicide Tank Number One

Suicide Tank Number Two

Suicide Wash

Suizo Mountains

Suizo Wash

Suizo Well

5 U Knolls

Sulfite Mine

Sullivan Buttes

Sullivan Canyon

Sullivan Dam

Sullivan Draw

Sullivan Lake

Sullivan Peak

Sullivan Reservoir

Sullivan Reservoir

See Blake Pond

Sullivans Canyon

Sullivan Spring

Sullivans Spring

Sullivan Tank

Sullivan Tank

Sullivan Tanks

Sulpher Spring Valley

See Sulphur Springs Valley

Sulphide Tunnels

Sulphur Draw

Sulphur Hills

Sulphur Peak

Sulphur Spring

Sulphur Spring

Sulphur Spring School

Sulphur Springs Valley

Sulpher Spring Valley

Sulphur Spring Valley

Valle de Agua Prieta

\section{FEATURE}

summit

STAT

COUNTY

COOROINATE

$335258 \mathrm{N1} 101325 \mathrm{~W}$

summit

summit

VARIANT Gila

BGN Cochise

BGN 1977 Cochise

VARIANT

summit

summit

BGN

BGN

summit

summit

summ it

summit

summit

summit

summit

summit

summit

summit

summit

reservoir

reservoir

reservoir

reservoir

reservoir

BGN

BGN
BGN
BGN

BGN

BGN

BGN

BGN

BGN 1933

VARIANT

BGN

BGN

BGN

BGN

reservoir

valley

cliff

ridge

ridge

spring

reservoir

reservoir

reservoir

reservoir

BGN
BGN
BGN
BGN
BGN
BGN
BGN
BGN
BGN
BGN

Maricopa

Maricopa

Gila

Maricopa

Yavapai

Yavapa

Yavapa

Mohave

Mohave

Mohave

Yuma

Coconino

Yavapai

Gila

Coconino

Yavapai

Yavapai

Yavapai

reservoir

arroyo

summit

stream

well

summit

mine

summit

valley

dam

BGN

$B G N$
$B G N$
$B G N$

UNOFF

BGN

UNOFF

UNOFF
BGN
BGN

UNOFF

Mohave

Greenlee

Mohave

Gila

Coconino

Mohave

Yavapai

Coconino

Mohave

Gila

Gila

Mohave

Pinal

Pinal

Pinal

Apache

Gila

Yavapai

Yavapa

Yavapai

valley

reservoir

sunmit

reservoir

reservoir

valley

spring

spring

reservoir

BGN

BGN

Mohave

BGN 1932 Yavapai

Mohave

VARIANT

Mohave

BGN
$B G N$
$B G N$

Mohave

Mohave

Yavapai

reservoir

reservoir

BGN

Yavapai

valley

mine

valley

summit

summ it

spring

VARIANT

UNOFF

BGN

BGN

BGN

VARIANT

spring

school

BGN

UNOFF

$\begin{array}{ll}\text { UNOFF } & \text { Cochise } \\ \text { BGN } 1959 & \text { Cochise }\end{array}$

Yavapai

Cochise

Gila

Cochise

Cochise

Cochise

Cochise

Cochise

VARIANT

VARIANT

VARIANT
$334041 \mathrm{N1130303 \textrm {W }}$

$334147 \mathrm{N1113147 \textrm {W }}$

$335258 \mathrm{N1101325 \textrm {W }}$

$335442 \mathrm{~N} 1115748 \mathrm{~W}$

$340943 \mathrm{~N} 1123641 \mathrm{~W}$

$343251 \mathrm{N1} 123622 \mathrm{~W}$

$345423 \mathrm{~N} 1115942 \mathrm{~W}$

$351210 \mathrm{~N} 1142609 \mathrm{~W}$

$352314 N 1141837 \mathrm{~W}$

$36002 B N 1144412 \mathrm{~W}$

333801 N1141855W

$352148 N 1113651 \mathrm{~W}$

$352214 N 1131221 W$

$335239 \mathrm{~N} 1101433 \mathrm{~W}$

$343640 \mathrm{N1113145W}$

$352231 \mathrm{~N} 1131303 \mathrm{~W}$

$345403 \mathrm{N1115937W}$

$345442 N 1115941 \mathrm{~W}$

$363241 N 1131851 \mathrm{~W}$

$331538 \mathrm{~N} 1090826 \mathrm{~W}$

$360206 \mathrm{~N} 1133216 \mathrm{~W}$

$340433 \mathrm{~N} 1112703 \mathrm{~W}$

$364312 N 1122151 \mathrm{~W}$

$360144 N 1133152 \mathrm{~W}$

354437 N1115848W

360506 N1133123W

$340439 \mathrm{~N} 1112332 \mathrm{~W}$

$340438 \mathrm{N1112330 \textrm {W }}$

$343337 \mathrm{N1} 132056 \mathrm{~W}$

324008N1110720W

$323702 N 1111933 \mathrm{~W}$

$323855 \mathrm{~N} 1110800 \mathrm{~W}$

$335433 \mathrm{~N} 1092434 \mathrm{~W}$

$331753 \mathrm{~N} 1105538 \mathrm{~W}$

$345032 \mathrm{~N} 1123413 \mathrm{~W}$

$350932 \mathrm{N1125548W}$

$345148 \mathrm{~N} 1122736 \mathrm{~W}$

$364437 \mathrm{N1133256 \textrm {W }}$

$345149 \mathrm{~N} 1122735 \mathrm{~W}$

361606 N1115906W

363601 H1133313W

$363936 \mathrm{~N} 1133154 \mathrm{~W}$

$365624 N 1134906 \mathrm{~W}$

340921N1121B54W

$364814 N 1134723 \mathrm{~W}$

341054 N1125202W

$350814 N 1125842 W$

$351421 N 1124501 \mathrm{~W}$

$322955 N 1100149 \mathrm{~W}$

$332355 \mathrm{~N} 1105357 \mathrm{~W}$

$315021 \mathrm{~N} 1090658 \mathrm{~W}$

$315730 \mathrm{~N} 1094403 \mathrm{~W}$

314930N1091121W

315011 N1090851W

$320004 N 1094755 \mathrm{~W}$

$20305 N 1094645 \mathrm{~W}$

$322955 \mathrm{N1} 100149 \mathrm{~W}$ 


\section{FEATURE NAME}

Valle de la Agua Prieta

See Sulphur Springs Valley

Sultana-Arizona Mine

Sultan Mine

See Chilchinbito Canyon

Sumac Springs Canyon

See Chilchinbito Canyon

Sumida Park

Summerfield Tank

Summerfield Tank

Summerhaven

Mount Lemmon
Sulphur Spring Valley

Sumac Spring Canyon

Carters Camp

\section{FEATURE}

CLASS

STATUS

TATUS

VARIANT

VARIANT

valley

mine

UNOFF

mine

valley

valley

park

reservoir

reservoir

pp 1

UNOFF

VARIANT

VARIANT

AOMIN

BGN

$B G N$

BGN

VARIANT

VARIANT

\section{Summerland}

See Stanfield

Summer Mesa (subdivision)

Summerplace Green (subdivision)

Summer Place Trails

(subdivision)

Summer Place Village

(subdivision)

Summers Spring

See Parsons Spring

Summit, The

Summit Campground

Summit Canyon

Summit Canyon

Summit Mine

Summit Mine

Summit Motorway

Summit Motorway 39A

Summit Mountain

Summit Peak

See Polaris Mountain

Summit Peak

Summit Reservoir

Summit Spring

Summit Spring

Summit Spring

Summit Spring

Summit Tank

Summit Tank

Summit Valley

Summit Well

Summit Well

Sumner Butte

See Sumner Point

Sumner Butte

Sumner Point

Sumner Butte

Sun Altar

Sun Angel Stadium (track and

field arena)

Sun Bowl Plaza Shopping Center

pp 1

VARIANT

Dpl BG

$\begin{array}{ll}\text { ppl } & \text { BGN } \\ \text { ppl } & \text { BGN }\end{array}$

$p p l$

spring

BGN

spring

VARIANT

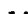

park

valley

valley

mine

mine

trail

trail

summit

summit

BGN 1917
ADNIN
BGN
BGN
UNOFF
UNOFF
UNOFF
UNOFF
BGN
VARIANT

Pinal

Maricopa

Maricopa

Maricopa

Maricopa

Yavapai

Yavapai

Gila

Apache

Yuma

Gila

Gila

Santa Cruz

Santa Cruz

Coconino

Yuma

summit

reservoir

spring

spring

spring

spring

reservoir

reservoir

valley

BGN
BGN
BGN
BGN
BGN
BGN
BGN
BGN
BGN
UNO

Yuma

Santa Cruz

Green lee

Maricopa

Gila

Coconino

Graham

Gila

Coconino

Gila

well UNOFF Gila

sumnit

summit

summit

summit

locale

locale

VARIANT

BGN

BGN 1932

VARIANT

BGN

UNOFF

Gila

Coconino

Coconino

Navajo

Maricopa

UNOFF

Maricopa

Sunburst School

Sun City

Marinette

Sun City Community Hall

Sun City Post Office

Sun City West

Sun Creek

Suncrest Villas Chandler

(subdivision)

Suncrest Villas East

(subdivision) well

park

locale

school

pp 1

building UNOFF Maricopa 333450N1121646W

building UNOFF Maricopa 333B18N1121614W

pDl BGN Maricopa $333943 \mathrm{N1122026 \textrm {W }}$

$\begin{array}{llll}\text { stream } & \text { BGN } & \text { Apache } & 335449 N 1094424 \mathrm{~W}\end{array}$

pp

ppl

$\begin{array}{ll}\text { UNOFF } & \text { Mohave } \\ \text { BGN } & \text { Maricopa } \\ \text { ADMIN } & \text { Maricopa } \\ \text { UNOFF } & \text { Maricopa } \\ \text { UNOFF } & \text { Maricopa } \\ \text { BGN } & \text { Maricopa } \\ \text { VARIANT } & \\ \text { UNOFF } & \text { Maricopa } \\ \text { UNOFF } & \text { Maricopa } \\ \text { BGN } & \text { Maricopa } \\ \text { BGN } & \text { Apache } \\ \text { BGN } & \text { Maricopa } \\ \text { BGN } & \text { Maricopa }\end{array}$

$344854 N 1132907 \mathrm{~W}$

$332803 \mathrm{~N} 1121115 \mathrm{~W}$

$333800 \mathrm{~N} 1120928 \mathrm{~W}$

333818 N1120910W

$333654 \mathrm{N1} 120938 \mathrm{~W}$

$333551 \mathrm{N1121616 \textrm {W }}$

$331810 \mathrm{~N} 1115617 \mathrm{~W}$

$335344 N 1093907 \mathrm{~W}$

333819 N1120159W
SOURCE ELEV

MAP NAME

Kearny

Thorn Peak

Sunnys lope

Quayle Hill

Quayle Hill

Mt Lemmon

$\begin{array}{ll}1270 & \text { Buckhorn } \\ 1240 & \text { Mesa } \\ 1240 & \text { Mesa } \\ 1240 & \text { Mesa }\end{array}$

Sycamore Bas in

3988 Salt River Peak

7700 West of Window Rock

Palm Canyon

North Peak

Buckhead Mesa

Stockton Hill

Alamo Spring

Ruby

7797 Williams South

Palm Canyon

Ruby

Bee Canyon

Maverick Mtn

Buckhead Mesa

May Tank Pocket

429B Bronco Gulch

Rockinstraw Mtn

Buck Pasture Canyon

$365220 \mathrm{N1120932W}$

Salt River Peak

Rockinstraw Mtn

5160 Phantom Ranch

5160 Phantom Ranch

Sun Altar

Tempe

1120 El Mirage

4277 Cedar Basin

1070 Fowler

Hedgpeth Hills

Hedgpeth Hills

Glendale

El Mirage

E1 Mirage

Calderwood Butte

Calderwood Butte

1165 Guadalupe

1425 Union Hills 
FEATURE NANE

Suncrest Villas Mesa

(subdivision)

Suncrest Villas West

(subdivision)

Sundad

Sundance Mine

Sunday Pass

Sun Devil Stadium (football)

Sundial Mobile Park

Sundown Girls Ranch

Sunf ish Cove

Sunf lower

Sunflower Butte Pumpkin Flower Butte

Sunflower Butte Wash

Sunflower Butte We11

Sunflower Canal

Sunf lower Flat

Sunf lower Flat

Sunflower Mesa

Sun Flower Mesa

Sun Flower Mesa

See Sunflower Mesa

Sunf lower Mes a

Sunf lower Mesa

Sunflower Mesa Tank

Sunf lower Mine

Sunflower Ranger Station

Sunflower Saddle

Sunflower Spring

Sunflower Tank

Sunflower Valley

Sunflower Work Center

Sungabi Creek

Sun Grove Mobile Home Park

Sunizona

Sun Lakes

Sun land Gin Road Interchange

Sun Land Memorial Park Sunland Memorial Park

Sunland Memorial Park

See Sun Land Memorial Park

Sunland School

Sunlight Mission

Sunlit Sprin

Sunny Acres Trailer Village

Sunnybrook Mine

Sunnybrook Spring

Sunnybrook Tank

Sunnycove Dam

Sunny Flat Picnic Ground

Sunny Park Draw

Sunnyside

Sunnyside Canyon

Sunnyside Cemetery

Sunnyside Dam

Sunnyside Junior High School

Sunnyside Mesa

Sunnys ide Park

Sunnyside Ranch

Sunnys ide Ranch

Sunnys ide Reservoir

Sunnys ide School

Sunnys ide School

Sunnyside Spring

See Shato Spring

Sunnys ide Spring

Sunnys lope

Sunnys lope Community Center

Park

\section{FEATURE
CLASS}

STATUS

COUNTY

ppl

BGN

Maricopa

pp 1

BGN

Maricopa

COORDINATE

$332320 \mathrm{~N} 1114647 \mathrm{~W}$

ppl

BGN

mine

gap

locale

locale

locale

bay

locale

summit

valley BGN

UNOFF

BGN
UNOFF

UNOFF

UNOFF

BGN
BGN

BGN

VARIANT

we

cana

flat

flat

summit

UNOFF

BGN

BGN

BGN

BGN

VARIANT

summit

$B G N$

summit

$B G N$

BGN

reservoir

mine

BGN
UNOFF

UNOFF

gap

spring

reservoir

valley

locale

stream

locale

BGN

BGN

BGN

BGN

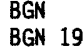

BGN 1943
UNOFF

pp1

ppl

crossing

BGN

cemetery

BGN

UNOFF

UNOFF

VARIANT

VARIANT

cemetery

school

locale

UNOFF

church

UNOFF

spring

locale

mine

spring

reservoir

dam

park

valley

locale

valley

BG

UNOFF

UNOFF

BGN

BGN
UNOFF

UNOFF

BGN

BGN

cemetery

UNOFF

dam

school

summit

park

locale

locale

reservoir

school

school

UNOFF
UNOFF

BGN

BGN

UNOFF

UNOFF

BGN

BGN

UNOFF

Yavapai

Yuma

Maricopa

Maricopa

Navajo

Mohave

Maricopa

Navajo

Navajo

Navajo

Graham

Yavapai

Coconino

Greenlee

Greenlee

Greenlee

Gila

Greenlee

Maricopa

Maricopa

Greenlee

Maricopa

Greenlee

Maricopa

Maricopa

Mohave

Maricopa

Cochise

Maricopa

Pinal

Maricopa

Maricopa

Maricopa

Maricopa

Navajo

Navajo

Maricopa

Yavapai

Yavapai

Cochise

Yavapai

Cochise

Navajo

Cochise

Cochise

Cochise

Apache

Pima

Apache

Pima

Cochise

Pinal

Apache

Pima

Maricopa

spring

spring

ppl

locale
VARIANT

$$
\text { BGN }
$$

BGN
Navajo

Apache

Maricopa
33402BN1120850W

331053N1131407W

$342519 N 1122548 \mathrm{~W}$

321833 N1133350W

$332535 \mathrm{~N} 1115555 \mathrm{~W}$

$332713 \mathrm{~N} 1114944 \mathrm{~W}$

$342300 \mathrm{~N} 1102519 \mathrm{~W}$

$360755 N 1140517 \mathrm{~W}$

$335151 N 1112801 \mathrm{~W}$

351833N1101251W

351657N1100852W

$351810 \mathrm{~N} 1101304 \mathrm{~W}$

$325012 N 1094231 \mathrm{~W}$

$341952 \mathrm{~N} 1125635 \mathrm{~W}$

$350735 \mathrm{~N} 1120225 \mathrm{~W}$

$331223 \mathrm{~N} 1091236 \mathrm{~W}$

$331223 \mathrm{~N} 1091236 \mathrm{~W}$

$331555 \mathrm{~N} 1092903 \mathrm{~W}$

$341849 \mathrm{~N} 1111844 \mathrm{~W}$

$331540 N 1092918 \mathrm{~W}$

$335720 \mathrm{~N} 1112940 \mathrm{~W}$

$335336 \mathrm{~N} 1112856 \mathrm{~W}$

$331515 \mathrm{~N} 1090816 \mathrm{~W}$

$335023 \mathrm{~N} 1112745 \mathrm{~W}$

$331240 N 109124 \mathrm{BW}$

$335323 \mathrm{~N} 1112848 \mathrm{~W}$

$335337 \mathrm{~N} 1112855 \mathrm{~W}$ 


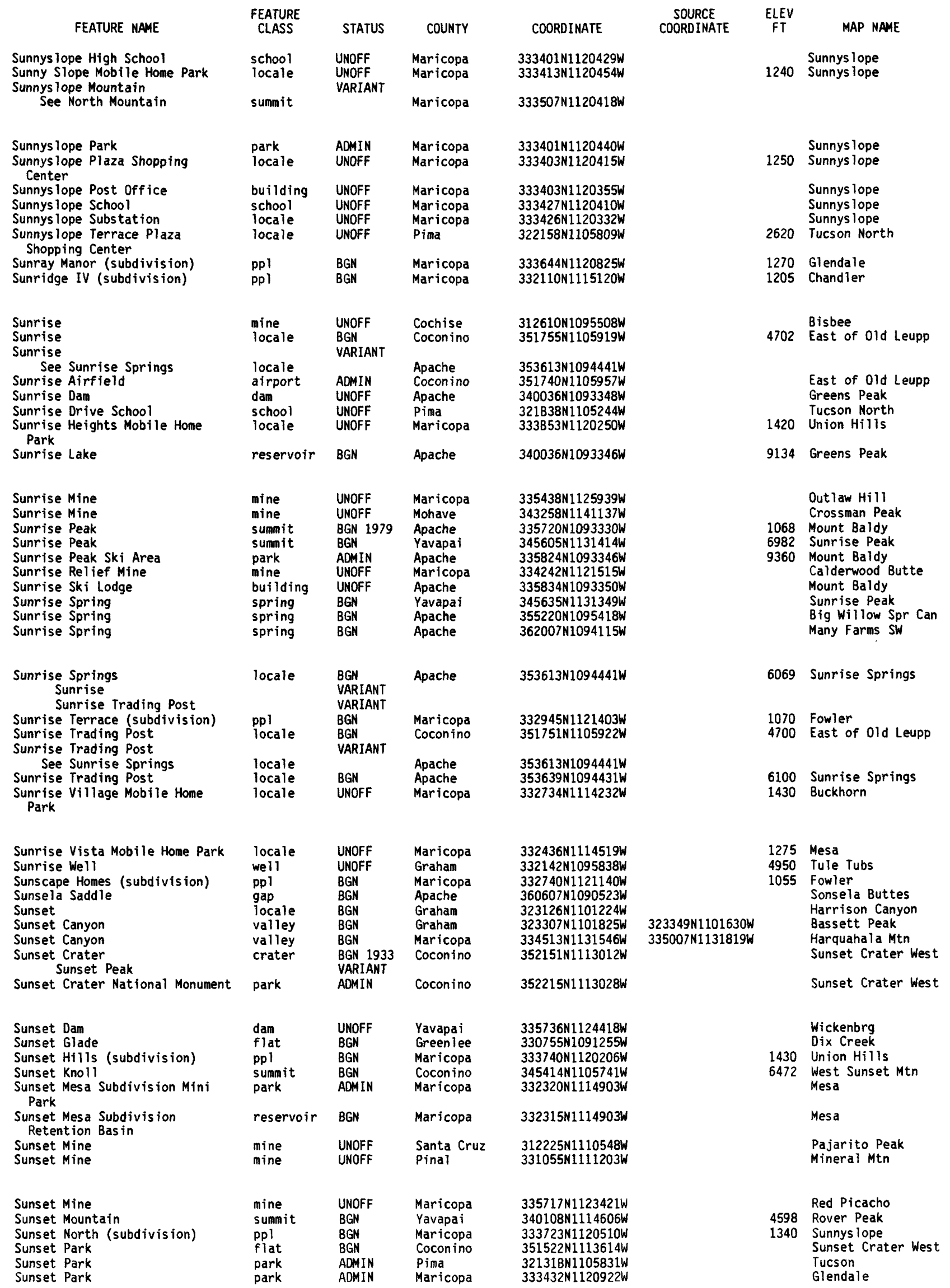




\section{FEATURE NAME}

Sunset Pass

Sunset Pass

Sunset Pass Spring

Sunset Pass Tank

Sunset Peak

See Sunset Crater

Sunset Peak

Sunset Peak

Sunset Peak

Sunset Playground

Sunset Point

Sunset Point

Sunset Point Interchange

Sunset Point Rest Area

Sunset Ridge I (subdivision)

Sunset Rock

See Cathedral Rock

Sunset Rock

Sunset School

Sunset Spring

Sunset Tank

Sunset Tank

Sunset Tank

Sunset Trail Ranch (trailer park)

Sunset Valley Ranch

Sunset Village (subdivision)

Sunset Vista (subdivision)

Suns Eye

Sunshine

$$
\text { 0jos }
$$

Sunshine Acres

Sunshine Boulevard Interchange

Sunshine Draw

Sunshine Gulch

Sunshine Microwave Relay

Station

Sunshine Mine

Sunshine Mine

Sunshine Mine

Sunshine Overpass

Sunshine Point

Sunshine Pond

Sunshine Railroad Station

Sunshine Ridge

Sunshine Spring

Sunshine Tank

Sunshine Trail

Sunshine Valley Mobile Home

Park

Sun Sites

$$
\text { See Pearce }
$$

Sunsites

See Arizona Sun Sites

Suns ites Community Center

Sun Tech (subdivision)

Sun Trailer Park

Suntrails (subdivision)

Suntree (subdivision)

Sun Valley

Sun Valley Airport

Sun Valley Mobile Home Park

Sun Valley Plaza Shopping Center

Sunvalley Square Shopping Center

Sun Valley Trailer Park

Sunview (subdivision)

Supai

Supai
FEATURE
CLASS

STATUS

COUNTY

COORDINATE

gap

gap

spring

$B G N$

$B G N$

Maricopa

Coconino

Navajo

Navajo

VARIANT

crater

summit

summit

cliff

summit $\quad B G$

crossing UNOFF

locale BGN

$\mathrm{pp} 1$

pillar

pillar

school

spring

reservoir

reservoir

reservoir

locale

BGN

VARIANT

BGN

UNOFF

BGN

BGN

$B G N$

$B G N$

$\begin{array}{llll}\text { locale } & \text { UNOFF } & \text { Graham } & 323036 \text { N1101157W } \\ \text { ppl } & \text { BGN } & \text { Maricopa } & 333533 N 1121534 W \\ \text { ppl } & \text { BGN } & \text { Maricopa } & 3338551121118 W \\ \text { summit } & \text { BGN } & \text { Navajo } & 3654481100455 W \\ \text { locale } & \text { BGN } & \text { Coconino } & 350726 N 1110151 W \\ & \text { VARIANT } & & \\ \text { ppl } & \text { BGN } & \text { Maricopa } & 332837 N 1114250 W \\ \text { crossing } & \text { UNOFF } & \text { Pinal } & 3244061113259 W \\ \text { valley } & \text { BGN } & \text { Mohave } & 3638151132015 W \\ \text { valley } & \text { BGN } & \text { Yuma } & 33394111142433 W\end{array}$

valley

tower

mine

mine

mine

crossing

summit

reservoir

building UNOFF

ridge $B G M$

$\begin{array}{ll}\text { spring } & B G M \\ \text { reservoir } & B G N \\ \text { trail } & U N O F\end{array}$

locale UNOFF

VARIANT

PPI VARIANT

$\mathrm{ppl}$

building

UNOFF

ppl

local
$\mathrm{ppl}$
$\mathrm{ppl}$
local

locale

rport

locale

locale

BGN

UNOFF

BGN

$B G N$
$B G N$

ADMIN

UNOFF

UNOFF

UNOFF

Coconino

Pima

Maricopa

Mohave

Coconino

Mohave

Mohave

Coconino

Mohave

Navajo

Mohave

Mohave

Maricopa

Cochise

Cochise

Cochise

Maricopa

Maricopa

Maricopa

Maricopa

Navajo

Mohave

Maricopa

Maricopa

Maricopa

locale

ppl

locale

UNOFF
BGN

BGN

ppl

VARIANT

Maricopa

Maricopa

Coconino

Coconino
$334939 \mathrm{~N} 1131843 \mathrm{~W}$

$345110 N 1105526 \mathrm{~W}$

335806 N1095306

$335809 \mathrm{~N} 109532 \mathrm{BW}$

$352151 \mathrm{N1113012 \textrm {W }}$

$314314 N 1091924 \mathrm{~W}$

323416 N1101637W

$330721 N 1091333 \mathrm{~W}$

$351247 N 1113846 \mathrm{~W}$

$341101 \mathrm{N1120B26 \textrm {W }}$

$333115 N 1122142 \mathrm{~W}$

341137 N1120749h

341108 N1120BO1W

333736 N1115650W

$364942 \mathrm{~N} 1113820 \mathrm{~W}$

$364947 \mathrm{~N} 1113806 \mathrm{~W}$

33291 BN1121200W

330746 N1091407W

$314157 \mathrm{N1092125 \textrm {W }}$

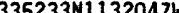

$332448 \mathrm{~N} 1113840 \mathrm{~W}$

350657 N1110202W

$315232 \mathrm{~N} 1111606 \mathrm{~W}$

$335202 \mathrm{~N} 1131651 \mathrm{~W}$

$352106 \mathrm{N1134606 \textrm {W }}$

350558N1105823W

$363425 \mathrm{N1} 124037 \mathrm{~W}$

364949N1132340W

$350723 \mathrm{~N} 1110142 \mathrm{~W}$

$363838 \mathrm{N1124B45W}$

352649N1100150W

$363719 N 1132051 \mathrm{~W}$

$365000 \mathrm{~N} 1132345 \mathrm{~W}$

$331654 \mathrm{N1115040 \textrm {W }}$

315418N1094912W

$315500 N 1095730 \mathrm{~W}$

$315633 \mathrm{~N} 1095010 \mathrm{~W}$

$331948 N 1115149 \mathrm{~W}$

$332706 \mathrm{~N} 1120622 \mathrm{~W}$

$332350 \mathrm{~N} 1114526 \mathrm{~W}$

$332300 \mathrm{N1114555 \textrm {W }}$

$345850 \mathrm{~N} 1100327 \mathrm{~W}$

$350045 N 1143445 \mathrm{~W}$

$333533 \mathrm{~N} 1115906 \mathrm{~W}$

332457 N111403OW

332452N1114059W

$332753 \mathrm{~N} 1120032 \mathrm{~W}$

$332235 \mathrm{~N} 1114740 \mathrm{~W}$

$35134 \mathrm{BN} 1121411 \mathrm{~W}$

361413 N1124118W

$\begin{array}{cc}\text { SOURCE } & \text { ELEV } \\ \text { COORDINATE } & \text { FT }\end{array}$

MAP NAME

Harquahala Mtn

Sunset Pass

Alchesay Flat
Alchesay Flat

7066 Swede Peak

7104 Bassett Peak

69B0 Rattlesnake Spring Flagstaff West

3118 Bumble Bee El Mirage Bumble Bee

3400 Bumble Bee

1460 Currys Corner

3760 Navajo Bridge Fowler Dix Creek Swede Peak

Swede Peak

Gladden

1490 Buckhorn

$363614 N 1132155 \mathrm{~W}$

333957 N1142409W

4700 Harrison Canyon

1120 El Mirage

1260 Hedgpeth Hills Mitten Buttes Meteor Crater

Buckhorn

Eloy South

The Grandstand

La Paz Mtn

Meteor Crater

Stevens Mtn

Harquahala Mtn

Peacock Peak

Tucker Mesa SW

Grama Spring

Hole-N-Wall Canyon

Meteor Crater

Sunshine Ridge

Indian Wells

Russell Spring

Hole-N-Wall Canyon

1210 Chandler

Pearce

1200 Chandler

1070 Phoenix

1255 Mes a

1245 Mesa

Sun Valley

725 Davis Dam SE

1380 Paradise Valley

Buckhorn 


\section{FEATURE NAME}

\begin{tabular}{|c|}
\hline $\begin{array}{l}\text { Supai Camp } \\
\text { Supai Falls } \\
\text { Supai Mesa } \\
\text { Supai Middle School } \\
\text { Supai Tank }\end{array}$ \\
\hline $\begin{array}{l}\text { Superior } \\
\text { Hastings } \\
\text { Superior Airport } \\
\text { See Superior Municipal } \\
\text { Airport } \\
\text { Superior Dump } \\
\text { Superior High School } \\
\text { Superior Mine } \\
\text { Superior Mine } \\
\text { Superior Municipal Airport } \\
\text { Superior Airport }\end{array}$ \\
\hline $\begin{array}{l}\text { Superior Stadium } \\
\text { Superior Tank } \\
\text { Superior Water Tank } \\
\text { Superstition Country } \\
\text { Subdivision } \\
\text { Superstition Interchange } \\
\text { See Interchange One } \\
\text { Hundred Fifty Four } \\
\text { Superstition Mountain } \\
\text { Monte de la Expuma } \\
\text { Superstition Peak }\end{array}$ \\
\hline $\begin{array}{l}\text { Superstition Mountain Monument } \\
\text { Superstition Mountains } \\
\text { Massasal Mountains } \\
\text { Salt Mountain } \\
\text { Sierra de la Espuma } \\
\text { Superstition Mountain School } \\
\text { Superstition Park } \\
\text { See Superstition Park } \\
\text { East Number Two } \\
\text { Superstition Park } \\
\text { See Superstition Park } \\
\text { West Number One }\end{array}$ \\
\hline $\begin{array}{l}\text { Superstition Park East Number } \\
\text { Two } \\
\text { Superstition Park } \\
\text { Superstition Park West Number } \\
\text { One } \\
\text { Superstition Park } \\
\text { Superstition Peak } \\
\text { Superstition Peak } \\
\text { See Superstition Mountain } \\
\text { Superstition Shadows Mobile } \\
\text { Home Park }\end{array}$ \\
\hline
\end{tabular}

Superstition Substation

Sup Hor Spring

Supi Oidak

$$
\text { Coldfield }
$$

Supolvre Creek

$$
\text { See Pulcifer Creek }
$$

Supui Tank

Surprise

$$
\text { Ennis }
$$

Surprise Canyon

$$
\begin{aligned}
& \text { Surprise Canyon } \\
& \text { Surprise Canyon } \\
& \text { Surprise Canyon } \\
& \text { Green Spring Canyon } \\
& \text { Surprise Canyon } \\
& \text { See Twin Spring Canyon } \\
& \text { Surprise Creek } \\
& \text { See Green Tank } \\
& \text { Surprise Creek } \\
& \text { See Seven Springs Wash }
\end{aligned}
$$

park

park

building

reservoir

reservoir

ppl

crossing

summit

park

summ it

schoo

park

park

VARIANT

park

ADMIN

VARIANT

ADNIN

VARIANT

summit

summit

locale

BGN

VARIANT

UNOFF

local

spring

locale

UNOFF

BGN

VARIANT

VARIANT

stream

reservoir BGN

ppl

valley

BGN

VARIANT

BGN

\section{valiey}

valley

valley

BGN

BGN
VARIANT

VARIANT

valley

reservoir VARIANT

VARIANT

VARIANT

strean

mine

UNOFF
COORDINATE

355511 N1124610W $361442 \mathrm{~N} 1124157 \mathrm{~W}$ $362348 N 1091809 \mathrm{~W}$ $332733 \mathrm{~N} 1115605 \mathrm{~W}$ $355532 \mathrm{~N} 1124637 \mathrm{~W}$

$331738 N 1110544 W$

331657 N1110735W

Pinal

Pinal

Pinal

Cochise

Gila

Pinal

$331723 \mathrm{~N} 1110758 \mathrm{~W}$

$331742 N 1110538 \mathrm{~W}$ $312335 N 1095037 \mathrm{~W}$ $332605 N 1104518 \mathrm{~W}$

$331657 N 1110735 \mathrm{~W}$

$331711 \mathrm{~N} 1110656 \mathrm{~W}$ $331425 N 1111944 \mathrm{~W}$ $331806 \mathrm{~N} 1110506 \mathrm{~W}$ $332401 N 1113745 \mathrm{~W}$

332321 N1115800W

332440N1112400W

Pinal

Pinal

Pinal

Maricopa

Maricopa

$332010 \mathrm{N1112625 \textrm {W }}$

332543N1112503W

332430 N1113349W

$332512 N 1113235 \mathrm{~W}$

Pina

Pinal

Pinal

Pinal

Pinal

Pinal

Maricopa

Pinal

Pinal

Pima

Apache

Coconino

Maricopa

Cochise

\section{Yuma}

Yuma

Mohave

Mohave

Pinal

Apache

Pima $351352 \mathrm{~N} 1121440 \mathrm{~W}$

355847N1133333W

$324312 \mathrm{~N} 1111031 \mathrm{~W}$

$344229 N 1094014 W$
$332515 N 1113238 W$

$332512 \mathrm{~N} 1113235 \mathrm{~W}$

$332515 N 1113238 W$

332440 N1112400W

$332440 \mathrm{~N} 1112400 \mathrm{~W}$

$332500 \mathrm{~N} 1113527 \mathrm{~W}$

$332453 \mathrm{~N} 1113158 \mathrm{~W}$ $331222 \mathrm{~N} 1110206 \mathrm{~W}$

$314107 N 1114632 \mathrm{~W}$

$341418 N 1094126 \mathrm{~W}$ $333750 N 1121957 \mathrm{~W}$

320039N1092111W 320100N1092015W

$322038 \mathrm{~N} 1134945 \mathrm{~W}$ $332329 N 1140256 \mathrm{~W}$

$321918 N 1134616$ 355116 N1133940W $355847 \mathrm{~N} 1133333 \mathrm{~W}$
ELEV
FT MAP NAME

5778 Supai Camp Supai

6535 Bad Bug Butte Tempe

Supai Camp

2830 Superior

Picketpost Mtn

Superior

Bisbee NE

Globe

2646 Picketpost Mtn

Superior

Florence NE

Superior

1500 Buckhorn

Goldfield

Superstition Mts SW 4642 Goldfield

Apache Junction

Apache Junction

Apache Junction

5057 Goldfield

1620 Apache Junction

Apache Junction Teapot Mountain South Komelik

Williams South

1178 Calderwood Butte

Cochise Head

Cabeza Prieta Peak

Livingston Hills

Spencer Canyon

Gunsight 


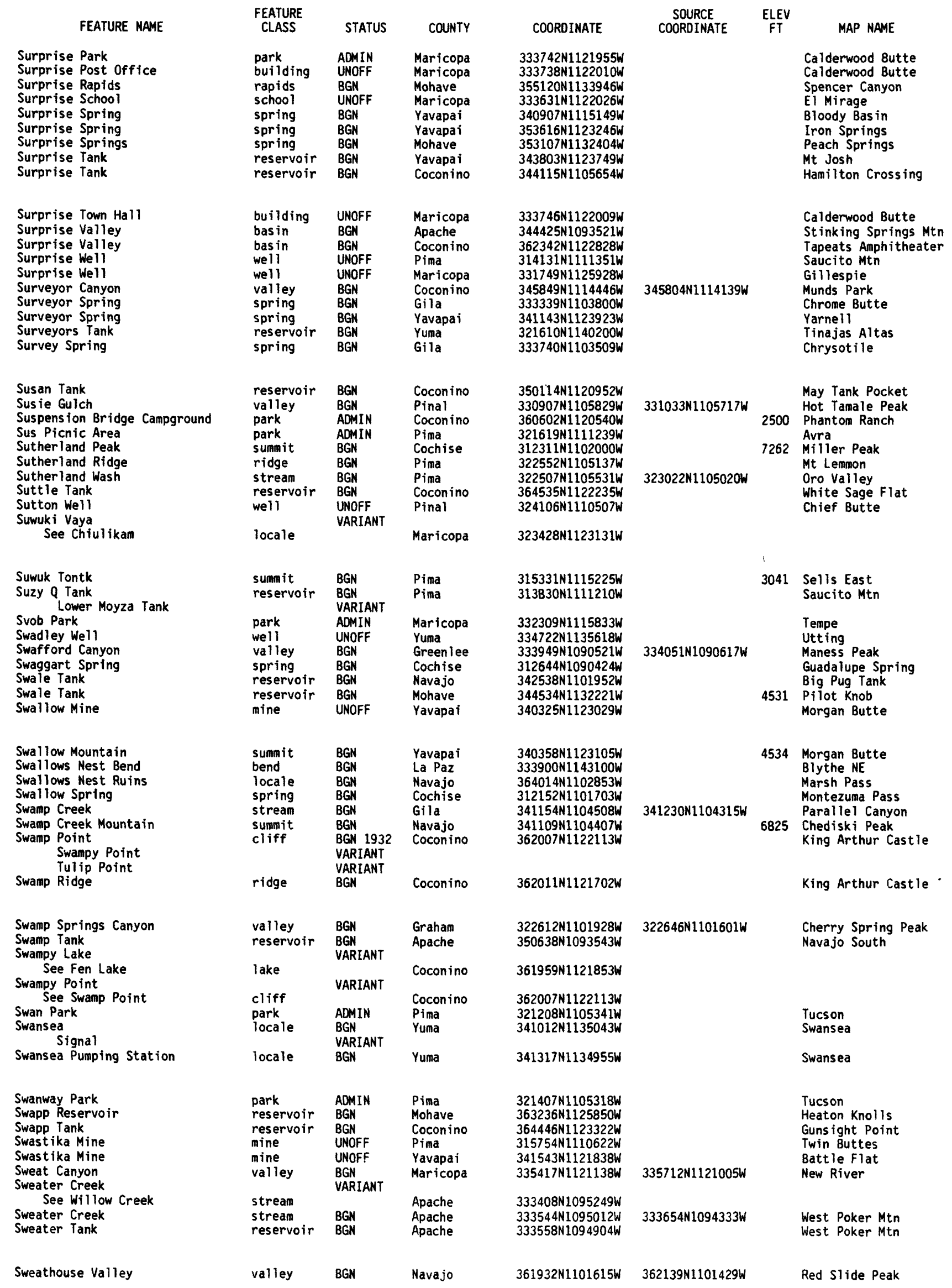


NATIONAL GAZETTEER--ARIZONA 1986

\section{FEATURE NAME}

Sweat Peak

Sweat Spring

Swede Camp Spring

Swede Peak

Swede Spring

Swede Spring

Swede Tank

Sweet ie Canyon

Sweetie Spring

Sweetmeat Draw

Sweet Meat Spring Dan

Sweetwater

See Siovi Shuatak

Sweetwater

Sweetwater

$$
\text { Siovi Shuatak }
$$

Sweetwater

See Totacon 143

Sweetwater Garden (subdivision) Sweetwater Mes

Sweetwater Park

Sweetwater Pass

Sweetwater Ranch

Sweetwater Ranch

Sweetwater Spring

Sweetwater Spring

Sweetwater Spring

Sweetwater Spring

Sweetwater Tank

Sweetwater Trail

Sweetwater Wash

Sweetwater Well

Sweetwater Well

Sweet Water Well

Sweet Water Well

Sweetwood Tank

Swicker Spring

Swiettendick Place Well

Swift Canyon

Swift Canyon Wash

Swift Trail Junction

Swilling Butte

Swilling Gulch

Swinborne Spring

Swinburne Flat

Swinburne Spring

Swinging $H$ Ranch

Swingle Wash

\section{Swiss Bell Mine}

Swiss Canyon

Swisshelm Lodge

Swisshelm Mountain

Swisshelm Mountains See Pedregosa Mountains

Swisshelm Mountains

Switchbacks Spring, The

Switchback Tank

Switchback Tank

Switzer Canyon
Switzer Mesa
Switzer Mesa
See McMillan Mesa
S W Tank
S X Ranch
Sycamore
Sycamore Bas in
The Bas in
Sycamore Bas in

Sycamore Bas in Tank

FEATURE

summi

spring

summit

spring

spring

reservoir

valley

spring

valley

dan

locale

ppl

locale

locale

trail

ppl

park

park

gap

ppl

spring

spring

spring

spring

STATUS COUNTY

COORDINATE

BGN Maricopa

Maricopa

Pinal

Gila

Gila

Gila

Greenlee

BGN 1941

VARIANT

Apach

UNOFF

Santa Cruz

stream

locale

summit

valley

spring

flat

spring

locale

stream

mine

valley

locale

summit

range

ridge

spring

reservoir

reservoir

BGN

BGN 1932

Yavapai

Apache

Apache

UNOFF

BGN

Santa Cruz
Cochise $314328 N 1091745 \mathrm{~W}$

$333135 \mathrm{~N} 1110326 \mathrm{~W}$

$33453 \mathrm{BN} 1101940 \mathrm{~W}$

$334532 \mathrm{~N} 1102132 \mathrm{~W}$

$33334 B N 1091053 \mathrm{~W}$

$333249 N 1090931 \mathrm{~W}$

$333207 N 1090918 W$

$332559 \mathrm{~N} 1100551 \mathrm{~W}$ $332030 \mathrm{~N} 1100600 \mathrm{~W}$

$315703 \mathrm{~N} 1123551 \mathrm{~W}$

$315739 N 1123500 \mathrm{~W}$

$330755 \mathrm{~N} 1115024 \mathrm{~W}$

BGN Pima

$365100 \mathrm{~N} 1092530 \mathrm{~W}$

$314205 \mathrm{~N} 1104908 \mathrm{~W}$

331B46N1100519W

.

$\begin{array}{ll}\text { SOURCE } & \text { ELEV } \\ \text { COORDINATE } & \text { FT MAP NAME }\end{array}$

reservoir BGN Gila 341448N1110731W

trail UNOFF Pima 321610N1110742W

$\begin{array}{llll}\text { trail } & \text { UNOFF } & \text { Pima } & 321610 \mathrm{~N} 1110742 \mathrm{~W} \\ \text { stream } & \text { BGN } & \text { Apache } & 365047 \mathrm{~N} 1092804 \mathrm{~W}\end{array}$

well UNOFF Yavapai 342839N1125930W

well UNOFF Apache 350233N1094150W

well UNOFF Coconino 354134N1105218W

well UNOFF Coconino 354547N1105607W

reservoir BGN Coconino $351904 \mathrm{~N} 1121047 \mathrm{~W}$

spring BGN Mohave 352812N1141100W

well UNOFF Yavapai 342152N1121440W

valley BGN Graham 324203N1094613W

$324434 \mathrm{~N} 1094215 \mathrm{~W}$

$324347 \mathrm{~N} 1094248 \mathrm{~W}$

$361423 \mathrm{~N} 1115430 \mathrm{~W}$

$340300 \mathrm{~N} 1121746 \mathrm{~W}$

$340459 \mathrm{~N} 1093355 \mathrm{~W}$

$342548 \mathrm{~N} 1093104 \mathrm{~W}$

$342437 \mathrm{~N} 1093127 \mathrm{~W}$

$313543 \mathrm{~N} 1102936 \mathrm{~W}$

$325606 \mathrm{~N} 1104442 \mathrm{~W}$

$342823 \mathrm{~N} 1130633 \mathrm{~W}$

$365154 \mathrm{~N} 1132630 \mathrm{~W}$

$314057 \mathrm{~N} 1093538 \mathrm{~W}$

$314028 \mathrm{~N} 1093205 \mathrm{~W}$

$364940 \mathrm{~N} 1132923 \mathrm{~W}$

$313612 \mathrm{~N} 1092326 \mathrm{~W}$

$314028 \mathrm{~N} 1093205 \mathrm{~W}$

$335034 \mathrm{~N} 1105450 \mathrm{~W}$

$331508 \mathrm{~N} 1105323 \mathrm{~W}$

$332120 \mathrm{~N} 110215 \mathrm{BW}$

valley BGN Coconino 351142N1113800W

bench BGN Coconino 351312N1113803W

$333315 \mathrm{~N} 1121505 \mathrm{~W}$

$344432 \mathrm{~N} 1094414 \mathrm{~W}$

$313930 \mathrm{~N} 1103646 \mathrm{~W}$

$345150 N 1120557 \mathrm{~W}$

$342835 \mathrm{~N} 1113830 \mathrm{~W}$

$345714 \mathrm{~N} 1120314 \mathrm{~W}$

$324108 \mathrm{~N} 1094721 \mathrm{~W}$

$324112 \mathrm{~N} 1094722 \mathrm{~W}$

$340317 N 1121704 \mathrm{~W}$

$325355 N 110532 B W$

2872 New River

New River

Haunted Canyon

7505 Swede Peak

Two Bar Mtn

Carrizo SE

Carrizo SE

Bear Mountain

Bear Mountain

Ash Creek NE

Ash Creek Ranch

2094 Pia 0ik

1212 Gila Butte

Mt Wrightson

1400 Paradise Valley Sweetwater Mesa

Paradise Valley

Diaz Peak

Jaynes

1420 Paradise Valley

Mt Wrights on

Rocky Ridge NE

Sweathouse Peak

5898 Chilchinbito

McDonald Mtn

Avra

Walker Butte

3242 Hillside

5432 Pinta

Garces Mesas NE

Dinnebito Spring

Williams North

Chloride

cleator

Mt Graham

Artesia

Artesia

Walhalla Plateau

Columbia

Greens Peak

Concho

Concho

Pyeatt Ranch

Dudleyville

Malpais Mesa NE

Hole-N-Wall Canyon

Swissheln Mtn

7185 Swisshelm Mtn

7185 Swisshelm Mtn

Aztec Peak

Pinal Ranch

Mount Triplet

$351403 N 1113834$

Flagstaff West

Flagstaff West

Potter Mesa Tank

4B70 Elgin

Clarkdale

Hackberry Mtn

Sycamore Bas in

Hackberry Mtn 
FEATURE NAME

Sycamore Bas in Tank

Sycamore Basin Trail

Sycamore Buttes

Sycamore Camp

Sycamore Canyon

Sycamore Canyon

Sycamore Canyon

Sycamore Canyon

Sycamore Canyon

Sycamore Canyon

Sycamore Canyon

Sycamore Canyon

Sycamore Canyon

Sycamore Canyon

Sycamore Canyon

Sycamore Canyon

Sycamore Canyon

Sycamore Canyon

Sycamore Canyon

Sycamore Canyon

Sycamore Canyon

Sycamore Canyon

Sycamore Canyon

Sycamore Canyon

Sycamore Canyon

Sycamore Canyon

Sycamore Canyon

Cottonwood Canyon

Sycamore Canyon

Sycamore Canyon

Sycamore Canyon Wilderness

Sycamore Creek

Sycamore Creek

See Turkey Creek

Sycamore Creek

Sycamore Creek

Sycamore Creek

Sycamore Creek

See Sevenmile Wash

Sycamore Creek

Sycamore Creek

Sycamore Creek

See Fox Gulch Sycamore Creek

Sycamore Creek

Cline Creek

Sycamore Creek

Sycamore Creek

Sycamore Creek

Sycamore Creek

Dragoon Creek

Dragoon Fork

Dry Creek

Sycamore Creek

Sycamore Creek

Sycamore Creek

See Fox Gulch

Sycamore Dam

Sycamore Forest Camp

Sycamore Gulch

Sycamore Gulch

See Lyle Canyon

Sycamore Gulch

Sycamore Gulch

Sycamore Mesa

Sycamore Mesa

Sycamore Pass

See Cottonwood Pass

Sycamore Pass

Sycamore Pass Tank

Sycamore Point
FEATURE

CLASS

STATUS

reservoir

trail

summit

locale

valley

valley

valley

valley

valley

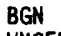

UNOFF

BGN

BGN

$B G$

BGN

BGN

BGN

BGN

valley

valley

valley

valley

valley

valley

valley

valley

valley

valley

BGN Pima

BGN Pima

BGN 1982 Pima

BGN Pima

BGN Pima

Graham

Graham

Pinal

Graham

Graham

valley

valley

valley

valley

valley

valley

valley

valley

valley

valley

park

strean

stream

stream

stream

stream

stream

BGN

BGN

BGN

BGN

BGN

$B G M$

BGN 1974

VARIANT

BGN

Graham

Greenlee

Gila

Gila

Maricopa

Maricopa

Yavapai

Gila

Yavapai

BGN 1964

ADMIN

BGN

VARIANT

BGN

BGN

VARIANT

Yavapai

Yavapai

Cochise

Pima

Pima

Gila

Gila

strean

stream

BGN

BGN

VARIANT

stream

stream

BGN 1965

VARIANT

BGN

strean

stream

stream

$B G N$

BGN

stream

BGN 196

VARIANT

VARIANT

VARIANT

stream

stream

valley

dam

locale

BGN

VARIANT

Yavapai

Mohave

Gila

UNOFF Yavapai

$B G N$

Gila

valley

BGN

valley

valley

valley

summit

gap

gap

VARIANT

BGN

BGN

BGN

BGN

VARIANT

BGN

Santa Cruz

Cochise

Greenlee

Graham

Yavapai

Yavapai

Yuma

Yavapai

reservoir

BGN

BGN

Yavapai

Coconino

COORDINATE

345621 N1120110W

$345736 \mathrm{~N} 1120230 \mathrm{~W}$

342B41N1113857W

$344311 \mathrm{~N} 1132327 \mathrm{~W}$

$311600 \mathrm{~N} 1112300 \mathrm{~W}$

$312155 \mathrm{~N} 1104624 \mathrm{~W}$

$312235 N 1102326 \mathrm{~W}$

$313616 \mathrm{~N} 1102705 \mathrm{~W}$

$314625 N 1092032 \mathrm{~W}$

$314804 \mathrm{~N} 1104605 \mathrm{~W}$

$314817 \mathrm{N1113808W}$

$315426 \mathrm{~N} 1104706 \mathrm{~W}$

$321219 N 1102906 \mathrm{~W}$

$322057 \mathrm{N1} 104446 \mathrm{~W}$

$322711 \mathrm{N1101B52W}$

$322 B 38 \mathrm{~N} 1094326 \mathrm{~W}$

$324932 \mathrm{~N} 1102947 \mathrm{~W}$

$325550 \mathrm{~N} 1101157 \mathrm{~W}$

325946 N1093239W

$330942 \mathrm{~N} 1092943 \mathrm{~W}$

$332720 \mathrm{~N} 1091042 \mathrm{~W}$

$333 B 06 N 1104735 \mathrm{~W}$

$335252 \mathrm{~N} 1111952 \mathrm{~W}$

$335505 \mathrm{~N} 1114 \mathrm{~B} 40 \mathrm{~W}$

$340042 N 1115722 \mathrm{~W}$

$340605 \mathrm{~N} 1120304 \mathrm{~W}$

$341340 \mathrm{~N} 1110257 \mathrm{~W}$

$342630 \mathrm{~N} 1114722 \mathrm{~W}$

$345150 \mathrm{~N} 1120415 \mathrm{~W}$

$345718 \mathrm{N1120231 \textrm {W }}$

$312633 N 1090801 \mathrm{~W}$

$320910 N 1102710 \mathrm{~W}$

$321124 \mathrm{M1} 103007 \mathrm{~W}$

$324140 \mathrm{~N} 1102013 \mathrm{~W}$

$331310 \mathrm{~N} 1104930 \mathrm{~W}$

$332210 N 1102632 \mathrm{~W}$

$332447 \mathrm{M11} 12825 \mathrm{~K}$

$333801 \mathrm{~N} 1113955 \mathrm{~W}$

$335551 \mathrm{N1112836 \textrm {W }}$

$334348 \mathrm{~N} 1111226 \mathrm{~W}$

$334902 N 1111642 W$

$340443 \mathrm{~N} 1114216 \mathrm{~W}$

340838N11

$341804 N 1112128 \mathrm{~W}$

$334503 N 1112202 W$

$340718 N 1113345$

$340820 \mathrm{~N} 1121459 \mathrm{~W}$

$342216 \mathrm{~N} 1112500 \mathrm{~W}$

341808 N1114700W

343910 N1133442W

343244N1124520W

$334337 \mathrm{~N} 1111716 \mathrm{~W}$

$343827 N 1124745 \mathrm{~W}$

341811 N1112130W

313727 N1102756W

$313807 N 1102601 \mathrm{~W}$

$330831 N 1091648 \mathrm{~W}$

$331148 \mathrm{~N} 1101926 \mathrm{~W}$

$341913 N 1120053 \mathrm{~W}$ 
NATIONAL GAZETTEER--ARIZONA 1986

\section{FEATURE NAME}

Sycanore Railroad Station

Sycanore Ranger Station

Sycanore Reservoir Sycamore Spring Reservoir

Sycanore Rim

Sycamore Spring

Sycamore Spring

Sycamore Spring

Sycamore Spring

Sycamore Spring

Sycamore Spring

Sycamore Spring

Sycamore Spring

See Cake Mountain Spring

Sycamore Spring

Sycamore Spring

Sycamore Spring

Sycamore Spring

Sycamore Spring

Sycamore Spring

Sycamore Spring

Sycamore Spring

Sycanore Spring

Sycamore Spring

Sycamore Spring

Sycamore Spring

Sycanore Spring

Sycanore Spring

Sycamore Spring

Sycanore Spring

Sycanore Spring

Sycamore Spring

Sycamore Spring

Cottonwood Spring

Sycanore Spring

Sycanore Spring

Sycanore Spring

Sycanore Spring

Sycamore Spring Reservoir See Sycamore Reservoir

Sycamore Springs

Sycanore Substation

Sycamore Tank

Sycamore Tank

Sycanore Tank

Sycamore Tank

Sycanore Tank

Sycamore Tank

Sycamore Tank Number One

Sycamore Tank Number Two

Sycamore Trail (loop)

Sycamore Wash

Sycamore Well

Sycamore Well

Sydney

See Buckeye

Syke Knob

Sykes Knob Picnic Area

Sykes Spring

Sylvester Spring

Syndicate Wash

Syracuse Mine

$$
\begin{aligned}
& \text { FEATURE } \\
& \text { CLASS } \\
& \text { building } \\
& \text { locale } \\
& \text { reservoir } \\
& \text { cliff } \\
& \text { spring } \\
& \text { spring } \\
& \text { spring } \\
& \text { spring } \\
& \text { spring } \\
& \text { spring } \\
& \text { spring } \\
& \text { spring } \\
& \text { spring } \\
& \text { spring } \\
& \text { spring } \\
& \text { spring } \\
& \text { spring }
\end{aligned}
$$$$
\text { spring }
$$$$
\text { spring }
$$$$
\text { spring }
$$$$
\text { spring }
$$$$
\text { spring }
$$$$
\text { spring }
$$$$
\text { spring }
$$$$
\text { spring }
$$$$
\text { spring }
$$$$
\text { spring }
$$$$
\text { spring }
$$$$
\text { spring }
$$$$
\text { spring }
$$$$
\text { spring }
$$$$
\text { spring }
$$$$
\text { spring }
$$$$
\text { spring }
$$$$
\text { spring }
$$

STATUS

COUNTY

Yavapai

Yavapai

UMOFF

BMOFF 198

VARIANT

BGN

BGN

$B G N$
$B G N$

Yavapai

Cochise

Coch ise

Cochise

$\begin{array}{ll}\text { BGN } & \text { Pima } \\ \text { BGN } & \text { Pima } \\ \text { BGN } & \text { Pima } \\ \text { BGN } & \text { Graham } \\ \text { VARIANT } & \\ & \text { Graham } \\ \text { BGN } & \text { Graham } \\ \text { BGN } & \text { Graham } \\ \text { BGN } & \text { Graham } \\ \text { BGN } & \text { Graham }\end{array}$

Pina

Pima

Graham

Graham

Graham

Graham

BGN Graham 330457N1101905W

BGN Gila

BGN

BGN

BGN

BGN

BGN

BGN

BGN

Gila

Gila

Pinal

Gila

Gila

Gila

Maricopa

Gila

Maricopa

$315255 \mathrm{~N} 1104535 \mathrm{~W}$

$321319 \mathrm{~N} 1102909 \mathrm{~W}$

$321445 \mathrm{~N} 1102830 \mathrm{~W}$

$322844 \mathrm{~N} 1094429 \mathrm{~W}$

$324406 \mathrm{~N} 1102449 \mathrm{~W}$

$325350 \mathrm{~N} 1100902 \mathrm{~W}$

$325509 \mathrm{~N} 1101147 \mathrm{~W}$

$330037 \mathrm{~N} 1093131 \mathrm{~W}$

$330037 \mathrm{~N} 1102310 \mathrm{~W}$

BGN
BGN
BGN

Maricopa

Gila

Gila

Yavapai

BGN 1974 Gila

VARIANT

BGN

YGN Yavapa

Yavapai

Yavapai

Yavapai

$332358 \mathrm{~N} 1105536 \mathrm{~W}$

$332551 \mathrm{~N} 1105502 \mathrm{~W}$

$332728 \mathrm{~N} 1110547 \mathrm{~W}$

$333215 \mathrm{~N} 1104430 \mathrm{~W}$

$333528 \mathrm{~N} 1104707 \mathrm{~W}$

$334905 \mathrm{~N} 1105000 \mathrm{~W}$

$334937 \mathrm{~N} 1113349 \mathrm{~W}$

$335140 \mathrm{~N} 1112105 \mathrm{~W}$

$335530 \mathrm{~N} 1114807 \mathrm{~W}$

BGN

reservoir

spring
locale

reservoir

reservoir

reservoir

reservoir

reservoir

reservoir

VARIANT

UNOFF

BGN

BGN

BGN

BGN

BGN

reservoir

reservoir

trail

stream

well

well

pp)

summit

park

BGN

BGN

BGN

UNOFF

UNOFF

VARIANT

Graham

Yavapai

Santa Cruz

Graham

Gila

Yavapai

Yavapai

Yavapai

$335614 \mathrm{~N} 1112659 \mathrm{~W}$

$340701 \mathrm{N1112119 \textrm {W }}$

$340739 \mathrm{~N} 1112037 \mathrm{~W}$

$341125 \mathrm{~N} 1115357 \mathrm{~W}$

$341342 \mathrm{~N} 1110211 \mathrm{~W}$

$342340 \mathrm{~N} 1131758 \mathrm{~W}$

$342443 \mathrm{~N} 1115302 \mathrm{~W}$

$342858 \mathrm{N1114140 \textrm {W }}$

$343947 \mathrm{N1} 125157 \mathrm{~W}$

322057 N1104446W

$331021 \mathrm{~N} 1093338 \mathrm{~W}$

$342140 \mathrm{N1115732 \textrm {W }}$

$312204 \mathrm{~N} 1104636 \mathrm{~W}$

$331049 \mathrm{~N} 1093306 \mathrm{~W}$

$334135 \mathrm{~N} 1102920 \mathrm{~W}$

$342704 \mathrm{~N} 1114632 \mathrm{~W}$

$342838 \mathrm{~N} 1114256 \mathrm{~W}$

$345502 \mathrm{~N} 1120434 \mathrm{~W}$

Maricopa

Maricopa

Greenlee

Gila

Gila

Gila

Maricopa

Pima

$340130 \mathrm{~N} 1115802 \mathrm{~W}$

$340136 \mathrm{~N} 1115850 \mathrm{~W}$

$333330 \mathrm{N1} 1090425 \mathrm{~W}$

340657 N1112115W

$332800 \mathrm{~N} 1102903 \mathrm{~W}$

$333535 \mathrm{~N} 1104708 \mathrm{~W}$

$332213 N 1123459 \mathrm{~W}$

$322552 \mathrm{~N} 1104456 \mathrm{~W}$

$322555 \mathrm{~N} 1104455 \mathrm{~W}$

spring

spring

strean

ADMIN

Gila

BGN
BGN
BGN

Santa Cruz

$331645 N 1105240 \mathrm{~W}$

$314255 \mathrm{~N} 1105144 \mathrm{~W}$

$335221 \mathrm{N1} 124847 \mathrm{~W}$

Maricopa
Apache

$364602 \mathrm{~N} 1090316 \mathrm{~W}$
Pina

$\begin{array}{ll}\text { SOURCE } & \text { ELEV } \\ \text { COORDINATE } & \text { FT MAP NAME }\end{array}$

3604 Clarkdale

Dugas

Agua Caliente Hill

Swith Mesa

Huachuca Peak

Chiricahua Peak

Haberstock $\mathrm{Hill}$

Corona de Tucson

Happy Valley 


\section{FEATURE NAME}

Tabaha Well

Tabahinez Mesa

Tabernacle, The

Tablelands, The

The Table Lands

Table Mesa Interchange

Table Mountain

Table Mountain See Table Top

Table Mountain

Table Mountain

Table Mountain

Table Mountain

Table Mountain

Table Mountain

Table Mountain

Table Mountain

Table Mountain

Table Mountain

Table Mountain

Table Mountain

Table Mountain

Table Mountain

Table Mountain Canyon

Table Mountain Mine

Table Mountain Plateau

Table Mountain Spring

Table Mountain Tank

Table Mountain Tank

Table Mountain Tank

Table Mountain Tank

Table Mountain Trail

Table Rock

Table Rock

See Table Top

Table Rock Canyon

Table Rock Spring

Table Rock Tank

Table Spring

Table Top

Table Mountain

Table Rock

Table Top Mountain

Table Top

Table Top Peak

Table Top See Flat Top

Table Top

Table Top

See Stanfield

Table Top Mesa

Table Top Mountain See Table Top

Table Top Mountain See Flat Top

Table Top Mountain

Table Top Mountain

Table Top Mountains

Table Top Number Two Tank

Table Top Peak See Table Top

Table Top Tank

Table Top Tank

Table Top Valley

Taceo

See Picacho Peak

Tachitoa

See Hickiwan

See Noah

Tacna Landing Strip
FEATURE
CLASS

STATUS

COUNTY

well

summit

summit

bench

\section{UNOFF}

BGN 1906 Coconino

VARIANT

crossing

summit

BGN

VARIANT

summit

summit

summit

summit

summit

summit

summit

BGN

BGN

BGN

BGN

BGN

$B G N$

summit

summit

summit

summit

summit

summit

summit

summit

valley

mine

\section{BGN}

BGN

BGN

$B G N$

$B G N$

BGN

BGN

BGN

BGN

Maricopa

Pima

Pinal

Pinal

Graham

Greenlee

Maricopa

Yavapai

Yavapai

Gila

Yavapai

Yavapai

Yavapai

Yavapai

Yavapai

Coconino

Mohave

Gila

Pinal

plain

spring

reservoir

reservoir

reservoir

trail

pillar

$B G N$
$B G N$
$B G N$

BGN

BGN

BGN

BGN

UNOFF

BGN

summit

Mohave

Yavapai

Yavapai

Yavapai

Coconino

Yavapai

Yavapai

Coconino

Pinal

valley

spring

reservoir

spring

BGN

BGN

BGN

BGN 1941

VARIANT

VARIANT

VARIANT

summit

BGN

VARIANT

summit

summit

pp 1

summit

BGN

VARIANT

BGN

VARIANT

summit

VARIANT

summit

summit

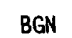

BGN

summit

summit

reservoir

BGN 19
BGN

VARIANT

summit

reservoir

reservoir

BGN

$B G M$

BGN

VARIANT

Coconino

Coconino

Coconino

Gila

Pinal

Greenlee

331303N1091004W

340520 N1091550W

$340936 \mathrm{N1111821 \textrm {W }}$

325257 N1115741W

$331054 \mathrm{N1090645 \textrm {W }}$

324533N1120728W

340520N1091550W

Apache

Yavapai

Yavapai

Pinal

Pinal

Gila

Gila

Pinal

summit

Pinal

VARIANT

ppl

locale

airport
VARIANT

Pima

Yuma
Yuma

ADMIN
$364245 \mathrm{~N} 1122800 \mathrm{~W}$

$364100 N 1122525$

$340923 \mathrm{~N} 1111839 \mathrm{~W}$

$324533 N 1120728$ W

SOURCE

COORDINATE

ELEV

MAP NAME

6563 Hunters Point

6214 Toadindaaska Mesa

4830 Cape Royal

Christmas

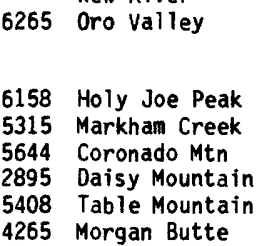

6265 Oro Valley

6158 Holy Joe Peak

5315 Markham Creek

5644 Coronado Mtn

2895 Daisy Mountain

5408 Table Mountain

4265 Morgan Butte

4130 North Peak

2944 Wet Bottom Mesa

5088 Horner Mtn

4621 Middle Verde

5571 Jerome Canyon

6197 Apache Maid Mtn

6613 Sunset Pass

3696 Mt Tipton

North Peak

Oak Grove Canyon

White Hills East

Horner Mtn

Wet Bottom Mesa

Horner Mtn

Apache Maid Mtn

Apache Maid Mtn

Table Mountain

Toothpick Ridge

$364012 N 1122328 W$

Toothpick Ridge

Toothpick Ridge

Toothpick Ridge

Payson South

4373 Indian Butte

5104 Dix Creek 


\section{FEATURE NAME}

Tacna Post Office

Tadpole Tank

Ta Enta Creek

See Laguna Creek

Taft Canyon

Taft Elementary School

Taft Mine

Taft Spring

Tah-aith-cheed Wash Teh-Aith Cheed Wash

Tahchee Teh-Aith Cheed
Toh Alth Wash

Tah Chee Wash Tahchito Creek

Tah-chito Creek

See Burnt Corn Wash

Tahchito Creek

$$
\text { See Tah Chee Wash }
$$

Tahdahatooc

Tah nih choa ah Spring

Tahoe Park

Taht Mahmeli

$$
\text { See Tat Momoli }
$$

Taht Mahmelia

See Tat Momoli

Taht Mahneli

See Tat Momoli

Tahuta Point

Tahuta Terrace

Tailhold Mesa

See Tailholt Mesa

Tailholt Mesa Tailhoid Mesa

Tailings Dam

See Tin Horn Tailing Dam

Tailings Pond Number One

Tailings Pond Number Three

Tailings Pond Number Two

Tailings Water Reclamation Dam

Tailings Water Reclamation

Reservoir

Takalai, Lake

Talahogan

See Awatobi (site)

Talahogan Canyon

Talahogan Spring

See Awatobi Spring

Talahogan Spring

Tala Hogan Wash

See Talahogan Wash

Talahogan Wash

Tala Hogan Wash

Talhchoze Tohe Meadow

Talies in

See Talies in West

Talies in West

Talies in

Taliverde (subdivision)

Talla-Hogan

See Awatobi (site)

Talla-Hogran

See Awatobi (site)

Tall Cone

Talley Spring

Talley Wash

Tall Mesa

Ta11 Mountain

Dzilnez Mesa

Zilh-nez Mesa

Zillnez Mesa

Zilner Mesa

Zilnez Mesa
FEATURE

\section{CLASS}

STATUS

COUNTY

COORDINATE

building

reservoir

stream

valley

school

mine

spring

valley

locale

stream

stream

UNOFF

BARIANT

BGN

Yuma

Greenlee

Apache

Yavapai

UNOFF Maricopa

UNOFF Yuma

BGN Yavapa

BGN Apache

VARIANT

VARIANT

BGN

Apache

VARIANT

VARIANT

Navajo

VARIANT

stream

summit

spring

park

locale

locale

locale

BGN

BGN

ADNIN

VARIANT

VARIANT

VARIANT

Apache

Apache

Apache

Pima

Pina 1

Pinal

Pinal

cliff

BGN 1925

BGN 1932 VARIANT

summit

summit

BGN

VARIANT

VARIANT

dam

reservoir

BGN

reservoir

BGN

reservoir $B G$

reservoir

UNOFF

BGN

reservoir BGN

locale

VARIANT

valley

BGN

VARIANT

spring

Coconino

Coconino

Yavapai

Yavapai

Gila

Gila

Gila

Gila

Greenlee

Greenlee

Gila

Navajo

Navajo

Navajo

spring

BGN

VARIANT

stream

stream BGN

flat

locale

locale

BGN

VARIANT

BGN

VARIANT

ppl

BGN

locale

locale

summit

spring

strean

pillar

summit

Maricopa

Maricopa

Maricopa
324150 N1135710W

$334146 \mathrm{~N} 1092425 \mathrm{~W}$

$365340 \mathrm{~N} 1094435 \mathrm{~W}$

342302 N112191OW

$332535 \mathrm{~N} 111370 \mathrm{BW}$

$331554 \mathrm{~N} 1132148 \mathrm{~W}$

$342406 \mathrm{~N} 1121954 \mathrm{~W}$

$355 B 13 N 1093020 \mathrm{~W}$

$361343 N 1095338 \mathrm{~W}$

$361400 \mathrm{~N} 1095345 \mathrm{~W}$

(1)

6660 Blue Gap

355908 N1100835W

$361400 \mathrm{~N} 1095345 \mathrm{~W}$

$362420 \mathrm{~N} 1091703 \mathrm{~W}$

$363902 \mathrm{~N} 1095751 \mathrm{~W}$

$321452 \mathrm{~N} 1105629 \mathrm{~W}$

323614N1115140W

$323614 \mathrm{~N} 1115140 \mathrm{~W}$

323614 N1115140W

$362145 N 1123020 \mathrm{~W}$

$362241 \mathrm{N1123151W}$

344541 N1124550W

$344541 \mathrm{N1} 12455 \mathrm{OW}$

$332654 N 1105018 \mathrm{~W}$

$332502 \mathrm{~N} 1105144 \mathrm{~W}$

$332454 \mathrm{N1} 105028 \mathrm{~W}$

$332500 \mathrm{~N} 1105111 \mathrm{~W}$

$330100 \mathrm{~N} 1092000 \mathrm{~W}$

$330223 \mathrm{~N} 109200 \mathrm{BW}$

332312 N1102548W

354331 N1101639W

$354404 \mathrm{~N} 1101814 \mathrm{~W}$

$354325 N 1101641 W$

$354407 N 1101631 W$

$354002 \mathrm{~N} 1102609 \mathrm{~W}$

$354002 N 1102609 \mathrm{~W}$

$355140 N 1090811 \mathrm{~W}$

$333625 N 1115033 W$

$333625 \mathrm{~N} 1115033 \mathrm{~W}$

333105 N1120140W

$354331 N 1101639 W$

354331 N1101639W

$362235 \mathrm{~N} 1091633 \mathrm{~W}$

$325936 \mathrm{~N} 1093905 \mathrm{~W}$

$325242 N 1094551 \mathrm{~W}$

Apache $\quad 364229 N 1094817 \mathrm{~W}$

$\begin{array}{ll}\text { Apache } & 364229 N 1094817 \mathrm{~W} \\ \text { Navajo } & 364731 \mathrm{N1} 103537 \mathrm{~W}\end{array}$

Bad Bug Butte

Red Point Mesa

Tucson

6508 Fossil Bay

Fishtail

5814 Seepage Mtn

Globe

Globe

Globe

Clifton

Clifton

Natural Corral

Star Mountain

Star Mountain

354446N1101552W Snake Butte

Piney $\mathrm{Hill}$

Sawik Mountain

1200 Sunnys lope

6700 Bad Bug Butte
Weber Peak

Weber

$325854 N 1093931 \mathrm{~W}$

5388 Tall Mesa

7596 Tall Mountain 


FEATURE
CLASS
well
reservoir
summit
locale
reservoir
reservoir
summit
well
locale
crossing

STATUS

UNOFF
BGN
BGN
UNOFF
BGN
BGN
BGN
UNOFF
UNOFF
UNOFF

Navajo
Navajo
Apache
Apache
Apache
Apache
Gila
Coconino
Yavapai

stream
locale

summit

reservoir

Tangle $P$

Tangle Peak Tank

Tan House Creek

See Rock House Creek

Tank, Lake

Tank 8utte

See Cowboy Butte

Tank Butte

See Bull Butte

Tank Canyon

Tank Canyon

See Tanks Canyon

Tank Canyon

Tank Canyon

Tank Canyon

Tank Creek

Tank Creek

Tank Creek

Tank Creek Mesa

Tank Creek Tank

Tank Dam

Tank Gulch

Tank Gulch Tank

Tank Hill

Tank in the Road

Tank Mountains

Frenchman Mountain

Puzzles Mountains

White Tank Mountains

Tank Pass

Tanks Canyon

Tank Canyon

Tanks Canyon Tank

Tank Wash

Tank Wash

Tank Water Tank

Tanner Canyon

See Garden Canyon

Tanner Canyon

Tanner Canyon Rapids

Tanner Crossing

See Tanners Crossing

Tanner Peak

Tanner Ranch

Tanners Crossing

Tanner Crossing

Tanner Springs

Tanner Tank

Tanner Wash

See Jacobs Wash

Tanner Wash

Tanner Wash

Tanner Wash

Roundy Creek

Tanner Well

Tanque

Tanque Aloma

Tanque Aloma

Antelope $\mathrm{Hill}$

Antelope Hills Stage

summit

VARIANT

sumat

VARIANT

Gila

Gila

valle

8GN

VARIANT

valley

valley

valley

valley

stream

stream

stream

BGN

BGN

BGN

BGN

BGN

Pima

Gila

Gila

Yavapai

Mohave

Gila

Yavapai

Yavapai

reservoir

dam

valley

ridge

reservoir $B$

ridge

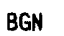

UNOFF

BGN

BGN
BGN
BGN
BGN

VARIANT

VARIANT

VARIANT

BGN
BGN
VARIANT

reservoir

stream

BGN

BGN

stream BGM

reservoir $B G N$

VARIANT

valley

BGN 190

Gila

Gila

Maricopa

Yavapai

Yavapai

Cochise

Coconino

rapids

BGN

VARIANT

locale

Coconino

Coconino

local

UNOFF

BGN 1905

VARIANT

locale BGN

Gila

Coconino

reservoir BGN

Apache

VARIANT

arroyo

Coconino

Navajo

$\begin{array}{lll}\text { arroyo } & \text { BGN } & \text { Navajo } \\ \text { stream } & \text { BGN } & \text { Navajo } \\ \text { stream } & \text { BGN } & \text { Coconino } \\ & \text { VARIANT } & \\ \text { well } & \text { UNOFF } & \text { Coconino } \\ \text { locale } & \text { BGN } & \text { Graham } \\ \text { reservoir } & \text { BGN } & \text { Yavapai } \\ \text { ppl } & \text { BGN } & \text { Yuma } \\ & \text { VARIANT } & \\ & \text { VARIANT } & \end{array}$

BGN 1981 Yavapai 340505N1114236W

BGN Y401 340858N1114804W

BGN Yavapai 340721N1114420W

BGN Yavapai 340924N1114526W

Gila 335745N1104211W

lake BGN Mohave 353948N1140620W

334730N1101505W

$334800 \mathrm{~N} 1101602 \mathrm{~W}$

$315106 \mathrm{~N} 1111243 \mathrm{~W}$

$334602 \mathrm{~N} 1102632 \mathrm{~W}$

$335208 \mathrm{~N} 1103113 \mathrm{~W}$

$341934 \mathrm{~N} 1115009 \mathrm{~W}$

$362220 N 1135513 W$

$334048 \mathrm{~N} 1110319 \mathrm{~W}$

$341215 \mathrm{~N} 1120533 \mathrm{~W}$

$343551 \mathrm{~N} 1125324 \mathrm{~W}$

$343423 N 1125056 \mathrm{~W}$

Yavapai 343407N1125012W

Gila 334006Ni102000W

Gila 341B26N1112810W

Gila 341933N1112838W

Cochise 312644N1095508

Coconino 344143N1110601W

Yuma 330937N1134142W

gap BGN Yuma 335209N1134218W 334602 N11D2632W

$334602 N 1102632 \mathrm{~W}$

$334249 N 1103001 \mathrm{~W}$

$334148 \mathrm{~N} 1124754 \mathrm{~W}$

$342740 \mathrm{~N} 1130204 \mathrm{~W}$

343450 N1125128W

$312930 \mathrm{~N} 1101900 \mathrm{~W}$

$360609 N 1114951 \mathrm{~W}$

$360608 \mathrm{~N} 1115012 \mathrm{~W}$

$355150 \mathrm{~N} 1112311 \mathrm{~W}$

$334952 \mathrm{~N} 1110106 \mathrm{~W}$

335148 N1105947W

$355150 \mathrm{~N} 1112311 \mathrm{~W}$

$355150 \mathrm{~N} 1112311 \mathrm{~W}$

$354137 \mathrm{~N} 1113301 \mathrm{~W}$

345609N1101057W

$345625 \mathrm{~N} 1101904 \mathrm{~W}$

345616 N1101052W

$364155 N 1114237 \mathrm{~W}$

$362245 N 1113236 \mathrm{~W}$

$363621 N 1113933 \mathrm{~W}$

$323632 N 1093215 \mathrm{~W}$

$343046 \mathrm{~N} 1113555 \mathrm{~W}$

$324150 \mathrm{~N} 1135725 \mathrm{~W}$
315225N1111301W

Batamote Hills

$335206 N 1102648 W$

$342024 \mathrm{~N} 1114736 \mathrm{~W}$

$362150 \mathrm{~N} 1134640 \mathrm{~W}$

$334819 N 1110347 \mathrm{~W}$

$341118 N 1115834 \mathrm{~W}$

$343324 N 1124722 W$

$342053 N 1112927$ W

$345935 N 1101904 W$

$35022 B N 1101211 \mathrm{~W}$

MAP NAME

7342 Tall Mountain Clay Springs Tall Tree Mesa

8000 Nutrioso Nutrioso Milky Ranch

4633 Hayden

5331 Preston Well Dugas

Marana

Chalk Mountain Bloody Bas in

3542 Chalk Mountain 8 loody Basin

Red Lake

Mule Hoof Bend

Tule Mesa

Gyp Hills

Windy $\mathrm{Hill}$

Joes $\mathrm{Hill}$

Muleshoe Ranch

Mart in Mtn

Martin Mtn

Popcorn Canyon Buckhead Mesa Buckhead Mesa

8 is bee

Quayle Hill

Palomas Mts West

334040 N1103312W

$335316 N 1125342 \mathrm{~W}$

2793 Harcuvar Beckers Butte

Chrysotile

Star Well

Malpais Mesa NE

Martin Mtn

Desert View

Desert View

6917 Armer Mountain

Aztec Peak

Cameron South

Tanner Springs

Campbell Francis Wsh

Joseph City

Holbrook

Bitter Springs

Tanner Well

Tanque

Buckhorn Mountain

347 Tacna 
NATIONAL GAZETTEER--ARIZONA 1986

$\begin{array}{lcc}\text { FEATURE NAME } & \begin{array}{c}\text { FEATURE } \\ \text { CLASS }\end{array} & \text { STATUS } \\ \text { Station } & & \\ \text { Gael } & & \text { VARIANT } \\ \text { New Tacna } & \\ \text { Raiphs Hill } & \text { VARIANT } \\ \text { Ralphs Mill } & & \text { VARIANT } \\ & & \text { VARIANT }\end{array}$

Tanque Verde

Tanque Verde Canyon

Tanque Verde Creek

Tanque Verde Falls

Tanque Verde Mountains See Rincon Mountains

Tanque Verde Mountains

See Tanque Verde Ridge

Tanque Verde Peak

Tanque Verde Ranch

\section{Tanque Verde Ridge}

Agua Verde Range

Tanque Verde Mountains

Tanque Verde School

Tanque Verde Shopping Center

Tanque Verde Trail

Tanque Verde Wash

Tapaha Well

Tapco

Tapco Cliff Dwellings

Tapco Power Plant and Substation

Tapco Railroad Station

Tapeats Amphitheater

Tapeats Cave

Tapeats Creek

Thunder River

apeats Creek

See Timp Canyon

Tapeats Rapids

Tapeats Spring

Tapeats Terrace

Tapon Tank

Tappan Spring

Tappan Spring Canyon

Tappan Wash Cedar Wash

Tappen Spring

Tap Tank

Tarantula Tank

Tar Box Canyon

Tar Mine

Tartron

Tartron Well

Tar Wash

Tascala Canyon

Taskeles Canyon

Tascala Tank

Taskeles Tank

Tascal Ravine

Tascal Tank

Tascuela Canyon

Tascuela Wash

Taskeles Canyon

See Tascala Canyon

Taskeles Tank

See Tascala Tank

Tassi Ranch

Tassi Spring

Tassi Wash

Tatahatso Point

Tatahatso Wash

Tatahoysa Wash

Tatai Toak

Perigua

Tatia Toak pp

valley

stream

falls

ridge

ridge

summit

locale

ridg

schoo

locale

trail

strean

well

locale

locale

BGN Pima

BGN Pima

Pima

Pima

VARIANT Pima

VARIANT

BGN

Pima

Pima

UNOFF

BGN 1976 Pima

VARIANT

VARIANT

UNOFF

UNOFF

UNOFF

UNOFF Coconino

BGN

locale UNOFF Yavapai

building

bas in

cave

stream

UNOFF

BGN

Coconino

VARIANT

VARIANT

valley

rapids

BGN 1932

spring

bench

reservoir

spring

valley

stream

spring

BGN

BGN 1932 Coconino

BGN

BGN

1964 Coconino

ARIANT

BGN

reservoir

valley $B G N$

mine $U$ UNOFF

locale

we 11

stream

valley

reservoir

valley

BGN

UNOFF

BGN

VARIANT

BGN 1982

VARIANT

reservoir

valley

strean

BGN

BGN

VARIANT

valley

reservoir

locale

spring

VARIANT

UNOFF

BGN

BGN

cliff

strean

stream

locale

BGN

BGN

BGN

BGN 1964

VARIANT
VARIANT
BGN 1982 Santa Cruz
Pina

Yavapai

Yavapai

Coconino

Coconino

Coconino

Coconino

Yavapai

Coconino

321506N1104412W $321443 \mathrm{N1} 104104 \mathrm{~W}$

$321607 N 1105230 \mathrm{~W}$

$321515 N 1103921 \mathrm{~W}$

320755N1 103108W

$321224 N 1103646 \mathrm{~W}$

$321149 \times 1103751 \mathrm{~W}$

321430N1104057W

$321224 N 1103646 W$

$321459 N 1104517 \mathrm{~W}$

$321510 \mathrm{~N} 1105020 \mathrm{~W}$

$321035 \mathrm{~N} 1104100 \mathrm{~W}$

$321609 \mathrm{N1} 105231 \mathrm{~W}$

$361957 \mathrm{N1111915 \textrm {W }}$

$344741 \mathrm{NL} 120246 \mathrm{~W}$

344741 N1120353h

$344740 \mathrm{~N} 1120246 \mathrm{~W}$

$344754 \mathrm{~N} 1120301 \mathrm{~W}$

362352 N1122427W

$362427 N 1122545 \mathrm{~W}$

$362214 N 1122807 \mathrm{~W}$

$362322 \mathrm{~N} 1122315 \mathrm{~W}$

362212 N1122809W

$362424 \mathrm{~N} 1122546 \mathrm{~W}$

$362245 \mathrm{~N} 1122535 \mathrm{~W}$

315429 N1110945W

$355130 \mathrm{~N} 1112630 \mathrm{~W}$

$355253 \mathrm{N1112603 \textrm {W }}$

$355257 \mathrm{~N} 1112608 \mathrm{~W}$

351056 N1114655

$344522 \mathrm{N1113606 \textrm {W }}$

354424NI115327W

$321318 N 1093222 \mathrm{~W}$

$324337 N 1104245 \mathrm{~W}$

$325244 N 1130557 \mathrm{~W}$

$325405 N 1131232 \mathrm{~W}$

$324458 \mathrm{~N} 1103916 \mathrm{~W}$

312431N1105040W

312446 N1104910W

Pinal

$323245 \mathrm{~N} 1105534 \mathrm{~W}$

$323249 N 1105524 W$

Pinal

Pima

Pima

Santa Cruz

315151N1111634k

315031N1111949W

312431N1105040W

Santa Cruz

Mohave

Mohave

Mohave

Coconino

Coconino

Pima

$312446 \mathrm{~N} 1104910 \mathrm{~W}$

361521 N1135724W

$361524 N 1135727 \mathrm{~N}$

361525 N113565IW

$362442 \mathrm{~N} 1115116 \mathrm{~W}$

$362619 N 1115047 \mathrm{~W}$

$362337 N 1115042 \mathrm{~W}$

$322347 N 1122945 \mathrm{~W}$

SOURCE
COORDINATE

AZ623

FT MAP NAME

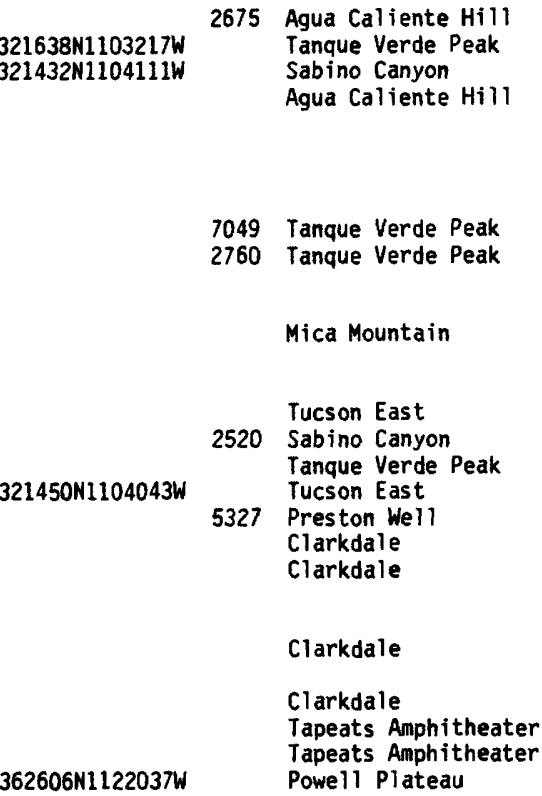

$355125 \mathrm{~N} 1112639 \mathrm{~W}$

$355212 N 1114640 \mathrm{~W}$

$362128 N 1113937 \mathrm{~W}$
$361642 N 1114858 \mathrm{~W}$

$315242 \mathrm{~N} 1111326 \mathrm{~W}$

$315241 N 1111327 \mathrm{~W}$

Powell Plateau

Tapeats Amphitheater

Tapeats Amphitheater

Samaniego Peak

Cameron South

Cameron North

Cameron North

Bellemonit

Stoneman Lake

Dog Knobs

Dos Cabezas

Manmoth

Sentinel NE

Sentinel Peak

Mammoth

Cumero Canyon

Cumero Canyon

Oracle Junction

Oracle Junction

Penitas Hills

Penitas Hills

Gyp Hills

Gyp Hills

Gyp Hills

Tatahatso Point

Tatahatso Point

Tatahatso Point

Cimarron Peak 


\begin{tabular}{|c|c|c|c|c|c|c|c|}
\hline FEATURE NAME & $\begin{array}{l}\text { FEATURE } \\
\text { CLASS }\end{array}$ & STATUS & COUNTY & COORDINATE & $\begin{array}{l}\text { SOURCE } \\
\text { COORDINATE }\end{array}$ & $\underset{\mathrm{FT}}{\mathrm{ELEV}}$ & MAP NAME \\
\hline $\begin{array}{c}\text { Tatria Toak } \\
\text { Tatamumera } \\
\text { See Tat Momoli } \\
\text { Tata Munerikut } \\
\text { See Tat Momoli }\end{array}$ & $\begin{array}{l}\text { locale } \\
\text { locale }\end{array}$ & $\begin{array}{l}\text { VARIANT } \\
\text { VARIANT } \\
\text { VARIANT }\end{array}$ & $\begin{array}{l}\text { Pinal } \\
\text { Pinal }\end{array}$ & 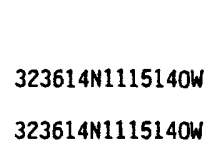 & & & \\
\hline $\begin{array}{l}\text { Tatamumerikut } \\
\text { See Tat Momoli } \\
\text { Tater Canyon } \\
\text { Tater Canyon Springs } \\
\text { Tater Point } \\
\text { Tater Ridge } \\
\text { Tatezaka Tank } \\
\text { Tatia Toak }\end{array}$ & $\begin{array}{l}\text { locale } \\
\text { valley } \\
\text { spring } \\
\text { cliff } \\
\text { ridge } \\
\text { reservoir }\end{array}$ & $\begin{array}{l}\text { VARIANT } \\
\text { BGN } \\
\text { BGN } \\
\text { BGN } \\
\text { BGN } \\
\text { BGN } 1915 \\
\text { VARIANT }\end{array}$ & $\begin{array}{l}\text { Pinal } \\
\text { Coconino } \\
\text { Coconino } \\
\text { Coconino } \\
\text { Coconino } \\
\text { Apache }\end{array}$ & $\begin{array}{l}323614 N 1115140 \mathrm{~W} \\
362857 N 1115914 \mathrm{~W} \\
362943 \mathrm{N1120414W} \\
363147 \mathrm{N1120529W} \\
363059 \mathrm{N1} 120544 \mathrm{~W} \\
360645 \mathrm{~N} 1092300 \mathrm{~W}\end{array}$ & $362744 \mathrm{~N} 1120622 \mathrm{~W}$ & & $\begin{array}{l}\text { Buffalo Ranch } \\
\text { Dog Point } \\
\text { Cane } \\
\text { Cane } \\
\text { Three Turkey Canyon }\end{array}$ \\
\hline $\begin{array}{l}\text { See Tatai Toak } \\
\text { Tatk Kam Vo } \\
\text { Iranit } \\
\text { Nestors }\end{array}$ & $\begin{array}{l}\text { locale } \\
\text { locale }\end{array}$ & $\begin{array}{l}\text { BGN } 1941 \\
\text { VARIANT } \\
\text { VARIANT }\end{array}$ & $\begin{array}{l}\text { Pima } \\
\text { Pima }\end{array}$ & $\begin{array}{l}322347 \mathrm{~N} 1122945 \mathrm{~W} \\
315924 \mathrm{~N} 1122035 \mathrm{~W}\end{array}$ & & 1791 & Kon Vo \\
\hline $\begin{array}{l}\text { Tatkum Vo } \\
\text { Serape } \\
\text { Tat Momoli } \\
\text { Jack Rabbit } \\
\text { Jackrabbit } \\
\text { Jack Rabbit We11 } \\
\text { Jackrabbit Well } \\
\text { Taht Mahmeli } \\
\text { Taht Mahmelia } \\
\text { Taht Mahneli } \\
\text { Tatamumera } \\
\text { Tata Mumerikut } \\
\text { Tatamumerikut } \\
\text { Tatmumerikut }\end{array}$ & $\begin{array}{l}\text { locale } \\
\text { locale }\end{array}$ & $\begin{array}{l}\text { BGN } 1941 \\
\text { VARIANT } \\
\text { BGN } \\
\text { VARIANT } \\
\text { VARIANT } \\
\text { VARIANT } \\
\text { VARIANT } \\
\text { VARIANT } \\
\text { VARIANT } \\
\text { VARIANT } \\
\text { VARIANT } \\
\text { VARIANT } \\
\text { VARIANT } \\
\text { VARIANT }\end{array}$ & $\begin{array}{l}\text { Pima } \\
\text { Pinal }\end{array}$ & $\begin{array}{l}314005 \mathrm{~N} 1120723 \mathrm{~W} \\
323614 \mathrm{~N} 1115140 \mathrm{~W}\end{array}$ & & 2296 & $\begin{array}{l}\text { Tecolote Ranch } \\
\text { Silver Reef Mts SE }\end{array}$ \\
\hline $\begin{array}{l}\text { Tat Momolikot Dam } \\
\text { Tat Momoli Mountains } \\
\text { Silver Reef Mountains }\end{array}$ & $\begin{array}{l}\text { dam } \\
\text { summit }\end{array}$ & $\begin{array}{l}\text { UNOFF } \\
\text { BGN } \\
\text { VARIANT }\end{array}$ & $\begin{array}{l}\text { Pinal } \\
\text { Pinal }\end{array}$ & $\begin{array}{l}343903 N 1115612 W \\
323957 N 1115323 W\end{array}$ & & 1509 & $\begin{array}{l}\text { Vaiva Vu } \\
\text { Vaiva Vo }\end{array}$ \\
\hline $\begin{array}{l}\text { Tat Momoli Pass } \\
\text { Tat Momoli Valley } \\
\text { Tat Momoli Wash } \\
\text { Aquirre Valley } \\
\text { Jack Rabbit Wash } \\
\text { Tatmumerikut } \\
\text { See Tat Momoli }\end{array}$ & $\begin{array}{l}\text { gap } \\
\text { valley } \\
\text { stream }\end{array}$ & $\begin{array}{l}\text { BGN } \\
\text { BGN } \\
\text { BGN } \\
\text { VARIANT } \\
\text { VARIANT } \\
\text { VARIANT }\end{array}$ & $\begin{array}{l}\text { Pinal } \\
\text { Pinal } \\
\text { Pinal }\end{array}$ & 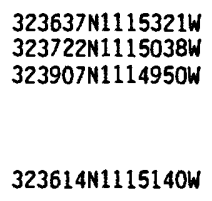 & $\begin{array}{l}323243 \mathrm{~N} 1114827 \mathrm{~W} \\
322845 \mathrm{~N} 1114715 \mathrm{~W}\end{array}$ & & $\begin{array}{l}\text { North Komelik } \\
\text { Silver Reef Mts SE } \\
\text { Silver Reef Mts }\end{array}$ \\
\hline $\begin{array}{l}\text { Tatnick } \\
\text { Tator Hills } \\
\text { Tatria Toak } \\
\quad \text { See Tatai Toak }\end{array}$ & $\begin{array}{l}\text { locale } \\
\text { surmit } \\
\text { locale }\end{array}$ & $\begin{array}{l}\text { BGN } \\
\text { BGN } \\
\text { VARIANT }\end{array}$ & $\begin{array}{l}\text { Pima } \\
\text { Pinal } \\
\text { Pima }\end{array}$ & 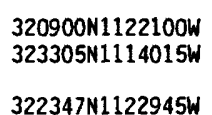 & & 1901 & $\begin{array}{l}\text { Wahak Hotrontk } \\
\text { Greene Reservoir }\end{array}$ \\
\hline $\begin{array}{l}\text { Tatum Baca } \\
\text { Tatum Tank } \\
\text { Tauabit } \\
\text { See Totopitk } \\
\text { Taul Creek } \\
\text { See Towel Creek }\end{array}$ & $\begin{array}{l}\text { lake } \\
\text { reservoir } \\
\text { locale } \\
\text { strear }\end{array}$ & $\begin{array}{l}\text { BGN } \\
\text { BGN } \\
\text { VARIANT } \\
\text { VARIANT }\end{array}$ & $\begin{array}{l}\text { Navajo } \\
\text { Yavapai } \\
\text { Maricopa } \\
\text { Yavapai }\end{array}$ & $\begin{array}{l}341953 \mathrm{N1103738W} \\
344859 \mathrm{~N} 1123407 \mathrm{~W} \\
323348 \mathrm{~N} 1121244 \mathrm{~W} \\
342450 \mathrm{~N} 1114650 \mathrm{~W}\end{array}$ & & & $\begin{array}{l}\text { Brookbank Point } \\
\text { Sullivan Buttes }\end{array}$ \\
\hline $\begin{array}{l}\text { Taul Peaks } \\
\text { See Towel Peaks } \\
\text { Taul Spring } \\
\text { See Towel Spring } \\
\text { Tautabit } \\
\text { See Totopitk } \\
\text { Taut Creek } \\
\text { See Towel Creek } \\
\text { Tavan Elementary School } \\
\text { Tavasci Mine }\end{array}$ & $\begin{array}{l}\text { ridge } \\
\text { spring } \\
\text { locale } \\
\text { stream } \\
\text { school } \\
\text { mine }\end{array}$ & $\begin{array}{l}\text { VARIANT } \\
\text { VARIANT } \\
\text { VARIANT } \\
\text { VARIANT } \\
\text { UNOFF } \\
\text { UNOFF }\end{array}$ & $\begin{array}{l}\text { Yavapai } \\
\text { Yavapai } \\
\text { Maricopa } \\
\text { Yavapai } \\
\text { Maricopa } \\
\text { Yuma }\end{array}$ & $\begin{array}{l}342350 \mathrm{~N} 1114315 \mathrm{~W} \\
342435 \mathrm{~N} 1114253 \mathrm{~W} \\
323348 \mathrm{~N} 1121244 \mathrm{~W} \\
342450 \mathrm{~N} 1114650 \mathrm{~W} \\
332918 \mathrm{~N} 1115854 \mathrm{~W} \\
323920 \mathrm{~N} 1134259 \mathrm{~W}\end{array}$ & & & $\begin{array}{l}\text { Tempe } \\
\text { Mowhawk Mts NW }\end{array}$ \\
\hline $\begin{array}{l}\text { Tavasel Marsh } \\
\text { Tavern School } \\
\text { Ta-vo-num } \\
\text { See Brownell Peak } \\
\text { Tawa Park } \\
\text { Tawa Point } \\
\text { Point Tawa } \\
\text { Taylor } \\
\text { Taylor Airport } \\
\text { Taylor Basin }\end{array}$ & $\begin{array}{l}\text { Swamp } \\
\text { school } \\
\text { summit } \\
\text { park } \\
\text { cliff }\end{array}$ & $\begin{array}{l}\text { BGN } \\
\text { UNOFF } \\
\text { VARIANT } \\
\text { ADMIN } \\
\text { BGN } \\
\text { VARIANT } \\
\text { BGN } \\
\text { ADMIN } \\
\text { BGN }\end{array}$ & $\begin{array}{l}\text { Yavapai } \\
\text { Maricopa } \\
\text { Pima } \\
\text { Maricopa } \\
\text { Apache }\end{array}$ & 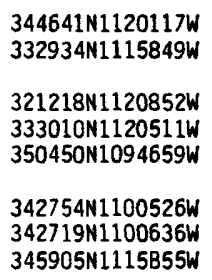 & & $\begin{array}{l}5600 \\
4560\end{array}$ & $\begin{array}{l}\text { Taylor } \\
\text { Taylor } \\
\text { Loy Butte }\end{array}$ \\
\hline
\end{tabular}




\section{FEATURE NAME}

Taylor Bas in Tank

Taylor Butte

Taylor Cabin Trail

Taylor Canyon

See North Timp Point

Taylor Cemetery

Taylor Field

Taylor Gulch

Taylor Knoll

Taylor Pass

Taylor Place

Taylor Ranch

Taylor Ranch

Taylor Reservoir Dan Carnero Lake Dam

Taylor Spring

Taylor Tank

Taylor Tank

T-Bar Ranch

T-Bar Tank

T-bar Tank Number One

T-bar Tank Number Two

T Bar Y Tank

T-Bench-Bar Ranch

$T$ Bone Tank

T-Bone Tank

TB Spring

Tcacca

See Picacho Peak

T D Tank

Tea Cup Ranch

Teague Spring

Teague Spring

Teague Spring Canyon

Tea Kettle Mountain See Tule Tank

Tea Kettle Mountain

See Hat Mountain

Teakettle Pass

Teal Coves

Tea Pot

Teapot Mountain

Teaque Tank

Tear Spring

Teas Toh

See Tees Toh

Tea Tank

Teclote Windmill

Tecolate

See Chukut Kuk

Tecolete (historical)

Tecoleto

See Chukut Kuk

Tecolote

See Chukut Kuk

Tecolote Ranch

Tecolote Ranch

Tecolote Valley

Tecota

See Green Valley

Teddy Chee Spring

Ted Spring

Teds Wash

Ted Tank

Teece Nas Pas

See Teec Nos Pos

Teec Nid Suen Wash

See Ti is Ndi itsooi Wash

Teec Nos Pas

See Teec Nos Pos
FEATURE
CLASS

STATUS

reservoir

summit

locale

$B G N$ Coconino

$B$ Cochise

cliff VARIANT

cemetery UNOFF

park ADMIN

valley

$B G N$

gap

locale

locale

dam

spring

reservoir

reservoir

locale

BGN 1932 Graham

BGN Cochise

UNOFF Cochise

UNOFF Yavapai

UNOFF Apache

BGN

$\begin{array}{ll}\text { BGN } & \text { Yavapai } \\ \text { UNOFF } & \text { Coconino }\end{array}$

reservoir

reservoir

reservoir

locale

reservoir

reservoir

spring

$B G N$
$B G N$
$B G N$

BGN
BGN

UNOFF

BGN

$B G N$

VARIANT

summit

reservoir

locale

spring

spring

valley

reservoir

summit

gap

BGN

UNOFF

$B G N$

$B G N$

BGN

VARIANT

VARIANT

BGN

bay

pillar

summit

spring

BGN
BGN

$B G N$
$B G N$
$B G N$

VARIANT

locale

reservoir

locale

BGN

BGN

VARIANT

locale

BGN

locale

locale

locale

locale

locale

valley

ppl

VARIANT

UNOFF

UNOFF

BGN 1941

VARIANT

spring

spring

reservoir

$B G M$

BGN

$B G N$

VARIANT

pp 1

VARIANT

stream

VARIANT

ppl
COUNTY

Coconino

Coconino

Navajo

Maricopa

Yavapai

Navajo

Coconino

Gila

Yavapai

Coconino

Coconino

Coconino

Coconino

Pima

Maricopa

Maricopa

Yavapai

Pinal

Yavapai

Pinal

Graham

Graham

Graham

Graham

Maricopa

Mohave

Mohave

Apache

Pinal

Cochise

Yavapai

Navajo

Coconino

Apache

Pima

Pima

Pima

Pima

Pima

Pinal

Pima

Pima

COORDINATE

345912 N1115905W

$345917 \mathrm{N1115915 \textrm {W }}$

$350001 N 1115716 \mathrm{~W}$

$362325 \mathrm{N1122136 \textrm {W }}$

$342752 \mathrm{~N} 1100550 \mathrm{~W}$

$332417 \mathrm{N1114940 \textrm {W }}$

$340910 N 1122156 \mathrm{~W}$

$342726 \mathrm{~N} 1100215 \mathrm{~W}$

$324408 \mathrm{~N} 1100042 \mathrm{~W}$

$320434 \mathrm{~N} 1091927 \mathrm{~W}$

$312742 \mathrm{~N} 1090700 \mathrm{~W}$

$345516 \mathrm{~N} 1125142 \mathrm{~W}$

$360636 \mathrm{~N} 1093142 \mathrm{~W}$

351710 N1114441W

$342047 \mathrm{N111} 3048 \mathrm{~W}$

345504 N1115429W

$344344 \mathrm{N1113146 \textrm {W }}$

344259 N1113139W

$344029 \mathrm{N1113020 \textrm {W }}$

$344350 \mathrm{~N} 1113131 \mathrm{~W}$

$350935 \mathrm{~N} 1121732 \mathrm{~W}$

$322803 \mathrm{~N} 1110349 \mathrm{~W}$

$334338 \mathrm{~N} 1120641 \mathrm{~W}$

$335846 \mathrm{~N} 1130834 \mathrm{~W}$

$341022 \mathrm{N1122635 \textrm {W }}$

323806N1112400W

$342045 \mathrm{~N} 1121521 \mathrm{~W}$

$330038 N 1110351 \mathrm{~W}$

$330136 \mathrm{~N} 1093236 \mathrm{~W}$

$330336 \mathrm{~N} 1095246 \mathrm{~W}$

$330140 \mathrm{~N} 1095529 \mathrm{~W}$

$332041 \mathrm{N1095507 \textrm {W }}$

323807 N1124430W

$360149 \mathrm{~N} 1143835 \mathrm{~W}$

$360424 \mathrm{~N} 1142012 \mathrm{~W}$

$352254 \mathrm{~N} 1090433 \mathrm{~W}$

$331151 \mathrm{N1110135 \textrm {W }}$

312537 N1092131W

$341147 \mathrm{~N} 1115028 \mathrm{~W}$

$352958 \mathrm{~N} 1102418 \mathrm{~W}$

$350831 \mathrm{~N} 1112657 \mathrm{~W}$

350125 N1092651W

314556 N1120616W

314300 N1120600W

$314556 \mathrm{~N} 1120616 \mathrm{~W}$

$314556 \mathrm{~N} 1120616 \mathrm{~W}$

$314440 \mathrm{~N} 1120522 \mathrm{~W}$

$325534 \mathrm{N1105727 \textrm {W }}$

314738 N1121250W

$315115 N 1105935 \mathrm{~W}$

$361312 \mathrm{~N} 1090317 \mathrm{~W}$

$340236 \mathrm{~N} 1091406 \mathrm{~W}$

$344646 \mathrm{~N} 1094756 \mathrm{~W}$

$314653 \mathrm{~N} 1112227 \mathrm{~W}$

Apache

Pima

Apache

Apache

Apache

$\begin{array}{ccc}\text { SOURCE } & \text { ELEV } \\ \text { COORDINATE } & \text { FT NAP NAME }\end{array}$

Loy Butte

4659 Leslie Canyon

Loy Butte

Sycamore Point

Taylor

Mesa

340931N1122039W Crown King

5910 Taylor

Blue Jay Peak 
NATIONAL GAZETTEER--ARIZONA 1986

FEATURE NAME

Teec Nos Pas Canyon See Teec Nos Pos Canyon

Teec Nos Pas Canyon Teec Nos Pos Canyon Tisnasbas Canyon

Teec Nos Pas Wash See Teec Nos Pos Wash

Teec Nos Pos Carrizo

Teece Nas Pas

Teec Nos Pas

Teec Nos Pos

Tes Nos Pas

Tes Nos Pas Trading Post

Tes Nos Pes

Tisnasbas

Teec Nos Pos

See Teec Nos Pos

Teec Nos Pos Boarding School

Teec Nos Pos Canyon Teec Nos Pas Canyon Tisnasbas Canyon

Teec Nos Pos Canyon

See Teec Nos Pas Canyon

Teec Nos Pos Chapter House

Teec Nos Pos Landing Strip

Teec Nos Pos Wash Teec Nos Pas Wash

Tee Ranch

Tees Spa Spring

Tees To

See Cedar Springs

Tees To

See Tees Toh

Tees Toh

Teas Toh

Tees To

Tees Toh Spring

Tees Toh Wash

Corn Wash

North 8ranch Corn Wash

North Fork Corn Wash

Seba Dalkai Wash

Tegakwitha Indian Mission and School

See Tegakwithan Mission

Tegakwithan Mission Tegakwitha Indian Mission and School

Teh-Aith Cheed Wash See Tah-aith-cheed Wash

Tehua Hills

$$
\text { Little Alps }
$$
Tejua Hills

Tejano Spring

Tejanos Spring

Tejua Hills

$$
\text { See Tehua Hills }
$$

Telegraph Canyon

Telegraph Pass

Telegraph Pass

Telegraph Spring Windmill

Telegraph Wash

Telegraph Wash

Telephone Canyon

Telephone Canyon

Telephone Dam

Telephone Draw Tank

Telephone $\mathrm{Hil}$

Telephone Lake (sewage

disposal

Telephone Line Ridge

Telephone Mesa

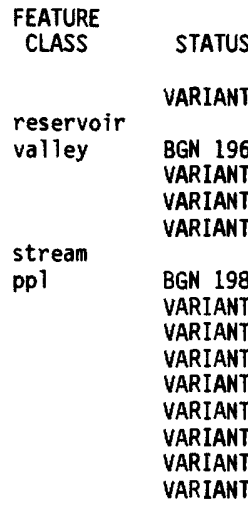

VARIANT

school

reservoir

UNOFF

BGN 1983

Apache

Apache

VARIANT

VARIANT

valley

building

airport

VARIANT

stream

locale

spring

locale

locale

locale

UNOFF
ADMIN

Apache

Apache

Apache

BGN 1983 Apache

VARIANT

UNOFF

BGN

VARIANT

VARIANT

BGN

VARIANT

VARIANT

spring

BGN

BARIANT

VARIAN

VARIAN

VARIANT

VARIANT

school

school

UNOFF

VARIANT

Apache

Apache

VARIANT

valley

range

BGN 1917

VARIANT

VARIANT

spring

spring

range

valley

BGN

VARIANT

BGN

gap $\quad B G N$

gap

stream

stream

valley

valley

dam

reservoir

summit

$B G N$

BGN

$B G N$
$B G N$

BGN

BGN

UNOFF

BGN

BGN
BGN

lake

BGN

ridge

summit
Apache

Santa Cruz

Maricopa

Pinal

Yuma

Maricopa

Yavapai

Graham

Graham

Gila

Navajo

Yavapai

Yavapai

Coconino

Navajo

Navajo

Greenlee
$365516 \mathrm{N1090506 \textrm {W }}$

$365417 N 1090615 \mathrm{~W}$

$365225 \mathrm{~N} 1090710 \mathrm{~W}$

$365230 \mathrm{~N} 1090715 \mathrm{~W}$ $365436 \mathrm{~N} 1090626 \mathrm{~W}$

$365443 \mathrm{~N} 1090351 \mathrm{~W}$

$365830 \mathrm{~N} 1090549 \mathrm{~W}$

335818N1120629w

363912N1101826W

$352706 \mathrm{~N} 1102149 \mathrm{~W}$

$352958 \mathrm{~N} 1102418 \mathrm{~W}$

$352958 \mathrm{N1} 102418 \mathrm{~W}$

$352926 \mathrm{~N} 1101821 \mathrm{~W}$ $352941 \mathrm{N1} 103449 \mathrm{~W}$

$352836 \mathrm{~N} 1101702 \mathrm{~W}$

351638 N1091258W

$351638 \mathrm{~N} 1091258 \mathrm{~W}$

365225N1090710W

355813N1093020W

UNKNOWN

$313434 N 1105510 \mathrm{~W}$

$334234 \mathrm{N1} 112214 \mathrm{~W}$

UNKNOWN

331547N1110807W

331229 N1110854W

$323938 N 1141935 \mathrm{~W}$

$331913 \mathrm{N1} 120400 \mathrm{~W}$

$342559 \mathrm{~N} 1123412 \mathrm{~W}$

$325 \mathrm{BO} N 1100453 \mathrm{~W}$

$325835 \mathrm{~N} 1102508 \mathrm{~W}$

$335657 N 1112511 \mathrm{~W}$

$340739 N 1100925 \mathrm{~W}$

$341646 \mathrm{~N} 1125313 \mathrm{~W}$

345659 N1121140W

$363244 \mathrm{~N} 1120939 \mathrm{~W}$

341735 N1100240W

$341103 \mathrm{~N} 1103225 \mathrm{~W}$

$332710 \mathrm{~N} 1092214 \mathrm{~W}$
Teec Nos Pos

Daisy Mountain

Kayenta West

5745 Shonto Butte

Dilkon

Montezumas Chair

Houck

Teec Nos Pos Bellemont

Teec Nos Pos

5450 Teec Nos Pos$$
\text { Chair }
$$

San Cayetano Mts Four Peaks

Picketpost Mtn

Ligurta

Lone Butte

Wilhoit

Telegraph Wash

Booger Canyon

Reno Pass

Red Top Mtn

Seligman West

Perkinsville

Telephone Hill

Show Low North

Pepper Canyon 8402 Rose Peak 
FEATURE NAME

Telephone Ridge

Telephone Ridge

Telephone Ridge

Telephone Ridge

Telephone Ridge

Telephone Ridge

Telephone Spring

Telephone Spring

Telephone Tank

Telephone Tank

Telephone Tank

Telephone Tank

Telephone Tank

Telles Ranch

Temecha Creek

See Tuntsa Creek

Tempe

Butte City

Haydens Butte

Haydens Ferry

Haydens Mill

San Pablo

Tempe Beach Park

Tempe Park

Tempe Butte

Tempe Canp

Tempe Cana 1

Utah Canal

Tempe Cascade (trailer park)

Tempe Cemetery

Tempe Community Center

Tempe Community Hospital

See Tempe Saint Lukes Hospital

Tempe Cross Cut Canal

Tempe Drainage District

Number Two Ditch

Tempe High School

Tempe High School Tennis and

Racquetball Courts

Tempe Historical Museum

Tempe Junction

Tempe Junction Railroad

Station (historical)

Tempe Municipal Stadium Diablo Stadium

Tempe Park

See Tempe Beach Park

Tempe Park

Tempe Public Library

Tempe Royal Palms (subdivision)

Tempe Saint Lukes Hospital Tempe Community Hospital

Tempe Shopping Center

Tempe Square Shopping Center

Tempe Travel Trailer Villa

Temple Bar Airport

Temple Bar Boat Anchorage

Temple Bar Marina

Temple Bar Wash

See Temple Wash

Temple Bas in

Temple Butte

Temple of Om

See Tyndall Dome

Temple Pond

Temple Trail

Temple Trail Tank

Temple Wash

Temple Bar Wash

Temporal Gulch
FEATURE
CLASS

STATUS

COUNTY

ridge

ridge

ridge

ridge

ridge

ridge

\section{BGN}

Greenlee

Navajo

Navajo

Coconino

Coconino

spring

spring

reservoir

reservoir

reservoir

reservoir

reservair

locale

stream

BGN
BGN
BGN
BGN
BGN
BGN
BGN
UNOFF
VARIANT

Navajo

Apache

Gila

Apache

Coconino

Yavapai

Coconino

Cochise

Apache

pp1

BGN

VARIANT

VARIANT

VARIANT

VARIANT

VARIANT

park ADMIN

$\begin{array}{ll} & \text { VARIANT } \\ \text { summit } & \text { BGN } 1917\end{array}$

locale

BGN

Maricopa

Maricopa

Coconino

canal

BGN

locale

cemetery

building

hospital

VARIANT

UNOFF

UNOFF

UNOFF

VARIANT

Maricopa

Maricopa

Maricopa

Maricopa

Maricopa

cana

canal

BGN

Maricopa

Maricopa

$332550 \mathrm{~N} 1115625 \mathrm{~W}$

$332541 \mathrm{~N} 1115606 \mathrm{~W}$

$345428 \mathrm{~N} 1112630 \mathrm{~W}$

$332358 N 1115301 \mathrm{~W}$

$332527 \mathrm{N1115312 \textrm {W }}$

$332423 \mathrm{~N} 1115824 \mathrm{~W}$

$332331 \mathrm{~N} 1115544 \mathrm{~W}$

$332443 \mathrm{~N} 1115624 \mathrm{~W}$

$332612 \mathrm{~N} 1114920 \mathrm{~W}$

$332502 \mathrm{~N} 1115925 \mathrm{~W}$

schoo
local

UNOFF

locale

building

locale

building

BGN

UNOFF

building

UNOFF

VARIANT

VARIANT

park

$\begin{array}{ll}\text { park } & \text { ADMIN } \\ \text { building } & \text { UNOFF }\end{array}$

pp 1

hospital UNOFF

VARIANT

locale UNOFF
locale

locale UNOFF
locale UNOFF

airport ADMIN

harbor

$B G N$

harbor

BGN

VARIANT

stream

basin

summit

BGN

VARIANT

summit

reservoir

BGN

UNOFF

reservoir

BGN

Coconino

Mohave

Mohave

Mohave

stream BGN 1948 Mohave

VARIANT

valley $B G N$

$332430 \mathrm{~N} 1115625 \mathrm{~W}$

$332434 \mathrm{N1} 115625 \mathrm{~W}$

$332330 \mathrm{N1115544 \textrm {W }}$

$332451 N 1115634 \mathrm{~W}$

$332455 N 1115634 \mathrm{~W}$

332404N1115810W

$332550 \mathrm{~N} 1115625 \mathrm{~W}$

$332630 \mathrm{~N} 1115600 \mathrm{~W}$

$332332 \mathrm{~N} 1115544 \mathrm{~W}$

$332054 \mathrm{~N} 1115415 \mathrm{~W}$

332443 NI115624K

$332145 \mathrm{~N} 1115444 \mathrm{~W}$

$332448 \mathrm{~N} 1115422 \mathrm{~W}$

$360112 N 1142004 W$

$360208 \mathrm{N1141916 \textrm {W }}$

360133 N1141906W

$360212 N 1142006 \mathrm{~W}$

$360303 \mathrm{N1} 141851 \mathrm{~W}$

$360943 \mathrm{~N} 1114926 \mathrm{~W}$

$361337 N 1122122 \mathrm{~W}$

$363905 \mathrm{~N} 1131622 \mathrm{~W}$

$365150 \mathrm{~N} 1132129 \mathrm{~W}$

$363917 \mathrm{N1131305W}$
SOURCE

COORDINATE

ELEV
FT

MAP NAME

Bear Mountain

6736 Red Top Mtn

Chediski Peak

Day Spring

Weimer Point

Blue Ridge Reservoir

Red Top Mtn

Sponseller Mtn

San Carlos

Sponseller Mtn

Long Valley

Paulden

Munds Park

Turquoise Mountain

Tempe

Tempe

1495 Tempe

Mormon Lake

Tempe

1185 Tempe

Tempe

Tempe

Mesa

Tempe

$332514 \mathrm{~N} 1115617 \mathrm{~W}$

$360212 \mathrm{~N} 1142006 \mathrm{~W} \quad 355546 \mathrm{~N} 1141944 \mathrm{~W}$

$313131 N 1104642 \mathrm{~W} \quad 314009 \mathrm{~N} 1105053 \mathrm{~W}$

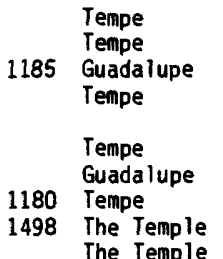

The Temple

The Temple

5308 Cape Solitude

The Grandstand

Gyp Pocket

Antelope Knoll

The Temple

Patagonia 


\begin{tabular}{|c|c|c|c|c|c|c|c|}
\hline FEATURE NAME & $\begin{array}{l}\text { FEATURE } \\
\text { CLASS }\end{array}$ & STATUS & COUNTY & COORDINATE & $\begin{array}{l}\text { SOURCE } \\
\text { COORDINATE }\end{array}$ & $\begin{array}{c}\text { ELEV } \\
\text { FT }\end{array}$ & MAP NAME \\
\hline $\begin{array}{l}\text { Temporal Pass } \\
\text { Temp Pothole Spring } \\
\text { Ten, Canal (historical) } \\
\text { Canal Salado } \\
\text { Tenahatchip Pass } \\
\text { Tenderfoot Hill } \\
\text { Tenderfoot Hill Park }\end{array}$ & $\begin{array}{l}\text { gap } \\
\text { spring } \\
\text { canal } \\
\text { gap } \\
\text { summit } \\
\text { park }\end{array}$ & $\begin{array}{l}\text { BGN } \\
\text { BGN } \\
\text { BGN } \\
\text { VARIANT } \\
\text { BGN } \\
\text { BGN } \\
\text { AONIN }\end{array}$ & $\begin{array}{l}\text { Pima } \\
\text { Yavapai } \\
\text { Maricopa } \\
\text { Yuma } \\
\text { Yavapai } \\
\text { Yavapai }\end{array}$ & $\begin{array}{l}321652 \mathrm{~N} 1130219 \mathrm{~W} \\
344102 \mathrm{~N} 1125044 \mathrm{~W} \\
332540 \mathrm{~N} 1120146 \mathrm{~W} \\
\\
334607 \mathrm{N1} 132932 \mathrm{~W} \\
341047 \mathrm{N1} 125137 \mathrm{~W} \\
341038 \mathrm{N1} 125130 \mathrm{~W}\end{array}$ & & 3477 & $\begin{array}{l}\text { Temporal Pass } \\
\text { Smith Mesa } \\
\text { Phoenix } \\
\text { Socorro Peak } \\
\text { Congress } \\
\text { Congress }\end{array}$ \\
\hline $\begin{array}{l}\text { Tenebito Spring } \\
\text { See Dinnebito Spring } \\
\text { Tenebito Wash } \\
\text { See Dinnebito Wash } \\
\text { Ten-en-ta Creek } \\
\text { See Laguna Creek } \\
\text { Ten Ewe Canyon } \\
\text { Ten Ewe Mountain } \\
\text { Tengs Isaac Shopping Center } \\
\text { Tenmile Cedars }\end{array}$ & $\begin{array}{l}\text { spring } \\
\text { valley } \\
\text { stream } \\
\text { valley } \\
\text { summit } \\
\text { locale } \\
\text { woods }\end{array}$ & $\begin{array}{l}\text { VARIANT } \\
\text { VARIANT } \\
\text { VARIANT } \\
\text { BGN } \\
\text { BGN } \\
\text { UNOFF } \\
\text { BGN }\end{array}$ & $\begin{array}{l}\text { Coconino } \\
\text { Coconino } \\
\text { Apache } \\
\text { Yuma } \\
\text { Yuma } \\
\text { Maricopa } \\
\text { Navajo }\end{array}$ & $\begin{array}{l}354749 N 1105437 \mathrm{~W} \\
352845 N 1111415 \mathrm{~W} \\
365340 N 1094435 \mathrm{~W} \\
332206 \mathrm{~N} 1140341 \mathrm{~W} \\
332126 \mathrm{N1} 140416 \mathrm{~W} \\
332755 N 1120805 \mathrm{~W} \\
343811 N 1100557 \mathrm{~W}\end{array}$ & 332117 N1140400W & & $\begin{array}{l}\text { Palm Canyon } \\
\text { Palm Canyon } \\
\text { Fowler } \\
\text { Tenmile Cedars }\end{array}$ \\
\hline $\begin{array}{l}\text { Tenmile Draw } \\
\text { Tenmile Tank } \\
\text { Tenmile Wash } \\
\text { Childs Wash } \\
\text { Rio Cornez } \\
\text { Rio Cornez Wash } \\
\text { Rio Tenmile Wash } \\
\text { Tenmile Well } \\
\text { Tenneco Well } \\
\text { Tennehleto Spring } \\
\text { See Moenkopi }\end{array}$ & $\begin{array}{l}\text { valley } \\
\text { reservoir } \\
\text { stream }\end{array}$ & $\begin{array}{l}\text { BGN } \\
\text { BGN } \\
\text { BGN } \\
\text { VARIANT } \\
\text { VARIANT } \\
\text { VARIANT } \\
\text { VARIANT } \\
\text { UNOFF } \\
\text { UNOFF } \\
\text { VARIANT }\end{array}$ & $\begin{array}{l}\text { Yuma } \\
\text { Cochise } \\
\text { Coconino }\end{array}$ & $\begin{array}{l}335917 \mathrm{~N} 1140719 \mathrm{~W} \\
315117 \mathrm{~N} 1100006 \mathrm{~W} \\
360640 \mathrm{~N} 1111318 \mathrm{~W}\end{array}$ & $\begin{array}{l}343657 N 1101350 \mathrm{~W} \\
322624 \mathrm{~N} 1123733 \mathrm{~W}\end{array}$ & 5113 & $\begin{array}{l}\text { Tenmile Cedars } \\
\text { Hackberry Mtn } \\
\text { Aztec Hills }\end{array}$ \\
\hline $\begin{array}{l}\text { Tennessee Mine } \\
\text { Tennessee Wash } \\
\text { Tenney Mountain } \\
\text { Tenneys Camp } \\
\text { See Woodruff } \\
\text { Tenney Tank } \\
\text { Tenny Flat } \\
\text { Ten of Diamonds Creek } \\
\text { Ten of Diamonds Ranch } \\
\text { Ten Ranch }\end{array}$ & $\begin{array}{l}\text { mine } \\
\text { stream } \\
\text { summit } \\
\text { ppl } \\
\text { reservoir } \\
\text { flat } \\
\text { stream } \\
\text { locale } \\
\text { locale }\end{array}$ & $\begin{array}{l}\text { UNOFF } \\
\text { BGN } \\
\text { BGN } \\
\text { VARIANT } \\
\text { BGN } \\
\text { BGN } \\
\text { BGN } \\
\text { UNOFF } \\
\text { UNOFF }\end{array}$ & $\begin{array}{l}\text { Mohave } \\
\text { Mohave } \\
\text { Apache } \\
\text { Navajo } \\
\text { Apache } \\
\text { Navajo } \\
\text { Apache } \\
\text { Apache } \\
\text { Graham }\end{array}$ & $\begin{array}{l}352456 \mathrm{~N} 1141105 \mathrm{~W} \\
351535 \mathrm{~N} 1141713 \mathrm{~W} \\
334837 \mathrm{~N} 1091341 \mathrm{~W} \\
344653 \mathrm{~N} 1100234 \mathrm{~W} \\
334745 \mathrm{~N} 1090530 \mathrm{~W} \\
340953 \mathrm{~N} 1095250 \mathrm{~W} \\
333524 \mathrm{~N} 1093846 \mathrm{~W} \\
333518 \mathrm{~N} 1093844 \mathrm{~W} \\
322754 \mathrm{~N} 1094306 \mathrm{~W}\end{array}$ & $352721 \mathrm{~N} 1141019 \mathrm{~W}$ & 9058 & $\begin{array}{l}\text { Chloride } \\
\text { Grasshopper Junc SE } \\
\text { Alpine } \\
\text { Luna Lake } \\
\text { Lakeside } \\
\text { Maverick SW } \\
\text { Maverick SW } \\
\text { Monk Draw }\end{array}$ \\
\hline $\begin{array}{l}\text { Tenstrike Mine } \\
\text { T-en-ta } \\
\text { See Tyende Mesa } \\
\text { Ten Tank } \\
\text { Tenth Street Park } \\
\text { Ten X Campground } \\
\text { Ten X Tank } \\
\text { Tepee Butte } \\
\text { Tepees, The } \\
\text { Tequa Tewa }\end{array}$ & $\begin{array}{l}\text { mine } \\
\text { summit } \\
\text { reservoir } \\
\text { park } \\
\text { park } \\
\text { reservoir } \\
\text { summit } \\
\text { pillar } \\
\text { locale }\end{array}$ & $\begin{array}{l}\text { UNOFF } \\
\text { VARIANT } \\
\text { BGN } \\
\text { ADNIN } \\
\text { ADNIN } \\
\text { BGN } \\
\text { 8GN } \\
\text { BGN } \\
\text { BGN } 1915 \\
\text { VARIANT }\end{array}$ & $\begin{array}{l}\text { Graham } \\
\text { Navajo } \\
\text { Coconino } \\
\text { Cochise } \\
\text { Coconino } \\
\text { Coconino } \\
\text { Pima } \\
\text { Apache } \\
\text { Navajo }\end{array}$ & $\begin{array}{l}325419 \mathrm{~N} 110192 \mathrm{BW} \\
364759 \mathrm{~N} 1102004 \mathrm{~W} \\
354416 \mathrm{~N} 1120424 \mathrm{~W} \\
312040 \mathrm{~N} 1093309 \mathrm{~W} \\
355613 \mathrm{~N} 1120720 \mathrm{~W} \\
355712 \mathrm{~N} 1120502 \mathrm{~W} \\
321856 \mathrm{N1} 125856 \mathrm{~W} \\
345650 \mathrm{N1} 1094629 \mathrm{~W} \\
\text { UNKNOWN }\end{array}$ & & $\begin{array}{l}6650 \\
1936\end{array}$ & $\begin{array}{l}\text { Cobre Grande Mtn } \\
\text { Molly Anne Draw } \\
\text { Douglas } \\
\text { Tusayan East } \\
\text { Tusayan East } \\
\text { Chico Shunie } \\
\text { Adamana }\end{array}$ \\
\hline $\begin{array}{l}\text { Tequa Spring } \\
\text { Tewa Spring } \\
\text { Tequila Tank } \\
\text { Tequila Tank } \\
\text { Teran Basin } \\
\text { Teran Wash } \\
\text { Teresa Tank } \\
\text { Terimate Tank } \\
\text { Terrapin Pass } \\
\text { Territorial Government } \\
\text { Formation Site Historical } \\
\text { Monument }\end{array}$ & $\begin{array}{l}\text { spring } \\
\text { reservoir } \\
\text { reservoir } \\
\text { basin } \\
\text { stream } \\
\text { reservoir } \\
\text { reservoir } \\
\text { gap } \\
\text { park }\end{array}$ & $\begin{array}{l}\text { BGN } 1915 \\
\text { VARIANT } \\
\text { BGN } \\
\text { BGN } \\
\text { BGN } \\
\text { BGN } \\
\text { BGN } \\
\text { BGN } \\
\text { BGN } \\
\text { ADMIN }\end{array}$ & $\begin{array}{l}\text { Navajo } \\
\text { Pima } \\
\text { Pima } \\
\text { Cochise } \\
\text { Cochise } \\
\text { Graham } \\
\text { Pinal } \\
\text { Pinal } \\
\text { Apache }\end{array}$ & $\begin{array}{l}\text { UNKNOWN } \\
313805 N 1112651 \mathrm{~W} \\
321758 N 1103920 \mathrm{~W} \\
321751 \mathrm{N1} 101529 \mathrm{~W} \\
321538 \mathrm{~N} 1102026 \mathrm{~W} \\
325119 \mathrm{~N} 1101535 \mathrm{~W} \\
325306 \mathrm{~N} 1111930 \mathrm{~W} \\
332625 \mathrm{~N} 1112202 \mathrm{~W} \\
350601 \mathrm{N1} 1092945 \mathrm{~W}\end{array}$ & $321929 N 1101546 \mathrm{~W}$ & 3189 & $\begin{array}{l}\text { Las Guijas } \\
\text { Agua Caliente Hill } \\
\text { Soza Mesa } \\
\text { Soza Mesa } \\
\text { Klondike } \\
\text { Cactus Forest } \\
\text { Weavers Needle } \\
\text { Navajo Springs }\end{array}$ \\
\hline $\begin{array}{l}\text { Terruno Canyon } \\
\text { See Toruno Canyon } \\
\text { Terry Flat } \\
\text { Terry Number One Tank } \\
\text { Terry Number Three Tank } \\
\text { Terry Number Two Tank } \\
\text { Terry Ranch } \\
\text { Teruno Canyon } \\
\text { See Turuno Canyon } \\
\text { Teruno Canyon } \\
\text { See Toruno Canyon }\end{array}$ & $\begin{array}{l}\text { valley } \\
\text { flat } \\
\text { reservoir } \\
\text { reservoir } \\
\text { reservoir } \\
\text { locale } \\
\text { valley } \\
\text { valley }\end{array}$ & $\begin{array}{l}\text { VARIANT } \\
\text { BGN } \\
\text { BGN } \\
\text { BGN } \\
\text { BGN } \\
\text { UNOFF } \\
\text { VARIANT } \\
\text { VARIANT }\end{array}$ & $\begin{array}{l}\text { Santa Cruz } \\
\text { Apache } \\
\text { Apache } \\
\text { Apache } \\
\text { Apache } \\
\text { Yuma } \\
\text { Santa Cruz } \\
\text { Santa Cruz }\end{array}$ & $\begin{array}{l}312720 \mathrm{~N} 1110205 \mathrm{~W} \\
335402 \mathrm{~N} 1090704 \mathrm{~W} \\
335337 \mathrm{~N} 1090628 \mathrm{~W} \\
335348 \mathrm{~N} 1090704 \mathrm{~W} \\
335425 \mathrm{~N} 1090718 \mathrm{~W} \\
324628 \mathrm{~N} 1135600 \mathrm{~W} \\
312724 \mathrm{~N} 1110203 \mathrm{~W} \\
312720 \mathrm{~N} 1110205 \mathrm{~W}\end{array}$ & & & $\begin{array}{l}\text { Escudilla Mtn } \\
\text { Escudilla Mtn } \\
\text { Escudilla Mtn } \\
\text { Escudilla Mtn } \\
\text { Roll }\end{array}$ \\
\hline
\end{tabular}


NATIONAL GAZETTEER--ARIZONA 1986

\section{FEATURE NAME}

Teruno Tank

See Toruno Tank

See Bidahochi Wash

Teshbi

See Bidahochi Wash

Tesihim Butte

Tes Nez Iah

Tes Nos Pas

See Teec Nos Pos

Tes Nos Pas Trading Post See Teec Nos Pos

Tes Nos Pes

See Teec Nos Pos

Tesoro, Paso de

Tesota

See Gila Bend

Test Hole Tank

Tetterman Spring

Teuajo Alta

See Cabeza Prieta Pass

Teuson

See Tucson

Tevs Rocks

Tewa

See Tequa

Tewa

Tewa Spring

See Tequa Spring

Tewksbury Spring

Texas Canyon

Texas Canyon Summit

See Texas Canyon Summit

Texas Canyon Sumnit

Texas Canyon Summit

Texas Gulch

Texas $\mathrm{Hill}$

Texas $\mathrm{Hill}$

See Stoval

Texas Hill Canal

Texas Mine

Texas Shaft

Texas Windmill

Tex Canyon

Tex Canyon

Tex Canyon Spring

Tex Canyon Tank

Te-ye-ba-a-kit Lake

See Debebekid Lake

Tezinie Canyon

Tezinie Wash

Tezotal

See Gila Bend

T G Barr School

Thacker Latera

Thatcher

Thatcher Cemetery

Thatcher City Hall

Thatcher Elementary School

Thatcher Fire Department

Thatcher High School

Thatcher Post Office

Thatch Hut Spring Number One

Thatch Hut Spring Number Two

The Adobe

The Arrowhead

See Arrowhead Mountain

The Aztec

Theba

Theba Elementary School

Theba Interchange

BGN Gila

$320347 N 1100427 \mathrm{~W}$

$313914 N 1091829 \mathrm{~W}$
FEATURE

STATUS

COUNTY

COORDINATE

$\begin{array}{cc}\text { SOURCE } & \text { ELEV } \\ \text { COORDINATE } & \text { FT }\end{array}$

MAP NAME

\begin{tabular}{|c|c|c|c|}
\hline & VARIANT & & \\
\hline eservoir & YAB & Santa Cruz & $312634 \mathrm{~N} 1110530 \mathrm{~W}$ \\
\hline$r e$ & VARIANT & Navajo & $351815 N 1100615 W$ \\
\hline $\begin{array}{l}\text { tream } \\
\text { ummit } \\
\text { ocale }\end{array}$ & $\begin{array}{l}\text { BGN } \\
\text { BGN } \\
\text { VARIANT }\end{array}$ & $\begin{array}{l}\text { Navajo } \\
\text { Navajo } \\
\text { Apache }\end{array}$ & $\begin{array}{l}351815 \mathrm{~N} 1100615 \mathrm{~W} \\
353123 \mathrm{~N} 1100535 \mathrm{~W} \\
365635 \mathrm{~N} 1094230 \mathrm{~W}\end{array}$ \\
\hline & & Apache & $365516 \mathrm{~N} 1090506 \mathrm{~W}$ \\
\hline
\end{tabular}

$365516 \mathrm{~N} 1090506 \mathrm{~W}$

VARIANT

pp

ppl

gap

ppl

reservoir

spring

gap

VARIANT

Apache

Apache

BGN 1917 Pinal

VARIANT

BGN

Maricopa

Yavapai

BGN Yavapai

Yuma

$365516 \mathrm{~N} 1090506 \mathrm{~W}$

UNKNOWN

325652N1124258W

$345313 \mathrm{~N} 1114517 \mathrm{~W}$

$340748 N 1122727 W$

321B51N1134926W

ppl

pillar

VARIANT

locale

ppl

spring

spring

valley

gap

valley

summit

locale

canal

mine

mine

locale

valley

spring

lake

valley

valley

BGN

VARIANT

BGN

VARIANT

VARIANT

BGN 19B4
VARIANT

BGN

BGN
VARIANT

BGN Yuma

UNOFF

UNOFF

BGN

BGN

BGN

VARIANT

$B G N$

BGN

Cochise

Cochise

Yavapai

Yuma

Santa Cruz

$321318 N 1105533 \mathrm{~W}$

$320915 N 1092630 \mathrm{~W}$

UNKNOWN

355120N1102300W

UNKNOWN

334732N1105405

$320016 \mathrm{~N} 1100819 \mathrm{~W}$

$320347 N 1100427 W$

$34304 \mathrm{BN} 1121334 \mathrm{~W}$ $324953 \mathrm{~N} 1134134 \mathrm{~W}$

$324554 N 1133717 \mathrm{~W}$

$325019 \mathrm{~N} 1134259 \mathrm{~W}$

$312229 N 1104124 \mathrm{~W}$

$344511 N 1120545 \mathrm{~W}$

$342653 N 1123925 \mathrm{~W}$

$343421 \mathrm{N1} 120708 \mathrm{~W}$

$343534 \mathrm{~N} 1120909 \mathrm{~W}$

$343521 N 1120845 \mathrm{~W}$

$314347 N 1092112$

Cochis

Yavapa

Yavapai

Navajo

362237 N1101313W

$362021 N 1093118$

$361746 \mathrm{~N} 1092543 \mathrm{~W}$ $362024 \mathrm{~N} 1093120 \mathrm{~W}$

6467 White Cone Mexican Water

Camp Verde

Minnehaha

Polacca

Aztec Peak
Navajo $362144 N 1093325 \mathrm{~W}$

Bowie Mtn North

320355N1100418W San Pedro Ranch

\begin{tabular}{|c|c|c|}
\hline \multirow{3}{*}{$343611 \mathrm{~N} 1120947 \mathrm{~W}$} & 4950 & Dragoon \\
\hline & $7 \mathrm{BO}$ & $\begin{array}{l}\text { Humboldt } \\
\text { Texas Hill }\end{array}$ \\
\hline & & $\begin{array}{l}\text { Texas Hill } \\
\text { Duquesne }\end{array}$ \\
\hline $\begin{array}{l}314347 \mathrm{~N} 1092112 \mathrm{~W} \\
343642 \mathrm{~N} 1120921 \mathrm{~W}\end{array}$ & 4419 & $\begin{array}{l}\text { Clarkdale } \\
\text { Kirkland } \\
\text { Swede Peak } \\
\text { Cherry } \\
\text { Humboldt } \\
\text { Humboldt }\end{array}$ \\
\hline $\begin{array}{l}361746 \mathrm{~N} 1092543 \mathrm{~W} \\
362024 \mathrm{~N} 1093120 \mathrm{~W}\end{array}$ & & $\begin{array}{l}\text { Many Farms } \\
\text { Many Farms }\end{array}$ \\
\hline
\end{tabular}

$325652 \mathrm{~N} 1124258 \mathrm{~W}$

$332307 N 1120210 \mathrm{~W}$

$324058 \mathrm{N11} 143929 \mathrm{~W}$

$325057 \mathrm{N1} 094531 \mathrm{~W}$

$325000 N 1094543 \mathrm{~W}$

$325057 \mathrm{N1094538 \textrm {W }}$

$325058 N 1094523 \mathrm{~W}$

325059 N1094538W

$325058 \mathrm{~N} 1094526 \mathrm{~W}$

$325054 \mathrm{~N} 1094538 \mathrm{~W}$

$344702 \mathrm{~N} 1120544 \mathrm{~W}$

$344700 \mathrm{~N} 1120518 \mathrm{~W}$

321615N1125717W

$\begin{array}{ll}\text { BGN } & \text { Yavapai } \\ \text { BGN } & \text { Yavapai }\end{array}$

BGN

VARIANT

summ it

locale

BGN

BGN

UNOFF

Pima

$335300 \mathrm{~N} 1112800 \mathrm{~W}$

341659 N1091103W

$325510 \mathrm{~N} 1125338 \mathrm{~W}$

325515 N1125319W

$325515 N 1125315 \mathrm{~W}$

Maricopa

Maricopa

Phoenix
Yuma West
Thatcher
Thatcher
2900 Thatcher
2900 Thatcher
2900 Thatcher
2900 Thatcher

2900 Thatcher
Clarkdale
Clarkdale
Chico Shunie

Voigt Ranch
Theba
Theba
Theba




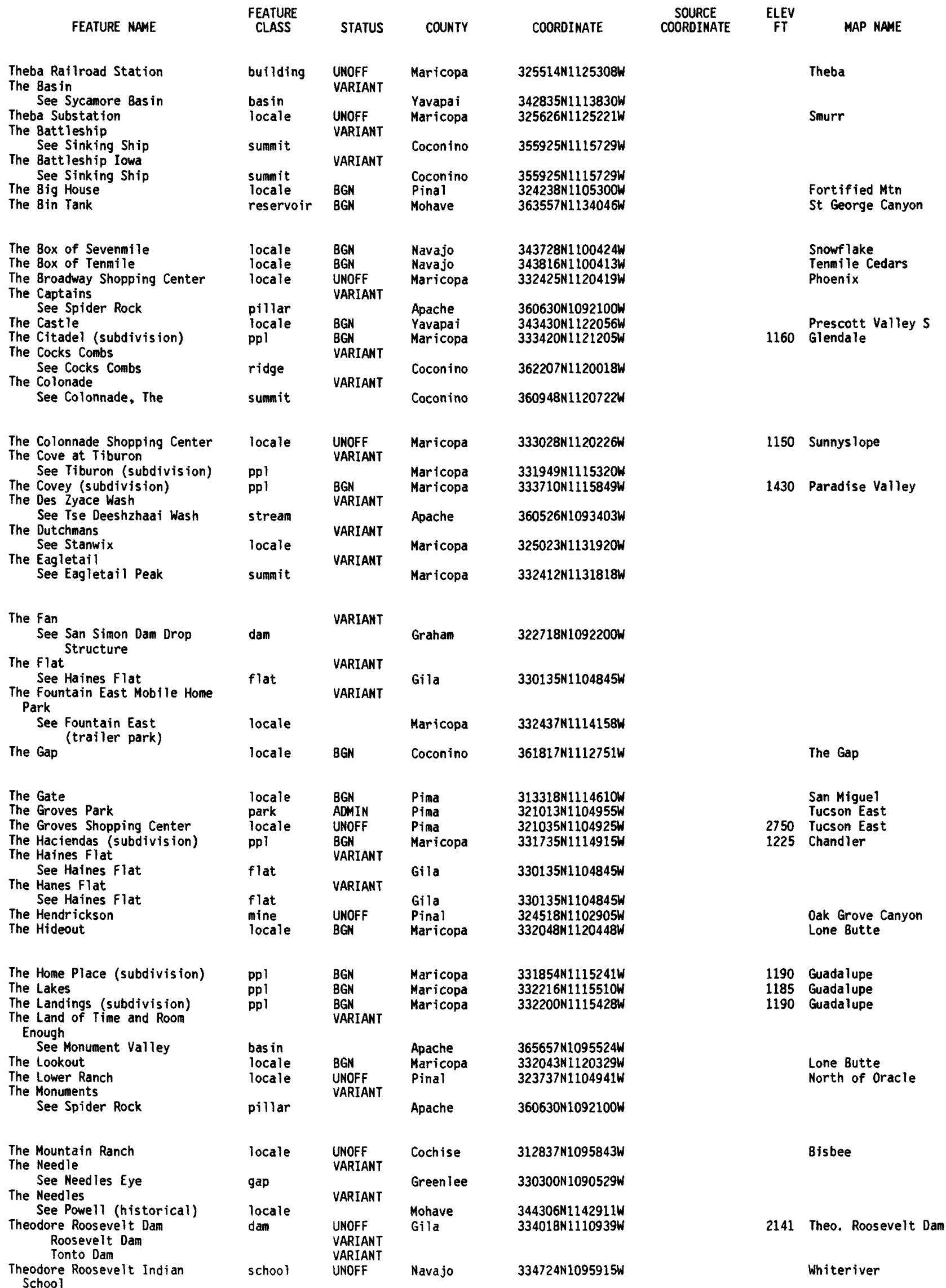




\begin{tabular}{|c|c|c|c|c|c|c|c|}
\hline FEATURE NAME & $\begin{array}{l}\text { FEATURE } \\
\text { CLASS }\end{array}$ & STATUS & COUNTY & COORDINATE & $\begin{array}{l}\text { SOURCE } \\
\text { COORDINATE }\end{array}$ & $\begin{array}{l}\text { ELEV } \\
\text { FT }\end{array}$ & MAP NAME \\
\hline $\begin{array}{l}\text { Theodore Roosevelt Lake } \\
\text { Roosevelt Lake } \\
\text { Roosevelt Reservoir } \\
\text { The Old Fort Historical } \\
\text { Monument } \\
\text { The Old Windmill } \\
\text { The Perky } \\
\text { See Puerco River } \\
\text { The Phoenix-Scottsdale Mobile } \\
\text { Home Park }\end{array}$ & $\begin{array}{l}\text { reservoir } \\
\text { park } \\
\text { locale } \\
\text { stream } \\
\text { locale }\end{array}$ & $\begin{array}{l}\text { BGN } 1959 \\
\text { VARIANT } \\
\text { VARIANT } \\
\text { ADMIN } \\
\text { BGN } \\
\text { VARIANT } \\
\text { UNOFF }\end{array}$ & $\begin{array}{l}\text { Navajo } \\
\text { Coconino } \\
\text { Navajo } \\
\text { Maricopa }\end{array}$ & $\begin{array}{l}365638 \mathrm{~N} 1104725 \mathrm{~W} \\
345459 \mathrm{N1} 100526 \mathrm{~W} \\
333816 \mathrm{~N} 1120112 \mathrm{~W}\end{array}$ & & 2120 & $\begin{array}{l}\text { Theo. Roosevelt Dam } \\
\text { Joseph City } \\
\text { Chaiyahi Rim NE } \\
\text { Union Hills }\end{array}$ \\
\hline $\begin{array}{l}\text { The Pines Tank } \\
\text { The Pointe (subdivision) } \\
\text { The Pointe at South Mountain } \\
\text { (subdivision) } \\
\text { The Point Recreation Site } \\
\text { The Preserve (subdivision) } \\
\text { The Rim } \\
\text { See Mogollon Rim } \\
\text { The Rock House } \\
\text { The Rocks } \\
\text { See Black Rocks, The }\end{array}$ & $\begin{array}{l}\text { reservoir } \\
\text { ppl } \\
\text { ppl } \\
\text { park } \\
\text { ppl } \\
\text { cliff } \\
\text { locale } \\
\text { summit }\end{array}$ & $\begin{array}{l}\text { BGN } \\
\text { BGN } \\
\text { BGN } \\
\text { ADNIN } \\
\text { BGN } \\
\text { VARIANT } \\
\text { BGN } \\
\text { VARIANT }\end{array}$ & $\begin{array}{l}\text { Yavapai } \\
\text { Maricopa } \\
\text { Maricopa } \\
\text { Maricopa } \\
\text { Maricopa } \\
\text { Coconino } \\
\text { Coconino } \\
\text { Mohave }\end{array}$ & $\begin{array}{l}345319 \mathrm{~N} 1125511 \mathrm{~W} \\
333315 \mathrm{~N} 1120245 \mathrm{~W} \\
332228 \mathrm{~N} 1115832 \mathrm{~W} \\
333325 \mathrm{~N} 1112438 \mathrm{~W} \\
333449 \mathrm{~N} 1120115 \mathrm{~W} \\
341501 \mathrm{~N} 1104501 \mathrm{~W} \\
350407 \mathrm{~N} 1110339 \mathrm{~W} \\
363736 \mathrm{~N} 1130719 \mathrm{~W}\end{array}$ & & $\begin{array}{l}1300 \\
1220\end{array}$ & $\begin{array}{l}\text { Juniper Mts } \\
\text { Sunnys lope } \\
\text { Guadalupe } \\
\text { Mormon Flat Dam } \\
\text { Sunnys lope }\end{array}$ \\
\hline $\begin{array}{l}\text { The Ruiz } \\
\text { The Sahuaro School } \\
\text { The Sierra Blanca River } \\
\text { See White River } \\
\text { The Summit } \\
\text { See Fish Creek Peak } \\
\text { The Summit } \\
\text { See Coronado Summit } \\
\text { (historical) } \\
\text { The Table Lands } \\
\text { See Tablelands. The }\end{array}$ & $\begin{array}{l}\text { locale } \\
\text { school } \\
\text { stream } \\
\text { summit } \\
\text { summit }\end{array}$ & $\begin{array}{l}\text { BGN } \\
\text { UNOFF } \\
\text { VARIANT } \\
\text { VARIANT } \\
\text { VARIANT } \\
\text { VARIANT }\end{array}$ & $\begin{array}{l}\text { Pinal } \\
\text { Pina } \\
\text { Gila } \\
\text { Maricopa } \\
\text { Maricopa } \\
\text { Pinal }\end{array}$ & $\begin{array}{l}324853 \mathrm{~N} 1105430 \mathrm{~W} \\
321320 \mathrm{~N} 1105147 \mathrm{~W} \\
334420 \mathrm{~N} 1101330 \mathrm{~W} \\
333123 \mathrm{~N} 1111710 \mathrm{~W} \\
333123 \mathrm{~N} 1111710 \mathrm{~W} \\
330048 \mathrm{~N} 1103804 \mathrm{~W}\end{array}$ & & & $\begin{array}{l}\text { Black Mountain } \\
\text { Tucson East }\end{array}$ \\
\hline $\begin{array}{l}\text { The Three Castles } \\
\text { See Sinking Ship } \\
\text { The Town Square (subdivision) } \\
\text { The Trails III (subdivision) } \\
\text { The Trancept } \\
\text { See Transept, The } \\
\text { The Tunnel } \\
\text { The Virgin Mary } \\
\text { See Our Lady of Arizona } \\
\text { The Well }\end{array}$ & $\begin{array}{l}\text { summit } \\
\text { ppl } \\
\text { ppl } \\
\text { valley } \\
\text { tunnel } \\
\text { cliff } \\
\text { well }\end{array}$ & $\begin{array}{l}\text { VARIANT } \\
\text { BGN } \\
\text { BGN } \\
\text { VARIANT } \\
\text { BGN } \\
\text { VARIANT } \\
\text { UNOFF }\end{array}$ & $\begin{array}{l}\text { Coconino } \\
\text { Maricopa } \\
\text { Maricopa } \\
\text { Coconino } \\
\text { Gila } \\
\text { Maricopa } \\
\text { Mohave }\end{array}$ & $\begin{array}{l}355925 N 1115729 \mathrm{~W} \\
333829 \mathrm{N1} 120407 \mathrm{~W} \\
332711 \mathrm{N1115340 \textrm {W }} \\
361036 \mathrm{~N} 1120234 \mathrm{~W} \\
342600 \mathrm{~N} 1111600 \mathrm{~W} \\
\text { UNKNOWN } \\
365749 \mathrm{~N} 1132728 \mathrm{~W}\end{array}$ & & $\begin{array}{l}1380 \\
1190\end{array}$ & $\begin{array}{l}\text { Union Hills } \\
\text { Sawbuck Mtn } \\
\text { Kehl Ridge } \\
\text { Yellowhorse Flat }\end{array}$ \\
\hline $\begin{array}{l}\text { The West Winds Trailer Court } \\
\text { Thicket Spring } \\
\text { Thicket Spring } \\
\text { Thicket Tank } \\
\text { Thicket Tank } \\
\text { Thief Rock } \\
\text { See Saneneheck Rock } \\
\text { Thimble Mountain } \\
\text { Squaw Tit } \\
\text { Thimble Peak } \\
\text { Rock Peak }\end{array}$ & $\begin{array}{l}\text { locale } \\
\text { spring } \\
\text { spring } \\
\text { reservoir } \\
\text { reservoir } \\
\text { summit } \\
\text { summit } \\
\text { summit }\end{array}$ & $\begin{array}{l}\text { UNOFF } \\
\text { BGN } \\
\text { BGN } \\
\text { BGN } \\
\text { BGN } \\
\text { VARIANT } \\
\text { BGN } \\
\text { VARIANT } \\
\text { BGN } \\
\text { VARIANT }\end{array}$ & $\begin{array}{l}\text { Maricopa } \\
\text { Maricopa } \\
\text { Yavapai } \\
\text { Coconino } \\
\text { Coconino } \\
\text { Navajo } \\
\text { Mohave } \\
\text { Pima }\end{array}$ & $\begin{array}{l}331820 \mathrm{~N} 1114954 \mathrm{~W} \\
335927 \mathrm{N11} 12902 \mathrm{~W} \\
341146 \mathrm{~N} 1114819 \mathrm{~W} \\
343129 \mathrm{N1} 111603 \mathrm{~W} \\
345919 \mathrm{N1} 113149 \mathrm{~W} \\
363208 \mathrm{~N} 1103810 \mathrm{~W} \\
350241 \mathrm{~N} 1141812 \mathrm{~W} \\
322015 \mathrm{~N} 1104625 \mathrm{~W}\end{array}$ & & $\begin{array}{l}4062 \\
5323\end{array}$ & $\begin{array}{l}\text { Chandler } \\
\text { Reno Pass } \\
\text { Bloody Bas in } \\
\text { Long Valley } \\
\text { Mormon Mountain } \\
\text { Mount Nutt } \\
\text { Sabino Canyon }\end{array}$ \\
\hline $\begin{array}{l}\text { Thin Mountain } \\
\text { Thin Rock Mesa } \\
\text { T Hinton Ranch } \\
\text { Third Forest } \\
\text { See Limestone Canyon } \\
\text { Third Hollow } \\
\text { Third Mesa } \\
\text { See Oraibi Mesa } \\
\text { Third Mesa } \\
\text { Oraibi Mesa }\end{array}$ & $\begin{array}{l}\text { summit } \\
\text { summit } \\
\text { locale } \\
\text { valley } \\
\text { valley } \\
\text { summit } \\
\text { summit }\end{array}$ & $\begin{array}{l}\text { BGN } \\
\text { BGN } \\
\text { UNOFF } \\
\text { VARIANT } \\
\text { BGN } \\
\text { VARIANT } \\
\text { BGN } \\
\text { VARIANT }\end{array}$ & $\begin{array}{l}\text { Pinal } \\
\text { Navajo } \\
\text { Graham } \\
\text { Gila } \\
\text { Navajo } \\
\text { Navajo } \\
\text { Navajo }\end{array}$ & $\begin{array}{l}330130 \mathrm{~N} 1113924 \mathrm{~W} \\
361326 \mathrm{~N} 1103947 \mathrm{~W} \\
325704 \mathrm{~N} 1100950 \mathrm{~W} \\
\\
341426 \mathrm{~N} 1112719 \mathrm{~W} \\
340219 \mathrm{~N} 1100026 \mathrm{~W} \\
\\
355423 \mathrm{~N} 1104154 \mathrm{~W} \\
355610 \mathrm{~N} 1103 \mathrm{~B} 51 \mathrm{~W}\end{array}$ & $340201 \mathrm{~N} 1095738 \mathrm{~W}$ & 6356 & $\begin{array}{l}\text { Sacaton } \\
\text { Rocky Ridge NW } \\
\text { Jackson Mtn }\end{array}$ \\
\hline $\begin{array}{l}\text { Third Mesa } \\
\text { Thirsty Mesa } \\
\text { Thirteen, Canal (historical) } \\
\text { Canal Pima } \\
\text { Thirteenmile Rock Butte } \\
\text { Thirteen Mile Spring } \\
\text { Thirteenmile Tank } \\
\text { Thirteen Mile Tank } \\
\text { Thirteenmile Wash }\end{array}$ & $\begin{array}{l}\text { summit } \\
\text { summit } \\
\text { canal } \\
\text { summit } \\
\text { spring } \\
\text { reservoir } \\
\text { reservoir } \\
\text { stream }\end{array}$ & $\begin{array}{l}\text { BGN } \\
\text { BGN } \\
\text { BGN } \\
\text { VARIANT } \\
\text { BGN } \\
\text { BGN } \\
\text { BGN } \\
\text { BGN } \\
\text { BGN }\end{array}$ & $\begin{array}{l}\text { Navajo } \\
\text { Apache } \\
\text { Maricopa } \\
\text { Yavapai } \\
\text { Yavapai } \\
\text { Yavapai } \\
\text { Coconino } \\
\text { Mohave }\end{array}$ & $\begin{array}{l}360129 \mathrm{~N} 1103353 \mathrm{~W} \\
363244 \mathrm{~N} 1091740 \mathrm{~W} \\
332745 \mathrm{~N} 1115132 \mathrm{~W} \\
\\
343016 \mathrm{~N} 1114035 \mathrm{~W} \\
343025 \mathrm{~N} 1113953 \mathrm{~W} \\
343028 \mathrm{~N} 1113942 \mathrm{~W} \\
351336 \mathrm{~N} 1122203 \mathrm{~W} \\
350552 \mathrm{~N} 1141257 \mathrm{~W}\end{array}$ & 351637 N1140640W & 7632 & $\begin{array}{l}\text { Rocky Ridge SE } \\
\text { Mexican Cry Mesa } \\
\text { Mesa } \\
\text { Walker Mtn } \\
\text { Walker Mtn } \\
\text { Walker Mtn } \\
\text { McLellan Reservoir } \\
\text { Kingman SW }\end{array}$ \\
\hline
\end{tabular}


FEATURE NAME

Thirteen Mile Wash

Thirteen Mile Wash

See Thirteenmile Wash

Thirteen Ranch

Thirteen Tank

Thirty Day Tank

Thirtyfive Tank

Thirtynine Spring

Thirtyone Tank

Thirtys ix Tank

Thirtys ix Tank

Thirtys ix Tank

Thirtythree, Tank

Thirtythree Tank

Thirtytwo, Tank

Thirtytwo Well

Thistle Flat Pond

Thistle Hollow

Burton Draw

Thistle Tank

Thistle Tank

Thistle Tank

Thistle Tank

Thistle Tank

Thistle Well

Thode Cabin

Thomas, Mount

Thomas, Mount

Thomas Canyon

Thomas Canyon

Thomas Canyon Wash

Thomas Creek

Rousensock Creek

Thomas Creek

Thomas Creek

Thomas Creek Spring

Thomas Creek Weir

Thomas Draw

Thomas East Shopping Center

Thomas Jay Regional Park

Thomas Lake

Thomas Mall

Thomas Peak

See Baldy Peak

Thomas Point Tank

Thomas Road Rest Stop

Thomas Spring

Thomas Spring

Thonas Spring

Thomas Tank

Thomas Tank

Thomas Tank

Thomas Tank

Thomas Trailer Court

Thomas Well

Thomas Windmi1 1

Thompson Arboretum

Thompson Bay

Thompson Butte

Thompson Canyon

Thompson Creek

Thompson Creek

Thompson Draw

Thompson Draw

Thompson Draw Thompson Wash

Thompson Ladder

Thompson Mesa

Thompson Mine

Thompson Park
FEATURE
CLASS

STATUS

COUNTY

COORDINATE

VARIANT

strea

locale

reservoir

reservoir

reservoir

spring

reservoir $B G N$

reservoir BGN

reservoir BGN

reservoir BGN

reservoir BGN

reservoir $B G$

reservoir

well

reservoir

valley

reservoir

BGN

reservoir

reservoir

reservoir

reservoir

well

locale

summit

sumnit

valley

valley

VARIANT

UNOFF

$B G N$

BGN

$B G N$

BGN

GN

BGN

UNOFF

BGN

Navajo 342258N1100633W

I

Navajo

$342123 N 1100840 \mathrm{~W}$

strean

stream

strean

strean

spring

dam

valley

locale

park

lake

locale

summit

reservoir

park

spring

spring

spring

reservoir

BGN

BGN

VARIANT

BGN

GGN

UNOFF

UNOFF

ADM IN

reservoir $B G N$

reservoir BG

reservoir BGN

locale

well

locale

park

bay

summit

valley

stream

strean

valley

valley

valley

trail

summit

mine

flat
BGN

UNOFF

VARIANT

BGN

ADMIN

BGN

BGN

BGN

(BGN

Greenlee

Maricopa

Apache

Coconino

Maricopa

Apache

Gila

Pima

Navajo

Navajo

Yavapai

Maricopa

Pima

Navajo

Pinal

Mohave

Yavapai

$B G N$

BGN

BGN 1932

Coconino

\section{BGN}

BGN

BGN

BGN

BGN 1974

VARIANT

UNOFF

BGN

BGN
UNOFF

BGN

Gila

Coconino
Navajo

Yavapai

Coconino

Coconino

Navajo

Apache

Apache

Yavapai

Pima

Gila

Pima

Greenlee

Greenlee

Apache

Green lee

Greenlee

Navajo

Maricopa

Pima

$342127 \mathrm{~N} 1100711 \mathrm{~W}$

$342130 \mathrm{~N} 1115010 \mathrm{~W}$

344456 N1111359W

$344459 N 1110107 \mathrm{~W}$

$342118 \mathrm{~N} 1100830 \mathrm{~W}$

$340718 \mathrm{~N} 1093747 \mathrm{~W}$

$335444 N 1093306 \mathrm{~W}$

341911 N1115159W

$314402 N 1113339 \mathrm{~W}$

$340310 \mathrm{~N} 1110319 \mathrm{~W}$

314358 N1112539W

$332338 \mathrm{N1} 091221 \mathrm{~W}$

$334230 \mathrm{~N} 1091509 \mathrm{~W}$

$335150 \mathrm{N1090340 \textrm {W }}$

$332701 N 1091549 \mathrm{~W}$

334040 N1091543

341949 N1101320

$332850 N 1120215$

$320817 N 1105212 \mathrm{~W}$

$333247 \mathrm{~N} 1091116 \mathrm{~W}$

$332835 \mathrm{~N} 1115902 \mathrm{~W}$

$335422 N 1093344 W$

$345857 \mathrm{~N} 1114406 \mathrm{~W}$

$332846 \mathrm{~N} 1115445 \mathrm{~W}$

$340315 N 1110213$

$350214 N 1113624 \mathrm{~W}$

$314947 N 1110825 \mathrm{~W}$

$342231 N 1101550 \mathrm{~W}$

$342742 \mathrm{~N} 1101102 \mathrm{~W}$

$345331 \mathrm{~N} 1115737 \mathrm{~W}$

$332851 N 1120222 \mathrm{~W}$

$314351 N 1113309 \mathrm{~W}$

$342738 \mathrm{~N} 1101142 \mathrm{~W}$

$331646 \mathrm{~N} 1110924 \mathrm{~W}$

342728 N1142030W

$341206 \mathrm{~N} 1122607 \mathrm{~W}$

$361319 N 1120335 \mathrm{~W}$

$335325 N 1092850 \mathrm{~W}$ $340753 \mathrm{~N} 1095535 \mathrm{~W}$

$323706 \mathrm{~N} 1090321 \mathrm{~W}$

$340807 \mathrm{~N} 1112244 \mathrm{~W}$

341556 N1110510W

345454 N1114300W

$334824 \mathrm{~N} 1110325 \mathrm{~W}$

$341103 \mathrm{~N} 1093547 \mathrm{~W}$
$340956 \mathrm{~N} 1112212 \mathrm{~W}$

$\begin{array}{cc}\text { SOURCE } & \text { ELEV } \\ \text { COORDINATE } & \text { FT MAP NAME }\end{array}$

6170 Woods Canyon Flagstaff East Scratch Canyon Date Creek Ranch SW Salt River Peak Quayle Hill

Buckhead Mesa

May Tank Pocket

Seligman East Bonita Tank 
FEATURE

CLASS

STATUS

summi

Thompson Peak

Bismarck Mountain

Thompson Point

Thompson Ranch

Thompsons Ladder Fourteen

Thompsons Point

Thompson Spring

Thompson Spring

Thompson Spring

Thomps on Spring

Thompsons Valley

See Thompson Valley

Thompson Tank

Thompson Tank

Thompson Tank

Thomps on Tank

Thompson Tank

Thompson Tank

Thompson Valley

Thompsons valley

Thompson Valley School

Thompson Wash

See Thompson Draw

Thompson Well

Thorne Spring

Thorn Peak

Thorn Peak Tank

Thornton Lookout Tower

Thornton Tank

Thornton Wash

Thorn Valley

Thornydale School

Thoroughbred Pasture Tank

Thorpe Park

Thorpe Tank

Thors Hammer

See Thor Temple

Thor Temple

Thors Hanme

Thorton Road Interchange

Thous and Pockets

Thous and Wells

Thous and Spring

Thous and Wells

See Thous and Pockets

$\mathrm{T}-\mathrm{H}$ Ranch

Three, Canal (historical)$$
\text { Canal Primero }
$$

Three, $\mathrm{Hill}$

$$
\text { Bear Hill }
$$

Three, Lake

Three Bar Cabin

Three Bar Watershed Research

Area

Three Bar Wildlife Area

Three Black Rocks

Three Brothers Hills, The

Three Buttes

Three Camp Mountain See Timber Camp Mountain

Three Canyon

Three Castles See Sinking Ship

Three Corner Well

Three C Ranch

Three C Tank

Three D Street Schoo

Three Dunes Campgrounds

Three Feathers Tank

Three Forks

$\begin{array}{llll}\text { summit } & \text { BGN } & \text { Maricopa } & 333839 \text { N1114841W } \\ \text { summit } & \text { BGN 1972 } & \text { Yavapai } & 342914 \text { N1125604W } \\ & \text { VARIANT } & & \\ \text { cliff } & \text { BGN 1908 } & \text { Coconino } & 361750 \text { N1122607W } \\ \text { locale } & \text { UNOFF } & \text { Apache } & 335322 \text { N1092822W } \\ \text { trail } & \text { UNOFF } & \text { Coconino } & 345500 \text { N1114253W } \\ \text { cliff } & \text { BGN } & \text { Coconino } & 345506 \text { N1114303W } \\ \text { spring } & \text { BGN } & \text { Pinal } & 331531 \text { N1110733W } \\ \text { spring } & \text { BGN } & \text { Gila } & 333917 \text { N111080OW } \\ \text { spring } & \text { BGN } & \text { Navajo } & 340750 N 1095358 W\end{array}$

spring BGN Mohave 353325N1140906W

valley

reservoir BGN Maricopa 323604N1131952W

reservoir BGN Apache 344413N1094801W

reservoir BGN $35535 \mathrm{N1} 130232 \mathrm{~W}$

VARIANT

valley

well

spring

summit

tower

reservoir

stream

Gila

YNOFF

BGN Mohave

BGN Yavapai

BGN $\quad$ Yavapai

Coconino

Coconino

school

reservoir

reservoir

summit

summit

crossing

BGN

BGN

basin

BGN

spring BGN

VARIANT

bas in

locale

canal

summit

UNOFF

BGN

VARIANT

BGN 1983 VARIANT

Navajo

Pima

Gila

Coconino

Graham

Coconino

Coconino

Pinal

Coconino

Yavapai

Coconino

Apache

Maricopa

Coconino

\section{BGN}

lake

locale

BGN

BGN

park

pillar

summit

summit

summit

\section{ADNIN}

BGN

BGN

VARIANT

Coconino

Gila

Gila

Maricopa

Apache

Cochise

Pinal

Gila

valley

BGN

VARIANT

summit

we 11

locale

reservoir

school

park

reservoir

locale

342518N1125453W

$341556 \mathrm{~N} 1110510 \mathrm{~W}$ $335837 \mathrm{N1} 135936 \mathrm{~W}$

$351553 \mathrm{~N} 1142110 \mathrm{~W}$

$342612 \mathrm{~N} 1131056 \mathrm{~W}$

$342618 \mathrm{~N} 1131148 \mathrm{~W}$

355048 N1130314W

$355123 N 1130209 \mathrm{~W}$

$355054 \mathrm{~N} 1130252 \mathrm{~W}$

$361559 \mathrm{~N} 1100313 \mathrm{~W}$

$322045 \mathrm{~N} 1110320 \mathrm{~W}$

$335415 \mathrm{~N} 1110137 \mathrm{~W}$

$351216 \mathrm{~N} 1113930 \mathrm{~W}$

$324805 \mathrm{~N} 1094718 \mathrm{~W}$

$360750 \mathrm{~N} 1115848 \mathrm{~W}$

$360750 \mathrm{~N} 1115848 \mathrm{~W}$

$324941 \mathrm{~N} 1114625 \mathrm{~W}$

$343955 \mathrm{N1094934 \textrm {W }}$

$332333 \mathrm{~N} 1121005 \mathrm{~W}$

$350605 \mathrm{~N} 1120414 \mathrm{~W}$

$363048 N 1095804 \mathrm{~W}$

$314241 \mathrm{~N} 1100744 \mathrm{~W}$

$323853 \mathrm{~N} 1110306 \mathrm{~W}$

$333920 \mathrm{~N} 1103537 \mathrm{~W}$

Santa Cruz 312956N1104851W

$355925 \mathrm{~N} 1115729 \mathrm{~W}$

Coconino $\quad 355925 N 1115729 \mathrm{~W}$

Apache $\quad 345250 \mathrm{~N} 1104211 \mathrm{~W}$

Santa Cruz 312149N1110515W

$\begin{array}{ll}\text { Santa Cruz } & 312149 \mathrm{~N} 1110515 \mathrm{~W} \\ \text { Maricopa } & 332438 \mathrm{~N} 1120405 \mathrm{~W}\end{array}$

Mohave 342143N1141146W

Pima 321700N1103748W

Apache 335117N1091849W valley BGN 1972 Yavapai 342845N1125445W

school UNOFF

BGN
VARIANT
COUNTY

COORDINATE

$333839 N 1114841 W$

SOURCE

COORDINATE

FLEV

MAP NAME

3982 McDowell Peak

4704 Hillside

Powell Plateau

Big Lake North

Munds Park

Munds Park

Picketpost Mtn

Theo. Roosevelt Dam

Lakeside

Mt Tipton

Hay Mountain

Aguila Mts SE

Little Milky Ranch

Bellemont

Sunset Crater West

$342830 \mathrm{~N} 1125000 \mathrm{~W}$

Prospect Point

Hillside

Hillside

$355220 \mathrm{~N} 1130015 \mathrm{~W}$

$361633 \mathrm{~N} 1100217 \mathrm{~W}$

Jaynes

Copper Mtn

Flagstaff West

Thatcher

6719 Walhalla Plateau

1408 Chuichu

Ferry Swale

Wagoner

Little Milky Ranch

Fowler

7301 White Horse Lake

Woods Canyon

Four Peaks

Four Peaks

Horse Mesa Dam

Sweetwater Mesa

Fairbank
$312810 \mathrm{~N} 1104525 \mathrm{~W}$

Cumero Canyon

Ninemile Seep

Campo Bonito

Phoenix

Gene Wash

Agua Caliente $\mathrm{Hill}$

Buffalo Crossing
Pajarito Peak 
FEATURE NAME

Three Fountains (trailer park)

Three-Jin Tank

Three Lakes

Three Lakes Corral

Threemile Lake

Threemile Lake

Three Peaks

Three Point Airport

Three Point Bend

Three Points

Three R Tank

Three Sisters

Three Sisters

Three Sisters

Three Sisters Buttes

Three Sisters Mountain

Mangas Mountain

Three Sisters Tank

Three Sisters Tank

Three Springs Canyon

Three Turkey Canyon

Three Turkey Ruins

Three Turkey Ruins Navajo

Tribal Park

Three $V$ Tank

Three Wall Tank

Three Way

Threeway Gulch

Threeway Tank

Three Way Tank

Three Way Tank

Threeway Wash

Three Wise Men

Thsohotso Wash

Thumb

Thumb Butte

Thumb Butte

Thumb Butte

Thumb Butte

Thumb Butte Campground

Thumb Butte Mine

Thumb Butte Park

Thumb Butte Tank

Thumb Flat

Thumb Peak

Thumb Rock Picnic Area

Thumb Rock Well

Thump Butte

Thunderbird Academ

Thunderbird High School

Thunderbird Mesa

Thunderbird Min

Thunderbird

(subdivision)

Thunderbird Park

Thunderbird Plaza Shopping

Center

Thunderbird Ranch

Thunderbird Recreation Area Thunderbird Regional Park Thunderbird

Semi-regional Park

Thunderbird Regional Park See Thunderbird Recreation Area

Thunderbird Semi-regional Park See Thunderbird Recreation Area

Thunderbird Shopping Village

Thunderbird Square Shopping

Center
FEATURE

CLASS

STATUS

COUNTY

COORDINATE

SOURCE
COOROINATE

MAP NAME

\begin{tabular}{|c|c|c|c|}
\hline $\begin{array}{l}\text { locale } \\
\text { reservoir } \\
\text { lake } \\
\text { locale } \\
\text { lake } \\
\text { lake } \\
\text { summit } \\
\text { airport } \\
\text { bend } \\
\text { locale }\end{array}$ & $\begin{array}{l}\text { UNOFF } \\
\text { BGN } \\
\text { BGN } \\
\text { BGN } \\
\text { BGN } \\
\text { BGN } \\
\text { BGN } \\
\text { ADMIN } \\
\text { BGN } \\
\text { BGN }\end{array}$ & $\begin{array}{l}\text { Maricopa } \\
\text { Yavapai } \\
\text { Coconino } \\
\text { Coconino } \\
\text { Mohave } \\
\text { Coconino } \\
\text { Pima } \\
\text { Pinal } \\
\text { La Paz } \\
\text { Pima }\end{array}$ & $\begin{array}{l}333107 N 1121117 \mathrm{~W} \\
344341 \mathrm{N11} 3858 \mathrm{~W} \\
363818 \mathrm{~N} 1121312 \mathrm{~W} \\
363834 \mathrm{N1} 120654 \mathrm{~W} \\
344846 \mathrm{~N} 1143344 \mathrm{~W} \\
351745 \mathrm{~N} 1121132 \mathrm{~W} \\
314046 \mathrm{~N} 1113749 \mathrm{~W} \\
325410 \mathrm{~N} 1114538 \mathrm{~W} \\
330300 \mathrm{~N} 1143500 \mathrm{~W} \\
320436 \mathrm{~N} 1111847 \mathrm{~W}\end{array}$ \\
\hline
\end{tabular}

reservoir BGN Santa Cruz 312B40N1104735W

summit BGN Mohave $350823 N 1132203 \mathrm{~W}$

summit BGN Coconino 351609N1121351W

sumnit BGN Navajo 365657N1100552W

summit BGN Cochise 315941N1094612W

summit BGN 1917 Gila 335026N1110814w

reservoir BGN Monave 350810N1132243W

reservoir BGN $\quad$ Coconino $351657 N 1121319 \mathrm{~W}$

valley BGN Coconino 355308N1131828W

valley BGN Apache 360527N1093410W

locale BGN Apache 360144N1092452W

park ADMIN Apache

reservoir $B G$

reservoir $B G$

locale $B G$

reservoir BGN

reservoir BGN

reservoir

strean

arch

valley

sumait

sumanit

summit

sumnit

summit

park

mine

park

reservoir

flat

summit

summit
park
well

summit

school

school

summit

mine

ppl

park
locale

locale

locale
park

BGN
BGN
BGN
BGN
$8 G N$
BGN
BGN
BGN
BGN

Gila

Yavapai

Greenlee

Pinal

Pinal

Navajo

Navajo

Pinal

Coconino

Apache

Mohave

Santa Cruz

Greenlee

Yuma

Mohave

Yavapai

$360137 N 1092456 \mathrm{~W}$

$340338 N 1112041 \mathrm{~W}$

$344301 \mathrm{~N} 1113554 \mathrm{~W}$

$325654 \mathrm{~N} 1091347 \mathrm{~W}$

$323636 \mathrm{~N} 1105544 \mathrm{~W}$

$323635 N 1105454 \mathrm{~W}$

$340347 N 1104005 \mathrm{~W}$

$343327 N 1102225 \mathrm{~W}$ 323639 N1105552W

$360614 N 1111232 \mathrm{~W}$

$353848 N 1090545 \mathrm{~W}$

$354310 \mathrm{N1132117 \textrm {W }}$

$312402 \mathrm{~N} 1110732 \mathrm{~W}$

$325034 N 1091958 \mathrm{~W}$

$330004 N 1140527 \mathrm{~W}$

$351040 \mathrm{~N} 1142550 \mathrm{~W}$

$343307 \mathrm{~N} 1123116 \mathrm{~W}$

325824N1140907W

$343310 \mathrm{N1123106 \textrm {W }}$

$335856 \mathrm{~N} 1140735 \mathrm{~W}$

$350434 \mathrm{~N} 1115939 \mathrm{~W}$

$330132 \mathrm{~N} 1140610 \mathrm{~W}$

$312359 N 1110517 \mathrm{~W}$

$350342 \mathrm{~N} 1132222 \mathrm{~W}$

$343248 \mathrm{~N} 1123108 \mathrm{~W}$

$33363 N 1115509$

333648N1120543W

Yavapai

Maricopa

Maricopa

Navajo 365534N1100437W

Pima

Maricopa

$333634 \mathrm{~N} 1121059 \mathrm{~W}$

$\begin{array}{ll}\text { ADMIN } & \text { Maricopa } \\ \text { UNOFF } & \text { Maricopa }\end{array}$

334133 N1121107W

$333630 \mathrm{~N} 1121605$

Pima

UNOFF
ADMIN

AOMIN

VARIANT

Maricopa

320823N1104337W

$334130 \mathrm{~N} 1121059 \mathrm{~W}$

VARIANT

park

park

locale

locale
VARIANT

Maricopa

Maricopa

334130 N1121059W

UNOFF

UNOFF

\section{$323715 N 1105307 \mathrm{~W}$}

$354028 N 1090653 \mathrm{~N}$
1128 Glendale Casner Butte

Jacob Lake

House Rock

Need les

Williams North

4899 Aquirre Peak

1389 Casa Grande West

Picacho

2339 Three Points

Cumero Canyon

5800 Fort Rock Ranch

7643 Williams North

Mitten Buttes

4827 Pearce

5444 Greenback Creek

Bull Spring

Williams North

Granite Park

Lt 1 White Hse Ruins Three Turkey Canyon Three Turkey Canyon

Gisela

Apache Maid Mtn

York

Oracle Junction

Oracle Junction

Oak Creek Ranch

Sheepskin Wash

Oracle Junction

Moenkopi

Window Rock

5305 Peach Springs NE

5300 Pena Blanca Lake

Ash Peak

Slumgullion Pass

3168 Union Pass

Iron Springs

Red Bluff Mtn NW

Iron Springs

Red Bluff Mtn NW

Sycamore Point

3407 Slumgullion Pass

3850 Pena Blanca Lake

4845 Oevils Hump

Iron Springs

Paradise Valley

Sunnys lope

5650 Mitten Buttes

Avra

1220 Glendale

Hedgpeth Hills

1155 El Mirage

2900 Tanque Verde Peak

1450 Hedgpeth Hills 
NATIONAL GAZETTEER--ARIZONA 1986

\begin{tabular}{|c|c|c|c|c|c|c|c|}
\hline FEATURE NAME & $\begin{array}{l}\text { FEATURE } \\
\text { CLASS }\end{array}$ & STATUS & COUNTY & COORDINATE & $\begin{array}{l}\text { SOURCE } \\
\text { COORDINATE }\end{array}$ & $\begin{array}{c}\text { ELEV } \\
\text { FT }\end{array}$ & MAP NAME \\
\hline $\begin{array}{l}\text { Thunderbird Square Shopping } \\
\text { Center }\end{array}$ & locale & UNOFF & Maricopa & $333643 N 1115528 \mathrm{~W}$ & & & Paradise Valley \\
\hline $\begin{array}{l}\text { Thunderbird Valley Number Two } \\
\text { (subdivision) } \\
\text { Thunderbolt Mine } \\
\text { Thunder Cave } \\
\text { Thunderhead Airport } \\
\text { Thunder Mine } \\
\text { Thunder Mine Road } \\
\text { Thunder Mountain } \\
\text { Thunder River } \\
\text { See Tapeats Creek }\end{array}$ & $\begin{array}{l}\text { ppl } \\
\text { mine } \\
\text { cave } \\
\text { airport } \\
\text { mine } \\
\text { trail } \\
\text { summit } \\
\text { stream }\end{array}$ & $\begin{array}{l}\text { BGN } \\
\text { UNOFF } \\
\text { BGN } \\
\text { ADMIN } \\
\text { UNOFF } \\
\text { UNOFF } \\
\text { BGN } \\
\text { VARIANT }\end{array}$ & $\begin{array}{l}\text { Maricopa } \\
\text { Yavapai } \\
\text { Coconino } \\
\text { Pima } \\
\text { Santa Cruz } \\
\text { Santa Cruz } \\
\text { Maricopa } \\
\text { Coconino }\end{array}$ & $\begin{array}{l}333655 \mathrm{~N} 1120644 \mathrm{~W} \\
341408 \mathrm{~N} 1121222 \mathrm{~W} \\
362348 \mathrm{~N} 1122728 \mathrm{~W} \\
320721 \mathrm{~N} 1104238 \mathrm{~W} \\
312641 \mathrm{~N} 1104454 \mathrm{~W} \\
312726 \mathrm{~N} 1104441 \mathrm{~W} \\
332819 \mathrm{~N} 1113 \mathrm{~B} 23 \mathrm{~W} \\
362214 \mathrm{~N} 1122807 \mathrm{~W}\end{array}$ & & 1300 & $\begin{array}{l}\text { Sunnys lope } \\
\text { Bumble Bee } \\
\text { Tapeats Amphitheater } \\
\text { Vail } \\
\text { Harshaw } \\
\text { Harshaw } \\
\text { Buckhorn }\end{array}$ \\
\hline $\begin{array}{l}\text { Thunder River } \\
\text { Thunder Spring } \\
\text { Thurber Ranch } \\
\text { Thurlo Tank } \\
\text { Thurlo Wildlife Tanks } \\
\text { Thurman Lateral } \\
\text { Thurso } \\
\text { See Wallace Butte } \\
\text { Thurso Butte } \\
\text { See Wallace Butte }\end{array}$ & $\begin{array}{l}\text { stream } \\
\text { spring } \\
\text { locale } \\
\text { reservoir } \\
\text { reservoir } \\
\text { canal } \\
\text { summit } \\
\text { summit }\end{array}$ & $\begin{array}{l}\text { BGN } \\
\text { BGN } 1932 \\
\text { UNOFF } \\
\text { BGN } \\
\text { BGN } \\
\text { BGN } \\
\text { VARIANT } \\
\text { VARIANT }\end{array}$ & $\begin{array}{l}\text { Coconino } \\
\text { Coconino } \\
\text { Pima } \\
\text { Gila } \\
\text { Gila } \\
\text { Yuma } \\
\text { Coconino } \\
\text { Coconino }\end{array}$ & $\begin{array}{l}362331 \mathrm{~N} 1122702 \mathrm{~W} \\
362346 \mathrm{~N} 1122728 \mathrm{~W} \\
314631 \mathrm{N1} 104323 \mathrm{~W} \\
340752 \mathrm{~N} 1110130 \mathrm{~W} \\
340755 \mathrm{~N} 1110111 \mathrm{~W} \\
323216 \mathrm{~N} 1144355 \mathrm{~W} \\
361326 \mathrm{~N} 1122146 \mathrm{~W} \\
361326 \mathrm{~N} 1122146 \mathrm{~W}\end{array}$ & $362345 \mathrm{~N} 1122728 \mathrm{~W}$ & & $\begin{array}{l}\text { Tapeats Amphitheater } \\
\text { Tapeats Amphitheater } \\
\text { Empire Ranch } \\
\text { Diamond Butte } \\
\text { Diamond Butte } \\
\text { Somerton }\end{array}$ \\
\hline $\begin{array}{l}\text { Thurston Tank } \\
\text { Tiajuana Mine } \\
\text { Tia Juana Ridge } \\
\text { Tiba Dah Silahi } \\
\text { Tiburon (subdivision) } \\
\text { The Cove at Tiburon } \\
\text { Ticonderoga Gulch } \\
\text { Tidwell Canal } \\
\text { Tidwell Wash } \\
\text { Tie Park }\end{array}$ & $\begin{array}{l}\text { reservoir } \\
\text { mine } \\
\text { ridge } \\
\text { area } \\
\text { ppl } \\
\text { valley } \\
\text { canal } \\
\text { stream } \\
\text { flat }\end{array}$ & $\begin{array}{l}\text { BGN } \\
\text { UNOFF } \\
\text { BGN } \\
\text { BGN } \\
\text { BGN } \\
\text { VARIANT } \\
\text { BGN } \\
\text { BGN } \\
\text { BGN } \\
\text { BGN }\end{array}$ & $\begin{array}{l}\text { Coconino } \\
\text { Santa Cruz } \\
\text { Santa Cruz } \\
\text { Apache } \\
\text { Maricopa } \\
\text { Yavapai } \\
\text { Graham } \\
\text { Graham } \\
\text { Coconino }\end{array}$ & $\begin{array}{l}360259 N 1122223 \mathrm{~W} \\
314006 \mathrm{N1} 105224 \mathrm{~W} \\
314000 \mathrm{N1} 105245 \mathrm{~W} \\
360743 \mathrm{~N} 1092935 \mathrm{~W} \\
331949 \mathrm{N1} 115320 \mathrm{~W} \\
\\
342858 \mathrm{~N} 1121706 \mathrm{~W} \\
325131 \mathrm{N1} 1093346 \mathrm{~W} \\
324956 \mathrm{~N} 1093753 \mathrm{~W} \\
345101 \mathrm{~N} 1112716 \mathrm{~W}\end{array}$ & $\begin{array}{l}342828 \mathrm{~N} 1122010 \mathrm{~W} \\
325501 \mathrm{~N} 1093457 \mathrm{~W}\end{array}$ & $\begin{array}{l}6178 \\
1190\end{array}$ & $\begin{array}{l}\text { Piute Point } \\
\text { Mt Wrightson } \\
\text { Mt Hopkins } \\
\text { Del Muerto } \\
\text { Guadalupe } \\
\text { Poland Junction } \\
\text { San Jose } \\
\text { Safford } \\
\text { Hutch Mtn }\end{array}$ \\
\hline $\begin{array}{l}\text { Tiger Well } \\
\text { Tigre Mine, El } \\
\text { Tigre Mine, El } \\
\text { Tiis Holoni } \\
\text { Tiis Nditsooi Wash } \\
\text { Teec Nid Suen Wash } \\
\text { Tiki Tai Village (trailer park) } \\
\text { Tillie Hall Canyon } \\
\text { Hall Canyon } \\
\text { Tillman Draw }\end{array}$ & $\begin{array}{l}\text { well } \\
\text { mine } \\
\text { mine } \\
\text { locale } \\
\text { stream } \\
\text { locale } \\
\text { valley } \\
\text { valley }\end{array}$ & $\begin{array}{l}\text { UNOFF } \\
\text { UNOFF } \\
\text { UNOFF } \\
\text { BGN } \\
\text { BGN } \\
\text { VARIANT } \\
\text { UNOFF } \\
\text { BGN } \\
\text { VARIANT } \\
\text { BGN }\end{array}$ & $\begin{array}{l}\text { Maricopa } \\
\text { Cochise } \\
\text { Maricopa } \\
\text { Coconino } \\
\text { Apache } \\
\text { Maricopa } \\
\text { Greenlee } \\
\text { Coconino }\end{array}$ & $\begin{array}{l}334544 \mathrm{~N} 1131420 \mathrm{~W} \\
315604 \mathrm{~N} 1091704 \mathrm{~W} \\
334437 \mathrm{~N} 1131120 \mathrm{~W} \\
353354 \mathrm{~N} 1110312 \mathrm{~W} \\
360637 \mathrm{~N} 1093356 \mathrm{~W} \\
\\
333150 \mathrm{~N} 1121050 \mathrm{~W} \\
325859 \mathrm{~N} 1090254 \mathrm{~W} \\
344304 \mathrm{~N} 1105204 \mathrm{~W}\end{array}$ & $\begin{array}{l}330109 N 1090043 \mathrm{~W} \\
343714 \mathrm{N1105622W}\end{array}$ & 1145 & $\begin{array}{l}\text { Tiger Well } \\
\text { Rustler Park } \\
\text { Little Horn Peak } \\
\text { White Water Tank } \\
\text { Ltl White Hse Ruins } \\
\text { Glendale } \\
\text { Tillie Hall Peak } \\
\text { Chevelon Butte }\end{array}$ \\
\hline $\begin{array}{l}\text { Tillman Ranch } \\
\text { Tillman Spring } \\
\text { Tillmans Wash } \\
\text { Tillman Tank } \\
\text { Tillman Tank } \\
\text { Tillman Water Catchment } \\
\text { Tillman Well } \\
\text { Tillotson Peak } \\
\text { Tilly Starbuck Mine } \\
\text { Tilted Mesa }\end{array}$ & $\begin{array}{l}\text { locale } \\
\text { spring } \\
\text { stream } \\
\text { reservoir } \\
\text { reservoir } \\
\text { reservoir } \\
\text { well } \\
\text { summit } \\
\text { mine } \\
\text { summit }\end{array}$ & $\begin{array}{l}\text { UNOFF } \\
\text { BGN } \\
\text { BGN } \\
\text { BGN } \\
\text { BGN } \\
\text { BGN } \\
\text { UNOFF } \\
\text { BGN } \\
\text { UNOFF } \\
\text { BGN } 1927\end{array}$ & $\begin{array}{l}\text { Coconino } \\
\text { Pinal } \\
\text { Pinal } \\
\text { Coconino } \\
\text { Coconino } \\
\text { Coconino } \\
\text { Coconino } \\
\text { Pima } \\
\text { Yavapai } \\
\text { Coconino }\end{array}$ & $\begin{array}{l}342653 \mathrm{~N} 1105209 \mathrm{~W} \\
331357 \mathrm{N1} 105856 \mathrm{~W} \\
331358 \mathrm{~N} 1105921 \mathrm{~W} \\
343837 \mathrm{N1} 105543 \mathrm{~W} \\
345922 \mathrm{~N} 1111226 \mathrm{~W} \\
343708 \mathrm{~N} 1105558 \mathrm{~W} \\
343430 \mathrm{~N} 1105353 \mathrm{~W} \\
320133 \mathrm{~N} 1124501 \mathrm{~W} \\
342423 \mathrm{~N} 1122645 \mathrm{~W} \\
361759 \mathrm{~N} 1115344 \mathrm{~W}\end{array}$ & $331416 N 1105802 \mathrm{~W}$ & 3374 & $\begin{array}{l}\text { Weimar Point } \\
\text { Hot Tamale Peak } \\
\text { Hot Tamale Peak } \\
\text { Hamilton Crossing } \\
\text { Chavez Mtn NW } \\
\text { Grama Oraw } \\
\text { Grama Draw } \\
\text { Tillotson } \\
\text { Groom Creek } \\
\text { Point Imperial }\end{array}$ \\
\hline $\begin{array}{l}\text { Tilton Springs } \\
\text { Timber-Antelope Well } \\
\text { Timber Bench Tank } \\
\text { Timber Camp } \\
\text { Timber Camp Mountain } \\
\text { Three Camp Mountain } \\
\text { Timber Camp Mountains } \\
\text { Timber Camp Mountain } \\
\text { See Carol Spring Mountain }\end{array}$ & $\begin{array}{l}\text { spring } \\
\text { well } \\
\text { reservoir } \\
\text { locale } \\
\text { summit }\end{array}$ & $\begin{array}{l}\text { BGN } \\
\text { UNOFF } \\
\text { BGN } \\
\text { BGN } \\
\text { BGN 1967 } \\
\text { VARIANT } \\
\text { VARIANT } \\
\text { VARIANT }\end{array}$ & $\begin{array}{l}\text { Coconino } \\
\text { Mohave } \\
\text { Apache } \\
\text { Gila } \\
\text { Gila }\end{array}$ & $\begin{array}{l}363932 N 1122019 W \\
350115 N 1134217 W \\
335228 N 1091139 W \\
33411 B N 1103414 W \\
333920 N 1103537 W\end{array}$ & & 6527 & $\begin{array}{l}\text { Warm Springs Canyon } \\
\text { Bottleneck Wash } \\
\text { Alpine } \\
\text { Chrysotile } \\
\text { Chrysotile }\end{array}$ \\
\hline
\end{tabular}




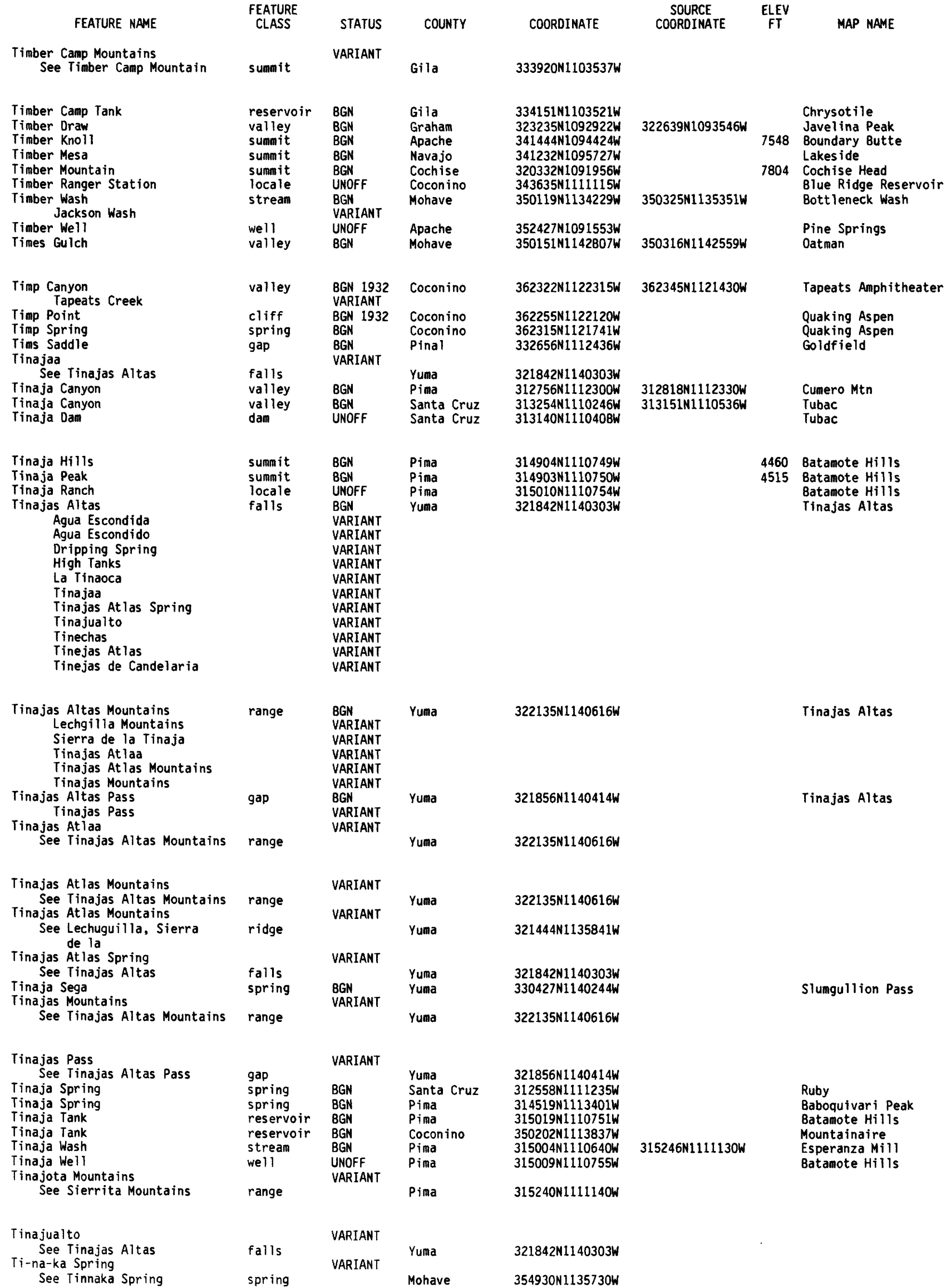


NATIONAL GAZETTEER--ARIZONA 1986

FEATURE NAME

Tina Larga Tank

Tin Barn Well

Tin Can Oraw

Tincanebitts Canyon

Tincanebitts Point

Tincanebitts Spring

Tincanebitts Tank

Tin Can Tank

Tin Can Tank

Tin Can Tank

Tin Can Wash

Tincup Basin

Tincup Springs

Tinds ley Spring

Tinebbito Spring

See Dinnebito Spring

Tinebbito Wash

See Dinnebito Wash

Tinechas

See Tinajas Altas

Tinejas At las

See Tinajas Altas

Tinejas de Candelaria

See Tinajas Altas

Tin Horn Tailing Dam

Tailings Dam

Tinhorn Wash

Tin House

Tin House

Tin House Spring

Tin House Tank

Tinhouse Tank

Tin House Well

Tinker Canyon

Tinker Dam

Tinker Tank

Tin Mountain

Tinnakah Spring

See Tinnaka Spring

Tinnaka Spring

Tinnakah Spring

Ti-na-ka Spring

Tinny Spring

Tinny Tank

Tinny Tank

Tinny Tank

Tin Roof Tank

Tin Shack Spring

Tin Shack Tank

Tin Shack Tank Number One

Tin Tank

Tin Tank Spring

Tintown

Tin Trough Spring

Tin Trough Spring

Tin Trough Spring

Tin Tub Spring

Tin Yeh Toh

Tiny Tank

Tio Cruz Spring

Tiohuerro Tank

Tios Tank

Tipoff, The

Tiponi Point

Tipover Canyon

Tipover Spring

Tipperary Mine

Tipperary Tank

Tipperary Wash

Tipperary Wel

Tipping Spring

\section{FEATURE}

reservoir

well

valley

valley

summit

spring

STATUS

COUNTY

Pima

Mohave

Yavapai

Mohave

Mohave

Mohave

reservoir

reservoir

reservoir

valley

basin

spring

spring

spring

Mohave

Maricopa

Yavapai

Coconino

Coconino

Gila

Gila

Yavapai

Coconino 354749N1105437W

COORDINATE

$321335 \mathrm{N1103833W}$ $350022 \mathrm{~N} 1135720 \mathrm{~W}$

$342643 \mathrm{~N} 1113234 \mathrm{~W}$

$360103 \mathrm{~N} 1134646 \mathrm{~W}$

$360634 \mathrm{~N} 1134354 \mathrm{~W}$

$360705 N 1134208 \mathrm{~W}$

$360757 N 1134223 W$

$334456 \mathrm{~N} 1120320 \mathrm{~W}$

$342116 \mathrm{~N} 1123905 \mathrm{~W}$

$342 \mathrm{~B} 47 \mathrm{N1113253 \textrm {W }}$

$365837 \mathrm{~N} 1104710 \mathrm{~W}$

$331331 \mathrm{N1103641 \textrm {W }}$

331331 N1103630W

$342627 \mathrm{~N} 1131211 \mathrm{~W}$

VARIANT

$\begin{array}{llll}\text { valley } & \text { VARIANT } & & \\ \text { falls } & \text { VARIANT } & \text { Coconino } & 352845 \mathrm{~N} 1111415 \mathrm{~W} \\ \text { falls } & \text { VARIANT } & \text { Yuma } & 321842 \mathrm{~N} 1140303 \mathrm{~W} \\ \text { falls } & \text { VARIANT } & \text { Yuma } & 321842 \mathrm{~N} 1140303 \mathrm{~W} \\ \text { dam } & \begin{array}{l}\text { UNOFF } \\ \text { VARIANT }\end{array} & \text { Gila } & 321842 \mathrm{~N} 1140303 \mathrm{~W} \\ & & & 332654 \mathrm{~N} 1105018 \mathrm{~W}\end{array}$

stream

locale

locale

spring

reservoir

reservoir

well

valley

dam

reservoir

summit

spring

spring

$\begin{array}{ll} & \text { VARIANT } \\ & \text { VARIANT } \\ \text { spring } & \text { BGN }\end{array}$

reservoir $B G$

reservoir BGI

reservoir $B G N$

reservoir

spring

reservoir

reservoir

reservoir

spring

ppl

spring

pring

spring

BGN Gila

BGN Graham

BGN

BGN

BGN

UNOFF

BGN

BGN

BGN

spring $\quad B G N$

spring

reservoir

spring

reservoir

reservoir

summit

cliff

valley

spring

\section{BGN}

BGN

BGN

BGN

BGN

BGN

BGN

BGN

Coconino

Gila

Gila

Coconino

Coch ise

Santa Cruz

Santa Cruz

$332655 N 1105017 \mathrm{~W}$

$324534 \mathrm{~N} 1094758 \mathrm{~W}$

$354152 \mathrm{~N} 1123243 \mathrm{~W}$

$335150 \mathrm{~N} 1110627 \mathrm{~W}$

$335651 \mathrm{~N} 1103533 \mathrm{~W}$

$351545 \mathrm{~N} 1122149 \mathrm{~W}$

$322541 \mathrm{~N} 1113102 \mathrm{~W}$

$312836 \mathrm{~N} 1101807 \mathrm{~W}$

$312116 \mathrm{~N} 1110717 \mathrm{~W}$

$312248 N 1110809 \mathrm{~W}$

$351040 \mathrm{~N} 1133303 \mathrm{~W}$

$354930 \mathrm{~N} 1135730 \mathrm{~W}$

$354930 \mathrm{~N} 1135730 \mathrm{~W}$

Mohave

Coconino

$332145 \mathrm{~N} 1091703 \mathrm{~W}$

Coconino $345020 N 1112605 \mathrm{~W}$

Yavapai 344012N1113338W

$334020 \mathrm{~N} 1105630 \mathrm{~W}$

$334302 \mathrm{~N} 1095849 \mathrm{~W}$

Gila 333923N1100054W

Gila 334344N1110536W

Yavapai 343921N1121109W

Cochise 312451N1095352W

$340357 \mathrm{~N} 1115648 \mathrm{~W}$

Yavapai

Yavapai $\quad 344034$ N1123420W

Yavapai 343851N1121109W

Apache 362653N1095318W

Coconino $343756 \mathrm{~N} 1111106 \mathrm{~W}$

Cochise $322457 \mathrm{N1101527W}$

Pima 314014N1112931W

Pima 315211N1111027W

$360529 \mathrm{~N} 1120522 \mathrm{~W}$

Apache 350425N1094645W

Coconino 362039N1121332W

Coconino $362046 \mathrm{~N} 1121320 \mathrm{~W}$

mine

reservoir

stream

UNOFF

BGN

Mohave

Pinal

Pinal

VARIANT
$345548 \mathrm{~N} 1142219 \mathrm{~W}$

$324333 N 1105828 \mathrm{~W}$

$324228 \mathrm{~N} 1110037 \mathrm{~W}$

$324340 \mathrm{~N} 1105819 \mathrm{~W}$

$\begin{array}{cc}\text { SOURCE } & \text { ELEV } \\ \text { COORDINATE } & \text { FT }\end{array}$

Tanque Verde Peak

Hualapai Peak

Strawberry

Bat Cave

$343203 \mathrm{~N} 1113259 \mathrm{~W}$

6244 Tincanebitts Point

Tincanebitts Point

Snap Draw

Union Hills

Peeples Valley

Strawberry

$370014 N 1104942 \mathrm{~W}$

Chaiyahi Rim NE

Coolidge Dam

Coolidge Dan

Thorn Peak

Globe

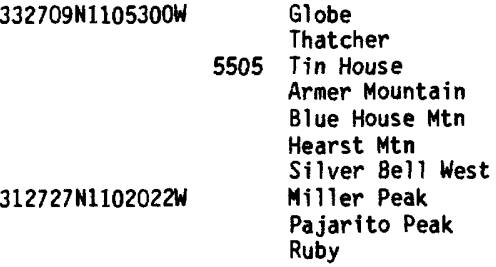

5928 Tin Mountain

Quartermaster Can SW

Hutch Mtn

Pipestem Mtn

Apache Maid Mtn

Hutch Mtn

Apache Maid Mtn

Meddler Wash

Bonito Prairie

Velasquez Butte

Windy $\mathrm{Hill}$

Hickey Mountain

Bisbee

Cooks Mesa

Batt leship Butte

Jerome Canyon

Hickey Mountain

Rough Rock NW

Hay Lake

Cherry Spring Peak

Las Guijas

Batamote $\mathrm{Hills}$

Phantom Ranch

Kachina Point

Kanabownits Spring

Kanabownits Spring

Warm Springs 


\begin{tabular}{|c|c|c|c|c|c|c|c|}
\hline FEATURE NAME & $\begin{array}{l}\text { FEATURE } \\
\text { CLASS }\end{array}$ & STATUS & COUNTY & COORDINATE & $\begin{array}{l}\text { SOURCE } \\
\text { COORDINATE }\end{array}$ & $\underset{\mathrm{FT}}{\mathrm{ELEV}}$ & MAP NAME \\
\hline $\begin{array}{l}\text { See Dripping Spring } \\
\text { Tip Tank } \\
\text { Tip Tank } \\
\text { Tipton, Mount } \\
\text { Tipton Canyon }\end{array}$ & $\begin{array}{l}\text { spring } \\
\text { reservoir } \\
\text { reservoir } \\
\text { summit } \\
\text { valley }\end{array}$ & $\begin{array}{l}\text { BGN } \\
B G N \\
B G N \\
B G N\end{array}$ & $\begin{array}{l}\text { Yavapai } \\
\text { Gila } \\
\text { Coconino } \\
\text { Mohave } \\
\text { Mohave }\end{array}$ & $\begin{array}{l}341837 \mathrm{N1121120W} \\
341713 \mathrm{N1112757W} \\
351231 \mathrm{N1112947 \textrm {W }} \\
353220 \mathrm{N1141131W} \\
353223 \mathrm{N1140627W}\end{array}$ & $353210 N 1141121 \mathrm{~W}$ & 7148 & $\begin{array}{l}\text { Buckhead Mesa } \\
\text { Winona } \\
\text { Mt Tipton } \\
\text { Mt Tipton SE }\end{array}$ \\
\hline $\begin{array}{l}\text { Tip Top Mine } \\
\text { Tiptop Mine } \\
\text { Tiptop Tank } \\
\text { Tiptop Trail } \\
\text { Tire Wash }\end{array}$ & $\begin{array}{l}\text { mine } \\
\text { mine } \\
\text { reservoir } \\
\text { trail }\end{array}$ & $\begin{array}{l}\text { UNOFF } \\
\text { UNOFF } \\
\text { BGN } \\
\text { UNOFF } \\
\text { VARIANT }\end{array}$ & $\begin{array}{l}\text { Pima } \\
\text { Yavapai } \\
\text { Coconino } \\
\text { Yavapai }\end{array}$ & 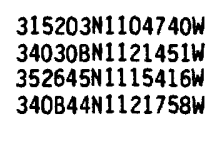 & & & $\begin{array}{l}\text { Helvetia } \\
\text { Black Canyon City } \\
\text { Moritz Ridge } \\
\text { Crown King }\end{array}$ \\
\hline $\begin{array}{l}\text { See Wagon Tire Wash } \\
\text { Tiro Pit, El } \\
\text { Tiro Wash, El } \\
\text { Tishepi Spring } \\
\text { Tisnasbas } \\
\text { See Teec Nos Pos }\end{array}$ & $\begin{array}{l}\text { stream } \\
\text { bas in } \\
\text { stream } \\
\text { spring } \\
\text { ppl } 1\end{array}$ & $\begin{array}{l}\text { BGN } \\
\text { BGN } \\
\text { BGN } \\
\text { VARIANT }\end{array}$ & $\begin{array}{l}\text { Yavapai } \\
\text { Pima } \\
\text { Pima } \\
\text { Coconino } \\
\text { Apache }\end{array}$ & $\begin{array}{l}34562 \mathrm{BN} 1121843 \mathrm{~W} \\
322505 \mathrm{~N} 1113217 \mathrm{~W} \\
322714 \mathrm{N1114151 \textrm {W }} \\
354130 \mathrm{N1105700 \textrm {W }} \\
365516 \mathrm{~N} 1090506 \mathrm{~W}\end{array}$ & $322511 \mathrm{N1113235 \textrm {W }}$ & & $\begin{array}{l}\text { Silver Be1l West } \\
\text { Gap Tank } \\
\text { Sand Springs }\end{array}$ \\
\hline $\begin{array}{l}\text { Tisnasbas Canyon } \\
\text { See Teec Nos Pos Canyon } \\
\text { Tisnasbas Canyon } \\
\text { See Teec Nos Pas Canyon } \\
\text { Tistah Wash } \\
\text { See Tsitah Wash } \\
\text { Tis Ya Toh Spring } \\
\text { Tithumiji Point } \\
\text { Titus (historical) } \\
\text { Tiyo Point } \\
\text { Jupiter Point }\end{array}$ & $\begin{array}{l}\text { reservoir } \\
\text { valley } \\
\text { strean } \\
\text { spring } \\
\text { cliff } \\
\text { locale } \\
\text { cliff }\end{array}$ & $\begin{array}{l}\text { VARIANT } \\
\text { VARIANT } \\
\text { VARIANT } \\
\text { BGN } \\
\text { BGN } 1925 \\
\text { BGN } \\
\text { BGN } 1906 \\
\text { VARIANT }\end{array}$ & $\begin{array}{l}\text { Apache } \\
\text { Apache } \\
\text { Apache } \\
\text { Navajo } \\
\text { Coconino } \\
\text { Santa Cruz } \\
\text { Coconino }\end{array}$ & $\begin{array}{l}365225 \mathrm{~N} 1090710 \mathrm{~W} \\
365230 \mathrm{~N} 1090715 \mathrm{~W} \\
370944 \mathrm{~N} 1090815 \mathrm{~W} \\
360427 \mathrm{N1104321 \textrm {W }} \\
361245 \mathrm{~N} 1123812 \mathrm{~W} \\
31330 \mathrm{~N} 1104900 \mathrm{~W} \\
361049 \mathrm{~N} 1120743 \mathrm{~W}\end{array}$ & & 7762 & $\begin{array}{l}\text { Rocky Ridge SW } \\
\text { Supai } \\
\text { Patagonia } \\
\text { Shiva Temple }\end{array}$ \\
\hline $\begin{array}{l}\text { Tiyo Point Trail } \\
\text { Tjeavolitak } \\
\text { See Chiawuli Tak } \\
\text { Tjiuvak } \\
\text { See Covered Wells } \\
\text { Tjuitjo } \\
\text { See Chuichu } \\
\text { Tjukutko } \\
\text { See Chukut Kuk } \\
\text { Tjuulik } \\
\text { See Choulic }\end{array}$ & $\begin{array}{l}\text { trail } \\
\text { locale } \\
\text { locale } \\
\text { ppl } \\
\text { locale } \\
\text { locale }\end{array}$ & $\begin{array}{l}\text { UNOFF } \\
\text { VARIANT } \\
\text { VARIANT } \\
\text { VARIANT } \\
\text { VARIANT } \\
\text { VARIANT }\end{array}$ & $\begin{array}{l}\text { Coconino } \\
\text { Pima } \\
\text { Pima } \\
\text { Pinal } \\
\text { Pima } \\
\text { Pima }\end{array}$ & $\begin{array}{l}361355 \mathrm{~N} 1120658 \mathrm{~W} \\
31560 \mathrm{BN} 1114649 \mathrm{~W} \\
321000 \mathrm{~N} 1120730 \mathrm{~W} \\
324507 \mathrm{~N} 1114657 \mathrm{~W} \\
314556 \mathrm{~N} 1120616 \mathrm{~W} \\
314002 \mathrm{~N} 1114634 \mathrm{~W}\end{array}$ & & & Bright Angel Point \\
\hline $\begin{array}{l}\text { T K Bar Ranch } \\
\text { T K Tank } \\
\text { TK Tank } \\
\text { Tloi Eechii Cliffs } \\
\text { To-adin-da-aska Mesa } \\
\text { See Toadindaaska Mesa } \\
\text { Toadinda-aska Mesa } \\
\text { See Toadindaaska Mesa } \\
\text { Toadindaaska Mesa } \\
\text { Black Mountain } \\
\text { To at in da haska } \\
\text { To-adin-da-aska Mesa } \\
\text { Toadinda-aska Mesa } \\
\text { To atin da haska Mesa } \\
\text { Toatindahaska Mesa } \\
\text { Toh-ahtndahska Mesa }\end{array}$ & $\begin{array}{l}\text { locale } \\
\text { reservoir } \\
\text { reservoir } \\
\text { cliff } \\
\text { summit } \\
\text { summit } \\
\text { summit }\end{array}$ & $\begin{array}{l}\text { UNOFF } \\
\text { BGN } \\
\text { BGN } \\
\text { BGN } \\
\text { VARIANT } \\
\text { VARIANT } \\
\text { BGN I915 } \\
\text { VARIANT } \\
\text { VARIANT } \\
\text { VARIANT } \\
\text { VARIANT } \\
\text { VARIANT } \\
\text { VARIANT } \\
\text { VARIANT }\end{array}$ & $\begin{array}{l}\text { Yavapai } \\
\text { Yavapai } \\
\text { Coconino } \\
\text { Coconino } \\
\text { Apache } \\
\text { Apache } \\
\text { Apache }\end{array}$ & 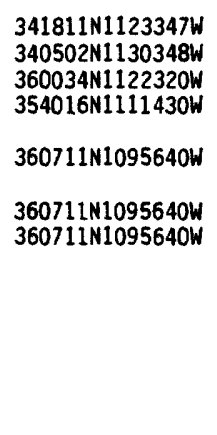 & & & $\begin{array}{l}\text { Wainut Grove } \\
\text { Date Creek Ranch SE } \\
\text { Chamisa Tank } \\
\text { Badger Spring }\end{array}$ \\
\hline $\begin{array}{l}\text { Toad Tank } \\
\text { Toapit } \\
\text { See Stoa Pitk } \\
\text { Toapit } \\
\text { See Totopitk } \\
\text { To atin da haska } \\
\text { See Toadindaaska Mesa } \\
\text { Toat indahaska Mesa } \\
\text { See Toadindaaska Mesa } \\
\text { To at in da haska Mesa } \\
\text { See Toadindaaska Mesa }\end{array}$ & $\begin{array}{l}\text { reservoir } \\
\text { ppl } \\
\text { locale } \\
\text { summit } \\
\text { summit } \\
\text { summit }\end{array}$ & $\begin{array}{l}\text { BGN } \\
\text { VARIANT } \\
\text { VARIANT } \\
\text { VARIANT } \\
\text { VARIANT } \\
\text { VARIANT }\end{array}$ & $\begin{array}{l}\text { Yavapai } \\
\text { Pina } \\
\text { Maricopa } \\
\text { Apache } \\
\text { Apache } \\
\text { Apache }\end{array}$ & $\begin{array}{l}350724 \mathrm{~N} 1125508 \mathrm{~W} \\
322906 \mathrm{~N} 1123058 \mathrm{~W} \\
323348 \mathrm{~N} 1121244 \mathrm{~W} \\
360711 \mathrm{~N} 1095640 \mathrm{~W} \\
360711 \mathrm{~N} 1095640 \mathrm{~W} \\
360711 \mathrm{~N} 1095640 \mathrm{~W}\end{array}$ & & & Turkey Canyon \\
\hline $\begin{array}{l}\text { Toatipk } \\
\text { See Stoa Pitk } \\
\text { Tobar Terrace } \\
\text { Tobenayoli Pond } \\
\text { To Cai } \\
\text { Tocha Park } \\
\text { Todastoni Wash } \\
\text { See Toh Dahst ini Wash }\end{array}$ & $\begin{array}{l}\text { ppl } \\
\text { bench } \\
\text { lake } \\
\text { spring } \\
\text { park } \\
\text { stream }\end{array}$ & $\begin{array}{l}\text { VARIANT } \\
\text { BGN } 1908 \\
\text { BGN } \\
\text { BGN } \\
\text { ADMIN } \\
\text { VARIANT }\end{array}$ & $\begin{array}{l}\text { Pima } \\
\text { Coconino } \\
\text { Navajo } \\
\text { Navajo } \\
\text { Maricopa } \\
\text { Montezuma (CO }\end{array}$ & $\begin{array}{l}322906 \mathrm{~N} 1123058 \mathrm{~W} \\
361534 \mathrm{N1122B17 \textrm {W }} \\
353027 \mathrm{N1103511 \textrm {W }} \\
360216 \mathrm{N1103625 \textrm {W }} \\
332555 \mathrm{~N} 1120520 \mathrm{~W} \\
370035 \mathrm{~N} 1090233 \mathrm{~W}\end{array}$ & & & $\begin{array}{l}\text { Powell Plateau } \\
\text { Tovar Mesa East } \\
\text { Rocky Ridge SE } \\
\text { Phoenix }\end{array}$ \\
\hline
\end{tabular}


NATIONAL GAZETTEER--ARIZONA 1986

\section{FEATURE NAME}

Todd Bas in

Todd Draw

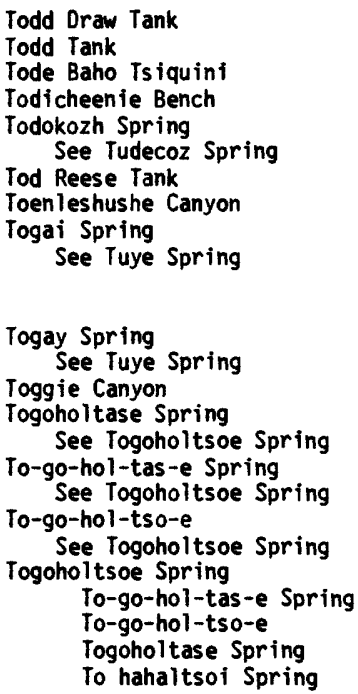

Toh De Niihe

Tohe Thlany Begay Mine

\section{FEATURE \\ CLASS}

STATUS

COUNTY

COORDINATE

\begin{tabular}{|c|c|c|}
\hline $\begin{array}{l}\text { basin } \\
\text { valley }\end{array}$ & $\begin{array}{l}\text { BGN } \\
B G N\end{array}$ & $\begin{array}{l}\text { Mohave } \\
\text { Coconino }\end{array}$ \\
\hline $\begin{array}{l}\text { reservoir } \\
\text { reservoir } \\
\text { spring } \\
\text { bench }\end{array}$ & $\begin{array}{l}\text { BGN } \\
\text { BGN } \\
\text { BGN } \\
\text { BGN } \\
\text { VARIANT }\end{array}$ & $\begin{array}{l}\text { Coconino } \\
\text { Coconino } \\
\text { Navajo } \\
\text { Navajo }\end{array}$ \\
\hline $\begin{array}{l}\text { spring } \\
\text { reservoir } \\
\text { valley }\end{array}$ & $\begin{array}{l}\text { BGN } \\
\text { BGN } \\
\text { VARIANT }\end{array}$ & $\begin{array}{l}\text { Apache } \\
\text { Yavapai } \\
\text { Coconino }\end{array}$ \\
\hline spring & & Apache \\
\hline
\end{tabular}

VARIANT

spring valley

spring

spring

spring

spring

BGN

VARIANT

VARIANT

VARIANT

VARIANT

VARIANT

VARIANT

VARIANT

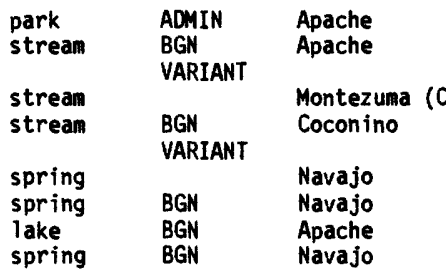

VARIANT

summit

valley

spring

spring

sumait

sumnit

VARIANT

VARIANT

BGN

VARIANT

BGN 1960

VARIANT

VARIANT

Apache

Apache

Navajo

Apache

Apache

Apache

VARIANT

spring

spring

spring

valley

valley

summit

VARIANT

BGN

BGN

VARIANT

BGN 1960

VARIANT

VARIANT

BGN

Navajo

Coconino

Apache

Apache

Apache

Apache

Navajo
351948 N1140758W $343800 \mathrm{~N} 1111605 \mathrm{~W}$

$343555 N 1111601 \mathrm{~W}$ $343759 N 1111623 \mathrm{~W}$ $351934 \mathrm{N1} 101929 \mathrm{~W}$ $365239 \mathrm{~N} 1102425 \mathrm{~W}$

353611 N1092714W $344150 N 1131204 \mathrm{~W}$ $364053 \mathrm{~N} 1104941 \mathrm{~W}$ 354521N1095042W

$365525 \mathrm{~N} 1090530 \mathrm{~W}$ $370012 N 1090122 \mathrm{~W}$

$370035 N 1090233 \mathrm{~W}$ $354219 N 1111812 W$

360145 N1101930W $360734 \mathrm{N1} 103932 \mathrm{~W}$ $363134 N 1095824 \mathrm{~W}$ $360424 N 1103659 \mathrm{~W}$

$364300 \mathrm{~N} 1103130 \mathrm{~W}$

$364300 \mathrm{~N} 1103130 \mathrm{~W}$

$351649 \mathrm{~N} 1101737 \mathrm{~W}$

364817 N1092206W

364817 N1092206W

364912N1091547W

364648 N1091150W

5189 Teec Nos Pos

$365523 N 1090458 W$

354111 N1110049W

Teec Nos Pos

Wupatki NE

Rocky Ridge NW Sweetwater Mesa Rocky Ridge SE

Round Rock

Toh At in Mesa West

Toh Bin Nosteny

French Butte

Toh Chin Lini Mesa

Toh Chin Lini Mesa

Windy Valley

Cow Butte

Teec Nos Pos

spring BGN 1983 Apache 365529N1091057W

BGN 1983 Montezuma (CO 370035N1090233W

$365528 \mathrm{~N} 1091058 \mathrm{~W}$

Burnt Corn Spring

$360827 \mathrm{N1} 100610 \mathrm{~W}$

$362309 \mathrm{~N} 1095602 \mathrm{~W}$

$355052 \mathrm{~N} 1095329 \mathrm{~W}$

$355159 \mathrm{~N} 1095231 \mathrm{~W}$

$364328 \mathrm{~N} 1101524 \mathrm{~W}$

360548 N1093934W

364349 N1091231W
COORDINATE FT MAP NAME

urkey Mtn

Bozarth Mesa

Ltl Black Spot Mtn

th

$335045 N 1095451 \mathrm{~W}$ Whiteriver
Lt1 Black Spot Mtn




\section{FEATURE NAME}

Toh $\mathrm{Ha} \mathrm{Ha} \mathrm{Clah}$

Toh Ha Hao Cheen

Toh Ha Tsil Dize

Toh Honi Ni Toh

Tohnalchai Spring

Toh-na-lea Mesa

See Tohnali Mesa

Toh Nalen

Tohnali

Tohnali Mesa

To-no-1in Mesa

Toh-na-lea Mesa

Toh Nee Di Kishi

Toh Ne Zhonnie Spring

Toh Ne Zhonnie Valley

Toh Ne Zhonnie Wash

Tohotso Creek

Toilet Paper Tank

Toison

See Tucson

Tokezje Spring

To Kla Daa Aakee Pond

Tolacon

See Totacon

Tolah Nascin

Tolah Nascin

Tolani

Tolani Lake

Tolani Lake

See Tolani

Tolani Lake Day School

Tolani Lakes

To thlani Lakes

Tolapai Draw

Grey Water Draw

Greywater Wash

Tolapai Spring

Tolbert Cabin

To1-Chaco

See Little Colorado River Tolchaco

See Tolchico

Tolchaco Gap

Tolchico

Tolchaco
Tolchiko

Tolchiko

See Tolchico

Tolleson

Tolleson Elementary School Tolleson Unit I School

Tolleson Post Office

Tolleson Substation

Tolleson Town Hall

Tolleson Town Park Number One

Tolleson Town Park Number Two

Tolleson Unit II School

Tolleson Unit I Schoo

See Tolleson Elementary School

Tollgate (site)

Tollgate Canyon

Tollgate Tank

Tollgate Wash Yuma Wash

Toll Horse Canyon

See Tollhouse Canyon

Toll House Canyon

See Tol Thouse Canyon

Toll thouse Canyon

Toll Horse Canyon

Toll House Canyon
FEATURE

CLASS

STATUS

COUNTY

Coconino

spring

spring

spring

spring

summit

wel1

BGN

$B G N$

BGN

BGN

VARIANT

UNOFF

spring
summit

BGH

BGN

VARIANT

spring

spring

valley

valley

stream

reservoir

BGN

BGN

BGN

$B G N$

BGN

ppl

spring

VARIANT

lake

locale

reservoir

spring

lake

ppl

$$
\begin{aligned}
& B G \\
& B G \\
& \text { VA } \\
& B G \\
& B G \\
& B G \\
& B G
\end{aligned}
$$

Pima

VARIANT

BGN

BGN

VARIANT

Coconino

Navajo

Navajo

Navajo

Apache

VARIANT

pp 1

spl
school
lake

UNOFF

BGN 1915

VARIANT

valley

BGN 1974

VARIANT

VARIANT

spring

BGN

BGN

Navajo

Navajo

Apache

Coconino

locale

VARIANT

stream

locale

gap

locale

VARIANT

BGN

BGN 1915

VARIANT

VARIANT

VARIANT

locale

Coconino

Coconino

Coconino

Apache

Apache

Greenlee

Coconino

Coconino

Coconino

Coconino

Coconino

$352336 \mathrm{~N} 1110626 \mathrm{~W}$

pp 1

school

BGN

UNOFF

VARIANT

building

UNOFF

locale

building

park

park

school

UNOFF

UNOFF

ADMIN

ADMIN

UNOFF

school

VARIANT

Maricopa

Maricopa

Maricopa

Maricopa

Maricopa

Maricopa

Maricopa

Maricopa

Maricopa

332700 N1121531W

$332655 \mathrm{~N} 112153 \mathrm{OW}$

$332700 \mathrm{~N} 1121526 \mathrm{~W}$

$332708 \mathrm{~N} 1121414 \mathrm{~W}$

332659 N1121551W

$332651 \mathrm{N1121532 \textrm {W }}$

$332722 \mathrm{~N} 1121548 \mathrm{~W}$

332710 N1121533W

332655N1121530W

local

valley

reservoir

stream

BGN

$B G N$

BGN

Graham

Greenlee

Graham

Graham

ARIANT

valley

valley

valley

VARIANT

Greenlee

Greenlee

Greenlee

VARIANT

VARIANT

$325028 N 1092347 \mathrm{~W}$

$325026 \mathrm{~N} 1092229 \mathrm{~W}$

$325032 N 1092401 \mathrm{~W}$

$324954 N 1092835 \mathrm{~W}$

$325600 \mathrm{N1091355W}$

325600 N1091355W

325600 N1091355W

$\begin{array}{cc}\text { SOURCE } & \text { ELEV } \\ \text { COORDINATE } & \text { FT }\end{array}$

MAP NAME

Bat Spring

Pinon

Burnt Corn Spring

Rocky Ridge SE

Sammill

6310 Steamboat Canyon

Moenkopi

Goldtooth

Moenave SE

Toh ME Zhonnie Spr Red Slide Peak

$362200 \mathrm{~N} 1100926 \mathrm{~W}$

$362058 \mathrm{N1} 101326 \mathrm{~W}$

$362728 \mathrm{~N} 1090700 \mathrm{~W}$

Toh NE Zhonnie Spr

Bad Bug Butte

Calloway Butte

Sawmill

White Water Tank

Rocky Ridge SW

Ltl Black Spot Mtn

Tolani

4920 Tolani Lake

Tolani Lake

Newberry Mesa

351147 N1090658W

Sanders

Tolapai Spring

5580 Bear Mountain

Bodaway Mesa

Grand Falls NE

Avondale

Tolleson

Tolleson

Fowler

Tolleson

Tolleson

Tolleson

Tolleson

$325005 N 1091733 \mathrm{~W}$

Tollgate Tank

Ash Peak

Tollgate Tank

325010N1091714W

Toolgate Tank

$325145 N 1091730 \mathrm{~W}$

York 


\section{FEATURE}

CLASS

STATUS
COUNTY

COORDINATE

$321236 N 1110113 W$

$324732 \mathrm{~N} 1113651 \mathrm{~W}$

$324732 N 1113651 \mathrm{~W}$

$324924 \mathrm{~N} 1113747 \mathrm{~W}$

Toltec Buttes

Toltec City See Toltec

Toltec Divide

Toltec Elementary School

Toltec Interchange

See Interchange Two Hundred Three

Toltec Mini Park

Toltec Point

Tolteo Point

Toltec School

Tolted Pyramid

\begin{tabular}{|c|c|c|c|}
\hline school & $\begin{array}{l}\text { UNOFF } \\
\text { VARIANT }\end{array}$ & Pima & $321236 N 1110113 \mathrm{~W}$ \\
\hline $\begin{array}{l}\mathrm{ppl} \\
\mathrm{ppl}\end{array}$ & $\begin{array}{l}\text { BGN } \\
\text { VARIANT } \\
\text { VARIANT }\end{array}$ & $\begin{array}{l}\text { Pinal } \\
\text { Pinal }\end{array}$ & $\begin{array}{l}324732 \mathrm{N1113651W} \\
324732 \mathrm{~N} 1113651 \mathrm{~W}\end{array}$ \\
\hline summit & $\begin{array}{l}\text { BGN } \\
\text { VARIANT }\end{array}$ & Pinal & $324924 \mathrm{~N} 1113747 \mathrm{~W}$ \\
\hline $\begin{array}{l}\text { ppl } \\
\text { ridge }\end{array}$ & $B G N$ & $\begin{array}{l}\text { Pinal } \\
\text { Coconino }\end{array}$ & $\begin{array}{l}324732 \mathrm{N1} 113651 \mathrm{~W} \\
350029 \mathrm{N1} 104645 \mathrm{~W}\end{array}$ \\
\hline school & $\begin{array}{l}\text { UNOFF } \\
\text { VARIANT }\end{array}$ & Pina? & $324720 \mathrm{N1113703W}$ \\
\hline crossing & & Pinal & $324638 \mathrm{~N} 1113708 \mathrm{~W}$ \\
\hline $\begin{array}{l}\text { park } \\
\text { cliff }\end{array}$ & $\begin{array}{l}\text { AOMIN } \\
\text { BGN 190B } \\
\text { VARIANT }\end{array}$ & $\begin{array}{l}\text { Pinal } \\
\text { Coconino }\end{array}$ & $\begin{array}{l}324743 N 1113710 \mathrm{~W} \\
361046 \mathrm{~N} 1122429 \mathrm{~W}\end{array}$ \\
\hline $\begin{array}{l}\text { building } \\
\text { school } \\
\text { summit }\end{array}$ & $\begin{array}{l}\text { UNOFF } \\
\text { UNOFF } \\
\text { BGN } 1917\end{array}$ & $\begin{array}{l}\text { Pinal } \\
\text { Pinal } \\
\text { Maricopa }\end{array}$ & $\begin{array}{l}324729 \text { N1113706W } \\
324702 \text { N1113710W } \\
\text { UNKNOWN }\end{array}$ \\
\hline
\end{tabular}

Toltec Railroad Station

Canyon

Mule Pass Gulch

Tombstone Canyon

Tombstone City Park

Tombstone Gulch

Tombstone Hills

Tombstone Municipal Airfield Tombstone Municipal Airport

Tombstone Municipal Airport See Tombstone Municipal Airfield

Tombstone Post Office

Tombstone Spring

Tom Camp Spring

Ton Canovis Spring

Tom Hunters Well

Tom Joe Spring

Tom Ketchum Canyon

Tom Ketchum Tank

Tom Ketchum Tank

Tonkins Tank

Tom Lamb Reservoir

Tom Lockett Draw Partridge Canyon

Tom Lockett Tank

Tommie Spring

Tommies Tank

Tommie Tank

Tom Mix Monument

Tom Mix Wash

Tom Niece Spring

\section{Tomomacori}

See Tumacacori

Tompkins Canyon

Tompkins Canyon

Tompkins Memorial Park

Tom Reed Mine

Toms Creek

Tom Spring

Toms Tank

Toms Tank cliff

mine

reservoir

stream

lake

valley

ppl

valley

VARIANT

Maricopa

Apache

Mohave

Mohave

Mohave

Cochise

Cochise

BGN 1960

VARIANT

VARIANT

valley BGN 1979 Mohave 364943N1133945W

park ADMIN Cochise 314246N1100401W

valley $\quad$ BGN $\quad$ Cochise 314401 N1100558W

summit BGN Cochise 314219N1100525W

airport ADMIN Cochise 314015N1100120W

VARIANT

VARIANT

airport

Cochise

$314015 \mathrm{~N} 1100120 \mathrm{~W}$

$\begin{array}{llll}\text { building } & \text { UNOFF } & \text { Cochise } & 314244 N 1100355 \mathrm{~W} \\ \text { spring } & \text { BGN } & \text { Mohave } & 364533 N 1133741 \mathrm{~W} \\ \text { spring } & \text { BGN } & \text { Gila } & 333026 N 1104642 \mathrm{~W} \\ \text { spring } & \text { BGN } & \text { Apache } & 341111 \text { N1094406W } \\ \text { well } & \text { UNOFF } & \text { Navajo } & 360146 \mathrm{~N} 1100510 \mathrm{~W} \\ \text { spring } & \text { BGN } & \text { Apache } & 352545 N 1092745 \mathrm{~W} \\ \text { valley } & \text { BGN } & \text { Cochise } & 313509 \mathrm{~N} 1092434 \mathrm{~W} \\ \text { reservoir } & \text { BGN } & \text { Cochise } & 313524 N 1092417 \mathrm{~W} \\ \text { reservoir } & \text { BGN } & \text { Cochise } & 313703 N 1092311 \mathrm{~W} \\ \text { reservoir } & \text { BGN } & \text { Yavapai } & 343102 N 1115451 \mathrm{~W}\end{array}$

reservoir BGN Yavapai $343102 N 1115451 \mathrm{~W}$

reservoir BGN Mohave 363907N1124622W

valley BGN 1975 Yavapai 351226N1123602W

reservoir

spring

reservoir

reservoir

park

stream

spring

VARIANT

BGN

BGN

BGN

BGN

Apache

335609N1092754W

$351449 N 1123919 \mathrm{~W}$

335609 N1092754W

$343336 \mathrm{~N} 1114025 \mathrm{~W}$

$345107 \mathrm{~N} 1111011 \mathrm{~W}$

$325044 \mathrm{~N} 1111845 \mathrm{~W}$

$330410 \mathrm{~N} 1095840 \mathrm{~W}$

Grat

VARIANT

$\mathrm{ppl}$
valley

valley

cemetery

mine

stream

spring

reservoir

reservoir

BGN
BGN
UNOFF
UNOFF
BGN
BGN
BGN
BGN

Santa Cruz

Mohave

Mohave

Cochise

Mohave

Coconino

Graham

Cochise

Coconino
313407 N1110306W $344425 \mathrm{~N} 1135208 \mathrm{~W}$ $344512 \mathrm{N1} 133636 \mathrm{~W}$ $313157 \mathrm{~N} 1101725 \mathrm{~W}$ $350125 \mathrm{~N} 1142247 \mathrm{~W}$ 343146 N1112244W 330B54N1095728W $313706 \mathrm{~N} 1094903 \mathrm{~W}$ $343221 \mathrm{~N} 1112354 \mathrm{~W}$
$325041 \mathrm{N1110430 \textrm {W }}$

$\begin{array}{cc}\text { SOURCE } & \text { ELEV } \\ \text { COORDINATE } & \text { FT MAP NAME }\end{array}$

Cat Mountain

Eloy North

1625 Casa Grande Mts

Tucker Mesa

Eloy North

Eloy North

Explorers Monument

Eloy North

Eloy North

Goldfield

Stinking Springs Mtn

Red Pockets

Fort Rock Ranch

Tom Brown Canyon

Tombstone

Bisbee

364838 N1133944W

Wolf Hole Mtn West

Tombstone

Tombs tone

Tombstone

4679 Tombstone

313659 N1092255W

$351610 \mathrm{~N} 1124043 \mathrm{~W}$

Tombstone

Wolf Hole Mtn West

Rockinstraw Mtn

Boundary Butte

Whippoorwill Spring

Wide Ruins

Pedregosa Mts West

Pedregosa Mts West

Pedregosa Mts West

Middle Verde

Sunshine Ridge

Cathedral Caves

Picacho Butte

Big Lake North

Waiker Mtn

Chavez Mtn West

Ninetysix Hills SW

Picacho Reservoir SE

Fort Thomas

$344601 \mathrm{~N} 1135033 \mathrm{~W}$

Beecher Canyon

Tule Wash

Fort Huachuca

Oatman

343000N1112353W Calloway Butte

Gi la Peak

Gleeson SE

Calloway Butte 
FEATURE CLASS STATUS

COUNTY

COORDINATE

$\begin{array}{lll}\text { reservoir } & \text { BGN } & \text { Gila } \\ \text { reservoir } & \text { BGN } & \text { Coconino } \\ \text { reservoir } & \text { BGN } & \text { Coconino } \\ \text { reservoir } & \text { BGN } & \text { Coconino } \\ \text { summit } & \text { BGN } & \text { Maricopa } \\ \text { cemetery } & \text { UNOFF } & \text { Maricopa } \\ \text { locale } & \text { BGN } & \text { Cochise } \\ \text { spring } & \text { BGN } & \text { Coconino } \\ \text { valley } & \text { BGN } & \text { Coconino } \\ \text { school } & \text { UNOFF } & \text { Maricopa }\end{array}$

Tom Tank

Tom Tank

Tom Tank

Tom Tanks

Tom Thumb

Tom Walder Memorial Park

Tom Will is Camp

Tonahakaad Spring

Tonahakaad Wash

Tonalea Elementary School

Tonalea Post Office

See Red Lake

Toney Tank

Toney Tank Number Two

Tongue Verde Falls

Tonk in Well

Tonoka Valley

Tonoka Well

To-no-lih Mesa

See Tohnali Mesa

Tonopah Post Office

Tonopah

Tonopah-Belmont Mine

Tonopah Desert

Tonopah Substation

Tonoweap Valley

See Toroweap Valley

Tonto (cliff dwellings)

$$
\text { Lower Ru in }
$$

Upper Ruin

Tonto-Apache Reservation

See Payson Indian Reservation

Tonto Basin

Tonto Bas in See Punkin Center

Tontobas in

See Punkin Center

Tonto Basin Post Office

Tonto Basin Ranger Station

Tonto Basin Rim See Mogollon Rim

Tonto Canyon

Tonto Cliff Dwellings

Tonto Creek

Tonto Creek

Tonto Creek Campground

Tonto Creek Valley See Grass Valley
(historical)

Tonto Dam

See Theodore Roosevelt Dam Tonto Dam

Tonto Lake

Tonto Mountain

Tonto Mountain Tank Number One

Tonto Mountain Tank Number

Three

Tonto Mountain Tank Number Two

Tonto National Forest See Crook National Forest (historical)

\footnotetext{
Tonto National Forest Crook National Forest

Tonto National Forest

Seismological Observatory

Tonto National Monument

Tonto National Monument

Headquarters

Tonto Natural Bridge

Natural Bridge
}

\section{ppl \\ VARIANT}

reservoir

reservoir

falls

well

valley

well

summit

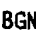

BGN

BGN

UNOFF

BGN

UNOFF

VARIANT

building UNOFF Maricopa

ppl

mine UNOFF

plain

valley

BGN

UNOFF

VARIANT

locale

BGN 1917

VARIANT

VARIANT

VARIANT

$\begin{array}{lll}\text { reserve } & & \text { Gila } \\ \text { basin } & \begin{array}{l}\text { BGN 1973 } \\ \text { VARIANT }\end{array} & \text { Gila } \\ \text { ppl } & \text { Gila } \\ \text { ppl } & \text { VARIANT } & \text { Gila } \\ \text { locale } & \text { UNOFF } & \text { Gila } \\ \text { locale } & \text { UNOFF } & \text { Gila }\end{array}$

VARIANT

cliff

valley

locale

stream

stream

park

valley

BGN
BGN 1917
BGN
BGN
ADMIN
VARIANT

Coconino

Santa Cruz

Gila

Apache

Gila

Gila

VARIANT

dam

dan

reservoir

summit

reservoir

reservoir

reservoir

forest

UNOFF
BGN
BGN
BGN
BGN
BGN
VARIANT

Gila

Apache

Apache

Yavapai

Yavapai

Yavapai

Yavapai

Gila

\begin{tabular}{|c|c|}
\hline $\begin{array}{l}\text { forest } \\
\text { building }\end{array}$ & $\begin{array}{l}\text { AOMIN } \\
\text { VARIANT } \\
\text { UNOFF }\end{array}$ \\
\hline $\begin{array}{l}\text { park } \\
\text { buil Iding }\end{array}$ & $\begin{array}{l}\text { ADMIN } \\
\text { UNOFF }\end{array}$ \\
\hline arch & $\begin{array}{l}\text { BGN } \\
\text { VARIANT }\end{array}$ \\
\hline
\end{tabular}

$340647 N 1111523 \mathrm{~W}$ $352620 \mathrm{~N} 1122803 \mathrm{~W}$ $353106 \mathrm{~N} 1121321 \mathrm{~W}$ $353910 \mathrm{~N} 1114033 \mathrm{~W}$ $323200 \mathrm{~N} 1123505 \mathrm{~W}$ $335626 \mathrm{N1} 131023 \mathrm{~W}$ $312909 \mathrm{~N} 1102614 \mathrm{~W}$ $354644 \mathrm{~N} 1111257 \mathrm{~W}$ 354500N1111901W 332820 N1115558w

$354824 \mathrm{~N} 1110641 \mathrm{~W}$

$361921 N 1105655 \mathrm{~W}$ $334423 \mathrm{~N} 1103513 \mathrm{~W}$ 334459 N1103441W $321516 \mathrm{~N} 1103919 \mathrm{~W}$ $313116 N 111$ $320353 N 1123405 \mathrm{~W}$ $320359 \mathrm{N1} 124001 \mathrm{~W}$

355825 N1111210w

332840 N1125618W $332937 N 1125611 \mathrm{~W}$ 333852 N1125556W

$333305 \mathrm{~N} 1125646 \mathrm{~W}$

$332940 \mathrm{~N} 1125453 \mathrm{~W}$

361229 N1130524W

$333830 \mathrm{~N} 1110655 \mathrm{~W}$

341317N1111940W

335549N1111829W

$335220 \mathrm{~N} 1111845 \mathrm{~W}$

$335220 \mathrm{~N} 1111845 \mathrm{~W}$

$335022 \mathrm{~N} 1111802 \mathrm{~W}$

335207 N1111B48W

$341501 N 1104501 \mathrm{~W}$ $312241 \mathrm{~N} 1111258 \mathrm{~W}$ 333852 N1110655W $333859 \mathrm{~N} 1095122 \mathrm{~W}$ $334048 \mathrm{~N} 1110903 \mathrm{~W}$ $341945 \mathrm{~N} 1110531 \mathrm{~W}$

$312205 N 1110953 \mathrm{~W}$ $334408 \mathrm{N1093605W}$ 342337 N1110450W

$\begin{array}{cc}\text { SOURCE } & \text { ELEV } \\ \text { COORDINATE } & \text { FT MAP NAME }\end{array}$

isela

Stanford Tank Howard Lake Additional Hill

2818 Ton Thumb

Aguila

Huachuca Peak

The Landmark

Wupatki NE

Tempe

Chrysotile

Chrysotile

Agua Caliente Hill

Arivaca

Gu Vo

Mount Ajo

Tonopah

1119 Tonopah

Belmont Mtn

Hot Rock Mtn

Tonopah

Windy Hill

Kayler Butte

Tonto Bas in

Tonto Basin

Ruby

Windy $\mathrm{Hill}$

Corn Creek

Theo. Roosevelt Dam

Promontory Butte
$334018 N 1110939 \mathrm{~W}$

$334130 N 1093542 \mathrm{~W}$

$334130 \mathrm{N1093540 \textrm {W }}$

$343756 \mathrm{~N} 1124000 \mathrm{~W}$

$343908 \mathrm{~N} 1124004 \mathrm{~W}$

343737 N1123925W

343806N1123923W

$324501 \mathrm{N1} 101501 \mathrm{~W}$

335000 N1112500W

$341533 N 1111634 \mathrm{~W}$

333852 N1110650W

$333840 \mathrm{~N} 1110644 \mathrm{~W}$

341914 N1112721W
Maverick

7698 Maverick

5631 Mt Josh

Mt Josh

Mt Josh

Mt Josh

Boulder Mtn

Payson North

Windy $\mathrm{Hill}$

2800 Windy $\mathrm{Hill}$

Buckhead Mesa 


\begin{tabular}{|c|c|c|c|c|c|c|c|}
\hline FEATURE NAME & $\begin{array}{l}\text { FEATURE } \\
\text { CLASS }\end{array}$ & STATUS & COUNTY & COORDINATE & $\begin{array}{l}\text { SOURCE } \\
\text { COORDINATE }\end{array}$ & $\begin{array}{l}\text { ELEV } \\
\text { FT }\end{array}$ & MAP NAME \\
\hline $\begin{array}{l}\text { Tontonteac Mountain } \\
\text { See Totonteac Mountain }\end{array}$ & summit & VARIANT & Maricopa & UNKNOWN & & & \\
\hline $\begin{array}{l}\text { Tonto Pasture Spring } \\
\text { Tonto Ranger Station Spring } \\
\text { Tonto Rim } \\
\text { See Mogollon Rim } \\
\text { Tonto Rim Tank } \\
\text { Tonto School } \\
\text { Tonto Spring } \\
\text { Tonto Spring } \\
\text { Tonto Springs Ranger Station } \\
\text { Tonto State Fish Hatchery }\end{array}$ & $\begin{array}{l}\text { spring } \\
\text { spring } \\
\text { cliff } \\
\text { reservoir } \\
\text { school } \\
\text { spring } \\
\text { spring } \\
\text { locale } \\
\text { locale }\end{array}$ & $\begin{array}{l}\text { BGN } \\
\text { BGN } \\
\text { VARIANT } \\
\text { BGN } \\
\text { UNOFF } \\
\text { BGN } \\
\text { BGN } \\
\text { UNOFF } \\
\text { UNOFF }\end{array}$ & $\begin{array}{l}\text { Yavapai } \\
\text { Yavapai } \\
\text { Coconino } \\
\text { Apache } \\
\text { Maricopa } \\
\text { Gila } \\
\text { Yavapai } \\
\text { Yavapai } \\
\text { Gila }\end{array}$ & $\begin{array}{l}343547 N 1124123 \mathrm{~W} \\
343618 \mathrm{~N} 1124132 \mathrm{~W} \\
341501 \mathrm{~N} 1104501 \mathrm{~W} \\
333828 \mathrm{~N} 1095113 \mathrm{~W} \\
332822 \mathrm{N1} 115506 \mathrm{~W} \\
342311 \mathrm{N11} 10540 \mathrm{~W} \\
343735 \mathrm{N1} 23955 \mathrm{~W} \\
343606 \mathrm{N1124103W} \\
342258 \mathrm{~N} 1110550 \mathrm{~W}\end{array}$ & & & $\begin{array}{l}\text { Skull Valley } \\
\text { Skull Valley } \\
\text { Corn Creek } \\
\text { Tempe } \\
\text { Knoll Lake } \\
\text { Mt Josh } \\
\text { Skuil Valley } \\
\text { Knoll Lake }\end{array}$ \\
\hline $\begin{array}{l}\text { Tonto Tank } \\
\text { Tonto Tank } \\
\text { Tonto Trail } \\
\text { Tonto Village } \\
\text { Tonto Wash } \\
\text { Tonuk Vo } \\
\text { Tony Lopez Ranch } \\
\text { Tony Pond } \\
\text { Tony Ranch } \\
\text { Tony Ranch Spring }\end{array}$ & $\begin{array}{l}\text { reservoir } \\
\text { reservoir } \\
\text { trail } \\
\text { ppl } \\
\text { stream } \\
\text { reservoir } \\
\text { locale } \\
\text { lake } \\
\text { locale } \\
\text { spring }\end{array}$ & $\begin{array}{l}\text { BGN } \\
\text { BGN } \\
\text { BGN } 1906 \\
\text { BGN } \\
\text { BGN } \\
\text { BGN } \\
\text { UNOFF } \\
\text { BGN } \\
\text { UNOFF } \\
\text { BGN }\end{array}$ & $\begin{array}{l}\text { Santa Cruz } \\
\text { Yavapai } \\
\text { Coconino } \\
\text { Gila } \\
\text { Yavapai } \\
\text { Pima } \\
\text { Pinal } \\
\text { Mohave } \\
\text { Pinal } \\
\text { Pinal }\end{array}$ & $\begin{array}{l}312228 \mathrm{~N} 1111011 \mathrm{~W} \\
343615 \mathrm{~N} 1124215 \mathrm{~W} \\
360743 \mathrm{~N} 1121431 \mathrm{~W} \\
341858 \mathrm{~N} 1110753 \mathrm{~W} \\
343623 \mathrm{~N} 1124100 \mathrm{~W} \\
315518 \mathrm{~N} 1121147 \mathrm{~W} \\
32552 \mathrm{~N} 1105516 \mathrm{~W} \\
362522 \mathrm{~N} 1132053 \mathrm{~W} \\
332315 \mathrm{~N} 1110314 \mathrm{~W} \\
332324 \mathrm{~N} 1110311 \mathrm{~W}\end{array}$ & $343756 \mathrm{~N} 1123623 \mathrm{~W}$ & & $\begin{array}{l}\text { Alamo Spring } \\
\text { Skull Valley } \\
\text { Shiva Temple } \\
\text { Diamond Point } \\
\text { Skull Valley } \\
\text { Kupk } \\
\text { Crozier Peak } \\
\text { Jones Hill } \\
\text { Haunted Canyon } \\
\text { Haunted Canyon }\end{array}$ \\
\hline $\begin{array}{l}\text { Tonys Tank } \\
\text { Tony Tank } \\
\text { Tony Tank } \\
\text { Toohey Tank } \\
\text { Toohidazdii } \\
\text { Toolbox Draw } \\
\text { Toothaker Place } \\
\text { See Liberty } \\
\text { Toothpick Canyon } \\
\text { Toothpick Ridge }\end{array}$ & $\begin{array}{l}\text { reservoir } \\
\text { reservoir } \\
\text { reservoir } \\
\text { reservoir } \\
\text { summit } \\
\text { valley } \\
\text { ppl } \\
\text { valley } \\
\text { ridge }\end{array}$ & $\begin{array}{l}\text { BGN } \\
\text { BGN } \\
\text { BGN } \\
\text { BGN } \\
\text { BGN } \\
\text { BGN } \\
\text { VARIANT } \\
\text { BGN } \\
\text { BGN }\end{array}$ & $\begin{array}{l}\text { Coconino } \\
\text { Maricopa } \\
\text { Yavapai } \\
\text { Yavapai } \\
\text { Apache } \\
\text { Apache } \\
\text { Maricopa } \\
\text { Coconino } \\
\text { Coconino }\end{array}$ & $\begin{array}{l}345601 N 1112432 \mathrm{~W} \\
323003 \mathrm{~N} 1131619 \mathrm{~W} \\
341356 \mathrm{~N} 1114735 \mathrm{~W} \\
344130 \mathrm{~N} 1124318 \mathrm{~W} \\
362716 \mathrm{~N} 1091934 \mathrm{~W} \\
335455 \mathrm{~N} 1090713 \mathrm{~W} \\
\\
332239 \mathrm{~N} 1122910 \mathrm{~W} \\
364246 \mathrm{N1122713W} \\
364242 \mathrm{~N} 1122501 \mathrm{~W}\end{array}$ & $335552 N 1090703 \mathrm{~W}$ & & $\begin{array}{l}\text { Mormon Lake } \\
\text { Aguila Mt's SE } \\
\text { Bloody Basin } \\
\text { Mt Josh } \\
\text { Bad Bug Butte } \\
\text { Escudilla Mtn } \\
\\
\text { Toothpick Ridge } \\
\text { Toothpick Ridge }\end{array}$ \\
\hline $\begin{array}{l}\text { Tooth Rock } \\
\text { Topacoba Gorge } \\
\text { Tope Kobe Gorge } \\
\text { Topahua } \\
\text { See Topawa } \\
\text { Topahua Well } \\
\text { See Topawa } \\
\text { Topawa } \\
\text { Gokasmuk } \\
\text { Koksumok } \\
\text { Topahua } \\
\text { Topahua Well } \\
\text { Topawo } \\
\text { Topowa } \\
\text { Tupewa }\end{array}$ & $\begin{array}{l}\text { ppl } \\
\text { ppl } \\
\text { ppl }\end{array}$ & $\begin{array}{l}\text { BGN } \\
\text { BGN } \\
\text { VARIANT } \\
\text { VARIANT } \\
\text { VARIANT } \\
\text { BGN } 1941 \\
\text { VARIANT } \\
\text { VARIANT } \\
\text { VARIANT } \\
\text { VARIANT } \\
\text { VARIANT } \\
\text { VARIANT } \\
\text { VARIANT }\end{array}$ & $\begin{array}{l}\text { Coconino } \\
\text { Coconino } \\
\text { Pima } \\
\text { Pima } \\
\text { Pima }\end{array}$ & $\begin{array}{l}362233 \mathrm{~N} 1113856 \mathrm{~W} \\
361215 \mathrm{~N} 1123430 \mathrm{~W} \\
314850 \mathrm{~N} 1114930 \mathrm{~W} \\
314850 \mathrm{~N} 1114930 \mathrm{~W} \\
314850 \mathrm{~N} 1114930 \mathrm{~W}\end{array}$ & $361110 \mathrm{~N} 1123218 \mathrm{~W}$ & 2473 & $\begin{array}{l}\text { Shinumo Altar } \\
\text { Topocoba Hilltop }\end{array}$ \\
\hline $\begin{array}{l}\text { Topawa Hills } \\
\text { Topawa Wash } \\
\text { Topawa Well } \\
\text { Topawo } \\
\text { See Topawa } \\
\text { Topaz Basin } \\
\text { Topaz Canyon } \\
\text { Topaz Railroad Station } \\
\text { Topaz Tank } \\
\text { Topeka Tank }\end{array}$ & $\begin{array}{l}\text { summit } \\
\text { stream } \\
\text { well } \\
\text { ppl } \\
\text { basin } \\
\text { valley } \\
\text { building } \\
\text { reservoir } \\
\text { reservoir }\end{array}$ & $\begin{array}{l}\text { BGN } 1941 \\
\text { BGN } \\
\text { UNOFF } \\
\text { VARIANT } \\
\text { BGN } \\
\text { BGN } 1908 \\
\text { UNOFF } \\
\text { BGN } \\
\text { BGN }\end{array}$ & $\begin{array}{l}\text { Pima } \\
\text { Pima } \\
\text { Pima } \\
\text { Pima } \\
\text { Yavapai } \\
\text { Coconino } \\
\text { Pinal } \\
\text { Graham } \\
\text { Coconino }\end{array}$ & $\begin{array}{l}314717 \mathrm{~N} 1115120 \mathrm{~W} \\
314540 \mathrm{~N} 1115639 \mathrm{~W} \\
314814 \mathrm{~N} 1114854 \mathrm{~W} \\
\\
314850 \mathrm{~N} 1114930 \mathrm{~W} \\
342938 \mathrm{~N} 1115720 \mathrm{~W} \\
360637 \mathrm{~N} 1121428 \mathrm{~W} \\
325008 \mathrm{~N} 1113036 \mathrm{~W} \\
325129 \mathrm{~N} 1092711 \mathrm{~W} \\
351712 \mathrm{~N} 1121228 \mathrm{~W}\end{array}$ & $314757 \mathrm{~N} 1114045 \mathrm{~W}$ & & $\begin{array}{l}\text { Arnold Mesa } \\
\text { Grand Canyon } \\
\text { Eloy North } \\
\text { Tollgate Tank } \\
\text { Williams North }\end{array}$ \\
\hline $\begin{array}{l}\text { Tope Kobe Gorge } \\
\text { See Topacoba Gorge } \\
\text { Top Notch Mine } \\
\text { Topock } \\
\text { Mellen } \\
\text { Mellon } \\
\text { Mullen } \\
\text { Needles } \\
\text { Powell } \\
\text { Red Crossing } \\
\text { Red Rock }\end{array}$ & $\begin{array}{l}\text { valley } \\
\text { mine } \\
\text { locale }\end{array}$ & $\begin{array}{l}\text { VARIANT } \\
\text { UNOFF } \\
\text { BGN } 1932 \\
\text { VARIANT } \\
\text { VARIANT } \\
\text { VARIANT } \\
\text { VARIANT } \\
\text { VARIANT } \\
\text { VARIANT } \\
\text { VARIANT }\end{array}$ & $\begin{array}{l}\text { Coconino } \\
\text { Yavapai } \\
\text { Mohave }\end{array}$ & $\begin{array}{l}361215 \mathrm{~N} 1123430 \mathrm{~W} \\
340217 \mathrm{~N} 1121755 \mathrm{~W} \\
344306 \mathrm{~N} 1142911 \mathrm{~W}\end{array}$ & & & $\begin{array}{l}\text { Columbia } \\
\text { Topock }\end{array}$ \\
\hline $\begin{array}{l}\text { Topock Bay } \\
\text { Topock Gorge } \\
\text { Topock Marsh }\end{array}$ & $\begin{array}{l}\text { bay } \\
\text { valley } \\
\text { swamp }\end{array}$ & $\begin{array}{l}\text { BGN } \\
\text { BGN } \\
\text { BGN } 1970\end{array}$ & $\begin{array}{l}\text { Mohave } \\
\text { Mohave } \\
\text { Mohave }\end{array}$ & $\begin{array}{l}344324 \mathrm{~N} 1142858 \mathrm{~W} \\
343940 \mathrm{~N} 1142716 \mathrm{~W} \\
344635 \mathrm{~N} 1143049 \mathrm{~W}\end{array}$ & $343848 \mathrm{~N} 1142637 \mathrm{~W}$ & & $\begin{array}{l}\text { Topock } \\
\text { Topock } \\
\text { Needles }\end{array}$ \\
\hline
\end{tabular}




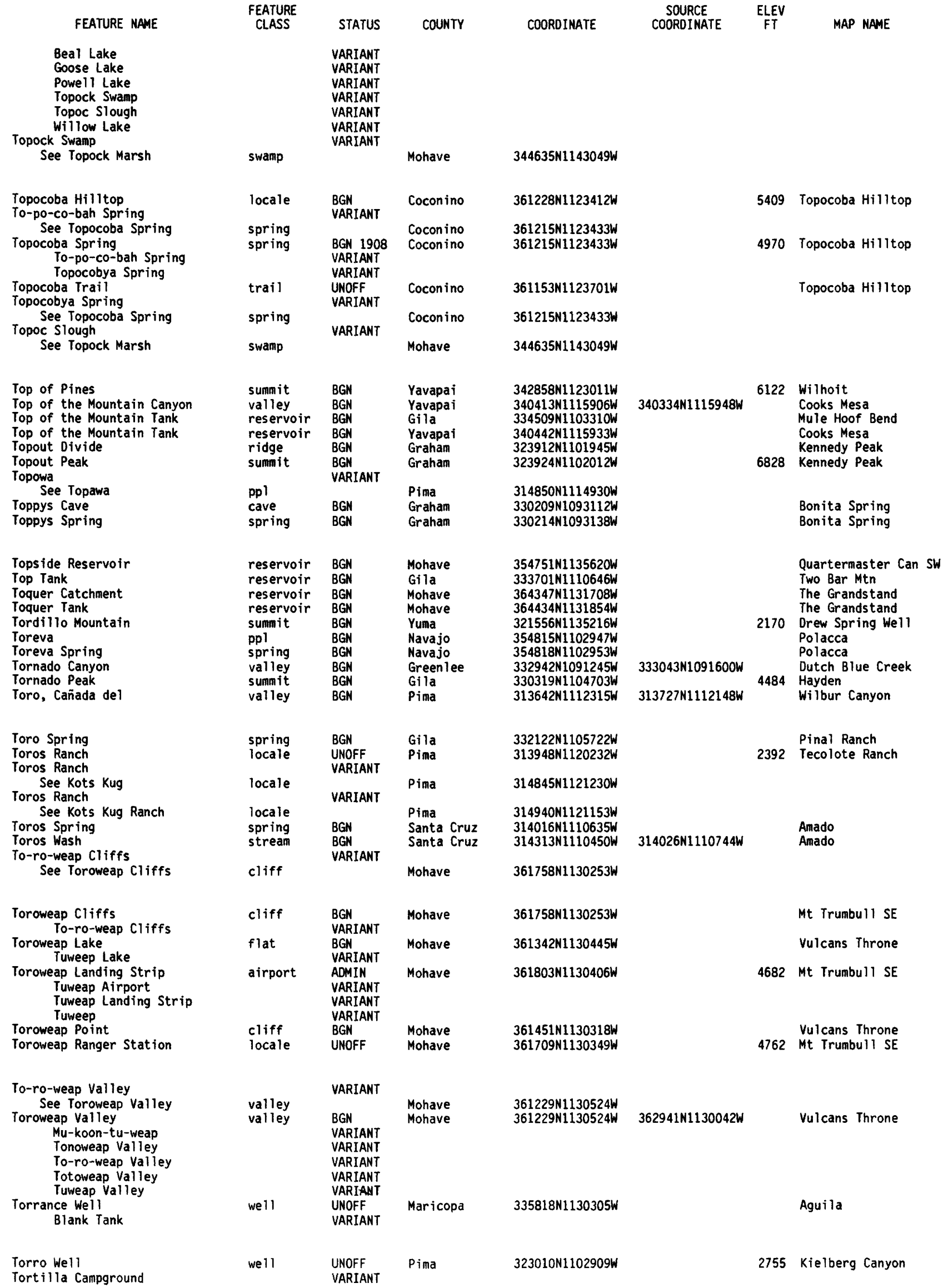


NATIONAL GAZETTEER--ARIZONA 1986

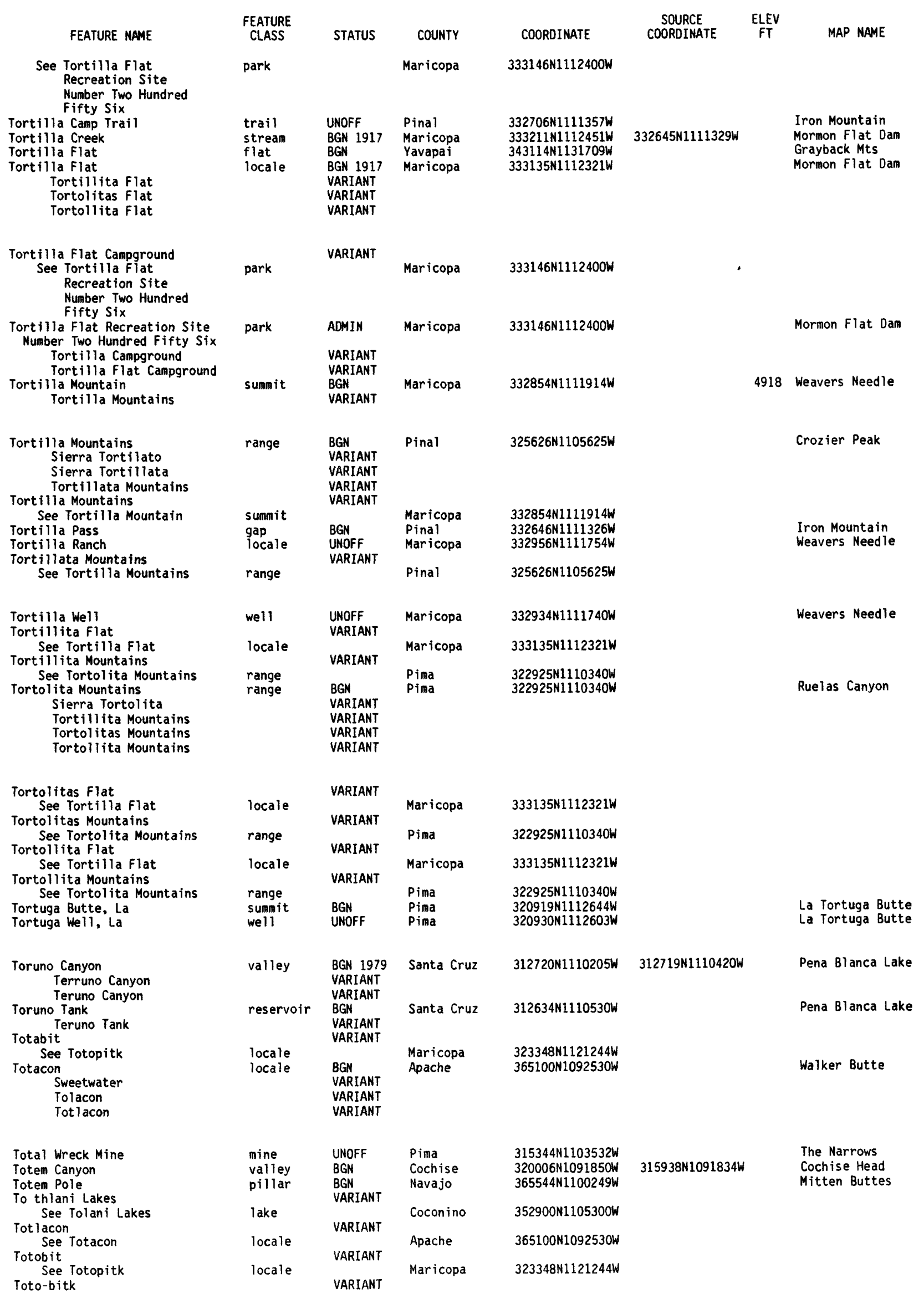




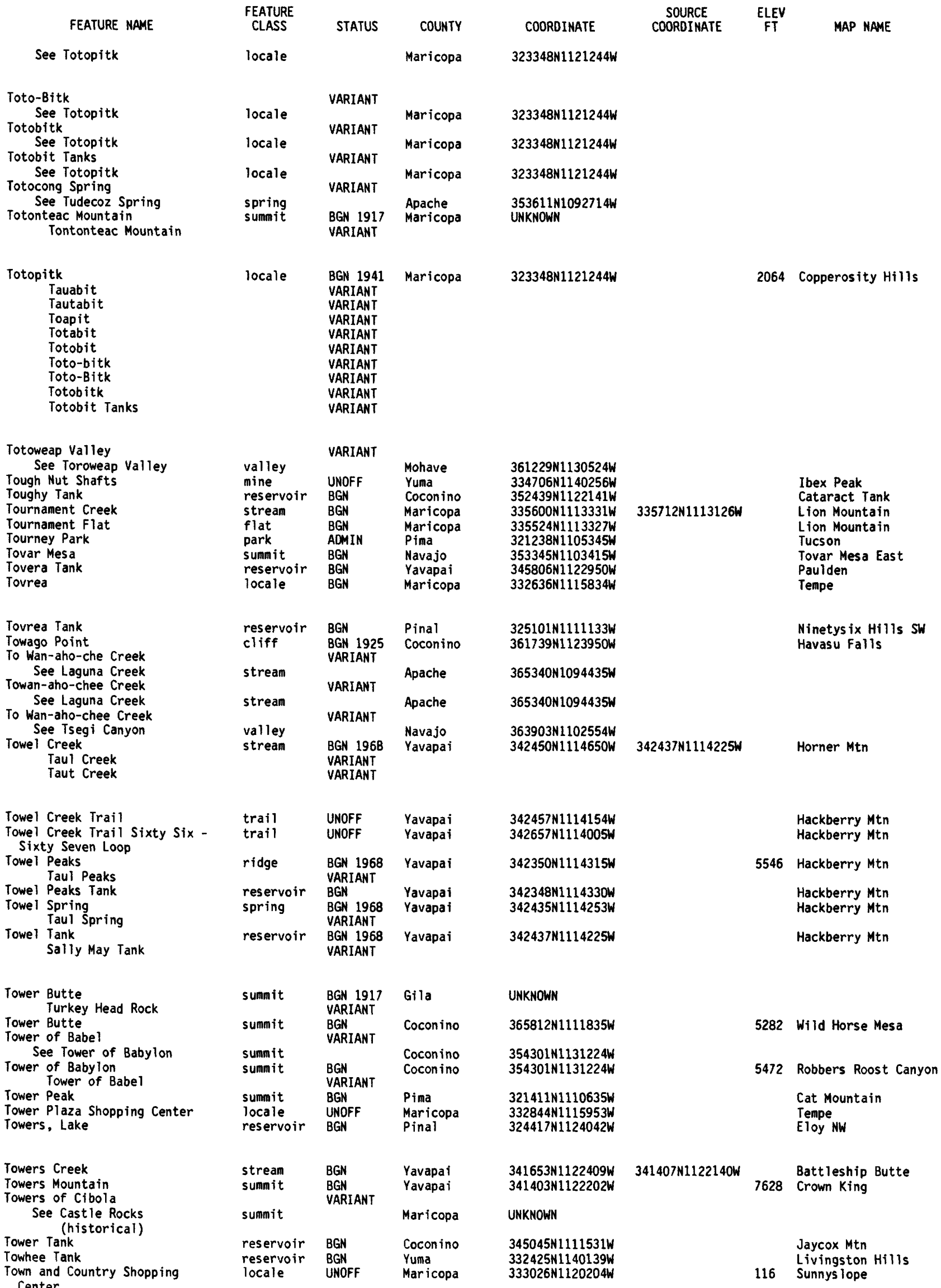




\begin{tabular}{|c|c|c|c|c|c|c|c|}
\hline FEATURE NAME & $\begin{array}{l}\text { FEATURE } \\
\text { CLASS }\end{array}$ & STATUS & COUNTY & COORDINATE & $\begin{array}{l}\text { SOURCE } \\
\text { COORDIMATE }\end{array}$ & $\begin{array}{l}\text { ELEV } \\
\text { FT }\end{array}$ & MAP NAME \\
\hline Town and Country Valley Mall & locale & UNOFF & Yavapai & $343515 N 1121943 W$ & & 5110 & Prescott Valley S \\
\hline $\begin{array}{l}\text { Town Draw } \\
\text { Towne Mine } \\
\text { Townsend Butte } \\
\text { Townsend Junior High School } \\
\text { Townsend Park } \\
\text { Townsend Well } \\
\text { Township Butte } \\
\text { Township Corner Tank } \\
\text { Township Tank } \\
\text { Town Tank }\end{array}$ & $\begin{array}{l}\text { valley } \\
\text { mine } \\
\text { summit } \\
\text { school } \\
\text { park } \\
\text { well } \\
\text { summit } \\
\text { reservoir } \\
\text { reservoir } \\
\text { reservoir }\end{array}$ & $\begin{array}{l}\text { BGN } \\
\text { UNOFF } \\
\text { BGN } \\
\text { UNOFF } \\
\text { AOMIN } \\
\text { UNOFF } \\
\text { BGN } \\
\text { BGN } \\
\text { BGN } \\
\text { BGN }\end{array}$ & $\begin{array}{l}\text { Navajo } \\
\text { Mohave } \\
\text { Yavapai } \\
\text { Pima } \\
\text { Maricopa } \\
\text { Pima } \\
\text { Cochise } \\
\text { Coconino } \\
\text { Mohave } \\
\text { Navajo }\end{array}$ & $\begin{array}{l}342703 \mathrm{~N} 1101209 \mathrm{~W} \\
352332 \mathrm{~N} 1141128 \mathrm{~W} \\
341636 \mathrm{~N} 1121238 \mathrm{~W} \\
321454 \mathrm{~N} 1105241 \mathrm{~W} \\
332755 \mathrm{~N} 1120358 \mathrm{~W} \\
320226 \mathrm{~N} 1112408 \mathrm{~W} \\
315340 \mathrm{~N} 1094525 \mathrm{~W} \\
360112 \mathrm{~N} 1130454 \mathrm{~W} \\
343240 \mathrm{~N} 1135238 \mathrm{~W} \\
341553 \mathrm{~N} 1100938 \mathrm{~W}\end{array}$ & $341803 \mathrm{N1101806 \textrm {W }}$ & $\begin{array}{l}2666 \\
4731\end{array}$ & $\begin{array}{l}\text { Cactus Flat } \\
\text { Chloride } \\
\text { Cleator } \\
\text { Tucson } \\
\text { Phoenix } \\
\text { San Pedro } \\
\text { Pearce } \\
\text { Vulcans Throne SE } \\
\text { Dutch Flat SW } \\
\text { Pinedale }\end{array}$ \\
\hline $\begin{array}{l}\text { Town Well } \\
\text { Towser Ranch } \\
\text { Towser Tank } \\
\text { Toyei } \\
\text { Toyei School } \\
\text { Toyei School Airport } \\
\text { Track Tank } \\
\text { Tracy Maintenance Camp } \\
\text { Tracys Trading Post } \\
\text { See Wahak Hotrontk }\end{array}$ & $\begin{array}{l}\text { well } \\
\text { locale } \\
\text { reservoir } \\
\text { ppl } \\
\text { school } \\
\text { airport } \\
\text { reservoir } \\
\text { locale } \\
\text { ppl }\end{array}$ & $\begin{array}{l}\text { UNOFF } \\
\text { UNOFF } \\
\text { BGN } \\
\text { BGN } \\
\text { UNOFF } \\
\text { ADMIN } \\
\text { BGN } \\
\text { UNOFF } \\
\text { VARIANT }\end{array}$ & $\begin{array}{l}\text { Navajo } \\
\text { Apache } \\
\text { Apache } \\
\text { Apache } \\
\text { Apache } \\
\text { Apache } \\
\text { Yavapai } \\
\text { Pima } \\
\text { Pima }\end{array}$ & $\begin{array}{l}342557 \mathrm{~N} 1101750 \mathrm{~W} \\
3401511090306 \mathrm{~W} \\
3401551090307 \mathrm{~W} \\
354209 \mathrm{~N} 1095615 \mathrm{~W} \\
354215 \mathrm{~N} 1095613 \mathrm{~W} \\
354215 \mathrm{~N} 1095625 \mathrm{~W} \\
343516 \mathrm{N1123514W} \\
321108 \mathrm{~N} 1122215 \mathrm{~W} \\
321058 \mathrm{~N} 1122154 \mathrm{~W}\end{array}$ & & 6523 & $\begin{array}{l}\text { Big Pug Tank } \\
\text { Loco Knoll } \\
\text { Loco Knoll } \\
\text { Toyei School } \\
\text { Toyei School } \\
\text { Toyei School } \\
\text { Iron Springs } \\
\text { Wahak Hotrontk }\end{array}$ \\
\hline $\begin{array}{l}\text { Trading Post Wash } \\
\text { Trail Canyon } \\
\text { Trail Canyon } \\
\text { Trail Canyon } \\
\text { Trail Canyon } \\
\text { Trail Canyon } \\
\text { Trail Canyon } \\
\text { Trail Canyon } \\
\text { Trailer Corral (trailer park) } \\
\text { Trailer House Spring }\end{array}$ & $\begin{array}{l}\text { valley } \\
\text { valley } \\
\text { valley } \\
\text { valley } \\
\text { valley } \\
\text { valley } \\
\text { valley } \\
\text { valley } \\
\text { locale } \\
\text { spring }\end{array}$ & $\begin{array}{l}\text { BGN } \\
\text { BGN } \\
\text { BGN } \\
\text { BGN } \\
\text { BGN } \\
\text { BGN } \\
\text { BGN } \\
\text { BGN } \\
\text { UNOFF } \\
\text { BGN }\end{array}$ & $\begin{array}{l}\text { Apache } \\
\text { Pima } \\
\text { Greenlee } \\
\text { Navajo } \\
\text { Navajo } \\
\text { Mohave } \\
\text { Mohave } \\
\text { Coconino } \\
\text { Maricopa } \\
\text { Gila }\end{array}$ & $\begin{array}{l}363633 \mathrm{~N} 109421 \mathrm{~W} \\
314650 \mathrm{~W} 110423 \mathrm{~W} \\
330010 \mathrm{~N} 1092004 \mathrm{~W} \\
341423 \mathrm{~N} 1102551 \mathrm{~W} \\
341617 \mathrm{N1102039W} \\
355020 \mathrm{~W} 1131938 \mathrm{~W} \\
3616371132001 \mathrm{~W} \\
364518 \mathrm{~N} 1120403 \mathrm{~W} \\
332708 \mathrm{N1120848W} \\
334950 \mathrm{~N} 1101114 \mathrm{~W}\end{array}$ & $\begin{array}{l}362240 \mathrm{~N} 1095217 \mathrm{~W} \\
314802 \mathrm{~N} 1104354 \mathrm{~W} \\
325933 \mathrm{N1091914 \textrm {W }} \\
341631 \mathrm{N1102220 \textrm {W }} \\
341532 \mathrm{N1102202 \textrm {W }} \\
355350 \mathrm{N1132356 \textrm {W }} \\
361835 \mathrm{~N} 113212 \mathrm{~W} \\
364213 \mathrm{~N} 1120943 \mathrm{~W}\end{array}$ & 1058 & $\begin{array}{l}\text { Rock Point SW } \\
\text { Empire Ranch } \\
\text { Clifton } \\
\text { Bear Ridge } \\
\text { Clay Springs } \\
\text { Diamond Peak } \\
\text { Cold Spring } \\
\text { House Rock Spring SE } \\
\text { Fowler } \\
\text { Cone 8utte }\end{array}$ \\
\hline $\begin{array}{l}\text { Trailing R Mobile Park } \\
\text { Trail Inn Lodge (trailer park) } \\
\text { Trail Pond } \\
\text { Trail Rapids 8ay } \\
\text { Trail Rapids Wash } \\
\text { Trai1-R-Dale Mobile Home Park } \\
\text { Trail Riders Holiday Park } \\
\text { (trailer park) }\end{array}$ & $\begin{array}{l}\text { locale } \\
\text { locale } \\
\text { reservoir } \\
\text { bay } \\
\text { stream } \\
\text { locale } \\
\text { locale }\end{array}$ & $\begin{array}{l}\text { UNOFF } \\
\text { UNOFF } \\
\text { BGN } \\
\text { BGN } \\
\text { BGN } \\
\text { UNOFF } \\
\text { UNOFF }\end{array}$ & $\begin{array}{l}\text { Maricopa } \\
\text { Maricopa } \\
\text { Mohave } \\
\text { Mohave } \\
\text { Mohave } \\
\text { Maricopa } \\
\text { Maricopa }\end{array}$ & $\begin{array}{l}332504 \mathrm{~N} 1113831 \mathrm{~W} \\
332706 \mathrm{N1120725W} \\
363815 \mathrm{N1130745W} \\
360244 \mathrm{N1142004W} \\
360218 \mathrm{~N} 1142055 \mathrm{~W} \\
332530 \mathrm{N1122057W} \\
332503 \mathrm{~N} 1114633 \mathrm{~W}\end{array}$ & $355105 \mathrm{~N} 1141819 \mathrm{~W}$ & $\begin{array}{l}965 \\
1260\end{array}$ & $\begin{array}{l}\text { Buckhorn } \\
\text { Phoenix } \\
\text { Antelope Knoll } \\
\text { The Temple } \\
\text { The Temple } \\
\text { Tolleson } \\
\text { Mesa }\end{array}$ \\
\hline $\begin{array}{l}\text { Trail Ridge } \\
\text { Trails End Airstrip }\end{array}$ & $\begin{array}{l}\text { ridge } \\
\text { airport }\end{array}$ & $\begin{array}{l}\text { BGN } \\
\text { ADMIN }\end{array}$ & $\begin{array}{l}\text { Gila } \\
\text { Yavapai }\end{array}$ & $\begin{array}{l}341909 \mathrm{~N} 1113503 \mathrm{~W} \\
340533 \mathrm{~N} 1120425 \mathrm{~W}\end{array}$ & & 2280 & $\begin{array}{l}\text { Cane Springs Mtn } \\
\text { Squaw Creek Mesa }\end{array}$ \\
\hline $\begin{array}{l}\text { Trails End Mine } \\
\text { Trail Spring } \\
\text { Trail Springs } \\
\text { Trails West Mobile Home Park } \\
\text { Trail Tank } \\
\text { Trail Tank } \\
\text { Trail Tank } \\
\text { Trail Tank } \\
\text { Trail Tank } \\
\text { Trail Tank }\end{array}$ & $\begin{array}{l}\text { mine } \\
\text { spring } \\
\text { spring } \\
\text { locale } \\
\text { reservoir } \\
\text { reservoir } \\
\text { reservoir } \\
\text { reservoir } \\
\text { reservoir } \\
\text { reservoir }\end{array}$ & $\begin{array}{l}\text { UNOFF } \\
\text { BGN } \\
\text { BGN } \\
\text { UNOFF } \\
\text { BGN } \\
\text { BGN } \\
\text { BGN } \\
\text { BGN } \\
\text { BGN } \\
\text { BGN }\end{array}$ & $\begin{array}{l}\text { Yavapai } \\
\text { Gila } \\
\text { Maricopa } \\
\text { Maricopa } \\
\text { Pima } \\
\text { Pima } \\
\text { Pinal } \\
\text { Greenlee } \\
\text { Gila } \\
\text { Apache }\end{array}$ & $\begin{array}{l}341907 \mathrm{~N} 1122538 \mathrm{~W} \\
335646 \mathrm{~N} 1101307 \mathrm{~W} \\
335820 \mathrm{N1113820 \textrm {W }} \\
332436 \mathrm{N1113521 \textrm {W }} \\
321925 \mathrm{N1} 103438 \mathrm{~W} \\
322026 \mathrm{N1103435 \textrm {W }} \\
332030 \mathrm{~N} 1110222 \mathrm{~W} \\
3320321092122 \mathrm{~W} \\
334953 \mathrm{~N} 1101917 \mathrm{~W} \\
335417 \mathrm{~N} 1091454 \mathrm{~W}\end{array}$ & & 1600 & $\begin{array}{l}\text { Battleship Butte } \\
\text { Cedar Creek } \\
\text { Horseshoe Dam } \\
\text { Apache Junction } \\
\text { Piety Hill } \\
\text { Piety Hill } \\
\text { Superior } \\
\text { Pipestem Mtn } \\
\text { Carrizo SE } \\
\text { Nutrioso }\end{array}$ \\
\hline $\begin{array}{l}\text { Trail Tank } \\
\text { Trail Tank } \\
\text { Trail Tank } \\
\text { Trail Tank } \\
\text { Trail Tank } \\
\text { Trail Tank } \\
\text { Trail Tank } \\
\text { Trail Tank } \\
\text { Trail Tank } \\
\text { Trail Tank }\end{array}$ & $\begin{array}{l}\text { reservoir } \\
\text { reservoir } \\
\text { reservoir } \\
\text { reservoir } \\
\text { reservoir } \\
\text { reservoir } \\
\text { reservoir } \\
\text { reservoir } \\
\text { reservoir } \\
\text { reservoir }\end{array}$ & $\begin{array}{l}\text { BGN } \\
B G N \\
B G N \\
B G N \\
B G N \\
B G N \\
B G N \\
B G N \\
B G N \\
B G N\end{array}$ & $\begin{array}{l}\text { Yavapai } \\
\text { Gila } \\
\text { Yavapai } \\
\text { Gila } \\
\text { Yavapai } \\
\text { Yavapai } \\
\text { Yavapai } \\
\text { Mohave } \\
\text { Coconino } \\
\text { Coconino }\end{array}$ & $\begin{array}{l}340202 \mathrm{~N} 1115203 \mathrm{~W} \\
340304 \mathrm{~N} 1104534 \mathrm{~W} \\
340912 \mathrm{N1114543W} \\
341015 \mathrm{N1105425W} \\
343129 \mathrm{N1} 122030 \mathrm{~W} \\
343922 \mathrm{N1113745W} \\
344238 \mathrm{N1113443 \textrm {W }} \\
353503 \mathrm{N1} 133349 \mathrm{~W} \\
353750 \mathrm{~N} 1121602 \mathrm{~W} \\
355445 \mathrm{~N} 112034 \mathrm{~W}\end{array}$ & & 5532 & $\begin{array}{l}\text { Rover Peak } \\
\text { Gentry Mtn } \\
\text { Bloody Basin } \\
\text { Parallel Canyon } \\
\text { Prescott Valley S } \\
\text { Casner Butte } \\
\text { Apache Maid Mtn } \\
\text { Milkweed Canyon SE } \\
\text { Miller Tank } \\
\text { Tusayan East }\end{array}$ \\
\hline $\begin{array}{l}\text { Trail Well } \\
\text { Trainer Dam } \\
\text { Trainer Tank } \\
\text { Tramline Tank } \\
\text { Trampa Spring } \\
\text { Trampled Water Canyon } \\
\text { Tramway Tank } \\
\text { Transcendent Mine } \\
\text { Transept, The } \\
\text { The Trancept }\end{array}$ & $\begin{array}{l}\text { well } \\
\text { dam } \\
\text { reservoir } \\
\text { reservoir } \\
\text { spring } \\
\text { valley } \\
\text { reservoir } \\
\text { mine } \\
\text { valley }\end{array}$ & $\begin{array}{l}\text { UNOFF } \\
\text { UNOFF } \\
\text { BGN } \\
\text { BGN } \\
\text { BGN } \\
\text { BGN } \\
\text { BGN } \\
\text { UNOFF } \\
\text { BGN 1906 } \\
\text { UARIANT }\end{array}$ & $\begin{array}{l}\text { Coconino } \\
\text { Graham } \\
\text { Graham } \\
\text { Graham } \\
\text { Pima } \\
\text { Coconino } \\
\text { Coconino } \\
\text { Yavapai } \\
\text { Coconino }\end{array}$ & $\begin{array}{l}361633 \mathrm{~N} 1111644 \mathrm{~W} \\
331930 \mathrm{~N} 102330 \mathrm{~W} \\
331950 \mathrm{N1} 102337 \mathrm{~W} \\
324813 \mathrm{~N} 1095259 \mathrm{~W} \\
32245 \mathrm{BN} 1103852 \mathrm{~W} \\
365104 \mathrm{~N} 1105555 \mathrm{~W} \\
343358 \mathrm{~N} 111251 \mathrm{~W} \\
342643 \mathrm{~N} 1122447 \mathrm{~W} \\
361036 \mathrm{~N} 1120234 \mathrm{~W}\end{array}$ & $\begin{array}{l}365452 \mathrm{~N} 1105129 \mathrm{~W} \\
361308 \mathrm{~N} 1120449 \mathrm{~W}\end{array}$ & 5307 & $\begin{array}{l}\text { Preston Well } \\
\text { San Carlos } \\
\text { San Carlos } \\
\text { Shingle Mill Mtn } \\
\text { Mount Bigelow } \\
\text { Chaiyahi Rim SW } \\
\text { Calloway Butte } \\
\text { Groom Creek } \\
\text { Bright Angel Point }\end{array}$ \\
\hline
\end{tabular}


FEATURE CLASS
COUNTY

COORDINATE

Transept Trail Campgrounds

Transwestern Pipeline Number

Four Airstrip

Transwestern Pipeline Number One Airport

Transwestern Pipeline Number Three Airport

Tran Tank

Trap Canyon

Music Canyon

Trap Canyon

Trap Canyon Spring

Trap Corral Canyon

Trap Corral Spring

Trap Mesa Spring

Trap Number One Spring

Trap Number Two Spring

Trap Peak

Trappman Ranch

Trap Spring

Trap Spring

Trap Spring

Trap Spring

Trap Spring

Trap Spring

Trap Spring

Trap Tank

Trap Tank

Trap Tank

Trap Tank

Trap Tank

Trap Tank

Trash Dam

Trask Ranch

Trask Well

Travertine Canyon

Travertine Canyon

Travert ine Falls

Travertine Rapids

Treadway Mountain

Treadway Spring

Treasure Park

Treasure Vault Mine

Treckell Road Interchange

Treehaven School

Tree Pond

Tree Spring

Tree Spring

Tree Tank

Trekell Park

Tremain

See Tremaine
Tremaine

Tremain

Tremaine Lake

Trench Camp

Trench Mine

Trench Mine

See Trench Camp

Trendt Windmill

Trenton Mine

Trepida

Tres Alamos

Tres Alamos Ranch

Tres Alamos Spring

Tres Alamos Wash

Tres Amegos Gulch

See Warsaw Canyon

Tres Amegos Gulch

See Tres Amigos Gulch

VARIANT

locale

BGN

VARIANT

ppl

BGN

VARIANT

valley

VARIANT

Santa Cruz

\begin{tabular}{|c|c|c|c|}
\hline $\begin{array}{l}\text { trail } \\
\text { park } \\
\text { airport }\end{array}$ & $\begin{array}{l}\text { UNOFF } \\
\text { ADMIN } \\
\text { ADMIN }\end{array}$ & $\begin{array}{l}\text { Coconino } \\
\text { Coconino } \\
\text { Apache }\end{array}$ & $\begin{array}{l}361203 \mathrm{~N} 1120325 \mathrm{~W} \\
361250 \mathrm{~N} 1120338 \mathrm{~W} \\
353405 \mathrm{~N} 1092239 \mathrm{~W}\end{array}$ \\
\hline airport & ADMIN & Mohave & $351227 \mathrm{~N} 1132232 \mathrm{~W}$ \\
\hline airport & ADMIN & Coconino & $351800 \mathrm{~N} 1105000 \mathrm{~W}$ \\
\hline $\begin{array}{l}\text { reservoir } \\
\text { valley }\end{array}$ & $\begin{array}{l}\text { BGN } \\
\text { BGN } \\
\text { VARIANT }\end{array}$ & $\begin{array}{l}\text { Navajo } \\
\text { Pinal }\end{array}$ & $\begin{array}{l}341526 \mathrm{~N} 1102224 \mathrm{~W} \\
332607 \mathrm{~N} 1111908 \mathrm{~W}\end{array}$ \\
\hline $\begin{array}{l}\text { valley } \\
\text { spring } \\
\text { valley } \\
\text { spring } \\
\text { spring } \\
\text { spring } \\
\text { spring } \\
\text { summit } \\
\text { locale } \\
\text { spring }\end{array}$ & $\begin{array}{l}\text { BGN } \\
\text { BGN } \\
\text { BGN } \\
\text { BGN } \\
\text { BGN } \\
\text { BGN } \\
\text { BGN } \\
\text { BGN } \\
\text { UNOFF } \\
\text { BGN }\end{array}$ & $\begin{array}{l}\text { Yavapai } \\
\text { Pinal } \\
\text { Gila } \\
\text { Yavapai } \\
\text { Gila } \\
\text { Gila } \\
\text { Gila } \\
\text { Graham } \\
\text { Cochise } \\
\text { Graham }\end{array}$ & $\begin{array}{l}341306 \mathrm{~N} 1114605 \mathrm{~W} \\
332616 \mathrm{~N} 1111858 \mathrm{~W} \\
331327 \mathrm{~N} 1105158 \mathrm{~W} \\
342738 \mathrm{~N} 1123331 \mathrm{~W} \\
333635 \mathrm{~N} 1104414 \mathrm{~W} \\
335909 \mathrm{~N} 1102445 \mathrm{~W} \\
335911 \mathrm{~N} 1102358 \mathrm{~W} \\
324341 \mathrm{~N} 1095032 \mathrm{~W} \\
313608 \mathrm{~N} 1100347 \mathrm{~W} \\
323613 \mathrm{~N} 1095018 \mathrm{~W}\end{array}$ \\
\hline $\begin{array}{l}\text { spring } \\
\text { spring } \\
\text { spring } \\
\text { spring } \\
\text { spring } \\
\text { spring } \\
\text { reservoir } \\
\text { reservoir } \\
\text { reservoir } \\
\text { reservoir }\end{array}$ & $\begin{array}{l}\text { BGN } \\
\text { BGN } \\
\text { BGN } \\
\text { BGN } \\
\text { BGN } \\
\text { BGN } \\
\text { BGN } \\
B G N \\
\text { BGN } \\
\text { BGN }\end{array}$ & $\begin{array}{l}\text { Gila } \\
\text { Maricopa } \\
\text { Apache } \\
\text { Yavapai } \\
\text { Mohave } \\
\text { Mohave } \\
\text { Graham } \\
\text { Gila } \\
\text { Navajo } \\
\text { Yavapai }\end{array}$ & $\begin{array}{l}331931 N 1105344 W \\
335350 N 1113124 W \\
335649 N 1092655 W \\
343713 N 1120954 W \\
345435 N 1133207 W \\
351944 N 1134548 W \\
324902 N 1091839 W \\
333856 N 1102802 W \\
344153 N 1104047 W \\
344354 N 1125020 W\end{array}$ \\
\hline $\begin{array}{l}\text { reservoir } \\
\text { reservoir } \\
\text { dam } \\
\text { locale } \\
\text { well } \\
\text { valley } \\
\text { valley } \\
\text { falls } \\
\text { rapids } \\
\text { summit }\end{array}$ & $\begin{array}{l}\text { BGN } \\
\text { BGN } \\
\text { UNDFF } \\
\text { UNOFF } \\
\text { UNOFF } \\
\text { BGN } \\
\text { BGN } 1932 \\
\text { BGN } \\
\text { BGN } \\
\text { BGN }\end{array}$ & $\begin{array}{l}\text { Yavapai } \\
\text { Coconino } \\
\text { Coconino } \\
\text { Santa Cruz } \\
\text { Cochise } \\
\text { Mohave } \\
\text { Coconino } \\
\text { Mohave } \\
\text { Mohave } \\
\text { Grahan }\end{array}$ & $\begin{array}{l}350230 \mathrm{N1} 131410 \mathrm{~W} \\
360610 \mathrm{N1} 121140 \mathrm{~W} \\
355715 \mathrm{N11} 15308 \mathrm{~W} \\
312156 \mathrm{N1104009W} \\
315315 \mathrm{N1} 102356 \mathrm{~W} \\
354504 \mathrm{N11} 132526 \mathrm{~W} \\
360608 \mathrm{~N} 1121307 \mathrm{~W} \\
354521 \mathrm{N1} 132649 \mathrm{~W} \\
354505 \mathrm{~N} 1132521 \mathrm{~W} \\
330422 \mathrm{~N} 1094537 \mathrm{~W}\end{array}$ \\
\hline $\begin{array}{l}\text { spring } \\
\text { park } \\
\text { mine } \\
\text { crossing } \\
\text { school } \\
\text { lake } \\
\text { spring } \\
\text { spring } \\
\text { reservoir } \\
\text { park }\end{array}$ & $\begin{array}{l}\text { BGN } \\
\text { ADMIN } \\
\text { UNOFF } \\
\text { UNOFF } \\
\text { UNOFF } \\
\text { BGN } \\
\text { BGN } \\
\text { BGN } \\
\text { BGN } \\
\text { ADMIN }\end{array}$ & $\begin{array}{l}\text { Graham } \\
\text { Graham } \\
\text { Santa Cruz } \\
\text { Pinal } \\
\text { Pima } \\
\text { Mohave } \\
\text { Coconino } \\
\text { Navajo } \\
\text { Coconino } \\
\text { Pinal }\end{array}$ & $\begin{array}{l}330400 \mathrm{~N} 1094647 \mathrm{~W} \\
323940 \mathrm{~N} 1095214 \mathrm{~W} \\
314204 \mathrm{~N} 110532 \mathrm{~W} \\
324942 \mathrm{~N} 1114421 \mathrm{~W} \\
321348 \mathrm{~N} 1105225 \mathrm{~W} \\
362913 \mathrm{~N} 1132330 \mathrm{~W} \\
345210 \mathrm{~N} 1112959 \mathrm{~W} \\
352630 \mathrm{~N} 1100650 \mathrm{~W} \\
350926 \mathrm{~N} 1114546 \mathrm{~W} \\
324507 \mathrm{~N} 1113350 \mathrm{~W}\end{array}$ \\
\hline
\end{tabular}

$341752 N 1114651 \mathrm{~W}$

$331606 \mathrm{~N} 1105029 \mathrm{~W}$

Weavers Needle

El Capitan Mtn

Wilhoit

Chrome Butte

Cibecue Peak

Cibecue Peak

8106 Mt Graham

Tombstone SE

Stockton Pass

Pinal Ranch

Lion Mountain

Big Lake North

Humboldt

Tom Brown Canyon

Peacock Peak

Ash Peak

Brushy Canyon

Potato Wash North

Smith Mesa

Anvil Rock Ranch

Williams South

Grandview Point

Duquesne

354244N1132710W

$360447 \mathrm{~N} 1121426 \mathrm{~W}$

5001 Mesca

Travertine Rapids

Grand Canyon

Travertine Rapids

Travertine Rapids

5907 Markhan Creek

Markhan Creek

Mt Graham

Mt Hopkins

1429 Casa Grande Mts

Tucs on East

Poverty Knoll

Hutch Mtn

Indian Wells

Bellemont

Eloy North

Maricopa 332132N1114954W

$332132 \mathrm{~N} 1114954 \mathrm{~W}$

reservoir BGN Coconino 344536N1111300W

$\begin{array}{ll}\text { Coconino } & 344536 \mathrm{~N} 1111300 \mathrm{~W} \\ \text { Santa Cruz } & 312752 \mathrm{~N} 1104343 \mathrm{~W}\end{array}$

locale BGN Cochise 321603N1093109W

$313559 N 1105134 \mathrm{~W}$

$\begin{array}{llll}\text { reservoir } & \text { BGN } & \text { Pima } & 322007 N 1103758 \mathrm{~W} \\ \text { summit } & \text { BGN } & \text { Yavapai } & 341448 N 1131044 \mathrm{~W} \\ \text { locale } & \text { UNOFF } & \text { Cochise } & 320342 \mathrm{~N} 1102038 \mathrm{~W} \\ \text { spring } & \text { BGN } & \text { Yavapai } & 341333 \mathrm{~N} 1130826 \mathrm{~W}\end{array}$

$\begin{array}{llll}\text { reservoir } & \text { BGN } & \text { Pima } & 322007 N 1103758 \mathrm{~W} \\ \text { summit } & \text { BGN } & \text { Yavapai } & 341448 N 1131044 \mathrm{~W} \\ \text { locale } & \text { UNOFF } & \text { Cochise } & 320342 \mathrm{~N} 1102038 \mathrm{~W} \\ \text { spring } & \text { BGN } & \text { Yavapai } & 341333 \mathrm{~N} 1130826 \mathrm{~W}\end{array}$

$\begin{array}{llll}\text { reservoir } & \text { BGN } & \text { Pima } & 322007 N 1103758 \mathrm{~W} \\ \text { summit } & \text { BGN } & \text { Yavapai } & 341448 N 1131044 \mathrm{~W} \\ \text { locale } & \text { UNOFF } & \text { Cochise } & 320342 \mathrm{~N} 1102038 \mathrm{~W} \\ \text { spring } & \text { BGN } & \text { Yavapai } & 341333 \mathrm{~N} 1130826 \mathrm{~W}\end{array}$

$\begin{array}{llll}\text { spring } & \text { BGN } & \text { Yavapai } & 341333 N 1130826 \mathrm{~W} \\ \text { stream } & \text { BGN } & \text { Cochise } & 320351 \mathrm{~N} 1102005 \mathrm{~W}\end{array}$

$320814 N 1100239 \mathrm{~W}$

$312410 \mathrm{~N} 1111430 \mathrm{~W}$

Santa Cruz 312456N1111450W 
NATIONAL GAZETTEER--ARIZONA 1986 FEATURE NAME CLAS

STATUS

COUNTY

COORDINATE

$\begin{array}{cc}\text { SOURCE } & \text { ELEV } \\ \text { COORDINATE } & \text { FT }\end{array}$

MAP NAME

Tres Amigos Gulch

See Warsaw Canyon

Tres Amigos Gulch

Tres Amegos Gulch

Tres Bellotas Canyon

Tres 8ellotas Ranch

Tres Bellotas We11

Las Tres Bellotas

Tres Dedos Well

Tres de Mayo Tank

Tres de Mayo Well

Ires Pipas Canyon

Tres Puertas Tank

Tres Puertas Well

Tres Rios (subdivision)

Trestle Tank

Trevor Brown High School

Trevorrow Lateral

Trezise Tank

Triangle Canyon

Triangle HC Ranch

Triangle L Ranch

Triangle N Camp

Triangle N Canyon

Triangle N Tank

Triangle Ranch

Triangle Ranch

Triangle Spring

Triangle Tank

Triangle Tank

Triangle Tank

Triangle T Ranch

Triangle U Ranch

Triangle Well

Tribal Headstart Preschool

Trible Tank

Tri-City Mall

Trick Number Two Tank

Trick Tank

Trick Tank

Trick Tank

Trick Tank

Irico Compressor Station

Irigo, Cerro Cerro Negro

Irigo Mountains

Irigo Mountains See Chocolate Mountains

Irigo Pass

Trigo Wash

Trilby Wash

Panoche Creek

Trilleby Wash

Trilby Wash Basin

Trilby Wash Oetention Bas in

Trilby Wash Detention Bas in See Trilby Wash Bas in

Trilleby Wash

See Trilby Wash

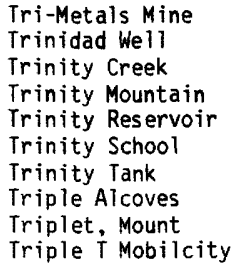

\begin{tabular}{|c|c|c|c|}
\hline $\begin{array}{l}\text { valley } \\
\text { valley }\end{array}$ & $\begin{array}{l}\text { VARIANT } \\
\text { BGN } 1978 \\
\text { VARIANT }\end{array}$ & $\begin{array}{l}\text { Santa Cruz } \\
\text { Santa Cruz }\end{array}$ & $\begin{array}{l}312410 \mathrm{~N} 1111430 \mathrm{~W} \\
312456 \mathrm{~N} 1111450 \mathrm{~W}\end{array}$ \\
\hline $\begin{array}{l}\text { valley } \\
\text { locale } \\
\text { well }\end{array}$ & $\begin{array}{l}\text { BGN } \\
\text { UNOFF } \\
\text { UNOFF } \\
\text { VARIANT }\end{array}$ & $\begin{array}{l}\text { Santa Cruz } \\
\text { Santa Cruz } \\
\text { Santa Cruz }\end{array}$ & $\begin{array}{l}311935 \mathrm{~N} 1112030 \mathrm{~W} \\
312543 \mathrm{~N} 1112117 \mathrm{~W} \\
312822 \mathrm{~N} 1112134 \mathrm{~W}\end{array}$ \\
\hline $\begin{array}{l}\text { well } \\
\text { reservoir }\end{array}$ & $\begin{array}{l}\text { UNOFF } \\
\text { BGN }\end{array}$ & $\begin{array}{l}\text { Pima } \\
\text { Santa Cruz }\end{array}$ & $\begin{array}{l}314136 \mathrm{~N} 1111025 \mathrm{~W} \\
312637 \mathrm{~N} 1104735 \mathrm{~W}\end{array}$ \\
\hline $\begin{array}{l}\text { well } \\
\text { valley } \\
\text { reservoir } \\
\text { well } \\
\text { ppl } \\
\text { reservoir } \\
\text { school } \\
\text { canal } \\
\text { reservoir } \\
\text { valley }\end{array}$ & $\begin{array}{l}\text { UNOFF } \\
\text { BGN } \\
\text { BGN } \\
\text { UNOFF } \\
\text { BGN } \\
\text { BGN } \\
\text { UNOFF } \\
\text { BGN } \\
\text { BGN } \\
\text { BGN }\end{array}$ & $\begin{array}{l}\text { Santa Cruz } \\
\text { Pima } \\
\text { Santa Cruz } \\
\text { Santa Cruz } \\
\text { Yavapai } \\
\text { Yavapai } \\
\text { Maricopa } \\
\text { Yuma } \\
\text { Gila } \\
\text { Cochise }\end{array}$ & $\begin{array}{l}312644 N 1104758 \mathrm{~W} \\
321558 \mathrm{~N} 1102903 \mathrm{~W} \\
313822 \mathrm{~N} 1110542 \mathrm{~W} \\
314150 \mathrm{~N} 1110550 \mathrm{~W} \\
343350 \mathrm{~N} 1115051 \mathrm{~W} \\
345547 \mathrm{~N} 1121418 \mathrm{~W} \\
332900 \mathrm{~N} 1121306 \mathrm{~W} \\
323520 \mathrm{~N} 1144350 \mathrm{~W} \\
340940 \mathrm{~N} 1112158 \mathrm{~W} \\
320517 \mathrm{~N} 1091418 \mathrm{~W}\end{array}$ \\
\hline $\begin{array}{l}\text { locale } \\
\text { locale } \\
\text { locale } \\
\text { valley } \\
\text { reservoir } \\
\text { locale } \\
\text { locale } \\
\text { spring } \\
\text { reservoir } \\
\text { reservoir }\end{array}$ & $\begin{array}{l}\text { UNOFF } \\
\text { UNOFF } \\
\text { BGN } \\
\text { BGN } \\
\text { BGN } \\
\text { UNOFF } \\
\text { UNOFF } \\
\text { BGN } \\
\text { BGN } \\
\text { BGN }\end{array}$ & $\begin{array}{l}\text { Yavapai } \\
\text { Pinal } \\
\text { Yavapai } \\
\text { Yavapai } \\
\text { Yavapai } \\
\text { Santa Cruz } \\
\text { Cochise } \\
\text { Coconino } \\
\text { Coconino } \\
\text { Yavapai }\end{array}$ & $\begin{array}{l}344802 N 1125801 \mathrm{~W} \\
323732 \mathrm{~N} 104722 \mathrm{~W} \\
345740 \mathrm{N1} 131319 \mathrm{~W} \\
345828 \mathrm{~N} 1131240 \mathrm{~W} \\
345757 \mathrm{N1} 131312 \mathrm{~W} \\
313350 \mathrm{~N} 1103144 \mathrm{~W} \\
321949 \mathrm{~N} 1091621 \mathrm{~W} \\
351018 \mathrm{~N} 1115728 \mathrm{~W} \\
343914 \mathrm{N1} 111717 \mathrm{~W} \\
344841 \mathrm{~N} 1115452 \mathrm{~W}\end{array}$ \\
\hline $\begin{array}{l}\text { reservoir } \\
\text { locale } \\
\text { locale } \\
\text { well } \\
\text { school } \\
\text { reservoir } \\
\text { locale } \\
\text { reservoir } \\
\text { reservoir } \\
\text { reservoir }\end{array}$ & $\begin{array}{l}\text { BGN } \\
\text { UNOFF } \\
\text { UNOFF } \\
\text { UNOFF } \\
\text { UNOFF } \\
\text { BGN } \\
\text { UNOFF } \\
\text { BGN } \\
\text { BGN } \\
\text { BGN }\end{array}$ & $\begin{array}{l}\text { Apache } \\
\text { Cochise } \\
\text { Yavapai } \\
\text { Apache } \\
\text { Navajo } \\
\text { Coconino } \\
\text { Maricopa } \\
\text { Yavapai } \\
\text { Pima } \\
\text { Yavapai }\end{array}$ & $\begin{array}{l}345125 N 1093345 \mathrm{~W} \\
320241 \mathrm{~N} 1100509 \mathrm{~W} \\
345446 \mathrm{~N} 1125007 \mathrm{~W} \\
345250 \mathrm{~N} 1093328 \mathrm{~W} \\
354818 \mathrm{~N} 1102952 \mathrm{~W} \\
354015 \mathrm{~N} 1130243 \mathrm{~W} \\
332500 \mathrm{~N} 1115217 \mathrm{~W} \\
344433 \mathrm{~N} 1115027 \mathrm{~W} \\
313048 \mathrm{~N} 1112442 \mathrm{~W} \\
344829 \mathrm{~N} 1121527 \mathrm{~W}\end{array}$ \\
\hline $\begin{array}{l}\text { reservoir } \\
\text { reservoir } \\
\text { locale } \\
\text { summit }\end{array}$ & $\begin{array}{l}\text { BGN } \\
\text { BGN } \\
\text { UNOFF } \\
\text { BGN } \\
\text { VARIANT }\end{array}$ & $\begin{array}{l}\text { Coconino } \\
\text { Coconino } \\
\text { Pima } \\
\text { Apache }\end{array}$ & $\begin{array}{l}352512 \mathrm{~N} 1112407 \mathrm{~W} \\
352932 \mathrm{~N} 1112349 \mathrm{~W} \\
322643 \mathrm{~N} 1111814 \mathrm{~W} \\
341135 \mathrm{~N} 1093413 \mathrm{~W}\end{array}$ \\
\hline range & $\begin{array}{l}\text { BGN } \\
\text { VARIANT }\end{array}$ & Yuma & $331817 N 1143247 \mathrm{~W}$ \\
\hline $\begin{array}{l}\text { summit } \\
\text { gap } \\
\text { stream }\end{array}$ & $\begin{array}{l}\text { BGN } \\
\text { BGN }\end{array}$ & $\begin{array}{l}\text { Yuma } \\
\text { Yuma } \\
\text { Yuma }\end{array}$ & $\begin{array}{l}331105 \mathrm{~N} 1142329 \mathrm{~W} \\
332621 \mathrm{~N} 1141943 \mathrm{~W} \\
333128 \mathrm{~N} 1143240 \mathrm{~W}\end{array}$ \\
\hline reservoir & $\begin{array}{l}\text { BGN } \\
\text { VARIANT } \\
\text { VARIANT } \\
\text { BGN } 1972 \\
\text { VARIANT }\end{array}$ & Maricopa & $333931 N 1122721 \mathrm{~W}$ \\
\hline $\begin{array}{l}\text { reservoir } \\
\text { stream }\end{array}$ & $\begin{array}{l}\text { VARIANT } \\
\text { VARIANT }\end{array}$ & $\begin{array}{l}\text { Maricopa } \\
\text { Maricopa }\end{array}$ & $\begin{array}{l}334117 N 1122522 W \\
333931 N 1122721 W\end{array}$ \\
\hline $\begin{array}{l}\text { mine } \\
\text { well } \\
\text { stream } \\
\text { summit } \\
\text { reservoir } \\
\text { school } \\
\text { reservoir } \\
\text { basin } \\
\text { summit } \\
\text { locale }\end{array}$ & $\begin{array}{l}\text { UNOFF } \\
\text { UNOFF } \\
\text { BGN } 1906 \\
\text { BGN } \\
\text { BGN } \\
\text { UNOFF } \\
\text { BGN } \\
\text { BGN } \\
\text { BGN } \\
\text { UNOFF }\end{array}$ & $\begin{array}{l}\text { Yavapai } \\
\text { Mohave } \\
\text { Coconino } \\
\text { Coconino } \\
\text { Apache } \\
\text { Maricopa } \\
\text { Coconino } \\
\text { Coconino } \\
\text { Graham } \\
\text { Maricopa }\end{array}$ & $\begin{array}{l}342723 \mathrm{~N} 1120 \mathrm{~B} 37 \mathrm{~W} \\
343808 \mathrm{~N} 1132419 \mathrm{~W} \\
360622 \mathrm{~N} 1120909 \mathrm{~W} \\
352703 \mathrm{~N} 1124814 \mathrm{~W} \\
340215 \mathrm{~N} 1091310 \mathrm{~W} \\
333349 \mathrm{~N} 1120357 \mathrm{~W} \\
352742 \mathrm{~N} 1124756 \mathrm{~W} \\
362213 \mathrm{~N} 1115357 \mathrm{~W} \\
332037 \mathrm{~N} 1102056 \mathrm{~W} \\
333228 \mathrm{~N} 1121155 \mathrm{~W}\end{array}$ \\
\hline
\end{tabular}

\begin{tabular}{|c|c|c|}
\hline $312504 \mathrm{~N} 1111519 \mathrm{~W}$ & & Ruby \\
\hline $312938 \mathrm{~N} 1112153 \mathrm{~W}$ & & $\begin{array}{l}\text { Bartlett Mtn } \\
\text { Bartlett Mtn } \\
\text { Bartlett Mtn }\end{array}$ \\
\hline & & $\begin{array}{l}\text { Saucito Mtn } \\
\text { Cumero Canyon }\end{array}$ \\
\hline $321353 \mathrm{~N} 1103012 \mathrm{~W}$ & & $\begin{array}{l}\text { Cumero Canyon } \\
\text { Soza Canyon } \\
\text { Amado } \\
\text { Amado }\end{array}$ \\
\hline $320504 N 1091715 \mathrm{~W}$ & 3100 & $\begin{array}{l}\text { Camp Verde } \\
\text { Perkinsville } \\
\text { Fowler } \\
\text { Somerton } \\
\text { Payson South } \\
\text { Blue Mountain }\end{array}$ \\
\hline
\end{tabular}

$345632 \mathrm{~N} 1131505 \mathrm{~W}$

Camp Wood North of Oracle

5510 Sunrise Peak Sunrise Peak Sunrise Peak

4960 O'Donnell Canyon

olga

Garland Prairie

Turkey Mtn

Page Springs

Seven Springs

Dragoon

Indian Peak

Ninemile Seep

Polacca

Crater Canyon

Mesa

Lake Montezuma

Wilbur Canyon

King Canyon

Strawberry Crater Strawberry Crater West of Marana

8614 Whiting Knoll

Cibola SE

Trigo Pass

332458N1141917W $\quad \begin{aligned} & \text { Trigo } \\ & \text { Biythe }\end{aligned}$

335951N1123135W McMicken Dam

1354 McMicken Dam

$360934 \mathrm{N1121050 \textrm {N }}$ Grand Canyon

7160 Trinity Mtn Nelson Reservoir Sunnys lope Trinity Mtn Point Imperial 5299 Mount Triplet 1135 Glendale 


\begin{tabular}{|c|c|c|c|c|c|c|c|}
\hline FEATURE NAME & $\begin{array}{l}\text { FEATURE } \\
\text { CLASS }\end{array}$ & STATUS & COUNTY & COORDINATE & $\begin{array}{l}\text { SOURCE } \\
\text { COORDINATE }\end{array}$ & $\begin{array}{l}\text { ELEV } \\
\text { FT }\end{array}$ & MAP NAME \\
\hline $\begin{array}{l}\text { Triplets Tank } \\
\text { Triplet Wash } \\
\text { Triplet Wash } \\
\text { Triplet Wash }\end{array}$ & $\begin{array}{l}\text { reservoir } \\
\text { stream } \\
\text { stream }\end{array}$ & $\begin{array}{l}\text { BGN } \\
\text { BGN } \\
\text { BGN } \\
\text { VARIANT }\end{array}$ & $\begin{array}{l}\text { Graham } \\
\text { Graham } \\
\text { Graham }\end{array}$ & 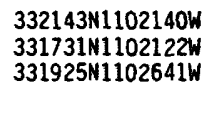 & 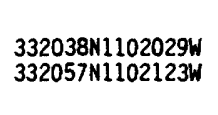 & & $\begin{array}{l}\text { Mount Triplet } \\
\text { Mount Triplet } \\
\text { San Carlos }\end{array}$ \\
\hline $\begin{array}{l}\text { See Hackberry Oraw } \\
\text { Trip Mountain } \\
\text { Tripp and Underwood Wash } \\
\text { Underwood Wash } \\
\text { Tripp Canyon }\end{array}$ & $\begin{array}{l}\text { valley } \\
\text { summit } \\
\text { stream }\end{array}$ & $\begin{array}{l}\text { BGN } \\
\text { BGN } 1975 \\
\text { VARIANT } \\
\text { VARIANT }\end{array}$ & $\begin{array}{l}\text { Grahan } \\
\text { Yuma } \\
\text { Graham }\end{array}$ & $\begin{array}{l}331321 N 1102151 \mathrm{~W} \\
331321 \mathrm{N1142635 \textrm {W }} \\
325530 \mathrm{~N} 1095332 \mathrm{~W}\end{array}$ & $325038 \mathrm{N1100308W}$ & 983 & $\begin{array}{l}\text { Red Hill } \\
\text { Eden }\end{array}$ \\
\hline See Bellows Canyon & valley & & Graham & $324612 \mathrm{~N} 1100433 \mathrm{~W}$ & & & \\
\hline $\begin{array}{l}\text { Tripp Canyon } \\
\text { Tri-State Viewpoint } \\
\text { Tritle, Mount } \\
\text { Tritle Peak } \\
\text { TriumphaI Arch Rapids } \\
\text { Trophy Lake } \\
\text { Trophy Lake Dam } \\
\text { Trot and Holler Canyon } \\
\text { Trot and Holler Well } \\
\text { Trough Spring }\end{array}$ & $\begin{array}{l}\text { valley } \\
\text { locale } \\
\text { summit } \\
\text { summit } \\
\text { rapids } \\
\text { reservoir } \\
\text { dam } \\
\text { valley } \\
\text { well } \\
\text { spring }\end{array}$ & $\begin{array}{l}\text { BGN } 1975 \\
\text { BGN } \\
\text { BGN } \\
\text { BGN } 1932 \\
\text { BGN } \\
\text { BGN } \\
\text { UNOFF } \\
\text { BGN } \\
\text { UNOFF } \\
\text { BGN }\end{array}$ & $\begin{array}{l}\text { Graham } \\
\text { Mohave } \\
\text { Yavapai } \\
\text { Coconino } \\
\text { Mohave } \\
\text { Navajo } \\
\text { Navajo } \\
\text { Yavapai } \\
\text { Mohave } \\
\text { Navajo }\end{array}$ & $\begin{array}{l}325038 \mathrm{~N} 1100308 \mathrm{~W} \\
350248 \mathrm{~N} 1142151 \mathrm{~W} \\
342501 \mathrm{N1} 122632 \mathrm{~W} \\
361327 \mathrm{N1} 115651 \mathrm{~W} \\
355622 \mathrm{~N} 1134405 \mathrm{~W} \\
342148 \mathrm{~N} 1100242 \mathrm{~W} \\
342148 \mathrm{~N} 1100242 \mathrm{~W} \\
343931 \mathrm{N1131830 \textrm {W }} \\
34391 \mathrm{~N} 113200 \mathrm{~W} \\
341936 \mathrm{~N} 1102446 \mathrm{~W}\end{array}$ & $324612 \mathrm{~N} 1100433 \mathrm{~W}$ & 7782 & $\begin{array}{l}\text { Tripp Canyon } \\
\text { Mount Nutt } \\
\text { Groom Creek } \\
\text { Walhalla Plateau } \\
\text { Devils Slide Rapids } \\
\text { Show Low North } \\
\text { Show Low North } \\
\text { Negro Ed } \\
\text { Negro Ed } \\
\text { Day Spring }\end{array}$ \\
\hline $\begin{array}{l}\text { Trough Spring } \\
\text { Trough Spring Draw } \\
\text { Trough Springs } \\
\text { Troughs Spring, The } \\
\text { Trout Creek } \\
\text { Trout Creek }\end{array}$ & $\begin{array}{l}\text { spring } \\
\text { valley } \\
\text { spring } \\
\text { spring } \\
\text { stream }\end{array}$ & $\begin{array}{l}\text { BGN } \\
\text { BGN } \\
B G N \\
\text { BGN } \\
\text { BGN } \\
\text { VARIANT }\end{array}$ & $\begin{array}{l}\text { Mohave } \\
\text { Navajo } \\
\text { Pinal } \\
\text { Yavapai } \\
\text { Apache }\end{array}$ & $\begin{array}{l}350830 N 1142027 W \\
342018 N 1102431 W \\
331312 N 1110854 W \\
341930 N 1121829 W \\
340217 N 1095012 W\end{array}$ & $\begin{array}{l}341832 \mathrm{~N} 1102522 \mathrm{~W} \\
335913 \mathrm{~N} 1094322 \mathrm{~W}\end{array}$ & & $\begin{array}{l}\text { Secret Pass } \\
\text { Day Spring } \\
\text { Mineral Mtn } \\
\text { Battle Flat } \\
\text { MeNary }\end{array}$ \\
\hline $\begin{array}{l}\text { See Sacramento Wash } \\
\text { Trout Creek } \\
\text { Bill Williams Fork } \\
\text { Muddy Creek }\end{array}$ & $\begin{array}{l}\text { stream } \\
\text { stream }\end{array}$ & $\begin{array}{l}\text { BGN } 1979 \\
\text { VARIANT } \\
\text { VARIANT }\end{array}$ & $\begin{array}{l}\text { Mohave } \\
\text { Mohave }\end{array}$ & $\begin{array}{l}344349 \mathrm{N1142914W} \\
345521 \mathrm{N1133735W}\end{array}$ & $351100 \mathrm{~N} 1131430 \mathrm{~W}$ & & Pilgrim Wash \\
\hline $\begin{array}{l}\text { Troweek } \\
\text { Troy } \\
\text { Skinner Village } \\
\text { Skinnerville }\end{array}$ & $\begin{array}{l}\text { locale } \\
\text { locale }\end{array}$ & $\begin{array}{l}\text { BGN } \\
\text { BGN } 1965 \\
\text { VARIANT } \\
\text { VARIANT }\end{array}$ & $\begin{array}{l}\text { Apache } \\
\text { Pinal }\end{array}$ & $\begin{array}{l}335544 \mathrm{N1} 1090336 \mathrm{~W} \\
330837 \mathrm{N1} 105355 \mathrm{~W}\end{array}$ & & & $\begin{array}{l}\text { Escudilla Mtn } \\
\text { Hot Tamale Peak }\end{array}$ \\
\hline $\begin{array}{l}\text { Troy Mountain } \\
\text { Troy Ranch } \\
\text { Troy Tank } \\
\text { Truax Canyon } \\
\text { True Blue Mine } \\
\text { Trujillo Canyon }\end{array}$ & $\begin{array}{l}\text { summit } \\
\text { locale } \\
\text { reservoir } \\
\text { valley } \\
\text { mine } \\
\text { valley }\end{array}$ & $\begin{array}{l}\text { BGN } \\
\text { UNOFF } \\
\text { BGN } \\
\text { BGN } \\
\text { UNOFF } \\
\text { BGN }\end{array}$ & $\begin{array}{l}\text { Pinal } \\
\text { Pinal } \\
\text { Coconino } \\
\text { Navajo } \\
\text { Yuma } \\
\text { Grahar }\end{array}$ & $\begin{array}{l}330920 \mathrm{~N} 1105530 \mathrm{~W} \\
330845 \mathrm{N1105354W} \\
353617 \mathrm{N1} 120714 \mathrm{~W} \\
340535 \mathrm{~N} 1103141 \mathrm{~W} \\
334705 \mathrm{~N} 1134322 \mathrm{~W} \\
330112 \mathrm{N1092442W}\end{array}$ & $\begin{array}{l}340441 \mathrm{N1} 103344 \mathrm{~W} \\
330055 \mathrm{N1093046 \textrm {W }}\end{array}$ & 4965 & $\begin{array}{l}\text { Hot Tamale Peak } \\
\text { Hot Tamale Peak } \\
\text { Hobble Tank } \\
\text { Spotted Mountain } \\
\text { Harcuvar } \\
\text { Copperplate Gulch }\end{array}$ \\
\hline $\begin{array}{l}\text { Trumbul1, Mount } \\
\text { Trunk Canyon } \\
\text { Trunk Canyon Tank } \\
\text { Truxton (siding) } \\
\text { Truxton } \\
\text { Truxton Canyon } \\
\text { Truxton Railroad Station } \\
\text { Truxton Spring } \\
\text { Truxton Wash } \\
\text { Hackberry Wash }\end{array}$ & $\begin{array}{l}\text { summit } \\
\text { valley } \\
\text { reservoir } \\
\text { locale } \\
\text { ppl } \\
\text { valley } \\
\text { building } \\
\text { spring } \\
\text { stream }\end{array}$ & $\begin{array}{l}\text { BGN } \\
\text { BGN } \\
\text { BGN } \\
\text { BGN } \\
\text { BGN } \\
\text { BGN } \\
\text { UNOFF } \\
\text { BGN } \\
\text { BGN } \\
\text { VARIANT }\end{array}$ & $\begin{array}{l}\text { Mohave } \\
\text { Cochise } \\
\text { Cochise } \\
\text { Mohave } \\
\text { Mohave } \\
\text { Mohave } \\
\text { Mohave } \\
\text { Mohave } \\
\text { Mohave }\end{array}$ & $\begin{array}{l}362436 \mathrm{~N} 1130815 \mathrm{~W} \\
315658 \mathrm{~N} 1092635 \mathrm{~W} \\
315701 \mathrm{N1092618 \textrm {W }} \\
352728 \mathrm{~N} 1133552 \mathrm{~W} \\
352906 \mathrm{~N} 1133346 \mathrm{~W} \\
352615 \mathrm{~N} 1134610 \mathrm{~W} \\
352716 \mathrm{~N} 1133610 \mathrm{~W} \\
352612 \mathrm{~N} 113374 \mathrm{~W} \\
353722 \mathrm{~N} 1140259 \mathrm{~W}\end{array}$ & $\begin{array}{l}315726 \mathrm{~N} 1092529 \mathrm{~W} \\
352718 \mathrm{~N} 1133606 \mathrm{~W} \\
352515 \mathrm{~N} 1132152 \mathrm{~W}\end{array}$ & 8029 & $\begin{array}{l}\text { Mt Trumbull NW } \\
\text { Fife Peak } \\
\text { Fife Peak } \\
\text { Truxton } \\
\text { Truxton } \\
\text { Antares } \\
\text { Truxton } \\
\text { Valentine } \\
\text { Mt Tipton SE }\end{array}$ \\
\hline $\begin{array}{l}\text { Tsaaadidosi Spring } \\
\text { Tsagieto Canyon } \\
\text { Tsail }\end{array}$ & $\begin{array}{l}\text { spring } \\
\text { valley }\end{array}$ & $\begin{array}{l}\text { BGN } \\
\text { BGN } \\
\text { VARIANT }\end{array}$ & $\begin{array}{l}\text { Apache } \\
\text { Coconino }\end{array}$ & $\begin{array}{l}354045 \mathrm{~N} 1094228 \mathrm{~W} \\
370106 \mathrm{~N} 1105905 \mathrm{~W}\end{array}$ & $365955 \mathrm{N1105612W}$ & & $\begin{array}{l}\text { Cornfields } \\
\text { Rainbow Bridge }\end{array}$ \\
\hline $\begin{array}{c}\text { See Tsaile } \\
\text { Tsaile } \\
\text { Salec } \\
\text { Sehili } \\
\text { Tsail } \\
\text { Tse-a-lee } \\
\text { Tsehili }\end{array}$ & $\begin{array}{l}\mathrm{ppl} \\
\mathrm{pp} 1\end{array}$ & $\begin{array}{l}\text { BGN } 1915 \\
\text { VARIANT } \\
\text { VARIANT } \\
\text { VARIANT } \\
\text { VARIANT } \\
\text { VARIANT }\end{array}$ & $\begin{array}{l}\text { Apache } \\
\text { Apache }\end{array}$ & $\begin{array}{l}361647 \mathrm{~N} 1091002 \mathrm{~W} \\
361647 \mathrm{N1091002 \textrm {W }}\end{array}$ & & & Tsaile \\
\hline $\begin{array}{l}\text { Tsaile Creek } \\
\text { Schili Creek } \\
\text { Spruce Brook } \\
\text { Tsa-lee Creek } \\
\text { Tse Aa le Creek } \\
\text { Tsehili Creek } \\
\text { Tsaile Dam } \\
\text { Tsaile Elementary School } \\
\text { Tsaile Lake } \\
\text { Tsaile Lake Campground }\end{array}$ & $\begin{array}{l}\text { dam } \\
\text { school } \\
\text { reservoir } \\
\text { park }\end{array}$ & $\begin{array}{l}\text { BGN } 1968 \\
\text { VARIANT } \\
\text { VARIANT } \\
\text { VARIANT } \\
\text { VARIANT } \\
\text { VARIANT } \\
\text { UNOFF } \\
\text { UNOFF } \\
\text { BGN } \\
\text { ADMIN }\end{array}$ & $\begin{array}{l}\text { Apache } \\
\text { Apache } \\
\text { Apache } \\
\text { Apache }\end{array}$ & $\begin{array}{l}361612 \mathrm{~N} 1091124 \mathrm{~W} \\
361807 \mathrm{~N} 1091239 \mathrm{~W} \\
361628 \mathrm{~N} 1091223 \mathrm{~W} \\
361655 \mathrm{~N} 1091210 \mathrm{~W}\end{array}$ & $362706 \mathrm{~N} 1090528 \mathrm{~W}$ & $\begin{array}{l}7037 \\
7040\end{array}$ & $\begin{array}{l}\text { Tsaile } \\
\text { Tsaile } \\
\text { Tsaile } \\
\text { Tsaile }\end{array}$ \\
\hline
\end{tabular}


NATIONAL GAZETTEER--ARIZONA 1986

\begin{tabular}{|c|c|c|c|c|c|c|c|}
\hline FEATURE NAME & $\begin{array}{l}\text { FEATURE } \\
\text { CLASS }\end{array}$ & STATUS & COUNTY & COORDINATE & $\begin{array}{l}\text { SOURCE } \\
\text { COORDINATE }\end{array}$ & $\begin{array}{c}\text { ELEV } \\
\text { FT }\end{array}$ & MAP NAME \\
\hline $\begin{array}{l}\text { Tsaile Peak } \\
\text { Tsaiskizzia Rock } \\
\text { See Tsai Skizzi Rock } \\
\text { Tsai Skizzie Rock } \\
\text { See Tsai Skizzi Rock } \\
\text { Tsai Skizzi Rock } \\
\text { Tsaiskizzia Rock } \\
\text { Tsai Skizzie Rock } \\
\text { Tsa-lee Creek } \\
\text { See Tsaile Creek }\end{array}$ & $\begin{array}{l}\text { summit } \\
\text { pillar } \\
\text { pillar } \\
\text { pillar }\end{array}$ & $\begin{array}{l}\text { BGN } \\
\text { VARIANT } \\
\text { VARIANT } \\
\text { BGN } \\
\text { VARIANT } \\
\text { VARIANT } \\
\text { VARIANT }\end{array}$ & $\begin{array}{l}\text { Apache } \\
\text { Coconino } \\
\text { Coconino } \\
\text { Coconino }\end{array}$ & 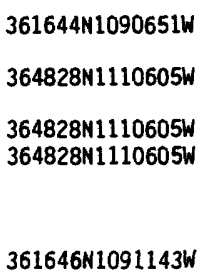 & & 9182 & Tsaile Butte \\
\hline $\begin{array}{l}\text { Tsa-tsil-too Springs } \\
\text { See Setsiltso Springs } \\
\text { Tsa Yah Das Iahi Spring } \\
\text { Tsay O Ah Butte } \\
\text { Tsay-se-zhin Butte } \\
\text { Tschiulikam } \\
\quad \text { See Chiulikam } \\
\text { Tse Aa le Creek } \\
\text { See Tsaile Creek } \\
\text { Tse Abe I }\end{array}$ & $\begin{array}{l}\text { spring } \\
\text { spring } \\
\text { summit } \\
\text { summit } \\
\text { locale } \\
\text { stream } \\
\text { pillar }\end{array}$ & $\begin{array}{l}\text { VARIANT } \\
\text { BGN } \\
\text { BGN } \\
\text { BGN } \\
\text { VARIANT } \\
\text { VARIANT } \\
\text { BGN }\end{array}$ & $\begin{array}{l}\text { Apache } \\
\text { Apache } \\
\text { Apache } \\
\text { Gila } \\
\text { Maricopa } \\
\text { Apache } \\
\text { Apache }\end{array}$ & $\begin{array}{l}364343 \mathrm{~N} 1094004 \mathrm{~W} \\
363525 \mathrm{~N} 1092244 \mathrm{~W} \\
335440 \mathrm{~N} 1094854 \mathrm{~W} \\
334618 \mathrm{~N} 1100500 \mathrm{~W} \\
323428 \mathrm{~N} 1123131 \mathrm{~W} \\
361646 \mathrm{~N} 1091143 \mathrm{~W} \\
360948 \mathrm{~N} 1094413 \mathrm{~W}\end{array}$ & & $\begin{array}{l}7745 \\
5962\end{array}$ & $\begin{array}{l}\text { Round Rock } \\
\text { Hawley Lake West } \\
\text { Canyon Day }\end{array}$ \\
\hline $\begin{array}{l}\text { Tse-a-lee } \\
\text { See Tsaile } \\
\text { Tse Ba Ni Zi Ni Wash } \\
\text { Tse-Ba-Zi-Ni Wash } \\
\text { See Balakai Wash } \\
\text { Tse Biyi } \\
\text { Tse Bonita Tribal Park } \\
\text { Tse Bonita Wash } \\
\text { See Tse Bonita Wash } \\
\text { Tse Bonita Wash } \\
\text { Tse Bonita Wash }\end{array}$ & $\begin{array}{l}\text { ppl } \\
\text { valley } \\
\text { valley } \\
\text { basin } \\
\text { park } \\
\text { valley } \\
\text { valley }\end{array}$ & $\begin{array}{l}\text { VARIANT } \\
\text { BGN } \\
\text { VARIANT } \\
\text { BGN } \\
\text { ADMIN } \\
\text { VARIANT } \\
\text { BGN } 1983 \\
\text { VARIANT }\end{array}$ & $\begin{array}{l}\text { Apache } \\
\text { Apache } \\
\text { Apache } \\
\text { Navajo } \\
\text { Apache } \\
\text { Apache } \\
\text { Apache }\end{array}$ & $\begin{array}{l}361647 \mathrm{~N} 1091002 \mathrm{~W} \\
360423 \mathrm{~N} 1093912 \mathrm{~W} \\
\\
360645 \mathrm{~N} 1093945 \mathrm{~W} \\
365519 \mathrm{N1} 100405 \mathrm{~W} \\
353953 \mathrm{~N} 1090251 \mathrm{~W} \\
\\
353759 \mathrm{~N} 1090447 \mathrm{~W} \\
353759 \mathrm{~N} 1090447 \mathrm{~W}\end{array}$ & $354309 N 1085515 \mathrm{~W}$ & & $\begin{array}{l}\text { Mitten Buttes } \\
\text { Window Rock }\end{array}$ \\
\hline $\begin{array}{l}\text { Tse Bonito Campground } \\
\text { Tse Bonito Museum } \\
\text { See Navajo Tribal Museum } \\
\text { and Zoo } \\
\text { Tse Chizzi Spring } \\
\text { Tse Chizzi Wash } \\
\text { Tse Da Ahoodzo Canyon } \\
\text { Tse Da Ahoodzo Peak } \\
\text { Tsedadahotsosi } \\
\text { Tsedatoh Canyon }\end{array}$ & $\begin{array}{l}\text { park } \\
\text { locale } \\
\text { spring } \\
\text { stream } \\
\text { valley } \\
\text { summit } \\
\text { summit } \\
\text { valley }\end{array}$ & $\begin{array}{l}\text { BGN } \\
\text { BGN } \\
\text { BGN } \\
\text { BGN } \\
\text { BGN } \\
\text { BGN }\end{array}$ & $\begin{array}{l}\text { Apache } \\
\text { Apache } \\
\text { Navajo } \\
\text { Navajo } \\
\text { Apache } \\
\text { Apache } \\
\text { Apache } \\
\text { Apache }\end{array}$ & $\begin{array}{l}354116 \mathrm{N1} 1090321 \mathrm{~W} \\
353920 \mathrm{~N} 1090406 \mathrm{~W} \\
355433 \mathrm{N1} 100114 \mathrm{~W} \\
355854 \mathrm{N1} 100911 \mathrm{~W} \\
361618 \mathrm{~N} 1095059 \mathrm{~W} \\
361627 \mathrm{N1} 1094840 \mathrm{~W} \\
362625 \mathrm{N1} 092132 \mathrm{~W} \\
362610 \mathrm{N1} 092403 \mathrm{~W}\end{array}$ & $\begin{array}{l}355334 \mathrm{~N} 1100112 \mathrm{~W} \\
361620 \mathrm{~N} 1094848 \mathrm{~W} \\
362010 \mathrm{~N} 1091000 \mathrm{~W}\end{array}$ & 7683 & $\begin{array}{l}\text { Low Mountain } \\
\text { Echo Canyon } \\
\text { Sweathouse Peak } \\
\text { Sweathouse Peak } \\
\text { Bad Bug Butte } \\
\text { Fire Dance Mesa }\end{array}$ \\
\hline $\begin{array}{l}\text { Tse Deeshzhaai Wash } \\
\text { The Des Zyace Wash } \\
\text { Tsegi } \\
\text { Tsegi Branch of Laguna Canyon } \\
\text { See Betatakin Canyon } \\
\text { Tsegi Canyon } \\
\text { Laguna Canyon } \\
\text { To Wan-aho-chee Creek } \\
\text { Tsegi Canyon Campground } \\
\text { Tsegihatsosi Canyon } \\
\text { See Tseyi-Hatsosi Canyon }\end{array}$ & $\begin{array}{l}\text { stream } \\
\text { locale } \\
\text { valley } \\
\text { valley }\end{array}$ & $\begin{array}{l}\text { BGN } \\
\text { VARIANT } \\
\text { BGN } \\
\text { VARIANT } \\
\text { BGN } \\
\text { VARIANT } \\
\text { VARIANT } \\
\text { ADMIN } \\
\text { VARIANT }\end{array}$ & $\begin{array}{l}\text { Apache } \\
\text { Navajo } \\
\text { Navajo } \\
\text { Navajo } \\
\text { Navajo } \\
\text { Navajo }\end{array}$ & $\begin{array}{l}360526 \mathrm{~N} 1093403 \mathrm{~W} \\
363858 \mathrm{~N} 1102543 \mathrm{~W} \\
364109 \mathrm{~N} 1103042 \mathrm{~W} \\
363903 \mathrm{N1} 102554 \mathrm{~W} \\
363712 \mathrm{N1} 102759 \mathrm{~W} \\
365212 \mathrm{~N} 1101952 \mathrm{~W}\end{array}$ & $364111 \mathrm{N1103031 \textrm {W }}$ & $62 \mathrm{BO}$ & $\begin{array}{l}\text { Ltl White Hse Ruins } \\
\text { Marsh Pass } \\
\text { Marsh Pass } \\
\text { Long House Valley }\end{array}$ \\
\hline $\begin{array}{l}\text { Tsegi Mesas } \\
\text { See Segi Mesas } \\
\text { Tsegi Overlook } \\
\text { Tsegi Point } \\
\text { Tsegi Point Overlook } \\
\text { Tse Gis Toh } \\
\text { Tsegitoe Spring } \\
\text { See Tsegito Spring } \\
\text { Tsegitoe Spring } \\
\text { See Tsegitoe Spring }\end{array}$ & $\begin{array}{l}\text { summit } \\
\text { locale } \\
\text { cliff } \\
\text { locale } \\
\text { spring } \\
\text { spring } \\
\text { spring }\end{array}$ & $\begin{array}{l}\text { VARIANT } \\
\text { BGN } \\
\text { BGN } \\
\text { BGN } \\
\text { BGN } \\
\text { VARIANT } \\
\text { VARIANT }\end{array}$ & $\begin{array}{l}\text { Navajo } \\
\text { Apache } \\
\text { Navajo } \\
\text { Navajo } \\
\text { Navajo } \\
\text { Apache } \\
\text { Apache }\end{array}$ & $\begin{array}{l}365100 \mathrm{~N} 1101200 \mathrm{~W} \\
360820 \mathrm{~N} 1093041 \mathrm{~W} \\
364122 \mathrm{N1} 103113 \mathrm{~W} \\
364034 \mathrm{N1} 103215 \mathrm{~W} \\
352441 \mathrm{N1} 100920 \mathrm{~W} \\
354807 \mathrm{~N} 1091942 \mathrm{~W} \\
355514 \mathrm{~N} 1092327 \mathrm{~W}\end{array}$ & & & $\begin{array}{l}\text { Chinle } \\
\text { Betatakin Ruin } \\
\text { Betatakin Ruin } \\
\text { Na Ah Tee Canyon }\end{array}$ \\
\hline $\begin{array}{l}\text { Tsegitoe Spring } \\
\text { Tsegitoe Spring } \\
\text { Tsegito Spring } \\
\text { Segetoa Spring } \\
\text { Tsegitoe Spring } \\
\text { Tseyi To-e Spring } \\
\text { Tsegito Spring } \\
\text { Segetoa Spring } \\
\text { Tsegi Trading Post } \\
\text { Tseh Any }\end{array}$ & $\begin{array}{l}\text { spring } \\
\text { spring }\end{array}$ & $\begin{array}{l}\text { BGN } 1983 \\
\text { VARIANT } \\
\text { BGN } 1983 \\
\text { VARIANT } \\
\text { VARIANT } \\
\text { VARIANT } \\
\text { BGN 1983 } \\
\text { VARIANT } \\
\text { BGN } \\
\text { BGN }\end{array}$ & $\begin{array}{l}\text { Apache } \\
\text { Apache }\end{array}$ & $\begin{array}{l}355514 N 1092327 \mathrm{~W} \\
354807 N 1091942 \mathrm{~W}\end{array}$ & & 6200 & $\begin{array}{l}\text { White Rock Wash } \\
\text { Marsh Pass } \\
\text { Walker Butte }\end{array}$ \\
\hline
\end{tabular}


NATIONAL GAZETTEER--ARIZONA 1986

\begin{tabular}{|c|c|c|c|c|c|c|c|}
\hline FEATURE NAME & $\begin{array}{l}\text { FEATURE } \\
\text { CLASS }\end{array}$ & STATUS & COUNTY & COORDINATE & $\begin{array}{l}\text { SOURCE } \\
\text { COORDINATE }\end{array}$ & $\underset{\text { FTEV }}{\text { ELEV }}$ & MAP NAME \\
\hline $\begin{array}{l}\text { Tsehili } \\
\text { See Sehili } \\
\text { Tsehili } \\
\text { See Tsaile } \\
\text { Tsehili Creek } \\
\text { See Tsaile Creek } \\
\text { Tseh Ligi } \\
\text { See Tse Ligai } \\
\text { Tsehotsoi Bizazhe Canyon } \\
\text { See Dennehotso Canyon }\end{array}$ & $\begin{array}{l}\text { locale } \\
\text { ppl } \\
\text { stream } \\
\text { bas in } \\
\text { valley }\end{array}$ & $\begin{array}{l}\text { VARIANT } \\
\text { VARIANT } \\
\text { VARIANT } \\
\text { VARIANT } \\
\text { VARIANT }\end{array}$ & $\begin{array}{l}\text { Apache } \\
\text { Apache } \\
\text { Apache } \\
\text { Apache } \\
\text { Apache }\end{array}$ & $\begin{array}{l}\text { UNKNOWN } \\
361647 \text { N1091002W } \\
361646 \mathrm{~N} 1091143 \mathrm{~W} \\
364600 \mathrm{~N} 1091815 \mathrm{~W} \\
365338 \mathrm{~N} 1094435 \mathrm{~W}\end{array}$ & & & \\
\hline $\begin{array}{l}\text { Tsehotsoibizazhe Canyon } \\
\text { See Oennehotso Canyon } \\
\text { Tseh-Ya-Kin Canyon } \\
\text { Tseitsokit } \\
\text { See Mishongnovi } \\
\text { Tsekadebehgon } \\
\text { Tseklagai-deza Canyon } \\
\text { See Tseligaideeza Canyon } \\
\text { Tse Lagai } \\
\text { See Balakai Mesa }\end{array}$ & $\begin{array}{l}\text { valley } \\
\text { valley } \\
\text { ppl } \\
\text { cliff } \\
\text { valley } \\
\text { summit }\end{array}$ & $\begin{array}{l}\text { VARIANT } \\
\text { BGN } \\
\text { VARIANT } \\
\text { BGN } \\
\text { VARIANT } \\
\text { VARIANT }\end{array}$ & $\begin{array}{l}\text { Apache } \\
\text { Apache } \\
\text { Navajo } \\
\text { Apache } \\
\text { Apache } \\
\text { Apache }\end{array}$ & $\begin{array}{l}365338 \mathrm{~N} 1094435 \mathrm{~W} \\
361339 \mathrm{~N} 1092125 \mathrm{~W} \\
354818 \mathrm{~N} 1102931 \mathrm{~W} \\
362516 \mathrm{~N} 1092801 \mathrm{~W} \\
364608 \mathrm{~N} 1092412 \mathrm{~W} \\
355902 \mathrm{~N} 1095614 \mathrm{~W}\end{array}$ & $361325 N 1092012 \mathrm{~W}$ & & Mummy Cave Ruins \\
\hline $\begin{array}{l}\text { Tselani } \\
\text { See Salina } \\
\text { Tse layai dez-a Canyon } \\
\text { See Tseligaideeza Canyon } \\
\text { Tselayazhe } \\
\text { Tselayazhe Wash } \\
\text { Tse Lichii Dah Azka } \\
\text { Tse Lichii Point } \\
\text { Tse Ligai } \\
\text { Tseh Ligi }\end{array}$ & $\begin{array}{l}\text { ppl } \\
\text { valley } \\
\text { summit } \\
\text { valley } \\
\text { summit } \\
\text { cliff } \\
\text { basin }\end{array}$ & $\begin{array}{l}\text { VARIANT } \\
\text { VARIANT } \\
\text { BGN } \\
\text { BGN } \\
\text { BGN } \\
\text { BGN } \\
\text { BGN } 1983 \\
\text { VARIANT }\end{array}$ & $\begin{array}{l}\text { Apache } \\
\text { Apache } \\
\text { Apache } \\
\text { Apache } \\
\text { Apache } \\
\text { Coconino } \\
\text { Apache }\end{array}$ & $\begin{array}{l}360120 \mathrm{~N} 1095200 \mathrm{~W} \\
364608 \mathrm{~N} 1092412 \mathrm{~W} \\
360238 \mathrm{~N} 1095441 \mathrm{~W} \\
360439 \mathrm{~N} 1095247 \mathrm{~W} \\
360633 \mathrm{~N} 1094315 \mathrm{~W} \\
353613 \mathrm{~N} 1111643 \mathrm{~W} \\
364600 \mathrm{~N} 1091815 \mathrm{~W}\end{array}$ & $360242 \mathrm{~N} 1095532 \mathrm{~W}$ & 5963 & $\begin{array}{l}\text { Toadindaaska Mesa } \\
\text { Toadindaaska Mesa } \\
\text { Toh De Niihe } \\
\text { Wupatki SE } \\
\text { Toh Chin Lini Mesa }\end{array}$ \\
\hline $\begin{array}{l}\text { Tseligaideeza Canyon } \\
\text { Seklagaidesa Canyon } \\
\text { Tseklagai-deza Canyon } \\
\text { Tse layai dez-a Canyon } \\
\text { Tse it gai Sinil Well } \\
\text { Tsenakaahn } \\
\text { See Round Rock } \\
\text { Tsenakahn } \\
\text { See Round Rock } \\
\text { Tsenakahn } \\
\text { See Round Rock }\end{array}$ & $\begin{array}{l}\text { well } \\
\text { locale } \\
\text { summit } \\
\text { locale }\end{array}$ & $\begin{array}{l}\text { BGN } 1983 \\
\text { VARIANT } \\
\text { VARIANT } \\
\text { VARIANT } \\
\text { UNOFF } \\
\text { VARIANT } \\
\text { VARIANT } \\
\text { VARIANT }\end{array}$ & $\begin{array}{l}\text { Apache } \\
\text { Apache } \\
\text { Apache } \\
\text { Apache }\end{array}$ & $\begin{array}{l}354550 \mathrm{~N} 1092234 \mathrm{~W} \\
363047 \mathrm{~N} 1092822 \mathrm{~W} \\
363009 \mathrm{~N} 1093311 \mathrm{~W} \\
363047 \mathrm{~N} 1092822 \mathrm{~W}\end{array}$ & $364550 \mathrm{~N} 1091745 \mathrm{~W}$ & & Walker Butte \\
\hline $\begin{array}{l}\text { Tsenakahn Butte } \\
\text { See Round Rock } \\
\text { Tse nakani } \\
\text { See Round Rock } \\
\text { Tsenakani } \\
\text { See Round Rock } \\
\text { Tse No Dozz } \\
\text { Tse Notahs Pond } \\
\text { Tse Taa Ruins } \\
\text { Tse Tai De Linne Well }\end{array}$ & $\begin{array}{l}\text { summit } \\
\text { summit } \\
\text { summit } \\
\text { spring } \\
\text { reservoir } \\
\text { locale } \\
\text { well }\end{array}$ & $\begin{array}{l}\text { VARIANT } \\
\text { VARIANT } \\
\text { VARIANT } \\
\text { BGN } \\
\text { BGN } \\
\text { BGN } \\
\text { UNOFF }\end{array}$ & $\begin{array}{l}\text { Apache } \\
\text { Apache } \\
\text { Apache } \\
\text { Navajo } \\
\text { Apache } \\
\text { Apache } \\
\text { Navajo }\end{array}$ & $\begin{array}{l}363009 \mathrm{N1} 109331 \mathrm{~W} \\
363009 \mathrm{~N} 109331 \mathrm{~W} \\
363009 \mathrm{~N} 109331 \mathrm{~W} \\
360745 \mathrm{N1} 101824 \mathrm{~W} \\
353502 \mathrm{N1090615W} \\
360726 \mathrm{N1092659 \textrm {W }} \\
360434 \mathrm{N1} 102326 \mathrm{~W}\end{array}$ & & & $\begin{array}{l}\text { Coat Spring } \\
\text { Hunters Point } \\
\text { Three Turkey Canyon } \\
\text { Hard Rocks }\end{array}$ \\
\hline $\begin{array}{l}\text { Tse To Baah Naali Spring } \\
\text { Tse To Baah Naali Wash } \\
\text { Tse Tonte } \\
\text { Tsetsiltso Springs } \\
\text { See Setsiltso Springs } \\
\text { Tseyah } \\
\text { Tseya-Kins ikadi Spring } \\
\text { Tseya Neechee Canyon } \\
\text { Tse Ya Toe Spring } \\
\text { Tseye-ha-tsazi Cañon } \\
\text { See Tseyi-Hatsosi Canyon }\end{array}$ & $\begin{array}{l}\text { spring } \\
\text { streamm } \\
\text { summit } \\
\text { spring } \\
\text { summit } \\
\text { spring } \\
\text { valley } \\
\text { spring } \\
\text { valley }\end{array}$ & $\begin{array}{l}\text { BGN } \\
\text { BGN } \\
\text { BGN } \\
\text { VARIANT } \\
\text { BGN } \\
\text { BGN } \\
\text { BGN } \\
\text { BGN } \\
\text { VARIANT }\end{array}$ & $\begin{array}{l}\text { Coconino } \\
\text { Coconino } \\
\text { Coconino } \\
\text { Apache } \\
\text { Apache } \\
\text { Apache } \\
\text { Navajo } \\
\text { Navajo } \\
\text { Navajo }\end{array}$ & $\begin{array}{l}354121 \mathrm{~N} 1111028 \mathrm{~W} \\
354216 \mathrm{~N} 1111037 \mathrm{~W} \\
365501 \mathrm{~N} 1111401 \mathrm{~W} \\
\\
364343 \mathrm{~N} 1094004 \mathrm{~W} \\
362256 \mathrm{N1092756 \textrm {W }} \\
354700 \mathrm{~N} 1092132 \mathrm{~W} \\
365332 \mathrm{N1101059W} \\
365156 \mathrm{~N} 1104303 \mathrm{~W} \\
365212 \mathrm{~N} 1101952 \mathrm{~W}\end{array}$ & 365036 N1101122W & 6070 & $\begin{array}{l}\text { Badger Spring } \\
\text { Badger Spring } \\
\text { Face Canyon } \\
\text { Fire Dance Mesa } \\
\text { Oak Creek Mtn } \\
\text { Mystery Valley } \\
\text { Oak Springs }\end{array}$ \\
\hline $\begin{array}{l}\text { Tseyi Hatsos } i \text { Canyon } \\
\text { See Tsey } i \text {-Hatsos } i \text { Canyon } \\
\text { Tsey-Hatsos } i \text { Canyon } \\
\text { See Tsey-Hatsosi Canyon } \\
\text { Tsey } i \text {-Hatsos } i \text { Canyon } \\
\text { Sagi ot Sos } i \text { Canyon } \\
\text { Sagy at Sos } i \text { Canyon } \\
\text { Segahatosi Canyon } \\
\text { Tsegihatsosi Canyon } \\
\text { Tseye-ha-tsazi Cañon }\end{array}$ & $\begin{array}{l}\text { valley } \\
\text { valley } \\
\text { valley }\end{array}$ & $\begin{array}{l}\text { VARIANT } \\
\text { VARIANT } \\
\text { BGN } 1915 \\
\text { VARIANT } \\
\text { VARIANT } \\
\text { VARIANT } \\
\text { VARIANT } \\
\text { VARIANT }\end{array}$ & $\begin{array}{l}\text { Navajo } \\
\text { Navajo } \\
\text { Navajo }\end{array}$ & $\begin{array}{l}365212 N 1101952 \mathrm{~W} \\
365212 \mathrm{~N} 1101952 \mathrm{~W}\end{array}$ & $364856 \mathrm{~N} 1102128 \mathrm{~W}$ & & Tseyi-Hatsosi \\
\hline
\end{tabular}


NATIONAL GAZETTEER--ARIZONA 1986 FEATURE NAME

Tseyi Hatsosi Canyon Tseyi-Hatsos i Canyon

Tseyi To-e Spring See Tsegito Spring sezhini See Black Pinnacle Tsezhini

See Black Rock Butte

Tshiuliseik

See Chiuli Shaik

Tshuhutsho

See Chuichu

Tsi Na Jinnie Spring
Ts in Beskunt Well
Ts in Naan Tee
Ts innie Well
Ts intaa Yiti Ii
Ts in Yatoh
Ts itah Wash
Anido Creek
Arido Creek
Tistah Wash

T-Six Canyon

T-Six Mountain

T-Six Point

T-Six Spring

T-Six Tank

Tsosie Well

Tsos Trading Post

Tso Tsosic Wash

$T$-Square Tank

TT Ranch

T T Tank Number One

T T Tank Number Three

$T T$ Tank Number Two

$T$ T Well

Tuakay Hot Springs Tuakay Springs

Tuakay Springs See Tuakay Hot Springs Tub A Tuba

See Tuba City

Tuba Butte

Tubac

Tubac Creek

Tubac Interchange

Tuba City

$$
\text { Tuba }
$$

Tuba City Airport

Tuba City Elementary Schoo

Tuba City High School

Tuba City Hospital

Tuba City Junior High School

Tuba City Road Tank

Tuba City Substation

Tubac Presidio State

Historical Park

Tub B

Tubb Spring

Tub Oraw

Tub Number One

Tub Number One

Tub Number Three

Tub Number Three

Tub Number Two

Tub Number Two

Tubon

See Tucson

Tub Pond

Tub Pond

FEATURE
CLASS

STATUS

COUNTY

COORDINATE

VARIAN

VARIANT

VARIANT

spring

pillar

VARIAN

Apache

Apache

VARIANT

summit

VARIANT

Apache

locale

VARIANT

Pima

Pinal

Navajo

spring

well

well

pp I

spring

stream

BGN
UNOFF
BGN
UNOFF
BGN
BGN
BGN 1964
VARIANT
VARIANT
VARIANT

valley

summit

summit

spring

reservoir

well

locale

valley

reservoir

locale

reservoir

reservoir

spring

BGN

BGN

BGN

BGN

BGN

BGN

BGN

BGN

Coconino

Navajo

Coconino

Apache

Navajo

Apache

VARIANT

Coconino

Coconino

Coconino

Coconino

Coconino

Navajo

Apache

Apache

Coconino

Yavapai

UNKNOWN

ppl

Coconino

$\begin{array}{lll}\text { summit } & \text { BGN } & \text { Coconino } \\ \text { ppl } & \text { BGN } & \text { Santa Cruz } \\ \text { stream } & \text { BGN } & \text { Santa Cruz } \\ \text { crossing } & \text { UNOFF } & \text { Santa Cruz } \\ \text { ppl } & \text { BGN 1957 } & \text { Coconino } \\ & \text { VARIANT } & \\ \text { airport } & \text { ADNIN } & \text { Coconino } \\ \text { school } & \text { UNOFF } & \text { Coconino } \\ \text { school } & \text { UNOFF } & \text { Coconino } \\ \text { hospital } & \text { UNOFF } & \text { Coconino }\end{array}$

ppl

lake

Pima

Mohave
SOURCE
COORDINATE

ELEV
FT

MAP NAME

$354807 N 1091942 W$

$361508 N 1090924 W$

$345213 \mathrm{~N} 1113710 \mathrm{~W}$

$345500 \mathrm{~N} 1113622 \mathrm{~W}$

$345429 \mathrm{~N} 1113646 \mathrm{~W}$

$345425 \mathrm{~N} 1113543 \mathrm{~W}$

$345332 \mathrm{~N} 1113350 \mathrm{~W}$

$351124 N 1102122 \mathrm{~W}$

$360937 \mathrm{~N} 1093441 \mathrm{~W}$

$365522 \mathrm{~N} 1091401 \mathrm{~W}$

351109 N1121638W

$341052 N 1114723 \mathrm{~W}$

340450 N1091543W

$340217 N 1091607 \mathrm{~W}$

$340234 \mathrm{~N} 1091638 \mathrm{~W}$

$340448 \mathrm{~N} 1091539 \mathrm{~W}$

$\begin{array}{llll}\text { spring } & & \text { Maricopa } & \text { UNKNOWN } \\ \text { reservoir } & \text { BGN } & \text { Coconino } & 354050 \text { N1123045W }\end{array}$

$360806 \mathrm{~N} 1111421 \mathrm{~W}$

$361124 N 1112102 \mathrm{~W}$

$313645 \mathrm{~N} 1110243 \mathrm{~W}$

$313634 \mathrm{~N} 1110224 \mathrm{~W}$

$313625 \mathrm{~N} 1110302 \mathrm{~W}$

$360806 \mathrm{~N} 1111421 \mathrm{~W}$

360807 N1111400W

$360823 \mathrm{~N} 1111424 \mathrm{~W}$

$360821 \mathrm{~N} 1111408 \mathrm{~W}$

$360810 \mathrm{~N} 1111418 \mathrm{~W}$

school UNOFF Coconino 360821N1111418W

reservoir BGN Coconino 353034N1113300W

locale UNOFF Coconino 360700N1111435W

park ADMIN Santa Cruz 313641N1110243W

reservoir BGN Coconino 353855N1125342W

spring BGN Yavapai 343347N1124446W

valley BGN Gila $\quad 341317 N 1113024 \mathrm{~W}$

reservoir BGN Coconino 352336N1114120W

reservoir BGN Coconino 353951N1125717W

reservoir BGN Coconino 352556N1113946W

reservoir BGN Coconino $354214 \mathrm{N1125645 \textrm {W }}$

reservoir BGN Coconino 354103N1125720W

$364901 \mathrm{~N} 1133332 \mathrm{~W}$

$363120 \mathrm{~N} 1130045 \mathrm{~W}$
$345523 \mathrm{~N} 1113549 \mathrm{~W}$

Stoneman Lake

7244 Mormon Mountain

7135 Mormon Mountain

Mormon Mountain

Mormon Mountain

5519 Rotten Bananas Butte

$364945 N 1091238 W$

5490 Chinle

Cow Butte

McLellan Reservoir

Bloody Bas in

Eagar

Eagar

Eagar

Eagar

Rose Well Camp West

$\begin{array}{rrl}313648 \text { N1110641W } & 5786 & \begin{array}{l}\text { Moenave } \\ \text { Tubac } \\ \text { Tubac } \\ \text { Tubac } \\ \text { Tuba City }\end{array} \\ & 4966 & \begin{array}{l}\text { Tuba City } \\ \text { Tuba City } \\ \text { Tuba City } \\ \text { Tuba City }\end{array} \\ & & \end{array}$

Tuba City

East of S P Mtn

Moenkopi

Tubac

Rose Well Camp West

Skull Valley

Cypress Butte

White Horse Hills

Rose Well Camp West

White Horse Hills

Rose Well Camp West

White Horse Hills

Rose Well Camp West

Wolf Hole Mtn East

Hat Knoll 
A2654

NATIONAL GAZETTEER--ARIZONA 1986

\begin{tabular}{|c|c|c|c|c|c|c|c|}
\hline FEATURE NAME & $\begin{array}{l}\text { FEATURE } \\
\text { CLASS }\end{array}$ & STATUS & COUNTY & COORDINATE & $\begin{array}{l}\text { SOURCE } \\
\text { COORDINATE }\end{array}$ & $\begin{array}{c}\text { ELEV } \\
\text { FT }\end{array}$ & MAP NAME \\
\hline $\begin{array}{l}\text { Tub Ranch } \\
\text { Tubson } \\
\text { See Tucson }\end{array}$ & $\begin{array}{l}\text { locale } \\
\text { ppl }\end{array}$ & $\begin{array}{l}\text { UNOFF } \\
\text { VARIANT }\end{array}$ & $\begin{array}{l}\text { Coconino } \\
\text { Pima }\end{array}$ & $\begin{array}{l}353609 \mathrm{~N} 1114512 \mathrm{~W} \\
321318 \mathrm{~N} 1105533 \mathrm{~W}\end{array}$ & & & Chapel Mtn \\
\hline $\begin{array}{l}\text { Tub Spring } \\
\text { Tub Spring } \\
\text { Tub Spring } \\
\text { Tub Spring Wash } \\
\text { Tubs Spring } \\
\text { Tubutana Mine } \\
\text { Tuckayou Wash } \\
\text { Cactus Pass }\end{array}$ & $\begin{array}{l}\text { spring } \\
\text { spring } \\
\text { spring } \\
\text { stream } \\
\text { spring } \\
\text { mine } \\
\text { stream }\end{array}$ & $\begin{array}{l}\text { BGN } \\
\text { BGN } \\
\text { BGN } \\
\text { BGN } \\
\text { BGN } \\
\text { UNOFF } \\
\text { BGN } \\
\text { VARIANT }\end{array}$ & $\begin{array}{l}\text { Cochise } \\
\text { Maricopa } \\
\text { Yavapai } \\
\text { Maricopa } \\
\text { Yavapai } \\
\text { Santa Cruz } \\
\text { Mohave }\end{array}$ & $\begin{array}{l}315245 \mathrm{~N} 1091657 \mathrm{~W} \\
335658 \mathrm{~N} 1123606 \mathrm{~W} \\
344027 \mathrm{~N} 1124825 \mathrm{~W} \\
335601 \mathrm{~N} 1123700 \mathrm{~W} \\
343927 \mathrm{~N} 1125104 \mathrm{~W} \\
313127 \mathrm{~N} 1105804 \mathrm{~W} \\
351111 \mathrm{~N} 1132739 \mathrm{~W}\end{array}$ & $\begin{array}{l}335902 \mathrm{~N} 1123453 \mathrm{~W} \\
351800 \mathrm{~N} 1132946 \mathrm{~W}\end{array}$ & & $\begin{array}{l}\text { Rustler Park } \\
\text { Red Picacho } \\
\text { Smith Mesa } \\
\text { Red Picacho } \\
\text { Smith Mesa } \\
\text { San Cayetano Mts } \\
\text { Bul1 Spring }\end{array}$ \\
\hline $\begin{array}{l}\text { Tucker } \\
\text { Tucker Box }\end{array}$ & $\begin{array}{l}\text { locale } \\
\text { bas in }\end{array}$ & $\begin{array}{l}\text { BGN } \\
\text { BGN }\end{array}$ & $\begin{array}{l}\text { Gila } \\
\text { Gila }\end{array}$ & $\begin{array}{l}333827 \mathrm{~N} 1103624 \mathrm{~W} \\
334602 \mathrm{~N} 1110239 \mathrm{~W}\end{array}$ & & 4880 & $\begin{array}{l}\text { Chrysotile } \\
\text { Armer Mountain }\end{array}$ \\
\hline $\begin{array}{l}\text { Tucker Canyon } \\
\text { Tucker Flat } \\
\text { Tucker Flat Wash } \\
\text { Tucker Mesa } \\
\text { Tucker Railroad Station } \\
\text { Tucker Siding } \\
\text { Tucker Spring } \\
\text { Tucker Spring } \\
\text { Tucker Tank } \\
\text { Tucket Canyon } \\
\text { See Tuckup Canyon }\end{array}$ & $\begin{array}{l}\text { valley } \\
\text { flat } \\
\text { valley } \\
\text { summit } \\
\text { building } \\
\text { locale } \\
\text { spring } \\
\text { spring } \\
\text { reservoir } \\
\text { valley }\end{array}$ & $\begin{array}{l}\text { BGN } \\
\text { BGN } \\
\text { 8GN } \\
\text { BGN } \\
\text { UNOFF } \\
\text { BGN } \\
\text { BGN } \\
\text { BGN } \\
\text { BGN } \\
\text { VARIANT }\end{array}$ & $\begin{array}{l}\text { Yavapai } \\
\text { Navajo } \\
\text { Coconino } \\
\text { Coconino } \\
\text { Yavapai } \\
\text { Yavapai } \\
\text { Navajo } \\
\text { Yavapai } \\
\text { Gila } \\
\text { Mohave }\end{array}$ & $\begin{array}{l}350838 \mathrm{~N} 1124227 \mathrm{~W} \\
350803 \mathrm{~N} 1104254 \mathrm{~W} \\
350312 \mathrm{~N} 1104631 \mathrm{~W} \\
350616 \mathrm{~N} 1104725 \mathrm{~W} \\
344534 \mathrm{~N} 1123659 \mathrm{~W} \\
344534 \mathrm{~N} 1123659 \mathrm{~W} \\
350640 \mathrm{~N} 1104453 \mathrm{~W} \\
350839 \mathrm{~N} 1123926 \mathrm{~W} \\
333405 \mathrm{~N} 1105505 \mathrm{~W} \\
361647 \mathrm{~N} 1125230 \mathrm{~W}\end{array}$ & $\begin{array}{l}351005 N 1123747 W \\
350124 N 1104835 W\end{array}$ & 5047 & $\begin{array}{l}\text { Picacho Butte } \\
\text { Winslow NW } \\
\text { Tucker Mesa } \\
\text { Tucker Mesa } \\
\text { Sullivan Buttes } \\
\text { Sullivan Buttes } \\
\text { Winslow } \\
\text { Picacho Butte } \\
\text { Salt River Peak }\end{array}$ \\
\hline $\begin{array}{l}\text { Tuckup Canyon } \\
\text { Hundred And Sixtyfour } \\
\text { Mile Canyon } \\
\text { Tucket Canyon } \\
\text { Tuckup Point } \\
\text { Tuckup Rocky Point } \\
\text { Tuckup Trait } \\
\text { Tucson } \\
\text { Fucson } \\
\text { Lucson } \\
\text { San Cosme Del Tucson } \\
\text { Teuson } \\
\text { Toison } \\
\text { Tubon } \\
\text { Tubson } \\
\text { Tucsson } \\
\text { Tuczon } \\
\text { Tugson } \\
\text { Tuguison } \\
\text { Tuison } \\
\text { Tulquson } \\
\text { Tuozon } \\
\text { Tuquisson } \\
\text { Tuquison }\end{array}$ & $\begin{array}{l}\text { cliff } \\
\text { cliff } \\
\text { trail } \\
\text { ppl }\end{array}$ & $\begin{array}{l}8 G N 1964 \\
\text { VARIANT } \\
\text { VARIANT } \\
\text { BGN } \\
\text { BGN } \\
\text { UNOFF } \\
\text { BGN 194\& } \\
\text { VARIANT } \\
\text { VARIANT } \\
\text { VARIANT } \\
\text { VARIANT } \\
\text { VARIANT } \\
\text { VARIANT } \\
\text { VARIANT } \\
\text { VARIANT } \\
\text { VARIANT } \\
\text { VARIANT } \\
\text { VARIANT } \\
\text { VARIANT } \\
\text { VARIANT } \\
\text { VARIANT } \\
\text { VARIANT } \\
\text { VARIANT }\end{array}$ & $\begin{array}{l}\text { Mohave } \\
\text { Mohave } \\
\text { Mohave } \\
\text { Pima }\end{array}$ & $\begin{array}{l}361743 \mathrm{~N} 1130012 \mathrm{~W} \\
361831 \mathrm{~N} 1125450 \mathrm{~W} \\
362046 \mathrm{~N} 1125304 \mathrm{~W} \\
321318 \mathrm{N1} 105533 \mathrm{~W}\end{array}$ & $362330 \mathrm{~N} 1125500 \mathrm{~W}$ & 5986 & $\begin{array}{l}\text { Mt Trumbull SE } \\
\text { Fern Glen Canyon } \\
\text { Fern Glen Canyon } \\
\text { Tucson }\end{array}$ \\
\hline $\begin{array}{l}\text { Tucson Botanical Garden } \\
\text { Tucsoncito } \\
\text { See Ali Chukson } \\
\text { Tucson Community Center } \\
\text { Tucson Community School } \\
\text { Tucson Compressor Station } \\
\text { Tucson Country Club Estates } \\
\text { Tucson Country Day School } \\
\text { Tucson Estates } \\
\text { Tucson Estates Shopping Center }\end{array}$ & $\begin{array}{l}\text { park } \\
\text { ppl } \\
\text { park } \\
\text { school } \\
\text { locale } \\
\text { ppl } \\
\text { school } \\
\text { ppl } \\
\text { locale }\end{array}$ & $\begin{array}{l}\text { ADMIN } \\
\text { VARIANT } \\
\text { ADMIN } \\
\text { UNOFF } \\
\text { UNOFF } \\
\text { BGN } \\
\text { UNOFF } \\
\text { BGN } \\
\text { UNOFF }\end{array}$ & $\begin{array}{l}\text { Pima } \\
\text { Pima } \\
\text { Pima } \\
\text { Pima } \\
\text { Pima } \\
\text { Pima } \\
\text { Pima } \\
\text { Pima } \\
\text { Pima }\end{array}$ & $\begin{array}{l}321456 \mathrm{~N} 1105430 \mathrm{~W} \\
315449 \mathrm{~N} 1114755 \mathrm{~W} \\
321311 \mathrm{~N} 1105825 \mathrm{~W} \\
321548 \mathrm{~N} 1105621 \mathrm{~W} \\
322147 \mathrm{~N} 1112226 \mathrm{~W} \\
321533 \mathrm{~N} 1105129 \mathrm{~W} \\
321345 \mathrm{~N} 1105444 \mathrm{~W} \\
321115 \mathrm{~N} 1110525 \mathrm{~W} \\
321134 \mathrm{~N} 1110510 \mathrm{~W}\end{array}$ & & $\begin{array}{l}2460 \\
2620 \\
2700\end{array}$ & $\begin{array}{l}\text { Tucson } \\
\text { Tucson Morth } \\
\text { West of Avra } \\
\text { Sabino Canyon } \\
\text { Tucson } \\
\text { Cat Mountain } \\
\text { Cat Mountain }\end{array}$ \\
\hline $\begin{array}{l}\text { Tucson General Hospital } \\
\text { Tucson High School } \\
\text { Tucson Hill } \\
\text { See Ali Chukson } \\
\text { Tucsonimon } \\
\text { See Sacaton } \\
\text { Tucson International Airport } \\
\text { Tucsonito } \\
\text { See Ali Chukson } \\
\text { Tucson Mall }\end{array}$ & $\begin{array}{l}\text { hospital } \\
\text { school } \\
\text { ppl } \\
\text { pp1 } \\
\text { airport } \\
\text { ppl } \\
\text { locale }\end{array}$ & $\begin{array}{l}\text { UNOFF } \\
\text { UNOFF } \\
\text { VARIANT } \\
\text { VARIANT } \\
\text { ADMIN } \\
\text { VARIANT } \\
\text { UNOFF }\end{array}$ & $\begin{array}{l}\text { Pima } \\
\text { Pima } \\
\text { Pima } \\
\text { Pinal } \\
\text { Pima } \\
\text { Pima } \\
\text { Pima }\end{array}$ & $\begin{array}{l}321636 \mathrm{~N} 1105630 \mathrm{~W} \\
321337 \mathrm{~N} 1105739 \mathrm{~W} \\
315449 \mathrm{~N} 1114755 \mathrm{~W} \\
330436 \mathrm{~N} 1114419 \mathrm{~W} \\
320705 \mathrm{~N} 1105635 \mathrm{~W} \\
315449 \mathrm{~N} 1114755 \mathrm{~W} \\
321719 \mathrm{~N} 1105830 \mathrm{~W}\end{array}$ & & 2630 & $\begin{array}{l}\text { Tucson North } \\
\text { Tucson }\end{array}$ \\
\hline $\begin{array}{l}\text { Tucson Medical Center } \\
\text { Tucson Medical Center Heliport } \\
\text { Tucson Mountain County Park } \\
\text { Tucson Mountains } \\
\text { Tucson Mountain Wildlife Area }\end{array}$ & $\begin{array}{l}\text { hospital } \\
\text { airport } \\
\text { park } \\
\text { range } \\
\text { park }\end{array}$ & $\begin{array}{l}\text { UNOFF } \\
\text { ADMIN } \\
\text { ADMIN } \\
\text { BGN } \\
\text { ADMIN }\end{array}$ & $\begin{array}{l}\text { Pima } \\
\text { Pima } \\
\text { Pima } \\
\text { Pima } \\
\text { Pima }\end{array}$ & $\begin{array}{l}321509 N 1105244 \mathrm{~W} \\
321504 \mathrm{~N} 1105237 \mathrm{~W} \\
321327 \mathrm{~N} 1110931 \mathrm{~W} \\
321348 \mathrm{~N} 1110549 \mathrm{~W} \\
321700 \mathrm{~N} 1111000 \mathrm{~W}\end{array}$ & & 2470 & $\begin{array}{l}\text { Tucson North } \\
\text { Tucson North } \\
\text { Brown Mtn } \\
\text { Cat Mountain } \\
\text { Avra }\end{array}$ \\
\hline
\end{tabular}




\begin{tabular}{|c|c|c|c|c|c|c|c|}
\hline FEATURE NAME & $\begin{array}{l}\text { FEATURE } \\
\text { CLASS }\end{array}$ & STATUS & COUNTY & COORDINATE & $\begin{array}{l}\text { SOURCE } \\
\text { COORDINATE }\end{array}$ & $\begin{array}{c}\text { ELEV } \\
\text { FT }\end{array}$ & MAP NAME \\
\hline $\begin{array}{l}\text { Tucson National Estates } \\
\text { Tucson Sports Center } \\
\text { Tucson Veterans Hospital } \\
\text { Tucson Wash } \\
\text { Tucsson } \\
\text { See Tucson }\end{array}$ & $\begin{array}{l}\text { ppl } \\
\text { building } \\
\text { hospital } \\
\text { stream } \\
\text { ppl }\end{array}$ & $\begin{array}{l}\text { BGN } \\
\text { UNOFF } \\
\text { UNOFF } \\
\text { BGN 1961 } \\
\text { VARIANT }\end{array}$ & $\begin{array}{l}\text { Pima } \\
\text { Pima } \\
\text { Pima } \\
\text { Pinal } \\
\text { Pima }\end{array}$ & $\begin{array}{l}322111 \mathrm{~N} 1110130 \mathrm{~W} \\
321309 \mathrm{~N} 1105858 \mathrm{~W} \\
321052 \mathrm{~N} 1105752 \mathrm{~W} \\
324415 \mathrm{~N} 1103855 \mathrm{~W} \\
\\
321318 \mathrm{~N} 1105533 \mathrm{~W}\end{array}$ & $323515 \mathrm{~N} 1104610 \mathrm{~W}$ & 2320 & $\begin{array}{l}\text { Jaynes } \\
\text { Tucson } \\
\text { Tucson } \\
\text { Mammoth }\end{array}$ \\
\hline $\begin{array}{l}\text { Tuczon } \\
\text { See Tucson } \\
\text { Tudecoz Spring } \\
\text { Todokozh Spring } \\
\text { Totocong Spring } \\
\text { Tufa Stone Dan } \\
\text { Tufa Stone Tank } \\
\text { Tuffet Tank } \\
\text { Tuff Tank } \\
\text { Tug-Of-War Historical Marker }\end{array}$ & $\begin{array}{l}\text { dam } \\
\text { reservoir } \\
\text { reservoir } \\
\text { reservoir } \\
\text { park }\end{array}$ & $\begin{array}{l}\text { VARIANT } \\
\text { BGN } 1974 \\
\text { VARIANT } \\
\text { VARIANT } \\
\text { UNOFF } \\
\text { BGN } \\
\text { BGN } \\
\text { BGN } \\
\text { ADMIN }\end{array}$ & $\begin{array}{l}\text { Gila } \\
\text { Gila } \\
\text { Pima } \\
\text { Apache } \\
\text { Navajo }\end{array}$ & $\begin{array}{l}321318 N 1105533 W \\
353611 N 1092714 W \\
332224 N 1102852 W \\
332224 N 1102858 W \\
321653 N 1104040 W \\
340857 N 1094923 W \\
355238 N 1103828 W\end{array}$ & & 2784 & $\begin{array}{l}\text { Tudecoz Spring } \\
\text { San Carlos } \\
\text { San Carlos } \\
\text { Agua Caliente Hill } \\
\text { Sponseller Mtn } \\
\text { Hotevilla }\end{array}$ \\
\hline $\begin{array}{l}\text { Tugson } \\
\text { See Tucson } \\
\text { Tuguison } \\
\text { See Tucson } \\
\text { Tuhavi Park } \\
\text { Tuison } \\
\text { See Tucson } \\
\text { Tulapai Creek } \\
\text { Ranch Creek } \\
\text { Tutapai Creek } \\
\text { See Ranch Creek }\end{array}$ & $\begin{array}{l}\text { ppl } \\
\text { ppl } \\
\text { park } \\
\text { ppl } \\
\text { strean } \\
\text { strean }\end{array}$ & $\begin{array}{l}\text { VARIANT } \\
\text { VARIANT } \\
\text { ADMIN } \\
\text { VARIANT } \\
\text { BGN } 1970 \\
\text { VARIANT } \\
\text { VARIANT }\end{array}$ & $\begin{array}{l}\text { Pima } \\
\text { Pima } \\
\text { Maricopa } \\
\text { Pima } \\
\text { Gila } \\
\text { Gila }\end{array}$ & $\begin{array}{l}321318 N 1105533 \mathrm{~W} \\
321318 \mathrm{~N} 1105533 \mathrm{~W} \\
332402 \mathrm{~N} 1120101 \mathrm{~W} \\
321318 \mathrm{~N} 1105533 \mathrm{~W} \\
331403 \mathrm{~N} 110405 \mathrm{~W} \\
332110 \mathrm{~N} 1103847 \mathrm{~W}\end{array}$ & $331150 \mathrm{~N} 1104020 \mathrm{~W}$ & & Mescal Warm Spring \\
\hline $\begin{array}{l}\text { Tule Basin } \\
\text { Tule Butte } \\
\text { Tule Canyon } \\
\text { See Dry Creek } \\
\text { Tule Canyon } \\
\text { Tule Canyon } \\
\text { Tule Canyon } \\
\text { Tule Canyon } \\
\text { Tule Canyon Creek }\end{array}$ & $\begin{array}{l}\text { bas in } \\
\text { summit } \\
\text { stream } \\
\text { valley } \\
\text { valley } \\
\text { valley } \\
\text { valley } \\
\text { valley }\end{array}$ & $\begin{array}{l}\text { BGN } 1977 \\
\text { BGN } \\
\text { VARIANT } \\
\text { BGN } \\
\text { BGN } \\
\text { BGN } \\
\text { BGN } 1968 \\
\text { VARIANT } \\
\text { BGN }\end{array}$ & $\begin{array}{l}\text { Coconino } \\
\text { Coconino } \\
\text { Yavapai } \\
\text { Graham } \\
\text { Pinal } \\
\text { Gila } \\
\text { Yavapai } \\
\text { Coconino }\end{array}$ & $\begin{array}{l}350650 \mathrm{~N} 1121850 \mathrm{~W} \\
343233 \mathrm{~N} 1113001 \mathrm{~W} \\
342050 \mathrm{~N} 1115648 \mathrm{~W} \\
325652 \mathrm{N1102021 \textrm {W }} \\
331930 \mathrm{~N} 1111807 \mathrm{~W} \\
333452 \mathrm{~N} 1110355 \mathrm{~W} \\
342023 \mathrm{~N} 1115438 \mathrm{~W} \\
\\
343407 \mathrm{~N} 1113002 \mathrm{~W}\end{array}$ & 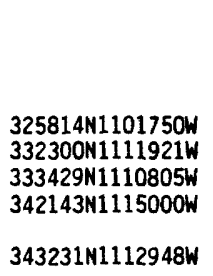 & & $\begin{array}{l}\text { Matterhorn } \\
\text { Buckhorn Mountain } \\
\text { Cobre Grande Mtn } \\
\text { Florence Junction } \\
\text { Two Bar Mtn } \\
\text { Dugas } \\
\text { Buckhorn Mountain }\end{array}$ \\
\hline $\begin{array}{l}\text { Tule Canyon } \\
\text { Lee Canyon } \\
\text { Tule Canyon } \\
\text { See Lee Canyon } \\
\text { Tule Canyon Tank } \\
\text { Tule Creek } \\
\text { Tule Creek } \\
\text { Tule Desert } \\
\text { Tule Lake } \\
\text { Tule Mesa }\end{array}$ & $\begin{array}{l}\text { valley } \\
\text { reservoir } \\
\text { stream } \\
\text { stream } \\
\text { plain } \\
\text { lake } \\
\text { summit }\end{array}$ & $\begin{array}{l}\text { BGN } \\
\text { VARIANT } \\
\text { VARIANT } \\
\text { BGN } \\
\text { BGN } \\
\text { BGN } \\
\text { BGN } \\
\text { BGN } \\
\text { BGN }\end{array}$ & $\begin{array}{l}\text { Coconino } \\
\text { Yavapai } \\
\text { Graham } \\
\text { Yavapai } \\
\text { Yuma } \\
\text { Coconino } \\
\text { Yavapai }\end{array}$ & $\begin{array}{l}350204 N 1120201 W \\
342218 N 1115113 W \\
331106 N 1093006 \mathrm{~W} \\
335724 N 1121409 W \\
321622 N 1133820 W \\
353419 N 1124044 W \\
342215 N 1114849 W\end{array}$ & $\begin{array}{l}331332 \mathrm{~N} 1092458 \mathrm{~W} \\
340248 \mathrm{N1} 121643 \mathrm{~W}\end{array}$ & 6678 & $\begin{array}{l}\text { Tule Mesa } \\
\text { Elevator Mtn } \\
\text { New River } \\
\text { Christmas Pass } \\
\text { Bishop Lake } \\
\text { Tule Mesa }\end{array}$ \\
\hline $\begin{array}{l}\text { Tule Mountains } \\
\text { Cabeza Prieta Mountains } \\
\text { Cordillera del Tule } \\
\text { Cordillera Del Tule } \\
\text { Mesa de Malpais } \\
\text { Sierra del Tule } \\
\text { Tuseral Mountains } \\
\text { Tule Mountains } \\
\text { See Cabeza Prieta Mountains } \\
\text { Tule Mountain Tank }\end{array}$ & $\begin{array}{l}\text { range } \\
\text { reservoir }\end{array}$ & $\begin{array}{l}\text { BGN } \\
\text { VARIANT } \\
\text { VARIANT } \\
\text { VARIANT } \\
\text { VARIANT } \\
\text { VARIANT } \\
\text { VARIANT } \\
\text { VARIANT } \\
\text { BGN }\end{array}$ & $\begin{array}{l}\text { Yuma } \\
\text { Yavapai }\end{array}$ & $\begin{array}{l}322059 N 1134924 W \\
342225 N 1114906 W\end{array}$ & & & Tule Mountains \\
\hline $\begin{array}{l}\text { Tule Spring } \\
\text { Tule Spring } \\
\text { Tule Spring } \\
\text { Tule Spring } \\
\text { Tule Spring } \\
\text { Tule Spring } \\
\text { Tule Springs } \\
\text { Tule Springs } \\
\text { Tule Springs } \\
\text { Tule Springs Ranch }\end{array}$ & $\begin{array}{l}\text { spring } \\
\text { spring } \\
\text { spring } \\
\text { spring } \\
\text { spring } \\
\text { spring } \\
\text { spring } \\
\text { spring } \\
\text { spring } \\
\text { locale }\end{array}$ & $\begin{array}{l}\text { BGN } \\
\text { BGN } \\
\text { BGN } \\
\text { BGN } \\
\text { BGN } \\
\text { BGN } \\
\text { BGN } \\
\text { BGN } \\
\text { BGN } \\
\text { UNOFF }\end{array}$ & $\begin{array}{l}\text { Pinal } \\
\text { Graham } \\
\text { Maricopa } \\
\text { Maricopa } \\
\text { Yavapai } \\
\text { Mohave } \\
\text { Greenlee } \\
\text { Graham } \\
\text { Yuma } \\
\text { Greenlee }\end{array}$ & $\begin{array}{l}323127 N 1104229 W \\
325704 N 1101957 W \\
333510 N 1110633 W \\
335240 N 1122140 W \\
340041 N 1121627 W \\
361636 N 1125553 W \\
331247 N 1092705 W \\
332037 N 1095353 W \\
333321 N 1142106 W \\
331246 N 1092704 W\end{array}$ & & 5120 & $\begin{array}{l}\text { Campo Bonito } \\
\text { Cobre Grande Mtn } \\
\text { Two Bar Mtn } \\
\text { Governors Peak } \\
\text { Columbia } \\
\text { Fern Glen Canyon } \\
\text { Coronado Mtn } \\
\text { Tule Tubs } \\
\text { Cunningham Mtn } \\
\text { Coronado Mtn }\end{array}$ \\
\hline $\begin{array}{l}\text { Tule Tank } \\
\text { Tule Tank } \\
\text { Tule Tank } \\
\text { Tea Kettle Mountain }\end{array}$ & $\begin{array}{l}\text { reservoir } \\
\text { reservoir } \\
\text { reservoir }\end{array}$ & $\begin{array}{l}\text { BGN } \\
\text { BGN } \\
\text { BGN } \\
\text { VARIANT }\end{array}$ & $\begin{array}{l}\text { Yuma } \\
\text { Cochise } \\
\text { Graham }\end{array}$ & $\begin{array}{l}321335 N 1134743 W \\
322441 N 1091015 W \\
332041 N 1095507 W\end{array}$ & & & $\begin{array}{l}\text { Tule Mountains } \\
\text { Orange Butte } \\
\text { Tule Tubs }\end{array}$ \\
\hline
\end{tabular}


NATIONAL GAZETTEER--ARIZONA 1986

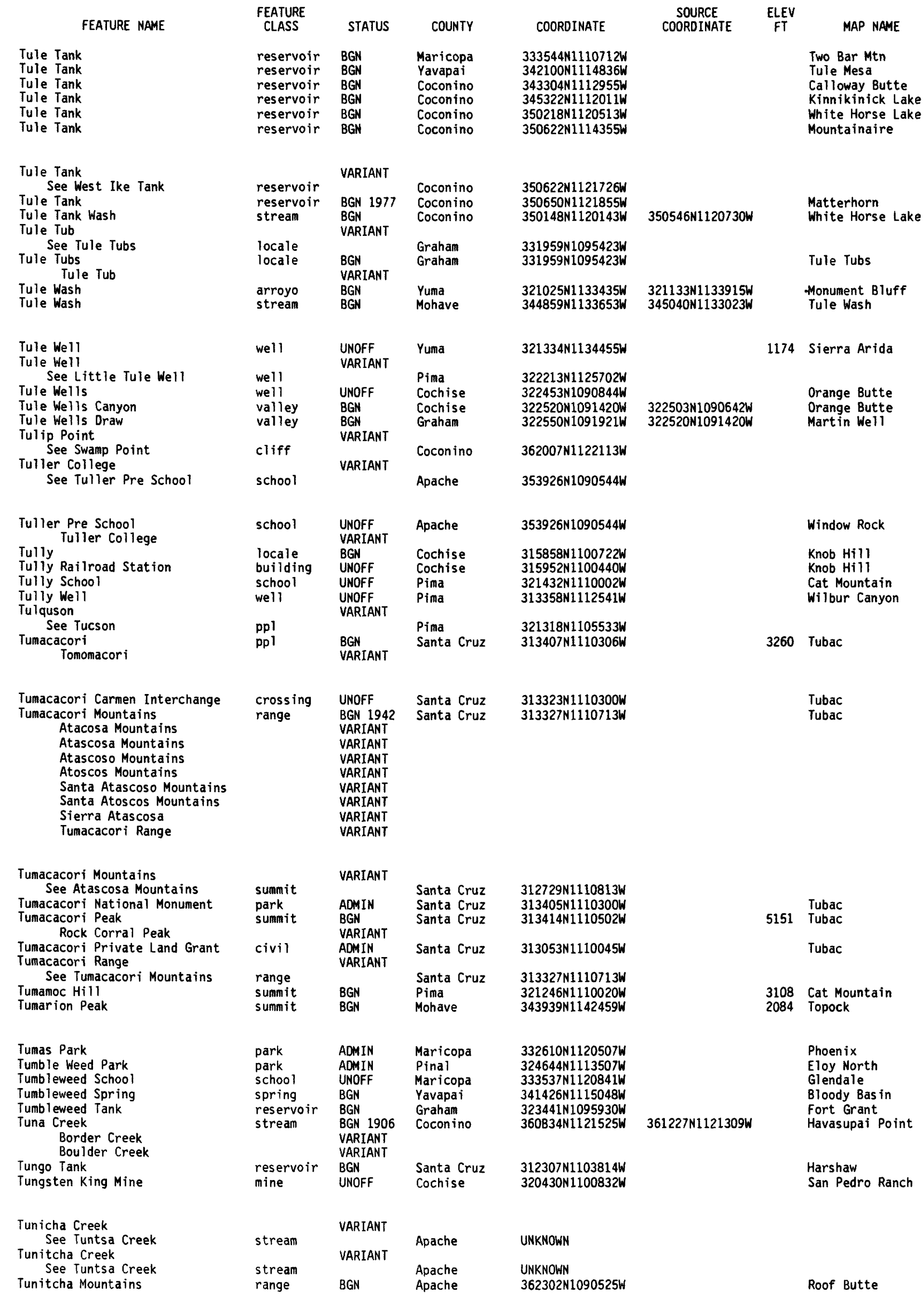


NATIONAL GAZETTEER--ARIZONA 1986

\section{FEATURE NAME}

Tunnel Canyon

Tunnel Canyon

Tunnel Canyon

Tunnel Dam

Tunnel Mine

Tunnel Mine Canyon

Tunnel Peak

Tunnel Ranch

Tunnel Reservoir

Tunnel Spring

Tunnel Spring

Tunnel Spring

Tunnel Spring

Tunnel Spring

Tunnel Spring

Tunnel Spring

Mays Gap Tunnel Spring

Tunnel Spring

Tunnel Spring

Tunnel Spring

Tunnel Spring

Tunnel Spring

Tunnel Spring

Tunnel Spring

Tunnel Spring

Tunnel Spring

Tunnel Spring

Tunnel Spring Mine

Tunnel Springs

Tunnel Springs Canyon

Tunnel Tank

Tunnel Well

Tunney Dam

Tuntsa Creek

Temecha Creek

Tunicha Creek

Tunitcha Creek

Tuozon

See Tucson

Tupewa

See Topawa

Tuquisson

See Tucson

Tuquison

See Tucson

Turey Seep Tank

Turf Airport

Turf Mobile Manor

Turf Paradise Travel Trailer

Park

Turf Trailer Lodge

Turkey Butte

Turkey Butte Tank

Turkey Canyon

See Turkey Creek

Turkey Canyon

Turkey Canyon

Turkey Canyon

Turkey Canyon We 11

Turkey Creek

Coches Canyon

Lyle Canyon

Turkey Canyon

Turkey Creek

See East Turkey Creek

Turkey Creek

Morse Canyon

Turkey Creek

Sycamore Creek

Turkey Creek

Turkey Creek
FEATURE

CLASS

STATUS

COUNTY

valley
valley

valley

dam

BGN

$B G N$

$B G N$

UNOFF

UNOFF

Graham

Coconino

Apache

Apache

Yavapai

vall

locale

reservoir

spring

spring

spring

pring

spring

spring

BGN YU

UNOFF Yuma

Pinal

$\begin{array}{ll}\text { BGN } & \text { Apache } \\ \text { BGN } & \text { Santa Cruz }\end{array}$

BGN Cochise

Pima

Cochise
Graham

Gila

spring $B G$

VARIANT

spring

spring

spring

spring

spring

spring

spring

spring

BGN

BGN

BGN

$B G N$

$B G N$

BGN

$B G N$
$B G N$

Gila

Pinal

Maricopa

Maricopa

Gila

Yavapai

Yavapai

Yavapa $i$

Yavapai

spring BGN Yavapai

spring $\quad B G$

mine

spring

valley

reservoir

well

dam

stream

Coconino

UNOFF

8GN

BGN

UNOFF
UNOFF

BGN

VARIANT

VARIANT

VARIANT

Yuma

Yuma

Yuma

Yavapai

Pima

Coconino

Apache

VARIANT

pp 1

VARIANT

ppl

Pima

$321318 N 1105533 W$

ppl

VARIANT

Pima

$314850 \mathrm{~N} 1114930 \mathrm{~W}$

ppl

ppl

reservoir

VARIANT

Pima

Pima

locale UNOFF

locale

UNOFF

UNOFF

BGN

summit $B C N$

$\begin{array}{ll}\text { reservoir } & \text { BGN } \\ & \text { VARIAN }\end{array}$

stream

valley

BGN

valley

$B G N$

valley

well

stream

BGN

UNOFF

BGN 1960

VARIANT

VARIANT

VARIANT

VARIANT

stream

BGN

Cochise

VARIANT

Maricopa

Maricopa

Maricopa

Coconino

Coconino

Santa Cruz

Navajo

Navajo

Yavapai

Yavapai

Santa Cruz

$321318 N 1105533 \mathrm{~W}$

$321318 \mathrm{~N} 1105533 \mathrm{~W}$

$345707 N 1113312$

$333758 \mathrm{~N} 1120527 \mathrm{~W}$

$333738 \mathrm{~N} 1120551 \mathrm{~W}$

$333740 \mathrm{~N} 1120545 \mathrm{~W}$

$333830 \mathrm{~N} 1120540 \mathrm{~W}$

$350156 \mathrm{~N} 1115412 \mathrm{~W}$

$350145 \mathrm{~N} 1115400 \mathrm{~W}$

$313514 \mathrm{~N} 1102949 \mathrm{~W}$

$340643 N 1101901 \mathrm{~W}$

$342023 \mathrm{~N} 1103927 \mathrm{~W}$

341156 N1101930W

$351123 N 1125356 \mathrm{~W}$

$350248 N 1125730 \mathrm{~W}$

$313514 \mathrm{~N} 1102949 \mathrm{~W}$

$350012 N 1125954 \mathrm{~W}$

$312744 \mathrm{~N} 1102717$

$315955 \mathrm{~N} 1090736 \mathrm{~W}$

315956 N1 $094903 \mathrm{~W}$

Cochise

(

$320910 \mathrm{~N} 1102710 \mathrm{~W}$

$321142 N 1103138 \mathrm{~W}$

$325350 \mathrm{~N} 1102636 \mathrm{~W} \quad 324730 \mathrm{~N} 1102531 \mathrm{~W}$

stream

BGN 1959

BGN

BGN
Graham

Green lee
Mormon Mountain

Union Hills

1330 Union $\mathrm{Hills}$

1330 Union Hills

1335 Union Hills

7374 Sycamore Point

Sycamore Point

Limestone Canyon $S$

Brookbank Point

Purcell Canyon

5999 Turkey Canyon

Pyeatt Ranch

(1)

Pearce

Happy Valley

Booger Canyon

Pipestem Mtn 


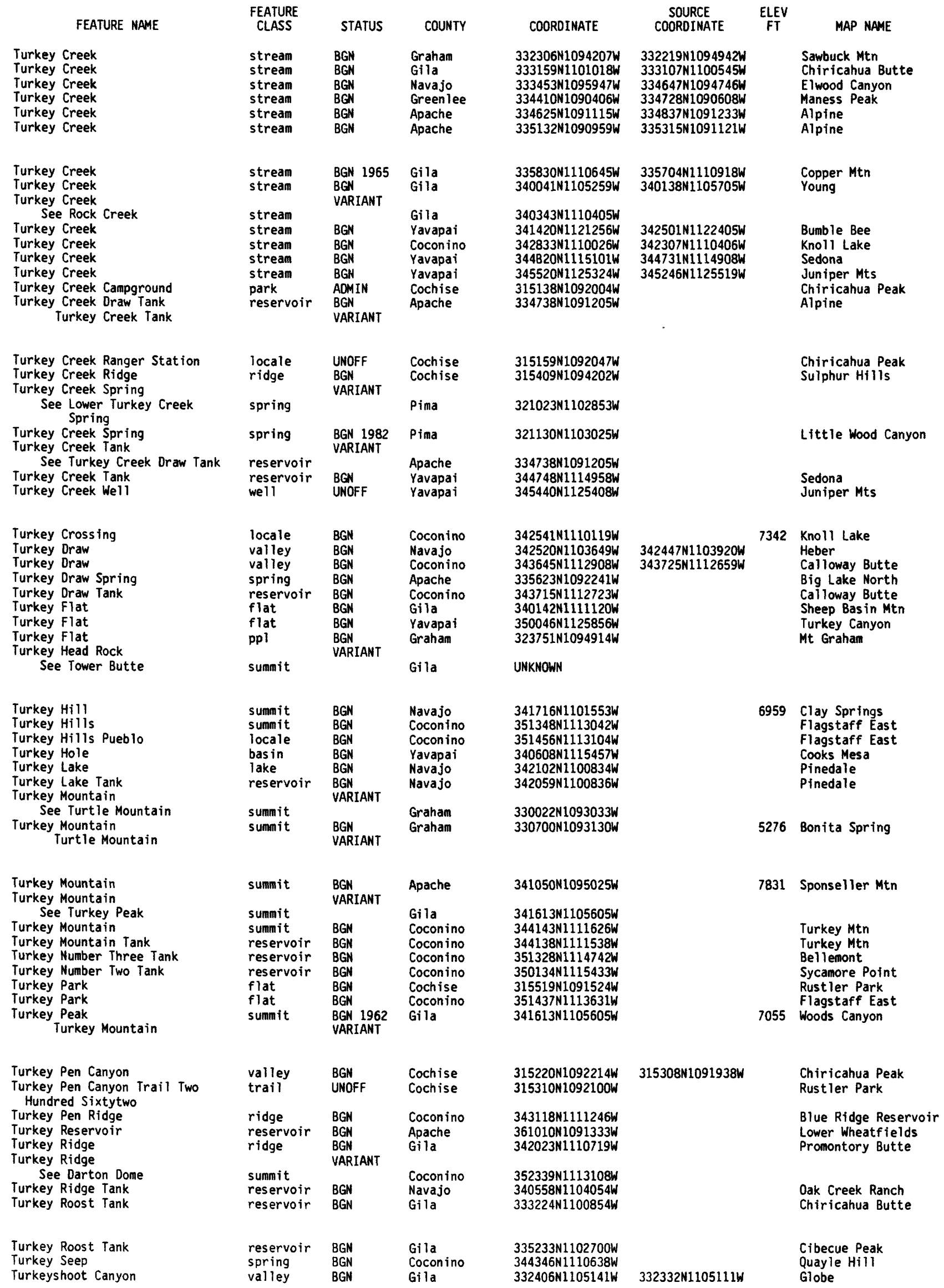


NATIONAL GAZETTEER--ARIZONA 1986 FEATURE NAME

Turkey Spring

Turkey St

Turkey Spring

Turkey Spring

Turkey Spring

Turkey Spring

Turkey Spring

\section{Turkey Spring}

Turkey Spring

Turkey Spring

Turkey Spring

Turkey Spring

Turkey Spring

Turkey Spring Corral

Turkey Springs

Turkey Tank

Turkey Tank

Turkey Tank
Turkey Tank
Turkey Tank
Turkey Tank
Turkey Tank
Turkey Tank
Turkey Tank
Turkey Tank
Turkey Tank
Turkey Tank

Turkey Tank

Turkey Tanks

Turkey Tank Spring

Turkey Track Butte

Turkey Track Flat Tank

Turkey Track Flat Tank Dam

Turkey Track Mine

Turkeytrack Ranch

Turkey Trap Tank

Turkey Tree Tank

Turkey Water Catchment

Turkey Water Tank

Turley Tank

Turnaround Tank

Turnbull, Mount Turnbull Mountain

Turnbull Mountain

See Turnbul1, Mount

Turnbull Mountains

See Santa Teresa Mountains

Turner Ranch

Turners Ranch (historical)

Turner Tank

Turner Windmil

Turney, Canal (historical) Second Canal System

Turney Gulch Campground

Turney Spring

Turning Hill

Turning Point Mine

Turn off the Wash

Turnout Spring

Turn Wash Tank

Turquoise Butte

Turquoise Canyon

Turquoise Mountain

Turquoise Mountain

Turquoise Park

Turquoise Peak

Turret Butte

See Turret Peak

Turret Peak

Turret Butte

Turt leback Mountain
FEATURE
CLASS

STATUS

COUNTY

COORDINATE

Cochise

spring

spring

spring

spring

spring

spring

spring

BGN
BGN
BGN
BGN
BGN
BGN
BGN

Grahar

Grahan

Graham

Greenlee

Gila

Gila

spring

spring

spring

spring

spring

spring

locale

spring

reservoir
reservoir

BGN
BGN
BGN
BGN
BGN
BGN
BGN
BGN
BGN
BGN

Navajo

Apache

Gila

Yavapai

Gila

Coconino

Graham

Navajo

Cochise

Gila

reservoir

reservoir

reservoir

reservoir

reservoir

reservoir

reservoir

reservoir

reservoir

\section{$B G N$}

BGN

BGN

BGN

$B G N$

BGN

$B G N$

BGN

$\begin{array}{ll}\text { Apache } & 341042 \mathrm{~N} 1094951 \mathrm{~W} \\ \text { Navajo } & 341848 \mathrm{~N} 1101225 \mathrm{~W} \\ \text { Coconino } & 342413 \mathrm{~N} 1110256 \mathrm{~W} \\ \text { Coconino } & 343054 \mathrm{~N} 1112037 \mathrm{~W} \\ \text { Coconino } & 343904 \mathrm{~N} 1110236 \mathrm{~W} \\ \text { Yavapai } & 344318 \mathrm{~N} 1121031 \mathrm{~W} \\ \text { Coconino } & 344331 \mathrm{~N} 1111808 \mathrm{~W} \\ \text { Coconino } & 350020 \mathrm{~N} 1115428 \mathrm{~W} \\ \text { Coconino } & 350421 \mathrm{N1} 115013 \mathrm{~W} \\ \text { Coconino } & 351516 \mathrm{~N} 1112431 \mathrm{~W}\end{array}$

reservoir

dan

spring

reservoir

dam

mine

locale

reservoir

reservoir

BGN

UNOFF

BGN

UNOFF

UNOFF

UNOFF

BGN

BGN

Coconino

Coconino

Gila

Navajo

Gila

Maricopa

Mohave

Coconino

Coconino

bas in

reservoir

reservoir

reservoir

sumait

UNOFF
BGN
BGN

BGN

BGN

VARIANT

VARIANT

Suma it

range

VARIANT

Navajo

$343324 N 1104613 \mathrm{~W}$

$343455 N 1103052 \mathrm{~W}$

Gila 332044N1104918W

Grahar $330426 \mathrm{N1101537W}$

Graham 330426N1101537W

Grahar

locale

UNOFF

locale

reservoir

locale

canal

park

spring

summit

mine

bend

spring

reservoir

summit

valley

summit

summit

park

summit

summit

UNOFF

BGN

BGN

VARIANT

ADMIN

BGN

BGN

UNOFF

Santa Cruz

Santa Cruz

Santa Cruz

Cochise

Maricopa

Yavapai

Maricopa

Apache

Pinal

BGN Mohave

BGN Gila

$B G N$

BGN Navajo

BGN 1908 Coconino

VARIANT

Graharl

Yavapai

summit

BGN

summ it
$355556 \mathrm{~N} 1130555 \mathrm{~W}$

$333631 \mathrm{~N} 1101534 \mathrm{~W}$

$351209 N 1101031 \mathrm{~W}$

335856 N1 $101052 \mathrm{~W}$

335856 N1101052W

$342413 \mathrm{~N} 1110254 \mathrm{~W}$

$325340 \mathrm{~N} 1101133 \mathrm{~W}$

313101 N1104107W

$313822 N 1102835 \mathrm{~W}$

$312518 \mathrm{N1111920 \textrm {W }}$

$312859 N 1092347 \mathrm{~W}$

$332829 \mathrm{N1120407 \textrm {W }}$

$341024 N 112171 \mathrm{BW}$

$332918 \mathrm{N1110752 \textrm {W }}$

$352933 \mathrm{~N} 1094316 \mathrm{~W}$

$365212 \mathrm{~N} 1131405 \mathrm{~W}$

$333740 N 1104813 \mathrm{~W}$

$363513 \mathrm{~N} 1131138 \mathrm{~W}$

$352654 \mathrm{~N} 1101718 \mathrm{~W}$

$360910 \mathrm{~N} 1121811 \mathrm{~W}$

$314624 \mathrm{N1094916 \textrm {W }}$

$352110 N 1140858 \mathrm{~W}$

$351247 N 1113821 \mathrm{~W}$

324728N1102509W

341453N1115151W

341453N1115151W

330823N1132341W
53006N1141753W

$323600 \mathrm{N1115347 \textrm {W }}$
BGN Cochise

BGN Mohave

ADMIN Coconino

SOURCE

COORDINATE

ELEV

MAP NAME

Dos Cabezas

Blue Jay Peak

Point of Pines East

Stove Canyon

Baidy Bill Point

McFadden Peak

Gentry Mtn

Red Top Mtn

Boundary Butte

Payson South

Battle Flat

Pine

Dane Canyon

Park Creek Cabins

Brookbank Point

Stanford Canyon

Chrysotile

Sponseller Mtn

Pinedale

Knoll Lake

Long Valley

Quayle Hill

Hickey Mountain

Turkey Mtn

Sycamore Point

Dutton $\mathrm{Hil}$

Sunset Crater East

Prospect Point

Sunset Crater East

Sontag Creek

Turkey Track Butte

5747 Cedar Creek

5745 Cedar Creek

Union Hills

Dolan Springs 


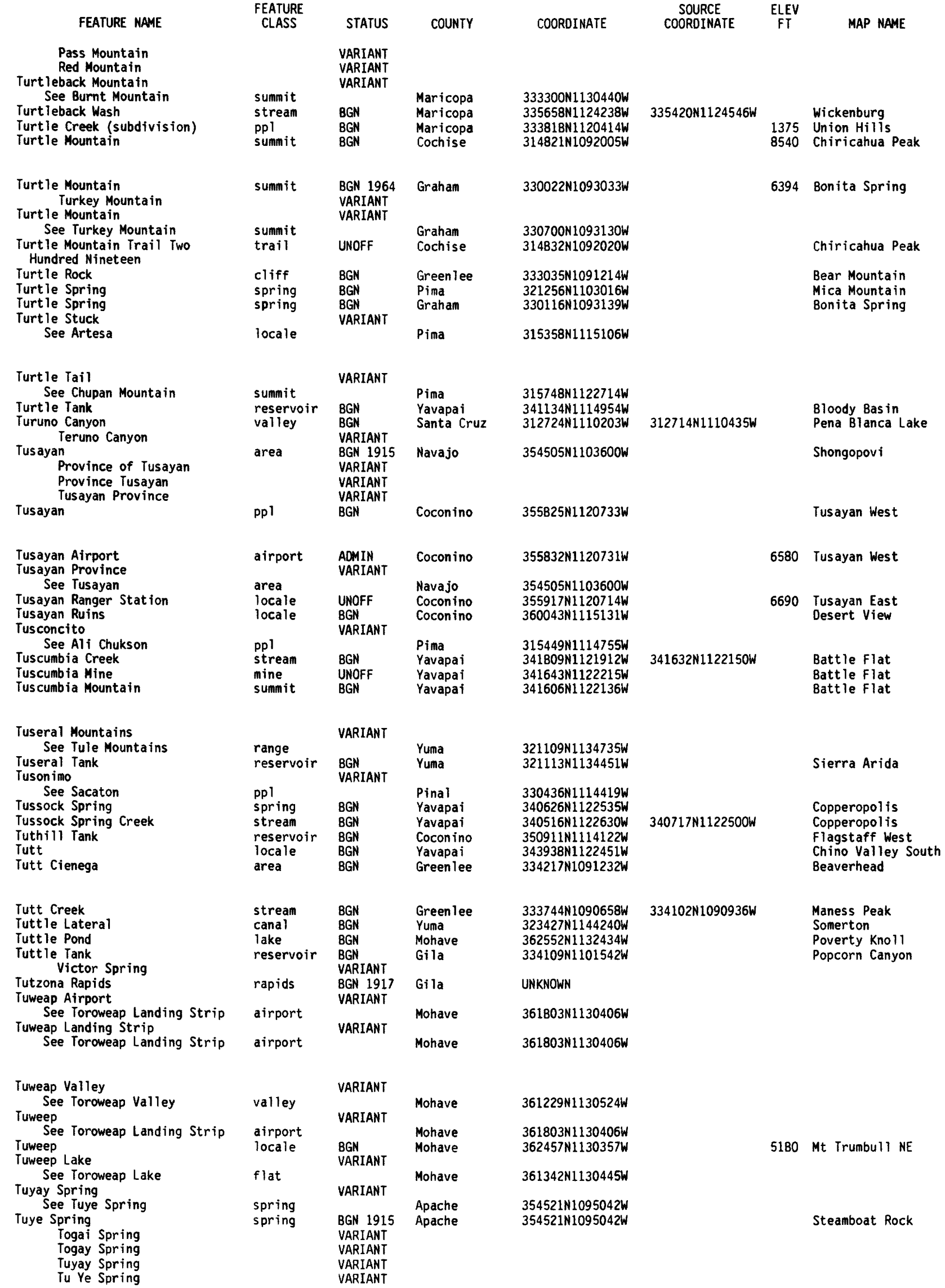


NATIONAL GAZETTEER--ARIZONA 1986

FEATURE NAME

FEATURE
CLASS

STATUS

COORDINATE

SOURCE
COORDINATE

ELEV
FT

MAP NAME

Tu Ye Spring

See Tuye Spring

Tuzigoot National Monument

Tuzigoot Trail

$\mathrm{T} V \mathrm{Hill}$

Tweedie Hollow

Tweedie Hollow Tank

Tweed Mine

Tweeds Points

Twelfth Street Junior High

School

$\begin{array}{llll}\text { spring } & \text { VARIANT } & & \\ \text { park } & \text { ADMIN } & \begin{array}{l}\text { Apache } \\ \text { Yavapai }\end{array} & 354521 \mathrm{~N} 1095042 \mathrm{~W} \\ \text { trail } & \text { UNOFF } & \text { Yavapai } & 344615 \mathrm{~N} 1120131 \mathrm{~W} \\ \text { summit } & \text { BGN } & \text { Coconino } & 351436 \mathrm{~N} 1120136 \mathrm{~W} \\ \text { valley } & \text { BGN } & \text { Mohave } & 363606 \mathrm{~N} 113611 \mathrm{~W} \\ \text { reservoir } & \text { BGN } & \text { Mohave } & 363533 \mathrm{~N} 1134128 \mathrm{~W} \\ \text { mine } & \text { UNOFF } & \text { Yuma } & 331717 \text { N1141753W } \\ \text { summit } & \text { BGN } & \text { Mohave } & 363402 \mathrm{~N} 1134206 \mathrm{~W} \\ \text { school } & \text { UNOFF } & \text { Cochise } & 312049 \mathrm{~N} 1093255 \mathrm{~W}\end{array}$

Twelve, Canal (historical) Canal Cashion

Twelvemile Slough

Twelvemile Well

Twelve Tank

Twenieth Street School

Twentieth Century Mine

Twentieth Street School

Twentyeight Mile Tank

Twentyeight Tank

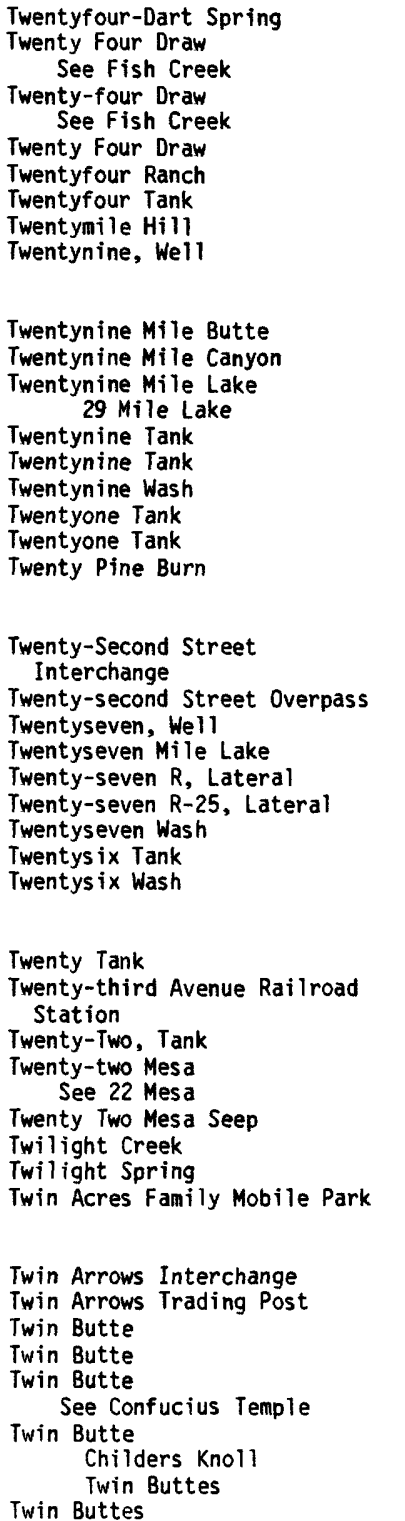

school UNOFF Cochise 312049N1093255W

\begin{tabular}{|c|c|c|c|}
\hline canal & $\begin{array}{l}\text { BGN } \\
\text { VARIANT }\end{array}$ & Maricopa & $332352 \mathrm{~N} 1121625 \mathrm{~W}$ \\
\hline $\begin{array}{l}\text { gut } \\
\text { well }\end{array}$ & $\begin{array}{l}\text { BGN } \\
\text { UNOFF }\end{array}$ & $\begin{array}{l}\text { Yuma } \\
\text { Yuma }\end{array}$ & $\begin{array}{l}340112 \mathrm{~N} 1142324 \mathrm{~W} \\
333114 \mathrm{~N} 1140650 \mathrm{~W}\end{array}$ \\
\hline $\begin{array}{l}\text { reservoir } \\
\text { school } \\
\text { mine } \\
\text { summit } \\
\text { reservoir } \\
\text { reservoir }\end{array}$ & $\begin{array}{l}\text { BGN } \\
\text { UNOFF } \\
\text { UNOFF } \\
\text { BGN } \\
\text { BGN } \\
\text { BGN }\end{array}$ & $\begin{array}{l}\text { Santa Cruz } \\
\text { Maricopa } \\
\text { Mohave } \\
\text { Navajo } \\
\text { Navajo } \\
\text { Coconino }\end{array}$ & $\begin{array}{l}312147 N 1103836 \mathrm{~W} \\
332613 \mathrm{~N} 1120219 \mathrm{~W} \\
352315 \mathrm{~N} 1141042 \mathrm{~W} \\
352702 \mathrm{~N} 1102715 \mathrm{~W} \\
344114 \mathrm{N1} 104453 \mathrm{~W} \\
353646 \mathrm{~N} 1121041 \mathrm{~W}\end{array}$ \\
\hline spring & $\begin{array}{l}\text { BGN } \\
\text { VARIANT }\end{array}$ & Navajo & $340139 N 1100057 \mathrm{~W}$ \\
\hline stream & VARIANT & Apache & $340407 N 1092650 \mathrm{~W}$ \\
\hline $\begin{array}{l}\text { stream } \\
\text { valley } \\
\text { locale } \\
\text { reservoir } \\
\text { summit } \\
\text { well }\end{array}$ & $\begin{array}{l}\text { BGN } \\
\text { UNOFF } \\
\text { BEN } \\
\text { BGN } \\
\text { UNOFF }\end{array}$ & $\begin{array}{l}\text { Apache } \\
\text { Apache } \\
\text { Apache } \\
\text { Coconino } \\
\text { Navajo } \\
\text { Pinal }\end{array}$ & $\begin{array}{l}340407 N 1092650 \mathrm{~W} \\
340406 \mathrm{~N} 1092650 \mathrm{~W} \\
341719 \mathrm{~N} 1092450 \mathrm{~W} \\
353721 \mathrm{~N} 1121414 \mathrm{~W} \\
344517 \mathrm{~N} 1104233 \mathrm{~W} \\
323138 \mathrm{~N} 1105508 \mathrm{~W}\end{array}$ \\
\hline
\end{tabular}

$\begin{array}{ll}340157 N 1093149 W & \text { Greer } \\ & \text { Lyman Lake SW } \\ \text { Howard Lake } \\ \text { Relic Point }\end{array}$

summit BGN Coconino 342905N1112647 W

valley BGN Coconino 363150N1114958W

lake BGN Coconino 342822N1112659W

7258 Pine

362945 N1114650W $\begin{aligned} & \text { North Canyon Point } \\ & \text { Pine }\end{aligned}$

$\begin{array}{llll}\text { reservoir } & \text { BGN } & \text { Coconino } & 342949 N 1112716 \mathrm{~W} \\ \text { reservoir } & \text { BGN } & \text { Coconino } & 343950 \mathrm{~N} 1110609 \mathrm{~W}\end{array}$

$\begin{array}{llll}\text { reservoir } & \text { BGN } & \text { Coconino } & 342949 \mathrm{~N} 1112716 \mathrm{~W} \\ \text { reservoir } & \text { BGN } & \text { Coconino } & 343950 \mathrm{~N} 1110609 \mathrm{~W}\end{array}$

$\begin{array}{llll}\text { reservoir } & \text { BGN } & \text { Coconino } & 343950 N 1110505 \\ \text { stream } & B G N & \text { Pinal } & 323108 N 1105550 W\end{array}$

reservoir BGN Coconino 344040N1110508W

reservoir BGN Yavapai 352203N1130740W

area BGN Coconino 354020N1130741W

crossing UNOFF Pima 321225N1105844W

Pima

$\begin{array}{lll}\text { reservoir } & B G N & \text { Mohave } \\ \text { stream } & B G N & \text { Mohave }\end{array}$

reservoir BGN Gila 341635N1110651W

building UNOFF Maricopa 332640N1120639W

VARIANT

summit

spring

stream

spring

BGN

BGN

BGN

Yavapai

Yavapai

Graham

Graham

crossing UNOFF

locale

BGN

summit

summit

BGN

VARIANT

summit

summit

BGN

VARIANT

VARIANT

summit
BGN
$321225 \mathrm{~N} 1104720 \mathrm{~W}$

$323150 \mathrm{~N} 1105339 \mathrm{~W}$

$343004 \mathrm{N1} 112753 \mathrm{~W}$

$340556 \mathrm{N1} 142126 \mathrm{~W}$

$340327 \mathrm{~N} 1142306 \mathrm{~W}$

$323000 \mathrm{~N} 1105437 \mathrm{~W}$

$342137 N 1135945 \mathrm{~W}$

$353452 N 1140458 \mathrm{~W}$

$323143 N 1105350 \mathrm{~W}$

$323314 N 1105254 W$

$353509 N 1141147 \mathrm{~W}$

$341810 \mathrm{~N} 1115405 \mathrm{~W}$

$341935 N 1115515 \mathrm{~W}$

$323905 \mathrm{~N} 1094808 \mathrm{~W}$

$323805 \mathrm{N1} 1094946 \mathrm{~W}$

$332449 \mathrm{~N} 1113657 \mathrm{~W}$

$350940 \mathrm{N1111615 \textrm {W }}$

$350940 \mathrm{~N} 1111642 \mathrm{~W}$

332411 N1115819W

$334719 \mathrm{~N} 1111345 \mathrm{~W}$

361049 N1121316W

$363310 \mathrm{~N} 1131935 \mathrm{~W}$
Cochise 315358 N1102511W

Clarkdale

Clarkdale

Flagstaff East

St George Canyon

St George Canyon

Douglas

Tolleson

Parker SW

Crystal $\mathrm{Hill}$

Duquesne

Phoenix

Chloride

6178 Shonto Butte

Potato Wash North

Howard Lake

Faught Ridge

Relic Point

Oracle Junction

Pine

Quayle Hill

Oracle Junction

Quayle Hill

Sugarloaf Peak

Robbers Roost Canyon

Tucson

Tucson

Oracle Junction

Calloway Butte

Parker SE

Parker SW

Oracle Junction

Castaneda Hills SW

Mt Tipton SE

Promontory Butte

Phoenix

Mixon Tank

Dugas

Mt Graham

Mt Graham

1560 Apache Junction

Ange 11

Angell

1334 Tempe

Greenback Creek

6055 Russell Spring reservoir BGN Coconino 353710N1121639W

1636 Tweed Mine 
NATIONAL GAZETTEER--ARIZONA 1986

FEATURE NAME

Twin Buttes

Twin Buttes

Twin Buttes

Twin Buttes

Twin Buttes

Twin Buttes

See Bubby Buttes

Twin Buttes

Twin Buttes

Bubby Buttes

Twin Buttes

Twin Buttes

Twin Buttes

$$
\text { Twin Mesas }
$$

Zuni Mesas

Twin Buttes

Twin Buttes

Twin Buttes

See Twin Butte

Twin Buttes

Twin Buttes

$$
\text { See Twin Buttes Trading }
$$

Twin Buttes

Twin Buttes Cemetery

Twin Buttes Mine

Twin Buttes Tailings Dam

Twin Buttes Tank

Twin Buttes Trading Post Twin Buttes

Twin Buttes Wash

See Pueblo Colorado Wash

Twin Butte Tank

Twin Buzzards Mine

Twin Cedar Tank

Iwin Coves

Twin Creek Canyon

Twin Dam

Twin Dams

Twin Dams

Twin Domes

Twin Falls

Twin fills

Twin Hills

Twin Joe Tank

Twin Knolls

Twin Knolls

Twin Knolls (trailer park) Desert Sage

Twin Lakes

Twin Lakes

Twin Lakes

Twin Lakes

Twin Lakes

Twin Mesas

See Twin Buttes

Twin Mills

Twin Oak Canyon

Twin Peaks

Twin Peaks

Twin Peaks

Twin Peaks

Twin Peaks

Twin Peaks

Twin Peaks

Twin Peaks

Twin Peaks

Twin Peaks

Twin Peaks

Twin Peaks Trail
FEATURE
CLASS

STATUS

COUNTY

COORDINATE

summit

summit

summit

summit

summit

summit

summit

summit

BGN Pina

BGN Pinal

BGN Maricopa

Gila

BGN Yavapai

VARIANT

Yavapa

Yavapar
Apache

Yavapai

VARIANT

summit

summit

summit

BGN Navajo

BGN Yavapai

BGN 1971 Navajo

VARIANT

VARIANT

summit

summit

BGN

BGN

VARIANT

summit

BGM

Navajo

Coconino

Mohave

Pima

VARIANT

locale

ppl

cemetery

mine

dam

reservoir

locale

VARTANT

BGN

UNOFF

UNOFF

BGN

VARIANT

Navajo

Navajo

Pima

Pima

Pima

Yavapai

Navajo

VARIANT

arroyo
reservoir
mine
reservoir
bay
valley
dam
dam
dam

BGN

UNOFF

BGN

BGN

UNOFF

UNOFF

Navajo

Gila

Maricopa

Yavapai

Mohave

Mohave

Greenlee

Navajo

Apache

summit

locale

summit

summit

reservoir

summit

summit

locale

lake

BGN Pinal

$B G N$ Apach

$B G N$

$B G N$

BGN

BGN

UNOFF

VARIANT

BGN

Maricopa

Graham

Navajo

Maricopa

Pima

BGN Navajo

lake

lake

lake

summit

summit

valley

summit

summit

summit

summit

summit

summit

summit

summit

summ it

summit

summit

trail
BGN
BGN
$B G N$

BGN

VARIANT

$\begin{array}{ll}\text { BGN } & \text { Navajo } \\ \text { BGN } & \text { Mohave } \\ \text { BGN } & \text { Navajo } \\ \text { Bima }\end{array}$

BGN

BGN
BGN
BGN
BGN
BGN
BGN
BGN
BGN
BGN
UNOFF

BGN
$B G N$
BGN
BGN
BGN
$B G N$
$B G N$
$B G N$
BGN
UNOFF

Pima

Pima

Greenle

Yuma

Yuma

Maricopa

Yavapai

Apache

Navajo

Yavapai
$315441 \mathrm{~N} 1110240 \mathrm{~W}$

$330519 N 1113339 \mathrm{~W}$

$334710 \mathrm{~N} 1121949 \mathrm{~W}$

342057N1113445W

$343626 \mathrm{~N} 1124938 \mathrm{~W}$

$343717 N 1092728 \mathrm{~W}$

$343744 N 1124601 W$

$345511 N 1095444 \mathrm{~W}$

$351742 \mathrm{N1} 130109 \mathrm{~W}$

$352434 N 1101651 W$

$361029 \mathrm{~N} 1121345 \mathrm{~W}$

$363310 \mathrm{~N} 1131935 \mathrm{~W}$

$315409 \mathrm{N1} 110336 \mathrm{~W}$

352440 N1092500W

352607 N1095412W

$315415 N 1110357 \mathrm{~W}$

$315335 \mathrm{~N} 1110206 \mathrm{~W}$

$315300 \mathrm{~N} 1110200 \mathrm{~W}$

343558 N1113529W

352440 N1092500W

$351620 \mathrm{N1} 100850 \mathrm{~W}$

$334654 \mathrm{~N} 1111335 \mathrm{~W}$

$335522 \mathrm{N1} 124751 \mathrm{~W}$

$344 B 35 N 1123535 \mathrm{~W}$

$361058 \mathrm{~N} 1140150 \mathrm{~W}$

$360318 \mathrm{~N} 1133419 \mathrm{~W}$

323120 N109032BW

354934 N1100839W

$360937 N 1091741 W$

330907 N1105906W

$365149 \mathrm{~N} 1090607 \mathrm{~W}$

$321222 \mathrm{N1} 104500 \mathrm{~W}$

$321335 \mathrm{~N} 1110305 \mathrm{~W}$

$335509 M 1125313 \mathrm{~W}$

$324635 \mathrm{~N} 1092356 \mathrm{~W}$

$341232 \mathrm{~N} 1095433 \mathrm{~W}$

332448N1113902W

$322935 N 1105444 W$

$341551 N 1103835 \mathrm{~W}$

$341645 \mathrm{~N} 1104327 \mathrm{~W}$

$343705 \mathrm{~N} 1102115 \mathrm{~W}$

355652 N1115707W

$352330 \mathrm{~N} 1095400 \mathrm{~W}$

$352012 \mathrm{~N} 1142401 \mathrm{~W}$

$341025 \mathrm{~N} 1102318 \mathrm{~W}$

$313523 N 1111437 \mathrm{~W}$

315738N1124908W

$321635 \mathrm{~N} 1113604 \mathrm{~W}$

$322108 \mathrm{~N} 1111150 \mathrm{~W}$

$325622 \mathrm{N1090340 \textrm {W }}$

333550 N1135558W

$334527 \mathrm{~N} 1133017 \mathrm{~W}$

$335435 \mathrm{~N} 1124933 \mathrm{~W}$

$341134 \mathrm{~N} 1121551 \mathrm{~W}$

$342816 \mathrm{~N} 1094149 \mathrm{~W}$

$352030 \mathrm{~N} 1100245 \mathrm{~W}$

$341201 N 1121542 \mathrm{~W}$

$\begin{array}{lll}\text { SOURCE } & \text { ELEV } \\ \text { COORDINATE } & \text { FT }\end{array}$

Twin Buttes

1841 Blackwater

2194 Baldy Mtn

6016 Cane Springs Mtn

6258 Buckhorn Mountain

Zion Reservoir

5592 Smith Mesa

5685 Carrizo Butte

5792 Yampai SE

6320 Greasewood Spring

6468 Dilkon

6997 Shiva Temple

Twin Buttes

5800 Greasewood Spring

Twin Buttes 


\section{FEATURE NAME}

Twin Point

Twin Ponds

Twin Red Hills

Twins Mine

Twin Spires

Twin Spires Canyon

Twin Spring

Twin Spring Canyon

Surprise Canyon

Twin Springs Canyon

Twin Springs

Twin Springs

Twin Springs

Twin Springs

Twin Springs

Twin Springs Canyon

See Twin Spring Canyon

Twin Tank

Twin Tank

Twin Tank

Twin Tank

Twin Tank

Twin Tank

Twin Tank Draw

Twin Tanks

Twin Tanks

Twin Tanks

Twin Tanks

Twin Tanks

Twin Tanks

Twin Tanks

Twin Tanks

Twin Tanks

Twin Tanks

Twin Tanks

Twin Tanks

Twin Tanks

Twin Tanks

Twin Tanks

Iwin Tanks

Twin Tanks

Twin Tanks

Twin Tanks

Twin Tanks

Espl in Twin Tanks

Twin Tanks Dam

Twin Tanks Wash

Twin Trail Canyon

Twin Tree Canyon

Twin Tunnel Spring

Twin Wash

Twist Hills

Two, Hill

Two, Lake

Two Bar Canyon

Two Bar Mountain

Two Bar Ranch

Two-Bar Ridge

See Two Bar Ridge

Two Bar Ridge

$$
\text { Two-Bar Ridge }
$$

Two Bit Tank

Two BS Mine

Two E Spring

Two E Wash

Mansen Canyon
Two Guns

Two Gun Town

Two Guns Interchange

Two Gun Town

\section{FEATURE}

cliff

reservoir

summit

mine

summit

valley

spring

valley

STATUS

COUNTY

COORDINATE

$\begin{array}{ll}\text { BGN } & \text { Mohave } \\ \text { BGN } & \text { Pima } \\ \text { BGN } & \text { Apache } \\ \text { UNOFF } & \text { Mohave } \\ \text { BGN } & \text { Yuma } \\ \text { BGN } & \text { Yuma } \\ \text { BGN } & \text { Mohave } \\ \text { BGN } & \text { Mohave } \\ \text { VARIANT } & \\ \text { VARIANT } & \end{array}$

$360201 N 1133717 \mathrm{~W}$

$314917 \mathrm{~N} 1111357 \mathrm{~W}$

$363410 N 1092647 \mathrm{~W}$

$351739 \mathrm{N1} 140832 \mathrm{~W}$

$332505 \mathrm{~N} 1140445 \mathrm{~W}$

$332533 \mathrm{~N} 1140533 \mathrm{~W}$

$360536 \mathrm{~N} 1133539 \mathrm{~W}$

$355847 \mathrm{N1} 133333 \mathrm{~W}$

$332429 \times 1140400 \mathrm{~W}$

$360555 \mathrm{~N} 1133612 \mathrm{~W}$

$\begin{array}{cc}\text { SOURCE } & \text { ELEV } \\ \text { COORDINATE } & \text { FT }\end{array}$

MAP NAME

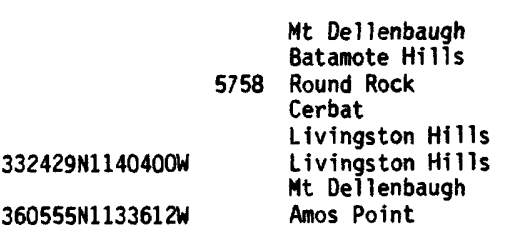

spring

spring

spring

spring

spring

valley

reservoir

reservoir

reservoir

BGN

BGN

BGN

BGN

$B G N$

VARIANT

$B G N$

$B G N$

Navajo

Navajo

Yavapai

Mohave

Coconino

$342035 \mathrm{N1} 104331 \mathrm{~W}$

$344135 \mathrm{~N} 1120618 \mathrm{~W}$

$350210 \mathrm{N1141901 \textrm {W }}$

351006 N1121327W

Mohave 355847N1133333W

Santa Cruz 312636N1110150W

Gila 332025N1104758W

Navajo

$342022 N 1104355 \mathrm{~W}$

reservoir

reservoir

reservoir

valley

reservoir

reservoir

reservoir

reservoir

reservoir

reservoir

BGN Navajo

BGM

Coconino

Coconino

Coconino

Pima

Pima

Pima

Pima

Pima

Pima

reservoir

reservoir

reservoir

reservoir

reservoir

reservoir

reservoir

reservoir

reservoir

reservoir

$\begin{array}{ll}\text { BGN } & \text { Gila } \\ \text { BGN } & \text { Maricopa }\end{array}$

$B G N$

BGN

BGN

BGN

$B G N$

BGN

BGN

reservoir

reservoir

reservoir

reservoir

dan

stream

valley

valley

spring

$B G N$

$B G N$

$B G N$

Maricopa

Yavapai

Navajo

Coconino

Coconino

Coconino

Coconino

Coconino

343758 N1103539W

$351507 \mathrm{N1122757W}$

$355524 \mathrm{~N} 1120130 \mathrm{~W}$

360451 N1124031W

$31432 \mathrm{BN} 1113016 \mathrm{~W}$

$315013 N 1110855 \mathrm{~W}$

$315440 \mathrm{~N} 1104003 \mathrm{~W}$

$32075 \mathrm{BN} 1111520 \mathrm{~W}$

$321403 \mathrm{~N} 1102651 \mathrm{~W}$

$331446 \mathrm{N1112137W}$

332139 N1103733W

$334415 \mathrm{N1125448 \textrm {W }}$

$334926 \mathrm{N1130917 \textrm {W }}$

$342658 \mathrm{~N} 1131252 \mathrm{~W}$

345005 N1104210W

$345139 \mathrm{N1110416 \textrm {W }}$

$350357 \mathrm{N1113B31 \textrm {W }}$

$351425 \mathrm{N1114552 \textrm {W }}$

$352200 \mathrm{~N} 1120221 \mathrm{~W}$

353B50N1121B3OW

Coconino

Coconino

Mohave

Mohave

VARIANT

UNOFF Graham

BGN Yuma

BGN Apache

BGN Navajo

Gila

stream

BGN Navajo

BGN Mohave

summit BGN 1983 Coconino

VARIANT

lake

valley

summit

BGN Coconino

BGN Maricopa

BGN Maricopa

UNOFF

Gila

ridge

Maricopa

$355852 \mathrm{~N} 1130739 \mathrm{~W}$

$360441 N 1123918 \mathrm{~W}$

$363138 \mathrm{N1125234 \textrm {W }}$

363B3ON1132616W

$332100 \mathrm{~N} 1095630 \mathrm{~W}$

324409 N1141746W

$361114 N 1092305 \mathrm{~W}$

$341330 \mathrm{N1102237 \textrm {W }}$

$331851 \mathrm{N1105626 \textrm {W }}$

345749N1095902W

$364455 \mathrm{~N} 1132738 \mathrm{~W}$

$350523 \mathrm{~N} 1120400 \mathrm{~W}$

$341825 \mathrm{~N} 1105120 \mathrm{~W}$

$333413 N 1110408 \mathrm{~W}$

$333214 \mathrm{N1110647 \textrm {W }}$

333639 N1110523W

333337N1110742W

ridge BGN 1965 Maricopa

333337 N1110742W

reservoir

mine

spring

VARIANT

BGN

BGN 1975 Graham

BGN

VARIANT

locale

BGN

VARIANT

crossing

UNOFF

Coconino

VARIANT

355753N1124400W

$324601 \mathrm{N1141523 \textrm {W }}$

361057 N1091916W

$341408 \mathrm{N1102333 \textrm {W }}$

345931 N1095857W

Carrizo Butte

6910 White Horse Lake

$333318 N 1110743 W$

0 W Point

Two Bar Mtn

5212 Two Bar Mtn

Two Bar Mtn

$335927 \mathrm{~N} 1101442 \mathrm{~W}$

$355453 \mathrm{~N} 1143657 \mathrm{~W}$

$324244 \mathrm{N1100706 \textrm {W }}$

324038N1101134W

$324430 \mathrm{~N} 1100425 \mathrm{~W}$ 
NATIONAL GAZETTEER--ARIZONA 1986

\begin{tabular}{|c|c|c|c|c|c|c|c|}
\hline FEATURE NAME & $\begin{array}{l}\text { FEATURE } \\
\text { CLASS }\end{array}$ & STATUS & COUNTY & COORDINATE & $\begin{array}{l}\text { SOURCE } \\
\text { COORDINATE }\end{array}$ & $\begin{array}{l}\text { ELEV } \\
\text { FT }\end{array}$ & MAP NAME \\
\hline $\begin{array}{l}\text { See Two Guns } \\
\text { Two Hole Ruin } \\
\text { Two Holes Tank } \\
\text { Two Hundred and Fifteenmile } \\
\text { Creek }\end{array}$ & $\begin{array}{l}\text { locale } \\
\text { locale } \\
\text { reservoir } \\
\text { stream }\end{array}$ & $\begin{array}{l}B G N \\
B G N \\
B G N\end{array}$ & $\begin{array}{l}\text { Coconino } \\
\text { Apache } \\
\text { Coconino } \\
\text { Coconino }\end{array}$ & $\begin{array}{l}350704 \mathrm{~N} 1110534 \mathrm{~W} \\
360716 \mathrm{N1091510 \textrm {W }} \\
345345 \mathrm{~N} 1113130 \mathrm{~W} \\
355341 \mathrm{~N} 1131844 \mathrm{~W}\end{array}$ & $355518 N 1131807 \mathrm{~W}$ & 6500 & $\begin{array}{l}\text { Spider Rock } \\
\text { Mormon Mountain } \\
\text { Granite Park }\end{array}$ \\
\hline $\begin{array}{l}\text { Two Hundred and Fivemile Creek } \\
\text { Two Hundred and Fivemile Rapids } \\
\text { Two Hundred and Fortymile } \\
\text { Rapids }\end{array}$ & $\begin{array}{l}\text { stream } \\
\text { falls } \\
\text { rapids }\end{array}$ & $\begin{array}{l}B G N \\
B G N \\
B G N\end{array}$ & $\begin{array}{l}\text { Coconino } \\
\text { Coconino } \\
\text { Mohave }\end{array}$ & $\begin{array}{l}360028 \mathrm{~N} 1132025 \mathrm{~W} \\
360020 \mathrm{N1132029W} \\
354954 \mathrm{~N} 1133452 \mathrm{~W}\end{array}$ & $360331 N 1131849 \mathrm{~W}$ & & $\begin{array}{l}\text { Whitmore Point SE } \\
\text { Whitmore Point SE } \\
\text { Separation Canyon }\end{array}$ \\
\hline $\begin{array}{l}\text { Two Hundred and Fortyone Mile } \\
\text { Rapids }\end{array}$ & rapids & BGN & Mohave & $355027 \mathrm{~N} 1133535 \mathrm{~W}$ & & & Separation Canyon \\
\hline $\begin{array}{l}\text { Two Hundred and Fourteenmile } \\
\text { Creek }\end{array}$ & stream & BGN & Mohave & $355409 \mathrm{~N} 1131926 \mathrm{~W}$ & $355436 \mathrm{~N} 1132227 \mathrm{~W}$ & & Granite Park \\
\hline $\begin{array}{l}\text { Two Hundred and Ninemile Canyon } \\
\text { Indian Canyon }\end{array}$ & valley & $\begin{array}{l}\text { BGN } \\
\text { VARIANT }\end{array}$ & Mohave & $355810 \mathrm{~N} 1131906 \mathrm{~W}$ & 355437 N1132631W & & Granite Park \\
\hline $\begin{array}{l}\text { Two Hundred and Seventeenmile } \\
\text { Canyon } \\
\text { Two Hundred and Seventeen } \\
\text { Mile Canyon Rapids }\end{array}$ & valley & BGN & Coconino & $355137 \mathrm{~N} 1131837 \mathrm{~W}$ & 355047 N1131417W & & Diamond Peak \\
\hline $\begin{array}{l}\text { See Two Hundred and } \\
\text { Seventeen Mile Rapids }\end{array}$ & rapids & & Mohave & 355141N1131839W & & & \\
\hline $\begin{array}{l}\text { Two Hundred And Seventeenmile } \\
\text { Canyon Rapids }\end{array}$ & & VARIANT & & & & & \\
\hline $\begin{array}{l}\text { See Roadrunner Rapids } \\
\text { Two Hundred and Seventeen } \\
\text { Mile Rapids }\end{array}$ & $\begin{array}{l}\text { rapids } \\
\text { rapids }\end{array}$ & BGN & $\begin{array}{l}\text { Mohave } \\
\text { Mohave }\end{array}$ & $\begin{array}{l}355141 \mathrm{~N} 1131840 \mathrm{~W} \\
355141 \mathrm{N1} 131839 \mathrm{~W}\end{array}$ & & & Diamond Peak \\
\hline $\begin{array}{l}\text { Two Hundred and } \\
\text { Seventeen Mile Canyon } \\
\text { Rapids }\end{array}$ & & VARIANT & & & & & \\
\hline $\begin{array}{l}\text { Two Hundred And Seventeenmile } \\
\text { Rapids } \\
\text { See Roadrunner Rapids }\end{array}$ & rapids & VARIANT & Mohave & $355141 \mathrm{~N} 1131840 \mathrm{~W}$ & & & \\
\hline $\begin{array}{l}\text { Two Hundred and Thirtyfour } \\
\text { Mile Rapids }\end{array}$ & rapids & BGN & Mohave & 354557 N1133009W & & & Separation Canyon \\
\hline $\begin{array}{l}\text { Two Hundred and Thirtyone } \\
\text { Mile Rapids }\end{array}$ & rapids & BGN & Mohave & $354533 N 1132713 W$ & & & Travertine Rapids \\
\hline $\begin{array}{l}\text { Two Hundred and Thirtyseven } \\
\text { Mile Rapids }\end{array}$ & rapids & BGN & Mohave & $354747 \mathrm{~N} 1133242 \mathrm{~W}$ & & & Separation Canyon \\
\hline $\begin{array}{l}\text { Two Hundred and Thirtytwo } \\
\text { Mile Rapids }\end{array}$ & rapids & BGN & Mohave & $354554 N 1132807 W$ & & & Travertine Rapids \\
\hline $\begin{array}{l}\text { Two Hundred and } \\
\text { Twentyeightmile Canyon }\end{array}$ & valley & BGN & Mohave & $354508 N 1132421 \mathrm{~W}$ & 354307N1132413W & & Peach Springs Canyon \\
\hline $\begin{array}{l}\text { Two Hundred and Twentyfour } \\
\text { Mile Canyon }\end{array}$ & valley & BGN & Mohave & 354705 N113203BW & $354558 \mathrm{~N} 1131746 \mathrm{~W}$ & & Diamond Peak \\
\hline $\begin{array}{l}\text { Two Hundred and Twentyfour } \\
\text { Mile Rapids }\end{array}$ & rapids & BGN & Mohave & $354706 \mathrm{~N} 1132042 \mathrm{~W}$ & & & Diamond Peak \\
\hline $\begin{array}{l}\text { Two Hundred and Twentymile } \\
\text { Canyon }\end{array}$ & valley & BGN & Mohave & 354953N1131937W & 354931 N1132509W & & Diamond Peak \\
\hline $\begin{array}{l}\text { Two Hundred and Twentytwo } \\
\text { Mile Creek }\end{array}$ & stream & BGN & Coconino & 354819N1131954W & $354701 N 1131827 W$ & & Diamond Peak \\
\hline $\begin{array}{l}\text { Two Iron Tank } \\
\text { See Two Lion Tank }\end{array}$ & reservoir & VARIANT & Yavapai & $345400 \mathrm{~N} 1125440 \mathrm{~W}$ & & & \\
\hline $\begin{array}{l}\text { Two Jim Tank } \\
\text { Two Lion Tank } \\
\text { Two Iron Tank }\end{array}$ & $\begin{array}{l}\text { reservoir } \\
\text { reservoir }\end{array}$ & $\begin{array}{l}\text { BGN } \\
\text { BGN } \\
\text { VARIANT }\end{array}$ & $\begin{array}{l}\text { Coconino } \\
\text { Yavapai }\end{array}$ & $\begin{array}{l}344309 N 1111913 \mathrm{~W} \\
345400 \mathrm{~N} 1125440 \mathrm{~W}\end{array}$ & & & $\begin{array}{l}\text { Turkey Mtn } \\
\text { Juniper Mts }\end{array}$ \\
\hline $\begin{array}{l}\text { Two Mesas } \\
\text { Two Mile } \\
\text { Twomile Corrals } \\
\text { Two Mile Reservoir } \\
\text { Twomile Seep } \\
\text { Two Mile Seep }\end{array}$ & $\begin{array}{l}\text { summit } \\
\text { locale } \\
\text { locale } \\
\text { reservoir } \\
\text { spring }\end{array}$ & $\begin{array}{l}\text { BGN } \\
\text { BGN } \\
\text { BGN } \\
\text { BGN } \\
\text { BGN } \\
\text { VARIANT }\end{array}$ & $\begin{array}{l}\text { Coconino } \\
\text { Coconino } \\
\text { Mohave } \\
\text { Coconino } \\
\text { Mohave }\end{array}$ & $\begin{array}{l}362817 N 1104716 \mathrm{~W} \\
364911 \mathrm{N1120341W} \\
365258 \mathrm{~N} 1124203 \mathrm{~W} \\
364913 \mathrm{~N} 1120332 \mathrm{~W} \\
365047 \mathrm{~N} 1123941 \mathrm{~W}\end{array}$ & & 6074 & $\begin{array}{l}\text { Cow Springs } \\
\text { House Rock Spring SE } \\
\text { Kaibab } \\
\text { House Rock Spring } \\
\text { Pipe Spring }\end{array}$ \\
\hline See Twomile Wash & stream & & Mohave & $365052 \mathrm{~N} 1124023 \mathrm{~W}$ & & & \\
\hline $\begin{array}{l}\text { Twomile Spring } \\
\text { Twomile Spring Tank } \\
\text { Twoni le Wash } \\
\text { Two Mile Seep }\end{array}$ & $\begin{array}{l}\text { spring } \\
\text { reservoir } \\
\text { stream }\end{array}$ & $\begin{array}{l}\text { BGN } \\
\text { BGN } \\
\text { BGN } \\
\text { VARIANT }\end{array}$ & $\begin{array}{l}\text { Apache } \\
\text { Apache } \\
\text { Mohave }\end{array}$ & $\begin{array}{l}340627 \mathrm{~N} 1095045 \mathrm{~W} \\
340627 \mathrm{N1095046 \textrm {W }} \\
365052 \mathrm{~N} 1124023 \mathrm{~W}\end{array}$ & 365404 N1124339W & & $\begin{array}{l}\text { McNary } \\
\text { McNary } \\
\text { Pipe Spring }\end{array}$ \\
\hline $\begin{array}{l}\text { Twomile Well } \\
\text { Two Mill Tank } \\
\text { Two Peaks } \\
\text { Two Queens Mine } \\
\text { Two Red Mesas } \\
\text { Two Red Peaks Valley }\end{array}$ & $\begin{array}{l}\text { well } \\
\text { reservoir } \\
\text { summit } \\
\text { mine } \\
\text { summit } \\
\text { valley }\end{array}$ & $\begin{array}{l}\text { UNOFF } \\
\text { BGN } \\
\text { BGN } \\
\text { UNOFF } \\
\text { BGN } \\
\text { BGN }\end{array}$ & $\begin{array}{l}\text { Mohave } \\
\text { Navajo } \\
\text { Maricopa } \\
\text { Pinal } \\
\text { Coconino } \\
\text { Navajo }\end{array}$ & $\begin{array}{l}345615 N 1134145 \mathrm{~W} \\
351329 \mathrm{~N} 1095250 \mathrm{~W} \\
332119 \mathrm{N1} 120130 \mathrm{~W} \\
330128 \mathrm{~N} 1104159 \mathrm{~W} \\
363936 \mathrm{~N} 1105523 \mathrm{~W} \\
361339 \mathrm{~N} 1101349 \mathrm{~W}\end{array}$ & 361756N1101306W & $\begin{array}{l}2205 \\
6325\end{array}$ & $\begin{array}{l}\text { Pilgrim Wash } \\
\text { Pilot Rock } \\
\text { Lone Butte } \\
\text { Christmas } \\
\text { Two Red Mesas } \\
\text { Pinon NW }\end{array}$ \\
\hline
\end{tabular}




\begin{tabular}{|c|c|c|c|c|c|c|c|}
\hline FEATURE NAME & $\begin{array}{l}\text { FEATURE } \\
\text { CLASS }\end{array}$ & STATUS & COUNTY & COORDINATE & $\begin{array}{l}\text { SOURCE } \\
\text { COORDINATE }\end{array}$ & $\begin{array}{l}\text { ELEV } \\
\text { FT }\end{array}$ & MAP NAME \\
\hline $\begin{array}{l}\text { Two Red Rocks } \\
\text { Two Rock Mountain } \\
\text { Two Rocks } \\
\text { Two Section Tank } \\
\text { Two Section Tank } \\
\text { Two Section Tank Number Two } \\
\text { Two Springs Ridge } \\
\text { Two Story Trading Post } \\
\text { Two Tanks } \\
\text { Two-thirteen Well }\end{array}$ & $\begin{array}{l}\text { pillar } \\
\text { summit } \\
\text { island } \\
\text { reservoir } \\
\text { reservoir } \\
\text { reservoir } \\
\text { ridge } \\
\text { locale } \\
\text { reservoir } \\
\text { well }\end{array}$ & $\begin{array}{l}\text { BGN } \\
\text { BGN } \\
B G N \\
B G N \\
\text { BGN } \\
\text { BGN } \\
\text { BGN } \\
\text { BGN } \\
\text { BGN } \\
\text { UNOFF }\end{array}$ & $\begin{array}{l}\text { Apache } \\
\text { Yavapai } \\
\text { Mohave } \\
\text { Coconino } \\
\text { Navajo } \\
\text { Navajo } \\
\text { Coconino } \\
\text { Apache } \\
\text { Coconino } \\
\text { Mohave }\end{array}$ & $\begin{array}{l}363646 \mathrm{N1} 1092155 \mathrm{~W} \\
343553 \mathrm{~N} 1123354 \mathrm{~W} \\
354330 \mathrm{N1} 144200 \mathrm{~W} \\
345651 \mathrm{N1111327W} \\
350439 \mathrm{N1} 100057 \mathrm{~W} \\
350509 \mathrm{~N} 1095910 \mathrm{~W} \\
362141 \mathrm{N1} 121754 \mathrm{~W} \\
353934 \mathrm{N1} 1090652 \mathrm{~W} \\
352123 \mathrm{~N} 1114730 \mathrm{~W} \\
342742 \mathrm{~N} 1135953 \mathrm{~W}\end{array}$ & & 6904 & $\begin{array}{l}\text { Mexican Cry Mesa } \\
\text { Iron Springs } \\
\text { Willow Beach } \\
\text { Chavez Mtn NW } \\
\text { Hennessy Buttes } \\
\text { Ltl Lithodendron Tk } \\
\text { King Arthur Castle } \\
\text { Window Rock } \\
\text { Wing Mountain } \\
\text { Castaneda Hills }\end{array}$ \\
\hline $\begin{array}{l}\text { Two Troughs Canyon } \\
\text { Little Cottonwood Canyon } \\
\text { Two Troughs Spring } \\
\text { Two Troughs Spring Tank } \\
\text { Two Two Mesa } \\
\text { Two U D Rest Area } \\
\text { Two VF Tank } \\
\text { Twoweeks Spring Canyon } \\
\text { Two White Rocks Wash } \\
\text { Tyende Creek } \\
\text { Bambo Wash } \\
\text { Blackhorse Wash }\end{array}$ & $\begin{array}{l}\text { valley } \\
\text { spring } \\
\text { reservoir } \\
\text { summit } \\
\text { park } \\
\text { reservoir } \\
\text { valley } \\
\text { valley } \\
\text { stream }\end{array}$ & $\begin{array}{l}\text { BGN } 1975 \\
\text { VARIANT } \\
\text { BGN } \\
\text { BGN } \\
\text { BGN } \\
\text { ADMIN } \\
\text { BGN } \\
\text { BGN } \\
\text { BGN } \\
\text { BGN 1970 } \\
\text { VARIANT } \\
\text { VARIANT }\end{array}$ & $\begin{array}{l}\text { Graham } \\
\text { Graham } \\
\text { Graham } \\
\text { Yavapai } \\
\text { Coconino } \\
\text { Gila } \\
\text { Cochise } \\
\text { Navajo } \\
\text { Apache }\end{array}$ & $\begin{array}{l}325040 \mathrm{~N} 1100309 \mathrm{~W} \\
324755 \mathrm{~N} 1100439 \mathrm{~W} \\
324719 \mathrm{~N} 1100457 \mathrm{~W} \\
341904 \mathrm{~N} 1115504 \mathrm{~W} \\
351206 \mathrm{N1112754W} \\
33212 \mathrm{BN} 1104934 \mathrm{~W} \\
314320 \mathrm{~N} 1090825 \mathrm{~W} \\
362634 \mathrm{~N} 1101327 \mathrm{~W} \\
364955 \mathrm{~N} 1094300 \mathrm{~W}\end{array}$ & $\begin{array}{l}314433 \mathrm{~N} 1090840 \mathrm{~W} \\
362500 \mathrm{~N} 1101223 \mathrm{~W} \\
363455 \mathrm{~N} 1100312 \mathrm{~W}\end{array}$ & 4798 & $\begin{array}{l}\text { Tripp Canyon } \\
\text { Tripp Canyon } \\
\text { Tripp Canyon } \\
\text { Dugas } \\
\text { Winona } \\
\text { Pinal Peak } \\
\text { Apache } \\
\text { Cliff Rose Hil1 } \\
\text { Mexican Water SW }\end{array}$ \\
\hline $\begin{array}{l}\text { Tyende Creek } \\
\text { See Laguna Creek } \\
\text { Tyende Mesa } \\
\text { Kayenta } \\
\text { Ke-en-ta } \\
\text { T-en-ta } \\
\text { Tyende Wash } \\
\text { See Laguna Creek } \\
\text { Tyndall Dome } \\
\text { Temple of Om }\end{array}$ & $\begin{array}{l}\text { stream } \\
\text { summit }\end{array}$ & $\begin{array}{l}\text { VARIANT } \\
\text { BGN } 1915 \\
\text { VARIANT } \\
\text { VARIANT } \\
\text { VARIANT } \\
\text { VARIANT } \\
\text { BGN } 1908 \\
\text { VARIANT }\end{array}$ & $\begin{array}{l}\text { Apache } \\
\text { Coconino }\end{array}$ & $\begin{array}{l}365340 \mathrm{N1094435 \textrm {W }} \\
361337 \mathrm{N1122122 \textrm {W }}\end{array}$ & & & Havasupai Point \\
\hline $\begin{array}{l}\text { Tyro Mine } \\
\text { Tyro Wash } \\
\text { Tyson } \\
\text { Tyson } \\
\text { See Quartzsite } \\
\text { Tyson Wash } \\
\text { Big Arroyo } \\
\text { Tzelena Canyon } \\
\text { T } 4 \text { Ranch } \\
\text { T4 Springs }\end{array}$ & $\begin{array}{l}\text { mine } \\
\text { stream } \\
\text { locale } \\
\text { ppl } \\
\text { valley } \\
\text { valley } \\
\text { locale } \\
\text { spring }\end{array}$ & $\begin{array}{l}\text { UNOFF } \\
\text { BGN } \\
\text { BGN } \\
\text { VARIANT } \\
\text { BGN } \\
\text { VARIANT } \\
\text { BGN } \\
\text { UNOFF } \\
\text { BGN } 1972\end{array}$ & $\begin{array}{l}\text { Mohave } \\
\text { Mohave } \\
\text { Yuma } \\
\text { Yuma } \\
\text { Yuma } \\
\text { Apache } \\
\text { Santa Cruz } \\
\text { Santa Cruz }\end{array}$ & $\begin{array}{l}351338 \mathrm{~N} 1142701 \mathrm{~W} \\
351703 \mathrm{~N} 1143501 \mathrm{~W} \\
324748 \mathrm{~N} 1135251 \mathrm{~W} \\
\\
333950 \mathrm{~N} 1141345 \mathrm{~W} \\
334731 \mathrm{~N} 1142616 \mathrm{~W} \\
\\
363507 \mathrm{~N} 1091942 \mathrm{~W} \\
312710 \mathrm{~N} 1105005 \mathrm{~W} \\
313807 \mathrm{~N} 1102827 \mathrm{~W}\end{array}$ & $\begin{array}{l}331517 N 1141218 \mathrm{~W} \\
363348 \mathrm{~N} 1091735 \mathrm{~W}\end{array}$ & 4000 & $\begin{array}{l}\text { Moon Mtn } \\
\text { Mexican Cry Mesa } \\
\text { Cumero Canyon } \\
\text { Mustang Mountains }\end{array}$ \\
\hline
\end{tabular}

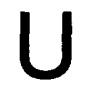

U A Tank

Ubank Place

U Bar Tank

U B Rangeline Cabin

U-Cross Ranch

Udall Draw

Udall Draw Springs

Uda11 Park

Udall Park Tank

U-Diamond Ranch

\section{Uhs Kug}

Uhs Kug
See Blackwater

See Gila Bend

Uinkaret Mountains

High Mountains

North Side Mountains

Pine Mountains

Uinkaret Plateau

Ukwal la Point

\begin{tabular}{|c|c|c|c|}
\hline $\begin{array}{l}\text { reservoir } \\
\text { locale } \\
\text { reservoir } \\
\text { locale } \\
\text { locale } \\
\text { valley } \\
\text { spring } \\
\text { flat } \\
\text { reservoir } \\
\text { locale }\end{array}$ & $\begin{array}{l}\text { BGN } \\
\text { BGN } \\
\text { BGN } \\
\text { BGN } \\
\text { UNOFF } \\
\text { BGN } \\
\text { BGN } \\
\text { BGN } \\
\text { BGN } \\
\text { UNOFF }\end{array}$ & $\begin{array}{l}\text { Gila } \\
\text { Navajo } \\
\text { Gila } \\
\text { Graham } \\
\text { Yavapai } \\
\text { Apache } \\
\text { Apache } \\
\text { Apache } \\
\text { Apache } \\
\text { Pima }\end{array}$ & $\begin{array}{l}342213 N 1113140 \mathrm{~W} \\
345439 \mathrm{~N} 1095703 \mathrm{~W} \\
341909 \mathrm{~N} 1111800 \mathrm{~W} \\
330028 \mathrm{~N} 1102505 \mathrm{~W} \\
342605 \mathrm{~N} 1121024 \mathrm{~W} \\
340814 \mathrm{~N} 1093550 \mathrm{~W} \\
340608 \mathrm{~N} 1093555 \mathrm{~W} \\
340650 \mathrm{~N} 1093555 \mathrm{~W} \\
340657 \mathrm{~N} 1093600 \mathrm{~W} \\
320055 \mathrm{~N} 1112742 \mathrm{~W}\end{array}$ \\
\hline locale & $\begin{array}{l}\text { BGN } \\
\text { VARIANT }\end{array}$ & Pima & $315758 \mathrm{~N} 1113307 \mathrm{~W}$ \\
\hline ppl & VARIANT & Pinal & $330152 \mathrm{~N} 1113455 \mathrm{~W}$ \\
\hline $\begin{array}{l}\mathrm{ppl} \\
\text { range }\end{array}$ & $\begin{array}{l}\text { BGN } 1969 \\
\text { VARIANT } \\
\text { VARIANT } \\
\text { VARIANT }\end{array}$ & $\begin{array}{l}\text { Maricopa } \\
\text { Mohave }\end{array}$ & $\begin{array}{l}325652 \mathrm{~N} 112425 \mathrm{BW} \\
361911 \mathrm{~N} 1131045 \mathrm{~W}\end{array}$ \\
\hline area & BGN & Mohave & $362830 \mathrm{~N} 1130629 \mathrm{~W}$ \\
\hline
\end{tabular}

cliff BGN 1925 Coconino 361633N1124129W
Cane Springs Mtn

Carrizo Butte

Payson North

Rawhide Mtn

$340607 N 1093427 \mathrm{~W}$

Mayer

Whiting Knoll

Greens Peak

Greens Peak

Greens Peak

San Pedro

Kitt Peak

Mount Logan

Mt Trumbull NE

Havasu Falls 
NATIONAL GAZETTEER--ARIZONA 1986

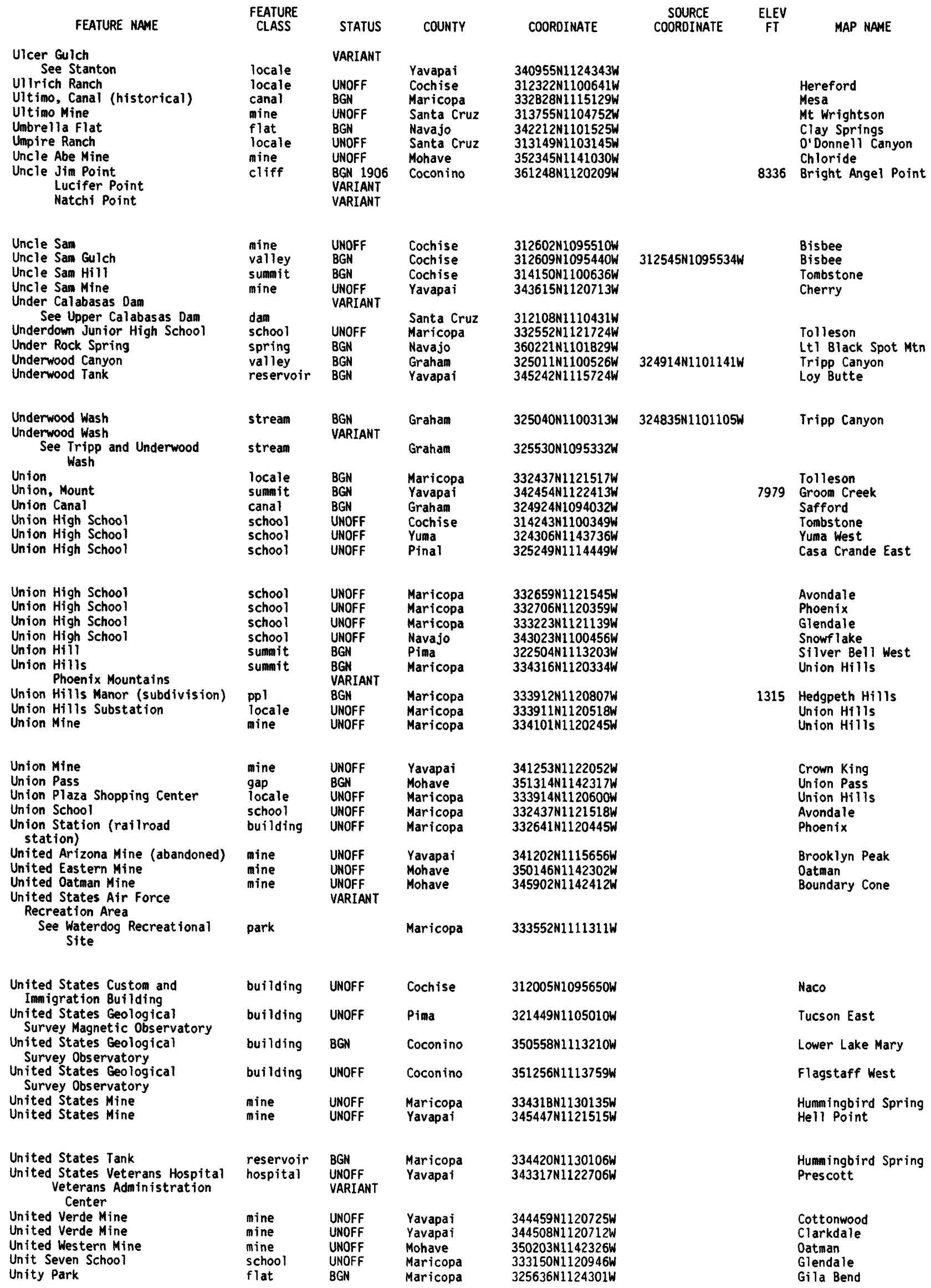




\section{FEATURE NAME}

University Activity Center (basketball arena)

\section{FEATURE \\ CLASS}

building

COUNTY

Maricopa

COORDINATE

$332527 N 1115548 \mathrm{~W}$

$332111 \mathrm{~N} 1094436 \mathrm{~W}$

University of Arizon

University of Arizona

Hospital and Medical Center University Park

University Post Office

University Square Shopping Center

Unkar Creek

Unkar Creek Rapids

Unknown Tank

Uparsoytac

See Gila Bend

Upasoitac

See Gila Bend

Upeart Park

Upper Alamo Tank

pper Alder Creek Spring

Upper Antelope

Upper Ash Creek Tank

Upper Ash Spring

Upper Bald Mountain Tank

Upper Bas in

Upper Bas in Spring

Upper Bas in Tank

Upper Bear Spring

Upper Bear Spring

Upper Beecher Well

Upper Bell Tank

Upper Belmont Wel1

Upper Big Dey Tank

Upper Bitter Creek Well

Upper Black Top Mesa Pass

Upper Blue Campground

Upper Blue Spring

Upper Bouse Wash Bouse Wash

Upper Bouse Wash

See Bouse Wash

Upper Brady Tank

Upper Bruno Tank

Upper Bryant Canyon Tank

Upper Buck Spring

Upper Bull Canyon Tank

Upper Bull Pond

Upper Buss Tank

Upper Cabin Tank

Upper Calabasas Dam Under Calabasas Dam

Upper Calf Creek Tank

Upper Campaign Spring

Upper Canyon Creek Tank

Upper Carrizo Well

Upper Centennial Control Dam

Upper Charcoal Tank

Upper Chavez Tank

Upper Cherry Spring

Upper Cherum Spring

Upper Cienega Spring

Upper Clayhole Reservoirs

Upper Clayhole Valley Antelope Valley

Upper Clover Tank

Upper Con Canyon Spring $332133 \mathrm{~N} 1094415 \mathrm{~W}$ $321537 \mathrm{~N} 1110006 \mathrm{~W}$ $321416 \mathrm{~N} 1105724 \mathrm{~W}$ $315817 \mathrm{N1110605W}$ $332501 \mathrm{~N} 1115522 \mathrm{~W}$ $321352 \mathrm{N1} 105707 \mathrm{~W}$ $321427 \mathrm{~N} 1105744 \mathrm{~W}$

$\begin{array}{llll}\text { school } & \text { UNOFF } & \text { Graham } & 332111 N 1094436 \mathrm{~W} \\ \text { reservoir } & \text { BGN } & \text { Graham } & 332133 N 1094415 \mathrm{~W} \\ \text { crossing } & \text { UNOFF } & \text { Pima } & 321537 N 1110006 \mathrm{~W} \\ \text { school } & \text { UNOFF } & \text { Pima } & 321416 \mathrm{N1105724W} \\ \text { mine } & \text { UNOFF } & \text { Pima } & 315817 N 1110605 \mathrm{~W} \\ \text { locale } & \text { UNOFF } & \text { Maricopa } & 332501 N 1115522 \mathrm{~W} \\ \text { school } & \text { UNOFF } & \text { Pima } & 321352 N 1105707 \mathrm{~W} \\ \text { hospital } & \text { UNOFF } & \text { Pima } & 321427 N 1105744 \mathrm{~W}\end{array}$

park ADMIN Maricopa 332709N1120512W

building UNOFF Pima $321355 \mathrm{N1105725 \textrm {W }}$ $321356 \mathrm{~N} 1105730 \mathrm{~W}$

$360449 \mathrm{~N} 1115224 \mathrm{~W}$ $360442 \mathrm{~N} 1115214 \mathrm{~W}$

$345440 \mathrm{~N} 1112344 \mathrm{~W}$

ppl

Coconino

Maricopa

Maricopa

$325652 \mathrm{~N} 1124258 \mathrm{~W}$

reservoir

spring

sumait

reservoir

spring

reservoir

bas in

spring

reservoir

ADMIN

Pinal

Santa Cruz

Maricopa

Mohave

Pima

1975 Graham

Mohave

Coconino

Yavapai

Coconino

spring

spring

reservoir

well

reservoir

well

gap

park

spring

stream

$$
\text { VARIAN }
$$

BGN 1964

strean

reservoir $B G$

reservoir $B G$

reservoir

spring

reservoir

lake

reservoir

reservoir

dam

reservoir

spring

reservoir

well

dan

reservoir

BGN Cochise

BGN Greenlee

Mohave

Gila

Maricopa

Greenlee

Mohave

Pinal

Greenlee

Greenlee

$325245 \mathrm{~N} 1114500 \mathrm{~W}$

$312225 \mathrm{~N} 1110045 \mathrm{~W}$

$335420 \mathrm{~N} 1113037 \mathrm{~W}$

$365513 \mathrm{~N} 1131439 \mathrm{~W}$

$315316 \mathrm{~N} 1111330 \mathrm{~W}$

$323058 \mathrm{~N} 1101629 \mathrm{~W}$

$350130 \mathrm{~N} 1132358 \mathrm{~W}$

$355611 \mathrm{N1} 114943 \mathrm{~W}$

$343125 \mathrm{~N} 1123446 \mathrm{~W}$

355454N1114B24W

$321510 N 1093248 \mathrm{~W}$

$333336 \mathrm{~N} 1092413 \mathrm{~W}$

$344125 \mathrm{~N} 1135035 \mathrm{~W}$

$340217 \mathrm{N1} 104 \mathrm{~B} 15 \mathrm{~W}$

$333723 \mathrm{~N} 1125623 \mathrm{~W}$

$331918 N 1092331 \mathrm{~W}$

$34440 \mathrm{BN} 1132557 \mathrm{~W}$

$332658 \mathrm{~N} 1112242 \mathrm{~W}$

$334142 \mathrm{~N} 1090417 \mathrm{~W}$

$334133 \mathrm{~N} 1090410 \mathrm{~W}$

$333900 \mathrm{~N} 1134530 \mathrm{~W}$

Yuma

La Paz

Coconino

Cochise

Gila

Coconino

Gila

Mohave

340250N1141942W

$344201 N 1112 B 17 \mathrm{~W}$

$314109 N 1092216 \mathrm{~W}$

$340330 \mathrm{~N} 1110009 \mathrm{~W}$

$342534 \mathrm{~N} 1110849 \mathrm{~W}$

341629 N1110203W

$362923 \mathrm{~N} 1133243 \mathrm{~W}$

$351724 \mathrm{~N} 1121741 \mathrm{~W}$

$355306 \mathrm{~N} 1114651 \mathrm{~W}$

$312108 N 1110431 \mathrm{~W}$

334753N1101147W

$332745 \mathrm{~N} 1110 \mathrm{BO} 6 \mathrm{~W}$

$334617 \mathrm{~N} 1090743 \mathrm{~W}$

343642 N1091515W

$335506 \mathrm{~N} 1132312 \mathrm{~W}$

$343031 \mathrm{~N} 1121935 \mathrm{~W}$

reservoir BGN Coconino 344719N1110925W

spring BGN Cochise 320535N1091714k

spring BGN Mohave 352345N1140650W

spring BGN Greenlee 331710N1090827W

reservoir BGN Mohave $364204 \mathrm{~N} 1130355 \mathrm{~W}$

valley

reservoir

Mohave

$363900 \mathrm{~N} 1130000 \mathrm{~W}$
$325652 \mathrm{~N} 1124258 \mathrm{~W}$
$364631 \mathrm{N1125905 \textrm {W }}$

SOURCE
COORDINATE

ELEV
FT

MAP NAME

Tempe

5940 Point of Pines East

5902 Point of Pines East

2290 Jaynes

Tucs on

Twin Buttes

1170 Tempe

Tucson

Tucson

Phoenix

2420 Tucson

2420 Tucs on

360859 N1115357W

Desert View

Desert View

Mormon Lake

Casa Grande West

Pajarito Peak

Lion Mountain

Lost Spring Mtn West

Samaniego Peak

Bassett Peak

Penitentiary Mtn

Deer Tank

Iron Springs

Deer Tank

Luzena

Baldy Bill Point

Beecher Canyon

Gentry Mtn

Hot Rock Mtn

Bee Canyon

4064 Elephant Mtn

Goldfield

6400 Maness Peak

Maness Peak

Vicksburg

Happy Jack

Swede Peak

Buzzard Roost Mesa

Dane Canyon

Promontory Butte

Poverty Spring

Hearst Mtn

Deer Tank

Pajarito Peak

Cone Butte

Iron Mountain

Alpine

St Johns North

Webber Canyon

Prescott valley $S$

Chavez Mtn West

Cochise Head

Elements Canyon

Fritz Canyon

Little Clayhole Val

Little Clayhole Val

Stove Canyon 
FEATURE NAME

FEATURE
CLASS

STATUS

COUNTY

See Upper Cox Canyon Spring spring

Upper Cook Spring

Upper Corn Creek Tank

Upper Cornwall Well

Upper Corral

See Winter Camp

Upper Corral Canyon

Upper Co Tank

Upper Cox Canyon Spring Upper Con Canyon Spring

Upper Crossing

Upper Crossing Spring

Upper Cypress Spring

Upper Dam

Upper Dead Cow Spring

Upper Deadman Tank

Upper Dillman Tank

Upper Dog Valley Tank

Upper Double R Spring

Upper Dry Pasture Tank

Upper Earl Park

Upper Falls Spring

Upper Fishhook Canyon

Upper Flat Spring

Upper Forest Mountain

Upper Four Tank

Upper French Gulch Windmill

Upper Frio Canyon Tank

Upper George Pond

Upper Goat Camp Spring

Upper Goldwater Lake

Goldwater Lake

Upper Grand Wash Cliffs Grand Wash Cliffs

Upper Grapevine Spring

Upper Greasewood Trading Post Greasewood

Upper Haunted Canyon Spring

Upper Hidden Simmons Gonzales

Upper Highway Tank

Upper Highway Tank Dam

Upper Hog Canyon Spring

Upper Hog Canyon Tank

Upper Holding Ravine

Upper Holding Tank

Upper Hole Tank

Upper Hull Spring

Upper Hurricane Valley

Upper Hyde Spring

Upper Indian Spring

Upper Juan Miller Campground

Upper Juan Miller Picnic Area

Upper Jump Canyon

Upper Jump Springs

Upper Junction Tank

Upper Kelly Spring

Upper LaBarge Box Canyon

Upper LaBarge Spring

Upper Lake Goldwater Dam

Upper Lake Mary

Lake Mary

Upper Lake Mary Dam

Upper Last Chance Spring

Upper Lee Trail

Upper Limestone Dam

See Upper Limestone Tank$$
\text { Dam }
$$

Dam
Upper Limestone Tank

Upper Limestone Tank Oam

Upper Limestone Dam

Upper Little Joe Pond

$$
\begin{aligned}
& \text { spr } \\
& \text { rese } \\
& \text { wel } \\
& \text { loca } \\
& \text { val } \\
& \text { rese } \\
& \text { spr } \\
& \text { rese }
\end{aligned}
$$

$\begin{array}{ll}\text { spring } & \text { BGN } \\ \text { reservoir } & \text { BGN } \\ \text { well } & \text { UNOFF } \\ & \text { VARIANT } \\ \text { locale } & \\ \text { valley } & \text { BGN } \\ \text { reservoir } & \text { BGN } \\ \text { spring } & \text { BGN } \\ & \text { VARIANT } \\ \text { reservoir } & \text { BGN }\end{array}$

$$
\text { Gila }
$$

Yavapai

Apache

Mohave

Gila

Gila

Gila

Yavapai

$\begin{array}{ll}\text { spring } & \text { BGN } \\ \text { spring } & \text { BGN } \\ \text { dam } & \text { UNOFF } \\ \text { spring } & \text { BGN } \\ \text { reservoir } & \text { BGN } \\ \text { reservoir } & \text { BGN } \\ \text { reservoir } & \text { BGN } \\ \text { spring } & \text { BGN } \\ \text { reservoir } & \text { BGN } \\ \text { flat } & \text { BGN }\end{array}$

Navajo

Yavapai

Yavapai

Yavapai

Graham

Coconino

Coconino

Cochise

Yavapa $i$

Apache

spring BGN Graha

valley
spring

summit

reservoir

locale

reservoir

lake

spring

reservoir

BGN
BGN
BGN

BGN

BGN

$B G N$

BGN

BGN

BGN

BGN 1976

VARIANT

$\begin{array}{llll}\text { cliff } & \text { BGN } & \text { Mohave } & 361150 \mathrm{~N} 1134340 \mathrm{~W} \\ & \text { VARIANT } & & \\ \text { spring } & \text { BGN } & \text { Mohave } & 352933 \mathrm{~N} 1134202 \mathrm{~W} \\ \text { locale } & \text { BGN } & \text { Apache } & 362206 \mathrm{~N} 1091440 \mathrm{~W} \\ & \text { VARIANT } & & \\ \text { spring } & \text { BGN } & \text { Pinal } & 332404 \mathrm{~N} 1110430 \mathrm{~W} \\ \text { summit } & \text { BGN } & \text { Mohave } & 345623 \mathrm{~N} 1132749 \mathrm{~W} \\ \text { reservoir } & \text { BGN } & \text { Gila } & 334204 \mathrm{~N} 1103047 \mathrm{~W} \\ \text { dam } & \text { UNOFF } & \text { Gila } & 334205 \mathrm{~N} 1103046 \mathrm{~W} \\ \text { spring } & \text { BGN } & \text { Gila } & 340845 \mathrm{~N} 1111925 \mathrm{~W}\end{array}$

$\begin{array}{llll}\text { reservoir } & B G N & \text { Greenlee } & 331442 \mathrm{~N} 1090843 \mathrm{~W} \\ \text { arroyo } & B G N & \text { Pinal } & 323415 \mathrm{~N} 1105608 \mathrm{~W}\end{array}$

$B G N$

reservoir BGN

reservoir $B G$

$\begin{array}{ll}\text { spring } & B G N \\ \text { valley } & B G N\end{array}$

spring

spring

park

BGN

BGN

park

$$
\text { Pinal }
$$

Pinal

Navajo

Mohave

Yavapai

Mohave

Greenlee

Greenlee

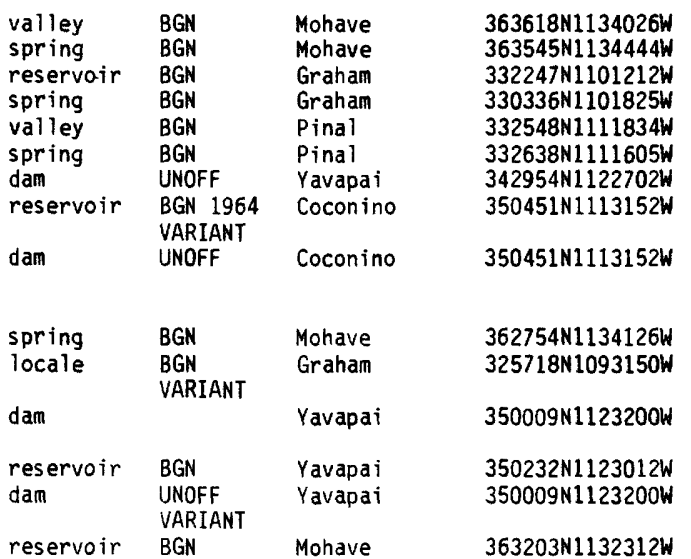

325002 N1100854W

331302 N10959181

323327 N1101941W

$355909 \mathrm{N1092017 \textrm {W }}$

$312357 \mathrm{~N} 1103930 \mathrm{~W}$

$341746 \mathrm{~N} 1123616 \mathrm{~W}$

62B21 $1133221 \mathrm{~W}$

$330343 \mathrm{~N} 1101756 \mathrm{~W}$

$342955 N 1122657 \mathrm{~W}$

$323606 \mathrm{~N} 1105305 \mathrm{~W}$

335003 N1095547

$350840 \mathrm{~N} 1115749 \mathrm{~W}$

3634D8N1132039W

$345100 \mathrm{~N} 1125343 \mathrm{~W}$

353335 N11412

$331608 \mathrm{~N} 1092050 \mathrm{~W}$

$331608 \mathrm{~N} 1092051 \mathrm{~W}$ $\begin{array}{cc}\text { SOURCE } & \text { ELEV } \\ \text { COORDINATE } & \text { FT MAP NAME }\end{array}$

Bismarck Mesa

6276 Corn Creek

3704 Elephant Mtn

334409 N1104559W

Haystack Butte

Deer Tank

Chrome Butte

Scratch Canyon

Oak Springs

Burro Mesa

Prescott Valley

Crown king

Thatcher

Red Butte

Chavez Mtn East

Cherry Spring Peak

Dugas

Hawley Lake East

$331306 \mathrm{~N} 1095704 \mathrm{~W}$

Buford $\mathrm{Hill}$

Gila Peak

Bassett Peak

7572 White Rock Wash

Harshaw

Walnut Grove

Young

Poverty Spring

Mt Turnbul

5986 Groom Creek

$323611 \mathrm{~N} 1105228 \mathrm{~W}$

362356 N1131948W

Snap Draw

Valentine

Tsaile

Haunted Canyon

5384 Gonzales Wash

5621 Chrysotile

Chrysotile

Payson South

Dix Creek

Oracle Junction Oracle Junction

Whiteriver

Garland Prairie

Russell Spring

Camp Wood

Mt Tipton

Pipestem Mtn

Pipestem Mtn

363626 N1133834W

St George Canyon

St George Canyon

Bronco Gulch

Mt Turnbull

332608N1111707W

Weavers Needle

Weavers Needle

5986 Groom Creek

6829 Lower Lake Mary

6815 Lower Lake Mary

Last Chance Canyon

Lone Star Mtn

Picacho Butte SE

Picacho Butte SE

Sullivan Draw South 


\section{FEATURE NAME}

Upper Little Park

Upper Live Water Spring

Upper Lockwood Tank

Upper Long Hollow Tank

Upper Long Valley Tank

Upper Lucky Canyon Spring

Upper Lyman Ditch

Upper Lyt le Spring

Upper McBride Spring

Upper McCauley Tank

Upper McDermit Spring

Leroux Spring

Upper Mckinney Tank

Upper Martinez Tank

Upper Mesa Tank

Upper Mesquite Canyon Spring

Upper Middle Tank

Upper Moccas in Springs

Upper Mohave Tank

Upper Monk Tank

Upper Mormon Pocket Tank

Upper Moss Spring

Upper Mount Hope Spring

Upper Mud Spring

Upper New Tank

Upper North Canyon

Upper Oak Creek Windmill

Upper One Tank

Upper Pacheta Cienega

Upper Parson Well

Upper Pasture Spring

Upper Peach Spring

See Red Spring

Upper Peck Spring

Upper Pesqueira Tank Upper Pesquiera Tank

Upper Pesquiera Tank

See Upper Pesqueira Tank

Upper Pigeon Spring

Upper Pinal Recreation Area

Upper Pinery Canyon Campground

Upper Pine Spring

Upper Pinto Spring

Upper Potter Mesa Tank

Upper Pueblo Tank

See Upper Puerto Tank

Upper Puerto Tank

Upper Pueblo Tank

Upper Racetrack Mesa

Race Track Mesa

Upper Railroad Tank

Upper Rattlesnake Spring

Upper Rattlesnake Tank

Upper Reiley Tank

Upper Rim Campgrounds

Upper Rim Tank

Upper Ringtail Tank

Upper Ruin

See Tonto (cliff dwellings)

Upper Rustler Spring

Upper Saddle Horse Tank

Upper Saginaw Reservoir

Upper Sahuarita Dam

Upper Salida Tank

Upper Salt Ground Tank

Upper Salt House Tank

Upper Sam Canyon Tank

Upper Sampson Tank

Upper San Luis Well

Upper Seep Tank

Upper Sevenmile Tank
FEATURE
CLASS

STATUS

COUNTY

flat

BGN

Coconino

COORDINATE

$361935 \mathrm{~N} 1120652 \mathrm{~W}$

$350526 \mathrm{~N} 1132722 \mathrm{~W}$

354305 N1114910W

$342407 N 1102721 \mathrm{~W}$

$343516 N 1111838 \mathrm{~W}$

343127 N1115403W

$342939 N 1092452 \mathrm{~W}$

$365512 \mathrm{~N} 1130835 \mathrm{~W}$

$333243 \mathrm{~N} 1092434 \mathrm{~W}$

$351205 \mathrm{~N} 1121936 \mathrm{~W}$

351625 N1115448W

Greenlee

Coconino

reservoir

spring

VARIANT

reservoir

reservoir

reservoir

spring

reservoir

spring

reservoir

reservoir

reservoir

spring

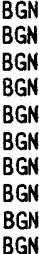

spring

spring

reservoir

valley

locale

reservoir

swamp

well?

spring

spring

spring

BGN

reservoir

BGN

VARIANT

reservoir

spring

park

park

spring

spring

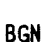

BGN

ADMIN

BGN

BGN

reservoir $B G$

VARIANT

reservoir

reservoir

summit

reservoir

spring

reservoir

reservoir

park

reservoir

reservoir

locale

spring

reservoir

reservoir

dam

BGN 1981

VARIANT

BGN
VARIANT

BGN

$B G N$
$B G N$

Graham
Navajo
Yavapa
Pima
Yavapa
Mohave
Mohave
Graham
Yavapa
Mohave

$330953 \mathrm{~N} 1100030 \mathrm{~W}$

$340631 \mathrm{~N} 1103731 \mathrm{~W}$

$341955 \mathrm{~N} 1121213 \mathrm{~W}$

$321101 N 1102903 \mathrm{~W}$

$342851 N 1121204 \mathrm{~W}$

365457 N1124B08W

$342759 N 1140327 \mathrm{~W}$

$322750 \mathrm{~N} 1094538 \mathrm{~W}$

$345102 \mathrm{~N} 1120826 \mathrm{~W}$

$350150 \mathrm{N1135331 \textrm {W }}$

345637 N113055OW

$331827 \mathrm{~N} 1105839 \mathrm{~W}$

$353855 \mathrm{~N} 1112741 \mathrm{~W}$

362354 N1120449W

$340848 \mathrm{~N} 1122716 \mathrm{~W}$

$312228 \mathrm{~N} 1104001 \mathrm{~W}$

$335006 \mathrm{~N} 1093105 \mathrm{~W}$

$345730 \mathrm{~N} 1133141 \mathrm{~W}$

$343707 N 1123636 \mathrm{~W}$

353332N1132518W

Mohave

Yavapai

Santa Cruz

$341448 \mathrm{~N} 1121916 \mathrm{~W}$

$312303 \mathrm{~N} 1110117 \mathrm{~W}$

Santa Cruz 312303N1110117W

Mohave 361732N1133949W

Gila 331704N1104916W

$315550 \mathrm{~N} 1091617 \mathrm{~W}$

Coconino 355032N1130648W

$332003 N 1105242 \mathrm{~W}$

$344335 N 1094321 \mathrm{~W}$

$313641 \mathrm{N1110755 \textrm {W }}$

$313641 \mathrm{~N} 1110755 \mathrm{~W}$

Santa Cruz

Gila

Yavapai

$342156 \mathrm{N1121217 \textrm {W }}$

$330508 \mathrm{~N} 1091000 \mathrm{~W}$

$344629 N 1113940 \mathrm{~W}$

$322442 \mathrm{~N} 1100452 \mathrm{~W}$

$32231 \mathrm{BN} 1104204 \mathrm{~W}$

$322612 \mathrm{~N} 1101502 \mathrm{~W}$

$324200 \mathrm{~N} 1102219 \mathrm{~W}$

$333830 \mathrm{~N} 1110655 \mathrm{~W}$

$315411 N 1091648 \mathrm{~W}$

355821 N1114550W

$351418 \mathrm{~N} 1121118 \mathrm{~W}$

$323259 \mathrm{~N} 1105936 \mathrm{~W}$

$\begin{array}{llll}\text { reservoir } & \text { BGN } & \text { Yavapai } & 343113 \text { N1122101W } \\ \text { reservoir } & \text { BGN } & \text { Greenlee } & 331504 N 1090919 \mathrm{~W} \\ \text { reservoir } & \text { BGN } & \text { Mohave } & 360903 N 1134034 \mathrm{~W} \\ \text { reservoir } & \text { BGN } & \text { Navajo } & 340201 \mathrm{N1} 103829 \mathrm{~W} \\ \text { reservoir } & \text { BGN } & \text { Graham } & 330859 \mathrm{~N} 110030 \mathrm{BW} \\ \text { well } & \text { UNOFF } & \text { Pima } & 313336 \mathrm{~N} 1112508 \mathrm{~W} \\ \text { reservoir } & \text { BGN } & \text { Cochise } & 313647 \mathrm{N1} 092620 \mathrm{~W} \\ \text { reservoir } & \text { BGN } & \text { Navajo } & 334533 \mathrm{~N} 1095601 \mathrm{~W}\end{array}$

SOURCE

ELEV

MAP NAME

Little Park Lane

Penitentiary Mtn

Lockwood Canyon

Aripine

Long Valley

Middle Verde

Salado

Lost Spring Mtn West

Baldy Bill Point

McLellan Reservoir

Parks

Bylas

Oak Creek Ranch

Cleator

Happy Valley

Mayer

Moccas in

Mohave Springs

Greasewood Mountain

Munds Draw

Hualapai Peak

Mount Hope

Pinal Ranch

Gray Mountain

$361944 N 1120506 \mathrm{~W}$

Dog Point

4322 Minnehaha

Duquesne

Bonito Rock

Tom Brown Canyon

Iron Springs

Crown King

Pena Blanca Lake

Mustang Point

Pinal Peak

Rustler Park

Frazier Wells

Pinal Ranch

Potter Mesa Tank

Murphy Peak

5150 Wet Bottom Mesa

Cleator

Rattlesnake Spring

Munds Mountain

Reiley Peak

6800 Mount Bigelow

Cherry Spring Peak

Kennedy Peak

Rustler Park

Deer Tank

Williams South

Oracle Junction

Prescott Valley $S$

Fritz Canyon

Snap Oraw

Oak Creek Ranch

Bylas

Wilbur Canyon

Pedregosa Mts West

Whiteriver 
FEATURE CLASS

Upper Sevenmile Well Upper Sharp Tank

Upper Sheep Creek Spring Upper Simmons Well

Upper Spring

Upper Spring

Jpper Spring

Upper Spring Water Windmil

Upper Squaw Tank

Upper Stratton Spring

Upper Sweater Tank

Upper Sycamore Spring

Upper Sycamore Spring

Upper Sycamore Tank

Upper Tailholt Spring

Upper Tank

Upper Tank

Upper Tank

Upper Tank

Upper Tank

Upper Tank

Upper Tank

Upper Tank

Upper Tank

Upper Tank

Upper Tank

Upper Tank

Upper Tank

Upper Tank

Upper Tank

Upper Tank

Upper Tank Draw

Upper Tater Canyon

Upper Ten $X$ Tank

Upper Tex Tank

Upper Thirteen Tank

Upper Thompson Mesa Tank

Upper Thompson Spring

Upper Tincup Spring

Upper Tom Brown Well

Upper Turner Tank

Upper Two Bar Spring

Upper Two Spring

Upper Wagner Tank

Upper Wakefield Spring

Upper Walker Tank

Upper Walnut Spring

Upper Water

Upper Water Spring

Upper Waters Spring

Upper Well

Upper Well

Upper Wel

Upper Well

Upper West Fork Spring

Upper Wheatfields

Upper White Lakes Oraw

Upper Wildcat Tank

Upper Wolf Creek Campground

Upper Yankee Joe Spring

Upper Yarrow Tank

Upper Yellow Jacket Tank

Up Rock Point

Upset Rapids

Uptown Plaza Shopping Center

Uranium Spring

Uranium Tank

Urie Bas in

Urie Spring

U.S. Electronics Proving Ground See Fort Horn Monument

spring

spring

spring

spring

well

spring

spring

spring

reservoir

spring

well

spring

spring

spring

spring

spring

well

wel1

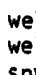

we

pal

park

spring

rapids

locale

spring

bas in

spring

park

$\begin{array}{llll}\text { well } & \text { UNOFF } & \text { Gila } & 332554 N 1102913 \mathrm{~W} \\ \text { reservoir } & \text { BGN } & \text { Navajo } & 342305 N 1103954 \mathrm{~W}\end{array}$

spring BGN Maricopa 335530N1113112

reservoir

reservoir $B G$

spring $\quad B G$

reservoir

reservoir

reservoir $B G$

reservoir $B G$

reservoir BGN

reservoir

reservoir BG

reservoir $B G$

reservoir $B G$

reservoir $B G N$

reservoir $B G$

reservoir $B G$

reservoir $B G$

reservoir $B G$

reservoir $B G$

reservoir BGM

valley $B G N$

valley

reservoir $B G N$

reservoir BGN

reservoir $B G N$

reservoir $B G N$

spring BGN

$B G N$

reservoir

reservoir $B G$

spring $B G$

\section{Mohave}

Pima

342051N1121918W

Mohave

Pima

Navajo

Pima

Apache

Graham

$345624 N 1132808 \mathrm{~W}$

$314713 \mathrm{~N} 1103150 \mathrm{~W}$

$343455 \mathrm{~N} 1103801 \mathrm{~W}$

$322942 N 1104332 \mathrm{~W}$

$333635 N 1094750 \mathrm{~W}$

$322802 \mathrm{~N} 1101644 \mathrm{~W}$

Yavapai 340830N1121411W

Graham 323947N1101936

Yavapai 344701N1124605

$313126 \mathrm{~N} 1112250 \mathrm{~W}$

Cochise 313720N109221BW

Cochise 314632N1102355W

Cochise 320838N1102510W

Pima 321826N1103102W

$325538 \mathrm{~N} 1110254 \mathrm{~W}$

Pinal 331630N1111704W

Gila 340439N1105B54W

Gila

Yavapai

Apache

Navajo

Navajo

Coconino

Yavapai

Coconino

Coconino

Coconino

Coconino

Cochise

Santa Cruz

Gila

Coconino

Cochise

Mohave

Santa Cruz

Maricopa

340740N1105208W

$342543 \mathrm{~N} 1090935 \mathrm{~W}$

$342719 \mathrm{~N} 1102254 \mathrm{~W}$

$343403 N 1100331 \mathrm{~W}$

$343716 \mathrm{~N} 1112841 \mathrm{~W}$

$350733 N 1113207 \mathrm{~W}$

343527 N1113029W

$362744 N 1120622 W$

$355 B 19 N 1120315 W$

$314224 \mathrm{~N} 1092121 \mathrm{~W}$

312119 N1103913h

334910 N1110303W

$361533 \mathrm{~N} 112031 \mathrm{BW}$

312437 N1092547W

345427 N1132945

312546 N1111904W

$333340 \mathrm{~N} 1110727 \mathrm{~W}$

Coconino

Coconino

Cochise

Santa Cruz

Gila

Yavapai

Gila

Graham

Pima

Gila

362154N1121753W

360038 N1121B41W

$315201 N 110250 \mathrm{BW}$

314019 N1104856W

$335941 \mathrm{~N} 1100501 \mathrm{~W}$

$341940 N 1115621 \mathrm{~W}$

340445N1110930W

330640 N1094945W

$313126 \mathrm{~N} 1112256 \mathrm{~W}$

$333317 \mathrm{~N} 1104747 \mathrm{~W}$

reservoir

reservoir

reservoir

UNOFF

UNOFF

Maricopa

Mohave

Pima

Apache

Apache

Yavapai

Yavapai

Gila

Navajo

Yavapai

\section{cliff $\quad B G$}

BGN 1925

reservoir

UNOF

BGN

BGN

BGN

VARIANT
Navajo

Mohave

Maricopa

Apache

Navajo

Yavapai

Yavapai

Yuma

SOURCE
COORDINATE

FT

MAP NAME

2901 Natural Corral Hanks Oraw

Lion Mountain

Gonzales Wash

Happy Valley

Battle Flat

Gonzales Wash

Spring Water Canyon

Potato Wash South

Mount Bigelow

West Poker Mtn

Cherry Spring Peak

Bumble Bee

Kennedy Peak

Seepage Mtn

Wilbur Canyon

Pedregosa Mts East

Apache Peak

Happy Vạlley

Piety $\mathrm{Hi} 11$

Ninetysix Hills NE

Florence Junct ion

Young

Parailel Canyon

Battleship Butte

Mesa Parada NW

Aripine

Snowf lake

Calloway Butte 


\begin{tabular}{|c|c|c|c|c|c|c|c|}
\hline FEATURE NAME & $\begin{array}{c}\text { FEATURE } \\
\text { CLASS }\end{array}$ & STATUS & COUNTY & COORDINATE & $\begin{array}{l}\text { SOURCE } \\
\text { COORDINATE }\end{array}$ & $\begin{array}{c}\text { ELEV } \\
\text { FT }\end{array}$ & MAP NAME \\
\hline Usery Mountain & sumnit & BGN & Maricopa & $332957 N 1113829 \mathrm{~W}$ & & 2959 & Buckhorn \\
\hline $\begin{array}{l}\text { Usery Mountain } \\
\text { See Usery Mountains } \\
\text { Usery Mountain Recreation Area } \\
\text { Usery Mountains } \\
\text { Usery Mountain } \\
\text { Usery Pass } \\
\text { USGSA Depot } \\
\text { Utah Canal } \\
\text { See Tempe Canal } \\
\text { Utahville } \\
\text { See Lehi }\end{array}$ & $\begin{array}{l}\text { summit } \\
\text { park } \\
\text { summit } \\
\text { gap } \\
\text { locale } \\
\text { canal } \\
\text { ppl }\end{array}$ & $\begin{array}{l}\text { VARIANT } \\
\text { ADMIN } \\
\text { BGN } \\
\text { VARIANT } \\
\text { BGN } \\
\text { BGN } \\
\text { VARIANT } \\
\text { VARIANT }\end{array}$ & $\begin{array}{l}\text { Maricopa } \\
\text { Maricopa } \\
\text { Maricopa } \\
\text { Maricopa } \\
\text { Yuma } \\
\text { Maricopa } \\
\text { Maricopa }\end{array}$ & 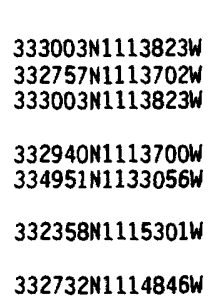 & & $\begin{array}{l}2972 \\
2115\end{array}$ & $\begin{array}{l}\text { Apache Junction } \\
\text { Granite Reef Dam } \\
\text { Apache Junction } \\
\text { Salome }\end{array}$ \\
\hline $\begin{array}{l}\text { Ute Creek } \\
\quad \text { See Paria River } \\
\text { Ute Mountain } \\
\text { Ute Mountains } \\
\text { Ute Mountains } \\
\quad \text { See Black Mountains } \\
\text { Utevak } \\
\text { Ute Valley } \\
\text { Utopia Tank } \\
\text { Utterback Junior High }\end{array}$ & $\begin{array}{l}\text { stream } \\
\text { summit } \\
\text { range } \\
\text { range } \\
\text { ppl } \\
\text { valley } \\
\text { reservoir } \\
\text { school }\end{array}$ & $\begin{array}{l}\text { VARIANT } \\
\text { BGN } \\
\text { BGN } \\
\text { VARIANT } \\
\text { BGN } \\
\text { BGN } \\
\text { BGN } \\
\text { UNOFF }\end{array}$ & $\begin{array}{l}\text { Coconino } \\
\text { Mohave } \\
\text { Mohave } \\
\text { Mohave } \\
\text { Pima } \\
\text { Navajo } \\
\text { Yavapai } \\
\text { Pina }\end{array}$ & $\begin{array}{l}365131 N 1113600 \mathrm{~W} \\
345745 \mathrm{~N} 1142145 \mathrm{~W} \\
345853 \mathrm{~N} 1142425 \mathrm{~W} \\
\\
352814 \mathrm{~N} 1143038 \mathrm{~W} \\
314208 \mathrm{~N} 114456 \mathrm{~W} \\
361716 \mathrm{N1101741W} \\
343731 \mathrm{~N} 1113427 \mathrm{~W} \\
321114 \mathrm{~N} 1105608 \mathrm{~W}\end{array}$ & 361537 N1101859W & $\begin{array}{l}3622 \\
4000 \\
2620\end{array}$ & $\begin{array}{l}\text { Aguirre Peak } \\
\text { Red Slide Peak } \\
\text { Apache Maid Mtn } \\
\text { Tucson }\end{array}$ \\
\hline $\begin{array}{l}\text { Utting } \\
\text { Hagua Hali } \\
\text { Utting Siding Airstrip } \\
\text { Uturitu } \\
\text { See Sacaton } \\
\text { Uupatoitak } \\
\quad \text { See Gila Bend }\end{array}$ & $\begin{array}{l}\text { locale } \\
\text { airport } \\
\text { ppl } \\
\text { ppl }\end{array}$ & $\begin{array}{l}\text { BGN } \\
\text { VARIANT } \\
\text { AONIN } \\
\text { VARIANT } \\
\text { VARIANT }\end{array}$ & $\begin{array}{l}\text { Yuma } \\
\text { La Paz } \\
\text { Pinal } \\
\text { Maricopa }\end{array}$ & $\begin{array}{l}335020 \mathrm{~N} 1135310 \mathrm{~W} \\
335010 \mathrm{~N} 1135245 \mathrm{~W} \\
330436 \mathrm{~N} 1114419 \mathrm{~W} \\
325652 \mathrm{~N} 1124258 \mathrm{~W}\end{array}$ & & 1150 & $\begin{array}{l}\text { Utting } \\
\text { East of Utting }\end{array}$ \\
\hline $\begin{array}{l}\text { Vaca Hills } \\
\text { Vaca Ranch } \\
\text { Vaheja } \\
\quad \text { See Sikul Himatk }\end{array}$ & $\begin{array}{l}\text { summit } \\
\text { locale } \\
\text { ppl }\end{array}$ & $\begin{array}{l}\text { BGN } 1941 \\
\text { UNOFF } \\
\text { VARIANT }\end{array}$ & $\begin{array}{l}\text { Pima } \\
\text { Santa Cruz } \\
\text { Pima }\end{array}$ & $\begin{array}{l}321627 N 1114422 W \\
312835 N 1103552 W \\
320654 N 1120206 W\end{array}$ & & & $\begin{array}{l}\text { Queens Well } \\
\text { Canelo Pass }\end{array}$ \\
\hline $\begin{array}{l}\text { Vail } \\
\text { Vail Elementary School } \\
\text { Vail Junior High School } \\
\text { Vail Lake } \\
\text { Lambing Lake } \\
\text { Vail Overpass } \\
\text { Vail Trap Spring } \\
\text { See Van Trap Spring } \\
\text { Vainom Kug } \\
\text { Kvitak } \\
\text { Kvitatk } \\
\text { Pumphouse } \\
\text { Quijotoa Well } \\
\text { Stean Pump } \\
\text { Steam Pump Village } \\
\text { Vainomkux }\end{array}$ & $\begin{array}{l}\text { Ppl } \\
\text { school } \\
\text { school } \\
\text { lake } \\
\text { crossing } \\
\text { spring } \\
\text { locale }\end{array}$ & $\begin{array}{l}\text { BGN } \\
\text { UNOFF } \\
\text { UNOFF } \\
\text { BGN 1964 } \\
\text { VARIANT } \\
\text { UNOFF } \\
\text { VARIANT } \\
\text { BGN } 1941 \\
\text { VARIANT } \\
\text { VARIANT } \\
\text { VARIANT } \\
\text { VARIANT } \\
\text { VARIANT } \\
\text { VARIANT } \\
\text { VARIANT }\end{array}$ & $\begin{array}{l}\text { Pima } \\
\text { Pima } \\
\text { Pima } \\
\text { Coconino } \\
\text { Pima } \\
\text { Pima } \\
\text { Pima }\end{array}$ & $\begin{array}{l}320252 \mathrm{~N} 1104241 \mathrm{~W} \\
320302 \mathrm{~N} 1104237 \mathrm{~W} \\
321249 \mathrm{~N} 1105239 \mathrm{~W} \\
350525 \mathrm{~N} 1113045 \mathrm{~W} \\
320142 \mathrm{~N} 1104314 \mathrm{~W} \\
320430 \mathrm{~N} 110331 \mathrm{~W} \\
320248 \mathrm{~N} 1120326 \mathrm{~W}\end{array}$ & & $\begin{array}{l}3225 \\
7187\end{array}$ & $\begin{array}{l}\text { Vail } \\
\text { Vail } \\
\text { Tucson } \\
\text { Lower Lake Mary } \\
\text { Vail } \\
\text { Vainom Kug }\end{array}$ \\
\hline $\begin{array}{l}\text { Vainomkux } \\
\text { See Vainom Kug } \\
\text { Vaiva Hills } \\
\text { Vaiva Vo } \\
\text { Cocklebur } \\
\text { Cockleburr } \\
\text { San Angelo del Botum } \\
\text { Vaivavo } \\
\text { Vaivavo } \\
\text { See Vaiva Vo }\end{array}$ & $\begin{array}{l}\text { locale } \\
\text { summit } \\
\text { ppl }\end{array}$ & $\begin{array}{l}\text { VARIANT } \\
\text { BGN } 1941 \\
\text { BGN } \\
\text { VARIANT } \\
\text { VARIANT } \\
\text { VARIANT } \\
\text { VARIANT } \\
\text { VARIANT }\end{array}$ & $\begin{array}{l}\text { Pima } \\
\text { Pinal } \\
\text { Pinal }\end{array}$ & $324304 N 1115533 W$ & & & $\begin{array}{l}\text { Vaiva Vo } \\
\text { Vaiva Vo }\end{array}$ \\
\hline $\begin{array}{l}\text { Vakamok } \\
\text { Comot } \\
\text { Comoti } \\
\text { Popolo Vakamakatuk } \\
\text { Rusty Shovel }\end{array}$ & locale & $\begin{array}{l}\text { BGN } 1941 \\
\text { VARIANT } \\
\text { VARIANT } \\
\text { VARIANT } \\
\text { VARIANT }\end{array}$ & Pima & $314220 N 1120149 \mathrm{~W}$ & & 2263 & Tecolote Ranch \\
\hline
\end{tabular}




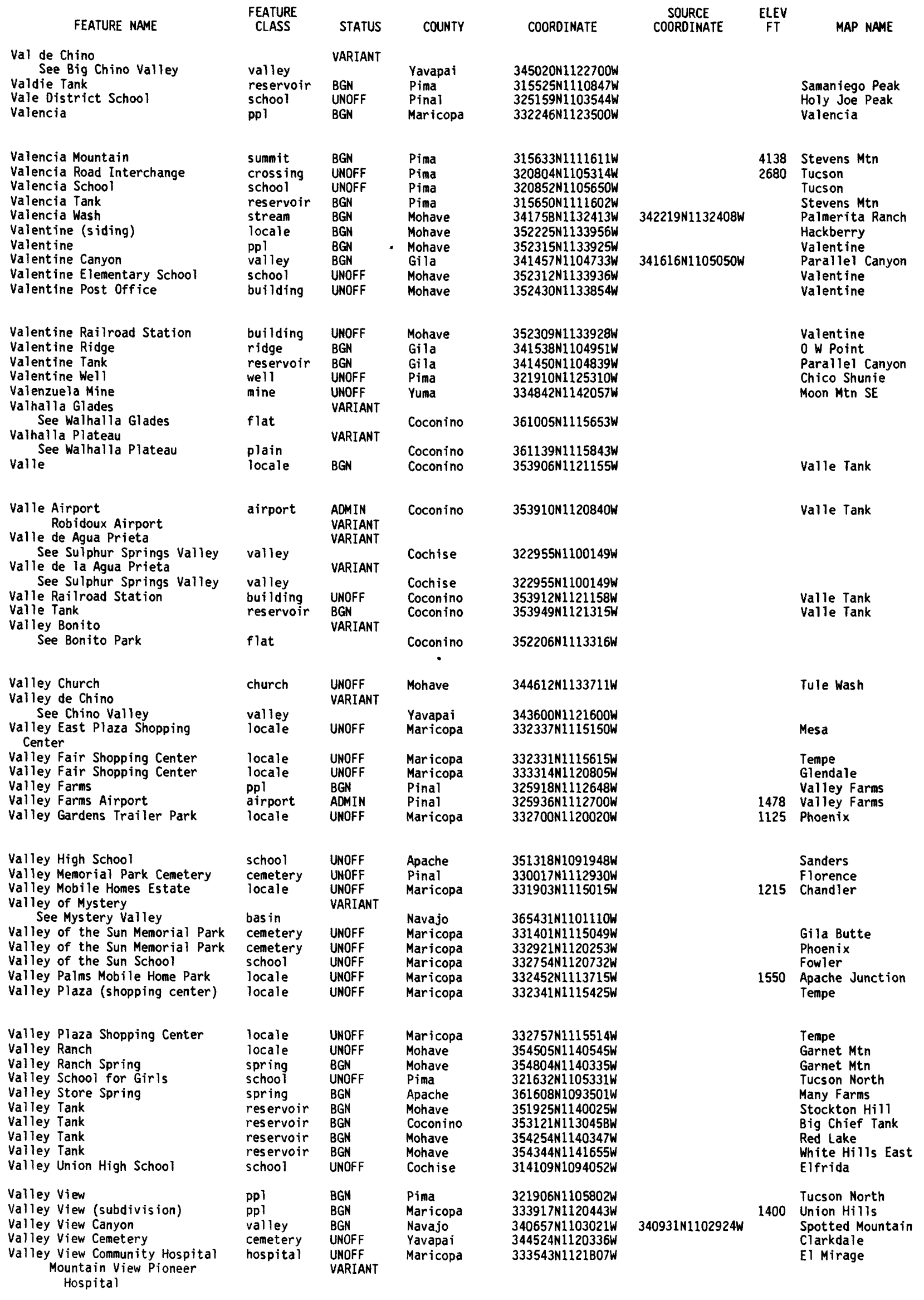


NATIONAL GAZETTEER--ARIZONA 1986

FEATURE NAME

Valley View Picnic Area

Valley View Point

Valley View Ranch

Valley View School

Valley View Tank

Valley West Mall

Val me

See Big Chino Valley

Valpee

See Walpi

Val-shima Wash

See Vamori Wash

Valshnia Wash

See Vamori Wash

Valshni Wash

See Vanori Wash

Valshuni Wash

See Vamori Wash

Vals Tank

Valve House

Val Verde

See Humboldt

Val Vista Trailer Park

Val Vista Village Trailer

Park Mini Park

Val Vista Village Trailer

Park Water Retention Basin

Vamori

Vamori Valley

Vamori Wash

Gu Oidak Wash

Val-shima Wash

Valshni Wash

Vaishnia Wash

Valshuni Wash

Wah-shing Wash

Vampire Mine

Vanadium Mine

Vanadium Shaft

Vanadium Springs

Vanar

Vanar Railroad Station

Vanar Wash

Van Buskirk School

$\checkmark$ an Deemen Mine

Vandenburg Village

Van Deren Spring

Van Dyke Shaft

Van Dyke Spring

Van Horne School

Vanori Wash

See San Simon Wash

Van Trap Spring

Vail Trap Spring

Van Valer Canyon

Van Valer Spring

Van Vaiter Tank

Van Winkle Canyon

Van Winkle Ranch

Van Winkle Spring

Vaquero Mesa

See Horse Mesa

Virney Park

Vaseys Paradise

Vesey Paradise

Vasquez Well

VA Tank

Vaughn Canyon

Vaughn Spring

Vault Mine Trail One Hundred Forty
FEATURE

BGN $\quad$ Navajo $\quad 340722$ N1102856

$312225 \mathrm{~N} 1100142 \mathrm{~W}$

School UNOFF Maricopa 332215N1120459W

reservoir BGN Navajo 340706N1102943W

locale UNOFF Maricopa

valley VARIANT Yavapai 345020N1122700W

locale

VARIANT

Navajo

$354956 \mathrm{~N} 1102350 \mathrm{~W}$

stream

VARIANT

Pima

315750 N1121935W

stream

Pima

$315750 N 1121935 W$

VARIANT

stream Pima 315750N1121935W

stream

locale

ppl

locale

park

VARIANT

BGN

BGN

Pima

Coconino

Coconino

$315750 N 1121935 \mathrm{~W}$

$343822 N 1110447 \mathrm{~W}$

$351613 N 1121852 \mathrm{~W}$

Yavapai

$343003 \mathrm{N1121412W}$

$333934 \mathrm{~N} 1120156 \mathrm{~W}$
$332506 \mathrm{~N} 1114513 \mathrm{~W}$

$\begin{array}{ll}\text { UNOFF } & \text { Maricopa } \\ \text { ADIN } & \text { Maricopa }\end{array}$

$\begin{array}{ll}\text { reservoir } & \text { BGN } \\ \text { ppl } & \text { BGN } \\ \text { valley } & \text { BGN } \\ \text { stream } & \text { BGN 1964 } \\ & \text { VARIANT } \\ & \text { VARIANT } \\ & \text { VARIANT } \\ & \text { VARIANT } \\ & \text { VARIANT } \\ & \text { VARIANT }\end{array}$

Maricopa

$332507 N 1114512 \mathrm{~W}$

Pima

Pima

Pima

ARIANT

DART

VARIANT

$\begin{array}{llll}\text { mine } & \text { UNOFF } & \text { Yuma } & 341308 N 1140102 \mathrm{~W} \\ \text { mine } & \text { UNOFF } & \text { Gila } & 330758 \mathrm{~N} 1104956 \mathrm{~W} \\ \text { mine } & \text { UNOFF } & \text { Gila } & 332745 \mathrm{~N} 1104822 \mathrm{~W} \\ \text { spring } & \text { BGN } & \text { Pinal } & 330800 \mathrm{~N} 1105343 \mathrm{~W} \\ \text { locale } & \text { BGN } & \text { Cochise } & 321428 \mathrm{~N} 1090540 \mathrm{~W} \\ \text { building } & \text { UNOFF } & \text { Cochise } & 321430 \mathrm{N1090547W} \\ \text { stream } & \text { BGN } & \text { Cochise } & 321304 N 1090830 \mathrm{~W} \\ \text { school } & \text { UNOFF } & \text { Pima } & 321016 \mathrm{N1105733W} \\ \text { mine } & \text { UNOFF } & \text { Mohave } & 354149 N 1143313 \mathrm{~W} \\ \text { ppl } & \text { BGN } & \text { Pima } & 321049 N 1105202 \mathrm{~W}\end{array}$

spring BGN Coconino 34500BN1112643W

mine

spring

choo

stream

spring

valley

UNOFF

BGN

UNOFF

VARIANT

BGN

VARIANT

BGN

Graham

reservoir

valley $B G$

locale

spring

Graham

Gila

Gila

sumait

VARIANT

park

area

ADMIM

Maricop

Maricopa

Coconino

well

reservoir

valley

spring

BGN

VARIANT

Pima

BGN Coconino

BGN 1959 Santa Cruz

BGN Coconino

UNOFF
$314316 \mathrm{~N} 1115417 \mathrm{~W}$

$314838 N 1115717 \mathrm{~W}$

$315750 \mathrm{~N} 1121935 \mathrm{~W}$

BGN Graham

$\begin{array}{cc}\text { SOURCE } & \text { ELEV } \\ \text { COOROINATE } & \text { FT MAP NAME }\end{array}$

Avra

Cibecue

Lone Butte

Cibecue
Glendale

Quayle Hill

Hearst Mtn

1505 Union Hills Mesa

Mesa

Vamori

Cowlic

Kom Vo 
FEATURE NAME

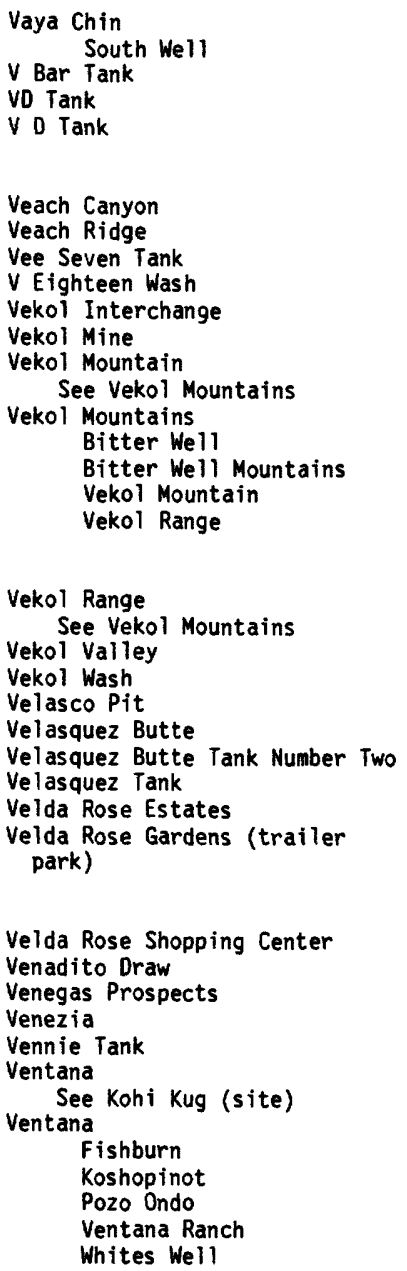

Ventana Canyon Rock Canyon Ventano Canyon

Ventana Canyon Wash

Ventana Cave

Ventana Mesa Mesa la Ventana

Ventana Pass

Ventana Ranch

See Ventana

Ventana Tank

Ventana Windmill

Ventano Canyon

See Ventana Canyon

Ventura Esperero Trail

Twenty-five

Venture Out (trailer park)

Venturoso Park

Venus Temple

Verba Buena Ranch

Verde

See Camp Verde
Verde
See Clemenceau
Verde Central Shaft
Verde Combination Shaft
Verde Hot Springs
Verde Indian Hot Springs
Verde Indian Hot Springs
See Verde Hot Springs

ppl
reservoir
reservoir
reservoir

valley
ridge
reservoir
stream
crossing
mine
range
range

BGN 1941 Pima

VARIANT

BGN

BGN

BGN

BGN

BGN

BGN

BGN

UNOFF

UNOFF
VARIANT

range

BGN

VARIANT

VARIANT

VARIANT

VARIANT

range

valley

stream

mine

summit

reservoir

reservoir

ppl

locale

VARIANT

$\begin{array}{ll}\text { BGN 1941 } & \text { Pinal } \\ \text { Maricopa } \\ \text { UNOFF } & \text { Pinal } \\ \text { BGN } & \text { Gila } \\ \text { BGN } & \text { Gila } \\ \text { BGN } & \text { Gila } \\ \text { BGN } & \text { Maricopa } \\ \text { UNOFF } & \text { Maricopa }\end{array}$

locale

valley

mine

locale

reservoir

locale

ppl

UNOFF
BGN
UNOFF
BGN
BGN
VARIANT
BGN
VARIANT
VARIANT
VARIANT
VARIANT
VARIANT

valley

BGN 1941

VARIANT

VARIANT

stream

cave

sumnit

gap

ppl

BGN

BGI 191

VARIANT

Maricopa

Apache

Yuma

Yavapai

Yavapai

Pima

Pima

avapai

avapai

342617 N1120625W

$341 B 26 N 1101225 \mathrm{~W}$

$344430 N_{1113418 W}$

$323836 \mathrm{N1094354W}$

$323850 N 1094724 \mathrm{~W}$

$343030 \mathrm{~N} 1114847 \mathrm{~W}$

$340044 \mathrm{~N} 1102817 \mathrm{~W}$

$325032 \mathrm{~N} 1121516 \mathrm{~W}$

$323613 \mathrm{~N} 1120826 \mathrm{~W}$

$323521 N 1120718 \mathrm{~W}$

$323521 \mathrm{~N} 1120718 \mathrm{~W}$

323756 N1094830

$340306 \mathrm{~N} 1102517 \mathrm{~W}$

SOURCE COORDINATE

ELEV

MAP NAME

2130 Vaya Chin

Estler Peak

Pinedale

Apache Maid Mtn

Artesia

Mt Graham

Camp Verde

Cibecue

Lost Horse Peak

Copperosity Hills

Kohatk

$323521 \mathrm{N1120718 \textrm {W }}$

$325543 N 1121411$

$331122 \mathrm{~N} 1120820 \mathrm{~W}$

$330400 \mathrm{~N} 1104730 \mathrm{~W}$

$334307 \mathrm{~N} 1100252 \mathrm{~W}$

$334159 \mathrm{~N} 1100222 \mathrm{~W}$

$334401 \mathrm{N1} 100119 \mathrm{~W}$

$332510 \mathrm{N1114121 \textrm {W }}$

$332445 \mathrm{~N} 1114246 \mathrm{~W}$

$323829 N 1121107 \mathrm{~W}$

$323923 N 1121155$

Haley Hills Montezuma Peak Hayden

6132 Velasquez Butte Velasquez Butte Velasquez Butte Buckhorn

Buckhorn

$332458 N 1114232 \mathrm{~W}$ $345139 \mathrm{N1} 090329 \mathrm{~W}$ $321056 \mathrm{~N} 1134631 \mathrm{~W}$ $342335 N 1122458 \mathrm{~W}$

344713N1130506W

345032 N1084608W

$315033 \mathrm{~N} 1113934 \mathrm{~W}$

$322758 \mathrm{~N} 1121433 \mathrm{~W}$

322001 N1105122W

$322250 N 1105213 W$

$321559 N 1105053 \mathrm{~W}$

$322250 N 1105213 k$

$322313 \mathrm{~N} 1121403 \mathrm{~W}$

360947 N1093931W

322410N1121405W

$322758 N 1121433 W$

$322909 \mathrm{~N} 1103812 \mathrm{~W}$

$322849 \mathrm{~N} 1103836 \mathrm{~W}$

$322001 \mathrm{N1} 105122 \mathrm{~W}$

$322055 \mathrm{N1} 104936 \mathrm{~W}$

$332442 \mathrm{~N} 1114324 \mathrm{~W}$

$333656 \mathrm{~N} 1120042 \mathrm{~W}$

$360725 \mathrm{~N} 1115258 \mathrm{~W}$

$312223 \mathrm{~N} 1105105 \mathrm{~W}$

park ADMIN Maricopa

BGN 1906 Coconino

Santa Cruz

VARIANT

ppl

locale

mine

mine

spring

VARIANT

Yavapai

343349 N1115113W

UNOFF

Yavapai

Yavapai

$344355 N 1120133 \mathrm{~W}$

$344424 \mathrm{~N} 1120716 \mathrm{~W}$

$344410 \mathrm{~N} 1120603 \mathrm{~W}$

$342119 \mathrm{~N} 1114233 \mathrm{~W}$

Cottonwood

1968

Yavapai

VARIANT

VARIANT

Yavapai
342119 N1114233W
Sabino Canyon

Sunnys lope

Buckhorn

Ceadro Spring SE

e Mountains

Scratch Canyon

Ventana

Sabino Canyon

Ventana

Ventana Mesa

Ventana

Mount Bigelow

Mount Bigelow

Sabino Canyon

Buckhorn

6257 Cape Royal

3960 Kino Springs spring 


\begin{tabular}{|c|c|c|c|c|c|c|c|}
\hline FEATURE NAME & $\begin{array}{l}\text { FEATURE } \\
\text { CLASS }\end{array}$ & STATUS & COUNTY & COORDINATE & $\begin{array}{l}\text { SOURCE } \\
\text { COORDINATE }\end{array}$ & $\begin{array}{l}\text { ELEV } \\
\text { FT }\end{array}$ & MAP NAME \\
\hline $\begin{array}{l}\text { Verde Meadows Park } \\
\text { Verde Park } \\
\text { Verde Real (subdivision) } \\
\text { Verde Rim } \\
\text { Verde Rim Trail } \\
\text { Verde River } \\
\quad \text { Rio Azul } \\
\text { Rio Verde } \\
\text { Verde River Meadows One } \\
\text { (subdivision) }\end{array}$ & $\begin{array}{l}\text { park } \\
\text { park } \\
\text { ppl } \\
\text { cliff } \\
\text { trail } \\
\text { stream }\end{array}$ & $\begin{array}{l}\text { ADMIN } \\
\text { ADNIN } \\
\text { BGN } \\
\text { BGN } 1981 \\
\text { UNOFF } \\
\text { BGN } \\
\text { VARIANT } \\
\text { VARIANT } \\
\text { BGN }\end{array}$ & $\begin{array}{l}\text { Pima } \\
\text { Maricopa } \\
\text { Maricopa } \\
\text { Yavapai } \\
\text { Yavapai } \\
\text { Maricopa } \\
\text { Yavapai }\end{array}$ & $\begin{array}{l}320943 \mathrm{~N} 1105710 \mathrm{~W} \\
332708 \mathrm{~N} 1120336 \mathrm{~W} \\
333736 \mathrm{~N} 1120854 \mathrm{~W} \\
342150 \mathrm{~N} 1114828 \mathrm{~W} \\
341713 \mathrm{~N} 1114735 \mathrm{~W} \\
333249 \mathrm{~N} 1113936 \mathrm{~W} \\
343458 \mathrm{~N} 1115213 \mathrm{~W}\end{array}$ & $345150 \mathrm{~N} 1122736 \mathrm{~W}$ & 1275 & $\begin{array}{l}\text { Tucson } \\
\text { Phoenix } \\
\text { Hedgpeth Hills } \\
\text { Tule Mesa } \\
\text { Tule Mesa } \\
\text { Granite Reef Dam } \\
\text { Camp Verde }\end{array}$ \\
\hline $\begin{array}{l}\text { Verde River Trail Number Eleven } \\
\text { Verde Saddle Tank } \\
\text { Verde Spring } \\
\text { Verde Tank } \\
\text { Verde Valley Lookout } \\
\text { Verde Valley School } \\
\text { Verdugo Park } \\
\text { Vermilion Cliffs Lodge } \\
\text { Vermillion Cliffs } \\
\quad \text { See Echo Cliffs }\end{array}$ & $\begin{array}{l}\text { trail } \\
\text { reservoir } \\
\text { spring } \\
\text { reservoir } \\
\text { locale } \\
\text { school } \\
\text { park } \\
\text { locale } \\
\text { cliff }\end{array}$ & $\begin{array}{l}\text { UNOFF } \\
\text { BGN } \\
\text { BGN } \\
\text { BGN } \\
\text { BGN } \\
\text { UNDFF } \\
\text { ADNIN } \\
\text { BGN } \\
\text { VARIANT }\end{array}$ & $\begin{array}{l}\text { Yavapai } \\
\text { Yavapai } \\
\text { Coconino } \\
\text { Yavapai } \\
\text { Yavapai } \\
\text { Yavapai } \\
\text { Pima } \\
\text { Coconino } \\
\text { Coconino }\end{array}$ & $\begin{array}{l}340706 \mathrm{~N} 1114212 \mathrm{~W} \\
342119 \mathrm{~N} 1114537 \mathrm{~W} \\
350159 \mathrm{~N} 1121058 \mathrm{~W} \\
342644 \mathrm{~N} 1114812 \mathrm{~W} \\
344543 \mathrm{~N} 1120420 \mathrm{~W} \\
344817 \mathrm{~N} 1114819 \mathrm{~W} \\
321237 \mathrm{~N} 1105858 \mathrm{~W} \\
364725 \mathrm{~N} 1114059 \mathrm{~W} \\
\\
362445 \mathrm{~N} 1113129 \mathrm{~W}\end{array}$ & & & $\begin{array}{l}\text { Chalk Mountain } \\
\text { Tule Mesa } \\
\text { May Tank Pocket } \\
\text { Horner Mtn } \\
\text { Clarkdale } \\
\text { Sedona } \\
\text { Tucson } \\
\text { Navajo Bridge }\end{array}$ \\
\hline $\begin{array}{l}\text { Vermillion Cliffs } \\
\text { Vernon } \\
\text { Vernon, Mount } \\
\text { Vernon Cemetery } \\
\text { Vernon Creek } \\
\text { Vernon Tank } \\
\text { Vesey Paradise } \\
\text { See Vaseys Paradise } \\
\text { Vesey School } \\
\text { Vesta Temple }\end{array}$ & $\begin{array}{l}\text { cliff } \\
\text { ppl } \\
\text { summit } \\
\text { cemetery } \\
\text { stream } \\
\text { reservoir } \\
\text { area } \\
\text { school } \\
\text { summit }\end{array}$ & $\begin{array}{l}\text { BGN } \\
\text { BGN } \\
\text { BGN } \\
\text { UNOFF } \\
\text { BGN } \\
\text { BGN } \\
\text { VARIANT } \\
\text { UNOFF } \\
\text { BGN } 1908\end{array}$ & $\begin{array}{l}\text { Mohave } \\
\text { Apache } \\
\text { Yavapai } \\
\text { Apache } \\
\text { Apache } \\
\text { Yavapai } \\
\text { Coconino } \\
\text { Pima } \\
\text { Coconino }\end{array}$ & $\begin{array}{l}365708 \mathrm{~N} 1124258 \mathrm{~W} \\
341527 \mathrm{~N} 1094132 \mathrm{~W} \\
335916 \mathrm{~N} 1123218 \mathrm{~W} \\
341432 \mathrm{~N} 1094157 \mathrm{~W} \\
341252 \mathrm{~N} 1094100 \mathrm{~W} \\
343335 \mathrm{~N} 1114220 \mathrm{~W} \\
362945 \mathrm{~N} 1115136 \mathrm{~W} \\
320935 \mathrm{~N} 1110425 \mathrm{~W} \\
360537 \mathrm{~N} 1121605 \mathrm{~W}\end{array}$ & $340635 N 1093754 W$ & 6913 & $\begin{array}{l}\text { Kaibab } \\
\text { Vernon } \\
\text { Red Picacho } \\
\text { Boundary Butte } \\
\text { Boundary Butte } \\
\text { Walker Mtn }\end{array}$ \\
\hline $\begin{array}{l}\text { Veterans Administration Center } \\
\text { See United States } \\
\quad \text { Veterans Hospital } \\
\text { Veterans Administration } \\
\text { Hospita? } \\
\text { V Fortytwo Spring } \\
\text { V-F Spring } \\
\text { VF Tank } \\
\text { V H Lassen Junior High School } \\
\text { Via Santee } \\
\text { See Viason Chin }\end{array}$ & $\begin{array}{l}\text { hospital } \\
\text { hospital } \\
\text { spring } \\
\text { spring } \\
\text { reservoir } \\
\text { school } \\
\text { locale }\end{array}$ & $\begin{array}{l}\text { VARIANT } \\
\text { UNOFF } \\
\text { BGN } \\
\text { BGN } \\
\text { BGN } \\
\text { UNOFF } \\
\text { VARIANT }\end{array}$ & $\begin{array}{l}\text { Yavapai } \\
\text { Maricopa } \\
\text { Navajo } \\
\text { Cochise } \\
\text { Gila } \\
\text { Maricopa } \\
\text { Pima }\end{array}$ & $\begin{array}{l}343317 N 1122706 \mathrm{~W} \\
332945 \mathrm{~N} 1120358 \mathrm{~W} \\
340716 \mathrm{~N} 1103307 \mathrm{~W} \\
321510 \mathrm{~N} 1101332 \mathrm{~W} \\
332030 \mathrm{~N} 1104953 \mathrm{~W} \\
332302 \mathrm{N1} 120502 \mathrm{~W} \\
320055 \mathrm{~N} 1121723 \mathrm{~W}\end{array}$ & & & $\begin{array}{l}\text { Phoenix } \\
\text { Spotted Mountain } \\
\text { Hookers Hot Springs } \\
\text { Pinal Peak } \\
\text { Phoenix }\end{array}$ \\
\hline $\begin{array}{l}\text { Via Santee } \\
\text { See Viason Chin } \\
\text { Viasoh Chin } \\
\text { See Viason Chin } \\
\text { Viason Chin } \\
\text { Baileys } \\
\text { Chico Baileys } \\
\text { Hardimui } \\
\text { Santi Vaya } \\
\text { Via Santee } \\
\text { Via Santee } \\
\text { Viasoh Chin } \\
\text { Visan Chin }\end{array}$ & $\begin{array}{l}\text { locale } \\
\text { locale } \\
\text { locale }\end{array}$ & $\begin{array}{l}\text { VARIANT } \\
\text { VARIANT } \\
\text { BGN 1941 } \\
\text { VARIANT } \\
\text { VARIANT } \\
\text { VARIANT } \\
\text { VARIANT } \\
\text { VARIANT } \\
\text { VARIANT } \\
\text { VARIANT } \\
\text { VARIANT }\end{array}$ & $\begin{array}{l}\text { Pima } \\
\text { Pima } \\
\text { Pima }\end{array}$ & $\begin{array}{l}320055 \mathrm{~N} 1121723 \mathrm{~W} \\
320055 \mathrm{~N} 1121723 \mathrm{~W} \\
320055 \mathrm{~N} 1121723 \mathrm{~W}\end{array}$ & & & Pisinimo \\
\hline $\begin{array}{l}\text { Viceroy Mine } \\
\text { Vicksburg } \\
\text { Vicksburg Junction } \\
\text { See Oesert Wells } \\
\text { Vicksburg Junction } \\
\text { Vicksburg Railroad Station } \\
\text { Victoria Mine } \\
\text { Victoria Mine } \\
\text { Victoria Peak } \\
\text { Victorine Crossing }\end{array}$ & $\begin{array}{l}\text { mine } \\
\text { ppl } \\
\text { ppl } \\
\text { locale } \\
\text { building } \\
\text { mine } \\
\text { mine } \\
\text { summit } \\
\text { locale }\end{array}$ & $\begin{array}{l}\text { UNOFF } \\
\text { BGN } \\
\text { VARIANT } \\
\text { BGN } \\
\text { UNOFF } \\
\text { UNOFF } \\
\text { UNOFF } \\
\text { BGN } \\
\text { BGN }\end{array}$ & $\begin{array}{l}\text { Santa Cruz } \\
\text { Yuma } \\
\text { Yuma } \\
\text { La Paz } \\
\text { La Paz } \\
\text { Pima } \\
\text { Mohave } \\
\text { Gila } \\
\text { Coconino }\end{array}$ & $\begin{array}{l}313613 \mathrm{~N} 1105025 \mathrm{~W} \\
334440 \mathrm{~N} 1134505 \mathrm{~W} \\
334230 \mathrm{~N} 1134915 \mathrm{~W} \\
33430 \mathrm{BN} 1134600 \mathrm{~W} \\
334443 \mathrm{~N} 1134512 \mathrm{~W} \\
315546 \mathrm{~N} 1125014 \mathrm{~W} \\
352024 \mathrm{~N} 1133705 \mathrm{~W} \\
334727 \mathrm{N1} 110800 \mathrm{~W} \\
343416 \mathrm{~N} 1110403 \mathrm{~W}\end{array}$ & & 5373 & $\begin{array}{l}\text { Vicksburg } \\
\text { Vicksburg } \\
\text { Lukeville } \\
\text { Valentine SE } \\
\text { Greenback Creek } \\
\text { Leonard Canyon }\end{array}$ \\
\hline $\begin{array}{l}\text { Victorine Tank } \\
\text { Victorio Peak } \\
\text { Victor Mine } \\
\text { Victor Mine } \\
\text { Victor Pasture } \\
\text { Victor Spring }\end{array}$ & $\begin{array}{l}\text { reservoir } \\
\text { summit } \\
\text { mine } \\
\text { mine } \\
\text { flat }\end{array}$ & $\begin{array}{l}\text { BGN } \\
\text { BGN } 1917 \\
\text { UNOFF } \\
\text { UNOFF } \\
\text { BGN } \\
\text { VARIANT }\end{array}$ & $\begin{array}{l}\text { Coconino } \\
\text { Gila } \\
\text { Santa Cruz } \\
\text { Yavapai } \\
\text { Gila }\end{array}$ & $\begin{array}{l}343439 \mathrm{~N} 1110506 \mathrm{~W} \\
\text { UNKNOWN } \\
313605 \mathrm{~N} 1104949 \mathrm{~W} \\
342741 \mathrm{~N} 1122313 \mathrm{~W} \\
334101 \mathrm{~N} 1101528 \mathrm{~W}\end{array}$ & & & $\begin{array}{l}\text { Leonard Canyon } \\
\text { Patagonia } \\
\text { Groom Creek } \\
\text { Popcorn Canyon }\end{array}$ \\
\hline
\end{tabular}




\begin{tabular}{|c|c|c|c|c|c|c|c|}
\hline FEATURE NAME & $\begin{array}{l}\text { FEATURE } \\
\text { CLASS }\end{array}$ & STATUS & COUNTY & COORDINATE & $\begin{array}{l}\text { SOURCE } \\
\text { COORDIMATE }\end{array}$ & $\begin{array}{c}\text { ELEV } \\
\text { FT }\end{array}$ & MAP MAME \\
\hline $\begin{array}{l}\text { Victory Lake } \\
\text { Viejo Central Branch, Canal } \\
\text { (historical) }\end{array}$ & $\begin{array}{l}\text { lake } \\
\text { canal }\end{array}$ & $\begin{array}{l}\text { BGN } \\
B G N\end{array}$ & $\begin{array}{l}\text { Coconino } \\
\text { Maricopa }\end{array}$ & $\begin{array}{l}353327 \mathrm{~N} 1114432 \mathrm{~W} \\
332417 \mathrm{~N} 1120142 \mathrm{~W}\end{array}$ & & & $\begin{array}{l}\text { S P Mountain } \\
\text { Phoenix }\end{array}$ \\
\hline $\begin{array}{l}\text { Viet Spring } \\
\text { View Point } \\
\text { View Point } \\
\text { Viewpoint Lake } \\
\text { View Points } \\
\text { View Point Trai? Number One } \\
\text { Hundred Five } \\
\text { View Point Well } \\
\text { Vigil Run } \\
\text { Vigor of Life Spring }\end{array}$ & $\begin{array}{l}\text { spring } \\
\text { cliff } \\
\text { summit } \\
\text { lake } \\
\text { bend } \\
\text { trail } \\
\text { well } \\
\text { stream } \\
\text { spring }\end{array}$ & $\begin{array}{l}\text { BGN } \\
\text { BGN } \\
\text { BGN } 1915 \\
\text { BGN } \\
\text { BGN } \\
\text { UNOFF } \\
\text { UNOFF } \\
\text { BGN } \\
\text { BGN }\end{array}$ & $\begin{array}{l}\text { Coconino } \\
\text { Coconino } \\
\text { Apache } \\
\text { Maricopa } \\
\text { Yavapai } \\
\text { Yavapai } \\
\text { Coconino } \\
\text { Apache } \\
\text { Gila }\end{array}$ & $\begin{array}{l}351824 N 1114244 \mathrm{~W} \\
345941 \mathrm{~N} 1114638 \mathrm{~W} \\
363155 \mathrm{~N} 1090948 \mathrm{~W} \\
333628 \mathrm{~N} 1121659 \mathrm{~W} \\
341206 \mathrm{~N} 112455 \mathrm{~W} \\
344135 \mathrm{~N} 1120735 \mathrm{~W} \\
\\
355754 \mathrm{~N} 1111419 \mathrm{~W} \\
341733 \mathrm{~N} 1092110 \mathrm{~W} \\
332436 \mathrm{~N} 1105536 \mathrm{~W}\end{array}$ & $341632 \mathrm{~N} 1092347 \mathrm{~W}$ & 5227 & $\begin{array}{l}\text { Humphreys Peak } \\
\text { Wilson Mountain } \\
\text { Cove } \\
\text { E) Mirage } \\
\text { Congress } \\
\text { Hickey Mountain } \\
\text { Goldtooth } \\
\text { Lyman Lake } \\
\text { Inspiration }\end{array}$ \\
\hline $\begin{array}{l}\text { Villa Buena } \\
\text { Villa Buena Ruin } \\
\text { Villa Buena Ruin } \\
\text { See Villa Buena } \\
\text { Villa Carmel Mobile Home Park } \\
\text { Villa de Paz (subdivision) } \\
\text { Village Center Shopping Center } \\
\text { Village Fairways (subdivision) } \\
\text { Village Grove Shopping Center } \\
\text { Village Meadows (subdivision) }\end{array}$ & $\begin{array}{l}\text { locale } \\
\text { locale } \\
\text { ppl } \\
\text { locale } \\
\text { ppl } \\
\text { locale } \\
\text { ppl }\end{array}$ & $\begin{array}{l}\text { BGN } \\
\text { VARIANT } \\
\text { VARIANT } \\
\text { UNOFF } \\
\text { BGN } \\
\text { UNOFF } \\
\text { BGN } \\
\text { UNOFF } \\
\text { BGN }\end{array}$ & $\begin{array}{l}\text { Maricopa } \\
\text { Maricopa } \\
\text { Maricopa } \\
\text { Maricopa } \\
\text { Maricopa } \\
\text { Maricopa } \\
\text { Maricopa } \\
\text { Cochise }\end{array}$ & $\begin{array}{l}332100 \mathrm{~N} 1121235 \mathrm{~W} \\
332100 \mathrm{~N} 1121235 \mathrm{~W} \\
333803 \mathrm{~N} 1120140 \mathrm{~W} \\
332959 \mathrm{~N} 112165 \mathrm{~W} \\
332148 \mathrm{~N} 1114716 \mathrm{~W} \\
333542 \mathrm{~N} 1115850 \mathrm{~W} \\
332705 \mathrm{~N} 1114710 \mathrm{~W} \\
313300 \mathrm{~N} 1101615 \mathrm{~W}\end{array}$ & & $\begin{array}{l}1425 \\
1030 \\
1380\end{array}$ & $\begin{array}{l}\text { Union Hills } \\
\text { Tolleson } \\
\text { Chandler } \\
\text { Paradise Valley } \\
\text { Mesa } \\
\text { Fort Huachuca }\end{array}$ \\
\hline $\begin{array}{l}\text { Village Meadows Elementary } \\
\text { School } \\
\text { Village Meadows School } \\
\text { Village of Gila Springs } \\
\text { (subdivision) } \\
\text { Village on the Lakes } \\
\text { (subdivision) } \\
\text { Village Park (subdivision) } \\
\text { Village Square Shopping Center } \\
\text { Villa Monte Vista (subdivision) }\end{array}$ & $\begin{array}{l}\text { school } \\
\text { school } \\
\text { ppl } \\
\text { ppl } \\
\text { ppl } \\
\text { locale } \\
\text { ppl }\end{array}$ & $\begin{array}{l}\text { UNOFF } \\
\text { UNOFF } \\
\text { BGN } \\
\text { BGN } \\
\text { BGN } \\
\text { UNOFF } \\
\text { BGN }\end{array}$ & $\begin{array}{l}\text { Cochise } \\
\text { Maricopa } \\
\text { Maricopa } \\
\text { Maricopa } \\
\text { Maricopa } \\
\text { Maricopa } \\
\text { Maricopa }\end{array}$ & $\begin{array}{l}313246 \mathrm{~N} 1101558 \mathrm{~W} \\
333857 \mathrm{~N} 1120610 \mathrm{~W} \\
331842 \mathrm{~N} 1115619 \mathrm{~W} \\
333055 \mathrm{~N} 1120045 \mathrm{~W} \\
\\
333503 \mathrm{~N} 1121200 \mathrm{~W} \\
332140 \mathrm{~N} 1114724 \mathrm{~W} \\
332340 \mathrm{~N} 1120320 \mathrm{~W}\end{array}$ & & $\begin{array}{l}1165 \\
1250 \\
1175 \\
1110\end{array}$ & $\begin{array}{l}\text { Fort Huachuca } \\
\text { Union Hills } \\
\text { Guadalupe } \\
\text { Sunnys lope } \\
\text { Glendale } \\
\text { Chandler } \\
\text { Phoenix }\end{array}$ \\
\hline $\begin{array}{l}\text { Vineyard Canyon } \\
\text { Vineyard Mountain } \\
\text { Vineyard Road Dam } \\
\text { Vineyard Spring } \\
\text { Vineyard Tank } \\
\text { Violas Peak } \\
\text { Violas Tit } \\
\text { Violas Tit } \\
\text { See Violas Peak } \\
\text { Violet Point }\end{array}$ & $\begin{array}{l}\text { valley } \\
\text { summit } \\
\text { dam } \\
\text { spring } \\
\text { reservoir } \\
\text { summit }\end{array}$ & $\begin{array}{l}\text { BGN } \\
\text { BGN } \\
\text { UNOFF } \\
\text { BGN } \\
\text { BGN } \\
\text { BGN } \\
\text { VARIANT } \\
\text { VARIANT } \\
\text { BGN } 1908\end{array}$ & $\begin{array}{l}\text { Gila } \\
\text { Gila } \\
\text { Pinal } \\
\text { Gila } \\
\text { Coconino } \\
\text { Yavapai }\end{array}$ & $\begin{array}{l}334152 \mathrm{~N} 1111036 \mathrm{~W} \\
334015 \mathrm{~N} 1111043 \mathrm{~W} \\
331918 \mathrm{~N} 1113142 \mathrm{~W} \\
334047 \mathrm{~N} 1111213 \mathrm{~W} \\
345955 \mathrm{~N} 1121328 \mathrm{~W} \\
341931 \mathrm{~N} 1131239 \mathrm{~W}\end{array}$ & $334023 \mathrm{~N} 1111302 \mathrm{~W}$ & 3832 & $\begin{array}{l}\text { Theo. Roosevelt Dam } \\
\text { Theo. Roosevelt Dam } \\
\text { Desert Well } \\
\text { Theo. Roosevelt Dam } \\
\text { Perkinsville } \\
\text { Ives Peak }\end{array}$ \\
\hline $\begin{array}{l}\text { Viopoli } \\
\text { See San Pedro } \\
\text { Viopuli } \\
\text { See San Pedro } \\
\text { Viopuli Wash } \\
\text { Virgen } \\
\text { See Virgin Canyon } \\
\text { Virgen Canyon } \\
\text { See Virgin Canyon } \\
\text { Virgen River } \\
\text { See Virgin River }\end{array}$ & $\begin{array}{l}\text { ppl } \\
\text { ppl } \\
\text { stream } \\
\text { valley } \\
\text { valiey } \\
\text { stream }\end{array}$ & $\begin{array}{l}\text { VARIANT } \\
\text { VARIANT } \\
\text { BGN } \\
\text { VARIANT } \\
\text { VARIANT } \\
\text { VARIANT }\end{array}$ & $\begin{array}{l}\text { Pima } \\
\text { Pima } \\
\text { Pima } \\
\text { Mohave } \\
\text { Mohave } \\
\text { Mohave }\end{array}$ & $\begin{array}{l}320500 \mathrm{~N} 1112915 \mathrm{~W} \\
320500 \mathrm{~N} 1112915 \mathrm{~W} \\
321538 \mathrm{~N} 1113519 \mathrm{~W} \\
360250 \mathrm{~N} 1140632 \mathrm{~W} \\
360250 \mathrm{~N} 1140632 \mathrm{~W} \\
360818 \mathrm{~N} 1142531 \mathrm{~W}\end{array}$ & $320023 N 1113152 \mathrm{~W}$ & & Koht Kohl Hill \\
\hline $\begin{array}{l}\text { Virgin Basin } \\
\text { Middle Basin } \\
\text { Middle Division } \\
\text { Middle Lake }\end{array}$ & bas in & $\begin{array}{l}\text { BGN } 1948 \\
\text { VARIANT } \\
\text { VARIANT } \\
\text { VARIANT }\end{array}$ & Mohave & $360718 \mathrm{~N} 1142645 \mathrm{~W}$ & & 1221 & Bonelli Bay \\
\hline
\end{tabular}


NATIONAL GAZETTEER--ARIZONA 1986

\begin{tabular}{|c|c|c|c|c|c|c|c|}
\hline FEATURE NAME & $\begin{array}{l}\text { FEATURE } \\
\text { CLASS }\end{array}$ & STATUS & COUNTY & COORDINATE & $\begin{array}{l}\text { SOURCE } \\
\text { COORDINATE }\end{array}$ & $\begin{array}{l}\text { ELEV } \\
\text { FT }\end{array}$ & MAP NAME \\
\hline $\begin{array}{l}\text { Virginia City (site) } \\
\text { New Virginia } \\
\text { Virginia Hill }\end{array}$ & $\begin{array}{l}\text { locale } \\
\text { summit }\end{array}$ & $\begin{array}{l}\text { BGN } \\
\text { VARIANT } \\
\text { BGN }\end{array}$ & $\begin{array}{l}\text { Mohave } \\
\text { Cochise }\end{array}$ & $\begin{array}{l}342 \mathrm{~B} 10 \mathrm{~N} 1133735 \mathrm{~W} \\
321437 \mathrm{~N} 1093430 \mathrm{~W}\end{array}$ & & & $\begin{array}{l}\text { Signal } \\
\text { Dos Cabezas }\end{array}$ \\
\hline $\begin{array}{l}\text { Virginia Park } \\
\text { Virgin Mountains } \\
\text { Bunkerville Mountains }\end{array}$ & $\begin{array}{l}\text { park } \\
\text { range }\end{array}$ & $\begin{array}{l}\text { ADMIN } \\
\text { BGN } 1962 \\
\text { VARIANT }\end{array}$ & $\begin{array}{l}\text { Maricopa } \\
\text { Mohave }\end{array}$ & $\begin{array}{l}332835 \mathrm{~N} 1120256 \mathrm{~W} \\
364905 \mathrm{~N} 1135032 \mathrm{~W}\end{array}$ & & & $\begin{array}{l}\text { Phoenix } \\
\text { Mount Bangs }\end{array}$ \\
\hline $\begin{array}{l}\text { Virgin Peak } \\
\text { Virgin Peak Ridge } \\
\text { Virgin River } \\
\text { Adams River } \\
\text { Pah-Roose River } \\
\text { Pilar River } \\
\text { Rio Fulfureo de las } \\
\text { Pyramides } \\
\text { Rio Pilar } \\
\text { Rio Virgen } \\
\text { Santa Clara River } \\
\text { Virgen River }\end{array}$ & $\begin{array}{l}\text { park } \\
\text { ridge } \\
\text { stream }\end{array}$ & $\begin{array}{l}\text { ADMIN } \\
\text { BGN } 1962 \\
\text { BGN } 1895 \\
\text { VARIANT } \\
\text { VARIANT } \\
\text { VARIANT } \\
\text { VARIANT } \\
\\
\text { VARIANT } \\
\text { VARIANT } \\
\text { VARIANT } \\
\text { VARIANT }\end{array}$ & $\begin{array}{l}\text { Yuma } \\
\text { Mohave } \\
\text { Mohave }\end{array}$ & $\begin{array}{l}332009 \mathrm{~N} 1133814 \mathrm{~W} \\
363740 \mathrm{~N} 1140610 \mathrm{~W} \\
360818 \mathrm{~N} 1142531 \mathrm{~W}\end{array}$ & $370944 N 1130051 \mathrm{~W}$ & 2646 & $\begin{array}{l}\text { Cementosa Wash } \\
\text { Hen Spring } \\
\text { Mesquite }\end{array}$ \\
\hline $\begin{array}{l}\text { Virgin Snow } \\
\text { See San Francisco Mountain } \\
\text { Virgus Canyon } \\
\text { Virtud Tank } \\
\text { Visan Chin }\end{array}$ & $\begin{array}{l}\text { summit } \\
\text { valley } \\
\text { reservoir }\end{array}$ & $\begin{array}{l}\text { VARIANT } \\
\text { BGN } \\
\text { BGN } \\
\text { VARIANT }\end{array}$ & $\begin{array}{l}\text { Coconino } \\
\text { Pinal } \\
\text { Pima }\end{array}$ & $\begin{array}{l}352027 \mathrm{~N} 1114057 \mathrm{~W} \\
325500 \mathrm{~N} 1103118 \mathrm{~W} \\
315222 \mathrm{~N} 1113432 \mathrm{~W}\end{array}$ & $324704 \mathrm{~N} 1102759 \mathrm{~W}$ & & $\begin{array}{l}\text { Brandenburg Mtn } \\
\text { Baboquivari Peak }\end{array}$ \\
\hline $\begin{array}{l}\quad \text { See Viason Chin } \\
\text { Vishnu Creek } \\
\text { Vishnu Temple } \\
\text { Visitor Center Campground } \\
\text { Vista Alegre (subdivision) }\end{array}$ & $\begin{array}{l}\text { locale } \\
\text { stream } \\
\text { summit } \\
\text { park } \\
\text { ppl }\end{array}$ & $\begin{array}{l}\text { BGN } 1906 \\
\text { BGN } 1906 \\
\text { ADMIN } \\
\text { BGN }\end{array}$ & $\begin{array}{l}\text { Pima } \\
\text { Coconino } \\
\text { Coconino } \\
\text { Coconino } \\
\text { Maricopa }\end{array}$ & $\begin{array}{l}320055 \mathrm{~N} 1121723 \mathrm{~W} \\
360319 \mathrm{~N} 1115945 \mathrm{~W} \\
360521 \mathrm{~N} 1115607 \mathrm{~W} \\
360257 \mathrm{N1} 120700 \mathrm{~W} \\
332225 \mathrm{~N} 1115017 \mathrm{~W}\end{array}$ & $360648 \mathrm{~N} 1115635 \mathrm{~W}$ & $\begin{array}{l}7529 \\
7000 \\
1210\end{array}$ & $\begin{array}{l}\text { Cape Royal } \\
\text { Cape Royal } \\
\text { Phantor Ranch } \\
\text { Chandler }\end{array}$ \\
\hline $\begin{array}{l}\text { Vista Catalina } \\
\text { See Catalina } \\
\text { Vista Catalina } \\
\text { Vista del Camino Park } \\
\text { Vista del Cerro (subdivision) } \\
\text { Vista del Prado Park } \\
\text { Vista del Pueblo Park } \\
\text { Vista Encantada } \\
\text { Vista School } \\
\text { VJ Tank }\end{array}$ & $\begin{array}{l}\text { ppl } \\
\text { ppl } \\
\text { park } \\
\text { ppl } \\
\text { park } \\
\text { park } \\
\text { locale } \\
\text { school } \\
\text { reservoir }\end{array}$ & $\begin{array}{l}\text { VARIANT } \\
\text { BGN } \\
\text { ADMIN } \\
\text { BGN } \\
\text { ADMIN } \\
\text { ADMIN } \\
\text { BGN } 1924 \\
\text { UNOFF } \\
\text { BGN }\end{array}$ & $\begin{array}{l}\text { Pima } \\
\text { Pima } \\
\text { Maricopa } \\
\text { Maricopa } \\
\text { Pima } \\
\text { Pima } \\
\text { Coconino } \\
\text { Maricopa } \\
\text { Graham }\end{array}$ & $\begin{array}{l}323000 \mathrm{~N} 1105514 \mathrm{~W} \\
323005 \mathrm{~N} 1105524 \mathrm{~W} \\
332732 \mathrm{~N} 1115451 \mathrm{~W} \\
333419 \mathrm{~N} 1115950 \mathrm{~W} \\
321103 \mathrm{~N} 1105041 \mathrm{~W} \\
321210 \mathrm{~N} 1110016 \mathrm{~W} \\
361350 \mathrm{~N} 1115822 \mathrm{~W} \\
333010 \mathrm{~N} 1120105 \mathrm{~W} \\
325447 \mathrm{~N} 1100207 \mathrm{~W}\end{array}$ & & $\begin{array}{l}3138 \\
1470\end{array}$ & $\begin{array}{l}\text { Oracle Junction } \\
\text { Tempe } \\
\text { Paradise Valley } \\
\text { Tucson East } \\
\text { Cat Mountain } \\
\text { Walhalla Plateau } \\
\text { Sunnys lope } \\
\text { Telegraph Wash }\end{array}$ \\
\hline $\begin{array}{l}\text { V J Tank } \\
\text { V K Windmill } \\
\text { V Lazy Y Cabin } \\
\text { V L Bar Tank } \\
\text { Vock Canyon } \\
\text { Vock Spring } \\
\text { Vock Wash } \\
\text { Vodka Tank } \\
\text { Voight Ranch } \\
\text { See Voigt Ranch }\end{array}$ & $\begin{array}{l}\text { reservoir } \\
\text { locale } \\
\text { locale } \\
\text { reservoir } \\
\text { valley } \\
\text { spring } \\
\text { stream } \\
\text { reservoir } \\
\text { locale }\end{array}$ & $\begin{array}{l}\text { BGN } \\
\text { BGN } \\
\text { BGN } \\
\text { BGN } \\
\text { BGN } \\
\text { BGN } \\
\text { BGN } \\
\text { BGN } \\
\text { VARIANT }\end{array}$ & $\begin{array}{l}\text { Coconino } \\
\text { Navajo } \\
\text { Yavapai } \\
\text { Coconino } \\
\text { Mohave } \\
\text { Mohave } \\
\text { Mohave } \\
\text { Pima } \\
\text { Apache }\end{array}$ & $\begin{array}{l}345650 \mathrm{~N} 1112457 \mathrm{~W} \\
350007 \mathrm{~N} 1101029 \mathrm{~W} \\
343122 \mathrm{~N} 1113503 \mathrm{~W} \\
353614 \mathrm{~N} 1123152 \mathrm{~W} \\
352616 \mathrm{~N} 1140124 \mathrm{~W} \\
352431 \mathrm{~N} 1140616 \mathrm{~W} \\
352853 \mathrm{~N} 1135913 \mathrm{~W} \\
321649 \mathrm{~N} 1103849 \mathrm{~W} \\
341944 \mathrm{~N} 1091347 \mathrm{~W}\end{array}$ & $\begin{array}{l}352452 \mathrm{~N} 1140842 \mathrm{~W} \\
352452 \mathrm{~N} 1140842 \mathrm{~W}\end{array}$ & 5141 & $\begin{array}{l}\text { Mormon Lake } \\
\text { Lee Mountain } \\
\text { Buckhorn Mountain } \\
\text { Howard Spring } \\
\text { Elements Canyon } \\
\text { Elements Canyon } \\
\text { Long Mountain } \\
\text { Agua Caliente Hill }\end{array}$ \\
\hline $\begin{array}{l}\text { Voigt Ranch } \\
\text { Voigt Ranch } \\
\quad \text { Voight Ranch } \\
\text { Vokjvaxia } \\
\text { See Chiulikam } \\
\text { Volcanic Mountain } \\
\text { Volcanic Well } \\
\text { Volunteer Canyon } \\
\text { Volunteer Mountain } \\
\text { Volunteer Tank }\end{array}$ & $\begin{array}{l}\text { locale } \\
\text { sumait } \\
\text { well } \\
\text { valley } \\
\text { summit } \\
\text { reservoir }\end{array}$ & $\begin{array}{l}\text { UNOFF } \\
\text { UNOFF } \\
\text { VARIANT } \\
\text { VARIANT } \\
\text { BGN } \\
\text { UNOFF } \\
\text { BGN } \\
\text { BGN } \\
\text { BGN }\end{array}$ & $\begin{array}{l}\text { Maricopa } \\
\text { Apache } \\
\text { Maricopa } \\
\text { Coconino } \\
\text { Coconino } \\
\text { Coconino }\end{array}$ & $\begin{array}{l}323428 \mathrm{~N} 1123131 \mathrm{~W} \\
343434 \mathrm{~N} 1093056 \mathrm{~W} \\
332132 \mathrm{~N} 1130630 \mathrm{~W} \\
350601 \mathrm{~N} 1115751 \mathrm{~W} \\
351305 \mathrm{~N} 1115341 \mathrm{~W} \\
351406 \mathrm{~N} 1115542 \mathrm{~W}\end{array}$ & $351425 \mathrm{~N} 1114701 \mathrm{~W}$ & & $\begin{array}{l}\text { Stinking Springs } \\
\text { Forth of July Butte } \\
\text { Sycamore Point } \\
\text { Garland Prairie } \\
\text { Garland Prairie }\end{array}$ \\
\hline $\begin{array}{l}\text { Volunteer Wash } \\
\text { Volunteer Wash } \\
\text { V O Mine } \\
\text { Vopelohavooka }\end{array}$ & $\begin{array}{l}\text { stream } \\
\text { stream } \\
\text { mine }\end{array}$ & $\begin{array}{l}\text { BGN } \\
\text { BGN } \\
\text { UNOFF } \\
\text { VARIANT }\end{array}$ & $\begin{array}{l}\text { Coconino } \\
\text { Coconino } \\
\text { Pima }\end{array}$ & $\begin{array}{l}350559 \mathrm{~N} 1115753 \mathrm{~W} \\
351501 \mathrm{~N} 1115002 \mathrm{~W} \\
321341 \mathrm{~N} 1120703 \mathrm{~W}\end{array}$ & $\begin{array}{l}351416 N 1114650 \mathrm{~W} \\
352047 \mathrm{~N} 1114411 \mathrm{~W}\end{array}$ & & $\begin{array}{l}\text { Sycamore Point } \\
\text { Wing Mountain } \\
\text { Gurli Put Vo }\end{array}$ \\
\hline $\begin{array}{l}\text { See Vopolo Havoka } \\
\text { Vopoki Ridge } \\
\text { Vopolo Havoka } \\
\text { Vopolo Havoka } \\
\text { Burro Pond } \\
\text { Burro Pond Village } \\
\text { Burro Pond Villages } \\
\text { Vopelohavooka }\end{array}$ & $\begin{array}{l}\text { locale } \\
\text { ridge } \\
\text { park } \\
\text { locale }\end{array}$ & $\begin{array}{l}\text { BGN } \\
\text { ADMIN } \\
\text { BGN } 1941 \\
\text { VARIANT } \\
\text { VARIANT } \\
\text { VARIANT } \\
\text { VARIANT }\end{array}$ & $\begin{array}{l}\text { Pima } \\
\text { Yuma } \\
\text { Pima } \\
\text { Pima }\end{array}$ & $\begin{array}{l}314533 N 1115525 \mathrm{~W} \\
322819 \mathrm{~N} 1141638 \mathrm{~W} \\
314609 \mathrm{~N} 1115636 \mathrm{~W} \\
314533 \mathrm{~N} 1115525 \mathrm{~W}\end{array}$ & & & $\begin{array}{l}\text { Vopoki Ridge } \\
\text { Cowlic } \\
\text { Cowlic }\end{array}$ \\
\hline Vosberg Mountain & summit & BGN & Gila & $340225 \mathrm{~N} 1105211 \mathrm{~W}$ & & 6150 & Gentry Mtn \\
\hline
\end{tabular}




\section{FEATURE NAME}

Vosburg Tank

Vosburg Trick Tank

V R Camp

$\checkmark$ Spring

$\checkmark \mathrm{THill}$

$\checkmark$ Thirtyseven Spring

V T Lake

See De Motte Park

V T Park Landing Strip

$\checkmark$ T Park Tourist Ranch

See De Motte Park

$\checkmark$ I Ridge Number One Tank

$V$ T Ridge Number Two Tank

Vturituc

See Sacaton

$V$-two Tank

Vulcan Mine

Vulcan Rapid

See Lava Falls Rapids

Vulcan Rapids

See Lava Falls Rapids

Vulcans Throne

Vultee Arch

Vultee Arch Twenty Two

Vuiture

Pumpkin Patch

Vulture City

Vulture City

See Vulture

Vulture Gold Mine Landing Strip

Vulture Mine

Vulture Mountains Vulture Range

Vulture Peak

Vulture Range

See Vulture Mountains

Vulture Siding

See Morristown
FEATURE
CLASS

reservoir

reservoir

locale

spring

summit

spring

lake

flat

airport ADMIN Coconino

flat

reservoir

reservoir

ppl

reservoir

mine

falls

falls

summit

arch

trail

locale

locale

airport

mine

range

sumait

range

ppl
STATUS

BGN Gila

BGN Gila

BGN

BGN

BGN

BGN

VARIANT

VARIANT

BGN

BGN

VARIANT

BGN

VARIANT

VARIANT

BGN

BGN
UNOFF

UNOFF

BGN
VARIANT

VARIANT

VARIANT

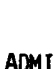

UNOFF

UNOF

VARIANT

BGN

VARIANT

VARIANT

Gila

Pima
COOROINATE

$340217 N 1105200 \mathrm{~W}$

$340320 \mathrm{~N} 1105243 \mathrm{~W}$

$314930 \mathrm{~N} 1104402 \mathrm{~W}$

$340312 N 1102452 \mathrm{~W}$

$362651 \mathrm{~N} 1120801 \mathrm{~W}$

335822 N1101520W

$362650 \mathrm{N1} 120739 \mathrm{~W}$

362509 N1120756W

362311 N1120750W

Coconino

Coconino

Coconino

Pinal

Coconino

Coconino

Mohave

Coconino

Coconino

Maricopa

Maricopa

Maricopa

Maricopa

Maricopa

Maricopa

Maricopa

Maricopa
$362509 \mathrm{~N} 1120756 \mathrm{~W}$

$362533 \mathrm{~N} 1120918 \mathrm{~W}$

$362405 N 1120915 \mathrm{~W}$

$330436 \mathrm{~N} 1114419 \mathrm{~W}$

$334048 \mathrm{~N} 1100003 \mathrm{~W}$

315857 N1110539W

361151 N1130459W

361151 N1130459W

$361308 \mathrm{~N} 1130436 \mathrm{~W}$

$345630 \mathrm{~N} 1114605 \mathrm{~W}$

$345620 \mathrm{~N} 1114633 \mathrm{~W}$

$334917 \mathrm{~N} 1125004 \mathrm{~W}$

$334917 N 1125004 \mathrm{~W}$

$334928 \mathrm{~N} 1124938 \mathrm{~W}$

$334918 \mathrm{~N} 1125006 \mathrm{~W}$

335306 N1124738W

335244N1124739W

335306 N1124738W
335124N1123721W $\begin{array}{ll}\text { SOURCE } & \text { ELEV } \\ \text { COORDINATE } & \text { FT }\end{array}$

MAP NAME

Gentry Mtn

Young

Empire Ranch

Cibecue

Kanabownits Spring

Carrizo

Kanabownits Spring

8785 De Motte Park

De Motte Park

De Motte Park

Velasquez Butte

Twin Buttes

5102 Vulcans Throne Wilson Mountain Wilson Mountain Vulture Mine

2110 Vulture Mine Vulture Mine Vuiture Peak

3658 Vulture Peak
W

Wabash Trailer Court

Wabayuma Peak

W A Canyon

Wadde 11

Waddell Substation

Wade Hampton Pit

Wade Hampton Pit Mine

Wades Butte

Wadsworths (historical)

Waggoner School

Waggoner Tank

Wagner Hill

Wagner Ranch

Wagner Tank

Wagner Tank

Wagner Tank

Wagner Tank

Wagner Tank

Wagner Wash

Wagner Wash Well

Wagon Bow Ranch

Wagon Box Oraw

Wagon Canyon

Wagon Canyon

\begin{tabular}{|c|c|c|c|}
\hline locale & UNOFF & Maricopa & $333413 \mathrm{~N} 1120351 \mathrm{~W}$ \\
\hline $\begin{array}{l}\text { sumnit } \\
\text { valley } \\
\text { locale } \\
\text { locale } \\
\text { basin } \\
\text { mine } \\
\text { sumit } \\
\text { spring } \\
\text { locale } \\
\text { school }\end{array}$ & $\begin{array}{l}\text { BGN } \\
\text { BGN } \\
\text { BGN } \\
\text { UNOFF } \\
\text { BGN } \\
\text { UNOFF } \\
\text { BGN } \\
\text { BGN } \\
\text { BGN } \\
\text { UNOFF }\end{array}$ & $\begin{array}{l}\text { Mohave } \\
\text { Graham } \\
\text { Maricopa } \\
\text { Maricopa } \\
\text { Cochise } \\
\text { Cochise } \\
\text { Yavapai } \\
\text { Coconino } \\
\text { Santa Cruz } \\
\text { Maricopa }\end{array}$ & $\begin{array}{l}345821 \mathrm{~N} 1135647 \mathrm{~W} \\
322945 \mathrm{~N} 1094230 \mathrm{~W} \\
333641 \mathrm{~N} 1122535 \mathrm{~W} \\
333545 \mathrm{~N} 1122530 \mathrm{~W} \\
312437 \mathrm{~N} 1095455 \mathrm{~W} \\
312436 \mathrm{~N} 1095455 \mathrm{~W} \\
340934 \mathrm{~N} 1123440 \mathrm{~W} \\
351805 \mathrm{~N} 1120208 \mathrm{~W} \\
313500 \mathrm{~N} 1104501 \mathrm{~W} \\
332034 \mathrm{~N} 1115521 \mathrm{~W}\end{array}$ \\
\hline $\begin{array}{l}\text { reservoir } \\
\text { summit } \\
\text { locale } \\
\text { reservoir } \\
\text { reservoir } \\
\text { reservoir } \\
\text { reservoir } \\
\text { reservoir } \\
\text { stream } \\
\text { well }\end{array}$ & $\begin{array}{l}\text { BGN } \\
\text { BGN } \\
\text { UNOFF } \\
\text { BGN } \\
\text { BGN } \\
\text { BGN } \\
\text { BGN } \\
\text { BGN } \\
\text { BGN } \\
\text { UNOFF }\end{array}$ & $\begin{array}{l}\text { Coconino } \\
\text { Coconino } \\
\text { Pinal } \\
\text { Maricopa } \\
\text { Coconino } \\
\text { Coconino } \\
\text { Coconino } \\
\text { Coconino } \\
\text { Maricopa } \\
\text { Maricopa }\end{array}$ & $\begin{array}{l}355601 \mathrm{~N} 1115147 \mathrm{~W} \\
350101 \mathrm{~N} 1120727 \mathrm{~W} \\
325413 \mathrm{~N} 1103359 \mathrm{~W} \\
334108 \mathrm{~N} 1123717 \mathrm{~W} \\
352011 \mathrm{~N} 1125100 \mathrm{~W} \\
354305 \mathrm{~N} 1121316 \mathrm{~W} \\
355955 \mathrm{~N} 1122023 \mathrm{~W} \\
360057 \mathrm{~N} 1122533 \mathrm{~W} \\
333521 \mathrm{~N} 1124355 \mathrm{~W} \\
333642 \mathrm{~N} 1124215 \mathrm{~W}\end{array}$ \\
\hline $\begin{array}{l}\text { locale } \\
\text { valley } \\
\text { valley } \\
\text { valley }\end{array}$ & $\begin{array}{l}\text { UNOFF } \\
\text { BGN } \\
\text { BGN } \\
\text { BGN }\end{array}$ & $\begin{array}{l}\text { Mohave } \\
\text { Coconino } \\
\text { Mohave } \\
\text { Apache }\end{array}$ & $\begin{array}{l}345407 \mathrm{~N} 1132613 \mathrm{~W} \\
350711 \mathrm{~N} 1110604 \mathrm{~W} \\
345231 \mathrm{~N} 1132937 \mathrm{~W} \\
365333 \mathrm{~N} 1094332 \mathrm{~W}\end{array}$ \\
\hline
\end{tabular}

$323027 N 1094457 W$

1280 Sunnys lope

7601 Wabayuma Peak Monk Draw Waddell

Wadde 11

Bisbee Bisbee

5344 Wagoner Sitgreaves Mtn Patagonia Guadalupe

Deer Tank

6710 May Tank Pocket Brandenburg Mtn White Tank Mts NE Seligman East Valle Tank Metzger Tank Chamisa Tank Wagner Wash Well Wagner Wash Well

Gonzales Wash Meteor Crater Gonzales Wash Mexican Water 
NATIONAL GAZETTEER--ARIZONA 1986 FEATURE NAME

Wagon Canyon Spring

Wagon Draw

Wagon Draw Tank

Wagoner

Wagoner Plaza Shopping Center

Wagoner Trail Number Two

Hundred Thirteen

Cellar Basin Trail

Wagon Lake Tank

Wagon Road Tank

Wagon Spring

Wagon Tire Flat

Wagon Tire Tank

Wagon Tire Wash

Tire Wash

Wagon Tongue Tank

Wagon Wheel Campground

Wagon Wheel Canyon

Wagon Wheel Lake

Wagon Wheel Mobile Ranch

Wagon Wheel Rest Area

Wagon Wheel Shopping Center

Wagon Wheel Trading Post

Wagon Wheel Wash

Wagon Wheel Well

Wagon Wheel Well

Wahak Hotontk

See Wahak Hotrontk

Wahak Hotrontk

San Simon

San Simon Indian Village

Tracys Trading Post

Wahak Hotontk

Wahl Knoll

awk Hudunik

Wah-shing Wash

See Vamori Wash

Wahweap

Wahweap Airport

Wahweap Bay

Wahweap Creek

Wahweap Lodge and Marina

Waif Mine

Wakefield Camp

Wakefield Canyon

Wakefield Junior High School

Wakefield Mine

Wakefield Spring

Walapa

Huaipai

Hualapai

Hualpai

Wallapai

Walapai Point

Walapai Point

See Montezuma Point

Walapai Railroad Station

Waldrip Airstrip

Waldroup Place Tank

Wa1droup Tank

Waldroup Tank

Walhalla Glades

$$
\text { Greenland Glades }
$$
Valhalla Glades

Walhalla Plateau Greenland Plateau Walker Valhalla Plateau

Walker Basin

Walker Bas in

Walker Bas in Tank
FEATURE

CLASS

STATUS COUNTY

COORDINATE

spring

reservoir

locale

locale

trail

BGN
$B G N$
$B G N$
BGN
UNOFF
UNOFF

Mohave

Navajo

Coconino

Yavapai

Maricopa

Yavapai

VARIANT

reservoir

reservoir

spring

reservoir

stream

reservoir

park

valley

BGN

BGN

BGN

BGN

BGN

VARIANT

BGN

Yavapai

BGN

Navajo

Gila

Greenlee

Yavapai

Yavapai

Yavapai

Apache

lake

locale

park

locale

locale

wel1

well

ppl

BGN Navajo

UNOFF

ADMIN

UNOFF

BGN

$B G N$

UNOFF

UNOFF

VARIANT

Maricopa

Mavajo

Maricopa

Coconino

Mohave

Gila

Mohave

Pima

Pima

VARIANT

VARIANT

VARIANT

VARIANT

VARIANT

VARIANT

VARIANT

stream

ppl

BGN

Apache

Pima

Coconino

$335929 N 1092247 \mathrm{~W}$

$315750 \mathrm{~N} 1121935 \mathrm{~W}$

$365948 \mathrm{~N} 1112922 \mathrm{~W}$

airport ADMIN Coconino 365920N1112947W

bay

strean

locale

mine

locale

valley

school

mine

spring

locale

Coconino

$370002 N 1112831 \mathrm{~W}$

$370002 \mathrm{~N} 1112831 \mathrm{~W}$

$36571 \mathrm{BN1112911 \textrm {W }}$

$341139 \mathrm{~N} 1112232 \mathrm{~W}$

$312402 \mathrm{~N} 1102128 \mathrm{~W}$

$315649 \mathrm{~N} 1103117 \mathrm{~W}$

$321105 \mathrm{~N} 1105814 \mathrm{~W}$

$312416 \mathrm{~N} 1102052 \mathrm{~W}$

315549 N1102952W

$352040 \mathrm{~N} 1135300 \mathrm{~W}$

$360915 \mathrm{~N} 1122031 \mathrm{~W}$

$361011 N 1122520 \mathrm{~W}$

$352048 \times 1135252 \mathrm{~W}$

$340900 \mathrm{~N} 1105600 \mathrm{~W}$

building UNOFF Mohave

airpore

reservoir

reservoir

reservoir

flat

BGN Yavapai

BGN Coconino

BGN Yavapai

BGN 1906 Coconino

VARIANT

VARIANT

plain BGN 1906 Coconino 361139N1115843W

VARIANT

VARIANT

ppl BGN

Yavapai

$342721 N 1122239 \mathrm{~W}$

basin BGN Santa Cruz 314008N1104853W

basin BGN Yavapai 343634N1113932W

reservoir BGN Yavapai 343637 N1113928W
$343935 N 1111527 \mathrm{~W}$ summit BGN
SOURCE
COORDINATE

Gonzales Wash

Potato Wash South

Chevelon Crossing

Wagoner

Glendale

Minnehaha

Hennessy Buttes

Forks Butte

Coronado Mtn

Matterhorn

Hell Point

350535N1122122W Hell Point

Pilot Knob

Lukachukai

Chediski Peak

$341800 \mathrm{~N} 1104259 \mathrm{~W}$

Pepper Canyon

1175 Tempe

Kayenta West

Tempe

$345434 \mathrm{N1134732W}$

4388 Caneron South

Pilgrim Wash

Mescal Warm Spring

Pilgrim Wash

Wahak Hotrontk

9764 Big Lake North

Page

3850 Page

373620N1114737W Warm Creek Bay

Page

Page

North Peak

Miller Peak

The Narrows

Tucson

Miller Peak

Mescal

Kingman Airport

Havasupai Point

Kingman Airport

5636 Oxbow Mtn

Apache Maid Mtn

Turkey Mtn

Apache Maid Mtn

Walhalla Plateau

Walhalla Plateau

Groom Creek

5520 Mt Wrightson

Walker Mtn

Walker Mtn 
FEATURE NAME

Walker Bas in Trai

Walker Bas in Trail

Walker Basin Trail Number One

Hundred Thirty Six

Walker Butte

Walker Butt

Walker Butte

Walker Butte Spring

Walker Canyon

Walker Canyon

Walker Canyon

See Walker Springs Canyon

Walker Creek

See Spring Creek

Walker Creek
Walker Creek

Gothic Wash

Walker Creek Reservoir

Walker Creek Spring

Walker Creek Tank

Walker Dam

Walker Gulch

Walker Hill

Walker Hill Tank

Walker Lake

Walker Lake

Walker Mine

Walker Mountain

Walker Park Tank

Walker Peak

Walker Place Windmil

Walker Ranch

Walker Rim Tank

Walker School

Walker Spring

See Walker Springs

Walker Spring Canyon

See Walker Springs Canyon

Walker Springs

$$
\text { Walker Spring }
$$

Walker Springs

Walker Springs Canyon

Walker Canyon

Walker Spring Canyon

Walker Substation

Walker Tank

Walker Tank

Walker Tank

Walker Tank

Walker Tank

Walker Tank

Walking Cane Ranch

Walk Moore Canyon

Walkover Mine

Walkover Tank

Wall

See Kuakatch

Linskey

Wallace Administrative City (USFS)

Wallace Butte

Thurso

Thurso Butte

Wallace Canyon

Wallace Lake

Wallace School

Wallace Spring

Wallace Tank

Wallace Tank

Wallace Tank

\section{FEATURE}

CLASS

STATUS

COUNTY

trai

trai

UNOFF

UNOFF

Yavapai

Santa Cruz

COORDINATE

trail

summit

BGN
BGN
BGN

Pinal

Greenle

Apache

BGN Greenlee

spring

valley

valley

stream

stream

stream

BGN $\quad$ Santa Cruz

Santa Cruz

VARIANT

VARIANT

Pinal

Yavapai

Yavapai

BGN 1915 Apache

VARIANT

reservoir
spring
reservoir
dam
valley
summit
reservoir
lake
lake
mine

BGN
BGN
BGN
UNOFF
BGN
BGN
BGN
BGN
BGN 1933
UNOFF

Apache

Yavapai

Yavapai

Santa Cruz

Yavapai

Coconino

Coconino

Santa Cruz

summit

reservoir

summit

locale

locale

reservoir

school

BGN

BGN

BGN

BGN

UNOFF

BGN

spring

VARIANT

valley

VARIANT

Yavapai

Gila

Mohave

Yavapai

Cochise

Pinal

Pinal

spring

spring

valley

local

reservoir

reservoir

reservoir

BGN

VARIANT

BGN

VARIANT

VARIANT

UNOFF

BGN

BGN

reservoir

reservoir

reservoir

locale

valley

mine

reservoir

ppl
locale

BGN
BGN
BGN

BGN

UNOFF

BGN

UNOFF
BGN

VARIANT

UNOFF

VARIANT

Pinal

Mohave

Pinal

Yavapai

Santa Cruz

Gila

Coconino

Yavapai

Yavapai

Yavapai

Coconino

Gila

Mohave

Mohave

Pima

La Paz

locale

UNOFF

Coconino

summit

valley

lake

school

spring

reservoir

BGN 1908

VARIANT

VARIANT

BGN

BGN

BGN

UNOFF
BGN

$B G N$
$B G N$

Coconino

Coconino

Yuma

Coconino

Apache

reservoir

reservoir
BGN

BGN
Coconino

Coconino
$312029 \mathrm{~N} 1110539 \mathrm{~W}$

$345422 \mathrm{~N} 1132026 \mathrm{~W}$
$343358 \mathrm{~N} 1105435 \mathrm{~W}$

$343625 \mathrm{~N} 1113817 \mathrm{~W}$

$343819 N 1114058 \mathrm{~W}$

$330353 \mathrm{~N} 1113050 \mathrm{~W}$

$331110 \mathrm{N1091824 \textrm {W }}$

364613 N1092920W

$331133 \mathrm{~N} 1091843 \mathrm{~W}$

$312539 N 1110316 \mathrm{~W}$

313955 N1104710W

$330210 \mathrm{~N} 1103319 \mathrm{~W}$

343738 N1113934W

$343859 N 1114355 \mathrm{~W}$

$365742 N 1094133 \mathrm{~W}$

$365642 \mathrm{~N} 1093623 \mathrm{~W}$

$340238 \mathrm{~N} 1122523 \mathrm{~W}$

$343703 \mathrm{~N} 1113908 \mathrm{~W}$

$340132 \mathrm{~N} 1122531 \mathrm{~W}$

$351652 \mathrm{~N} 1115048 \mathrm{~W}$

$351713 \mathrm{~N} 1115112 \mathrm{~W}$

$342505 \mathrm{~N} 1101557 \mathrm{~W}$

$352334 \mathrm{~N} 1114355 \mathrm{~W}$

$314003 \mathrm{~N} 1104914 \mathrm{~W}$

343705 N1113936W

$333617 N 1102002 \mathrm{~W}$

$342038 \mathrm{~N} 1123718 \mathrm{~W}$

$320417 \mathrm{~N} 1100449 \mathrm{~W}$

$343551 \mathrm{~N} 1113859 \mathrm{~W}$

$321807 N 1110006 \mathrm{~W}$

330312N1103117W

$330210 N 1103319 \mathrm{~W}$

330312 N1103117W

350029 N1141920W

$330210 \mathrm{~N} 1103319 \mathrm{~W}$

$342730 \mathrm{~N} 1122226 \mathrm{~W}$

$312410 \mathrm{~N} 1110334 \mathrm{~W}$

$335703 \mathrm{~N} 1100311 \mathrm{~W}$

$343400 \mathrm{~N} 1112603 \mathrm{~W}$

343847 N1124738W

$345925 \mathrm{~N} 1131347 \mathrm{~W}$

$351223 \mathrm{~N} 1112031 \mathrm{~W}$

$342208 \mathrm{~N} 1111416 \mathrm{~W}$

$352048 \mathrm{~N} 1133608 \mathrm{~W}$

$352503 N 1133417 \mathrm{~W}$

$320815 \mathrm{~N} 1123944 \mathrm{~W}$

$335945 \mathrm{~N} 1140927 \mathrm{~W}$

$342256 \mathrm{~N} 1111319 \mathrm{~W}$

$361326 \mathrm{~N} 1122146 \mathrm{~W}$

$350405 N 1110353 \mathrm{~W}$

$345456 \mathrm{~N} 1112536 \mathrm{~W}$

$340 \mathrm{~B} 29 \mathrm{~N} 1141722 \mathrm{~W}$

$345529 N 1112927 \mathrm{~W}$

$345225 \mathrm{~N} 1094502 \mathrm{~W}$

$350113 \mathrm{~N} 1110916 \mathrm{~W}$

$352916 \mathrm{~N} 1114936 \mathrm{~W}$

$\begin{array}{cc}\text { SOURCE } & \text { ELEV } \\ \text { COORDINATE } & \text { FT }\end{array}$

Walker Mtn

Casner Butte

Mt Wrightson

1988 Blackwater 


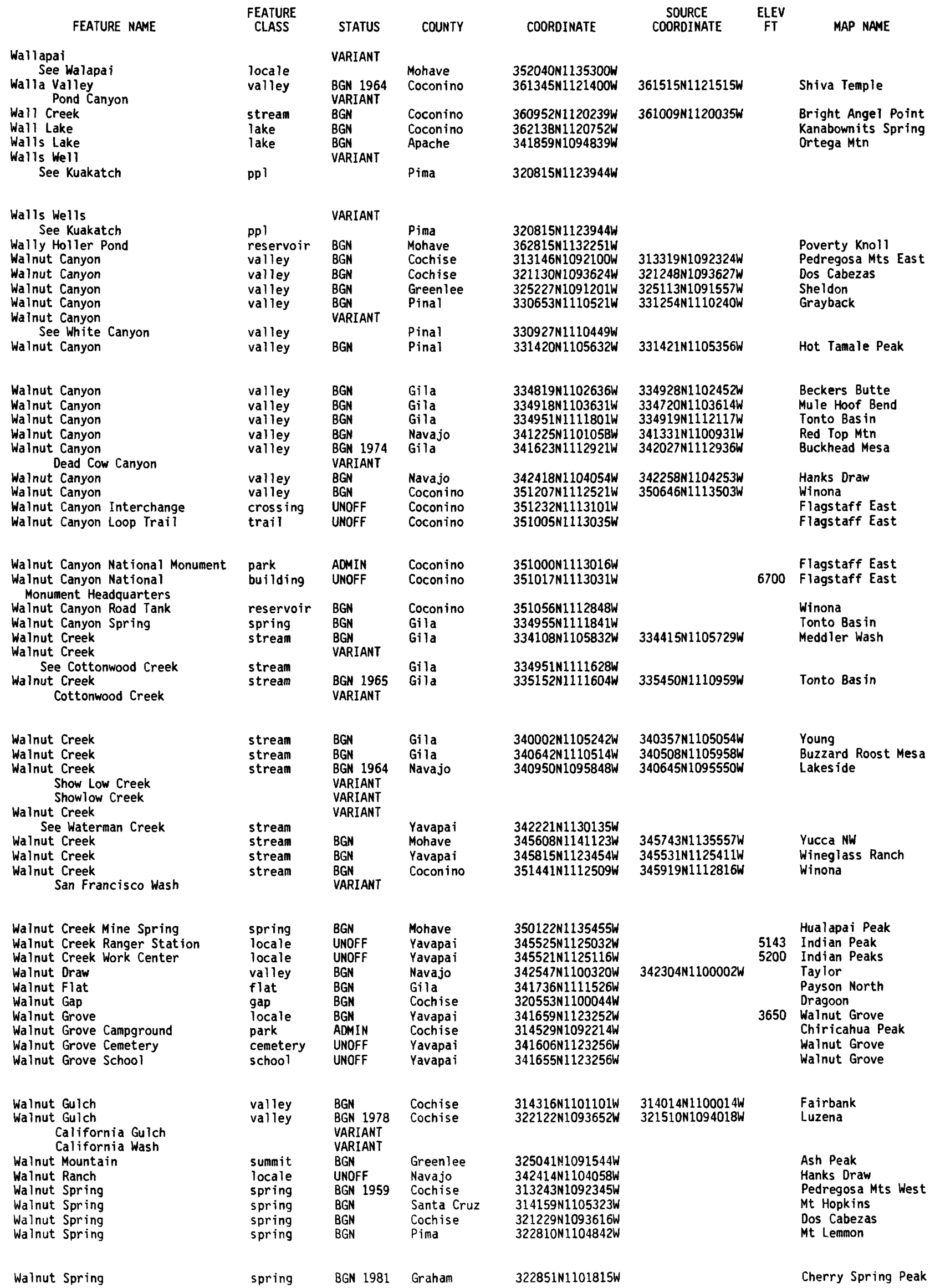




\section{FEATURE MAME}

Walnut Spring

Walnut Spring

Walnut Spring

Walnut Spring

Walnut Spring

Walnut Spring

Walnut Spring

Walnut Spring

Walnut Spring

Walnut Spring

Walnut Spring

Walnut Spring

Walnut Spring

Walnut Spring

Walnut Spring

Walnut Spring

Walnut Spring

Walnut Spring

Walnut Spring

Walnut Spring

Walnut Spring

Walnut Spring

Walnut Spring

Walnut Spring

Walnut Spring

Walnut Spring

Walnut Spring

Walnut Spring

Walnut Spring

Walnut Spring

Walnut Spring Canyon

Walnut Springs

Walnut Springs

Walnut Springs

Walnut Springs

Walnut Tank

Wainut Tank

Walnut Wash

Walnut Well

Walnut Well

Walpi

Ash Hill Terrace

Gaspe

Gualpi

Hualpi

Kuchapturela

Valpee

Wolpi

Wa]tenburg Canyon

See Walthenberg Canyon

Waltenburg Rapids

See Walthenberg Rapids

Walter Douglas School

Douglas School

Waiter $J$ Meyer School

Walter Shelley Reservoir Walter Shelly Reservoir

Walter Shelly Reservoir

See Waiter Shelley Reservoir

Walter Spreader Tank

Walters Well

Walthenberg Canyon Waltenburg Canyon Wal thenburg Canyon

Walthenberg Rapids

Waltenburg Rapids

Wal thenburg Rapids

Walthenburg Canyon

See Waithenberg Canyon
FEATURE
CLASS

spring

spring

spring

spring

spring

spring

spring

spring

spring

spring

spring

spring

spring

spring

spring

spring

spring

spring

spring

spring

spring

spring

spring

spring

spring

spring

spring

spring

spring

spring

valley

spring

spring

spring

spring

reservoir

reservoir

stream

well

locale

$$
\text { UNOFF }
$$

UNOFF

BGN

VARIANT

VARIANT

VARIANT

VARIANT

VARIANT

VARIANT

VARIANT

VARIANT

valley

rapids

school

school

reservoir

reservoir

VARIANT

UNOFF

VARIANT

UNOFF

VARIANT

VARIANT

Coconino

361421N1122420W

Coconino

Pima

Cochise

Mohave

Mohave

$361415 N 1122430 \mathrm{~W}$

$314258 \mathrm{N1} 100334 \mathrm{~W}$

363230 N11 $32509 \mathrm{~W}$

363230N1132509W

reservoir

well

valley

BGN

UNOFF

Yavapai

Coconino

BGN 1964 Coconino

VARIANT

VARIANT

rapids

BGN 1964

VARIANT

VARIANT

VARIANT

valley

Coconino

$350230 N 1124735 \mathrm{~W}$

$350035 N 1111723 \mathrm{~W}$

$361421 \mathrm{~N} 1122420 \mathrm{~W}$

$361415 N 1122430 \mathrm{~W}$ $\begin{array}{cc}\text { SOURCE } & \text { ELEV } \\ \text { COORDINATE } & \text { FT }\end{array}$

MAP NAME

Greasewood Mountain

Eureka Ranch

Oak Grove Canyon

Markhan Creek

Teapot Mountain

Mitchell Peak

Hot Tamale Peak

Mitchell Peak

Iron Mountain

Inspiration

Pinyon Mtn

Chrome Butte

Strayhorse

Chrome Butte

Picture Mtn

Lion Mountain

Round Top Mtn

Humboldt Mtn

Cibecue

Gentry Mtr

Lakes ide

Brooklyn Peak

Parallel Canyon

Battleship Butte

Buckhead Mesa

Taylor

Horner Mtn

Cherry

4823 Cedar Basin

Mohon Peak

Valent ine

Humboldt Mtn

Black Diamond Peak

Ash Peak

Weber Peak

Hickey Mountain

Strayhorse

Red Top Mtn

Cochise

Oracle Junction

Sheep Basin Mtn

Polacca

Tucson North

Tombstone

Little Tanks

Red Mountain

$361421 N 1122420 \mathrm{~W}$

Explore

Explorers Monument 
NATIONAL GAZETTEER--ARIZONA 1986

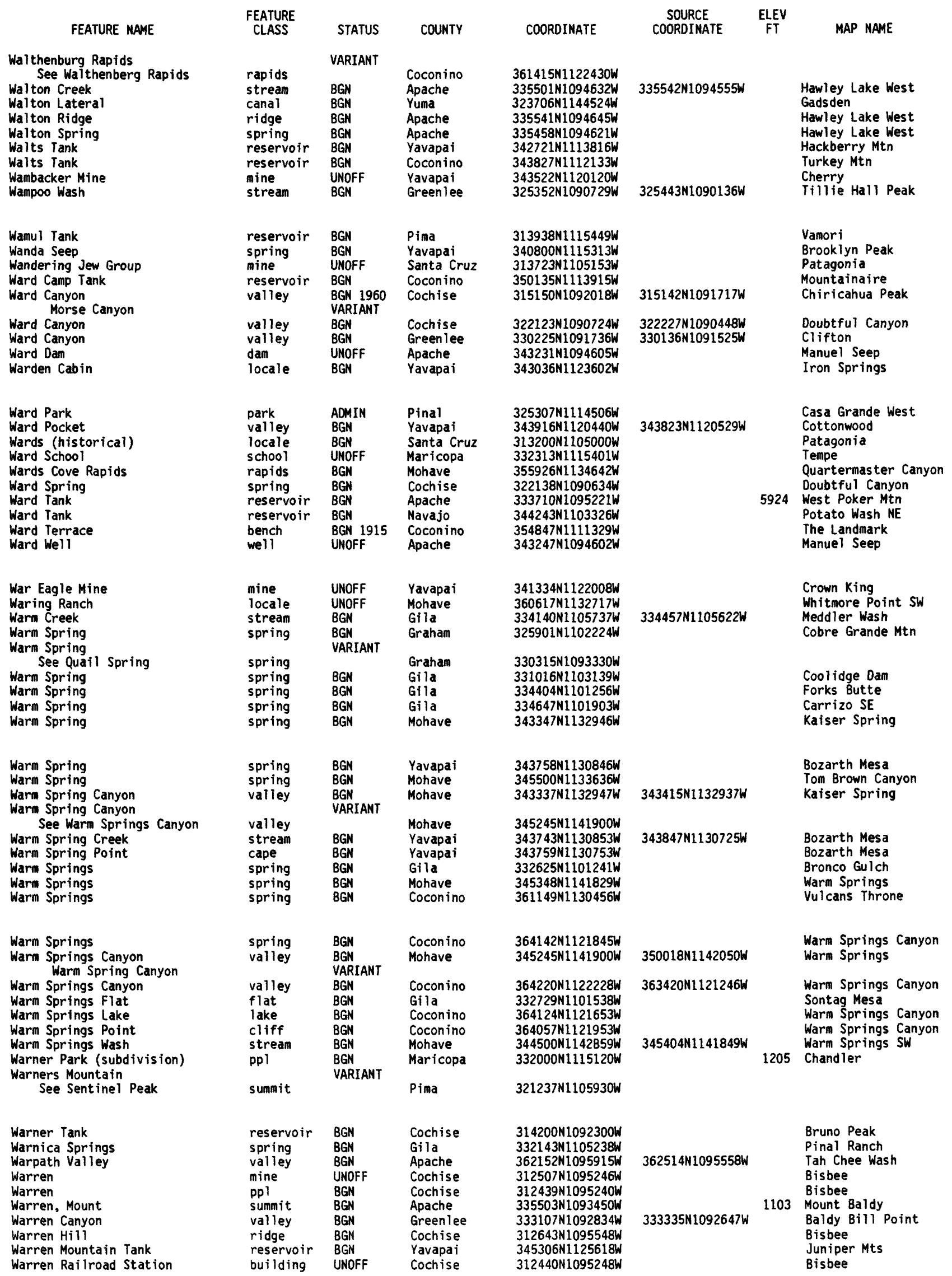


NATIONAL GAZETTEER--ARIZONA 1986

\section{FEATURE NAME}

Warren School

Warren Well

Warrior Canyon

Wars aw Canyon

Tres Anegos Gulch

Wars aw Guch

See Scribner Gulch

Warsaw Spring

Warsaw Tank

Washboard Creek

See Washboard Wash

Washboard Wash

Washboard Creek

Washboard Well

Wash de Flag

See Flag, Rio de

Wash Dug Wel

Washedout Tank

Washington, Mount

Washington Camp

Washington Elementary School

Washington Elementary School

Washington Gulch

Washington High School

Washington Mini Park Site

Washington Park

Washington Park

Washington School

Washington School

Washington School

Washington School

Washington Spring

Washington Trailer Park

Washington Well

Wash Out Tank

Wash Tank

Wash Tub Tank

Wasp Canyon

Wasp Spring

Wasson Peak

Amole Peak

Wassons Peak

Wasson Peak

Wassons Peak

See Wasson Peak

Watahomigi Point

Watahomiji Tank

W A Tank

Wata Ridges, The

Wata Spring

Water Bag Spring

Water Canyon

Water Canyon

Water Canyon

Water Canyon

Water Canyon

Water Canyon

Water Canyon

Water Canyon Creek

Water Canyon Point

Water Canyon Reservoir

Waterdog Recreational Site United States Air Force Recreation Area

Water Dog Tank

Waterfall Canyon

Waterfall Dam

Waterfall Rapids

Waterfall Spring

Waterfa11 Spring
FEATURE
CLASS

school

well

valley

valley

valley
spring

reservoir

STATUS

COUNTY

UNOFF

UNOFF

BGN

BGN 1978

VARIANT

VARIANT

VARIANT

\section{VARIAN}

stream

stream

well

\section{BGN}

VARIANT

UNOFF

VARIANT

stream

well

reservoir

UNOFF

BGN

summit

locale

school

school

valley

school

park

park

ppl

school

school

\section{BGN}

UNOFF

BGN

UNOFF
ADMIN

ADMIN

$B G N$

UNOFF

UNOFF

\section{Pima}

Cochise

Gila

Santa Cruz

Santa Cruz

Santa Cruz

$312353 \mathrm{~N} 1111450 \mathrm{~W}$

$312522 \mathrm{~N} 1111548 \mathrm{~W}$

$320845 N 1110224 \mathrm{~W}$

$332424 N 105031 \mathrm{~W}$

$312410 \mathrm{~N} 1111430 \mathrm{~W}$

$312542 \mathrm{N1111629W}$

Navajo

Navajo

Navajo

Coconino

Navajo

Coconino

Santa Cruz

$344843 \mathrm{~N} 1100402 \mathrm{~W}$
$344843 \mathrm{N1} 100402 \mathrm{~W}$

344030N1101519W

$351430 \mathrm{~N} 111250 \mathrm{~W}$

$351053 \mathrm{~N} 1102149 \mathrm{~W}$

$360622 \mathrm{~N} 1122746 \mathrm{~W}$

312112 N1104329W

Santa Cruz

Maricopa

Navajo

Santa Cruz

Maricopa

Pinal

Maricopa

Gila

Maricopa

Maricopa

schoo

UNOFF

Maricopa

Yavapai

school
spring

spring

well

BGN

UNOFF

reservoir

reservoir

reservoir $B G N$

valley

spring

$B G N$

BGN

BGN

summit

BGN 1969 Pima

VARIANT

VARIANT

summit BGN 1941 Yavapai

VARIANT

summit

cliff

reservoir

reservoir

ridge

$\begin{array}{ll}\text { BGN 1925 } & \text { Pima } \\ \text { BGN } & \text { Coconino } \\ \text { BGN } & \text { Graham } \\ \text { BGN } & \text { Maricopa }\end{array}$

$312255 \mathrm{~N} 1104126 \mathrm{~W}$

$332303 \mathrm{~N} 1115245 \mathrm{~W}$

350142 N1104151W

$312152 \mathrm{~N} 1104000 \mathrm{~W}$

333216 N1120622W

$324525 \mathrm{~N} 1113338 \mathrm{~W}$

333200 N1120618W

342528 N1111601W

$332527 \mathrm{N111} 4945 \mathrm{~W}$

332655 N1 $120340 \mathrm{~W}$

333315 N1120656W $343235 \mathrm{~N} 1122751 \mathrm{~W}$ $342603 \mathrm{~N} 1111619 \mathrm{~W}$

$332655 \mathrm{N1120025 \textrm {W }}$

$353215 \mathrm{~N} 1091154 \mathrm{~W}$

350717 N1122556W

323435 N1094318W

$350949 \mathrm{~N} 1122212 \mathrm{~W}$

$315002 \mathrm{~N} 1104355 \mathrm{~W}$

$321019 \mathrm{~N} 1103726 \mathrm{~W}$

$321624 N 1110848 W$

$341105 \mathrm{~N} 1122041 \mathrm{~W}$

$321624 N 1110848 \mathrm{~W}$

$361450 \mathrm{~N} 1124302 \mathrm{~W}$

$360637 \mathrm{N1122524 \textrm {W }}$

$322952 \mathrm{N1094353W}$

$334039 \mathrm{~N} 1112252 \mathrm{~W}$

spring

spring

valley

valley

valley

valley

valley

valley

valley

BGN Maricopa 333903N1112438W

BGN Navajo 340535N1103308W

BGN Graham

BGN Pinal

BGN Greenlee

BGN Apache

BGN Navajo

BGN Mohave

$B G N$

Coconino

stream

Apache

cliff
reservoir

BGN

BGN

VARIANT

Mohave

Apache

park

reservoir

valley

dam

rapids

$B G N$

$B G N$

UNOFF

BGN

Graham

Navajo

Mohave

spring

BGN

Gila

$324918 N 1100623 \mathrm{~W}$

$330426 \mathrm{~N} 1102735 \mathrm{~W}$

$331621 \mathrm{~N} 1092927 \mathrm{~W}$

$340643 \mathrm{~N} 1091842 \mathrm{~W}$

$341516 \mathrm{~N} 1101417 \mathrm{~W}$

363354 N1124519W

$364312 \mathrm{~N} 1123728 \mathrm{~W}$

$340648 \mathrm{~N} 1091843 \mathrm{~W}$

343809 N1101808W

Woodruff

Dry Lake NE

5459 Rotten Bananas Butte Chamisa Tank

7221 Duquesne

Harshaw

Tempe

Winslow

$312310 \mathrm{N1104230 \textrm {W }}$

Duquesne

Sunnys lope

Eloy North

Sunnys lope

Kehl Ridge

Mesa

Phoen ix

$314926 \mathrm{~N} 1104557 \mathrm{~W}$

324852 N1101045W 
NATIONAL GAZETTEER--ARIZONA 1986

\section{FEATURE NAME}

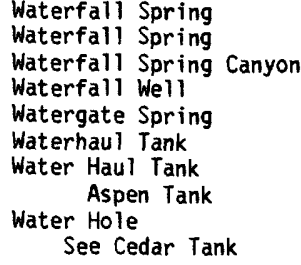

Waterfall Spring

Waterfall Spring

Waterfall Spring Canyon

Waterfall Well

Watergate Spring

Waterhaul Tank

Water Haul Tank Aspen Tank

Water Hole

See Cedar Tank

Waterhole Canyon

Waterhole Spring

Jim Creek Waterhole Spring

Water Hole Tank

Waterman Creek

WaInut Creek

Waterman Mountains

Waterman Mountains

See Silver Bell Mountains

Waterman Pass

Waterman Peak

Waterman Wash

Watermelon Tank

Water on the Rock Spring

Water Pockets

Water Pockets Tank

Waters Draw

Waters Draw Spring

Waters Peak

Water Spring

Waters Wash

Water Tank Number Eight

Water Tank Number One

Water Tank Number One and One-Half

Water Tank Number Seven

Water Tank Number Six

Water Tank Number Two

Water Thief Canyon

Water Trough Canyon

Water Trough Spring

Water Trough Well

Water under the Rock Pond

Water Users Camp Ten

Water Users Yaqui Camp

Watkins Ranch

Watson Lake

Watson Lake

Watson Lake Park

Watson Ranch

Watson Spring

Watson Tank

Watson Wash

Watson Windmill

Watters Tank

Watts Airport

Watts Creek

Watts Spring

Watt Windmili

Waughtal Spring

Wauneta Trading Post

Wavuer Mountain

See Sentinel Peak

W A Wash

W A Well

Wawk Hudunik

See Wahak Hotrontk

Wayne

Waynes Well

W C P Peak
FEATURE
CLASS

STATUS

COUNTY

COORDINATE

$\begin{array}{ll}\text { spring } & \text { BGN } \\ \text { spring } & \text { BGN } \\ \text { valley } & \text { BGN } \\ \text { well } & \text { UNOFF } \\ \text { spring } & \text { BGN } \\ \text { reservoir } & \text { BGN } \\ \text { reservoir } & \text { BGN } \\ & \text { VARIANT } \\ & \text { VARIANT }\end{array}$

reservoir

ARIANT

valley

spring

BGN

BGN

VARIANT

reservoir

stream

summit

\section{BGN}

BGN

VARIANT

BGN

summit

gap

summit

reservoi

spring

basin

reservoir

valley

spring

summit

BGN
BGN
BG
BG
BGN
BGN
BGI
BG
BGN
BG

spring

stream

reservoir

reservoir

reservoir

reservoir

reservoir

reservoir

valley

spring

we 1

lake

locale

locale

locale

lake

reservoir

park

locale

spring

reservoir

stream

locale

reservoir

airport

stream

spring

locale

BGN

$B G N$

BGN

BGN

BGN

BGN

Coconino

Coconino

Coconino

BGN Gila

BGN

UNOFF

BGN

UNOFF

UNOFF

UNOFF

BGN

BGN

Gila

Coconino

Coconino

Maricopa

Maricopa

Cochise

Coconino

Yavapai

Yavapai

UNOFF Cochise

BGN Yavapai

BGN

BGN

Coconino

Graham

Cochise

Yavapai

Maricopa

Apache

BGN

Coconino

Cochise

spring

BGN
BGN

Cochise

locale

summit

stream

well

ppl

locale

well

BGN

La Paz
$344319 N 1114230 \mathrm{~W}$

$360656 \mathrm{~N} 1110728 \mathrm{~W}$

\begin{tabular}{ccc}
$\begin{array}{c}\text { SOURCE } \\
\text { COORDINATE }\end{array}$ & $\begin{array}{c}\text { ELEV } \\
\text { FT }\end{array}$ & \multicolumn{1}{c}{ MAP NAME } \\
361820 N1094854W & & $\begin{array}{l}\text { Sweathouse Peak } \\
\text { Walker Creek Res }\end{array}$ \\
& 5753 & $\begin{array}{l}\text { Sweathouse Peak } \\
\text { Chambers } \\
\text { Arivaca } \\
\text { Sorrel Horse Mesa } \\
\text { Wing Mountain }\end{array}$ \\
& &
\end{tabular}

$342136 \mathrm{N1121631W}$

$360444 N 1113904 \mathrm{~W}$ $340802 \mathrm{N1121649W}$

$334421 N 1111954 \mathrm{~W}$ $342221 \mathrm{N1130135W}$

$322134 \mathrm{~N} 1112835 \mathrm{~W}$

$342137 N 1125555 \mathrm{~W}$

Malpais

Waterman Peak

322451N1112953W

$321831 N 1112842 W$

$322059 N 1112822 W$

$332056 \mathrm{~N} 1123152 \mathrm{~W}$

$360855 \mathrm{~N} 1101802 \mathrm{~W}$

$365718 \mathrm{~N} 1113932 \mathrm{~W}$

$361240 \mathrm{~N} 1135053 \mathrm{~W}$

$342734 \mathrm{N1} 105602 \mathrm{~W}$

$342 \mathrm{~B} 20 \mathrm{~N} 1105550 \mathrm{~W}$

343258 N1131240W

$341515 \mathrm{~N} 1112255 \mathrm{~W}$

$324514 \mathrm{~N} 1090843 \mathrm{~W}$

$354750 \mathrm{~N} 1124632 \mathrm{~W}$

354703 N1125159W

354931N1125109W

354657 N1124822W

$354516 \mathrm{~N} 1125045 \mathrm{~W}$

$355046 N 1124922$

$335630 \mathrm{~N} 1101555 \mathrm{~W}$

$335642 N 1101421 \mathrm{~W}$

$363929 N 1110305 \mathrm{~W}$

$355629 \mathrm{~N} 1111334 \mathrm{~W}$

$332127 \mathrm{N1115134 \textrm {W }}$

332911 N1115624W

$312852 \mathrm{~N} 1095907 \mathrm{~W}$

$353209 \mathrm{~N} 1123629 \mathrm{~W}$

$343545 \mathrm{~N} 1122454 \mathrm{~W}$

$343537 N 1122519 \mathrm{~W}$

312458 N1093338W

$342420 \mathrm{~N} 1122123 \mathrm{~W}$

355727 N1120119W

$325321 \mathrm{~N} 1094628 \mathrm{~W}$

$312838 \mathrm{~N} 1092620 \mathrm{~W}$

$342814 N 1115708 \mathrm{~W}$

$332445 N 1125000 \mathrm{~W}$

$340106 \mathrm{~N} 1091038 \mathrm{~W}$

$362248 N 1121630 \mathrm{~W}$

$312529 N 1092727 \mathrm{~W}$

$321137 N 1093704 \mathrm{~W}$

$354030 \mathrm{~N} 1113020 \mathrm{~W}$

321237 N1105930W

323549 N1093136W

$322931 \mathrm{N1094216 \textrm {W }}$

$322935 \mathrm{~N} 1094218 \mathrm{~W}$

Monk Draw

1163 Waddel1

Pakoon Springs

3200 Cunningham Pass 


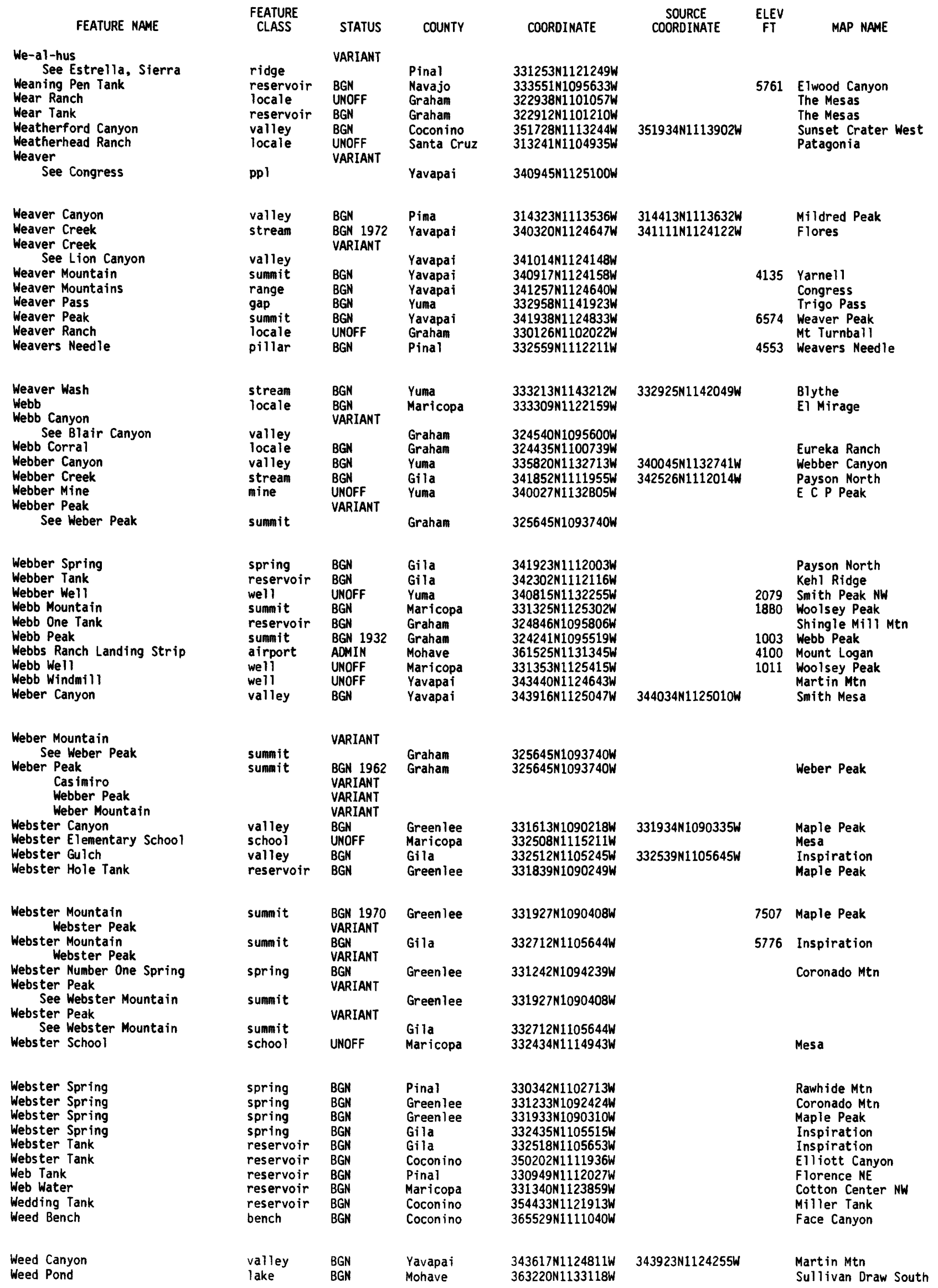




\section{FEATURE MAME}

Weed Reservoir

Weedville

Weekes Wash

Weeping Cliff

See Weeping Cliffs

Weeping Cliffs Weeping $\mathrm{Cliff}$

Weepo Spring

See Wepo Spring

Weigles Butte

Weimer Canyon

Weimer Point

Weimer Spring

Weimer Tank

Weimer Tank

Weimer Tank

We imer Tank

Wein-Bahi Spring

Weir Number Eight

Weir Number Eleven

Weir Number Nine

Weir Number Seven

Weir Valley

Weir Wash

Weiss Spring

Weitzel School

Welch Interchange

Welch Spring

Welch Tank

Welcome Home Mobile Park

Weldon Hill

Weldon Mine

Weldy Windmill

Well Camp Canyon

Well Camp Tank

Well Canyon

Well Canyon

Well Canyon Tank

Well Canyon Tank Number One

Well Canyon Tank Number Three

Well Canyon Tank Number Two

Well Cement Tank

Well ington Court (subdivision) Hickory Shadows II

Well Spring

Wells Ranch

Wells Spring

Wells Tank

Wells Tank

Well Tank

Well Tank

Well that Johnny Dug

Wellton

Saint Peter San Pedro

Wellton Airport

Wellton Canal

Wellton Elementary School

Wellton Hills

Wellton Lateral 7.7

Wellton Mesa

Wellton Mohawk Canal

Wellton Mohawk Main Channel

Wellton Overpass

Wellton Underpass

Wellton 4.2 Lateral

Well under the Rock

Wenden

Wendendale
FEATURE

CLASS

STATUS

COUNTY

COORDINATE

$\begin{array}{llll}\text { reservoir } & \text { BGN } & \text { Coconino } & 362717 \text { N1114112W } \\ \text { ppl } & \text { BGN } & \text { Maricopa } & 333650 \text { 1121253W }\end{array}$

stream BGN Pinal 332142N1113252W

cliff

VARIANT

cliff

BGN 1948

Mohave

Mohave

VARIANT

VARIAMT

spring

Navajo

$360523 N 11354344$

$360523 \mathrm{~N} 1135434 \mathrm{~W}$

$355327 N 1102155 \mathrm{~W}$

summit $\quad B G N \quad$ Pima

cliff

spring

reservoir

reservoir

spring

BGN
BGN
$B G N$
$B G N$
$B G N$
$B G N$
$B G N$
$B G N$

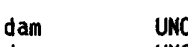

stream BGN Maricopa 334208N1121307W

spring BGN Maricopa 335134N1112459W

school UNOFF Coconino 351314N1113649

crossing UNOFF Coconino 351259M1122236W

$313503 N 1103229 \mathrm{~W}$

reservoir BGN Coconino 351442N1122204W

$\begin{array}{llll}\text { locale } & \text { UNOFF } & \text { Maricopa } & 333057 \text { N1120645W } \\ \text { sunmit } & \text { BGN } & \text { Maricopa } & 334243 N 1131922 W \\ \text { mine } & \text { UNOFF } & \text { Pima } & 320348 N 1120900 \mathrm{~W} \\ \text { locale } & \text { BGN } & \text { Cochise } & 312352 N 1091935 \mathrm{~W} \\ \text { valley } & \text { BGN } & \text { Gila } & 335342 N 1104519 \mathrm{~W} \\ \text { reservoir } & \text { BGN } & \text { Gila } & 335310 N 1104703 \mathrm{~W} \\ \text { valley } & \text { BGN } & \text { Pinal } & 324501 N 1103451 \mathrm{~W} \\ \text { valley } & \text { BGN } & \text { Gila } & 335044 N 1102530 \mathrm{~W} \\ \text { reservoir } & \text { BGN } & \text { Gila } & 335201 N 1102543 \mathrm{~W} \\ \text { reservoir } & \text { BGN } & \text { Gila } & 335408 N 1102357 \mathrm{~W}\end{array}$

$\begin{array}{llll}\text { reservoir } & \text { BGN } & \text { Gila } & 335411 \text { N1102324W } \\ \text { reservoir } & \text { BGN } & \text { Gila } & 335445 N 1102322 \mathrm{~W}\end{array}$

$\begin{array}{llll}\text { reservoir } & \text { BGN } & \text { Gila } & 335445 N 1102322 \mathrm{~W} \\ \text { reservoir } & \text { BGN } & \text { Coconino } & 353829 N 1121446 \mathrm{~W}\end{array}$

pp1 BGN Maricopa 333535N1121155W

spring BGN Greenlee 331331N1092216

locale UNOFF Cochise 312810 N1093147W

spring BGN Yavapai 342900N1115454W

spring BGN Mohave 365750N1130716

reservoir BGN Cochise 312819N1091634W

reservoir BGN Yavapai-344530N1121229W

reservoir BGN Coconino 343124N1111328W

reservoir $B G N$ Mohave

UNOFF Maricopa-

pDI BGN Yuma $324022 N 1140846 \mathrm{~W}$

VARIANT

VARIANT

airport ADMIM Yuma 323906N1140614W

canal BGN Yuma

school UNOFF Yuma 324020N1140827W

$\begin{array}{llll}\text { ridge } & \text { BGN } & \text { Yuma } & 323259 N 1140637 \mathrm{~W} \\ \text { canal } & \text { BGN } & \text { Yuma } & 324054 N 1140727 \mathrm{~W} \\ \text { summit } & \text { BGN } & \text { Yuma } & 324048 N 1140303 W \\ \text { canal } & \text { BGN } & \text { Yuma } & 324048 N 1141643 \mathrm{~W} \\ \text { canal } & \text { BGN } & \text { Yuma } & 324042 \mathrm{~N} 1141420 \mathrm{~W} \\ \text { crossing } & \text { UNOFF } & \text { Yuma } & 324022 N 1140705 \mathrm{~W} \\ \text { crossing } & \text { UNOFF } & \text { Yuma } & 323942 N 1140832 \mathrm{~W} \\ \text { canal } & \text { BGN } & \text { Yuma } & 324026 N 1141000 \mathrm{~W} \\ \text { Spring } & \text { BGN } & \text { Coconino } & 362148 N 1104806 \mathrm{~W} \\ \text { ppl } & \text { BGN } & \text { Yuma } & 334921 N 1133227 \mathrm{~W}\end{array}$

airport ADMIN La Paz 334850N1133240W $\begin{array}{ccc}\text { SOURCE } & \text { ELEV } \\ \text { COORDINATE } & \text { FT MAP NAME }\end{array}$

Shinumo Altar

Glendale

Desert We11

Columbine Falls

6284 Helvetia

Weimar Point

Weimar Point

Mormon Mountain

Payson North

Weimar Point

Leonard Canyon

Mormon Mountain

Sun Altar

Stoneman Lake

Apache Maid Mtn

Stoneman Lake

Stoneman Lake

Hedgpeth Hills

Hedgpeth Hills

Boulder Mtn

Flagstaff East

Ash Fork

Q' Donnell Canyon

McLellan Reservoir

1150 Sunnys lope

Weldon Hill

Ben Nevis Mtn

Cinder Hill

Rock House

Rock House

Clark Ranch

Beckers Butte

Beckers Butte

Cibecue Peak

Cibecue Peak

Cibecue Peak

Valle Tank

1185 Glendale

Mitchell Peak

Douglas NE

Arnold Mesa

Lost Spring Mtn East

Cinder $\mathrm{Hill}$

Munds Draw

Blue Ridge Reservoir

Red Lake

Deadman Gap

Wellton

334 Wellton Mesa

Wellton Mesa

Wellton

Wellton SE

Wellton Mesa

337 Weliton Mesa

Ligurta

Wellton

Wellton Mesa

Wellton

Wellton

John Daw Mes a

1869 Salome

1850 Salome 
NATIONAL GAZETTEER--ARIZONA 1986

\begin{tabular}{|c|c|c|c|c|c|c|c|}
\hline FEATURE NAME & $\begin{array}{l}\text { FEATURE } \\
\text { CLASS }\end{array}$ & STATUS & COUNTY & COORDINATE & $\begin{array}{l}\text { SOURCE } \\
\text { COORDINATE }\end{array}$ & $\begin{array}{l}\text { ELEV } \\
\text { FT }\end{array}$ & MAP NAME \\
\hline $\begin{array}{l}\text { Wendendale } \\
\text { See Wenden } \\
\text { Wenden Elementary School } \\
\text { Wepo Spring } \\
\text { Weepo Spring } \\
\text { Wepo Springs } \\
\text { Wipho } \\
\text { Wipo Spring } \\
\text { Wepo Springs } \\
\text { See Wepo Spring }\end{array}$ & $\begin{array}{l}\text { ppl } \\
\text { school } \\
\text { spring }\end{array}$ & $\begin{array}{l}\text { VARIANT } \\
\text { UNOFF } \\
\text { BGN } \\
\text { VARIANT } \\
\text { VARIANT } \\
\text { VARIANT } \\
\text { VARIANT } \\
\text { VARIANT }\end{array}$ & $\begin{array}{l}\text { Yuma } \\
\text { La Paz } \\
\text { Navajo }\end{array}$ & $\begin{array}{l}334921 N 1133227 \mathrm{~W} \\
334929 \times 1133226 \mathrm{~W} \\
355327 \mathrm{N1} 102155 \mathrm{~W}\end{array}$ & & & $\begin{array}{l}\text { Salome } \\
\text { Wepo Vill lage }\end{array}$ \\
\hline $\begin{array}{l}\text { Wepo Valley } \\
\text { Wepo Village } \\
\text { Wepo Wash } \\
\text { Wescogame Point } \\
\text { Wes ley Tank } \\
\text { West Adamana Tank } \\
\text { West Ash Fork Interchange } \\
\text { West Babcock Canyon } \\
\text { West Bear Canyon } \\
\text { West Benson Interchange }\end{array}$ & $\begin{array}{l}\text { valley } \\
\text { locale } \\
\text { stream } \\
\text { cliff } \\
\text { reservoir } \\
\text { reservoir } \\
\text { crossing } \\
\text { valley } \\
\text { valley } \\
\text { crossing }\end{array}$ & $\begin{array}{l}\text { BGN } 1915 \\
\text { BGN } \\
\text { BGN } 1915 \\
\text { BGN } 1925 \\
\text { BGN } \\
\text { BGN } \\
\text { UNOFF } \\
\text { BGN } \\
\text { BGN } \\
\text { UNOFF }\end{array}$ & $\begin{array}{l}\text { Navajo } \\
\text { Navajo } \\
\text { Navajo } \\
\text { Coconino } \\
\text { Graham } \\
\text { Navajo } \\
\text { Yavapai } \\
\text { Graham } \\
\text { Coconino } \\
\text { Cochise }\end{array}$ & $\begin{array}{l}354514 \mathrm{~N} 1102748 \mathrm{~W} \\
355336 \mathrm{~N} 1102224 \mathrm{~W} \\
354514 \mathrm{~N} 1102748 \mathrm{~W} \\
361209 \mathrm{~N} 1124309 \mathrm{~W} \\
330224 \mathrm{~N} 1093506 \mathrm{~W} \\
343752 \mathrm{~N} 1101604 \mathrm{~W} \\
351318 \mathrm{~N} 1122945 \mathrm{~W} \\
32412 \mathrm{~N} 109595 \mathrm{~W} \\
342729 \mathrm{~N} 1111257 \mathrm{~W} \\
315823 \mathrm{~N} 1101923 \mathrm{~W}\end{array}$ & $\begin{array}{l}361722 \mathrm{~N} 1095948 \mathrm{~W} \\
361722 \mathrm{~N} 1095948 \mathrm{~W} \\
324312 \mathrm{~N} 1095904 \mathrm{~W} \\
342653 \mathrm{~N} 1111400 \mathrm{~W}\end{array}$ & 5140 & $\begin{array}{l}\text { Polacca } \\
\text { Onion Spring } \\
\text { Polacca } \\
\text { Supai } \\
\text { Bonita Spring } \\
\text { Dry Lake NE } \\
\text { Ash Fork } \\
\text { Webb Peak } \\
\text { Dane Canyon } \\
\text { Benson }\end{array}$ \\
\hline $\begin{array}{l}\text { West Blue Lake } \\
\text { West Boulder Canyon } \\
\text { West Fork Boulder Canyon } \\
\text { West Boulder Trail } \\
\text { West Boulevard Interchange } \\
\text { West Bowie Interchange } \\
\text { West Branch Santa Cruz River } \\
\text { Westbriar (subdivision) } \\
\text { Westbrook Village (subdivision) } \\
\text { West Broomy Valley Tank }\end{array}$ & $\begin{array}{l}\text { lake } \\
\text { valley } \\
\text { trail } \\
\text { crossing } \\
\text { crossing } \\
\text { stream } \\
\mathrm{ppl} \\
\mathrm{ppl} \\
\text { reservoir }\end{array}$ & $\begin{array}{l}\text { BGN } \\
\text { BGN } 1969 \\
\text { VARIANT } \\
\text { UNOFF } \\
\text { UNOFF } \\
\text { UNOFF } \\
\text { BGN } \\
\text { BGN } \\
\text { BGN } \\
\text { BGN }\end{array}$ & $\begin{array}{l}\text { Navajo } \\
\text { Pinal } \\
\text { Pinal } \\
\text { Cochise } \\
\text { Cochise } \\
\text { Pima } \\
\text { Maricopa } \\
\text { Maricopa } \\
\text { Coconino }\end{array}$ & $\begin{array}{l}341607 \mathrm{~N} 1103912 \mathrm{~W} \\
332755 \mathrm{~N} 1112323 \mathrm{~W} \\
\\
332603 \mathrm{~N} 1112342 \mathrm{~W} \\
312706 \mathrm{~N} 1095604 \mathrm{~W} \\
321945 \mathrm{~N} 1093042 \mathrm{~W} \\
321207 \mathrm{N1105921W} \\
332953 \mathrm{~N} 1121506 \mathrm{~W} \\
333926 \mathrm{~N} 1121639 \mathrm{~W} \\
345047 \mathrm{~N} 1111320 \mathrm{~W}\end{array}$ & $332423 \mathrm{~N} 1112221 \mathrm{~W}$ & $\begin{array}{l}1050 \\
1230\end{array}$ & $\begin{array}{l}\text { Brookbank Point } \\
\text { Goldfield } \\
\text { Goldfield } \\
\text { Bisbee } \\
\text { Luzena } \\
\text { Tucson } \\
\text { Tolleson } \\
\text { Calderwood Butte } \\
\text { Chavez Mtn West }\end{array}$ \\
\hline $\begin{array}{l}\text { West Brown Tank } \\
\text { West Brown Tank } \\
\text { West Brushy Canyon } \\
\text { West Brushy Canyon Tank } \\
\text { West Buckskin Tank } \\
\text { West Buckskin Trail } \\
\text { West Burn Tank } \\
\text { West Buzzard Point } \\
\text { West Camp } \\
\text { West Canal Ancho (historical) } \\
\text { Canal Fourteen Branch }\end{array}$ & $\begin{array}{l}\text { reservoir } \\
\text { reservoir } \\
\text { valley } \\
\text { reservoir } \\
\text { reservoir } \\
\text { trail } \\
\text { reservoir } \\
\text { cliff } \\
\text { locale } \\
\text { canal }\end{array}$ & $\begin{array}{l}\text { BGN } \\
\text { BGN } \\
\text { BGN } \\
\text { BGN } \\
\text { BGN } \\
\text { UNOFF } \\
\text { BGN } \\
\text { BGN } \\
\text { BGN } \\
\text { BGN } \\
\text { VARIANT }\end{array}$ & $\begin{array}{l}\text { Pima } \\
\text { Coconino } \\
\text { Cochise } \\
\text { Green lee } \\
\text { Navajo } \\
\text { Navajo } \\
\text { Navajo } \\
\text { Coconino } \\
\text { Apache } \\
\text { Maricopa }\end{array}$ & $\begin{array}{l}314459 \mathrm{~N} 1113005 \mathrm{~W} \\
35485 \mathrm{~W} 1122003 \mathrm{~W} \\
321540 \mathrm{~N} 1093624 \mathrm{~W} \\
330442 \mathrm{~N} 1091346 \mathrm{~W} \\
342117 \mathrm{N1} 103719 \mathrm{~W} \\
341554 \mathrm{N1} 103538 \mathrm{~W} \\
340322 \mathrm{N1100629W} \\
350101 \mathrm{~N} 1114952 \mathrm{~W} \\
343822 \mathrm{~N} 109114 \mathrm{~W} \\
332802 \mathrm{~N} 111535 \mathrm{~W}\end{array}$ & $321421 \mathrm{~N} 1093659 \mathrm{~W}$ & 6012 & $\begin{array}{l}\text { Mildred Peak } \\
\text { Howard Hill } \\
\text { Luzena } \\
\text { Rattlesnake Spring } \\
\text { Outlaw Draw } \\
\text { Outlaw Draw } \\
\text { Faught Ridge } \\
\text { Dutton Hill } \\
\text { Valle Bonito } \\
\text { Tempe }\end{array}$ \\
\hline $\begin{array}{l}\text { West Canyon Creek } \\
\text { West Canyon Picnic Grounds } \\
\text { West Cataract Creek } \\
\text { West Cataract Creek Dam } \\
\text { West Cedar Creek } \\
\text { West Cedar Mountain } \\
\text { West Cedar Mountain Tank } \\
\text { West Chandler } \\
\text { Hansen Junction } \\
\text { Kyrene }\end{array}$ & $\begin{array}{l}\text { stream } \\
\text { park } \\
\text { stream } \\
\text { dam } \\
\text { stream } \\
\text { summit } \\
\text { reservoir } \\
\text { locale }\end{array}$ & $\begin{array}{l}\text { BGN } \\
\text { ADMIN } \\
\text { BGN } \\
\text { UNOFF } \\
\text { BGN } \\
\text { BGN } \\
\text { BGN } \\
\text { BGN } \\
\text { VARIANT } \\
\text { VARIANT }\end{array}$ & $\begin{array}{l}\text { Coconino } \\
\text { Graham } \\
\text { Coconino } \\
\text { Coconino } \\
\text { Gila } \\
\text { Yavapai } \\
\text { Yavapai } \\
\text { Maricopa }\end{array}$ & $\begin{array}{l}370224 \mathrm{~N} 1111245 \mathrm{~W} \\
323903 \mathrm{~N} 109484 \mathrm{~W} \\
351451 \mathrm{~N} 1121315 \mathrm{~W} \\
351509 \mathrm{~N} 1121248 \mathrm{~W} \\
335352 \mathrm{~W} 1101017 \mathrm{~W} \\
340652 \mathrm{~N} 1114909 \mathrm{~W} \\
340604 \mathrm{~W} 1114958 \mathrm{~W} \\
331819 \mathrm{~N} 1115642 \mathrm{~W}\end{array}$ & $\begin{array}{l}365441 \mathrm{~N} 1105936 \mathrm{~W} \\
351215 \mathrm{~N} 1121232 \mathrm{~W} \\
340324 \mathrm{~N} 1100545 \mathrm{~W}\end{array}$ & $\begin{array}{l}5489 \\
1165\end{array}$ & $\begin{array}{l}\text { Gregory Butte } \\
\text { Mt Grahan } \\
\text { Williams South } \\
\text { Williams North } \\
\text { Cedar Creek } \\
\text { Rover Peak } \\
\text { Rover Peak } \\
\text { Guadalupe }\end{array}$ \\
\hline $\begin{array}{l}\text { West Chandler Railroad Station } \\
\text { West Cheveion Canyon } \\
\text { West Chevelon Creek } \\
\text { West Chevelon Creek } \\
\text { West Fork Chevelon Creek } \\
\text { West Chevelon Creek } \\
\text { See West Chevelon Canyon } \\
\text { West Chevelon Crossing } \\
\text { Barts Crossing } \\
\text { West Clear Creek } \\
\text { Clear Creek } \\
\text { Clear Fork }\end{array}$ & $\begin{array}{l}\text { building } \\
\text { valley } \\
\text { stream }\end{array}$ & $\begin{array}{l}\text { UNOFF } \\
\text { BGN } 1966 \\
\text { VARIANT } \\
\text { BGN } \\
\text { VARIANT } \\
\text { VARIANT } \\
\text { BGN } 1962 \\
\text { VARIANT } \\
\text { BGN } \\
\text { VARIANT } \\
\text { VARIANT }\end{array}$ & $\begin{array}{l}\text { Maricopa } \\
\text { Coconino } \\
\text { Coconino }\end{array}$ & $\begin{array}{l}331822 \mathrm{~N} 1115731 \mathrm{~W} \\
343655 \mathrm{~N} 1104606 \mathrm{~W} \\
343657 \mathrm{~N} 1104608 \mathrm{~W} \\
343655 \mathrm{~N} 1104606 \mathrm{~W} \\
342817 \mathrm{~N} 1105528 \mathrm{~W} \\
343015 \mathrm{~N} 1114940 \mathrm{~W}\end{array}$ & $\begin{array}{l}342251 \mathrm{~N} 1105858 \mathrm{~W} \\
342300 \mathrm{~N} 1105848 \mathrm{~W}\end{array}$ & & $\begin{array}{l}\text { Guadalupe } \\
\text { Chevelon Crossing } \\
\text { Chevelon Crossing }\end{array}$ \\
\hline $\begin{array}{l}\text { West Clear Creek Canyon } \\
\text { Westcliff Park (subdivision) } \\
\text { West Coast Tank } \\
\text { West Coast Tank } \\
\text { West Cocopah Reservation } \\
\text { See Cocopah Indian } \\
\text { Reservation }\end{array}$ & $\begin{array}{l}\text { valley } \\
\text { ppl } \\
\text { reservoir } \\
\text { reservoir } \\
\text { reserve }\end{array}$ & $\begin{array}{l}\text { BGN } 1970 \\
\text { BGN } \\
\text { BGN } \\
\text { BGN } \\
\text { VARIANT }\end{array}$ & $\begin{array}{l}\text { Yavapai } \\
\text { Maricopa } \\
\text { Pima } \\
\text { Pima }\end{array}$ & $\begin{array}{l}343015 \mathrm{~N} 1114940 \mathrm{~W} \\
333647 \mathrm{~N} 1120914 \mathrm{~W} \\
314547 \mathrm{~N} 1112021 \mathrm{~W} \\
314801 \mathrm{N1112156 \textrm {W }} \\
323715 \mathrm{~N} 1144545 \mathrm{~W}\end{array}$ & $343304 \mathrm{~N} 1112410 \mathrm{~W}$ & 1255 & $\begin{array}{l}\text { Camp Verde } \\
\text { Glendale } \\
\text { Penitas Hills } \\
\text { Penitas Hills }\end{array}$ \\
\hline $\begin{array}{l}\text { West Copper Mountain Tank } \\
\text { Westcor Hel iport (Paradise }\end{array}$ & $\begin{array}{l}\text { reservoir } \\
\text { airport }\end{array}$ & $\begin{array}{l}\text { BGN } \\
\text { ADMIN }\end{array}$ & $\begin{array}{l}\text { Gila } \\
\text { Maricopa }\end{array}$ & $\begin{array}{l}335622 \mathrm{~N} 1110551 \mathrm{~W} \\
333533 \mathrm{~N} 1115840 \mathrm{~W}\end{array}$ & & 1370 & $\begin{array}{l}\text { Copper Mtn } \\
\text { Paradise Valley }\end{array}$ \\
\hline
\end{tabular}


NATIONAL GAZETTEER--ARIZONA 1986 FEATURE NAME
FEATURE CLASS
STATUS

COUNTY
West Dutchman Tank

West Eaton Canyon

West Elk Spring

West End

Western Acres Mobile Home Park

Western Acres Mobile Park

Western Avra Cotton Gin

Western Canal

See Kyrene Branch Canal

Western Canal

Western Canyon

Government Tank Canyon

Western Manor Park

Western Navaho Reservation

See Navajo Indian Reservation

Western Palms Mobile Home

Community

Western Palms Shopping Center

Western Park

Western Union Mine

Western Well

Westerra (subdivision)

West Flagstaff Interchange

West Forestdale Tank

West Fork

See Crystal Creek

West Fork Aliso Spring

West Fork Bass Canyon

West Fork Beaver Wash

See Beaver Dan Wash

West Fork Black Canyon

West Fork Black Canyon

West Fork Black Creek

West Fork Black River

West Fork Bonito creek See Bonita Creek

West Fork Boulder Canyon

See West Boulder Canyon

West Fork Bright Angel Creek

See Phantom Creek

West Fork Brookbank Canyon

West Fork Buckskin Draw

West Fork Campground

West Fork Canyon Creek

West Fork Carbon Creek

West Fork Chevelon Creek See West Chevelon Creek

West Fork Circle Bar Draw

West Fork Cooper Canyon

West Fork Copperas Canyon

West Fork Cottonwood Wash

West Fork Forest Camp

West Fork Hot Air Canyon

West Fork Little Colorado River West Fork Little Springs Canyon West Fork Markham Wash

See Left Fork Markham Creek West Fork Oak Creek

West Fork Oak Creek

West Fork Oraibi Wash reservoir $B G$

valley

spring

locale

locale UNOFF

locale UNOFF

locale

canal

canal

valley

park

reserve

locale

BGN

VARIANT

BGN

Maricopa

BGN 1959 Santa Cruz

VARIANT

ADMIN

Pinal

Apache

locale

UNOFF

Maricopa

park

UNOFF

Maricopa

La Paz

\section{mine}

$\begin{array}{llll}\text { mine } & \text { UNDFF } & \text { Mohave } & 351828 \text { N1140629W } \\ \text { well } & \text { UNOFF } & \text { Santa Cruz } & 313108 \text { N1103257W }\end{array}$

ppl BGN Maricopa 333555N1121122W

crossing UNOFF Coconino 351125N1114325W

reservoir BGN Navajo 341032N1100624W

stream

spring

spring
valley

Coconino

BGN 1981 Pima

BGN Cochise

VARIANT

valley Mohave 365342N1135510W

valley Mohave 365342N1135510W

$360808 \mathrm{~N} 1121436 \mathrm{~W}$

$321505 \mathrm{~N} 1102956 \mathrm{~W}$

$322310 \mathrm{~N} 1101342 \mathrm{~W}$

$322454 N 1101445 W$

$\begin{array}{cc}\text { SOURCE } & \text { ELEV } \\ \text { COORDINATE } & \text { FT }\end{array}$

MAP NAME

$\begin{array}{llll}\text { valley } & \text { BGN } & \text { Navajo } & 341952 \text { N1104200W } \\ \text { valley } & \text { BGN } & \text { Mohave } & 363407 \text { N1130417W } \\ \text { stream } & \text { BGN } & \text { Apache } & 352242 \text { N1091220W } \\ \text { stream } & \text { BGN } & \text { Apache } & 334503 \text { N1092149W } \\ \text { stream } & \text { VARIANT } & & \\ \text { valley } & \text { VARIANT } & \text { Graham } & 325336 \text { N1092840W } \\ \text { stream } & \text { VARIANT } & \text { Pinal } & 332755 \text { N1112323W } \\ & & \text { Coconino } & 360658 \text { N1120513W }\end{array}$

$342154 \mathrm{~N} 1103847 \mathrm{~W}$

$363117 N 1130857 \mathrm{~W}$

$353329 \mathrm{~N} 1091734 \mathrm{~W}$

$335421 \mathrm{~N} 1093330 \mathrm{~W}$

Brookbank Point

Hat Knoll

Uranium Spring

Buffalo Crossing

1045 Fowler

Fowler

Parker

Stockton $\mathrm{Hill}$

'Donnell Canyon

1200 Glendale

7225 Flagstaff West

Show Low South

Soza Canyon

The Mesas

valley BGN Navajo

valley BGN Navajo

ADMIN Apache

stream

stream

Maricopa

BGN

BGN Coconino

stream

valley

VARIANT

Coconino

BGN

BGN

Coconino

valley

BGN

Navajo

Greenlee

$342204 N 1104225 \mathrm{~W}$

342020 N1103440

$334637 N 1092452$

$340022 N 1120251 \mathrm{~W}$

$360941 \mathrm{~N} 1115012 \mathrm{~W}$

$343657 N 1104608 \mathrm{~W}$

$342842 \mathrm{~N} 1105104 \mathrm{~W}$

$370140 \mathrm{~N} 1102815 \mathrm{~W}$

$331440 \mathrm{~N} 1090609 \mathrm{~W}$

$342743 \mathrm{~N} 1105237 \mathrm{~W}$

$365537 \mathrm{~N} 1102610 \mathrm{~W}$

$331616 \mathrm{~N} 1090557 \mathrm{~W}$

$341752 \mathrm{~N} 1102015 \mathrm{~W}$

stream

Navajo

locale

BGN

BGN

Apache

Greenlee

Apache

stream

valley

BGN

VARIANT

stream

stream

stream

$B G N$
$B G N$

Coconino

334719 N1092443

$332859 N 1092357 \mathrm{~W}$

$340014 N 1092721 \mathrm{~W}$

$342438 \mathrm{~N} 1104726 \mathrm{~W}$

$341822 \mathrm{~N} 1102502 \mathrm{~W}$

$332726 \mathrm{N1092526 \textrm {W }}$

335453 N1093330W

$342322 \mathrm{~N} 1104837 \mathrm{~W}$

330337 N1094715W

$B G N$
$B G N$
Graham

Navajo
$345914 \mathrm{~N} 1114443 \mathrm{~W}$

$362107 \mathrm{N1} 100425 \mathrm{~W}$
$335102 \mathrm{~N} 1104725 \mathrm{~W}$

$350245 \mathrm{~N} 1115446 \mathrm{~W}$

$362801 \mathrm{~N} 1100640 \mathrm{~W}$
Brookbank Point Outlaw Draw 8000 Big Lake South Squaw Creek Mesa Cape Solitude

Weimar Point Big Point Harden Cienega

Clay Springs Big Lake South Robinson Mesa Greer Weimar Point

Sombrero Peak Munds Park Hole In Rock Valley 
FEATURE CLASS

valley

West Fork Parashant Wash Parashant Wash

West Fork Phantom Creek See Phanton Creek

West Fork Phoenix Park Canyon

West Fork Pinto Creek Pinto Creek

West Fork Sabino Canyon

West Fork Separation Canyon

West Fork Sunset Canyon

West Fork Sycamore Creek Alder Creek

West Fork Sycamore Creek

West Fork Tank

West Fork Wet Prong Creek See Wet Prong Creek

West Fork Yuma Wash

West Granite Mountain

Westgreen Estates (subdivision)

West Gypsum Bay

West Gypsum Creek

West Hay Hollow Draw

West Hearn Lateral

West Holbrook Interchange

West Holcomb Trail

West Hy Pond

West Ike Tank Tule Tank

West Indian Pine Tank

West Indian Tank

West Jack Tank

West Kehl Canyon

West Lacy Fork

West Lake

West l ake Mine

West Lake Point

West Larimore Tank

West Leonard Canyon

West Lincoln Trail

West Long Hollow Tank

West Main Canal

West Main Canal

West Mesa

West Mesa

West Mesa

West Mesa

West Mesa

West Mesa Tank

West Mesa Trailer Court

West Mine Well Park

West Mitten Butte

West Mohave Wash

West Moonshine Draw

Moonshine Draw

West Moonshine Spring

West Mountain

West Ninemile Well

West Nine Section Tank

West Nine Tank

Westover Spring

Westown II Shopping Center

Westown Park

Westown Shopping Center

West Park

West Park Dam

West Park Draw

West Park Tank

West Pasture Tank

West Pasture Tank

West Pasture Well

valley

lake

mine

trail

cana

canal

sumnit

summit

sumnit

summit

sumnit

local

park

summit

stream

spring

summit

well

spring

locale

park

park

park

valley

well

\begin{tabular}{|c|c|c|c|}
\hline ralley & $\begin{array}{l}\text { BGN } 1973 \\
\text { VARIANT } \\
\text { VARIANT }\end{array}$ & Mohave & $361439 \mathrm{~N} 1133409 \mathrm{~W}$ \\
\hline $\begin{array}{l}\text { stream } \\
\text { valley } \\
\text { stream }\end{array}$ & $\begin{array}{l}\text { BGN } \\
\text { BGN } \\
\text { VARIANT }\end{array}$ & $\begin{array}{l}\text { Coconino } \\
\text { Navajo } \\
\text { Pinal }\end{array}$ & $\begin{array}{l}360658 \mathrm{~N} 1120513 \mathrm{~W} \\
341425 \mathrm{~N} 1103200 \mathrm{~W} \\
332731 \mathrm{~N} 1110018 \mathrm{~W}\end{array}$ \\
\hline $\begin{array}{l}\text { valley } \\
\text { valley } \\
\text { valley }\end{array}$ & $\begin{array}{l}\text { BGN } \\
\text { BGN } \\
\text { BGN }\end{array}$ & $\begin{array}{l}\text { Pima } \\
\text { Mohave } \\
\text { Yuma }\end{array}$ & $\begin{array}{l}322241 \mathrm{~N} 1104741 \mathrm{~W} \\
355129 \mathrm{~N} 1133239 \mathrm{~W} \\
334901 \mathrm{N1} 131817 \mathrm{~W}\end{array}$ \\
\hline tream & $\begin{array}{l}\text { BGN } \\
\text { VARIANT }\end{array}$ & Maricopa & $335551 \mathrm{~N} 1112836 \mathrm{~W}$ \\
\hline $\begin{array}{l}\text { stream } \\
\text { reservoir }\end{array}$ & $\begin{array}{l}\text { BGN } \\
\text { BGN } \\
\text { VARIANT }\end{array}$ & $\begin{array}{l}\text { Mohave } \\
\text { Greenlee }\end{array}$ & $\begin{array}{l}344317 \mathrm{~N} 1132330 \mathrm{~W} \\
332808 \mathrm{~N} 1092433 \mathrm{~W}\end{array}$ \\
\hline $\begin{array}{l}\text { stream } \\
\text { stream } \\
\text { summit } \\
\text { ppl } \\
\text { bay }\end{array}$ & $\begin{array}{l}\text { BGN } \\
\text { BGN } \\
\text { BGN } \\
\text { BGN }\end{array}$ & $\begin{array}{l}\text { Greenlee } \\
\text { Yuma } \\
\text { Maricopa } \\
\text { Maricopa } \\
\text { Mohave }\end{array}$ & $\begin{array}{l}332635 \mathrm{~N} 1092926 \mathrm{~W} \\
330453 \mathrm{~N} 1143146 \mathrm{~W} \\
334748 \mathrm{~N} 1113427 \mathrm{~W} \\
333355 \mathrm{~N} 1121505 \mathrm{~W} \\
360551 \mathrm{~N} 1142449 \mathrm{~W}\end{array}$ \\
\hline $\begin{array}{l}\text { stream } \\
\text { valley } \\
\text { canal } \\
\text { crossing } \\
\text { trail } \\
\text { reservoir } \\
\text { reservoir }\end{array}$ & $\begin{array}{l}\text { BGN } \\
\text { BGN } \\
\text { BGN } \\
\text { UNOFF } \\
\text { UNOFF } \\
\text { BGN } \\
\text { BGN 1977 } \\
\text { VARIANT }\end{array}$ & $\begin{array}{l}\text { Apache } \\
\text { Navajo } \\
\text { Yuma } \\
\text { Navajo } \\
\text { Navajo } \\
\text { Mohave } \\
\text { Coconino }\end{array}$ & $\begin{array}{l}365808 \mathrm{~N} 1095855 \mathrm{~W} \\
344103 \mathrm{~N} 1095227 \mathrm{~W} \\
323430 \mathrm{~N} 1144335 \mathrm{~W} \\
345416 \mathrm{~N} 1101110 \mathrm{~W} \\
341713 \mathrm{~N} 1104201 \mathrm{~W} \\
363141 \mathrm{~N} 1133043 \mathrm{~W} \\
350622 \mathrm{~N} 1121726 \mathrm{~W}\end{array}$ \\
\hline $\begin{array}{l}\text { reservoir } \\
\text { reservoir }\end{array}$ & $\begin{array}{l}\text { BGN } \\
\text { BGN }\end{array}$ & $\begin{array}{l}\text { Navajo } \\
\text { Navajo }\end{array}$ & $\begin{array}{l}340448 N 1095431 W \\
343202 N 1103627 W\end{array}$ \\
\hline
\end{tabular}

\section{reservoir BGN Mohave 352018N1132104W}

valley BGN Coconino 342854N1111837W

cliff

valley $B G N$

reservoir

BGN

reservoir

reservoir

reservoir

reservoir

reservoir

reservoir

Gila

Coconino

Gila

Coconino

Mohave

Coconino

Navajo

Navajo

$\begin{array}{ll}\text { BGN } & \text { Yuma } \\ \text { BGN } & \text { Yuma }\end{array}$

$B G N$
$B G N$

BGN

BGN

BM

BGN

$B G N$

UNOFF

BGN

BGN

BGN 1973

VARIANT

BGN

BGN

UNOFF

BGN

BGM

\section{Yavapai}

Yavapai

Coconino

Apache

Mohave

Yavapai

Maricopa

$342854 N 1111837 \mathrm{~W}$

$335747 N 1110324 W$
$363127 N 1122243 \mathrm{~W}$

$331802 N 1105130 \mathrm{~N}$

363151 N1122409W

$363134 N 1130341 \mathrm{~W}$

$342800 \mathrm{~N} 1110527 \mathrm{~W}$

341922N1102938

342540 N1102639W

324110 N1144402W

$324854 \mathrm{~N} 1142946 \mathrm{~W}$

345827 N1130910

$350003 \mathrm{~N} 1130850 \mathrm{~W}$

$353345 \mathrm{~N} 1112947 \mathrm{~W}$

363602 N1091618W

365235 N1132622W

$345957 N 1130930 \mathrm{~W}$

332451 N1115057W

331825 N1115032W

$365927 \mathrm{~N} 1100544 \mathrm{~W}$

$342358 \mathrm{~N} 1140109 \mathrm{~W}$

342905 N1110835W

342858 N1110837W

335854 N1124305

$345937 N 1093237 \mathrm{~W}$

$343921 \mathrm{~N} 1101824 \mathrm{~W}$

$312245 \mathrm{~N} 1103830 \mathrm{~W}$

$350031 \mathrm{~N} 1101821 \mathrm{~W}$

33612N1120706W

$333604 \mathrm{~N} 1120705 \mathrm{~W}$

$325829 N 1113151 \mathrm{~W}$

$333500 \mathrm{~N} 1120454 \mathrm{~W}$

341B26N1103217

$341 B 30 N 1103212 \mathrm{~W}$

$343021 N 1120821 \mathrm{~W}$

$35453 \mathrm{BN} 1121627$

$341711 \mathrm{~N} 1093629 \mathrm{~W}$
$342707 N 1111916 \mathrm{~W}$

$335650 \mathrm{~N} 1110351 \mathrm{~W}$

$342332 N 1110841 W$

341719N1103314W Pepper Canyon

332552N1110945W Haunted Canyon

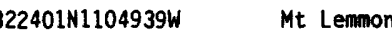

355451N1133221W Separation Canyon

334835N1132031W Harquahala Mtn

340015N1112817W Reno Pass

$344440 N 1132458$.

Elephant Mtn

Robinson Mesa

$331010 N 1143408 \mathrm{~W}$

Picacho

4555 Maverick Mtn

1110 El Mirage

Bonelli Bay

370026N1100554W Rooster Rock

343158N1095843W Little Milky Ranch

Somerton

5060 Holbrook

Brookbank Point

Sullivan Draw South

Matterhorn

Indian Pine

Red Knoll

Blye Canyon SE

Kehl Ridge

Copper Mtn

Sowats Spring

Pinal Peak

Sowats Spring

Hat Knoll

Knoll Lake

Day Spring

Aripine

Yuma West

Laguna Dan

6193 Sunrise Peak

6153 Anvil Rock Ranch

5571 Wupatki SH

Mexican Cry Mesa

4409 Yellowhorse Flat

Sunrise Peak

1235 Mesa

Chandler

$342900 \mathrm{~N} 1140640 \mathrm{~W}$

Mitten Buttes

Mohave Springs

Dane Canyon

Dane Canyon

Wickenburg

Ninemile Seep

Dry Lake NE

Harshaw

Blairs Spring

1280 Sunnys lope Glendale
$341733 N 1103406 \mathrm{~W}$
Sunnys lope

Coolitge

Sunnys lope

Outlaw Draw

Out law Draw

Humboldt

Howard $\mathrm{Hill}$

Cerro Hueco 


\begin{tabular}{|c|c|c|c|c|c|c|c|}
\hline FEATURE NAME & $\begin{array}{l}\text { FEATURE } \\
\text { CLASS }\end{array}$ & STATUS & COUNTY & COORDINATE & $\begin{array}{l}\text { SOURCE } \\
\text { COORDINATE }\end{array}$ & $\begin{array}{c}\text { ELEV } \\
\text { FT }\end{array}$ & MAP NAME \\
\hline $\begin{array}{l}\text { West Peak } \\
\text { West Pershing Plaza } \\
\text { West Phoenix High School } \\
\text { West Pit } \\
\text { West Plaza Park } \\
\text { West Plaza Shopping Center } \\
\text { West Point } \\
\text { West Poker Mountain } \\
\text { West Polecat Canyon } \\
\text { West Polles Tank Number One }\end{array}$ & $\begin{array}{l}\text { summit } \\
\text { ppl } \\
\text { school } \\
\text { lake } \\
\text { park } \\
\text { locale } \\
\text { cliff } \\
\text { summit } \\
\text { valley } \\
\text { reservoir }\end{array}$ & $\begin{array}{l}\text { BGN } 1932 \\
\text { BGN } \\
\text { UNOFF } \\
\text { BGN } \\
\text { ADMIN } \\
\text { UNOFF } \\
\text { BGN } \\
\text { BGN } \\
\text { BGN } \\
\text { BGN }\end{array}$ & $\begin{array}{l}\text { Graham } \\
\text { Cochise } \\
\text { Maricopa } \\
\text { Pinal } \\
\text { Maricopa } \\
\text { Maricopa } \\
\text { Maricopa } \\
\text { Apache } \\
\text { Cochise } \\
\text { Gila }\end{array}$ & $\begin{array}{l}324414 N 1100216 \mathrm{~W} \\
313318 \mathrm{~N} 1102055 \mathrm{~W} \\
332855 \mathrm{~N} 120601 \mathrm{~W} \\
331037 \mathrm{~N} 1110021 \mathrm{~W} \\
333155 \mathrm{~N} 1120859 \mathrm{~W} \\
333133 \mathrm{~N} 1120753 \mathrm{~W} \\
335728 \mathrm{~N} 1120250 \mathrm{~W} \\
333156 \mathrm{~N} 1094805 \mathrm{~W} \\
321616 \mathrm{~N} 1093824 \mathrm{~W} \\
341552 \mathrm{~N} 1113325 \mathrm{~W}\end{array}$ & $321445 N 1093803 \mathrm{~W}$ & $\begin{array}{l}8684 \\
1160 \\
672 B\end{array}$ & $\begin{array}{l}\text { Blue Jay Peak } \\
\text { Fort Huachuca } \\
\text { Phoenix } \\
\text { Teapot Mountain } \\
\text { Glendale } \\
\text { Glendale } \\
\text { Daisy Mountain } \\
\text { West Poker Mtn } \\
\text { Railroad Pass } \\
\text { Cane Springs Mtn }\end{array}$ \\
\hline $\begin{array}{l}\text { West Prong Creek } \\
\text { See Wet Prong Creek } \\
\text { West Prong Gentry Creek } \\
\text { West Prong Waterman Wash } \\
\text { West Quartzsite Interchange } \\
\text { West Ranch } \\
\text { West Ranch } \\
\text { Westridge Mall } \\
\text { Westridge Park (subdivision) } \\
\text { West Rustiers Spring }\end{array}$ & $\begin{array}{l}\text { stream } \\
\text { stream } \\
\text { stream } \\
\text { crossing } \\
\text { locale } \\
\text { locale } \\
\text { locale } \\
\text { ppl } \\
\text { spring }\end{array}$ & $\begin{array}{l}\text { VARIANT } \\
\text { BGN } \\
\text { BGN } \\
\text { UNOFF } \\
\text { UNOFF } \\
\text { UNOFF } \\
\text { UNOFF } \\
\text { BGN } \\
\text { BGN }\end{array}$ & $\begin{array}{l}\text { Greenlee } \\
\text { Gila } \\
\text { Maricopa } \\
\text { La Paz } \\
\text { Graham } \\
\text { Navajo } \\
\text { Maricopa } \\
\text { Maricopa } \\
\text { Greenlee }\end{array}$ & $\begin{array}{l}332635 N 1092926 \mathrm{~W} \\
340634 \mathrm{~N} 1104839 \mathrm{~W} \\
331034 \mathrm{~N} 1122157 \mathrm{~W} \\
333930 \mathrm{~N} 1141425 \mathrm{~W} \\
325823 \mathrm{~N} 1093749 \mathrm{~W} \\
340639 \mathrm{~N} 1100241 \mathrm{~W} \\
332 \mathrm{~B} 3 \mathrm{~N} 1121325 \mathrm{~W} \\
332735 \mathrm{~N} 1121216 \mathrm{~W} \\
330343 \mathrm{~N} 1090800 \mathrm{~W}\end{array}$ & $\begin{array}{l}340851 \mathrm{~N} 1104921 \mathrm{~W} \\
330025 \mathrm{~N} 1122211 \mathrm{~W}\end{array}$ & 1050 & $\begin{array}{l}\text { Gentry Mtn } \\
\text { Mobile NE } \\
\text { Quartzsite } \\
\text { Weber Peak } \\
\text { Faught Ridge } \\
\text { Fowler } \\
\text { Fowler } \\
\text { Rattlesnake Spring }\end{array}$ \\
\hline $\begin{array}{l}\text { West San Simon Interchange } \\
\text { West Sawmill Canyon } \\
\text { Dowdle Canyon } \\
\text { Sawmill Canyon } \\
\text { Saw Mill Canyon } \\
\text { West School } \\
\text { West Sedona Elementary School } \\
\text { West Seligman Interchange } \\
\text { West Sevenmile Tank } \\
\text { West Shumway Ditch }\end{array}$ & $\begin{array}{l}\text { school } \\
\text { school } \\
\text { crossing } \\
\text { reservoir } \\
\text { canal }\end{array}$ & $\begin{array}{l}\text { UNOFF } \\
\text { BGN I981 } \\
\text { VARIANT } \\
\text { VARIANT } \\
\text { VARIANT } \\
\text { UNOFF } \\
\text { UNOFF } \\
\text { UNOFF } \\
\text { BGN } \\
\text { BGN }\end{array}$ & $\begin{array}{l}\text { Pinal } \\
\text { Yavapai } \\
\text { Yavapai } \\
\text { Navajo } \\
\text { Navajo }\end{array}$ & $\begin{array}{l}325 \mathrm{~B} 2 \mathrm{BN} 1113143 \mathrm{~W} \\
345150 \mathrm{~N} 1124715 \mathrm{~W} \\
351913 \mathrm{~N} 1125332 \mathrm{~W} \\
334617 \mathrm{~N} 1095659 \mathrm{~W} \\
342450 \mathrm{~N} 1100415 \mathrm{~W}\end{array}$ & $314400 N 1104947 \mathrm{~W}$ & 5240 & $\begin{array}{l}\text { Coolidge } \\
\text { Sedona } \\
\text { Seligman West } \\
\text { Whiteriver } \\
\text { Taylor }\end{array}$ \\
\hline $\begin{array}{l}\text { West Side Park } \\
\text { West Side Tank } \\
\text { Wests ide Tank } \\
\text { West Side Windmill } \\
\text { West Silver Bell Mountains } \\
\text { West Silverbell Mountains } \\
\text { West Silverbell Mountains } \\
\text { See West Silver Bell } \\
\text { Mountains } \\
\text { West Six Tank }\end{array}$ & $\begin{array}{l}\text { park } \\
\text { reservoir } \\
\text { reservoir } \\
\text { locale } \\
\text { summit }\end{array}$ & $\begin{array}{l}\text { AOMIN } \\
\text { BGN } \\
\text { BGN } \\
\text { BGN } \\
\text { BGN 1961 } \\
\text { VARIANT } \\
\text { VARIANT }\end{array}$ & $\begin{array}{l}\text { Pinal } \\
\text { Yavapai } \\
\text { Coconino } \\
\text { Pima } \\
\text { Pima }\end{array}$ & $\begin{array}{l}325328 \mathrm{~N} 1114540 \mathrm{~W} \\
345113 \mathrm{~N} 1121758 \mathrm{~W} \\
351752 \mathrm{~N} 1122720 \mathrm{~W} \\
315600 \mathrm{~N} 1112452 \mathrm{~W} \\
322739 \mathrm{~N} 1113746 \mathrm{~W} \\
322739 \mathrm{~N} 1113746 \mathrm{~W} \\
312520 \mathrm{~N} 1103837 \mathrm{~W}\end{array}$ & & & $\begin{array}{l}\text { Casa Grande West } \\
\text { King Canyon } \\
\text { Fitzgerald Hill } \\
\text { Palo Alto Ranch } \\
\text { Gap Tank }\end{array}$ \\
\hline $\begin{array}{l}\text { West Skinner Tank } \\
\text { See Skinner Pasture Tank } \\
\text { West Skinner Tank } \\
\text { West Skinner Tank } \\
\text { See Skunk Spring } \\
\text { West Snowflake Ditch } \\
\text { West Split Tank } \\
\text { West Spring } \\
\text { West Spring } \\
\text { West Spring }\end{array}$ & $\begin{array}{l}\text { reservoir } \\
\text { reservoir } \\
\text { spring } \\
\text { canal } \\
\text { reservoir } \\
\text { spring } \\
\text { spring } \\
\text { spring }\end{array}$ & $\begin{array}{l}\text { VARIANT } \\
\text { BGN } 1979 \\
\text { VARIANT } \\
\text { BGN } \\
\text { BGN } \\
\text { BGN } \\
\text { BGN } \\
\text { BGN }\end{array}$ & $\begin{array}{l}\text { Coconino } \\
\text { Coconino } \\
\text { Navajo } \\
\text { Navajo } \\
\text { Yavapai } \\
\text { Pima } \\
\text { Pinal } \\
\text { Apache }\end{array}$ & $\begin{array}{l}355415 \mathrm{~N} 1115930 \mathrm{~W} \\
355449 \mathrm{~N} 1115959 \mathrm{~W} \\
354503 \mathrm{~N} 1101159 \mathrm{~W} \\
343114 \mathrm{~N} 1100512 \mathrm{~W} \\
345736 \mathrm{~N} 1131030 \mathrm{~W} \\
321950 \mathrm{~N} 1104023 \mathrm{~W} \\
332625 \mathrm{~N} 1110508 \mathrm{~W} \\
340652 \mathrm{~N} 1093851 \mathrm{~W}\end{array}$ & & & $\begin{array}{l}\text { Grandview Point } \\
\text { Snowflake } \\
\text { Sunrise Peak } \\
\text { Agua Cal iente Hill } \\
\text { Haunted Canyon } \\
\text { Horseshoe Cienega }\end{array}$ \\
\hline $\begin{array}{l}\text { West Spruce Mountain } \\
\text { West Steep Hill Valley } \\
\text { West Sunset Mountain } \\
\text { West Tank } \\
\text { West Tank } \\
\text { West Tank } \\
\text { West Tank } \\
\text { West Tank } \\
\text { West Tank } \\
\text { West Tank }\end{array}$ & $\begin{array}{l}\text { summit } \\
\text { valley } \\
\text { summit } \\
\text { reservoir } \\
\text { reservoir } \\
\text { reservoir } \\
\text { reservoir } \\
\text { reservoir } \\
\text { reservoir } \\
\text { reservoir }\end{array}$ & $\begin{array}{l}\text { BGN } \\
B G N \\
B G N \\
B G N \\
B G N \\
B G N \\
B G N \\
B G N \\
B G N \\
B G N\end{array}$ & $\begin{array}{l}\text { Yavapai } \\
\text { Navajo } \\
\text { Coconino } \\
\text { Pima } \\
\text { Pima } \\
\text { Maricopa } \\
\text { Pinal } \\
\text { Gila } \\
\text { Apache } \\
\text { Navajo }\end{array}$ & $\begin{array}{l}343218 N 1123521 W \\
361715 N 1100753 W \\
345233 N 1105620 W \\
315247 N 1112813 W \\
321141 N 1112719 W \\
331156 N 1122821 W \\
332025 N 1112219 W \\
332107 N 1104 B 47 W \\
333245 N 1094905 W \\
341959 N 1101130 W\end{array}$ & $361813 \mathrm{~N} 1100350 \mathrm{~W}$ & 6612 & $\begin{array}{l}\text { Iron Springs } \\
\text { Toh NE Zhonnie Spr } \\
\text { West Sunset Mtn } \\
\text { Palo Alto Ranch } \\
\text { La Tortuga Butte } \\
\text { Mobile NW } \\
\text { Florence Junction } \\
\text { Pinal Peak } \\
\text { West Poker Mtn } \\
\text { Pinedale }\end{array}$ \\
\hline $\begin{array}{l}\text { West Tank } \\
\text { West Tank } \\
\text { West Tank } \\
\text { West Tank } \\
\text { West Tank } \\
\text { West Tank } \\
\text { West Taylor Ditch } \\
\text { West Triangle Tank } \\
\text { West Turkey Creek } \\
\text { West Turkey Creek Campground }\end{array}$ & $\begin{array}{l}\text { reservoir } \\
\text { reservoir } \\
\text { reservoir } \\
\text { reservoir } \\
\text { reservoir } \\
\text { reservoir } \\
\text { canal } \\
\text { reservoir } \\
\text { stream } \\
\text { park }\end{array}$ & $\begin{array}{l}\text { BGN } \\
\text { BGN } \\
\text { BGN } \\
\text { BGN } \\
\text { BGN } \\
\text { BGN } \\
\text { BGN } \\
\text { BGN } \\
\text { BGN } \\
\text { ADMIN }\end{array}$ & $\begin{array}{l}\text { Coconino } \\
\text { Coconino } \\
\text { Apache } \\
\text { Mohave } \\
\text { Coconino } \\
\text { Mohave } \\
\text { Navajo } \\
\text { Coconino } \\
\text { Apache } \\
\text { Cochise }\end{array}$ & $\begin{array}{l}343406 \mathrm{~N} 1112428 \mathrm{~W} \\
344350 \mathrm{~N} 1112316 \mathrm{~W} \\
345302 \mathrm{~N} 109441 \mathrm{BW} \\
352151 \mathrm{~N} 1132523 \mathrm{~W} \\
352231 \mathrm{~N} 1115021 \mathrm{~W} \\
364756 \mathrm{~N} 1133747 \mathrm{~W} \\
342801 \mathrm{N1} 100519 \mathrm{~W} \\
354924 \mathrm{~N} 1122449 \mathrm{~W} \\
334241 \mathrm{~N} 1095251 \mathrm{~W} \\
315152 \mathrm{~N} 1092131 \mathrm{~W}\end{array}$ & 334713 N1095040W & & $\begin{array}{l}\text { Calloway Butte } \\
\text { Happy Jack } \\
\text { Sorrel Horse Mesa } \\
\text { Tuckayou Spring } \\
\text { Kendrick Peak } \\
\text { Wolf Hole Mtn West } \\
\text { Taylor } \\
\text { Little Harpo Canyon } \\
\text { Bonito Prairie } \\
\text { Chiricahua Peak }\end{array}$ \\
\hline
\end{tabular}


FEATURE NAME

West Twin Peak

est Twin Peak

See Gadsden Peak

West Twin Wash

West Two Tank

West Walker Tank

West Wash

West Wash

West Water Canyon

West Water Spring

Westwater Wash

Black Canyon Wash

West Webber Creek

West Well

West Wel1

West Well

West Well

West We?

West Well

West Well

West We 11

West Well

West Well Corral

West Well Detention Dam

West Wells

West Wells

See Maish Vaya

West Whitetail Creek

West Willcox Interchange

Westwind (subdivision)

West Windmill

West Windmill

West Wing Mountain

West Winslow

Westwood Christian Schoo

Westwood High School

Westwood High School

Westwood Plaza Shopping Center

Westwood School

West Yucca Interchange

West Zuni Windmill

Wes White Canyon

Wet Beaver Creek

See Beaver Creek

Wet Beaver Creek Beaver Creek

Wet Beaver Creek

See Jacks Canyon

Wet Bottom Creek

Wet Bottom Mesa

Wet Canyon

Wet Canyon

Wet Canyon Campground

Wetherill Canyon

Wetherill Mesa

Wetmore Park

Wetmore School

Wet Prong Creek

West Fork Wet Prong Creek

West Prong Creek

Wet Prong Spring

Weymouth Flat

W F Cattle Company Dam

Whaleback

Whalen Cemetery

Whalen Tank

What Fo Canyon

W H Draw

Wheat Field Cienega

Wheatfield Creek

See Wheatfields Creek

\section{FEATURE
CLASS}

summit

summit

stream

reservoir

reservoir

strean

stream

valley

spring

str
stre
well
well
well
well
well
well
wel

stream
stream
well
well
well
well
well
well
well

wel1

well

locale

well UNOFF

ppl

stream

crossing 1978

ing UNOFF

BGN

well

locale

summit

ppl

school

school

school

locale

school

crossing

UNOFF

BGN

Maricopa $\quad 334415 N 1121437 \mathrm{~W}$

BGN 1970 Navajo 350225N1104430W

UNOFF Maricopa 333037N1120628W

UNOFF

UNOFF

UNOFF

UNOFF

Maricopa

Maricopa

Maricopa

Maricopa

we

valley

stream

stream

UNOFF

BGN

VARIANT

BGN

VARIANT

valley

stream

VARIANT

summit

BGN
BGN

Gila

valley

valley

park

summit

school

stream

$\begin{array}{ll}\text { BGN } & \text { Graham } \\ \text { BGN } & \text { Yavapai } \\ \text { ADMIN } & \text { Graham } \\ \text { BGN 1979 } & \text { Coconino } \\ \text { BGN } & \text { Navajo } \\ \text { ADMIN } & \text { Pima } \\ \text { UNOFF } & \text { Pima } \\ \text { BGN } & \text { Greenlee } \\ \text { VARIANT } & \\ \text { VARIANT } & \end{array}$

Apache

Greenlee

Yavapai

Yavapai

conino

Gila

VARIANT

$\begin{array}{llll}\text { spring } & \text { 8GN } & \text { Yavapai } & 342431 N 1114345 \mathrm{~W} \\ \text { flat } & \text { BGN } & \text { Gila } & 341024 \mathrm{N1} 111718 \mathrm{~W} \\ \text { dam } & \text { UNOFF } & \text { Mohave } & 352818 \mathrm{~N} 1133424 \mathrm{~W} \\ \text { summit } & \text { BGN } & \text { Pima } & 321926 \mathrm{~N} 1105058 \mathrm{~W} \\ \text { cemetery } & \text { UNOFF } & \text { Graham } & 324300 \mathrm{~N} 1101218 \mathrm{~W} \\ \text { reservoir } & \text { BGN } & \text { Graham } & 322558 \mathrm{~N} 1101037 \mathrm{~W} \\ \text { valley } & \text { BGN } & \text { Yuma } & 322334 \mathrm{~N} 1133835 \mathrm{~W} \\ \text { valley } & \text { BGN } & \text { Greenlee } & 331756 \mathrm{~N} 1090423 \mathrm{~W} \\ \text { flat } & \text { BGN } & \text { Navajo } & 340053 \mathrm{~N} 1095300 \mathrm{~W}\end{array}$

stream
VARIANT

Apache
$344101 \mathrm{~N} 1113125 \mathrm{~W}$

341017 N1114122W

$370420 \mathrm{~N} 1110625 \mathrm{~W}$

$321715 \mathrm{~N} 1105757 \mathrm{~W}$

$321708 \mathrm{~N} 1105855 \mathrm{~W}$

$332635 \mathrm{~N} 1092926 \mathrm{~W}$

$360813 \mathrm{~N} 1091126 \mathrm{~W}$ $\begin{array}{cc}\text { SOURCE } & \text { ELEV } \\ \text { COORDINATE } & \text { FT MAP NAME }\end{array}$

2615 Lukeville

\begin{tabular}{|c|c|}
\hline $\begin{array}{l}324521 \mathrm{~N} 1141557 \mathrm{~W} \\
342858 \mathrm{N11} 40640 \mathrm{~W} \\
353550 \mathrm{~N} 1134822 \mathrm{~W}\end{array}$ & $\begin{array}{l}\text { Carrizo Butte } \\
\text { Harshaw } \\
\text { Chavez Mtn NE } \\
\text { Ligurta } \\
\text { Mohave Springs } \\
\text { Milkweed Canyon NW } \\
\text { Milkweed Canyon SW }\end{array}$ \\
\hline $342008 \mathrm{~N} 1130104 \mathrm{~W}$ & Malpais Mesa SW \\
\hline $342613 \mathrm{~N} 1112315 \mathrm{~W}$ & $\begin{array}{l}\text { Kehl Ridge } \\
\text { Empire Ranch } \\
\text { Mescal } \\
\text { Olga } \\
\text { North of Oracle } \\
\text { Aztec SE } \\
\text { Forth of July Butte } \\
\text { Cortez Peak }\end{array}$ \\
\hline
\end{tabular}

4976 Humpy Camp Well

Peacock Peak

Olga

Sulphur Hills

$320310 \times 1091922$

Bowie Mtn South Red Bird Hills

1185 Glendale

Manuel Seep

6217 Cactus Flat

1930 Hedgpeth Hills

Winslow

Sunnys lope

Mesa

Mesa

Mesa

Sunnys lope

Yucca

Stinking Springs Mtn Sheldon

Lake Montezuma

$340911 \mathrm{~N} 1114241 \mathrm{~W}$

$340850 \mathrm{~N} 1112920 \mathrm{~W}$

Wet Bottom Mesa

3168 Wet Bottom Mesa

$323905 \mathrm{~N} 1094814 \mathrm{~W} \quad 323850 \mathrm{~N} 1095045 \mathrm{~W}$

$345355 \mathrm{~N} 1131530 \mathrm{~W} \quad 345432 \mathrm{~N} 1131622 \mathrm{~W}$

323005

$332807 N 1093505 \mathrm{~W}$

Mt Graham

Mohon Peak

Mt Graham

Cathedral Canyon

Mystery Valley

Tucson North

Tucson North

Robinson Mesa

Hackberry Mtn

Pays on South

Truxton

2961 Sabino Canyon

Eureka Ranch

The Mesas

322321N1133753W Point of the Pintas

Maple Peak

Indian Pine 
NATIONAL GAZETTEER--ARIZONA 1986 FEATURE NAME

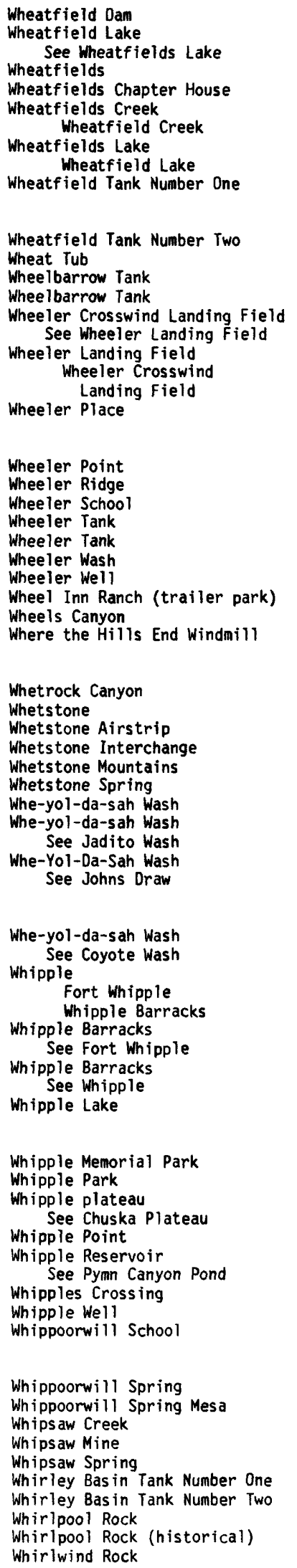

\section{FEATURE}

CLASS

dam

lake

building
stream

lake

reservoir

STATUS

COUNTY

UNOFF VARIANT

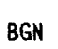

BGN

BGN

VARIANT

BGN

VARIANT

BGN

reservoir

reservoir

reservoir

reservoir

$B G N$

BGN

$B G N$

BANIANT

airport

airport

ADMIN

VARIANT

locale

BGN

cliff

ridge

school

reservoir

reservoir

stream

well

locale

valley

locale

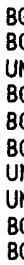

valley

Tocale

airport

summit

spring

arroyo

stream

valley

\section{BGN}

BGN

UNOFF

BGN

BGN

VARIANT

VARIANT

locale

VARIANT

BGN

VARIANT

VARIANT

VARIANT

locale

locale

VARIANT

lake

cemetery

park

area
cliff

cliff

lake

well

school

BGN

Yavapai

Navajo

UNOFF

ADM IN VARIANT

BGN

VARIANT

BGN

UNOFF
UNOFF

Navajo

Yavapai

Apache

Apache

Mohave

Mohave

Navajo

Navajo

spring

summit

strean

mine

spring

reservoir

reservoir

summit

summit valley

$\begin{array}{ll}\text { BGN } & \text { Navajo } \\ \text { BGN } & \text { Navajo } \\ \text { BGN } & \text { Yavapai } \\ \text { UNOFF } & \text { Yavapai } \\ \text { BGN } & \text { Yavapai } \\ \text { BGN } & \text { Apache } \\ \text { BGN } & \text { Apache } \\ \text { BGN 1917 } & \text { Maricopa } \\ \text { BGN 1917 } & \text { Maricopa } \\ \text { BGN } & \text { Coconino }\end{array}$

COORDINATE

361224N1090548W

$361226 \mathrm{~N} 1090536 \mathrm{~W}$ 361416 N1090741W $361414 N 1090734 \mathrm{~W}$ 360813N1091126W

361226 N1090536W

345158 N1115930W

$345143 \mathrm{~N} 1115942 \mathrm{~W}$ $354452 \mathrm{~N} 1125320 \mathrm{~W}$

$354007 \mathrm{~N} 1113318 \mathrm{~W}$

$332556 \mathrm{~N} 1104318 \mathrm{~W}$

$332556 \mathrm{~N} 1104318 \mathrm{~W}$

$321553 \mathrm{~N} 1090458 \mathrm{~W}$

$361519 N 1122532 \mathrm{~W}$

$361023 N 1140123 \mathrm{~W}$

$321156 \mathrm{~N} 1105058 \mathrm{~W}$

$350354 \mathrm{~N} 1134532 \mathrm{~W}$

$350952 \mathrm{~N} 1123038 \mathrm{~W}$

$350212 \mathrm{~N} 1133938 \mathrm{~W}$

$332750 \mathrm{~N} 1124600 \mathrm{~W}$

$332733 \mathrm{~N} 1115543 \mathrm{~W}$

$340903 \mathrm{~N} 1122247 \mathrm{~W}$

355124N111051OW

$332407 N 1111435 \mathrm{~W}$

$315726 \mathrm{N1102029 \textrm {W }}$

$314101 N 1101722 \mathrm{~W}$

$315752 \mathrm{~N} 1102046 \mathrm{~W}$

$314841 \mathrm{~N} 1102505 \mathrm{~W}$

$332405 \mathrm{~N} 111440 \mathrm{~W}$

$352323 \mathrm{N1} 104709 \mathrm{~W}$

352133N1105028W

351900N1103120W

$352330 N 1104445 \mathrm{~W}$

$343324 \mathrm{~N} 1122656 \mathrm{~W}$

343317N1122707W

$343324 \mathrm{~N} 1122656 \mathrm{~W}$

$341646 \mathrm{~N} 1095827 \mathrm{~W}$

$350129 \mathrm{~N} 1104027 \mathrm{~W}$

$343300 \mathrm{~N} 1122730 \mathrm{~W}$

$360205 N 1093053 \mathrm{~W}$

350400 N1094758 W

$361708 \mathrm{~N} 1132546 \mathrm{~W}$

$344700 \mathrm{~N} 1143300 \mathrm{~W}$

$341631 \mathrm{N1} 100113 \mathrm{~W}$

$360147 \mathrm{~N} 1100448 \mathrm{~W}$

$360152 \mathrm{~N} 1100503 \mathrm{~W}$

$360116 \mathrm{~N} 1100643 \mathrm{~W}$

$340257 \mathrm{N1122749 \textrm {W }}$

$340247 \mathrm{N1122849 \textrm {W }}$

$340238 \mathrm{~N} 1122837 \mathrm{~W}$

$333440 \mathrm{~N} 1094234 \mathrm{~W}$

$333331 \mathrm{~N} 1094242 \mathrm{~W}$

$333600 \mathrm{~N} 1112800 \mathrm{~W}$

$333600 \mathrm{~N} 1112800 \mathrm{~W}$

$363643 \mathrm{~N} 1104504 \mathrm{~W}$

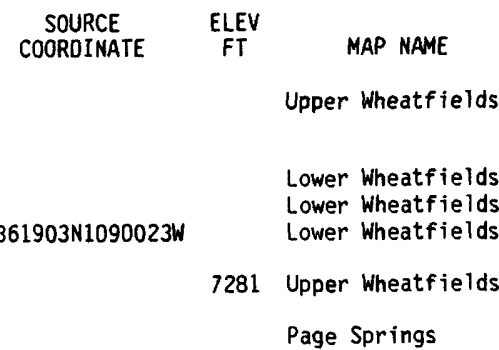

Page Springs Rose Well Camp West Hanks Draw Campbell Francis Wsh

3872 Cammerman Wash

Doubtful Canyon

Powell Plateau

Iceberg Canyon

Tucson East

Dean Peak

350449N1135359W $\quad \begin{aligned} & \text { Cathedral Caves } \\ & \text { Bottleneck Wash }\end{aligned}$

Bott leneck Wash

$340925 \mathrm{~N} 1122359 \mathrm{~W}$

1235 Tempe

Minnehaha

Gold Spring

$332355 N 1111319 W$

Iron Mountain

Benson

4225 Huachuca City

Benson

Apache Peak

Iron Mount a in

$352123 N 1114437 W$

Tolani Lake

Prescott

Silver Springs

Wins low

Prescott

Kachina Point

Needles

Show Low North

Whippoorwill Spring

Whippoorwill Spring

Whippoorwill Spring

Copperopol is

Copperopol is

Copperopol is

Maverick SW

Maverick SW

Mormon Flat Dam

6516 Whirlwind Rock 
FEATURE NAME

Whiskey Basin
Whiskey Bottle Rock
Whiskey Canyon
Whiskey Creek
Whiskey Reservoir
Whiskey Ridge Tank
Whiskey Spring
Whiskey Spring
Whiskey Spring
Whiskey Spring

Whiskey Spring
Whiskey Spring
Whiskey Spring
Whiskey Spring
Whiskey Spring
Whiskey Spring
Whiskey Spring
Whiskey Spring Canyon
Whiskey Spring Trail
Whiskey Tank
Whiskey Tank
Whiskey Trail
Whiskey Well
Whisky Spring
Whisky Spring
Whispering Pines
Whistle Stop Mall (shopping
center)
Whistle Tank
Whistling Spring
White Area Canyon
Whitcomb Hill
Whitcomb Spring
See Whitcom Spring
Whitcomb Spring
Whitcon Spring

White Ash Peak Whitebank Spring White Bas in Tank White Bluff White Bluffs White Bluffs White Bluff Tank White Butte White Canyon Walnut Canyon

Whitecap Peak

White Chief Mine

White Clay

White Clay Dam

White Clay $\mathrm{Hill}$

White Clay Spring Wash

White Clay Windmill

White Cliff Creek

See Cottonwood Creek

White Cliff Creek

See Willow Creek

White Cliff Tank

White Cloud Mine

Whitecomb Spring

See Whitcom Spring

White Cone

White Cone

White Cone Peak

White Cone Spring

White Corral Windmills
FEATURE
CLASS

STATUS

basin
summit
valley
stream
reservoir
reservoir
spring
spring
spring
spring

BGN

BGN

BGN

GN

GN

BN

GN

spring

BGN

spring

spring

spring

spring

spring

spring

valley

trail

reservoir

BGN

BGN

BGN

BGN

BGN

BGN

BGN

BGN

reservoir

trail

well

spring

spring

locale
locale

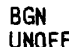

UNOFF

UNOFF

BGN

BGN

reservoir

UNOFF

spring

BGN

summit

BGN 1966 VARIANT

spring

spring

valley

valley

spring
spring

BGN

VARIANT

VARIANT

BGN

BGN

summit

spring

reservoir

summit

cliff

cliff

summit

summit
valley

BGN
BGN
BGN
BGN
BGN
BGN
BGN
BGN
BGN

BGN

BGN

$B G N$

$B G N$

BGN

VARIANT

summit

spring

mine

locale

dam

summ it

stream

well

stream

BGN

BGN

UNOFF

BGN

UNOFF

BGN

BGN
BGN

UNOFF

VARIANT

Apache

Gila

Greenlee

Pinal

Yavapai

Greenlee

Apache

Pinal

Yavapai

Navajo

Mohave

Apache

Navajo

Apache

Apache

Apache

Mohave

VARIANT

stream

reservoir

mine

BGN

UNOFF VARIANT

spring

ppl

summit

BGN

BGN
$B G N$
$B G N$

BGN

Maricopa
Mohave

Gila

Navajo

Apache

Navajo

Navajo

Navajo

Apache
COORDINATE

350048 N1135923W $363457 \mathrm{N11} 10132 \mathrm{~W}$ $341530 \mathrm{~N} 1103401 \mathrm{~W}$ $360720 \mathrm{~N} 1090927 \mathrm{~W}$ 360649 N1090856W $331224 \mathrm{~N} 1094217 \mathrm{~W}$ $332518 N 1111829 \mathrm{~W}$

$332914 \mathrm{~N} 1110835 \mathrm{~W}$

$335341 \mathrm{~N} 1112656 \mathrm{~W}$

335448N1121253W

340039 N1122539W $340957 N 1121900 \mathrm{~W}$ $341754 \mathrm{~N} 1103406 \mathrm{~W}$ 343559 N1124207W $350432 \mathrm{~N} 1142319 \mathrm{~W}$ $350630 \mathrm{~N} 1135531 \mathrm{~W}$ 361849 N1135850W 332546 N1111837W

$332456 \mathrm{~N} 1111845 \mathrm{~W}$

$334552 \mathrm{~N} 1110327 \mathrm{~W}$

$340350 \mathrm{~N} 1104750 \mathrm{~W}$

$340323 N 1104400 \mathrm{~W}$

$331203 \mathrm{~N} 1094246 \mathrm{~W}$

$322715 \mathrm{~N} 1094454 \mathrm{~W}$

$354446 \mathrm{~N} 1105623 \mathrm{~W}$

$334349 \mathrm{~N} 109032 \mathrm{OW}$

$351159 N 1113847 \mathrm{~W}$

345147 N1130415W

342654N1111123W

315748 N1110530W

$340845 N 1095215 \mathrm{~W}$

340845 N1095215W

$363745 \mathrm{~N} 1092824 \mathrm{~W}$

$363731 N 1092805 \mathrm{~W}$

$355155 \mathrm{~N} 1092243 \mathrm{~W}$

$363238 \mathrm{~N} 1091705 \mathrm{~W}$

$332833 N 1105409 \mathrm{~W}$

$331558 \mathrm{~N} 1091003 \mathrm{~W}$

$334510 \mathrm{~N} 1090350 \mathrm{~W}$

$330640 \mathrm{~N} 1103030 \mathrm{~W}$

$335808 \mathrm{~N} 1121254 \mathrm{~W}$

$331622 \mathrm{~N} 1091002 \mathrm{~W}$

$361143 \mathrm{~N} 1091511 \mathrm{~W}$

$330927 N 1110449 W$

$342702 \mathrm{~N} 1131147 \mathrm{~W}$

$360222 \mathrm{~N} 1103902 \mathrm{~W}$

$350016 \mathrm{~N} 1142313 \mathrm{~W}$

$360354 \mathrm{~N} 1091305 \mathrm{~W}$

$353341 \mathrm{~N} 1103011 \mathrm{~W}$

$362842 \mathrm{~N} 1091813 \mathrm{~W}$

$354622 N 1090334 W$

$360029 \mathrm{~N} 1091106 \mathrm{~W}$

350818 N1133340W

351011 N1133110W $335940 \mathrm{~N} 1102253 \mathrm{~W}$ $335700 \mathrm{~N} 1123357 \mathrm{~W}$

$340845 N 1095215 \mathrm{~W}$

$361115 N 1090450 \mathrm{~W}$

$353619 \mathrm{~N} 1100403 \mathrm{~W}$

$353437 \mathrm{~N} 1100254 \mathrm{~W}$

$353545 \mathrm{~N} 1100234 \mathrm{~W}$

$342324 N 1092715 \mathrm{~W}$

\begin{tabular}{|c|c|c|}
\hline $\begin{array}{l}\text { SOURCE } \\
\text { COORDINATE }\end{array}$ & $\underset{\text { FT }}{\text { ELEV }}$ & MAP NAME \\
\hline $\begin{array}{l}341719 \mathrm{N1} 103435 \mathrm{~W} \\
361349 \mathrm{~N} 1085632 \mathrm{~W}\end{array}$ & 6778 & $\begin{array}{l}\text { Hualapai Peak } \\
\text { Kaibito } \\
\text { Outlaw Draw } \\
\text { White Clay } \\
\text { White Clay } \\
\text { Park Creek Cabins } \\
\text { Weavers Needle } \\
\text { Iron Mountain } \\
\text { Reno Pass } \\
\text { New River }\end{array}$ \\
\hline $332444 \mathrm{~N} 1111805 \mathrm{~W}$ & & $\begin{array}{l}\text { Copperopolis } \\
\text { Crown King } \\
\text { Outlaw Draw } \\
\text { Skull Valley } \\
\text { Oatman } \\
\text { Hualapai Peak } \\
\text { Gyp Hillis } \\
\text { Weavers Needle } \\
\text { Weavers Needle } \\
\text { Armer Mountain }\end{array}$ \\
\hline & $\begin{array}{l}6500 \\
6910\end{array}$ & $\begin{array}{l}\text { Gentry Mtn } \\
\text { Oak Creek Ranch } \\
\text { Park Creek Cabins } \\
\text { Monk Oraw } \\
\text { Sand Springs } \\
\text { Maness Peak } \\
\text { Flagstaff West }\end{array}$ \\
\hline & & $\begin{array}{l}\text { Scratch Canyon } \\
\text { Dane Canyon }\end{array}$ \\
\hline & 3640 & Twin Buttes \\
\hline & & Sponseller Mtn \\
\hline $364152 N 1092351 \mathrm{~W}$ & & $\begin{array}{l}\text { White Area Canyon } \\
\text { White Area Canyon } \\
\text { Red Clay Wash }\end{array}$ \\
\hline
\end{tabular}

8840 Mexican Cry Mesa Inspiration Fritz Canyon Luna Lake

Jerusalem Mtn

New River

Fritz Canyon

7410 Mummy Cave Ruins

$331207 N 1110355 \mathrm{~W}$

Teapot Mountain

$354825 \mathrm{~N} 1085756 \mathrm{~W}$

Thorn Peak

Rocky Ridge SW

Oatman

White Clay

Tovar Mesa East

Bad Bug Butte

Fort Defiance

7533 White Clay

Cibecue Peak

Red Picacho

8511 Upper Wheatfields

6094 White Cone

6428 White Cone

White Cone

Salado 


\section{FEATURE NAME}

White Cow Canyon

White Creek

White Cross Cemetery

White Dam

White Dome Tank

White Dyke Canyon

White Dyke Spring

White Eagle Mine

White Eagle Mine

\section{White Elephant Mine}

White Elephant Wash

Whitefield Wash

White Flat

White Flat Tank

White Hair Spring

White Hair Valley

White Hawk Canyon

See Hawk Canyon

Whitehead Ranch

Whitehead Ranch

Whitehead Ridge

Whitehead Well

White $\mathrm{Hill}$

White $\mathrm{Hill}$

White Hill

White Hills

White Hills

White Hills

White Hills

\section{White Hills}

White Hills

White Hills

White Hills Tank

White Hills Tank

White Hills Tank

White Hill Tank

Whitehorn Spring

White Horse Butte

Whitehorse Canyon

White Horse Canyon

White Horse Draw

See Martinez Draw

White Horse Hills

Marble Hills

Marble Mountain

White Horse Knoll

White Horse Lake

See Wildhorse Lake

White Horse Lake White House Lake White Lake

White Horse Lake Campground

White Horse Pass

White Horse Ranger Station

White Horse Recreation Area

White Horse Spring

White Horse Tank

White Horse Tank

See Wildhorse Tank

White Horse Tank

White House

White House Dam

White House Lake

See White Horse Lake

White House Overlook

Whitehouse Ruins

White House Ruins

White House Tank

White House Valley

Whitehouse Well
FEATURE
CLASS

STATUS COUNTY

valley

stream

cemetery

reservoir

valley

spring

mine UNOFF

mine

BGN

BGN 1932 Coconino

UNOFF

UNOFF

Apache

Coconino

Yavapai

Yavapai

Maricopa

Mohave

mine

stream

flat

reservoir

spring

valley

valley

UNOFF

UNOFF Mohave 351705N1140820W

BGN Mohave 355424N1141013W

BGN

BGN

BGN

BGN

BGN

VARIANT

locale

UNOFF

Greenlee

Yavapai

Yavapai

Apache

Navajo

Pinal

Cochise

local

ridge

summit

summit
s ummit

summit

range

range

summit

sumit

UNOFF

BGN

UNOFF

BGN

BGN

BGN

BGN

BGN

BGN

BGN

summit $\quad B G N$

summit $\quad B G N$

BGN

locale BGN

$\begin{array}{ll}\text { reservoir } & B G N \\ \text { reservoir } & B G N\end{array}$

reservoir $B G N$

reservoir $B G N$

spring $B G N$

$\begin{array}{ll}\text { summit } & B G N \\ \text { valley } & B G N\end{array}$

Yavapai

Cochise

Pinal

Pima

Coconino

Apache

Gila

Mohave

Maricopa

Maricopa

Yavapai

Apache

Mohave

Graham

Gila

Yavapai

Yavapai

Greenlee

Apache

Graham

valley $\quad B G$

valley

VARIAN

summit

BGN 1935

VARIANT

VARIANT

VARIANT

summit

BGN

lake

VARIANT

Coconino

350711N1120104W

Navajo

$341557 N 1104014 W$

lake

BGN

VARIANT

VARIANT

park ADMIN

gap BGN

locale UNOFF

park

spring

reservoir

UNOFF
ADMIN
BGN

BGN

VARIANT

reservoir

VARIANT

Coconino

$350701 \mathrm{~N} 1120046 \mathrm{~W}$

Coconino

Pinal

Coconino

Coconino

Navajo

Yavapai

Yavapai

reservoir

BGN

$\begin{array}{ll}\text { reservoir } & \text { BGN } \\ \text { locale } & \text { BGN } \\ \text { dam } & \text { UNOFF } \\ & \text { VARIANT }\end{array}$

lake

locale

locale

locale

reservoir

valley

BGN
BGN
BGN
BGN
BG

well

UNOFF

$344902 \mathrm{~N} 1115350 \mathrm{~W}$

$344858 N 1115403 \mathrm{~W}$

$363135 N 1091931 \mathrm{~W}$

361401 N1102622W

$314622 N 1093430$

$341553 N 1123622 W$

$314553 \mathrm{~N} 1093626 \mathrm{~W}$

$315836 \mathrm{~N} 1110605$

$353321 \mathrm{~N} 1120338 \mathrm{~W}$

$360036 N 1094717 \mathrm{~W}$

$341618 N 1112728 \mathrm{~W}$

$324615 \mathrm{~N} 1121748 \mathrm{~W}$

$324752 \mathrm{~N} 1125044 \mathrm{~W}$

$343917 N 1115122 \mathrm{~W}$

$362614 N 1094452 \mathrm{~W}$

354417 N1142348

$325120 \mathrm{~N} 1100501 \mathrm{~W}$

$341709 \mathrm{~N} 1112707 \mathrm{~W}$

$343240 \mathrm{~N} 1114857 \mathrm{~W}$

$331258 N 1092923 \mathrm{~W}$

$360722 \mathrm{N1094251 \textrm {W }}$

322718N1091051

$352530 N 1114032 W$

$343329 N 1094709 \mathrm{~W}$

352322N1114213W

$354758 N 1141613 W$

$324206 N 1090727 \mathrm{~W}$

$361731 N 1102827 \mathrm{~W}$

$\begin{array}{cc}\text { SOURCE } & \text { ELEV } \\ \text { COORDINATE } & \text { FT }\end{array}$

MAP NAME

$333712 \mathrm{~N} 1100911 \mathrm{~W} \quad$ Velasquez Butte

362003N1122102W King Arthur Castle

Galleta Flat West

Lower Wheatfields

hite Dome

Cooks Mesa

Cooks Mesa

Cave Creek

Stockton Hill

Cerbat

Garnet Mtn NW

Duncan

Page Springs

Page Springs

Mexican Cry Mesa

Big Mountain Dam

Squaretop Hills East

Walnut Grove

Squaretop Hills East

3686 Putnam Wash

Hobble Tank

6395 Salina

Buckhead Mesa

Senator Mtn NE

Lost Horse Peak

Black Gap

Lake Montezuma

Windy Valley

White Hills West

Tripp Canyon

Buckhead Mesa

Paulden

Camp Verde

Coronado Mt

Toh De Ni ihe

Orange Butte

$322526 N 1090947 W$

352127 N1114059W 


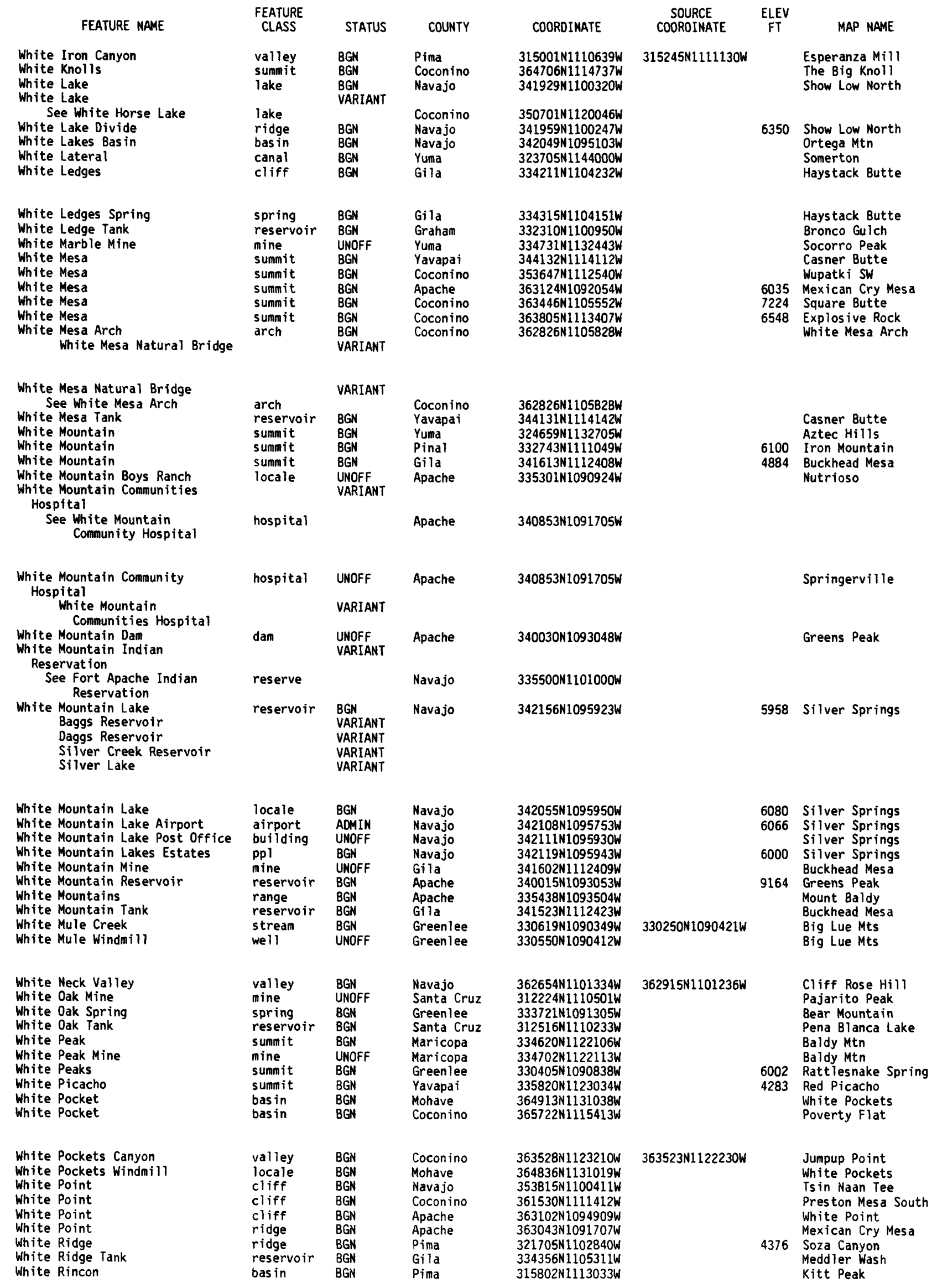




\begin{tabular}{|c|c|c|c|c|c|c|c|}
\hline FEATURE NAME & $\begin{array}{l}\text { FEATURE } \\
\text { CLASS }\end{array}$ & STATUS & COUNTY & COORDINATE & $\begin{array}{l}\text { SOURCE } \\
\text { COORDINATE }\end{array}$ & $\begin{array}{l}\text { ELEV } \\
\text { FT }\end{array}$ & MAP NAME \\
\hline $\begin{array}{l}\text { White River } \\
\text { North Fork Salt River } \\
\text { The Sierra Blanca River }\end{array}$ & stream & $\begin{array}{l}\text { BGN } \\
\text { VARIANT } \\
\text { VARIANT }\end{array}$ & Gila & $334420 \mathrm{~N} 1101330 \mathrm{~W}$ & $334729 N 1095941 \mathrm{~W}$ & & Forks Butte \\
\hline $\begin{array}{l}\text { White River } \\
\text { See Whitewater Draw } \\
\text { Whiteriver } \\
\text { Whiteriver Airport } \\
\text { White River Canyon } \\
\text { See Rucker Canyon } \\
\text { Whiteriver Cemetery } \\
\text { Whiteriver City Hall } \\
\text { Whiteriver Elementary School } \\
\text { Whiteriver Fire Station }\end{array}$ & $\begin{array}{l}\text { valley } \\
\text { ppl } \\
\text { airport } \\
\text { valley } \\
\text { cemetery } \\
\text { building } \\
\text { school } \\
\text { building }\end{array}$ & $\begin{array}{l}\text { VARIANT } \\
\text { BGN } \\
\text { ADMIN } \\
\text { VARIANT } \\
\text { UNOFF } \\
\text { UNOFF } \\
\text { UNOFF } \\
\text { UNOFF }\end{array}$ & $\begin{array}{l}\text { Cochise } \\
\text { Navajo } \\
\text { Navajo } \\
\text { Cochise } \\
\text { Navajo } \\
\text { Navajo } \\
\text { Navajo } \\
\text { Navajo }\end{array}$ & $\begin{array}{l}310400 \mathrm{~N} 1091900 \mathrm{~W} \\
335013 \mathrm{~N} 1095749 \mathrm{~W} \\
334845 \mathrm{~N} 1095910 \mathrm{~W} \\
\\
314510 \mathrm{~N} 1092545 \mathrm{~W} \\
334958 \mathrm{~N} 1095827 \mathrm{~W} \\
335010 \mathrm{N1095750W} \\
335004 \mathrm{~N} 1095803 \mathrm{~W} \\
335010 \mathrm{~N} 1095756 \mathrm{~W}\end{array}$ & & $\begin{array}{l}5200 \\
5200\end{array}$ & $\begin{array}{l}\text { Whiteriver } \\
\text { Whiteriver } \\
\text { Whiteriver } \\
\text { Whiteriver } \\
\text { Whiteriver } \\
\text { Whiteriver }\end{array}$ \\
\hline $\begin{array}{l}\text { Whiteriver Post office } \\
\text { White Rock } \\
\text { White Rock } \\
\text { White Rock Canyon } \\
\text { White Rock Canyon } \\
\text { Whiterock Canyon } \\
\text { Whiterock Corral } \\
\text { White Rock Dam } \\
\text { White Rock Mesa } \\
\text { See Whiterock Mesa }\end{array}$ & $\begin{array}{l}\text { building } \\
\text { pillar } \\
\text { summit } \\
\text { valley } \\
\text { valley } \\
\text { valley } \\
\text { locale } \\
\text { dam } \\
\text { summit }\end{array}$ & $\begin{array}{l}\text { UNOFF } \\
\text { BGN } \\
\text { BGN } \\
\text { BGN } \\
\text { BGN } \\
\text { BGN } \\
\text { BGN } \\
\text { UNOFF } \\
\text { VARIANT }\end{array}$ & $\begin{array}{l}\text { Navajo } \\
\text { Coconino } \\
\text { Apache } \\
\text { Greenlee } \\
\text { Mohave } \\
\text { Coconino } \\
\text { Gila } \\
\text { Santa Cruz } \\
\text { Gila }\end{array}$ & $\begin{array}{l}335005 \mathrm{~N} 1095750 \mathrm{~W} \\
363920 \mathrm{~N} 1113430 \mathrm{~W} \\
354643 \mathrm{~N} 1095224 \mathrm{~W} \\
331212 \mathrm{~N} 1091128 \mathrm{~W} \\
355748 \mathrm{~N} 1144344 \mathrm{~W} \\
361156 \mathrm{N1} 124533 \mathrm{~W} \\
341645 \mathrm{~N} 1112638 \mathrm{~W} \\
312757 \mathrm{N1} 110935 \mathrm{~W} \\
\\
341700 \mathrm{~N} 1113100 \mathrm{~W}\end{array}$ & $\begin{array}{l}331049 N 1091029 \mathrm{~W} \\
360225 \mathrm{~N} 1143806 \mathrm{~W} \\
361029 \mathrm{~N} 1124709 \mathrm{~W}\end{array}$ & $\begin{array}{l}5200 \\
6534\end{array}$ & $\begin{array}{l}\text { Whiteriver } \\
\text { Explosive Rock } \\
\text { Steamboat Rock } \\
\text { Dix Creek } \\
\text { Ringbolt Rapids } \\
\text { Yunosi Point } \\
\text { Buckhead Mesa } \\
\text { Ruby }\end{array}$ \\
\hline $\begin{array}{l}\text { Whiterock Mesa } \\
\text { White Rock Mesa } \\
\text { White Rock Mesa } \\
\text { White Rock Mesa Windmill } \\
\text { White Rock Point } \\
\text { White Rocks Cabin } \\
\text { Whiterock Soapstone Reservoir } \\
\text { White Rock Spring } \\
\text { White Rock Spring } \\
\text { White Rock Spring }\end{array}$ & $\begin{array}{l}\text { summit } \\
\text { summit } \\
\text { locale } \\
\text { summit } \\
\text { locale } \\
\text { reservoir } \\
\text { spring } \\
\text { spring } \\
\text { spring }\end{array}$ & $\begin{array}{l}\text { BGN } 1968 \\
\text { VARIANT } \\
\text { BGN } \\
\text { BGN } \\
\text { BGN } \\
\text { BGN } \\
\text { BGN } \\
\text { BGN } \\
\text { BGN } \\
\text { BGN }\end{array}$ & $\begin{array}{l}\text { Gila } \\
\text { Apache } \\
\text { Navajo } \\
\text { Apache } \\
\text { Greenlee } \\
\text { Mohave } \\
\text { Cochise } \\
\text { Cochise } \\
\text { Pinal }\end{array}$ & $\begin{array}{l}341700 \mathrm{~N} 1113100 \mathrm{~W} \\
363511 \mathrm{N1} 1095834 \mathrm{~W} \\
363341 \mathrm{~N} 1100118 \mathrm{~W} \\
360449 \mathrm{~N} 1095245 \mathrm{~W} \\
332451 \mathrm{N1} 1090909 \mathrm{~W} \\
364346 \mathrm{~N} 1133454 \mathrm{~W} \\
321008 \mathrm{~N} 1093119 \mathrm{~W} \\
321557 \mathrm{~N} 1093301 \mathrm{~W} \\
332745 \mathrm{N1112148W}\end{array}$ & & 4895 & $\begin{array}{l}\text { Cane Springs Mtn } \\
\text { Sweetwater Mesa } \\
\text { Chilchinbito } \\
\text { Toadindaaska Mesa } \\
\text { Dutch Blue Creek } \\
\text { Sullivan Draw North } \\
\text { Dos Cabezas } \\
\text { Luzena } \\
\text { Weavers Needle }\end{array}$ \\
\hline $\begin{array}{l}\text { White Rock Spring } \\
\text { White Rock Spring } \\
\text { Whiterock Spring } \\
\text { White Rock Spring } \\
\text { White Rock Spring } \\
\text { White Rock Spring Loop Trail } \\
\text { Number Thirty Eight }\end{array}$ & $\begin{array}{l}\text { spring } \\
\text { spring } \\
\text { spring } \\
\text { spring } \\
\text { spring } \\
\text { trail }\end{array}$ & $\begin{array}{l}\text { BGN } \\
\text { BGN } \\
\text { BGN } \\
\text { BGN } \\
\text { BGN } \\
\text { UNOFF }\end{array}$ & $\begin{array}{l}\text { Maricopa } \\
\text { Yavapai } \\
\text { Gila } \\
\text { Yavapai } \\
\text { Apache } \\
\text { Yavapai }\end{array}$ & $\begin{array}{l}333548 \mathrm{~N} 1111043 \mathrm{~W} \\
340755 \mathrm{~N} 1114718 \mathrm{~W} \\
341612 \mathrm{~N} 1113104 \mathrm{~W} \\
343732 \mathrm{~N} 1123518 \mathrm{~W} \\
355414 \mathrm{N1} 1091632 \mathrm{~W} \\
343714 \mathrm{~N} 1123603 \mathrm{~W}\end{array}$ & & & $\begin{array}{l}\text { Pinyon Mtn } \\
\text { Bloody Basin } \\
\text { Cane Springs Mtn } \\
\text { Jerome Canyon } \\
\text { White Rock Wash } \\
\text { Iron Springs }\end{array}$ \\
\hline $\begin{array}{l}\text { White Rock Tank } \\
\text { White Rock Tanks } \\
\text { White Rock Wash }\end{array}$ & $\begin{array}{l}\text { reservoir } \\
\text { reservoir } \\
\text { valley }\end{array}$ & $\begin{array}{l}\text { BGN } \\
\text { BGN } \\
\text { BGN }\end{array}$ & $\begin{array}{l}\text { Mohave } \\
\text { Mohave } \\
\text { Apache }\end{array}$ & $\begin{array}{l}350954 N 1132638 \mathrm{~W} \\
364347 \mathrm{N1} 133455 \mathrm{~W} \\
355549 \mathrm{~N} 1092147 \mathrm{~W}\end{array}$ & $355415 N 1091610 \mathrm{~W}$ & & $\begin{array}{l}\text { Bull Spring } \\
\text { Sullivan Draw North } \\
\text { White Rock Wash }\end{array}$ \\
\hline $\begin{array}{l}\text { White Rock Wash } \\
\text { White Rock Well } \\
\text { White Ruin Canyon } \\
\text { White Saddle Spring } \\
\text { White Sage Flat } \\
\text { White Sage Wash } \\
\text { White Sand Ruins } \\
\text { White Sand Well } \\
\text { Whites Butte } \\
\text { White School }\end{array}$ & $\begin{array}{l}\text { valley } \\
\text { well } \\
\text { valley } \\
\text { spring } \\
\text { flat } \\
\text { stream } \\
\text { locale } \\
\text { well } \\
\text { sumnit } \\
\text { school }\end{array}$ & $\begin{array}{l}\text { BGN } \\
\text { UNOFF } \\
\text { BGN } \\
\text { BGN } \\
\text { BGN } \\
\text { BGN } \\
\text { BGN } \\
\text { UNOFF } \\
\text { BGN } 1932 \\
\text { UNOFF }\end{array}$ & $\begin{array}{l}\text { Apache } \\
\text { Mohave } \\
\text { Navajo } \\
\text { Mohave } \\
\text { Coconino } \\
\text { Coconino } \\
\text { Apache } \\
\text { Coconino } \\
\text { Coconino } \\
\text { Pima }\end{array}$ & $\begin{array}{l}364319 N 1091955 \mathrm{~W} \\
350748 \mathrm{~N} 1132525 \mathrm{~W} \\
361203 \mathrm{~N} 1104408 \mathrm{~W} \\
363418 \mathrm{~N} 1140010 \mathrm{~W} \\
364548 \mathrm{~N} 1122316 \mathrm{~W} \\
365700 \mathrm{~N} 1122214 \mathrm{~W} \\
360650 \mathrm{~N} 1092608 \mathrm{~W} \\
361937 \mathrm{N1} 111735 \mathrm{~W} \\
360552 \mathrm{~N} 1121351 \mathrm{~W} \\
320905 \mathrm{~N} 1110100 \mathrm{~W}\end{array}$ & $\begin{array}{l}364525 N 1091401 \mathrm{~W} \\
361759 \mathrm{~N} 1102 \mathrm{~B} 31 \mathrm{~W} \\
370401 \mathrm{~N} 1121034 \mathrm{~W}\end{array}$ & $\begin{array}{l} \\
5322 \\
4871\end{array}$ & $\begin{array}{l}\text { Kinusta Mesa } \\
\text { Bull Spring } \\
\text { Rocky Ridge NW } \\
\text { Virgin Peak } \\
\text { White Sage Flat } \\
\text { Muggins Flat } \\
\text { Three Turkey Canyon } \\
\text { Preston Well } \\
\text { Grand Canyon } \\
\text { Cat Mountain }\end{array}$ \\
\hline $\begin{array}{l}\text { Whites Mill } \\
\quad \text { See Cas a Blanca } \\
\text { White Spar Campground } \\
\text { White Spar Mine } \\
\text { White Spar Windmill } \\
\text { Whitespot Tank } \\
\text { White Spring } \\
\text { White Spring } \\
\text { White Spring } \\
\text { White Spring }\end{array}$ & $\begin{array}{l}\text { ppl } \\
\text { park } \\
\text { mine } \\
\text { locale } \\
\text { reservoir } \\
\text { spring } \\
\text { spring } \\
\text { spring } \\
\text { spring }\end{array}$ & $\begin{array}{l}\text { VARIANT } \\
\text { AOMIN } \\
\text { UNOFF } \\
\text { BGN } \\
\text { BGN } \\
\text { BGN } \\
\text { BGN } \\
\text { BGN } \\
\text { BGN }\end{array}$ & $\begin{array}{l}\text { Pinal } \\
\text { Yavapai } \\
\text { Yavapai } \\
\text { Yavapai } \\
\text { Navajo } \\
\text { Graham } \\
\text { Navajo } \\
\text { Yavapai } \\
\text { Mohave }\end{array}$ & $\begin{array}{l}330713 \mathrm{~N} 1115315 \mathrm{~W} \\
343033 \mathrm{~N} 1122833 \mathrm{~W} \\
342504 \mathrm{~N} 1123238 \mathrm{~W} \\
342522 \mathrm{~N} 1123310 \mathrm{~W} \\
334956 \mathrm{~N} 1095228 \mathrm{~W} \\
325852 \mathrm{N1} 101227 \mathrm{~W} \\
341109 \mathrm{~N} 1103055 \mathrm{~W} \\
343717 \mathrm{~N} 1131005 \mathrm{~W} \\
354924 \mathrm{~N} 1134336 \mathrm{~W}\end{array}$ & & & $\begin{array}{l}\text { Prescott } \\
\text { Wilhoit } \\
\text { Wilhoit } \\
\text { Corn Creek Plateau } \\
\text { Jackson Mtn } \\
\text { Pepper Canyon } \\
\text { Bagdad } \\
\text { Spencer Canyon }\end{array}$ \\
\hline $\begin{array}{l}\text { White Spring } \\
\text { White Spring } \\
\text { White Spring Wash } \\
\text { White Spring Well } \\
\text { White Streaks Canyon } \\
\text { Whites Well } \\
\text { See White Well (dry) } \\
\text { Whites Well }\end{array}$ & $\begin{array}{l}\text { spring } \\
\text { spring } \\
\text { stream } \\
\text { well } \\
\text { valley } \\
\text { well }\end{array}$ & $\begin{array}{l}\text { BGN } \\
\text { BGN } \\
\text { BGN } \\
\text { UNOFF } \\
\text { BGN } \\
\text { VARIANT } \\
\text { VARIANT }\end{array}$ & $\begin{array}{l}\text { Navajo } \\
\text { Coconino } \\
\text { Yavapai } \\
\text { Mohave } \\
\text { Graham } \\
\text { Yuma }\end{array}$ & $\begin{array}{l}355124 \mathrm{~N} 1103127 \mathrm{~W} \\
363241 \mathrm{~N} 1123026 \mathrm{~W} \\
343720 \mathrm{~N} 1131000 \mathrm{~W} \\
345426 \mathrm{~N} 1133300 \mathrm{~W} \\
324933 \mathrm{~N} 1095105 \mathrm{~W} \\
323540 \mathrm{~N} 1133231 \mathrm{~W}\end{array}$ & $\begin{array}{l}343702 \mathrm{~N} 1130907 \mathrm{~W} \\
324542 \mathrm{~N} 1095330 \mathrm{~W}\end{array}$ & & $\begin{array}{l}\text { Shongopovi } \\
\text { Jumpup Point } \\
\text { Bagdad } \\
\text { Tom Brown Canyon } \\
\text { Thatcher }\end{array}$ \\
\hline
\end{tabular}


NATIONAL GAZETTEER--ARIZONA 1986

FEATURE NAME

See Ventana

Whitetail Creek

Whitetail Creek

See East Whitetail Creek

White Tail Deer

Whitetail Lake

Whitetail Pass

Whitetail Ridge

White Tail Spring

Whitetail Spring

Whitetail Tank

Whitetail Tank

Whitetail Tank

White Tank

White Tank

White Tank

White Tank

White Tank

White Tank

White Tank

White Tank

White Tank

White Tank

White Tank

Tank

White Tank

White Tank

White Tank

White Tank

White Tank

White Tank

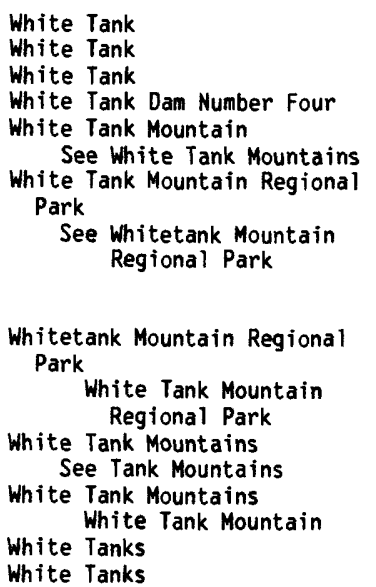

stream VARIANT Cochise 320B55N1090926W mine UNOFF Cochise 312501N1095504h lake BGN Navajo 340948N1103145

aap

ridge

BGN

spring $\quad B G N$

spring $\quad B G$

reservoir BGN

reservoir $B G N$

reservoir $B G$

reservoir BGN

reservoir BGN

reservoir BGN

reservoir BGN

reservoir $B G$

reservoir $B G$

reservoir BGN

reservoir $B G M$

reservoir $B G$

reservoir $B G$

reservoir $B G \mathrm{~A}$

reservoir $B G$

reservoir $B G$

reservoir $B G$

reservoir $B G$

reservoir $8 G$

reservoir

reservoir BGN

reservoir reservoir

reservoir

dam

ridge

park

park

ADMIN

VARIANT

ridge

ridge

reservoir

ppl

locale

summit

summit

valley

valley

valley

spring

valley

valley

stream

valley

strean

Cochise 320236N1091952W

Navajo 341141N1103416W

Gila 333323N1101500W

Apache 335300N1091132W

Pima 321853N1104150W

$335516 N 1095849 \mathrm{~W}$

Coconino

Santa Cruz

Santa Cruz

Cochise

Pima

Pima

Pima

Maricopa

Yuma

Gila

Gila

Gila

Yavapai

Apache

Navajo

Navajo

Apache

Yavapai

Coconino

Coconino

$35031 B N 1120137 \mathrm{~W}$

$313326 N 1103553 \mathrm{~W}$

$313353 \mathrm{~N} 111094 \mathrm{BW}$

314654 N1101619W

$320750 \mathrm{~N} 1112306 \mathrm{~W}$

$321829 \mathrm{~N} 1103434 \mathrm{~W}$

$322630 \mathrm{~N} 1103614 \mathrm{~W}$

$324520 \mathrm{~N} 1121814 \mathrm{~W}$

$331035 \mathrm{~N} 1133805 \mathrm{~W}$

$332016 \mathrm{~N} 1104737 \mathrm{~W}$

$334401 \mathrm{~N} 1103222 \mathrm{~W}$

$341519 \mathrm{~N} 1112436 \mathrm{~W}$

$341820 \mathrm{~N} 1121303 \mathrm{~W}$

$344242 \mathrm{~N} 1093452 \mathrm{~W}$

$344326 \mathrm{~N} 1102126 \mathrm{~W}$

$344833 \mathrm{~N} 1104354 \mathrm{~W}$

$344930 \mathrm{~N} 1094242 \mathrm{~W}$

$345432 \mathrm{~N} 1121939 \mathrm{~W}$

$352832 N 112302 \mathrm{BW}$

$352839 \mathrm{~N} 1115531 \mathrm{~W}$

Coconino 353107N1122232W

Mohave

$\begin{array}{ll}\text { BGN } & \text { Mohave } \\ \text { UNOFF } & \text { Maricopa }\end{array}$

$353336 \mathrm{~N} 1140246 \mathrm{~W}$

362959 N1130045

$332700 \mathrm{~N} 1122906 \mathrm{~W}$

Maricopa

$333155 N 1123421 \mathrm{~W}$

VARIANT

Maricopa

$333518 N 1123422 \mathrm{~W}$

Maricopa

$333518 N 1123422 \mathrm{~W}$

VARIANT

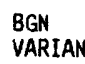

VARIANT

BGN

BGN

Yuma

Maricopa

$330937 \mathrm{~N} 1134142 \mathrm{~W}$

$332812 \mathrm{~N} 1142714 \mathrm{~W}$

Maricopa $\quad 333615 N 1121755 \mathrm{~W}$

UNOFF

VARIANT

Maricopa

$332956 \mathrm{~N} 1122958 \mathrm{~W}$

BGN 1915 Apache

BGN Apache

VARIANT

BGN

BGN

BGN

BGN

Graham

Greenlee

Navajo

Navajo

8GN Pinal

BGN Apache

VARIANT

VARIANT

Greenlee

Cochise

BGN

VARIANT

VARIANT reservoir BGN

\begin{tabular}{|c|c|c|c|c|c|c|}
\hline $\begin{array}{l}\text { FEATURE } \\
\text { CLASS }\end{array}$ & STATUS & COUNTY & COORDINATE & $\begin{array}{l}\text { SOURCE } \\
\text { COORDINATE }\end{array}$ & $\begin{array}{c}\text { ELEV } \\
\text { FT }\end{array}$ & MAP NAME \\
\hline $\begin{array}{l}\text { ppl } \\
\text { stream }\end{array}$ & BGN & $\begin{array}{l}\text { Pima } \\
\text { Cochise }\end{array}$ & $\begin{array}{l}322758 \mathrm{~N} 1121433 \mathrm{~W} \\
320855 \mathrm{~N} 1090925 \mathrm{~W}\end{array}$ & $315840 \mathrm{~N} 1091430 \mathrm{~W}$ & & Blue Mountain \\
\hline
\end{tabular}

$352300 N 1092800 \mathrm{~W}$

$363158 \mathrm{~N} 1095004 \mathrm{~W}$

$325813 \mathrm{~N} 1092322 \mathrm{~W}$

$325817 N 1092323 \mathrm{~W}$

$360620 \mathrm{~N} 1102425 \mathrm{~W}$

354839 N1103141W

$325457 N 1092315 \mathrm{~W}$

325500 N1092315W

360B04N1101611

$325352 N 1$ i03358W

351707 N1090B14W

330948 N1092936W

$314510 \mathrm{~N} 1092545 \mathrm{~W}$

330948 N1092936W
Bisbee

Pepper Canyon

Cochise Head

Pepper Canyon

Chiricahua Butte

Nutrioso

Agua Caliente $\mathrm{Hill}$

Alchesay Flat

White Horse Lake

O'Donnell Canyon

Murphy Peak

McGrew Spring

La Tortuga Butte

Piety $\mathrm{Hill}$

Buehman Canyon

Lost Horse Peak

Palomas Mts West

Pinal Peak

Chrysotile

Buckhead Mesa

Cleator

Stinking Springs Mtn

Dry Lake NE

Relic Point

Milky Ranch

Hell Point

Eagle Nest Mtn

Moritz Ridge

Red Hill Ranch

Mt Tipton SE

Mt Trumbull NE

Perryville

White Tank Mts SE

White Tank Mts

North Trigo Peaks

E1 Mirage

Perryville

Wide Ruins White Point

Gila Box

Gila Box

Hard Rocks

Shongopovi

Brandenburg Mtn

Houck

Coronado Mtn 


\begin{tabular}{|c|c|c|c|c|c|c|c|}
\hline FEATURE NAME & $\begin{array}{l}\text { FEATURE } \\
\text { CLASS }\end{array}$ & STATUS & COUNTY & COORDINATE & $\begin{array}{l}\text { SOURCE } \\
\text { COORDIMATE }\end{array}$ & $\begin{array}{l}\text { ELEV } \\
\text { FT }\end{array}$ & MAP MAME \\
\hline See Whitewater Draw & valley & & Cochise & $310400 \mathrm{~N} 1091900 \mathrm{~W}$ & & & \\
\hline $\begin{array}{l}\text { Whitewater Oraw } \\
\text { White River } \\
\text { Whitewater Creek } \\
\text { White Water Reservoir } \\
\text { White Water Spring } \\
\text { White Water Tank } \\
\text { White Water Wash } \\
\text { White Water Wash } \\
\text { White Well } \\
\text { White Well (dry) } \\
\text { Whites Well }\end{array}$ & $\begin{array}{l}\text { valley } \\
\text { reservoir } \\
\text { spring } \\
\text { reservoir } \\
\text { stream } \\
\text { valley } \\
\text { well } \\
\text { well }\end{array}$ & $\begin{array}{l}\text { BGN } 1959 \\
\text { VARIANT } \\
\text { VARIANT } \\
\text { BGN } \\
\text { BGN } \\
\text { BGN } \\
\text { BGN } \\
\text { BGN } \\
\text { UNOFF } \\
\text { UNOFF } \\
\text { VARIANT }\end{array}$ & $\begin{array}{l}\text { Apache } \\
\text { Pinal } \\
\text { Coconino } \\
\text { Coconino } \\
\text { Apache } \\
\text { Pima } \\
\text { Yuma }\end{array}$ & 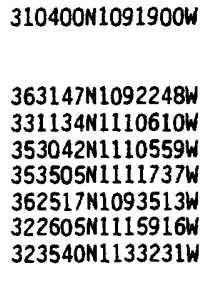 & $\begin{array}{l}353447 N 1110941 W \\
362416 N 1093034 W\end{array}$ & & $\begin{array}{l}\text { Douglas } \\
\text { Round Rock } \\
\text { Teapot Mountain } \\
\text { White Water Tank } \\
\text { Wupatki SE } \\
\text { Many Farms ME } \\
\text { Santa Rosa Mts NW } \\
\text { Mohawk Mts SE }\end{array}$ \\
\hline $\begin{array}{l}\text { White Well } \\
\text { White Well } \\
\text { White Wing Ranch } \\
\text { Whitford Canyon } \\
\text { Whiting Honestead } \\
\text { Whiting Knoll } \\
\text { Whiting Tank } \\
\text { Whiting Tank } \\
\text { Whiting Tank } \\
\text { Whiting Tank }\end{array}$ & $\begin{array}{l}\text { well } \\
\text { locale } \\
\text { locale } \\
\text { valley } \\
\text { locale } \\
\text { summit } \\
\text { reservoir } \\
\text { reservoir } \\
\text { reservoir } \\
\text { reservoir }\end{array}$ & $\begin{array}{l}\text { UNOFF } \\
\text { BGN } \\
\text { UNOFF } \\
\text { BGN } \\
\text { BGN } \\
\text { BGN } \\
\text { BGN } \\
\text { BGN } \\
\text { BGN } \\
\text { BGN }\end{array}$ & $\begin{array}{l}\text { Yavapai } \\
\text { Apache } \\
\text { Yuma } \\
\text { Pinal } \\
\text { Apache } \\
\text { Apache } \\
\text { Apache } \\
\text { Navajo } \\
\text { Coconino } \\
\text { Coconino }\end{array}$ & $\begin{array}{l}342355 \mathrm{~N} 1122517 \mathrm{~W} \\
350607 \mathrm{~N} 1090842 \mathrm{~W} \\
325819 \mathrm{~N} 1132947 \mathrm{~W} \\
331902 \mathrm{~N} 1110937 \mathrm{~W} \\
341118 \mathrm{~N} 1093438 \mathrm{~W} \\
340932 \mathrm{~N} 1093451 \mathrm{~W} \\
341351 \mathrm{N1094653 \textrm {W }} \\
341635 \mathrm{~N} 1101418 \mathrm{~W} \\
350912 \mathrm{N1120320 \textrm {W }} \\
365220 \mathrm{~N} 1122710 \mathrm{~W}\end{array}$ & $332119 \mathrm{~N} 1110754 \mathrm{~W}$ & $\begin{array}{l}6337 \\
6483\end{array}$ & $\begin{array}{l}\text { Groom Creek } \\
\text { Deep Lake } \\
\text { Aztec NW } \\
\text { Picketpost Mtn } \\
\text { Whiting Knoll } \\
\text { Whiting Knoll } \\
\text { Sponseller Mtn } \\
\text { Pinedale } \\
\text { Davenport Hill } \\
\text { White Sage Flat }\end{array}$ \\
\hline $\begin{array}{l}\text { Whit ing Wash } \\
\text { Whit lock Cienega } \\
\text { Whit lock Detention Dan } \\
\text { Whit lock Mountains } \\
\text { Whit lock Peak } \\
\text { Whit lock Valley } \\
\text { Whit lock Wash } \\
\text { Whitlock Wash } \\
\text { Whit low Canyon } \\
\text { Whitlow Corral }\end{array}$ & $\begin{array}{l}\text { valley } \\
\text { locale } \\
\text { dam } \\
\text { range } \\
\text { sumnit } \\
\text { basin } \\
\text { stream } \\
\text { stream } \\
\text { valley } \\
\text { locale }\end{array}$ & $\begin{array}{l}\text { BGN } \\
\text { BGN } \\
\text { UNOFF } \\
\text { BGN } \\
\text { BGN } \\
\text { BGN } \\
\text { BGN } \\
\text { BGN } \\
\text { BGN } \\
\text { BGN }\end{array}$ & $\begin{array}{l}\text { Apache } \\
\text { Graham } \\
\text { Graham } \\
\text { Graham } \\
\text { Greenlee } \\
\text { Graham } \\
\text { Graham } \\
\text { Pinal } \\
\text { Pinal } \\
\text { Pinal }\end{array}$ & $\begin{array}{l}341635 N 1093934 \mathrm{~W} \\
323310 \mathrm{N1092007W} \\
323212 \mathrm{~N} 1092042 \mathrm{~W} \\
323554 \mathrm{~N} 1092406 \mathrm{~W} \\
323605 \mathrm{~N} 1091302 \mathrm{~W} \\
323918 \mathrm{~N} 1091814 \mathrm{~W} \\
323326 \mathrm{~N} 1091752 \mathrm{~W} \\
323613 \mathrm{N1103224W} \\
331752 \mathrm{~N} 1111849 \mathrm{~W} \\
332336 \mathrm{N1111735W}\end{array}$ & 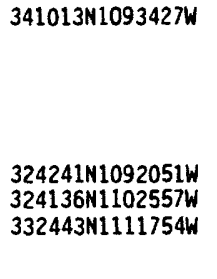 & & $\begin{array}{l}\text { Vernon } \\
\text { Whitlock Cienega } \\
\text { Whitlock Cienega } \\
\text { Javelina Peak } \\
\text { Whit lock Peak } \\
\text { Whit lock Mts NE } \\
\text { Whitlock Cienega } \\
\text { Peppersauce Wash } \\
\text { Florence Junction } \\
\text { Weavers Needle }\end{array}$ \\
\hline $\begin{array}{l}\text { Whitlow Ranch Dan } \\
\text { Whitlow Ranch Flood Control } \\
\text { Bas in } \\
\text { Queen Creek Reservoir } \\
\text { Whitlow Ranch Reservoir } \\
\text { Whitlow Reservoir } \\
\text { Whitlow Ranch Reservoir } \\
\text { See Whitlow Ranch Flood } \\
\text { Control Bas in } \\
\text { Whit low Reservoir } \\
\text { See Whitlow Ranch Flood } \\
\text { Control Bas in }\end{array}$ & $\begin{array}{l}\text { dam } \\
\text { reservoir }\end{array}$ & $\begin{array}{l}\text { UNOFF } \\
\text { BGN } \\
\text { VARIANT } \\
\text { VARIANT } \\
\text { VARIANT } \\
\text { VARIANT }\end{array}$ & $\begin{array}{l}\text { Pinal } \\
\text { Pinal }\end{array}$ & $\begin{array}{l}331756 \mathrm{~N} 1111630 \mathrm{~W} \\
331756 \mathrm{~N} 1111630 \mathrm{~W}\end{array}$ & & 2166 & $\begin{array}{l}\text { Florence Junction } \\
\text { Florence Junct ion }\end{array}$ \\
\hline $\begin{array}{l}\text { Whitman Elementary School } \\
\text { Whitmore Canyon } \\
\text { See Whitmore Wash } \\
\text { Whitmore Canyon } \\
\text { Queantowcap Valley } \\
\text { Whitmore Wash } \\
\text { Whitmore Point } \\
\text { Whitmore Point Pond } \\
\text { Whitmore Rapids } \\
\text { Whitmore School } \\
\text { W } \forall \text { Whitmore School }\end{array}$ & $\begin{array}{l}\text { school } \\
\text { stream } \\
\text { valley }\end{array}$ & $\begin{array}{l}\text { UNOFF } \\
\text { VARIANT } \\
\text { BGN } \\
\text { VARIANT } \\
\text { VARIANT } \\
\text { BGN } \\
\text { BGN } \\
\text { BGN } \\
\text { UNOFF } \\
\text { VARIANT }\end{array}$ & $\begin{array}{l}\text { Maricopa } \\
\text { Mohave } \\
\text { Mohave }\end{array}$ & $\begin{array}{l}361107 N 1131543 W \\
361608 N 1131757 W \\
360844 N 1131159 W \\
321526 N 1105242 W\end{array}$ & $362355 \mathrm{N1131830 \textrm {W }}$ & & $\begin{array}{l}\text { Whitmore Rapids } \\
\text { Whitmore Point } \\
\text { Cold Spring } \\
\text { Whitmore Rapids } \\
\text { Tucson North }\end{array}$ \\
\hline $\begin{array}{l}\text { Whitmore Spring (historical) } \\
\text { Whittmore Spring } \\
\text { Whitmore Spring } \\
\text { See Big Spring } \\
\text { Whitmore Wash } \\
\text { Whitmore Canyon } \\
\text { Whitmore Wash }\end{array}$ & $\begin{array}{l}\text { spring } \\
\text { stream }\end{array}$ & $\begin{array}{l}\text { BGN } 1915 \\
\text { VARIANT } \\
\text { VARIANT } \\
\text { BGN } \\
\text { VARIANT } \\
\text { VARIANT }\end{array}$ & $\begin{array}{l}\text { Mohave } \\
\text { Mohave }\end{array}$ & $\begin{array}{l}362000 \mathrm{~N} 1131400 \mathrm{~W} \\
362013 \mathrm{~N} 1131126 \mathrm{~W} \\
360840 \mathrm{~N} 1131202 \mathrm{~W}\end{array}$ & $362355 \mathrm{N1} 131830 \mathrm{~W}$ & & Whitmore Rapids \\
\hline $\begin{array}{l}\text { See Whitmore Canyon } \\
\text { Whitney Ranch } \\
\text { Whittaker Ranch }\end{array}$ & $\begin{array}{l}\text { valley } \\
\text { locale } \\
\text { locale }\end{array}$ & $\begin{array}{l}\text { UNOFF } \\
\text { UNOFF }\end{array}$ & $\begin{array}{l}\text { Mohave } \\
\text { Santa Cruz } \\
\text { Pinal }\end{array}$ & $\begin{array}{l}360840 \mathrm{~N} 1131202 \mathrm{~W} \\
313110 \mathrm{N1103043W} \\
325350 \mathrm{~N} 1103824 \mathrm{~W}\end{array}$ & & 5100 & $\begin{array}{l}\text { 0'Donnell Canyon } \\
\text { Dudleyville }\end{array}$ \\
\hline $\begin{array}{l}\text { Whitted Place } \\
\text { Whittier Elementary School } \\
\text { Whittier School } \\
\text { Whitting Spring } \\
\text { Whittman } \\
\text { See Wittmann }\end{array}$ & $\begin{array}{l}\text { locale } \\
\text { school } \\
\text { school } \\
\text { spring } \\
\text { ppl }\end{array}$ & $\begin{array}{l}\text { BGN } \\
\text { UNOFF } \\
\text { UNOFF } \\
\text { BGN } \\
\text { VARIANT }\end{array}$ & $\begin{array}{l}\text { Coconino } \\
\text { Maricopa } \\
\text { Maricopa } \\
\text { Pinal } \\
\text { Maricopa }\end{array}$ & $\begin{array}{l}344355 \mathrm{~N} 1105735 \mathrm{~W} \\
332543 \mathrm{~N} 1115149 \mathrm{~W} \\
332813 \mathrm{~N} 1120253 \mathrm{~W} \\
324327 \mathrm{N1} 102928 \mathrm{~W} \\
\\
334635 \mathrm{~N} 1123140 \mathrm{~W}\end{array}$ & & 6179 & $\begin{array}{l}\text { Hamilton Crossing } \\
\text { Mesa } \\
\text { Phoenix } \\
\text { Rhodes Peak }\end{array}$ \\
\hline
\end{tabular}




\begin{tabular}{|c|c|c|c|c|c|c|c|}
\hline FEATURE NAME & $\begin{array}{l}\text { FEATURE } \\
\text { CLASS }\end{array}$ & STATUS & COUNTY & COORDINATE & $\begin{array}{l}\text { SOURCE } \\
\text { COORDINATE }\end{array}$ & $\begin{array}{c}\text { ELEV } \\
\text { FT }\end{array}$ & MAP NAME \\
\hline $\begin{array}{l}\text { Whittmore Spring } \\
\text { See Whitmore Spring } \\
\text { (historical) } \\
\text { Whittum } \\
\text { See Blue }\end{array}$ & locale & VARIANT & Greenlee & $\begin{array}{l}362000 \mathrm{~N} 1131400 \mathrm{~W} \\
333636 \mathrm{~N} 1090622 \mathrm{~W}\end{array}$ & & & \\
\hline $\begin{array}{l}\text { Whoa Canyon } \\
\text { Wholfhole } \\
\text { See Wolf Hole Lake } \\
\text { Why Rocky Point Junction } \\
\text { Wickchoupai } \\
\text { Wickenburg } \\
\text { Wickenburg Ranch } \\
\text { Wickenburg Community Hospital } \\
\text { Wickenburg High School }\end{array}$ & $\begin{array}{l}\text { valley } \\
\text { lake } \\
\text { ppl } \\
\text { locale } \\
\text { ppl } \\
\text { hospital } \\
\text { school }\end{array}$ & $\begin{array}{l}\text { BGN } \\
\text { VARIANT } \\
\text { BGN } \\
\text { VARIANT } \\
\text { BGN } \\
\text { BGN } \\
\text { VARIANT } \\
\text { UNOFF } \\
\text { UNOFF }\end{array}$ & $\begin{array}{l}\text { Greenlee } \\
\text { Mohave } \\
\text { Pima } \\
\text { Pima } \\
\text { Maricopa } \\
\text { Maricopa } \\
\text { Maricopa }\end{array}$ & $\begin{array}{l}333329 \mathrm{~N} 1090603 \mathrm{~W} \\
364539 \mathrm{~N} 113322 \mathrm{BW} \\
321607 \mathrm{~N} 1124417 \mathrm{~W} \\
320014 \mathrm{~N} 1115516 \mathrm{~W} \\
335807 \mathrm{~N} 1124344 \mathrm{~W} \\
335842 \mathrm{~N} 1124422 \mathrm{~W} \\
335804 \mathrm{~N} 1124338 \mathrm{~W}\end{array}$ & $333131 N 1090524 W$ & 2903 & $\begin{array}{l}\text { Sikort Chuapo } \\
\text { Ko Vaya } \\
\text { Wickenburg } \\
\text { Wickenburg } \\
\text { Wickenburg }\end{array}$ \\
\hline $\begin{array}{l}\text { Wickenburg Massacre } \\
\text { Historical Monument } \\
\text { Wickenburg Mountains } \\
\text { Wickenburg Municipal Airport } \\
\text { Wickenburg Post Office } \\
\text { Wickenburg Railroad Station } \\
\text { Wickenburg Ranch } \\
\text { See Wickenburg } \\
\text { Wickenburg Substation } \\
\text { Wickenburg Town Hall }\end{array}$ & $\begin{array}{l}\text { park } \\
\text { range } \\
\text { airport } \\
\text { building } \\
\text { building } \\
\text { pp1 } \\
\text { locale } \\
\text { building }\end{array}$ & $\begin{array}{l}\text { ADMIN } \\
\text { BGN } \\
\text { ADMIN } \\
\text { UNOFF } \\
\text { UNOFF } \\
\text { VARIANT } \\
\text { UNOFF } \\
\text { UNOFF }\end{array}$ & $\begin{array}{l}\text { Maricopa } \\
\text { Yavapai } \\
\text { Maricopa } \\
\text { Maricopa } \\
\text { Maricopa } \\
\text { Maricopa } \\
\text { Maricopa } \\
\text { Maricopa }\end{array}$ & $\begin{array}{l}335748 N 1124748 \mathrm{~W} \\
335815 \mathrm{~N} 1123220 \mathrm{~W} \\
335811 \mathrm{~N} 1124744 \mathrm{~W} \\
335810 \mathrm{~N} 1124339 \mathrm{~W} \\
335808 \mathrm{~N} 1124356 \mathrm{~W} \\
\\
335807 \mathrm{~N} 1124344 \mathrm{~W} \\
335858 \mathrm{~N} 1124417 \mathrm{~W} \\
335812 \mathrm{~N} 1124338 \mathrm{~W}\end{array}$ & & $\begin{array}{l}2349 \\
2423\end{array}$ & $\begin{array}{l}\text { Vulture Peak } \\
\text { Red Picacho } \\
\text { Vulture Peak } \\
\text { Wickenburg } \\
\text { Wickenburg }\end{array}$ \\
\hline $\begin{array}{l}\text { Wickieup } \\
\text { See Wikieup } \\
\text { Wickiup Canyon } \\
\text { Wickiup Creek } \\
\text { Wide Ruin } \\
\text { Wickiup Pit Tank } \\
\text { Wickiup Tank } \\
\text { See Goswick Tank } \\
\text { Wickiup Tank Number One } \\
\text { Wickiup Tank Number Two }\end{array}$ & $\begin{array}{l}\text { locale } \\
\text { valley } \\
\text { stream } \\
\text { reservoir } \\
\text { reservoir } \\
\text { reservoir } \\
\text { reservoir }\end{array}$ & $\begin{array}{l}\text { VARIANT } \\
\text { BGN } \\
\text { BGN 1974 } \\
\text { VARIANT } \\
\text { BGN } \\
\text { VARIANT } \\
\text { BGN } \\
\text { BGN }\end{array}$ & $\begin{array}{l}\text { Mohave } \\
\text { Yavapai } \\
\text { Yavapai } \\
\text { Yavapai } \\
\text { Yavapai } \\
\text { Yavapai } \\
\text { Yavapai }\end{array}$ & $\begin{array}{l}344212 \mathrm{~N} 1133638 \mathrm{~W} \\
344838 \mathrm{~N} 1124655 \mathrm{~W} \\
343102 \mathrm{~N} 1114845 \mathrm{~W} \\
344701 \mathrm{~N} 1124850 \mathrm{~W} \\
343410 \mathrm{~N} 1114605 \mathrm{~W} \\
343524 \mathrm{~N} 1114231 \mathrm{~W} \\
343534 \mathrm{~N} 1114401 \mathrm{~W}\end{array}$ & $\begin{array}{l}344640 \mathrm{~N} 1124958 \mathrm{~W} \\
343532 \mathrm{~N} 1114000 \mathrm{~W}\end{array}$ & & $\begin{array}{l}\text { Seepage Mtn } \\
\text { Camp Verde } \\
\text { Seepage Mtn } \\
\text { Walker Mtn } \\
\text { Walker Mtn }\end{array}$ \\
\hline $\begin{array}{l}\text { Wide Butte } \\
\text { Wide Hollow } \\
\text { Wide Mesa } \\
\text { Wide Mouth Canyon } \\
\text { Wide Mouth Tank } \\
\text { Wide Reeds Ruins } \\
\text { Wide Ruin } \\
\text { See Wickiup Creek } \\
\text { Wide Ruin } \\
\text { See Wide Ruins }\end{array}$ & $\begin{array}{l}\text { summit } \\
\text { valley } \\
\text { summit } \\
\text { valley } \\
\text { reservoir } \\
\text { locale } \\
\text { stream } \\
\text { ppl }\end{array}$ & $\begin{array}{l}\text { BGN } \\
\text { BGN } \\
\text { BGN } \\
\text { BGN } \\
\text { BGN } \\
\text { BGN } \\
\text { VARIANT } \\
\text { VARIANT }\end{array}$ & $\begin{array}{l}\text { Navajo } \\
\text { Graham } \\
\text { Apache } \\
\text { Graham } \\
\text { Graham } \\
\text { Apache } \\
\text { Yavapai } \\
\text { Apache }\end{array}$ & $\begin{array}{l}352106 \mathrm{~N} 1101828 \mathrm{~W} \\
325900 \mathrm{~N} 1095407 \mathrm{~W} \\
362233 \mathrm{~N} 1091822 \mathrm{~W} \\
324958 \mathrm{~N} 1095847 \mathrm{~W} \\
324758 \mathrm{~N} 1100123 \mathrm{~W} \\
354235 \mathrm{~N} 1093312 \mathrm{~W} \\
343102 \mathrm{~N} 1114845 \mathrm{~W} \\
352510 \mathrm{~N} 1092945 \mathrm{~W}\end{array}$ & $\begin{array}{l}325955 \mathrm{~N} 1094912 \mathrm{~W} \\
324638 \mathrm{~N} 1100206 \mathrm{~W}\end{array}$ & 6730 & $\begin{array}{l}\text { French Butte } \\
\text { Eden } \\
\text { Bad Bug Butte } \\
\text { Shingle Mill Mtn } \\
\text { Tripp Canyon } \\
\text { Ganado }\end{array}$ \\
\hline $\begin{array}{l}\text { Wide Ruins } \\
\text { Wide Ruin } \\
\text { Wide Ruin Valley } \\
\text { Wide Ruin Wash } \\
\text { Wide Ruin Wash } \\
\text { Wide Ruin Wash } \\
\text { See Wide Ruin Valley } \\
\text { Widforss Point } \\
\text { McKinnon Point } \\
\text { Wids Tank }\end{array}$ & $\begin{array}{l}\text { ppl } \\
\text { valley } \\
\text { stream } \\
\text { valley } \\
\text { cliff } \\
\text { reservoir }\end{array}$ & $\begin{array}{l}\text { BGN } 1974 \\
\text { VARIANT } \\
\text { BGN 1915 } \\
\text { VARIANT } \\
\text { BGN 1915 } \\
\text { VARIANT } \\
\text { BGN } 1937 \\
\text { VARIANT } \\
\text { BGN }\end{array}$ & $\begin{array}{l}\text { Apache } \\
\text { Apache } \\
\text { Navajo } \\
\text { Apache } \\
\text { Coconino } \\
\text { Yavapai }\end{array}$ & $\begin{array}{l}352510 \mathrm{~N} 1092945 \mathrm{~W} \\
353735 \mathrm{~N} 1092119 \mathrm{~W} \\
351333 \mathrm{~N} 1095137 \mathrm{~W} \\
353735 \mathrm{~N} 1092119 \mathrm{~W} \\
361046 \mathrm{~N} 1120458 \mathrm{~W} \\
342752 \mathrm{~N} 1115749 \mathrm{~W}\end{array}$ & $\begin{array}{l}354008 \mathrm{~N} 1091336 \mathrm{~W} \\
354054 \mathrm{~N} 1091353 \mathrm{~W}\end{array}$ & 6263 & $\begin{array}{l}\text { Wide Ruins } \\
\text { Kinlichee } \\
\text { Chinde Mesa } \\
\text { Bright Angel Point } \\
\text { Arnold Mesa }\end{array}$ \\
\hline $\begin{array}{l}\text { Wiek Ranch } \\
\text { Wier Number Five } \\
\text { Wier Number One } \\
\text { Wier Number Six } \\
\text { Wier Number Three } \\
\text { Wier Number Two } \\
\text { Wiggins Crossing } \\
\text { Wiggins Ranch } \\
\text { Wiggins Tank } \\
\text { Wigleeva }\end{array}$ & $\begin{array}{l}\text { locale } \\
\text { dam } \\
\text { dam } \\
\text { dam } \\
\text { dam } \\
\text { dam } \\
\text { locale } \\
\text { locale } \\
\text { reservoir } \\
\text { cliff }\end{array}$ & $\begin{array}{l}\text { UNOFF } \\
\text { UNOFF } \\
\text { UNOFF } \\
\text { UNOFF } \\
\text { UNOFF } \\
\text { UNOFF } \\
\text { BGN } \\
\text { UNOFF } \\
\text { BGN } \\
\text { BGN }\end{array}$ & $\begin{array}{l}\text { Cochise } \\
\text { Yavapai } \\
\text { Yavapai } \\
\text { Yavapai } \\
\text { Yavapai } \\
\text { Yavapai } \\
\text { Coconino } \\
\text { Coconino } \\
\text { Yavapai } \\
\text { Coconino }\end{array}$ & $\begin{array}{l}312359 \mathrm{~N} 1100550 \mathrm{~W} \\
344443 \mathrm{~N} 1113349 \mathrm{~W} \\
344340 \mathrm{~N} 1113910 \mathrm{~W} \\
344402 \mathrm{~N} 1113350 \mathrm{~W} \\
344337 \mathrm{N1114010W} \\
344340 \mathrm{~N} 1113937 \mathrm{~W} \\
343100 \mathrm{~N} 1105916 \mathrm{~W} \\
343057 \mathrm{~N} 1110024 \mathrm{~W} \\
344532 \mathrm{~N} 1130614 \mathrm{~W} \\
361401 \mathrm{~N} 1124135 \mathrm{~W}\end{array}$ & . & & $\begin{array}{l}\text { Hereford } \\
\text { Apache Maid Mtn } \\
\text { Casner Butte } \\
\text { Apache Maid Mtn } \\
\text { Casner Butte } \\
\text { Casner Butte } \\
\text { Grama Draw } \\
\text { Leonard Canyon } \\
\text { Scratch Canyon } \\
\text { Supai }\end{array}$ \\
\hline $\begin{array}{l}\text { Wigwam Spring } \\
\text { Wigwam Villa Mobile Home Park } \\
\text { Wikieup } \\
\quad \text { Wickieup } \\
\text { Wikieup Post Office } \\
\text { Wikieup Tank }\end{array}$ & $\begin{array}{l}\text { spring } \\
\text { locale } \\
\text { locale } \\
\text { building } \\
\text { reservoir }\end{array}$ & $\begin{array}{l}\text { BGN } \\
\text { UNOFF } \\
\text { BGN 1941 } \\
\text { VARIANT } \\
\text { UNOFF } \\
\text { BGN }\end{array}$ & $\begin{array}{l}\text { Gila } \\
\text { Maricopa } \\
\text { Mohave } \\
\text { Mohave } \\
\text { Yavapai }\end{array}$ & $\begin{array}{l}335932 \mathrm{~N} 1100945 \mathrm{~W} \\
332807 \mathrm{~N} 1120523 \mathrm{~W} \\
344212 \mathrm{~N} 1133638 \mathrm{~W} \\
\\
344150 \mathrm{~N} 1133625 \mathrm{~W} \\
344832 \mathrm{~N} 1131918 \mathrm{~W}\end{array}$ & . & 1085 & $\begin{array}{l}\text { Cedar Creek } \\
\text { Phoenix } \\
\text { Wikieup } \\
\text { Wikieup } \\
\text { Pilot Knob }\end{array}$ \\
\hline
\end{tabular}


NATIONAL GAZETTEER--ARIZONA 1986

\section{FEATURE NAME}

Wilbanks Cabin

Wilbur Canyon

Wilbur Canyon

Wilbur Canyon

Wilbur Tank Number One

Wilbur Tank Number Two

Wilbur Wash

Wilbur Well

Wilcox

See Willcox

Wilcox High School

Wilcox Ranch

Wildband Canyon

Wild Band Pockets

Wild Band Reservoir

Wildband Spring

Wild Band Valley

Wild Bee Canyon

See Oripping Springs Canyon

Wild Beef Trap

Wild Bee Spring

Wild Bill Hill

Government Knoll

Government Knolls

Wild Bill Tank

Wild Bill Tank

Wild Bull Spring

Wild Bunch Canyon

Wild Bunch Tank

Wild Burro Canyon

Wild Burro Mesa

Wildcat Canyon

Wildcat Canyon

Wildcat Canyon

Wildcat Canyon

Wildcat Canyon Little Wildcat Canyon

Wildcat Canyon

Wildcat Canyon

Wildcat Canyon

Wildcat Canyon

Wildcat Creek

Wildcat Creek

Wildcat Creek

Wildcat Draw

Wildcat $\mathrm{Hill}$

Wildcat Hill

Wildcat $\mathrm{Hill}$

Wildcat Hill Waste Water

Treatment Plant

Wildcat Mine

Wildcat Peak

Wildcat Peak

Wildcat Peak

Nic do it soe

Nic-doit-soe

Nishduitso

Wildcat Point

Wildcat Ranch

Wildcat Seep

Wildcat Spring

Wildcat Spring

Wildcat Spring

Wildcat Spring

Wildcat Tank

Wildcat Tank

Wildcat Tank

Wildcat Wash

Wildcat Well

Wildcat Well

Wildcat Well

FEATURE
CLASS

STATUS

COUNTY

COORDIMATE

$313553 N 1112618 \mathrm{~W}$

$343335 \mathrm{~N} 1112726 \mathrm{~W}$

$344051 \mathrm{~N} 1115726 \mathrm{~W}$

valley

BGN
$B G N$
BGN

Yuma

Coconino

Yavapai

reservoir

reservoir BGH

well

BGN

BGN

$p p 1$

school

locale

valley

bas in

UNOFF

UNOFF

BGN

BGY

Coconino

Coconino

Pima

Yavapai

Cochise

Coch ise

Cochise

Coconino

Mohave

reservoir

spring

BGN

Mohave

valley

valley

cliff

spring

BGN

VARIANT

Mohave

Mohave

BGN Gila

BGN

Coconino

$343224 \mathrm{~N} 1112709 \mathrm{~W}$

313529 N1112156W

343903 N1115826W

312527 N1101424W

$364023 N 1125404 \mathrm{~W}$

$333710 N 1102821$

$351935 \mathrm{~N} 1115102 \mathrm{~W}$

VARIANT

Coconino

Coconino

Gila

Greenlee

Greenlee

Pima

Yavapai

Cochise

Cochise

Cochise

valley

valley

valley

valley

BGM

BGN
BGN 1962
VARIANT

valley

valley

valley

valley

stream

strean

stream

BGN

Gila

Navajo

Coconino

Coconino

Mavajo

Coconino

Gila

Apache

Apache

valle

summit

summit

locale

mine

summit

summit

$B G N$

BGN

BGN

BGN

BGN

$B G N$

UNOFF

UNOFF

BGN

BGN

BGN 1915

VARIANT

VARIANT

VARIANT

summit

locale

spring

spring

spring

spring

spring

reservoir

reservoir

reservoir

BGN

UNOFF

BGN

BGN

BGN

BGN

BGH

BGN

$B G N$

Yavapai

Maricopa

Coconino

Coconino

Coconino

Santa Cruz

Cochise

Pinal

Coconino

353419 N1115850W

331634 N1091123W

331723H1091018W

$322 B 30 N 1110523 \mathrm{~W}$

$312721 \mathrm{N1095501 \textrm {W }}$

$322117 \mathrm{M} 1101546 \mathrm{~W}$ $343800 \mathrm{~N} 1104300 \mathrm{~W}$

$351358 \mathrm{~N} 1112804 \mathrm{~W}$

$333721 \mathrm{N1} 105957 \mathrm{~W}$

334340 N1092628

$335010 N 1114951 \mathrm{~W}$

$351322 \mathrm{~N} 1113300 \mathrm{~W}$

$352338 N 1120319 \mathrm{~W}$

$322201 \mathrm{~N} 1101544 \mathrm{~W}$
$332023 N 1135913 \mathrm{~W}$

$343228 \times 1112712 \mathrm{~W}$

$321510 \mathrm{~N} 1094953 \mathrm{~W}$

321522 N1095030W

$364303 \mathrm{~N} 1123043 \mathrm{~W}$

$364129 \mathrm{~N} 1124935 \mathrm{~W}$

$364300 \mathrm{~N} 1123034 \mathrm{~W}$

$364234 \mathrm{~N} 1124848 \mathrm{~W}$

350358 N1133825W

$333613 N 1102854 \mathrm{~W}$

351843 N1114948W

$335045 \mathrm{~N} 1101348 \mathrm{~W}$

$335721 \mathrm{~N} 1121242 \mathrm{~W}$

$312921 \mathrm{N1095608 \textrm {W }}$

$333545 \mathrm{~N} 1110128 \mathrm{~W}$

$362630 \mathrm{~N} 1115744 \mathrm{~W}$

$363933 \mathrm{~N} 1102704 \mathrm{~W}$

$365423 \mathrm{~N} 1122722 \mathrm{~W}$

$341753 \mathrm{N1093029W}$

345349 N1121313W

$351332 \mathrm{~N} 1113321 \mathrm{~W}$

$313954 \mathrm{~N} 1105036 \mathrm{~W}$

$323444 N 1114449 \mathrm{~W}$

$362232 \mathrm{~N} 1110214 \mathrm{~W}$

$331816 \mathrm{N1090820 \textrm {W }}$

323117N1110231W

312741 N1095530W

$312834 \mathrm{N1095714W}$

$322319 N 1101620 \mathrm{~W}$

$333301 \mathrm{N1110259W}$

$341946 \mathrm{~N} 1104516 \mathrm{~W}$

$351200 \mathrm{~N} 1113056 \mathrm{~W}$

$362052 \mathrm{~N} 1120300 \mathrm{~W}$

$364411 \mathrm{~N} 1102557 \mathrm{~W}$

$365001 \mathrm{N1121826 \textrm {W }}$

$333302 \mathrm{~N} 1110259 \mathrm{~W}$

$334723 \mathrm{~N} 1092905 \mathrm{~W}$

$341338 \mathrm{~N} 1093453 \mathrm{~W}$

344830N1121734W

Perkinsville

3257 Wildcat Hill

7024 Flagstaff East

Squaw Mtn

Flagstaff East

Mt Wrightson

4876 Soza Mesa

2533 Greene Reservoir

6805 Big Whisker WeIl

Ebert Mtn

Cone Butte

Fritz Canyon

New River

Bisbee

Soza Mesa

Two Bar Mtn

Buffalo Ranch

Marsh Pass

Hoodoo Knob

Cerro Hueco 
FEATURE NAME

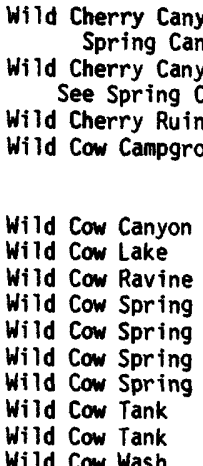

Wild Deer Spring

Wild Dove Butte

Wilder Creek

Wilder Mesa

See Bozarth Point

Wilder Mesa

Wilder Mesa

Wilderness of Rocks

Wilderness Tank

Wilder Point

Wilder Spring

Wilder Springs

Wild Flower (subdivision)

Wild Flower Gulch

Wild Flower Mine

Wild Flower Saddle

Wild Geese Nest Spring

Wild Hog Basin

Wild Hog Canyon

Wild Hog Mountain

Wi Thorse Bas in

Wi Idhorse Canyon Wild Horse Canyon

Wild Horse Canyon

See Wildhorse Canyon

Wild Horse Canyon

Wild Horse Canyon

Wild Horse Cieneg

Wild Horse Corral

Wild Horse Hill

Wildhorse Lake White Horse Lake

Wildhorse Lake Campground

Wild Horse Mesa

Wild Horse Mesa

Wildhorse Mine

Wildhorse Mountain

Wildhorse Park

Wild Horse Ranch

Wild Horse Spring

Wild Horse Spring

Wild Horse Spring

Wild Horse Spring

Wildhorse Spring

Wild Horse Spring Wildhorse Spring

Wildhorse Spring

See Wild Horse Spring

Wildhorse Spring

Wild Horse Spring

Wild Horse Tank

Wild Horse Tank

Wi ldhorse Tank

Wildhorse Tank

Wildhorse Tank

FEATURE
CLASS

valley

STATUS

COUNTY

BGN 1959 Apache

VARIANT

VARIANT

valle

local

park

BGN
ADMIN

Apache

Apache

Mohave

valley

lake

valley

spring

spring

spring

spring

reservoir

reservoir

stream

BGN
BGN
$B G N$
$B G N$
BGN
BGN
BGN
BGN
BGN
$B G N$

Pima

Apache

Pinal

Pima

Pima

Gila

Mohave

Pinal

Gila

Apache

spring

summit

stream

cape

summit

summit

area

reservoir

cliff

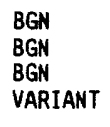

BGN

BGN
$B G N$
$B G N$

BGN

GN

spring

spring

ppl

mine

gap

spring

bas in

valley

summit

BGN

BGN

BGN

BGN
UNOFF
BGN

BGN

BGN

BGN

BGN

BGN

bas in

valley

BGN
BGN
VARIAN

VARIANT

valley

valley

valley

flat

locale

BGN 1964

BGN

BGN

summit

BGN

lake

park

summit

summit

mine

summit

flat

locale

spring

BGN

VARIANT

ADMIN

BGN

BGN

UNOFF

BGN

BGN

UNOFF

BGN

\section{Graham}

Gila

Yavapai

Yavapai

Yavapai

Yavapai

Pima

Gila

Yavapai

Yavapai

Coconino

Maricopa

Yavapai

Yavapai

Yavapai

Apache

Yavapai

Santa Cruz

Pima

Yavapai

Graham

Graham

Coconino

Coconino

Apache

Pima

Coconino

Navajo

Navajo

Yavapa $i$

Coconino

Mohave

Cochise

Coconino

Pima

Gila

spring

spring

spring

spring

spring

BGN Gila

BGN Apache

BGN Yavapai

BGN Mohave

BGN 1964 Coconino

VARIANT

spring

spring

VARIANT

spring

BGN

Coconino

Mohave

Coconino

reservoir $B G N$

reservoir $B G N$

reservoir BGN

reservoir $B G N$

reservoir BGN

Pima

Maricopa

Navajo

Coconino

COORDINATE

$360630 \mathrm{~N} 1092515 \mathrm{~W}$

$360700 \mathrm{~N} 1092630 \mathrm{~W}$

$360707 \mathrm{N1092640 \textrm {W }}$

$350355 N 1135212 \mathrm{~W}$

314739 N1102820W

345734N1090910W

$323916 \mathrm{~N} 1105648 \mathrm{~W}$

$314756 \mathrm{~N} 1102726 \mathrm{~W}$

$322942 \mathrm{~N} 1104650 \mathrm{~W}$

$331541 \mathrm{~N} 1105044 \mathrm{~W}$

$350401 \mathrm{N1} 135336 \mathrm{~W}$

$323916 \mathrm{~N} 1105636 \mathrm{~W}$

$335138 \mathrm{~N} 1104748 \mathrm{~W}$

$344342 \mathrm{~N} 1094859 \mathrm{~W}$

330228 N1093114W

$335521 \mathrm{~N} 1102106 \mathrm{~W}$

343824N1131212

344029N1131440W

343824N1131555W

344338N1130624k

$322502 N 1104649 \mathrm{~W}$

$341916 \mathrm{~N} 1113319 \mathrm{~W}$

344154 N1130848W

344231N1130739W

$353917 N 1131138 \mathrm{~W}$

$334013 \mathrm{~N} 1120449 \mathrm{~W}$

$341540 \mathrm{~N} 1122009 \mathrm{~W}$

$341409 N 1122117 \mathrm{~W}$

$341354 N 1122124 \mathrm{~W}$

$362534 \mathrm{~N} 1090750 \mathrm{~W}$

$342923 \mathrm{N1} 125709 \mathrm{~W}$

312251 N1105003W

322354 N1113033W

$312435 \mathrm{~N} 1104516 \mathrm{~W}$

343858N1130503W

$331236 \mathrm{N1} 101449 \mathrm{~W}$

$331236 \mathrm{~N} 1101449 \mathrm{~W}$

$350405 \mathrm{~N} 1121200 \mathrm{~W}$

$352840 \mathrm{~N} 1115511 \mathrm{~W}$

$340456 \mathrm{~N} 1094133 \mathrm{~W}$

$321227 \mathrm{~N} 1104004 \mathrm{~W}$

$352816 \mathrm{~N} 1115835 \mathrm{~W}$

341557N1104014W

341602 N1104014W

$341015 N 1123744 \mathrm{~W}$

365731 N1111733W

$351903 N 1140852 \mathrm{~W}$

$320854 \mathrm{~N} 1102209 \mathrm{~W}$

$364533 \mathrm{~N} 1121213 \mathrm{~W}$

$321951 \mathrm{~N} 1110632 \mathrm{~W}$

$331042 \mathrm{~N} 1104158 \mathrm{~W}$

$331339 N 1103227 \mathrm{~W}$

$340509 \mathrm{~N} 1094145 \mathrm{~W}$

$341210 \mathrm{~N} 1123850 \mathrm{~W}$

$343042 \mathrm{~N} 11326521$

350528N1120950W

350528 N1120950W

$360015 \mathrm{~N} 1143606 \mathrm{~W}$

$360840 \mathrm{N1105235 \textrm {W }}$

$320119 N 1124334 \mathrm{~W}$

$335850 \mathrm{~N} 1125541 \mathrm{~W}$

$340201 \mathrm{~N} 1102632 \mathrm{~W}$ 
NATIONAL GAZETTEER--ARIZONA 1986

\section{FEATURE NAME}

Wild Horse Tank

White Horse Tank

Wild Horse Tank

Wild Horse Tank

Wildhorse Tank

Wild Horse Tank

Wild Horse Trap Mesa

Wild Horse Wash See Wildhorse Wash

wildhorse Wash Wild Horse Wash

Wild Man Mesa

Wildman Tank

Wild Monkey Trap

Wild ox Spring

Wild Pigeon Spring

Wild Ram Valley

Wild Rose Spring

Wild Steer Dam

Wild Steer Mesa

Wild Steer Tank

Wildwood Estates

Wiley Ranch

Wilford Canyon

Wilford Spring

Wilhoit

Wilkerson Ranch

Wilkerson Tank

Wilkins Canyon

Wilkins Trick Tank

Wilk Spring

Willaha

Willaha Railroad Station

Willaha Tank

Willard Spring

Willard Springs Interchange

Willa Zhinni Toh

Willcox

Wilcox

Willcox City Hall

Will cox Community Center Park

Willcox Dry Lake

See Willicox Playa

Willcox Elementary School

Willcox Flat

See Willcox Playa

Willcox Junior High School

Willcox Playa

Alkali Flats

Dry Lake

Lake Cochise

Playa de los Pimas

Soda Lake

Willcox Dry Lake

Willcox Flat

Willcox Post Office

Willcox Tank

Willets Siding

William Carmichael School

William Mesa

See Williams Mesa

Wi11i ams

See Aubrey Landing

Willians (historical)

Williams Camp

Williams Canyon

Williams Creek

Williams Creek

See Bones Canyon
FEATURE

CLASS

reservoir

reservoir

reservoir

reservoir

reservoir

reservoir

summit

stream

stream

summit

reservoir

cliff

spring

spring

valley

spring

dam

summit

reservoir

ppl

locale

valley

spring

locale

reservoir

valley

reservoir

spring

locale

reservoir

STATUS COUNTY

COORDINATE

BGN Coconino

BGN 1981 Yavapai

VARIANT

BGN Coconino

Coconino

BGN Coconino

BGN Coconino

VARIANT

BGN

VARIANT

spring BGN

crossing

spring

ppl

building

park

flat

school

UNO

BGN

VARIANT

UNOFF

ADMIN

VARIANT

UNOFF

VARIANT

flat

school

flat

UNOFF

UNOF

VARIANT

VARIANT

VARIANT

VARIANT

VARIANT

VARIANT

VARIANT

building UNOFF

reservoir

locale

school

BGN

BGN

UNOFF

VARIANT

sumnit

locale

VARIAN

$p p 1$

BGN

locale

valley

strean

valley
Coconino

Coconino

Coconino
Yavapai

Graham

Gila

Yavapai

Navajo

Coconino

Gila

Coconino

Gila

Yavapai

Pinal

Navajo

Navajo

Yavapai

Greenlee

Greenlee

Coconino

Coconino

Graham

Coconino

Coconino

Coconino

Coconino

Navajo

Cochise

Cochise

Cochise

Cochise

Cochise
Cochise

Cochise

Cochise
$344538 N 1111927 \mathrm{~W}$

345110N1130033W

$350143 \mathrm{~N} 1113145 \mathrm{~W}$

$350425 \mathrm{~N} 1121042 \mathrm{~W}$

$353742 \mathrm{~N} 1121910 \mathrm{~W}$

$360500 N 1122443 \mathrm{~W}$

364130N1111921W

350159 N1095223W

350159N1095223W

$362943 N 1104732 W$

$345247 \mathrm{N1} 13082 \mathrm{WW}$

$332711 N 1100027 \mathrm{~W}$

$334853 N 1101434 \mathrm{~W}$

$341425 \mathrm{~N} 1122109 \mathrm{~W}$

$362903 \mathrm{~N} 1102558 \mathrm{~W}$

$361300 \mathrm{N11} 10729 \mathrm{~W}$

$335719 N 1102107 \mathrm{~W}$

$350533 \mathrm{~N} 1121530 \mathrm{~W}$

$335719 \mathrm{N1} 102037 \mathrm{~W}$

$343427 \mathrm{~N} 1123027 \mathrm{~W}$

$330054 N 1120800 \mathrm{~W}$

$342151 \mathrm{N11} 103839 \mathrm{~W}$

$342146 N 1103833 \mathrm{~W}$

$342533 \mathrm{~N} 1123510 \mathrm{~W}$

325721 N1091809W

325546 N1092117W

$343803 \mathrm{~N} 1110053 \mathrm{~W}$

$343609 N 1110112 \mathrm{~W}$

$330041 \mathrm{N1} 101332 \mathrm{~W}$

$354543 \mathrm{~N} 112154 \mathrm{BW}$

354543 N1121548W

354603 N1 121549W

345823N1114049W

345B53N1114107W

360037 N1100611W

$321510 N 1094953 \mathrm{~W}$

321509 N1094950W

$321520 \mathrm{~N} 1095003 \mathrm{~W}$

$320822 \mathrm{~N} 1095046 \mathrm{~W}$

$321520 \mathrm{N1095006 \textrm {W }}$

$320822 \mathrm{N1095046 \textrm {W }}$

$321527 \mathrm{N1} 1095031 \mathrm{~W}$

$320 \mathrm{~B} 22 \mathrm{~N} 1095046 \mathrm{~W}$

Cochise

Cochise

Yuma

Cochise

Yavapai

Mohave

Coconino

Pinal

Apache

Apache

Apache
$321506 \mathrm{~N} 1095002 \mathrm{~W}$

313930N1092359W

$324100 \mathrm{~N} 1144410 \mathrm{~W}$

$313344 \mathrm{~N} 1101805 \mathrm{~W}$

340110N1121236W

$341800 \mathrm{~N} 1140436 \mathrm{~W}$

$351458 N 1121125 W$

$332535 \mathrm{~N} 1112049 \mathrm{~W}$

$335016 \mathrm{~N} 1094753 \mathrm{~W}$

$340302 \mathrm{~N} 1094927 \mathrm{~W}$

$335303 N 1094746 \mathrm{~W}$

$340342 \mathrm{N1} 094832 \mathrm{~W}$

$\begin{array}{lc}\text { SOURCE } & \text { ELEV } \\ \text { COORDINATE } & \text { FT }\end{array}$

Jaycox Mtn

6230 Scratch Canyon

Lower Lake Mary

May Tank Pocket

Miller Tank

Chamisa Tank

5800 Many Ghosts Hill

350417N1095523W

Kachina Point

6153 Cow Springs

Sunrise Peak

Ash Creek NE

Cone Butte

Crown King

363054N1102301W Great Spring

5467 Middle Mesa

Carrizo

6804 Matterhorn 
NATIONAL GAZETTEER--ARIZONA 1986

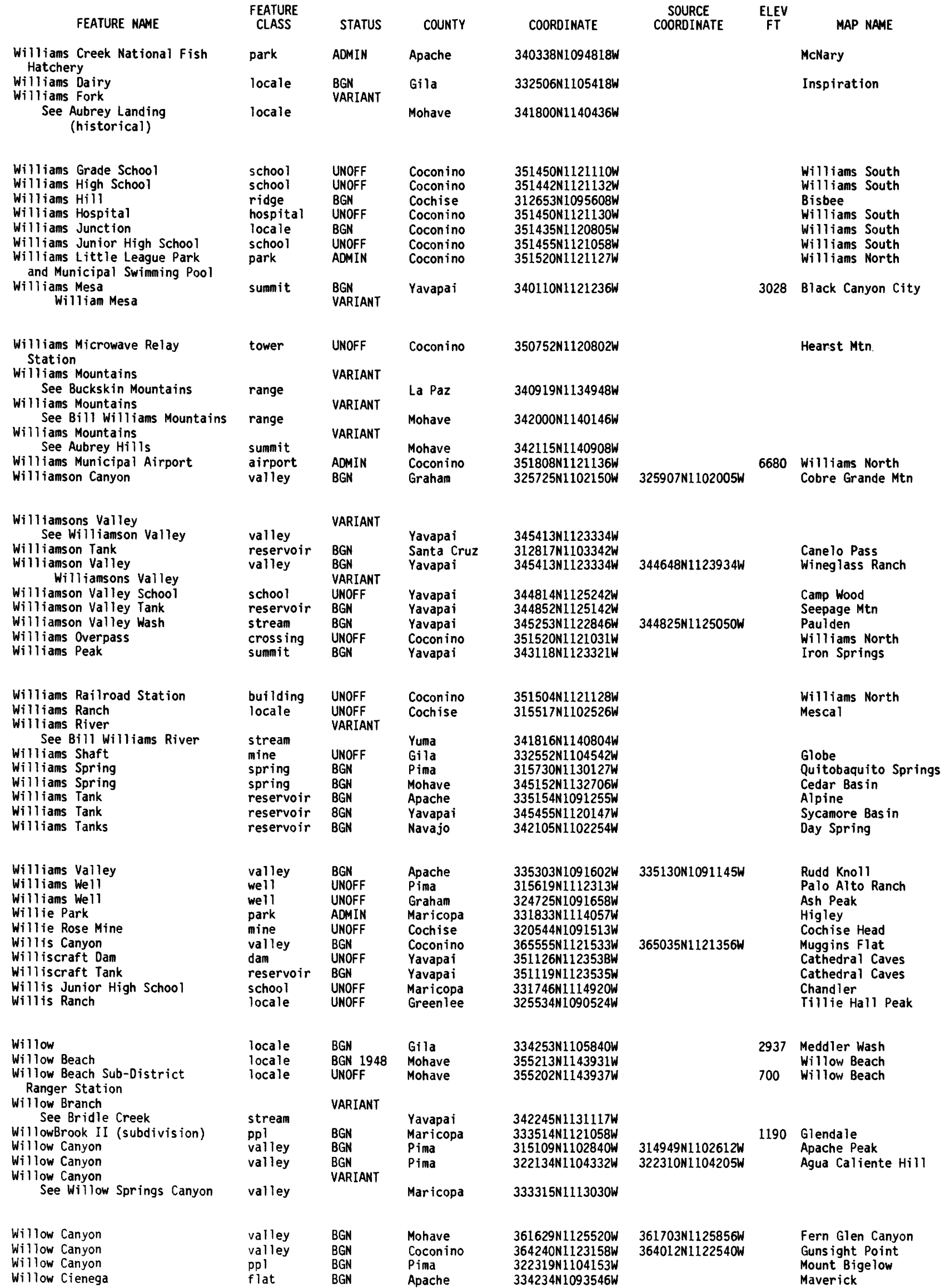


FEATURE NAME

Willow Creek

Willow Creek

Willow Creek

Willow Creek

Willow Creek

Willow Creek

Willow Creek
Willow Creek

Burnt Corral Creek Sweater Creek

Willow Creek

Willow Creek

Willow Creek

Willow Creek

Willow Creek

Willow Creek

Willow Creek

Willow Creek

Willow Creek

willow Creek

See Cottonmood Creek

Willow Creek

Cottonwood Creek

White Cliff Creek

Willow Creek

Willow Creek Canyon

Willow Creek Dam

Willow Creek Park

Willow Creek Reservoir

Willow Creek Weir

Willow Dam Tank

Willow Gulch Canyon

Willow Lake

Willow Lake

Willow Lake

See Topock Marsh

Willow Lake Park

Willow Mountain

Mount Beauchamp

Willow Mountain Tank

Willow Number Two Spring

See Willow Spring Number

Two

Willow Park

Willow Patch Draw

Willow Point

Willow Ranger Station

Willows Camp

Willow Spring

Willow Spring

Willow Spring

Willow Spring

Willow Spring

Willow Spring

Willow Spring

Willow Spring

Willow Spring

Willow Spring

Willow Spring

Willow Spring

Willow Spring

Willow Spring

Willow Spring

Willow Spring

Willow Spring

Willow Spring

Willow Spring

Willow Spring

Willow Spring

Willow Spring
FEATURE

CLASS

STATUS COUNTY

strean

stream

stream

stream

stream

BGN Graham

BGN Greenlee

Greenlee

Greenlee

Maricopa

stream

stream

BGN 1965 Maricopa

BGN

VARIANT

VARIANT

stream

stream

stream

stream

strean

stream

BGN

BGN

BGN

BGN

BGN

stream

stream

stream

strean

stream

$\begin{array}{lll}\text { stream } & B G N & \text { Coconino } \\ \text { valley } & 8 G N & \text { Coconino }\end{array}$

BGN Mohave

BGN Yavapai

BGN

VARIANT

VARIAN

dam UNOFF Yavapai 343606N1122550W

park ADMIN Yavapai 343617 N1122706W

reservoir BGN Yavapai 343607N1122549W

dam UNOFF Greenlee 333954N1091847W

dam BGN Graham 322920N1094510W

valley BGN Cochise 320932N1092637W

lake BGN Cochise 320348N1102041W

lake BGN Mohave 344646N1143130W

Swamp

VARIANT

Mohave

park

Yavapai

$344635 \mathrm{~N} 1143049 \mathrm{~W}$

reservoir BGN GANT Gaham 332635N1093805W

332714N1110710W

spring Pinal

park ADMIN Maricopa

park ADMIN Maricopa

valley BGN Navajo

cliff

locale

locale

spring

spring

spring

spring

spring

spring

spring

BGN Coconino

UNOFF Yavapai

BGN

BGN

BGN

BGN

BGN

BGN

BGN 1975

Coconino

Pima

Pima

Pima

Graham

Graham

Graham

Graham

spring

spring

spring

spring

spring

spring

spring

spring

spring

spring

spring

spring

spring

spring

spring

\begin{tabular}{|c|c|c|}
\hline $\begin{array}{l}\text { BGN } \\
\text { BGN } \\
\text { BGN } \\
\text { BGN } \\
\text { BGN } \\
\text { BGN } \\
\text { BGN } \\
\text { BGN } \\
\text { BGN } \\
\text { BGN }\end{array}$ & $\begin{array}{l}\text { Graham } \\
\text { Graham } \\
\text { Pinal } \\
\text { Graham } \\
\text { Gila } \\
\text { Pinal } \\
\text { Graham } \\
\text { La Paz } \\
\text { Gila } \\
\text { Gila }\end{array}$ & $\begin{array}{l}324506 \mathrm{~N} 1102416 \mathrm{~W} \\
330155 \mathrm{~N} 1101402 \mathrm{~W} \\
330637 \mathrm{N1} 102822 \mathrm{~W} \\
331816 \mathrm{~N} 1102027 \mathrm{~W} \\
332522 \mathrm{~N} 1105432 \mathrm{~W} \\
332556 \mathrm{N1} 112330 \mathrm{~W} \\
332557 \mathrm{N1} 1093607 \mathrm{~W} \\
332637 \mathrm{N1} 132140 \mathrm{~W} \\
333031 \mathrm{N1} 110337 \mathrm{~W} \\
333521 \mathrm{~N} 1104424 \mathrm{~W}\end{array}$ \\
\hline $\begin{array}{l}\text { BGN } \\
\text { BGN } \\
\text { BGN } \\
\text { BGN } \\
\text { BGN }\end{array}$ & $\begin{array}{l}\text { Greenlee } \\
\text { Gila } \\
\text { Gila } \\
\text { Maricopa } \\
\text { Gila }\end{array}$ & $\begin{array}{l}333714 \mathrm{~N} 1091907 \mathrm{~W} \\
333917 \mathrm{~N} 1103810 \mathrm{~W} \\
334245 \mathrm{~N} 1105720 \mathrm{~W} \\
334309 \mathrm{~N} 1112437 \mathrm{~W} \\
334437 \mathrm{~N} 1103927 \mathrm{~W}\end{array}$ \\
\hline
\end{tabular}

$332712 \mathrm{~N} 1120704 \mathrm{~W}$

$344307 N 1102531 \mathrm{~W}$

$364229 \mathrm{~N} 1123102 \mathrm{~W}$

$343545 \mathrm{~N} 1123057 \mathrm{~W}$

$354804 \mathrm{~N} 1114321 \mathrm{~W}$

$314616 \mathrm{~N} 1104817 \mathrm{~W}$

$314933 \mathrm{~N} 1102743 \mathrm{~W}$

$321507 N 1102835 \mathrm{~W}$

$322804 N 1101732 \mathrm{~W}$

$22945 \mathrm{~N} 1094549 \mathrm{~W}$

$324200 \mathrm{~N} 1101858 \mathrm{~W}$

$324413 \mathrm{~N} 1102420 \mathrm{~W}$ $\begin{array}{ll}\text { SOURCE } & \text { ELEV } \\ \text { COOROINATE } & \text { FT NAP NAME }\end{array}$

324106N1101914W Kennedy Peak

324429N1102439W Rhodes Peak

Tillie Hall Peak

York

Bee Canyon

Iron Mountain

Mormon Flat Dam

Elwood Canyon

Hannagan Meadow

Double Buttes

Columbia

Chediski Peak

Prescott

Hamilton Crossing

Yucca

Mohon Peak

Hualapai Peak

Tin Mountain

$351509 N 1133045 \mathrm{~W}$

Willow Springs

Grama Draw

Prescott

Prescott

5140 Prescott

Hannagan Meadow

$320841 N 1092823$

Greas ewood Mountain

Bowie Mtn North

3435 Galleta Flat East

Needles

Prescott

7817 Willow Mtn

Sawbuck Mtn

Phoenix

Phoenix

Dry Lake NW

$344110 \mathrm{N1102640 \textrm {W }}$

Gunsight Point

5560

prings

Helvetia

Apache Peak

Soza Canyon

Cherry Spring Peak

Greasewood Mountain

Kennedy Peak

Rhodes Peak

Oak Grove Canyon

Beargrass Bas in

Rawhide Mtn

Mount Triplet

Inspiration

Goldfield

Willow Mtn

Phoenix

Two Bar Mtn

Chrome Butte

Strayhorse

Hays tack Butte

Meddler Wash

Mine Mountain

Haystack Butte 
FEATURE NAME

Willow Spring

Willow Spring

Willow Spring

Willow Spring

Willow Spring

Willow Spring Roy Spring

Willow Spring

Willow Spring

Willow Spring

Willow Spring

Willow Spring

Willow Spring

Willow Spring

Willow Spring

Willow Spring

Willow Spring

Willow Spring

Willow Spring

Willow Spring

Willow Spring

Willow Spring

Willow Spring

Willow Spring

Willow Spring

Willow Spring

Willow Spring

Willow Spring

Willow Spring

Willow Spring

Willow Spring June Spring

Willow Spring

Willow Spring

Willow Spring

Willow Spring

Willow Spring

Willow Spring

Willow Spring Basin

Willow Spring Canyon

Willow Spring Canyon

Willow Spring Canyon

Willow Spring Canyon

Willow Spring Canyon

Willow Spring Canyon

Willow Spring Canyon Willowspring Canyon

Willowspring Canyon

See Willow Spring Canyon

Willow Spring Girl Scout Camp

Willow Spring Gulch

Willow Spring Gulch

Willow Spring Lake Recreation

Site

Willow Spring Mountain

Willow Spring Number Two Willow Number Two Spring

Willow Springs

Willow Springs

Willow Springs

Willow Springs Bas in Tank

Willow Springs Canyon

Willow Springs Canyon

$$
\text { Willow Canyon }
$$

Willow Springs Canyon

Willow Springs Dam

Willow Springs Lake

Willow Springs Lake

See Bear Canyon Lake

Willow Springs Ranch

Willow Springs Ranch

\section{FEATURE}

spring

spring

spring

spring

spring

spring

spring

spring

spring

spring

spring

spring

spring

spring

spring

spring

spring

spring

spring

spring

spring

spring

spring

spring

spring

spring

spring

spring

spring

spring

spring

spring

locale

bas in

valley

valley

valley

valley

valley

valley

valley

\section{BGN}

BGN 1974

VARIANT

valley

locale

valley

valley

park

summit

\section{$B G N$}

BGN

BGN

ADMIN

BGN

spring

spring

spring

locale

reservoir

valley

valley

valley

\section{BGN}

VARIANT

BGN

BGN

BGN

BGN

BGN 1965

VARIANT

BGN

dam

lake

reservoir

locale

locale

BGN VARIANT

UNOFF

\begin{tabular}{|c|c|}
\hline COUNTY & COORDINATE \\
\hline $\begin{array}{l}\text { Gila } \\
\text { Gila } \\
\text { Gila } \\
\text { Maricopa } \\
\text { Yavapai }\end{array}$ & $\begin{array}{l}335124 \mathrm{~N} 1111030 \mathrm{~W} \\
335138 \mathrm{~W} 1104729 \mathrm{~W} \\
335501 \mathrm{N1} 102126 \mathrm{~W} \\
335718 \mathrm{~N} 1114410 \mathrm{~W} \\
340744 \mathrm{~N} 1121444 \mathrm{~W}\end{array}$ \\
\hline Gila & $340907 \mathrm{~N} 1111700 \mathrm{~W}$ \\
\hline $\begin{array}{l}\text { Yavapai } \\
\text { Apache } \\
\text { Yavapai } \\
\text { Yavapai } \\
\text { Yavapai } \\
\text { Yavapa } \\
\text { Yavapa } \\
\text { Yavapai }\end{array}$ & $\begin{array}{l}340911 N 1115223 \mathrm{~W} \\
341150 N 1094329 \mathrm{~W} \\
341454 \mathrm{N1} 22557 \mathrm{~W} \\
341754 \mathrm{N1} 22259 \mathrm{~W} \\
341823 \mathrm{N1} 114803 \mathrm{~W} \\
342119 \mathrm{N11} 15343 \mathrm{~W} \\
342544 \mathrm{N1} 131220 \mathrm{~W} \\
342630 \mathrm{1} 11401\end{array}$ \\
\hline
\end{tabular}

UNOFF
Yavapai 342723N1130835W

Coconino 342B01N1111623W

Yavapai 343622N1120250W

Yavapai 343721N1125023W

Yavapai 343B53N1124430W

Mohave 350242N1135918W

Mohave 350451 N1132048W

Coconino 350802N1120139W

Mohave 351748N1142235W

Mohave 352143N1134758W

Mohave

Coconino $354506 \mathrm{N1110331 \textrm {W }}$

$354721 N 1140026 \mathrm{~W}$

Mohave

Apache 354B29N1095748W

$\begin{array}{ll}\text { Coconino } & 360653 \mathrm{~N} 1104703 \mathrm{~W} \\ \text { Mohave } & 361805 \mathrm{~N} 1125720 \mathrm{~W}\end{array}$

Navajo 362520N1104343W

Mavajo 363357 N1124408W

Coconino 364235N1123142W

Apache 365430N1093115W

Mohave 365849N1124536W

Yavapai 344012N1125145W

Yavapai 340522N1113545W

Santa Cruz 312731N1104012W

Graham 322838N1094325W

Pinal

Gila

Yavapai

Gila

$330925 \mathrm{~N} 1102853 \mathrm{~W}$

$335405 \mathrm{N1} 104429 \mathrm{~W}$

$4429 \mathrm{~W}$

$340543 \mathrm{~N} 1120355 \mathrm{~W}$

$340808 \mathrm{~N} 1111531 \mathrm{~W}$

$342145 \mathrm{~N} 1111652 \mathrm{~W}$

Gila

Gila

Yavapa 1

Gila

Yavapai

Coconino

Maricopa

Pinal

Pinal

Coconino

Coconino

Maricopa

Greenlee

Maricopa

Coconino

UNOFF Coconino
Coconino

Coconino

Greenlee
Pinal
$342145 \mathrm{~N} 1111652 \mathrm{~W}$

$343310 \mathrm{~N} 1123245 \mathrm{~W}$

$332443 \mathrm{~N} 1105400 \mathrm{~W}$

$342143 \mathrm{~N} 1115558 \mathrm{~W}$

341840 N1105238W

332714N1110710W

$324300 \mathrm{~N} 1105205 \mathrm{~W}$

361049 N1112239W

$361122 \mathrm{~N} 1112335 \mathrm{~W}$

$333100 N 1112901 \mathrm{~W}$

$322720 \mathrm{N1090342 \textrm {W }}$

$333315 \mathrm{~N} 1113030 \mathrm{~W}$

SOURCE
COORDINATE

MAP NAME

Greenback Creek

Sombrero Peak

Carrizo

Horseshoe Dam

Bumble Bee

Payson South

Bloody Bas in

Boundary Butte

Minnehaha

Battleship Butte

Tule Mesa

Dugas

Thorn Peak

Hackberry Mtn

Thorn Peak

Kehl Ridge

Cherry

Martin Mtn

Mount Josh

Hualapai Peak

Devils Hump

Davenport Hill

Burns Spring

Peacock Peak

Milkweed Canyon NW

Gold Spring

Garnet Mtn

Big Willow Spr Can

Bat Spring

Fern Glen Canyon

Black Mesa Wash NW

Grama Spring

Gunsight Point

Walker Creek Res

Moccas in

4813 Smith Mesa

Table Mountain

Harshaw

$312555 \mathrm{~N} 1104140 \mathrm{~W}$

$322945 \mathrm{~N} 1094546 \mathrm{~W}$

$330508 \times 1102652 \mathrm{~W}$

$335134 \mathrm{N1104747 \textrm {W }}$

$340453 \mathrm{~N} 1115928 \mathrm{~W}$

$340927 N 1111722 \mathrm{~W}$

Oraw

San Carlos Reservoir

Double Buttes

Squaw Creek Mesa

Payson South

Payson North

$332531 \mathrm{N1105452 \textrm {W }}$

$342140 \mathrm{N1} 115138 \mathrm{~W}$

5880

Iron Springs

Inspiration

Dugas

7580 Woods Canyon

4974 Humboldt Mtn 
NATIONAL GAZETTEER--ARIZONA 1986

\section{FEATURE NAME}

Manlyville

Willow Springs Wash

Willow Springs Well

Willow Springs Well

Willow Spring Tank

Willow Spring Tank

Willow Spring Tank

Willow Spring Trail

Willow Spring Trail

Willow Spring Wash

Willow Spring Wash

Willow Spring Wash Tank

Willows Tank

Willows Tanks

Willows Trick Tank

Willows West (subdivision)

Willow Tank

Willow Tank

Willow Tank

Willow Tank

Willow Tank

Willow Tank

Willow Tank

Willow Tank Willow Tanks

Willow Tank Dam

Willow Tanks

Willow Tanks

See Willow Tank

Willow Trap

Willow Trap Springs

Willow Trap Tank

Willow Valley

Willow Valley Dam

Willow Valley Lake

Willow Valley Tank

Willow Wash

Willow Wash

Willow Wash

Willow Wash Spring

Willy Canyon

Wilmonts Pond

Wilmot

Wilmot Interchange

Wilmot Plaza Shopping Center

Wilmot Railroad Station

Wilshire Heights Park

Wilson, Mount

Wilson Canyon

Wilson Creek

Wilson Draw

Wilson Mountain

Wilson Mountain Trail

Wilson Ranch

Wils on Ridge

Wilson School

Wilson Seep

Wilson Spring

Wilson Tank

Wilson Tank

Wilson Wash

Wilson Windmill

Wiltbank Spring

Winchester Canyon

Winchester Mountains

Winchester Peak

Winchester Peak

Winchester Reservoir

Wind around the Rock Well

Windemere (subdivision) Hayden Estates

\begin{tabular}{|c|c|c|c|}
\hline $\begin{array}{l}\text { FEATURE } \\
\text { CLASS }\end{array}$ & STATUS & COUNTY & COORDINATE \\
\hline $\begin{array}{l}\text { stream } \\
\text { well } \\
\text { well }\end{array}$ & $\begin{array}{l}\text { VARIANT } \\
\text { BGN } \\
\text { UNOFF } \\
\text { UNOFF }\end{array}$ & $\begin{array}{l}\text { Maricopa } \\
\text { Maricopa } \\
\text { Mohave }\end{array}$ & $\begin{array}{l}335039 \mathrm{~N} 1115750 \mathrm{~W} \\
333027 \mathrm{~N} 1112755 \mathrm{~W} \\
345130 \mathrm{~N} 1132425 \mathrm{~W}\end{array}$ \\
\hline $\begin{array}{l}\text { reservoir } \\
\text { reservoir } \\
\text { reservoir } \\
\text { trail } \\
\text { trail } \\
\text { stream } \\
\text { stream } \\
\text { reservoir } \\
\text { reservoir } \\
\text { reservoir }\end{array}$ & $\begin{array}{l}\text { BGN } \\
\text { BGN } \\
\text { BGN } \\
\text { UNOFF } \\
\text { UNOFF } \\
\text { BGN } \\
\text { BGN } \\
\text { BGN } \\
\text { BGN } \\
\text { BGN }\end{array}$ & $\begin{array}{l}\text { Pinal } \\
\text { Yavapai } \\
\text { Coconino } \\
\text { Yavapai } \\
\text { Yavapai } \\
\text { Graham } \\
\text { Apache } \\
\text { Yavapai } \\
\text { Yavapai } \\
\text { Coconino }\end{array}$ & $\begin{array}{l}324136 \mathrm{~N} 1105515 \mathrm{~W} \\
342151 \mathrm{~N} 1115208 \mathrm{~W} \\
352038 \mathrm{~N} 1120318 \mathrm{~W} \\
340614 \mathrm{~N} 1113348 \mathrm{~W} \\
340844 \mathrm{~N} 1121536 \mathrm{~W} \\
323351 \mathrm{~N} 1093044 \mathrm{~W} \\
365303 \mathrm{~N} 1093211 \mathrm{~W} \\
342143 \mathrm{~N} 1115310 \mathrm{~W} \\
345503 \mathrm{~N} 1120148 \mathrm{~W} \\
354 \mathrm{~B} 00 \mathrm{~N} 111431 \mathrm{~W}\end{array}$ \\
\hline $\begin{array}{l}\text { reservoir } \\
\text { ppl } \\
\text { reservoir } \\
\text { reservoir } \\
\text { reservoir } \\
\text { reservoir } \\
\text { reservoir } \\
\text { reservoir } \\
\text { reservoir } \\
\text { reservoir }\end{array}$ & $\begin{array}{l}\text { BGN } \\
\text { BGN } \\
\text { BGN } \\
\text { BGN } \\
\text { BGN } \\
\text { BGN } \\
\text { BGN } \\
\text { BGN } \\
\text { BGN } \\
\text { BGN } \\
\text { VARIANT }\end{array}$ & $\begin{array}{l}\text { Coconino } \\
\text { Maricopa } \\
\text { Santa Cruz } \\
\text { Graham } \\
\text { Apache } \\
\text { Gila } \\
\text { Gila } \\
\text { Yavapai } \\
\text { Mohave } \\
\text { Coconino }\end{array}$ & $\begin{array}{l}354540 \mathrm{~N} 1114400 \mathrm{~W} \\
332953 \mathrm{~N} 1121322 \mathrm{~W} \\
312305 \mathrm{~N} 1111047 \mathrm{~W} \\
332440 \mathrm{~N} 1093803 \mathrm{~W} \\
333658 \mathrm{~N} 1094936 \mathrm{~W} \\
335546 \mathrm{~N} 110344 \mathrm{WW} \\
340045 \mathrm{~N} 1111634 \mathrm{~W} \\
342515 \mathrm{~N} 1114040 \mathrm{~W} \\
353932 \mathrm{~N} 1134343 \mathrm{~W} \\
365531 \mathrm{~N} 1113412 \mathrm{~W}\end{array}$ \\
\hline
\end{tabular}

dan UNOFF Apache 333700N1094942W

reservoir BGN Yavapai 343927N1124232W

reservoir Coconino 365531N1113412W

valley BGN Navajo 334442N1095534W

spring BGN Gila $\quad 335512$ N1101919w

reservoir BGN Apache 333744N1094811W

valley BGN Coconino 343305N1112410

dam UNOFF Coconino

reservoir BGN Coconino

reservoir BGN Coconino 343B45N1112120W

stream $B G N \quad$ Cochise $314448 \mathrm{~N} 1101144 \mathrm{~W}$

stream BGN Navajo 342413N1102354K

tream BGN Mohave 342837N1142117 W

spring BGN Yavapai 353544N1123121W

valley BGN Navajo 345204N1103152W

reservoir BGN

locale BGN

crossing UNOFF Pima 320653N1105127W

locale UNOFF Pima 321314N1105133W

building UNOFF Pima 320718N1105033W

park ADMIN Pima 321300N1105212W

$355948 \mathrm{N11436}$

Mohave

valley BGN Coconino 345307N1114430w

stream BGN Gila $\quad 335857$ N1105258W

valley BGN Navajo

summit BGN Coconino

trail UNOFF Coconino

locale

ridge $\quad B G N$

Pima

Mohave

$345504 \mathrm{~N} 1114501 \mathrm{~W}$

$345359 \mathrm{N1114422 \textrm {W }}$

$314414 N 1104101 \mathrm{~W}$

$355 \mathrm{~B} 44 \mathrm{~N} 1143529 \mathrm{~W}$

School UNOFF Maricopa 332611N1120145W

spring BGN Coconino 350138N1114236W

spring BGN Yavapai $342 B 30 N 1115514 \mathrm{~W}$

reservoir BGN Coconino 345543N1114556W

reservoir BGN Coconino 350148N1114220W

stream BGN Graham 325043N1094206W

locale BGN Graham 323917 N110090BW

valley

idge

$B G N$

BGN

summit

BGN

summit

reservoir

well

BGN

UNOFF

BGN

VARIANT

341630 N1092400

$325716 \mathrm{~N} 1090255 \mathrm{~W}$

322028 N1100420W

Cochise

$322 B 12 \mathrm{~N} 1090924 \mathrm{~W}$

$334544 \mathrm{~N} 1134142 \mathrm{~W}$

$335302 \mathrm{N1133304 \textrm {W }}$

$354845 N 1091514 \mathrm{~W}$

$333155 N 1115412 \mathrm{~W}$
SOURCE
COORDINATE

MAP NAME

335312N1115433W Cave Creek

Mormon Flat Dam

Penitentiary Mtn

Fortified Mtn

Tule Mesa

Sitgreaves Mtn

Table Mountain

Crown King

$\begin{array}{ll}322838 \mathrm{~N} 1094325 \mathrm{~W} & \text { Tanque } \\ 365547 \mathrm{~N} 1092659 \mathrm{~W} & \text { Walker Creek Res }\end{array}$

Dugas

Sycamore Basin

Willows Camp

Willows Camp

1080 Fowler

Sawbuck Mtn

West Poker Mtn

81 ue House Mtn

Gisela

Hackberry Mtn

Milkweed Canyon NW

Ferry Swale

Corn Creek

Mount Josh

334436N1095504W Bonito Prairie

Carrizo

Corn Creek

344154N1111726W Calloway Butte

6790 Turkey Mtn

6790 Turkey Mtn

315048N1095614W $\quad \begin{aligned} & \text { Turkey Mtn } \\ & \text { Fairbank }\end{aligned}$

Aripine

Lake Havasu City S
Iron Springs

McCauley Sinks

Red Rock

Tucson SE

2776 Tucs on SE

2570 Tucs on East

$325932 N 1090022 \mathrm{~W}$

$342847 \mathrm{~N} 1141959 \mathrm{~W}$

$345430 \mathrm{~N} 1114457 \mathrm{~W}$

$342013 N 1101531 \mathrm{~W}$

Tucson SE

Tucson East

5445 Mt Wilson

Munds Park

McFadden Peak

Cactus flat

7122 Wilson Mountain

Munds Park

Sonoita

Mt Wilson

Phoenix

Mountainaire

Arnold Mesa

Wilson Mountain

Mountainaire

325627N1093756W Safford

4242 Eureka Ranch

Lyman Lake SW

6921 Muskhog Mountain

5127 Orange Butte

2766 Harcuvar

Cunningham Pas

Oak Creek Mtn

1275 Paradise Valley
$45059 N 1103336$

$340223 \mathrm{~N} 1104915 \mathrm{~W}$

Tillie Hall Peak 


\section{FEATURE NAME}

Winden Tank

Windfall Spring

Windmill (subdivision)

Windmill Draw

Windmill Mountain
Windmi 11 Number Two
Windmill Ranch
Windmi11 Ranch
Windmill Tank
Windmill Tank
Windmill Tank
Windmi1 I Tank
Window, The
Window Mount

See Window Mountain

Window Mountain

La Ventana

Window Mount

Window Mountains

Window Mountains

See Window Mountain

Window Mountain Well

Window Rock

Window Rock

Window Rock

Window Rock

Window Rock

Window Rock

Window Rock

Window Rock

Window Rock Airport

Window Rock Elementary School

Window Rock High School

Window Rock Interchange

Window Rock Post office

Window Rock Pumping Station

Window Valley

Wind Rock

Wind Rock

Wind Rock Point

Wind Rock Valley

Windsong (subdivision)

Windsor Cabin

See Windsor Camp

Winds or Camp

Windsor Cabin

Windsor Mobile Home Park

Windsor Park

Winds or Spring

Windsor Square (subdivision)

Windsor Square Shopping Center

Windsor Valley

Windswept Terrace

Badger Butte

Five Houses Butte

Windswept Terrace Butte

Windswept Terrace Butte

See Windswept Terrace

Wind Tank

Wind Whistle Canyon

Windy Bob Canyon

Windy Bob Tank

Windy Canyon

Windy Canyon

Windy $\mathrm{Hill}$

Cerro del Temporal

Windy Hill Boat Ramp

Windy $\mathrm{Hill}$ Point Recreational

Area

Windy Hill Recreation Area

Windy Pass

\section{FEATURE \\ CLASS}

STATUS

COUNTY

reservoir

spring

ppl

BGN
$B G N$
$B G N$

BGN
BGN

Coconino

Coconino

Maricopa

Coconino

summit

well

locale

locale

reservoir

reservoir

reservoir

reservoir

arch

summit

\section{BGN}

UNOFF

UNOFF

BGN

BGN

$B G N$
$B G N$
$B G N$

BGN

Yavapai

Yavapai

Yavapai

Mohave

Gila

Coconino

Yavapai

Coconino

Apache

Pima

summit

BGN 1941 Pima

VARIANT

VARIANT

VARIANT

VARIANT

summit

well

arch

arch

arch

UN
$B G N$
$B G N$

Pima

Pima

Apache

Coconino

Apache

pillar

pillar

pillar

summit

ppl

airport

school

school

crossing

building

locale

valley

pillar

summit

cliff

valley

ppl

locale

locale

park

spring

pp1

locale

bas in

bench

BGN
BGN
BGN
BGN
BGN
ADMI
UNOFF
UNOFF
UNOFF
UNOFF

Pima

Apache

Apache

Apache

Apache

Apache

Apache

Apache

Apache

Apache

Apache

UNOFF

BGN

BGN

BGN

BGN

BGN

VARIANT

BGN

VARIANT

Pima

Apache

Coconino

Navajo

Apache

Maricopa

Gila

Gila

UNOFF
ADNIN
BGN
BGN
UNOFF
BGN
BGN
VARIANT
VARIANT
VARIANT

Maricopa

Maricopa

Gila

Maricopa

Maricopa

Apache

Navajo

VARIANT

VARIANT

bench

reservoir

valley

valley

reservoir

valley

valley

summit

park

UNOFF

park ADMIN

gap BGN
COORDINATE

$345637 \mathrm{~N} 1113407 \mathrm{~W}$

$342825 \mathrm{~N} 1112150 \mathrm{~W}$

$333550 \mathrm{~N} 1121341 \mathrm{~W}$

$343820 \mathrm{~N} 1111713 \mathrm{~W}$

$345103 \mathrm{N1115414W}$

$345737 \mathrm{N1130427W}$

$345048 \mathrm{~N} 1115559 \mathrm{~W}$

$350140 \mathrm{~N} 1133937 \mathrm{~W}$

$332035 N 1104647 W$

$343633 \mathrm{~N} 1113306 \mathrm{~W}$

$345050 \mathrm{~N} 1115311 \mathrm{~W}$

$352123 \mathrm{~N} 1114448 \mathrm{~W}$

$360626 \mathrm{~N} 1092345 \mathrm{~W}$

322127 N1121434W

$322127 N 1121434 \mathrm{~W}$

$322127 \mathrm{~N} 1121434 \mathrm{~W}$

$321549 \mathrm{~N} 1121525 \mathrm{~W}$

$361645 \mathrm{~N} 1094120 \mathrm{~W}$

$363253 \mathrm{~N} 1105720 \mathrm{~W}$

$365328 N 109341 B W$

$322233 \mathrm{~N} 1105119 \mathrm{~W}$

$354058 \mathrm{~N} 1090254 \mathrm{~W}$

$362318 \mathrm{~N} 1094104 \mathrm{~W}$

$362948 \mathrm{~N} 1093327 \mathrm{~W}$

$354050 \mathrm{~N} 1090307 \mathrm{~W}$

$353910 \mathrm{~N} 1090356 \mathrm{~W}$

$354103 \mathrm{~N} 1090326 \mathrm{~W}$

$354421 \mathrm{~N} 1090349 \mathrm{~W}$

$352016 \mathrm{~N} 1090404 \mathrm{~W}$

$353957 \mathrm{~N} 1090324 \mathrm{~W}$

$353657 N 1090727 \mathrm{~W}$

322009 N1120130W

$362046 \mathrm{~N} 1095604 \mathrm{~W}$

$363135 \mathrm{~N} 1110937 \mathrm{~W}$

$361222 \mathrm{N1100428 \textrm {W }}$

$362143 \mathrm{~N} 1095902 \mathrm{~W}$

$333834 \mathrm{~N} 1115541 \mathrm{~W}$

$340051 N 1112744 \mathrm{~W}$

$340051 N 1112744 \mathrm{~W}$

$332446 N 1114641 \mathrm{~W}$

$333037 N 1121143 \mathrm{~W}$

$340328 \mathrm{~N} 1112806 \mathrm{~W}$

$333356 \mathrm{~N} 1121030 \mathrm{~W}$

$333215 \mathrm{~N} 1120805 \mathrm{~W}$

$342404 \mathrm{~N} 1094147 \mathrm{~W}$

$354519 \mathrm{~N} 1102220 \mathrm{~W}$

$354519 N 1102220 \mathrm{~W}$

$314605 \mathrm{~N} 1103227 \mathrm{~W}$

$355535 \mathrm{~N} 1100554 \mathrm{~W}$ 332058 N1093433W $332509 \mathrm{~N} 1093351 \mathrm{~W}$ $330434 \mathrm{Ml} 1093416 \mathrm{~W}$ 330434N1093416

$334026 \mathrm{~N} 1110440 \mathrm{~W}$

$334012 \mathrm{~N} 1110501 \mathrm{~W}$

$334001 \mathrm{~N} 1110530 \mathrm{~W}$

$334013 N 1110512 \mathrm{~W}$

$333051 \mathrm{~N} 1111112 \mathrm{~W}$

\begin{tabular}{ccc}
$\begin{array}{c}\text { SOURCE } \\
\text { COORDINATE }\end{array}$ & $\begin{array}{c}\text { ELEV } \\
\text { FT }\end{array}$ & \multicolumn{1}{c}{ MAP NAME } \\
343424N1111516W 1160 & $\begin{array}{l}\text { Mormon Mountain } \\
\text { Keht Ridge } \\
\text { Glendale } \\
\text { Turkey Mtn }\end{array}$ \\
& 4651 & $\begin{array}{l}\text { Page Springs } \\
\text { Mount Hope } \\
\text { Page Springs } \\
\text { Bottleneck Wash } \\
\text { Pinal Peak } \\
\text { Buckhorn Mountain } \\
\text { Page Springs } \\
\text { Humphreys Peak } \\
\text { Three Turkey Canyon }\end{array}$
\end{tabular}

2961 Window Mtn

2259 Vaya Chin

5810 Many Farms SW

Square Butte

Walker Creek Res

Mt Lemmon

Window Rock

Windy Valley

Many Farms NE

Window Rock

6737 Window Rock

Window Rock

Window Rock

6160 Lupton

Window Rock

$321912 N 1121457 \mathrm{~W}$

Hunters Point

Gu Ach 1

Tah Chee Wash

6060 Arrowhead Mes

6875 Burnt Corn Spring

Tah Chee Wash

1530 Currys Corner

Mazatzal Peak

1255 Mesa

Glendale 
NATIONAL GAZETTEER--ARIZONA 1986

\section{FEATURE NAME}

Windy Pass Tank

Windy Point

Windy Point Campground

Windy Point Vista

Windy Ridge

Windy Ridge

Windy Ridge Spring

Windy Ridge Tank

Windy Roberts Tank

Windy Saddle Tank

Windy Spring

Windy Tank

Windy Tank

Windy Tank

Windy Tank

Windy Valley

Windy Well

Windy Well

Windy Wilson Tank

Wineglass Ranch

Winfield Scott School

Winfred Mine

Winger Spring

Wingfield

Wingfield Corral

Wingfield Mesa

Wingfield Tank

Wing Mine

Wing Mountain

Mount Wing

Winifred Harelson Elementary

School

See Harelson School

Winkelman

Wink leman

Winkelman Elementary Schoo

Winkelman Post Office

Winkleman

See Winkelman

Winkler Ranch

Winkler Tank

Winn Campground

Winn Center

Winn Falls

Winn School

Winnwood Homes (subdivision)

Winona

Winona Interchange

Winona Substation

Winona Tank

Wino Tank

Wino Tank

Wino Tank

Winslow

Winslow Canyon

Winslow City Hall

Winslow City Park

Winslow Civic Center

Wins low High School

Winslow Job Corps Civilian Conservation Center

Winslow Junior High School

Winslow Memorial Hospital

Winslow Municipal Airport

Wins low Municipal Well Field

Winslow Post Office

Winslow Public Library

Winslow Railroad Station

Wins low Tank

Winsor Latera

Winsor Tank

\section{FEATURE \\ CLASS}

STATUS

COUNTY

reservoir

cape

park

locale

cliff

BGN
BGN
ADMIN
BGN
BGN

ridge

spring

reservoir

reservoir

reservoir

spring

reservoir

reservoir

reservoir

reservoir

BGN
BGN
BGN
BGN
BGN
BGN
BGN
BGN
BGN
BGN

valle

well

well

reservoir

locale

school

mine

spring

locale

locale

summit

reservoir

mine

summit

BGN
UNOFF
UNOFF
BGN
UNOFF
UNOFF
UNOFF
BGN
BGN
BGN

BGN Yavapai

BGN Yavapai

UNOFF Mohave

VARIANT

VARIANT

school

ppl

BE

VARIANT

school UNOFF Gila

building UNOFF Gila

ppl

VARIANT

locale

reservoir

park

UNOFF

BGN

ADMIN

ADMIN
UNOFF

$\begin{array}{lll}\text { building } & \text { UNOFF } & \text { Maricopa } \\ \text { falls } & \text { BGN 1957 } & \text { Cochise }\end{array}$

school UNOFF Maricopa

ppl

locale

crossing

locale

reservoir

reservoir

reservoir

ppl

valley

BGN Coconino

UNOFF Coconino

BGN Coconino

BGN Pima

BGN Pima

BGN Cochise

BGN 1943 Navajo

BG

building UNOFF Navajo

building UNOFF Navajo

school UNOFF Navajo

school UNOFF Coconino

school UNOFF Navajo

building UNOFF Navajo

airport AOMIN Navajo

locale UNOFF

building

building

building

reservoir

canal

reservoir
UNO
UNOF
UNO
BGN
BGN
BGN

UNOFF
UNOFF
UNOFF
BGN
BGN
BGN

COORDINATE

BGN 1933 Coconino

UNOFF Coconino

park ADMIN Navajo
Gila

Mohave

Pima

Yavapai

Yavapa

Yavapai

Yavapai

Yavapai

Yavapai

Graham

Graham

Yavapai

Coconino

Apache

Graham

Maricopa

Coconino

Yavapai

Maricopa

Santa Cruz

Maricopa

Maricopa

Coconino

Pima

Gila

Cochise

Cochis

Cochise

Apache

Mohave

Coconino

$340105 \mathrm{~N} 1104604 \mathrm{~W}$

$322206 \mathrm{~N} 1104256 \mathrm{~W}$

$352608 \mathrm{~N} 1140936 \mathrm{~W}$

(3)

$344350 \mathrm{~N} 1130440 \mathrm{~W}$

344618 N1125120W

$344332 \mathrm{~N} 1130549 \mathrm{~W}$

$350152 \mathrm{~N} 1130044 \mathrm{~W}$

340527 N1121559W

$330756 \mathrm{~N} 1093430 \mathrm{~W}$

$330747 N 1093516 \mathrm{~W}$

$352345 \mathrm{~N} 1131320 \mathrm{~W}$

$354838 \mathrm{~N} 1110317 \mathrm{~W}$

$362615 \mathrm{~N} 1093830 \mathrm{~W}$

330804 N1093431W

$334947 \mathrm{~N} 1122113 \mathrm{~W}$

353605 N1122932W

$345540 \mathrm{~N} 1123129 \mathrm{~W}$

$332944 \mathrm{~N} 1115512 \mathrm{~W}$

$312407 \mathrm{~N} 1104300 \mathrm{~W}$

$333404 N 1111128 \mathrm{~W}$

$343415 N 1111817 \mathrm{~W}$

$344055 \mathrm{~N} 1112033 \mathrm{~W}$

$342951 \mathrm{N1114708 \textrm {W }}$

$342827 \mathrm{~N} 1120022 \mathrm{~W}$

$343448 \mathrm{~N} 1141704 \mathrm{~W}$

$351625 \mathrm{~N} 1114659 \mathrm{~W}$

322038 N1105909W

$325915 \mathrm{~N} 1104613 \mathrm{~W}$

$325925 \mathrm{~N} 1104615 \mathrm{~W}$

325916 N1104615W

$325915 N 1104613 \mathrm{~W}$

$314518 N 1092444 \mathrm{~W}$

$314440 \mathrm{~N} 1092305 \mathrm{~W}$

$335804 \mathrm{~N} 1092903 \mathrm{~W}$

$331740 \mathrm{~N} 1115018 \mathrm{~W}$

$315120 \mathrm{N1091537 \textrm {W }}$

$331740 \mathrm{~N} 1115021 \mathrm{~W}$

$332656 \mathrm{~N} 1122030 \mathrm{~W}$

$351218 \mathrm{~N} 1112427 \mathrm{~W}$

$351206 \mathrm{~N} 1112423 \mathrm{~W}$

$351116 \mathrm{~N} 1112454 \mathrm{~W}$

$351029 \mathrm{~N} 1112512 \mathrm{~W}$

$314408 \mathrm{~N} 1111434 \mathrm{~W}$

$314940 \mathrm{~N} 1110340 \mathrm{~W}$

$321451 \mathrm{~N} 1102445 \mathrm{~W}$

$350127 \mathrm{~N} 1104148 \mathrm{~W}$

$345538 \mathrm{N1} 132414 \mathrm{~W}$

345508 N1132030W

$350120 \mathrm{~N} 1104150 \mathrm{~W}$

$350137 \mathrm{~N} 1104118 \mathrm{~W}$

$350105 N 1104256 \mathrm{~W}$

$350138 \mathrm{~N} 1104130 \mathrm{~W}$

350454 N1104950W

350150 N1104123W

$350205 \mathrm{~N} 1104129 \mathrm{~W}$

$350120 \mathrm{~N} 110432 \mathrm{WW}$

345740 N11 $04833 \mathrm{~W}$

Navajo

Navajo

Navajo

Mohave

Yuma

Coconino

$350202 \mathrm{~N} 1104152 \mathrm{~W}$

$350113 \mathrm{~N} 1104135 \mathrm{~W}$

$345508 \mathrm{~N} 1132305 \mathrm{~W}$

$324023 \mathrm{~N} 1144000 \mathrm{~W}$

$345539 \mathrm{~N} 1113003 \mathrm{~W}$

$\begin{array}{ll}\text { SOURCE } & \text { ELEV } \\ \text { COORDINATE } & \text { FT MAP NAME }\end{array}$

Gentry Mtn

Agua Caliente $\mathrm{Hill}$

Chloride

6400 Agua Caliente Hill

Scratch Canyon

Behm Mes

Seepage Mtn

5291 Behm Mesa

Anvil Rock

Columbia

Elevator Mtn

Elevator Mtn

Chavez Mtn East

Yampai 


\begin{tabular}{|c|c|c|c|c|c|c|c|}
\hline FEATURE NAME & $\begin{array}{l}\text { FEATURE } \\
\text { CLASS }\end{array}$ & STATUS & COUNTY & COORDINATE & $\begin{array}{l}\text { SOURCE } \\
\text { CDORDINATE }\end{array}$ & $\begin{array}{l}\text { ELEV } \\
\text { FT }\end{array}$ & MAP NAME \\
\hline $\begin{array}{l}\text { Winsor Wash } \\
\text { Winter Cabin } \\
\text { Winter Cabin Spring } \\
\text { Winter Cabin Tank }\end{array}$ & $\begin{array}{l}\text { stream } \\
\text { locale } \\
\text { spring } \\
\text { reservoir }\end{array}$ & $\begin{array}{l}\text { BGN } \\
B G N \\
B G N \\
B G N\end{array}$ & $\begin{array}{l}\text { Navajo } \\
\text { Greenlee } \\
\text { Yavapai } \\
\text { Yavapai }\end{array}$ & $\begin{array}{l}345628 N 1095859 \mathrm{~W} \\
332738 \mathrm{N1090838 \textrm {W }} \\
344106 \mathrm{N1114608 \textrm {W }} \\
344126 \mathrm{N1114605 \textrm {W }}\end{array}$ & $345239 N 1095625 \mathrm{~W}$ & & $\begin{array}{l}\text { Carrizo Butte } \\
\text { Outch Blue Creek } \\
\text { Lake Montezuma } \\
\text { Lake Montezuma }\end{array}$ \\
\hline $\begin{array}{l}\text { Winter Cabin Tank } \\
\text { Winter Camp } \\
\text { Upper Corral } \\
\text { Winter Camp } \\
\text { Winter Camp Tank } \\
\text { Winter Camp Tank } \\
\text { Winter Camp Tank } \\
\text { Winter Camp Tank } \\
\text { Winter Camp Tank } \\
\text { Winter Camp Well }\end{array}$ & $\begin{array}{l}\text { reservoir } \\
\text { locale } \\
\text { locale } \\
\text { reservoir } \\
\text { reservoir } \\
\text { reservoir } \\
\text { reservoir } \\
\text { reservoir } \\
\text { well }\end{array}$ & $\begin{array}{l}\text { BGN } \\
\text { BGN } 1974 \\
\text { VARIANT } \\
\text { BGN } \\
\text { BGN } \\
\text { BGN } \\
\text { BGN } \\
\text { BGN } \\
\text { BGN } \\
\text { UNOFF }\end{array}$ & $\begin{array}{l}\text { Yavapai } \\
\text { Gila } \\
\text { Navajo } \\
\text { Greenlee } \\
\text { Yavapai } \\
\text { Coconino } \\
\text { Coconino } \\
\text { Coconino } \\
\text { Gila }\end{array}$ & 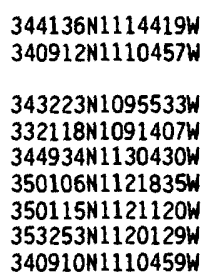 & & & $\begin{array}{l}\text { Casner Butte } \\
\text { Diamond Butte } \\
\text { Point of the Mtn } \\
\text { Fritz Canyon } \\
\text { Scratch Canyon } \\
\text { Matterhorn } \\
\text { May Tank Pocket } \\
\text { Hobble Tank } \\
\text { Diamond Butte }\end{array}$ \\
\hline $\begin{array}{l}\text { Wintercone Park (trailer park) } \\
\text { Winter Fat Tank } \\
\text { Wintergreen Mink Ranch } \\
\text { Winter Pasture Tank } \\
\text { Winters burg } \\
\text { Winters Ranch } \\
\text { Winters Ranch } \\
\text { Winters Wash } \\
\text { Winters Well } \\
\text { Winters Well }\end{array}$ & $\begin{array}{l}\text { locale } \\
\text { reservoir } \\
\text { locale } \\
\text { reservoir } \\
\text { locale } \\
\text { locale } \\
\text { locale } \\
\text { stream } \\
\text { well } \\
\text { locale }\end{array}$ & $\begin{array}{l}\text { UNOFF } \\
\text { BGN } \\
\text { UNOFF } \\
\text { BGN } \\
\text { BGN } \\
\text { UNOFF } \\
\text { UNOFF } \\
\text { BGN } \\
\text { UNOFF } \\
\text { BGN }\end{array}$ & $\begin{array}{l}\text { Maricopa } \\
\text { Coconino } \\
\text { Cochise } \\
\text { Gila } \\
\text { Maricopa } \\
\text { Gila } \\
\text { Gila } \\
\text { Maricopa } \\
\text { Gila } \\
\text { Maricopa }\end{array}$ & $\begin{array}{l}332658 \mathrm{~N} 1114906 \mathrm{~W} \\
345252 \mathrm{~N} 1110716 \mathrm{~W} \\
312322 \mathrm{~N} 110141 \mathrm{WW} \\
33456 \mathrm{~N} 1105118 \mathrm{~W} \\
332528 \mathrm{~N} 1125202 \mathrm{~W} \\
333252 \mathrm{N1} 10423 \mathrm{~W} \\
342228 \mathrm{N1} 110631 \mathrm{~W} \\
331940 \mathrm{N1125257 \textrm {W }} \\
333255 \mathrm{N1} 104242 \mathrm{~W} \\
332648 \mathrm{~N} 1125430 \mathrm{~W}\end{array}$ & 333649 N1125639W & 4927 & $\begin{array}{l}\text { Mesa } \\
\text { Chavez Mtn NE } \\
\text { Nicksville } \\
\text { Dagger Peak } \\
\text { Wintersburg } \\
\text { Chrome Butte } \\
\text { Promontory Butte } \\
\text { Gillespie } \\
\text { Chrome Butte } \\
\text { Tonopah }\end{array}$ \\
\hline $\begin{array}{l}\text { Winter Tank } \\
\text { Winter Tank } \\
\text { Winter Wells School } \\
\text { Winton Well } \\
\text { Wipala Wiki Ranch } \\
\text { Wipho } \\
\text { See Wepo Spring } \\
\text { Wipo Spring } \\
\text { See Wepo Spring } \\
\text { Wire Corral }\end{array}$ & $\begin{array}{l}\text { reservoir } \\
\text { reservoir } \\
\text { school } \\
\text { well } \\
\text { locale } \\
\text { spring } \\
\text { spring } \\
\text { locale }\end{array}$ & $\begin{array}{l}\text { BGN } \\
\text { BGN } \\
\text { UNOFF } \\
\text { UNOFF } \\
\text { UNOFF } \\
\text { VARIANT } \\
\text { VARIANT } \\
\text { BGN }\end{array}$ & $\begin{array}{l}\text { Navajo } \\
\text { Coconino } \\
\text { Maricopa } \\
\text { Coconino } \\
\text { Gila } \\
\text { Navajo } \\
\text { Navajo } \\
\text { Pinal }\end{array}$ & 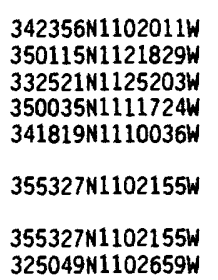 & & & $\begin{array}{l}\text { Big Pug Tank } \\
\text { Matterhorn } \\
\text { Wintersburg } \\
\text { Elliott Canyon } \\
\text { Promontory Butte }\end{array}$ \\
\hline $\begin{array}{l}\text { Wire Corral Draw } \\
\text { Wire Corral Draw } \\
\text { See Parsons Canyon } \\
\text { Wire Corral Mesa } \\
\text { Wire Corral Mesa } \\
\text { Wire-Corral Spring } \\
\text { Wire Corral Tank } \\
\text { Wire Corral Tank } \\
\text { Wire Corral Tank } \\
\text { Wire Gold Tank }\end{array}$ & $\begin{array}{l}\text { valley } \\
\text { valley } \\
\text { summit } \\
\text { summit } \\
\text { spring } \\
\text { reservoir } \\
\text { reservoir } \\
\text { reservoir } \\
\text { reservoir }\end{array}$ & $\begin{array}{l}\text { BGN } 1975 \\
\text { VARIANT } \\
\text { BGN } \\
\text { BGN } \\
\text { BGN } \\
\text { BGN } \\
\text { BGN } \\
\text { BGN } \\
\text { BGN }\end{array}$ & $\begin{array}{l}\text { Pinal } \\
\text { Pinal } \\
\text { Graham } \\
\text { Greenlee } \\
\text { Graham } \\
\text { Pima } \\
\text { Yavapai } \\
\text { Coconino } \\
\text { Yavapai }\end{array}$ & 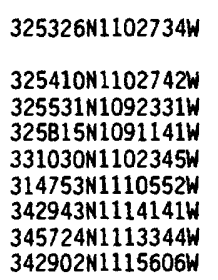 & 324955 N1102810W & & $\begin{array}{l}\text { Gila Box } \\
\text { York } \\
\text { San Carlos Reservoir } \\
\text { Esperanza Mill } \\
\text { Hackberry Mtn } \\
\text { Mormon Mountain } \\
\text { Arnold Mesa }\end{array}$ \\
\hline $\begin{array}{l}\text { Wiregrass Lake } \\
\text { Wire Spring } \\
\text { Wire Spring } \\
\text { Wiscons in Canyon } \\
\text { Wiscons in Mine } \\
\text { Wiscons in Mine } \\
\text { Wisdom Tank } \\
\text { Wise Mesa } \\
\text { Wishbone Mountain } \\
\text { Wishing Shrine }\end{array}$ & $\begin{array}{l}\text { lake } \\
\text { spring } \\
\text { spring } \\
\text { valley } \\
\text { mine } \\
\text { mine } \\
\text { reservoir } \\
\text { summit } \\
\text { summit } \\
\text { church }\end{array}$ & $\begin{array}{l}\text { BGN } \\
\text { BGN } \\
\text { BGN } \\
\text { BGN } \\
\text { UNOFF } \\
\text { UNOFF } \\
\text { BGN } \\
\text { BGN } \\
\text { BGN } \\
\text { UNOFF }\end{array}$ & $\begin{array}{l}\text { Apache } \\
\text { Yavapai } \\
\text { Yavapai } \\
\text { Cochise } \\
\text { Pima } \\
\text { Maricopa } \\
\text { Santa Cruz } \\
\text { Santa Cruz } \\
\text { Apache } \\
\text { Pima }\end{array}$ & $\begin{array}{l}341938 N 1092643 \mathrm{~W} \\
342058 \mathrm{~N} 1121841 \mathrm{~W} \\
342442 \mathrm{~N} 1115330 \mathrm{~W} \\
312527 \mathrm{~N} 1101937 \mathrm{~W} \\
314657 \mathrm{~N} 110464 \mathrm{~W} \\
334341 \mathrm{~N} 1131247 \mathrm{~W} \\
312432 \mathrm{N1} 11003 \mathrm{~W} \\
31272 \mathrm{WN} 1110427 \mathrm{~W} \\
340906 \mathrm{~N} 109435 \mathrm{~W} \\
321240 \mathrm{~N} 1105823 \mathrm{~W}\end{array}$ & 312443N1101923W & 8823 & $\begin{array}{l}\text { Lyman Lake SW } \\
\text { Battle Flat } \\
\text { Arnold Mesa } \\
\text { Miller Peak } \\
\text { Helvetia } \\
\text { Little Horn Peak } \\
\text { Pena Blanca Lake } \\
\text { Pena Blanca Lake } \\
\text { Boundary Butte } \\
\text { Tucson }\end{array}$ \\
\hline $\begin{array}{l}\text { Wishing Well Cove } \\
\text { Cathedral Cove } \\
\text { Wishing Well Trailer Park }\end{array}$ & bay & $\begin{array}{l}\text { BGN } 1948 \\
\text { VARIANT }\end{array}$ & Mohave & $360830 \mathrm{~N} 1143452 \mathrm{~W}$ & & 1230 & Boulder Canyon \\
\hline $\begin{array}{l}\text { Wishing Well Irailer Park } \\
\text { Witch Canyon } \\
\text { See South Witch Canyon } \\
\text { Witch Canyon Trail Two }\end{array}$ & $\begin{array}{l}\text { locale } \\
\text { valley } \\
\text { trail }\end{array}$ & $\begin{array}{l}\text { UNOFF } \\
\text { VARIANT } \\
\text { UNOFF }\end{array}$ & $\begin{array}{l}\text { Maricopa } \\
\text { Cochise } \\
\text { Cochise }\end{array}$ & $\begin{array}{l}331823 \mathrm{~N} 1114940 \mathrm{~W} \\
315621 \mathrm{~N} 1092614 \mathrm{~W} \\
315429 \mathrm{~N} 1092500 \mathrm{~W}\end{array}$ & & 1220 & Fife Peak \\
\hline $\begin{array}{l}\text { Hundred Sixty } \\
\text { Witch Creek } \\
\text { Witches Pool } \\
\text { See Witch Pool (historical) }\end{array}$ & $\begin{array}{l}\text { stream } \\
\text { lake }\end{array}$ & $\begin{array}{l}\text { BGN } \\
\text { VARIANT }\end{array}$ & $\begin{array}{l}\text { Cochise } \\
\text { Coconino }\end{array}$ & $\begin{array}{l}315703 \mathrm{~N} 1092838 \mathrm{~W} \\
362700 \mathrm{~N} 1131000 \mathrm{~W}\end{array}$ & $315621 \mathrm{~N} 1092614 \mathrm{~W}$ & & Fife Peak \\
\hline $\begin{array}{l}\text { Witch Pool } \\
\text { Witch Pool (historical) } \\
\text { Witches Pool } \\
\text { Witch Well Ranch } \\
\text { Witch Well Trading Post } \\
\text { Wittman } \\
\text { See Wittmann }\end{array}$ & $\begin{array}{l}\text { lake } \\
\text { lake } \\
\text { locale } \\
\text { locale } \\
\text { ppl }\end{array}$ & $\begin{array}{l}\text { BGN } \\
\text { BGN } 1897 \\
\text { VARIANT } \\
\text { UNOFF } \\
\text { BGN } \\
\text { VARIANT }\end{array}$ & $\begin{array}{l}\text { Mohave } \\
\text { Coconino } \\
\text { Apache } \\
\text { Apache } \\
\text { Maricopa }\end{array}$ & $\begin{array}{l}362533 \mathrm{~N} 1130457 \mathrm{~W} \\
362700 \mathrm{~N} 1131000 \mathrm{~W} \\
345359 \mathrm{~N} 1091445 \mathrm{~W} \\
345410 \mathrm{~N} 1091413 \mathrm{~W}\end{array}$ & & 6220 & $\begin{array}{l}\text { Mt Trumbul1 ME } \\
\text { Cliff Rose } \mathrm{Hill}\end{array}$ \\
\hline
\end{tabular}


FEATURE NAME

Wittman

Nadaburg

Whittman

Wittman

Witty Tom Tank

W J Murphy Park

$W$ Mountain

Wob Tank

Wodo, Mount

Mount Wado

Wohlenberg Draw

Wolcott Peak

Wolf Canyon

Wolf Canyon Tank

Wolf Creek

Wolf Creek

Wolf Creek Tank

Wolf Crossing

Wolf Hole

See Wolf Hole Lake

Wolf Hole

Wolf Hole Lake

Wholfhole

Wolf Hole

Wolf Hole Mountain

Wolf Hole Pass

Wolf Hole Spring

Wolf Hole Tank

Wolf Hole Valley

Wolf Hole Valley Pond

Wolf Hole Wildlife Reservoir

Wolf Knoll

Wolfley $\mathrm{Hill}$

Shrug Nakya

Wolfleys $\mathrm{Hill}$

Wolfleys $\mathrm{Hill}$

See Wolfley $\mathrm{Hill}$

Wolf lok We 11

Wolf Mine

Wolf Mountain

Wolf Pass Well

Wolf Point

Wolf Spring

Wolf Spring

Wolf Spring

Wolf Tank

Wolpi

See Walpi

Wolverine Mines

Wolverton Mountain

Wolverton Mountain

Womack Airstrip

Womack East (subdivision)

Womans Trail

Wonder Gulch

Wonderland Park

Wonder Rift

Woodberry Canyon

Woodbridge Crossing

(subdivision)

Woodbridge Tank

Woodbury Cabin

Wood Camp Cabin

Wood Camp Canyon

Woodcamp Spring

Wood Camp Tank

Wood Canyon

Wood Canyon

See Dry Canyon

Wood Canyon

Wood Canyon

FEATURE
CLASS

ppl

STATUS

BGN 197B
VARIANT
VARIANT
VARIANT

COORDINATE

334635N1123140W

$\begin{array}{ll}\text { reservoir } & \text { BGN } \\ \text { park } & \text { ADMIN } \\ \text { summit } & \text { BGN } \\ \text { reservoir } & \text { BGN } \\ \text { summit } & \text { BGN 1925 } \\ & \text { VARIANT } \\ \text { valley } & \text { BGN } \\ \text { summit } & \text { BGN } \\ \text { valley } & \text { BGN } \\ \text { reservoir } & \text { BGN }\end{array}$

Yavapai

Maricopa

Maricopa

Gila

Coconino

Apache

Pima

Apache
Santa Cruz

$345712 N 1121322 \mathrm{~W}$

$333222 \mathrm{~N} 1121102 \mathrm{~W}$

$335853 \mathrm{~N} 1124306 \mathrm{~W}$

$331257 N 1104103 \mathrm{~W}$

$361219 N 1123857 \mathrm{~W}$

$335940 \mathrm{~N} 1094048 \mathrm{~W}$

$322640 \mathrm{~N} 1112856 \mathrm{~W}$

$362047 \mathrm{~N} 1095529 \mathrm{~W}$

$312915 \mathrm{~N} 1110602 \mathrm{~W}$

stream
stream
reservoir
locale
lake
locale
lake

BGN Yavapai

BGN Yavapai

BGN Yavapai

AARIANT

Mohave

BGN Mohave

BGN Mohave

VARIANT

summit $\quad$ BGN 1979

gap

spring

reservoir

valley

reservoir

reservoir

summit

summit

BGN

BGN

BGN

$B G N$

BGN

BGN

BGN

BGN 1941

VARIANT
VARIANT

VARIANT

summit
well
mine
summit
well
cliff
spring
spring
spring

reservoir

locale

mine

summit

summit

airport

ppl

trail

valley

UNO
UNOFF
$B G N$
UNOFF
$B G N$
$B G M$
BGI
BG

Pima

Coconino

Maricopa

Apache

Navajo

Coconino

Gila

Coconino

Mohave

341858 N1121713W

$342714 \mathrm{~N} 1122832 \mathrm{~W}$

$341913 \mathrm{~N} 1121655 \mathrm{~W}$

$352340 \mathrm{~N} 1110627 \mathrm{~W}$

364539 N1133228W

$364546 \mathrm{~N} 1133255 \mathrm{~W}$

$364539 \mathrm{~N} 1133228 \mathrm{~W}$

$364740 \mathrm{~N} 1133638 \mathrm{~W}$

$364243 \mathrm{~N} 1133101 \mathrm{~W}$

364606 N1133533W

$343501 \mathrm{~N} 1112038 \mathrm{~W}$

$364532 \mathrm{~N} 1133238 \mathrm{~W}$

$364315 N 1133307 \mathrm{~W}$

$365146 \mathrm{~N} 1133736 \mathrm{~W}$

$370035 N 1115254 \mathrm{~W}$

$313821 \mathrm{N1} 120020 \mathrm{~W}$

364104N1133720W

42523N1122114W

$342735 N 1122431 \mathrm{~W}$

$335635 N 1093642 W$

$362257 N 1095355 \mathrm{~W}$

$313821 \mathrm{N1120020 \textrm {W }}$

$345655 \mathrm{~N} 1110451 \mathrm{~W}$

$335158 \mathrm{~N} 1124040 \mathrm{~W}$

$341152 N 1094422 W$

$353131 N 1101953 \mathrm{~W}$

$355924 N 1111059 \mathrm{~W}$

$340041 \mathrm{~N} 1104820 \mathrm{~W}$

$36363 \mathrm{BN} 1104959 \mathrm{~W}$

$365854 N 1123807 \mathrm{~W}$

350654 N1125835W

BGN Yavapai

Navajo

Cochise

Gila

Yavapai

Pinal

Maricopa

Apache

Gila

locale

locale

valley

ppl

reservoir

locale

locale

valley

spring

BGN Apache

BGN Maricopa

BGN Mohave

BGN

Maricopa

BGN Coconino

BGN Pinal

BGN Yavapai

Pinal

Gila

reservoir

valley

BGN Yavapai

BGN Cochise

valley

valley

valley
VARIANT

BGN 1959 Santa Cruz

BGN Santa Cruz

Pina
$354956 \mathrm{~N} 110235 \mathrm{OW}$

312518 N1095520W

$341012 \mathrm{N111121BW}$

$343016 \mathrm{~N} 1123035 \mathrm{~W}$

$332212 \mathrm{~N} 1113410 \mathrm{~W}$

$332049 \mathrm{~N} 1115115 \mathrm{~W}$

$360744 \mathrm{~N} 1092825 \mathrm{~W}$

$341118 \mathrm{~N} 1112248 \mathrm{~W}$

$340145 \mathrm{~N} 1092530 \mathrm{~W}$

$332101 \mathrm{N1120108 \textrm {W }}$

$365613 \mathrm{~N} 1125122 \mathrm{~W}$

332305 N1114745W

$355245 \mathrm{N1114755W}$

$332500 \mathrm{NI} 111227 \mathrm{~W}$

$341215 \mathrm{~N} 1115401 \mathrm{~W}$

$332119 N 1110754 \mathrm{~W}$

333409 N1104304W

$350845 \mathrm{~N} 1122346 \mathrm{~W}$

$312709 \mathrm{~N} 1095555 \mathrm{~W}$

$313700 \mathrm{~N} 1104410 \mathrm{~W}$

$313715 \mathrm{~N} 1104300 \mathrm{~W}$

$315115 N 1103402 \mathrm{~W}$
$341331 \mathrm{N1112248W}$

$365341 \mathrm{~N} 1125030 \mathrm{~W}$

$\begin{array}{cc}\text { SOURCE } & \text { ELEV } \\ \text { COORDINATE } & \text { FT MAP NAME }\end{array}$

Wittmann

Perkinsville

Glendale

2330 Wickenburg

Mescal Warm Spring

5130 Supai

Hawley Lake East

Silver Bell East

Tah Chee Wash

Pena Blanca Lake

Battle Flat

Groom Creek

Battle flat

Grand Falls NE

Wolf Hole Mtn East Wolf Hole Mtn East

6416 Wolf Hole Mtn East

5200 Sullivan Draw North Wolf Hole Mtn East Long Valley

Wolf Hole Mtn East Sullivan Draw North Wolf Hole Mtn West

4842 West Clark Bench

2665 Tecolote Ranch

Chavez Mtn NE Wickenburg SW

8288 Boundary Butte Hauke Mesa

5572 Goldtooth

Gentry Mtn

Whirlwind Rock

Kaibab

Turkey Canyon

Bisbee

4494 McDonald Mtn

6704 Iron Springs

1565 Desert Well

1205 Chandler

Del Muerto

Payson South

8480 Greer

Lone Butte

1230 Mesa

Deer Tank

Iron Mountain

Brooklyn Peak 


\begin{tabular}{|c|c|c|c|c|c|c|c|}
\hline FEATURE NAME & $\begin{array}{l}\text { FEATURE } \\
\text { CLASS }\end{array}$ & STATUS & COUNTY & COORDINATE & $\begin{array}{l}\text { SOURCE } \\
\text { COORDINATE }\end{array}$ & $\begin{array}{c}\text { ELEV } \\
\text { FT }\end{array}$ & MAP NAME \\
\hline $\begin{array}{l}\text { Wood Canyon } \\
\text { Wood Canyon } \\
\text { Wood Canyon } \\
\text { Wood Canyon }\end{array}$ & $\begin{array}{l}\text { valley } \\
\text { valley } \\
\text { valley } \\
\text { valley }\end{array}$ & $\begin{array}{l}\text { BGN } \\
B G N \\
B G N \\
B G N\end{array}$ & $\begin{array}{l}\text { Cochise } \\
\text { Cochise } \\
\text { Cochise } \\
\text { Cochise }\end{array}$ & $\begin{array}{l}320149 N 1100049 \mathrm{~W} \\
320754 \mathrm{~N} 1092939 \mathrm{~W} \\
320831 \mathrm{N1091643 \textrm {W }} \\
322057 \mathrm{N1100131W}\end{array}$ & 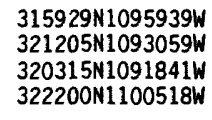 & & $\begin{array}{l}\text { Dragoon } \\
\text { Bowie Mtn North } \\
\text { Little Wood Canyon } \\
\text { Muskhog Mountain }\end{array}$ \\
\hline $\begin{array}{l}\text { Wood Canyon } \\
\text { See Monk Draw } \\
\text { Wood Canyon } \\
\text { Monk Draw }\end{array}$ & $\begin{array}{l}\text { valley } \\
\text { valley }\end{array}$ & $\begin{array}{l}\text { VARIANT } \\
\text { BGN } \\
\text { VARIANT }\end{array}$ & $\begin{array}{l}\text { Cochise } \\
\text { Cochise }\end{array}$ & $\begin{array}{l}322129 \mathrm{~N} 1093704 \mathrm{~W} \\
322323 \mathrm{~N} 1094229 \mathrm{~W}\end{array}$ & $322841 \mathrm{~N} 1094653 \mathrm{~W}$ & & Monk Draw \\
\hline $\begin{array}{l}\text { Wood Canyon } \\
\text { Wood Canyon } \\
\text { Wood Canyon }\end{array}$ & $\begin{array}{l}\text { valley } \\
\text { valley }\end{array}$ & $\begin{array}{l}\text { BGN } \\
\text { BGN } \\
\text { VARIANT }\end{array}$ & $\begin{array}{l}\text { Cochise } \\
\text { Graham }\end{array}$ & $\begin{array}{l}322431 \mathrm{N1} 1090401 \mathrm{~W} \\
323534 \mathrm{N1} 101206 \mathrm{~W}\end{array}$ & $\begin{array}{l}322327 \mathrm{~N} 1090452 \mathrm{~W} \\
323517 \mathrm{~N} 1101536 \mathrm{~W}\end{array}$ & & $\begin{array}{l}\text { Engine Mtn } \\
\text { Harrison Canyon }\end{array}$ \\
\hline $\begin{array}{l}\text { See Knight Canyon } \\
\text { Wood Canyon } \\
\text { Kinght Canyon }\end{array}$ & $\begin{array}{l}\text { valley } \\
\text { valley }\end{array}$ & $\begin{array}{l}\text { BGN } 1964 \\
\text { VARIANT }\end{array}$ & $\begin{array}{l}\text { Greenlee } \\
\text { Greenlee }\end{array}$ & $\begin{array}{l}330820 \mathrm{~N} 1092930 \mathrm{~W} \\
330901 \mathrm{~N} 1092718 \mathrm{~W}\end{array}$ & $331056 \mathrm{~N} 1092326 \mathrm{~W}$ & & Coronado Mtn \\
\hline $\begin{array}{l}\text { Wood Canyon } \\
\text { Wood Canyon Park } \\
\text { Wood Canyon Spring } \\
\text { Wood Canyon Wash } \\
\text { Wood Chop Mesa } \\
\text { Woodchopper Spring } \\
\text { Woodchopper Wash } \\
\text { Woodchute Mountain } \\
\text { Woodchute Tank } \\
\text { Woodchute Trail }\end{array}$ & $\begin{array}{l}\text { valley } \\
\text { flat } \\
\text { spring } \\
\text { stream } \\
\text { summit } \\
\text { spring } \\
\text { stream } \\
\text { sumnit } \\
\text { reservoir } \\
\text { trail }\end{array}$ & $\begin{array}{l}\text { BGN } \\
B G N \\
B G N \\
B G N \\
B G N \\
B G N \\
B G N \\
B G N \\
\text { BGN } \\
\text { UNOFF }\end{array}$ & $\begin{array}{l}\text { Pinal } \\
\text { Cochise } \\
\text { Pinal } \\
\text { Cochise } \\
\text { Navajo } \\
\text { Pinal } \\
\text { Maricopa } \\
\text { Yavapai } \\
\text { Yavapai } \\
\text { Yavapai }\end{array}$ & $\begin{array}{l}331449 \mathrm{~N} 1110641 \mathrm{~W} \\
320339 \mathrm{~N} 1091857 \mathrm{~W} \\
331252 \mathrm{~N} 1110629 \mathrm{~W} \\
322153 \mathrm{~N} 1095804 \mathrm{~W} \\
352701 \mathrm{~N} 1100112 \mathrm{~W} \\
331217 \mathrm{~N} 1105621 \mathrm{~W} \\
334349 \mathrm{~N} 1125449 \mathrm{~W} \\
344459 \mathrm{~N} 1121030 \mathrm{~W} \\
344419 \mathrm{~N} 1121003 \mathrm{~W} \\
344352 \mathrm{~N} 1120935 \mathrm{~W}\end{array}$ & $\begin{array}{l}331053 \mathrm{~N} 1110726 \mathrm{~W} \\
322200 \mathrm{~N} 1100517 \mathrm{~W} \\
334236 \mathrm{~N} 1130118 \mathrm{~W}\end{array}$ & & $\begin{array}{l}\text { Teapot Mountain } \\
\text { Cochise Head } \\
\text { Teapot Mountain } \\
\text { Square Mountain } \\
\text { Indian Wells } \\
\text { Hot Tamale Peak } \\
\text { Belmont Mtn } \\
\text { Hickey Mountain } \\
\text { Hickey Mountain } \\
\text { Hickey Mountain }\end{array}$ \\
\hline $\begin{array}{l}\text { Wood Creek } \\
\text { Wood Creek } \\
\text { Woodcreek (subdivision) } \\
\text { Wood Creek Spring } \\
\text { Woodcutters Canyon } \\
\text { Wooded Tank } \\
\text { Wooden Tank } \\
\text { Wooden Tower Tank } \\
\text { Wooden Trough Spring } \\
\text { Woodglen (subdivision) }\end{array}$ & $\begin{array}{l}\text { strean } \\
\text { strean } \\
\text { ppl } \\
\text { spring } \\
\text { valley } \\
\text { reservoir } \\
\text { reservoir } \\
\text { reservoir } \\
\text { spring } \\
\text { ppl }\end{array}$ & $\begin{array}{l}\text { BGN } \\
\text { BGN } \\
\text { BGN } \\
B G N \\
\text { BGN } \\
\text { BGN } \\
\text { BGN } \\
\text { BGN } \\
\text { BGN } \\
\text { BGN }\end{array}$ & $\begin{array}{l}\text { Pinal } \\
\text { Yavapai } \\
\text { Maricopa } \\
\text { Pinal } \\
\text { Cochise } \\
\text { Coconino } \\
\text { Navajo } \\
\text { Mohave } \\
\text { Pima } \\
\text { Maricopa }\end{array}$ & $\begin{array}{l}332355 \mathrm{~N} 1110059 \mathrm{~W} \\
342817 \mathrm{~N} 1124907 \mathrm{~W} \\
332300 \mathrm{~N} 1115212 \mathrm{~W} \\
332342 \mathrm{~N} 1110101 \mathrm{~W} \\
313013 \mathrm{~N} 1101938 \mathrm{~W} \\
364401 \mathrm{~N} 1110206 \mathrm{~W} \\
345337 \mathrm{~N} 1095904 \mathrm{~W} \\
35025 \mathrm{BN1} 134607 \mathrm{~W} \\
322659 \mathrm{~N} 1105110 \mathrm{~W} \\
332111 \mathrm{~N} 1115217 \mathrm{~W}\end{array}$ & $\begin{array}{l}332211 \mathrm{~N} 1110244 \mathrm{~W} \\
343118 \mathrm{~N} 1124700 \mathrm{~W} \\
312936 \mathrm{~N} 1102224 \mathrm{~W}\end{array}$ & 1210 & $\begin{array}{l}\text { Haunted Canyon } \\
\text { Bismarck Mesa } \\
\text { Mesa } \\
\text { Haunted Canyon } \\
\text { Fort Huachuca } \\
\text { White Hill } \\
\text { Carrizo Butte } \\
\text { Dean Peak } \\
\text { Mt Lemmon } \\
\text { Chandler }\end{array}$ \\
\hline $\begin{array}{l}\text { Woodhouse Mesa } \\
\text { Woodin } \\
\text { Woodland Campground } \\
\text { Woodland Dam } \\
\text { Woodland Heights (subdivision) } \\
\text { Woodland Parkway } \\
\text { Woodland Plaza Shopping Center } \\
\text { Woodland Plaza Shopping Center } \\
\text { Woodland Reservoir } \\
\text { Woodland Tank }\end{array}$ & $\begin{array}{l}\text { summit } \\
\text { locale } \\
\text { park } \\
\text { dam } \\
\text { ppl } \\
\text { park } \\
\text { locale } \\
\text { locale } \\
\text { reservoir } \\
\text { reservoir }\end{array}$ & $\begin{array}{l}\text { BGN } \\
\text { BGN } \\
\text { ADMIN } \\
\text { UNOFF } \\
\text { BGN } \\
\text { ADMIN } \\
\text { UNOFF } \\
\text { UNOFF } \\
\text { BGN } \\
\text { BGN }\end{array}$ & $\begin{array}{l}\text { Coconino } \\
\text { Coconino } \\
\text { Navajo } \\
\text { Navajo } \\
\text { Maricopa } \\
\text { Maricopa } \\
\text { Pima } \\
\text { Maricopa } \\
\text { Navajo } \\
\text { Navajo }\end{array}$ & $\begin{array}{l}353011 N 1112256 \mathrm{~W} \\
355056 \mathrm{~N} 1121518 \mathrm{~W} \\
340736 \mathrm{~N} 1095655 \mathrm{~W} \\
340736 \mathrm{~N} 1095712 \mathrm{~W} \\
332325 \mathrm{~N} 1114527 \mathrm{~W} \\
332704 \mathrm{N1} 120510 \mathrm{~W} \\
321507 \mathrm{N1} 104916 \mathrm{~W} \\
333825 \mathrm{~N} 1120805 \mathrm{~W} \\
340737 \mathrm{N1} 1095709 \mathrm{~W} \\
342642 \mathrm{~N} 1102000 \mathrm{~W}\end{array}$ & & $\begin{array}{l}6900 \\
6893 \\
1255 \\
2520 \\
6893\end{array}$ & $\begin{array}{l}\text { Wupatki SW } \\
\text { Howard Hill } \\
\text { Lakeside } \\
\text { Lakeside } \\
\text { Mesa } \\
\text { Phoenix } \\
\text { Sabino Canyon } \\
\text { Hedgpeth Hills } \\
\text { Lakeside } \\
\text { Big Pug Tank }\end{array}$ \\
\hline $\begin{array}{l}\text { Woodleaf (subdivision) } \\
\text { Woodleaf II (subdivision) } \\
\text { Wood Mountain } \\
\text { Woodpecker Mine } \\
\text { Wood Ranch } \\
\text { Woodridge Lakes (subdivision) } \\
\text { Woodridge VI (subdivision) } \\
\text { Wood Road Well } \\
\text { Woodrows Tank } \\
\text { Woodrow Windmill }\end{array}$ & $\begin{array}{l}\text { ppl } \\
\text { ppl } \\
\text { summit } \\
\text { mine } \\
\text { locale } \\
\text { ppl } \\
\text { ppl } \\
\text { well } \\
\text { reservoir } \\
\text { locale }\end{array}$ & $\begin{array}{l}\text { BGN } \\
\text { BGN } \\
\text { BGN } \\
\text { UNOFF } \\
\text { UNOFF } \\
\text { BGN } \\
\text { BGN } \\
\text { UNOFF } \\
\text { BGN } \\
\text { BGN }\end{array}$ & $\begin{array}{l}\text { Maricopa } \\
\text { Maricopa } \\
\text { Cochise } \\
\text { Pinal } \\
\text { Santa Cruz } \\
\text { Maricopa } \\
\text { Maricopa } \\
\text { Gila } \\
\text { Pinal } \\
\text { Cochise }\end{array}$ & $\begin{array}{l}333120 \mathrm{~N} 1115414 \mathrm{~W} \\
333536 \mathrm{~N} 1115745 \mathrm{~W} \\
320716 \mathrm{~N} 1092000 \mathrm{~W} \\
331251 \mathrm{N1111144W} \\
313516 \mathrm{~N} 1103450 \mathrm{~W} \\
332620 \mathrm{~N} 1114808 \mathrm{~W} \\
333930 \mathrm{~N} 1121010 \mathrm{~W} \\
333057 \mathrm{N1} 10472 \mathrm{~W} \\
325239 \mathrm{~N} 1102943 \mathrm{~W} \\
321707 \mathrm{~N} 1093208 \mathrm{~W}\end{array}$ & & $\begin{array}{l}1270 \\
1380 \\
7326 \\
\\
1260 \\
1290 \\
\\
4041\end{array}$ & $\begin{array}{l}\text { Paradise Valley } \\
\text { Paradise Valley } \\
\text { Cochise Head } \\
\text { Mineral Mtn } \\
\text { O'Donnell Canyon } \text { Mesa } \\
\text { Hedgpeth Hills } \\
\text { Rockinstraw Mtn } \\
\text { Booger Canyon } \\
\text { Luzena }\end{array}$ \\
\hline $\begin{array}{l}\text { Woodruff } \\
\quad \text { Tenneys Camp }\end{array}$ & ppl & $\begin{array}{l}\text { BGN } \\
\text { VARIANT }\end{array}$ & Navajo & $344653 \mathrm{~N} 1100234 \mathrm{~W}$ & & & Woodruff \\
\hline $\begin{array}{l}\text { Woodruff Butte } \\
\text { Woodruff Dam } \\
\text { Woodruff Oitch } \\
\text { Woodruff Lake } \\
\text { Woodruff Reservoir } \\
\text { Woods, Lake of the } \\
\text { Woods Canyon } \\
\text { Woods Canyon }\end{array}$ & $\begin{array}{l}\text { summit } \\
\text { dam } \\
\text { canal } \\
\text { lake } \\
\text { reservoir } \\
\text { reservoir } \\
\text { valley } \\
\text { valley }\end{array}$ & $\begin{array}{l}\text { BGN } \\
\text { UNOFF } \\
\text { BGN } \\
\text { BGN } \\
\text { BGN } \\
\text { BGN } \\
\text { BGN } \\
\text { BGN }\end{array}$ & $\begin{array}{l}\text { Navajo } \\
\text { Navajo } \\
\text { Navajo } \\
\text { Navajo } \\
\text { Navajo } \\
\text { Navajo } \\
\text { Greenlee } \\
\text { Greenlee }\end{array}$ & $\begin{array}{l}344756 \mathrm{~N} 1100231 \mathrm{~W} \\
344417 \mathrm{N1} 100214 \mathrm{~W} \\
344441 \mathrm{~N} 1100228 \mathrm{~W} \\
344715 \mathrm{~N} 1100142 \mathrm{~W} \\
344418 \mathrm{~N} 1100214 \mathrm{~W} \\
340942 \mathrm{~N} 1095836 \mathrm{~W} \\
324411 \mathrm{~N} 1090736 \mathrm{~W} \\
331114 \mathrm{~N} 1091510 \mathrm{~W}\end{array}$ & $\begin{array}{l}323745 N 1091211 \mathrm{~W} \\
331246 \mathrm{~N} 1091702 \mathrm{~W}\end{array}$ & 5671 & $\begin{array}{l}\text { Woodruff } \\
\text { Tenmile Cedars } \\
\text { Tenmile Cedars } \\
\text { Woodruff } \\
\text { Tenmile Cedars } \\
\text { Lakeside } \\
\text { Hot Well } \\
\text { Mitchell Peak }\end{array}$ \\
\hline $\begin{array}{l}\text { Woods Canyon } \\
\text { Woods Canyon } \\
\text { Woods Canyon Bridge } \\
\text { Woods Canyon Creek } \\
\text { Woods Canyon Dam } \\
\text { Woods Canyon Lake } \\
\text { Woods Canyon Lake Recreation }\end{array}$ & $\begin{array}{l}\text { valley } \\
\text { valley } \\
\text { bridge } \\
\text { stream } \\
\text { dam } \\
\text { reservoir } \\
\text { park }\end{array}$ & $\begin{array}{l}\text { BGN } 1973 \\
\text { BGN } \\
\text { UNOFF } \\
\text { BGN } \\
\text { UNOFF } \\
\text { BGN } \\
\text { ADMIN }\end{array}$ & $\begin{array}{l}\text { Coconino } \\
\text { Yavapai } \\
\text { Coconino } \\
\text { Coconino } \\
\text { Coconino } \\
\text { Coconino } \\
\text { Coconino }\end{array}$ & $\begin{array}{l}342130 \mathrm{~N} 1105319 \mathrm{~W} \\
344554 \mathrm{~N} 1114252 \mathrm{~W} \\
345155 \mathrm{~N} 1113732 \mathrm{~W} \\
342130 \mathrm{~N} 1105319 \mathrm{~W} \\
342000 \mathrm{~N} 1105606 \mathrm{~W} \\
342022 \mathrm{~N} 1105706 \mathrm{~W} \\
342003 \mathrm{~N} 1105610 \mathrm{~W}\end{array}$ & $\begin{array}{l}342105 \mathrm{~N} 1105835 \mathrm{~W} \\
345106 \mathrm{~N} 1112919 \mathrm{~W} \\
\\
342203 \mathrm{~N} 1105921 \mathrm{~W}\end{array}$ & 7507 & $\begin{array}{l}\text { Woods Canyon } \\
\text { Munds Mountain } \\
\text { Munds Mountain } \\
\text { Woods Canyon } \\
\text { Woods Canyon } \\
\text { Woods Canyon } \\
\text { Woods Canyon }\end{array}$ \\
\hline
\end{tabular}




\section{FEATURE NAME}

Wood School

Woods Creek

Woods Creek Spring

Woods Ditch

Woodside (subdivision)

Woods Lake

Wood Spring

Wood Spring

Wood Spring

Wood Spring

Wood Spring

Wood Springs

Woodsprings

See Woodspring Trading Post Wood Springs

See Woodspring Trading Post

Wood Springs Wash

Woodspring Trading Post

Wood Springs

Woodsprings

Wood Spurger Tank

Woods Ranch

Woods Ranch

Woods Ranch

Woods Spring

Woods Spring

Woods Tank

Woods Tank

Woods Tank

Woods Tank

Wood Tank

Wood Trail Tank

Wood Trap

Woodward Junior High School

Wood Well

Woodyard Canyon

Woody Mountain

Woody Pond

Woody Ridge

Woody Spring

Woodys Tank

Woody Tank

Woody Wash

Wool aroc

Wool Cutter Spring

Wooley Mine

Wooley Railroad Station

Wooley Spring

Wool Growers Windmill

Woolhouse Mountain

Woolhouse Tank

Woolsey Butte

\section{Woolsey Butte Peak}

See Woolsey Peak

Woolseyes

See Dewey

Woolsey Lake

Woolsey Peak

$$
\text { Woolsey Butte Peak }
$$

Woolsey Point

Woolsey Spring

Woolsey Wash

Woolsey Wash

Woosh Clo Oee Toh

Wootan Spring

Work Circle Cemetery

Workman Creek

Workman Creek Falls

Worlds Fair Mine

Wotans Throne
FEATURE
CLASS

STATUS

COUNTY

COORDINATE

SOURCE

COORDINATE

ELEV
FT

MAP NANE

$\begin{array}{llll}\begin{array}{l}\text { school } \\ \text { stream }\end{array} & \begin{array}{l}\text { UNOFF } \\ \text { BGN }\end{array} & \begin{array}{l}\text { Maricopa } \\ \text { Apache }\end{array} & \begin{array}{l}332217 N 1115704 \mathrm{~W} \\ 340059 \mathrm{~N} 1090930 \mathrm{~W}\end{array} \\ \text { spring } & \text { BGN } & \begin{array}{l}\text { Apache } \\ \text { Yavapai }\end{array} & 335845 \mathrm{~N} 1090752 \mathrm{~W} \\ \text { canal } & \text { BGN } & \text { Maricopa } & 33253 \mathrm{~N} 1115200 \mathrm{~W} \\ \text { ppl } & \text { BGN } & \text { Apache } & 34184 \mathrm{~N} 1114555 \mathrm{~W} \\ \text { lake } & \text { BGN } & \text { Gila } & 333222 \mathrm{~N} 1105025 \mathrm{~W} \\ \text { spring } & \text { BGN } & \text { Gila } & 333725 \mathrm{~N} 1103544 \mathrm{~W} \\ \text { spring } & \text { BGN } & \text { Yavapai } & 342936 \mathrm{~N} 1122148 \mathrm{~W} \\ \text { spring } & \text { BGN } & \text { Yavapai } & 343652 \mathrm{~N} 1124700 \mathrm{~W} \\ \text { spring } & \text { BGN } & \text { Apache } & 354931 \mathrm{N1092656 \textrm {W }} \\ \text { spring } & \text { BGN } & \text { Apache } & 354845 \mathrm{~N} 1092741 \mathrm{~W} \\ \text { ppl } & \text { BGN } & \text { A } & \end{array}$

$335825 \mathrm{~N} 1090800 \mathrm{~W}$

Guadalupe

(

Nelson Reservoir

VARIANT

locale

stream

locale

VARIANT

Apache

354952 N1092602W

BGN

Apache

BGN Gila

VARIANT

VARIANT

reservoir

BGN

locale

UNOFF

Yavapai

Pinal

locale

locale

spring

spring

reservoir

reservoir

reservoir

reservoir

reservoir

reservoir

UNOFF

UNOFF

BGN

BGN

BGN

$B G N$

BGN

BGN

BGN

Coconino

Mohave

Greenlee

Coconino

Pima

Coconino

Coconino

Mohave

Yavapai

Yavapai

locale $B G$

Yavapai

choo

well

valley

summit

reservoir

ridge

spring

reservoir

reservoir

UNOFF Yuma

UNOFF

Yavapai

Santa Cruz

Coconino

Mohave

Coconino

Coconino

Navajo

Coconino

stream

locale

spring

mine

building

spring

well

summ it

reservoir

summit

BGN

BGN

BGN

UNOFF

BGN

BGN

BGN

BGN 1932

Coconino

Greenlee

Gila

Pinal

Pinal

Mohave

Yavapai

Navajo

Navajo

Coconino

VARIANT

summit

locale

swamp

summit

cliff

spring

VARIANT

Maricopa

Yavapai

BGN

VARIANT

BGN

BGN

Apache

Maricopa

Coconino

Maricopa

Maricopa

stream BGN Yavapai

spring

spring

cemetery

stream

falls

mine

summit
Graham 322819N1102147W

UNOFF Maricopa 332643N1120B00W

BGN Gila 335238N1110219W

UNOFF Santa Cruz

Coconino
$312846 \mathrm{~N} 1104416 \mathrm{~W}$

$360557 N 1115813 \mathrm{~W}$
$360011 \mathrm{~N} 1100704 \mathrm{~W}$

BGN Gila $334905 N 1105550 \mathrm{~W}$
Nutrioso

Camp Verde

1245 Mesa

Lyman Lake SW

Rockinstraw Mtn

Sevenmile Mts

Poland Junction

Mart in Mtn

Red Clay Wash

6780 Red Clay Wash

333334N1104526W Rockinstraw Mtn

6910 Red Clay Wash

Date Creek Ranch

Brandenburg Mtn

Munds Mountain

Mount Logan

Mitchell Peak

Stoneman Lake

Agua Caliente Hill

Hay Lake

Stoneman Lak

Mount Logan

Date Creek Ranch SE

Munds Draw

Mart in Mt

Yuma West

Date Creek Ranch SW

Pyeatt Ranch

8045 Bellemont

Russell Spring

Dutton $\mathrm{Hill}$

Bellemont

Clay Springs

Flagstaff West

Mountainaire

Bee Canyon

Cibecue Peak

Grayback

Grayback

Moccas in

Middle Verde

6850 Lakeside

Lakeside

Point Imperial

Hawley Lake West

3171 Woolsey Peak

Point Imperial

Woolsey Peak

Dendora Valley

Skull Valley

Whippoorwill Spring

Cherry Spring Peak

Fowler

Copper Mtn

Aztec Peak

Harshaw

Cape Royal 
FEATURE NAME

Wounded Ranger Knoll

Wounded Ranger Tank

Wranglers Roost

Wrather Arch

Wright Cabin

Wright Canyon

Wright Canyon Tank

Wright Hill

Wright School

Wrightson, Mount

Baldy

Baldy Mountain

0ld Baldy

Santa Rita Peak

Wrightstown School

Wright Tank

Wrigley Mine

Wrigley Peak

Wrong Mountain

W 5 Lake

W S Mountain

W-Triangle Tank

Wukoki Ruin

Wukopapabi

See Ganado

Wupatki Bas in

Wupatki Mational Monument

Wupatki Ruin

Wupatki Spring

W Whitmore School

See Whitmore School

Wyatt Tank

Wymola

Wymola Railroad Station

Wyrick Ranch

Wyrick Ranch

Wyrick Tank

\section{FEATURE}

\section{summit}

summit

STATUS

COUNTY

Coconino

Coconino

locale

arch

locale

valley

reservoir

summit

school

summit

BGN
BGN 1965
BGN
BGN
BGN
BGN
UNOFF
BGN 1930
VARIANT
VARIANT
VARIANT
VARIANT

Maricopa

Coconino

Yavapai

Mohave

Mohave

Coconino

Pima

Santa Cruz

WWFF

school

reservoir

mine

summit

summit

lake

summit

reservoir

locale

BGN

UNOFF

BGN

1982 Pima

BGN Greenlee

BGN

BGN

BGN

ppl

VARIANT

\section{basin $\quad B G$}

park

spring

school

reservoir

locale

building

locale

reservoir
BGN
AOMIN

AOMIN

$B G N$

BGN

BGN

BGN

BGN

UNOFF

UNOFF

BGN
Greenlee

Coconino

Apache

Coconino

Coconino

Coconino

Coconino

Pima

Gila

Pinal

Pinal

Navajo

Navajo

Navajo
$321432 \mathrm{~N} 1104802 \mathrm{~W}$ $354044 \mathrm{N1} 121916 \mathrm{~W}$ $345828 \mathrm{~N} 1142301 \mathrm{~W}$ $345831 \mathrm{~N} 1142309 \mathrm{~W}$ $320646 \mathrm{~N} 1103110 \mathrm{~W}$ $333142 \mathrm{~N} 1090322 \mathrm{~W}$ $333134 \mathrm{~N} 1090430 \mathrm{~W}$ $352255 \mathrm{~N} 1115908 \mathrm{~W}$ 353152 N1111943W

354241 N1093229W

$353355 \mathrm{~N} 1112002 \mathrm{~W}$ $353330 \mathrm{~N} 1112110 \mathrm{~W}$ $353116 \mathrm{~N} 1112218 \mathrm{~W}$ $353119 \mathrm{N1112231 \textrm {W }}$

$321526 \mathrm{~N} 1105242 \mathrm{~W}$ $332200 N 1104732 \mathrm{~W}$ $323929 \mathrm{~N} 1112414 \mathrm{~W}$ $323928 \mathrm{~N} 1112414 \mathrm{~W}$ $342842 \mathrm{~N} 1103828 \mathrm{~W}$

342B59N1104300W $342815 \mathrm{~N} 1104137 \mathrm{~W}$

\begin{tabular}{|c|c|c|}
\hline $\begin{array}{l}\text { SOURCE } \\
\text { COORDINATE }\end{array}$ & $\begin{array}{c}\text { ELEV } \\
\text { FT }\end{array}$ & MAP NAME \\
\hline & 7715 & $\begin{array}{l}\text { Williams South } \\
\text { Williams South }\end{array}$ \\
\hline $351826 \mathrm{~N} 1133225 \mathrm{~W}$ & $\begin{array}{l}7826 \\
9453\end{array}$ & $\begin{array}{l}\text { Daisy Mountain } \\
\text { Wrather Arch } \\
\text { Brooklyn Peak } \\
\text { Valent ine } \\
\text { Tuckayou Spring } \\
\text { Parks } \\
\text { Tucson } \\
\text { Mt Wrightson }\end{array}$ \\
\hline
\end{tabular}

Tucson East Miller Tank Boundary Cone

3062 Boundary Cone

7786 Rincon Peak

Blue

8430 Blue

Moritz Ridge

Wupatki SE

Wupatki SE

Wupatki SE

Wupatki SE

Wupatki SW

Pinal Peak

Newman Peak

Newman Peak

Hanks Draw

Hanks Draw

Hanks Draw

\section{$X$}

$X$ A Tank

Xavier High School

$X$ Bar One Ranch Rubel Ranch

X Bar One Ranch Airstrip

$X$ B Tank Rubel Ranch Landing Strip

$X$ Canyon

$X$ E Tank

XIL Tank

$X$ I Tank

$x$ I Wel

$x 9$ Ranch reservoir

school

locale

airport

reservoir

valley

reservoir

reservoir

reservoir

well

locale
BGN

UNOFF
UNOFF

VARIANT

ADMIN

VARIANT

BGN

BGN

BGN

BGN

UNOFF
Coconino

Maricopa

Yavapai

Yavapai

Coconino

Graham

Apache

Navajo

Coconino

Coconino

Pima
$351021 \mathrm{~N} 1121554 \mathrm{~W}$ $333019 N 1120401 \mathrm{~W}$ $352233 \mathrm{~N} 1131812 \mathrm{~W}$

$352251 \mathrm{N1131800 \textrm {W }}$

$355121 N 1121217 \mathrm{~W}$

$324528 \mathrm{~N} 1094748 \mathrm{~W}$

$335120 \mathrm{~N} 1091413 \mathrm{~W}$

$342358 \mathrm{N1} 102036 \mathrm{~W}$

$354703 \mathrm{~N} 1130647 \mathrm{~W}$

$354702 \mathrm{N1} 130646 \mathrm{~W}$

$320754 \mathrm{~N} 1103643 \mathrm{~W}$
McLellan Reservoir Sunnys lope 5560 Blye Canyon NE

5585 Blye Canyon NE

Red Butte SW Thatcher

Alpine

Big Pug Tank Frazier Wells Frazier Wells Mica Mountain

\section{Y}

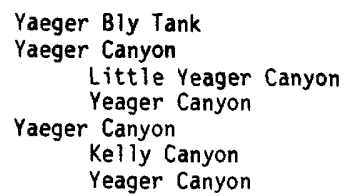

reservoir

valley

BGN

BGN

VARIANT

VARIANT

valley

BGI

VARIANT
Coconino

Yavapai

Coconino
354657 N1120626W

343548 N1121617W

$350250 N 1110403$
344227 N1120908W

345616 N1111B12W

Red Butte

Prescott Valley $S$

Meteor Crater 
FEATURE

$\begin{array}{llll}\text { locale } & \text { UNOFF } & \text { Yavapai } & 344041 N 1121025 \mathrm{~W} \\ \text { lake } & \text { BGN } & \text { Coconino } & 345630 N 1111 \mathrm{~B} 29 \mathrm{~W} \\ \text { mine } & \text { UNOFF } & \text { Yavapai } & 34394 \mathrm{BN} 1121105 \mathrm{~W} \\ \text { spring } & \text { BGN } & \text { Yavapai } & 343940 N 1121111 \mathrm{~W} \\ \text { building } & \text { UNOFF } & \text { Yavapai } & 343704 N 1121720 \mathrm{~W} \\ \text { spring } & \text { BGN 1976 } & \text { Yavapai } & 344035 N 1121003 \mathrm{~W} \\ & \text { VARIANT } & & \\ & \text { VARIANT } & & \\ \text { reservoir } & & \text { Maricopa } & 32371 \mathrm{BN1131938W} \\ \text { reservoir } & \text { BGN } & \text { Coconino } & 345632 N 1111 \mathrm{~W} 26 \mathrm{~W}\end{array}$

$\begin{array}{llll}\text { school } & \text { UNOFF } & \text { Navajo } & 345419 N 1100945 \mathrm{~W} \\ \text { cliff } & \text { BGN 1906 } & \text { Coconino } & 360331 N 1120459 \mathrm{~W} \\ \text { cliff } & \text { BGN 1915 } & \text { Apache } & 362233 N 1095015 \mathrm{~W} \\ \text { well } & \text { UNOFF } & \text { Pinal } & 323827 N 1104515 \mathrm{~W} \\ \text { valley } & \text { BGN } & \text { Greenlee } & 332905 N 1090502 \mathrm{~W} \\ \text { ppl } & \text { BGN } & \text { Yavapai } & 352922 N 1131159 \mathrm{~W} \\ \text { valley } & \text { BGN } & \text { Mohave } & 352937 N 1132942 \mathrm{~W} \\ \text { ridge } & \text { BGN 1979 } & \text { Yavapai } & 352945 N 1131200 \mathrm{~W} \\ \text { building } & \text { UNOFF } & \text { Yavapai } & 352941 N 1131221 \mathrm{~W} \\ \text { reservoir } & \text { BGN } & \text { Yavapai } & 352305 N 1131545 \mathrm{~W}\end{array}$

locale BGN Coconino $360030 \mathrm{N1114600 \textrm {W }}$ mine UNOFF Yavapai 341916 N1122420W summit BGN Yavapai $342343 N 1122406 \mathrm{~W}$ trail UNOFF Yavapai 34234BN1122401W mine UNOFF Yavapai 342557 N1122620W valley BGN Gila 334149 N1104405W spring BGN Gild $334000 N 1104255 \mathrm{~W}$ spring BGN Gild $333425 N 1104409 \mathrm{~W}$ valley BGN Santa Cruz 312544N1111127W spring BGN Santa Cruz

spring Santa Cruz $312930 \mathrm{~N} 1111739 \mathrm{~W}$ $\begin{array}{llll}\text { spring } & \text { 8GN } & \text { Santa Cruz } & 312930 N 1111739 W \\ \text { reservoir } & \text { BGN } & \text { Santa Cruz } & 312530 N 1111057 W\end{array}$ park ADMIN Maricopa 332411N1120121W valley BGN spring BGN Cochise reservoir BGN Yuma $\quad 331827$ N1135542W stream BGN Yuma 331526N1135708W spring BGN 1976 Yavapai 343009N1120900W stream BGN 1976 Yavapai 342307N1120755W VARIANT

\begin{tabular}{|c|c|c|c|}
\hline well & $\begin{array}{l}\text { UNOFF } \\
\text { VARIANT }\end{array}$ & Yavapai & $343112 \mathrm{~N} 1120753 \mathrm{~W}$ \\
\hline $\begin{array}{l}\text { mine } \\
\text { school }\end{array}$ & $\begin{array}{l}\text { UNOFF } \\
\text { UNOFF } \\
\text { VARIANT }\end{array}$ & $\begin{array}{l}\text { Yavapai } \\
\text { Yavapai }\end{array}$ & $\begin{array}{l}342732 \mathrm{~N} 1120747 \mathrm{~W} \\
343258 \mathrm{~N} 1120925 \mathrm{~W}\end{array}$ \\
\hline stream & VARIANT & Yavapai & $342307 \mathrm{~N} 1120755 \mathrm{~W}$ \\
\hline $\begin{array}{l}\text { well } \\
\text { ppl } \\
\text { building }\end{array}$ & $\begin{array}{l}\text { BGN } \\
\text { UNOFF }\end{array}$ & $\begin{array}{l}\text { Yavapai } \\
\text { Yavapai } \\
\text { Yavapai }\end{array}$ & $\begin{array}{l}343112 N 1120753 W \\
341318 N 1124448 W \\
34131 B N 1124449 W\end{array}$ \\
\hline $\begin{array}{l}\text { stream } \\
\text { school } \\
\text { mine } \\
\text { building } \\
\text { spring } \\
\text { canal } \\
\text { locale } \\
\text { school } \\
\text { hospital }\end{array}$ & $\begin{array}{l}\text { BGN } \\
\text { UNOFF } \\
\text { UNOFF } \\
\text { UNOFF } \\
\text { BGN } \\
\text { BGN } \\
\text { BGN } \\
\text { UNOFF } \\
\text { UNOFF } \\
\text { VARIANT }\end{array}$ & $\begin{array}{l}\text { Yavapai } \\
\text { Yavapai } \\
\text { Yavapai } \\
\text { Yavapai } \\
\text { Yavapai } \\
\text { Yuma } \\
\text { Yavapai } \\
\text { Yavapai } \\
\text { Yavapai }\end{array}$ & $\begin{array}{l}341113 N 1124335 \mathrm{~W} \\
341325 \mathrm{~N} 1124438 \mathrm{~W} \\
341222 \mathrm{~N} 1124452 \mathrm{~W} \\
341315 \mathrm{~N} 1124449 \mathrm{~W} \\
341315 \mathrm{~N} 1124113 \mathrm{~W} \\
323825 \mathrm{~N} 1143859 \mathrm{~W} \\
342819 \mathrm{~N} 1125323 \mathrm{~W} \\
343254 \mathrm{~N} 1122712 \mathrm{~W} \\
343336 \mathrm{~N} 112285 \mathrm{~W}\end{array}$ \\
\hline civil & VARIANT & Gila & $333100 \mathrm{~N} 1103100 \mathrm{~W}$ \\
\hline civil & VARIANT & Gila & $333100 \mathrm{~N} 1103100 \mathrm{~W}$ \\
\hline $\begin{array}{l}\text { civil } \\
\text { civil }\end{array}$ & $\begin{array}{l}\text { ADMIN } \\
\text { VARIANT }\end{array}$ & $\begin{array}{l}\text { Maricopa } \\
\text { Yavapai }\end{array}$ & $\begin{array}{l}333100 \mathrm{~N} 1120100 \mathrm{~W} \\
343030 \mathrm{~N} 1122230 \mathrm{~W}\end{array}$ \\
\hline $\begin{array}{l}\text { civil } \\
\text { building } \\
\text { park } \\
\text { locale }\end{array}$ & $\begin{array}{l}\text { UNOFF } \\
\text { ADMIN } \\
\text { UNOFF }\end{array}$ & $\begin{array}{l}\text { Coconino } \\
\text { Yavapai } \\
\text { Yavapai } \\
\text { Yavapai }\end{array}$ & $\begin{array}{l}360500 \mathrm{~N} 1120800 \mathrm{~W} \\
343227 \mathrm{~N} 1122808 \mathrm{~W} \\
343305 \mathrm{~N} 1122900 \mathrm{~W} \\
343326 \mathrm{~N} 1122833 \mathrm{~W}\end{array}$ \\
\hline
\end{tabular}

SOURCE
COORDINATE ELEV

Hickey Mountain Kinnikinick Lake Hickey Mountain Hickey Mountain Prescott Valley S Hickey Mountain

Kinnikinick Lake

Holbrook

7260 Phantom Ranch

Rough Rock

North of Oracle

Alma Mesa

Yampai

$333022 N 1090241 \mathrm{~W}$

Cherokee Point

352B43N1131330W

5585 Yampai

Yampai

Blye Canyon NE

Desert View

Battleship Butte

Groom Creek

Groom Creek

Groom Creek

333424N1104408W Haystack Butte

Hays tack Butte

Ruby

Bartlett Mtn

Ruby

Phoenix

$312033 N 1101644$

Montezuma Pass

Montezuma Pass

Kofa Butte

331B43N1135710W Kofa Butt

Humboldt

$343505 N 1120848 \mathrm{~W}$ Mayer

Humbolt

Mayer

4912 Humbolt

47BO Yarnell

Yarnel1

\section{N1124453W Yarnell}

Yarnel1

Yarnell

Yarnel1

Yarnell

Yuma West

Hillside

Prescott

Prescott

Nelson

Prescott 


\begin{tabular}{|c|c|c|c|c|c|c|c|}
\hline FEATURE NAME & $\begin{array}{l}\text { FEATURE } \\
\text { CLASS }\end{array}$ & STATUS & COUNTY & COORDINATE & $\begin{array}{l}\text { SOURCE } \\
\text { COORDINATE }\end{array}$ & $\underset{F T}{\text { ELEV }}$ & MAP NAME \\
\hline $\begin{array}{c}\text { Yavapai Elementary School } \\
\text { Yavapai Hills } \\
\text { Yavapai Indian Reservation } \\
\text { Yavapai-Prescott } \\
\text { Reservation }\end{array}$ & $\begin{array}{l}\text { school } \\
\text { ppl } \\
\text { reserve }\end{array}$ & $\begin{array}{l}\text { UNOFF } \\
\text { BGN } \\
\text { UNOFF } \\
\text { VARIANT }\end{array}$ & $\begin{array}{l}\text { Maricopa } \\
\text { Yavapai } \\
\text { Yavapai }\end{array}$ & $\begin{array}{l}332718 \mathrm{~N} 1115458 \mathrm{~W} \\
343342 \mathrm{N1122258 \textrm {W }} \\
343330 \mathrm{N1122640 \textrm {W }}\end{array}$ & & 5400 & $\begin{array}{l}\text { Tempe } \\
\text { Prescott } \\
\text { Prescott }\end{array}$ \\
\hline $\begin{array}{l}\text { Yavapai Lake } \\
\text { Yavapai Point } \\
\text { O'Neill Point } \\
\text { Yavapai-Prescott Reservation } \\
\text { See Yavapai Indian } \\
\text { Reservation }\end{array}$ & $\begin{array}{l}\text { lake } \\
\text { cliff } \\
\text { reserve }\end{array}$ & $\begin{array}{l}\text { BGN } \\
\text { BGN } 1906 \\
\text { VARIANT } \\
\text { VARIANT }\end{array}$ & $\begin{array}{l}\text { Yavapai } \\
\text { Coconino }\end{array}$ & $\begin{array}{l}343610 \mathrm{~N} 1121840 \mathrm{~W} \\
360400 \mathrm{~N} 1120703 \mathrm{~W} \\
343330 \mathrm{~N} 1122640 \mathrm{~W}\end{array}$ & & & $\begin{array}{l}\text { Prescott Valley } S \\
\text { Phantom Ranch }\end{array}$ \\
\hline $\begin{array}{l}\text { Yazzi } \\
\text { Yazzie Mesa } \\
\text { Y Bar Basin } \\
\text { Bar Bas in } \\
\text { Y Bar Tanks } \\
\text { Y Cienega } \\
\text { Yeager Canyon } \\
\text { Buck Creek } \\
\text { Yellow Canyon } \\
\text { Yeager Canyon } \\
\text { See Yaeger Canyon }\end{array}$ & $\begin{array}{l}\text { locale } \\
\text { summit } \\
\text { basin } \\
\text { reservoir } \\
\text { flat } \\
\text { valley }\end{array}$ & $\begin{array}{l}\text { BGN } \\
\text { BGN } \\
\text { BGN } 1973 \\
\text { VARIANT } \\
\text { BGN } \\
\text { BGN } \\
\text { BGN } \\
\text { VARIANT } \\
\text { VARIANT } \\
\text { VARIANT }\end{array}$ & $\begin{array}{l}\text { Apache } \\
\text { Apache } \\
\text { Gila } \\
\text { Gila } \\
\text { Apache } \\
\text { Coconino }\end{array}$ & $\begin{array}{l}363445 \mathrm{~N} 1091325 \mathrm{~W} \\
365646 \mathrm{~N} 1095322 \mathrm{~W} \\
340303 \mathrm{~N} 1112728 \mathrm{~W} \\
340308 \mathrm{~N} 1112718 \mathrm{~W} \\
334428 \mathrm{~N} 1093400 \mathrm{~W} \\
343359 \mathrm{N1110B32 \textrm {W }}\end{array}$ & $342423 \mathrm{~N} 1111009 \mathrm{~W}$ & $\begin{array}{l}6260 \\
5364\end{array}$ & $\begin{array}{l}\text { Cove } \\
\text { Rooster Rock } \\
\text { Mazatzal Peak } \\
\text { Mazatzal Peak } \\
\text { Maverick } \\
\text { Blue Ridge Reservoir }\end{array}$ \\
\hline $\begin{array}{l}\text { Yeager Canyon } \\
\text { See Yaeger Canyon } \\
\text { Yeager Number One Tank } \\
\text { Yeager Spring } \\
\text { See Yaeger Spring } \\
\text { Yeager Tank } \\
\text { Yei Bichei } \\
\text { Yei Bichei Mesa } \\
\text { Yei Bichei Mesa } \\
\text { See Yei Bichei }\end{array}$ & $\begin{array}{l}\text { valley } \\
\text { reservoir } \\
\text { spring } \\
\text { reservoir } \\
\text { summit } \\
\text { summit }\end{array}$ & $\begin{array}{l}\text { VARIANT } \\
\text { BGN } \\
\text { VARIANT } \\
\text { BGN } \\
\text { BGN } \\
\text { VARIANT } \\
\text { VARIANT }\end{array}$ & $\begin{array}{l}\text { Coconino } \\
\text { Coconino } \\
\text { Yavapai } \\
\text { Coconino } \\
\text { Navajo }\end{array}$ & $\begin{array}{l}350250 \mathrm{~N} 1110403 \mathrm{~W} \\
345635 \mathrm{~N} 1111840 \mathrm{~W} \\
344035 \mathrm{~N} 1121003 \mathrm{~W} \\
3528541122105 \mathrm{~W} \\
365541 \mathrm{~N} 1100238 \mathrm{~W} \\
365541 \mathrm{~N} 1100238 \mathrm{~W}\end{array}$ & & & $\begin{array}{l}\text { Cataract Tank } \\
\text { Mitten Buttes }\end{array}$ \\
\hline $\begin{array}{l}\text { Yellow Bird Mine } \\
\text { Yellow Bluff Tank } \\
\text { Yellow Breast Mine } \\
\text { Yellow Bull Spring } \\
\text { Yellowbush Well } \\
\text { Yellow Butte } \\
\text { Yellow Butte } \\
\text { Yellow Butte } \\
\text { Yellow Butte Wash } \\
\text { Yellow Canyon } \\
\text { See Yeager Canyon }\end{array}$ & $\begin{array}{l}\text { mine } \\
\text { reservoir } \\
\text { mine } \\
\text { spring } \\
\text { well } \\
\text { summit } \\
\text { summit } \\
\text { summit } \\
\text { valley } \\
\text { valley }\end{array}$ & $\begin{array}{l}\text { UNOFF } \\
\text { BGN } \\
\text { UNOFF } \\
\text { BGN } \\
\text { UNOFF } \\
\text { BGN } \\
\text { BGN } \\
\text { BGN } \\
\text { BGN } \\
\text { VARIANT }\end{array}$ & $\begin{array}{l}\text { Pima } \\
\text { Mohave } \\
\text { Yuma } \\
\text { Greenlee } \\
\text { Apache } \\
\text { Navajo } \\
\text { Coconino } \\
\text { Navajo } \\
\text { Coconino } \\
\text { Coconino }\end{array}$ & $\begin{array}{l}315507 \mathrm{~N} 1111751 \mathrm{~W} \\
343737 \mathrm{N1132132 \textrm {W }} \\
331514 \mathrm{N1132246 \textrm {W }} \\
330027 \mathrm{N1} 1090517 \mathrm{~W} \\
361046 \mathrm{~N} 1091415 \mathrm{~W} \\
352404 \mathrm{N1102140 \textrm {W }} \\
362147 \mathrm{N1104536 \textrm {W }} \\
362223 \mathrm{~N} 1104408 \mathrm{~W} \\
362118 \mathrm{~N} 1104817 \mathrm{~W} \\
343359 \mathrm{N1} 110832 \mathrm{~W}\end{array}$ & $362433 \mathrm{~N} 1104503 \mathrm{~W}$ & $\begin{array}{l}6334 \\
6917\end{array}$ & $\begin{array}{l}\text { Stevens Mtn } \\
\text { Negro Ed } \\
\text { Nottbusch Butte } \\
\text { Big Lue Mts } \\
\text { Lower Wheatfields } \\
\text { Dilkon } \\
\text { John Daw Mesa } \\
\text { Kydestea Spring } \\
\text { John Daw Mesa }\end{array}$ \\
\hline $\begin{array}{l}\text { Yellow Cow Tank } \\
\text { Yellow Dog Mine } \\
\text { Yellow Door Corral } \\
\text { Yellow Flat } \\
\text { Yellow Flat Tank } \\
\text { Yellow Flower Creek } \\
\text { Yellow Flower Spring } \\
\text { Yellowhair Spring } \\
\text { Yellow Hammer Mill } \\
\text { Yellow Hammer Tank }\end{array}$ & $\begin{array}{l}\text { reservoir } \\
\text { mine } \\
\text { locale } \\
\text { flat } \\
\text { reservoir } \\
\text { stream } \\
\text { spring } \\
\text { spring } \\
\text { locale } \\
\text { reservoir }\end{array}$ & $\begin{array}{l}\text { BGN } \\
\text { UNOFF } \\
\text { BGN } \\
\text { BGN } \\
\text { BGN } \\
\text { BGN } \\
\text { BGN } \\
\text { BGN } \\
\text { BGN } \\
\text { BGN }\end{array}$ & $\begin{array}{l}\text { Coconino } \\
\text { Yuma } \\
\text { Coconino } \\
\text { Coconino } \\
\text { Coconino } \\
\text { Mohave } \\
\text { Mohave } \\
\text { Apache } \\
\text { Cochise } \\
\text { Yavapai }\end{array}$ & $\begin{array}{l}351954 \mathrm{~N} 1122813 \mathrm{~W} \\
333558 \mathrm{~N} 114180 \mathrm{~W} \\
362928 \mathrm{~N} 1114013 \mathrm{~W} \\
350538 \mathrm{~N} 1115013 \mathrm{~W} \\
350532 \mathrm{~N} 1115006 \mathrm{~W} \\
350603 \mathrm{~N} 1140055 \mathrm{~W} \\
350411 \mathrm{N1135452W} \\
360350 \mathrm{~N} 1090920 \mathrm{~W} \\
322148 \mathrm{~N} 1091717 \mathrm{~W} \\
344819 \mathrm{N1} 130539 \mathrm{~W}\end{array}$ & $350430 \mathrm{~N} 1135407 \mathrm{~W}$ & 3500 & $\begin{array}{l}\text { Fitzgerald Hill } \\
\text { Cunningham Mtn } \\
\text { Shinumo Altar } \\
\text { Dutton Hill } \\
\text { Dutton Hill } \\
\text { Kingman SE } \\
\text { Hualapai Peak } \\
\text { White Clay } \\
\text { Olga } \\
\text { Scratch Canyon }\end{array}$ \\
\hline $\begin{array}{l}\text { Yellowhorse Flat } \\
\text { Yellow Iron Mountains } \\
\text { See Goldf ield Mountains } \\
\text { Yellowjacket Canyon } \\
\text { Yellow Jacket Canyon } \\
\text { Yellow Jacket Canyon } \\
\text { Yellow Jacket Cienega } \\
\text { Yellow Jacket Creek } \\
\text { Spring Creek } \\
\text { Yellowjacket Gulch }\end{array}$ & $\begin{array}{l}\text { flat } \\
\text { summit } \\
\text { valley } \\
\text { valley } \\
\text { valley } \\
\text { flat } \\
\text { stream }\end{array}$ & $\begin{array}{l}\text { BGN } \\
\text { VARIANT } \\
\text { BGN } \\
\text { BGN } \\
\text { BGN } \\
\text { BGN } \\
\text { BGN } 1968 \\
\text { VARIANT } \\
\text { VARIANT }\end{array}$ & $\begin{array}{l}\text { Mohave } \\
\text { Maricopa } \\
\text { Grahan } \\
\text { Yavapai } \\
\text { Coconino } \\
\text { Apache } \\
\text { Yavapai }\end{array}$ & $\begin{array}{l}365416 \mathrm{~N} 1132607 \mathrm{~W} \\
333112 \mathrm{~N} 1113046 \mathrm{~W} \\
331138 \mathrm{~N} 1100344 \mathrm{~W} \\
341230 \mathrm{~N} 1114614 \mathrm{~W} \\
351257 \mathrm{N11} 110634 \mathrm{~W} \\
340704 \mathrm{N1094055W} \\
342315 \mathrm{~N} 1120115 \mathrm{~W}\end{array}$ & $\begin{array}{l}331409 \mathrm{~N} 1100434 \mathrm{~W} \\
341651 \mathrm{~N} 1114735 \mathrm{~W} \\
350129 \mathrm{~N} 1112219 \mathrm{~W} \\
342555 \mathrm{~N} 1115415 \mathrm{~W}\end{array}$ & & $\begin{array}{l}\text { Yellowhorse Flat } \\
\text { Bylas } \\
\text { Bloody Basin } \\
\text { Canyon Diablo } \\
\text { Horseshoe Cienega } \\
\text { Estler Peak }\end{array}$ \\
\hline $\begin{array}{l}\text { Yellow Jacket Dam } \\
\text { Yellow Jacket Dam } \\
\text { Yellow Jacket Draw } \\
\text { Yellowjacket Gulch } \\
\text { See Yellow Jacket Creek } \\
\text { Yellow Jacket Gulch } \\
\text { Yellowjacket Gulch } \\
\text { See Rice Gulch }\end{array}$ & $\begin{array}{l}\text { dam } \\
\text { dam } \\
\text { valley } \\
\text { stream } \\
\text { valley } \\
\text { valley }\end{array}$ & $\begin{array}{l}\text { UNOFF } \\
\text { UNDFF } \\
\text { BGN } \\
\text { VARIANT } \\
\text { BGN } \\
\text { VARIANT }\end{array}$ & $\begin{array}{l}\text { Pima } \\
\text { Graham } \\
\text { Coconino } \\
\text { Yavapai } \\
\text { Yavapai } \\
\text { Yavapai }\end{array}$ & $\begin{array}{l}313032 \mathrm{~N} 1112752 \mathrm{~W} \\
331700 \mathrm{~N} 109583 \mathrm{~W} \\
343812 \mathrm{~N} 1111436 \mathrm{~W} \\
342315 \mathrm{~N} 1120115 \mathrm{~W} \\
34230 \mathrm{~N} 1120055 \mathrm{~W} \\
342503 \mathrm{~N} 1115529 \mathrm{~W}\end{array}$ & $343629 \mathrm{~N} 1111621 \mathrm{~W}$ & & $\begin{array}{l}\text { Wilbur Canyon } \\
\text { Tule Tubs } \\
\text { Hay Lake }\end{array}$ \\
\hline
\end{tabular}


NATIONAL GAZETTEER--ARIZONA 1986

\section{FEATURE NAME}

Yellow Jacket Hill

See Fraguita Peak

Yellow Jacket Mesa

Yellow Jacket Mesa

Yellow Jacket Mine

Yellow Jacket Spring

Yellowjacket Spring

Yellowjacket Spring

Yellow Jacket Spring

Yellowjacket Spring

Yellowjacket Spring

Yellow Jacket Spring

Yellow Jacket Spring

Yellow Jacket Spring

Yellow Jacket Spring

Yellow Jacket Spring

Yellow Jacket Spring

Yellow Jacket Spring

Yellow Jacket Spring

Yellow Jacket Spring

Yellow Jacket Spring

Yellow Jacket Spring

Yellow Jacket Tank

Yellowjacket Tank

Yellowjacket Tank

Yellow jacket Tank

Yellow Jacket Tank

Yellow Jacket Tank

Yell low Jacket Tank

Yellow Jacket Tank Number One

Yellow Jacket Tank Number One

Yellow Jacket Tank Number Two

Yellow Jacket Tank Number Two

Yellow Jacket Wash

Yellow Jacket Wash

Yellowjacket Well

Yellowjacket Well

Yell lowjack Wash

Yellow John Mountain

Yellow Knolls

Yellow Man Spring

Yellow Meadow

Yellow Medicine Butte

Yellow Medicine Hills

Yellow Medicine Tank

Yellow Medicine Wash

Yellow Peak

Yellow Peak

Yellow Pine Spring

Yellow Pine Tank

Yellow Point

Yellow Pond

Yellow Rock Spring National Monument

See Pipe Spring National Monument

Yellow Rocksprings National Monument

See Pipe Spring National Monument

Yellow Spring

Yellow Spring

Yellowstone Canyon

Yellowstone Canyon

Yellowstone Canyon

Yellowstone Canyon

Yellowstone Mesa

Yellowstone Point

Yellowstone Spring

Yellowstone Spring

Yellows tone Tank

\section{FEATURE}

STATUS

COUNTY

COORDINATE

VARIANT

summit

Santa Cruz

$313025 \mathrm{~N} 1111955 \mathrm{~W}$

$\begin{array}{ll}\text { summit } & \text { BGN } \\ \text { summit } & \text { BGN } \\ \text { mine } & \text { UNOFF } \\ \text { spring } & \text { BGN } \\ \text { spring } & \text { BGN } \\ \text { spring } & \text { BGN } \\ \text { spring } & \text { BGN } \\ \text { spring } & \text { BGN } \\ \text { spring } & \text { BGN } \\ \text { spring } & \text { BGN }\end{array}$

Yavapai

Yavapai

Santa Cruz

Gila

Greenlee

Pinal

Maricopa

Gila

Maricopa

$341636 \mathrm{~N} 1114728 \mathrm{~W}$
$342427 \mathrm{~N} 1115547 \mathrm{~W}$
$312955 \mathrm{~N} 111185 \mathrm{~W}$
$313002 \mathrm{~N} 1111839 \mathrm{~W}$
$331141 \mathrm{~N} 1104526 \mathrm{~W}$
$331354 \mathrm{~N} 1091843 \mathrm{~W}$
$332549 \mathrm{~N} 1110504 \mathrm{~W}$
$333453 \mathrm{~N} 1110932 \mathrm{~W}$
$334306 \mathrm{~N} 1103930 \mathrm{~W}$
$334758 \mathrm{~N} 1113530 \mathrm{~W}$

spring

spring

spring

spring

spring

spring

spring

spring

spring

spring

$\begin{array}{lll}\text { BGN } & \text { Gila } & 334853 \text { N1110923W } \\ \text { BGN } & \text { Gila } & 334920 N 1104934 W \\ \text { BGN } & \text { Gila } & 335217 \text { N1100335W } \\ \text { BGN } & \text { Navajo } & 335646 \text { N1095852W } \\ \text { BGN } & \text { Yavapai } & 340405 N 1121626 \mathrm{~W} \\ \text { BGN } & \text { Gila } & 340448 N 1112409 W \\ \text { BGN } & \text { Yavapai } & 342441 N 1115721 W \\ \text { BGN } & \text { Yavapai } & 343704 N 1120513 W \\ \text { BGN } & \text { Coconino } & 344423 N 1112504 W \\ \text { BGN } & \text { Coconino } & 350133 N 1112146 W\end{array}$

reservoir

reservoir

reservoir

reservoir

reservoir

reservoir

reservoir

reservoir

reservoir

reservoir

stream

valley

well

well

stream

summit

summ it

spring

flat

BGN
BGN
$B G N$
$B G N$
$B G N$
$B G N$
$B G N$
$B G N$
$B G N$
$B G N$

BGN

BGN

UNOFF

UNOFF

BGN

BGN

BGN

BGN

$B G N$
$B G N$

summit

summit

reservoir

stream

summit

summit

spring

reservoir

cliff

lake

BGN
BGN
BGN
BGN
BGN
BGN
BGN
BGN
BGN
BGN

Santa Cruz

Greenlee

Graham

Navajo

Yavapai

Coconino

Coconino

Yavapai

Coconino

Yavapai

Coconino

Santa Cruz

Navajo

Pinal

Graham

Pinal

Mohave

Mohave

Apache

Apache

Maricopa

Maricopa

Maricopa

Maricopa

Pinal

Maricopa

Mohave

Graham

Apache

Mohave

VARIANT

park

Mohave

VARIANT

park

spring

BGN

Mohave

Greenlee

valley

valley

valley

valley

summit

summit

spring

spring

reservoir
365143N1124411W

365143 N1124411W

$332505 \mathrm{~N} 1091345 \mathrm{~W}$ 353958 N1111749W

312958 N1111907W

$331355 \mathrm{~N} 1091256 \mathrm{~W}$

$341424 \mathrm{~N} 1101352 \mathrm{~W}$

341954N1121449W

343710 N1111435W

$352413 N 1114128 \mathrm{~W}$

344421 N1112510W

$341518 \mathrm{~N} 1114624 \mathrm{~W}$

344411 N1112507W

313424 N1111957W

$362304 N 1100604 \mathrm{~W}$

324755 N1105102W

$331346 N 1100955 \mathrm{~W}$

$360912 \mathrm{~N} 1132812 \mathrm{~W}$

$365834 N 1134427 \mathrm{~W}$

$353856 \mathrm{N1} 1090632 \mathrm{~W}$

$331358 \mathrm{N11} 30959 \mathrm{~W}$

331648 N1125758W

$331421 \mathrm{~N} 1131056 \mathrm{~W}$

$330525 N 1130322 \mathrm{~W}$

330655 N1113851W

332821 N1112356W

350703 N11 35116W

333447 N1093301

362358 N1095020W

$315231 N 1113713 \mathrm{~W}$

$325113 N 1092440 \mathrm{~W}$

341101 N1101152W

$362542 \mathrm{~N} 1092635 \mathrm{~W}$

$364532 \mathrm{~N} 1125441 \mathrm{~W}$

$361739 \mathrm{~N} 1105150 \mathrm{~W}$

362957 N1134230W

$364351 N 1125632 \mathrm{~W}$

$321723 \mathrm{~N} 1103801 \mathrm{~W}$
362626N1095617W
SOURCE
COORDINATE

Arnold Mesa

Bartlett Mtn

Arivaca

E1 Capitan Mtn

Mitchell Peak

Haunted Canyon

Pinyon Mtn

Haystack Butte

Maverick Mtn

Greenback Creek

Sombrero Peak

Canyon Day

Alchesay Flat

Columbia

Mazatzal Peak

Arnold Mesa

Cherry

Happy Jack

Elliott Canyon

Bartlett Mtn

Big Lue Mts

Ash Creek Ranch

Red Top Mtn

Cleator

Blue Ridge Reservoir

White Horse Hills

Bloody Bas in

Happy Jack

Tule Mesa

\begin{tabular}{|c|c|c|}
\hline $313008 \mathrm{~N} 1111927 \mathrm{~W}$ & & $\begin{array}{l}\text { Happy Jack } \\
\text { Bart lett Mtn } \\
\text { Chilchinbito Canyon }\end{array}$ \\
\hline & 3490 & $\begin{array}{l}\text { Chilchinoito Canyon } \\
\text { Putnam Wash } \\
\text { Calva }\end{array}$ \\
\hline $1931 \mathrm{~N} 1110438 \mathrm{~W}$ & $\begin{array}{l}6757 \\
2668\end{array}$ & $\begin{array}{l}\text { Superior } \\
\text { Yellow John Mtn } \\
\text { Purgatory Canyon } \\
\text { Rough Rock NW } \\
\text { Window Rock }\end{array}$ \\
\hline
\end{tabular}

2308 Yel. Medicine Butte

1615 Gillespie Yel. Medicine Butte

331523N1131247W Dendora Valley

2159 Sacaton

3061 Goldfield

Dean Peak

Freezeout Mtn

Rough Rock

Poverty Knoll
Dutch Blue Creek

Wupatki NE

315357 N1113622W

325309 N1091906W

$341443 \mathrm{~N} 1101219 \mathrm{~W}$

$361943 \mathrm{~N} 1092125 \mathrm{~W}$

Kitt Peak

Tollgate Tank

Fire Dance Mesa

Maroney Well

John Daw Mesa 


\section{FEATURE MAME}

Yellowstone Tank

Yellowstone Tank

Yellowstone Tank

Yellowstone Wash

Yellow Tank

Yellow Tank

Yellow Water Canyon

Yerba Buena Canyon

Yerba Senta Butte

Yerra Basin

Yerra Basin Spring

Y H Tank

Yle Canyon

YLE Tank

$Y$-Lightning Ranch

$Y L$ Ranch

Yoas Mountain

Yocum Lateral

Yodi Tank

Yolo Cabin

Yolo Ranch

Yolo Ranch

Yolo Ranch Airstrip

Yon Dot Mountains

York North Side Mountains Yorks

York Creek

See Rocky John Canyon

York Railroad Station

Yorks

See York

York Valley

Yo Tambien Tunnel

Young

Young America Homes

(subdivision)

Young America West

(subdivision)

Youngberg

Youngsberg

Youngblood Hill

Young Canyon

See Youngs Canyon

Youngker Tank

Young Mens Christian

Association Camp

Young Mens Christian

Association Camp

Young Mens Christian

Association Ramada

Young Mens Christian

Association Ramada

See Young Mens Christian Association Camp

Young Mountain

Young Mountain Number Two Tank

Young Ranch

Youngsberg

See Youngberg

Youngsberg

See Goldfield

Youngs Canyon

Young Canyon

Youngs Canyon Dam

Youngs Canyon Tank

Young Seep Spring

Youngs Lake

Camel Francis Lake

Youngs Spring

\begin{tabular}{|c|c|c|c|}
\hline $\begin{array}{l}\text { FEATURE } \\
\text { CLASS }\end{array}$ & STATUS & COUNTY & COORDIMATE \\
\hline reservoir & BGN & Graham & $325200 \mathrm{~N} 1092125 \mathrm{~W}$ \\
\hline $\begin{array}{l}\text { reservoir } \\
\text { reservoir } \\
\text { stream } \\
\text { reservoir } \\
\text { reservoir } \\
\text { valley } \\
\text { valley } \\
\text { summit } \\
\text { basin } \\
\text { spring }\end{array}$ & $\begin{array}{l}\text { BGN } \\
B G N \\
B G N \\
B G N \\
B G N \\
B G N \\
B G N \\
B G N \\
B G N \\
B G N\end{array}$ & $\begin{array}{l}\text { Greenlee } \\
\text { Navajo } \\
\text { Mohave } \\
\text { Apache } \\
\text { Coconino } \\
\text { Navajo } \\
\text { Santa Cruz } \\
\text { Gila } \\
\text { Greenlee } \\
\text { Greenlee }\end{array}$ & $\begin{array}{l}331810 \mathrm{~N} 1091303 \mathrm{~W} \\
341247 \mathrm{N1101243W} \\
364107 \mathrm{N1125233W} \\
350154 \mathrm{N1} 1090832 \mathrm{~W} \\
354321 \mathrm{N111} 3657 \mathrm{~W} \\
362937 \mathrm{N1102558W} \\
312242 \mathrm{N1} 105153 \mathrm{~W} \\
341407 \mathrm{N1111713W} \\
332611 \mathrm{N1} 1091543 \mathrm{~W} \\
332559 \mathrm{~N} 1091527 \mathrm{~W}\end{array}$ \\
\hline $\begin{array}{l}\text { reservoir } \\
\text { valley } \\
\text { locale } \\
\text { reservoir } \\
\text { locale } \\
\text { locale } \\
\text { summit } \\
\text { canal } \\
\text { reservoir } \\
\text { locale }\end{array}$ & $\begin{array}{l}\text { BGN } \\
\text { BGN } \\
\text { UNOFF } \\
\text { BGN } \\
\text { UNOFF } \\
\text { UNOFF } \\
\text { BGM } \\
\text { BGM } \\
\text { BGN } \\
\text { BGN }\end{array}$ & $\begin{array}{l}\text { Gila } \\
\text { Pinal } \\
\text { Graham } \\
\text { Graham } \\
\text { Cochise } \\
\text { Graham } \\
\text { Santa Cruz } \\
\text { Yuma } \\
\text { Pima } \\
\text { Yavapai }\end{array}$ & $\begin{array}{l}342305 \mathrm{~N} 1113141 \mathrm{~W} \\
323447 \mathrm{N1} 103029 \mathrm{~W} \\
323621 \mathrm{N1} 102535 \mathrm{~W} \\
323638 \mathrm{N1} 102421 \mathrm{~W} \\
312708 \mathrm{N1101151W} \\
325742 \mathrm{N1100047W} \\
314251 \mathrm{N1} 1105726 \mathrm{~W} \\
323732 \mathrm{N1} 144124 \mathrm{~W} \\
320748 \mathrm{N1111742W} \\
343639 \mathrm{N1125810W}\end{array}$ \\
\hline $\begin{array}{l}\text { locale } \\
\text { locale } \\
\text { airport } \\
\text { summit }\end{array}$ & $\begin{array}{l}\text { UNOFF } \\
\text { UNOFF } \\
\text { AOMIN } \\
\text { BGN } \\
\text { VARIANT }\end{array}$ & $\begin{array}{l}\text { Yuma } \\
\text { Yavapai } \\
\text { Yavapai } \\
\text { Coconino }\end{array}$ & $\begin{array}{l}325418 \mathrm{~N} 1133137 \mathrm{~W} \\
344734 \mathrm{~N} 1125803 \mathrm{~W} \\
344755 \mathrm{N1} 125810 \mathrm{~W} \\
361850 \mathrm{~N} 1113715 \mathrm{~W}\end{array}$ \\
\hline locale & $\begin{array}{l}\text { BGN } \\
\text { VARIANT } \\
\text { VARIANT }\end{array}$ & Greenlee & $325337 \mathrm{N1091208W}$ \\
\hline $\begin{array}{l}\text { valley } \\
\text { building }\end{array}$ & UNOFF & $\begin{array}{l}\text { Greenlee } \\
\text { Greenlee }\end{array}$ & $\begin{array}{l}325330 \mathrm{N1} 1091210 \mathrm{~W} \\
325338 \mathrm{~N} 1091239 \mathrm{~W}\end{array}$ \\
\hline $\begin{array}{l}\text { locale } \\
\text { valley } \\
\text { mine } \\
\text { ppl } \\
\text { ppl }\end{array}$ & $\begin{array}{l}\text { VARIANT } \\
\text { BGN } \\
\text { UNOFF } \\
\text { BGN } \\
\text { BGN }\end{array}$ & $\begin{array}{l}\text { Greenlee } \\
\text { Greenlee } \\
\text { Gila } \\
\text { Gila } \\
\text { Maricopa }\end{array}$ & $\begin{array}{l}325337 \mathrm{N1} 1091208 \mathrm{~W} \\
325316 \mathrm{~N} 1091226 \mathrm{~W} \\
332234 \mathrm{~N} 1105827 \mathrm{~W} \\
340605 \mathrm{~N} 1105747 \mathrm{~W} \\
332834 \mathrm{~N} 1120908 \mathrm{~W}\end{array}$ \\
\hline $\mathrm{ppl}$ & BGN & Maricopa & $332934 \mathrm{N1121536 \textrm {W }}$ \\
\hline locale & $\begin{array}{l}\text { BGN } \\
\text { VARIANT }\end{array}$ & Pinal & $332727 \mathrm{N1112925 \textrm {W }}$ \\
\hline summit & $\begin{array}{l}\text { BGM } \\
\text { VARIANT }\end{array}$ & Cochise & $312653 \mathrm{N1} 095433 \mathrm{~W}$ \\
\hline $\begin{array}{l}\text { valley } \\
\text { reservoir } \\
\text { park }\end{array}$ & $\begin{array}{l}\text { BGN } \\
\text { AOMIN }\end{array}$ & $\begin{array}{l}\text { Coconino } \\
\text { Maricopa } \\
\text { Pinal }\end{array}$ & $\begin{array}{l}351240 \mathrm{N1} 111115 \mathrm{WW} \\
331212 \mathrm{~N} 1122539 \mathrm{~W} \\
323344 \mathrm{~N} 1104305 \mathrm{~W}\end{array}$ \\
\hline park & ADMIN & Maricopa & $332117 \mathrm{~N} 1120652 \mathrm{~W}$ \\
\hline
\end{tabular}

VARIAMT

park

summit

reservoir

locale

locale

locale

valley

dam

reservoir

spring

lake

spring

\begin{tabular}{|c|c|}
\hline & Maricopa \\
\hline $\begin{array}{l}\text { BGN } \\
\text { BGN } \\
\text { UNOFF } \\
\text { VARIANT }\end{array}$ & $\begin{array}{l}\text { Yavapai } \\
\text { Yavapai } \\
\text { Gila }\end{array}$ \\
\hline & Pinal \\
\hline & Pinal \\
\hline $\begin{array}{l}\text { N } 1964 \\
\text { RIANT }\end{array}$ & Coconino \\
\hline $\begin{array}{l}\text { UNOFF } \\
\text { BGN } \\
\text { BGN } \\
\text { BGN } 1964 \\
\text { VARIANT }\end{array}$ & $\begin{array}{l}\text { Coconino } \\
\text { Coconino } \\
\text { Yavapai } \\
\text { Coconino }\end{array}$ \\
\hline & Coconino \\
\hline
\end{tabular}
$343512 N 1124512 \mathrm{~W}$ 330526 N1104313W

332727N1112925W

$332732 \mathrm{~N} 1112912 \mathrm{~W}$

351240N1111150W

$350942 \mathrm{~N} 1112430 \mathrm{~W}$

350942 N1112330W

$350512 \mathrm{~N} 1112815 \mathrm{~W}$

$350517 \mathrm{N1112839 \textrm {W }}$

$$
\begin{gathered}
\text { SOURCE } \\
\text { COORDIMATE }
\end{gathered}
$$

Ash Peak

Fritz Canyon

Red Top Mtn

Wild Band Pockets

Deep Lake

Campbell Francis Wsh

$363926 \mathrm{N1} 101936 \mathrm{~W}$

$312035 \mathrm{N1} 105334 \mathrm{~W}$

Great Spring

Cumero Canyon

5173 Payson South

Rose Peak

Rose Peak

Peppersauce Wash

Kielberg Canyon

Kielberg Canyon

Nicksville

Telegraph Wash

4430 Mt Hopkins

Yuma West

2431 Cocoraque Butte

Muleshoe Ranch

Horn

Camp Wood

5950 Juniper Mts

Bodaway Mesa

York

3493 York

$325608 \mathrm{~N} 1091404 \mathrm{~W}$

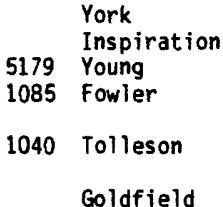

Bisbee

Mobile NW

4460 Campo Bonito

Lone Butte
5684 Skull valley Mart in Mtn Christmas

$350434 \mathrm{~N} 1112939 \mathrm{~W}$

Babbitt Wash

Winona

Winona

Hickey Mountain

Ashurst Lake

Ashurst Lak 
NATIONAL GAZETTEER--ARIZONA 1986

FEATURE NAME

Youngs Spring Tank

Youngs Tank

Young Tank

Youngstown

See Youngtown

Young Tank

See Youngs Tank

Young Tank

Young Tank

Youngtown

Youngs town

Youngtown City Hall

Youngtown Post Office

Youngtown Shopping Center

Young Windmill

Youtcy Canyon

Youtcy Ranch

Youtey Pasture Tank

Youth Camp Tank

Youtsey Tank

Y-seven Tank

Y Spring

Y Strip Airport

Y-thirtyone Canyon

$Y$-thirtyone Tank

Yucca

Yucca Cave Ruins

Yucca Elementary School

Number Three

Yucca Flat

Yucca Flat Wash

Yucca Ford Automotive Proving Grounds

Yucca Ford Proving Grounds
Control Tower
Yucca Hill
Yucca Mine
Yucca Mine
Yucca Post Office
Yucca Powerplant
Yucca Railroad Station
Yucca Wash
Yule Park
See Buell Park

Yuma Arizona
Arizona City
Colorado City
Doonys io
La Purisima Concepcion
Pueblo de la Concepcion
San Dionisio
San Dionysio
Yuma City
Yumas

Yuma Cemetery

Yuma City

See Yuma

Yuma City Hall

Yuma Civic and Convention

Center

Yuma County

Dona Ana County

Castle Dome County

Yuma County

See La Paz County

Yuma County Fairgrounds

Yuma County Juvenile Home

Yuma Courthouse

Yuma Desert

Yuma Fire Department
FEATURE
CLASS

reservoir

reservoir

STATUS

COUNTY

COORDINATE

BGN Coconino

BGN Coconino

VARIANT

VARIANT

ppl

reservoir

reservoir

reservoir

ppl

building

building

locale

locale

valley

locale

reservoir

reservoir

reservoir

reservoir

spring

airport

valley

reservoir

ppl

locale

school

flat

valley

area

tower

summ it

mine

mine

building

locale

building

stream

flat

VARIANT

BGN

BGN

BGN

VARIANT

UNOFF

UNOFF Maricopa

BGN Yavapai

BGN Pima

UNOFF

Pima

Coconino

Pinal

Coconino

Yavapai

Pinal

Navajo

Navajo

Mohave

Apache

Mohave

Navajo

Navajo

Mohave

ppl

BGN 1943

VARIANT

VARIANT

VARIANT

VARIANT

VARIANT

VARIAN

VARIANT

VARIANT

VARIANT

VARIANT

cemetery UNOFF

VARIANT

ppl

building

building

civil

UNOFF

UNOFF

ADMIN

VARIANT

VARIAN

VARIAN

civil

locale

building

building

plain

BGN
UNOFF

UNOFF

BGN

UNOFF
333730 N1135230W

$324029 N 1143535 \mathrm{~W}$

$324041 \mathrm{N1} 143858 \mathrm{~W}$

$324325 \mathrm{~N} 1143719 \mathrm{~W}$

$323140 \mathrm{~N} 1143413 \mathrm{~W}$

$324312 \mathrm{~N} 1143720 \mathrm{~W}$
Mohave

Navajo

Mohave

Mohave

Mohave

Yuma

Mohave

Mohave

Apache

Yuma

$324331 N 1143725 \mathrm{~W}$

345252N1 140749W

362407 N1101848W

$343809 \mathrm{~N} 1142236 \mathrm{~W}$

$343909 \mathrm{~N} 1142228 \mathrm{~W}$

$345225 \mathrm{N1} 140910 \mathrm{~W}$

$324315 \mathrm{~N} 1144233 \mathrm{~W}$

$345227 \mathrm{~N} 1140917 \mathrm{~W}$

$341542 N 1135738 \mathrm{~W}$

$355400 \mathrm{~N} 1090548 \mathrm{~W}$

341852 N1135802W
Peterson Flat

Little Tanks

El Mirage

El Mirage

1140 El Mirage Peeples Valley

Soza Canyon

Piety $\mathrm{Hill}$

Piety $\mathrm{Hill}$

Frazier Wells

Cactus Forest

Hay Lake

Minnehaha

1585 Eloy NW

Whiteriver

Whiteriver

1817 Yucca

Mummy Cave Ruins

Yucca

Yucca Hill

Great Spring

Yucca NE

Yucca NW

7022 Yucca Hill

Topock

Franconia

Yucca

Yuma West

Yucca

Castaneda Hills SW

Yuma East

$324215 N 1143704 W$

Yuma East

$324331 N 1143725 \mathrm{~W}$

$324332 N 1143713 \mathrm{~W}$

$323943 \mathrm{~N} 1143815 \mathrm{~W}$

330001 N1140010W

Yuma West

Slumgullion Pass
Yuma East

Yuma West

Yuma East

Yuma SE

Yuma East 


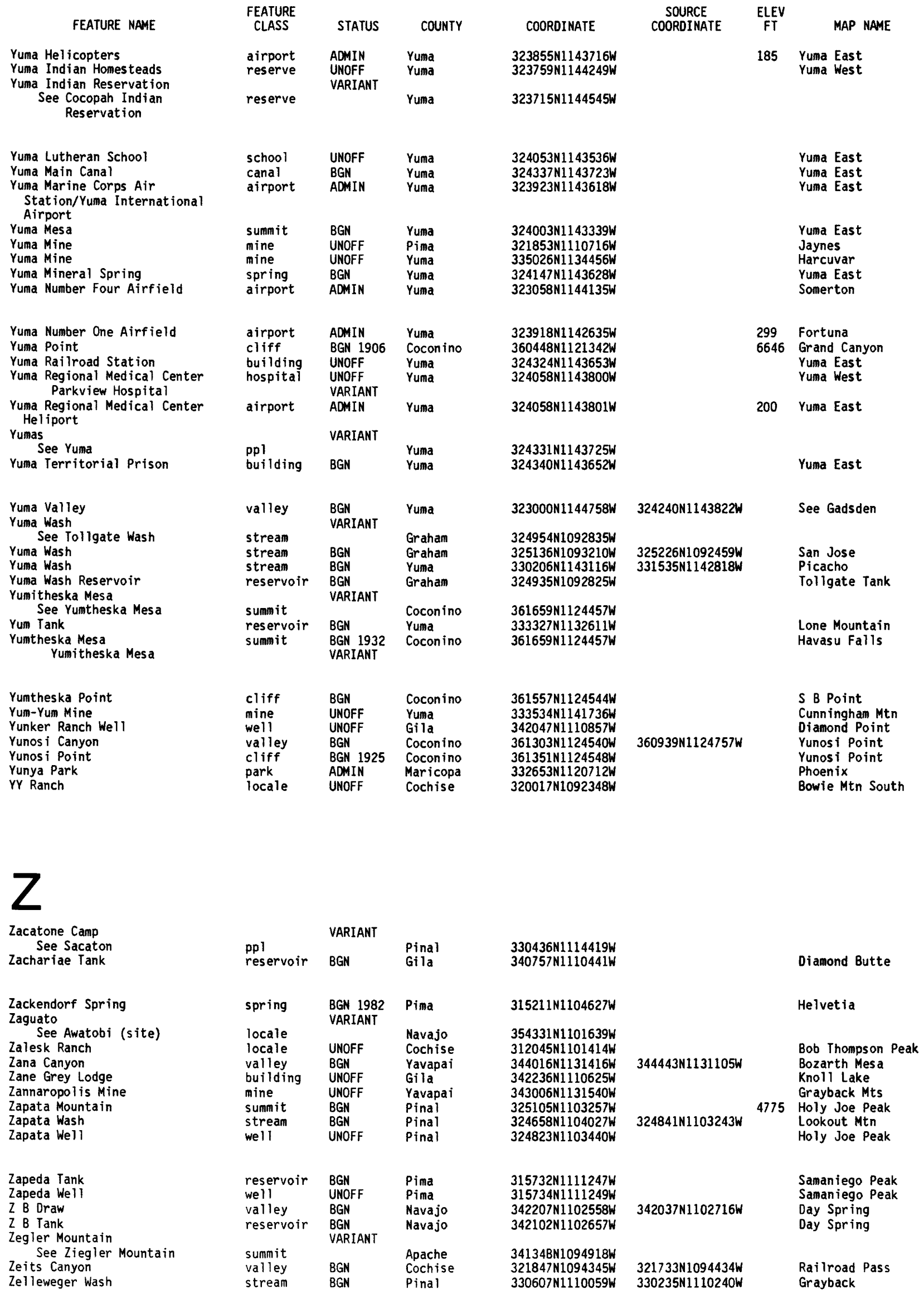


NATIONAL GAZETTEER--ARIZONA 1986

Zeniff

Zeniff Substation

Zenos

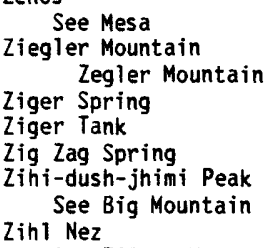

Zihl Nez

See Zilnez Mesa

Zila River

See Gila River

Zilbetod Peak Leaden Peak

Zildassaani

See Fluted Rock

Zilh-in-sah Mesa

See Little Black Spot

Mountain
Zilh-le-sah Mesa

See Little Black Spot Mountain

Zilh-nez Mesa See Tall Mountain Zilh-tah-jimi Peak

See Big Mountain

Zilh-tah-jini Peak

See Ziltahjini Peak

Zilh-Tusayan

See Fluted Rock

Zillesa Mesa

See Little Black Spot Mountain

Zillesa Peak See Little Black Spot Mountain

Zillinez

See Zilnez Mesa

Zillnez Mesa

See Tall Mountain

Zi iner Mesa

See Tall Mountain

Zilnez Mesa

See Tall Mountain

Zilnez Mesa

Zih1 Nez

Zillnez

Zilth Nez Mesa

Zil-ni-tsai

See Big Mountain

Ziltahjimi Mesa

See Big Mountain

Ziltahjimi Peak

See Big Mountain

Ziltahjini Mesa

See Ziltahjini Peak

Ziltahjini Peak

Zilh-tah-jini Peak

Ziltahjini Mesa

Zilth-dush-jhini

See Little Black Spot

Mountain

Zilth Dush Jimi

See Big Mountain

Zilth Nez Mesa

See Zilnez Mesa

Zilth Tah Jimi Peak

See Big Mountain
FEATURE

CLASS

STATUS

COUNTY

locale

BGN

UNOFF

Navajo

Navajo

COORDINATE

locale

VARIANT

ppl

summit

DGM

BGN

VARIANT

spring

reservoir BGN

spring $B G N$

summit

VARIANT

sumar

VARIANT

stream

stream
summit

VARIANT

summit

summit

summit

summit

BGN

VARIANT

VARIANT

VARIANT

VARIANT

Navajo

Maricopa

Apache

Yavapai

Yavapai

Yavapai

Navajo

Navajo

$343438 \mathrm{~N} 1102239 \mathrm{~W}$

$343023 N 1101929 \mathrm{~W}$

$332520 \mathrm{~N} 1114919 \mathrm{~W}$

$341348 \mathrm{N1} 094918 \mathrm{~W}$

$341310 \mathrm{~N} 1124816 \mathrm{~W}$

$341330 \mathrm{~N} 1124848 \mathrm{~W}$

$341041 \mathrm{~N} 1114729 \mathrm{~W}$

361812 N1102835W

$364902 N 1103705 W$

Yuma

Apache

$324311 \mathrm{~N} 1143316 \mathrm{~W}$

$364830 \mathrm{~N} 1090944 \mathrm{~W}$

Apache

360457 N1101948W

360457 N1101948W

VARIANT

summit

VARIANT

summit

summit

summit

VARIANT

VARIANT

VARIANT

summit

Navajo

$364731 N 1103537 \mathrm{~W}$

Navajo

$361812 N 1102835 \mathrm{~W}$

Navajo

$361304 N 1102916 \mathrm{~W}$

Apache

$355309 N 1091454 \mathrm{~W}$

Navajo

360457 N1101948W

VARIANT

summit

Navajo

360457 N1101948W

VARIANT

summit

summit

summit

summit

summit

BGN

VARIANT

VARIANT

VARIANT

VARIANT

summit

VARIANT

summit

summit

VARIANT

vajo

Navajo

Navajo

Navajo

$364902 \mathrm{~N} 1103705 \mathrm{~W}$

Navajo

364731 N1103537W

Navajo

364731 N1103537W

Navajo

364731 N1103537W

Navajo

364902 N1103705W

361812 N1102835W

361812 N1 102835W

361812N1102835W

VARIANT

summit

summit

BGN

VARIANT

VARIANT

VARIANT

summit

VARIANT

summit

360457 N1101948W

Navajo

$361 B 12 N 1102835 \mathrm{~W}$

VARIANT

summit

summit

VARIANT

Navajo

$364902 \mathrm{~N} 1103705 \mathrm{~W}$

Navajo

361812 N1102835W
$355309 \mathrm{~N} 1091454 \mathrm{~W}$ $\begin{array}{cc}\text { SOURCE } & \text { ELEV } \\ \text { COORDINATE } & \text { FT MAP NAME }\end{array}$

5886 Zeniff Sheepskin Wash

7721 Sponseller Mtn

Congress

Congress

Bloody Bas in

9284 Pastora Peak 
NATIONAL GAZETTEER--ARIZONA 1986

\begin{tabular}{|c|c|c|c|c|c|c|c|}
\hline FEATURE NAME & $\begin{array}{l}\text { FEATURE } \\
\text { CLASS }\end{array}$ & STATUS & COUNTY & COORDINATE & $\begin{array}{l}\text { SOURCE } \\
\text { COORDINATE }\end{array}$ & $\begin{array}{l}\text { ELEV } \\
\text { FT }\end{array}$ & MAP NAME \\
\hline $\begin{array}{l}\text { Zil-yazi-zin-daah Mesa } \\
\text { See Little Black Spot } \\
\text { Mountain } \\
\text { Zimmerman Point } \\
\text { Zion Dam } \\
\text { Zion Reservoir }\end{array}$ & $\begin{array}{l}\text { summit } \\
\text { summit } \\
\text { dam } \\
\text { reservoir }\end{array}$ & $\begin{array}{l}\text { BGN } \\
\text { UNOFF } \\
\text { BGN }\end{array}$ & $\begin{array}{l}\text { Gila } \\
\text { Apache } \\
\text { Apache }\end{array}$ & $\begin{array}{l}360457 N 1101948 W \\
334551 N 1105601 W \\
343635 N 1092845 W \\
343635 N 1092 B 45 W\end{array}$ & & 6874 & $\begin{array}{l}\text { Aztec Peak } \\
\text { Zion Reservoir } \\
\text { Zion Reservoir }\end{array}$ \\
\hline $\begin{array}{l}\text { Zonia Mine } \\
\text { Zorilla Tank } \\
\text { Zoroaster Canyon } \\
\text { Zoroaster Temple } \\
\text { Z T Ranch } \\
\text { Zuguato } \\
\text { See Awatobi (site) } \\
\text { Zula Tank Number Two } \\
\text { Zulu Mine } \\
\text { Zulu Tank }\end{array}$ & $\begin{array}{l}\text { mine } \\
\text { reservoir } \\
\text { valley } \\
\text { summit } \\
\text { locale } \\
\text { locale } \\
\text { reservoir } \\
\text { mine } \\
\text { reservoir }\end{array}$ & $\begin{array}{l}\text { UNOFF } \\
\text { BGN } \\
\text { BGN } \\
\text { 8GN } 1906 \\
\text { UNOFF } \\
\text { VARIANT } \\
\text { BGN } \\
\text { UNOFF } \\
\text { BGN }\end{array}$ & $\begin{array}{l}\text { Yavapai } \\
\text { Graham } \\
\text { Coconino } \\
\text { Coconino } \\
\text { Gila } \\
\text { Navajo } \\
\text { Gila } \\
\text { Gila } \\
\text { Gila }\end{array}$ & $\begin{array}{l}341804 \mathrm{~N} 1123757 \mathrm{~W} \\
325256 \mathrm{~N} 1092240 \mathrm{~W} \\
360512 \mathrm{~N} 1120233 \mathrm{~W} \\
360707 \mathrm{~N} 1120241 \mathrm{~W} \\
335935 \mathrm{~N} 1110622 \mathrm{~W} \\
\\
354331 \mathrm{~N} 1101639 \mathrm{~W} \\
340935 \mathrm{~N} 1112331 \mathrm{~W} \\
340923 \mathrm{~N} 1112306 \mathrm{~W} \\
341008 \mathrm{~N} 1112327 \mathrm{~W}\end{array}$ & $360720 \mathrm{~N} 1120212 \mathrm{~W}$ & $712 \mathrm{~B}$ & $\begin{array}{l}\text { Peeples Valley } \\
\text { Gila Box } \\
\text { Phanton Ranch } \\
\text { Phantom Ranch } \\
\text { Copper Mtn }\end{array}$ \\
\hline $\begin{array}{l}\text { Zulu Wash } \\
\text { Zumwait Detention Dam } \\
\text { Zuni Basin } \\
\text { Zuni Mesas } \\
\text { See Twin Buttes } \\
\text { Zuni Park } \\
\text { Zuni Park } \\
\text { Zuni Point } \\
\text { Zuni River } \\
\text { Zuni Spring }\end{array}$ & $\begin{array}{l}\text { stream } \\
\text { dam } \\
\text { basin } \\
\text { summit } \\
\text { park } \\
\text { park } \\
\text { cliff } \\
\text { stream } \\
\text { spring }\end{array}$ & $\begin{array}{l}\text { BGN } \\
\text { UNOFF } \\
\text { BGN } \\
\text { VARIANT } \\
\text { ADMIN } \\
\text { ADMIN } \\
\text { BGN } 1906 \\
\text { BGN } \\
\text { BGN }\end{array}$ & $\begin{array}{l}\text { Gila } \\
\text { Mohave } \\
\text { Greenlee } \\
\text { Navajo } \\
\text { Maricopa } \\
\text { Maricopa } \\
\text { Coconino } \\
\text { Apache } \\
\text { Greenlee }\end{array}$ & $\begin{array}{l}340809 \mathrm{~N} 1112246 \mathrm{~W} \\
362655 \mathrm{~N} 1132153 \mathrm{~W} \\
332323 \mathrm{~N} 1090739 \mathrm{~W} \\
\\
352330 \mathrm{~N} 1095400 \mathrm{~W} \\
333146 \mathrm{~N} 1120456 \mathrm{~W} \\
333235 \mathrm{~N} 1115347 \mathrm{~W} \\
360056 \mathrm{~N} 1115443 \mathrm{~W} \\
343844 \mathrm{~N} 1094026 \mathrm{~W} \\
332258 \mathrm{~N} 1090712 \mathrm{~W}\end{array}$ & $341016 \mathrm{~N} 1112320 \mathrm{~W}$ & 7278 & $\begin{array}{l}\text { North Peak } \\
\text { Jones Hill } \\
\text { Dutch Blue Creek } \\
\text { Sunnys lope } \\
\text { Paradise Valley } \\
\text { Cape Royal } \\
\text { Potter Mesa Tank } \\
\text { Alma Mesa }\end{array}$ \\
\hline $\begin{array}{l}\text { Zuni Trail } \\
\text { Zuni Wash Bridge } \\
\text { Zuni Well } \\
\text { Zuni Well } \\
7 \text { - B Dam } \\
22 \text { Mesa } \\
\text { Twenty-two Mesa } \\
29 \text { Mile Lake } \\
\text { See Twentynine Mile Lake } \\
76 \text { Gulch } \\
\text { See Seventysix Gulch }\end{array}$ & $\begin{array}{l}\text { trail } \\
\text { bridge } \\
\text { well } \\
\text { well } \\
\text { dam } \\
\text { summit }\end{array}$ & $\begin{array}{l}\text { UNOFF } \\
\text { UNOFF } \\
\text { UNOFF } \\
\text { UNOFF } \\
\text { UNOFF } \\
\text { BGN 1968 } \\
\text { VARIANT } \\
\text { VARIANT } \\
\text { VARIANT }\end{array}$ & $\begin{array}{l}\text { Apache } \\
\text { Apache } \\
\text { Apache } \\
\text { Apache } \\
\text { Graham } \\
\text { Yavapai }\end{array}$ & $\begin{array}{l}360633 \mathrm{~N} 1092540 \mathrm{~W} \\
344303 \mathrm{~N} 1091540 \mathrm{~W} \\
344650 \mathrm{~N} 1091134 \mathrm{~W} \\
345613 \mathrm{~N} 1091055 \mathrm{~W} \\
332000 \mathrm{~N} 1095750 \mathrm{~W} \\
341810 \mathrm{~N} 1115405 \mathrm{~W} \\
342 \mathrm{~B} 22 \mathrm{~N} 1112659 \mathrm{~W} \\
321647 \mathrm{~N} 1093903 \mathrm{~W}\end{array}$ & & 5245 & $\begin{array}{l}\text { Three Turkey Canyon } \\
\text { Schnebly Well } \\
\text { Ceadro Spring } \\
\text { Wild Cow Lake } \\
\text { Tule Tubs } \\
\text { Dugas }\end{array}$ \\
\hline
\end{tabular}

